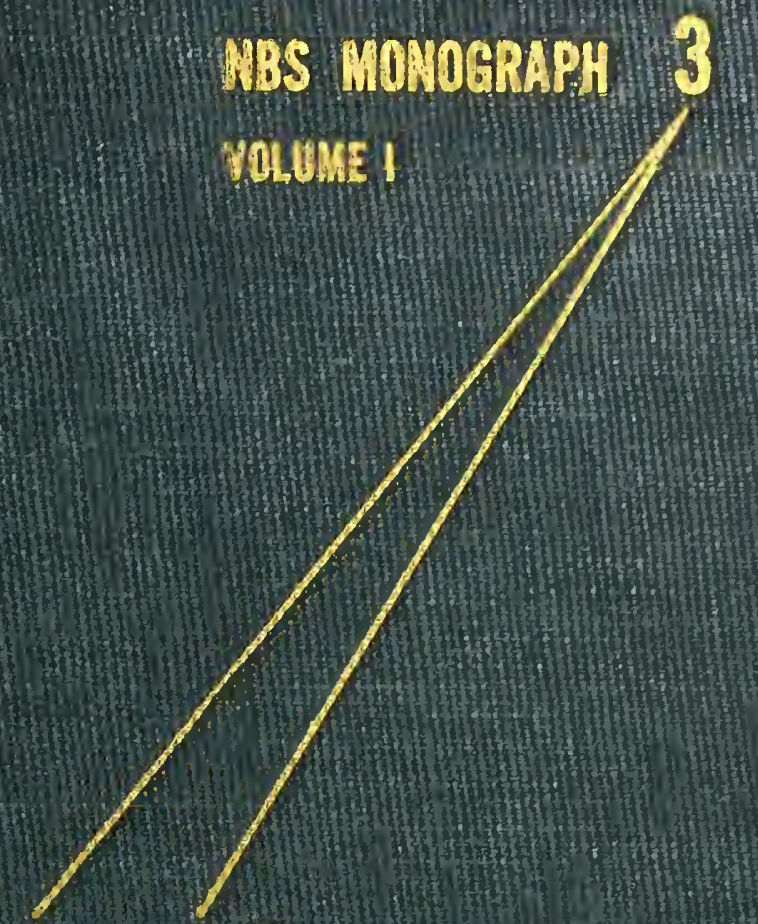

Table of Wavenumbers

2000 A to $7000 \mathrm{~A}$

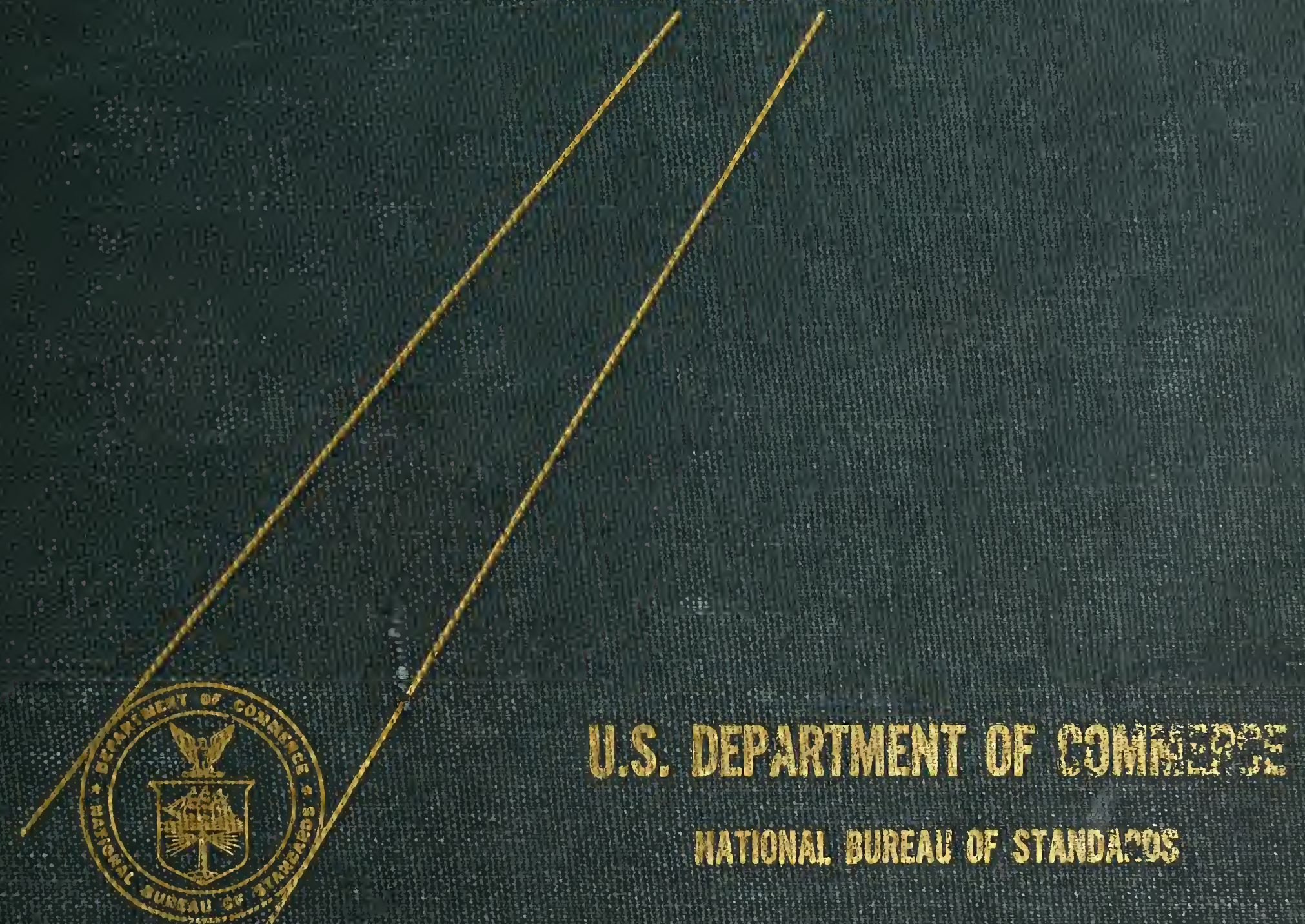







\section{Table of Wavenumbers}

\section{Volume I}

$2000 \mathrm{~A}$ to $7000 \mathrm{~A}$

Charles DeWitt Coleman, William R. Bozman, and William F. Meggers

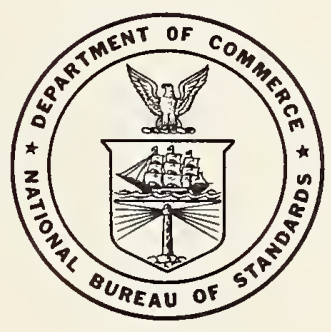

National Bureau of Standards, Monograph 3

Issued May 2, 1960

For sale by the Superintendent of Documents, U.S. Government Printing Office, Washington 25, D.C.

Price $\$ 6.00$ 
AUG $5 \quad 1960$

102,711

1) $=1.30$

11556

CONTENTS

1. Introduction $\ldots \ldots$ III

2. Edlén's formula $\ldots \ldots$ III

3. Extension of tables

4. References

5. Appendix I. Formulas for interpolating wavelength $\ldots \ldots$ v

Table 1. Air density factors $\left(d-d_{\mathrm{o}}\right) / d_{\mathrm{o}} \ldots \ldots \ldots$ VI

Table 2. Wavelength correction table $\delta=\lambda_{0}\left(n_{0}-n_{0}^{\prime}\right)\left[\left(d-d_{0}\right) / d_{0}\right]_{\ldots} \ldots \ldots-$ VII

Table 3. Table of wavenumbers $2000 \mathrm{~A}$ to $7000 \mathrm{~A} \ldots \ldots \ldots$ 


\title{
Table of Wavenumbers
}

\section{Charles DeWitt Coleman, William R. Bozman, and William F. Meggers}

\begin{abstract}
A two-volume table for converting wavelengths in standard air to wavenumbers in vacuum was computed by using the equation $\sigma_{\mathrm{vac}}=1 /\left(n \lambda_{\mathrm{a} i \mathrm{r}}\right)$, where $n$ was computed from Edlén's 1953 equation for the refractive index of air. Wavenumbers are given to the nearest $0.001 \mathrm{~K}\left(\mathrm{~cm}^{-1}\right)$ for wavelengths from 2000 to $7000 \mathrm{~A}$ in volume $\mathrm{I}$, and $7000 \mathrm{~A}$ to 1000 $\mu$ in volume II. Proportional tables are given for linear interpolation between entries of $\lambda$. Also included are the vacuum increase in wavelength, $(n-1)$; and the refractivity of standard air in the form $(n-1) \times 1000$.
\end{abstract}

\section{Introduction}

In 1883, W. N. Hartley [1] ${ }^{1}$ discovered empirically that constant differences occurred between spectral lines if the latter were mapped according to their inverse wavelengths, or their oscillation frequencies, instead of in the usual manner on wavelength scales. Oscillation frequencies, $\nu=c / \lambda$, ( $c$ is the velocity of light, and $\lambda$ the wavelength) are ungainly numbers (of the order of $10^{14}$ ), so inverse wavelengths, that is the number of waves per centimeter, have been preferred. It was recognized that wavelengths measured in air were variously affected by atmospheric refractivity, and real numerical relations between wavenumbers could be found only if the measured wavelengths were corrected to vacuum values by multiplying each wavelength, $\lambda$, by the refractive index of air, $n$, appropriate for that wavelength. During three decades a considerable number of regularities were thus found in relatively simple atomic spectra; it was shown that in a particular spectrum the wavenumbers of a large number of lines could be represented as differences between a smaller number of derived quantities called spectral terms, but the physical meaning of this remained obscure.

In 1913 Niels Bohr suggested that the derived spectral terms represented stationary atomic energy states, and that a spectral line originated in a transition between two such states according to $E_{1}-E_{2}=h \nu$, in which $E_{1}$ and $E_{2}$ are the initial and final atomic energies involved and $h$ is Planck's constant. In little more than a decade this suggestion developed into the quantum theory of spectra as it is known today. All atomic spectra became amenable to interpretation, and during the past 35 years, thousands of scientific papers have been published on atomic energy levels derived from analyses of optical spectra. The quantum interpretation of spectra led to deductions of the electronic structure of atoms and ions, and its extension to spectral hyperfine structure disclosed many properties of atomic nuslei, thus speeding the arrival of this atomic-nuclear age.

Since the observational data consisted mainly of wavelengths measured in standard air, all required conversion to vacuum. For this purpose, W. F. Meggers and C. G. Peters [2] provided a dispersion formula based upon index of refraction measurements for wavelengths between 2200 and $9000 \mathrm{~A}$. But the calculation of the refractive index, $n$, for each wavelength, $\lambda$, the multiplication of these two quantities, $n \lambda$, and the computation of the reciprocal of this product to obtain wavenumbers, $\sigma=1 / n \lambda$, cost much time and labor. In order to save most of this cost, H. Kayser, in 1925, produced his Tabelle der Schwingungszahlen [3] based on the abovementioned dispersion formula. That table was computed with an 8-place desk calculator and gave 8-figure reciprocals of wavelengths (converted to vacuum) at intervals of $0.1 \mathrm{~A}$ between 2000 and $7000 \mathrm{~A}$, and intervals of $1 \mathrm{~A}$ between 7000 and $10000 \mathrm{~A}$. Proportional tables enabled the user to take account of hundredths and thousandths of an angstrom. This table was revised by W. F. Meggers and reprinted in 1944 [3]. These two editions of Kayser's table of wavenumbers have served spectroscopic sciences over a third of a century, minimizing the labor of converting wavelengths in air to wavenumbers in vacuum, essential for all work dealing with the energy levels of atoms and molecules.

In 1950, W. F. Meggers and K. G. Kessier [4] accurately measured relative values of ${ }^{198} \mathrm{Hg}$ wavelengths to eight figures and showed that the Meggers and Peters dispersion formula was slightly in error when rigidly tested by the combination principle of spectroscopy.

\section{Edlén's Formula}

In 1952 the Joint Commission for Spectroscopy recommended [5] the use of a dispersion formula synthesized by B. Edlén [6] who combined the index measurements of three independent observers (H. Barrell and J. E. Sears [7]; J. Koch [8]; W. Traub [9]) and thus derived a new formula which satisfied the combination principle when tested with ${ }^{198} \mathrm{Hg}$ wavelengths. According to Edlén's formula, the Kayser Tabelle der Schwingungszahlen gives wavenumbers accurately at $2500 \mathrm{~A}$, but requires corrections of +8 units in the seventh figure of wavenumbers for $2000 \mathrm{~A},-3$ units for $3500 \mathrm{~A}$, and -0.2 units for $10000 \mathrm{~A}$.

Because of recent improvements in spectroscopic light sources, standard wavelengths, and spectrographic dispersions, wavelengths now can be measured more accurately and it was decided to produce from Edlén's formula a new, expanded, and extended table for obtaining the wavenumber $\sigma$ from the wavelength $\lambda$. Since a table of this size and precision would be nearly impossible to compute by desk calculator, the computations were performed by an electronic computer.

1 Figures in brackets indicate the literature references on page $\mathbf{v}$.
A multiphase electronic computer program had been used for the automatic reduction of spectroscopic data (description of the program in preparation). This program had been written to search for new atomic energy levels utilizing measured spectrum lines and previously identified atomic energy levels. The program included the use of Edlén's formula to compute the wavenumbers of the given lines; this portion of the program code was modified to set up the wavelengths in chosen increments and compute their wavenumbers. The index of refraction of air, and the difference $\left(\lambda_{\text {vac }}-\lambda_{\text {air }}\right)$ were computed for each wavelength given in the lefthand column of the present table. The wavenumbers were computed by an iterative method by using the equation $\sigma_{\mathrm{vac}}=1 /\left(n \lambda_{\mathrm{a} 1 \mathrm{r}}\right)$ where $n$, the index of refraction of air, is a function of $\sigma_{\mathrm{vac}}$. Iterations continued until successive values of the wavenumber (for that wavelength) differed by less than one part in a hundred million. When the complete page of the table was computed and set up in page format, it was written on a magnetic tape for sibsequent listing on a tape-controlled printer. Printing plates were photographically produced from these master pages. 
Edlén's formula for the refractive index of standard (dry) air at $15^{\circ} \mathrm{C}$ and $760 \mathrm{~mm} \mathrm{Hg}$ pressure, upon which this table is based, is:

$$
n=1+6432.8 \times 10^{-8}+\frac{2,949,810}{146 \times 10^{8}-\sigma^{2}}+\frac{25,540}{41 \times 10^{8}-\sigma^{2}}
$$

in which $\sigma$ is the vacuum wavenumber in kaysers $(\mathbf{K})$, that is, waves per centimeter in a vacuum, $\left(K=\mathrm{cm}^{-1}\right)$. This formula appears to give relative values of the index of refraction with an accuracy of $\pm 1 \times 10^{-8}$ for any wavelength greater than $2000 \mathrm{~A}$.

Since this formula was derived from measurements of $n$ for $\lambda$ shorter than $6439 \mathrm{~A}$, it was somewhat doubtful if it could be extrapolated reliably to $10000 \mathrm{~A}$ and beyond. Fortunately, $n$ has recently been measured for $\lambda$ greater than $10000 \mathrm{~A}$; in all cases these measurements confirm Edlén's formula. Thus, measurements of the dispersion of air from 3651 to 15300 A by D. H. Rank et al. [10] "show that within experimental error, which is very small, the Edlén formula is completely correct over the wavelength region investigated". Also new measurements of the refractivity of air in the near infrared by D. J. Schuster and E. R. Peck [11] lead to the conclusion "that these separate absolute measurements show no evidence of failure of Edlén's formula up to a wavelength of $2 \mu$ ". Finally, L. Essen [12] pointed out that "the Edlén formula fits present measurements in the microwave region within the errors of observation".

\section{Extension of Tables}

Although the present limit of spectral observation by photoggraphy is only slightly above $10000 \mathrm{~A}$, recent improvements in infrared detectors and infrared spectrographs have greatly extended the range in which accurate measurements of longer waves can be made. The infrared is very important in atomic spectroscopy and even more so in molecular spectroscopy. There are, therefore, four good reasons for publishing this new table of wavenumbers: (1) It is based on a new formula that satisfies the combination principle; (2) increased accuracy in wavelength measurements justifies a 10-fold expansion of this table over Kayser's; (3) improvements in observing infrared radiation requires its extension beyond $10000 \mathrm{~A}$; and (4) the human labor of preparing this table can be largely circumvented by programing an electronic computer to carry out the calculations and write the table on magnetic tape.

This table is designed to give wavenumbers directly for all wavelengths between $2000 \mathrm{~A}$ and $10000000 \mathrm{~A}=1000 \mu=1 \mathrm{~mm}$. The left-hand column of the table contains the wavelengths, $\lambda$, in standard air, given in angstroms from $2000 \mathrm{~A}$ to $10000 \mathrm{~A}$, and in microns from $10000 \mathrm{~A}=1 \mu$ to $1000 \mu=1 \mathrm{~mm}$. The main body of the table contains the corresponding wavenumbers, $\sigma=1 / n \lambda$, in vacuum. Proportional tables at the bottom of each page are to be used for linear interpolation between successive entries of $\sigma$.

The extreme right-hand column gives $\lambda(n-1)$ which is the amount to be added to $\lambda_{\text {air }}$ to obtain $\lambda_{\mathrm{vac}}$, and the second column from the right shows $(n-1) \times 1,000$, where $n$ is the refractive index of standard air for the wavelength appearing in the left-hand column of the table.

Because of its range and size, this table of wavenumbers is in two volumes, Volume I presenting wavenumbers for all wavelengths between 2000 and $7000 \mathrm{~A}$, and Volume II giving wavenumbers for all wavelengths from $7000 \mathrm{~A}$ to $10000000 \mathrm{~A}=1 \mathrm{~mm}$. In some cases Volume I may suffice for ionic spectra, and in others Volume II may be adequate for molecular spectra, but in general both volumes will be needed to cover the entire range of spectral wavelengths measured in standard air.

The present table for obtaining vacuum wavenumbers from wavelengths in air applies to all optical wavelengths that are determined by interpolation between internationally adopted standard wavelengths with values valid for standard air at a temperature of $15^{\circ} \mathrm{C}$ and a pressure of $760 \mathrm{~mm} \mathrm{Hg}$. If the prism or grating spectrograms are made under other atmospheric conditions this procedure is still permissible provided the spectrum containing standards is simultaneously superposed on the unknown spectrum (in the same grating order). However, the effect of the temperature and pressure of the air must be taken into account in all accurate comparisons of wavelengths made either by the overlapping-orders coincidence method with diffraction gratings, or with interferometers. The wavelength correction required on account of nonstandard air density is $\lambda_{0}-\lambda_{\text {meas }}=$ $\lambda_{0}\left(n_{0}-n_{0}^{\prime}\right)\left[\left(d-d_{0}\right) / d_{0}\right]$, where $d$ represents air density, $n$ refractive index, the subscript 0 indicates normal air, and the prime an index for a standard wavelength. W. F. Meggers and C. G. Peters [13] provided two tables to obviate the calculation of this correction, one for the density factor $\left(d-d_{0}\right) / d_{0}$, and another to give the appropriate wavelength correction for any density factor and the wavelength interval between the standard and measured line. These tables have been recalculated and extended over a greater range with an electronic computer; they are presented here as tables 1 and 2. Table 1 gives air-density factors for temperatures from $9^{\circ} \mathrm{C}$ to $35^{\circ} \mathrm{C}$, and pressures from 780 to 485 $\mathrm{mm} \mathrm{Hg}$ (to serve spectroscopists working on high mountains). Table 2 has been recomputed and is based on the green radiation from ${ }^{198} \mathrm{Hg}$ with a wavelength of $5460.7529 \mathrm{~A}$ in standard air; it provides the proper correction for any wavelength relative to $5460 \mathrm{~A}$ on account of air-density departures from standard.

For wavelengths measured relative to standards other than $5460 \mathrm{~A}$, the following formula still applies: $\lambda_{0}-\lambda_{\text {meas }}=\lambda_{0}\left(n_{0}-n_{0}^{\prime}\right)$ $\left[\left(d-d_{0}\right) / d_{0}\right] . \quad\left(d-d_{0}\right) / d_{0}$ is taken from table 1 and $n_{0}$ and $n_{0}^{\prime}$ are now taken from table 3.

The above tables and formulas pertain to the calculation of the wavelength shift due to a density change from standard air, where a wavelength $\lambda_{m}$ is measured relative to a standard line. If direct calculation is desired, the following formula from Edlén can be used, relative to any desired standard line:

$$
\lambda-\lambda_{m}=\left(\Delta \lambda_{m}-\Delta \lambda_{s} \cdot \lambda_{m} / \lambda_{s}\right)\left(\frac{0.0013882 p}{1+0.00367 t}-1\right)
$$

where $\lambda$ is the value of the measured line at standard temperature and pressure, $\lambda_{m}$ is the wavelength as measured in nonstandard air, $\Delta \lambda_{m}$ is the vacuum correction: $\Delta \lambda_{m}=\lambda_{v}-\lambda$, which is the wavelength difference of the measured line in a vacuum and in normal air, as given in the right-hand column of table $1 ; \lambda_{s}$ is the vacuum correction for the standard wavelength (e.g., the vacuum correction for the green $\mathrm{Hg} 5460 \mathrm{~A}$ line is $1.5175 \mathrm{~A}$ ); $p$ is the atmospheric pressure in millimeters of $\mathrm{Hg}$; and $t$ is the temperature in ${ }^{\circ} \mathrm{C}$.

For high-precision work, an additional correction must be made for water vapor:

$$
\lambda-\lambda_{m}=\left[+0.63\left(1+\lambda_{m} / \lambda_{s}\right)\left(\sigma_{m}-\sigma_{s}\right) f\right] \times 10^{-9},
$$

where $\lambda$ is in angstroms, $f$ is in millimeters $(\mathrm{Hg})$ of water vapor, and $\sigma$ is in $\mathrm{cm}^{-1}$. This formula, based on the measurements of Barrell and Sears [7] is the same as that given by Edlén [6] except that $\sigma$ is given here in $\mathrm{cm}^{-1}$ instead of $\mu^{-1}$.

To obtain the actual wavelength of any line, including any standard line, at conditions other than standard air, for applications such as metrology, the following equation adapted from Barrell and Sears may be used:

$$
\begin{array}{r}
\left(n_{t, p, f}-1\right) 10^{6}=\left[\frac{(n-1) 10^{6}}{720.8826}\right] \times\left[\frac{p\left\{1+(1.049-0.0157 t) p \times 10^{-6}\right\}}{1+0.003661 t}\right] \\
-\left[0.0624-\frac{0.0680}{\lambda^{2}}\right] \frac{f}{1+0.003661 t}
\end{array}
$$

Where $n_{t, p, f}$ is the index at nonstandard temperature, pressure and water vapor, and $n$ is the index in standard air as given in table 1 . Barrell and Sears state that this equation is applicable for the 
ranges $t=10-30^{\circ} \mathrm{C}$ and $p=720-800 \mathrm{~mm}$. Their measurements for water vapor covered the range from 4358 to $6438 \mathrm{~A}$. The water vapor $f$ is measured in millimeters $(\mathrm{Hg})$ pressure, and the wavelength $\lambda$ is in angstroms. T. Masui [14] also gives a general formula for calculating the corrections to Edlén's formula at nonstandard conditions:

$$
\begin{aligned}
\left(n_{t, p, f, k}-1\right)= & (n-1)+C /[1+0.00348(t-15)] \\
\text { where } C= & \left(0.9845+5.75 \sigma^{2} \times 10^{-11}\right)(t-15) \\
& +\left(0.3588+2.17 \sigma^{2} \times 10^{-11}\right)(p-760) \\
& -\left(0.052-4.5 \sigma^{2} \times 10^{-12}\right) f \\
& +\left(0.0145+1.1 \sigma^{2} \times 10^{-12}\right)(k-3)
\end{aligned}
$$

where the temperature, $t$, is in ${ }^{\circ} \mathrm{C}$; the pressure, $p$ is in millimeters $(\mathrm{Hg})$; the water vapor, $f$, is in millimeters $(\mathrm{Hg})$; and, $k$, the $\mathrm{CO}_{2}$ content is in hundredths of a percent. Masui states that this formula is applicable to the visible spectrum near standard conditions.
Also included, in appendix, section 5, are tested formulas for interpolating wavelengths in prismatic spectrograms and in grating spectrograms. The direct evaluation of three constants in the Hartmann dispersion formula is especially convenient because it avoids struggles with the solution of simultaneous equations.

We wish to acknowledge the assistance given by all concerned with this publication, and especially to $\mathrm{K}$. G. Kessler for many helpful suggestions from the very beginning; to J. L. Tech, who encouraged us to start the project; to P. J. O'Hara, G. M. Galler, and V. Dantzler who operated the electric computer; to B. F. Scribner for assistance and advice especially during preparation of the manuscript; to $\mathrm{E}$. K. Plyler for suggestions concerning the infrared portion of the table. We are especially indebted to Bengt Edlén for advice, and for a copy of his mimeographed (October 1958) "Vacuum Corrections for Wavelengths from $2000 \mathrm{~A}$ to $50000 \mathrm{~A}$," which in this range served as a check on our machine calculations. The cooperation and careful work of the Publications Section concerning many details of publication are also gratefully acknowledged.

\section{References}

[1] W. N. Hartley, J. Chem Soc. 43, 390 (1883).

[2] W. F. Meggers and C. G. Peters, BS. Sci. Pap. 14, 697 (1918).

[2] H. Kayser, Tabelle der Schwingungszahlen, S. Hirzel, Leipzig (1925). Revised by W. F. Meggers (Edwards Brothers, Inc., Ann Arbor, Mich., 1944).

[4] W. F. Meggers and K. G. Kessler, J. Opt. Soc. Am. 40, 737 (1950).

[5] Joint Commission for Spectroscopy, J. Opt. Soc. Am. 43, 412 (1953).

[6] B. Edlén, J. Opt. Soc. Am. 43, 339 (1953).
[7] H. Barrell and J. E. Sears, Trans. Roy. Soc. (London A238, I (1939).

[8] J. Koch, Arkiv Mat. Astron. Fysik 8, No. 20 (1912).

[9] W. Traub, Ann Physik 61, 533 (1920).

[10] D. H. Rank, et al., J. Opt. Soc. Am. 48, 455 (1958).

1111 D. J. Schuster and E. R. Peck, J. Opt. Soc. Am. 48, 313 (1958).

[12] L. Essen, Trans. Int. Astron. Union 9, 218 (1957).

[13] W. F. Meggers and C. G. Peters, BS. Sci. Pap. 14, 724 (1918).

[14] Revue d'Optique 36, 281 (1957).

\section{Appendix I. Formulas for Interpolating Wavelengths}

Hartman dispersion formula (for prism spectrographs)

$$
\lambda=\lambda_{0}+\frac{c}{d-d_{0}}
$$

evaluation of constants $\lambda_{0}, c$, and $d_{0}$ :

$$
\begin{aligned}
& \lambda_{1}^{\prime}=\lambda_{1}-\lambda_{3} \\
& \lambda_{2}^{\prime}=\lambda_{2}-\lambda_{3} \\
& S=\frac{\lambda_{1}^{\prime}-\lambda_{2}^{\prime}}{\lambda_{2}^{\prime}} \\
& \lambda_{0}=\lambda_{3}+\frac{\lambda_{1}^{\prime}\left(d_{1}-d_{2}\right)}{S\left(d_{3}-d_{2}\right)+\left(d_{1}-d_{2}\right)} \\
& d_{0}=\frac{\left(\lambda_{0}-\lambda_{3}\right)\left(d_{3}-d_{2}\right)}{\lambda_{2}^{\prime}}+d_{2}
\end{aligned}
$$

$$
c=\left(\lambda_{0}-\lambda_{3}\right)\left(d_{0}-d_{3}\right) .
$$

Where $d_{1}, d_{2}$, and $d_{3}$ are the comparator readings at known wavelengths $\lambda_{1}, \lambda_{2}$, and $\lambda_{3}$, respectively.

Linear interpolation formula (for grating spectrographs)

$$
\lambda=\lambda_{0}+\frac{\Delta \lambda}{\Delta d} d
$$

where $\frac{\Delta \lambda}{\Delta d}=\frac{\lambda_{2}-\lambda_{1}}{d_{2}-d_{1}}$ is computed from the comparator readings $d_{1}$ and $d_{2}$ at known wavelengths $\lambda_{1}$ and $\lambda_{2}$, respectively, and $\lambda_{0}=\lambda_{1}$ $-\frac{\Delta \lambda}{\Delta d} d_{1}$.

Washington, April 22, 1959. 


\section{Table 3}

\section{Table of Wavenumbers}

$2000 \mathrm{~A}$ to $7000 \mathrm{~A}$ 



\begin{tabular}{|c|c|c|c|c|c|c|c|c|c|c|c|c|}
\hline (A) & .00 & .01 & .02 & .03 & .04 & .05 & .06 & .07 & .08 & .09 & $(n-1) \times 1000$ & $\lambda(n-1)$ \\
\hline $\begin{array}{r}2000.0 \\
0.12 \\
0.2 \\
0.3 \\
0.4 \\
0.5 \\
0.6 \\
0.7 \\
0.8 \\
0.9\end{array}$ & $\begin{array}{r}49983.804 \\
81.306 \\
78.808 \\
76.310 \\
73.812 \\
71.314 \\
68.816 \\
66.320 \\
63.822 \\
61.326\end{array}$ & $\begin{array}{l}83.555 \\
81.056 \\
78.558 \\
76.060 \\
73.562 \\
71.064 \\
68.566 \\
66.070 \\
63.572 \\
61.076\end{array}$ & $\begin{array}{l}83.305 \\
80.807 \\
78.308 \\
75.810 \\
73.312 \\
70.814 \\
68.317 \\
65.820 \\
63.322 \\
60.827\end{array}$ & $\begin{array}{l}83.055 \\
80.557 \\
78.058 \\
75.560 \\
73.062 \\
70.564 \\
68.0567 \\
65.570 \\
63.074 \\
60.577\end{array}$ & $\begin{array}{l}82.806 \\
80.307 \\
77.809 \\
75.310 \\
72.812 \\
70.314 \\
67.818 \\
65.320 \\
62.824 \\
60.327\end{array}$ & $\begin{array}{l}82.556 \\
80.057 \\
77.559 \\
75.060 \\
72.563 \\
70.065 \\
67.568 \\
65.071 \\
62.574 \\
60.077\end{array}$ & $\begin{array}{l}82.306 \\
79.807 \\
77.309 \\
74.811 \\
72.313 \\
69.815 \\
67.318 \\
64.821 \\
62.324 \\
59.828\end{array}$ & $\begin{array}{l}82.056 \\
79.557 \\
77.0559 \\
74.561 \\
72.063 \\
69.565 \\
67.068 \\
64.571 \\
62.075 \\
59.578\end{array}$ & $\begin{array}{l}81.806 \\
79.307 \\
76.810 \\
74.311 \\
71.813 \\
69.315 \\
66.819 \\
64.322 \\
61.825 \\
59.329\end{array}$ & $\begin{array}{l}81.557 \\
79.058 \\
76.560 \\
74.061 \\
71.563 \\
69.066 \\
66.569 \\
64.072 \\
61.576 \\
59.079\end{array}$ & $\begin{array}{l}0.324028 \\
0.324020 \\
0.324013 \\
0.324005 \\
0.323998 \\
0.323990 \\
0.323983 \\
0.323975 \\
0.323968 \\
0.323960\end{array}$ & $\begin{array}{l}0.648055 \\
0.648073 \\
0.648090 \\
0.648107 \\
0.648125 \\
0.648142 \\
0.648160 \\
0.648177 \\
0.648194 \\
0.648212\end{array}$ \\
\hline $\begin{array}{r}2001.0 \\
1.1 \\
1.2 \\
1.3 \\
1.4 \\
1.5 \\
1.5 \\
1.7 \\
1.8 \\
1.9\end{array}$ & $\begin{array}{r}49958.829 \\
56.333 \\
53.837 \\
51.341 \\
48.846 \\
46.351 \\
43.855 \\
41.361 \\
38.866 \\
36.373\end{array}$ & $\begin{array}{l}58.580 \\
56.083 \\
53.587 \\
51.092 \\
48.596 \\
46.101 \\
43.506 \\
41.111 \\
38.617 \\
36.123\end{array}$ & $\begin{array}{l}58.330 \\
55.834 \\
53.338 \\
50.842 \\
48.347 \\
45.852 \\
43.356 \\
40.862 \\
38.367 \\
35.874\end{array}$ & $\begin{array}{l}58.081 \\
55.0584 \\
53.089 \\
50.593 \\
48.098 \\
45.062 \\
43.108 \\
40.613 \\
38.119 \\
35.624\end{array}$ & $\begin{array}{l}57.831 \\
55.334 \\
52.839 \\
50.343 \\
47.848 \\
45.353 \\
42.858 \\
40.363 \\
37.869 \\
35.375\end{array}$ & $\begin{array}{l}57.581 \\
55.085 \\
52.589 \\
50.093 \\
47.599 \\
45.104 \\
42.009 \\
40.114 \\
37.620 \\
35.125\end{array}$ & $\begin{array}{l}57.332 \\
54.835 \\
52.340 \\
49.844 \\
47.349 \\
44.854 \\
42.359 \\
39.864 \\
37.371 \\
34.876\end{array}$ & $\begin{array}{l}57.082 \\
54.586 \\
52.090 \\
49.594 \\
47.100 \\
44.604 \\
42.110 \\
39.615 \\
37.121 \\
34.626\end{array}$ & $\begin{array}{l}56.833 \\
54.336 \\
51.841 \\
49.345 \\
46.850 \\
44.354 \\
41.860 \\
39.366 \\
36.871 \\
34.377\end{array}$ & $\begin{array}{l}56.583 \\
54.086 \\
51.591 \\
49.095 \\
46.501 \\
44.105 \\
41.611 \\
39.116 \\
36.622 \\
34.127\end{array}$ & $\begin{array}{l}0.323953 \\
0.323945 \\
0.323938 \\
0.323930 \\
0.323923 \\
0.323915 \\
0.323908 \\
0.323900 \\
0.323893 \\
0.323885\end{array}$ & $\begin{array}{l}0.648229 \\
0.648247 \\
0.648264 \\
0.648281 \\
0.648299 \\
0.648316 \\
0.648334 \\
0.648351 \\
0.648368 \\
0.648386\end{array}$ \\
\hline $\begin{array}{r}.002 .0 \\
2.1 \\
2.2 \\
2.3 \\
2.4 \\
2.5 \\
2.5 \\
2.7 \\
2.8 \\
2.9\end{array}$ & $\begin{array}{r}49933.878 \\
31.385 \\
28.891 \\
26.398 \\
23.905 \\
21.413 \\
18.919 \\
16.428 \\
13.936 \\
11.444\end{array}$ & $\begin{array}{l}33.629 \\
31.135 \\
28.642 \\
26.149 \\
23.655 \\
21.164 \\
18.670 \\
16.179 \\
13.687 \\
11.195\end{array}$ & $\begin{array}{l}33.379 \\
30.486 \\
28.392 \\
25.899 \\
23.406 \\
20.914 \\
18.421 \\
15.929 \\
13.437 \\
10.946\end{array}$ & $\begin{array}{l}33.131 \\
30.637 \\
28.144 \\
25.650 \\
23.158 \\
20.665 \\
18.172 \\
15.680 \\
13.188 \\
10.696\end{array}$ & $\begin{array}{l}32.881 \\
30.387 \\
27.895 \\
25.401 \\
22.908 \\
20.415 \\
17.923 \\
15.431 \\
12.939 \\
10.448\end{array}$ & $\begin{array}{l}32.632 \\
30.138 \\
27.645 \\
25.151 \\
22.059 \\
20.166 \\
17.674 \\
15.182 \\
12.690 \\
10.198\end{array}$ & $\begin{array}{l}32.383 \\
29.888 \\
27.396 \\
24.902 \\
22.410 \\
19.917 \\
17.425 \\
14.933 \\
12.441 \\
09.949\end{array}$ & $\begin{array}{l}32.133 \\
29.639 \\
27.146 \\
24.653 \\
22.161 \\
19.667 \\
17.175 \\
14.683 \\
12.192 \\
09.700\end{array}$ & $\begin{array}{l}31.884 \\
29.390 \\
26.897 \\
24.403 \\
21.912 \\
19.418 \\
16.926 \\
14.434 \\
11.942 \\
090451\end{array}$ & $\begin{array}{l}31.634 \\
29.141 \\
26.647 \\
24.154 \\
21.662 \\
19.169 \\
16.677 \\
14.185 \\
11.693 \\
09.202\end{array}$ & $\begin{array}{l}0.323878 \\
0.323870 \\
0.323863 \\
0.323855 \\
0.323848 \\
0.323840 \\
0.323833 \\
0.323825 \\
0.323818 \\
0.323811\end{array}$ & $\begin{array}{l}0.648403 \\
0.648421 \\
0.648438 \\
0.648455 \\
0.648473 \\
0.648490 \\
0.648508 \\
0.648525 \\
0.648543 \\
0.648560\end{array}$ \\
\hline $\begin{array}{r}2003.0 \\
3.1 \\
3.2 \\
3.3 \\
3.4 \\
3.5 \\
3.5 \\
3.7 \\
3.8 \\
3.9\end{array}$ & $\begin{array}{r}49908.952 \\
06.461 \\
03.970 \\
01.480 \\
49898.989 \\
96.500 \\
94.009 \\
91.520 \\
89.029 \\
86.541\end{array}$ & $\begin{array}{l}08.703 \\
06.212 \\
03.721 \\
01.231 \\
98.740 \\
96.250 \\
93.760 \\
91.271 \\
88.781 \\
86.292\end{array}$ & $\begin{array}{l}08.454 \\
05.963 \\
03.472 \\
00.981 \\
98.491 \\
96.001 \\
93.511 \\
91.021 \\
88.532 \\
86.043\end{array}$ & $\begin{array}{l}08.206 \\
05.714 \\
03.224 \\
00.732 \\
98.242 \\
95.752 \\
93.263 \\
90.773 \\
88.284 \\
85.793\end{array}$ & $\begin{array}{l}07.957 \\
05.465 \\
02.974 \\
00.483 \\
97.994 \\
95.503 \\
93.014 \\
90.523 \\
88.035 \\
85.545\end{array}$ & $\begin{array}{l}07.707 \\
05.216 \\
02.726 \\
00.234 \\
97.745 \\
95.254 \\
92.765 \\
90.274 \\
87.785 \\
85.296\end{array}$ & $\begin{array}{l}07.458 \\
04.967 \\
02.477 \\
* 99.985 \\
97.496 \\
95.005 \\
92.515 \\
90.026 \\
87.537 \\
85.047\end{array}$ & $\begin{array}{r}07.209 \\
04.718 \\
02.227 \\
* 99.736 \\
97.246 \\
94.756 \\
92.267 \\
89.776 \\
87.288 \\
84.798\end{array}$ & $\begin{array}{r}06.960 \\
04.468 \\
01.978 \\
* 99.487 \\
96.998 \\
94.507 \\
92.018 \\
89.528 \\
87.039 \\
84.549\end{array}$ & $\begin{array}{r}06.710 \\
04.219 \\
01.729 \\
* 99.238 \\
96.748 \\
94.258 \\
91.769 \\
89.278 \\
86.790 \\
84.300\end{array}$ & $\begin{array}{l}0.323803 \\
0.323796 \\
0.323788 \\
0.323781 \\
0.323773 \\
0.323766 \\
0.323758 \\
0.323751 \\
0.323743 \\
0.323736\end{array}$ & $\begin{array}{l}0.648578 \\
0.648595 \\
0.648612 \\
0.648630 \\
0.648647 \\
0.648665 \\
0.648682 \\
0.648700 \\
0.648717 \\
0.648735\end{array}$ \\
\hline $\begin{array}{r}2004.0 \\
4.1 \\
4.2 \\
4.3 \\
4.4 \\
4.5 \\
4.6 \\
4.7 \\
4.8 \\
4.9\end{array}$ & $\begin{array}{r}49884.051 \\
81.563 \\
79.074 \\
76.586 \\
74.098 \\
71.610 \\
69.123 \\
66.636 \\
64.148 \\
61.663\end{array}$ & $\begin{array}{l}83.803 \\
81.314 \\
78.825 \\
76.337 \\
73.849 \\
71.362 \\
68.874 \\
66.387 \\
63.900 \\
61.0113\end{array}$ & $\begin{array}{l}83.554 \\
81.065 \\
78.576 \\
76.088 \\
73.601 \\
71.113 \\
68.625 \\
66.139 \\
63.651 \\
61.165\end{array}$ & $\begin{array}{l}83.305 \\
80.816 \\
78.329 \\
75.840 \\
73.352 \\
70.864 \\
68.377 \\
65.890 \\
63.403 \\
60.916\end{array}$ & $\begin{array}{l}83.056 \\
80.567 \\
78.080 \\
75.591 \\
73.104 \\
70.615 \\
68.128 \\
65.641 \\
63.155 \\
60.667\end{array}$ & $\begin{array}{l}82.808 \\
80.319 \\
77.831 \\
75.342 \\
72.854 \\
70.367 \\
67.880 \\
65.392 \\
62.906 \\
60.419\end{array}$ & $\begin{array}{l}82.559 \\
80.070 \\
77.582 \\
75.093 \\
72.605 \\
70.118 \\
67.631 \\
65.144 \\
62.657 \\
60.170\end{array}$ & $\begin{array}{l}82.310 \\
79.821 \\
77.333 \\
74.845 \\
72.357 \\
69.869 \\
67.382 \\
64.895 \\
62.408 \\
59.921\end{array}$ & $\begin{array}{l}82.061 \\
79.572 \\
77.084 \\
74.596 \\
72.108 \\
69.621 \\
67.133 \\
64.646 \\
62.160 \\
59.673\end{array}$ & $\begin{array}{l}81.812 \\
79.323 \\
76.835 \\
74.347 \\
71.859 \\
69.372 \\
66.885 \\
64.397 \\
61.911 \\
59.424\end{array}$ & $\begin{array}{l}0.323729 \\
0.323721 \\
0.323714 \\
0.323706 \\
0.323699 \\
0.323691 \\
0.323684 \\
0.323677 \\
0.323669 \\
0.323662\end{array}$ & $\begin{array}{l}0.648752 \\
0.648770 \\
0.648787 \\
0.648805 \\
0.648822 \\
0.648840 \\
0.648857 \\
0.648875 \\
0.648892 \\
0.648910\end{array}$ \\
\hline $\begin{array}{r}005.0 \\
5.1 \\
5.2 \\
5.3 \\
5.4 \\
5.5 \\
5.6 \\
5.7 \\
5.8 \\
5.9\end{array}$ & $\begin{array}{r}49859.175 \\
56.689 \\
54.203 \\
51.718 \\
49.232 \\
46.747 \\
44.262 \\
41.777 \\
39.292 \\
36.809\end{array}$ & $\begin{array}{l}58.927 \\
56.441 \\
53.954 \\
51.469 \\
48.983 \\
46.499 \\
44.013 \\
41.528 \\
39.044 \\
36.560\end{array}$ & $\begin{array}{l}58.678 \\
50.192 \\
53.706 \\
51.220 \\
48.735 \\
46.250 \\
43.765 \\
41.280 \\
38.795 \\
36.312\end{array}$ & $\begin{array}{l}58.430 \\
55.943 \\
53.458 \\
50.972 \\
48.486 \\
46.001 \\
43.517 \\
41.032 \\
38.547 \\
36.063\end{array}$ & $\begin{array}{l}58.181 \\
55.695 \\
53.209 \\
50.723 \\
48.238 \\
45.752 \\
43.269 \\
40.783 \\
38.299 \\
35.814\end{array}$ & $\begin{array}{l}57.933 \\
55.446 \\
52.960 \\
50.475 \\
47.990 \\
45.504 \\
43.020 \\
40.535 \\
38.050 \\
35.566\end{array}$ & $\begin{array}{l}57.684 \\
55.197 \\
52.712 \\
50.226 \\
47.741 \\
45.256 \\
42.771 \\
40.286 \\
37.802 \\
35.317\end{array}$ & $\begin{array}{l}57.435 \\
54.949 \\
52.463 \\
49.978 \\
47.492 \\
45.007 \\
42.522 \\
40.038 \\
37.554 \\
35.069\end{array}$ & $\begin{array}{l}57.187 \\
54.7000 \\
52.2115 \\
49.729 \\
47.244 \\
44.758 \\
42.274 \\
39.790 \\
37.305 \\
34.821\end{array}$ & $\begin{array}{l}56.938 \\
54.452 \\
51.966 \\
49.480 \\
46.995 \\
44.510 \\
42.026 \\
39.541 \\
37.057 \\
34.572\end{array}$ & $\begin{array}{l}0.323654 \\
0.323647 \\
0.323640 \\
0.323632 \\
0.323625 \\
0.323617 \\
0.323610 \\
0.323603 \\
0.323595 \\
0.323588\end{array}$ & $\begin{array}{l}0.648927 \\
0.648945 \\
0.648962 \\
0.648980 \\
0.648997 \\
0.649015 \\
0.649032 \\
0.649050 \\
0.649067 \\
0.649085\end{array}$ \\
\hline $\begin{array}{r}006.0 \\
6.1 \\
6.2 \\
6.3 \\
6.4 \\
6.5 \\
6.6 \\
6.7 \\
6.8 \\
6.9\end{array}$ & $\begin{array}{r}49834.324 \\
31.840 \\
29.357 \\
26.874 \\
24.391 \\
21.908 \\
19.425 \\
16.943 \\
14.461 \\
11.979\end{array}$ & $\begin{array}{l}34.076 \\
31.0592 \\
29.100 \\
26.625 \\
24.142 \\
21.6660 \\
19.177 \\
16.695 \\
14.0213 \\
11.731\end{array}$ & $\begin{array}{l}33.827 \\
31.344 \\
28.860 \\
26.377 \\
23.894 \\
21.411 \\
18.929 \\
16.447 \\
13.964 \\
11.483\end{array}$ & $\begin{array}{l}33.579 \\
31.095 \\
28.612 \\
26.129 \\
23.646 \\
21.163 \\
18.680 \\
16.199 \\
13.716 \\
11.234\end{array}$ & $\begin{array}{l}33.331 \\
30.847 \\
28.364 \\
25.880 \\
23.398 \\
20.915 \\
18.433 \\
15.950 \\
13.469 \\
10.986\end{array}$ & $\begin{array}{l}33.083 \\
30.599 \\
28.116 \\
25.632 \\
23.149 \\
20.067 \\
18.185 \\
15.702 \\
13.020 \\
10.739\end{array}$ & $\begin{array}{l}32.834 \\
30.350 \\
27.868 \\
25.384 \\
22.901 \\
20.418 \\
17.936 \\
15.454 \\
12.972 \\
10.490\end{array}$ & $\begin{array}{l}32.586 \\
30.102 \\
27.619 \\
25.135 \\
22.653 \\
20.170 \\
17.688 \\
15.206 \\
12.724 \\
10.242\end{array}$ & $\begin{array}{l}32.337 \\
29.853 \\
27.371 \\
24.887 \\
22.405 \\
19.922 \\
17.439 \\
14.957 \\
12.476 \\
09.994\end{array}$ & $\begin{array}{l}32.089 \\
29.605 \\
27.122 \\
24.639 \\
22.156 \\
19.674 \\
17.191 \\
14.709 \\
12.228 \\
09.746\end{array}$ & $\begin{array}{l}0.323580 \\
0.323573 \\
0.323566 \\
0.323558 \\
0.323551 \\
0.323543 \\
0.323536 \\
0.323529 \\
0.323521 \\
0.323514\end{array}$ & $\begin{array}{l}0.649102 \\
0.649120 \\
0.649137 \\
0.649155 \\
0.649172 \\
0.649190 \\
0.649207 \\
0.649225 \\
0.649242 \\
0.649260\end{array}$ \\
\hline $\begin{array}{r}007.0 \\
7.1 \\
7.2 \\
7.3 \\
7.4 \\
7.5 \\
7.5 \\
7.7 \\
7.8 \\
7.9\end{array}$ & $\begin{array}{r}49809.498 \\
07.017 \\
04.535 \\
02.055 \\
49799.574 \\
97.094 \\
94.613 \\
92.134 \\
89.654 \\
37.175\end{array}$ & $\begin{array}{l}09.250 \\
06.7688 \\
04.287 \\
01.807 \\
99.326 \\
96.846 \\
94.366 \\
91.886 \\
89.406 \\
66.927\end{array}$ & $\begin{array}{l}09.001 \\
06.521 \\
04.039 \\
01.559 \\
99.078 \\
96.590 \\
94.117 \\
91.638 \\
89.158 \\
86.679\end{array}$ & $\begin{array}{l}08.753 \\
06.272 \\
03.791 \\
01.311 \\
98.830 \\
96.350 \\
93.869 \\
91.390 \\
88.910 \\
86.431\end{array}$ & $\begin{array}{l}08.504 \\
06.024 \\
03.542 \\
01.062 \\
98.582 \\
96.102 \\
93.621 \\
91.142 \\
88.662 \\
86.184\end{array}$ & $\begin{array}{l}08.257 \\
05.776 \\
03.295 \\
00.814 \\
98.334 \\
95.854 \\
93.375 \\
90.894 \\
88.414 \\
85.935\end{array}$ & $\begin{array}{l}08.009 \\
05.527 \\
03.047 \\
00.566 \\
98.086 \\
95.606 \\
93.126 \\
90.646 \\
88.167 \\
85.687\end{array}$ & $\begin{array}{l}07.761 \\
05.280 \\
02.799 \\
00.318 \\
97.838 \\
95.357 \\
92.878 \\
90.398 \\
87.919 \\
85.439\end{array}$ & $\begin{array}{l}07.513 \\
05.031 \\
02.551 \\
00.070 \\
97.590 \\
95.109 \\
92.630 \\
90.150 \\
87.671 \\
85.192\end{array}$ & $\begin{array}{l}89.902 \\
87.423 \\
84.944\end{array}$ & & $\begin{array}{l}0.649278 \\
0.649295 \\
0.649313 \\
0.649330 \\
0.649348 \\
0.649365 \\
0.649383 \\
0.649400 \\
0.649418 \\
0.649436\end{array}$ \\
\hline $\begin{array}{r}008.0 \\
8.1 \\
8.2 \\
8.3 \\
8.4 \\
8.5 \\
8.5 \\
8.7 \\
8.8 \\
8.9\end{array}$ & $\begin{array}{r}49784.695 \\
82.217 \\
79.738 \\
77.260 \\
74.782 \\
72.305 \\
69.827 \\
67.350 \\
64.872 \\
62.396\end{array}$ & $\begin{array}{l}84.448 \\
81.969 \\
79.490 \\
77.013 \\
74.534 \\
72.057 \\
69.579 \\
67.102 \\
64.625 \\
62.148\end{array}$ & $\begin{array}{l}84.200 \\
81.722 \\
79.243 \\
76.704 \\
74.286 \\
71.809 \\
69.331 \\
66.854 \\
64.376 \\
61.900\end{array}$ & $\begin{array}{l}83.952 \\
81.474 \\
78.995 \\
76.517 \\
74.038 \\
71.561 \\
69.083 \\
66.606 \\
64.129 \\
61.652\end{array}$ & $\begin{array}{l}83.704 \\
81.226 \\
78.747 \\
76.269 \\
73.791 \\
71.313 \\
68.835 \\
66.358 \\
63.881 \\
61.405\end{array}$ & $\begin{array}{l}83.456 \\
80.978 \\
78.499 \\
76.021 \\
73.543 \\
71.0055 \\
68.587 \\
66.110 \\
63.633 \\
61.0157\end{array}$ & $\begin{array}{l}83.209 \\
80.730 \\
78.252 \\
75.773 \\
73.295 \\
70.817 \\
68.339 \\
65.863 \\
63.386 \\
60.909\end{array}$ & $\begin{array}{l}82.961 \\
80.482 \\
78.004 \\
75.525 \\
73.048 \\
70.569 \\
68.093 \\
65.615 \\
63.139 \\
60.662\end{array}$ & $\begin{array}{l}82.713 \\
80.234 \\
77.756 \\
75.277 \\
72.800 \\
70.322 \\
67.845 \\
65.368 \\
62.891 \\
60.414\end{array}$ & $\begin{array}{l}82.465 \\
79.986 \\
77.508 \\
75.030 \\
72.552 \\
70.074 \\
67.597 \\
65.119 \\
62.643 \\
60.166\end{array}$ & $\begin{array}{l}0.323433 \\
0.323426 \\
0.323418 \\
0.323411 \\
0.323403 \\
0.323396 \\
0.323389 \\
0.323381 \\
0.323374 \\
0.323367\end{array}$ & $\begin{array}{l}0.649453 \\
0.649471 \\
0.649488 \\
0.649506 \\
0.649523 \\
0.649541 \\
0.649559 \\
0.649576 \\
0.649594 \\
0.649611\end{array}$ \\
\hline $\begin{array}{l}09.0 \\
9.1 \\
9.2 \\
9.3 \\
9.4 \\
9.5 \\
9.6 \\
9.7 \\
9.8 \\
9.9\end{array}$ & $\begin{array}{r}49759.918 \\
57.442 \\
54.966 \\
52.491 \\
50.015 \\
47.540 \\
45.064 \\
42.590 \\
40.115 \\
37.641\end{array}$ & $\begin{array}{l}59.671 \\
57.195 \\
54.718 \\
52.243 \\
49.767 \\
47.292 \\
44.816 \\
42.342 \\
39.867 \\
37.393\end{array}$ & $\begin{array}{l}59.423 \\
56.947 \\
54.471 \\
51.995 \\
49.520 \\
47.044 \\
44.569 \\
42.095 \\
39.619 \\
37.146\end{array}$ & $\begin{array}{l}56.699 \\
54.223 \\
51.748 \\
49.272 \\
46.797 \\
44.322 \\
41.847 \\
39.372 \\
36.898\end{array}$ & $\begin{array}{l}44.074 \\
41.600 \\
39.125 \\
36.651\end{array}$ & $\begin{array}{l}51.252 \\
48.777 \\
46.302 \\
43.827 \\
41.352 \\
38.877 \\
36.403\end{array}$ & $\begin{array}{l}48.529 \\
46.054 \\
43.579 \\
41.105 \\
38.0330 \\
36.155\end{array}$ & $\begin{array}{l}55.709 \\
53.232 \\
50.757 \\
48.282 \\
45.807 \\
43.332 \\
40.857 \\
38.382 \\
35.908\end{array}$ & $\begin{array}{l}43.059 \\
43.084 \\
40.609 \\
38.135 \\
35.661\end{array}$ & $\begin{array}{l}57.690 \\
55.214 \\
52.738 \\
50.262 \\
47.787 \\
45.312 \\
42.837 \\
40.362 \\
37.888 \\
35.414\end{array}$ & $\begin{array}{l}0.323352 \\
0.032345 \\
0.323337 \\
0.32330 \\
0.323323 \\
0.323315 \\
0.023308 \\
0.323301 \\
0.323294\end{array}$ & $\begin{array}{l}0.649647 \\
0.649664 \\
0.649682 \\
0.649700 \\
0.649717 \\
0.649735 \\
0.649752 \\
0.649770 \\
0.649788\end{array}$ \\
\hline & \multicolumn{2}{|c|}{.001} & .002 & .003 & & & .006 & .007 & .008 & .009 & .010 & \\
\hline & $\begin{array}{l}.025 \\
.025 \\
.025\end{array}$ & & & & .099 & & .148 & $\begin{array}{l}.174 \\
.173\end{array}$ & $\begin{array}{r}.199 \\
.198 \\
.198\end{array}$ & $\begin{array}{r}.224 \\
.223 \\
.222\end{array}$ & .247 & \\
\hline
\end{tabular}




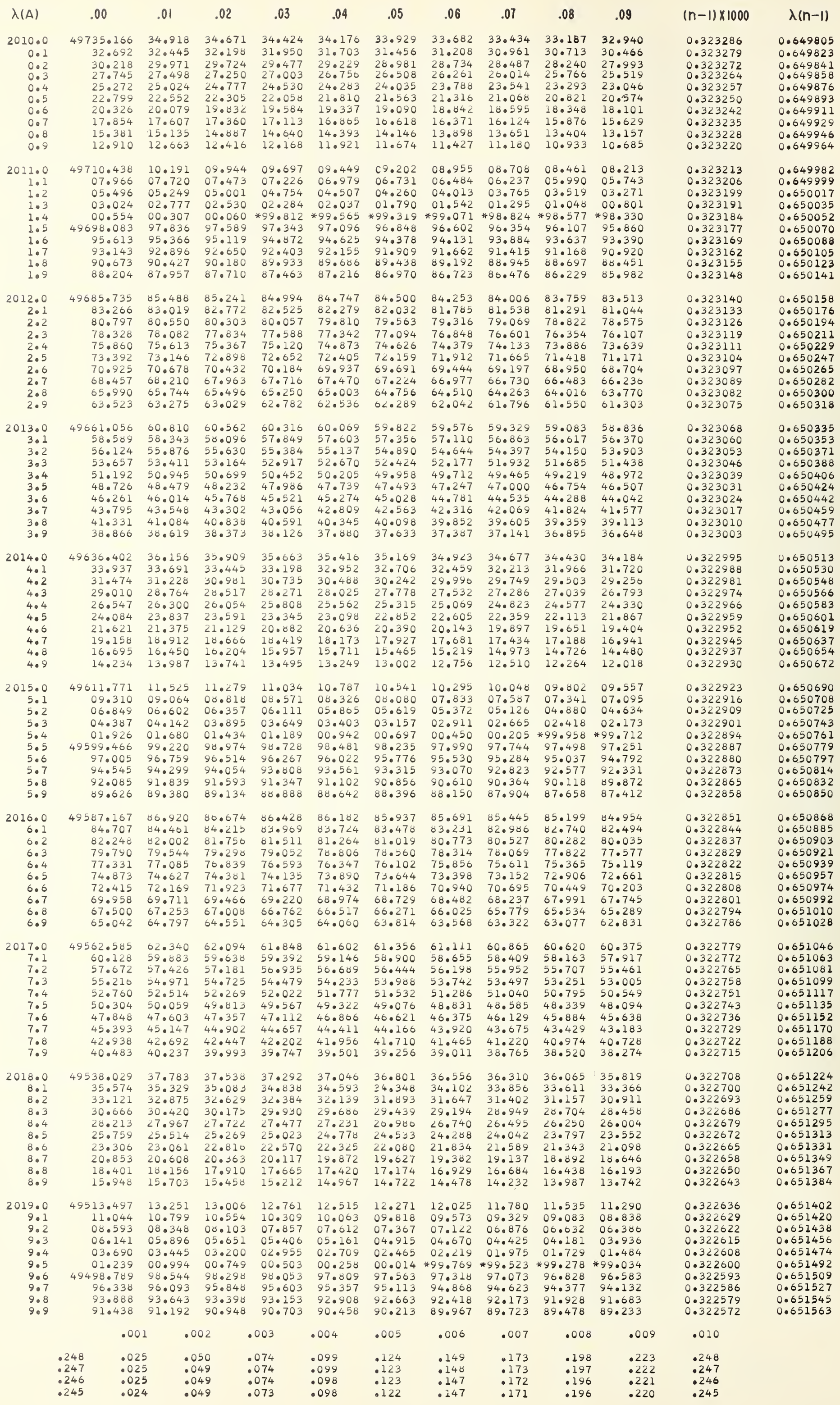




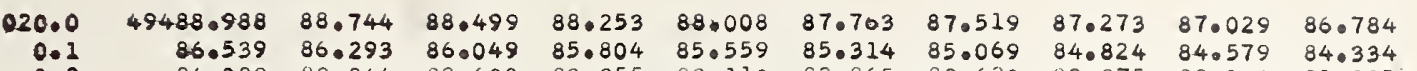
$\begin{array}{llllllllllll}0.1 & 86.539 & 86.293 & 86.049 & 85.804 & 85.559 & 85.314 & 85.069 & 84.824 & 84.579 & 84.334 \\ 0.3 & 84.089 & 83.844 & 83.600 & 83.355 & 83.110 & 82.865 & 82.620 & 82.375 & 82.130 & 81.885\end{array}$ $\begin{array}{llllllllllll}0.3 & 81.641 & 81.396 & 81.150 & 80.906 & 80.661 & 80.416 & 80.171 & 79.926 & 79.681 & 79.436\end{array}$ $\begin{array}{lllll}79.191 & 78.946 & 78.702 & 78.457 & 78.212 \\ 76.743 & 76.499 & 76.253 & 76.009 & 75.764\end{array}$ $\begin{array}{lllll}76.743 & 76.499 & 70.253 & 76.009 & 75.764 \\ 74.294 & 74.050 & 73.805 & 73.560 & 73.316 \\ 71.847 & 71.602 & 71.357 & 71.113 & 70.868\end{array}$

2026.0<smiles>[131IH]</smiles>

0.322002

0.321995

0.321981

0.321967

0.321960

0.321946
0.311939

0.321932

0.321925

0.321911

0.321897

0.321890
0.321883

0.321883
0.321877

0.321870

0.651582

0.651599

0.651635

0.651670

0.651688
0.651706

0.651724

0.651760

0.651778

0.651814

0.651832

0.651867

0.651885

0.651921

0.651939

0.651957

0.651993

0.652011

0.652047

0.652083

0.652118

0.652136

0.652172

0.652190

0.052226

0.652244

0.652262
0.652280

0.652298

0.652316

0.652352

0.652370

0.652406

0.652424

0.652460

0.652496

0.652532

0.652550

0.652586

0.652604
0.652622

0.652640

0.652658

0.652676
0.652694

0.652694

0.652730

0.652748

0.652766

0.652802

0.652839

0.652857

0.652875

0.652911

0.652929

0.652965

0.653001

0.653019

0.653037
0.653055

0.653073

0.653092

0.653128

0.653164

0.653200

0.653218

0.653254

0.653291

0.653309

0.653327

0.653363

.010

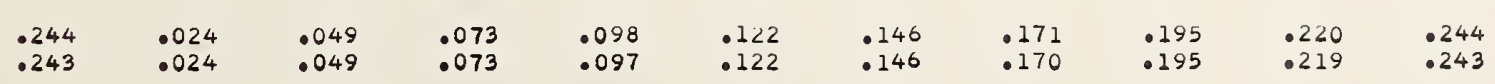


$\lambda(n-1)$
2030.0
0.1

0.2

0.4
0.5

0.6

0.8
0.9

2031.0

l.

1.3

1.5
1.6

1.6
1.7

1.8
1.9

2032.

2.1
2.2
2.3

2.3

2.5

2.6
2.7

2.8
2.9

2033.

3.

$3 \cdot 3$

3.5

3.6
3.7

3.8
3.9

2034 .

$$
\begin{array}{r}
4 . \\
40 \\
4 . \\
4 . \\
4 . \\
40 \\
4 . \\
4 . \\
4 .
\end{array}
$$

2035.0

5.2

5.3

5.4

5.6

5.7

5.8

2036.0

6.1
6.2

6.3

6.4
6.5

6.6
6.7

6.8

2037.

$$
\begin{array}{r}
037.0 \\
7 . \\
7.2 \\
7.3
\end{array}
$$$$
\begin{aligned}
& 7.1 \\
& 7.2 \\
& 7.3 \\
& 7.4 \\
& 7.5
\end{aligned}
$$$$
7.5
$$$$
\begin{aligned}
& 7.65 \\
& 7.7 \\
& 7.8
\end{aligned}
$$$$
\begin{aligned}
& 7.8 \\
& 7.9
\end{aligned}
$$

2038.

$$
\begin{array}{r}
8.2 \\
8.2 \\
8.3
\end{array}
$$

8.1
8.2

8.3
8.4
8.5

8.5
8.6
8.7$$
\begin{aligned}
& 8.7 \\
& 8.8
\end{aligned}
$$

2039.

$$
\begin{array}{r}
039.0 \\
9.1 \\
9.2 \\
9.3 \\
9.4 \\
9.5 \\
9.6 \\
9.7 \\
9.8 \\
9.9
\end{array}
$$
$\begin{array}{lllllllllll}40.389 & 42.566 & 42.324 & 42.081 & 41.839 & 41.597 & 41.354 & 41.111 & 40.868 & 40.627 \\ 40.142 & 39.899 & 39.657 & 39.414 & 39.172 & 38.929 & 38.687 & 38.444 & 38.201\end{array}$ $\begin{array}{llllllllll}35.534 & 35.292 & 35.050 & 34.807 & 34.565 & 34.322 & 34.080 & 33.837 & 33.595 & 33.353\end{array}$ $\begin{array}{llllllllll}33.110 & 32.868 & 32.62 b & 32.383 & 32.140 & 31.898 & 31.655 & 31.413 & 31.170 & 30.928 \\ 30.685 & 30.443 & 30.201 & 29.958 & 29.716 & 29.474 & 29.231 & 28.989 & 28.747 & 28.504\end{array}$

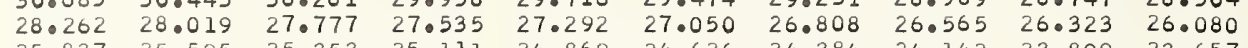
$\begin{array}{llllllllll}25.837 & 25.595 & 25.353 & 25.111 & 24.869 & 24.626 & 24.384 & 24.142 & 23.899 & 23.657 \\ 23.415 & 23.172 & 22.930 & 22.687 & 22.445 & 22.203 & 21.960 & 21.718 & 21.476 & 21.233\end{array}$ 
$\begin{array}{lllllll}3.149 & 02.909 & 02.669 & 02.429 & 02.188 & 01.948 & 01.708\end{array}$

0.321179

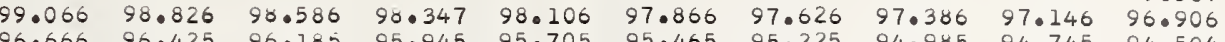

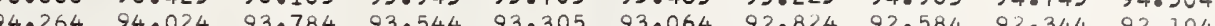

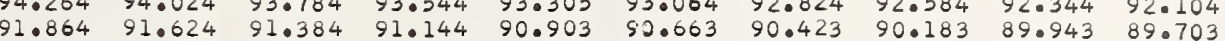
$\begin{array}{llllllllll}89.463 & 89.223 & 88.983 & 88.743 & 88.502 & 88.263 & 88.022 & 87.783 & 87.543 & 87.303\end{array}$ $\begin{array}{lllllllllll}87.063 & 86.823 & 86.583 & 86.343 & 86.103 & 85.863 & 85.623 & 85.383 & 85.143 & 84.902\end{array}$ $\begin{array}{llllllllll}84.663 & 84.423 & 84.183 & 83.942 & 83.703 & 83.462 & 83.223 & 82.983 & 82.742 & 82.503\end{array}$ $\begin{array}{lllllllllll}9979.863 & 79.624 & 79.383 & 79.144 & 78.903 & 78.664 & 78.424 & 78.183 & 77.943 & 77.704\end{array}$ $\begin{array}{lll}77.464 & 77.224 & 76.984 \\ 75.065 & 74.825 & 74.585\end{array}$ $\begin{array}{lll}72.666 & 72.426 & 72.180 \\ 70.268 & 70.027 & 69.786\end{array}$ $\begin{array}{lll}67.869 & 67.629 & 67.389\end{array}$ 65.47105 .231 $63.07362 .833 \quad 62.593$ $\begin{array}{lll}60.675 & 60.436 & 60.196 \\ 58.278 & 58.038 & 57.798\end{array}$

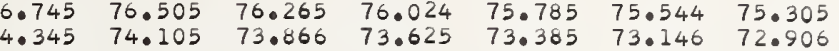

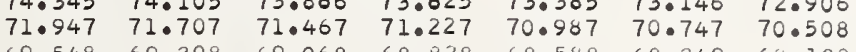

$\begin{array}{lllllllllll} & .001 & .002 & .003 & .004 & .005 & .006 & .007 & .008 & .009 & .010 \\ .240 & .024 & .048 & .072 & .096 & .120 & .144 & .168 & .192 & .216 & .240 \\ .239 & .024 & .048 & .072 & .095 & .119 & .143 & .167 & .191 & .215 & .239 \\ & .024 & .048 & .071 & .095 & .119 & .143 & .166 & .190 & .214 & .238\end{array}$ 


\begin{tabular}{|c|c|c|c|c|c|c|c|c|c|c|c|c|}
\hline $\begin{array}{l}50.0 \\
0.2 \\
0.2 \\
0.3 \\
0.4 \\
0.5 \\
0.6 \\
0.7 \\
0.8 \\
0.9\end{array}$ & $\begin{array}{r}8764.859 \\
62.480 \\
60.103 \\
57.725 \\
55.347 \\
52.969 \\
50.592 \\
48.216 \\
45.839 \\
43.462\end{array}$ & $\begin{array}{l}64.622 \\
62.243 \\
59.865 \\
57.487 \\
55.0109 \\
52.732 \\
50.035 \\
47.078 \\
45.002 \\
43.225\end{array}$ & $\begin{array}{l}64.383 \\
62.005 \\
59.627 \\
57.250 \\
54.872 \\
52.495 \\
50.118 \\
47.740 \\
45.364 \\
42.988\end{array}$ & $\begin{array}{l}64.146 \\
61.768 \\
59.390 \\
57.012 \\
54.634 \\
52.257 \\
49.879 \\
47.503 \\
45.126 \\
42.750\end{array}$ & $\begin{array}{l}63.907 \\
61.530 \\
59.152 \\
56.774 \\
54.396 \\
52.019 \\
49.643 \\
47.265 \\
44.889 \\
42.512\end{array}$ & $\begin{array}{l}63.670 \\
61.292 \\
58.014 \\
56.536 \\
54.159 \\
51.782 \\
49.404 \\
47.028 \\
44.651 \\
42.275\end{array}$ & $\begin{array}{l}63.432 \\
61.054 \\
58.676 \\
56.299 \\
53.921 \\
51.544 \\
49.167 \\
46.791 \\
44.413 \\
42.036\end{array}$ & $\begin{array}{l}63.195 \\
60.817 \\
58.438 \\
56.061 \\
53.683 \\
51.306 \\
48.929 \\
46.552 \\
44.175 \\
41.799\end{array}$ & $\begin{array}{l}62.958 \\
60.579 \\
58.201 \\
55.823 \\
53.445 \\
51.068 \\
48.691 \\
46.314 \\
43.937 \\
41.562\end{array}$ & $\begin{array}{l}62.719 \\
60.341 \\
57.962 \\
55.585 \\
53.208 \\
50.831 \\
48.453 \\
46.077 \\
43.700 \\
41.324\end{array}$ & $\begin{array}{l}0.320512 \\
0.320506 \\
0.320499 \\
0.320493 \\
0.320486 \\
0.320480 \\
0.320473 \\
0.320466 \\
0.320460 \\
0.320453\end{array}$ & $\begin{array}{l}0.657050 \\
0.657069 \\
0.657088 \\
0.657106 \\
0.657125 \\
0.657143 \\
0.657162 \\
0.657180 \\
0.657199 \\
0.657218\end{array}$ \\
\hline $\begin{array}{l}51.0 \\
1.1 \\
1.2 \\
1.3 \\
1.4 \\
1.5 \\
1.6 \\
1.7 \\
1.8 \\
1.9\end{array}$ & $\begin{array}{r}48741.086 \\
38.710 \\
36.335 \\
33.959 \\
31.583 \\
29.209 \\
26.833 \\
24.460 \\
22.085 \\
19.711\end{array}$ & $\begin{array}{l}40.850 \\
38.473 \\
36.098 \\
33.722 \\
31.0346 \\
28.9972 \\
26.5997 \\
24.222 \\
21.848 \\
19.473\end{array}$ & $\begin{array}{l}40.612 \\
38.235 \\
35.860 \\
33.484 \\
31.109 \\
28.734 \\
26.358 \\
23.984 \\
21.609 \\
19.236\end{array}$ & $\begin{array}{l}40.374 \\
37.998 \\
35.623 \\
33.247 \\
30.871 \\
28.496 \\
26.121 \\
23.747 \\
21.372 \\
18.999\end{array}$ & $\begin{array}{l}40.136 \\
37.760 \\
35.384 \\
33.008 \\
30.633 \\
28.258 \\
25.884 \\
23.509 \\
21.135 \\
18.761\end{array}$ & $\begin{array}{l}39.898 \\
37.522 \\
35.146 \\
32.771 \\
30.396 \\
28.021 \\
25.646 \\
23.272 \\
20.897 \\
18.524\end{array}$ & $\begin{array}{l}39.661 \\
37.284 \\
34.910 \\
32.534 \\
30.159 \\
27.784 \\
25.409 \\
23.035 \\
20.660 \\
18.287\end{array}$ & $\begin{array}{l}39.423 \\
37.047 \\
34.672 \\
32.296 \\
29.921 \\
27.546 \\
25.172 \\
22.797 \\
20.422 \\
18.049\end{array}$ & $\begin{array}{l}39.186 \\
36.810 \\
34.434 \\
32.058 \\
29.684 \\
27.309 \\
24.935 \\
22.560 \\
20.186 \\
17.812\end{array}$ & $\begin{array}{l}38.948 \\
36.572 \\
34.196 \\
31.821 \\
29.446 \\
27.071 \\
24.0697 \\
22.323 \\
19.949 \\
17.574\end{array}$ & $\begin{array}{l}0.320447 \\
0.320440 \\
0.320434 \\
0.320427 \\
0.320420 \\
0.320414 \\
0.320407 \\
0.320401 \\
0.320394 \\
0.320388\end{array}$ & $\begin{array}{l}0.657236 \\
0.657255 \\
0.657273 \\
0.657292 \\
0.657310 \\
0.657329 \\
0.657348 \\
0.657366 \\
0.657385\end{array}$ \\
\hline $\begin{array}{r}52.0 \\
2.1 \\
2.2 \\
2.3 \\
2.4 \\
2.5 \\
2.6 \\
2.7 \\
2.8 \\
2.9\end{array}$ & $\begin{array}{r}48717.337 \\
14.962 \\
12.589 \\
10.216 \\
07.843 \\
05.470 \\
03.098 \\
00.726 \\
48698.354 \\
95.981\end{array}$ & $\begin{array}{l}17.099 \\
14.726 \\
12.352 \\
09.979 \\
07.605 \\
05.233 \\
02.861 \\
00.488 \\
98.117 \\
95.744\end{array}$ & $\begin{array}{l}16.862 \\
14.480 \\
12.115 \\
09.741 \\
07.369 \\
04.996 \\
02.624 \\
00.251 \\
97.879 \\
95.508\end{array}$ & $\begin{array}{l}16.624 \\
14.251 \\
11.878 \\
09.504 \\
07.131 \\
04.758 \\
02.386 \\
00.014 \\
97.643 \\
95.270\end{array}$ & $\begin{array}{r}16.387 \\
14.014 \\
11.640 \\
09.268 \\
06.894 \\
04.521 \\
02.149 \\
* 99.777 \\
97.405 \\
95.033\end{array}$ & $\begin{array}{r}16.150 \\
13.776 \\
11.403 \\
09.030 \\
06.657 \\
04.284 \\
01.912 \\
\# 99.540 \\
97.167 \\
94.796\end{array}$ & $\begin{array}{r}15.912 \\
13.539 \\
11.166 \\
08.793 \\
06.420 \\
04.047 \\
01.675 \\
* 99.303 \\
96.930 \\
94.558\end{array}$ & $\begin{array}{r}15.675 \\
13.302 \\
10.928 \\
08.556 \\
06.182 \\
03.810 \\
01.437 \\
* 99.064 \\
96.693 \\
94.321\end{array}$ & $\begin{array}{l}15.438 \\
13.064 \\
10.691 \\
08.318 \\
05.945 \\
03.573 \\
01.200 \\
+98.827 \\
96.456 \\
94.084\end{array}$ & $\begin{array}{r}15.200 \\
12.827 \\
10.454 \\
08.081 \\
05.708 \\
03.335 \\
00.962 \\
* 98.591 \\
96.219 \\
93.847\end{array}$ & $\begin{array}{l}0.320381 \\
0.320375 \\
0.320368 \\
0.320362 \\
0.320355 \\
0.320348 \\
0.320342 \\
0.320335 \\
0.320329 \\
0.320322\end{array}$ & $\begin{array}{l}0.657422 \\
0.657441 \\
0.657459 \\
0.657478 \\
0.657497 \\
0.657515 \\
0.657534 \\
0.657552 \\
0.657571 \\
0.657590\end{array}$ \\
\hline $\begin{array}{l}53.0 \\
3.1 \\
3.2 \\
3.3 \\
3.4 \\
3.5 \\
3.6 \\
3.7 \\
3.8 \\
3.9\end{array}$ & $\begin{array}{r}48693.609 \\
91.238 \\
88.868 \\
86.497 \\
84.126 \\
81.756 \\
79.385 \\
77.015 \\
74.646 \\
72.276\end{array}$ & $\begin{array}{l}93.373 \\
91.002 \\
88.630 \\
86.260 \\
83.889 \\
81.519 \\
79.148 \\
76.779 \\
74.409 \\
72.038\end{array}$ & $\begin{array}{l}93.136 \\
90.765 \\
88.393 \\
86.022 \\
83.652 \\
81.282 \\
78.911 \\
76.541 \\
74.171 \\
71.802\end{array}$ & $\begin{array}{l}92.899 \\
90.527 \\
88.156 \\
85.786 \\
83.415 \\
81.044 \\
78.673 \\
76.305 \\
73.935 \\
71.564\end{array}$ & $\begin{array}{l}92.663 \\
90.291 \\
87.919 \\
85.548 \\
83.177 \\
80.808 \\
78.437 \\
76.067 \\
73.697 \\
71.328\end{array}$ & $\begin{array}{l}92.424 \\
90.053 \\
87.682 \\
85.311 \\
82.940 \\
80.570 \\
78.200 \\
75.830 \\
73.460 \\
71.092\end{array}$ & $\begin{array}{l}92.187 \\
89.815 \\
87.445 \\
85.074 \\
82.703 \\
80.313 \\
77.962 \\
75.594 \\
73.224 \\
70.854\end{array}$ & $\begin{array}{l}91.950 \\
89.579 \\
87.208 \\
84.837 \\
82.466 \\
80.096 \\
77.726 \\
75.356 \\
72.986 \\
70.617\end{array}$ & $\begin{array}{l}91.713 \\
89.341 \\
86.971 \\
84.600 \\
82.230 \\
79.859 \\
77.489 \\
75.120 \\
72.750 \\
70.381\end{array}$ & $\begin{array}{l}91.476 \\
89.104 \\
86.734 \\
84.363 \\
81.993 \\
79.622 \\
77.252 \\
74.8833 \\
72.513 \\
70.144\end{array}$ & $\begin{array}{l}0.320316 \\
0.320309 \\
0.320303 \\
0.320296 \\
0.320290 \\
0.320283 \\
0.320277 \\
0.320270 \\
0.320264 \\
0.320257\end{array}$ & $\begin{array}{l}0.657608 \\
0.657627 \\
0.657646 \\
0.657664 \\
0.657683 \\
0.657701 \\
0.657720 \\
0.657739 \\
0.657757 \\
0.657776\end{array}$ \\
\hline $\begin{array}{l}54.0 \\
4.1 \\
4.2 \\
4.03 \\
4.04 \\
4.5 \\
4.6 \\
4.7 \\
4.8 \\
4.0\end{array}$ & $\begin{array}{r}669.907 \\
67.537 \\
65.169 \\
62.800 \\
60.432 \\
58.063 \\
55.695 \\
53.328 \\
50.960 \\
48.593\end{array}$ & $\begin{array}{l}69.670 \\
67.300 \\
64.932 \\
62.562 \\
60.194 \\
57.827 \\
55.458 \\
53.091 \\
50.723 \\
48.356\end{array}$ & $\begin{array}{l}69.433 \\
67.063 \\
64.695 \\
62.326 \\
59.958 \\
57.590 \\
55.222 \\
52.854 \\
50.486 \\
48.120\end{array}$ & $\begin{array}{l}69.195 \\
66.826 \\
64.458 \\
62.089 \\
59.721 \\
57.353 \\
54.985 \\
52.618 \\
50.250 \\
47.883\end{array}$ & $\begin{array}{l}68.959 \\
66.590 \\
64.221 \\
61.852 \\
59.484 \\
57.117 \\
54.749 \\
52.381 \\
50.013 \\
47.646\end{array}$ & $\begin{array}{l}68.722 \\
66.353 \\
63.984 \\
61.615 \\
59.248 \\
56.879 \\
54.512 \\
52.144 \\
49.777 \\
47.410\end{array}$ & $\begin{array}{l}68.485 \\
66.116 \\
63.746 \\
62.379 \\
59.011 \\
56.643 \\
54.275 \\
51.908 \\
49.541 \\
47.172\end{array}$ & $\begin{array}{l}68.248 \\
65.880 \\
63.511 \\
61.142 \\
58.774 \\
56.406 \\
54.039 \\
51.670 \\
49.303 \\
46.936\end{array}$ & $\begin{array}{l}68.011 \\
65.643 \\
63.274 \\
60.905 \\
58.538 \\
56.168 \\
53.801 \\
51.433 \\
49.066 \\
46.699\end{array}$ & $\begin{array}{l}67.774 \\
65.406 \\
63.037 \\
60.668 \\
58.300 \\
55.932 \\
53.564 \\
51.197 \\
48.830 \\
46.462\end{array}$ & $\begin{array}{l}0.320251 \\
0.320244 \\
0.320238 \\
0.320231 \\
0.320225 \\
0.320218 \\
0.320212 \\
0.320205 \\
0.320199 \\
0.320192\end{array}$ & $\begin{array}{l}0.657795 \\
0.657813 \\
0.657832 \\
0.657851 \\
0.657869 \\
0.657888 \\
0.657907 \\
0.657925 \\
0.657944 \\
0.657963\end{array}$ \\
\hline $\begin{array}{l}55.0 \\
5.1 \\
5.2 \\
5.3 \\
5.4 \\
5.5 \\
5.6 \\
5.7 \\
5.8 \\
5.9\end{array}$ & $\begin{array}{r}646.226 \\
43.859 \\
41.493 \\
39.126 \\
36.760 \\
34.394 \\
32.029 \\
29.664 \\
27.299 \\
24.934\end{array}$ & $\begin{array}{l}45.990 \\
43.623 \\
41.256 \\
38.890 \\
36.523 \\
34.158 \\
31.0793 \\
29.427 \\
27.062 \\
24.697\end{array}$ & $\begin{array}{l}45.752 \\
43.386 \\
41.019 \\
38.653 \\
36.286 \\
33.921 \\
31.556 \\
29.190 \\
26.825 \\
24.460\end{array}$ & $\begin{array}{l}45.516 \\
43.149 \\
40.783 \\
38.417 \\
36.051 \\
33.685 \\
31.318 \\
28.954 \\
26.589 \\
24.224\end{array}$ & $\begin{array}{l}45.280 \\
42.913 \\
40.546 \\
38.180 \\
35.813 \\
33.449 \\
31.083 \\
28.717 \\
26.352 \\
23.987\end{array}$ & $\begin{array}{l}45.043 \\
42.676 \\
40.309 \\
37.943 \\
35.577 \\
33.212 \\
30.846 \\
28.480 \\
26.115 \\
23.751\end{array}$ & $\begin{array}{l}44.805 \\
42.439 \\
40.073 \\
37.707 \\
35.340 \\
32.975 \\
30.609 \\
28.244 \\
25.879 \\
23.514\end{array}$ & $\begin{array}{l}44.568 \\
42.203 \\
39.836 \\
37.470 \\
35.104 \\
32.738 \\
30.373 \\
28.008 \\
25.643 \\
23.277\end{array}$ & $\begin{array}{l}44.333 \\
41.966 \\
39.599 \\
37.233 \\
34.868 \\
32.502 \\
30.136 \\
27.771 \\
25.406 \\
23.042\end{array}$ & $\begin{array}{l}44.096 \\
41.729 \\
39.363 \\
36.997 \\
34.631 \\
32.266 \\
29.900 \\
27.536 \\
25.170 \\
22.805\end{array}$ & $\begin{array}{l}0.320186 \\
0.320179 \\
0.320173 \\
0.320166 \\
0.320160 \\
0.320153 \\
0.320147 \\
0.320140 \\
0.320134 \\
0.320127\end{array}$ & $\begin{array}{l}0.657981 \\
0.658000 \\
0.658019 \\
0.658037 \\
0.658056 \\
0.658075 \\
0.658093 \\
0.658112 \\
0.658131 \\
0.658149\end{array}$ \\
\hline $\begin{array}{l}56.0 \\
6.1 \\
6.2 \\
6.3 \\
6.4 \\
6.5 \\
6.6 \\
6.7 \\
6.8 \\
6.9\end{array}$ & $\begin{array}{r}3622.569 \\
20.204 \\
17.839 \\
15.476 \\
13.111 \\
10.748 \\
08.384 \\
06.022 \\
03.659 \\
01.296\end{array}$ & $\begin{array}{l}22.333 \\
19.967 \\
17.603 \\
15.239 \\
12.875 \\
10.512 \\
08.149 \\
05.786 \\
03.423 \\
01.060\end{array}$ & $\begin{array}{l}22.096 \\
19.731 \\
17.366 \\
15.002 \\
12.639 \\
10.276 \\
07.912 \\
05.549 \\
03.186 \\
00.825\end{array}$ & $\begin{array}{l}21.859 \\
19.494 \\
17.131 \\
14.767 \\
12.402 \\
10.040 \\
07.676 \\
05.313 \\
02.951 \\
00.588\end{array}$ & $\begin{array}{l}21.623 \\
19.258 \\
16.895 \\
14.530 \\
12.166 \\
09.804 \\
07.440 \\
05.077 \\
02.714 \\
00.352\end{array}$ & $\begin{array}{l}21.387 \\
19.022 \\
15.658 \\
14.293 \\
11.930 \\
09.567 \\
07.204 \\
04.841 \\
02.478 \\
00.116\end{array}$ & $\begin{array}{l}21.150 \\
18.785 \\
16.422 \\
14.058 \\
11.694 \\
09.331 \\
06.967 \\
04.605 \\
02.242 \\
* 99.879\end{array}$ & & & & & $\begin{array}{l}0.658168 \\
0.658187 \\
0.658205 \\
0.658224 \\
0.658243 \\
0.658262 \\
0.658280 \\
0.658299 \\
0.658318 \\
0.658336\end{array}$ \\
\hline $\begin{array}{l}57.0 \\
7.1 \\
7.2 \\
7.3 \\
7.4 \\
7.5 \\
7.6 \\
7.7 \\
7.8 \\
7.9\end{array}$ & $\begin{array}{r}48598.934 \\
96.571 \\
94.210 \\
91.848 \\
89.487 \\
87.125 \\
84.764 \\
82.404 \\
80.043 \\
77.683\end{array}$ & $\begin{array}{l}98.698 \\
96.335 \\
93.974 \\
91.612 \\
89.250 \\
86.890 \\
84.529 \\
82.168 \\
79.807 \\
77.447\end{array}$ & $\begin{array}{l}98.462 \\
96.099 \\
93.738 \\
91.375 \\
89.015 \\
86.653 \\
84.293 \\
81.932 \\
79.571 \\
77.210\end{array}$ & $\begin{array}{l}98.226 \\
95.863 \\
93.502 \\
91.140 \\
88.779 \\
86.417 \\
84.057 \\
81.695 \\
79.334 \\
76.975\end{array}$ & $\begin{array}{l}97.990 \\
95.627 \\
93.266 \\
90.904 \\
88.542 \\
86.181 \\
83.820 \\
81.459 \\
79.099 \\
76.738\end{array}$ & $\begin{array}{l}97.753 \\
95.392 \\
93.028 \\
90.667 \\
88.306 \\
85.945 \\
83.584 \\
81.223 \\
78.863 \\
76.503\end{array}$ & $\begin{array}{l}97.516 \\
95.154 \\
92.793 \\
90.431 \\
88.070 \\
85.708 \\
83.348 \\
80.987 \\
78.627 \\
76.267\end{array}$ & $\begin{array}{l}97.280 \\
94.919 \\
92.557 \\
90.194 \\
87.833 \\
85.472 \\
83.112 \\
80.751 \\
78.391 \\
76.030\end{array}$ & $\begin{array}{l}97.044 \\
94.683 \\
92.320 \\
89.959 \\
87.598 \\
85.236 \\
82.876 \\
80.515 \\
78.155 \\
75.795\end{array}$ & & & $\begin{array}{l}0.658355 \\
0.658374 \\
0.658392 \\
0.658411 \\
0.658430 \\
0.658449 \\
0.658467 \\
0.658486 \\
0.658505 \\
0.658524\end{array}$ \\
\hline $\begin{array}{l}58.0 \\
8.1 \\
8.2 \\
8.3 \\
8.4 \\
8.5 \\
8.6 \\
8.7 \\
8.8 \\
8.9\end{array}$ & $\begin{array}{r}48575.323 \\
72.963 \\
70.604 \\
68.244 \\
65.884 \\
63.525 \\
61.166 \\
58.808 \\
56.450 \\
54.092\end{array}$ & $\begin{array}{l}75.087 \\
72.727 \\
70.367 \\
68.008 \\
65.648 \\
63.290 \\
60.931 \\
58.572 \\
56.214 \\
53.855\end{array}$ & $\begin{array}{l}74.850 \\
72.491 \\
70.130 \\
67.771 \\
65.413 \\
63.053 \\
60.695 \\
58.336 \\
55.976 \\
53.620\end{array}$ & $\begin{array}{l}74.614 \\
72.254 \\
69.895 \\
67.536 \\
65.177 \\
62.817 \\
60.459 \\
58.101 \\
55.743 \\
53.384\end{array}$ & $\begin{array}{l}74.378 \\
72.019 \\
69.659 \\
67.300 \\
64.940 \\
62.583 \\
60.224 \\
57.865 \\
55.507 \\
53.148\end{array}$ & & & & $\begin{array}{l}71.075 \\
68.715 \\
66.356 \\
63.998 \\
61.639 \\
59.280 \\
56.921 \\
54.563 \\
52.205\end{array}$ & & & \\
\hline $\begin{array}{l}59.0 \\
9.1 \\
9.2 \\
9.3 \\
9.4 \\
9.5 \\
9.6 \\
9.7 \\
9.8 \\
9.9\end{array}$ & $\begin{array}{r}48551.734 \\
49.376 \\
47.019 \\
44.662 \\
42.305 \\
39.948 \\
37.591 \\
35.236 \\
32.880 \\
30.524\end{array}$ & $\begin{array}{l}51.499 \\
49.141 \\
46.783 \\
44.426 \\
42.069 \\
39.713 \\
37.356 \\
35.000 \\
32.644 \\
30.288\end{array}$ & $\begin{array}{l}51.263 \\
46.905 \\
40.547 \\
44.190 \\
41.834 \\
39.478 \\
37.121 \\
34.765 \\
32.408 \\
30.053\end{array}$ & $\begin{array}{l}51.027 \\
48.669 \\
46.312 \\
43.955 \\
41.598 \\
39.242 \\
36.885 \\
34.530 \\
32.173 \\
29.817\end{array}$ & $\begin{array}{l}50.792 \\
48.434 \\
46.077 \\
43.719 \\
41.362 \\
39.006 \\
36.649 \\
34.293 \\
31.937 \\
29.582\end{array}$ & $\begin{array}{l}38.770 \\
36.413 \\
34.057 \\
21.701 \\
29.346\end{array}$ & $\begin{array}{l}50.320 \\
47.962 \\
45.605 \\
43.248 \\
40.891 \\
38.534 \\
36.177 \\
33.822 \\
31.466 \\
29.111\end{array}$ & $\begin{array}{l}50.083 \\
47.726 \\
45.369 \\
43.012 \\
40.655 \\
38.298 \\
35.942 \\
33.586 \\
31.230 \\
28.875\end{array}$ & $\begin{array}{l}49.848 \\
47.490 \\
45.133 \\
42.776 \\
40.420 \\
38.063 \\
35.707 \\
33.351 \\
30.995 \\
28.640\end{array}$ & $\begin{array}{l}37.827 \\
35.471 \\
33.116 \\
30.759 \\
28.404\end{array}$ & & \\
\hline & \multicolumn{2}{|c|}{.001} & .002 & & .004 & .005 & .006 & .007 & .008 & .009 & .010 & \\
\hline & $\begin{array}{l}.02 \\
.02 \\
.02\end{array}$ & & & & 0.094 & 11 & $\begin{array}{l}.142 \\
.142 \\
.141\end{array}$ & 16 & $\begin{array}{l}.190 \\
.189 \\
.188\end{array}$ & $\begin{array}{l}0214 \\
: 213 \\
0212\end{array}$ & $\begin{array}{r}.236 \\
.235\end{array}$ & \\
\hline
\end{tabular}


$\lambda(A)$

2060.0

$$
\begin{aligned}
& 2060.0 \\
& 0.0 \\
& 0.0 \\
& 0.04 \\
& 0.5 \\
& 0.0 \\
& 0.0 \\
& 0.0
\end{aligned}
$$$$
\text { 206:. }
$$$$
\text { 06:.0 } 18504
$$$$
1.1
$$$$
\begin{aligned}
& 1.2 \\
& 1.5
\end{aligned}
$$$$
\text { i: }
$$$$
2062 .
$$$$
2062
$$

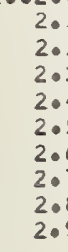

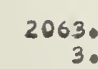




\begin{tabular}{|c|c|}
\hline$\lambda(A)$ & .00 \\
\hline 2070.0 & 48293.763 \\
\hline 0.1 & 91.430 \\
\hline $\begin{array}{l}0.2 \\
0.3\end{array}$ & 89.098 \\
\hline $\begin{array}{l}0.3 \\
0.4\end{array}$ & 86.766 \\
\hline $\begin{array}{l}0.4 \\
0.5\end{array}$ & 84.434 \\
\hline $\begin{array}{l}0.5 \\
0.6\end{array}$ & $82 \cdot 102$ \\
\hline $\begin{array}{l}0.6 \\
0.7\end{array}$ & $\begin{array}{l}79.771 \\
77.439\end{array}$ \\
\hline 0.8 & 75.109 \\
\hline 0.9 & 72.778 \\
\hline 2071.0 & 48270.447 \\
\hline & 68.117 \\
\hline 1.2 & 65.787 \\
\hline $1 \cdot 3$ & 63.457 \\
\hline 1.4 & 61.127 \\
\hline 1.5 & 58.798 \\
\hline 1.6 & 56.468 \\
\hline 1.7 & $54 \cdot 140$ \\
\hline $\begin{array}{l}1.8 \\
1.9\end{array}$ & $\begin{array}{l}51.811 \\
49.482\end{array}$ \\
\hline & 48247.154 \\
\hline 2.1 & 44.826 \\
\hline 2.2 & 42.498 \\
\hline $2 \cdot 3$ & $40 \cdot 170$ \\
\hline 2.4 & 37.842 \\
\hline 2.5 & 35.515 \\
\hline 2.6 & 33.187 \\
\hline $2 \cdot 7$ & 30.862 \\
\hline $2 \cdot 8$ & 28.535 \\
\hline 2.9 & 26.208 \\
\hline $\begin{array}{r}2073.0 \\
3.1\end{array}$ & $\begin{array}{r}48223.882 \\
21.556\end{array}$ \\
\hline 3.2 & 19.231 \\
\hline 3.3 & 16.906 \\
\hline 3.4 & 14.581 \\
\hline 3.5 & 12.255 \\
\hline 3.6 & 09.930 \\
\hline 3.7 & 07.607 \\
\hline 3.8 & 05.282 \\
\hline 3.9 & 02.958 \\
\hline $\begin{array}{r}2074.0 \\
4.1\end{array}$ & 48200.634 \\
\hline & 48198.310 \\
\hline $\begin{array}{l}4 \cdot 2 \\
4.3\end{array}$ & $\begin{array}{l}95.987 \\
93.6664\end{array}$ \\
\hline 4.2 & $\begin{array}{l}93.064 \\
91.341\end{array}$ \\
\hline 4.5 & 89.018 \\
\hline 4.6 & 86.696 \\
\hline 4.7 & 84.373 \\
\hline 4.8 & 82.051 \\
\hline $4 \cdot 9$ & 79.729 \\
\hline $\begin{array}{r}2075.0 \\
5.1\end{array}$ & $\begin{array}{r}48177.407 \\
75.086\end{array}$ \\
\hline 5.2 & 72.765 \\
\hline $5 \cdot 3$ & 70.444 \\
\hline 5.4 & 68.124 \\
\hline 5.5 & 65.803 \\
\hline 5.6 & 63.482 \\
\hline 5.7 & 61.163 \\
\hline 5.8 & 58.843 \\
\hline 5.9 & 56.523 \\
\hline 2076.0 & $48154 \cdot 204$ \\
\hline 6.1 & 51.885 \\
\hline $\begin{array}{l}6 \cdot 2 \\
6 \cdot 3\end{array}$ & $\begin{array}{r}49.566 \\
47.248\end{array}$ \\
\hline $\begin{array}{l}0.3 \\
6.4\end{array}$ & $\begin{array}{l}44.048 \\
44.929\end{array}$ \\
\hline 6.5 & 42.610 \\
\hline 6.6 & 40.292 \\
\hline 6.7 & 37.975 \\
\hline 6.8 & 35.657 \\
\hline $6 \bullet 9$ & 33.340 \\
\hline & 48131.022 \\
\hline $7 \bullet 1$ & $\begin{array}{r}28.706 \\
26.388\end{array}$ \\
\hline $7 \cdot 2$ & $\begin{array}{l}26.388 \\
24.072\end{array}$ \\
\hline 7.4 & $\begin{array}{l}21.755 \\
21.75\end{array}$ \\
\hline 7.5 & 19.440 \\
\hline 7.6 & 17.124 \\
\hline 7.7 & 14.808 \\
\hline 1.08 & 126493 \\
\hline 7.9 & 10.178 \\
\hline 8.0 & 63 \\
\hline & \\
\hline 8.2 & 4 \\
\hline 8.3 & 0 \\
\hline 8.4 & 48098.605 \\
\hline 8.5 & 96.292 \\
\hline $8 \cdot 6$ & 93.978 \\
\hline $8 \cdot 7$ & 91.666 \\
\hline $\begin{array}{l}8 \cdot 8 \\
8.9\end{array}$ & $\begin{array}{l}89.352 \\
87.039\end{array}$ \\
\hline & 87.039 \\
\hline & \\
\hline $\begin{array}{l}9.1 \\
9.2\end{array}$ & \\
\hline 9.3 & $\begin{array}{l}80.102 \\
77.790\end{array}$ \\
\hline 9.4 & 77.790 \\
\hline 9.5 & \\
\hline & i \\
\hline 9.7 & 68.546 \\
\hline 0 & 66.232 \\
\hline 9.9 & 63.921 \\
\hline & .00 \\
\hline & .233 \\
\hline & .232 \\
\hline & \\
\hline
\end{tabular}




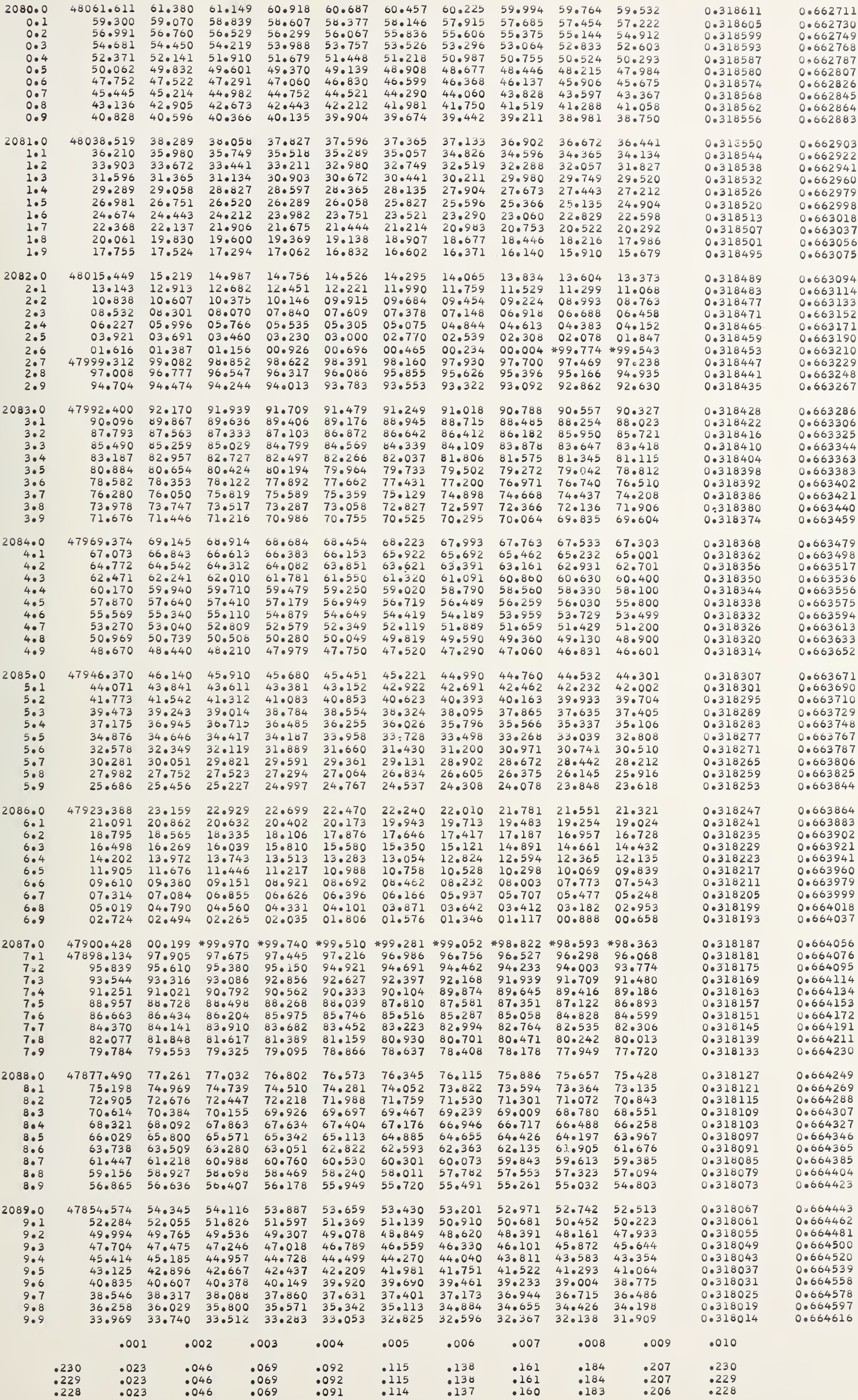


$\begin{array}{lllllllllll}2090.0 & 47831.680 & 31.452 & 31.223 & 30.994 & 30.765 & 30.537 & 30.308 & 30.079 & 29.850 & 29.621\end{array}$

$\begin{array}{lllllllllll}0.1 & 29.392 & 29.164 & 28.935 & 28.706 & 28.477 & 28.248 & 28.019 & 27.791 & 27.562 & 27.333\end{array}$

$\begin{array}{lllllllllll}0.2 & 27.104 & 26.875 & 26.646 & 26.417 & 26.188 & 25.760 & 25.731 & 25.502 & 25.273 & 25.045 \\ 0.3 & 24.817 & 24.588 & 24.359 & 24.130 & 23.901 & 23.672 & 23.444 & 23.215 & 22.986 & 22.758\end{array}$

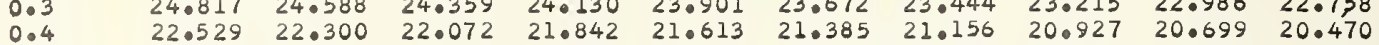

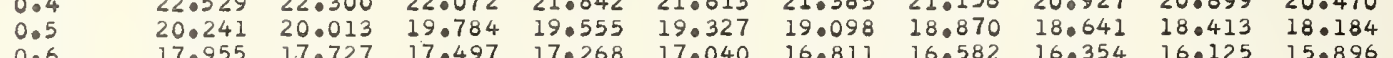

$\begin{array}{lllllllllll}0.6 & 17.955 & 17.727 & 17.497 & 17.268 & 17.040 & 16.811 & 16.582 & 16.354 & 16.125 & 15.896\end{array}$

$\begin{array}{lllllllllll}0.7 & 15.668 & 15.439 & 15.209 & 14.981 & 14.752 & 14.524 & 14.295 & 14.067 & 13.838 & 13.610 \\ 0.8 & 13.382 & 13.152 & 12.923 & 12.695 & 12.466 & 12.237 & 12.009 & 11.781 & 11.552 & 11.324 \\ 0.9 & 11.095 & 10.865 & 10.637 & 10.408 & 10.180 & 09.952 & 09.723 & 09.494 & 09.266 & 09.037\end{array}$

$0.637 \quad 10.408$

$\begin{array}{ll}12.406 & 12.237 \\ 10.180 & 09.952\end{array}$

$\begin{array}{llll}12.009 & 11.781 & 11.552 & 11.324 \\ 09.723 & 09.494 & 09.266 & 09.037\end{array}$

\begin{tabular}{rrrllllllll}
2091.0 & 47808.808 & 08.580 & 08.351 & 08.122 & 07.894 & 07.666 & 07.437 & 07.208 & 06.980 & 06.751 \\
\hline 1.1 & 06.522 & 06.293 & 06.065 & 05.836 & 05.608 & 05.379 & 05.150 & 04.922 & 04.694 & 04.465
\end{tabular}

$1 \cdot 1$

04.2360404 .007

$1 \cdot 3$

$1 \cdot 5$

1.6

$\begin{array}{llllllllll}4799.665 & 99.437 & 99.208 & 98.980 & 98.751 & 98.523 & 98.294 & 98.066 & 97.838 & 97.608\end{array}$

$\begin{array}{llllllllll}97.380 & 97.152 & 96.923 & 96.694 & 96.466 & 96.238 & 96.010 & 95.781 & 95.553 & 95.324\end{array}$

$94.410 \quad 94.182 \quad 93.953 \quad 93.725 \quad 93.497 \quad 93.267 \quad 93.039$

$\begin{array}{llllllllll}90.526 & 90.298 & 90.069 & 89.841 & 89.613 & 89.384 & 89.156 & 88.928 & 88.698 & 88.470 \\ 88.242 & 88.013 & 87.785 & 87.557 & 87.328 & 87.100 & 86.872 & 86.643 & 86.415 & 86.186\end{array}$

2092.0

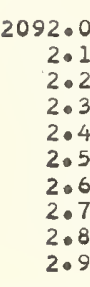
87.785 $\begin{array}{rlllll}4785.958 & 85.729 & 85.501 & 85.272 & 85.044 & 8408 \\ 83.674 & 83.446 & 83.217 & 82.989 & 82.761 & 82.5 \\ 81.391 & 81.162 & 80.934 & 80.706 & 80.477 & 80.2 \\ 79.107 & 78.879 & 78.650 & 78.423 & 78.194 & 770 \\ 76.824 & 76.595 & 76.368 & 76.139 & 75.911 & 7506\end{array}$ 76.82476 .595 $74.541-74.313$ $72.258 \quad 72.030$ 76.368
74.084 $69.976 \quad 69.748 \quad 71.802$

$\begin{array}{lll}67.693 & 67.465 & 67.237 \\ 65.412 & 65.183 & 64.956\end{array}$

$78.423 \quad 78.477$

$\begin{array}{ll}78.423 & 78.194 \\ 76.139 & 75.91\end{array}$

0.317594

0.317582

0.317576

0.317570

0.317564

0.317553

0.317547
0.317541

0.317535

0.317529

0.317523

0.317512

0.317506 0.317494 0.317488 0.317482

0.317477

0.317471
0.317465

0.317459

0.317453
0.317447

0.317442
0.317436

0.317436
0.317430

0.317424

0.664810

0.664829

0.664849
0.664868

0.664887

0.664907
0.664926

0.664926

0.664965

0.664984

0.665023

0.665042

0.665081

0.665100 0.665139 0.665159 0.665197

0.665217

0.665236 0.665294 0.665314 0.665333 0.665353 0.665372
0.665391

0.665411 0.665430 0.665450 0.665469

0.665488

0.665527

0.665547

0.665566
0.665586

0.665605
0.665624

0.665644 0.665663 0.665702 0.665722 0.665741 0.665780

0.665799 0.665819 0.665838 0.665877 0.665897 0.665916

0.665935
0.665955

0.665955
0.665974

0.665994

0.666013

0.666033

0.666052

0.666091

0.666112 


$$
\begin{aligned}
& 0.1 \\
& 0: \\
& 0 \\
& 0 \\
& 0 \\
& 0 \\
& 0 \\
& 0
\end{aligned}
$$

2101.0

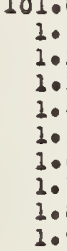

2102.

$$
\begin{array}{r}
102 . \\
2 .
\end{array}
$$$$
\begin{aligned}
& 2.2 \\
& 2.3
\end{aligned}
$$$$
2.4
$$

2.4

2.5
2.6
2.7

2.7
2.8
2.9

2103.

3.
3.
3.
3.
3.5
3.6
3.7
3.0

2104.

$$
4 .
$$

4.3

4.4
4.5

4.6
4.7

4.8
4.9

2105.

5

5.3

5.4
5.5

5.6

5.7

5.9

2106.$$
6 .
$$

6.

6.3

6.5

6.6

6.8

2107.

$$
707 .
$$$$
7.3
$$

7.4
7.5

7.6
7.7

7.7
7.8
7.9

2108 .

$$
8108 .
$$

8.3
8.5
8.5

8.5
8.6

8.6
8.7

8.8

2109.0

$$
\begin{array}{r}
109 . \\
9.1 \\
9.3 \\
9.4 \\
9.6 \\
9.7 \\
9.0
\end{array}
$$
$\begin{array}{lllll}85.812 & 85.586 & 85.359 & 85.398 & 87.172\end{array}$ $\begin{array}{lll}85.512 & 85.586 & 85.359 \\ 83.321 & 83.095\end{array}$

$\begin{array}{rllllll}47581.283 & 81.057 & 80.831 & 80.604 & 80.378 & 80 \\ 79.019 & 78.792 & 78.566 & 78.339 & 78.114 & 770\end{array}$ $\begin{array}{lll}76.755 & 76.529 & 76.302 \\ 74.491 & 74.265 & 74.038\end{array}$ $\begin{array}{lll}74.491 & 74.265 & 74.038 \\ 72.227 & 72.000 & 71.775\end{array}$ $69.964 \quad 69.738$ 67.043865 .47248 $63.175 \quad 62.949$

62.722

$5558.650 \quad 58.424$ $56.388 \quad 56.162 \quad 55.1936$ $56.38850 .162 \quad 55.930$
53.89 51.86551 .638510412 $42.820 \quad 42.593$ $\begin{array}{lll}40.559 & 40.333 & 40.367\end{array}$ $\begin{array}{lll}38.298 & 38.072 & 37.847\end{array}$

$76.077 \quad 75.850$

$73.812 \quad 73.586$

$\begin{array}{ll}69.285 & 69.060 \\ 67.021 & 66.796\end{array}$

$\begin{array}{ll}67.021 & 66.796 \\ 64.760 & 64.533\end{array}$

$\begin{array}{ll}62.497 & 62.270 \\ 60.233 & 60.007\end{array}$

47536

36.03935.

$33.778 \quad 33.553 \quad 35.587$

$\begin{array}{lll}31.519 & 31.292 & 31.065\end{array}$

$\begin{array}{ll}29.259 & 29.033 \\ .7 .000 & 26.773\end{array}$

$24.740 \quad 24.515$

22.481

$20.223 \quad 19.996$

$\begin{array}{ll}17.965 & 17.738 \\ 15.706 & 15.479\end{array}$

20.547

$\begin{array}{ll}57.972 & 57.746 \\ 55.709 & 55.483\end{array}$

$\begin{array}{ll}55.709 & 55.483 \\ 53.448 & 53.222 \\ 51.186 & 50.960\end{array}$

$\begin{array}{ll}51.186 & 50.960 \\ 48.924 & 48.698\end{array}$

$\begin{array}{ll}46.964 & 46.438 \\ 44.402 & 44.176\end{array}$

$\begin{array}{ll}44.402 & 44.176 \\ 42.142 & 41.916\end{array}$

$\begin{array}{ll}39.881 & 39.654 \\ 37.620 & 37.394\end{array}$

$\begin{array}{ll}30.840 & 30.614 \\ 28.581 & 28.355\end{array}$

$\begin{array}{ll}26.321 & 26.095 \\ 24.062 & 23.837\end{array}$

$\begin{array}{lll}24.289 & 24.062 & 23.837 \\ 22.029 & 21.803 & 21.578\end{array}$

$\begin{array}{lll}7.512 & 17.287 & 17.061 \\ 5.254 & 15.028 & 14.802\end{array}$

$47513.447 \quad 13.222 \quad 12.997$

$12.771 \quad 12.545$ $66.078 \quad 65.853 \quad 65.627$ $\begin{array}{llllll}63.825 & 63.599 & 63.374 & 63.149 & 62.923\end{array}$ $\begin{array}{lll}43.553 & 43.328 & 43.103 \\ 41.303 & 41.077 & 40.852\end{array}$ $39.052 \quad 38.82$ $36.801 \quad 36.575 \quad 36.351$ $34.325 \quad 34.100$

32.29932 .074

$25.549 \quad 25.325$

31.399

$47423.300 \quad 23.076$

$\begin{array}{lll}18.802 & 18.577 & 18.35\end{array}$

$16.553 \quad 16.328 \quad 16.103$

12.05611 .832

12005611.83211 .606

$07.560 \quad 07.335$

$\begin{array}{ll}05.312 & 05.087 \\ 03.064 & 02.839\end{array}$

07.110

02.83

04.862

24.875

26.899 $80.600 \quad 80.375 \quad 80.151$

$79.927 \quad 79.701$

$\begin{array}{rlllllllll}47603.938 & 03.712 & 03.485 & 03.258 & 03.032 & 02.805 & 02.579 & 02.352 & 02.125 & 01.898 \\ 01.672 & 01.446 & 01.218 & 00.991 & 00.765 & 00.539 & 00.312 & 00.086 & * 99.859 & \# 99.633 \\ 47599.407 & 99.179 & 98.952 & 98.726 & 98.500 & 98.272 & 98.046 & 97.820 & 97.593 & 97.367\end{array}$ $\begin{array}{rllllllll} & & & \end{array}$

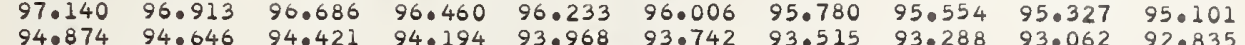

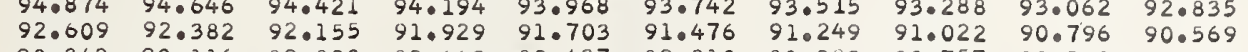
$\begin{array}{llllllllll}90.342 & 90.116 & 89.890 & 89.663 & 89.437 & 89.210 & 88.983 & 88.757 & 88.531 & 88.305\end{array}$

26686.040

$\begin{array}{lllll}82.417 & 82.454 & 84.228 & 84.001 & 83.774 \\ & 82.190 & 81.963 & 81.737 & 81.510\end{array}$

$\begin{array}{lllll}80.152 & 79.925 & 79.698 & 79.473 & 79.245 \\ 77.887 & 77.661 & 77.435 & 77.208 & 76.981\end{array}$

\begin{tabular}{lllll}
75.624 & 75.397 & 75.171 & 74.204 & 76.981 \\
\hline & 74.918
\end{tabular}

$73.359 \quad 73.133 \quad 72.907 \quad 72.680 \quad 72.454$

$68.833 \quad 68.606 \quad 68.37968 .153 \quad 67.927$

$66.56966 .343 \quad 66.116 \quad 65.890 \quad 65.664$

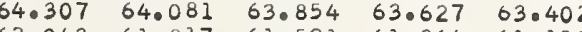

$\begin{array}{lllll}59.781 & 59.555 & 59.329 & 59.103 & 58.876\end{array}$

$\begin{array}{lllll}57.520 & 57.292 & 57.066 & 56.840 & 56.614 \\ 55.257 & 55.030 & 54.804 & 54.578 & 54.352\end{array}$

$\begin{array}{lllll}55.257 & 55.030 & 54.804 & 54.578 & 54.352 \\ 52.995 & 52.769 & 52.543 & 52.316 & 52.091\end{array}$

$50.733 \quad 50.507 \quad 50.281 \quad 50.055 \quad 49.829$

$\begin{array}{lllll}48.472 & 48.246 & 48.020 & 47.794 & 47.568 \\ 46.211 & 45.984 & 45.758 & 45.533 & 45.307\end{array}$

$\begin{array}{lllll}43.950 & 43.723 & 43.498 & 43.271 & 43.045\end{array}$

$\begin{array}{lllll}41.689 & 41.463 & 41.237 & 41.011 & 40.786\end{array}$

$\begin{array}{llllllll}35.360 & 35.134 & 34.908 & 34.682 & 34.456 & 34.230 & 34.004\end{array}$

$\begin{array}{lllllll}33.100 & 32.874 & 32.648 & 32.422 & 32.196 & 31.970 & 31.744 \\ 30.840 & 30.614 & 30.389 & 30.163 & 29.937 & 29.711 & 29.485\end{array}$

$28.1<9 \quad 27.903 \quad 27.677 \quad 27.451 \quad 27.226$

$\begin{array}{lllll}25.870 & 25.644 & 25.417 & 25.192 & 24.966 \\ 23.611 & 23.385 & 23.159 & 22.934 & 22.708\end{array}$

$\begin{array}{lllll}23.611 & 23.385 & 23.159 & 22.934 & 22.708 \\ 21.352 & 21.126 & 20.900 & 20.674 & 20.448\end{array}$

$\begin{array}{lllll}19.093 & 18.868 & 18.642 & 18.416 & 18.191\end{array}$

$\begin{array}{llllll}10.287 & 10.061 & 09.835 & 09.610 & 09.384 & 09.158\end{array}$

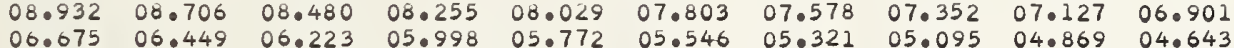

$\begin{array}{llllllllll}04.417 & 04.191 & 03.966 & 03.740 & 03.515 & 03.290 & 03.063 & 02.837 & 02.012 & 02.386\end{array}$ $\begin{array}{llllllllll}02.160 & 01.935 & 01.709 & 01.483 & 01.259 & 01.033 & 00.807 & 00.581 & 00.356 & 00.129\end{array}$

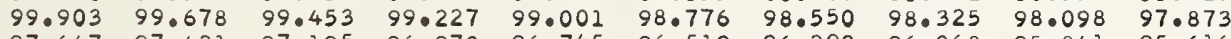
$\begin{array}{llllllllll}97.647 & 97.421 & 97.195 & 96.970 & 96.745 & 96.519 & 96.293 & 96.068 & 95.841 & 95.616\end{array}$ $\begin{array}{llllllllll}95.391 & 95.166 & 94.939 & 94.714 & 94.489 & 94.263 & 94.038 & 93.812 & 93.585 & 93.360 \\ 93.135 & 92.909 & 92.684 & 92.458 & 92.232 & 92.007 & 91.781 & 91.555 & 91.330 & 91.104\end{array}$ $\begin{array}{rlllllllll}47490.878 & 90.653 & 90.427 & 90.202 & 89.977 & 89.751 & 89.526 & 89.299 & 89.074 & 88.849 \\ 88.623 & 88.398 & 88.172 & 87.946 & 87.721 & 87.496 & 87.270 & 87.044 & 86.818 & 86.593\end{array}$ $\begin{array}{llllllllll}86.368 & 86.142 & 85.916 & 85.691 & 85.465 & 85.240 & 85.015 & 84.789 & 84.562 & 84.338\end{array}$ $\begin{array}{llllllllll}84.112 & 83.887 & 83.661 & 83.437 & 83.210 & 82.985 & 82.759 & 82.534 & 82.308 & 82.083\end{array}$ $\begin{array}{llllllllll}81.857 & 81.631 & 81.407 & 81.181 & 80.955 & 80.730 & 80.504 & 80.278 & 80.053 & 79.828 \\ 79.602 & 79.377 & 79.151 & 78.926 & 78.701 & 78.475 & 78.249 & 78.024 & 77.799 & 77.573\end{array}$ $\begin{array}{llllllllll}77.348 & 77.123 & 76.897 & 76.671 & 76.446 & 76.221 & 75.995 & 75.770 & 75.544 & 750318\end{array}$ $\begin{array}{llllllllll}75.094 & 74.868 & 74.642 & 74.417 & 74.192 & 73.965 & 73.741 & 73.515 & 73.290 & 73.064\end{array}$ $\begin{array}{llllllllll}72.839 & 72.613 & 72.388 & 72.164 & 71.938 & 71.712 & 71.487 & 71.261 & 71.036 & 70.811 \\ 70.585 & 70.360 & 70.135 & 69.909 & 69.684 & 69.458 & 69.232 & 69.007 & 68.782 & 68.557\end{array}$

$\begin{array}{llllllllll}47468.331 & 68.106 & 67.881 & 67.655 & 67.430 & 67.204 & 66.979 & 66.753 & 66.528 & 66.303\end{array}$ $\begin{array}{llllllllll}1.571 & 61.346 & 01.120 & 60.896 & 60.669 & 60.444 & 60.220 & 59.994 & 59.769 & 59.544\end{array}$ $\begin{array}{lllllllllll}59.318 & 59.093 & 58.868 & 58.642 & 58.417 & 58.192 & 57.966 & 57.741 & 57.516 & 57.291\end{array}$ $\begin{array}{llllllllll}57.065 & 56.841 & 56.615 & 56.389 & 56.165 & 55.939 & 55.713 & 55.488 & 55.263 & 55.038\end{array}$ $\begin{array}{llllllllll} & & 54.137 & 53.912 & 53.687 & 53.461 & 53.237 & 53.011 & 52.786 \\ \end{array}$

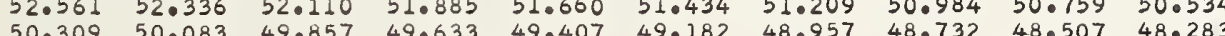

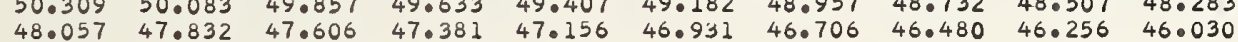

$\begin{array}{llllll}44.679 & 44.454 & 44.229 & 44.004 & 43.779\end{array}$

$\begin{array}{lllllll}42.878 & 42.653 & 42.428 & 42.203 & 41.979 & 41.753 & 41.528 \\ 40.627 & 40.402 & 40.177 & 39.952 & 39.727 & 39.501 & 39.277\end{array}$

$\begin{array}{lllllll}38.376 & 38.151 & 37.925 & 37.701 & 37.476 & 37.250 & 37.026\end{array}$

$\begin{array}{lllllll}36.125 & 35.900 & 35.676 & 35.451 & 35.225 & 35.000 & 34.775\end{array}$

$33.200 \quad 32.975 \quad 32.750 \quad 32.525$

$\begin{array}{lllll}28.924 & 28.700 & 28.475 & 28.250 & 28.025 \\ 26.674 & 26.450 & 26.225 & 26.000 & 25.774\end{array}$

$\begin{array}{lllllll}22.625 & 22.401 & 22.176 & 21.951 & 21.726 & 21.501 & 21.275\end{array}$

$\begin{array}{lllllll}20.175 & 20.151 & 19.926 & 19.701 & 19.478 & 19.252 & 19.026 \\ 18.128 & 17.903 & 17.078 & 17.453 & 17.228 & 17.002 & 16.778\end{array}$

$\begin{array}{lllllll}15.878 & 15.653 & 15.428 & 15.204 & 14.979 & 14.753 & 14.529\end{array}$

$\begin{array}{lllllll}13.629 & 13.405 & 13.181 & 12.956 & 12.731 & 12.506 & 12.281\end{array}$

$\begin{array}{lllllll}09.133 & 08.909 & 08.684 & 08.458 & 08.234 & 08.009 & 07.784\end{array}$

$\begin{array}{lllllll}06.886 & 06.661 & 06.436 & 06.212 & 05.986 & 05.761 & 05.537\end{array}$

$\begin{array}{lllllll}0.886 & 06.661 & 06.436 & 06.212 & 05.986 & 05.761 & 05.537 \\ 04.638 & 04.413 & 04.188 & 03.964 & 03.738 & 03.513 & 03.289\end{array}$

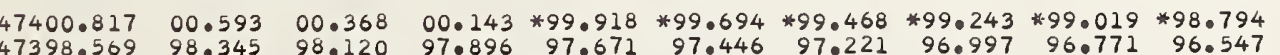

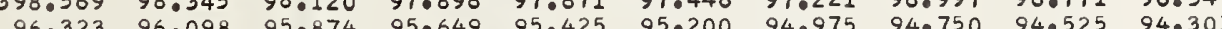

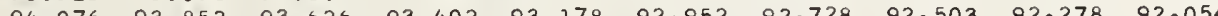

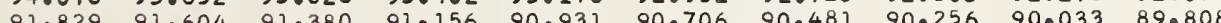
$\begin{array}{llllllllll}89.583 & 89.359 & 89.134 & 88.910 & 88.686 & 88.460 & 88.235 & 88.010 & 87.786 & 87.562\end{array}$

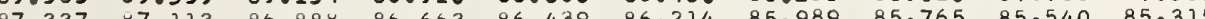

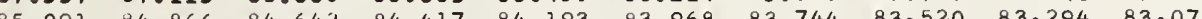

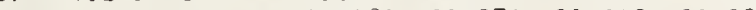
$\begin{array}{llllllllll}82.846 & 82.621 & 82.396 & 82.172 & 81.947 & 81.722 & 81.498 & 81.273 & 81.049 & 80.825\end{array}$

79.4

0.317418

17308

316997

316963

316957

0.316900

0.316888

0.668518

$\begin{array}{lllllllllll} & .001 & .002 & .003 & .004 & .005 & .006 & .007 & .008 & .009 & .010 \\ .226 & .023 & .045 & .068 & .090 & .0113 & .136 & .158 & .181 & .203 & .226 \\ .225 & .023 & .045 & .068 & .090 & .113 & .135 & .158 & .180 & .203 & .225 \\ .224 & .022 & .045 & .067 & .090 & .112 & .134 & .157 & .179 & .202 & .224\end{array}$




$$
\begin{aligned}
& 10 . \\
& 0.1 \\
& 0.0 \\
& 0.0 \\
& 0.0 \\
& 0.0 \\
& 0.7 \\
& 0.0
\end{aligned}
$$

$\begin{array}{llll}54.568 & 54.344 & 54.120 & 53.896 \\ 52.325 & 52.102 & 51.877 & 51.652\end{array}$ $29.013 \quad 28.078$ 30.806
28.564 32.822 $26.772 \quad 26.54$ 24.53224 .308 $26.324 \quad 26.101$ 32.598
30.358
28.117 $22.292 \quad 22.069$

$\begin{array}{lll}17.813 & 17.589 & 17.365\end{array}$

$\begin{array}{ll}13.574 & 15.350 \\ 13.335 & 13.111\end{array}$

47244.027 $\begin{array}{lllll}41.795 & 41.572 & 41.349 & 41.125 & 40.135 \\ 39.563 & 39.340 & 39.116 & 38 & 40.0\end{array}$ $\begin{array}{llllllllll}39.340 & 39.116 & 38.894 & 38.670 & 38.447 & 30.456 & 40.233 & 40.009 & 39.786 \\ 38.024 & 38000 & 37.777 & 37.554\end{array}$

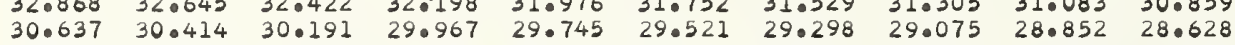
$\begin{array}{llllllllll}28.406 & 28.183 & 27.959 & 27.737 & 27.514 & 27.290 & 27.067 & 26.844 & 26.621 & 26.398\end{array}$ $\begin{array}{llllllllll}26.175 & 25.952 & 25.728 & 25.505 & 25.282 & 25.059 & 24.836 & 24.613 & 24.390 & 24.167 \\ 23.944 & 23.721 & 23.499 & 23.275 & 23.052 & 22.830 & 22.605 & 22.382 & 22.160 & 21.937\end{array}$

47221.71 .3 21.41 .3210100 $19.483 \quad 19.260$ $15.024 \quad 14.801$

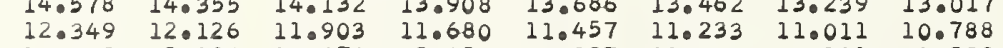
$\begin{array}{lllllllllll}10.564 & 10.342 & 10.119 & 09.896 & 09.673 & 09.450 & 09.227 & 09.004 & 08.781 & 08.558\end{array}$ $\begin{array}{llllllllll}08.335 & 08.0113 & 07.890 & 07.667 & 07.443 & 07.220 & 06.998 & 06.775 & 06.553 & 06.330\end{array}$

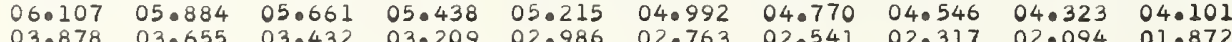

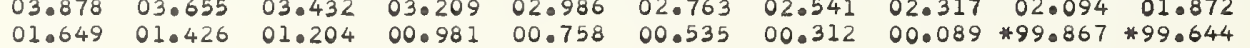
$\begin{array}{llllllllll}47199.421 & 99.199 & 98.976 & 98.752 & 98.530 & 98.307 & 98.084 & 97.861 & 97.639 & 97.416\end{array}$ $\begin{array}{llllllllll}97.192 & 96.970 & 96.747 & 96.523 & 96.301 & 96.079 & 95.855 & 95.633 & 95.410 & 95.187 \\ 94.966 & 94.743 & 94.520 & 94.297 & 94.074 & 93.851 & 930628 & 93.406 & 93.183 & 92.960\end{array}$ $\begin{array}{llllllllll}94.966 & 94.743 & 94.520 & 94.297 & 94.074 & 93.851 & 93.628 & 93.406 & 93.183 & 92.960 \\ 92.738 & 92.515 & 92.292 & 92.069 & 91.846 & 91.623 & 91.401 & 91.178 & 90.955 & 90.732\end{array}$ $\begin{array}{llllllllll}92.738 & 92.515 & 92.292 & 92.069 & 91.846 & 91.623 & 91.401 & 91.178 & 90.955 & 90.732 \\ 90.510 & 90.287 & 90.064 & 89.841 & 89.618 & 89.396 & 89.173 & 88.951 & 88.729 & 88.505\end{array}$ $\begin{array}{llllllllll}90.510 & 90.287 & 90.064 & 89.841 & 89.618 & 89.396 & 89.173 & 88.951 & 88.729 & 88.505 \\ 88.283 & 88.061 & 87.837 & 87.614 & 87.392 & 87.169 & 86.946 & 86.723 & 86.501 & 86.278\end{array}$ $\begin{array}{llllllllll}88.283 & 88.061 & 87.837 & 87.614 & 87.392 & 87.169 & 86.946 & 86.723 & 86.501 & 86.278 \\ 86.055 & 85.833 & 85.609 & 85.387 & 85.165 & 84.941 & 84.719 & 84.497 & 84.274 & 84.051\end{array}$ $\begin{array}{llllllllll}86.055 & 85.833 & 85.609 & 85.387 & 85.165 & 84.941 & 84.719 & 84.497 & 84.274 & 84.051 \\ 83.829 & 83.606 & 83.382 & 83.161 & 82.938 & 82.715 & 82.493 & 82.270 & 82.047 & 81.825\end{array}$

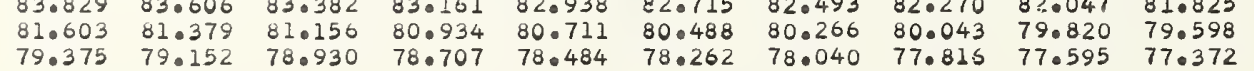

$\begin{array}{rr}7177.149 & 76.927 \\ 74.923 & 74.701 \\ 72.097 & 72.474\end{array}$

$\begin{array}{llllllllll}74.923 & 74.921 & 74.476 & 74.255 & 74.033 & 73.810 & 73.587 & 73.365 & 73.143 & 72.920 \\ 72.697 & 72.474 & 72.251 & 72.029 & 71.807 & 71.584 & 71.362 & 71.140 & 70.917 & 70.695 \\ 70.472 & 72.049 & 70.026 & 69.8004 & 69.582 & 69.359 & 69.137 & 68.914 & 68.091 & 68.469\end{array}$

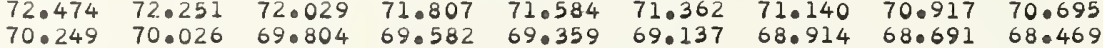
$\begin{array}{llllllllll}68.246 & 68.023 & 67.801 & 67.579 & 67.356 & 67.134 & 66.911 & 66.688 & 66.466 & 66.244 \\ 66.021 & 65.798 & 65.576 & 65.353 & 65.132 & 64.909 & 64.687 & 64.46 .4 & 64.242 & 64.019\end{array}$ $\begin{array}{llllllllll}63.796 & 63.574 & 63.351 & 63.128 & 62.907 & 62.684 & 62.461 & 62.239 & 62.017 & 61.0793\end{array}$ $\begin{array}{lllllllllll}61.571 & 61.349 & 61.126 & 60.904 & 60.682 & 60.459 & 60.237 & 60.014 & 59.792 & 59.569\end{array}$ $\begin{array}{llllllllll}59.347 & 59.125 & 58.902 & 58.680 & 58.458 & 58.235 & 58.013 & 57.790 & 57.567 & 57.345 \\ 57.123 & 56.900 & 56.678 & 56.455 & 56.233 & 56.011 & 55.788 & 55.565 & 55.344 & 55.121\end{array}$

$$
.001
$$
000

\begin{abstract}
.003
\end{abstract}
.022

.045
.045

.005

\begin{abstract}
.006
\end{abstract}
.007

0.316786

0.316780

0.316775

0.316769

0.316763

0.316752

0.316746

0.316741
0.316735

0.316729

0.316724

0.316718
0.316712

0.316707

0.316701

0.316695

0.316690

0.316678

0.316673

0.316667

0.316656

0.316650

0.316644

0.316633

0.316627

0.316616

0.316605

0.316599

0.316594

0.316588

0.316582

0.316571

0.316560

0.316554

0.316549

0.316543
0.316537

0.316537

0.316532

0.316521

0.316515

0.316504

0.316498

0.316492

0.316487

0.316481

0.316470

0.316464

0.316459
0.316453

0.316448 0.316442
0.316436 0.316436 0.316425 0.316425
0.316420 0.316414 0.316409 0.316403
0.316397

0.316392 0.316386 0.316381 0.316375 0.316369

0.316364
0.316358

0.316353

0.316347
0.316342

0.316336 0.316330 0.316325 0.316319 0.316314 0.316303 0.316297 0.316291 0.668558 0.668597 0.668617 0.668656 0.668696 0.668715

0.668735 0.668755 0.668774 0.668794 0.668814 0.668834 0.668853 


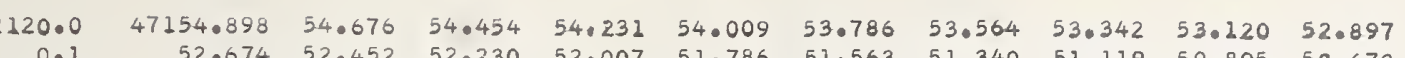

$\begin{array}{lllllllllll}0.1 & 52.674 & 52.452 & 52.230 & 52.007 & 51.786 & 51.563 & 51.340 & 51.119 & 50.895 & 50.673 \\ 0.2 & 50.451 & 50.229 & 50.006 & 49.784 & 49.562 & 49.339 & 49.117 & 48.895 & 48.671 & 48.450\end{array}$

$\begin{array}{lllllllllll}0.3 & 48.227 & 48.004 & 47.782 & 47.560 & 49.562 & 49.339 & 49.117 & 48.895 & 48.671 & 48.450 \\ & 46.004 & 450792 & 45.116 & 46.894 & 46.671 & 46.448 & 46.227\end{array}$

0.316175

0.316169 0.316158 0.316153
0.316147 0.316142 0.316131

0.316125

0.316114 0.316103 0.316092

0.316086

0.316075

0.316064

0.316059

0.316048

0.3166037

0.316031

0.316026

0.316015

0.316009

0.316004

0.315993

.315987

0.315982

0.315971

0.315965
0.315960

0.315954

0.315949

0.315943
0.315938
0.31532

0.315932
0.315927
0.31527

0.315921

0.315916

0.315905
0.315900

0.315894

0.315889
0.31583

0.315878

0.315872
0.315867

0.315861
0.315856
0.31560

0.315850

0.315839

0.315834

0.315823

0.315818

0.315807

0.315802
0.315790
0.31590

0.315790

0.315785
0.315779
0.31574

0.315779

0.315774
0.315769
0.3159

0.315763
0.315758
0.31542

0.315752

0.315747

0.315741 0.670554 0.670574

0.670613

0.670653

0.670673
0.670693

0.670723

0.670732

0.670772

0.670792

0.670832

0.670872

0.670891

0.670911

0.670951

9.670971

0.671012

0.671031

0.671050
0.671070

0.671090

0.671110
0.672130
0.67210

0.671250

0.671170

0.671209

0.671249

0.67269

0.671309

0.671349

0.671369

0.671409

0.671428

0.671468

0.671508

0.671528
0.671548
0.67558

0.071568

0.671588

0.071628

0.671648

0.671667
0.671687

0.672707

0.671727
0.677747

0.671787

0.671807

.

0.671847

0.671887

0.671907 0.671927 0.671967

0.67987

0.672026

0.072046

0.672086

0.672106

0.6721266
0.672246

0.0672166

0.672186
0.672206
0.67226

0.672226

0.672246

0.672306

0.672326

0.672366

0.672386

0.672426

0.672446

0.672466

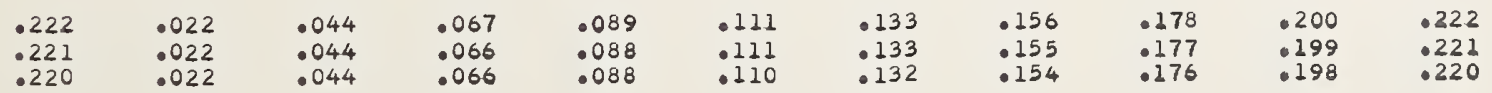




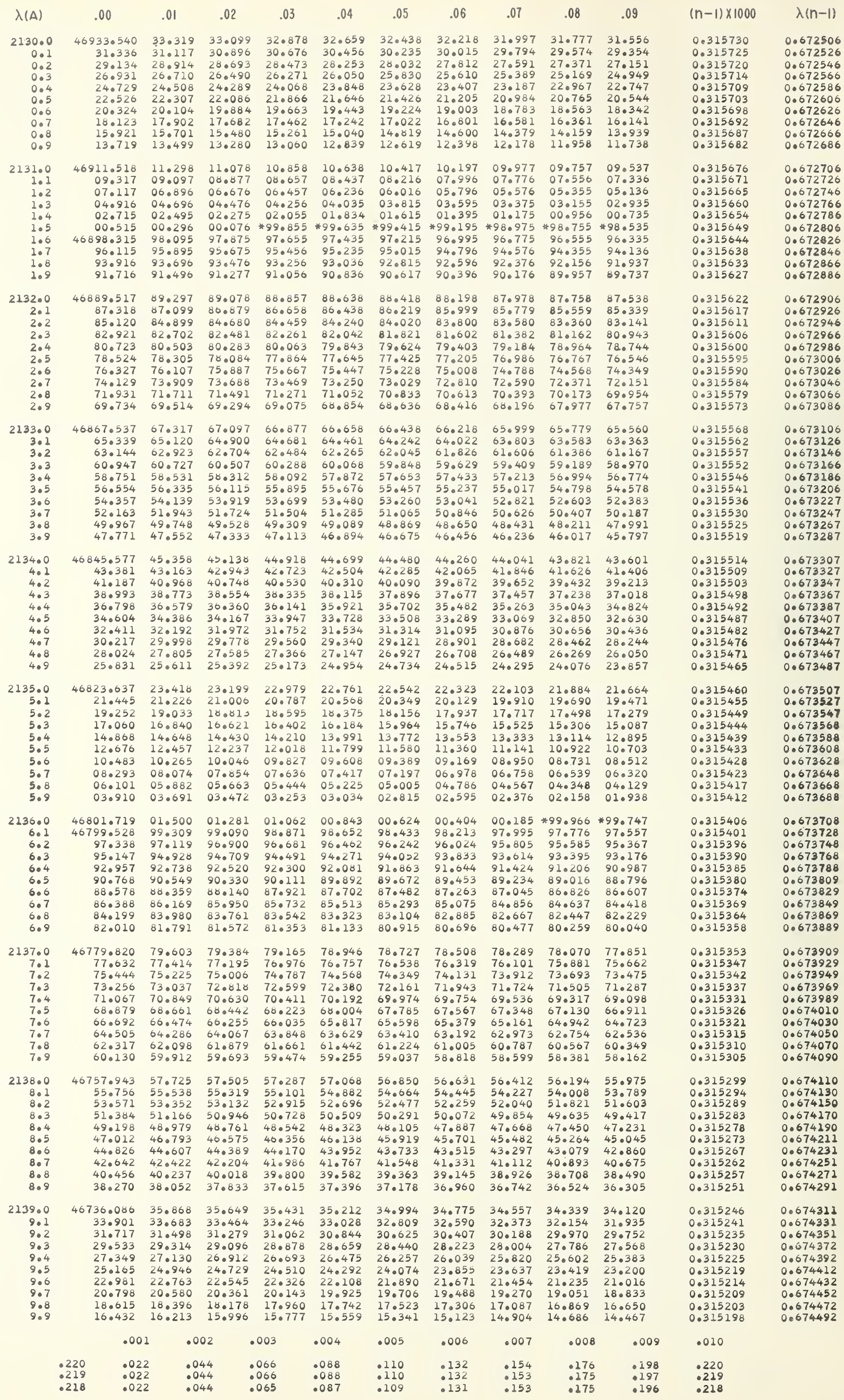


$\begin{array}{rrrrrrrrrrr}2140.0 & 46714.249 & 14.031 & 13.812 & 13.594 & 13.376 & 13.158 & 12.939 & 12.721 & 12.504 & 12.285 \\ 0.1 & 12.066 & 11.849 & 11.630 & 11.412 & 11.194 & 10.976 & 10.757 & 10.540 & 10.320 & 10.102\end{array}$

$\begin{array}{lllllllllll}0.1 & 12.066 & 11.849 & 11.630 & 11.412 & 11.194 & 10.976 & 10.757 & 10.540 & 10.320 & 10.102 \\ 0.2 & 09.884 & 09.666 & 09.448 & 09.230 & 09.012 & 08.793 & 08.575 & 08.357 & 08.138 & 07.920\end{array}$

$\begin{array}{lllllllllll}0.2 & 09.884 & 09.666 & 09.448 & 09.230 & 09.012 & 08.793 & 08.575 & 08.357 & 08.138 & 07.920 \\ 0.3 & 07.702 & 07.483 & 07.265 & 07.047 & 06.829 & 06.611 & 06.394 & 06.175 & 05.956 & 05.739\end{array}$

$\begin{array}{lllllllllll}0.4 & 05.520 & 05.302 & 05.084 & 04.866 & 04.647 & 04.430 & 04.211 & 03.993 & 03.775 & 03.557 \\ 0.5 & 03.338 & 03.121 & 02.902 & 02.684 & 02.466 & 02.248 & 02.029 & 01.811 & 01.593 & 01.375\end{array}$

$0.6 \quad 01.156 \quad 00.938 \quad 00.720 \quad 00.502 \quad 00.285 \quad 00.067 * 99.848 * 99.631 * 99.412 * 99.193$

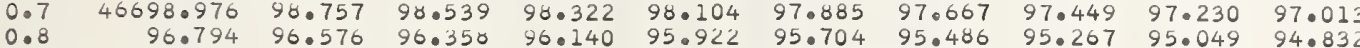

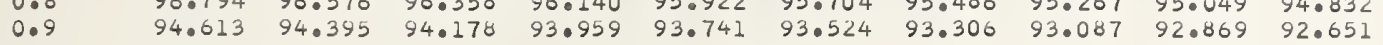

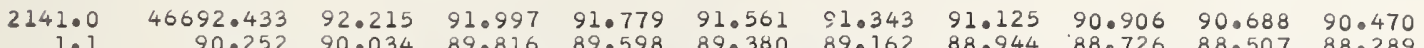

$\begin{array}{lllllllllll}1.1 & 90.252 & 90.034 & 89.816 & 89.598 & 89.380 & 89.162 & 88.944 & 88.726 & 88.507 & 88.289\end{array}$

$\begin{array}{lllllllllll}1.2 & 88.072 & 87.854 & 87.636 & 87.418 & 87.200 & 86.982 & 86.765 & 86.546 & 86.328 & 86.110 \\ 1.3 & 85.892 & 85.674 & 85.456 & 85.238 & 85.020 & 84.802 & 84.583 & 84.366 & 84.147 & 83.930\end{array}$

$\begin{array}{lllllllllll}1.4 & 83.712 & 83.494 & 83.276 & 83.058 & 82.840 & 82.6<2 & 82.403 & 82.186 & 81.969 & 81.750\end{array}$

$\begin{array}{lllllllllll}1.5 & 81.532 & 81.315 & 81.097 & 80.878 & 80.661 & 80.443 & 80.224 & 80.006 & 79.789 & 79.570 \\ 1.6 & 79.353 & 79.135 & 78.917 & 78.699 & 78.481 & 78.263 & 78.044 & 77.827 & 77.609 & 77.391\end{array}$

$\begin{array}{lllllllllll}1.6 & 79.353 & 79.135 & 78.917 & 78.699 & 78.481 & 78.263 & 78.044 & 77.827 & 77.609 & 77.391 \\ 1.7 & 77.173 & 76.956 & 70.737 & 76.520 & 76.302 & 76.083 & 75.866 & 75.648 & 75.430 & 75.213\end{array}$

$\begin{array}{lllllllllll}1.8 & 74.995 & 74.776 & 74.559 & 74.341 & 74.123 & 73.905 & 73.687 & 73.469 & 73.251 & 73.034 \\ 1.9 & 72.815 & 72.597 & 72.380 & 72.162 & 71.944 & 71.726 & 71.508 & 71.290 & 71.072 & 70.854\end{array}$

$\begin{array}{lllllllllll}2142.0 & 46670.636 & 70.419 & 70.201 & 69.983 & 69.766 & 69.548 & 69.330 & 69.111 & 68.894 & 68.676\end{array}$

$\begin{array}{lllllllllll}2.1 & 68.458 & 68.241 & 68.023 & 67.805 & 67.587 & 67.369 & 67.151 & 60.934 & 66.715 & 66.498\end{array}$

$\begin{array}{lllllllllll}2.2 & 66.280 & 60.062 & 65.844 & 65.627 & 65.409 & 65.190 & 64.973 & 64.755 & 64.537 & 64 \cdot 320\end{array}$

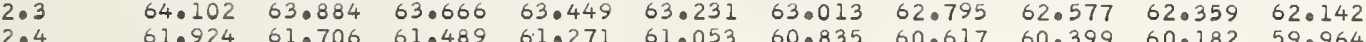

$\begin{array}{lllllllllll}2.4 & 61.924 & 61.706 & 61.489 & 6.1 .271 & 61.053 & 60.835 & 60.617 & 60.399 & 60.182 & 59.964 \\ 2.5 & 59.746 & 59.529 & 59.311 & 59.093 & 58.875 & 58.657 & 53.439 & 58.221 & 58.004 & 57.786\end{array}$

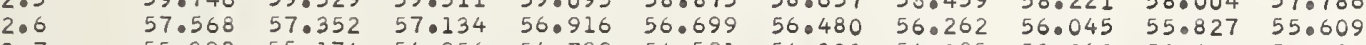

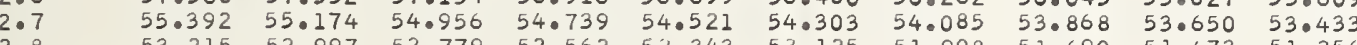

$\begin{array}{lllllllllll}2.8 & 53.215 & 52.997 & 52.779 & 52.562 & 52.343 & 52.125 & 51.908 & 51.690 & 51.473 & 51.256 \\ 2.9 & 51.038 & 50.820 & 50.603 & 50.385 & 50.107 & 49.950 & 49.732 & 498514 & 49.297 & 49.079\end{array}$

2143.0

$\begin{array}{lllll}47.772 & 47.555 & 47.337 & 47.120 & 46.902\end{array}$

3.1

3.2

$3 \cdot 3$

3.5

3.6

$\begin{array}{lll}44.509 & 44.291 & 44.073\end{array}$

$42.333 \quad 42.115$

40.156 39.938

$37.981 \quad 37.764$

$\begin{array}{ll}48.208 & 47.990 \\ 46.031 & 45.813 \\ 43.856 & 43.638 \\ 41.679 & 41.461\end{array}$

$35.805 \quad 35.58$

37.546
35.371

$31.456 \quad 31.23$

33.19

3.8
3.9

2144.0

44
4.
40
4.3
4.4
4.5
4.6
4.7
4.8
4.9

26.688

$24.931 \quad 24.714 \quad 20.671$

$\begin{array}{lll}18.410 & 18.192 & 17.975\end{array}$

$14.062 \quad 13.846 \quad 13.627$

$\begin{array}{lll}11.890 & 11.671 & 11.454 \\ 09.716 & 09.498 & 09.281\end{array}$

$\begin{array}{ll}09.716 & 09.498 \\ 07.543 & 07.326\end{array}$

$\begin{array}{lllll}45.596 & 45.378 & 45.162 & 44.944 & 44.726 \\ 43.420 & 43.203 & 42.985 & 42.768 & 42.550\end{array}$

$\begin{array}{lllll}43.420 & 43.203 & 42.985 & 42.768 & 42.550 \\ 41.244 & 41.027 & 40.809 & 40.591 & 40.374\end{array}$

$\begin{array}{lllllll}37.320 & 37.111 & 39.068 & 38.851 & 38.633 & 38.417 & 38.199\end{array}$

$\begin{array}{lllllll}35.152 & 34.935 & 34.817 & 36.675 & 36.458 & 36.241 & 36.023\end{array}$

$\begin{array}{lllllll}32.977 & 32.760 & 32.542 & 32.326 & 32.108 & 31.890 & 31.673\end{array}$

$\begin{array}{lllllll}30.803 & 30.585 & 30.367 & 30.150 & 29.933 & 29.715 & 29.498\end{array}$

0.315193

0.315182

0.31572

0.315161

0.315156

0.315145

0.315140

0.315129

0.315118

0.315103

0.315097

0.315087

0.315081

0.315071

0.315066

0.315055

0.315044

0.315034

0.315029

0.315018

0.315013

0.315007

0.314997

0.314992

0.314981

$\begin{array}{lllllll}26.453 & 26.236 & 26.019 & 25.801 & 25.583 & 25.367 & 25.149 \\ 24.278 & 24.062 & 23.844 & 23.626 & 23.410 & 23.192 & 22.974\end{array}$

$\begin{array}{lllllll}24.278 & 24.062 & 23.844 & 23.626 & 23.410 & 23.192 & 22.974 \\ 22.104 & 21.887 & 21.669 & 21.453 & 21.235 & 21.018 & 20.800\end{array}$

$\begin{array}{lllllll}19.931 & 19.713 & 19.496 & 19.279 & 19.062 & 18.844 & 18.627\end{array}$

$\begin{array}{lllllll}17.757 & 17.540 & 17.322 & 17.105 & 16.887 & 16.670 & 16.453 \\ 15.583 & 15.366 & 15.148 & 14.931 & 14.713 & 14.497 & 14.280\end{array}$

$\begin{array}{lllllll}13.410 & 13.193 & 12.976 & 12.758 & 12.543 & 14.497 & 14.280 \\ 12.324 & 12.106\end{array}$

0.3149

0.314965

0.314960

0.314955

0.314944

0.314939

$\begin{array}{lllllllllll}5.1 & 46005.371 & 05.153 & 04.936 & 04.718 & 04.501 & 04.284 & 04.067 & 03.850 & 03.633 & 03.416\end{array}$

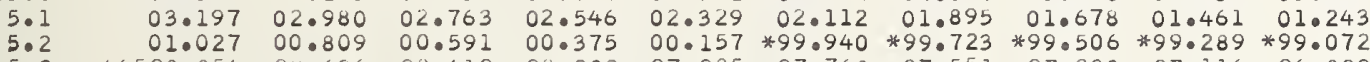

$\begin{array}{lllllllllll}5.3 & 46598.854 & 98.636 & 98.419 & 98.202 & 97.985 & 97.768 & 97.551 & 97.333 & 97.116 & 96.899\end{array}$

5.5

5.6

5.7

96.68296 .46496 .246

$94.510 \quad 94.293 \quad 94.076$

$90.167 \quad 89.950 \quad 89.734$

$\begin{array}{lll}87.997 & 87.780 & 87.562 \\ 85.826 & 85.608 & 85.392\end{array}$

$\begin{array}{ll}96.030 & 95.813 \\ 93.859 & 93.642\end{array}$

$\begin{array}{llllll}9.642 & 93.425 & 93.208 & 92.990 & 92.774 & 92.55\end{array}$

5.9

2146.0

6.

46583.656

$\begin{array}{lll}85.392 & 85.175 & 84.958\end{array}$

$89.083 \quad 88.866 \quad 88.049080320 .384$

0.314928

0.314923

0.314913

0.314907

0.314902
0.314897

0.314886

0.314876

0.314871

0.314860

0.314855

0.314839

0.314834
0.314829

$\begin{array}{llllllllll}72.805 & 72.589 & 72.372 & 72.155 & 71.938 & 71.721 & 71.504 & 71.288 & 71.071 & 70.854 \\ 70.636 & 70.420 & 70.203 & 69.985 & 69.769 & 69.552 & 69.335 & 69.119 & 68.901 & 68.684\end{array}$

$\begin{array}{llllllllll}68.467 & 68.250 & 68.033 & 67.817 & 67.600 & 67.383 & 67.166 & 66.949 & 66.731 & 66.515\end{array}$

$\begin{array}{llllllllll}66.298 & 66.081 & 65.864 & 65.647 & 65.431 & 65.213 & 64.998 & 64.781 & 64.563 & 64.347 \\ 64.129 & 63.913 & 63.696 & 63.479 & 63.262 & 63.046 & 62.829 & 62.612 & 62.395 & 62.178\end{array}$

$\begin{array}{rrrrrrrrrrr}2147.0 & 46561.960 & 61.744 & 61.527 & 61.310 & 61.094 & 60.877 & 60.660 & 60.443 & 60.226 & 60.009\end{array}$

$\begin{array}{llllllllll}59.792 & 59.576 & 59.358 & 59.142 & 58.926 & 58.709 & 58.492 & 58.276 & 58.058 & 57.841\end{array}$

$\begin{array}{llllllllll}57.625 & 57.408 & 57.191 & 56.975 & 56.757 & 50.541 & 56.324 & 56.106 & 55.890 & 55.673\end{array}$

$\begin{array}{llllllllll}55.457 & 55.239 & 55.022 & 54.806 & 54.589 & 54.373 & 54.156 & 53.938 & 53.722 & 53.505 \\ 53.289 & 53.071 & 52.855 & 52.639 & 52.422 & 52.206 & 51.989 & 51.771 & 51.555 & 51.338\end{array}$

$\begin{array}{llllllllll}51.121 & 50.905 & 50.688 & 50.471 & 50.255 & 50.038 & 49.821 & 49.604 & 49.387 & 49.170\end{array}$

$\begin{array}{llllllllll}48.954 & 48.737 & 48.521 & 48.303 & 48.087 & 47.870 & 47.653 & 47.437 & 47.220 & 47.003\end{array}$

$\begin{array}{lllllllllll}46.787 & 46.570 & 46.354 & 46.137 & 45.920 & 45.704 & 45.487 & 45.270 & 45.053 & 44.837\end{array}$

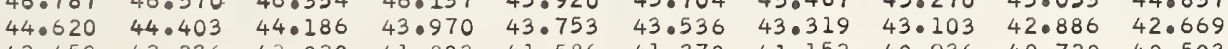

0.314823

0.314813

.314808

0.314797

0.314792

0.314787

0.314782

$\begin{array}{llllllllll}42.453 & 42.236 & 42.020 & 41.803 & 41.586 & 41.370 & 41.152 & 40.936 & 40.720 & 40.503\end{array}$

0.314771

0.314766

0.314761

0.314750

0.314745

0.314740

0.314735
0.314729

0.314724

0.314719

0.314714

0.314703

0.314698

0.314693

0.314688

0.314677

0.314672

0.674513

. 674533

0.674553
0.674573

0.674593

0.674613

0.674633

0.674694

0.674714

0.674754

.674775

0.674815

0.674835

0.674875

0.674916

0.674956

0.674976

0.674996

0.675037

0.675057

0.675097

0.675127

0.675138

0.675178

0.675198

0.675239

0.675259

0.675279
0.675299

0.675319

0.675340
0.675360

0.675380

0.675400

0.675441

0.675461

0.675501

0.675522

0.675542

0.675582

0.675602
0.675622

0.675643

0.675663

0.675703

0.675724

0.675744
0.675764

0.675784

0.675805

0.675845

0.675865

0.675885

0.675926

0.675966

0.675987

0.676027

0.676047

0.676068
0.676088

0.676088

0.676149

0.676169

0.676189

0.676230

0.676250

0.676291

0.676331

0.676351

0.676372

0.676412

0.676432

0.676453

0.676493

0.676493
0.676514

.010

\begin{tabular}{|c|c|c|c|c|c|c|c|c|c|}
\hline & .001 & .002 & .003 & .004 & .005 & .006 & .007 & .008 & .009 \\
\hline $\begin{array}{r}218 \\
.217\end{array}$ & $\begin{array}{r}.022 \\
.022\end{array}$ & $\begin{array}{l}.044 \\
.043\end{array}$ & $\begin{array}{l}.065 \\
.065\end{array}$ & $\begin{array}{l}.087 \\
.087\end{array}$ & $\begin{array}{l}.109 \\
.108\end{array}$ & $\begin{array}{l}.131 \\
.130\end{array}$ & $\begin{array}{r}.152 \\
.152\end{array}$ & $\begin{array}{l}.174 \\
.173\end{array}$ & $\begin{array}{l}.196 \\
.195\end{array}$ \\
\hline
\end{tabular}




\begin{tabular}{|c|}
\hline$\lambda(A)$ \\
\hline 2150.0 \\
\hline 0.1 \\
\hline $\begin{array}{l}0.2 \\
0.3\end{array}$ \\
\hline 0.3 \\
\hline 0.5 \\
\hline 0.6 \\
\hline 0.7 \\
\hline 0.8 \\
\hline 0.9 \\
\hline 2151.0 \\
\hline 1.12 \\
\hline 1.2 \\
\hline 1.3 \\
\hline $\begin{array}{l}104 \\
1.5\end{array}$ \\
\hline 1.6 \\
\hline 1.7 \\
\hline .8 \\
\hline 1.9 \\
\hline 2152.0 \\
\hline 2.1 \\
\hline 2.2 \\
\hline 2.3 \\
\hline 2.4 \\
\hline $2 \cdot 5$ \\
\hline 2.6 \\
\hline 2.7 \\
\hline 2.8 \\
\hline 2.9 \\
\hline $\begin{array}{r}2153.0 \\
3.1\end{array}$ \\
\hline \\
\hline $\begin{array}{l}3.2 \\
3.3\end{array}$ \\
\hline $\begin{array}{l}3.3 \\
3.4\end{array}$ \\
\hline $\begin{array}{l}3.4 \\
3.5\end{array}$ \\
\hline $\begin{array}{l}3.5 \\
3.6\end{array}$ \\
\hline $\begin{array}{l}3.6 \\
3.7\end{array}$ \\
\hline $\begin{array}{l}3.7 \\
3.8\end{array}$ \\
\hline 3.9 \\
\hline 54.0 \\
\hline \\
\hline $\begin{array}{l}4.2 \\
4.3\end{array}$ \\
\hline $\begin{array}{l}4.3 \\
4.4\end{array}$ \\
\hline $\begin{array}{l}4.4 \\
4.5\end{array}$ \\
\hline $\begin{array}{l}4.5 \\
4.6\end{array}$ \\
\hline $\begin{array}{l}4.6 \\
4.7\end{array}$ \\
\hline $\begin{array}{l}4.7 \\
4.8\end{array}$ \\
\hline $\begin{array}{l}4.8 \\
4.9\end{array}$ \\
\hline 409 \\
\hline $\begin{array}{r}2155.0 \\
5.1\end{array}$ \\
\hline $\begin{array}{l}5.1 \\
5.2\end{array}$ \\
\hline $\begin{array}{l}5.2 \\
5.3\end{array}$ \\
\hline 5.4 \\
\hline 5.5 \\
\hline 5.6 \\
\hline 5.7 \\
\hline 5.8 \\
\hline 5.9 \\
\hline 2156.0 \\
\hline 6.12 \\
\hline 6 \\
\hline 6.4 \\
\hline 6.5 \\
\hline 6.6 \\
\hline 6.7 \\
\hline 6.8 \\
\hline 6.9 \\
\hline 57.0 \\
\hline \\
\hline 7.2 \\
\hline $7 \cdot 3$ \\
\hline 7.4 \\
\hline 7.5 \\
\hline 706 \\
\hline 7. \\
\hline 7.8 \\
\hline 7.9 \\
\hline \\
\hline \\
\hline 80 \\
\hline 8. \\
\hline $\begin{array}{l}8.4 \\
8.5\end{array}$ \\
\hline 8. \\
\hline 8. \\
\hline $8 . \varepsilon$ \\
\hline 8.9 \\
\hline 59.0 \\
\hline \\
\hline - \\
\hline 9 \\
\hline 9. \\
\hline 95 \\
\hline \\
\hline \\
\hline \\
\hline 9.9 \\
\hline \\
\hline \\
\hline \\
\hline
\end{tabular}




$$
\begin{aligned}
& 160.0 \\
& 0.1 \\
& 0.2 \\
& 0.3 \\
& 0.4 \\
& 0.5 \\
& 0.7 \\
& 0.7 \\
& 0.0 \\
& 0.9
\end{aligned}
$$

60.0
0.1
0.2
0.3
0.4
0.5
0.6
0.7
0.8
0.9

$\begin{array}{lll}81.758 & 81.543 & 81.329 \\ 79.615 & 79.401 & 79.187\end{array}$

$\begin{array}{lllllll}81.115 & 80.901 & 80.687 & 80.472 & 80.258 & 80.044 & 79.830\end{array}$

$\begin{array}{lllllllllll}2161.0 & 46260.344 & 60.130 & 59.916 & 59.702 & 59.488 & 59.273 & 59.060 & 58.845 & 58.632 & 58.417\end{array}$

$\begin{array}{lllllllllll}1.1 & 58.203 & 57.989 & 57.775 & 57.561 & 57.347 & 57.133 & 56.919 & 56.706 & 56.491 & 56.277\end{array}$

1.2

$\begin{array}{lllll}56.063 & 55.849 & 55.634 & 55.421 & 55.207 \\ 53.922 & 53.709 & 53.495 & 53.281 & 53.067\end{array}$

$\begin{array}{lllll}52.853 & 52.640 & 52.425 & 52.211 & 51.998 \\ 50.714 & 50.500 & 50.286 & 50.072 & 49.858\end{array}$

1.04

1.6

$49.643 \quad 49.430 \quad 49.216 \quad 49$

$47.504 \quad 47.29$

49.216
47.077

$\begin{array}{ll}51.141 & 50.927 \\ 49.001 & 48.788\end{array}$

$\begin{array}{ll}52.211 & 51.998 \\ 50.072 & 49.858\end{array}$

$\begin{array}{llllllllll}43.326 & 43.012 & 42.0798 & 42.584 & 42.371 & 44.295 & 44.042 & 43.868 & 43.6545 & 43.440\end{array}$

1.08

$41.087 \quad 40.012$

42.798
40.660

$\begin{array}{ll}42.584 & 42.37 \\ 40.446 & 40.23\end{array}$

$\begin{array}{rr}62.0 & 4623 \\ 2.1 & 3 \\ 2.2 & 3 \\ 2.3 & 32 . \\ 2.4 & 3 \\ 2.5 & 2 \\ 2.5 & \end{array}$

$\begin{array}{lll}238.949 & 38.735 & 38.521 \\ 36.810 & 36.597 & 36.382 \\ 34.672 & 34.458 & 34.245\end{array}$

$32.534 \quad 32.320 \quad 32.106$

$\begin{array}{lll}30.396 & 30.182 & 29.969 \\ 28.259 & 28.045 & 27.832\end{array}$

86.25725 .045

$23.121 \quad 25.908 \quad 25.694$

$\begin{array}{lll}21.848 & 21.634 & 21.420 \\ 19.710 & 19.497 & 19.283\end{array}$

$38.307 \quad 38.094$

40.01

41.943
39.805

$\begin{array}{lll}.729 & 41.515 & 41.3402\end{array}$

0.314142

0.314132

0.314122

0.314112

0.314101

0.314091

0.314081

314071

0.314056

0.314051

0.314046

0.314036

$\begin{array}{llllll}817 & 33.604 & 33.390 & 33.176 & 32.962 & 32.748\end{array}$

$\begin{array}{lllllll}31.893 & 31.679 & 31.465 & 31.252 & 31.038 & 30.824 & 30.610\end{array}$

2.6

$\begin{array}{llll}27.618 & 27.404 & 27.190 & 26.977 \\ 25.480 & 25.267 & 255053 & 24.939\end{array}$

$\begin{array}{lll}28.900 & 28.687 & 28.473 \\ 26.763 & 26.549 & 26.335\end{array}$

2163.0

63.0
3.1
3.
3.3
3.4
3.5
3.6
3.7
3.
3.9

46217.573

$\begin{array}{ll}17.573 & 17.360\end{array}$

$\begin{array}{ll}360 & 17.146 \\ 224 & 15.0010\end{array}$

$21.207 \quad 20.9$

$22.916 \quad 22.702 \quad 22.488 \quad 22.275 \quad 22.062$

0.314020

0.314010

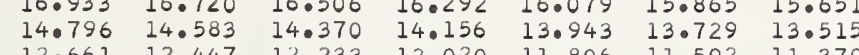

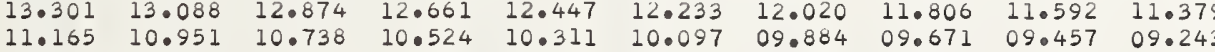

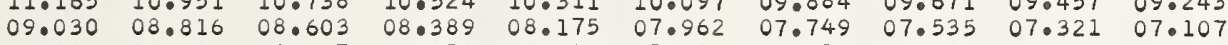

$\begin{array}{llllllllll}06.894 & 06.681 & 06.467 & 06.253 & 06.040 & 05.826 & 05.613 & 05.399 & 05.185 & 04.972\end{array}$

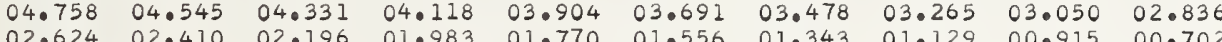

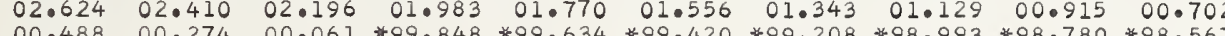

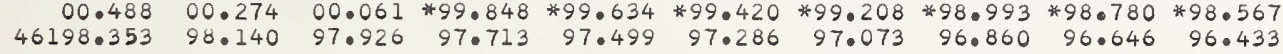

2164.0

164.0
4.1
4.2
4.3
4.4
4.5
4.6
4.7
4.8
4.9

94.08496 .006

93.00695 .792

$91.950 \quad 91.736 \quad 91.523 \quad 91.310 \quad 93.096$

$87.616 \quad 89.603 \quad 89.389 \quad 89.176 \quad 88.963$

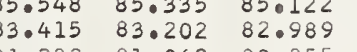

$\begin{array}{lllll} & \end{array}$

$\begin{array}{lll}79.149 & 78.935 & 78.722 \\ 77.016 & 76.803 & 76.590\end{array}$

8.908
84.695
82.775
82.562

95.15

94.93

94.724

$90.883 \quad 90.670$

88.74
86.61

$86.616 \quad 86.402$

90.457

94.511

94.297

4.6
4.7
4.8
4.9

2165.

5.

5.2
5.3
5.4

46174.8

$\begin{array}{rll}77.08 & 74.670 & 74.4 \\ 72.750 & 72.538 & 72.324 \\ 70.618 & 70.406 & 70.192\end{array}$

$70.619 \quad 70.406 \quad 70.192$

$\begin{array}{llll}70.406 & 68.060 & 69.879 & 69.766 \\ & 67.847 & 67.634\end{array}$

$\begin{array}{llllll}65.634 & 67.420 & 67.207 & 66.994 & 66.780 & 66.568\end{array}$

$\begin{array}{lllllllllll}64.223 & 64.010 & 63.797 & 63.584 & 63.371 & 63.158 & 62.074 & 64.862 & 64.650 & 64.437 \\ & 62.731 & 62.518 & 62.305\end{array}$

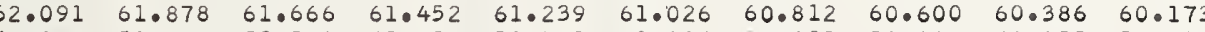

50

$59.960 \quad 59.747 \quad 59.534 \quad 59.322 \quad 59.108$

$\begin{array}{lllll}57.830 & 57.616 & 57.404 & 57.190 & 56.977 \\ 55.698 & 55.485 & 55.272 & 55.059 & 54.846\end{array}$

$58.895 \quad 58.682 \quad 58.469 \quad 58.255 \quad 58.043$

5.8

2166.0

6.

46153.567

$\begin{array}{lll}51.437 & 51.225 & 51.0 \\ 49.307 & 49.094 & \end{array}$

$\begin{array}{lll}47.177 & 46.963 & 46.751\end{array}$

$45.047-44.834 \quad 44.62$

$42.917 \quad 42.705$

$\begin{array}{lll}38.659 & 38.446 & 38.232 \\ 36.529 & 36.316 & 36.104\end{array}$

$\begin{array}{ll}52.929 & 52.716 \\ 50.798 & 50.5\end{array}$

54.633

56.551
54.419

56.337
54.206

56.124
53.994

53.780
53.012

0.314000

0.313990

0.313980

0.313975

0.313965

0.313960

0.313950

0.313945

0.313939

0.313929

0.313924

0.313914

0.313904

0.313899
0.313894

0.313889

0.313879

-10
-13864

0.313859

0.678610

0.678651

0.678692

0.678732

0.678773

0.678814

0.678855

0.678896

.678916

0.678957

0.678978

0.678998

0.67903

0.679080

0.679100

0.679141

0.679182

0.67920

0.67924

0.679264

0.679285

.679325

0.679346

0.679387

0.679407

0.679448

0.679469

.679510

0.679530

0.679571

$34.400 \quad 34.187 \quad 33.975$

$\begin{array}{lllllll}46.539 & 46.325 & 46.111 & 45.899 & 45.686 & 45.473 & 45.260\end{array}$

$44.408 \quad 44.195 \quad 43.982 \quad 43.769 \quad 43.556 \quad 43.343 \quad 43.130$

$\begin{array}{lllllll}42.278 & 42.066 & 41.852 & 41.639 & 41.426 & 41.213 & 41.000 \\ 40.149 & 39.937 & 39.723 & 39.510 & 39.297 & 39.084 & 38.871\end{array}$

$\begin{array}{lllllll}38.020 & 37.807 & 37.593 & 37.381 & 37.168 & 36.955 & 36.742\end{array}$

6.8

2167.0

$67.0 \quad 46132.271$

$2.271 \quad 32.05900$

$28.015 \quad 29.931 \quad 29.7170$

$\begin{array}{lllll}25.887 & 25.802 & 27.589 & 27.377 & 27.164 \\ 25.676 & 25.467 & 25.249 & 25035\end{array}$

$\begin{array}{lllllllll} & 22.057 & 21.844\end{array}$

$\begin{array}{llllllllll}19.503 & 19.291 & 19.078 & 18.865 & 18.652 & 18.439 & 18.227 & 18.014 & 17.801 & 17.588\end{array}$

$\begin{array}{lllllllllll}17.376 & 17.164 & 16.951 & 16.738 & 16.525 & 16.312 & 16.100 & 15.887 & 15.674 & 15.462\end{array}$

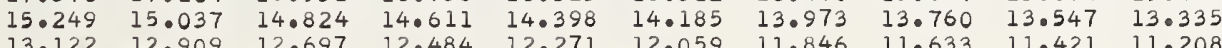

$\begin{array}{llllllllll}13.122 & 12.909 & 12.697 & 12.484 & 12.271 & 12.059 & 11.846 & 11.633 & 11.421 & 11.20 \\ & 12.09 & \end{array}$

$\begin{array}{rrrrrrrrrrr}2168.0 & 46110.995 & 10.783 & 10.570 & 10.357 & 10.145 & 09.932 & 09.719 & 09.507 & 09.294 & 09.081 \\ 8.1 & 08.868 & 08.657 & 08.444 & 08.231 & 08.018 & 07.806 & 07.593 & 07.380 & 07.167 & 06.955\end{array}$

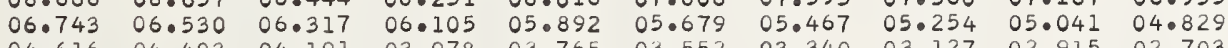
$\begin{array}{llllllllll}04.616 & 04.403 & 04.191 & 03.978 & 03.765 & 03.552 & 03.340 & 03.127 & 02.915 & 02.703\end{array}$ $02.490 \quad 02.278 \quad 02.066 \quad 01.853 \quad 01.640 \quad 01.427 \quad 01.215 \quad 01.002 \quad 00.790 \quad 00.577$ $00.36400 .152 * 99.939 * 99.726 * 99.514 * 99.301 * 99.089 * 98.876 * 98.664 * 98.451$

$\begin{array}{lllllllllll}46098.238 & 98.026 & 97.814 & 97.601 & 97.388 & 97.176 & 96.963 & 96.751 & 96.538 & 96.326\end{array}$ $\begin{array}{llllllllll}96.114 & 95.901 & 95.688 & 95.476 & 95.263 & 95.051 & 94.838 & 94.626 & 94.413 & 94.201 \\ 93.989 & 93.776 & 93.564 & 93.351 & 93.138 & 92.925 & 92.713 & 92.500 & 92.288 & 92.076\end{array}$

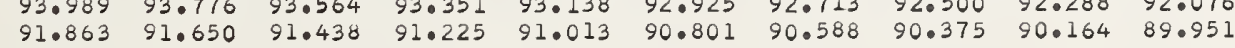

0.313849

0.313839

0.313829

0.313824

0.313819

0.313809

0.679592

0.679633

0.679674

0.679694

0.679715

0.679756
0.679776

0.313799
0.313794

0.313789

0.313784
0.313779

0.313774

0.313769

0.313759

0.313754

0.313749

0.313744
0.313739

0.013734

.0313724

0.313719

0.313714
0.313709

0.323704

0.679797

0.679817

0.679858
0.679879

0.679899

0.679920

0.679961

0.679981

.680002

0.680043

0.680063

0.680084

0.680125

.0680145

0.680166

0.680207

0.680227
.0680248

0.680268

0.680289

0.680330

0.680351

0.680371

0.313699

0.313694
0.313689

0.680412

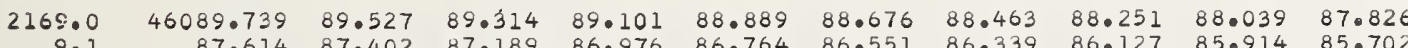
$\begin{array}{llllllllll}87.614 & 87.402 & 87.189 & 86.976 & 86.764 & 86.551 & 86.339 & 86.127 & 85.914 & 85.702 \\ 85.490 & 85.277 & 85.064 & 84.852 & 84.639 & 84.427 & 84.215 & 84.002 & 83.790 & 83.578\end{array}$

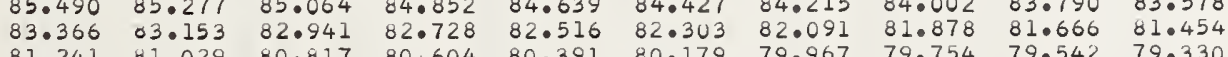
$\begin{array}{llllllllll}81.241 & 81.029 & 80.817 & 80.604 & 80.391 & 80.179 & 79.967 & 79.754 & 79.542 & 79.330\end{array}$ $\begin{array}{llllllllll}79.117 & 78.905 & 78.692 & 78.479 & 78.268 & 70.055 & 77.843 & 77.631 & 77.418 & 77.206 \\ 76.994 & 76.782 & 76.569 & 76.356 & 76.145 & 75.932 & 75.720 & 75.508 & 75.295 & 75.083\end{array}$ $\begin{array}{llllllllll}76.994 & 76.782 & 76.569 & 76.356 & 76.145 & 75.932 & 75.720 & 75.508 & 75.295 & 75.083 \\ 74.871 & 74.658 & 74.445 & 74.233 & 74.021 & 73.809 & 73.597 & 73.384 & 73.171 & 72.960\end{array}$

.0313684

0.313679

0.313669

0.313664

0.313659

0.680433

0.680474

0.680494

0.680515

0.680556

0.680577

0.680597

$\begin{array}{lllllllllll} & .001 & .002 & .003 & .004 & .005 & .006 & .007 & .008 & .009 & .010 \\ .215 & .021 & .043 & .064 & .086 & .0107 & .129 & .150 & .172 & .193 & .215 \\ .214 & .021 & .043 & .064 & .086 & .107 & .128 & .150 & .171 & .192 & .214 \\ .213 & .021 & .043 & .064 & .085 & .106 & .128 & .149 & .170 & .192 & .213 \\ .212 & .021 & .042 & .064 & .085 & .106 & .127 & .148 & .169 & .191 & .212\end{array}$


$\lambda(n-1)$

$\begin{array}{lllllllllll}2170.0 & 46068.501 & 68.290 & 68.077 & 67.864 & 67.652 & 67.440 & 67.228 & 67.016 & 66.803 & 66.591\end{array}$

$\begin{array}{lllllllllll}0.1 & 66.378 & 66.167 & 65.954 & 55.741 & 65.529 & 65.317 & 65.104 & 64.893 & 64.680 & 64.468\end{array}$

$\begin{array}{lllllllllll}0.2 & 64.257 & 64.044 & 63.832 & 63.620 & 63.407 & 63.195 & 62.983 & 62.771 & 62.559 & 62.347 \\ 0.3 & 62.134 & 61.922 & 61.709 & 61.497 & 61.285 & 61.072 & 60.861 & 60.648 & 60.436 & 60.224\end{array}$

$\begin{array}{llllllllllll}0.4 & 60.012 & 59.799 & 59.587 & 59.375 & 59.103 & 58.951 & 58.738 & 58.526 & 58.314 & 58.102\end{array}$

$\begin{array}{lllllllllll}0.5 & 57.890 & 57.679 & 57.460 & 57.253 & 57.042 & 55.829 & 56.617 & 56.405 & 56.193 & 55.980\end{array}$

$\begin{array}{lllllllllll}0.6 & 55.768 & 55.557 & 55.344 & 55.131 & 54.920 & 54.708 & 54.495 & 54.283 & 54.071 & 53.859\end{array}$

$\begin{array}{lllllllllll}0.7 & 53.647 & 53.434 & 53.222 & 53.010 & 52.798 & 52.585 & 52.374 & 52.162 & 51.949 & 51.738 \\ 0.8 & 51.526 & 51.314 & 51.102 & 50.889 & 50.677 & 50.465 & 50.253 & 50.041 & 49.829 & 49.617\end{array}$

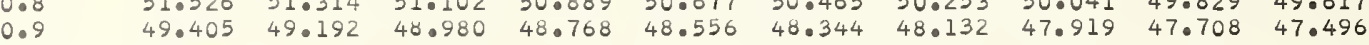

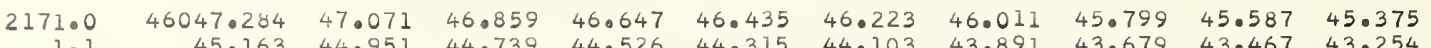

$\begin{array}{lllllllllll}1.1 & 45.163 & 44.951 & 44.739 & 44.526 & 44.315 & 44.103 & 43.891 & 43.679 & 43.467 & 43.254 \\ 1.2 & 43.043 & 42.830 & 42.618 & 42.406 & 42.194 & 41.982 & 41.771 & 41.558 & 41.346 & 41.134 \\ 1.3 & 40.922 & 40.709 & 40.498 & 40.286 & 40.074 & 39.861 & 39.650 & 39.437 & 39.226 & 39.014\end{array}$

$\begin{array}{llllll}40.922 & 40.709 & 40.498 & 40.286 & 40.074\end{array}$

$\begin{array}{llllllllll}38.803 & 38.590 & 38.378 & 38.166 & 37.954 & 37.742 & 37.530 & 37.318 & 37.106 & 36.895 \\ 36.682 & 36.470 & 36.258 & 36.046 & 35.834 & 35.622 & 35.410 & 35.199 & 34.986 & 34.774\end{array}$

1.6

$\begin{array}{llllllllll}34.562 & 14.350 & 34.130 & 33.926 & 33.714 & 33.502 & 33.290 & 33.079 & 32.867 & 32.654 \\ 32.444 & 32.231 & 32.019 & 31.807 & 31.595 & 31.383 & 31.172 & 30.959 & 30.748 & 30.536\end{array}$

\title{
8.
}

\section{4}

8.5
8.6

8.7
8.8

8.8
8.9

2179.0

9.1
9.2
9.3
9.4

9.4
9.5

9.6

46004.906 $02.790 \quad 04.69$

$00.674 \quad 00.462$

96.440

94.325
92.208

$87.978 \quad 87.767$

25.662
23.543
21.424
19.307
17.188
15.070
12.953
10.834
08.717
06.601

29.687

$31.595 \quad 31.383 \quad 31.172$

28.

$\begin{array}{llll}25.450 & 25.238 & 25.026 & 24.814 \\ 23.331 & 23.119 & 22.907 & 22.695\end{array}$

$\begin{array}{lll}21.212 & 21.000 \\ 19.095 & 18.883\end{array}$

14.858
12.741

$12.741 \quad 12.529$

08.506

12.529
10.412

18.070
16.553

14.435

$12.317 \quad 12.105$

18.459
16.341

14.223
12.105

04.483

06.177

\begin{abstract}
05.966
\end{abstract}

\begin{abstract}
07.871
05.754
\end{abstract}
24.603

22

$\begin{array}{lll}8.247 & 18.035 & 19.942\end{array}$

$\begin{array}{lll}16.129 & 15.917 & 15.706\end{array}$

$\begin{array}{lll}14.011 & 13.799 & 13.58\end{array}$ 85.062

45983.747

81.633
79.518

79.578

$\begin{array}{ll}77.403 & 77.1 \\ 75.290 & 75.078\end{array}$

$73.175 \quad 72.964$

$68.948 \quad 68.73$

$\begin{array}{ll}66.834 & 66.623 \\ 64.721 & 64.509\end{array}$

$\begin{array}{ll}60.495 & 60.2 \\ 58.382 & 58.1\end{array}$

$\begin{array}{lll}56.270 & 56.059 & 57.95 \\ 54.048\end{array}$

$\begin{array}{lll}54.157 & 53.946 & 53.735 \\ 52.045 & 51.834 & 51.623\end{array}$

$\begin{array}{lll}49.933 & 49.723 & 49.511\end{array}$

$\begin{array}{lll}47.822 & 47.611 & 47.399 \\ 45.710 & 45.499 & 45.286\end{array}$

$\begin{array}{lll}45.710 & 45.499 & 45.280 \\ 43.598 & 43.387 & 43.177\end{array}$

45941.487

$39 \cdot 376$
37.266

35.155

30.034

28.825

26.715

24.605
22.496

$45920 \cdot 387$

$\begin{array}{lll}20.387 & 20.176 & 19.965 \\ 18.277 & 18.067 & 17.855 \\ 16.169 & 15.958 & 15.747\end{array}$

$\begin{array}{lll}14.061 & 13.849 & 13.639 \\ 11.952 & 11.741 & 11.530\end{array}$

$\begin{array}{lll}09.844 & 09.633 & 09.422\end{array}$

$\begin{array}{lll}07.735 & 07.525 & 07.314\end{array}$

$\begin{array}{lll}05.627 & 05.417 & 05.206 \\ 03.521 & 03.310 & 03.099\end{array}$

01.413

$\begin{array}{lll}95.198 & 96.988 & 96.8777\end{array}$

$\begin{array}{lll}92.984 & 92.773 & 92.563\end{array}$

$90.878 \quad 90.667 \quad 90.458$

$\begin{array}{lll}88.771 & 88.562 & 88.351 \\ 86.665 & 86.455 & 86.244\end{array}$

$84.560-84.350$

$82.454 \quad 82.244 \quad 82.03$

5878.243

.24378 .033

$\begin{array}{lll}76.138 & 75.928 & 75.822\end{array}$

$71.929 \quad 73.82$

$69.824 \quad 69.018-71.50$

67.71967 .50967 .290

$65.615 \quad 65.405 \quad 65.195$

$63.51163 .301 \quad 63.090$

$\begin{array}{lll}61.407 & 61.197 & 60.987 \\ 59.304 & 59.093 & 58.884\end{array}$
04.271

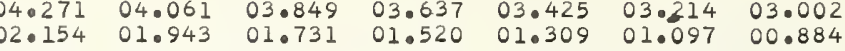

$90.03 * 99.827 * 99.615 * 99.404 * 99.192 * 98.980 * 98.770$

$\begin{array}{lllllll}95.806 & 95.594 & 97.383 & 97.288 & 97.076 & 96.864 & 96.652 \\ & 95.171 & 94.959 & 94.748 & 94.537\end{array}$

$\begin{array}{lllllll}93.690 & 93.479 & 93.267 & 93.056 & 92.844 & 92.633 & 92.421\end{array}$

$\begin{array}{lllllll}91.574 & 91.363 & 91.151 & 90.939 & 90.729 & 90.517 & 90.304\end{array}$

$\begin{array}{lllllll}89.458 & 89.247 & 89.035 & 88.824 & 88.613 & 88.401 & 88.190\end{array}$

$\begin{array}{lllllll}87.344 & 87.132 & 86.920 & 86.709 & 86.498 & 86.286 & 86.074 \\ 85.228 & 85.017 & 84.806 & 84.594 & 84.382 & 84.171 & 83.959\end{array}$

$\begin{array}{lllllll}83.113 & 82.902 & 82.690 & 82.479 & 82.268 & 82.056 & 81.844 \\ 80.999 & 80.788 & 80.576 & 80.364 & 80.153 & 79.941 & 79.729\end{array}$

$\begin{array}{llllllll}80.999 & 80.788 & 80.576 & 80.364 & 80.153 & 79.941 & 79.729\end{array}$

$\begin{array}{lllllll}78.834 & 78.672 & 73.461 & 78.250 & 78.038 & 77.827 & 77.615 \\ 74.655 & 74.558 & 76.346 & 76.135 & 75.924 & 75.712 & 75.500 \\ 74.234 & 74.233 & 74.021 & 73.810 & 73.599 & 73.387\end{array}$

$\begin{array}{lllllll}72.541 & 72.330 & 72.119 & 71.907 & 71.696 & 71.485 & 71.272\end{array}$

$\begin{array}{lllllll}70.427 & 70.216 & 70.004 & 69.793 & 69.582 & 69.370 & 69.158\end{array}$

$\begin{array}{lllllll}68.314 & 68.103 & 67.891 & 67.680 & 67.469 & 67.257 & 67.046\end{array}$

$\begin{array}{lllllll}66.201 & 65.989 & 65.777 & 65.567 & 65.355 & 65.144 & 64.932 \\ 64.087 & 63.875 & 63.665 & 63.453 & 63.242 & 63.030 & 62.819\end{array}$

$\begin{array}{lllllll}61.974 & 61.763 & 61.552 & 61.340 & 61.130 & 60.918 & 60.706\end{array}$

$\begin{array}{llllllll}59.861 & 59.650 & 59.439 & 59.228 & 59.017 & 58.805 & 58.593\end{array}$

$\begin{array}{lllllll}57.749 & 57.537 & 57.326 & 57.115 & 56.904 & 56.691 & 56.481 \\ 55.637 & 55.425 & 55.214 & 55.003 & 54.792 & 54.580 & 54.369\end{array}$

$\begin{array}{lllllll}53.524 & 53.312 & 53.102 & 52.891 & 52.679 & 52.468 & 52.256\end{array}$

$\begin{array}{lllllll}51.412 & 51.201 & 50.989 & 50.778 & 50.567 & 50.355 & 50.144\end{array}$

$\begin{array}{lllllll}49.300 & 49.089 & 48.878 & 48.667 & 48.456 & 48.244 & 48.033\end{array}$

$\begin{array}{lll}45.077 & 44.9766 & 44 \\ 42.966 & 42.754 & 42.5\end{array}$

40.854

40.64

44.654
42.54

44.443
42.333

44.232

4.021

43.810

0.313649

0.313639

0.313629

0.313624

0.313614

0.313609

0.313604

0.313599

0.313594

0.313584

0.313579

0.313569

0.313554

0.313549

0.00

0.313534

0.313529

0.313524

0.373515

0.313510

0.313500

0.313490

0.313485

0.313475

0.313470

0.313465

0.313460
0.313455

0.313450

0.313445

0.313440

0.313430

0.313426

0.313416

0.313411

0.313406

0.313401

0.313396

0.313386

0.313381

0.313376

0.313366

0.313361

0.313352
0.313347

0.313342

0.313337

0.313332

0.313327
0.313322

0.313317

0.313312

0.313302

0.313298

0.313288

0.313278
0.313273

0.313273

0.313268

0.313258

0.313253

0.313249

0.313244

0.313234

0.313229

0.313224

0.313219

0.313214
0.313209

0.313205

0.313200

0.313195

0.313190

0.313180

0.313175

0.313170

0.313161

0.680618

(580638

0.680659

0.680700

0.680720

0.680762

0.680782

0.680823

0.680823
0.680844

0.680864

0.680906

0.680926

0.680947

0.680967

0.680988

0.681008

0.681029

0.681050

0.681070

0.681111

0.681132

0.681152
0.681173

0.681194

0.681214 


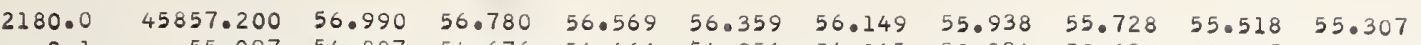

$\begin{array}{lllllllllll}0.1 & 55.097 & 54.887 & 54.676 & 54.466 & 54.256 & 54.045 & 53.834 & 53.625 & 53.415 & 53.205 \\ 0.2 & 52.995 & 52.784 & 52.574 & 52.364 & 52.153 & 51.943 & 51.732 & 51.522 & 51.312 & 51.0202\end{array}$

$\begin{array}{lllllllllll}0.3 & 50.892 & 50.681 & 50.471 & 50.261 & 50.050 & 49.839 & 49.629 & 49.419 & 49.208 & 48.999\end{array}$

$\begin{array}{llllllllllll}0.4 & 48.789 & 48.578 & 48.368 & 48.158 & 47.947 & 47.737 & 47.527 & 47.316 & 47.107 & 46.896 \\ 0.5 & 46.687 & 46.477 & 46.266 & 46.056 & 45.846 & 45.636 & 45.425 & 45.215 & 45.004 & 44.794\end{array}$

$\begin{array}{lllllllllll}0.6 & 44.583 & 44.374 & 44.164 & 43.953 & 43.744 & 43.533 & 43.322 & 43.112 & 42.902 & 42.692\end{array}$

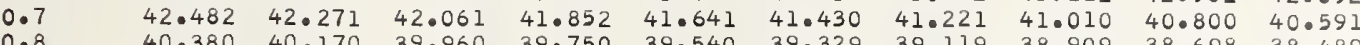
$\begin{array}{lllllllllll}0.8 & 40.380 & 40.170 & 39.960 & 39.750 & 39.540 & 39.329 & 39.119 & 38.909 & 38.698 & 38.489 \\ 0.8 & 38.278 & 38.068 & 37.858 & 37.648 & 37.438 & 37.228 & 37.017 & 36.807 & 36.597 & 36.387\end{array}$

35.757

$35.546 \quad 35.337$

37.228

i:

836.177
34.076 35.967

$\begin{array}{ll}31.975 & 31.765 \\ 29.874 & 29.665\end{array}$

$\begin{array}{ll}29.874 & 29.663 \\ 27.773 & 27.563\end{array}$

$\begin{array}{lll}31.556 & 33.445 & 33.236\end{array}$

35.126
33.025
30.923

34.916

34.706

$34.496 \quad 34.286$

$25.672 \quad 25.46$

$\begin{array}{lll}27.354 & 29.244 & 29.03\end{array}$

30.923
28.822

30.714

32.605
30.5
28.402

$32.395 \quad 32.185$

$\begin{array}{lll}27.354 & 27.143 & 26.933 \\ 25.25< & 25.042 & 24.83\end{array}$

26.723
24.622

28.613

28.402
26.302

$28.192 \quad 27.983$

$\begin{array}{lllll}21.473 & 21.262 & 21.052 & 22.942 & 22.732\end{array}$

$17.372 \quad 19.162$

21.052
18.953
16.853

$22.521 \quad 22.31$

24.202
22.102

$23.992 \quad 23.782$ 17.272

$\begin{array}{ll}20.843 & 20.632 \\ 18.742 & 18.532\end{array}$

$20.421 \quad 20.212$

20.002

2182.

$45815.172 \quad 14.963$ $10.974 \quad 12.864$ $08.875 \quad 08.665$ $\begin{array}{ll}06.776 & 06.566 \\ 04.678 & 04.468\end{array}$

$02.579 \quad 02.370$

政

14.543

16.43

16.22

$\begin{array}{rr}00.481 & 00.271 \\ 798.383 & 98.173\end{array}$

$\begin{array}{llll}14.753 & 14.543 & 14.333 & 14.123 \\ 12.654 & 12.443 & 12.234 & 12.023 \\ 10.554 & 10.345 & 10.134 & 09.924\end{array}$

$\begin{array}{llll}06.357 & 06.246 & 08.036 & 07.825\end{array}$

$\begin{array}{lllll}0.057 & 06.147 & 05.937 & 05.727 & 05.616\end{array}$

$02.160 \quad 01.950 \quad 01.741$

17.902
15.802

21.681

$19.792 \quad 19.583$

0.313156

0.313151

0.313141

0.313136

0.313126

0.313117

0.313107

0.313102

0.313092
0.313087

0.313083

0.313078

0.313063

0.313058

0.313049

0.313044

0.313034

0.313029
0.313024

0.313019

2183. 96.285

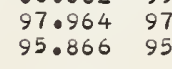

$9.852 * 99.6$

$\begin{array}{llllll}01.530 & 01.320 & 03.209 & 02.999 & 02.789\end{array}$

$01.11100 .901 \quad 00.691$

0.313015

0.313010

0.313005

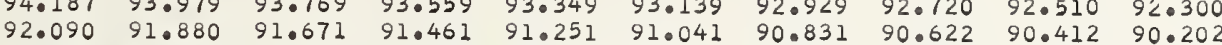

3.

$89.993 \quad 89.783$

$87.896 \quad 87.687$

$\begin{array}{lll}89.573 & 89.364 & 89.15\end{array}$

91.041
88.944

90.831
88.735

$\begin{array}{lll}90.622 & 90.412 & 90.202 \\ 88.525 & 88.315 & 88.106\end{array}$

$83.702 \quad 83.493$

$\begin{array}{ll}85.380 & 85.170 \\ 83.283 & 83.07\end{array}$

87.057
84.959

84.750
82.654

$84.541 \quad 86.428 \quad 86.218 \quad 86.009$

$\begin{array}{ll}81.606 & 81.396 \\ 79.510 & 79.300\end{array}$

$\begin{array}{ll}81.187 & 80.977 \\ 79.090 & 78.88\end{array}$

$\begin{array}{ll}82.863 & 82.654 \\ 80.767 & 80.55\end{array}$

$82.444 \quad 82.235 \quad 82.025 \quad 81.815$

3.7

3.8
3.9

$\begin{array}{ll}77.414 & 77.204 \\ 75.318 & 75.108\end{array}$

2184

i:

45773

$773.222 \quad 73.013$

79.095
74.8959
74.899

$\begin{array}{lllllll}76.671 & 70.461 & 78.252 & 78.042 & 77.832 & 77.623\end{array}$

0.3129

0.312990

0.31298

0.312976

0.312966

0.312961

0.312956

0.312947

0.312942

0.312932

$\begin{array}{llllllllll}62.746 & 62.537 & 62.328 & 62.118 & 61.908 & 61.699 & 61.489 & 61.280 & 61.070 & 60.861 \\ 60.651 & 60.442 & 60.233 & 60.023 & 59.813 & 59.604 & 59.395 & 59.186 & 58.976 & 58.766\end{array}$

68.65160 .442

$\begin{array}{llll}58.557 & 58.348 & 58.138 & 57 . \\ 56.463 & 56.254 & 56.045 & 55.1 \\ 54.369 & 54.160 & 53.951 & 50 .\end{array}$

$\begin{array}{ll}60.023 & 59.813 \\ 57.929 & 57.719\end{array}$

2185.0

5.

$\begin{array}{ll}52.06 \\ 182 & 49.973 \\ .08 & 47.879\end{array}$

51.85
49.76

53.531

$55.416 \quad 55.20$

$\begin{array}{lll}57.091 & 56.882 & 56.673 \\ 5.0997 & 54.788 & 54.579\end{array}$

0.312918

0.312913

0.312908

0.312899

0.312894

0.031287

0.312874

5.8
5.9

$41.809 \quad 41.600 \quad 41.391$

$43.274 \quad 43.064$

$\begin{array}{lllll} & \end{array}$

42.855

$\begin{array}{lllll}42.646 & 42.437 & 42.228 & 42.019\end{array}$

$\begin{array}{llllllllll}39.716 & 39.507 & 39.298 & 39.088 & 38.879 & 38.669 & 38.460 & 38.251 & 38.042 & 37.833\end{array}$

$\begin{array}{llllllllll}35.532 & 35.323 & 35.206 & 36.997 & 36.787 & 36.578 & 36.369 & 36.160 & 35.950 & 35.741 \\ & 34.904 & 34.694 & 34.485 & 34.276 & 34.067 & 33.857 & 33.649\end{array}$

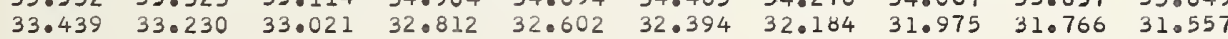

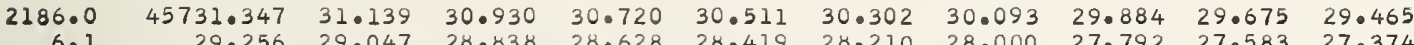

$\begin{array}{lllllllllll}6.1 & 29.256 & 29.047 & 28.838 & 28.628 & 28.419 & 28.210 & 28.000 & 27.792 & 27.583 & 27.374\end{array}$

$\begin{array}{lllllllllll}6.2 & 27.165 & 26.956 & 26.746 & 26.537 & 26.328 & 25.118 & 25.910 & 25.700 & 25.491 & 25.282 \\ 6.3 & 25.073 & 24.864 & 24.656 & 24.446 & 24.237 & 24.027 & 23.819 & 23.609 & 23.400 & 23.191\end{array}$

6.3

$25.073 \quad 24.864 \quad 24.656 \quad 24.446 \quad 24.237$

$\begin{array}{lllll}22.982 & 22.773 & 22.564 & 22.354 & 22.145 \\ 20.891 & 20.683 & 20.473 & 20.263 & 20.055 \\ 18.800 & 18.591 & 18.382 & 18.173 & 17.964\end{array}$

6.5

6.6

$\begin{array}{llllll}16.710 & 16.501 & 16.292 & 16.083 & 17.964\end{array}$

$\begin{array}{lll}14.620 & 14.411 & 14.202 \\ 12.529 & 12.320 & 12.111\end{array}$

$16.083 \quad 15.874$

24.027

$\begin{array}{llll}23.819 & 23.609 & 23.400 & 23.191\end{array}$

0.312865

0.312860

0.312855

0.312846

0.312841

0.312831

0.312826

0.312817

$\begin{array}{lllllllllll}2187.0 & 45710.439 & 10.231 & 10.022 & 09.812 & 09.604 & 09.395 & 09.185 & 08.977 & 08.768 & 08.559\end{array}$

$\begin{array}{lllllllllll}7.1 & 08.350 & 08.141 & 07.932 & 07.722 & 07.514 & 07.304 & 07.095 & 06.887 & 06.678 & 06.469\end{array}$

$\begin{array}{lllllllllll}7.2 & 0.260 & 06.051 & 05.841 & 05.633 & 05.424 & 05.215 & 05.007 & 04.798 & 04.588 & 04.380 \\ 7.3 & 04.171 & 03.962 & 03.753 & 03.544 & 03.334 & 03.125 & 02.917 & 02.708 & 02.499 & 02.291\end{array}$

$\begin{array}{lllllllllll}7.3 & 04.171 & 03.962 & 03.753 & 03.544 & 03.334 & 03.125 & 02.917 & 02.708 & 02.499 & 02.291 \\ 7.4 & 02.082 & 01.873 & 01.664 & 01.454 & 01.245 & 01.037 & 00.828 & 00.619 & 00.410 & 00.201 \\ 7.5 & 99.992 & 99.784 & 99.574 & 99.365 & 99.157 & 98.947 & 98.739 & 98.531 & 98.322 & 98.113\end{array}$

7.5

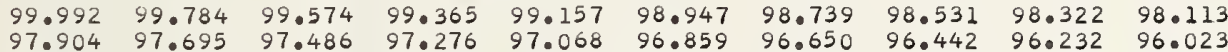

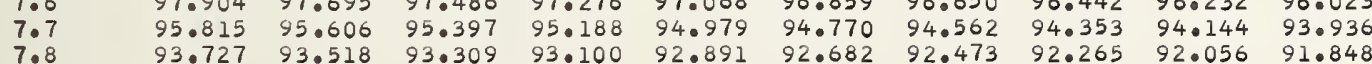

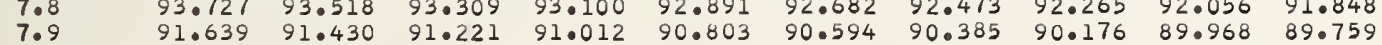

$\begin{array}{lllllllllll}2188.0 & 45689.550 & 89.342 & 89.133 & 88.923 & 88.715 & 88.506 & 88.297 & 88.089 & 87.880 & 87.671\end{array}$

$\begin{array}{lllllllllll}8.1 & 87.462 & 87.253 & 87.044 & 86.835 & 86.627 & 86.418 & 86.209 & 86.000 & 85.792 & 85.583\end{array}$

$\begin{array}{lllllllllll}8.2 & 85.375 & 85.167 & 84.958 & 84.749 & 84.540 & 84.331 & 84.123 & 83.914 & 83.705 & 83.496 \\ 8.3 & 83.288 & 83.079 & 82.870 & 82.661 & 82.452 & 82.243 & 82.035 & 81.826 & 81.617 & 81.409\end{array}$

$\begin{array}{lllllllllll}8.4 & 81.200 & 80.991 & 80.782 & 80.573 & 80.364 & 80.156 & 79.947 & 79.738 & 79.530 & 79.321 \\ 8.5 & 79.213 & 78.905 & 78.686 & 78.486 & 78.278 & 78.069 & 77.860 & 77.652 & 77.443 & 77.234\end{array}$

$\begin{array}{lllllllllll}8.5 & 79.113 & 78.905 & 78.696 & 78.486 & 78.278 & 78.069 & 77.860 & 77.652 & 77.443 & 77.234 \\ 8.6 & 77.026 & 76.817 & 76.608 & 76.399 & 76.191 & 75.982 & 75.773 & 75.565 & 75.356 & 75.0147\end{array}$

$\begin{array}{lllllllllll}8.6 & 77.026 & 76.817 & 76.608 & 76.399 & 76.191 & 75.982 & 75.773 & 75.565 & 75.356 & 75.147 \\ 8.7 & 74.939 & 74.730 & 74.521 & 74.313 & 74.104 & 73.895 & 73.687 & 73.478 & 73.0270 & 73.061\end{array}$

$\begin{array}{llllllllllll}8.7 & 74.939 & 74.730 & 74.521 & 74.313 & 74.104 & 73.895 & 73.687 & 73.478 & 73.270 & 73.061 \\ 8.8 & 72.853 & 72.644 & 72.436 & 72.227 & 72.018 & 71.809 & 71.601 & 71.392 & 71.183 & 70.975\end{array}$ $\begin{array}{lllllllllll}8.8 & 72.853 & 72.644 & 72.436 & 72.227 & 72.018 & 71.809 & 71.601 & 71.392 & 71.183 & 70.975 \\ 8.9 & 70.766 & 70.556 & 70.349 & 70.140 & 69.931 & 69.723 & 69.514 & 69.306 & 69.097 & 68.889\end{array}$

2189.0

$\begin{array}{lllll}67.637 & 67.428 & 67.220 & 67.011 & 66.802\end{array}$

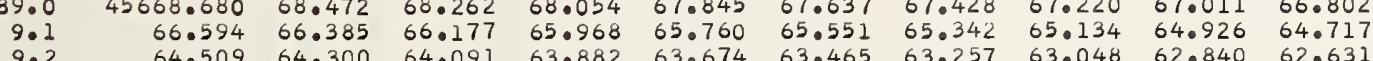

$\begin{array}{lllllllllll}9.2 & 64.509 & 64.300 & 64.091 & 63.882 & 63.674 & 63.465 & 63.257 & 63.048 & 62.840 & 62.631 \\ 9.3 & 62.423 & 62.214 & 62.005 & 61.797 & 61.588 & 61.379 & 61.171 & 60.962 & 60.754 & 60.546\end{array}$

(9.6)

$62.423 \quad 62.21462 .005 \quad 61.797 \quad 61.58$

$\begin{array}{llllllllll}60.337 & 60.128 & 59.920 & 59.711 & 59.503 & 59.295 & 59.086 & 58.877 & 58.669 & 58.461\end{array}$

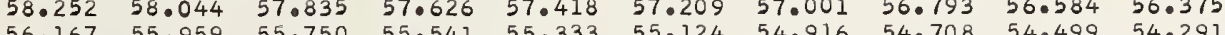

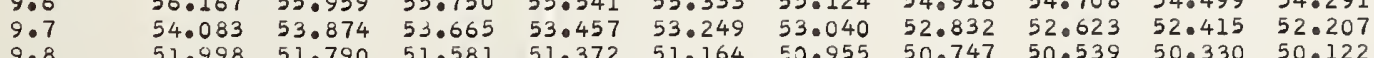

9.8

$49.913 \quad 49.705$

$\begin{array}{lll}53.665 & 53.457 & 53.249 \\ 51.581 & 51.372 & 51.164 \\ 49.496 & 49.288 & 49.079\end{array}$

50.747

$0.53950 .330 \quad 50.122$

0.3128

0.312807

0.312802

0.312793

0.312788

0.312783

0.312778

0.312769

0.312764

0.312759

0.312749

0.312745

0.312735

0.312730

0.312721

0.312716

0.312706

0.312702

0.312697

0.312687

0.312682

0.682679

0.682721

0.682762

0.682783

0.682803
0.682824

0.682845
0.682866

0.682886

0.682907

0.682948

0.682969

0.683010

0.683031

0.683072

0.683093

0.683135

0.683155

0.683176

0.68321

0.683238

0.683259

0.683300

0.683321

0.683362

0.683383

.683425

0.683445

0.683466
0.683487

0.683508

0.683528
0.683549

0.68357

0.683590

0.683611

0.683653

0.683673

0.683715

0.683736

0.683756

0.683798

0.683819

0.683839

0.683860

0.683902

0.683922

0.683943

0.683964 


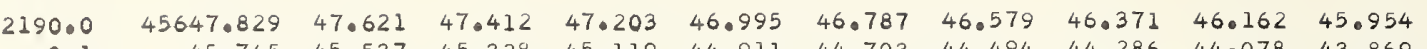
$\begin{array}{llllllllllll}0.1 & 45.745 & 45.537 & 45.328 & 45.119 & 44.911 & 44.703 & 44.494 & 44.286 & 44.078 & 43.869 \\ 0.2 & 43.661 & 43.453 & 43.244 & 43.036 & 42.827 & 42.619 & 42.411 & 42.202 & 41.994 & 41.786\end{array}$ $0.3 \quad 41.57741 .36941 .16040 .95240 .743 \quad 40.53540 .328 \quad 40.119 \quad 39.911 \quad 39.703$

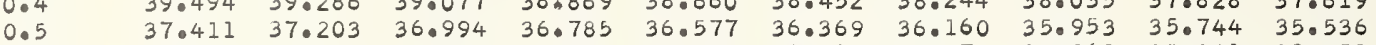

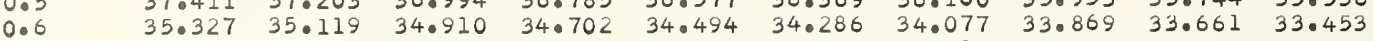
$\begin{array}{lllllllllll}0.7 & 33.245 & 33.037 & 32.828 & 32.620 & 32.411 & 32.203 & 31.995 & 31.787 & 31.578 & 31.371\end{array}$ 0.9 $\begin{array}{lll}31.162 & 30.954 & 30.745 \\ 29.079 & 28.871 & 28.662\end{array}$ $\begin{array}{lllll}26.997 & 26.790 & 26.581 & 20.372 & 26.164 \\ 24.915 & 24.707 & 24.498 & 24.290 & 24.082 \\ 22.833 & 22.625 & 22.416 & 22.208 & 22.000\end{array}$ $\begin{array}{llllllllll}22.833 & 22.625 & 22.416 & 22.208 & 22.000 & 21.791 & 21.583 & 21.375 & 21.167 & 20.959 \\ 20.751 & 20.543 & 20.330 & 20.126 & 19.918 & 19.710 & 19.502 & 19.294 & 19.085 & 18.878 \\ 18.669 & 18.461 & 18.253 & 18.044 & 17.836 & 17.629 & 17.440 & 17.212 & 17.004 & 16.796\end{array}$

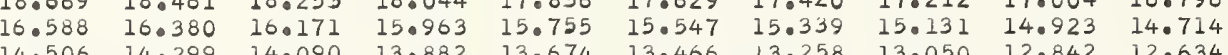
$\begin{array}{llllllllll}14.506 & 14.299 & 14.090 & 13.882 & 13.674 & 13.466 & 13.258 & 13.050 & 12.842 & 12.634 \\ 12.426 & 12.218 & 12.009 & 11.801 & 11.593 & 11.385 & 11.177 & 10.969 & 10.761 & 10.553\end{array}$ $\begin{array}{llllllllll}10.345 & 10.137 & 09.929 & 09.720 & 09.512 & 09.304 & 09.096 & 08.888 & 08.680 & 08.472 \\ 08.264 & 08.055 & 07.848 & 07.640 & 07.432 & 07.224 & 07.016 & 06.808 & 06.600 & 06.392\end{array}$ 4. 10405.977 $02.023 \quad 01.81503 .687$ $99.944 \quad 99.736 \quad 99.52$ $\begin{array}{lll}97.864 & 97.655 & 97.448 \\ 95.784 & 95.576 & 95.368\end{array}$ $93.705 \quad 93.498 \quad 93.289$ $\begin{array}{lll}91.626 & 91.417 & 91.209 \\ 89.547 & 89.338 & 89.13\end{array}$ 87.261

$\begin{array}{rl}564.614 & 64.407 \\ 62.538 & 62.330\end{array}$ $60.462 \quad 60.330 \quad 62.1236$ $58.386 \quad 58.178 \quad 50.046$ $\begin{array}{lllll}56.310 & 56.101 & 55.894 & 55.687\end{array}$ $\begin{array}{lllll}54.234 & 54.026 & 53.819 & 53.611\end{array}$

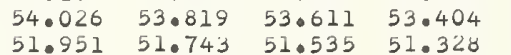
$\begin{array}{llllll}50.083 & 49.875 & 49.667 & 49.460 & 49.252 & 49 .\end{array}$ $\begin{array}{lllll}48.009 & 47.800 & 47.593 & 47.386 & 470 \\ 45.933 & 45.725 & 45.518 & 45.311\end{array}$ 5543.8
41.7
39.7 $\begin{array}{lll}41.784 & 41.650 & 43.4 \\ 39.710 & 41.36\end{array}$ $\begin{array}{lll}37.635 & 37.027 & 39.29\end{array}$ $\begin{array}{lll}35.562 & 35.354 & 35.146\end{array}$ $\begin{array}{lll}33.487 & 33.280 & 33.07\end{array}$ $29.341 \quad 29.133 \quad 26.925$ $\begin{array}{lll}27.268 & 27.059 & 26.853 \\ 25.194 & 24.986 & 24.779\end{array}$ 22.914 $18.976 \quad 18.768 \quad 18.63$ $16.903 \quad 16.695 \quad 16.489$ $\begin{array}{lll}14.832 & 14.624 & 14.417 \\ 12.759 & 12.552 & 12.345\end{array}$ $10.687 \quad 10.480 \quad 10.273$ $\begin{array}{lll}08.617 & 08.409 & 08.202 \\ 06.545 & 06.337 & 06.130\end{array}$ $\begin{array}{lll}06.545 & 06.337 & 06.130 \\ 04.474 & 04.266 & 04.059\end{array}$ $43.235 \quad 43.028 \quad 42$. 41.0161
39.08 34.939

\section{$32.865 \quad 32.658$}

$$
\begin{array}{ll}
05.352 \\
03.271 \\
01.191
\end{array}
$$

政

$05.144 \quad 04.936 \quad 04.728 \quad 04.52004 .312$ $\begin{array}{lllll}0.063 & 02.855 & 02.647 & 02.439 & 02.231\end{array}$ $\begin{array}{lllllll}01.399 & 01.191 & 00.983 & 00.776 & 00.568 & 00.360 & 00.152 \\ 99.320 & 99.111 & 98.903 & 98.696 & 98.488 & 98.280 & 98.072\end{array}$ $\begin{array}{rllllll}97.240 & 97.032 & 96.824 & 96.616 & 96.408 & 96.200 & 95.992 \\ 95.160 & 94.952 & 94.745 & 94.537 & 94.330 & 94.121 & 93.913\end{array}$ $\begin{array}{lllllll}93.081 & 92.874 & 92.666 & 92.458 & 92.250 & 92.042 & 91.834\end{array}$ $\begin{array}{lllllll}81.002 & 90.794 & 90.586 & 90.378 & 90.170 & 89.962 & 89.755 \\ 88.923 & 88.715 & 88.507 & 88.299 & 88.092 & 87.884 & 87.677\end{array}$ $\begin{array}{lllllll}84.766 & 84.559 & 84.351 & 84.143 & 83.935 & 83.727 & 83.519\end{array}$ \begin{tabular}{lllllll}
82.687 & 82.479 & 82.272 & 82.064 & 81.856 & 81.649 & 81.441 \\
\hline
\end{tabular} $\begin{array}{lllllll}80.610 & 80.402 & 80.194 & 79.987 & 79.779 & 79.571 & 79.363 \\ 78.532 & 78.324 & 78.116 & 77.909 & 77.701 & 77.493 & 77.285\end{array}$ $\begin{array}{lllllll}76.454 & 76.246 & 76.039 & 75.831 & 75.623 & 75.415 & 75.208 \\ 74.376 & 74.109 & 73.961 & 73.753 & 73.546 & 73.338 & 73.030\end{array}$ $\begin{array}{lllllll}72.299 & 72.091 & 71.883 & 71.676 & 71.468 & 71.261 & 71.053\end{array}$ $\begin{array}{lllllll}70.222 & 70.014 & 69.806 & 69.599 & 69.391 & 69.183 & 68.976\end{array}$ $\begin{array}{lllllll}66.068 & 65.860 & 65.053 & 65.445 & 65.237 & 65.030 & 64.822\end{array}$ 5502.403 300.332 $02.196 \quad 01.0988$ $\begin{array}{lllll}34.5924 & 36.3917 & 36.183 & 35.976 & 35.769 \\ 34.009 & 33.902 & 33.695\end{array}$ $\begin{array}{lllllll}26.645 & 26.437 & 26.230 & 26.023 & 25.816 & 25.608 & 25.401 \\ 24.572 & 24.364 & 24.157 & 23.950 & 23.743 & 23.536 & 23.328\end{array}$

0.685170

0.312568

0.312563

0.312558

0.312554

0.312544

0.312539
0.312535

0.685191

0.685211

0.685253

0.685274

0.685295

0.685316

0.685336
0.685357

0.312530

0.312525

0.312516

0.312511

0.312497

0.312492
0.312487

0.685378

0.685420

0.685441

0.685462

0.685503

0.685524

0.685545
0.685566

0.312483

0.312473

0.312468

0.312464

0.312459

0.312454

0.312445

0.312440

0.312435

0.312430

0.312421

0.312416

0.312407

0.312402

0.312397

0.685587

0.685628

0.685628

0.685670

0.685691

0.685712

0.685753

0.685753

0.312388

0.312383

0.312378

0.312374

0.312364

0.312360

0.312350

0.685795

0.685816

0.685858

0.685879

0.685920

0.685941

0.685962

0.685983

0.686004 0.686025 0.686046 0.686066 0.686087 0.686108 0.686129 0.686150 0.686171

0.312341

0.6866313 0.312336

0.312331

0.312322
0.312317

0.312317

0.312313

0.312303 $\begin{array}{llllllllll}87.912 & 89.773 & 89.566 & 89.359 & 89.153 & 88.946 & 88.739 & 88.532 & 88.325 & 88.110 \\ 87.704 & 87.497 & 87.290 & 87.083 & 86.876 & 86.669 & 86.462 & 86.255 & 86.049\end{array}$

$\begin{array}{llllllllll}85.842 & 85.634 & 85.427 & 85.220 & 85.013 & 84.806 & 84.600 & 84.393 & 84.186 & 83.979 \\ 83.772 & 83.565 & 83.358 & 83.151 & 82.944 & 82.738 & 82.531 & 82.324 & 82.117 & 81.910\end{array}$

0.312298

0.312294

0.312284

0.312280

0.312275

0.312266

0.312261

0.312251

0.686234

0.686275

0.686296

0.686317

0.686338

0.686359

0.686380

0.686422

0.686442

0.686484

0.686505
0.686526

0.686547

0.686568

0.686610 


.02

.03

.04

.05

.06

.07

.08

.09

$\begin{array}{lllll}5440.360 & 40.153 & 39.947 & 39.740 & 39.534\end{array}$

$\begin{array}{lllllllllll}0.1 & 38.295 & 38.088 & 37.881 & 37.675 & 37.469 & 37.263 & 37.056 & 36.850 & 36.644 & 36.437\end{array}$

$\begin{array}{llllllllllll}0.2 & 36.230 & 36.023 & 35.817 & 35.611 & 35.404 & 35.197 & 34.992 & 34.785 & 34.578 & 34.372 \\ 0.3 & 34.166 & 33.958 & 33.752 & 33.546 & 33.339 & 33.192 & 32.926 & 32.720 & 32.513 & 32.307\end{array}$

$\begin{array}{lllllllllll}0.4 & 32.101 & 31.894 & 31.687 & 31.481 & 31.274 & 31.068 & 30.862 & 30.656 & 30.450 & 30.243\end{array}$

$\begin{array}{lllllllllll}0.5 & 30.037 & 29.830 & 29.624 & 29.417 & 29.211 & 29.004 & 28.798 & 28.592 & 28.385 & 28.179 \\ 0.6 & 27.972 & 27.766 & 27.559 & 27.352 & 27.146 & 26.940 & 26.733 & 26.527 & 26.321 & 26.114\end{array}$

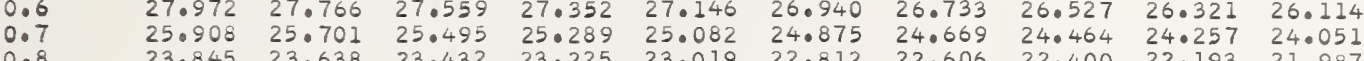

$\begin{array}{lllllllllll}0.8 & 23.845 & 23.638 & 23.432 & 23.225 & 23.019 & 22.812 & 22.606 & 22.400 & 22.193 & 21.987 \\ 0.9 & 21.781 & 21.574 & 21.360 & 21.161 & 20.955 & 20.749 & 20.542 & 20.336 & 20.130 & 19.923\end{array}$

2201.0

$\begin{array}{lrllll}01.0 & 45419.717 & 19.510 & 19.304 & 19.098 & 18.892 \\ 1.1 & 17.654 & 17.447 & 17.241 & 17.035 & 16.829 \\ 1.2 & 15.591 & 15.384 & 15.170 & 14.972 & 14.705 \\ 1.3 & 13.528 & 13.321 & 13.115 & 12.909 & 12.702 \\ 1.4 & 11.465 & 11.258 & 11.053 & 10.846 & 10.640 \\ 1.5 & 09.403 & 09.196 & 08.990 & 08.783 & 08.578 \\ 1.6 & 07.340 & 07.134 & 06.927 & 06.721 & 06.515 \\ 1.7 & 05.278 & 05.071 & 04.865 & 04.660 & 04.453 \\ 1.8 & 03.216 & 03.009 & 02.804 & 02.597 & 02.391 \\ 1.9 & 01.154 & 00.947 & 00.742 & 00.535 & 00.329\end{array}$

$\begin{array}{lllllll}19.098 & 18.892 & 18.685 & 18.479 & 18.273 & 18.066 & 17.860 \\ 17.035 & 16.829 & 16.622 & 16.416 & 16.210 & 16.003 & 15.797\end{array}$

$\begin{array}{lllllll}17.035 & 16.829 & 16.622 & 16.416 & 16.210 & 16.003 & 15.797 \\ 14.972 & 14.765 & 14.559 & 14.353 & 14.146 & 13.940 & 13.734\end{array}$

$\begin{array}{lllllll}12.909 & 12.702 & 12.496 & 12.290 & 12.083 & 11.877 & 11.671\end{array}$

$\begin{array}{lllllll}10.846 & 10.640 & 10.434 & 10.228 & 10.021 & 09.815 & 09.609 \\ 08.783 & 08.578 & 08.371 & 08.165 & 07.959 & 07.753 & 07.546\end{array}$

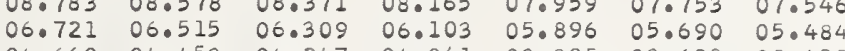

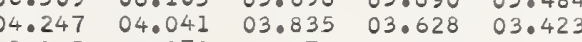

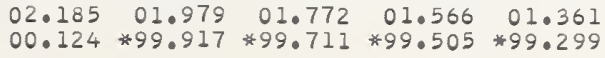

0.312200

0.686840

0.312191

.312181

0.312177

0.312167

0.312163
0.312158

0.68688

0.68694

0.686965

0.686986

0.687028

0.312153

.

0.312139

0.312130

0.312125

0.312116

2202 .

2

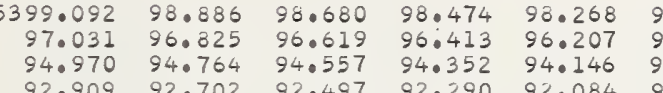

$\begin{array}{lllll}98.062 & 97.856 & 97.650 & 97.444 & 97.238\end{array}$

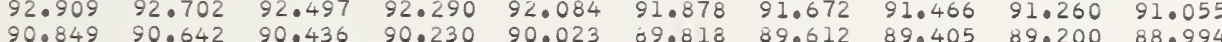

$\begin{array}{lllllllllll}2.4 & 90.849 & 90.642 & 90.436 & 90.230 & 90.023 & 89.818 & 89.612 & 89.405 & 89.200 & 88.994\end{array}$

$\begin{array}{llllllllllll}2.5 & 88.788 & 80.581 & 80.375 & 88.169 & 85.902 & 85.696 & 85.490 & 85.285 & 85.079 & 84.873\end{array}$

$\begin{array}{lllllllllll}2.7 & 84.667 & 84.460 & 84.254 & 84.049 & 83.843 & 83.636 & 83.431 & 83.225 & 83.019 & 82.813\end{array}$

$\begin{array}{lllllllllll}2.8 & 82.607 & 82.400 & 80.194 & 81.988 & 81.782 & 81.576 & 81.371 & 81.165 & 80.958 & 80.753 \\ 2.9 & 80.546 & 80.340 & 80.134 & 79.928 & 79.722 & 79.517 & 79.311 & 79.104 & 78.899 & 78.693\end{array}$

$\begin{array}{rrrrrrrrrrr}2203.0 & 45378.486 & 78.282 & 78.075 & 77.869 & 77.664 & 77.457 & 77.251 & 77.045 & 76.839 & 76.633\end{array}$

$\begin{array}{llllllllllll}3.1 & 76.427 & 76.221 & 76.015 & 75.809 & 75.604 & 75.397 & 75.191 & 74.986 & 74.780 & 74.574 \\ 3.2 & 74.368 & 74.162 & 73.956 & 73.750 & 73.544 & 73.338 & 73.132 & 72.926 & 72.720 & 72.515\end{array}$

$\begin{array}{lllllllllll}3.3 & 72.309 & 72.102 & 71.896 & 71.691 & 71.485 & 71.279 & 71.074 & 70.868 & 70.662 & 70.456\end{array}$

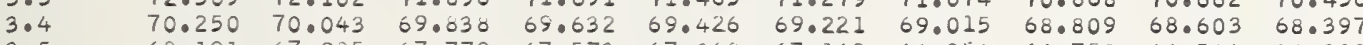

$\begin{array}{lllllllllll}3.5 & 68.191 & 67.985 & 67.779 & 67.573 & 67.368 & 67.162 & 66.956 & 66.750 & 66.544 & 66.338\end{array}$

$\begin{array}{lllllllllll}3.6 & 66.132 & 65.926 & 65.720 & 65.514 & 65.309 & 65.104 & 64.897 & 64.692 & 64.486 & 64.280\end{array}$

$\begin{array}{lllllllllll}3.7 & 64.075 & 63.869 & 63.662 & 63.457 & 63.250 & 63.044 & 62.839 & 62.633 & 62.427 & 62.222 \\ 3.8 & 62.016 & 61.810 & 61.604 & 61.398 & 61.192 & 60.986 & 00.781 & 60.575 & 60.369 & 60.164\end{array}$

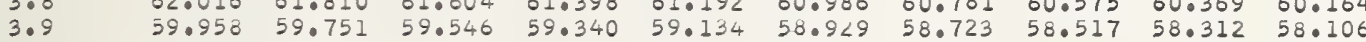

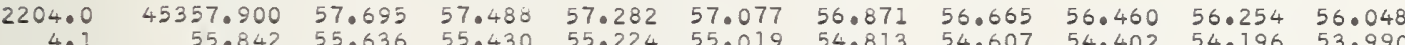

$\begin{array}{lllllllllll}4.1 & 55.842 & 55.636 & 55.430 & 55.224 & 55.019 & 54.813 & 54.607 & 54.402 & 54.196 & 53.990 \\ 4.2 & 53.785 & 53.578 & 53.373 & 53.167 & 52.961 & 52.755 & 52.550 & 52.344 & 52.138 & 51.934\end{array}$

$\begin{array}{lllllllllll}4.2 & 53.785 & 53.578 & 53.373 & 53.167 & 52.961 & 52.755 & 52.550 & 52.344 & 52.138 & 51.934 \\ 4.3 & 51.728 & 51.522 & 51.316 & 51.110 & 50.904 & 50.699 & 50.493 & 50.288 & 50.082 & 49.876\end{array}$

$\begin{array}{lllllllllll}4.3 & 51.728 & 51.522 & 51.316 & 51.110 & 50.904 & 50.699 & 50.493 & 50.288 & 50.082 & 49.876 \\ 4.4 & 49.670 & 49.464 & 49.259 & 49.053 & 48.847 & 48.642 & 48.436 & 48.230 & 48.025 & 47.819\end{array}$

$\begin{array}{lllllllllll}4.5 & 47.613 & 47.407 & 47.20< & 46.996 & 46.791 & 46.584 & 46.379 & 46.174 & 45.968 & 45.762 \\ 4.6 & 45.556 & 45.352 & 45.145 & 44.939 & 44.734 & 44.528 & 44.3<2 & 44.117 & 43.912 & 43.706\end{array}$

$\begin{array}{lllllllllll}4.6 & 45.556 & 45.352 & 45.145 & 44.939 & 44.734 & 44.528 & 44.3<2 & 44.117 & 43.912 & 43.706 \\ 4.7 & 43.500 & 43.295 & 43.086 & 42.803 & 42.677 & 42.472 & 42.266 & 42.061 & 41.855 & 41.649\end{array}$

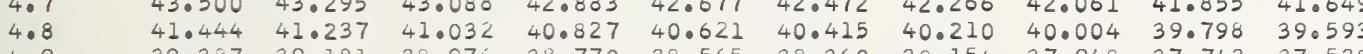

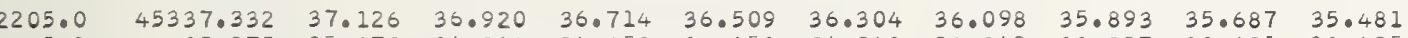

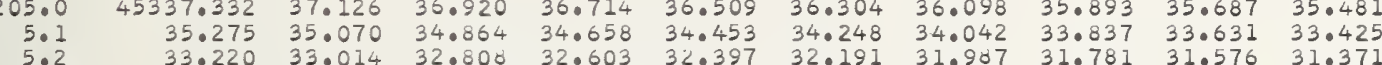

$\begin{array}{lllllllllll}5.2 & 33.220 & 33.014 & 32.800 & 32.603 & 32.397 & 32.191 & 31.987 & 31.781 & 31.576 & 31.371 \\ 5.3 & 31.165 & 30.959 & 30.753 & 30.548 & 30.342 & 30.137 & 29.932 & 29.726 & 29.520 & 29.315\end{array}$

$\begin{array}{llllllllll}28.904 & 28.698 & 28.493 & 28.287 & 28.082 & 27.876 & 27.670 & 27.465 & 27.0260\end{array}$

$\begin{array}{lllllllllll}5.5 & 27.054 & 26.849 & 20.643 & 26.437 & 26.232 & 26.026 & 25.821 & 25.616 & 25.411 & 25.205 \\ 5.6 & 25.000 & 24.794 & 24.580 & 24.383 & 24.178 & 23.972 & 23.766 & 23.562 & 23.356 & 23.150\end{array}$

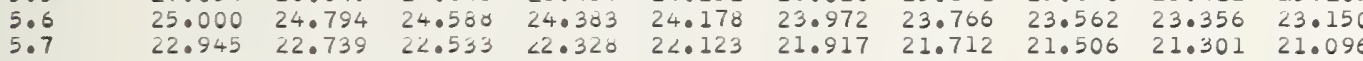

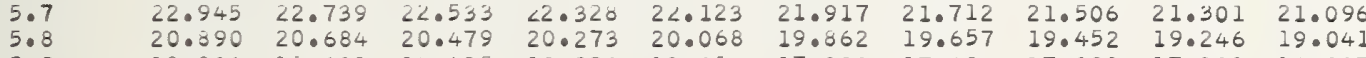

5.9

18.836

2206.

6.
6.
6.
6.
6.
6.
6.
6.

2207

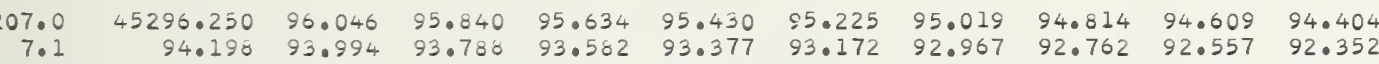

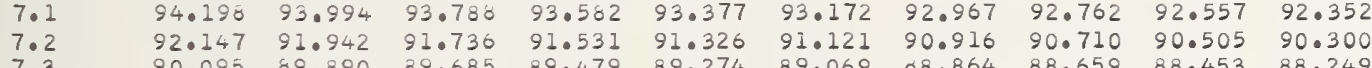

$\begin{array}{lllllllllll}7.3 & 90.095 & 89.890 & 89.685 & 89.479 & 89.274 & 89.069 & 08.864 & 88.659 & 88.453 & 88.249\end{array}$

$\begin{array}{lllllllllll}7.4 & 88.043 & 87.838 & 87.633 & 87.427 & 87.222 & 87.018 & 86.812 & 86.607 & 86.402 & 86.197\end{array}$

$\begin{array}{lllllllllll}7.5 & 85.992 & 85.787 & 85.582 & 85.376 & 85.172 & 84.966 & 84.761 & 84.557 & 84.352 & 84.146 \\ 7.6 & 83.941 & 63.736 & 83.530 & 03.325 & 83.121 & 82.915 & 82.710 & 82.505 & 82.300 & 82.095\end{array}$

$\begin{array}{lllllllllll}7.7 & 81.890 & 01.685 & 81.479 & 81.274 & 81.069 & 80.864 & 80.659 & 80.454 & 80.249 & 80.044 \\ 7.8 & 79.839 & 79.634 & 79.429 & 79.223 & 79.019 & 70.013 & 78.609 & 78.404 & 78.8199 & 77.994\end{array}$

$\begin{array}{lllllllllll}7.8 & 79.839 & 79.634 & 79.429 & 79.223 & 79.019 & 70.013 & 78.609 & 78.404 & 78.199 & 77.994 \\ 7.9 & 77.789 & 77.583 & 77.370 & 77.173 & 76.908 & 76.763 & 76.558 & 76.353 & 76.148 & 75.943\end{array}$

$\begin{array}{llllllllllll}2208.0 & 45275.738 & 75.534 & 75.320 & 75.123 & 74.918 & 74.713 & 74.507 & 74.303 & 74.098 & 73.893\end{array}$

$\begin{array}{lllllllllll}8.1 & 73.607 & 73.483 & 73.277 & 73.072 & 72.807 & 72.662 & 72.458 & 72.253 & 72.048 & 71.843\end{array}$

$\begin{array}{lllllllllll}8.2 & 71.638 & 71.433 & 71.228 & 71.023 & 70.818 & 70.613 & 70.408 & 70.203 & 69.998 & 69.793\end{array}$

$\begin{array}{lllllllllll}8.3 & 69.588 & 69.383 & 69.170 & 68.973 & 68.768 & 68.562 & 68.358 & 68.153 & 67.948 & 67.743 \\ 8.4 & 67.538 & 67.333 & 67.126 & 66.923 & 66.718 & 66.513 & 66.308 & 66.103 & 65.898 & 65.694\end{array}$

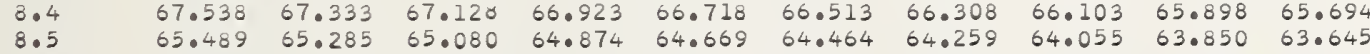

$\begin{array}{lllllllllll}8.6 & 63.439 & 63.235 & 63.029 & 62.824 & 62.620 & 62.415 & 62.209 & 62.005 & 61.800 & 61.595\end{array}$

$\begin{array}{llllllllllll}8.7 & 61.391 & 61.186 & 60.980 & 60.775 & 60.570 & 60.365 & 60.161 & 59.956 & 59.751 & 59.546\end{array}$

$\begin{array}{lllllllllll}8.8 & 59.341 & 59.137 & 50.933 & 58.727 & 58.522 & 58.317 & 58.112 & 57.907 & 57.702 & 57.498 \\ 8.9 & 57.293 & 57.008 & 56.083 & 56.678 & 56.473 & 56.269 & 56.063 & 55.858 & 55.654 & 55.449\end{array}$

0.312106

0.312102

0.312093

.31208

0.312079

0.312074

0.312065

0.312060

0.31205

0.312046

0.312041

0.312032

0.312027

0.312023
0.312018

0.312013

0.312004

0.312000

0.31199

0.311986

0.31198

0.687049

0.687070

0.687112

0.687133

0.687175

0.687196

.68723

0.687258

0.687300

0.687321

0.687342

0.687384

0.687405

0.687426

0.311972

0.311967

0.311962

0.311953
0.31195

.311949

0.311944
.311939

.311935

0.311930

0.311921

0.311916

0.311912

0.311902

.31189

0.311893
0.311888

0.311884

0.311879

0.311875

0.311870

0.311861

0.311856

0.311847

0.311842

0.311838

0.311828

0.311824

0.311819

0.311810

0.311805

0.311796

0.311792

0.687468

0.68748

0.687531

0.687552

0.687573
0.687594

0.687615

0.687636
0.687657

0.687678

0.687699

0.687741

0.687762

0.687803

0.687824

0.68784

0.687887

0.687908

0.68792

0.687950

0.687992

0.688013

0.688055

0.688076

0.688097

0.688118

0.68139

0.688181

0.688202

0.688223

0.688265

0.688286

0.688307

0.68832

0.688349

0.688370

0.688412

0.688433

0.688454

0.688475
0.688496

0.688517

0.688538

0.68855

0.68860

0.688622

688664

0.680685

$0.311782 \quad 0.688727$

$0.311778 \quad 0.688749$

$0.311769 \quad 0.688791$

$0.311764 \quad 0.688812$

$0.311760 \quad 0.688833$

$0.311755 \quad 0.688854$

$\begin{array}{ll}0.311746 & 0.688896 \\ 0.311741 & 0.688917\end{array}$

9.8

$\begin{array}{llllllllll}42.957 & 42.752 & 42.547 & 42.342 & 42.138 & 41.933 & 41.728 & 41.523 & 41.319 & 41.114 \\ 40.910 & 40.705 & 40.499 & 40.295 & 40.090 & 39.885 & 39.681 & 39.476 & 39.272 & 39.067\end{array}$ $\begin{array}{llllllllll}38.863 & 38.658 & 38.454 & 38.248 & 38.043 & 37.838 & 37.634 & 37.430 & 37.225 & 37.021 \\ 36.115 & 36.611 & 36.407 & 36.201 & 35.996 & 35.792 & 35.587 & 35.382 & 35.178 & 34.973\end{array}$

$\begin{array}{lllllllllll} & .001 & .002 & .003 & .004 & .005 & .006 & .007 & .008 & .009 & .010 \\ .207 & .021 & .041 & .062 & .083 & .0104 & .124 & .145 & .166 & .186 & .207 \\ .206 & .021 & .041 & .062 & .082 & .103 & .124 & .144 & .165 & .185 & .026 \\ .205 & .021 & .041 & .062 & .082 & .0103 & .123 & .144 & .164 & .185 & .205\end{array}$ 


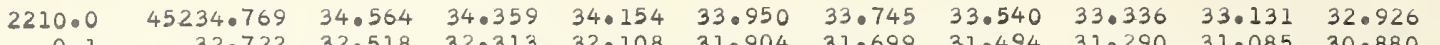

$\begin{array}{lllllllllll}0.1 & 32.722 & 32.518 & 32.313 & 32.108 & 31.904 & 31.699 & 31.494 & 31.290 & 31.085 & 30.880 \\ 0.2 & 30.676 & 30.472 & 30.267 & 30.062 & 29.857 & 29.652 & 29.448 & 29.244 & 29.039 & 28.834 \\ 0.3 & 28.630 & 28.425 & 28.221 & 28.016 & 27.811 & 27.606 & 27.402 & 27.197 & 26.992 & 26.788\end{array}$

$\begin{array}{lllllllllll}0.3 & 28.630 & 28.425 & 28.221 & 28.016 & 27.811 & 27.606 & 27.402 & 27.197 & 26.992 & 26.788 \\ 0.4 & 26.583 & 26.379 & 26.175 & 25.970 & 25.765 & 25.561 & 25.356 & 25.151 & 24.947 & 24.743\end{array}$

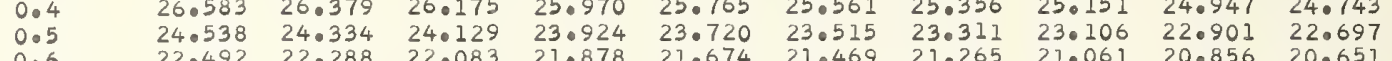

0.6 $\begin{array}{lll}22.492 & 22.288 & 22.083 \\ 20.447 & 20.242 & 20.037\end{array}$

0.8

2211.0 $\begin{array}{lll}20.447 & 20.242 & 20.037 \\ 18.402 & 18.197 & 17.993\end{array}$ 19.833

$16.357 \quad 16.152 \quad 15.948$

.628
.583

\section{$\begin{array}{ll}21.069 & 21.265 \\ 19.424 & 19.220\end{array}$}

214.312

1.

\section{$\begin{array}{rlll}173.453 & 73.250 & 73.045 & 720 \\ 71.413 & 71.209 & 71.004 & 70 .\end{array}$} $69.372 \quad 69.167 \quad 68.963$ $\begin{array}{lll}67.331 & 67.127 & 66.923 \\ 65.291 & 65.087 & 64.883\end{array}$ $63.250 \quad 63.047 \quad 62.843$ $\begin{array}{lll}61.210 & 61.006 & 60.802 \\ 59.171 & 58.967 & 58.763\end{array}$ $\begin{array}{llll}57.131 & 56.927 & 56.724 & 560 \\ 55.091 & 54.887 & 54.684 & 540\end{array}$

$\begin{array}{rrrr}45153.052 & 52.848 & 52.645 & 5 \\ 51.013 & 50.809 & 50.605 & 50 \\ 48.974 & 48.770 & 48.566 & 48 \\ 46.935 & 46.731 & 46.527 & 46 \\ 44.896 & 44.693 & 44.489 & 440 \\ 42.858 & 42.655 & 42.451 & 420 \\ 40.819 & 40.616 & 40.412 & 400 \\ 38.782 & 38.579 & 38.375 & 380 \\ 36.744 & 36.540 & 36.337 & 36 \\ 34.706 & 34.502 & 34.299 & 340\end{array}$

$$
\begin{array}{llll} 
& 52.440 & 52.235 & 5 \\
5 & 50.401 & 50.197 & 4 \\
5 & 48.363 & 48.158 & 4 \\
7 & 46.324 & 46.119 & 4 \\
9 & 44.285 & 44.081 & 43 \\
1 & 42.247 & 42.042 & 4 \\
2 & 40.208 & 40.004 & 3 \\
5 & 38.171 & 37.967 & 3 \\
7 & 36.133 & 35.929 & 3 \\
9 & 34.095 & 33.891 & 3
\end{array}
$$$$
\begin{array}{lll}
46.324 & 46.1119 & 450 \\
44.285 & 44.081 & 43
\end{array}
$$$$
\begin{array}{llll}
40.208 & 40.004 & 39.800 & 39.596
\end{array}
$$

0.311737

0.311727

0.311718

0.311714

0.311704

0.311700

0.311691

0.311686

0.311677

0.311672

0.311659

0.311654

0.311645

0.311640

0.311631

0.311627

0.311622

0.311613

0.311609

0.311599

0.311595
0.311590
0.01156

0.311586

0.311581

0.311577

0.311567

0.311563
0.311558

0.311554

0.311549

0.311540

0.311536

0.311531

0.311517

0.311513

0.311508

0.311499

0.311495

0.311490

0.311486

0.311481

0.311477
0.311472
0.31146

0.311468

0.311463

0.311454
0.311449
0.31445

0.311445

0.311436

0.311427

0.311422

0.311418

0.311413

0.311409

0.311400

0.311395

0.311391

. 311382

0.311373

0.311368

0.311364
0.311359

0.311355

0.311350

0.311346

0.311336

0.311327

0.311323
0.311318
0.31314

.311314

0.311309

0.311305

0.311300
0.311296

0.311291
0.31287

0.688938

0.688959

0.688980

0.689022

0.689064

0.689085

0.689106

0.689127

0.689148

0.689169
0.689190

0.689211

0.689232

689253

0.689275

0.689296

0.689317

0.689359

0.689380

0.689401

0.689443

0.689464

0.689506
0.689527

0.689548

0.689569

0.689590

0.689612

0.689633

0.689654

0.689675

0.689696

0.689717

0.689738
0.689759

0.689780

0.689801

0.689822

0.689843

0.689865

0.689886

0.689907

0.689928

0.689949
0.689970

0.689991

0.690012

0.690054

0.690075

0.690097

0.690118

0.690139

0.690160
0.690181

0.690202

.6690223

0.690244
0.690265

0.690265

0.690308

0.690329

0.600350

0.690371

0.690413

0.690434

0.690455

0.690476

0.690498

0.690519

0.690561

0.690582

0.690624

0.690645 


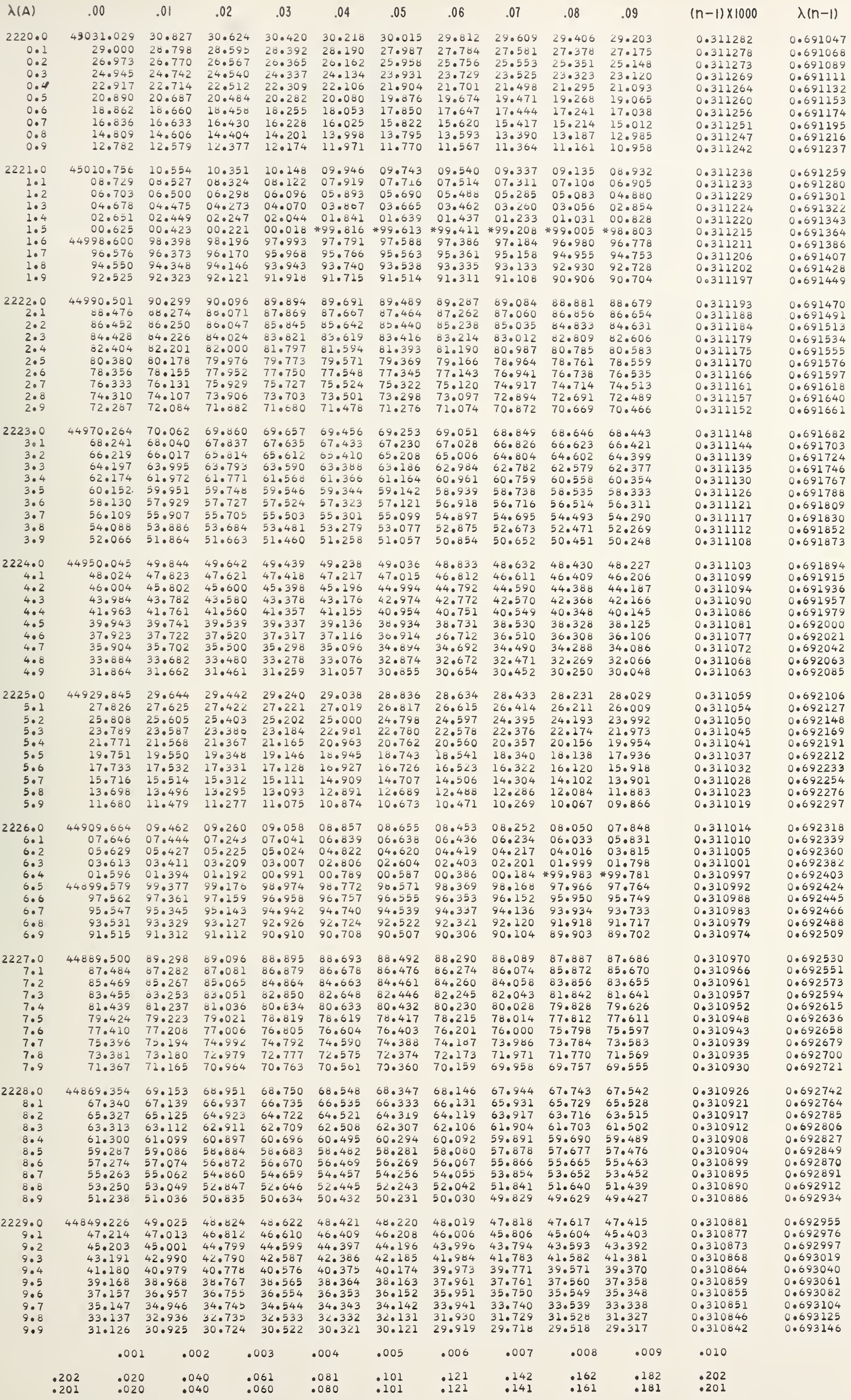




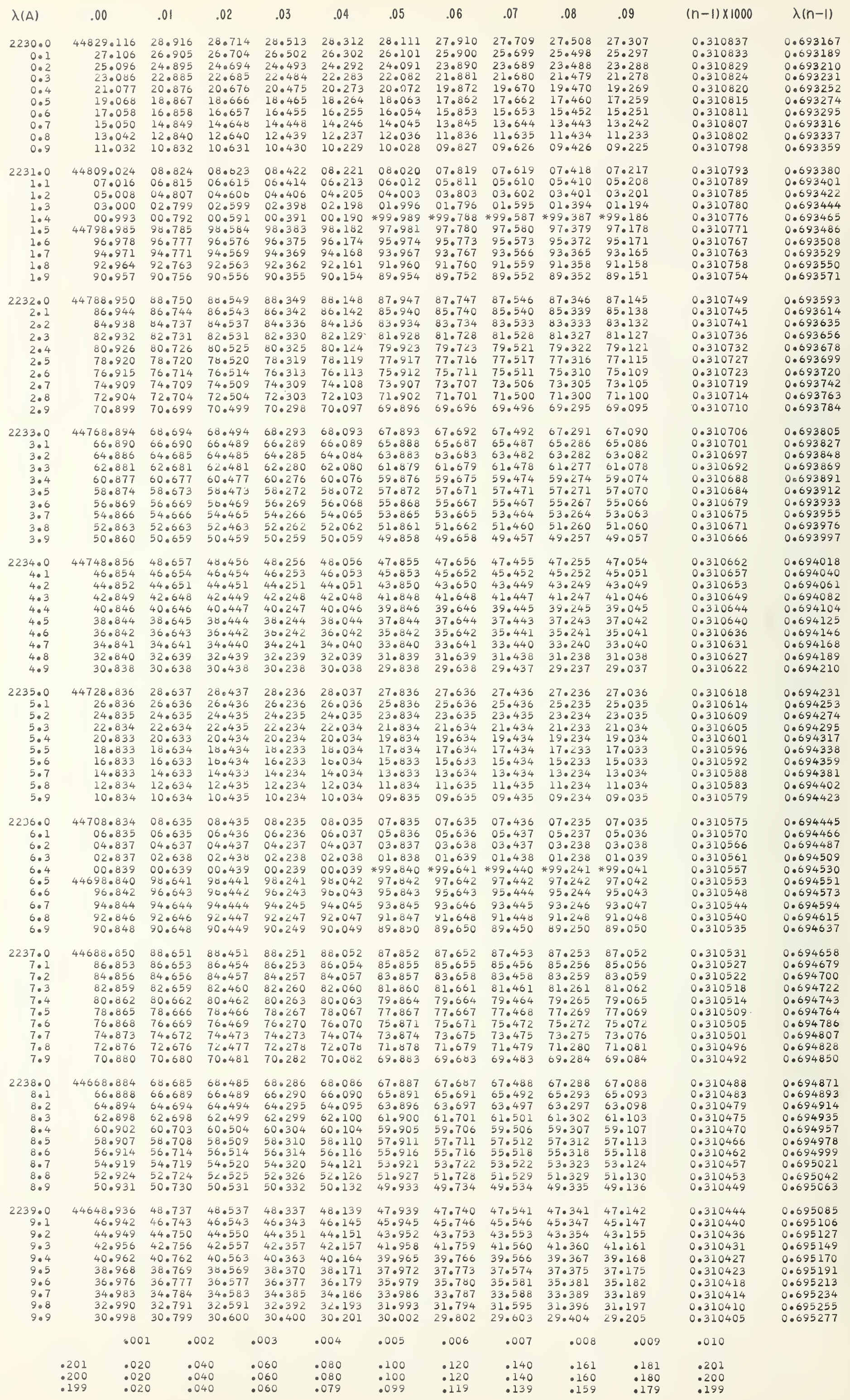




\begin{tabular}{|c|c|c|c|}
\hline$\lambda(A)$ & .00 & .01 & .02 \\
\hline 2240.0 & 44629.005 & 28.807 & 28.607 \\
\hline $0: 1$ & $\begin{array}{l}27.013 \\
25.021\end{array}$ & $\begin{array}{l}26.814 \\
24.822\end{array}$ & $\begin{array}{l}26.614 \\
24.622\end{array}$ \\
\hline 0.3 & 23.030 & 22.831 & 22.632 \\
\hline 0.4 & 21.038 & 20.839 & 20.640 \\
\hline 0.5 & $19 \cdot 046$ & 18.848 & 10.648 \\
\hline 0.6 & 17.056 & 16.857 & 16.658 \\
\hline 0.7 & $\begin{array}{l}15.065 \\
13.074\end{array}$ & 14.866 & 14.667 \\
\hline $\begin{array}{l}0.8 \\
0.8\end{array}$ & $\begin{array}{l}13.074 \\
11.083\end{array}$ & $\begin{array}{l}12.875 \\
10.884\end{array}$ & $\begin{array}{l}12.676 \\
10.685\end{array}$ \\
\hline $2241 \cdot 0$ & 44609.093 & 08.894 & 08.695 \\
\hline $\begin{array}{l}1.1 \\
1.2\end{array}$ & 07.102 & 06.903 & 06.705 \\
\hline $\begin{array}{l}1.2 \\
1.3\end{array}$ & $\begin{array}{l}05.112 \\
03.123\end{array}$ & 04.913 & $\begin{array}{l}04.714 \\
02.725\end{array}$ \\
\hline $\begin{array}{l}1 \cdot 3 \\
1.4\end{array}$ & 03.123 & $\begin{array}{l}02.923 \\
00.934\end{array}$ & $\begin{array}{l}02.725 \\
00.735\end{array}$ \\
\hline $\begin{array}{l}1.4 \\
1.5\end{array}$ & & $\begin{array}{l}00.934 \\
98.944\end{array}$ & $\begin{array}{l}00.735 \\
98.745\end{array}$ \\
\hline $\begin{array}{l}1.5 \\
1.6\end{array}$ & $\begin{array}{r}44599 \cdot 143 \\
97.153\end{array}$ & $\begin{array}{l}98.944 \\
96.955\end{array}$ & $\begin{array}{l}98.745 \\
96.756\end{array}$ \\
\hline $\begin{array}{l}1.6 \\
1.7\end{array}$ & $\begin{array}{l}97.153 \\
95.165\end{array}$ & $\begin{array}{l}96.955 \\
94.965\end{array}$ & $\begin{array}{l}96.756 \\
94.767\end{array}$ \\
\hline 1.8 & 93.175 & $\begin{array}{l}94.965 \\
92.976\end{array}$ & $\begin{array}{l}94.767 \\
92.778\end{array}$ \\
\hline 1.9 & 91.186 & 90.987 & 90.789 \\
\hline $2242 \cdot 0$ & 44589.198 & & \\
\hline $2 \cdot 1$ & 87.209 & 87.010 & 86.812 \\
\hline $2 \cdot 2$ & 85.221 & $85 \cdot 022$ & 84.823 \\
\hline $2 \cdot 3$ & 83.232 & 83.033 & 82.835 \\
\hline $2 \cdot 4$ & 81.245 & 81.045 & 80.847 \\
\hline $2 \cdot 5$ & $79 \cdot 256$ & 79.058 & 76.859 \\
\hline 2.6 & $77 \cdot 269$ & 77.070 & 76.871 \\
\hline 2.7 & $75 \cdot 282$ & 75.083 & 74.884 \\
\hline $\begin{array}{l}2.8 \\
2.9\end{array}$ & $\begin{array}{l}73.294 \\
71.307\end{array}$ & 73.095 & 72.897 \\
\hline 2.9 & 71.307 & $71 \cdot 108$ & 70.910 \\
\hline $\begin{array}{r}2243.0 \\
3.1\end{array}$ & $\begin{array}{r}44569.320 \\
67.333\end{array}$ & & $\begin{array}{l}68.923 \\
66.930\end{array}$ \\
\hline 3.2 & 65.347 & 65.148 & $\begin{array}{l}64.940 \\
64.94\end{array}$ \\
\hline $\begin{array}{l}3.3 \\
3.4\end{array}$ & 63.360 & 63.162 & 62.963 \\
\hline $\begin{array}{l}3.4 \\
3.5\end{array}$ & 61.375 & 61.175 & 60.978 \\
\hline $\begin{array}{l}3.5 \\
3.6\end{array}$ & $\begin{array}{l}59 \cdot 388 \\
57.402\end{array}$ & $\begin{array}{l}59.190 \\
57.204\end{array}$ & $\begin{array}{l}58.991 \\
57.005\end{array}$ \\
\hline $\begin{array}{l}3.6 \\
3.7\end{array}$ & $\begin{array}{l}57.402 \\
55.417\end{array}$ & $\begin{array}{l}57.204 \\
55.218\end{array}$ & $\begin{array}{l}57.005 \\
55.020\end{array}$ \\
\hline $\begin{array}{l}3.7 \\
3.8\end{array}$ & $\begin{array}{l}55.417 \\
53.431\end{array}$ & $\begin{array}{l}55.218 \\
53.232\end{array}$ & $\begin{array}{l}55.020 \\
53.034\end{array}$ \\
\hline $\begin{array}{l}\begin{array}{l}3.8 \\
3.9\end{array} \\
.9\end{array}$ & $\begin{array}{l}53.431 \\
51.445\end{array}$ & $\begin{array}{l}53.232 \\
51.247\end{array}$ & $\begin{array}{l}53.034 \\
51.049\end{array}$ \\
\hline $244 \cdot 0$ & 44549.460 & 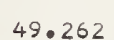 & \\
\hline 4.1 & 47.476 & 47.277 & 47.079 \\
\hline 4.2 & 45.491 & 45.292 & 45.094 \\
\hline 4.3 & 43.506 & 43.307 & 43.109 \\
\hline $4 \cdot 4$ & 41.522 & 41.323 & 41.125 \\
\hline 4.5 & 39.537 & 39.339 & 39.141 \\
\hline 4.6 & 37.553 & 37.355 & 37.156 \\
\hline 4.7 & 35.569 & 35.371 & 35.172 \\
\hline $4 \cdot 8$ & 33.585 & 33.387 & 33.189 \\
\hline $4 \cdot 9$ & 31.602 & 31.403 & 31.206 \\
\hline $\begin{array}{r}45 \cdot 0 \\
5.1\end{array}$ & 4529.618 & 29.420 & $\begin{array}{l}29.222 \\
27.239\end{array}$ \\
\hline $\begin{array}{l}5.1 \\
5.2\end{array}$ & & & $\begin{array}{l}27.239 \\
25.255\end{array}$ \\
\hline $5 \cdot 3$ & $\begin{array}{l}25.652 \\
23.609\end{array}$ & $\begin{array}{l}25.454 \\
23.471\end{array}$ & $\begin{array}{l}25.255 \\
23.273\end{array}$ \\
\hline 5.4 & 21.686 & 21.488 & 21.290 \\
\hline 5.5 & 19.704 & 19.506 & $19 \cdot 300$ \\
\hline 5.6 & 17.721 & 17.523 & $17 \cdot 325$ \\
\hline 5.7 & 15.740 & 15.541 & 15.343 \\
\hline 5.8 & 13.758 & 13.560 & 13.362 \\
\hline 5.9 & 11.776 & 11.578 & 11.380 \\
\hline & 509.794 & 09.596 & 09.398 \\
\hline & 2 & 07.614 & 07.416 \\
\hline $\begin{array}{l}6.2 \\
6.3\end{array}$ & 05.832 & 05.633 & $\begin{array}{r}05.435 \\
03.455\end{array}$ \\
\hline $\begin{array}{l}6.3 \\
6.4\end{array}$ & 03.850 & 03.652 & 03.455 \\
\hline 6.5 & $\begin{array}{l}01.869 \\
99.889\end{array}$ & $\begin{array}{l}01.671 \\
99.691\end{array}$ & $\begin{array}{l}01.473 \\
99.493\end{array}$ \\
\hline $\begin{array}{l}6.5 \\
6.6\end{array}$ & $\begin{array}{l}99.888 \\
97.900\end{array}$ & $\begin{array}{l}99.691 \\
97.710\end{array}$ & $\begin{array}{l}99.493 \\
97.512\end{array}$ \\
\hline 6.7 & 8 & 95 & 1 \\
\hline 6.8 & .947 & 93 & 93.551 \\
\hline 6.9 & 91.967 & 91.769 & 91.572 \\
\hline $\begin{array}{r}47 \\
7\end{array}$ & 7 & 8 & 89.591 \\
\hline $\begin{array}{l}7.1 \\
7.2\end{array}$ & & & \\
\hline $\begin{array}{l}7.2 \\
7.3\end{array}$ & 86.029 & & 85.6 \\
\hline 7• & $\begin{array}{l}84.049 \\
82.069\end{array}$ & $83 \cdot 6$ & $83.6 \quad$ \\
\hline 1.9 & 82.069 & & 4 \\
\hline 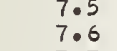 & 0 & $79 \cdot 8$ & $78-2>$ \\
\hline 7. & $\begin{array}{l}78 \\
7\end{array}$ & & $770^{\circ}$ \\
\hline 7 & 55 & $\begin{array}{l}75 \cdot 936 \\
73.957\end{array}$ & $\begin{array}{l}75.737 \\
73.759\end{array}$ \\
\hline $\begin{array}{l}7.8 \\
7.9\end{array}$ & & 73.957 & 73.759 \\
\hline & & & \\
\hline & 68.221 & 68.022 & $\begin{array}{l}69.803 \\
67.825\end{array}$ \\
\hline $8 .>2>$ & 3 & & \\
\hline $8 \bullet$ & 6 & 64 & 0 \\
\hline 8 & & $62+2>$ & 2 \\
\hline 8 & 1 & 60.1 & 59. \\
\hline 8. & 4 & 50. & 57.690 \\
\hline 8. & 7 & 56. & 5 \\
\hline $\begin{array}{l}8.8 \\
8.9\end{array}$ & $\begin{array}{l}54.380 \\
52.403\end{array}$ & & $\begin{array}{l}53 . \\
52^{\circ}\end{array}$ \\
\hline & 3 & 520 & $52 \cdot$ \\
\hline $\begin{array}{r}2249.0 \\
9.1\end{array}$ & $\begin{array}{r}44450.427 \\
48.451\end{array}$ & $\begin{array}{l}50.230 \\
48.254\end{array}$ & $\begin{array}{l}.0032 \\
8.055\end{array}$ \\
\hline 9.1 & 4 & & \\
\hline 9.3 & 500 & 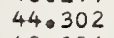 & 34 \\
\hline 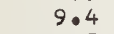 & $5=$ & & \\
\hline 9.5 & & & \\
\hline 9. & 2 & 38.375 & 2 \\
\hline 9.7 & .598 & & \\
\hline 9.8 & 34.623 & 34.425 & 34.228 \\
\hline 9.9 & 32.648 & 32.450 & 32.253 \\
\hline & - & & \\
\hline & & & \\
\hline & $\begin{array}{l}.02 \\
.02\end{array}$ & & \\
\hline
\end{tabular}




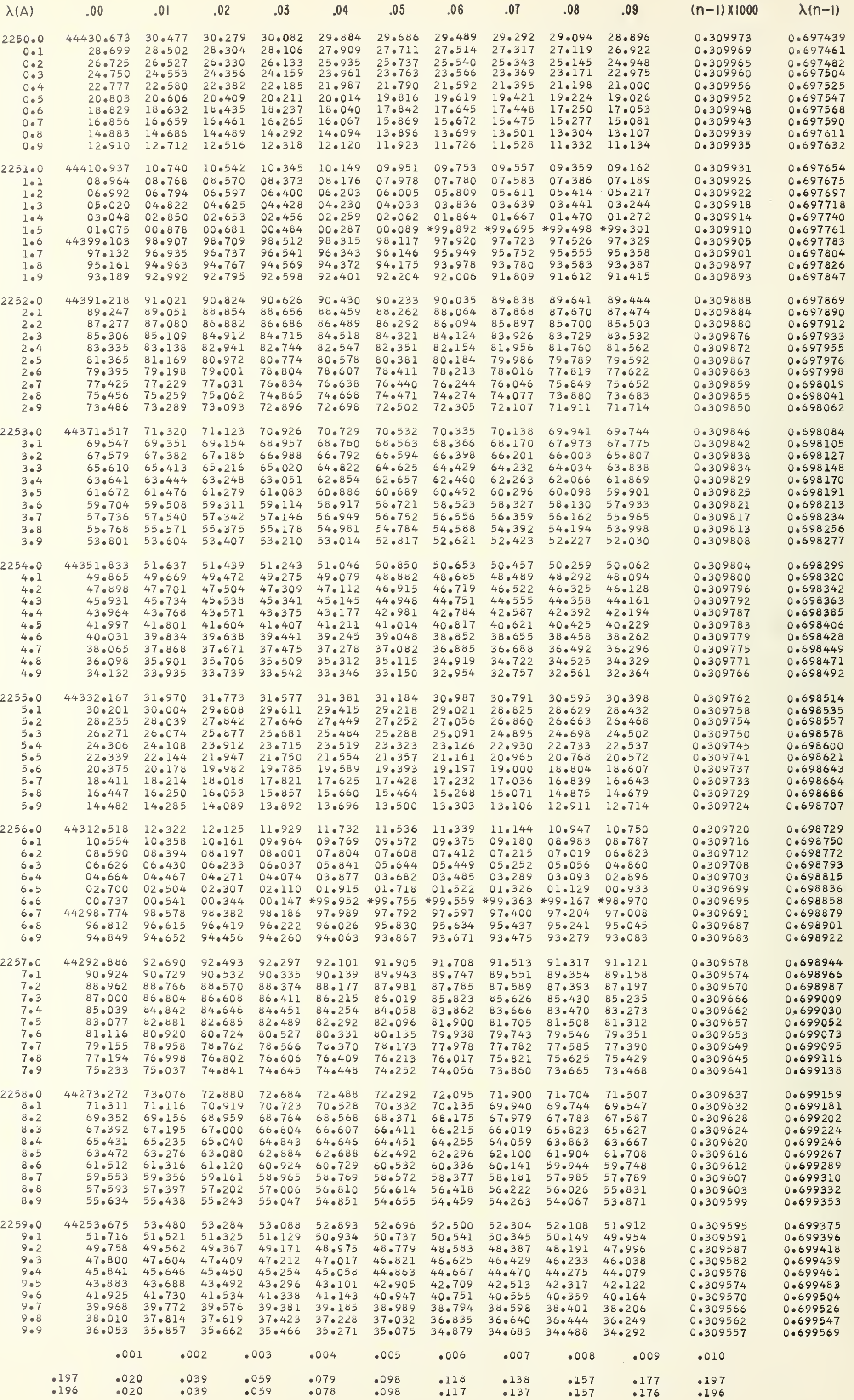




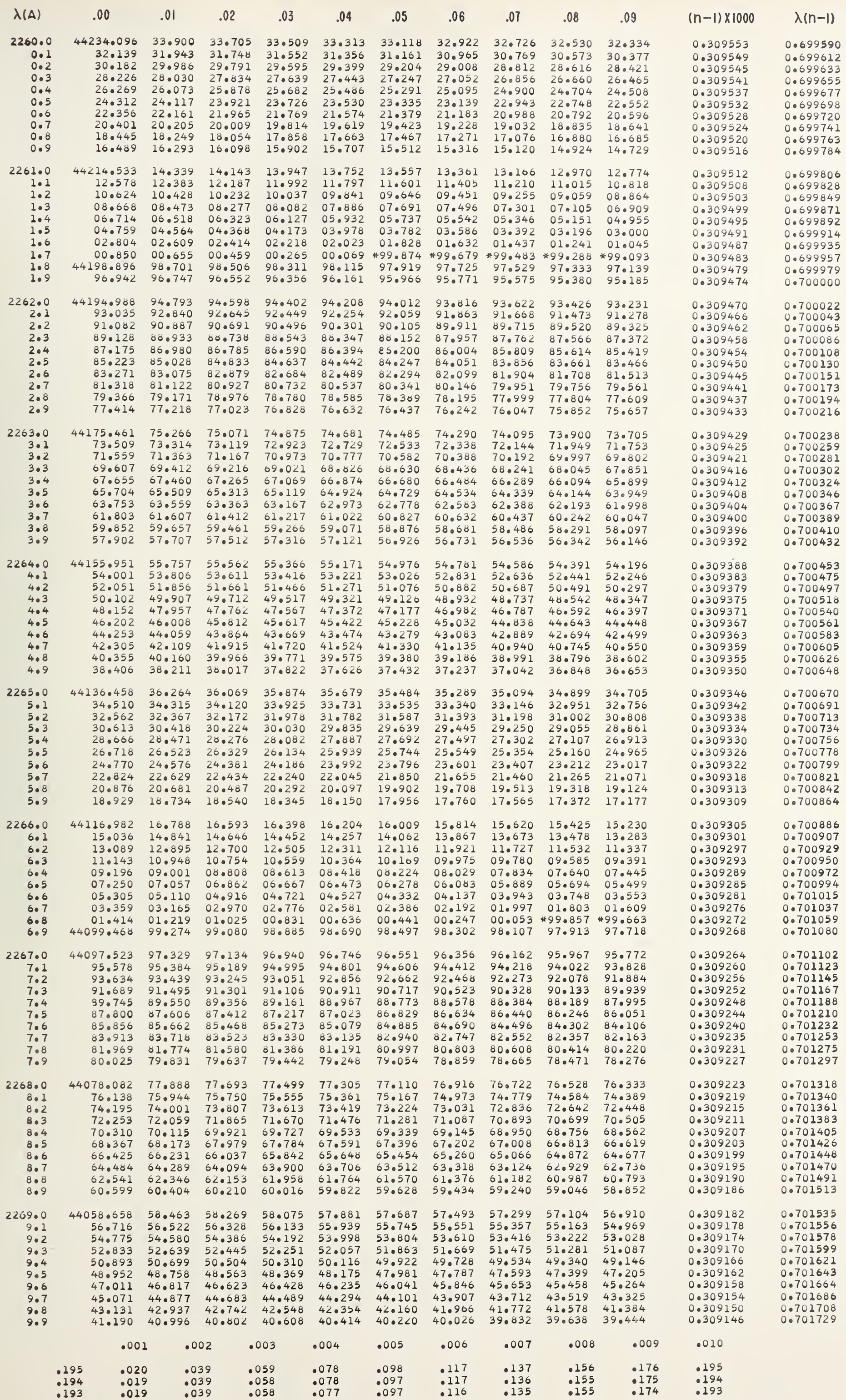




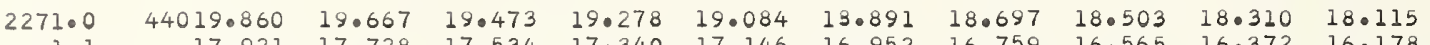

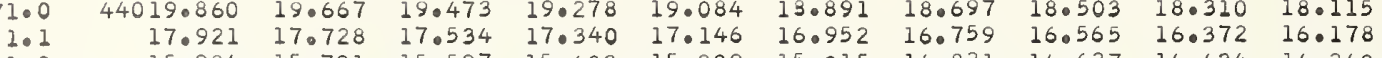

$\begin{array}{llllllllllll}1.2 & 15.984 & 15.791 & 15.597 & 15.403 & 15.209 & 15.015 & 14.821 & 14.627 & 14.434 & 14.240\end{array}$

$1 \cdot 3$

1.4

1.6

13.04613 .853

$12.108 \quad 11.915 \quad 11.721$

$\begin{array}{llllllllll}10.171 & 09.978 & 09.784 & 09.590 & 09.397 & 09.203 & 09.009 & 08.815 & 08.622 & 08.428 \\ 08.234 & 08.041 & 07.847 & 07.653 & 07.459 & 07.265 & 07.071 & 06.878 & 06.684 & 06.490\end{array}$

$\begin{array}{lllll}13.077 & 12.884 & 12.689 & 12.496 & 12.302\end{array}$

02.424

$.653 \quad 07.459$

.26507 .07

$\begin{array}{lll}06.878 & 06.684 & 06.490\end{array}$

02.230

2.1

$2 \cdot 2$

$2 \cdot 4$
2.5

2.5
2.6
2.7

$2 \cdot 7$

3998.550

$96.614 \quad 96.420$

$94.678 \quad 94.485$

$90.806 \quad 90.613$

88.871

$86.936 \quad 86.742$

03.973
02.037

$\begin{array}{ll}03.779 & 03.585 \\ 01.843 & 01.649\end{array}$

03.391

05.135
03.198
01.261

03.004

04.747

04.554

$00.100 * 99.906 * 99.713 * 99.519 * 99.325 * 99.131 * 98.937 * 98.744$

$\begin{array}{llllllll}96.227 & 97.969 & 97.776 & 97.583 & 97.388 & 97.195 & 97.001 & 96.807\end{array}$

$\begin{array}{llllllll}96.227 & 96.034 & 95.840 & 95.646 & 95.454 & 95.259 & 95.065 & 94.872 \\ 94.292 & 94.098 & 93.904 & 93.710 & 93.517 & 93.323 & 93.129 & 92.936\end{array}$

$\begin{array}{llllllll}94.292 & 94.098 & 93.904 & 93.710 & 93.517 & 93.323 & 93.129 & 92.936 \\ 92.355 & 92.162 & 91.968 & 91.775 & 91.581 & 91.387 & 91.194 & 91.000\end{array}$

$\begin{array}{llllllll}88.484 & 88.291 & 88.098 & 87.904 & 87.710 & 87.517 & 87.323 & 87.129\end{array}$

83.065

86.549

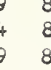

$86 \cdot 162$
84.227

2273.

73.0
3.1
3.2
3.3
3.4

3.4
3.5
3.6

3.6

3.8

$2274 \circ$

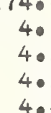

4.2
4.3
4.4
4.5

4.4
4.5
4.6
4.7

4.6
4.7
4.8

2275.0

!n:

5.4
5.5

5.6

5.7
5.8
5.9

2276.

79.196
77.262

$\begin{array}{ll}79.196 & 79.003 \\ 77.262 & 77.068 \\ 75.327 & 75.133 \\ 73.393 & 73.200\end{array}$

71.459

69.52569 .332

$\begin{array}{lllll}69.525 & 69.332 & 69.138 & 68.945 & 68.752 \\ 67.591 & 67.398 & 67.204 & 67.012 & 66.818 \\ 65.658 & 65.465 & 65.272 & 65.078 & 64.885\end{array}$

439610

$\begin{array}{ll}961.791 & 61.598 \\ 59.858 & 59.666 \\ 57.926 & 57.732 \\ 55.993 & 55.800 \\ 54.060 & 53.867 \\ 52.129 & 51.936 \\ 50.196 & 50.003 \\ 48.264 & 48.071 \\ 46.332 & 46.139 \\ 44.401 & 44.208\end{array}$

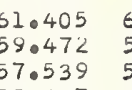

$\begin{array}{ll}61.211 & 61.019 \\ 59.279 & 59.086\end{array}$

$\begin{array}{lll}55.607 & 55.414 & 55.220 \\ 53.674 & 53.480 & 53.287\end{array}$

$\begin{array}{ll}53.674 & 53.480 \\ 51.742 & 51.549\end{array}$

$\begin{array}{lll}9.810 & 49.616 & 49.424\end{array}$

7.877
5.946

43942.470

$40.538 \quad 42.276$

38.608
36.677

$\begin{array}{ll}30.677 & 36.48 \\ 34.746 & 34.55\end{array}$

30.885

$\begin{array}{ll}27.024 & 26.831 \\ 25.094 & 24.901\end{array}$

42.083
40.151

$\begin{array}{ll}45.753 & 45.560 \\ 43.821 & 43.628\end{array}$

84.033
82.098

.77

89.064
87.129

5.194

\begin{tabular}{|l|l|l|l|l|l|} 
& \\
\hline
\end{tabular}

$(n-1) \times 1000$

0.701751

0.309137

0.309133
0.309129

0.309125

0.309121

0.309113

0.309109
0.309105

0.309101

0.309093

0.309088

0.309084

0.309080

0.309076

0.309072
0.309068

0.309064

0.309060

0.309056

0.309052

0.309044
0.309040

0.309036

0.309032

0.309028

0.309019

0.309015

0.309011

0.309003

0.308999

0.308995

0.308991

0.308987
0.308983

0.701773

0.701794
0.701816

0.701838

0.701859

0.701881

0.701924

0.701968

0.701989

0.702011
0.702033

0.702054

0.702076

0.702119

0.702141

0.702184

0.702206

0.702228

0.702271

0.702293

0.702314
0.702336

0.702358

0.702401

0.702423

0.702444

0.702466

0.702488
0.702510

0.702531

0.702553

0.702575
0.702596

0.308979

0.308975

0.308971

0.308967

0.308963

0.308959

0.308951

0.308951

0.308942

0.702618

0.702640

0.702683

0.702705

0.702726

0.702748

0.702770
0.702792

0.308938

0.308934

0.308930

0.308922

0.308918

0.308914

0.308910

0.308906
0.308902

43923.165

24.90124 .738
24.708

0.308898

0.308894

0.308890

0.3088862

0.308878

0.308874

0.308866
0.308862

0.702813

0.308858

0.308854

0.308850

0.308846

0.308838

0.308834

0.308830

0.308826
0.308822

0.702835

0.7702857
0.702878

0.702900

0.702922

0.702965

0.702987

0.703009
0.703030

0.703052

0.703074

0.703095
0.703117

0.703139

0.703161

0.703182

0.703226

0.703269

0.703291

0.703313
0.703334

0.703334

0.703378

0.703399

0.703421

0.703443
0.703465

0.308818

0.703486

0.308814

0.308810

0.308805

0.308801

0.308793

0.308789

0.308785
0.308781

0.703508

0.703552

0.703573

0.703595

0.703617

0.703638

0.7703660
0.703682

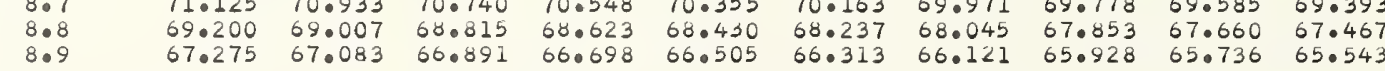

0.308777

0.703704

0.308773

0.308765

0.703725

0.308761

0.703769

0.308757

0.703791

0.308753

0.308749
0.308745

0.703812
0.703834

$\begin{array}{ll}0.308745 & 0.703856 \\ 0.308741 & 0.703898\end{array}$

$\begin{array}{lllllllllll}9.7 & 51.883 & 51.690 & 51.498 & 51.300 & 51.114 & 50.921 & 50.729 & 50.537 & 50.344 & 50.152\end{array}$

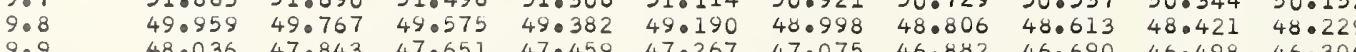
$\begin{array}{llllllllll}48.036 & 47.843 & 47.651 & 47.459 & 47.267 & 47.075 & 46.882 & 46.690 & 46.498 & 46.306\end{array}$

0.703899

$\begin{array}{lllllllllll} & .001 & .002 & .003 & .004 & .005 & .006 & .007 & .008 & .009 & .010 \\ .193 & .019 & .039 & .058 & .077 & .097 & .116 & .135 & .155 & .174 & .193 \\ .192 & .019 & .038 & .058 & .077 & .096 & .115 & .135 & .154 & .173 & .192\end{array}$




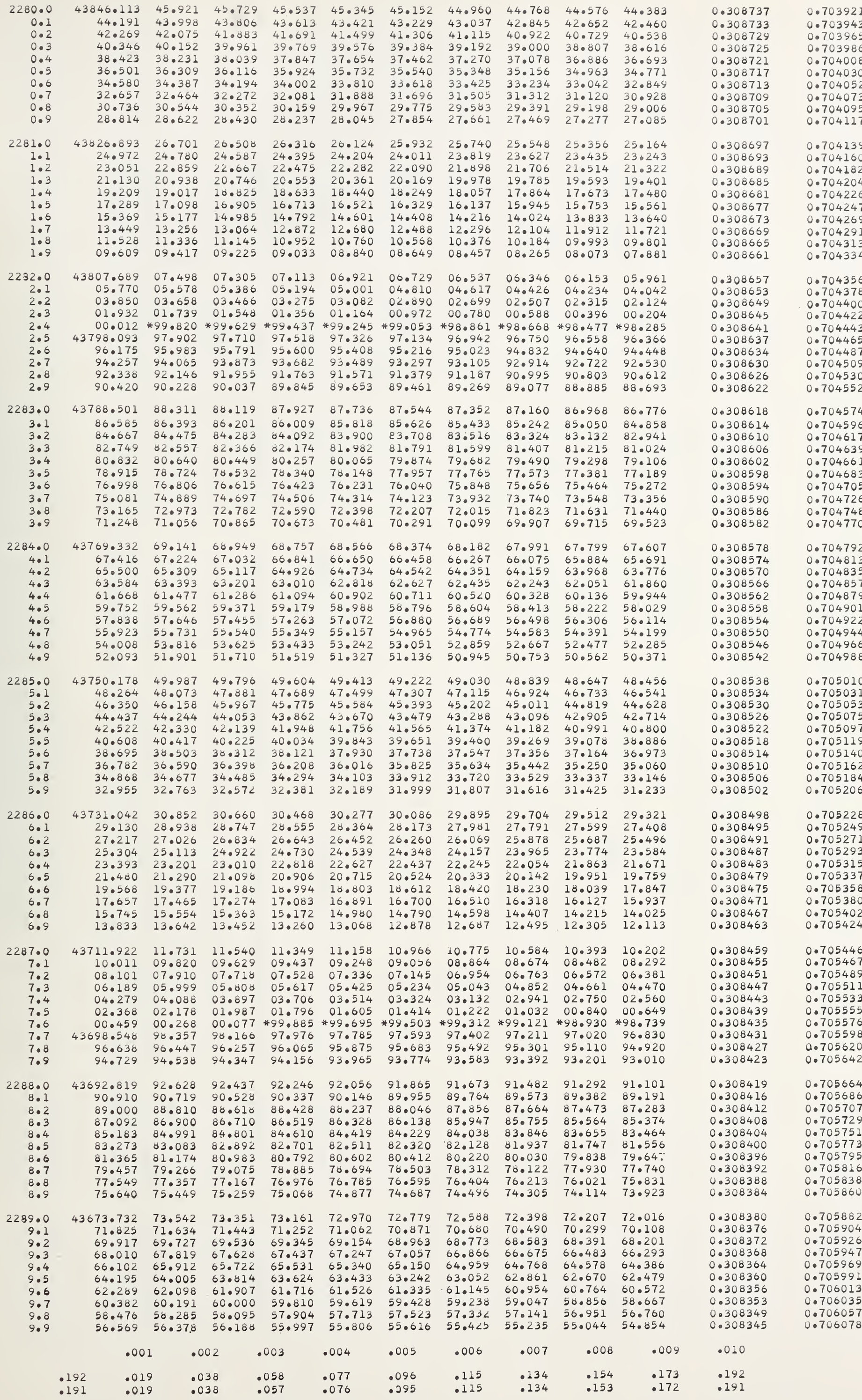




.03

.04

.05

.06

.07

.08

$$
\begin{array}{r}
290.0 \\
0.2 \\
0.2 \\
0.3 \\
0.4 \\
0.5 \\
0.6 \\
0.7 \\
0.8 \\
0.9
\end{array}
$$

0.1
0.2
0.3

0.3
0.4

0.7
0.8
0.9$$
\begin{aligned}
& 1.0 \\
& 1.1 \\
& 1.2 \\
& 1.3 \\
& 1.4 \\
& 1.5 \\
& 1.6 \\
& 1.7 \\
& 1.8 \\
& 1.9
\end{aligned}
$$

2292.0

20

$2 \cdot 3$

2.4
2.5

2.6

2.7

2293.0

3.1
3.2
3.2

$3 \cdot 2$

3.4

3.5

3.6
3.7
3.8

3. 8

2294.0

t:

$4 \cdot 4$
$4 \cdot 5$

$4 \cdot 6$
4.7

4.8
4.9

2295.

5.1
5.2

$5 \cdot 3$
$5 \cdot 4$

5.4
$5: 5$

5.6
5.7

5.7
5.8

5.8
5.9

2296.

6.1
6.2
6.3

6.3

6.5

6.6

6.8
6.9

2297.0

7.:

$7 \cdot 3$

$7 \cdot 5$

7.6

7.8
7.9

2298.0

8.1

8.3

8.4

8.6

8.6

8.8

2299.0

9.1

9.2

9.3
9.4

9.4
9.5

9.6

9.7

9.9 $\begin{array}{llllllllll}54.663 & 54.472 & 54.281 & 54.091 & 53.900 & 53.710 & 53.519 & 53.329 & 53.138 & 52.947 \\ 52.757 & 52.566 & 52.375 & 52.185 & 51.994 & 51.804 & 51.613 & 51.423 & 51.232 & 51.042\end{array}$

$\begin{array}{llllllllll}50.852 & 50.660 & 50.470 & 50.279 & 50.089 & 49.898 & 49.708 & 49.517 & 49.327 & 49.136\end{array}$

$\begin{array}{llllllllll}48.946 & 48.754 & 48.564 & 48.374 & 48.183 & 47.993 & 47.802 & 47.611 & 47.420 & 47.230 \\ 47.040 & 46.849 & 46.658 & 46.468 & 46.277 & 46.087 & 45.896 & 45.706 & 45.516 & 45.325\end{array}$

\begin{tabular}{llllllllll}
45.134 & 44.943 & 44.753 & 44.562 & 44.373 & 44.182 & 43.991 & 43.801 & 43.610 & 43.420 \\
\hline
\end{tabular}

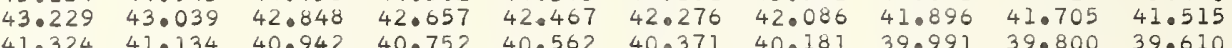

$\begin{array}{llllllllll}39.319 & 41.134 & 40.942 & 40.752 & 40.562 & 40.371 & 40.181 & 39.991 & 39.800 & 39.610 \\ 39.229 & 39.038 & 38.847 & 38.657 & 38.467 & 38.276 & 38.085 & 37.895 & 37.705\end{array}$

$\begin{array}{llllllllll}37.514 & 37.324 & 37.134 & 36.943 & 36.752 & 36.562 & 36.372 & 36.181 & 35.991 & 35.800\end{array}$

$\begin{array}{rrrrrrrrrr}43635.610 & 35.420 & 35.229 & 35.038 & 34.848 & 34.658 & 34.467 & 34.277 & 34.086 & 33.896 \\ 33.706 & 33.515 & 33.324 & 33.133 & 32.943 & 32.753 & 32.562 & 32.373 & 32.182 & 31.991\end{array}$ \begin{tabular}{llllllllll}
33.706 & 33.515 & 33.324 & 33.133 & 32.943 & 32.753 & 32.562 & 32.373 & 32.182 & 31.991 \\
\hline
\end{tabular} $\begin{array}{llllllllll}31.801 & 31.611 & 31.419 & 31.229 & 31.039 & 30.849 & 30.659 & 30.468 & 30.277 & 30.087 \\ 29.897 & 29.707 & 29.517 & 29.326 & 29.135 & 28.945 & 28.755 & 28.564 & 28.374 & 28.184\end{array}$ $\begin{array}{llllllllll}27.993 & 27.803 & 27.613 & 27.422 & 27.231 & 27.042 & 26.851 & 26.660 & 26.470 & 26.280\end{array}$

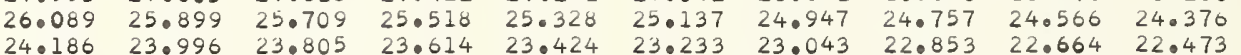

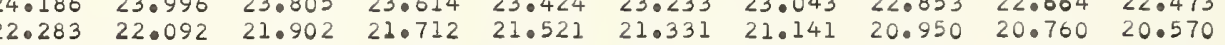

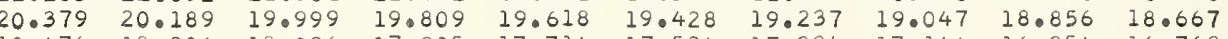

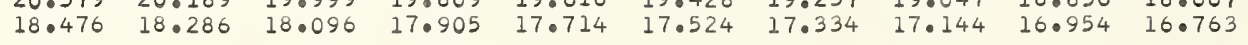

\footnotetext{
$43616.573 \quad 16.383 \quad 16.193$
} $2.768 \quad 12.48780 .290$ $10.866 \quad 10.675 \quad 10.387$ $\begin{array}{lll}0.963 & 08.772 & 08.583\end{array}$

$\begin{array}{lll}07.061 & 06.872 & 06.681\end{array}$

03.25804 .969

01.35601 .166

02.877

00.976

16.002

15.812

$15.622 \quad 15.431$

$15.242 \quad 15.051 \quad 14.861$

$\begin{array}{lllllll}14.100 & 13.910 & 13.719 & 13.529 & 13.339 & 13.148 & 12.958\end{array}$

$\begin{array}{lllllll}10.295 & 10.104 & 09.914 & 09.724 & 09.534 & 09.343 & 09.153\end{array}$

$\begin{array}{lllllll}08.393 & 08.202 & 08.013 & 07.822 & 07.632 & 07.442 & 07.251\end{array}$

$\begin{array}{lllllll}06.491 & 06.301 & 06.111 & 05.920 & 05.730 & 05.540 & 05.349\end{array}$

$\begin{array}{lllllll}04.589 & 04.399 & 04.208 & 04.018 & 03.828 & 03.638 & 03.447\end{array}$

$\begin{array}{llllll}02.497 & 02.307 & 02.116 & 01.926 & 01.736 & 01.546\end{array}$

43599.455

$43597.553 \quad 97.363$

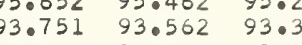

$\begin{array}{lllllllll}91.661 & 91.471 & 91.281 & 91.090 & 90.901 & 90.710 & 90.520 & 90.330 & 90.140\end{array}$

$\begin{array}{llllllll}89.380 & 89.189 & 89.000 & 88.810 & 88.619 & 88.430 & 88.239\end{array}$

$\begin{array}{llllllllll}86.150 & 85.959 & 85.770 & 85.579 & 85.390 & 85.200 & 85.009 & 84.820 & 84.629 & 84.439\end{array}$

$\begin{array}{llllllllll}84.250 & 84.059 & 83.869 & 83.680 & 83.489 & 83.299 & 83.110 & 82.919 & 82.729 & 82.539\end{array}$

$\begin{array}{llllllllll}82.349 & 82.159 & 81.970 & 81.779 & 81.589 & 81.400 & 81.209 & 81.020 & 80.829 & 80.639\end{array}$

$\begin{array}{rlllllllll}43578.550 & 78.360 & 78.170 & 77.980 & 77.791 & 77.601 & 77.411 & 77.221 & 77.031 & 76.840 \\ 76.0551 & 76.460 & 76.271 & 76.081 & 75.891 & 75.701 & 75.511 & 75.321 & 75.131 & 74.941\end{array}$

$\begin{array}{llllllllll}76.651 & 76.460 & 76.271 & 76.081 & 75.891 & 75.701 & 75.511 & 75.321 & 75.131 & 74.941 \\ 74.751 & 74.561 & 74.371 & 74.182 & 73.992 & 73.801 & 73.612 & 73.422 & 73.232 & 73.042\end{array}$

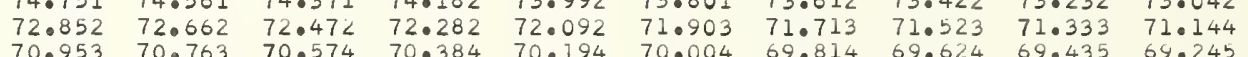

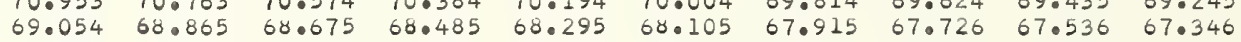

$\begin{array}{llllllllll}67.156 & 66.966 & 60.776 & 66.586 & 66.396 & 66.207 & 66.017 & 65.827 & 65.637 & 05.447\end{array}$

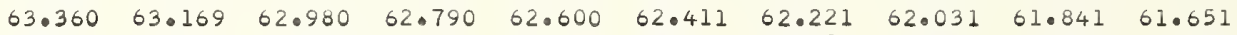

$\begin{array}{llllllllll}61.461 & 61.271 & 61.082 & 60.892 & 60.702 & 60.512 & 60.322 & 60.132 & 59.943 & 59.753\end{array}$

$\begin{array}{rlllllllll}3559.562 & 59.373 & 59.183 & 58.993 & 58.804 & 58.614 & 58.424 & 58.235 & 58.045 & 57.855 \\ 57.665 & 57.477 & 57.286 & 57.096 & 56.907 & 56.717 & 56.527 & 56.337 & 56.147 & 55.958\end{array}$

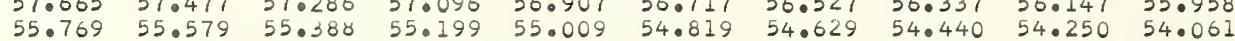

$\begin{array}{llllllllll}53.871 & 53.680 & 53.491 & 53.301 & 53.111 & 52.922 & 52.732 & 52.542 & 52.352 & 52.163\end{array}$

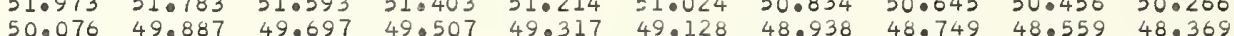

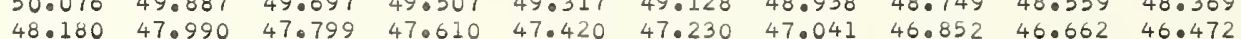

$\begin{array}{llllllllll}46.283 & 46.093 & 45.992 & 47.610 & 47.420 & 47.230 & 47.041 & 46.852 & 46.662 & 46.472 \\ 45.03 & 45.523 & 45.333 & 45.145 & 44.955 & 44.765 & 44.576\end{array}$

$\begin{array}{llllllllll}44.386 & 44.196 & 44.006 & 43.816 & 43.626 & 43.437 & 43.248 & 43.058 & 42.868 & 42.679 \\ 42.490 & 42.300 & 42.111 & 41.920 & 41.730 & 41.542 & 41.352 & 41.162 & 40.973 & 40.783\end{array}$

$\begin{array}{llllllllll}43540.593 & 40.404 & 40.214 & 40.024 & 39.834 & 39.645 & 39.455 & 39.266 & 39.076 & 38.886\end{array}$ $\begin{array}{llllllllll}38.697 & 38.507 & 38.318 & 38.127 & 37.938 & 37.749 & 37.559 & 37.370 & 37.180 & 36.990\end{array}$

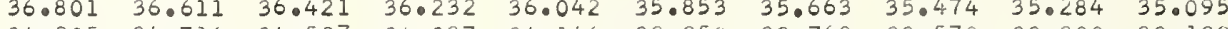
$\begin{array}{llllllllll}34.905 & 34.716 & 34.527 & 34.337 & 34.146 & 33.958 & 33.768 & 33.578 & 33.388 & 33.199\end{array}$ $\begin{array}{llllllllll}31.114 & 32.820 & 32.631 & 32.441 & 32.251 & 32.062 & 31.872 & 31.682 & 31.493 & 31.304\end{array}$ $\begin{array}{llllllllll}29.219 & 29.029 & 28.839 & 28.650 & 28.400 & 28.271 & 28.082 & 27.893 & 27.703 & 27.513\end{array}$ $\begin{array}{llllllllll}27.324 & 27.134 & 26.945 & 26.756 & 26.566 & 26.376 & 26.187 & 25.997 & 25.808 & 25.619\end{array}$ $\begin{array}{llllllllll}25.429 & 25.239 & 25.050 & 24.860 & 24.671 & 24.481 & 24.292 & 24.102 & 23.913 & 23.723 \\ 23.534 & 23.344 & 23.155 & 22.965 & 22.776 & 22.586 & 22.396 & 22.207 & 22.016 & 21.829\end{array}$

$\begin{array}{rlllllllll}43521.639 & 21.450 & 21.260 & 21.071 & 20.882 & 20.692 & 20.502 & 20.313 & 20.124 & 19.934 \\ 19.745 & 19.556 & 19.366 & 19.176 & 18.987 & 18.798 & 18.608 & 18.419 & 18.229 & 18.040\end{array}$ $\begin{array}{llllllll}19.745 & 19.556 & 19.366 & 19.176 & 18.987 & 18.798 & 18.608 & 18.419\end{array}$ $\begin{array}{llllllllll}15.956 & 15.661 & 17.474 & 17.283 & 17.093 & 16.903 & 16.714 & 16.524 & 16.335 & 16.146 \\ 15.578 & 15.388 & 15.199 & 15.010 & 14.819 & 14.630 & 14.440 & 14.25\end{array}$ $\begin{array}{llllllllll}14.062 & 13.873 & 13.684 & 13.495 & 13.305 & 13.116 & 12.927 & 12.736 & 12.547 & 12.358\end{array}$ $\begin{array}{llllllllll}10.275 & 10.085 & 09.896 & 11.601 & 11.412 & 11.222 & 11.033 & 10.843 & 10.654 & 10.464\end{array}$ $\begin{array}{llllllllll}0.381 & 08.192 & 08.002 & 07.813 & 07.624 & 07.435 & 07.245 & 07.056 & 06.866 & 06.677\end{array}$ $\begin{array}{llllllllll}06.488 & 06.299 & 06.110 & 05.920 & 05.731 & 05.542 & 05.353 & 05.163 & 04.973 & 04.784 \\ 04.595 & 04.405 & 04.217 & 04.027 & 03.838 & 03.649 & 03.459 & 03.270 & 03.081 & 02.891\end{array}$

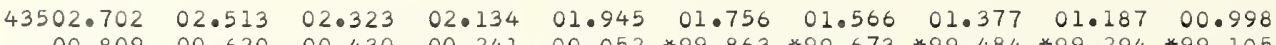

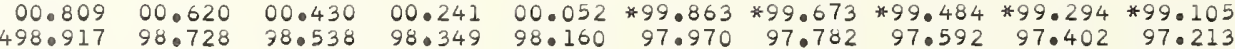

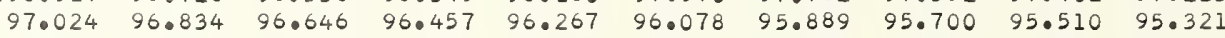
$\begin{array}{llllllllll}95.131 & 94.942 & 94.753 & 94.564 & 94.375 & 94.186 & 93.997 & 93.807 & 93.618 & 93.428\end{array}$

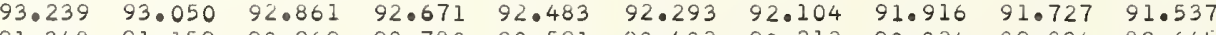

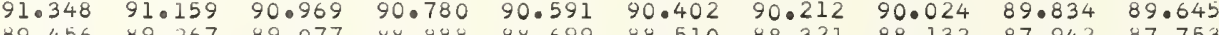

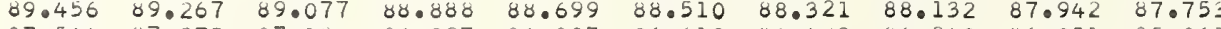
$\begin{array}{llllllllll}87.564 & 87.375 & 87.180 & 86.997 & 86.807 & 86.619 & 86.449 & 86.240 & 86.051 & 85.861\end{array}$

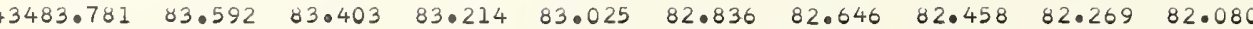
$\begin{array}{llllllllll}81.890 & 81.701 & 81.512 & 81.322 & 81.134 & 80.944 & 80.755 & 80.566 & 80.377 & 80.188\end{array}$ $\begin{array}{llllllllll}79.999 & 79.810 & 79.621 & 79.432 & 79.243 & 79.053 & 78.865 & 78.675 & 78.486 & 78.297\end{array}$ $\begin{array}{llllllllll}76.218 & 76.028 & 75.839 & 75.541 & 77.352 & 77.104 & 76.974 & 76.785 & 76.596 & 76.407\end{array}$ $\begin{array}{llllllllll}74.327 & 74.138 & 73.949 & 73.760 & 73.571 & 73.382 & 73.193 & 73.004 & 72.815 & 72.625\end{array}$ $\begin{array}{llllllllll}72.437 & 72.248 & 72.058 & 71.869 & 71.681 & 71.491 & 71.302 & 71.114 & 70.924 & 70.735\end{array}$ $\begin{array}{llllllllll}70.547 & 70.357 & 70.168 & 69.980 & 69.791 & 69.602 & 69.413 & 69.224 & 69.035 & 68.846\end{array}$ $66.767 \quad 06.578 \quad 60.38966 .199 \quad 66.010 \quad 65.822 \quad 650633 \quad 650443 \quad 65.255 \quad 650.066$
0.308341

0.308337

0.308333

0.308325

0.308321

0.308317

0.308313

0.308309
0.308305

0.308301

0.308298

0.308294

0.308286

0.308282

0.308278

0.308274

0.308266

0.308262

0.308251

0.308247

0.308243

0.308235

0.308231
0.308227

0.308223

0.308219

0.308211

0.308208

0.308204
0.308200

0.308196

0.308196

0.308188

0.308184

0.308176

0.308172

0.308165

0.308161

.308153

0.308145

0.308141

0.308134

0.308130

0.308122

0.308118

0.308114

0.308106

0.308102

0.308099

0.308095

0.308087

0.308083

0.308079

0.308075
0.308071

0.308067

0.308060

0.308056

0.308052

0.308048

0.308044

0.308040

0.308036
0.308033

0.308029

.308025

0.308017

0.308013

0.308009

0.308009

0.308002

.0307994

0.307990

0.307986

0.307982
0.307978

0.307975

0.307971

0.307967

0.307963
0.307959

0.307959

.010

1
.190
.189

0.706100

0.706144

0.706166

0.706209

0.706231

0.706253

0.706275
0.706297

0.706319

0.706341

.706362
.706384

0.706406

0.706428

0.706472

0.706493

0.706515

0.706537

0.706581

0.706603

0.706625

0.706668

0.706690

0.706712

0.706756

0.706778
0.706799

0.706821

0.706843

0.706865

0.706887
0.706909

0.706909
0.706931

0.706953

0.706974

0.706996

0.707018

0.707062

0.707106

0.707149

0.707171

0.707193

0.707215

0.707259

0.707281

0.707324 


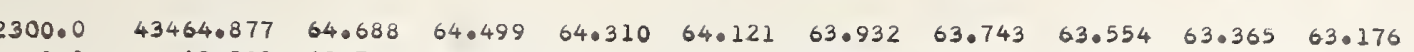

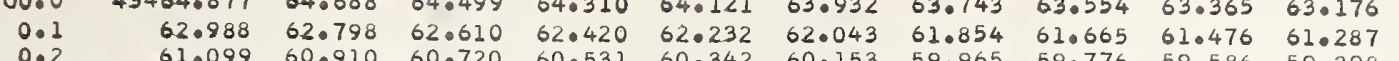
$\begin{array}{lllllllllll}0.2 & 61.099 & 60.910 & 60.720 & 60.531 & 60.342 & 60.153 & 59.965 & 59.776 & 59.586 & 59.398 \\ 0.3 & 59.209 & 59.020 & 58.632 & 58.642 & 58.453 & 58.264 & 58.075 & 57.886 & 57.697 & 57.509\end{array}$ $\begin{array}{lllllllllll}0.3 & 59.209 & 59.020 & 58.832 & 58.642 & 58.453 & 58.264 & 58.075 & 57.886 & 57.587 & 57.509 \\ 0.4 & 57.320 & 57.131 & 56.942 & 56.752 & 56.563 & 56.375 & 56.186 & 55.997 & 55.009 & 55.620\end{array}$ $\begin{array}{lllllllllll}0.4 & 57.320 & 57.131 & 56.942 & 56.752 & 56.563 & 56.375 & 56.186 & 55.997 & 55.809 & 55.620 \\ 0.5 & 55.431 & 55.243 & 55.054 & 54.865 & 54.676 & 54.487 & 54.298 & 54.109 & 53.920 & 53.731\end{array}$ $\begin{array}{lllllllllll}0.6 & 53.543 & 53.354 & 53.165 & 52.976 & 52.787 & 52.598 & 52.409 & 52.220 & 52.031 & 51.842\end{array}$ $\begin{array}{lllllllllll}0.7 & 51.654 & 51.465 & 51.276 & 51.087 & 50.898 & 50.709 & 50.521 & 50.332 & 50.143 & 49.954\end{array}$

0.307917

0.307915

0.307905

0.307897

0.307894

.

0.307882

0.307878

0.307874

0.30786

0.307867

0.307859

0.30785

0.30785.

0.307844

0.307836

0.307828

0.307825

0.307821

0.307817

0.307809

0.30780

0.307798

0.307790

0.307786

0.307782

0.307775

0.307767

0.307763

0.708332

.708376

0.708398

0.708420

0.708464

0.708508 08529

0.708573

0.708595

0.708617

0.708661

0.708683

0.708727

0.708771

0.708793

0.708815

0.708859

0.708880

0.70892

0.708946

0.708968

0.709012

0.709056

0.709078

0.709100

0.709122

0.307759

0.307756

0.307748

0.307740

0.307733

0.307729

0.709166

.70918

0.709232

0.709254

0.709276

0.709298

0.709342

0.709342

0.709385 0.709407 0.709451 0.709517 0.709539 0.709561 0.709583

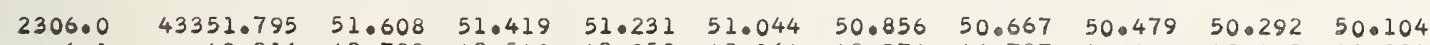

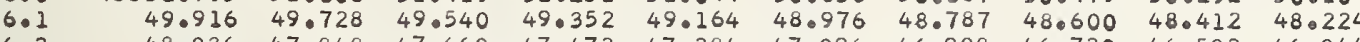
$\begin{array}{lllllllllll}6.2 & 48.036 & 47.848 & 47.660 & 47.472 & 47.284 & 47.096 & 46.908 & 46.720 & 46.532 & 46.344 \\ 6.3 & 46.156 & 45.968 & 45.781 & 45.593 & 45.405 & 45.218 & 45.030 & 44.841 & 44.653 & 44.465\end{array}$

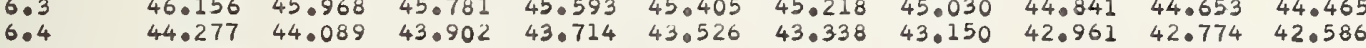
$\begin{array}{lllllllllll}6.5 & 42.398 & 42.210 & 42.022 & 41.834 & 41.647 & 41.459 & 41.271 & 41.08 .3 & 40.895 & 40.707\end{array}$

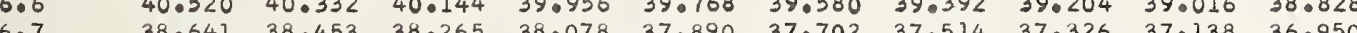

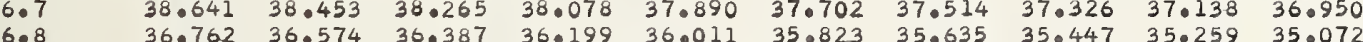
$\begin{array}{lllllllllll}6.8 & 36.762 & 36.574 & 36.387 & 36.199 & 36.011 & 35.823 & 35.635 & 35.447 & 35.259 & 35.072 \\ 6.9 & 34.884 & 34.696 & 34.508 & 34.320 & 34.132 & 33.945 & 33.757 & 33.569 & 33.381 & 33.193\end{array}$ $\begin{array}{llllllllll}4333.005 & 32.818 & 32.630 & 32.442 & 32.254 & 32.066 & 31.878 & 31.691 & 31.502 & 31.314\end{array}$ $\begin{array}{lllllllllll}7.1 & 31.127 & 30.939 & 30.752 & 30.564 & 30.376 & 30.188 & 30.001 & 29.813 & 29.625 & 29.437\end{array}$ $\begin{array}{lllllllllll}7.2 & 29.250 & 29.062 & 28.874 & 28.687 & 28.499 & 28.311 & 28.123 & 27.936 & 27.748 & 27.560 \\ 7.3 & 27.372 & 27.184 & 26.997 & 26.809 & 26.621 & 26.433 & 26.245 & 26.058 & 25.870 & 250682\end{array}$ $\begin{array}{lllllllllll}7.3 & 27.372 & 27.184 & 26.997 & 26.809 & 26.621 & 26.433 & 26.245 & 26.058 & 25.870 & 25.682 \\ 7.4 & 25.494 & 25.306 & 25.119 & 24.931 & 24.743 & 24.556 & 24.368 & 24.180 & 23.992 & 23.804\end{array}$

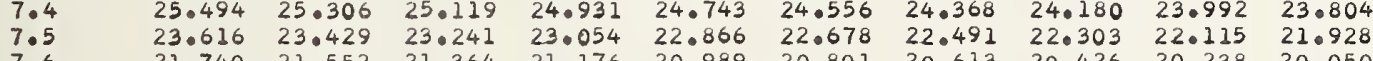
$\begin{array}{lllllllllll}7.6 & 21.740 & 21.552 & 21.364 & 21.176 & 20.989 & 20.801 & 20.613 & 20.426 & 20.238 & 20.050 \\ 7.7 & 19.862 & 19.674 & 19.487 & 19.299 & 19.111 & 18.924 & 18.736 & 18.548 & 18.361 & 18.173\end{array}$

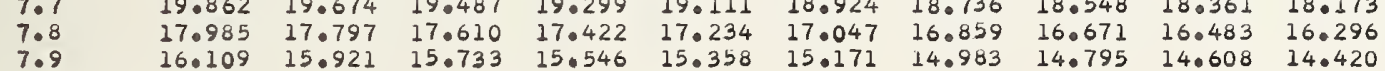

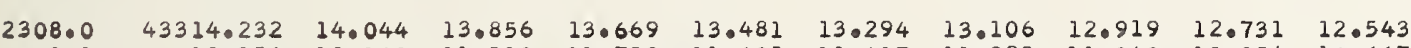

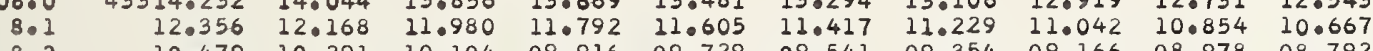
$\begin{array}{lllllllllll}8.2 & 10.479 & 10.291 & 10.104 & 09.916 & 09.729 & 09.541 & 09.354 & 09.166 & 08.978 & 08.792\end{array}$ $\begin{array}{lllllllllll}8.3 & 08.604 & 08.416 & 08.228 & 08.041 & 07.853 & 07.666 & 07.478 & 07.290 & 07.103 & 06.915 \\ 8.4 & 06.728 & 06.540 & 06.352 & 06.164 & 05.977 & 05.790 & 05.602 & 05.414 & 05.227 & 05.039\end{array}$ $\begin{array}{llllllllllll}8.4 & 06.728 & 06.540 & 06.352 & 06.164 & 05.977 & 05.790 & 05.602 & 05.414 & 05.227 & 05.039\end{array}$ $\begin{array}{lllllllllll}8.5 & 04.852 & 04.664 & 04.476 & 04.288 & 04.101 & 03.914 & 03.726 & 03.539 & 03.351 & 03.163 \\ 8.6 & 02.976 & 02.789 & 02.600 & 02.413 & 02.225 & 02.038 & 01.850 & 01.663 & 01.475 & 01.288\end{array}$ $\begin{array}{lrlllllll}8.7 & 01.101 & 0.913 & 00.726 & 00.538 & 00.350 & 00.163 & * 99.976 * 99.788 * 99.600 & * 99.413\end{array}$ $\begin{array}{rrrrrrrrrrr}8.8 & 43299.225 & 99.038 & 98.851 & 98.662 & 98.475 & 98.288 & 98.100 & 97.912 & 97.725 & 97.538 \\ 8.9 & 97.350 & 97.162 & 96.975 & 96.787 & 96.599 & 96.412 & 96.225 & 96.037 & 95.850 & 95.662\end{array}$

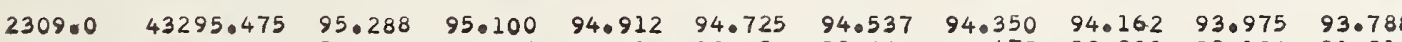

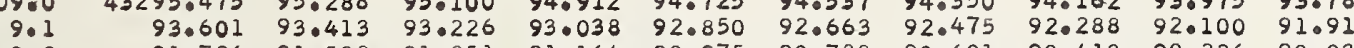
$\begin{array}{lllllllllll}9.2 & 91.726 & 91.538 & 91.351 & 91.164 & 90.975 & 90.788 & 90.601 & 90.413 & 90.226 & 90.039 \\ 9.3 & 89.851 & 89.663 & 89.476 & 89.289 & 89.101 & 88.914 & 88.726 & 88.539 & 88.351 & 88.164\end{array}$ $\begin{array}{lllllllllll}9.4 & 87.976 & 87.789 & 87.602 & 87.414 & 87.226 & 87.039 & 86.852 & 86.665 & 86.478 & 86.290\end{array}$ $\begin{array}{llllllllllll}9.5 & 86.103 & 85.916 & 85.728 & 85.541 & 85.354 & 85.165 & 84.978 & 84.791 & 84.603 & 84.416 \\ 9.6 & 84.229 & 84.041 & 83.854 & 83.066 & 83.479 & 83.291 & 83.104 & 82.917 & 82.729 & 82.542\end{array}$ $\begin{array}{lllllllllll}9.6 & 84.229 & 84.041 & 83.854 & 83.666 & 83.479 & 83.291 & 83.104 & 82.917 & 82.729 & 82.542 \\ 9.7 & 82.354 & 82.167 & 81.979 & 81.792 & 81.605 & 81.417 & 81.230 & 81.042 & 80.855 & 80.668\end{array}$

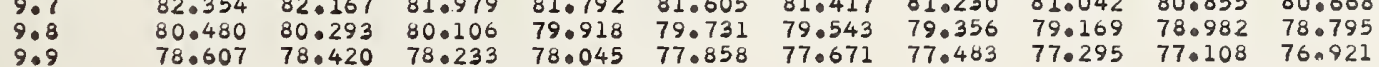

0.307721

0.307717

0.307710

0.30770

0.307702

0.307695

0.30769

0.307687

0.307683

0.30767

0.307672

0.307668

0.307664

0.30766

0.307656

0.307653

0.307645

0.307641

0.307637

0.307630

0.307626

0.307622

0.307618

0.307615
0.307611

0.709605 0.709627 0.709649 0.709693 0.709715
0.709737 0.709759 0.709781

0.709825 0.709847 0.709869
0.709891 0.709913 0.709935 0.709957 0.709979 0.710001
0.710023

0.710045 0.710067 0.710089 0.710133 0.710155 0.710177 0.710199

0.307607 0.307603 0.307600 0.307596 0.307592 0.307588 0.307584 0.307581 0.307577
0.307573 0.710243

0.710265 0.710287 0.710331 0.710353 0.710375
0.710397 0.710419 0.710441

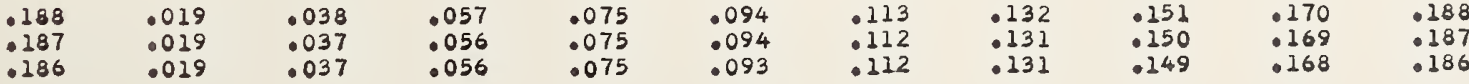


$\lambda(A)$

$10.0 \quad 43276.734$

0.2

0.3

0.5

0.6

0.8
0.9

2311.0

$1 \cdot 1$
1.2
1.3

1.4

1.6

1.7
1.8

1.9

2312.

2.

$2: 3$
$2: 4$

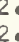

2.7

2313.

3.

3.

$3 \cdot 5$

3.6
3.7
3.8

3.9

2314.

4.
40
40
4.5
40
407
4.8
40

2315.

$$
5 .
$$

5.2
5.3
5.4

5.6

5.6
5.7

5.8
5.9

2316.0

6.

6.4
6.5

6.6
6.7

6.7
6.8
6.9

2317.

7.

7.5

\section{8.}

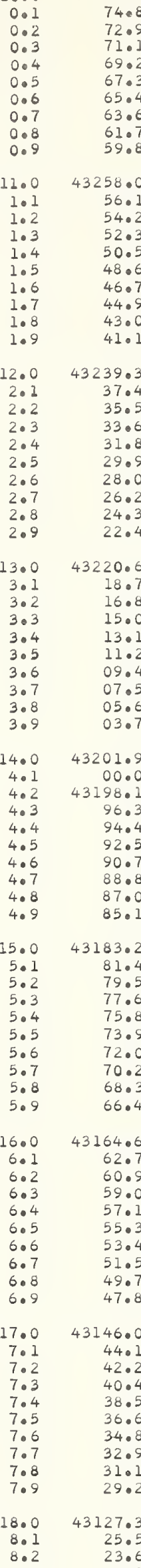

8.2
8.3
8.4

8.5

8.6
8.7

8.7
8.9

2319.

$$
\begin{array}{r}
9 . \\
9 . \\
9 . \\
9 . \\
9 . \\
9 . \\
9 . \\
9 .
\end{array}
$$
$\begin{array}{lll}72.800 & 72.013\end{array}$ $\begin{array}{lll} & 0.0252 & 68.868\end{array}$ $6.497 \quad 65.310$
65.122 $\begin{array}{lll}.625 & 63.437 & 63.250\end{array}$ $\begin{array}{lll}61.565 & 61.378\end{array}$

.03

.04

.05

.06

.07

$\begin{array}{lllll}75.797 & 75.609 & 75.422 & 75.235 & 75.048\end{array}$

$\begin{array}{lllllll}74.298 & 74.111 & 73.924 & 73.736 & 73.549 & 73.362 & 73.174 \\ 72.426 & 72.238 & 72.051 & 71.865 & 71.677 & 71.489 & 71.302\end{array}$

$\begin{array}{lllllll}70.553 & 70.366 & 70.179 & 69.992 & 69.804 & 69.616 & .69 .429\end{array}$

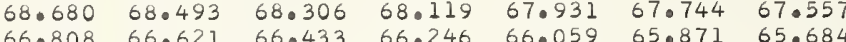

$\begin{array}{llllllll}64.935 & 64.748 & 64.561 & 64.374 & 64.187 & 63.999 & 63.812\end{array}$

$63.063 \quad 62.876 \quad 62.68962 .502 \quad 62.31562 .127 \quad 61.940$

61.19161 .004

62.689

60.630

62.315

$\begin{array}{ll}62.127 & 61.940 \\ 60.254 & 60.068\end{array}$

$\begin{array}{lllllll}57.447 & 57.260 & 57.074 & 56.886 & 56.700 & 56.512 & 56.325\end{array}$

$7.822 \quad 57.634$

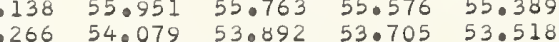

$2350.336 \quad 50.149$

. 46.408

$43.041 \quad 42.853$

44.537

$51.833 \quad 51.646$

55.202
53.330

56.886
55.015

$51.459 \quad 51.272 \quad 52.927$

52.76952 .582

$50.897 \quad 50.710$

$\begin{array}{lllll}49.401 & 49.214 & 49.027 & 48.840\end{array}$

$\begin{array}{llll}45.659 & 45.473 & 45.286 & 45.098\end{array}$

$\begin{array}{ll}46.220 & 46.034 \\ 44.350 & 44.163\end{array}$

$\begin{array}{lll}47.718 & 47.530 & 47.344 \\ 45.847 & 45.659 & 45.473\end{array}$

45.847

3.60

43.228
41.358

$239.301 \quad 39.113 \quad 38.926$

$37.431 \quad 37.243$

$\begin{array}{lll}35.561 & 35.373 & 35.186 \\ 33.691 & 33.504 & 33.317\end{array}$

$\begin{array}{llll}31.635 & 31.417 & 33.130 & 32.943 \\ 31.260 & 31.073\end{array}$

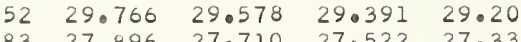

$\begin{array}{lll}.214 & 26.896 & 27.710\end{array}$

$\begin{array}{lll}2.346 & 24.159 & 23.972 \\ 2.477 & 22.290 & 22.103\end{array}$

$25.653 \quad 25.466$

$\begin{array}{ll}23.785 & 23.466 \\ 21.916 & 21.729\end{array}$

40.236

40.049

9.86

39.675

37.618

$\begin{array}{lllll}36.495 & 36.308 & 36.122 & 35.935 & 35.748\end{array}$

$\begin{array}{lllll}34.626 & 34.439 & 34.252 & 34.065 & 33.878\end{array}$

$30.887 \quad 30.700 \quad 30.513 \quad 30.326 \quad 30.13$

$\begin{array}{lllll}29.018 & 28.831 & 28.644 & 28.457 & 28.270 \\ 27.148 & 26.961 & 26.775 & 26.588 & 26.401\end{array}$

$\begin{array}{lllll}25.279 & 25.093 & 24.906 & 26.588 & 26.401\end{array}$

$\begin{array}{lllll}23.411 & 23.224 & 23.037 & 22.850 & 22.664 \\ 21.542 & 21.355 & 21.168 & 20.982 & 20.795\end{array}$

20.42120 .235

$20.048 \quad 19.861$

$\begin{array}{llllll}19.674 & 19.487 & 19.301 & 19.114 & 18.927\end{array}$

$\begin{array}{lll}8.740 & 18.553 & 18.366\end{array}$

$\begin{array}{lll}5.003 & 14.816 & 14.630\end{array}$

$\begin{array}{lll}1.268 & 11.948 & 12.763 \\ 0.082 & 10.895\end{array}$

$\begin{array}{lll}0.401 & 09.214 & 09.027 \\ 07.533 & 07.346 & 07.159\end{array}$

$\begin{array}{ll}18.179 & 17.992 \\ 16.312 & 16.124\end{array}$

14.443
12.576

14.256

$\begin{array}{lll}17.806 & 17.619 & 17.43\end{array}$

14.069

13.882
12.015

13.695

$\begin{array}{ll}17.245 & 17.058\end{array}$

$\begin{array}{lll}10.708 & 10.521 & 10.334\end{array}$

$06.973 \quad 06.786$

08.466
06.599

08.279

09.961

$\begin{array}{ll}5.666 & 05.479\end{array}$

05.293
03.426

$\begin{array}{ll}03.106 & 04.919 \\ 03.239 & 03.052\end{array}$

04.733
02.866

04.545
02.678

08.09

$\begin{array}{ll}13.509 & 13.322\end{array}$

$\begin{array}{ll}11.642 & 11.455\end{array}$

$07.906 \quad 07.719$

$06.039 \quad 05.853$

$04.172 \quad 03.986$

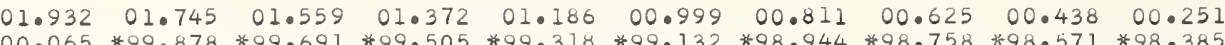

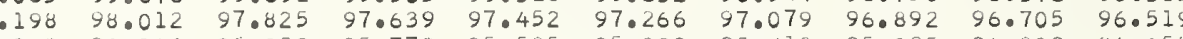
$\begin{array}{llllllllll}96.332 & 96.146 & 95.959 & 95.772 & 95.585 & 95.399 & 95.213 & 95.025 & 94.839 & 94.652 \\ \end{array}$

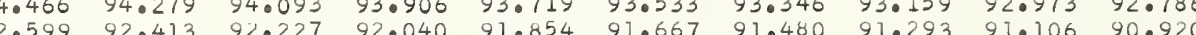
$\begin{array}{llllllllll}90.734 & 90.547 & 90.361 & 90.174 & 89.988 & 89.801 & 89.614 & 89.428 & 89.241 & 89.054\end{array}$

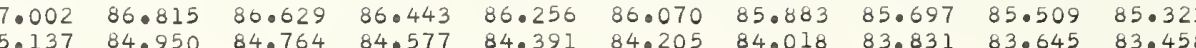

$\begin{array}{llllllllll}3183.271 & 83.085 & 82.899 & 82.712 & 82.526 & 82.339 & 82.153 & 81.967 & 81.780 & 81.593\end{array}$ $\begin{array}{llllllllll}81.407 & 81.220 & 81.034 & 80.847 & 80.661 & 80.474 & 80.288 & 80.102 & 79.915 & 79.728 \\ 79.542 & 79.355 & 79.160 & 78.982 & 78.795 & 78.609 & 78.423 & 78.236 & 78.050 & 77.863\end{array}$ $\begin{array}{llllllllll}77.676 & 77.490 & 77.304 & 77.1117 & 76.931 & 76.745 & 76.558 & 76.372 & 76.185 & 76.000\end{array}$ $\begin{array}{llllllllll} & \end{array}$

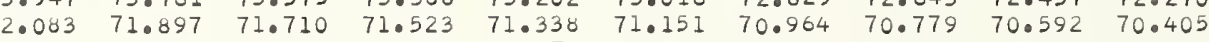

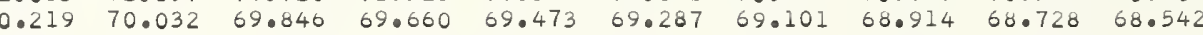
$\begin{array}{lllllllllll}60.356 & 68.168 & 67.983 & 67.796 & 67.610 & 67.424 & 67.237 & 67.051 & 66.0864 & 66.678\end{array}$

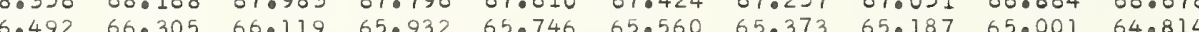

$\begin{array}{rlllllllll}164.628 & 64.441 & 04.255 & 64.068 & 63.882 & 63.696 & 63.509 & 63.323 & 63.137 & 62.950 \\ 62.765 & 62.578 & 62.391 & 62.205 & 62.019 & 61.832 & 61.646 & 61.460 & 61.273 & 61.087\end{array}$

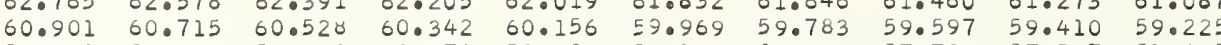
$\begin{array}{llllllllll}9.038 & 58.852 & 58.065 & 58.479 & 58.292 & 58.106 & 57.920 & 57.733 & 57.547 & 57.361\end{array}$

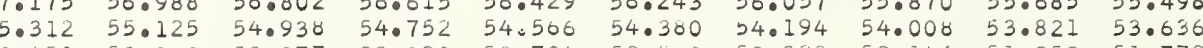
$\begin{array}{llllllllll}3.450 & 53.263 & 53.077 & 52.890 & 52.704 & 52.518 & 52.332 & 52.146 & 51.959 & 51.772\end{array}$ $\begin{array}{llllllll} & \end{array}$ $\begin{array}{llllllllll}49.724 & 49.538 & 49.352 & 49.165 & 48.979 & 48.793 & 48.606 & 48.420 & 48.234 & 48.048 \\ 47.862 & 47.675 & 47.490 & 47.303 & 47.116 & 46.931 & 46.744 & 46.558 & 46.372 & 46.187\end{array}$ $\begin{array}{llllllllll}46.000 & 45.814 & 45.628 & 45.441 & 45.255 & 45.069 & 44.882 & 44.697 & 44.510 & 44.324\end{array}$ $\begin{array}{lllllllllll}4.138 & 43.952 & 43.766 & 43.580 & 43.393 & 43.207 & 43.021 & 42.834 & 42.648 & 42.462\end{array}$

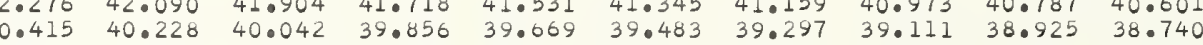
$\begin{array}{llllllllll}38.553 & 38.367 & 38.181 & 37.995 & 37.809 & 37.623 & 37.436 & 37.250 & 37.064 & 36.878\end{array}$ $\begin{array}{llllllllll}3.831 & 36.506 & 36.320 & 36.134 & 35.948 & 35.761 & 35.575 & 35.389 & 35.203 & 35.017 \\ 34.645 & 34.458 & 34.272 & 34.086 & 33.900 & 33.713 & 33.528 & 33.342 & 33.155\end{array}$

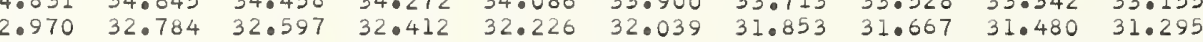
$\begin{array}{llllllllll}31.109 & 30.923 & 30.737 & 30.551 & 30.365 & 30.179 & 29.993 & 29.807 & 29.620 & 29.435 \\ 29.249 & 29.062 & 28.876 & 28.690 & 28.504 & 28.318 & 28.132 & 27.946 & 27.760 & 27.574\end{array}$$$
\begin{array}{lll}
27.388 & 27.202 & 27.016
\end{array}
$$$$
26.830 \quad 26.644
$$$$
26.458 \quad 26.271 \quad 26.085 \quad 25.899 \quad 25.713
$$

$\begin{array}{llllllllll}25.568 & 25.341 & 25.155 & 24.969 & 24.784 & 24.598 & 24.411 & 24.225 & 24.039 & 23.854\end{array}$

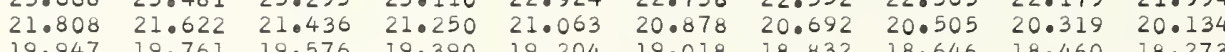

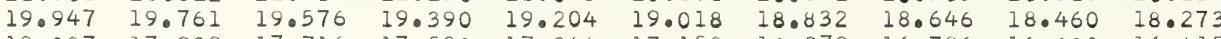
$\begin{array}{llllllllll}18.087 & 17.902 & 17.716 & 17.530 & 17.344 & 17.158 & 16.972 & 16.786 & 16.600 & 16.415 \\ 16.229 & 16.043 & 15.857 & 15.671 & 15.485 & 15.299 & 15.113 & 14.928 & 14.741 & 14.555\end{array}$

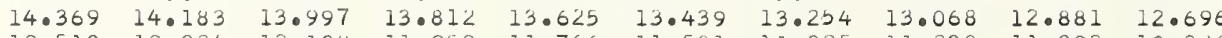

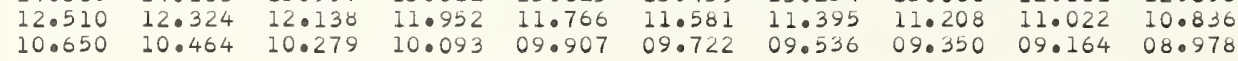

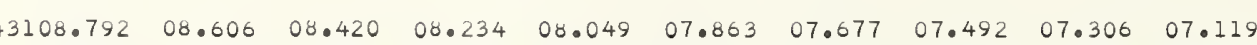
$\begin{array}{llllllllll}06.934 & 06.748 & 06.562 & 06.375 & 06.190 & 06.004 & 05.818 & 05.633 & 05.447 & 05.260\end{array}$ $\begin{array}{llllllllll}05.075 & 04.889 & 04.703 & 04.518 & 04.332 & 04.146 & 03.960 & 03.774 & 03.588 & 03.402\end{array}$ $\begin{array}{llllllllll}03.216 & 03.030 & 02.845 & 02.659 & 02.473 & 02.288 & 02.102 & 01.916 & 01.729 & 01.545 \\ 01.358 & 01.172 & 00.987 & 00.801 & 00.615 & 00.430 & 00.244 & 00.058 & * 99.873 & * 99.687\end{array}$

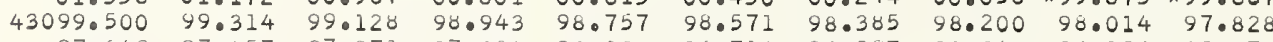

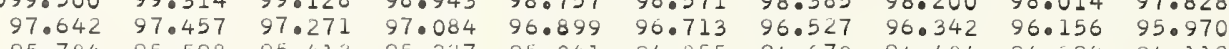

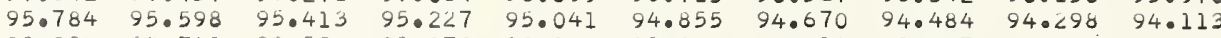
$\begin{array}{llllllllll}93.928 & 93.741 & 93.550 & 93.370 & 93.184 & 92.999 & 92.813 & 92.627 & 92.441 & 92.256 \\ 92.070 & 91.883 & 91.698 & 91.512 & 91.326 & 91.141 & 90.955 & 90.770 & 90.584 & 90.398\end{array}$

$$
.001 \quad .002
$$$$
.001
$$$$
.003
$$$$
.004
$$

.005

.006

$\begin{array}{rrr}.007 & .008 \quad .009\end{array}$

0.307562

0.307558

0.307554

0.307546

0.307543

0.307539

0.307531

0.307528

0.307524

0.307520

0.307512

0.307509

0.307505

0.307501
0.307497

0.307494

0.307490

0.307486
0.307482

0.307478

0.307475

0.307471

0.307463

0.307460

0.307456 .

0.307452

0.307445

0.307441
0.307437

0.307433

0.307430

0.307426

0.307418

0.307414

0.30741

0.307407

0.307407

0.307399

0.307396
0.307392

0.307392

0.307384

0.307381

0.307377

0.307373

0.307369

0.307366
0.307362

0.307362

0.307358

0.307354

0.307351
0.307347

0.307343

0.307339

0.307336

0.307332

0.307324

0.307321

0.307317

0.307313
0.307309

0.307306

0.307302

0.307298
0.307295

0.307291

0.307287

0.307283

0.307280

0.307272

0.307268

0.307265

0.307261
0.307257

0.307253

0.307250

0.307246

0.307242

0.307239

0.307231
0.307227

0.307224

0.307220

0.307216

0.307212

0.307209 


\begin{tabular}{|c|c|c|c|c|c|c|c|c|}
\hline$\lambda(A)$ & .00 & .01 & .02 & .03 & .04 & .05 & .06 & .07 \\
\hline $20 \cdot 0$ & 43090.212 & 90.026 & 89.841 & 89.655 & 89.470 & 89.284 & 89.098 & 88.913 \\
\hline 0.1 & 88.355 & 88.169 & 87.983 & 87.797 & 87.612 & 87.426 & 87.241 & 87.055 \\
\hline $\begin{array}{l}0.2 \\
0.3\end{array}$ & $\begin{array}{l}86.499 \\
84.642\end{array}$ & $\begin{array}{l}86.313 \\
84.456\end{array}$ & 86.126 & 85.941 & $\begin{array}{l}85.756 \\
83\end{array}$ & 85.570 & 85.385 & 85.199 \\
\hline $\begin{array}{l}0.3 \\
0.4\end{array}$ & $\begin{array}{l}84.642 \\
82.785\end{array}$ & $\begin{array}{l}84.456 \\
82.599\end{array}$ & $\begin{array}{l}84.270 \\
82.414\end{array}$ & $\begin{array}{l}84.084 \\
82.228\end{array}$ & $\begin{array}{l}83.898 \\
82.042\end{array}$ & $\begin{array}{l}83.713 \\
81.856\end{array}$ & $\begin{array}{l}83.528 \\
81.671\end{array}$ & $\begin{array}{l}83.342 \\
81.485\end{array}$ \\
\hline 0.5 & 80.928 & 80.743 & 80.557 & 80.371 & 80.186 & 80.000 & 79.814 & 79.629 \\
\hline 0.6 & $79 \cdot 6$ & 78.887 & 78.701 & 78.515 & 78.330 & 78.144 & 77.958 & 77.773 \\
\hline $\begin{array}{l}0.7 \\
0.8\end{array}$ & $\begin{array}{l}77.216 \\
75.360\end{array}$ & $\begin{array}{l}77.031 \\
75.174\end{array}$ & $\begin{array}{l}76.845 \\
74.989\end{array}$ & 76.659 & 76.474 & $\begin{array}{l}76.288 \\
74.432\end{array}$ & 76.103 & 75.917 \\
\hline $\begin{array}{l}0.8 \\
0.9\end{array}$ & $\begin{array}{l}75.360 \\
73.504\end{array}$ & $\begin{array}{l}75.174 \\
73.318\end{array}$ & $\begin{array}{l}74.989 \\
73.133\end{array}$ & $\begin{array}{l}74.803 \\
72.947\end{array}$ & $\begin{array}{l}74.617 \\
72.761\end{array}$ & $\begin{array}{l}74.432 \\
72.576\end{array}$ & $\begin{array}{l}74.247 \\
72.391\end{array}$ & $\begin{array}{l}74.061 \\
72.205\end{array}$ \\
\hline 23.0 & 43071.649 & 71.463 & 71.278 & 71.092 & & 21 & 35 & 350 \\
\hline & 69.793 & & $69 \cdot 422$ & 69.236 & & & & \\
\hline $\begin{array}{l}1.2 \\
1.3\end{array}$ & $670^{\circ}$ & $\begin{array}{l}67.752 \\
65.897\end{array}$ & $\begin{array}{l}67.560 \\
65.712\end{array}$ & 67.381 & 67.195 & 67.010 & 66.825 & 66. \\
\hline $\begin{array}{l}1.3 \\
1.4\end{array}$ & $\begin{array}{l}66.083 \\
64.228\end{array}$ & $\begin{array}{l}65.897 \\
64.042\end{array}$ & $\begin{array}{l}65.712 \\
63.857\end{array}$ & $\begin{array}{l}65.526 \\
63.671\end{array}$ & $\begin{array}{l}65.340 \\
63.486\end{array}$ & $\begin{array}{l}65.155 \\
63.301\end{array}$ & $\begin{array}{l}64.969 \\
63.125\end{array}$ & $\begin{array}{l}64.784 \\
62.829\end{array}$ \\
\hline 1.5 & 62.373 & $\begin{array}{l}04.042 \\
62.187\end{array}$ & $\begin{array}{l}02.031 \\
62.002\end{array}$ & 61.816 & 61.631 & $\begin{array}{l}53.301 \\
61.446\end{array}$ & $\begin{array}{l}63.115 \\
61.259\end{array}$ & $\begin{array}{l}62.929 \\
61.075\end{array}$ \\
\hline 1.6 & 60.518 & 60.333 & 60.147 & 59.961 & 59.776 & 59.590 & 59.405 & $\begin{array}{l}0.015 \\
59.220\end{array}$ \\
\hline 1.7 & 58.664 & 58.478 & 58.292 & 58.107 & 57.922 & 57.735 & 57.550 & 57.365 \\
\hline $\begin{array}{l}1.8 \\
1.9\end{array}$ & 56.810 & 56.624 & 56.439 & 56.253 & 56.068 & 55.883 & 55.697 & 55.511 \\
\hline 1.9 & 54.955 & 54.770 & 54.584 & 54.399 & 54.213 & 54.028 & 53.843 & 53.657 \\
\hline $\begin{array}{r}22.0 \\
2.1\end{array}$ & $\begin{array}{r}43053.101 \\
51.247\end{array}$ & $\begin{array}{l}52.916 \\
51.062\end{array}$ & $\begin{array}{l}52.730 \\
50.876\end{array}$ & $\begin{array}{l}52.544 \\
50.590\end{array}$ & $\begin{array}{l}52.359 \\
50.505\end{array}$ & $\begin{array}{l}52.174 \\
50.320\end{array}$ & $\begin{array}{l}51.988 \\
50.134\end{array}$ & $\begin{array}{l}51.803 \\
49.949\end{array}$ \\
\hline 2.2 & 49.394 & 49.208 & 49.022 & $\begin{array}{l}50.690 \\
48.837\end{array}$ & $\begin{array}{l}20.505 \\
48.652\end{array}$ & $\begin{array}{l}50.320 \\
48.466\end{array}$ & $\begin{array}{l}50.134 \\
48.282\end{array}$ & $\begin{array}{l}49.949 \\
48.096\end{array}$ \\
\hline $2 \cdot 3$ & 47.540 & 47.354 & 47.169 & 46.984 & 46.798 & 46.613 & 46.428 & 46.242 \\
\hline 2.4 & 45.686 & 45.500 & 45.315 & 45.130 & $44 \cdot 945$ & 44.760 & 44.574 & 44.389 \\
\hline 2.5 & 43.833 & 43.647 & 43.462 & 43.276 & 43.092 & 42.906 & 42.721 & 42.536 \\
\hline 2.6 & 41.980 & 41.795 & 41.609 & 41.424 & 41.239 & 41.054 & 40.868 & 40.683 \\
\hline 2.7 & $\begin{array}{l}40.127 \\
38.274\end{array}$ & $\begin{array}{l}39.941 \\
38.088\end{array}$ & $\begin{array}{l}39.756 \\
37.904\end{array}$ & $\begin{array}{l}39.571 \\
37.718\end{array}$ & $\begin{array}{l}39.386 \\
37.533\end{array}$ & $\begin{array}{l}39 \cdot 200 \\
37.348\end{array}$ & $\begin{array}{l}39.016 \\
37.163\end{array}$ & $\begin{array}{l}38.830 \\
36.077\end{array}$ \\
\hline $\begin{array}{l}2.8 \\
2.9\end{array}$ & $\begin{array}{l}38.274 \\
36.421\end{array}$ & $\begin{array}{l}38.088 \\
36.236\end{array}$ & $\begin{array}{l}37.904 \\
36.051\end{array}$ & $\begin{array}{l}37.718 \\
35.865\end{array}$ & $\begin{array}{l}37.533 \\
35.680\end{array}$ & $\begin{array}{l}37.348 \\
35.495\end{array}$ & $\begin{array}{l}37.163 \\
35.310\end{array}$ & $\begin{array}{l}36.977 \\
35.125\end{array}$ \\
\hline 23.0 & 43034.569 & 34.384 & 34.199 & 34.013 & 33.829 & 33.643 & 33.458 & \\
\hline & & 32.531 & 32.346 & 32.161 & 31.976 & 31.791 & 31. & 31. \\
\hline $\begin{array}{l}3.2 \\
3.3\end{array}$ & 30.864 & 30.679 & 30.494 & 30.309 & 30.124 & 29.938 & 29. & 29. \\
\hline $\begin{array}{l}3.3 \\
3.4\end{array}$ & 29.012 & 28.827 & 20.642 & 28.457 & 28.271 & 28.086 & 27.901 & 27.716 \\
\hline $\begin{array}{l}3.4 \\
3.5\end{array}$ & $\begin{array}{l}27.161 \\
25.309\end{array}$ & 26.975 & 26.791 & 26.605 & 26.420 & 26.235 & 26.050 & 25. \\
\hline $\begin{array}{l}3.5 \\
3.6\end{array}$ & $\begin{array}{l}25.309 \\
23.458\end{array}$ & $\begin{array}{l}25.124 \\
23.272\end{array}$ & $\begin{array}{l}24.938 \\
23.087\end{array}$ & 24.753 & 24.569 & 24.383 & 24.198 & 24 . \\
\hline 3.7 & $\begin{array}{l}23.458 \\
21.606\end{array}$ & $\begin{array}{l}23.272 \\
21.420\end{array}$ & $\begin{array}{l}23.087 \\
21.235\end{array}$ & $\begin{array}{l}22.902 \\
21.051\end{array}$ & $\begin{array}{l}22.717 \\
20.865\end{array}$ & $\begin{array}{l}22.532 \\
20.680\end{array}$ & $\begin{array}{l}22.346 \\
20.496\end{array}$ & $\begin{array}{l}22.162 \\
20.310\end{array}$ \\
\hline 3.8 & 19.755 & 19.570 & 19.385 & 19.200 & 19.015 & 18.830 & 18.645 & 18.459 \\
\hline 3.9 & 17.904 & 17.719 & 27.534 & 17.349 & 17.163 & 16.979 & 16.793 & 16.608 \\
\hline $24 \cdot 0$ & 3016.053 & 15.869 & 15.683 & 15.498 & 15.313 & 15.127 & 14.942 & 14.758 \\
\hline & 14.203 & 14.018 & 23.832 & 13.646 & 13.462 & 13.277 & 13.091 & 12.907 \\
\hline $\begin{array}{l}4.2 \\
4.3\end{array}$ & $\begin{array}{l}12.352 \\
10.502\end{array}$ & 12.167 & 11.982 & $\begin{array}{l}11.797 \\
09.946\end{array}$ & 11.612 & 11.427 & 11.242 & 11.057 \\
\hline $\begin{array}{l}4.3 \\
4.4\end{array}$ & $\begin{array}{l}10.502 \\
08.651\end{array}$ & $\begin{array}{l}10.316 \\
08.466\end{array}$ & $\begin{array}{l}10.132 \\
08.282\end{array}$ & $\begin{array}{l}09.946 \\
08.096\end{array}$ & $\begin{array}{l}09.761 \\
07.911\end{array}$ & $\begin{array}{l}09.577 \\
07.726\end{array}$ & $\begin{array}{l}09.391 \\
07.541\end{array}$ & $\begin{array}{l}09.206 \\
07.356\end{array}$ \\
\hline 4.5 & $\begin{array}{l}0.651 \\
06.801\end{array}$ & $\begin{array}{l}08.466 \\
06.616\end{array}$ & $\begin{array}{l}08.282 \\
06.431\end{array}$ & $\begin{array}{l}08.096 \\
06.246\end{array}$ & $\begin{array}{l}07.911 \\
06.061\end{array}$ & $\begin{array}{l}07.726 \\
05.876\end{array}$ & $\begin{array}{l}07.541 \\
05.691\end{array}$ & $\begin{array}{l}07.356 \\
05.506\end{array}$ \\
\hline 4.6 & 04.951 & 04.767 & 04.582 & 04.396 & 04.211 & 04. & 03.841 & 03.657 \\
\hline $4 \cdot 7$ & 03.102 & 02.917 & 02.731 & 02.547 & 02.361 & 02. & 01.992 & 01.807 \\
\hline $\begin{array}{l}4.8 \\
4.9\end{array}$ & $\begin{array}{r}01.252 \\
42999.402\end{array}$ & $\begin{array}{l}01.067 \\
99.217\end{array}$ & $\begin{array}{l}00.882 \\
99.033\end{array}$ & $\begin{array}{l}00.697 \\
98.848\end{array}$ & $\begin{array}{l}00.512 \\
98.662\end{array}$ & $\begin{array}{l}00.327 \\
93.478\end{array}$ & 00.142 & *99.957 \\
\hline 0 & & & & & & & & \\
\hline $\begin{array}{l}5.1 \\
5.2\end{array}$ & & 95. & 95.334 & 95.149 & $\begin{array}{l}96.814 \\
94.905\end{array}$ & $\begin{array}{l}96.628 \\
94.779\end{array}$ & $\begin{array}{l}96.443 \\
94.594\end{array}$ & $\begin{array}{l}96.259 \\
94.410\end{array}$ \\
\hline $\begin{array}{l}5.2 \\
5.3\end{array}$ & 93.855 & 93.670 & 93.485 & 93. & 93. & & +6 & 92. \\
\hline $\begin{array}{l}5.3 \\
5.4\end{array}$ & 92.006 & 91.821 & 91.637 & 91.452 & 91.267 & & 96 & 90. \\
\hline $\begin{array}{l}5.4 \\
5.5\end{array}$ & $\begin{array}{l}90.157 \\
88.309\end{array}$ & $\begin{array}{l}89.972 \\
88.125\end{array}$ & $\begin{array}{l}89.789 \\
87.940\end{array}$ & $\begin{array}{l}89.604 \\
87.755\end{array}$ & $\begin{array}{l}89.418 \\
87.570\end{array}$ & 89.234 & 89.049 & 88.863 \\
\hline 5.6 & 86.2 & $\begin{array}{l}88.125 \\
86.276\end{array}$ & 86.091 & $\begin{array}{l}81.152 \\
85.906\end{array}$ & $\begin{array}{l}87.570 \\
85.722\end{array}$ & $\begin{array}{l}87.385 \\
85.537\end{array}$ & $\begin{array}{l}87.200 \\
85.351\end{array}$ & $\begin{array}{l}87.016 \\
85.0167\end{array}$ \\
\hline 5.7 & 84.613 & 84.428 & 84.243 & 84.0 & 83.874 & $\begin{array}{l}85.237 \\
83.688\end{array}$ & $\begin{array}{l}85.321 \\
83.503\end{array}$ & 83. \\
\hline 5.8 & 82.764 & 82.580 & 82.395 & 82.211 & 82.026 & 81.841 & 81.656 & 81.472 \\
\hline 5.9 & 80.917 & 80.732 & 80.547 & 80.363 & 80.178 & 79.993 & 79.809 & 79.624 \\
\hline & $\begin{array}{r}42979.069 \\
77.222\end{array}$ & 78.884 & $\begin{array}{l}78.700 \\
76.852\end{array}$ & $7 \varepsilon$ & 78. & 78. & & $\begin{array}{l}77.7 \\
75.5\end{array}$ \\
\hline $\begin{array}{l}6.1 \\
6.2\end{array}$ & $\begin{array}{l}77.0222 \\
75.374\end{array}$ & $\begin{array}{l}75.037 \\
75.189\end{array}$ & $\begin{array}{l}76.852 \\
75.004\end{array}$ & 76. & 74.636 & $740^{\circ}$ & & $740^{\circ}$ \\
\hline 6.3 & .527 & 73.3 & 73.156 & 72.9 & 8 & & & \\
\hline 6.4 & .680 & 71.495 & 71.311 & 71. & 70. & 70 & 70 & 70. \\
\hline 8.5 & .833 & 69.648 & 69.463 & 69. & 4 & & 68. & \\
\hline $\begin{array}{l}6.6 \\
6.7\end{array}$ & .986 & 67.801 & 67.617 & 67. & . 248 & 67 & 66. & 66. \\
\hline $\begin{array}{l}6.7 \\
6.8\end{array}$ & 140 & 65.955 & 65.771 & 65. & 65.401 & & 65. & 64.848 \\
\hline $\begin{array}{l}6.8 \\
6.9\end{array}$ & $\begin{array}{l}.293 \\
.447\end{array}$ & 64.108 & 63.924 & $\begin{array}{l}63.739 \\
61.893\end{array}$ & $\begin{array}{l}63.555 \\
61.708\end{array}$ & $\begin{array}{l}63 \\
61\end{array}$ & & $\begin{array}{l}63.001 \\
61.154\end{array}$ \\
\hline & & & & & & & & \\
\hline 7.2 & $\begin{array}{r}.960 .600 \\
58.756\end{array}$ & $\begin{array}{l}60.416 \\
58.570\end{array}$ & $\begin{array}{l}60.231 \\
58.386\end{array}$ & $\begin{array}{l}60.046 \\
58.201\end{array}$ & $\begin{array}{l}59.863 \\
58.017\end{array}$ & $\begin{array}{l}59.678 \\
57.832\end{array}$ & $\begin{array}{l}59.494 \\
57.647\end{array}$ & $\begin{array}{l}59.310 \\
57.463\end{array}$ \\
\hline $7 \cdot 2$ & 56.910 & 56.725 & 56. & 56 & 1 & & & \\
\hline 7. & 54 & 54. & 3 & & 5 & 5 & & \\
\hline 7. & 53.2 & 53. & & & & & & \\
\hline $\begin{array}{l}7 \\
7 .\end{array}$ & 51.373 & 51. & 51. & 50. & 5 & 50 & 6 & \\
\hline 7 & 49.528 & $49 \cdot 3$ & 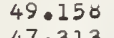 & & 0 & & & \\
\hline $\begin{array}{l}7 \cdot 7 \\
7.8\end{array}$ & 47.683 & 47. & $470^{\circ}$ & $470^{\circ}$ & & 46. & & $460^{\circ}$ \\
\hline $\begin{array}{l}7.8 \\
7.5\end{array}$ & $\begin{array}{l}45.838 \\
43.994\end{array}$ & & 9 & $450^{\circ}$ & $\begin{array}{l}.100 \\
3.255\end{array}$ & $\begin{array}{l}44.916 \\
43.071\end{array}$ & $\begin{array}{l}4.731 \\
2.887\end{array}$ & $\begin{array}{l}44.547 \\
42.702\end{array}$ \\
\hline & 43.994 & 43. & 8.0 & 430. & 0.202 & 420011 & & 20102 \\
\hline 8. & $\begin{array}{r}42942.149 \\
40.305\end{array}$ & 41.5 & $\begin{array}{l}0 \\
6\end{array}$ & ${ }^{41} 0^{\circ}$ & & $\begin{array}{l}41 \\
39\end{array}$ & +2 & \\
\hline 8. & $\begin{array}{l}40.305 \\
38.460\end{array}$ & $\begin{array}{l}40 . \\
38 .\end{array}$ & 38.0 & $\begin{array}{l}390^{\circ} \\
37 .\end{array}$ & 22 & & & \\
\hline & 36.616 & 36.2 & 36. & 36. & 8 & & & \\
\hline 8.4 & 772 & 34. & & & & & & \\
\hline $\begin{array}{l}8.5 \\
8.6\end{array}$ & 5 & $32 \cdot$ & 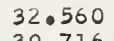 & 32 & & & & \\
\hline $\begin{array}{l}8.6 \\
8.7\end{array}$ & $\begin{array}{l}31.085 \\
29.242\end{array}$ & 30. & 5 & & & & & \\
\hline $\begin{array}{l}8.7 \\
8.8\end{array}$ & $\begin{array}{l}29.242 \\
27.398\end{array}$ & $\begin{array}{l}29.0 \\
27.2\end{array}$ & $28 \cdot 8$ & & & & & \\
\hline $\begin{array}{l}8.8 \\
8.9\end{array}$ & $\begin{array}{l}27.398 \\
25.555\end{array}$ & $\begin{array}{l}27.214 \\
25.371\end{array}$ & $\begin{array}{l}27.030 \\
25.187\end{array}$ & $\begin{array}{l}26.846 \\
25.002\end{array}$ & & & & \\
\hline & & & & & 24.818 & 24.6 & 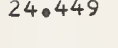 & 24.265 \\
\hline & & $\begin{array}{l}23.528 \\
21.686\end{array}$ & $\begin{array}{l}344 \\
501\end{array}$ & 21 & 5 & & & \\
\hline 9. & 7 & 19. & & & & & & \\
\hline 9. & 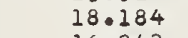 & & & & & & & \\
\hline 9. & 1 & 16.1 & & & & & & \\
\hline 9. & 0 & & & & & & & \\
\hline & 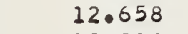 & & & & & & & \\
\hline 9. & 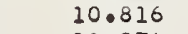 & 10.6 & & & & & & \\
\hline 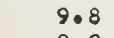 & 08.974 & 08.790 & 08. & 08.4 & 08.238 & & & 07. \\
\hline 9.9 & 133 & 06.949 & 06.765 & 06.581 & 06.396 & 06.213 & 06.028 & 05.844 \\
\hline & & & & & 04 & .005 & 006 & 007 \\
\hline & & & & & & & $\begin{array}{l}.112 \\
.111\end{array}$ & $\begin{array}{l}130 \\
.130\end{array}$ \\
\hline
\end{tabular}




\begin{tabular}{|c|c|c|}
\hline$\lambda(A)$ & .00 & .01 \\
\hline 2330.0 & 42905.292 & 05.107 \\
\hline $\begin{array}{l}0.1 \\
0.2\end{array}$ & $\begin{array}{l}03.451 \\
01.609\end{array}$ & 03.266 \\
\hline 0.3 & 42899.769 & $\begin{array}{l}01.425 \\
99.584\end{array}$ \\
\hline 0.4 & 97.928 & \\
\hline 0.5 & 96.087 & 95.903 \\
\hline 0.6 & 94.247 & 94.062 \\
\hline 0.7 & 92.407 & 92.223 \\
\hline 0.8 & 90.567 & 90.3 \\
\hline 0.9 & 88.727 & \\
\hline $\begin{array}{r}31.0 \\
1.01\end{array}$ & 42886.887 & 86.703 \\
\hline 1.1 & $\begin{array}{l}85.047 \\
83.208\end{array}$ & $\begin{array}{l}84.864 \\
83.024\end{array}$ \\
\hline 1.3 & 81.369 & 81.185 \\
\hline 1.4 & 79.529 & 79.345 \\
\hline 1.5 & 77.690 & 77.506 \\
\hline 1.06 & 75.852 & 75.668 \\
\hline $\begin{array}{l}1.7 \\
1.8\end{array}$ & 74.013 & 73.829 \\
\hline $\begin{array}{l}1.8 \\
1.0\end{array}$ & $72 \cdot 1$ & 71.990 \\
\hline $\begin{array}{r}1.9 \\
2332.0\end{array}$ & 70.335 & 70.152 \\
\hline $\begin{array}{r}2332.0 \\
2.1\end{array}$ & 42868.498 & 68.314 \\
\hline $2 \bullet 2$ & $\begin{array}{l}66.660 \\
64.822\end{array}$ & $\begin{array}{l}66.476 \\
64.638\end{array}$ \\
\hline 2.3 & 62.984 & 62.800 \\
\hline 2.4 & 61.146 & 60.963 \\
\hline 2.5 & 59.309 & 59.125 \\
\hline 2.6 & 57.472 & 57.288 \\
\hline 2.7 & 55.635 & 55.451 \\
\hline 2.8 & 53.798 & 53.614 \\
\hline 2.9 & 51.961 & 51.777 \\
\hline $\begin{array}{r}2333.0 \\
3.1\end{array}$ & 42850.124 & 49.941 \\
\hline & 48.288 & $\begin{array}{l}48.104 \\
46.268\end{array}$ \\
\hline $\begin{array}{l}3.2 \\
3.3\end{array}$ & $\begin{array}{l}46.452 \\
44.616\end{array}$ & $\begin{array}{l}46.268 \\
44.432\end{array}$ \\
\hline $\begin{array}{l}3.3 \\
3.4\end{array}$ & $\begin{array}{l}\text {.6. } \\
.0179\end{array}$ & $\begin{array}{l}44.432 \\
42.596\end{array}$ \\
\hline 3.5 & 43 & 40.760 \\
\hline 3.6 & 39.108 & 38.925 \\
\hline $\begin{array}{l}3.7 \\
3.8\end{array}$ & 37.272 & 37.089 \\
\hline $\begin{array}{l}3.8 \\
3.9\end{array}$ & 35.437 & 35.253 \\
\hline $\begin{array}{r}3.9 \\
23340\end{array}$ & 33.602 & 33.418 \\
\hline $\begin{array}{r}2334.0 \\
4.1\end{array}$ & $\begin{array}{r}42831.767 \\
29.933\end{array}$ & $\begin{array}{r}31.583 \\
29.749\end{array}$ \\
\hline 4.2 & 28.096 & 27.914 \\
\hline 4.3 & 26.263 & 26.079 \\
\hline 4.4 & 24.429 & 24.245 \\
\hline 4.5 & 22.594 & 22.411 \\
\hline 4.6 & 20.760 & 20.577 \\
\hline 4.7 & 18.926 & 18.743 \\
\hline $\begin{array}{l}4.8 \\
4.9\end{array}$ & 17.093 & 16.909 \\
\hline 4.9 & 15.259 & 15.075 \\
\hline $\begin{array}{r}35.0 \\
5.1\end{array}$ & 42813.425 & 13.242 \\
\hline & 11.592 & 11.409 \\
\hline $\begin{array}{l}5.2 \\
5.3\end{array}$ & 09.759 & 09.576 \\
\hline $\begin{array}{l}5.3 \\
5.4\end{array}$ & $\begin{array}{l}07.926 \\
06.093\end{array}$ & 07.743 \\
\hline $\begin{array}{l}5.4 \\
5.5\end{array}$ & $\begin{array}{l}06.093 \\
04.260\end{array}$ & 05.909 \\
\hline 5.6 & .2628 & 02.244 \\
\hline 5.7 & 00.596 & 00.412 \\
\hline $\begin{array}{l}5.8 \\
5.9\end{array}$ & 798.763 & 98.580 \\
\hline 5.9 & 96.931 & 96.748 \\
\hline & 2795.099 & 94 \\
\hline & 93.268 & 93.084 \\
\hline $\begin{array}{l}6.2 \\
6.3\end{array}$ & 91.436 & 91.252 \\
\hline $\begin{array}{l}6.3 \\
6.4\end{array}$ & .604 & 89.421 \\
\hline $\begin{array}{l}6.4 \\
6.5\end{array}$ & .772 & 87.589 \\
\hline $\begin{array}{l}6.5 \\
6.6\end{array}$ & 942 & 85.759 \\
\hline $\begin{array}{l}6.6 \\
6.7\end{array}$ & 11 & 83.928 \\
\hline $\begin{array}{l}6.7 \\
6.8\end{array}$ & 280 & 82.097 \\
\hline $\begin{array}{l}6.8 \\
6.9\end{array}$ & 80.449 & 80.266 \\
\hline & 78.619 & 78.436 \\
\hline $\begin{array}{r}2337.0 \\
7.1\end{array}$ & $\begin{array}{r}2776 \\
74\end{array}$ & \\
\hline 7.2 & 73 & \\
\hline 7.3 & 9 & 71.1 \\
\hline $7 \cdot 4$ & 9 & 69. \\
\hline 7.5 & 9 & 67 \\
\hline $7 \cdot 6$ & 0 & 65 \\
\hline 7.7 & 63 & 63.7 \\
\hline 7.8 & 62 & 61. \\
\hline 7.9 & 60.323 & 60.140 \\
\hline & 42758.494 & $5 \varepsilon$ \\
\hline & 6 & 5 \\
\hline 8 & 7 & 5 \\
\hline 80 & 53.0 & $52 \cdot 8$ \\
\hline 8 & 51.180 & 50.997 \\
\hline 8 . & 49.352 & 49.169 \\
\hline 8.6 & $\begin{array}{l}47.525 \\
45.607\end{array}$ & 47.342 \\
\hline $\begin{array}{l}8.7 \\
8.8\end{array}$ & $\begin{array}{l}45.697 \\
43.869\end{array}$ & $\begin{array}{l}45.514 \\
43.687\end{array}$ \\
\hline 8.9 & 42.042 & 41.859 \\
\hline & & \\
\hline & & \\
\hline 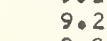 & & \\
\hline & & 34. \\
\hline & & \\
\hline 9 & & \\
\hline & & 25 \\
\hline 8 & & 27.2 \\
\hline 9 & & 25.420 \\
\hline 9.9 & 23.777 & 23.594 \\
\hline & - & \\
\hline & .0 & \\
\hline & .0 & \\
\hline
\end{tabular}




.04

.05

.06

.07

.08

.09

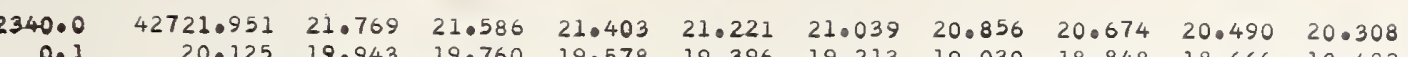

$\begin{array}{lllllllllll}0.1 & 20.125 & 19.943 & 19.760 & 19.578 & 19.396 & 19.213 & 19.030 & 18.848 & 18.666 & 18.482 \\ 0.2 & 18.300 & 18.118 & 17.935 & 17.753 & 17.570 & 17.388 & 17.206 & 17.023 & 16.840 & 16.658\end{array}$

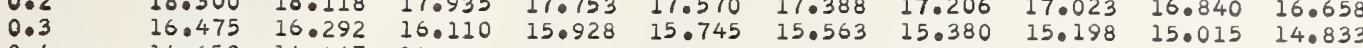

$\begin{array}{lllllllllll}0.4 & 14.650 & 14.467 & 14.285 & 14.103 & 13.920 & 13.738 & 13.555 & 13.373 & 13.190 & 13.007 \\ 0.5 & 12.825 & 12.643 & 12.460 & 12.277 & 12.095 & 11.913 & 11.730 & 13.548 & 130355 & 10.048\end{array}$

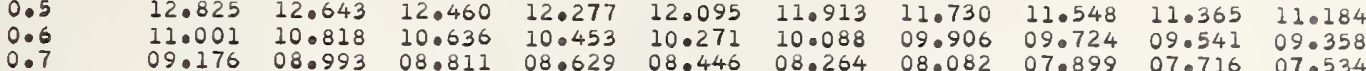

$\begin{array}{lllllllllll}0.7 & 09.176 & 08.993 & 08.811 & 08.629 & 08.446 & 08.264 & 08.082 & 07.899 & 07.716 & 07.534 \\ 0.8 & 07.351 & 07.169 & 06.987 & 06.804 & 06.622 & 06.439 & 06.257 & 06.074 & 05.892 & 05.710 \\ 0.9 & 05.527 & 05.344 & 05.162 & 04.979 & 04.797 & 04.615 & 04.433 & 04.250 & 04.068 & 03.886\end{array}$

0.9

$05.527 \quad 05.344$

2341.0

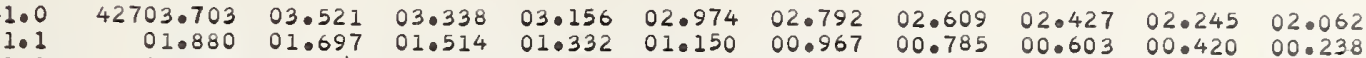

$1.2 \quad 00.056 * 99.874 * 99.690 * 99.508 * 99.326 * 99.144 * 98.961 * 98.779 * 98.596 * 98.415$

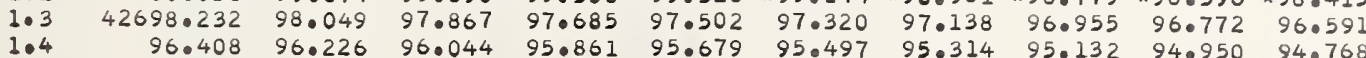

$\begin{array}{lllllllllll}1.5 & 94.585 & 94.403 & 94.221 & 94.038 & 93.856 & 93.673 & 93.491 & 93.309 & 93.127 & 92.944\end{array}$

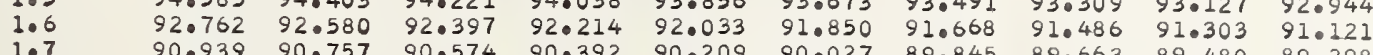

$\begin{array}{lllllllllll}1.7 & 90.939 & 90.757 & 90.574 & 90.392 & 90.209 & 90.027 & 89.845 & 89.663 & 89.480 & 89.298\end{array}$

1.9

$\begin{array}{lllll}89.116 & 88.934 & 88.752 & 88.569 & 88.387 \\ 87.293 & 87.111 & 86.929 & 86.747 & 86.564\end{array}$

2342

$\begin{array}{rrrr}42685.471 & 85.289 & 85.106 & 840 \\ 83.649 & 83.466 & 83.284 & 830\end{array}$

$$
\begin{array}{llll}
81.826 & 81.644 & 81.461 & 810 \\
80.004 & 79.822 & 79.640 & 790
\end{array}
$$

$.924 \quad 84.742$

88.205
86.382

86.200

$\begin{array}{lll}87.840 & 87.658 & 87.476 \\ 86.018 & 85.835 & 85.653\end{array}$

0.306463

0.717124

0.306456

0.306452

0.306445

0.306442

0.306434

0.717146

0.717190

0.717235

0.71725

0.717302

0.717346

0.306420

0.306416

0.306409

0.306409

0.306402

0.306395

0.717368

0.717413

0.717435

0.717457

0.717502

0.306391

0.30638

0.306381

0.306377 $\begin{array}{llllllllll} & \end{array}$ $\begin{array}{lllllllllll}78.182 & 78.000 & 77.818 & 77.636 & 77.454 & 77.271 & 77.089 & 76.907 & 76.725 & 76.542 \\ 76.360 & 76.179 & 75.996 & 75.814 & 75.632 & 75.449 & 75.267 & 75.085 & 74.903 & 74.721\end{array}$

$\begin{array}{lllllllllll}2.6 & 74.539 & 74.357 & 74.174 & 73.992 & 73.811 & 73.627 & 73.445 & 73.264 & 73.082 & 72.899 \\ 2.7 & 72.718 & 72.536 & 72.354 & 72.171 & 71.989 & 71.807 & 71.625 & 71.442 & 71.260 & 71.079\end{array}$

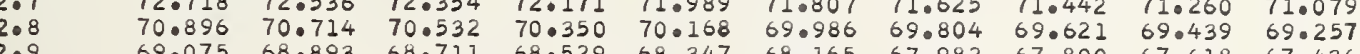

0.306370

0.306366

0.306359

$\begin{array}{lllllllllll}2343.0 & 42667.253 & 67.072 & 60.890 & 66.708 & 66.526 & 66.344 & 66.162 & 65.979 & 65.797 & 65.615\end{array}$

$\begin{array}{lllllllllll}3.1 & 65.434 & 65.251 & 65.069 & 64.887 & 64.706 & 64.523 & 64.341 & 64.159 & 63.977 & 63.794\end{array}$

$\begin{array}{lllllllllll}3.2 & 63.613 & 63.431 & 63.249 & 63.067 & 62.885 & 62.702 & 62.521 & 62.338 & 62.156 & 61.974 \\ 3.3 & 61.792 & 61.610 & 61.428 & 61.246 & 61.064 & 60.882 & 60.700 & 60.518 & 60.335 & 60.153\end{array}$

$59.971 \quad 59.789 \quad 59.607 \quad 590$

$\begin{array}{llllllllll}58.151 & 57.970 & 57.788 & 57.425 & 59.243 & 59.062 & 58.879 & 58.697 & 58.515 & 58.333\end{array}$

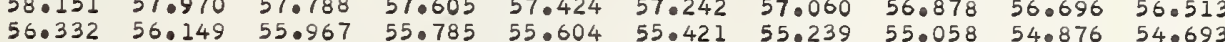

3.6

$56.332 \quad 56.149 \quad 55.967$

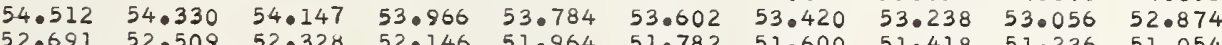

3.8

50.87250 .689

344

4: $4: \frac{1}{40.3}$

$\begin{array}{lllll}649.053 & 48.871 & 48.689 & 48.507 & 48.325 \\ 47.234 & 47.052 & 46.870 & 46.687 & 46.506 \\ 45.415 & 45.232 & 45.050 & 44.869 & 44.687\end{array}$

$43.596 \quad 43.413$

$41.777 \quad 41.595 \quad 41.413$

$\begin{array}{lll}38.958 & 39.777 & 39.594 \\ 38.140 & 37.958 & 37.775\end{array}$

$\begin{array}{lll}38.140 & 37.958 & 37.77 \\ 36.321 & 36.139 & 35.95 \\ 34.503 & 34.321 & 34.140\end{array}$

$\begin{array}{llll}34.503 & 34.321 & 34.140 & 33.95\end{array}$

$\begin{array}{lllllll}39.231 & 39.049 & 38.867 & 38.686 & 38.503 & 38.321\end{array}$

$\begin{array}{llllll}37.412 & 37.230 & 37.048 & 36.867 & 36.685 & 36.503 \\ 35.594 & 35.412 & 35.230 & 35.049 & 34.867 & 34.686\end{array}$

0.306356

(1)

0.306345

0.306341

0.306334

0.306327

0.306324

0.306320

0.306316

0.306313

0.306306

0.306302

0.30629

0.306291

0.306288

2345.

42630.867

$\begin{array}{lll}30.686 & 30.504 & 30.321\end{array}$

$\begin{array}{lll}33.230 & 33.048 & 32.867 \\ 31.412 & 31.231 & 31.049\end{array}$

0.30628

0.306277

0.306277

0.306267

0.30626

0.306259

0.306256

0.306249

0.306245

0.306242

0.306238

0.306231

0.306228

0.306224

0.306217

0.306213

0.306210

0.306206

0.306203

0.306196

0.306192

0.306189

0.306185

0.306178

0.306174

0.306167

0.306164

0.306160

0.306153

0.306150

$\begin{array}{llllllllll}67.5327 & 65.158 & 66.977 & 66.795 & 66.615 & 66.433 & 66.251 & 66.071 & 65.890 & 65.708 \\ 65.56 & 65.165 & 64.983 & 64.802 & 64.621 & 64.439 & 64.258 & 64.077 & 63.896\end{array}$

$\begin{array}{llllllllll}63.715 & 63.534 & 63.352 & 63.171 & 62.990 & 62.808 & 62.627 & 62.446 & 62.265 & 62.084\end{array}$

$\begin{array}{llllllllll}61.903 & 61.721 & 61.541 & 61.359 & 61.178 & 60.997 & 60.815 & 60.634 & 60.453 & 60.272 \\ 60.090 & 59.909 & 59.729 & 59.547 & 59.366 & 59.185 & 59.004 & 58.822 & 58.642 & 58.460\end{array}$

0.306146

0.306143

0.306136

0.306132

0.306128

0.306122

0.306118

0.306114

.717546

0.717569

0.717613

0.717658

0.717702

0.717769

0.717791

0.717836

0.727858

0.717880

0.717925

0.717969

0.718014

0.718036

0.718081

0.718103

0.718148

0.718170

0.718215

0.718237

0.718281

0.718326

0.718348

0.718371

0.718393

0.718415

0.718460

0.718482

0.718504
0.718527

0.718549

0.718571

0.718616

0.718638

0.718683

0.718705

0.718750

0.718772

0.718794

0.718839

0.718861

0.718906

0.718928

0.718973

0.718995

0.719017

0.719040

0.719084

0.719107

$\begin{array}{rrrllllllll}349.0 & 42558.279 & 58.098 & 57.917 & 57.736 & 57.555 & 57.374 & 57.192 & 57.011 & 56 \cdot 830 & 56.64 \\ 9.1 & 56.468 & 56.287 & 56.105 & 55.924 & 55.743 & 55.562 & 55.380 & 55.200 & 55.018 & 54.83 \\ 9.2 & 54.656 & 54.475 & 54.294 & 54.113 & 53.932 & 53.750 & 53.569 & 53.388 & 53.207 & 53.026 \\ 9.3 & 52.845 & 52.664 & 52.483 & 52.302 & 52.120 & 51.939 & 51.758 & 51.577 & 51.396 & 51.21 \\ 9.4 & 51.034 & 50.853 & 50.672 & 50.491 & 50.310 & 50.129 & 49.948 & 49.767 & 49.585 & 49.40 \\ 9.5 & 49.223 & 49.042 & 48.861 & 48.680 & 48.499 & 48.318 & 48.137 & 47.956 & 47.774 & 47.59 \\ 9.6 & 47.412 & 47.231 & 47.050 & 46.869 & 46.688 & 46.507 & 46.326 & 46.145 & 45.963 & 45.78 \\ 9.7 & 45.602 & 45.420 & 45.239 & 45.059 & 44.877 & 44.696 & 44.516 & 44.334 & 44.152 & 43.97 \\ 9.8 & 43.791 & 43.610 & 43.430 & 43.249 & 43.067 & 42.887 & 42.706 & 42.524 & 42.343 & 42.16 \\ 9.8 & 41.981 & 41.800 & 41.619 & 41.438 & 41.257 & 41.076 & 40.895 & 40.714 & 40.533 & 40.35\end{array}$

0.719129

0.719151

0.719196

0.719218

0.719240
0.719263

0.719285

0.719330

.010

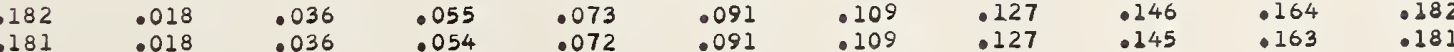




.04

.05

.06

.07

.08

$\begin{array}{lllllllllll}2350.0 & 42540.170 & 39.990 & 39.809 & 39.627 & 39.447 & 39.266 & 39.084 & 38.904 & 38.723 & 38.541\end{array}$ $\begin{array}{llllllllllll}0.1 & 38.361 & 38.180 & 37.999 & 37.817 & 37.637 & 37.456 & 37.274 & 37.094 & 36.913 & 36.731 \\ 0.2 & 36.551 & 36.370 & 36.188 & 36.008 & 35.827 & 35.646 & 35.465 & 35.285 & 35.104 & 34.923\end{array}$ $\begin{array}{lllllllllll}0.2 & 36.551 & 36.370 & 36.188 & 36.008 & 35.827 & 35.646 & 35.465 & 35.285 & 35.104 & 34.923 \\ 0.3 & 34.741 & 34.560 & 34.379 & 34.198 & 34.017 & 33.837 & 33.656 & 33.475 & 33.293 & 33.113\end{array}$ $\begin{array}{lllllllllll}0.4 & 32.931 & 32.750 & 32.570 & 32.389 & 32.208 & 32.027 & 31.846 & 31.665 & 31.484 & 31.303\end{array}$ $\begin{array}{lllllllllll}0.5 & 31.122 & 30.941 & 30.760 & 30.579 & 30.398 & 30.217 & 30.037 & 29.856 & 29.675 & 29.494 \\ 0.6 & 29.313 & 29.132 & 28.951 & 28.770 & 28.589 & 28.409 & 28.228 & 28.047 & 27.866 & 27.685\end{array}$ $\begin{array}{lllllllllll}0.7 & 27.504 & 27.324 & 27.142 & 26.961 & 26.780 & 26.600 & 26.419 & 26.238 & 26.057 & 25.876\end{array}$ $\begin{array}{lllllllllll}0.8 & 25.695 & 25.514 & 25.333 & 25.152 & 24.971 & 24.791 & 24.610 & 24.429 & 24.248 & 24.067 \\ 0.9 & 23.886 & 23.706 & 23.524 & 23.343 & 23.163 & 22.982 & 22.801 & 22.620 & 22.439 & 22.258\end{array}$

$\begin{array}{rlll}42522.078 & 21.897 & 21.715 & 210 \\ 20.270 & 20.089 & 19.908 & 190 \\ 18.461 & 18.280 & 18.100 & 170 \\ 16.653 & 16.472 & 16.292 & 160 \\ 14.845 & 14.664 & 14.483 & 140 \\ 13.037 & 12.857 & 12.676 & 120 \\ 11.230 & 11.049 & 10.868 & 100 \\ 09.422 & 09.241 & 09.060 & 080 \\ 07.614 & 07.434 & 07.253 & 070 \\ 05.807 & 05.626 & 25.446 & 050\end{array}$

\section{$21.535 \quad 21.354$}

$21.173 \quad 20.992 \quad 20.812 \quad 20.631 \quad 20.450$

1.1
1.2
1.5
1.7
1.9

$2504.000 \quad 03.820$ $\begin{array}{rrrrrrrrrr}04.000 & 03.820 & 03.639 & 03.458 & 03.278 & 03.097 & 02.916 & 02.735 & 02.555 & 02.374 \\ 02.193 & 02.013 & 01.832 & 01.651 & 01.471 & 01.290 & 01.108 & 00.926 & 00.748 & 00.567 \\ 00.386 & 00.206 & 00.025 & * 99.845 & * 99.664 & * 99.483 & * 99.302 & * 99.122 & * 98.940 & * 98.760\end{array}$

$17.918 \quad 17.737$

$14.302 \quad 14.121$

$\begin{array}{lllll}19.305 & 19.184 & 19.004 & 18.823 & 18.642\end{array}$

$\begin{array}{lllll}17.557 & 17.376 & 17.195 & 17.014 & 16.834\end{array}$

$\begin{array}{lllll}13.940 & 13.760 & 13.579 & 13.398 & 13.217\end{array}$

$\begin{array}{lllllll}12.495 & 12.314 & 12.133 & 11.952 & 11.772 & 11.591 & 11.410 \\ 10.687 & 10.507 & 10.325 & 10.145 & 09.964 & 09.783 & 09.603\end{array}$

$\begin{array}{lllllll}08.880 & 08.698 & 08.518 & 08.337 & 08.156 & 07.976 & 07.795\end{array}$ $\begin{array}{llllllll}07.072 & 06.891 & 06.710 & 06.530 & 06.349 & 06.168 & 05.988\end{array}$

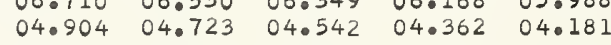
98.399 $98.219 * 99.845 * 99.664 * 99.483 * 99.302 * 99.122 * 98.940 * 98.760$ $\begin{array}{llllllllll}96.773 & 96.593 & 96.413 & 96.231 & 96.051 & 95.871 & 95.690 & 95.509 & 95.328 & 95.147\end{array}$

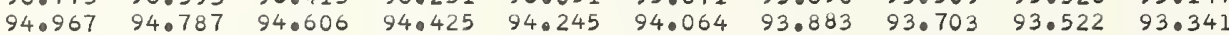

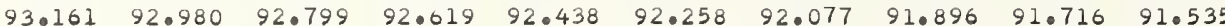

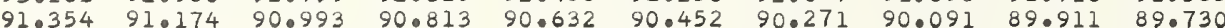
$\begin{array}{llllllllll}89.549 & 89.369 & 89.188 & 89.008 & 88.827 & 88.647 & 88.466 & 88.285 & 88.104 & 87.924\end{array}$ $\begin{array}{llllllllll}87.743 & 87.562 & 87.382 & 87.202 & 87.021 & 86.841 & 86.660 & 86.479 & 86.299 & 86.118\end{array}$

$\begin{array}{lllllllllll}2353.0 & 42485.937 & 85.757 & 85.577 & 85.396 & 85.216 & 85.035 & 84.854 & 84.674 & 84.494 & 84.312\end{array}$

0.306107

0.306100

0.306097

0.306093

0.306086

0.306083

0.306079

0.306072

0.306069

0.306065

0.306058

0.306054
0.306051

0.306047

0.306044

0.306040

0.306037

0.306030

0.306026

0.306023

0.306016

0.306012

0.306005

0.306002

0.305995
0.305991

0.305988

0.305984

0.305981

0.305974

0.305970

0.305967

0.305963

0.305960

0.305956

0.305949

0.305946

0.305942

0.305939
0.305935

0.305932

0.305928

0.305925

0.305918

0.305914

0.305911
0.305907

.305904

0.305900

0.305897

0.305893

0.305890

0.305883

0.305879
0.305876

.305872

0.305869
0.305865

0.305862

0.305858

0.305851

0.305848

0.305845

0.305841

0.305834

0.305831

0.305827

0.305824
0.305820

0.305820

0.305813

0.305810

0.305803

0.305799

0.305796

0.305792

0.305789

0.305785

0.305778

0.305775
0.305772

0.305768

0.305765
0.305761

.010

0.719374

0.719397

0.719441

0.719464

0.719508

0.719531

0.719575

0.719598

0.719620
0.719642

0.719665

0.719687
0.719709
0.719732

0.719732

0.719754
0.719776

0.719799

0.7197921
0.719843

0.719866

0.719888
0.719910
0.71993

0.719933

0.719955

0.719977
0.720000

0.720022

0.720044
0.720067

0.720067
0.720089

0.720111

0.720134

0.720156
0.720179

0.720201

0.720223

0.720246 0.720268 0.720290 0.720335 0.720357 0.720380 0.720402 0.720424
0.720447

0.720469 0.720492 0.720514
0.720536 0.720559 0.720581

0.720603

0.720626 0.720648
0.720670

0.720693 0.720715 0.720760 0.720782 0.720805 0.720827 0.720849 0.720872
0.720894

0.720917 0.720939 


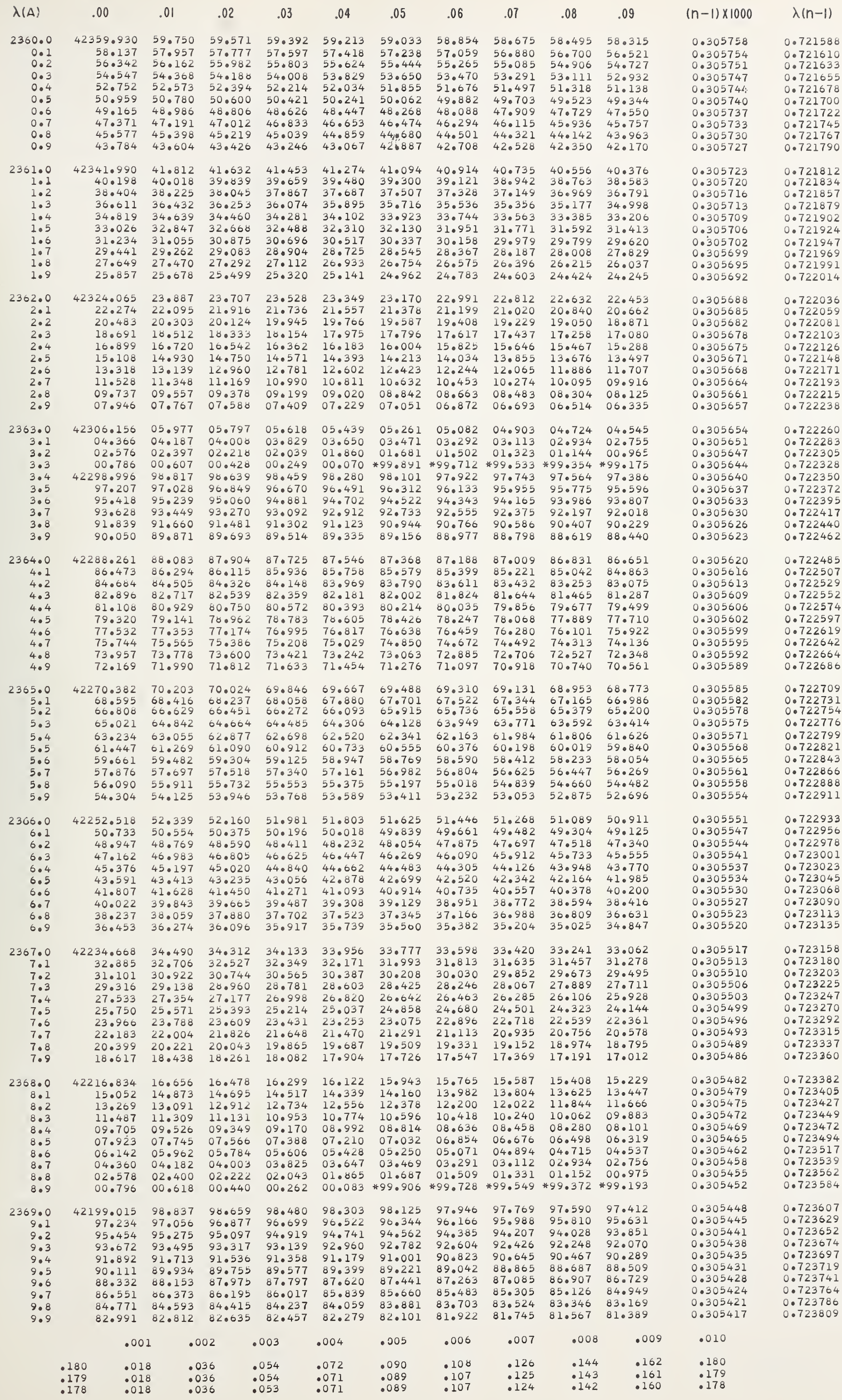


2371.0

2373.

2374.

2375.

2376.

.02

.03

.04

$$
\begin{array}{r}
2370 . \\
0.1 \\
0 . \\
0.3 \\
0.4 \\
0.5 \\
0 . \\
0.7 \\
0.0 \\
0.0
\end{array}
$$

1.2

1. 3

1.5

1.6
1.7
1.8

1.8
1.9

2.

2.4

2.5

2.7

2.8
2.9

3.1
3.2
3.3
3.4
3.5
3.6
3.7
3.8
3.9

4.1
4.2
4.3
4.4

4.3
4.4
4.5

406

4.6
4.7
4.8
4.9$$
5.1
$$

5.2
5.3
5.4

5.4
5.5

5.6
5.7

5.8
5.9

$$
\begin{array}{r}
376.0 \\
6.1 \\
6.2 \\
6.3 \\
6.4 \\
6.5 \\
6.6 \\
6.7 \\
6.8 \\
6.9
\end{array}
$$

\begin{tabular}{|c|c|c|c|c|c|}
\hline 78.0 & 039.318 & 39.142 & 38.964 & 38.788 & 38.611 \\
\hline & & 4 & 37.197 & 37.020 & 36.843 \\
\hline 8.2 & 35.7 & 35. & 35.429 & 35.252 & 35.076 \\
\hline 8.3 & 3 & 33. & 2 & 5 & . 308 \\
\hline 8.4 & & & & & \\
\hline 8.5 & & & & & \\
\hline 8.6 & & & & & \\
\hline 8. & & & & & \\
\hline 8. & & & & & \\
\hline $8 \cdot 9$ & & & 2 & & \\
\hline 2 & 48 & & & & \\
\hline & & & & & \\
\hline & & & & & \\
\hline 9. & & & & & \\
\hline 9. & $\begin{array}{l}44 \\
8\end{array}$ & & $\begin{array}{l}140^{\circ} \\
120\end{array}$ & $\begin{array}{l}14.055 \\
12.289\end{array}$ & \\
\hline 0 & & & & & \\
\hline 0 & & & $0\}$ & & \\
\hline प्र० & & & 07. & 06. & 06.8 \\
\hline 9.9 & 05,758 & 05.582 & 05.405 & 05.229 & 05.052 \\
\hline
\end{tabular}

.05

$\begin{array}{lllll}80.322 & 80.144 & 79.966 & 79.788 & 79.609 \\ 70.542 & 78.364 & 78.186 & 78.008 & 77.830\end{array}$

$\begin{array}{lllll}76.763 & 76.585 & 76.406 & 76.229 & 76.051\end{array}$

$\begin{array}{llllll}74.983 & 74.806 & 74.627 & 74.449 & 74.271\end{array}$

$\begin{array}{lllll}73.205 & 73.027 & 72.849 & 72.671 & 72.493 \\ 71.426 & 71.248 & 71.070 & 70.892 & 70.713\end{array}$

$\begin{array}{lllll}69.646 & 69.469 & 69.291 & 69.113 & 68.935\end{array}$

$67.868 \quad 67.690 \quad 67.512 \quad 67.334 \quad 67.156$

68.979060 .57900 .40168 .22460 .046

65.20065 .800

42163.42

$61.644-63.245$

$59.866 \quad 59.466$

$58.088 \quad 57.910$

$\begin{array}{lll}54.533 & 54.356 & 54.178 \\ 52.756 & 52.579 & 52.400\end{array}$

$50.979 \quad 50.801 \quad 50.623$

$\begin{array}{lll}49.202 & 49.024 & 48.847 \\ 47.425 & 47.247 & 47.070\end{array}$

43.872

$\begin{array}{lllll}40.319 & 40.141 & 39.964 & 39.780 & 39.600\end{array}$

$36.767 \quad 36.585 \quad 30.187 \quad 36.01034 \quad 36.057$

$33.215 \quad 33.038 \quad 32.860$

$\begin{array}{lll}31.439 & 31.262 & 31.085 \\ 29.664 & 29.486 & 29.309\end{array}$

$32.683 \quad 34.281$

32.683
30.907
30.505
29.729

42127.889

$26.114 \quad 25.937$

$22.564 \quad 22.387$

20.78920 .612

$17.241 \quad 17.837 \quad 18.66$

(3.

$\begin{array}{lll}13.692 & 13.515 & 13.338 \\ 11.918 & 11.741 & 11.563\end{array}$

\subsection{6}

28.954

$06.598 \quad 06.420$

01.27

2099.506
97.733

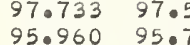

$94.188 \quad 95.783$

42092.416

$90.644-92.23$

$88.872 \quad 88.694$

$\begin{array}{ll}87.100 & 86.923 \\ 85.328 & 85.151\end{array}$

$83.557 \quad 83.380$

$81.786 \quad 81.60$

(1.0431

$76.472 \quad 76.295$

6.3

6.5

6.5
6.6
6.7

6.8

2074.701

72.93174 .524

$71.161 \quad 70.983$

67.620

$67.6250-67.442$

$65.850 \quad 65.073$

$60.541-62.13356050$

$\begin{array}{lll}50.541 & 60.364 & 60.187 \\ 58.771 & 58.594 & 58.417\end{array}$

$23.807-23.629$

$22.032 \quad 21.854$

18.483

16.708

18.306

16.531
14.757

$\begin{array}{ll}1.160 & 12.983 \\ 1.386 & 11.208\end{array}$

$\begin{array}{ll}9.613 & 09.436 \\ 7.839 & 07.662\end{array}$

$0.066 \quad 05.888$

$\begin{array}{ll}.292 & 04.115 \\ 2.520 & 02.342\end{array}$

9.973 9 90197

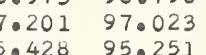

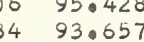

95.25
93.479

$162.533 \quad 62.355$

$\begin{array}{lll}65.734 & 65.555 & 65.379 \\ 63.956 & 63.778 & 63.600\end{array}$

$\begin{array}{lllll}60.755 & 60.577 & 62.178 & 62.000 & 61.822\end{array}$

$\begin{array}{lllll}58.0977 & 60.577 & 60.370 & 62.000 & 61.022\end{array}$

$\begin{array}{lllll}57.200 & 57.022 & 56.844 & 56.667 & 56.489 \\ 55.422 & 55.244 & 55.006 & 54.889 & 54.711\end{array}$

$\begin{array}{lllll}53.645 & 53.467 & 53.289 & 53.111 & 52.934\end{array}$

$\begin{array}{lllll}50.867 & 51.689 & 51.512 & 51.334 & 51.156\end{array}$

$\begin{array}{lllll}50.090 & 49.913 & 49.735 & 49.557 & 49.380 \\ 48.313 & 48.136 & 47.958 & 47.780 & 47.603\end{array}$

$\begin{array}{lllll}48.313 & 48.136 & 47.958 & 47.780 & 47.603 \\ 46.537 & 46.359 & 46.181 & 46.003 & 45.826\end{array}$

$\begin{array}{lllll}44.760 & 44.582 & 44.404 & 44.227 & 44.049 \\ 42.983 & 42.805 & 42.628 & 42.450 & 42.272\end{array}$

$\begin{array}{lllll}41.207 & 41.029 & 40.852 & 40.674 & 40.497 \\ 39.431 & 39.253 & 39.075 & 38.897 & 38.720\end{array}$

$\begin{array}{lllll}39.431 & 39.253 & 39.075 & 38.897 & 38.720 \\ 37.654 & 37.477 & 37.299 & 37.122 & 36.944\end{array}$

$\begin{array}{lllll}35.878 & 35.701 & 35.523 & 35.346 & 35.168\end{array}$

$32.328 \quad 32.150 \quad 31.972 \quad 31.794 \quad 31.617$

$\begin{array}{lllll}30.552 & 30.374 & 30.196 & 30.019 & 29.842 \\ 28.777 & 28.599 & 28.421 & 28.244 & 28.066\end{array}$

$\begin{array}{lllll}27.001 & 26.823 & 26.647 & 26.469 & 26.292 \\ 25.227 & 25.049 & 24.872 & 24.694 & 24.516\end{array}$

$\begin{array}{lllll}23.452 & 23.274 & 23.097 & 22.919 & 22.742\end{array}$

$\begin{array}{lllll}21.677 & 21.500 & 21.322 & 21.144 & 20.967 \\ 19.902 & 19.725 & 19.547 & 19.370 & 19.192\end{array}$

$\begin{array}{lllll}18.128 & 17.951 & 17.773 & 17.596 & 17.418\end{array}$

$\begin{array}{lllll}16.354 & 16.176 & 15.999 & 15.822 & 15.644 \\ 14.580 & 14.402 & 14.225 & 14.047 & 13.870\end{array}$

$\begin{array}{lllll}12.806 & 12.628 & 12.451 & 12.273 & 12.096 \\ 11.032 & 10.854 & 10.677 & 10.500 & 10.323\end{array}$

$\begin{array}{llllll}09.258 & 09.081 & 08.904 & 08.727 & 08.549\end{array}$

$\begin{array}{lllll}07.484 & 07.307 & 07.130 & 06.953 & 06.775\end{array}$

$\begin{array}{lllll}03.711 & 05.534 & 05.356 & 05.179 & 05.002 \\ 03.938 & 03.761 & 03.583 & 03.406 & 03.229\end{array}$

$\begin{array}{lllll}02.165 & 01.988 & 01.811 & 01.633 & 01.456\end{array}$

$\begin{array}{lllll}00.392 & 00.215 & 00.038 & * 99.860 & * 99.683\end{array}$

$\begin{array}{lllll}96.846 & 96.669 & 96.492 & 96.314 & 96.138\end{array}$

$\begin{array}{lllll}95.075 & 94.897 & 94.720 & 94.542 & 94.366\end{array}$

$\begin{array}{llllll}93.302 & 93.125 & 92.947 & 92.771 & 92.593\end{array}$

$\begin{array}{lllllll} & & \end{array}$

$\begin{array}{lllllll}90.112 & 89.935 & 87.757 & 89.580 & 89.403 & 89.226 & 89.048\end{array}$

$\begin{array}{llllllll}80.569 & 86.392 & 86.215 & 86.037 & 85.860 & 85.682 & 85.505\end{array}$

$\begin{array}{lllll}86.215 & 86.037 & 85.860 & 85.682 & 85.505 \\ 84.443 & 84.265 & 84.088 & 83.911 & 83.734\end{array}$

$\begin{array}{lllll}82.671 & 82.494 & 82.317 & 82.140 & 81.962\end{array}$

$\begin{array}{lllllll}83.025 & 82.849 & 82.671 & 82.494 & 82.317 & 82.140 & 81.962 \\ 81.254 & 81.077 & 80.900 & 80.722 & 80.545 & 80.368 & 80.191\end{array}$

$\begin{array}{llllllll}81.254 & 81.077 & 80.900 & 80.722 & 80.545 & 80.368 & 80.191\end{array}$

$\begin{array}{lllll}79.129 & 78.952 & 78.774 & 78.597 & 78.420\end{array}$

$\begin{array}{lllll}77.358 & 77.181 & 77.003 & 76.826 & 76.649 \\ 75.587 & 75.410 & 75.232 & 75.056 & 74.878\end{array}$

$\begin{array}{llllll}73.816 & 73.639 & 73.462 & 73.285 & 73.107\end{array}$

$\begin{array}{lllll}72.045 & 71.868 & 71.692 & 71.515 & 71.337\end{array}$

$\begin{array}{lllll}70.275 & 70.099 & 69.921 & 69.745 & 69.567 \\ 68.505 & 68.328 & 68.151 & 67.974 & 67.797\end{array}$

$66.735 \quad 66.558 \quad 66.381 \quad 66.204 \quad 66.026$

$64.965 \quad 64.788 \quad 640611 \quad 64.434 \quad 64.256$

$\begin{array}{lllll}63.195 & 63.018 & 62.842 & 62.665 & 62.487\end{array}$

$\begin{array}{lllll}59.425 & 51.249 & 61.072 & 60.895 & 60.718\end{array}$

$56.118 \quad 55.941 \quad 55.764 \quad 55.587 \quad 55.410$

7.1

7.3

7.4

$7 \cdot 6$

$\begin{array}{lllll}55.234 & 55.057 & 54.0779 & 54.702 & 54.525 \\ 53.464 & 53.280 & 53.110 & 52.934 & 52.756 \\ 51.695 & 51.519 & 53.043 & 52.065 & 50.987\end{array}$

$49.62651 .519 \quad 51.341$

$48.158 \quad 47.982 \quad 47.805$

$46.390 \quad 46.213 \quad 46.036 \quad 45.628 \quad 47.451$

$\begin{array}{lllll}46.0 & \end{array}$

$\begin{array}{lllll}44.622 & 44.445 & 44.268 & 44.091 & 43.914\end{array}$

$\begin{array}{lllll}42.854 & 42.676 & 42.500 & 42.323 & 42.146 \\ 41.085 & 40.908 & 40.732 & 40.555 & 40.378\end{array}$

54.349

52.580
50.811

$\begin{array}{lllll}47.274 & 47.097 & 46.920 & 46.744 & 46.566 \\ 45.505 & 45.329 & 45.152 & 44.975 & 44.798\end{array}$

$\begin{array}{llllll}43.737 & 43.561 & 43.384 & 43.207 & 43.030\end{array}$

$\begin{array}{lllll}41.969 & 41.792 & 41.615 & 41.438 & 41.262 \\ 40.202 & 40.025 & 39.848 & 39.671 & 39.495\end{array}$

$\begin{array}{lllll}38.434 & 38.257 & 38.081 & 37.904 & 37.727\end{array}$

$\begin{array}{lllll}36.666 & 36.489 & 36.313 & 36.136 & 35.959 \\ 34.8988 & 34.722 & 34.545 & 34.368 & 34.192\end{array}$

$\begin{array}{lllll}34.898 & 34.722 & 34.545 & 34.368 & 34.192 \\ 33.131 & 32.955 & 32.778 & 32.602 & 32.425\end{array}$

$\begin{array}{llllll}31.365 & 31.188 & 31.011 & 30.834 & 30.658\end{array}$

$\begin{array}{llllll}24.598 & 29.421 & 29.244 & 29.067 & 28.891\end{array}$

$\begin{array}{lllll}27.831 & 27.654 & 27.477 & 27.300 & 27.124 \\ 25.064 & 25.888 & 25.710 & 25.534 & 25.357\end{array}$

$\begin{array}{lllll}24.298 & 24.122 & 23.945 & 23.768 & 23.591 \\ 22.532 & 22.355 & 22.178 & 22.002 & 21.825\end{array}$

$\begin{array}{lllll}20.705 & 20.588 & 20.412 & 20.235 & 20.058\end{array}$

$\begin{array}{lllll}18.999 & 18.822 & 18.646 & 18.469 & 18.292\end{array}$

$\begin{array}{llllll}17.232 & 17.057 & 16.880 & 16.704 & 16.527 \\ 15.468 & 15.291 & 15.114 & 14.937 & 14.76\end{array}$

$13.702 \quad 13.525 \quad 13.349 \quad 13.172 \quad 12.996$

$\begin{array}{lllll}11.936 & 11.759 & 11.583 & 11.407 & 11.230\end{array}$

$\begin{array}{lllll}10.170 & 09.994 & 09.818 & 09.641 & 09.464\end{array}$

$\begin{array}{lllll}08.406 & 08.229 & 08.053 & 07.876 & 07.700 \\ 06.641 & 06.464 & 06.288 & 06.111 & 05.935\end{array}$

$\begin{array}{lllll}04.841 & 06.464 & 06.288 & 06.111 & 05.935 \\ 04.876 & 04.699 & 04.522 & 04.347 & 04.170\end{array}$ $(n-1) \times 1000$

$\lambda(n-1)$

0.305414

0.305407

0.305404

0.305400
0.305397
0.30534

0.305397
0.305394

0.305390

0.305387
0.305383

0.305380

0.305377

0.305373

0.305366

0.305360

0.305356

0.305353

0.305346

0.305343

.005333

0.305329

0.305326

0.305322

0.305316

0.305312

0.305305

.305302

0.305299

0.305295

0.305292

0.305288

0.305282

0.305278

0.305275

0.305258

0.305265

0.305261

0.305258

.

0.305251

0.305244

0.305241

0.305238

0.305234

0.305228

0.305224

0.305221

0.305218
0.305214

0.305211

0.305207

0.305204

0.305201

0.305194

0.305191

0.305187

0.305184
0.305180

0.305177

0.305174

0.305170

0.305167

0.305164

0.305160

0.305157

0.305154

0.305150

0.305143

0.305140

0.305137

0.305133

0.305130

0.305127

0.305123

0.305120

0.305117
0.305113

0.305110

0.305107

0.305103

0.305100

0.305093

0.305090

0.305086

. .305083
0.305080

.010

.177
.176
.175 
$\begin{array}{rrrrrrrrrrr}2380.0 & 42003.993 & 03.817 & 03.640 & 03.463 & 03.288 & 03.111 & 02.934 & 02.758 & 02.582 & 02.405 \\ 0.1 & 02.229 & 02.052 & 01.875 & 01.699 & 01.522 & 01.346 & 01.170 & 00.994 & 00.817 & 00.641\end{array}$

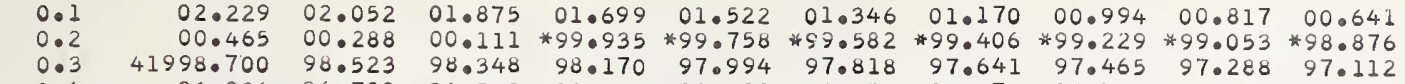
$\begin{array}{lrlllllllll}0.4 & 41998.700 & 98.523 & 98.348 & 98.170 & 97.994 & 97.818 & 97.641 & 97.465 & 97.288 & 97.112\end{array}$ $\begin{array}{lllllllllll}0.4 & 96.936 & 96.759 & 96.583 & 96.406 & 96.229 & 96.053 & 95.877 & 95.700 & 95.524 & 95.348 \\ 0.5 & 95.171 & 94.995 & 94.819 & 94.642 & 94.466 & 94.289 & 94.113 & 93.937 & 93.760 & 93.583\end{array}$

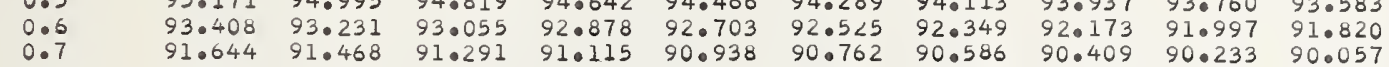
$\begin{array}{lllllllllll}0.8 & 89.880 & 89.704 & 89.528 & 89.352 & 89.175 & 88.999 & 88.822 & 88.646 & 88.469 & 88.293 \\ 0.9 & 88.117 & 87.940 & 87.764 & 87.588 & 87.411 & 87.235 & 87.058 & 86.882 & 86.706 & 86.529\end{array}$

$\begin{array}{lllllllllll} & .001 & .002 & .003 & .004 & .005 & .006 & .007 & .008 & .009 & .010 \\ .176 & .018 & .035 & .053 & .070 & .088 & .0105 & .123 & .141 & .158 & .176 \\ .175 & .017 & .035 & .052 & .070 & .087 & .105 & .122 & .140 & .157 & .175 \\ .174 & .017 & .035 & .052 & .070 & .087 & .104 & .122 & .139 & .156 & .174\end{array}$

0.305070

0.305066
0.305063

.30506

3050

0.305050
0.305046

0.305043

0.305040

0.305033

0.305030

0.305023

0.305013

0.726104
0.726127

0.726149

0.726194

0.726240
0.72626

0.726307

0.726330

0.726375

0.726397

0.726442
0.726465

0.305010
0.305006

0.305003

0.304996

0.304993

0.30498

0.304983
0.304979

0.726510

0.304976

0.304973

0.304966

0.304963

0.30495

0.304953

0.304946

0.304943

0.304936

0.304930

0.304926

0.304920

0.304913

0.726555

0.726578

0.726623

0.726645
0.726668

0.72669

0.726713
0.726736

0.304910

0.304903

0.304900

0.304893

0.304890

0.304886
0.30488

0.304880

0.304876

0.304867

0.304863

0.304860

0.304853

0.304850

0.726758

0.726781

0.726826

0.726848

0.726894

0.726916

0.726961

0.304843

0.304840

0.304833

0.304830

0.304824

0.304824

0.304817

0.304810

0.304807

0.304804

0.304797

0.304794

0.304790

0.304784
0.304781

0.726984
0.727006

0.727029

0.727074

0.727097

0.727142

0.727164
0.727187

0.304777

0.304774
0.304771

0.304767

0.304764

0.304751

0.727210
0.727232

0.727255

0.727300

0.727322
0.727345

0.727368

0.727390
0.727413

0.727435

0.727480

0.727503
0.727526

0.727548

0.727593

0.727616

0.727661

0.727684
0.727706

0.727706
0.727729

0.72775
0.727774

0.727797

0.727819
0.727842

0.727887

0.727932

0.727932
0.727955

0.727977
0.728000

0.728023

0.728045

0.728090

0.728113

0.728136

0.728181

0.728226

0.728249

0.728294 


\begin{tabular}{|c|c|c|c|c|c|c|c|c|c|c|c|c|}
\hline & .00 & .01 & .02 & .03 & .04 & .05 & .06 & .07 & .08 & .09 & $\times 1000$ & (n- \\
\hline $\begin{array}{l}70.0 \\
0.1 \\
0.2 \\
0.3 \\
0.4 \\
0.5 \\
0.6 \\
0.7 \\
0.8 \\
0.9\end{array}$ & $\begin{array}{r}41828.258 \\
26.509 \\
24.759 \\
23.009 \\
21.259 \\
19.510 \\
17.762 \\
16.0112 \\
14.263 \\
12.514\end{array}$ & $\begin{array}{l}28.083 \\
26.333 \\
24.583 \\
22.833 \\
21.084 \\
19.0336 \\
17.586 \\
15.837 \\
14.088 \\
12.339\end{array}$ & $\begin{array}{l}27.908 \\
26.158 \\
24.408 \\
22.659 \\
20.909 \\
19.160 \\
17.411 \\
15.662 \\
13.913 \\
12.164\end{array}$ & $\begin{array}{l}27.733 \\
25.983 \\
24.234 \\
22.484 \\
20.734 \\
18.985 \\
17.236 \\
15.487 \\
13.738 \\
11.989\end{array}$ & $\begin{array}{l}27.559 \\
25.809 \\
24.059 \\
22.309 \\
20.559 \\
18.811 \\
17.062 \\
15.312 \\
13.503 \\
11.814\end{array}$ & $\begin{array}{l}27.384 \\
25.633 \\
23.884 \\
22.134 \\
20.385 \\
18.636 \\
16.886 \\
15.137 \\
13.389 \\
11.640\end{array}$ & $\begin{array}{l}27.208 \\
25.458 \\
23.709 \\
21.959 \\
20.209 \\
18.460 \\
16.711 \\
14.962 \\
13.213 \\
11.465\end{array}$ & $\begin{array}{l}27.034 \\
25.284 \\
23.534 \\
21.784 \\
20.035 \\
18.286 \\
16.537 \\
14.788 \\
13.039 \\
11.290\end{array}$ & $\begin{array}{l}26.859 \\
25.109 \\
23.359 \\
21.609 \\
19.860 \\
18.111 \\
16.362 \\
14.613 \\
12.864 \\
11.116\end{array}$ & $\begin{array}{l}26.684 \\
24.934 \\
23.184 \\
21.435 \\
19.686 \\
17.936 \\
16.187 \\
14.438 \\
12.689 \\
10.941\end{array}$ & $\begin{array}{l}0.304744 \\
0.304741 \\
0.304738 \\
0.304734 \\
0.304731 \\
0.304728 \\
0.304725 \\
0.304721 \\
0.304718 \\
0.304715\end{array}$ & $\begin{array}{l}0.728339 \\
0.728362 \\
0.728384 \\
0.728407 \\
0.728429 \\
0.728452 \\
0.728475 \\
0.728497 \\
0.728520 \\
0.728542\end{array}$ \\
\hline $\begin{array}{l}91.0 \\
1.1 \\
1.2 \\
1.3 \\
1.4 \\
1.5 \\
1.6 \\
1.7 \\
1.8 \\
1.9\end{array}$ & $\begin{array}{r}41810.766 \\
09.018 \\
07.269 \\
05.521 \\
03.773 \\
02.025 \\
00.277 \\
41798.529 \\
96.782 \\
95.035\end{array}$ & $\begin{array}{l}10.591 \\
08.843 \\
07.094 \\
05.346 \\
03.598 \\
01.851 \\
00.003 \\
98.354 \\
96.607 \\
94.860\end{array}$ & 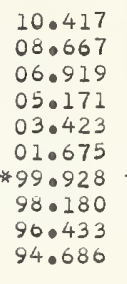 & $\begin{array}{l}10.241 \\
08.493 \\
06.745 \\
04.996 \\
03.249 \\
01.500 \\
* 99.752 \\
98.005 \\
96.258 \\
94.511\end{array}$ & $\begin{array}{r}10.066 \\
08.318 \\
06.569 \\
04.821 \\
03.074 \\
01.326 \\
* 99.578 \\
97.831 \\
96.083 \\
94.336\end{array}$ & $\begin{array}{l}09.892 \\
08.143 \\
06.394 \\
04.646 \\
02.899 \\
01.151 \\
* 99.403 \\
97.656 \\
95.909 \\
94.162\end{array}$ & $\begin{array}{l}09.716 \\
07.968 \\
06.220 \\
04.472 \\
02.724 \\
00.976 \\
* 99.228 \\
97.481 \\
95.734 \\
93.987\end{array}$ & $\begin{array}{l}09.542 \\
07.793 \\
06.045 \\
04.296 \\
02.549 \\
00.801 \\
* 99.054 \\
97.306 \\
95.560 \\
93.812\end{array}$ & $\begin{array}{r}09.367 \\
07.618 \\
05.870 \\
04.122 \\
02.375 \\
00.626 \\
* 98.879 \\
97.131 \\
95.384 \\
93.637\end{array}$ & $\begin{array}{l}09.192 \\
07.443 \\
05.695 \\
03.947 \\
02.200 \\
00.452 \\
* 98.704 \\
96.957 \\
95.209 \\
93.462\end{array}$ & $\begin{array}{l}0.304711 \\
0.304708 \\
0.304705 \\
0.304702 \\
0.304698 \\
0.304695 \\
0.304692 \\
0.304688 \\
0.304685 \\
0.304682\end{array}$ & $\begin{array}{l}0.728565 \\
0.728588 \\
0.728610 \\
0.728633 \\
0.728656 \\
0.728678 \\
0.728701 \\
0.728723 \\
0.728746 \\
0.728769\end{array}$ \\
\hline $\begin{array}{r}92.0 \\
2.1 \\
2.2 \\
2.3 \\
2.4 \\
2.5 \\
2.6 \\
2.7 \\
2.8 \\
2.9\end{array}$ & $\begin{array}{l}793.288 \\
91.541 \\
89.793 \\
88.047 \\
86.300 \\
84.554 \\
82.808 \\
81.062 \\
79.316 \\
77.570\end{array}$ & $\begin{array}{l}93.113 \\
91.366 \\
89.619 \\
87.873 \\
86.125 \\
84.379 \\
82.633 \\
80.887 \\
79.141 \\
77.395\end{array}$ & $\begin{array}{l}92.938 \\
91.191 \\
89.444 \\
87.698 \\
85.951 \\
84.205 \\
82.458 \\
80.712 \\
78.967 \\
77.221\end{array}$ & $\begin{array}{l}92.763 \\
91.016 \\
89.0270 \\
87.523 \\
85.776 \\
84.030 \\
82.284 \\
80.538 \\
78.792 \\
77.046\end{array}$ & $\begin{array}{l}92.589 \\
90.842 \\
89.095 \\
87.349 \\
85.602 \\
83.855 \\
82.109 \\
80.363 \\
78.617 \\
76.871\end{array}$ & $\begin{array}{l}92.414 \\
90.667 \\
88.920 \\
87.174 \\
85.428 \\
83.681 \\
81.935 \\
80.188 \\
78.443 \\
76.697\end{array}$ & $\begin{array}{l}92.239 \\
90.492 \\
88.746 \\
87.000 \\
85.253 \\
83.506 \\
81.760 \\
80.015 \\
78.269 \\
76.522\end{array}$ & $\begin{array}{l}92.065 \\
90.0318 \\
88.571 \\
86.825 \\
85.078 \\
83.332 \\
81.585 \\
79.840 \\
78.094 \\
76.348\end{array}$ & $\begin{array}{l}91.890 \\
90.143 \\
88.396 \\
86.650 \\
84.904 \\
83.157 \\
81.411 \\
79.665 \\
77.0119 \\
76.173\end{array}$ & $\begin{array}{l}91.715 \\
89.968 \\
08.221 \\
86.475 \\
84.729 \\
82.982 \\
81.235 \\
79.491 \\
77.745 \\
75.999\end{array}$ & $\begin{array}{l}0.304679 \\
0.304675 \\
0.304672 \\
0.304669 \\
0.304666 \\
0.304662 \\
0.304659 \\
0.304656 \\
0.304652 \\
0.304649\end{array}$ & $\begin{array}{l}0.728791 \\
0.728814 \\
0.728836 \\
0.728859 \\
0.728882 \\
0.728904 \\
0.728927 \\
0.728950 \\
0.728972 \\
0.728995\end{array}$ \\
\hline $\begin{array}{r}93.0 \\
3.1 \\
3.2 \\
3.3 \\
3.4 \\
3.5 \\
3.6 \\
3.7 \\
3.8 \\
3.9\end{array}$ & $\begin{array}{r}775.824 \\
74.079 \\
72.333 \\
70.588 \\
68.843 \\
67.098 \\
65.353 \\
63.609 \\
61.864 \\
60.120\end{array}$ & $\begin{array}{l}75.649 \\
73.904 \\
72.159 \\
70.414 \\
68.668 \\
66.924 \\
65.179 \\
63.434 \\
61.689 \\
59.945\end{array}$ & $\begin{array}{l}75.475 \\
73.729 \\
71.984 \\
70.240 \\
68.494 \\
66.749 \\
65.004 \\
63.260 \\
61.516 \\
59.771\end{array}$ & $\begin{array}{l}75.300 \\
73.554 \\
71.810 \\
70.064 \\
68.319 \\
66.574 \\
64.830 \\
63.085 \\
61.341 \\
59.596\end{array}$ & $\begin{array}{l}75.126 \\
73.380 \\
71.635 \\
69.890 \\
68.145 \\
66.400 \\
64.655 \\
62.911 \\
61.167 \\
59.422\end{array}$ & $\begin{array}{l}74.951 \\
73.206 \\
71.460 \\
69.716 \\
67.970 \\
66.225 \\
64.480 \\
62.736 \\
60.992 \\
59.247\end{array}$ & $\begin{array}{l}74.776 \\
73.031 \\
71.287 \\
69.541 \\
67.796 \\
66.051 \\
64.306 \\
62.562 \\
60.817 \\
59.073\end{array}$ & $\begin{array}{l}74.603 \\
72.857 \\
71.112 \\
69.366 \\
67.621 \\
65.876 \\
64.132 \\
62.387 \\
60.643 \\
58.898\end{array}$ & $\begin{array}{l}74.428 \\
72.082 \\
70.937 \\
69.192 \\
67.447 \\
65.702 \\
63.958 \\
62.213 \\
60.469 \\
58.724\end{array}$ & & $\begin{array}{l}0.304646 \\
0.304643 \\
0.304639 \\
0.304636 \\
0.304633 \\
0.304629 \\
0.304626 \\
0.304623 \\
0.304620 \\
0.304616\end{array}$ & $\begin{array}{l}0.729017 \\
0.729040 \\
0.729063 \\
0.72085 \\
0.729108 \\
0.729131 \\
0.729153 \\
0.729176 \\
0.729199 \\
.729221\end{array}$ \\
\hline $\begin{array}{l}94.0 \\
4.1 \\
4.2 \\
4.3 \\
4.4 \\
4.5 \\
4.6 \\
4.7 \\
4.8 \\
4.9\end{array}$ & $\begin{array}{l}758.375 \\
56.631 \\
54.888 \\
53.144 \\
51.399 \\
49.656 \\
47.914 \\
46.170 \\
44.427 \\
42.684\end{array}$ & $\begin{array}{l}58.201 \\
56.457 \\
54.713 \\
52.969 \\
51.225 \\
49.482 \\
47.739 \\
45.996 \\
44.252 \\
42.509\end{array}$ & $\begin{array}{l}58.026 \\
56.283 \\
54.539 \\
52.795 \\
51.051 \\
49.308 \\
47.564 \\
45.821 \\
44.078 \\
42.335\end{array}$ & $\begin{array}{l}57.852 \\
56.109 \\
54.365 \\
52.621 \\
50.876 \\
49.133 \\
47.391 \\
45.647 \\
43.904 \\
42.161\end{array}$ & $\begin{array}{l}57.678 \\
55.934 \\
54.190 \\
52.446 \\
50.702 \\
48.959 \\
47.216 \\
45.473 \\
43.729 \\
41.986\end{array}$ & $\begin{array}{l}57.503 \\
55.760 \\
54.016 \\
52.272 \\
50.528 \\
48.785 \\
47.042 \\
45.298 \\
43.556 \\
41.812\end{array}$ & $\begin{array}{l}57.328 \\
55.584 \\
53.841 \\
52.097 \\
50.353 \\
48.609 \\
46.867 \\
45.123 \\
43.381 \\
41.638\end{array}$ & $\begin{array}{l}57.154 \\
55.411 \\
53.667 \\
51.922 \\
50.179 \\
48.436 \\
46.693 \\
44.950 \\
43.207 \\
41.403\end{array}$ & $\begin{array}{l}56.980 \\
55.236 \\
53.492 \\
51.749 \\
50.005 \\
48.262 \\
46.518 \\
44.775 \\
43.032 \\
41.289\end{array}$ & & $\begin{array}{l}0.304613 \\
0.304610 \\
0.304607 \\
0.304603 \\
0.304600 \\
0.304597 \\
0.304594 \\
0.304590 \\
0.304587 \\
0.304584\end{array}$ & $\begin{array}{l}0.729244 \\
0.729266 \\
0.729289 \\
0.729312 \\
0.729334 \\
0.729357 \\
0.729380 \\
0.729402 \\
0.729425 \\
0.729448\end{array}$ \\
\hline $\begin{array}{l}95.0 \\
5.1 \\
5.2 \\
5.3 \\
5.4 \\
5.5 \\
5.6 \\
5.7 \\
5.8 \\
5.9\end{array}$ & $\begin{array}{r}170.940 \\
39.199 \\
37.456 \\
35.713 \\
33.971 \\
32.229 \\
30.488 \\
28.746 \\
27.004 \\
25.263\end{array}$ & $\begin{array}{l}40.767 \\
39.024 \\
37.282 \\
35.539 \\
33.796 \\
32.056 \\
30.313 \\
28.572 \\
26.830 \\
25.088\end{array}$ & $\begin{array}{l}40.592 \\
38.850 \\
37.107 \\
35.365 \\
33.623 \\
31.881 \\
30.139 \\
28.397 \\
26.656 \\
24.914\end{array}$ & $\begin{array}{l}40.418 \\
38.6776 \\
36.933 \\
35.191 \\
33.448 \\
31.007 \\
29.965 \\
28.223 \\
26.481 \\
24.740\end{array}$ & $\begin{array}{l}40.245 \\
38.001 \\
36.759 \\
35.017 \\
33.274 \\
31.533 \\
29.791 \\
28.049 \\
26.307 \\
24.565\end{array}$ & $\begin{array}{l}40.070 \\
38.327 \\
36.584 \\
34.843 \\
33.100 \\
31.358 \\
29.017 \\
27.875 \\
26.133 \\
24.392\end{array}$ & $\begin{array}{l}39.896 \\
38.153 \\
36.411 \\
34.668 \\
32.926 \\
31.184 \\
29.442 \\
27.701 \\
25.959 \\
24.218\end{array}$ & $\begin{array}{l}39.722 \\
37.979 \\
36.236 \\
34.0494 \\
32.751 \\
31.010 \\
29.269 \\
27.526 \\
25.785 \\
24.043\end{array}$ & $\begin{array}{l}39.547 \\
37.805 \\
36.062 \\
34.0320 \\
32.578 \\
30.836 \\
29.094 \\
27.352 \\
25.611 \\
23.870\end{array}$ & $\begin{array}{l}27.178 \\
25.437 \\
23.0696\end{array}$ & $\begin{array}{l}0.304580 \\
0.304577 \\
0.304574 \\
0.304571 \\
0.304567 \\
0.304564 \\
0.304561 \\
0.304558 \\
0.304554 \\
0.304551\end{array}$ & $\begin{array}{l}.729470 \\
0729493 \\
0729515 \\
0729538 \\
0729561 \\
0729583 \\
0729606 \\
.729629 \\
729651 \\
7729674\end{array}$ \\
\hline $\begin{array}{l}96.0 \\
6.1 \\
6.2 \\
6.3 \\
6.4 \\
6.5 \\
6.6 \\
6.7 \\
6.8 \\
6.9\end{array}$ & $\begin{array}{l}723.521 \\
21.781 \\
20.039 \\
18.298 \\
16.557 \\
14.817 \\
13.077 \\
11.336 \\
09.596 \\
07.856\end{array}$ & $\begin{array}{l}23.348 \\
21.006 \\
19.865 \\
18.124 \\
16.383 \\
14.643 \\
12.002 \\
11.162 \\
09.421 \\
07.682\end{array}$ & $\begin{array}{l}23.173 \\
21.432 \\
19.691 \\
17.950 \\
16.210 \\
14.469 \\
12.729 \\
10.988 \\
09.248 \\
07.508\end{array}$ & $\begin{array}{l}22.999 \\
21.258 \\
19.517 \\
17.776 \\
16.036 \\
14.295 \\
12.555 \\
10.814 \\
09.074 \\
07.334\end{array}$ & $\begin{array}{l}22.825 \\
21.083 \\
19.0342 \\
17.6001 \\
15.861 \\
14.121 \\
12.0380 \\
10.640 \\
08.900 \\
07.160\end{array}$ & $\begin{array}{l}22.651 \\
20.909 \\
19.168 \\
17.428 \\
15.687 \\
13.946 \\
12.206 \\
10.465 \\
08.726 \\
06.986\end{array}$ & $\begin{array}{l}22.477 \\
20.735 \\
18.995 \\
17.253 \\
15.513 \\
13.772 \\
12.032 \\
10.292 \\
08.553 \\
06.812\end{array}$ & $\begin{array}{l}22.303 \\
20.562 \\
18.820 \\
17.079 \\
15.339 \\
13.599 \\
11.858 \\
10.118 \\
08.378 \\
06.638\end{array}$ & $\begin{array}{l}22.128 \\
20.387 \\
18.646 \\
16.906 \\
15.165 \\
13.424 \\
11.684 \\
09.943 \\
08.204 \\
06.464\end{array}$ & $\begin{array}{l}16.731 \\
14.991 \\
13.250 \\
11.510 \\
09.770 \\
08.030 \\
06.290\end{array}$ & $\begin{array}{l}0.304548 \\
0.304545 \\
0.304541 \\
0.304538 \\
0.304535 \\
0.304532 \\
0.304528 \\
0.304525 \\
0.304522 \\
0.304519\end{array}$ & $\begin{array}{l}.729697 \\
.729719 \\
.729742 \\
.729765 \\
0729787 \\
.729810 \\
.729832 \\
.729855 \\
.729878 \\
.729900\end{array}$ \\
\hline $\begin{array}{l}97.0 \\
7.1 \\
7.2 \\
7.3 \\
7.4 \\
7.5 \\
7.6 \\
7.7 \\
7.8 \\
7.9\end{array}$ & $\begin{array}{r}41706.116 \\
04.376 \\
02.637 \\
00.897 \\
41699.158 \\
97.418 \\
95.680 \\
93.941 \\
92.203 \\
90.464\end{array}$ & $\begin{array}{l}05.942 \\
04.202 \\
02.462 \\
00.723 \\
98.984 \\
97.245 \\
95.506 \\
93.767 \\
92.028 \\
90.290\end{array}$ & $\begin{array}{l}05.768 \\
04.028 \\
02.289 \\
00.550 \\
98.811 \\
97.071 \\
95.332 \\
93.593 \\
91.855 \\
90.116\end{array}$ & $\begin{array}{l}05.594 \\
03.854 \\
02.115 \\
00.376 \\
98.636 \\
96.897 \\
95.158 \\
93.4119 \\
91.681 \\
89.942\end{array}$ & $\begin{array}{l}01.941 \\
00.202 \\
98.462 \\
96.724 \\
94.984 \\
93.245 \\
91.507 \\
89.768\end{array}$ & $\begin{array}{l}05.247 \\
03.506 \\
01.767 \\
00.028 \\
98.289 \\
96.549 \\
94.811 \\
93.071 \\
91.333 \\
89.595\end{array}$ & $\begin{array}{r}05.072 \\
03.333 \\
01.593 \\
* 99.854 \\
98.115 \\
96.375 \\
94.636 \\
92.898 \\
91.160 \\
89.421\end{array}$ & $\begin{array}{l}04.898 \\
03.158 \\
01.418 \\
99.6880 \\
97.941 \\
96.202^{\circ} \\
94.463 \\
92.724\end{array}$ & $\begin{array}{r}04.724 \\
02.984 \\
01.245 \\
* 99.507 \\
97.767 \\
96.028 \\
94.289 \\
92.550 \\
90.812 \\
89.073\end{array}$ & $\begin{array}{r}04.550 \\
02.810 \\
01.071 \\
* 99.332 \\
97.593 \\
95.854 \\
94.114 \\
92.377 \\
90.638 \\
88.899\end{array}$ & & $\begin{array}{l}0.729923 \\
0.729946 \\
0.729968 \\
0729991 \\
0.730014 \\
0.730036 \\
0730059 \\
0.730082 \\
0730104 \\
.730127\end{array}$ \\
\hline $\begin{array}{r}98.0 \\
8.1 \\
8.2 \\
8.3 \\
8.4 \\
8.5 \\
8.6 \\
8.7 \\
8.8 \\
8.9\end{array}$ & $\begin{array}{r}41688.726 \\
86.987 \\
85.249 \\
83.511 \\
81.773 \\
80.035 \\
78.298 \\
76.561 \\
74.824 \\
73.086\end{array}$ & $\begin{array}{l}88.551 \\
86.813 \\
85.075 \\
83.337 \\
81.600 \\
79.862 \\
78.124 \\
76.387 \\
74.650 \\
72.912\end{array}$ & $\begin{array}{l}88.377 \\
86.039 \\
84.901 \\
83.164 \\
81.426 \\
79.0688 \\
77.950 \\
76.213 \\
74.477 \\
72.739\end{array}$ & $\begin{array}{l}88.204 \\
86.466 \\
84.728 \\
82.990 \\
81.251 \\
79.514 \\
77.776 \\
76.040 \\
74.303 \\
72.565\end{array}$ & $\begin{array}{l}84.534 \\
82.816 \\
81.078 \\
79.340 \\
77.603 \\
75.866 \\
74.128 \\
72.391\end{array}$ & $\begin{array}{l}86.118 \\
84.380 \\
82.643 \\
80.094 \\
79.167 \\
77.429 \\
75.692 \\
73.955 \\
72.218\end{array}$ & $\begin{array}{l}87.682 \\
85.944 \\
84.207 \\
82.468 \\
80.730 \\
78.993 \\
77.255 \\
75.519 \\
73.781 \\
72.044\end{array}$ & $\begin{array}{l}78.819 \\
77.082 \\
75.345 \\
73.607 \\
71.870\end{array}$ & $\begin{array}{l}87.335 \\
85.597 \\
83.859 \\
82.121 \\
80.383 \\
78.646 \\
76.908 \\
75.171 \\
73.434 \\
71.697\end{array}$ & $\begin{array}{l}76.734 \\
74.998 \\
73.260 \\
71.5233\end{array}$ & & $\begin{array}{l}0.730150 \\
0.0730172 \\
0.730195 \\
0.730218 \\
0.730240 \\
0.730263 \\
0.730286 \\
0.730308 \\
0.730331 \\
0.730354\end{array}$ \\
\hline $\begin{array}{l}99.0 \\
9.1 \\
9.2 \\
9.3 \\
9.4 \\
9.5 \\
9.6 \\
9.7 \\
9.8 \\
9.9\end{array}$ & $\begin{array}{r}41671.349 \\
69.612 \\
67.876 \\
66.139 \\
64.403 \\
62.666 \\
60.930 \\
59.195 \\
57.458 \\
55.723\end{array}$ & $\begin{array}{l}71.176 \\
69.438 \\
67.702 \\
65.965 \\
64.229 \\
62.493 \\
60.757 \\
59.021\end{array}$ & $\begin{array}{l}69.265 \\
67.528 \\
65.792 \\
64.056 \\
62.319 \\
60.583 \\
58.847 \\
57.112 \\
55.376\end{array}$ & $\begin{array}{l}69.091 \\
67.355 \\
65.619 \\
63.882 \\
62.146 \\
60.410 \\
58.674 \\
56.938 \\
55.202\end{array}$ & 55.028 & $\begin{array}{l}67.008 \\
65.271 \\
63.535 \\
61.798 \\
60.063 \\
58.327 \\
50.591 \\
54.855\end{array}$ & 54.682 & $\begin{array}{l}57.979 \\
56.244 \\
54.508\end{array}$ & $\begin{array}{l}68.223 \\
66.486 \\
64.750 \\
63.014 \\
61.277 \\
59.542 \\
57.806 \\
56.070 \\
54.334\end{array}$ & $\begin{array}{l}68.049 \\
66.313 \\
64.5756 \\
62.840 \\
61.104 \\
59.0368 \\
57.632 \\
55.896 \\
54.161\end{array}$ & $\begin{array}{l}0.304447 \\
0.304444 \\
0.304441 \\
0.304437 \\
0.304434 \\
0.304431 \\
0.304428 \\
0.304424 \\
0.304421\end{array}$ & $\begin{array}{l}.730399 \\
0.730422 \\
0.730444 \\
0730467 \\
0.730490 \\
0.730512 \\
0730535 \\
0.730558 \\
0730580\end{array}$ \\
\hline & \multicolumn{2}{|c|}{$\therefore 001$} & .002 & .003 & .004 & .005 & .000 & .008 & .008 & .003 & .010 & \\
\hline & .0. & & & & .070 & .087 & .104 & .122 & 13 & .156 & - 174 & \\
\hline
\end{tabular}




$$
48
$$

$\begin{array}{llllllllll}52.252 & 52.814 & 53.640 & 53.466 & 53.293 & 53.120 & 52.946 & 52.773 & 52.600 & 52.426\end{array}$ $\begin{array}{lllllllllll}50.517 & 50.343 & 50.169 & 49.997 & 49.823 & 49.649 & 49.476 & 49.302 & 49.129 & 48.690\end{array}$ $\begin{array}{lllllllllll}48.782 & 48.608 & 48.435 & 48.261 & 48.087 & 47.915 & 47.741 & 47.567 & 47.394 & 47.221\end{array}$ $\begin{array}{llllllllll}47.046 & 46.873 & 46.700 & 46.526 & 46.353 & 46.179 & 46.006 & 45.832 & 45.659 & 45.48\end{array}$ $\begin{array}{llllllllll}45.312 & 45.138 & 44.965 & 44.791 & 44.619 & 44.445 & 44.271 & 44.098 & 43.925 & 43.751\end{array}$ $\begin{array}{llllllllll}43.578 & 43.404 & 43.230 & 43.057 & 42.884 & 42.710 & 42.537 & 42.363 & 42.190 & 42.016 \\ 41.843 & 41.670 & 41.496 & 41.323 & 41.149 & 40.976 & 40.802 & 40.629 & 40.455 & 40.282\end{array}$ $\begin{array}{llllllllll}40.109 & 39.935 & 39.762 & 39.588 & 39.415 & 39.241 & 39.068 & 38.895 & 38.721 & 38.548\end{array}$

2401.0

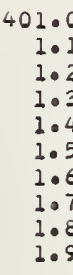

41636.64 $\begin{array}{lll}36.641 & 30.467 & 36.294 \\ 34.907 & 34.733 & 34.560 \\ 33.173 & 33.000 & 32.826\end{array}$ $\begin{array}{lllll}31.4730 & 3.000 & 32.826 & 32.653 & 32.479\end{array}$ $29.705 \quad 29.532 \quad 29.359 \quad 30.91950 .745$ $\begin{array}{lll}27.972 & 27.799 & 27.625\end{array}$ $26.239 \quad 26.066 \quad 25.892$ $\begin{array}{lll}24.506 & 24.333 & 24.159 \\ 22.772 & 22.599 & 22.426\end{array}$ $21.040 \quad 20.866 \quad 20.694$

$\begin{array}{ll}27.452 & 27.279 \\ 25.719 & 25.546\end{array}$

$\begin{array}{ll}25.719 & 25.546 \\ 23.986 & 23.81\end{array}$

$\begin{array}{ll}23.986 & 23.812 \\ 22.253 & 22.08 \\ 20.521 & 20.34\end{array}$

$37.507 \quad 37.333$

38.895

38.721
36.987

38.548

2402.

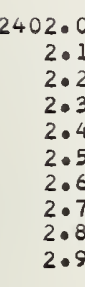

2403.0

3.
3.
3.
3.
3.
3.
3.

$2404 \cdot 0$
$4 \cdot 1$
$4 \cdot 2$
$4 \cdot 3$
4.4
$4 \cdot 5$
$4 \cdot 6$
$4 \cdot 7$
4.8
4.9

$\begin{array}{rll}41619.307 & 19.134 & 18.961 \\ 17.575 & 17.402 & 17.229 \\ 15.843 & 15.669 & 15.496 \\ 14.110 & 13.937 & 13.764 \\ 12.378 & 12.205 & 12.032 \\ 10.646 & 10.474 & 10.300 \\ 08.915 & 08.741 & 08.568 \\ 07.183 & 07.010 & 06.836 \\ 05.451 & 05.278 & 05.105 \\ 03.721 & 03.547 & 03.374\end{array}$

$\begin{array}{ll}10.788 & 18.615 \\ 17.056 & 16.882\end{array}$

$32.132 \quad 31.959 \quad 31.785 \quad 31.612$

$\begin{array}{llll}30.225 & 30.052 & 29.878\end{array}$

$\begin{array}{lllll}27.105 & 28.066 & 28.492 & 28.319 & 28.146\end{array}$

$\begin{array}{ll}25.105 & 26.932 \\ 25.199\end{array}$

23.639
21.90

26.759
25.025

26.585

26.412
24.679

$\begin{array}{llll}21.733 & 21.560 & 21.387 & 21.213\end{array}$

$\begin{array}{lllll}16.441 & 18.208 & 18.095 & 17.921 & 17.748\end{array}$

$\begin{array}{lllllll}17.036 & 15.882 & 16.709 & 16.536 & 16.362 & 16.189 & 16.015\end{array}$

$\begin{array}{lllllll}13.591 & 13.417 & 13.245 & 13.071 & 12.897 & 12.725 & 12.552\end{array}$

$\begin{array}{lllllll}11.591 & 13.417 & 13.245 & 13.071 & 12.897 & 12.725 & 12.552 \\ 11.859 & 11.686 & 11.513 & 11.339 & 11.166 & 10.993 & 10.819\end{array}$

$\begin{array}{lllllll}11.859 & 11.686 & 11.513 & 11.339 & 11.166 & 10.993 & 10.819 \\ 10.127 & 09.954 & 09.781 & 09.607 & 09.435 & 09.261 & 09.087\end{array}$

$\begin{array}{lllllll}08.396 & 08.222 & 08.049 & 07.875 & 07.435 & 09.261 & 09.087 \\ 06.664 & 06.490 & 06.317 & 06.144 & 05.971 & 07.529 & 07.355 \\ 05.798 & 05.625\end{array}$

$03.721 \quad 03.547 \quad 03.374$

$06.317 \quad 06.144$

05.971
04.240

05.79

07.355
05.625

$41601.989 \quad 01.816 \quad 01.643$

$\begin{array}{rrrr}00.258 & 00.084 * 99.912 & * 99.469 & 01.297\end{array}$

$01.124 \quad 00.950$

02.50

$00.604 \quad 00.4$

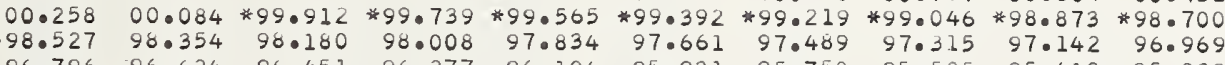

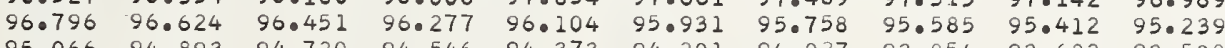

$93.33593 .163 \quad 92.72094 .546 \quad 94.333940201 \quad 94.027 \quad 93.85493 .68293 .508$

$91.605 \quad 91.432 \quad 91.259 \quad 91.016 \quad 92.64392 .47092 .29792 .124 \quad 91095191.778$

$89.875 \quad 89.702 \quad 89.528 \quad 89.355 \quad 890182 \quad 89.000 \quad 88.536 \quad 88.664 \quad 88.49190 .047$

$88.145 \quad 87.972 \quad 87.799$

6.24286 .069

2405.

5.

$5 \cdot 4$

5.5
5.7

5.8

41584.685

$82.956 \quad 84.512$

$82.956 \quad 82.783 \quad 82.009$

$\begin{array}{lllll}81.226 & 81.053 & 80.880 & 80.707 & 80.535 \\ 79.497 & 79.324 & 79.151 & 78.978 & 78.805\end{array}$

$\begin{array}{llllllllll}77.594 & 77.422 & 77.249 & 77.076 & 76.903 & 76.730 & 76.557 & 76.384 & 76.211\end{array}$

$\begin{array}{llllllllll}74.038 & 75.866 & 75.693 & 75.520 & 75.347 & 75.174 & 75.001 & 74.828 & 74.655 & 74.482 \\ 74.137 & 73.963 & 73.791 & 73.618 & 73.445 & 73.272 & 73.099 & 72.926 & 72.753\end{array}$

$\begin{array}{llllllllll}72.581 & 72.408 & 72.235 & 72.062 & 71.890 & 71.717 & 71.544 & 71.371 & 71.198 & 71.025\end{array}$

$\begin{array}{llllllllll}70.852 & 70.679 & 70.507 & 70.334 & 70.161 & 69.988 & 69.815 & 69.643 & 69.470 & 69.296 \\ 69.124 & 68.951 & 68.778 & 68.605 & 68.432 & 68.260 & 68.087 & 67.914 & 67.741 & 67.568\end{array}$

$65.667 \quad 65.223 \quad 67.050$

$66.876 \quad 66.704$

66.5312

$\begin{array}{llllllllll}62.211 & 62.039 & 61.866 & 61.693 & 61.520 & 61.348 & 61.175 & 61.002 & 60.830 & 60.657 \\ 60.483 & 60.311 & 60.138 & 59.965 & 59.792 & 59.620 & 59.447 & 59.274 & 59.102 & 58.929\end{array}$

$\begin{array}{llllllllll}58.755 & 58.583 & 50.410 & 58.237 & 58.065 & 57.892 & 57.719 & 57.547 & 57.374 & 57.201\end{array}$

$\begin{array}{llllllllll}57.029 & 56.855 & 56.683 & 56.511 & 56.338 & 56.165 & 55.992 & 55.820 & 55.647 & 55.474 \\ 55.302 & 55.129 & 54.956 & 54.783 & 54.610 & 54.437 & 54.265 & 54.092 & 53.919 & 53.747\end{array}$

$\begin{array}{llllllllll}53.574 & 53.401 & 53.229 & 53.056 & 52.883 & 52.711 & 52.538 & 52.365 & 52.193 & 52.020\end{array}$

$\begin{array}{llllllllll}51.847 & 51.674 & 51.501 & 51.329 & 51.156 & 50.983 & 50.811 & 50.638 & 50.466 & 50.293\end{array}$

$\begin{array}{lllllllllll}2406.0 & 41550.120 & 49.948 & 49.774 & 49.602 & 49.429 & 49.256 & 49.083 & 48.912 & 48.739 & 48.566\end{array}$ $\begin{array}{lllllllllll}48.394 & 48.221 & 48.048 & 47.876 & 47.703 & 47.530 & 47.357 & 47.185 & 47.012 & 46.839\end{array}$ $\begin{array}{lllllllllll}46.667 & 46.495 & 46.322 & 46.149 & 45.976 & 45.803 & 45.631 & 45.458 & 45.286 & 45.113\end{array}$ $\begin{array}{llllllllll}44.940 & 44.768 & 44.596 & 44.423 & 44.250 & 44.077 & 43.904 & 43.732 & 43.560 & 43.013\end{array}$ $\begin{array}{llllllllll}41.488 & 41.315 & 41.143 & 40.970 & 40.797 & 40.625 & 40.452 & 40.280 & 40.107 & 39.935\end{array}$ $\begin{array}{llllllllll}39.762 & 39.590 & 39.417 & 39.245 & 39.072 & 38.899 & 38.726 & 38.554 & 38.381 & 38.208\end{array}$ $\begin{array}{llllllllll}38.036 & 37.864 & 37.691 & 37.519 & 37.346 & 37.173 & 37.000 & 36.828 & 36.655 & 36.483\end{array}$

$\begin{array}{lllllllllll}6.8 & 36.311 & 36.138 & 35.965 & 35.793 & 35.620 & 35.448 & 35.275 & 35.102 & 34.930 & 34.757 \\ 6.9 & 34.584 & 34.412 & 34.240 & 34.067 & 33.895 & 33.722 & 33.549 & 33.376 & 33.204 & 33.032\end{array}$

$\begin{array}{lllllllllll}2407.0 & 41532.859 & 32.687 & 32.514 & 32.342 & 32.170 & 31.997 & 31.824 & 31.652 & 31.479 & 31.307\end{array}$

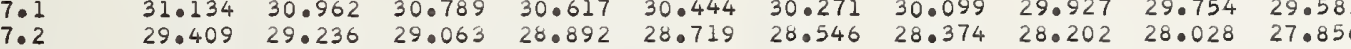

$\begin{array}{lllllllllll}7.3 & 27.684 & 27.511 & 27.339 & 27.167 & 26.994 & 26.822 & 26.649 & 26.477 & 26.304 & 26.13\end{array}$

$\begin{array}{lllllllllll}7.4 & 25.958 & 25.786 & 25.014 & 25.441 & 25.209 & 25.097 & 24.944 & 24.751 & 24.580 & 24.407\end{array}$

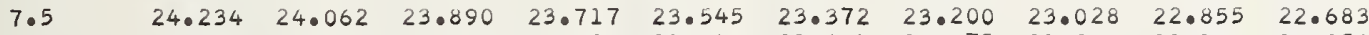

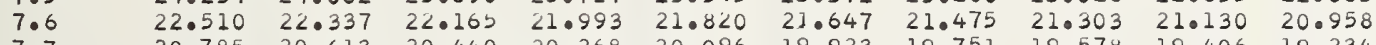

$\begin{array}{lllllllllll}7.7 & 20.785 & 20.613 & 20.440 & 20.268 & 20.096 & 19.923 & 19.751 & 19.578 & 19.406 & 19.234\end{array}$

$\begin{array}{lllllllllll}7.9 & 19.061 & 18.888 & 18.716 & 18.543 & 18.371 & 18.199 & 18.026 & 17.854 & 17.682 & 17.509\end{array}$

$\begin{array}{llllllllll}17.336 & 17.164 & 16.992 & 16.819 & 16.646 & 16.475 & 16.303 & 16.130 & 15.958 & 15.786\end{array}$

$\begin{array}{rrrrrrrrrrr}2408.0 & 41515.613 & 15.441 & 15.268 & 15.096 & 14.923 & 14.751 & 14.579 & 14.407 & 14.234 & 14.062 \\ 8.1 & 13.890 & 13.717 & 13.544 & 13.372 & 13.200 & 13.027 & 12.854 & 12.683 & 12.510 & 12.337\end{array}$

$\begin{array}{lllllllllll}8.1 & 13.890 & 13.717 & 13.544 & 13.372 & 13.200 & 13.027 & 12.854 & 12.683 & 12.510 & 12.337 \\ 8.2 & 12.166 & 11.993 & 11.820 & 11.648 & 11.476 & 11.303 & 11.131 & 10.958 & 10.786 & 10.634\end{array}$

$\begin{array}{lllllllllll}8.2 & 12.166 & 11.993 & 11.820 & 11.648 & 11.476 & 11.303 & 11.131 & 10.958 & 10.786 & 10.614 \\ 8.3 & 10.442 & 10.269 & 10.097 & 09.924 & 09.752 & 09.580 & 09.407 & 09.235 & 09.063 & 08.891\end{array}$

$\begin{array}{lllllllllll}8.3 & 10.442 & 10.269 & 10.097 & 09.924 & 09.752 & 09.580 & 09.407 & 09.235 & 09.063 & 08.891 \\ 8.4 & 08.718 & 08.545 & 08.374 & 08.202 & 08.029 & 07.857 & 07.684 & 07.512 & 07.340 & 07.167\end{array}$

$\begin{array}{lllllllllll}8.5 & 06.995 & 06.823 & 06.651 & 06.478 & 06.306 & 06.133 & 05.961 & 05.789 & 05.617 & 05.444\end{array}$

$\begin{array}{lllllllllll}8.6 & 05.272 & 05.100 & 04.927 & 04.755 & 04.583 & 04.410 & 04.238 & 04.065 & 03.893 & 03.721\end{array}$

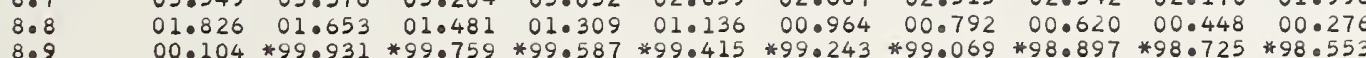

$\begin{array}{rlllllllll}1498.380 & 98.208 & 98.036 & 97.864 & 97.692 & 97.520 & 97.347 & 97.175 & 97.002 & 96.830 \\ 96.658 & 96.486 & 96.313 & 96.142 & 95.969 & 95.797 & 95.624 & 95.453 & 95.280 & 95.108\end{array}$

409.0 $\begin{array}{llllllllll}96.658 & 96.486 & 96.313 & 96.142 & 95.969 & 95.797 & 95.624 & 95.453 & 95.280 & 95.108\end{array}$

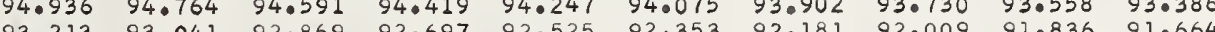

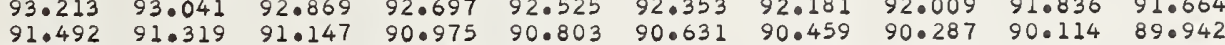

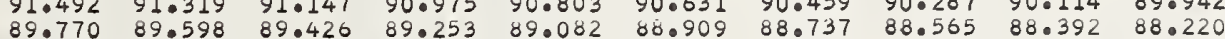
$\begin{array}{llllllllll}88.048 & 87.876 & 87.704 & 87.532 & 87.359 & 87.187 & 87.015 & 86.843 & 86.670 & 86.498\end{array}$ $\begin{array}{llllllllll}88.048 & 87.876 & 87.704 & 87.532 & 87.359 & 87.187 & 87.015 & 86.843 & 86.670 & 86.498\end{array}$

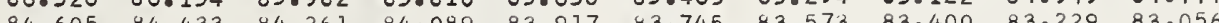
$84.605 \quad 84.43384 .261 \quad 84.08983 .917 \quad 83.745$ 83.573 83.400 83.22983 .056

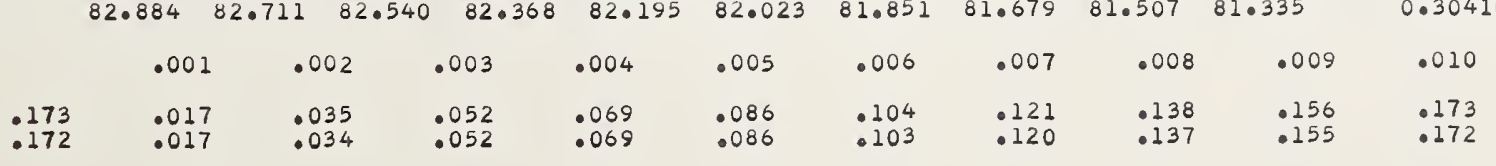

005

1.85

.679
.007

$\begin{array}{rr}.507 & 81.335 \\ .008 & .009\end{array}$

0.304415

0.304408

.304405

0.304399

0.304395

0.304392
0.304389

0.304386

0.304382
0.304379

0.304376

0.304373
0.304369

0.304366

0.304360

0.304353

0.304350

0.304344

0.304337

0.304334

0.304327
0.304324

.304321

0.304318

0.304311

.30430

0.304302

0.304295

0.304289

0.304286

0.30427

0.304270

0.304263

0.304257

0.30425

.004244

$\underset{0.304237}{0.30424}$

0.304234

0.304228

0.304225

0.304218

0.304215

0.304212

.304205

0.30419

0.304196

0.304193

.0304189

0.304183

0.304180

.304177

0.304170

0.304164

0.304161

0.30415

0.30415

0.304148

0.30414

0.304135

0.304135

0.304129

0.304126

0.304122

0.304116

0.304113

0.304106

0.304103 0.304100

.730603

0.730626

0.730671
0.730694

0.730716

0.730739

0.73078

0.730830

0.730852
0.730875

.730898

0.730943

0.730966

.0 .730989

0.731057

0.731079

.731125

0.731170

0.731215

0.731261

0.731283

0.731329

.731374

0.731397

.731442

0.731465
0.731488

0.731510

0.731556

0.731579

0.73162

0.731647

0.731692
0.731715

0.731737

0.73178
0.073176

0.731828

0.731851

0.731896

0.731919
0.731942

0.731965

0.732033

0.732055

0.73210

0.73214

0.732169

0.73221

0.732237

0.732283

0.732305

0.732328

0.732373

0.732419

0.732442

0.732487

0.732510

0.732555

0.732601

0.732646

0.73266

0.732714

0.732737

0.732783

0.732828

.010 


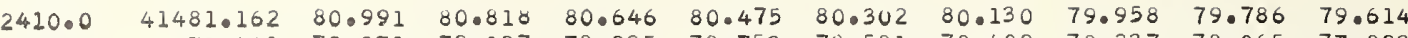

$\begin{array}{lllllllllll}77.721 & 77.548 & 77.376 & 77.205 & 77.032 & 76.860 & 76.688 & 76.516 & 76.344 & 76.172\end{array}$

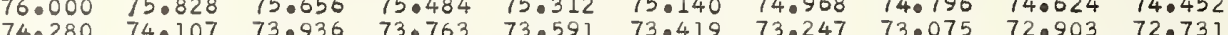

$\begin{array}{llllllllll}72.559 & 72.387 & 72.215 & 72.042 & 71.871 & 71.699 & 71.527 & 71.355 & 71.183 & 71.011\end{array}$

$\begin{array}{lllllllllll}70.839 & 70.667 & 70.494 & 70.323 & 70.150 & 69.979 & 69.806 & 69.635 & 69.462 & 69.291\end{array}$

$69.11968 .947 \quad 68.77468 .603 \quad 68.430 \quad 68.25868 .087 \quad 67.915067 .74367 .571$

$65.679-65.507 \quad 65.335$

$\begin{array}{lllllll}66.883 & 66.710 & 66.539 & 66.367 & 66.195 & 66.023 & 65.851 \\ 65.163 & 64.990 & 64.8119 & 64.647 & 64.475 & 64.303 & 64.131\end{array}$

0.304097

0.732874

0.30409

0.304087

0.304081

0.304078

0.304075

0.304071

0.732896

0.732919

0.732965

0.733010

0.733033

2411.0

1.0

41463

$63.959 \quad 63.788 \quad 63.615$

63.44363 .271

$\begin{array}{lllll}63.099 & 62.927 & 62.755 & 62.583 & 62.411\end{array}$

0.304065

0.304062

0.304056

0.304052

0.304049

0.304046

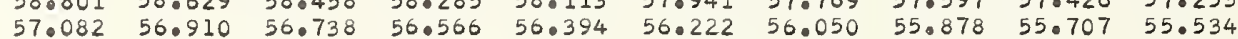

$\begin{array}{llllllllll}55.362 & 55.191 & 55.019 & 54.847 & 54.675 & 54.503 & 54.331 & 54.159 & 53.987 & 53.815\end{array}$

$\begin{array}{llllllllll}53.644 & 53.472 & 53.300 & 53.128 & 52.956 & 52.784 & 52.612 & 52.440 & 52.268 & 52.096\end{array}$

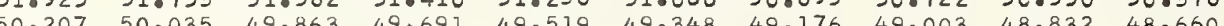

1.8
1.9

$50.207 \quad 50.035 \quad 49.863$

$49.691 \quad 49.519$

$\begin{array}{lllll}49.348 & 49.176 & 49.003 & 48.832 & 48.660 \\ 47.629 & 47.457 & 47.285 & 47.113 & 46.941\end{array}$

0.304040

0.304037

2412.

$2 \cdot 2$

41446.769

46.76946 .598

$45.051 \quad 44.879 \quad 46.426$

$46.254 \quad 46.083$

$\begin{array}{llllll}45.911 & 45.739 & 45.567 & 45.395 & 45.223\end{array}$

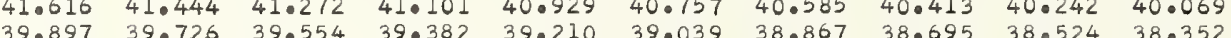

$38.180 \quad 38.008 \quad 39.554 \quad 39.382 \quad 39.210 \quad 390$

$\begin{array}{llllllllll}38.180 & 38.008 & 37.836 & 37.665 & 37.493 & 37.321 & 37.149 & 36.978 & 36.806 & 36.634 \\ 36.462 & 36.291 & 36.119 & 35.948 & 35.776 & 35.604 & 35.433 & 35.261 & 35.089 & 34.917\end{array}$

$\begin{array}{lllll}34.746 & 34.574 & 34.402 & 34.230 & 34.059\end{array}$

2.8

2413

$\begin{array}{lll}33.029 & 32.856 & 32.685 \\ 31.312 & 31.139 & 30.968\end{array}$

$$
\begin{aligned}
& 3 . \\
& 3 . \\
& 3 . \\
& 3 . \\
& 3 . \\
& 3 . \\
& 3 . \\
& 3 . \\
& 3 .
\end{aligned}
$$$$
\begin{array}{rrr}
1429.594 & 29.422 & 29.2 \\
27.878 & 27.707 & 27.5 \\
26.162 & 25.990 & 25.8
\end{array}
$$$$
\begin{array}{lll}
26.162 & 25.990 & 25.81 \\
24.445 & 24.273 & 24.10
\end{array}
$$$$
22.729 \quad 22.557 \quad 22.385
$$

$\begin{array}{lll}21.012 & 20.841 & 20.669\end{array}$

$\begin{array}{lll}19.297 & 19.125 & 18.953\end{array}$

$\begin{array}{lll}15.865 & 15.693 & 15.522 \\ 14.149 & 13.977 & 13.806\end{array}$

$\begin{array}{ll}32.513 & 32.341 \\ 30.796 & 30.624\end{array}$

0.304033

0.304030

0.304024

0.304021

0.304014

0.304011

0.304008

0.733101

0.733124

0.733146

0.733192

0.733215
0.733237

0.733260

0.733283
0.733306

0.733328

0.733351

0.733374
0.733397

0.733419

0.733442

0.733465

0.733488

0.733510
0.733533

0.304002

0.303998

0.303995

0.303992

0.303983

0.303979

0.303976

0.733556
0.733579

$\begin{array}{lllllll}22.213 & 22.042 & 21.870 & 21.698 & 21.527 & 21.355 & 21.184 \\ 20.497 & 20.326 & 20.154 & 19.982 & 19.811 & 19.640 & 1.468\end{array}$

$\begin{array}{lllllll}18.782 & 18.610 & 18.438 & 18.267 & 18.095 & 17.923 & 17.752 \\ 17.066 & 16.895 & 16.722 & 16.551 & 16.379 & 16.208 & 16.037\end{array}$

0.303970

0.303964

0.303961

0.303957

0.303951

0.303948

0.303942

0.303938

0.303935

0.303932

0.303926

0.303923

0.303919

0.303916

0.303910

$\begin{array}{llllllllll}83.293 & 83.122 & 82.950 & 82.779 & 82.607 & 82.436 & 82.265 & 82.093 & 81.922 & 81.751\end{array}$

$\begin{array}{llllllllll}81.580 & 81.408 & 81.237 & 81.065 & 80.894 & 80.723 & 80.552 & 80.380 & 80.209 & 80.038 \\ 79.867 & 79.695 & 79.524 & 79.353 & 79.182 & 79.011 & 78.839 & 78.668 & 78.497 & 78.326\end{array}$

0.303907

0.303904

0.303901

0.303897

0.303894

0.303891

0.303885

0.303882

0.733601
0.733624

0.733647

0.733670

0.733693

0.733715

0.733738
0.733761

0.733784

0.733829

0.733852

0.733875

0.733897

0.733920

0.733943

0.733966
0.733988

0.734011

0.734034

0.734057

0.734080
0.734202

0.734125

0.734125

0.734148

0.734171

0.734216

0.734239

0.734262

0.734262
0.734307

0.734330

0.734353

0.734376

0.734398

0.734421
0.734444

6.9

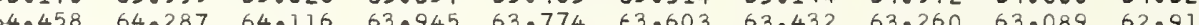

$\begin{array}{llllllllll}64.458 & 64.287 & 64.116 & 63.945 & 63.774 & 63.603 & 63.432 & 63.260 & 63.089 & 62.918 \\ 62.747 & 62.576 & 62.405 & 62.234 & 62.063 & 61.892 & 61.721 & 61.550 & 61.379 & 61.207\end{array}$

0.303875

0.303872

0.303869

0.303866

0.303860

0.303857

0.303853

0.303850
0.303847

0.734467

0.734490

0.734512
0.734535

0.734558

0.734581

0.734603

0.734626

0.734649
0.734672

$\begin{array}{llllllllll}47.352 & 47.180 & 47.009 & 46.838 & 46.667 & 46.497 & 46.326 & 46.155 & 45.984 & 45.813 \\ 45.642 & 45.471 & 45.300 & 45.128 & 44.958 & 44.787 & 44.616 & 44.445 & 44.274 & 44.103\end{array}$

0.303844

0.734695

.303838

.303835

.303831

0.303828

0.303825

0.303822

0.303819

0.734717

0.734763

0.734786

0.734809

0.734831

0.734854
0.734877

0.734900

0.303813

0.734923

0.303806

0.303806

0.303800

0.734945

0.303797

0.303794

0.303791

0.734991

0.735014

0.735037
0.735059

0.735082

0.303787
0.303784

0.735105
0.735128

.010

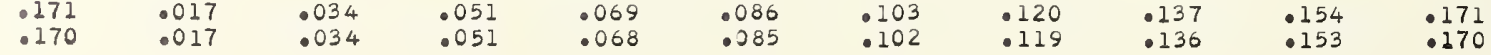




\begin{tabular}{|c|c|c|c|c|c|c|c|c|c|c|c|c|}
\hline (A) & .00 & .01 & .02 & .03 & .04 & .05 & .06 & .07 & .08 & .09 & 1000 & $\lambda(n-1)$ \\
\hline $\begin{array}{l}20.0 \\
0.1 \\
0.2 \\
0.3 \\
0.4 \\
0.5 \\
0.6 \\
0.7 \\
0.8 \\
0.9\end{array}$ & $\begin{array}{r}41309.766 \\
08.060 \\
06.353 \\
04.646 \\
02.939 \\
01.233 \\
41299.527 \\
97.822 \\
96.116 \\
94.410\end{array}$ & $\begin{array}{l}09.595 \\
07.888 \\
06.182 \\
04.476 \\
02.769 \\
01.063 \\
99.356 \\
97.651 \\
95.945 \\
94.239\end{array}$ & $\begin{array}{l}09.424 \\
07.717 \\
06.011 \\
04.305 \\
02.599 \\
00.892 \\
99.186 \\
97.480 \\
95.775 \\
94.069\end{array}$ & $\begin{array}{l}09.253 \\
07.547 \\
05.841 \\
04.134 \\
02.427 \\
00.721 \\
99.015 \\
97.310 \\
95.604 \\
93.898\end{array}$ & $\begin{array}{l}09.083 \\
07.376 \\
05.670 \\
03.963 \\
02.256 \\
00.551 \\
98.844 \\
97.139 \\
95.433 \\
93.728\end{array}$ & $\begin{array}{l}08.913 \\
07.206 \\
05.499 \\
03.793 \\
02.086 \\
00.380 \\
98.674 \\
96.968 \\
95.263 \\
93.557\end{array}$ & $\begin{array}{l}08.742 \\
07.035 \\
05.329 \\
03.622 \\
01.916 \\
00.209 \\
98.503 \\
96.798 \\
95.092 \\
93.386\end{array}$ & $\begin{array}{l}08.571 \\
06.864 \\
05.158 \\
03.451 \\
01.745 \\
00.039 \\
98.333 \\
96.627 \\
94.921 \\
93.215\end{array}$ & 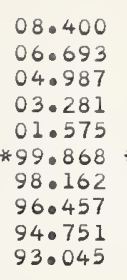 & $\begin{array}{r}08.229 \\
06.523 \\
04.817 \\
03.110 \\
01.404 \\
* 99.698 \\
97.992 \\
96.286 \\
94.580 \\
92.875\end{array}$ & $\begin{array}{l}0.303781 \\
0.303778 \\
0.303775 \\
0.303772 \\
0.303769 \\
0.303766 \\
0.303762 \\
0.303759 \\
0.303756 \\
0.303753\end{array}$ & $\begin{array}{l}0.735151 \\
0.735173 \\
0.735196 \\
0.735219 \\
0.735242 \\
0.735265 \\
0.735287 \\
0.735310\end{array}$ \\
\hline $\begin{array}{l}21.0 \\
1.1 \\
1.2 \\
1.3 \\
1.4 \\
1.5 \\
1.6 \\
1.7 \\
1.8 \\
1.9\end{array}$ & $\begin{array}{r}41292.704 \\
90.999 \\
89.294 \\
87.588 \\
85.883 \\
84.178 \\
82.474 \\
80.770 \\
79.065 \\
77.360\end{array}$ & $\begin{array}{l}92.534 \\
90.828 \\
89.123 \\
87.418 \\
85.712 \\
84.008 \\
82.303 \\
80.599 \\
78.894 \\
77.189\end{array}$ & $\begin{array}{l}92.363 \\
90.657 \\
88.953 \\
87.248 \\
85.542 \\
83.837 \\
82.0132 \\
80.420 \\
78.724 \\
77.020\end{array}$ & $\begin{array}{l}92.192 \\
90.487 \\
88.782 \\
87.077 \\
85.372 \\
83.667 \\
81.962 \\
80.258 \\
78.554 \\
76.849\end{array}$ & $\begin{array}{l}92.022 \\
90.316 \\
88.612 \\
86.906 \\
85.201 \\
83.497 \\
81.792 \\
80.087 \\
78.383 \\
76.679\end{array}$ & $\begin{array}{l}91.851 \\
90.146 \\
88.441 \\
86.736 \\
85.031 \\
83.326 \\
81.622 \\
79.917 \\
78.213 \\
75.508\end{array}$ & $\begin{array}{l}91.680 \\
89.976 \\
88.271 \\
86.565 \\
84.860 \\
83.156 \\
81.451 \\
79.747 \\
78.042 \\
76.338\end{array}$ & $\begin{array}{l}91.510 \\
89.805 \\
88.100 \\
86.395 \\
84.689 \\
82.885 \\
81.281 \\
79.577 \\
77.872 \\
76.167\end{array}$ & $\begin{array}{l}91.339 \\
89.635 \\
87.929 \\
86.225 \\
84.520 \\
82.814 \\
81.110 \\
79.406 \\
77.702 \\
75.998\end{array}$ & $\begin{array}{l}91.169 \\
89.464 \\
87.759 \\
86.054 \\
84.349 \\
82.644 \\
80.939 \\
79.235 \\
77.531 \\
75.826\end{array}$ & $\begin{array}{l}0.303750 \\
0.303747 \\
0.303744 \\
0.303741 \\
0.303737 \\
0.303734 \\
0.303731 \\
0.303728 \\
0.303725 \\
0.303722\end{array}$ & $\begin{array}{l}0.735379 \\
0.735401 \\
0.735424 \\
0.735447 \\
0.735470 \\
0.735493 \\
0.735515 \\
0.735538 \\
0.735561 \\
0.735584\end{array}$ \\
\hline $\begin{array}{r}22.0 \\
2.1 \\
2.2 \\
2.3 \\
2.4 \\
2.5 \\
2.6 \\
2.7 \\
2.8 \\
2.9\end{array}$ & $\begin{array}{r}275.656 \\
73.952 \\
72.249 \\
70.545 \\
68.841 \\
67.138 \\
65.435 \\
63.732 \\
62.028 \\
60.325\end{array}$ & $\begin{array}{l}75.486 \\
73.782 \\
72.078 \\
70.0374 \\
68.670 \\
66.968 \\
65.265 \\
63.562 \\
61.858 \\
60.155\end{array}$ & $\begin{array}{l}75.315 \\
73.612 \\
71.908 \\
70.204 \\
68.500 \\
66.797 \\
65.094 \\
63.0391 \\
61.688 \\
59.985\end{array}$ & $\begin{array}{l}75.145 \\
73.441 \\
71.738 \\
70.034 \\
68.330 \\
66.626 \\
64.924 \\
63.221 \\
61.518 \\
59.815\end{array}$ & $\begin{array}{l}74.975 \\
73.271 \\
71.567 \\
69.863 \\
68.159 \\
66.457 \\
64.753 \\
63.050 \\
61.347 \\
59.644\end{array}$ & $\begin{array}{l}74.804 \\
73.101 \\
71.346 \\
69.693 \\
67.989 \\
66.286 \\
64.583 \\
62.879 \\
61.177 \\
59.474\end{array}$ & $\begin{array}{l}74.634 \\
72.930 \\
71.227 \\
69.523 \\
67.819 \\
66.115 \\
64.413 \\
62.709 \\
61.006 \\
59.004\end{array}$ & $\begin{array}{l}74.464 \\
72.0760 \\
71.056 \\
69.0532 \\
67.648 \\
65.045 \\
64.243 \\
62.539 \\
60.836 \\
59.133\end{array}$ & $\begin{array}{l}74.293 \\
72.589 \\
70.886 \\
69.182 \\
67.479 \\
65.775 \\
64072 \\
62.369 \\
60.0666 \\
58.963\end{array}$ & $\begin{array}{l}74.123 \\
72.419 \\
70.716 \\
69.012 \\
67.308 \\
65.604 \\
63.902 \\
62.199 \\
60.496 \\
58.793\end{array}$ & $\begin{array}{l}0.303719 \\
0.303716 \\
0.303712 \\
0.303709 \\
0.303706 \\
0.303703 \\
0.303700 \\
0.303697 \\
0.303694 \\
0.303691\end{array}$ & $\begin{array}{l}0.735607 \\
0.735629 \\
0.735652 \\
0.735675 \\
0.735698 \\
0.735721 \\
0.735744 \\
0.735766\end{array}$ \\
\hline $\begin{array}{r}23.0 \\
3.1 \\
3.2 \\
3.3 \\
3.4 \\
3.5 \\
3.6 \\
3.7 \\
3.8 \\
3.9\end{array}$ & $\begin{array}{r}41258.623 \\
56.921 \\
55.218 \\
53.516 \\
51.813 \\
50.111 \\
48.410 \\
46.708 \\
45.006 \\
43.304\end{array}$ & $\begin{array}{l}58.453 \\
56.750 \\
55.047 \\
53.345 \\
51.643 \\
49.941 \\
48.239 \\
46.538 \\
44.835 \\
43.134\end{array}$ & $\begin{array}{l}58.282 \\
56.580 \\
54.877 \\
53.175 \\
51.473 \\
49.771 \\
48.069 \\
46.367 \\
44.666 \\
42.964\end{array}$ & $\begin{array}{l}58.112 \\
56.410 \\
54.708 \\
53.005 \\
51.303 \\
49.600 \\
47.899 \\
46.197 \\
44.496 \\
42.794\end{array}$ & $\begin{array}{l}57.941 \\
56.240 \\
54.537 \\
52.834 \\
51.132 \\
49.431 \\
47.729 \\
46.027 \\
44.325 \\
42.624\end{array}$ & $\begin{array}{l}57.771 \\
56.069 \\
54.367 \\
52.665 \\
50.962 \\
49.261 \\
47.559 \\
45.857 \\
44.155 \\
42.454\end{array}$ & $\begin{array}{l}57.601 \\
55.898 \\
54.196 \\
52.494 \\
50.792 \\
49.090 \\
47.388 \\
45.687 \\
43.985 \\
42.284\end{array}$ & $\begin{array}{l}57.431 \\
55.729 \\
54.026 \\
52.324 \\
50.621 \\
48.920 \\
47.219 \\
45.517 \\
43.815 \\
42.113\end{array}$ & $\begin{array}{l}57.261 \\
55.058 \\
53.855 \\
52.054 \\
50.451 \\
48.750 \\
47.048 \\
45.346 \\
43.0645 \\
41.943\end{array}$ & $\begin{array}{l}57.090 \\
55.388 \\
53.686 \\
51.983 \\
50.281 \\
48.580 \\
46.877 \\
45.176 \\
43.475 \\
41.773\end{array}$ & $\begin{array}{l}0.303688 \\
0.303684 \\
0.303681 \\
0.303678 \\
0.303675 \\
0.303672 \\
0.303669 \\
0.303666 \\
0.303663 \\
0.303659\end{array}$ & $\begin{array}{l}35858 \\
55880 \\
55903 \\
35926 \\
55949 \\
55972 \\
35995\end{array}$ \\
\hline $\begin{aligned} 124.0 \\
4.1 \\
4.2 \\
4.3 \\
4.4 \\
4.5 \\
4.6 \\
4.7 \\
4.8 \\
4.9\end{aligned}$ & $\begin{array}{r}41241.603 \\
39.902 \\
38.201 \\
36.500 \\
34.799 \\
33.098 \\
31.399 \\
29.698 \\
27.998 \\
26.297\end{array}$ & $\begin{array}{l}41.433 \\
39.732 \\
38.031 \\
36.3330 \\
34.628 \\
32.929 \\
31.2229 \\
29.528 \\
27.828 \\
26.127\end{array}$ & $\begin{array}{l}41.263 \\
39.562 \\
37.860 \\
36.160 \\
34.459 \\
32.759 \\
31.058 \\
29.357 \\
27.657 \\
25.957\end{array}$ & $\begin{array}{l}41.093 \\
39.392 \\
37.691 \\
35.990 \\
34.289 \\
32.588 \\
30.888 \\
29.187 \\
27.487 \\
25.787\end{array}$ & $\begin{array}{l}40.923 \\
39.222 \\
37.521 \\
35.819 \\
34.119 \\
32.419 \\
30.718 \\
29.018 \\
27.317 \\
25.617\end{array}$ & $\begin{array}{l}40.753 \\
39.052 \\
37.350 \\
35.650 \\
33.949 \\
32.249 \\
30.548 \\
28.847 \\
27.147 \\
25.447\end{array}$ & $\begin{array}{l}40.583 \\
38.881 \\
37.181 \\
35.479 \\
33.779 \\
32.079 \\
30.378 \\
28.678 \\
26.978 \\
25.277\end{array}$ & $\begin{array}{l}40.413 \\
38.711 \\
37.010 \\
35.310 \\
33.608 \\
31.909 \\
30.208 \\
28.508 \\
26.807 \\
25.107\end{array}$ & $\begin{array}{l}40.243 \\
38.542 \\
36.840 \\
35.140 \\
33.0439 \\
31.739 \\
30.038 \\
28.0337 \\
26.0638 \\
24.937\end{array}$ & $\begin{array}{l}40.072 \\
38.371 \\
36.670 \\
34.969 \\
33.269 \\
31.568 \\
29.868 \\
28.168 \\
26.468 \\
24.768\end{array}$ & $\begin{array}{l}0.303656 \\
0.303653 \\
0.303650 \\
0.303647 \\
0.303644 \\
0.303641 \\
0.303638 \\
.303635 \\
0.303632 \\
0.303628\end{array}$ & $\begin{array}{l}105 \\
132 \\
152 \\
177 \\
200 \\
223\end{array}$ \\
\hline $\begin{array}{r}25.0 \\
5.1 \\
5.2 \\
5.3 \\
5.4 \\
5.5 \\
5.6 \\
5.7 \\
5.8 \\
5.9\end{array}$ & $\begin{array}{r}41224.598 \\
22.898 \\
21.198 \\
19.499 \\
17.799 \\
16.100 \\
14.401 \\
12.702 \\
11.003 \\
09.304\end{array}$ & $\begin{array}{l}24.428 \\
22.728 \\
21.028 \\
19.329 \\
17.629 \\
15.931 \\
14.0231 \\
12.532 \\
10.833 \\
09.134\end{array}$ & $\begin{array}{l}24.258 \\
22.558 \\
20.858 \\
19.159 \\
17.459 \\
15.761 \\
14.061 \\
12.362 \\
10.664 \\
08.965\end{array}$ & $\begin{array}{l}24.088 \\
22.389 \\
20.6888 \\
18.989 \\
17.290 \\
15.590 \\
13.892 \\
12.192 \\
10.494 \\
08.795\end{array}$ & $\begin{array}{l}23.918 \\
22.218 \\
20.518 \\
18.818 \\
17.119 \\
15.421 \\
13.722 \\
12.022 \\
10.324 \\
08.625\end{array}$ & $\begin{array}{l}23.748 \\
22.048 \\
20.348 \\
18.649 \\
15.949 \\
15.251 \\
13.552 \\
11.853 \\
10.194 \\
08.456\end{array}$ & $\begin{array}{l}23.578 \\
21.878 \\
20.178 \\
18.479 \\
16.779 \\
15.081 \\
13.381 \\
11.683 \\
09.983 \\
08.286\end{array}$ & $\begin{array}{l}23.408 \\
21.708 \\
20.008 \\
18.309 \\
16.610 \\
14.911 \\
13.211 \\
11.513 \\
09.813 \\
08.116\end{array}$ & $\begin{array}{l}23.238 \\
21.538 \\
19.838 \\
18.0139 \\
16.440 \\
14.741 \\
13.042 \\
11.343 \\
09.044 \\
07.946\end{array}$ & $\begin{array}{l}23.068 \\
21.368 \\
19.669 \\
17.969 \\
16.270 \\
14.571 \\
12.872 \\
11.173 \\
09.474 \\
07.776\end{array}$ & & $\begin{array}{l}.73629 \\
.73631 \\
.73633\end{array}$ \\
\hline $\begin{array}{l}26.0 \\
6.1 \\
6.2 \\
6.3 \\
6.4 \\
6.5 \\
6.6 \\
6.7 \\
6.8 \\
6.9\end{array}$ & $\begin{array}{r}41207.606 \\
05.908 \\
04.209 \\
02.511 \\
00.813 \\
41199.115 \\
97.418 \\
95.720 \\
94.022 \\
92.325\end{array}$ & $\begin{array}{l}07.437 \\
05.738 \\
04.040 \\
02.341 \\
00.643 \\
98.946 \\
97.248 \\
95.550 \\
93.853 \\
92.156\end{array}$ & $\begin{array}{l}07.267 \\
05.568 \\
03.870 \\
02.172 \\
00.474 \\
98.776 \\
97.078 \\
95.380 \\
93.683 \\
91.986\end{array}$ & $\begin{array}{l}7.097 \\
55.398 \\
3.700 \\
20.002 \\
00.304 \\
98.606 \\
96.909 \\
95.211 \\
93.513 \\
91.816\end{array}$ & $\begin{array}{l}06.927 \\
05.229 \\
03.530 \\
01.832 \\
00.134 \\
98.437 \\
96.739 \\
95.041 \\
93.344 \\
91.646\end{array}$ & $\begin{array}{l}06.757 \\
05.059 \\
03.360 \\
01.663 \\
* 99.965 \\
98.267 \\
96.569 \\
94.871 \\
93.174 \\
91.478\end{array}$ & $\begin{array}{l}06.587 \\
04.889 \\
03.191 \\
01.493 \\
* 99.795 \\
98.097 \\
96.399 \\
94.702 \\
93.004 \\
91.308\end{array}$ & $\begin{array}{l}06.418 \\
04.719 \\
03.021 \\
01.323 \\
* 99.625 \\
97.928 \\
96.230 \\
94.532 \\
92.834 \\
91.138\end{array}$ & $\begin{array}{l}06.247 \\
04.549 \\
02.851 \\
01.0153 \\
* 99.456 \\
97.758 \\
96.060 \\
94.362 \\
92.665 \\
90.968\end{array}$ & $\begin{array}{r}00.983 \\
\text { *99.286 } \\
97.588 \\
95.890 \\
94.193 \\
92.495 \\
90.798\end{array}$ & & 0.73672 \\
\hline $\begin{array}{r}27.0 \\
7.1 \\
7.2 \\
7.3 \\
7.4 \\
7.5 \\
7.6 \\
7.7 \\
7.8 \\
7.9\end{array}$ & $\begin{array}{r}41190.628 \\
88.932 \\
87.235 \\
85.538 \\
83.842 \\
82.145 \\
80.449 \\
78.752 \\
77.056 \\
75.361\end{array}$ & $\begin{array}{l}90.459 \\
88.762 \\
87.065 \\
85.368 \\
83.672 \\
81.976 \\
80.279 \\
78.583 \\
76.887 \\
75.191\end{array}$ & $\begin{array}{l}90.289 \\
88.592 \\
86.895 \\
85.198 \\
83.502 \\
81.806 \\
80.109 \\
78.413 \\
76.717 \\
75.022\end{array}$ & & $\begin{array}{l}89.950 \\
88.253 \\
86.556 \\
84.859 \\
83.163 \\
81.466 \\
79.770 \\
78.074 \\
76.378 \\
74.683\end{array}$ & & $\begin{array}{l}89.610 \\
87.913 \\
86.217 \\
84.520 \\
82.824 \\
81.127 \\
79.431 \\
77.735 \\
76.039 \\
74.343\end{array}$ & $\begin{array}{l}89.441 \\
87.744 \\
86.047 \\
84.350 \\
82.654 \\
80.958 \\
79.261 \\
77.565 \\
75.869 \\
74.173\end{array}$ & $\begin{array}{l}89.271 \\
87.0744 \\
85.877 \\
84.0181 \\
82.484 \\
80.788 \\
79.092 \\
77.096 \\
75.700 \\
74.004\end{array}$ & & & $\begin{array}{l}794 \\
817 \\
840 \\
862 \\
885\end{array}$ \\
\hline $\begin{array}{r}28.0 \\
8.1 \\
8.2 \\
8.3 \\
8.4 \\
8.5 \\
8.6 \\
8.7 \\
8.8 \\
8.9\end{array}$ & $\begin{array}{r}4173.665 \\
71.970 \\
70.274 \\
68.578 \\
66.883 \\
65.188 \\
63.494 \\
61.798 \\
60.104 \\
58.410\end{array}$ & $\begin{array}{l}63.324 \\
61.029 \\
59.934 \\
58.240\end{array}$ & $\begin{array}{l}71.630 \\
69.935 \\
68.240 \\
66.544 \\
64.850 \\
63.154 \\
61.459 \\
59.765 \\
58.071\end{array}$ & $\begin{array}{l}59.596 \\
57.901\end{array}$ & $\begin{array}{l}04.711 \\
62.815 \\
61.121 \\
59.426 \\
57.732\end{array}$ & $\begin{array}{l}72.817 \\
71.122 \\
69.426 \\
67.731 \\
66.036 \\
64.341 \\
62.646 \\
60.951 \\
59.257 \\
57.563\end{array}$ & $\begin{array}{l}59.088 \\
57.393\end{array}$ & $\begin{array}{l}72.478 \\
70.782 \\
69.087 \\
67.392 \\
65.697 \\
64.002 \\
62.307 \\
60.612 \\
58.918 \\
57.224\end{array}$ & $\begin{array}{l}72.309 \\
70.613 \\
68.917 \\
67.223 \\
65.528 \\
63.833 \\
62.138 \\
60.443 \\
58.749 \\
57.055\end{array}$ & & & $\begin{array}{l}0.737022 \\
0.737045 \\
0.737068 \\
0.737091 \\
0.73714 \\
0.737137 \\
0.73759 \\
0.737182\end{array}$ \\
\hline $\begin{array}{l}29.0 \\
9.1 \\
9.2 \\
9.3 \\
9.4 \\
9.5 \\
9.6 \\
9.7 \\
9.8 \\
9.9\end{array}$ & $\begin{array}{r}41156.715 \\
55.021 \\
53.327 \\
51.633 \\
49.939 \\
48.246 \\
46.553 \\
44.859 \\
43.166 \\
41.473\end{array}$ & $\begin{array}{l}56.546 \\
54.852 \\
53.157 \\
51.064 \\
49.770 \\
48.077 \\
46.383 \\
44.689 \\
42.997 \\
41.303\end{array}$ & $\begin{array}{l}56.376 \\
54.0682 \\
52.988 \\
51.295 \\
49.601 \\
47.907 \\
46.014 \\
44.520 \\
42.828 \\
41.134\end{array}$ & $\begin{array}{l}56.207 \\
54.513 \\
52.819 \\
51.125 \\
49.431 \\
47.737 \\
46.044 \\
44.351 \\
42.658 \\
40.965\end{array}$ & $\begin{array}{l}56.038 \\
54.343 \\
52.649 \\
50.956 \\
49.262 \\
47.568 \\
45.875 \\
44.181 \\
42.489 \\
40.795\end{array}$ & $\begin{array}{l}55.868 \\
54.174 \\
52.479 \\
50.787 \\
49.093 \\
47.399 \\
45.705 \\
44.012 \\
42.319 \\
40.626\end{array}$ & $\begin{array}{l}45.536 \\
43.843 \\
42.150 \\
40.457\end{array}$ & $\begin{array}{l}53.835 \\
52.141 \\
50.448 \\
48.754 \\
47.061 \\
45.367 \\
43.673 \\
41.980 \\
40.287\end{array}$ & $\begin{array}{l}53.666 \\
51.972 \\
50.279 \\
48.585 \\
46.891 \\
45.197 \\
430.504 \\
41.812 \\
40.118\end{array}$ & $\begin{array}{l}41.642 \\
39.949\end{array}$ & $\begin{array}{l}0.303498 \\
0.303495 \\
0.303492 \\
0.303489 \\
0.303486 \\
0.303483 \\
0.303480 \\
0.303477 \\
0.303474\end{array}$ & $\begin{array}{l}.737228 \\
.737251 \\
737274 \\
737297 \\
.737319 \\
737342 \\
.737365 \\
737388 \\
.737411\end{array}$ \\
\hline & \multicolumn{2}{|l|}{.001} & $\begin{array}{l}341.134 \\
.002\end{array}$ & $\begin{array}{l}40.965 \\
.003\end{array}$ & & 005 & .006 & .007 & .008 & .009 & \multicolumn{2}{|l|}{.010} \\
\hline & .01 & & & & & & .102 & $\begin{array}{r}.119 \\
.118\end{array}$ & $\begin{array}{r}.136 \\
.135\end{array}$ & .152 & $\begin{array}{l}.170 \\
.269\end{array}$ & \\
\hline
\end{tabular}


2430.0
0.1

0.1
0.2
0.3

0.4

0.5

0.6
0.7

0.8
0.9

2431.0

$1 \cdot 1$
$1 \cdot 2$
$1 \cdot 3$

1.4

1.5

1.7

1.8
1.9

2432.

2. 1

2.3

2.5

2.7
2.8

2.9

2433.0

3.2
3.3

3.4

3.6

3.7
3.8

3.

2434.

4.2
4.3

4.4
4.5

4.6
4.7

4.8
4.9

2435.

5.2

5.

5.5

5.6

5.8
5.9

2436.0

6.1

6.

6.4

$6 \cdot 6$
6.7

$6 \cdot 8$
$6 \cdot 9$

2437.0

$7 \cdot 1$
$7 \cdot 2$
$7 \cdot 3$

$7 \cdot 2$
$7 \cdot 3$
$7 \cdot 5$

7.5
7.6

7.7

7.8
7.9

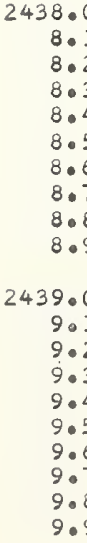

$\begin{array}{lllll}38.087 & 37.917 & 39.441 & 39.272 & 39.103 \\ 36.394 & 36.225 & 30.055 & 37.580 & 37.410\end{array}$

$\begin{array}{lllll}36.394 & 36.225 & 36.055 & 35.887 & 35.717\end{array}$

$\begin{array}{lllll}34.702 & 34.533 & 34.364 & 34.194 & 34.025 \\ 33.009 & 32.840 & 32.671 & 32.502 & 32.333\end{array}$

$31.317 \quad 31.148 \quad 30.97$

$\begin{array}{lllll}31.317 & 31.148 & 30.979 & 30.009 & 30.641\end{array}$

$\begin{array}{lllll}27.933 & 27.764 & 27.594 & 27.425 & 27.256\end{array}$

$\begin{array}{lllll}26.241 & 26.072 & 25.903 & 25.734 & 25.564 \\ 24.549 & 24.380 & 24.211 & 24.042 & 23.873\end{array}$

$41122.857 \quad 22.68$

$21.167 \quad 20.997$

$17.775 \quad 19.306 \quad 19.136$

$\begin{array}{lllll}17.785 & 17.615 & 17.446 & 17.277 & 18.798\end{array}$

$\begin{array}{lllll}16.093 & 15.924 & 13.755 & 15.586 & 15.417\end{array}$

$\begin{array}{lllll}14.402 & 14.233 & 14.064 & 13.895 & 13.726 \\ 12.712 & 12.542 & 12.373 & 12.204 & 12.035\end{array}$

$\begin{array}{lllll}11.021 & 10.852 & 10.682 & 10.514 & 10.344 \\ 09.331 & 09.162 & 08.993 & 08.824 & 08.654\end{array}$

$07.041 \quad 07.471$

41105.950

$04.260 \quad 04.09$

$\begin{array}{ll}02.570 & 02.401 \\ 00.881 & 00.711\end{array}$

$95.812 \quad 95.643$

$94.123 \quad 93.954$

$90.745 \quad 90.57$

41089.056

$87.368 \quad 87.199$

85.679
83.091 8.510

83.991

82.30282 .133

$\begin{array}{lll}80.614 & 80.446 & 80.277\end{array}$

$\begin{array}{llllll}78.926 & 78.757 & 76.586 & 78.420 & 78.25\end{array}$

$\begin{array}{ll}75.239 & 77.070 \\ 75.551 & 75.38\end{array}$

$73.864 \quad 73.695$

41072.176

68.80260 .633

$\begin{array}{ll}67.115 & 66.946 \\ 65.428 & 65.25\end{array}$

$63.741 \quad 63.573$

$62.05561 .886 \quad 61.717$

$\begin{array}{lll}60.369 & 60.200 & 60.03\end{array}$

$\begin{array}{lll}58.682 & 58.514 & 58.34 \\ 56.996 & 56.827 & 56.65\end{array}$

41055.310

$51.938 \quad 51.770 \quad 53.287$

$\begin{array}{lll}50.253 & 50.084 & 49.91 \\ 48.567 & 48.398 & 48.230\end{array}$

$46.882 \quad 46.713 \quad 46.545$

$\begin{array}{lll}45.197 & 45.028 & 44.85\end{array}$

$41.828 \quad 41.658 \quad 41.490$

40.143

1038.458

36.773
35.089

$\begin{array}{lll}36.773 & 36.604 & 36.437\end{array}$

$\begin{array}{lll}31.721 & 31.2362 & 33.068\end{array}$

$\begin{array}{lll}30.037 & 29.869 & 29.700\end{array}$

$\begin{array}{lll}28.353 & 28.185 & 28.01 \\ 26.669 & 26.501 & 26.33\end{array}$

$\begin{array}{lll}24.986 & 24.817 & 24.649 \\ 23.302 & 23.134 & 22.966\end{array}$

1021.019

$19.936 \quad 11.45$

$\begin{array}{lll}19.936 & 19.768 & 19.600\end{array}$

$16.570 \quad 16.402 \quad 16.234$

$13.205 \quad 13.037 \quad 14.551$

$11.523 \quad 11.354 \quad 11.18$

$\begin{array}{llllll}1.8940 & 09.672 & 09.504 & 09.019 & 10.85\end{array}$

$\begin{array}{lllll}11.523 & 11.354 & 11.187 & 11.019 & 10.850\end{array}$

$\begin{array}{lllll}06.476 & 06.308 & 06.140 & 05.972 & 05.80\end{array}$

1004.794

03.11302 .945

$4.750 \quad 99.582$

$98.068 \quad 97.900$

$94.707 \quad 94.539$

$93.026 \quad 92.857 \quad 92.689$

$\begin{array}{lll}91.345 & 91.177 & 91.009 \\ 89.664 & 89.496 & 89.328\end{array}$

04.290

04.122

2.776

02.608
00.927

$\begin{array}{rr}99.245 & 99.07\end{array}$

95.882

$90.841 \quad 90.672$

86.98
86.304

$86.136 \quad 85.967$

87.479

87.311

$\begin{array}{lllll}7.240 & 37.071 & 36.902 & 36.732 & 36.563\end{array}$

$\begin{array}{lllll}5.547 & 35.378 & 35.209 & 35.040 & 34.871\end{array}$

$\begin{array}{lllll}33.856 & 33.687 & 33.517 & 33.348 & 33.179 \\ 32.164 & 31.994 & 31.824 & 31.656 & 31.486\end{array}$

$\begin{array}{lllll}20.471 & 30.302 & 30.132 & 29.963 & 29.794\end{array}$

$\begin{array}{lllll}28.779 & 28.609 & 28.440 & 28.271 & 28.102\end{array}$

$\begin{array}{lllll}25.087 & 26.918 & 26.748 & 26.580 & 26.411\end{array}$

$\begin{array}{lllll}23.704 & 23.535 & 23.365 & 23.197 & 23.027\end{array}$

0.303471

0.303468

0.303461

0.303458
0.303455

0.303452

0.303449

0.303446
0.303443

0.303440

0.303437

0.303434

0.303428

0.303425

0.303421

0.303418

0.303412

0.303409

0.303406

0.303400

0.303397

0.303394
0.303391

0.303385
0.303382

0.303379

0.303375

0.303372

0.303369

0.30336

0.303360

0.303357

0.303354

0.303348

0.30334

0.303342

0.303339

0.303336

0.303330

0.303326

0.30332

0.303317
0.303314

0.303308

0.303308
0.303305

0.303302

0.303296

0.303293

0.303290

0.303287

0.303284
0.303281

0.303278

0.303275

0.30327

0.30326

0.303262
0.303259

0.303256

0.30325

0.303250
0.303247

0.303244

0.303241

0.303238

0.303235

0.303229

0.303226

0.303223

0.303220

0.303214

0.303211

0.303208

0.303205

0.303199

0.303196

0.303192

0.303189

0.303183

0.303180

0.303177

0.303171

0.303168

0.737617
0.737640

0.737662

0.737685

0.737731

0.737754

0.737800

0.737822

0.737868

0.737891

0.7378914
0.0737937
0.737960

0.737960

0.737983
0.738005

0.738028

0.738051

0.738097

0.738120

0.738143
0.738166

0.73818

0.738211

0.738234
0.738257
0.738280

0.738280

0.738303
0.738326

0.738349

0.7338372
0.738394

0.738394
0.738417

0.738440

0.738463

0.738486

0.738532

0.73855

0.738578

0.738600
0.738623

0.738646

0.738692

0.738715

0.738761

0.738784

0.738807

0.738829

0.738852

0.738875

0.738921

0.738944

0.738967

0.738990
0.739013

0.739036

0.739059

0.739081
0.739104

0.739127

0.739150

0.739173

0.739196

0.739219
0.739242

0.739265

0.739288 
$\begin{array}{lllll}70.347 & 70.179 & 70.012 \quad 69.844 & 69.676\end{array}$

0.303165

0.739723

$\begin{array}{lllllllllll}0.2 & 67.829 & 67.661 & 67.493 & 67.325 & 67.157 & 66.968 & 68.500 & 68.333 & 68.165 & 67.997 \\ 0 & 66.8622 & 66.654 & 66.486 & 66.318\end{array}$

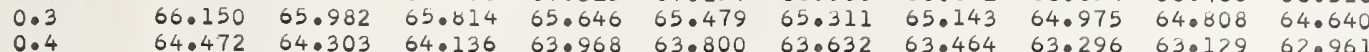

$\begin{array}{lllllllllll}0.4 & 64.472 & 64.303 & 64.136 & 63.968 & 63.800 & 63.632 & 63.464 & 63.296 & 63.129 & 62.961\end{array}$

$\begin{array}{lllllllllll}0.5 & 62.793 & 62.625 & 62.457 & 62.289 & 62.122 & 61.954 & 61.786 & 61.619 & 61.451 & 61.283 \\ 0.6 & 61.115 & 60.947 & 60.780 & 60.612 & 60.444 & 60.276 & 60.108 & 59.940 & 59.772 & 59.604\end{array}$

$\begin{array}{lllllllllll}0.7 & 59.437 & 59.269 & 59.101 & 58.933 & 58.765 & 58.598 & 58.430 & 58.262 & 58.094 & 57.927\end{array}$

$\begin{array}{lllllllllll}0.8 & 57.759 & 57.591 & 57.423 & 57.255 & 57.087 & 56.920 & 56.752 & 56.584 & 56.417 & 56.249 \\ 0.9 & 56.081 & 55.913 & 55.746 & 55.577 & 55.409 & 55.242 & 55.074 & 54.906 & 54.739 & 54.571\end{array}$

303159

0.303153

0.303147

0.303141
0.303138 $\begin{array}{rrr}2441.0 & 40954.403 & 54.235 \\ 1.1 & 52.726 & 52.558 \\ 1.2 & 51.048 & 50.880 \\ 1.3 & 49.371 & 49.203 \\ 1.4 & 47.693 & 47.525 \\ 1.5 & 46.016 & 45.849 \\ 1.5 & 44.340 & 44.172 \\ 1.7 & 42.663 & 42.495 \\ 1.8 & 40.986 & 40.818 \\ 1.9 & 39.310 & =39.142\end{array}$

54.067
52.390
50.712
49.036
47.358
45.681
44.004
42.328
40.651
38.975

$53.900 \quad 53.733$

$\begin{array}{lllll}53.564 & 53.396 & 53.229 & 53.062 & 52.894 \\ 51.887 & 51.719 & 51.551 & 51.384 & 51.216\end{array}$

0.30313

0.303129

0.303123

0.303117

0.303114

2442 .

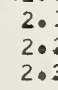
$\begin{array}{ll}35.958 & 35.790 \\ 34.281 & 34.114\end{array}$

$37.298 \quad 37.131$

$32.605 \quad 32.437$

$\begin{array}{lll}33.022 & 35.455 & 35.963\end{array}$

36.796
35.120

2.4

$\begin{array}{llll}30.929 & 30.761 & 30.594 \quad 30.426\end{array}$

2.6

$\begin{array}{ll}29.253 & 29.087 \\ 27.579 & 27.411\end{array}$

$28.919 \quad 28.75$

31.93

$\begin{array}{ll}25.903 & 25.736 \\ 24.228 & 24.060 \\ 22.553 & 22.035\end{array}$

$\begin{array}{ll}24.228 & 24.060 \\ 22.553 & 22.385\end{array}$

$\begin{array}{lll}27.243 & 27.076 & 26.908\end{array}$

$\begin{array}{lllll} & \end{array}$

$\begin{array}{llll}31.600 & 31.432 & 31.265 & 31.097\end{array}$

$\begin{array}{llll}29.924 & 29.756 & 29.589 & 29.421 \\ 28.249 & 28.082 & 27.914 & 27.746\end{array}$

2.9

40920.877

20.711

22.217

23.70
22.05

23.55

$\begin{array}{lllll}25.065 & 26.573 & 26.406 & 26.238 & 26.070\end{array}$

3.
3.
30
3.0
3.
30
3.0
3.0
3.0

19.203
17.528
15.854

20.543
18.060

20.37

20.208

21.715

23.223
21.547

$\begin{array}{lll}24.730 & 24.562 & 24.396 \\ 23.055 & 22.888 & 22.720\end{array}$

$20.041 \quad 19.873 \quad 19.706 \quad 19.538 \quad 19.371$

$\begin{array}{llllllllll}17.854 & 15.361 & 17.193 & 17.026 & 16.858 & 16.090 & 16.0243 & 16.356 & 16.863 & 17.695 \\ 15.0519 & 15.352 & 15.184 & 15.016 & 16.849 & 14.681 & 14.514 & 14.0217\end{array}$

$\begin{array}{llllllllll}14.179 & 14.011 & 13.844 & 13.677 & 13.509 & 13.342 & 13.174 & 13.006 & 12.539 & 14.347\end{array}$

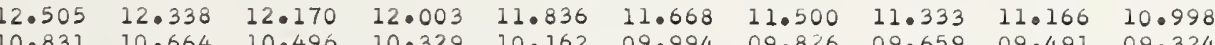

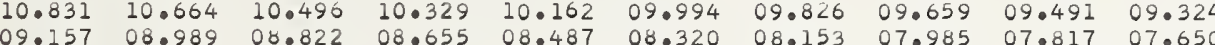

$\begin{array}{llllllllll}07.483 & 07.315 & 07.146 & 06.981 & 06.813 & 06.646 & 06.479 & 06.311 & 06.144 & 05.976 \\ 05.809 & 05.641 & 05.474 & 05.307 & 05.139 & 04.972 & 04.805 & 04.637 & 04.470 & 04.302\end{array}$

$\begin{array}{llllllllll}9004.135 & 03.968 & 03.801 & 03.633 & 03.467 & 03.299 & 03.132 & 02.965 & 02.797 & 02.629\end{array}$

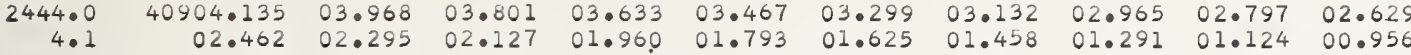
$00.78900 .621 \quad 00.454 \quad 00.267 \quad 00.120 * 99.952 * 99.785 * 99.610 * 99.450 * 99.283$

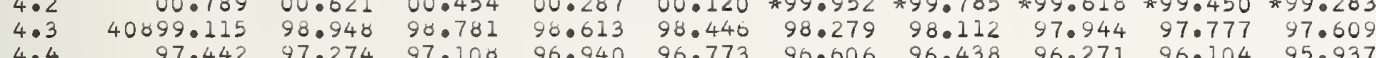

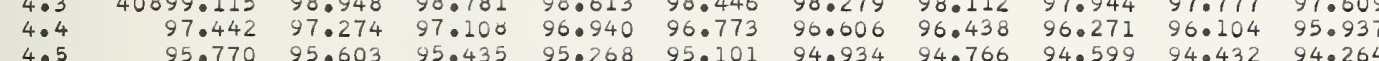

94.09793 .930

$92.424 \quad 92.257$

93.762

95.268
93.595
91.922

93.428

93.2607

94.766

$\begin{array}{lll}94.599 & 94.432 & 94.264 \\ 92.926 & 92.759 & 92.591\end{array}$

$89.079 \quad 88.912$

91.922
88.257

90.083

91.587

$\begin{array}{llll}91.421 & 91.253 & 91.086 & 90.919 \\ 89.748 & 89.581 & 89.414 & 89.247\end{array}$

4.8
4.9

2445.

5.

$\begin{array}{rrr}0887.407 & 87.240 & 87.073 \\ 85.735 & 85.568 & 85.40\end{array}$

年

$84.063 \quad 83.896 \quad 83.729$

86.906
85.234
83.562

86.738

88.24

$\begin{array}{lllll}88.076 & 87.908 & 87.741 & 87.575\end{array}$

82.39102 .224

$79.048 \quad 70.552 \quad 80.38$

61.890

83.394

86.571
8.899
83.227

86.404
84.731

$86.237 \quad 86.069 \quad 85.902$

5.

5.6

$\begin{array}{lllll}80.719 & 60.552 & 80.385 & 80.218 & 80.050 \\ 79.048 & 78.881 & 70.714 & 76.547 & 78.380 \\ 77.377 & 77.209 & 77.042 & 76.875 & 76.708\end{array}$

$\begin{array}{lll}75.706 & 75.538 & 75.371 \\ 74.034 & 73.867 & 73.700\end{array}$

70.87

83.555

$84.564 \quad 84.397 \quad 84.230$

$\begin{array}{llllll}70.213 & 78.045 & 77.878 & 77.711 & 77.543\end{array}$

5.8
5.9

$\begin{array}{ll}74.034 & 73.867 \\ 72.363 & 72.195\end{array}$

2446.

40870.692

6.2 $69.022 \quad 70.525 \quad 70.3$ $\begin{array}{llll}69.022 & 68.854 & 68.687 & 70.191\end{array}$ $67.351-67.018467 .017$ $65.680 \quad 65.513 \quad 65.346$ $64.010 \quad 63.843 \quad 63.676$ 64.01063 .043 60.67062 .17302 .006

6.5

6.6

6.8

$\begin{array}{llll}59.000 & 58.833 & 56.666 & 58.499\end{array}$

55.661

2447

7.

7.3
7.4
7.5

7.5
7.6
7.7
7.8

$40853.991 \quad 53.825$

$\begin{array}{ll}52.3225 & 52.025 \quad 53.650\end{array}$

$\begin{array}{lllll}52.322 & 52.155 & 51.988 & 51.821 & 51.654\end{array}$

$47.314 \quad 47.147 \quad 46.981$

$\begin{array}{lll}45.646 & 45.479 & 45.31 \\ 43.978 & 43.811 & 43.644\end{array}$

$\begin{array}{lll}43.978 & 43.811 & 43.64 \\ 42.309 & 42.142 & 41.975\end{array}$

$42.309 \quad 42.142$

$\begin{array}{ll}40.640 & 40.473 \\ 38.971 & 38.805\end{array}$

$41.808 \quad 41.64$

$\begin{array}{lllll}76.541 & 76.374 & 76.207 & 76.040 & 75.872 \\ 74.870 & 74.703 & 74.535 & 74.368 & 74.201\end{array}$

0.30310

0.303105

0.303099

0.303093

0.303087

0.303084

0.303078

0.303075

0.303068

0.303065

0.303062

0.303056

0.303053

0.303047

0.303044

0.30304
0.30303

0.303035

0.303032

0.303026

0.303023
0.303020

0.303020

0.303014

0.303011

0.303005

0.303002

0.302996

0.302993

0.302987

0.302984

0.302978

0.302972

0.30296

0.302963

0.302960

0.302957

0.302954
0.302951

0.302948

0.302945

0.302942

0.302939

0.302936

0.302930

0.302927

2448.0

$\begin{array}{lllllllllll}8.0 & 40837.304 & 37.137 & 36.970 & 36.803 & 36.637 & 36.470 & 36.303 & 36.136 & 35.969 & 35.802\end{array}$

$\begin{array}{llllllllllll}8.1 & 35.636 & 35.469 & 35.302 & 35.136 & 34.969 & 34.802 & 34.635 & 34.468 & 34.301 & 34.134 \\ 8 & 33.968 & 33.801 & 33.634 & 33.468 & 33.301 & 33.134 & 32.967 & 32.800 & 32.633 & 32.467\end{array}$

$\begin{array}{llllllllllll}8.2 & 33.968 & 33.801 & 33.634 & 33.468 & 33.301 & 33.134 & 32.967 & 32.800 & 32.633 & 32.467 \\ 8.3 & 32.300 & 32.133 & 31.966 & 31.800 & 31.633 & 31.466 & 31.299 & 31.133 & 30.966 & 30.799\end{array}$

$\begin{array}{lllllllllll}8.3 & 32.300 & 32.133 & 31.966 & 31.800 & 31.633 & 31.466 & 31.299 & 31.133 & 30.966 & 30.799 \\ 8.4 & 30.632 & 30.465 & 30.299 & 30.132 & 29.965 & 29.799 & 29.632 & 29.465 & 29.299 & 29.132\end{array}$

$\begin{array}{lllllllllll}8.4 & 30.632 & 30.465 & 30.299 & 30.132 & 29.965 & 29.799 & 29.632 & 29.465 & 29.299 & 29.132 \\ 8.5 & 28.965 & 28.798 & 28.631 & 28.465 & 28.298 & 28.131 & 27.965 & 27.798 & 27.631 & 27.465\end{array}$

$\begin{array}{lllllllllll}8.6 & 28.965 & 28.798 & 28.631 & 28.465 & 28.298 & 28.131 & 27.965 & 27.798 & 27.631 & 27.465 \\ 8.296 & 27.131 & 26.964 & 26.798 & 26.631 & 26.464 & 26.297 & 26.131 & 25.964 & 25.797\end{array}$

$\begin{array}{lllllllllll}8.7 & 25.630 & 25.463 & 25.297 & 25.130 & 24.903 & 24.797 & 24.630 & 24.463 & 24.297 & 24.130\end{array}$

$\begin{array}{lllllllllll}8.8 & 23.963 & 23.796 & 23.630 & 23.463 & 23.296 & 23.130 & 22.963 & 22.796 & 22.630 & 22.463 \\ 8.9 & 22.296 & 22.129 & 21.963 & 21.796 & 21.629 & 21.463 & 21.296 & 21.130 & 20.963 & 20.797\end{array}$

0.302924

0.302921

0.302915

0.302912

0.302906

0.30290

0.302900

$\begin{array}{lllllllllll}2449.0 & 40820.630 & 20.464 & 20.296 & 20.129 & 19.963 & 19.796 & 19.630 & 19.463 & 19.297 & 19.130\end{array}$

$\begin{array}{lllllllllll}9.1 & 18.963 & 18.797 & 10.629 & 18.463 & 18.296 & 18.130 & 17.963 & 17.797 & 17.630 & 17.463\end{array}$

$\begin{array}{llllllllllll}9.2 & 17.297 & 17.130 & 10.963 & 16.796 & 16.630 & 16.463 & 16.297 & 16.130 & 15.963 & 15.797 \\ 9.3 & 15.630 & 15.463 & 15.297 & 15.130 & 14.963 & 14.797 & 14.630 & 14.463 & 14.297 & 14.130\end{array}$

$\begin{array}{lllllllllll}9.4 & 15.630 & 15.463 & 15.297 & 15.130 & 14.963 & 14.797 & 14.630 & 14.463 & 14.297 & 14.130 \\ & 13.964 & 13.797 & 13.630 & 13.463 & 13.297 & 13.131 & 12.964 & 12.798 & 12.631 & 12.465\end{array}$

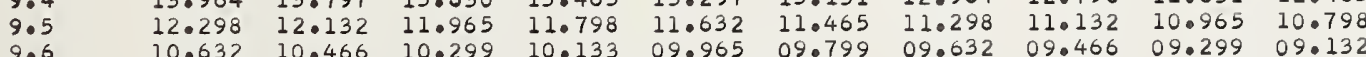

$\begin{array}{lllllllllll}9.6 & 10.632 & 10.466 & 10.299 & 10.133 & 09.965 & 09.799 & 09.632 & 09.466 & 09.299 & 09.132 \\ 9.7 & 08.966 & 08.800 & 08.633 & 08.467 & 08.300 & 08.133 & 07.967 & 07.800 & 07.633 & 07.467 \\ 9.8 & 07.300 & 07.134 & 06.967 & 06.801 & 06.634 & 05.467 & 06.301 & 06.134 & 05.968 & 05.801\end{array}$

9.9

$\begin{array}{lll}07.300 & 07.134 & 06.96 \\ 05.635 & 05.468 & 05.302\end{array}$

.003

.004

.005

0.635

0.30289

0.302891

0.302888

0.302885

0.302883

0.302880

0.302877
0.302874

0.302874

0.302868

.739769

.

.739838

0.739861

0.739906

0.739952

0.739975

0.740044

0.740090

0.740113

0.740159

0.74020

0.74025

0.740273

0.740319

0.74036

0.740388

.74041

0.740434
0.74045

0.740480

.

0.740572

0.740595

0.740640

0.740663

0.740709
0.74073

0.740755

0.740801

0.740824
0.740847

0.740870

0.740916

0.740939

0.740962

0.741008

0.741054
0.741077

0.741099

0.741122

0.741168

0.741191

0.74223

0.741283

0.741329

0.74135

0.741398

0.741421

0.741467

0.741490

0.741536

0.741559

0.74160

0.74165 


\begin{tabular}{|c|c|c|c|c|c|c|c|c|c|c|c|c|}
\hline & .00 & .01 & .02 & .03 & .04 & .05 & .06 & .07 & .08 & .09 & 00 & $1-1)$ \\
\hline $\begin{array}{l}50.0 \\
0.1 \\
0.2 \\
0.3 \\
0.4 \\
0.5 \\
0.6 \\
0.7 \\
0.8 \\
0.9\end{array}$ & $\begin{array}{r}40803.969 \\
02.305 \\
00.639 \\
40798.974 \\
97.309 \\
95.645 \\
93.980 \\
92.315 \\
90.651 \\
88.986\end{array}$ & $\begin{array}{l}03.803 \\
02.138 \\
00.473 \\
98.807 \\
97.142 \\
95.478 \\
93.813 \\
92.149 \\
90.484 \\
88.820\end{array}$ & $\begin{array}{l}03.637 \\
01.971 \\
00.306 \\
98.641 \\
96.976 \\
95.312 \\
93.647 \\
91.982 \\
90.318 \\
88.654\end{array}$ & $\begin{array}{l}03.470 \\
01.805 \\
00.140 \\
98.475 \\
96.810 \\
95.145 \\
93.481 \\
91.816 \\
90.151 \\
88.487\end{array}$ & $\begin{array}{r}03.304 \\
01.638 \\
* 99.973 \\
98.308 \\
96.643 \\
94.979 \\
93.314 \\
91.649 \\
89.985 \\
88.321\end{array}$ & $\begin{array}{r}03.137 \\
01.472 \\
* 99.807 \\
98.142 \\
96.477 \\
94.812 \\
93.147 \\
91.483 \\
89.819 \\
88.155\end{array}$ & $\begin{array}{r}02.971 \\
01.305 \\
* 9.9 .640 \\
97.975 \\
96.310 \\
94.646 \\
92.981 \\
91.317 \\
89.652 \\
87.988\end{array}$ & $\begin{array}{r}02.804 \\
01.139 \\
* 99.473 \\
97.808 \\
96.144 \\
94.479 \\
92.815 \\
91.150 \\
89.486 \\
87.822\end{array}$ & $\begin{array}{r}02.637 \\
00.972 \\
* 99.307 \\
97.642 \\
95.978 \\
94.313 \\
92.648 \\
90.984 \\
89.320 \\
87.656\end{array}$ & $\begin{array}{r}02.471 \\
00.805 \\
* 99.141 \\
97.476 \\
95.811 \\
94.146 \\
92.481 \\
90.817 \\
89.153 \\
87.490\end{array}$ & $\begin{array}{l}0.302865 \\
0.302862 \\
0.302859 \\
0.302856 \\
0.302853 \\
0.302850 \\
0.302847 \\
0.302844 \\
0.302841 \\
0.302838\end{array}$ & $\begin{array}{l}0.742018 \\
0.742041 \\
0.742064 \\
0.742087 \\
0.742110 \\
0.742133 \\
0.742156 \\
0.742179 \\
0.7422002 \\
0.742225\end{array}$ \\
\hline $\begin{array}{l}51.0 \\
1.1 \\
1.2 \\
1.3 \\
1.4 \\
1.5 \\
1.6 \\
1.7 \\
1.8 \\
1.9\end{array}$ & $\begin{array}{r}40787.323 \\
85.659 \\
83.996 \\
82.332 \\
80.668 \\
79.005 \\
77.342 \\
75.678 \\
74.015 \\
72.352\end{array}$ & $\begin{array}{l}87.157 \\
85.492 \\
83.829 \\
82.165 \\
80.501 \\
78.839 \\
77.175 \\
75.512 \\
73.849 \\
72.186\end{array}$ & $\begin{array}{l}86.990 \\
85.326 \\
83.662 \\
81.999 \\
80.335 \\
78.672 \\
77.009 \\
75.346 \\
73.683 \\
72.020\end{array}$ & $\begin{array}{l}86.824 \\
85.160 \\
83.496 \\
81.832 \\
80.168 \\
78.506 \\
76.843 \\
75.180 \\
73.517 \\
71.854\end{array}$ & $\begin{array}{l}85.658 \\
84.993 \\
83.330 \\
81.666 \\
80.002 \\
78.339 \\
76.676 \\
75.013 \\
73.350 \\
73.687\end{array}$ & $\begin{array}{l}86.491 \\
84.827 \\
83.163 \\
81.500 \\
79.836 \\
78.173 \\
76.510 \\
74.846 \\
73.184 \\
71.521\end{array}$ & $\begin{array}{l}86.324 \\
84.6600 \\
82.9977 \\
81.333 \\
79.669 \\
78.006 \\
76.343 \\
74.680 \\
73.017 \\
71.354\end{array}$ & $\begin{array}{l}86.158 \\
84.495 \\
82.831 \\
81.167 \\
79.503 \\
77.840 \\
76.177 \\
74.514 \\
72.851 \\
71.188\end{array}$ & $\begin{array}{l}85.992 \\
84.328 \\
82.6664 \\
81.0000 \\
79.337 \\
77.6774 \\
76.0111 \\
74.348 \\
72.685 \\
71.022\end{array}$ & $\begin{array}{l}85.825 \\
84.162 \\
82.498 \\
80.834 \\
79.171 \\
77.508 \\
75.844 \\
74.182 \\
72.519 \\
70.856\end{array}$ & $\begin{array}{l}0.302835 \\
0.302832 \\
0.302829 \\
0.302826 \\
0.302823 \\
0.302820 \\
0.302817 \\
0.302814 \\
0.302811 \\
0.302808\end{array}$ & $\begin{array}{l}0.742248 \\
0.742277 \\
0.742294 \\
0.742317 \\
0.742340 \\
0.742363 \\
0.742386 \\
0.742409 \\
0.742432 \\
0.742455\end{array}$ \\
\hline $\begin{array}{r}52.0 \\
2.1 \\
2.2 \\
2.3 \\
2.4 \\
2.5 \\
2.6 \\
2.7 \\
2.8 \\
2.9\end{array}$ & $\begin{array}{r}770.690 \\
69.027 \\
67.365 \\
65.702 \\
64.040 \\
62.378 \\
60.716 \\
59.055 \\
57.393 \\
55.731\end{array}$ & $\begin{array}{l}70.524 \\
68.861 \\
67.198 \\
65.536 \\
63.874 \\
62.212 \\
60.550 \\
58.888 \\
57.227 \\
55.565\end{array}$ & $\begin{array}{l}70.357 \\
68.695 \\
67.032 \\
65.370 \\
63.708 \\
62.046 \\
60.384 \\
58.722 \\
57.061 \\
55.399\end{array}$ & $\begin{array}{l}70.191 \\
68.529 \\
66.866 \\
65.204 \\
63.542 \\
61.880 \\
60.218 \\
58.556 \\
56.895 \\
55.233\end{array}$ & $\begin{array}{l}70.025 \\
68.362 \\
66.700 \\
65.038 \\
63.375 \\
61.714 \\
60.052 \\
58.390 \\
56.728 \\
55.006\end{array}$ & $\begin{array}{l}69.859 \\
68.196 \\
60.534 \\
64.872 \\
63.209 \\
61.547 \\
59.886 \\
58.224 \\
56.562 \\
54.901\end{array}$ & $\begin{array}{l}69.692 \\
68.029 \\
66.367 \\
64.705 \\
63.042 \\
61.381 \\
59.719 \\
58.058 \\
56.396 \\
54.734\end{array}$ & $\begin{array}{l}69.526 \\
67.863 \\
66.201 \\
64.539 \\
62.877 \\
61.215 \\
59.553 \\
57.892 \\
56.230 \\
54.569\end{array}$ & $\begin{array}{l}69.360 \\
67.697 \\
66.035 \\
64.373 \\
62.711 \\
61.049 \\
59.387 \\
57.725 \\
56.064 \\
54.403\end{array}$ & $\begin{array}{l}69.193 \\
67.531 \\
65.869 \\
64.206 \\
62.544 \\
60.882 \\
59.220 \\
57.559 \\
55.897 \\
54.237\end{array}$ & $\begin{array}{l}0.302805 \\
0.302802 \\
0.302799 \\
0.302796 \\
0.302793 \\
0.302790 \\
0.302787 \\
0.302784 \\
0.302781 \\
0.302778\end{array}$ & $\begin{array}{l}0.742478 \\
0.742501 \\
0.742524 \\
0.742547 \\
0.742570 \\
0.742593 \\
0.742616 \\
0.742639 \\
0.742662 \\
0.742685\end{array}$ \\
\hline $\begin{array}{r}53.0 \\
3.1 \\
3.2 \\
3.3 \\
3.4 \\
3.5 \\
3.6 \\
3.7 \\
3.8 \\
3.9\end{array}$ & $\begin{array}{r}754.070 \\
52.410 \\
50.748 \\
49.087 \\
47.426 \\
45.766 \\
44.105 \\
42.445 \\
40.784 \\
39.124\end{array}$ & $\begin{array}{l}53.904 \\
52.243 \\
50.582 \\
48.920 \\
47.259 \\
45.000 \\
43.939 \\
42.279 \\
40.618 \\
38.958\end{array}$ & $\begin{array}{l}53.738 \\
52.077 \\
50.415 \\
48.755 \\
47.094 \\
45.434 \\
43.773 \\
42.112 \\
40.453 \\
38.792\end{array}$ & $\begin{array}{l}53.572 \\
51.911 \\
50.250 \\
48.588 \\
46.927 \\
45.267 \\
43.607 \\
41.946 \\
40.286 \\
38.626\end{array}$ & $\begin{array}{l}53.406 \\
51.745 \\
50.083 \\
40.422 \\
46.761 \\
45.102 \\
43.441 \\
41.780 \\
40.120 \\
38.459\end{array}$ & $\begin{array}{l}53.240 \\
51.578 \\
49.917 \\
48.256 \\
46.596 \\
44.935 \\
43.274 \\
41.0614 \\
39.954 \\
38.294\end{array}$ & $\begin{array}{l}53.073 \\
51.412 \\
49.751 \\
48.090 \\
46.429 \\
44.769 \\
43.108 \\
41.448 \\
39.788 \\
38.128\end{array}$ & $\begin{array}{l}52.908 \\
51.247 \\
49.585 \\
47.924 \\
46.264 \\
44.604 \\
42.943 \\
41.282 \\
39.622 \\
37.961\end{array}$ & $\begin{array}{l}52.742 \\
51.080 \\
49.0419 \\
47.758 \\
46.098 \\
44.437 \\
42.776 \\
41.116 \\
39.456 \\
37.796\end{array}$ & $\begin{array}{l}52.575 \\
50.914 \\
49.253 \\
47.592 \\
45.932 \\
44.271 \\
42.610 \\
40.950 \\
39.290 \\
37.630\end{array}$ & $\begin{array}{l}0.302775 \\
0.302772 \\
0.302769 \\
0.302766 \\
0.302764 \\
0.302761 \\
0.302758 \\
0.302755 \\
0.302752 \\
0.302749\end{array}$ & $\begin{array}{l}0.742708 \\
0.742731 \\
0.742754 \\
0.742777 \\
0.742800 \\
0.742823 \\
0.742846 \\
0.742869 \\
0.742892 \\
0.742915\end{array}$ \\
\hline $\begin{array}{l}54.0 \\
4.1 \\
4.2 \\
4.3 \\
4.4 \\
4.5 \\
4.6 \\
4.7 \\
4.8 \\
4.9\end{array}$ & $\begin{array}{r}737.464 \\
35.805 \\
34.145 \\
32.485 \\
30.825 \\
29.166 \\
27.507 \\
25.848 \\
24.189 \\
22.530\end{array}$ & $\begin{array}{l}37.299 \\
35.639 \\
33.079 \\
32.319 \\
30.659 \\
29.000 \\
27.341 \\
25.682 \\
24.023 \\
22.0364\end{array}$ & $\begin{array}{l}37.132 \\
35.473 \\
33.812 \\
32.153 \\
30.494 \\
28.834 \\
27.175 \\
25.516 \\
23.857 \\
22.198\end{array}$ & $\begin{array}{l}36.966 \\
35.307 \\
33.647 \\
31.987 \\
30.328 \\
28.668 \\
27.010 \\
25.351 \\
23.691 \\
22.032\end{array}$ & $\begin{array}{l}36.801 \\
35.141 \\
33.481 \\
31.821 \\
30.102 \\
28.503 \\
26.844 \\
25.185 \\
23.525 \\
21.866\end{array}$ & $\begin{array}{l}36.635 \\
34.975 \\
33.315 \\
31.656 \\
29.996 \\
28.337 \\
26.078 \\
25.019 \\
23.360 \\
21.701\end{array}$ & $\begin{array}{l}36.468 \\
34.808 \\
33.149 \\
31.489 \\
29.830 \\
28.171 \\
26.512 \\
24.853 \\
23.194 \\
21.535\end{array}$ & $\begin{array}{l}36.302 \\
34.643 \\
32.982 \\
31.323 \\
29.665 \\
28.005 \\
26.346 \\
24.687 \\
23.028 \\
21.369\end{array}$ & $\begin{array}{l}36.136 \\
34.477 \\
32.816 \\
31.157 \\
29.498 \\
27.839 \\
26.180 \\
24.521 \\
22.862 \\
21.204\end{array}$ & $\begin{array}{l}35.970 \\
34.310 \\
32.651 \\
30.991 \\
29.332 \\
27.673 \\
26.014 \\
24.355 \\
22.696 \\
21.038\end{array}$ & & $\begin{array}{l}0.742938 \\
0.742961 \\
0.742984 \\
0.743007 \\
0.743030 \\
0.743053 \\
0.743076 \\
0.743099 \\
0.743122 \\
0.743145\end{array}$ \\
\hline $\begin{array}{l}55.0 \\
5.1 \\
5.2 \\
5.3 \\
5.4 \\
5.5 \\
5.6 \\
5.7 \\
5.8 \\
5.9\end{array}$ & $\begin{array}{r}40720.872 \\
19.213 \\
17.555 \\
15.897 \\
14.238 \\
12.581 \\
10.923 \\
09.265 \\
07.607 \\
05.950\end{array}$ & $\begin{array}{l}20.706 \\
19.047 \\
17.389 \\
15.730 \\
14.0772 \\
12.416 \\
10.757 \\
09.100 \\
07.441 \\
05.784\end{array}$ & $\begin{array}{l}20.540 \\
18.881 \\
17.223 \\
15.565 \\
13.907 \\
12.250 \\
10.591 \\
08.934 \\
07.276 \\
05.619\end{array}$ & $\begin{array}{l}0.374 \\
8.716 \\
7.057 \\
5.399 \\
3.741 \\
2.083 \\
0.425 \\
8.768 \\
7.110 \\
5.452\end{array}$ & $\begin{array}{l}20.208 \\
18.550 \\
16.892 \\
15.233 \\
13.575 \\
11.917 \\
10.260 \\
08.602 \\
06.944 \\
05.287\end{array}$ & $\begin{array}{l}20.042 \\
18.384 \\
16.746 \\
15.067 \\
13.409 \\
11.751 \\
10.094 \\
08.436 \\
06.779 \\
05.121\end{array}$ & $\begin{array}{l}19.876 \\
18.218 \\
16.560 \\
14.902 \\
13.243 \\
11.586 \\
09.928 \\
08.271 \\
06.613 \\
04.955\end{array}$ & $\begin{array}{l}19.711 \\
18.053 \\
16.394 \\
14.736 \\
13.078 \\
11.420 \\
09.762 \\
08.104 \\
06.447 \\
04.790\end{array}$ & $\begin{array}{l}19.545 \\
17.887 \\
16.228 \\
14.570 \\
12.912 \\
11.254 \\
09.597 \\
07.939 \\
06.282 \\
04.624\end{array}$ & $\begin{array}{l}19.379 \\
17.721 \\
16.062 \\
14.404 \\
12.747 \\
11.088 \\
09.431 \\
07.773 \\
06.116 \\
04.458\end{array}$ & $\begin{array}{l}.302716 \\
.302713 \\
.302710 \\
0.302707 \\
.302704 \\
.302703 \\
.302698 \\
.302695 \\
.302692 \\
.302690\end{array}$ & $\begin{array}{l}0.743168 \\
0.743191 \\
0.743214 \\
0.743237 \\
0.743260 \\
0.743283 \\
0.743306 \\
0.743329 \\
0.743352 \\
0.743375\end{array}$ \\
\hline $\begin{array}{l}56.0 \\
6.1 \\
6.2 \\
6.3 \\
6.4 \\
6.5 \\
6.6 \\
6.7 \\
6.8 \\
6.9\end{array}$ & $\begin{array}{r}40704.293 \\
02.636 \\
00.979 \\
40699.322 \\
97.665 \\
96.008 \\
94.352 \\
92.695 \\
91.039 \\
89.383\end{array}$ & $\begin{array}{l}04.127 \\
02.470 \\
00.813 \\
99.156 \\
97.499 \\
95.843 \\
94.187 \\
92.530 \\
90.874 \\
89.217\end{array}$ & $\begin{array}{l}03.961 \\
02.304 \\
00.647 \\
98.991 \\
97.333 \\
95.677 \\
94.021 \\
92.364 \\
90.708 \\
89.052\end{array}$ & $\begin{array}{l}3.796 \\
2.139 \\
0.482 \\
8.825 \\
7.168 \\
5.512 \\
3.855 \\
2.199 \\
0.542 \\
8.886\end{array}$ & $\begin{array}{l}03.630 \\
01.973 \\
00.316 \\
98.659 \\
97.002 \\
95.346 \\
93.889 \\
92.033 \\
90.376 \\
88.720\end{array}$ & $\begin{array}{l}03.464 \\
01.807 \\
00.149 \\
98.493 \\
96.837 \\
95.181 \\
93.524 \\
91.867 \\
90.211 \\
88.555\end{array}$ & $\begin{array}{r}03.298 \\
01.641 \\
* 99.984 \\
98.327 \\
96.670 \\
95.015 \\
93.358 \\
91.702 \\
90.046 \\
88.390\end{array}$ & $\begin{array}{r}03.133 \\
01.476 \\
099.818 \\
98.162 \\
96.505 \\
94.850 \\
93.193 \\
91.536 \\
89.880 \\
88.224\end{array}$ & $\begin{array}{r}02.967 \\
01.310 \\
* 99.653 \\
97.996 \\
96.339 \\
94.683 \\
93.026 \\
91.370 \\
89.714 \\
88.058\end{array}$ & $\begin{array}{r}02.801 \\
01.144 \\
* 99.487 \\
97.831 \\
96.173 \\
94.518 \\
92.861 \\
91.205 \\
89.548 \\
87.893\end{array}$ & & $\begin{array}{l}0.743398 \\
0.743421 \\
0.743444 \\
0.743467 \\
0.743490 \\
0.743513 \\
0.743536 \\
0.743559 \\
0.743582 \\
0.743605\end{array}$ \\
\hline $\begin{array}{l}57.0 \\
7: 1 \\
7.2 \\
7.3 \\
7: 4 \\
7.5 \\
7.6 \\
7.7 \\
7.8 \\
7.9\end{array}$ & $\begin{array}{r}40687.727 \\
86.072 \\
84.416 \\
82.760 \\
81.104 \\
79.449 \\
77.795 \\
76.140 \\
74.485 \\
72.830 .\end{array}$ & $\begin{array}{l}87.562 \\
85.906 \\
84.250 \\
82.594 \\
80.938 \\
79.285 \\
77.629 \\
75.974 \\
74.319 \\
72.664\end{array}$ & $\begin{array}{l}87.396 \\
85.740 \\
84.084 \\
82.429 \\
80.773 \\
79.119 \\
77.464 \\
75.809 \\
74.154 \\
72.499\end{array}$ & $\begin{array}{l}87.230 \\
85.575 \\
83.919 \\
82.264 \\
80.608 \\
78.953 \\
77.298 \\
75.643 \\
73.988 \\
72.333\end{array}$ & $\begin{array}{l}87.065 \\
85.409 \\
83.753 \\
82.098 \\
80.442 \\
78.788 \\
77.132 \\
75.478 \\
73.822 \\
72.167\end{array}$ & $\begin{array}{l}86.899 \\
85.244 \\
83.588 \\
81.933 \\
80.277 \\
78.622 \\
76.967 \\
75.312 \\
73.657 \\
72.002\end{array}$ & $\begin{array}{l}86.734 \\
85.078 \\
83.423 \\
81.767 \\
80.111 \\
78.457 \\
76.801 \\
75.146 \\
73.492 \\
71.837\end{array}$ & $\begin{array}{l}86.569 \\
84.913 \\
83.257 \\
81.601 \\
79.946 \\
78.292 \\
76.636 \\
74.981 \\
73.326 \\
71.671\end{array}$ & $\begin{array}{l}86.403 \\
84.747 \\
83.091 \\
81.436 \\
79.781 \\
78.126 \\
76.4711 \\
74.815 \\
73.161 \\
71.506\end{array}$ & $\begin{array}{l}82.926 \\
81.271 \\
79.615 \\
77.960 \\
76.305 \\
74.650 \\
72.995 \\
71.340\end{array}$ & & $\begin{array}{l}0.743628 \\
0.743651 \\
0.743674 \\
0.743698 \\
0.743721 \\
0.743744 \\
0.743767 \\
0.743790 \\
0.743813 \\
0.743836\end{array}$ \\
\hline $\begin{array}{r}58.0 \\
8.1 \\
8.2 \\
8.3 \\
8.4 \\
8.5 \\
8.6 \\
8.7 \\
8.8 \\
8.9\end{array}$ & $\begin{array}{r}40671.175 \\
69.521 \\
67.867 \\
66.212 \\
64.558 \\
62.904 \\
61.251 \\
59.597 \\
57.943 \\
56.290\end{array}$ & $\begin{array}{l}69.355 \\
67.701 \\
66.047 \\
64.0393 \\
62.739 \\
61.085 \\
59.432 \\
57.778 \\
56.124\end{array}$ & $\begin{array}{l}69.190 \\
67.536 \\
65.882 \\
64.228 \\
62.574 \\
60.920 \\
59.266 \\
57.613 \\
55.959\end{array}$ & $\begin{array}{l}69.025 \\
67.371 \\
65.716 \\
64.062 \\
62.408 \\
60.755 \\
59.101 \\
57.447 \\
55.794\end{array}$ & $\begin{array}{l}67.205 \\
65.551 \\
63.896 \\
62.243 \\
60.589 \\
58.936 \\
57.282 \\
55.628\end{array}$ & $\begin{array}{l}68.693 \\
67.039 \\
65.385 \\
63.731 \\
62.078 \\
60.424 \\
58.770 \\
57.117 \\
55.463\end{array}$ & $\begin{array}{l}63.003 \\
61.913 \\
60.258 \\
28.605 \\
56.952 \\
55.298\end{array}$ & $\begin{array}{l}3 \\
8 \\
4 \\
0 \\
7 \\
3\end{array}$ & $\begin{array}{l}68.197 \\
66.543 \\
64.889 \\
63.235 \\
61.582 \\
59.927 \\
58.274 \\
56.621 \\
54.967\end{array}$ & $\begin{array}{l}56.450 \\
54.802\end{array}$ & & $\begin{array}{l}0.743859 \\
0.743882 \\
0.743905 \\
0.743928 \\
0.743951 \\
0.743974 \\
0.743997 \\
0.744020 \\
0.744043 \\
0.744066\end{array}$ \\
\hline $\begin{array}{r}59.0 \\
9.1 \\
9.2 \\
9.3 \\
9.4 \\
9.5 \\
9.6 \\
9.7 \\
9.8 \\
9.9\end{array}$ & $\begin{array}{l}52.984 \\
51.331 \\
49.678 \\
48.024 \\
46.372 \\
44.721 \\
43.068 \\
41.416 \\
39.764\end{array}$ & $\begin{array}{l}49.512 \\
47.859 \\
46.207 \\
44.555 \\
42.903 \\
41.250 \\
39.598\end{array}$ & $\begin{array}{l}52.653 \\
51.000 \\
49.347 \\
47.694 \\
46.042 \\
44.390 \\
42.737 \\
41.085 \\
39.433\end{array}$ & $\begin{array}{l}42.572 \\
40.920 \\
39.268\end{array}$ & $\begin{array}{l}47.364 \\
45.712 \\
44.059 \\
42.407 \\
40.754 \\
39.102\end{array}$ & $\begin{array}{l}42.241 \\
40.590 \\
38.937\end{array}$ & $\begin{array}{l}43.129 \\
42.077 \\
40.424 \\
38.772\end{array}$ & $\begin{array}{l}43.563 \\
41.911 \\
40.259 \\
38.607\end{array}$ & $\begin{array}{l}40.094 \\
380.442\end{array}$ & $\begin{array}{l}39.929 \\
38.277\end{array}$ & 0.302572 & \\
\hline & \multicolumn{2}{|c|}{.001} & .002 & & .004 & .005 & .006 & .007 & .008 & .009 & .010 & \\
\hline & .0 & & & & 66 & .083 & .09 & .116 & & & .16 & \\
\hline
\end{tabular}


$\begin{array}{lllllllllll}2460.0 & 40638.111 & 37.947 & 37.781 & 37.617 & 37.452 & 37.286 & 37.121 & 36.956 & 36.791 & 36.625\end{array}$

$\begin{array}{llllllllllll}0.1 & 36.460 & 36.295 & 30.130 & 35.965 & 35.800 & 35.634 & 35.469 & 35.304 & 35.139 & 34.973 \\ 0.2 & 34.809 & 34.643 & 34.478 & 34.313 & 34.148 & 33.982 & 33.817 & 33.652 & 33.487 & 33.322\end{array}$

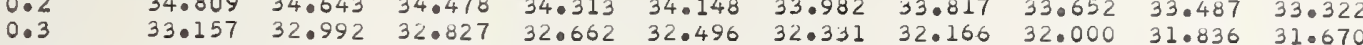

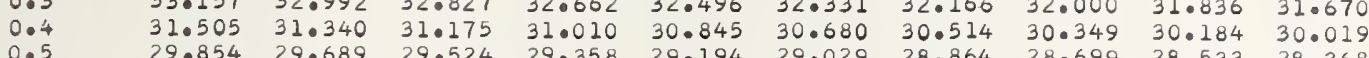

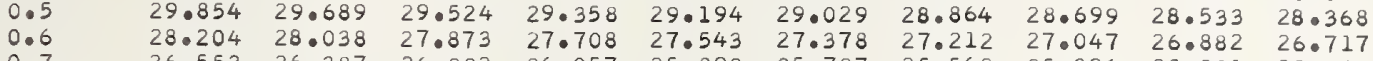

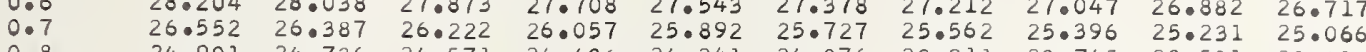

$0.8 \quad 24.901 \quad 24.736$

$23.250 \quad 23.085$

24.57124 .406

$\begin{array}{lllll}24.076 & 23.911 & 23.745 & 23.581 & 23.416\end{array}$

0.302569

0.744319

$1.0 \quad 40621.600$

$19.950 \quad 21.435$

$21.270 \quad 21 \cdot 10$

22.590

$\begin{array}{lllll}20.774 & 20.610 & 20.445 & 20.280 & 20.115 \\ 19.125 & 18.959 & 18.795 & 18.629 & 18.464\end{array}$

$1.2 \quad 18.299 \quad 18.134$

$\begin{array}{ll}1.3 & 16.649 \\ 1.4 & 14.999\end{array}$

1.4
$2 \cdot 5$
1.6

$\begin{array}{llll}14.999 & 14.833 & 14.669 & 14.50\end{array}$

1.6

$\begin{array}{llll}13.349 & 13.184 & 13.019 & 12.85 \\ 11.700 & 11.535 & 11.370 & 11.205\end{array}$

1.8
1.9

$\begin{array}{lll}10.050 & 09.885 & 09.7 \\ 08.400 & 08.235 & 08.070\end{array}$

11.205
09.555
07.905

19.290

$\begin{array}{ll}19.125 & 18.95 \\ 17.474 & 17.31\end{array}$

14.339

$12.6890-12.174$

15.659

$\begin{array}{lll}18.795 & 18.629 & 18.464\end{array}$

$1.040 \quad 10.875$

12.359
10.709

$\begin{array}{lll}15.494 & 15.330 & 15.165 \\ 13.844 & 13.679 & 13.514\end{array}$

$\begin{array}{lll}12.195 & 12.030 & 11.865\end{array}$

$\begin{array}{llll}06.751 & 06.586 & 06.421 & 06.256\end{array}$

09.225

09.061
07.41

$08.895 \quad 08.730 \quad 10.215$

40605.102

2462.

$2 \cdot 1$
$2 \cdot 2$
$2 \cdot 3$

03.453

04.93
03.28

$04.771 \quad 04.606$

04.442

04.277

04.112

05.596

07.081
05.432

06.916
05.267

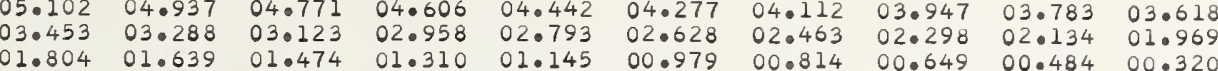

$2 \cdot 4$

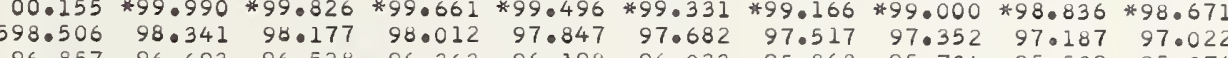

$00.97900 .814 \quad 00.649 \quad 00.484 \quad 00.320$

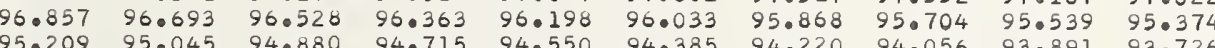

$\begin{array}{llllllllll}95.209 & 95.045 & 94.880 & 94.715 & 94.550 & 94.385 & 94.220 & 94.056 & 93.891 & 93.726 \\ 93.561 & 93.396 & 93.231 & 93.067 & 92.902 & 92.737 & 92.573 & 92.407 & 92.242 & 92.078\end{array}$

2.0

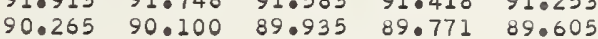

92.737

2.8

$\begin{array}{rllll}40588.616 & 88.452 & 88.287 & 88.122 & 87.958 \\ 86.970 & 86.805 & 86.640 & 86.475 & 86.311\end{array}$

3
3
3
3
3
3
3
3
3
3

$\begin{array}{lllll}85.322 & 85.157 & 84.940 & 86.475 & 86.311 \\ & 84.828 & 84.663\end{array}$

$83.67483 .509 \quad 83.345$

8.02683015

$80.379 \quad 80.214 \quad 80.050 \quad 79.885 \quad 79.721$

$78.73278 .568 \quad 78.403$

$\begin{array}{lllll}78.732 & 78.568 & 78.403 & 78.239 & 78.074 \\ 77.086 & 76.921 & 76.756 & 76.591 & 76.427\end{array}$

$\begin{array}{lll}75.439 & 75.274 & 75.109 \\ 73.792 & 73.627 & 73.462\end{array}$

87.793

89.27

$9.111 \quad 88.946 \quad 88.781$

0.302563

0.302557

.302554

0.302551

0.302545

0.302540

.302534

.302531

0.302522

0.302513

0.302510

0.302504

.302490

0.302487

0.302481

0.302478

.302472

.302466

0.302464

.30245

0.302452

2464.0

$\begin{array}{rrrr}40572.145 & 71.981 & 71.816 & 71.6 \\ 70.499 & 70.334 & 70.170 & 70.0\end{array}$

$\begin{array}{llllll}70.499 & 70.334 & 70.170 & 70.005 & 71.487\end{array}$

$\begin{array}{lllll}70.853 & 68.688 & 60.523 & 68.359 & 68.194\end{array}$

$67.207-67.04266 .878$

$63.915 \quad 63.750 \quad 63.585$

$\begin{array}{lll}62.269 & 62.104 & 61.939 \\ 60.624 & 60.459 & 60.294\end{array}$

63.421 63.05

82.851

$\begin{array}{llll}82.686 & 82.521 & 82.356 & 82.192\end{array}$

$\begin{array}{llllll}79.556 & 79.391 & 79.227 & 79.062 & 78.897\end{array}$

$\begin{array}{lllll}6.262 & 76.098 & 75.933 & 75.768 & 75.604\end{array}$

$\begin{array}{lll}58.978 & 58.813 & 58.649 \\ 57.333 & 57.167 & 57.003\end{array}$

$60.130 \quad 59.965$

$\begin{array}{lllll}72.909 & 74.451 & 74.286 & 74.122 & 73.957 \\ 72.639 & 72.475 & 72.310\end{array}$

0.302449

.30244

0.302437

0.302429

2465.

$\begin{array}{rrrr}40555.687 & 55.523 & 55.358 & 5 \\ 54.042 & 53.877 & 53.713 & 5\end{array}$

$55.193 \quad 55.02$

$\begin{array}{llllll}59.446 & 61.282 & 61.117 & 60.953 & 60.788\end{array}$

$\begin{array}{lllll}59.001 & 59.637 & 59.471 & 59.307 & 59.143\end{array}$

0.302423

0.302420

$\begin{array}{lllll}54.865 & 54.700 & 54.536 & 54.371 & 54.206\end{array}$

$\begin{array}{lllll}52.397 & 52.233 & 52.068 & 51.904 & 51.740\end{array}$

$50.752 \quad 50.588 \quad 50.424$

$\begin{array}{lll}49.107 & 48.943 & 48.779 \\ 47.463 & 47.299 & 47.134\end{array}$

$\begin{array}{lllll}45.819 & 45.654 & 45.490 & 45.326 & 45.161 \\ 44.175 & 44.011 & 43.846 & 43.682 & 43.517\end{array}$

$42.531 \quad 42.366 \quad 42.202$

$\begin{array}{lllll}51.575 & 51.411 & 51.246 & 51.082 & 50.917 \\ 49.931 & 49.766 & 49.601 & 49.437 & 49.272\end{array}$

$\begin{array}{lllll}49.281 & 49.766 & 49.601 & 49.437 & 49.272 \\ 48.286 & 48.121 & 47.957 & 47.792 & 47.628\end{array}$

$\begin{array}{lllll}46.641 & 46.477 & 46.312 & 46.148 & 45.983 \\ 44.997 & 44.833 & 44.608 & 44.504 & 44.339\end{array}$

$\begin{array}{lllll}44.997 & 44.833 & 44.608 & 44.504 & 44.339 \\ 43.353 & 43.188 & 43.024 & 42.859 & 42.695\end{array}$

0.3024

0.30240

0.302405

0.302399

0.302397

0.302394

0.302391

0.302388

0.30238

0.30237

0.302376

0.302370

0.302368 $\begin{array}{llllllllll}27.739 & 27.575 & 27.411 & 27.247 & 27.083 & 26.918 & 26.754 & 26.589 & 26.425 & 26.261\end{array}$ $\begin{array}{llllllllll}26.097 & 25.932 & 25.768 & 25.604 & 25.439 & 25.275 & 25.111 & 24.946 & 24.782 & 24.618 \\ 24.454 & 24.289 & 24.125 & 23.961 & 23.796 & 23.633 & 23.468 & 23.303 & 23.140 & 22.975\end{array}$

.30236

0.30235

0.30235

0.30235

0.302350

0.302344

0.302339

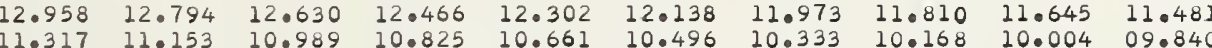

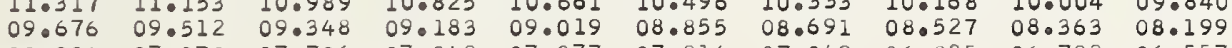

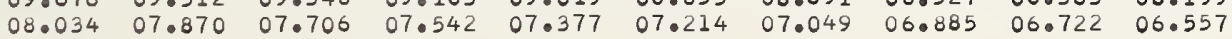

0.302336

0.302333

0.302327

0.302324

0.302321

0.302318

0.302312

0.302307

0.302304

0.302301

0.302295

0.302292

0.302289

0.302284

0.302281

.74441

0.744458

0.744527

0.744550

0.744579

.0744596

0.744688

0.744757

0.744780

0.74482

0.74487

74491

0.744965

0.74501

0.74505

(745126

0.74514

0.745195

0.74524

745288

74538

.74542

0.74547

0.74551

0.745564

0.74558

0.745634

0.745680

0.745703

0.745749

0.74577

0.74584

0.745864

0.745910

0.745934

0.745980

0.746003

0.746049

0.746072

0.746118

.74614

0.746164

0.746210

0.746234

0.746280

0.746303

0.746326

0.746372

0.746395

0.746418

0.746464
0.746488

0.746511

0.746534

0.746557

0.746580

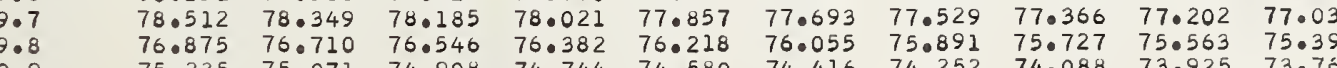

\begin{tabular}{|c|c|c|c|c|c|c|c|c|c|}
\hline & .001 & .002 & .003 & .004 & .005 & .006 & .007 & .008 & .009 \\
\hline $\begin{array}{l}165 \\
164\end{array}$ & $\begin{array}{l}.016 \\
.016\end{array}$ & $\begin{array}{l}.033 \\
.033\end{array}$ & $\begin{array}{l}.049 \\
.049\end{array}$ & $\begin{array}{l}.066 \\
.065\end{array}$ & $\begin{array}{l}.082 \\
.082\end{array}$ & $\begin{array}{l}.099 \\
.098\end{array}$ & $\begin{array}{l}.115 \\
.114\end{array}$ & $\begin{array}{l}.132 \\
.131\end{array}$ & $\begin{array}{r}.148 \\
.147\end{array}$ \\
\hline
\end{tabular}




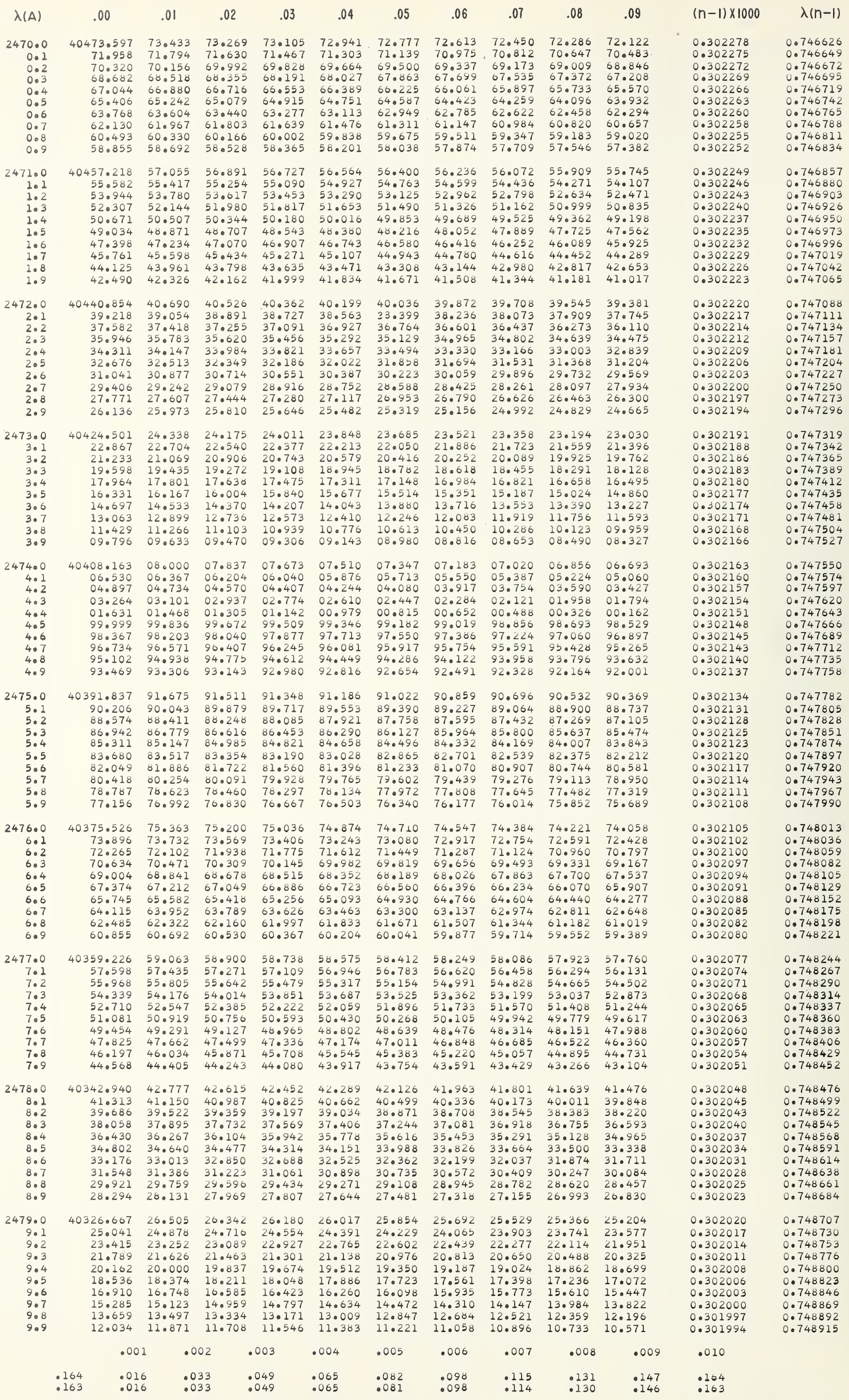




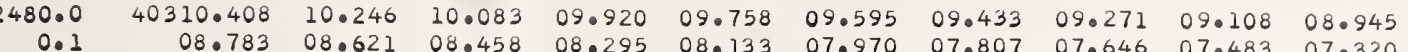
$\begin{array}{lllllllllll}0.1 & 08.783 & 08.621 & 08.458 & 08.295 & 08.133 & 07.970 & 07.807 & 07.646 & 07.483 & 07.320 \\ 0.2 & 07.158 & 06.996 & 06.833 & 06.671 & 06.508 & 06.345 & 06.183 & 06.021 & 05.058 & 05.696\end{array}$

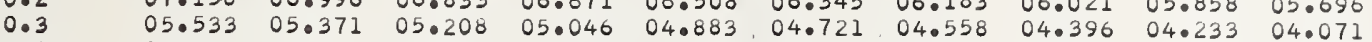
$\begin{array}{llllllllllll}0.4 & 03.908 & 03.746 & 03.583 & 03.421 & 03.258 & 03.096 & 02.933 & 02.771 & 02.608 & 02.446\end{array}$ $\begin{array}{lllllllllll}02.283 & 02.121 & 01.958 & 01.796 & 01.634 & 01.471 & 01.308 & 01.146 & 00.983 & 00.821\end{array}$ 40299.035 (1).496 $00.333 \quad 00.171 \quad 00.009 * 99.846 * 99.684 * 99.521 * 99.359 * 99.197$

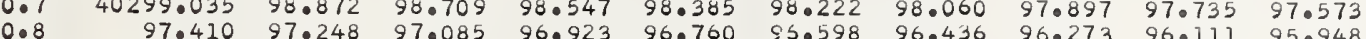

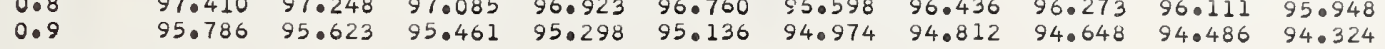

$\begin{array}{rrrrrrrrrrr}2486.0 & 40213.125 & 12.964 & 12.802 & 12.640 & 12.479 & 12.316 & 12.155 & 11.993 & 11.832 & 11.669\end{array}$ $\begin{array}{lllllllllll}11.508 & 11.346 & 11.185 & 11.023 & 10.861 & 10.699 & 10.537 & 10.376 & 10.214 & 10.052 \\ 09.891 & 09.729 & 09.567 & 09.406 & 09.244 & 09.082 & 08.920 & 08.758 & 08.597 & 08.435\end{array}$

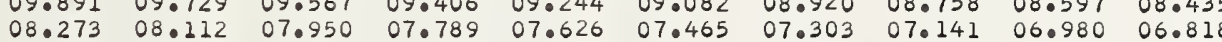
$\begin{array}{llllllllll}06.656 & 06.494 & 06.333 & 06.171 & 06.009 & 05.848 & 05.686 & 05.524 & 05.363 & 05.201\end{array}$ $\begin{array}{llllllllll}05.040 & 04.878 & 04.716 & 04.555 & 04.394 & 04.231 & 04.070 & 03.908 & 03.746 & 03.584 \\ 03.423 & 03.261 & 03.100 & 02.938 & 02.776 & 02.615 & 02.453 & 02.291 & 02.129 & 01.968\end{array}$ $\begin{array}{llllllllll}03.423 & 03.261 & 03.100 & 02.938 & 02.776 & 02.015 & 02.453 & 02.291 & 02.129 & 01.968\end{array}$

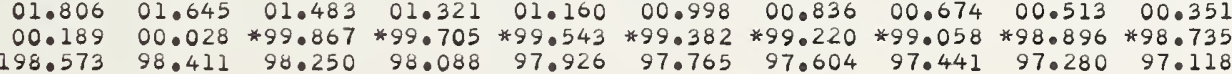

0.301966

0.301963

0.301960

0.301954

0.301952

0.301946

0.301943

0.301937

0.301935

0.301932
0.301929

0.301926

0.301923

0.301920

0.301915

0.301912
0.301909

0.301906

0.301903

0.301901

0.301898

0.301892

0.301889

0.301886

0.301884
0.301881

0.301878

0.301875

0.301872

0.301867

0.301864
0.301861

0.301858

0.301855

0.301850

0.301847

0.301844

0.301838

0.301836

0.301833

0.301830

0.301824

0.301822
0.301819

0.301816

0.301813

0.301810

0.301805

0.301802

0.301799
0.301796

0.301793

0.301791

0.301785

0.301782

0.301777

0.301774

0.301768

0.301765

0.301760

0.301757

0.301754
0.301751

0.301749

0.301746

0.301743
0.301740

0.301737

0.301735

0.301732

0.301726

0.301723

0.301721

0.301718

0.301718

0.749239

0.749286

0.749309

0.749355

0.749402

0.749448

0.749494

0.749541

0.749587

0.749633

0.749656
0.749680

0.749703

0.749749

0.749795

0.749819
0.749842

0.749865

0.749888
0.749911

0.749911
0.749934
0.749958

0.749981

0.7450004
0.750027

0.750050
0.750073

0.750097

0.750120
0.750143

0.750166

0.750189
0.750213

0.750236

0.750259

0.750305

0.750328

0.750375
0.750325

0.0750398
0.750422

0.750444

0.750468

0.75044
0.750491
0.750514

0.750537

0.750560
0.750583

0.750607

0.750630

0.750676

0.750699

0.750723

0.750723
0.750769

0.750792

0.750815
0.750839

0.750862

0.750885

0.750908

0.750955

0.750978
0.751001

$\begin{array}{ll}.301715 & 0.751210 \\ .301712 & 0.751233\end{array}$

0.751024

0.751047

0.751094

0.751140

0.751163

.010

.162 


\section{$\begin{array}{rr}148.530 & 48.369 \\ 46.918 & 46.757\end{array}$}

48.208

$48.046 \quad 47.885$

0.1
0.2
0.3

0.5

0.6
0.7

0.8

2491.0

1.2

1.3

1.5

1.6
1.7

1.8
1.9

2492.

$2 \cdot 3$

$$
\begin{array}{lll}
34.987 & 35.827 & 35.66 \\
34.384 & 34.223 & 34.00 \\
32.781 & 32.621 & 32.46 \\
31.178 & 31.018 & 30.85 \\
29.575 & 29.415 & 29.25 \\
27.973 & 27.812 & 27.65 \\
26.370 & 26.210 & 26.04 \\
24.768 & 24.607 & 24.44 \\
23.166 & 23.005 & 22.84 \\
21.563 & 21.403 & 21.24
\end{array}
$$




\begin{tabular}{|c|c|c|c|c|c|c|c|c|}
\hline$\lambda(A)$ & .00 & .01 & .02 & .03 & .04 & .05 & .06 & .07 \\
\hline 2500.0 & 39987.947 & 87.788 & 87.627 & & & & 86.988 & 86.828 \\
\hline $\begin{array}{l}0.1 \\
0.2\end{array}$ & $\begin{array}{l}86.348 \\
84.749\end{array}$ & $\begin{array}{l}86.188 \\
84.589\end{array}$ & $\begin{array}{l}86.028 \\
84.429\end{array}$ & $\begin{array}{l}85.869 \\
84.269\end{array}$ & $\begin{array}{l}85.708 \\
84.109\end{array}$ & $\begin{array}{l}85.548 \\
83.949\end{array}$ & 85.388 & 85.229 \\
\hline $\begin{array}{l}0.2 \\
0.3\end{array}$ & $\begin{array}{l}84.749 \\
83.149\end{array}$ & $\begin{array}{l}84.589 \\
82.989\end{array}$ & $\begin{array}{l}84.429 \\
82.830\end{array}$ & $\begin{array}{l}84.269 \\
82.670\end{array}$ & $\begin{array}{l}84.109 \\
82.510\end{array}$ & $\begin{array}{l}83.949 \\
82.350\end{array}$ & $\begin{array}{l}83.790 \\
82\end{array}$ & 83.629 \\
\hline 0.4 & 81.550 & 81.391 & 81.231 & 81.071 & 80.911 & $\begin{array}{l}82.350 \\
80.751\end{array}$ & $\begin{array}{l}82.190 \\
80.592\end{array}$ & $\begin{array}{l}82.030 \\
80.432\end{array}$ \\
\hline 0.5 & 79.952 & 79.792 & 79.632 & 79.472 & 79.312 & 79.153 & 78.993 & $\begin{array}{l}80.432 \\
78.833\end{array}$ \\
\hline 0.6 & 78.354 & 78.193 & 78.033 & 77.874 & 77.714 & 77.554 & 77.394 & 77.234 \\
\hline 0.7 & 76.754 & 76.595 & 76.435 & 76.275 & 76.115 & 75.955 & 75.796 & 75.636 \\
\hline 0.8 & 75.156 & 74.996 & 74.836 & 74.676 & 74.517 & 74.357 & 74.197 & 74.037 \\
\hline 0.9 & 73.557 & 73.397 & 73.238 & 73.078 & 72.918 & 72.759 & 72.599 & 72.439 \\
\hline $\begin{array}{r}2501.0 \\
1.1\end{array}$ & $\begin{array}{r}39971.960 \\
70.362\end{array}$ & $\begin{array}{l}71.800 \\
70.202\end{array}$ & $\begin{array}{l}71.640 \\
70.042\end{array}$ & $\begin{array}{l}71.480 \\
69.882\end{array}$ & $\begin{array}{l}71.321 \\
69.722\end{array}$ & $\begin{array}{l}71.161 \\
69.562\end{array}$ & $\begin{array}{l}71.001 \\
69.402\end{array}$ & 70.841 \\
\hline $\begin{array}{l}1.1 \\
1.2\end{array}$ & $\begin{array}{l}70.362 \\
68.764\end{array}$ & $\begin{array}{l}70.202 \\
68.604\end{array}$ & $\begin{array}{l}70.042 \\
68.444\end{array}$ & $\begin{array}{l}9.882 \\
8.284\end{array}$ & $\begin{array}{l}69.722 \\
68.125\end{array}$ & $\begin{array}{l}69.562 \\
67.964\end{array}$ & $\begin{array}{l}69.402 \\
67.805\end{array}$ & $\begin{array}{l}69.243 \\
67.645\end{array}$ \\
\hline 1.3 & 67.166 & 67.006 & 66.847 & 6.686 & 66.526 & 66.367 & 66.207 & 66.047 \\
\hline 1.4 & 65.568 & 65.408 & 65.249 & 5.088 & 64.929 & 64.769 & 64.609 & 64.449 \\
\hline $\begin{array}{l}1.5 \\
1.6\end{array}$ & $\begin{array}{l}\begin{array}{l}63.971 \\
62.374\end{array} \\
62.37\end{array}$ & $\begin{array}{l}63.812 \\
02.214\end{array}$ & $\begin{array}{l}63.651 \\
62.054\end{array}$ & $\begin{array}{l}63.492 \\
61.895\end{array}$ & $\begin{array}{l}63.332 \\
61.735\end{array}$ & 63.172 & 63.012 & 62.853 \\
\hline 1.07 & $\begin{array}{l}60.776 \\
60.776\end{array}$ & $\begin{array}{l}62.214 \\
60.616\end{array}$ & $\begin{array}{l}62.054 \\
60.457\end{array}$ & $\begin{array}{l}1.895 \\
.297\end{array}$ & $\begin{array}{l}61.735 \\
60.137\end{array}$ & $\begin{array}{l}E 1.574 \\
59.077\end{array}$ & & 61.255 \\
\hline 1.8 & 59.179 & 59.019 & 50.859 & 58.700 & 58.540 & 58.380 & $\begin{array}{l}59.817 \\
58.220\end{array}$ & 59.658 \\
\hline 1.9 & 57.582 & 57.421 & 57.262 & 57.103 & 56.943 & 56.783 & 56.623 & $\begin{array}{l}58.0061 \\
56.4633\end{array}$ \\
\hline $\begin{array}{r}2502.0 \\
2.1\end{array}$ & $\begin{array}{r}39955.984 \\
54.388\end{array}$ & $\begin{array}{l}55.825 \\
54.229\end{array}$ & $\begin{array}{l}55.665 \\
54.069\end{array}$ & $\begin{array}{l}55.505 \\
53.909\end{array}$ & $\begin{array}{l}55.347 \\
53.750\end{array}$ & $\begin{array}{l}55.187 \\
53.590\end{array}$ & 55.027 & 54.868 \\
\hline 2.2 & 52.792 & 52.632 & $\begin{array}{l}24.047 \\
52.472\end{array}$ & 52.312 & 52.153 & 51.993 & $\begin{array}{l}53.430 \\
51.833\end{array}$ & $\begin{array}{l}53.271 \\
51.674\end{array}$ \\
\hline $2 \cdot 3$ & 51.195 & 51.035 & 50.875 & 50.716 & 50.556 & 50.397 & 50.237 & $\begin{array}{l}51.614 \\
50.077\end{array}$ \\
\hline 2.4 & 49.598 & 49.438 & 49.279 & 49.119 & 48.959 & 48.800 & 48.641 & 48.481 \\
\hline 2.5 & 48.001 & 47.842 & 47.683 & 47.523 & 47.364 & 47.204 & 47.044 & 46.885 \\
\hline 2.6 & $\begin{array}{l}46.407 \\
44.811\end{array}$ & $\begin{array}{l}46.247 \\
44.650\end{array}$ & 46.087 & 45.927 & 45.768 & 45.608 & 45.448 & 45.289 \\
\hline $\begin{array}{l}2.7 \\
2.8\end{array}$ & 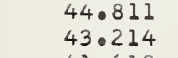 & $\begin{array}{l}44.650 \\
43.054\end{array}$ & $\begin{array}{l}44.490 \\
42.895\end{array}$ & $\begin{array}{l}44.331 \\
42.735\end{array}$ & $\begin{array}{l}44.171 \\
42.576\end{array}$ & $\begin{array}{l}44.012 \\
42.417\end{array}$ & $\begin{array}{l}43.853 \\
42.256\end{array}$ & $\begin{array}{l}43.693 \\
42.097\end{array}$ \\
\hline 2.9 & 41.618 & 41.458 & 41.299 & 41.139 & 40.979 & 40.820 & 40.661 & 40.501 \\
\hline 503.0 & 39940.022 & 39.863 & 39.703 & $39 \cdot 543$ & 39.384 & 39.225 & 39.065 & 38.906 \\
\hline $\begin{array}{l}3.1 \\
3.2\end{array}$ & $\begin{array}{l}38.427 \\
36.832\end{array}$ & $\begin{array}{l}38.268 \\
36.672\end{array}$ & 38.107 & .949 & $\begin{array}{l}37.789 \\
36\end{array}$ & 37.629 & 37.470 & 37.311 \\
\hline 3.3 & $\begin{array}{l}35.037 \\
35.237\end{array}$ & $\begin{array}{l}36.672 \\
35.077\end{array}$ & $\begin{array}{l}36.513 \\
34.918\end{array}$ & .354 & $\begin{array}{l}36.193 \\
34598\end{array}$ & 36.034 & 35.875 & 35.715 \\
\hline 3.4 & 33.641 & 33.481 & $\begin{array}{l}33.323 \\
33.310\end{array}$ & 33.163 & $\begin{array}{l}34.058 \\
33.003\end{array}$ & $\begin{array}{l}34.439 \\
32.844\end{array}$ & $\begin{array}{l}34 . \\
32\end{array}$ & $\begin{array}{l}34.120 \\
32.524\end{array}$ \\
\hline 3.5 & 32.046 & 31.887 & 31.728 & .068 & 31.408 & 31. & 310 & $\begin{array}{l}32.524 \\
30.930\end{array}$ \\
\hline 3.6 & 30.452 & 30.292 & 30.132 & $\begin{array}{r}.973 \\
.379\end{array}$ & 29.813 & 29.653 & 29.494 & 29.335 \\
\hline 3.7 & 28.857 & 28.697 & 28.538 & 26.379 & 28.219 & 28.060 & 27.900 & 27.740 \\
\hline $\begin{array}{l}3.8 \\
3.9\end{array}$ & $\begin{array}{l}27.262 \\
25.667\end{array}$ & $\begin{array}{l}27.103 \\
25.508\end{array}$ & $\begin{array}{l}26.943 \\
25.349\end{array}$ & $\begin{array}{l}26.784 \\
25.189\end{array}$ & $\begin{array}{l}26.625 \\
25.030\end{array}$ & $\begin{array}{l}26.465 \\
24.871\end{array}$ & $\begin{array}{l}26.300 \\
24.711\end{array}$ & $\begin{array}{l}26.146 \\
24.551\end{array}$ \\
\hline & $1 / 3$ & 23 & & 5 & & & 23. & 22.8 \\
\hline $4 \cdot 1$ & 22.479 & 22.319 & 22.160 & 22.001 & 21.841 & 2 & 230. & $\begin{array}{l}21.363 \\
21.363\end{array}$ \\
\hline 4.2 & 20.885 & 20.726 & 20.566 & 20.407 & 20.248 & 20.088 & 19.929 & 19.770 \\
\hline $4 \cdot 3$ & 19.291 & 19.131 & 18.972 & 18.813 & 18.653 & 18.494 & 18.335 & 18.175 \\
\hline $\begin{array}{l}4.4 \\
4.5\end{array}$ & 17.697 & 17.537 & 17.378 & 17.219 & 17.059 & 16.900 & 16.741 & 16.582 \\
\hline $\begin{array}{l}4.5 \\
4.6\end{array}$ & 16.103 & 15.944 & 15.784 & 15.625 & 15.466 & 15.307 & 15.147 & 14.988 \\
\hline $\begin{array}{l}4.6 \\
4.7\end{array}$ & 14.510 & 14.350 & 14.190 & 14.032 & 13.872 & 13.713 & 13.553 & 13.394 \\
\hline $\begin{array}{l}4.7 \\
4.8\end{array}$ & 12.916 & 12.756 & 12.597 & 12.438 & 12.278 & $\begin{array}{l}12.119 \\
10.526\end{array}$ & 11.960 & 11.801 \\
\hline 4.9 & $\begin{array}{l}11.323 \\
09.730\end{array}$ & $\begin{array}{l}11.164 \\
09.570\end{array}$ & $\begin{array}{l}11.005 \\
09.012\end{array}$ & $\begin{array}{l}10.845 \\
09.251\end{array}$ & $\begin{array}{l}10.686 \\
09.092\end{array}$ & $\begin{array}{l}10.526 \\
08.933\end{array}$ & $\begin{array}{l}10.367 \\
08.774\end{array}$ & $\begin{array}{l}10.208 \\
08.614\end{array}$ \\
\hline $\begin{array}{r}2505.0 \\
5.1\end{array}$ & $\begin{array}{r}39908.137 \\
06.544\end{array}$ & $\begin{array}{l}07.978 \\
06.384\end{array}$ & $\begin{array}{l}07.818 \\
06.225\end{array}$ & $\begin{array}{l}07.658 \\
06.065\end{array}$ & $\begin{array}{l}07.500 \\
05.906\end{array}$ & $\begin{array}{l}07.340 \\
65.747\end{array}$ & $\begin{array}{l}07.181 \\
05.587\end{array}$ & $\begin{array}{l}07.021 \\
05.429\end{array}$ \\
\hline 5.2 & 04.951 & 04.792 & 04.632 & 04.473 & 3 & 04.154 & 03.995 & 03.835 \\
\hline $5 \cdot 3$ & 03.358 & 03.199 & 03.040 & 02.881 & 02.721 & 02. & & \\
\hline 5.4 & 01.766 & 01.606 & 01.447 & 01.288 & 01.128 & 00.970 & 00.810 & 00.650 \\
\hline 5.5 & 00.173 & 00.014 & 499.854 & *99.695 & \#99.537 & *99.377 & *99.217 & *99.059 \\
\hline 5.6 & 39898.581 & 98.421 & 98.262 & 98.1 & 97.944 & 97. & 97. & 97.4 \\
\hline $\begin{array}{l}5.7 \\
5.8\end{array}$ & 96.988 & 96.829 & 96.670 & 96.511 & 96.352 & 96.192 & 96.033 & 95.874 \\
\hline $\begin{array}{l}5.8 \\
5.9\end{array}$ & $\begin{array}{l}95.396 \\
93.804\end{array}$ & $\begin{array}{l}95.237 \\
93.645\end{array}$ & $\begin{array}{l}95.078 \\
93.486\end{array}$ & $\begin{array}{l}94.918 \\
93.327\end{array}$ & $\begin{array}{l}94.759 \\
93.167\end{array}$ & $\begin{array}{l}94.601 \\
93.009\end{array}$ & $\begin{array}{l}94.442 \\
92.850\end{array}$ & 94.282 \\
\hline & & 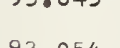 & & & & & 72.050 & 7206 \\
\hline 6.1 & $\begin{array}{l}92.212 \\
90.621\end{array}$ & $\begin{array}{l}92.054 \\
90.462\end{array}$ & $\begin{array}{l}91.894 \\
90.302\end{array}$ & $\begin{array}{l}91.735 \\
90.144\end{array}$ & $\begin{array}{l}.576 \\
.984\end{array}$ & $\begin{array}{l}91.417 \\
89.825\end{array}$ & $\begin{array}{l}91.258 \\
89.666\end{array}$ & $\begin{array}{l}91.099 \\
89.507\end{array}$ \\
\hline $\begin{array}{l}6.2 \\
6.3\end{array}$ & 89.029 & 88.870 & 88.7 & 88.5 & 3 & 88. & 88 & 87.9 \\
\hline $\begin{array}{l}6.3 \\
6.4\end{array}$ & 87.437 & 87.278 & 87.120 & 86.960 & 1 & 86.642 & & 86.324 \\
\hline $\begin{array}{l}6.4 \\
6.5\end{array}$ & 85.847 & 85.687 & 85.528 & 85.369 & 85.210 & 85.051 & 84.892 & 8 \\
\hline & .255 & 84.097 & 3.937 & & & 83.460 & & \\
\hline $\begin{array}{l}6.6 \\
6.7\end{array}$ & $\begin{array}{l}82.665 \\
81.074\end{array}$ & 82.505 & 82.346 & & & 81.869 & 9 & 81.551 \\
\hline 6.8 & $\begin{array}{l}81.074 \\
79.482\end{array}$ & $\begin{array}{l}80.915 \\
79.323\end{array}$ & $\begin{array}{l}80.755 \\
79.164\end{array}$ & $\begin{array}{l}80.596 \\
79.005\end{array}$ & $\begin{array}{l}80.437 \\
78.846\end{array}$ & $\begin{array}{l}80.278 \\
78.687\end{array}$ & $\begin{array}{l}80.119 \\
78.528\end{array}$ & $\begin{array}{l}79.959 \\
78.369\end{array}$ \\
\hline 6.9 & 77.892 & 77.732 & 77.573 & 77.414 & 77.255 & 77.097 & 76. & 76.778 \\
\hline $\begin{aligned} 07.0 \\
7.11\end{aligned}$ & 301 & 76.143 & 5.983 & 75 & .665 & 75.506 & 75.347 & 75. \\
\hline & & & & & & & & \\
\hline $\begin{array}{l}7.2 \\
7.3\end{array}$ & 73.121 & 72.961 & $72 \cdot$ & 72 & & & & \\
\hline $\begin{array}{l}7 \cdot 3 \\
7.4\end{array}$ & $\begin{array}{l}71.530 \\
69.940\end{array}$ & 71. & 2 & & & & & \\
\hline $\begin{array}{l}7.4 \\
7.5\end{array}$ & $\begin{array}{l}69.940 \\
68.351\end{array}$ & 69.7 & $\begin{array}{l}69.623 \\
68.033\end{array}$ & $\begin{array}{l}69 \\
67 \\
67\end{array}$ & $\begin{array}{l}4 \\
5 \\
5\end{array}$ & 69. & $\begin{array}{l}68.986 \\
67.399\end{array}$ & 67.238 \\
\hline 7.6 & $\begin{array}{l}68.351 \\
66.761\end{array}$ & $\begin{array}{l}68.192 \\
66.602\end{array}$ & .0443 & 66 & & 65. & & 8 \\
\hline $\begin{array}{l}7.7 \\
7.8\end{array}$ & .171 & 65.012 & & & & & & \\
\hline $\begin{array}{l}7.8 \\
7.9\end{array}$ & $\begin{array}{l}63.582 \\
61.992\end{array}$ & $\begin{array}{l}63.422 \\
651833\end{array}$ & $\begin{array}{l}63.264 \\
61.674\end{array}$ & $\begin{array}{l}63.104 \\
61.515\end{array}$ & $\begin{array}{l}62.946 \\
61.356\end{array}$ & $\begin{array}{l}62.787 \\
61.197\end{array}$ & $\begin{array}{l}62.628 \\
61.039\end{array}$ & $\begin{array}{l}62.469 \\
60.879\end{array}$ \\
\hline & & & 0 & & & & & \\
\hline $88^{\circ}$ & $\begin{array}{r}39860.402 \\
58.814\end{array}$ & $\begin{array}{l}60.244 \\
58.655\end{array}$ & $\begin{array}{l}.084 \\
.496\end{array}$ & $\begin{array}{l}59.926 \\
58.337\end{array}$ & 88 & $\begin{array}{l}8 \\
9\end{array}$ & & \\
\hline 8.2 & a & 57.0 & 7 & 56 & & & & \\
\hline 8 & 55.636 & 55.4 & $55 .:$ & 9 & & & & \\
\hline 8. & 50047 & 53.888 & 53.7 & 53. & & 53. & & \\
\hline & & - & & & & & & \\
\hline & & & 2 & & & & & \\
\hline 8. & 82 & & & & & & & \\
\hline 8.9 & & & & & & & & \\
\hline & 46. & +6 & 8 & 45.628 & 69 & 45.311 & 45.152 & 44.993 \\
\hline $\begin{array}{r}2509.0 \\
9.1\end{array}$ & & & & & & & & \\
\hline 9. & & & & & & & & \\
\hline 9. & & 39 & $\begin{array}{l}4 \\
3 \\
3\end{array} \quad x$ & & & & & \\
\hline 9. & & & & & & & & \\
\hline 9 & & & & & & & & \\
\hline 9. & 1 & 3 & 4 & & & & & \\
\hline 0. & 33 & 33.2 & 33.087 & 32 & & & & \\
\hline $9 \cdot 8$ & 817 & 31.659 & .500 & 31 & & & & \\
\hline 9.9 & 30.230 & 30.072 & 29.913 & 29.754 & 29.596 & 29.437 & 29.278 & 29.120 \\
\hline & .0 & & & 03 & 04 & .005 & .006 & .007 \\
\hline & & & & & & .08 & & .112 \\
\hline & & & & & & & & \\
\hline
\end{tabular}


$\begin{array}{lllllllllll}0.0 & 39828.643 & 28.485 & 28.326 & 28.167 & 28.009 & 27.850 & 27.691 & 27.533 & 27.375 & 27.216\end{array}$

$\begin{array}{lllllllllll}0.1 & 27.057 & 26.898 & 26.739 & 26.581 & 26.422 & 26.264 & 26.105 & 25.946 & 25.788 & 25.629 \\ 0.2 & 25.470 & 25.312 & 25.153 & 24.995 & 24.836 & 24.677 & 24.519 & 24.360 & 24.202 & 24.043\end{array}$

$\begin{array}{lllllllllll}0.3 & 23.885 & 23.726 & 23.567 & 23.408 & 23.250 & 23.091 & 22.933 & 22.774 & 22.616 & 22.457\end{array}$

$\begin{array}{lllllllllll}0.4 & 22.298 & 22.140 & 21.980 & 21.822 & 21.663 & 21.505 & 21.346 & 21.187 & 21.029 & 20.871 \\ 0.5 & 20.712 & 20.554 & 20.395 & 20.236 & 20.077 & 19.918 & 19.760 & 19.602 & 19.443 & 19.284\end{array}$

\section{$16.307 \quad 17.727$}

$\begin{array}{lll}16.307 & 16.148 & 15.991\end{array}$

$\begin{array}{llll}13.151 & 12.993 & 12.835 & 12.67\end{array}$ $\begin{array}{llllllllll}11.573 & 11.416 & 11.258 & 11.101 & 10.943 & 10.785 & 10.627 & 10.470 & 10.312 & 10.154\end{array}$ $\begin{array}{llllllllll}0.997 & 09.839 & 09.681 & 09.523 & 09.366 & 09.208 & 09.050 & 08.893 & 08.735 & 08.577\end{array}$ $\begin{array}{llllllllll}06.842 & 06.685 & 06.526 & 06.369 & 06.211 & 06.053 & 05.896 & 05.738 & 05.581 & 05.423\end{array}$ $\begin{array}{llllllllll}05.265 & 05.107 & 04.950 & 04.792 & 04.634 & 04.477 & 04.319 & 04.161 & 04.004 & 03.846 \\ 030688 & 03.531 & 03.0373 & 03.215 & 03.057 & 02.0300 & 02.742 & 02.584 & 02.427 & 02.270\end{array}$

$39686.351 \quad 86.194$

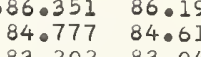

7.5
9.6
9.7 $75.328 \quad 75.170 \quad 75.012$ 76.42976 .272 $\begin{array}{lll}73.753 & 73.595 & 73.438 \\ 72.178 & 72.021 & 71.864\end{array}$

73.855
71.706

0.301131

0.301129

0.301126

0.301120

0.301118

0.301115
0.30112

0.301110

0.301107

0.301104

0.301101
0.301099
0.30106

0.301096

0.301093
0.301091
0.301090

0.301088

0.301085

0.301080

0.301077

0.301072

0.301069

0.301066

0.301061
0.3064

0.30158

0.301053

0.301050

0.301045

0.301042
0.301039
0.3019

0.301037

0.301034

0.31031

0.301029
0.301026

0.301023

0.301021

.301018
0.301015
0.3015

0.301012

.301010
0.301007
.

0.301004

0.300999

0.300996

0.300994

0.300991

0.300986

0.300983

0.300980

0.300978

0.300975
0.300972

0.300970

0.300967

0.300964
0.300961
0.30059

0.300959

0.300956

0.0300953
0.30095

0.30095
0.30094

0.300945

0.300943

0.3300940
0.300937

0.0300935

0.000932

0.300927

0.300924

0.0300921
0.300919

0.300916

0.300913

0.300908

0.300905

0.300903

0.300900
0.300897
0.30095

0.300895

0.300895
0.300892

0.755907 0.755931 0.7555914
0.755594
0.75977

0.756001 0.756024 0.756071
0.75074 0.756071
0.750944 0.756117

0.756141 0.756164 0.7561818
0.756210
0.75625 0.756234 0.756257 0.756280 0.756304
0.756327
0.75635 0.7562327
0.756350

0.756374 0.756397
0.756420
0.75644 0.756444 0.756467
0.756490
0.75614 0.756490
0.756514
0 0.756537 0.756560
0.756584

0.756607 0.756630 0.756654
0.756677 0.756700 0.756724 0.756747 0.756770 0.756794
0.756817

0.756840 0.756863
0.756887 0.756910 0.756933 0.756957 0.756980 0.757003
0.757027 0.757027
0.75050

0.757073 0.757097 0.757120
0.757143
0.75750 0.757167 0.757190 0.757237 0.757283 0.757307 0.757330 0.757353
0.757377 0.757577
0.75740 0.757424 0.757447 0.757470
0.757494 0.7574749
0.757517 


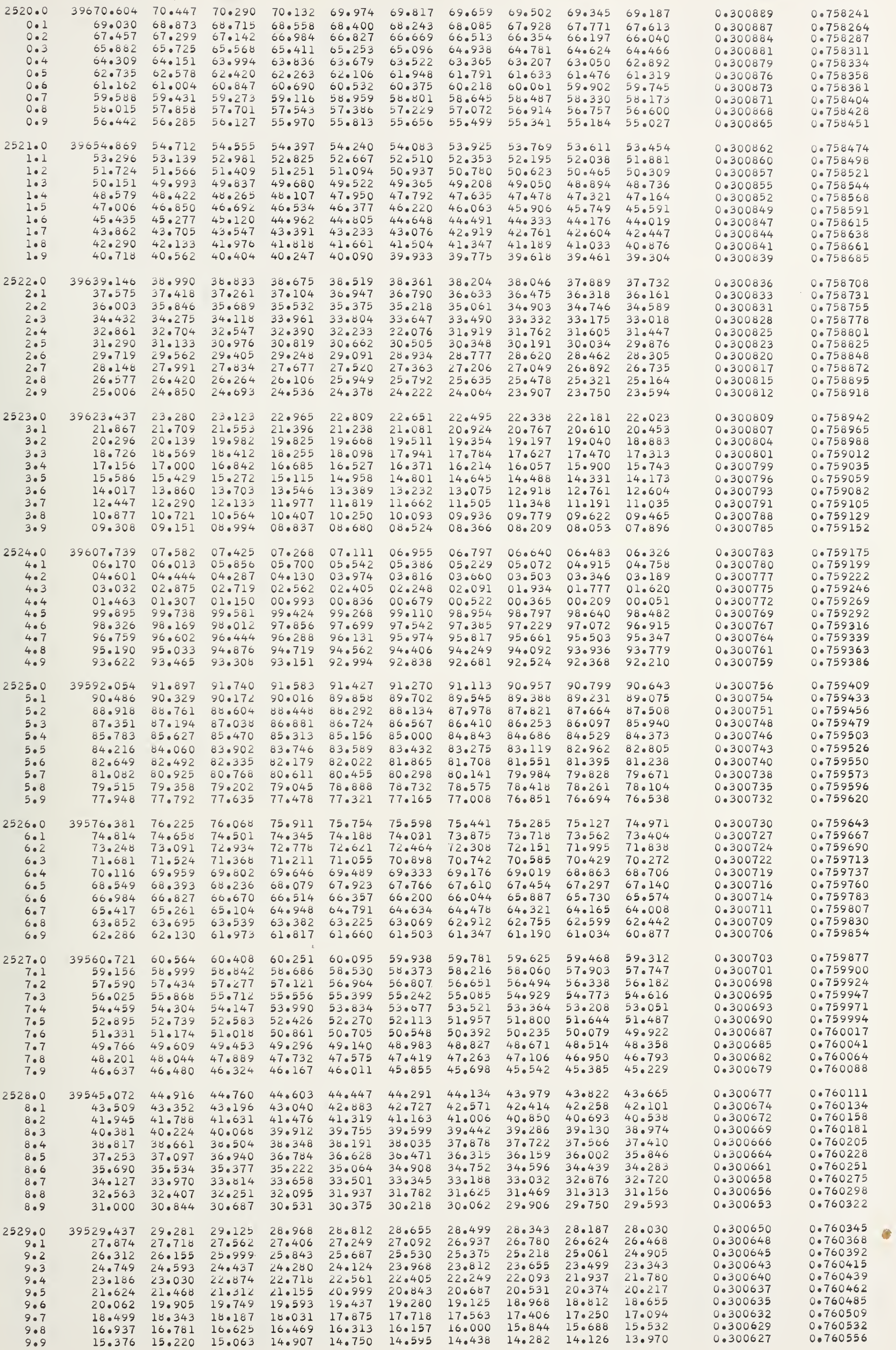

\begin{tabular}{|c|c|c|c|c|c|c|c|c|c|c|}
\hline & .001 & .002 & .003 & .004 & .005 & .006 & .007 & .008 & .009 & .010 \\
\hline $\begin{array}{l}.157 \\
.156\end{array}$ & $\begin{array}{l}.016 \\
.016\end{array}$ & $\begin{array}{l}.031 \\
.031\end{array}$ & $\begin{array}{l}.047 \\
.047\end{array}$ & $\begin{array}{l}.063 \\
.062\end{array}$ & $\begin{array}{l}.079 \\
.078\end{array}$ & $\begin{array}{l}.094 \\
.094\end{array}$ & $\begin{array}{r}110 \\
.109\end{array}$ & $\begin{array}{l}.126 \\
.125\end{array}$ & .142 & $\begin{array}{l}.157 \\
.156\end{array}$ \\
\hline
\end{tabular}




\begin{tabular}{|c|c|c|c|}
\hline$\lambda(A)$ & .00 & .01 & .02 \\
\hline 2530.0 & 39513.814 & 13.658 & 13.501 \\
\hline 0.1 & 12.252 & 12.096 & 11.939 \\
\hline $\begin{array}{l}0.2 \\
0.3\end{array}$ & 10.691 & 10.534 & 10.378 \\
\hline $\begin{array}{l}0.3 \\
0.4\end{array}$ & $\begin{array}{l}09.129 \\
07.568\end{array}$ & $\begin{array}{l}08.973 \\
07.413\end{array}$ & $\begin{array}{l}08.818 \\
07.256\end{array}$ \\
\hline $\begin{array}{l}0.4 \\
0.5\end{array}$ & $\begin{array}{l}07.568 \\
06.007\end{array}$ & $\begin{array}{l}07.413 \\
05.851\end{array}$ & $\begin{array}{l}07.256 \\
05.695\end{array}$ \\
\hline 0.6 & 04.446 & 04.290 & 04.134 \\
\hline 0.7 & 02.885 & 02.729 & 02.573 \\
\hline 0.8 & $\begin{array}{r}01.324 \\
39499.764\end{array}$ & $\begin{array}{l}01.168 \\
99.608\end{array}$ & $\begin{array}{l}01.012 \\
99.452\end{array}$ \\
\hline 0.9 & 39499 & & \\
\hline $\begin{array}{r}2531.0 \\
1.1\end{array}$ & 39498.203 & 98.047 & 97.891 \\
\hline 1.1 & 96.643 & 96.486 & 96.331 \\
\hline $\begin{array}{l}1.2 \\
1.3\end{array}$ & & 94.926 & 94.770 \\
\hline 1.3 & 93.522 & 93.366 & 93. \\
\hline $\begin{array}{l}1.4 \\
1.5\end{array}$ & & 91.806 & $910^{\circ}$ \\
\hline $\begin{array}{l}1.5 \\
1.6\end{array}$ & $\begin{array}{l}90.402 \\
88.842\end{array}$ & $\begin{array}{l}90.246 \\
88.687\end{array}$ & $\begin{array}{l}90.090 \\
88.530\end{array}$ \\
\hline $\begin{array}{l}1.6 \\
1.7\end{array}$ & $\begin{array}{l}88.842 \\
87.283\end{array}$ & $\begin{array}{l}88.687 \\
87.126\end{array}$ & $\begin{array}{l}88.530 \\
86.970\end{array}$ \\
\hline 1.8 & 85.723 & 85.567 & 85.411 \\
\hline 1.9 & 84.164 & 84.008 & 83.852 \\
\hline $\begin{array}{r}32.0 \\
2.1\end{array}$ & 39482.604 & 82.448 & 82.292 \\
\hline & 81.046 & 80.890 & 80.734 \\
\hline $\begin{array}{l}2.2 \\
2.3\end{array}$ & $\begin{array}{l}79.486 \\
77.927\end{array}$ & $\begin{array}{l}79.331 \\
77.771\end{array}$ & $\begin{array}{l}79.174 \\
77.616\end{array}$ \\
\hline & 76.368 & 76.213 & 76.057 \\
\hline 2.5 & 74.810 & 74.654 & 74.498 \\
\hline 2.6 & 73.251 & 73.096 & 72.939 \\
\hline 2.7 & 71.693 & 71.537 & 71.381 \\
\hline $\begin{array}{l}2.8 \\
2.9\end{array}$ & $\begin{array}{l}70.134 \\
68.576\end{array}$ & $\begin{array}{l}69.979 \\
68.420\end{array}$ & $\begin{array}{l}69.823 \\
68.265\end{array}$ \\
\hline $2 \cdot 9$ & 68.576 & 68.420 & 68.265 \\
\hline $\begin{array}{r}2533.0 \\
3.1\end{array}$ & $\begin{array}{r}39467.018 \\
65.460\end{array}$ & $\begin{array}{l}66.862 \\
65.304\end{array}$ & $\begin{array}{l}66.707 \\
65.148\end{array}$ \\
\hline 3.2 & 63.902 & $\begin{array}{l}63.304 \\
63.747\end{array}$ & $\begin{array}{l}03.148 \\
63.591\end{array}$ \\
\hline 3.3 & 62.345 & 62.188 & 62.033 \\
\hline 3.4 & 60.787 & 60.631 & 60.476 \\
\hline $\begin{array}{l}3.5 \\
3.6\end{array}$ & 59.229 & 59.074 & 58.918 \\
\hline $\begin{array}{l}3.6 \\
3.7\end{array}$ & $\begin{array}{l}57.672 \\
56.115\end{array}$ & $\begin{array}{l}57.516 \\
55.959\end{array}$ & $\begin{array}{l}57.360 \\
55.803\end{array}$ \\
\hline 3.8 & 54.558 & 54.402 & 54.247 \\
\hline 3.9 & 53.001 & 52.846 & 52.690 \\
\hline $\begin{array}{r}34.0 \\
4.1\end{array}$ & $\begin{array}{r}39451.444 \\
49.888\end{array}$ & $\begin{array}{l}51.289 \\
49.732\end{array}$ & $\begin{array}{l}51.133 \\
49.576\end{array}$ \\
\hline 4.2 & $\begin{array}{l}48.331 \\
48.331\end{array}$ & 48.175 & $\begin{array}{l}47.510 \\
48.020\end{array}$ \\
\hline $4 \cdot 3$ & 46.774 & 46.619 & 46.463 \\
\hline 404 & 45.218 & 45.063 & 44.907 \\
\hline 4.5 & 43.662 & 43.506 & 43.351 \\
\hline 4.6 & 42.106 & 41.950 & 41.794 \\
\hline 4.7 & 40.550 & 40.394 & 40.238 \\
\hline 4.8 & 38.994 & 38.838 & 38.683 \\
\hline 4.9 & 37.438 & 37.283 & 37.127 \\
\hline 535.0 & 435.862 & 35.727 & 35.571 \\
\hline 5.2 & $\begin{array}{l}34.327 \\
32.771\end{array}$ & 34.171 & \\
\hline $\begin{array}{l}5.2 \\
5.3\end{array}$ & $\begin{array}{l}.071 \\
.216\end{array}$ & $\begin{array}{l}32.616 \\
31.061\end{array}$ & 32.460 \\
\hline 5.4 & 29.661 & $\begin{array}{l}31.061 \\
29.505\end{array}$ & 29.350 \\
\hline 5.5 & 28.106 & 27.951 & 27.796 \\
\hline 5.6 & 0.552 & 26.396 & 26.241 \\
\hline 5.7 & 24.997 & 24.841 & 24.686 \\
\hline 5.8 & 23.442 & 23.287 & 23.131 \\
\hline 5.9 & 21.887 & 21.732 & 21.577 \\
\hline 36.0 & 39420.333 & $20 \cdot 178$ & 20.022 \\
\hline & & 18.6 & 18. \\
\hline $\begin{array}{l}6.2 \\
6.3\end{array}$ & 7.225 & 17.069 & 16.914 \\
\hline $\begin{array}{l}6.3 \\
6.4\end{array}$ & 15.670 & 15.515 & 15.360 \\
\hline $\begin{array}{l}6.4 \\
6.5\end{array}$ & 0.117 & $13 \cdot 9$ & 13. \\
\hline $\begin{array}{l}6.5 \\
6.6\end{array}$ & .562 & $12 \cdot 4$ & 12.2 \\
\hline $\begin{array}{l}6.6 \\
6.7\end{array}$ & 11.010 & 10.854 & 10.699 \\
\hline $\begin{array}{l}6.7 \\
6.8\end{array}$ & 09.456 & 09.300 & 09.145 \\
\hline $\begin{array}{l}6.8 \\
6.9\end{array}$ & $\begin{array}{l}07.902 \\
06.349\end{array}$ & $\begin{array}{l}07.747 \\
06.194\end{array}$ & $\begin{array}{l}07.592 \\
06.039\end{array}$ \\
\hline & & & \\
\hline & & $0=3$ & \\
\hline 7.2 & 0 & 01.9 & 01 \\
\hline 7.3 & 38 & *99.982 & *99.827 \\
\hline $7 \cdot 4$ & 39398.584 & 98.430 & 98.274 \\
\hline 7.5 & 32 & 96 & 96 \\
\hline 7.6 & 79 & 95 & 9 \\
\hline $7 \cdot 7$ & 7 & 93 & 7 \\
\hline 7.8 & .375 & 92.220 & 92.065 \\
\hline 7.9 & 90.823 & 90.668 & 90.513 \\
\hline 38. & 71 & 89 & 1 \\
\hline & & & \\
\hline 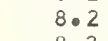 & & 86 & \\
\hline 8.3 & 6 & 84.2 & \\
\hline & & 82 & \\
\hline 8 & & 81 & \\
\hline 8 & 2 & 79.807 & 79.651 \\
\hline 8. & 0411 & 78.2 & 78.1 \\
\hline $\begin{array}{l}8.8 \\
8.9\end{array}$ & 76.859 & 76.704 & $76 \cdot 5$ \\
\hline 8.9 & 75.310 & 75.155 & 74.999 \\
\hline $\begin{array}{r}2539.0 \\
9.1\end{array}$ & $\begin{array}{r}39373.758 \\
72.208\end{array}$ & $\begin{array}{l}73.604 \\
72.053\end{array}$ & $\begin{array}{l}73.449 \\
71.898\end{array}$ \\
\hline 9.2 & & & \\
\hline 9.3 & 7 & 68.5 & 7 \\
\hline 20 & .557 & 67.402 & 67.247 \\
\hline 0 & 007 & & \\
\hline 9. & 457 & 64.302 & \\
\hline 8 & & 62.752 & 62.597 \\
\hline & 1.357 & 61.202 & 61.047 \\
\hline 9.9 & 9.807 & 59.652 & 0.498 \\
\hline & & & \\
\hline & & & \\
\hline & & & \\
\hline
\end{tabular}


$9358.257 \quad 58.103$

0.2

$55.159 \quad 55.004$

$\begin{array}{lll}53.610 & 53.455 & 53.84\end{array}$

$52.061 \quad 51.906 \quad 51.751500146$

$\begin{array}{lllll}48.964 & 48.809 & 40.654 & 48.499 & 48.344\end{array}$

$47.415 \quad 47.260 \quad 47.10$

$\begin{array}{ll}45.867 & 45 \cdot 71 \\ 44.318 & 44.16\end{array}$

2541.0

4100
1.1
1.2
$1: 2$
1.5
1.6
1.7
1.8
1.9

39342

342.770
41.222 41.6

$1: 4$

$\begin{array}{ll}.519 & 39.912 \\ 39.364\end{array}$

$38.125 \quad 37.971$

$\begin{array}{lll}36.578 & 36.423 & 36.269\end{array}$

$\begin{array}{llll}35.030 & 34.875 & 34.721 & 34.566\end{array}$

$\begin{array}{lllll}3.402 & 33.328 & 33.173 & 33.019 & 32.804\end{array}$

$31.93531 .780 \quad 31.625$

$\begin{array}{ll}30.388 & 30.233 \\ 28.840 & 28.686\end{array}$

2542.

2.
2.
2
2
2
2
2
2

39327.29

$22.293 \quad 27.13$

$\begin{array}{ll}25.747 & 25.592 \\ 24.200 & 24.045 \\ 22.653 & 22.498\end{array}$

$21.107 \quad 20.953$

$\begin{array}{ll}19.560 & 19.406 \\ 18.014 & 17.859\end{array}$

$\begin{array}{ll}14.468 & 16.313 \\ 14.921 & 14.767\end{array}$

13.375

2543.0

3.0
3
3
3
3
3
3.6
3.7
3.8
3

$39311.830 \quad 11.67$

10.28
08.738

10.12

\begin{tabular}{ll}
7 & 110 \\
4 & 0 \\
8 & 0 \\
4 & 0 \\
\hline & 050
\end{tabular}

.97509 .82

$\begin{array}{lllll}05.647 & 05.493 & 05.338 & 05.184 & 05.029\end{array}$

$02.557 \quad 02.403 \quad 02.248 \quad 02.094 \quad 01.939$

$\begin{array}{lllll}01.012 & 00.857 & 00.703 & 00.549 & 00.394\end{array}$

39299.467
97.922

99.312

99.158

99.004

96.849
97.304

2544.0

39296.377

$94.834 \quad 94.679$

96.06

97.459

$91.745 \quad 91.590 \quad 91.437 \quad 91.281$

$88.656 \quad 88.502 \quad 88.348$

$87.113 \quad 86.958$

$85.569 \quad 85.415 \quad 85.260$

$\begin{array}{lll}84.025 & 83.871 & 83.717 \\ 82.481 & 82.328 & 82.173\end{array}$

9.73

95.760
94.216

9280.93

2545

5.

$\begin{array}{lll}79.395 & 79.241 & 80 .\end{array}$

$5 \cdot 3$

$\begin{array}{ll}77.852 & 77.697 \\ 76.309 & 76.154\end{array}$

$74.766 \quad 74.612$

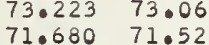

$70.138 \quad 69.98$

5.6

5.8

$\begin{array}{ll}68.596 & 68.441 \\ 67.053 & 66.899\end{array}$

2546.0

66.89968 .287

5.106

91.671

89.583

86.495

84.952

82.019

81.864

0.629
9.086
7.543

80.475
78.932

80.321
78.778

$\begin{array}{lll}76.000 & 75.846 & 75.23 \\ 74.450 & 74.303 & 74.148\end{array}$

$74.458 \quad 74.303$

$\begin{array}{ll}71.315 & 72.760 \\ 61.218\end{array}$

74.148

72.606

71.063
69.521

$\begin{array}{ll}69.675 & 69.521 \\ 68.133 & 67.979\end{array}$

9265.51

6.96

$63.969 \quad 63.357$

$\begin{array}{ll}.661 & 63.506 \\ 6.116 & 61.96\end{array}$

$\begin{array}{lllllll}66.436 & 66.282 & 66.128 & 65.973 & 65.819 & 65.6065\end{array}$

$\begin{array}{lllll}.511 & 09.356 & 09.202 & 09.047 & 08.893\end{array}$

$\begin{array}{llllll}07.965 & 07.811 & 07.656 & 07.501 & 07.347\end{array}$

$\begin{array}{lllll}06.420 & 06.265 & 06.111 & 05.957 & 05.802 \\ 04.875 & 04.720 & 04.565 & 04.411 & 04.257\end{array}$

$\begin{array}{lllll}03.330 & 03.175 & 03.021 & 02.867 & 02.711\end{array}$

$00.240 \quad 00.085 * 99.931 * 99.776 * 99.622$

$\begin{array}{lllll}98.695 & 98.541 & 98.386 & 98.232 & 98.077 \\ 97.150 & 96.996 & 96.841 & 96.687 & 96.532\end{array}$

$\begin{array}{lllll}95.605 & 95.451 & 95.297 & 95.143 & 94.988\end{array}$

$\begin{array}{lllll}92.517 & 92.363 & 92.208 & 92.054 & 91.899\end{array}$

$90.973 \quad 90.818 \quad 90.664 \quad 90.510 \quad 90.355$

$\begin{array}{lllll}87.884 & 87.730 & 87.576 & 87.421 & 87.267\end{array}$

$\begin{array}{lllll}86.341 & 86.187 & 86.032 & 85.878 & 85.723\end{array}$

$\begin{array}{lllll}3.254 & 83.099 & 82.944 & 82.791 & 82.636\end{array}$

$\begin{array}{lllll}80.167 & 80.012 & 79.858 & 79.704 & 79.549\end{array}$

$\begin{array}{lllll}78.623 & 78.469 & 78.314 & 78.160 & 78.005 \\ 77.081 & 76.926 & 76.772 & 76.618 & 76.463\end{array}$

$\begin{array}{lllll}75.538 & 75.383 & 75.229 & 75.075 & 74.920\end{array}$

$\begin{array}{lllll}73.995 & 73.840 & 73.686 & 73.532 & 73.377\end{array}$

$\begin{array}{lllll}70.909 & 70.755 & 70.601 & 70.446 & 70.292\end{array}$

$\begin{array}{lllll}69.366 & 69.212 & 69.058 & 68.903 & 68.750\end{array}$

$64.894 \quad 64.740 \quad 64.585 \quad 64.432 \quad 64.277 \quad 64.123$ $\begin{array}{lllllll}61.810 & 61.655 & 61.501 & 61.347 & 61.193 & 61.039\end{array}$

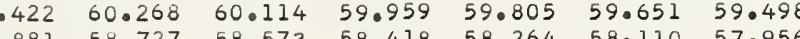
$\begin{array}{llllllllll}57.802 & 57.648 & 57.494 & 57.339 & 57.186 & 57.031 & 56.076 & 56.723 & 56.568 & 56.414\end{array}$ $\begin{array}{llllllllll}56.260 & 56.106 & 55.952 & 55.798 & 55.644 & 55.490 & 55.335 & 55.181 & 55.027 & 54.873\end{array}$

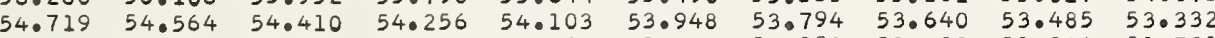
$\begin{array}{llllllllllll}53 & 177 & 53.023 & 52.870 & 52.715 & 52.561 & 52.407 & 52.253 & 52.098 & 51.944 & 51.791\end{array}$ 51.63651 .482

$250.095 \quad 49.941$ $48.555-48.941$

$48.555 \quad 48.400$

$45.473 \quad 45.319$

$43.932 \quad 43.778$

$\begin{array}{ll}42.392 & 42.238 \\ 40.853 & 40.698\end{array}$

$\begin{array}{ll}40.853 & 40.698 \\ 39.312 & 39.15\end{array}$

$\begin{array}{ll}37.772 & 37.61 \\ 36.232 & 36.078\end{array}$

7.8
7.8

2548 .

8.1

39234.692340

$33.152 \quad 32.99$

$\begin{array}{ll}31.613 & 31.459 \\ 30.074 & 29.919\end{array}$

$\begin{array}{ll}28.534 & 28.380 \\ 26.995 & 26.84\end{array}$

$\begin{array}{ll}26.995 & 26.84 \\ 25.456 & 25.30\end{array}$

$\begin{array}{ll}23.917 & 23.763 \\ 22.378 & 22.224\end{array}$

$\begin{array}{ll}22.378 & 22.224 \\ 20.839 & 20.686\end{array}$

$\begin{array}{rrrrrrrrrrr}49.0 & 39219.301 & 19.147 & 18.993 & 18.839 & 18.686 & 18.532 & 18.378 & 18.224 & 18.070 & 17.917 \\ 9.1 & 17.762 & 17.608 & 17.455 & 17.301 & 17.147 & 16.993 & 16.840 & 16.686 & 16.532 & 16.378\end{array}$

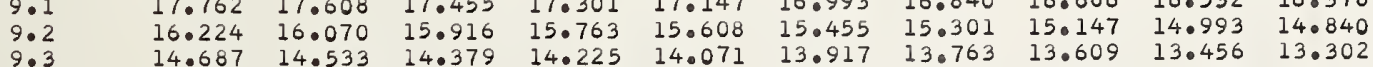

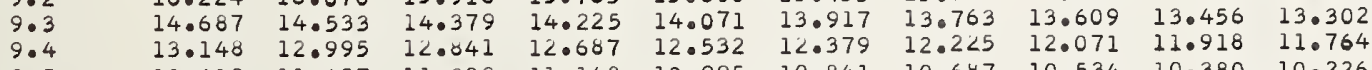
$\begin{array}{llllllllll}11.610 & 11.457 & 11.303 & 11.148 & 10.995 & 10.841 & 10.687 & 10.534 & 10.380 & 10.226 \\ 10.072 & 09.918 & 09.765 & 09.611 & 09.457 & 09.303 & 09.149 & 08.996 & 08.842 & 08.688\end{array}$ $\begin{array}{lllllllllll}08.534 & 08.380 & 08.227 & 08.073 & 07.919 & 07.765 & 07.612 & 07.458 & 07.304 & 07.150\end{array}$ $\begin{array}{llllllllll}06.997 & 06.843 & 06.689 & 06.536 & 06.381 & 06.228 & 06.074 & 05.920 & 05.767 & 05.62 .3\end{array}$

$\begin{array}{llll}.154 & .001 & .002 & .003 \\ .015 & .031 & .046\end{array}$

$\begin{array}{ll}.154 & .015 \\ .153 & .015\end{array}$

.031

.046

$\begin{array}{llll}.006 & .007 \quad .008 \quad .009\end{array}$

.139
.138

\section{$(n-1) \times 1000$}

$\lambda(n-1)$

0.300363

0.300358

0.300355

0.300350

0.300348

0.300345

0.300340

0.300337

0.300335

0.300329

0.300327

0.300322

0.300319

0.300314

0.300311

0.300306

0.300304

0.300301

0.300298

0.300293

0.300291

0.300286

0.300283

0.300278

0.300275

0.300273

0.300267

0.300265

0.300260

0.300252

0.300247

0.300244

0.300239

0.300237

0.300234

0.300229

0.300226

0.300224

0.300219

0.300216

0.300211

0.300208

0.300206

0.300201

0.300198

0.300195

0.300190

0.300188

0.300183

0.300180

0.300178

0.30017 .5

0.300170

0.300167

0.300165

0.300162

0.300157

0.300154

0.300152

0.300147

0.300144

0.300142

0.300137

0.300131

0.300129

0.300126

0.300124

0.300119

0.300116

0.300114

0.300111

.010

.154
.153

0.762922

.762969

0.762993
0.763016

0.763039

0.763086

0.763110
0.763133

0.763157

0.763180

0.763227

0.763251
0.763274

0.763297
0.763321

0.763344

0.763391

0.763415

0.763462

0.763509

0.763532

0.763556
0.763579

.

763626

0.763649

0.763696

0.763743

0.763767

0.763790
0.763814

0.763837

0.763861

0.763908

0.763931

0.763978

0.764002

0.764049

0.764096

0.764142

0.764166
0.764189

0.764213

0.764236

0.764260

0.764283

0.764330 


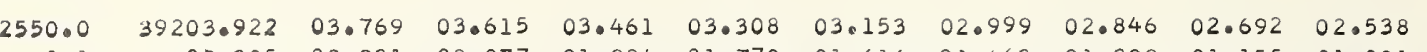

$\begin{array}{lllllllllll}0.1 & 02.385 & 02.231 & 02.077 & 01.924 & 01.770 & 01.616 & 01.463 & 01.309 & 01.0155 & 01.001\end{array}$

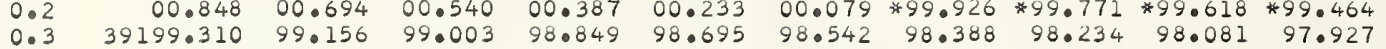

$\begin{array}{lllllllllll}0.4 & 97.773 & 97.620 & 97.466 & 97.312 & 97.159 & 97.005 & 96.852 & 96.698 & 96.545 & 96.391\end{array}$

$\begin{array}{lllllllllll}0.5 & 96.237 & 96.083 & 95.930 & 95.776 & 95.623 & 95.469 & 95.315 & 95.162 & 95.008 & 94.854 \\ 0.6 & 94.700 & 94.546 & 94.393 & 94.239 & 94.086 & 93.932 & 93.779 & 93.625 & 93.471 & 93.317\end{array}$

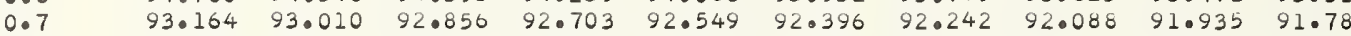

$\begin{array}{lllllllllll}0.8 & 91.627 & 91.473 & 91.320 & 91.166 & 91.013 & 90.859 & 90.706 & 90.552 & 90.398 & 90.245 \\ 0.9 & 90.090 & 89.937 & 89.784 & 89.630 & 89.476 & 89.323 & 89.169 & 89.015 & 88.862 & 88.708\end{array}$

2551.0

1.1

1.4

1.5

1.7

1.7

2552.0

2.1
2.2
2.3

2.4

2.6

2.8

2.9

2553.0

3.1
3.2

3.3
3.4

3.5

3.6
3.7
3.8

3.8
3.9

2554.0

4.2

4.03

4.5

4.6
4.7

4.8
4.9

2555.

5.2

5.3

5.5

5.7

5.8
5.9

2556.0

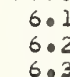

6.3

6.4

6.6

6.8

2557.

70

7.4

7.7

7.9

2558.0

8.2

8.3

8.5

8.6

8.8
8.9

2559.0

9.

9.3

9.5

9.6

9.8 $\begin{array}{rrl}39188.554 & 88.401 & 8 \\ 87.020 & 86.866 & 86 \\ 85.483 & 85.330 & 8 \\ 83.947 & 83.793 & 83 . \\ 82.411 & 82.258 & 82 . \\ 80.875 & 80.722 & 80 \\ 79.340 & 79.187 & 79 \\ 77.805 & 77.652 & 77 \\ 76.270 & 76.116 & 75 \\ 74.734 & 74.582 & 74\end{array}$

71.635

70.130

73.0411
69.977

67.061

$65.526 \quad 65.374$

$63.993 \quad 63.839$

$62.458 \quad 62.305 \quad 62.75$

$59.391 \quad 60.771 \quad 60.618$

56.

$54.790 \quad 54.170$

$53.256 \quad 53.103$

$51.723 \quad 51.570 \quad 51.417$

$50.190 \quad 50.037 \quad 49.88$

$\begin{array}{lll}48.657 & 48.503 & 48.350 \\ 47.124 & 46.970 & 46.817\end{array}$

$\begin{array}{lll}47.124 & 46.970 & 46.817 \\ 45.591 & 45.437 & 45.285\end{array}$

39142.526
40.994
39.461

$30.994 \quad 40.840$

$\begin{array}{llll}49.461 & 39.308 & 30.687\end{array}$

$34.865 \quad 34.711 \quad 34.558$

$33.333 \quad 33.180 \quad 33.027$

31.80231 .648

$30.270 \quad 30.117$

31.495

$88.093 \quad 87.940$

89.323

87.633

$87.480 \quad 87.326 \quad 87.172$

$\begin{array}{lllllll}86.558 & 86.404 & 86.251 & 86.098 & 85.944 & 85.790 & 85.636\end{array}$

$\begin{array}{lllllll}85.022 & 84.868 & 84.715 & 84.562 & 84.408 & 84.254 & 84.101 \\ 83.486 & 83.333 & 83.179 & 83.025 & 82.872 & 82.719 & 82.565\end{array}$

$\begin{array}{lllllll}81.951 & 81.796 & 81.644 & 81.490 & 81.336 & 81.183 & 81.029\end{array}$

$\begin{array}{llllllll}80.415 & 80.261 & 80.108 & 79.954 & 79.801 & 79.647 & 79.494 \\ 78.880 & 78.727 & 78.573 & 78.419 & 78.266 & 78.112 & 77.958\end{array}$

$\begin{array}{llllllll}77.345 & 77.191 & 77.038 & 76.884 & 76.730 & 76.577 & 76.423 \\ 75.810 & 75.656 & 75.503 & 75.349 & 75.195 & 75.042 & 74.8888\end{array}$

$\begin{array}{lllllll}74.274 & 74.121 & 73.967 & 73.814 & 73.600 & 73.507 & 73.353\end{array}$

$\begin{array}{lllllll}72.739 & 72.586 & 72.433 & 72.279 & 72.125 & 71.972 & 71.818\end{array}$

$\begin{array}{lllllll}71.205 & 71.051 & 70.897 & 70.744 & 70.590 & 70.437 & 70.283\end{array}$

$\begin{array}{lllllll}69.670 & 69.517 & 69.363 & 69.210 & 69.056 & 68.903 & 68.750\end{array}$

$\begin{array}{lllllll}66.1351 & 67.982 & 67.829 & 67.675 & 67.521 & 67.369 & 67.215 \\ 66.447 & 66.294 & 66.141 & 65.987 & 65.834 & 65.680\end{array}$

$\begin{array}{lllllll}65.066 & 64.913 & 64.760 & 64.606 & 64.453 & 64.299 & 64.146\end{array}$

$\begin{array}{lllllll}63.532 & 63.379 & 63.225 & 63.072 & 62.918 & 62.765 & 62.612\end{array}$

$\begin{array}{lllllll}60.464 & 60.311 & 60.158 & 60.004 & 59.851 & 59.698 & 59.544 \\ 58.931 & 58.777 & 58.624 & 58.470 & 58.317 & 58.164 & 58.0020\end{array}$

$\begin{array}{lllllll}57.397 & 57.243 & 57.090 & 56.937 & 56.783 & 56.630 & 56.477\end{array}$

$\begin{array}{lllllll}55.863 & 55.709 & 55.556 & 55.403 & 55.250 & 55.096 & 54.943\end{array}$

$\begin{array}{lllllll}52.796 & 52.642 & 52.489 & 52.336 & 52.183 & 52.029 & 51.876\end{array}$

$\begin{array}{llllllll}51.263 & 51.110 & 50.957 & 50.803 & 50.649 & 50.497 & 50.343\end{array}$

$\begin{array}{lllllll}49.730 & 49.577 & 49.423 & 49.270 & 49.117 & 48.963 & 48.810 \\ 48.197 & 48.044 & 47.891 & 47.737 & 47.583 & 47.430 & 47.277\end{array}$

$\begin{array}{lllllll}46.664 & 48.0411 & 46.851 & 47.737 & 47.583 & 47.430 & 47.277 \\ 46.205 & 46.051 & 45.897 & 45.744\end{array}$

$\begin{array}{lllllll}46.664 & 46.511 & 46.357 & 46.205 & 46.051 & 45.897 & 45.744 \\ 45.131 & 44.978 & 44.825 & 44.671 & 44.518 & 44.365 & 44.211\end{array}$

(28.432

$39127.207 \quad 27.054 \quad 26.900$

$\begin{array}{lll}25.676 & 25.522 & 25.36 \\ 24.145 & 23.992 & 23.83\end{array}$

$22.614 \quad 22.460 \quad 22.308$

$21.083 \quad 20.930 \quad 20.776$

$\begin{array}{lll}19.551 & 19.399 & 19.24 \\ 18.021 & 17.868 & 17.071\end{array}$

$\begin{array}{lll}16.490 & 16.337 & 16.1 \\ 14.961 & 14.807 & 14.154\end{array}$

$\begin{array}{lll}14.961 & 14.807 & 14.654 \\ 13.430 & 13.277 & 13.124\end{array}$

10.370
08.840
0.08 .216

07.31008 .687

05.78105 .62

04.25104 .098

$01.192 \quad 01.03$

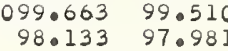

11.594

08.533

05.475

03.945
02.416

02.416

42.06

41.913

$43.292 \quad 43.139$

42.98

42.83

$\begin{array}{ll}42.00634 & 40.360 \\ 39.001 & 38.8\end{array}$

$37.469 \quad 37.316$

$\begin{array}{ll}35.937 & 35.7 \\ 34.405 & 34.252\end{array}$

$\begin{array}{ll}32.874 & 32.7 \\ 31.342 & 31.18\end{array}$

$40.760 \quad 41.606$

$\begin{array}{ll}40.227 & 40.074 \\ 38.695 & 38.542\end{array}$

41.454
39.921

$41.300 \quad 41.147$

$\begin{array}{ll}29.811 & 29.657 \\ 28.279 & 28.0\end{array}$

$26.747 \quad 26.595$

$25.216 \quad 25.0063$

$\begin{array}{ll}23.686 & 23.0532 \\ 22.154 & 22.001\end{array}$

$\begin{array}{ll}22.154 & 22.001 \\ 20.624 & 20.470\end{array}$

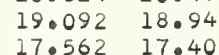

$\begin{array}{ll}17.562 & 17.409 \\ 16.031 & 15.87\end{array}$

$\begin{array}{ll}14.501 & 14.348 \\ 12.971 & 12.818\end{array}$

12.44011 .28

$\begin{array}{ll}11.440 & 11.288 \\ 09.911 & 09.758\end{array}$

06.852

05.32205 .168

$03.792 \quad 03.640$

$\begin{array}{ll}02.263 & 02.110 \\ 00.733 & 00.581\end{array}$

$\begin{array}{lllll} & 36.00\end{array}$

$\begin{array}{llllll}34.099 & 33.946 & 33.793 & 33.640 & 33.486\end{array}$

$2.567 \quad 32.414 \quad 32.261 \quad 32.108 \quad 31.955$

$\begin{array}{lllll}29.504 & 29.351 & 29.197 & 29.044 & 28.892\end{array}$

$\begin{array}{lllll}26.441 & 26.288 & 26.135 & 25.981 & 25.828\end{array}$

$\begin{array}{lllll}24.910 & 24.758 & 24.604 & 24.451 & 24.297 \\ 23.379 & 23.227 & 23.073 & 22.919 & 22.767\end{array}$

$\begin{array}{lllll}21.849 & 21.027 & 23.073 & 22.919 & 22.767 \\ 21.542 & 21.389 & 21.236\end{array}$

$\begin{array}{lllll}20.317 & 20.164 & 20.011 & 19.858 & 19.705 \\ 18.787 & 18.633 & 18.480 & 18.327 & 18.174\end{array}$

$\begin{array}{lllll}18.787 & 18.633 & 18.480 & 18.327 & 18.174 \\ 17.256 & 17.103 & 16.950 & 16.796 & 16.643 \\ 15.726 & 15.573 & 15.420 & 15.267 & 15.114\end{array}$

$39096.605 \quad 96.452$

95.076

93.54793 .923

$88.961 \quad 88.809 \quad 88.656$

$\begin{array}{lll}87.434 & 87.281 & 87.12 \\ 85.906 & 85.753 & 85.600\end{array}$

$84.377 \quad 84.22$

$82.850 \quad 82.697$

84.072

97.675

99.051
97.522

$14.195 \quad 15.573$

15.420

$\begin{array}{lllll} & & \end{array}$

$\begin{array}{lllll}11.135 & 10.981 & 10.829 & 10.676 & 10.523\end{array}$

$09.604 \quad 09.452 \quad 09.299 \quad 09.146 \quad 08.993$

$\begin{array}{lllll}00.075 & 07.922 & 07.769 & 07.616 & 07.463\end{array}$

$\begin{array}{llllll}05.016 & 04.863 & 04.709 & 04.557 & 04.404\end{array}$

$\begin{array}{lllll}03.486 & 03.333 & 03.180 & 03.027 & 02.874\end{array}$

$01.957 \quad 01.804 \quad 01.651 \quad 01.498 \quad 01.345$

$00.427 \quad 00.274 \quad 00.122 * 99.968 * 99.816$

$\begin{array}{lllll}98.898 & 98.745 & 98.592 & 98.439 & 98.287 \\ 97.370 & 97.217 & 97.064 & 96.911 & 96.758\end{array}$

$\begin{array}{lllllll}96.146 & 95.994 & 95.841 & 95.687 & 95.535 & 95.382 & 95.229\end{array}$

$\begin{array}{lllllll}93.089 & 92.465 & 94.312 & 94.159 & 94.006 & 93.053 & 93.70 \\ & 92.783 & 92.630 & 92.478 & 92.324 & 92.17\end{array}$

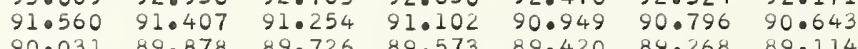

$\begin{array}{lllllll}90.031 & 89.878 & 89.726 & 89.573 & 89.420 & 89.268 & 89.114 \\ 88.503 & 88.351 & 88.198 & 88.045 & 87.893 & 87.740 & 87.586\end{array}$

$\begin{array}{lllllll}86.975 & 86.822 & 86.669 & 86.517 & 86.364 & 86.211 & 86.058\end{array}$

$\begin{array}{llllllll}85.447 & 85.294 & 85.141 & 84.989 & 84.836 & 84.683 & 84.530\end{array}$

$\begin{array}{lllllll}83.919 & 83.766 & 83.614 & 83.460 & 83.308 & 83.155 & 83.002 \\ 82.391 & 82.238 & 82.085 & 81.933 & 81.780 & 81.627 & 81.475\end{array}$

$79.794 \quad 79.642 \quad 79.0469$

$78.267 \quad 78.114 \quad 77.961$

$\begin{array}{llllllllll}76.739 & 76.586 & 76.434 & 76.281 & 76.050 & 75.502 & 77.350 & 77.197 & 77.044 & 76.892\end{array}$

$\begin{array}{lllllllllll}75.212 & 75.060 & 74.907 & 74.754 & 74.601 & 74.448 & 74.295 & 74.143 & 73.990 & 73.837\end{array}$

$\begin{array}{llllllllll}73.158 & 72.532 & 73.0379 & 73.227 & 73.074 & 72.921 & 72.768 & 72.616 & 72.463 & 72.310\end{array}$

$\begin{array}{llllllllll}70.631 & 70.478 & 70.325 & 70.173 & 70.020 & 69.868 & 69.715 & 69.562 & 69.409 & 69.257\end{array}$

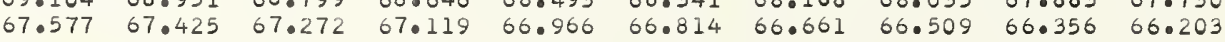

$39066.050 \quad 65.898 \quad 65.745 \quad 65.592 \quad 65.440$

$62.998 \quad 62.845620 .692 \quad 62.54063 .914$

$61.472 \quad 61.319 \quad 61.167 \quad 61.014 \quad 60.861$

$59.946 \quad 59.793 \quad 59.640 \quad 59.488 \quad 59.33$

$58.419 \quad 58.268 \quad 58.114$

$\begin{array}{lllll}56.894 & 56.741 & 56.588 & 56.436 & 56.203 \\ 55.368 & 55.215 & 55.062 & 54.910 & 54.757\end{array}$

$\begin{array}{lllll}55.368 & 55.215 & 55.062 & 54.9110 & 54.757 \\ 53.842 & 53.689 & 53.538 & 53.384 & 53.231\end{array}$

$65.288 \quad 65.135 \quad 64.982 \quad 64.830 \quad 64.676$

$63.76163 .608 \quad 63.456 \quad 63.303 \quad 63.150$

$\begin{array}{lllll}62.234 & 62.082 & 61.929 & 61.777 & 61.625 \\ 60.709 & 60.556 & 60.403 & 60.251 & 60.099\end{array}$

$59.183 \quad 59.030 \quad 58.877 \quad 58.725 \quad 58.572$

$\begin{array}{lllll}57.657 & 57.504 & 57.352 & 57.199 & 57.046\end{array}$

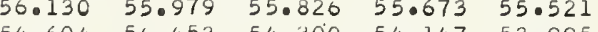

$\begin{array}{lllll}54.604 & 54.453 & 54.300 & 54.147 & 53.995\end{array}$

$2.317 \quad 52.165 \quad 52.012$

$(n-1) \times 1000$

$\lambda(n-1)$

0.300206

0.300103

0.300101

0.300098

.300096

0.300091

.300088

0.300085

0.300083

0.300080

.300075

0.300073

0.300068

0.300065

0.300063
0.300060

0.300057

0.300055

0.300052

0.300047

0.300045

0.300042

0.300040

0.300037

0.300032

0.300030

0.300027

0.300022

0.300019

0.300017

0.300014

0.300009

0.300004

0.300002

0.299999

0.299997

0.299991

0.299989

0.299986

0.299981

0.299979

0.299976

0.299971

0.299966

0.299964

.

0.299959

0.299953

0.299951

0.299943

0.299938 
$\begin{array}{lllllllllll}2560.0 & 39050.792 & 50.639 & 50.487 & 50.334 & 50.182 & 50.029 & 49.876 & 49.724 & 49.571 & 49.418\end{array}$

$\begin{array}{lllllllllll}0.1 & 49.267 & 49.114 & 48.961 & 48.809 & 48.656 & 48.504 & 48.351 & 48.198 & 48.046 & 47.893\end{array}$

$\begin{array}{lllllllllll}0.3 & 46.741 & 47.588 & 47.436 & 47.284 & 47.131 & 46.979 & 46.026 & 46.673 & 46.521 & 46.369\end{array}$

$\begin{array}{lllllllllll}0.4 & 44.691 & 44.539 & 44.386 & 44.233 & 44.081 & 43.929 & 43.776 & 43.624 & 43.472 & 43.843\end{array}$

$\begin{array}{llllllllllll}0.5 & 43.166 & 43.014 & 42.861 & 42.709 & 42.557 & 42.404 & 42.251 & 42.100 & 41.947 & 41.794 \\ 0.6 & 41.642 & 41.489 & 41.337 & 41.185 & 41.032 & 40.879 & 40.728 & 40.575 & 40.422 & 40.269\end{array}$

$\begin{array}{llllllllllll}0.7 & 40.117 & 39.964 & 39.812 & 39.660 & 39.507 & 39.355 & 39.203 & 39.050 & 38.897 & 38.745\end{array}$

$\begin{array}{lllllllllll}0.8 & 38.592 & 38.440 & 38.280 & 38.135 & 37.983 & 37.831 & 37.678 & 37.525 & 37.374 & 37.221 \\ 0.9 & 37.068 & 36.916 & 36.763 & 36.611 & 36.458 & 36.306 & 36.154 & 36.001 & 35.849 & 35.697\end{array}$

$\begin{array}{lllllllllll}2561.0 & 39035.543 & 35.392 & 35.239 & 35.086 & 34.935 & 34.782 & 34.630 & 34.478 & 34.325 & 34.173\end{array}$

$\begin{array}{lllllllllll}1.1 & 34.021 & 33.868 & 33.715 & 33.563 & 33.411 & 33.258 & 33.106 & 32.954 & 32.801 & 32.648 \\ 1.2 & 32.497 & 32.344 & 32.191 & 32.039 & 31.887 & 31.734 & 31.582 & 31.430 & 31.277 & 31.125\end{array}$

$\begin{array}{lllllllllll}1.3 & 32.497 & 32.344 & 32.191 & 32.039 & 31.887 & 31.734 & 31.582 & 31.430 & 31.277 & 31.125 \\ 1.3 & 30.973 & 30.820 & 30.668 & 30.515 & 30.362 & 30.210 & 30.058 & 29.906 & 29.753 & 29.601\end{array}$

$\begin{array}{lllllllllll}1.4 & 29.449 & 29.296 & 29.144 & 28.991 & 28.839 & 28.687 & 28.534 & 28.382 & 28.229 & 28.077 \\ 1.5 & 27.925 & 27.773 & 27.620 & 27.467 & 27.315 & 27.163 & 27.010 & 26.858 & 26.706 & 26.554\end{array}$

$\begin{array}{lllllllllll}1.6 & 26.401 & 26.249 & 26.097 & 25.944 & 25.792 & 25.639 & 25.488 & 25.335 & 25.183 & 25.030 \\ 1.7 & 24.878 & 24.726 & 24.574 & 24.421 & 24.269 & 24.117 & 23.964 & 23.812 & 23.659 & 23.507\end{array}$

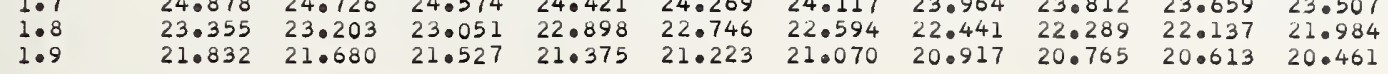

$\begin{array}{lllllllllll}2562.0 & 39020.309 & 20.157 & 20.004 & 19.852 & 19.700 & 19.547 & 19.395 & 19.243 & 19.090 & 18.938\end{array}$

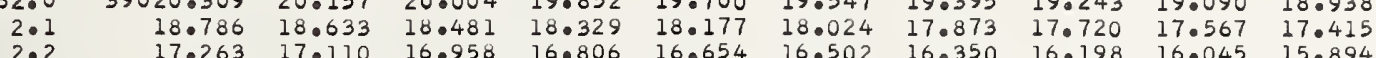

$\begin{array}{lllllllllll}2.2 & 17.263 & 17.110 & 16.958 & 16.806 & 16.654 & 16.502 & 16.350 & 16.198 & 16.045 & 15.894 \\ 2.3 & 15.741 & 15.588 & 15.436 & 15.284 & 15.131 & 14.979 & 14.827 & 14.675 & 14.523 & 14.371\end{array}$

$\begin{array}{lllllllllll}2.4 & 14.218 & 14.066 & 13.914 & 13.761 & 13.609 & 13.457 & 13.305 & 13.152 & 13.000 & 12.848 \\ 2.5 & 12.695 & 12.543 & 12.391 & 12.239 & 12.087 & 11.935 & 11.782 & 11.630 & 11.478 & 11.326\end{array}$

$\begin{array}{lllllllllll}2.6 & 11.173 & 11.021 & 10.869 & 10.717 & 10.564 & 10.412 & 10.260 & 10.108 & 09.956 & 09.803 \\ 2.7 & 09.651 & 09.499 & 09.346 & 09.194 & 09.042 & 08.890 & 08.738 & 08.585 & 08.433 & 08.281\end{array}$

$\begin{array}{lllllllllll}2.7 & 09.651 & 09.499 & 09.346 & 09.194 & 09.042 & 08.890 & 08.738 & 08.585 & 08.433 & 08.281 \\ 2.8 & 08.128 & 07.976 & 07.824 & 07.672 & 07.520 & 07.369 & 07.216 & 07.064 & 06.912 & 06.760\end{array}$

$\begin{array}{lllllllllll}2.8 & 08.128 & 07.976 & 07.824 & 07.672 & 07.520 & 07.369 & 07.216 & 07.064 & 06.912 & 06.760 \\ 2.9 & 06.607 & 06.456 & 06.303 & 06.150 & 05.998 & 05.846 & 05.694 & 05.542 & 05.390 & 05.238\end{array}$

$\begin{array}{llllllllllll}2563.0 & 39005.085 & 04.934 & 04.781 & 04.628 & 04.477 & 04.324 & 04.172 & 04.021 & 03.868 & 03.716\end{array}$

$\begin{array}{lllllllllll}3.1 & 03.564 & 03.412 & 03.259 & 03.107 & 02.955 & 02.803 & 02.651 & 02.499 & 02.346 & 02.194 \\ 3.2 & 02.042 & 01.890 & 01.738 & 01.586 & 01.433 & 01.281 & 01.129 & 00.977 & 00.825 & 00.673\end{array}$

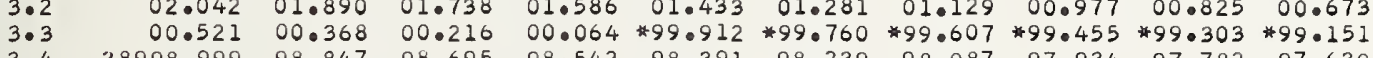

$\begin{array}{lrlllllllll}3.4 & 38998.999 & 98.847 & 98.695 & 98.542 & 98.391 & 98.239 & 98.087 & 97.934 & 97.782 & 97.630 \\ 3.5 & 97.478 & 97.326 & 97.174 & 97.022 & 96.870 & 96.718 & 96.565 & 96.414 & 96.261 & 96.109\end{array}$

$\begin{array}{lllllllllll}3.6 & 95.957 & 95.805 & 95.653 & 95.501 & 95.340 & 96.718 & 96.565 & 96.414 & 96.261 & 96.109 \\ 3.197 & 95.045 & 94.892 & 94.740 & 94.588\end{array}$

$\begin{array}{lllllllllll}3.7 & 94.436 & 94.284 & 94.131 & 93.980 & 93.828 & 93.675 & 93.524 & 93.371 & 93.219 & 93.067\end{array}$

$\begin{array}{lllllllllll}3.8 & 92.915 & 92.763 & 92.611 & 92.459 & 92.307 & 92.155 & 92.003 & 91.850 & 91.698 & 91.546 \\ 3.9 & 91.394 & 91.242 & 91.090 & 90.938 & 90.786 & 90.634 & 90.482 & 90.330 & 90.177 & 90.025\end{array}$

$\begin{array}{lllllllllll}2564.0 & 38989.873 & 89.721 & 89.569 & 89.417 & 89.266 & 89.114 & 88.961 & 88.810 & 88.658 & 88.505\end{array}$

$\begin{array}{lllllllllll}4.1 & 88.354 & 88.201 & 80.049 & 87.897 & 87.745 & 87.593 & 87.441 & 87.289 & 87.137 & 86.985 \\ 4.2 & 86.833 & 86.681 & 86.528 & 86.377 & 86.225 & 86.073 & 85.921 & 85.769 & 85.617 & 85.465\end{array}$

$\begin{array}{lllllllllll}4.3 & 85.313 & 85.160 & 85.008 & 84.856 & 84.704 & 84.553 & 84.400 & 84.249 & 84.097 & 83.944\end{array}$

$\begin{array}{lllllllllll}4.4 & 83.792 & 83.640 & 83.488 & 83.336 & 83.184 & 83.032 & 82.880 & 82.728 & 82.576 & 82.424 \\ 4.5 & 82.272 & 82.120 & 81.968 & 81.816 & 81.664 & 81.512 & 81.360 & 81.208 & 81.056 & 80.904\end{array}$

$\begin{array}{llllllllllll}4.6 & 80.752 & 80.600 & 80.448 & 80.297 & 81.604 & 81.35 & 79.993 & 79.841 & 79.689 & 79.537 & 79.385 \\ 4.7 & 79.233 & 79.081 & 78.929 & 78.877 & 70.625 & 78.473 & 78.321 & 78.169 & 78.017 & 77.855\end{array}$

$\begin{array}{lllllllllll}4.7 & 79.233 & 79.081 & 78.929 & 78.777 & 78.625 & 78.473 & 78.321 & 78.169 & 78.017 & 77.865 \\ 4.8 & 77.713 & 77.561 & 77.410 & 77.257 & 77.105 & 76.953 & 76.801 & 76.649 & 76.498 & 76.345\end{array}$

$\begin{array}{llllllllll}76.193 & 76.042 & 75.890 & 75.738 & 75.585 & 75.434 & 75.281 & 75.129 & 74.978 & 74.826\end{array}$

$\begin{array}{rrrllllllll}2565.0 & 38974.674 & 74.522 & 74.370 & 74.218 & 74.066 & 73.914 & 73.762 & 73.610 & 73.458 & 73.306 \\ 5.1 & 73.155 & 73.002 & 72.851 & 72.699 & 72.547 & 72.395 & 72.243 & 72.091 & 71.939 & 71.787\end{array}$

$\begin{array}{lllllllllll}5.1 & 73.155 & 73.002 & 72.851 & 72.699 & 72.547 & 72.395 & 72.243 & 72.091 & 71.939 & 71.787 \\ 5.2 & 71.635 & 71.483 & 71.331 & 71.180 & 71.028 & 70.876 & 70.725 & 70.572 & 70.420 & 70.269\end{array}$

$\begin{array}{lllllllllll}5.3 & 70.116 & 69.964 & 69.813 & 69.661 & 69.509 & 69.357 & 69.205 & 69.053 & 68.901 & 68.749\end{array}$

$\begin{array}{lllllllllll}5.5 & 67.078 & 66.927 & 66.775 & 66.623 & 66.471 & 66.319 & 66.167 & 66.016 & 65.863 & 65.711\end{array}$

$\begin{array}{lllllllllll}5.6 & 65.560 & 65.408 & 65.256 & 65.104 & 64.952 & 64.800 & 64.649 & 64.497 & 64.344 & 64.192\end{array}$

$\begin{array}{lllllllllll}5.7 & 64.041 & 63.889 & 63.737 & 63.585 & 63.434 & 63.282 & 63.130 & 62.978 & 62.826 & 62.674\end{array}$

$\begin{array}{lllllllllll}5.8 & 62.522 & 62.370 & 62.219 & 62.067 & 61.916 & 61.764 & 61.612 & 61.460 & 61.309 & 61.157 \\ 5.9 & 61.004 & 60.853 & 60.701 & 60.549 & 60.397 & 60.245 & 60.093 & 59.941 & 59.790 & 59.638\end{array}$

$\begin{array}{lllllllllll}2566.0 & 38959.486 & 59.334 & 59.182 & 59.030 & 58.879 & 58.727 & 58.575 & 58.423 & 58.271 & 58.120\end{array}$

$\begin{array}{llllllllllll}6.1 & 57.968 & 57.816 & 57.664 & 57.513 & 57.360 & 57.208 & 57.057 & 56.905 & 56.753 & 56.602\end{array}$

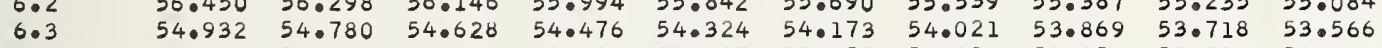

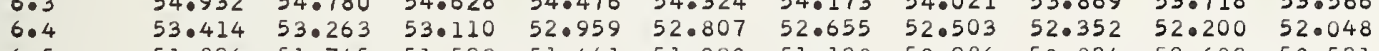

$\begin{array}{lllllllllll}6.4 & 53.414 & 53.263 & 53.110 & 52.959 & 52.807 & 52.655 & 52.503 & 52.352 & 52.200 & 52.048 \\ 6.5 & 51.896 & 51.745 & 51.593 & 51.441 & 51.290 & 51.138 & 50.986 & 50.834 & 50.683 & 50.531\end{array}$

$\begin{array}{lllllllllll}6.6 & 50.379 & 50.228 & 50.076 & 49.924 & 49.775 & 49.620 & 49.469 & 49.317 & 49.165 & 49.013 \\ 6.7 & 48.862 & 48.710 & 48.558 & 48.407 & 48.255 & 48.103 & 47.951 & 47.799 & 47.647 & 47.496\end{array}$

$\begin{array}{lllllllllll}6.7 & 48.862 & 48.710 & 48.558 & 48.407 & 40.255 & 48.103 & 47.951 & 47.799 & 47.647 & 47.496\end{array}$

$\begin{array}{lllllllllll}6.8 & 47.344 & 47.192 & 47.041 & 46.889 & 46.737 & 46.585 & 46.434 & 46.282 & 46.130 & 45.979 \\ 6.9 & 45.827 & 45.675 & 45.523 & 45.372 & 45.220 & 45.068 & 44.917 & 44.765 & 44.613 & 44.461\end{array}$

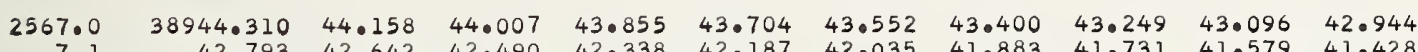

$\begin{array}{lllllll}7.1 & 42.793 & 42.642 & 42.490 & 42.338 & 42.187 & 42.035\end{array}$

$\begin{array}{lllllllllll}7.2 & 41.276 & 41.125 & 40.973 & 40.821 & 40.669 & 40.518 & 40.366 & 40.215 & 40.063 & 39.911 \\ 7.3 & 39.759 & 39.607 & 39.456 & 39.304 & 39.153 & 39.001 & 38.050 & 38.698 & 38.546 & 38.394\end{array}$

$\begin{array}{lllllllllll}7.4 & 38.243 & 38.091 & 37.939 & 37.788 & 37.636 & 37.484 & 37.333 & 37.181 & 37.030 & 36.877\end{array}$

$\begin{array}{lllllllllll}7.5 & 36.726 & 36.575 & 36.423 & 36.271 & 36.120 & 35.968 & 35.816 & 35.665 & 35.513 & 35.361 \\ 7.6 & 35.209 & 35.058 & 34.907 & 34.755 & 34.604 & 34.452 & 34.301 & 34.149 & 33.997 & 33.845\end{array}$

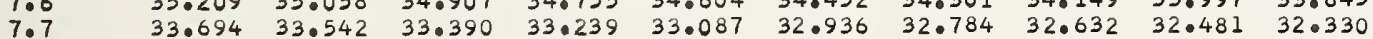

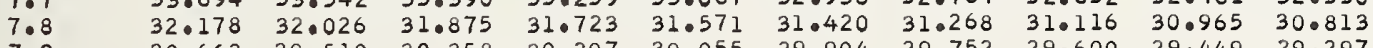

$\begin{array}{lllllllllll}2568.0 & 38929.146 & 28.994 & 28.843 & 28.690 & 28.539 & 28.388 & 28.236 & 28.084 & 27.933 & 27.781\end{array}$

$\begin{array}{lllllllllll}8.1 & 27.630 & 27.479 & 27.327 & 27.175 & 27.023 & 26.872 & 26.720 & 26.569 & 26.417 & 26.265\end{array}$

$\begin{array}{lllllllllll}8.2 & 26.114 & 25.962 & 25.812 & 25.660 & 25.508 & 25.356 & 25.205 & 25.053 & 24.902 & 24.750 \\ 8.3 & 24.599 & 24.447 & 24.296 & 24.145 & 23.993 & 23.841 & 23.689 & 23.538 & 23.387 & 23.235\end{array}$

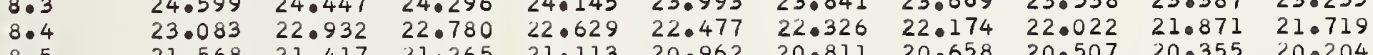

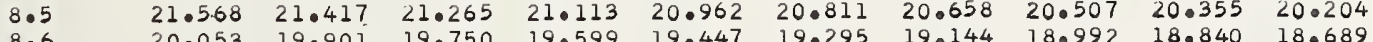

$\begin{array}{lllllllllll}8.6 & 20.053 & 19.901 & 19.750 & 19.599 & 19.447 & 19.295 & 19.144 & 18.992 & 18.840 & 18.689 \\ 8.7 & 18.538 & 18.386 & 18.234 & 18.083 & 17.932 & 17.780 & 17.628 & 17.477 & 17.325 & 17.174\end{array}$

$\begin{array}{lllllllllll}8.7 & 18.538 & 18.386 & 18.234 & 18.083 & 17.932 & 17.780 & 17.628 & 17.477 & 17.325 & 17.164 \\ 8.8 & 17.022 & 16.871 & 16.720 & 16.568 & 16.417 & 16.266 & 16.114 & 15.962 & 15.812 & 15.660\end{array}$

$\begin{array}{lllllllllll}569.0 & 38913.993 & 13.842 & 13.690 & 13.539 & 13.388 & 13.236 & 13.084 & 12.933 & 12.782 & 12.630\end{array}$

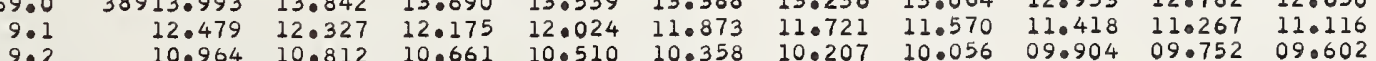

$\begin{array}{lllllllllll}9.2 & 10.964 & 10.812 & 10.661 & 10.510 & 10.358 & 10.207 & 10.056 & 09.904 & 09.752 & 09.602 \\ 9.3 & 09.449 & 09.298 & 09.147 & 08.995 & 08.844 & 08.692 & 08.541 & 08.390 & 08.238 & 08.087\end{array}$

$\begin{array}{llllllllllll}9.4 & 07.935 & 07.784 & 07.633 & 07.481 & 07.330 & 07.179 & 07.027 & 06.875 & 06.725 & 06.573\end{array}$

$\begin{array}{lllllllllll}9.5 & 06.421 & 06.271 & 06.119 & 05.967 & 05.816 & 05.665 & 05.513 & 05.362 & 05.210 & 05.059 \\ 9.6 & 04.908 & 04.756 & 04.605 & 04.453 & 04.302 & 04.150 & 03.999 & 03.848 & 03.696 & 03.545\end{array}$

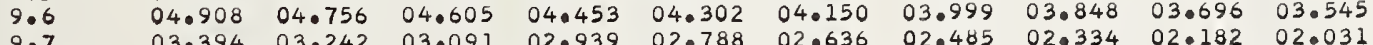

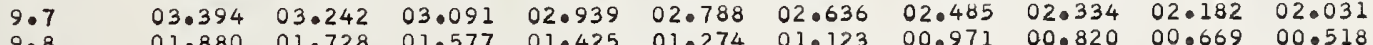

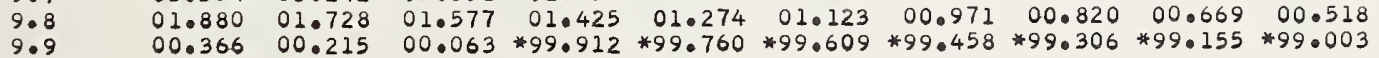

0.299853

0.299850

0.299848

.299843

0.299837

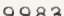

0.299832

0.299827

0.299825

299820

0.299817

0.299815

0.299810

0.29980

0.299802

0.299800

99795

0.299792
0.299790

0.299787

0.299785

0.299780

0.299777

0.299775

0.299770

0.29976

0.299762

0.29975

0.299755

0.299752

0.299747

0.299745

0.299740

0.299737

0.299735

0.299730

0.299727

0.299720

0.29717

0.299712

0.299710

0.299707

0.299702

0.299697

0.299695

0.299692

0.299690

.

0.299685

0.299680

0.299677

0.299675

0.299672

0.299670
0.299668

0.299665

0.299663

0.299658

0.299655

0.299653

0.299650

0.299648
0.299645

0.299638

0.299630

0.299628

0.299625

0.299623

.299618

0.299615

0.290610

0.29910

0.299608
0.299605

0.767623

0.767646

0.767670
0.767693

0.767717

0.767764

0.767787

0.767835

0.767858

0.767882
0.767905

0.767929

0.767976

0.767999

0.768023
0.768047

0.768047
0.768070

0.768094

0.768141

0.768164

0.768188

0.768235

0.768259

0.768282

0.768329

0.768353

0.768400

0.768423

0.768447

0.768494

0.768518
0.768541

0.768565

0.768588

0.768612

0.768659

0.768683

0.768706

0.768730
0.768753

0.768777

0.768802

0.768848

0.768871

0.768895

0.768942

0.768966

0.768989
0.769023

0.769036

0.769060

0.769107

0.769131

0.769154
0.769178

0.769201

0.769225

0.769272

0.769296

0.769319

0.769366

0.769390

0.769414
0.769437

0.769437

0.769484

0.769508

0.769531

0.769555

0.769602

0.769626

0.769649

0.769697

0.769744

0.769767

0.769791

0.769838

0.769862

0.769885

0.769909

0.769956

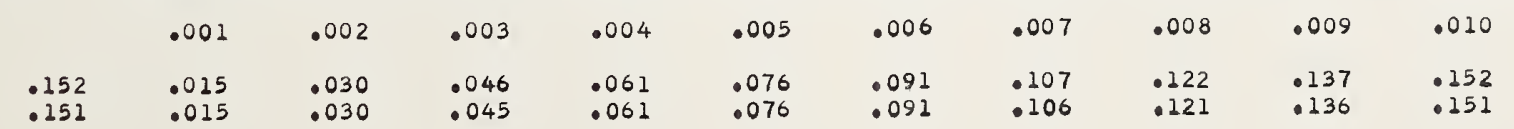



$\begin{array}{llllllllll}82.211 & 82.060 & 81.909 & 81.758 & 81.606 & 81.455 & 81.304 & 81.153 & 81.001 & 80.850\end{array}$ $\begin{array}{llllllllll}80.699 & 80.547 & 80.396 & 80.246 & 80.095 & 79.943 & 79.792 & 79.641 & 79.490 & 79.339 \\ 79.189 & 79.036 & 78.885 & 78.734 & 78.583 & 78.432 & 78.280 & 78.129 & 77.978 & 77.827\end{array}$ $\begin{array}{llllllllll}79.187 & 79.036 & 78.885 & 78.734 & 78.583 & 78.432 & 78.280 & 78.129 & 77.978 & 77.827 \\ 77.675 & 77.524 & 77.374 & 77.222 & 77.070 & 76.919 & 76.768 & 76.617 & 76.466 & 76.315\end{array}$ $\begin{array}{llllllllll}76.164 & 76.013 & 75.861 & 75.710 & 75.559 & 75.408 & 75.256 & 75.105 & 74.954 & 74.803\end{array}$ $\begin{array}{llllllllll}74.652 & 74.501 & 74.350 & 74.199 & 74.047 & 73.896 & 73.745 & 73.594 & 73.442 & 73.291\end{array}$ $\begin{array}{llllllllll}73.141 & 72.989 & 72.838 & 72.687 & 72.536 & 72.384 & 72.233 & 72.082 & 71.931 & 71.780\end{array}$ $\begin{array}{llllllllll}71.629 & 71.478 & 71.327 & 71.176 & 71.025 & 70.874 & 70.723 & 70.571 & 70.420 & 70.269 \\ 70.118 & 69.967 & 69.816 & 69.665 & 69.513 & 69.362 & 69.211 & 69.060 & 68.909 & 68.758\end{array}$ 69.66569 .513

$$
\begin{array}{r}
9.0 \\
9.0 \\
9.0 \\
9.0 \\
9.5 \\
9.0 \\
9.0 \\
9 \\
9 .
\end{array}
$$

0.299578

0.299576

0.299573

0.299568

0.299566

0.299561

0.299556

0.299554 0.299551
0.299549 0.299546

0.299544

0.299541

0.299536

0.299534

0.299529

0.299526

0.299524

0.299519

0.299517

0.299514

0.299512

0.299507

0.299504

0.299502

0.299499

0.299494

0.299492

.

0.299482

0.299480

0.299477

0.299472

0.299470

0.299465

0.299462

0.299460

0.299455

0.299453

0.299450

0.299445

0.299443

0.299440

0.299438

0.299433

0.299430 0.299428 0.299426
0.299423 0.299421 0.299418 0.299416 0.299413 0.299408

0.299406 0.299404 0.299401 0.299396 0.299394

0.299391

0.299386

0.299386

0.299382

0.299379

0.299374

0.299372
0.299369

0.299369

0.299367

0.299362

0.299360

0.769980

0.770003

0.770027

0.770074

0.770098

0.770145

0.770168
0.770192

0.770216

0.770239

0.770263
0.770286

0.770310

0.770357
0.770381
0.770404

0.770404

0.770428

0.770452
0.770475 0.770499 0.770522 0.770546 0.770570 0.770593 0.770617 0.770640

0.770688

0.770711

0.770735
0.770758

0.770782

0.770806

0.770829

0.770877

0.770924

0.770947

0.770971

0.770995

0.771042

0.771065

0.771113

0.771160

0.771184

0.771231

0.771254

0.771278

0.771325

0.771349

0.771396

0.771420

0.771443
0.771467

0.771491

0.771514

0.771561

0.771585
0.771609

0.771632

0.771656

0.771703

0.771727
0.771750

0.771774

0.771798

0.771845

0.771869

0.771892

0.771939

0.771963
0.771987 
$\begin{array}{rrrrrrrrrrr}581.0 & 38733.080 & 32.930 & 32.780 & 32.629 & 32.479 & 32.329 & 32.179 & 32.029 & 31.879 & 31.729 \\ 1.1 & 31.579 & 31.429 & 31.279 & 31.129 & 30.979 & 30.829 & 30.679 & 30.529 & 30.378 & 30.229\end{array}$ 35.63036 .981 $\begin{array}{lllll}38.332 & 38.183 & 38.032 & 37.882 & 37.732\end{array}$ $\begin{array}{lllll}36.831 & 36.681 & 36.531 & 36.381 & 36.231 \\ 35.331 & 35.180 & 35.030 & 34.880 & 34.730\end{array}$

0.299357 0.299355 0.299350 0.299347 0.299345 0.00

0.299338

$\begin{array}{llllllllll}31.579 & 31.429 & 31.279 & 31.129 & 30.979 & 30.829 & 30.679 & 30.529 & 30.378 & 30.229 \\ 30.079 & 29.929 & 29.778 & 29.029 & 29.478 & 29.328 & 29.178 & 29.028 & 28.878 & 28.729\end{array}$

$\begin{array}{llllll}1.3 & 28.578 & 28.428 & 28.278 & 28.128 & 27.978\end{array}$

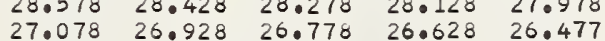
$25.578 \quad 250.428 \quad 250.778$ $25.578 \quad 25.428 \quad 25.278 \quad 25 \cdot 127$ $24.078 \quad 23.928 \quad 23.778 \quad 23.628 \quad 23.479$ $21.078 \quad 220428 \quad 22.278 \quad 22.128 \quad 21.979$ $\begin{array}{lll}21.078 & 20.928 & 20.779 \\ 19.579 & 19.429 & 19.279\end{array}$

$\begin{array}{lllll}27.828 & 27.678 & 27.528 & 27.378 & 27.228\end{array}$

$\begin{array}{lllll}26.328 & 26.178 & 26.027 & 25.878 & 25.728 \\ 24.828 & 24.678 & 24.528 & 24.378 & 24.228\end{array}$

$\begin{array}{lllll}24.828 & 24.678 & 24.528 & 24.378 & 24.228 \\ 23.328 & 23.179 & 23.028 & 22.878 & 22.728\end{array}$

20.628
19.129

$\begin{array}{lllll}21.828 & 21.679 & 21.528 & 21.378 & 21.229\end{array}$

1.8
3.9

2582.

2.1
2.2
2.3
2.4
2.
2.7
2.

$38718.079 \quad 17.929 \quad 17.779$

27.629 $16.580-16.929$ $15.081 \quad 14.430 \quad 16.280$ $13.00213 .431-13.781$ $12.083 \quad 11.933 \quad 11.78$ $\begin{array}{lll}10.583 & 10.434 & 10.283\end{array}$ 0.0835 $06.088 \quad 05.937$

$04.589 \quad 04.438$

8.784

$\begin{array}{ll}16.130 & 15.980 \\ 14.631 & 14.481\end{array}$

$11.632 \quad 11.482$

$\begin{array}{ll}10.133 & 09.984 \\ 08.635 & 08.485\end{array}$

05.788

$07.136 \quad 06.986$

2583.0

$3 \cdot 1$

3.4

04.140

05.488
03.990

$\begin{array}{llll}18.829 & 18.679 & 18.529 & 18.379\end{array}$

$\begin{array}{lllll}17.330 & 17.279 & 17.030 & 16.879 & 16.729\end{array}$

$\begin{array}{lllll}15.830 & 15.681 & 15.531 & 15.381 & 15.230 \\ 14.331 & 14.181 & 14.031 & 13.881 & 13.732\end{array}$

$\begin{array}{lllll}12.832 & 12.682 & 12.532 & 12.382 & 12.232\end{array}$

$\begin{array}{lllll}11.333 & 11.183 & 11.033 & 10.883 & 10.733 \\ 09.834 & 09.684 & 09.534 & 09.384 & 09.234\end{array}$

$\begin{array}{lllll}09.834 & 09.684 & 09.534 & 09.384 & 09.234 \\ 08.335 & 08.186 & 08.036 & 07.885 & 07.735\end{array}$

$\begin{array}{llllll}06.836 & 06.687 & 06.537 & 06.387 & 06.238\end{array}$

$\begin{array}{lllll}0.836 & 06.687 & 06.537 & 06.387 & 06.238 \\ 05.338 & 05.188 & 05.039 & 04.889 & 04.739\end{array}$

$\begin{array}{lllll}703.090 & 02.941 & 02.791 & 02.641 & 02.492\end{array}$

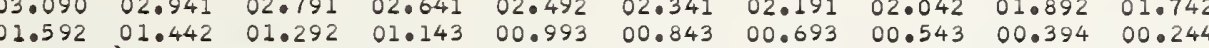
.94**99.794*99.645*99.495*99.345*99.195*99.04.5*98.896*98.746 $\begin{array}{llllllllll}97.099 & 96.949 & 96.799 & 96.649 & 96.500 & 96.350 & 96.200 & 96.050 & 95.901 & 95.750\end{array}$

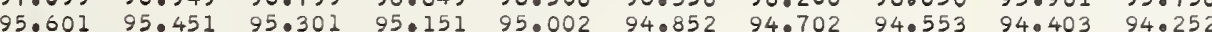

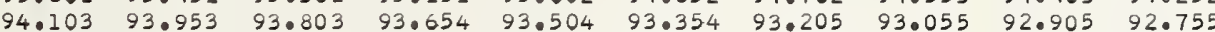
$92.60592 .456 \quad 92.306 \quad 92.156 \quad 92.006 \quad 91.856 \quad 91.707 \quad 91.557 \quad 91.407 \quad 91.258$

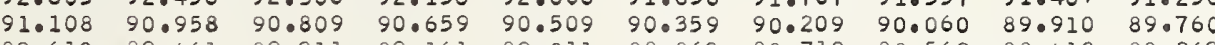
$89.610 \quad 89.461$

2584

3.8
3.9

25840

4.

38688.100 $888.114 \quad 87.964 \quad 87$. $\begin{array}{ll}86.617 & 86.467 \\ 85.120 & 84.970\end{array}$ $83.623 \quad 83.473$ $82.126 \quad 81.977$ $80.629 \quad 80.480$ $80.330 \quad 80.180 \quad 80.030$ $\begin{array}{lllll}77.637 & 78.983 & 78.834 & 78.685 & 78.535\end{array}$ $\begin{array}{lllll}76.140 & 75.991 & 75.841 & 75.691 & 75.542 \\ 74.644 & 74.495 & 74.345 & 74.195 & 74.045\end{array}$

4.8
4.9

2585 2.0
5
5
5
5
5
5
5
5
5
5 $673.248 \quad 72$

2.99972 .849 71.652
70.156 $70.502 \quad 71.353$ $\begin{array}{lllll}70.156 & 70.006 & 69.857 & 69.708 & 69.054\end{array}$ $\begin{array}{lllll}67.165 & 67.016 & 66.866 & 66.716 & 66.567\end{array}$ $65.66965 .520 \quad 65.371 \quad 65.22165 .072$ 64.17564 .02463 .875 $62.679 \quad 62.529 \quad 62.379$ $\begin{array}{lll}61.184 & 61.034 & 60.889 \\ 59.689 & 59.540 & 59.391\end{array}$

\title{
62.23062 .081
} $62.230 \quad 62.081$

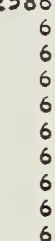

$$
\begin{array}{r}
3865 \\
5 \\
5 \\
5 \\
5 \\
5 \\
490 \\
470 \\
460 \\
440
\end{array}
$$
$\begin{array}{lll}658.194 & 58.045 & 57.896 \\ 56.700 & 56.550 & 56.400\end{array}$ $55.205 \quad 55.055 \quad 54.90$ $53.561 \quad 53.412$ $52.066 \quad 51.917$ $49.228 \quad 49.078 \quad 40.929$ $47.733 \quad 47.584 \quad 47.43$ $\begin{array}{lll}46.239 & 46.090 & 45.941 \\ 44.745 & 44.596 & 44.447\end{array}$

\begin{abstract}
$57.746 \quad 57.596$
\end{abstract}
$\begin{array}{ll}56.251 & 56.102 \\ 54.757 & 54.606\end{array}$

$53.262 \quad 53.112$ $51.768 \quad 51.618$ 48.779048 .630 $\begin{array}{ll}47.285 & 47.136 \\ 45.791 & 45.642\end{array}$

2587

7.

$38643.251 \quad 43.103 \quad 42.953$ 44.29744 .148

$\begin{array}{llllll}87.365 & 87.215 & 87.066 & 86.916 & 86.766\end{array}$ $\begin{array}{lllll}85.868 & 85.719 & 85.569 & 85.419 & 85.269 \\ 84.371 & 84.222 & 84.072 & 83.922 & 83.772\end{array}$ $\begin{array}{lllll}82.875 & 82.725 & 82.575 & 82.425 & 82.276\end{array}$ $\begin{array}{llllll}81.377 & 81.228 & 81.078 & 80.929 & 80.779\end{array}$ $\begin{array}{lllll}78.381 & 79.731 & 79.582 & 79.432 & 79.282 \\ 78.385 & 78.235 & 78.085 & 77.936 & 77.786\end{array}$ $\begin{array}{llllll}76.889 & 76.739 & 76.589 & 76.439 & 76.290 \\ 75.393 & 75.242 & 75.093 & 74.943 & 74.793\end{array}$ $\begin{array}{lllll}75.393 & 75.242 & 75.093 & 74.943 & 74.793 \\ 73.896 & 73.747 & 73.596 & 73.447 & 73.297\end{array}$

0.299333 0.299330 0.299325 0.299323

0.29320

0.299318

0.299313

0.299311

0.299308

0.299306

0.299301

0.299299

0.299294

0.299291

0.299289
0.299286

0.299284

0.299282

0.299279

0.299274

0.299272

0.299269

0.299267
0.299265

0.299262

0.299260

0.299257

.299252

0.299250

0.299245

0.299243

0.299238

0.772341

0.772389

0.772436

0.772483

0.772507

0.772554

0.772578

0.772625

0.772649

0.772696

0.772743

0.7772767
0.772790

0.772814

0.772861

0.772909

0.772956

0.773003

0.773051

0.773098

0.773145

0.773192

0.773240

0.773287

0.773311

0.773358

0.773405

0.773429

0.773476

0.299235

0.299233

0.299228

0.299223

0.299219

0.299216

0.773524

0.773547
0.773571

0.773595

0.773642

$\begin{array}{llllll}63.427 & 64.772 & 64.623 & 64.474 & 64.324 \\ 63.277 & 63.128 & 62.978 & 62.829\end{array}$

$\begin{array}{lllll}61.931 & 61.782 & 61.632 & 61.483 & 61.333 \\ 60.437 & 60.287 & 60.138 & 59.988 & 59.839\end{array}$

0.773689

0.773713
0.773737

0.299211

0.299206

$\begin{array}{lllll}57.447 & 57.297 & 57.148 & 56.999 & 56.849 \\ 55.952 & 55.803 & 55.653 & 55.503 & 55.354\end{array}$

$\begin{array}{lllll}54.457 & 54.308 & 54.158 & 54.009 & 53.860\end{array}$

$\begin{array}{lllll}52.963 & 52.813 & 52.664 & 52.515 & 52.365 \\ 51.468 & 51.320 & 51.170 & 51.021 & 50.871\end{array}$

$\begin{array}{lllll}49.975 & 49.825 & 49.676 & 49.526 & 49.376\end{array}$

$\begin{array}{lllll}48.480 & 48.332 & 48.182 & 48.032 & 47.882 \\ 46.986 & 46.837 & 46.688 & 46.538 & 46.389\end{array}$

$\begin{array}{lllll}45.493 & 45.343 & 45.194 & 45.044 & 44.895 \\ 43.999 & 43.849 & 43.700 & 43.550 & 43.401\end{array}$

0.299199

0.299197

0.299192

0.773760

0.773784

0.773831

0.773879

0.773902
0.773926

0.773950

0.299187

0.299185

0.299182

$\begin{array}{llllllllll}38.771 & 38.622 & 38.473 & 38.323 & 38.174 & 38.025 & 37.875 & 37.726 & 37.577 & 37.428\end{array}$

$\begin{array}{llllllllll}35.785 & 35.636 & 35.486 & 35.336 & 35.187 & 36.532 & 36.382 & 36.233 & 36.083 & 35.934 \\ \end{array}$

$\begin{array}{llllllllll}34.292 & 34.143 & 33.993 & 33.844 & 33.694 & 33.545 & 33.396 & 33.247 & 33.097 & 32.948\end{array}$

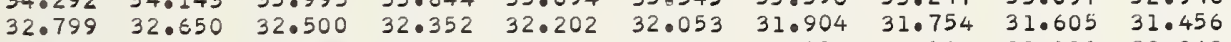

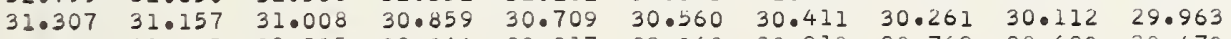

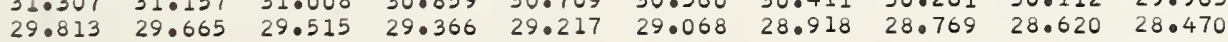

0.299177

0.299175

0.299173

0.299170
0.299168

0.299165

0.773997

0.774021

0.774068

0.774092

0.774139

0.774163

0.777186
0.774210

\begin{tabular}{lllllllllll}
2588.0 & 38628.321 & 28.172 & 28.022 & 27.873 & 27.725 & 27.575 & 27.425 & 27.276 & 27.127 & 26.978 \\
\hline & 26.32 & 26.679 & 26.530 & 26.381 & 26.232 & 26.083 & 25.333 & 25.784 & 25.634 & 25.485
\end{tabular} $\begin{array}{llllllllll}26.829 & 26.679 & 26.530 & 26.381 & 26.232 & 26.083 & 25.334 & 25.784 & 25.634 & 25.485 \\ 25.336 & 25.187 & 25.038 & 24.889 & 24.739 & 24.590 & 24.440 & 24.292 & 24.142 & 23.993\end{array}$

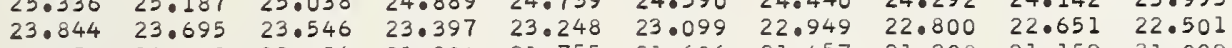
$\begin{array}{llllllllll}22.352 & 22.203 & 22.054 & 21.904 & 21.755 & 21.606 & 21.457 & 21.308 & 21.159 & 21.009\end{array}$ $\begin{array}{lllllllll}10.860 & 20.711 & 20.562 & 20.412 & 20.264 & 20.114 & 19.965 & 19.816 & 19.667\end{array}$

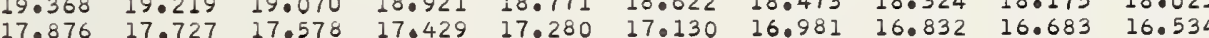

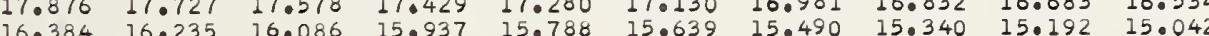

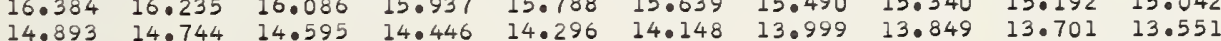

0.299163 0.299161 0.299156 0.299153 0.299151 0.299148 0.299148 0.299146

0.299141

0.774234

0.774281

0.774305

0.774352

0.774376

0.774423

0.299139

0.299136

0.299134
0.299132

0.299129

0.299127

0.299122

0.299120

.774447 


\begin{tabular}{|c|c|c|c|}
\hline$\lambda(A)$ & .00 & .01 & .02 \\
\hline 90.0 & 38598.494 & 98.345 & 98.196 \\
\hline 0.1 & 97.004 & 96.854 & 96.706 \\
\hline 0.2 & $\begin{array}{l}95.515 \\
94.024\end{array}$ & $\begin{array}{l}95.365 \\
93.875\end{array}$ & $\begin{array}{l}95.216 \\
93.726\end{array}$ \\
\hline $\begin{array}{l}0.3 \\
0.4\end{array}$ & $\begin{array}{l}94.024 \\
92.535\end{array}$ & $\begin{array}{l}93.875 \\
92.385\end{array}$ & $\begin{array}{l}93.726 \\
92.236\end{array}$ \\
\hline 0.5 & 91.044 & 90.896 & 90.747 \\
\hline 0.6 & 89.555 & 89.406 & 89.257 \\
\hline 0.7 & 88.065 & 87.917 & 87.767 \\
\hline $\begin{array}{l}0.8 \\
0.9\end{array}$ & $\begin{array}{l}86.577 \\
85.087\end{array}$ & $\begin{array}{l}86.428 \\
84.938\end{array}$ & $\begin{array}{l}86.279 \\
84.790\end{array}$ \\
\hline 0.9 & 85.087 & 84.938 & 84.790 \\
\hline 591.0 & $\begin{array}{r}38583.598 \\
82.109\end{array}$ & $\begin{array}{l}83.449 \\
81.960\end{array}$ & $\begin{array}{l}83.300 \\
81.811\end{array}$ \\
\hline $\begin{array}{l}1.1 \\
1.2\end{array}$ & $\begin{array}{l}82.109 \\
80.620\end{array}$ & $\begin{array}{l}81.960 \\
80.471\end{array}$ & $\begin{array}{l}81.811 \\
80.322\end{array}$ \\
\hline 1.3 & 79.131 & 78.982 & 78.833 \\
\hline 1.4 & 77.642 & 77.494 & 77.345 \\
\hline 1.5 & $\begin{array}{l}76.154 \\
74.666\end{array}$ & 76.005 & 75.856 \\
\hline $\begin{array}{l}1.6 \\
1.7\end{array}$ & $\begin{array}{l}74.6666 \\
73.177\end{array}$ & $\begin{array}{l}74.517 \\
73.028\end{array}$ & $\begin{array}{l}74.368 \\
72.879\end{array}$ \\
\hline 1.8 & 71.689 & 71.540 & 71.392 \\
\hline 1.9 & 70.201 & 70.052 & 69.903 \\
\hline & 568.712 & 68.564 & 68.415 \\
\hline $\begin{array}{l}2.1 \\
2.2\end{array}$ & 67.226 & 67.077 & 66.928 \\
\hline $\begin{array}{l}2.2 \\
2.3\end{array}$ & $\begin{array}{l}65.738 \\
64.250\end{array}$ & 65.589 & 65.440 \\
\hline $\begin{array}{l}2.3 \\
2.4\end{array}$ & $\begin{array}{l}64.250 \\
62.763\end{array}$ & 64.101 & 63.953 \\
\hline 2.5 & $\begin{array}{l}62.763 \\
61.275\end{array}$ & $\begin{array}{l}62.614 \\
61.126\end{array}$ & $\begin{array}{l}62.465 \\
60.978\end{array}$ \\
\hline 2.6 & 59.788 & $\begin{array}{l}11.126 \\
59.639\end{array}$ & 59.490 \\
\hline 2.7 & 58.301 & 58.152 & 58.003 \\
\hline 2.8 & & 56.665 & 56.517 \\
\hline 2.9 & 55.327 & 55.178 & 55.029 \\
\hline $\begin{array}{r}93.0 \\
3.1\end{array}$ & $\begin{array}{r}38553.840 \\
52.353\end{array}$ & $\begin{array}{l}53.691 \\
52.205\end{array}$ & $\begin{array}{l}53.542 \\
52.056\end{array}$ \\
\hline 3.2 & 50.867 & 50.718 & 50.569 \\
\hline $3 \cdot 3$ & 49.380 & 49.231 & 49.083 \\
\hline 3.4 & 47.894 & 47.746 & 47.597 \\
\hline 3.5 & 46.408 & 46.259 & 46.110 \\
\hline 3.6 & 44.922 & 44.773 & 44.624 \\
\hline 3.7 & 43.436 & 43.287 & 43.138 \\
\hline 3.8 & 41.950 & $\begin{array}{l}41.800 \\
40.316\end{array}$ & 41.652 \\
\hline 3.9 & 40.464 & 40.316 & 40.167 \\
\hline & 538.978 & 38.830 & 38.681 \\
\hline 4.1 & $\begin{array}{l}37.493 \\
36.000\end{array}$ & $\begin{array}{l}37.344 \\
35.859\end{array}$ & $\begin{array}{l}37.196 \\
35.710\end{array}$ \\
\hline $\begin{array}{l}2 \\
3\end{array}$ & $\begin{array}{l}36.007 \\
34.5222\end{array}$ & $\begin{array}{l}35.859 \\
34.373\end{array}$ & $\begin{array}{l}35.710 \\
34.225\end{array}$ \\
\hline 4 & $\begin{array}{l}34.0226 \\
33.037\end{array}$ & 32 & $32:$ \\
\hline 4.5 & 31.551 & 31.403 & 31.255 \\
\hline 4.6 & 30.067 & 29.918 & 29.770 \\
\hline $4 \cdot 7$ & 28.582 & 28.433 & 28.285 \\
\hline 4.8 & 27.097 & 26.948 & 26.800 \\
\hline 409 & 25.612 & 25.464 & 25.315 \\
\hline 0 & $\begin{array}{r}38524.127 \\
22.643\end{array}$ & $\begin{array}{l}23.979 \\
22.495\end{array}$ & $\begin{array}{l}23.831 \\
22.346\end{array}$ \\
\hline 5.2 & $\begin{array}{l}22.043 \\
21.160\end{array}$ & 21.011 & $\begin{array}{l}22.346 \\
20.862\end{array}$ \\
\hline 5.3 & .675 & 19.527 & 19.378 \\
\hline .4 & 18.191 & 18.043 & 17.894 \\
\hline 5.5 & 16.707 & 16.559 & 16.410 \\
\hline & .223 & 15.075 & 14.926 \\
\hline 5.7 & 13.739 & 13.591 & 13.442 \\
\hline 5.8 & 12.256 & 12.107 & 11.959 \\
\hline 5.9 & 10.772 & 10.625 & 10.476 \\
\hline & 509.289 & 09.141 & 08.992 \\
\hline & 66 & 07.657 & 07.509 \\
\hline 02 & .322 & 06.1 & 06.026 \\
\hline .3 & 6 & 04.6 & 04.5 \\
\hline & 356 & 03.208 & 03.060 \\
\hline 5 & 874 & 01.726 & 01.577 \\
\hline & 00.391 & 00.243 & 00.094 \\
\hline 7 & 38498.908 & 98.760 & 98.612 \\
\hline 6.8 & 97.426 & 97.277 & 97.129 \\
\hline 6.9 & 95.944 & 95.795 & 95.647 \\
\hline & 38494 & 94.3 & $94 \cdot$. \\
\hline & & 92.8 & 92.683 \\
\hline & 8 & $91 \cdot 3$ & 91.0 \\
\hline & 889 & 89.8 & 89.7 \\
\hline & 88. & 88. & 88.237 \\
\hline $\begin{array}{l}7.5 \\
7.6\end{array}$ & $\begin{array}{l}87.052 \\
85.570\end{array}$ & 86.5 & $860^{\circ}$ \\
\hline 7 & $\begin{array}{l}85.570 \\
84.089\end{array}$ & $\begin{array}{l}85.422 \\
83.941\end{array}$ & $\begin{array}{l}85.274 \\
83.793\end{array}$ \\
\hline & 2.608 & 82. & 82.3 \\
\hline 7.9 & 81.126 & 80.979 & 80.831 \\
\hline & & & \\
\hline & & & \\
\hline & & 76. & \\
\hline & & & \\
\hline & & & \\
\hline 8.5 & 72.2 & 72.6 & 71.9 \\
\hline & & & 70 \\
\hline & & 69 & 68 \\
\hline & & 67. & 67.5 \\
\hline $8 \cdot 9$ & 66.321 & 66.173 & 66.025 \\
\hline & 3846 & 64 & 64.545 \\
\hline & 63.361 & 63. & $63 \cdot 0$ \\
\hline 9 & 61.881 & 61. & 61. \\
\hline & 60.401 & 60.253 & 60.106 \\
\hline & $\begin{array}{l}58.922 \\
57.442\end{array}$ & $58^{\circ}$ & 58.626 \\
\hline & 57.442 & $\begin{array}{l}57.294 \\
555\end{array}$ & 57.146 \\
\hline & $\begin{array}{l}55.964 \\
544.484\end{array}$ & 55.815 & 55.667 \\
\hline 9. & $\begin{array}{l}54.484 \\
53.005\end{array}$ & 54.336 & $54 \cdot 188$ \\
\hline $\begin{array}{l}9.8 \\
9.9\end{array}$ & $\begin{array}{l}53.005 \\
51.526\end{array}$ & $\begin{array}{l}52.857 \\
51.378\end{array}$ & $\begin{array}{l}52.709 \\
51.230\end{array}$ \\
\hline & .0 & 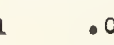 & \\
\hline & 148 & & \\
\hline & & & \\
\hline
\end{tabular}


$\begin{array}{ll}93.937 & 93.789 \\ 92.462 & 92.315\end{array}$

2604.0

38390.98

4.

$\begin{array}{lll}89.908 & 90.841 & 90.693\end{array}$

$\begin{array}{lll}88.040 & 87.893 & 87.745\end{array}$

$\begin{array}{lll}86.566 & 86.418 & 86.27 \\ 85.092 & 84.945 & 84.797\end{array}$

$\begin{array}{ll}24.482 & 24.334 \\ 23.005 & 22.857\end{array}$

$\begin{array}{lllll}30.095 & 29.947 & 29.799 & 29.652 & 29.503 \\ 28.618 & 28.470 & 28.322 & 28.175 & 28.027\end{array}$

$\begin{array}{lllll}27.141 & 26.993 & 26.845 & 26.698 & 26.550\end{array}$

$\begin{array}{lllll}25.064 & 25.516 & 25.368 & 25.221 & 25.073 \\ 24.187 & 24.039 & 23.891 & 23.744 & 23.596\end{array}$

03.618 43. 0.471

84.797
83.323

82.146

$80.672 \quad 80.524$

81.050
80.37

$\begin{array}{ll}79.198 & 79.051 \\ 77.725 & 77.578\end{array}$

2605

$$
\begin{aligned}
& 74.779 \\
& 73.306 \\
& 71.033
\end{aligned}
$$

76.104

78.903

20.05219 .905

21.233

22.562

$\begin{array}{lll}23.891 & 23.744 & 23.596 \\ 22.415 & 22.267 & 22.119\end{array}$

0.298876

40

0.298871

0.298869

0.298864

0.298862

0.298857

0.298852

0.298850

0.298845

0.298843

0.298838

0.298836

0.298831

0.298829

0.298826

0.298821

0.298819

0.298814

0.298812

0.298810

0.298805

0.298803

0.298800
0.293798

0.298796

0.298791

0.298788

0.298786
0.298784

0.29878

0.298779

0.2298777

0.298772

0.298770

0.298765

0.298763
0.298760

0.298758

0.298755
0.298753

0.298751

$\begin{array}{lllllllllll}71.033 & 7.6866 & 71.539 & 71.391 & 71.244 & 71.097 & 70.949 & 70.802 & 70.655 & 70.507\end{array}$

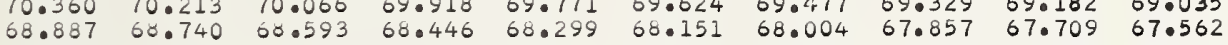

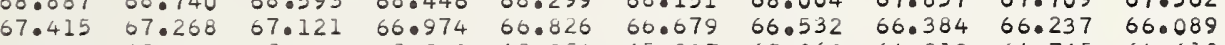
$\begin{array}{llllllllll}65.943 & 65.795 & 65.648 & 65.501 & 65.354 & 65.207 & 65.060 & 64.912 & 64.765 & 64.618\end{array}$

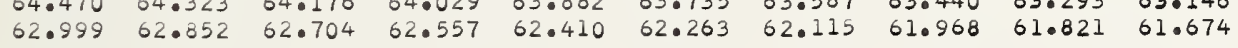

$\begin{array}{lllllllllll}2606.0 & 38361.526 & 61.379 & 61.232 & 61.084 & 60.938 & 60.791 & 60.643 & 60.497 & 60.349 & 60.202\end{array}$

$\begin{array}{lllllllllll}6.1 & 60.055 & 59.907 & 59.760 & 59.613 & 59.466 & 59.318 & 59.172 & 59.024 & 58.877 & 58.730\end{array}$

$\begin{array}{lllllllllllll}6.2 & 58.583 & 58.435 & 58.288 & 58.141 & 57.994 & 57.847 & 57.700 & 57.552 & 57.405 & 57.258\end{array}$

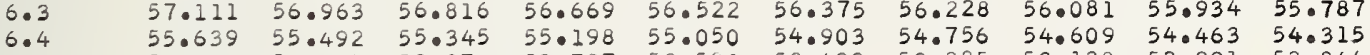

$\begin{array}{llllllllllll}6.5 & 54.168 & 54.021 & 53.874 & 53.727 & 53.580 & 53.433 & 53.285 & 53.138 & 52.991 & 52.844\end{array}$

$\begin{array}{lllllllllll}6.6 & 52.697 & 52.550 & 52.403 & 52.256 & 52.108 & 51.961 & 51.814 & 51.667 & 51.520 & 51.373 \\ 6.7 & 51.226 & 51.079 & 50.931 & 50.785 & 50.637 & 50.490 & 50.343 & 50.196 & 50.048 & 49.901\end{array}$

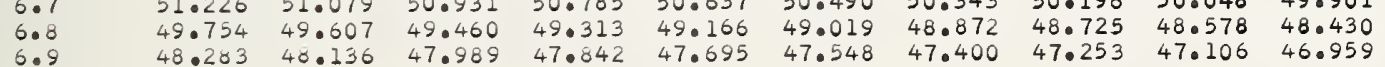

$\begin{array}{lllllllllll}2607.0 & 38346.812 & 46.666 & 46.518 & 46.371 & 46.224 & 46.077 & 45.930 & 45.783 & 45.636 & 45.488\end{array}$

$\begin{array}{llllllllllll}7.1 & 45.342 & 45.195 & 45.048 & 44.901 & 44.754 & 44.606 & 44.460 & 44.312 & 44.165 & 44.018\end{array}$

$\begin{array}{llllllllllll}7.2 & 43.871 & 43.724 & 43.577 & 43.430 & 43.283 & 43.136 & 42.989 & 42.842 & 42.694 & 42.548 \\ 7.3 & 40.00 & 42.253 & 42.0706 & 41.959 & 41.812 & 41.666 & 41.519 & 41.371 & 41.225 & 41.077\end{array}$

$\begin{array}{lllllllllll}7.3 & 42.400 & 42.253 & 42.0106 & 41.959 & 41.812 & 41.666 & 41.519 & 41.371 & 41.225 & 41.077 \\ 7.4 & 40.930 & 40.783 & 40.636 & 40.489 & 40.342 & 40.195 & 40.048 & 39.901 & 39.754 & 39.606\end{array}$

$\begin{array}{llllllllllll}7.5 & 39.459 & 39.312 & 39.166 & 39.019 & 38.872 & 38.725 & 38.578 & 38.431 & 38.284 & 38.136\end{array}$

$\begin{array}{lllllllllll}7.6 & 37.989 & 37.842 & 37.695 & 37.548 & 37.401 & 37.254 & 37.107 & 36.960 & 36.813 & 36.666 \\ 7.7 & 36.519 & 36.372 & 36.225 & 36.078 & 35.932 & 35.785 & 35.638 & 35.491 & 35.344 & 35.197\end{array}$

$\begin{array}{lllllllllll}7.8 & 35.050 & 34.903 & 34.756 & 34.608 & 34.461 & 34.315 & 34.167 & 34.021 & 33.874 & 33.727 \\ 7.9 & 33.580 & 33.433 & 33.286 & 33.139 & 32.991 & 32.845 & 32.698 & 32.551 & 32.404 & 32.257\end{array}$

$\begin{array}{lllllllllll}2608.0 & 38332.110 & 31.963 & 31.816 & 31.668 & 31.522 & 31.375 & 31.228 & 31.081 & 30.934 & 30.787\end{array}$

$\begin{array}{lllllllllll}8.1 & 30.641 & 30.493 & 30.346 & 30.199 & 30.052 & 29.905 & 29.758 & 29.611 & 29.464 & 29.317\end{array}$

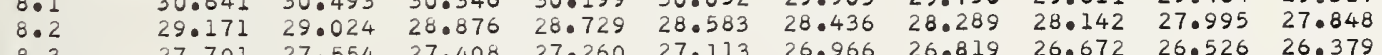

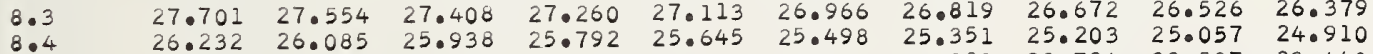

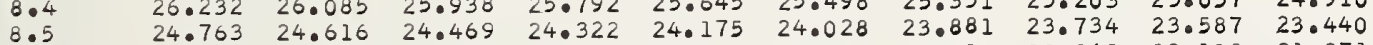

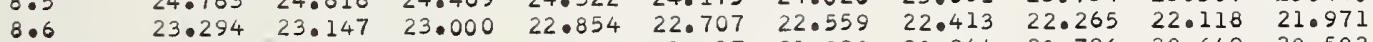

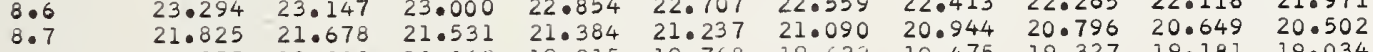

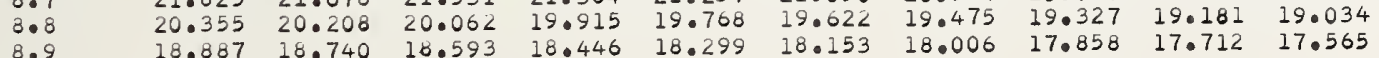

$\begin{array}{lllllllllll}2609.0 & 38317.418 & 17.272 & 17.125 & 16.978 & 16.832 & 16.685 & 16.538 & 16.391 & 16.244 & 16.097\end{array}$

$\begin{array}{lllllllllll}9.1 & 15.951 & 15.803 & 15.656 & 15.510 & 15.363 & 15.216 & 15.069 & 14.922 & 14.775 & 14.628 \\ 9.2 & 14.682 & 14.334 & 14.187 & 14.041 & 13.894 & 13.747 & 13.601 & 13.454 & 13.307 & 13.161\end{array}$

$\begin{array}{lllllllllll}9.2 & 14.482 & 14.334 & 14.187 & 14.041 & 13.894 & 13.747 & 13.601 & 13.454 & 13.307 & 13.161 \\ 9.3 & 13.014 & 12.866 & 12.720 & 12.573 & 12.426 & 12.279 & 12.132 & 11.985 & 11.839 & 11.692 \\ 9.3 & 1.0545 & 11.398 & 11.051 & 11.104 & 10.958 & 10.811 & 10.664 & 10.517 & 10.371 & 10.224\end{array}$

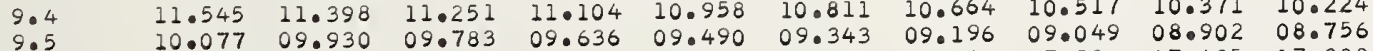

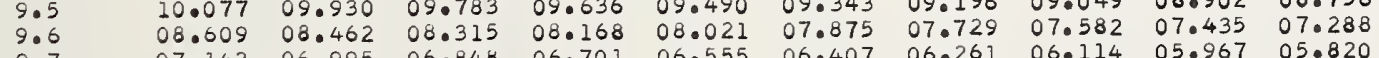

$\begin{array}{lllllllllll}9.7 & 07.142 & 06.995 & 06.848 & 06.701 & 06.555 & 06.407 & 06.261 & 06.114 & 05.967 & 05.820 \\ 9.05 & 05.074 & 05.527 & 05.380 & 05.233 & 05.086 & 04.940 & 04.793 & 04.646 & 04.500 & 04.353\end{array}$

9.8

$\begin{array}{llllllllll} & .001 & .002 & .003 & .004 & .005 & .006 & .007 & .008 & .009 \\ .148 & .015 & .030 & .044 & .059 & .074 & .089 & .0104 & .118 & .133 \\ .147 & .015 & .029 & .044 & .059 & .073 & .088 & .103 & .118 & .132 \\ .146 & .015 & .029 & .044 & .058 & .073 & .088 & .102 & .117 & .131\end{array}$
0.298746 0.298744 0.298741 0.298737

0.298734

0.298732

0.298730

0.298727

0.298725

0.298720

0.298718

0.298716

0.298711

0.298708

0.298704

0.298701

0.298697

0.298694

0.298692

0.298687

0.298685

0.298683

0.298680

0.298676

0.298673

0.298671

0.298666

0.777077
0.777101

0.777125

0.777149
0.0777172

0.777196

0.777243

0.777267
0.777291

0.777315

0.777362

0.777386
0.777410

0.777433
0.777457

0.777481

0.777504
0.777528

0.777552

0.777576
0.777599

0.777623
0.777647

0.777671

0.777694

0.777742

0.298664 0.298662 0.298657 0.298655 0.298652 0.298650 0.298648 0.298645

0.777789

0.777813

0.777860

0.777884

0.777932

0.777979
0.778003

0.778027 0.778050 0.778074 0.778122 0.778345 0.778169 0.778217 0.778264 0.778288 0.778312 0.778359 0.778383 0.778407 0.778430 0.778478 0.778502 0.778525 0.778549

0.778573
0.778597

0.778620

0.778644

0.778692
0.778715

0.778739

0.778763

0.778810

0.778834

0.778858

0.778882
0.778905

0.778929

0.778977

0.779000

0.779024

0.779048
0.779072

0.779095

0.779119

0.779167

0.779214

0.779238

0.779285

0.779309

0.779333
0.779357

0.779381

0.779404
0.779428 


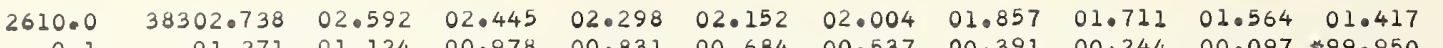

$\begin{array}{llllllllll}0.1 & 01.271 & 01.124 & 00.978 & 00.831 & 00.684 & 00.537 & 00.391 & 00.244 & 00.097 \\ 0.2 & 38299.99 .950\end{array}$

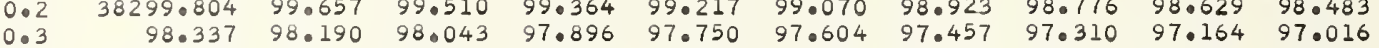

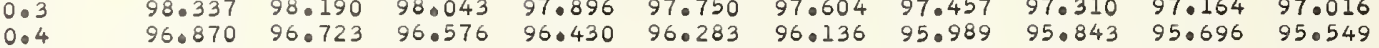

$\begin{array}{lllllllllll}0.5 & 95.402 & 95.256 & 95.109 & 94.962 & 94.816 & 94.669 & 94.522 & 94.376 & 94.229 & 94.082\end{array}$

$\begin{array}{lllllllllll}0.6 & 93.936 & 93.789 & 93.642 & 93.496 & 93.349 & 93.202 & 93.056 & 92.909 & 92.762 & 92.615\end{array}$

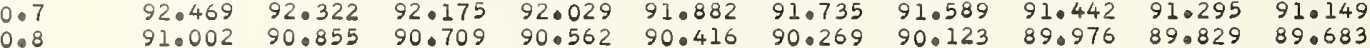

$\begin{array}{llllllllll}89.535 & 89.389 & 89.242 & 89.096 & 88.949 & 80.803 & 88.656 & 88.509 & 88.363 & 88.216\end{array}$

$\begin{array}{lllllllllll}2611.0 & 38288.070 & 87.923 & 87.777 & 87.629 & 87.483 & 87.336 & 87.189 & 87.043 & 86.896 & 86.750\end{array}$

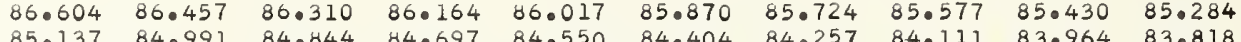

$\begin{array}{lllllllllll}1.2 & 85.137 & 84.991 & 84.844 & 84.697 & 84.550 & 84.404 & 84.257 & 84.111 & 83.964 & 83.818 \\ 1.3 & 83.671 & 83.524 & 83.378 & 83.231 & 83.084 & 82.938 & 82.792 & 82.645 & 82.499 & 82.352 \\ 1.4 & 82.205 & 82.059 & 81.912 & 81.765 & 81.618 & 81.472 & 81.325 & 81.179 & 81.032 & 80.886\end{array}$

$\begin{array}{llllllllllll}1.4 & 82.205 & 82.059 & 81.912 & 81.765 & 81.618 & 81.472 & 81.325 & 81.179 & 81.032 & 80.886 \\ 1.5 & 80.739 & 80.593 & 80.446 & 80.299 & 80.153 & 80.006 & 79.859 & 79.713 & 79.567 & 79.420\end{array}$

$\begin{array}{lllllllllll}1.6 & 79.274 & 79.127 & 78.980 & 78.834 & 78.687 & 78.541 & 78.395 & 78.248 & 78.101 & 77.955 \\ 1.7 & 77.808 & 77.662 & 77.515 & 77.369 & 77.222 & 77.075 & 76.929 & 76.782 & 76.635 & 76.489\end{array}$

$\begin{array}{lllllllllll}1.8 & 76.342 & 76.196 & 76.050 & 75.903 & 75.756 & 75.610 & 75.463 & 75.316 & 75.170 & 75.023\end{array}$

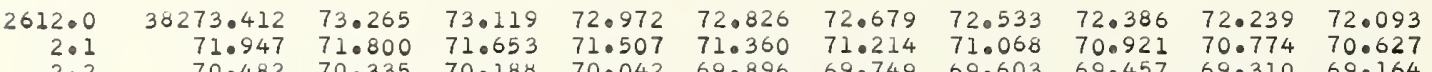

$\begin{array}{lllllllllll}2.2 & 70.482 & 70.335 & 70.188 & 70.042 & 69.896 & 69.749 & 69.603 & 69.457 & 69.310 & 69.164 \\ 2.3 & 69.017 & 68.870 & 68.724 & 68.577 & 68.431 & 68.285 & 68.138 & 67.992 & 67.845 & 67.699\end{array}$

$\begin{array}{llllllllll}67.552 & 67.406 & 67.259 & 67.112 & 66.966 & 66.820 & 66.673 & 66.526 & 66.380 & 66.234 \\ 66.087 & 65.941 & 65.794 & 65.647 & 65.501 & 65.355 & 65.208 & 65.062 & 64.916 & 64.769\end{array}$

$\begin{array}{llllllllll}66.087 & 65.941 & 65.794 & 65.647 & 65.501 & 65.355 & 65.208 & 65.062 & 64.916 & 64.769 \\ 64.623 & 64.477 & 64.330 & 64.183 & 64.037 & 63.890 & 63.744 & 63.598 & 63.451 & 63.304\end{array}$

2.7

2613.0

13.0
3.1
3.2
3.3
3.4

3.4
3.5 $57.302 \quad 58.61$ 55.837 54.374 $52.910 \quad 52.764$ $51.446 \quad 51.30$ $\begin{array}{ll}49.983 & 49.837 \\ 48.520 & 48.373\end{array}$ $\begin{array}{ll}47.056 & 46.910 \\ 45.593 & 45.447\end{array}$
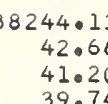

$4 \cdot 4$

4.6

4.7
4.8

4.9

$\begin{array}{llllllll}57.009 & 56.863 & 56.716 & 56.570 & 56.423 & 56.276 & 56.130 & 55.983\end{array}$

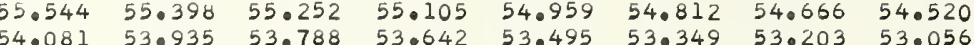
$52.01753 .935 \quad 53.780 \quad 53.64253 .495 \quad 53.349 \quad 53.20353 .056$ $51.154 \quad 51.007 \quad 50.861 \quad 50.715 \quad 50.568 \quad 50.422 \quad 50.276 \quad 50.129$ $\begin{array}{llllllll}49.690 & 49.544 & 49.398 & 49.251 & 49.105 & 48.959 & 48.812 & 48.666\end{array}$ $\begin{array}{llll}40.227 & 48.081 & 47.935 & 470 \\ 46.764 & 46.617 & 46.471\end{array}$ $\begin{array}{llll}46.764 & 46.617 & 46.471 & 46 . \\ 45.300 & 45.154 & 45.008 & 44\end{array}$

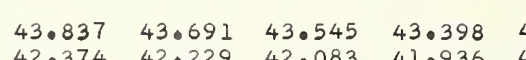

0.298638 0.298636 0.298634 0.298631 0.298628 0.298629 0.298624 0.298622

0.298617

0.298613

0.298613

0.298608

0.298606

0.298603

0.298599

0.298594

0.298592

0.298589
0.298587

0.298585

0.298582

0.298580

0.298575

0.298573

0.298571

0.298566

0.298564

0.298561

0.298557

0.298554

0.298552

0.298547

0.298545

0.298540

0.298538

0.298536

0.0298533

0.298529

0.298526

0.298524 0.298522
0.298519 0.298517 0.298515 0.298513 0.298510 0.298508 0.298506 0.298503

0.298501

0.298499

0.298496

0.298492

0.298489

0.298485

0.298482

0.298480

0.298478 0.298475 0.298471 0.298469 0.298464 0.298464 0.298459 0.298459
0.298457

0.298455 0.298452 0.298450 0.298448 0.298445 0.298443 0.298441 0.298439 0.298436 0.298434 0.298432 0.298429 0.298425 0.298422 0.298420 0.298415 0.298413 0.779452 0.779476 0.779523 0.779547 0.779571 0.7779594
0.779618
0.779686 0.779642 0.779689 0.779713
0.779737 0.779761 0.779785 0.779832 0.779856 0.779880 0.779927 0.779951
0.779975 0.779975 0.780022 0.780046 0.780070 0.780117 0.780141 0.780165 0.780189 0.780213 0.780236 0.780260 0.780284 0.780308 0.780331 0.780355
0.780379

0.780403 0.780427 0.780450 0.780474
0.780498 0.780498 0.780522 0.780545
0.780569 


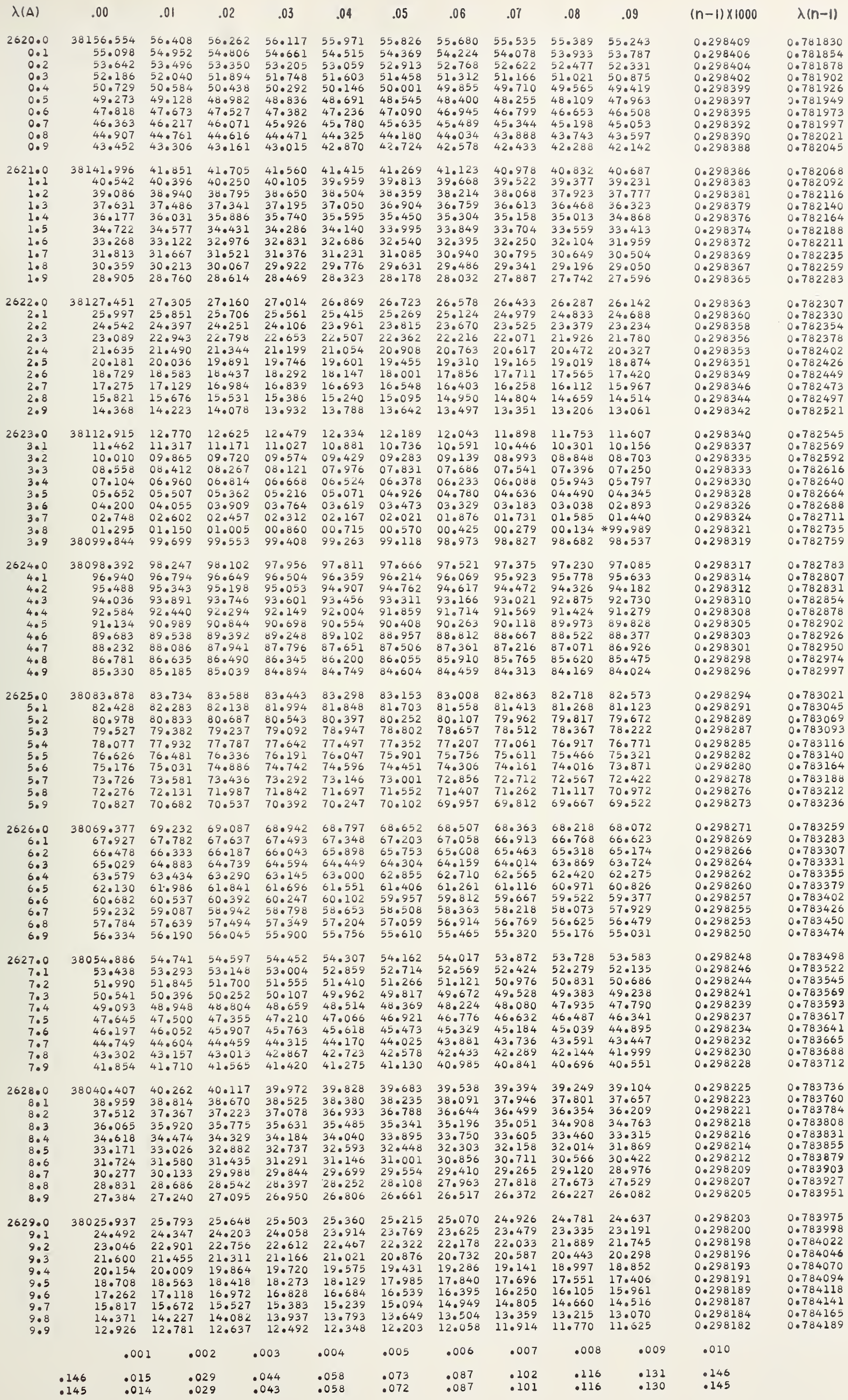


0.297999

0.297997

0.297992

0.297990

0.297986

0.297983

0.297981

0.784428

0.784451
0.784475

0.784499

0.784523
0.784547

0.784571

0.784595

0.784642

0.784690

0.784714
0.784738 0.784762 0.784785 0.784809 0.784857
0.784881 0.784905

0.784929 0.784952 0.784976
0.785000 0.785024 0.785048 0.785072

0.785096

0.785143

0.785167 0.785191
0.785215 0.785239
0.785239
0.785263 0.785263
0.785286 0.785310 0.785334
0.785358 0.785382 0.785406
0.785430 0.785406
0.785453
0.785477 0.785501 0.785525 0.785549
0.785573

0.785573

0.785644

0.785668

0.785692
0.785716

0.785740

0.785764
0.785788

0.785788

0.785835
0.785859

$\begin{array}{ll}0.297975 & 0.786361 \\ 0.297572 & 0.786385\end{array}$

$0.297972 \quad 0.786408$

$\begin{array}{ll}0.297972 & 0.786408 \\ 0.297970 & 0.786432 \\ 0.297968 & 0.786456\end{array}$

$\begin{array}{ll}0.297968 & 0.786456 \\ 0.297966 & 0.786480\end{array}$

$0.297963 \quad 0.786504$

$\begin{array}{ll}0.297961 & 0.786528 \\ 0.297959 & 0.786552\end{array}$

$\begin{array}{ll}0.297959 & 0.786552 \\ 0.297957 & 0.786576\end{array}$

$\begin{array}{ccccccccccc} & .001 & .002 & .003 & .004 & .005 & .006 & .007 & .008 & .009 & .010 \\ .144 & .014 & .029 & .043 & .058 & .072 & .086 & .0101 & .115 & .130 & .144 \\ 143 & .014 & .029 & .043 & .057 & .072 & .086 & .100 & .114 & .129 & .143\end{array}$




\begin{tabular}{|c|c|c|c|c|c|c|c|c|c|c|c|c|}
\hline (A) & .00 & .01 & .02 & .03 & .04 & .05 & .06 & .07 & .08 & .09 & $(n-1) \times 1000$ & $\lambda(n$ \\
\hline $\begin{array}{l}40.0 \\
0.1 \\
0.2 \\
0.3 \\
0.4 \\
0.5 \\
0.6 \\
0.7 \\
0.8 \\
0.9\end{array}$ & $\begin{array}{r}867.506 \\
66.072 \\
64.638 \\
63.204 \\
61.770 \\
60.336 \\
58.902 \\
57.469 \\
56.035 \\
54.601\end{array}$ & $\begin{array}{l}67.363 \\
65.928 \\
64.494 \\
63.060 \\
61.626 \\
60.193 \\
58.759 \\
57.325 \\
55.892 \\
54.458\end{array}$ & $\begin{array}{l}67.219 \\
65.785 \\
64.351 \\
62.917 \\
61.483 \\
60.049 \\
58.615 \\
57.182 \\
55.749 \\
54.315\end{array}$ & $\begin{array}{l}67.075 \\
65.641 \\
64.207 \\
62.774 \\
61.340 \\
59.906 \\
58.472 \\
57.039 \\
55.605 \\
54.172\end{array}$ & $\begin{array}{l}66.932 \\
65.498 \\
64.063 \\
62.0630 \\
61.197 \\
59.763 \\
58.029 \\
56.895 \\
55.461 \\
54.029\end{array}$ & $\begin{array}{l}66.789 \\
65.354 \\
63.920 \\
62.487 \\
61.053 \\
59.619 \\
58.186 \\
56.751 \\
55.318 \\
53.885\end{array}$ & $\begin{array}{l}66.645 \\
65.211 \\
63.777 \\
62.343 \\
60.909 \\
59.476 \\
58.042 \\
56.609 \\
55.175 \\
53.742\end{array}$ & $\begin{array}{l}66.502 \\
65.068 \\
63.634 \\
62.200 \\
60.766 \\
59.332 \\
57.898 \\
56.465 \\
55.031 \\
53.599\end{array}$ & $\begin{array}{l}66.358 \\
64.924 \\
63.490 \\
62.057 \\
60.623 \\
59.189 \\
57.755 \\
56.321 \\
54.888 \\
53.456\end{array}$ & $\begin{array}{l}66.215 \\
64.781 \\
63.347 \\
61.913 \\
60.479 \\
59.045 \\
57.612 \\
56.178 \\
54.745 \\
53.312\end{array}$ & $\begin{array}{l}0.297954 \\
0.297952 \\
0.297950 \\
0.297948 \\
0.297945 \\
0.297943 \\
0.297941 \\
0.297939 \\
0.297936 \\
0.297934\end{array}$ & $\begin{array}{l}0.7866 \\
0.7866 \\
0.7866 \\
0.7866 \\
0.7866 \\
0.7867 \\
0.7867 \\
0.7867 \\
0.7867 \\
0.7868\end{array}$ \\
\hline $\begin{array}{l}41 \cdot 0 \\
1.1 \\
1.2 \\
1.3 \\
1.4 \\
1.5 \\
1.5 \\
1.7 \\
1.8 \\
1.9\end{array}$ & $\begin{array}{r}37853.169 \\
51.736 \\
50.303 \\
48.870 \\
47.437 \\
46.003 \\
44.5772 \\
43.139 \\
41.707 \\
40.274\end{array}$ & $\begin{array}{l}53.025 \\
51.592 \\
50.159 \\
48.726 \\
47.293 \\
45.861 \\
44.428 \\
42.996 \\
41.563 \\
40.131\end{array}$ & $\begin{array}{l}52.882 \\
51.449 \\
50.015 \\
48.583 \\
47.150 \\
45.717 \\
44.285 \\
42.853 \\
41.420 \\
39.988\end{array}$ & $\begin{array}{l}52.738 \\
51.306 \\
49.873 \\
48.439 \\
47.006 \\
45.573 \\
44.142 \\
42.109 \\
41.277 \\
39.844\end{array}$ & $\begin{array}{l}52.596 \\
51.162 \\
49.729 \\
48.296 \\
46.863 \\
45.431 \\
43.999 \\
42.566 \\
41.133 \\
39.702\end{array}$ & $\begin{array}{l}52.452 \\
51.019 \\
49.585 \\
48.153 \\
46.720 \\
45.287 \\
43.855 \\
42.422 \\
40.991 \\
39.558\end{array}$ & $\begin{array}{l}52.309 \\
50.876 \\
49.443 \\
48.010 \\
46.577 \\
45.144 \\
43.712 \\
42.279 \\
40.847 \\
39.415\end{array}$ & $\begin{array}{l}52.166 \\
50.732 \\
49.299 \\
47.866 \\
46.433 \\
45.001 \\
43.569 \\
42.136 \\
40.704 \\
39.271\end{array}$ & $\begin{array}{l}52.022 \\
50.589 \\
49.156 \\
47.723 \\
46.291 \\
44.857 \\
43.425 \\
41.993 \\
40.561 \\
39.128\end{array}$ & $\begin{array}{l}51.879 \\
50.446 \\
49.013 \\
47.580 \\
46.147 \\
44.714 \\
43.282 \\
41.850 \\
40.417 \\
38.985\end{array}$ & $\begin{array}{l}0.297932 \\
0.297930 \\
0.297928 \\
0.297925 \\
0.297923 \\
0.297921 \\
0.297919 \\
0.297916 \\
0.297914 \\
0.297912\end{array}$ & $\begin{array}{l}0.7868 \\
0.7868 \\
0.7868 \\
0.7869\end{array}$ \\
\hline $\begin{array}{r}42.0 \\
2.1 \\
2.2 \\
2.3 \\
2.4 \\
2.5 \\
2.6 \\
2.7 \\
2.8 \\
2.9\end{array}$ & $\begin{array}{r}37838.842 \\
37.410 \\
35.978 \\
34.546 \\
33.114 \\
31.682 \\
30.251 \\
28.819 \\
27.388 \\
25.957\end{array}$ & $\begin{array}{l}38.699 \\
37.267 \\
35.834 \\
34.403 \\
32.971 \\
31.540 \\
30.108 \\
28.676 \\
27.245 \\
25.814\end{array}$ & $\begin{array}{l}38.555 \\
37.123 \\
35.691 \\
34.260 \\
32.828 \\
31.396 \\
29.964 \\
28.533 \\
27.102 \\
25.670\end{array}$ & $\begin{array}{l}38.412 \\
36.980 \\
35.548 \\
34.117 \\
32.685 \\
31.253 \\
29.822 \\
28.390 \\
26.958 \\
25.527\end{array}$ & $\begin{array}{l}38.269 \\
36.837 \\
35.405 \\
33.977 \\
32.542 \\
31.110 \\
29.679 \\
28.247 \\
26.815 \\
25.385\end{array}$ & $\begin{array}{l}38.126 \\
36.694 \\
35.262 \\
33.831 \\
32.398 \\
30.967 \\
29.535 \\
28.104 \\
26.673 \\
25.242\end{array}$ & $\begin{array}{l}37.982 \\
36.550 \\
35.1119 \\
33.687 \\
32.255 \\
30.824 \\
29.093 \\
27.961 \\
26.529 \\
25.099\end{array}$ & $\begin{array}{l}37.839 \\
36.407 \\
34.976 \\
33.544 \\
32.112 \\
30.681 \\
29.249 \\
27.818 \\
26.386 \\
24.956\end{array}$ & $\begin{array}{l}37.696 \\
36.264 \\
34.833 \\
33.401 \\
31.969 \\
30.538 \\
29.106 \\
27.674 \\
26.244 \\
24.812\end{array}$ & $\begin{array}{l}37.553 \\
36.121 \\
34.689 \\
33.258 \\
31.826 \\
30.395 \\
28.963 \\
27.532 \\
26.100 \\
24.669\end{array}$ & $\begin{array}{l}0.297910 \\
0.297907 \\
0.297905 \\
0.297903 \\
0.297901 \\
0.297898 \\
0.297896 \\
0.297894 \\
0.297892 \\
0.297890\end{array}$ & $\begin{array}{l}0.78 \\
0.78\end{array}$ \\
\hline $\begin{array}{r}43.0 \\
3.1 \\
3.2 \\
3.3 \\
3.4 \\
3.5 \\
3.6 \\
3.7 \\
3.8 \\
3.9\end{array}$ & $\begin{array}{r}824.526 \\
23.095 \\
21.665 \\
20.233 \\
18.803 \\
17.372 \\
15.942 \\
14.512 \\
13.081 \\
11.651\end{array}$ & $\begin{array}{l}24.383 \\
22.952 \\
21.521 \\
20.090 \\
18.060 \\
17.229 \\
15.0799 \\
14.369 \\
12.938 \\
11.0508\end{array}$ & $\begin{array}{l}24.240 \\
22.809 \\
21.370 \\
19.948 \\
18.517 \\
17.086 \\
15.656 \\
14.226 \\
12.795 \\
11.365\end{array}$ & $\begin{array}{l}24.097 \\
22.667 \\
21.235 \\
19.804 \\
18.374 \\
16.943 \\
15.513 \\
14.083 \\
12.652 \\
11.222\end{array}$ & $\begin{array}{l}23.954 \\
22.522 \\
21.092 \\
19.061 \\
18.231 \\
16.800 \\
15.8370 \\
13.0939 \\
12.509 \\
11.079\end{array}$ & $\begin{array}{l}23.811 \\
22.379 \\
20.948 \\
19.518 \\
18.087 \\
16.657 \\
15.227 \\
13.796 \\
12.367 \\
10.936\end{array}$ & $\begin{array}{l}23.667 \\
22.237 \\
20.806 \\
19.375 \\
17.944 \\
16.313 \\
15.084 \\
13.654 \\
12.223 \\
10.793\end{array}$ & $\begin{array}{l}23.524 \\
22.094 \\
20.663 \\
19.231 \\
17.801 \\
16.371 \\
14.941 \\
13.511 \\
12.080 \\
10.650\end{array}$ & $\begin{array}{l}23.381 \\
21.950 \\
20.520 \\
19.089 \\
17.658 \\
16.228 \\
14.798 \\
13.368 \\
11.937 \\
10.507\end{array}$ & $\begin{array}{l}23.238 \\
21.808 \\
20.376 \\
18.946 \\
17.515 \\
16.084 \\
14.655 \\
13.224 \\
11.794 \\
10.364\end{array}$ & $\begin{array}{l}0.297887 \\
0.297885 \\
0.297883 \\
0.297881 \\
0.297878 \\
0.297876 \\
0.297874 \\
0.297872 \\
0.297870 \\
0.297867\end{array}$ & 0.787 \\
\hline $\begin{array}{r}44.0 \\
4.1 \\
4.2 \\
4.3 \\
4.4 \\
4.5 \\
4.6 \\
4.7 \\
4.8 \\
4.9\end{array}$ & $\begin{array}{r}37810.221 \\
08.791 \\
07.361 \\
05.932 \\
04.502 \\
03.073 \\
01.644 \\
00.214 \\
37798.785 \\
97.355\end{array}$ & $\begin{array}{l}10.078 \\
08.648 \\
07.218 \\
05.789 \\
04.360 \\
02.930 \\
01.500 \\
00.071 \\
98.642 \\
97.213\end{array}$ & $\begin{array}{r}09.935 \\
08.505 \\
07.075 \\
05.646 \\
04.217 \\
02.787 \\
01.357 \\
* 99.928 \\
98.499 \\
97.070\end{array}$ & $\begin{array}{r}09.792 \\
08.362 \\
06.932 \\
05.503 \\
04.073 \\
02.644 \\
01.015 \\
* 99.786 \\
98.356 \\
96.927\end{array}$ & $\begin{array}{l}09.649 \\
08.219 \\
06.789 \\
05.360 \\
03.931 \\
02.501 \\
01.071 \\
99.0642 \\
98.213 \\
96.785\end{array}$ & $\begin{array}{l}09.506 \\
08.076 \\
06.646 \\
05.217 \\
03.788 \\
02.358 \\
00.928 \\
* 99.499 \\
98.070 \\
96.642\end{array}$ & $\begin{array}{l}09.363 \\
07.934 \\
06.503 \\
05.074 \\
03.645 \\
02.215 \\
00.786 \\
499.356 \\
97.927 \\
96.499\end{array}$ & $\begin{array}{l}09.220 \\
07.791 \\
06.361 \\
04.931 \\
03.501 \\
02.072 \\
00.643 \\
99.213 \\
97.784 \\
96.356\end{array}$ & $\begin{array}{r}09.077 \\
07.647 \\
06.218 \\
04.789 \\
03.359 \\
01.929 \\
00.500 \\
* 99.070 \\
97.642 \\
96.213\end{array}$ & $\begin{array}{r}08.934 \\
07.504 \\
06.075 \\
04.646 \\
03.216 \\
01.786 \\
00.357 \\
* 98.928 \\
97.499 \\
96.070\end{array}$ & $\begin{array}{l}0.297865 \\
0.297863 \\
0.297861 \\
0.297858 \\
0.297856 \\
0.297854 \\
0.2978552 \\
0.297849 \\
0.297847 \\
0.297845\end{array}$ & 0.1817 \\
\hline $\begin{array}{r}45.0 \\
5.1 \\
5.2 \\
5.3 \\
5.4 \\
5.5 \\
5.6 \\
5.7 \\
5.8 \\
5.9\end{array}$ & $\begin{array}{r}37795.927 \\
94.499 \\
93.069 \\
91.6441 \\
90.212 \\
88.784 \\
87.0355 \\
85.928 \\
84.500 \\
83.072\end{array}$ & $\begin{array}{l}95.784 \\
94.355 \\
92.926 \\
91.498 \\
90.069 \\
88.641 \\
87.213 \\
85.785 \\
84.357 \\
82.929\end{array}$ & $\begin{array}{l}95.644 \\
94.212 \\
92.784 \\
91.355 \\
89.927 \\
88.498 \\
87.070 \\
85.642 \\
84.214 \\
82.786\end{array}$ & $\begin{array}{l}95.499 \\
94.070 \\
92.641 \\
91.212 \\
89.784 \\
88.355 \\
86.928 \\
85.499 \\
84.071 \\
82.643\end{array}$ & $\begin{array}{l}95.356 \\
93.927 \\
92.498 \\
91.069 \\
89.641 \\
88.212 \\
86.785 \\
85.356 \\
83.928 \\
82.500\end{array}$ & $\begin{array}{l}95.213 \\
93.784 \\
92.355 \\
90.927 \\
89.498 \\
88.070 \\
86.642 \\
85.213 \\
83.786 \\
82.357\end{array}$ & $\begin{array}{l}95.070 \\
93.642 \\
92.212 \\
90.784 \\
89.355 \\
87.927 \\
86.499 \\
85.071 \\
83.643 \\
82.215\end{array}$ & $\begin{array}{l}94.927 \\
93.499 \\
92.070 \\
90.641 \\
89.212 \\
87.784 \\
86.356 \\
84.928 \\
83.500 \\
82.072\end{array}$ & $\begin{array}{l}94.784 \\
93.355 \\
91.926 \\
90.499 \\
89.070 \\
87.641 \\
86.213 \\
84.785 \\
83.357 \\
81.0929\end{array}$ & $\begin{array}{l}94.641 \\
93.212 \\
91.784 \\
90.355 \\
88.926 \\
87.498 \\
86.071 \\
84.643 \\
83.214 \\
81.787\end{array}$ & $\begin{array}{l}0.297843 \\
0.297841 \\
0.297838 \\
0.297836 \\
0.297834 \\
0.297832 \\
0.297829 \\
0.297827 \\
0.297825 \\
0.297823\end{array}$ & 0.7877 \\
\hline $\begin{array}{l}646.0 \\
6.1 \\
6.2 \\
6.3 \\
6.4 \\
6.5 \\
6.6 \\
6.7 \\
6.8 \\
6.9\end{array}$ & $\begin{array}{r}37781.644 \\
80.216 \\
78.788 \\
77.361 \\
75.934 \\
74.506 \\
73.079 \\
71.652 \\
70.225 \\
68.797\end{array}$ & $\begin{array}{l}81.501 \\
80.073 \\
78.646 \\
77.218 \\
75.791 \\
74.363 \\
72.936 \\
71.509 \\
70.082 \\
68.655\end{array}$ & $\begin{array}{l}81.358 \\
79.930 \\
78.502 \\
77.076 \\
75.648 \\
74.221 \\
72.793 \\
71.366 \\
69.939 \\
68.512\end{array}$ & $\begin{array}{l}81.215 \\
79.888 \\
78.360 \\
76.933 \\
75.505 \\
74.078 \\
72.651 \\
71.224 \\
69.796 \\
68.370\end{array}$ & $\begin{array}{l}81.072 \\
79.645 \\
78.217 \\
76.790 \\
75.363 \\
73.936 \\
72.0508 \\
71.081 \\
69.054 \\
68.227\end{array}$ & $\begin{array}{l}80.930 \\
79.501 \\
78.074 \\
76.647 \\
75.220 \\
73.792 \\
72.365 \\
70.938 \\
69.511 \\
68.084\end{array}$ & $\begin{array}{l}80.787 \\
79.359 \\
77.932 \\
76.505 \\
75.077 \\
73.650 \\
72.223 \\
70.796 \\
69.369 \\
67.942\end{array}$ & $\begin{array}{l}80.644 \\
79.216 \\
77.789 \\
76.361 \\
74.934 \\
73.507 \\
72.080 \\
70.653 \\
69.226 \\
67.799\end{array}$ & $\begin{array}{l}80.501 \\
79.074 \\
77.646 \\
76.219 \\
74.792 \\
73.364 \\
71.937 \\
70.510 \\
69.083 \\
67.657\end{array}$ & $\begin{array}{l}80.358 \\
78.931 \\
77.504 \\
76.076 \\
74.649 \\
73.221 \\
71.794 \\
70.367 \\
68.940 \\
67.514\end{array}$ & $\begin{array}{l}0.297818 \\
0.297816 \\
0.297814 \\
0.297812 \\
0.297810 \\
0.297807 \\
0.297805 \\
0.297803 \\
0.297801\end{array}$ & $\begin{array}{l}0.788 \\
0.788 \\
0.788 \\
0.788\end{array}$ \\
\hline $\begin{array}{r}347.0 \\
7.1 \\
7.2 \\
7.3 \\
7.4 \\
7.5 \\
7.6 \\
7.7 \\
7.8 \\
7.9\end{array}$ & $\begin{array}{r}37767.372 \\
65.945 \\
64.518 \\
63.092 \\
61.665 \\
60.239 \\
58.813 \\
57.387 \\
55.961 \\
54.535\end{array}$ & $\begin{array}{l}67.229 \\
65.802 \\
64.375 \\
62.949 \\
61.523 \\
60.096 \\
58.670 \\
57.244 \\
55.818 \\
54.393\end{array}$ & $\begin{array}{l}67.086 \\
65.659 \\
64.232 \\
62.806 \\
61.379 \\
59.953 \\
58.527 \\
57.102 \\
55.676 \\
54.250\end{array}$ & $\begin{array}{l}65.517 \\
64.090 \\
62.664 \\
61.237 \\
59.811 \\
58.386 \\
56.959 \\
55.533 \\
54.107\end{array}$ & $\begin{array}{l}4 \\
7 \\
1 \\
5 \\
8 \\
-3 \\
7\end{array}$ & & & & & & & \\
\hline $\begin{array}{r}548.0 \\
8.1 \\
8.2 \\
8.3 \\
8.4 \\
8.5 \\
8.6 \\
8.7 \\
8.8 \\
8.9\end{array}$ & $\begin{array}{r}37753.109 \\
51.684 \\
50.258 \\
48.833 \\
47.408 \\
45.982 \\
44.558 \\
43.133 \\
41.708 \\
40.283\end{array}$ & $\begin{array}{l}52.967 \\
51.541 \\
50.115 \\
48.690 \\
47.265 \\
45.840 \\
44.415 \\
42.990 \\
41.564 \\
40.141\end{array}$ & $\begin{array}{l}52.824 \\
51.390 \\
49.973 \\
48.548 \\
47.123 \\
45.697 \\
44.272 \\
42.847 \\
41.422 \\
39.998\end{array}$ & $\begin{array}{l}49.831 \\
48.405 \\
46.980 \\
45.555 \\
44.130 \\
42.705 \\
41.280 \\
39.855\end{array}$ & $\begin{array}{l}52.539 \\
51.114 \\
49.688 \\
48.263 \\
46.838 \\
45.413 \\
43.987 \\
42.562 \\
41.137 \\
39.713\end{array}$ & $\begin{array}{l}52.396 \\
50.971 \\
49.545 \\
48.121 \\
46.695 \\
45.270 \\
43.845 \\
42.420 \\
40.995 \\
39.570\end{array}$ & $\begin{array}{l}52.254 \\
50.829 \\
49.403 \\
47.978 \\
46.553 \\
45.127 \\
43.703 \\
42.278 \\
40.853 \\
39.428\end{array}$ & $\begin{array}{l}32.111 \\
50.686 \\
49.260 \\
47.835 \\
46.410 \\
44.985 \\
43.560 \\
42.135 \\
40.710 \\
39.285\end{array}$ & $\begin{array}{l}51.969 \\
50.543 \\
49.117 \\
47.693 \\
46.268 \\
44.843 \\
43.417 \\
41.993 \\
40.568 \\
39.144\end{array}$ & $\begin{array}{l}51.826 \\
50.401 \\
48.975 \\
47.551 \\
46.125 \\
44.700 \\
43.275 \\
41.850 \\
40.425 \\
39.001\end{array}$ & & 0.7887 \\
\hline $\begin{array}{l}49.0 \\
9.1 \\
9.2 \\
9.3 \\
9.4 \\
9.5 \\
9.6 \\
9.7 \\
9.8 \\
9.9\end{array}$ & $\begin{array}{r}37738.858 \\
37.434 \\
36.010 \\
34.585 \\
33.161 \\
31.736 \\
30.0113 \\
28.889 \\
27.465 \\
26.042\end{array}$ & $\begin{array}{l}38.716 \\
37.292 \\
35.867 \\
34.442 \\
33.019 \\
31.594 \\
30.170 \\
28.747 \\
27.323 \\
25.899\end{array}$ & $\begin{array}{l}38.574 \\
37.149 \\
35.725 \\
34.300 \\
32.876 \\
31.452 \\
30.028 \\
28.604 \\
27.181 \\
25.757\end{array}$ & $\begin{array}{l}37.007 \\
35.583 \\
34.158 \\
32.734 \\
31.0310 \\
29.886 \\
28.462 \\
27.038 \\
25.014\end{array}$ & $\begin{array}{l}36.864 \\
35.440 \\
34.016 \\
32.592 \\
31.167 \\
29.743 \\
28.320 \\
26.896 \\
25.473\end{array}$ & $\begin{array}{l}28.177 \\
26.754 \\
25.330\end{array}$ & $\begin{array}{l}36.579 \\
35.155 \\
33.730 \\
32.306 \\
30.882 \\
29.459 \\
28.035 \\
26.611 \\
25.187\end{array}$ & $\begin{array}{l}36.437 \\
35.012 \\
33.588 \\
32.164 \\
30.740 \\
29.316 \\
27.893 \\
26.469 \\
25.045\end{array}$ & $\begin{array}{l}37.719 \\
36.294 \\
34.870 \\
33.446 \\
32.021 \\
30.597 \\
29.174 \\
27.750 \\
26.327 \\
24.903\end{array}$ & $\begin{array}{l}27.608 \\
26.184 \\
24.761\end{array}$ & $\begin{array}{l}0.297739 \\
0.297736 \\
0.297734\end{array}$ & 0.0 \\
\hline & \multicolumn{2}{|c|}{.001} & .002 & & & 005 & .000 & .007 & .008 & .00 & .010 & \\
\hline & .0 & & & & & & .085 & .099 & & .128 & $\cdot 142$ & \\
\hline
\end{tabular}


$\begin{array}{lll}966 & 08.824 & 10.104 \\ 08.682\end{array}$ $\begin{array}{lll}07.544 & 07.402 & 07.259\end{array}$ $04.700 \quad 04.558$ $03.277 \quad 03.135 \quad 02.993$ $01.856 \quad 01.713 \quad 01.571$ $\begin{array}{rr}37699.013 & 98.871 \\ 97.591 & 97.450\end{array}$ 0.150
9.729
7.307

$37696.170 \quad 96.028$ $\begin{array}{ll}94.749 & 94.606 \\ 93.327 & 93.185\end{array}$ $\begin{array}{ll}93.327 & 93.185 \\ 91.906 & 91.764\end{array}$ $\begin{array}{ll}90.485 & 90.344 \\ 89.064 & 88.922\end{array}$ $\begin{array}{ll}89.064 & 88.922 \\ 87.644 & 87.501\end{array}$ $86.223 \quad 86.081$ $\begin{array}{ll}84.802 & 84.660 \\ 83.382 & 83.240\end{array}$

95.886
94.464

94.464 91.622 88.780

2653.0

;i:

$3 \cdot 3$

3.5
3.6

0.297710

0.297708

0.297703

0.297701

0.297699
0.297697

0.297695

0.297692

0.297688

0.297686

0.297681

0.297679

0.297677
0.297675

0.297673

0.297670

0.297666

0.297664

0.297662
0.297659

0.297657

0.297655

0.29765

0.297651

0.297648

0.297644

0.297640

0.297637

0.297633

0.297631

0.297629
0.297626

0.297624

0.297622

0.297620

0.297615

0.297615

0.297611

0.297609

0.297607
0.297605

0.297605

0.297600

0.297598

0.297596
0.297594

0.297591

0.29758

0.297587
0.297585

0.297583

0.297578

0.297576

0.297572

0.297572

0.297567

0.297563

0.297561
0.297559

0.297556

0.297554
0.297552

0.297552
0.297550

0.297548

0.297546

0.297543

0.297541
0.297539

0.297537

0.788990 0.789014 0.789038 0.789086 0.789110

0.789133

0.789157

0.789181

0.789229

0.789253
0.789277
0.789301

0.789301

0.789325

0.789349

0.789373

0.789421

0.789468 


.07

0.297513

0.297508

0.297506

.297502

0.297500

0.297493

0.297491

0.297489
0.297487

0.297485

0.297480

0.297478

0.297476

0.297474
0.297472

0.297469

0.297467

0.297463

0.297461

0.297456

0.297454
0.297452

0.297452
0.297450

0.297448

0.297446

0.297443
0.297441

0.297439

0.297437
0.297435

0.297433

0.297430

0.297426

0.297424

0.297420

0.297420
0.297417
0.29745

0.297415

0.297413
0.297411

0.297409

0.297409
0.297407

0.297404

0.297400

0.297398

0.297396

0.297391

0.297389

0.297385

0.297383

0.297381

0.297378

0.297374

0.297372
0.297370

0.297370

0.297368

0.297363

0.297361

0.297359

0.297355

0.297353

0.297348

. 297346

0.297344
0.297342

0.297340

0.297338

0.297335
0.297333

0.297331

0.297329

0.297327

. 297322

0.297318

0.297316

0.297314

0.297310

0.297307

0.297305

0.297301

0.297299

.791384

0.791432

0.791456
0.791480

0.791504

0.7791504
0.791552

0.791576

0.791624
0.791648

0.791672

0.791696
0.791720

0.791744

0.791768

.791816

0.791840

0.791863

0.791887

0.791935

0.791959
0.791983

0.792007

0.792055

0.792079

0.792103

0.792127

0.792175

0.792199

0.792247

0.792271

0.792295
0.792319

0.792343

0.792367

0.792415

0.792463

0.792487

0.792535

792559

0.792583

0.792607

0.792655

0.792679
0.792703

0.792727

0.792775 


.05

.06

.07

.08

.09

$(n-1) \times 1000$

$\lambda(n-1)$

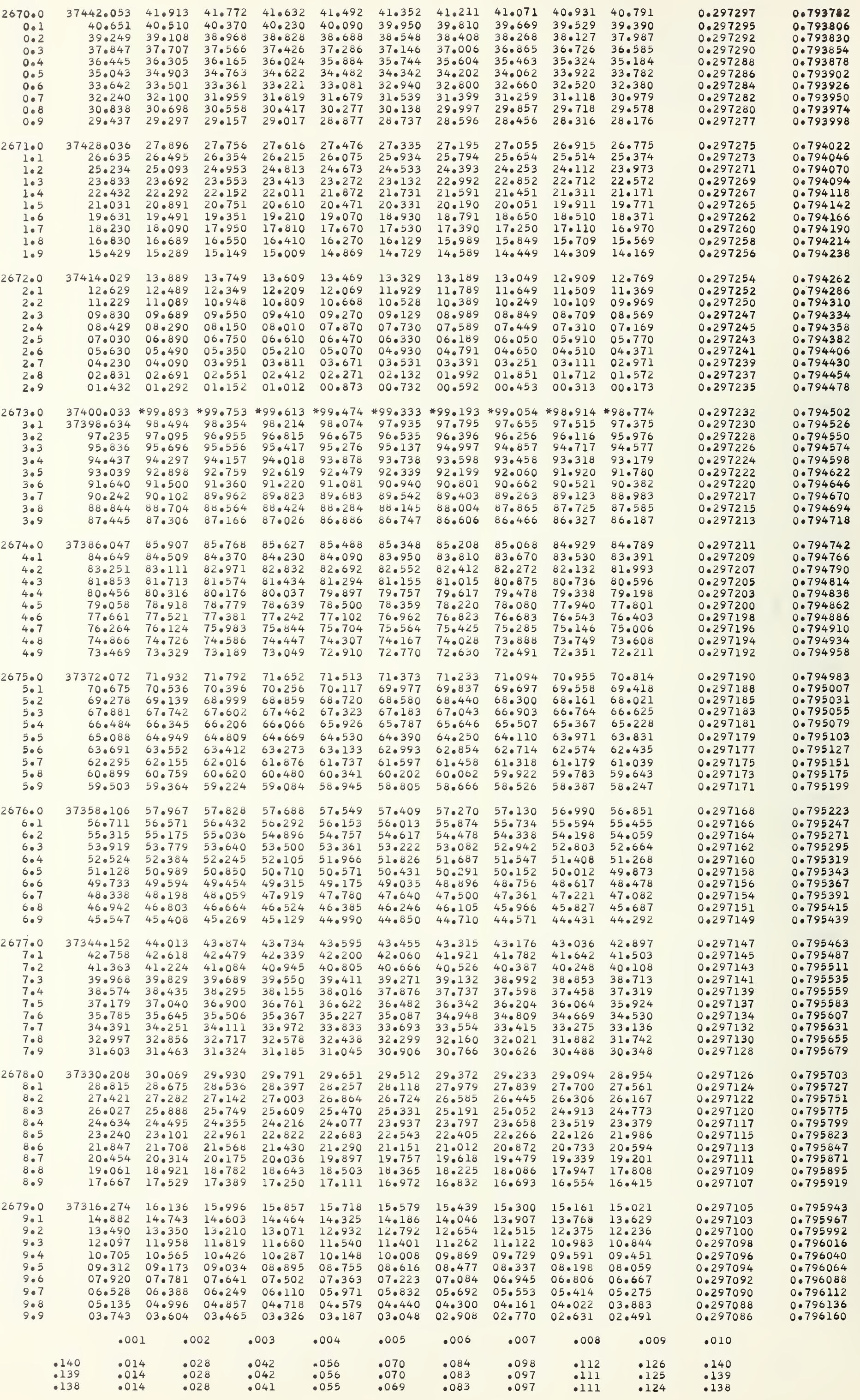




$$
\begin{array}{r}
2680 . \\
0.0 \\
0.0 \\
0.0 \\
0.0 \\
0.0 \\
0.0 \\
0.0 \\
0.0 \\
0 . \\
681 . \\
1 . \\
1 . \\
1 . \\
1 . \\
1 . \\
1 . \\
1 . \\
1 . \\
1 . \\
1 .
\end{array}
$$

$\begin{array}{rrrrrrrrrrr}0.0 & 37302.352 & 02.213 & 02.074 & 01.934 & 01.795 & 01.656 & 01.517 & 01.378 & 01.239 & 01.099 \\ 0.1 & 00.960 & 00.821 & 00.682 & 00.543 & 00.403 & 00.264 & 00.125 & * 99.986 & * 99.847 & * 99.708\end{array}$

$\begin{array}{rrlllllllll}0.2 & 37299.568 & 99.429 & 99.290 & 99.151 & 99.012 & 98.873 & 98.734 & 98.594 & 98.455 & 98.316\end{array}$ $\begin{array}{lllllllllll}0.3 & 98.177 & 98.038 & 97.898 & 97.759 & 97.620 & 97.481 & 97.342 & 97.203 & 97.064 & 96.925 \\ 0.4 & 96.785 & 96.646 & 96.507 & 96.368 & 90.229 & 96.090 & 95.951 & 95.811 & 95.672 & 95.533\end{array}$ 0.5

0.7 $95.394 \quad 95.255 \quad 95.116$ 92.612 92.063 $\begin{array}{ll}91.221 & 91.082 \\ 89.830 & 89.691\end{array}$

$\begin{array}{lllllll}. .368 & 90.229 & 96.090 & 95.951 & 95.811 & 95.672 & 95.533 \\ 4.976 & 94.837 & 94.698 & 94.559 & 94.420 & 94.281 & 94.142\end{array}$ $\begin{array}{lllllll}93.585 & 93.446 & 93.307 & 93.168 & 93.029 & 92.890 & 92.751\end{array}$

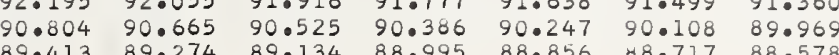
$\begin{array}{llllllll}88.021 & 87.883 & 87.743 & 87.604 & 87.465 & 87.326 & 87.187\end{array}$ $\begin{array}{lllllll}86.631 & 86.492 & 86.353 & 86.214 & 86.075 & 85.936 & 85.797\end{array}$ $\begin{array}{lllllll}85.241 & 85.102 & 84.962 & 84.823 & 84.684 & 84.545 & 84.406\end{array}$ $\begin{array}{lllllll}82.450 & 83.711 & 83.572 & 83.433 & 83.293 & 83.155 & 83.016 \\ 82.321 & 82.182 & 82.043 & 81.904 & 81.765 & 81.625\end{array}$ $\begin{array}{lllllll}81.069 & 80.931 & 80.792 & 80.652 & 80.514 & 80.375 & 80.235 \\ 79.679 & 79.541 & 79.401 & 79.263 & 70.124 & 78.984 & 78.846\end{array}$ $\begin{array}{lllllll}79.679 & 79.541 & 79.401 & 79.263 & 79.124 & 78.984 & 78.846 \\ 78.289 & 78.150 & 78.011 & 77.872 & 77.733 & 77.594 & 77.456\end{array}$ $\begin{array}{lllllll}76.899 & 76.760 & 76.621 & 76.482 & 76.343 & 76.205 & 76.065 \\ 75.509 & 75.371 & 75.231 & 75.092 & 74.953 & 74.814 & 74.675\end{array}$

\section{$\begin{array}{lllllll}74.119 & 73.980 & 73.841 & 73.702 & 73.563 & 73.425 & 73.286\end{array}$} $\begin{array}{lllllll}72.730 & 72.591 & 72.452 & 72.313 & 72.174 & 72.035 & 71.896\end{array}$ $\begin{array}{lllllll}71.341 & 71.201 & 71.062 & 70.924 & 70.785 & 70.646 & 70.507 \\ 69.951 & 69.812 & 69.673 & 69.534 & 69.395 & 69.256 & 69.118\end{array}$ $\begin{array}{llllllll}60.562 & 68.423 & 68.284 & 68.145 & 68.006 & 67.867 & 67.728\end{array}$ $\begin{array}{lllllll}65.784 & 65.034 & 66.895 & 66.755 & 66.617 & 66.478 & 66.339 \\ 65.505 & 65.366 & 65.228 & 65.088 & 64.950\end{array}$ $\begin{array}{lllllll}64.394 & 64.255 & 64.116 & 63.977 & 63.838 & 63.699 & 63.561\end{array}$ $\begin{array}{lllllll}63.005 & 62.867 & 62.728 & 62.589 & 62.450 & 62.312 & 62.172 \\ 61.617 & 61.478 & 61.339 & 61.200 & 61.061 & 60.922 & 60.784\end{array}$ $\begin{array}{llllllllll}37260.644 & 60.506 & 60.367 & 60.228 & 60.089 & 59.950 & 59.811 & 59.673 & 59.534 & 59.395\end{array}$ $\begin{array}{llllllllll}59.256 & 59.117 & 58.978 & 58.839 & 58.700 & 58.562 & 58.423 & 58.284 & 58.145 & 58.006 \\ 57.867 & 57.728 & 57.589 & 57.451 & 57.312 & 57.173 & 57.034 & 56.896 & 56.756 & 56.618\end{array}$ $\begin{array}{llllllllll}56.479 & 56.339 & 56.201 & 56.062 & 55.923 & 55.785 & 55.646 & 55.507 & 55.368 & 55.229\end{array}$ $\begin{array}{llllllllll}55.090 & 54.952 & 54.812 & 54.674 & 54.535 & 54.396 & 54.257 & 54.118 & 53.980 & 53.841 \\ 53.703 & 53.554 & 53.425 & 53.286 & 53.147 & 53.008 & 52.86 & 52.731 & 52.592 & 52.453\end{array}$ $\begin{array}{llllllllll}52.314 & 52.176 & 52.037 & 51.898 & 51.759 & 51.620 & 51.481 & 51.343 & 51.204 & 51.065\end{array}$ $\begin{array}{llllllllll}50.926 & 50.788 & 50.648 & 50.510 & 50.371 & 50.232 & 50.093 & 49.955 & 49.815 & 49.677\end{array}$ $\begin{array}{llllllllll}49.538 & 49.399 & 49.261 & 49.122 & 48.983 & 48.844 & 48.706 & 48.566 & 48.428 & 48.289 \\ 48.150 & 48.012 & 47.873 & 47.734 & 47.596 & 47.457 & 47.317 & 47.179 & 47.040 & 46.901\end{array}$

0.297084

0.297081

0.297077

0.297073

.297069

.297067
.297064

0.297062
0.297060

0.297058

0.297056

0.297052

0.297048

0.297045

0.297041
0.297039
0.297035

0.297037

0.297033

.0297031
0.297029

0.297026

0.297024

0.297020
0.297018

0.297016

0.297014

0.297010

0.297005

0.297003

0.296999

0.296997
0.296995
0.29699

0.296993

0.296991

0.296986

0.296984
0.296982

0.296980

0.296978

0.296974

0.296972

0.296970
0.296968
0.29695

0.296965

0.296963

0.296961
0.296959

0.296957

0.296955

0.296951

0.296949

0.2969474

0.296942

0.296940

0.296936
0.296934

0.296932

0.296930
0.296928

0.296926

0.296921

0.296919
0.296917

0.296915

0.296913

0.296909

0.296907

0.296903

0.296900
0.296898

0.296896

0.296894

0.296892

0.296888

0.296886

0.296884
0.296882

0.296880

0.296877

.010

.139

0.796184

0.796232

0.796256
0.796280

0.796328

0.796352

0.796376
0.796400

0.796424
0.796448

0.796472

0.796520

0.796544
0.796568

0.796592

0.796616

0.796665
0.796689

0.796713
0.796737

0.796761
0.796785

0.796809

0.796857

0.796905

0.796929

0.796977

0.0797025

0.797073

0.797097
0.797121

0.797145

0.797170

0.797218

0.797266

0.797290

0.797314
0.797336

0.797386 
$\begin{array}{rrrrrrrrrrr}0.1 & 6.308 & 63.551 & 63.413 & 63.274 & 63.137 & 62.999 & 62.860 & 62.723 & 62.584 & 62.446 \\ 0.169 & 62.031 & 61.894 & 61.755 & 61.617 & 61.479 & 61.341 & 61.203 & 61.065\end{array}$

$\begin{array}{llllllllll}60.926 & 60.788 & 60.650 & 60.512 & 60.374 & 60.235 & 60.098 & 59.959 & 59.821 & 59.684\end{array}$ $\begin{array}{llllllllll}59.545 & 59.407 & 59.269 & 59.131 & 58.993 & 58.854 & 58.716 & 58.578 & 58.440 & 58.302 \\ 58.164 & 58.026 & 57.886 & 57.750 & 57.612 & 57.474 & 57.335 & 57.197 & 57.059 & 56.921\end{array}$ $\begin{array}{llllllllll}58.164 & 58.026 & 57.888 & 57.750 & 57.612 & 57.474 & 57.335 & 57.197 & 57.059 & 56.921 \\ 5 & 56.645 & 56.506 & 56.368 & 56.230 & 56.092 & 55.954 & 55.816 & 55.678 & 55.540\end{array}$ $\begin{array}{llllllllll}56.783 & 56.645 & 56.506 & 56.368 & 56.230 & 56.092 & 55.954 & 55.816 & 55.678 & 55.540\end{array}$ $\begin{array}{llllllllll}55.402 & 55.265 & 55.126 & 54.988 & 54.850 & 54.712 & 54.574 & 54.436 & 54.297 & 54 \cdot 160 \\ 54.021 & 53.883 & 53.745 & 53.607 & 53.469 & 53.331 & 53.193 & 53.055 & 52.917 & 52.770\end{array}$ $\begin{array}{llllllllll}52.641 & 52.502 & 52.365 & 52.227 & 52.088 & 51.950 & 51.812 & 51.674 & 51.536 & 51.398 \\ 51.260 & 51.122 & 50.984 & 50.846 & 50.708 & 50.570 & 50.432 & 50.293 & 50.156 & 50.018\end{array}$

$$
\text { l. }
$$

0.799071 0.799119

0.799143

0.799167
0.799191

0.799215

0.799239

0.799263
0.799287

0.799311

0.799335

0.799359
0.799384

0.799384
0.799408

0.799432

0.799456
0.799480

0.799504

0.799552 0.799576 0.799600 0.799624 0.799648
0.799673 0.799697 0.799721

0.799769

0.799793

0.799817
0.799841

0.799865

0.799889
0.799913

0.799913
0.799938

0.799962

0.799986
0.800010

0.800034

0.800058

0.800082
0.800106

0.800130

0.800154

0.800178

0.800203

0.800252

0.800275

0.800323

0.800347

0.800371

0.800395

0.800443

0.800468
0.800492

0.800516

0.800540

0.800564
0.800588

0.800612

0.800636

0.800660
0.800684

0.800709

0.800733

0.800757

0.800805

0.800853

0.800853
0.800877

0.800901

0.800925

0.800950
0.800974

$\begin{array}{lllllllllll} & .001 & .002 & .003 & .004 & .005 & .006 & .007 & .008 & .009 & .010 \\ .138 & .014 & .028 & .041 & .055 & .069 & .083 & .096 & .110 & .124 & .238 \\ .137 & .014 & .027 & .041 & .055 & .068 & .082 & .096 & .0109 & .123 & .0237\end{array}$




\subsection{6} $\begin{array}{ll}10.976 & 12.209 \\ 10.839\end{array}$

12.072 $\begin{array}{ll}14.676 & 14.539 \\ 13.305 & 13.168\end{array}$

$\begin{array}{lllll}14.402 & 14.265 & 14.127 & 13.991 & 13.854 \\ 13.031 & 12.894 & 12.757 & 12.620 & 12.483\end{array}$

0.296666

0.296664

0.296660

0.296656

0.296654

0.296649

$11.935 \quad 11.798$

11.66

11.524

$06.866 \quad 06.729$

$05.496 \quad 05.359$

09.332

$\begin{array}{ll}10.565 & 10.428 \\ 09.195 & 09.058\end{array}$

06.592

$04.127 \quad 03.990$

05.222

$07.825 \quad 07.687$

1.6

1.8

$01.387 \quad 01.250$

02.483

$06.455 \quad 06.318$

$\begin{array}{llllll}10.291 & 10.154 & 10.017 & 09.879 & 09.743\end{array}$

$00.018 * 99.881 * 99.744 * 98$

$03.715 \quad 03.579$

$\begin{array}{llllll}07.551 & 07.414 & 07.276 & 07.509 & 08.373 \\ & 07.002\end{array}$

$\begin{array}{llllll}06.181 & 06.044 & 05.907 & 05.771 & 05.633\end{array}$

$\begin{array}{llllll}04.811 & 04.674 & 04.538 & 04.400 & 04.263 \\ 03.441 & 03.305 & 03.168 & 03.031 & 02.894\end{array}$

6998.04

2702.

2.1

$$
97.27
$$

$8.648 \quad 98.512$

$\begin{array}{lll}95.911 & 95.143 & 97.006 \\ 94.542 & 94.404 & 95.037\end{array}$

$93.172 \quad 93.036$

$91.803 \quad 91.667 \quad 91.530$

90.435 90.298 900161

$\begin{array}{lll}89.066 & 88.929 & 88.792 \\ 87.698 & 87.561 & 87.424\end{array}$

$86.330 \quad 86.193$

87.424
86.056

2703.0

3.
3.
3.3
3.4
3.
3.6
3.
3.
3.0

36984

$84.961 \quad 34.825$

$\begin{array}{lll}83.320 & 04\end{array}$

$80.857 \quad 80.720 \quad 80.584$

$\begin{array}{lll}79.489 & 79.353 & 79.216 \\ 78.121 & 77.985 & 77.848\end{array}$

$\begin{array}{lll}76.754 & 76.617 & 76.480\end{array}$

$\begin{array}{lll}75.087 & 75.250 & 75.113 \\ 74.019 & 73.882 & 73.746 \\ 72.051 & 72.515 & 72.378\end{array}$

2704

4.
4.0
4.0
4.4
4.5
4.0
4.0

$36971.284 \quad 71.147 \quad 71.011$

$69.917 \quad 69.780 \quad 69.644 \quad 69.0507$

$\begin{array}{llll}67.184 & 67.047 & 66.910 & 68.140 \\ 06.773\end{array}$

$\begin{array}{ll}67.1846 & 65.0470\end{array}$

64.313

65.543

$60.350 \quad 60.213$

64.039
62.673
61.307

$65.039-65.270$

62.536
51.169

58.710

2705

5.1

36957.627

$\begin{array}{ll}57.617 & 57 . \\ 56.251 & 56.115\end{array}$

$54.885 \quad 54.749$

57.344

58.574

59.80
58.437

*99.3

0.296645

.296643

0.296641

0.296637

0.296633

0.296631

0.296627

0.296625

0.296623

0.296619

0.296617

0.296612

0.296608

0.296606

$\begin{array}{ll}.749 & 54.612 \\ .382 & 53.246\end{array}$

$52.153 \quad 52.017$

$57.208 \quad 57.07$

$\begin{array}{ll}55.842 & 55.705 \\ 54.476 & 54.0339 \\ 53.309 & 52.073\end{array}$

$49.422 \quad 49.285$

51.880
50.514

53.10952 .973

$\begin{array}{llll}48.056 & 47.919 \quad 47.783\end{array}$

$\begin{array}{ll}46.691 & 46.555 \\ 45.326 & 45.189\end{array}$

$\begin{array}{ll}49.012 & 48.875 \\ 47.046 & 47.510\end{array}$

5.7
5.8
5.9

2706.

6.

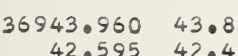

$\begin{array}{lll}42.595 & 42.459 & 43.687\end{array}$

$\begin{array}{lll}41.230 & 41.094 \quad 40.95\end{array}$

$\begin{array}{lll}41.8305 & 39.094 & 30.5592 \\ 38.500 & 38.364 & 38.592\end{array}$

$37.236 \quad 37.000 \quad 36.863$

$35.771 \quad 35.635 \quad 35.498$

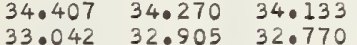

$31.677 \quad 31.542$

32.770
31.405

2707.

67.0
7.0
7.02
7.0
7.4
7.5
7
7.0
7.9

$\begin{array}{lll}36930.313 & 30.177 & 30.041\end{array}$

$\begin{array}{lll}28.949 & 28.812 & 28.676 \\ 27.535 & 27.449 & 27.313\end{array}$

$\begin{array}{lll}26.222 & 26.085 & 25.949 \\ 24.858 & 24.722 & 24.585\end{array}$

$\begin{array}{lll}23.494 & 23.358 & 23.230\end{array}$

$22.130 \quad 21.994 \quad 21.85$

$20.767 \quad 20.630 \quad 20.494$

$\begin{array}{lll}19.403 & 19.267 & 19.131 \\ 18.040 & 17.904 & 17.767\end{array}$

$44.917 \quad 44.780$

$\begin{array}{ll}43.551 & 43.414 \\ 42.186 & 42.049\end{array}$

$\begin{array}{ll}42.186 & 42.049 \\ 40.821 & 40.684 \\ 39.456 & 39.319\end{array}$

$\begin{array}{lllllll}39.456 & 39.319 & 39.183 & 39.046 & 38.910 & 38.773 & 38.637\end{array}$

$\begin{array}{lllllll}38.091 & 37.955 & 37.818 & 37.681 & 37.544 & 37.408 & 37.272 \\ 36.727 & 36.590 & 36.454 & 36.317 & 36.181 & 36.044 & 35.907\end{array}$

$\begin{array}{lllllll}33.998 & 35.226 & 35.089 & 34.953 & 34.816 & 34.680 & 34.543\end{array}$

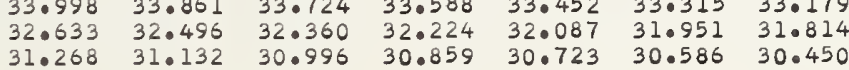

0.296604

0.296600

0.296596

0.296594

0.296590

0.296586

0.296584

0.296582

0.296578

0.296576

0.296571

0.296567

0.800998

0.801046

0.801094

0.801118

0.801167

0.801191

.801263

0.801311

0.801335

.801384

0.801432

0.801480

0.801504

0.801552

.801601

0.801625

0.801673

0.801721

0.801745

0.802793

0.801818

0.801866

0.801914

0.801938

0.296563

0.296561

0.296557

0.296555

0.296553

0.296549

0.296547

0.801962

0.801986

0.802035

0.802059

0.802107

0.802155

0.802203

0.802228
0.802252

0.802276

0.802300

0.802348

0.802372

0.296543

0.296539

0.296537

0.296535
0.296533

0.296531

0.296528

0.296524

0.802445

0.802493

0.802517

0.802565

0.802589

0.802614

0.802662

0.296522

0.802686

$\begin{array}{lllllll}29.904 & 29.768 & 29.631 & 29.495 & 29.359 & 29.222 & 29.086 \\ 20.540 & 28.404 & 28.267 & 28.131 & 27.995 & 27.858 & 27.722\end{array}$

0.296520

0.802710

0.296516

$\begin{array}{lllllll}25.812 & 25.676 & 25.540 & 25.403 & 25.267 & 25.131 & 24.994\end{array}$

$\begin{array}{lllllll}24.449 & 24.312 & 24.176 & 24.039 & 23.903 & 23.767 & 23.630 \\ 23.085 & 22.949 & 22.812 & 22.675 & 22.540 & 22.403 & 22.267\end{array}$

0.296514

0.296512

0.296510

0.296506

$\begin{array}{lllllll}21.722 & 21.585 & 21.448 & 21.312 & 21.176 & 21.039 & 20.909 \\ 20.358 & 20.221 & 20.084 & 19.949 & 19.812 & 19.676 & 19.540\end{array}$

0.296504

0.802758

0.802783

0.802807

0.802855

0.802879

2708.
8.
8
8.
8
8
8
8
8
8

$36916.677 \quad 16.541$

\subsection{4}

17.63117 .495

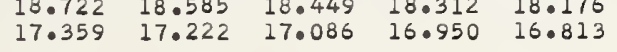

0.296502

0.296500

0.296496

0.296494

0.296492

0.296488

0.296486 $\begin{array}{llllllllll}11.225 & 11.088 & 10.952 & 10.816 & 10.680 & 10.543 & 10.407 & 10.271 & 10.135 & 09.996 \\ 09.862 & 09.726 & 09.589 & 09.453 & 09.317 & 09.181 & 09.044 & 08.908 & 08.772 & 08.636\end{array}$ $\begin{array}{llllllllll}08.500 & 08.363 & 08.227 & 08.091 & 07.954 & 07.818 & 07.682 & 07.546 & 07.410 & 07.274\end{array}$ $\begin{array}{llllllllll}07.138 & 07.001 & 06.865 & 06.729 & 06.592 & 06.456 & 06.320 & 06.184 & 06.047 & 05.911\end{array}$

$\begin{array}{llllllllll}05.775 & 05.639 & 05.502 & 05.366 & 05.230 & 05.094 & 04.958 & 04.821 & 04.685 & 04.549 \\ 04.413 & 04.276 & 04.140 & 04.004 & 03.868 & 03.731 & 03.595 & 03.458 & 03.323 & 03.187\end{array}$

0.296484

0.802927

0.802951

0.803000

0.803024

0.803072

0.803096

0.803145

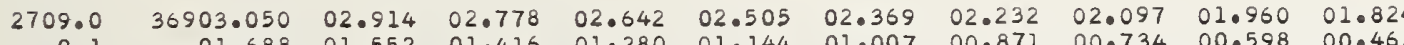
$\begin{array}{llllllllll}01.688 & 01.552 & 01.416 & 01.280 & 01.144 & 01.007 & 00.871 & 00.734 & 00.598 & 00.462\end{array}$ $00.326 \quad 00.189 \quad 00.053 * 99.917 * 99.781 * 99.645 * 99.509 * 99.373 * 99.236 * 99.100$

0.803169

0.296480

0.296476

0.296473

0.296471

0.296467

0.296465
0.296463

0.803193

0.803241

0.803265 


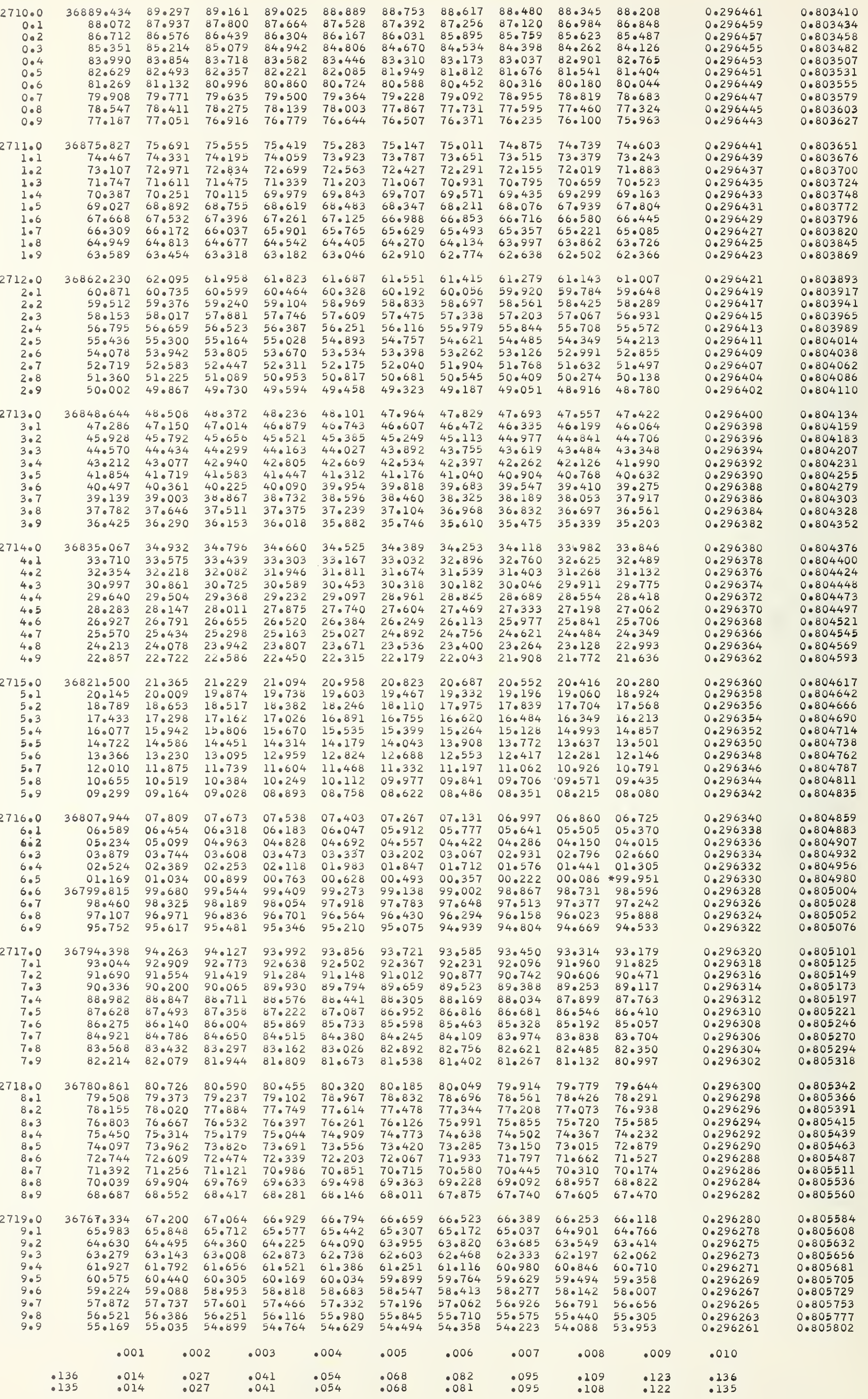


$\begin{array}{lllllllllll}2720.0 & 36753.818 & 53.683 & 53.548 & 53.413 & 53.278 & 53.143 & 53.007 & 52.872 & 52.737 & 52.602\end{array}$ $\begin{array}{lllllllllll}0.1 & 52.467 & 52.332 & 52.197 & 52.062 & 51.927 & 51.792 & 51.656 & 51.521 & 51.386 & 51.251 \\ 0.2 & 51.116 & 50.980 & 50.846 & 50.710 & 50.576 & 50.440 & 50.306 & 50.170 & 50.035 & 49.900\end{array}$ $\begin{array}{llllllllllll}0.3 & 49.765 & 49.629 & 49.495 & 49.360 & 49.225 & 49.090 & 48.955 & 48.819 & 48.684 & 48.549\end{array}$ $\begin{array}{lllllllllll}0.4 & 48.414 & 48.279 & 48.144 & 48.009 & 47.874 & 47.739 & 47.604 & 47.468 & 47.333 & 47.199\end{array}$ $\begin{array}{lllllllllll}0.5 & 47.063 & 46.929 & 46.793 & 46.658 & 46.523 & 46.388 & 46.253 & 46.118 & 45.983 & 45.848 \\ 0.6 & 45.713 & 45.578 & 45.442 & 45.308 & 45.173 & 45.038 & 44.903 & 44.768 & 44.632 & 44.498\end{array}$ $\begin{array}{lllllllllll}0.7 & 44.363 & 44.227 & 44.092 & 43.957 & 43.822 & 43.687 & 43.552 & 43.417 & 43.282 & 43.147\end{array}$ $\begin{array}{lllllllllll}0.8 & 43.012 & 42.877 & 42.742 & 42.606 & 42.472 & 42.337 & 42.202 & 42.066 & 41.932 & 41.797\end{array}$

$\begin{array}{rrrrrrrrrrr}2721.0 & 36740.311 & 40.176 & 40.041 & 39.906 & 39.771 & 39.636 & 39.501 & 39.366 & 39.231 & 39.096 \\ 1.1 & 38.961 & 38.826 & 38.691 & 38.556 & 38.421 & 38.286 & 38.151 & 38.016 & 37.881 & 37.746\end{array}$ $\begin{array}{lllllllllll}1.1 & 38.961 & 38.826 & 38.691 & 38.556 & 38.421 & 38.286 & 38.151 & 38.016 & 37.881 & 37.746 \\ 1.2 & 37.611 & 37.476 & 37.341 & 37.207 & 37.071 & 36.937 & 36.801 & 36.666 & 36.531 & 36.396\end{array}$ $\begin{array}{lllllllllll}1.2 & 37.611 & 37.476 & 37.341 & 37.207 & 37.071 & 36.937 & 36.801 & 36.666 & 36.531 & 36.396 \\ 1.3 & 36.261 & 36.126 & 35.992 & 35.856 & 35.722 & 35.587 & 35.452 & 35.316 & 35.182 & 35.046\end{array}$ $\begin{array}{lllllllllll}1.4 & 34.912 & 34.777 & 34.642 & 34.506 & 34.372 & 34.237 & 34.102 & 33.966 & 33.832 & 33.697 \\ 1.5 & 33.562 & 33.427 & 33.292 & 33.157 & 33.022 & 32.887 & 32.752 & 32.617 & 32.482 & 32.347\end{array}$ $\begin{array}{lllllllllll}1.6 & 32.212 & 32.077 & 31.942 & 31.807 & 31.672 & 31.537 & 31.403 & 31.267 & 31.132 & 30.998\end{array}$

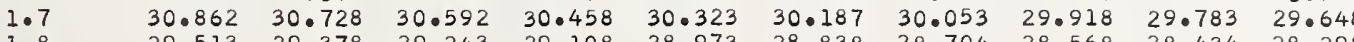
$\begin{array}{lllllllllll}1.8 & 29.513 & 29.378 & 29.243 & 29.108 & 28.973 & 28.838 & 28.704 & 28.568 & 28.434 & 28.298 \\ 1.9 & 28.163 & 28.029 & 27.894 & 27.759 & 27.624 & 27.489 & 27.354 & 27.219 & 27.085 & 26.950\end{array}$

$$
\begin{array}{rll}
726.815 & 26.680 & 26.545 \\
25.466 & 25.331 & 25.195 \\
24.117 & 23.981 & 23.846
\end{array}
$$
$\begin{array}{lllll}16.024 & 15.889 & 15.755 & 15.620 & 15.485 \\ 14.676 & 14.542 & 14.406 & 14.271 & 14.137\end{array}$

$\begin{array}{rllll}36713.327 & 13.193 & 13.058 & 12.923 & 12.789 \\ 11.979 & 11.845 & 11.709 & 11.575 & 11.440 \\ 10.631 & 10.497 & 10.361 & 10.227 & 10.092 \\ 09.283 & 09.148 & 09.014 & 08.879 & 08.744 \\ 07.935 & 07.801 & 07.666 & 07.531 & 07.396 \\ 06.588 & 06.454 & 06.319 & 06.184 & 06.049 \\ 05.241 & 05.106 & 04.971 & 04.836 & 04.701 \\ 03.893 & 03.758 & 03.623 & 03.488 & 03.354 \\ 02.545 & 02.411 & 02.276 & 02.141 & 02.006 \\ 01.198 & 01.063 & 00.929 & 00.794 & 00.659\end{array}$

\section{$\begin{array}{lllll}12.654 & 12.519 & 12.384 & 12.249 & 12.114\end{array}$} $\begin{array}{lllll}12.654 & 12.519 & 12.384 & 12.249 & 12.114 \\ 11.305 & 11.171 & 11.036 & 10.901 & 10.766 \\ 09.957 & 09.823 & 09.688 & 09.553 & 09.418\end{array}$ $\begin{array}{lllll}09.957 & 09.823 & 09.688 & 09.553 & 09.418\end{array}$ $\begin{array}{lllll}08.609 & 08.475 & 08.340 & 08.205 & 08.070 \\ 07.262 & 07.127 & 06.992 & 06.858 & 06.723\end{array}$ $\begin{array}{lllll}05.214 & 07.127 & 06.992 & 06.858 & 06.723 \\ 05.779 & 05.645 & 05.510 & 05.375\end{array}$ $\begin{array}{lllll}04.566 & 04.432 & 04.297 & 04.162 & 04.028\end{array}$

$4 \cdot 6$

4.8

2725.0

5.2

5.4

5.5

5.7

5.8
5.9

2726.0

6.

6.2

6.4

6.5

6.6

6.8

6.9

2727.

$7 \cdot 1$

$7 \cdot 2$

7.4

7.6

$7 \cdot 6$

7.8

2728.

$$
8728.0
$$

2729

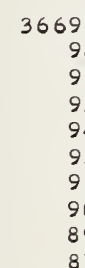

$\begin{array}{lllllllllll} & .001 & .002 & .003 & .004 & .005 & .006 & .007 & .008 & .009 & .010 \\ .135 & .013 & .027 & .040 & .054 & .067 & .081 & .094 & .0108 & .121 & .135 \\ .134 & .013 & .027 & .040 & .054 & .067 & .080 & .094 & .067 & .120 & .134\end{array}$

0.296257

0.296255

0.296253

0.296249

0.006245

0.296241

0.296239

0.296237

0.296233

0.296231

0.296227

0.296225

0.296221

0.296219

0.296217

0.296213

0.296209

0.296207

0.296203

0.296199

0.296193

0.296189

0.296187

0.296183

0.296181

0.296179
0.296177

0.296175

0.296173

0.296170

0.296168

0.296164

0.296160

0.296158

0.296154

0.296152

0.296150

0.296146

0.296144
0.296142

0.296140

0.296136
0.296134

0.296132

0.296130

0.296128

0.296124

0.296120

0.296118

0.296116

0.296112

0.296108

0.296106

0.296104
0.296102

0.296100 0.296098 0.296096 0.296092 0.296090 0.296088 0.296086 0.296082

3.296080 0.296078 0.296076 0.296072 0.296070 0.296068 0.296066 0.296064

.010

.135
.134

0.805826

0.805850

0.805898

0.805947

0.805971

.805995

0.806043

0.806067

0.806092
0.806116

0.806140

.806164

0.806213

.806237

.

806309

.

0.806430

806478

0.806527

0.806551

0.806599

0.806624

.8806672

0.806696

0.806769

0.806793

0.806841

0.806865
0.806890

0.806914
0.806938

0.806962

0.806986

0.807035

.807059

0.807107

0.807132

0.807180

0.807204

0.807228 


$$
\begin{aligned}
& 0 . \\
& 0.0 \\
& 0.0 \\
& 0.4 \\
& 0.0 \\
& 0.7 \\
& 0.0 \\
& 0.0
\end{aligned}
$$

$$
\begin{array}{r}
731.0 \\
1.1 \\
1.2 \\
1.5 \\
1.5 \\
1.5 \\
1.7 \\
1 .
\end{array}
$$$$
\begin{aligned}
& 3.0 \\
& 3 . \\
& 3 . \\
& 3 .
\end{aligned}
$$

2734.0

$\begin{array}{llllllllll}36605.788 & 05.654 & 05.520 & 05.386 & 05.252 & 05.118 & 04.984 & 04.850 & 04.716 & 04.582\end{array}$ $\begin{array}{llllllllll}04.448 & 04.314 & 04.180 & 04.046 & 03.912 & 03.778 & 03.644 & 03.510 & 03.376 & 03.242\end{array}$ $\begin{array}{llllllllll}03.107 & 02.974 & 02.839 & 02.706 & 02.572 & 02.437 & 02.304 & 02.169 & 02.036 & 01.901 \\ 01.768 & 01.633 & 01.500 & 01.365 & 01.231 & 01.098 & 00.963 & 00.830 & 00.696 & 00.562\end{array}$

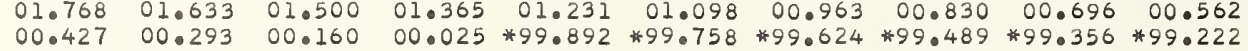
$\begin{array}{llllllllll}36599.087 & 98.954 & 98.819 & 98.686 & 98.552 & 98.417 & 98.284 & 98.150 & 98.016 & 97.882\end{array}$ $\begin{array}{llllllllll}97.748 & 97.614 & 97.479 & 97.346 & 97.212 & 97.078 & 96.944 & 96.810 & 96.676 & 96.542 \\ 96.408 & 96.274 & 96.140 & 96.007 & 95.873 & 95.738 & 95.604 & 95.471 & 95.336 & 95.203\end{array}$ $\begin{array}{llllllllll}95.069 & 94.935 & 94.801 & 94.667 & 94.533 & 94.399 & 94.265 & 94.131 & 93.998 & 93.863 \\ 93.729 & 93.596 & 93.461 & 93.328 & 93.193 & 93.060 & 92.925 & 92.792 & 92.658 & 92.524\end{array}$

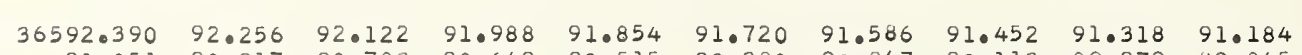

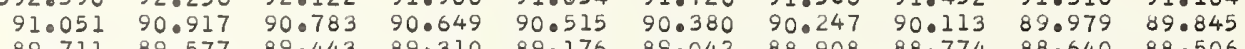
$\begin{array}{llllllllll}89.711 & 89.577 & 89.443 & 89.310 & 89.176 & 89.042 & 88.908 & 88.774 & 88.640 & 88.506 \\ 88.372 & 88.238 & 88.104 & 87.971 & 87.836 & 87.703 & 87.568 & 87.435 & 87.301 & 87.167\end{array}$ $\begin{array}{llllllllll}87.033 & 86.899 & 86.765 & 86.631 & 86.498 & 86.364 & 86.229 & 86.095 & 85.963 & 85.828\end{array}$ $\begin{array}{llllllllll}85.694 & 85.561 & 85.427 & 85.293 & 85.159 & 85.025 & 84.891 & 84.758 & 84.624 & 84.490 \\ 84.356 & 84.222 & 84.088 & 83.954 & 83.820 & 83.687 & 83.553 & 83.419 & 83.285 & 83.151\end{array}$

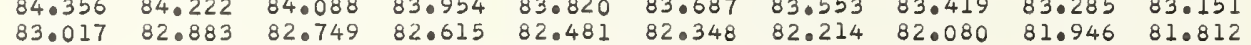
$\begin{array}{llllllllll}81.678 & 81.544 & 81.411 & 81.2777 & 81.143 & 81.009 & 80.875 & 80.741 & 80.608 & 80.474 \\ 80.340 & 80.206 & 80.072 & 79.938 & 79.805 & 79.670 & 79.537 & 79.403 & 79.269 & 79.135\end{array}$

$$
\begin{array}{ll}
3.4 \\
3.5 \\
3.5
\end{array}
$$

4.02

$4 \cdot 2$
4.3
4.4

4.4
4.5
4.6

4.6
4.7

4.8
4.9

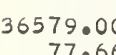

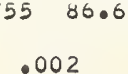

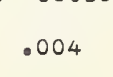

.005

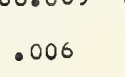

$$
.007
$$

0.296060 0.296058 0.296054 0.296052 0.296050 0.296048
0.296046 0.296045

0.296041

0.296039
0.296037

0.296037
0.296035

0.296033

0.296031

0.296029

0.296027

0.296025
0.296023

0.296021

0.296019

0.296017
0.296015

0.296013

0.296011

0.296009

0.296007

0.296003

0.296001

0.295999

0.295997

0.295995

0.295993

0.295991

0.295987

0.295985

0.295981

0.295979
0.295977

0.295976

0.295974

0.295970

0.295968

0.295966

0.295964

0.295962

0.295960

0.295956

0.295954

0.295952

0.295950

0.295948

0.295946
0.295944

0.295942

0.295940

0.295938

0.295936

0.295934
0.295932

0.295932
0.295930

0.295928

0.295926

0.295923

0.29592

0.295919

0.295917

0.295915

0.295911

0.295909

0.295907
0.295905

0.295903

0.29590

0.295899

0.295897

0.295895

0.295893

0.295891

0.295889

0.295887
0.295885

0.295883 0.295881 0.295879 0.295878 0.295876 0.295874 0.295872 0.295870 0.295868 0.295866

0.808487

0.808511

0.808535
0.808559

0.808584

0.808608

0.808632

0.808656
0.808680

0.808705

0.808729

0.808753

0.808777
0.808802

0.808826

0.808850

0.808874

0.808898
0.808923

0.808947

0.808971

0.808995

0.809019

0.809044

0.809068

0.809092

0.809116

0.809141

0.809165

0.809165
0.809189

0.809213

0.809237
0.809262

0.809262

0.809286

0.809334

0.809383

0.809407

0.809431

0.809455

0.809480

0.809504
0.809528

0.809528
0.809552

0.809552
0.809577

0.809601

0.809625

0.809673

0.809698

0.809722

0.809746

0.809770

0.809795

0.809819
0.809843

0.809867

0.809891 
$\begin{array}{rllll}485.556 & 85.423 & 85.290 & 85.156 & 85.023 \\ 84.225 & 84.092 & 83.959 & 83.826 & 83.693\end{array}$

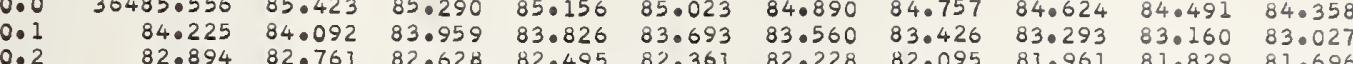

$\begin{array}{lllllllllll}0.2 & 82.894 & 82.761 & 82.628 & 82.495 & 82.361 & 82.228 & 82.095 & 81.961 & 81.829 & 81.696 \\ 0.3 & 81.562 & 81.429 & 81.296 & 81.363 & 81.030 & 80.897 & 80.764 & 80.630 & 80.498 & 80.364\end{array}$

$\begin{array}{lllllllllll}0.3 & 81.562 & 81.429 & 81.296 & 81.163 & 81.030 & 80.897 & 80.764 & 80.630 & 80.498 & 80.364 \\ 0.4 & 80.231 & 80.098 & 79.965 & 79.832 & 79.699 & 79.566 & 79.433 & 79.299 & 79.166 & 79.033\end{array}$

$\begin{array}{lllllllllll}0.4 & 80.231 & 80.098 & 79.965 & 79.832 & 79.699 & 79.566 & 79.433 & 79.299 & 79.166 & 79.033 \\ 0.5 & 78.900 & 78.767 & 78.634 & 78.500 & 78.368 & 78.234 & 78.102 & 77.968 & 77.835 & 77.702\end{array}$

$\begin{array}{lllllllllll}0.5 & 78.900 & 78.767 & 78.634 & 78.500 & 78.368 & 78.234 & 78.102 & 77.968 & 77.835 & 77.702 \\ 0.6 & 77.569 & 77.436 & 77.303 & 77.170 & 77.037 & 76.903 & 76.771 & 76.638 & 76.504 & 76.371\end{array}$

$\begin{array}{lllllll}0.7 & 76.238 & 76.105 & 75.972 & 75.839 & 75.706 & 75\end{array}$

0.8

2741.

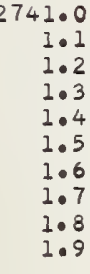

2742

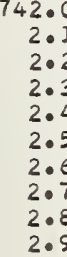

$\begin{array}{ll}74.907 & 74.774 \\ 73.577 & 73.444\end{array}$

$\begin{array}{rr}36472.246 & 72.113 \\ 70.916 & 70.783\end{array}$

$\begin{array}{lll}70.916 & 70.783 & 70.650\end{array}$

$\begin{array}{ll}69.585 & 69.452 \\ 68.255 & 68.122\end{array}$

68.25568 .12267 .989

$\begin{array}{ll}65.594 & 65.461 \\ 64.265 & 64.132\end{array}$

$\begin{array}{ll}64.265 & 64.132 \\ 62.935 & 62.802\end{array}$

$\begin{array}{ll}61.605 & 61.472 \\ 60.275 & 60.142\end{array}$

$\begin{array}{lll}65.329 & 65.195 & 65.062 \\ 63.999 & 63.866 & 63.733 \\ 62.669 & 62.536 & 62.403\end{array}$

61.339

$61.206 \quad 61.073$

$\begin{array}{rrr}36458.945 & 58.812 & 500 \\ 57.616 & 57.483 & 570\end{array}$

$\begin{array}{ll}56.286 & 56.153 \\ 54.957 & 54.824 \\ 53.628 & 53.496\end{array}$

$52.299 \quad 52.167$

$50.970 \quad 50.837$

$48.312 \quad 48.179$

$\begin{array}{lll}58.680 & 58.546 & 58.41 \\ 57.350 & 57.217 & 57.08\end{array}$

$\begin{array}{lll}56.021 & 55.888 & 55.754 \\ 54.691 & 54.558 & 54.425\end{array}$

$53.363 \quad 53.229 \quad 53.097 \quad 54.29$

$\begin{array}{llll}52.033 & 51.900 & 51.767 & 51.634\end{array}$

$50.704 \quad 50.571 \quad 50.438 \quad 50.305 \quad 51.501$

$49.375 \quad 49.242 \quad 49.109 \quad 48.976 \quad 48.843$

2743.0

3.

3.
3.
3.
3.
3.
3.
3.
3.
3.

2744

44.
40
40
40
40
4.0
4.7
4.0

2745.

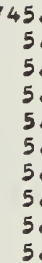

$36445.654 \quad 45.521$

$\begin{array}{ll}44.326 & 44.193 \\ 42.998 & 42.865\end{array}$

$41.669 \quad 41.536$

$40.341 \quad 40.208$

$\begin{array}{ll}39.012 & 38.880 \\ 37.685 & 37.552\end{array}$

37.685

$35.029 \quad 34.896$

$33.701 \quad 33.569$

45.389
44.060
42.732
41.404

$41.404 \quad 41.271 \quad 41.13$

$\begin{array}{lll}40.075 & 39.942 & 39.810\end{array}$

$\begin{array}{lll}38.747 & 38.614 & 38.481 \\ 37.419 & 37.286 & 37.153\end{array}$

36432.374

$31.046 \quad 30.913$

$29.718 \quad 29.585$

$\begin{array}{ll}27.063 & 26.931 \\ 25.736 & 25.604\end{array}$

$\begin{array}{ll}25.736 & 25.604 \\ 24.409 & 24.276\end{array}$

$\begin{array}{ll}24.409 & 24.276 \\ 23.083 & 22.050\end{array}$

$21.756 \quad 21.623$

20.429

36419.10

$\begin{array}{ll}17.775 & 18.969\end{array}$

$\begin{array}{ll}17.775 & 17.643 \\ 16.449 & 16.316\end{array}$

$15.142 \quad 16.316$

$13.795 \quad 13.663$

$12.470 \quad 12.33$

$\begin{array}{ll}09.817 & 09.685 \\ 08.491 & 08.359\end{array}$

07.166

2746.0

\begin{abstract}
6405.83905 .707
\end{abstract}
$\begin{array}{ll}.033 & 06.900 \\ 5.707 & 05.575\end{array}$

6.

6.3
6.4
6.5

6.5

6.6
6.7
6.8

$03.188 \quad 03.056$

$01.863 \quad 01.731$

$\begin{array}{rr}00.538 & 00.40 \\ 36399.212 & 99.08\end{array}$

96.56297 .755

$\begin{array}{ll}95.237 & 95.104 \\ 93.912 & 93.780\end{array}$

$34 \cdot 763$
33.436

34.630
33.303

34.497
33.170

$32.108 \quad 31.97$

$\begin{array}{lll}30.780 & 30.648 & 30.515\end{array}$

$28.125 \quad 27.993 \quad 27.860$

$\begin{array}{lll}26.798 & 26.665 & 26.533 \\ 25.471 & 25.338 & 25.206\end{array}$

$\begin{array}{lll}24.144 & 24.011 & 23.878 \\ 22.817 & 22.685 & 22.552\end{array}$

$\begin{array}{lll}21.490 & 21.357 & 21.225 \\ 20.163 & 20.030 & 19.898\end{array}$

$\begin{array}{ll}48.976 & 48.843 \\ 47.647 & 47.515\end{array}$

$\begin{array}{lll}75.307 & 75.173 & 75.040 \\ 73.976 & 73.843 & 73.710\end{array}$

$\begin{array}{ll}71.581 & 71.44 \\ 70.250 & 70.118\end{array}$

$\begin{array}{lll}71.315 & 71.182 & 71.049 \\ 69.984 & 69.851 & 69.719\end{array}$

$\begin{array}{lllll}66.259 & 66.126 & 65.994 & 65.860 & 65.728\end{array}$

$\begin{array}{llllll}63.600 & 63.467 & 63.334 & 63.201 & 63.068\end{array}$

$\begin{array}{lllll}59.610 & 59.478 & 50.674 & 60.541 & 60.408 \\ & 59.345 & 59.212 & 59.078\end{array}$

0.295864

0.295860

0.295858

0.295856

0.295852

0.295850

0.295848
0.295846

0.295844

0.295840

0.295839

0.295837

0.295833

0.29583

0.295829
0.295827

0.295825

0.295821

0.295819

0.29581

0.295813

0.295811

0.295809
0.295807

0.295805

0.295803

0.295800

0.295798

0.295796

0.295792

0.295790
0.295788

0.295786

0.295784

0.295782
0.295780

0.295778

0.295776
0.295774

0.295774
0.295772

0.295770
0.295769

0.295767

0.295765
0.295763

0.29576

0.295759

0.295757

0.295753

0.295749

.810667

0.810715

0.810740

0.810764

0.81081
0.81083

0.810861

0.810885

0.810909

0.81093

0.810982

0.811006

0.811055

0.812103
0.811128

0.81115

0.811176

0.81122

0.81127

0.811297

0.811346

0.811394

0.811419

0.81146

.81151

0.811540

0.811588

0.811637

0.81166

0.811685

0.811734

0.81175

0.811807

0.811831
0.811855

0.812879

0.811904

0.81195

0.811976

0.812025

0.812049

0.812098

0.295747

0.295745

0.295743

0.295741

0.295738

0.295736

0.29573

0.295730

0.812122

0.812146

0.812195

0.812219

0.812267

0.812292

0.812340

0.295728

0.812364

0.29572

0.295720

0.295718

0.295714

0.295712

$\begin{array}{lllllllllll}84.508 & 84.375 & 84.244 & 84.111 & 83.979 & 83.847 & 83.714 & 83.582 & 83.449\end{array}$

$\begin{array}{llllllllll}83.316 & 83.184 & 83.052 & 82.919 & 82.787 & 82.654 & 82.522 & 82.390 & 82.258 & 82.125\end{array}$

$\begin{array}{llllllllll}81.993 & 81.860 & 81.729 & 81.596 & 81.463 & 81.331 & 81.199 & 81.066 & 80.934 & 80.801 \\ 80.669 & 80.537 & 80.404 & 80.272 & 80.140 & 80.007 & 79.875 & 79.742 & 79.610 & 79.478\end{array}$

0.295709

0.295707

0.295705

0.295703

0.295699

0.295697

0.295695

0.295693

0.295689

0.295687

0.295685

0.295683

0.295682

0.295678

0.295676

0.295674

238

0.812437

0.812462

0.812510

0.812534

0.812583

0.812607

0.812631

0.812680

0.812704

0.812753

0.812801

0.812826

0.812850

0.812874

0.812923

0.812947

0.812995

0.813020

0.813044

.010

\begin{tabular}{|c|c|c|c|c|c|c|c|c|c|}
\hline & .002 & .002 & .003 & .004 & .005 & .006 & .007 & .008 & .009 \\
\hline $\begin{array}{r}.133 \\
.132\end{array}$ & $\begin{array}{l}.013 \\
.013\end{array}$ & $\begin{array}{l}.027 \\
.026\end{array}$ & $\begin{array}{r}.040 \\
.040\end{array}$ & $\begin{array}{l}.053 \\
.053\end{array}$ & $\begin{array}{l}.066 \\
.066\end{array}$ & $\begin{array}{l}.080 \\
.079\end{array}$ & $\begin{array}{l}.093 \\
.092\end{array}$ & $\begin{array}{l}.106 \\
.105\end{array}$ & $\begin{array}{l}.120 \\
.118\end{array}$ \\
\hline
\end{tabular}




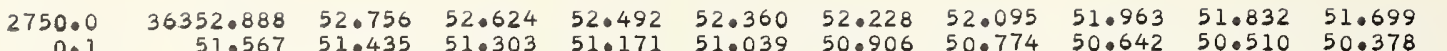
3.9

4.

4.2
4.3
4.4

4.4
4.5

4.6
4.7
4.8

4.8
4.9 $\begin{array}{lllllllllll}0.1 & 51.567 & 51.435 & 51.303 & 51.171 & 51.039 & 50.906 & 50.774 & 50.642 & 50.510 & 50.378 \\ 0.2 & 50.246 & 50.113 & 49.981 & 49.849 & 49.717 & 49.584 & 49.453 & 49.320 & 49.188 & 49.056\end{array}$ $\begin{array}{lllllllllll}0.2 & 50.246 & 50.113 & 49.981 & 49.849 & 49.717 & 49.584 & 49.453 & 49.320 & 49.188 & 49.056 \\ 0.3 & 48.924 & 48.792 & 48.659 & 48.527 & 48.395 & 48.263 & 48.131 & 47.999 & 47.867 & 47.734\end{array}$ $\begin{array}{lllllllllll}0.3 & 48.924 & 48.792 & 48.659 & 48.527 & 48.395 & 48.263 & 48.131 & 47.999 & 47.867 & 47.734 \\ 0.4 & 47.602 & 47.470 & 47.338 & 47.206 & 47.074 & 46.941 & 46.809 & 46.677 & 46.545 & 46.413\end{array}$ $\begin{array}{lllllllllll}0.4 & 47.602 & 47.470 & 47.338 & 47.206 & 47.074 & 46.941 & 46.809 & 46.677 & 46.545 & 46.413 \\ 0.5 & 46.281 & 46.149 & 46.016 & 45.884 & 45.752 & 45.620 & 45.488 & 45.356 & 45.224 & 45.091\end{array}$ $\begin{array}{lllllllllll}0.6 & 44.959 & 44.827 & 44.695 & 44.563 & 44.431 & 44.298 & 44.167 & 44.034 & 43.902 & 43.771\end{array}$ $\begin{array}{lllllllllll}0.7 & 43.638 & 43.506 & 43.374 & 43.241 & 43.109 & 42.977 & 42.845 & 42.713 & 42.581 & 42.449\end{array}$ $\begin{array}{lllllllllll}0.7 & 43.638 & 43.506 & 43.374 & 43.241 & 43.109 & 42.977 & 42.845 & 42.713 & 42.581 & 42.449 \\ 0.8 & 42.317 & 42.185 & 42.053 & 41.920 & 41.788 & 41.657 & 41.525 & 41.392 & 41.260 & 41.128 \\ 0.9 & 40.996 & 40.864 & 40.732 & 40.600 & 40.468 & 40.336 & 40.204 & 40.071 & 39.939 & 39.807\end{array}$ $40.996 \quad 40.864 \quad 40.732$

$\begin{array}{lllllllllll}2751.0 & 36339.675 & 39.543 & 39.411 & 39.279 & 39.147 & 39.015 & 38.883 & 38.751 & 38.618 & 38.486\end{array}$ $\begin{array}{llllllllllll}1.1 & 38.354 & 38.222 & 38.090 & 37.958 & 37.826 & 37.694 & 37.562 & 37.430 & 37.297 & 37.166 \\ 1.2 & 37.033 & 36.901 & 36.770 & 36.637 & 36.505 & 36.373 & 36.241 & 36.109 & 35.977 & 35.845\end{array}$ $\begin{array}{lllllllllll}1.2 & 37.033 & 36.901 & 36.770 & 36.637 & 36.505 & 36.373 & 36.241 & 36.109 & 35.977 & 35.845 \\ 1.3 & 35.712 & 35.581 & 35.449 & 35.316 & 35.185 & 35.053 & 34.920 & 34.788 & 34.657 & 34.524\end{array}$ $\begin{array}{lllllllllll}1.3 & 35.712 & 35.581 & 35.449 & 35.316 & 35.185 & 35.053 & 34.920 & 34.788 & 34.657 & 34.524 \\ 1.4 & 34.392 & 34.260 & 34.128 & 33.996 & 33.864 & 33.732 & 33.600 & 33.468 & 33.336 & 33.203\end{array}$ $\begin{array}{lllllllllll}1.5 & 33.071 & 32.939 & 32.807 & 32.675 & 32.543 & 32.411 & 32.279 & 32.147 & 32.015 & 31.883 \\ 1.6 & 31.751 & 31.619 & 31.488 & 31.355 & 31.223 & 31.091 & 30.959 & 30.828 & 30.695 & 30.563\end{array}$ $\begin{array}{lllllllllll}1.7 & 30.432 & 30.299 & 30.167 & 30.035 & 29.903 & 29.771 & 29.639 & 29.507 & 29.375 & 29.243\end{array}$

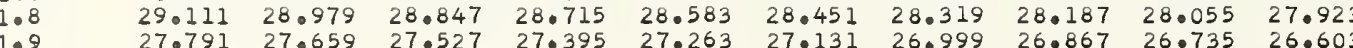
$\begin{array}{rrrrrrrrrrr}2752.0 & 36326.471 & 26.339 & 26.207 & 26.075 & 25.943 & 25.811 & 25.679 & 25.547 & 25.415 & 25.283 \\ 2.1 & 25.151 & 25.019 & 24.887 & 24.755 & 24.623 & 24.491 & 24.359 & 24.227 & 24.095 & 23.963\end{array}$

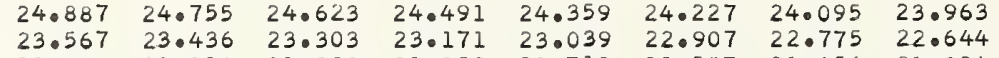

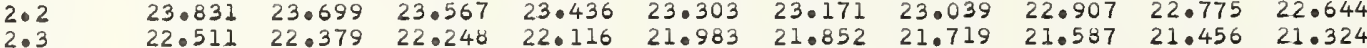
$\begin{array}{lllllllllll}2.4 & 21.192 & 21.060 & 20.928 & 20.796 & 20.665 & 20.533 & 20.400 & 20.269 & 20.137 & 20.004\end{array}$ $\begin{array}{lllllllllll}2.5 & 19.872 & 19.741 & 19.608 & 19.477 & 19.345 & 19.213 & 19.081 & 18.949 & 18.817 & 18.685 \\ 2.6 & 18.553 & 18.421 & 18.289 & 18.157 & 18.025 & 17.894 & 17.762 & 17.630 & 17.498 & 17.366\end{array}$ $\begin{array}{lllllllllll}2.6 & 18.553 & 18.421 & 18.289 & 18.157 & 18.025 & 17.894 & 17.762 & 17.630 & 17.498 & 17.366\end{array}$ $\begin{array}{lllllllllll}2.7 & 17.233 & 17.102 & 16.970 & 16.838 & 16.706 & 16.574 & 16.442 & 16.310 & 16.178 & 16.047 \\ 2.8 & 15.914 & 15.782 & 15.650 & 15.519 & 15.387 & 15.255 & 15.123 & 14.991 & 14.859 & 14.728 \\ 2.9 & 14.595 & 14.463 & 14.332 & 14.199 & 14.068 & 13.936 & 13.804 & 13.672 & 13.540 & 13.408\end{array}$ $\begin{array}{ll}15.914 & 15.782 \\ 14.595 & 14.463\end{array}$

$14 \cdot 728$ $\begin{array}{lll}05.364 & 05.232 & 05.101\end{array}$

$\begin{array}{lll}10.375 & 10.243 & 10.111\end{array}$

$\begin{array}{ll}12.617 & 12.485\end{array}$ $\begin{array}{lll}09.057 & 08.924 & 08.792 \\ 07.738 & 07.606 & 07.474\end{array}$ $09.979 \quad 09.848$

12.353
11.034

12.221
10.902

12.089
10.771 $\begin{array}{ll}02.728 & 02.595 \\ 01.409 & 01.277\end{array}$ 03.782 $\begin{array}{ll}06.287 & 06.156 \\ 04.969 & 04.837\end{array}$ $\begin{array}{ll}08.661 & 08.529 \\ 07.342 & 07.210\end{array}$ 09.715
08.396 09.583 09.452

$36300.092 * 99.960 * 99.828 * 99.696 * 99.564 * 99$ $298.774 \quad 98.642 \quad 98.510 * 98.378 * 98.247 * 9.433 * 99.301 * 99.169 * 99.037 * 98.905$

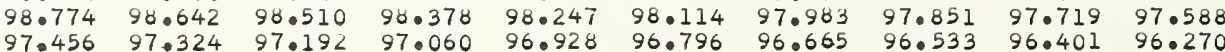
$\begin{array}{llllllllll}96.138 & 96.006 & 95.874 & 95.742 & 95.610 & 95.479 & 95.347 & 95.215 & 95.084 & 94.952\end{array}$

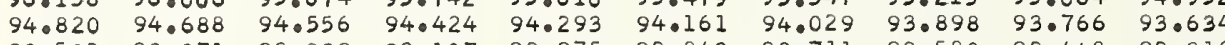
$\begin{array}{llllllllll}93.502 & 93.371 & 93.239 & 93.107 & 92.975 & 92.843 & 92.711 & 92.580 & 92.448 & 92.316\end{array}$

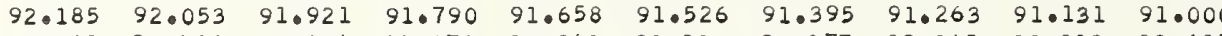
$\begin{array}{llllllllll}90.868 & 90.736 & 90.604 & 90.473 & 90.341 & 90.209 & 90.077 & 89.945 & 89.813 & 89.682\end{array}$ $\begin{array}{llllllllll}89.550 & 89.418 & 89.287 & 89.155 & 89.023 & 88.892 & 88.760 & 88.628 & 88.497 & 88.365 \\ 88.233 & 88.102 & 87.970 & 87.838 & 87.707 & 87.575 & 87.443 & 87.311 & 87.179 & 87.048\end{array}$

\section{1}

2756.0$$
6.2
$$$$
6.5
$$$$
6.6
$$$$
6.8
$$

2757.0$$
\begin{aligned}
& 7.1 \\
& 7.2 \\
& 7.3 \\
& 7.4
\end{aligned}
$$$$
7.4
$$$$
7 \cdot 6
$$$$
7.7
$$$$
7.8
$$

2758.0$$
\begin{aligned}
& 8.1 \\
& 8.2 \\
& 8.3 \\
& 8.4
\end{aligned}
$$

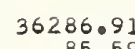

$$
\begin{array}{r}
85.95 \\
84.28
\end{array}
$$$$
\begin{aligned}
& 84.282 \\
& 82.965
\end{aligned}
$$$$
\begin{array}{llll}
81.648 & 81.833 & 82.702 \\
81.517 & 81.385
\end{array}
$$$$
\begin{array}{lllll}
79.016 & 78.884 & 78.752 & 78.621 & 78.489
\end{array}
$$$$
\begin{array}{lllll}
77.699 & 77.567 & 77.436 & 77.304 & 77.17 \\
76.383 & 76.251 & 76.120 & 75.987 & 75.85 \\
75.066 & 74.935 & 74.803 & 74.671 & 74.54
\end{array}
$$

$\begin{array}{rl}273.750 & 73.619 \\ 72.434 & 72.302 \\ 71.118 & 70.986 \\ 69.802 & 69.671 \\ 68.486 & 68.355 \\ 67.170 & 67.040 \\ 65.855 & 65.724 \\ 64.540 & 64.408 \\ 63.224 & 63.092 \\ 61.909 & 61.777\end{array}$

73.487

\begin{abstract}
73.355
\end{abstract}

\subsection{4}

$\begin{array}{lll}72.171 & 72.040 & 71.907 \\ 70.855 & 70.723 & 70.592\end{array}$

69.540
68.224

$68.224 \quad 68.09267 .960$

65.592
64.277

$66.776 \quad 66.645$

$\begin{array}{ll}65.461 & 65.32 \\ 64.145 & 64.01\end{array}$

$\begin{array}{ll}62.830 & 62.698 \\ 61.514 & 61.383\end{array}$

36260.5

$59.279 \quad 59.147$

$57.964 \quad 57.833 \quad 57.701$

$55.334 \quad 55.203 \quad 55.071 \quad 54.93954 .809$

$54.019 \quad 53.88$

$\begin{array}{llllll}52.705 & 52.573 & 52.441 & 52.311 & 52.179\end{array}$

$51.390 \quad 51.258$

$50.076 \quad 49.944 \quad 49.813$

36247.447

46.133

$44.819 \quad 44.68$

$\begin{array}{lllll}43.505 & 43.373 & 43.242 & 43.111 & 42.979\end{array}$

$\begin{array}{lllll}42.191 & 42.060 & 41.928 & 41.797 & 41.666\end{array}$

$\begin{array}{lllll}39.563 & 39.432 & 39.314 & 40.483 & 40.352\end{array}$

$\begin{array}{lllll}38.250 & 38.119 & 37.988 & 37.856 & 37.0725\end{array}$

$\begin{array}{lllll}36.937 & 36.805 & 36.674 & 36.543 & 36.412 \\ 35.623 & 35.492 & 35.361 & 35.229 & 35.098\end{array}$

$36234 \cdot 310$

$\begin{array}{lllll}34.310 & 34.179 & 34.047 & 33.916 & 33.785 \\ 32.997 & 32.865 & 32.734 & 32.603 & 32.472\end{array}$

$\begin{array}{lllll}30.370 & 30.239 & 30.108 & 29.977 & 29.845\end{array}$

$\begin{array}{lllll}29.057 & 28.926 & 28.795 & 28.664 & 28.533 \\ 27.745 & 27.614 & 27.482 & 27.351 & 27.220\end{array}$

$\begin{array}{lllll}27.745 & 27.614 & 27.482 & 27.351 & 27.220 \\ 26.433 & 26.301 & 26.170 & 26.039 & 25.907 \\ 25.120 & 24.988 & 24.857 & 24.726 & 24.594\end{array}$

$\begin{array}{lllll}25.120 & 24.988 & 24.857 & 24.726 & 24.594 \\ 23.807 & 23.676 & 23.545 & 23.413 & 23.282\end{array}$

$22.495 \quad 22.364 \quad 22.232$$$
\begin{array}{llllll}
80.332 & 80.201 & 81.385 & 81.253 & 81.122 \\
79.068 & 79.937 & 79.806
\end{array}
$$

$\begin{array}{llllll}86.258 & 86.126 & 85.994 & 85.862 & 85.730\end{array}$

$\begin{array}{lllll}83.940 & 84.809 & 84.677 & 84.545 & 84.414\end{array}$

$\begin{array}{llllll}82.307 & 82.175 & 82.043 & 81.912 & 81.780\end{array}$

$\begin{array}{lllll}80.990 & 80.858 & 80.727 & 80.595 & 80.463 \\ 79.674 & 79.542 & 79.411 & 79.279 & 79.147\end{array}$

$\begin{array}{lllll}78.074 & 79.542 & 79.411 & 79.279 & 79.147\end{array}$

\begin{tabular}{llllll}
77.041 & 76.909 & 78.094 & 77.962 & 77.831 \\
\hline & 76.777 & 76.646 & 76.515
\end{tabular}

$\begin{array}{lllll}75.725 & 75.593 & 75.461 & 75.330 & 75.198 \\ 74.408 & 74.276 & 74.145 & 74.013 & 73.882\end{array}$

$\begin{array}{lllll}73.092 & 72.960 & 72.829 & 72.697 & 72.565\end{array}$

$\begin{array}{lllll}71.776 & 71.645 & 71.513 & 71.381 & 71.250\end{array}$

$\begin{array}{llllll}69.145 & 69.013 & 68.881 & 68.750 & 68.618\end{array}$

$\begin{array}{lllll}67.829 & 67.697 & 67.566 & 67.435 & 67.302\end{array}$

$\begin{array}{llllll}65.197 & 65.066 & 66.250 & 66.119 & 65.986\end{array}$

$\begin{array}{llllll}63.882 & 63.750 & 63.619 & 63.487 & 63.356\end{array}$

$\begin{array}{lllll}62.567 & 62.435 & 62.304 & 62.172 & 62.041 \\ 61.251 & 61.120 & 60.989 & 60.857 & 60.725\end{array}$

$\begin{array}{lllll}59.936 & 59.804 & 59.674 & 59.542 & 59.411\end{array}$

$\begin{array}{lllll}57.306 & 57.175 & 57.043 & 56.912 & 56.781\end{array}$

$\begin{array}{lllll}55.992 & 55.860 & 55.729 & 55.597 & 55.466\end{array}$

$\begin{array}{llllll}53.362 & 54.545 & 54.414 & 54.282 & 54.151\end{array}$

$\begin{array}{lllll}52.047 & 51.916 & 51.784 & 51.653 & 51.521\end{array}$

$\begin{array}{lllll}50.733 & 50.601 & 50.470 & 50.338 & 50.207\end{array}$

$\begin{array}{lllll}49.419 & 49.288 & 49.156 & 49.025 & 48.893 \\ 48.104 & 47.973 & 47.842 & 47.710 & 47.579\end{array}$

$\begin{array}{lllll}46.790 & 46.659 & 46.527 & 46.396 & 46.265\end{array}$

$\begin{array}{llllll}45.476 & 45.345 & 45.213 & 45.082 & 44.951 \\ 44.162 & 44.031 & 43.899 & 43.768 & 43.637\end{array}$

$\begin{array}{lllll}42.848 & 42.717 & 42.585 & 42.454 & 42.323\end{array}$

$\begin{array}{lllll}40.220 & 40.089 & 39.958 & 39.826 & 39.695\end{array}$

$\begin{array}{lllll}38.907 & 38.776 & 38.645 & 38.513 & 38.382\end{array}$

$\begin{array}{lllll}37.594 & 37.462 & 37.331 & 37.199 & 37.068 \\ 36.280 & 36.149 & 36.017 & 35.886 & 35.754\end{array}$

$\begin{array}{lllll}36.280 & 36.149 & 36.017 & 35.886 & 35.754 \\ 34.967 & 34.835 & 34.704 & 34.573 & 34.441\end{array}$

$\begin{array}{lllll}33.653 & 33.522 & 33.391 & 33.259 & 33.128\end{array}$

$\begin{array}{lllll}32.340 & 32.209 & 32.078 & 31.946 & 31.815\end{array}$

$\begin{array}{lllll}31.027 & 30.896 & 30.765 & 30.633 & 30.502\end{array}$

$\begin{array}{lllll}28.401 & 28.270 & 28.139 & 28.008 & 27.876\end{array}$

$\begin{array}{llllll}27.089 & 26.957 & 26.826 & 26.695 & 26.563\end{array}$

$\begin{array}{llllll}24.463 & 25.645 & 25.514 & 25.382 & 25.251\end{array}$

$\begin{array}{lllll}24.463 & 24.332 & 24.201 & 24.069 & 23.938 \\ 23.151 & 23.020 & 22.888 & 22.757 & 22.626\end{array}$

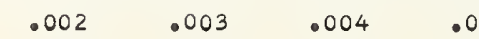

.005

.006

.007

$.008 \quad .009$

0.295670

0.295666

0.295664

0.295662

0.295658

0.29565

0.295655

0.295653

0.295651

0.295647

0.295647

0.295645

0.295641

0.295639

0.295635

0.295633

0.295632

0.295630

0.295626

0.295624

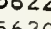

0.295620

0.295616

0.295614

0.295612

0.295608

0.295607

0.295605

0.295603

0.295601

0.295597

0.295593

0.295591

0.295589

0.295586

0.295584

0.295582

0.295578

0.295576

0.295574

0.295570

0.295568

0.295564

0.295563

0.295561

0.295559
0.295557

0.295555

0.295551

.295549

0.295547

0.295545

0.295543

.295542

0.295540

0.295536

0.295534

0.295530

0.295528

0.295526

0.295524

0.295522

0.295521

0.295517

0.295515

0.295513

0.295509

0.295507

.295505

0.295503

0.295500

0.295498

0.295496

0.295494
0.295492

0.295490

0.295488

.

0.29548

0.295482
0.295481

.010

.13

.01

.026

.040

.053
.052

.066
.065

.079

$.092 \quad .105 \quad .119$ 
$\begin{array}{lllllllllll}2760.0 & 36221.182 & 21.051 & 20.920 & 20.789 & 20.657 & 20.526 & 20.395 & 20.264 & 20.132 & 20.001\end{array}$ $\begin{array}{lllllllllll}0.1 & 19.870 & 19.739 & 19.0607 & 19.477 & 19.0545 & 19.213 & 19.083 & 18.951 & 18.820 & 18.689 \\ 0.2 & 18.558 & 18.427 & 18.296 & 18.165 & 18.033 & 17.902 & 17.071 & 17.640 & 17.508 & 17.0377\end{array}$

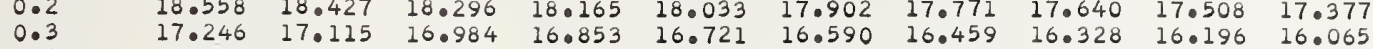
$\begin{array}{lllllllllll}0.3 & 17.246 & 17.115 & 16.984 & 16.853 & 16.721 & 16.590 & 16.459 & 16.328 & 16.196 & 16.065 \\ 0.4 & 15.934 & 15.803 & 15.671 & 15.541 & 15.410 & 15.278 & 15.147 & 15.016 & 14.885 & 14.753 \\ 0.5 & 14.622 & 14.491 & 14.0359 & 14.229 & 14.088 & 13.966 & 13.835 & 13.704 & 13.573 & 13.441\end{array}$ $\begin{array}{lllllllllll}0.5 & 14.622 & 14.491 & 14.359 & 14.229 & 14.098 & 13.966 & 13.835 & 13.704 & 13.573 & 13.441 \\ 0.6 & 13.310 & 13.179 & 13.048 & 12.917 & 12.786 & 12.054 & 12.523 & 12.392 & 12.261 & 12.129\end{array}$ $\begin{array}{lllllllllll}0.7 & 11.999 & 11.867 & 11.736 & 11.605 & 11.474 & 11.342 & 11.211 & 11.081 & 10.949 & 10.818 \\ 0.8 & 10.687 & 10.555 & 10.424 & 10.293 & 10.162 & 10.031 & 09.900 & 09.769 & 09.638 & 090507\end{array}$

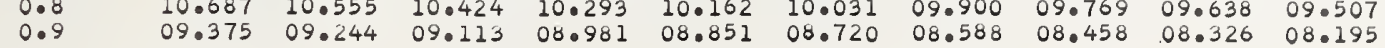

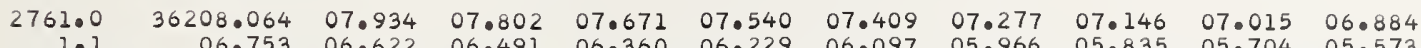

$\begin{array}{lllllllllll}1.1 & 06.753 & 06.622 & 06.491 & 06.360 & 06.229 & 06.097 & 05.966 & 05.835 & 05.704 & 05.573 \\ 1.2 & 05.442 & 05.311 & 05.180 & 05.049 & 04.917 & 04.786 & 04.655 & 04.524 & 04.393 & 04.262\end{array}$

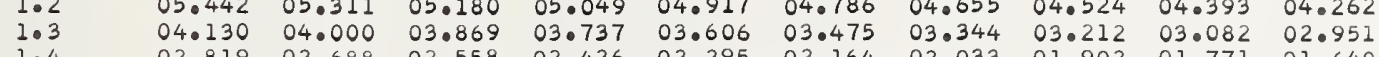

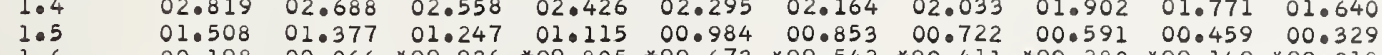

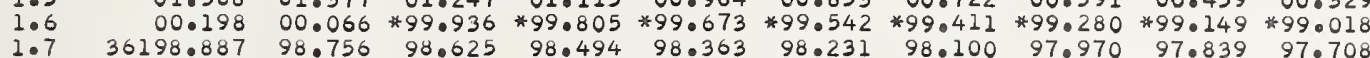

$\begin{array}{lrlllllllll}1.7 & 36198.887 & 98.756 & 98.625 & 98.494 & 98.363 & 98.231 & 98.100 & 97.970 & 97.839 & 97.708 \\ 1.8 & 97.577 & 97.445 & 97.314 & 97.184 & 97.052 & 96.921 & 96.791 & 96.659 & 96.528 & 96.397\end{array}$

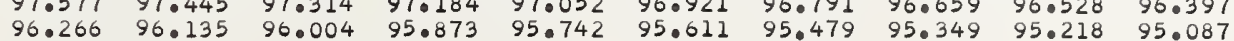

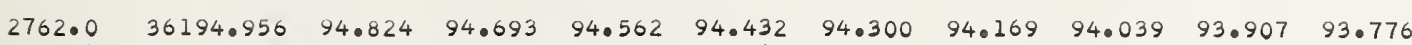

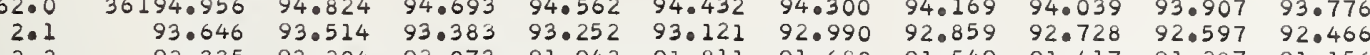

$\begin{array}{lllllllllll}2.2 & 92.335 & 92.204 & 92.073 & 91.942 & 91.811 & 91.680 & 91.549 & 91.417 & 91.287 & 92.466\end{array}$

$\begin{array}{lllllllllll}2.3 & 91.025 & 90.894 & 90.763 & 90.631 & 90.500 & 90.370 & 90.238 & 90.107 & \$ 90977 & 89.846\end{array}$

$\begin{array}{lllllllllll}2.4 & 88.744 & 89.584 & 89.452 & 89.321 & 89.190 & 89.060 & 88.928 & 88.798 & 88.667 & 88.536 \\ 2.5 & 88.404 & 88.273 & 88.142 & 88.011 & 87.880 & 87.750 & 87.619 & 87.488 & 87.357 & 87.226\end{array}$

$\begin{array}{llllllllllll}2.6 & 87.095 & 86.964 & 86.833 & 86.702 & 86.571 & 86.440 & 86.309 & 86.178 & 86.047 & 85.916\end{array}$

$\begin{array}{lllllllllll}2.7 & 85.785 & 85.654 & 85.523 & 85.393 & 85.261 & 85.130 & 84.999 & 84.868 & 84.737 & 84.606\end{array}$

$\begin{array}{lllllllllll}2.8 & 84.475 & 84.344 & 84.21 .4 & 84.083 & 83.952 & 83.821 & 83.690 & 83.558 & 83.428 & 83.297 \\ 2.9 & 83.166 & 83.035 & 82.904 & 82.773 & 82.642 & 82.511 & 82.380 & 82.249 & 82.118 & 81.987\end{array}$

$\begin{array}{lllllllllll}2763.0 & 36181.856 & 81.725 & 81.594 & 81.463 & 81.333 & 81.202 & 81.070 & 80.939 & 80.809 & 80.677\end{array}$

$\begin{array}{lllllllllll}3.1 & 80.547 & 80.416 & 80.285 & 80.154 & 80.023 & 79.892 & 79.761 & 79.630 & 79.499 & 79.368 \\ 3.2 & 79.237 & 79.106 & 78.976 & 78.845 & 78.714 & 78.583 & 78.452 & 78.321 & 78.189 & 78.059\end{array}$

$\begin{array}{lllllllllll}3.2 & 79.237 & 79.106 & 78.976 & 78.845 & 78.714 & 78.583 & 78.452 & 78.321 & 78.189 & 78.059 \\ 3.3 & 77.928 & 77.797 & 77.667 & 77.535 & 77.404 & 77.274 & 77.143 & 77.012 & 76.881 & 76.750\end{array}$

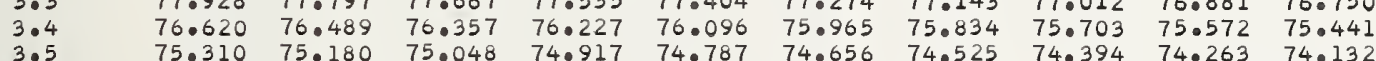

$\begin{array}{lllllllllll}3.5 & 75.310 & 75.180 & 75.048 & 74.917 & 74.787 & 74.656 & 74.525 & 74.394 & 74.263 & 74.132 \\ 3.6 & 74.001 & 73.871 & 73.740 & 73.609 & 73.478 & 73.347 & 73.216 & 73.085 & 72.954 & 721024\end{array}$

$\begin{array}{lllllllllll}3.7 & 72.692 & 72.562 & 72.431 & 72.300 & 72.169 & 72.038 & 71.907 & 71.776 & 71.645 & 72.824\end{array}$

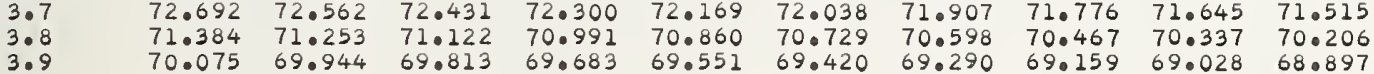

$\begin{array}{lllllllllll}2764.0 & 36168.766 & 68.636 & 68.505 & 68.374 & 68.243 & 68.112 & 67.981 & 67.851 & 67.719 & 67.588\end{array}$ $\begin{array}{llllllllll}67.458 & 67.327 & 67.196 & 67.066 & 66.935 & 66.804 & 66.674 & 66.542 & 66.411 & 66.281\end{array}$ $\begin{array}{llllllllll}66.150 & 66.019 & 65.889 & 65.757 & 65.626 & 65.496 & 65.365 & 65.234 & 65.103 & 64 \cdot 972\end{array}$ $\begin{array}{llllllllll}64.841 & 64.710 & 64.580 & 64.449 & 64.318 & 64.187 & 64.057 & 63.926 & 63.795 & 63.664 \\ 63.533 & 63.403 & 63.271 & 63.141 & 63.010 & 62.879 & 62.749 & 62.618 & 62.487 & 62.356\end{array}$ $\begin{array}{llllllllll}63.533 & 63.403 & 63.271 & 63.141 & 63.010 & 62.879 & 62.749 & 62.618 & 62.487 & 62.356 \\ 62.225 & 62.094 & 61.963 & 61.833 & 61.702 & 61.571 & 61.440 & 61.310 & 61.179 & 61.048\end{array}$ $\begin{array}{llllllllll}62.225 & 62.094 & 61.963 & 61.833 & 61.702 & 61.571 & 61.440 & 61.310 & 61.179 & 61.046\end{array}$

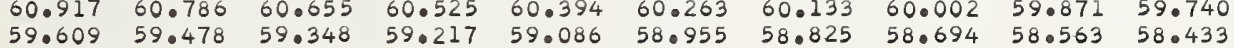

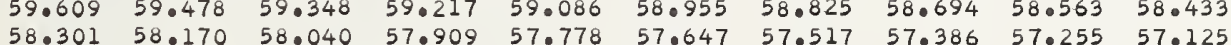
$\begin{array}{llllllllll}58.301 & 58.170 & 58.040 & 57.909 & 57.778 & 57.647 & 57.517 & 57.386 & 57.255 & 57.125 \\ 56.993 & 56.863 & 56.733 & 56.602 & 56.471 & 56.340 & 56.209 & 56.079 & 55.948 & 55.817\end{array}$

$36155.687 . \quad 55.556 \quad 5504$

$\begin{array}{lllllllll}55.425 & 55.294 & 55.164 & 55.033 & 54.902 & 54.771 & 54.640 & 54.510\end{array}$

0.295462

0.295460

0.295456

0.29545

0.295450

0.295445

0.295441

0.295439
0.295437

0.295435

0.295433

0.295429

0.295427

0.295426

0.295424

0.295422

0.295420

0.295416

0.295414
0.295412

0.29541

0.295409

0.295407

0.295403

0.295401

0.295397

0.295395

0.295390

0.295388
0.295386

0.295384

0.295378

0.295375

0.295373

0.295371

0.295367

0.815983

0.816007

0.816032

0.816080

0.816129

0.816153

0.816177

0.816202

0.816250

0.816275

0.816323

0.816348

0.816396

0.816421

0.816445

0.816493

0.816518

0.816542

0.816591

0.816615

0.816664

0.816688
0.816712

0.816737

0.81676

0.816810

0.816834

0.816858

0.816907

0.816932

0.295365

0.295363

0.295359

0.295358

0.295356 $\begin{array}{llllllllll}37.096 & 38.565 & 38.435 & 38.304 & 38.173 & 38.043 & 37.912 & 37.781 & 37.651 & 37.521\end{array}$ $\begin{array}{llllllllll}37.390 & 37.259 & 37.128 & 36.998 & 36.867 & 36.736 & 36.606 & 36.476 & 36.345 & 36.214 \\ 36.083 & 35.954 & 35.823 & 35.692 & 35.562 & 35.431 & 35.300 & 35.169 & 35.039 & 34.908\end{array}$ $\begin{array}{lllllllllll}34.778 & 34.647 & 34.517 & 34.386 & 34.255 & 34.125 & 33.994 & 33.863 & 33.733 & 33.603\end{array}$ $\begin{array}{llllllllll}33.472 & 33.341 & 33.211 & 33.080 & 32.949 & 32.819 & 32.688 & 32.557 & 32.427 & 32.296 \\ 32.166 & 32.035 & 31.905 & 31.074 & 31.644 & 31.513 & 31.382 & 31.251 & 31.121 & 30.990\end{array}$

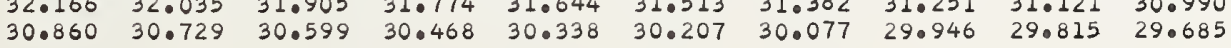

0.295352

0.295350

0.816980 0.817004
0.817028
0.817053

0.81705

0.817077

0.817126

0.817126

0.817174

0.295346

0.817223

0.295344

0.295341

0.295339

0.295337

0.295333

0.295331

0.817272

0.817296

0.817345

0.817369

0.817393

0.817442

0.295327

0.295326

0.295322

0.295320

0.295318

0.295314

0.295312

0.817466

0.817491

0.817539

0.817564
0.817588

0.817588

0.817637

0.817661

0.295309

0.295307

0.295303

0.295301

0.295299

0.295297

0.295294

0.817710

0.817758

0.817783

0.817807

0.817831

0.817880

0.817880

$\begin{array}{llllllllll}95.639 & 95.508 & 95.378 & 95.248 & 95.117 & 94.987 & 94.857 & 94.727 & 94.597 & 94.466 \\ 94.336 & 94.206 & 94.075 & 93.945 & 93.814 & 93.684 & 93.554 & 93.424 & 93.293 & 93.163\end{array}$

$\begin{array}{lllllllllll}9.7 & 94.336 & 94.206 & 94.075 & 93.945 & 93.814 & 93.684 & 93.554 & 93.424 & 93.293 & 93.163 \\ 9.8 & 93.033 & 92.902 & 92.772 & 92.642 & 92.511 & 92.381 & 92.251 & 92.121 & 91.991 & 91.860\end{array}$

0.295292

0.817929

$\begin{array}{lllllllllll} & .001 & .002 & .003 & .004 & .005 & .006 & .007 & .008 & .009 & .010 \\ .131 & .013 & .026 & .039 & .052 & .065 & .079 & .092 & .0105 & .118 & .0131 \\ .130 & .013 & .026 & .039 & .052 & .065 & .078 & .091 & .104 & .117 & .130\end{array}$


$\begin{array}{lll}89.427 & 90.296 & 90.166 \\ 89.124 & 88.994 & 88.863\end{array}$

0.2

$\begin{array}{llll}78.705 & 78.575 & 78.444 & 78.314\end{array}$

2771.0
1.
1.
1.
1.0
1.7
1.9
2772.0
2.1
2.2
2.
2.4
2.5
2
2
2

$$
\begin{array}{r}
71.0 \\
1.1 \\
1.2 \\
1.3 \\
1.4 \\
1.5 \\
1.6 \\
1.7 \\
1.8 \\
1.9 \\
7.9 \\
2.1 \\
2.2 \\
2.3 \\
2.4 \\
2.5 \\
2.6 \\
2.7 \\
2.8 \\
2.9
\end{array}
$$


$0.611 \quad 60.482$ $\begin{array}{lll}58.319 & 59.189 & 59.353\end{array}$

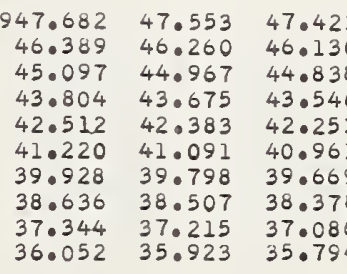

$\begin{array}{lllllllll}.001 & .002 & .003 & .004 & .005 & .006 & .007 & .008 & .009\end{array}$

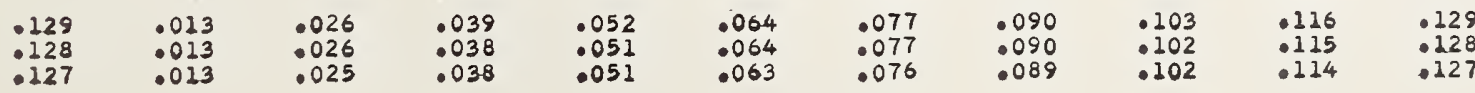


$\lambda(A)$

.00

.01

.02

.03

.04

.05

.06

.07

.08

.09

$(n-1) \times 1000$

$\lambda(n-1)$

2790.0
0.1
0.0
0.3
0.4
0.5
0.6
0.7
0.8
0.9

0.1
0.2
0.3
0.4
0.5
0.6
0.7
0.8
0.9

2791.

$$
\text { (1) }
$$

92.0
20
20

2.3
2.4

2.5
2.6

2.7

2.8
2.9

2793.

3.0
$3: 1$
3.
3.
3.
3.
3.
3.
3.0

2794 .

$4 \cdot 1$
$4 \cdot 2$
$4 \cdot 3$

4.4
4.5

4.6
4.7

$4 \cdot 8$
$4 \cdot 9$

2795.

55

$5 \cdot 2$
5.3
5.4
5.5

5.5
5.6
5.7

5.7

5.9

2796.

6.1
6.2
6.3
6.4
6.5
6.5
6.7
6.8
6.9

6.8

2797.0

7.1

7.2
$7 \cdot 3$
$7 \cdot 4$

7.5

$7 \cdot 7$

7.8

2798.0

8.1
8.2
8.3
8.4
8.5
8.6
8.7
8.8
8.9
99.0
9.1
9.2
9.3
9.4
9.5
9.6
9.7
9.8
9.9

2799

9.0
9.1
9.2
9.3
9.4
9.5
9.6
9.7
9.8
9.9

$\begin{array}{llll}1.471 & 31.342 & 31.214 & 31.085 \\ 0.186 & 30.058 & 29.930 & 29.801\end{array}$ $\begin{array}{lllll}30.443 & 30.314 & 30.186 & 30.058 & 290 . \\ 29.159 & 29.030 & 28.902 & 28.774 & 28\end{array}$ $\begin{array}{llllll}27.875 & 27.746 & 27.618 & 27.490 & 27.361 & 27.517\end{array}$ $26.591 \quad 26.462$ $\begin{array}{llllll}25.307 & 25.179 & 25.050 & 24.922 & 26.078 & 25.949 \\ & 24.793 & 24.665\end{array}$ $\begin{array}{llllll}22.740 & 22.612 & 22.484 & 22.355 & 22.227 & 22.098\end{array}$ $21.457 \quad 21.328$

35818.890 $17.606 \quad 17.478$ 16.32316 .195 $\begin{array}{ll}15.040 & 14.912 \\ 13.757 & 13.629\end{array}$ $\begin{array}{ll}08.626 & 08.498 \\ 07.343 & 07.215\end{array}$ $\begin{array}{rr}5806.061 & 05.933 \\ 04.779 & 04.050\end{array}$ $03.497 \quad 03.368$ $02.214 \quad 02.086$ $35799.650 \quad 99.522$ $98.369 \quad 98.240$

$95.805 \quad 95.676$

95.805
$94.523 \quad 94.395$

$35793.241 \quad 93.113$ $\begin{array}{ll}91.961 & 91.833 \\ 90.679 & 90.551\end{array}$

$89.398 \quad 89.270$ $\begin{array}{ll}88.117 & 87.989 \\ 86.835 & 86.708\end{array}$ $85.555 \quad 85.427$ $84.274 \quad 84.146$ $\begin{array}{ll}82.993 & 82.865 \\ 81.712 & 81.584\end{array}$ 81.584 $\begin{array}{ll}79.151 & 79.023 \\ 77.871 & 77.743\end{array}$

$76.590 \quad 76.462$

$75.310 \quad 75.182$ $\begin{array}{ll}74.030 & 73.902 \\ 72.750 & 72.622\end{array}$ $71.470 \quad 71.342$ $\begin{array}{ll}70.190 & 70.062 \\ 68.911 & 68.783\end{array}$

66.351

65.07
63.792
6.523

$\begin{array}{ll}63.792 & 63.66 \\ 62.513 & 62.38\end{array}$

$61.233 \quad 61.106$

$\begin{array}{ll}59.955 & 59.827 \\ 58.676 & 58.548\end{array}$

$\begin{array}{ll}57.397 & 57.269 \\ 56.118 & 55.990\end{array}$

35754.839

53.56
52.282

51.083

54.71

48.319

$\begin{array}{ll}44.612 & 44.484 \\ 43.334 & 43.207\end{array}$

35742.056

40.778
39.501

$\begin{array}{ll}40.778 & 40.650 \\ 38.224 & 38.374 \\ 36.096\end{array}$

$36.946 \quad 36.818$

$34.391 \quad 34.264$

$33.114 \quad 32.986$

$30.560 \quad 30.432$

35729.283

$28.006 \quad 27.878$

$\begin{array}{llll}25.453 & 25.325 & 25.197 & 25.06\end{array}$

$\begin{array}{llll}24.176 & 24.049 & 23.920 & 23.79 \\ 22.899 & 22.772 & 22.644 & 22.516\end{array}$

$21.623 \quad 21.496 \quad 21.367 \quad 21.240$

$\begin{array}{llll}19.070 & 18.943 & 18.816 & 18.68 \\ 17.794 & 17.667 & 17.540 & 17.412\end{array}$

$716.519 \quad 16.391$

$\begin{array}{ll}15.243 & 15.11 \\ 13.967 & 13.83\end{array}$

$12.691 \quad 12.56$

$10.139 \quad 10.012$

$\begin{array}{ll}14.987 & 14.860\end{array}$

$12.436 \quad 12.308$

$\begin{array}{llll}0.864 & 08.736 & 08.609 & 08.482\end{array}$

$06.314 \quad 06.186 \quad 06.059 \quad 05.93$

$05.039,04.911$

92.729

02.601

$81.201 \quad 81.072$

$\begin{array}{ll}79.920 & 79.792 \\ 78.639 & 78.511 \\ 77.358 & 77.230\end{array}$

$54.328 \quad 54.199$ $\begin{array}{llllll}24.024 & 23.896 & 23.767 & 23.639 & 23.510 & 23.382\end{array}$ $12.474 \quad 12.346$ $11.191 \quad 11.063$

$16.263 \quad 16.136$

$\begin{array}{llll}30.957 & 30.828 & 30.700 & 30.571 \\ 29.673 & 29.544 & 29.416 & 29.288\end{array}$

$\begin{array}{llll}28.389 & 28.260 & 28.131 & 28.003\end{array}$

$\begin{array}{llll}27.104 & 26.976 & 26.848 & 26.719\end{array}$

$\begin{array}{llll}24.537 & 24.409 & 24.280 & 24.151\end{array}$

$\begin{array}{llll}23.254 & 23.125 & 22.997 & 22.869\end{array}$

$\begin{array}{llll}21.970 & 21.841 & 21.713 & 21.585 \\ 20.687 & 20.558 & 20.430 & 20.301\end{array}$

$\begin{array}{llll}19.403 & 19.275 & 19.146 & 19.018\end{array}$

$\begin{array}{llll}18.119 & 17.991 & 17.863 & 17.734\end{array}$

$\begin{array}{llll}15.553 & 15.425 & 15.296 & 15.168\end{array}$

$\begin{array}{llll}14.270 & 14.142 & 14.014 & 13.885 \\ 12.988 & 12.859 & 12.731 & 12.603\end{array}$

$\begin{array}{llll}12.988 & 12.859 & 12.731 & 12.603 \\ 11.705 & 11.577 & 11.448 & 11.319\end{array}$

$\begin{array}{llll}10.422 & 10.294 & 10.166 & 10.038\end{array}$

$\begin{array}{llll}09.139 & 09.011 & 08.882 & 08.754\end{array}$

$\begin{array}{llll}07.856 & 07.728 & 07.600 & 07.472 \\ 06.574 & 06.446 & 06.318 & 06.189\end{array}$

$\begin{array}{llll}05.292 & 05.164 & 05.035 & 04.907\end{array}$

$04.00903 .881 \quad 03.753 \quad 03.625$

$01.44501 .317 \quad 01.18901 .061$

$00.163 \quad 00.035 * 99.907 * 99.778$

$\begin{array}{llll}98.881 & 98.753 & 98.625 & 98.497\end{array}$

$\begin{array}{llll}97.600 & 97.471 & 97.343 & 97.215\end{array}$

$\begin{array}{llll}95.036 & 94.907 & 94.779 & 94.651 \\ 93.754 & 93.626 & 93.498 & 93.370\end{array}$

92.473

3.626

$92.217 \quad 92.089$

$\begin{array}{llllll}90.167 & 90.320 & 91.192 & 91.063 & 90.936 & 90.808 \\ & 90.038 & 89.911 & 89.782 & 89.654 & 89.526\end{array}$

$\begin{array}{llllll}88.885 & 88.757 & 88.629 & 88.501 & 88.373 & 88.245\end{array}$

$\begin{array}{lllllll}86.323 & 86.195 & 86.067 & 85.939 & 85.811 & 85.683\end{array}$

$\begin{array}{lllllll}85.042 & 84.914 & 84.786 & 84.658 & 84.530 & 84.402\end{array}$

$\begin{array}{lllllll}83.761 & 83.633 & 83.505 & 83.377 & 83.249 & 83.121\end{array}$

$\begin{array}{llllll}82.480 & 82.353 & 82.224 & 82.097 & 81.969 & 81.840\end{array}$

80.944

$8.816 \quad 80.688$

80.560

$\begin{array}{llll}79.664 & 79.536 & 79.408 & 79.279 \\ 78.383 & 78.255 & 78.127 & 77.999\end{array}$

$\begin{array}{llll}78.383 & 78.255 & 78.127 & 77.999\end{array}$

$\begin{array}{llll}77.103 & 76.975 & 76.847 & 76.718 \\ 75.822 & 75.694 & 75.566 & 75.438\end{array}$

$\begin{array}{lllll}74.542 & 74.414 & 74.286 & 74.158\end{array}$

$\begin{array}{lllll}73.262 & 73.134 & 73.006 & 72.878\end{array}$

$\begin{array}{llll}71.982 & 71.854 & 71.726 & 71.599\end{array}$

$\begin{array}{llll}70.702 & 70.574 & 70.446 & 70.318\end{array}$

$\begin{array}{llll}69.422 & 69.294 & 69.167 & 69.039\end{array}$

$\begin{array}{llll}66.863 & 66.735 & 66.607 & 66.479\end{array}$

$\begin{array}{llll}65.583 & 65.456 & 65.327 & 65.200\end{array}$

$\begin{array}{llll}64.304 & 64.176 & 64.048 & 63.920 \\ 63.025 & 62.896 & 62.769 & 62.641\end{array}$

$61.745 \quad 61.617 \quad 61.489 \quad 61.36$

$\begin{array}{lllll}60.466 & 60.339 & 60.211 & 60.083\end{array}$

$\begin{array}{llll}59.187 & 59.060 & 58.932 & 58.804 \\ 57.908 & 57.780 & 57.652 & 57.525\end{array}$

$\begin{array}{llllll}58.164 & 58.036 & 57.908 & 57.780 & 57.652 & 57.525 \\ 56.885 & 56.757 & 56.629 & 56.501 & 56.374 & 56.246 \\ 55.606 & 55.479 & 55.351 & 55.223 & 55.095 & 54.967\end{array}$

$\begin{array}{llllll}58.164 & 58.036 & 57.908 & 57.780 & 57.652 & 57.525 \\ 56.885 & 56.757 & 56.629 & 56.501 & 56.374 & 56.246 \\ 55.606 & 55.479 & 55.351 & 55.223 & 55.095 & 54.967\end{array}$

52.793

$53.944 \quad 53.816 \quad 53.688$

$\begin{array}{llll}50.237 & 50.108 & 49.981 & 49.853\end{array}$

$\begin{array}{llll}48.958 & 48.831 & 48.702 & 48.574 \\ 47.680 & 47.552 & 47.424 & 47.296\end{array}$

$46.402 \quad 46.274 \quad 46.146 \quad 46.018$

$\begin{array}{llll}45.124 & 44.996 & 44.868 & 44.740\end{array}$

$\begin{array}{llll}43.845 & 43.717 & 43.590 & 43.462\end{array}$

$41.290 \quad 41.162 \quad 41.034 \quad 40.906$

$\begin{array}{llll}40.012 & 39.884 & 39.757 & 39.629\end{array}$

$\begin{array}{llll}38.734 & 38.607 & 38.479 & 38.352\end{array}$

$\begin{array}{llll}36.179 & 36.052 & 35.924 & 35.796\end{array}$

$\begin{array}{llll}34.902 & 34.774 & 34.646 & 34.519\end{array}$

$33.625 \quad 33.497 \quad 33.369 \quad 33.242$

$\begin{array}{llll}32.348 & 32.220 & 32.092 & 31.964 \\ 31.070 & 30.942 & 30.815 & 30.687\end{array}$

$\begin{array}{llll}29.793 & 29.666 & 29.539 & 29.411\end{array}$

$\begin{array}{llllll}28.772 & 28.645 & 28.517 & 28.390 & 28.262 & 28.134 \\ 27.496 & 27.368 & 27.240 & 27.112 & 26.985 & 26.857\end{array}$

$\begin{array}{llllll}26.219 & 26.091 & 25.963 & 25.835 & 25.708 & 25.581\end{array}$

$\begin{array}{llllll}24.942 & 24.814 & 24.687 & 24.559 & 24.432 & 24.304\end{array}$

$\begin{array}{llllll}22.389 & 22.261 & 22.133 & 22.006 & 21.878 & 21.750\end{array}$

$\begin{array}{llllll}21.112 & 20.985 & 20.857 & 20.729 & 20.602 & 20.475\end{array}$

$\begin{array}{llllll}18.561 & 18.433 & 18.305 & 18.177 & 18.050 & 17.922\end{array}$

$\begin{array}{lllllll}16.008 & 15.881 & 15.753 & 15.625 & 15.498 & 15.370\end{array}$

$\begin{array}{llllll}14.732 & 14.604 & 14.478 & 14.350 & 14.222 & 14.094\end{array}$

$\begin{array}{lllllll}13.457 & 13.329 & 13.202 & 13.074 & 12.946 & 12.818\end{array}$

$\begin{array}{llllll}10.905 & 10.777 & 10.650 & 10.522 & 10.395 & 10.267\end{array}$

$\begin{array}{lllllll}09.629 & 09.502 & 09.374 & 09.247 & 09.119 & 08.991\end{array}$

$\begin{array}{llllll}08.354 & 08.227 & 08.099 & 07.972 & 07.844 & 07.717 \\ 07.079 & 06.951 & 06.824 & 06.696 & 06.569 & 06.441\end{array}$

$\begin{array}{ccccccccccc} & .001 & .002 & .003 & .004 & .005 & .006 & .007 & .008 & .009 & .010 \\ .128 & .013 & .026 & .038 & .051 & .064 & .077 & .090 & .102 & .115 & .128 \\ .127 & .013 & .025 & .038 & .051 & .063 & .076 & .089 & .102 & .114 & .127 \\ .126 & .013 & .025 & .038 & .050 & .063 & .076 & .088 & .101 & .113 & .126\end{array}$

$0.294920 \quad 0.822826$ $0.294918 \quad 0.822850$ $0.294914 \quad 0.822874$ $0.294912 \quad 0.822923$ $0.294910 \quad 0.822948$ $0.294909-0.822972$ $0.294905 \quad 0.823021$

$0.294903 \quad 0.823045$

0.294901 0.294900 0.294898 0.294894 0.294892
0.294890 .294889 294887

.294885

0.294883 0.294881 0.294878 0.294876 0.294874 .294872 0.294870 0.294869
0.294867

0.294865 0.294863

0.294861 .294858 0.294854 0.294852 0.294850 0.294849

0.823070

0.823094

0.823118
0.823143

0.823143

0.823167
0.823192

0.823216

0.823240

0.823265

0.823314

0.823338

0.823362

0.823411

0.823436

0.823460

0.823484

0.823533

0.823558

0.823582

0.823631

0.823680

0.823680

0.823704

0.823728
0.823753

0.823777

0.294847

0.294845

0.294843

0.294839

0.294838

0.294836

0.294834

0.294830 

$\begin{array}{lllllllll} & 0.91 & 0.321 & 00.193 & 00.066\end{array}$ $\begin{array}{llllllllll}98.664 & 98.536 & 98.409 & 98.281 & 98.154 & 98.026 & 97.899 & 97.772 & 97.645 & 97.517\end{array}$ $\begin{array}{llllllllll}96.115 & 97.262 & 97.134 & 97.007 & 96.879 & 96.752 & 96.625 & 96.497 & 96.370 & 96.242\end{array}$ $\begin{array}{llllllllll}96.115 & 95.987 & 95.859 & 95.732 & 95.605 & 95.477 & 95.350 & 95.223 & 95.095 & 94.968 \\ 94.840 & 94.712 & 94.585 & 94.458 & 94.330 & 94.203 & 94.076 & 93.948 & 93.820 & 93.693\end{array}$ $\begin{array}{llllllllll}94.840 & 94.712 & 94.585 & 94.458 & 94.330 & 94.203 & 94.076 & 93.948 & 93.820 & 93.693 \\ 93.566 & 93.438 & 93.311 & 93.183 & 93.056 & 92.929 & 92.801 & 92.673 & 92.546 & 92.4119\end{array}$

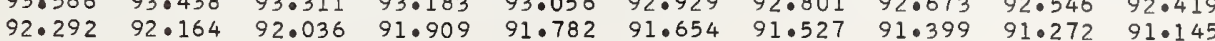

2801
1
1
1
1
1
1
1
1
1
2802
2.0
2
2.1
2
2.4
2.5
2.6
2.7
2.8
2.9

$\begin{array}{rrrrr}1.0 & 35691.017 & 90.890 & 90.762 & 90.6 \\ 1.1 & 89.743 & 89.616 & 89.488 & 89.3 \\ 1.2 & 88.469 & 88.341 & 88.214 & 88.0\end{array}$

$\begin{array}{llll}87.195 & 87.341 & 88.214 & 88.08\end{array}$

$\begin{array}{llllll}.4 & 85.921 & 85.794 & 85.667 & 85.53\end{array}$

$\begin{array}{llllll}.5 & 84.647 & 84.520 & 84.393 & 84.2 \\ .6 & 83.374 & 83.247 & 83.119 & 82.992\end{array}$

1.8 $\begin{array}{llll}100 & 81.973 & 81.846 & 81.71\end{array}$

$\begin{array}{ll}80.827 & 80.69\end{array}$

35678.279

$$
\begin{array}{r}
78.27 \\
77.0 \\
75.7 \\
74.4 \\
73.1 \\
71.9 \\
70.6 \\
69.0 \\
68.0 \\
66.8
\end{array}
$$$$
78.152
$$$$
\begin{array}{ll}
81.846 \\
80.572 \\
\hline 9
\end{array}
$$$$
2803.0
$$$$
3.1
$$$$
\begin{aligned}
& 3.2 \\
& 3.3 \\
& 3.4 \\
& 3.5
\end{aligned}
$$$$
\begin{aligned}
& 3.5 \\
& 3.6
\end{aligned}
$$$$
\begin{aligned}
& 3.6 \\
& 3.7 \\
& 3.8
\end{aligned}
$$$$
\begin{aligned}
& 3.8 \\
& 3.9
\end{aligned}
$$$$
2804.0
$$$$
4 \cdot 1
$$$$
\begin{aligned}
& 4.2 \\
& 4.3 \\
& 4.4
\end{aligned}
$$$$
\begin{aligned}
& 4.4 \\
& 4.5
\end{aligned}
$$$$
\begin{aligned}
& 4.5 \\
& 4.6
\end{aligned}
$$$$
\begin{aligned}
& 4.7 \\
& 4.8 \\
& 4.9
\end{aligned}
$$$$
2805.0
$$$$
\begin{aligned}
& 5.1 \\
& 5.2 \\
& 5.3
\end{aligned}
$$$$
\begin{aligned}
& 5.2 \\
& 5.3 \\
& 5.4
\end{aligned}
$$$$
\begin{aligned}
& 5.4 \\
& 5.5
\end{aligned}
$$$$
\begin{aligned}
& 5.6 \\
& 5.7 \\
& 5.8
\end{aligned}
$$$$
\begin{aligned}
& 5.8 \\
& 5.9
\end{aligned}
$$$$
2806
$$$$
6.1
$$$$
6.3
$$$$
\begin{aligned}
& 6.2 \\
& 6.4 \\
& 6.5 \\
& 6.6
\end{aligned}
$$$$
\begin{aligned}
& 6.6 \\
& 6.7 \\
& 6.8
\end{aligned}
$$$$
6.9
$$$$
2807 .
$$$$
\begin{aligned}
& 7.1 \\
& 7.2 \\
& 7.3 \\
& 7.4
\end{aligned}
$$$$
7.4
$$$$
\begin{aligned}
& 7.4 \\
& 7.5 \\
& 7.7 \\
& 7.8
\end{aligned}
$$$$
7.78
$$

2808.0

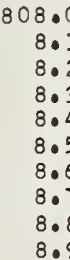$$
2809 .
$$$$
\begin{array}{r}
809.0 \\
9.1 \\
9.2 \\
9 . \\
9.5 \\
9.5 \\
9.7 \\
9.9
\end{array}
$$

$\begin{array}{rll}68.097 & 67.969 & 67 \\ 66.824 & 66.697 & 66 \\ 35665.552 & 65.425 & 65 \\ 64.280 & 64.152 & 64\end{array}$

$61.736 \quad 61.608$

$59.191 \quad 59.064 \quad 58.937$

$57.920 \quad 57.792$

$56.648 \quad 56.521 \quad 56.394$

$\begin{array}{ll}55.376 & 55.249 \\ 54.104 & 53.978\end{array}$

35652.833

$$
\begin{array}{ll}
52.833 & 52.706 \\
51.562 & 51.435 \\
50.291 & 50.163
\end{array}
$$

$\begin{array}{lll}50.291 & 50.163 & 50.0 \\ 49.019 & 48.892\end{array}$

$\begin{array}{ll}47.748 & 47.621 \\ 46.477 & 46.35\end{array}$

$\begin{array}{ll}46.477 & 46.350 \\ 45.207 & 45.080\end{array}$

43.936
42.665 42.809

$\begin{array}{ll}42.665 & 42.538 \\ 41.394 & 41.267\end{array}$

$5640.123 \quad 39.997$

$\begin{array}{ll}38.853 & 38.726 \\ 37.583 & 37.456\end{array}$

$\begin{array}{ll}36.312 & 36.185 \\ 35.042 & 34.915\end{array}$

$33.772 \quad 33.645$

$32.502 \quad 32.375 \quad 32.248$

31.23231 .105

$\begin{array}{ll}28.9692 & 28.565\end{array}$

35627.422

$26.153 \quad 27.295 \quad 27.168$

$24.883 \quad 24.075$

$\begin{array}{llll}22.345 & 22.218 & 22.091 & 23.034\end{array}$

$\begin{array}{llll}21.807 & 20.949 & 20.822 & 20.695\end{array}$

$\begin{array}{llll}18.538 & 19.680 & 19.553 & 19.426 \\ 18.211 & 18.284 & 18.157\end{array}$

$\begin{array}{llll}17.269 & 17.141 & 17.015 & 16.888 \\ 16.000 & 15.873 & 15.746 & 15.619\end{array}$

35614.73$$
13.463
$$$$
\begin{aligned}
& 13.463 \\
& 12.194 \\
& 10.925
\end{aligned}
$$

$\begin{array}{lll}13.336 & 13.208 & 13.08\end{array}$

$\begin{array}{llll}10.098 & 11.940 & 11.082 \\ 0.057 & 10.798 & 10.672 & 10.544\end{array}$

$08.388 \quad 08.262 \quad 08.135 \quad 08.008$

$\begin{array}{llll}05.852 & 05.725 & 05.599 & 05.472\end{array}$

$\begin{array}{llll}04.584 & 04.457 & 04.331 & 04.204 \\ 03.316 & 03.189 & 03.062 & 02.936\end{array}$

5602.048

$\begin{array}{rlll}35602.048 & 01.922 & 01.795 & 01.668 \\ 00.781 & 00.654 & 00.527 & 00.400 \\ 35599.513 & 99.386 & 99.259 & 99.133\end{array}$

$\begin{array}{llll}98.245 & 98.118 & 99.259 & 99.133 \\ 96.992 & 97.865\end{array}$

$96.978 \quad 96.851 \quad 96.724 \quad 96.597$

$\begin{array}{llll}95.710 & 95.583 & 95.457 & 95.330 \\ 94.443 & 94.316 & 94.189 & 94.052\end{array}$

$93.176 \quad 93.048 \quad 92.922 \quad 92.795$

91.90991 .782

91.65
90.38

91.529

$\begin{array}{llll}35589.375 & 89.248 & 89.121 & 88.995\end{array}$

$$
\begin{array}{llll}
88.108 & 87.981 & 87.854 & 87.728 \\
86.841 & 86.714 & 86.588 & 86.461
\end{array}
$$

$\begin{array}{llll}86.841 & 86.714 & 86.588 & 86.461 \\ 85.574 & 85.447 & 85.321 & 85.194 \\ 83.047 & 85.181 & 0 . .054 & 83.927\end{array}$

$\begin{array}{llll}84.307 & 84.181 & 84.054 & 83.927 \\ 83.041 & 82.915 & 82.788 & 82.661\end{array}$

$81.775 \quad 81.648 \quad 81.521 \quad 81.395$

$\begin{array}{llll}80.509 & 80.382 & 80.255 & 80.128\end{array}$

$\begin{array}{llll}77.976 & 77.850 & 77.723 & 77.596\end{array}$ $\begin{array}{lllllll}90.507 & 90.380 & 90.252 & 90.125 & 89.998 & 89.870\end{array}$

$\begin{array}{lllllll}87.959 & 87.832 & 87.705 & 87.577 & 87.450 & 87.323\end{array}$

$\begin{array}{lllllll}86.686 & 86.559 & 86.431 & 86.303 & 86.176 & 86.049\end{array}$

$\begin{array}{lllllll}85.412 & 85.285 & 85.157 & 85.030 & 84.902 & 84.775\end{array}$

$\begin{array}{lllllll}82.864 & 82.737 & 82.610 & 82.482 & 82.354 & 82.228\end{array}$

$\begin{array}{lllllll}81.591 & 81.463 & 81.336 & 81.209 & 81.081 & 80.954\end{array}$

$\begin{array}{llllll}79.044 & 78.917 & 78.789 & 79.035 & 79.808 & 79.680 \\ 7862 & 78.535 & 78.407\end{array}$

$\begin{array}{lllllll}77.771 & 77.643 & 77.516 & 77.389 & 77.261 & 77.134 \\ 76.498 & 76.370 & 76.243 & 76.116 & 75.988 & 75.861\end{array}$

$\begin{array}{lllllll}75.225 & 75.097 & 74.970 & 74.843 & 74.715 & 74.588\end{array}$

$\begin{array}{llllll}73.951 & 73.824 & 73.697 & 73.569 & 73.442 & 73.315\end{array}$

$\begin{array}{llllll}71.406 & 71.278 & 71.424 & 72.297 & 72.169 & 72.042 \\ 71.0224 & 70.896 & 70.769\end{array}$

$\begin{array}{llllll}70.133 & 70.005 & 69.878 & 69.751 & 69.624 & 69.497\end{array}$

$\begin{array}{llllll}68.860 & 68.733 & 68.606 & 68.479 & 68.351 & 68.224\end{array}$

$\begin{array}{llllll}66.316 & 66.188 & 66.061 & 65.935 & 65.807 & 65.679\end{array}$

$\begin{array}{lllllll}65.043 & 64.916 & 64.789 & 64.662 & 64.535 & 64.407\end{array}$

$\begin{array}{llllll}63.771 & 63.644 & 63.517 & 63.390 & 63.262 & 63.135 \\ 62.499 & 62.372 & 62.245 & 62.117 & 61.990 & 61.863\end{array}$

$\begin{array}{llllll}61.227 & 61.100 & 60.972 & 60.845 & 60.718 & 60.591\end{array}$

$\begin{array}{lllllll}59.955 & 59.828 & 59.700 & 59.573 & 59.446 & 59.319\end{array}$

$\begin{array}{lllllll}57.411 & 57.283 & 58.428 & 58.301 & 58.174 & 58.047 \\ & 56.157 & 57.029 & 56.902 & 56.775\end{array}$

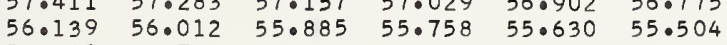

$\begin{array}{llllll}54.868 & 54.741 & 54.613 & 54.486 & 54.359 & 54.232 \\ 53.597 & 53.469 & 53.342 & 53.215 & 53.087 & 52.960\end{array}$

$\begin{array}{lllllll}52.325 & 52.198 & 52.070 & 51.943 & 51.816 & 51.689\end{array}$

$\begin{array}{llllll}51.053 & 50.926 & 50.799 & 50.672 & 50.544 & 50.417\end{array}$

$\begin{array}{llllll}49.782 & 49.655 & 49.528 & 49.401 & 49.273 & 49.146 \\ 48.511 & 48.384 & 48.257 & 48.129 & 48.002 & 47.875\end{array}$

$\begin{array}{llllll}47.240 & 47.113 & 46.985 & 46.858 & 46.731 & 46.604\end{array}$

$\begin{array}{lllllll}45.969 & 45.841 & 45.714 & 45.587 & 45.460 & 45.333 \\ 44.698 & 44.571 & 44.444 & 44.317 & 44.189 & 44.063\end{array}$

$\begin{array}{llllll}43.427 & 43.300 & 44.444 & 44.317 & 44.189 & 44.063 \\ 3 & 43.046 & 43.046 & 42.919 & 42.792\end{array}$

$\begin{array}{llllll}42.156 & 42.029 & 41.902 & 41.775 & 41.648 & 41.521 \\ 40.886 & 40.759 & 40.631 & 40.505 & 40.377 & 40.250\end{array}$

$\begin{array}{lllllll}39.615 & 39.488 & 39.361 & 39.234 & 39.107 & 38.980\end{array}$

$\begin{array}{llllll}38.344 & 38.217 & 38.091 & 37.963 & 37.836 & 37.709 \\ 37.074 & 36.947 & 36.820 & 36.693 & 36.566 & 36.439\end{array}$

$\begin{array}{lllllll}35.804 & 35.677 & 35.550 & 35.422 & 35.296 & 35.169 \\ 34.534 & 34.407 & 34.280 & 34.153 & 34.026 & 33.899\end{array}$

$\begin{array}{lllllll}33.264 & 33.137 & 33.010 & 32.883 & 32.756 & 32.629 \\ 31.994 & 31.867 & 31.740 & 31.613 & 31.486 & 31.359\end{array}$

$\begin{array}{llllll}31.994 & 31.867 & 31.740 & 31.613 & 31.486 & 31.359 \\ 30.724 & 30.597 & 30.470 & 30.343 & 30.216 & 30.089\end{array}$

$\begin{array}{llllll}29.454 & 29.327 & 29.200 & 29.073 & 28.946 & 28.819 \\ 28.185 & 28.058 & 27.930 & 27.804 & 27.677 & 27.549\end{array}$

26.91526 .788

$\begin{array}{ll}25.645 & 25.518 \\ 24.375 & 24.24\end{array}$

$23.106 \quad 22.980$

$21.837 \quad 21.710$

$\begin{array}{ll}19.299 & 19.172 \\ 18.030 & 17.90\end{array}$

$\begin{array}{ll}16.761 & 16.634 \\ 15.492 & 15.365\end{array}$

$14.223 \quad 14.096$

$11.686 \quad 11.559$

09.14909 .022

$06.613 \quad 06.48$

$05.344 \quad 05.21$

$\begin{array}{ll}04.077 & 03.950 \\ 02.810 & 02.683\end{array}$

25.661

$\begin{array}{lll}26.534 & 26.407 & 26.280\end{array}$

$\begin{array}{llll}25.391 & 25.264 & 25.137 & 25.011 \\ 24.122 & 23.995 & 23.868 & 23.741\end{array}$

$\begin{array}{llll}22.853 & 22.726 & 22.599 & 22.472\end{array}$

$\begin{array}{llll}21.583 & 21.457 & 21.330 & 21.203 \\ 20.314 & 20.187 & 20.060 & 19.933\end{array}$

$\begin{array}{llll}19.045 & 18.918 & 18.791 & 18.665 \\ 17.776 & 17.649 & 17.522 & 17.396\end{array}$

$\begin{array}{llll}17.776 & 17.649 & 17.522 & 17.396 \\ 16.507 & 16.380 & 16.253 & 16.126\end{array}$

$15.238 \quad 15.112 \quad 14.984 \quad 14.857$

$\begin{array}{llll}13.969 & 13.843 & 13.715 & 13.588 \\ 12.701 & 12.574 & 12.448 & 12.321\end{array}$

$\begin{array}{llll}11.433 & 11.306 & 11.179 & 11.052\end{array}$

$\begin{array}{llll}10.164 & 10.037 & 09.911 & 09.784\end{array}$

$\begin{array}{llll}08.896 & 08.769 & 08.642 & 08.515 \\ 07.627 & 07.500 & 07.374 & 07.247\end{array}$

$06.359 \quad 06.232 \quad 06.105 \quad 05.979$

$\begin{array}{llll}05.091 & 04.964 & 04.837 & 04.711\end{array}$

$01.542 \quad 01.415 \quad 01.288 \quad 01.161 \quad 01.034 \quad 00.907$

$00.273 \quad 00.146$

$97.738 \quad 97.611$

$5.203 \quad 95.077$

$93.936 \quad 93.809$

92.668

91.402

92.542
91.275

$88.868 \quad 88.741$

86.33486 .475

85.06784 .94

82.53582 .408

$81.269 \quad 81.142$

$\begin{array}{lll}80.0262 & 81.0142 \quad 81.015\end{array}$

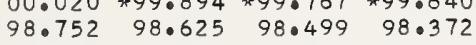

$97.48597 .358 \quad 97.231 \quad 97.104$

$96.217 \quad 96.091 \quad 95.964 \quad 95.837$

$\begin{array}{llll}94.950 & 94.823 & 94.696 & 94.569 \\ 93.683 & 93.556 & 93.429 & 93.303\end{array}$

$92.415 \quad 92.289 \quad 92.162 \quad 92.036$

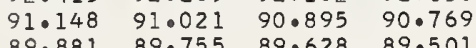

$88.614 \quad 88.488 \quad 88.361 \quad 88.234$

$87.348 \quad 87.221 \quad 87.094 \quad 86.968$

$\begin{array}{llll}86.081 & 85.954 & 85.827 & 85.701\end{array}$

$\begin{array}{llll}84.814 & 84.687 & 84.561 & 84.434\end{array}$

$\begin{array}{llll}82.281 & 83.421 & 83.294 & 83.167\end{array}$

$\begin{array}{llll}81.015 & 80.889 & 80.762 & 80.635\end{array}$

$\begin{array}{llllll}78.735 & 78.075 & 79.749 & 79.622 & 79.496 & 79.369 \\ 77.409 & 78.482 & 78.356 & 78.229 & 78.103\end{array}$

$\begin{array}{llllll}77.470 & 77.343 & 77.216 & 77.090 & 76.963 & 76.836\end{array}$

0.294738

294736

0.294734

0.294731

0.294727

0.294722

0.294720

0.294716

0.294713

0.294711

0.294709

0.294707
0.294706

0.294704

0.294702

0.294700

0.294698

0.294695

0.294693

0.294691

0.294688

0.294684

0.294682

0.294680

0.294679
0.294677
0.294675

0.294675

0.294673

0.294671

0.294668

0.294666

0.294664

0.294662
0.294661

0.294659

0.294657
0.294655

0.29465

0.294652

0.294648

0.294646

0.294645

0.294643

0.294639

0.294637

0.294636

0.294632

0.294630

0.294628

0.294623

0.294618

0.294616

0.294612

0.294611

0.294609 
$\lambda(n-1)$

$\begin{array}{lllllllllll}2810.0 & 35576.710 & 76.583 & 76.457 & 76.330 & 76.204 & 76.077 & 75.950 & 75.824 & 75.697 & 75.570\end{array}$ $\begin{array}{lllllllllll}0.1 & 75.444 & 75.317 & 75.191 & 75.064 & 74.937 & 74.811 & 74.685 & 74.558 & 74.431 & 74.305 \\ 0.2 & 74.178 & 74.051 & 73.925 & 73.798 & 73.0711 & 73.545 & 73.418 & 73.292 & 73.165 & 73.039\end{array}$ $\begin{array}{lllllllllll}0.3 & 72.912 & 72.786 & 72.659 & 72.533 & 72.406 & 72.279 & 72.152 & 72.026 & 71.899 & 71.773\end{array}$

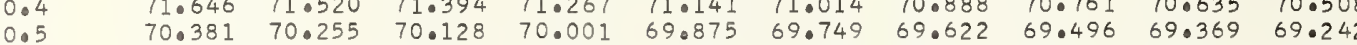

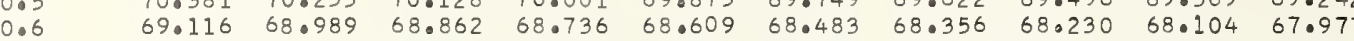
$\begin{array}{lllllllllll}0.7 & 67.850 & 67.724 & 67.597 & 67.471 & 67.344 & 67.217 & 67.091 & 66.964 & 66.838 & 66.711\end{array}$ $\begin{array}{lllllllllll}0.8 & 66.584 & 66.458 & 66.332 & 66.205 & 66.079 & 65.952 & 65.826 & 65.6999 & 65.573 & 65.446 \\ 0.9 & 65.319 & 65.193 & 65.066 & 64.940 & 64.813 & 64.687 & 64.560 & 64.434 & 64.308 & 64.181\end{array}$

11.0
1.1
1.2
1.3
1.4
1.5
1.6
1.7
1.8
1.9 50.144 5564.054 63.928 $65.066 \quad 64.940$ $62.790-62.663$ $62.536 \quad 62.410$ 63.54 63.422

64.434 $63.042 \quad 62.916$ $60.260 \quad 60.133$ $\begin{array}{ll}58.995 & 56.869 \\ 57.730 & 57.604\end{array}$ $60.007 \quad 59.880$ $\begin{array}{ll}62.283 & 62.156 \\ 61.018 & 60.89\end{array}$ $56.465 \quad 56.339$ $\begin{array}{ll}58.742 & 58.615 \\ 57.477 & 57.351\end{array}$ $\begin{array}{ll}57.477 & 57.351 \\ 56.212 & 56.086\end{array}$ 58.48 59.627
58.36 62.030
60.765 $\begin{array}{ll}53.936 & 53.810 \\ 52.672 & 52.545\end{array}$

$\begin{array}{ll}54.948 & 54.821 \\ 53.084 & 53.557\end{array}$

$\begin{array}{ll}57.225 & 57.098 \\ 55.959 & 55.83\end{array}$

59.500

61.904
60.639
59.374

60.5

61.651

$\begin{array}{lll}58.109 & 57.983 & 57.856 \\ 56.845 & 56.718 & 56.5992\end{array}$

$\begin{array}{llllll}54.695 & 54.568 & 55.707 & 55.580 & 55.454 & 55.327 \\ & 54.442 & 54.315 & 54.189 & 54.062\end{array}$

$\begin{array}{lll}54.315 & 54.189 & 54.062 \\ 53.051 & 52.925 & 52.798\end{array}$

\subsection{5}

\subsection{8}

52.167

$\begin{array}{lll}47.489 & 47.363 & 47.236\end{array}$

46.352

48.627
47.36
46.0

47.236
45.972

50.902
49.638

50.775

53.178
51.913

$47.110 \quad 48.248$

$\begin{array}{ll}45.846 & 45.720 \\ 44.582 & 44.456\end{array}$

3.

$3 \cdot 2$

$3 \cdot 4$

3.6
3.7

3.9

281400

$4 \cdot 1$
$4 \cdot 2$
$4 \cdot 3$

$4 \cdot 3$
$4 \cdot 4$

4.5
4.6

4.8
4.9

2815.0

5.1
5.2

$5 \cdot 3$
$5 \cdot 4$

5.5

5.6
5.7

5.8

2816.

6.1

$6 \cdot 2$

6.4
6.5

6.6

6.7

6. 8

2817.

7.1
7.2
7.3

$7 \cdot 4$

7.7

7.9

2818.0

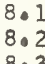

8.3

8.5

8.6

8.8

2819.

9.1

9.3

9.4

9.5

9.7

9.9
3558.770
37.507
36.244

36.244
34.980

33.717

31.192

29.929
28.667

$27 \cdot 404$
39.907

38.644
$37 \cdot 380$
$36 \cdot 117$

$36 \cdot 117$

$32 \cdot 591$

31.065

41.044

42.182
$4 \quad 40.918$

43.318

40

38.518

35.99
34.72

33.46
32.20

30.939

$38 \cdot 39$
37.128

35.865
34.602

33.338
32.076

30.813

35.73

3

$3.212 \quad 33.086$

$30.687 \quad 30.56$

$\begin{array}{ll}29.424 & 29.297 \\ 28.162 & 28.035\end{array}$

26.89

26.773

50.649
49.385

50.523

$\begin{array}{llll}49.385 & 49.259 & 49.132 & 49.006\end{array}$

$\begin{array}{llll}45.593 & 45.467 & 45.341 & 45.214\end{array}$

$\begin{array}{llll}44.329 & 44.203 & 44.077 & 43.950\end{array}$

$41.802 \quad 42.939 \quad 42.813 \quad 42.687$

$\begin{array}{llll}40.539 & 40.412 \quad 40.286 & 40.160\end{array}$

$\begin{array}{llll}39.276 & 39.150 & 39.023 & 38.896 \\ 38.012 & 37.886 & 37.760 & 37.633\end{array}$

$\begin{array}{ll}25.889 & 25.763\end{array}$

24.87924 .753

$23.617 \quad 23.491$

$21.092 \quad 20.966$

$\begin{array}{ll}19.830 & 19.70 \\ 18.568 & 18.442\end{array}$

$\begin{array}{ll}17.307 & 17 \cdot 1 \\ 16.045 & 15.919\end{array}$

23.36523 .238

24.375
23.112

24.5248
22.986

$\begin{array}{llll}20.840 & 20.714 & 20.588 & 21.724\end{array}$

16.045
14.783

35513.522

$12.260-13 \cdot 396$

$10.999 \quad 10.873$

$08.476 \quad 08.611$

$07.215 \quad 07.089$

$04.693 \quad 04.567$

$\begin{array}{ll}03.433 & 03.306 \\ 02.171 & 02.046\end{array}$

$18.316 \quad 19.452$

$\begin{array}{ll}19.326 & 19.199 \\ 18.064 & 17.938\end{array}$

$\begin{array}{ll}17.055 & 16.928 \\ 15.793 & 15.667\end{array}$

$16.802 \quad 16.676$

15.540
14.27

16.676

$13.270 \quad 13.143$

$\begin{array}{llllllll}3.270 & 13.143 & 13.017 & 12.891 & 12.765 & 12.639 & 12.513 & 12.386 \\ 2.008 & 11.882 & 11.755 & 11.629 & 11.503 & 11.377 & 11.251 & 11.125\end{array}$

36.623 .359

36.4

37.633

$\begin{array}{llll}34.223 & 34.096 & 33.970 & 33.844\end{array}$

$\begin{array}{llll}32.960 & 32.833 & 32.708 & 32.581\end{array}$

$\begin{array}{llll}30.434 & 30.308 & 30.182 & 30.056\end{array}$

$\begin{array}{llll}29.171 & 29.045 & 28.918 & 28.793 \\ 27.909 & 27.783 & 27.057 & 27.530\end{array}$

$\begin{array}{llll}26.646 & 26.521 & 26.394 & 26.268\end{array}$

$\begin{array}{llll}25.384 & 25.258 & 25.131 & 25.005 \\ 24.122 & 23.996 & 23.869 & 23.743\end{array}$

$\begin{array}{llll}22.860 & 22.733 & 22.607 & 22.481\end{array}$

$\begin{array}{llll}21.598 & 21.471 & 21.345 & 21.219 \\ 20.335 & 20.209 & 20.083 & 19.957\end{array}$

$\begin{array}{llll}19.073 & 18.947 & 18.820 & 18.694\end{array}$

$\begin{array}{llll}17.812 & 17.686 & 17.559 & 17.434\end{array}$

$\begin{array}{llll}16.550 & 16.424 & 16.297^{\circ} & 16.171 \\ 15.288 & 15.162 & 15.036 & 14.910\end{array}$

$\begin{array}{lllllll}10.621 & 10.494 & 10.368 & 10.242 & 10.116 & 09.990 & 09.864\end{array}$

08.224 .08 .359

09.23209 .107

08.98

$06.963 \quad 06.83$

06.71106 .585

$\begin{array}{llllllll}0.963 & 06.837 & 06.711 & 06.585 & 06.459 & 06.333 & 06.207 & 06.080 \\ 05.702 & 05.576 & 05.450 & 05.324 & 05.198 & 05.072 & 04.946 & 04.819\end{array}$

07.59

08.729

08.603 02.17

499.651
98.390

00.785

97.129

99.524
98.264

94.609

97.003

93.349

95.744

92.089
90.829

90.829
89.569

1.963

03.180
01.919

04.315
03.054

0

$\begin{array}{ll}00.659 & 00.533 \\ 99.398 & 99.272\end{array}$

$98.138 \quad 98.012$

$\begin{array}{rr}95.878 & 96.752 \\ 95.618 & 95.491\end{array}$

95.491
94.231
92.971

$\begin{array}{llll}02.676 & 02.550 & 02.424 & 02.298\end{array}$

$00.407 \quad 00.281 \quad 00.154 \quad 00.029 * 99.903 * 99.776$

$\begin{array}{llllll}99.146 & 99.020 & 98.894 & 98.768 & 98.642 & 98.516 \\ 97.886 & 97.759 & 97.634 & 97.507 & 97.381 & 97.255\end{array}$

$\begin{array}{llllll}96.626 & 96.500 & 96.374 & 96.248 & 96.122 & 95.996\end{array}$

$\begin{array}{llllll}95.366 & 95.240 & 95.113 & 94.987 & 94.861 & 94.735 \\ 94.105 & 93.979 & 93.853 & 93.727 & 93.601 & 93.475\end{array}$

$\begin{array}{llll}3.097 & 92.971 & 92.845 & 92.719\end{array}$

$\begin{array}{llll}93.853 & 93.727 & 93.601 & 93.475 \\ 92.593 & 92.467 & 92.341 & 92.215\end{array}$

$\begin{array}{llllll}91.585 & 91.459 & 91.333 & 91.207 & 91.081 & 90.95\end{array}$

$89.443 \quad 89.317 \quad 89.19$

89.32590 .199

$\begin{array}{llll}90.073 & 89.947 & 89.821 & 89.695 \\ 88.813 & 88.687 & 88.561 & 88.435\end{array}$

$\begin{array}{lll}8.073 & 88.057\end{array}$

$\begin{array}{ll}87.049 & 86.923 \\ 85.791 & 85.665\end{array}$

$\begin{array}{llll}84.531 & 84.405 & 85.539 & 85.412\end{array}$

$83.271 \quad 83.146 \quad 83.020 \quad 82.893$

$\begin{array}{llll}82.012 & 81.886 & 81.760 & 81.634\end{array}$

$\begin{array}{llll}80.753 & 80.627 & 80.500 & 80.375\end{array}$

$\begin{array}{llll}78.234 & 78.108 & 77.982 & 77.856\end{array}$

78

87.805

$\begin{array}{llllll}87.805 & 87.679 & 87.553 & 87.428 & 87.301 & 87.175\end{array}$

$\begin{array}{lllllll}85.286 & 85.160 & 85.035 & 84.909 & 84.783 & 84.657 \\ 84.027 & 83.901 & 83.775 & 83.649 & 83.523 & 83.397\end{array}$

$\begin{array}{llllll}82.768,82.642 & 82.516 & 82.390 & 82.264 & 82.138\end{array}$

$\begin{array}{lllllll}81.508 & 81.382 & 81.256 & 81.130 & 81.004 & 80.878\end{array}$

$\begin{array}{llll}76.975 & 76.850 & 76.724 & 76.598\end{array}$

$\begin{array}{llll}79.997 & 79.871 & 79.745 & 79.620\end{array}$

$35475.716 \quad 75.591$

$\begin{array}{ll}73.458 & 74.33 \\ 73.199 & 73.07\end{array}$

$\begin{array}{ll}72.948 & 72.822 \\ 71.689 & 71.563\end{array}$

$\begin{array}{llll}70.682 & 70.556 & 70.430 & 70.304\end{array}$

$\begin{array}{llll}69.423 & 69.297 & 69.171 & 69.045 \\ 68.166 & 68.039 & 67.913 & 67.788\end{array}$

$66.907 \quad 66.781 \quad 66.655 \quad 66.529$

$\begin{array}{ll}65.648 & 65.522 \\ 64.391 & 64.265\end{array}$

65.39

65.271
64.014

650.

6

$75.213 \quad 75.087$

$\begin{array}{llll}77.479 & 77.353 & 77.227 & 77.101\end{array}$

$\begin{array}{llll}76.220 & 76.094 & 75.968 & 75.84\end{array}$ 
$\begin{array}{llll}49.301 & 40.432 & 50.307 & 50.181\end{array}$ $\begin{array}{llll}48.044 & 47.918 & 47.792 & 47.667\end{array}$ $46.787 \quad 46.661 \quad 46.536 \quad 46.410$ $\begin{array}{llll}45.530 & 45.405 & 45.279 & 45.153 \\ 44.273 & 44.148 & 44.022 & 43.896\end{array}$ $\begin{array}{llll}43.017 & 42.892 & 42.766 & 42.640\end{array}$ $41.761 \quad 41.635 \quad 41.509 \quad 41.384$ $39.248 \quad 39.122$

$\begin{array}{llllll}48.798 & 49.929 & 49.803 & 49.678 & 49.552 & 49.426 \\ 47.672 & 48.546 & 48.421 & 48.295 & 48.169\end{array}$ $\begin{array}{lllllll}47.541 & 47.415 & 47.290 & 47.164 & 47.038 & 46.913\end{array}$ $\begin{array}{llllll}45.028 & 44.901 & 44.776 & 44.650 & 44.524 & 44.399\end{array}$ $\begin{array}{llllll}43.771 & 43.646 & 43.520 & 43.395 & 43.269 & 43.143\end{array}$ 
2830

0.1
0.2
0.3

0.2
0.3
0.4

0.5

0.6
0.7

0.8
0.9

2831.

1.

1.2

1. 4

1.6
1.7

1.8
1.9

2832$$
\begin{array}{r}
2.1 \\
2.2 \\
2.3
\end{array}
$$$$
2 \cdot 3
$$$$
2.5
$$$$
\begin{aligned}
& 2.6 \\
& 2.7
\end{aligned}
$$$$
\text { 2. } 8
$$$$
2833 .
$$$$
\begin{array}{r}
833.0 \\
3.1 \\
3.2 \\
3.3 \\
3.4
\end{array}
$$$$
\begin{aligned}
& 3.4 \\
& 3.5
\end{aligned}
$$$$
\begin{aligned}
& 3.5 \\
& 3.6
\end{aligned}
$$$$
\begin{aligned}
& 3.7 \\
& 3.8
\end{aligned}
$$$$
\begin{aligned}
& 3.8 \\
& 3.9
\end{aligned}
$$$$
2834.0
$$$$
4.1
$$$$
\begin{aligned}
& 4 \cdot 2 \\
& 4 \cdot 3
\end{aligned}
$$$$
\text { 4. } 4
$$$$
\text { 4. } 5
$$$$
\text { 4. } 7
$$$$
\begin{aligned}
& 4.8 \\
& 4.9
\end{aligned}
$$$$
2835.0
$$$$
\begin{aligned}
& 5.1 \\
& 5.2 \\
& 5.3
\end{aligned}
$$$$
5.3
$$$$
5.4
$$$$
\begin{aligned}
& 5 \cdot 6 \\
& 5.7
\end{aligned}
$$$$
\begin{aligned}
& 5.8 \\
& 5.9
\end{aligned}
$$$$
2836.0
$$$$
\begin{aligned}
& 6.1 \\
& 6.2 \\
& 6.3
\end{aligned}
$$$$
\begin{aligned}
& 6.4 \\
& 6.5
\end{aligned}
$$$$
\begin{aligned}
& 6.5 \\
& 6.6
\end{aligned}
$$$$
6.7
$$$$
\begin{aligned}
& 6.8 \\
& 6.5
\end{aligned}
$$$$
2837.0
$$

2838.

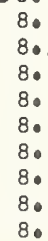

2839.

$$
\begin{array}{r}
2839.0 \\
9 . \\
9 . \\
9 . \\
90 \\
9 . \\
90 \\
9 . \\
9 . \\
9 .
\end{array}
$$

$\begin{array}{lllllll}25.297 & 25.172 & 25.047 & 24.922 & 24.798 & 24.673 & 24.54 \\ 24.049 & 23.924 & 23.799 & 23.675 & 23.550 & 23.424 & 23.300\end{array}$$$
21.553 \quad 21.428
$$$$
20.305
$$$$
19.057 \quad 18.932
$$$$
15.314 \quad 15.189
$$$$
21.303 \quad 21.178
$$$$
\begin{aligned}
& 22.302 \\
& 21.054
\end{aligned}
$$$$
22.17
$$$$
22.052
$$$$
\begin{array}{llll}
18.808 & 18.683 & 19.806 & 19.681 \\
18.558 & 18.433
\end{array}
$$$$
17.560 \quad 17.435
$$$$
\begin{array}{ll}
18.558 & 18.433 \\
17.310 & 17.186
\end{array}
$$$$
\begin{aligned}
& 19.556 \\
& 18.308
\end{aligned}
$$$$
17.061
$$$$
14.067 \quad 13.942
$$

$35312.819 \quad 12.695$

$\begin{array}{ll}11.572 & 11.448 \\ 10.325 & 10.200\end{array}$

$\begin{array}{ll}09.078 & 08.953 \\ 07.831 & 07.707\end{array}$

$\begin{array}{ll}07.831 & 07.707 \\ 06.584 & 06.459\end{array}$

$05.337 \quad 05.212$

$04.091 \quad 03.966$

02.844
01.597

$35300.351 \quad 00.226$ 35299.104

$97.858 \quad 97.733$

96.61296 .487

$95.366 \quad 95.241$

$\begin{array}{ll}9.120 & 93.996 \\ 92.874 & 92.750\end{array}$

$91.628 \quad 91.503$

$\begin{array}{ll}90.382 & 90.258 \\ 89.137 & 89.012\end{array}$

35287.891

86.646
85.400

$85.400 \quad 85.275$

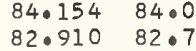

$81.665 \quad 81.541$

$\begin{array}{ll}80.420 & 80.295 \\ 79.175 & 79.050\end{array}$

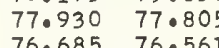

$\begin{array}{ll}15.065 & 14.940 \\ 13.817 & 13.692\end{array}$

16.06

$12.570 \quad 12.445$

$\begin{array}{lll}11.322 & 11.198 & 12.32 \\ 11.07\end{array}$

08.829

$\begin{array}{lll}07.582 & 07.457 & 07\end{array}$

$06.334 \quad 06.210 \quad 06.08$

$\begin{array}{ll}03.087 & 04.963 \\ 03.841 & 03.717\end{array}$

04.838
03.592

15.937

-813
.566
.318

$\begin{array}{lll}24.423 & 24.298 & 24.173 \\ 23.175 & 23.050 & 22.926\end{array}$

$21.927 \quad 21.802 \quad 21.678$

$20.679 \quad 20.554 \quad 20.430$

$\begin{array}{lll}19.431 & 19.307 & 19.182\end{array}$

$\begin{array}{lll}6.936 & 16.811 & 16.687\end{array}$

$\begin{array}{lll}15.688 & 15.563 & 15.439\end{array}$

$75.440 \quad 75.315$

74.195

$72.951 \quad 72.826$

$71.707 \quad 71.582$

$69.218 \quad 69.093$

$67.974 \quad 67.849$

$\begin{array}{ll}66.730 & 66.605 \\ 65.485 & 65.361\end{array}$

64.24264 .117

$35262.998 \quad 62.874$

$\begin{array}{ll}61.754 & 61.630 \\ 60.511 & 60.386\end{array}$

$59.267 \quad 59.143$

$56.780 \quad 56.656$

$55.537 \quad 55.412$

$53.050 \quad 52.926$

$51.807 \quad 51.683$

$49.322 \quad 50.440$

$48.079 \quad 47.955$

$\begin{array}{ll}46.836 & 46.712 \\ 45.593 & 45.469\end{array}$

$44.351 \quad 44 \cdot 227$

$\begin{array}{ll}43.108 & 42.984 \\ 41.866 & 41.742\end{array}$

$40.624 \quad 40.500$

5238.140

$36.140 \quad 38.016$

$\begin{array}{ll}36.898 & 36.773 \\ 35.656 & 35.531\end{array}$

$34.414 \quad 34.290$

$\begin{array}{ll}33.172 & 33.048 \\ 31.930 & 31.807\end{array}$

$\begin{array}{ll}31.930 & 31.807 \\ 30.689 & 30.565\end{array}$

$\begin{array}{ll}28.207 & 28.082 \\ 26.965 & 26.841\end{array}$

$* 99.977 * 99$
98.730

$\begin{array}{llll}9.609 & 97.484 & 97.359 & 97.235 \\ 6.363 & 96.238 & 96.113 & 95.989\end{array}$

$\begin{array}{llll}96.992 & 94.867 & 94.743\end{array}$

$\begin{array}{llll}.625 & 92.500 & 92.376 & 92.251\end{array}$

$\begin{array}{ll}91.254 \\ 0.133 & 90.009\end{array}$

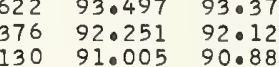

$\begin{array}{ll}8.884 & 89.760 \\ 8.639 & 88.514\end{array}$

87.268

89.63

89.635
88.389

86.396

.517
6.272
85.026

$8.906 \quad 83.781$

$\begin{array}{lll}82.536 & 82.412 & 82.532\end{array}$

$80.170 \quad 80.046$

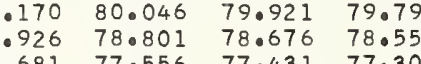

$\begin{array}{ll}76.481 & 77.55 \\ 76.31\end{array}$

$\begin{array}{ll}77.431 & 77.307 \\ 76.187 & 76.062\end{array}$

87.144

84.653

83.408

80.917

79.672
78.428

$77 \cdot 183$
$75 \cdot 937$

$75 \cdot 191$
73.946
72.702

75.066
73.822

74.942

74.817

7

$\begin{array}{llll}1.458 & 71.333 & 71.209 & 71.084 \\ 70.213 & 70.089 & 69.965 & 69.840\end{array}$

$\begin{array}{llll}68.969 & 68.844 & 68.720 & 68.596\end{array}$

$\begin{array}{llll}66.481 & 66.356 & 66.232 & 66.3507\end{array}$

65.112

$62.749 \quad 62.624$

$63.744 \quad 63.620$

73.448

$72 \cdot 205$
70.960

70.835

$\begin{array}{ll}68.471 & 68.347 \\ 67.228 & 67.103\end{array}$

68.347
67.103
$65 \cdot 859$

6.859

$64 \cdot 73$
63.495

$\begin{array}{ll}66.979 & 66.854 \\ 65.734 & 65.610\end{array}$

$\begin{array}{llllllll}505 & 61.381 & 61.257 & 61.132 & 61.251 & 62.127 & 62.002 & 61.878\end{array}$

$\begin{array}{llll}60.138 & 60.013 & 59.889\end{array}$

$61.008 \quad 60.884 \quad 60.759 \quad 60.635$

$\begin{array}{llll}57.775 & 57.650 & 57.526 & 57.402\end{array}$

$\begin{array}{llll}58.521 & 58.396 & 58.272\end{array}$

$\begin{array}{lllllll}57.407 & 56.283 & 56.158 & 56.034 & 57.153 & 57.029 & 56.904 \\ & 55.910 & 55.785 & 55.661\end{array}$

$\begin{array}{llll}55.164 & 55.040 & 54.915\end{array}$

$\begin{array}{llll}56.034 & 55.910 & 55.785 & 55.661 \\ 54.791 & 54.667 & 54.542 & 54.417\end{array}$

$\begin{array}{llll}54.791 & 54.667 & 54.542 & 54.417 \\ 53.548 & 53.423 & 53.299 & 53.17\end{array}$

$53.796 \quad 53.672$

$50.316 \quad 50.191$

$\begin{array}{lllllll}50.191 & 50.067 & 49.943 & 49.818 & 49.695 & 49.570 & 49.446 \\ 48.949 & 48.824 & 48.700 & 48.576 & 48.452 & 48.327 & 48.203\end{array}$

51.06

52.180

$52.056 \quad 51.931$

$\begin{array}{llllllll}7.831 & 47.706 & 47.582 & 47.457 & 47.333 & 47.209 & 47.084 & 46.960\end{array}$

$\begin{array}{llllllll}46.588 & 46.463 & 46.339 & 46.215 & 46.090 & 45.966 & 45.842 & 45.718\end{array}$

$\begin{array}{llllllll}45.345 & 45.221 & 45.097 & 44.972 & 44.848 & 44.724 & 44.599 & 44.475\end{array}$

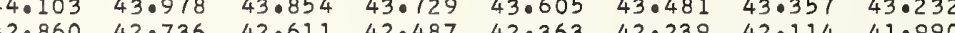

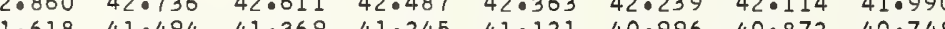

40.37540 .251

$37.891 \quad 37.767$

37.767

$\begin{array}{ll}3.649 & 36.525 \\ 5.407 & 35.283\end{array}$

$34.166 \quad 34.041$

$\begin{array}{ll}30.440 & 30.316 \\ 29.200 & 29.076\end{array}$

$\begin{array}{ll}27.958 & 27.83 \\ 26.717 & 26.59\end{array}$

24.48425 .600

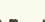

26.469

. 127

38.761

$\begin{array}{llll}41.121 & 40.996 & 40.872 & 40.7 .4\end{array}$

40.7 .48
39.506

$\begin{array}{lllllll}37.643 & 37.519 & 37.395 & 37.271 & 37.146 & 37.022\end{array}$

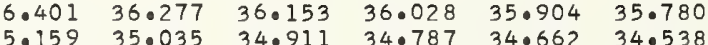

$\begin{array}{llllll} & 34.035 & 34.911 & 34.787 & 34.662 & 34.538 \\ 3.917 & 33.793 & 33.669 & 33.544 & 33.421 & 33.296\end{array}$

$\begin{array}{llllll}32.675 & 32.551 & 32.427 & 32.303 & 32.179 & 32.055\end{array}$

$\begin{array}{llllll}.434 & 31.310 & 31.185 & 31.062 & 30.937 & 30.813 \\ .192 & 30.068 & 29.944 & 29.820 & 29.695 & 29.572\end{array}$

$\begin{array}{llllll}9 & 28.827 & 28.703 & 28.579 & 28.455 & 28.331 \\ & 27.510 & \end{array}$

$\begin{array}{lll}28.579 & 28.455 & 28.331 \\ 27.337 & 27.213 & 27.089 \\ 26.097 & 25.972 & 25.848\end{array}$

$\begin{array}{lllllll}25.228 & 25.103 & 24.979 & 24.855 & 24.730 & 24.606\end{array}$

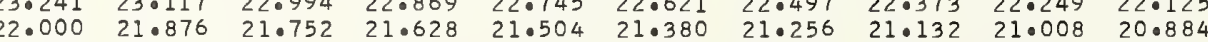

$\begin{array}{llllllllll}20.759 & 20.636 & 20.511 & 20.387 & 20.264 & 20.139 & 20.015 & 19.891 & 19.767 & 19.643\end{array}$

$\begin{array}{llllllllll}19.519 & 19.395 & 19.271 & 19.146 & 19.022 & 18.898 & 18.774 & 18.651 & 18.527 & 18.402\end{array}$

$\begin{array}{llllllllll}18.279 & 18.155 & 18.030 & 17.907 & 17.782 & 17.658 & 17.534 & 17.410 & 17.286 & 17.162 \\ 17.038 & 16.914 & 16.790 & 16.666 & 16.542 & 16.417 & 16.293 & 16.160 & 16.045 & 15.921\end{array}$

$\begin{array}{llllllllll}17.038 & 16.914 & 16.790 & 16.666 & 16.542 & 16.417 & 16.293 & 16.169 & 16.045 & 15.921 \\ 15.797 & 15.673 & 15.549 & 15.425 & 15.301 & 15.177 & 15.053 & 14.929 & 14.805 & 14.681\end{array}$

$\begin{array}{llllllllll}14.557 & 14.433 & 14.309 & 14.185 & 14.061 & 13.937 & 13.812 & 13.688 & 13.564 & 13.440\end{array}$

$\begin{array}{rlllllllll}35213.316 & 13.192 & 13.068 & 12.944 & 12.821 & 12.696 & 12.572 & 12.448 & 12.324 & 12 \cdot 200 \\ 12.076 & 11.952 & 11.828 & 11.705 & 11.580 & 11.456 & 11.332 & 11.208 & 11.084 & 10.960\end{array}$

$\begin{array}{llllllllll}10.836 & 10.712 & 10.588 & 10.464 & 10.340 & 10.216 & 10.092 & 09.968 & 09.844 & 09.720\end{array}$

$\begin{array}{llllllllll}09.596 & 09.472 & 09.348 & 09.224 & 09.100 & 08.976 & 08.852 & 08.728 & 08.604 & 08.480\end{array}$

$\begin{array}{llllllllll}0.355 & 08.232 & 08.108 & 07.984 & 07.860 & 07.736 & 07.612 & 07.489 & 07.365 & 07.241 \\ 07.316 & 06.992 & 06.868 & 06.744 & 06.621 & 06.497 & 06.373 & 06.249 & 06.125 & 06.000\end{array}$

$\begin{array}{llllllllll}07.116 & 06.992 & 06.868 & 06.744 & 06.621 & 06.497 & 06.373 & 06.249 & 06.125 & 06.000\end{array}$

$\begin{array}{llllllllll}05.877 & 05.753 & 05.628 & 05.504 & 05.380 & 05.256 & 05.133 & 05.009 & 04.885 & 04.761 \\ 04.637 & 04.513 & 04.389 & 04.265 & 04.141 & 04.017 & 03.893 & 03.769 & 03.645 & 03.521\end{array}$

$\begin{array}{llllllllll}03.397 & 03.273 & 03.149 & 03.025 & 02.901 & 02.777 & 02.653 & 02.529 & 02.406 & 02.282\end{array}$

$02.158 \quad 02.034 \quad 01.910 \quad 010$

01.662
01.53
01.414

$01.290 \quad 01.166 \quad 01.042$

0.294207

0.294205

0.294202

0.294200

0.294198

0.294195

0.294193

0.294192

0.294190

0.294188
0.294186

0.294185

0.294183
0.294181

0.294179

0.294178

0.294176
0.294174

0.294172

0.294171

0.294169

0.294167

.294164

0.294162

0.294159
0.294157

0.294155 
2840.0
0.1
0.2
0.3
0.4
0.5
0.6
0.7
0.8
0.9

$\begin{array}{rrr}0.1 & 35199.679 \\ 0.2 & 98.439 & 99.0 \\ 0.3 & 97.200\end{array}$

$\begin{array}{lllll}0.1 & 98.439 & 98.315 & 99.431 & 99.307 \\ 0.3 & 97.200 & 97.076 & 96.953 & 98.068\end{array}$ $95.961-95.037$ $95.961 \quad 95.837$ 94.72 3.483 93.35 $89.767 \quad 89.643 \quad 80.758 \quad 90.63$

2841

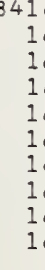

0.294035 0.294031

0.294029

0.294026

0.294024

0.294023

0.294019

0.294018

0.294016
0.294014

0.294012

0.294011
0.294009

0.294006

0.294004

0.294000

0.293999

0.293997

0.293994

0.293992

0.293988

0.293987
0.293985

0.293983

0.293982
0.293980

0.293978

0.293976
0.293975

0.293973

0.293971
0.293970

0.293968

0.293966

0.293965

0.293963

0.293961
0.293959

0.293958

0.293956

0.293954
0.293953
0.293951

0.293951

0.293949

0.293946

0.293942

0.293939

0.293937

0.293936
0.293934

0.293932

0.293930

0.293927

0.293924

0.293922

0.293920

0.293917

0.293915

0.293913

0.293910

0.293908

0.293907

0.293903

0.293900

0.293898

0.293896

0.293895
0.293893

0.293891

0.293890

0.293888
0.293886

0.293886
0.293885

0.293883

0.293881

0.293880

0.293876

0.293874
0.293873

0.293871 .

0.293869

0.293868
0.293866

.010

.124

0.835328
0.835353

0.835377

0.835426

0.835475

0.835525

0.835549

0.835574
0.835598

0.835623

0.835672 
$\begin{array}{lllllllll}74.828 & 74.935 & 75.812 & 75.689 & 75.566 & 75.443 & 75.320 & 75.197 & 75.074\end{array}$

$\begin{array}{lllllllllll}.2 & 74.951 & 74.828 & 74.705 & 74.582 & 74.458 & 74.336 & 74.213 & 74.089 & 73.966 & 73.843 \\ .3 & 73.720 & 73.597 & 73.474 & 73.351 & 73.228 & 73.105 & 72.982 & 72.859 & 72.736 & 72.613 \\ .4 & 72.490 & 72.367 & 72.244 & 72.121 & 71.998 & 71.875 & 71.751 & 71.629 & 71.505 & 71.382\end{array}$

$\begin{array}{lll}72.490 & 72.367 & 72 \\ 0.5 & 71.259 & 71.136\end{array}$

7 $\begin{array}{ll}70.029 & 69.906 \\ 68.799 & 68.676\end{array}$

$72.244 \quad 72 \cdot 121$

$\begin{array}{ll}68.799 & 68.676 \\ 67.568 & 67.446\end{array}$

64.002

$$
\begin{array}{ll}
052.815 & 52.692 \\
51.586 & 51.463 \\
50.357 & 50.234 \\
49.128 & 49.005 \\
47.899 & 47.777 \\
46.671 & 46.548 \\
45.442 & 45.320 \\
44.214 & 44.091 \\
42.985 & 42.863 \\
41.757 & 41.635
\end{array}
$$
$\begin{array}{lll}03.601 & 03.479 & 03.355\end{array}$ $\begin{array}{lllll}0.273 & 0.375 & 02.253 & 03.131\end{array}$ $00.047 * 99.925 * 99.802 * 99.080 *$
$34998.822 * 98.700$
98.577

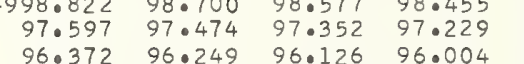
$\begin{array}{llll}96.372 & 96.249 & 96.126 & 96.004 \\ 95.146 & 950.024 & 94.002 & 94.779 \\ 93.0921 & 93.799 & 93.067 & 93.554\end{array}$ $\begin{array}{lllll}93.921 & 93.799 & 93.677 & 93.554 \\ 92.696 & 92.574 & 92.052 & 92.329\end{array}$

34991.473 91.47391 .350

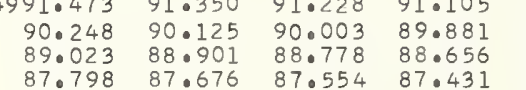
$86.574 \quad 86.652 \quad 87.554 \quad 87.431$ $\begin{array}{llll}86.574 & 86.452 & 86.329 & 86.207 \\ 85.350 & 85.228 & 85.105 & 84.982\end{array}$ $\begin{array}{llll}84.125 & 84.003 & 83.880 & 83.758\end{array}$ $\begin{array}{llll}82.901 & 82.779 & 82.657 & 82.534 \\ 81.677 & 81.555 & 81.433 & 81.310 \\ 80.454 & 80.332 & 80.208 & 80.086\end{array}$

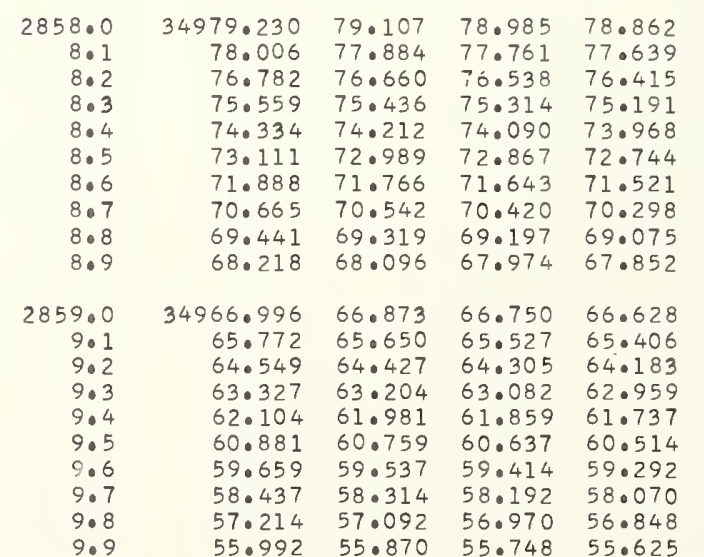

$\begin{array}{llllll}63.388 & 63.264 & 63.142 & 63.019 & 62.896 & 62.772 \\ 62.158 & 62.035 & 61.912 & 61.789 & 61.666 & 61.543\end{array}$ $\begin{array}{llll}60.682 & 60.559 & 60.436 & 60.313 \\ 59.452 & 59.330 & 59.207 & 59.083\end{array}$ $\begin{array}{llll}59.452 & 59.330 & 59.207 & 59.083\end{array}$ $\begin{array}{lllllll}58.469 & 58.346 & 58.223 & 58.100 & 57.977 & 57.854 \\ 57.240 & 57.117 & 56.994 & 56.871 & 56.748 & 56.625 \\ 56.011 & 55.888 & 55.765 & 55.642 & 55.519 & 55.396 \\ 54.781 & 54.659 & 54.536 & 54.413 & 54.290 & 54.167\end{array}$ $\begin{array}{llllll}57.240 & 57.117 & 56.994 & 56.871 & 56.748 & 56.625 \\ 56.011 & 55.888 & 55.765 & 55.642 & 55.519 & 55.396 \\ 54.781 & 54.659 & 54.536 & 54.413 & 54.290 & 54.167\end{array}$ $\begin{array}{llllll}54.781 & 54.659 & 54.536 & 54.413 & 54.290 & 54.167 \\ 53.552 & 53.429 & 53.306 & 53.184 & 53.061 & 52.938\end{array}$ $\begin{array}{llllll}52.323 & 52.200 & 52.077 & 51.955 & 51.832 & 51.708\end{array}$ $\begin{array}{llllll}51.094 & 50.971 & 50.849 & 50.726 & 50.603 & 50.480 \\ 49.865 & 49.743 & 49.620 & 49.497 & 49.374 & 49.251\end{array}$ $\begin{array}{llllll}48.636 & 48.514 & 48.391 & 48.268 & 48.145 & 48.022\end{array}$ $\begin{array}{llllll}47.408 & 47.285 & 47.162 & 47.040 & 46.917 & 46.793 \\ 46.179 & 46.056 & 45.933 & 45.812 & 45.688 & 45.565\end{array}$ $\begin{array}{llllll}44.951 & 44.828 & 44.9306 & 45.812 & 45.688 & 45.565 \\ 43.583 & 44.459 & 44.337\end{array}$

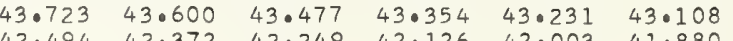
$\begin{array}{llllll}42.494 & 42.372 & 42.249 & 42.126 & 42.003 & 41.880 \\ 41.266 & 41.143 & 41.021 & 40.898 & 40.775 & 40.652\end{array}$ $\begin{array}{llllll}40.038 & 39.915 & 39.792 & 39.669 & 39.547 & 39.424 \\ 38.810 & 38.587 & 38.564 & 38.441 & 38.318 & 38.196\end{array}$ $\begin{array}{lllllll}38.810 & 38.687 & 38.564 & 38.441 & 38.318 & 38.196 \\ 37.582 & 37.459 & 37.336 & 37.213 & 37.090 & 36.968\end{array}$ $\begin{array}{lllllll}36.354 & 36.231 & 36.108 & 35.985 & 35.863 & 35.740\end{array}$ $\begin{array}{llllll}35.126 & 35.003 & 34.880 & 34.758 & 34.635 & 34.512\end{array}$ $\begin{array}{llllll}32.671 & 32.548 & 32.425 & 32.302 & 32.180 & 32.057\end{array}$ $\begin{array}{llllll}31.443 & 31.321 & 31.198 & 31.075 & 30.952 & 30.830\end{array}$ $\begin{array}{llllll}28.989 & 28.866 & 28.743 & 28.620 & 28.497 & 28.375\end{array}$ $\begin{array}{llllll}27.761 & 27.638 & 27.516 & 27.393 & 27.270 & 27.147\end{array}$ $\begin{array}{llllll}26.534 & 26.411 & 26.289 & 26.166 & 26.042 & 25.920 \\ 25.307 & 25.184 & 25.062 & 24.938 & 24.815 & 24.693\end{array}$ $\begin{array}{llllll}25.307 & 25.184 & 25.062 & 24.938 & 24.815 & 24.693 \\ 24.080 & 23.958 & 23.834 & 23.712 & 23.589 & 23.466\end{array}$ $\begin{array}{llllll}22.853 & 22.730 & 22.607 & 22.485 & 22.362 & 22.239\end{array}$ $\begin{array}{llllll}21.626 & 21.503 & 21.380 & 21.258 & 21.135 & 21.013 \\ 20.399 & 20.276 & 20.154 & 20.031 & 19.908 & 19.786\end{array}$ $\begin{array}{llllll}19.172 & 19.050 & 18.927 & 18.804 & 18.682 & 18.559\end{array}$ $\begin{array}{llllll}17.945 & 17.823 & 17.700 & 17.578 & 17.455 & 17.333 \\ 16.720 & 16.597 & 16.474 & 16.352 & 16.229 & 16.106\end{array}$ $\begin{array}{llllll}15.493 & 15.370 & 15.247 & 15.125 & 15.002 & 14.879\end{array}$ $\begin{array}{llllll}13.041 & 12.918 & 12.795 & 12.673 & 12.550 & 12.428\end{array}$ $\begin{array}{llllll}11.814 & 11.692 & 11.569 & 11.446 & 11.324 & 11.201 \\ 10.588 & 10.466 & 10.343 & 10.221 & 10.098 & 09.975\end{array}$ $\begin{array}{lllllll}09.362 & 09.239 & 09.117 & 08.995 & 08.872 & 08.749\end{array}$ $\begin{array}{lllllll}08.136 & 08.013 & 07.891 & 07.769 & 07.646 & 07.523\end{array}$ $\begin{array}{llllll}06.910 & 06.788 & 06.665 & 06.542 & 06.420 & 06.297 \\ 05.684 & 05.562 & 05.439 & 05.316 & 05.194 & 05.072\end{array}$ $\begin{array}{llllll}04.459 & 04.336 & 04.213 & 04.091 & 03.969 & 03.846\end{array}$ $\begin{array}{lllllll}03.233 & 03.110 & 02.988 & 02.866 & 02.743 & 02.620\end{array}$ $\begin{array}{llllll}0.783 & 00.660 & 00.538 & 00.415 & 00.292 & 00.170\end{array}$

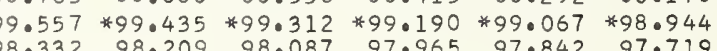
$\begin{array}{llllll}.332 & 98.209 & 98.087 & 97.965 & 97.842 & 97.719 \\ 96.08 & 96.862 & 96.739 & 96.617 & 96.494\end{array}$

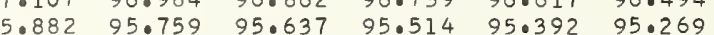
$94.657 \quad 94.534 \quad 94.412 \quad 94.289 \quad 94.167 \quad 94.044$ $\begin{array}{llllll}93.432 & 93.310 & 93.187 & 93.064 & 92.942 & 92.819 \\ 92.207 & 92.084 & 91.962 & 91.840 & 91.717 & 91.595\end{array}$ $\begin{array}{lllllll}90.982 & 90.860 & 90.737 & 90.615 & 90.493 & 90.370\end{array}$ $\begin{array}{llllll}89.758 & 89.635 & 89.513 & 89.391 & 89.268 & 89.146 \\ 88.533 & 88.411 & 88.288 & 88.166 & 88.043 & 87.921\end{array}$ $\begin{array}{llllll}87.309 & 87.187 & 88.288 & 88.166 & 88.043 & 87.921 \\ & 87.064 & 86.941 & 86.819 & 86.696\end{array}$ $\begin{array}{lllllll}86.084 & 85.962 & 85.839 & 85.717 & 85.595 & 85.472\end{array}$ $\begin{array}{llllll}84.860 & 84.738 & 84.615 & 84.493 & 84.370 & 84.248\end{array}$ \begin{tabular}{llllll}
8.436 & 83.513 & 83.391 & 83.269 & 83.146 & 83.024 \\
\hline
\end{tabular} $\begin{array}{lllllll}1.187 & 81.065 & 80.943 & 80.820 & 80.698 & 80.576\end{array}$ $\begin{array}{lllllll}78.740 & 78.618 & 78.495 & 78.373 & 78.250 & 78.128\end{array}$ $\begin{array}{lllllll}77.516 & 77.394 & 77.271 & 77.149 & 77.027 & 76.905\end{array}$ $\begin{array}{llllll}77.292 & 76.170 & 76.048 & 75.925 & 75.803 & 75.681 \\ 75.068 & 74.046 & 74.824 & 74.702 & 74.580 & 74.457\end{array}$ $\begin{array}{llllll}73.845 & 73.723 & 73.601 & 73.479 & 73.356 & 73.233\end{array}$ $\begin{array}{llllll}72.622 & 72.500 & 72.377 & 72.255 & 72.132 & 72.010\end{array}$ $\begin{array}{llllll}71.398 & 71.276 & 71.154 & 71.031 & 70.909 & 70.787\end{array}$ $\begin{array}{llllll}70.175 & 70.053 & 69.930 & 69.808 & 69.687 & 69.564 \\ 68.952 & 68.830 & 68.708 & 68.585 & 68.463 & 68.341\end{array}$ $\begin{array}{llllll}67.729 & 67.607 & 67.485 & 67.363 & 67.240 & 67.118\end{array}$ $\begin{array}{llllll}66.506 & 66.384 & 66.262 & 66.140 & 66.017 & 65.895\end{array}$ $\begin{array}{llllll}65.283 & 65.161 & 65.039 & 64.917 & 64.794 & 64.672 \\ 64.060 & 63.938 & 63.816 & 63.693 & 63.571 & 63.449\end{array}$ $\begin{array}{llllll}62.837 & 62.715 & 62.593 & 62.471 & 62.349 & 62.226\end{array}$ $\begin{array}{llllll}61.615 & 61.493 & 61.370 & 61.248 & 61.126 & 61.003\end{array}$ $\begin{array}{llllll}60.392 & 60.270 & 60.147 & 60.025 & 59.903 & 59.781\end{array}$ $\begin{array}{llllll}59.169 & 59.047 & 58.925 & 58.803 & 58.681 & 58.559 \\ 57.948 & 57.826 & 57.703 & 57.581 & 57.458 & 57.336\end{array}$

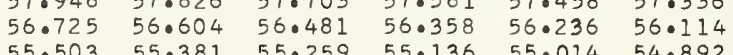
.005

0.293864 0.293863 0.293859 0.293858 0.293854 0.293852 0.293851 0.293849

0.293847 0.293846 0.293844
0.293842 0.293841 0.293839 0.293837 0.293836 0.293834
0.293832

0.293830 0.293829 0.293825 0.293824 0.293822 0.293820 0.293819 0.293817
0.293815

0.293814 0.293812 0.293810 0.293807 0.293805 0.293803 0.293802 0.293800 0.293798

0.293797 0.293795 0.293792 0.293790 0.293788 0.293788
0.293787 0.293785 0.293783 0.293782

0.293780 0.293778 0.293777 0.293775
0.293773 0.293772 0.293770 0.293768 0.293766
0.293765

0.293763 0.293761 0.293758 0.293758
0.293756 0.293756 0.293753 0.293751
0.293750 0.293748

0.293746 0.293745 0.293743

0.293740

0.293738

0.293736

0.293735
0.293733 0.293731

0.293730 0.293728 0.293726 0.293723 0.293721 0.293720 0.293718 0.293716
0.293714

0.293713 0.293711 0.293708 0.293706 0.293704 
$\begin{array}{rrrrrrrrrrr}2860.0 & 34954.770 & 54.647 & 54.525 & 54.403 & 54.281 & 54 \cdot 159 & 54.037 & 53.915 & 53.792 & 53.669\end{array}$

$\begin{array}{llllllllllll}0.1 & 53.547 & 53.425 & 53.303 & 53.181 & 53.059 & 52.937 & 52.814 & 52.692 & 52.570 & 52.448\end{array}$

$\begin{array}{lllllllllll}0.2 & 52.325 & 52.203 & 52.081 & 51.959 & 51.836 & 51.715 & 51.592 & 51.470 & 51.348 & 51.226 \\ 0.3 & 51.104 & 50.981 & 50.859 & 50.737 & 50.615 & 50.493 & 50.371 & 50.248 & 50.126 & 50.003\end{array}$

$\begin{array}{lllllllllll}0.4 & 49.881 & 49.759 & 49.637 & 49.515 & 49.393 & 49.271 & 49.148 & 49.027 & 48.904 & 48.782 \\ 0.5 & 48.660 & 48.538 & 48.416 & 48.293 & 48.171 & 48.049 & 47.927 & 47.805 & 47.683 & 47.561\end{array}$

$\begin{array}{lllllllllll}0.5 & 48.660 & 48.538 & 48.416 & 48.293 & 48.171 & 48.049 & 47.927 & 47.805 & 47.683 & 47.561 \\ 0.6 & 47.439 & 47.316 & 47.194 & 47.072 & 46.950 & 46.828 & 46.706 & 46.583 & 46.461 & 46.339\end{array}$

$\begin{array}{llllllllllll}0.7 & 46.217 & 46.095 & 45.973 & 45.851 & 45.728 & 45.606 & 45.484 & 45.362 & 45.240 & 45.118\end{array}$

$\begin{array}{lllllllllll}0.8 & 44.996 & 44.873 & 44.751 & 44.629 & 44.507 & 44.385 & 44.262 & 44.140 & 44.018 & 43.896 \\ 0.9 & 43.774 & 43.652 & 43.530 & 43.408 & 43.286 & 43.163 & 43.041 & 42.919 & 42.797 & 42.675\end{array}$

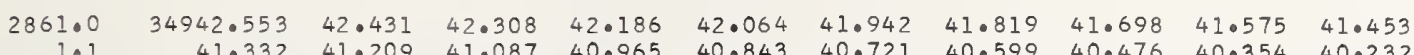

$\begin{array}{lllllllllll}1.1 & 41.332 & 41.209 & 41.087 & 40.965 & 40.843 & 40.721 & 40.599 & 40.476 & 40.354 & 40.232 \\ 1.2 & 40.110 & 39.988 & 39.866 & 39.744 & 39.622 & 39.500 & 39.377 & 39.255 & 39.133 & 39.011\end{array}$

$\begin{array}{lllllllllll}1.2 & 40.110 & 39.988 & 39.866 & 39.744 & 39.622 & 39.500 & 39.377 & 39.255 & 39.133 & 39.011 \\ 1.3 & 38.889 & 38.767 & 38.645 & 38.522 & 38.400 & 38.279 & 38.156 & 38.034 & 37.912 & 37.790\end{array}$

$\begin{array}{lllllllllll}1.4 & 37.667 & 37.546 & 37.424 & 37.302 & 37.180 & 37.058 & 36.936 & 36.814 & 36.692 & 36.570\end{array}$

$\begin{array}{lllllllllll}1.5 & 36.448 & 36.325 & 36.203 & 36.081 & 35.959 & 35.837 & 35.715 & 35.593 & 35.471 & 35.349 \\ 1.6 & 35.227 & 35.104 & 34.982 & 34.860 & 34.738 & 34.616 & 34.494 & 34.372 & 34.250 & 34.128\end{array}$

$\begin{array}{lllllllllll}1.7 & 34.006 & 33.884 & 33.762 & 33.640 & 33.517 & 33.396 & 33.273 & 33.151 & 33.029 & 32.907 \\ 1.8 & 32.785 & 32.663 & 32.541 & 32.419 & 32.296 & 32.175 & 32.053 & 31.931 & 31.809 & 31.687\end{array}$

$\begin{array}{lllllllllll}1.8 & 32.785 & 32.663 & 32.541 & 32.419 & 32.296 & 32.175 & 32.053 & 31.931 & 31.809 & 31.687 \\ 1.9 & 31.564 & 31.443 & 31.320 & 31.198 & 31.076 & 30.954 & 30.832 & 30.710 & 30.588 & 30.466\end{array}$

2862.0

$\begin{array}{rr}62.0 & 3493 \\ 2.1 & 2 \\ 2.2 & 27 \\ 2.3 & 2 \\ 2.4 & 2 \\ 2.5 & 2 \\ 2.6 & 2 \\ 2.7 & 2 \\ 2.8 & 2 \\ 2.9 & 190\end{array}$

31.56431 .443

$30.100 \quad 29.978$

$\begin{array}{llll}29.124 & 29.001 & 28.879 & 28.757 \\ 27.903 & 27.781 & 27.659 & 27.537\end{array}$

$\begin{array}{llll}26.683 & 26.561 & 26.439 & 26.317\end{array}$

25.341

$\begin{array}{ll}26.439 & 26.31 \\ 25.219 & 25.097\end{array}$

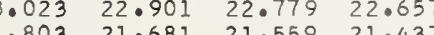

$\begin{array}{llll}0.583 & 20.461 & 20.339 & 20.217\end{array}$

2863.0

63.0
3.
3.
3
3.
3
3
3
3
3
3
3

$\begin{array}{ll}3.0 & 3491 \\ 3.1 & 1 \\ 3.2 & 1 \\ 3.3 & 1 \\ 3.4 & 1 \\ 3.5 & 120 \\ 3.6 & 100 \\ 3.7 & \\ 3.8 & \\ 3.9 & \end{array}$

$18.144 \quad 18.022$

2864.0

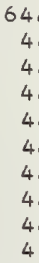

$16.924 \quad 18.022 \quad 17.900$

$15.705 \quad 15.583$

$\begin{array}{lll}15.364 & 15.461 & 15.339\end{array}$

$\begin{array}{llll}.267 & 13.145 & 13.023 & 12.901\end{array}$

$\begin{array}{llll}12.047 & 11.925 & 11.803 & 11.681 \\ 10.828 & 10.706 & 10.584 & 10.462\end{array}$

$\begin{array}{llll}0.609 & 09.487 & 09.365 & 09.243\end{array}$

$\begin{array}{llll}08.390 & 08.268 & 08.146 & 08.024 \\ 07.171 & 07.049 & 06.927 & 06.805\end{array}$

$29.855 \quad 29.733$

30.832

$\begin{array}{lllll}27.293 & 27.171 & 27.049 & 26.927 & 26.805\end{array}$

$\begin{array}{llllll}24.975 & 26.073 & 25.951 & 25.829 & 25.707 & 25.585 \\ & 24.853 & 24.731 & 24.609 & 24.487 & 24.365\end{array}$

$\begin{array}{llllll}23.755 & 23.633 & 23.511 & 23.389 & 23.267 & 23.145\end{array}$

$\begin{array}{llllll}22.535 & 22.413 & 22.292 & 22.169 & 22.047 & 21.925\end{array}$

$\begin{array}{llllll}21.315 & 21.193 & 21.071 & 20.949 & 20.827 & 20.706 \\ 20.095 & 19.974 & 19.852 & 19.729 & 19.608 & 19.486\end{array}$

0.293696

.293694

0.293691

.293689

0.293686

0.293683
0.293681

0.293679

0.293678
0.293676

0.293674
0.293673

.293669

0.293668

0.293666
0.293664

0.293663

0.293661
0.293659

0.293658

0.293656

0.293653

0.293651
0.293649

0.293648

0.293646

0.293644
0.293643

0.293641
0.293639

0.293638

0.293636

0.293634
0.293633

0.293631

0.839971

0.840020

0.840045

80094

0.840118

0.840168

0.840192

0.840217

0.840241

0.840290

0.840340

0.840364

0.840413

0.840463

0.840487

0.840536

0.840561

0.840610

0.840635

0.840684

0.840709

0.840733
0.840758

0.840782

0.840807

0.840856

0.840881

0.840930

0.293629

0.293628

0.840955

$\begin{array}{llllllllll}04.733 & 05.831 & 05.708 & 05.586 & 05.465 & 05.343 & 05.221 & 05.100 & 04.978 & 04.855 \\ 04.611 & 04.490 & 04.368 & 04.247 & 04.125 & 04.003 & 03.881 & 03.759 & 03.638\end{array}$

$\begin{array}{llllllllll}0.52 .516 & 03.394 & 03.272 & 03.150 & 03.028 & 02.906 & 02.784 & 02.662 & 02.541 & 02.419 \\ 02.297 & 02.175 & 02.053 & 01.0332 & 01.809 & 01.687 & 0.565 & 01.444 & 01.322 & 01.200\end{array}$

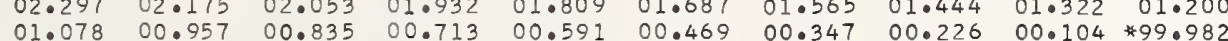

$\begin{array}{llll}34899.076 & 00.957 & 00.835 & 00.713\end{array}$

$\begin{array}{rrrr}99.860 & 99.738 & 99.616 & 99.495 \\ 98.642 & 98.520 & 98.398 & 98.276\end{array}$

$97.423 \quad 97.302 \quad 97.180 \quad 97.058$

$96.205 \quad 96.083$

$\begin{array}{llllll}99.373 & 99.250 & 00.347 & 00.226 & 00.104 & * 99.982 \\ 90.129 & 99.007 & 98.885 & 98.763\end{array}$

$\begin{array}{llllll}98.154 & 98.032 & 97.911 & 97.789 & 97.667 & 97.545 \\ 96.936 & 96.814 & 96.692 & 96.570 & 96.449 & 96.327\end{array}$

$2865.0 \quad 34893.770 \quad 93.647 \quad 93.525 \quad 93.404$

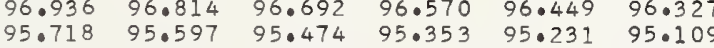

0.293624

0.293623

0.293621

0.293619

0.293616

0.840979

0.841028

0.841053

0.841102

0.841127

0.293613

$\begin{array}{lllllllllll}5.1 & 92.552 & 92.430 & 92.308 & 92.187 & 92.064 & 91.943 & 91.821 & 91.699 & 91.578 & 91.456 \\ 5.2 & 91.334 & 91.212 & 91.090 & 90.969 & 90.847 & 90.725 & 90.604 & 90.481 & 90.360 & 90.238 \\ 5.3 & 90.116 & 89.994 & 89.873 & 89.751 & 89.629 & 89.507 & 89.386 & 89.264 & 89.143 & 89.021 \\ 5.4 & 88.899 & 88.777 & 88.655 & 88.533 & 88.412 & 88.290 & 88.168 & 88.046 & 87.925 & 87.803 \\ 5.5 & 87.682 & 87.560 & 87.437 & 87.315 & 87.194 & 87.072 & 86.951 & 86.829 & 86.707 & 86.585 \\ 5.6 & 86.464 & 86.342 & 86.220 & 86.099 & 85.977 & 85.855 & 85.733 & 85.611 & 85.490 & 85.368 \\ 5.7 & 85.247 & 85.125 & 85.003 & 84.881 & 84.759 & 84.638 & 84.516 & 84.394 & 84.272 & 84.151 \\ 5.8 & 84.029 & 83.907 & 83.786 & 83.664 & 83.542 & 83.420 & 83.298 & 83.177 & 83.055 & 82.934 \\ 5.9 & 82.812 & 82.690 & 82.568 & 82.447 & 82.326 & 82.204 & 82.082 & 81.960 & 81.838 & 81.717\end{array}$

0.293611

0.293608

0.293606

0.293603

0.293601

0.293599

0.841201

0.841250

0.841274

0.841299

0.841348

0.841373

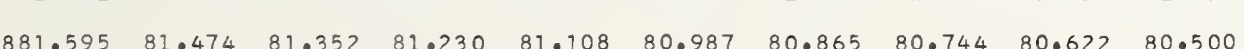

$\begin{array}{rrrrrrrrrrr}2866.0 & 34881.595 & 81.474 & 81.352 & 81.230 & 81.108 & 80.987 & 80.865 & 80.744 & 80.622 & 80.500 \\ 6.1 & 80.378 & 80.256 & 80.135 & 80.013 & 79.892 & 79.770 & 79.648 & 79.526 & 79.405 & 79.283\end{array}$

$\begin{array}{lllllllllll}6.1 & 80.378 & 80.256 & 80.135 & 80.013 & 79.892 & 79.770 & 79.648 & 79.526 & 79.405 & 79.283 \\ 6.2 & 79.161 & 79.040 & 78.918 & 78.796 & 78.674 & 78.553 & 78.431 & 78.310 & 78.187 & 78.066\end{array}$

$\begin{array}{llllllllllll}6.3 & 77.944 & 77.822 & 77.701 & 77.579 & 77.458 & 77.336 & 77.214 & 77.093 & 76.971 & 76.849 \\ 6.4 & 76.727 & 76.606 & 76.484 & 76.362 & 76.241 & 76.119 & 75.998 & 75.876 & 75.754 & 75.633\end{array}$

$\begin{array}{llllllllllll}6.4 & 76.727 & 76.606 & 76.484 & 76.362 & 76.241 & 76.119 & 75.998 & 75.876 & 75.754 & 75.633 \\ 6.5 & 75.511 & 75.389 & 75.268 & 75.146 & 75.024 & 74.902 & 74.781 & 74.659 & 74.538 & 74.416\end{array}$

$\begin{array}{llllllllllll}6.6 & 74.294 & 74.172 & 74.051 & 73.929 & 73.808 & 73.686 & 73.564 & 73.443 & 73.321 & 73.200\end{array}$

$\begin{array}{lllllllllll}6.7 & 73.078 & 72.956 & 72.834 & 72.713 & 72.591 & 72.470 & 72.348 & 72.226 & 72.104 & 71.983\end{array}$

$\begin{array}{lllllllllll}6.8 & 71.861 & 71.739 & 71.618 & 71.497 & 71.375 & 71.253 & 71.132 & 71.010 & 70.889 & 70.767 \\ 6.9 & 70.646 & 70.524 & 70.402 & 70.280 & 70.159 & 70.038 & 69.916 & 69.794 & 69.672 & 69.551\end{array}$

$\begin{array}{lllllllllll}2867.0 & 34869.429 & 69.308 & 69.186 & 69.064 & 68.943 & 68.821 & 68.699 & 68.578 & 68.456 & 68.334\end{array}$

$\begin{array}{llllllllllll}7.1 & 68.213 & 68.091 & 67.970 & 67.848 & 67.727 & 67.605 & 67.483 & 67.361 & 67.240 & 67.119\end{array}$

$\begin{array}{lllllllllll}7.2 & 66.997 & 66.875 & 66.754 & 66.632 & 66.510 & 66.389 & 66.268 & 66.146 & 66.024 & 65.902 \\ 7.3 & 65.781 & 65.659 & 65.538 & 65.416 & 65.294 & 65.173 & 65.051 & 64.929 & 64.808 & 64.0887\end{array}$

$\begin{array}{lllllllllll}7.3 & 65.786 & 65.659 & 65.538 & 65.416 & 65.294 & 65.173 & 65.051 & 64.929 & 64.808 & 64.687 \\ 7.4 & 64.564 & 64.443 & 64.322 & 64.200 & 64.079 & 63.957 & 63.835 & 63.714 & 63.592 & 63.470\end{array}$

$\begin{array}{lllllllllll}7.5 & 63.349 & 63.228 & 63.106 & 62.984 & 62.863 & 62.741 & 62.620 & 62.498 & 62.376 & 62.254\end{array}$

$\begin{array}{lllllllllll}7.6 & 62.133 & 62.012 & 61.890 & 61.769 & 61.647 & 61.525 & 61.404 & 61.282 & 61.161 & 61.039 \\ 7.7 & 60.917 & 60.796 & 60.674 & 60.553 & 60.432 & 60.311 & 60.189 & 60.067 & 59.945 & 59.824\end{array}$

$\begin{array}{lllllllllll}7.7 & 60.917 & 60.796 & 60.674 & 60.553 & 60.432 & 60.311 & 60.189 & 60.067 & 59.945 & 59.824 \\ 7.8 & 59.703 & 59.581 & 59.459 & 59.337 & 59.216 & 59.095 & 58.973 & 58.852 & 58.730 & 58.608\end{array}$

$\begin{array}{lllllllllll}7.9 & 58.487 & 58.366 & 58.244 & 58.122 & 58.001 & 57.879 & 57.757 & 57.636 & 57.515 & 57.393\end{array}$

0.293596

0.293595

293593

0.293590

0.293588

0.293586

0.293583

0.293581

0.293580

0.293578

0.293576
0.293575

0.293575
0.293573

0.293571

0.293570

0.293568
0.293566

0.293565

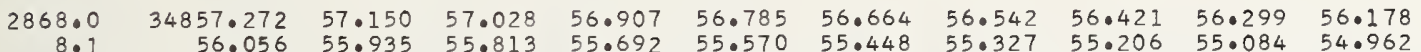

$\begin{array}{lllllllllll}8.1 & 56.056 & 55.935 & 55.813 & 55.692 & 55.570 & 55.448 & 55.327 & 55.206 & 55.084 & 54.962 \\ 8.2 & 54.841 & 54.719 & 54.598 & 54.477 & 54.354 & 54.233 & 54.112 & 53.990 & 53.869 & 53.748\end{array}$

$\begin{array}{lllllllllll}8.3 & 53.626 & 53.504 & 53.383 & 53.261 & 53.140 & 53.018 & 52.896 & 52.775 & 52.654 & 52.532\end{array}$

$\begin{array}{lllllllllll}8.4 & 52.411 & 52.290 & 52.168 & 52.046 & 51.925 & 51.803 & 51.682 & 51.560 & 51.438 & 51.317\end{array}$

$\begin{array}{lllllllllll}8.5 & 51.196 & 51.074 & 50.953 & 50.831 & 50.710 & 50.588 & 50.466 & 50.345 & 50.224 & 50.102 \\ 8.6 & 49.981 & 49.859 & 49.738 & 49.617 & 49.495 & 49.374 & 49.252 & 49.131 & 49.009 & 48.888\end{array}$

$\begin{array}{lllllllllll}8.7 & 48.766 & 48.645 & 48.523 & 48.402 & 48.280 & 48.159 & 48.038 & 47.916 & 47.794 & 47.673\end{array}$

$\begin{array}{lllllllllll}8.8 & 47.552 & 47.430 & 47.309 & 47.187 & 47.065 & 46.944 & 46.823 & 46.701 & 46.580 & 46.458 \\ 8.9 & 46.337 & 46.215 & 46.094 & 45.973 & 45.851 & 45.729 & 45.608 & 45.487 & 45.365 & 45.244\end{array}$

0.293563

0.293561

0.293560

0.293558

0.293556

0.293553

0.293551

0.293548

$\begin{array}{lllllllllll}2869.0 & 34845.123 & 45.001 & 44.879 & 44.758 & 44.637 & 44.515 & 44.394 & 44.272 & 44 \cdot 151 & 44.029\end{array}$

$\begin{array}{lllllllllll}9.1 & 43.908 & 43.787 & 43.665 & 43.543 & 43.422 & 43.301 & 43.179 & 43.058 & 42.937 & 42.815 \\ 9.2 & 42.694 & 42.572 & 42.451 & 42.329 & 42.208 & 42.086 & 41.965 & 41.843 & 41.722 & 41.601\end{array}$

$\begin{array}{llllllllll}42.694 & 42.572 & 42.451 & 42.329 & 42.208 & 42.086 & 41.965 & 41.843 & 41.722 & 41.601 \\ 41.479 & 41.358 & 41.237 & 41.115 & 40.993 & 40.872 & 40.750 & 40.629 & 40.508 & 40.386\end{array}$

$\begin{array}{llllllllll}41.479 & 41.358 & 41.237 & 41.115 & 40.993 & 40.872 & 40.750 & 40.629 & 40.508 & 40.386 \\ 40.265 & 40.144 & 40.022 & 39.900 & 39.779 & 39.658 & 39.536 & 39.415 & 39.293 & 39.172\end{array}$

$\begin{array}{llllllllll}39.051 & 38.930 & 38.808 & 38.687 & 38.566 & 38.444 & 38.323 & 38.202 & 38.080 & 37.958\end{array}$

$\begin{array}{lllllllllll}37.837 & 37.716 & 37.594 & 37.473 & 37.352 & 37.230 & 37.109 & 36.988 & 36.866 & 36.745\end{array}$

0.293546

0.293545

0.293543

0.293542

0.293538

0.293537
0.293535

0.293535

0.293533
0.293532

0.841447

0.841471

0.841496
0.841520

0.841545

.841570

0.841619

0.841643
0.841668

0.841693

0.841717

0.841766

0.841791

0.841840

0.841865

0.841890

0.841963

0.841988
0.842013

0.842037

0.842062

0.842086

0.842136
0.842160

0.842185

0.842234

0.842259

0.842308

0.842333
0.842357

0.842382

$\begin{array}{llllllllll}35.409 & 35.288 & 35.167 & 35.045 & 34.924 & 34.803 & 34.681 & 34.560 & 34.438 & 34.317 \\ 34.195 & 34.074 & 33.953 & 33.831 & 33.710 & 33.589 & 33.467 & 33.346 & 33.225 & 33.103\end{array}$

0.842406

$\begin{array}{lllllllllll} & .001 & .002 & .003 & .004 & .005 & .006 & .007 & .008 & .009 & .010 \\ .123 & .012 & .025 & .037 & .049 & .061 & .074 & .086 & .098 & .110 & .123 \\ .0122 & .012 & .024 & .036 & .049 & .061 & .073 & .085 & .097 & .109 & .122\end{array}$


$\begin{array}{lll}32.860 & 32.739 & 32.618\end{array}$ $\begin{array}{llll}31.768 & 31.646 & 31.525 & 310 \\ 30.554 & 30.433 & 30.312 & 30 \\ 29.341 & 29.219 & 29.099 & 28\end{array}$

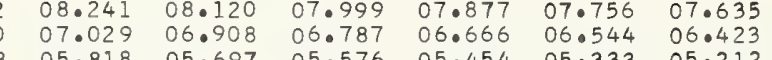
$\begin{array}{lllllllllll}9.2 & 21.684 & 21.563 & 21.443 & 21.322 & 21.202 & 21.081 & 20.960 & 20.840 & 20.719 & 20.599 \\ 9.3 & 20.478 & 20.357 & 20.237 & 20.116 & 19.996 & 19.875 & 19.754 & 19.634 & 19.514 & 19.393\end{array}$

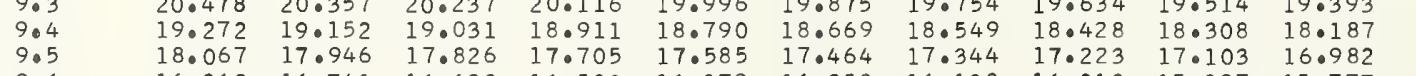

$\begin{array}{llllll}20.365 & 20.243 & 20.122 & 20.000 & 19.879 & 19.758\end{array}$

$\begin{array}{llllll}19.152 & 19.030 & 18.910 & 18.788 & 18.667 & 18.545 \\ 17.939 & 17.818 & 17.697 & 17.575 & 17.454 & 17.333\end{array}$

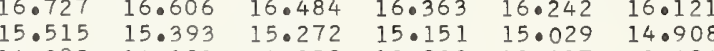

$\begin{array}{llllll}13.089 & 12.968 & 14.059 & 13.938 & 13.817 & 13.696 \\ 12.847 & 12.726 & 12.604 & 12.484\end{array}$

$\begin{array}{llllll}10.665 & 11.756 & 11.635 & 11.514 & 11.392 & 11.271 \\ 0.0 .5423 & 10.301 & 10.181 & 10.059\end{array}$

$\begin{array}{llllll}04.606 & 04.485 & 04.364 & 04.243 & 04.122 & 04.000\end{array}$

$\begin{array}{llllll}02.183 & 02.062 & 03.152 & 03.031 & 02.910 & 02.789 \\ 0.940 & 01.819 & 01.698 & 01.577\end{array}$ *99.9710 $00.850 \quad 00.729 \quad 00.608 \quad 00.487 \quad 00.366$ $\begin{array}{llllll}98.548 & 98.427 & 98.306 & 98 \cdot 185 & 98 \cdot 064 & 97.943 \\ 97.337 & 97.216 & 97.095 & 96.974 & 96.853 & 96.732\end{array}$

$\begin{array}{llllll}96.126 & 96.005 & 95.884 & 95.763 & 95.642 & 95.521 \\ 94.915 & 94.794 & 94.674 & 94.552 & 94.431 & 94.310\end{array}$

$\begin{array}{llllll}93.705 & 93.584 & 93.462 & 93.341 & 93.220 & 93.099\end{array}$

$\begin{array}{llllll}92.494 & 92.373 & 92.251 & 92.130 & 92.009 & 91.888\end{array}$

$\begin{array}{lllllll}90.072 & 89.951 & 89.830 & 89.709 & 89.588 & 89.466 \\ 88.861 & 88.740 & 88.620 & 88.499 & 88.377 & 88.256\end{array}$

$\begin{array}{llllll}87.651 & 87.530 & 87.409 & 87.288 & 87.167 & 87.046 \\ 86.440 & 86.319 & 86.198 & 86.077 & 85.957 & 85.835\end{array}$

$\begin{array}{lllllll}85.230 & 85.109 & 84.988 & 84.867 & 84.746 & 84.625\end{array}$

$\begin{array}{llllll}84.020 & 83.899 & 83.778 & 83.657 & 83.536 & 83.415 \\ 82.810 & 82.688 & 82.568 & 82.447 & 82.326 & 82.205\end{array}$ $\begin{array}{lllllll}81.600 & 81.479 & 81.357 & 81.236 & 81.115 & 80.995 \\ 80.390 & 80.269 & 80.147 & 80.026 & 79.906 & 79.785\end{array}$ $\begin{array}{llllll}79.180 & 79.059 & 78.937 & 78.817 & 78.696 & 78.575\end{array}$ $\begin{array}{llllll}77.970 & 77.849 & 77.728 & 77.007 & 77.486 & 77.365 \\ 76.760 & 76.639 & 76.518 & 76.397 & 76.276 & 76.155\end{array}$ $\begin{array}{llllll}75.550 & 75.430 & 75.309 & 75.187 & 75.066 & 74.945\end{array}$ $\begin{array}{llllll}74.340 & 74.220 & 74.099 & 73.978 & 73.856 & 73.736 \\ 73.131 & 73.010 & 72.890 & 72.769 & 72.548 & 72.527\end{array}$ $\begin{array}{llllll}71.922 & 71.801 & 71.680 & 71.559 & 71.438 & 71.317 \\ 70.712 & 70.591 & 70.471 & 70.350 & 70.229 & 70.108\end{array}$ $\begin{array}{llllll}69.503 & 69.382 & 69.261 & 69.141 & 69.020 & 68.899\end{array}$ $\begin{array}{llllll}68.294 & 68.173 & 68.052 & 67.931 & 67.811 & 67.689\end{array}$ $\begin{array}{lllllll}65.876 & 65.755 & 65.634 & 65.513 & 65.392 & 65.271\end{array}$ $\begin{array}{llllll}64.667 & 64.546 & 64.425 & 64 \cdot 304 & 64.183 & 64.062 \\ 63.458 & 63.337 & 63.216 & 63.095 & 62.974 & 62.854\end{array}$ $\begin{array}{llllll}62.249 & 62.128 & 62.007 & 61.887 & 61.767 & 61.646 \\ 61.041 & 60.920 & 60.799 & 60.679 & 60.558 & 60.437\end{array}$ $\begin{array}{lllllll}59.833 & 59.711 & 59.590 & 59.470 & 59.349 & 59.228\end{array}$ $\begin{array}{llllll}57.415 & 57.294 & 57.382 & 58.261 & 58.140 & 58.020 \\ 56.207 & 56.086 & 55.965 & 55.053 & 56.932 & 56.811 \\ & 55.844 & 55.724 & 55.003\end{array}$ $\begin{array}{llllll}56.207 & 56.086 & 55.965 & 55.844 & 55.724 & 55.603 \\ 54.999 & 54.878 & 54.757 & 54.636 & 54.516 & 54.395 \\ 53.791 & 53.659 & 53.548 & 53.428 & 53.307 & 53.186\end{array}$ $\begin{array}{llllll}53.591 & 53.669 & 53.548 & 53.428 & 53.307 & 53.186 \\ 52.582 & 52.461 & 52.341 & 52.220 & 52.099 & 51.979\end{array}$ $\begin{array}{llllll}51.374 & 51.253 & 51.133 & 51.012 & 50.891 & 50.771\end{array}$ $\begin{array}{llllll}50.167 & 50.046 & 49.925 & 49.804 & 49.684 & 49.562 \\ 48.959 & 48.838 & 48.717 & 48.597 & 48.476 & 48.354\end{array}$

$\begin{array}{llllll}47.751 & 47.630 & 47.509 & 47.389 & 47.268 & 47.147\end{array}$

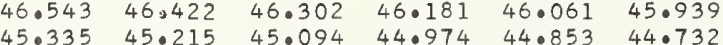
$\begin{array}{llllll}44.128 & 44.007 & 43.887 & 43.766 & 43.646 & 43.524 \\ 42.921 & 42.800 & 42.679 & 42.559 & 42.438 & 42.317\end{array}$ $41.713 \quad 41.592 \quad 41.472 \quad 41.351 \quad 41.230 \quad 41.110$ $\begin{array}{llllll}39.299 & 39.179 & 40.265 & 40.144 & 40.023 & 39.958 \\ 39.058 & 38.937 & 38.816 & 38.696\end{array}$ $\begin{array}{llllll}38.092 & 37.972 & 37.851 & 37.730 & 37.609 & 37.489 \\ 36.885 & 36.765 & 36.644 & 36.523 & 36.402 & 36.281\end{array}$

$\begin{array}{llllll}35.678 & 35.558 & 35.437 & 35.316 & 35.195 & 35.075\end{array}$ $\begin{array}{llllll}33.265 & 33.144 & 33.023 & 32.902 & 32.781 & 32.661\end{array}$ $\begin{array}{llllll}30.852 & 30.730 & 30.610 & 30.489 & 30.368 & 30.248\end{array}$ $\begin{array}{llllll}29.645 & 29.524 & 29.403 & 29.283 & 29.162 & 29.041 \\ 28.438 & 28.318 & 28.197 & 28.077 & 27.956 & 27.835 \\ 27.232 & 27.112 & 26.991 & 26.870 & 26.750 & 25.029\end{array}$ $\begin{array}{llllll}27.232 & 27.112 & 26.991 & 26.870 & 26.750 & 26.629\end{array}$ $\begin{array}{llllll}24.820 & 24.699 & 24.578 & 24.458 & 24.337 & 24.217\end{array}$ $\begin{array}{llllll}23.614 & 23.493 & 23.372 & 23.252 & 23.131 & 23.010\end{array}$ $22.40822 .287222 .167 \quad 22.046210 .725 \quad 21.805$

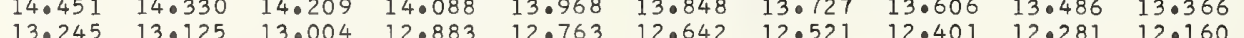

\begin{tabular}{|c|c|c|c|c|c|c|c|c|c|}
\hline .001 & .002 & .003 & .004 & .005 & .006 & .007 & .008 & .009 & .010 \\
\hline $\begin{array}{l}122 \\
.121\end{array}$ & $\begin{array}{l}.024 \\
.024\end{array}$ & $\begin{array}{l}.036 \\
.036\end{array}$ & $\begin{array}{l}.049 \\
.048\end{array}$ & $\begin{array}{l}.061 \\
.060\end{array}$ & $\begin{array}{l}.073 \\
0072\end{array}$ & $\begin{array}{r}.085 \\
.084\end{array}$ & $\begin{array}{l}.097 \\
.096\end{array}$ & $\begin{array}{l}109 \\
.109\end{array}$ & $\begin{array}{l}122 \\
: 121\end{array}$ \\
\hline
\end{tabular}

0.293513

0.293512

0.293509

0.293507

0.293504

0.293502

0.293499

0.293497

0.293495

0.293490

.293489

0.293485

0.293484

0.293481

0.293477

0.293476

0.293474

0.293469

0.293466

0.293464

0.293462

0.293461
0.293459

0.293459

0.293456

0.293454

0.293451

0.293449

0.293448

0.293446

0.293441

0.293439

0.293438

0.293435

0.293431

0.293430

0.293428
0.293426

0.293425

0.293423

0.293421

0.293420

0.293418
0.293417

$\begin{array}{ll}0.293530 & 0.842431 \\ 0.293528 & 0.842456 \\ 0.293527 & 0.842480 \\ 0.293525 & 0.842505 \\ 0.293523 & 0.842529 \\ 0.293522 & 0.842554 \\ 0.293520 & 0.842579 \\ 0.293518 & 0.842603 \\ 0.293517 & 0.842628 \\ 0.293515 & 0.842653\end{array}$

0.842677

0.842702

0.842726
0.842751

0.842776

0.842800

0.842825

0.842849
0.842874

0.842899

0.842923 0.842948
0.842973 0.842997 0.843022 0.843046 0.843071
0.843096 0.843120 0.843145

0.843170 0.843194 0.843243 0.843268 0.843293 0.843317 0.843342 0.843367

0.843416 0.843440 0.843465 0.843465
0.843514 0.843490
0.843534 0.843564 0.843588 0.843613
0.843637 0.843662 0.843687 0.843711 0.843736 0.843785 0.843810 0.843834
0.843859 0.843859
0.843884

0.843908 
$\begin{array}{lllllllllll}2880.0 & 34712.040 & 11.919 & 11.798 & 11.678 & 11.558 & 11.437 & 11.316 & 11.196 & 11.076 & 10.955\end{array}$

$\begin{array}{lllllllllll}0.1 & 10.834 & 10.714 & 10.593 & 10.473 & 10.352 & 10.231 & 10.111 & 09.991 & 09.870 & 09.750 \\ 0.2 & 09.629 & 09.509 & 09.389 & 09.268 & 09.147 & 09.027 & 08.906 & 08.786 & 08.665 & 08.545\end{array}$

$\begin{array}{llllllllllll}0.3 & 08.424 & 08.304 & 08.184 & 08.062 & 07.942 & 07.822 & 07.701 & 07.581 & 07.4600 & 07.340\end{array}$

$\begin{array}{lllllllllll}0.4 & 07.219 & 07.099 & 06.979 & 06.858 & 06.738 & 06.617 & 06.497 & 06.376 & 06.256 & 06.135\end{array}$

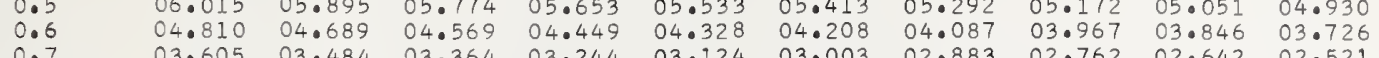

$\begin{array}{llllllllllll}0.7 & 03.605 & 03.484 & 03.364 & 03.244 & 03.124 & 03.003 & 02.883 & 02.762 & 02.642 & 02.521 \\ 0.8 & 02.400 & 02.280 & 02.160 & 02.039 & 01.918 & 01.798 & 01.678 & 01.557 & 0.0437 & 01.317\end{array}$

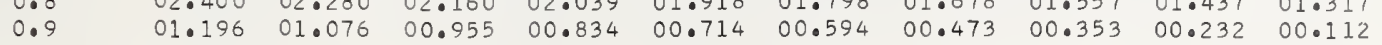

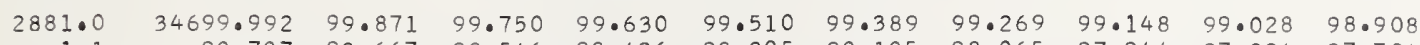

$\begin{array}{lllllllllll}1.1 & 98.787 & 98.667 & 98.546 & 98.426 & 98.305 & 98.185 & 98.065 & 97.944 & 97.824 & 97.704 \\ 1.2 & 97.583 & 97.462 & 97.342 & 97.222 & 97.101 & 96.981 & 96.860 & 96.740 & 96.619 & 96.499\end{array}$

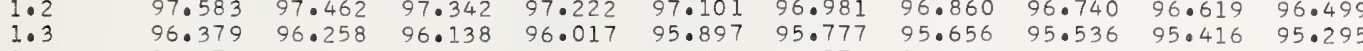

$\begin{array}{lllllllllll}1.4 & 95.175 & 95.055 & 94.934 & 94.813 & 94.693 & 94.573 & 94.452 & 94.332 & 94.211 & 94.091 \\ 1.5 & 93.971 & 93.851 & 93.730 & 93.609 & 93.489 & 93.369 & 93.248 & 93.128 & 93.007 & 92.887\end{array}$

$\begin{array}{lllllllllll}1.6 & 92.767 & 92.646 & 92.526 & 92.406 & 92.286 & 92.165 & 92.045 & 91.924 & 91.804 & 91.684\end{array}$

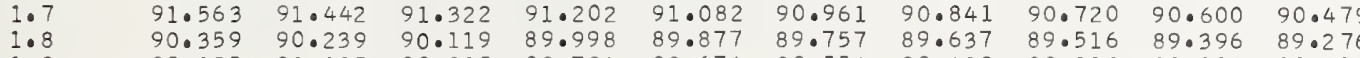

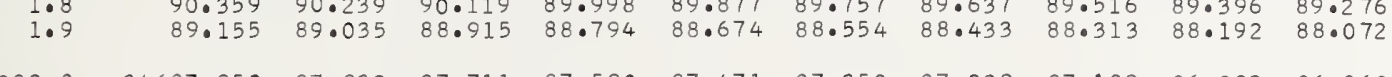

$\begin{array}{llllllllllll}2882.0 & 34687.952 & 87.832 & 87.711 & 87.590 & 87.471 & 87.350 & 87.229 & 87.109 & 86.989 & 86.868\end{array}$

$\begin{array}{lllllllllll}2.1 & 86.748 & 86.628 & 86.507 & 86.387 & 86.267 & 86.146 & 86.026 & 85.906 & 85.786 & 85.665 \\ 2.2 & 85.544 & 85.424 & 85.304 & 85.184 & 85.063 & 84.943 & 84.823 & 84.703 & 84.583 & 84.462\end{array}$

$\begin{array}{lllllllllll}2.3 & 84.342 & 84.222 & 84.102 & 83.980 & 83.860 & 83.740 & 83.620 & 83.500 & 83.379 & 83.259 \\ 2.4 & 83.139 & 83.019 & 82.898 & 82.778 & 82.657 & 82.537 & 82.417 & 82.296 & 82.176 & 82.056\end{array}$

$\begin{array}{lllllllllll}2.5 & 81.936 & 81.815 & 81.695 & 81.574 & 81.454 & 81.333 & 81.213 & 81.093 & 820.973 & 80.853 \\ 2.6 & 80.732 & 80.612 & 80.492 & 80.372 & 80.251 & 80.130 & 80.010 & 79.890 & 79.770 & 79.649\end{array}$

$\begin{array}{lllllllllll}2.7 & 79.529 & 79.409 & 79.289 & 79.168 & 79.048 & 78.928 & 78.807 & 78.687 & 78.566 & 78.446\end{array}$

$\begin{array}{lllllllllll}2.8 & 78.326 & 78.206 & 78.086 & 77.965 & 77.845 & 77.725 & 77.604 & 77.484 & 77.364 & 77.244 \\ 2.9 & 77.123 & 77.003 & 76.883 & 76.762 & 76.643 & 76.522 & 76.401 & 76.281 & 76.161 & 76.041\end{array}$

$\begin{array}{rrrrrrrrrrr}2883.0 & 34675.920 & 75.800 & 75.680 & 75.560 & 75.439 & 75.319 & 75.198 & 75.079 & 74.958 & 74.838 \\ 3.1 & 74.718 & 74.598 & 74.477 & 74.357 & 74.237 & 74.116 & 73.997 & 73.875 & 73.956 & 73.636\end{array}$

$\begin{array}{lllllllllll}3.1 & 74.718 & 74.598 & 74.477 & 74.357 & 74.237 & 74.116 & 73.997 & 73.875 & 73.756 & 73.636 \\ 3.2 & 73.516 & 73.395 & 73.275 & 73.155 & 73.034 & 72.915 & 72.794 & 72.674 & 72.553 & 72.434\end{array}$

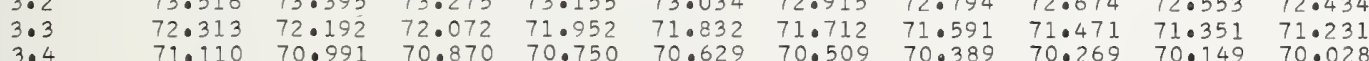

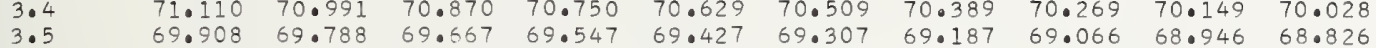

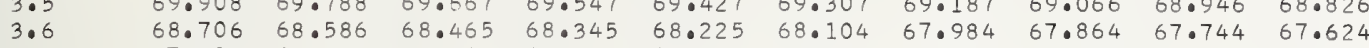

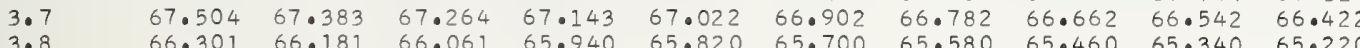

$\begin{array}{lllllllllll}3.8 & 66.301 & 66.181 & 66.061 & 65.940 & 65.820 & 65.700 & 65.580 & 65.460 & 65 \cdot 340 & 65.220 \\ 3.9 & 65.099 & 64.979 & 64.859 & 64.739 & 64.619 & 64.498 & 64.378 & 64.258 & 64.138 & 64.018\end{array}$

$\begin{array}{lllllllllll}2884.0 & 34663.897 & 63.777 & 63.657 & 63.537 & 63.417 & 63.296 & 63.176 & 63.056 & 62.936 & 62.816\end{array}$ $\begin{array}{lllllllllll}4.1 & 62.696 & 62.576 & 62.456 & 62.335 & 62.215 & 62.095 & 61.975 & 61.855 & 61.735 & 61.614 \\ 4.2 & 61.494 & 61.374 & 61.254 & 61.134 & 61.014 & 60.894 & 60.773 & 60.653 & 60.533 & 60.413\end{array}$

$\begin{array}{lllllllllll}4.2 & 61.494 & 61.374 & 61.254 & 61.134 & 61.014 & 60.894 & 60.773 & 60.653 & 60.533 & 60.413 \\ 4.3 & 60.292 & 60.172 & 60.052 & 59.932 & 59.812 & 59.692 & 59.572 & 59.451 & 59.332 & 59.211\end{array}$

$\begin{array}{lllllllllll}4.4 & 59.090 & 58.971 & 58.851 & 58.730 & 58.010 & 58.490 & 58.370 & 58.250 & 58.130 & 58.009 \\ 4.5 & 57.889 & 57.769 & 57.649 & 57.529 & 57.409 & 57.289 & 57.168 & 57.048 & 56.928 & 56.808\end{array}$

$\begin{array}{lllllllllll}4.5 & 57.889 & 57.769 & 57.649 & 57.529 & 57.409 & 57.289 & 57.168 & 57.048 & 56.928 & 56.808 \\ 4.6 & 56.687 & 56.567 & 56.447 & 56.328 & 56.207 & 56.087 & 55.967 & 55.847 & 55.727 & 55.607\end{array}$

$\begin{array}{lllllllllll}4.7 & 55.487 & 55.366 & 55.246 & 55.126 & 55.006 & 54.886 & 54.766 & 54.646 & 54.525 & 54.405\end{array}$

$\begin{array}{lllllllllll}4.8 & 54.285 & 54.165 & 54.045 & 53.925 & 53.804 & 53.685 & 53.564 & 53.444 & 53.324 & 53.204 \\ 4.9 & 53.084 & 52.964 & 52.843 & 52.723 & 52.604 & 52.483 & 52.363 & 52.243 & 52.123 & 52.003\end{array}$

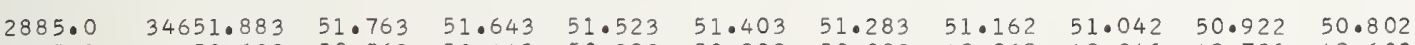

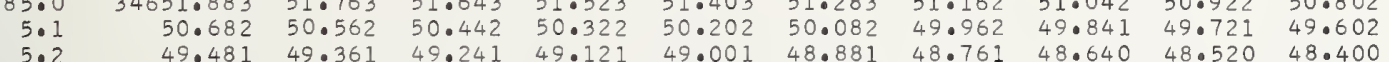

$\begin{array}{lllllllllll}5.2 & 49.481 & 49.361 & 49.241 & 49.121 & 49.001 & 48.881 & 48.761 & 48.640 & 48.520 & 48.400 \\ 5.3 & 48.280 & 48.160 & 48.040 & 47.920 & 47.800 & 47.680 & 47.560 & 47.439 & 47.320 & 47.199\end{array}$

$\begin{array}{lllllllllll}5.4 & 47.079 & 46.959 & 46.839 & 46.719 & 46.599 & 46.479 & 46.359 & 46.239 & 46.119 & 45.999 \\ 5.5 & 45.879 & 45.759 & 55.639 & 45.519 & 45.398 & 45.278 & 45.558 & 45.039 & 44.918 & 44.798\end{array}$

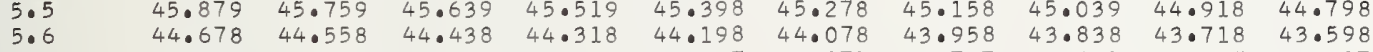

$\begin{array}{lllllllllll}5.7 & 43.478 & 43.357 & 43.237 & 43.117 & 42.997 & 42.877 & 42.757 & 42.637 & 42.517 & 42.397\end{array}$

$\begin{array}{lllllllllll}5.8 & 42.277 & 42.157 & 42.037 & 41.917 & 41.797 & 41.677 & 41.557 & 41.437 & 41.317 & 41.196 \\ 5.9 & 41.076 & 40.957 & 40.836 & 40.717 & 40.597 & 40.477 & 40.357 & 40.237 & 40.117 & 39.997\end{array}$

$\begin{array}{lllllllllll}2886.0 & 34639.877 & 39.757 & 39.637 & 39.517 & 39.396 & 39.276 & 39.156 & 39.037 & 38.917 & 38.796\end{array}$

$\begin{array}{lllllllllll}6.1 & 38.677 & 38.557 & 38.437 & 38.317 & 38.196 & 38.076 & 37.957 & 37.836 & 37.716 & 37.597\end{array}$

$\begin{array}{lllllllllll}6.2 & 37.477 & 37.356 & 37.237 & 37.117 & 36.997 & 36.876 & 36.756 & 36.636 & 36.516 & 36.396 \\ 6.3 & 36.276 & 36.156 & 36.037 & 35.917 & 35.796 & 35.676 & 35.556 & 35.436 & 35.316 & 35.196\end{array}$

$\begin{array}{lllllllllll}6.4 & 35.076 & 34.957 & 34.836 & 34.716 & 34.597 & 34.477 & 34.356 & 34.236 & 34.116 & 33.997\end{array}$

$\begin{array}{lllllllllll}6.5 & 33.876 & 33.757 & 33.637 & 33.517 & 33.397 & 33.277 & 33.156 & 33.037 & 32.917 & 32.796 \\ 6.6 & 32.677 & 32.557 & 32.437 & 32.317 & 32.197 & 32.077 & 31.957 & 31.837 & 31.717 & 31.597\end{array}$

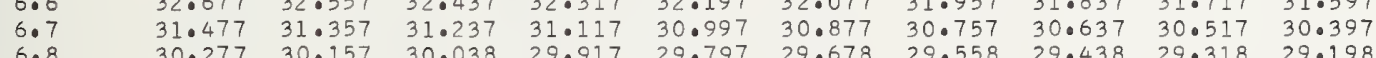

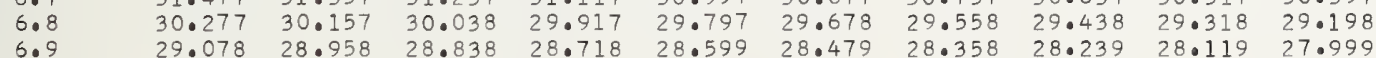

$\begin{array}{lllllllllll}2887.0 & 34627.879 & 27.759 & 27.639 & 27.519 & 27.399 & 27.279 & 27.159 & 27.039 & 26.919 & 26.799\end{array}$

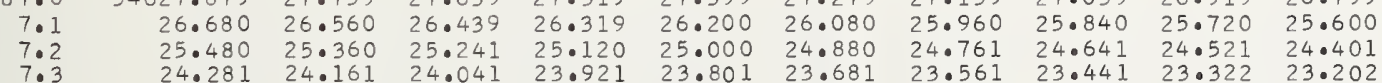

$\begin{array}{lllllllllll}7.3 & 24.281 & 24.161 & 24.041 & 23.921 & 23.801 & 23.681 & 23.561 & 23.441 & 23.322 & 23.202 \\ 7.4 & 23.082 & 22.962 & 22.842 & 22.722 & 22.602 & 22.482 & 22.362 & 22.243 & 22.123 & 22.002\end{array}$

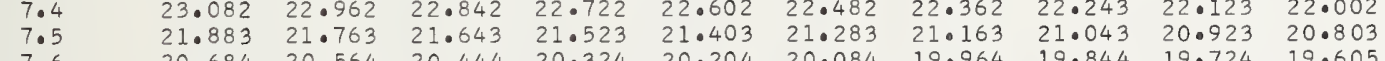

$\begin{array}{lllllllllll}7.6 & 20.684 & 20.564 & 20.444 & 20.324 & 20.204 & 20.084 & 19.964 & 19.844 & 19.724 & 19.605 \\ 7.7 & 19.485 & 19.365 & 19.245 & 19.125 & 19.005 & 18.885 & 18.765 & 18.646 & 18.526 & 19.406\end{array}$

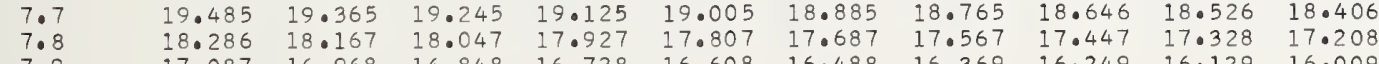

$\begin{array}{lrlllllllll}1.9 & 17.087 & 16.968 & 16.848 & 16.728 & 16.608 & 16.488 & 16.369 & 16.249 & 16.129 & 16.00\end{array}$

$\begin{array}{rrrrrrrrrrr}2888.0 & 34615.889 & 15.769 & 15.649 & 15.529 & 15.410 & 15.290 & 15.170 & 15.050 & 14.930 & 14.811 \\ 8.1 & 14.690 & 14.570 & 14.451 & 14.331 & 14.211 & 14.091 & 13.972 & 13.852 & 13.731 & 13.612\end{array}$

$\begin{array}{lllllllllll}8.1 & 14.690 & 14.570 & 14.451 & 14.331 & 14.211 & 14.091 & 13.972 & 13.852 & 13.731 & 13.612 \\ 8.2 & 13.492 & 13.372 & 13.252 & 13.132 & 13.013 & 12.893 & 12.773 & 12.053 & 12.533 & 12.414\end{array}$

$\begin{array}{llllllllllll}8.3 & 12.293 & 12.173 & 12.054 & 11.934 & 11.814 & 11.694 & 11.575 & 11.455 & 11.335 & 11.215 \\ 8.4 & 11.095 & 10.976 & 10.855 & 10.735 & 10.616 & 10.496 & 10.376 & 10.257 & 10.137 & 10.017\end{array}$

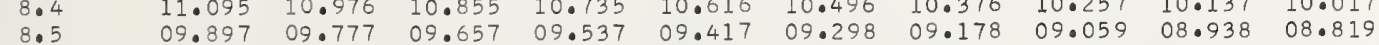

$\begin{array}{lllllllllll}8.6 & 08.699 & 08.579 & 08.459 & 08.339 & 08.220 & 08.100 & 07.980 & 07.860 & 07.740 & 07.621\end{array}$

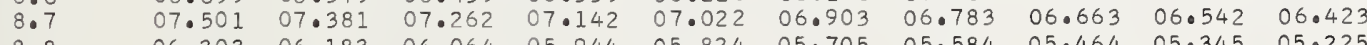

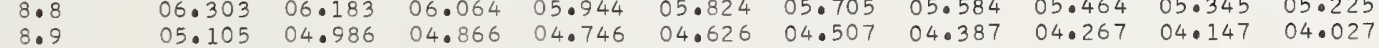

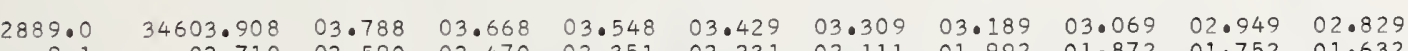

$\begin{array}{lllllllllll}9.1 & 02.710 & 02.590 & 02.470 & 02.351 & 02.231 & 02.111 & 01.992 & 01.872 & 01.752 & 01.632\end{array}$

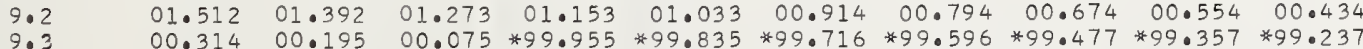

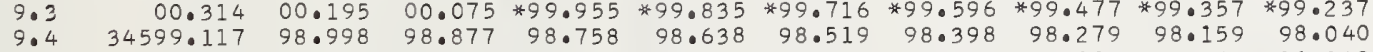

$\begin{array}{lrlllllllll}9.5 & 97.920 & 97.800 & 97.680 & 97.560 & 97.441 & 97.321 & 97.201 & 97.082 & 96.962 & 96.842\end{array}$

$\begin{array}{lllllllllll}9.6 & 96.722 & 96.603 & 96.483 & 96.364 & 96.244 & 96.124 & 96.004 & 95.885 & 95.765 & 95.646\end{array}$

$\begin{array}{lllllllllll}9.7 & 95.526 & 95.406 & 95.287 & 95.167 & 95.047 & 94.927 & 94.807 & 94.687 & 94.568 & 94.448\end{array}$

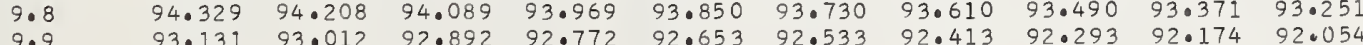

.293366

.293364

0.293361

0.293358

0.293353

0.293350

0.293348

0.293345

0.293341

93338

0.293337
0.293335

0.293333

0.293332
0.293330
0.29332

0.293328

0.293327
0.293325
0.29332

0.293324

0.293322

0.293319

0.293317

0.293315
0.293314
0.293312

0.293312

0.293311
0.293309

0.293307
0.293306

0.293304

0.293302

0.293301

0.293299

0.293296

0.293294

0.293293

0.29328

0.293288
0.293286

0.844894

0.293285

0.293283

0.293280

0.293278

0.293275

0.293273

0.293270

0.293268

0.293267

0.293265

0.293262

0.293260

0.293257

0.293255

0.293252

0.293251

0.293249

0.293246

0.293243

0.293241

0.293239

0.293236

0.293236

0.293233

0.293231

0.293228

0.293226

0.293223

0.293223
0.293222

.844968

.0845017

0.845091

0.845140

0.84518

0.845263

0.84533

0.84538

0.845436
0.84546

0.845485
0.845510

0.845559

0.845608

0.845633

0.845682

0.845732

0.845781

0.845806

0.845830

0.845880

0.845904

0.845954

0.845978
0.846003

0.846028

0.846077

0.293220

0.293218

0.293217

0.293215

0.293212

0.293210

0.293209

0.293209
0.293207

0.846126

0.846175

0.846225

0.846249

0.846274
0.846299

0.846348

0.846373

0.846422

0.846471

0.846496

0.846521

0.846545
0.846570

0.846595

0.846619

0.846669

0.846693

0.846743

0.846767
0.846792

0.846817

0.846866

0.846891

0.846940
0.846964

0.846989

0.847014

0.847063

0.847112
0.847137

0.847162

0.847211

0.847236
0.847260

0.847285
0.847310

$0.293205 \quad 0.847334$

$\begin{array}{lllllllllll} & .001 & .002 & .003 & .004 & .005 & .006 & .007 & .008 & .009 & .010 \\ .121 & .012 & .024 & .036 & .048 & .060 & .072 & .084 & .096 & .109 & .121 \\ .120 & .012 & .024 & .036 & .048 & .060 & .072 & .084 & .096 & .108 & .120\end{array}$


$800.0 \quad 34591.035 \quad 91.015$

$$
\begin{aligned}
& 0.1 \\
& 0.2 \\
& 0.3 \\
& 0.4 \\
& 0.5 \\
& 0.6 \\
& 0.7 \\
& 0.8 \\
& 0.9
\end{aligned}
$$

2891 .

$$
\begin{aligned}
& 891 . \\
& 1 . \\
& 1 . \\
& 1 . \\
& 1 . \\
& 1 .
\end{aligned}
$$

$$
\text { , }
$$

2893.

$$
\begin{array}{r}
93.0 \\
3.1 \\
3.2 \\
3.3 \\
3.4 \\
3.5 \\
3.6 \\
3.7 \\
3.8 \\
3.9
\end{array}
$$$$
2894 .
$$$$
\begin{array}{r}
4 . \\
4 .
\end{array}
$$$$
\begin{aligned}
& 4 \cdot 3 \\
& 4 \cdot 4
\end{aligned}
$$$$
\begin{aligned}
& 4 \cdot 4 \\
& 4 \cdot 5
\end{aligned}
$$$$
\begin{aligned}
& 4 \cdot 6 \\
& 4 \cdot 7
\end{aligned}
$$

2895.

9.0
5.1
5.2
5.3
5.4
5.5
5.6
5.7
5.8
5.9

2896.

6.1

$6 \cdot 3$
$6 \cdot 4$

$6 \cdot 4$
6.5

6.6

6.7
6.8
6.9

2897.

$$
\begin{array}{r}
2897.0 \\
7.1 \\
7.2 \\
7.3 \\
7.5 \\
706 \\
7.7 \\
7.8
\end{array}
$$

$\begin{array}{ll}89.738 & 90.618 \\ 89.541 & 89.421\end{array}$

$\begin{array}{ll}88.344 & 88.224 \\ 87.147 & 87.028\end{array}$

$85.951 \quad 85.831$

$\begin{array}{ll}83.559 & 83.438 \\ 82.362 & 82.242\end{array}$

$81.166 \quad 81.046$

$90.498 \quad 90.378$

$\begin{array}{lll}89.182 & 89.062 & 88.942\end{array}$

$85.711 \quad 85.592$

$84.516 \quad 84.396$

$86.669 \quad 86.549 \quad 86.42$

$\begin{array}{lll}85.472 & 85.353 & 85.23 \\ 84.276 & 84.156 & 84.037\end{array}$

4579.970

$78.773 \quad 78.654$

76.38177 .458

$75.186 \quad 75.066$

$73.991 \quad 73.871$

$\begin{array}{ll}72.795 & 72.675 \\ 71.600 & 71.479\end{array}$

$\begin{array}{ll}70.404 & 70.284 \\ 69.208 & 69.089\end{array}$

$82.122 \quad 82.003$

$83.080 \quad 82.960$

84.037
82.840

$79.730 \quad 79.611$

$77.338 \quad 78.415$

$76.143 \quad 76.023$

$\begin{array}{ll}74.947 & 74.827 \\ 73.751 & 73.631\end{array}$

$\begin{array}{ll}72.556 & 72.436 \\ 71.360 & 71.241\end{array}$

$\begin{array}{ll}71.360 & 71.241 \\ 70.165 & 70.045\end{array}$

79.491

78.29
77.09

75.903
74.708

73.512
72.316

72.316

69.925
68.730

80.567

81.644
80.448

78.17

76.979
75.784

74.588
73.393

72.197
71.001

71.001
68.806

79.251

78.056
76.860

75.664
74.468

74.468
73.273

72.078
70.882

70.882
69.687

69.687
68.491

$34568.013 \quad 67.894$

66.818

$65.623 \quad 65.503$

$64.427 \quad 64.308$

$62.038 \quad 61.918$

$\begin{array}{ll}60.843 & 60.724 \\ 59.648 & 59.529\end{array}$

$\begin{array}{ll}59.648 & 59.529 \\ 58.454 & 58.334 \\ 57.259 & 57.140\end{array}$

$67.773 \quad 67.654$

$67.535 \quad 67.415$

67.295

66

$\begin{array}{llll}64.188 & 64.069 & 65.144 & 65.025 \\ 64.949 & 63.830\end{array}$

$62.994 \quad 62.875$

$\begin{array}{llll}61.799 & 51.679 & 61.560 & 61.440\end{array}$

$\begin{array}{llll}64.905 & 64.786 & 64.667 & 64.547 \\ 63.710 & 63.591 & 63.472 & 63.35\end{array}$

$\begin{array}{llll}62.516 & 62.397 & 62.277 & 62.157\end{array}$

$\begin{array}{llll}58.454 & 58.334 & 58.215 & 58.095 \\ 57.259 & 57.140 & 57.02 \mathrm{C} & 56.900\end{array}$

$34556.064 \quad 55.945$

$\begin{array}{ll}54.871 & 54.7 \\ 53.676 & 53.5\end{array}$

$\begin{array}{ll}52.481 & 52.362 \\ 51.288 & 51.168\end{array}$

$50.094 \quad 49.975$

$\begin{array}{ll}48.900 & 48.780\end{array}$

$\begin{array}{ll}46.512 & 46.393 \\ 45.318 & 45.199\end{array}$

55.826

54.63
53.437

52.24
51.04

49.855
48.661

$48.661 \quad 48.54$

$47.467 \quad 47.34$

$\begin{array}{ll}46.273 & 46.154 \\ 45.080 & 44.960\end{array}$

$\begin{array}{rr}34544.125 & 44.005 \\ 42.931 & 42.812\end{array}$

43.88

43.766

$40.544 \quad .40 .425$

$\begin{array}{ll}39.351 & 39.232\end{array}$

$36.965 \quad 36.845$

$41.499 \quad 41.379$

$30.306 \quad 40.187$

$\begin{array}{ll}39.113 & 38.993 \\ 37.919 & 37.800\end{array}$

$36.726 \quad 36.607$

$\begin{array}{ll}35.771 & 35.652 \\ 34.579 & 34.459\end{array}$

$\begin{array}{ll}35.533 & 35.414 \\ 34.340 & 34.22\end{array}$

$33.385 \quad 33.267$

$31.000 \quad 30.88$

$31.954 \quad 31.835$

$\begin{array}{ll}31.954 & 31.83 \\ 30.761 & 30.64\end{array}$

$29.808 \quad 29.68$

$27.423 \quad 27.304$

$26.230 \quad 26.11$

$\begin{array}{ll}2.2 .653 & 22.534 \\ 21.461 & 21.342\end{array}$

$28.376 \quad 29.450$

$\begin{array}{ll}27.184 & 27.06 \\ 25.992 & 25.87\end{array}$

$24.799 \quad 24.680$

23.607

20.270

$$
\begin{aligned}
& 19.077 \\
& 17.886
\end{aligned}
$$

$20 \cdot 150$

22.415
21.223

23.48
22.29

$20.031 \quad 19.912$

17.0896767

$15.502 \quad 15.383$

$14.311 \quad 14.19$

$13.120 \quad 13.000$

$\begin{array}{ll}11.0736 & 10.617 \\ 09.545 & 09.426\end{array}$

$08.354 \quad 08.235$

$7 \cdot 1$
$7 \cdot 2$
$7 \cdot 3$

$7 \cdot 3$

7.6

$7 \cdot 8$
7.9

$07.163 \quad 07.044$

$04.781 \quad 04.662$

$\begin{array}{ll}03.590 & 03.471 \\ 02.399 & 02.280\end{array}$

$01.208 \quad 01.089$ $00.018 * 99.899$

$\begin{array}{ll}18.839 & 18.7 \\ 17.647 & 17.528\end{array}$

$16.456 \quad 16.336$

$\begin{array}{ll}14.072 & 13.95 \\ 12.880 & 12.76\end{array}$

$12.880 \quad 12.762$

$\begin{array}{ll}11.689 & 11.570 \\ 10.498 & 10.379\end{array}$

$09.307 \quad 09.187$

$08.116 \quad 07.996$

06.925

$05.734 \quad 05.615$

$04.543 \quad 04.424$

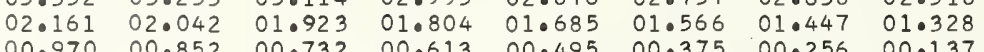

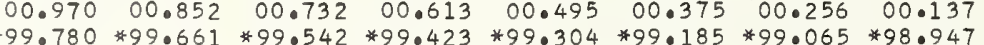

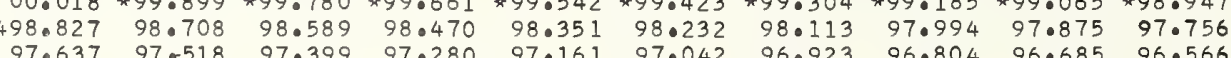

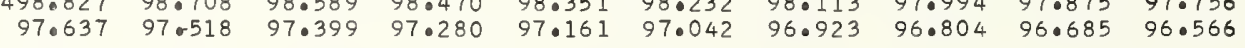

$\begin{array}{llllllllll}34496.447 & 96.328 & 96.209 & 96.090 & 95.971 & 95.852 & 95.733 & 95.614 & 95.495 & 95.375\end{array}$

$\begin{array}{lllllllllll}8.1257 & 95.138 & 95.019 & 94.900 & 94.781 & 94.662 & 94.542 & 94.424 & 94.305 & 94.186\end{array}$

$\begin{array}{llllllllll}94.067 & 93.948 & 93.829 & 93.710 & 93.591 & 93.472 & 93.353 & 93.233 & 93.114 & 92.996 \\ 92.876 & 92.757 & 92.639 & 92.520 & 92.400 & 92.282 & 92.162 & 92.043 & 91.924 & 91.805\end{array}$

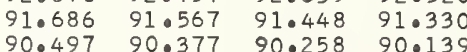

$91.210 \quad 91.092 \quad 90.973 \quad 90.854 \quad 90.734 \quad 90.615$

$\begin{array}{llllllllll}89.307 & 89.187 & 89.068 & 88.950 & 88.831 & 89.901 & 89.783 & 89.664 & 89.544 & 89.425 \\ & 89.711 & 88.593 & 88.474 & 88.354 & 88.236\end{array}$

$\begin{array}{llllllllll}88.117 & 87.998 & 87.879 & 87.760 & 87.641 & 87.522 & 87.403 & 87.284 & 87.165 & 87.046\end{array}$

$\begin{array}{llllllllll}86.927 & 86.808 & 86.689 & 86.570 & 86.451 & 86.333 & 86.213 & 86.094 & 85.975 & 85.856\end{array}$

$\begin{array}{llllllllll}85.737 & 85.619 & 85.500 & 85.381 & 85.262 & 85.143 & 85.024 & 84.905 & 84.786 & 84.667\end{array}$

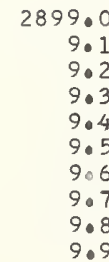

84.31184 .19

$\begin{array}{llllll}84.072 & 83.953 & 83.834 & 83.716 & 83.597 & 83.478\end{array}$

$\begin{array}{lllllllllll}83.359 & 83.240 & 83.121 & 83.002 & 82.883 & 82.764 & 82.645 & 82.526 & 82.407 & 82.289\end{array}$

$\begin{array}{llllllllll}80.980 & 80.861 & 81.932 & 81.813 & 81.693 & 81.575 & 81.456 & 81.337 & 81.218 & 81.099\end{array}$

$\begin{array}{lllllllllll}79.791 & 79.672 & 79.553 & 79.434 & 79.315 & 79.196 & 79.077 & 78.958 & 78.839 & 78.720\end{array}$

$\begin{array}{lllllllllll}78.602 & 78.483 & 78.364 & 78.245 & 78.126 & 78.007 & 77.888 & 77.769 & 77.650 & 77.531\end{array}$

$\begin{array}{lllllllllll}77.413 & 77.293 & 77.175 & 77.056 & 76.937 & 76.818 & 76.699 & 76.580 & 76.461 & 76.343\end{array}$

$73.846 \quad 73.728$

73.608

73.489

73.37

$\begin{array}{ll}74.440 & 74.322 \\ 73.252 & 73.133\end{array}$

$\begin{array}{lll}75.391 & 75.272 & 75.153 \\ 74.203 & 74.084 & 73.965\end{array}$

$(n-1) \times 1000$

$\lambda(n-1)$

0.293204

0.293201

0.07

0.293197

0.293194

0.293193

0.293189

0.293188

0.293186

0.293185

0.293183
0.293181

0.293180

0.293178

0.293176

0.293175
0.293173

0.293172

0.293170

0.293168

0.293165

0.293164

0.293162

0.293160

0.293159
0.293157

0.293156

0.293154

0.293152

0.29315

0.293148

0.293146

0.293144

0.293143

0.293140

0.293136

0.293135

0.293133

0.293130

0.293128

0.293128

0.293127

0.293124

0.293122

0.293120

0.293119

0.293116

0.293114

0.293112

0.293111
0.293109

0.293108

0.293104

0.293103

0.293101

0.293100

0.293098

0.293096

0.293093

0.293092

0.293090

0.293088

0.293085

0.293084

0.293082

0.293080

0.293079
0.293077

0.293076

0.293074

0.293072

0.293071

0.293069

0.293066

0.293063
0.293061

0.293060

0.293058

0.293055

0.293053

0.293052 


.05

.06

.07

.08

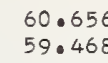

$$
\begin{array}{r}
344 \\
4 \\
4 \\
4 \\
4 \\
4 \\
4 \\
4 \\
3 \\
3
\end{array}
$$

$\begin{array}{lllllllllll} & .001 & .002 & .003 & .004 & .005 & .006 & .007 & .008 & .009 & .010 \\ .119 & .012 & .024 & .036 & .048 & .060 & .071 & .083 & .095 & .107 & .119 \\ .118 & .012 & .024 & .035 & .047 & .059 & .071 & .083 & .095 & .106 & .0118\end{array}$


0.292881

0.292879
0.292878

0.292876

0.292875

0.292872
0.292828

0.292870

0.292868
0.292867

0.292865

$\begin{array}{llllllll}39.804 & 39.687 & 39.568 & 39.451 & 39.332 & 39.214 & 39.096 & 38.979\end{array}$

37.563

$37.425 \quad 38.507$

38.389

$\begin{array}{ll}36.266 & 36.148 \\ 35.086 & 34.969\end{array}$

36.974

$38.035 \quad 37.917 \quad 37.799$

34.025

$\begin{array}{ll}33.908 & 33.790 \\ 32.729 & 32.510\end{array}$

$\begin{array}{lll}36.030 & 35.912 & 35.79 \\ 34.851 & 34.733 & 34.61\end{array}$

$\begin{array}{lll}36.855 & 36.737 & 36.620\end{array}$

$\begin{array}{lll}35.676 & 35.558 & 35.440 \\ 34.497 & 34.379 & 34.261\end{array}$

$\begin{array}{ll}32.729 & 32.610 \\ 31.549 & 31.431\end{array}$

$\begin{array}{ll}32.492 & 32.375\end{array}$

$33 \cdot 436$
32.25

$\begin{array}{lll}33.318 & 33.200 & 33.08\end{array}$

2912.0

$2 \cdot 1$

$2 \cdot 3$

2.5

2.6
2.7

2.7

2913.$$
\text { : }
$$

3.4
3.5

3.6
3.7

3.8
3.9

2914.0

$4 \cdot 1$
$4 \cdot 2$
$4: 3$
$4 \cdot 4$

$4 \cdot 4$
$4 \cdot 5$

$4 \cdot 6$

$4 \cdot 8$
$4 \cdot 9$

2915.

5.1

$5 \cdot 3$
$5 \cdot 4$

5.4
5.5

5.6
5.7

5.8
5.9

2916.0

6.2

$6 \cdot 3$

$6 \cdot 5$

6.6
6.7
6.8

6.9

2917.

7.1

$7 \cdot 2$
$7: 3$

7.5

7.7

7.8

2918.0 $\begin{array}{rr}34330.606 & 30.48 \\ 29.427 & 29.3\end{array}$

$28.249 \quad 28.131$

$27.070 \quad 26.952$

$\begin{array}{ll}25.891 & 25.774 \\ 24.713 & 24.595\end{array}$

$23.535 \quad 23.417$

$22.356 \quad 22.238$

$\begin{array}{ll}21.178 & 21.060 \\ 19.999 & 19.882\end{array}$ 17.6
16.466

$14.110 \quad 15.170$

$12.932 \quad 12.814$

11.75

$10.577 \quad 10.459$

08.222

34307.044

05.868
04.69

03.514

01.160

99.983

96.452

34295.276

94.100

91.747

90.57190 .454

$89.395-89.277$

$\begin{array}{ll}88.219 & 88.101 \\ 87.043 & 86.925\end{array}$

$\begin{array}{ll}85.867 & 85.750 \\ 84.691 & 84.574\end{array}$

82.3

81.16
79.98
78.81

$77.638 \quad 77.521$

$\begin{array}{ll}76.463 & 76.345 \\ 75.288 & 75.170\end{array}$

$\begin{array}{ll}74.113 & 73.99 \\ 72.938 & 72.821\end{array}$

$34271.764 \quad 71.646$

70.588

68.23

68.23968 .122

67.06466 .947

$\begin{array}{ll}65.890 & 65.772 \\ 64.715 & 64.598\end{array}$

$\begin{array}{ll}63.541 & 63.423 \\ 62.367 & 62.249\end{array}$

$\begin{array}{ll}62.367 & 62.249 \\ 61.193 & 61.076\end{array}$

$8 \cdot 1$

$8 \cdot 2$

8.4

8.5

8.7

2919

$$
\begin{array}{r}
919.0 \\
9 . \\
9 . \\
9 . \\
9.5 \\
9.5 \\
9.7 \\
9 .
\end{array}
$$

$\begin{array}{lll}30.370 & 30.252 & 30 \\ 29.191 & 29.074 & 28\end{array}$

$\begin{array}{lllll}29.191 & 29.074 & 28.956 & 28.838 & 28 \\ 28.013 & 27.896 & 27.777 & 27.660 & 27\end{array}$

$\begin{array}{llll}26.834 & 26.717 & 26.599 & 26.480 \\ 25.656 & 25.538 & 25.420 & 25.302\end{array}$

$\begin{array}{llll}24.477 & 24.359 & 24.242 & 24.124\end{array}$

$\begin{array}{lll}23.299 & 23.181 & 23 . \\ 22.121 & 22.002 & 21.0\end{array}$

$\begin{array}{ll}22.121 & 22.002 \\ 20.942 & 20.824 \\ 19.764 & 19.646\end{array}$

\section{$18.585 \quad 18.468$}

$\begin{array}{llll}17.408 & 17.290 & 17.172 & 17.055\end{array}$

$\begin{array}{llll}16.230 & 16.112 & 15.994 & 15.877\end{array}$

$\begin{array}{llll}15.052 & 14.934 & 14.816 & 14.699 \\ 13.875 & 13.757 & 13.639 & 13.52\end{array}$

$\begin{array}{llll}12.697 & 12.579 & 12.461 & 12.343 \\ 11.519 & 11.401 & 11.283 & 11.166\end{array}$

$10.342 \quad 10.224$

9.164

06.809

05.632
04.455

$03.278 \quad 03.160$

$00.924 \quad 00.806$

$99.747 \quad 99.629$

$\begin{array}{ll}98.571 & 98.453 \\ 97.394 & 97.276\end{array}$

96.217

95.041

93.864
92.688

91.512
90.335

$\begin{array}{ll}86.808 & 87.866 \\ 85.690\end{array}$

85.632
84.456

85.514
84.338

83.28183 .163

$\begin{array}{ll}82.105 & 81.988 \\ 80.930 & 80.812 \\ 79.754 & 79.636\end{array}$

79.754
78.579

78.57978 .461

$\begin{array}{ll}76.228 & 76.110 \\ 75.053 & 74.936\end{array}$

$73.878 \quad 73.760$

$72.704 \quad 72.586$

$\begin{array}{ll}71.528 & 71.41 \\ 70.354 & 70.23\end{array}$

$\begin{array}{ll}69.179 & 69.062 \\ 68.004 & 67.887\end{array}$

$66.830 \quad 66.712$

65.655
64.450

$\begin{array}{ll}64.480 & 64.363 \\ 63.306 & 63.189\end{array}$

$\begin{array}{ll}6.306 & 63.189 \\ 2.132 & 62.015\end{array}$

$10.106 \quad 11.166$

$08.928 \quad 08.81$

29.898

30.960

30.8

31.903
30.724

0.292861

0.292859

0.292856

0.292854

0.292853

0.292851

0.292850
0.292848

0.292846

0.292845

0.292843

0.292840

0.292839

0.292837

0.292835

0.292832

0.292831

0.29282

0.292826

0.292825

0.292823

0.292821

0.292818

0.292817

0.292815

0.292814
0.292812

0.292810

0.292809

0.292807

0.292806

0.292804

0.292801

0.292800

0.292796

0.292793

0.292792

0.292790

0.292787

0.292785

0.292784

0.292782

0.292781

0.292779

0.292776

0.292775

0.292771

0.292770

0.292768

0.292767
0.292765

0.292765

0.292762

0.292761

0.292759

0.292757

0.292754

0.202753

0.292753

0.292751

$\begin{array}{lllllllll}51.685 & 51.568 & 51.450 & 51.333 & 51.216 & 51.098 & 50.980 & 50.863 & 50.746\end{array}$

$\begin{array}{llllllllll}50.628 & 50.512 & 50.395 & 50.277 & 50.160 & 50.042 & 49.925 & 49.808 & 49.691 & 49.573\end{array}$

0.292747

0.292745

0.292743

0.292742

0.292740

0.292739

0.292737

0.292736

0.292734

0.292731

.85229

0.852322

0.852371

0.852396

0.852421

0.852446

0.852495

0.852544

.852569

0.852619

0.852643

0.852668

0.852693

0.852717

0.852767

0.852792

0.852816

0.852866

0.852891 


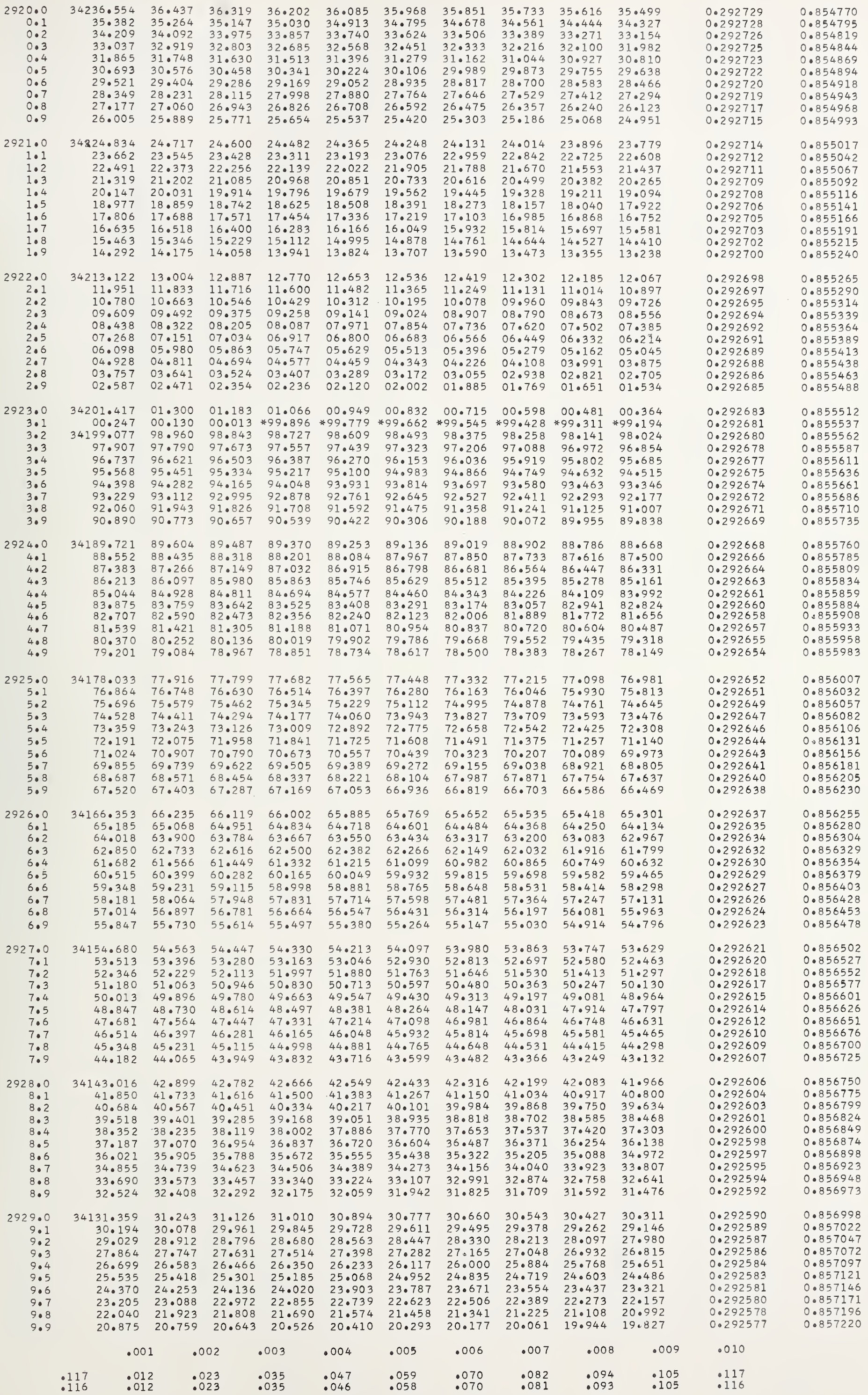




$$
\begin{array}{r}
930.0 \\
0.1 \\
0.2 \\
0.3 \\
0.4 \\
0.5 \\
0.5 \\
0.7 \\
0.8 \\
0.9
\end{array}
$$

2931.

$$
931 .
$$

2933.
3.
3.
3.3
3.4
3.
3.6
3.
3.
3.

$$
2934 .
$$$$
\begin{array}{r}
934.0 \\
4.1 \\
4.2 \\
4.3
\end{array}
$$$$
\begin{aligned}
& 4.4 \\
& 4.5 \\
& 4.6
\end{aligned}
$$$$
\begin{aligned}
& 405 \\
& 4.6 \\
& 4.7
\end{aligned}
$$$$
\begin{aligned}
& 406 \\
& 408
\end{aligned}
$$$$
2935 .
$$$$
\begin{aligned}
& 35.0 \\
& 5.1 \\
& 5.2 \\
& 5.3 \\
& 5.4 \\
& 5.5 \\
& 5 . \\
& 5.7 \\
& 5.8 \\
& 5.9
\end{aligned}
$$

18.546
17.382

16.218
15.054

13.890

$12.726 \quad 12.609$

$\begin{array}{ll}11.562 & 11.445 \\ 10.398 & 10.282\end{array}$

09.234

34108.071

06.9907
05.743

$05.743 \quad 05.791$

$04.580 \quad 04.463$

$\begin{array}{ll}03.417 & 03.300 \\ 02.253 & 02.137\end{array}$

$01.090 \quad 00.974$

$\begin{array}{ll}99.927 & 99.811 \\ 98.764 & 98.647 \\ 97.601 & 97.484\end{array}$

096.43

34096.438
95.275 95.275
94.1
92.9
91.787 $92.950 \quad 92.833$ $91.787-91.671$ $89.462 \quad 89.346$

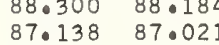
$\begin{array}{lll}85.975 & 85.859\end{array}$

34084.813
83.
82.48

83.651
82.48
81.328
80.166

$81.32 \quad 82.373$

$80.166 \quad 80.050$

$\begin{array}{ll}79.004 & 78.888 \\ 77.843 & 77.727\end{array}$

$76.681 \quad 76.565$

$\begin{array}{ll}75.520 & 75.403 \\ 74.358 & 74.242\end{array}$

$34073.197 \quad 73.081$

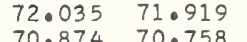

$69.713 \quad 69.597$

$68.552 \quad 68.437$

$67.392 \quad 67.275$

$65.070 \quad 64.954$

$63.909 \quad 63.793$

$34061.588 \quad 61.47$

$$
\begin{aligned}
& 60.427 \\
& 59.267 \\
& 58.107
\end{aligned}
$$

$58.107 \quad 57.991$

$56.947 \quad 56.83$

$\begin{array}{ll}54.627 & 54.511\end{array}$

$52.307 \quad 52.190$

$51.147 \quad 51.031$

$34049.987 \quad 49.87$

48.82

47.668
46.508

$46.508 \quad 46.393$

$44.190 \quad 45.233$

$43.031 \quad 42.915$

41.872

40.712
39.553

41.755
40.596

40.596
39.437

34038.39

$\begin{array}{ll}37.235 & 37.11 \\ 36.077 & 35.960\end{array}$

$\begin{array}{ll}34.918 & 34.802\end{array}$

$32.601 \quad 32.48$

$31.442 \quad 31.326$

$\begin{array}{ll}29.125 & 29.009 \\ 27.967 & 27.852\end{array}$

$026.810 \quad 26.693$

$\begin{array}{ll}25.651 & 25.53 \\ 24.493 & 24.377\end{array}$

$23.335 \quad 23.21$

$22.177 \quad 22.062$

$19.862 \quad 19.746$

$\begin{array}{ll}17.546 & 17.58 \\ 16.389 & 16.431\end{array}$

$16.389 \quad 16.27$

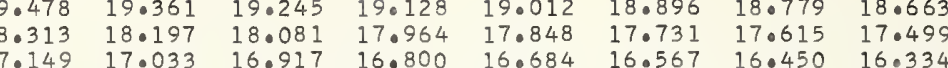

$\begin{array}{llllllll}15.985 & 15.869 & 16.917 & 16.000 & 16.684 & 16.5603 & 16.450 & 16.334\end{array}$

$\begin{array}{llll}14.821 & 14.705 & 14.588 & 14.472 \\ 13.657 & 13.541 & 13.424 & 13.308 \\ 11.33\end{array}$

$\begin{array}{llll}12.493 & 12.3777 & 12.260 & 12.144\end{array}$

$10.329 \quad 11.213$

09.00108 .885

$\begin{array}{lll}07.837 & 07.721 & 07 \\ 06.674 & 06.558 & 06\end{array}$

$\begin{array}{lll}05.511 & 05.394 & 050 \\ 04.347 & 04.231 & 040\end{array}$

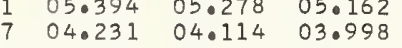

$\begin{array}{llll}02.021 & 01.904 & 02.952 & 02.835 \\ 0.988 & 01.672 \\ 9 & 01.072\end{array}$

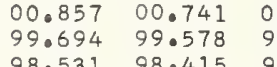

00.62500 .508

98.29

99.346

15.519

13.191
12.028

$15.403 \quad 15.287 \quad 15.171$

$13.075 \quad 12.959 \quad 12.842$

$11.911 \quad 11.795 \quad 11.679$

$09.583 \quad 00.467 \quad 10.515$

$08.420 \quad 08.303 \quad 08.187$

$07.372 \quad 07.256 \quad 07.140 \quad 07.023$

$06.208 \quad 06.092 \quad 05.976 \quad 05.860$

$\begin{array}{llll}05.045 & 04.929 & 04.812 & 04.696 \\ 03.882 & 03.766 & 03.649 & 03.533\end{array}$

$\begin{array}{llll}02.719 & 02.603 & 02.486 & 02.370\end{array}$

$\begin{array}{llll}01.555 & 01.439 & 01.323 & 01.206\end{array}$

$\begin{array}{llll}0 . .393 & 00.276 & 00.160 & 00.043 \\ 99.229 & 99.113 & 98.997 & 98.880\end{array}$

$\begin{array}{llll}98.066 & 97.950 & 97.833 & 97.717 \\ 96.903 & 96.787 & 96.670 & 96.554\end{array}$

$96.20596 .089 \quad 9509$

95.973

$93.880 \quad 93.763$ 93.0.

92.717 92.601

90.39290 .276

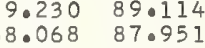

$91.323 \quad 91.207$

94.578

92.25

$94.46194 .345 \quad 94.22$

$93.298 \quad 93.182 \quad 93.066$

$\begin{array}{lll}92.136 & 92.020 & 91.904 \\ 90.974 & 90.857 & 90.741\end{array}$

$\begin{array}{llllll}90.160 & 90.044 & 89.927 & 89.811 & 89.695 & 89.579 \\ 88.998 & 88.881 & 88.765 & 88.649 & 88.532 & 88.417\end{array}$

6.905
$5.743 \quad 8507$

0.789
5.626

(87.835 87.719

$88.532 \quad 88.417$

$84.581 \quad 84.464$

84.34

86.557
85.395

86.440

$85.162 \quad 86.208 \quad 86.091$

$\begin{array}{llllllll}82.257 & 82.141 & 82.024 & 81.909 & 81.792 & 81.676 & 81.560 & 81.444\end{array}$

$\begin{array}{llllllll}79.934 & 80.979 & 80.863 & 80.747 & 80.630 & 80.514 & 80.398 & 80.282 \\ 79.817 & 79.702 & 79.585 & 79.469 & 79.353 & 79.236 & 79.120\end{array}$

$\begin{array}{lllllllll}78.772 & 78.656 & 78.540 & 78.423 & 78.307 & 78.191 & 78.075 & 77.958 \\ 77.610 & 77.494 & 77.378 & 77.262 & 77.146 & 77.029 & 76.913 & 76.797\end{array}$

76.610077 .494

76.449
75.287
74.126

75.171

$\begin{array}{llll}75.055 & 76.101 & 75.98 \\ 73.98 & 0\end{array}$

75.868

76.913

75.751

76.797

72.964

70.642
69.481

72.84

$72.732 \quad 72.616$

73.661

73.545

8.320

65.99965 .883

63.677

63.561

$61.356 \quad 61.240$

$\begin{array}{ll}60.195 & 60.080 \\ 59.035 & 58.91\end{array}$

$\begin{array}{ll}57.875 & 57.759 \\ 56.715 & 56.599\end{array}$

55.555
54.395

$54.395 \quad 54.27$

52.07
50.915

49.755

$\begin{array}{ll}48.595 & 48.47 \\ 47.436 & 47.32\end{array}$

46.277
45.117

$\begin{array}{ll}45.117 & 45.001 \\ 43.958 & 43.842\end{array}$

$\begin{array}{ll}42.798 & 42.683 \\ 41.740 & 41.523\end{array}$

$41.640 \quad 41.523$

$\begin{array}{ll}40.480 & 40.364 \\ 39.321 & 39.205\end{array}$

71.571
70.410

70.410
69.249

68.088

$66.927 \quad 66.871$

65.767
64.605

63.44564 .489

$\begin{array}{ll}63.445 & 63.329 \\ 62.285 & 62.168\end{array}$

72.500

72.384

73.42

74.474
73.312

61.12

59.963
59.847

$58.803 \quad 58.687$

56.48
55.32

$55.323 \quad 55.207$

53.00354 .046

$51.842 \quad 52.887$

50.683

$49.523 \quad 49.407$
4.040

$48.364 \quad 48.247$

$\begin{array}{ll}47.204 & 47.088 \\ 46.045 & 45.929\end{array}$

$\begin{array}{ll}44.886 & 44.770 \\ 43.726 & 43.610\end{array}$

$\begin{array}{ll}42.567 & 42.45 \\ 41.407 & 41.0292\end{array}$

$41.407 \quad 41.292$

70.178
69.017

67.85

$\begin{array}{lll}1.223 & 71.106 & 70.990\end{array}$

$68.90169 .945 \quad 69.830$

$67.740 \quad 67.624$

64.374

65.418

65.30

67.507
66.347

65.186

$63.212 \quad 63.096 \quad 62.980 \quad 62.864$

$60.891 \quad 60.775 \quad 60.659 \quad 60.543$

$59.731 \quad 59.015 \quad 50.659 \quad 60.543$

$57.41157 .205 \quad 57.179057 .223$

$\begin{array}{llll}56.250 & 56.135 & 56.019 & 55.903\end{array}$

$\begin{array}{lllll}55.090 & 54.975 & 54.858 & 54.743\end{array}$

$\begin{array}{llll}51.611 & 51.455 & 52.539 & 52.423\end{array}$

$\begin{array}{llll}51.411 & 51.495 & 51.379 & 51.263\end{array}$

$\begin{array}{lllll}49.291 & 49.175 & 49.059 & 48.943\end{array}$

$\begin{array}{llll}48.131 & 48.016 & 47.899 & 47.784\end{array}$

45.973

44.653

43.494

45.697

44.538

43.378
42.219

46.741

45.582

43.26

$\begin{array}{lllll}41.176 & 41.060 & 40.944 & 40.828\end{array}$

$\begin{array}{llll}40.017 & 39.901 & 39.785 & 39.669 \\ 38.857 & 38.742 & 38.626 & 38.510\end{array}$

$38.163 \quad 38.046$

$\begin{array}{ll}37.003 & 36.888 \\ 35.845 & 35.729\end{array}$

$\begin{array}{ll}34.687 & 34.570 \\ 33.528 & 33.412\end{array}$

$32.369 \quad 32.253$

$31.210 \quad 31.095$

$\begin{array}{ll}28.894 & 28.778 \\ 27.735 & 27.620\end{array}$

37.93

$\begin{array}{llllll}37.931 & 37.814 & 37.699 & 37.583 & 37.467 & 37.351\end{array}$

$\begin{array}{llllll}36.771 & 36.655 & 36.540 & 36.424 & 36.308 & 36.192 \\ 35.613 & 35.498 & 35.382 & 35.266 & 35.150 & 35.034\end{array}$

$\begin{array}{llllll}34.455 & 34.039 & 35.382 & 35.266 & 35.150 & 35.034 \\ 34.223 & 34.107 & 33.991 & 33.875\end{array}$

$\begin{array}{lllllll}33.296 & 33.180 & 33.064 & 32.949 & 32.833 & 32.717\end{array}$

$\begin{array}{llllll}32.138 & 32.021 & 31.906 & 31.790 & 31.674 & 31.558\end{array}$

$\begin{array}{llllll}29.820 & 29.705 & 29.589 & 29.473 & 29.357 & 29.242\end{array}$

$\begin{array}{lllllll}28.662 & 28.546 & 28.431 & 28.314 & 28.199 & 28.083 \\ 27.504 & 27.388 & 27.272 & 27.157 & 27.041 & 26.925\end{array}$

$\begin{array}{ll}26.577 & 26.461 \\ 25.419 & 25.303 \\ 24.262 & 24.146\end{array}$

$26.346 \quad 26.230$

26.114

25.767

$\begin{array}{llllll}24.030 & 23.915 & 23.799 & 23.683 & 23.567 & 23.451\end{array}$

$\begin{array}{lllllll}22.872 & 22.757 & 22.641 & 22.525 & 22.409 & 22.293\end{array}$

$\begin{array}{llllll}21.714 & 21.599 & 21.483 & 21.367 & 21.251 & 21.135 \\ 20.557 & 20.441 & 20.325 & 20.209 & 20.094 & 19.978\end{array}$

$\begin{array}{llllll}19.399 & 19.283 & 19.167 & 19.052 & 18.936 & 18.820\end{array}$

20.788 


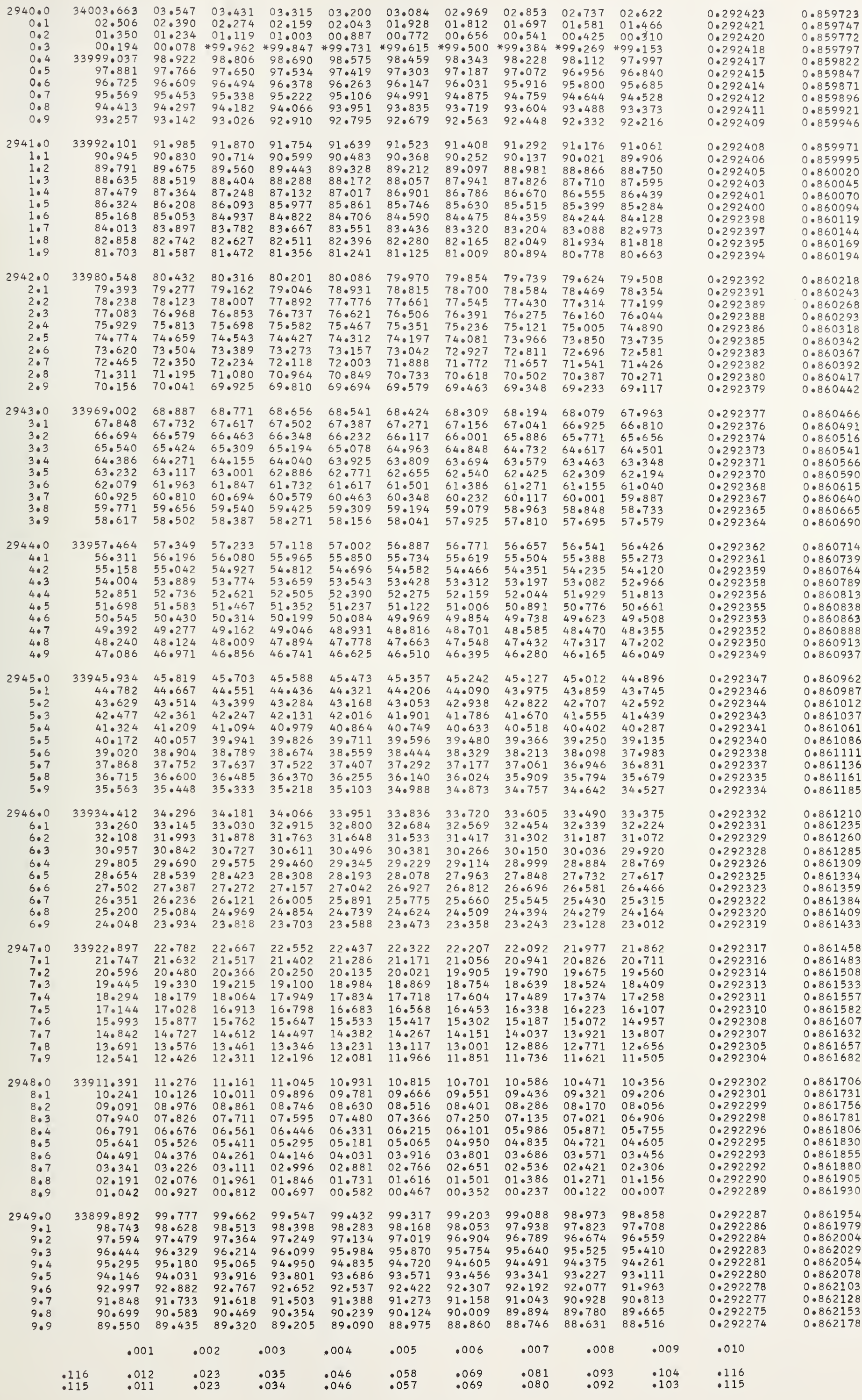




\subsection{2
1.04}

$1 \cdot 2$
1.3
1.4

$1 \cdot 4$

1.6
1.7
1.8

$33876.918 \quad 76.803$ $\begin{array}{ll}75.771 & 75.655 \\ 74.623 & 74.507\end{array}$ $\begin{array}{ll}74.623 & 74.507 \\ 73.475 & 73.360\end{array}$ $\begin{array}{ll}72.327 & 72.212 \\ 71.179 & 71.064\end{array}$ $\begin{array}{ll}71.179 & 71.064 \\ 70.032 & 69.917\end{array}$ $\begin{array}{ll}68.884 & 68.770 \\ 67.737 & 67.622\end{array}$ $\begin{array}{ll}81.280 & 81.166 \\ 70.132 & 80.018\end{array}$ $\begin{array}{lll}86.793 & 86.678 & 87.71 \\ 85.6645 & 85.530 & 85.415\end{array}$ $\begin{array}{lll}85.645 & 85.530 & 85.415 \\ 84.496 & 84.381 & 84.267\end{array}$ $\begin{array}{llll}83.496 & 84.381 & 84.267 & 84.15\end{array}$ 86.449
85.300 $\begin{array}{ll}87.482 & 87.367 \\ 86.334 & 86.210\end{array}$ $\begin{array}{ll}67.737 & 67.622 \\ 66.589 & 66.475\end{array}$ $77.836 \quad 77.721 \quad 77$. $63.148 \quad 63.034$ $62.001 \quad 61.887$ $\begin{array}{ll}60.854 & 60.740 \\ 59.708 & 59.593\end{array}$ $58.561 \quad 58.446$ $56.268 \quad 56.153$

$\begin{array}{ll}76.688 & 76.573 \\ 75.541 & 75.426\end{array}$ 81.05180 .936 $\begin{array}{llll}79.903 & 79.788 & 80.82 \\ 79.063\end{array}$ 81.855 $\begin{array}{ll}85.185 & 85.071 \\ 84.037 & 83.922\end{array}$ $82.888 \quad 82.773$ $81.740 \quad 81.625$

$76.000 \quad 75.885$ $\begin{array}{lll}74.967 & 74.852 & 74.737\end{array}$ $\begin{array}{lll}72.671 & 72.557 & 72.441\end{array}$ $\begin{array}{lll}71.524 & 71.409 & 71.294\end{array}$ $69.229 \quad 69.114 \quad 69.000$ $\begin{array}{lll}68.081 & 67.966 & 67.852\end{array}$ $\begin{array}{lll}66.934 & 66.819 & 66.705\end{array}$ $64.640 \quad 64.525 \quad 64.410$ $\begin{array}{lll}63.493 & 63.378 & 63.263 \\ 62.345 & 62.230 & 62.116\end{array}$ $\begin{array}{lll}62.345 & 62.230 & 62.116 \\ 61.199 & 61.084 & 60.969\end{array}$ $\begin{array}{ll}61.084 & 60.969 \\ 59.937 & 59.022\end{array}$ $58.791 \quad 58.675$ $57.644 \quad 57.529$ $56.497 \quad 56.383$ $\begin{array}{llll}55.580 & 55.465 & 55.351 & 55.236 \\ 54.433 & 54.319 & 54.204 & 54.089\end{array}$

3.2

3.4

3.5
3.6
3.7

3.8
3.9

54.0

$4 \cdot 2$
$4 \cdot 3$
$4 \cdot 4$

$4 \cdot 4$
$4 \cdot 5$

4.6

$4 \cdot 7$
$4 \cdot 8$
$4 \cdot 9$

\begin{tabular}{|c|c|c|c|c|c|c|c|c|c|c|}
\hline & .001 & .002 & .003 & .004 & .005 & .006 & .007 & .008 & .009 & .010 \\
\hline $\begin{array}{l}115 \\
114\end{array}$ & $\begin{array}{l}.012 \\
.011\end{array}$ & $\begin{array}{l}.023 \\
.023\end{array}$ & $\begin{array}{l}.035 \\
.034\end{array}$ & $\begin{array}{l}.046 \\
.046\end{array}$ & $\begin{array}{l}.058 \\
.057\end{array}$ & $\begin{array}{r}.069 \\
.069\end{array}$ & $\begin{array}{l}.081 \\
.080\end{array}$ & $\begin{array}{l}.092 \\
.091\end{array}$ & $\begin{array}{l}104 \\
.103\end{array}$ & $\begin{array}{r}0115 \\
: 114\end{array}$ \\
\hline
\end{tabular}




$\begin{array}{ll}0.0 & 337 \\ 0.1 & \\ 0.2 & \\ 0.3 & \\ 0.4 & \\ 0.5 & \\ 0.6 & \\ 0.7 & \\ 0.8 & \\ 0.9 & \end{array}$

\section{$72.778 \quad 72.664$}

67

$\begin{array}{lll}73.690 & 73.576 \\ 72.549 & 72.436 \\ 71.409 & 71.294 \\ 70.268 & 70.154 \\ 69.127 & 69.013 & \\ 67.986 & 67.872 & 67 \\ 66.846 & 66.732 & 66 \\ 65.706 & 55.591 & 65 \\ 64.565 & 64.451 & 64 \\ 63.424 & 63.311 & \end{array}$

$\begin{array}{ll}73.462 & 73.348 \\ 72.321 & 72.207\end{array}$

73.233

$\begin{array}{lll}73.120 & 73.006 & 72.892\end{array}$

$\begin{array}{llll}10.637 & 71.522 & 72 \\ 0.496 & 70.382 & 70\end{array}$

$69.355 \quad 69.241$

$67.074 \quad 66.960$

$\begin{array}{ll}65.934 & 65.819 \\ 64.793 & 64.679\end{array}$

$71.181 \quad 71.066$

68.89968 .785

$\begin{array}{ll}67.758 & 67.644 \\ 66.618 & 66.503\end{array}$

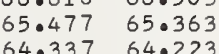

70.953

68.671
67.530

66.390

63.65263 .539

$63.197 \quad 63.083$

$64 \cdot 109$

$\begin{array}{lll}70.838 & 70.724 & 70.610 \\ 69.697 & 69.583 & 69.469\end{array}$

$\begin{array}{lll}68.557 & 68.442 & 68.329\end{array}$

$\begin{array}{lll}67.417 & 67.302 & 67.187 \\ 66.276 & 66.162 & 66.047\end{array}$

$\begin{array}{lll}66.276 & 66.162 & 66.047 \\ 65.135 & 65.021 & 64.907\end{array}$

$\begin{array}{lll}63.995 & 63.881 & 63.767 \\ 62.854 & 62.741 & 62.626\end{array}$

$\begin{array}{llllll}62.056 & 61.942 & 61.828 & 61.714 & 61.601 & 61.486\end{array}$

$\begin{array}{rllll}762.512 & 62.398 & 62.284 & 62.170 & 62.0 \\ 61.373 & 61.259 & 61.145 & 61.031 & 60 \\ 60.232 & 60.119 & 60.005 & 59.891\end{array}$

$60.232 \quad 60.119$

$\begin{array}{ll}59.092 & 58.979 \\ 57.952 & 57.839\end{array}$

$\begin{array}{ll}56.813 & 56.699 \\ 55.673 & 55.559\end{array}$

55.673

$\begin{array}{ll}54.533 & 54.419 \\ 53.393 & 53.279\end{array}$

$58.865 \quad 58.750$

59.91760 .802

60.688

$52.253 \quad 52.140$

$56.584 \quad 56.471$

$\begin{array}{ll}58.637 & 58.52 \\ 57.497 & 57.38\end{array}$

$\begin{array}{ll}56.357 & 56.243\end{array}$

58.408
57.269

56.129
54.989

54.989
53.850

$\begin{array}{lll}59.435 & 59.320 & 50.347\end{array}$

$\begin{array}{lll}58.294 & 58.181 & 58.066\end{array}$

$\begin{array}{lll}56.015 & 55.900 & 55.787\end{array}$

$\begin{array}{lll}53.735 & 53.621 & 53.507\end{array}$

$\begin{array}{lllllll}52.937 & 52.824 & 52.710 & 52.596 & 52.481 & 52.368\end{array}$

$51.798 \quad 51.68$

$\begin{array}{llll}51.570 & 51.457 & 51.342 & 51.228\end{array}$

2962.0

$2 \cdot 1$
$2 \cdot 2$
$2 \cdot 3$

$49.976 \quad 49.861$

$0.886 \quad 50.772$

$50.659 \quad 50.544$

$\begin{array}{lll}47.697 & 47.583\end{array}$

$\begin{array}{llll}46.558 & 46.444 & 46.330 & 46.216 \\ 45.418 & 45.305 & 45.190 & 45.077\end{array}$

$48.608 \quad 48.495$

$49.520 \quad 49.405$

50.431

$50 \cdot 317$

$50.203 \quad 50.089$

$48.380 \quad 48.267$

48.152
47.013

48.039

$47.924 \quad 47.811$

$44.279 \quad 44.166 \quad 44.052 \quad 43.938$

$46.102 \quad 45.988 \quad 45.874$

$\begin{array}{ll}44.963 & 44.849 \\ 43.824 & 43.710\end{array}$

44.735
43.596

45.760
44.62

$45.646 \quad 45.532$

2.7

$\begin{array}{ll}42.001 & 41.888 \\ 40.862 & 40.749\end{array}$

$\begin{array}{ll}42.913 & 42.79 \\ 41.774 & 41.660\end{array}$

$42.685 \quad 42.57$

$\begin{array}{lll}48.482 & 43.368 & 43.254\end{array}$

$\begin{array}{ll}40.635 & 40.52 \\ 39.496 & 39.382\end{array}$

2963

3.

38.586
37.447

39.610

3.472
7.333
3.195

$35.170 \quad 35.057$

34.032

33.918

$30.617 \quad 30.503$

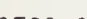

2964

4.0
4.
$4 \cdot 3$
$4 \cdot 4$
4.0
4.7
4.8
4.9

2965

5.0
5.1
5.
5.4
5.5
5.7
5.8
5.9

$\begin{array}{lll} & 16.966 & 16.853 \\ 2 & 15.829 & 15.715\end{array}$

$\begin{array}{ll}14.693 & 14.579 \\ 13.556 & 13.442\end{array}$

$12.419 \quad 12.305$

$11.282 \quad 11.168$

$\begin{array}{ll}10.146 & 10.032\end{array}$

$\begin{array}{ll}07.872 & 07.758 \\ 06.735 & 06.622\end{array}$

2966.0

$\begin{array}{ll}0.599 & 05.485\end{array}$

$\begin{array}{ll}04.463 & 04.349 \\ 03.327 & 03.213\end{array}$

$\begin{array}{ll}02.190 & 02.07\end{array}$

$99.919 \quad 99.80$

$98.783 \quad 98.669$

$97.647 \quad 97.533$

$\begin{array}{ll}96.511 & 96.397 \\ 95.375 & 95.262\end{array}$

$\begin{array}{ll}37.220 & 37.105\end{array}$

40.407

41.31

42.343
41.204

42.2

42.115
40.977

39.041

38.927

$38.813 \quad 38.699$

$34.943 \quad 34.829$

$38.130 \quad 38.016$

$36.992 \quad 36.87$

$\begin{array}{ll}34.715 & 34.601\end{array}$

36.764

37.789
36.650

34.374
33.235

$32.666 \quad 32.552$

$32.438 \quad 32.32$

33.349

32.097

$37.675 \quad 37.561$

$35.398 \quad 35.284$

$34 \cdot 260 \quad 34 \cdot 146$

$\begin{array}{ll}31.121 & 33.007 \\ 31.983 & 31.869\end{array}$

$30.845 \quad 30.731$

$\begin{array}{llllllll}29.352 & 30.276 & 30.162 & 30.048 & 29.934 & 29.820 & 29.707 & 29.593 \\ 29.138 & 29.024 & 28.911 & 28.796 & 28.683 & 28.569 & 28.455\end{array}$

$\begin{array}{llllll}27.886 & 27.772 & 27.659 & 27.545 & 27.431 & 27.317\end{array}$

$28.114 \quad 28.000$

$26.749 \quad 26.63$

$\begin{array}{ll}25.611 & 25.498 \\ 24.473 & 24.359\end{array}$

26.521

26.407

$26 \cdot 2$

$\begin{array}{ll}25.838 & 25.725 \\ 24.701 & 24.587\end{array}$

$23.563 \quad 23.449 \quad 23.335 \quad 23.222$

$24 \cdot 246$
23.108

$24 \cdot 132$

$\begin{array}{llll}23.108 & 22.995 & 22.881 & 22.767 \\ 21.970 & 21.857 & 21.743 & 21.629\end{array}$

24.019

$\begin{array}{llllllll}22.426 & 22.312 & 22.198 & 22.084 & 21.970 & 21.857 & 21.743 & 21.629 \\ 21.288 & 21.175 & 21.061 & 20.947 & 20.833 & 20.719 & 20.605 & 20.492 \\ 20.151 & 20.037 & 19.923 & 19.810 & 19.696 & 19.582 & 19.468 & 19.354\end{array}$

19.01420 .037

19.696

$\begin{array}{lll}19.582 & 19.468 & 19.354 \\ 18.444 & 18.331 & 18.217\end{array}$

16.73916 .625

$17.649 \quad 17.535$

$\begin{array}{llll}18.558 & 18.444 & 18.331 & 18.217 \\ 17.421 & 17.308 & 17.194 & 17.080\end{array}$

0.292123

0.292122

0.292120

0.292117

0.292116

0.292113

0.292111

0.292108

0.292107

0.292105
0.292104

0.292102

0.292100

0.292098

0.292097

0.292094

0.292092

0.292091

0.292089

0.292086

0.292083

0.292082

0.292080

0.292079

0.292077
0.292076

0.292074

0.292073
0.292071

0.292070

0.292069

0.292066

0.292064

0.292063

0.292060

0.292058
0.292057

0.292055

0.292054

0.292051

0.292049

0.292048

0.292045

0.292044

0.292042

0.292039

0.292038

0.292036

0.292035

0.292033

0.292032

0.292029

0.292027

0.292026

0.292024

0.292023
0.292021

0.292020

0.292019

0.292017
0.292016

0.292014

0.292013

0.292010

0.292008

0.292008
0.292007

$\begin{array}{lllllllllll}86.292 & 86.179 & 86.065 & 85.952 & 85.838 & 85.725 & 85.611 & 85.498 & 85.384 & 85.271\end{array}$

$\begin{array}{llllllllll}85.157 & 85.043 & 84.930 & 84.816 & 84.703 & 84.590 & 84.476 & 84.363 & 84.250 & 84.136 \\ 84.022 & 83.909 & 83.795 & 83.682 & 83.568 & 83.455 & 83.341 & 83.228 & 83.114 & 83.001\end{array}$

0.292005

0.292004

0.292001

0.291999

0.291998

0.291997

0.291995

0.291994

$\begin{array}{llllllllll}74.945 & 74.832 & 74.719 & 74.605 & 74.492 & 74.379 & 74 \cdot 265 & 74 \cdot 152 & 74 \cdot 039 & 73.925 \\ 73.811 & 73.698 & 73.584 & 73.471 & 73.357 & 73.244 & 73.131 & 73.017 & 72.904 & 72.791\end{array}$

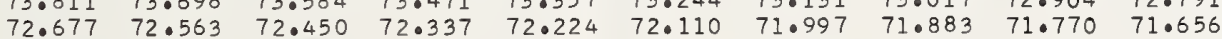

0.291991

0.291989

0.291988

0.291986

0.291985

0.291982

0.291980

0.291979

$\begin{array}{lllllllllll}64.740 & 64.627 & 64.513 & 64.400 & 64.287 & 64.173 & 64.060 & 63.947 & 63.833 & 63.720\end{array}$

$\begin{array}{llllllllll}63.606 & 63.493 & 63.380 & 63.267 & 63.153 & 63.040 & 62.927 & 62.813 & 62.700 & 62.586\end{array}$

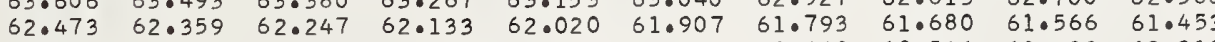

0.864685

0.86470

.86475

0.864784

0.864834

0.864908

0.864933

0.864958

0.865032

.865082

0.865132

0.865156

0.86518

0.865206

.865256

0.865305

0.865330

0.86538

0.865430

0.865454

0.865504

0.865529

.865579

0.865604

0.865628

0.865678

0.865703

0.865753

0.865777

0.865827

0.865852

0.865902 
0.291970

0.291969

0.291967
0.291966

0.291964

$\begin{array}{llll}50.010 & 49.896 & 49.783 & 49.670\end{array}$

54.088
52.955

55.108

$\begin{array}{lllll}56.127 & 56.014 & 55.901 & 550787\end{array}$

$\begin{array}{llll}54.994 & 54.881 & 54.768 & 54.654 \\ 53.861 & 53.748 & 53.635 & 53.521\end{array}$

$\begin{array}{llll}52.729 & 52.615 & 52.501 & 52.389 \\ 51.596 & 51.482 & 51.369 & 51.256\end{array}$

$\begin{array}{llll}51.596 & 51.482 & 51.369 & 51.256 \\ 50.463 & 50.350 & 50.236 & 50.123\end{array}$

0.291963

0.291961

0.291960

0.291959

0.291956

0.291956

0.291953

0.291951

0.291948

0.291947

0.291945

0.291944
0.291942

0.291941

0.291940
0.291938

0.291937

0.291935
0.291934

0.291932

0.291931
0.291929

0.291928

0.291926
0.291925

0.291924

0.291922
0.291921

0.291919

\section{$\begin{array}{ll}16.971 & 16.857 \\ 15.840 & 15.727\end{array}$}

$4 \cdot 3$

4.5 $\begin{array}{llllllllll}12.675 & 12.562 & 12.449 & 12.336 & 12.354 & 13.240 & 13.127 & 13.014 & 12.901 & 12.788 \\ 12.110 & 11.997 & 11.884 & 11.771 & 11.659\end{array}$ $\begin{array}{llllllllll}11.545 & 11.432 & 11.319 & 11.207 & 11.093 & 10.980 & 10.868 & 10.754 & 10.642 & 10.529\end{array}$ $\begin{array}{llllllllll}10.416 & 10.303 & 10.189 & 10.076 & 09.964 & 09.851 & 09.737 & 09.625 & 09.512 & 09.398\end{array}$ $\begin{array}{llllllllll}09.286 & 09.172 & 09.060 & 08.947 & 08.833 & 08.721 & 08.607 & 08.495 & 08.382 & 08.269 \\ 08.156 & 08.043 & 07.930 & 07.817 & 07.704 & 07.591 & 07.478 & 07.365 & 07.252 & 07.139\end{array}$ $\begin{array}{llllllllll}07.026 & 06.913 & 06.800 & 06.687 & 06.574 & 06.461 & 06.348 & 06.235 & 06.123 & 06.009\end{array}$ $\begin{array}{llllllllll}05.896 & 05.783 & 05.670 & 05.557 & 05.444 & 05.332 & 05.218 & 05.105 & 04.993 & 04.879 \\ 04.767 & 04.654 & 04.541 & 04.427 & 04.315 & 04.202 & 04.089 & 03.976 & 03.863 & 03.950\end{array}$

$\begin{array}{llllllllll}33603.637 & 03.524 & 03.411 & 03.298 & 03.185 & 03.072 & 02.959 & 02.846 & 02.733 & 02.620\end{array}$ $\begin{array}{llllllllll}02.508 & 02.395 & 02.282 & 02.169 & 02.056 & 01.942 & 01.830 & 01.717 & 01.604 & 01.491\end{array}$ $\begin{array}{llllllllll}01.378 & 01.265 & 01.152 & 01.040 & 00.926 & 00.813 & 00.700 & 00.587 & 00.475 & 00.362\end{array}$ $\begin{array}{llllllllll}33599.120 & 99.007 & 98.894 & 98.781 & 98.668 & 98.555 & 98.442 & 98.330 & 98.217 & 98.104\end{array}$ $\begin{array}{llllllllll}97.991 & 97.878 & 97.765 & 97.652 & 97.539 & 97.426 & 97.313 & 97.201 & 97.087 & 96.975\end{array}$ $\begin{array}{llllllllll}96.862 & 96.749 & 96.636 & 96.523 & 96.410 & 96.297 & 96.185 & 96.071 & 95.958 & 95.846\end{array}$

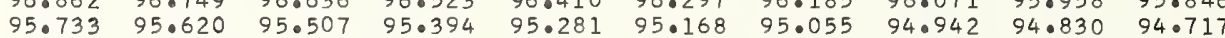
$\begin{array}{llllllllll}94.604 & 94.491 & 94.378 & 94.265 & 94.152 & 94.039 & 93.926 & 93.813 & 93.701 & 93.588 \\ 93.475 & 93.362 & 93.249 & 93.136 & 93.023 & 92.910 & 92.797 & 92.685 & 92.572 & 92.459\end{array}$

0.291918 0.291916 0.291913 0.291912 0.291910 0.291908 0.291906
0.291905

0.291903 0.291902
0.291900 0.291899 0.291897 0.291896 0.291894 0.291892 0.291890

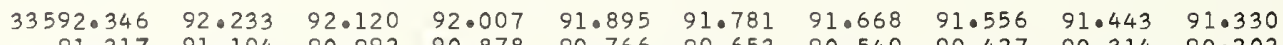

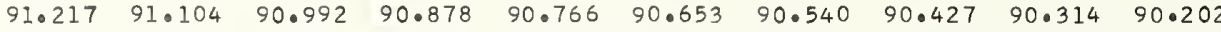
$\begin{array}{llllllllll}90.089 & 89.976 & 89.863 & 89.750 & 89.637 & 89.524 & 89.411 & 89.298 & 89.186 & 89.073\end{array}$ $\begin{array}{llllllllll}88.960 & 88.847 & 88.734 & 88.622 & 88.509 & 88.396 & 88.283 & 88.170 & 88.058 & 87.945\end{array}$ $\begin{array}{llllllllll}86.704 & 86.591 & 86.478 & 86.365 & 86.352 & 86.268 & 87.155 & 87.042 & 86.929 & 86.816 \\ 86.026 & 85.914 & 85.801 & 85.687\end{array}$ $\begin{array}{llllllllll}86.704 & 86.591 & 86.478 & 86.365 & 86.252 & 86.139 & 86.026 & 85.914 & 85.801 & 85.687 \\ 85.575 & 85.462 & 85.349 & 85.237 & 85.124 & 85.011 & 84.898 & 84.786 & 84.672 & 34.560\end{array}$ $\begin{array}{llllllllll}84.447 & 84.334 & 84.221 & 84.108 & 83.996 & 83.883 & 83.770 & 83.657 & 83.544 & 83.432\end{array}$ $\begin{array}{llllllllll}83.318 & 83.206 & 83.093 & 82.980 & 82.867 & 82.755 & 82.642 & 82.529 & 82.417 & 82.303 \\ 82.190 & 82.078 & 81.965 & 81.852 & 81.739 & 81.626 & 81.514 & 81.401 & 81.288 & 81.175\end{array}$

0.291889 0.291886 0.291884 0.291883 0.291881 0.291880 0.291878 0.291877 $\begin{array}{llllllllll}33581.063 & 80.950 & 80.837 & 80.724 & 80.611 & 80.499 & 80.386 & 80.273 & 80.160 & 80.047\end{array}$ $\begin{array}{llllllllll}79.935 & 79.822 & 79.708 & 79.596 & 79.483 & 79.371 & 79.258 & 79.145 & 79.032 & 78.919\end{array}$ $\begin{array}{llllllllll}78.807 & 78.694 & 78.581 & 78.468 & 78.355 & 78.243 & 78.130 & 78.017 & 77.904 & 77.792\end{array}$ $\begin{array}{llllllllll}77.679 & 77.566 & 77.454 & 77.340 & 77.228 & 77.115 & 77.002 & 76.890 & 76.777 & 76.664 \\ 76.551 & 76.439 & 76.326 & 76.213 & 76.101 & 75.988 & 75.875 & 75.762 & 75.649 & 75.537\end{array}$ $\begin{array}{llllllllll}76.551 & 76.439 & 76.326 & 76.213 & 76.101 & 75.988 & 75.875 & 75.762 & 75.649 & 75.537 \\ 75.424 & 75.311 & 75.198 & 75.086 & 74.973 & 74.860 & 74.747 & 74.635 & 74.521 & 74.409\end{array}$ $\begin{array}{llllllllll}74.296 & 74.184 & 74.071 & 73.958 & 73.845 & 73.732 & 73.620 & 73.507 & 73.394 & 73.281\end{array}$ $\begin{array}{llllllllll}73.168 & 73.056 & 72.943 & 72.831 & 72.718 & 72.605 & 72.492 & 72.379 & 72.267 & 72.154\end{array}$ $\begin{array}{llllllllll}72.041 & 71.928 & 71.816 & 71.703 & 71.590 & 71.478 & 71.365 & 71.252 & 71.140 & 71.027 \\ 70.914 & 70.801 & 70.688 & 70.576 & 70.463 & 70.350 & 70.237 & 70.125 & 70.012 & 69.899\end{array}$

0.291874 0.291873 0.291871 0.00180 0.291868 0.291867 0.291864 0.291864 0.291861

0.867169 0.867169
0.867194
0.86721 .9 0.867243 0.867268 0.867293 0.867293
0.867318 0.867343 0.867368 0.867393

0.867417 0.867442 0.867467 0.867517 0.867542 0.867567 0.867591 0.867641 0.867666 0.867691 0.867716
0.867741 0.867765 0.867790
0.867815 67840 0.867865
0.867890

0.867915 0.867940 0.867964
0.867989

0.868014

0.868039

0.868064

0.868089

0.868114
0.868138

0.868163 0.868188 0.868213 0.868263 0.868288 0.868312 0.868337 0.868362
0.868387

0.868412 0.868437 0.868462 0.868511 0.868536 0.868561 0.868586 0.868611
0.868636

0.868661 0.868685 0.868710 0.868735
0.868760 0.868785 0.868810 0.868835 0.868860
0.868884

0.868909 0.868934 0.868959 0.868984 0.869009 0.869059 0.869083
0.869108 0.869133 0.291860 0.291858 0.291857 0.291855 0.291854 0.291852
0.291851 0.291850 0.291848 0.869158 0.869183 0.869208 0.869258 0.869282 0.869307 0.869332 0.869357
0.869382

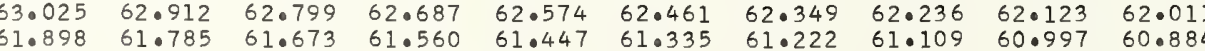
$\begin{array}{llllllllll}60.771 & 60.659 & 60.546 & 60.434 & 60.321 & 60.208 & 60.096 & 59.983 & 59.871 & 59.757 \\ 59.645 & 59.532 & 59.419 & 59.307 & 59.194 & 59.082 & 58.969 & 58.856 & 58.744 & 58.631\end{array}$ 0.291847

0.869407 0.291845 0.291844 0.291842 0.291841
0.291839 0.291838 0.291836 0.291835 0.291832 0.869432
0.869456 0.869481 0.869506 0.869531 0.869556 0.869581
0.869606 0.869631 
$47 \cdot 258$ $\begin{array}{llll}46.132 & 46.019 & 45.907 & 45.920 \\ 45.006 & 44.894 & 44.781 & 44068\end{array}$ $\begin{array}{llll}45.006 & 44.894 & 44.781 & 44.668\end{array}$ $\begin{array}{llll}43.880 & 43.768 & 43.656 & 43.543\end{array}$ $\begin{array}{llll}42.755 & 42.643 & 42.530 & 42.417\end{array}$

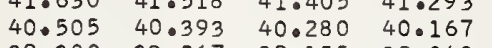
$\begin{array}{llll}39.380 & 39.267 & 39.155 & 39.042 \\ 38.254 & 38.142 & 38.030 & 37.917\end{array}$ $\begin{array}{llll}38.254 & 38.142 & 38.030 & 37.917 \\ 37.129 & 37.017 & 36.904 & 36.792\end{array}$

$\begin{array}{ll}46.807 & 46.695 \\ 45.682 & 45.569\end{array}$ $\begin{array}{ll}44.556 & 44.444 \\ 43.430 & 43.318\end{array}$ $\begin{array}{ll}42.305 & 42.192 \\ 41.180 & 41.067\end{array}$ $\begin{array}{ll}41.180 & 41.067 \\ 40.055 & 39.942\end{array}$

(36
1.

2982 82
2
2
2
2
2
2
2
2
2
2

2983.0 83.
3.
3.
3.
3.
3.
3.
3.7
3.
3. $3 \cdot 3$ $3 \cdot 4$

2984 .<smiles>[SiH3]</smiles>

$4 \cdot 2$
$4 \cdot 3$

4.4
4.5

$4 \cdot 7$
$4 \bullet 8$
$4 \cdot 9$

2985

5.1
5.2
5.3
5
5
5
5.7
5
5.8

33536.004
34.879 35.892

34.879
33.754 33.767

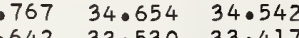

$32.517 \quad 32.405 \quad 32.292$

$\begin{array}{llll}31.505 & 31.393 & 31.280 & 31.167\end{array}$

$\begin{array}{llll}30.356 & 30.269 & 30.156 & 30.044 \\ 29.144 & 29.031 & 28.919\end{array}$

28.0.132 28.019 $29.031 \quad 28.919$

$\begin{array}{llll}27.007 & 26.895 & 26.783 & 26.670\end{array}$

33524.75

$24.759 \quad 24.646$

$\begin{array}{llll}23.635 & 23.522 & 24.534 & 24.422\end{array}$

$\begin{array}{llll}22.510 & 22.398 & 22.286 & 22.173\end{array}$

$\begin{array}{llll}21.386 & 21.274 & 21.162 & 21.049 \\ 20.262 & 20.150 & 20.038 & 19.925\end{array}$

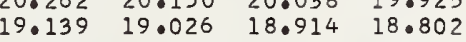

$\begin{array}{llll}18.015 & 17.903 & 17.791 & 17.678\end{array}$

$\begin{array}{llll}16.892 & 16.779 & 16.667 & 16.555 \\ 15.768 & 15.655 & 15.543 & 15.431\end{array}$

$\begin{array}{llll}14.644 & 15.655 & 15.543 & 15.431 \\ & 14.532 & 14.419 & 14.307\end{array}$

33513.5

$12.397 \quad 13.40$

$\begin{array}{llll}12.397 & 12.285 & 12.172 & 12.061\end{array}$

$\begin{array}{llll}10.150 & 10.038 & 09.926 & 09.813\end{array}$

$09.027 \quad 08.915 \quad 08.803 \quad 08.690$

07.90407 .792

$\begin{array}{llll}06.782 & 06.669 & 06.557 & 06.445\end{array}$

$\begin{array}{llll}05.659 & 05.546 & 05.434 & 05.322\end{array}$

$\begin{array}{llll}04.536 & 04.423 & 04.311 & 04.199 \\ 03.413 & 03.301 & 03.188 & 03.076\end{array}$

33502.290

$\begin{array}{llll}0.290 & 02.178 & 02.065 & 01.954\end{array}$

$\begin{array}{lllll}01.167 & 01.055 & 00.943 & 00.831\end{array}$

$\begin{array}{rrrr}33498.922 & 98.810 & 98.698 & 98.585\end{array}$

$\begin{array}{llll}9.7 .800 & 97.687 & 97.575 & 97.463 \\ 96.677 & 96.565 & 96.453 & 96.341\end{array}$

$\begin{array}{llll}96.677 & 96.565 & 96.453 & 96.341 \\ 95.556 & 95.443 & 95.331 & 95.219\end{array}$

$\begin{array}{llll}94.434 & 94.321 & 94.209 & 94.097\end{array}$

$\begin{array}{ll}93.311 & 93.199 \\ 92.189 & 92.077\end{array}$

$\begin{array}{ll}93.086 & 92.974 \\ 91.964 & 91.852\end{array}$

$33491.067 \quad 90.95$

$89.945 \quad 89.833 \quad 90.843 \quad 90.730$

$\begin{array}{llll}88.823 & 88.711 & 88.599 & 88.487\end{array}$

$\begin{array}{llll}87.701 & 87.589 & 87.477 & 87.365\end{array}$

$85.458 \quad 85.346 \quad 85.234 \quad 85.122$

$84.336 \quad 84.224$

$83.215 \quad 83.103$

$\begin{array}{ll}82.094 & 81.981 \\ 80.973 & 80.860\end{array}$

$2.991 \quad 82.879$

3479.85279 .740

80.749

2986

6.1
6
6
6
6
6
6
6
6

$\begin{array}{llll}78.730 & 78.618 & 78.506 & 78.3 \\ 77.609 & 77.497 & 77.385 & 77.272\end{array}$

$\begin{array}{llll}76.488 & 76.376 & 76.264 & 76.151\end{array}$

$\begin{array}{llll}75.367 & 75.255 & 75.143 & 75.031\end{array}$

$\begin{array}{llll}73.125 & 73.013 & 72.901 & 72.790\end{array}$

$\begin{array}{llll}72.005 & 71.893 & 71.781 & 71.669\end{array}$

$69.764 \quad 69.652 \quad 69.540 \quad 69.428$

33468

$67.523 \quad 67.4$

.531
7.411
6.291
65.170

$68.419 \quad 68.307$

$65.282 \quad 65.170$

63.04262 .930

61.92261 .810

$60.579 \quad 60.466$

$\begin{array}{llll}59.682 & 59.570 & 59.458 & 59.34\end{array}$

57.331

57.219

57.107

2988.

$\begin{array}{llllllllllll}8.2 & 55.204 & 55.091 & 54.979 & 54.868 & 54.756 & 54.644 & 54.532 & 54.420 & 54.308 & 54.196\end{array}$

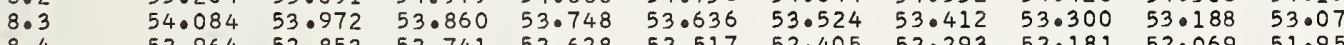

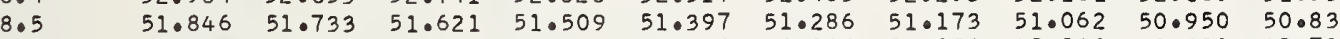

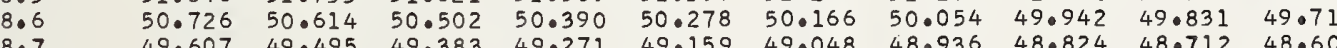

$49.607 \quad 49.495 \quad 49.38349 .271 \quad 49.159 \quad 49.048 \quad 48.936448 .824 \quad 48.712 \quad 48.600$

$\begin{array}{llllllllllll}8.8 & 48.488 & 48.376 & 48.264 & 48.152 & 48.040 & 47.929 & 47.816 & 47.705 & 47.593 & 47.48 \\ 8.9 & 47.369 & 47.257 & 47.145 & 47.033 & 46.921 & 46.810 & 46.697 & 46.586 & 46.474 & 46.361\end{array}$

2989.0

9.1

$\begin{array}{llll}3446.250 & 46.138 & 46.026 & 45.915\end{array}$

$\begin{array}{llll}45.131 & 45.019 & 44.907 & 44.795 \\ 44.012 & 43.900 & 43.789 & 43.676\end{array}$

$\begin{array}{llll}44.012 & 43.900 & 43.789 & 43.676 \\ 42.893 & 42.781 & 42.669 & 42.558\end{array}$

$\begin{array}{llll}42.893 & 42.781 & 42.669 & 42.558 \\ 41.774 & 41.663 & 41.551 & 41.439\end{array}$

$\begin{array}{llll}40.656 & 40.544 & 40.432 & 40.320\end{array}$

$\begin{array}{llll}39.538 & 39.425 & 39.313 & 39.202\end{array}$

$38.419 \quad 38.307 \quad 38.195 \quad 38.083$

$45.802 \quad 45.690$

$\begin{array}{llllll}44.684 & 44.571 & 44.579 & 45.467 & 45.355 & 45.243 \\ 43.348 & 44.236 & 44.124\end{array}$

$\begin{array}{llllll}43.564 & 43.453 & 43.341 & 43.229 & 43.117 & 43.005\end{array}$

$\begin{array}{llllll}42.446 & 42.334 & 42.222 & 42.110 & 41.999 & 41.887\end{array}$

$40.208 \quad 40.097 \quad 39.984 \quad 39.873 \quad 39.761 \quad 39.649$

$\begin{array}{llllll}39.090 & 38.978 & 38.866 & 38.754 & 38.643 & 38.531\end{array}$

$\begin{array}{llll}37.301 & 37.189 & 37.077 & 36.965 \\ 36.183 & 36.071 & 35.959 & 35.847\end{array}$

$\begin{array}{llllll}87.860 & 37.748 & 37.636 & 37.524 & 37.413\end{array}$

$\begin{array}{llllll}35.735 & 35.624 & 35.512 & 35.400 & 35.288 & 350176\end{array}$

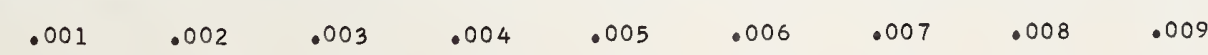

0.291829

0.291826

0.291825

0.291822

0.00180

0.291818

0.291826

0.291815

0.291812

0.291810
0.291809

0.291808

0.291806

0.291803

0.291802

0.291800

0.291799
0.291798

0.291796

0.291793

0.291792
0.291790

0.291789

0.291787

0.291786

0.291785

0.291782

0.291780
0.291779

0.291777

0.291774

0.291773

0.291772
0.291770

0.291769

0.291767

0.291766

0.291763

0.291762
0.291760

0.291755

0.291757

0.291756

0.291753

0.291750

0.291747

0.291744

0.291741

0.291740

0.291739

0.291736

0.291734

0.291734

0.291733

0.291730

0.291729
0.291727

0.291727

0.291726

0.291723

0.291721

0.291720

0.291719

0.291716

0.291714

0.291713

0.291711

0.291708

0.291707

0.291706

0.291704

0.291701

0.291700

0.291698

0.291697

291694

0.291693

0.291691

0.291688

.869655

0.869680

0.869730

0.869755

0.869805

869830

0.869879

0.869904

0.869929

.869979

0.870004

0.870029

.870078

0.870103
0.870128

0.870153

0.870178

.870228

0.870253

.870302

0.870327

0.870352

0.870402

0.870427

870477

0.870501

.870551

0.870576

0.870626

0.870651

0.870676
0.870701

0.870725

.870750
0.870775

0.870800

0.870825

0.870850
0.870875

0.870900

0.870924

0.870949

0.870974

0.871024

0.871049

(1)

0.871099
0.871124

0.871148

0.871173

0.871223

0.871248

0.871298

0.871323

0.871348
0.871373

0.871397

0.871422

0.871472

0.871497

0.871522
0.871547

0.871597
0.871621

0.871646

0.871671

0.871696

0.871746

0.871771

0.871796

0.871845

0.871895

0.871920

0.871970

0.871995

0.872020

0.872045

0.872070

0.872119

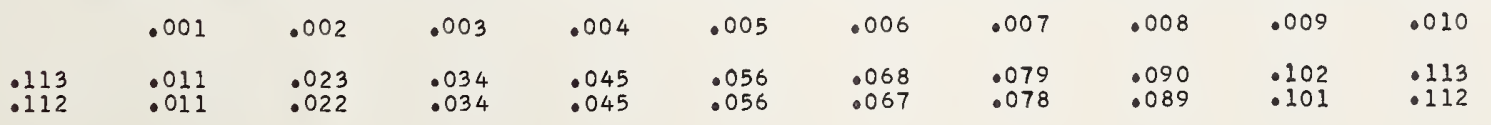


$2990.0 \quad 33435.064$

0.3

0.6

0.8
0.9

2991.0

i:

2992.0

$2 \cdot 1$

2.3

2.5

2.6

2.8
2.9

2993.0

3.

3.3
3.4

3.5

3.7
3.8

3.9

2994

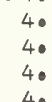

$4 \cdot 3$

4.5

4.7

4.9

2995.0

5.2

5.4

5.6
5.7

5.8

2996.0

6.

$6 \cdot 2$

6.4

6.5

6.7

2997.

7.

7.

7.5

7.

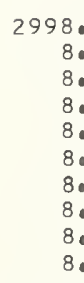

33412.716

11.599
10.482

02.668 3399.32

33356.974

$8 \cdot 1$

8.

8.8
8.9 $\begin{array}{llllllllll}33.946 & 33.834 & 34.841 & 34.729 & 34.617 & 34.505 & 34.394 & 34.282 & 34.169 & 34.058 \\ 33.722 & 33.611 & 33.499 & 33.387 & 33.275 & 33.164 & 33.052 & 32.940\end{array}$

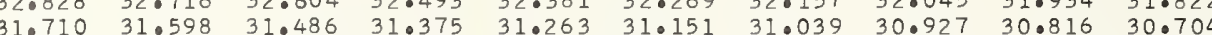
$\begin{array}{llllllllll}30.592 & 30.480 & 30.368 & 30.256 & 30.145 & 30.033 & 29.921 & 29.810 & 29.698 & 29.586\end{array}$ $\begin{array}{llllllllll}29.474 & 29.362 & 29.250 & 29.139 & 29.027 & 28.915 & 28.803 & 28.692 & 28.580 & 28.468\end{array}$ $\begin{array}{llllllllll}28.356 & 28.244 & 28.132 & 28.021 & 27.909 & 27.797 & 27.686 & 27.574 & 27.462 & 27.351\end{array}$ \begin{tabular}{llllllllll}
27.239 & 27.015 & 26.903 & 26.792 & 26.680 & 26.568 & 26.456 & 26.345 & 26.233 \\
\hline
\end{tabular}

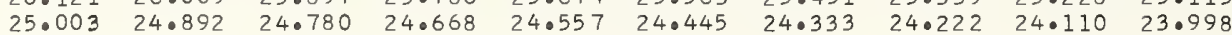
22.76922 .657

20.53420 .422

18.30019 .305

16.065015 .054

$\begin{array}{ll}14.949 & 14 \cdot 837 \\ 13.833 & 13.721\end{array}$

12.604

11.487
10.371

$09.366 \quad 09.254$

$07.133 \quad 07 \cdot 021$

$06.017 \quad 05.905$

$04.900 \quad 04.78$

$33401.553 \quad 01.441$ 9.20598 .093 5.974
95.862 $94.858 \quad 94 \cdot 747$ $93.742 \quad 93.631$
$92.627 \quad 92.515$ 91.51191 .400

23.663

$\begin{array}{lll}22.434 & 23.439 & 23.328\end{array}$

$\begin{array}{llll}20.311 & 21.316 & 21.205 & 21.093\end{array}$

$\begin{array}{llll}19.193 & 19.082 & 18.970 & 18.858 \\ 18.076 & 17.965 & 17.853 & 17.741\end{array}$

$\begin{array}{llll}16.959 & 16.848 & 16.736 & 16.624\end{array}$

15.84215 .730

$\begin{array}{ll}16.736 & 16.624 \\ 15.619 & 15.507\end{array}$

13.609

$12.492 \quad 12.381$

11.375

09.143

$06.910 \quad 06.798$

$05.793 \quad 05.682$

03.561

0.565
3.449

010330

01.218

14.50
13.38

15.507
14.391
13.27

$12 \cdot 26$
$11 \cdot 15$

$12 \cdot 157$

$\begin{array}{ll}10.036 & 09.924 \\ 08.919 & 08.808\end{array}$

$\begin{array}{ll}07.803 & 07.691 \\ 06.687 & 06.575\end{array}$

$05.570 \quad 05.458$

$\begin{array}{ll}04.454 & 04.342 \\ 03.337 & 03.226\end{array}$

$\begin{array}{llll}23.216 & 23.104 & 22.992 & 22.880 \\ 22.099 & 21.987 & 21.875 & 21.763\end{array}$

20.981 20.987 21.87521 .763

$\begin{array}{llll}19.864 & 19.752 & 19.640 & 19.528\end{array}$

$\begin{array}{llll}6.513 & 16.401 & 16.289 & 16.178\end{array}$

$\begin{array}{lll}15.284 & 15.172 & 15.06\end{array}$

$14 \cdot 279$
13.162

$4 \cdot 16$

$\begin{array}{llll}12.045 & 11.934 & 11.822 & 11.710\end{array}$

$\begin{array}{llll}10.929 & 10.817 & 10.706 & 10.594\end{array}$

$\begin{array}{llll}08.696 & 08.584 & 08.473 & 08.361\end{array}$

$\begin{array}{llll}07.580 & 07.468 & 07.356 & 07.244\end{array}$

$\begin{array}{llll}06.463 & 06.352 & 06.240 & 06.128 \\ 05.347 & 05.235 & 05.124 & 05.012\end{array}$

$\begin{array}{llll}04.231 & 04.119 & 04.008 & 03.896\end{array}$

$\begin{array}{llll}03.115 & 03.003 & 02.892 & 02.780\end{array}$

$02.223 \quad 02.110$

$00.213 \quad 00.102 * 90$

$\begin{array}{rrr}1.106 & 00.994 \quad 00 . \\ 9.990 * 99.879 * 99.0\end{array}$

$00.883 \quad 00.771 \quad 00.660 \quad 00.548$

$\begin{array}{llllllll}97.982 & 97.870 & 97.759 & 97.647 & 97.535 & 97.424 & 97.312 & 97.201\end{array}$

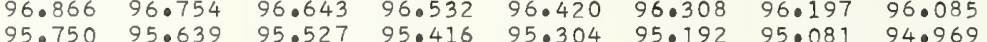

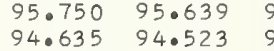

$95.52795 .416 \quad 95.30495 .192 \quad 95.081 \quad 94.969$

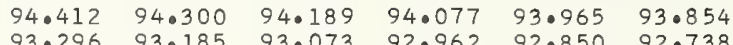

$\begin{array}{llllllll}9.520 & 93.408 & 93.296 & 93.185 & 93.073 & 92.962 & 92.850 & 92.738 \\ 2.404 & 92.292 & 92.181 & 92.069 & 91.958 & 91.846 & 91.735 & 91.623\end{array}$

$\begin{array}{rll}390.397 & 90.286 & 90.174 \\ 89.282 & 89.170 & 89.05\end{array}$

$\begin{array}{llll}88.167 & 88.055 & 87.944 & 87.83\end{array}$

$\begin{array}{llll}87.051 & 86.940 & 86.829 & 86.717\end{array}$

$\begin{array}{ll}84.822 & 84.710 \\ 83.707 & 83.59\end{array}$

$33379.248 \quad 79 \cdot 137$

$\begin{array}{ll}78.134 & 78.02 \\ 77.020 & 76.908\end{array}$

$\begin{array}{ll}75.905 & 75.794 \\ 74.791 & 74.680\end{array}$

$73.677 \quad 73.566$

$71.449 \quad 71.337$

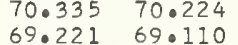

$\begin{array}{ll}79.026 & 78.915 \\ 77.911 & 77.800\end{array}$

$76.797 \quad 76.686$

75.683

$73.454 \quad 73.343$

7.34072 .229

$\begin{array}{rr}0.112 & 70.001\end{array}$

$33368.107 \quad 67.996$

$64.767-64.656$

$63.653 \quad 63.542$

$61.427 \quad 61.315$

60.31360 .20

$58.087 \quad 57.976$

$67.885 \quad 67.773$

$65.658 \quad 65.546$

$64.544 \quad 64.433$

$\begin{array}{ll}63.431 & 63.319 \\ 62.317 & 62.207\end{array}$

$61.204 \quad 61.093$

$\begin{array}{ll}60.091 & 59.979 \\ 58.978 & 58.866\end{array}$

54.749
53.636 53.63

$52.523-52.412$

$51.411 \quad 51.29$

$49.186 \quad 49.074$

$48.073 \quad 47.96$

$345.848 \quad 45.737$

2999.0

9.1
9.0
9.04
9.5
9.5
9.7
9.9

$44.736 \quad 44.62$

$42.512 \quad 42.401$

$41.400 \quad 41 \cdot 28$

$40.289 \quad 40.177$

$38.064 \quad 37.954$

$\begin{array}{ll}36.953 & 36.842 \\ 35.841 & 35.730\end{array}$

56.75

57.753

90.842

$\begin{array}{lll}.731 & 90.620 & 90.508\end{array}$

$\begin{array}{llllll}87.721 & 87.609 & 87.498 & 87.386 & 87.274 & 87.163\end{array}$

$\begin{array}{llllll}85.405 & 86.494 & 86.382 & 86.271 & 86.160 & 86.048\end{array}$

$\begin{array}{llllll}84.376 & 84.264 & 84.152 & 84.041 & 83.930 & 83.81\end{array}$

$\begin{array}{lllllll}83.261 & 83.149 & 83.038 & 82.926 & 82.815 & 82.704\end{array}$

$\begin{array}{llllll}82.146 & 82.035 & 81.923 & 81.812 & 81.700 & 81.589\end{array}$

$\begin{array}{lllllll}78.803 & 78.691 & 78.580 & 78.469 & 78.357 & 78.246\end{array}$

$\begin{array}{lllllll}77.688 & 77.577 & 77.466 & 77.354 & 77.243 & 77.131\end{array}$

$\begin{array}{lllllll}76.574 & 76.463 & 76.351 & 76.240 & 76.128 & 76.017 \\ 75.460 & 75.348 & 75.237 & 75.125 & 75.014 & 74.903\end{array}$

$\begin{array}{llllll}74.346 & 74.234 & 74.123 & 74.011 & 73.900 & 73.789\end{array}$

$\begin{array}{llllll}73.231 & 73.120 & 73.008 & 72.897 & 72.786 & 72.674 \\ 72.118 & 72.006 & 71.895 & 71.783 & 71.671 & 71.561\end{array}$

$\begin{array}{llllll}71.003 & 70.892 & 70.780 & 70.669 & 70.558 & 70.446\end{array}$

$\begin{array}{llllll}69.890 & 69.778 & 69.667 & 69.555 & 69.444 & 69.333 \\ 68.776 & 68.665 & 68.553 & 68.441 & 68.330 & 68.219\end{array}$

$\begin{array}{llllll}67.662 & 67.551 & 67.439 & 67.328 & 67.217 & 67.105\end{array}$

$\begin{array}{llllll}66.549 & 66.437 & 66.326 & 66.215 & 66.103 & 65.992\end{array}$

$\begin{array}{llllll}64.321 & 64.210 & 64.099 & 63.987 & 63.876 & 63.765\end{array}$

$\begin{array}{llllll}63.208 & 63.097 & 62.985 & 62.874 & 62.763 & 62.651\end{array}$

$\begin{array}{llllll}60.981 & 60.870 & 60.759 & 60.647 & 50.536 & 60.425\end{array}$

$\begin{array}{llllll}59.868 & 59.757 & 59.646 & 59.534 & 59.423 & 59.312\end{array}$

$\begin{array}{llllll}8.755 & 58.644 & 58.532 & 58.421 & 58.310 & 58.198 \\ 7.642 & 57.531 & 57.419 & 57.308 & 57.197 & 57.085\end{array}$

$\begin{array}{llllllll}5.638 & 55.528 & 56.529 & 56.417 & 56.306 & 56.195 & 56.083 & 55.972\end{array}$

$\begin{array}{llllllll}4.526 & 54.415 & 54.303 & 54.192 & 54.081 & 53.970 & 53.858 & 53.747\end{array}$

$\begin{array}{llllllll}53.414 & 53.302 & 53.190 & 53.080 & 52.968 & 52.857 & 52.746 & 52.634\end{array}$

$\begin{array}{llllllll}51.188 & 51.077 & 50.965 & 50.854 & 50.743 & 50.632 & 50.521 & 50.409\end{array}$

$\begin{array}{llllllll}0.075 & 49.964 & 49.853 & 49.741 & 49.630 & 49.519 & 49.408 & 49.297\end{array}$

$48.740 \quad 48.629$

$4.518 \quad 4805070$

$46.738 \quad 46.627$

46.51

46.404

$45.625 \quad 45.515$

$43.402 \quad 43.291$

42.290

$\begin{array}{ll}37.842 & 37.731\end{array}$

44.291

$43.179 \quad 43.068$

$\begin{array}{llllll}42.067 & 41.956 & 41.845 & 41.734 & 41.623 & 41.511 \\ 40.956 & 40.844 & 40.733 & 40.622 & 40.511 & 40.399\end{array}$

$\begin{array}{llllll}38.7431 & 39.732 & 39.621 & 39.510 & 39.399 & 39.288 \\ 38.620 & 38.509 & 38.398 & 38.287 & 38.176\end{array}$

$\begin{array}{lll}360 & 35.619 & 35.508\end{array}$

37.509

$\begin{array}{llllll}35.285 & 35.174 & 35.063 & 34.952 & 34.841\end{array}$

.1

$33.618 \quad 33.507$

$34.507 \quad 34.396$

$34 \cdot 285$

34.174

$\begin{array}{llll}34.062 & 33.952 & 33.840 & 33.729\end{array}$

$\begin{array}{lllllllll}32.396 & 32.285 & 32.174 & 32.062 & 31.952 & 31.840 & 31.729 & 31.619 & 32.618\end{array}$

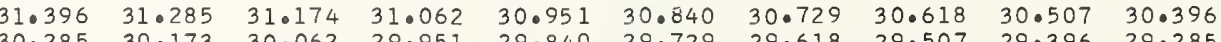

$\begin{array}{llllllllll}30.285 & 30.173 & 30.062 & 29.951 & 29.840 & 29.729 & 29.618 & 29.507 & 29.396 & 29.285\end{array}$

$\begin{array}{llllllllll}29.174 & 29.062 & 28.951 & 28.840 & 28.729 & 28.618 & 28.506 & 28.396 & 28.285 & 28.173\end{array}$

$\begin{array}{llllllllll}26.951 & 26.840 & 26.729 & 26.618 & 26.507 & 26.396 & 26.285 & 26.173 & 26.062 & 25.952\end{array}$

$\begin{array}{llll}25.840 & 25.729 & 25.618 & 25.507 \\ 24.729 & 24.619 & 24.507 & 24.396\end{array}$

.003

004

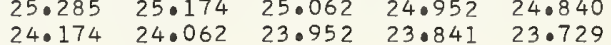

$0.291687-0.872144$

$0.291686 \quad 0.872169$

$0.291683 \quad 0.872219$

$0.291681 \quad 0.872244$

$0.291678 \quad 0.872294$

$0.291677 \quad 0.872319$

0.872343

0.291673

0.291671

0.291670

0.291667

0.291666

0.291664

0.291663

0.291660

0.291659

0.291657

0.291654

0.291653

0.291651

0.291650

0.291649

0.291646

0.291644

0.291643 


\section{.03}

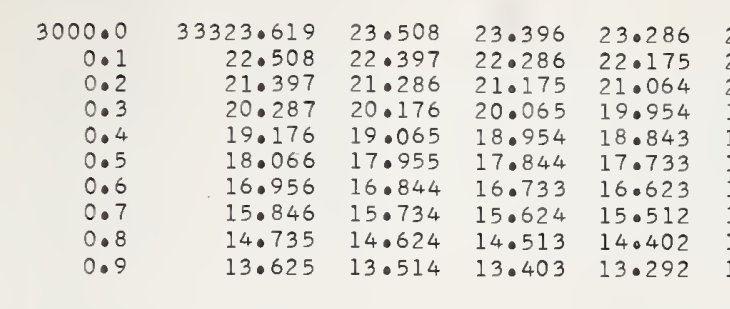

$\begin{array}{rl}3001 & : 0 \\ 1 & : 1 \\ 1 & : 2 \\ 1 & : 3 \\ 1 & : 5 \\ 1 & 1: 7 \\ 1 & 1.8\end{array}$

1.0
1.1
1.2
1.3
1.4
1.5
1.6
1.7
1.8
1.9

3002.0
2.1
2.2
2.3
2.4
2.5
2.6
2.7
2.8
2.9

3003.0

3.1
$3 \cdot 2$
$3 \cdot 3$
3.4
$3 \cdot 5$
$3 \cdot 6$
$3 \cdot 5$
3.

$\begin{array}{lll}.0 & 33301.419 \quad 01.308\end{array}$ $\begin{array}{llll}12.515 & 12.404 & 12.293 & 12.182 \\ 11.405 & 11.294 & 11.183 & 11.072\end{array}$ $\begin{array}{llll}10.295 & 10.184 & 10.073 & 09.962 \\ 09.185 & 09.074 & 08.963 & 08.852\end{array}$ $\begin{array}{llll}08.076 & 07.965 & 07.954 & 07.743 \\ 06.966 & 06.855 & 06.744 & 06.533\end{array}$ $\begin{array}{llll}06.966 & 06.855 & 06.744 & 06.533 \\ 05.856 & 05.745 & 05.634 & 05.523\end{array}$ $\begin{array}{llll}04.747 & 04.636 & 04.525 & 04.414 \\ 03.638 & 03.526 & 03.416 & 03.304\end{array}$ $\begin{array}{llll}03.638 & 03.526 & 03.416 & 03.304 \\ 02.528 & 02.417 & 02.306 & 02.195\end{array}$

33301.419
00.310
33299.200

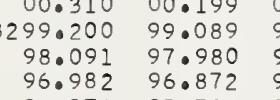

$\begin{array}{ll}95.874 & 95.76 \\ 94.765 & 94.65\end{array}$

$93.656 \quad 93.545$

$\begin{array}{ll}92.547 & 92.436 \\ 91.438 & 91.328\end{array}$

33290.330

$\begin{array}{ll}99.330 & 90.219 \\ 89.221 & 89.110\end{array}$

89.221

$87.004 \quad 88.002$

$85.004 \quad 86.894$

$84.789 \quad 84.677$

$83.680 \quad 83.56$

$\begin{array}{ll}81.464 & 81.35 \\ 80.356 & 80.24\end{array}$

3004.0

$4 \cdot 1$
4.2
$4 \cdot 3$
$4 \cdot 4$

$\begin{array}{ll}78.248 & 79.137 \\ 77.033 & 78.029\end{array}$

$\begin{array}{ll}77.033 & 73.92 \\ 75.925 & 75.81\end{array}$

$74.817 \quad 74.707$

$\begin{array}{lll}72.603 & 72.492 \quad 73.381\end{array}$

$\begin{array}{ll}71.496 & 71.38 \\ 70.388 & 70.277\end{array}$

4.8

$69.281 \quad 690$

33268.174

$\begin{array}{ll}68.174 & 68.063 \\ 67.067 & 66.956\end{array}$

$5 \cdot 1$

65.960

$65.960 \quad 65.849$

$64.853 \quad 64.742$

$62.640 \quad 62.52$

$62.418 \quad 62.308$

$61.533 \quad 61.423 \quad 61.312 \quad 61.202$

$\begin{array}{llll}59.320 & 59.209 & 59.099 & 58.98\end{array}$

58.213

$33257.107 \quad 56.997$

6.1

56.001

56.997
55.890
54.784

56.886

57.882

.04

.05

.06

.07

.08

.09

$(n-1) \times 1000$

$\lambda(n-1)$

$\begin{array}{ll}23.174 & 23.063 \\ 22.063 & 21.952 \\ 20.953 & 20.842 \\ 19.843 & 19.732 \\ 18.732 & 18.621 \\ 17.622 & 17.511 \\ 16.512 & 16.400 \\ 15.401 & 15.291 \\ 14.291 & 14.180 \\ 13.181 & 13.070\end{array}$

$\begin{array}{llll}22.952 & 22.841 & 22.730 & 22.619 \\ 21.841 & 21.730 & 21.619 & 21.508\end{array}$

$\begin{array}{llll}21.841 & 21.730 & 21.619 & 21.508 \\ 20.730 & 20.620 & 20.509 & 20.398\end{array}$

$\begin{array}{llll}19.621 & 19.510 & 19.399 & 19.288\end{array}$

$\begin{array}{llll}18.510 & 18.399 & 18.288 & 18.177 \\ 17.400 & 17.289 & 17.178 & 17.067\end{array}$

$\begin{array}{llll}17.400 & 17.289 & 17.178 & 17.067 \\ 16.290 & 16.179 & 16.067 & 15.957\end{array}$

$\begin{array}{llll}15.179 & 15.068 & 14.058 & 15.9546\end{array}$

$\begin{array}{llllll}12.071 & 11.960 & 11.849 & 11.738 & 11.627 & 11.516\end{array}$

$\begin{array}{llllll}10.961 & 10.850 & 10.739 & 10.628 & 10.517 & 10.406\end{array}$

$\begin{array}{llllll}09.851 & 09.740 & 09.629 & 09.518 & 09.407 & 09.296\end{array}$

$\begin{array}{lllllll}07.632 & 07.521 & 07.410 & 07.299 & 07.188 & 07.077\end{array}$

$\begin{array}{llllll}06.522 & 06.411 & 06.300 & 06.189 & 06.079 & 05.967 \\ 05.413 & 05.302 & 05.191 & 05.080 & 04.969 & 04.858\end{array}$

$\begin{array}{llllll}04.303 & 04.192 & 04.081 & 03.970 & 04.969 & 04.858 \\ 03 & 03.85 & 03.749\end{array}$

$02.084 \quad 01.973 \quad 01.862 \quad 01.751 \quad 01.641 \quad 01.530$

0.291545

0.291542

0.29153

0.291538
0.291537
0.291535

0.291535

0.291534

0.291531

.

0.291528

0.291525

0.291522

0.291521

0.291518

0.291517

0.291515

0.291514

0.2915

0.291507

0.291506

0.291503

0.291501

0.291499

0.291497

0.291494

0.291493

0.291490

0.291489

0.291487

0.291485

0.29148

0.291482

0.291479

0.291477
0.291476

0.291475

0.291473

0.291472

0.291470

0.29146

0.291466

0.291465

0.291462

0.291461

0.291459

0.29145

0.291456

0.291455

0.291452

0.291451
0.291449 $\begin{array}{llllllllll}51.577 & 51.466 & 51.355 & 51.245 & 51.134 & 51.023 & 50.913 & 50.802 & 50.692 & 50.581\end{array}$

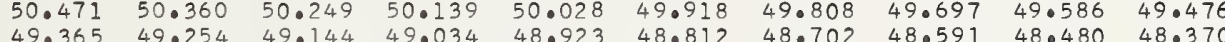

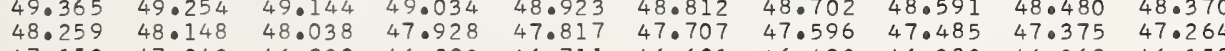
$47.153 \quad 47.043 \quad 46.933 \quad 46.822$

$46.711 \quad 46.601 \quad 46.590 \quad 46.380 \quad 46.375 \quad 47.264$

0.291448

3007.0

7.2

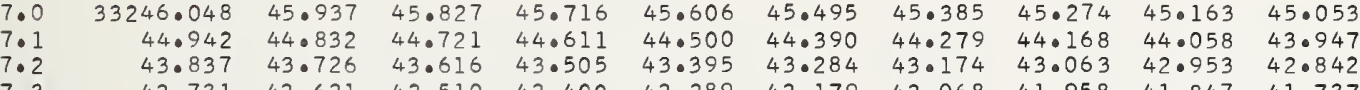
$\begin{array}{llllllllll}42.731 & 42.621 & 42.510 & 42.400 & 42.289 & 42.179 & 42.068 & 41.958 & 41.847 & 41.737\end{array}$

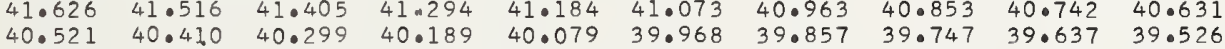
$\begin{array}{llllllllll}40.521 & 40.410 & 40.294 & 40.189 & 40.079 & 39.968 & 39.857 & 39.747 & 39.637 & 39.526 \\ 39.416 & 39.305 & 39.194 & 39.084 & 38.974 & 38.863 & 38.752 & 38.642 & 38.531 & 38.421\end{array}$ $\begin{array}{llllllllll}39.416 & 39.305 & 39.194 & 39.084 & 38.974 & 38.863 & 38.752 & 38.642 & 38.531 & 38.421 \\ 38.311 & 38.200 & 38.090 & 37.979 & 37.869 & 37.759 & 37.648 & 37.537 & 37.427 & 37.316\end{array}$ $\begin{array}{llllllllll}38.311 & 38.200 & 38.090 & 37.979 & 37.869 & 37.759 & 37.648 & 37.537 & 37.427 & 37.0116 \\ 37.206 & 37.095 & 36.985 & 36.875 & 36.764 & 36.653 & 36.542 & 36.432 & 36.322 & 36.211\end{array}$ $\begin{array}{llllllllll}37.206 & 37.095 & 36.985 & 36.875 & 36.764 & 36.653 & 36.542 & 36.432 & 36.322 & 36.211 \\ 36.101 & 35.990 & 35.880 & 35.769 & 35.659 & 35.548 & 35.438 & 35.327 & 35.217 & 35.106\end{array}$

7.0
8.1
8.2
8.4
8.5
8.6

$33234.996 \quad 34.88$

$34.775 \quad 34.665$

$\begin{array}{llllll}34.554 & 34.443 & 34.333 & 34.222 & 34.112 & 34.001\end{array}$

$\begin{array}{llllllllll}33.891 & 33.780 & 33.670 & 33.560 & 33.449 & 33.338 & 33.229 & 33.118 & 33.007 & 32.897 \\ 32.786 & 32.676 & 32.565 & 32.455 & 332.344 & 32.234 & 32.0124 & 32.013 & 31.002 & 31.792\end{array}$

$\begin{array}{llllllllll}32.786 & 32.676 & 32.565 & 32.455 & 32.344 & 32.234 & 32.124 & 32.013 & 31.902 & 31.792 \\ 31.682 & 31.571 & 31.460 & 31.350 & 31.240 & 31.129 & 31.019 & 30.908 & 30.798 & 30.687\end{array}$

$\begin{array}{llllllllll}31.682 & 31.571 & 31.460 & 31.350 & 31.240 & 31.129 & 31.019 & 30.908 & 30.798 & 30.687 \\ 30.577 & 30.466 & 30.356 & 30.246 & 30.135 & 30.025 & 29.914 & 29.804 & 29.693 & 29.583\end{array}$

$\begin{array}{llllllllll}30.577 & 30.466 & 30.356 & 30.246 & 30.135 & 30.025 & 29.914 & 29.804 & 29.693 & 29.583 \\ 29.472 & 29.362 & 29.251 & 29.141 & 29.031 & 28.020 & 28.810 & 28.099 & 28.589 & 28.479\end{array}$

$\begin{array}{llllllllll}29.472 & 29.362 & 29.251 & 29.141 & 29.031 & 28.920 & 28.810 & 28.699 & 28.589 & 28.479 \\ 28.368 & 28.257 & 28.147 & 28.037 & 27.926 & 27.815 & 27.706 & 27.595 & 27.484 & 27.374\end{array}$

$\begin{array}{llllllllll}28.368 & 28.257 & 28.147 & 28.037 & 27.926 & 27.815 & 27.706 & 27.595 & 27.484 & 27.374 \\ 27.263 & 27.153 & 27.042 & 26.932 & 26.822 & 26.711 & 26.601 & 26.490 & 26.380 & 26.270\end{array}$

$\begin{array}{llllllllll}27.263 & 27.153 & 27.042 & 26.932 & 26.822 & 26.711 & 26.601 & 26.490 & 26.380 & 26.270 \\ 26.160 & 26.049 & 25.939 & 25.829 & 25.718 & 25.608 & 25.497 & 25.386 & 25.276 & 25.0166\end{array}$

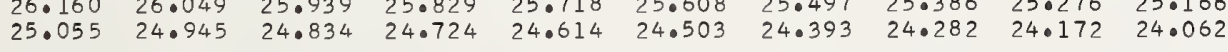

3009.0

9.0
9.0
9.3
9.5
9.6
9.8

33223.951

$223.951-23.841$

$\begin{array}{llllll}23.510 & 23.399 & 23.289 & 23.178 & 23.068 & 22.957\end{array}$

$\begin{array}{llllllllll}22.847 & 22.737 & 22.626 & 22.516 & 22.406 & 22.295 & 22.185 & 22.074 & 21.963 & 21.854 \\ 21.743 & 21.632 & 21.522 & 21.412 & 21.301 & 21.191 & 21.081 & 20.970 & 20.860 & 20.750\end{array}$

$\begin{array}{llllllllll}20.639 & 20.528 & 20.418 & 20.308 & 20.197 & 20.087 & 19.977 & 19.866 & 19.756 & 19.646\end{array}$

$\begin{array}{llllllllll}19.535 & 19.425 & 19.314 & 19.204 & 19.094 & 18.983 & 18.873 & 18.763 & 18.652 & 18.542 \\ 10.431 & 18.321 & 18.210 & 18.101 & 17.990 & 17.879 & 17.769 & 17.659 & 17.548 & 170437\end{array}$

$\begin{array}{llllllllll}18.431 & 18.321 & 18.210 & 18.101 & 17.990 & 17.879 & 17.769 & 17.559 & 17.548 & 17.437 \\ 17.328 & 17.217 & 17.106 & 16.997 & 16.886 & 16.776 & 16.666 & 16.555 & 16.445 & 16.334\end{array}$

$\begin{array}{lllllllllll}16.224 & 16.113 & 16.003 & 15.893 & 15.782 & 15.672 & 15.562 & 15.452 & 15.341 & 15.231\end{array}$

$\begin{array}{llllllllll}15.120 & 15.010 & 14.899 & 14.789 & 14.679 & 14.569 & 14.458 & 14.348 & 14.238 & 14.127\end{array}$

$\begin{array}{llll}14.017 & 13.907 & 13.797 & 13.686\end{array}$

13.576

13.465

$\begin{array}{llll}13.355 & 13.245 & 13.134 & 13.024\end{array}$

0.291447

0.291445

0.291442

0.29144

0.291433

0.291437

0.291435
0.291434

0.291433

0.291431

0.29143

0.291428

0.291427

0.291424

0.291423

0.29142

0.291420

0.291419

0.291417

0.291414

0.29141

0.291412

0.291410

0.291409

0.291408

0.291406

0.874635

0.874660
0.874685

0.874710

0.874735

0.874785

0.874810

0.874859

0.874884

0.874909

0.874959

0.875009

0.875034
0.875059
0.875084

0.875084
0.875109

0.875134

0.875183

0.875208

0.875283

0.875308

0.875358

0.875383

0.875408

0.875458

0.875483

0.875507

0.875557

0.875582

0.875632

0.875657

0.875707

0.875732

0.875782

0.875807

0.875832

0.875881

0.875906

0.875931

0.875981

0.876005

0.876056

0.876081

0.876131

0.876156

0.876181

0.876230

0.876255

0.876280

0.876330

0.876380

0.876405

0.876430

0.87648

0.876505

0.876555

0.876580

0.876629

0.876654

0.876679

0.876729

0.876754

0.876779

0.876829

0.876854

0.876879

0.876904

0.876954

0.876979

0.877003

0.877028

0.877053

0.877103

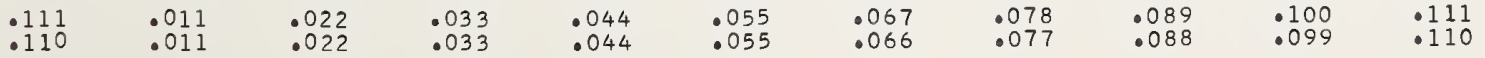


$\lambda(A)$

.00

3010.

3011

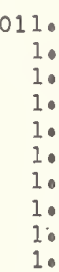

3013.

3.1
3.2
3.
3.
3.
3.
3.7
3.
3.

3014.0

$4 \cdot 1$
$4 \cdot 2$
$4 \cdot 3$

$4 \cdot 4$
$4 \cdot 5$

$4 \cdot 6$
4.7

$4 \cdot 8$

3015.0

5.
5.2
5.3
5.4
5.
5.
5.
5.9

$$
\begin{array}{r}
3016.0 \\
6.0 \\
6.0 \\
6.0 \\
6 \cdot 5 \\
6.6 \\
6 \cdot 7 \\
6.8 \\
6.9
\end{array}
$$

7.

$7 \cdot 4$
7.5

7.5
7.7

7.8

3018.0
8.1
8.2
8.3
8.4
8.5
8.5
8.7
8.8
8.9
3019.0
9.1
9.2
9.3
9.4
9.5
9.5
9.7
9.8
9.9

8.6 0.1
0.2
0.3
0.4
0.7
0.7
0.8
0.0
3212.914
11.811
10.707
09.604
08.500
07.398
06.294
05.191
04.089
02.986

33201.884 00.781

$33199.679 \quad 00.671$

$98.576 \quad 98.568$

$97.474 \quad 97.363$

$96.372 \quad 96.261$

95.26995 .159

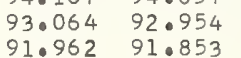

$\begin{array}{rl}3190.861 & 90.751 \\ 89.759 & 89.649 \\ 88.657 & 88.547 \\ 87.556 & 87.445 \\ 86.454 & 86.344 \\ 85.353 & 85.242 \\ 84.250 & 84.141 \\ 83.149 & 83.039 \\ 82.048 & 81.937 \\ 80.946 & 80.836\end{array}$

$$
\begin{array}{ll}
179.845 & 79.735 \\
78.745 & 78.534 \\
77.644 & 77.533 \\
76.542 & 76.432 \\
75.441 & 75.332 \\
74.341 & 74.230 \\
73.240 & 73.129 \\
72.139 & 72.029 \\
71.038 & 70.928 \\
69.937 & 69.828
\end{array}
$$

33168.837

67.737

65.537

64.436

62.236

$61.136 \quad 61.026$

58.936

.02

.03

.04

.05

.06

.07

.08

09

$(n-1) \times 1000$

0.291405

0.291403

0.291401

0.291399

0.291398

0.291396

0.291394

0.291392

0.291391

0.291389

0.291388
0.291387

0.291385

0.291384
0.291382

0.291381

0.291380

0.291378

0.291377

0.291375

0.291373

0.291371

0.291370

0.291367

0.291366

0.291363

0.291362

0.291360

0.291357

0.291356

0.291355

0.291353

0.291352

0.291349

0.291348

0.291346

0.291343

0.291342

0.291341

0.291339

0.291338

0.291335

0.291332

0.291330

0.291330
0.291328

0.291328
0.291327

0.291325

0.291324
0.291323

0.291321

0.291320

0.291319

0.291317

0.291314

0.291313
0.291312

0.291310

0.291309

0.291307

0.291306

0.291305
0.291303

0.291302

0.291301

0.291299

0.291298

0.291296

$\begin{array}{llllllllll}29.04 & 28.939 & 28.040 & 28.720 & 28.610 & 28.500 & 28.390 & 28.281\end{array}$

$\begin{array}{llllllllll}28.171 & 28.061 & 27.952 & 27.842 & 27.731 & 27.622 & 27.512 & 27.402 & 27.293 & 27.183 \\ 27.073 & 26.963 & 26.854 & 26.744 & 26.534 & 26.524 & 26.415 & 26.305 & 26.195 & 26.085\end{array}$

$25.975 \quad 25.866 \quad 25.756 \quad 25.646$

$33124.878 \quad 24.768$

$23.780 \quad 23.670 \quad 23.561 \quad 23.451$

22.68322 .573

$21.585 \quad 21.476 \quad 21.366 \quad 21.256$

$\begin{array}{llllll}.146 & 21.037 & 20.927 & 20.817 & 20.708 & 20.598\end{array}$

$\begin{array}{llllllllll}18.294 & 18.185 & 18.074 & 17.965 & 17.855 & 17.745 & 17.636 & 17.526 & 17.417 & 17.307\end{array}$

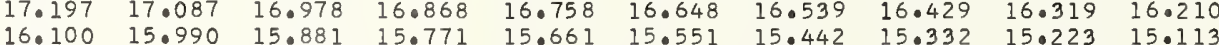

$\begin{array}{llllllllll}15.003 & 14.894 & 14.784 & 14.674 & 14.564 & 14.455 & 14.345 & 14.235 & 14.125 & 14.016\end{array}$

$\begin{array}{lllllllllll}19.0 & 33113.906 & 13.796 & 13.687 & 13.577 & 13.467 & 13.357 & 13.248 & 13.138 & 13.029 & 12.919\end{array}$

$\begin{array}{llllllllll}12.810 & 12.700 & 12.590 & 12.480 & 12.371 & 12.261 & 12.151 & 12.042 & 11.932 & 11.822\end{array}$

$\begin{array}{llllllllll}10.616 & 10.506 & 10.396 & 10.287 & 11.274 & 11.164 & 11.055 & 10.942 & 11.932 & 11.828 \\ \end{array}$

$\begin{array}{llllllllll}09.519 & 09.410 & 09.300 & 09.190 & 09.081 & 08.971 & 08.861 & 08.752 & 08.642 & 08.532\end{array}$

$\begin{array}{llllllllll}08.423 & 08.313 & 08.204 & 08.094 & 07.985 & 07.875 & 07.765 & 07.656 & 07.546 & 07.437\end{array}$

$\begin{array}{llllllllll}07.327 & 07.217 & 07.107 & 06.998 & 06.888 & 06.778 & 06.669 & 06.560 & 06.450 & 06.340\end{array}$

$\begin{array}{llllllllll}06.230 & 06.121 & 06.011 & 05.901 & 05.792 & 05.682 & 05.573 & 05.463 & 05.354 & 05.244 \\ 05.134 & 05.024 & 04.915 & 04.805 & 04.695 & 04.586 & 04.476 & 04.367 & 04.257 & 04.147\end{array}$

$04.038 \quad 03.929$ $\begin{array}{ll}04.915 & 04.805 \\ 03.819 & 03.709\end{array}$
0.291294

0.291292

0.291291

0.291289

0.291287

0.291285

0.291284

0.291283
0.291281

0.291280

0.291278

0.291277
0.291276

0.291274

0.291272

0.291272

0.291270

0.291267 $\lambda(n-1)$

0.877128 0.877153

.877203

0.877228

0.877278

0.877303

0.877353

0.877378

0.877403

0.877427
0.877452

0.877477

0.877502

.877527
.877552

0.877577

877627

.877652
.877677

0.877702

0.877727

0.877752
0.877777

0.877802

0.877827
0.877852

0.877877 0.877901

0.877951

0.877976

0.878001

0.878051

0.878076

0.878101

0.878126

0.878151

0.878201

0.878226

0.878251

0.878276

0.878326

0.878351

0.878375
0.878400

0.878425
0.878450

0.878450

0.878475

0.878525 0.878550

0.878575
0.878600

0.878625

0.878650

0.878675

0.878725

0.878750

0.878775

0.878800

0.878825

0.878875

0.878900

0.878924

0.878949

0.878974

0.878999

0.879024

0.879049

0.879074
0.879099

0.879124

.879149
0.879174

0.879199

0.879224

0.879249

0.879274
0.879299

0.879324

0.879349

0.879374

0.879399

0.879424

0.879474

0.879474
0.879498

0.879498
0.879523

0.879548

0.879573
0.879598

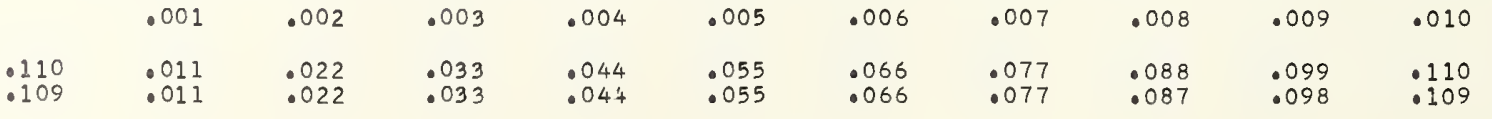




$$
\begin{aligned}
& 7081.03 \\
& 79 . \\
& 77 . \\
& 76 . \\
& 75 \\
& 74 . \\
& 73 . \\
& 72 . \\
& 71 .
\end{aligned}
$$

$\begin{array}{lllllllllll}3028.0 & 33015.487 & 15.378 & 15.269 & 15.160 & 15.051 & 14.941 & 14.833 & 14.724 & 14 \cdot 615 & 14.505\end{array}$ $\begin{array}{lllllllllll}8.1 & 14.397 & 14.288 & 14.179 & 14.070 & 13.960 & 13.851 & 13.743 & 13.633 & 13.524 & 13.416 \\ 8.2 & 13.307 & 13.198 & 13.089 & 12.980 & 12.871 & 12.762 & 12.653 & 12.544 & 12.435 & 12.326\end{array}$ $\begin{array}{lllllllllll}8.2 & 13.307 & 13.198 & 13.089 & 12.980 & 12.871 & 12.762 & 12.653 & 12.544 & 12.435 & 12.326 \\ 8.3 & 12.216 & 12.107 & 11.999 & 11.890 & 11.781 & 11.672 & 11.562 & 11.454 & 11.345 & 11.236\end{array}$ $\begin{array}{llllllllllll}8.4 & 11.126 & 11.018 & 10.909 & 10.799 & 10.691 & 10.582 & 10.473 & 10.364 & 10.255 & 10.146\end{array}$ $\begin{array}{lllllllllll}8.5 & 10.037 & 09.928 & 09.818 & 09.710 & 09.601 & 09.492 & 09.382 & 09.274 & 09.165 & 09.056 \\ 0 & 08.947 & 08.837 & 08.729 & 08.0520 & 08.511 & 08.401 & 08.293 & 08.184 & 08.075 & 07.966\end{array}$ $\begin{array}{llllllllllll}8.6 & 08.947 & 08.837 & 08.729 & 08.620 & 08.511 & 08.401 & 08.293 & 08.184 & 08.075 & 07.966 \\ 8.7 & 07.857 & 07.748 & 07.639 & 07.530 & 07.421 & 07.312 & 07.203 & 07.094 & 06.985 & 06.876\end{array}$ $\begin{array}{llllllllllll}8.8 & 06.767 & 06.658 & 06.549 & 06.440 & 06.331 & 06.222 & 06.113 & 06.004 & 05.896 & 05.786\end{array}$ $\begin{array}{lllllllllll}05.677 & 05.568 & 05.459 & 05.350 & 05.241 & 05.132 & 05.023 & 04.915 & 04.806 & 04.697\end{array}$

$\begin{array}{lllllllllll}3029.0 & 33004.588 & 04.479 & 04.370 & 04.261 & 04.152 & 04.042 & 03.934 & 03.825 & 03.716 & 03.607\end{array}$ $\begin{array}{lllllllllll}9.1 & 03.498 & 03.389 & 03.280 & 03.171 & 03.062 & 02.953 & 02.844 & 02.735 & 02.626 & 02.518\end{array}$ $\begin{array}{lllllllllll}9.2 & 02.409 & 02.300 & 02.191 & 02.082 & 01.973 & 01.864 & 01.755 & 01.646 & 01.538 & 01.428\end{array}$ $\begin{array}{llllllllllll}9.3 & 01.319 & 01.210 & 01.102 & 00.993 & 00.884 & 00.775 & 00.666 & 00.557 & 00.448 & 00.339\end{array}$

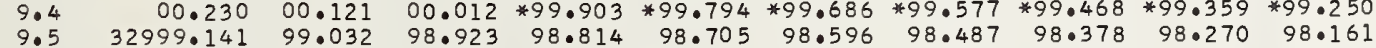
$\begin{array}{lllllllllll}9.6 & 98.052 & 97.942 & 97.833 & 97.725 & 97.616 & 97.507 & 97.398 & 97.290 & 97.180 & 97.072\end{array}$ $\begin{array}{lllllllllll}9.7 & 96.963 & 96.854 & 96.745 & 96.636 & 96.527 & 96.418 & 96.309 & 96.200 & 96.091 & 95.982\end{array}$ $\begin{array}{lllllllllll}9.8 & 95.874 & 95.764 & 95.656 & 95.546 & 95.437 & 95.329 & 95.220 & 95.111 & 95.002 & 94.894 \\ 9.8 & 94.0785 & 94.676 & 94.566 & 94.458 & 94.349 & 94.240 & 94.131 & 94.022 & 93.914 & 93.804\end{array}$

$\begin{array}{lllllllllll} & .001 & .002 & .003 & .004 & .005 & .006 & .007 & .008 & .009 & .010 \\ .110 & .011 & .022 & .033 & .044 & .055 & .066 & .077 & .088 & .099 & .110 \\ .109 & .011 & .022 & .033 & .044 & .054 & .065 & .076 & .087 & .098 & .109\end{array}$




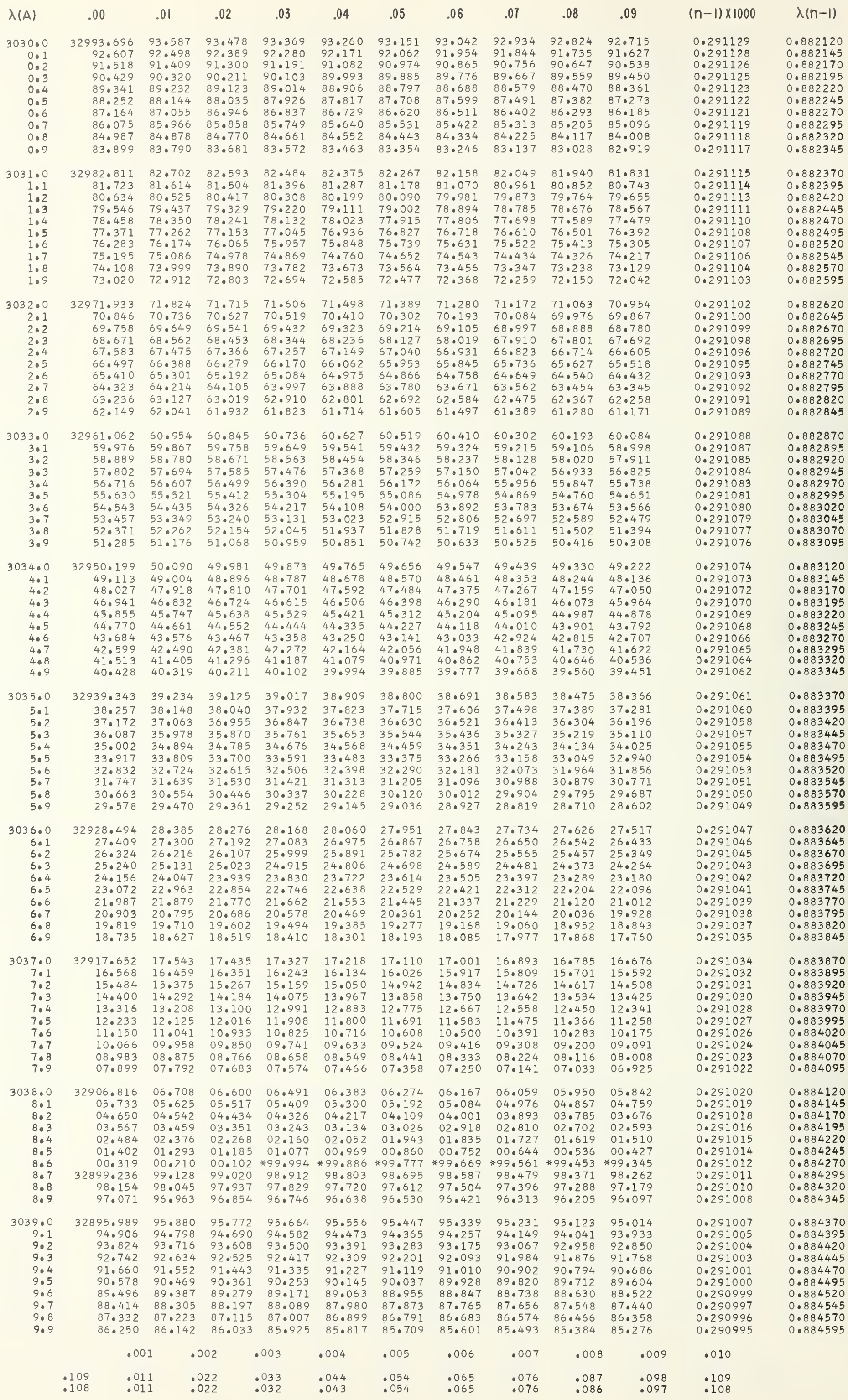




.06

\section{$\begin{array}{rlllll}2874.355 & 74.247 & 74.138 & 74.030 & 73 . \\ 73.274 & 73.166 & 73.057 & 72.949 & 72 . \\ 72.193 & 72.084 & 70.977 & 770.788 & 70 .\end{array}$} $\begin{array}{lllll}72.193 & 72.084 & 71.077 & 71.9488 \\ 71.112 & 71.004 & 70.896 & 70.788 & 710\end{array}$ $\begin{array}{lllll}70.031 & 69.923 & 69.815 & 69.707 & 69 \\ 68.951 & 68.843 & 68.734 & 68.627 & 68\end{array}$ $\begin{array}{lllll}68.951 & 68.843 & 68.734 & 68.627 \\ 67.870 & 67.762 & 67.654 & 67.546\end{array}$

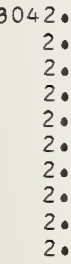

0.290956
0.290954

0.290953

0.290952

0.290949

0.290948

0.290945

0.290944
0.290942

0.290941

0.290940

0.290938

0.290936

0.290934

0.290933

0.290930

0.290929
0.290927

0.290926

0.290925

0.290922

0.290919

0.290918

0.290917

0.290915
0.290914

0.290913

0.290911

0.290909

0.290907
0.290906

0.290905

0.290903

0.290901

0.290899

0.290898

0.290897

0.290894

0.290893

0.290891

0.290889

0.290887

0.290886
0.290885

0.290883

0.290882

0.290879

0.290878
0.290877

0.290875
0.290874

0.290873

0.290870

0.290869 0.290867 0.290866 0.290865 0.290863 0.290862 0.290862
0.290861

0.885345

0.885370

0.885420

0.885445

0.885495

0.885520

0.885570

0.885620

0.885645

0.885695

0.885720

0.885770

0.885795

0.885820

0.885870

0.885895

0.885945 


\begin{tabular}{|c|c|c|c|c|c|c|c|c|c|c|c|c|}
\hline A) & .00 & .01 & .02 & .03 & 4 & .05 & .06 & .07 & .08 & .09 & 100 & $n-1)$ \\
\hline $\begin{array}{l}50.0 \\
0.1 \\
0.2 \\
0.3 \\
0.4 \\
0.5 \\
0.6 \\
0.7 \\
0.8 \\
0.9\end{array}$ & $\begin{array}{r}32777.353 \\
76.278 \\
75.203 \\
74.129 \\
73.054 \\
71.980 \\
70.906 \\
69.832 \\
68.758 \\
67.684\end{array}$ & $\begin{array}{l}77.245 \\
76.170 \\
75.096 \\
74.021 \\
72.947 \\
71.873 \\
70.798 \\
69.724 \\
68.650 \\
67.576\end{array}$ & $\begin{array}{l}77.137 \\
76.062 \\
74.088 \\
73.914 \\
72.840 \\
71.065 \\
70.691 \\
69.017 \\
68.543 \\
67.469\end{array}$ & $\begin{array}{l}77.030 \\
75.955 \\
74.880 \\
73.807 \\
72.732 \\
71.658 \\
70.583 \\
69.509 \\
68.435 \\
67.361\end{array}$ & $\begin{array}{l}76.922 \\
75.848 \\
74.773 \\
73.699 \\
72.625 \\
71.551 \\
70.476 \\
69.402 \\
68.328 \\
67.254\end{array}$ & $\begin{array}{l}76.815 \\
75.740 \\
74.666 \\
73.592 \\
72.518 \\
71.443 \\
70.369 \\
69.295 \\
68.221 \\
67.147\end{array}$ & $\begin{array}{l}76.707 \\
75.633 \\
74.558 \\
73.484 \\
72.410 \\
71.335 \\
70.262 \\
69.187 \\
68.113 \\
67.039\end{array}$ & $\begin{array}{l}76.600 \\
75.525 \\
74.451 \\
73.377 \\
72.303 \\
71.229 \\
70.154 \\
69.080 \\
68.006 \\
66.932\end{array}$ & $\begin{array}{l}76.493 \\
75.418 \\
74.344 \\
73.270 \\
72.195 \\
71.121 \\
70.046 \\
68.973 \\
67.899 \\
66.824\end{array}$ & $\begin{array}{l}76.385 \\
75.311 \\
74.236 \\
73.162 \\
72.087 \\
71.013 \\
69.939 \\
68.865 \\
67.791 \\
66.717\end{array}$ & $\begin{array}{l}0.290859 \\
0.290858 \\
0.290857 \\
0.290855 \\
0.290854 \\
0.290853 \\
0.290851 \\
0.290850 \\
0.290849 \\
0.290847\end{array}$ & $\begin{array}{l}0.887121 \\
0.887146 \\
0.887171 \\
0.887196 \\
0.887221 \\
0.887246 \\
0.887271 \\
0.887296 \\
0.887321 \\
0.887346\end{array}$ \\
\hline $\begin{array}{l}51.0 \\
1.1 \\
1.2 \\
1.3 \\
1.4 \\
1.5 \\
1.6 \\
1.7 \\
1.8 \\
1.9\end{array}$ & $\begin{array}{r}32766.610 \\
65.536 \\
64.462 \\
63.388 \\
62.315 \\
61.241 \\
60.167 \\
59.094 \\
58.021 \\
56.947\end{array}$ & $\begin{array}{l}66.502 \\
65.428 \\
64.354 \\
63.281 \\
62.208 \\
61.134 \\
60.060 \\
58.987 \\
57.913 \\
56.840\end{array}$ & $\begin{array}{l}66.395 \\
65.321 \\
64.247 \\
63.174 \\
62.100 \\
61.026 \\
59.953 \\
58.879 \\
57.806 \\
56.733\end{array}$ & $\begin{array}{l}66.288 \\
65.214 \\
64.140 \\
63.066 \\
61.993 \\
60.919 \\
59.846 \\
58.772 \\
57.698 \\
56.625\end{array}$ & $\begin{array}{l}66.180 \\
65.106 \\
64.032 \\
62.958 \\
61.885 \\
60.812 \\
59.738 \\
58.665 \\
57.591 \\
56.518\end{array}$ & $\begin{array}{l}66.073 \\
64.999 \\
63.925 \\
62.851 \\
61.778 \\
60.704 \\
59.631 \\
58.558 \\
57.484 \\
56.411\end{array}$ & $\begin{array}{l}65.965 \\
64.891 \\
63.818 \\
62.744 \\
61.671 \\
60.597 \\
59.524 \\
58.450 \\
57.377 \\
56.303\end{array}$ & $\begin{array}{l}65.858 \\
64.784 \\
63.710 \\
62.636 \\
61.563 \\
60.490 \\
59.416 \\
58.343 \\
57.269 \\
56.196\end{array}$ & $\begin{array}{l}65.750 \\
64.677 \\
63.603 \\
62.529 \\
61.456 \\
60.382 \\
59.309 \\
58.236 \\
57.162 \\
56.089\end{array}$ & $\begin{array}{l}65.643 \\
64.569 \\
63.496 \\
62.422 \\
61.348 \\
60.275 \\
59.202 \\
58.128 \\
57.055 \\
55.981\end{array}$ & $\begin{array}{l}0.290846 \\
0.290845 \\
0.290843 \\
0.290842 \\
0.290841 \\
0.290839 \\
0.290838 \\
0.290837 \\
0.290835 \\
0.290834\end{array}$ & $\begin{array}{l}0.887371 \\
0.887396 \\
0.887421 \\
0.887446 \\
0.887471 \\
0.887496 \\
0.887521 \\
0.887546 \\
0.887571 \\
0.887596\end{array}$ \\
\hline $\begin{array}{r}52.0 \\
2.1 \\
2.2 \\
2.3 \\
2.4 \\
2.5 \\
2.6 \\
2.7 \\
2.8 \\
2.9\end{array}$ & $\begin{array}{r}32755.874 \\
54.801 \\
53.728 \\
52.655 \\
51.582 \\
50.509 \\
49.436 \\
48.363 \\
47.291 \\
46.218\end{array}$ & $\begin{array}{l}55.767 \\
54.694 \\
53.620 \\
52.547 \\
51.474 \\
50.401 \\
49.329 \\
48.256 \\
47.183 \\
46.111\end{array}$ & $\begin{array}{l}55.659 \\
54.586 \\
53.513 \\
52.440 \\
51.367 \\
50.294 \\
49.221 \\
48.149 \\
47.076 \\
46.003\end{array}$ & $\begin{array}{l}55.552 \\
54.479 \\
53.406 \\
52.333 \\
51.259 \\
50.187 \\
49.115 \\
48.042 \\
46.969 \\
45.896\end{array}$ & $\begin{array}{l}55.445 \\
54.371 \\
53.298 \\
52.225 \\
51.152 \\
50.080 \\
49.007 \\
47.0934 \\
46.862 \\
45.789\end{array}$ & $\begin{array}{l}55.337 \\
54.264 \\
53.191 \\
52.118 \\
51.045 \\
49.973 \\
48.900 \\
47.827 \\
46.754 \\
45.682\end{array}$ & $\begin{array}{l}55.230 \\
54.157 \\
53.084 \\
52.011 \\
50.937 \\
49.865 \\
48.793 \\
47.720 \\
46.647 \\
45.574\end{array}$ & $\begin{array}{l}55.123 \\
54.050 \\
52.976 \\
51.903 \\
50.831 \\
49.758 \\
48.685 \\
47.613 \\
46.540 \\
45.467\end{array}$ & $\begin{array}{l}55.015 \\
53.942 \\
52.869 \\
51.796 \\
50.723 \\
49.651 \\
48.578 \\
47.506 \\
46.433 \\
45.360\end{array}$ & $\begin{array}{l}54.908 \\
53.835 \\
52.762 \\
51.689 \\
50.616 \\
49.543 \\
48.471 \\
47.398 \\
46.325 \\
45.253\end{array}$ & $\begin{array}{l}0.290833 \\
0.290831 \\
0.290830 \\
0.290829 \\
0.290827 \\
0.290826 \\
0.290825 \\
0.290823 \\
0.290822 \\
0.290821\end{array}$ & $\begin{array}{l}.887621 \\
.887646 \\
0.887671 \\
.887696 \\
.887721 \\
0.887747 \\
.887772 \\
.887797 \\
0.887822 \\
.8887847\end{array}$ \\
\hline $\begin{array}{l}53.0 \\
3.1 \\
3.2 \\
3.3 \\
3.4 \\
3.5 \\
3.6 \\
3.7 \\
3.8 \\
3.9\end{array}$ & $\begin{array}{r}2745.146 \\
44.073 \\
43.000 \\
41.928 \\
40.856 \\
39.784 \\
38.711 \\
37.640 \\
36.568 \\
35.496\end{array}$ & $\begin{array}{l}45.038 \\
43.966 \\
42.893 \\
41.821 \\
40.749 \\
39.677 \\
38.604 \\
37.532 \\
36.460 \\
35.389\end{array}$ & $\begin{array}{l}44.931 \\
43.858 \\
42.786 \\
41.714 \\
40.641 \\
39.569 \\
38.497 \\
37.425 \\
36.353 \\
35.281\end{array}$ & $\begin{array}{l}44.824 \\
43.751 \\
42.679 \\
41.606 \\
40.534 \\
39.462 \\
38.390 \\
37.318 \\
36.246 \\
35.174\end{array}$ & $\begin{array}{l}44.716 \\
43.0644 \\
42.571 \\
41.499 \\
40.427 \\
39.0354 \\
38.283 \\
37.211 \\
36.139 \\
35.067\end{array}$ & $\begin{array}{l}44.609 \\
43.537 \\
42.464 \\
41.392 \\
40.320 \\
39.247 \\
38.176 \\
37.104 \\
36.032 \\
34.960\end{array}$ & $\begin{array}{l}44.502 \\
43.429 \\
42.357 \\
41.285 \\
40.212 \\
39.140 \\
38.069 \\
36.997 \\
35.925 \\
34.853\end{array}$ & $\begin{array}{l}44.395 \\
43.322 \\
42.250 \\
41.177 \\
40.105 \\
39.033 \\
37.961 \\
36.889 \\
35.817 \\
34.746\end{array}$ & $\begin{array}{l}44.287 \\
43.215 \\
42.143 \\
41.070 \\
39.998 \\
38.926 \\
37.854 \\
36.782 \\
35.710 \\
34.638\end{array}$ & $\begin{array}{l}44 \cdot 180 \\
43.108 \\
42.035 \\
40.963 \\
39.891 \\
38.818 \\
37.747\end{array}$ & $\begin{array}{l}.290819 \\
.290818 \\
.290817 \\
.290815 \\
.290314 \\
.290813 \\
.290811 \\
.290810 \\
.290809 \\
.290807\end{array}$ & $\begin{array}{l}0.887872 \\
0.887897 \\
0.887922 \\
0.887947 \\
0.887972 \\
0.889997 \\
0.888022 \\
0.888047 \\
0.888072 \\
0.888097\end{array}$ \\
\hline $\begin{aligned} 54.0 \\
4.1 \\
4.2 \\
4.3 \\
4.4 \\
4.5 \\
4.6 \\
4.7 \\
4.8 \\
4.9\end{aligned}$ & $\begin{array}{r}32734.424 \\
33.352 \\
32.281 \\
31.209 \\
30.137 \\
29.066 \\
27.994 \\
26.923 \\
25.852 \\
24.780\end{array}$ & $\begin{array}{l}34.317 \\
33.245 \\
32.173 \\
31.102 \\
30.030 \\
28.958 \\
27.887 \\
26.815 \\
25.744 \\
24.673\end{array}$ & $\begin{array}{l}34.209 \\
33.137 \\
32.066 \\
30.994 \\
29.923 \\
28.851 \\
27.780 \\
26.708 \\
25.637 \\
24.566\end{array}$ & $\begin{array}{l}34.102 \\
33.031 \\
31.959 \\
30.887 \\
29.815 \\
28.744 \\
27.673 \\
26.601 \\
25.530 \\
24.459\end{array}$ & $\begin{array}{l}33.995 \\
32.923 \\
31.852 \\
30.780 \\
29.708 \\
28.637 \\
27.565 \\
26.494 \\
25.423 \\
24.352\end{array}$ & $\begin{array}{l}33.888 \\
32.816 \\
31.745 \\
30.673 \\
29.601 \\
28.530 \\
27.458 \\
26.387 \\
25.316 \\
24.245\end{array}$ & $\begin{array}{l}33.781 \\
32.709 \\
31.637 \\
30.566 \\
29.494 \\
28.422 \\
27.351 \\
26.280 \\
25.209 \\
24.138\end{array}$ & $\begin{array}{l}33.674 \\
32.602 \\
31.530 \\
30.458 \\
29.387 \\
28.315 \\
27.244 \\
26.173 \\
25.102 \\
24.031\end{array}$ & $\begin{array}{l}33.566 \\
32.495 \\
31.423 \\
30.352 \\
29.280 \\
28.208 \\
27.137 \\
26.066 \\
24.995 \\
23.924\end{array}$ & $\begin{array}{l}33.459 \\
32.388 \\
31.316 \\
30.244 \\
29.173 \\
28.101 \\
27.030 \\
25.959 \\
24.888 \\
23.816\end{array}$ & $\begin{array}{l}6 \\
5 \\
3 \\
2 \\
1 \\
1 \\
0 \\
8 \\
7\end{array}$ & $\begin{array}{l}8122 \\
8147 \\
8172 \\
8197 \\
8222 \\
8247 \\
8272 \\
8297 \\
8222\end{array}$ \\
\hline $\begin{array}{l}55.0 \\
5.1 \\
5.2 \\
5.3 \\
5.4 \\
5.5 \\
5.6 \\
5.7 \\
5.8 \\
5.9\end{array}$ & $\begin{array}{r}32723.709 \\
22.638 \\
21.567 \\
20.496 \\
19.425 \\
18.355 \\
17.284 \\
16.213 \\
15.142 \\
14.072\end{array}$ & $\begin{array}{l}23.602 \\
22.531 \\
21.460 \\
20.389 \\
19.318 \\
18.248 \\
17.177 \\
16.106 \\
15.035 \\
13.965\end{array}$ & $\begin{array}{l}23.495 \\
22.424 \\
21.353 \\
20.282 \\
19.211 \\
18.140 \\
17.070 \\
15.999 \\
14.928 \\
13.858\end{array}$ & $\begin{array}{l}23.388 \\
22.317 \\
21.246 \\
20.175 \\
19.104 \\
18.033 \\
16.962 \\
15.892 \\
14.821 \\
13.751\end{array}$ & $\begin{array}{l}23.281 \\
22.210 \\
21.139 \\
20.068 \\
18.997 \\
17.926 \\
16.855 \\
15.784 \\
14.714 \\
13.644\end{array}$ & $\begin{array}{l}23.174 \\
22.103 \\
21.032 \\
19.961 \\
18.890 \\
17.819 \\
16.748 \\
15.678 \\
14.607 \\
13.537\end{array}$ & $\begin{array}{l}23.066 \\
21.996 \\
20.925 \\
19.854 \\
18.783 \\
17.712 \\
16.641 \\
15.571 \\
14.500 \\
13.430\end{array}$ & $\begin{array}{l}22.960 \\
21.888 \\
20.817 \\
19.746 \\
18.676 \\
17.605 \\
16.534 \\
15.463 \\
14.393 \\
13.323\end{array}$ & $\begin{array}{l}22.853 \\
21.781 \\
20.711 \\
19.640 \\
18.569 \\
17.498 \\
16.427 \\
15.357 \\
14.286 \\
13.216\end{array}$ & $\begin{array}{l}22.745 \\
21.675 \\
20.604 \\
19.532 \\
18.461 \\
17.391 \\
16.320 \\
15.250 \\
14.179 \\
13.109\end{array}$ & & $\begin{array}{l}8372 \\
3397 \\
3422 \\
8447 \\
8472 \\
8497 \\
8522 \\
8547 \\
8572\end{array}$ \\
\hline $\begin{array}{l}56.0 \\
6.1 \\
6.2 \\
6.3 \\
6.4 \\
6.5 \\
6.6 \\
6.7 \\
6.8 \\
6.9\end{array}$ & $\begin{array}{r}32713.002 \\
11.931 \\
10.861 \\
09.791 \\
08.720 \\
07.651 \\
06.581 \\
05.510 \\
04.440 \\
03.371\end{array}$ & $\begin{array}{l}12.895 \\
11.824 \\
10.754 \\
09.683 \\
08.614 \\
07.544 \\
06.473 \\
05.403 \\
04.333 \\
03.264\end{array}$ & $\begin{array}{l}12.788 \\
11.717 \\
10.647 \\
09.577 \\
08.506 \\
07.436 \\
06.366 \\
05.297 \\
04.227 \\
03.157\end{array}$ & $\begin{array}{l}12.681 \\
11.610 \\
10.540 \\
09.469 \\
08.399 \\
07.329 \\
06.259 \\
05.189 \\
04.120 \\
03.050\end{array}$ & $\begin{array}{l}12.574 \\
11.503 \\
10.433 \\
09.363 \\
08.292 \\
07.222 \\
06.152 \\
05.082 \\
04.012 \\
02.943\end{array}$ & $\begin{array}{l}12.467 \\
11.396 \\
10.326 \\
09.256 \\
08.186 \\
07.115 \\
06.045 \\
04.975 \\
03.906 \\
02.835\end{array}$ & $\begin{array}{l}12.359 \\
11.289 \\
10.219 \\
09.149 \\
08.078 \\
07.008 \\
05.938 \\
04.868 \\
03.798 \\
02.729\end{array}$ & & $\begin{array}{l}12.146 \\
11.075 \\
10.005 \\
08.935 \\
07.865 \\
06.794 \\
05.724 \\
04.055 \\
03.585 \\
02.515\end{array}$ & 02.408 & & \\
\hline $\begin{array}{r}057.0 \\
7.1 \\
7.2 \\
7.3 \\
7.4 \\
7.5 \\
7.6 \\
7.7 \\
7.8 \\
7.9\end{array}$ & $\begin{array}{r}32702.301 \\
01.231 \\
00.162 \\
32699.093 \\
98.023 \\
96.954 \\
95.884 \\
94.815 \\
93.746 \\
92.676\end{array}$ & $\begin{array}{l}02.194 \\
01.125 \\
00.055 \\
98.985 \\
97.916 \\
96.847 \\
95.777 \\
94.708 \\
93.0638 \\
92.570\end{array}$ & $\begin{array}{r}02.087 \\
01.017 \\
* 99.948 \\
98.878 \\
97.809 \\
96.739 \\
95.670 \\
94.601 \\
93.532 \\
92.463\end{array}$ & $\begin{array}{r}01.980 \\
00.911 \\
* 99.841 \\
98.771 \\
97.702 \\
96.633 \\
95.563 \\
94.494 \\
93.425 \\
92.356\end{array}$ & $\begin{array}{r}01.874 \\
00.804 \\
* 99.734 \\
98.664 \\
97.595 \\
96.526 \\
95.456 \\
94.387 \\
93.318 \\
92.249\end{array}$ & $\begin{array}{r}01.766 \\
00.697 \\
* 99.627 \\
98.558 \\
97.488 \\
96.419 \\
95.349 \\
94.280 \\
93.211 \\
92.142\end{array}$ & $\begin{array}{r}01.659 \\
00.590 \\
* 99.520 \\
98.451 \\
97.381 \\
96.312 \\
95.242 \\
94.173 \\
93.104 \\
92.035\end{array}$ & & $\begin{array}{r}01.446 \\
00.376 \\
* 99.306 \\
98.237 \\
97.167 \\
96.098 \\
95.029 \\
93.959 \\
92.890 \\
91.821\end{array}$ & $\begin{array}{l}* 99.199 \\
98.130 \\
97.060 \\
95.991 \\
94.922 \\
93.853 \\
92.783 \\
91.714\end{array}$ & & 0.88909 \\
\hline $\begin{array}{l}58.0 \\
8.1 \\
8.2 \\
8.3 \\
8.4 \\
8.5 \\
8.6 \\
8.7 \\
8.8 \\
8.9\end{array}$ & $\begin{array}{r}32691.607 \\
90.538 \\
89.470 \\
88.401 \\
87.332 \\
86.264 \\
85.195 \\
84.126 \\
83.058 \\
81.989\end{array}$ & $\begin{array}{l}91.500 \\
90.431 \\
89.363 \\
88.294 \\
87.225 \\
86.157 \\
85.088 \\
84.019 \\
82.951 \\
81.883\end{array}$ & $\begin{array}{l}89.256 \\
88.187 \\
87.118 \\
86.049 \\
84.981 \\
83.913 \\
82.844 \\
81.776\end{array}$ & $\begin{array}{l}90.218 \\
89.149 \\
88.080 \\
87.011 \\
85.943 \\
84.874 \\
83.805 \\
82.737 \\
81.669\end{array}$ & $\begin{array}{l}90.111 \\
89.042 \\
87.973 \\
86.905 \\
85.836 \\
84.767 \\
83.698 \\
82.630 \\
81.562\end{array}$ & $\begin{array}{l}90.004 \\
88.936 \\
87.866 \\
86.798 \\
85.729 \\
84.660 \\
83.592 \\
82.523 \\
81.455\end{array}$ & $\begin{array}{l}89.897 \\
88.829 \\
87.760 \\
86.691 \\
85.622 \\
84.554 \\
83.485 \\
82.417 \\
81.348\end{array}$ & & $\begin{array}{l}89.684 \\
88.615 \\
87.546 \\
86.477 \\
85.408 \\
84.340 \\
83.271 \\
82.203 \\
81.135\end{array}$ & & & 0.88934 \\
\hline $\begin{array}{l}9.0 \\
9.1 \\
9.2 \\
9.3 \\
9.4 \\
9.5 \\
9.6 \\
9.7 \\
9.8 \\
9.9\end{array}$ & $\begin{array}{r}32680.921 \\
79.853 \\
78.784 \\
77.716 \\
76.648 \\
75.581 \\
74.512 \\
73.445 \\
72.377 \\
71.309\end{array}$ & $\begin{array}{l}80.814 \\
79.746 \\
78.577 \\
77.609 \\
76.542 \\
75.473 \\
74.0406 \\
73.338 \\
72.270 \\
71.202\end{array}$ & $\begin{array}{l}79.639 \\
78.571 \\
77.503 \\
76.435 \\
75.366 \\
74.299 \\
73.231 \\
72.163 \\
71.095\end{array}$ & $\begin{array}{l}79.532 \\
78.464 \\
77.396 \\
76.328 \\
75.260 \\
74.192 \\
73.124 \\
72.056 \\
70.988\end{array}$ & $\begin{array}{l}79.425 \\
78.357 \\
77.289 \\
76.221 \\
75.153 \\
74.085 \\
73.017 \\
71.949 \\
70.882\end{array}$ & $\begin{array}{l}79.318 \\
78.250 \\
77.182 \\
76.114 \\
75.046 \\
73.978 \\
72.911 \\
71.843 \\
70.775\end{array}$ & $\begin{array}{l}78.143 \\
77.076 \\
76.007 \\
74.939 \\
73.872 \\
72.804 \\
71.0736 \\
70.668\end{array}$ & $\begin{array}{l}79.104 \\
78.036 \\
76.969 \\
75.901 \\
74.833 \\
73.765 \\
72.697 \\
71.629 \\
70.562\end{array}$ & $\begin{array}{l}78.998 \\
77.9930 \\
76.8362 \\
75.794 \\
74.726 \\
73.658 \\
72.590 \\
71.522 \\
70.455\end{array}$ & $\begin{array}{l}75.687 \\
74.619 \\
73.552 \\
72.483 \\
71.416 \\
70.348\end{array}$ & $\begin{array}{l}0.290739 \\
0.290737 \\
0.290736 \\
0.290735 \\
0.290733 \\
0.290732 \\
0.290731 \\
0.290729 \\
0.290728\end{array}$ & $\begin{array}{l}.88957 \\
0.88959\end{array}$ \\
\hline & \multicolumn{2}{|c|}{.001} & .002 & .003 & .004 & .005 & .006 & .007 & .008 & .009 & .010 & \\
\hline & & & & 32 & & .05 & .064 & .0 & & & .10 & \\
\hline
\end{tabular}


$\begin{array}{lllllllllll}32670.241 & 70.135 & 70.028 & 69.921 & 69.814 & 69.707 & 69.600 & 69.494 & 69.387 & 69.280\end{array}$ $\begin{array}{lllllllllll}0.1 & 69.174 & 69.067 & 68.960 & 68.854 & 68.746 & 68.639 & 68.533 & 68.426 & 68.319 & 68.213 \\ 0.2 & 68.106 & 67.999 & 67.893 & 6.7 .786 & 67.679 & 67.572 & 67.465 & 67.359 & 67.252 & 67.145\end{array}$ $\begin{array}{lllllllllll}0.3 & 67.039 & 66.932 & 66.825 & 66.718 & 66.612 & 66.505 & 66.398 & 66.291 & 66.185 & 66.078\end{array}$

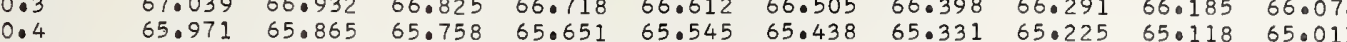
$\begin{array}{lllllllllll}0.4 & 65.971 & 65.865 & 65.758 & 65.651 & 65.545 & 65.438 & 65.331 & 65.225 & 65.118 & 65.011 \\ 0.5 & 64.905 & 64.797 & 64.691 & 64.584 & 64.477 & 64.371 & 64.264 & 64.157 & 64.051 & 63.944\end{array}$ $\begin{array}{lllllllllll}0.6 & 63.837 & 63.730 & 63.623 & 63.517 & 63.410 & 63.303 & 63.197 & 63.090 & 62.983 & 62.877\end{array}$ $\begin{array}{lllllllllll}0.7 & 62.770 & 62.663 & 62.556 & 62.449 & 62.343 & 62.236 & 62.129 & 62.023 & 61.916 & 61.810 \\ 0.8 & 61.703 & 61.596 & 61.489 & 61.382 & 61.276 & 61.169 & 61.062 & 60.956 & 60.849 & 60.742\end{array}$

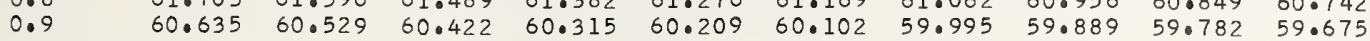

$\begin{array}{lllllllllll}3061.0 & 32659.569 & 59.462 & 59.355 & 59.249 & 59.142 & 59.035 & 58.928 & 58.822 & 58.715 & 58.608\end{array}$ $\begin{array}{lllllllllll}1.1 & 58.502 & 58.395 & 58.288 & 58.182 & 58.075 & 57.968 & 57.862 & 57.755 & 57.648 & 57.542\end{array}$ $\begin{array}{llllllllllll}1.2 & 57.435 & 57.328 & 57.222 & 57.115 & 57.008 & 56.901 & 56.795 & 56.688 & 56.582 & 56.47\end{array}$ $\begin{array}{lllllllllll}1.3 & 56.368 & 56.261 & 56.155 & 56.048 & 55.941 & 55.835 & 55.728 & 55.621 & 55.515 & 55.408 \\ 1.4 & 55.301 & 55.195 & 55.088 & 54.981 & 54.875 & 54.768 & 54.661 & 54.555 & 54.448 & 54.341\end{array}$ $\begin{array}{lllllllllll}1.4 & 55.301 & 55.195 & 55.088 & 54.981 & 54.875 & 54.768 & 54.661 & 54.555 & 54.448 & 54.341 \\ 1.5 & 54.235 & 54.128 & 54.021 & 53.915 & 53.809 & 53.702 & 53.595 & 53.489 & 53.382 & 53.275\end{array}$ $\begin{array}{lllllllllll}1.5 & 54.235 & 54.128 & 54.021 & 53.915 & 53.809 & 53.702 & 53.595 & 53.489 & 53.382 & 53.275 \\ 1.6 & 53.169 & 53.062 & 52.955 & 52.849 & 52.742 & 52.635 & 52.529 & 52.422 & 52.315 & 52.209\end{array}$ $\begin{array}{lllllllllll}1.6 & 53.169 & 53.062 & 52.955 & 52.849 & 52.742 & 52.635 & 52.529 & 52.422 & 52.315 & 52.209 \\ 1.7 & 52.102 & 51.996 & 51.889 & 51.782 & 51.675 & 51.569 & 51.462 & 51.355 & 51.249 & 51.142\end{array}$ $\begin{array}{lllllllllll}1.8 & 51.036 & 50.929 & 50.822 & 50.716 & 50.609 & 50.502 & 50.396 & 50.289 & 50.183 & 50.076 \\ 1.9 & 49.969 & 49.863 & 49.756 & 49.649 & 49.543 & 49.436 & 49.329 & 49.223 & 49.116 & 49.010\end{array}$

32648.903 $\begin{array}{llll}47.837 & 47.730 & 47.690 & 48.583 \\ 46.777 & 46.654 & 46.558 & 46.517\end{array}$ $\begin{array}{lllllllllll}45.705 & 45.598 & 45.491 & 45.385 & 45.344 & 46.238 & 46.131 & 46.024 & 45.918 & 45.811\end{array}$ $\begin{array}{llllllllll}44.638 & 44.532 & 44.425 & 44.319 & 44.212 & 44.105 & 43.999 & 43.892 & 43.786 & 43.679\end{array}$ $\begin{array}{llllllllll}43.573 & 43.466 & 43.359 & 43.253 & 43.146 & 43.040 & 42.933 & 42.826 & 42.720 & 42.613\end{array}$

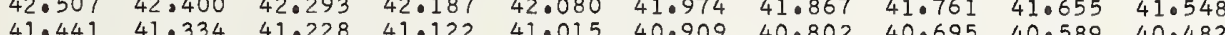
$40.376 \quad 40.269 \quad 40.162 \quad 40.056 \quad 39.949 \quad 39.843 \quad 39.736 \quad 30.630 \quad 30.58340 .482$ $\begin{array}{llllllllll}40.376 & 40.269 & 40.162 & 40.056 & 39.949 & 39.843 & 39.736 & 39.630 & 39.523 & 39.417 \\ 39.310 & 39.204 & 39.097 & 38.990 & 38.884 & 38.777 & 38.670 & 38.564 & 38.458 & 38.351\end{array}$

3053.0 3263

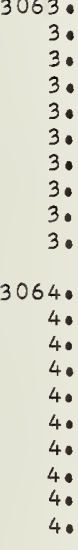
$638.24538 \cdot 138$ $36.114 \quad 36.007$ $35.048 \quad 34.94$ $32.917 \quad 32.811$ $31.852 \quad 31.746$ 30.787
29.722
29.616 28.657 3065

$$
\begin{array}{r}
065 . \\
5 . \\
5 . \\
5 . \\
5 . \\
5 . \\
5 . \\
5 . \\
5 . \\
5 .
\end{array}
$$

$\begin{array}{rrr}5.0 & 32616.948 & 16.842 \\ 5.1 & 15.884 & 15.778 \\ 5.2 & 14.820 & 14.713\end{array}$

15.884

$\begin{array}{ll}13.756 & 13.71 \\ 13.64\end{array}$

$12.692 \quad 12.586$

$11.628 \quad 11.522$

$09.500 \quad 09.394$

$\begin{array}{ll}08.437 & 08 \cdot 330 \\ 07.373 & 07.267\end{array}$

$38.031 \quad 37.925$

37.818

37.71

37.670

$35.901 \quad 35.794$

$\begin{array}{lll}34.835 & 34.729 & 34.62\end{array}$

$\begin{array}{ll}32.704 & 32.59 \\ 31.639 & 31.533\end{array}$

.515

36.540

37.499

37.392

37.285
36.220

$\begin{array}{lllllll}.663 & 33.557 & 33.450 & 33.343 & 33.237 & 33.130 & 33.024 \\ 598 & 32.491 & 32.385 & 32.278 & 32.172 & 32.065 & 31.958\end{array}$

$\begin{array}{lllll}.639 & 31.533 & 31.426 & 31.320 & 31.213 \\ .574 & 30.468 & 30.361 & 30.255 & 30.148\end{array}$

8.616

\begin{abstract}
28.444
\end{abstract}
28.33

29.29
28.23

30.255

32.065

$\begin{array}{ll}31.000 & 30.894\end{array}$

$\begin{array}{llll}.083 & 28.977 & 28.871 & 28.764 \\ .019 & 27.912 & 27.806 & 27.699\end{array}$

$\begin{array}{ll}26.528 & 26.421 \\ 25.463 & 25.357\end{array}$

4.398

$5 \cdot 357$
4.292

$26.315 \quad 27 \cdot 273$

$27 \cdot 167$

27.060

26.954

26.847

26.741

26.034
25.570

$\begin{array}{llllllll}24.186 & 24.079 & 23.972 & 23.866 & 23.760 & 23.653 & 23.547 & 23.440 \\ 23.121 & 23.014 & 22.908 & 22.801 & 22.695 & 22.589 & 22.482 & 22.375\end{array}$

$22 \cdot 163$

$\begin{array}{ll}22.056 & 21.950 \\ 20.992 & 20.885\end{array}$

22.908
21.844

2.589

22.482

$\begin{array}{lll}1.482 & 22.375 \\ 1.417 & 21.311\end{array}$

$\begin{array}{lllll}0.673 & 20.566 & 20.459 & 20.353 & 20.247\end{array}$

$\begin{array}{llll}20.566 & 20.459 & 20.353 & 20.247 \\ 19.501 & 19.395 & 19.289 & 19.182\end{array}$

$\begin{array}{llll}9.927 & 19.821 & 19.715 & 19.608\end{array}$

17.799 17.

8757
.692

$\begin{array}{lll}16.735 & 16.629 & 16.522 \\ 15.671 & 15.564 & 15.458\end{array}$

17.480

$\begin{array}{llll}18.437 & 18.331 & 18.225 & 18.118 \\ 17.374 & 17.267 & 17.161 & 17.054\end{array}$

$\begin{array}{lll}14.607 & 14.500 & 14.39\end{array}$

$\begin{array}{llll}13.543 & 13.437 & 13.330 & 13.22\end{array}$

$\begin{array}{llll}12.479 & 12.373 & 12.266 & 12.160 \\ 11.415 & 11.309 & 11.203 & 11.096\end{array}$

$\begin{array}{lll}10.351 & 10.245 & 10.139\end{array}$

5.7
5.8
5.9

3066.

6.1
6.2
6.3

6.3
6.4
6.5

6.5

6.7
6.8

6.9

3067.

7.1
7.2
7.3

7.4

$7 \cdot 5$
7.6

7.6
7.7
7.8
7.9

3068 .

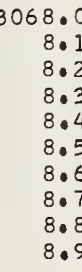

32606.310 $\begin{array}{rr}606.310 & 06.2 \\ 05.247 & 05.1\end{array}$ $\begin{array}{lll}05.247 & 05.140 & 06.0 \\ 04.183 & 04.077 & 03 .\end{array}$

$03.120 \quad 03.014$

$0.994 \quad 00.887$

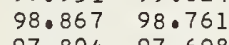

$\begin{array}{ll}97.804 & 97.698 \\ 96.741 & 96.635\end{array}$

8.22408 .118

$\begin{array}{ll}10.139 & 10.032 \\ 09.075 & 08.96\end{array}$

08.01
06.948

07.905
06.84

$\begin{array}{llll}16.309 & 16.203 & 16.097 & 15.990\end{array}$

$\begin{array}{llll}15.245 & 15.139 & 15.032 & 14.926 \\ 14.181 & 14.075 & 13.969 & 13.862\end{array}$

$\begin{array}{lllll}13.117 & 13.011 & 12.905 & 12.798\end{array}$

$\begin{array}{llll}10.989 & 10.883 & 10.777 & 10.670\end{array}$

$\begin{array}{llll}09.926 & 09.819 & 09.713 & 09.607 \\ 08.862 & 08.756 & 08.650 & 08.543\end{array}$

$\begin{array}{llll}08.862 & 08.756 & 08.650 & 08.543\end{array}$

$06.097 \quad 05.991$

05.884

05.778

06.73

$\begin{array}{lll}07.629 & 06.522 & 06.416\end{array}$

$\begin{array}{llll}05.672 & 05.565 & 05.459 & 05.35\end{array}$

$\begin{array}{llllllll}02.907 & 02.801 & 02.694 & 02.588 & 02.482 & 02.375 & 02.270 & 02.163\end{array}$

$\begin{array}{llllllll}01.844 & 01.738 & 01.632 & 01.525 & 01.419 & 01.313 & 01.206 & 01.100 \\ 00.781 & 00.675 & 00.568 & 00.462 & 00.355 & 00.250 & 00.143 & 00.037\end{array}$

$9.718 \quad 99.612$

99.50500 .462

99.293

$\begin{array}{ll}.655 & 98.549 \\ 7.592 & 97.486\end{array}$

99.505
98.442
97.379
$96 \cdot 317$

$97.379 \quad 97 \cdot 273$

98.017

98.974
97.911

32595.679

93.55

$95.573 \quad 95.466 \quad 95.360$

95.25

95.147

$96.104 \quad 95.998$

95.89195 .785

$\begin{array}{llll}92.491 & 92.385 & 92.279 & 92.135\end{array}$

$90.366 \quad 90.260$

$89.304 \quad 89.198$

$87.179 \quad 87.073$

91.21691 .110

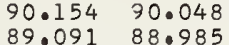

$88.029 \quad 87.923$

$\begin{array}{llll}86.117 & 86.011 & 85.967 & 86.861 \\ & 85.905 & 85.798\end{array}$

$9.19194 .085 \quad 93.979$

$93.129 \quad 93.023$

$91.004 \quad 90.897$

$\begin{array}{ll}89.941 & 89.835 \\ 88.879 & 88.772\end{array}$

87.817

87.710

92.916

91.854

90.79
89.72
88.667

88.667
87.604

86.542

94.935

$\begin{array}{lll}94.828 & 94.722\end{array}$

$\begin{array}{lll}88.560 & 88.454 & 88.348 \\ 87.498 & 87.392 & 87.285\end{array}$

$32585.055 \quad 84.949$

$84.843 \quad 84.737$

$85.692 \quad 85.586$

84.418

85.374

85.161

$\begin{array}{lllllllllll}83.993 & 83.886 & 83.780 & 83.674 & 83.568 & 83.462 & 83.356 & 83.249 & 83.143 & 83.037\end{array}$

$\begin{array}{llllllllll}2.931 & 82.824 & 82.719 & 82.612 & 82.506 & 82.400 & 82.294 & 82.187 & 82.081 & 81.975\end{array}$

$\begin{array}{llllllllll}81.869 & 81.762 & 81.656 & 81.550 & 81.444 & 81.338 & 81.232 & 81.126 & 81.020 & 80.914\end{array}$

$\begin{array}{llllllllll}79.746 & 79.640 & 79.533 & 79.427 & 79.321 & 79.215 & 79.108 & 79.003 & 78.896 & 78.790\end{array}$

$\begin{array}{lllllllllll}78.684 & 78.578 & 78.472 & 78.366 & 78.259 & 78.153 & 78.047 & 77.941 & 77.834 & 77.729\end{array}$

$\begin{array}{llllllllll}77.623 & 77.516 & 77.410 & 77.304 & 77.198 & 77.092 & 76.985 & 76.879 & 76.773 & 76.667\end{array}$

$\begin{array}{llllllllll}76.561 & 76.455 & 76.349 & 76.242 & 76.136 & 76.030 & 75.924 & 75.818 & 75.712 & 75.605 \\ 75.499 & 75.393 & 75.287 & 75.181 & 75.075 & 74.969 & 74.862 & 74.756 & 74.650 & 74.544\end{array}$

3069.0

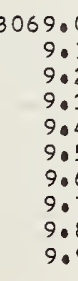

75.07574 .969

$74.86274 .756 \quad 74.650 \quad 74.544$

$\begin{array}{llllllllll}73.376 & 74.332 & 74.226 & 74.120 & 74.013 & 73.907 & 73.801 & 73.695 & 73.589 & 73.482\end{array}$

$\begin{array}{llllllllll}72.315 & 72.209 & 72.103 & 71.997 & 71.891 & 71.785 & 71.679 & 71.572 & 71.427 & 72.421 \\ 71.0254 & 71.148 & 71.042 & 70.936 & 70.829 & 70.724 & 70.617 & 70.511 & 70.405 & 70.269\end{array}$

$\begin{array}{llllllllll}71.254 & 71.148 & 71.042 & 70.936 & 70.829 & 70.724 & 70.617 & 70.511 & 70.405 & 70.299\end{array}$

$\begin{array}{llllllllll}70.193 & 70.087 & 69.980 & 69.875 & 69.769 & 69.662 & 69.556 & 69.450 & 69.344 & 69.238 \\ 69.132 & 69.026 & 68.920 & 68.814 & 68.708 & 68.602 & 68.495 & 68.389 & 68.283 & 68.177\end{array}$

$\begin{array}{lllllllllll}68.071 & 67.965 & 67.959 & 67.814 & 68.708 & 68.602 & 68.495 & 68.389 & 68.283 & 68.177\end{array}$

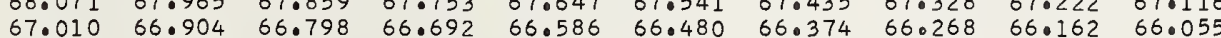

$\begin{array}{llllllllll}65.949 & 65.843 & 65.737 & 65.631 & 65.525 & 65.419 & 65.313 & 65.207 & 65.101 & 64.995\end{array}$

0.290727
0.290726

0.290724

0.290723

0.290722

0.290720
0.290719

0.290719
0.290718

0.290716

0.290714

0.290712

0.290711

0.290708

290707

0.290706

0.290704

0.290702

0.290701

0.290699

0.290698

0.290695

0.290694

0.290693
0.290691

0.290690

0.290690
0.290689

0.290687

0.290686

0.290685

0.290682

0.290681

.290680

0.290678

0.290676

0.290674

0.290673
0.290672

0.290670

0.290669

0.290666

0.290665

0.290662

0.889624

0.889649
0.889674

0.889699

0.889724

0.889749

0.889774

0.889824

0.290661

0.290660

0.290659

0.290656

0.290655

0.290653 


\begin{tabular}{|c|c|c|c|c|c|c|c|c|c|c|c|c|}
\hline $\begin{array}{l}70.0 \\
0.1 \\
0.2 \\
0.3 \\
0.4 \\
0.5 \\
0.6 \\
0.7 \\
0.8 \\
0.9\end{array}$ & $\begin{array}{r}563.828 \\
62.767 \\
61.707 \\
60.646 \\
59.585 \\
58.525 \\
57.465 \\
56.405 \\
55.345 \\
54.285\end{array}$ & $\begin{array}{l}63.722 \\
62.661 \\
61.600 \\
60.540 \\
59.479 \\
58.419 \\
57.359 \\
56.299 \\
55.239 \\
54.179\end{array}$ & $\begin{array}{l}63.616 \\
62.555 \\
61.495 \\
60.434 \\
59.373 \\
58.313 \\
57.252 \\
56.193 \\
55.133 \\
54.073\end{array}$ & $\begin{array}{l}63.510 \\
62.449 \\
61.388 \\
60.328 \\
59.267 \\
58.207 \\
57.147 \\
56.087 \\
55.027 \\
53.967\end{array}$ & $\begin{array}{l}63.404 \\
62.343 \\
61.282 \\
60.222 \\
59.162 \\
58.101 \\
57.041 \\
55.981 \\
54.921 \\
53.861\end{array}$ & $\begin{array}{l}63.298 \\
62.237 \\
61.177 \\
60.116 \\
59.055 \\
57.995 \\
56.935 \\
55.875 \\
54.815 \\
53.754\end{array}$ & $\begin{array}{l}63.191 \\
62.131 \\
61.070 \\
60.010 \\
58.949 \\
57.889 \\
56.829 \\
55.769 \\
54.708 \\
53.648\end{array}$ & $\begin{array}{l}63.085 \\
62.025 \\
60.964 \\
59.904 \\
58.844 \\
57.783 \\
56.723 \\
55.663 \\
54.603 \\
53.543\end{array}$ & $\begin{array}{l}62.979 \\
61.918 \\
60.858 \\
59.798 \\
58.737 \\
57.677 \\
56.617 \\
55.557 \\
54.497 \\
53.437\end{array}$ & $\begin{array}{l}62.873 \\
61.812 \\
60.752 \\
59.691 \\
58.631 \\
57.571 \\
56.511 \\
55.451 \\
54.391 \\
53.331\end{array}$ & $\begin{array}{l}0.290596 \\
0.290595 \\
0.290593 \\
0.290592 \\
0.290591 \\
0.290589 \\
0.290588 \\
0.290587 \\
0.290585 \\
0.290584\end{array}$ & $\begin{array}{l}0.892129 \\
0.892154 \\
0.892179 \\
0.892204 \\
0.892229 \\
0.892255 \\
0.892280 \\
0.892305 \\
0.892330 \\
0.892355\end{array}$ \\
\hline $\begin{array}{r}071.0 \\
1.1 \\
1.2 \\
1.3 \\
1.4 \\
1.5 \\
1.6 \\
1.7 \\
1.8 \\
1.9\end{array}$ & $\begin{array}{r}553.225 \\
52.165 \\
51.105 \\
50.045 \\
48.985 \\
47.926 \\
46.866 \\
45.806 \\
44.747 \\
43.688\end{array}$ & $\begin{array}{l}53.119 \\
52.059 \\
50.999 \\
49.939 \\
48.879 \\
47.819 \\
46.760 \\
45.700 \\
44.641 \\
43.582\end{array}$ & $\begin{array}{l}53.013 \\
51.953 \\
50.893 \\
49.833 \\
48.773 \\
47.713 \\
46.654 \\
45.594 \\
44.535 \\
43.476\end{array}$ & $\begin{array}{l}52.907 \\
51.847 \\
50.787 \\
49.727 \\
48.667 \\
47.608 \\
46.548 \\
45.488 \\
44.429 \\
43.370\end{array}$ & $\begin{array}{l}52.801 \\
51.741 \\
50.681 \\
49.621 \\
48.561 \\
47.502 \\
46.442 \\
45.382 \\
44.323 \\
43.264\end{array}$ & $\begin{array}{l}52.695 \\
51.635 \\
50.575 \\
49.515 \\
48.455 \\
47.396 \\
46.336 \\
45.277 \\
44.217 \\
43.158\end{array}$ & $\begin{array}{l}52 \cdot 588 \\
51.529 \\
50.469 \\
49.409 \\
48 \cdot 349 \\
47 \cdot 290 \\
46.230 \\
45 \cdot 171 \\
44 \cdot 111 \\
43.052\end{array}$ & $\begin{array}{l}52.483 \\
51.423 \\
50.363 \\
49.303 \\
48.244 \\
47.184 \\
46.124 \\
45.064 \\
44.005 \\
42.946\end{array}$ & $\begin{array}{l}52 \cdot 376 \\
51.316 \\
50.257 \\
49.197 \\
48.137 \\
47.077 \\
46.018 \\
44.959 \\
43.900 \\
42.840\end{array}$ & $\begin{array}{l}52.271 \\
51.211 \\
50.151 \\
49.091 \\
48.031 \\
46.971 \\
45.912 \\
44.853 \\
43.794 \\
42.734\end{array}$ & $\begin{array}{l}0.290583 \\
0.290582 \\
0.290580 \\
0.290579 \\
0.290578 \\
0.290576 \\
0.290575 \\
0.290574 \\
0.290572 \\
0.290571\end{array}$ & $\begin{array}{l}0.892380 \\
0.892405 \\
0.892430 \\
0.892455 \\
0.892480 \\
0.892505 \\
0.892530 \\
0.892555 \\
0.892580 \\
0.892605\end{array}$ \\
\hline $\begin{array}{r}072.0 \\
2.1 \\
2.2 \\
2.3 \\
2.4 \\
2.5 \\
2.6 \\
2.7 \\
2.8 \\
2.9\end{array}$ & $\begin{array}{r}32542.628 \\
41.569 \\
40.510 \\
39.451 \\
38.391 \\
37.333 \\
36.274 \\
35.215 \\
34.156 \\
33.097\end{array}$ & $\begin{array}{l}42 \cdot 522 \\
41.463 \\
40.404 \\
39 \cdot 344 \\
38 \cdot 286 \\
37 \cdot 227 \\
36.168 \\
35.109 \\
34.050 \\
32.991\end{array}$ & $\begin{array}{l}42.417 \\
41.357 \\
40.298 \\
39.239 \\
38.180 \\
37.121 \\
36.062 \\
35.003 \\
33.944 \\
32.885\end{array}$ & $\begin{array}{l}42.311 \\
41.251 \\
40.192 \\
39.133 \\
38.074 \\
37.015 \\
35.956 \\
34.897 \\
33.838 \\
32.780\end{array}$ & $\begin{array}{l}42.205 \\
41.146 \\
40.086 \\
39.027 \\
37.968 \\
36.909 \\
35.850 \\
34.791 \\
33.732 \\
32.674\end{array}$ & $\begin{array}{l}42.099 \\
41.040 \\
39.980 \\
38.921 \\
37.862 \\
36.803 \\
35.744 \\
34.686 \\
33.627 \\
32.568\end{array}$ & $\begin{array}{l}41.992 \\
40.934 \\
39.875 \\
38.815 \\
37.756 \\
36.697 \\
35.638 \\
34.580 \\
33.521 \\
32.462\end{array}$ & $\begin{array}{l}41.887 \\
40.827 \\
39.768 \\
38.709 \\
37.651 \\
36.592 \\
35.532 \\
34.474 \\
33.415 \\
32.357\end{array}$ & $\begin{array}{l}41.781 \\
40.721 \\
39.663 \\
38.603 \\
37.544 \\
36.485 \\
35.427 \\
34.368 \\
33.309 \\
32.251\end{array}$ & $\begin{array}{l}41.675 \\
40.616 \\
39.557 \\
38.497 \\
37.438 \\
36.379 \\
35.321 \\
34.262 \\
33.203 \\
32.145\end{array}$ & $\begin{array}{l}0.290570 \\
0.290569 \\
0.290567 \\
0.290566 \\
0.290565 \\
0.290563 \\
0.290562 \\
0.290561 \\
0.290559 \\
0.290558\end{array}$ & $\begin{array}{l}0.892630 \\
0.892656 \\
0.892681 \\
0.892706 \\
0.892731 \\
0.892756 \\
0.892781 \\
0.892806 \\
0.892831 \\
0.892856\end{array}$ \\
\hline $\begin{array}{r}3073.0 \\
3.1 \\
3.2 \\
3.3 \\
3.4 \\
3.5 \\
3.6 \\
3.7 \\
3.8 \\
3.9\end{array}$ & $\begin{array}{r}32532.039 \\
30.980 \\
29.922 \\
28.863 \\
27.805 \\
26.747 \\
25.688 \\
24.630 \\
23.572 \\
22.514\end{array}$ & $\begin{array}{l}31.933 \\
30.875 \\
29.816 \\
28.757 \\
27.699 \\
26.641 \\
25.583 \\
24.524 \\
23.466 \\
22.408\end{array}$ & $\begin{array}{l}31.827 \\
30.769 \\
29.710 \\
28.652 \\
27.593 \\
26.535 \\
25.477 \\
24.419 \\
23.360 \\
22.302\end{array}$ & $\begin{array}{l}31.722 \\
30.663 \\
29.604 \\
28.546 \\
27.487 \\
26.429 \\
25.371 \\
24.313 \\
23.255 \\
22.197\end{array}$ & $\begin{array}{l}31.616 \\
30.557 \\
29.499 \\
28.440 \\
27.382 \\
26.323 \\
25.265 \\
24.207 \\
23.149 \\
22.091\end{array}$ & $\begin{array}{l}31.510 \\
30.451 \\
29.393 \\
28.334 \\
27.276 \\
26.218 \\
25 \cdot 159 \\
24 \cdot 101 \\
23.043 \\
21.985\end{array}$ & $\begin{array}{l}31.404 \\
30.345 \\
29.287 \\
28.229 \\
27.170 \\
26.112 \\
25.054 \\
23.995 \\
22.937 \\
21.879\end{array}$ & $\begin{array}{l}31.298 \\
30.239 \\
29.181 \\
28.122 \\
27.064 \\
26.006 \\
24.948 \\
23.890 \\
22.831 \\
21.774\end{array}$ & $\begin{array}{l}31.192 \\
30.133 \\
29.075 \\
28.017 \\
26.958 \\
25.900 \\
24.842 \\
23.784 \\
22.726 \\
21.668\end{array}$ & $\begin{array}{l}31.086 \\
30.028 \\
28.969 \\
27.911 \\
26.852 \\
25.794 \\
24.736 \\
23.678 \\
22.620 \\
21.562\end{array}$ & $\begin{array}{l}0.290557 \\
0.290556 \\
0.290554 \\
0.290553 \\
0.290552 \\
0.290550 \\
0.290549 \\
0.290548 \\
0.290546 \\
0.290545\end{array}$ & $\begin{array}{l}0.892881 \\
0.892906 \\
0.892931 \\
0.892956 \\
0.892981 \\
0.893006 \\
0.893032 \\
0.893057 \\
0.893082 \\
0.893107\end{array}$ \\
\hline $\begin{array}{r}3074.0 \\
4.1 \\
4.2 \\
4.3 \\
4.3 \\
405 \\
4.6 \\
4.7 \\
4.8 \\
4.9\end{array}$ & $\begin{array}{r}32521.456 \\
20.399 \\
19.341 \\
18.283 \\
17.225 \\
16.168 \\
15.110 \\
14.052 \\
12.995 \\
11.937\end{array}$ & $\begin{array}{l}21.350 \\
20.293 \\
19.235 \\
18.177 \\
17.120 \\
16.062 \\
15.004 \\
13.947 \\
12.889 \\
11.832\end{array}$ & $\begin{array}{l}21.244 \\
20.187 \\
19.129 \\
18.072 \\
17.014 \\
15.956 \\
14.898 \\
13.841 \\
12.784 \\
11.726\end{array}$ & $\begin{array}{l}21.139 \\
20.081 \\
19.023 \\
17.966 \\
16.908 \\
15.851 \\
14.793 \\
13.735 \\
12.678 \\
11.620\end{array}$ & $\begin{array}{l}21.033 \\
19.976 \\
18.918 \\
17.860 \\
16.802 \\
15.745 \\
14.687 \\
13.629 \\
12.572 \\
11.515\end{array}$ & $\begin{array}{l}20.927 \\
19.870 \\
18.812 \\
17.754 \\
16.697 \\
15.639 \\
14.581 \\
13.524 \\
12.467 \\
11.409\end{array}$ & $\begin{array}{l}20.821 \\
19.764 \\
18.706 \\
17.648 \\
16.591 \\
15.533 \\
14.476 \\
13.418 \\
12.361 \\
11.303\end{array}$ & $\begin{array}{l}20.716 \\
19.658 \\
18.600 \\
17.542 \\
16.485 \\
15.427 \\
14.370 \\
13.312 \\
12.255 \\
11.198\end{array}$ & $\begin{array}{l}20.610 \\
19.552 \\
18.495 \\
17.437 \\
16.379 \\
15.321 \\
14.264 \\
13.207 \\
12.149 \\
11.092\end{array}$ & $\begin{array}{l}20.504 \\
19.447 \\
18.389 \\
17.331 \\
16.273 \\
15.216 \\
14.158 \\
13.101 \\
12.043 \\
10.986\end{array}$ & $\begin{array}{l}0.290544 \\
0.290543 \\
0.290541 \\
0.290540 \\
0.290539 \\
0.290537 \\
0.290536 \\
0.290535 \\
0.290533 \\
0.290532\end{array}$ & $\begin{array}{l}0.893132 \\
0.893157 \\
0.893182 \\
0.893207 \\
0.893232 \\
0.893257 \\
0.893282 \\
0.893307 \\
0.893332 \\
0.893357\end{array}$ \\
\hline $\begin{array}{r}3075.0 \\
5.1 \\
5.2 \\
5.3 \\
5.4 \\
5.5 \\
5.6 \\
5.7 \\
5.8 \\
5.9\end{array}$ & $\begin{array}{r}32510.880 \\
09.823 \\
08.766 \\
07.709 \\
06.652 \\
05.595 \\
04.539 \\
03.482 \\
02.425 \\
01.368\end{array}$ & $\begin{array}{l}10.775 \\
09.717 \\
08.660 \\
07.604 \\
06.547 \\
05.490 \\
04.433 \\
03.376 \\
02.319 \\
01.263\end{array}$ & $\begin{array}{l}10.669 \\
09.612 \\
08.555 \\
07.498 \\
06.441 \\
05.384 \\
04.327 \\
03.271 \\
02.214 \\
01.157\end{array}$ & $\begin{array}{l}10.563 \\
09.506 \\
08.449 \\
07.392 \\
06.335 \\
05.279 \\
04.222 \\
03.165 \\
02.108 \\
01.051\end{array}$ & $\begin{array}{l}10.458 \\
09.400 \\
08.344 \\
07.287 \\
06.230 \\
05.173 \\
04.116 \\
03.059 \\
02.002 \\
00.946\end{array}$ & $\begin{array}{l}10.352 \\
09.294 \\
08.238 \\
07.181 \\
06.124 \\
05.067 \\
04.010 \\
02.954 \\
01.897 \\
00.840\end{array}$ & $\begin{array}{l}10.246 \\
09.189 \\
08.132 \\
07.075 \\
06.018 \\
04.961 \\
03.905 \\
02.848 \\
01.791 \\
00.734\end{array}$ & $\begin{array}{l}10.140 \\
00.083 \\
08.026 \\
06.969 \\
05.913 \\
04.856 \\
03.799 \\
02.742 \\
01.685 \\
00.629\end{array}$ & $\begin{array}{l}10.035 \\
08.978 \\
07.921 \\
06.864 \\
05.807 \\
04.750 \\
03.693 \\
02.637 \\
01.580 \\
00.523\end{array}$ & $\begin{array}{l}09.929 \\
08.872 \\
07.815 \\
06.758 \\
05.701 \\
04.644 \\
03.587 \\
02.531 \\
01.474 \\
00.417\end{array}$ & $\begin{array}{l}0.290531 \\
0.290530 \\
0.290528 \\
0.290527 \\
0.290526 \\
0.290524 \\
0.290523 \\
0.290522 \\
0.290521 \\
0.290519\end{array}$ & $\begin{array}{l}.893382 \\
.893408 \\
.893433 \\
.893458 \\
.893483 \\
.893508 \\
.893533 \\
.893558 \\
.893583 \\
.893608\end{array}$ \\
\hline $\begin{array}{r}076.0 \\
6.1 \\
6.2 \\
6.3 \\
6.4 \\
6.5 \\
6.6 \\
6.7 \\
6.8 \\
6.9\end{array}$ & $\begin{array}{r}32500.312 \\
32499.255 \\
98.199 \\
97.142 \\
96.086 \\
95.030 \\
93.974 \\
92.918 \\
91.862 \\
90.806\end{array}$ & $\begin{array}{l}00.206 \\
99.149 \\
98.093 \\
97.036 \\
95.981 \\
94.925 \\
93.868 \\
92.812 \\
91.756 \\
90.700\end{array}$ & $\begin{array}{l}00.100 \\
99.044 \\
97.987 \\
96.931 \\
95.875 \\
94.819 \\
93.763 \\
92.707 \\
91.651 \\
90.594\end{array}$ & $\begin{array}{r}* 99.995 \\
98.938 \\
97.882 \\
96.825 \\
95.770 \\
94.713 \\
93.657 \\
92.601 \\
91.545 \\
90.489\end{array}$ & $\begin{array}{r}* 99.889 \\
98.833 \\
97.776 \\
96.719 \\
95.664 \\
94.608 \\
93.552 \\
92.495 \\
91.439 \\
90.384\end{array}$ & $\begin{array}{r}* 99.783 \\
98.727 \\
97.671 \\
96.614 \\
95.558 \\
94.502 \\
93.446 \\
92.390 \\
91.334 \\
90.278\end{array}$ & $\begin{array}{r}\# 99.678 \\
98.621 \\
97.565 \\
96.509 \\
95.453 \\
94.396 \\
93.341 \\
92.284 \\
91.228 \\
90.172\end{array}$ & $\begin{array}{l}* 99.572 \\
98.516 \\
97.459 \\
96.403 \\
95.347 \\
94.291 \\
93.235 \\
92.179 \\
91.123 \\
90.067\end{array}$ & $\begin{array}{r}99.467 \\
98.410 \\
97 \cdot 354 \\
96 \cdot 297 \\
95.241 \\
94 \cdot 185 \\
93.129 \\
92.073 \\
91.017 \\
89.961\end{array}$ & $\begin{array}{l}* 99.361 \\
98.305 \\
97.248 \\
96.192 \\
95.136 \\
94.079 \\
93.023 \\
91.967 \\
90.911 \\
89.855\end{array}$ & $\begin{array}{l}0.290518 \\
0.290517 \\
0.290515 \\
0.290514 \\
0.290513 \\
0.290511 \\
0.290510 \\
0.290509 \\
0.290508 \\
0.290506\end{array}$ & $\begin{array}{l}0.893633 \\
0.893658 \\
0.893683 \\
0.893708 \\
0.893734 \\
0.893759 \\
0.893784 \\
0.893809 \\
0.893834 \\
0.893859\end{array}$ \\
\hline $\begin{array}{r}3077.0 \\
7.1 \\
7.2 \\
7.3 \\
7.4 \\
7.5 \\
7.6 \\
7.7 \\
7.8 \\
7.9\end{array}$ & $\begin{array}{r}32489.750 \\
88.694 \\
87.638 \\
86.583 \\
85.527 \\
84.471 \\
83.416 \\
82.361 \\
81.305 \\
80.250\end{array}$ & $\begin{array}{l}89 \cdot 644 \\
88 \cdot 588 \\
87 \cdot 532 \\
86 \cdot 477 \\
85 \cdot 422 \\
84 \cdot 366 \\
83 \cdot 311 \\
82 \cdot 255 \\
81 \cdot 200 \\
80 \cdot 145\end{array}$ & $\begin{array}{l}89.539 \\
88.483 \\
87.427 \\
86.371 \\
85.316 \\
84.260 \\
83.205 \\
82.150 \\
81.094 \\
80.039\end{array}$ & $\begin{array}{l}89.433 \\
88.377 \\
87.322 \\
86.266 \\
85.210 \\
84.155 \\
83.100 \\
82.044 \\
80.989 \\
79.933\end{array}$ & $\begin{array}{l}89.328 \\
88.272 \\
87.216 \\
86.160 \\
85.105 \\
84.049 \\
82.994 \\
81.938 \\
80.883 \\
79.828\end{array}$ & $\begin{array}{l}89.222 \\
88.166 \\
87.110 \\
86.055 \\
84.999 \\
83.944 \\
82.888 \\
81.833 \\
80.778 \\
79.722\end{array}$ & $\begin{array}{l}89.116 \\
88.061 \\
87.005 \\
85.949 \\
84.893 \\
83.839 \\
82.783 \\
81.728 \\
80.672 \\
79.617\end{array}$ & $\begin{array}{l}89.011 \\
87.955 \\
86.899 \\
85.844 \\
84.788 \\
83.733 \\
82.677 \\
81.622 \\
80.567 \\
79.512\end{array}$ & $\begin{array}{l}88.905 \\
87.849 \\
86.794 \\
85.738 \\
84.682 \\
83.627 \\
82.572 \\
81.516 \\
80.461 \\
79.406\end{array}$ & $\begin{array}{l}88.800 \\
87.744 \\
86.688 \\
85.633 \\
84.577 \\
83.521 \\
82.466 \\
81.411 \\
80.355 \\
79.300\end{array}$ & $\begin{array}{l}0.290505 \\
0.290504 \\
0.290502 \\
0.290501 \\
0.290500 \\
0.290499 \\
0.290497 \\
0.290496 \\
0.290495 \\
0.290493\end{array}$ & $\begin{array}{l}0.893884 \\
0.893909 \\
0.893934 \\
0.893959 \\
0.893984 \\
0.894009 \\
0.894034 \\
0.894059 \\
0.894085 \\
0.894110\end{array}$ \\
\hline $\begin{array}{r}3078.0 \\
8.1 \\
8.2 \\
8.3 \\
8.4 \\
8.5 \\
8.6 \\
8.7 \\
8.8 \\
8.9\end{array}$ & $\begin{array}{r}32479.195 \\
78.140 \\
77.084 \\
76.030 \\
74.975 \\
73.920 \\
72.865 \\
71.811 \\
70.756 \\
69.701\end{array}$ & $\begin{array}{l}79.089 \\
78.034 \\
76.979 \\
75.924 \\
74.869 \\
73.814 \\
72.760 \\
71.705 \\
70.651 \\
69.596\end{array}$ & $\begin{array}{l}78.984 \\
77.928 \\
76.874 \\
75.819 \\
74.763 \\
73.708 \\
72.654 \\
71.600 \\
70.545 \\
69.490\end{array}$ & $\begin{array}{l}78.878 \\
77.823 \\
76.768 \\
75.713 \\
74.658 \\
73.603 \\
72.548 \\
71.494 \\
70.439 \\
69.385\end{array}$ & $\begin{array}{l}78.773 \\
77.718 \\
76.662 \\
75.607 \\
74.553 \\
73.498 \\
72.443 \\
71.389 \\
70.334 \\
69.280\end{array}$ & $\begin{array}{l}78.667 \\
77.612 \\
76.557 \\
75.502 \\
74.447 \\
73.392 \\
72.337 \\
71.283 \\
70.229 \\
69.174\end{array}$ & $\begin{array}{l}78.562 \\
77.507 \\
76.452 \\
75.396 \\
74.342 \\
73.287 \\
72.232 \\
71.178 \\
70.123 \\
69.069\end{array}$ & $\begin{array}{l}78.456 \\
77.401 \\
76.346 \\
75.291 \\
74.236 \\
73.181 \\
72.126 \\
71.072 \\
70.018 \\
68.963\end{array}$ & $\begin{array}{l}78 \cdot 351 \\
77 \cdot 296 \\
76 \cdot 241 \\
75 \cdot 186 \\
74 \cdot 131 \\
73 \cdot 076 \\
72 \cdot 021 \\
70 \cdot 967 \\
69 \cdot 912 \\
68 \cdot 858\end{array}$ & $\begin{array}{l}78.245 \\
77.190 \\
76.135 \\
75.080 \\
74.025 \\
72.970 \\
71.916 \\
70.861 \\
69.807 \\
68.752\end{array}$ & $\begin{array}{l}0.290492 \\
0.290491 \\
0.290490 \\
0.290488 \\
0.290487 \\
0.290486 \\
0.290484 \\
0.290483 \\
0.290482 \\
0.290481\end{array}$ & $\begin{array}{l}0.894135 \\
0.894160 \\
0.894185 \\
0.894210 \\
0.894235 \\
0.894260 \\
0.894285 \\
0.894310 \\
0.894335 \\
0.894360\end{array}$ \\
\hline $\begin{array}{l}79.0 \\
9.1 \\
9.2 \\
9.3 \\
9.4 \\
9.5 \\
9.6 \\
9.7 \\
9.8 \\
9.9\end{array}$ & $\begin{array}{r}32468.647 \\
67.592 \\
66.538 \\
65.484 \\
64.429 \\
63.375 \\
62.321 \\
61.267 \\
60.213 \\
59.159\end{array}$ & $\begin{array}{l}68 \cdot 541 \\
67 \cdot 487 \\
66 \cdot 432 \\
65 \cdot 378 \\
64 \cdot 324 \\
63 \cdot 270 \\
62 \cdot 216 \\
61 \cdot 161 \\
60.108 \\
59 \cdot 054\end{array}$ & $\begin{array}{l}68.436 \\
67.381 \\
66.327 \\
65.272 \\
64.218 \\
63.164 \\
62.110 \\
61.056 \\
60.002 \\
58.948\end{array}$ & $\begin{array}{l}67.276 \\
66.221 \\
65.167 \\
64.113 \\
63.059 \\
62.005 \\
60.950 \\
59.896 \\
58.843\end{array}$ & $\begin{array}{l}68.225 \\
67.170 \\
66.116 \\
65.062 \\
64.008 \\
62.953 \\
61.899 \\
60.845 \\
59.791 \\
58.738\end{array}$ & $\begin{array}{l}68.119 \\
67.065 \\
66.011 \\
64.956 \\
63.902 \\
62.848 \\
61.794 \\
60.740 \\
59.686 \\
58.632\end{array}$ & $\begin{array}{l}68.014 \\
66.960 \\
65.905 \\
64.851 \\
63.797 \\
62.743 \\
61.688 \\
60.634 \\
59.581 \\
58.527\end{array}$ & $\begin{array}{l}67.909 \\
66.854 \\
65.800 \\
64.745 \\
63.691 \\
62.637 \\
61.583 \\
60.529 \\
59.476 \\
58.422\end{array}$ & $\begin{array}{l}67.803 \\
66.749 \\
65.695 \\
64.640 \\
63.586 \\
62.532 \\
61.478 \\
60.424 \\
59.370 \\
58.316\end{array}$ & $\begin{array}{l}67.698 \\
66.644 \\
65.589 \\
64.535 \\
63.480 \\
62.426 \\
61.372 \\
60.318 \\
59.265 \\
58.211\end{array}$ & $\begin{array}{l}0.290478 \\
0.290477 \\
0.290475 \\
0.290474 \\
0.290473 \\
0.290471 \\
0.290470 \\
0.290469 \\
0.290468\end{array}$ & $\begin{array}{l}0.894385 \\
0.894411 \\
0.894436 \\
0.894461 \\
0.894486 \\
0.894511 \\
0.894536 \\
0.894561 \\
0.894586 \\
0.894611\end{array}$ \\
\hline
\end{tabular}




.05

0.0
0.1
0.2
0.3
0.4
0.5
0.6
0.7
0.8
0.9

$58.105 \quad 58.000$ $\begin{array}{ll}57.052 & 56.946 \\ 55.998 & 55.892\end{array}$

$53.891 \quad 53.785$

$52.837 \quad 52.732$

56.84
55.787
54.73
53.68
52.62
51.57
50.52
49.467

. \\ .}

$\begin{array}{lllllll}789 & 57.684 & 57.579 & 57.473 & 57.368 & 57.262 & 57.157 \\ 0 & 56.630 & 56.525 & 56.419 & 56.314 & 56.209 & 56.104\end{array}$

$\begin{array}{ll}447.571 & 47.465 \\ 46.518 & 46.412 \\ 45.465 & 45.359 \\ 44.412 & 44.307 \\ 43.359 & 43.254 \\ 42.306 & 42.201 \\ 41.253 & 41.148 \\ 40.201 & 40.095 \\ 39.148 & 39.043 \\ 38.095 & 37.990\end{array}$

$47.360 \quad 47.255$

$\begin{array}{ll}54.523 & 54.41 \\ 53.469 & 53.36\end{array}$

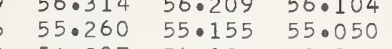

$\begin{array}{llllll}51.362 & 51.257 & 51.152 & 51.046 & 50.941 & 50.836 \\ 50.309 & 50.204 & 50.098 & 49.993 & 49.888 & 49.782\end{array}$

$\begin{array}{llllllllll}48.677 & 49.572 & 49.467 & 49.361 & 49.255 & 49.150 & 49.045 & 48.939 & 48.834 & 48.729 \\ 48.624 & 48.519 & 48.413 & 48.308 & 48.202 & 48.097 & 47.992 & 47.886 & 47.781 & 47.676\end{array}$

1.1
$1: 2$
$1:$
10
106
$1: 7$
1.

$\begin{array}{ll}45 \cdot 307 & 46.202 \\ 45.254 & 45.149\end{array}$

$47.150 \quad 47.044$

46.939

46.83

46.729

$\begin{array}{ll}44.201 & 44.096 \\ 43.148 & 43.043\end{array}$

$\begin{array}{ll}46.097 & 45.991 \\ 45.043 & 44.93\end{array}$

$\begin{array}{ll}45.886 & 45.781 \\ 44.833 & 44.728\end{array}$

44.623

46.623
45.570

$\begin{array}{lll} & \end{array}$

43.780
42.727
40.675

42.622

$43.570 \quad 43.464$

$\begin{array}{lllllll}41.885 & 41.780 & 41.675 & 41.569 & 41.464 & 41.350\end{array}$

$\begin{array}{llllllll}1.042 & 40.937 & 40.832 & 40.727 & 40.622 & 40.516 & 40.411 & 40.306 \\ 9.990 & 39.885 & 39.779 & 39.674 & 39.569 & 39.464 & 39.359 & 39.253\end{array}$

$38.095 \quad 37.990$

3082

2.

38.938

38.832
37.779

38.727
37.674

38.622
37.565

38.516

39.253

$36.833 \quad 36.72$

$\begin{array}{ll}36.622 & 36.517 \\ 35.569 & 35.46\end{array}$

$\begin{array}{llll}36.412 & 36.306 & 36.201 & 36.096 \\ 35.359 & 35.254 & 35.149 & 35.044\end{array}$

(4.938 $34 \cdot 833$

$32.834 \quad 32.729$

$31.782 \quad 31.677$

$\begin{array}{ll}30.730 & 30.625 \\ 29.678 & 29.573\end{array}$

$\begin{array}{llll}34.728 & 34.623 & 34.518 & 34.413\end{array}$

$\begin{array}{llll}33.676 & 33.571 & 33.465 & 33.360 \\ 32.624 & 32.518 & 32.413 & 32.30\end{array}$

$35 \cdot 359$
$34 \cdot 307$

35.096

2.5

2.6

$2 \cdot 8$

$\begin{array}{ll}28.626 & 28.521 \\ 27.574 & 27.469\end{array}$

$31.57131 .466 \quad 31.361 \quad 31.256$

$\begin{array}{llll}33.255 & 33.150 & 33.045 & 32.939\end{array}$

$\begin{array}{llll}31.151 & 31.045 & 31.992 & 31.887\end{array}$

$29.467 \quad 29.362$

$\begin{array}{ll}30.309 & 30.204 \\ 29.257 & 29.152\end{array}$

$30.099 \quad 29.993 \quad 29.880$

29.783

$\begin{array}{llllllll}28.416 & 28.310 & 28.205 & 28.100 & 27.995 & 27.889 & 27.784 & 27.679\end{array}$

3083.0

83.0
3.1
3.2
3.3
3.4
3.5
3.6
3.7
3.8
3.9

$32426.522 \quad 26.417$

$26.312 \quad 26.207$

27.15327 .048

$\begin{array}{llll}25.891 & 25.786 & 25.681 & 25.575\end{array}$

$\begin{array}{ll}25.470 & 25.365 \\ 24.419 & 24.313\end{array}$

$23.367 \quad 23.262$

$22.316 \quad 22 \cdot 211$

$\begin{array}{llllllllll}21.265 & 21.159 & 21.054 & 20.949 & 20.844 & 20.739 & 20.634 & 20.529 & 20.423 & 20.318 \\ 20.213 & 20.108 & 20.003 & 19.898 & 19.792 & 19.687 & 19.583 & 19.477 & 19.372 & 19.267 \\ 19.162 & 19.057 & 18.951 & 18.0846 & 18.741 & 18.636 & 18.531 & 18.426 & 18.321 & 18.216\end{array}$

$\begin{array}{ll}25.260 & 25 \cdot 155 \\ 24.208 & 24.103\end{array}$

$23.157 \quad 23.052$

$\begin{array}{ll}26.101 & 25.996 \\ 25.050 & 24.944 \\ 23.998 & 23.893\end{array}$

25.89
24.839
23.78

$\begin{array}{ll}25.786 & 25.68 \\ 24.734 & 24.629 \\ 23.682 & 23.577\end{array}$

$\begin{array}{llllll}23.998 & 23.893 & 23.788 & 23.682 & 23.577 & 23.472 \\ 22.947 & 22.842 & 22.737 & 22.631 & 22.527 & 22.421\end{array}$

$\begin{array}{ll}22.106 & 22.000 \\ 21.054 & 20.949\end{array}$

$\begin{array}{llllll}.896 & 21.790 & 21.685 & 21.580 & 21.475 & 21.370\end{array}$

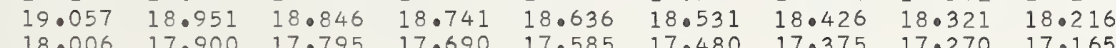

308400

4.0
4.1
4.3
4.4
4.5
40.
4.7
40
4.9

16.954

$\begin{array}{ll}17.900 & 17.795 \\ 16.849 & 16.744\end{array}$

17.690
16.639
16.58

$\begin{array}{llll}18.531 & 18.426 & 18.321 & 18.216 \\ 17.480 & 17.375 & 17.270 & 17.165\end{array}$

$32416.008 \quad 15.903$

$15.798 \quad 15.693$

$15.588 \quad 15.482$

15.378

$15.272 \quad 15.167 \quad 15 \cdot 062$

$\begin{array}{ll}13.906 & 13.801 \\ 12.855 & 12.750\end{array}$

$\begin{array}{llll}13.804 & 12.750 & 12.645 & 12.540\end{array}$

$1.8711 .69911 .594 \quad 11.489$

$\begin{array}{llll}10.754 & 10.649 & 10.544 & 10.439\end{array}$

08.6530 .0854

$\begin{array}{ll}07.602 & 07.497 \\ 06.552 & 06.447\end{array}$

$08.442 \quad 08.337$

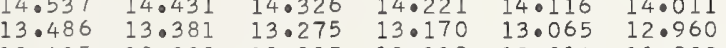

$\begin{array}{llllll}12.435 & 12.330 & 12.225 & 12.119 & 12.014 & 11.909\end{array}$

$\begin{array}{llllll}11.384 & 11.279 & 11.174 & 11.069 & 10.964 & 10.858 \\ 10.334 & 10.229 & 10.124 & 10.019 & 09.913 & 09.808\end{array}$

07.392

3085.0

5.0
5.
5.2
5.
5.
5.
5.0
5.7
5.8
5.9

32405.50

$04.451 \quad 04.346$

$\begin{array}{ll}03.400 & 03.295 \\ 02.350 & 02.245\end{array}$

$01.300 \quad 01.19$

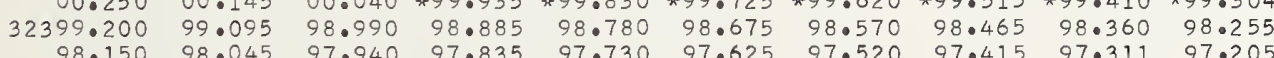

08.23209 .178

08.022

$\begin{array}{lll}08.968 & 08.863 & 08.758\end{array}$

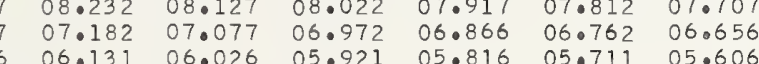

$(n-1) \times 1000$

$\lambda(n-1)$

0.290466

0.394636

0.290465

0.290462

0.290460

0.290457

0.290456

0.290453

0.29045

0.290450

0.290446

0.290443

0.290441

0.290438

0.290437
0.290435

0.290434

0.290433

0.290430
0.290429

0.290428

0.29042

0.290425

0.290423

0.290421

0.290419

0.290417

0.290415

0.290414
0.290412

0.290411

0.290410

0.290407

0.290406

0.290405

0.290402

0.290401
0.290400

0.290400

0.290397

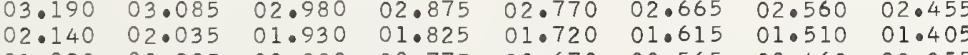

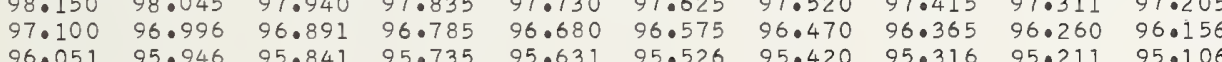

96.05195 .946

96.680

.575
5.526

9.470
5.420

3086.

6.

94.896

94.79

94.686

94.581

94.47

94.371

95.316

0.2903

0.290393

0.290392

0.290389

0.290388

0.290387

0.290385

0.290384

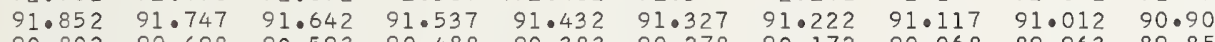

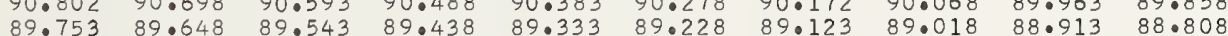

80.70458 .589

$89.543 \quad 89.43$

$\begin{array}{llllll}89.333 & 89.228 & 89.123 & 89.018 & 88.913 & 88.808\end{array}$

6.6

6.7

$86.605 \quad 86.500$

$\begin{array}{lllllll}88.284 & 88.179 & 88.074 & 87.969 & 87.864 & 87.759 \\ 87.234 & 87.130 & 87.025 & 86.919 & 86.815 & 86.710\end{array}$

0.290382

0.290380

0.290379
0.290378

0.290377

3087.0

32384.50

$384.507 \quad 84.402$

$85.347 \quad 85.241$

$\begin{array}{llllll}86.186 & 86.081 & 85.976 & 85.871 & 85.766 & 85.661 \\ 85.137 & 85.032 & 84.927 & 84.822 & 84.717 & 84.612\end{array}$

0.290375

0.290374

0.290371

0.290371

0.290369

0.290368

0.290366

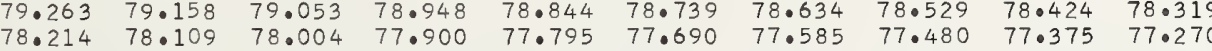

$\begin{array}{llllllllll}77.165 & 77.061 & 76.956 & 76.851 & 76.746 & 76.641 & 76.536 & 76.431 & 76.327 & 76.222 \\ 76.156 & 76.012 & 75.907 & 75.002 & 750.698 & 75.593 & 75.488 & 755.383 & 75.278 & 75.173\end{array}$

$\begin{array}{llllllllll}76.117 & 76.012 & 75.907 & 75.802 & 75.698 & 75.593 & 75.488 & 75.383 & 75.278 & 75.173 \\ 75.068 & 74.964 & 74.859 & 74.754 & 74.649 & 74.544 & 74.439 & 74.335 & 74.229 & 74.125\end{array}$

0.290364

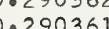

0.290360

0.290359

0.290357

0.290356

0.290355

0.290354
0.290352

0.290351

0.290350

0.290348

0.290346

0.290345

0.290343

0.290342
0.290341

0.290340

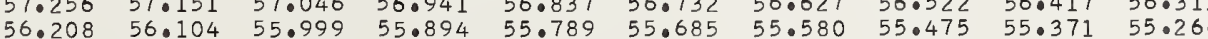

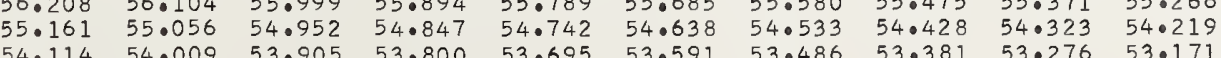

.010

.010

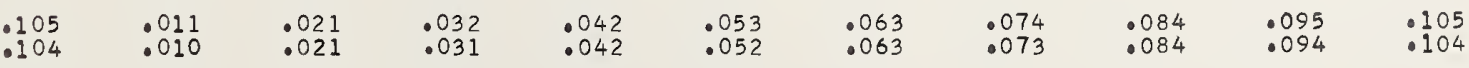


$\begin{array}{rrrrrrrrrrr}0.0 & 32353.067 & 52.962 & 52.857 & 52.753 & 52.648 & 52.543 & 52.439 & 52.334 & 52.229 & 52.124 \\ 0.1 & 52.020 & 51.915 & 51.810 & 51.706 & 51.601 & 51.496 & 51.392 & 51.287 & 51.182 & 51.078 \\ 0.2 & 50.973 & 50.868 & 50.764 & 50.659 & 50.554 & 50.450 & 50.345 & 50.240 & 50.136 & 50.031\end{array}$

$\begin{array}{lllllllllll}0.2 & 50.973 & 50.868 & 50.764 & 50.659 & 50.554 & 50.450 & 50.345 & 50.240 & 50.136 & 50.031 \\ 0.3 & 49.926 & 49.822 & 49.717 & 49.613 & 49.508 & 49.403 & 49.298 & 49.194 & 49.089 & 48.984\end{array}$

$\begin{array}{lllllllllll}0.4 & 48.880 & 48.775 & 48.670 & 48.566 & 48.461 & 48.356 & 48.251 & 48.147 & 48.042 & 47.938 \\ 0 & 47.83 & 47.729 & 47.624 & 47.519 & 47.415 & 47.310 & 47.205 & 47.100 & 46.096 & 46.891\end{array}$

$\begin{array}{lllllllllll}0.5 & 47.833 & 47.729 & 47.624 & 47.519 & 47.415 & 47.310 & 47.205 & 47.100 & 46.996 & 46.891 \\ 0.6 & 46.786 & 46.682 & 46.577 & 46.473 & 46.368 & 46.263 & 46.158 & 46.054 & 45.949 & 45.844\end{array}$

$\begin{array}{lllllllllll}0.6 & 46.786 & 46.682 & 46.577 & 46.473 & 46.368 & 46.263 & 46.158 & 46.054 & 45.949 & 45.844 \\ 0.7 & 45.740 & 45.635 & 45.531 & 45.426 & 45.321 & 45.217 & 45.112 & 45.007 & 44.903 & 44.798\end{array}$

$\begin{array}{lllllllllll}0.8 & 44.693 & 44.589 & 44.484 & 44.379 & 44.275 & 44.170 & 44.066 & 43.960 & 43.856 & 43.751 \\ 0.9 & 43.647 & 43.542 & 43.437 & 43.333 & 43.229 & 43.124 & 43.019 & 42.915 & 42.810 & 42.705\end{array}$

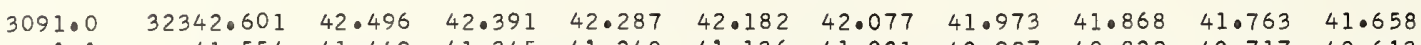

$\begin{array}{lllllllllll}1.1 & 41.554 & 41.449 & 41.345 & 41.240 & 41.136 & 41.031 & 40.927 & 40.822 & 40.717 & 40.613\end{array}$

$\begin{array}{lllllllllll}1.2 & 40.508 & 40.403 & 40.299 & 40.194 & 40.089 & 39.985 & 39.880 & 39.776 & 39.671 & 39.566 \\ 1.3 & 30.462 & 39.357 & 39.252 & 39.148 & 39.043 & 38.939 & 38.834 & 38.729 & 38.625 & 38.521\end{array}$

$\begin{array}{lllllllllll}1.3 & 39.462 & 39.357 & 39.252 & 39.148 & 39.043 & 38.939 & 38.834 & 38.729 & 38.625 & 38.521 \\ 1.4 & 38.415 & 38.311 & 38.206 & 38.102 & 37.997 & 37.893 & 37.788 & 37.684 & 37.579 & 37.474\end{array}$

$\begin{array}{llllll}1.5 & 37.370 & 37.266 & 37.161 & 37.057 & 3\end{array}$ $\begin{array}{ll}23.778 & 23.674 \\ 22.733 & 22.629\end{array}$ $27.750 \quad 27.645$ 26.704
25.659 $\begin{array}{ll}25.659 & 25.554 \\ 24.615 & 24.510\end{array}$

0.290338

0.290336

0.290334

0.290332

0.290331

0.290329

0.290328
0.290327

0.290326

0.290324

0.290323

0.290322

0.290320
0.290319

0.290318

0.290317

0.290315

0.290313

0.290312

0.290310
0.290309

0.290308

0.290306

0.290305

0.290303

0.290301

0.290300

0.290299

0.290298
0.290296

0.290295

0.290294
0.290293

0.290291

0.290290

0.290289

0.290287

0.290286

0.290285

0.290282

0.290281

0.290279

0.290277

0.290276

0.290275

0.290272

0.290271

0.290270

0.290268

0.290267

0.290265

0.290262

0.290261

0.290260

0.290258

0.290257

0.290255

0.29025

0.290252
0.290251

0.290249

0.290248

0.290247
0.290246

0.290244

0.290243

0.290242

0.290241
0.290239

0.290239
0.290238

0.290237

0.290236

0.290234
0.290233

0.290232

0.290231

0.290229

0.290227

0.290225

0.290224

0.290223

0.290222
0.290220

0.290219

0.290218

0.290215

0.290214

0.290213

0.897145

0.897170

0.897220

0.897246 

$\begin{array}{rrrrrrrrrrr}3100.0 & 32248.707 & 48.603 & 48.499 & 48.394 & 48.290 & 48.186 & 48.083 & 47.978 & 47.874 & 47.770 \\ 0.1 & 47.666 & 47.562 & 47.458 & 47.354 & 47.250 & 47.146 & 47.042 & 46.938 & 46.834 & 46.730\end{array}$ $\begin{array}{lllllllllllll}0.2 & 46.626 & 46.522 & 46.418 & 46.314 & 46.210 & 46.106 & 46.002 & 45.898 & 45.794 & 45.690\end{array}$

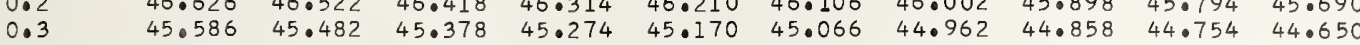

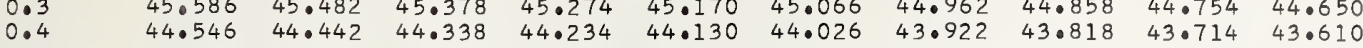
$\begin{array}{llllllllllll}0.5 & 43.506 & 43.402 & 43.298 & 43.194 & 43.090 & 42.986 & 42.882 & 42.778 & 42.674 & 42.570\end{array}$ $\begin{array}{lllllllllll}0.6 & 42.466 & 42.362 & 42.258 & 42.154 & 42.050 & 41.946 & 41.842 & 41.738 & 41.634 & 41.530\end{array}$ $\begin{array}{llllllllllll}0.7 & 41.426 & 41.322 & 41.218 & 41.114 & 41.010 & 40.906 & 40.802 & 40.698 & 40.594 & 40.490\end{array}$ $\begin{array}{lllllllllll}0.8 & 40.386 & 40.282 & 40.178 & 40.074 & 39.970 & 39.867 & 39.763 & 39.658 & 39.555 & 39.450\end{array}$

$\begin{array}{lllllllllll}3101.0 & 32238.308 & 38.204 & 38.100 & 37.996 & 37.892 & 37.788 & 37.684 & 37.580 & 37.476 & 37.372\end{array}$ $\begin{array}{llllllllllll}1.1 & 37.268 & 37.164 & 37.060 & 36.956 & 36.852 & 36.748 & 36.644 & 36.540 & 36.436 & 36.333 \\ 1.2 & 36.229 & 36.125 & 36.021 & 35.917 & 35.812 & 35.709 & 35.605 & 35.501 & 35.397 & 35.293\end{array}$ $\begin{array}{llllllllllll}1.2 & 36.229 & 36.125 & 36.021 & 35.917 & 35.812 & 35.709 & 35.605 & 35.501 & 35.397 & 35.293 \\ 1.3 & 35.189 & 35.085 & 34.981 & 34.877 & 34.773 & 34.669 & 34.565 & 34.461 & 34.357 & 34.253\end{array}$ $\begin{array}{lllllllllll}1.3 & 35.189 & 35.085 & 34.981 & 34.877 & 34.773 & 34.669 & 34.565 & 34.461 & 34.357 & 34.253 \\ 1.4 & 34.149 & 34.046 & 33.942 & 33.838 & 33.734 & 33.630 & 33.526 & 33.422 & 33.318 & 33.214 \\ 1.5 & 33.110 & 33.006 & 32.902 & 32.799 & 32.695 & 32.591 & 32.487 & 32.383 & 32.279 & 32.175\end{array}$ $\begin{array}{llllllllllll}1.5 & 33.110 & 33.006 & 32.902 & 32.799 & 32.695 & 32.591 & 32.487 & 32.383 & 32.279 & 32.175 \\ 1.6 & 32.071 & 31.967 & 31.863 & 31.760 & 31.656 & 31.552 & 31.448 & 31.344 & 31.240 & 31.136\end{array}$ $\begin{array}{lllllllllll}1.6 & 32.071 & 31.967 & 31.863 & 31.760 & 31.656 & 31.552 & 31.448 & 31.344 & 31.240 & 31.136 \\ 1.7 & 31.032 & 30.928 & 30.824 & 30.720 & 30.616 & 30.512 & 30.409 & 30.304 & 30.201 & 30.097\end{array}$ $\begin{array}{lllllllllll}1.7 & 31.032 & 30.928 & 30.824 & 30.720 & 30.616 & 30.512 & 30.409 & 30.304 & 30.201 & 30.097 \\ 1.8 & 29.993 & 29.889 & 29.785 & 29.681 & 29.577 & 29.473 & 29.369 & 29.265 & 29.161 & 29.058\end{array}$

$\begin{array}{lllllllllll}3102.0 & 32227.915 & 27.811 & 27.707 & 27.603 & 27.499 & 27.395 & 27.292 & 27.188 & 27.083 & 26.979\end{array}$ $\begin{array}{rrrllllllll}2.1 & 26.876 & 26.772 & 26.668 & 26.565 & 26.461 & 26.357 & 26.253 & 26.149 & 26.045 & 25.941\end{array}$ $\begin{array}{lllllllllll}2.2 & 25.838 & 25.734 & 25.630 & 25.526 & 25.422 & 25.318 & 25.214 & 25.110 & 25.007 & 24.903 \\ 2.3 & 24.799 & 24.695 & 24.591 & 24.487 & 24.383 & 24.279 & 24.175 & 24.071 & 23.968 & 23.064\end{array}$ $\begin{array}{lllllllllll}2.3 & 24.799 & 24.695 & 24.591 & 24.487 & 24.383 & 24.279 & 24 \cdot 175 & 24.071 & 23.968 & 23.864 \\ 2.4 & 23.760 & 23.656 & 23.552 & 23.448 & 23.345 & 23.240 & 23.137 & 23.033 & 22.929 & 22.825\end{array}$ $\begin{array}{lllllllllll}2.4 & 23.761 & 23.656 & 23.552 & 23.448 & 23.345 & 23.240 & 23.137 & 23.033 & 22.929 & 22.825 \\ 2.5 & 22.721 & 22.618 & 22.514 & 22.410 & 22.306 & 22.202 & 22.098 & 21.994 & 21.890 & 21.786\end{array}$

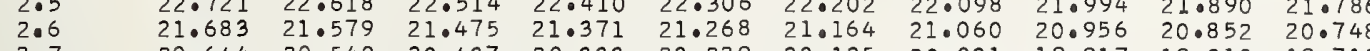
$\begin{array}{llllllllll}20.644 & 20.540 & 20.437 & 20.333 & 20.229 & 20.125 & 20.021 & 19.917 & 19.813 & 19.710\end{array}$

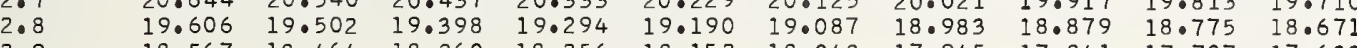
$\begin{array}{llllllllll}19.606 & 19.502 & 19.398 & 19.294 & 19.190 & 19.087 & 18.983 & 18.879 & 18.775 & 18.671 \\ 18.567 & 18.464 & 18.360 & 18.256 & 18.152 & 18.048 & 17.945 & 17.841 & 17.737 & 17.633\end{array}$ 32217.529

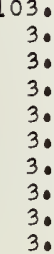

3104.0 4.1

\author{
3105.0
} 105.0
5.1
5.2
5.3
5.4
5.5
5.6
5.7
5.8
5.9
106.0

3106.0 6.1
6.2
6.3
6.4
6.5
6.5
6.7
6.

3107.0

$$
\begin{array}{r}
107.0 \\
7 \\
7 \\
7 \\
7 \\
7 \\
7.5 \\
7 \\
7 \\
7 .
\end{array}
$$

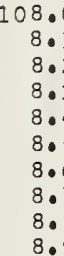

$$
\begin{array}{rr}
3108.0 & 32165.7 \\
8.1 & 64.6
\end{array}
$$

$\begin{array}{lllllllllll} & .001 & .002 & .003 & .004 & .005 & .006 & .007 & .008 & .009 & .010 \\ .104 & .010 & .021 & .031 & .042 & .052 & .063 & .073 & .083 & .094 & .0104 \\ 103 & .010 & .021 & .031 & .041 & .052 & .062 & .072 & .083 & .093 & .103\end{array}$

0.290212
0.290210

0.290209

0.290208

0.290205

0.290204

0.290203

0.290200

0.290199

0.290198

0.290195

0.290194

0.290191

0.290186

.290185

0.290184
0.290183

290181

0.290180
0.290179

0.290178

0.290176
0.290175

0.290174

0.290173

0.290170

0.290169

0.290166

0.290164

0.290163

0.290161

0.290160
0.290159

0.290158

0.290156
0.290155

0.290154

0.290151

0.290149

0.290148

0.290145

0.290144

0.290141

0.290140

0.290139

0.290136

0.290135

0.290133

0.290131

0.290130

0.290128

0.290126

0.290124

0.290120

0.290119

0.290116

0.290115

0.290113

0.290111

0.290110

0.290108

0.290106

0.290104

0.290103

0.290100

0.290099

0.290098

0.290096

0.290094

0.290093

0.290091

0.290090

0.290089

010
0.899656

0.899681

0.899731

0.899782

0.899782

0.899832

0.89985

0.899907

0.899932

0.8995

0.900008

0.90003

0.900083

0.90010

0.900158

0.900183

0.900209
0.900234

0.900234

0.900284

0.900309

0.900334

0.900384

0.900410

0.900435

0.900485

0.900510

0.900535

0.900560

0.900611

0.900661

0.900686

0.900711

0.900761

0.900786
0.900812

0.900837

0.900862
0.900887

0.900912

0.900937

0.900987

0.901013

0.901038

0.901063
0.901088

0.901113

0.901163

0.901188

0.901214

0.901264

0.901314

0.901339

0.901364
0.901390

0.901415

0.901440
0.901465

0.901465

0.901515

0.901565

0.901591

0.901616

0.901666

0.901716

0.901741

0.901766

0.901817

0.901867

0.901867

0.901917

0.901968

0.901993

0.902018

0.902068

0.902093
0.902118

0.902118 

34.581 $\begin{array}{ll}32.652 & 33.548 \\ 32.619 & 32.515\end{array}$ $\begin{array}{ll}31.586 & 31.483 \\ 30.553 & 30.450\end{array}$ 30.553
29.521 $\begin{array}{ll}29.521 & 29.417 \\ 28.488 & 28.385\end{array}$ $27.456 \quad 27.353$ $\begin{array}{ll}26.424 & 26.321 \\ 25.391 & 25.288\end{array}$

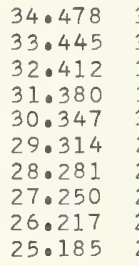

$36.337 \quad 36.234$

36.131

24.359

3113.0

3.1
3.2
3.3

3.3

3.4
3.5

3.6
3.7

3.8
3.9

32114.040 $13.009 \quad 13.9$

11.997

$08.883 \quad 08.780$

$07.852 \quad 07.748$

$\begin{array}{ll}06.820 & 06.717 \\ 05.789 & 05.686\end{array}$

04.758

3114 .

$4 \cdot 1$

$4 \cdot 2$

$4 \cdot 4$

$4 \cdot 5$

$4 \cdot 7$

$4 \cdot 9$

3115.

$5 \cdot 1$
$5 \cdot 2$
$5 \cdot 3$

$5 \cdot 4$

5.6

5.8

32103.72

$02.697 \quad 02.594$

$\begin{array}{ll}0.666 & 01.563\end{array}$

$98.604 \quad 99.501$

$\begin{array}{ll}98.574 & 98.471 \\ 97.543 & 97.440\end{array}$

$\begin{array}{ll}96.513 & 96.409 \\ 95.482 & 95.379 \\ 94.452 & 94.349\end{array}$

116.

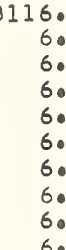$$
32093.42293 .318
$$$$
\begin{array}{rr}
92.391 & 92.288 \\
91.361 & 91.258 \\
90.331 & 90.229
\end{array}
$$$$
\begin{array}{llll}
89.301 & 89.198 & 89.095 & 88.992
\end{array}
$$$$
\begin{array}{lllll}
88.271 & 88.168 & 88.065 & 87.963
\end{array}
$$$$
87.241 \quad 87.138
$$

$\begin{array}{ll}86.211 & 86.108 \\ 85.182 & 85.079\end{array}$

$84.152 \quad 84.049$

$87.035 \quad 86.933$

$\begin{array}{ll}86.006 & 85.903 \\ 84.976 & 84.873\end{array}$

$32083 \cdot 12$

$\begin{array}{rr}083.122 & 83.019 \\ 82.093 & 81.990\end{array}$

81.06380 .960
$80.034 \quad 79.911$

$79.004 \quad 78.901$
77.076

$\begin{array}{lll}77.976 & 77.873 \\ 76.946 & 76.843\end{array}$

$\begin{array}{lll}75.917 & 75.0414 \\ 74.888 & 74.785\end{array}$

$\begin{array}{llll}74.888 & 74.785 \\ 73.859 & 73.756\end{array}$

3117.0

7.0
$7: 2$
$7: 0$
7.5
$7: 9$
7.9

3118.

18.0
8.1
8.2
8.4
8.4
8.6
8.7
8.8 $\begin{array}{rr}072.830 & 72.727 \\ 71.801 & 71.698\end{array}$ 71.8017

$69.743 \quad 69.640 \quad 60.566 \quad 70.463$

$\begin{array}{llll}68.715 & 68.612 & 68.509 & 68.406\end{array}$

$67.686 \quad 67.583$

$66.657 \quad 66.555$

$\begin{array}{ll}64.601 & 64.498 \\ 63.572 & 63.469\end{array}$

66.45166 .34

$062.544 \quad 62.441$

$61.516 \quad 61.413$

$\begin{array}{lll}60.488 & 60.385 \\ 59.459 & 59.357 & \end{array}$

$\begin{array}{llll}58.431 & 58.329 & \\ 57.404 & 57.301 & 5\end{array}$

$\begin{array}{lll}57.404 & 57.301 \\ 56.375 & 56.273 \\ 55.340 & 55.245\end{array}$

$\begin{array}{lll}55.348 & 55.245 \\ 54.320 & 54.217 & \\ 53.25 & 5.190\end{array}$

64.39
63.36

62.338

61.31
60.28
59.254

$\begin{array}{ll}59.254 \quad 59.15 \\ 57.258 & 57.095\end{array}$

$\begin{array}{lll}34.271 & 34.168 & 34.0 \\ 33.0238 & 33.135 & 3.0 \\ 32.006 & 32.102 & 3109\end{array}$

34.065
33.032

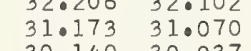

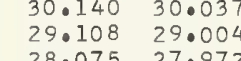

$\begin{array}{ll}28.075 & 27.997 \\ 27.043 & 26: 040 \\ 26.010 & 25.907\end{array}$

31.999
30.966

29.93
28.90
27

\begin{tabular}{l}
$27.869 \quad 27.76$ \\
\hline
\end{tabular}

26.837
25.80
2.872

24.978

24.875

24.772

$\begin{array}{ll}23.946 & 23.843 \\ 22.914 & 22.810 \\ & \end{array}$

23.740
22.707
21.675

22.0.5.

$20.643 \quad 20.540 \quad 20.0437 \quad 20.333$

$\begin{array}{llllll}20.850 & 20.746 & 20.643 & 20.540 & 20.437 & 20.333 \\ 19.818 & 19.715 & 19.611 & 19.508 & 19.405 & 19.002 \\ 18.786 & 18.682 & 18.580 & 18.476 & 18.373 & 18.270\end{array}$

$\begin{array}{llllll}18.086 & 18.682 & 18.580 & 18.046 & 18 \cdot 373 & 18.270 \\ 17.754 & 17.551 & 17.548 & 17.444 & 17.341 & 17.238\end{array}$

$\begin{array}{lll}15.722 & 16.619 \\ 15.690 & 11.587 \\ 14.5 & 15.596\end{array}$

$\begin{array}{llll}16.516 & 16.412 & 16 \cdot 309 & 16.206 \\ 15.484 & 15.381 & 15.278 & 15.175\end{array}$

$\begin{array}{llll}14.452 & 14.350 & 14.246 & 14.143\end{array}$

$13.627 \quad 13.524$

13.421

13.318

13.215

13.111
12.080

$\begin{array}{llllll}10.533 & 10.430 & 10.326 & 10.223 & 10.120 & 10.017\end{array}$

$\begin{array}{lllllll}09.502 & 09.398 & 09.295 & 09.192 & 09.089 & 08.986\end{array}$

$\begin{array}{lllllll}08.470 & 08.367 & 08.264 & 08.161 & 08.058 & 07.954\end{array}$

$\begin{array}{llllll}06.408 & 07.336 & 07.233 & 07.130 & 07.026 & 06.923\end{array}$

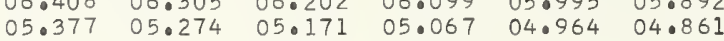

$\begin{array}{lllllll}04.346 & 04.243 & 04.140 & 04.037 & 03.934 & 03.830\end{array}$

$\begin{array}{llllll}03.315 & 03.212 & 03.109 & 03.006 & 02.903 & 02.800\end{array}$

$\begin{array}{llllll}02.284 & 02.181 & 02.078 & 01.975 & 01.872 & 01.769 \\ 01.254 & 01.150 & 01.047 & 00.944 & 00.841 & 00.738\end{array}$

$00.223 \quad 00.120 \quad 00.017 * 99.913 * 99.811 * 99.708$

$\begin{array}{lllllll}99.192 & 99.089 & 98.986 & 98.883 & 98.780 & 98.677\end{array}$

$\begin{array}{cccccc}98.162 & 98.059 & 97.956 & 97.852 & 97.749 & 97.646 \\ 97.131 & 97.028 & 96.925 & 96.822 & 96.719 & 96.616\end{array}$

$\begin{array}{lllllll}96.100 & 95.998 & 95.895 & 95.792 & 95.688 & 95.585\end{array}$

$\begin{array}{llllll}95.070 & 94.967 & 94.864 & 94.761 & 94.658 & 94.555 \\ 94.040 & 93.937 & 93.833 & 93.731 & 93.628 & 93.524\end{array}$

$\begin{array}{llllll}93.010 & 92.906 & 92.803 & 92.700 & 92.597 & 92.494\end{array}$

$\begin{array}{llllll}91.979 & 91.876 & 91.773 & 91.670 & 91.567 & 91.464\end{array}$

$\begin{array}{llllll}90.949 & 90.846 & 90.743 & 90.640 & 90.538 & 90.434 \\ 89.919 & 89.817 & 89.713 & 89.610 & 89.507 & 89.404\end{array}$

$\begin{array}{lllllll}88.890 & 88.0786 & 88.083 & 88.580 & 88.0477 & 88.374\end{array}$

$\begin{array}{lllllll}87.860 & 87.756 & 87.654 & 87.550 & 87.447 & 87.344\end{array}$

$\begin{array}{llllll}86.830 & 86.727 & 86.624 & 86.521 & 86.417 & 86.314\end{array}$

$\begin{array}{llllll}85.800 & 85.697 & 85.594 & 85.491 & 85.388 & 85.285\end{array}$

$\begin{array}{llllll}84.770 & 84.667 & 84.564 & 84.461 & 84.358 & 84.255 \\ 83.740 & 83.637 & 83.534 & 83.432 & 83.328 & 83.225\end{array}$

0.290086

0.290084

0.290083

0.290081

0.290079

0.290078

0.290076

0.290074

0.290073

0.290071

0.290070
0.290069

0.290068

0.290066

0.290065

0.290064

.290063

0.290062

0.290059

0.290058

0.290057

0.290055

0.290053

0.290052

0.290050

0.290049

0.290048

0.290047

0.290044

0.290043

0.290042

0.29040

0.290038

0.290037

0.290035

0.290034

0.290032

0.290030

0.290029

0.290028

0.290027
0.290026

0.290024

0.290023

0.290022

0.290019

0.290018

0.290017

0.290016

0.290014

0.290012

0.290011

0.290008

0.290007

0.290006

0.290004

0.290003

0.290003

0.290001

0.290000

0.289998

0.289996

0.289993

0.289992

0.289991

0.289990

0.289987

0.289986

0.289985

0.289983

0.289982

0.289980

0.289979

0.289977

0.289975

0.289974

0.289972

0.289971
0.289970

0.289969

0.289967

0.289966

0.289965

0.289964

.010

0.902169

0.902219

0.902244

.902269

0.902319

.902345

0.902370

0.902420

0.902470

0.902495

0.902546

0.902571

0.902596

0.902646 
0.289944

0.289942

0.289940

$\begin{array}{rrrrrrrrrrr}122.0 & 32021.466 & 21.364 & 21.261 & 21.158 & 21.056 & 20.953 & 20.851 & 20.748 & 20.645 & 20.543 \\ 2.1 & 20.440 & 20.338 & 20.235 & 20.133 & 20.030 & 19.927 & 19.825 & 19.722 & 19.620 & 19.517\end{array}$ $\begin{array}{lllllllllll}2.2 & 19.415 & 19.312 & 19.210 & 19.107 & 19.005 & 18.902 & 18.800 & 18.697 & 18.594 & 18.492\end{array}$ $\begin{array}{lllllllllll}2.3 & 18.389 & 18.287 & 18.184 & 18.082 & 17.979 & 17.877 & 17.774 & 17.671 & 17.569 & 17.466 \\ 2.4 & 17.364 & 17.261 & 17.159 & 17.056 & 16.954 & 16.851 & 16.749 & 16.646 & 16.543 & 16.441\end{array}$

0.289926 0.289923 0.289922 289920 0.289918

0.289916

0.289913 0.289911 0.289910 0.289907 0.289906 0.289905

0.289902

0.289901

0.289899

0.289897

0.289895

.289894

0.289890

0.289889 0.289888
0.289886 0.289885 0.289883 0.089880 0.289879 0.289878

0.289877
0.289875

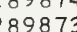
0.289872 0.289871

0.289868

0.289867

0.289864

0.08963

0.289862

0.289860

0.289858

0.289856

0.289855

0.289852

0.289851

0.289850

0.289847

0.289846

0.289845 0.289844 0.289841

.905664

0.905689 0.905740 0.905790 0.905815 0.905840 0.905916

0.905941 0.905966 0.906016 0.906042
0.906067 0.906092 0.906117 0.906142
0.906167

0.906193 0.906218
0.906243 0.906268 0.906293 0.906344 0.906369 0.906394
0.906419

0.906444 0.906469
0.906495 0.906520 0.906570 0.906595 0.906620

0.906646
0.906671

0.906696 0.906746 0.906771 0.906822 0.906847
0.906872 0.906897 0.906922

\subsection{8} 0.906973 0.906998 0.907048 0.907073 0.907099
0.907124 0.907149
0.907174 $\begin{array}{lllllllllll} & .001 & .002 & .003 & .004 & .005 & .006 & .007 & .008 & .009 & .010 \\ .103 & .010 & .021 & .031 & .041 & .051 & .062 & .072 & .082 & .093 & .0103 \\ .102 & .010 & .020 & .031 & .041 & .051 & .061 & .071 & .081 & .092 & .102\end{array}$ 


$\begin{array}{ll}919.230 & 19.128 \\ 18.211 & 18.109 \\ 17.192 & 17.090 \\ 16.174 & 16.072 \\ 15.155 & 15.053 \\ 14.136 & 14.034 \\ 13.117 & 13.015 \\ 12.098 & 11.996 \\ 11.080 & 10.978 \\ 10.061 & 09.959\end{array}$

$31909.042 \quad 08.941$ $08.024 \quad 07.922$ $\begin{array}{ll}07.006 & 06.904 \\ 05.987 & 05.885\end{array}$ $\begin{array}{ll}05.987 & 05.885 \\ 04.969 & 04.867\end{array}$ $03.951 \quad 03.850$ $\begin{array}{ll}02.933 & 02.832 \\ 01.915 & 01.813\end{array}$ $\begin{array}{rr}00.897 & 00.796 \\ 899.879 & 99.778\end{array}$

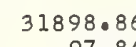

9.1 $47.038 \quad 46.937$ $47.850 \quad 47.749$ $\begin{array}{llll}46.024 & 45.922 & 46.835 & 46.734 \\ 45.821 & 45.719\end{array}$

$$
.002
$$$$
.003
$$ 
$\begin{array}{rrrrrrrrrrr}0.0 & 31837.911 & 37.809 & 37.708 & 37.607 & 37.505 & 37.403 & 37.302 & 37.201 & 37.099 & 36.998 \\ 0.1 & 36.897 & 36.795 & 36.694 & 36.593 & 36.491 & 36.390 & 36.288 & 36.187 & 36.085 & 35.984\end{array}$

$\begin{array}{llllllllllll}0.2 & 36.897 & 36.795 & 36.694 & 36.593 & 36.491 & 36.390 & 36.288 & 36.187 & 36.085 & 35.984 \\ 0.2 & 35.883 & 35.781 & 35.680 & 35.579 & 35.477 & 35.376 & 35.274 & 35.173 & 35.072 & 34.970\end{array}$

$\begin{array}{llllllllllll}0.3 & 34.869 & 34.768 & 34.666 & 34.565 & 34.463 & 34.362 & 34.261 & 34.159 & 34.058 & 33.957 \\ 0.4 & 33.855 & 33.754 & 33.653 & 33.551 & 33.450 & 33.349 & 33.247 & 33.146 & 33.044 & 32.943\end{array}$

$\begin{array}{lllllllllll}0.5 & 32.842 & 32.740 & 32.639 & 32.538 & 32.436 & 32.335 & 32.234 & 32.132 & 32.031 & 31.929\end{array}$

$\begin{array}{lllllllllll}0.6 & 31.828 & 31.727 & 31.625 & 31.524 & 31.423 & 31.321 & 31.220 & 31.119 & 31.017 & 30.916\end{array}$

$\begin{array}{lllllllllll}0.7 & 30.814 & 30.713 & 30.612 & 30.510 & 30.409 & 30.308 & 30.207 & 30.105 & 30.004 & 29.902 \\ 0.8 & 29.801 & 29.700 & 29.598 & 29.497 & 29.396 & 29.294 & 29.193 & 29.092 & 28.990 & 28.889\end{array}$

$\begin{array}{lllllllllll}3141.0 & 31827.775 & 27.674 & 27.572 & 27.471 & 27.370 & 27.268 & 27.167 & 27.065 & 26.964 & 26.863\end{array}$

$\begin{array}{lllllllllll}1.1 & 26.761 & 26.660 & 26.559 & 26.458 & 26.356 & 26.255 & 26.154 & 26.052 & 25.951 & 25.850 \\ 1.2 & 25.748 & 25.647 & 25.546 & 25.445 & 25.343 & 25.242 & 25.141 & 25.039 & 24.938 & 24.836\end{array}$

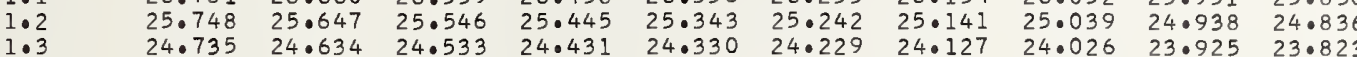

$\begin{array}{lllllllllll}1.3 & 24.735 & 24.634 & 24.533 & 24.431 & 24.330 & 24.229 & 24 \cdot 127 & 24.026 & 23.925 & 23.823 \\ 1.04 & 23.722 & 23.621 & 23.520 & 23.418 & 23.317 & 23.216 & 23.114 & 23.013 & 22.912 & 22.810\end{array}$

$\begin{array}{lllllllllll}1.5 & 22.709 & 22.608 & 22.506 & 22.405 & 22.304 & 22.203 & 22.102 & 22.000 & 21.899 & 21.797 \\ 1.5 & 21.696 & 21.595 & 21.493 & 21.392 & 21.291 & 21.190 & 21.089 & 20.987 & 20.886 & 20.784\end{array}$

$\begin{array}{lllllllllll}1.6 & 21.696 & 21.595 & 21.493 & 21.392 & 21.291 & 21.190 & 21.089 & 20.987 & 20.886 & 20.784 \\ 1.7 & 20.683 & 20.582 & 20.481 & 20.379 & 20.278 & 20.177 & 20.076 & 19.974 & 19.873 & 19.772\end{array}$

$\begin{array}{lllllllllll}1.8 & 19.670 & 19.569 & 19.468 & 19.366 & 19.265 & 19.164 & 19.063 & 18.961 & 18.860 & 18.759 \\ 1.9 & 18.657 & 18.556 & 18.455 & 18.354 & 18.253 & 18.151 & 18.050 & 17.949 & 17.848 & 17.746\end{array}$

31817.645

$16.633 \quad 16.531$

17.442

17.34

$\begin{array}{ll}17.240 & 17.139\end{array}$

17.03

$14.608 \quad 14.51$

$13.595 \quad 13.49$

$12.583 \quad 12.482$

11.57

$10.558 \quad 10.457$

$\begin{array}{llll}15.418 & 15.317 & 15.215 & 1.5 .114\end{array}$

13.39

08.534

3143.0

3.

$3 \cdot 2$
$3 \cdot 3$
$3 \cdot 4$

3.4

3.6

3.7

3.9

314400

$4 \cdot 1$
4.2
4.3
4.4
4.5
$4 \cdot 6$
4.7
4.8
4.9

$4 \cdot 6$

$4 \cdot 8$
$4 \cdot 9$

3145.

45.
5.
5.
5.
5.
5.
5.6
5.7
5.
5.

3146.

46
6
6
6
6
6
6
6
6

$807.522 \quad 07.421$

06.510

$05.498 \quad 05.397$

$03.475 \quad 03.374$

$\begin{array}{ll}02.463 & 02.362 \\ 01.452 & 01.350\end{array}$

$00.440 \quad 00.339$

31799.428

99.327

$31797.406 \quad 97.305$

96.395
95.395 .293

$\begin{array}{llll}95.383 & 95.282 & 95.181 & 95.080 \\ 94.372 & 94.271 & 94.170 & 94.068\end{array}$

$\begin{array}{llll}93.361 & 93.260 & 93.170 & 94.068\end{array}$

$\begin{array}{llll}92.350 & 92.249 & 92.147 & 92.047\end{array}$

91.339

88.307

90.227
$89 \cdot 216$

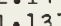

92.047
91.036

$\begin{array}{ll}14.203 & 14.102 \\ 13.191 & 13.089\end{array}$

15.01

$\begin{array}{lll}16.936 & 16.835 & 16.734 \\ 15.924 & 15.823 & 15.722\end{array}$

$\begin{array}{lll}13.292 & 13.191 & 13.089 \\ 12.280 & 12.178 & 12.077\end{array}$

$\begin{array}{lll}16.000 & 13.899 & 13.79\end{array}$

14.709

$787.296 \quad 87.195$

$9.115 \quad 89.014$

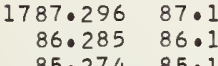

87.094

88.003

$84.264 \quad 84.163$

$83.253 \quad 83.153$

$82.142-82.041$

$5.073 \quad 84.971$

$81.233 \quad 81.132$

$\begin{array}{ll}79.212 & 79.111 \\ 78.202 & 78.102\end{array}$

$\begin{array}{rr}82.041 & 81.940 \\ 81.031 & 80.930\end{array}$

0.02079 .919

$\begin{array}{ll}10.154 & 10.052 \\ 09.141 & 09.040\end{array}$

11.976

2.887

12.785

12.684

$31777.192 \quad 77.0$

$\begin{array}{rr}777.192 & 77.091 \\ 76.182 & 76.08 \\ 75.172 & 75.071 \\ 74.162 & 74.062 \\ 73.152 & 73.052\end{array}$

$\begin{array}{ll}73.152 & 73.052 \\ 72.143 & 72.042\end{array}$

$71.133 \quad 71.032$

$\begin{array}{ll}70.123 & 70.022 \\ 69.114 & 69.013\end{array}$

$\begin{array}{ll}69.114 & 69.013 \\ 68.104 & 68.003\end{array}$

3147.

7.

$31767.095 \quad 66.994$

$66.086 \quad 65.985$

$\begin{array}{ll}65.076 & 64.975 \\ 64.067 & 63.966\end{array}$

$63.058 \quad 62.95$

$62.049 \quad 61.94$

$\begin{array}{ll}61.040 & 60.939 \\ 60.031 & 59.92\end{array}$

$\begin{array}{ll}59.021 & 58.921 \\ 58.012 & 57.912\end{array}$

$79.010 \quad 78.909$

08.12

08.028

08.939

.850

09.74909 .648

9.648

7.623

$\begin{array}{llll}.915 & 06.814 & 06.713 & 06.611\end{array}$

$\begin{array}{lllllll}.105 & 06.004 & 05.903 & 05.802 & 05.701 & 05.600 \\ 04.093 & 04.992 & 04.891 & 04.790 & 04.689 & 04.588\end{array}$

$\begin{array}{llllll}04.082 & 03.980 & 03.879 & 03.779 & 03.677 & 03.576\end{array}$

$\begin{array}{llllll}0.059 & 01.958 & 02.868 & 02.767 & 02.666 & 02.564 \\ 01.755 & 01.654 & 01.552\end{array}$

$\begin{array}{rrrrrr}01.047 & 00.946 & 00.845 & 00.744 & 00.643 & 00.542 \\ 00.035 & * 99.935 * 99.833 & * 99.732 & * 99.631 & * 99.530\end{array}$

$\begin{array}{rrrrrr}99.024 & 98.923 & 98.822 & 98.720 & 98.620 & 98.518 \\ 98.013 & 97.911 & 97.810 & 97.709 & 97.608 & 97.507\end{array}$

$\begin{array}{llllll}97.001 & 96.900 & 96.799 & 96.698 & 96.597 & 96.495\end{array}$

$\begin{array}{llllll}95.990 & 95.889 & 95.788 & 95.687 & 95.585 & 95.484 \\ 94.979 & 94.878 & 94.776 & 94.675 & 94.574 & 94.473\end{array}$

$\begin{array}{llllll}93.967 & 93.866 & 93.765 & 93.664 & 93.563 & 93.462\end{array}$

$\begin{array}{llllll}92.956 & 92.855 & 92.754 & 92.653 & 92.552 & 92.451 \\ 91.945 & 91.844 & 91.743 & 91.642 & 91.541 & 91.440\end{array}$

$\begin{array}{llllll}90.9435 & 91.844 & 91.743 & 91.642 & 91.541 & 91.440 \\ 90.933 & 90.733 & 90.632 & 90.531 & 90.429 \\ 8.924 & 89.823 & 89.722 & 89.621 & 89.520 & 89.418\end{array}$

$\begin{array}{llllll}88.913 & 88.812 & 88.711 & 88.610 & 88.509 & 88.408\end{array}$

$\begin{array}{llllll}87.902 & 87.801 & 87.700 & 87.599 & 87.498 & 87.397\end{array}$

$\begin{array}{llllll}86.891 & 86.790 & 86.689 & 86.588 & 86.487 & 86.386\end{array}$

$\begin{array}{lllllll}84.870 & 84.769 & 84.679 & 85.578 & 85.477 & 85.376 \\ 84.668 & 84.567 & 84.466 & 84.365\end{array}$

$\begin{array}{llllll}83.859 & 83.759 & 83.657 & 83.556 & 83.456 & 83.354\end{array}$

$\begin{array}{llllll}81.839 & 81.738 & 81.637 & 81.536 & 81.435 & 81.333\end{array}$

$\begin{array}{llllll}80.829 & 80.727 & 80.626 & 80.525 & 80.424 & 80.323\end{array}$

$\begin{array}{lllllll}79.818 & 79.717 & 79.616 & 79.515 & 79.414 & 79.313\end{array}$

$76.990 \quad 76.889$

$\begin{array}{ll}75.980 & 75.879 \\ 74.970 & 74.869\end{array}$

$73.960 \quad 73.859$

$\begin{array}{ll}72.950 & 72.849 \\ 71.941 & 71.840\end{array}$

70.93170 .830

$\begin{array}{ll}69.921 & 69.820 \\ 68.912 & 68.811\end{array}$

$\begin{array}{ll}68.912 & 68.811 \\ 67.902 & 67.801\end{array}$

$76.788-76.687$

78.606
77.596

78.505
77.495

$78 \cdot 405$
$77 \cdot 394$

77.293

$\begin{array}{lllllll}74.768 & 74.667 & 74.5666 & 75.475 & 75.374 & 75.273 \\ 73.05 & 74.364 & 74.263\end{array}$

$\begin{array}{llllll}73.758 & 73.657 & 73.556 & 73.455 & 73.354 & 73.253 \\ 72.749 & 72.647 & 72.546 & 72.446 & 72.344 & 72.243\end{array}$

$\begin{array}{llllll}71.739 & 71.637 & 71.537 & 71.436 & 71.335 & 71.234\end{array}$

$\begin{array}{llllll}70.729 & 70.628 & 70.527 & 70.426 & 70.325 & 70.224 \\ 69.719 & 69.619 & 69.517 & 69.416 & 69.316 & 69.215\end{array}$

$\begin{array}{llllll}68.710 & 68.609 & 68.508 & 68.407 & 68.306 & 68.205\end{array}$

$\begin{array}{lllllllll}66.893 & 66.792 & 66.691 & 66.590 & 66.489 & 66.388 & 66.287 & 66.186\end{array}$

$\begin{array}{llllllll}65.884 & 65.783 & 65.682 & 65.581 & 65.480 & 65.379 & 65.278 & 65.177\end{array}$

$\begin{array}{llllllll}64.875 & 64.774 & 64.672 & 64.572 & 64 \cdot 471 & 64 \cdot 370 & 64 \cdot 269 & 64 \cdot 168 \\ 63.865 & 63.764 & 63.663 & 63.562 & 63.461 & 63.360 & 63.260 & 63.159\end{array}$

$\begin{array}{llllllll}62.856 & 62.755 & 62.654 & 62.553 & 62.452 & 62.351 & 62.250 & 62.149\end{array}$

$\begin{array}{llllllll}61.847 & 61.746 & 61.645 & 61.544 & 61.443 & 61.342 & 61.241 & 61.140\end{array}$

7.6

7.8

3148

48
8.
8.
8.
8.
8.
8.6
8.7
8
8.8

$31757.004 \quad 56.903 \quad 56.802$

$\begin{array}{llllll}60.636 & 60.535 & 60.434 & 60.333 & 60.232 & 60.132 \\ 59.627 & 59.526 & 59.425 & 59.324 & 59.223 & 59.123\end{array}$

$57.004 \quad 56.900$

$\begin{array}{llll}54.986 & 54.885 & 54.785 & 54.6\end{array}$

$\begin{array}{llll}53.978 & 53.877 & 53.776 & 53.675\end{array}$

$52.969 \quad 52.869 \quad 52.768 \quad 52.667$

$\begin{array}{llll}51.961 & 51.860 & 51.760 & 51.659 \\ 50.953 & 50.852 & 50.751 & 50.650\end{array}$

49.94449 .843

$\begin{array}{ll}48.936 & 48 \cdot 835 \\ 47.927 & 47.827\end{array}$

$49.743 \quad 49.642$

58.618

$\begin{array}{llllll}8 & 58.517 & 58.416 & 58.315 & 58.214 & 58.114 \\ 97.508 & 57.407 & 57.307 & 57.206 & 57.104\end{array}$

$\begin{array}{llllll}56.600 & 56.500 & 56.399 & 56.298 & 56.197 & 56.096 \\ 55.592 & 55.491 & 55.390 & 55.289 & 55.188 & 55.087\end{array}$

$\begin{array}{llllll}54.583 & 54.482 & 54.381 & 54.280 & 54.180 & 54.079\end{array}$

$\begin{array}{llllll}53.574 & 53.474 & 53.373 & 53.272 & 53.171 & 53.071\end{array}$

$\begin{array}{llllll}52.566 & 52.466 & 52.364 & 52.264 & 52.163 & 52.062\end{array}$

$\begin{array}{llll}47.927 & 47.827 & 47.726 & 47.625\end{array}$

$\begin{array}{llllll}50.549 & 50.448 & 50.348 & 50.247 & 50.146 & 50.045 \\ 49.541 & 49.440 & 49.339 & 49.238 & 49.138 & 49.037\end{array}$

149.0

49
9.0
9.0
9.0
9.5
9.6
9.7
9.8

9.1
9.2
9.3
9.5
9.5
9.7

$$
\begin{array}{r}
1746 \\
45 \\
44 \\
43 \\
42 \\
41 \\
40 \\
39 \\
38 \\
37
\end{array}
$$

$\begin{array}{rrr}746.920 & 46.819 & 46.718\end{array}$

$\begin{array}{llll}45.91 & 45.811 & 45.710 & 45.6 \\ 44.903 & 44.802 & 44.702 & 44.601\end{array}$

43.89543 .79

$41.880 \quad 41.787$

$\begin{array}{llllll}47.525 & 47.424 & 47.323 & 47.222 & 47.121 & 47.020\end{array}$

$\begin{array}{rr}872 & 40.771 \\ .865 & 39.764\end{array}$

$\begin{array}{llll}43.694 & 43.593 & 43.500 & 44.399\end{array}$

$\begin{array}{lllll}46.315 & 46.214 & 46.113 & 46.012\end{array}$

$\begin{array}{llll}46.315 & 46.214 & 46.113 & 46.012 \\ 45.307 & 45.206 & 45.105 & 45.004\end{array}$

$\begin{array}{llll}44.299 & 44.198 & 44.097 & 43.996 \\ 43.291 & 43.190 & 43.089 & 42.988\end{array}$

$\begin{array}{lllllllll}.787 & 42.686 & 42.585 & 42.484 & 42.384 & 42.283 & 42.182 & 42.081 & 41.980 \\ .779 & 41.678 & 41.577 & 41.476 & 41.375 & 41.275 & 41.174 & 41.073 & 40.972 \\ .771 & 40.671 & 40.570 & 40.469 & 40.368 & 40.268 & 40.167 & 40.066 & 39.965\end{array}$

$38.857 \quad 38.756$

$\begin{array}{llllll}38.454 & 38.353 & 38.260 & 39.159 & 39.058 & 38.958 \\ 37.252 & 38.151 & 38.051 & 37.950\end{array}$

$\begin{array}{llllll}37.446 & 37.345 & 37.245 & 37.144 & 37.043 & 36.942\end{array}$

0.289719

$\lambda(n-1)$

0.289718

0.289716
0.289715

0.289714

0.289713

.289710

0.289709

0.289707

.289706

0.289703

.289702

0.289700

0.289698

0.289696

0.289695

0.289694

0.289691

0.289690

0.289689
0.289688

0.289686

0.289685

0.289683

0.289682

0.289680

0.289678

0.289677

0.289674

0.289673

0.289671

0.289670

0.289668

0.289666

0.289665

0.289664
0.289662

0.289661

0.289660

0.289659

.289658

0.289656

0.289655

0.289653

0.289652

0.289650

0.289648

0.289647

0.289646

0.289644

0.289643

0.289642

0.289640

0.289638

0.289637

0.289635

0.289634

0.289632

0.289630

0.289629

0.289628

0.289627

0.289625
0.289624

0.289623

0.289622

0.289621

0.289618

0.289617

0.289616

0.289615

0.289613
0.289612

0.289611

0.289610

0.289609

289607

0.289606

0.289605

0.289603

0.289600

0.909717

0.909743
0.909768

.909793

0.909818 
0.289593

0.289592

0.289590

0.289588

0.289587

0.289586

0.289584

0.289581

0.289580

0.289578

0.289576

$\begin{array}{llllllllll}19.724 & 19.623 & 19.522 & 19.421 & 19.321 & 19.220 & 19.120 & 19.019 & 18.918 & 18.81\end{array}$

17.71

3153.0

$$
\begin{array}{r}
153.0 \\
3.1 \\
3.2 \\
3.3 \\
3.4 \\
3.5 \\
3.6 \\
3.6 \\
3.0 \\
3.0
\end{array}
$$

\title{
3154.
}

\section{4.
4.}

$4 \cdot 2$
$4 \cdot 3$
4.4

4.5
4.6
4.7

4.7
4.8
4.9

3155.

5.1
5.2
5.3
5.4

5.4
5.5

5.5
5.6
5.7

5.7
5.8
5.9

3156.

$56 \cdot 0$
6.1
6.2
6.3
6.4
6.5
6.6
6.7
6.8
6.9

6.8
6.9

3157.

$7: 2$

$7 \cdot 2$
$7 \cdot 3$
$7 \cdot 4$
$7 \cdot 5$

7.4
7.5
7.6
7.7

7.7
7.8
7.9

3158.0

8.2

$8 \cdot 2$
8.3
8.4

8.5
8.6

8.6
8.7
8.8

8.8
8.9

3159.0

9.1
9.2
9.3

9.4

9.6
9.7

9.7
9.8
9.9

$17.510 \quad 17.409$

$\begin{array}{ll}18.314 & 18.214 \\ 17.308 & 17.208\end{array}$

$\begin{array}{ll}18.113 & 18.012 \\ 17.107 & 17.006\end{array}$

$16.906 \quad 16.805$

0.289575

0.289574
0.289573

0.289573
0.289572

0.289571

0.289569

0.289568
0.289567

0.289566

$\begin{array}{llllllllll}08.657 & 08.557 & 08.456 & 08.355 & 08.255 & 08.154 & 09.059 & 08.959 & 08.858 & 08.758 \\ 0.0753 & 07.953 & 07.853 & 07.752\end{array}$

$\begin{array}{llllllllll}31706.646 & 06.545 & 06.445 & 06.344 & 06.244 & 06.143 & 06.042 & 05.942 & 05.841 & 05.740\end{array}$

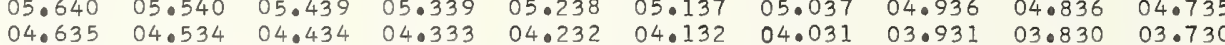
$\begin{array}{llllllllll}04.635 & 04.534 & 04.434 & 04.333 & 04.232 & 04.132 & 04.031 & 03.931 & 03.830 & 03.730 \\ 03.629 & 03.529 & 03.428 & 03.328 & 03.227 & 03.127 & 03.026 & 02.926 & 02.825 & 02.725\end{array}$ $\begin{array}{llllllllll}02.624 & 02.524 & 02.423 & 02.323 & 02.222 & 02.122 & 02.021 & 01.921 & 01.820 & 01.719\end{array}$ $\begin{array}{rlllllllll}01.619 & 01.519 & 01.418 & 01.317 & 01.217 & 01.116 & 01.016 & 00.915 & 00.815 & 00.714 \\ 00.614 & 00.513 & 00.413 & 00.312 & 00.211 & 00.111 & 00.011 & * 99.910 & * 99.810 & * 99.709\end{array}$

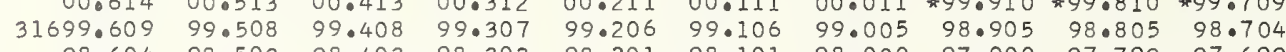
$\begin{array}{llllllllll}98.604 & 98.503 & 98.403 & 98.302 & 98.201 & 98.101 & 98.000 & 97.900 & 97.799 & 97.699 \\ 97.598 & 97.498 & 97.397 & 97.297 & 97.197 & 97.096 & 96.995 & 96.895 & 96.794 & 96.694\end{array}$

0.28956

0.289563

0.289561

0.289560

0.289559

0.289557

0.289555

0.289554

$31696.594 \quad 96.493$

$95.589 \quad 95.488$

$\begin{array}{ll}94.583 & 94.483 \\ 93.579 & 93.479\end{array}$

$91.569 \quad 91.469$

$\begin{array}{lll}80.561 & 80.465 & 90.364\end{array}$

$88.556 \quad 88.456 \quad 88.355 \quad 88.255$

$31686.548 \quad 86.447$

$$
85.5
$$

84.539

$83.535 \quad 83.438$

$82.531 \quad 82.430$

$80.522 \quad 80.422$

$\begin{array}{ll}79.519 & 79.418 \\ 78.515 & 78.415\end{array}$

$\begin{array}{ll}78.515 & 78.415 \\ 77.511 & 77.411\end{array}$

31676.50

75.50

$74.500 \quad 74.400$

$72.493 \quad 72.39$

71.49071 .390

$69.483 \quad 69.383$

$\begin{array}{ll}68.480 & 68.380 \\ 67.477 & 67.377\end{array}$

86.346

$85.342 \quad 85.242$

$\begin{array}{ll}83.334 & 83.233\end{array}$

$82.330 \quad 82.229$

$80.322 \quad 80.221$

$96.192 \quad 96.091$

96.995

95.890

95.78

95.689

0.28955

0.289552

0.28955

0.289549

0.289548

0.289547

0.289544

0.289541

0.289540

0.289537

0.289536

0.289534

0.289533

0.289531

0.289530
0.289529

0.289528

0.289527

0.289525

0.289524

0.289523
0.289522

0.289521

0.289520

0.289518

\begin{abstract}
65.47165 .371
\end{abstract}
$\begin{array}{ll}64.469 & 64 \cdot 3 \\ 63.466 & 63.365\end{array}$

36362.262

60.35760 .25761 .15

$\begin{array}{lll}59.455 & 59.354 & 59.25\end{array}$

$\begin{array}{lll}58.452 & 58.352 & 58.25 \\ 57.449 & 57.350 & 57.24\end{array}$

31656.447

$$
\begin{aligned}
& 55.445 \\
& 54.442
\end{aligned}
$$

$56 \cdot 347$
$55 \cdot 344$

$53.440 \quad 53.340$

$52.438 \quad 52.338$

$\begin{array}{ll}59.432 & 49.332\end{array}$

$\begin{array}{ll}48.430 & 48 \cdot 330 \\ 47.428 & 47.328\end{array}$

$45.425 \quad 46 \cdot 326$

$\begin{array}{ll}44.423 & 44.323 \\ 43.421 & 43.322\end{array}$

$\begin{array}{ll}43.421 & 43.322 \\ 42.420 & 42.320\end{array}$

$\begin{array}{ll}42.420 & 42 \cdot 32 \\ 41.418 & 41.31\end{array}$

$\begin{array}{llll}40.417 & 40.317 & 40.217 & 40.11\end{array}$

$\begin{array}{llll}38.415 & 38.315 & 38.214 & 38.11 \\ 37.414 & 37.314 & 37.213 & 37.11\end{array}$

.001

.002

.101

.010
.010

.020
.020

.003
.030
.030

$66.073 \quad 65.972$

$\begin{array}{ll}65.070 & 64.970 \\ 64.067 & 63.967\end{array}$

$\begin{array}{lll}0.067 & 63.967 & 63.867\end{array}$

$62.062 \quad 61.961$

$\begin{array}{ll}61.059 & 60.95 \\ 50.056 & 59.956\end{array}$

$\begin{array}{ll}59.053 & 58.953 \\ 58.051 & 57.951 \\ 57.049 & 56.948\end{array}$

56.04

\begin{abstract}
656.046
\end{abstract}
55.946

54.04153 .941

53.039
52.939

$51.035 \quad 50.935$

50.033
49.031

$49.031 \quad 48.931$

$\begin{array}{ll}48.029 & 47.929 \\ 47.028 & 46.927\end{array}$

46.026

46.026
45.024

$44.022 \quad 43.922$

$43.021 \quad 42.921$

$42.020 \quad 41.91$

$\begin{array}{ll}41.018 & 40.91 \\ 40.017 & 39.917\end{array}$

$\begin{array}{ll}40.017 & 39.917 \\ 39.015 & 38.916\end{array}$

$\begin{array}{ll}39.015 & 38.91 \\ 38.014 & 37.914\end{array}$
0.289516

65.872

$\begin{array}{llll}.0861 & 61.761 & 61.661 & 61.560\end{array}$

$\begin{array}{llll}60.859 & 60.758 & 60.658 & 60.558 \\ 59.856 & 59.756 & 59.655 & 59.555\end{array}$

$\begin{array}{llll}57.851 & 57.750 & 57.650 & 57.550\end{array}$

$\begin{array}{llll}55.846 & 55.746 & 55.645 & 55.545\end{array}$

$54.843 \quad 54.743 \quad 54.643 \quad 54.543$

$\begin{array}{lllll}53.841 & 53.741 & 53.641 & 53.541\end{array}$

$\begin{array}{llll}52.839 & 52.739 & 52.638 & 52.539\end{array}$

$\begin{array}{llll}51.837 & 51.737 & 51.637 & 51.537\end{array}$

$\begin{array}{llll}49.833 & 49.733 & 49.633 & 49.533\end{array}$

$\begin{array}{lllll}48.831 & 48.731 & 48.631 & 48.531\end{array}$

$\begin{array}{llll}47.829 & 47.729 & 47.629 & 47.529 \\ 46.827 & 46.727 & 46.627 & 46.527\end{array}$

$45.826 \quad 45.725 \quad 45.625 \quad 45.525$

$\begin{array}{llll}44.824 & 44.724 & 44.623 & 44.523\end{array}$

$\begin{array}{llll}43.822 & 43.722 & 43.622 & 43.522\end{array}$

$\begin{array}{llll}41.819 & 41.719 & 41.619 & 41.519\end{array}$

$\begin{array}{llll}40.818 & 40.717 & 40.617 & 40.517\end{array}$

$\begin{array}{llll}39.817 & 39.717 & 39.616 & 39.516 \\ 38.815 & 38.715 & 38.615 & 38.515\end{array}$

0.289515

0.289514

0.289511

0.289509

0.289508

0.289507

0.289504 0.289503

0.289502

0.289499

0.289498

0.289497

0.289496

0.289495

0.289492

0.289491

0.289491

0.289490

0.289488

0.289486

0.289483

0.289482

.010

0.912287

0.912313

.912363

0.912388 


\begin{tabular}{|c|c|c|c|c|c|}
\hline$\lambda(A)$ & .00 & .01 & .02 & .03 & .04 \\
\hline 60.0 & $\begin{array}{r}636.413 \\
35.411\end{array}$ & $36 \cdot 312$ & 36.212 & $\begin{array}{l}36 \cdot: \\
35\end{array}$ & 012 \\
\hline $\begin{array}{l}0.1 \\
0.2\end{array}$ & $\begin{array}{l}35.411 \\
34.410\end{array}$ & $\begin{array}{l}35 \cdot 311 \\
34 \cdot 310\end{array}$ & $\begin{array}{l}35.211 \\
34.210\end{array}$ & $\begin{array}{l}35 . \\
34 .\end{array}$ & 010 \\
\hline 0.3 & $\begin{array}{l}34.4109 \\
33.409\end{array}$ & 33.309 & 33.209 & $\begin{array}{l}34.110 \\
33.109\end{array}$ & $\begin{array}{l}34.010 \\
33.009\end{array}$ \\
\hline 0.4 & 32.408 & 32.308 & 32.208 & 32.108 & 32.008 \\
\hline 0.5 & 31.407 & 31.307 & 31.207 & 31.107 & 31.007 \\
\hline 0.6 & 30.406 & $30 \cdot 306$ & 30.206 & 30.106 & 30.006 \\
\hline $\begin{array}{l}0.7 \\
0.8\end{array}$ & 29.406 & $29 \cdot 306$ & 9.206 & 29.106 & 29.006 \\
\hline $\begin{array}{l}0.8 \\
0.9\end{array}$ & 28.405 & $28 \cdot 305$ & 8.205 & 28.105 & 28.005 \\
\hline 0.9 & 27.404 & 27.305 & 27.205 & $27 \cdot 105$ & 27.005 \\
\hline $\begin{array}{r}3161.0 \\
1.1\end{array}$ & 31626.405 & 26.304 & 26.204 & 26.104 & 26.004 \\
\hline $\begin{array}{l}1: 1 \\
1: 2\end{array}$ & $\begin{array}{l}25.404 \\
24.404\end{array}$ & $\begin{array}{l}25.304 \\
24.303\end{array}$ & 25.204 & 25.104 & 25.004 \\
\hline $\begin{array}{l}1.2 \\
1.3\end{array}$ & $\begin{array}{l}24.404 \\
23.403\end{array}$ & $\begin{array}{l}24.303 \\
23.303\end{array}$ & $\begin{array}{l}24.204 \\
23.203\end{array}$ & $\begin{array}{l}24.104 \\
23.103\end{array}$ & $\begin{array}{l}24.003 \\
23.003\end{array}$ \\
\hline 1.4 & 22.403 & 22.303 & 22.203 & 22.103 & 22.003 \\
\hline 1.5 & 21.403 & 21.303 & 21.203 & 21.103 & 21.003 \\
\hline 1.6 & 20.403 & 20.302 & 20.202 & 20.103 & 20.002 \\
\hline 1.7 & 19.402 & $19 \cdot 302$ & 19.202 & 19.102 & 19.002 \\
\hline $\begin{array}{l}1.8 \\
1.9\end{array}$ & $\begin{array}{l}18.402 \\
17.402\end{array}$ & $\begin{array}{l}18 \cdot 302 \\
17 \cdot 302\end{array}$ & $\begin{array}{l}18.202 \\
17.202\end{array}$ & $\begin{array}{l}18.102 \\
17.102\end{array}$ & $\begin{array}{l}18.002 \\
17.002\end{array}$ \\
\hline & & & & & \\
\hline $\begin{array}{r}62.0 \\
2.1\end{array}$ & $\begin{array}{r}31616.402 \\
15.403\end{array}$ & $\begin{array}{l}16.302 \\
15.302\end{array}$ & $\begin{array}{l}16.202 \\
15.202\end{array}$ & $\begin{array}{l}16.103 \\
15.103\end{array}$ & $\begin{array}{l}16.002 \\
15.003\end{array}$ \\
\hline 2.2 & 14.403 & 14.303 & 14.203 & 14.104 & 14.003 \\
\hline 2. & 13.404 & 13.304 & 13.204 & 13.104 & 13.004 \\
\hline 2.5 & 12.404 & $12 \cdot 304$ & 12.204 & 12.104 & 12.004 \\
\hline $\begin{array}{l}2.5 \\
2.6\end{array}$ & 11.404 & 11.304 & 11.204 & 11.104 & 11.005 \\
\hline $\begin{array}{l}2.6 \\
2.7\end{array}$ & 10.405 & 10.305 & 10.205 & 10.105 & 10.005 \\
\hline $\begin{array}{l}2.7 \\
2.8\end{array}$ & 09.405 & 09.305 & 09.206 & 09.105 & 09.005 \\
\hline $\begin{array}{l}2.8 \\
2.9\end{array}$ & 08.406 & 08.306 & 8.206 & 08.106 & 08.006 \\
\hline 2.9 & 07.406 & 07.307 & 07.207 & 07.106 & 07.007 \\
\hline $\begin{array}{r}3163.0 \\
3.1\end{array}$ & $\begin{array}{r}31606.407 \\
05.408\end{array}$ & $\begin{array}{l}06.307 \\
05.308\end{array}$ & $\begin{array}{l}06.207 \\
05.208\end{array}$ & $\begin{array}{l}06.107 \\
05.108\end{array}$ & $\begin{array}{l}06 \\
05\end{array}$ \\
\hline $\begin{array}{l}3.1 \\
3.2\end{array}$ & $\begin{array}{l}\begin{array}{l}5.408 \\
04.409\end{array}\end{array}$ & $\begin{array}{l}04.308 \\
04.309\end{array}$ & $\begin{array}{l}05.208 \\
04.209\end{array}$ & $\begin{array}{l}05.108 \\
04.109\end{array}$ & $\begin{array}{l}05.008 \\
04.009\end{array}$ \\
\hline 3.3 & 03.410 & 03.310 & 03.210 & 03.110 & 03.010 \\
\hline 3.4 & 02.411 & 02.311 & 02.211 & 02.111 & 02.011 \\
\hline 3.5 & 01.412 & 01.312 & 01.212 & 01.113 & 01.013 \\
\hline 3.6 & 00.413 & 00.313 & 00.213 & 00.114 & 00.014 \\
\hline 3.7 & 31599.414 & 99.314 & 99.215 & 99.115 & 99.015 \\
\hline 3.8 & 98.416 & 98.316 & 98.216 & 98.116 & 98.016 \\
\hline 3.9 & 97.417 & 97.317 & 97.217 & 97.117 & 97.018 \\
\hline 64.0 & 31596.418 & $96 \cdot 318$ & 96.219 & 96.119 & 19 \\
\hline & 95.420 & 95. & 95. & & \\
\hline $4 \cdot 2$ & 94.421 & $94^{\circ}$ & $94^{\circ}$ & 2 & \\
\hline $\begin{array}{l}4 \cdot 3 \\
4.4\end{array}$ & 93.423 & $93 \cdot$ & 93.2 & 93. & 93 \\
\hline $\begin{array}{l}4.4 \\
4.5\end{array}$ & 92.424 & $92 \cdot$ & 92.2 & 92. & 92. \\
\hline $\begin{array}{l}4.5 \\
4.6\end{array}$ & 91.426 & 91.326 & 91.226 & $91 \cdot 126$ & 91.027 \\
\hline $\begin{array}{l}4.6 \\
4.7\end{array}$ & 90.428 & 90.328 & 90.228 & 90.128 & 90.028 \\
\hline $\begin{array}{l}4.7 \\
4.8\end{array}$ & $\begin{array}{l}89.429 \\
88.432\end{array}$ & $\begin{array}{l}89.330 \\
88.332\end{array}$ & $\begin{array}{l}89.230 \\
88.232\end{array}$ & $\begin{array}{l}89.130 \\
888.137\end{array}$ & $\begin{array}{l}89.031 \\
88.032\end{array}$ \\
\hline 4.9 & 87.433 & 87.334 & $\begin{array}{l}87.234 \\
87.23\end{array}$ & $\begin{array}{l}87.134 \\
\end{array}$ & $\begin{array}{l}88.032 \\
87.035\end{array}$ \\
\hline 3165.0 & 31586.436 & 86.336 & 86. & 36 & 86.036 \\
\hline & 85.438 & 85. & 85. & & \\
\hline 5.2 & 84.440 & 84. & 84. & 40 & 1 \\
\hline $\begin{array}{l}5.3 \\
5.4\end{array}$ & $\begin{array}{l}83.442 \\
82.444\end{array}$ & 3 & 83. & 43 & \\
\hline 5.5 & $\begin{array}{l}82.444 \\
81.447\end{array}$ & 82. & 82 & 45 & 82 \\
\hline 5.6 & $\begin{array}{l}81.447 \\
80.449\end{array}$ & 81.347 & $81 \cdot 2$ & 81.147 & \\
\hline 5.7 & $\begin{array}{l}79.451 \\
79.445\end{array}$ & 79. & $\begin{array}{l}80.249 \\
79.252\end{array}$ & $\begin{array}{l}80.150 \\
79.152\end{array}$ & $\begin{array}{l}80.050 \\
79.052\end{array}$ \\
\hline 5.8 & 78.454 & 78. & 78.254 & 78.155 & $788^{\circ}$ \\
\hline 5.9 & 77.456 & 77.357 & 77.257 & 77.157 & 77.058 \\
\hline 56.0 & 31576 . & 0 & . & so & 261 \\
\hline & & & & & \\
\hline 6.2 & $74 \cdot 4$ & 5 & 6 & 6 & 7 \\
\hline $6 \cdot 3$ & 73.4 & 8 & 8 & 8 & \\
\hline 6.4 & 72. & 1 & 1 & 5 & 7 \\
\hline 6. & 71 & 7 & 7 & 7 & \\
\hline 6.6 & $70 \cdot 4$ & 7 & & & \\
\hline 6.7 & 69.4 & 6 & & & 65 \\
\hline 6.8 & 68.482 & 68.383 & 68.283 & $8 \cdot 184$ & 68 \\
\hline 6.9 & 67.486 & $67 \cdot 386$ & 67.286 & 7.187 & 67.0 \\
\hline & 31566.489 & & & & \\
\hline & & & & & \\
\hline $7: 2$ & 6 & 5 & & & \\
\hline $\begin{array}{l}7.3 \\
7.4\end{array}$ & 63 & 0 & 6 & & \\
\hline 7. & $\begin{array}{l}62 \cdot 5 \\
61 \cdot 5\end{array}$ & 62. & $\begin{array}{l}6 \\
6\end{array}$ & & $\begin{array}{l}4 \\
8\end{array}$ \\
\hline 7.6 & t & 6 & ( & & \\
\hline 7 & 50 & 4 & 5 & 5 & 5 \\
\hline 7.8 & 58.518 & 58.418 & 58.318 & & \\
\hline 7.9 & 57.521 & 57.422 & 57.322 & 57.222 & 57.123 \\
\hline & & & & & 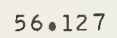 \\
\hline & & & & & \\
\hline & & & & & \\
\hline & $5=$ & 53.2 & & & \\
\hline & & & & & \\
\hline & & & & & \\
\hline & & & & & \\
\hline & & 49. & & & \\
\hline $8 \cdot 8$ & & 48. & & & \\
\hline 8.9 & 47.563 & 47.464 & 47.364 & 47.265 & 7.165 \\
\hline & & $\begin{array}{l}46.468 \\
45.473\end{array}$ & $\begin{array}{l}46.369 \\
45.373\end{array}$ & 9 & 0 \\
\hline & $45^{5} \quad-$ & & & & \\
\hline 3 & $\begin{array}{l}44 \\
43\end{array}$ & $\begin{array}{l}44 \\
43\end{array}$ & 3 & & 3 \\
\hline 9.4 & 42.586 & 42.487 & 42.387 & 42. & \\
\hline 9.5 & 41.592 & 41.492 & 41.392 & 41.293 & 3 \\
\hline s & - & (n) & 40.307 & 0.298 & \\
\hline & & & & & \\
\hline & & & & & \\
\hline & & 7.512 & & & \\
\hline
\end{tabular}

$\begin{array}{lllllllllll} & .001 & .002 & .003 & .004 & .005 & .006 & .007 & .008 & .009 & .010 \\ .100 & .010 & .020 & .030 & .040 & .050 & .060 & .070 & .080 & .090 & .100 \\ .099 & .010 & .020 & .030 & .040 & .050 & .060 & .070 & .079 & .089 & .099\end{array}$




.01

.02

.03

$$
\begin{array}{r}
3170 . \\
0.0 \\
0.2 \\
0.0 \\
0.0 \\
0.5 \\
0.6 \\
0.7 \\
0.0
\end{array}
$$

70.0 31536.617

$\begin{array}{rrr}0.1 & 31536.617 & 36.517 \\ 0.2 & 35.622 & 35.522\end{array}$

$\begin{array}{lll}0.1 & 35.622 & 35.522 \\ 0.2 & 34.627 & 34.527 \\ 0.3 & 33.632 & 33.533 \\ 0.4 & 32.638 & 32.538\end{array}$

0.5

0.7

$31.644 \quad 31.544$

$\begin{array}{ll}30.649 & 30.549 \\ 29.654 & 29.555\end{array}$

28.660
27.666

3171.0

$\begin{array}{rrr}1.0 & 31526.672 & 26.572 \\ 1.1 & 25.677 & 25.578 \\ 1.2 & 24.683 & 24.584 \\ 1.3 & 23.689 & 23.590 \\ 1.4 & 22.696 & 22.596 \\ 1.5 & 21.702 & 21.602 \\ 1.6 & 20.708 & 20.608 \\ 1.7 & 19.714 & 19.615 \\ 1.8 & 18.720 & 18.621 \\ 1.9 & 17.726 & 17.627\end{array}$

3172.

$2 \cdot 2$

2.4
2.5

2.6

2.8

3173.

$$
3 .
$$

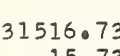

9.7
9.8
9.9

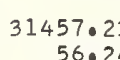

0.289294

0.289292

0.289291

0.289289

0.289288

0.289287

0.289285

0.289284
0.289283

0.917534

0.917559

0.917585
0.917610

0.917635

0.917660

0.917686

0.917711

0.917761

0.917787

0.917812

0.917862

0.917913

0.917938

0.917988

0.918014

0.918039

0.918089

0.918115

0.918140
0.918165

0.918190

0.918190

0.918241

0.918291

0.918317

0.918342

0.918392

0.918418

0.918443

0.918493

0.918544

0.918569

0.918620

0.918645

0.918695

0.918721

0.918771

0.918796

0.918822

0.918872

0.918897

0.918923

0.918948 


.04

.05

.06

.07

.08

.09

$\begin{array}{rr}36.448 & 37.34 \\ 35.460 & 36.361\end{array}$ $\begin{array}{llll}36.460 & 36.361 & 36.262 & 36.164\end{array}$ 34.48334 .373 $33.495 \quad 33.396$ $32.507 \quad 32.40$ $31.518 \quad 31.41$ $\begin{array}{ll}30.530 & 30.431 \\ 29.542 & 29.443\end{array}$ $\begin{array}{ll}29.542 & 29.443 \\ 28.553 & 28.455\end{array}$ $34.286 \quad 34.187$ 36.06 35.954
35.966
34.978 $\begin{array}{llll}350.867 & 36.756 & 36.657 & 36.559 \\ 35.768 & 350669 & 350571\end{array}$ $\begin{array}{lllll}34.078 & 34.780 & 34.681 & 34.582\end{array}$ 1.0
$1: 0$
10
10
10
10
1.
1. $\begin{array}{rr}31427.566 & 27.467 \\ 26.578 & 26.479\end{array}$ $\begin{array}{ll}26.578 & 26.479 \\ 25.590 & 25.491\end{array}$ 24.602224 .504 $23.615 \quad 23.516$ $\begin{array}{ll}22.627 & 22.528 \\ 21.639 & 21.541\end{array}$ $\begin{array}{ll}21.639 & 21.541 \\ 20.652 & 20.553 \\ 19.664 & 19.566\end{array}$ $\begin{array}{ll}19.664 & 19.566 \\ 18.677 & 18.578\end{array}$ $\begin{array}{llll}32.309 & 32.210 & 32.111 & 32.012 \\ 31.320 & 31.222 & 31.123 & 31.024 \\ 30.33 & 30.234 & 30.135 & 30.036\end{array}$ $30.333 \quad 30.234$ $\begin{array}{ll}29.344 & 29.245 \\ 28.356 & 28.257\end{array}$

$30.135 \quad 30.036$ 32.902 31.914 27.36
26.380
25.392
24.40
23.417
22.429
21.442
20.45
19.467
18.47 27.2
26.2
2502
2403
22.03
2103
20.3
19.3
18.3 27.270
25.281
24.293
23.318
22.331
21.343
20.356
19.368
18.381

3182

2.1
2.2
2.3
2.4
2.5
2.5
2.7
2.8
2.9

3183.0 3.0
3.0
3.0
3.0
3.5
3.0
3.7
3.0
3.9

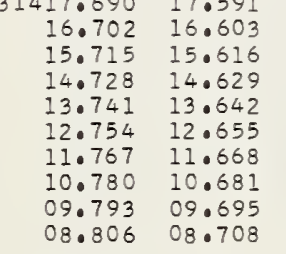
17.492
16.50
15.51
14.53
13.54
12.55
11.56
10.58
09.59
08.60 1703
1
1
1
1204
1
1
0
0

31407.820 $\begin{array}{ll}06.833 & 07.721 \\ 05.846 & 05.748\end{array}$

$05.846 \quad 05.748$ 07.622
06.635
05.549 $04.860 \quad 04.761$ $02.887 \quad 02.788$ $01.900 \quad 01.802$ $\begin{array}{lll}00.914 & 00.815 \\ 99.928 & 99.829\end{array}$ 98.94198 .843

3184.0<smiles>[13CH3]</smiles>
4.2 4.3 4.4
4.5
4.06

4.6
4.7
4.8 4.8

$31397.956 \quad 97.857$ $95.984 \quad 95.885$ $94.012 \quad 93.913$ $92.040 \quad 91.942$ $90.069 \quad 89.970$

$89.083 \quad 88.985$

05.649
04.663 03.676 $01.703 \quad 01.604$ $99.730 \quad 99.632$ 98.7

$$
\begin{array}{r}
3185.0 \\
50 \\
50 \\
5.0 \\
50 \\
50 \\
5.0 \\
50 \\
50 \\
5.0
\end{array}
$$

5.1
5.2
5.3
5.4
5.5
5.6
5.7
5.8
5.9

3186.0

86.0
6.1
6.2
6.
6.
6.5
6.
6.7
6.
6.

3187

87
7.0
7
7
7.3
7.5
7.6
7.7
7.0

$.014 \quad 86.915$

$\begin{array}{lll}05.142 & 86.028 \quad 85.930\end{array}$

$84.156 \quad 84.058$

$\begin{array}{ll}0.172 & 83.073\end{array}$

$32.186 \quad 82.078$

80.216
79.231

80.118
79.13

97.758
96.772
95.787

94.80

$93.815 \quad 93.716$

$92.829 \quad 92.730$

$90.857 \quad 90.759$

$8.886 \quad 88.788$

$\begin{array}{rr}1378.246 & 78.1 \\ 77.261 & 77.1\end{array}$

$$
\begin{aligned}
& 76.2 \\
& 75.2
\end{aligned}
$$

75.29275 .17

$74.307 \quad 74.209$

$\begin{array}{ll}73.323 & 73.224 \\ 72.339 & 72.240\end{array}$

72.339

$\begin{array}{ll}70.370 & 70.271 \\ 69.385 & 69.287\end{array}$

84.945

$84.860-84.86$

30.01
79.03

80.906
79.921

$78.049 \quad 77.951$

$\begin{array}{ll}77.064 & 76.966 \\ 76.080 & 75.981 \\ 75.095 & 74.997\end{array}$

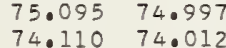

$\begin{array}{ll}74.110 & 74.012 \\ 73.125 & 73.027\end{array}$

$72.142 \quad 72.043$

$\begin{array}{ll}71.157 & 71.059 \\ 70.173 & 70.074\end{array}$

$\begin{array}{rr}31368.401 & 68.302 \\ 67.417 & 67.31\end{array}$

69.18

$66.433 \quad 66.334$

$\begin{array}{ll}65.449 & 65.350 \\ 64.465 & 64.366\end{array}$

$\begin{array}{ll}64.465 & 64.366 \\ 63.481 & 63.38\end{array}$

$\begin{array}{ll}63.481 & 63.382 \\ 62.497 & 62.398\end{array}$

$\begin{array}{ll}68.204 & 68.106 \\ 67.220 & 67.122\end{array}$

$66.236 \quad 66.137$

64.26864 .159

63.283

$\begin{array}{llll}61.513 & 61.414 & 61.316 & 61.218 \\ 60.529 & 60.431 & 60.332 & 60.23\end{array}$

$59.545 \quad 59.447$

3188.

$\begin{array}{rrrrrrrrrrr}8.0 & 31358.562 & 58.464 & 58.365 & 58.267 & 58.169 & 58.070 & 57.972 & 57.874 & 57.775 & 57.577 \\ 8.1 & 57.578 & 57.480 & 57.382 & 57.283 & 57.185 & -57.086 & 56.988 & 56.890 & 56.792 & 56.693\end{array}$

$\begin{array}{rrrrrrrrrrr}8.0 & 31358.562 & 58.464 & 58.365 & 58.267 & 58.169 & 58.070 & 57.972 & 57.874 & 57.775 & 57.677 \\ 8.1 & 57.578 & 57.480 & 57.382 & 57.283 & 57.185 & -57.086 & 56.988 & 56.890 & 56.792 & 56.693\end{array}$

59.34

59.250

$\begin{array}{lll}27.171 & 27.072 & 26.9 \\ 26.183 & 26.084 & 25.9\end{array}$

$28.949 \quad 28.850 \quad 28.752 \quad 28.652$

$\begin{array}{llll}26.973 & 26.874 & 26.775 & 26.677 \\ 25.985 & 25.886 & 25.788 & 25.689\end{array}$

$\begin{array}{llll}25.985 & 25.886 & 25.788 & 25.689\end{array}$

$\begin{array}{llll}24.0910 & 24.898 & 24.800 & 24.701\end{array}$

$\begin{array}{llll}23.022 & 22.924 & 22.824 & 22.726 \\ 22.035 & 21.936 & 21.837 & 21.738\end{array}$

$23.220 \quad 23.121$

22.035

21.738
20.751

$21.244 \quad 21.146$

$20.060 \quad 19.961 \quad 19.862 \quad 19.763$

$\begin{array}{llllll}19.269 & 19.171 & 19.072 & 18.973 & 18.875 & 18.776 \\ 18.282 & 18.183 & 18.084 & 17.986 & 17.887 & 17.788\end{array}$

$17.295 \quad 17.19$

$\begin{array}{llll}17.097 & 16.999 & 16.900 & 16.801\end{array}$

$\begin{array}{llllll}15.320 & 15.221 & 15.123 & 15.024 & 14.926 & 14.827\end{array}$

$\begin{array}{llllll}14.333 & 14.234 & 14.135 & 14.037 & 13.938 & 13.839 \\ 13.346 & 13.247 & 13.148 & 13.050 & 12.951 & 12.852\end{array}$

$\begin{array}{llll}14.135 & 14.037 & 13.938 & 13.83 \\ 13.148 & 13.050 & 12.951 & 12.852\end{array}$

$12.359 \quad 12.260$

$\begin{array}{llll}11.174 & 12.063 & 11.964 & 11.865\end{array}$

$\begin{array}{llll}10.188 & 10.089 & 09.991 & 09.892\end{array}$

$\begin{array}{lllllll}09.398 & 09.300 & 09.201 & 09.102 & 09.004 & 08.905 \\ 08.412 & 08.313 & 08.214 & 08.116 & 08.017 & 07.918\end{array}$

$\begin{array}{llllll}07.425 & 07.326 & 07.228 & 07.129 & 07.030 & 06.931\end{array}$

$\begin{array}{llllll}0.438 & 06.339 & 06.241 & 06.142 & 06.043 & 05.945\end{array}$

$\begin{array}{llllll}05.451 & 05.353 & 05.254 & 05.156 & 05.057 & 04.958 \\ 04.465 & 04.366 & 04.268 & 04.169 & 04.071 & 03.972\end{array}$

$\begin{array}{llllll}03.479 & 03.380 & 03.281 & 03.183 & 03.084 & 02.985 \\ 02.492 & 02.393 & 02.295 & 02.196 & 02.097 & 01.99\end{array}$

$\begin{array}{lllllll}01.506 & 01.407 & 01.309 & 01.210 & 01.111 & 01.013\end{array}$

$\begin{array}{llllll}00.520 & 00.421 & 00.322 & 00.223 & 00.125 & 00.026 \\ 99.533 & 99.435 & 99.336 & 99.237 & 99.139 & 99.040\end{array}$

$98.350 \quad 98.251 \quad 98.153 \quad 98.054$

97.56197 .463

97.364

$97.266 \quad 97.167 \quad 97.068$

$\begin{array}{llllll}96.575 & 96.477 & 96.378 & 96.280 & 96.181 & 96.083\end{array}$

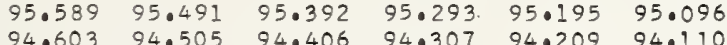

$\begin{array}{llllll}93.618 & 93.519 & 93.420 & 93.322 & 93.223 & 93.125\end{array}$

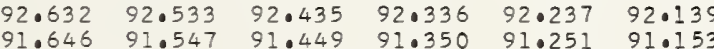

$\begin{array}{llllll}90.660 & 90.562 & 90.463 & 90.364 & 90.266 & 90.167\end{array}$

$\begin{array}{llllll}88.689 & 88.591 & 88.492 & 88.393 & 88.295 & 88.196\end{array}$

$\begin{array}{llllll}87.704 & 87.605 & 87.507 & 87.408 & 87.309 & 87.210\end{array}$

$\begin{array}{llllll}85.733 & 85.634 & 85.536 & 85.437 & 85.339 & 85.240\end{array}$

$\begin{array}{lllllll}84.748 & 84.649 & 84.551 & 84.452 & 84.354 & 84.255\end{array}$

$\begin{array}{lllllll}82.778 & 82.679 & 82.580 & 82.482 & 82.383 & 82.285\end{array}$

$\begin{array}{lllllll}81.792 & 81.694 & 81.595 & 81.497 & 81.398 & 81.300\end{array}$

$\begin{array}{llllll}80.807 & 80.709 & 80.610 & 80.511 & 80.413 & 80.315 \\ 79.822 & 79.724 & 79.625 & 79.527 & 79.428 & 79.330\end{array}$

$\begin{array}{llllll}78.837 & 78.739 & 78.640 & 78.542 & 78.443 & 78.345\end{array}$

$\begin{array}{lllllll}77.853 & 77.754 & 77.656 & 77.557 & 77.458 & 77.360 \\ 76.867 & 76.769 & 76.671 & 76.572 & 76.474 & 76.375\end{array}$

$\begin{array}{lllllll}75.883 & 75.784 & 75.686 & 75.587 & 75.489 & 75.391\end{array}$

$\begin{array}{lllllll}74.898 & 74.800 & 74.701 & 74.603 & 74.504 & 74.406\end{array}$

$\begin{array}{llllll}72.914 & 73.815 & 73.717 & 73.618 & 73.520 & 73.421 \\ 72.929 & 72.830 & 72.732 & 72.634 & 72.535 & 72.437\end{array}$

$\begin{array}{llllll}71.945 & 71.846 & 71.748 & 71.649 & 71.551 & 71.453\end{array}$

$\begin{array}{llllll}70.960 & 70.862 & 70.764 & 70.565 & 70.567 & 70.468 \\ 69.976 & 69.878 & 69.779 & 69.681 & 69.583 & 69.484\end{array}$

$\begin{array}{llllll}68.9792 & 69.878 & 69.779 & 69.681 & 69.583 & 69.484 \\ 68.992 & 68.893 & 68.795 & 68.697 & 68.598 & 68.499\end{array}$

$\begin{array}{lllllll}68.007 & 67.909 & 67.811 & 67.712 & 67.614 & 67.515 \\ 67.023 & 66.925 & 66.826 & 66.728 & 66.629 & 66.531\end{array}$

$\begin{array}{llllll}67.023 & 66.925 & 66.826 & 66.728 & 66.629 & 65.531 \\ 66.039 & 65.941 & 65.842 & 65.744 & 65.646 & 65.547\end{array}$

$\begin{array}{llllll}65.055 & 64.957 & 64.858 & 65.740 & 65.646 & 65.547 \\ & 64.050 & 64.061 & 64.5533\end{array}$

$\begin{array}{lllllll}64.071 & 63.972 & 63.874 & 63.776 & 63.677 & 63.579 \\ 63.087 & 62.989 & 62.890 & 62.792 & 62.693 & 62.595\end{array}$

$\begin{array}{llllll}62.103 & 62.989 & 62.890 & 62.792 & 62.693 & 62.595 \\ 62.004 & 61.906 & 61.808 & 61.709 & 61.611\end{array}$

$\begin{array}{llllll}61.119 & 61.021 & 60.922 & 60.824 & 60.726 & 60.627 \\ 60.135 & 60.037 & 59.939 & 59.840 & 59.743 & 59.644\end{array}$

$\begin{array}{llllll}60.135 & 60.037 & 59.939 & 59.840 & 59.743 & 59.644 \\ 59.152 & 59.054 & 58.956 & 58.857 & 58.759 & 58.660\end{array}$

$\begin{array}{llllllllllll}8.2 & 56.595 & 56.496 & 56.398 & 56.300 & 56.201 & 56.103 & 56.005 & 55.906 & 55.808 & 55.710\end{array}$

$\begin{array}{lllllllllll}8.3 & 55.611 & 55.513 & 55.415 & 55.316 & 55.218 & 55.120 & 55.021 & 54.923 & 54.825 & 54.726\end{array}$

$\begin{array}{lllllllllll}8.4 & 54.628 & 54.530 & 54.431 & 54.333 & 54.235 & 54.136 & 54.038 & 53.940 & 53.841 & 53.743 \\ 8.5 & 53.645 & 53.546 & 53.448 & 53.350 & 53.251 & 53.153 & 53.055 & 52.956 & 52.858 & 52.760\end{array}$

$\begin{array}{llllllllllll}8.6 & 52.661 & 52.563 & 52.465 & 52.366 & 52.268 & 52.169 & 52.071 & 51.973 & 51.875 & 51.776\end{array}$

$\begin{array}{llllllllll}51.678 & 51.580 & 51.482 & 51.383 & 51.284 & 51.187 & 51.088 & 50.990 & 50.892 & 50.793\end{array}$

$\begin{array}{lllllllllll}8.8 & 50.695 & 50.597 & 50.498 & 50.400 & 50.301 & 50.203 & 50.105 & 50.007 & 49.908 & 49.810 \\ 8.9 & 49.712 & 49.614 & 49.515 & 49.417 & 49.319 & 49.220 & 49.122 & 49.024 & 48.925 & 48.827\end{array}$

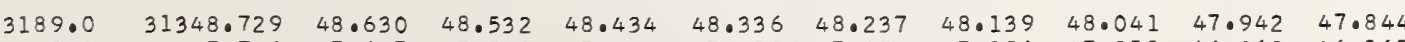

$\begin{array}{lllllllllll}9.1 & 47.746 & 47.647 & 47.549 & 47.451 & 47.355 & 47.254 & 47.156 & 47.058 & 46.960 & 46.862\end{array}$

$\begin{array}{lllllllllll}9.2 & 46.763 & 46.665 & 46.567 & 46.468 & 46.370 & 46.272 & 46.174 & 46.075 & 45.977 & 45.879 \\ 9.3 & 45.780 & 45.682 & 45.584 & 45.485 & 45.387 & 45.289 & 45.191 & 45.092 & 44.994 & 44.896\end{array}$

$\begin{array}{lllllllllll}9.4 & 44.798 & 44.699 & 44.601 & 44.502 & 44.404 & 44.306 & 44.208 & 44.110 & 44.994 & 44.896 \\ 9.5 & 43.815 & 43.0717 & 43.610 & 43.520 & 43.422 & 43.323 & 43.225 & 43.127 & 43.029 & 43.913\end{array}$

$\begin{array}{lllllllllll}9.5 & 43.815 & 43.717 & 43.618 & 43.520 & 43.422 & 43.323 & 43.225 & 43.127 & 43.029 & 42.930 \\ 9.6 & 42.832 & 42.734 & 42.635 & 42.538 & 42.439 & 42.341 & 42.242 & 42.144 & 42.046 & 41.948\end{array}$

$\begin{array}{llllllllllll}9.7 & 41.850 & 41.751 & 41.653 & 41.555 & 41.457 & 41.358 & 41.260 & 41.162 & 41.063 & 40.965\end{array}$

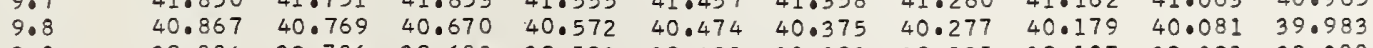

9.9 $\begin{array}{llll}39.492 & 39.393 \quad 39.295 \quad 39.197 \quad 39.098 \quad 39.000\end{array}$

0.289247

0.289246

0.289244

0.289243

0.289240

.289239

0.289237

0.289236

.289233

. 289231

0.289228
0.289227
0.289225

0.289225

0.289224

0.289222

0.289220

0.289219

0.289216

0.289215

0.289213

.289210

0.289209

0.289208
0.289207
0.28920

0.289206

0.289205
0.289204

0.289202

0.289201

0.289200

0.289198

0.289197

0.289196

0.289193

0.289192

0.289190

0.289189

0.289186

0.289185

0.289183

0.289181

0.289178

.

0.289176

0.289174

0.289173

0.289171

0.289169

0.289168

0.289167

0.289166

0.289163

0.289162

0.289160

0.289159

0.289158

0.289155

0.289154

0.289153

0.289151

0.289150

0.289149

0.289146

0.289144

0.289143

0.289142

0.289139

0.289138 


.06

0.1

0.3

0.5

0.6

0.8

1.0

1. 3

1.4

1.6

1. 8

3192.0

2.1
2.2

2.3

2. 5

2. 7

2.8
2.9

3193.0

3.1

3. 3

3.4
3.5

3.6
3.7

3.8
3.9

$$
\begin{array}{r}
3194.0 \\
4 . \\
4 . \\
4 . \\
4 . \\
4.5 \\
4.0 \\
4 . \\
4 . \\
4 .
\end{array}
$$

31950

5.

5.2

5.5

5.6

5.8
5.9

3196.

6.1
6.2
6.3

6.6

6.8

3197.

$$
\begin{aligned}
& 197.0 \\
& 7.0 \\
& 7.2 \\
& 7.0 \\
& 7.5 \\
& 7.6 \\
& 7.7 \\
& 7.8
\end{aligned}
$$

7.1
$7 \cdot 2$
7.3

7.3
7.4
7.5

7.6
7.7
7.8

3198.0

$\begin{array}{rrrrr}98.0 & 31260.509 & 60.411 & 60.313 & 60.215 \\ 8.1 & 59.531 & 59.433 & 59.335 & 59.238 \\ 8.2 & 58.554 & 58.456 & 58.358 & 58.260 \\ 8.3 & 57.576 & 57.479 & 57.381 & 57.283 \\ 8.4 & 56.599 & 56.502 & 56.404 & 56.306 \\ 8.5 & 55.622 & 55.524 & 55.427 & 55.329 \\ 8.6 & 54.645 & 54.547 & 54.449 & 54.352 \\ 8.7 & 53.668 & 53.570 & 53.472 & 53.375 \\ 8.8 & 52.691 & 52.594 & 52.495 & 52.398 \\ 8.9 & 51.714 & 51.616 & 51.518 & 51.421 \\ 99.0 & 31250.737 & 50.639 & 50.542 & 50.444 \\ 9.1 & 49.760 & 49.563 & 49.565 & 49.467 \\ 9.2 & 48.783 & 48.686 & 48.588 & 48.490 \\ 9.3 & 47.807 & 47.709 & 47.611 & 47.514 \\ 9.4 & 46.830 & 46.732 & 46.635 & 46.537 \\ 9.5 & 45.854 & 45.756 & 45.558 & 45.561 \\ 9.6 & 44.877 & 44.779 & 44.681 & 44.584 \\ 9.7 & 43.901 & 43.803 & 43.705 & 43.608 \\ 9.8 & 42.924 & 42.827 & 42.729 & 42.531 \\ 9.9 & 41.948 & 41.851 & 41.753 & 41.655\end{array}$

$\begin{array}{lllllllllll} & .001 & .002 & .003 & .004 & .005 & .006 & .007 & .008 & .009 & .010 \\ .098 & .010 & .020 & .030 & .039 & .049 & .059 & .069 & .079 & .089 & .098 \\ .097 & .010 & .019 & .029 & .039 & .049 & .058 & .068 & .078 & .088 & .097\end{array}$ $(n-1) \times 1000 \quad \lambda(n-1)$

$\begin{array}{ll}0.289133 & 0.922333 \\ 0.289131 & 0.922358 \\ 0.289130 & 0.922384 \\ 0.289129 & 0.922409 \\ 0.289128 & 0.922434 \\ 0.289127 & 0.922459 \\ 0.289126 & 0.922485 \\ 0.289125 & 0.922510 \\ 0.289123 & 0.922535 \\ 0.289122 & 0.922560\end{array}$

0.289121

0.922586 0.922611 0.922662 0.922687 0.922712 0.922737 0.922763 0.922788
0.922813

0.289112

0.289110

0.289108

0.289106
0.289105

0.289104

0.289103

0.289102

0.289100

0.289098

0.289097
0.289096

0.289095

0.289094

0.289092

0.289090

0.289089

0.289088

0.289087

0.289086

0.289085

0.289082

0.289081

0.289080

0.289078

0.289077

0.289076

0.289075

0.289073

0.289071

0.289070

0.289069

0.289067

0.289065

0.289064

0.289063

0.289061

0.289060

0.289059

0.289058

0.289056

0.289054

0.289053

0.289052

0.289051

0.289048

0.289047

0.289046

0.289045
0.289044

0.289043

0.289042

0.289041

0.28903

0.289038
0.289037

0.289036

0.289035

0.289033

0.289032

0.289030

0.289029

0.289028

0.289027

0.289026

0.289025

0.289024

0.289021

.289020

- 922838

0.922864

0.922889

0.922914

0.922965

0.922965
0.922990

0.922990

0.923015

0.923041
0.923066

0.923091

0.923116

0.923142

0.923167

0.923192

0.923218

0.923268

0.923293
0.923319

0.923344

0.923369

0.923395

0.923420
0.923445

0.923470

0.923496

0.923521

0.923546
0.923572

0.923597

0.923622

0.923647

0.923673
0.923698

0.923698
0.923723

0.923748

0.923774

0.923799

0.923850

0.923875

0.923900

0.923951

0.923976

0.924001

0.924027

0.924052

0.924102

0.924128

0.924153
0.924178

0.924178
0.924204

0.924204
0.924229

0.924229
0.924254

0.924254
0.924279

0.924305

0.924330

0.924355

0.924381

0.924406

0.924431

0.924482

0.924507

0.924558

0.924583

0.924608

0.924633

0.924659

0.924684

0.924709

0.924760

0.924785

0.924810
0.924836 
$\begin{array}{lrlllllllll}3200.0 & 31240.972 & 40.874 & 40.776 & 40.679 & 40.581 & 40.483 & 40.386 & 40.288 & 40.190 & 40.093\end{array}$

$\begin{array}{lllllllllll}0.1 & 39.995 & 39.898 & 39.800 & 39.703 & 39.605 & 39.507 & 39.410 & 39.312 & 39.214 & 39.117 \\ 0.2 & 39.019 & 38.922 & 38.824 & 38.727 & 38.629 & 38.531 & 38.433 & 38.336 & 38.238 & 38.1141\end{array}$

$\begin{array}{llllllllllll}0.2 & 39.019 & 38.922 & 38.824 & 38.727 & 38.629 & 38.531 & 38.433 & 38.336 & 38.238 & 38.141 \\ 0.3 & 38.043 & 37.946 & 37.848 & 37.750 & 37.653 & 37.555 & 37.457 & 37.360 & 37.262 & 37.165\end{array}$

$\begin{array}{llllllllllll}0.4 & 37.067 & 36.969 & 36.872 & 36.774 & 36.677 & 36.579 & 36.481 & 36.384 & 36.286 & 36.188 \\ 0.5 & 36.091 & 35.993 & 35.896 & 35.798 & 35.701 & 35.603 & 35.506 & 35.408 & 35.310 & 350213\end{array}$

$\begin{array}{lllllllllll}0.5 & 36.091 & 35.993 & 35.896 & 35.798 & 35.701 & 35.603 & 35.506 & 35.408 & 35.310 & 35.213 \\ 0.6 & 35.115 & 35.017 & 34.920 & 34.822 & 34.725 & 34.627 & 34.550 & 34.432 & 34.334 & 34.237\end{array}$

$\begin{array}{lllllllllll}0.6 & 35.115 & 35.017 & 34.920 & 34.822 & 34.725 & 34.627 & 34.530 & 34.432 & 34.334 & 34.237 \\ 0.7 & 34.139 & 34.042 & 33.944 & 33.846 & 33.749 & 33.651 & 33.554 & 33.456 & 33.358 & 33.261\end{array}$

$\begin{array}{lllllllllll}0.7 & 34.139 & 34.042 & 33.944 & 33.846 & 33.749 & 33.651 & 33.554 & 33.456 & 33.358 & 33.261 \\ 0.8 & 33.163 & 33.066 & 32.968 & 32.871 & 32.773 & 32.676 & 32.578 & 32.480 & 32.383 & 32.285\end{array}$

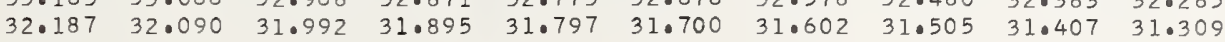

3201.

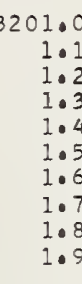

$31231.212 \quad 31.115$

$$
\begin{array}{llll}
31.992 & 31.895 & 31.797 & 31.70 \\
31.017 & 30.920 & 30.822 & 30.72
\end{array}
$$

$\begin{array}{llll}30.627 & 30.529 & 30.432 & 30.334 \\ 29.651 & 29.554 & 29.456 & 29.359\end{array}$ $\begin{array}{llllllllll}30.237 & 30.139 & 30.042 & 29.944 & 29.846 & 29.749 & 29.651 & 29.554 & 29.456 & 29.359 \\ 29.261 & 29.164 & 29.066 & 28.969 & 28.871 & 28.774 & 28.676 & 28.578 & 28.481 & 28.383\end{array}$

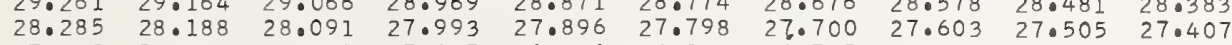
$27.310 \quad 27 \cdot 213$ $26.335 \quad 26.237$ $\begin{array}{llllllll}26.140 & 26.042 & 25.945 & 25.847 & 25.750 & 25.652 & 25.554 & 25.457 \\ 25.164 & 25.067 & 24.969 & 24.872 & 24.774 & 24.677 & 24.579 & 24.482\end{array}$ $\begin{array}{lllll}24.286 & 24.189 & 24.092 & 23.994 & 23.897\end{array}$ $\begin{array}{ll}23.409 & 23 \cdot 312 \\ 22.434 & 22 \cdot 336\end{array}$

$\begin{array}{llllllll}28.091 & 27.993 & 27.896 & 27.798 & 27.700 & 27.603 & 27.505 & 27.407 \\ 27.115 & 27.017 & 26.920 & 26.823 & 26.725 & 26.627 & 26.530 & 26.432\end{array}$ 


\begin{tabular}{|c|c|c|c|c|}
\hline$\lambda(A)$ & .00 & .01 & .02 & .03 \\
\hline 10.0 & 31143.651 & 43.554 & 43.457 & 43.360 \\
\hline 0.1 & 42.681 & 42.584 & 42.487 & 42.390 \\
\hline 0.2 & 41.711 & 41.614 & 41.517 & 41.420 \\
\hline 0.3 & 40.741 & 40.644 & $\begin{array}{l}40.547 \\
30\end{array}$ & 40.450 \\
\hline 0.4 & 39.771 & 39.674 & $\begin{array}{l}39.577 \\
388.607\end{array}$ & $\begin{array}{r}39.480 \\
38.510\end{array}$ \\
\hline 0.5 & $\begin{array}{l}38.801 \\
37.831\end{array}$ & 38.704 & & $\begin{array}{l}38.510 \\
37.541\end{array}$ \\
\hline $\begin{array}{l}0.6 \\
0.7\end{array}$ & $\begin{array}{l}37.831 \\
36861\end{array}$ & $\begin{array}{l}37.734 \\
36.764\end{array}$ & $\begin{array}{l}37.637 \\
36.668\end{array}$ & $\begin{array}{l}37.541 \\
36.571\end{array}$ \\
\hline $\begin{array}{l}0.7 \\
0.8\end{array}$ & $\begin{array}{l}36.861 \\
35.892\end{array}$ & $\begin{array}{l}36.764 \\
35.795\end{array}$ & $\begin{array}{l}36.668 \\
35.698\end{array}$ & 35.601 \\
\hline 0.9 & 34.922 & 34.825 & 34.728 & 34.631 \\
\hline 11.0 & 31133.952 & 33.855 & 33.758 & 33.662 \\
\hline & 32.983 & 32.886 & 32.789 & 32.692 \\
\hline $\begin{array}{l}1.2 \\
1.3\end{array}$ & $\begin{array}{l}32.013 \\
31.044\end{array}$ & $\begin{array}{l}31.916 \\
30.947\end{array}$ & $\begin{array}{l}31.820 \\
30.850\end{array}$ & $\begin{array}{l}31.722 \\
30.753\end{array}$ \\
\hline 1.4 & 30.074 & 29.978 & $\begin{array}{l}39.881 \\
29.850\end{array}$ & 29.783 \\
\hline 1.5 & 29.105 & 29.008 & 28.911 & 28.814 \\
\hline 1.6 & 28.136 & 28.039 & 27.942 & 27.846 \\
\hline 1.7 & 27.167 & 27.070 & 26.973 & 26.876 \\
\hline $\begin{array}{l}1.8 \\
1.9\end{array}$ & $\begin{array}{l}26.198 \\
25.229\end{array}$ & $\begin{array}{l}26.101 \\
25.132\end{array}$ & $\begin{array}{l}26.004 \\
25.035\end{array}$ & $\begin{array}{l}25.907 \\
24.938\end{array}$ \\
\hline 32120 & 25.229 & 25.132 & 25.035 & 23.969 \\
\hline $\begin{array}{r}3212.0 \\
2.1\end{array}$ & $\begin{array}{r}31124.260 \\
23.291\end{array}$ & $\begin{array}{l}24.163 \\
23.194\end{array}$ & $\begin{array}{l}24.066 \\
23.097\end{array}$ & $\begin{array}{l}23.969 \\
23.000\end{array}$ \\
\hline 2.2 & 22.322 & 22.225 & 22.128 & 22.031 \\
\hline 2.3 & 21.353 & 21.256 & 21.159 & 21.062 \\
\hline 2.4 & 20.384 & 20.287 & 20.190 & 20.094 \\
\hline 2.5 & 19.416 & 19.319 & 19.222 & 19.125 \\
\hline 2.6 & 18.447 & $18 \cdot 350$ & 18.253 & 18.1 \\
\hline 2.7 & 17.479 & $17 \cdot 382$ & 17.285 & $17 \cdot 188$ \\
\hline 2.8 & $\begin{array}{l}16.510 \\
15.541\end{array}$ & $\begin{array}{l}16.413 \\
15.445\end{array}$ & $\begin{array}{l}16 \cdot 316 \\
15\end{array}$ & $\begin{array}{l}16.219 \\
15.250\end{array}$ \\
\hline & & & & \\
\hline $\begin{array}{r}13.0 \\
3.1\end{array}$ & $\begin{array}{r}31114.573 \\
13.605\end{array}$ & $\begin{array}{l}14.476 \\
13.508\end{array}$ & 14.379 & $\begin{array}{l}14.283 \\
13.314\end{array}$ \\
\hline $\begin{array}{l}3.1 \\
3.2\end{array}$ & $\begin{array}{l}13.605 \\
12.636\end{array}$ & $\begin{array}{l}13.508 \\
12.540\end{array}$ & $\begin{array}{l}13.411 \\
12.443\end{array}$ & $\begin{array}{l}13 \cdot 314 \\
12 \cdot 346\end{array}$ \\
\hline 3.3 & $\begin{array}{l}11.668 \\
11.688\end{array}$ & 11.572 & 11.475 & 11.378 \\
\hline 3.4 & 10.7 & 10.604 & 10.506 & 10.410 \\
\hline $\begin{array}{l}3.5 \\
3.6\end{array}$ & 09.732 & 09.635 & 09.538 & 09.442 \\
\hline $\begin{array}{l}3.6 \\
3.7\end{array}$ & 08.764 & 08.667 & 08.570 & 08.474 \\
\hline $\begin{array}{l}3.7 \\
3.8\end{array}$ & & 07.699 & 07.603 & 07. \\
\hline $\begin{array}{l}3.8 \\
3.9\end{array}$ & $\begin{array}{l}06.828 \\
05.860\end{array}$ & $\begin{array}{l}06.731 \\
05.763\end{array}$ & $\begin{array}{l}06.635 \\
05.667\end{array}$ & 06.538 \\
\hline 3.9 & 05.860 & 05.763 & 05.667 & 05.570 \\
\hline $\begin{array}{r}14.0 \\
4.1\end{array}$ & $\begin{array}{r}31104.893 \\
03.925\end{array}$ & $\begin{array}{l}04.796 \\
03.828\end{array}$ & $\begin{array}{l}04.699 \\
03.731\end{array}$ & $\begin{array}{l}04.602 \\
03.635\end{array}$ \\
\hline $\begin{array}{l}4 \cdot 1 \\
4 \cdot 2\end{array}$ & $\begin{array}{l}03.925 \\
02.957\end{array}$ & $\begin{array}{l}03.828 \\
02.860\end{array}$ & $\begin{array}{l}03.731 \\
02.763\end{array}$ & $\begin{array}{l}03.635 \\
02.667\end{array}$ \\
\hline 4.3 & 01.990 & 01.893 & 01.796 & 01.699 \\
\hline 4.4 & 01.022 & 00.926 & 00.829 & 00.732 \\
\hline 4.5 & 00.055 & *99.958 & $* 99.861$ & *99.764 \\
\hline 4.6 & 31099.087 & 98.990 & 98.894 & 98.797 \\
\hline 4.7 & 98.120 & 98.023 & 97.927 & 97.8 \\
\hline $4 \cdot 8$ & 97.152 & 97.056 & 96.959 & 96.862 \\
\hline 4.9 & 96.185 & 96.089 & 95.992 & 95.895 \\
\hline $\begin{array}{r}3215 \cdot 0 \\
5.1\end{array}$ & 31095.218 & $95 \cdot 121$ & 95.024 & 94.928 \\
\hline $\begin{array}{l}5.1 \\
5.2\end{array}$ & $\begin{array}{l}94.251 \\
93.284\end{array}$ & $\begin{array}{l}94.154 \\
93.187\end{array}$ & $\begin{array}{l}94.057 \\
93.090\end{array}$ & 93.961 \\
\hline 5.3 & 92.316 & 92.220 & 92. & $\begin{array}{l}92.0 \\
92 .\end{array}$ \\
\hline 5.4 & 010 & 91.253 & 91. & 91. \\
\hline 5.5 & 3 & 90.286 & 90. & 90. \\
\hline 5.6 & 89.416 & $89 \cdot 319$ & 89.222 & 89.126 \\
\hline & 88.449 & $\begin{array}{l}88.353 \\
87.386\end{array}$ & 88.2 & 88.160 \\
\hline $\begin{array}{l}5.8 \\
5.9\end{array}$ & $\begin{array}{l}87.483 \\
86.516\end{array}$ & $\begin{array}{l}87.386 \\
86.419\end{array}$ & $\begin{array}{l}87.290 \\
86.323\end{array}$ & $\begin{array}{l}87.193 \\
86.226\end{array}$ \\
\hline & & & & \\
\hline & $\begin{array}{r}31085^{\circ} \\
84^{\circ}\end{array}$ & $85^{\circ}$ & $\begin{array}{l}85.356 \\
84.389\end{array}$ & 3 \\
\hline 6.2 & 83.616 & 0 & 83. & 6 \\
\hline 6.3 & 82.650 & 82.553 & 82.2 & 82. \\
\hline 6.4 & 81.683 & 81.587 & 81.490 & 81. \\
\hline 6.5 & $8 c$ & 80.621 & 80. & 80 \\
\hline 6.6 & & 79. & 79. & 79 \\
\hline 6.7 & & & 78. & \\
\hline $\begin{array}{l}6.8 \\
6.9\end{array}$ & 77 & 77.722 & 77.625 & 77.529 \\
\hline 6.9 & 76.853 & 76.756 & 76.659 & 76.562 \\
\hline 0 & 7 & 7 & 75.694 & 7 \\
\hline & & & & \\
\hline $7 \cdot 2$ & 5 & 73. & & \\
\hline $7 \cdot 3$ & 72 & 72 & & \\
\hline 7. & 72 & 71. & & \\
\hline 7. & 8 & 70. & & \\
\hline 7. & 2 & 69. & 69 & \\
\hline 7. & 65 & 69.0 & 68 & 6 \\
\hline $\begin{array}{l}7.8 \\
7.9\end{array}$ & $\begin{array}{l}68.161 \\
67.196\end{array}$ & $\begin{array}{l}68 . \\
670^{\circ}\end{array}$ & $\begin{array}{l}670^{\circ} \\
670^{\circ}\end{array}$ & $\begin{array}{l}67 \\
66\end{array}$ \\
\hline & 01.190 & $67 .^{\circ}$ & & \\
\hline & $\begin{array}{r}31066.230 \\
65.265\end{array}$ & $\begin{array}{l}66.134 \\
65.168\end{array}$ & $\begin{array}{l}66.037 \\
65.072\end{array}$ & $\begin{array}{l}65.940 \\
64.975\end{array}$ \\
\hline 8. & $0=$ & & $64^{\circ}$. & \\
\hline 8 & 63.334 & 63.238 & 63. & 63. \\
\hline 8. & 70 & 62.273 & 62. & \\
\hline 8 & 61.405 & 61. & 61.211 & 61. \\
\hline $\begin{array}{l}80 \\
80\end{array}$ & 60.439 & 60.3 & 60. & \\
\hline $\begin{array}{l}8.7 \\
8.8\end{array}$ & $\begin{array}{l}59.474 \\
58.509\end{array}$ & $59 \cdot 3$ & $59{ }^{\circ}$ & $590^{\circ}$ \\
\hline $\begin{array}{l}8.8 \\
8.9\end{array}$ & $\begin{array}{r}58.509 \\
57.544\end{array}$ & $\begin{array}{l}58.413 \\
57.448\end{array}$ & $\begin{array}{l}58.317 \\
57.352\end{array}$ & $\begin{array}{l}58.220 \\
57.255\end{array}$ \\
\hline & 31056.580 & & 56.387 & \\
\hline $9 \cdot 1$ & & & & \\
\hline & & & & \\
\hline & & & & \\
\hline & & & & \\
\hline & 7 & & & \\
\hline & & & & \\
\hline & 8 & 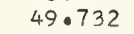 & 49. & \\
\hline 0 & 48.864 & 48.768 & 48.671 & 48.574 \\
\hline 9. & 47.899 & 47.803 & 47.707 & 47.610 \\
\hline & . & 01 & 002 & .003 \\
\hline & 997 & 10 & $\begin{array}{l}019 \\
019\end{array}$ & $\begin{array}{l}.029 \\
.029\end{array}$ \\
\hline
\end{tabular}


38.260

$43.657 \quad 43.561$

$42.694 \quad 42.597 \quad 42.501 \quad 42.405$

$43.272 \quad 43.175$

.288792

0.288791

0.288789

0.288788

0.930023

0.930049

0.288787

$\begin{array}{rrrr}31037.297 & 37.200 & 37.104 & 37.008 \\ 36.333 & 36.237 & 36.140 & 36.044\end{array}$

$\begin{array}{llll}36.333 & 36.237 & 36.140 & 36.044 \\ 35.370 & 35.273 & 35.177 & 35.081 \\ 34.406 & 34.310 & 34.214 & 34.117\end{array}$

$\begin{array}{ll}34.406 & 34.310 \\ 33.443 & 33.347\end{array}$

$\begin{array}{llll}32.479 & 32.383 & 32.287 & 32.191\end{array}$

$\begin{array}{llll}31.516 & 31.420 & 31.323 & 31.227 \\ 30.553 & 30.457 & 30.361 & 30.264\end{array}$

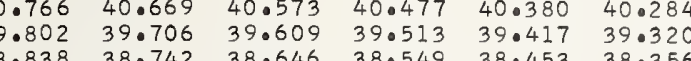

$\begin{array}{ll}29.590 & 29.494 \\ 28.627 & 28.531\end{array}$

3222.0

2

31027.66

$027.664 \quad 27.568$

$\begin{array}{ll}26.701 & 26.605 \\ 25.738 & 25.642\end{array}$

$\begin{array}{ll}24.775 & 24.679 \\ 23.812 & 23.717\end{array}$

$22.850 \quad 22 \cdot 754$

$21.888 \quad 21.791$

$19.962 \quad 19.866$

$\begin{array}{ll}29.397 & 29.301 \\ 28.434 & 28.338\end{array}$

6.91136 .815

37.682

37.586

$\begin{array}{ll}27.471 & 27.375 \\ 26.508 & 26.472\end{array}$

$\begin{array}{ll}26.508 & 26.412 \\ 25.546 & 25.449\end{array}$

24.583
23.620

$\begin{array}{llll}23.620 & 23.524 & 23.428 & 23.332 \\ 22.657 & 22.561 & 22.465 & 22.369\end{array}$

$19.000 \quad 18.90$

20.732
19.770

$20.636 \quad 20.540 \quad 20.444$

36.719
35.755
34.792

$\begin{array}{lll}36.622 & 36.526 & 36.430\end{array}$

0.288785

0.288784

0.288781

0.288780

0.288778

0.288777

0.288775

3223.0

3.1
3.2
3.
3.5
3.6
3.7
3.8
3.9

$31018.038 \quad 17.941$

$\begin{array}{lll}17.075 & 16.979 & 17.8\end{array}$

$\begin{array}{lll}15.150 & 15.054 & 14.9 \\ 14.188 & 14.092 & 13.996\end{array}$

17.749

$18.615 \quad 18.519$

$\begin{array}{lll}12.264 & 12.168 & 12.072\end{array}$

16.787
15.824

14.862

$10.341-11.206$

$\begin{array}{ll}12.072 & 11.976 \\ 11.110 & 11.014\end{array}$

09.379

0.245
9.283

3224

4.1
4.2
4.3

4.3

$4 \cdot 5$

$4 \cdot 6$

$4 \cdot 8$

3225

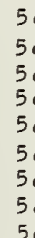

31008.417

$07.417 \quad 08 \cdot 321$

$\begin{array}{lll}07.455 & 07.35 & 08.225\end{array}$

$\begin{array}{lll}05.493 & 06.397 & 06.30\end{array}$

$\begin{array}{llll}0.647 & 02.551 & 02.455 & 02.359\end{array}$

$01.686 \quad 01.58901 .494 \quad 01.397$

$\begin{array}{rrrr}00.724 & 00.628 & 00.532 & 00.436 \\ 30999.763 & 99.667 & 99.571 & 99.475\end{array}$

30908.802

$\begin{array}{rll}998.802 & 98.706 & 98.6 \\ 97.841 & 97.745 & 97.6 \\ 96.880 & 96.784 & 96.688\end{array}$

$96.880 \quad 96.78496 .688$

$95.919 \quad 95.823$

$93.997 \quad 93.901$

$92.075 \quad 91.940 \quad 92.844$

$\begin{array}{llll}90.154 & 90.019 & 90.922 & 90.826 \\ & 89.962 & 89.865\end{array}$

$16.690 \quad 17.556$

$\begin{array}{ll}15.728 & 15.532 \\ 14.766 & 14.669\end{array}$

$\begin{array}{ll}14.766 & 14.669 \\ 13.804 & 13.707 \\ 12.842 & 12.745\end{array}$

$\begin{array}{ll}12.842 & 12.745 \\ 11.879 & 11.78 \\ 10.917 & 10.82\end{array}$

$\begin{array}{llll}32.865 & 32.769 & 32.672 & 32.576\end{array}$

$\begin{array}{llll}31.902 & 31.805 & 31.709 & 31.613 \\ 30.938 & 30.842 & 30.746 & 30.650\end{array}$

$\begin{array}{llll}29.975 & 29.879 & 29.783 & 29.687\end{array}$

0.288774

0.288774

0.288771

40

0.288768

0.288767

0.288765

0.288764

0.288763

0.288761

0.288760

0.288759

0.288757

.288756

0.288753

.930099

0.930150

0.930175

0.930201

0.930251

0.930302

930327

0.930353
0.930378

.030403

0.930428

0.930454

0.930504

0.930555

0.930580

0.930631

0.288752

0.288750

0.288749
0.288748

0.288747

0.288746
0.288745

0.288744

0.288743
0.288742

0.288741

0.288739
0.288738
0.288737

0.288737

0.288736

0.288734

0.288733

0.288732
0.288731

0.930682

0.930732

0.930758

0.930808

0.930834

0.930884

0.930910

0.930935

0.930960

0.931011

0.931062

0.931087

0.931138

0.931188

0.931239

0.931264
0.931290

0.931290

0.931340

.931366
.931391

0.288730

$\begin{array}{lllllllllll}3226.0 & 30989.194 & 89.097 & 89.001 & 88.905 & 88.809 & 88.713 & 88.617 & 88.521 & 88.425 & 88.329\end{array}$

$\begin{array}{lllllllllll}88.233 & 88.136 & 88.040 & 87.945 & 87.848 & 87.752 & 87.656 & 87.560 & 87.464 & 87.368\end{array}$

$\begin{array}{lllllllllll}87.272 & 87.176 & 87.080 & 86.984 & 86.888 & 86.792 & 86.696 & 86.600 & 86.504 & 86.408\end{array}$

$\begin{array}{llllllllll}86.312 & 86.216 & 86.120 & 86.023 & 85.927 & 85.832 & 85.735 & 85.639 & 85.543 & 85.447\end{array}$

$\begin{array}{llllllllll}85.351 & 85.255 & 85.159 & 85.063 & 84.968 & 84.872 & 84.776 & 84.680 & 84.584 & 840487 \\ 84.391 & 84.295 & 84.199 & 84.104 & 84.007 & 83.911 & 83.815 & 83.719 & 83.623 & 83.527\end{array}$

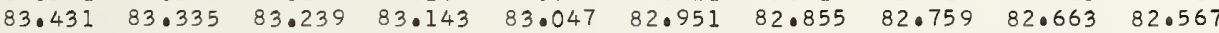

$\begin{array}{lllllllllll}82.471 & 82.375 & 82.279 & 82.183 & 82.087 & 81.991 & 81.895 & 81.799 & 81.703 & 81.607\end{array}$

$\begin{array}{llll}81.511 & 81.415 & 81.319 & 81.223 \\ 80.551 & 80.455 & 80.359 & 80.262\end{array}$

$\begin{array}{llllll}81.127 & 81.031 & 80.935 & 81.039 & 81.0703 & 81.607 \\ 80.167 & 80.071 & 79.975 & 79.879 & 70.743 & 80.647\end{array}$

0.28872

0.288727

0.288725

0.288724

0.288722

0.288721

0.288719

0.288716

0.288715

0.288714

0.288713

0.288712

0.288711

0.288709

0.288708

0.288707

0.288704

0.288704
0.288703

0.288702

0.288701

0.288700

0.288699

0.288697

0.288696

0.288694

0.288693

0.288692

0.288690

0.288689

0.288688

0.931442

0.931492

(

0.931568

.931594

0.931644

0.931695

0.931720

0.931771

0.931796
0.931822

0.931847

0.931872

0.931898

0.931974

0.932024

0.932050

0.932100

0.932126

0.932151

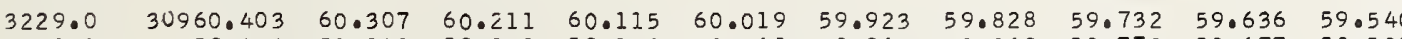

$\begin{array}{llllllllllll}9.2 & 59.444 & 59.348 & 59.252 & 59.156 & 59.060 & 58.965 & 58.869 & 58.773 & 58.677 & 58.582 \\ 9.2 & 58.486 & 58.390 & 58.294 & 58.198 & 58.102 & 58.006 & 57.910 & 57.814 & 57.719 & 57.623\end{array}$

$\begin{array}{lllllllllll}57.527 & 57.431 & 57.335 & 57.240 & 57.144 & 57.048 & 56.952 & 56.856 & 56.760 & 56.664\end{array}$

$\begin{array}{lllllllllll}55.610 & 55.514 & 55.418 & 55.323 & 55.227 & 55.131 & 55.035 & 54.939 & 54.843 & 54.747\end{array}$

$\begin{array}{llllllllll}53.693 & 53.597 & 53.501 & 53.405 & 53.310 & 53.214 & 53.118 & 53.022 & 52.926 & 52.830\end{array}$

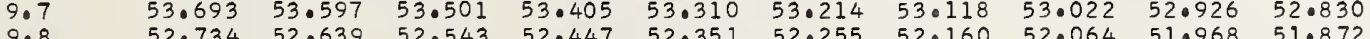

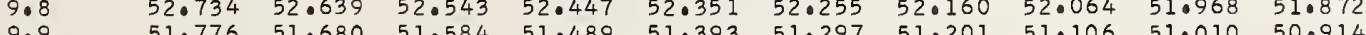

.010

0.932202

0.932252

0.932303

932328

0.932354

0.032 .404

0.932430 


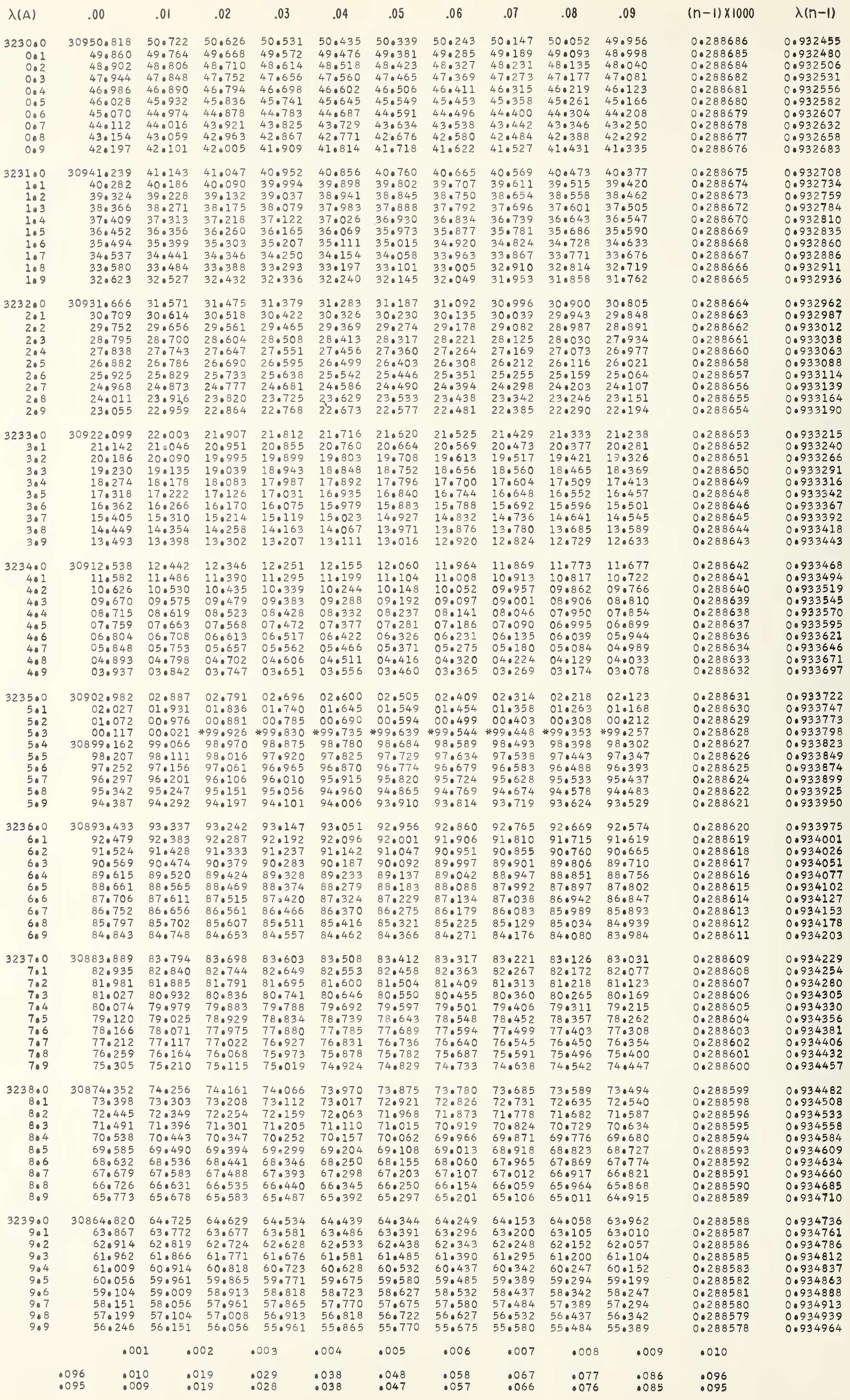


$\begin{array}{lllllllllll}3241.0 & 30845.774 & 45.679 & 45.584 & 45.489 & 45.394 & 45.298 & 45.203 & 45.108 & 45.013 & 440918\end{array}$ $\begin{array}{lllllllllll}101 & 44.823 & 44.727 & 44.632 & 44.537 & 44.442 & 44.346 & 440251 & 44.156 & 44.061 & 43.966\end{array}$

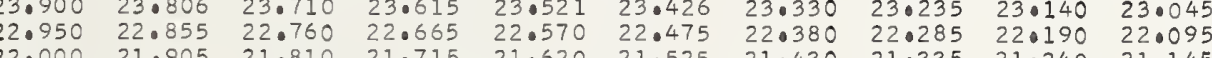

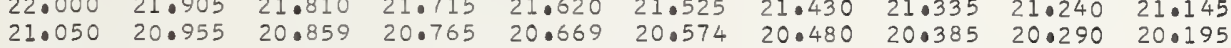

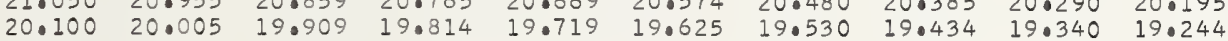

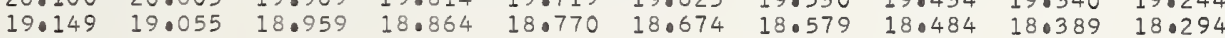

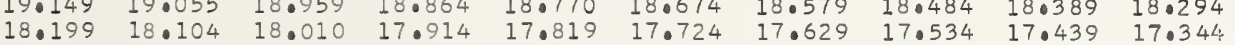
30817

4.0
40
40
40.04
405
406
40.0
400

3245

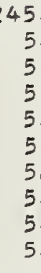

0.288512

0.288511

0.288509

0.288508

0.288506

0.288505

0.288504

0.288501 0.288500 0.288499 0.288498 0.288496 0.288495 0.288494

0.288493

0.288491
0.288490

0.288490

0.288488

0.288486

0.288485

0.288484

0.288483

0.288481

0.934989
.935015
0.935040

0.935040

0.935091

0.935141

0.935192

0.935243

0.935268
0.935294

0.935319

0.935344

0.935420

0.935496

0.935522

0.935572

0.935623

0.935648

0.935699

0.935750

0.935775
0.935801

0.935826

0.935851

0.935902

0.935953

0.288480

0.288479

0.288478
0.288477

0.288476

0.288475
0.288474

0.288474
0.288473

0.288471

0.936003

0.936029
0.936054

0.936080

0.936130

0.936181

0.936232

0.936257

0.936282

0.936333

0.936359

0.936409

0.936435

0.936485

0.936511

0.936536
0.936561

0.936587

0.936612
0.936637

0.936663

0.936688

0.936739

0.936764

0.936790

0.936815
0.936840

0.936866

0.936916

0.936942

0.936967

0.937018

0.937069

0.937094
0.937119

0.937145

0.937170

0.937221

0.937272
0.937297

0.937322

0.937348

0.937373
0.937398

0.937424

0.937474

$\begin{array}{lllllllllll} & .001 & .002 & .003 & .004 & .005 & .006 & .007 & .008 & .009 & .010 \\ .095 & .010 & .019 & .029 & .038 & .048 & .057 & .067 & .076 & .086 & .095 \\ .094 & .009 & .019 & .028 & .038 & .047 & .057 & .066 & .076 & .085 & .094\end{array}$


$\lambda(A)$

.00

.01

.02

.03

.04

.05

.06

.07

.08

.09

$(n-1) \times 1000$

$\lambda(n-1)$

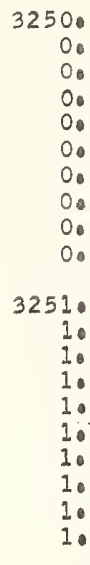

$\begin{array}{rlllll}30760.358 & 60.264 & 60.169 & 60.074 & 59.980 & 59.88 \\ 59.412 & 59.317 & 59.222 & 59.128 & 59.033 & 58.93\end{array}$

$58.465 \quad 58.371$

57.519
56.573
56.478

$55.627 \quad 55.532$

$\begin{array}{ll}54.680 & 54.586 \\ 53.734 & 53.640\end{array}$

$52.788 \quad 52 \cdot 69$

0750.897

\begin{abstract}
$49.951 \quad 49.885$
\end{abstract}
49.005

$48.059 \quad 47.96$

$47.114 \quad 47 \cdot 019$

$45.222 \quad 45.128$

$4.277 \quad 44 \cdot 18$

42.386

$58.276 \quad 58.182 \quad 58.087$

$\begin{array}{llll}57.330 & 57.235 & 57.141 & 57.046\end{array}$

$55.437 \quad 55.343 \quad 55.248 \quad 55.154$

$\begin{array}{llll}54.491 & 54.397 & 54.302 & 54.207\end{array}$

$53.545 \quad 53.450 \quad 53.356$

53.261

$\begin{array}{llll}59.790 & 59.696 & 59.601 & 59.507\end{array}$

$\begin{array}{llll}57.898 & 57.803 & 57.708 & 57.614\end{array}$

$\begin{array}{llll}56.951 & 56.857 & 56.762 & 56.667\end{array}$

$\begin{array}{llll}55.059 & 54.964 & 54.870 & 54.775\end{array}$

$\begin{array}{llll}54.113 & 54.018 & 53.924 & 53.829\end{array}$

400

$50.707 \quad 50.613$

51.46

50.423

52.221

3.072

$52.978 \quad 52.883$

$49.761-40.613$

$\begin{array}{ll}48.816 & 48.721 \\ 47.870 & 47.776\end{array}$

$46.925 \quad 46.830$

$\begin{array}{ll}45.979 & 45.885 \\ 45.033 & 44.939\end{array}$

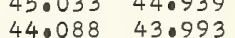

$\begin{array}{llllll}49.572 & 49.478 & 49.383 & 49.289 & 49.194 & 49.099 \\ 48.627 & 48.532 & 48.438 & 48.343 & 48.249 & 48.154 \\ 47.681 & 47.587 & 47.492 & 47.397 & 47.303 & 47.208\end{array}$

$50 \cdot 329$

51.180

$1.086 \quad 50.991$

$\begin{array}{llllll}47.681 & 47.587 & 47.492 & 47.397 & 47.303 & 47.208\end{array}$

$45.790 \quad 45.695 \quad 45.601 \quad 450506 \quad 45.412 \quad 450317$

$\begin{array}{llllll}45.790 & 45.695 & 45.601 & 45.506 & 45.412 & 45.317 \\ 44.844 & 44.750 & 44.655 & 44.561 & 44.466 & 44.372\end{array}$

$\begin{array}{ll}43 \cdot 142 & 43 \cdot 048 \\ 42.197 & 42.102\end{array}$

$42.954 \quad 43.804$

44.466
43.521

43.426

$42 \cdot 764$

42.67

42.57
41.630

42.481

0.288469

.288468

0.288467

0.288466

0.288464

0.288463

0.288462

0.288460

0.288459

0.288458

0.288455

288454

0.288453

0.288452

0.288450

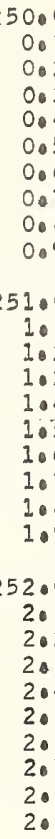

3253.
3.
30
30
30
3.
3.
30
30
30
32540
4.
4
40
4
4
4
4
4
40

253.0
3.1
3.2
3.3
3.4
3.5
3.6
3.7
308
3.9

25400
4.1
4.2
403
4.4
4.5
4.6
407
4.8
409

3255

$5 \cdot 1$
$5 \cdot 2$
$5 \cdot 3$

5.4
5.5

5.5
5.6

5.7
5.8

5.9

3256.0

6.1
6.2
6.3

6.4
6.5

6.6
6.7

6.7
6.8
6.9

3257.

7.

7.3
7.4

7.5
7.6

7.7
7.8
7.9

3258 .

8.1
8.2
8.3
8.4
8.5
8.6
8.7
8.8
8.9
59.0
9.1
9.2
9.3
9.4
9.5
9.6
907
9.8
9.9

30741.44

40.49
39.55

41.346
40.401
39.456

$\begin{array}{ll}37.660 & 37.566\end{array}$

$36.715 \quad 36.621$

$34.826 \quad 34.731$

$\begin{array}{ll}33.881 & 33.786 \\ 32.936 & 32.842\end{array}$

$41.252 \quad 41.157$

40

$39.362 \quad 39.267$

$\begin{array}{ll}38.416 & 38.322 \\ 37.471 & 37.376\end{array}$

$\begin{array}{ll}36.526 & 36.432 \\ 35.581 & 35.487\end{array}$

$34.636 \quad 34.542$

$31.991 \quad 31.8$

$31.047 \quad 30.952$

$29.157 \quad 29.06$

$\begin{array}{ll}28.213 & 28.118 \\ 27.268 & 27.174\end{array}$

26.32426 .174

$25.379 \quad 25.28$

$\begin{array}{ll}24.435 & 24.341 \\ 23.491 & 23.396\end{array}$

21.

21.60321 .509

$\begin{array}{ll}20.659 & 20.564 \\ 19.715 & 19.621\end{array}$

$18.771 \quad 18.677$

$16.883 \quad 16.789$

$\begin{array}{llll}14.996 & 15.845 & 15.751 & 15.656 \\ 14.902 & 14.807 & 14.713\end{array}$

$14.052 \quad 13.958$

$31.802 \quad 31.708$

$\begin{array}{ll}30.857 & 30.763 \\ 29.913 & 29.819\end{array}$

28.96928 .874

$27.079 \quad 26.985$

$\begin{array}{ll}26.135 & 26.041 \\ 25.191 & 25.096\end{array}$

$\begin{array}{ll}24.246 & 24.152 \\ 23.302 & 23.208\end{array}$

$22.358 \quad 22.264$

$1.414 \quad 21.320$

\section{(19)}

$22 \cdot 170 \quad 22 \cdot 075$

$\begin{array}{llll}40.874 & 40.779 & 40.685 & 40.590\end{array}$

$\begin{array}{llll}39.928 & 39.834 & 39.739 & 39.645\end{array}$

$\begin{array}{llll}38.038 & 37.889 & 38.794 & 38.700 \\ 37.038 & 37.849 & 37.755\end{array}$

$\begin{array}{llll}37.093 & 36.999 & 36.904 & 36.810\end{array}$

$\begin{array}{llll}36.148 & 36.053 & 35.959 & 35.865 \\ 35.204 & 35.109 & 35.014 & 34.920\end{array}$

$\begin{array}{lllllll}5.392 & 35.298 & 35.204 & 35.109 & 35.014 & 34.920 \\ 4.448 & 34.353 & 34.259 & 34.164 & 34.070 & 33.975 \\ 3.503 & 33.408 & 33.314 & 33.219 & 33.125 & 33.030\end{array}$

$\begin{array}{llllll}31.613 & 31.519 & 31.424 & 31.330 & 31.235 & 31.141\end{array}$

$\begin{array}{llllll}30.669 & 30.574 & 30.480 & 30.385 & 30.291 & 30.196 \\ 29.724 & 29.629 & 29.535 & 29.440 & 29.346 & 29.252\end{array}$

$\begin{array}{llllll}28.780 & 28.685 & 28.590 & 28.496 & 28.402 & 28.307 \\ 27.835 & 27.740 & 27.646 & 27.552 & 27.457 & 27.363\end{array}$

$\begin{array}{llllll}27.835 & 27.740 & 27.646 & 27.552 & 27.457 & 27.363 \\ 26.891 & 26.796 & 26.702 & 26.607 & 26.512 & 26.418\end{array}$

$\begin{array}{llllll}25.946 & 25.852 & 25.757 & 25.563 & 25.568 & 25.474 \\ 25.002 & 24.907 & 24.813 & 24.719 & 24.624 & 24.530\end{array}$

$\begin{array}{llllll}24.002 & 24.907 & 24.813 & 24.719 & 24.624 & 24.530 \\ 24.058 & 23.963 & 23.869 & 23.774 & 23.680 & 23.585 \\ 23.113 & 23.019 & 22.924 & 22.830 & 22.736 & 22.642\end{array}$

$30713.109 \quad 13.014$

$\begin{array}{ll}12.165 & 12.071 \\ 11.222 & 11.127\end{array}$

$\begin{array}{llll}11.222 & 11.127 & 11.976 & 11.882 \\ 10.278 & 10.184 & 10.033 & 10.938\end{array}$

$\begin{array}{llll}10.02785 & 10.184 & 10.090 & 09.995 \\ 08.09\end{array}$

$\begin{array}{llll}08.392 & 08.298 & 08.203 & 08.109\end{array}$

$\begin{array}{llll}07.449 & 07.354 & 07.260 & 07.166 \\ 06.505 & 06.411 & 06.317 & 06.223\end{array}$

$\begin{array}{llll}06.505 & 06.411 & 06.317 & 06.223 \\ 05.562 & 05.468 & 05.374 & 05.279 \\ 04.619 & 04.525 & 04.431 & 04.336\end{array}$

$\begin{array}{rlll}703.677 & 03.582 & 03.488 & 03.394 \\ 02.734 & 02.639 & 02.545 & 02.450\end{array}$

$\begin{array}{llll}01.841 & 01.696 & 01.602 & 01.508\end{array}$

$\begin{array}{lllll}30699.905 & 99.811 & 99.716 & 99.622\end{array}$

$98.962 \quad 98.868 \quad 98.774 \quad 98.679$

$\begin{array}{llll}98.020 & 97.925 & 97.831 & 97.737\end{array}$

$\begin{array}{llll}96.135 & 96.041 & 95.947 & 95.852 \\ 95.192 & 95.098 & 95.004 & 94.909\end{array}$

$694 \cdot 250 \quad 94 \cdot 156$

$\begin{array}{ll}93.308 & 93.21 \\ 92.365 & 92.27\end{array}$

$\begin{array}{ll}91.423 & 91.329 \\ 90.480 & 90.386\end{array}$

$\begin{array}{ll}89.539 & 89.444 \\ 88.596 & 88.502\end{array}$

$87.654 \quad 87.560$

$\begin{array}{ll}86.712 & 86.618 \\ 85.770 & 85.676\end{array}$

94.06193 .967

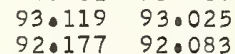

91.23591 .140

90.29290 .198

88.408
88.314

$87.466 \quad 87.372$

$\begin{array}{ll}8.524 & 86.430 \\ 85.582 & 85.488\end{array}$

$\begin{array}{ll}84.640 & 84.546 \\ 83.698 & 83.604\end{array}$

$\begin{array}{rr}8.829 & 84.734 \\ 83.887 & 83.79\end{array}$

$82.946 \quad 82.851$

$82.757 \quad 82.663$

$\begin{array}{ll}81.816 & 81.721 \\ 80.874 & 80.780 \\ 79.932 & 79.838\end{array}$

$\begin{array}{llll}81.062 & 80.968 & 80.874 & 80.780 \\ 80.121 & 80.026 & 79.932 & 79.838 \\ 79.179 & 79.085 & 78.991 & 78.897\end{array}$

$\begin{array}{llll}79.179 & 79.085 & 78.991 & 78.897 \\ 78.238 & 78.143 & 78.050 & 77.955\end{array}$

$\begin{array}{llll}77.296 & 77.202 & 77.108 & 77.014 \\ 76.355 & 76.261 & 76.167 & 76.073\end{array}$

$675.414 \quad 75.31$

75.22575 .131

$\begin{array}{lllllllllll} & & & & & & & & & & \\ 75.414 & 75.319 & 75.225 & 75 \cdot 131 & 75.037 & 74.943 & 74.849 & 74.755 & 74.661 & 74.567 \\ 74.473 & 74.378 & 74.284 & 74.190 & 74.096 & 74.002 & 73.908 & 73.814 & 73.719 & 73.625 \\ 73.531 & 73.437 & 73.343 & 73.249 & 73.155 & 73.061 & 72.967 & 72.873 & 72.779 & 72.684\end{array}$

1
0
9
8
7
6
5
4
4
6

$\begin{array}{lllll}21.131 & 21.037 & 20.942 & 20.848 & 20.753\end{array}$

$\begin{array}{llllll} & \end{array}$

$\begin{array}{llllll}18.394 & 18.299 & 18.205 & 18.111 & 18.016 & 17.921 \\ 17.450 & 17.355 & 17.261 & 17.167 & 17.072 & 16.978\end{array}$

$\begin{array}{llllll}16.506 & 16.411 & 16.317 & 16.223 & 16.128 & 16.034\end{array}$

$\begin{array}{llllll}15.562 & 15.468 & 15.374 & 15.279 & 15.185 & 15.091 \\ 14.619 & 14.524 & 14.430 & 14.335 & 14.241 & 14.147\end{array}$

$\begin{array}{llllll}13.675 & 13.581 & 13.486 & 13.392 & 13.297 & 13.203\end{array}$

$\begin{array}{llllll}12.731 & 12.637 & 12.543 & 12.448 & 12.354 & 12.260\end{array}$

$\begin{array}{llllll}1.788 & 11.693 & 11.599 & 11.505 & 11.410 & 11.316\end{array}$

$\begin{array}{llllll}09.901 & 09.807 & 09.712 & 09.618 & 09.524 & 09.429\end{array}$

$\begin{array}{llllll}08.958 & 08.864 & 08.769 & 08.675 & 08.581 & 08.486 \\ 08.015 & 07.920 & 07.826 & 07.732 & 07.637 & 07.543\end{array}$

$\begin{array}{llllll}07.072 & 06.977 & 06.883 & 06.789 & 06.694 & 06.600\end{array}$

$\begin{array}{llllll}06.128 & 06.034 & 05.940 & 05.845 & 05.751 & 05.657\end{array}$

$\begin{array}{llllll}04.242 & 04.148 & 04.053 & 03.959 & 03.865 & 03.771\end{array}$

$\begin{array}{llllll}03.299 & 03.205 & 03.111 & 03.016 & 02.922 & 02.828\end{array}$

$\begin{array}{llllll}02.356 & 02.262 & 02.168 & 02.073 & 01.979 & 01.885\end{array}$

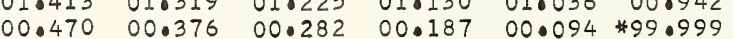

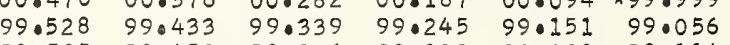

$\begin{array}{llllll}98.585 & 98.490 & 98.396 & 98.302 & 98.208 & 98.114\end{array}$

$\begin{array}{llllll}96.700 & 96.606 & 96.511 & 96.417 & 96.323 & 96.229\end{array}$

$\begin{array}{llllll}95.758 & 95.664 & 95.569 & 95.475 & 95.381 & 95.287\end{array}$

$93.873 \quad 93.779 \quad 93.685 \quad 93.590 \quad 93.496 \quad 93.402$

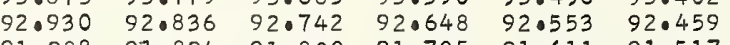

$\begin{array}{llllll}91.988 & 91.894 & 91.800 & 91.705 & 91.611 & 91.517 \\ 91.046 & 90.952 & 90.857 & 90.763 & 90.669 & 90.575\end{array}$

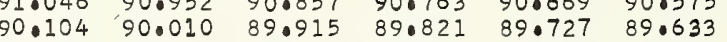

$\begin{array}{llllll}89.162 & 89.067 & 88.974 & 88.879 & 88.785 & 88.691 \\ 88.220 & 88.125 & 88.031 & 87.937 & 87.843 & 87.749\end{array}$

$\begin{array}{lllllll}87.278 & 87.125 & 88.031 & 87.937 & 87.843 & 87.749 \\ 87.089 & 86.995 & 86.901 & 86.807\end{array}$

$\begin{array}{llllll}86.336 & 86.241 & 86.147 & 86.053 & 85.959 & 85.865 \\ 85.394 & 85.300 & 85.205 & 85.111 & 85.017 & 84.923\end{array}$

$\begin{array}{lllllll}84.452 & 84.358 & 84.264 & 84.169 & 84.075 & 83.981\end{array}$

$\begin{array}{llllll}83.510 & 83.416 & 83.322 & 83.228 & 83.133 & 83.040 \\ 82.569 & 82.475 & 82.380 & 82.286 & 82.192 & 82.098\end{array}$

$\begin{array}{llllll}81.569 & 82.475 & 82.380 & 82.286 & 82.192 & 82.098 \\ 81.627 & 81.533 & 81.439 & 81.344 & 81.250 & 81.156\end{array}$

$\begin{array}{llllll}80.686 & 80.592 & 80.497 & 80.403 & 80.309 & 80.215\end{array}$

$\begin{array}{llllll}79.744 & 79.650 & 79.556 & 79.462 & 79.367 & 79.273 \\ 78.802 & 78.708 & 78.615 & 78.520 & 78.426 & 78.332\end{array}$

$\begin{array}{lllllll}77.861 & 77.767 & 77.615 & 78.520 & 78.426 & 78.332 \\ 76.573 & 77.579 & 77.485 & 77.390\end{array}$

$\begin{array}{llllll}76.920 & 76.826 & 76.731 & 76.637 & 76.543 & 76.449 \\ 75.979 & 75.884 & 75.790 & 75.696 & 75.602 & 75.508\end{array}$

$\begin{array}{llllllllll}71.649 & 71.555 & 71.461 & 71.367 & 71.273 & 71.178 & 71.084 & 70.990 & 70.896 & 70.802 \\ 70.708 & 70.614 & 70.520 & 70.426 & 70.332 & 70.238 & 70.144 & 70.050 & 69.955 & 69.862\end{array}$

$\begin{array}{llllllllll}69.768 & 69.673 & 69.579 & 69.485 & 69.391 & 69.297 & 69.203 & 69.109 & 69.015 & 68.921\end{array}$

$\begin{array}{llllllllll}68.827 & 68.732 & 68.639 & 68.544 & 68.450 & 68.356 & 68.262 & 68.168 & 68.074 & 67.980\end{array}$

$\begin{array}{llllllllll}67.886 & 67.792 & 67.698 & 67.604 & 67.510 & 67.416 & 67.322 & 67.227 & 67.134 & 67.039 \\ 66.945 & 66.851 & 66.757 & 66.663 & 66.569 & 66.475 & 66.381 & 66.287 & 66.193 & 66.099\end{array}$

.56966 .475

0.288448

0.288447

0.288446

0.288444

0.288443

0.288442

0.288440

0.288439
0.288438

0.288437

0.288436

0.288435

0.288434

0.288433
0.288432

0.288431

0.288430

0.288429

0.288428

0.288427

0.288425

0.288423

0.288422

0.288421

0.288420

0.288419

0.288417

0.288416

0.288415

0.288414

0.288413

0.288412

0.288411

.288410

0.288408

0.288407

0.288405

0.288404

0.288403

0.288402

0.288401

0.288400 
$\begin{array}{rrrrrrrrrrr}0.0 & 30666.005 & 65.911 & 65.816 & 65.722 & 65.628 & 65.534 & 65.440 & 65.346 & 65.252 & 65.158 \\ 0.1 & 65.064 & 64.970 & 64.876 & 64.781 & 64.687 & 64.593 & 64.500 & 64.406 & 64.311 & 64.218\end{array}$

0.288363 $\begin{array}{llllllllll}64.123 & 64.029 & 63.935 & 63.841 & 63.747 & 63.653 & 63.559 & 63.465 & 63.371 & 63.277 \\ 63.183 & 63.089 & 62.995 & 62.901 & 62.807 & 62.7112 & 62.618 & 62.524 & 62.430 & 62.336\end{array}$ $\begin{array}{lllllllllll}4 & 62.242 & 62.148 & 62.054 & 61.960 & 61.866 & 61.772 & 61.678 & 61.584 & 61.490 & 61.396\end{array}$ $\begin{array}{lllllllllll}0.5 & 61.302 & 61.208 & 61.114 & 61.020 & 60.926 & 60.832 & 60.738 & 60.644 & 60.550 & 60.456 \\ 0.6 & 60.362 & 60.267 & 60.173 & 60.080 & 59.985 & 59.891 & 59.797 & 59.703 & 59.609 & 59.515\end{array}$ $\begin{array}{llllllllllll}0.6 & 60.362 & 60.267 & 60.173 & 60.080 & 59.985 & 59.891 & 59.797 & 59.703 & 59.609 & 59.515 \\ 0.7 & 59.421 & 59.327 & 59.233 & 59.139 & 59.045 & 58.951 & 58.857 & 58.763 & 58.669 & 58.575\end{array}$ $\begin{array}{lllllllllll}0.7 & 58.481 & 58.387 & 58.293 & 58.199 & 58.105 & 58.011 & 57.817 & 58.763 & 58.669 & 58.575 \\ 0.8 & 57.541 & 57.447 & 57.353 & 57.259 & 57.165 & 57.071 & 56.977 & 56.883 & 57.729 & 57.635 \\ 0.9 & 57.541 & & & & & \end{array}$ .288362 0.288361 0.288359

0.288356

0.288355

0.288353

\title{
30647.203 \\ $\begin{array}{llll}7.203 & 47.109 & 47.015 & 46.921\end{array}$ $\begin{array}{llll}46.263 & 46.169 & 46.075 & 45.982\end{array}$
}

44.385

43.445

43.352

45.136

$47.767 \quad 47.673$

$49 \cdot 458$

$49.364 \quad 49.270$

49.176

$\begin{array}{llll}40.628 & 40.534 & 41.379 & 41.286\end{array}$

$\begin{array}{llll}40.628 & 40.534 & 40.440 & 40.346\end{array}$

38.750

38.656

3263.0

$$
\begin{array}{r}
63.0 \\
3.1 \\
3.2 \\
3.3 \\
3.4 \\
3.5 \\
3.6
\end{array}
$$

3.6

3.6
3.7
3.8

30637 .

$\begin{array}{ll}36.872 & 37.717\end{array}$

$\begin{array}{ll}35.872 & 36.778 \\ 35.933 & 35.839\end{array}$

$\begin{array}{ll}34.995 & 34.901 \\ 34.056 & 33.962\end{array}$

$\begin{array}{ll}34.056 & 33.962 \\ 33.117 & 33.023\end{array}$

$\begin{array}{ll}32.178 & 32.085 \\ 31.240 & 31.146\end{array}$

$\begin{array}{llllllllll}31.240 & 31.146 & 31.052 & 30.958 & 30.864 & 30.771 & 30.677 & 30.583 & 30.489 & 30.395 \\ 30.301 & 30.208 & 30.114 & 30.020 & 29.927 & 29.833 & 29.739 & 29.645 & 29.551 & 29.457 \\ 29.363 & 29.270 & 29.176 & 29.082 & 28.988 & 28.894 & 28.800 & 28.707 & 28.613 & 28.519\end{array}$

$38.562 \quad 38.468$

$\begin{array}{ll}46.827 & 46.733 \\ 45.888 & 45.794\end{array}$

46.639

$47.485 \quad 47.391 \quad 47.297$

0.288349

0.288348

0.288347

0.288345

0.288344
0.288343

0.288342

0.288341

0.288338

0.288337
0.288336

0.288336

0.288334

0.288333

0.288331

0.288330

0.288328

0.288327

0.288326

0.288325
0.288324

0.288324

0.288322

3264 .

4.9
$4: 5$
$4: 4$
$4: 5$
4.57
4.59

30628.

27.425287

$\begin{array}{llll}1.487 & 27.393 & 28.237 & 28.144 \\ & 27.299 & 27.205\end{array}$

$\begin{array}{llll}25.610 & 25.517 & 25.423 & 25.329\end{array}$

$\begin{array}{llll}24.672 & 24.578 & 24.484 & 24.391\end{array}$

$22.796 \quad 22.702 \quad 22.608 \quad 22.515$

$\begin{array}{llll}22.796 & 22.702 & 22.608 & 22.515 \\ 21.858 & 21.764 & 21.670 & 21.576\end{array}$

$\begin{array}{llll}20.920 & 20.826 & 20.732 & 20.638 \\ 19.982 & 19.888 & 19.794 & 19.700\end{array}$

$28.050 \quad 27.956$

27.86

$\begin{array}{lll}27.768 & 27.674 & 27.581\end{array}$

0.288320

0.288319

0.288318

0.288316

$\begin{array}{llllll}24.297 & 24.203 & 24.109 & 24.015 & 24.860 & 24.766 \\ 23.359 & 23.265 & 23.171 & 23.077 & 22.921 & 23.828 \\ 23 & 23.890\end{array}$

$\begin{array}{llllll}22.421 & 22.326 & 22.233 & 22.139 & 22.045 & 21.952\end{array}$

0.2883

0.288313

0.288311

3265.0

$\begin{array}{llll}30619.044 & 18.950 & 18.856 & 18.763\end{array}$

$\begin{array}{llll}18.106 & 18.012 & 17.919 & 17.825 \\ 17.168 & 17.075 & 16.981 & 16.888\end{array}$

$\begin{array}{llll}16.231 & 16.138 & 16.044 & 15.950 \\ 15.294 & 15.200 & 15.106 & 15.013\end{array}$

$\begin{array}{llll}14.356 & 14.263 & 14.169 & 14.075\end{array}$

$\begin{array}{llll}3.419 & 13.325 & 13.231 & 13.13\end{array}$

$\begin{array}{lll}12.388 & 12.294 & 12.200\end{array}$

$\begin{array}{llll}11.544 & 11.450 & 11.357 & 11.263 \\ 10.606 & 10.513 & 10.419 & 10.325\end{array}$

$18.669 \quad 18.575$

$\begin{array}{llllll}15.857 & 15.763 & 16.606 & 16.513 & 16.419 & 16.325\end{array}$

$\begin{array}{llllll}14.919 & 14.825 & 14.731 & 14.638 & 14.544 & 14.450\end{array}$

$\begin{array}{llllll}13.044 & 12.950 & 12.857 & 12.762 & 12.669 & 12.575\end{array}$

$\begin{array}{llllll}13.0406 & 12.950 & 12.857 & 12.762 & 12.669 & 12.575 \\ 12.106 & 12.013 & 11.919 & 11.825 & 11.731 & 11.638\end{array}$

5.8

3266.0

6.1
6.2
6.3

6.5

6.7

6.8
6.9

3267

7.

7.2

$7 \cdot 4$

7.6

$30609.669 \quad 09.576$

$\begin{array}{llll}0.732 & 08.538 & 08.545 & 08.451\end{array}$

$\begin{array}{llll}07.795 & 07.701 & 07.608 & 07.514\end{array}$

$\begin{array}{llll}07.858 & 06.764 & 06.671 & 06.577\end{array}$

$\begin{array}{llll}04.984 & 04.891 & 04.797 & 04.703\end{array}$

$\begin{array}{llll}04.047 & 03.954 & 03.860 & 03.766\end{array}$

$\begin{array}{llll}03.111 & 03.017 & 02.924 & 02.830\end{array}$

$01.237 \quad 01.144$

$\begin{array}{ll}1.987 & 01.893 \\ 0.050 & 00.956\end{array}$

11.16911 .075

$\begin{array}{llll}11.919 & 11.825 & 11.731 & 11.638 \\ 10.982 & 10.888 & 10.794 & 10.700\end{array}$

$\begin{array}{lllllll}09.295 & 09.201 & 09.107 & 09.014 & 08.920 & 08.826\end{array}$

$\begin{array}{lllllll}08.357 & 08.264 & 08.170 & 08.076 & 07.983 & 07.889\end{array}$

$\begin{array}{llllll}07.420 & 07.327 & 07.233 & 07.139 & 07.046 & 06.952 \\ 06.483 & 06.390 & 06.296 & 06.202 & 06.109 & 06.015\end{array}$

$\begin{array}{llllll}0.5 .546 & 05.453 & 05.359 & 05.265 & 05.172 & 05.078\end{array}$

$\begin{array}{llllll}04.609 & 04.516 & 04.422 & 04 \cdot 328 & 04.235 & 04 \cdot 141 \\ 03.672 & 03.579 & 03.486 & 03.392 & 03.298 & 03.205\end{array}$

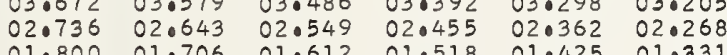

$\begin{array}{llll}30600.301 & 00.207 & 00.113 & 00.020\end{array}$

$\begin{array}{rrrr}30599.364 & 99.270 & 99.177 & 99.083 \\ 98.427 & 98.333 & 98.240 & 98.146\end{array}$

$\begin{array}{llll}98.427 & 98.333 & 98.240 & 98.146 \\ 97.491 & 97.397 & 97.303 & 97.210\end{array}$

$\begin{array}{llll}96.554 & 96.461 & 96.367 & 96.273\end{array}$

$\begin{array}{llll}94.682 & 94.588 & 94.494 & 94.401\end{array}$

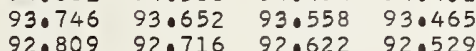

$91.873 \quad 91.780$

2.622
1.686

92.529

\begin{abstract}
00.86300 .76
\end{abstract}
0.288310

0.288308

0.288307

0.288305

0.288303

0.288302
0.288300

0.288299

0.288298

0.288297

0.288296

0.288294

0.288293

0.288292

0.288291

0.288289

0.288288

0.288287

0.288286

0.288285

0.288284

0.288282

0.288280
0.288279

.940063

0.940113
0.940139

0.940164

0.940215

0.940266

0.940291

.940316

.940342

0.940393

0.940418

0.940469

0.940494
0.940520

0.940545

0.940570

.940596

0.940621

0.940672

0.940723

0.940748

0.940799

0.940824

0.940850

0.940900

0.940951

0.940976

0.941002

0.941053

0.941078

0.941103

0.941154

0.941180

0.941230

0.941281

0.941332

0.041383

0.941408

0.941433

0.941484

0.941510

0.941560

0.941586

0.941611

0.941662

0.941713

0.941738

0.941764

0.941840

0.941865

0.941916

0.941942

0.941967

0.942017

0.942043

3268,0

80.00

$\begin{array}{lll}90.844 & 90.750 & 90.656 \\ 89.908 & 89.814 & 89.720\end{array}$

$\begin{array}{llllll}91.435 & 92.341 & 92.247 & 92.154 & 92.060 & 91.967\end{array}$

0.288278

0.288277

0.288276

0.288275

$\begin{array}{llllllllll}87.194 & 87.100 & 87.007 & 86.913 & 86.819 & 86.726 & 86.632 & 86.539 & 86.445 & 86.351\end{array}$

$\begin{array}{llllllllll}86.258 & 86.164 & 86.071 & 85.977 & 85.884 & 85.790 & 85.696 & 85.603 & 85.509 & 85.416\end{array}$

$\begin{array}{llllllllll}85.322 & 85.229 & 85.135 & 85.042 & 84.948 & 84.854 & 84.760 & 84.657 & 84.573 & 84.480\end{array}$

$\begin{array}{llllllllll}84.386 & 84.293 & 84.199 & 84.106 & 84.012 & 83.919 & 83.825 & 83.731 & 83.638 & 83.544\end{array}$

$\begin{array}{llll}83.451 & 83.357 & 83.264 & 83.170 \\ 82.515 & 82.422 & 82.328 & 82.234\end{array}$

$\begin{array}{llllll}83.077 & 82.983 & 82.889 & 82.795 & 82.702 & 82.609\end{array}$

0.288273

0.288272

0.288270

0.288269

0.942094
0.942119

0.942144

0.942195

0.942221

0.942246

0.942297

0.288268

0.288266

0.288265

0.288264

0.288262

0.288261

0.288259

0.288258

0.942348

0.942398

(1)

0.942475

0.942500

0.942525

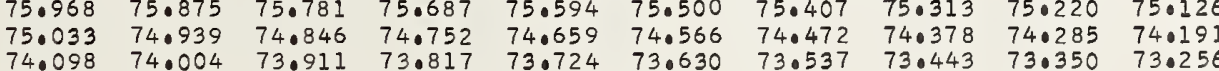

$\begin{array}{llllllllll}73.163 & 73.069 & 72.976 & 72.882 & 72.789 & 72.695 & 72.602 & 72.509 & 72.415 & 72.321\end{array}$

.010 
$\begin{array}{rrrrrrrrrrr}3270.0 & 30572.228 & 72.134 & 72.041 & 71.948 & 71.854 & 71.760 & 71.667 & 71.573 & 71.480 & 71.386\end{array}$

$\begin{array}{lllllllllll}0.1 & 71.293 & 71.199 & 71.106 & 71.012 & 70.919 & 70.825 & 70.732 & 70.639 & 70.545 & 70.452 \\ 0.2 & 70.358 & 70.264 & 70.171 & 70.078 & 69.984 & 69.891 & 69.797 & 69.704 & 69.611 & 69.517 \\ 0.3 & 69.423 & 69.330 & 69.236 & 69.143 & 69.050 & 68.956 & 68.863 & 68.769 & 68.676 & 68.582\end{array}$

$\begin{array}{llllll}68.489 & 68.330 & 69.236 & 69.143 & 69.050 & 68.956 \\ 68.302 & 68.208 & 68.115 & 68.021\end{array}$

$\begin{array}{lllllll}0.5 & 67.554 & 67.461 & 67.367 & 67.273 & 67.180 & 67.086 \\ 0.6 & 66.619 & 66.526 & 66.432 & 66.330 & 66.245 & 66.152\end{array}$

$\begin{array}{lllllll}0.6 & 66.619 & 66.526 & 66.432 & 66.339 & 66.245 & 66.152 \\ 0.7 & 65.685 & 65.591 & 65.498 & 65.404 & 65.311 & 65.218\end{array}$

0.

$\begin{array}{llllll}64.750 & 64.657 & 64.563 & 64.470 & 64.376 & 64.283 \\ 63.816 & 63.723 & 63.629 & 63.536 & 63.443 & 63.349\end{array}$

67.863

66.993

$\begin{array}{lll}67.834 & 67.741 & 67.647\end{array}$

$65 \cdot 12$

$65 \cdot 96$

$66.806 \quad 66 \cdot 713$

271.0

1.12

1.3

1.4

1.6

1. 8

62.788

$61.013 \quad 60.920$

$62.695 \quad 62.602$

$62.508 \quad 62.415$

64.096
63.162

64.003
63.069

64.844
63.909
62.975

$\begin{array}{llll}.826 & 60.733 & 60.639 & 60.546 \\ .892 & 59.799 & 59.705 & 59.61\end{array}$

$59.145-59.052$

$57.277 \quad 57 \cdot 183$

$\begin{array}{ll}55.409 & 55.316 \\ 54.475 & 54.382\end{array}$

$58.958 \quad 58.865$

$\begin{array}{lllll}58.024 & 57.931 & 57.837 & 57.744\end{array}$

$62 \cdot 322$

62.22

$62.135 \quad 62.041$

3272.0

2.

2.3

2.4

2.6

2.8

3.2

3.3

3.4

305

3.7

3.8

401
$4 \cdot 2$

4.3

4.5

406

408

3275.

5.1
5.2

5.3

5.4

5.6
5.7

5.8

3276.

6.1

6.2
6.3

6.5

6.6

6.9

3277

7.1
7.2
7.3
7.03
7.65

7.4

7.

3278

$$
\begin{array}{r}
8 . \\
8 . \\
8 . \\
8 . \\
8 . \\
8 . \\
8 . \\
8 . \\
8 . \\
279 . \\
9 . \\
9 . \\
9 . \\
9 . \\
9 . \\
9 . \\
9 . \\
9 .
\end{array}
$$

30553.541

$51.674 \quad 51.580$

50.740
49.807

$47.940 \quad 47.846$

$47.006 \quad 46.913$

46.073

$30544 \cdot 207$

42.340

41.407

39.541

$38.608 \quad 38.515$

$36.743 \quad 36.650$

$33.012 \quad 32.919$

$31.147 \quad 31.054$

$30.215 \quad 30.122$

28.35128 .257

$\begin{array}{ll}27.418 & 27.325 \\ 26.486 & 26.393\end{array}$

24.62

23.691
22.759

2.3 .597

21.734

$19.963 \quad 19.870$

$19.031 \quad 18.93$

17.168

30516.237

15.30
14.37

$12.511 \quad 12.418$

$11.580 \quad 11.487$

10.648

09.718709 .625

$07.855 \quad 07.763$

30506.92

$\begin{array}{ll}05.994 & 05.90 \\ 05.063 & 04.97\end{array}$

04.13204 .03

$\begin{array}{llll}0 & 02.178 & 02.084 & 01.992\end{array}$

$\begin{array}{rrrr}00.410 & 00.317 & 00.223 & 00.130 \\ 0.499 .479 & 99.386 & 99.293 & 99.200\end{array}$

$\begin{array}{rrrr}499.479 & 99.386 & 99.293 & 99.200 \\ 98.549 & 98.456 & 98.363 & 98.269\end{array}$

$96.688 \quad 96.595$

$\begin{array}{llll}96.758 & 96.595 & 96.502 & 96.40 \\ 95.655 & 95.572 & 95.47\end{array}$

$\begin{array}{llll}94.828 & 94.735 & 94.642 & 94.54\end{array}$

$92.968 \quad 92.875 \quad 92.781 \quad 92.688$

$92.038 \quad 91.945 \quad 91.852 \quad 91.758$

$\begin{array}{llll}91.107 & 91.014 & 90.922 & 90.828\end{array}$

$89.248 \quad 89.155$

$30488.318 \quad 88 \cdot 22$

87.29

$89.062 \quad 88.969$

$88.132 \quad 88.039$

$86.272 \quad 87.10$

$85.343 \quad 85.250$

$84.599 \quad 84.506 \quad 84.413 \quad 84.320$

$83.670 \quad 83.577$

$83.484 \quad 83.39$

$\begin{array}{llll}81.811 & 81.718 & 81.625 & 81.532 \\ 80.882 & 80.789 & 80.696 & 80.603\end{array}$

$\begin{array}{ll}80.882 & 80.789 \\ 79.952 & 79.859\end{array}$
58.58
7.87

$55.969 \quad 55.876$

$\begin{array}{ll}55.036 & 54.942 \\ 54.102 & 54.008\end{array}$

53.168

$\begin{array}{llllll}53.168 & 53.074 & 52.981 & 52.887 & 52.794 & 52.701 \\ 52.234 & 52.140 & 52.047 & 51.954 & 51.860 & 51.767\end{array}$

55.782

59.42

58.49

$60.266 \quad 61.107$

$59.332 \quad 59 \cdot 238$

$58.398 \quad 58 \cdot 304$

$56.623 \quad 56.529 \quad 56.436$

55.689
55.596 55.502

$\begin{array}{llll}53.915 & 53.821 & 53.728 & 53.634\end{array}$

$\begin{array}{lllllll}51.300 & 51.207 & 51.114 & 51.020 & 50.927 & 50.833\end{array}$

$\begin{array}{lllllll}49.433 & 49.340 & 40.180 & 50.087 & 49.994 & 49.900\end{array}$

$48.500 \quad 48.406 \quad 48.313 \quad 48.220 \quad 48.126 \quad 48.033$

$\begin{array}{llllll}47.567 & 47.473 & 47.380 & 47.286 & 47.193 & 47.100\end{array}$

$\begin{array}{llllll}46.633 & 46.540 & 46.446 & 46.353 & 46.260 & 46.167\end{array}$

$\begin{array}{llllll}45.700 & 45.607 & 45.513 & 45.419 & 45.326 & 45.233 \\ 44.767 & 44.673 & 44.580 & 44.487 & 44.393 & 44.300\end{array}$

$\begin{array}{llllll}43.833 & 43.740 & 43.647 & 43.553 & 43.460 & 43.367\end{array}$

$\begin{array}{llllll}42.900 & 42.807 & 42.714 & 42.620 & 42.527 & 42.434\end{array}$

$\begin{array}{lllllll}41.034 & 40.941 & 40.847 & 40.754 & 40.661 & 40.568\end{array}$

$\begin{array}{llllll}40.101 & 40.008 & 39.914 & 39.821 & 39.728 & 39.635\end{array}$

$\begin{array}{llllll}38.235 & 38.142 & 38.049 & 37.955 & 37.862 & 37.769\end{array}$

$\begin{array}{llllll}37.302 & 37.210 & 37.116 & 37.023 & 36.930 & 36.836 \\ 36.370 & 36.277 & 36.184 & 36.090 & 35.997 & 35.904\end{array}$

$\begin{array}{lllllll}35.437 & 35.344 & 35.251 & 35.158 & 35.064 & 34.971\end{array}$

$\begin{array}{llllll}34.505 & 34.411 & 34.318 & 34.225 & 34.132 & 34.038\end{array}$

$\begin{array}{llllll}32.630 & 33.479 & 33.386 & 33.292 & 33.199 & 33.106\end{array}$

$\begin{array}{llllll}31.707 & 31.614 & 31.521 & 31.427 & 31.334 & 31.241\end{array}$

$\begin{array}{llllll}30.775 & 30.681 & 30.588 & 30.495 & 30.402 & 30.308\end{array}$

$\begin{array}{llllll}28.910 & 28.816 & 29.656 & 29.562 & 29.469 & 29.376 \\ & 28.723 & 28.630 & 28.537 & 28.444\end{array}$

$\begin{array}{llllll}27.978 & 27.885 & 27.791 & 27.698 & 27.605 & 27.512\end{array}$

$\begin{array}{llllll}27.045 & 26.952 & 26.859 & 26.76 t & 26.673 & 26.579\end{array}$

$\begin{array}{llllll}25.181 & 25.088 & 24.995 & 24.902 & 24.808 & 24.715\end{array}$

$\begin{array}{llllll}24.249 & 24.156 & 24.063 & 23.969 & 23.877 & 23.784 \\ 23.318 & 23.225 & 23.131 & 23.038 & 22.945 & 22.852\end{array}$

$22.386 \quad 22.292 \quad 22.199 \quad 22.106 \quad 22.013210920$

$\begin{array}{llllll}21.454 & 21.361 & 21.267 & 21.175 & 21.081 & 20.98\end{array}$

$\begin{array}{llllll}20.522 & 20.429 & 20.336 & 20.243 & 20.149 & 20.056 \\ 19.590 & 19.497 & 19.404 & 19.311 & 19.218 & 19.125\end{array}$

$\begin{array}{llllll}18.659 & 18.565 & 18.472 & 18.379 & 18.286 & 18.193\end{array}$

$\begin{array}{llllll}17.727 & 17.634 & 17.541 & 17.447 & 17.354 & 17.261\end{array}$

$\begin{array}{lllllll}15.864 & 15.771 & 15.678 & 15.584 & 15.491 & 15.398\end{array}$

$\begin{array}{llllll}14.933 & 14.839 & 14.746 & 14.653 & 14.560 & 14.467 \\ 14.001 & 13.908 & 13.815 & 13.722 & 13.629 & 13.535\end{array}$

$\begin{array}{llllll}14.001 & 13.908 & 13.815 & 13.722 & 13.629 & 13.535 \\ 13.070 & 12.977 & 12.884 & 12.790 & 12.697 & 12.604\end{array}$

$\begin{array}{llllll}12.139 & 12.045 & 11.952 & 11.859 & 11.766 & 11.673\end{array}$

$\begin{array}{llllll}11.277 & 11.114 & 11.021 & 10.928 & 10.835 & 10.742 \\ 10.277 & 10.183 & 10.090 & 09.997 & 09.90 .4 & 09.811\end{array}$

$\begin{array}{llllll}0.345 & 09.252 & 09.159 & 09.066 & 08.973 & 08.880\end{array}$

$\begin{array}{llllll}08.415 & 08.322 & 08.228 & 08.135 & 08.042 & 07.949 \\ 07.483 & 07.390 & 07.297 & 07.204 & 07.111 & 07.018\end{array}$

$\begin{array}{llllll}06.552 & 06.459 & 06.366 & 06.273 & 06.180 & 06.087\end{array}$

$\begin{array}{llllll}05.622 & 05.528 & 05.436 & 05.342 & 05.249 & 05.156\end{array}$

$\begin{array}{llllll}04.691 & 04.598 & 04.505 & 04.411 & 04.319 & 04.225\end{array}$

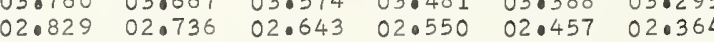

$\begin{array}{llllll}01.898 & 01.805 & 01.713 & 01.619 & 01.526 & 01.433\end{array}$

$\begin{array}{llllll}00.968 & 00.875 & 00.782 & 00.689 & 00.596 & 00.503\end{array}$

$\begin{array}{llllll}99.107 & 99.014 & 98.921 & 98.828 & 98.735 & 98.642 \\ 98.177 & 98.083 & 97.990 & 97.897 & 97.804 & 97.711\end{array}$

$\begin{array}{llllll}97.247 & 97.154 & 97.061 & 96.968 & 96.875 & 96.782\end{array}$

$\begin{array}{llllll}96.316 & 96.223 & 96.130 & 96.037 & 95.944 & 95.851\end{array}$

$\begin{array}{llllll}95.386 & 95 \cdot 293 & 95 \cdot 200 & 95 \cdot 107 & 95 \cdot 014 & 94 \cdot 921\end{array}$

$\begin{array}{llllll}93.526 & 93.433 & 93.339 & 93.247 & 93.154 & 93.061\end{array}$

$\begin{array}{llllll}92.595 & 92.502 & 92.410 & 92.316 & 92.223 & 92.131\end{array}$

$\begin{array}{llllll}91.665 & 91.572 & 91.479 & 91.386 & 91.293 & 91.201\end{array}$

$\begin{array}{llllll}90.735 & 90.643 & 90.550 & 90.456 & 90.364 & 90.271\end{array}$

$\begin{array}{llllll}88.876 & 88.782 & 88.689 & 88.597 & 88.504 & 88.411\end{array}$

$\begin{array}{llllll}87.946 & 87.853 & 87.760 & 87.667 & 87.574 & 87.481\end{array}$

$\begin{array}{lllllll}87.016 & 86.923 & 86.830 & 86.737 & 86.644 & 86.551 \\ 86.086 & 85.994 & 85.900 & 85.807 & 85.715 & 85.622\end{array}$

$\begin{array}{lllllll}85.157 & 85.064 & 84.971 & 84.878 & 84.785 & 84.692\end{array}$

$\begin{array}{llllll}84.227 & 84.134 & 84.041 & 83.949 & 83.856 & 83.763\end{array}$

$\begin{array}{llllll}82.368 & -82.275 & 82.183 & 82.090 & 81.997 & 81.904\end{array}$

$\begin{array}{llllll}81.439 & 81.346 & 81.253 & 81.160 & 81.068 & 80.975\end{array}$

$\begin{array}{ll}80.510 & 80.417 \\ 79.581 & 79.488\end{array}$

.288257

0.288256

0

0.288253

0.288251

0.288250

0.288249

0.288247

0.288245

0.288244

0.288243

0.288242

0.288240

0.288239

0.288236

0.288235

0.288234

0.288232

0.288231

0.288230

0.288229

0.288228
0.288227

0.288226

.288225
0.288224

0.288223

0.288222
0.288221

0.288220

0.288219

0.288218

0.288216

0.288214

0.288213

288212

0.288211

0.288210

288208

0.288207
0.288206

0.288205

0.288204

0.288203

0.288202

0.288201

0.288199

0.288198

0.288197

0.288195

0.288194

0.288193

0.288190

0.288189

0.288188

0.288187

0.288185

0.288184

0.288183

0.288181

0.288180

0.288179
0.288178 
$\begin{array}{lllllllllll}3280.0 & 30479.023 & 78.930 & 78.837 & 78.744 & 78.651 & 78.558 & 78.466 & 78.373 & 78.280 & 78.187\end{array}$

$\begin{array}{lllllllllll}0.1 & 78.094 & 78.001 & 77.908 & 77.815 & 77.722 & 77.629 & 77.537 & 77.443 & 77.350 & 77.258\end{array}$ $\begin{array}{llllllllllll}0.2 & 77.165 & 77.072 & 76.979 & 76.886 & 76.793 & 76.700 & 76.607 & 76.514 & 76.421 & 76.328 \\ 0.3 & 76.235 & 76.143 & 76.050 & 75.957 & 75.864 & 75.771 & 75.678 & 75.585 & 75.492 & 75.390\end{array}$ $\begin{array}{llllllllllll}0.4 & 75.306 & 75.214 & 75.121 & 75.028 & 74.935 & 74.842 & 74.749 & 74.656 & 74.563 & 74.470\end{array}$ $\begin{array}{lllllllllll}0.5 & 74.377 & 74.285 & 74.192 & 740099 & 74.006 & 73.913 & 73.820 & 73.727 & 73.635 & 73.542\end{array}$ $\begin{array}{lllllllllll}0.6 & 73.448 & 73.355 & 73.263 & 73.170 & 73.077 & 72.984 & 72.891 & 72.798 & 72.706 & 72.613\end{array}$

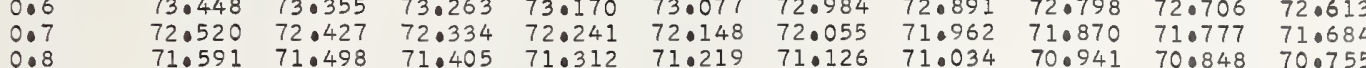
$\begin{array}{lllllllllll}0.8 & 71.591 & 71.498 & 71.405 & 71.312 & 71.219 & 71.126 & 71.034 & 70.941 & 70.848 & 70.755 \\ 0.9 & 70.662 & 70.570 & 70.477 & 70.384 & 70.291 & 70.198 & 70.105 & 70.013 & 69.919 & 69.827\end{array}$

0.288146

0.288145
0.288144

$\begin{array}{lllllllllll}3281.0 & 30469.734 & 69.641 & 69.548 & 69.456 & 69.363 & 69.270 & 69.177 & 69.084 & 68.991 & 68.898\end{array}$

$\begin{array}{lllllllllll}1.1 & 68.805 & 68.712 & 68.619 & 68.527 & 68.434 & 68.341 & 68.248 & 68.155 & 68.062 & 67.969 \\ 1.2 & 67.876 & 67.784 & 67.691 & 67.598 & 67.505 & 67.413 & 67.320 & 67.227 & 67.134 & 67.041\end{array}$

$\begin{array}{lllllllllll}1.2 & 67.876 & 67.784 & 67.691 & 67.598 & 67.505 & 67.413 & 67.320 & 67.227 & 67.134 & 67.041 \\ 1.3 & 66.948 & 66.855 & 66.762 & 66.669 & 66.577 & 66.484 & 66.391 & 66.298 & 66.206 & 66.113 \\ 1.4 & 66.020 & 65.927 & 65.834 & 65.741 & 65.648 & 65.555 & 65.463 & 65.370 & 65.277 & 65.184\end{array}$

$65.092 \quad 640998 \quad 640006 \quad 640813 \quad 640720 \quad 640627 \quad 65.463650370$

$\begin{array}{llllll}64.163 & 64.070 & 63.977 & 63.884 & 63.792 & 63.698\end{array}$

1.

1.7

64.235
62.306

61.378

$63.049 \quad 62.056$

$64.534 \quad 64.441$

$65.277 \quad 65.184$

$\begin{array}{ll}64 \cdot 349 & 64.256\end{array}$

$\begin{array}{ll}63.606 & 63.51 \\ 62.678 & 62.585\end{array}$

$62.420 \quad 63.328$

$61.564 \quad 61.471$

3282.0

30460.450

$50.450 \quad 60.357$

$\begin{array}{ll}357 & 60.264\end{array}$

$\begin{array}{ll}61.749 & 61.656 \\ 60.821 & 60.729\end{array}$

$9.708 \quad 59.615$

$\begin{array}{lllllll}58.594 & 58.501 & 58.408 & 58.316 & 58.223 & 58.130\end{array}$

$57.666 \quad 57.573$

$57.480 \quad 57.388$

$55.811 \quad 55.718$

$\begin{array}{llll}53.955 & 53.862 & 53.770 & 53.677\end{array}$

$\begin{array}{ll}53.027 & 52.93 \\ 52.100 & 52.00\end{array}$

$\begin{array}{ll}53.770 & 53.677 \\ 52.942 & 52.749\end{array}$

$57 \cdot 295$
56.367

58.130

59.89
58.96
58.037

59.800
58.872

$\begin{array}{ll}59.708 & 59.615 \\ 58.779 & 58.687\end{array}$

$\begin{array}{llll}58.037 & 57.944 & 57.852 & 57.759 \\ 57.110 & 57.017 & 56.924 & 56.831\end{array}$

$55.439 \quad 55.347$

$56 \cdot 182$
$55 \cdot 254$

56.08

$\begin{array}{ll}56.924 & 56.831 \\ 55.996 & 55.903\end{array}$

52.55
51.72

53.491

$\begin{array}{ll}54.326 & 54.233 \\ 53.398 & 53.306\end{array}$

$\begin{array}{ll}55.068 & 54.976 \\ 54.141 & 54.048\end{array}$

$\begin{array}{ll}54.141 & 54 \cdot 048 \\ 53.213 & 53.120\end{array}$

$\begin{array}{ll}50.172 & 51.080 \\ 49.317 & 49 \\ 48.22\end{array}$

$\begin{array}{rrrrrrrrrrr}3283.0 & 30451.172 & 51.080 & 50.987 & 50.894 & 50.801 & 50.708 & 50.616 & 50.523 & 50.430 & 50.338 \\ 3.1 & 50.245 & 50.152 & 50.059 & 49.967 & 49.874 & 49.781 & 49.688 & 49.595 & 49.503 & 49.410\end{array}$

$\begin{array}{lllllllllll}3283.0 & 30451.172 & 51.080 & 50.987 & 50.894 & 50.801 & 50.708 & 50.616 & 50.523 & 50.430 & 50.338\end{array}$

51.543

2.378

$51.358 \quad 51.265$

0.28814

.288142
.288141

0.288141

0.288139

0.288136

0.288135

0.288133

0.288132

0.288130

0.288128

0.288127

0.288126

0.288124 $\begin{array}{lllllllllll}49.317 & 49.224 & 49.132 & 49.039 & 48.946 & 48.854 & 48.761 & 48.668 & 48.575 & 48.483\end{array}$ $\begin{array}{llllllllll}48.390 & 48.297 & 48.204 & 48.112 & 48.019 & 47.926 & 47.833 & 47.740 & 47.648 & 47.555 \\ 47.462 & 47.370 & 47.277 & 47.184 & 47.092 & 46.999 & 46.906 & 46.814 & 46.720 & 46.628\end{array}$ $\begin{array}{llllllllll}47.462 & 47.370 & 47.277 & 47.184 & 47.092 & 46.999 & 46.906 & 46.814 & 46.720 & 46.628\end{array}$ $\begin{array}{llllllllll}46.535 & 46.442 & 46.350 & 46.257 & 46.164 & 46.072 & 45.979 & 45.886 & 45.793 & 45.701 \\ 45.608 & 45.515 & 45.422 & 45.330 & 45.237 & 45.144 & 45.052 & 44.959 & 44.866 & 44.773\end{array}$ $\begin{array}{llllllllll}45.608 & 45.515 & 45.422 & 45.330 & 45.237 & 45.144 & 45.052 & 44 \cdot 959 & 44 \cdot 866 & 44 \cdot 773 \\ 44.681 & 44.588 & 44.495 & 44.403 & 44.310 & 44.218 & 44.125 & 44.032 & 43.939 & 43.847 \\ 43.754 & 43.662 & 43.569 & 43.476 & 43.384 & 43.291 & 43.198 & 43.105 & 43.012 & 42.920\end{array}$ $\begin{array}{llllllllll}43.754 & 43.662 & 43.569 & 43.476 & 43.384 & 43.291 & 43.198 & 43.105 & 43.012 & 42.920 \\ 42.827 & 42.734 & 42.642 & 42.549 & 42.457 & 42.364 & 42.271 & 42.178 & 42.085 & 41.993\end{array}$

0.288122

0.288121

0.288120

0.288118

0.288117

0.288116

0.288115

0.288114

3284
4
4
40
40
405

3044

$\begin{array}{rr}4.0 & 3044 \\ 4.1 & 4 \\ 4.2 & 400 \\ 4.3 & 39 \\ 4.4 & 3 \\ 4.5 & 37 \\ 4.6 & 3 \\ 4.7 & 35 \\ 4.8 & 34 \\ 4.9 & 330 \\ & \\ 5.0 & 30432 \\ 5.1 & 310 \\ 5.2 & 30 \\ 5.3 & 2 \\ 5.4 & 2 \\ 5.5 & 28.5 \\ 5.6 & 270 \\ 5.7 & 260 \\ 5.8 & 250 \\ 5.9 & 240 \\ & \end{array}$

$\begin{array}{lll}40.880 & 40.7\end{array}$

$\begin{array}{llll}39.119 & 39.027 & 38.934 & 39.7\end{array}$

$\begin{array}{lllll}38.192 & 38.100 & 38.007 & 37.915\end{array}$

$\begin{array}{llll}36.339 & 36.247 & 36.154 & 36.061\end{array}$

35.320

$\begin{array}{ll}34.486 & 34.39 \\ 33.560 & 33.467\end{array}$

$35.227 \quad 35.135$

32.541

$31.707 \quad 31.6$

$29.854 \quad 29.762$

$\begin{array}{ll}28.928 & 28.836 \\ 28.002 & 27.90\end{array}$

$27.076 \quad 26.98$

$26.150 \quad 26.058250$

$\begin{array}{ll}25.224 & 25.132 \\ 24.298 & 24.206\end{array}$

3286

6.0

30423.37

$423.373 \quad 23.2$

$3.280 \quad 23.1$

$32.448 \quad 32.355$

$41.530 \quad 41.437$

$41 \cdot 344$

41.25

$41.158 \quad 41.066$

0.288112

0.288111

0.288109

0.288107

.288105

0.288104

0.288103

0.288101

0.288100

0.288099

0.288098

0.288095

0.288095

0.288094

0.288093
0.288092

445183

.945218

0.945269

.945294

0.945345

0.945421

.945472

0.945523

0.945549
0.945574

0.945599

0.945650

0.945676

0.945726

0.945777

0.945803

0.945854

0.945904

0.945930

0.945981

0.946006

0.946032

0.946082

0.946133

0.946159

0.946184

0.946235

0.946286

0.946311

0.946362

0.946413

0.946438

0.946489

0.946540

0.946565

0.946591

0.288091

0.288090

0.288089

0.288088

0.288086

$\begin{array}{llllllllll}19.669 & 19.577 & 19.484 & 19.392 & 19.299 & 19.207 & 19.114 & 19.021 & 18.929 & 18.836 \\ 18.744 & 18.651 & 18.559 & 18.466 & 18.374 & 18.281 & 18.189 & 18.096 & 18.003 & 17.911\end{array}$

$\begin{array}{llllllllll}17.818 & 17.726 & 17.633 & 17.541 & 17.448 & 17.355 & 17.263 & 17.170 & 17.078 & 16.986\end{array}$

$\begin{array}{llllllllll}16.893 & 16.801 & 16.708 & 16.616 & 16.523 & 16.430 & 16.338 & 16.245 & 16.153 & 16.060\end{array}$

$\begin{array}{llllllllll}15.968 & 15.875 & 15.783 & 15.690 & 15.598 & 15.505 & 15.412 & 15.320 & 15.228 & 15.135 \\ 15.042 & 14.950 & 14.857 & 14.765 & 14.673 & 14.580 & 14.487 & 14.395 & 14.302 & 14.209\end{array}$

0.008

0.288083

0.288082

0.946641

3287.

7.0

30414.117

13.11714 .025

$\begin{array}{llllllllll}13.099 & 13.007 & 12.914 & 12.822 & 12.729 & 12.637 & 12.544 & 12.451 & 12.359\end{array}$

$\begin{array}{llllllllll}10.416 & 10.324 & 10.231 & 10.139 & 10.047 & 09.954 & 09.861 & 09.769 & 09.676 & 09.584\end{array}$

$\begin{array}{llllllllll}0.49 & 09.399 & 09.306 & 09.214 & 09.121 & 09.029 & 08.937 & 08.844 & 08.751 & 08.659\end{array}$

$\begin{array}{llllllllll}08.566 & 08.474 & 08.381 & 08.289 & 08.197 & 08.104 & 08.011 & 07.919 & 07.826 & 07.734\end{array}$

$\begin{array}{llllllllll}07.641 & 07.549 & 07.457 & 07.364 & 07.271 & 07.179 & 07.087 & 06.994 & 06.902 & 06.809\end{array}$

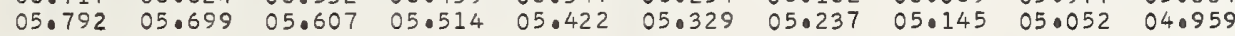

3288.0

$$
\begin{array}{r}
288.0 \\
8.1 \\
8.2 \\
8.3 \\
8.4 \\
8.5 \\
8.5 \\
8.7 \\
8.8 \\
8.9
\end{array}
$$

30404.867

$\begin{array}{rl}404.867 & 04.774 \\ 03.943 & 03.850\end{array}$

$\begin{array}{llll}04.682 & 04.590 & 04.497 & 04.405\end{array}$

$05.23705 .14505 .052 \quad 040959$

$02.094 \quad 02.001 \quad 01.00901 .816 \quad 01.72401 .631 \quad 01.53901 .446 \quad 010354 \quad 0.1862$

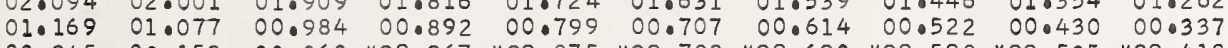

$\begin{array}{rlll}00.245 & 00.152 & 00.060 * 99.967 * 99.875 * 99.782 * 99.690 * 99.598 * 99.505 * 99.413\end{array}$

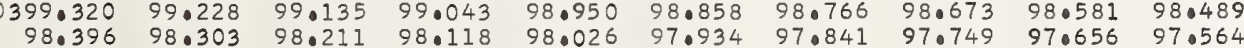

$\begin{array}{llllllllll}98.396 & 98.303 & 98.211 & 98.118 & 98.026 & 97.934 & 97.841 & 97.749 & 97.656 & 97.564 \\ 97.472 & 97.379 & 97.287 & 97.194 & 97.102 & 97.010 & 96.917 & 96.824 & 96.732 & 96.640\end{array}$

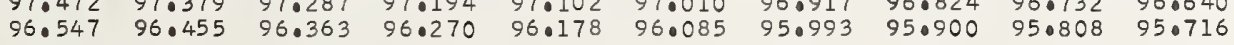

3289.0

$$
\text { : }
$$

$\begin{array}{llllllllll}30395.623 & 95.531 & 95.438 & 95.346 & 95.253 & 95.161 & 95.069 & 94.976 & 94.884 & 94.792\end{array}$

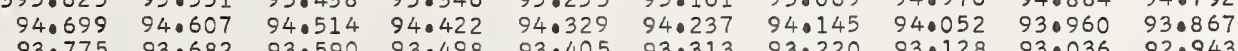

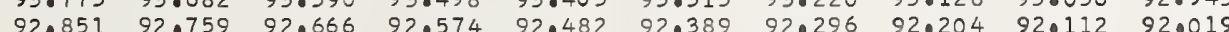

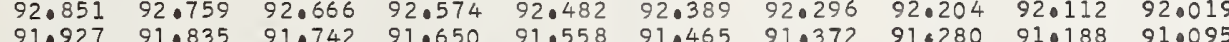

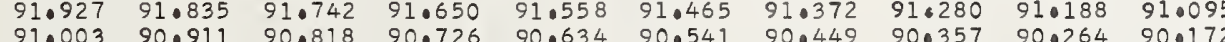
91.003
90.080 $\begin{array}{lllllllll}90.080 & 89.987 & 89.895 & 89.802 & 89.710 & 80.547 & 90.449 & 90.357 & 90.264\end{array}$

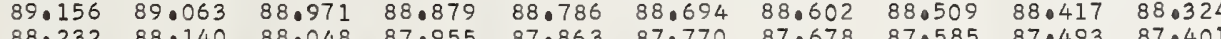
$\begin{array}{llllllllll}88.232 & 88.140 & 88.048 & 87.955 & 87.863 & 87.770 & 87.678 & 87.585 & 87.493 & 87.401 \\ 87.308 & 87.216 & 87.124 & 87.031 & 86.939 & 86.846 & 86.754 & 86.662 & 86.570 & 86.477\end{array}$

.288081 0.288080 0.288078 0.288077 0.288076 0.288074 0.288073 0.288072 0.288071

0.946667 0.946692 0.946718
0.946743 0.946769 0.946794 0.946819 0.946845 0.946870

0.288070

0.288068

0.288068
0.288067

0.288067

0.288066
0.288065

0.288065
0.288064

0.288064
0.288063

0.288062

0.946921 0.946947 0.946972 0.947023 0.947048 0.947099 0.947124

0.288060

0.288059

0.288058

0.288057

0.288055

0.288054

0.288053

0.288052

0.947175
0.947201

0.947226

0.947252

0.947302

0.947353

0.947379

0.947430

0.947455

0.947506

0.947531 


\begin{tabular}{|c|c|c|c|c|c|c|c|c|c|c|c|c|}
\hline A) & .00 & .01 & .02 & .03 & .04 & .05 & .06 & .07 & .08 & .09 & $(n-1) \times 1000$ & $\lambda(n-1)$ \\
\hline $\begin{array}{l}90.0 \\
0.1 \\
0.2 \\
0.3 \\
0.4 \\
0.5 \\
0.6 \\
0.7 \\
0.8 \\
0.9\end{array}$ & $\begin{array}{r}30386.385 \\
85.461 \\
84.538 \\
83.614 \\
82.691 \\
81.768 \\
80.844 \\
79.921 \\
78.998 \\
78.074\end{array}$ & $\begin{array}{l}86.292 \\
85.369 \\
84.445 \\
83.522 \\
82.599 \\
81.675 \\
80.752 \\
79.828 \\
78.8906 \\
77.982\end{array}$ & $\begin{array}{l}86.200 \\
85.276 \\
84.353 \\
83.430 \\
82.506 \\
81.583 \\
80.659 \\
79.736 \\
78.813 \\
77.889\end{array}$ & $\begin{array}{l}86 \cdot 108 \\
85.184 \\
84.261 \\
83.337 \\
82.4114 \\
81.491 \\
80.567 \\
79.644 \\
78.721 \\
77.798\end{array}$ & $\begin{array}{l}86.015 \\
85.092 \\
84.168 \\
83.245 \\
82.022 \\
81.398 \\
80.475 \\
79.052 \\
78.629 \\
77.706\end{array}$ & $\begin{array}{l}85.923 \\
84.999 \\
84.076 \\
83.153 \\
82.229 \\
81.306 \\
80.383 \\
79.459 \\
78.536 \\
77.613\end{array}$ & $\begin{array}{l}85.831 \\
84.907 \\
83.983 \\
83.060 \\
82.137 \\
81.214 \\
80.291 \\
79.367 \\
78.444 \\
77.521\end{array}$ & $\begin{array}{l}85.738 \\
84.815 \\
83.891 \\
82.968 \\
82.044 \\
81.121 \\
80.198 \\
79.075 \\
78.352 \\
77.429\end{array}$ & $\begin{array}{l}85.646 \\
84.722 \\
83.099 \\
82.875 \\
81.052 \\
81.029 \\
80.105 \\
79.183 \\
78.0260 \\
77.336\end{array}$ & $\begin{array}{l}85.554 \\
84.630 \\
83.707 \\
82.783 \\
81.860 \\
80.937 \\
80.013 \\
79.090 \\
78.167 \\
77.244\end{array}$ & $\begin{array}{l}0.288050 \\
0.288049 \\
0.288048 \\
0.288047 \\
0.288046 \\
0.288045 \\
0.288044 \\
0.288043 \\
0.288042 \\
0.288041\end{array}$ & $\begin{array}{l}0.947684 \\
0.947709 \\
0.947735 \\
0.947760 \\
0.947785 \\
0.947811 \\
0.947836 \\
0.947862 \\
0.947887 \\
0.947913\end{array}$ \\
\hline $\begin{array}{l}291.0 \\
1.1 \\
1.2 \\
1.3 \\
1.4 \\
1.5 \\
1.6 \\
1.7 \\
1.8 \\
1.9\end{array}$ & $\begin{array}{r}30377.152 \\
76.229 \\
75.306 \\
74.383 \\
73.460 \\
72.538 \\
71.615 \\
70.692 \\
69.770 \\
68.847\end{array}$ & $\begin{array}{l}77.059 \\
76.137 \\
75.214 \\
74.291 \\
73.368 \\
72.445 \\
71.0522 \\
70.000 \\
69.677 \\
68.755\end{array}$ & $\begin{array}{l}76.967 \\
76.044 \\
75.122 \\
74.199 \\
73.276 \\
72.0353 \\
71.0430 \\
70.508 \\
69.055 \\
68.662\end{array}$ & $\begin{array}{l}76.875 \\
75.952 \\
75.029 \\
74.106 \\
73.183 \\
72.061 \\
71.0338 \\
70.415 \\
69.493 \\
68.570\end{array}$ & $\begin{array}{l}76.783 \\
75.860 \\
74.937 \\
74.014 \\
73.091 \\
72.068 \\
71.0246 \\
70.323 \\
69.401 \\
68.478\end{array}$ & $\begin{array}{l}76.691 \\
75.768 \\
74.845 \\
73.922 \\
72.999 \\
72.076 \\
71.153 \\
70.231 \\
69.308 \\
68.386\end{array}$ & $\begin{array}{l}76.598 \\
75.676 \\
74.752 \\
73.830 \\
72.907 \\
71.984 \\
71.061 \\
70.139 \\
69.216 \\
68.293\end{array}$ & $\begin{array}{l}76.506 \\
75.583 \\
74.660 \\
73.737 \\
72.815 \\
71.892 \\
70.969 \\
70.046 \\
69.124 \\
68.201\end{array}$ & $\begin{array}{l}76.414 \\
75.490 \\
74.568 \\
73.645 \\
72.722 \\
71.800 \\
70.877 \\
69.954 \\
69.032 \\
68.109\end{array}$ & $\begin{array}{l}76.322 \\
75.398 \\
74.475 \\
73.552 \\
72.630 \\
71.707 \\
70.785 \\
69.862 \\
68.939 \\
68.017\end{array}$ & $\begin{array}{l}0.288040 \\
0.288038 \\
0.288037 \\
0.288036 \\
0.288035 \\
0.288034 \\
0.288033 \\
0.288032 \\
0.288031 \\
0.288030\end{array}$ & $\begin{array}{l}0.947938 \\
0.947963 \\
0.947989 \\
0.948014 \\
0.948040 \\
0.948065 \\
0.948091 \\
0.948116 \\
0.948141 \\
0.948167\end{array}$ \\
\hline $\begin{array}{r}92.0 \\
2.1 \\
2.2 \\
2.3 \\
2.4 \\
2.5 \\
2.6 \\
2.7 \\
2.8 \\
2.0\end{array}$ & $\begin{array}{r}30367.925 \\
67.002 \\
66.080 \\
65.157 \\
64.235 \\
63.313 \\
62.391 \\
61.469 \\
60.547 \\
59.625\end{array}$ & $\begin{array}{l}67.832 \\
66: 910 \\
65.987 \\
65.065 \\
64.143 \\
63.221 \\
62.299 \\
61.377 \\
60.455 \\
59.533\end{array}$ & $\begin{array}{l}67.740 \\
66.818 \\
65.896 \\
64.973 \\
64.051 \\
63.129 \\
62.206 \\
61.284 \\
60.363 \\
59.441\end{array}$ & $\begin{array}{l}67.648 \\
66.725 \\
65.803 \\
64.881 \\
63.958 \\
63.037 \\
62.115 \\
61.192 \\
60.270 \\
59.348\end{array}$ & $\begin{array}{l}67.555 \\
66.0633 \\
65.710 \\
64.788 \\
63.866 \\
62.944 \\
62.022 \\
61.100 \\
60.178 \\
59.256\end{array}$ & $\begin{array}{l}67.463 \\
66.541 \\
65.618 \\
64.696 \\
63.774 \\
62.852 \\
61.030 \\
61.008 \\
60.086 \\
59.164\end{array}$ & $\begin{array}{l}67.371 \\
66.449 \\
65.526 \\
640.604 \\
63.681 \\
62.760 \\
61.838 \\
60.916 \\
59.994 \\
59.072\end{array}$ & $\begin{array}{l}67.279 \\
66.356 \\
65.434 \\
64.511 \\
63.590 \\
62.688 \\
61.746 \\
60.823 \\
59.901 \\
58.980\end{array}$ & $\begin{array}{l}67.187 \\
66.264 \\
65.342 \\
64.119 \\
63.498 \\
62.0575 \\
61.653 \\
60.731 \\
59.809 \\
58.887\end{array}$ & $\begin{array}{l}67.094 \\
66.172 \\
65.250 \\
64.327 \\
63.406 \\
62.484 \\
61.561 \\
60.639 \\
59.717 \\
58.795\end{array}$ & $\begin{array}{l}0.288029 \\
0.288028 \\
0.288027 \\
0.288026 \\
0.288025 \\
0.288024 \\
0.288023 \\
0.288022 \\
0.288021 \\
0.288020\end{array}$ & $\begin{array}{l}0.948192 \\
0.948218 \\
0.948243 \\
0.948269 \\
0.948294 \\
0.948319 \\
0.948345 \\
0.948370 \\
0.948396 \\
0.948421\end{array}$ \\
\hline $\begin{array}{r}293.0 \\
3.1 \\
3.2 \\
303 \\
3.4 \\
305 \\
306 \\
3.7 \\
3.8 \\
3.9\end{array}$ & $\begin{array}{r}30358.703 \\
57.781 \\
56.859 \\
55.937 \\
55.016 \\
54.094 \\
53.173 \\
52.251 \\
51.329 \\
50.408\end{array}$ & $\begin{array}{l}58.611 \\
57.689 \\
56.767 \\
55.845 \\
54.924 \\
54.002 \\
53.080 \\
52.159 \\
51.237 \\
50.316\end{array}$ & $\begin{array}{l}58.519 \\
57.597 \\
56.675 \\
55.753 \\
54.832 \\
53.910 \\
52.988 \\
52.067 \\
51.145 \\
50.224\end{array}$ & $\begin{array}{l}58.427 \\
57.505 \\
56.083 \\
55.661 \\
54.739 \\
53.818 \\
52.896 \\
51.0975 \\
51.053 \\
50.132\end{array}$ & $\begin{array}{l}58.334 \\
57.412 \\
56.490 \\
55.569 \\
54.647 \\
53.726 \\
52.804 \\
51.882 \\
50.961 \\
50.040\end{array}$ & $\begin{array}{l}58.242 \\
57.320 \\
56.398 \\
55.477 \\
54.555 \\
53.633 \\
52.712 \\
51.790 \\
50.869 \\
49.948\end{array}$ & $\begin{array}{l}58.150 \\
57.0228 \\
56.306 \\
55.384 \\
54.462 \\
53.541 \\
52.620 \\
51.698 \\
50.777 \\
49.855\end{array}$ & $\begin{array}{l}58.058 \\
57.136 \\
56.214 \\
55.292 \\
54.371 \\
53.449 \\
52.527 \\
51.606 \\
50.684 \\
490763\end{array}$ & $\begin{array}{l}57.965 \\
57.043 \\
56.122 \\
55.200 \\
540278 \\
53.057 \\
52.435 \\
51.514 \\
50.593 \\
49.671\end{array}$ & $\begin{array}{l}57.874 \\
56.951 \\
56.030 \\
55.108 \\
54.186 \\
53.265 \\
52.343 \\
51.421 \\
50.500 \\
49.579\end{array}$ & $\begin{array}{l}0.288019 \\
0.288018 \\
0.288017 \\
0.288016 \\
0.288015 \\
0.288014 \\
0.288013 \\
0.288012 \\
0.288011 \\
0.288010\end{array}$ & $\begin{array}{l}0.948447 \\
0.948472 \\
0.948497 \\
0.948523 \\
0.948548 \\
0.948574 \\
0.948599 \\
0.948625 \\
0.948650 \\
0.948675\end{array}$ \\
\hline $\begin{array}{r}294.0 \\
4.1 \\
4.2 \\
4: 3 \\
4.4 \\
405 \\
4.6 \\
4.7 \\
4.8 \\
4.9\end{array}$ & $\begin{array}{r}30349.487 \\
48.566 \\
47.645 \\
46.723 \\
45.802 \\
44.881 \\
43.960 \\
43.039 \\
42.118 \\
41.197\end{array}$ & $\begin{array}{l}49 \cdot 395 \\
48.474 \\
47.552 \\
46.531 \\
45.710 \\
44.789 \\
43.868 \\
42.947 \\
42.026 \\
41.105\end{array}$ & $\begin{array}{l}49.303 \\
48.381 \\
47.460 \\
46.539 \\
45.618 \\
44.697 \\
43.77 .6 \\
42.855 \\
41.934 \\
41.013\end{array}$ & $\begin{array}{l}49.211 \\
48.290 \\
47.368 \\
46.047 \\
45.526 \\
44.605 \\
43.684 \\
42.763 \\
41.842 \\
40.921\end{array}$ & $\begin{array}{l}49.119 \\
48.197 \\
47.276 \\
46.355 \\
45.434 \\
44.513 \\
43.592 \\
42.670 \\
41.750 \\
40.829\end{array}$ & $\begin{array}{l}49.026 \\
48.105 \\
47.184 \\
46.263 \\
45.342 \\
44.420 \\
43.499 \\
42.579 \\
41.658 \\
40.737\end{array}$ & $\begin{array}{l}48.934 \\
48.013 \\
47.092 \\
46.171 \\
45.250 \\
44.329 \\
43.407 \\
42.486 \\
41.565 \\
40.645\end{array}$ & $\begin{array}{l}48 \cdot 842 \\
47.921 \\
47.000 \\
46.078 \\
450157 \\
44.236 \\
43.315 \\
42.394 \\
41.473 \\
40.553\end{array}$ & $\begin{array}{l}48 \cdot 750 \\
47.829 \\
46.907 \\
45.986 \\
45.065 \\
44.144 \\
43.223 \\
42.302 \\
41.381 \\
40.460\end{array}$ & $\begin{array}{l}48.658 \\
47.737 \\
46.815 \\
45.894 \\
44.973 \\
44.052 \\
43.131 \\
42.210 \\
41.289 \\
40.368\end{array}$ & $\begin{array}{l}0.288009 \\
0.288008 \\
0.288007 \\
0.288006 \\
0.288005 \\
0.288004 \\
0.288003 \\
0.288002 \\
0.288001 \\
0.288000\end{array}$ & $\begin{array}{l}0.948701 \\
0.948726 \\
0.948753 \\
0.948777 \\
0.948803 \\
0.948828 \\
0.948854 \\
0.948879 \\
0.948904 \\
0.948930\end{array}$ \\
\hline $\begin{array}{r}3295.0 \\
5.1 \\
5.2 \\
5.3 \\
5.04 \\
5.5 \\
5.6 \\
507 \\
5.8 \\
5.9\end{array}$ & $\begin{array}{r}30340.277 \\
39.356 \\
38.435 \\
37.514 \\
36.594 \\
35.673 \\
34.753 \\
33.833 \\
32.912 \\
31.992\end{array}$ & $\begin{array}{l}40.184 \\
39.263 \\
38.343 \\
37.422 \\
36.502 \\
35.581 \\
34.561 \\
33.740 \\
32.820 \\
31.900\end{array}$ & $\begin{array}{l}40.092 \\
39.171 \\
38.251 \\
37.330 \\
36.410 \\
35.489 \\
34.569 \\
33.648 \\
32.728 \\
31.808\end{array}$ & $\begin{array}{l}40.000 \\
39.079 \\
38.158 \\
37.238 \\
36.318 \\
35.397 \\
34.477 \\
33.556 \\
32.636 \\
31.716\end{array}$ & $\begin{array}{l}39.908 \\
38.987 \\
38.066 \\
37.146 \\
36.226 \\
35.305 \\
34.385 \\
33.464 \\
32.544 \\
31.624\end{array}$ & $\begin{array}{l}39.816 \\
38.895 \\
37.975 \\
37.054 \\
36.134 \\
35.213 \\
34.293 \\
33.372 \\
32.452 \\
31.532\end{array}$ & $\begin{array}{l}39.724 \\
38.803 \\
37.882 \\
36.962 \\
36.042 \\
35.121 \\
34.201 \\
33.280 \\
32.360 \\
31.0439\end{array}$ & $\begin{array}{l}39.632 \\
38.711 \\
37.790 \\
36.870 \\
35.950 \\
35.029 \\
34.109 \\
33.188 \\
32.268 \\
31.348\end{array}$ & $\begin{array}{l}39.540 \\
38.619 \\
37.698 \\
36.778 \\
35.858 \\
34.937 \\
34.017 \\
33.096 \\
32.176 \\
31.256\end{array}$ & $\begin{array}{l}39.448 \\
38.527 \\
37.606 \\
36.686 \\
35.766 \\
34.845 \\
33.925 \\
33.004 \\
32.084 \\
31.164\end{array}$ & $\begin{array}{l}0.287999 \\
0.287998 \\
0.287997 \\
0.287995 \\
0.287994 \\
0.287993 \\
0.287992 \\
0.287991 \\
0.287990 \\
0.287989\end{array}$ & $\begin{array}{l}0.948955 \\
0.948981 \\
0.949006 \\
0.949032 \\
0.949057 \\
0.949082 \\
0.949108 \\
0.949133 \\
0.949159 \\
0.949184\end{array}$ \\
\hline $\begin{array}{r}3296.0 \\
6.1 \\
6.2 \\
6.3 \\
6.4 \\
6.5 \\
6.5 \\
6.7 \\
6.8 \\
6.9\end{array}$ & $\begin{array}{r}30331.072 \\
30.151 \\
29.231 \\
28.311 \\
27.391 \\
26.471 \\
25.551 \\
24.631 \\
23.711 \\
22.792\end{array}$ & $\begin{array}{l}30.980 \\
30.059 \\
29.139 \\
28.219 \\
27.299 \\
26.379 \\
25.459 \\
24.539 \\
23.620 \\
22.700\end{array}$ & $\begin{array}{l}30.888 \\
29.967 \\
29.047 \\
28.127 \\
27.207 \\
26.287 \\
25.367 \\
24.448 \\
23.528 \\
22.608\end{array}$ & $\begin{array}{l}30.795 \\
29.875 \\
28.955 \\
28.035 \\
27.115 \\
26.195 \\
25.275 \\
24.355 \\
23.436 \\
22.516\end{array}$ & $\begin{array}{l}30.703 \\
29.783 \\
28.863 \\
27.943 \\
27.023 \\
26.103 \\
25.183 \\
24.263 \\
23.344 \\
22.424\end{array}$ & $\begin{array}{l}30.611 \\
29.691 \\
28.771 \\
27.851 \\
26.931 \\
26.011 \\
25.091 \\
24.172 \\
23.252 \\
22.332\end{array}$ & $\begin{array}{l}30.520 \\
29.599 \\
28.679 \\
27.759 \\
26.839 \\
25.919 \\
24.999 \\
24.080 \\
23.160 \\
22.240\end{array}$ & $\begin{array}{l}30.427 \\
29.507 \\
28.587 \\
27.667 \\
26.747 \\
25.827 \\
24.907 \\
23.987 \\
23.068 \\
22.148\end{array}$ & $\begin{array}{l}30.335 \\
29.415 \\
28.495 \\
27.575 \\
26.655 \\
25.735 \\
24.815 \\
23.896 \\
22.976 \\
22.056\end{array}$ & $\begin{array}{l}30.244 \\
29.323 \\
28.403 \\
27.483 \\
26.563 \\
25.643 \\
24.723 \\
23.803 \\
22.884 \\
21.964\end{array}$ & & $\begin{array}{l}0.949210 \\
0.949235 \\
0.949260 \\
0.949286 \\
0.949311 \\
0.949337 \\
0.949362 \\
0.949388 \\
0.949413 \\
0.949439\end{array}$ \\
\hline $\begin{array}{r}297.0 \\
7: 1 \\
7.2 \\
7.3 \\
7: 4 \\
7.5 \\
7.6 \\
7.7 \\
7.8 \\
7.9\end{array}$ & $\begin{array}{r}30321.873 \\
20.953 \\
20.033 \\
19.114 \\
18.194 \\
17.275 \\
16.355 \\
15.436 \\
14.517 \\
13.597\end{array}$ & $\begin{array}{l}21.781 \\
20.861 \\
19.941 \\
19.022 \\
18.102 \\
17.183 \\
16.263 \\
15.344 \\
14.425 \\
13.506\end{array}$ & $\begin{array}{l}21.688 \\
20.769 \\
19.849 \\
18.930 \\
18.010 \\
17.091 \\
16.171 \\
15.252 \\
14.333 \\
13.414\end{array}$ & $\begin{array}{l}21.597 \\
20.577 \\
19.757 \\
18.838 \\
17.918 \\
16.999 \\
16.080 \\
15.160 \\
14.241 \\
13.322\end{array}$ & $\begin{array}{l}21.505 \\
20.585 \\
19.665 \\
18.746 \\
17.826 \\
16.907 \\
15.988 \\
15.058 \\
14.149 \\
13.230\end{array}$ & $\begin{array}{l}21.412 \\
20.493 \\
19.574 \\
18.654 \\
17.735 \\
16.815 \\
15.896 \\
14.977 \\
14.057 \\
13.138\end{array}$ & & $\begin{array}{l}21.229 \\
20.309 \\
19.389 \\
18.470 \\
17.551 \\
16.631 \\
15.712 \\
14.792 \\
13.873 \\
12.954\end{array}$ & $\begin{array}{l}21.137 \\
20.217 \\
19.298 \\
18.378 \\
17.458 \\
16.539 \\
15.620 \\
14.701 \\
13.781 \\
12.862\end{array}$ & & & $\begin{array}{l}0.949464 \\
0.949489 \\
0.949515 \\
0.949540 \\
0.949566 \\
0.949591 \\
0.949617 \\
0.949642 \\
0.949667 \\
0.949693\end{array}$ \\
\hline $\begin{array}{r}3298.0 \\
8.1 \\
8.2 \\
8.3 \\
8.4 \\
8.5 \\
8.6 \\
8.7 \\
8.8 \\
8.9\end{array}$ & $\begin{array}{r}30312.678 \\
11.760 \\
10.840 \\
09.921 \\
09.003 \\
08.084 \\
07.165 \\
06.246 \\
05.328 \\
04.409\end{array}$ & $\begin{array}{l}12.586 \\
11.667 \\
10.748 \\
09.830 \\
08.911 \\
07.992 \\
07.073 \\
06.154 \\
05.236 \\
04.317\end{array}$ & $\begin{array}{l}12.494 \\
11.575 \\
10.656 \\
09.738 \\
08.819 \\
07.900 \\
06.981 \\
06.063 \\
05.144 \\
04.225\end{array}$ & $\begin{array}{l}12.403 \\
11.484 \\
10.564 \\
09.646 \\
08.727 \\
07.808 \\
06.889 \\
05.971 \\
05.052 \\
04.133\end{array}$ & $\begin{array}{l}12.311 \\
11.0392 \\
10.472 \\
09.554 \\
08.635 \\
07.717 \\
06.798 \\
05.879 \\
04.960 \\
04.042\end{array}$ & $\begin{array}{l}12.219 \\
11.300 \\
10.381 \\
09.462 \\
08.543 \\
07.625 \\
06.0706 \\
05.787 \\
04.868 \\
03.950\end{array}$ & $\begin{array}{l}12.127 \\
11.208 \\
10.289 \\
09.370 \\
08.451 \\
07.533 \\
06.614 \\
05.695 \\
04.776 \\
03.858\end{array}$ & $\begin{array}{l}12.035 \\
11.116 \\
10.197 \\
09.279 \\
08.360 \\
07.441 \\
06.522 \\
05.603 \\
04.685 \\
03.766\end{array}$ & $\begin{array}{l}11.943 \\
11.024 \\
10.105 \\
09.187 \\
08.268 \\
07.349 \\
06.430 \\
05.511 \\
04.593 \\
03.674\end{array}$ & $\begin{array}{l}11.852 \\
10.932 \\
10.013 \\
09.094 \\
08.176 \\
07.257 \\
06.338 \\
05.420 \\
04.501 \\
03.582\end{array}$ & $\begin{array}{l}0.287968 \\
0.287967 \\
0.287966 \\
0.287965 \\
0.287964 \\
0.287963 \\
0.287962 \\
0.287961 \\
0.287960 \\
0.287959\end{array}$ & $\begin{array}{l}0.949718 \\
0.949744 \\
0.949769 \\
0.949795 \\
0.949820 \\
0.949845 \\
0.949871 \\
0.949896 \\
0.949922 \\
0.949947\end{array}$ \\
\hline $\begin{array}{l}299.0 \\
9.1 \\
9.2 \\
9.3 \\
9.4 \\
905 \\
9.6 \\
9.7 \\
9.8 \\
9.9\end{array}$ & $\begin{array}{r}30303.491 \\
02.572 \\
01.654 \\
00.735 \\
30299.816 \\
98.898 \\
97.980 \\
97.052 \\
96.144 \\
95.226\end{array}$ & $\begin{array}{l}03.399 \\
02.480 \\
01.562 \\
00.643 \\
99.725 \\
98.806 \\
97.888 \\
96.970 \\
96.052 \\
95.134\end{array}$ & $\begin{array}{l}03.306 \\
02.388 \\
01.470 \\
00.552 \\
99.633 \\
98.715 \\
97.796 \\
96.878 \\
95.961 \\
95.042\end{array}$ & $\begin{array}{l}02.296 \\
01.378 \\
00.459 \\
99.541 \\
98.623 \\
97.705 \\
96.786 \\
95.868 \\
94.950\end{array}$ & $\begin{array}{l}02.204 \\
01.286 \\
00.038 \\
99.449 \\
98.531 \\
97.0613 \\
96.695 \\
95.777 \\
94.859\end{array}$ & $\begin{array}{l}02.113 \\
01.194 \\
00.276 \\
99.357 \\
98.439 \\
97.521 \\
96.003 \\
95.685 \\
94.0767\end{array}$ & $\begin{array}{l}02.021 \\
01.102 \\
00.184 \\
99.265 \\
98.347 \\
97.429 \\
96.511 \\
95.593 \\
94.675\end{array}$ & $\begin{array}{l}01.929 \\
01.010 \\
00.092 \\
99.174 \\
98.255 \\
97.337 \\
96.419 \\
95.501 \\
94.583\end{array}$ & $\begin{array}{l}01.837 \\
00.919 \\
00.000 \\
99.082 \\
98.164 \\
97.245 \\
96.328 \\
95.410 \\
94.492\end{array}$ & $\begin{array}{r}01.745 \\
00.827 \\
* 99.908 \\
98.990 \\
98.072 \\
97.154 \\
96.236 \\
95.318 \\
94.400\end{array}$ & $\begin{array}{l}0.287957 \\
0.287956 \\
0.287955 \\
0.287954 \\
0.287953 \\
0.287952 \\
0.287951 \\
0.287950 \\
0.287949\end{array}$ & $\begin{array}{l}0.949973 \\
0.949998 \\
0.950024 \\
0.950049 \\
0.950074 \\
0.950100 \\
0.950125 \\
0.950151 \\
0.950176 \\
0.950202\end{array}$ \\
\hline & \multicolumn{2}{|c|}{.001} & 02 & .003 & .004 & .005 & .006 & .007 & .0 & .009 & .010 & \\
\hline & $\begin{array}{l}.00 \\
.00\end{array}$ & & & & & 04 & .055 & .064 & & & .092 & \\
\hline
\end{tabular}




.03

.04

$93.941 \quad 93.849$

.06

.08

.09

0.287948

0.287947

0.287945

0.287943

0.287942
0.287940

0.287939
0.287938

0.950227 0.950252 0.950303

0.950329

0.950380

0.950405

0.950431

$\begin{array}{lrllllllllll}.0 & 30275.960 & 75.868 & 75.776 & 75.684 & 75.593 & 75.501 & 75.409 & 75.318 & 75.226 & 75.135 \\ .1 & 75.043 & 74.951 & 74.8599 & 74.767 & 74.676 & 74.584 & 74.492 & 740401 & 74.309 & 74.218\end{array}$

$\begin{array}{ll}83.112 & 83.038 \\ 82.021 \\ 82.196 & 82.104 \\ 8102\end{array}$

$83.846 \quad 83.754$

$84.580 \quad 84.489 \quad 840397 \quad 84 \cdot 305$

0.287937

0.950481

0.287935

0.287934

0.287932

0.287931

0.287929

0.287928

950507

0.950558

0.950583

50634

0.950660

0.95078

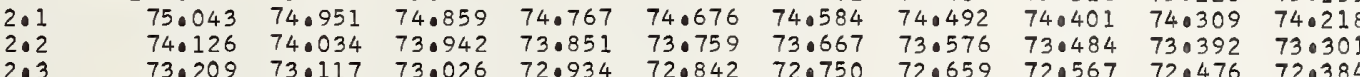

$\begin{array}{llllllllll}72.292 & 72.201 & 73.026 & 72.934 & 72.842 & 72.750 & 72.659 & 72.567 & 72.476 & 72.384 \\ 72.017 & 71.926 & 71.834 & 71.742 & 71.651 & 71.559 & 710467\end{array}$

$\begin{array}{llllllllll}71.376 & 71.284 & 71.192 & 71.101 & 71.009 & 70.917 & 70.826 & 70.734 & 70.642 & 70.551\end{array}$

$\begin{array}{llllllllll}70.459 & 70.367 & 70.276 & 70.184 & 70.093 & 70.000 & 69.909 & 69.817 & 69.726 & 69.634 \\ 69.542 & 69.45 & 69.360 & 69.268 & 69.176 & 69.085 & 68.993 & 68.901 & 68.010 & 68.018\end{array}$

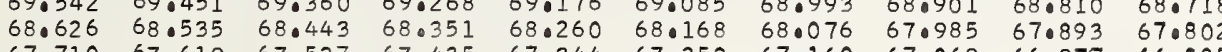

$\begin{array}{llllllllll}67.710 & 67.019 & 67.527 & 67.435 & 67.344 & 67.252 & 67.160 & 67.069 & 67.8937 & 67.802 \\ 66.885\end{array}$

0.287925

0.287924

0.287922

0.287921

0.287919

0.287918

3303.0

3.1
3.2
3.
3.
3.5
3.0
3.7
3.

30266.794

$66.610 \quad 66.5: 2$

66.42766 .335

66.244

$66.15266 .061 \quad 650969$

$\begin{array}{llllllllll}65.877 & 65.786 & 65.694 & 65.603 & 65.511 & 65.419 & 65.328 & 65.236 & 65.144 & 65005 \\ 64.961 & 64.869 & 64.778 & 64.686 & 64.594 & 64.503 & 640411 & 64.320 & 64.228 & 640136\end{array}$

$\begin{array}{llllllllll}64.045 & 63.953 & 63.862 & 63.770 & 63.679 & 63.587 & 63.495 & 63.403 & 63.312 & 63.220\end{array}$

$\begin{array}{llllllllll}63.129 & 63.037 & 62.946 & 62.854 & 62.762 & 62.670 & 62.579 & 62.488 & 62.396 & 62.304\end{array}$

$\begin{array}{llllllllll}62.213 & 62.121 & 62.029 & 61.938 & 61.846 & 61.755 & 61.663 & 61.571 & 61.480 & 61.0388\end{array}$

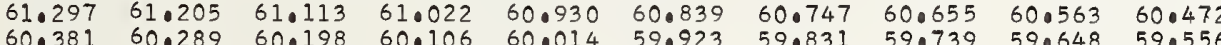

$\begin{array}{llllllllll}59.465 & 59.373 & 59.281 & 59.190 & 59.098 & 59.007 & 58.015 & 58.823 & 58.732 & 58.0640 \\ 58.549 & 58.457 & 58.365 & 58.274 & 58.183 & 58.091 & 57.099 & 57.908 & 57.816 & 57.724\end{array}$

0.287917

0.287916

0.287913

0.287912

0.287911

0.287909

$\begin{array}{lllllllllll}3304.0 & 30257.633 & 57.541 & 57.450 & 57.358 & 57.267 & 57.175 & 57.084 & 56.992 & 56 \cdot 900 & 56 \cdot 809\end{array}$

$\begin{array}{lllllllllll}4 \cdot 1 & 56.717 & 56.625 & 56.534 & 56.443 & 56.351 & 56.259 & 56 \cdot 168 & 56.076 & 550985 & 55.894\end{array}$

$\begin{array}{lllllllllll}55.802 & 55.710 & 55.619 & 55.527 & 55.436 & 55.344 & 55.252 & 55.161 & 55.070 & 54.978\end{array}$

$\begin{array}{llllllllll}54.886 & 54.795 & 54.703 & 54.612 & 54.520 & 54.429 & 54.337 & 54 \cdot 245 & 54.154 & 54.062\end{array}$

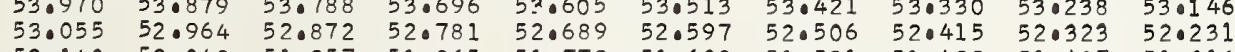

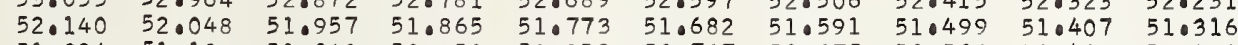

$\begin{array}{llllllllll}51.224 & 51.133 & 51.041 & 50.950 & 50.858 & 50.767 & 50.675 & 50.583 & 50.492 & 50.400\end{array}$

$\begin{array}{llllllllll}49.393 & 49.302 & 49.210 & 49.119 & 49.028 & 48.936 & 48.844 & 48.753 & 48.661 & 48.570\end{array}$

0.287907

0.287906
0.287905

0.287904

0.287903

0.287902

0.287900

0.287899

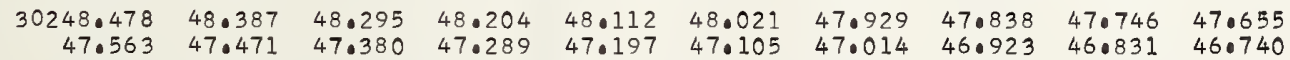

5.
5.2
5.
5.
5.5
5.
5.7
5.8
5.9

$\begin{array}{ll}48.295 & 48.204 \\ 47.380 & 47.289 \\ 46.365 & 46.373\end{array}$

$\begin{array}{llll}46.373 & 46.282 & 46.190\end{array}$

$45.733 \quad 45.642$

$43.903 \quad 43.812$

$45.550 \quad 45.458$

$45.367 \quad 45.275$

$46.099 \quad 46.007 \quad 45.916 \quad 45.824$

$\begin{array}{llllllllll}42.98 & 43.812 & 43.635 & 440543 & 440452 & 440360 & 440269 & 440177 & 440086 & 430994\end{array}$

$\begin{array}{lllllllllll}42.073 & 41.982 & 41.891 & 41.799 & 41.708 & 41.616 & 41.525 & 41.433 & 41.342 & 41.050\end{array}$

$\begin{array}{llllllllll}41.159 & 41.067 & 40.976 & 40.884 & 40.793 & 40.701 & 40.610 & 40.519 & 40.427 & 40.335 \\ 40.244 & 40.153 & 40.061 & 39.969 & 39.878 & 39.786 & 39.695 & 39.604 & 39.512 & 39.421\end{array}$

0.287897

0.287896

0.0287895

0.287893

0.287892

0.287891
0.287890

0.287889

0.950736

0.950761
0.950789

0.950812

0.955086

0.950889

0.950939
0.950965

0.950990

0.951016

0.951041

0.931092

0.951 .143

0.951168

0.951194
0.951219

0.287887

0.287886

0.287885

0.287884

0.287883

0.287882
0.287881

0.287881
0.287880

0.287880

0.287878

0.951245

0.951296

0.951321

0.951347

0.951397

0.951423
0.951448

0.951474

0.951499

0.951550

0.951576

0.951601

0.951652

0.951679

0.287877

0.287876

0.287875

0.287873

0.287872
0.287871

0.287870

0.287869
0.287868

0.95172

0.951754

0.951805

0.951830

0.95185

0.951908

0.951932

0.951983

0.952008

0.952034

0.952085

0.952110

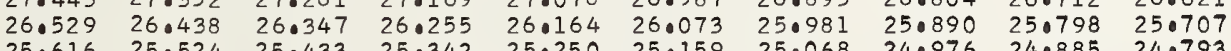

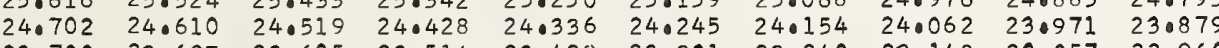

$\begin{array}{llllllllll}23.788 & 23.697 & 23.605 & 23.514 & 23.423 & 23.331 & 23.240 & 23.148 & 23.057 & 220.966 \\ 22.874 & 22.783 & 22.692 & 22.600 & 22.509 & 22.418 & 22.326 & 22.235 & 22.144 & 22.052\end{array}$

$\begin{array}{llllllllll}22.874 & 22.783 & 22.692 & 22.600 & 22.509 & 22.418 & 22.326 & 22.235 & 220144 & 22.052 \\ 21.960 & 21.869 & 21.778 & 21.687 & 21.595 & 21.504 & 21.413 & 21.321 & 21.230 & 21.138\end{array}$

0.952161

0.952186

0.952212

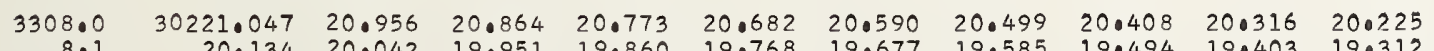

$\begin{array}{lllllllllll}8.1 & 20.134 & 20.042 & 19.951 & 19.860 & 19.768 & 19.677 & 19.585 & 19.494 & 19.403 & 19.312 \\ 8.2 & 19.220 & 19.128 & 19.037 & 18.946 & 18.854 & 18.763 & 18.672 & 18.581 & 180490 & 18.398\end{array}$

0.287867

0.952263

0.287866

0.287864

0.287863

0.287862

0.287861

0.287860

$\begin{array}{llllllllll}15.567 & 15.476 & 15.385 & 15.293 & 15.202 & 15.110 & 15.019 & 140928 & 14.836 & 14.745 \\ 14.654 & 14.562 & 14.471 & 14.380 & 14.289 & 14.198 & 140106 & 140015 & 13.924 & 13.832\end{array}$

$\begin{array}{llllllllll}13.740 & 13.649 & 13.558 & 13.467 & 13.375 & 13.284 & 13.193 & 13.102 & 13.010 & 12.919 \\ 12.828 & 12.736 & 12.645 & 12.553 & 12.462 & 12.371 & 12.280 & 12.188 & 12.097 & 12.006\end{array}$

0.287858

0.952288

0.952339

0.952365

0.952415

0.952441

0.952466

$\begin{array}{rrrrrrrrrrr}3309.0 & 30211.915 & 11.823 & 11.732 & 11.641 & 11.549 & 11.458 & 11.367 & 11.275 & 11.184 & 11.093 \\ 9.1 & 11.002 & 10.910 & 10.819 & 10.728 & 10.636 & 10.545 & 10.454 & 10.363 & 10.271 & 10.180 \\ 9.2 & 10.089 & 09.997 & 09.906 & 09.815 & 09.723 & 09.632 & 09.541 & 09.449 & 09.358 & 09.267 \\ 9.3 & 09.176 & 09.085 & 08.993 & 08.902 & 08.811 & 08.719 & 08.628 & 08.537 & 08.446 & 08.354 \\ 9.4 & 08.263 & 08.172 & 08.080 & 07.989 & 07.898 & 07.806 & 07.715 & 07.624 & 07.533 & 07.441 \\ 9.5 & 07.350 & 07.259 & 07.167 & 07.077 & 06.985 & 06.894 & 06.802 & 06.711 & 06.620 & 06.529 \\ 9.6 & 06.437 & 06.346 & 06.255 & 06.164 & 06.073 & 05.981 & 05.890 & 05.798 & 05.707 & 05.616 \\ 9.7 & 05.525 & 05.433 & 05.342 & 05.251 & 05.160 & 05.069 & 04.977 & 04.886 & 04.795 & 04.703 \\ 9.8 & 04.612 & 04.521 & 04.430 & 04.338 & 04.247 & 04.156 & 04.064 & 03.973 & 03.882 & 03.791 \\ 9.9 & 03.699 & 03.608 & 03.517 & 03.426 & 03.335 & 03.243 & 03.152 & 03.061 & 02.969 & 02.878\end{array}$

$0 .<87857$

0.952519

0.287856

0.287853

0.287852

0.287851

0.287849

0.287848

0.287847

0.952568

0.952619

0.952644

0.952695

0.952721

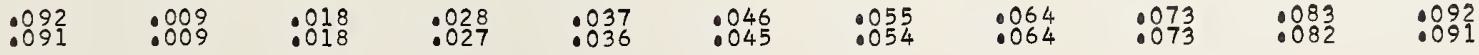


$\lambda(n-1)$

$\begin{array}{rrrrrrrrrrr}3310.0 & 30202.787 & 02.696 & 02.604 & 02.513 & 02.422 & 02.331 & 02.240 & 02.148 & 02.057 & 01.967 \\ 0.1 & 01.875 & 01.784 & 01.693 & 01.602 & 01.510 & 01.419 & 01.328 & 01.236 & 01.145 & 01.054\end{array}$ $\begin{array}{lllllllllll}0.2 & 0.875 & 01.784 & 01.693 & 01.602 & 01.510 & 01.419 & 01.328 & 01.236 & 01.145 & 01.054 \\ 0.963 & 00.871 & 0.0 .781 & 00.689 & 00.598 & 00.507 & 00.415 & 00.324 & 00.233 & 00.142\end{array}$ $0.3 \quad 00.050 * 99.959 * 99.868 * 99.777 * 99.686 * 99.594 * 99.503 * 99.412 * 99.321 * 99.229$

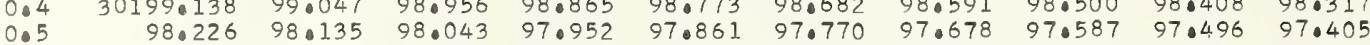

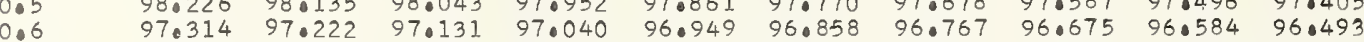

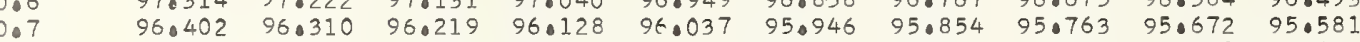
$\begin{array}{lllllllllll}0.8 & 95.490 & 95.398 & 95.307 & 95.216 & 95.125 & 95.034 & 94.942 & 94 \cdot 851 & 94.760 & 94 \cdot 669 \\ 0.9 & 94.577 & 94.486 & 94.395 & 94.304 & 94.213 & 94.122 & 94.030 & 93.939 & 93.848 & 93.757\end{array}$

$$
\begin{aligned}
& 1: 1 \\
& 1.2 \\
& 1: 3 \\
& 1.4 \\
& 1.5 \\
& 1.6 \\
& 1.7 \\
& 1.8 \\
& 1.9
\end{aligned}
$$$$
3312.0
$$$$
2
$$$$
2 \cdot 2
$$$$
2.4
$$$$
\begin{aligned}
& 2.5 \\
& 2.6 \\
& 2.7
\end{aligned}
$$$$
\begin{aligned}
& 2.7 \\
& 2.8 \\
& 2.9
\end{aligned}
$$$$
\begin{array}{r}
3313.0 \\
3.1 \\
3.2
\end{array}
$$$$
3.2
$$$$
\begin{aligned}
& 3.3 \\
& 3.4
\end{aligned}
$$$$
\begin{aligned}
& 3.5 \\
& 3.5 \\
& 3.7
\end{aligned}
$$$$
\begin{aligned}
& 3.7 \\
& 3.8 \\
& 3.9
\end{aligned}
$$

331400

$4 \cdot 1$
$4 \cdot 2$
$4 \cdot 3$
$4 \cdot 0$

4.4
4.5
4.6

4.6
4.7

4.8
4.9

33150

5.3

$5 \cdot 2$
5.3
5.4

5.4

5.6

5.8
5.9

3316.

6.1
6.2
6.3

6.3

6.4
6.5

6.6

6.7
6.8
6.9

3317.

7.

7.3

7.5
7.6

7.07
7.8

3318

18.0
8.1
8.2
8.3
8.4
8.5
8.6
8.7
8.8
8.9
919.0
9.1
9.2
9.3
9.4
9.5
9.6
9.7
9.8
9.9

30129.96

30175.439
74.528
73.618
72.707
71.796
70.886
69.975
69.065
68.154

30166.334 65.423

64.513

$61.783 \quad 61.602$

$60.874 \quad 60.782$

59.05358 .963

$30157 \cdot 23$

$56.325 \quad 56.23$

$\begin{array}{ll}55.415 & 55.3 \\ 54.505 & 54.41\end{array}$

$53.596 \quad 53.505$

$\begin{array}{ll}52.687 & 52.595 \\ 51.777 & 51.686\end{array}$

$50.867 \quad 50.776$

$49.049 \quad 48.958$

$47.231 \quad 47.04$

$\begin{array}{ll}46.322 & 46.231 \\ 45.413 & 45.322\end{array}$

$\begin{array}{ll}44.504 & 44.413 \\ 43.595 & 43.504\end{array}$

$42.686 \quad 42.59$

$\begin{array}{ll}41.777 & 41.686 \\ 40.868 & 40.778\end{array}$

$\begin{array}{ll}40.868 & 40.778 \\ 39.960 & 39.869\end{array}$

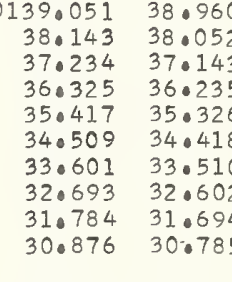

$29.060 \quad 28.96$

$\begin{array}{ll}28.152 & 28.061 \\ 27.244 & 27.153\end{array}$

$26.336 \quad 26.246$

$24.521 \quad 24.430$

$23.613 \quad 23.522$

$21.798 \quad 21.707$

$30120.890 \quad 20.800$

$\begin{array}{ll}19.983 & 19.892 \\ 19.076 & 18.985 \\ 18.168 & 18.078 \\ 17.261 & 17.170\end{array}$

$\begin{array}{ll}16.354 & 16.26 \\ 15.446 & 15.35\end{array}$

$15.446 \quad 15.356 \quad 15.265$

$13.632 \quad 13.542 \quad 13.451$

93.483
92.572
91.659
90.748
89.836
88.924
88.013
87.102
86.190
85.279

$3.392 \quad 93.3$

$\begin{array}{llllll}93.301 & 93.210 & 93.119 & 93.027 & 92.936 & 92.845 \\ 92.389 & 92.298 & 92.207 & 92.115 & 92.024 & 91.933\end{array}$

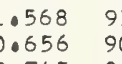

$.477 \quad 91.386$
.90

.386

$9.29591 .20491 .113 \quad 91.02$

.833880

$\begin{array}{llllll}.654 & 89.562 & 89.471 & 89.380 & 89.289 & 89.198\end{array}$

$\begin{array}{llllll}88.742 & 88.651 & 88.560 & 88.469 & 88.378 & 88.287\end{array}$

$\begin{array}{lllllll}87.831 & 87.740 & 87.649 & 87.557 & 87.466 & 87.375\end{array}$

$.010 \quad 86.099$

919
86.828

$84.367 \quad 84.276 \quad 840$

85.00

$\begin{array}{rl}.0456 & 83.365 \\ .545 & 82.454\end{array}$

$\begin{array}{ll}185 & 84.0 \\ 3.274 & 83 \\ .362 & 82.02\end{array}$

.094
.182

84014

4.823

4.732

85.552

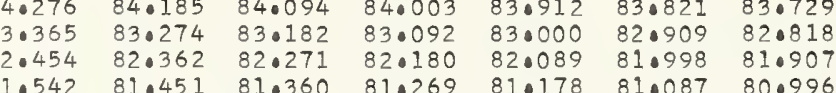

$\begin{array}{llllllll}80.631 & 80.540 & 81.360 & 81.269 & 81.178 & 81.087 & 80.996\end{array}$

$\begin{array}{llllllll} & & & \end{array}$

$\begin{array}{llllllll}.900 & 78.809 & 78.718 & 78.627 & 78.536 & 78.445 & 78.354 & 78.262 \\ .989 & 77.898 & 77.807 & 77.716 & 77.625 & 77.533 & 77.443 & 77.352\end{array}$

$\begin{array}{lll}7.078 & 76.987 & 76.0 \\ 76.167 & 76.076 & 75.0\end{array}$

$.896 \quad 76.805$

.625714770

$\begin{array}{llll}5.256 & 75.166 & 75.074 & 74.984\end{array}$

74.893

$75.712 \quad 75.621 \quad 75.530$

0.28784

0.287845

0.287844

0.287842

0.287841

0.287840

0.287838

0.287837

0.287836

0.287835

0.287833

0.287832

0.287830

0.287829

0.287828
0.287827

0.287826

0.2878

0.287823

0.287821

0.287820

0.28781

0.287818

0.287816

0.287815

0.287814

0.287812

0.287811

0.287810

0.287809
0.287808

0.287807

0.287806

0.28780

0.287803

0.287803

0.287802
0.287801

0.287800

0.28770

0.28770

0.2287799
0.287798
0.287797

0.287796

0.287795

0.287794
0.287793

0.287791
0.287790

0.28778

0.287788
0.287787

0.287786

0.287785
0.287784

0.28778

0.287782
0.287781
0.2287780

0.287780

0.287779

0.287778

0.287776

0.287775

0.28777

0.28777

0.287771

0.287770

0.28776

0.287767

0.287766

0.287765

0.287764

0.287762

0.287760

0.28775

0.287758
0.287757

0.287756

0.28775

0.287753

0.28775

0.287750

0.287749

0.287748

0.287747

0.952772

0.952797

0.952848

0.952874

0.952899

0.952924

0.952950

0.953001

0.953026

0.953032
0.953077

0.953103

0.953128

0.953154
0.953179

0.953204

0.953230

0.953281

.953306
.953332

0.953357

0.953383

0.953408

0.953434
0.953459

0.953484
0.953510

0.953535

0.953561

0.953612

0.953637

0.953663
0.953688

0.953714

0.953739

0.953790

0.953815
0.953841

0.953841

0.953866
0.953892

0.953892
0.953917

0.953917
0.953943

0.953943

0.953968

0.954019

0.954045

0.954070

0.954096

0.954121

0.095414
0.05472

0.054

0.954223
0.954248

0.954299

0.954325

0.954350

0.954376

0.954401
0.954427

0.954452

0.954477

0.954503
0.954528

0.954554

0.954579

0.954605

0.954656

0.954681

0.954707

0.954732

0.954783

0.954808

0.954834

0.954885

0.954910

0.954936

0.954961

0.954987

0.955012

0.955063

0.955089

0.955114

0.955140

0.955190

0.955216

0.955241
0.955267

0.9955267
0.955292 


.02

.03

.04

.05

.06

.07

.08

.09

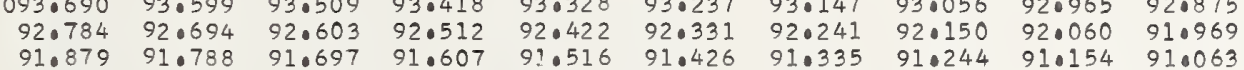

0.957356

0.957381
0.957407

0.957432

0.957458
0.957483

0.957509

0.957534

0.957610

0.957636

0.957661
0.957687
0.957712

0.957738

0.957789

0.957814
0.057840

.020

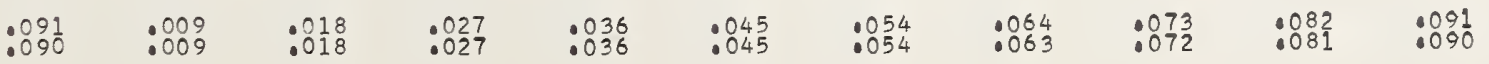




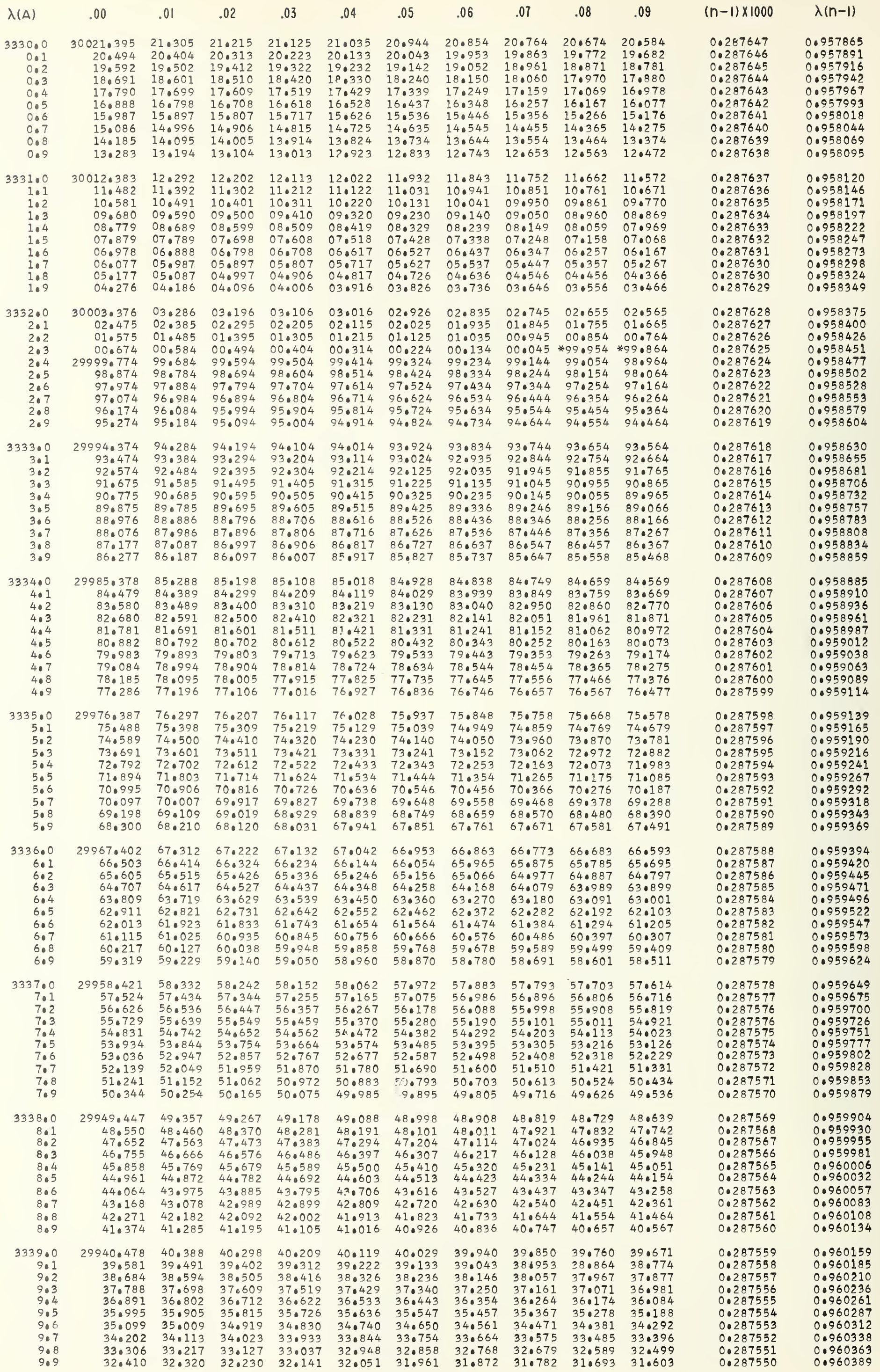

$\begin{array}{lllllllllll} & .001 & .002 & .003 & .004 & .005 & .006 & .007 & .008 & .009 & .010 \\ .8889 & : 888 & .818 & .837 & .838 & .845 & .854 & .8833 & .832 & .8880 & .8889\end{array}$ 


$.02 \quad .03$

.04

$29931.514 \quad 31.424 \quad 31.334 \quad 31.245$

$\begin{array}{llll}30.617 & 30.528 & 30.438 & 30.349 \\ 29.722 & 29.632 & 29.542 & 29.453\end{array}$

$\begin{array}{llll}28.826 & 28.736 & 28.646 & 28.557 \\ 27.930 & 27.840 & 27.750 & 27.66\end{array}$

$\begin{array}{llll}27.930 & 27.840 & 27.750 & 27.661 \\ 27.034 & 26.944 & 26.855 & 26.765 \\ 25.130 & 26.048 & 25.959 & 25.869\end{array}$

$\begin{array}{llll}26.138 & 26.048 & 25.959 & 25.869 \\ 25.242 & 25.153 & 25.063 & 24.974\end{array}$

$\begin{array}{llll}25.242 & 25.153 & 25.063 & 24.974 \\ 24.346 & 24.257 & 24.167 & 24.078 \\ 23.451 & 23.361 & 23.272 & 23.0182\end{array}$

3
2903
2804
26.5
2507
2308
2300
2201

$\begin{array}{lllllll}.155 & 31.065 & 30.976 & 30.886 & 30.797 & 30.707 \\ .259 & 30.169 & 30.080 & 29.990 & 29.901 & 29.812\end{array}$

$\begin{array}{llllll}29.363 & 29.274 & 29.184 & 29.094 & 290005 & 28.916 \\ 28.467 & 28.378 & 28.288 & 28.199 & 28.109 & 28.019\end{array}$

$\begin{array}{llllll}27.575 & 27.482 & 270392 & 270303 & 270213 & 270123 \\ 26.0 & 26.586 & 26.496 & 26.407 & 26.317 & 26.228\end{array}$

$\begin{array}{llllll}25.780 & 25.690 & 25.601 & 25.511 & 25.429 & 25.332\end{array}$

$922.555 \quad 22.466 \quad 22.376 \quad 22.287$

$\begin{array}{llllll}23.988 & 23.898 & 23.809 & 23.719 & 23.630 & 23.540 \\ 23.093 & 23.003 & 22.913 & 22.824 & 22.734 & 22.645\end{array}$

$\begin{array}{llllll}22.197 & 22.107 & 22.018 & 21.928 & 21.838 & 21.749\end{array}$

$\begin{array}{llll}19.868 & 19.779 & 19.689 & 19.600 \\ 18.973 & 18.884 & 18.794 & 18.704\end{array}$

$\begin{array}{llll}18.078 & 17.988 & 17.8898 & 17.809 \\ 17.182 & 17.093 & 17.003 & 16.914\end{array}$

$\begin{array}{llllll} & 19.421 & 190331 & 190242 & 190152 & 190062\end{array}$

1.6
1.7
1.8
1.9

$\begin{array}{llll}16.288 & 16.198 & 16.109 & 16.019 \\ 15.392 & 15.303 & 15.213 & 15.124 \\ 14.497 & 14.408 & 14.318 & 14.229\end{array}$

$16.824 \quad 16.735$

16.645

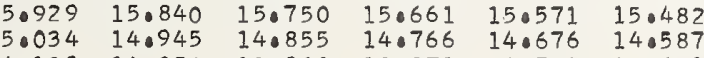

3342.0

2.1
202
20
20
20
20
207
20
20

29913.602

$12.707 \quad 12.667$

$13.423 \quad 13.334$

$14.139 \quad 14.050$

$\begin{array}{llll}13.960 & 13.871 & 13.781 & 13.691\end{array}$

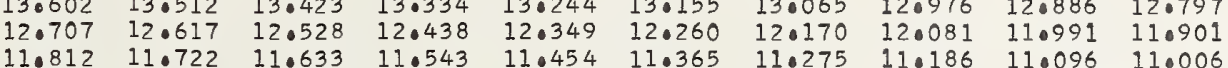

$\begin{array}{llllllllll}10.022 & 09.933 & 09.843 & 09.753 & 09.664 & 09.575 & 09.485 & 09.396 & 09.306 & 09.217\end{array}$

$\begin{array}{lllllllllll}09.127 & 09.038 & 08.948 & 08.859 & 08.769 & 08.680 & 08.591 & 08.501 & 08.411 & 08.322\end{array}$

$\begin{array}{lllllllllll}08.233 & 08.143 & 08.054 & 07.964 & 07.875 & 07.785 & 07.696 & 07.606 & 070517 & 070427\end{array}$

$\begin{array}{llllllllll}07.338 & 07.248 & 07.159 & 07.069 & 06.980 & 06.890 & 06.801 & 06.711 & 06.622 & 06.533 \\ 06.443 & 06.354 & 06.264 & 06.175 & 06.085 & 05.996 & 05.906 & 05.817 & 05.728 & 05.638\end{array}$

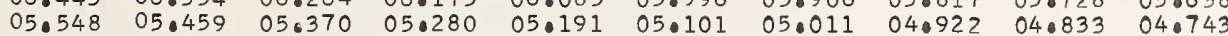

$\begin{array}{lllllllllll}3343.0 & 29904 \cdot 654 & 04.564 & 04.475 & 04.386 & 04.296 & 04.207 & 04.117 & 04.028 & 03.938 & 03.849\end{array}$

$\begin{array}{lllllllllll}3.1 & 03.760 & 03.670 & 03.581 & 03.491 & 03.401 & 03.312 & 03.223 & 03.133 & 03.044 & 02.0954 \\ 3.2 & 02.865 & 02.775 & 02.687 & 02.597 & 02.508 & 02.418 & 02.329 & 02.239 & 02.150 & 02.061\end{array}$

$\begin{array}{lllllllllll}3.2 & 02.865 & 02.775 & 02.687 & 02.597 & 02.508 & 02.418 & 02.329 & 02.239 & 02.150 & 02.06 \\ 3.3 & 01.971 & 01.882 & 01.792 & 01.702 & 01.613 & 01.524 & 01.434 & 01.345 & 01.256 & 0.166\end{array}$

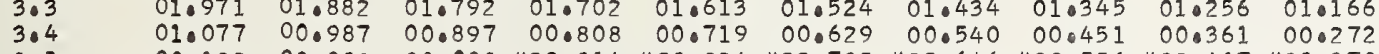

$00.182 \quad 00.093 \quad 00.003 * 99.914 * 99.824 * 99.735 * 99.0446 * 99.556 * 99.467 * 99.378$

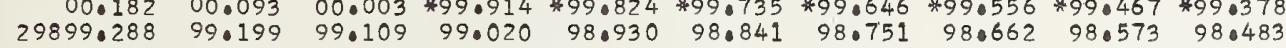
$\begin{array}{lllllllllll}98.394 & 98.304 & 98.215 & 98.126 & 98.036 & 97.947 & 97.857 & 97.768 & 97.679 & 97.589\end{array}$

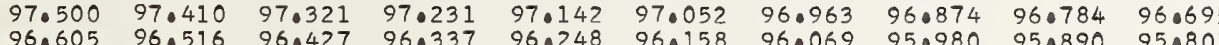

3.9

3344.0

4.0
40.
40
40
405
406
407
40.9

298950712

5.71295 .622

96.427
96.337

96.24896 .15

96.06

$950086 \quad 940996 \quad 940907$

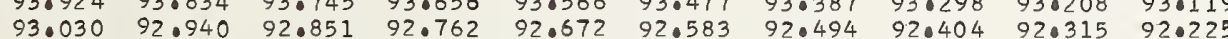

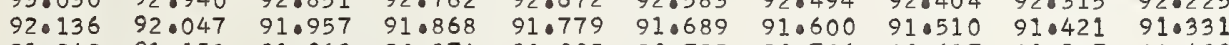

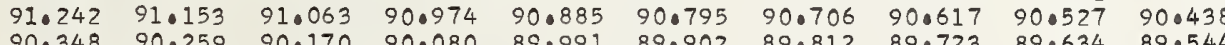

$\begin{array}{llllllllll}90.348 & 90.259 & 90.170 & 90.080 & 89.991 & 89.902 & 89.812 & 89.723 & 89.634 & 89.544\end{array}$

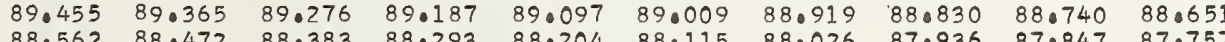

$\begin{array}{llll}88.562 & 88.472 & 88.383 & 88.293 \\ 87.668 & 87.579 & 87.489 & 87.400\end{array}$

$8.204 \quad 88.115$

3345.0

5.1
50
50
50.4
50.5
50.0
50.0
5
5

$86.775 \quad 86.685$

$\begin{array}{llllllllll}86.685 & 86.596 & 86.507 & 86.417 & 86.328 & 86.239 & 86.149 & 86.060 & 85.970 \\ 85.792 & 85.703 & 85.613 & 85.524 & 85.434 & 85.345 & 85.256 & 85.167 & 85.077\end{array}$

86.417

88.026

87.936

86.953

868864

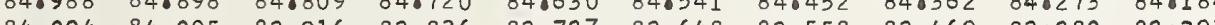

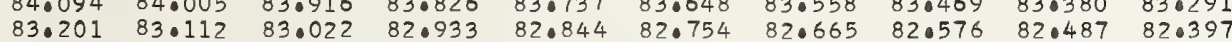

$\begin{array}{llllllllll}82.308 & 82.219 & 82.129 & 82.040 & 81.951 & 81.861 & 81.772 & 81.683 & 81.593 & 81.0504\end{array}$

$81.415 \quad 81.325 \quad 81.236 \quad 81.147$

$\begin{array}{llll}79.628 & 79.539 & 79.450 & 79.360 \\ 78.735 & 78.646 & 78.557 & 78.467\end{array}$

$81.057 \quad 80.968$

79.27
78.378

3346.0

6.0

29877.843

$\begin{array}{rlllll}78.735 & 78.646 & 78.557 & 78.467 & 7 \\ 76.843 & 77.753 & 77.664 & 77.575 & 7\end{array}$

$\begin{array}{llll}76.950 & 76.860 & 76.771 & 76.682\end{array}$

$\begin{array}{llll}76.057 & 75.967 & 75.878 & 75.789 \\ 75.164 & 75.075 & 74.986 & 74.896\end{array}$

$74.271 \quad 74.183 \quad 74.093 \quad 74.006$

$\begin{array}{llll}73.379 & 73.290 & 73.200 & 73.111 \\ 72.486 & 72.397 & 72.308 & 72.219\end{array}$

$71.594 \quad 71.504 \quad 71.415 \quad 71.326$

$\begin{array}{ll}71.701 & 70.612 \\ 69.809 & 69.719\end{array}$

$\begin{array}{ll}70.523 & 70.433 \\ 69.630 & 69.541\end{array}$

$\begin{array}{lllllll}77.485 & 77.396 & 77.307 & 77.218 & 77.128 & 77.039 \\ 76.592 & 76.503 & 76.414 & 76.324 & 76.235 & 76.146\end{array}$

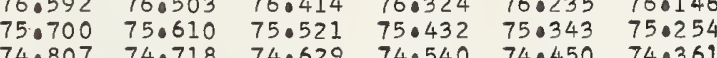

$\begin{array}{llllll}73.915 & 73.0185 & 74.629 & 74.0540 & 74.450 & 74.0361 \\ 73.036 & 73.0447 & 73.557 & 73.468\end{array}$

$\begin{array}{llllll}73.022 & 72.932 & 72.843 & 72.754 & 72.665 & 72.576 \\ 72.129 & 72.040 & 71.951 & 71.861 & 71.772 & 71.683\end{array}$

6.6

6.8

3347.0

$29868.916 \quad 68.827 \quad 68.738$

$\begin{array}{llllllllll}68.916 & 68.827 & 68.738 & 68.649 & 68.559 & 68.470 & 68.381 & 68.292 & 68.202 & 68.113 \\ 68.024 & 67.935 & 67.845 & 67.756 & 67.667 & 67.578 & 67.489 & 67.399 & 67.310 & 670221 \\ 67.131 & 67.0042 & 66.953 & 66.864 & 66.775 & 66.0886 & 66.596 & 66.507 & 66.418 & 66.328\end{array}$

$\begin{array}{llllll}70.346 & 71.147 & 71.058 & 70.969 & 70.880 & 70.790 \\ 70.255 & 70.166 & 70.076 & 69.987 & 69.8898\end{array}$

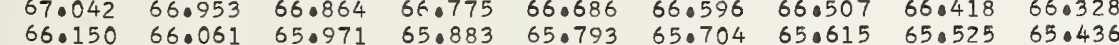

$\begin{array}{llllllllll}65.347 & 65.258 & 65.168 & 65.079 & 64.990 & 64.901 & 64 \cdot 812 & 640723 & 640633 & 640544 \\ 64.455 & 64.365 & 64.276 & 64.187 & 64.098 & 64.009 & 630920 & 63.831 & 63.741 & 63.652\end{array}$

$\begin{array}{llllllllll}63.563 & 63.473 & 63.384 & 63.295 & 63.206 & 63.116 & 63.028 & 62.938 & 62.849 & 620760\end{array}$

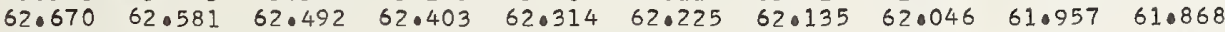

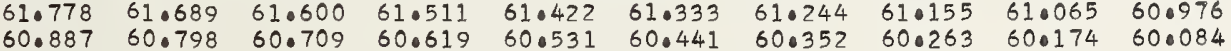

$\begin{array}{rrrrrrrrrrr}3348.0 & 29859.995 & 59.906 & 59.817 & 59.728 & 59.638 & 59.549 & 59.460 & 59.371 & 59.281 & 59.193 \\ 8.1 & 59.103 & 59.014 & 58.925 & 58.836 & 58.747 & 58.657 & 58.568 & 58.479 & 58.390 & 58.301\end{array}$

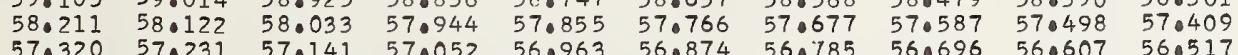

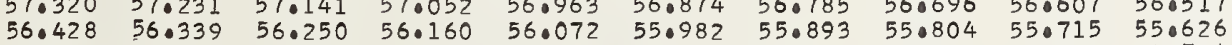
$\begin{array}{llllllllll}55.537 & 55.447 & 55.358 & 55.269 & 55.180 & 55.091 & 55.002 & 540912 & 54.823 & 54.734\end{array}$ $\begin{array}{lllllllllll}540645 & 54.556 & 54.467 & 54.377 & 54.288 & 540199 & 54.110 & 54.021 & 53.932 & 53.843\end{array}$ $\begin{array}{llllllllll}53.753 & 53.664 & 53.575 & 53.486 & 53.397 & 53.308 & 53.219 & 530129 & 53.040 & 52.951\end{array}$

$\begin{array}{llllllllll}52.862 & 52.773 & 52.684 & 52.594 & 52.505 & 52.416 & 52.327 & 52.238 & 52.149 & 52.060\end{array}$

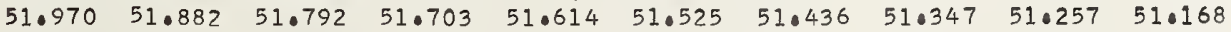

$\begin{array}{lllllllllll}3349.0 & 29851.079 & 50.990 & 50.901 & 50.812 & 50.722 & 50.633 & 50.544 & 50.455 & 50.366 & 50.277\end{array}$

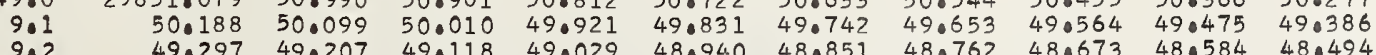

$\begin{array}{llllllllllll}9.2 & 49.297 & 49.207 & 49.118 & 49.029 & 48.940 & 48.851 & 48.762 & 48.673 & 48.584 & 48.494 \\ 9.3 & 48.405 & 48.316 & 48.227 & 48.138 & 48.049 & 47.960 & 470870 & 470782 & 470693 & 47.604\end{array}$

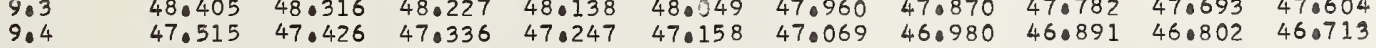

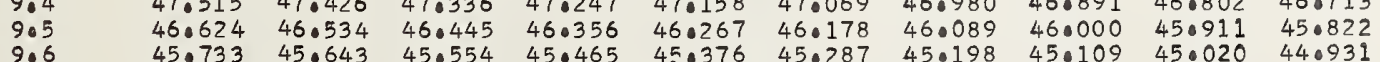

$\begin{array}{lllllllllll}9.6 & 45.733 & 45.643 & 45.554 & 450465 & 45.376 & 45.287 & 45.198 & 45.109 & 45 \cdot 020 & 44.931 \\ 9.7 & 44.842 & 44.752 & 44.663 & 44.574 & 44.0485 & 44.396 & 44.307 & 44.218 & 44.129 & 44.040\end{array}$

$\begin{array}{lllllllllll}9.7 & 440842 & 44.752 & 44.663 & 44.574 & 440485 & 44.396 & 440307 & 440218 & 440129 & 44.040 \\ 9.8 & 43.950 & 43.862 & 43.772 & 43.683 & 43.594 & 43.505 & 43.0416 & 43.327 & 43.238 & 43.149\end{array}$

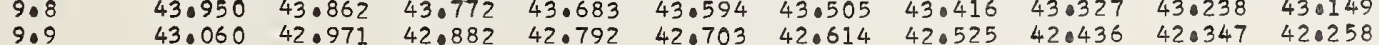

$\lambda(n-1) \times 1000$

0.287549

0.287548

0.287546

.

0.28754

0.287542

0.287540

0.287539

0.287538
0.287537

0.287536

(

0.287534

0.287532

0.287530

0.287528

0.287526

.287525

0.287523

0.287522

0.287520

0.287519

0.287517

. 287516

0.287515
0.287514

0.287513

0.287512
0.287511

0.287510

0.287509

0.287508
0.287507

0.287506

0.287505

0.287504

0.287502

0.287501

0.287500

0.0287490

0.287499

0.287498

0.287497
0.287496

0.287495

0.287494
0.287493

0.287492

0.960414

0.960440

0.960499

0.960516

0.960567

0.960593

0.960618

0.960669

0.960695

0.960746

0.960771

0.960822

0.960848

0.960899

0.960924

0.960973

0.961000

0.961026

0.961077

0.961102

0.961153

0.961179

0.961204

0.961255

0.961281

0.961306
0.961332

0.961357

0.961383
0.961408

0.961434

0.961459

0.961485
0.961510

0.961536

0.961561

0.961612

0.961638

0.961689

0.961714

0.961740

0.961791

0.961816

0.961842

0.287490

0.287489

0.287488
0.287487

0.287486

0.287485

0.287484

0.287483
0.287482

0.961944

0.961970

0.961995

0.962046

0.962072

0.962099

0.287481

0.962148

0.287480
0.287479

0.007878

0.0287478

0.287475

0.287474

0.287473
0.287472

0.962199

0.962225

0.962250

0.962276

0.962327

0.962352
0.962378

0.962403

0.287471

0.962454

0.287470
0.287469
0.287468

0.962480

0.287468

0.287467

0.287467

0.287465

0.287464

0.287464

0.287462

0.287461

0.287460

0.287458

0.28745

0.287456

0.287455

0.287454

0.962505

0.962556

0.962582

0.962633

0.962658

0.962709

0.962735

0.962760

0.962811

0.962862

0.962888

0.962913

.010

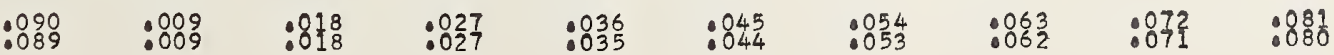

$: 898$ 


\begin{tabular}{|c|c|c|c|c|}
\hline$\lambda(A)$ & .00 & .01 & .02 & .03 \\
\hline $\begin{array}{r}3350.0 \\
0.1\end{array}$ & $\begin{array}{r}29842.169 \\
41.278\end{array}$ & $\begin{array}{l}42.080 \\
41.189\end{array}$ & $\begin{array}{l}41.990 \\
41.100\end{array}$ & $\begin{array}{l}41.902 \\
41.011\end{array}$ \\
\hline $0 . \frac{1}{2}$ & $\begin{array}{l}41.278 \\
40.387\end{array}$ & 40.298 & 40.209 & 40.120 \\
\hline 0.3 & 39.497 & 39.408 & 39.319 & 39.229 \\
\hline 0.4 & 38.606 & 38.517 & 38.428 & 38.339 \\
\hline $\begin{array}{l}0.5 \\
0.6\end{array}$ & $\begin{array}{l}37.715 \\
36.825\end{array}$ & 37.626 & 37.537 & 37.448 \\
\hline 0.7 & $\begin{array}{l}36.825 \\
35.934\end{array}$ & $\begin{array}{l}36.736 \\
35.845\end{array}$ & $\begin{array}{l}36.647 \\
35.756\end{array}$ & $\begin{array}{l}36.558 \\
35.667\end{array}$ \\
\hline 0.8 & $\begin{array}{l}35.044 \\
35.04\end{array}$ & $\begin{array}{l}34.845 \\
34.955\end{array}$ & $\begin{array}{l}35.756 \\
34.866\end{array}$ & $\begin{array}{l}35.657 \\
34.777\end{array}$ \\
\hline 0.9 & 34.154 & 34.065 & 33.976 & 33.887 \\
\hline 51.0 & 29833.264 & 33.175 & 33.086 & 32.997 \\
\hline 101 & 32.374 & 32.284 & 32.196 & 32.106 \\
\hline $\begin{array}{l}1.2 \\
1.3\end{array}$ & 310483 & 31.394 & 31.305 & 31.216 \\
\hline $\begin{array}{l}1.3 \\
1.4\end{array}$ & $\begin{array}{l}30.593 \\
29.703\end{array}$ & $\begin{array}{l}30.504 \\
220.614\end{array}$ & $\begin{array}{l}30.415 \\
30.555\end{array}$ & 30.326 \\
\hline 1.5 & $\begin{array}{l}29.703 \\
28.813\end{array}$ & $\begin{array}{l}29.614 \\
28.724\end{array}$ & $\begin{array}{l}29.525 \\
28.635\end{array}$ & $\begin{array}{l}29.436 \\
28.546\end{array}$ \\
\hline 1.6 & $\begin{array}{l}280813 \\
27.923\end{array}$ & $\begin{array}{l}28.724 \\
27.834\end{array}$ & $\begin{array}{l}28.635 \\
27.745\end{array}$ & $\begin{array}{l}28.546 \\
27.656\end{array}$ \\
\hline 1.7 & & 26.944 & 26.855 & 26.766 \\
\hline 1.8 & 26.143 & 26.054 & 25.965 & 25.876 \\
\hline 1.9 & & $25 \cdot 165$ & 25.075 & 24.986 \\
\hline 52.0 & $824 \cdot 364$ & 24.275 & 240186 & 24.097 \\
\hline $\begin{array}{l}2.1 \\
2.2\end{array}$ & 23.474 & $23 \cdot 385$ & 23.296 & 23.207 \\
\hline $\begin{array}{l}2.2 \\
2.3\end{array}$ & 22.584 & 22.495 & 22.406 & 22.317 \\
\hline $\begin{array}{l}2.3 \\
2.4\end{array}$ & 21.695 & 21.606 & 21.517 & 21.428 \\
\hline $\begin{array}{l}2.4 \\
2.5\end{array}$ & 20.805 & 20.716 & 20.627 & 20.538 \\
\hline $\begin{array}{l}2.5 \\
2.6\end{array}$ & 190916 & 19.827 & 19.738 & 19.649 \\
\hline $\begin{array}{l}2.6 \\
2.7\end{array}$ & 19.027 & 18.938 & 18.849 & 18.760 \\
\hline $\begin{array}{l}2.7 \\
2.8\end{array}$ & $\begin{array}{l}18.137 \\
17.248\end{array}$ & $\begin{array}{l}18.048 \\
17\end{array}$ & $\begin{array}{l}17.959 \\
17.070\end{array}$ & $\begin{array}{l}17.870 \\
16.981\end{array}$ \\
\hline $\begin{array}{l}2.8 \\
2.9\end{array}$ & $\begin{array}{l}17.248 \\
16.358\end{array}$ & $\begin{array}{l}17.159 \\
16.270\end{array}$ & $\begin{array}{l}17.070 \\
16.181\end{array}$ & $\begin{array}{l}16.981 \\
16.092\end{array}$ \\
\hline & 29815.469 & 15.380 & 15.291 & 15.203 \\
\hline & 140580 & 140491 & 14.402 & $14 \cdot 313$ \\
\hline 3.2 & 13.691 & 13.602 & 13.513 & 13.424 \\
\hline $3 \cdot 3$ & 120802 & 12.713 & 12.624 & 12.535 \\
\hline 3.4 & 110913 & 110824 & 11.735 & 11.646 \\
\hline 3.5 & 11.024 & 10.935 & 10.846 & 10.757 \\
\hline $\begin{array}{l}306 \\
307\end{array}$ & 10.135 & 10.046 & 09.957 & 09.868 \\
\hline $\begin{array}{l}3.7 \\
3.8\end{array}$ & 09.246 & $\begin{array}{l}09.157 \\
08\end{array}$ & 09.068 & 08.979 \\
\hline $\begin{array}{l}3.8 \\
3.9\end{array}$ & $\begin{array}{l}08.357 \\
07.469\end{array}$ & $\begin{array}{l}08.268 \\
07.379\end{array}$ & $\begin{array}{l}08.179 \\
07.291\end{array}$ & $\begin{array}{l}08.091 \\
07.202\end{array}$ \\
\hline & 2980 & 10 & 06.2 & 06. \\
\hline 4.1 & 05.691 & 3 & 4 & \\
\hline 4.2 & 04.803 & 04.714 & 04.625 & 04.536 \\
\hline 403 & 03.914 & 03.825 & 03.737 & 03.648 \\
\hline 4.4 & 03.026 & 02.937 & 02.848 & 02.759 \\
\hline 4.5 & 02.138 & 02.048 & 01.959 & 01.871 \\
\hline $4 \cdot 6$ & 01.249 & 01.160 & 01.071 & 00.982 \\
\hline 4.7 & 00.361 & 00.272 & 00.183 & 00.094 \\
\hline 4.8 & 29799.472 & 99.384 & 99.295 & 99.206 \\
\hline 409 & 98.584 & 98.495 & 98.406 & 98.318 \\
\hline & 29797.6966 & 97.607 & 97.518 & 97.430 \\
\hline 501 & 96.808 & 96.719 & 96.6 & 96. \\
\hline $5 \cdot 2$ & 95.920 & $95 \cdot 831$ & 95.7 & 950 \\
\hline $5 \cdot 3$ & 95.032 & 94.943 & 94.854 & $94 \cdot 765$ \\
\hline 504 & 940144 & $94 \cdot 0$ & 93.5 & 93.8 \\
\hline 505 & 93.256 & 93.167 & 93.078 & $92 \cdot$ \\
\hline 506 & 92.368 & 92.280 & 92.191 & $92 \cdot 102$ \\
\hline 5. & 91.481 & 91.392 & 91.303 & 91.214 \\
\hline 508 & $\begin{array}{l}90.593 \\
89.705\end{array}$ & $\begin{array}{l}90.504 \\
890616\end{array}$ & $\begin{array}{l}90.415 \\
89.538\end{array}$ & $\begin{array}{l}90.327 \\
89.439\end{array}$ \\
\hline & 89.705 & 89.616 & 89.528 & 89.439 \\
\hline & $\begin{array}{r}29788.818 \\
87930\end{array}$ & $\begin{array}{l}88.729 \\
87.847\end{array}$ & $\begin{array}{l}88.640 \\
87.752\end{array}$ & 88.551 \\
\hline $\begin{array}{l}6.1 \\
6.2\end{array}$ & $\begin{array}{r}87.930 \\
87.042\end{array}$ & $\begin{array}{l}87.841 \\
860953\end{array}$ & $870^{\circ}$ & $\begin{array}{l}87.664 \\
86.776\end{array}$ \\
\hline 6 & $\begin{array}{l}.042 \\
.155\end{array}$ & 86. & 85 & $\begin{array}{l}86.776 \\
85.888\end{array}$ \\
\hline 6.4 & .267 & 85. & 85.0 & 85 \\
\hline 6.5 & 0 & $84 \cdot 2$ & 84.202 & 84.114 \\
\hline 6.6 & 83.493 & 83.2 & 83.315 & 83.227 \\
\hline 6.7 & 82.605 & 82.516 & 82.428 & $82 \cdot 3$ \\
\hline 6.8 & 81.718 & 81.629 & 81.541 & 81.452 \\
\hline 6.9 & 80.831 & 80.742 & 80.653 & 80.565 \\
\hline & 29779.944 & 75 & 9. & 8 \\
\hline & & & & \\
\hline 702 & 0 & 78 & 7 & 77. \\
\hline 3 & 3 & 77 & 77 & 77 \\
\hline 704 & 76 & 76 & & \\
\hline 705 & 75.510 & $750^{\circ}-1$ & 75. & 75 \\
\hline $7 \cdot 6$ & 3 & $74 \cdot$ & & 74 \\
\hline 7 & 73. & $730^{\circ}$ & 73. & 730 \\
\hline 708 & 9 & $720^{\circ}$ & & $72 \cdot$ \\
\hline 7.9 & 71.962 & 71. & 71.78 & 71.697 \\
\hline & 29771 . & 70. & 70. & 70 \\
\hline $\begin{array}{l}8.1 \\
8.2\end{array}$ & $\begin{array}{l}70 \\
65 \\
\end{array}$ & & & \\
\hline 0. & & $68^{\circ}$ & $\begin{array}{l}69.1 \\
68.2\end{array}$ & \\
\hline 8 & 67.530 & 67.441 & 67.353 & 67. \\
\hline 0 & 66.644 & 66.555 & 66.466 & 66.378 \\
\hline 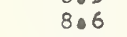 & 65.757 & 6 & 65.580 & 65.492 \\
\hline 8 & 64.872 & 64.7 & 64.695 & \\
\hline 8.8 & 63.985 & 63.897 & 63.808 & 63.720 \\
\hline 8.9 & 63.099 & 63.011 & 62.922 & 62.833 \\
\hline & 29762.213 & & & \\
\hline & & & & \\
\hline 9.2 & 41 & & & \\
\hline & 59.555 & 7 & & \\
\hline 9.4 & 69 & 58.581 & & \\
\hline & 34 & 5 & & \\
\hline 9. & 98 & 9 & & \\
\hline 9.7 & 56.012 & 55. & & \\
\hline 9.8 & 55.127 & 55.038 & 54.949 & 54.861 \\
\hline 909 & & 153 & 064 & $3 \bullet 975$ \\
\hline
\end{tabular}

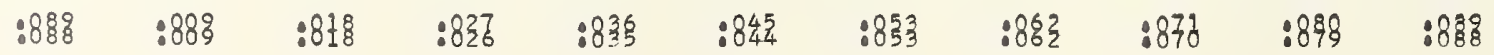


$\begin{array}{rrrrrrrrrrr}3360.0 & 29753.356 & 53.267 & 53.178 & 53.090 & 53.001 & 52.913 & 52.824 & 52.736 & 52.647 & 52.559 \\ 0.1 & 52.470 & 52.382 & 52.293 & 52.204 & 52.116 & 52.027 & 51.939 & 51.850 & 51.761 & 51.673\end{array}$

$\begin{array}{lllllllllll}0.1 & 52.470 & 52.382 & 52.293 & 52.204 & 52.116 & 52.027 & 51.939 & 51.850 & 51.761 & 51.673 \\ 0.2 & 51.584 & 51.496 & 51.408 & 51.319 & 51.231 & 51.142 & 51.054 & 50.965 & 50.877 & 50.788\end{array}$

$\begin{array}{lllllllllll}0.3 & 50.700 & 50.611 & 50.522 & 50.434 & 50.345 & 50.257 & 50.168 & 50.080 & 49.991 & 49.903 \\ 0.4 & 49.814 & 49.726 & 49.637 & 49.549 & 49.450 & 49.372 & 49.283 & 49.195 & 49.106 & 49.018\end{array}$

$\begin{array}{llllllllllll}0.4 & 49.814 & 49.726 & 49.637 & 49.549 & 49.460 & 49.372 & 49.283 & 49.195 & 49.106 & 49.018 \\ 0.5 & 48.929 & 48.841 & 48.752 & 48.653 & 48.575 & 48.486 & 48.398 & 48.309 & 48.021 & 48.133\end{array}$

$\begin{array}{llllllllllll}0.6 & 48.044 & 47.955 & 47.867 & 47.678 & 47.575 & 48.486 & 48.398 & 48.309 & 48.221 & 48.133\end{array}$

0.965822

0.965848

0.965899

0.965924

0.965975
0.966001

0.966052

0.966077

0.966128
0.966154

0.966179

0.966235

0.966281

0.966307

0.9663358

0.966384

0.0966435

0.966460

0.966537

0.966562

0.966613

0.966639

0.966690

0.966749

0.966792

0.966817

0.966869

0.966894
0.966920

0.966945

0.966996

0.967047

0.967073

0.967124

0.967149

0.967200

0.987226
0.967251

0.967303

0.967328

0.967354
0.967379

0.967405

0.967430
0.967456

0.967481

0.967507
0.967532

0.967558

0.967583
0.967609

0.967634

0.967660
0.967686

0.967711

0.967737
0.967762

0.967788

0.967813

0.967839
0.967864

0.967890

0.967915
0.967941

0.967966

0.967992

0.968017
0.968043

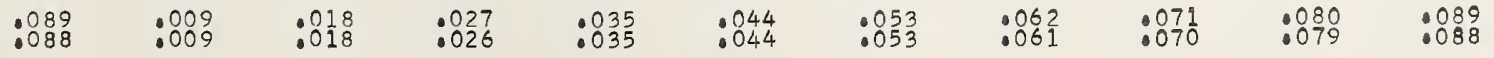




$.02 \quad .03$

.04

0.0
0.17
0.2
0.0
$0:$
$0:$
0.7
0.0

3371.0

1.1
$1: 2$
103

1.45

1.6

1.88

3372.0

2.1
2.2
2.3

2.3
2.4

2.5

2.6

2.8
2.9

3373.0

373.0
3.1
3.2
3.3

3.2
3.3
3.4

3.4
3.5

3.5
3.6

3.7
3.8

3.8
3.9

3374.0

$4 \cdot 1$
4.2
4.3

$4 \cdot 3$
4.4

4.4
405

4.6
4.7

4.8
4.9

337500

5.1
5.2
5.3

503

5.4
5.5
5.6

5.7
5.8

5.9

3376

60.1

6.2

6.3
6.4
6.5
6.6

6.6
6.7

6.8
6.9

33770

7.1
7.2
7.3

7.3
7.4

7.6

7.7
7.8
7.9

3378.0

8.1
8.2
8.3
8.4
8.5
8.6
8.7
80
8.9

3379.0

79.0
9.1
9.2
9.3
9.4
9.5
9.6
9.7
9.8
9.9
9665.070 63.189 62.429 $61.549-61.461$ $60.669-60.581$ $\begin{array}{ll}59.789 & 59.7 \\ 58.909 & 58.8\end{array}$

$\begin{array}{ll}58.029 & 57.941 \\ 57.149 & 57.061\end{array}$

$29656.270 \quad 56.182$

$55.390 \quad 55.302$

$54.510 \quad 54.423$

52.63153 .543

51.872

50.993
50.113

49.234

29647.475

46.596

$43.958 \quad 43.871$

$43.080 \quad 42.992$

$42.201 \quad 42.113$

$\begin{array}{ll}41.322 & 41.234 \\ 40.443 & 40.356 \\ 39.564 & 39.477\end{array}$

29638.686

36.929

$36.050 \quad 35.962$

$35.171 \quad 35.08$

$33.415 \quad 33.327$

$32.536 \quad 32.448$

$\begin{array}{ll}31.658 & 31.570 \\ 30.780 & 30.692\end{array}$

29629.902 $29.023 \quad 29.814$

$\begin{array}{ll}28.0235 & 28.936 \\ 27.145 & 28.057\end{array}$

$27.267 \quad 27 \cdot 180$

26.390226 .302

$\begin{array}{lllll}24.634 & 24.546 & 24.336 & 25.248\end{array}$

$23.756 \quad 23.668 \quad 23.581 \quad 23.492$

$\begin{array}{llll}22.878 & 22.791 & 22.703 & 22.61 \\ 22.000 & 21.913 & 21.825 & 21.73\end{array}$

$29621.123 \quad 21.035$

$\begin{array}{ll}20.245 & 20.157 \\ 19.367 & 19.280\end{array}$

$\begin{array}{ll}19.369 & 19.280 \\ 18.490 & 18.402\end{array}$

16.73516 .647

14.98015 .8903

$\begin{array}{ll}14 \cdot 103 & 14 \cdot 015 \\ 13.226 & 13.138\end{array}$

$\begin{array}{ll}17.437 & 17.34 \\ 16.560 & 16.47 \\ 15.0882 & 15.594\end{array}$

11
110
109

$09.718 \quad 0.507 \quad 10.420 \quad 10.332$

$\begin{array}{llll}0.841 & 08.753 & 09.542 & 09.455\end{array}$

07.08707 .000

$05.334 \quad 05.246$

06.91206 .824

05.15

$29603.581 \quad 03.493$

$\begin{array}{llll}03.581 & 03.493 & 03.405 & 03.317 \\ 02.704 & 02.616 & 02.529 & 02 .\end{array}$

$\begin{array}{lllllllll} & 01.564 & 02.476 & 02.265 & 02.178 & 02.090 & 02.002 & 01.915 \\ 0.389 & 01.301 & 01.213 & 01.126 & 01.038\end{array}$ $00.074 * 99.987 * 90.775 \quad 00.688 \quad 00.500 \quad 00.512 \quad 00.425 \quad 00.337 \quad 00.250 \quad 00.162$ $29599.19899 .11199 .023 \quad 98.935 \quad 98.848 \quad 98.760 \quad 98.673 \quad 98.585 \% 98.497 \quad 98.410$ $\begin{array}{llllllllll}98.322 & 98.234 & 98.147 & 98.059 & 97.971 & 97.884 & 97.796 & 97.708 & 97.621 & 97.533\end{array}$ $\begin{array}{llllllllll}97.446 & 97.358 & 97.271 & 97.183 & 97.095 & 97.008 & 96.920 & 96.832 & 96.745 & 96.65\end{array}$ $\begin{array}{llllllllll}95.693 & 95.606 & 95.518 & 95.430 & 95.343 & 95.255 & 95.167 & 95.080 & 94.8992 & 94.905\end{array}$

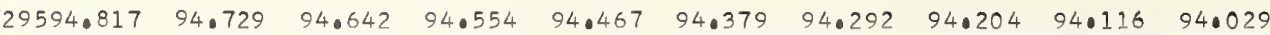

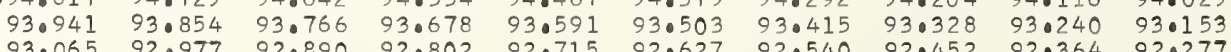
$\begin{array}{llll}9 & 0659\end{array}$

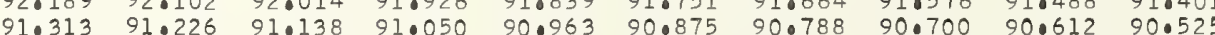

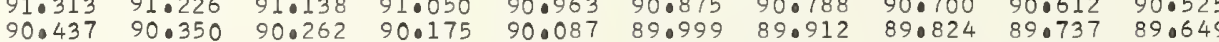
$\begin{array}{llllllllll}90.437 & 89.474 & 90.386 & 80.179 & 90.087 & 89.994 & 89.912 & 89.824 & 89.737 & 89.649\end{array}$ $\begin{array}{llllllllll}88.686 & 88.598 & 88.510 & 88.423 & 88.335 & 88.248 & 88.160 & 88.073 & 870985 & 87.898\end{array}$ $\begin{array}{llllllllll}87.810 & 87.722 & 87.635 & 87.547 & 87.460 & 87.372 & 87.284 & 87.197 & 87.110 & 87.022\end{array}$

$\begin{array}{llllllllll}86.934 & 86.847 & 86.759 & 86.671 & 86.584 & 86.496 & 86.409 & 86.322 & 86.234 & 86.146\end{array}$

$\begin{array}{llllllllll}29586.059 & 85.971 & 85.883 & 85.796 & 85.708 & 85.621 & 85.533 & 85.446 & 85.358 & 85.271\end{array}$ $\begin{array}{lllllllllll}85.184 & 85.096 & 85.009 & 84.921 & 84.833 & 84.746 & 84.658 & 84.571 & 84.483 & 84.396\end{array}$

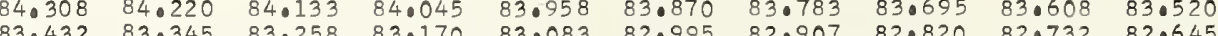
$\begin{array}{llllllllll}83.432 & 83.345 & 83.258 & 83.170 & 83.083 & 82.995 & 82.907 & 82.820 & 82.732 & 82.645 \\ 82.557 & 82.470 & 82.382 & 82.294 & 82.207 & 82.119 & 82.032 & 81.945 & 81.857 & 81.769\end{array}$ $\begin{array}{llllllllll}81.682 & 81.594 & 81.507 & 81.419 & 81.332 & 81.244 & 81.157 & 81.069 & 80.982 & 80.894\end{array}$ $\begin{array}{llllllllll}80.807 & 80.719 & 80.632 & 80.544 & 80.456 & 80.369 & 80.281 & 80.194 & 80.106 & 80.019\end{array}$ $\begin{array}{llllllllll}79.031 & 79.844 & 70.756 & 70.669 & 79.581 & 79.494 & 79.406 & 79.319 & 79.231 & 79.144\end{array}$ $\begin{array}{llllllllll}79.056 & 78.969 & 78.881 & 78.793 & 78.706 & 78.618 & 78.531 & 78.444 & 78.2356 & 78.269\end{array}$ $\begin{array}{llllllllll}79.056 & 78.969 & 78.88 & 78.793 & 78.706 & 78.618 & 78.531 & 78.444 & 78.356 & 78.069 \\ 78.181 & 78.094 & 78.006 & 77.918 & 77.831 & 77.743 & 77.656 & 77.568 & 77.481 & 77.393\end{array}$ $(n-1) \times 1000 \quad \lambda(n-1)$

$\begin{array}{ll}0.287261 & 0.968069 \\ 0.287260 & 0.968094 \\ 0.287259 & 0.968120 \\ 0.287258 & 0.968145 \\ 0.287257 & 0.968171 \\ 0.287256 & 0.968196 \\ 0.287255 & 0.968222 \\ 0.287254 & 0.968247 \\ 0.287253 & 0.968273 \\ 0.287252 & 0.968298\end{array}$

0.287251

0.287250
0.287249
0.287248

0.287248

0.287247

0.287246

0.0287245

0.287243

0.287242

0.287241

0.287240

0.287238

0.287237

0.287236

0.287235

0.287234
0.287233

0.287232

0.287231

0.287230

0.287229
0.287229

0.287228

0.287227

0.287226

0.287225

0.287223

0.287222

0.287221

0.287219

0.287218

0.287216

0.287215

0.287213

0.287213

0.287212

0.287210

0.287209

0.287207

0.287206

0.287204

0.287203
0.287202
0.287201

0.287202

0.287199

0.287198

0.287197
0.287197
0.287196

0.287196

0.287195

0.287194

0.287193

0.287192

0.287190

0.287189

0.287188
0.287187
0.287186

0.287187

0.287185

0.287184

0.287182

0.287181

0.287181

0.287179

0.287178
0.287177

0.287176

0.287175
0.287174

0.287173

0.287171

0.287170

0.287169

0.287168
0.287167

.010

0.968324

0.968349
0.968375

0.968400

0.968426

0.968452

0.968503

0.968528

0.968579

0.968605

0.968630

0.968656

0.968681

0.968707

0.968758

0.968784

0.968835

0.968860

0.968886

0.968911

0.968962

0.968988

0.969013

0.969064

0.969090

0.969126

0.969141

0.969167

0.969218

0.969243

0.969269

0.969294
0.969320

0.969345

0.969371

0.969396

0.969448

0.969473

0.969499

0.969550

0.969575

0.969601

0.969626

0.969652

0.969703

0.969729

0.969754

0.969805

0.969831

0.969856

0.969882

0.969907
0.969933

0.969933

0.969984

0.970010

0.970035

0.970061
0.970086

0.990112

0.970137

0.970188

0.970214

0.970239

0.970265

0.970316

0.970342

0.970367

0.970393

0.970444

0.970469

0.970495

0.970520

0.970546

0.970597

.001

.003

.004

.005

.006

$: 86 ?$

$.008 \quad .009$

$: 889$ 


$\begin{array}{ll}.0 & 295 \\ .1 & \\ .2 & \\ .3 & \\ .4 & \\ .5 & \\ .6 & \\ .7 & \\ .8 & \\ .9 & \end{array}$

76.431
75.556
74.681
73.806
72.931
72.056
71.182
70.307
69.433

$\begin{array}{lll}77.219 & 77.131 & 77.043 \\ 76.343 & 76.256 & 76.16\end{array}$

$\begin{array}{lllllll}76.956 & 76.868 & 76.781 & 76.693 & 76.606 & 76.519 \\ 76.081 & 75.993 & 75.906 & 75.818 & 75.731 & 75.643\end{array}$

0.287166

0.970623

$\begin{array}{lllllllllll} & \\ 75.56 & 75.468 & 75.381 & 75.293 & 75.206 & 75.118 & 75.031 & 74.943 & 74.856 & 74.768\end{array}$

$\begin{array}{llllllllll}73.719 & 73.631 & 73.543 & 73.456 & 73.369 & 73.281 & 73.194 & 73.106 & 73.019\end{array}$

$\begin{array}{lll}72.884 & 72.756 & 72.669\end{array}$

$7 ? .707 \quad 71.619 \quad 71.532$

72.194

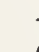

\subsection{0}

$71.357 \quad 71.270$

29568.558

1.2

66.809

68.471

68.383 .680

650060

65.847
64.973

67.50968 .296

69.083

68.908

63.312

63.224

$\begin{array}{ll}67.634 & 66.547 \\ 65.760 & 65.0672\end{array}$

$67.334 \quad 67.246$

68.033

67.946

$69.608 \quad 69.520$

$67.858 \quad 670771$

$\begin{array}{llllll}66.459 & 66.372 & 66.285 & 66.197 & 66.110 & 66.8972\end{array}$

$65.410 \quad 65.323 \quad 65.235 \quad 65.14$

$\begin{array}{llllll}64.711 & 64.623 & 64.536 & 64.448 & 64.361 & 64.273 \\ 63.836 & 63.749 & 63.662 & 63.574 & 63.487 & 63.399\end{array}$

61.563
60.689

64.01163 .924

62.787

$\begin{array}{ll}63.574 & 63.487 \\ 62.700 & 62.612\end{array}$

62.08

62.000

$\begin{array}{llll}61.913 & 61.826 & 62.612 & 62.525 \\ 61.651 & 61.651\end{array}$

3382.0

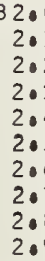

$\begin{array}{rllll}29559.815 & 59.728 & 59.640 & 59.553 & 50.0\end{array}$

$\begin{array}{llll}58.941 & 58.854 & 58.767 & 58.67 \\ 58.067 & 57.980 & 57.893 & 57.80 \\ 57.0194 & 57.106 & 57.019 & 56.932\end{array}$

$\begin{array}{lllll}56.320 & 56.233 & 56.145 & 56.93\end{array}$

54.573

$\begin{array}{lll}55.359 & 55.271 & 55.184 \\ 54.485 & 54.398 & 54.310\end{array}$

$\begin{array}{llll}53.699 & 53.611 & 53.524 & 53.437\end{array}$

52.825
51.951

3383.0

3.0
3.1
3.
3.
3.
3.
3.6
3.7
3.0
3.

29551.078

50.205
49.331

$50.991 \quad 50.903 \quad 50.816$

60.340

47.584

49.24

50.030
49.156

50.816
49.943
49.069
498.

$59.466 \quad 59.378$

$\begin{array}{ll}58.592 & 58.504 \\ 57.718 & 57.630\end{array}$

56.844

$55.970 \quad 55.883$

$\begin{array}{ll}54.223 & 55.009 \\ 54.135\end{array}$

$52.349 \quad 53.26$

52.476
51.602

$45.838 \quad 45.750$

$\begin{array}{ll}46.536 & 46.449\end{array}$

$50.729 \quad 50.641$

(6.165

$\begin{array}{lll}60.952 & 60.864 & 60.777 \\ 60.078 & 59.990 & 59.903\end{array}$

0.28716

0.287164

0.287162

0.287161

0.287159
0.287138

0.287157

0.287156

0.287155
0.287154
0.2815

0.28715
0.0287152

0.287151

0.287149

0.970674

0.970699

0.970750

0.970776

0.970827

0.970878

0.970904

0.970929
0.970955

0.970980

0.971031

0.971057

0.287148

0.971108

0.28714

0.287145

0.287144

0.287142

0.287141

0.287139

0.971134

0.971185

0.971236
0.971261

$54.048 \quad 53.961 \quad 53.873 \quad 53.786$

$\begin{array}{llll}53.175 & 53.087 & 53.000 & 52.913\end{array}$

0.287139

0.971312

0.971338

0.287137

0.287136

0.287135

0.287133

0.287131

0.971389

0.971415

0.971466

0.971491

0.971542

$\begin{array}{llllllllll}44.091 & 44.004 & 43.917 & 43.829 & 43.742 & 43.655 & 43.568 & 43.481 & 43.393 & 43030 \\ 43.219 & 43.132 & 43.044 & 42.057 & 42.870 & 42.702 & 42.695 & 2.008 & 42.520 & 420433\end{array}$

$\begin{array}{rrrrrrrrrrr}3384.0 & 29542.346 & 42.259 & 42.171 & 42.084 & 41.997 & 41.909 & 41.822 & 41.735 & 41.647 & 41.560 \\ 4.1 & 41.473 & 41.385 & 41.298 & 41.211 & 41.124 & 41.036 & 40.949 & 40.862 & 40.744 & 40.687\end{array}$

$\begin{array}{lllllllllll}4.2 & 40.600 & 40.512 & 40.425 & 40.338 & 40.251 & 40.164 & 40.076 & 39.8989 & 39.902 & 39.814\end{array}$

0.287129
0.287128
0.287127

0.287127

0.287125

0.287124

$\begin{array}{llllllllll}38.854 & 38.767 & 38.680 & 38.592 & 38.505 & 38.418 & 38.331 & 38.243 & 38.156 & 38.069 \\ 37.981 & 37.894 & 37.807 & 37.720 & 37.632 & 37.545 & 37.458 & 37.371 & 37.283 & 37.196 \\ 37.109 & 37.021 & 36.934 & 36.847 & 36.760 & 36.072 & 36.585 & 36.498 & 36.411 & 36.323\end{array}$

$4.5 \quad 37.981$

4.6

37.021

37.458

$37.371 \quad 37.283 \quad 37.196$

0.287123

0.287122

0.971594
0.971619

4.9
4.9

35.364

3385

5.1
5.2
5.3
5.4
5.5
5.6
5.7
5.

29533.6
32.746

33.531

$\begin{array}{ll}35.189 & 35.102 \\ 34.316 & 34.229\end{array}$

35.014
34.14

.927

$\begin{array}{llll}.712 & 35.625 & 35.538 & 35.451\end{array}$

$\begin{array}{lll}34.753 & 34.666 & 34.578 \\ 3.880 & 33.793 & 33.706\end{array}$

0.287120

0.287119

0.287117

0.2871916

0.287914

0.287112

$\begin{array}{lll}28.385 & 28.298 \\ 27.513 & 27.426 & 2\end{array}$

$26.641 \quad 26.553$

$28.211 \quad 28.123$

29.780

28.036
27.164
25.292

28.821
27.948

27.948
27.077 27.862

$27.774 \quad 27.687 \quad 270500$

$\begin{array}{lll}26.902 & 26.815 & 27.60728\end{array}$

0.287111

$\begin{array}{lllllllllll}3386.0 & 29524.897 & 24 \cdot 809 & 24.722 & 24 \cdot 635 & 24.548 & 24.461 & 24 \cdot 373 & 24 \cdot 286 & 24 \cdot 199 & 24 \cdot 112\end{array}$

$\begin{array}{lllllllllll}6.1 & 24.025 & 23.937 & 23.850 & 23.763 & 23.676 & 23.589 & 23.501 & 23.414 & 23.327 & 23.240\end{array}$

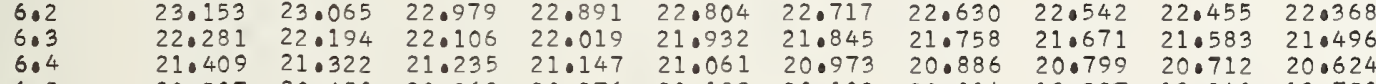

6.5

20.537

20.450

$21.235 \quad 21.147$

$\begin{array}{llll}20.886 & 20.799 & 20.712 & 20.624 \\ 20.014 & 10.927 & 19.840 & 19.753\end{array}$

$\begin{array}{llllllllll}19.666 & 19.578 & 19.491 & 19.404 & 19.317 & 19.230 & 19.143 & 19.056 & 18.968 & 18.881\end{array}$

$\begin{array}{llllllllll}17.922 & 17.835 & 17.748 & 17.661 & 17.574 & 17.487 & 17.399 & 17.312 & 17.0225 & 170138\end{array}$

0.287110

0.287109

0.287108

0.287106

0.287104

0.971645

0.971696

0.971921

0.971772

0.971823

0.971849

6.8

3387.

$29516.180 \quad 16.09$

$$
\text { in }
$$

$\begin{array}{ll}15.308 & 15.22 \\ 14.437 & 14.35\end{array}$

$13.566 \quad 13.479$

$\begin{array}{ll}12.694 & 12.607 \\ 11.823 & 11.736\end{array}$

$10.952 \quad 10.86$

$09.210 \quad 09.123$

$16.005 \quad 15.918$

$16.702 \quad 16.615$

$\begin{array}{llll}17.399 & 17.312 & 17.225 & 17.138 \\ 16.528 & 16.441 & 16.354 & 16.267\end{array}$

0.287102

0.971900

0.971926

0.971977

0.972002

0.972053

0.972105

.287101

0.287090

0.287099

0.287098

0.287096

0.287095

0.287094
0.287093

0.287092

0.287090

0.287089

0.287087

0.287086

0.287085

0.287084

0.972156

0.972181

0.972232

0.972258
0.972283

0.972309

0.972335

0.972360

0.972411

0.972437

0.972462

0.972513

0.972539

0.972565

0.972616

0.972667

0.972692

00972718

0.972769

$\begin{array}{llllllllll}03.984 & 03.897 & 03.810 & 03.723 & 03.636 & 03.549 & 03.462 & 03.375 & 03.288 & 03.201\end{array}$

$\begin{array}{llllllllll}03.114 & 03.027 & 02.940 & 02.853 & 02.766 & 02.678 & 02.592 & 02.504 & 02.417 & 02.330\end{array}$

$\begin{array}{llllllllll}01.373 & 01.286 & 01.199 & 01.112 & 01.025 & 0.0338 & 00.851 & 00.763 & 00.677 & 00.590\end{array}$

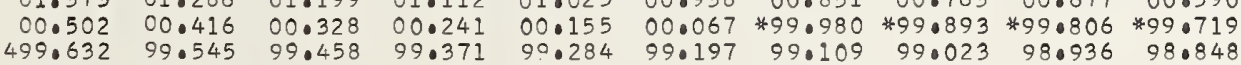

0.287083

0.972820

0.972846

0.972871

3389.0

9.0
9.1
9.3
9.4
9.6
9.7
9.8
9.9

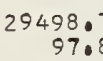

$\begin{array}{llllllllll}97.891 & 98.675 & 98.587 & 98.500 & 98.413 & 98.326 & 98.240 & 98.152 & 98.065 & 97.978 \\ 97.02 & 97.717 & 97.630 & 97.543 & 97.456 & 97.369 & 97.282 & 97.195 & 97.108\end{array}$

$\begin{array}{llllllllll}97.021 & 96.934 & 96.847 & 96.760 & 96.673 & 96.586 & 960499 & 96.412 & 96.324 & 96.237\end{array}$

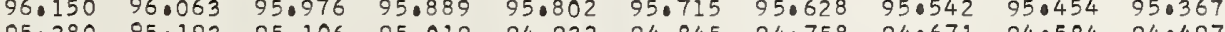
$95.280 \quad 95.193 \quad 95.106 \quad 95.019 \quad 94.932 \quad 94.845 \quad 94.75894067194 .58494 .497$

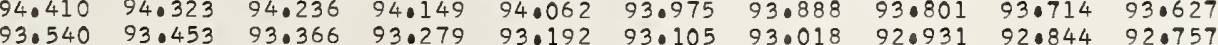

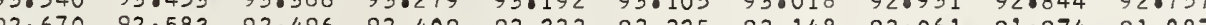

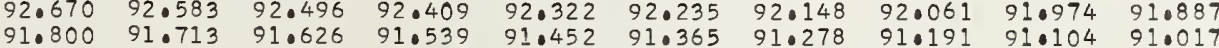

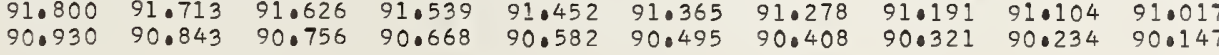

0.287082

0.972922

0.287082
0.287081
0.2870

0.287080

0.287079

0.287076

0.287095

$0: 972948$ 


.04

.05

.06

.07
$\begin{array}{llllllllll}89.060 & 89.973 & 89.885 & 89.799 & 89.712 & 89.625 & 89.538 & 89.451 & 89.364 & 89.277 \\ 89.190 & 89.103 & 89.016 & 88.929 & 88.842 & 88.755 & 88.668 & 88.581 & 88.494 & 88.407\end{array}$ $\begin{array}{llllllllll}88.320 & 88.233 & 88.146 & 88.059 & 87.972 & 87.885 & 87.799 & 87.712 & 87.625 & 87.538\end{array}$ $\begin{array}{llllllllll}87.450 & 87.364 & 87.277 & 87.190 & 87.103 & 87.016 & 86.929 & 86.842 & 86.755 & 86.668\end{array}$ $\begin{array}{llllllllll}86.581 & 86.494 & 86.407 & 86.320 & 86.233 & 86.146 & 86.059 & 85.972 & 85.885 & 85.798 \\ 85.711 & 85.625 & 85.537 & 85.450 & 85.363 & 85.276 & 85.190 & 85.103 & 85.016 & 84.929\end{array}$ $\begin{array}{llllllllll}84.842 & 84.755 & 84.668 & 84.581 & 84.494 & 84.407 & 84.320 & 84.233 & 84.146 & 84.059\end{array}$ $\begin{array}{llllllllll}83.972 & 83.885 & 83.798 & 83.711 & 83.624 & 83.537 & 83.450 & 83.363 & 83.277 & 83.189\end{array}$ $\begin{array}{llllllllll}83.103 & 83.016 & 82.929 & 82.842 & 82.755 & 82.668 & 82.581 & 82.494 & 82.407 & 82.320 \\ 82.233 & 82.146 & 82.059 & 81.972 & 81.885 & 81.798 & 81.711 & 81.625 & 81.538 & 81.450\end{array}$

$\begin{array}{ll}0.287073 & 0.973178 \\ 0.287072 & 0.973204 \\ 0.287071 & 0.973229 \\ 0.287070 & 0.973255 \\ 0.287069 & 0.9733280 \\ 0.287069 & 0.973306 \\ 0.287068 & 0.973331 \\ 0.287067 & 0.973357 \\ 0.287066 & 0.973382 \\ 0.287065 & 0.973408\end{array}$

$\begin{array}{ll}481.364 & 81.277 \\ 80.494 & 80.407 \\ 79.625 & 79.538 \\ 78.756 & 78.669 \\ 77.886 & 77.800 \\ 77.017 & 76.930 \\ 76.148 & 76.061 \\ 75.279 & 75.192 \\ 74.410 & 74.323 \\ 73.542 & 73.455 \\ & \\ 472.673 & 72.586 \\ 71.804 & 71.717 \\ 70.935 & 70.848 \\ 70.066 & 69.979 \\ 69.197 & 69.111 \\ 68.329 & 68.242 \\ 67.460 & 67.373 \\ 66.592 & 66.505 \\ 65.723 & 65.636 \\ 64.855 & 64.768\end{array}$

1.19081 .103

$81.016 \quad 80.929$

$80.842 \quad 80.755 \quad 80.668 \quad 80.581$

0.287064

0.973434

1.2

1.5

1.7

392.

2.2

2.4

2.5
2.6
2.7

3.2

63.900

$\begin{array}{lll}80.321 & 80.234 & 80 . \\ 79.451 & 79.364 & 79\end{array}$

$\begin{array}{lllllll}.147 & 80.059 & 79.973 & 79.886 & 79.799 & 79.712 \\ .277 & 79.190 & 79.103 & 79.016 & 78.930 & 78.843\end{array}$

$\begin{array}{llllllll}.582 & 78.495 & 78.408 & 78.321 & 78.234 & 78.147 & 78.060 & 77.973 \\ 713 & 77.626 & 77.539 & 77.452 & 77.365 & 77.278 & 77.191 & 77.104\end{array}$

76.844 76.757 $76.670 \quad 76.583$

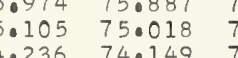

$\begin{array}{lll}7.801 & 75.583 \\ 7501\end{array}$

75.627

$\begin{array}{lll}77.409 & 76.322 & 76.235\end{array}$

$\begin{array}{lllllll} & \end{array}$

$73.802 \quad 73.715 \quad 73.628$

0.287062

0.287081

0.287060

0.287058

0.287057

0.287056

0.287055

0.287054

0.287053

0.287051

.2287050

0.287049
0.287048

0.287047

0.287046

0.973459
0.973485

0.973510

0.973536

0.973587

0.973613

0.973664

0.287045

0.287044

0.287044

0.287042

$\begin{array}{llllllllll}61.381 & 61.295 & 61.208 & 61.121 & 69.034 & 60.947 & 60.860 & 60.774 & 60.687 & 60.600\end{array}$

$\begin{array}{llllllllll}60.513 & 60.427 & 60.340 & 60.253 & 60.166 & 60.079 & 59.992 & 59.906 & 59.819 & 59.732 \\ 59.646 & 59.550 & 59.472 & 50.385 & 50.298 & 59.211 & 59.125 & 59.038 & 58.951 & 58.865\end{array}$

$\begin{array}{llllllllll}58.778 & 58.691 & 58.604 & 58.517 & 58.430 & 58.343 & 58.257 & 58.170 & 58.083 & 57.996\end{array}$

3.7

$57.302 \quad 570215 \quad 57.128$

0.287041

0.287040

0.287038

0.973689

0.973715
0.973740

0.973766

0.973792

0.973843

0.973843
0.973868

0.973894
0.973919

0.973945

0.973970

0.973996

0.974022

0.974073

0.974098

$55.132 \quad 55.045$

$\begin{array}{ll}55.895 & 56.607 \\ 55.739\end{array}$

0.287036

0.287035

0.287034

$\begin{array}{llllllllll}53.570 & 53.483 & 53.396 & 53.310 & 53.223 & 53.136 & 53.049 & 52.962 & 52.876 & 52.789\end{array}$

$\begin{array}{llllllllll}52.702 & 52.615 & 52.529 & 52.442 & 52.355 & 52.269 & 52.182 & 52.095 & 52.008 & 51.0921\end{array}$

$\begin{array}{llllllllll}51.834 & 51.748 & 51.661 & 51.574 & 51.488 & 51.401 & 51.314 & 51.227 & 51.140 & 51.053\end{array}$

$\begin{array}{llllllllll}50.967 & 50.880 & 50.793 & 50.707 & 50.620 & 50.533 & 50.447 & 50.360 & 50.273 & 50.186\end{array}$

$\begin{array}{llllllllll}49.232 & 49.145 & 49.058 & 48.971 & 48.885 & 48.798 & 48.711 & 48.625 & 48.538 & 49.319\end{array}$

$\begin{array}{lllllllllll}48.364 & 48.278 & 48.191 & 48.104 & 48.017 & 47.931 & 47.844 & 47.757 & 47.670 & 47.584\end{array}$

4.8
4.9

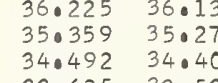

$33.625 \quad 33.59$

$\begin{array}{llll}32.0759 & 32.672 & 32.586 & 32.499\end{array}$

$31.026 \quad 300.940 \quad 30.853 \quad 310639$

$\begin{array}{ll}43.681 & 43.59\end{array}$

$42.814 \quad 42.72$

46.109
45.242
4.350

$41.080 \quad 40.99$

$43.508 \quad 430$

$\begin{array}{lll}.022 & 45.936 & 45.849\end{array}$

0.287027

0.2287026
0.287025

0.287024

0.287023
0.287022

0.287021

0.287020
0.287019
0.2870

0.287019

0.974201

0.974252

0.974277

0.974303

0.974328

0.974379

0.974405
0.974431

0.974456

0.974482

0.974533

0.974558

0.974584
0.974610

0.974635

0.974661

0.287018

0.287017

0.287015

0.287014

0.287012

0.287010

0.287009

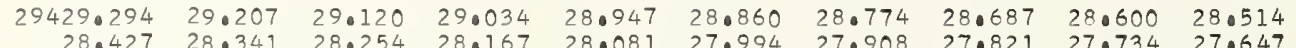

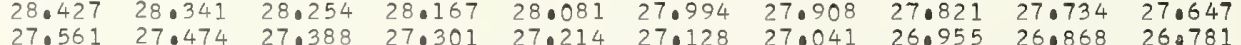

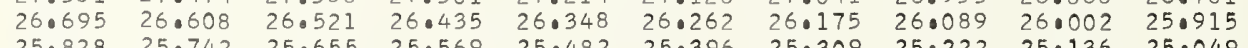

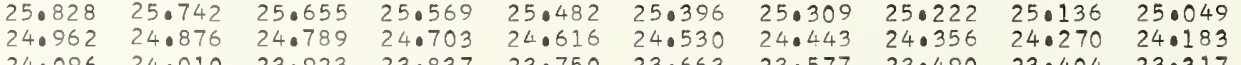

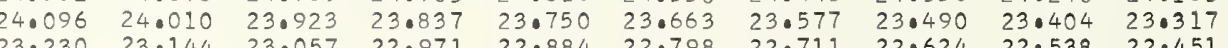

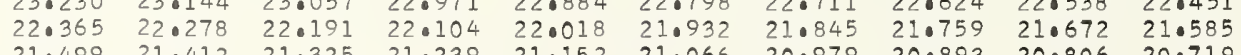

0.287008

0.287007

0.287006

0.287005

0.287003

0.287001

0.974712

$$
\begin{array}{r}
2920 . \\
19 . \\
18 . \\
18 . \\
17 . \\
16 . \\
15 \\
14 . \\
13 . \\
12 .
\end{array}
$$

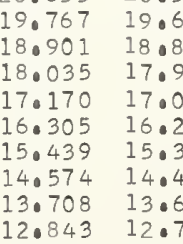

$\begin{array}{rrrrr}9.0 & 29411.978 & 11.891 & 11.804 & 11.718 \\ 9.1 & 11.112 & 11.026 & 10.939 & 10.853 \\ 9.2 & 10.247 & 10.160 & 10.074 & 09.988 \\ 9.3 & 09.382 & 09.295 & 09.209 & 09.122 \\ 9.4 & 08.517 & 08.430 & 08.344 & 08.257 \\ 9.5 & 07.652 & 07.565 & 07.479 & 07.392 \\ 9.6 & 06.787 & 06.700 & 06.614 & 06.527 \\ 9.7 & 05.921 & 05.835 & 05.749 & 05.662 \\ 9.8 & 05.056 & 04.970 & 04.884 & 04.797 \\ 9.9 & 04.191 & 04.105 & 04.019 & 03.932\end{array}$
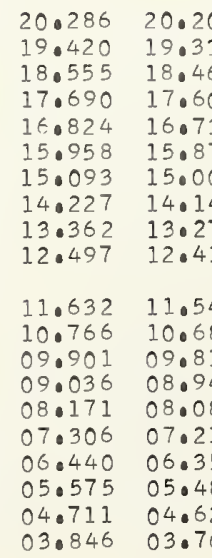

$\begin{array}{llll}20.113 & 20.027 & 19.940 \quad 19.854\end{array}$

0.286999

0.286998

0.286996

0.286996

0.286995

0.286993

0.286993
0.286992

0.286991

0.974737

0.974763
0.974789

0.974814

0.974840

0.974865

0.0974916

0.974968

0.974993

0.975019
0.975044

0.975070

0.975070

0.975121
0.975147

0.975147

0.975198

0.286990

0.286989

0.286988
0.286987

0.286986

0.286985

0.286984

0.286984

0.286983
0.286982

0.975223

0.975249

0.975274
0.975300

0.975326

0.975351

0.975402

0.975428

0.975479

0.975503

0.975556

0.975581

0.975632

0.975658
0.975684

0.975709

.010

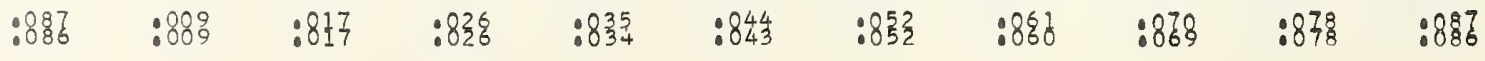


$\begin{array}{llllllllll}03.327 & 03.241 & 03.154 & 03.068 & 02.981 & 02.895 & 02.809 & 02.722 & 02.635 & 02.549 \\ 02.463 & 02.376 & 02.290 & 02.203 & 02.117 & 02.030 & 01.944 & 01.857 & 01.771 & 01.684\end{array}$

$\begin{array}{lllllllllll}0.2 & 01.598 & 01.511 & 01.425 & 01.338 & 01.252 & 01.166 & 01.079 & 00.993 & 00.906 & 00.820\end{array}$

$\begin{array}{lllllllllll}.4 & 2.9399 .968 & 99.782 & 99.696 & 99.609 & 99.523 & 99.436 & 99.350 & 99.263 & 99.177 & 99.091\end{array}$

$\begin{array}{lllllllllll}0.5 & 99.004 & 98.917 & 98.831 & 98.745 & 98.658 & 98.572 & 98.485 & 98.399 & 98.312 & 98.226 \\ 0.6 & 98.140 & 98.053 & 97.967 & 97.880 & 97.794 & 97.707 & 97.621 & 97.534 & 97.448 & 97.362\end{array}$

$\begin{array}{lllllllllll}0.6 & 98.140 & 98.053 & 97.967 & 97.880 & 97.794 & 97.707 & 97.621 & 97.534 & 97.448 & 97.362 \\ 0.7 & 97.275 & 97.188 & 97.102 & 97.016 & 96.929 & 96.843 & 96.756 & 96.670 & 96.583 & 96.497\end{array}$

$\begin{array}{llllllllll}96.411 & 96.324 & 96.238 & 96.151 & 96.065 & 95.978 & 95.892 & 95.806 & 95.719 & 95.633 \\ 95.546 & 95.460 & 95.374 & 95.287 & 95.200 & 95.114 & 95.027 & 94.941 & 94.855 & 94.768\end{array}$

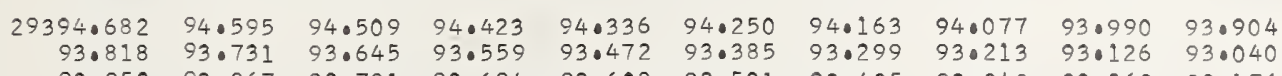

$\begin{array}{lllllllllll}1.2 & 92.953 & 92.867 & 92.781 & 92.694 & 92.608 & 92.521 & 92.435 & 92.348 & 92.262 & 92.176\end{array}$ $\begin{array}{llllllllll}92.089 & 92.003 & 91.917 & 91.830 & 91.744 & 91.657 & 91.571 & 91.484 & 91.398 & 91.312 \\ 91.225 & 91.139 & 91.052 & 90.966 & 90.880 & 90.793 & 90.707 & 90.620 & 90.534 & 90.447\end{array}$ $\begin{array}{llllllllll}91.225 & 91.139 & 91.052 & 90.966 & 96.880 & 90.793 & 90.707 & 90.620 & 90.534 & 90.447 \\ 90.361 & 90.275 & 90.188 & 90.102 & 90.016 & 89.929 & 89.843 & 89.757 & 89.670 & 89.584\end{array}$ $\begin{array}{llllllllll}89.498 & 89.411 & 89.325 & 89.239 & 89.152 & 89.065 & 88.979 & 88.893 & 88.806 & 88.720\end{array}$ $\begin{array}{lllllllllll}88.634 & 88.547 & 88.461 & 88.375 & 88.288 & 88.201 & 88.115 & 88.029 & 87.942 & 87.856\end{array}$ $\begin{array}{llllllllll}87.770 & 87.683 & 87.597 & 87.510 & 87.424 & 87.338 & 87.251 & 87.165 & 87.078 & 86.992 \\ 86.906 & 86.819 & 86.733 & 86.646 & 86.560 & 86.474 & 86.387 & 86.301 & 86.215 & 86.128\end{array}$

$\begin{array}{lllllllllll}3409.0 & 29325.703 & 25.617 & 25.531 & 25.445 & 25.359 & 25.272 & 25.187 & 25.101 & 25 \cdot 014 & 24 \cdot 929\end{array}$

$\begin{array}{lllllllllll}9.1 & 24.843 & 24.756 & 24.671 & 24.584 & 24.499 & 24.412 & 24.326 & 24.240 & 24.154 & 24.068 \\ 9.2 & 23.982 & 23.896 & 23.810 & 23.724 & 23.638 & 23.552 & 23.466 & 23.380 & 23.294 & 23.208 \\ 9.3 & 23.9122 & 23.036 & 22.950 & 22.864 & 23.778 & 22.692 & 22.606 & 22.520 & 22.434 & 22.348\end{array}$ $\begin{array}{llllllllll}23.122 & 23.036 & 22.950 & 22.864 & 22.778 & 22.692 & 22.506 & 22.520 & 22.434 & 22.348 \\ 22.262 & 22.176 & 22.090 & 22.004 & 21.918 & 21.832 & 21.746 & 21.660 & 21.574 & 21.488\end{array}$ $\begin{array}{llllllllll}21.402 & 21.316 & 21.230 & 21.144 & 21.058 & 20.972 & 20.886 & 20.800 & 20.714 & 20.628\end{array}$ $\begin{array}{lllllllllll}20.542 & 20.456 & 20.370 & 20.284 & 20.198 & 20.112 & 20.026 & 19.940 & 19.854 & 19.768 \\ 19.682 & 19.597 & 19.511 & 19.425 & 10.339 & 19.253 & 19.167 & 19.081 & 18.905 & 18.909\end{array}$ $\begin{array}{llllllllll}19.682 & 19.597 & 19.511 & 19.425 & 10.339 & 19.253 & 19.167 & 19.081 & 18.905 & 18.909 \\ 18.823 & 18.737 & 18.651 & 18.565 & 18.479 & 18.393 & 18.307 & 18.221 & 18.135 & 18.049\end{array}$ $\begin{array}{llllllllll}17.963 & 17.877 & 17.791 & 17.705 & 17.619 & 17.533 & 17.447 & 17.361 & 17.275 & 17.189\end{array}$

0.976067

0.976118

0.976169

0.976195
0.976221

0.976246

0.976272
0.976297

0.976323

0.976348
0.976374

0.976400

0.976451
0.976476

0.976502

0.976553

0.976604

0.976655

0.976707

0.976758

0.976809

0.976860

0.976886

0.976937

0.976988

0.977013
0.977039

0.977090

0.977116

$0: 997167$
0.971193

$0: 9772124$

0.977269

0.977295

0.977346

0.0979397

0.0977448

0.977474
0.977499

0.077525
0.977551

0.977551

0.977602

0.977653

0.977679

0.977730
0.977755

0.977781

0.977806
0.977832

0.997858

0.977883
0.977909

0.977934

0.977986

$0.97803^{-}$

0.978088

0.978113

0.978165

0.978190
0.978216

0.978241
0.978267

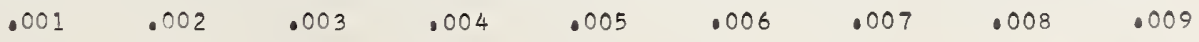

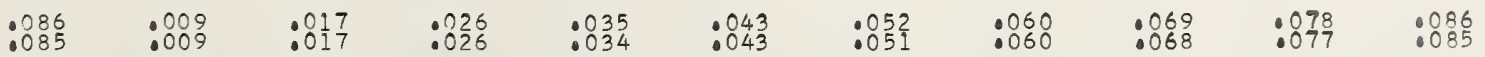


$\begin{array}{llllllllll}9308.509 & 08.423 & 08.337 & 08.250 & 08.165 & 08.079 & 07.993 & 07.907 & 07.821 & 07.735\end{array}$

0.286880

0.286879

0.286879
0.286878

0.286877

0.286876

0.286875

0.286874
0.286873
0.286872

0.286872

$\begin{array}{llllllllll}02.495 & 02.409 & 02.324 & 02.238 & 02.152 & 02.066 & 01.980 & 01.894 & 01.808 & 01.722\end{array}$

$\begin{array}{llllllllll}01.636 & 01.551 & 01.465 & 01.379 & 01.293 & 01.207 & 01.121 & 01.035 & 00.949 & 00.864 \\ 00.778 & 00.692 & 00.506 & 00.520 & 00.434 & 00.348 & 00.262 & 00.177 & 00.091 & 00.005\end{array}$

0.286871

0.286870

0.286869

0.286867

0.286867

0.286865

0.286865

0.286863

0.0978497
0.978523

0.978548

0.978574

0.978600

0.978625

0.978651

0.978702

0.978728
0.978753

0.978779

$\begin{array}{llllllllll}96.484 & 96.399 & 96.313 & 96.227 & 96.141 & 96.055 & 95.969 & 95.884 & 95.798 & 95.712\end{array}$

$\begin{array}{llllllllll}94.767 & 94.581 & 95.454 & 95.368 & 95.282 & 95.197 & 95.111 & 95.025 & 94.939 & 94.853 \\ & 94.596 & 94.510 & 94.424 & 94.338 & 94.252 & 94.167 & 94.081 & 93.995\end{array}$

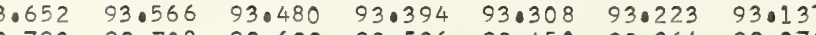

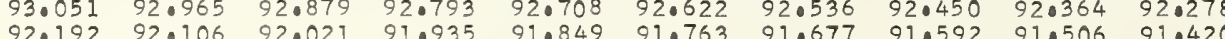

0.286862

0.286861

0.286860

0.286859

0.286858

0.286857

0.286856

0.286855

$\begin{array}{llllllllll}86.186 & 86.100 & 86.015 & 85.929 & 85.843 & 85.757 & 85.671 & 85.586 & 85.500 & 85.414 \\ 85.328 & 85.242 & 85.157 & 85.071 & 84.985 & 84.899 & 84.813 & 84.728 & 84.642 & 84.556\end{array}$

$\begin{array}{llllllllll}84.470 & 84.385 & 84.299 & 84.213 & 84.127 & 84.042 & 83.956 & 83.870 & 83.784 & 83.698 \\ 83.613 & 83.527 & 83.441 & 83.355 & 83.270 & 83.184 & 83.098 & 83.012 & 82.926 & 82.841\end{array}$

$\begin{array}{llllllllll}29282.755 & 82.669 & 82.583 & 82.498 & 82.412 & 82.326 & 82.240 & 82.154 & 82.069 & 81.983\end{array}$ $\begin{array}{llllllllll}81.897 & 81.811 & 81.726 & 81.640 & 81.554 & 81.468 & 81.383 & 81.297 & 81.211 & 81.125\end{array}$ $\begin{array}{llllllllll}81.040 & 80.954 & 80.868 & 80.782 & 80.697 & 80.611 & 80.525 & 80.439 & 80.354 & 80.268 \\ 80.182 & 80.096 & 80.010 & 79.925 & 79.839 & 79.753 & 79.667 & 79.582 & 79.496 & 79.410\end{array}$ $\begin{array}{llllllllll}79.324 & 79.239 & 79.153 & 79.067 & 78.981 & 78.896 & 78.810 & 78.724 & 78.638 & 78.552 \\ 78.467 & 78.381 & 78.295 & 78.210 & 78.124 & 78.038 & 77.953 & 77.867 & 77.781 & 77.695\end{array}$ $\begin{array}{llllllllll}78.467 & 78.381 & 78.295 & 78.210 & 78.124 & 78.038 & 77.953 & 77.867 & 77.781 & 77.695 \\ 77.609 & 77.523 & 77.438 & 77.352 & 77.267 & 77.181 & 77.095 & 77.010 & 76.924 & 76.838\end{array}$ $\begin{array}{llllllllll}76.752 & 76.667 & 76.581 & 76.495 & 76.409 & 76.324 & 76.238 & 76.152 & 76.067 & 75.981\end{array}$ $\begin{array}{llllllllll}75.895 & 75.810 & 75.724 & 75.638 & 75.552 & 75.467 & 75.381 & 75.295 & 75.209 & 75.123 \\ 75.038 & 74.952 & 74.866 & 74.781 & 74.695 & 74.609 & 74.523 & 74.438 & 74.352 & 74.266\end{array}$

0.286853

0.286852

0.286851

0.286850

0.286849

0.286848

0.286848

0.286847

0.286846
0.286845

0.978804

0.978830

0.978855

0.978881

0.978932

0.978958

0.978983

0.979009
0.979035

$\begin{array}{lllllllllll}29274.181 & 74.095 & 74.009 & 73.924 & 73.838 & 73.752 & 73.667 & 73.581 & 73.495 & 73.409\end{array}$ $\begin{array}{llllllllll}73.323 & 73.238 & 73.152 & 73.066 & 72.980 & 72.895 & 72.809 & 72.723 & 72.637 & 72.409 \\ 72.466 & 72.380 & 72.295 & 72.209 & 72.123 & 72.038 & 71.952 & 71.866 & 79.781 & 71.695\end{array}$ $\begin{array}{llllllllll}71.609 & 71.523 & 71.438 & 71.352 & 71.266 & 71.181 & 71.052 & 71.866 & 71.781 & 71.695 \\ \end{array}$ $\begin{array}{llllllllll}70.752 & 70.666 & 70.581 & 70.495 & 70.409 & 70.323 & 70.238 & 70.152 & 70.066 & 69.981\end{array}$

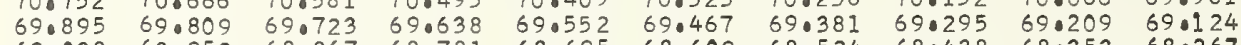
$\begin{array}{llllllllll}69.895 & 69.809 & 69.723 & 69.638 & 69.552 & 69.467 & 69.381 & 69.295 & 69.209 & 69.124 \\ 69.038 & 68.952 & 68.867 & 68.781 & 68.695 & 68.609 & 68.524 & 68.438 & 68.353 & 68.267\end{array}$ $\begin{array}{llllllllll}68.181 & 68.095 & 68.010 & 67.924 & 67.838 & 67.753 & 67.667 & 67.581 & 67.496 & 67.410\end{array}$ $\begin{array}{llllllllll}67.324 & 67.239 & 67.153 & 67.067 & 66.982 & 66.896 & 66.810 & 66.725 & 66.639 & 66.553 \\ 66.468 & 66.382 & 66.296 & 66.210 & 66.125 & 66.039 & 65.953 & 65.868 & 65.782 & 65.697\end{array}$

0.286844 0.286843 0.286842 0.286840 0.286839 0.286838 0.286838 0.286837

0.979060 0.979086 0.979111 0.9799163 0.979188 0.9979214 0.979239 0.979265
0.979290$$
40.788 \text { 40.7 }
$$

9.2
9.3
9.4

9.4

9.6

9.8
9.9

\section{$239.933 \quad 39.847 \quad 39.7$}

$\begin{array}{ll}39.077 & 38.992 \\ 38.222 & 38.137\end{array}$

$\begin{array}{ll}37.367 & 37.282 \\ 36.512 & 36.427\end{array}$

$\begin{array}{ll}35.657 & 35.572 \\ 34.803 & 34.717\end{array}$

$\begin{array}{ll}33.948 & 33.717 \\ 33.093 & 33.008\end{array}$

$39.761 \quad 39.676$

$\begin{array}{lllllll}48.145 & 48.059 & 47.974 & 470888 & 470803 & 47.717\end{array}$

0.286817

0.286816

0.286814

0.286814

0.286813

0.286811

0.286810

0.296809

0.979572

0.979598

0.979649

0.979674

0.979700

0.979751

0.0979802

0.979828

0.979853

0.0979905

0.0979930

0.979956

0.979981

0.980033

0.980058

0.980084

0.980109

0.98013
0.980161

0.980186

0.0980212

0.980237

0.980289

0.980340

0.0980365

0.9803917
0.980447
0

0.980442

0.980468
0.980493

0.980519
0.980543

0.286808

0.286807

0.286806
0.286805
0

0.286804

0.286803
0.286802

0.286801

0.2286801
0.286800 
$\begin{array}{lllllllllll}3420.0 & 29231.383 & 31.298 & 31.212 & 31.127 & 31.042 & 30.956 & 30.871 & 30.785 & 30.699 & 30.614\end{array}$

$\begin{array}{lllllllllll}0.1 & 30.529 & 30.443 & 30.358 & 30.272 & 30.187 & 30.102 & 30.016 & 29.930 & 29.845 & 29.760 \\ 0.2 & 29.674 & 29.588 & 29.503 & 29.417 & 29.332 & 29.247 & 29.161 & 29.076 & 28.990 & 28.905\end{array}$

$\begin{array}{lllllllllll}0.3 & 28.819 & 28.734 & 28.648 & 28.563 & 28.478 & 28.392 & 28.307 & 28.221 & 28.136 & 28.050\end{array}$

$\begin{array}{lllllllllll}0.4 & 27.965 & 27.879 & 27.794 & 27.708 & 27.623 & 27.538 & 27.452 & 27.367 & 27.281 & 27.196 \\ 0.5 & 27.110 & 27.025 & 26.939 & 26.854 & 26.769 & 26.683 & 26.598 & 26.512 & 26.427 & 26.342\end{array}$

$\begin{array}{lllllllllll}0.6 & 26.256 & 26.170 & 26.085 & 26.000 & 25.914 & 25.829 & 25.743 & 25.658 & 25.572 & 25.487\end{array}$

$\begin{array}{lllllllllll}0.7 & 25.402 & 25.316 & 25.231 & 25.145 & 25.060 & 24.974 & 24.889 & 24.803 & 24.718 & 24.633 \\ 0.8 & 24.547 & 24.462 & 24.376 & 24.291 & 24.206 & 24.120 & 24.034 & 23.949 & 23.864 & 23.778\end{array}$

$\begin{array}{llllllllll}23.693 & 23.608 & 23.522 & 23.436 & 23.351 & 23.266 & 23.180 & 23.095 & 23.010 & 22.924\end{array}$

0.286799 0.286798 0.286797
0.028696
0.28696

0.286795

0.286794

0.286792

0.286792
0.286791

0.286790

0.286789

0.286788

0.286786

0.286783

0.286782

0.286781

0.286780

0.286779
0.286778

0.286777

0.286776
0.286775
0.28674

0.286774

0.286774
0.286773

0.286772

0.028677
0.28677

0.286769

0.286768

0.286767
0.286766
0.28676

0.286765

0.286765
0.286764

0.286763

0.286762
0.286761
0.28676

0.286761
0.286760
0.28650

0.286759

0.286758

0.286757
0.286756
0.28656

0.286796

0.28675

0.286754

0.286753
0.286752

0.286751

0.286750
0.286749

0.286748
0.286748

0.286747
0.286746

0.286745

0.286744

0.286743
0.286742

0.0286741

0.286740
0.286739

0.286739
0.28679

0.286738
0.286737

0.286736

0.28673

0.286734

0.286733

0.286731
0.286731

0.28673

0.286729

0.286728

0.286727

0.286726

0.286725

0.28672

0.286722

0.286720

0.286720
0.286719

0.286718

0.286715

0.286714

0.286714

0.286712

0.286711
0.286710

.010

0.981005

0.981031

0.981082

0.981108

0.981133

0.981184

0.981210

0.981262

0.981287
0.981312

0.981364

0.981415

0.981440

0.981492

0.981517

0.981568

0.981620

0.981645

0.981696

0.981722

0.981773

0.981824

0.981876

0.981901

0.981933

0.981978

0.982029

0.982055

0.982882
0.982106

0.982132

0.982137
0.982183

0.982209

0.982234
0.982260

0.9882285

0.982337
0.982362

0.982388

0.982243

0.98249
0.082465
0.98465

0.982490

0.982516
0.083541

0.982569

0.0982893
0.982618

00982844

0.0982669

0.0982699

0.982721
0.088746

0.0982772
0.96727

0.0982797
0.9829

0.982823

0.982849
0.982874

0.982900

0.982925

0.982977

0.983002

0.0983028
0.983054

0.9883079
0.53909

0.993129
0.983130

0.983156

0.0933182
0.9883207
0.9828

0.9833233
0.983258

0.0983284

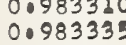

0.083361

0.983386

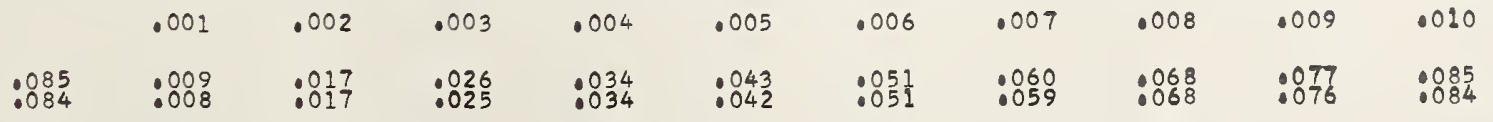


0.983643

1.6
1.7
1.8

$\begin{array}{llll}34.272 & 34.187 & 34.102 & 34.017 \\ 33.423 & 33.338 & 33.253 & 33.169\end{array}$

$\begin{array}{lllllll}34.781 & 34.697 & 34.612 & 34.527 & 34.442 & 34.3 & \end{array}$

$\begin{array}{llllll}33.083 & 32.999 & 32.914 & 32.829 & 32.744 & 32.659\end{array}$

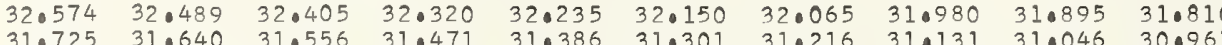

2.1

$2 \cdot 3$

2.5

2.6

2.8
2.9

3433 .

3.

3.2
3.3

3.4

3.7
3.8

3434.0

4.1
4.0
4.0
4.5
40.6
4.0
4.09

3435.

5.

5.

5.5
5.6

5.7
5.8
5.9

3436.

$6 \cdot 1$
$6 \cdot 2$
$6 \cdot 3$

6.4

6.5
6.6

$6 \cdot 7$

6.9

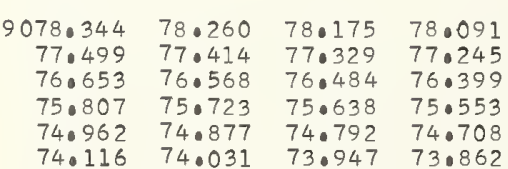

0.286700

(

0.286698

0.286697

0.286696

0.28669

0

0.286691

0.286689

0.286688

0.286687

0.286685

0.286684
0.286683

0.286682

0.286681

0.286681
0.286680
0.2868

0.286679

0.286678

0.286677

0.286676

0.286675
0.286674

0.983668

0.983694

0.983719
0.983745

0.983771

(1)

0.983822

0.983873

0.993924

0.983950

0.983975

0.984001

0.984052 0.984078 0.984104 0.984129
0.9884153

0.984180 0.984206 0.984232 0.984257
0.988283
0 0.984308 0.0984334 0.0984360 0.984385
0.984411

0.286673

0.984437 0.286673
0.286672 0.286671 0.286670
0.286669 0.286668 0.286667 0.286666

0.286665

0.286664

0.286662

0.286662
0.286661
0.28666

0.286660

0.286659

0.286858

0.286657
0.286657

0.286656

0.286655

0.286654

0.02865

0.286651

0.286650

0.286649

0.286649
0.286648

0.286647

0.286646 0.286645 0.286644
0.286643
0.286642 0.286643
0.286642 0.286641

0.28664

0.286640
0.286639

0.286638

0.286637
0.286636
0.28636

0.286635

0.286634

0.28663

0.286632

0.286631
0.286630

0.984462

0.984488

0.984539

0.0984565 0.984590 0.984516 0.984641
0.984667

0.984693 0.984718 0.984744
0.984770
0 0.0984795 0.984821

0.984846
0.984872

0.984872

0.984898
0.984923

0.984949

0.984974

0.985000

0.985026
0.9855051

0.985051
0.985077

0.985103

0.085128

0.985179

0.286629

0.286628

0.286626

0.286625

0.286624

0.286622

0.286621 
$\begin{array}{lllllllllll}3440.0 & 29061.438 & 61.354 & 61.270 & 61.185 & 61.101 & 61.016 & 60.932 & 60.847 & 60.763 & 60.678\end{array}$

$\begin{array}{lllllllllll}0.1 & 60.594 & 60.509 & 60.425 & 60.340 & 60.256 & 60.172 & 60.087 & 60.002 & 59.918 & 59.834 \\ 0.2 & 59.749 & 59.664 & 59.580 & 59.496 & 59.411 & 59.327 & 59.242 & 59.158 & 59.073 & 58.989\end{array}$

$\begin{array}{lllllllllll}0.2 & 59.749 & 59.664 & 59.580 & 59.496 & 59.411 & 59.327 & 59.242 & 59.158 & 59.073 & 58.989 \\ 0.3 & 58.905 & 58.820 & 58.735 & 58.651 & 58.567 & 58.482 & 58.397 & 58.313 & 58.229 & 58.144\end{array}$

$\begin{array}{lllllllllll}0.3 & 58.905 & 58.820 & 58.735 & 58.651 & 58.567 & 58.482 & 58.397 & 58.313 & 58.229 & 58.144 \\ 0.4 & 58.060 & 57.976 & 57.891 & 57.806 & 57.722 & 57.637 & 57.553 & 57.469 & 57.384 & 57.300\end{array}$

$\begin{array}{lllllllllll}0.5 & 57.215 & 57.131 & 57.046 & 56.962 & 56.877 & 56.793 & 56.708 & 56.624 & 56.540 & 56.455 \\ 0.6 & 56.371 & 56.286 & 56.202 & 56.117 & 56.033 & 55.948 & 55.864 & 55.780 & 55.695 & 55.611\end{array}$

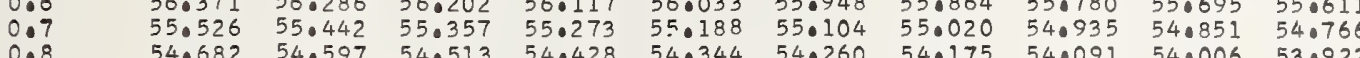

$\begin{array}{lllllllllll}0.8 & 54.682 & 54.597 & 54.513 & 54.428 & 54.344 & 54.260 & 54.175 & 54.091 & 54.006 & 53.922 \\ 0.9 & 53.837 & 53.753 & 53.668 & 53.584 & 53.500 & 53.415 & 53.331 & 53.246 & 53.162 & 53.097\end{array}$

$\begin{array}{lllllllllll}3441.0 & 29052.993 & 52.908 & 52.824 & 52.740 & 52.655 & 52.571 & 52.486 & 52.402 & 52.317 & 52.233\end{array}$

$\begin{array}{lllllllllll}1.1 & 52.149 & 52.064 & 51.980 & 51.896 & 51.811 & 51.727 & 51.642 & 51.558 & 51.473 & 51.389 \\ 1.2 & 51.304 & 51.220 & 51.136 & 51.051 & 50.967 & 50.883 & 50.798 & 50.713 & 50.629 & 50.545\end{array}$

$\begin{array}{lllllllllll}1.2 & 51.304 & 51.220 & 51.136 & 51.051 & 50.967 & 50.883 & 50.798 & 50.713 & 50.629 & 50.545 \\ 1.3 & 50.461 & 50.376 & 50.292 & 50.208 & 50.123 & 50.039 & 49.954 & 49.870 & 49.785 & 49.701\end{array}$

$\begin{array}{lllllllllll}1.4 & 49.617 & 49.532 & 49.448 & 49.363 & 49.279 & 49.194 & 49.110 & 49.026 & 48.941 & 48.857\end{array}$

$\begin{array}{lllllllllll}1.5 & 48.772 & 48.688 & 48.604 & 48.519 & 48.435 & 48.350 & 48.266 & 48.182 & 48.097 & 48.013 \\ 1.6 & 47.928 & 47.844 & 47.760 & 47.675 & 47.591 & 47.507 & 47.422 & 47.337 & 47.253 & 47.169\end{array}$

$\begin{array}{lllllllllll}47.084 & 47.000 & 46.916 & 46.831 & 46.747 & 46.663 & 46.578 & 46.493 & 46.409 & 4603 & \end{array}$

$\begin{array}{llllllllllll}1.8 & 46.240 & 46.156 & 46.072 & 45.987 & 45.903 & 45.819 & 45.734 & 45.650 & 45.565 & 45.481\end{array}$

3442.0

290440

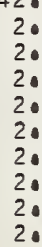

3443.0

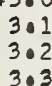

3.3

3.5

3.6

3.8
3.9

344400

$4 \cdot 1$

$4 \cdot 2$

4.4
$4 \cdot 5$

$4 \cdot 5$

4. 7

4.8
4.9

3445

5
5
5
5
50
5
5
5
5
5

$\begin{array}{llll}43.709 & 44.468 & 44.384 & 44.300\end{array}$

$\begin{array}{lllllllll}4.0624 & 43.540 & 43.456 & 43.371 & 43.287 & 43.203 & 43.118 & 43.034 & 42.950\end{array}$

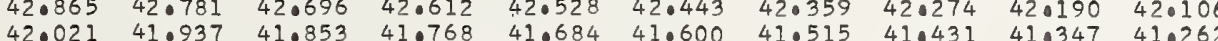

$41.178 \quad 41.093 \quad 41.000 \quad 40.025 \quad 40.840 \quad 40.756 \quad 40.071 \quad 40.587 \quad 40.503 \quad 40.418$

$40.334 \quad 40.250 \quad 40.165 \quad 40.083 \quad 30.007 \quad 30.912 \quad 30.828 \quad 30.744 \quad 30.503 \quad 40.418$

$39.491 \quad 30.406 \quad 30.322 \quad 39.238 \quad 39.153 \quad 39.059 \quad 380085 \quad 38.900 \quad 380816 \quad 38.731$

$\begin{array}{llllllllll}38.647 & 38.563 & 38.479 & 38.394 & 38.310 & 38.225 & 38.141 & 38.057 & 37.972 & 37.888\end{array}$

$\begin{array}{llll}37.804 & 37.719 & 37.635 & 37.550\end{array}$

29036.117

$35.190 \quad 35.105 \quad 35.021$

$33.58733 .503 \quad 3304193.178$

$32.744 \quad 32.660 \quad 32.576 \quad 32.491$

$31.901 \quad 31.817 \quad 31.733 \quad 31.648$

$31.058 \quad 30.974 \quad 30.890 \quad 30.805$

$\begin{array}{llll}29.372 & 29.288 & 29.204 & 29.119\end{array}$

28.445

$\begin{array}{llll}26.844 & 27.602 & 27.518 & 27.434\end{array}$

$\begin{array}{llll}26.844 & 26.759 & 26.675 & 26.591 \\ 26.001 & 25.916 & 25.832 & 25.748\end{array}$

$\begin{array}{llll}25.158 & 25.074 & 24.990 & 24.905\end{array}$

$\begin{array}{llll}24.315 & 24 \cdot 231 & 24 \cdot 147 & 24.062\end{array}$

$\begin{array}{llll}22.630 & 22.388 & 23.304 & 23.220 \\ & 22.462 & 22.377\end{array}$

$\begin{array}{llll}21.788 & 21.704 & 21.620 & 21.535 \\ 20.945 & 20.861 & 20.777 & 20.693 \\ 20.103 & 20.019 & 19.035 & 19.850\end{array}$

$20.10320 .019 \quad 19.93$

$29019.261 \quad 19.177$

$\begin{array}{llll}18.418 & 18.1734 & 19.092 & 19.008 \\ 18.250 & 18.166\end{array}$

$\begin{array}{llll}17.576 & 17.492 & 17.408 & 17.323\end{array}$

$15.892 \quad 15.808 \quad 15.723 \quad 15.639$

$\begin{array}{llll}15.050 & 14.965 & 14.88\end{array}$

$\begin{array}{llll}4.208 & 14.123 & 14.039 & 13.955\end{array}$

$\begin{array}{llll}13.365 & 13.281 & 13.197 & 13.11 \\ 12.523 & 12.439 & 12.355 & 12.27\end{array}$

37.888

$\begin{array}{lllllll}35.780 & 35.696 & 35.611 & 35.527 & 35.443 & 35.358\end{array}$

$\begin{array}{llllll}34.937 & 34.853 & 34.768 & 34.684 & 34.599 & 34.515\end{array}$

$34.093 \quad 34.009$

$\begin{array}{llll}33.925 & 33.840 & 33.756 & 33.672 \\ 33.082 & 32.997 & 32.913 & 32.829\end{array}$

$\begin{array}{lllllll}32.407 & 32.323 & 32.238 & 32.154 & 32.070 & 31.985\end{array}$

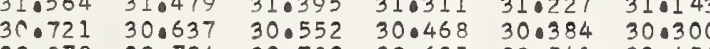

$\begin{array}{llllll}29.035 & 28.951 & 28.866 & 28.782 & 29.541 & 29.456 \\ & 28.698 & 28.614\end{array}$

0.286620

0.286618

0.286618

0.286616

0.286615

0.286614

0.286612

0.286611

0.286611
0.286610

0.286609

0.286608
0.286607
0.286606

0.286606

0.286605

0.286603

0.286603

0.286602
0.286601

0.286600

0.286599

0.286597

0.286596

0.286596
0.286595

0.286594

0.286593

0.286591

0.286590
0.286589

0.286588

0.286588

0.286586

0.286585

0.286584

0.286583

0.286582

0.286581

0.286580

0.286579

0.286577

0.985974

0.985999

0.986051

0.986076

0.986102

0.986153

0.986204

0.986230

0.986255

0.986307

0.986332

0.986384

0.986409

0.986460

0.986486

0.986512

0.986563

0.986589

0.986640

0.986665

0.986691

0.986742

0.986768

0.986819

0.986845

0.986896

0.986922

0.986947
0.986973

0.986999

0.987024

0.987050

0.987101

0.987127

0.987152

0.987204

0.286576

0.286575

0.286574
0.286574

0.286573

0.286572

0.286570

0.286569

0.286568

3446

29010

$0.840 \quad 10.75$

$\begin{array}{llllllll}11.513 & 11.429 & 11.345 & 11.261 & 11.176 & 11.092 & 11.008 & 10.924\end{array}$

0.286567

0.286566

0.286565

0.286564

$\begin{array}{llllllllll}08.314 & 08.230 & 08.146 & 08.062 & 07.978 & 07.894 & 07.809 & 07.726 & 07.641 & 07.559 \\ 07.473 & 07.389 & 07.305 & 07.220 & 07.136 & 07.052 & 06.968 & 06.884 & 06.800 & 06.715\end{array}$

$\begin{array}{llllllllll}06.631 & 06.547 & 06.463 & 06.379 & 06.295 & 06.210 & 06.126 & 06.042 & 05.958 & 05.874\end{array}$

$\begin{array}{lllllllllll}05.790 & 05.706 & 05.622 & 05.537 & 05.453 & 05.369 & 05.285 & 05 \cdot 200 & 05.116 & 05.032\end{array}$

$\begin{array}{llllllllll}04.948 & 04.864 & 04.780 & 04.696 & 04.612 & 04.528 & 04.443 & 04.359 & 04.275 & 04.191 \\ 04.106 & 04.022 & 03.938 & 03.854 & 03.770 & 03.686 & 03.602 & 03.518 & 03.434 & 03.349\end{array}$

$\begin{array}{llllllllll}03.265 & 03.181 & 03.097 & 03.013 & 02.929 & 02.844 & 02.760 & 02.676 & 02.592 & 02.308\end{array}$

0.286563

0.286562
0.286561

0.286561

0.286560

0.286559

0.286558

0.2865556

0.286555

0.286534

0.286552

0.28655

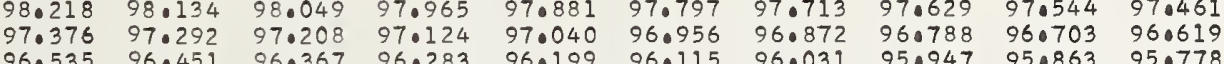

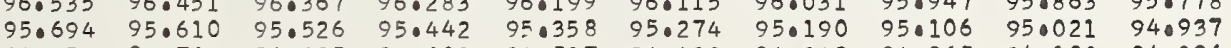

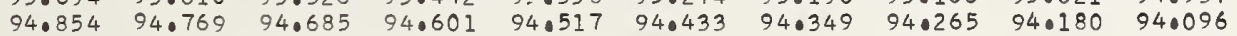

0.286550

0.286549

0.286548

0.28654

0.286546

0.286545

0.28654

0.28654

0.286543

0.286541

0.286540

0.28653

0.286538

0.28653

0.286536

0.28653

0.286534
0.286533

0.987255

0.987281

0.987306
0.987332

0.987357

0.987383

0.987434

0.987460

0.987311

0.987562

0.987588

0.987614

0.987665

0.987691

0.987716
0.987742

0.987767

0.987819

0.987844

0.987844
0.987870

0.987896

0.987921
0.987947

0.987972

0.988024

0.988049

0.988073

0.988126

0.988152

0.088203

0.988229

0.988280

0.988331

0.988357

0.988408

0.988434

0.9845

0.988485

.010

8884 
0.286532 0.286531 0.286530 0.286529 0.286527

0.286526

0.286524

0.286524 0.286523
0.286522 0.286521 0.286520 0.286518 0.286517 0.286516

0.286515 0.286513 0.286512 0.286511 0.286510 0.286509 0.286508

0.286506 . 0.286503 0.286503 0.286502 0.286501 0.00600 0.286499

0.286497 0.286496 0.286496 0.286495 0.286494
0.286493 0.286492 0.286491 0.286490
0.286490

0.286489 0.286488 0.286487
0.286486 0.286485 0.286484 0.286483 0.286483 0.286482

0.286480 0.286479 0.286478 0.286475 0.286474 0.286473

0.286471 0.286470
0.286469
0.286469 0.286469 0.286468 0.286466 0.286465 0.286464

0.286463 0.286462 0.286461 0.286459 0.286458 0.28645 0.286456 0.286454 0.286454 0.286452 0.286451 0.286450 0.286450 0.286449 0.286448 0.286447 0.286447
0.286446 0.988536 0.988 .562
0.988588 0.988613 0.988639 0.988665
0.988690 0.988690
0.988716 0.988741

0.988793 0.988818 0.988844 0.988895 0.988921 0.988972 0.988998
0.989023

0.989049 0.989075 0.9899126 0.0989152 0.989177 0.0989229 0.989254 0.989305 0.989331
0.989357
0 0.989357
0.989382 0.989408 0.989408
0.089434 0.9894434
0.0989459 0.0989459 0.989511 0.989536

0.989562 0.989587 0.989639 0.989664 0.989690 0.989716 0.989767 0.989818 0.989844 0.9889869 0.0989921 0.989946 0.989972 0.089998 0.990023
0.999049

0.990075 0.990100 0.990126 0.990152
0.990177 0.990203 0.990228 0.990254 0.990280
0.990305 0.990331 0.0990357 0.990382 0.990408
0.990434
0 0.0990459 0.0990459 0.990512 0.990536
0.990562 0.990587 0.990613 0.990639 0.990690 0.990716 0.990741 0.990793 0.990844 0.990870 
$\begin{array}{rlllllllll}92.458 & 93.375 & 93.291 & 93.208 & 93.125 & 93.041 & 92.958 & 92.874 & 92.791 & 92.707 \\ 92.624 & 92.540 & 92.457 & 92.373 & 92.290 & 92.206 & 92.123 & 92.039 & 91.955 & 91.872\end{array}$ $\begin{array}{llllllllll}91.789 & 91.705 & 91.622 & 91.538 & 91.455 & 91.371 & 91.287 & 91.204 & 91.121 & 91.037\end{array}$ $\begin{array}{llllllllll}90.954 & 90.870 & 90.787 & 90.703 & 90.620 & 90.536 & 90.452 & 90.369 & 90.286 & 90.202 \\ 90.119 & 90.035 & 89.952 & 89.868 & 89.785 & 89.701 & 99.618 & 89.534 & 89.451 & 89.367\end{array}$ $\begin{array}{llllllllll}90.119 & 90.035 & 89.952 & 89.868 & 89.785 & 89.701 & 89.618 & 89.534 & 89.451 & 89.367 \\ 89.284 & 89.200 & 89.117 & 89.033 & 88.950 & 88.866 & 88.783 & 88.699 & 88.616 & 88.532\end{array}$ $\begin{array}{llllllllll}89.284 & 89.200 & 89.117 & 89.033 & 88.950 & 88.866 & 88.783 & 88.699 & 88.616 & 88.532 \\ 88.449 & 88.365 & 88.282 & 88.199 & 88.115 & 88.032 & 87.948 & 87.865 & 87.781 & 87.698\end{array}$ $\begin{array}{llllllllll}88.449 & 88.365 & 88.282 & 88.199 & 88.115 & 88.032 & 87.948 & 87.865 & 87.781 & 87.698 \\ 87.614 & 87.531 & 87.447 & 87.364 & 87.280 & 87.197 & 87.114 & 87.030 & 86.947 & 86.863\end{array}$

$\begin{array}{llllllllll}86.779 & 86.696 & 86.613 & 86.529 & 86.446 & 86.362 & 86.279 & 86.196 & 86.112 & 86.028 \\ 85.945 & 85.861 & 85.778 & 85.694 & 85.611 & 85.528 & 85.444 & 85.361 & 85.277 & 85.194\end{array}$

3461 .

288850110 $885.110 \quad 85.027$

$\begin{array}{ll}84 \cdot 276 & 84 \cdot 192 \\ 83.441 & 83.357 \\ 82.607 & 82.523\end{array}$

$81.772 \quad 81.689$

$80.104 \quad 80.020$

$\begin{array}{ll}79.269 & 79.186 \\ 78.436 & 78.352 \\ 77.602 & 77.518\end{array}$

$84.943 \quad 84.860$

$\begin{array}{lll}85.361 & 85.277 & 85.194\end{array}$

0.286445

0.286444

0.286443

0.286441

0.286440

0.286438

0.286437

0.286437

0.286436
0.286435

0.286434

0.286433

0.286431

0.286430
0.286430

0.286429

3462.

2.

28876.767

75.93376 .684

$\begin{array}{ll}75.933 & 75.850 \\ 75.099 & 75.016\end{array}$

74.26574 .182

$72.597 \quad 72.514$

$71.763 \quad 71.680$

$70.930 \quad 70.846$

$\begin{array}{ll}70.096 & 70.013 \\ 69.262 & 69.179\end{array}$

3463.

3.

3.2
3.3
3.4

3.4

3.5

3.6
3.7
3.8

28868.428 $67.595 \quad 67.511$

$66.761 \quad 66.678$

$65.928 \quad 65.844$

65.09565 .011

63.42863 .34

62.511

$\begin{array}{llll}61.761 & 61.678 & 61.595 & 61.5 \\ 60.928 & 60.845 & 60.761 & 60.6\end{array}$

3464.0

4.1

$59.262 \quad 59.179$

$58.346 \quad 58.062$

$\begin{array}{lll}57.596 & 57.513 & 57.429\end{array}$

$55.930 \quad 55.847$

$55.097 \quad 55.014 \quad 54.931$

$\begin{array}{llll}53.431 & 53.348 & 53.265 & 53.182\end{array}$

4.8

3465.0

565.

28851

$851.766 \quad 51.683$

$50.933 \quad 50.850$

$50.101 \quad 50.018 \quad 49.935 \quad 49.852$

$\begin{array}{llll}49.269 & 49.186 & 49.102 & 49.019\end{array}$

$\begin{array}{llll}48.436 & 48.353 & 48.270 & 48.187 \\ 47.604 & 47.521 & 47.437 & 47.354\end{array}$

$\begin{array}{llll}47.604 & 47.521 & 47.437 & 47.354 \\ 46.771 & 46.688 & 46.605 & 46.522\end{array}$

$45.939 \quad 45.856 \quad 45.773 \quad 45.689$

$\begin{array}{llll}45.107 & 45.024 & 44.940 & 44.857 \\ 44.275 & 44.191 & 44.108 & 44.025\end{array}$

$\begin{array}{lllllll}79.770 & 79.687 & 79.603 & 79.520 & 79.436 & 79.35\end{array}$

$\begin{array}{lllllll}78.102 & 78.019 & 77.935 & 77.852 & 77.768 & 77.0519\end{array}$

$\begin{array}{llllll}77.268 & 77.184 & 77.101 & 77.018 & 76.934 & 76.851\end{array}$

0.286428

0.286427

0.286425

0.286424

0.286423

0.286422

0.286420

0.286419

0.286418

0.286417

0.286415

0.286413

0.286412
0.286411

0.286411

0.286410

0.286409

0.286407

0.286405

0.286405

0.286404

0.286402

0.286400

0.286399

0.286398

0.286397

0.286395

$\begin{array}{llllll}46.438 & 46.355 & 46.272 & 46.189 & 46.105 & 46.022\end{array}$

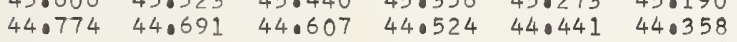

0.286395
0.286394

3466.0

28843.44

$42.610 \quad 42.52$

$.359 \quad 43.276 \quad 43.193$

$\begin{array}{llllll}43.109 & 43.026 & 42.943 & 42.860 & 42.777 & 42.694\end{array}$

$\begin{array}{llllllllll}41.778 & 41.695 & 41.612 & 41.528 & 41.277 & 42.194 & 42.111 & 42.028 & 41.944 & 41.861\end{array}$

$\begin{array}{lllllllllll} & 40.863 & 40.780 & 40.696 & 40.613 & 40.530 & 40.447 & 40.364 & 40.281 & 40.197\end{array}$

$\begin{array}{llllllllll}39.282 & 39.199 & 39.116 & 39.033 & 38.949 & 38.866 & 38.783 & 38.700 & 38.616 & 38.533\end{array}$

$\begin{array}{lllllllllll}38.450 & 38.367 & 38.284 & 38.201 & 38.117 & 38.034 & 37.951 & 37.868 & 37.784 & 37.701\end{array}$

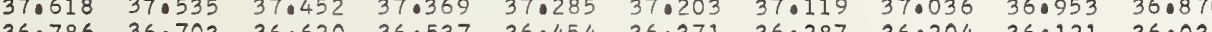

$35.785 \quad 35.872 \quad 35.788 \quad 35.706 \quad 35.622 \quad 35.539 \quad 35.456 \quad 350373 \quad 35.290 \quad 350.07$

0.286393

0.286392

0.286392

0.286390

0.286389

0.286388

0.286386

0.286386

0.286385

0.286384

0.286383

0.286381

0.286380

0.286380

0.286379

0.286377

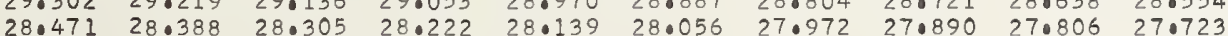

$\begin{array}{llll}28.471 & 28.388 & 28.305 & 28.222 \\ 27.640 & 27.557 & 27.474 & 27.390\end{array}$

$\begin{array}{llllll}28.139 & 28.056 & 27.972 & 27.890 & 27.806 & 27.723 \\ 27.308 & 27.224 & 27.141 & 27.058 & 26.975 & 26.892\end{array}$

0.286376

0.286375

$\begin{array}{rrrrrrrrrrr}3468.0 & 28826.809 & 26.726 & 26.642 & 26.559 & 26.476 & 26.393 & 26.310 & 26.227 & 26.144 & 26.061 \\ 8.1 & 25.978 & 25.894 & 25.811 & 25.728 & 25.645 & 25.562 & 25.479 & 25.396 & 25.312 & 25.22\end{array}$

$\begin{array}{llllllllll}25.978 & 25.894 & 25.811 & 25.728 & 25.645 & 25.562 & 25.479 & 25.396 & 25.312 & 25.229 \\ 25.146 & 25.063 & 24.980 & 24.897 & 24.814 & 24.731 & 24.648 & 24.564 & 24.482 & 24.398\end{array}$

$\begin{array}{llllllllll}25.146 & 25.063 & 24.980 & 24.897 & 24.814 & 24.731 & 24.648 & 24.564 & 24.482 & 24.398 \\ 24.315 & 24.232 & 24.149 & 24.066 & 23.983 & 23.900 & 23.817 & 23.734 & 23.650 & 23.567\end{array}$

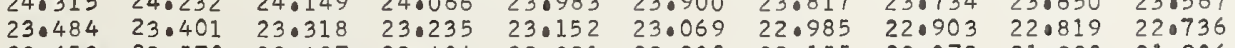

$\begin{array}{llllllllll}22.653 & 22.570 & 22.487 & 22.404 & 22.321 & 22.238 & 22.155 & 22.072 & 21.988 & 21.906\end{array}$

$\begin{array}{llllllllll}21.822 & 21.739 & 21.656 & 21.573 & 21.490 & 21.407 & 21.324 & 21.241 & 21.158 & 21.075 \\ 20.992 & 20.909 & 20.825 & 20.742 & 20.659 & 20.576 & 20.493 & 20.410 & 20.327 & 20.244\end{array}$

$\begin{array}{llllllllll}20.992 & 20.909 & 20.825 & 20.742 & 20.659 & 20.576 & 20.493 & 20.410 & 20.327 & 20.244 \\ 20.916 & 20.078 & 19.995 & 19.911 & 19.829 & 19.745 & 19.662 & 19.579 & 19.496 & 19.413\end{array}$

$\begin{array}{llllllllll}20.161 & 20.078 & 19.995 & 19.911 & 19.829 & 19.745 & 19.662 & 19.579 & 19.496 & 19.413 \\ 19.330 & 19.247 & 19.164 & 19.081 & 18.998 & 18.915 & 18.832 & 18.749 & 18.666 & 18.582\end{array}$

0.286374

0.286373

0.286371

0.286370

0.286369

0.286368

0.286367

0.286366
0.286365

0.286364

0.28636

0.286362

0.28636

0.286360

0.991100

0.991126

0.991177

01203

0.99125

0.991306

0.091331

0.991357

0.991382

0.091408

0.991459

0.991511

0.991536

0.991588

0.991613

0.991665

0.991690

0.991742

0.991793

0.991818

0.991870

0.991895

0.991947

0.991998

0.992024

0.992049

0.992075

0.992126

0.992152

0.992203

0.992229

0.992280

0.992331

0.992408
.0992434

0.992485

0.992511

0.992562

0.092614

0.992639

0.992665

0.992716

0.992768

0.992793

0.992819

0.992870

0.992896

0.992921

0.992947

0.992998

0.993024

0.993050

0.993101

0.993152

0.9931784

0.993229

0.993255

0.993306

0.993332

0.993383

0.993409

0.993460

0.993486

0.993512

0.993563

0.993588

$\begin{array}{llllllllll}13.516 & 13.433 & 13.350 & 13.267 & 13.184 & 13.101 & 13.018 & 12.935 & 12.851 & 12.768\end{array}$

$\begin{array}{llllllllll}11.855 & 11.772 & 11.689 & 11.606 & 11.523 & 11.440 & 11.357 & 11.274 & 11.191 & 11.107 \\ 11.025 & 10.941 & 10.858 & 10.775 & 10.692 & 10.609 & 10.526 & 10.444 & 10.360 & 10.277\end{array}$

.010

0.993640

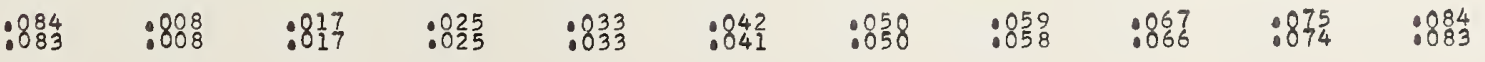




.02

.03

.04

.05

.06

.07

$\begin{array}{llllllllll}0.10 .028 & 09.945 & 09.862 & 09.779 & 09.696 & 09.613 & 09.530 & 09.447 \\ 09.364 & 09.281 & 09.198 & 09.115 & 0.0032 & 08.949 & 08.866 & 08.783 & 08.700 & 08.617 \\ 0.534 & 0.0 .451 & 08.368 & 08.285 & 08.202 & 08.199 & 08.036 & 07.953 & 07.870 & 07.787\end{array}$ $\begin{array}{llllllllll}08.534 & 08.451 & 08.368 & 08.285 & 08.202 & 08.119 & 08.036 & 07.953 & 07.870 & 07.787 \\ 07.704 & 07.621 & 07.538 & 07.455 & 07.372 & 07.289 & 07.206 & 07.123 & 07.040 & 06.957\end{array}$ $\begin{array}{llllllllll}06.874 & 06.791 & 06.708 & 06.625 & 06.542 & 06.459 & 06.376 & 06.293 & 06.210 & 06.127\end{array}$ $\begin{array}{llllllllll}06.044 & 05.961 & 05.878 & 05.795 & 05.712 & 05.629 & 05.546 & 05.463 & 05.380 & 05.297\end{array}$ $\begin{array}{llllllllll}05.214 & 05.131 & 05.048 & 04.965 & 04.882 & 04.799 & 04.716 & 04.633 & 04.550 & 04.467 \\ 04.384 & 04.301 & 04.218 & 04.135 & 04.052 & 03.969 & 03.886 & 03.803 & 03.720 & 03.637\end{array}$ $\begin{array}{llllllllll}03.554 & 03.471 & 03.388 & 03.305 & 03.222 & 03.139 & 03.056 & 02.973 & 02.890 & 02.807 \\ 02.724 & 02.641 & 02.558 & 02.475 & 02.392 & 02.309 & 02.226 & 02.144 & 02.060 & 01.977\end{array}$

$\begin{array}{lllllllllll}3471.0 & 28801.895 & 01.812 & 01.729 & 01.646 & 01.562 & 01.479 & 01.397 & 01.314 & 01.230 & 01.148\end{array}$

$\begin{array}{rrrrrrrrrrr}1.1 & 01.065 & 00.982 & 00.899 & 00.816 & 00.733 & 00.650 & 00.567 & 00.484 & 00.401 & 00.318 \\ 1.2 & 00.235 & 00.152 & 00.069 & * 99.986 & * 99.903 & * 99.820 & * 99.737 & * 99.654 & * 99.571 & * 99.488\end{array}$

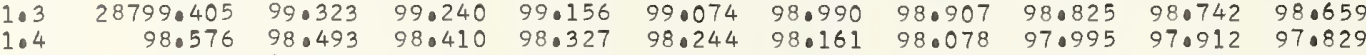

$\begin{array}{lllllllllll}1.4 & 98.576 & 98.493 & 98.410 & 98.327 & 98.244 & 98.161 & 98.078 & 97.995 & 97.912 & 97.829 \\ 1.5 & 97.746 & 97.663 & 97.580 & 97.497 & 97.414 & 97.331 & 97.249 & 97.165 & 97.082 & 97.000\end{array}$

$\begin{array}{lllllllllll}1.6 & 96.917 & 96.833 & 96.751 & 96.668 & 96.585 & 96.502 & 96.419 & 96.336 & 96.253 & 96.170\end{array}$

1.8

3472.0

$\begin{array}{llll}95.087 & 96.004 & 95.921 & 95.838 \\ 95.258 & 95.175 & 95.092 & 95.009\end{array}$

$2 \cdot 1$

2.3

2.4

2.6

2.8

3473.0

$3 \cdot 1$
$3 \cdot 2$
3.3

$3 \cdot 3$

3.6

3.7

3474.0

$4 \cdot 1$

$4 \cdot 3$

4.4

4.6

408

3475.0

5.

5.5

5.7

5.9

28793.599

$\begin{array}{llll}92.770 & 92.687 & 93.433 & 93.350\end{array}$

$\begin{array}{llllllllll}91.941 & 91.858 & 91.775 & 91.692 & 91.609 & 91.526 & 91.443 & 91.360 & 91.278 & 91.195\end{array}$

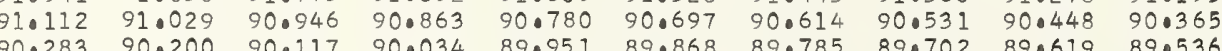

$\begin{array}{llllllllll}89.453 & 89.370 & 89.288 & 89.205 & 80.951 & 89.868 & 89.785 & 89.702 & 89.619 & 89.536\end{array}$

$\begin{array}{lllllllllll}88.624 & 88.541 & 88.459 & 88.376 & 88.293 & 88.210 & 88.127 & 88.044 & 87.961 & 87.878\end{array}$

$\begin{array}{lllllllllll}87.795 & 87.712 & 87.630 & 87.547 & 87.464 & 87.381 & 87.298 & 87.215 & 87.132 & 87.050\end{array}$

$\begin{array}{llllllllll}86.967 & 86.884 & 86.801 & 86.718 & 86.635 & 86.552 & 86.469 & 86.386 & 86.303 & 86.220\end{array}$

$\begin{array}{llllllllll}28785.309 & 85.226 & 85.143 & 85.060 & 84.977 & 84.894 & 84.812 & 84.729 & 84.646 & 84.563\end{array}$

$\begin{array}{llllllllll}84.480 & 84.397 & 84.314 & 84.231 & 84.148 & 84.066 & 83.983 & 83.900 & 83.817 & 83.734\end{array}$

$\begin{array}{llllllllll}82.822 & 82.740 & 82.657 & 82.574 & 82.491 & 82.408 & 82.325 & 82.242 & 82.159 & 82.077\end{array}$

$\begin{array}{llllllllll}81.994 & 81.911 & 81.828 & 81.745 & 81.662 & 81.579 & 81.496 & 81.414 & 81.331 & 81.248\end{array}$

$\begin{array}{llllllllll}81.165 & 81.082 & 80.999 & 80.917 & 80.834 & 80.751 & 80.668 & 80.585 & 80.502 & 80.419 \\ 80.337 & 80.254 & 80.171 & 80.088 & 80.005 & 79.923 & 79.839 & 79.756 & 79.674 & 79.591\end{array}$

$\begin{array}{llllllllll}78.679 & 78.597 & 78.514 & 78.431 & 78.348 & 78.265 & 78.183 & 78.100 & 78.017 & 770934\end{array}$

77.852

28777.023

76.19576 .940

$\begin{array}{ll}75.366 & 75.2 \\ 74.538 & 74.456\end{array}$

$\begin{array}{llll}73.710 & 73.627 & 74.373 & 74.290\end{array}$

$\begin{array}{rlll}72.882 & 72.799 & 72.716 & 72.634\end{array}$

$\begin{array}{llllllllll}70.398 & 70.1315 & 70.232 & 70.978 & 70.895 & 70.812 & 70.729 & 70.646 & 70.564 & 70.481\end{array}$

$\begin{array}{llllllllll}69.570 & 69.487 & 69.404 & 69.321 & 69.239 & 69.156 & 69.073 & 68.990 & 68.908 & 68.825\end{array}$

$\begin{array}{rlllllllll}28768.742 & 68.659 & 68.576 & 68.494 & 68.411 & 68.328 & 68.245 & 68.163 & 68 \cdot 080 & 67.997 \\ 67.914 & 67.832 & 67.749 & 67.666 & 67.583 & 67.500 & 67.417 & 67.335 & 67.252 & 67.169\end{array}$ $\begin{array}{lllllllllll}7.086 & 67.004 & 66.921 & 66.838 & 66.755 & 66.673 & 66.590 & 66.507 & 66.424 & 67.169\end{array}$ $\begin{array}{llllllllll}65.431 & 65.348 & 65.265 & 65.183 & 65.100 & 65.017 & 64.934 & 64.852 & 64.769 & 64.686\end{array}$ $\begin{array}{lllllllllll}64.603 & 64.521 & 64.438 & 64.355 & 64.272 & 64.189 & 64 \cdot 107 & 64 \cdot 024 & 63.941 & 63.858\end{array}$ $\begin{array}{llllllllll} & 63.693 & 63.611 & 63.528 & 63.445 & 63.362 & 63.280 & 63.197 & 63.114 & 63.031 \\ 62.948 & 62.866 & 62.783 & 62.700 & 62.617 & 62.535 & 62.452 & 62.369 & 62.287 & 62.204\end{array}$ $\begin{array}{llllllllll}62.121 & 62.038 & 61.956 & 61.873 & 61.790 & 61.707 & 61.624 & 61.542 & 61.459 & 61.376\end{array}$

52.112

50.54150 .458

$49.714 \quad 49.631$

$48.061 \quad 47.978$

$\begin{array}{ll}47.234 & 47.152 \\ 46.408 & 46.32\end{array}$

$45.581 \quad 45.499$

44.75 $\begin{array}{ll}52.029 & 51.946 \\ 51.202 & 51.119\end{array}$

$51.202 \quad 51.119$

$\begin{array}{ll}50.375 & 50.292 \\ 49.549 & 49.466 \\ 48.722 & 48.639\end{array}$

$\begin{array}{ll}48.722 & 48.639 \\ 47.895 & 47.813\end{array}$

$\begin{array}{ll}47.895 & 47.813 \\ 47.069 & 46.986 \\ 46.242 & 46.159\end{array}$

$\begin{array}{ll}46.242 & 46.159 \\ 45.416 & 45.333\end{array}$

$28743.928 \quad 43.845$

$40.623 \quad 40.540 \quad 40.457 \quad 40.37$

$\begin{array}{llll}39.796 & 39.714 & 39.631 & 39.549 \\ 38.970 & 38.887 & 38.805 & 38.722\end{array}$

(1)

$\begin{array}{ll}37.318 & 37.235 \\ 36.492 & 36.409\end{array}$

3479.0

9.1

9.3

9.5
9.6

9.7

9.8

$\begin{array}{ll}38.805 & 38.72 \\ 37.979 & 37.89\end{array}$

$37 \cdot 979$
$37 \cdot 153$
$36 \cdot 327$

37.896
37.070
36.244 $\begin{array}{llll}43.102 & 43.019 & 42.763 & 43.68\end{array}$

$41.449 \quad 41.366 \quad 41.284 \quad 41.027$

\begin{abstract}
$34.840 \quad 35.583$
$\begin{array}{ll}34.014 & 34.757 \\ 33.188 & 33.932\end{array}$

$32.363 \quad 32.280$

$\begin{array}{ll}31.537 & 31.454 \\ 30.711 & 30.629\end{array}$

$29.886 \quad 29.803$

$\begin{array}{ll}29.060 & 28.978 \\ 28.235 & 28.152\end{array}$

$35.500 \quad 35.418$
\end{abstract}

59.308

$\begin{array}{ll}58.480 & 58.398 \\ 57.653 & 57.571\end{array}$

$56.826 \quad 56.743$

55.999

55.172

55.916

55.08
54.262

53.518
52.691

51.864

$\begin{array}{lll}50.210 & 50.127 \\ 49.383 & 49.0301 & 490\end{array}$

$48.557 \quad 48.474$

$\begin{array}{ll}47.730 & 47.647 \\ 46.903 & 46.821\end{array}$

46.077

45.250
44.424

$\begin{array}{llll}59.970 & 59.887 & 59.804 & 59.721 \\ 59.142 & 59.059 & 58.077 & 58.894\end{array}$

$\begin{array}{llll}58.315 & 58.232 & 58.150 & 58.067\end{array}$

$\begin{array}{llll}56.661 & 57.405 & 57.322 & 57.240 \\ 5.678 & 56.495 & 56.412\end{array}$

$\begin{array}{llll}55.833 & 55.751 & 55.668 & 55.585\end{array}$

$\begin{array}{llll}55.006 & 54.924 & 54.841 & 54.758 \\ 54.179 & 54.096 & 54.014 & 53.931\end{array}$

$\begin{array}{llll}53.352 & 53.270 & 53.187 & 53.104 \\ 52.525 & 52.443 & 52.360 & 52.277\end{array}$

$\begin{array}{llll}51.698 & 51.616 & 51.533 & 51.450\end{array}$

$\begin{array}{llll}50.872 & 50.789 & 50.706 & 50.624\end{array}$

$\begin{array}{llll}49.218 & 49.136 & 49.053 & 48.970\end{array}$

$\begin{array}{llll}48.391 & 48.309 & 48.226 & 48.144 \\ 47.565 & 47.482 & 47.399 & 47.317\end{array}$

$\begin{array}{llll}46.738 & 46.656 & 46.573 & 46.490\end{array}$

$.912 \quad 45.829 \quad 45.746 \quad 45.664$

$430597 \quad 43.515 \quad 430432 \quad 430349 \quad 430267 \quad 43.184$

$\begin{array}{llllll}42.771 & 42.688 & 42.606 & 42.523 & 42.440 & 42.358\end{array}$

$\begin{array}{llllll}41.119 & 41.036 & 40.953 & 40.870 & 40.788 & 40.705\end{array}$

$\begin{array}{llllll}40.292 & 40.209 & 40.127 & 40.044 & 39.961 & 39.879\end{array}$

$\begin{array}{llllll}38.640 & 38.557 & 39.301 & 39.218 & 39.135 & 39.053 \\ 38.475 & 38.392 & 38.309 & 38.227\end{array}$

$\begin{array}{lllllll}37.813 & 37.731 & 37.648 & 37.566 & 37.483 & 37.400\end{array}$

$\begin{array}{llllll}36.988 & 36.905 & 37.648 & 37.566 & 37.483 & 37.400\end{array}$
35.335

36.905 $(n-1) \times 1000$

$\lambda(n-1)$

0.28635

0.286358

0.286356

0.286355

0.286355

0.286353

0.286352

0.286350

0.286349

0.286348

0.286346

0.286346
0.286345

0.286344

0.286343

0.286342

0.286341

0.286340
0.286339

0.236338

0.286337
0.286337
0.286336

0.286336

0.286335

0.286333

0.286332

.286331

0.286330

0.286329

0.286328

0.286327

0.286326

0.286325

0.286324

0.286322

0.286321
0.286320

0.286320

0.286319

0.286318
0.286317

0.286316

0.286315

0.286314

0.286313

0.286312

0.286311

0.286309

0.286308

0.286308

0.286306

0.286305

0.286303

0.286302

0.286302

0.286301

0.286299

0.286298

0.286296

0.286296

0.286295

0.286294

0.286293
0.286292

0.286291

0.286291

0.286290

0.286289
0.286288

0.286287

0.286286

0.286285

0.286284
0.286283

0.286282

0.286281

0.286280
0.286279

0.286279

0.286278

0.286277

0.286276

0.286274

.010

0.993665

0.993691

0.993742

0.993768

0.993794

0.993845

0.993871

0.993922

0.993948

0.9939 .99

0.994025

0.994050

0.994102

0.994127

0.994179

0.994204

0.094230

0.994281

0.994333

0.094358

0.994358

0.994384

0.994435

0.994461 


.04

.05

.06

.07

.08

.09

$(n-1) \times 1000$

$\lambda(n-1)$

$\begin{array}{rrrrrrrrrrr}3480.0 & 28727.409 & 27.326 & 27.244 & 27.161 & 27.079 & 26.996 & 26.914 & 26.831 & 26.749 & 26.666 \\ 0.1 & 26.583 & 26.501 & 26.418 & 26.336 & 26.253 & 26.171 & 26.088 & 26.006 & 25.923 & 25.841\end{array}$

$\begin{array}{lllllllllll}0.1 & 26.583 & 26.501 & 26.418 & 26.336 & 26.253 & 26.171 & 26.088 & 26.006 & 25.923 & 25.841 \\ 0.3 & 25.758 & 25.676 & 25.593 & 25.510 & 25.428 & 25.345 & 25.263 & 25.180 & 25.098 & 25.015 \\ 0.3 & 24.933 & 24.850 & 24.768 & 24.685 & 24.603 & 24.520 & 24.437 & 24.355 & 24.072 & 24.190\end{array}$

$\begin{array}{lllllllllll}0.3 & 24.933 & 24.850 & 24.768 & 24.685 & 24.603 & 24.520 & 24.437 & 24.355 & 24.272 & 24.190 \\ 0.4 & 24.107 & 24.025 & 23.942 & 23.860 & 23.777 & 23.695 & 23.612 & 23.530 & 23.447 & 23.365\end{array}$

$\begin{array}{lllllllllll}0.5 & 23.282 & 23.199 & 23.117 & 23.035 & 22.952 & 22.869 & 22.787 & 22.704 & 22.622 & 22.539\end{array}$

$\begin{array}{lllllllllll}0.6 & 22.457 & 22.374 & 22.292 & 22.209 & 22.127 & 22.044 & 21.962 & 21.879 & 21.796 & 21.714 \\ 0.7 & 21.632 & 21.549 & 21.467 & 21.384 & 21.302 & 21.219 & 21.136 & 21.054 & 20.971 & 20.889\end{array}$

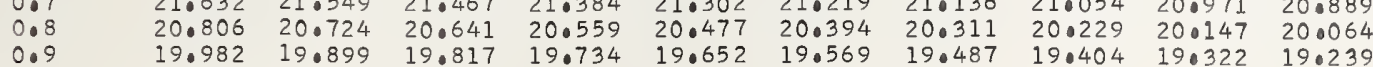

$\begin{array}{rrrrrrrrrrr}3481.0 & 28719.157 & 19.074 & 18.992 & 18.909 & 18.827 & 18.744 & 18.662 & 18.579 & 18.497 & 18.414 \\ 1.1 & 18.332 & 18.249 & 18.167 & 18.084 & 18.002 & 17.919 & 17.837 & 17.754 & 17.672 & 17.589 \\ 1.2 & 17.507 & 17.424 & 17.342 & 17.259 & 17.177 & 17.094 & 17.012 & 16.929 & 16.847 & 16.764\end{array}$

$\begin{array}{lllllllllll}1.2 & 17.507 & 17.424 & 17.342 & 17.259 & 17.177 & 17.094 & 17.012 & 16.929 & 16.847 & 16.764 \\ 1.3 & 16.682 & 16.599 & 16.517 & 16.434 & 16.352 & 16.270 & 16.187 & 16.105 & 16.022 & 15.939\end{array}$

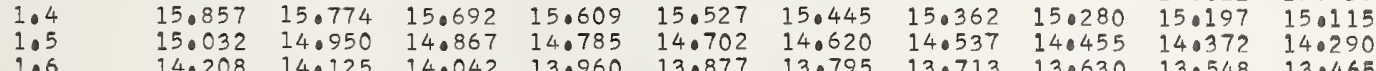

$\begin{array}{lllllllllll}1.6 & 14.208 & 14.125 & 14.042 & 13.960 & 13.877 & 13.795 & 13.713 & 13.630 & 13.548 & 13.465 \\ 1.7 & 13.383 & 13.300 & 13.218 & 13.135 & 12.053 & 12.970 & 12.888 & 12.805 & 12.723 & 12.641\end{array}$

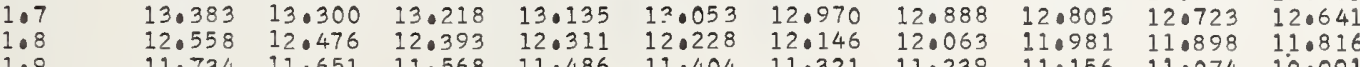

109

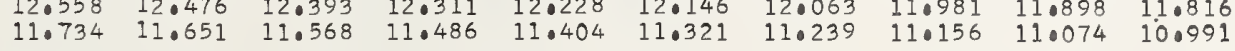

$\begin{array}{rrrrrrrrrrr}3482.0 & 28710.909 & 10.826 & 10.744 & 10.661 & 10.579 & 10.496 & 10.414 & 10.332 & 10.249 & 10.167 \\ 2.1 & 10.084 & 10.002 & 09.920 & 09.837 & 09.754 & 0.0972 & 09.590 & 09.507 & 09.425 & 09.342\end{array}$

$\begin{array}{lllllllllll}2.1 & 10.084 & 10.002 & 09.920 & 09.837 & 09.754 & 09.672 & 09.590 & 09.507 & 09.425 & 09.342 \\ 2.2 & 09.260 & 09.177 & 09.095 & 09.013 & 08.930 & 08.848 & 08.765 & 08.683 & 08.600 & 08.518\end{array}$

$\begin{array}{llllllllllll}2.3 & 08.435 & 08.353 & 08.271 & 08.188 & 08.106 & 08.023 & 07.941 & 07.858 & 07.776 & 07.693\end{array}$

$\begin{array}{lllllllllll}2.4 & 07.611 & 07.529 & 07.446 & 07.364 & 07.281 & 07.199 & 07.116 & 07.034 & 06.951 & 06.869\end{array}$

$\begin{array}{lllllllllll}2.5 & 05.962 & 05.880 & 05.798 & 05.716 & 05.653 & 05.375 & 06.292 & 06.209 & 06.127 & 06.045 \\ 2.6 & 05.551 & 05.468 & 05.386 & 05.303 & 05.221\end{array}$

$\begin{array}{llllllllllll}2.7 & 05.139 & 05.056 & 04.974 & 04.891 & 04.809 & 04.726 & 04.644 & 04.562 & 04.479 & 04.397\end{array}$

$\begin{array}{lllllllllll}2.8 & 04.314 & 04.232 & 04.150 & 04.067 & 03.985 & 03.902 & 03.820 & 03.738 & 03.655 & 03.573 \\ 2.9 & 03.490 & 03.408 & 03.325 & 03.243 & 03.161 & 03.078 & 02.996 & 02.913 & 02.831 & 02.748\end{array}$

$\begin{array}{lllllllllll}3483.0 & 28702.666 & 02.584 & 02.501 & 02.419 & 02.337 & 02.254 & 02.172 & 02.089 & 02 \cdot 007 & 01.925\end{array}$

$\begin{array}{llllllllll}01.018 & 00.936 & 00.853 & 00.771 & 00.688 & 00.606 & 00.524 & 00.441 & 00.359 & 00.276\end{array}$

$00.19400 .112 \quad 00.029 * 99.947 * 99.865 * 99.782 * 99.700 * 99.618 * 99.535 * 99.452$

$\begin{array}{lllllllllll}28699.370 & 99.288 & 99.205 & 99.123 & 99.041 & 98.958 & 98.876 & 98.794 & 98.711 & 98.628\end{array}$

$\begin{array}{llllllllll}98.546 & 98.464 & 98.381 & 98.299 & 98.217 & 98.134 & 98.052 & 97.970 & 97.887 & 97.805\end{array}$

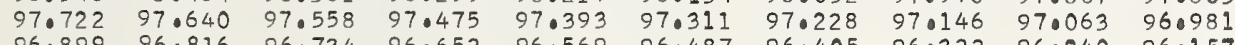

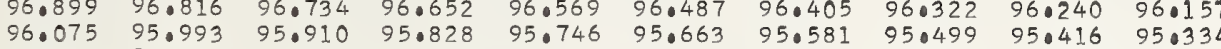

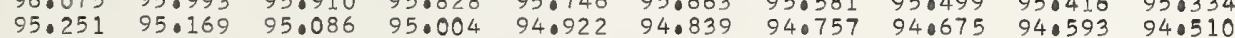

348400

$\begin{array}{llllllllll}28694.428 & 94.345 & 94.263 & 94.181 & 94.098 & 94.016 & 93.934 & 93.851 & 93.769 & 93.687\end{array}$

$\begin{array}{lllllllllll}4.1 & 93.604 & 93.522 & 93.440 & 93.357 & 93.275 & 93.192 & 93.110 & 93.028 & 92.945 & 92.863 \\ 4.2 & 92.781 & 92.698 & 92.616 & 92.534 & 92.451 & 92.369 & 92.286 & 92.204 & 92.122 & 92.040\end{array}$

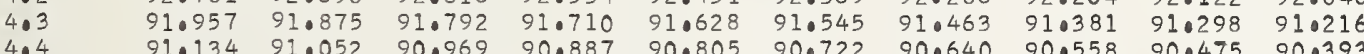

$\begin{array}{lllllllllll}4.4 & 91.134 & 91.052 & 90.969 & 90.887 & 90.805 & 90.722 & 90.640 & 90.558 & 90.475 & 90.393 \\ 4.5 & 90.311 & 90.229 & 90.146 & 90.064 & 89.981 & 89.899 & 89.817 & 89.734 & 89.652 & 89.570\end{array}$

$\begin{array}{lllllllllll}4.6 & 89.487 & 89.405 & 89.323 & 89.240 & 89.158 & 89.076 & 88.993 & 88.911 & 88.829 & 88.746\end{array}$

$\begin{array}{lllllllllll}4.7 & 88.664 & 88.582 & 88.500 & 88.417 & 89.334 & 88.252 & 88.170 & 88.088 & 88.005 & 87.923\end{array}$

$\begin{array}{lllllllllll}4.8 & 87.841 & 87.759 & 87.676 & 87.594 & 87.512 & 87.429 & 87.347 & 87.265 & 87.182 & 87.100 \\ 4.9 & 87.018 & 86.935 & 86.853 & 86.771 & 86.688 & 86.606 & 86.523 & 86.441 & 86.359 & 86.277\end{array}$

$\begin{array}{rrrrrrrrrrr}3485.0 & 28686.195 & 86.112 & 86.030 & 85.948 & 85.865 & 85.783 & 85.700 & 85.618 & 85.536 & 85.454 \\ 5.1 & 85.371 & 85.289 & 85.207 & 85.125 & 85.042 & 84.960 & 84.878 & 84.795 & 84.713 & 84.631 \\ 5.2 & 84.548 & 84.466 & 84.384 & 84.301 & 84.219 & 84.137 & 84.054 & 83.972 & 83.890 & 83.807\end{array}$

$\begin{array}{llllllllllll}5.2 & 84.548 & 84.466 & 84.384 & 84.301 & 84.219 & 84.137 & 84.054 & 83.972 & 83.890 & 83.807 \\ 5.3 & 83.725 & 83.643 & 83.561 & 83.478 & 83.396 & 83.314 & 83.231 & 83.149 & 83.067 & 82.984\end{array}$

$82.902 \quad 82.820 \quad 82.738 \quad 82.655$

$\begin{array}{lllll}82.491 & 82.408 & 82.326 & 82.244 & 82.161\end{array}$

$\begin{array}{llllllll}81.256 & 81.974 & 81.09 & 81.5103 & 81.421 & 81.339\end{array}$

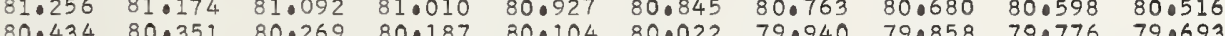

$\begin{array}{llllllllll}79.611 & 79.529 & 79.446 & 70.364 & 70.282 & 70.022 & 79.940 & 79.858 & 79.776 & 79.693\end{array}$

$\begin{array}{llllllllll}79.611 & 79.529 & 79.446 & 79.364 & 79.282 & 79.199 & 79.117 & 79.035 & 78.953 & 78.870 \\ 78.788 & 78.706 & 78.624 & 78.541 & 78.459 & 78.377 & 78.294 & 78.212 & 78.130 & 78.048\end{array}$

$\begin{array}{llllllllllll}3486.0 & 28677.966 & 77.883 & 77.801 & 77.719 & 77.636 & 77.554 & 77.472 & 77.390 & 77.307 & 77.225\end{array}$

$\begin{array}{lllllllllll}77.143 & 77.061 & 76.979 & 76.896 & 76.814 & 76.732 & 76.650 & 76.567 & 76.485 & 76.403 \\ 76.321 & 76.238 & 76.156 & 76.074 & 75.991 & 75.909 & 75.827 & 75.745 & 75.663 & 75.581\end{array}$

$\begin{array}{llllllllll}75.498 & 75.2316 & 76.156 & 76.074 & 75.991 & 75.909 & 75.827 & 75.745 & 75.663 & 75.581 \\ 75.33 & 75.251 & 75.169 & 75.087 & 75.005 & 74.923 & 74.840 & 74.758\end{array}$

$\begin{array}{llllllllll}74.676 & 74.593 & 74.511 & 74.429 & 74.347 & 74.264 & 74.182 & 74.100 & 74.018 & 73.935\end{array}$

$\begin{array}{llllllllll}73.853 & 73.771 & 73.688 & 73.606 & 73.524 & 73.442 & 73.360 & 73.278 & 73.195 & 73.113 \\ 73.031 & 72.948 & 72.866 & 72.784 & 72.702 & 72.620 & 72.537 & 72.455 & 72.373 & 72.291\end{array}$

$\begin{array}{llllllllll}72.208 & 72.126 & 72.044 & 71.962 & 71.879 & 71.797 & 71.715 & 71.633 & 71.551 & 71.468\end{array}$

$\begin{array}{llllllllll}71.386 & 71.304 & 71.222 & 71.139 & 71.057 & 70.975 & 70.893 & 70.811 & 70.728 & 70.646 \\ 70.564 & 70.482 & 70.399 & 70.317 & 70.235 & 70.153 & 70.070 & 69.988 & 69.906 & 69.824\end{array}$

$\begin{array}{lllllllllll}3487.0 & 28669.742 & 69.659 & 69.577 & 69.495 & 69.413 & 69.330 & 69.248 & 69 \cdot 166 & 69.084 & 69.002\end{array}$

$\begin{array}{lllllllllll}7.1 & 68.919 & 68.837 & 68.755 & 68.673 & 68.591 & 68.509 & 68.426 & 68.344 & 68.261 & 68.179 \\ 7.2 & 68.097 & 68.015 & 67.933 & 67.851 & 67.769 & 67.687 & 67.604 & 67.522 & 67.440 & 67.357\end{array}$

$\begin{array}{lllllllllll}7.2 & 68.097 & 68.015 & 67.933 & 67.851 & 67.769 & 67.687 & 67.604 & 67.522 & 67.440 & 67.357 \\ 7.3 & 67.275 & 67.193 & 67.111 & 67.029 & 66.947 & 66.864 & 66.782 & 66.700 & 66.618 & 66.535\end{array}$

$\begin{array}{lllllllllll}66.453 & 66.371 & 66.289 & 66.207 & 66.125 & 66.042 & 65.960 & 65.878 & 65.795 & 65.713\end{array}$

$\begin{array}{llllllllll}65.631 & 65.549 & 65.467 & 65.385 & 65.302 & 65.220 & 65.138 & 65.056 & 64.974 & 64.892\end{array}$

$\begin{array}{llllllllll}64.809 & 64.727 & 64.645 & 64.563 & 64.480 & 64.398 & 64.316 & 64.234 & 64 \cdot 152 & 64 \cdot 070 \\ 63.987 & 63.905 & 63.823 & 63.741 & 63.659 & 63.577 & 63.494 & 63.412 & 63.330 & 63.248\end{array}$

$\begin{array}{lllllllllll}7.8 & 63.166 & 63.083 & 63.001 & 62.919 & 62.837 & 62.755 & 62.673 & 62.591 & 62.508 & 62.426 \\ 7.9 & 62.344 & 62.262 & 62.180 & 62.098 & 62.016 & 61.933 & 61.851 & 61.769 & 61.687 & 61.604\end{array}$

$\begin{array}{lllllllllll}3488.0 & 28661.522 & 61.440 & 61.358 & 61.276 & 61.194 & 61.112 & 61.030 & 60.948 & 60.865 & 60.783\end{array}$

$\begin{array}{lllllllllll}8.1 & 60.701 & 60.619 & 60.537 & 60.454 & 60.372 & 60.290 & 60.208 & 60.126 & 60.043 & 59.961\end{array}$

$\begin{array}{llllllllllll}8.2 & 59.879 & 59.797 & 59.715 & 59.633 & 59.551 & 59.469 & 59.386 & 59.304 & 59.222 & 59.140 \\ 8.3 & 59.057 & 58.975 & 58.893 & 58.811 & 58.729 & 58.647 & 58.565 & 580483 & 58.400 & 58.318\end{array}$

$\begin{array}{lllllllllll}8.4 & 58.236 & 58.154 & 58.072 & 57.990 & 57.907 & 57.825 & 57.743 & 57.661 & 57.579 & 57.497\end{array}$

$\begin{array}{llllllllllll}8.5 & 57.415 & 57.332 & 57.250 & 57.168 & 57.086 & 57.004 & 56.922 & 56.840 & 56.757 & 56.675\end{array}$

$\begin{array}{llllllllllll}8.6 & 56.593 & 56.511 & 56.429 & 56.347 & 56.264 & 56.182 & 56.100 & 56.018 & 55.936 & 55.854 \\ 8.7 & 55.772 & 55.680 & 55.608 & 55.525 & 55.443 & 55.361 & 55.279 & 55.197 & 55.115 & 55.032\end{array}$

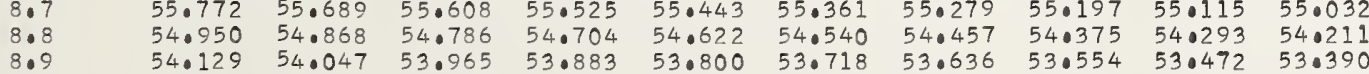

$\begin{array}{lllllllllll}3489.0 & 28653.308 & 53.226 & 53.143 & 53.062 & 52.979 & 52.897 & 52.815 & 52.733 & 52.651 & 52.569\end{array}$

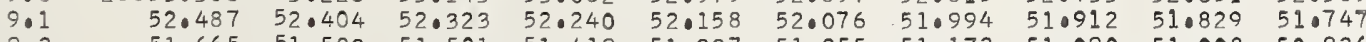

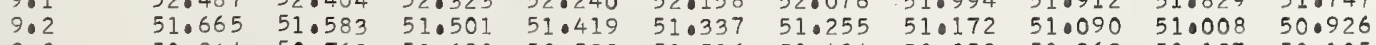
$\begin{array}{llllllllll}50.844 & 50.762 & 50.680 & 50.598 & 50.516 & 50.434 & 50.352 & 50.269 & 50.187 & 50.105\end{array}$ $\begin{array}{llllllllll}50.023 & 49.941 & 49.859 & 49.777 & 49.695 & 49.613 & 49.531 & 49.448 & 49.366 & 49.284\end{array}$ $\begin{array}{lllllllllll}49.202 & 49.120 & 49.038 & 48.956 & 48.874 & 48.792 & 48.710 & 48.627 & 48.545 & 48.463\end{array}$ $\begin{array}{llllllllll}48.381 & 48.299 & 48.217 & 48.135 & 48.053 & 47.971 & 47.889 & 47.806 & 47.725 & 47.643\end{array}$ $\begin{array}{llllllllll}47.561 & 47.478 & 47.396 & 47.314 & 47.232 & 47.150 & 47.068 & 46.986 & 46.904 & 46.822\end{array}$

$46.740 \quad 46.658 \quad 46.575 \quad 46.493$

$\begin{array}{llllll}46.411 & 46.329 & 46.247 & 46.165 & 46.083 & 46.001\end{array}$

0.286273

0.286273
0.286272

0.286271

0.286268

0.286268

0.286266

0.286265

0286264

0.286263

0.286262

286261

0.286259

0.286258
0.286257

0.286256

.286256

0.286254

0.286253

0.286252

0.286251

0.286250

0.286248

286247

0.286246

0.286245

0.286244

0.286243

0.286241

0.286240

0.286240

0.286239

0.286238

0.286236

0.286234

0.286234

0.286233
0.286232

0.286231

0.286230

0.286229

0.286229

0.286228

0.286227

0.286225

0.286224
0.286223

0.286223

0.286222

0.286221

0.286219

0.286218

0.286218
0.286217

0.286216

0.286215

0.286214

0.286213

0.286212

0.286212

0.286210

0.28620

0.286208

0.286207
0.286207

0.996232

0.996257
0.996283

0.996309

0.996334

0.996360

0.0966411

0.996437

0.096488

0.996314

0.996340

0.996565

0.996591

0.996642

0.996668

0.996694

0.996745

0.9967712

0.996822

0.996848

0.996873

0.996925

0.996950

0.997002

0.997053

0.997079
0.997104

0.997130

0.997156

0.997207

0.997259

0.997284

0.997310

$0: 997365$
0
0

0.997413

0.997438

0.997464
0.997490

0.286206

0.286205

0.28620

0.286203

0.286202

0.286202

0.286200

0.286199

0.999515

0.997542

0.997592

0.997618

0.997644

0.997695

0.997721
0.997746

0.997772

0.997798

0.997849

0.997875

0.997926

0.097952

0.998003

0.998029

0.998054

0.998080

0.998106

0.998157

0.998183

0.998209

.998260

0.286197

0.28619

0.286195

0.286194

0.286193

0.286191

0.286191

0.998286

0.998321
0.998337

0.998337

0.998388

0.998414

0.998465

0.998517

0.998542

0.998568

0.998619

0.998645

0.998672

0.998696

0.998748

0.998748
0.998773

.020

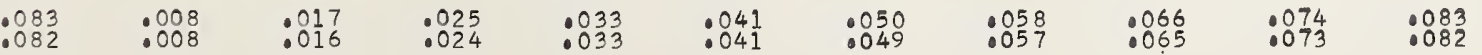



$\begin{array}{llllllllll}44 \cdot 277 & 44.195 & 44.113 & 44.031 & 43.949 & 43.867 & 43.785 & 43.703 & 43.621 & 43.539\end{array}$ $\begin{array}{llllllllll}43.457 & 43 \cdot 374 & 43.292 & 43.210 & 43.128 & 43.046 & 42.964 & 42.882 & 42.800 & 42.718\end{array}$

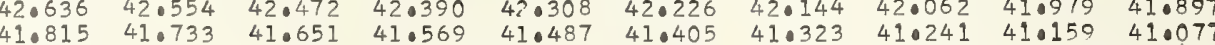
$\begin{array}{llllllllll}40.995 & 40.913 & 40.830 & 40.749 & 40.667 & 40.584 & 40.502 & 40.420 & 40.338 & 40.256\end{array}$ $\begin{array}{llllllllll}40.174 & 40.092 & 40.010 & 39.928 & 39.846 & 39.764 & 39.682 & 39.600 & 39.518 & 39.436\end{array}$ $\begin{array}{lllllllllll}39.354 & 39.272 & 39.189 & 39.107 & 39.025 & 38.944 & 38.861 & 38.779 & 38.698 & 38.615 \\ 38.533 & 38.451 & 38.369 & 38.287 & 38.205 & 38.123 & 38.041 & 37.959 & 37.877 & 37.795\end{array}$

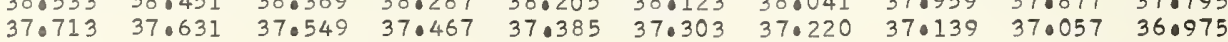


0.286105

0.286103

0.286103

0.286101

0.286100

0.28609

0.286098

53.468

\subsection{2}

\subsection{6}

49.391
48.575
47.760

53.386

$52.571 \quad 52.489$

$54.936 \quad 54.854$

$50.940 \quad 50.858 \quad 50.777$

$\begin{array}{lll}50.940 & 50.858 & 50.777 \\ 50.125 & 50.043 & 49.961\end{array}$

49.309
48.494

50.043
49.228

49.961
49.146
48.331

28546.945

$46.130 \quad 46.048$

$44.500 \quad 45.234$

$43.685 \quad 43.604$

$42.870 \quad 42.789$

$40.425 \quad 40.344$

46.782

46.700

58.51158 .770

59.504
58.688

$\begin{array}{llll}57.872 & 57.791 & 57.709 & 57.627\end{array}$

$\begin{array}{llllll}56.404 & 56.323 & 56.241 & 56.159 & 56.078 & 55.996\end{array}$

0.286097

0.286096

0.28609

0.286093

0.28609

0.286089

0.286088

0.286088

0.286086

0.286084

0.286083

0.286082

0.286081

3503 .

3.

28538

$$
\begin{array}{rl}
538.796 & 38.715 \\
37.981 & 37.900 \\
37.167 & 37.085 \\
36.352 & 36.271 \\
35.538 & 35.456 \\
34.723 & 34.642 \\
33.909 & 33.827 \\
33.094 & 33.013 \\
32.280 & 32.199 \\
31.466 & 31.384
\end{array}
$$

3504.0

4.0
4.
4.
4.
4.5
4.6
4.7
4.8
4.9

28530.65

$29.832 \quad 30.571$

$29.838 \quad 29.756$

$28.209 \quad 28.128$

26.58126 .500

$25.767 \quad 25.68$

$24.953 \quad 24.872$

$\begin{array}{ll}24.139 & 24.058 \\ 23.326 & 23.244\end{array}$

$38.633 \quad 38.552$

$\begin{array}{ll}37.818 & 37.737 \\ 37.004 & 36.922\end{array}$

$36.189 \quad 36.108$

$\begin{array}{ll}34.560 & 34.479\end{array}$

$33.746 \quad 33.664$

$\begin{array}{ll}32.932 & 32.850 \\ 32.117 & 32.003 \\ 31.303 & 31.022\end{array}$

37.65

36.84
36.02
364212

35.21
34.397
33.583

$33.583 \quad 33.516$

$32.768 \quad 32.687$

3

$30.489 \quad 30.407$

$\begin{array}{ll}29.675 & 29.593 \\ 28.861 & 28.779\end{array}$

$30.326 \quad 30.245$

$28.047 \quad 27.965$

$\begin{array}{ll}27.232 & 27.151 \\ 26.418 & 26.337\end{array}$

25.60
24.79

$24.791 \quad 24.709$

$\begin{array}{ll}27.884 & 27.802 \\ 27.070 & 26.988\end{array}$

26.256
25.442
26.176

25.442
24.628

23.000

23.547
22.91
22.91

3505.0

5.1
5.2

$\begin{array}{rl}28522.512 & 22.0430 \\ 210698 & 21.667 \\ 200.084 & 20.893\end{array}$

$22.349 \quad 22.268$

22.18

$\begin{array}{llll}20.884 & 20.803 & 20.722 & 20.640 \\ 20.071 & 19.989 & 19.908 & 19.826\end{array}$

$\begin{array}{lllll}19.257 & 19.176 & 19.094 & 19.013\end{array}$

$18.444 \quad 18.36$

$17.630 \quad 17.549$

$16.817 \quad 16.735$

$15.190 \quad 15.109$

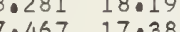

$16.654 \quad 16.573$

19.745

$18.932 \quad 18.850$

17.304

\begin{tabular}{ll}
8 & 18.037 \\
\hline 1.70223
\end{tabular}

$15.027 \quad 14.946$

3506.

28514.377

$13.377 \quad 14 \cdot 296$

$12.750 \quad 13.482 \quad 13.40$

3.401
2.588

$14 \cdot 133$

15.678
14.865

16.05

15.597
14.78

11.93711 .85

$10.311 \quad 10.230$

(1.775 11.506

11.693

$12.042512 .344 \quad 12.262 \quad 12094 \quad 120130120832$

9.49809 .417

$\begin{array}{ll}10.961 & 10.880 \\ 10.148 & 10.067\end{array}$

$\begin{array}{ll}07.872 & 07.79 \\ 07.059 & 06.97\end{array}$

08.52208 .441

$\begin{array}{llllll}11.612 & 11.531 & 11.449 & 11.368 & 11.287 & 11.205 \\ 10.799 & 10.717 & 10.636 & 10.555 & 10.474 & 10.392\end{array}$

$\begin{array}{llllll}10.799 & 10.717 & 10.636 & 10.555 & 10.474 & 10.392 \\ 09.986 & 09.904 & 09.823 & 09.742 & 09.660 & 09.579\end{array}$

$\begin{array}{llllll}09.173 & 09.092 & 09.010 & 08.929 & 08.847 & 08.766\end{array}$

$\begin{array}{lllllll}0.1360 & 08.279 & 08.197 & 08.116 & 08.035 & 07.953\end{array}$

6.8

3507

7.0
7.0
7.0
7.4
7.5
7
7.0
7.9

28506

$05.246 \quad 06.165$

06.083050002

06.734

$05.92105 .840 \quad 05.759 \quad 05.677 \quad 05.596 \quad 050515$

$\begin{array}{llllllllll}03.808 & 03.727 & 03.645 & 03.564 & 03.483 & 03.402 & 03.320 & 03.239 & 03.158 & 03.076\end{array}$

$\begin{array}{llllllllll}02.995 & 02.914 & 02.833 & 02.751 & 02.670 & 02.589 & 02.508 & 02.427 & 02.345 & 02.264\end{array}$

$\begin{array}{llllllllll}02.183 & 02.101 & 02.020 & 01.939 & 01.858 & 01.777 & 01.696 & 01.614 & 01.533 & 01.452\end{array}$

$\begin{array}{llllllllll}01.370 & 01.289 & 01.208 & 01.127 & 01.045 & 00.964 & 00.883 & 00.802 & 00.720 & 00.639\end{array}$

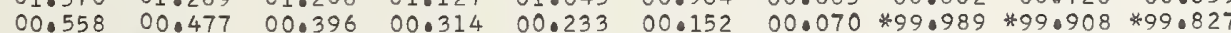

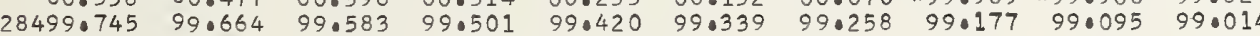

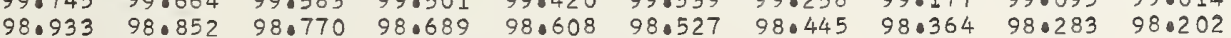

3508

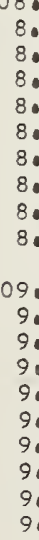

98.12198 .03

$97.308 \quad 97.227 \quad 97.958 \quad 97.877$

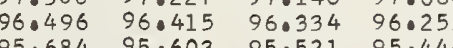

$94.872 \quad 94.790 \quad 94.70994 .628$

$94.059 \quad 93.97 .8 \quad 93.897 \quad 93.816$

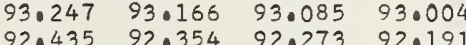

$\begin{array}{llll}92.435 & 92.354 & 92.273 & 92.191 \\ 91.623 & 91.542 & 91.461 & 91.379\end{array}$

$97.796 \quad 07.714$

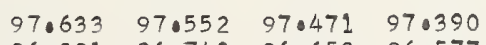

$\begin{array}{llllll}96.983 & 96.902 & 96.821 & 96.740 & 96.658 & 96.577 \\ 96.171 & 96.090 & 96.009 & 95.927 & 95.846 & 95.765\end{array}$

$\begin{array}{llllll}95.359 & 95.090 & 96.009 & 95.927 & 95.846 & 95.765 \\ & 95.196 & 95.115 & 95.034 & 94.953\end{array}$

$94.546 \quad 94.465 \quad 94.384 \quad 94.303 \quad 94.222 \quad 94 \cdot 140$

$93.735 \quad 93.653 \quad 93.572 \quad 93.491 \quad 93.409 \quad 93.328$

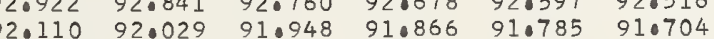

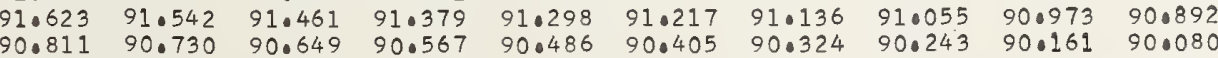

$\begin{array}{llllllllll}28489.999 & 89.918 & 89.837 & 89.756 & 80.674 & 89.593 & 89.512 & 89.431 & 89.349 & 89.268\end{array}$

$\begin{array}{llllllllll}89.187 & 89.106 & 89.025 & 88.944 & 88.863 & 88.781 & 88.700 & 88.619 & 88.538 & 88.457\end{array}$

$\begin{array}{llll}88.375 & 88.294 & 88.213 & 88.132 \\ 87.563 & 87.482 & 87.402 & 87.321\end{array}$

$\begin{array}{llll}87.563 & 87.482 & 87.402 & 87.321 \\ 86.752 & 86.671 & 86.590 & 86.509\end{array}$

$\begin{array}{llll}86.752 & 86.671 & 86.590 & 86.509 \\ 85.941 & 85.859 & 85.778 & 85.697\end{array}$

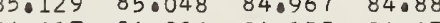

$83.506 \quad 83.425 \quad 83.155 \quad 84.074$

$\begin{array}{llllll}88.051 & 87.969 & 87.888 & 87.807 & 87.726 & 87.645\end{array}$

$\begin{array}{llllll}87.240 & 87.158 & 87.077 & 86.996 & 86.915 & 86.833 \\ 86.428 & 86.346 & 86.265 & 86.184 & 86.103 & 86.021\end{array}$

$\begin{array}{lllllll}85.616 & 85.535 & 85.454 & 85.373 & 85.291 & 85.210\end{array}$

$\begin{array}{lllllll}84.804 & 84.723 & 84.642 & 84.561 & 84.479 & 84.398\end{array}$

$\begin{array}{lllllll}83.993 & 83.912 & 83.830 & 83.749 & 83.668 & 83.587\end{array}$

$\begin{array}{ll}83.181 & 83.100 \\ 82.370 & 82.288\end{array}$

$2.207 \quad 82.938 \quad 82.857 \quad 82.775$

.001

.003

.004

.005

.006

.007

$.008 \quad .009$

0.286080

0.286078

0.285078

0.286076

0.286075

0.286073

0.286072

0.286071

0.286070

0.286069

.286068

0.286067

0.286066

0.286065
0.286064

0.286063

0.286062

0.286061

0.286060

0.286059

0.286058

0.286058

0.286056

0.286055

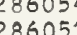

0.286053

0.286052

0.286051

0.286049

0.286049

0.286048

0.286047

0.286048

0.286045

0.286044

0.286043

0.28604

0.86040

0.286039

0.286038

0.286036

0.28035

0.286034

0.286033

0.286032

0.286030

0.28602

0.286029

0.286028

0.286027

0.286026

0.002

0.286024
0.286023

1.001368

.001393

.001445

2.001496

1.001522

1.001573

1.001599

1.001625

.001650

1.001676

1.001727
.0001753

.001779

.001830

1.001881

1.001933

9.002010

.002061
.002087

.002113 


$$
\begin{array}{r}
510.0 \\
0.1 \\
0.2 \\
0.3 \\
0.4 \\
0.5 \\
0.6 \\
0.7 \\
0.8 \\
0.9
\end{array}
$$

3511.

$$
511:
$$

3512$$
20
$$$$
2.5
$$$$
\begin{aligned}
& 2.7 \\
& 2.8
\end{aligned}
$$$$
2.9
$$$$
3513 .
$$$$
\text { , }
$$$$
\begin{aligned}
& 3.2 \\
& 3.3 \\
& 3.4
\end{aligned}
$$$$
\begin{aligned}
& 3.4 \\
& 3.5
\end{aligned}
$$$$
\begin{aligned}
& 3.6 \\
& 3.7
\end{aligned}
$$$$
\begin{aligned}
& 3.8 \\
& 3.9
\end{aligned}
$$$$
351400
$$$$
40
$$$$
\begin{aligned}
& 4.2 \\
& 4.3
\end{aligned}
$$$$
4.4
$$$$
\begin{aligned}
& 4.5 \\
& 4.6
\end{aligned}
$$$$
\begin{aligned}
& 4.6 \\
& 4.7 \\
& 4.8
\end{aligned}
$$$$
3515.0
$$

$$
\begin{aligned}
& 5.1 \\
& 5.2 \\
& 5.3
\end{aligned}
$$

5.3
5.4

5.5

5.6
5.7
5.8$$
3516 .
$$$$
6.1
$$$$
6.3
$$$$
6.5
$$$$
\begin{aligned}
& 6.7 \\
& 6.8 \\
& 6.9
\end{aligned}
$$$$
3517
$$$$
\begin{aligned}
& 17.0 \\
& 7 \\
& 70 \\
& 704 \\
& 7.5 \\
& 70 \\
& 7.0 \\
& 7.9
\end{aligned}
$$$$
\begin{array}{r}
3518.0 \\
8.1 \\
8.2 \\
8.3 \\
8.4 \\
8.5 \\
8.6 \\
8.7 \\
8.8 \\
8.9
\end{array}
$$$$
\begin{aligned}
& 19.0 \\
& 9.2 \\
& 9.3 \\
& 9.5 \\
& 9.5 \\
& 9.7 \\
& 9 .
\end{aligned}
$$

$\begin{array}{llllllll}81.720 & 81.639 & 81.558 & 81.477 & 81.396 & 81.315 & 81.234 & 81.153\end{array}$ $\begin{array}{lllllllllll}81.072 & 80.990 & 80.909 & 80.828 & 80.747 & 80.666 & 80.584 & 80.503 & 80.422 & 80.341\end{array}$ $\begin{array}{llllllllll}79.448 & 79.368 & 79.286 & 79.205 & 79.124 & 79.043 & 78.962 & 78.881 & 78.800 & 78.719\end{array}$ $\begin{array}{lllllllllll}78.637 & 78.556 & 78.475 & 78.394 & 78.313 & 78.232 & 78.150 & 78.069 & 77.988 & 77.907\end{array}$ $\begin{array}{llllllllll}77.826 & 77.745 & 77.664 & 77.583 & 77.501 & 77.420 & 77.339 & 77.258 & 77.177 & 77.096\end{array}$

$\begin{array}{llllllllll}77.015 & 76.934 & 76.853 & 76.772 & 76.690 & 76.609 & 76.528 & 76.447 & 76.366 & 76.285 \\ 76.204 & 76.123 & 76.042 & 75.960 & 75.879 & 75.798 & 75.717 & 75.636 & 75.555 & 75.474\end{array}$ $75 \cdot 393 \quad 75 \cdot 312$ 28473.771 72.959
72.149 71.338 $70.528 \quad 70.4 .46$ $68.906 \quad 68.825$ 08.014 67.284
66.474

28465.664 64.853 63.232 (6.0.530 59.18159 .910 58.371

28457.5 $56.751 \quad 57.480$ $55.941 \quad 55.860$ $55.131 \quad 55.050$ $53.511 \quad 53.430$

$52.701 \quad 52.620$ $\begin{array}{ll}51.082 & 51.001 \\ 50.272 & 50.191\end{array}$

$28449.462 \quad 49.382$ 48.653

47.844

$47.034 \quad 46.953$

$46 \cdot 225 \quad 46 \cdot 144$

44.606

$43.796 \quad 43.715$

$42.988 \quad 42.907$

40.56

39.751

$38.751 \quad 39.670$

$38.133 \quad 38.86$

$37.324 \quad 37 \cdot 243$

35.71536 .434

$\begin{array}{ll}34.897 & 34.817 \\ 34.089 & 34.00\end{array}$

28433.280

32.47
31.66

31.66
30.85
30.046

$29.237 . \quad 29.155$

$27.621 \quad 27.540$

$\begin{array}{ll}26.812 & 26.732 \\ 26.004 & 25.924\end{array}$

$28425.196 \quad 25.11$

$\begin{array}{ll}24.388 & 24.307 \\ 23.580 & 23.499\end{array}$

$\begin{array}{ll}22.771 & 22.691 \\ 21.964 & 21.88\end{array}$

$\begin{array}{ll}21.964 & 21.88 \\ 21.156 & 21.075\end{array}$

$20.347 \quad 20.267$

$\begin{array}{llllllllll}19.540 & 19.459 & 19.378 & 19.297 & 10.216 & 19.136 & 19.055 & 18.974 & 18.893 & 18.812 \\ 18.731 & 18.651 & 18.570 & 18.489 & 18.409 & 18.328 & 18.247 & 18.167 & 18.085 & 18.004 \\ 17.924 & 17.843 & 17.762 & 17.681 & 17.601 & 17.520 & 17.439 & 17.359 & 17.278 & 17.197\end{array}$

$\begin{array}{ll}75.230 & 75 \cdot 149 \\ 74.419 & 740338\end{array}$

75.879

75.798

74.90

$74.755 \quad 75.474$

$73.608 \quad 73.527$

$\begin{array}{ll}72.798 & 72.717 \\ 71.987 & 71.906\end{array}$

$\begin{array}{ll}71.176 & 71.095 \\ 70.365 & 70.284\end{array}$

$69.554 \quad 69.473$

67.933 67.

67.122

.852
.041

73.446
72.636

$74 \cdot 176$

$65.50165 .420 \quad 65$

$\begin{array}{ll}64.691 & 64.610 \\ 63.880 & 63.799\end{array}$

$\begin{array}{llll}64.691 & 64.610 & 64.529 & 64.448 \\ 63.880 & 63.799 & 63.718 & 63.637 \\ 63.070 & 62.989 & 62.908 & 62.827\end{array}$

$61.449 \quad 61.368 \quad 61.287$

60.63960 .558

60.477

$59.667 \quad 50.396$

61.206
60.396

61.125

60.315

59.50

$58.208 \quad 58.128$

57.318

58.047

57.966

54.969
54.888

$54.159 \quad 54.078$

$\begin{array}{ll}51.730 & 51.649 \\ 50.920 & 50.839\end{array}$

$50.110 \quad 50.029$

$\begin{array}{ll}49.301 & 49.220\end{array}$

$47.681 \quad 47.601$

46.06345 .981

$45.253 \quad 45.173$

$\begin{array}{ll}44.444 & 44.363\end{array}$

42.826
42.745

41.20841 .127

$\begin{array}{ll}40.398 & 40.318 \\ 39.589 & 39.508\end{array}$

$38.780 \quad 38.699$

$\begin{array}{ll}37.162 & 37.082\end{array}$

$3.354 \quad 36.273$

$\begin{array}{ll}34.736 & 34.655 \\ 33.927 & 33.846\end{array}$

$56.427 \quad 56.346$

57.075

$54.807 \quad 54.726$

$53.187 \quad 53.106$

$\begin{array}{ll}52.377 & 52.297 \\ 51.568 & 51.487\end{array}$

$\begin{array}{ll}50.758 & 50.677 \\ 49.948 & 49.867\end{array}$

$\begin{array}{ll}49.139 & 49.058 \\ 48.329 & 48.248\end{array}$

$\begin{array}{lllll}48.248 & 48.167 & 48.086 & 48.005 & 47.925\end{array}$

$\begin{array}{llllll}46.710 & 47.439 & 47.358 & 47.277 & 47.196 & 47.115 \\ & 46.629 & 46.548 & 46.468 & 46.386 & 46.305\end{array}$

$\begin{array}{lllllll}45.901 & 45.820 & 45.739 & 45.658 & 45.577 & 45.496\end{array}$

$\begin{array}{llllll}45.091 & 45.010 & 44.929 & 44.849 & 44.768 & 44.687\end{array}$

$\begin{array}{llllll}42.473 & 43.392 & 43.311 & 43.230 & 43.150 & 43.069\end{array}$

$42.664 \quad 42.583$

$39.427 \quad 39.346 \quad 39.266 \quad 39.185 \quad 39.104 \quad 39.023$

$\begin{array}{llllll}38.619 & 38.538 & 38.457 & 38.376 & 38.295 & 38.214\end{array}$

$\begin{array}{llllll}37.000 & 36.920 & 36.839 & 36.758 & 36.677 & 36.596\end{array}$

$36.192 \quad 36.111 \quad 36.030 \quad 35.949 \quad 35.868 \quad 35.787$

$\begin{array}{lllllll}35.383 & 35.302 & 35.221 & 35.140 & 35.060 & 34.978\end{array}$

$\begin{array}{llllll}34.574 & 34.493 & 34.412 & 34.332 & 34.251 & 340169 \\ 33.765 & 33.684 & 33.604 & 33.523 & 33.442 & 33.361\end{array}$

$33.118 \quad 33.038$

32.957

32.876

32.795

32.714

32.633

32.552

$\begin{array}{ll}31.501 & 31.420 \\ 30.692 & 30.612\end{array}$

$29.884 \quad 29.80$

$28.268 \quad 28.187$

27.450 .27 .378

31.33

$\begin{array}{lllll}30.450 & 31.178 & 31.097 & 31.016 & 30.935\end{array}$

$\begin{array}{llllll}28.914 & 28.833 & 28.753 & 28.672 & 28.591 & 28.510\end{array}$

$\begin{array}{llllll}270106 & 28.025 & 27.944 & 27.863 & 27.782 & 27.702\end{array}$

$26.489 \quad 26.408 \quad 26.327 \quad 26.247 \quad 26.166 \quad 26.085$

$\begin{array}{lllll}25.600 & 25.519 & 25.438 & 25.358 & 25.277\end{array}$

$25.034 \quad 24.954$

$24.226 \quad 24.146$

$22.610 \quad 22.529$

$\begin{array}{ll}21.802 & 21.72 \\ 20.994 & 20.91\end{array}$

$20.186 \quad 20.105$

$24.873 \quad 24.792$

$24.711 \quad 24.630 \quad 24.549 \quad 24.469$

$\begin{array}{llllll}24.064 & 23.984 & 23.903 & 23.822 & 23.741 & 23.660 \\ 23.256 & 23.176 & 23.095 & 23.014 & 22.933 & 22.852\end{array}$

$\begin{array}{llllll}22.448 & 22.368 & 22.287 & 22.206 & 22.125 & 22.044 \\ 21.640 & 21.560 & 21.479 & 21.398 & 21.317 & 21.236\end{array}$

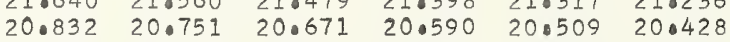

$\begin{array}{llllll}20.024 & 19.944 & 19.863 & 19.782 & 19.701 & 19.520 \\ 10.216 & 19.136 & 19.055 & 18.974 & 18.893 & 18.812\end{array}$

$28417.116 \quad 17.035$

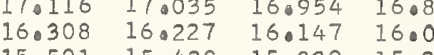

$\begin{array}{llllll}15.0501 & 15.420 & 15.339 & 15.258 & 15 & 15.177\end{array}$

$13.886 \quad 14.613 \quad 14.531 \quad 14.0450$

$\begin{array}{llll}13.078 & 12.997 & 12.917 & 12.836\end{array}$

$12.271 \quad 12.190 \quad 12.109 \quad 12.029$

11.46311 .382

$\begin{array}{llll}10.656 & 10.575 & 10.494 & 10.414 \\ 09.849 & 09.768 & 09.687 & 09.606\end{array}$

13.56314 .28

13.482

$11.948 \quad 11.867$

$11.140 \quad 11.060$

$\begin{array}{ll}10.333 & 10.2 \\ 0.0 .526 & 09.4\end{array}$

$\begin{array}{llll}16.632 & 16.551 & 16.470 & 16.389\end{array}$

$\begin{array}{llll}15.824 & 15.743 & 15.662 & 15.582\end{array}$

$14.208 \quad 14.128 \quad 14.047 \quad 13.966$

$\begin{array}{llll}13.401 & 13.321 & 13.240 & 13.159 \\ 12.594 & 12.513 & 12.432 & 12.352\end{array}$

$\begin{array}{llll}11.786 & 11.706 & 11.625 & 11.544\end{array}$

$\begin{array}{llll}10.171 & 10.098 & 10.817 & 10.737 \\ 0.090 & 10.010 & 09.929\end{array}$

$\begin{array}{lllllllllll}0.041 & 08.960 & 08.880 & 08.799 & 08.718 & 08.637 & 08.557 & 08.476 & 08.395 & 08.315 \\ 0.234 & 08.153 & 08.073 & 07.092 & 07.911 & 07.830 & 07.750 & 07.669 & 07.588 & 07.507\end{array}$

$\begin{array}{lllllllllll}06.619 & 06.539 & 06.458 & 06.377 & 06.297 & 06.216 & 06.135 & 06.054 & 05.974 & 05.893\end{array}$

$\begin{array}{llllllllll}05.005 & 04.925 & 04.844 & 04.763 & 04.682 & 04.602 & 04.521 & 04.440 & 04.359 & 04.279\end{array}$

$\begin{array}{llllllllll}04.198 & 04.117 & 04.037 & 03.956 & 03.875 & 03.795 & 03.714 & 03.633 & 03.552 & 03.472\end{array}$

$\begin{array}{llllllllll}03.391 & 03.310 & 03.230 & 03.149 & 03.068 & 02.988 & 02.907 & 02.826 & 02.746 & 02.665\end{array}$

$02.584 \quad 02.503 \quad 02.423 \quad 02.342$

02.261

02.181

.005

01.293

0.286022

0.286021

0.286020

0.286020

0.286018

0.286018

0.286016

0.286015

0.286015

0.286014

0.286013

0.286012
0.286011

0.286010

0.286010

0.286009

0.286008
0.286007

0.286006

0.286006

0.286005

0.286004
0.286003

0.286002

0.286001

0.286001

0.286000

0.285998

0.285997

0.285996

0.285995

0.285994

0.285993

0.285992

0.285992

0.285991

0.285989

0.285988

0.285987
0.285987

0.285986

0.285985

0.285984

0.285982 
$\lambda(A)$

.00

.01

.02

.03

.04

.05

.06

.07

.08

.09

$(n-1) \times 1000$

$\lambda(n-1)$

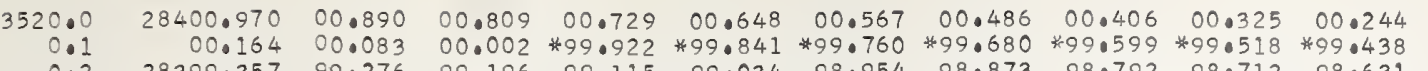

$\begin{array}{lrlllllllll}0.2 & 28399.357 & 99.276 & 99.196 & 99.115 & 99.034 & 98.954 & 98.873 & 98.792 & 98.712 & 98.631 \\ 0.3 & 98.550 & 98.470 & 98.389 & 98.308 & 98.228 & 98.147 & 98.066 & 97.986 & 97.905 & 97.824\end{array}$

$\begin{array}{lllllllllll}0.3 & 98.550 & 98.470 & 98.389 & 98.308 & 98.228 & 98.147 & 98.066 & 97.986 & 97.905 & 97.824\end{array}$

$\begin{array}{llllllllll}96.937 & 96.856 & 96.776 & 96.695 & 96.615 & 96.534 & 96.453 & 96.373 & 96.292 & 96.211 \\ 96.131 & 96.050 & 95.969 & 95.889 & 95.808 & 95.727 & 95.647 & 95.566 & 95.485 & 95.405\end{array}$

$\begin{array}{llllllllll}96.131 & 96.050 & 95.969 & 950889 & 95.808 & 95.727 & 95.647 & 95.566 & 95.485 & 95.405 \\ 95.324 & 95.243 & 95.163 & 95.082 & 95.001 & 94.921 & 94.840 & 94.760 & 94.679 & 94.598\end{array}$

$\begin{array}{llllllllll}94.518 & 94.437 & 94.356 & 94.275 & 94.195 & 94.114 & 94.034 & 93.953 & 93.872 & 93.792 \\ 93.711 & 93.631 & 93.550 & 93.469 & 93.388 & 93.308 & 93.227 & 93.147 & 93.066 & 92.985\end{array}$

0.8

3521.0
$1:$
$1:$
1
1
1
1

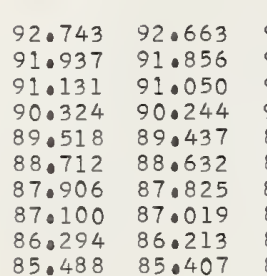

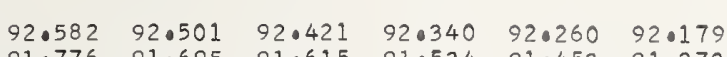

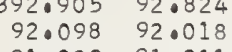

$91.292 \quad 91.211$

$89.680 \quad 89.599$

$\begin{array}{ll}88.873 & 88.793 \\ 88.067 & 87.987\end{array}$

$\begin{array}{ll}87.261 & 87.180\end{array}$

$\begin{array}{ll}86.455 & 86.375 \\ 85.649 & 85.568\end{array}$

3522.

$22 \cdot 0$
$2 \cdot 1$
2.2

28384.84
84.038

$\begin{array}{ll}84.038 & 83.7 \\ 83.957\end{array}$

84.682

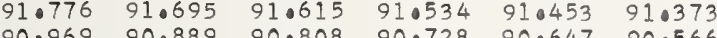

$\begin{array}{llllll}90.969 & 90.889 & 90.808 & 90.728 & 90.647 & 90.566 \\ 90.163 & 90.083 & 90.002 & 89.921 & 89.841 & 89.760\end{array}$

$\begin{array}{llllll}89.357 & 89.276 & 89.196 & 89.115 & 89.034 & 88.954\end{array}$

$\begin{array}{llllll}88.551 & 88.470 & 88.390 & 88.309 & 88.228 & 88.148\end{array}$

$\begin{array}{lllllll}87.745 & 87.664 & 87.584 & 87.503 & 87.422 & 87.342 \\ 86.938 & 86.858 & 86.778 & 86.697 & 86.616 & 86.536\end{array}$

$\begin{array}{lllllll}86.133 & 86.052 & 85.971 & 85.891 & 85.810 & 85.729 \\ 85.327 & 85.246 & 85.165 & 85.085 & 85.004 & 84.923\end{array}$

1.006508

0.285939

.

0.285938

0.285937

.

0.285933
0.285932

0.285932

.

0.285929

0.285928

0.285927

0.285926
0.285925

0.285925
0.285924

.00658

1.006611

.006662

.006714
.006739

2.3

83.23283 .151

$83.682 \quad 84.602$

84.52

84.440

$4.360 \quad 84.279 \quad 84 \cdot 199 \quad 84.118$

0.285923

0.285923

0.285921

$\begin{array}{llllllllll}82.426 & 82.345 & 82.265 & 82.184 & 82.104 & 82.023 & 81.942 & 81.862 & 81.781 & 81.701\end{array}$

$\begin{array}{lllllllll}81.540 & 81.459 & 81.378 & 81.298 & 81.217 & 81.137 & 81.056 & 80.976 & 80.895\end{array}$

$\begin{array}{llllllllll}80.814 & 80.734 & 80.653 & 80.573 & 80.492 & 80.412 & 80.331 & 80.250 & 80.170 & 80.090\end{array}$

$\begin{array}{lllllllllll}70.203 & 79.928 & 79.848 & 79.767 & 79.687 & 79.606 & 79.525 & 79.445 & 79.364 & 79.28\end{array}$

$\begin{array}{llllllllll}78.397 & 78.317 & 78.236 & 78.156 & 78.075 & 77.995 & 77.914 & 77.834 & 77.753 & 77.673 \\ 77.592 & 77.511 & 77.431 & 77.350 & 77.270 & 77.189 & 77.109 & 77.028 & 76.948 & 76.867\end{array}$

0.285920

0.285919

0.285918

0.285916

$\begin{array}{llllllllll}28376.787 & 76.706 & 76.625 & 76.545 & 76.464 & 76.384 & 76.303 & 76.223 & 76.142 & 76.062\end{array}$

$\begin{array}{ll}75.981 & 75.900 \\ 75.176 & 75.095 \\ 74.370 & 74.290\end{array}$

3.1

$\begin{array}{ll}73.565 & 73.485 \\ 72.760 & 72.679\end{array}$

$75.015 \quad 74.934$

74.20974 .129

$71.955 \quad 71.874$

$73.404 \quad 73.323$

$\begin{array}{ll}75.659 & 75.578 \\ 74.853 & 74.773\end{array}$

$75 \cdot 49$

$\begin{array}{lll}75.417 & 75.337 & 75.256\end{array}$

0.285915

0.285914

0.285913

$\begin{array}{lllllllll}71.874 & 71.793 & 71.713 & 71.632 & 71.552 & 71.471 & 71.391 & 71.310 & 71.230\end{array}$

$\begin{array}{lllllllllll}7 & 0.069 & 70.983 & 70.903 & 70.023 & 69.747 & 70.666 & 70.586 & 70.505 & 70.425\end{array}$

3.

$69.540 \quad 69.459 \quad 69.378 \quad 69.298$

28368.735

4.0
4.0
4.
4.0
406
4.07
4

.65468 .573

7368.493

$70.023 \quad 69.942$

$69.861 \quad 69.781 \quad 69.700 \quad 69.520$

0.285910

0.285909

0.285908

.006765

1.006817

9.00686

1.006894

1.006919

1.006971

1.007022

1.007048

1.007099

1.007151

1.007202

1.007228

1.007280

1.007331

1.007382

1.007382

1.007434

.007485

0.285907

0.285906

0.285905

0.285905

0.285904

$\begin{array}{lllllllllll}65.515 & 65.239 & 66.159 & 66.078 & 65.998 & 65.917 & 65.837 & 65.756 & 65.676 & 65.595\end{array}$

$\begin{array}{llllllllll}64.710 & 64.629 & 64.549 & 64.469 & 64.388 & 64.308 & 64.227 & 64.147 & 64.066 & 63.986\end{array}$

$\begin{array}{llllllllll}63.905 & 63.824 & 63.744 & 63.664 & 63.583 & 63.503 & 63.422 & 63.342 & 63.261 & 63.181\end{array}$

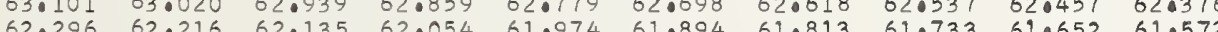

$\begin{array}{llllllllll}62.296 & 62.216 & 62.135 & 62.054 & 61.974 & 61.894 & 61.813 & 61.733 & 61.652 & 61.572 \\ 61.491 & 61.411 & 61.330 & 61.250 & 61.169 & 61.089 & 61.008 & 60.928 & 60.847 & 60.767\end{array}$

0.285901

0.285901

1.007537

1.007562

1.007614

1.0007640

1.007691

0.285899

0.285898

0.285897

0.285897

0.285896

0.285895

0.285894

0.285893
0.285892

$\begin{array}{llllllllll}55.860 & 55.780 & 55.699 & 55.619 & 55.538 & 55.458 & 55.378 & 55.297 & 55.217 & 55.137\end{array}$

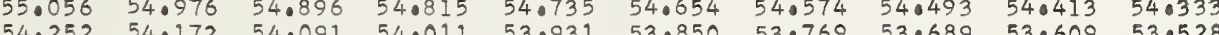

$\begin{array}{llll}53.252 & 54.172 & 54.091 & 54 \cdot 011 \\ 53.367 & 53.287 & 53.207\end{array}$

3526.0

26
6
6
6
6
6
6
6
6
6

28352.644

52.64452 .563

$52.483 \quad 52.403$

53.126

0.285892

0.285891

0.285890

0.285889

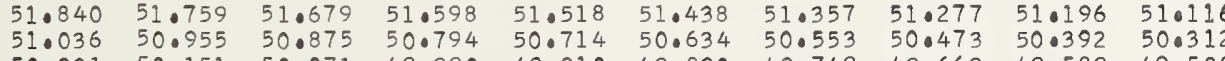

$\begin{array}{llllllllll}50.231 & 50.151 & 50.071 & 49.990 & 40.910 & 49.830 & 49.749 & 49.669 & 49.589 & 49.508\end{array}$

$\begin{array}{llllllllll}48.026 & 48.945 & 48.865 & 48.785 & 48.704\end{array}$

$\begin{array}{llllllllll}48.624 & 48.543 & 48.463 & 48.383 & 48.302 & 48.222 & 48.142 & 48.061 & 47.981 & 47.901 \\ 47.820 & 47.740 & 47.659 & 47.579 & 47.498 & 47.418 & 47.338 & 47.257 & 47.177 & 47.097\end{array}$

$47.016 \quad 46.936 \quad 46.855 \quad 46.775$

$\begin{array}{llll}46.212 & 46.132 & 46.052 & 45.971 \\ 45.409 & 45.328 & 45.248 & 45.167\end{array}$

$\begin{array}{llllll}46.695 & 46.614 & 46.534 & 46.453 & 46.373 & 46.293\end{array}$

0.285888

0.285887

0.285886

0.285885

0.285884
0.285884

0.285883

0.285882

0.285881

0.285880

0.285879

0.285879

0.285878

0.285879

0.285875

$\begin{array}{llllllllll}39.784 & 39.704 & 39.624 & 39.543 & 39.463 & 39.383 & 39.302 & 39.222 & 39.142 & 39.061 \\ 38.981 & 38.901 & 38.821 & 38.740 & 38.659 & 38.579 & 38.499 & 38.418 & 38.338 & 38.258\end{array}$

$\begin{array}{llllllllll}38.178 & 38.097 & 38.017 & 37.937 & 37.857 & 37.776 & 37.696 & 37.615 & 37.535 & 37.455 \\ 37.375 & 37.294 & 37.214 & 37.133 & 37.053 & 36.973 & 36.892 & 36.812 & 36.732 & 36.651\end{array}$

0.285875

0.285874

0.285873

0.285870

0.285868

1.007742
1.007768

1.007794

1.007820

1.0007871

10007897

1.007922

.0007974
.008000

.008025

.008051 .008102

1.008128

1.008180

1.008205

1.008231

1.008283

1.008308

1.0008334
1.008360

1.008385

1.008411

1.0008439
1.000863

1.008488

1.008514

1.008565

1.008591
1.008617

1.008643

1.008668

$\begin{array}{lllllllllll}33.0359 & 33.279 & 33.198 & 33.118 & 33.038 & 32.957 & 32.877 & 32.797 & 32.717 & 32.636\end{array}$

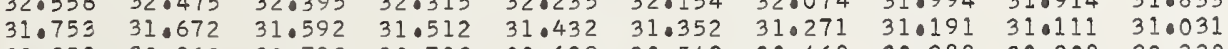

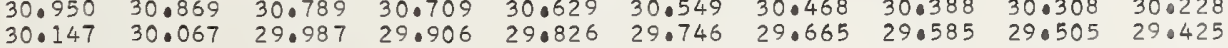

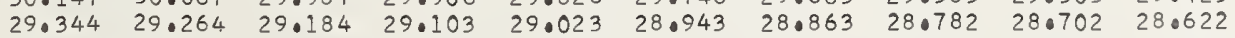

0.285866

0.285865

0.28586

0.285863

0.285862

0.28586

0.285860

1.008720

1.008746

.00879

1.008823

1.008848

1.008900
1.008926

1.008951

1.009003

1.009028

.010

$: 887$

$.001 \quad .002$

.003

.004

.005

.006

.007

.008

009

$: 88 \%$ 


.03
$\begin{array}{llllllllll}19.715 & 19.634 & 19.554 & 19.474 & 19.394 & 19.314 & 19.233 & 19.153 & 19.073 & 18.993 \\ 18.912 & 18.832 & 18.752 & 18.672 & 18.592 & 18.511 & 18.431 & 18.351 & 18.271 & 18.190\end{array}$ $\begin{array}{llllllllll}18.110 & 18.030 & 17.950 & 17.870 & 17.790 & 17.709 & 17.629 & 17.549 & 17.469 & 17.388 \\ 17.308 & 17.228 & 17.148 & 17.057 & 16.987 & 16.907 & 16.827 & 16.747 & 16.667 & 16.586\end{array}$ $\begin{array}{llllllllll}16.506 & 16.426 & 16.345 & 16.266 & 16.185 & 16.105 & 16.025 & 15.945 & 15.865 & 15.784\end{array}$ $\begin{array}{llllllllll}15.704 & 15.624 & 15.544 & 150463 & 15.383 & 15.303 & 15.223 & 15.143 & 15.062 & 14.982 \\ 14.902 & 14.822 & 14.742 & 140661 & 14.581 & 14.501 & 14.421 & 14.341 & 140261 & 14.180\end{array}$

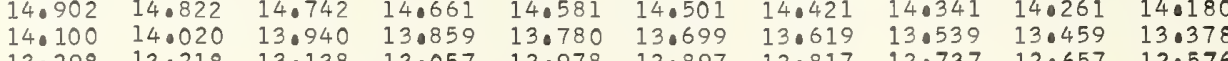

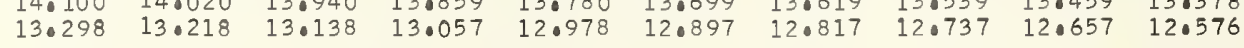

$\begin{array}{rlllllllll}28312.497 & 12.416 & 12.336 & 12.256 & 12.176 & 12.095 & 12.015 & 11.935 & 11.855 & 11.775 \\ 11.695 & 11.615 & 11.534 & 11.0454 & 11.374 & 11.294 & 11.214 & 11.134 & 11.053 & 10.974\end{array}$

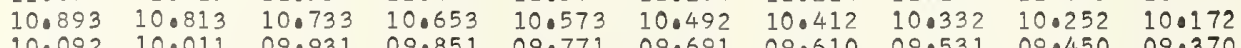
$\begin{array}{llllllllll}10.092 & 10.011 & 09.931 & 09.851 & 09.771 & 09.691 & 09.610 & 09.531 & 09.450 & 09.370 \\ 09.290 & 09.210 & 09.129 & 09.040 & 08.969 & 08.889 & 08.809 & 08.729 & 08.649 & 08.568\end{array}$ $\begin{array}{lllllllllll}08.488 & 08.408 & 08.328 & 08.248 & 08.167 & 08.087 & 08.007 & 07.927 & 07.847 & 07.767\end{array}$ $\begin{array}{lllllllllll}07.687 & 07.606 & 07.527 & 07.446 & 07.366 & 07.286 & 07.206 & 07.125 & 07.045 & 06.965\end{array}$ $\begin{array}{llllllllll}06.885 & 06.805 & 06.725 & 06.645 & 06.564 & 06.484 & 06.404 & 06.324 & 06.244 & 06.164 \\ 06.083 & 06.004 & 05.923 & 05.843 & 05.763 & 05.683 & 05.603 & 05.523 & 05.442 & 05.362\end{array}$ $\begin{array}{llllllllll}05.282 & 05.202 & 05.122 & 05.042 & 04.962 & 04.882 & 04 \cdot 801 & 04.721 & 04.641 & 040561\end{array}$

$\begin{array}{lllllllllll}28304.481 & 04.401 & 04.321 & 04.240 & 04.160 & 04.080 & 04.000 & 03.920 & 03.840 & 03.760\end{array}$ $\begin{array}{llllllllll}02.878 & 02.798 & 02.718 & 02.638 & 02.558 & 02.478 & 02.397 & 02.317 & 02.237 & 02.157 \\ 02.077 & 01.97 & 01.017 & 01.336 & 01.757 & 010676 & 0.596 & 01.516 & 01.436 & 01.356\end{array}$ $\begin{array}{lllllllllll}01.276 & 01.196 & 01.115 & 01.035 & 00.955 & 00.875 & 00.795 & 00.715 & 00.635 & 00.554\end{array}$ $00.475 \quad 00.394 \quad 00.314 \quad 00.234 \quad 00.154 \quad 00.074 * 99.994 * 99.914 * 99.834 * 99.754$ $\begin{array}{llllllllll}28299.673 & 99.593 & 99.513 & 99.433 & 90.353 & 99.273 & 99.193 & 99.113 & 99.032 & 980953\end{array}$

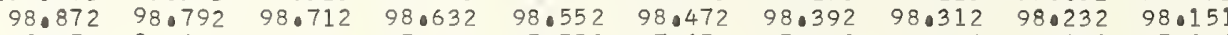
$\begin{array}{llllllllll}98.071 & 97.991 & 97.911 & 97.831 & 97.751 & 97.671 & 97.591 & 97.511 & 97.431 & 97.350 \\ 97.271 & 97.190 & 97.110 & 97.030 & 96.950 & 96.870 & 96.790 & 96.710 & 96.630 & 96.549\end{array}$

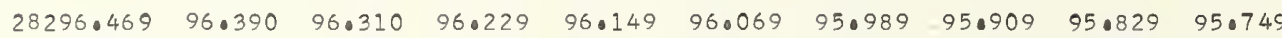
$\begin{array}{llllllllll}95.669 & 95.589 & 95.509 & 95.429 & 95.348 & 95.269 & 95.188 & 95.108 & 95.028 & 94.948\end{array}$

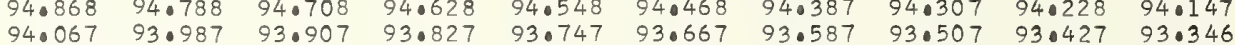

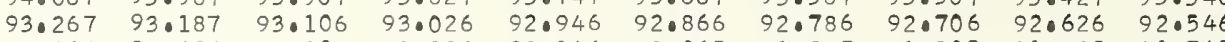

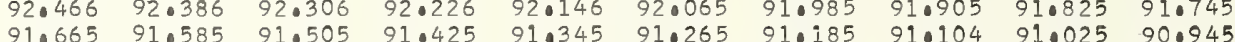

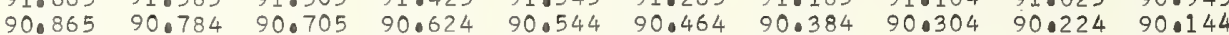

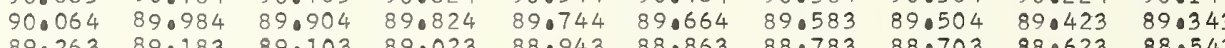
28288.463 88.38 $86.862-87.582$ $86.062 \quad 85.982$ $85.261 \quad 85.181$ $83.661 \quad 83.581$ $\begin{array}{ll}82.861 & 82.781 \\ 82.061 & 81.980\end{array}$ 81.26181 .181

$28280.461 \quad 80.3$

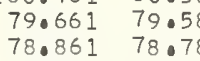
$\begin{array}{llll}78.061 & 77.091 & 78.701 & 79.42 \\ 77.061 & 77.901 & 77.821\end{array}$ $\begin{array}{ll}76.461 & 76.0382 \\ 75.062 & 75.588\end{array}$ $74.862 \quad 74.782$ $\begin{array}{ll}74.062 & 73.982 \\ 73.263 & 73.183\end{array}$

$28272.463 \quad 72.38$

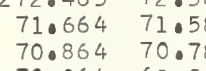

$70.064 \quad 69.985$

$69.26569 \cdot 185$

68.466
67.067 67.386

$66.857 \quad 66.788$ $65.269 \quad 65.189$

$88.303 \quad 88.223$

$\begin{array}{ll}87.502 & 87.422 \\ 86.702 & 86.622\end{array}$

$85.902 \quad 85.822$

84.301
83.501

84.221
83.421
82.621

81.900

81.820
81.021

$\begin{array}{llll}88.143 & 88.063 & 87.983\end{array}$

$87.342 \quad 87.262$

$85.742 \quad 85.662$

84.941
84.141
84.861

$83.341 \quad 83.261$

$\begin{array}{ll}81.740 & 82.461 .661 \\ 80.941 & 80.861\end{array}$

86.38

84.781

83.181

81.58
80.78

$80.141 \quad 80.06$

\title{
$\begin{array}{ll}80.301 & 80.221 \\ 79.501 & 79.421 \\ 78.701 & 78.621 \\ 77.901 & 77.821\end{array}$
}

$\begin{array}{ll}77.101 & 77.021 \\ 76.302 & 76.0221 \\ 75.502 & 75.422\end{array}$

$74.702 \quad 74.622$

$\begin{array}{ll}79.341 & 79.261 \\ 78.541 & 78.46\end{array}$

$\begin{array}{ll}77.741 & 77.661 \\ 76.941 & 76.861\end{array}$

$\begin{array}{ll}77.941 & 77.661 \\ 76.141 & 76.861 \\ 75.342 & 75.061\end{array}$

$74.542 \quad 740462$

$\begin{array}{ll}73.902 & 73.822 \\ 73.103 & 73.023\end{array}$

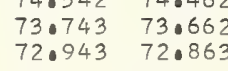

$79 \cdot 981$
$79 \cdot 1$
$78 \cdot 3$
77.5
$76 \cdot 781$
$75 \cdot 98$
$75 \cdot 182$
$74 \cdot 382$
73.582
72.783

72.30
71.50
70.704

72.223

\begin{abstract}
$72.143 \quad 72.063$
\end{abstract}

\begin{abstract}
71.98
\end{abstract}
$69.905 \quad 69.825$

68.306

67.507
66.708

68.226

67.427
66.628

$70.544 \quad 70.464$

$68.946 \quad 68.865$

$68.146 \quad 68.066$

$66.548 \quad 66.468$

650269650189

$$
65.10
$$

65.829
65.030

$64.950 \quad 64.870$

70.38

69.585
68.785

67.986

66.388

64.790

$\begin{array}{ll}63.671 & 63.591 \\ 62.872 & 62.792 \\ 62.073 & 61.993\end{array}$

$\begin{array}{ll}62.073 & 61.993 \\ 61.274 & 61.194\end{array}$

63.51
62.71
61.91

64.230
63.431
62.632

$64.150 \quad 64.07$

$\begin{array}{llll}60.475 & 60.395 & 61.114 & 61.034\end{array}$ $\begin{array}{lllll}59.676 & 59.596 & 59.517 & 59.437\end{array}$ $\begin{array}{ll}58.079 & 57.999 \\ 57.280 & 57.200\end{array}$

28256.481

$$
\begin{aligned}
& 55.68 \\
& 54.88 \\
& 54.08
\end{aligned}
$$

54.08554 .804

$53.287 \quad 53.207$

$51.690 \quad 51.611$

$\begin{array}{ll}50.892 & 50.81 \\ 50.094 & 50.01 \\ 49.296 & 49.21\end{array}$

3248.497

$47.699 \quad 48.417$

$46.0901 \quad 47.619$
46.901

$\begin{array}{ll}46.103 & 46.02 \\ 45.305 & 45.225\end{array}$

$44.507 \quad 44.427$

$43.709 \quad 43.629$

$\begin{array}{lll}42.911 & 42.831 \\ 42.113 & 42.033\end{array}$

$42 \cdot 113$
41.315

$(n-1) \times 1000$

$\lambda(n-1)$

$\begin{array}{ll}0.285858 & 1.009080 \\ 0.285858 & 1.009106 \\ 0.285857 & 1.009131 \\ 0.285856 & 1.009157 \\ 0.285855 & 1.009183 \\ 0.285854 & 1.009209 \\ 0.285853 & 1.009234 \\ 0.285853 & 1.009260 \\ 0.285552 & 1.009286 \\ 0.285851 & 1.009311\end{array}$

0.28585

0.28584

0.28584

0.285847

0.285846

0.285845

0.285844
0.285843

0.285842

0.285841

0.285840
0.285839

0.285838

.285837

0.285836

0.285835

0.285834

0.285833

0.285832

0.285831

0.285830

0.285828

0.285828

0.285827

1.009337 1.009363 1.009414 1.009440 1.009492 1.009517 1.009543
1.009569

1.009594 1.009620 1.009672

1.009697

1.0009723

1.009774

1.009800

1.009852

1.009877

1.009903
1.009929

1.009929

1.009980

1.010006

1.010032

0.285826

0.285825

0.285824
0.285824

0.285823

0.285822

0.285821
0.285820

0.285820

0.285819

.010083

0.285818

0.285817
0.285816

0.285815

0.285815

0.285814

0.285812

0.285811
0.285811

1.010109

1.010135

1.010160

1.010212

1.010238

1.010263

.010315

1.010366

1.010392

1.010418

1.010469

1.010495

1.010521

1.010572
19010598

0.285810

0.285808

0.285807

0.285807

0.285805

0.285804

0.285803

0.285802

0.285801
0.285800

0.285799

0.285799

0.285797

0.285796

0.285795
0.285795

0.285794

0.285793

0.285791

0.285790

0.285790

0.285789

0.285787

0.285786

0.285786

0.285785
0.285784

0.285783

0.285782
0.285782

0.285781

0.285780

0.285780
0.285779
0.285778

1.010624

.010649
.010675

1.010701

1.010752

1.010778

1.010804

1.010829

1.010881

1.010907

1.010958 

$\begin{array}{rrrrrrrrrrr}3540.0 & 28240.518 & 40.438 & 40.358 & 40.278 & 40.198 & 40.119 & 40.039 & 39.959 & 39.879 & 39.800 \\ 0.1 & 39.720 & 39.640 & 39.561 & 39.481 & 39.401 & 39.321 & 39.241 & 39.161 & 39.082 & 39.002 \\ 0.2 & 38.922 & 38.842 & 38.763 & 38.683 & 38.603 & 38.523 & 38.444 & 38.364 & 38.284 & 38.204\end{array}$ $\begin{array}{lllllllllll}0.2 & 38.922 & 38.842 & 38.763 & 38.683 & 38.603 & 38.523 & 38.444 & 38.364 & 38.284 & 38.204 \\ 0.3 & 38.124 & 38.045 & 37.965 & 37.885 & 37.806 & 37.726 & 37.646 & 37.566 & 37.486 & 37.406\end{array}$ $\begin{array}{lllllllllll}0.4 & 37.327 & 37.248 & 37.168 & 37.088 & 37.009 & 36.929 & 36.849 & 36.769 & 36.689 & 36.609\end{array}$ $\begin{array}{llllllllllll}0.5 & 36.530 & 36.450 & 36.370 & 36.291 & 36.211 & 36.131 & 36.052 & 35.971 & 35.892 & 35.812 \\ 0.6 & 35.732 & 35.652 & 35.573 & 35.493 & 35.413 & 35.334 & 35.254 & 35.174 & 35.094 & 35.015\end{array}$ $\begin{array}{llllllllllll}0.6 & 35.732 & 35.652 & 35.573 & 35.493 & 35.413 & 35.334 & 35.254 & 35.174 & 35.094 & 35.015 \\ 0.7 & 34.935 & 34.855 & 34.775 & 34.696 & 34.616 & 34.536 & 34.457 & 34.377 & 34.297 & 34.217\end{array}$ $\begin{array}{llllllllllll}0.8 & 34.137 & 34.058 & 33.978 & 33.898 & 33.819 & 33.739 & 33.659 & 33.579 & 33.500 & 33.420\end{array}$ 0.9 $\begin{array}{llllllllll}34.137 & 34.058 & 33.978 & 33.898 & 33.819 & 33.739 & 33.659 & 33.579 & 33.500 & 33.420 \\ 33.340 & 33.260 & 33.180 & 33.101 & 33.021 & 32.941 & 32.862 & 32.782 & 32.702 & 32.622\end{array}$

.006

.007

.008

.009

0.285778

0.285777

0.285775
0.0285774

0.285774

0.285773

0.285771

0.285770

0.285770

0.285769

0.285767

0.285756

0.285765

0.285764

0.285763

0.285762

0.285761

0.285759

0.285758
0.285758
0.285757

0.285758
0.285757

0.285756
0.285755

0.285755
0.285754

0.285754

0.28575

0.285751

0.285750

0.285750

0.285748
0.785747
0.285746

0.285747
0.285746

0.285746

0.285745

0.285744

0.285743

0.285742

0.285741
0.285740

0.285739

0.285738

0.285737

0.285736

0.285734

0.285734

0.285733
0.285732

0.285731
0.285730

0.285730

0.285729
0.285728

0.285727
0.285726

0.285726

0.285725

0.285724
0.285723

0.285723
0.285722

0.285722

0.285721
0.285720

0.28571

0.285718

0.285717

0.285716
0.285715

0.285714

.011653
.011679

1.011704

1.011730
1.011756

1.019789

1.011833
1.011859

10011884

1.011910

10011936

1.011987

1.012013

1.012065

1.012090

10012168

1.012219

1.012245

1.012296

1.012348

1.012373
1.012399

.012425
.012451

1.012476

1.012502

10012554

10012579

1.012631

1.012682

1.012708

.012760

1.012811

1.012868

1.012888

0.285794

0.285792

0.285710

0.285710

0.285709

0.285707

0.285706

0.285705

0.285704

0.285702

0.285702
0.285701

0.285700

0.285699

1.012940

1.012965

1.013017

1.013043

1.013094

1.013146

1.013197

1.013223

1.013274 


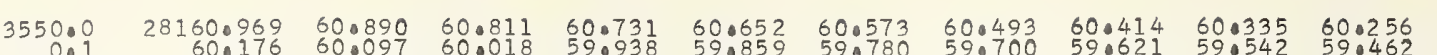

$\begin{array}{lllllllllll}0.2 & 590383 & 59.303 & 59.224 & 590145 & 59.066 & 58.986 & 58.0907 & 58.828 & 58.748 & 58.669\end{array}$

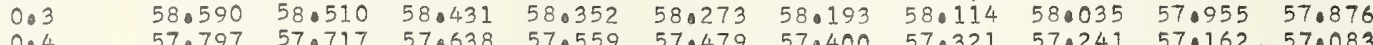
$\begin{array}{llllll}57.797 & 57.717 & 57.638 & 57.559 & 57.479 & 57.400\end{array}$ $56.210 \quad 56.131 \quad 56.052 \quad 55.973 \quad 55.893 \quad 55.814$

28153.039 $\begin{array}{lllll}52.246 & 52.959 & 52.880 & 52.801 & 52 \\ 52.167 & 52.088 & 52.008 & 510\end{array}$

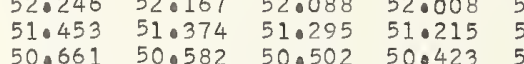

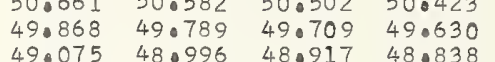
$\begin{array}{lllll}49.075 & 48.996 & 48.917 & 48.838 \\ 48.283 & 48.204 & 48.125 & 48.045\end{array}$ $\begin{array}{lllll}47.491 & 47.041 & 47.332 & 47.0253 & 47\end{array}$ $\begin{array}{llll}46.698 & 460619 & 460540 & 460450 \\ 450906 & 45.827 & 45.747 & 450668\end{array}$

1.014484

1.014510

1.014562

0
1.4587
10.14613

1.014639

1.014665

1.014716

10014742

1.014767

1.014819

1.0014870

1.014896

1.014922

1.014948
1.014973

1.014999

1.015051

1.015076

1.015128

1.015154

1.015179

1.015205
1.015231

1.015257

1.015282

1.015308

1.015334
1.015360

1.015385

9.015411

1.015463

1.015488

1.015514

1.015540

1.015591

1.015617

1.015643
1.015669

1.015694

1.015720
1.015746

1.015792

1.015797

1.015823
1.015849

1.015875
1.015900

1.015926

1.015952

1.015978

1.016029 
$28073.982 \quad 73.903$

$73.194 \quad 730$

$\frac{1}{1}: 2$

72.405
71.617

$70.041 \quad 69.962$

$68.465 \quad 680.386$

$\begin{array}{ll}67.677 & 67.598 \\ 66.889 & 66.810\end{array}$

$73.824 \quad 73.746$

$\begin{array}{ll}75.243 & 75.164 \\ 76.455 & 74.376\end{array}$

75.874

76.58
75.79

$\begin{array}{ll}93 & 770 \\ 5 & 76 \\ 6 & 750\end{array}$

76.426

066.101

2

3563.

3.1
3.2
3.3

3.4

3.6

3.

3564

4.

$64.525 \quad 64.446$

63.737

$61.374 \quad 61.295$

$60.586 \quad 60.507$

$59.011 \quad 58.932$

$\begin{array}{lll}72.957 & 72.878 & 72.800\end{array}$

73.509

$\begin{array}{ll}74.218 & 74.139\end{array}$

74.061

28058.224 57.436
56.649

56.649
55.861

$54.287 \quad 54.208$

53.500

51.925
51.138

3.421

2.634
51.847
51.060

$\begin{array}{lll}71.459 & 71.169 & 72.090 \\ 71.381 & 71.302\end{array}$

$\begin{array}{ll}70.671 & 70.593 \\ 69.883 & 69.804\end{array}$

$69.005 \quad 69.016 \quad 69.72$

72.011
71.223

$72 \cdot 72$
$71 \cdot 932$

72.64
71.854

70.356
69.568

$71 \cdot 06$
70.27

73.351
72.56
71.775

$73 \cdot 272$
72.484

69.64
68.85

69.568
68.780

69.48969 .410

70.90

$\begin{array}{llll}68.307 & 68.228 & 68.149 & 68.071\end{array}$

$67 \cdot 992$

67.913

68.622

69.332
68.543

66.73166 .652

$66.573 \quad 66.494$

$6 \cdot 41$

2805

050.351
49.564

50.272

49.564
48.777

49.485

47.203

45.630

44.843
44.056

46.338

$65.155 \quad 65.864$

$\begin{array}{ll}64.367 & 64.288 \\ 63.579 & 63.500\end{array}$

$65.785 \quad 65.706$

65.62
64.84

65.54

66.257

66.179

0.285816

0.285615

0.285613

0.285612
0.285611

0.285611
0.285610

0.28560

0.285607

0.285607

0.285605

0.285604

0.285603

0.285602

0.285600

0.285600

0.285598

0.285599

0.285596

1.017034

0.285595

0.285594

0.285593

0.285592

0.285589

0.285589

1.017059

1.017085
.017111

.017137

1.017188

.017240

1.017317

1.017369

1.017394
1.017420

1.017446

1.017472

1.017523

1.017575

1.017600

.017652

1.017678

1.017703
1.017729

1.017755

1.019781
1.017806

0.285587

1.017832

0.285585

0.285585

.285583

0.285582

0.285582
.285581

$\begin{array}{rrrrrrrrrrr}3565.0 & 28042.483 & 42.405 & 42.326 & 42.247 & 42.169 & 42.090 & 42.011 & 41.933 & 41.854 & 41.775\end{array}$

$\begin{array}{llllllllllll}5.1 & 41.697 & 41.618 & 41.540 & 41.461 & 41.382 & 41.304 & 41.225 & 41.146 & 41.068 & 40.989 \\ 5.2 & 40.910 & 40.831 & 40.753 & 40.674 & 40.595 & 40.517 & 40.438 & 40.360 & 40.281 & 40.202\end{array}$

$\begin{array}{lllllllllll}5.2 & 40.910 & 40.831 & 40.753 & 40.674 & 40.595 & 40.517 & 40.438 & 40.360 & 40.281 & 40.202 \\ 5.3 & 40.124 & 40.045 & 39.966 & 39.888 & 39.809 & 39.730 & 39.652 & 39.573 & 39.495 & 39.416\end{array}$

$\begin{array}{lllllllllll}5.4 & 39.337 & 39.259 & 39.180 & 39.101 & 39.023 & 38.944 & 38.865 & 38.787 & 38.708 & 38.629 \\ 5.5 & 38.551 & 38.472 & 38.393 & 38.315 & 38.236 & 38.157 & 38.079 & 38.000 & 37.922 & 37.843\end{array}$

5.

$\begin{array}{llll}37.0686 & 38.607 & 37.315\end{array}$

38.23

$\begin{array}{lllll}38.944 & 38.865 & 38.787 & 38.708 & 38.629 \\ 38.157 & 38.079 & 38.000 & 37.922 & 37.843 \\ 37.371 & 37.203 & 37.214 & 37.135 & 37.057\end{array}$

$36.978 \quad 36.899$

36.82136 .742

$36.650 \quad 37.371$

$36.506 \quad 36.214 \quad 37.135 \quad 37.05$

$35.406 \quad 35.327$

$35.249 \quad 35.170$

35.091

35.799

34.855

$35 \cdot 563$

34.698

3566.0

33.

$33.833 \quad 33.75$

$\begin{array}{ll}33.047 & 32.969 \\ 32.261 & 32.183\end{array}$

$31.475 \quad 31.396$

$30.689 \quad 30.61$

$29.903 \quad 29.824$

$\begin{array}{ll}29.117 & 29.039 \\ 28.332 & 28.253\end{array}$

$\begin{array}{ll}34.462 & 34.38 \\ 33.676 & 33.598\end{array}$

34.305

34.22
33.440

$34.148 \quad 34.069 \quad 33.990 \quad 33.912$

$\begin{array}{llllllll}32.890 & 32.812 & 32.733 & 32.654 & 32.576 & 32.497 & 32.418 & 32.340\end{array}$

$32.104 \quad 32.025$

$31.318 \quad 31.240 \quad 31.161 \quad 31.082$

$29.746 \quad 29.667$

$\begin{array}{llll}31.004 & 30.925 & 30.846 & 30.768 \\ 30.218 & 30.139 & 30.061 & 29.982\end{array}$

$27.546 \quad 27.468$

$28.175 \quad 28.096$

$29.589 \quad 29.510$

$\begin{array}{llll}30.218 & 30.139 & 30.061 & 29.982 \\ 29.432 & 29.353 & 29.275 & 29.196\end{array}$

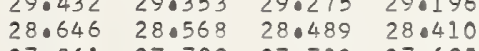

28026.760

26.682

$27 \cdot 31$

28.01

$\begin{array}{llll}27.861 & 27.782 & 27.703 & 27.625 \\ 27.075 & 26.996 & 26.918 & 26.979\end{array}$

3567.

7.1
7.2
7.3

$25.975 \quad 25.896 \quad 25.818 \quad 25.739$

$24.404 \quad 24.325 \quad 24.246 \quad 24.16$

$\begin{array}{llll}23.618 & 23.539 & 23.461 & 23.3 \\ 22.83 & 23.754 & 22.675 & 22.597\end{array}$

$22.833 \quad 22.754 \quad 22.675$

$\begin{array}{lll}21.890 & 21.811\end{array}$

$20.476 \quad 20.398 \quad 20.319 \quad 20.240$

$19.691 \quad 19.612$

$26.446 \quad 26.367$

26.289

26.210

$26.132 \quad 26.053$

$\begin{array}{llllll}24.875 & 24.796 & 24.718 & 24.639 & 24.561 & 24.482\end{array}$

$\begin{array}{llllll}24.089 & 24.011 & 23.932 & 23.854 & 23.775 & 23.697\end{array}$

$\begin{array}{llllll}22.518 & 22.439 & 22.361 & 22.282 & 22.204 & 22.125\end{array}$

$\begin{array}{llllll}21.733 & 21.654 & 21.576 & 21.497 & 21.419 & 21.340 \\ 20.947 & 20.869 & 20.790 & 20.712 & 20.633 & 20.555\end{array}$

7.7

3568

28018.906

$18.906 \quad 18.827$

$\begin{array}{lll}18.120 & 18.042 & 18.7 \\ 17.335 & 17.0256 & 17.963\end{array}$

$\begin{array}{llll}17.335 & 17.256 & 17.963 & 17.885 \\ 16.550 & 16.471 & 17.393 & 17.099\end{array}$

$\begin{array}{llll}17.0335 & 17.256 & 17.3783 & 17.009\end{array}$

14.19414 .116

$12.625 \quad 12.547$

$\begin{array}{lll}11.840 & 11.761 & 11.683\end{array}$

$\begin{array}{llll}5.451 & 15.372 & 15.293 & 15.21\end{array}$

8.5

8.7
8.8
8.9

3569

011.05510 .97

$10.270 \quad 10.192 \quad 10.114$

$\begin{array}{llll}10.270 & 10.192 & 10.114 & 10.035\end{array}$

$\begin{array}{llllll}08.701 & 08.622 & 08.544 & 0.250 & 09.176 & 08.387\end{array}$

$\begin{array}{llll}0.387 & 09.03\end{array}$

$\begin{array}{lllllll}07.917 & 07.838 & 07.759 & 07.681 & 07.602 & 07.524\end{array}$

$\begin{array}{llllll}07.132 & 07.053 & 06.974 & 06.896 & 06.818 & 06.739 \\ 06.347 & 06.269 & 06.190 & 06.112 & 06.033 & 05.955\end{array}$

$\begin{array}{llll}05.562 & 05.484 & 05.406 & 05.327\end{array}$

$\begin{array}{ll}06.033 & 05.955 \\ 05.248 & 05.170\end{array}$

20.790

$20.633 \quad 20.555$

0.285578

0.285578

0.285577

.285576

0.285575

0.285574

0.285573

0.285571

0.285570

0.285569

0.28556

0.285567
0.285567

0.285566

0.285564

0.285564

0.28558

0.285560

0.285560

0.285558

0.285556

0.285556

1.017858

1.017909

1.017935

1.017961
1.017987

1.018012

1.018084 
$\begin{array}{lllllllllll}3570.0 & 28003.209 & 03.131 & 03.052 & 02.974 & 02.895 & 02.817 & 02.738 & 02.660 & 02.581 & 02.503\end{array}$ $\begin{array}{lllllllllll}0.1 & 02.425 & 02.346 & 02.268 & 02.189 & 02.111 & 02.033 & 01.954 & 01.875 & 01.797 & 01.719 \\ 0.2 & 01.640 & 01.562 & 01.483 & 01.405 & 01.326 & 01.248 & 01.170 & 01.091 & 01.013 & 00.934\end{array}$

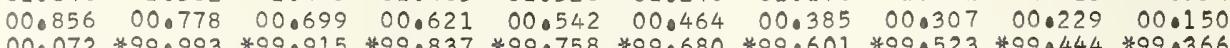

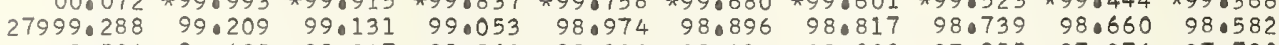
$\begin{array}{llllllllll}98.504 & 98.425 & 98.347 & 98.269 & 98.190 & 98.112 & 98.033 & 97.955 & 97.876 & 97.798\end{array}$

\section{$79.698 \quad 79.619$} $\begin{array}{llll}78.914 & 78.836 & 78.0758 & 78.079 \\ 78.131 & 78.053 & 77.975 & 77.8966 \\ 776.348 & 77.270 & 77.192 & 77.113\end{array}$ $\begin{array}{lll}76.566 & 77.270 \\ 76.487\end{array}$ $75.783 \quad 75.704$
$75.000 \quad 74.021$ 75.000
74.217
73.02139
73.434
73.0356

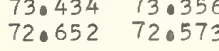

27971.86

$$
\begin{aligned}
& 71.086 \\
& 70.303 \\
& 69.521
\end{aligned}
$$

0.285540
0.285539
0.285538
0.285538
0.285537
0.285536
0.285535
0.285535
0.285534
0.285533

1.019378 1.019404 1.019455 1.019481 1.019533 1.019584 0.285533

0.285532 0.28553 0.285531 0.285529 0.285528

0.285528

0.285527
0.285526

0.285526
0.285525

0.285524 0.285524 0.285522 0.28552 0.28552

0.285520
0.085519

0.285518
0.28517

0.285517

0.285516
0.285519

0.285514

0.285514

0.285512

0.285511

0.285510

1.019610

1.019636 1.019661 1.019687
1.0019713 1.0019739 1.019764 10.019816 1.019842

1.019893 10019919 1.019971 1.019996 1.020022 1.020048 1.0020099 1.020125

1.020151 1.020177 1.020228 1.020254
10020280 1.020306 1.020331 1.020383

0.285509 0.285508
0.285507
0.255 0.285507 0.285506 0.285505 0.285504 0.285503

0.285502

0.285501 0.285500 0.285500 0.285499 0.285498 . 0.285496 0.285494

0.285493 0.285493 0.285492 0.285490 0.285489 0.285489
0.285489 0.285489
0.285488
0.2858 0.285488
0.285487 0.285486

1.020409 1.020434
1.020460 1.020486 1.0020512 1.020538 1.020563 1.020589 1.020641

1.020666 1.020692 1.020718 1.020744 1.020769 1.020821 1.020847 1.020873
1.0020898

0.285486 0.285485 0.285484
0.285483 0.285483
0.285482 0.285482 0.285481 0.285480 0.285479
0.285479 1.020924 1.020950 1.020976
1.0021001 1.021001
1.021027 1.021053 1.021079 1.021104 1.021130
1.021156

0.285478 0.285477 0.285476 0.285475 0.285475 0.285474 0.285473 0.285472 0.285471 1.021982 $\frac{1}{10} .021208$ 1.021259 10.021285 1.021336 1.021362 1.021414

0.285470 0.285469 0.285468 0.285467 0.285466 0.285465 0.285464 1.021440 1.021465 1.021517 1.021543 1.021568 1.021594 1.021620 1.021672 1.021697 1.021723 1.021775 1.021800 1.021826 
$\begin{array}{rrrrrrrrrrr}0.0 & 27924.990 & 24.912 & 24.834 & 24.756 & 24.678 & 24.600 & 24.522 & 24.444 & 24.366 & 24.288 \\ 0.1 & 24.210 & 24.132 & 24.054 & 23.976 & 23.898 & 23.821 & 23.742 & 23.664 & 23.586 & 23.508 \\ 0.2 & 23.430 & 23.352 & 23.274 & 23.196 & 23.118 & 23.041 & 22.962 & 22.884 & 22.806 & 22.728 \\ 0.3 & 22.650 & 22.573 & 22.494 & 22.416 & 22.339 & 22.260 & 22.182 & 22.104 & 22.026 & 21.948\end{array}$

$\begin{array}{lllllllllll}0.4 & 21.871 & 21.792 & 21.714 & 21.637 & 21.559 & 21.480 & 21.403 & 21.325 & 21.246 & 21.168 \\ 0.5 & 21.091 & 21.013 & 20.935 & 20.857 & 20.779 & 20.701 & 20.623 & 20.545 & 20.467 & 20.389\end{array}$

$\begin{array}{lllllllllll}0.6 & 21.091 & 21.013 & 20.935 & 20.857 & 20.779 & 20.701 & 20.623 & 20.545 & 20.467 & 20.389 \\ 0.6 & 20.311 & 20.233 & 20.155 & 20.077 & 19.999 & 19.921 & 19.843 & 19.765 & 19.687 & 19.609\end{array}$

$\begin{array}{lllllllllll}0.7 & 19.531 & 19.453 & 19.375 & 19.297 & 19.219 & 19.141 & 19.063 & 18.985 & 18.907 & 18.829 \\ 0.8 & 18.751 & 18.673 & 18.595 & 18.517 & 18.440 & 18.362 & 18.283 & 18.206 & 18.128 & 18.050\end{array}$

3581.

$\begin{array}{ll}18.751 & 18.673 \\ 17.972 & 17.894\end{array}$

$\begin{array}{llll}18.595 & 18.517 & 18.440 & 18.36 \\ 17.816 & 17.738 & 17.660 & 17.58\end{array}$

$\begin{array}{llll}18.283 & 18.206 & 18.128 & 18.050 \\ 17.504 & 17.426 & 17.348 & 17.270\end{array}$

0.285462

1.021955

竞:

$27917.192 \quad 17.114$

$\begin{array}{ll}16.413 & 16.3 \\ 15.633 & 15.5 \\ 14.854 & 14.776\end{array}$

$\begin{array}{lllll}17.036 & 16.958 & 16.880 & 16.80\end{array}$

$\begin{array}{llll}16.724 & 16.646 & 16.568 & 16.491 \\ 15.945 & 15.867 & 15.789 & 15.711\end{array}$

$\begin{array}{llllll}140854 & 140776 & 14.477 & 15.399 & 15.321 & 15.243\end{array}$

$\begin{array}{lllllll}14.074 & 13.996 & 13.918 & 13.841 & 13.762 & 13.684\end{array}$

$\begin{array}{llllll}13.295 & 13.217 & 13.139 & 13.061 & 12.983 & 12.905\end{array}$

$\begin{array}{llllll}12.515 & 12.437 & 12.360 & 12.282 & 12.204 & 12.126\end{array}$

$\begin{array}{llllll}10.737 & 10.878 & 10.801 & 10.723 & 10.8245 & 10.367 \\ 10.178 & 10.100 & 10.022 & 09.944 & 09.866 & 09.78\end{array}$

$\begin{array}{llll}15.165 & 15.087 & 15.010 & 14.931\end{array}$

$13.606 \quad 13.529 \quad 13.450 \quad 13.373$

$12.827 \quad 12.749 \quad 12.671 \quad 12.593$

11.268

3582.

2.
2.0
20
20
2.0
20
20
20
2.0

$27909 \cdot 398$

$\begin{array}{lll}909.398 & 09.320 & 09.2 \\ 08.620 & 08.542 & 08.464 \\ 07.841 & 07.762 & 07.685\end{array}$

07.06106 .984

$06.28206 .205 \quad 06.90$

$05.503 \quad 05.426$

04.72504 .647

$\begin{array}{ll}03.167 & 03.089 \\ 02.388 & 02.310\end{array}$

05.348

09.16509 .087

09.009

10.489
09.710

$\begin{array}{lll}1.190 & 11.892 & 11.814 \\ 11.035\end{array}$

$09.710 \quad 09.632 \quad 09.554 \quad 09.476$

.285461

.225450

0.285458
0.285458
0.285457

0285457

0.285455

0.285455

0.285454

0.285453
0.285452

0.285451

.285450

0.285448

0.285447

0.285446

0.285445

0.285444

0.285442

0.285441

$\begin{array}{llll}06.594 & 06.516 & 06.438 & 06.360 \\ 05.815 & 05.737 & 05.659 & 05.581\end{array}$

$05.036 \quad 04.958 \quad 04.880 \quad 04.802$

$\begin{array}{llll}04.257 & 04.179 & 04.102 & 04.024 \\ 03.479 & 03.401 & 03.323 & 03.245\end{array}$

100106

3583.0

$3 \cdot 1$

$\begin{array}{lllllllll}0 & 01.298 & 01.220 & 01.142 & 01.064 & 00.986 & 00.909\end{array}$ $\begin{array}{rrrrrrrrrr}00.831 & 00.753 & 00.675 & 00.597 & 00.519 & 00.441 & 00.364 & 00.286 & 00.208 & 00.130 \\ 00.052 & * 99.974 & * 99.896 & * 99.818 & * 99.740 & * 99.663 & * 99.585 & * 99.507 & * 99.429 & * 99.351\end{array}$

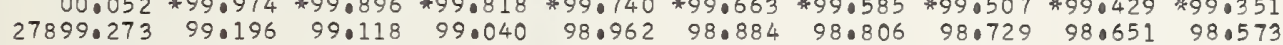

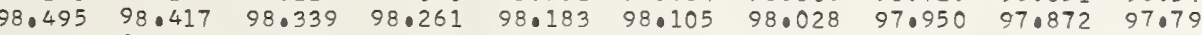
$\begin{array}{llllllllll}97.716 & 97.638 & 97.561 & 97.483 & 97.405 & 97.327 & 97.249 & 97.171 & 97.094 & 97.016\end{array}$ $\begin{array}{llllllllll}96.938 & 96.860 & 96.782 & 96.704 & 96.626 & 96.549 & 96.471 & 96.393 & 96.315 & 96.237 \\ 96.159 & 96.082 & 96.004 & 95.926 & 95.848 & 95.770 & 95.692 & 95.614 & 95.537 & 95.459\end{array}$ $\begin{array}{llllllllll}96.159 & 96.082 & 96.004 & 95.926 & 95.848 & 95.770 & 95.692 & 95.614 & 95.537 & 95.459\end{array}$ $\begin{array}{llllllllll}95.381 & 95.303 & 95.225 & 95 \cdot 147 & 95.070 & 94.992 & 94 \cdot 914 & 94.836 & 94.758 & 94.680 \\ 94.603 & 94.525 & 94.447 & 94.369 & 94.292 & 94.214 & 94.136 & 94.058 & 93.980 & 93.902\end{array}$

3584 $93.825 \quad 93.747 \quad 93.669 \quad 93.591$ $\begin{array}{llll}93.046 & 92.969 & 92.891 & 92.813 \\ 92.268 & 92.190 & 92.113 & 92.035\end{array}$ $91.490 \quad 91.412 \quad 91.334 \quad 91.257$ $90.712 \quad 90.634 \quad 90.556 \quad 90.479$ $89.934 \quad 89.856 \quad 89.778 \quad 89.700$ $89.156 \quad 89.078 \quad 89.000-88.922$ $88.378 \quad 88.300 \quad 88.222 \quad 88.144$ $\begin{array}{llll}87.600 & 87.522 & 87.444 & 87.366 \\ 86.822 & 86.744 & 86.666 & 86.589\end{array}$

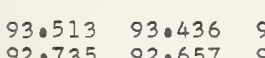

$92.735 \quad 92.657 \quad 93.358 \quad 93.280 \quad 93.202 \quad 93.124$ $\begin{array}{llllll}91.957 & 91.879 & 91.5802 & 92.502 & 92.424 & 92.346 \\ & 91.723 & 91.646 & 91.568\end{array}$ $\begin{array}{llllll}91.179 & 91.101 & 91.023 & 90.946 & 90.867 & 90.790\end{array}$ $\begin{array}{llllll}90.401 & 90.323 & 90.245 & 90.167 & 90.090 & 90.011 \\ 89.623 & 89.545 & 89.467 & 89.389 & 89.312 & 89.234\end{array}$ $\begin{array}{llllll}88.844 & 88.767 & 88.689 & 88.611 & 88.534 & 88.456\end{array}$ $88.066 \quad 87.989 \quad 87.911 \quad 87.833 \quad 87.756 \quad 87.678$

\begin{abstract}
$\begin{array}{llll}27886.044 & 85.966 & 85.888 & 85.811\end{array}$
\end{abstract} $\begin{array}{llll}85.266 & 85.188 & 85.111 & 85.033\end{array}$

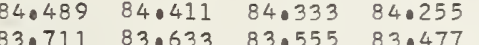
$82.933 \quad 82.855 \quad 82.778 \quad 82.700$ $\begin{array}{llll}82.156 & 82.078 & 82.000 & 81.922\end{array}$ $80.600 \quad 80.522 \quad 80.445 \quad 80.367$

$\begin{array}{llll}79.823 & 79.745 & 79.667 & 79.589\end{array}$

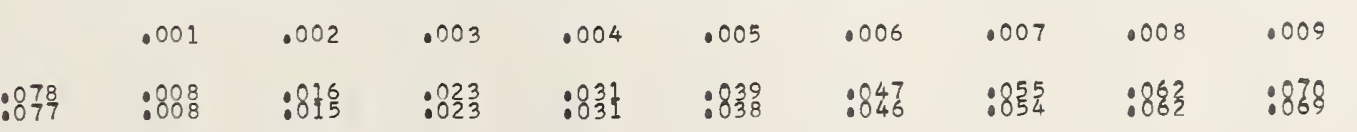

0.285439

0.285438

0.285437

0.285436

0.285435

0.285434

0.285433

0.285431

0.285431

0.285429

0.285428

0.285427

0.285426
0.285425

0.285424

0.285423
0.285422

0.285421

0.285420

0.285419

0.285418

0.285417

0.285416

0.285414

0.285414

0.285412

0.285411

0.285410
0.225400

0.285408

0.225408

0.285406

0.285405

0.285404

0.285403
0.28403

0.28540

0.285401

0.285400

0.285398

0.28539

0.28539

0.285395

0.28539

0.285393

0.28539

0.285391

0.285390

0.28538

0.28538

0.285387

0.285386

1.021981

1.022058

1.022110

1.022187

1.022213

1.022264

.022316

1.022367

.022393
1.022419
1.022445

1.022471

1.022522

1.022574

1.022625

1.022677
1.022703

1.022728

1.022754

1.022806

1.022831
1.022859

.022883
.022909

1.022935

1.022986

1.023012
1.023038

1.023064

1.023115

1.023167

1.023218

1.023244

1.023270
1.023296

1.023347

1.023373

1.023424

1.023476

1.023502

1.023553

1.023605

1.023631

1.023682

1.023734

1.023760

1.023811

1.02383

1.023889

1.023914
1.023940

1.023966

1.024017

1.024043

1.024121

1.024146

1.024224

1.024250

1.024275

1.024327

1.024378

1.024404

1.02430

1.024456
1.024482

.010

$: 879$ 
$\begin{array}{lllllll}46.896 & 46.819 & 46.741 & 46.664 & 46.586 & 46.509\end{array}$

$$
\begin{array}{ll}
816.215 & 16.137 \\
15.441 & 15.363 \\
14.667 & 14.589 \\
13.893 & 13.815 \\
13.119 & 13.042 \\
12.345 & 12.268 \\
11.572 & 11.494 \\
10.798 & 10.720 \\
10.024 & 09.947 \\
09.251 & 09.173
\end{array}
$$

$$
\begin{aligned}
& 7793.01 \\
& 92.24 \\
& 91.47 \\
& 90 . \\
& 89 . \\
& 89.25 \\
& 80^{\circ} \\
& 87 . \\
& 86 . \\
& 86.0
\end{aligned}
$$

$\begin{array}{lllllll}5.345 & 45.268 & 45.190 & 45.113 & 45.035 & 44.957\end{array}$

$43.794 \quad 43.717 \quad 43.630 \quad 430562 \quad 43.484 \quad 430406$

$\begin{array}{lllllll}43.019 & 42.941 & 42.864 & 42.786 & 42.708 & 42.631\end{array}$

$41.468 \quad 41.390 \quad 41.313 \quad 41.235 \quad 41.158 \quad 41.080$ $\begin{array}{llllll}40.693 & 40.615 & 40.537 & 40.460 & 40.383 & 40.305\end{array}$ $30.917 \quad 39.840 \quad 39.762 \quad 39.685 \quad 39.607 \quad 39.530$

$\begin{array}{lllllll}39.142 & 39.064 & 38.987 & 38.909 & 38.832 & 38.754\end{array}$ $\begin{array}{llllll}37.592 & 37.514 & 37.437 & 37.359 & 37.281 & 37.204\end{array}$ $\begin{array}{llllll}36.817 & 36.739 & 36.661 & 36.584 & 36.506 & 36.42\end{array}$ $\begin{array}{llllll}35.266 & 35.964 & 35.886 & 35.809 & 35.731 & 35.654 \\ 35.189 & 35.112 & 35.034 & 34.956 & 34.879\end{array}$ $\begin{array}{llllll}34.491 & 34.414 & 34.336 & 34.259 & 34.181 & 34.104\end{array}$ $32.042 \quad 32.865 \quad 32.787 \quad 33048433.407 \quad 330329$ $\begin{array}{llllll}32.167 & 32.090 & 32.012 & 31.935 & 31.857 & 31.779\end{array}$

$\begin{array}{lllllll}31.392 & 31.315 & 31.237 & 31.160 & 31.082 & 31.005\end{array}$ $\begin{array}{llllll}30.617 & 30.540 & 30.462 & 30.385 & 30.308 & 30.230 \\ 29.843 & 29.765 & 29.688 & 29.610 & 29.533 & 29.455\end{array}$ $\begin{array}{llllll}29.068 & 28.990 & 28.913 & 28.836 & 28.758 & 28.681\end{array}$ $\begin{array}{llllll}28.293 & 28.216 & 28.138 & 28.061 & 27.983 & 27.906 \\ 27.519 & 27.441 & 27.364 & 27.286 & 27.209 & 27.132\end{array}$ $\begin{array}{llllll}26.744 & 26.667 & 26.589 & 26.512 & 26.434 & 26.357 \\ 5.969 & 25.892 & 25.815 & 25.737 & 25.660 & 25.582\end{array}$ $\begin{array}{llllll}25.195 & 25.118 & 25.040 & 24.963 & 24 \cdot 885 & 24.808 \\ 24.421 & 24.343 & 24.266 & 24.188 & 24.111 & 24.033\end{array}$

$\begin{array}{llllll}23.646 & 23.569 & 23.491 & 23.414 & 23.336 & 23.259\end{array}$ $\begin{array}{lllllll}22.872 & 22.794 & 22.717 & 22.639 & 22.562 & 22.485\end{array}$ $\begin{array}{llllll}22.098 & 22.020 & 21.943 & 21.865 & 21.788 & 21.710 \\ 21.323 & 21.246 & 21.168 & 21.091 & 21.014 & 20.936\end{array}$ $\begin{array}{llllll}19.775 & 19.698 & 190620 & 19.543 & 19.465 & 19.388\end{array}$ $\begin{array}{llllll}19.001 & 18.924 & 18.846 & 18.769 & 18.692 & 18.614 \\ 18.227 & 18.150 & 18.072 & 17.995 & 17.917 & 17.840\end{array}$ $\begin{array}{llllll}17.453 & 17.376 & 17.298 & 17.221 & 17.143 & 17.066 \\ 16.679 & 16.602 & 16.524 & 16.447 & 16.369 & 16.292\end{array}$

$\begin{array}{llllll}15.905 & 150828 & 15.750 & 150673 & 15.595 & 150518\end{array}$ $\begin{array}{llllll}14.357 & 14 \cdot 280 & 14 \cdot 202 & 14 \cdot 125 & 14.048 & 13.970\end{array}$ $\begin{array}{llllll}13.583 & 13.506 & 13.429 & 130351 & 130274 & 13.197\end{array}$ $\begin{array}{llllll}12.036 & 11.958 & 11.881 & 11.804 & 11.726 & 11.649\end{array}$ $\begin{array}{llllll}11.262 & 11.185 & 11.107 & 11.030 & 10.953 & 10.875 \\ 10.488 & 10.411 & 10.334 & 10.256 & 10.179 & 10.102\end{array}$ $\begin{array}{llllll}09.715 & 09.637 & 09.560 & 09.483 & 09.406 & 09.328\end{array}$

$\begin{array}{lllllll}08.168 & 08.090 & 08.013 & 07.936 & 07.858 & 07.781\end{array}$ $\begin{array}{llllll}07.394 & 07.317 & 07.240 & 07.162 & 07.085 & 07.008 \\ 06.621 & 06.544 & 06.466 & 06.389 & 06.312 & 06.234\end{array}$ $\begin{array}{lllllll}05.848 & 05.770 & 05.693 & 05.615 & 05.538 & 05.461\end{array}$ $\begin{array}{lllllll}040301 & 04.223 & 04.146 & 04.069 & 03.991 & 03.914\end{array}$ $\begin{array}{llllll}03.528 & 03.451 & 03.373 & 03.296 & 03.219 & 03.141\end{array}$ $\begin{array}{llllll}02.755 & 02.677 & 02.600 & 02.522 & 02.445 & 02.368\end{array}$ $\begin{array}{llllll}01.981 & 01.904 & 01.827 & 01.750 & 01.672 & 01.595 \\ 01.208 & 01.131 & 01.054 & 00.977 & 00.899 & 00.822\end{array}$ $\begin{array}{llllll}00.435 & 00.358 & 00.281 & 00.203 & 00.126 & 00.049\end{array}$ $\begin{array}{lllllll}98.889 & 98.812 & 98.734 & 98.657 & 98.580 & 98.503\end{array}$ $\begin{array}{lllllll}98.116 & 98.039 & 97.961 & 97.884 & 97.807 & 97.730\end{array}$ $96.570 \quad 96.493 \quad 96.416 \quad 96.338 \quad 96.2619090184$ $\begin{array}{llllll}95.797 & 95.720 & 95.643 & 95.565 & 95.489 & 95.411\end{array}$ $94.252 \quad 94.175 \quad 94.097 \quad 94.020 \quad 93.043 \quad 93.865$

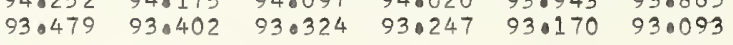
$92.707 \quad 92.529 \quad 92.552 \quad 92.475 \quad 920397 \quad 92.320$ $\begin{array}{llllll}91.934 & 91.857 & 91.779 & 91.0702 & 91.625 & 91.548\end{array}$ $90.389 \quad 90.312 \quad 90.234 \quad 90.157 \quad 90.080 \quad 90.002$ $\begin{array}{llllll}80.616 & 89.539 & 89.462 & 89.385 & 89.307 & 89.230 \\ 88.844 & 88.766 & 88.689 & 88.612 & 88.535 & 88.458\end{array}$ $\begin{array}{lllllll}88.072 & 87.995 & 87.917 & 87.840 & 87.0763 & 87.686\end{array}$ $\begin{array}{lllllll}87.299 & 87.222 & 87.145 & 87.068 & 86.990 & 86.913\end{array}$ $\begin{array}{llllll}86.527 & 86.450 & 86.373 & 86.295 & 86.218 & 86.141 \\ 85.755 & 85.677 & 85.600 & 85.523 & 85.446 & 85.368\end{array}$ $\begin{array}{lllllll}840982 & 840905 & 84.828 & 84.751 & 84.674 & 84.597\end{array}$ $\begin{array}{lllllll}84.210 & 84.133 & 84.056 & 83.979 & 83.902 & 83.824 \\ 83.438 & 83.361 & 83.284 & 83.206 & 83.129 & 83.052\end{array}$ $\begin{array}{lllllll}82.666 & 82.589 & 82.511 & 82.435 & 82.357 & 82.280\end{array}$ $\begin{array}{llllll}81.894 & 81.817 & 81.740 & 81.662 & 81.585 & 81.508 \\ 81.122 & 81.044 & 80.968 & 80.890 & 80.813 & 80.736\end{array}$ $\begin{array}{llllllll}80.350 & 80.273 & 80.196 & 80.118 & 80.041 & 79.964\end{array}$ $\begin{array}{llllll}79.578 & 79.501 & 79.424 & 79.346 & 79.269 & 79.192 \\ 78.806 & 78.729 & 78.652 & 78.574 & 78.497 & 78.420\end{array}$ $\begin{array}{lllllll}78.034 & 77.957 & 77 \bullet 880 & 77 \bullet 803 & 77.725 & 77.648\end{array}$

0.285383

0.285381

0.285381

0.285380

0.285378

0.285398

0.285377
0.285376

0.285375

0.285375

0.285373

0.285372

0.285371

0.285370

0.285369

0.285368
0.285368

0.285367

0.285366

0.285365

0.285364

0.285363

0.285362

0.285362

0.285361

0.285359

0.285358

0.285357

0.285356

0.285355 0.285354 0.285352 0.285352 0.285359

0.285350

0.285349

0.285348

0.285347

0.285346

0.285346

0.285344

0.285343

0.285342

0.285342

0.285340

0.285339

0.285339

0.285338

0.285337

0.285336

0.285335

0.285334
0.285333

0.285333

0.285332

0.285331
0.285330
0

0.285330
0.285330
0

0.285329
0.0285328

0.285328
0.285327

0.285326

0.285326
0.285325

0.285324

0.285323

0.285323
0.285322

0.28532

0.285320

0.285320

0.285318

0.285318
0.285317

0.285317

0.285316

0.285394

0.285313

0.2285312

0.285310

0.285310

1.024533

1.024559

1.024611

1.024636

1.024688

1.024714

.024739

1.024791

1.024817

1.024868

1.024894

1.024920

1.024946

1.024997

3.025049

1.025075
1.025101
1.025152

1.025152

1.025178

1.025204

1.025229
1.025255

1.025281 
$\begin{array}{lllllllllll}3600.0 & 27769.855 & 69.778 & 69.701 & 69.624 & 69.547 & 690470 & 69.393 & 69.316 & 69 \cdot 239 & 69.161\end{array}$ $\begin{array}{llllllllllll}0.1 & 69.084 & 69.007 & 68.930 & 68.853 & 68.776 & 68.698 & 68.621 & 68.544 & 68.467 & 68.390 \\ 0.2 & 68.313 & 68.236 & 68.158 & 68.081 & 68.004 & 67.927 & 67.850 & 67.773 & 67.696 & 67.610\end{array}$

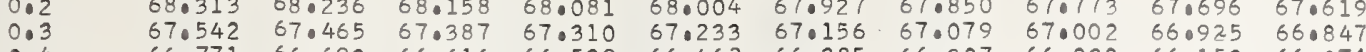
$\begin{array}{lllllllllll}0.4 & 66.771 & 66.693 & 66.616 & 66.539 & 66.062 & 66.385 & 66.307 & 66.230 & 66.153 & 66.076 \\ 0.5 & 65.999 & 65.922 & 65.845 & 65.768 & 65.691 & 65.613 & 65.536 & 65.459 & 65.382 & 65.305\end{array}$ $\begin{array}{llllllllllll}0.6 & 65.228 & 65.151 & 65.074 & 64.997 & 64.919 & 64.843 & 64.765 & 64.688 & 64.611 & 64.534\end{array}$ $\begin{array}{lllllllllll}0.7 & 64.457 & 64.380 & 64.303 & 64.226 & 64.148 & 64.071 & 63.994 & 63.917 & 630840 & 63.763 \\ 0.8 & 63.686 & 63.609 & 63.532 & 63.455 & 63.378 & 63.300 & 63.023 & 63.146 & 63.069 & 62.992\end{array}$ 0.9 $62.915 \quad 62.838$

3601.0 103 1.4 1.5

1.6

1.78

3602.0

2.1 2. 2.3

3603.0

$$
\begin{array}{r}
603 . \\
3 . \\
3 . \\
3 . \\
3 . \\
3 . \\
3 . \\
3 . \\
3 . \\
3 .
\end{array}
$$

3604 .

4.0
4.
4.
4.4
4.5
406
4.7
4.8
4.9

3605 5.0
501
5.2
50
50
50
5.6
5
5
50

3606

6.

6.2

6.4

6.5

6.6

6.8

3607

607.0
7.
7.
7.4
7.5
7
7
7

3608

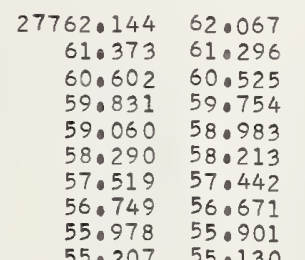

0.285307

0.285306

0.285304

0.285303

0.285301

0.285300

0.285298

0.285296

0.285295
0.285295

0.285294

0.285292

0.285291

0.285290

0.285289

0.285287

0.285286

0.285285

0.285284

0.285282

0.285282

0.285280

0.285279

0.285278

0.285276

0.285276

0.285274

0.285273

0.285271

0.285270

0.285269

0.285268
0.285267
0.2356

0.285267

0.285266

0.2285265
0.285264

1.027344

1.027370
1.037396

1.027422

448
473

1.027499

1.027577

1.027628

1.027680

1.027706

1.027783

.027835

0.285264

0.285263

0.285261

0.285261

0.285259

0.285258

0.285257
0.285257

1.027886

1.027938

1.027964

1.028015

1.028041

1.028093

0.285256

0.285255

0.285254
0.285254

0.285253

0.28525 .

0.285251

0.285249

0.285248

0.285248

0.285247

0.285246
0.285245

0.285245

0.285244

0.285243

.028144

1.028170
1.028196

1.028222

1.028273

1.028299

1.028351
1.0028376

1.028402

1.028428

1.028480

1.028505
1.028531

1.028557

1.028583

0.285241 
$\begin{array}{rrrrrrrrrrr}0.1 & 27692.933 & 92.856 & 92.779 & 92.703 & 92.626 & 92.549 & 92.473 & 92.396 & 92.319 & 92.242 \\ 0 & 92.166 & 92.089 & 92.012 & 91.936 & 91.859 & 91.782 & 91.705 & 91.629 & 91.552 & 91.475\end{array}$

$\begin{array}{lllllllllll}0.2 & 91.399 & 91.322 & 91.245 & 91.168 & 91.092 & 91.015 & 90.938 & 90.862 & 90.785 & 90.708\end{array}$

$\begin{array}{lllllllllll}0.3 & 90.632 & 90.555 & 90.478 & 90.402 & 90.325 & 90.248 & 90.171 & 90.095 & 90.018 & 89.941\end{array}$

$\begin{array}{lllllllllll}0.4 & 89.865 & 89.788 & 89.711 & 89.635 & 89.558 & 89.481 & 89.404 & 89.328 & 89.251 & 89.174 \\ .5 & 89.098 & 89.021 & 88.944 & 88.868 & 88.791 & 88.714 & 88.638 & 88.561 & 88.484 & 88.407\end{array}$

$\begin{array}{llllllllll}88.331 & 88.254 & 88.177 & 88.101 & 88.024 & 87.948 & 87.871 & 87.794 & 87.717 & 87.641 \\ 87.564 & 87.487 & 87.411 & 87.334 & 87.257 & 87.181 & 87.104 & 87.027 & 86.950 & 86.874\end{array}$

0.8

$86.797 \quad 860$
86.031

87.487

$27685 \cdot 264$

$84.497 \quad 85.187$

1.2

$1 \cdot 3$

$82.198 \quad 82.121$

$\begin{array}{ll}81.431 & 81.354 \\ 80.665 & 80.588\end{array}$

1.6

79.89879 .822

$\begin{array}{ll}79.132 & 79.055 \\ 78.366 & 78.289\end{array}$

$87.411 \quad 87.334$

$85.110 \quad 85.034 \quad 84$

$\begin{array}{ll}86.490 & 86.414 \\ 85.724 & 85.647\end{array}$

$86 \cdot 26$
85.49

$86 \cdot 184$
85.417

86.107
85.340

0.28523

0.285233

1.029692

0.285232

0.285231

0.285230

0.285229

0.285227

0.285227

1.029718

1.029770

1.020822

1.029847

1.029899

0.285226

0.285224

0.285224
0.285224
0.285223

0.285223

0.285221

0.285220
0.285219

1.029925

2.0
2.1
2.2
2.3
2.4
2.5
2.6
2.7
2.8
2.9
13.0
3.1
3.2
3.3
3.4
3.5
3.6
3.7
3.8
3.9

3613.

27677.599

$777.599 \quad 77.523$

1
3
4
5
6
7
8
9
0
1
2
3
4
5
6
7
8
9

3614.0

$4 \cdot 2$

$4 \cdot 3$

404

4.6

4.8

$\begin{array}{ll}76.833 & 76.756 \\ 76.067 & 75.990\end{array}$

$\begin{array}{lllll}76.067 & 75.990 & 75.914 & 75.837 \\ 75.301 & 75.224 & 75.147 & 75.071 & 76.0\end{array}$

$\begin{array}{lllllllllll}74.535 & 74.458 & 74.381 & 74.305 & 74.228 & 74.152 & 74.075 & 73.9098 & 73.982 & 74.611\end{array}$

$\begin{array}{llllllllll}73.769 & 73.692 & 73.615 & 73.539 & 73.462 & 73.1585 & 740075 & 73.998 & 73.922 & 730845 \\ 7309 & 73.232 & 73.156 & 73.079\end{array}$

$\begin{array}{llllllllll}73.002 & 72.926 & 72.849 & 72.773 & 72.696 & 72.620 & 72.543 & 72.466 & 72.390 & 72.313\end{array}$

$\begin{array}{lllllllllll}72.236 & 72.160 & 72.083 & 72.007 & 71.930 & 71.854 & 71.777 & 71.700 & 71.624 & 71.547\end{array}$

$\begin{array}{llllllllll}71.470 & 71.394 & 71.317 & 71.241 & 71.164 & 71.088 & 71.011 & 70.935 & 70.858 & 70.781 \\ 70.705 & 70.628 & 70.551 & 70.475 & 70.398 & 70.322 & 70.245 & 70.169 & 70.092 & 70.015\end{array}$

$69.173 \quad 69.096 \quad 69.020 \quad 68.943$

$68.407 \quad 68.331 \quad 68.254 \quad 68.177$

$67.641 \quad 67.565 \quad 67.488 \quad 67.412$

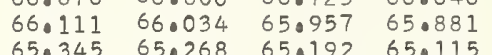

$64.579 \quad 64.503 \quad 64.426 \quad 64.350$

$\begin{array}{llll}63.814 & 63.737 & 63.661 & 63.584 \\ 63.048 & 62.972 & 62.895 & 62.819\end{array}$

69.63269 .556

$69.479 \quad 69.403 \quad 69.326 \quad 69.250$

$\begin{array}{llllll}68.866 & 68.790 & 68.714 & 68.637 & 68.561 & 68.484 \\ 68.101 & 68.024 & 67.948 & 67.871 & 67.795 & 67.718\end{array}$

$\begin{array}{llllll}67.335 & 67.259 & 67.182 & 67.106 & 67.029 & 66.953\end{array}$

$\begin{array}{llllll}66.570 & 66.493 & 66.417 & 66.340 & 66.264 & 66.187\end{array}$

$\begin{array}{llllll}65.804 & 65.728 & 65.651 & 65.574 & 65.498 & 65.422 \\ 65.039 & 64.962 & 64.885 & 64.809 & 64.733 & 64.656\end{array}$

$64.273 \quad 64.197 \quad 64 \cdot 120 \quad 64 \cdot 043 \quad 63 \cdot 967 \quad 63.890$

$\begin{array}{llllll}63.508 & 63.431 & 63.354 & 63.278 & 63.201 & 63.125 \\ 62.742 & 62.666 & 62.589 & 62.512 & 62.436 & 62.359\end{array}$

$\begin{array}{rllll}27662.283 & 62.206 & 62.130 & 62.053 & 610 \\ 61.518 & 61.441 & 61.365 & 61.288 & 610\end{array}$

$60.752 \quad 60.676 \quad 60.599 \quad 60.522$

$\begin{array}{llll}59.987 & 59.910 & 59.834 & 59.757 \\ 59.222 & 59.145 & 59.068 & 58.992\end{array}$

$\begin{array}{llll}58.456 & 58.380 & 58.303 & 58.227\end{array}$

$\begin{array}{llll}57.691 & 57.615 & 57.538 & 57.462 \\ 56.926 & 56.849 & 56.773 & 56.696\end{array}$

$\begin{array}{llll}56.161 & 56.084 & 56.008 & 55.931 \\ 55.396 & 55.319 & 55.243 & 55.166\end{array}$

$\begin{array}{llllll}61.977 & 61.900 & 61.824 & 61.747 & 61.670 & 61.594\end{array}$

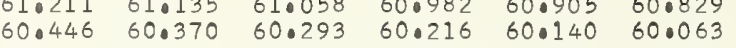

$\begin{array}{lllllll}59.681 & 59.604 & 59.528 & 59.451 & 59.375 & 59.298\end{array}$

$\begin{array}{lllllll}58.916 & 58.839 & 58.762 & 58.686 & 58.609 & 58.533 \\ 58.150 & 58.074 & 57.997 & 57.921 & 57.844 & 57.768\end{array}$

$\begin{array}{llllll}57.385 & 57.309 & 57.232 & 57.156 & 57.079 & 57.002\end{array}$

3615

50.1

5.3

5.5

5.6

5.8
5.9

3616.

6.1
6.2
6.3

6.4

6.5

6.6

6.8

$53.554 \quad 54.478$

$\begin{array}{llll}53.101 & 53.024 & 52.048 & 52.871\end{array}$

$52.336 \quad 52.260 \quad 52.183 \quad 52.106$

$50.807 \quad 50.730 \quad 50.654 \quad 50.577$

$50.042 \quad 49.966 \quad 49.889 \quad 49.812$

$\begin{array}{llll}48.512 & 48.436 & 48.360 & 48.283 \\ 47.748 & 47.672 & 47.595 & 47.519\end{array}$

$\begin{array}{llllll}55.855 & 55.778 & 55.702 & 55.625 & 55.549 & 55.472 \\ 55.090 & 55.013 & 54.937 & 54.860 & 54.784 & 54.707\end{array}$

$\begin{array}{lllll}56.543 & 56.467 & 56.390 & 56.314 & 56.238\end{array}$

0.285218

0.285218

0.285217

0.285215

0.285215

0.285214

0.285213

0.285212

1.029951

1.030002

1.030028

1.030054

1.030105

1.030131
1.030159

1.030157

1.030209

1.030234

1.030260
1.030286

.030312

1.030338

1.030363

1.030389

0.28521

0.285209

0.285209

0.285208

0.285207

0.285206

0.285206

0.285205

0.285203

0.285203
0.285202

0.285201

0.285200

0.285200

0.285199

0.285198

0.285197

0.285196

0.285195

0.285194

0.285193

0.285191

0.285190
80285189

0.285188

0.285188

0.285187

0.285185

0.285185
0.285184

0.285183

0.285182
0.285182

$\begin{array}{lllllllll} & & & \end{array}$

$\begin{array}{llllllllll}40.868 & 40.792 & 40.715 & 40.639 & 40.562 & 40.486 & 40.409 & 40.333 & 40.257 & 40.180 \\ 40.104 & 40.027 & 39.951 & 39.875 & 39.798 & 39.722 & 39.645 & 39.569 & 39.493 & 39.416\end{array}$

$\begin{array}{lllllllllll}3617.0 & 27639.340 & 39.263 & 39.187 & 39.110 & 39.034 & 38.958 & 38.881 & 38.805 & 38.728 & 38.652\end{array}$

$\begin{array}{llllllllllll}7.1 & 38.576 & 38.499 & 38.423 & 38.346 & 38.270 & 38.194 & 38.117 & 38.041 & 37.964 & 37.888 \\ 7.2 & 37.812 & 37.735 & 37.659 & 37.582 & 37.506 & 37.429 & 37.353 & 37.277 & 37.200 & 37.124\end{array}$

$\begin{array}{lllllllllll}7.3 & 37.047 & 36.971 & 36.895 & 36.818 & 36.742 & 36.666 & 36.589 & 36.513 & 36.437 & 36.360\end{array}$

$\begin{array}{llllllllll}36.284 & 36.208 & 36.131 & 36.055 & 35.978 & 35.902 & .35 .825 & 35.749 & 35.673 & 35.596\end{array}$

$\begin{array}{llllllllll}35.520 & 35.444 & 35.367 & 35.291 & 35.214 & 35.138 & 35.062 & 34.985 & 34.909 & 34.833\end{array}$

$\begin{array}{llllllllll}34.756 & 34.680 & 34.603 & 34.527 & 34.450 & 34.374 & 34.298 & 34.221 & 34.145 & 34.069 \\ 33.992 & 33.916 & 33.839 & 33.763 & 33.686 & 33.610 & 33.534 & 33.457 & 33.381 & 33.305\end{array}$

$\begin{array}{llllllllll}33.228 & 33.152 & 33.076 & 32.999 & 32.923 & 32.846 & 32.770 & 32.694 & 32.617 & 32.541 \\ 32.465 & 32.388 & 32.312 & 32.236 & 32.159 & 32.083 & 32.006 & 31.930 & 31.854 & 31.777\end{array}$

0.285181

0.285180

0.285179

0.285178

0.285177

0.285176
0.285176

0.285175

.030441

1.030467

1.030493
1.030518

1.030544

1.030570

1.030596

1.030622

1.030673

.030699

1.030725

1.030776

1.030802

1.030828
1.030854

.030854
.030880

1.030880
1.030905

1.030931

1.030983

1.031009

1.031035

1.031060

10031138

$\frac{2}{2}: 031189$

1.031241

1.031267

1.031293

1.031318
1.031344

1.031390

1.031396

1.031422
1.031448

1.031473

1.031499

1.031525

1.031577

1.031602

1.031628

1.031654

1
10.031706

0.285173

0.285173

0.285172

0.285170

0.285170

0.285169

0.285168

0.285167

1.031757

1.031783

1.031809

1.031861

1.031912

1.031938

1.031990

0.285166

1.032015

$0.285165 \quad 1.032041$

$0.285164 \quad 1.032093$

$0.285163 \quad 1.032119$

$0.285162 \quad 1.032145$

$0.285161 \quad 1.032196$

$0.285160 \quad 1.03222$

0.285150

1.032248

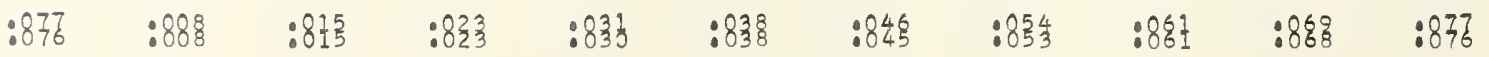




.04

0.285106

0.285106
0.285105

0.285104

0.285103
0.285103

0.285102

0.285101

0.285100

0.285099 0.285098
0.285098 0.285096 0.285095 0.285093
0.285092

0.285092 .0285091 0.285089
0.285089 0.285088 0.285087
0.285086 0.285086

1.033126

1.033177

1.033203
1.033229

1.033255

1.033306

1.033332

1.033358
1.033384

1.033410
1.033435

1.033469

1.033513

1.0335 .65

1.033590

1.033642

1.033668

1.033694
1.033719

1.033745

1.0033771
1.033797

1.033823

1.033849

1.033900

1.033926
1.033952

1.033952
1.033978

1.034004

1.034029
1.034055

1.034081

1.034107
1.034133

1.034158
1.034184

1.034210

1.034236
1.034262

1.034288

1. 0034339

1.034365

.0344417
.034427

1.034442

1.034494

1.034520

1.034546

1.034597

1.034623

1.034649
1.034675
1.034701

1.034727

1.034778

1.034804

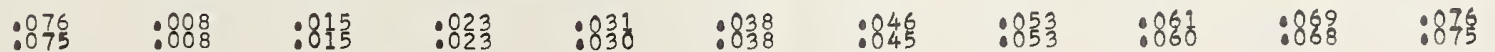




.04

.05

.06

.07

.08

.09

$(n-1) \times 1000$

$\lambda(n-1)$

3630.0
0.1
0.2
0.3
0.4
0.5
0.6
0.7
0.8

39.600

40
3
3
3
3

.524
.766

.448
.690

39.372
38.614
37.655

$\begin{array}{llllll}30.055 & 39.979 & 39.904 & 39.828 & 39.752 & 39.676 \\ 39.296 & 39.221 & 39.145 & 39.069 & 38.993 & 38.917\end{array}$

37.324

36.249

$37.173 \quad 37.097$

$37: 58$ 38 38.462

$\begin{array}{llll}38.386 & 38.310 & 38.235 & 38.159 \\ 37.628 & 37.552 & 37.476 & 37.400\end{array}$

35.807

34.291

3631.0

1.

7532.774

$32.016 \quad 31.698$

$31.257 \quad 31.940$

$30.499 \quad 30.424$

29.742

$28.983 \quad 28.908$

$\begin{array}{ll}28.225 & 28.150 \\ 27.467 & 27.392\end{array}$

$\begin{array}{ll}26.709 & 26.634 \\ 25.952 & 25.876\end{array}$

$\begin{array}{ll}35.414 & 36.338 \\ 34.656 & 35.580\end{array}$

$36.262 \quad 36.186 \quad 36.111 \quad 36.035 \quad 35.959 \quad 35.883$

$\begin{array}{llllll}35.504 & 35.428 & 35.352 & 35.276 & 35.201 & 35.125 \\ 34.746 & 34.670 & 34.594 & 34.518 & 34.442 & 34.366\end{array}$

$\begin{array}{ll}34.139 & 34.063 \\ 33.381 & 33.305\end{array}$

$33.987 \quad 33.911 \quad 33.836 \quad 33.760 \quad 33.684 \quad 33.608$

$32.622 \quad 32.547$

$33.229 \quad 33.153$

$33.077 \quad 33.001 \quad 32.926 \quad 32.850$

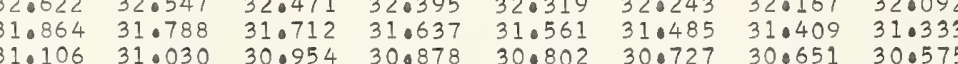

$\begin{array}{llllllll}30.348 & 31.030 & 30.954 & 30.878 & 30.802 & 30.727 & 30.651 & 30.575 \\ 30.196 & 30.120 & 30.044 & 29.969 & 29.893 & 29.817\end{array}$

$\begin{array}{llllllll}29.590 & 29.514 & 29.438 & 29.363 & 29.287 & 29.211 & 29.135 & 29.059 \\ 28.832 & 28.756 & 28.680 & 28.604 & 28.529 & 28.453 & 28.377 & 28.301\end{array}$

$\begin{array}{llllllll}28.074 & 27.998 & 27.922 & 27.847 & 27.771 & 27.695 & 27.619 & 27.543\end{array}$

1.9

3632

2.

2.3

2.6

2.8

3633.

3.1
3.2
3.3
3.4

3.5

3.6
3.7
3.8

3.8
3.9

3634

$4 \cdot 2$

4.3

$4 \cdot 4$
4.5

4.6
4.7

4.8
4.9

3635.

$5 \cdot 1$

5.3

5.4
5.5

5.6

5.8
5.9

3636.0

6.1

6.3
6.4

6.5

6.6
6.7

6.8
6.9

3637.0

$7 \cdot 1$
7.2
7.3

7.4

7.6
7.7

7.8
7.9

3638

8.1

8.3

8.4

8.6
8.7 $\begin{array}{r}7525 \cdot 194 \\ 24: 436\end{array} 24: 1$ 23.678
22.920

22.163

21.405

$19.132 \quad 19.814$

$26.558 \quad 26.248$

27.164

27.089

$25.648 \quad 25.57$

$25 \cdot 255$

$\begin{array}{lll}26.179 & 26.861 & 26.785 \\ & 26.103 & 26.027\end{array}$

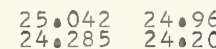

24.891

$24: 815$

$\begin{array}{lllll}240.739 & 24 & 24663 & 240587 & 24 \\ 230981 & 230905 & 230830 & 23 & 0154\end{array}$

$\begin{array}{llllllll}23.527 & 23.451 & 23.375 & 23.299 & 23.223 & 23.147 & 23.072 & 22.996\end{array}$

$\begin{array}{llllllll}22.769 & 22.693 & 22.617 & 22.542 & 22.466 & 22.390 & 22.314 & 22.238\end{array}$

18.375

$27517.617 \quad 17.542$

$\begin{array}{ll}16.860 & 16.784 \\ 16.102 & 16.027\end{array}$

$14.588 \quad 14.512$

13.074

$12.317-12.241$

$\begin{array}{ll}11.560 & 11.484 \\ 10.803 & 10.727\end{array}$

27510.046

$09.289 \quad 09.213$

08.53108 .456

$07.018 \quad 06.942$

$\begin{array}{ll}06.261 & 06.185 \\ 05.504 & 05.428\end{array}$

$\begin{array}{ll}04.747 & 04.672 \\ 03.990 & 03.915\end{array}$

$\begin{array}{ll}03.990 & 03.915 \\ 03.234 & 03.158\end{array}$

$27502.477 \quad 02.402$

$00.964 \quad 00.888$

27499.45199 .376

$98.695 \quad 98.620$

$97.183 \quad 97.107$

$\begin{array}{ll}96.426 & 96.35 \\ 95.670 & 95.594\end{array}$

27494.914

94.91493

$93.402 \quad 93.326$

$92.645 \quad 92.570$

$\begin{array}{rrr}91.738 & 91.66\end{array}$

90.37790 .302

$\begin{array}{ll}0.00 & 0.15\end{array}$

$\begin{array}{ll}88.865 & 88.79 \\ 88.110 & 88.034\end{array}$

$89.470 \quad 89.39$

$\begin{array}{llllll}21.860 & 21.784 & 21.708 & 21.632 & 21.556 & 21.481 \\ 21.102 & 21.026 & 20.950 & 20.875 & 20.799 & 20.723\end{array}$

$\begin{array}{llllllll}19.663 & 19.587 & 19.511 & 19.435 & 19.359 & 19.284 & 19.208\end{array}$

$\begin{array}{llllllll}17.466 & 17.390 & 17.314 & 17.239 & 17.163 & 17.087 & 17.011 & 16.936\end{array}$

$\begin{array}{llllllll}15.951 & 15.875 & 15.800 & 15.481 & 16.406 & 16.330 & 16.254 & 16.178 \\ 15.648 & 15.572 & 15.497 & 15.421\end{array}$

$\begin{array}{llllllll}15.194 & 15.118 & 15.042 & 14.967 & 14.891 & 14.815 & 14.740 & 14.664\end{array}$

$\begin{array}{llllllll}13.679 & 13.604 & 13.528 & 13.452 & 13.377 & 13.301 & 13.225 & 13.150\end{array}$

$\begin{array}{lllllllll}12.165 & 12.847 & 12.771 & 12.695 & 12.620 & 12.544 & 12.468 & 12.393\end{array}$

$\begin{array}{llllllll}1.408 & 11.332 & 11.257 & 11.181 & 11.105 & 11.030 & 10.954 & 10.878 \\ 10.651 & 10.575 & 10.500 & 10.424 & 10.348 & 10.273 & 10.197 & 1.0 .121\end{array}$

$\begin{array}{llllllll}09.894 & 09.818 & 09.742 & 09.667 & 09.591 & 09.516 & 09.440 & 09.364\end{array}$

$\begin{array}{lllllllll}09.137 & 09.062 & 08.986 & 08.910 & 08.834 & 08.759 & 08.683 & 08.607 \\ 08.380 & 08.304 & 08.229 & 08.153 & 08.077 & 08.001 & 07.926 & 07.850\end{array}$

$\begin{array}{llllllll}07.623 & 07.548 & 07.472 & 07.396 & 07.320 & 07.245 & 07.169 & 07.093\end{array}$

$\begin{array}{lllllllll}06.109 & 06.034 & 05.958 & 05.883 & 05.807 & 05.731 & 05.655 & 05.580\end{array}$

$\begin{array}{lllllllll}05.353 & 05.277 & 05.201 & 05.126 & 05.050 & 04.974 & 04.899 & 04.823\end{array}$

$\begin{array}{llllllll}0.839 & 03.764 & 03.688 & 03.612 & 03.537 & 03.461 & 03.342 & 04.066 \\ 03.83 & 03.310\end{array}$

$\begin{array}{lllllllll}0.326 & 02.250 & 02.175 & 02.099 & 02.023 & 01.948 & 01.872 & 01.797\end{array}$

$\begin{array}{llllllll}01.570 & 01.494 & 01.418 & 01.343 & 01.267 & 01.191 & 01.116 & 01.040\end{array}$

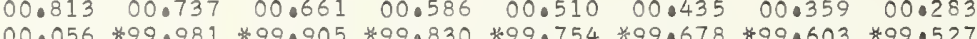

$99.300 \quad 99.225 \quad 99.149 \quad 99.073 \quad 98.998 \quad 98.922 \quad 98.847 \quad 98.771$

$\begin{array}{llllllll}98.544 & 98.468 & 98.393 & 98.317 & 98.241 & 98.166 & 98.090 & 98.015 \\ 97.788 & 97.712 & 97.636 & 97.561 & 97.485 & 97.409 & 97.334 & 97.258\end{array}$

$\begin{array}{llllllll}97.031 & 96.956 & 96.880 & 96.804 & 96.729 & 96.653 & 96.578 & 96.502\end{array}$

$\begin{array}{llllllll}96.275 & 96.199 & 96.124 & 96.048 & 95.972 & 95.897 & 95.821 & 95.746 \\ 95.519 & 95.443 & 95.367 & 95.292 & 95.216 & 95.141 & 95.065 & 94.989\end{array}$

$\begin{array}{llllllll}94.762 & 94.687 & 94.611 & 94.536 & 94.460 & 94.385 & 94.309 & 94.233 \\ 94.007 & 93.931 & 93.855 & 93.780 & 93.704 & 93.628 & 93.553 & 93.477\end{array}$

$\begin{array}{llllllll}94.007 & 93.931 & 93.855 & 93.780 & 93.704 & 93.628 & 93.553 & 93.477\end{array}$

$\begin{array}{llllll}93.099 & 93.023 & 92.948 & 92.872 & 92.797 & 92.721 \\ 92.343 & 92.268 & 92.192 & 92.116 & 92.041 & 91.965\end{array}$

$\begin{array}{llllll}91.587 & 91.511 & 91.436 & 91.360 & 91.284 & 91.209 \\ 90.831 & 90.755 & 90.680 & 90.604 & 90.529 & 90.453\end{array}$

$\begin{array}{llllll}90.075 & 90.755 & 90.680 & 90.604 & 90.529 & 90.453 \\ 90.000 & 89.924 & 89.848 & 89.773 & 89.697\end{array}$

$\begin{array}{rlllllllll}487.354 & 87.278 & 87.203 & 87.127 & 87.052 & 86.976 & 86.901 & 86.825 & 86.750 & 86.674 \\ 86.598 & 86.522 & 86.447 & 86.372 & 86.296 & 86.220 & 86.145 & 86.069 & 85.994 & 85.918\end{array}$ $\begin{array}{llllllllll}85.843 & 85.767 & 86.447 & 86.372 & 86.296 & 86.220 & 86.145 & 86.069 & 85.994 & 85.918\end{array}$ $\begin{array}{lllllllllll}85.087 & 85.011 & 84.936 & 84.860 & 84.785 & 84.709 & 84.634 & 85.313 & 85.238 & 85.163\end{array}$ $\begin{array}{lllllllllll}84.332 & 84.256 & 84.180 & 84.104 & 84.029 & 83.953 & 83.878 & 83.803 & 83.727 & 83.652\end{array}$ $\begin{array}{llllllllll}83.576 & 83.501 & 83.425 & 83.349 & 83.274 & 83.198 & 83.123 & 83.047 & 82.972 & 82.896\end{array}$ $\begin{array}{llllllllll}82.821 & 82.745 & 82.669 & 82.594 & 82.518 & 82.443 & 82.367 & 82.292 & 82.216 & 82.141\end{array}$ $\begin{array}{llllllllll} & 01.91 .910 & 81.914 & 81.838 & 81.763 & 81.687 & 81.612 & 81.536 & 81.461 & 81.385\end{array}$ $\begin{array}{llllllllll}81.310 & 81.234 & 81.159 & 81.083 & 81.007 & 80.932 & 80.856 & 80.781 & 80.705 & 80.630 \\ 80.554 & 80.479 & 80.403 & 80.328 & 80.252 & 80.176 & 80.101 & 80.025 & 79.950 & 79.874\end{array}$

$\begin{array}{rlllllllll}7479.799 & 79.723 & 79.648 & 79.572 & 79.497 & 79.421 & 79.346 & 79.270 & 79.194 & 79.119\end{array}$ $\begin{array}{llllllllll}79.043 & 78.968 & 78.893 & 78.817 & 78.741 & 78.666 & 78.590 & 78.515 & 78.439 & 78.364\end{array}$ $\begin{array}{llllllllll}78.288 & 78.213 & 78.137 & 78.062 & 77.986 & 77.911 & 77.835 & 77.759 & 77.684 & 77.608\end{array}$ $\begin{array}{llllllllll}77.573 & 77.458 & 77.382 & 77.306 & 77.231 & 77.156 & 77.080 & 77.004 & 76.929 & 76.853 \\ 76.778 & 76.702 & 76.627 & 76.551 & 76.476 & 76.400 & 76.325 & 76.249 & 76.174 & 76.098\end{array}$ $\begin{array}{lllllllllll}76.022 & 75.947 & 75.871 & 75.796 & 75.720 & 75.645 & 75.570 & 75.494 & 75.418 & 75.343\end{array}$ $\begin{array}{lllllllllll}75.267 & 75.192 & 75.116 & 75.041 & 74.965 & 74.890 & 74.814 & 74.739 & 74.664 & 74.588\end{array}$ $\begin{array}{llllllllll}74.512 & 74.437 & 74.361 & 74.286 & 74.210 & 74.135 & 74.059 & 73.984 & 73.908 & 73.833\end{array}$ $\begin{array}{llllllllll}73.002 & 72.982 & 73.606 & 73.531 & 73.455 & 73.380 & 73.304 & 73.229 & 73.153 & 73.078 \\ 72.851 & 72.776 & 72.700 & 72.625 & 72.549 & 72.474 & 72.398 & 72.323\end{array}$

$\begin{array}{lllllllllll}3639.0 & 27472.248 & 72.172 & 72.096 & 72.021 & 79.945 & 71.870 & 71.794 & 71.719 & 71.643 & 71.568\end{array}$

9.4

9.5

9.7

9.9

$\begin{array}{lll}71.492 & 71.417 & 71 \\ 70.738 & 70.662 & 70.5\end{array}$

$69.983 \quad 69.907 \quad 69.832$

68.47468 .398

$67.719 \quad 67.643 \quad 67.568$

$\begin{array}{llll}66.209 & 66.134 & 66.059 & 65.98 \\ 65.455 & 65.380 & 65.304 & 65.22\end{array}$

$\begin{array}{llllllll}0.511 & 70.436 & 70.360 & 70.285 & 70.209 & 70.134 & 70.058\end{array}$

$\begin{array}{lllllll}69.756 & 69.681 & 69.605 & 69.530 & 69.454 & 69.379 & 69.303 \\ 69.002 & 68.926 & 68.850 & 68.775 & 68.700 & 68.624 & 68.549 \\ 68.247 & 68.172 & 68.096 & 68.021 & 67.945 & 67.870 & 67.794\end{array}$

$\begin{array}{llllll}67.417 & 67.342 & 67.266 & 67.190 & 67.115 & 67.040\end{array}$

65.22

65.908

$\begin{array}{lllll}6.587 & 66.511 & 66.436 & 66.361 & 66.285\end{array}$

$.0,3$

.0041

65.078

65.002640

$\begin{array}{rrr}681 & 65.606 & 65.530\end{array}$

0.285084
0.285083
0.285083
0.285082
0.285081
0.285081
0.285080
0.285079
0.285078
0.28507

1.034856

1.034882

1.034933

1.034959
1.034985

$1.03501 \frac{11}{1.035036}$

1.035062

1.035088

0.285077

0.285076

0.285075

0.285074

0.285073

0.285072

0.285072

0.285070

1.035114

1.035140
1.035166

1.035191

1.035217
1.035243

1.035269

1.035295

1.035321
1.035346

0.28068

0.285068

0.285067

0.285066

0.285065

0.285064

0.285064
0.285063

0.285062

0.285061

0.285050

0.285059

0.285058

0.285058

0.285057

0.285056

0.285055

0.285054

0.285053

0.285053

0.285052

0.285051

0.285050

0.285050

0.285048

0.285047

0.285047

0.285046

0.285045

0.285044

0.285043

0.285042

0.285041
0.285041

0.285040

0.285039

0.285039

0.285038

0.285036

0.285036

0.285035

0.285034

0.285033

0.285032

0.28503 .

0.28502

0.285028

0.285028

0.285027
0.285026

1:08583572

1.035424

1.035476

1.035501

1.035553

1.035579
1.035605

1.035631
1.035656

1.035682

1.035708

1.035760

1.035786

1.035811

1.035837
1.035863

1.035889

1.035915
1.035940

1.035940 
$\begin{array}{rrrrrrrrrrr}0.0 & 27464.700 & 64.625 & 64.550 & 64.474 & 64.399 & 64.323 & 64.248 & 64.172 & 64.097 & 64.021 \\ 0.1 & 63.946 & 63.870 & 63.795 & 63.720 & 63.644 & 63.569 & 63.493 & 63.418 & 63.342 & 63.267\end{array}$

$\begin{array}{lllllllllll}0.3 & 63.191 & 63.116 & 63.041 & 62.965 & 62.890 & 62.814 & 62.739 & 62.663 & 62.588 & 62.512\end{array}$ $\begin{array}{llllllllll}62.437 & 62.362 & 62.286 & 62.211 & 62.135 & 62.060 & 61.984 & 61.909 & 61.833 & 61.758 \\ 61.683 & 61.607 & 61.532 & 61.457 & 61.381 & 61.305 & 61.230 & 61.155 & 61.079 & 61.004\end{array}$ $\begin{array}{llllllllll}60.928 & 60.853 & 60.777 & 60.702 & 60.627 & 60.551 & 60.476 & 60.400 & 60.325 & 60.250\end{array}$

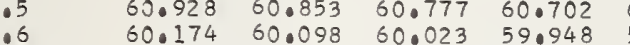

$60.174 \quad 60.098 \quad 60.023 \quad 59.948$

$\begin{array}{llll}58.666 & 58.590 & 58.515 & 58.439\end{array}$

$\begin{array}{llllll}60.627 & 60.551 & 60.476 & 60.400 & 60.325 & 60.250 \\ 50.872 & 59.797 & 59.721 & 59.646 & 59.571 & 59.495\end{array}$

57.91257 .836

$\begin{array}{lllllll}59.118 & 59.043 & 58.967 & 58.892 & 58.817 & 58.741\end{array}$

27419.505

$18.753 \quad 19.429$

$19.354 \quad 19.279$

6.1

18.000017 .925

$16.497 \quad 16.422 \quad 16.346 \quad 16027$

$15.745 \quad 15.670$

$14.993 \quad 14.918$

$14.843 \quad 14.76$

6.8
6.9

364

4700
$7: 1$
$7: 2$
$7: 3$
$7: 4$
$7: 5$
$7: 6$
$7: 7$
7
7.0 12.73

0$$
\begin{aligned}
& 1211.096 \\
& 11 \\
& 09 \\
& 08 \\
& 08989 \\
& 07.229 \\
& 0 \\
& 050726 \\
& 050224
\end{aligned}
$$

0.285010

0.285008

.285007

.285006

.0285005
0.285004

0.285003

0.285003
0.285002
0.28502

0.255001
0.285000
0.2800

0.285000

0.284999
0.284998

0.284997
0.284997

0.284996

0.284995

0.284994

0.284992

0.284992

0.284990
0.284989

0.284989

0.284988
0.284987

0.284987

0.284986

0.284985

0.284984

0.284983
0.284982

0.284981

0.284981

0.284979

0.284979

0.284977

0.284976

0.284975

0.284974

0.284973

0.284972

0.284970

0.284970

0.284968

0.284967

0.284966

0.284965

0.284964

0.284962

0.284961

0.284960

0.284960

0.28495

0.28495

0.284957

0.284956

0.284954

0.284954

0.284952

0.284952

0.284950

0.284949

0.284948

0.28494

0.284946

0.284945

0.284944

0.284943

0.284942

0.284941

0.284941

0.284940

0.284939
0.284938

1.037671

1.037697
1.037723

1.037749
1.037775

1.037800
1.037826
1.03787

1.037852

1.037904
1.037930

1.037956
1.037981

1.038007
1.038033

1.038059
1.038085

1.038136

1.038162
1.038188

1.038214

1.038266

1.038317

$\frac{1}{1.0038343}$

1.0038421

1.038472

1.038498

.038550

1.038601
1.038627

1.038653
1.038679

1.038731

1.038757

1.038834

1.038860

1.038886

$\frac{1}{1} .038912$

.038963

1.038989

$\frac{1}{1} .039015$

1.039067

$\frac{1}{1.003909118}$

1.039144

1.039196

1.039248

1.039290

1.039325

1.039377

1.039428

1.039480

1.039506

1.039583

1.039635

1.03968

1.039713
1.039739

1.039764

1.039790
1.039816

1.039842

1.039868

1.039894

1.039945

1.039971

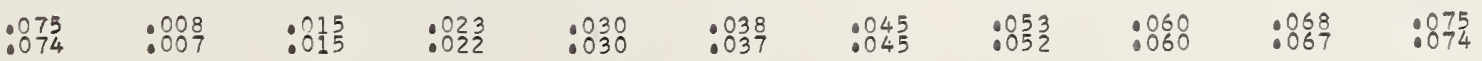


0.284938

0.284937

1.040023

1.040075

1.040100

$0.284934 \quad 1.040152$

$0.284933 \quad 1.040178$

$0.284932 \quad 1.040230$

$0.284932 \quad 1.040230$

0.284931

0.284929

0.284928
0.284928

0.284927

0.284926

0.284925
0.284925

0.284924

1. 040281

0.284923

0.284923

0.284922

0.284921
0.284920

0.284920

0.284919

0.284918

0.284917
0.284917

1.040333

1.040359

1.040385
1.040411

1.040436

1.040462

1.040514

0.284916

0.284915

0.284914

0.284913

0.284912

0.284912

0.284911

0.284910
0.284910

0.284909

0.284908

0.284907

0.284906

0.284905

0.284904

0.284904

0.284903
0.284902

0.284902

0.284901

0.284900

0.284899
0.284899

0.284899
0.284898

0.284897

0.284897

0.284896

0.284894

0.284894
0.284893

0.284893
0.284892

0.28489

0.284891
0.284890

0.284890

0.284889

0.284888

1.040540

1.040566

1.040591
1.040617

1.040643

1.040669

1.040695

1.040721
1.040747

1.040772

0.284887

0.284886

0.284886

0.28488

0.284884

0.28488

0.284882

0.284881

1. 040798

1.040824
1.040850

1.040876

1.040902

1.040953 


\section{.06}

.07

3666.0 $\begin{array}{llll}07.909 & 07.535 & 07.760 & 07.685\end{array}$

$27307 \cdot 163$ $06.417 \quad 07.08$ 05.677 $\begin{array}{lll}07.06 & 06.268 & 06.194 \\ 0.597 & 05.522 & 05.448\end{array}$ $\begin{array}{llll}03.434 & 03.105 & 04.031 & 03.956\end{array}$ $\begin{array}{lllll}02.688 & 02.614 & 02.540 & 02.465\end{array}$ $\begin{array}{ll}01.197 & 01.123 \\ 00.452 & 00.377\end{array}$

27299.706 98.96198 .986 $96.725 \quad 96.650 \quad 96.576 \quad 96.501$ 97.470
97.396

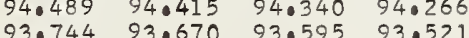
$92.999 \quad 92.925$

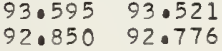

\section{$\begin{array}{llll}13.878 & 13.803 & 13.729 & 13.654\end{array}$ $\begin{array}{llll}13.132 & 13.057 & 12.982 & 12.908 \\ 12.385 & 12.311 & 12.236 & 12.162\end{array}$ $\begin{array}{llll}12.385 & 11.311 & 12.236 & 12.162 \\ 11.639 & 11.565 & 11.490 & 11.416 \\ 10.893 & 10.818 & 10.744 & 10.669\end{array}$ $\begin{array}{llll}10.893 & 10.818 & 10.744 & 10.669 \\ 10.147 & 10.072 & 09.998 & 09.923\end{array}$ $\begin{array}{llll}10.147 & 10.072 & 09.998 & 09.923 \\ 09.401 & 09.326 & 09.252 & 09.177\end{array}$} $95.235 \quad 95.160 \quad 95.085 \quad 95.011$

$\begin{array}{llllll}3.579 & 13.505 & 13.430 & 13.355 & 130281 & 13.206 \\ 1.833 & 12.759 & 12.684 & 12.6009 & 12.535 & 12.4600\end{array}$ $\begin{array}{llllll}2.087 & 12.012 & 11.938 & 11.863 & 11.789 & 11.714 \\ 1.341 & 11.266 & 11.192 & 11.117 & 11.042 & 10.968 \\ 0.595 & 10.520 & 10.446 & 10.371 & 10.296 & 10.222\end{array}$ $\begin{array}{llllll}09.849 & 09.774 & 09.699 & 09.625 & 09.551 & 09.476 \\ 09.103 & 09.028 & 08.953 & 08.879 & 08.804 & 08.730\end{array}$ $\begin{array}{llllll}08.357 & 08.282 & 08.208 & 08.133 & 08.058 & 07 \cdot 984 \\ 07.611 & 07.536 & 07.462 & 07.387 & 07.312 & 07.238\end{array}$ $\begin{array}{llllll}06.865 & 06.790 & 06.716 & 06.641 & 06.566 & 06.492 \\ 06.119 & 06.044 & 05.970 & 05.895 & 05.821 & 05.746 \\ 05.373 & 05.299 & 05.224 & 05.149 & 05.075 & 05.000\end{array}$ $\begin{array}{llllll}04.628 & 04.553 & 04.478 & 04.404 & 04 \cdot 329 & 04.254 \\ 03.882 & 03.807 & 03.732 & 03.658 & 03.583 & 03.509 \\ 03.136 & 03.062 & 02.087 & 02.012 & 02.838 & 02.763\end{array}$ $\begin{array}{llllll}03.136 & 03.062 & 02.987 & 02.912 & 02.838 & 02.763 \\ 02.390 & 02.316 & 02.241 & 02.167 & 02.092 & 02.018 \\ 01.645 & 01.570 & 01.496 & 01.421 & 01.347 & 01.272\end{array}$ $\begin{array}{llllll}00.899 & 00.825 & 00.750 & 00.676 & 00.601 & 00.526 \\ 00.154 & 00.079 & 00.005 & * 99.930 & * 99.855 & * 99.781\end{array}$ $\begin{array}{rlllll}98.663 & 98.589 & 98.514 & 98.439 & 98.365 & 98.290 \\ 97.917 & 97.84 .3 & 97.769 & 97.694 & 97.620 & 97.545 \\ 97.172 & 97.0098 & 97.023 & 96.949 & 96.874 & 96.800\end{array}$

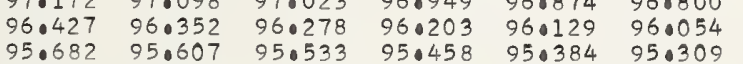
$\begin{array}{lllllll}94.036 & 94.862 & 94.787 & 940713 & 94.638 & 94.564 \\ 94.191 & 94.117 & 94.042 & 93.968 & 93.893 & 93.819\end{array}$ $\begin{array}{llllll}92.701 & 92.626 & 92.552 & 92.477 & 92.403 & 92.328 \\ 91.956 & 91.881 & 91.807 & 91.732 & 91.658 & 91.583\end{array}$ $\begin{array}{llllll}90.466 & 91.136 & 91.062 & 90.987 & 90.913 & 90.838 \\ 0.391 & 90.317 & 90.242 & 90.168 & 90.093 \\ 9.721 & 89.646 & 89.572 & 89.497 & 89.423 & 89.348\end{array}$ $\begin{array}{llllll}88.976 & 88.901 & 88.827 & 88.753 & 88.678 & 88.603 \\ 88.231 & 88.156 & 88.082 & 88.008 & 87.933 & 87.859\end{array}$ \begin{tabular}{llllll}
86.741 & 86.667 & 87.337 & 87.263 & 87.188 & 87.114 \\
\hline & 86.593 & 86.518 & 86.444 & 86.369
\end{tabular} $\begin{array}{lllllll}84.507 & 84.433 & 84.358 & 84.284 & 84.209 & 84.135\end{array}$

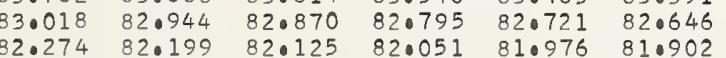

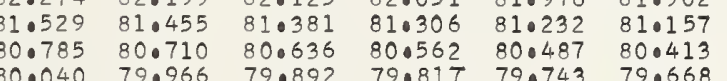
$\begin{array}{llllll}79.296 & 79.966 & 79.892 & 79.817 & 790743 & 79.668 \\ 79.147 & 79.073 & 780.998 & 78.924 \\ 77.508 & 78.477 & 79.403 & 78.328 & 78.054 & 78.170\end{array}$ $\begin{array}{lllllll}77.063 & 76.989 & 76.914 & 76.840 & 76.765 & 76.691 \\ 76.319 & 76.245 & 76.170 & 76.095 & 76.021 & 75.947\end{array}$ $\begin{array}{llllll}75.575 & 75.500 & 75.426 & 75.352 & 75.277 & 75.203 \\ 74.831 & 74.756 & 74.682 & 74.607 & 74.533 & 74.458\end{array}$

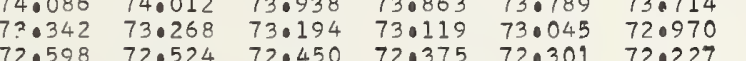
$\begin{array}{llllll}71.854 & 71.780 & 71.706 & 71.631 & 71.557 & 71.482 \\ 71.036 & 70.962 & 70.887 & 70.813 & 70.739 \\ 70.366 & 70.292 & 70.218 & 70.143 & 70.069 & 69.095\end{array}$ $\begin{array}{llllll}69.623 & 69.548 & 69.474 & 69.399 & 69.325 & 69.251 \\ 68.879 & 68.804 & 68.730 & 68.656 & 68.582 & 68.507\end{array}$ $\begin{array}{llllll}68.135 & 68.061 & 67.987 & 670912 & 670838 & 67.764 \\ 67: 392 & 67.317 & 67.243 & 67: 169 & 67.094 & 67.020 \\ 66.648 & 66.573 & 66.409 & 65.425 & 66.351 & 65.276\end{array}$

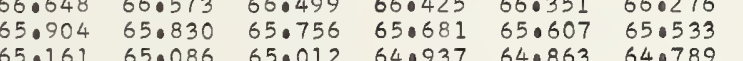
$\begin{array}{llllll}64.1617 & 65.086 & 65 \cdot 012 & 64 \cdot 937 & 64.863 & 64.0789 \\ 63.674 & 63.599 & 64.268 & 64 \cdot 194 & 64 \cdot 120 & 64.045 \\ 63.525 & 63.451 & 63.376 & 63.0302\end{array}$ $62.187 \quad 62.112 \quad 62.038 \quad 61.964 \quad 61.88961 .815$ $\begin{array}{llllll}60.700 & 60.626 & 60.551 & 60.477 & 60.403 & 60.328 \\ 59.957 & 59.882 & 59.808 & 59.734 & 590659 & 59.585 \\ 59.2130 & 59.139 & 59.065 & 58.990 & 50.916 & 58.842\end{array}$ $\begin{array}{llllll}5.213 & 59.139 & 59.065 & 58.990 & 58.916 & 58.842 \\ 58.470 & 58.396 & 58.322 & 58.247 & 58.173 & 58.099 \\ 57.727 & 57.653 & 57.578 & 57.504 & 57.430 & 57.355\end{array}$ $\begin{array}{lllllll}56.983 & 56.909 & 56.835 & 56.760 & 56.687 & 56.612 \\ 56.240 & 56.166 & 56.092 & 56.018 & 55.943 & 55.869\end{array}$ $\begin{array}{lllllll}5.497 & 55.423 & 55.349 & 55.274 & 55.200 & 550126\end{array}$ $\begin{array}{llllll} & & & & \\ .011 & 53.937 & 53.863 & 53.788 & 53.457 & 54.383 \\ 53.640\end{array}$

0.284808 0.284807 0.284807 0.28480 0.284805

0.284805

0.284804

0.284802

0.284803
0.284802

0.284801 .284800 0.284800 0.0284798 0.284797 000284797 0.284795 0.284795
0.284795

0.284861

.284860
. .284859

1.042634

0.284858

0.284857
0.284856

0.284855
0.284854

0.284853
0.284852

0.284851
0.284850

0.284850
0.284849
0.284848

0.284848

0.284845

0.284844

0.284843
0.284842

0.284840

0.284840

0.284838

4836

0.284835

0.284833

0.284832

0.284830

0.284828

0.284827

0.284825

0.284824

.042711

1.042763

1.042789
1.042815

1.042840

1.042866

1.042892

1.042944

1.042970

1.043021
1.043047

1.043073
1.043099

1.043125

1.043151

1.043202

1.043228
1.043254

1.043280

1.043306
1.043332

1.043383

1.043409

1.043435

1.043487

1.043513
1.043539

1.043564

1.043590
1.043616

1.043642

1.043668
1.043694

1.043720

1.043745
1.043771

1.043797

1.043823

$1.04390 \%$

1.043927

1.043952
1.043978

1.044004

1.044030

1.044056
1.044082

1.044108
1.044133

1.044159
1.044185

1.044211

1.044263

1.044289

1.044314

1.044366
1.044398

1.044418

1.044470

1.044495
1.044521

1.044547

1.044573

1.044599

1.044676

1.044702

1.044754

1.044780

1.044832

1.044858

1.044909

1.044935

1.044961

1.045013

1.045039

1.045064

1.045116

1.045142

.010 


\begin{tabular}{|c|c|c|c|c|c|c|c|c|c|c|c|c|}
\hline $\begin{array}{l}0.0 \\
0.1 \\
0.2 \\
0.3 \\
0.4 \\
0.5 \\
0.6 \\
0.7 \\
0.8 \\
0.9\end{array}$ & $\begin{array}{r}240.199 \\
39.457 \\
38.715 \\
37.972 \\
37.230 \\
36.489 \\
35.747 \\
35.005 \\
34.263 \\
33.521\end{array}$ & $\begin{array}{l}40.125 \\
39.383 \\
38.641 \\
37.898 \\
37.156 \\
36.415 \\
35.672 \\
34.931 \\
34.189 \\
33.447\end{array}$ & $\begin{array}{l}40.051 \\
39.309 \\
38.566 \\
37.824 \\
37.082 \\
36.340 \\
35.598 \\
34.856 \\
34.115 \\
33.373\end{array}$ & $\begin{array}{l}39.977 \\
39.234 \\
38.492 \\
37.750 \\
37.008 \\
36.266 \\
35.524 \\
34.782 \\
34.040 \\
33.298\end{array}$ & $\begin{array}{l}39.902 \\
39.160 \\
38.418 \\
37.676 \\
36.934 \\
36.192 \\
35.450 \\
34.708 \\
33.966 \\
33.224\end{array}$ & $\begin{array}{l}39.828 \\
39.086 \\
38.344 \\
37.602 \\
36.860 \\
36.118 \\
35.376 \\
34.634 \\
33.892 \\
33.150\end{array}$ & $\begin{array}{l}39.754 \\
39.011 \\
38.270 \\
37.527 \\
36.786 \\
36.044 \\
35.302 \\
34.560 \\
33.818 \\
33.076\end{array}$ & $\begin{array}{l}39.679 \\
38.937 \\
38.195 \\
37.453 \\
36.711 \\
35.969 \\
350227 \\
34.485 \\
33.744 \\
330002\end{array}$ & $\begin{array}{l}39.605 \\
38.863 \\
38.121 \\
37.379 \\
36.637 \\
35.895 \\
35.153 \\
34.411 \\
33.669 \\
32.927\end{array}$ & $\begin{array}{l}39.531 \\
38.789 \\
38.047 \\
37.304 \\
36.563 \\
35.821 \\
35.079 \\
34.337 \\
33.595 \\
32.853\end{array}$ & $\begin{array}{l}0.284794 \\
0.28493 \\
0.28493 \\
0.284992 \\
0.284791 \\
0.284790 \\
0.284790 \\
0.284789 \\
0.284788 \\
0.284788\end{array}$ & $\begin{array}{l}1.045194 \\
1.045220 \\
1.045245 \\
1.045271 \\
1.045297 \\
1.045323 \\
1.045349 \\
1.045375 \\
1.045401 \\
1.045426\end{array}$ \\
\hline $\begin{array}{l}71: 0 \\
1: 1 \\
1: 2 \\
1: 3 \\
1: 4 \\
1: 5 \\
1: 6 \\
1: 7 \\
1.8 \\
1.9\end{array}$ & $\begin{array}{r}27232.779 \\
32.037 \\
31.296 \\
30.554 \\
29.812 \\
29.071 \\
28.329 \\
27.587 \\
26.846 \\
26.104\end{array}$ & $\begin{array}{l}32.705 \\
31.963 \\
31.221 \\
30.480 \\
29.738 \\
28.996 \\
28.255 \\
27.513 \\
26.772 \\
26.030\end{array}$ & $\begin{array}{l}32.631 \\
31.889 \\
31.147 \\
30.405 \\
29.664 \\
28.922 \\
28.181 \\
27.439 \\
26.698 \\
25.956\end{array}$ & $\begin{array}{l}32.557 \\
31.815 \\
31.073 \\
30.331 \\
29.590 \\
28.848 \\
28.106 \\
27.365 \\
26.623 \\
25.882\end{array}$ & $\begin{array}{l}32.482 \\
31.740 \\
30.999 \\
30.257 \\
29.515 \\
28.774 \\
28.032 \\
27.291 \\
26.549 \\
25.808\end{array}$ & $\begin{array}{l}32.408 \\
31.667 \\
30.925 \\
30.183 \\
29.441 \\
28.699 \\
27.958 \\
27.216 \\
26.475 \\
25.733\end{array}$ & $\begin{array}{l}32.334 \\
31.592 \\
30.850 \\
30.109 \\
29.367 \\
28.625 \\
27.884 \\
27.142 \\
26.401 \\
25.659\end{array}$ & $\begin{array}{l}32.260 \\
31.518 \\
30.776 \\
30.035 \\
29.293 \\
28.551 \\
27.810 \\
27.068 \\
26.327 \\
25.585\end{array}$ & $\begin{array}{l}32.186 \\
31.444 \\
30.702 \\
29.960 \\
29.219 \\
28.477 \\
27.736 \\
26.994 \\
26.252 \\
25.511\end{array}$ & $\begin{array}{l}32.112 \\
31.370 \\
30.628 \\
29.886 \\
29.145 \\
28.403 \\
27.661 \\
26.920 \\
26.178 \\
25.437\end{array}$ & $\begin{array}{l}0.284787 \\
0.284786 \\
0.284785 \\
0.284785 \\
0.284784 \\
0.284783 \\
0.284783 \\
0.284782 \\
0.284781 \\
0.284780\end{array}$ & $\begin{array}{l}1.045452 \\
1.045478 \\
1.045504 \\
1.045530 \\
1.045556 \\
1.045582 \\
1.045608 \\
1.045633 \\
1.045659 \\
1.045685\end{array}$ \\
\hline $\begin{array}{r}72.0 \\
2.1 \\
2.2 \\
2.3 \\
2.4 \\
2.5 \\
2.6 \\
2.7 \\
2.8 \\
2.9\end{array}$ & $\begin{array}{r}27225.363 \\
24.621 \\
23.880 \\
23.138 \\
22.397 \\
21.656 \\
20.915 \\
20.174 \\
19.433 \\
18.692\end{array}$ & $\begin{array}{l}25.289 \\
24.547 \\
23.806 \\
23.064 \\
22.323 \\
21.582 \\
20.841 \\
20.100 \\
19.359 \\
18.618\end{array}$ & $\begin{array}{l}25.214 \\
24.473 \\
23.732 \\
22.990 \\
22.249 \\
21.508 \\
20.767 \\
20.026 \\
19.285 \\
18.543\end{array}$ & $\begin{array}{l}25.140 \\
24.399 \\
23.657 \\
22.916 \\
22.175 \\
21.434 \\
20.693 \\
19.952 \\
19.210 \\
18.470\end{array}$ & $\begin{array}{l}25.066 \\
24 \cdot 325 \\
23.583 \\
22.842 \\
22.101 \\
21.360 \\
20.619 \\
19.877 \\
19.137 \\
18.396\end{array}$ & $\begin{array}{l}24.992 \\
24.251 \\
23.509 \\
22.768 \\
22.027 \\
21.286 \\
20.545 \\
19.804 \\
19.062 \\
18.321\end{array}$ & $\begin{array}{l}24.918 \\
24.177 \\
23.435 \\
22.694 \\
21.953 \\
21.212 \\
20.471 \\
19.729 \\
18.988 \\
18.247\end{array}$ & $\begin{array}{l}24.844 \\
24 \cdot 102 \\
23 \cdot 361 \\
22.620 \\
21.879 \\
21.138 \\
20.396 \\
19.655 \\
18.914 \\
18.173\end{array}$ & $\begin{array}{l}24.770 \\
24.028 \\
23.287 \\
22.546 \\
21.804 \\
21.063 \\
20.323 \\
19.581 \\
18.840 \\
18.099\end{array}$ & $\begin{array}{l}24.696 \\
23.954 \\
23.213 \\
22.471 \\
21.730 \\
20.990 \\
20.248 \\
19.507 \\
18.766 \\
18.025\end{array}$ & $\begin{array}{l}0.284780 \\
0.284779 \\
0.284778 \\
0.284778 \\
0.284777 \\
0.284776 \\
0.284775 \\
0.284775 \\
0.284774 \\
0.284773\end{array}$ & $\begin{array}{l}1.045711 \\
1.045737 \\
1.045763 \\
1.045789 \\
10045814 \\
1.045840 \\
10045866 \\
10045892 \\
1.045918 \\
1.045944\end{array}$ \\
\hline $\begin{array}{l}73.0 \\
3.1 \\
3.2 \\
3.3 \\
3.4 \\
3.5 \\
3.6 \\
3.7 \\
3.8 \\
3.9\end{array}$ & $\begin{array}{r}27217.951 \\
17.210 \\
16.469 \\
15.728 \\
14.987 \\
14.246 \\
13.505 \\
12.765 \\
12.024 \\
11.283\end{array}$ & $\begin{array}{l}17.877 \\
17.136 \\
16.395 \\
15.654 \\
14.913 \\
14.172 \\
13.431 \\
12.691 \\
11.950 \\
11.209\end{array}$ & $\begin{array}{l}17.802 \\
17.062 \\
16.321 \\
15.580 \\
14.839 \\
14.098 \\
13.357 \\
12.616 \\
11.876 \\
11.135\end{array}$ & $\begin{array}{l}17.729 \\
16.988 \\
16.247 \\
15.505 \\
14.765 \\
14.024 \\
13.283 \\
12.542 \\
11.802 \\
11.061\end{array}$ & $\begin{array}{l}17.654 \\
16.913 \\
16.172 \\
15.432 \\
14.691 \\
13.950 \\
13.209 \\
12.468 \\
11.728 \\
10.987\end{array}$ & $\begin{array}{l}17.580 \\
16.839 \\
16.098 \\
15.357 \\
14.616 \\
13.876 \\
13.135 \\
12.395 \\
11.654 \\
10.913\end{array}$ & $\begin{array}{l}17.506 \\
16.765 \\
16.024 \\
15.283 \\
14.542 \\
13.802 \\
13.061 \\
12.320 \\
11.580 \\
10.839\end{array}$ & $\begin{array}{l}17.432 \\
16.691 \\
15.950 \\
15.209 \\
14.469 \\
13.728 \\
12.987 \\
12.246 \\
11.505 \\
10.765\end{array}$ & $\begin{array}{l}17.358 \\
16.617 \\
15.876 \\
15.135 \\
14.394 \\
13.654 \\
12.913 \\
12.172 \\
11.431 \\
10.691\end{array}$ & $\begin{array}{l}17.284 \\
16.543 \\
15.802 \\
15.061 \\
14.320 \\
13.580 \\
12.839 \\
12.098 \\
11.357 \\
10.616\end{array}$ & $\begin{array}{l}0.284773 \\
0.284772 \\
0.284771 \\
0.284770 \\
0.284770 \\
0.284769 \\
0.284768 \\
0.284768 \\
0.284767 \\
0.284766\end{array}$ & $\begin{array}{l}1.045970 \\
1.045996 \\
1.046021 \\
1.046047 \\
1.046073 \\
1.046099 \\
1.046125 \\
1.046151 \\
1.046177 \\
1.046202\end{array}$ \\
\hline $\begin{array}{r}674.0 \\
4 \bullet 1 \\
4 \bullet 2 \\
4.3 \\
4.4 \\
4.5 \\
4.6 \\
4 \bullet 7 \\
4.8 \\
4.9\end{array}$ & $\begin{array}{r}27210.542 \\
09.802 \\
09.061 \\
08.321 \\
07.580 \\
06.840 \\
06.100 \\
05.359 \\
04.619 \\
03.879\end{array}$ & $\begin{array}{l}10.469 \\
09.728 \\
08.987 \\
08.247 \\
07.506 \\
06.766 \\
06.026 \\
05.286 \\
04.545 \\
03.805\end{array}$ & $\begin{array}{l}10.394 \\
09.654 \\
08.913 \\
08.173 \\
07.432 \\
06.692 \\
05.952 \\
05.211 \\
04.471 \\
03.731\end{array}$ & $\begin{array}{l}10.321 \\
09.580 \\
08.839 \\
08.099 \\
07.358 \\
06.618 \\
05.878 \\
05.137 \\
04.397 \\
03.657\end{array}$ & $\begin{array}{l}10.246 \\
09.506 \\
08.765 \\
08.025 \\
07.284 \\
06.544 \\
05.804 \\
05.063 \\
04.323 \\
03.583\end{array}$ & $\begin{array}{l}10.172 \\
09.432 \\
08.691 \\
07.951 \\
07.210 \\
06.470 \\
05.730 \\
04.990 \\
04.249 \\
03.509\end{array}$ & $\begin{array}{l}10.098 \\
09.358 \\
08.617 \\
07.876 \\
07.136 \\
06.396 \\
05.656 \\
04.915 \\
04.175 \\
03.435\end{array}$ & $\begin{array}{l}10.024 \\
09.284 \\
08.543 \\
07.803 \\
07.062 \\
06.322 \\
05.582 \\
04.841 \\
04.101 \\
03.361\end{array}$ & $\begin{array}{l}09.950 \\
09.210 \\
08.469 \\
07.729 \\
06.988 \\
06.248 \\
05.508 \\
04.768 \\
04.027 \\
03.287\end{array}$ & $\begin{array}{l}09.876 \\
09.135 \\
08.395 \\
07.655 \\
05.914 \\
06.174 \\
05.434 \\
04.693 \\
03.953 \\
03.213\end{array}$ & $\begin{array}{l}0.284765 \\
0.284765 \\
0.284764 \\
0.284763 \\
0.284763 \\
0.284762 \\
0.284761 \\
0.284761 \\
0.284760 \\
0.284759\end{array}$ & $\begin{array}{l}1.046228 \\
1.046254 \\
1.046280 \\
1.046306 \\
10046332 \\
1.046358 \\
1.046384 \\
10046409 \\
10046433 \\
1.046461\end{array}$ \\
\hline $\begin{array}{r}675.0 \\
5.1 \\
5.2 \\
5.3 \\
5.4 \\
5.5 \\
5.6 \\
5.7 \\
5.8 \\
5.9\end{array}$ & $\begin{array}{r}27203.139 \\
02.399 \\
01.658 \\
00.918 \\
00.178 \\
27199.438 \\
98.698 \\
97.958 \\
97.218 \\
96.479\end{array}$ & $\begin{array}{l}03.065 \\
02.324 \\
01.584 \\
00.844 \\
00.104 \\
99.364 \\
98.624 \\
97.884 \\
97.144 \\
96.404\end{array}$ & $\begin{array}{l}02.990 \\
02.251 \\
01.510 \\
00.770 \\
00.030 \\
99.290 \\
98.550 \\
97.810 \\
97.070 \\
96.330\end{array}$ & $\begin{array}{r}02.917 \\
02.177 \\
01.437 \\
00.696 \\
* 99.956 \\
99.216 \\
98.476 \\
97.736 \\
96.996 \\
96.257\end{array}$ & $\begin{array}{r}02.843 \\
02.102 \\
01.362 \\
00.622 \\
* 99.882 \\
99.142 \\
98.402 \\
97.662 \\
96.922 \\
96.183\end{array}$ & $\begin{array}{r}02.769 \\
02.029 \\
01.288 \\
00.548 \\
* 99.808 \\
99.068 \\
98.328 \\
97.588 \\
96.848 \\
96.108\end{array}$ & $\begin{array}{r}02.695 \\
01.954 \\
01.214 \\
00.474 \\
* 99.734 \\
98.994 \\
98.254 \\
97.514 \\
96.774 \\
96.035\end{array}$ & $\begin{array}{l}02.621 \\
01.880 \\
01.140 \\
00.400 \\
* 99.660 \\
98.920 \\
98.180 \\
97.440 \\
96.700 \\
95.961\end{array}$ & $\begin{array}{r}02.547 \\
01.807 \\
01.066 \\
00.326 \\
* 99.586 \\
98.846 \\
98.106 \\
97.366 \\
96.626 \\
95.886\end{array}$ & $\begin{array}{r}02.473 \\
01.732 \\
00.992 \\
00.252 \\
* 99.512 \\
98.772 \\
98.032 \\
97.292 \\
96.552 \\
95.812\end{array}$ & $\begin{array}{l}0.284758 \\
0.284758 \\
0.284757 \\
0.284756 \\
0.284756 \\
0.284755 \\
0.284754 \\
0.284753 \\
0.284753 \\
0.284752\end{array}$ & $\begin{array}{l}1.046487 \\
1.046513 \\
1.046539 \\
1.046565 \\
1.046590 \\
1.046616 \\
1.046642 \\
1.046668 \\
1.046694 \\
1.046720\end{array}$ \\
\hline $\begin{array}{r}676.0 \\
6.1 \\
6.2 \\
6.3 \\
6.4 \\
6.5 \\
6.6 \\
6.7 \\
6.8 \\
6.9\end{array}$ & $\begin{array}{r}27195.739 \\
94.999 \\
94.259 \\
93.519 \\
92.780 \\
92.040 \\
91.301 \\
90.561 \\
89.822 \\
89.082\end{array}$ & $\begin{array}{l}95.665 \\
94.925 \\
94.185 \\
93.445 \\
92.706 \\
91.966 \\
91.226 \\
90.487 \\
89.748 \\
89.008\end{array}$ & $\begin{array}{l}95.591 \\
94.851 \\
94.111 \\
93.371 \\
92.632 \\
91.892 \\
91.153 \\
90.413 \\
89.674 \\
88.934\end{array}$ & $\begin{array}{l}95.517 \\
94.777 \\
94.037 \\
93.297 \\
92.558 \\
91.818 \\
91.078 \\
90.339 \\
89.600 \\
88.860\end{array}$ & $\begin{array}{l}95.443 \\
94.703 \\
93.963 \\
93.223 \\
92.484 \\
91.744 \\
91.004 \\
90.265 \\
89.526 \\
88.786\end{array}$ & $\begin{array}{l}95.369 \\
94.629 \\
93.889 \\
93.149 \\
92.410 \\
91.670 \\
90.931 \\
90.191 \\
89.452 \\
88.712\end{array}$ & $\begin{array}{l}95.295 \\
94.555 \\
93.815 \\
93.075 \\
92.336 \\
91.596 \\
90.857 \\
90.117 \\
89.378 \\
88.639\end{array}$ & $\begin{array}{l}95.221 \\
94.481 \\
93.741 \\
93.002 \\
92.262 \\
91.522 \\
90.783 \\
90.043 \\
89.304 \\
88.565\end{array}$ & $\begin{array}{l}95 \cdot 147 \\
94.407 \\
93.667 \\
92.927 \\
92.188 \\
91.448 \\
90.709 \\
89.970 \\
89.230 \\
88.491\end{array}$ & $\begin{array}{l}95.073 \\
94.333 \\
93.593 \\
92.854 \\
92.114 \\
91.375 \\
90.635 \\
89.896 \\
89.156 \\
88.417\end{array}$ & $\begin{array}{l}0.284731 \\
0.284751 \\
0.284750 \\
0.284749 \\
0.284748 \\
0.284748 \\
0.284747 \\
0.284746 \\
0.284746 \\
0.284745\end{array}$ & $\begin{array}{l}1.046746 \\
1.046772 \\
1.046797 \\
1.046823 \\
1.046849 \\
1.046875 \\
1.046901 \\
1.046927 \\
1.046953 \\
1.046979\end{array}$ \\
\hline $\begin{array}{r}677.0 \\
7: 1 \\
7.2 \\
7.3 \\
7.4 \\
7.5 \\
7.6 \\
7.7 \\
7.8 \\
7.9\end{array}$ & $\begin{array}{r}27188.343 \\
87.604 \\
86.864 \\
86.125 \\
85.385 \\
84.646 \\
83.907 \\
83.168 \\
82.428 \\
81.690\end{array}$ & $\begin{array}{l}88.269 \\
87.530 \\
86.790 \\
86.051 \\
85.312 \\
84.572 \\
83.833 \\
83.094 \\
82.355 \\
81.616\end{array}$ & $\begin{array}{l}88.195 \\
87.456 \\
86.716 \\
85.977 \\
85.238 \\
84.498 \\
83.759 \\
83.020 \\
82.281 \\
81.542\end{array}$ & $\begin{array}{l}88 \cdot 121 \\
87 \cdot 382 \\
86 \cdot 642 \\
85 \cdot 903 \\
85 \cdot 164 \\
84 \cdot 425 \\
83 \cdot 685 \\
82 \cdot 946 \\
82 \cdot 207 \\
81 \cdot 468\end{array}$ & $\begin{array}{l}88.047 \\
87.307 \\
86.568 \\
85.829 \\
85.090 \\
84.351 \\
83.611 \\
87.872 \\
82.133 \\
81.394\end{array}$ & $\begin{array}{l}87.973 \\
87.234 \\
86.494 \\
85.755 \\
85.016 \\
84.277 \\
83.538 \\
82.798 \\
82.059 \\
81.320\end{array}$ & $\begin{array}{l}87.899 \\
87 \cdot 160 \\
86.420 \\
85.681 \\
84 \cdot 942 \\
84 \cdot 203 \\
83.464 \\
82.724 \\
81.985 \\
81.246\end{array}$ & $\begin{array}{l}87.825 \\
87.086 \\
86.346 \\
85.607 \\
84.868 \\
84.129 \\
83.390 \\
82.650 \\
81.912 \\
81.172\end{array}$ & $\begin{array}{l}87.751 \\
87.012 \\
86.273 \\
85.533 \\
84.794 \\
84.055 \\
83.316 \\
82.577 \\
81.838 \\
81.098\end{array}$ & $\begin{array}{l}87.677 \\
86.938 \\
86.198 \\
85.459 \\
84.720 \\
83.981 \\
83.242 \\
82.502 \\
81.763 \\
81.024\end{array}$ & $\begin{array}{l}0.284744 \\
0.284743 \\
0.284743 \\
0.284742 \\
0.284741 \\
0.284741 \\
0.284740 \\
0.284739 \\
0.284739 \\
0.284738\end{array}$ & $\begin{array}{l}1.047004 \\
1.047030 \\
1.047056 \\
1.047082 \\
1.047108 \\
1.047134 \\
1.047160 \\
1.047186 \\
1.047211 \\
1.047237\end{array}$ \\
\hline $\begin{array}{r}3678.0 \\
8.1 \\
8.2 \\
8.3 \\
8.4 \\
8.5 \\
8.6 \\
8.7 \\
8.8 \\
8.9\end{array}$ & $\begin{array}{r}7180.951 \\
80.212 \\
79.473 \\
78.734 \\
77.995 \\
77.256 \\
76.517 \\
75.779 \\
75.040 \\
74.302\end{array}$ & $\begin{array}{l}80.877 \\
80.137 \\
79.399 \\
78.660 \\
77.921 \\
77.182 \\
76.443 \\
75.705 \\
74.966 \\
74.228\end{array}$ & $\begin{array}{l}80.803 \\
80.064 \\
79.325 \\
78.586 \\
77.847 \\
77.108 \\
76.370 \\
75.631 \\
74.892 \\
74.154\end{array}$ & $\begin{array}{l}80.729 \\
79.990 \\
79.251 \\
78.512 \\
77.773 \\
77.035 \\
76.296 \\
75.557 \\
74.819 \\
74.080\end{array}$ & $\begin{array}{l}80.655 \\
79.916 \\
79.177 \\
78.438 \\
77.699 \\
76.960 \\
76.222 \\
75.483 \\
74.745 \\
74.006\end{array}$ & $\begin{array}{l}80.581 \\
79.842 \\
79.103 \\
78.364 \\
77.625 \\
76.886 \\
76.148 \\
75.409 \\
74.671 \\
73.932\end{array}$ & $\begin{array}{l}80.507 \\
79.768 \\
79.029 \\
78.290 \\
77.552 \\
76.813 \\
76.074 \\
75.335 \\
74.597 \\
73.858\end{array}$ & $\begin{array}{l}80.433 \\
79.694 \\
78.955 \\
78.217 \\
77.478 \\
76.739 \\
76.000 \\
75.261 \\
74.523 \\
73.784\end{array}$ & $\begin{array}{l}80.359 \\
79.621 \\
78.882 \\
78.143 \\
77.404 \\
76.665 \\
75.926 \\
75.187 \\
74.449 \\
73.710\end{array}$ & $\begin{array}{l}79.547 \\
78.808 \\
78.069 \\
77.330 \\
76.591 \\
75.852 \\
75.114 \\
74.375 \\
73.637\end{array}$ & $\begin{array}{l}0.284737 \\
0.284736 \\
0.284736 \\
0.284735 \\
0.284734 \\
0.284734 \\
0.284733 \\
0.284732 \\
0.284731 \\
0.284731\end{array}$ & $\begin{array}{l}1.047263 \\
1.047289 \\
1.047315 \\
1.047341 \\
1.047367 \\
1.047392 \\
1.047418 \\
1.047444 \\
1.047470 \\
1.047495\end{array}$ \\
\hline $\begin{array}{r}79.0 \\
9.1 \\
9.2 \\
9.3 \\
9.4 \\
9.5 \\
9.6 \\
9.7 \\
9.8 \\
9.9\end{array}$ & $\begin{array}{r}173.563 \\
72.824 \\
72.086 \\
71.347 \\
70.609 \\
69.870 \\
69.132 \\
68.394 \\
67.655 \\
66.917\end{array}$ & $\begin{array}{l}73.489 \\
72.750 \\
72.012 \\
71.273 \\
70.535 \\
69.796 \\
69.058 \\
68.320 \\
67.582 \\
66.843\end{array}$ & $\begin{array}{l}73.415 \\
72.677 \\
71.938 \\
71.199 \\
70.461 \\
69.723 \\
68.984 \\
68.246 \\
67.508 \\
66.769\end{array}$ & $\begin{array}{l}73.342 \\
72.603 \\
71.864 \\
71.126 \\
70.387 \\
69.649 \\
68.910 \\
68.172 \\
67.434 \\
66.696\end{array}$ & $\begin{array}{l}73.268 \\
72.529 \\
71.790 \\
71.052 \\
70.313 \\
69.575 \\
68.836 \\
68.098 \\
67.360 \\
66.627\end{array}$ & $\begin{array}{l}73.193 \\
72.455 \\
71.717 \\
70.978 \\
70.240 \\
69.501 \\
68.763 \\
68.024 \\
67.286 \\
66.548\end{array}$ & $\begin{array}{l}72.381 \\
71.643 \\
70.904 \\
70.166 \\
69.427 \\
68.689 \\
67.951 \\
67.212 \\
66.474\end{array}$ & $\begin{array}{l}73.046 \\
72.307 \\
71.569 \\
70.830 \\
70.092 \\
69.354 \\
68.615 \\
67.877 \\
67.139 \\
66.400\end{array}$ & $\begin{array}{l}72.972 \\
72.233 \\
71.495 \\
70.756 \\
70.018 \\
69.280 \\
68.542 \\
67.803 \\
67.065 \\
66.326\end{array}$ & $\begin{array}{l}72.160 \\
71.421 \\
70.682 \\
69.944 \\
69.206 \\
68.468 \\
67.729 \\
66.991 \\
66.252\end{array}$ & $\begin{array}{l}0.284729 \\
0.284729 \\
0.284728 \\
0.284727 \\
0.284727 \\
0.284726 \\
0.284725 \\
0.284724 \\
0.284724\end{array}$ & $\begin{array}{l}1.047522 \\
1.047548 \\
1.047574 \\
1.047599 \\
1.047625 \\
1.047651 \\
1.047677 \\
1.047703 \\
1.0477729 \\
1.047755\end{array}$ \\
\hline
\end{tabular}
$.001 \quad .002$ 


.03

$\begin{array}{rrrrrrrrrrr}0.1 & 27166.179 & 66.105 & 66.031 & 65.957 & 65.884 & 65.810 & 65.736 & 65.662 & 65.588 & 65.515 \\ 0 & 65.441 & 65.367 & 65.293 & 65.219 & 65.145 & 65.072 & 64.998 & 64.924 & 64.850 & 64.776\end{array}$ $\begin{array}{lllllllllll} & 64.702 & 64 \cdot 629 & 64 \cdot 555 & 64 \cdot 481 & 64.407 & 64 \cdot 333 & 64 \cdot 260 & 64 \cdot 186 & 64 \cdot 112 & 64 \cdot 038\end{array}$ $\begin{array}{llllll}0.4 & 63.226 & 63.153 & 63.079 & 63.005 & 62.00\end{array}$
0.284719

0.284718

0.284717

0.284716

0.284715
0.284715

0.284714

0.284713
0.284712

0.284712

0.284711
0.284710

0.284710

0.284709

0.284708

0.284707

0.284706

0.284705

0.284704

0.284703
0.284703

0.284702

0.284701

0.284700

0.284699

0.284698
0.284698

0.284697

0.284696
0.284695

0.284695

0.284693

0.284693

0.284691

0.284691

0.284689
0.284688

0.284688

0.284686

0.284686

0.04684

0.284684

0.284683

0.284681

0.284681

0.284679

0.284679

0.284678

0.284677

0.284676

0.284674

0.284674

0.284673
0.284672
0.284672

0.284672

0.284671

0.284669

0.284669

0.284668
0.284667

0.284667

0.284666

0.284665
0.284665

0.284664

0.284663

0.284662

0.284661
0.284660

0.284660

0.284659

0.284658

0.284656
0.284655

0.284654
0.284653

.010
1.047781 1.047806 1.047858 1.047884
1.047920 1.047936 1.047962
1.047988 1.048013

1.048039 1.048065
1.048091 1.048117 1.048143 1.048195 .048220
.048246 1.048272

1.048298 1.048324 1.048376 1.048402 1.048453 1.048479 1.048531

1.048557 1.048583
1.048609 1.048634 1.048660 1.048686 1.048738 1.048764
1.048790

1.0488216 1.048841 1.048893 1.048919 1.048945 1.048997 1.049023

1.049074 1.049100 1.049152 1.049178 1.049230 1.049255 1.049281
1.049307 1.049333 1.049385 1.049411 1.049462 1.049488 1.049514 1.049540

1.049592 1.049618 1.049670 1.049695 1.049721 1.049773 1.049799 1.049851 1.049877 1.049928 1.049954 .050006 1.050032
1.050058 1.050109 1.050135
1.050161 1.050213 1.050239 1.050265 1.050317

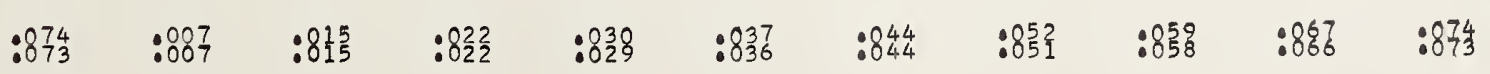


$\begin{array}{lllllllllll}3690.0 & 27092.560 & 92.486 & 92.413 & 92.340 & 92.266 & 92.193 & 92.119 & 92.046 & 91.972 & 91.899\end{array}$

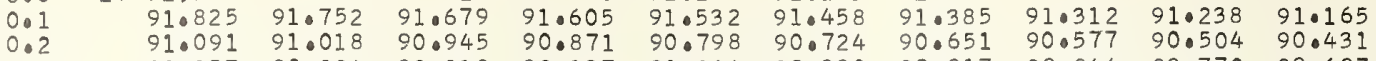
$\begin{array}{lllllllllll}0.3 & 90.357 & 90.284 & 90.210 & 90.137 & 90.064 & 89.990 & 89.917 & 89.844 & 89.770 & 89.697\end{array}$ $\begin{array}{lllllllllll}0.4 & 89.623 & 89.550 & 89.476 & 89.403 & 89.330 & 89.256 & 89.183 & 89.109 & 89.036 & 88.962 \\ 0.5 & 88.889 & 88.816 & 88.742 & 88.669 & 88.595 & 88.522 & 88.449 & 88.375 & 88.302 & 88.229\end{array}$ $\begin{array}{llllllllllll}0.6 & 88.155 & 88.082 & 88.009 & 87.935 & 87.861 & 87.788 & 87.715 & 87.641 & 87.568 & 87.495\end{array}$ $\begin{array}{lllllllllll}0.7 & 87.421 & 87.348 & 87.274 & 87.201 & 87.127 & 87.054 & 86.981 & 86.907 & 86.834 & 86.761 \\ 0.8 & 86.687 & 86.514 & 86.541 & 86.467 & 86.394 & 86.320 & 86.247 & 86.174 & 86.100 & 86.027\end{array}$ $\begin{array}{lllllllllll}0.8 & 86.687 & 86.614 & 86.541 & 86.467 & 86.394 & 86.320 & 86.247 & 86.174 & 86.100 & 86.027 \\ 0.9 & 85.954 & 85.880 & 85.807 & 85.733 & 85.660 & 85.586 & 85.513 & 85.440 & 85.366 & 85.293\end{array}$

$\begin{array}{ll}0.284653 & 1.050368 \\ 0.284652 & 1.050394 \\ 0.284651 & 1.050420 \\ 0.284651 & 1.050446 \\ 0.284650 & 1.050472 \\ 0.284649 & 1.050498 \\ 0.284648 & 1.050524 \\ 0.284648 & 1.050550 \\ 0.284647 & 1.050575 \\ 0.284646 & 1.050601 \\ 0.284646 & 1.050627 \\ 0.284645 & 1.050653 \\ 0.284644 & 1.050679 \\ 0.284644 & 1.050705 \\ 0.284643 & 1.050731 \\ 0.284642 & 1.050757 \\ 0.284641 & 1.050782 \\ 0.284641 & 1.050808 \\ 0.284640 & 1.050834 \\ 0.284639 & 1.050860\end{array}$

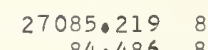




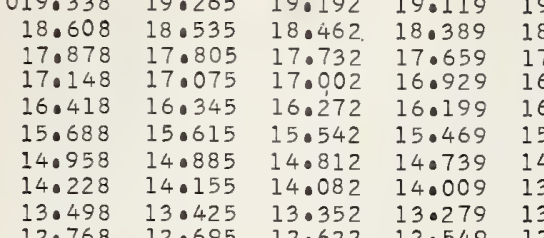

$\begin{array}{llllll}19.046 & 18.973 & 18.900 & 18.827 & 18.754 & 18.681\end{array}$ $\begin{array}{lllllllllll}0.2 & 17.878 & 17.805 & 17.732 & 17.659 & 17.586 & 17.513 & 17.440 & 17.367 & 17.294 & 17.221 \\ 0.3 & 17.148 & 17.075 & 17.002 & 16.929 & 16.856 & 16.783 & 16.710 & 16.637 & 16.564 & 16.491\end{array}$ $\begin{array}{lllllllllll}0.4 & 16.418 & 16.345 & 16.272 & 16.199 & 16.126 & 16.053 & 15.980 & 15.907 & 15.834 & 15.761\end{array}$ $\begin{array}{lllllllllll}0.5 & 15.688 & 15.615 & 15.542 & 15.469 & 15.396 & 15.323 & 15.250 & 15.177 & 15.104 & 15.031\end{array}$ $\begin{array}{lllllllllll}0.6 & 14.958 & 14.885 & 14.812 & 14.739 & 14.666 & 14.593 & 14.520 & 14.447 & 14.374 & 14.301 \\ 0.7 & 14.228 & 14.155 & 14.082 & 14.009 & 13.936 & 13.863 & 13.790 & 13.717 & 13.644 & 13.571\end{array}$ $\begin{array}{lllllllllll}0.8 & 13.498 & 13.425 & 13.352 & 13.279 & 13.206 & 13.133 & 13.060 & 12.987 & 12.914 & 12.841 \\ 0.9 & 12.768 & 12.695 & 12.622 & 12.549 & 12.476 & 12.403 & 12.330 & 12.257 & 12.184 & 12.111\end{array}$

$\begin{array}{llll}11.600 & 11.527 & 11.454 & 11.381\end{array}$ $\begin{array}{llllllllll}10.578 & 10.506 & 10.433 & 10.360 & 10.286 & 10.943 & 10.870 & 10.797 & 10.724 & 10.651\end{array}$

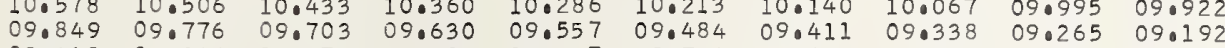
$\begin{array}{llllllllll}09.119 & 09.046 & 08.973 & 08.900 & 08.827 & 08.754 & 08.681 & 08.608 & 08.535 & 08.462\end{array}$ $\begin{array}{llllllllll}08.389 & 08.316 & 08.243 & 08.170 & 08.097 & 08.024 & 07.952 & 07.878 & 07.805 & 07.733\end{array}$ $\begin{array}{llllllllll}07.660 & 07.587 & 07.514 & 07.441 & 07.368 & 07.295 & 07.222 & 07.149 & 07.076 & 07.003 \\ 06.930 & 06.857 & 06.784 & 06.711 & 06.638 & 06.565 & 06.492 & 06.419 & 06.346 & 05.273\end{array}$ $\begin{array}{llllllllll}06.200 & 06.127 & 06.784 & 06.711 & 06.638 & 06.565 & 06.492 & 06.419 & 06.346 & 05.273 \\ 06.254 & 05.981 & 05.909 & 05.836 & 05.763 & 05.690 & 05.617 & 05.544\end{array}$

$04.887 \quad 04.814$

$$
\begin{array}{lllllllll}
02.408 & 02.335 & 02.262 & 02.189 & 02.116 & 02.043 & 01.970 & 01.897 \\
01.678 & 01.605 & 01.532 & 01.460 & 01.387 & 01.314 & 01.241 & 01.168 \\
00.949 & 00.876 & 00.803 & 00.730 & 00.657 & 00.584 & 00.511 & 00.439 \\
00.220 & 00.147 & 00.074 & 00.001 & 099.928 & * 99.855 & * 99.782 & * 99.709
\end{array}
$$$$
\begin{array}{llllllll}
01.678 & 01.605 & 01.532 & 01.460 & 01.387 & 01.314 & 01.241 & 01.168
\end{array}
$$$$
98.178
$$

98.835

3703.

3.
3.
3.
3.
3.0
3.7
3.0

3704

4.
4.
4.
4.
4.
4.
4.0
4.9

3705

5.0
5.
5.
5.
5.4
50
5.7
5
5 $\begin{array}{rrr}5.0 & 26982.876 & 82.8 \\ 5.1 & 82.148 & 82.0 \\ 5.2 & 81.419 & 81.347\end{array}$

5.2

5.4

5.5

5.6
5.7
5.8
5.9

96.720
95.991

95.262
94.533

$97 \cdot 376$

98.032

93.804

95.918

$92 \cdot 346$

91.618
90.889

93.731

$\begin{array}{ll}97.303 & 97.230\end{array}$

$\begin{array}{ll}96.574 & 96.501 \\ 95.845 & 95.77\end{array}$

$\begin{array}{ll}95.116 & 95.043 \\ 94.387 & 94.315\end{array}$

$93.658 \quad 93.586$

$\begin{array}{lll}.274 & 92.201 & 92.128\end{array}$

000.16

89.432
88.703
87.975

91.472

91.399

90.01

89.359
88.631

87.247

$87 \cdot 902$
$87 \cdot 174$

$88.558 \quad 89.21$

$88.558 \quad 88.484$
87.829
87.756

$\begin{array}{ll}86.101 & 87.02 \\ 86.372 & 86.299 \\ 85.644 & 85.571 \\ 8.616 & 0.573\end{array}$

$85.790 \quad 85.717$

$85.061 \quad 84.988$

84.333
83.604

85.644
84.916

85.571
84.843

98.616

99.27
98.543

*99.928 99.199

$9.854 * 99.782 * 99.709$

81.419

$70.691 \quad 80.61$

$79.963-79.890$

$79.235 \quad 79.162$

78.507

77.051
76.323

3706.

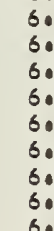

26975.595

74.867
74.139

75.522
74.79
94.067
73.39

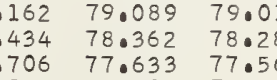

97.15

97.08

97.77107 .0120

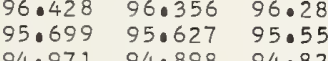

94.242

$94.169 \quad 94.096$

92.784

92.71

93.367

91.32

$9: 1.253$

91.909

$98.397 \quad 980324 \quad 98.251$

$96.939 \quad 960866 \quad 96.793$

$96.210 \quad 96.137 \quad 96.064$

$94.752 \quad 95.408 \quad 950335$

$94.023 \quad 93.950 \quad 930877$

92.056593022193 .148

9204939290419
91.764990691

91.83691 .764910691

$\begin{array}{llllllll}89.869 & 89.796 & 89.723 & 89.650 & 89.577 & 89.505\end{array}$

$\begin{array}{llllll}89.140 & 89.068 & 88.995 & 88.922 & 88.849 & 88.776\end{array}$

$\begin{array}{llllll}88.412 & 88.339 & 88.266 & 880193 & 88.120 & 88.047 \\ 87.683 & 87.610 & 87.537 & 87.065 & 87.392 & 87.319\end{array}$

$\begin{array}{lllllll}86.955 & 86.882 & 86.809 & 86.737 & 86.664 & 86.591 \\ 86.227 & 86.154 & 86.081 & 85000 & 85.935 & 85.863\end{array}$

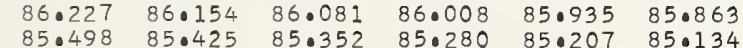

$\begin{array}{llllll}85.498 & 85.425 & 85.352 & 85 \cdot 280 & 850207 & 850134 \\ 84.070 & 84.697 & 84.624 & 84.0551 & 840478 & 84.406\end{array}$

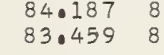

84.042
63.313

83.96
83.240

83.896
83.167

$\begin{array}{lll}83.823 & 83.750 & 83.677 \\ 83.094 & 83.022 & 82.949\end{array}$

\subsection{002}

$.058 \quad 82.58$

82.512

$\begin{array}{llll}82.439 & 82.366 & 82.293 & 82.221\end{array}$

$\begin{array}{llllllll}01.274 & 81.201 & 81.0128 & 81.056 & 80.983 & 80.910 & 810565 & 810.492 \\ 00.837 & 80.764\end{array}$

$\begin{array}{llllll}80.400 & 80.327 & 80.254 & 80.182 & 80 \cdot 109 & 80 \cdot 036 \\ 79.672 & 79.599 & 79.527 & 79.454 & 79 \cdot 381 & 79.308\end{array}$

$\begin{array}{lllllll}78.944 & 78.871 & 78.0298 & 78.0726 & 78 \cdot 653 & 78.580 \\ 78.216 & 78.143 & 78.070 & 770997 & 770925 & 77.5852\end{array}$

$78.216 \quad 78 \cdot 143$
77.488
77.415

$79.342 \quad 77.269 \quad 77 \cdot 197 \quad 77 \cdot 124$

$\begin{array}{lllllll}76.760 & 76.687 & 76.614 & 76.542 & 76.0469 & 76.396 \\ 76.032 & 75.959 & 75.886 & 75.813 & 75.0411 & 750668\end{array}$

0.284583

0.284582

0.284580

0.284580

0.284579

0.284577

0.284576

0.284575

0.284574

0.284573

0.284572

0.28457

0.284570
0.284570

0.284569

456

0.284567

.28456

0.284565
0.284564
0.28564

0.28456

0.284562

0.284561

0.284560

0.284559

0.284559

0.284557

0.284557

0.284556

0.284555

0.284555

0.284554
0.284553
0.28553

0.284553

0.284552
0.284551

0.284550

0.284550
0.284549

0.284548

0.284548

0.284546

0.284545

0.284544

0.284543
0.284542

0.284541

0.284541

0.284539

0.284539

0.284538

0.284537

0.284536

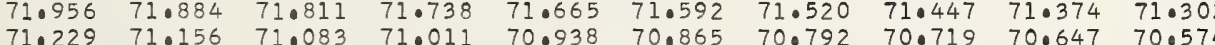

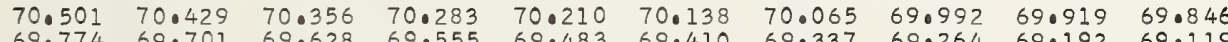

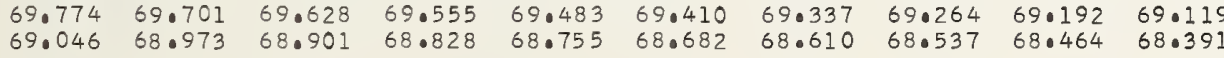

3707.0

26968.310

67.51968 .226

$66.864 \quad 66.791$

65.40066 .063

64.682

$63.954 \quad 63.888$

$63.227 \quad 63.155$

$\begin{array}{ll}62.500 & 62.427 \\ 61.773 & 61.700\end{array}$

68.173

68.101

68.02

67.95

$\begin{array}{lll}67.810 & 67.737 & 67.664 \\ 67.082 & 67.010 & 66.937\end{array}$

$\begin{array}{llllllll}66.718 & 66.646 & 66.573 & 56.500 & 66.427 & 66.354 & 66.282 & 66.209\end{array}$

$\begin{array}{llllllll}65.991 & 65.918 & 65.845 & 65.773 & 65.700 & 65.627 & 65.554 & 65.482\end{array}$

$\begin{array}{lllllllll}65.263 & 65.191 & 65.118 & 65.045 & 64.973 & 64.900 & 64 \cdot 827 & 64 \cdot 754 \\ 64.536 & 64.463 & 64.391 & 64.318 & 64.245 & 64.173 & 64.100 & 64.027\end{array}$

$\begin{array}{llll}64.536 & 64.463 & 64.391 & 64.318 \\ 63.809 & 63.736 & 63.663 & 63.591\end{array}$

63.80963 .736

63.591

$64 \cdot 245$

62.79

$63.445 \quad 63.373 \quad 63.300$

62.427
$61.700 \quad 62.35$
61.627

62.282

62.2092

61.409

61.336

61.99161 .918 61.845

0.284535

0.0284534

0.284532

0.284532

0.284530

0.284530

0.284529

$\begin{array}{lllllllllll}3708.0 & 26961.046 & 60.973 & 60.900 & 60.828 & 60.755 & 60.682 & 60.609 & 60.537 & 60.464 & 60.391\end{array}$ $\begin{array}{llllllllll}60.319 & 60.246 & 60.173 & 60.101 & 60.028 & 59.955 & 59.882 & 59.810 & 59.737 & 59.664 \\ 59.592 & 59.519 & 59.446 & 59.374 & 59.301 & 59.228 & 59.155 & 59.083 & 59.010 & 58.937\end{array}$ $\begin{array}{llllllllll}58.865 & 58.792 & 58.719 & 58.646 & 58.574 & 58.501 & 58.428 & 58.356 & 58.283 & 58.210\end{array}$ $\begin{array}{llllllllll}58.138 & 58.065 & 57.992 & 57.920 & 57.847 & 57.0774 & 57.702 & 57.629 & 57.556 & 57.483\end{array}$ $\begin{array}{llllllllll}57.411 & 57.338 & 57.265 & 57.193 & 57.120 & 57.047 & 56.975 & 56.902 & 56.829 & 56.756\end{array}$ $\begin{array}{llllllllll}56.684 & 56.611 & 56.538 & 56.466 & 56.393 & 56.320 & 56.248 & 56.175 & 56.103 & 56.030\end{array}$ $\begin{array}{lllllllllll}55.957 & 55.884 & 55.812 & 55.739 & 55.667 & 55.594 & 55.521 & 55.448 & 55.376 & 55.303\end{array}$

$\begin{array}{llllllllll}55.230 & 55.158 & 55.085 & 55.012 & 54.040 & 54.867 & 54.794 & 54.722 & 54.649 & 54.576 \\ 54.504 & 54.431 & 54.358 & 54.286 & 54.213 & 54.140 & 54.068 & 53.995 & 53.922 & 53.849\end{array}$

$\begin{array}{lrlllllllll}3709.0 & 26953.777 & 53.704 & 53.632 & 53.559 & 53.486 & 53.414 & 53.341 & 53.268 & 53.196 & 53.123\end{array}$

$\begin{array}{lllllllllll}9.1 & 53.050 & 52.978 & 52.905 & 52.832 & 52.760 & 52.687 & 52.614 & 52.542 & 52.469 & 52.396 \\ 9.2 & 52.324 & 52.251 & 52.178 & 52.105 & 52.033 & 51.960 & 51.888 & 51.815 & 51.742 & 51.670\end{array}$

$\begin{array}{lllllllllll}9.2 & 52.324 & 52.251 & 52.178 & 52.105 & 52.033 & 51.960 & 51.888 & 51.815 & 51.742 & 51.670 \\ 9.3 & 51.597 & 51.524 & 51.452 & 51.379 & 51.306 & 51.234 & 51.161 & 51.088 & 51.016 & 50.043\end{array}$

$\begin{array}{llllllllll}51.597 & 51.524 & 51.452 & 51.379 & 51.306 & 51.234 & 51.161 & 51.088 & 51.016 & 50.943 \\ 50.871 & 50.798 & 50.725 & 50.053 & 50.580 & 50.507 & 50.435 & 50.362 & 50.289 & 50.217\end{array}$

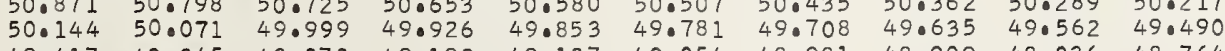

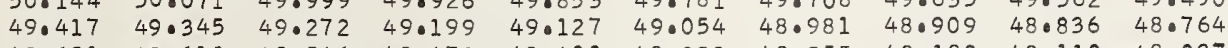

$\begin{array}{llllllllll}48.691 & 48.618 & 48.546 & 48.473 & 48.400 & 48.328 & 48.255 & 48.182 & 48.110 & 48.037\end{array}$

$\begin{array}{llllllllll}47.964 & 47.892 & 47.819 & 47.747 & 47.674 & 47.601 & 47.529 & 47.456 & 47.383 & 47 \cdot 311\end{array}$

0.284528

0.284527

0.284526

0.0284525

0.284524

0.284524

0.284522

0.284522

0.284521

0.284520

0.284519

0.284518

0.284517

0.284516

0.284516

0.284515

.010

052957

05298 


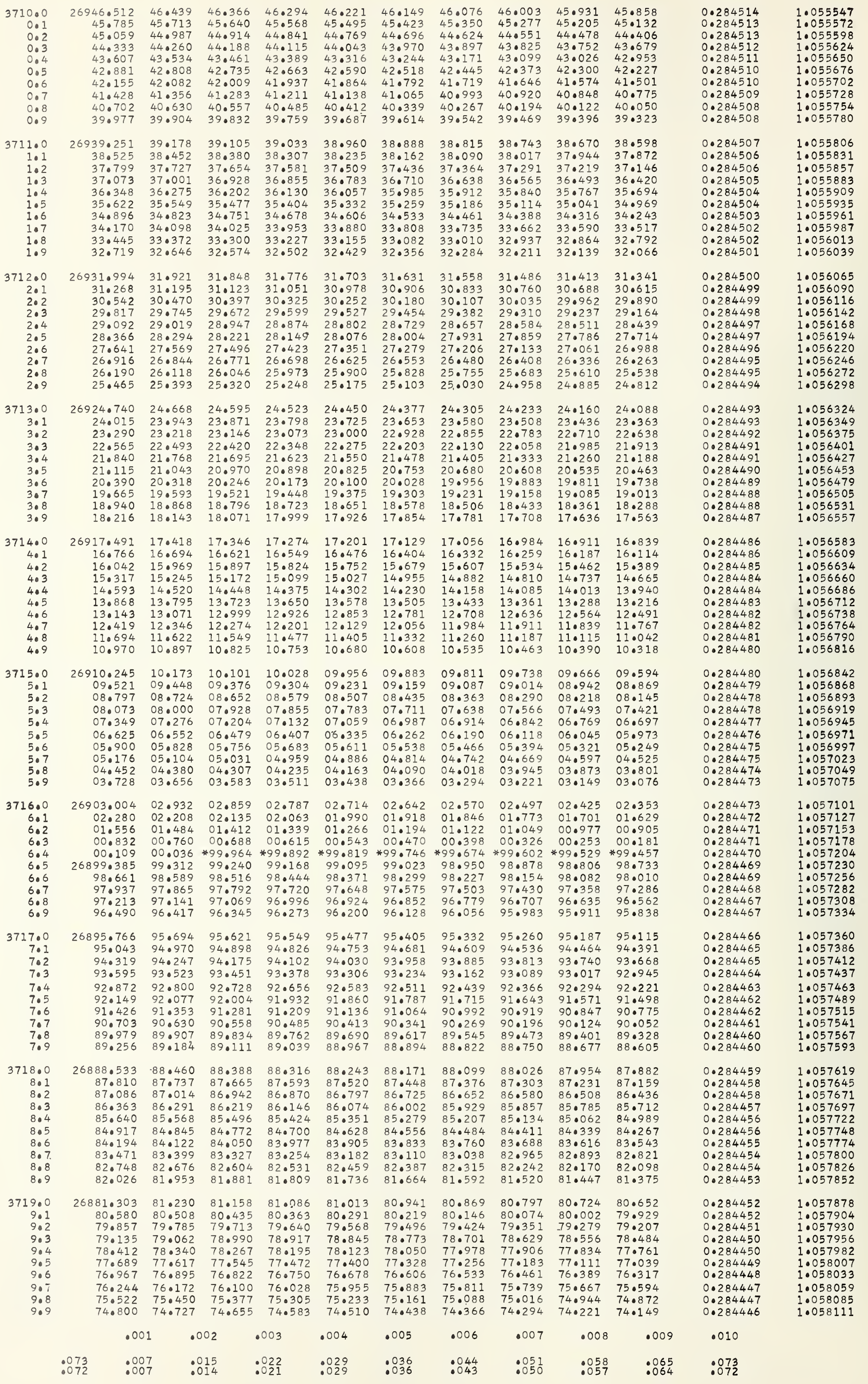


0.284398

0.284397
0.284397

0.284396

0.284395

0.284394

0.284393

0.284392

0.284391 0.284390

0.284389

0.284388

0.284388

0.284387
0.284386

0.284386

1.058344
1.058370

.058396
1.058422

1.058448
1.058474

1.058500

1.058552

1.058603

1.058655

1.058681

1.058733
1.058759

1.058785

1.058837

1.058862
1.058888

0.284384

0.284383

0.284382

0.284382
0.284381
0.284380

0.284380

0.284380

0.284379
0.284378

1.058914

1.058940

1.058992

1.059044

1.059096

1.059148

1.059173

1.059199

1.059251

1.059277

1.059329

1.059381

1.059433

1.059458

1.059510

1.059562

1.059588

1.059640

1.059692

1.059718

1.059769

1.059821

1.059873

1.059899
1.059925

1.059951

1.060003

1.060029

1.060080

1.060106
1.060132

1.060158
1.080184

1.050210

1.060236

1.060288

1.060340

1.060365

1.0080417

1.080469

1.060521

1.060547

1.060599

1.060625

1.060677

.010

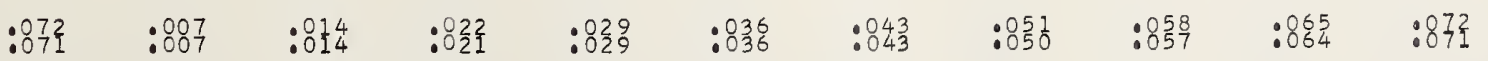


$\begin{array}{lllllllllll}3730.0 & 26802.030 & 01.958 & 01.886 & 01.815 & 01.743 & 01.671 & 01.599 & 01.527 & 01.455 & 01.383\end{array}$

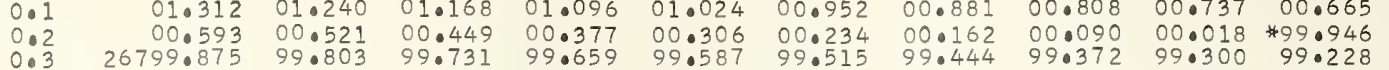

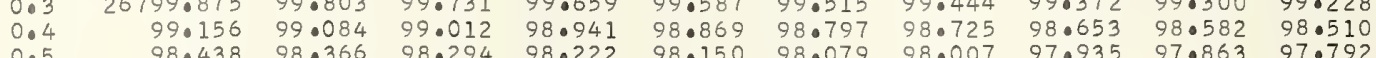

$\begin{array}{lllllllllll}0.5 & 98.438 & 98.366 & 98.294 & 98.222 & 98.150 & 98.079 & 98.007 & 97.935 & 97.863 & 97.792 \\ 0.6 & 97.720 & 97.648 & 97.576 & 97.504 & 97.432 & 97.361 & 97.289 & 97.217 & 97.146 & 97.073 \\ 0.7 & 97.001 & 96.930 & 96.858 & 96.786 & 96.714 & 96.643 & 96.571 & 96.499 & 96.427 & 96.355\end{array}$

$0.7 \quad 97.001 \quad 96.930$ 960

0.8
0.9

3731.
1
1
1
1.
1.7
1.7
1.9

$26794.847 \quad 940775$

$\begin{array}{ll}96.858 & 96.786 \\ 96.140 & 96.068\end{array}$

96.57

$\begin{array}{ll}96.283 & 96.211 \\ 95.565 & 95.493\end{array}$

1.1
1.2
1.3
1.4
1.5
1.6
1.7
1.8
1.9

26766.152

3736

6.1
6.2

6.0

$6 \cdot 4$

6.6

6.7

6.8

3737.0

7.02

7.3

7.5

7.7

7.9

738.0

8.1
8.2
8.23

8.3

8.5

8.6

$26758.988 \quad 58.916$

26751.827

26744.670

9.1
9.2
9.3

9.3

9.5

9.7
9.8

9.8
9.9

\section{$72.603 \quad 73 \cdot 24$}

$7710886 \quad 72.531$

70.45270 .380

$\begin{array}{lll}69.735 & 69.663\end{array}$

68.30168 .230

67.584
66.868

$\begin{array}{rr}766.152 & 66.080 \\ 650435 & 65.0363\end{array}$

64.00264 .647

$63.286 \quad 63.930 \quad 63.85$

$62.569 \quad 62.497$

$\begin{array}{llll}61.853 & 61.781 \quad 61.709\end{array}$

$\begin{array}{lll}61.136 & 61.065 & 60.993 \\ 60.420 & 60.348 & 60.277 \\ 59.704 & 59.632 & 59.56\end{array}$

$$
\begin{array}{ll}
58.271 & 58.199 \\
57.555 & 57.483 \\
56.839 & 56.767 \\
56.123 & 56.051 \\
55.407 & 55.335 \\
54.060 & 54.0619 \\
53.974 & 53.903 \\
53.259 & 53.187 \\
52.543 & 52.471
\end{array}
$$

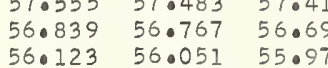

$\begin{array}{rl}51.827 & 51.755 \\ 50.111 & 51.039 \\ 50.395 & 50.323\end{array}$

40.00323

$48.964 \quad 48.892$
40.248

$\begin{array}{ll}48.248 & 48.17 \\ 47.533 & 47.4\end{array}$

$\begin{array}{ll}46 \cdot 817 & 46.74 \\ 46.102 & 46.03 \\ 45.386 & 45.31\end{array}$

$43.955 \quad 440590$

$\begin{array}{lll}43.240 & 43.883 & 43.8 \\ 42.52 & 43.097\end{array}$

$\begin{array}{llll}42.524 & 42.453 & 42.3 \\ 41.809 & 41.737 & 42.36\end{array}$

$41.094 \quad 41.022 \quad 40.056 \quad 41.054$

$\begin{array}{lllll}40.378 & 40.022 & 40.6550 & 40.879\end{array}$

$\begin{array}{lllllll}30.663 & 39.592 & 39.520 & 30.1648 & 40.092 & 40.021\end{array}$

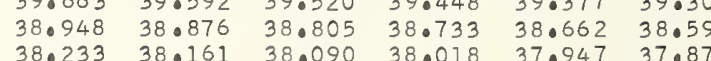

$26737.518 \quad 37.446 \quad 37.374 \quad 37.303$

$\begin{array}{llllll}.841 & 93.770 & 94.416 & 94.344 & 94.272 & 94.201 \\ & 93.698 & 93.626 & 93.554 & 93.482\end{array}$

$\begin{array}{llllll}23 & 93.052 & 92.980 & 92.908 & 92.836 & 92.764\end{array}$

$\begin{array}{llllll}.687 & 91.615 & 91.261 & 92.190 & 92.118 & 92.046\end{array}$

$\begin{array}{lllll}91.615 & 91.544 & 91.472 & 91.400 & 91.328 \\ 90.897 & 90.826 & 90.754 & 90.682 & 90.610\end{array}$

$\begin{array}{lllll}90.179 & 90.108 & 90.036 & 89.964 & 89.892\end{array}$

$\begin{array}{lllll}8.4462 & 89.390 & 89.318 & 89.246 & 89.175 \\ 88.744 & 88.672 & 88.600 & 88.528 & 88.457\end{array}$

$\begin{array}{llll}88.672 & 88.600 & 88.528 & 88.457 \\ 87.954 & 87.882 & 87.811 & 87.739\end{array}$

87.308
86.591

87.237

87.165

$87.093 \quad 87.021$

$\begin{array}{llllll}85.873 & 85.801 & 850729 & 85.058 & 85.586\end{array}$

$\begin{array}{llllll}85.155 & 85.083 & 85.012 & 84 \cdot 940 & 84.868\end{array}$

$\begin{array}{llll}85.083 & 85.012 & 84.940 & 84.868 \\ 84.366 & 84.0294 & 84.222 & 84.150\end{array}$

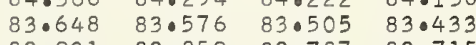

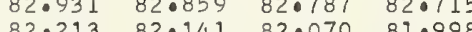

$\begin{array}{llll}82.213 & 82 \cdot 141 & 82.070 & 81.099\end{array}$

$\begin{array}{llll}81.0496 & 81.424 & 81.353 & 81.0281 \\ 80.779 & 80.0707 & 80.635 & 80.563\end{array}$

$\begin{array}{lllll}80.061 & 790990 & 79 \cdot 918 & 79 \cdot 846\end{array}$

$\begin{array}{llll}79.344 & 79.272 & 79 \cdot 2200 & 79.129 \\ 78.626 & 78.555 & 78.483 & 78.411\end{array}$

$\begin{array}{lllll}77.909 & 77.837 & 770766 \quad 770694\end{array}$

$\begin{array}{llll}77.192 & 77.120 & 77.048 & 76.977 \\ 76.403 & 76.331 & 76.260\end{array}$

$\begin{array}{lllll}75.758 & 75.686 & 75.614 & 75.542\end{array}$

$\begin{array}{lllll}75.041 & 74.969 & 74.897 & 74.0825\end{array}$

$\begin{array}{lllll}74.323 & 74.252 & 74 \cdot 180 & 74 \cdot 108 \\ 73.606 & 73.535 & 73.463 & 73.391\end{array}$

$74.46750 \quad 74.3978$
73.0678

$\begin{array}{lllll}72.889 & 72.818 & 72.746 & 72.674\end{array}$

$\begin{array}{llll}72.172 & 72.101 & 72.029 & 71.657 \\ 710.455 & 71.384 & 71.0312 & 71.240\end{array}$

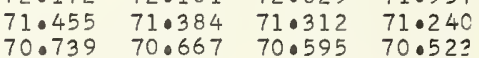

$\begin{array}{llll}70.022 & 69.0950 & 70.595 & 70.0522 \\ 69.878 & 69.807\end{array}$

$69.305 \quad 69 \cdot 233 \quad 69 \cdot 161 \quad 69.090$

$\begin{array}{llll}68.588 & 68.516 & 68.445 & 68.0773 \\ 67.871 & 67800 & 67.728 & 67.056\end{array}$

$\begin{array}{llll}67.155 & 67.083 & 67.011 & 66.0939\end{array}$

$\begin{array}{lllll}66.438 & 66.366 & 66.294 & 66.223\end{array}$

$\begin{array}{rrrr}05.722 & 65.650 & 65.578 & 65.507\end{array}$

$\begin{array}{llll}65.005 & 64.933 & 64.8862 & 64.0790\end{array}$

$\begin{array}{llll}64 \cdot 289 & 64 \cdot 217 & 64 \cdot 145 & 64 \cdot 073 \\ 63.572 & 63.500 & 63.429 & 63.357\end{array}$

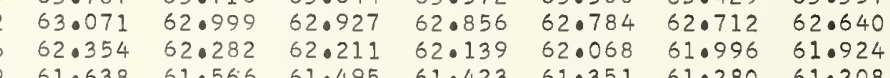

$\begin{array}{lllllll}61.6638 & 61.566 & 61.4995 & 61.423 & 61.0351 & 61.280 & 61.208\end{array}$

$60.707 \quad 60.63560 .563 \quad 60.492$

$\begin{array}{llll}59 \cdot 990 & 59 \cdot 919 & 59.847 & 59 \cdot 775 \\ 59 \cdot 274 & 59 \cdot 202 & 59 \cdot 131 & 59.059\end{array}$

$\begin{array}{llll}58.558 & 58.486 & 58.414 & 58.343 \\ 57.841 & 57.770 & 57.698 & 57.626 \\ 57.125 & 57.053 & 56.982 & 56.010\end{array}$

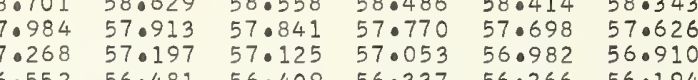

$\begin{array}{lllllll}0.552 & 56.481 & 56.409 & 56.337 & 56.266 & 56.194 \\ .0836 & 55.764 & 55.693 & 55.621 & 55.550 & 55.478\end{array}$

$\begin{array}{llllllllll}55.263 & 55.192 & 55.120 & 55.048 & 54.977 & 54.905 & 540833 & 54.762\end{array}$

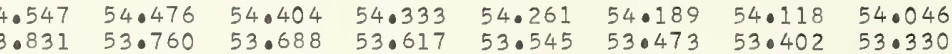

53.115
52.399
52.0328

52.025

52.901
52.185

$52.113 \quad 52.042 \quad 51.970 \quad 51.898$

$\begin{array}{llllllll} & 51.00\end{array}$

$\begin{array}{lllllllll}0.252 & 50.181 & 50.109 & 50.038 & 49.966 & 49.895 & 49.823 & 49.751\end{array}$

$\begin{array}{llllllll}9.537 & 49.465 & 49 \cdot 394 & 49 \cdot 322 & 49 \cdot 250 & 49 \cdot 179 & 49 \cdot 107 & 49 \cdot 035 \\ 8.821 & 48.749 & 48.678 & 48.606 & 48.535 & 48.463 & 480392 & 48.320\end{array}$

$\begin{array}{llllllll}48.105 & 48.034 & 47.962 & 47.890 & 47.819 & 47.747 & 47.676 & 47 \cdot 604 \\ 7.0390 & 47.318 & 47.246 & 47.175 & 47.103 & 470032 & 46.960 & 46.889\end{array}$

$46.388 \quad 46.316 \quad 46.245 \quad 46 \cdot 173$

$\begin{array}{llll}45.672 & 45.601 & 45.529 & 45.458 \\ 44.957 & 44.885 & 44.813 & 44.742\end{array}$

$\begin{array}{lll}450815 & 45.744 \\ 45.100 & 45.028\end{array}$

$44.384 \quad 440312$

$\begin{array}{llll}44.241 & 44.170 & 44.098 & 44.027\end{array}$

$42.810 \quad 42.739$
42.667 $\quad 42.596$

$42.095 \quad 42.023 \quad 41.952 \quad 41.880$

$40.665 \quad 40.593 \quad 40.521 \quad 41.165$

$\begin{array}{llll}39.949 & 39.878 & 39.0806 & 39.734\end{array}$

$\begin{array}{llll}39.949 & 39.878 & 39 \cdot 806 & 39.734 \\ 39.234 & 39.162 & 39.091 & 39.019\end{array}$

$\begin{array}{llllll}36.516 & 36.445 & 37.089 & 36.017 & 36.0446 & 36.874 \\ 36.0302 & 360.230 & 36.159\end{array}$

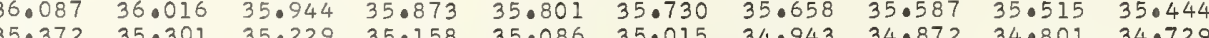

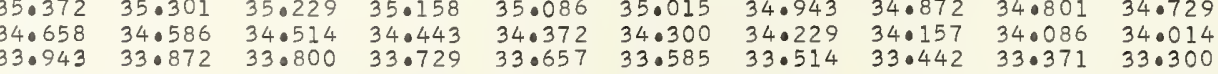

$\begin{array}{llllllllll}228 & 33.156 & 33.085 & 33.013 & 32.942 & 32.871 & 32.799 & 32.0728 & 32.656 & 32.585\end{array}$

$\begin{array}{lllllllll}32.370 & 32.299 & 32.227 & 32.156 & 32.084 & 32.013 & 31.041 & 31.870\end{array}$

$\begin{array}{llll}31.798 & 31.0727 & 31.656 & 31.584 \\ 31.084 & 31.012 & 30.941 & 30.869\end{array}$
.002

.003

30.798

0.284378

0.284377

0.284376

0.284375

0.284374

0.284373

0.284372

0.284371

0.284370

0.284369

0.284368

0.284367
0.284367

0.284366

0.284365

0.284365

0.284364

0.284363

0.284363

0.284361

0.284361

0.284360

0.284359

0.284358

0.284357

0.284357

0.284356

0.284355

0.284355
0.284354

0.284353

0.284353

0.284351

0.284351

0.284350

0.284349
0.284349

0.284348

0.284347

0.284347

0.284346

0.284345
0.284345

0.284344

0.284343

0.284343

0.284342

0.284341

0.284341
0.284340

0.284339

0.284338
0.284338

0.284337

0.284336

0.284335

0.284334

0.284334

0.284333

0.284332

0.284332
0.284331

0.284330

0.284330
0.284329

0.284329
0.284328

0.284328
0.284328

0.284327

0.284326

0.284326
0.284325

0.284325
0.284324

0.284324

0.284323

0.284322

0.284322

0.284321

0.284320

0.284319

0.284318
0.284318 
<smiles>[As]=[As]</smiles>

0.2
0.3

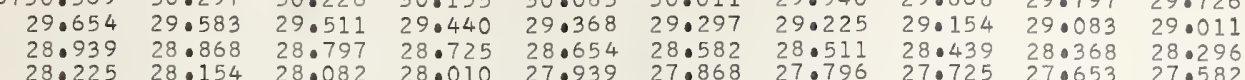

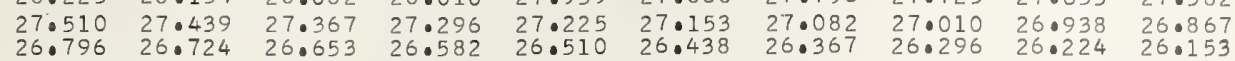

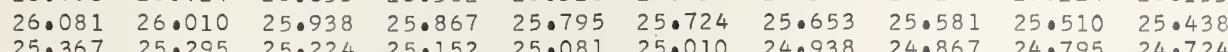
$\begin{array}{llllllllll}25.367 & 25 \cdot 295 & 25.224 & 25.152 & 25 \cdot 081 & 25 \cdot 010 & 24 \cdot 938 & 24 \cdot 867 & 24 \cdot 795 & 24.724 \\ 24.652 & 24.581 & 24.510 & 24.438 & 24.0367 & 24.295 & 24.224 & 24 \cdot 152 & 24.081 & 24.010 \\ 23.938 & 23.866 & 23.795 & 23.724 & 23.652 & 23.581 & 23.510 & 23 \cdot 438 & 23.366 & 23.295\end{array}$

0.284310

0.284309
0.284308

0.284308

284306

0.284305

0.284304

0.284303

0.284302

0.284301

0.284300

0.284298

0.284298

0.284297

0.284296

0.284294

0.284294

0.284292

0.284292

0.284290

0.284290
0.284289
0.2828

0.284288
0.284288

0.284287
0.284286

0.284286

0.284285

0.284284

0.284283

0.284282

0.284281

0.284280

0.284279

0.284278
0.284278

0.284277

0.284276

0.284275

0.284274

0.284273

0.284272

0.284270

0.284270
0.284269

0.284268

0.284268
0.284267

0.284266

0.284266
0.284265
0.0284264

0.284264

0.284264
0.284263

0.284262

0.284262

0.284260

0.284260

0.284259

0.284257

0.284256

0.284255

0.284254

0.284253

0.284252

0.284252

0.284250

0.284250

0.284248

0.284248

0.284247

0.284246

0.284245

0.284244 


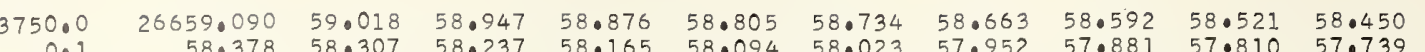

$\begin{array}{llllllllllll}0.1 & 58.378 & 58.307 & 58.237 & 58.165 & 58.094 & 58.023 & 57.952 & 57.881 & 57.810 & 57.739 \\ 0.2 & 57.668 & 57.597 & 57.526 & 57.454 & 57.383 & 57.312 & 57.241 & 57.170 & 57.099 & 57.028\end{array}$

$\begin{array}{llllllllllll}0.3 & 56.957 & 56.886 & 56.815 & 56.744 & 56.673 & 56.602 & 56.531 & 56.459 & 56.388 & 56.317\end{array}$

0.4

0.6

550176455.0450 .033

$54.825 \quad 54.753 \quad 54.683 \quad 54.612$

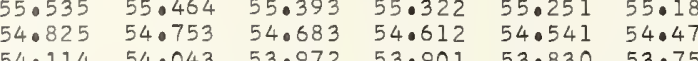

0.8

53.404
52.693

3751 .

10
10
10
10
100
107
10

3752.0

2
2
2
2
2
2
2
2

3753.

$3 \cdot 1$
3.2
3.3

3.3

3.4
3.5

3.7

3754

54.0
40.
4.2
4.3
4.4
4.5
40
4.7
4.8
4.9

. 26644.879 44.169
43.459

42.749

42.039

$41.329-41.258$

40.61940 .548

$\begin{array}{ll}39.199 & 39.128 \\ 38.490 & 38.419\end{array}$

26637.780

37.070
36.361
35.651

35.651
34.941

34.232

$32.812 \quad 32.742$

$\begin{array}{ll}32 \cdot 103 & 32.032 \\ 31.394 & 31.323\end{array}$

$26630.684 \quad 30.613$

29.975

$29.266 \quad 29.195$

$\begin{array}{ll}28.556 & 28.485 \\ 27.847 & 27.776\end{array}$

$\begin{array}{ll}27.138 & 27.067 \\ 26.428 & 26.358\end{array}$

$\begin{array}{ll}25.719 & 25.649 \\ 25.010 & 24.939 \\ 24.301 & 24.230\end{array}$

26623.592

22.8

$22.175 \quad 22.812$

$21.466 \quad 21.395$
20.757
20.086

$20.048 \quad 11.977$

19.33919 .268

$17.922 \quad 17.851$

26616.504

$\begin{array}{ll}16.504 & 16.433 \\ 15.796 & 15.725 \\ 15.087 & 15.016\end{array}$

$\begin{array}{ll}14.378 & 15.016\end{array}$

$13.670 \quad 13.599$

$12.962 \quad 12.891$

$\begin{array}{ll}12.253 & 12.182 \\ 11.545 & 11.474 \\ 10.836 & 10.766\end{array}$

$\begin{array}{ll}10.836 & 10.766 \\ 10.128 & 10.057\end{array}$

26609.420

$08.712 \quad 08.64$

$08.003 \quad 07.93$

$\begin{array}{ll}07.295 & 07.22 \\ 06.588 & 06.51\end{array}$

$05.879 \quad 05.809$

$04.463 \quad 04.393$

$03.755 \quad 03.68$

26602.339

$01.632 \quad 01.26$

$00.924 \quad 00.85$

$26599.508 \quad 99.437$

$98.801 \quad 98.72$

$\begin{array}{ll}98.093 & 98.02 \\ 97.385 & 97.31\end{array}$

$96.677 \quad 96.607$

$6595.262 \quad 95.192$

$94.555 \quad 94.484$

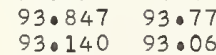

$92.433 \quad 92.362$

$91.725 \quad 91.655$

$90.311 \quad 90.240$

$\begin{array}{ll}89.604 & 89.533 \\ 88.897 & 88.826\end{array}$

$\begin{array}{ll}5.972 & 53.901 \\ 3.262 & 53.190\end{array}$

$\begin{array}{lllll}54.470 & 54.390 & 55.038 & 54.967 & 54.896\end{array}$

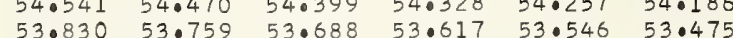

$53.120 \quad 53.04952 .077 \quad 52.006 \quad 52.835 \quad 52.764$

$52.551 \quad 52.480$

$\begin{array}{llll}51.840 & 51.770 & 51.698 & 51.627\end{array}$

$50.420 \quad 50.349$

$\begin{array}{ll}49.709 & 49.638 \\ 48.999 & 48.928\end{array}$

$\begin{array}{ll}48.288 & 48.218 \\ 47.578 & 47.507\end{array}$

47.578

46.157

46.797

50.98

$50.277 \quad 50.207$

$\begin{array}{ll}49.567 & 49.496 \\ 48.857 & 48.786\end{array}$

$\begin{array}{ll}48.146 & 48.075 \\ 47.436 & 47.365\end{array}$

$\begin{array}{ll}47.436 & 47.365 \\ 46.726 & 46.655\end{array}$

$\begin{array}{ll}46.726 & 46.655 \\ 46.016 & 45.945\end{array}$

$52 \cdot 977$
52.26

$52 \cdot 906$
$52 \cdot 196$

52.83
52.12

52.054

$44.737 \quad 44.666$

44.59

44.524

$\begin{array}{ll}51.556 & 51.485 \\ 50.846 & 50.775\end{array}$

$\begin{array}{ll}51.414 & 51.343 \\ 50.704 & 50.633\end{array}$

$50.135 \quad 50.064 \quad 49.993 \quad 49.922$

$\begin{array}{llll}49.425 & 49.354 & 49.283 & 49.212\end{array}$

$\begin{array}{llll}48.715 & 48.644 & 48.573 & 48.501\end{array}$

$\begin{array}{llll}48.004 & 47.933 & 47.862 & 47.791\end{array}$

$46.584-46.223$

47.081
46.371

$\begin{array}{lll}46.512 & 46.442 & 46.371\end{array}$

$\begin{array}{ll}45.874 & 45.803 \\ 45.164 & 45.093\end{array}$

45.02

$44 \cdot 950$

$43.317 \quad 43.246$

$\begin{array}{ll}42.607 & 42.53 \\ 41.897 & 41.82\end{array}$

$\begin{array}{ll}41.187 & 41.116 \\ 40.477 & 40.406\end{array}$

39.057

39.057
38.348

39.696
38.986

$\begin{array}{ll}43.885 & 43.814 \\ 43.175 & 43.10\end{array}$

42.465

$41.755 \quad 41.684$

40.335

38.

40.19

$\begin{array}{llllll}.625 & 39.554 & 39.483 & 39.412 & 39.341 & 39.270 \\ .916 & 38.844 & 38.774 & 38.703 & 38.632 & 38.561\end{array}$

44.382
43.672

42.962

41.542

40.122

$43.601 \quad 43.530$

$42.891 \quad 42.820$

$42.181 \quad 42.110$

$40.761 \quad 40.690$

$40.051 \quad 39.980$

38.206

38.135

38.064

37.993

$\begin{array}{ll}7.922 & 37.851\end{array}$

$37.638 \quad 37.567$

37.496
36.786

37.425

$\begin{array}{llll}37.354 & 37.283 & 37.212 & 37.141\end{array}$

$\begin{array}{llll}36.644 & 36.573 & 36.503 & 36.432 \\ 35.935 & 35.864 & 35.793 & 35.722\end{array}$

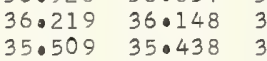

36.006

$\begin{array}{lllll}35.296 & 35.225 & 35.154 & 35.083 & 35.012 \\ 34.586 & 34.516 & 34.445 & 34.374 & 34.30\end{array}$

$\begin{array}{llllllll}34.799 & 34.729 & 34.657 & 34.586 & 34.516 & 34.445 & 34.374 & 34.302 \\ 34.090 & 34.019 & 33.948 & 33.877 & 33.806 & 33.735 & 33.654 & 33.593 \\ 33.380 & 33.309 & 33.238 & 33.167 & 33.096 & 33.025 & 32.955 & 32.884\end{array}$

$33.380 \quad 33.309$

$\begin{array}{lll}31.961 & 31.890 & 3 \\ 31.252 & 31.181\end{array}$

$32.529 \quad 32.45$

$\begin{array}{llll}32.387 & 32.316 & 32.245 & 32.174\end{array}$

$30.542-30.471$

30.400

31.039

$29.833 \quad 29.762$

$29.124 \quad 29.052 \quad 28.982$

30.32
29.620

30.968

$30.897 \quad 30.826 \quad 30.755$

$\begin{array}{lllllll}28.343 & 28.272 & 28.201 & 28.131 & 28.060 & 27.998 & 28.627 \\ 27.918\end{array}$

$\begin{array}{llllllll}27.705 & 27.634 & 27.563 & 27.492 & 27.421 & 27.351 & 27.280 & 27.208 \\ 26.996 & 26.925 & 26.854 & 26.783 & 26.712 & 26.641 & 26.570 & 26.500\end{array}$

$\begin{array}{llll}26.287 & 26.216 & 26.145 & 26.074\end{array}$

$\begin{array}{ll}24.868 & 24.79 \\ 24.159 & 24.08\end{array}$

24.727
24.01

25.36
24.65
23.94

$\begin{array}{llll}26.003 & 25.932 & 25.861 & 25.790 \\ 25.294 & 25.223 & 25.152 & 25.081\end{array}$

$\begin{array}{llll}24.585 & 24.514 & 24.443 & 24.337\end{array}$

$\begin{array}{ll}23.450 & 23.379 \\ 22.742 & 22.671\end{array}$

23.30

$23 \cdot 23$
22.52

.

$23.025 \quad 22.954$

$\begin{array}{llllllll}21.324 & 21.253 & 21.182 & 21.111 & 21.040 & 20.969 & 20.899 & 20.827\end{array}$

$\begin{array}{llllllll}20.615 & 20.544 & 20.473 & 20.402 & 20.332 & 20.261 & 20.190 & 20.119 \\ 19.906 & 19.835 & 19.764 & 19.693 & 19.623 & 19.552 & 19.481 & 19.410\end{array}$

$\begin{array}{llllllll}19.197 & 19.126 & 19.055 & 18.985 & 18.914 & 18.843 & 18.772 & 18.701\end{array}$

$\begin{array}{ll}18.489 & 18.418 \\ 17.780 & 17.709\end{array}$

$16.363-16.292$

$8.347 \quad 18.276$

$18.914 \quad 18.843 \quad 18 \cdot 772 \quad 18.701$

$\begin{array}{llll}17.496 & 17.426 & 17.0355 & 17.984 \\ 16.788 & 16.717 & 16.646 & 16.575\end{array}$

$\begin{array}{lllllll}16.292 & 16.221 & 16.150 & 16.079 & 16.008 & 15.937 & 15.867\end{array}$

$\begin{array}{llllllll}14.946 & 14.875 & 14.804 & 14.733 & 14.662 & 14.591 & 14.520 & 14.449\end{array}$

$\begin{array}{llllllll}14.237 & 14.166 & 14.095 & 14.024 & 13.953 & 13.883 & 13.812 & 13.741 \\ 13.528 & 13.458 & 13.387 & 13.316 & 13.245 & 13.174 & 13.103 & 13.032 \\ 12.820 & 12.749 & 12.678 & 12.507 & 12.537 & 12.466 & 12.395 & 12.324\end{array}$

$\begin{array}{llll}12.820 & 12.749 & 12.678 & 12.607\end{array}$

$12.112 \quad 12.041 \quad 11.970 \quad 11.899$

$\begin{array}{llll}12.537 & 12.466 & 12.395 & 12.324 \\ 11.828 & 11.757 & 11.686 & 11.615\end{array}$

$\begin{array}{ll}10.695 & 10.624 \\ 09.986 & 09.91\end{array}$

09.845

10.482
09.774

11.120

$\begin{array}{lll}11.757 & 11.686 & 11.615 \\ 11.049 & 10.978 & 10.907 \\ 10.341 . & 10.270 & 10.199\end{array}$

$\begin{array}{llllllll}09.278 & 09.207 & 09.136 & 09.065 & 08.995 & 08.924 & 08.853 & 08.782\end{array}$

$\begin{array}{llllllll}08.570 & 08.499 & 08.428 & 08.357 & 08.287 & 08.216 & 08.145 & 08.074\end{array}$

$\begin{array}{llllllll}07.862 & 07.791 & 07.720 & 07.649 & 07.578 & 07.508 & 07.437 & 07.366\end{array}$

$\begin{array}{llllllll}06.446 & 06.375 & 06.304 & 06.233 & 06.163 & 06.092 & 06.021 & 05.950\end{array}$

$\begin{array}{llllllll}05.738 & 05.667 & 05.596 & 05.525 & 05.455 & 05.384 & 05.313 & 05.242\end{array}$

$\begin{array}{llllllll}0.030 & 0.959 & 04.888 & 04.817 & 04.746 & 04.676 & 04.605 & 04.534\end{array}$

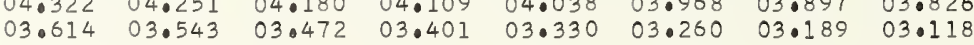

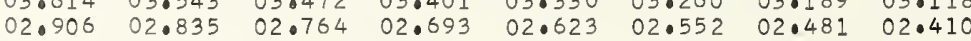

$\begin{array}{llllllll}02.198 & 02.127 & 02.056 & 01.985 & 01.915 & 01.844 & 01.773 & 01.702\end{array}$

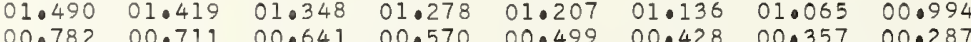

$00.074 \quad 00.003 * 09.033 * 0.062 * 9.00791 * 0.428 \quad 00.357 \quad 00.287$

$99.366 \quad 99.296 \quad 99.225 \quad 99.154 \quad 99.084 \quad 99.013 \quad 98.942 \quad 98.879$

$\begin{array}{llllllll}98.659 & 98.588 & 98.517 & 98.447 & 98.376 & 98.305 & 98.234 & 98.164\end{array}$

$97.244 \quad 97.173 \quad 97.10297 .03196 .96096 .890 \quad 96.81996 .748$

96.53597 .173

$\begin{array}{ll}73 & 9701 \\ 65 & 9603 \\ 58 & 9506\end{array}$

$\begin{array}{llllll}97.102 & 97.031 & 96.960 & 96.890 & 96.819 & 96.748 \\ 96.395 & 96.324 & 96.253 & 96.182 & 96.112 & 96.041\end{array}$

$\begin{array}{llllllll}95.121 & 95.050 & 94.979 & 94.908 & 94.838 & 94.767 & 94.696 & 94.626\end{array}$

$\begin{array}{llllllll}94.414 & 94.343 & 94.272 & 94.201 & 94.130 & 94.060 & 93.989 & 93.918\end{array}$

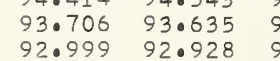

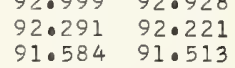

$90.877 \quad 90.806$

$\begin{array}{ll}90.170 & 90.099 \\ 89.463 & 89.392\end{array}$

93.56493 .494

92.786

$\begin{array}{ll}91.150 & 92.079 \\ 91.442 & 91.372\end{array}$

$\begin{array}{ll}90.736 & 90.66 \\ 90.028 & 89.958\end{array}$

$\begin{array}{llll}93.423 & 93.352 & 93.281 & 93.211 \\ 92.716 & 92.645 & 92.574 & 92.503\end{array}$

$\begin{array}{llll}92.008 & 91.937 & 91.867 & 91.796\end{array}$

$91.30191 .230 \quad 91.159 \quad 91.089$

$\begin{array}{llll}90.594 & 90.523 & 90.453 & 90.382\end{array}$

$89.179 \quad 89.816$

$89.745 \quad 89.675$

$89.038 \quad 88.967$

$\begin{array}{ll}89.321 & 89.250 \\ 88.614 & 88.543\end{array}$

.473

$.008 \quad .009$

0.284244

0.284243

0.284242

0.284241

0.284240

0.284240

0.284238

0.284237

.284236 
$\begin{array}{lllllllllll}3760.0 & 26588.190 & 88.119 & 88.048 & 87.978 & 87.907 & 87.836 & 87.765 & 87.695 & 87.624 & 87.553\end{array}$

$\begin{array}{llllllllllll}0.1 & 87.482 & 87.412 & 87.341 & 87.271 & 87.200 & 87.129 & 87.058 & 86.988 & 86.917 & 86.846 \\ 0.2 & 86.775 & 86.705 & 86.634 & 86.563 & 86.492 & 86.422 & 86.351 & 86.281 & 86.210 & 86.139\end{array}$ $\begin{array}{lllllllllll}0.3 & 86.068 & 85.998 & 85.927 & 86.563 & 86.492 & 86.422 & 86.351 & 86.281 & 86.210 & 86.139 \\ 0.4 & 85.361 & 85.291 & 85.220 & 85.149 & 85.786 & 85.715 & 85.644 & 85.574 & 85.503 & 85.432\end{array}$ $\begin{array}{lllllllllll}0.4 & 85.361 & 85.291 & 85.220 & 85.149 & 85.079 & 85.008 & 84.937 & 84.867 & 84.796 & 84.725 \\ 0.5 & 84.655 & 84.583 & 84.513 & 84.442 & 84.372 & 84.301 & 84.230 & 84.160 & 84.089 & 84.018\end{array}$ $\begin{array}{lllllllllll}0.6 & 83.948 & 83.877 & 83.806 & 83.735 & 83.665 & 83.594 & 83.523 & 83.453 & 83.382 & 83.311 \\ 0.7 & 83.241 & 83.170 & 83.099 & 83.028 & 82.958 & 82.887 & 82.816 & 82.746 & 82.675 & 82.604\end{array}$ $\begin{array}{lllllllllll}0.8 & 82.534 & 82.463 & 82.393 & 82.322 & 82.251 & 82.180 & 82.110 & 82.039 & 81.968 & 81.898 \\ 0.9 & 81.827 & 81.756 & 81.686 & 81.615 & 81.544 & 81.473 & 81.403 & 81.332 & 81.261 & 81.191\end{array}$

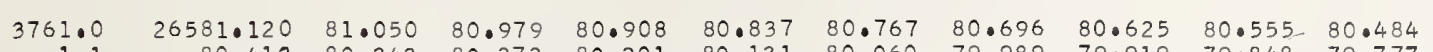

$\begin{array}{lllllllllll}1.1 & 80.413 & 80.343 & 80.272 & 80.201 & 80.131 & 80.060 & 79.989 & 79.919 & 79.848 & 79.777\end{array}$

$\begin{array}{lllllllllll}1.2 & 79.707 & 79.636 & 79.565 & 79.495 & 79.424 & 79.354 & 79.283 & 79.212 & 79.141 & 79.071 \\ 1.3 & 79.000 & 78.929 & 78.859 & 78.788 & 78.718 & 78.647 & 78.576 & 78.505 & 78.435 & 78.364\end{array}$

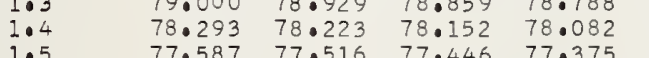

$\begin{array}{llll}77.587 & 77.516 & 77.446 & 77.375 \\ 76.880 & 76.810 & 76.739 & 76.668\end{array}$

$\begin{array}{llll}76.880 & 76.810 & 76.739 & 76.66 \\ 76.174 & 76.103 & 76.032 & 75.96\end{array}$

$\begin{array}{llll}75.467 & 75.397 & 75.326 & 75.255 \\ 74.761 & 74.691 & 74.620 & 74.550\end{array}$

$\begin{array}{llllll}78.011 & 77.940 & 77.870 & 77.799 & 77.728 & 77.657 \\ 77.304 & 77.234 & 77.163 & 77.092 & 77.021 & 76.951\end{array}$

$\begin{array}{llllll}77.304 & 77.234 & 77.163 & 77.092 & 77.021 & 76.951 \\ 76.598 & 76.527 & 76.457 & 76.386 & 76.315 & 76.244\end{array}$

1.7
1.8
$1 \bullet 9$

3762

2

$26574.055 \quad 73.98$

$\begin{array}{ll}73.348 & 73.27 \\ 72.642 & 72.57\end{array}$

$71.936 \quad 71.865$

$\begin{array}{ll}71.230 & 71.159 \\ 70.523 & 70.453\end{array}$

$73.914 \quad 73.843$

75.891

$75 \cdot 18$
$74 \cdot 47$

$69.676 \quad 69.60$

$68.405 \quad 58.334 \quad 68.264 \quad 68.193$

$73.772 \quad 73.702$

75.750
75.0

$75 \cdot 679$
74.973

$75 \cdot 609$

75.538
74.832

$\begin{array}{lllll}73.631 & 73.561 & 73.490 & 73.419\end{array}$

3763

63.
3.
3.
3.
3
3.
3.
3.
3.
3.

$\begin{array}{rrr}26566.993 & 66.922 & 66.85 \\ 66.287 & 66.216 & 66.146\end{array}$

$\begin{array}{ll}65.287 & 66.216 \\ 64.581 & 65.510\end{array}$

$\begin{array}{ll}64.875 & 64.804 \\ 64.169 & 64.099\end{array}$

$63.463 \quad 63.393$

$62.052 \quad 61.981 \quad 61.911$

61.01056 .840

$60.641 \quad 60.570$

3764

$\begin{array}{ll}59.864 & 59.79\end{array}$

4.2

$\begin{array}{llll}59.229 & 59.159 & 59.088 & 59.01 \\ 58.524 & 58.454 & 58.383 & 58.31\end{array}$

$\begin{array}{lll}57.818 & 57.748 & 57.67\end{array}$

$57.113 \quad 57.042$

56.407
55.70

$\begin{array}{lll}57.042 & 56.972 & 56.90 \\ 56.337 & 56.266 & 56.196\end{array}$

72.36

$71.053-71.583$

$70.241 \quad 70.170$

$\begin{array}{ll}69.535 & 69.464 \\ 68.829 & 68.758\end{array}$

72.925
72.219
71.512

70.806

$\begin{array}{lll}72.854 & 72.784 & 72.713 \\ 72.148 & 72.077 & 72.007 \\ 71.442 & 71.371 & 71.300\end{array}$

$\begin{array}{llll}68.687 & 69.323 & 69.252 & 69.182 \\ 68.617 & 68.546 & 68.476\end{array}$

$\begin{array}{rr}68.123 & 68.052 \\ 67.417 & 67.346\end{array}$

67.981
67.275

$68.546 \quad 68 \cdot 476$

$\begin{array}{lllllll}66.711 & 66.640 & 66.570 & 66.499 & 66.428 & 66.358\end{array}$

$\begin{array}{llll}55.702 & 55.631 & 55.561 & 55.49 \\ 54.997 & 54.926 & 54.856 & 54.78\end{array}$

$\begin{array}{llll}54.291 & 54.221 & 54.150 & 54.080 \\ 53.586 & 53.515 & 53.445 & 53.375\end{array}$

$\begin{array}{ll}66.005 & 65.934 \\ 65.299 & 65.228\end{array}$

$\begin{array}{ll}64.593 & 64.522 \\ 63.887 & 63.816\end{array}$

$\begin{array}{llll}65.864 & 65.793 & 65.722 & 65.652 \\ 65.157 & 65.087 & 65.016 & 64.946\end{array}$

$\begin{array}{llll}64.157 & 65.087 & 65.016 & 64.946 \\ 64.452 & 64.381 & 64.311 & 64.240\end{array}$

$\begin{array}{lllllll}63.181 & 63.110 & 63.040 & 62.969 & 62.899 & 62.828\end{array}$

$\begin{array}{llllll}62.475 & 62.405 & 62.334 & 62.263 & 62.193 & 62.123 \\ 61.770 & 61.699 & 61.628 & 61.558 & 61.487 & 61.417\end{array}$

$\begin{array}{llllll}61.064 & 60.993 & 60.923 & 60.852 & 60.781 & 60.711 \\ 60.358 & 60.288 & 60.217 & 60.146 & 60.076 & 60.005\end{array}$

0.284178

0.284177

0.284176

0.284174
0.284174

0.284173

0.284172

0.284171

0.284170

0.284168

0.284168
0.284167

0.284166

0.284166
0.284165

0.284164
0.284164
0.284163

0.284164
0.284163

0.284162

0.284161

0.284160
0.284160

0.284159
0.284158

1.068508

0.284158

0.284157

0.284157
0.284156

0.284155
0.284155

0.28415

0.284153
0.284153

0.284152

1.068585
1.068611

1.068663
1.068689

1.068715
.068741

0.284151

0.284151

0.284149

0.284149

0.284148

0.284147

0.284145

1.068767

.068819

1.068871

.068923

1.068975
1.069000

1.069026

1.069052
1.069078

1.069104
1.069130

1.069156

1.069208

1.069260

1.069286

1.069338

1.069364

1.069416

1.069442

1.069467
1.069493

1.069545

1.069571

1.069623

1.069649

$\begin{array}{llllll}56.831 & 56.760 & 56.3950 & 57.325 & 57.254 & 57.183 \\ 56.619 & 56.549 & 56.478\end{array}$

$\begin{array}{llllll}56.125 & 56.055 & 55.984 & 55.914 & 55.843 & 55.773 \\ 55.420 & 55.350 & 55.279 & 55.208 & 55.138 & 55.067 \\ 54.715 & 54.644 & 54.573 & 54.503 & 54.432 & 54.362\end{array}$

5.009
3.304

$\begin{array}{llll}55.279 & 55.208 & 55.138 & 55.067 \\ 54.573 & 54.503 & 54.432 & 54.362 \\ 53.868 & 53.798 & 53.727 & 53.656\end{array}$

$\begin{array}{lllllllllll}3765.0 & 26552.881 & 52.810 & 52.740 & 52.669 & 52.599 & 52.528 & 52.458 & 52.387 & 52.317 & 52.246\end{array}$

$\begin{array}{llllllllllll}5.1 & 52.175 & 52.105 & 52.034 & 51.964 & 51.893 & 51.823 & 51.752 & 51.682 & 51.612 & 51.541\end{array}$

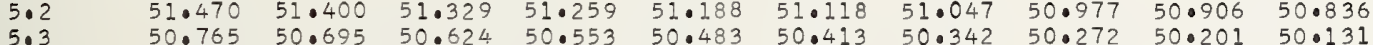

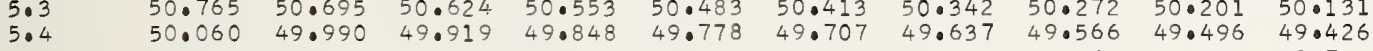

$\begin{array}{lllllllllll}5.5 & 49.355 & 49.284 & 49.214 & 49.143 & 49.073 & 49.002 & 48.932 & 48.861 & 48.791 & 48.720\end{array}$

$\begin{array}{lllllllllll}5.6 & 48.650 & 48.579 & 48.509 & 48.438 & 48.368 & 48.297 & 48.227 & 48.156 & 48.086 & 48.015\end{array}$

$\begin{array}{llllllllllll}5.7 & 47.945 & 47.875 & 47.804 & 47.733 & 47.663 & 47.592 & 47.522 & 47.451 & 47.381 & 47.310\end{array}$

5.9

$\begin{array}{llll}46.535 & 46.465 & 46.394 & 46.32\end{array}$

$\begin{array}{lllllllllll}3766.0 & 26545.830 & 45.760 & 45.689 & 45.619 & 45.548 & 45.478 & 45.407 & 45.337 & 45.266 & 45.196\end{array}$

$\begin{array}{lllllllllll}6.1 & 45.125 & 45.055 & 44.984 & 44.914 & 44.843 & 44.773 & 44.702 & 44.632 & 44.561 & 44.491\end{array}$

$\begin{array}{lllllllllll}6.2 & 44.420 & 44.350 & 44.280 & 44.209 & 44.139 & 44.068 & 43.998 & 43.927 & 43.856 & 43.786\end{array}$

6.3

$43.715 \quad 43.645 \quad 43.575 \quad 43.504$

$43.011 \quad 42.940 \quad 42.870 \quad 42.800$

$\begin{array}{lllll}42.659 & 42.589 & 42.518 & 42.447 & 42.377\end{array}$

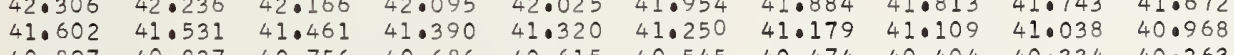

$\begin{array}{llllllllll}40.897 & 40.827 & 40.756 & 40.686 & 40.615 & 40.545 & 40.474 & 40.404 & 40.334 & 40.263\end{array}$

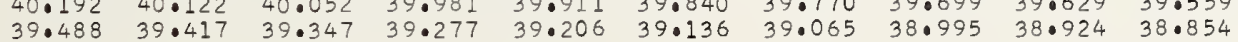

0.284145

0.28414

0.284143

0.28414

0.284141

0.284140

0.284139

0.284138

0.284137

0.284137

0.284136

0.284135

0.284134

0.284132

6.8
6.9

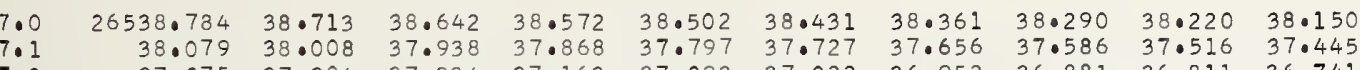

3767.

$\begin{array}{llllllllllll}7.2 & 37.375 & 37.304 & 37.234 & 37.163 & 37.093 & 37.022 & 36.952 & 36.881 & 36.811 & 36.741\end{array}$

$\begin{array}{lllllllllll}7.3 & 36.670 & 36.600 & 36.529 & 36.459 & 36.388 & 36.318 & 36.247 & 36.177 & 36.107 & 36.036\end{array}$

$\begin{array}{lllllllllll}7.3 & 36.670 & 36.600 & 36.529 & 36.459 & 36.388 & 36.318 & 36.247 & 36.177 & 36.107 & 36.036 \\ 7.4 & 35.966 & 35.896 & 35.825 & 35.755 & 35.684 & 35.614 & 35.543 & 35.473 & 35.402 & 35.332 \\ 7.5 & 35.26 & 35.191 & 35.121 & 35.050 & 34.979 & 34.909 & 34.839 & 34.768 & 34.698 & 34.628\end{array}$

$\begin{array}{llll}35 \cdot 261 & 35 \cdot 191 & 35.121 & 35 \cdot 05 \\ 34.557 & 34.487 & 34.417 & 34.346\end{array}$

7.7
7.8
7.9

$33 \cdot 148 \quad 33 \cdot 078$

$33.712 \quad 33.642 \quad 33.571$

$\begin{array}{llllll}34.205 & 34.135 & 34.064 & 33.994 & 33.923 \\ 33.501 & 33.430 & 33.360 & 33.290 & 33.219\end{array}$

0.284132

0.284131

0.284130

0.284129

0.284128

0.284128

0.284127
0.284126

0.284126

$\begin{array}{lllllllllll}3768.0 & 26531.740 & 31.670 & 31.599 & 31.529 & 31.459 & 31.388 & 31.318 & 31.248 & 31.177 & 31.107\end{array}$ $\begin{array}{lllllllllll}31.036 & 30.966 & 30.896 & 30.825 & 30.754 & 30.684 & 30.614 & 30.543 & 30.473 & 30.402 \\ 30.332 & 30.262 & 30.191 & 30.121 & 30.051 & 29.980 & 29.910 & 29.839 & 29.769 & 29.698\end{array}$ $\begin{array}{llllllllll}30.332 & 30.262 & 30.191 & 30.121 & 30.051 & 29.980 & 29.910 & 29.839 & 29.769 & 29.698 \\ 29.628 & 29.558 & 29.487 & 29.417 & 29.346 & 29.276 & 29.206 & 29.135 & 29.065 & 28.994\end{array}$

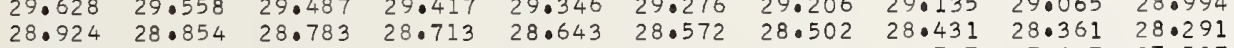
$\begin{array}{llllllllll}28.924 & 28.854 & 28.783 & 28.713 & 28.643 & 28.572 & 28.502 & 28.431 & 28.361 & 28.291 \\ 28.220 & 28.150 & 28.079 & 28.009 & 27.938 & 27.868 & 27.798 & 27.727 & 27.657 & 27.587\end{array}$ $\begin{array}{llllllllll}28.220 & 28.150 & 28.079 & 28.009 & 27.938 & 27.868 & 27.798 & 27.727 & 27.657 & 27.587 \\ 27.516 & 27.446 & 27.375 & 27.305 & 27.234 & 27.164 & 27.094 & 27.023 & 26.953 & 26.883\end{array}$ $\begin{array}{llllllllll}27.516 & 27.446 & 27.375 & 27.305 & 27.234 & 27.164 & 27.094 & 27.023 & 26.953 & 26.883 \\ 26.812 & 26.742 & 26.672 & 26.601 & 26.531 & 26.461 & 26.390 & 26.320 & 26.250 & 26.179\end{array}$

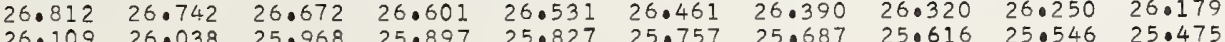
$\begin{array}{llllllllll}26.109 & 26.038 & 25.968 & 25.897 & 25.827 & 25.757 & 25.687 & 25 \cdot 616 & 25.546 & 25 \cdot 475 \\ 25.405 & 25.335 & 25.264 & 25.194 & 25.124 & 25.053 & 24.983 & 24.912 & 24.842 & 24.772\end{array}$

0.284125

0.28412

0.284123

0.284122

0.284122

0.28412

0.284121
0.284120

0.284119

1.069675

1.069727

..069779

1.069805

1.069831

1.069883

1.069909

1.069986

1.070012

1.070064

1.070116

.

1.070194

1.070226

10.070272

1.070324

1.070376

1.070402

1.070454

1.070479

1.070531

1.070583

1.070609

1.070661

1.070713

10070739

1.070791

0.284119

0.284118

0.284117
0.284117

0.284116

0.284115

0.28411

0.284113

1.070843

1.070895

1.070921

1.070973

$\begin{array}{llllllllll}21.886 & 21.816 & 21.746 & 21.676 & 21.605 & 21.535 & 21.464 & 21.394 & 21.323 & 21.253 \\ 21.183 & 21.113 & 21.042 & 20.972 & 20.902 & 20.831 & 20.761 & 20.690 & 20.620 & 20.550\end{array}$

$\begin{array}{llllllllll}20.479 & 20.409 & 20.339 & 20.268 & 20.198 & 20.128 & 20.057 & 19.987 & 19.917 & 19.846\end{array}$

$\begin{array}{llllllllll}19.776 & 19.706 & 19.635 & 19.565 & 19.495 & 19.424 & 19.354 & 19.283 & 19.213 & 19.143 \\ 19.072 & 19.002 & 18.932 & 18.861 & 18.791 & 18.721 & 18.650 & 18.580 & 18.510 & 18.439\end{array}$

1.071024

1.071050

.010

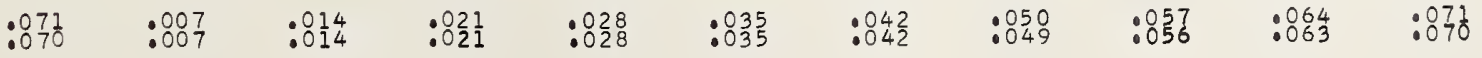




.02

.06

3770.

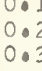

0.5
0.6

0.7

3771.

3774
40
4.
4.
4.
4.
4.0
4.7
4.
4.9
3775.0
5.1
5.
5.3
5.4
5.5
5
5
5
5

$$
\begin{array}{r}
3776 . \\
6 . \\
6 \\
6 . \\
6 . \\
6 . \\
6 . \\
6 . \\
6 .
\end{array}
$$

$$
\begin{array}{r}
777 . \\
7 \\
7 \\
7 \\
7 \\
7 \\
7 \\
7 \\
7 \\
7
\end{array}
$$

9.1
9.2
9.3
9.4
9.5
9.6
9.7
9.8
9.9

$\begin{array}{rr}6517.666 & 17.595 \\ 16.962 & 16.89 \\ 16.250 & 16.188\end{array}$

$\begin{array}{ll}16.259 & 16.1 \\ 15.555 & 15.4 \\ 14.852 & 14.7\end{array}$

$14.149 \quad 14.079$

$13.446 \quad 13.375$

$\begin{array}{ll}12.743 & 12.673 \\ 12.040 & 11.969 \\ 11.337 & 11.266\end{array}$

09.931
09.228

$\begin{array}{ll}09.228 & 09.8 \\ 0.251\end{array}$

$\begin{array}{ll}08.525 & 09.158 \\ 07.822 & 07.755\end{array}$

$\begin{array}{ll}07.822 & 07.752 \\ 07.119 & 07.049 \\ 06.417 & 06.346\end{array}$

$\begin{array}{ll}05.714 & 05.644 \\ 05.011 & 04.941 \\ 04.308 & 04.238\end{array}$

$26503.606 \quad 03.535$ 02.903

$02.200 \quad 02.1$

00.79

26499.39
98.68 97.986

26496.581

95.87995 .808

$\begin{array}{ll}95.177 & 95 \cdot 106 \\ 94.475 & 94.4 \\ 93.773 & 93.702\end{array}$

$93.071 \quad 93.000$

$91.667 \quad 91.596$

90.26390 .192

$\begin{array}{rr}489.561 & 89.490 \\ 88.859 & 88.789\end{array}$

$\begin{array}{lll}88.859 & 88.789 & 88.71\end{array}$

$87.455 \quad 87.385$

$86.683-87.315$

$85.350 \quad 85.280$

$83.947 \quad 83.876 \quad 83.508$

$6482 \cdot 54$

$81.842-810473$

$\begin{array}{lll}81.842 & 81.772 & 81.702 \\ 81.141 & 81.071 & 81.0 \\ 80.439 & 80.369 & 80.2\end{array}$

$\begin{array}{lllll}80.439 & 80.369 & 81.000 & 81.0 .932 \\ 79.799 & 80.229\end{array}$

$\begin{array}{llll}79.036 & 78.668 & 79.597 & 79.5 \\ 78.966 & 78.896 & 78.826\end{array}$

$\begin{array}{llll}78.896 & 78.826 & 78.756 & 78.6\end{array}$

$\begin{array}{llllll}77.634 & 77.265 & 78.195 & 78.125 & 78.055 & 77.985\end{array}$

76.93376 .863

26475.531

74.82975 .460

74.128
73.427 7.05

$73.357 \quad 73.287$

72.58672 .516

$\begin{array}{llll}71.324 & 71.254 & 71.184 & 71.114 \\ 70.624 & 70.553 & 70.483 & 70.413\end{array}$

$\begin{array}{rlll}69.923 & 69.853 & 69.783 & 70.413 \\ 69.222 & 69.152 & 60.082 & 69.712\end{array}$

$26468.521 \quad 68 \cdot 451 \quad 68.381 \quad 68 \cdot 31$

$67.820 \quad 67.750 \quad 67.680 \quad 67.610$

$\begin{array}{llll}67.119 & 67.050 & 66.979 & 66.909 \\ 66.419 & 66.349 & 66.279 & 66.208\end{array}$

$\begin{array}{llll}65.718 & 65.648 & 65.578 & 65.508 \\ 65.017 & 64.947 & 64.877 & 64.807\end{array}$

$\begin{array}{llll}64.317 & 64.247 & 64.177 & 64.107 \\ 63.616 & 63.546 & 63.476 & 63.406\end{array}$

$\begin{array}{llll}62.916 & 62.846 & 62.776 & 62.706 \\ 62.216 & 62.146 & 62.076 & 62.006\end{array}$

62.146

60.8

$\begin{array}{llll}60.815 & 60.745 & 60.675 & 60.6 \\ 60.115 & 60.045 & 59.974 & 59.904 \\ 59.414 & 59.344 & 59.274 & 59.204\end{array}$

$\begin{array}{llll}58.714 & 59.344 & 59.274 & 59.204 \\ 58.014 & 57.944 & 58.574 & 58.504 \\ 57.874 & 57.804\end{array}$

$\begin{array}{llll}57.313 & 57.243 & 57.174 & 57.103 \\ 56.613 & 56.543 & 56.473 & 56.403\end{array}$

$\begin{array}{llll}56.613 & 56.543 & 56.473 & 56.403 \\ 55.913 & 55.843 & 55.773 & 55.703 \\ 55.213 & 55.143 & 55.073 & 55.003\end{array}$

$6454.513 \quad 54.443 \quad 54.373 \quad 54 \cdot 30$

$\begin{array}{llll}53.813 & 53.743 & 53.673 & 53.603 \\ 53.113 & 53.043 & 52.973 & 52.003\end{array}$

$\begin{array}{llll}52.413 & 52.343 & 52.273 & 52.20 \\ 51.713 & 51.643 & 51.573 & 51.503\end{array}$

$\begin{array}{llll}51.013 & 50.943 & 50.873 & 50.803 \\ 50.313 & 50.243 & 50.174 & 50.104\end{array}$

$\begin{array}{llll}49.614 & 49.544 & 49.474 & 49.404\end{array}$

$\begin{array}{llll}48.914 & 48.844 & 48.774 & 48.704 \\ 48.214 & 48.144 & 48.074 & 48.004\end{array}$

$4.214 \quad 48.144 \quad 48.074 \quad 48.00$

$\begin{array}{ccc}.07 & .08 & .09 \\ 17.173 & 17.103 & 17.033 \\ 16.470 & 16.400 & 16.329 \\ 15.766 & 15.696 & 15.626 \\ 15.063 & 14.993 & 14.923 \\ 14.360 & 14.290 & 14.219 \\ 13.657 & 13.586 & 13.516 \\ 12.954 & 12.883 & 12.813 \\ 12.250 & 12.180 & 12.110 \\ 11.547 & 11.477 & 11.407 \\ 10.844 & 10.774 & 10.704\end{array}$

20082

$(n-1) \times 1000$

$\lambda(n-1)$

0.284112

1.071102

$.284111 \quad 1.071154$

$0.284109 \quad 1.07180$

$0.284109 \quad 1.071232$

284108

.284107

0.284107
0.284106

0.284105

0.284105

0.284104
0.284104

0.284103

0.284102

0.284102

0.284101

0.284100
0.284100

0.284099

0.284098

0.284098

0.284096

0.284096

0.284095

0.284094

0.284093

1.071258

1.071284

1.071310
1.071336

1.071362

1.071388

1.071440

1.071466
1.071492

1.071518

1.071543

1.071569

1.071621

1.071647

1.071699

1.071725

1.071751

1.071803

1.071829

0.284092

0.284092

0.284091

0.284090

0.284089

0.284089

0.284088

0.284087

0.284086

0.284085

0.284084

0.284083

0.284083

0.284081

0.284081

0.284079

0.284079
0.284079

0.284078

0.284078
0.284077
0.284076

0.284077

0.284076

0.284076

0.284074

0.284074

0.284073

0.284072

0.284072

0.284071

0.284070

0.284070

0.284069
0.284068

0.284068

0.284067

0.284066

0.284066
0.284065

0.284065

0.284064

0.284063

0.284063
0.284062

0.284061

0.284061

0.284060

0.284059
0.284059

0.284058

0.284057

0.284057

0.284056

0.284055

0.284055
0.284054

.071881

1.071907

1.071933

1.071985

1.072011
1.072037

1.072063

1.072089

1.072089

1.072140

1.072166
1.072192

.072192
1.072218

1.072244
1.072270

1.072270
1.072296

1.072322

1.072348

1.072400

1.072426

1.072452
1.072478

1.072478

1.072504

1.072556

1.072582

1.072608

1.072660

1.072685

1.072711

1.072763

1.072815

1.072841

1.072867
1.072893

1.072919

I. 072945

1.072971

1.073023

1.073049

1.073075

1.073127

1.073179

1.073205

1.073231

1.073257
1.073283

1.073308

1.073334

1.073360

1.073386
1.073412

0.284054

0.284053

1.073438

0.284052

0.284051

0.284050

0.284050

0.284049

0.284048

.073464
.073490

1.073516

1.073542

1.073568
1.073594

1.073620

1.073646
1.073672

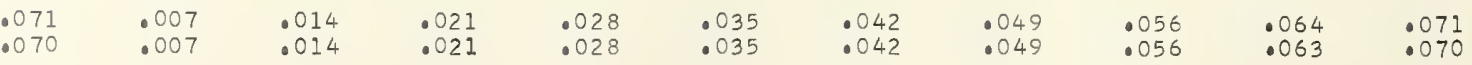


3780.
0
0
0
0
0
0
0
0
0
0
3781
$1:$
1
$1:$
1
1
1
1
1
1
1
1

$\begin{array}{rr}3782.0 & 26433 \\ 2.1 & \\ 2.2 & \\ 2.3 & \\ 2.4 & \\ 2.5 & \\ 2.6 & \\ 2.7 & \\ 2.8 & \\ 2.9 & \end{array}$

3783.

3.1
3.2
3.3

3.3
3.4
3.5

3.4
3.5
3.6

3.0
3.0
3.0

3.8
3.9

3784.0

4.1
4.2
4.3
$4:$
40
40
4.7
4.9

3785.0

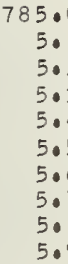

3786.0

$786 \cdot 0$
$6 \cdot 1$
$6 \cdot 2$
$6 \cdot 3$
$6 \cdot 4$
$6 \cdot 5$
$6 \cdot 5$
$6: 7$
6.8
$6 \cdot 9$

3787

787
7
7.0
7
7.04
7
7
7
7
7
7

3788.0

$$
\begin{array}{r}
3788 . \\
8 \\
8 \\
8 \\
8 \\
8 \\
8 \\
8 \\
8 \\
8.0 \\
8.9
\end{array}
$$

3789 $\begin{array}{rlll}26447.515 & 47.445 & 47.375 & 47.305 \\ 46.815 & 46.745 & 46.675 & 46.605 \\ 46.116 & 46.046 & 45.976 & 45.906 \\ 45.416 & 45.346 & 45.276 & 45.206 \\ 44.717 & 44.647 & 44.577 & 44.507 \\ 44.017 & 43.947 & 43.877 & 43.807 \\ 43.318 & 43.248 & 43.178 & 43.108 \\ 42.618 & 42.548 & 42.478 & 42.408 \\ 41.919 & 41.849 & 41.779 & 41.709 \\ 41.219 & 41.149 & 41.079 & 41.010\end{array}$

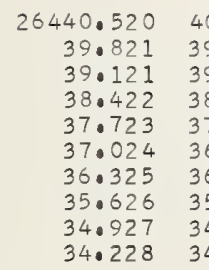

40.450

$\begin{array}{ll}0.450 & 40.380 \\ 9.751 & 39.6\end{array}$

40.380
39.681
38.982
38.282

$\begin{array}{ll}38.352 & 38.282 \\ 37.653 & 37.5883\end{array}$

$\begin{array}{ll}36.954 & 36.884 \\ 36.255 & 36.185\end{array}$

$\begin{array}{lll}36.255 & 36.185 & 36.814\end{array}$

$\begin{array}{ll}35.486 & 36.1115 \\ 34.787 & 35.416 \\ 34.088 & 34.017\end{array}$

$34.228 \quad 34.158$

$33.529 \quad 33.459 \quad 33.389$

$\begin{array}{lll}32.830 & 32.760 & 32.6\end{array}$

$\begin{array}{ll}32.131 & 32.061 \\ 31.432 & 31.363\end{array}$

$\begin{array}{ll}30.734 & 30.664 \\ 30.035 & 29.965\end{array}$

$\begin{array}{lll}0.035 & 29.965 \quad 29.59 \\ 29 & 295\end{array}$

$\begin{array}{llll}30.336 & 29.266 & 29.197 & 29.8\end{array}$

$\begin{array}{llllll}28.638 & 28.568 & 28.498 & 28.428 & 29.057 & 28.987 \\ 27.08 & 28.08 & 28.289\end{array}$

$\begin{array}{llllll}27.939 & 27.869 & 27.799 & 27.729 & 27.060 & 27.590 \\ 27.240 & 27.170 & 27.101 & 27.031 & 26.961 & 26.891\end{array}$

26426.54

$\begin{array}{llll}26.542 & 26.472 & 26.402 & 26 \cdot 33 \\ 25.844 & 25.773 & 25.704 & 25.634 \\ 25.045 & 25.075 & 25.005 & 24.035\end{array}$

$26.262 \quad 26.192$

$\begin{array}{llllll}25.145 & 25.075 & 25.005 & 24.935 & 24.865 & 25.494 \\ 24.096\end{array}$

$\begin{array}{ll}24.446 & 24.377 \\ 23.748 & 23.678\end{array}$

$23.050 \quad 22.980$

$\begin{array}{lll} & \\ 22.3513 & 22.281 & 22.012\end{array}$ $\begin{array}{ll}20.054 & 20.885 \\ 20.256 & 20.187\end{array}$

23.608

$\begin{array}{ll}24 \cdot 237 & 24.167 \\ 23.538 & 23.469\end{array}$

24.796
24.097
23.3990

$26 \cdot 123$
25.424
24.726

24.72

$\begin{array}{llll}23.329 & 23.958 & 23.888 & 23.818\end{array}$

26419.55

20.8115

$\begin{array}{ll}22.142 & 22.072 \\ 21.443 & 21.37\end{array}$

22.002

21.932

22.56
21.86

20.745
20.047

20.675
19.97

20.605
19.907

$\begin{array}{llll} & \\ .234 & 21.164 & 21.792 & 21.723 \\ .535 & 20.466 & 21.094 & 21.024 \\ 19.396 & 20.326\end{array}$

$\begin{array}{llll}9.838 & 19.468 & 20.396 & 20.326 \\ 19.698 & 19.628\end{array}$

$\begin{array}{llll}18.860 & 18.790 & 18.7\end{array}$

19.349

$19.279 \quad 19.209$

$\begin{array}{llll}19.139 & 19.070 & 18.999 & 18.930\end{array}$

$\begin{array}{lllllllllll}17.162 & 18.092 & 18.022 & 17.952 & 17.883 & 17.813 & 17.743 & 17.673 & 17.604 & 17.533\end{array}$

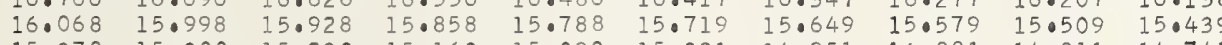

$15.370 \quad 15.300$

$\begin{array}{ll}14.672 & 14.602 \\ 13.974 & 13.904\end{array}$

$\begin{array}{ll}13.974 & 13.904 \\ 13.276 & 13.207\end{array}$

15.230

$15.160 \quad 15.090$

15.02

$\begin{array}{llll}15 \cdot 649 & 15.579 & 15.509 & 15.439 \\ 14.951 & 14.881 & 14.811 & 14.741\end{array}$

$\begin{array}{llll}14.951 & 14.881 & 14.811 & 14.741 \\ 14.253 & 14.183 & 14 \cdot 113 & 14.043\end{array}$

26412.57

$\begin{array}{lll}11.581 & 12.509 \\ 11.811\end{array}$

$11.881111 .811,11.434$

$\begin{array}{llll}3.136 & 13.765 & 13.69 \\ 13.067 & 12.997\end{array}$

12.927

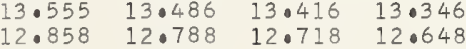

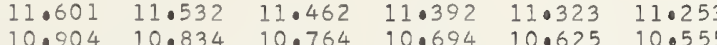
$\begin{array}{llllllllll}10.485 & 10.416 & 10.346 & 10.276 & 10.206 & 10.136 & 10.066 & 09.997 & 09.927 & 09.857\end{array}$ $\begin{array}{llllllll}0.648 & 09.578 & 09.509 & 09.439 & 09.369 & 09.299 & 09.229 & 09.160\end{array}$

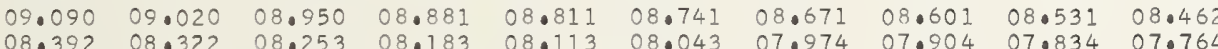

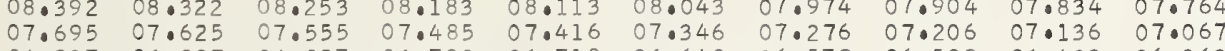

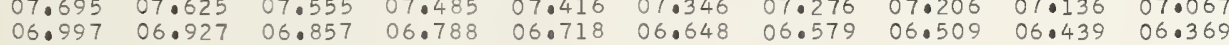
$\begin{array}{llllllllll}06.300 & 06.230 & 06.160 & 06.090 & 06.021 & 05.951 & 05.881 & 05.811 & 05.742 & 05.672\end{array}$

05.462

05.393

05.323

05.253

$04.207 \quad 04.137$

$02.813 \quad 02.743 \quad 02.673 \quad 02.603$

$\begin{array}{ll}04.625 & 04.556 \\ 03.928 & 03.85\end{array}$

$05.184 \quad 05.114 \quad 05.044 \quad 04.975$

$\begin{array}{llllll}01.139 & 01.069 & 01.000 \quad 00.930 \quad 00.860 & 00.791\end{array}$

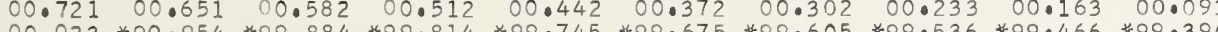

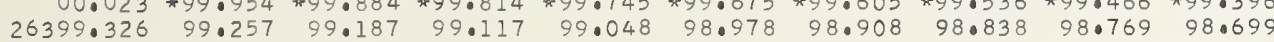

$998.629 \quad 98.560$

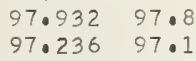

$96.539 \quad 96.469$

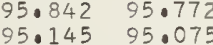

$94.448 \quad 94 \cdot 378$

$93.751 \quad 93.681$

$93.054 \quad 92.985$

$98.490 \quad 98.420$

$\begin{array}{ll}97.793 & 97.724 \\ 97.096 & 97.027\end{array}$

98.35
97.65

98.281

$96.399 \quad 96.330$

$95.702 \quad 95.633$

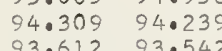

$96.957 \quad 96.887$

$\begin{array}{ll}96.260 & 96.190 \\ 95.563 & 95.49\end{array}$

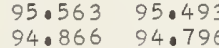

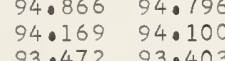

$\begin{array}{llll}98.211 & 98.141 & 98.072 & 98.002 \\ 97.514 & 97.445 & 97.375 & 97.305\end{array}$

$\begin{array}{llll}97.514 & 97.445 & 97.375 & 97.305 \\ 96.818 & 96.748 & 96.678 & 96.608\end{array}$

$\begin{array}{lllll}96.121 & 96.051 & 95.981 & 95.911\end{array}$

$\begin{array}{llll}95.424 & 95 \cdot 354 & 95 \cdot 284 & 95.215\end{array}$

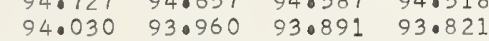

$\begin{array}{llllllll}92.915 & 92.845 & 92.776 & 92.706 & 92.636 & 92.567 & 92.497 & 92.427 \\ 2.218 & 92.148 & 92.079 & 92.009 & 91.939 & 91.870 & 91.800 & 91.730\end{array}$

$26391.661 \quad 91.591 \quad 91.521$

$90.964 \quad 90.894 \quad 91.521 \quad 91.452$

$90.267 \quad 90.198$

$\begin{array}{ll}89.571 & 89 \cdot 50 \\ 88.874 & 88.80\end{array}$

$88.178 \quad 88 \cdot 10$

$\begin{array}{ll}87.481 & 87.41 \\ 86.784 & 86.71\end{array}$

$\begin{array}{ll}86.088 & 86.019 \\ 85.392 & 85.322\end{array}$

90.128

$89.431 \quad 89.058$

$\begin{array}{ll}88.735 & 88.665 \\ 88.038 & 87.069\end{array}$

$\begin{array}{llll}87.342 & 87.272 & 87.202 & 87.013\end{array}$

$\begin{array}{lllll}86.645 & 86.576 & 86.506 & 86.437\end{array}$

$5.949 \quad 85.879$

$\begin{array}{ll}85.810 & 85.74 \\ 85.113 & 85.04\end{array}$

$26384.695 \quad 84.62$

85.252

85.183

$\begin{array}{lllll}83.999 & 83.0220 & 84.556 & 84.487\end{array}$

$\begin{array}{llll}83.303 & 83.233 & 83.860 & 83.790 \\ 83.164 & 83.094\end{array}$

$\begin{array}{lllll}82.606 & 82.537 & 82.467 & 82.397\end{array}$

$\begin{array}{llll}81.910 & 81.841 & 81.771 & 81.701\end{array}$

$\begin{array}{llll}81.215 & 81.145 & 81.075 & 81.006 \\ 80.518 & 80.449 & 80.379 & 80.309\end{array}$

$\begin{array}{llll}80.518 & 80.449 & 80.379 & 80.309\end{array}$

$\begin{array}{llll}79.822 & 79.753 & 79.683 & 79.61 \\ 79.126 & 79.057 & 78.987 & 78.917 \\ 78.430 & 78.036 & 78.291 & 78.221\end{array}$

$\begin{array}{ll}84.417 & 84.34 \\ 83.720 & 83.65\end{array}$

$\begin{array}{ll}83.720 & 83.65 \\ 83.024 & 82.95 \\ 82.328 & 82.25\end{array}$

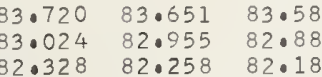

$8.632-82.258 \quad 82.18$
80.636

$80.936 \quad 80.86$

$\begin{array}{ll}80.240 & 80.170 \\ 79.544 & 79.47\end{array}$

$7.848 \quad 78.77$
78.152

$\begin{array}{llll}78.430 & 78.361 \quad 78.291\end{array}$

$$
.001
$$

.002

.003

.004

.005

.005
.035
.035 $(n-1) \times 1000$

$\lambda(n-1)$

0.284047

1.073698

0.284046

0.284045
0.284044

0.284044

.28404

0.284042
0.284041

0.284041

0.284039

0.284039

0.284037

0.284037

0.284035

0.284035

0.284034

0.284033

0.284032

0.284032

0.284030

0.284030

0.284028

0.284028

0.284026

0.284026

0.284025

0.284024

0.284023

0.284022

0.28402

0.284020

0.284019

0.284019

0.284017

0.284016

0.284015
0.284014
0.284014

0.284014

0.284013

0.284012

0.284011

0.284010

0.284009

0.284008

0.284007

0.284006

0.284005

.284004

0.284003

0.284002

0.284001

0.284000

0.28399

0.283999

0.283997

0.283997

0.283996

0.283995

0.283994

0.283994

0.283992

0.283992

0.283991

0.283990

0.283989

0.283988

0.283988

0.283987

0.283986

0.283985

0.283985
0.283984

0.283984

.010

.07375

.07380

.07385

.07390

1.07395

.073983

.

1.074087

1.074139
1.074165

1.074217

(

1.074321

1.074373

1.074425

1.074477

1.074477
.074529

1.07458

1.074607

1.074632
1.074658

1.074684
1.074710

1.074736

1.074788

.074814

1.074866

1.074918

.074944
.074970

1.074996

.075048

1.075074
1.075100

1.075126

1.075152 


\section{.03}

.04

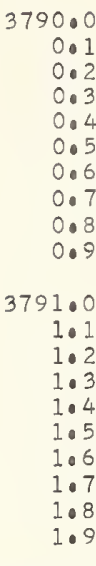

3792 .

2
2
2
2
2
2
2
2
2

3795

5.

$5 \cdot 2$
5.3
5.4

5.5
5.6
5.7

5.7
5.8
5.9

\section{6
6
6
6
6
6
6
6
6}

3797.

\section{3.}

$7 \cdot 3$
7.4
7.5

7.5
7.6
7.7

7.7
7.8
7.9

3798 .

98.0
8.1
$8 \cdot 2$
$8 \cdot 3$
8.4

8.4
8.5

8.6

8.7

3799.0

99.0
9.
9.
9.
9.5
906
907
90

377.734
77.038
76.342
75.646
74.950

74.255
73.559

$72.863 \quad 72.794$

$72 \cdot 167$
71.472

26370.776

70.081
69.385
68.689

68.68969 .316

$67.994 \quad 67.925$

$\begin{array}{ll}67.299 & 67.229 \\ 66.603 & 66.533\end{array}$

$66.603 \quad 66.533$

65.213
64.518

26363.822

$63 \cdot 127.63 \cdot 753$

$\begin{array}{ll}63.127 & 63.057 \\ 62.432 & 62.362\end{array}$

$61.737 \quad 61.66752 .29$

$61.042 \quad 60.972 \quad 60.902$

$\begin{array}{llll}60.346 & 60.277 & 60.902 & 60.83\end{array}$

$\begin{array}{llll}59.651 & 59.582 & 59.512 & 59.44 \\ 58.956 & 58.887 & 58.817 & 58.74\end{array}$

$\begin{array}{llll}58.261 & 58.192 & 58.122 & 58.053 \\ 57.567 & 57.497 & 57.427 & 57.358\end{array}$

$26356.872 \quad 56.802$

56.177

55.48
54.787

54.09254 .718

$53.398 \quad 53.328$

52.703
52.008

51.313
50.619

51.939
51.244

26349.925

49.230
48.5

49.85
49.161
48.467

47.842
47.147
$47: 7$

$46.453 \quad 46.3$
45.559
45.6

$\begin{array}{ll}45.064 & 44.9 \\ 44.370 & 44.3 \\ 43.676 & 43.6\end{array}$

26342.982

42.287
41.5

$41.593-41.524$

$\begin{array}{llll}40.899 & 40.830 & 41.455 & 41.385\end{array}$

$\begin{array}{llll}40.205 & 40.136 & 40.066 & 39.997\end{array}$

$\begin{array}{llll}39.511 & 39.442 & 39.372 & 39.3 \\ 38.817 & 38.748 & 38.679 & 38.609\end{array}$

$\begin{array}{lll}38.817 & 38.748 & 38.6 \\ 38.124 & 38.054 & 37.9\end{array}$

$\begin{array}{lll}37.430 & 37.360 & 37.29 \\ 36.736 & 36.667 & 36.5\end{array}$

26336.042

$\begin{array}{ll}35.348 & 35.9 \\ 35.27\end{array}$

$\begin{array}{ll}34.655 & 34.5 \\ 33.961 & 33.8\end{array}$

$33.267 \quad 33.198$

$32.574 \quad 32.505 \quad 33.128$

$\begin{array}{lll}31.187 & 31.811 & 31.7 \\ 31.117 & 31.048\end{array}$

$\begin{array}{lll}30.493 & 30.424 & 30.35 \\ 29.800 & 29.730 & 29.66\end{array}$

$26329.106 \quad 29.037$

28.413
27.719
27.026

27.02626 .0657

$26.333 \quad 26.263 \quad 26.887$

$\begin{array}{lll}25.640 & 25.571 & 25.501\end{array}$

$24.947 \quad 24.877 \quad 24.808 \quad 25.432$

$24.253 \quad 24.184 \quad 24.115 \quad 24.04$

23.560
22.867

$26322 \cdot 17$

21.48

20.78
20.09
19.402

18.709

$18.016 \quad 17.947$

$\begin{array}{ll}17.323 & 17.25 \\ 16.631 & 16.56 \\ 15.938 & 15.86\end{array}$

22.105

.10522 .035

$\begin{array}{ll}2.035 & 21.966 \\ 2.343 & 21.273\end{array}$

$\begin{array}{ll}1.343 & 21.27 \\ 20.649 & 20.580\end{array}$

$\begin{array}{ll}19.956 & 19.887 \\ 19.263 & 19.194\end{array}$

$\begin{array}{ll}18.571 & 18.50 \\ 17.878 & 17.80\end{array}$

$\begin{array}{ll}17.185 & 17.115 \\ 16.492 & 16.42 \\ 15.800 & 15.731\end{array}$

15.938

$\begin{array}{rr}15.246 & 15.176 \\ 14.553 & 14.484\end{array}$

$\begin{array}{lll}14.553 & 15.176 & 15.107 \\ 13.860 & 13.479 & 14.415\end{array}$

$\begin{array}{lll}13.860 & 13.791 & 13.72 \\ 13.168 & 13.099 & 13.02\end{array}$

$\begin{array}{llll}11.783 & 11.713 & 11.337 & 12.268 \\ 11.090 & 11.021 & 10.952 & 11.575 \\ 10.883\end{array}$

$\begin{array}{llll}11.090 & 11.021 & 10.952 & 10.883 \\ 10.398 & 10.329 & 10.259 & 10.190 \\ 09.705 & 09.636 & 09.567 & 09.498 \\ 09.013 & 08.944 & 08.875 & 08.80\end{array}$

$\begin{array}{llll}09.705 & 09.636 & 09.567 & 09.498 \\ 09.013 & 08.944 & 08.875 & 08.805\end{array}$
.05

.06

.07

.08

.09

$(n-1) \times 1000$

$\lambda(n-1)$

0.28398

0.283982
0.283981

0.283981

0.283980
0.283979

0.283979

0.283978

0.283978
0.283977

0.283976

0.283976

0.283975

0.283974
0.283974
0.283973

0.283973

0.283972

0.283972

0.283971
0.283970

0.283970

0.283969

0.283969
0.283968

0.283967

0.283967

0.283966

0.283965
0.283965

0.283964

0.283963

0.283963
0.283962

0.283962

0.283961

0.283960
0.283960

0.283959

0.283958
0.283958

1.076294

1.076320
1.076346

1.076372

1.076398
1.076424

1.076450

1.076476

1.076502
1.076528

1.076554

1.076580

1.076606
1.076632

1.076658

1.076684

1.076710
1.076736

1.076762
1.076788

1.076814

1.076840

1.076866
1.076892

1.076918

1.076944

1.076970

1.076995

1.077021
1.077047

1.077073

1.077099

1.077125

1.077151
1.077177

1.077203
1.077229

1.077255

1.077281
1.077307

0.283957

0.283956

0.283956

0.283955

0.283954

0.283953

0.283952

0.283951

1.077333

1.077359

1.077411

1.077437

1.077463
1.077489

1.077515

1.077541
1.077567

0.283951

0.283950

0.283949
0.283949

0.283948

0.283947
0.283947
0.283946

0.283947

0.283946

0.283944

0.283944

0.283944
0.283943

0.283942

0.283942

0.283941

0.283940

0.283940
0.283939

0.283939
0.283939

1.077593

1.077619
1.077645

1.077671

1.077697
1.077723

1.077723
1.077749

1.077749

1.077801

1.077853

1.077879

1.077904

1.077930

1.077956

1.077982
1.078008

1.078008
1.078034

.078034
1.078060

0.283938

0.283937

1.078112

0.283937

0.283936
0.283935

0.283935

0.283934

0.283933

0.283933
0.283932

1.078138

1.078164

1.078190

1.078216
1.078242

1.078268

1.078294

1.078320
1.078346

0.283932

0.283931

1.078372 1.078398 1.078424 1.078450 1.078476
1.078502 1.078528 1.078554 1.078580
1.078606

0.283927

0.283926

1.078632

0.283925
0.283925

0.283925
0.283924

0.283923

0.283923

0.283922
0.283921

0.283921
0.283921

0.283920

1.078658

1.078684
1.078710

1.078736

1.078762

1.078788

1.078814

1.078840
1.078866

.010

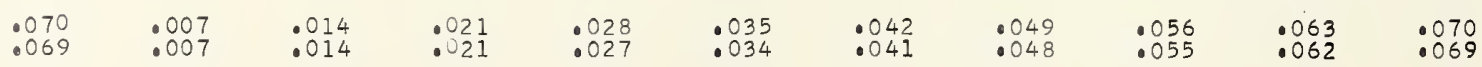




\begin{abstract}
.02
\end{abstract}

.03

3800.0
0.1
0.2
0.3
0.4
0.5
0.6
0.7
0.8
0.9

3801.0
1.1
1.2
$1 \cdot 3$
$1: 4$
1.5
$1: 7$
1.9

3802.0
2.1
2.2
2.3
2.4
2.5
2.6
2.7
2.8
2.9

3803

3.0
$3 \bullet$
$3 \bullet$
$3 \bullet$
$3 \bullet$
$3 \bullet$
$3 \bullet$
3.

3804

804.0
$4 \cdot 1$
$4 \cdot 2$
4.3
4.4
4.5
4.6
4.7
4.8
4.9

3805 .

5.0
50
50
50
50
50
50
50

3806

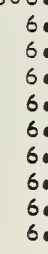

3807

807.0
7
70
703
704
705
706
708

$\begin{array}{lrllll}7.0 & 26259.948 & 59.879 & 59.810 & 59.741 & 59 \\ 7.1 & 59.259 & 59.189 & 59.121 & 59.052 & 58 \\ 7.2 & 58.569 & 58.500 & 58.431 & 58.362 & 589 \\ 7.3 & 57.879 & 57.810 & 57.741 & 57.672 & 57 \\ 7.4 & 57.189 & 57.120 & 57.052 & 56.983 & 56 \\ 7.5 & 56.500 & 56.431 & 56.362 & 56.293 & 56 \\ 7.6 & 55.810 & 55.741 & 55.672 & 55.603 & 55 \\ 7.7 & 55.121 & 55.052 & 54.983 & 54.914 & 54 \\ 7.8 & 54.431 & 54.362 & 54.293 & 54.224 & 54 \\ 7.9 & 53.742 & 53.673 & 53.604 & 53.535 & 53 \\ & & & & & \\ 8.0 & 26253.052 & 52.983 & 52.914 & 52.845 \\ 8.1 & 52.363 & 52.294 & 52.225 & 52.156 \\ 8.2 & 51.674 & 51.605 & 51.536 & 51.467 \\ 8.3 & 50.984 & 50.916 & 50.846 & 50.778 \\ 8.4 & 50.295 & 50.226 & 50.157 & 50.088 \\ 8.5 & 49.606 & 49.537 & 49.468 & 49.399 \\ 8.6 & 48.917 & 48.848 & 48.779 & 48.710 \\ 8.7 & 48.228 & 48.159 & 48.090 & 48.021 \\ 8.8 & 47.538 & 47.469 & 47.401 & 47.332 \\ 8.9 & 46.849 & 46.781 & 46.711 & 46.643\end{array}$ $\begin{array}{lllll}308.321 & 08.251 & 08.182 & 08.113 & 0 \\ 07.628 & 07.559 & 07.490 & 07.421 & 07 \\ 06.936 & 06.867 & 06.798 & 06.728 & 0 \\ 06.244 & 06.175 & 06.105 & 06.036 & 0 \\ 05.552 & 05.482 & 05.413 & 05.344 & 0 \\ 04.860 & 04.790 & 04.721 & 04.652 & 0 \\ 04.167 & 04.098 & 04.029 & 03.960 & 0 \\ 03.475 & 03.406 & 03.337 & 03.268 & 0 \\ 02.783 & 02.714 & 02.645 & 02.576 & 0 \\ 02.091 & 02.022 & 01.953 & 01.884 & 0\end{array}$

.04

\begin{abstract}
.05
\end{abstract}

.06

$\begin{array}{llll}07.905 & 07.836 & 07.767 & 07.698 \\ 07.213 & 07.144 & 07.075 & 07.005 \\ 06.521 & 06.451 & 06.382 & 06.313 \\ 05.828 & 05.759 & 05.690 & 05.621 \\ 05.136 & 05.067 & 04.998 & 04.929 \\ 04.444 & 04.375 & 04.306 & 04.237 \\ 03.752 & 03.683 & 03.614 & 03.544 \\ 03.060 & 02.991 & 02.922 & 02.852 \\ 02.368 & 02.299 & 02.229 & 02.160 \\ 01.676 & 01.607 & 01.538 & 01.469\end{array}$

$\begin{array}{rlllllllll}26301.399 & 01.330 & 01.261 & 01.192 & 01.123 & 01.053 & 00.984 & 00.915 & 00.845 & 00.776 \\ 00.707 & 00.638 & 00.569 & 00.500 & 00.431 & 00.362 & 00.292 & 00.223 & 00.154 & 00.085\end{array}$ $\begin{array}{rrrrrrrrrr}00.707 & 00.638 & 00.569 & 00.500 & 00.431 & 00.362 & 00.292 & 00.223 & 00.154 & 00.085 \\ 00.016 & * 99.947 & * 99.877 & * 99.808 & * 99.739 & * 99.670 & * 99.601 & * 99.531 & * 99.462 & * 99.393 \\ 299.324 & 99.255 & 99.186 & 99.116 & 99.047 & 98.978 & 98.909 & 98.840 & 98.770 & 98.701\end{array}$ $\begin{array}{llllllllll}98.632 & 98.563 & 98.494 & 98.425 & 98.355 & 98.286 & 98.909 & 98.840 & 98.770 & 98.701 \\ 97.940 & 97.871 & 97.802 & 97.733 & 97.564 & 97.594 & 97.525 & 97.148 & 98.078 & 98.010\end{array}$ $\begin{array}{llllllllll}97.940 & 97.871 & 97.802 & 97.733 & 97.664 & 97.594 & 97.525 & 97.456 & 97.387 & 97.318\end{array}$ $\begin{array}{llllllllll}97.248 & 97.179 & 97.110 & 97.041 & 96.972 & 96.903 & 96.833 & 96.764 & 96.695 & 96.626 \\ 96.557 & 96.488 & 96.418 & 96.349 & 96.280 & 96.211 & 96.142 & 96.073 & 96.003 & 95.934\end{array}$ $\begin{array}{llllllllll}96.557 & 96.488 & 96.418 & 96.349 & 96.280 & 96.211 & 96.142 & 96.073 & 96.003 & 95.934\end{array}$ $\begin{array}{llllllllll}95.865 & 95.796 & 95.727 & 95.657 & 95.588 & 95.519 & 95.450 & 95.381 & 95.312 & 95.243 \\ 95.173 & 95.104 & 95.035 & 94.966 & 94.897 & 94.828 & 94.759 & 94.689 & 94.620 & 94.551\end{array}$

26294.482 $\begin{array}{rrr}6294.482 & 94.413 & 94 . \\ 93.790 & 93.721 & 930 \\ 93.099 & 93.030 & 920 \\ 92.407 & 92.338 & 92 \\ 91.716 & 91.647 & 9 \\ 91.024 & 90.955 & 90 . \\ 90.333 & 90.264 & 90 . \\ 89.641 & 89.573 & 8 \\ 88.950 & 88.881 & 8 \\ 88.259 & 88.190 & 88\end{array}$

94.34394 .274

$94 \cdot 205$

940136

$94.067 \quad 93.998 \quad 93.928 \quad 93.860$

$26287.568 \quad 87.499 \quad 87$.

$.960 \quad 92.891$

.269
1.52 .199
91.509

92.822

93.445

45
53
70

$\begin{array}{rr}92.131 & 92.061 \\ 91.439 & 91.370 \\ 90.748 & 90.678 \\ 90.056 & 89.987\end{array}$

93.375
92.684
91.992

91.301

93.306
92.61
91.92

91.232

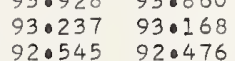

$91.854 \quad 91.785$

0.19590 .125

89.36

$\begin{array}{ll}89.918 \\ .296 & 89.227\end{array}$

$\begin{array}{lll}90.540 & 90.471 & 90.402 \\ 89.849 & 89.780 & 89.711\end{array}$

$9.157 \quad 89.088 \quad 89.019$

$\begin{array}{llll}86.876 & 86.807 & 86.738 & 86.669\end{array}$

$\begin{array}{llll}86.185 & 86.116 & 86.047 & 85.978\end{array}$

$84.803 \quad 84.734 \quad 84.665 \quad 84.596$

$84.112 \quad 84.043 \quad 83.974$

$83.421 \quad 83.352 \quad 83.283 \quad 83.214$

$\begin{array}{llll}82.730 & 82.661 & 82.592 & 82.523 \\ 82.039 & 81.970 & 81.901 & 81.83\end{array}$

81.34

26280.65

$79.658 \quad 80.588$

$\begin{array}{llll}79.276 & 79.897 & 79.829 & 79.760\end{array}$

$\begin{array}{llll}78.585 & 78.516 & 78.447 & 78.06\end{array}$

$\begin{array}{llll}77.895 & 77.825 & 77.756 & 77.687\end{array}$

$\begin{array}{llll}76.513 & 76.444 & 76.375 & 76.30\end{array}$

75.132

$74 \cdot 441$

75.063
74.372

$26273.750 \quad 73.681$

$72.370 \quad 72.301$

$71.679 \quad 71.610$

2070.8

$70.299 \quad 70.229 \quad 70.160-70$.

$\begin{array}{llll}69.608 & 69.539 & 69.470 & 69.40\end{array}$

$68.228 \quad 68.159 \quad 68.090 \quad 68.02$

67.538

$66.158 \quad 66.779 \quad 66.710$

$63.397 \quad 63.328$

$63.260 \quad 63.19163 .81263 .742$

$\begin{array}{llll}62.570 & 62.500 & 62.432 & 62.363\end{array}$

61.328

61.259
60.569

$7 \cdot 291$

$86.600 \quad 86.531$

$\begin{array}{ll}85.909 & 85.84 \\ 5.218 & 85.14\end{array}$

$83.836 \quad 83.76$

$\begin{array}{ll}83.145 & 83.07 \\ 82.454 & 82.38\end{array}$

87.844

$\begin{array}{lll}8.466 & 88.397 & 88.328 \\ 7.775 & 87.706 & 87.637\end{array}$

$\begin{array}{llll}87.153 & 87.084 & 87.014 & 86.946\end{array}$

$\begin{array}{llll}85.771 & 85.701 & 85.633 & 85.2563\end{array}$

$\begin{array}{llll}85.079 & 85.010 & 84.941 & 84.872 \\ 84.388 & 84.320 & 84.250 & 84.182\end{array}$

$83.698 \quad 83.629 \quad 83.560 \quad 83.490$

$83.007 \quad 82.937 \quad 82.869 \quad 82.800$

$\begin{array}{llllll}1.763 & 81.694 & 81.625 & 81.247 & 82.178 & 82.108 \\ 81.072 & 81.003 & 80.934 & 80.865 & 81.487 & 81.417\end{array}$

$\begin{array}{ll}80.381 & 80.312 \\ 79.690 & 79.621\end{array}$

80.2

$80.174 \quad 80.105 \quad 80.036$

$79.000 \quad 78.930$

77.618

76.237

75.54
74.85

76.85

78.86
78.170

78.170

76.09

$79 \cdot 483$

$\begin{array}{ll}80.105 & 80.036 \\ 79.414 & 79.345\end{array}$

$\begin{array}{lll}78.102 & 78.032 & 78.654 \\ 77.963\end{array}$

$\begin{array}{lll}77.411 & 77.342 & 77.273 \\ 76.720 & 76.651 & 76.582\end{array}$

$76.030 \quad 75.960 \quad 75.891$

$\begin{array}{lll}75.0339 & 75.960 & 75.891 \\ 75.270 & 75.201\end{array}$

74.717

$\begin{array}{lll}74.648 & 74.579 & 74.510 \\ 73.958 & 73.889 & 73.820\end{array}$

73.474

73.405

73.3

$\begin{array}{lll}73.267 & 73 \cdot 198 & 73 \cdot 129\end{array}$

$\begin{array}{lllllll}72.094 & 72.024 & 71.955 & 71.886 & 71.817 & 71.748\end{array}$

$\begin{array}{lllllll}70.022 & 69.953 & 69.884 & 69.815 & 69.746 & 69.677\end{array}$

$\begin{array}{llllll}68.642 & 69.263 & 69.194 & 69.125 & 69.056 & 68.987 \\ 68.573 & 68.504 & 68.435 & 68.366 & 68.297\end{array}$

$\begin{array}{llll}68.504 & 68.435 & 68.366 & 68.297 \\ 67.814 & 67.745 & 67.676 & 67.607\end{array}$

67.952
67.262
67.88

$67.124 \quad 67.055 \quad 66.986 \quad 66.917$

$\begin{array}{llll}66.434 & 66.365 & 66.296 & 66.227 \\ 65.744 & 65.675 & 65.606 & 65.537\end{array}$ $65.054 \quad 64.984 \quad 64.916 \quad 64.846$ $\begin{array}{llll}64.364 & 64.295 & 64.225 & 64.156\end{array}$ $\begin{array}{llll}63.674 & 63.605 & 63.536 & 63.467 \\ 62.984 & 62.915 & 62.846 & 62.777\end{array}$ $\begin{array}{llll}62.984 & 62.915 & 62.846 & 62.777 \\ 62.294 & 62.225 & 62.156 & 62.087\end{array}$

$\begin{array}{llll}62.294 & 62.225 & 62.156 & 62.087 \\ 61.604 & 61.535 & 61.466 & 61.397\end{array}$ $\begin{array}{llllll}.052 & 60.983 & 60.914 & 60.845 & 60.776 & 60.707\end{array}$

$\begin{array}{llllll}.672 & 59.603 & 59.534 & 59.465 & 59.396 & 59.327\end{array}$

$\begin{array}{llllll}58.982 & 58.914 & 58.844 & 58.776 & 58.707 & 58.638\end{array}$ $\begin{array}{llllll}58.293 & 58.224 & 58.155 & 58.086 & 58.017 & 57.948 \\ 7.603 & 57.534 & 57.465 & 57.396 & 57.327 & 57.258\end{array}$ $\begin{array}{llllll}56.914 & 56.844 & 56.776 & 56.707 & 56.637 & 56.569\end{array}$ $\begin{array}{lllllll}56.224 & 56.155 & 56.086 & 56.017 & 55.948 & 55.879\end{array}$ $\begin{array}{llllll}55.534 & 55.466 & 55.396 & 55.327 & 55.259 & 55.189 \\ 54.845 & 54.776 & 54.707 & 54.638 & 54.569 & 54.500\end{array}$ $54.155 \quad 54.086 \quad 54.017 \quad 53.949 \quad 53.880 \quad 53.810$ $\begin{array}{lllllll}52.776 & 52.708 & 52.639 & 52.570 & 52.501 & 52.432\end{array}$ $\begin{array}{llllll}52.087 & 52.018 & 51.949 & 51.880 & 51.812 & 51.743\end{array}$

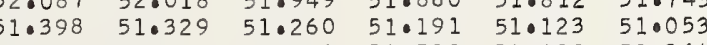
$\begin{array}{llllll}50.709 & 50.640 & 50.571 & 50.502 & 50.433 & 50.364 \\ 50.020 & 49.950 & 49.882 & 49.813 & 49.744 & 49.675\end{array}$ $\begin{array}{llllll}50.020 & 49.950 & 49.882 & 49.813 & 49.744 & 49.675 \\ 49.330 & 49.261 & 49.192 & 49.124 & 49.054 & 48.986\end{array}$ $\begin{array}{llllll}49.330 & 49.261 & 49.192 & 49.124 & 49.054 & 48.986 \\ 48.641 & 48.572 & 48.503 & 48.434 & 48.365 & 48.296\end{array}$ $\begin{array}{llllll}47.952 & 47.883 & 47.814 & 47.745 & 47.676 & 47.607\end{array}$ $\begin{array}{llllll}47.263 & 47.194 & 47.125 & 47.056 & 46.987 & 46.918 \\ 46.574 & 46.505 & 46.436 & 46.367 & 46.298 & 46.229\end{array}$

909.0

$26246.160 \quad 46.091 \quad 46.022 \quad 45.954 \quad 450$ $\begin{array}{llllllllll}45.471 & 45.402 & 45.333 & 45.264 & 45.885 & 45.815 & 45.747 & 45.678 & 45.609 & 45.540\end{array}$ $\begin{array}{llllllllll}44.782 & 44.713 & 44.645 & 44.575 & 44.1907 & 45.127 & 45.058 & 44.989 & 44.920 & 44.851 \\ 4 & 44.438 & 44.369 & 44.300 & 44.231 & 44.162\end{array}$ $\begin{array}{llllllllll}44.093 & 44.024 & 43.955 & 43.886 & 43.818 & 43.749 & 43.680 & 43.611 & 43.542 & 43.473\end{array}$ $\begin{array}{llllllllll}43.404 & 43.335 & 43.266 & 43.198 & 43.129 & 43.060 & 42.991 & 42.922 & 42.853 & 42.784 \\ 42.715 & 42.646 & 42.577 & 42.509 & 42.440 & 42.371 & 42.302 & 42.233 & 42.164 & 42.095\end{array}$ $\begin{array}{llllllllll}42.026 & 41.958 & 41.889 & 41.820 & 41.751 & 41.682 & 41.613 & 41.544 & 41.476 & 41.0407\end{array}$ $\begin{array}{llllllllll}41.338 & 41.269 & 41.200 & 41.131 & 41.062 & 40.993 & 40.924 & 40.855 & 40.787 & 40.718\end{array}$ $\begin{array}{llllllllll}40.649 & 40.580 & 40.511 & 40.442 & 40.374 & 40.304 & 40.236 & 40.167 & 40.098 & 40.029\end{array}$ $\begin{array}{llllllllll}39.960 & 39.891 & 39.822 & 39.754 & 39.685 & 39.616 & 39.547 & 39.478 & 39.409 & 39.341\end{array}$

$0.283919 \quad 1.078892$

0.283918
0.283918
0.283917

1.078918

0.283916

0.28391

1.078969

0.283914

1.079021

0.283914
0.283913

1.079073

0.283912

0.283912
0.283911

1.079099

.283910

.28390

.283908

0.283907

0.283906

0.283905

0.283904

0.283903

0.283902

0.283902
0.283901

0.283900

0.283900

0.283899

0.283898

0.283897

0.283896

0.283895

0.283894

0.283893

0.283893

0.283892

0.283891
0.283890

0.283890

0.283888

0.283887

0.283886

0.283886
0.283885

0.283885
0.283885

0.283884

0.283883

0.283882

0.283882

0.283880

0.283880

0.283879

0.283878
0.283878

0.283877

0.2283876
0.283876

0.283875

0.283874

0.283874

0.283873

0.283872

0.283871

0.283871

0.283870

0.283869

1.079151

1.079203
1.079229

1.079255

1.079359

2.07941

1.079463
1.07948

1.079515

1.079541
1.079567

1.07961

1.079671

1.079723

1.079775

1.079801
1.079827

1.079879

1.07990 .5

1.079931

1.079983

1.080009

1.080035

1.080061

1. 080113

1.080139
1.080164

1.080190

1.080242

1.080268
1.080294

1.080320

1.080372

1.080398

0.283868

0.283868

0.283867

0.283866

0.283865

0.283864

0.283864

0.283863
0.283862

1.080450

1.080476

1.080528

1.080554

1.080606

1.080632

1.080658

0.283862

0.283861
0.283861

0.283860

0.283859

0.283858

0.283857

0.283857
0.283856

1.080710

1.080762

1.080788

1.080814 
$\begin{array}{lll}32.318 & 32.249 & 32.180\end{array}$

32.111

32.731

$\begin{array}{llll}30.941 & 30.873 & 31.49 & 30.803 \\ 30.253 & 30.184 & 30.115\end{array}$

29.634
28.946

$\begin{array}{lll}28.188 & 28.808 & 28.739\end{array}$

31.42
30.735

31.045
30.66

31.97

32.59

33.213

33.832

26218.628

17.990
17.2
16.565

$\begin{array}{ll}11.5252 & 17.1 \\ 16.555 & 16.4\end{array}$

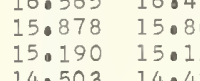

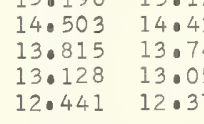

$\begin{array}{lll}28.120 & 28.051 & 28.670 \\ 27.982 & 27.082\end{array}$

29.290

30.597

$31 \cdot 217$
30.528
29

$\begin{array}{ll}31.836 & 31.767 \\ 310148 & 310079\end{array}$

3814

4.1
4.2

26211.753
11.066
10.039
09.692
09.005
09003

11.685
10.997

405

4.6
4.9

4.8
4.9

3815.

5.

5.3
5.4
5.5

5.5

5.6
5.7
5.8

5.9

0.0718
0.631
06.943

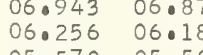

10.310
00.623
08.936
08.249
007.562
00.875
060.188
05.501

26204.883

03.509

02.136

010449
00.762

26199.389

04.81
04.127
03.440
02.754

年

26.675

29.221

$\begin{array}{llll}29.040 & 29.0771 \quad 29.702\end{array}$

$\begin{array}{lll}29.152 & 29.083 & 29 \cdot 014 \\ 28.44 & 28.395 & 28.026\end{array}$

$\begin{array}{llll}27.844 & 27.076 & 27.707 & 27.638 \\ 27.156 & 27.087 & 27.019 & 27.0350\end{array}$

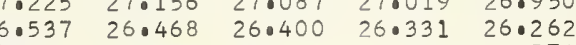

$\begin{array}{llllllllll}25.436 & 25 \cdot 367 & 25.299 & 25 \cdot 230 & 25 \cdot 161 & 25.092 & 25 \cdot 023 & 24 \cdot 055 & 24 \cdot 886\end{array}$

$\begin{array}{lllllllll}4.748 & 24.680 & 24.611 & 24.542 & 24.473 & 24.404 & 24.335 & 240267 & 24 \cdot 198 \\ 24.061 & 23.992 & 23.923 & 23.854 & 23.785 & 23.717 & 23.648 & 23.579 & 23.510\end{array}$

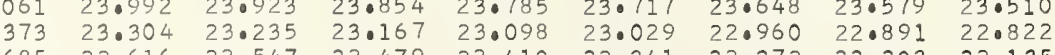

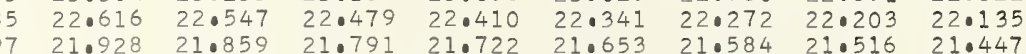
$\begin{array}{llllllll} & \end{array}$

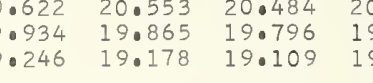

\title{
.0415
}

$\begin{array}{llll}.346 & 20.278 & 20 \cdot 209 & 20 \cdot 140 \quad 20.071\end{array}$

$\begin{array}{llll}0.278 & 20.209 & 20.140 & 20.071 \\ 9.590 & 19.521 & 19.0452 & 19.384 \\ 18.903 & 18.834 & 18.0765 & 18.697\end{array}$

\section{$\begin{array}{lll}18.490 & 18.421 & 18.353\end{array}$}

18.28

$\begin{array}{llll}18.215 & 18.146 & 18.078 & 18.009\end{array}$

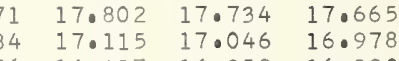

17.596

17.528

$\begin{array}{lll}18.146 & 18.078 & 18.009 \\ 17.459 & 17.0390 & 17.321 \\ 16.771 & 16.0703 & 16.034\end{array}$

$\begin{array}{llllllll}160427 & 16 \cdot 359 & 16 \cdot 290 & 16 \cdot 221 & 16 \cdot 152 & 16 \cdot 084 & 16 \cdot 015 & 15 \cdot 946 \\ 15.740 & 15 \cdot 671 & 15.003 & 15.534 & 15.465 & 15.396 & 15.327 & 15.259\end{array}$ $\begin{array}{lllllllll}15.052 & 14.984 & 14.015 & 14.846 & 14.778 & 14.709 & 14.640 & 14.572\end{array}$

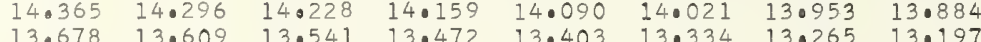

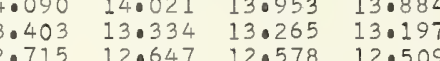
12.990
12.303
12.023

\subsection{16}

12.784

12.028

$11.959 \quad 11.891 \quad 11.822$

tarase

1.34

11.27

$\begin{array}{ll}11.203 & 11.135 \\ 10.517 & 10.448\end{array}$

$\begin{array}{ll}10.6261 & 1 \\ 00.241 & 10.017 \\ 09.554 & 09.48\end{array}$

\section{0} 08.1700
07.0806
06.8119 7.49
6.80
6.11
6.112 年

05.432

4.745
4.059
0.37

06.050
05.36

04.372
0.68
1.99
1.09

04.677
03.990
03.30
02.3010

$\begin{array}{llll}02.067 & 01.998 & 01.9 \\ 01.380 & 01.312 & 01.243\end{array}$

02.616
01.030
0.243

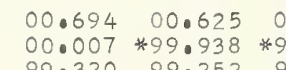

26198.016

97.33
96.643

$98.565 \quad 98.497$

.870
.183
.497

816.0

6.2

$6 \cdot 3$

$6 \cdot 4$

6.6
6.7

6.8
6.9

3817.0

7.01

$95.957 \quad 95.848$

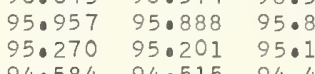

94.554494 .515

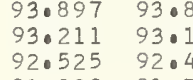

91.83

77.3

7.5

706

7.8

3818

8.1
8.2
8.03

8.04

8.5

8.7

8.8
8.9

3819.0

9.1
9.2
9.03

9.3

9.5

9.6
9.7

9.8

$$
\begin{array}{r}
85.65 \\
85.66 \\
84.97 \\
2184.29 \\
83.60 \\
82.92 \\
82.23 \\
81.55
\end{array}
$$

$\begin{array}{rr}191.152 & 91.08 \\ 90.466 & 90.397 \\ 89.780 & 89.712\end{array}$

89.094
880408
870.02

$88.408 \quad 88.339$

$87.722 \quad 87.653 \quad 88.2$

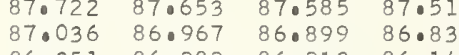

26184.29

$82.236 \quad 82.077$

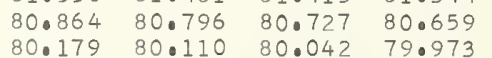

$\begin{array}{lllll}79.493 & 79 \cdot 425 & 79 \cdot 356 & 79 \cdot 287\end{array}$

$\begin{array}{lllll}78.807 & 79.425 & 79.0356 & 79.287 & 78.070 \\ 78.122 & 78.053 & 77.985 & 78.602 & 77.917\end{array}$

11.645
09.967
00.280

$\begin{array}{llll}090898 & 090829 & 09.760\end{array}$

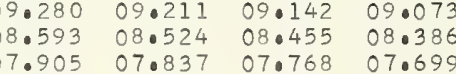

(1)

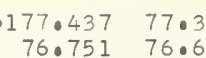

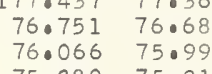

75.380
70.695
74.35

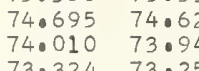

$77.299 \quad 77.231$

07.35

07.974

07.90

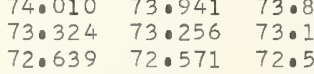

$\begin{array}{lll}71.054 & 71.886 & 71.517 \\ 71.269 & 71.8200 & 71.0132\end{array}$

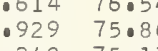

05.982
05.29

07.218

$\begin{array}{llll}07.149 & 07.081 & 07.012\end{array}$

$\begin{array}{llll}.8314 & 06.462 & 06.394 & 06.325 \\ 0.844 & 05.776 & 05.707 & 05.663\end{array}$

\subsection{0}

\begin{abstract}
05.22
\end{abstract}
05.157

05.089

$\begin{array}{ll}0.020 & 04.951\end{array}$

0.283856

0.28385

0.283854
0.283854

0.283853

0.283852

0.283851

0.283851

0.283850

0.283849

0.283849
0.283848

0.283848
0.283847

0.283847

0.283846

0.283845

0.283845

0.283844
0.283844

0.283843

0.283842

0.283842
0.283841

0.283840

0.283840

0.283839

0.283839
0.283838

0.283837

0.283837

0.283836
0.283835
0.2283835

0.283835

0.283834

0.283834

0.283832

0.283832

0.283831

1.081490

1.081516

1.081568

1.081594
1.081620

1.081646

1.081671

1.081697
1.081723

1.081749

1.081775

1.081801
1.081827

1.081853

1.08185

1.081931

1.081957
1.081983

1.082009

1.082035
1.082061

1.082087

1.082113

1.0082165

1.082191

1.082217

0.283830
0.283830
0.2283829

0.283829

0.283828

0.283827

0.283827

0.283826

0.283825
0.283825

1.082269

1.082295

1.082321

1.082373

1.082399

1.082425

1.082477
1.082503 


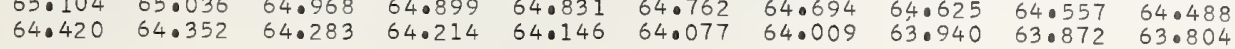

0.283793

0.283792

0.283792

0.283790

0.283789

0.283788

1.084088

26163.735063 .667

$63.598 \quad 63.530$

64.146

63.393

$\begin{array}{llllll}63.050 & 62.982 & 62.914 & 62.845 & 62.776 & 62.708 \\ 62.366 & 62.297 & 62.229 & 62.160 & 62.092 & 62.023\end{array}$

$61.681 \quad 61.613 \quad 61.544 \quad 61.476 \quad 61.407 \quad 61.339$

60.99760 .022060 .85960 .79160

$\begin{array}{llllll}60.312 & 60.243 & 60.175 & 60.106 & 60.038 & 59 .\end{array}$

$58.94359 .559590 .80059 .422 \quad 50.05459 .285$

$58.258 \quad 58.190$

3822.

2.0
2.0
2.
2.
2.0
2.0
2.0
2

26156.889

56.88956 .821

58.053
57.36

$\begin{array}{llll}63.324 & 63.256 & 63.187 & 63.119 \\ 62.639 & 62.571 & 62.503 & 62.434\end{array}$

$\begin{array}{llll}62.639 & 62.571 & 62.503 & 62.434 \\ 61.955 & 61.886 & 61.818 & 61.750\end{array}$

$\begin{array}{llll}61.270 & 61 \cdot 202 & 61.133 & 61.065 \\ 60.586 & 60.517 & 60.449 & 60.380\end{array}$

$\begin{array}{llll}50.586 & 60.517 & 60.449 & 60.380 \\ 59.901 & 59.833 & 59.764 & 59.696\end{array}$ $\begin{array}{llllll}55.521 & 55.452 & 55.384 & 55.315 & 55.247 \\ 54.836 & 54.768 & 54.699 & 54.631 & 54.0563\end{array}$

$\begin{array}{lll}56.136 & 56.068 & 56.684\end{array}$

$\begin{array}{ll}3 & 57.98 \\ 9 & 57.300\end{array}$

57.916
57.232

$\begin{array}{llll}59.217 & 59.148 & 59.080 & 59.011 \\ 58.532 & 58.464 & 58.395 & 58.327\end{array}$

$54.152 \quad 54.08454 .015 \quad 53.948 \quad 53.879$

$52.784 \quad 52.716 \quad 52.647 \quad 52.579 \quad 52.510$

$\begin{array}{lllll}5.547 & 56.479 & 56.410 & 56.342 & 56.274 \\ 55.863 & 55.795 & 55.726 & 55.658 & 55.589\end{array}$

$52.100 \quad 52.032 \quad 51.963$

51.416
50.732

3823.0

3.0
30
30
30
30
30
30
30
30
3.0

26150.04

$50.048 \quad 49.979$

$\begin{array}{lll}.348 & 51.279 & 5 \\ .664 & 50.595 & 50 .\end{array}$

52.510
52.442

54.426
53.742

$\begin{array}{lll}55.042 & 54.973 & 54.905 \\ 54.358 & 54.289 & 54.221\end{array}$

$49.364 \quad 49.295$

$\begin{array}{lll}48.680 & 48.612 & 48.543 \\ 47.996 & 47.928 & 47.859\end{array}$

$47.312 \quad 47.244 \quad 47 \cdot 175 \quad 47 \cdot 107$

$\begin{array}{llll}46.628 & 46.560 & 46.491 & 46.423 \\ 45.944 & 45.876 & 45.808 & 45.739\end{array}$

$\begin{array}{llll}45.260 & 45.192 & 45.124 & 45.055 \\ 44.577 & 44.509 & 44.440 & 44.372\end{array}$

$\begin{array}{llll}44.577 & 44.509 & 44.440 & 44.372 \\ 43.893 & 43.825 & 43.756 & 43.688\end{array}$

$\begin{array}{ll}51.142 & 51.074 \\ 50.458 & 50.390\end{array}$

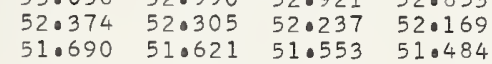

$53.674 \quad 53.605 \quad 53.537$

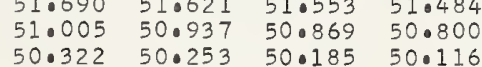

0.283787

0.283786

0.283785

0.283784

0.28378

0.283782

0.283782
0.283781

1.084140

1.084192

1.084244

1.084296

0.283780

0.283780

0.283778

0.283778
0.283777

0.283777

0.283776
0.283775
0.283775

0.283775

1.084348

0.283774

0.283773
0.283773

0.283772

0.283771

0.283770

0.283768

3824.0

24.0
4.1
4.2
$4: 3$
40
$4: 5$
40
$4: 7$
4.8
4.9

$\begin{array}{rll}26143.210 & 43.141 & 43.073 \\ 42.526 & 42.458 & 42.389 \\ 41.842 & 41.774 & 41.706\end{array}$

$\begin{array}{llllllllll}41.842 & 41.774 & 41.706 & 41.321 & 42.252 & 42.184 & 42.116 & 42.047 & 41.979 & 41.911\end{array}$

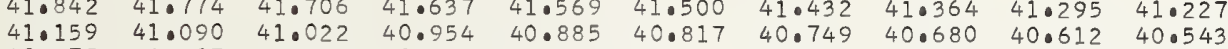

$\begin{array}{llllllllll}40.475 & 40.407 & 40.338 & 40.270 & 40.202 & 40.133 & 40.065 & 39.997 & 39.928 & 39.860 \\ 39.792 & 39.723 & 39.655 & 39.5877 & 39.518 & 39.450 & 39.382 & 39.313 & 39.245 & 39.177\end{array}$

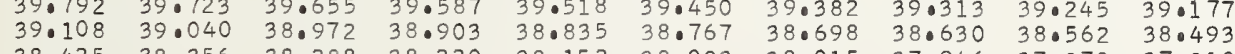

$\begin{array}{llll}38.425 & 38.356 & 38.288 & 38.220 \\ 37.741 & 37.673 & 37.2805 & 38.537\end{array}$

$\begin{array}{llll}37.058 & 36.990 & 36.922 & 36.85\end{array}$

38.152
37.46
36.78

3825.0

26136.375

35.37536 .307

36.922

36.170

$36 \cdot 102$
35.418

38.083
37.400
36.717

$\begin{array}{llll}38.015 & 37.946 & 37.0878 & 38.493 \\ 37.332 & 37.263 & 37.8105 & 37.8127\end{array}$

$\begin{array}{llll}35.008 & 35.623 & 35.555 & 35.487\end{array}$

36.033

36.649

$34.325 \quad 34.257-34018934.120$

$33.642 \quad 33.574 \quad 33.505$

$32.276 \quad 32.891 \quad 32 \cdot 82$

33.437
32.754

34.735
34.052
33.0369

35.350
34.667
33.08

35.96

36.580

36.512

0.283768

0.283767

0.283766

0.283765

0.283764

0.283763

0.283762

1.084374

1.084426

1.084478

1.084530

1.084582

5.5

$31.593 \quad 31.525$

$\begin{array}{ll}30.910 & 30.842 \\ 30.227 & 30.158\end{array}$

$32.139 \quad 32.071$

$\begin{array}{ll}33.369 & 33.301 \\ 32.686 & 32.617\end{array}$

34.599

$\begin{array}{lll}35.897 & 35.828 & 35.760\end{array}$

0.283762

0.283761

0.283760

0.283759

0.283759

0.283758
0.283757

0.283757

3826.0

26.0
6.
6.
6.0
6.0
6.0
6.0
6.0
6.0
6

26129.54

$29.544 \quad 29 \cdot 475$

$\begin{array}{ll}30.090 & 30.702 \\ 20.022\end{array}$

30.636

31.251

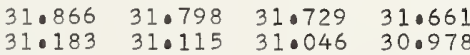

0.283756

0.28375

0.283754

0.283754

0.283754

0.283752

0.283752

0.283750 $\begin{array}{llllllllll}26 \cdot 129 & 26.061 & 25.993 & 25 \cdot 925 & 25 \cdot 856 & 25.788 & 25 \cdot 720 & 25.652 & 25 \cdot 583 & 25.515 \\ 25.447 & 25.378 & 25.310 & 25.242 & 25.174 & 25.105 & 25.037 & 24.969 & 24.901 & 24.83\end{array}$ $\begin{array}{llllllllll}25.447 & 25.378 & 25.310 & 25.242 & 25.174 & 25.105 & 25.037 & 24.969 & 24.901 & 24.833 \\ 24.764 & 24.696 & 24.627 & 24.559 & 24.491 & 24.423 & 24.354 & 24.286 & 24.218 & 24.150\end{array}$ $\begin{array}{llllllllll}24.081 & 24.013 & 23.945 & 23.876 & 23.808 & 23.740 & 23.672 & 23.604 & 23.535 & 23.467\end{array}$

0.283750

3827.0

7.0
$7:$
$7:$
$7:$
$7:$
$7:$
$7: 9$
70
7

26122.716

$22.716 \quad 22.648$

$\begin{array}{lll}82.579 & 22.511\end{array}$

$23.126 \quad 23.057$

$\begin{array}{llll}22.989 & 22.921 & 22.853 \quad 22,78\end{array}$

0.283749

0.283749

0.283748

0.283747

0.283746

0.283745

0.283745

0.283744

$19.304 \quad 19.236$

$\begin{array}{llllllllll}18.622 & 18.553 & 18.485 & 18.417 & 18.349 & 18.281 & 18 \cdot 212 & 18.144 & 18.076 & 18 \cdot 008 \\ 17.939 & 17.871 & 17.803 & 17.735 & 17.667 & 17.598 & 17.530 & 17.461 & 17.393 & 17.325 \\ 17.257 & 17.189 & 17.121 & 17.052 & 16.984 & 16.916 & 16.847 & 16.779 & 16.711 & 16.643\end{array}$

$19.850 \quad 19.782$

$\begin{array}{ll}19 \cdot 167 & 19 \cdot 09 \\ 18.485 & 18.417 \\ 17.803 & 17.73\end{array}$

$\begin{array}{ll}19 \cdot 713 & 19.645 \\ 19.031 & 18.963\end{array}$

$20.259 \quad 20.191 \quad 20.123 \quad 20.05$

$\begin{array}{llll}19.577 & 19.509 & 19.440 & 19 \cdot 372 \\ 18.895 & 18.826 & 18.758 & 18.690\end{array}$

$16.575 \quad 16.506$

$\begin{array}{ll}16.438 & 16.37\end{array}$

3828.

8.
8.
8.
8.
8.0
8.0
8.0
8.0

$26115.892 \quad 15.824 \quad 15.756$

$\begin{array}{llllll}15.822 & 15.824 & 15.756 & 15.688 & 15.620 & 15.55 \\ 14.528 & 15.142 & 15.074 & 15.006 & 14.937 & 14.86 \\ 14.460 & 14.392 & 14.323 & 14.255 & 14.18\end{array}$

$\begin{array}{llllll}13.846 & 13.778 & 13.709 & 13.641 & 13.573 & 13.505\end{array}$

$\begin{array}{llll}13.164 & 13.095 & 13.027 & 12.959\end{array}$

$12.482 \quad 12.413$

$\begin{array}{llll}11.800 & 11.731 & 11.663 & 11.595\end{array}$

$\begin{array}{ll}11.118 & 11.050 \\ 10.436 & 10.368\end{array}$

$\begin{array}{ll}11.663 & 11.595 \\ 10.981 & 10.913\end{array}$

$\begin{array}{ll}12.891 & 12.823 \\ 12.209 & 12.141\end{array}$

$\begin{array}{ll}12.209 & 12.141 \\ 11.527 & 11.459 \\ 10.845 & 10.777\end{array}$

$\begin{array}{lllll}16.847 & 16.779 & 16.711 & 16.643\end{array}$

0.283743

0.28374

0.283742

0.283741

0.283740

0.283739

0.283739

0.283738
0.283737

1.084608

.1 .084634

.084686

1.084738

1.084790

1.084842

1.084868

1.084894

1.084946

1.084998

1.085024

1.085076

.

.085128

1.085154
1.085180

1.085206

1.085232

1.085284

1.085336

1.085388

1.085414

1.085466

1.085492

1.085544

1.085596

1.085648

1.085674

1.085726

1.085752

1.085804

1.085804

.085856

1.085908

1.085934

1.085960

1.086012

1.086064

1.086090

1.086116

1.086168

1.086194

1.086246

1.086272

1.086324

1.086350

1.086376

3829.0

29.0
9.0
9.2
9.
9.5
9.6
9.7
9.9

26109.072

08.07209 .004

$08.936 \quad 08.867$

$\begin{array}{llllll}10.163 & 10.095 & 10.026 & 09.958 & 09.890 & 09.822\end{array}$

0.283737

1.086428

1.086454

1.086480

1.086532

0.283734

$\begin{array}{llllllllll}06.345 & 06.276 & 06.208 & 06.140 & 06.072 & 06.004 & 05.936 & 05.867 & 05.799 & 05.731\end{array}$

$\begin{array}{llllllllll}0.663 & 05.595 & 05.526 & 05.458 & 05.390 & 05.322 & 05.254 & 05.186 & 05.118 & 05.049\end{array}$

$\begin{array}{llllllllll}04.981 & 04.913 & 04.845 & 04.777 & 04.709 & 04.641 & 04.573 & 04.504 & 04.436 & 04.368\end{array}$

$\begin{array}{llllllllll}04.300 & 04.232 & 04.164 & 04.095 & 04.027 & 03.959 & 03.891 & 03.823 & 03.755 & 03.687\end{array}$

$\begin{array}{llllllllll}03.618 & 03.550 & 03.482 & 03.414 & 03.346 & 03.278 & 03.209 & 03.141 & 03.073 & 03.005 \\ 02.937 & 02.869 & 02.800 & 02.732 & 02.064 & 02.596 & 02.528 & 02.460 & 02.392 & 02.32\end{array}$

0.283732

1.086558

1.086584 
$\begin{array}{lllllllllll}3830.0 & 26102.255 & 02.187 & 02.119 & 02.051 & 01.983 & 01.914 & 01.846 & 01.778 & 01.710 & 01.642\end{array}$ $\begin{array}{lllllllllll}0.1 & 01.574 & 01.505 & 01.437 & 01.369 & 01.301 & 01.233 & 01.165 & 01.097 & 01.029 & 00.960 \\ 0.2 & 00.892 & 00.824 & 00.756 & 00.688 & 00.620 & 00.552 & 00.483 & 00.415 & 00.347 & 00.279\end{array}$ $0.3 \quad 00.211 \quad 00.143 \quad 00.074 \quad 00.006 * 99.938 * 99.870 * 99.802 * 99.734 * 99.666 * 99.598$ $\begin{array}{rrrrrrlllll}0.4 & 26099.530 & 99.461 & 99.393 & 99.325 & 99.257 & 99.189 & 99.121 & 99.052 & 98.984 & 98.916 \\ 0.5 & 98.848 & 98.780 & 98.712 & 98.644 & 98.575 & 98.507 & 98.439 & 98.371 & 98.303 & 98.235\end{array}$ $\begin{array}{lllllllllll}0.5 & 98.848 & 98.780 & 98.712 & 98.644 & 98.575 & 98.507 & 98.439 & 98.371 & 98.303 & 98.235 \\ 0.6 & 98.167 & 98.099 & 98.031 & 97.962 & 97.894 & 97.826 & 97.758 & 97.690 & 97.622 & 97.554\end{array}$

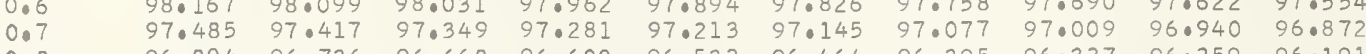
$\begin{array}{lllllllllll}0.8 & 96.804 & 96.736 & 96.668 & 96.600 & 96.532 & 96.464 & 96.395 & 96.327 & 96.259 & 96.191 \\ 0.9 & 96.123 & 96.055 & 95.987 & 95.919 & 95.851 & 95.782 & 95.715 & 95.646 & 95.578 & 95.510\end{array}$

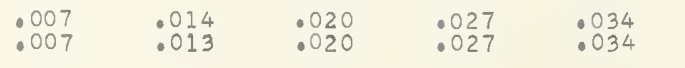

.006

0.283732

0.283730

0.283729

0.283728

0.283727

0.283726

0.283726

0.283725

0.283724

0.283724

0.283723

0.283723
0.283722

0.283721

0.283721

0.283719

0.283719
0.283719

0.283718

0.283718
0.283717

0.283717
0.283716

0.283716

0.283715
0.283714

0.283714

0.283713

0.283712

0.283711
0.283711

0.283710

0.283710

0.283708

0.283707
0.283706

0.283706

0.283705
0.283705

0.283704

0.283703

0.283703

0.283702

0.283701

0.283700

0.283700

0.283698

0.283698

0.283698
0.283697

0.283697

0.283696

0.283695

0.283694

0.283694

0.283693

0.283692

0.283692

0.283691

0.283690

0.283689

0.283689

0.283687

0.283686
0.283685

0.283685

0.283684

0.283683

0.283682
0.283682

0.283681

0.283681
0.283680

0.283679

0.283679

0.283678

0.283678

0.283677

0.283676

.086688

1.086740

1.086740
1.086766

1.086792

1.086844

1.086870

1.086896

1.086922

1.086948

.0086974

1.087000

1.087052

1.087078

1.087104

1.087156

1.087182

1.087208

1.087234

1.087260

1.087286

1.087312
1.087338

1.087364

1.087390

1.087416
1.087442

1.087468

1.087494

1.087520

1.087572

1.087598

1.087650

1.087676
1.087702

1.087728

1.087754
1.087780

1.087806

1.087832

1.087858

1.087884
1.087910

1.087936

1.087988

1.088040

1.088066

1.088092

1.088144

1.088170

1.088196

1.088248

1.088274

1.088300

1.088326

1.088352

1.088404

1.088430
1.088456

1.088456
1.088482

1.088508

1.088534

1.088560

1.088586

1.088638

1.088664

1.088690

1.088716
1.088742

1.088768

1.088794
1.088820

1.088846

1.088872

1.088898

1.088924

1.088950

1.0889002

$0.283675 \quad 1.089028$

$0.283674 \quad 1.089054$

$0.283674 \quad 1.089080$

$\begin{array}{ll}0.283673 & 1.089107 \\ 0.283673 & 1.089133\end{array}$

$0.283672 \quad 1.089159$

$0.283671 \quad 1.089185$

$\begin{array}{ll}0.283671 & 1.089211 \\ 0.283670 & 1.089237\end{array}$

$0.283670 \quad 1.089263$

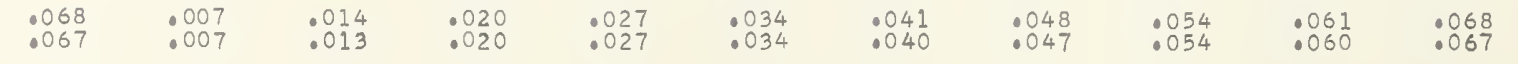


0.283669

0.283668

0.283667

283666

0.283665

283664

0.28366

.283662

0.283661
0.283660
0.2836

(

.283658

0.283658
0.283657

0.283657

0.283656
0.283655

.283655

0.283654
0.283653
0.2835

0.283652
0.283652

0.283651

0.283650

.283649

.283648

.283647

0.283646

0.283644

0.283644

0.283643

0.283641

0.283640

0.283639
0.283639

0.283638

0.283638

0.283636

0.283365

0.283635

0.283633

0.283632

0.283632

0.283630

0.283630

0.283628

0.283627
0.283627

0.283626

0.283625

0.283625
0.283624
0.283624

0.283624

0.283623

0.283622

0.283621

0.283620

0.283619

0.283618

0.283617

0.283617

0.283616

0.283616
0.283615

0.283614

0.283614

0.283613

0.283613
0.283612

0.283611

0.283611

0.283610
0.283610
0.283609

0.283610
0.283609

0.283608

1.089289

.089315

1.089367

1.089419

1.089471

1.089523

1.089549

1.089601

.089627

(1.089679

1.089731

1.089783

1.089809

1.089835

1.089861
1.08987

1.089913

1.089939
1.008965
1.09001

1.089991

1.090043

1.090069

1.090121

1.090173

1.090225

1.090251

1.090303

1.090329
1.090355

1.090381

1.090433

1.090459
1.090485

1.090511

1.090537
1.009563

1.090589

1.090615

1.090667
1.0090693

1.090719

1.090771

1.090797
1.090823

1.090849

10090875

1.090927

1.090979

1.091005

1.091031

1.091083

1.091109

1.091135

.091187

1.091239

1.091291

1.001317

1.091369

1.091395

1.091448

1.091474
1.091500

1.091526

1.091552

1.091578
1.091604

1.091630

1.091682

1.091708

1.091734
1.0091760

1.091786 


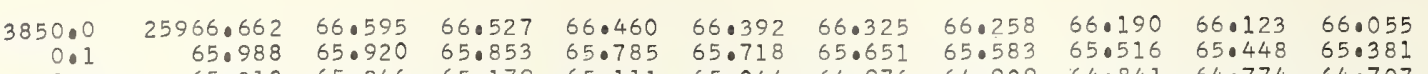

0.7

0.9

3851.

10

102

1.5

106

1.8

3852 .

$$
\begin{array}{r}
852.0 \\
2.01 \\
20.2 \\
2.03 \\
20.4 \\
20.5 \\
2.0 \\
2.07 \\
2.0 \\
2.0
\end{array}
$$

3853.0

然:

$3 \cdot 4$

3.6
3.7

3.8
3.9

3854 .

$4 \cdot 1$
4.2
4.3

$4 \cdot 3$
4.4

4.5
4.6

4.7
4.8
4.9

3855 .

5.1

5.3
5.4

$5 \cdot 5$

5.6
5.7

5.8
5.9

3856 .

6.1
6.2

6.3

6.3
6.4
6.5

6.6

6.7
6.8
6.9

3857 .

7.

7.6

7.8

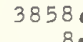

8.

8.2
8.3

8.5

8.6

8.7

8.8
8.9

3859.

9.1

9.2

9.3
9.4

9.5
9.6

9.7
9.8

9.8
9.9

$\begin{array}{llllllllll}65.313 & 65.246 & 65.179 & 65.111 & 65.718 & 65.651 & 65.583 & 65.516 & 65.448 & 65.381 \\ \end{array}$ $\begin{array}{llllllllll}64.639 & 64.572 & 64.504 & 64.437 & 64.369 & 64 \cdot 302 & 64 \cdot 234 & 64 \cdot 167 & 64 \cdot 100 & 64 \cdot 032\end{array}$

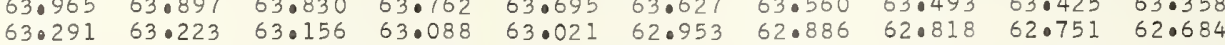
$\begin{array}{llllllllll}62.616 & 62.549 & 62.481 & 62.414 & 62.346 & 62.279 & 62.211 & 62.144 & 62.077 & 62.009\end{array}$ $\begin{array}{llllllllll}61.942 & 61.875 & 61.807 & 61.740 & 61.672 & 61.605 & 61.537 & 61.470 & 61.403 & 61.335\end{array}$ $\begin{array}{llllllllll}61.268 & 61.200 & 61.133 & 61.065 & 60.998 & 60.931 & 60.863 & 60.796 & 60.728 & 60.661 \\ 60.594 & 60.526 & 60.458 & 60.391 & 60.324 & 60.256 & 60.189 & 60.122 & 60.054 & 59.987\end{array}$

$\begin{array}{llllllllll}25959.919 & 59.852 & 59.784 & 59.717 & 59.650 . & 59.582 & 59.515 & 59 \cdot 448 & 59 \cdot 380 & 59.313\end{array}$ $\begin{array}{lllllllllll}59.245 & 59.178 & 59.111 & 59.043 & 58.976 & 58.908 & 58.841 & 58.773 & 58.706 & 58.639 \\ 58.571 & 58.504 & 58.437 & 58.369 & 58.302 & 58.234 & 58.167 & 58.099 & 58.032 & 57.965\end{array}$ $\begin{array}{llllllllll}57.897 & 57.830 & 57.762 & 57.695 & 57.628 & 57.560 & 57.493 & 57.426 & 57.358 & 57.291\end{array}$ $\begin{array}{llllllllll}57.223 & 57.156 & 57.088 & 57.021 & 56.954 & 56.886 & 56.819 & 56.752 & 56.685 & 56.617\end{array}$ $\begin{array}{llllllllll}56.550 & 56.482 & 56.415 & 56.347 & 56.280 & 56.213 & 56.145 & 56.078 & 56 \cdot 010 & 55.943\end{array}$ $\begin{array}{llllllllll}55.876 & 55.808 & 55.741 & 55.674 & 55.606 & 55.539 & 55.471 & 55.404 & 55.337 & 55.269 \\ 55.202 & 55.135 & 55.067 & 55.000 & 54.932 & 54.865 & 54.798 & 54.730 & 54.663 & 54.59\end{array}$ $\begin{array}{llllllllll}54.528 & 54.461 & 54.393 & 54.326 & 54.259 & 54.191 & 54.124 & 54.056 & 53.989 & 53.922\end{array}$

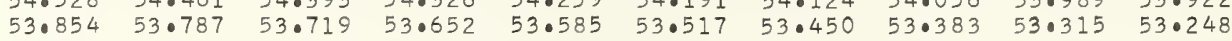

$\begin{array}{rlllllllll}25953.180 & 53.113 & 53.046 & 52.979 & 52.911 & 52.844 & 52.776 & 52.709 & 52.641 & 52.574 \\ 52.507 & 52.439 & 52.372 & 52.305 & 52.237 & 52.170 & 52.102 & 52.035 & 51.968 & 51.900\end{array}$

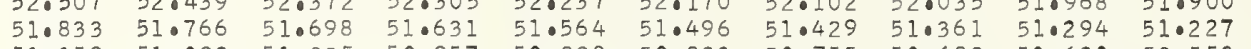
$\begin{array}{llllllllll}51.159 & 51.092 & 51.025 & 50.957 & 50.890 & 50.823 & 50.755 & 50.688 & 50.620 & 50.553\end{array}$ $\begin{array}{llllllllll}50.486 & 50.418 & 50.351 & 50.284 & 50.216 & 50.149 & 50.082 & 50.014 & 49.947 & 49.879\end{array}$ $\begin{array}{llllllllll}49.812 & 49.745 & 49.677 & 49.610 & 49.543 & 49.475 & 49.408 & 49.341 & 49.273 & 49.206\end{array}$ $\begin{array}{llllllllll}49.138 & 49.071 & 49.004 & 48.937 & 48.869 & 48.802 & 48.734 & 48.667 & 48.600 & 48.532\end{array}$ $\begin{array}{llllllllll}48.465 & 48.398 & 48.330 & 48.263 & 48.196 & 48.128 & 48.061 & 47.993 & 47.926 & 47.859\end{array}$ $\begin{array}{llllllllll}47.791 & 47.724 & 47.657 & 47.589 & 47.522 & 47.455 & 47.387 & 47.320 & 47.253 & 47.185 \\ 47.118 & 47.051 & 46.983 & 46.916 & 46.849 & 46.781 & 46.714 & 46.647 & 46.579 & 46.5112\end{array}$

$\begin{array}{llllllllll}25946.445 & 46.377 & 46.310 & 46.243 & 46.175 & 46.108 & 46.041 & 45 \cdot 973 & 45.906 & 45.839\end{array}$ $\begin{array}{llllllllll}45.771 & 45.704 & 45.636 & 45.569 & 45.502 & 45.435 & 45.367 & 45.300 & 45.233 & 45.165\end{array}$ $\begin{array}{llllllllll}45.098 & 45.031 & 44.963 & 44.896 & 44.829 & 44.761 & 44.694 & 44.626 & 44.559 & 44.492 \\ 44.425 & 44.357 & 44.290 & 44.223 & 44.155 & 44.088 & 44.021 & 43.953 & 43.886 & 43.819\end{array}$ $\begin{array}{llllllllll}43.751 & 43.684 & 43.617 & 43.549 & 43.482 & 43.415 & 43.347 & 43.280 & 43.213 & 43.146\end{array}$ $\begin{array}{llllllllll}43.078 & 43.011 & 42.943 & 42.876 & 42.809 & 42.741 & 42.674 & 42.607 & 42.539 & 42.472\end{array}$ $\begin{array}{llllllllll}42.405 & 42.337 & 42.270 & 42.203 & 42.135 & 42.068 & 42.001 & 41.933 & 41.866 & 41.79\end{array}$

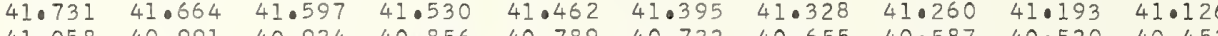
$\begin{array}{llllllllll}41.058 & 40.991 & 40.924 & 40.856 & 40.789 & 40.722 & 40.655 & 40.587 & 40.520 & 40.452 \\ 40.385 & 40.318 & 40.251 & 40.184 & 40.116 & 40.049 & 39.982 & 39.915 & 39.847 & 39.780\end{array}$ 39.040

$37.693 \quad 37.626$

$\begin{array}{ll}37.021 & 36.9 \\ 36.348 & 36.280\end{array}$

35.675
35.002
35.6

$\begin{array}{ll}34.329 & 34 \cdot 2 \\ 33.657 & 33 \cdot 5\end{array}$

25932.984

32.311
31.638

30.966
30.293

29.621

28.94828 .881

$\begin{array}{lll}28.276 & 28.881 & 28.8 \\ 28.14\end{array}$

27.603
26.931

25926.259

25.58926 .191

$\begin{array}{ll}25.586 & 25 \cdot 5 \\ 24.914 & 24 \cdot 847\end{array}$

$\begin{array}{ll}24.241 & 24 \cdot 17 \\ 23.570 & 23.5\end{array}$

$\begin{array}{llll}23.570 & 23.502 & 23.435 & 24.04 \\ 22.897 & 22.830 & 22.763 & 22.06\end{array}$

$\begin{array}{llll}22.225 & 22.158 & 22.763 & 22.69 \\ 22.091 & 22.024\end{array}$

$21.553 \quad 21.486 \quad 21.41$

$\begin{array}{ll}20.881 & 20.81 \\ 20.209 & 20.142\end{array}$

2501905

$25919.537 \quad 19.470$

$\begin{array}{lll}18.865 & 18.798 & 18.7\end{array}$

$\begin{array}{ll}17.521 & 17.454 \\ 16.849 & 16.7\end{array}$

$\begin{array}{ll}16.177 & 16.110 \\ 15.506 & 15.438\end{array}$

$\begin{array}{ll}14.834 & 14.76 \\ 14.162 & 14.095\end{array}$

$\begin{array}{ll}17.387 & 17.31 \\ 16.715 & 16.64\end{array}$

$\begin{array}{ll}16.0115 & 16.648 \\ 16.043 & 15.976 \\ 15.371 & 15.304\end{array}$

39.443
38.770

39.376

39.309

$39 \cdot 242$

$\begin{array}{ll}39.174 & 39.107 \\ 38.501 & 38.434\end{array}$

$\begin{array}{llllll}.097 & 38.030 & 37.963 & 37.896 & 37.828 & 37.761\end{array}$

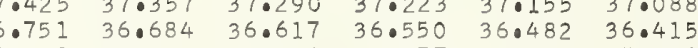

$\begin{array}{lllllll}36.079 & 36.011 & 35.944 & 35.877 & 35.809 & 35.742 \\ 35.406 & 35.339 & 35.271 & 35.204 & 35.137 & 35.069\end{array}$

$\begin{array}{llllll}34.733 & 34.666 & 34.598 & 34.531 & 34.464 & 34.396\end{array}$

340.06
33.307

34.666

$34 \cdot 531$

35.464

$34 \cdot 396$
$33 \cdot 724$

$12.810 \quad 12.751$

$12.147 \quad 12.080 \quad 12.684$

$\begin{array}{llllllllll}11.475 & 11.408 & 11.341 & 11.274 & 11.207 & 11.140 & 11.072 & 11.005 & 10.938 & 10.871\end{array}$ $\begin{array}{llllllllll}10.132 & 10.065 & 0.699 & 10.602 & 10.535 & 10.468 & 10.401 & 10.333 & 10.266 & 10.199\end{array}$ $\begin{array}{llllllllll}09.461 & 09.394 & 09.326 & 09.259 & 09.192 & 09.125 & 09.058 & 08.991 & 08.923 & 08.856\end{array}$ $\begin{array}{llllllllll}08.789 & 08.722 & 08.655 & 08.588 & 08.521 & 08.454 & 08.386 & 08.319 & 08.252 & 08.185\end{array}$ $\begin{array}{llllllllll}08.118 & 08.051 & 07.983 & 07.916 & 07.849 & 07.782 & 07.715 & 07.648 & 07.581 & 07.514\end{array}$ $\begin{array}{llllllllll}07.446 & 07.379 & 07.312 & 07.245 & 07.178 & 07.111 & 07.044 & 06.977 & 06.910 & 06.842 \\ 06.775 & 06.708 & 06.641 & 06.574 & 06.507 & 06.440 & 06.373 & 06.305 & 06.238 & 06.171\end{array}$

$\begin{array}{llllllllll}25906.104 & 06.037 & 05.970 & 05.903 & 05.835 & 05.768 & 05.701 & 05.634 & 05.567 & 05.500\end{array}$ $\begin{array}{lllllllllll}05.433 & 05.365 & 05.299 & 05.231 & 05.164 & 05.097 & 05.030 & 04.963 & 04.896 & 04.829\end{array}$ $\begin{array}{llllllllll}04.761 & 04.695 & 04.627 & 04.560 & 04.493 & 04.426 & 04.359 & 04.292 & 04.225 & 04.157 \\ 04.090 & 04.023 & 03.956 & 03.889 & 03.822 & 03.755 & 03.687 & 03.620 & 03.553 & 03.486\end{array}$

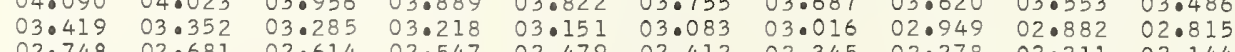

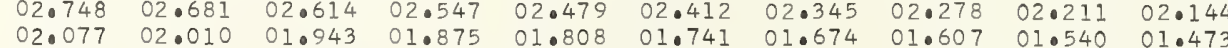

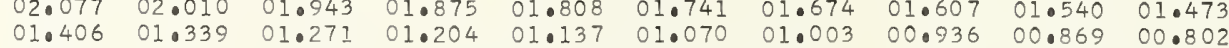

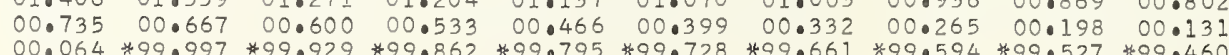

0.283608

0.283607

0.283607
0.283606

0.283605

0.283605

0.283604

0.283603

0.283602

0.283602

0.283601

0.283600

0.283599

0.283599
0.283598

0.283598
0.283597

0.283597

0.283596

.283595
0.283594

0.283594
0.283594

0.283593

0.283593

0.283592

0.283591

0.283590

0.283589

0.283588

0.283587

0.283586

0.283585
0.283584

0.283583

0.28358

0.283582

0.283582

0.283580

0.283580

0.283579

0.283578

0.283577

0.283577

0.283576

0.283575

0.283574

0.283574

0.283573

0.283573
0.283572

0.283571

0.283571

0.283570

0.283569

0.283569

0.283568
0.283567

0.283566

0.283565

0.283565

0.283564

0.283563

0.283562

0.283562

0.283561

0.283560

0.283559

0.283559

0.283558
0.283557

0.283557

0.283556

0.283556

0.283555

0.283554

0.283554

0.283553

.283552

0.283551

0.283551
0.283550

0

0.283549

0.283548

.010

1.091890

1.091916

1.091968

1.091994
1.092020

1.092046

1.092072

.092098
.092124

1.092150

.092202

1.092228

1.092254

.0922806

1.092332

1.092358

.092384

.092410

.092436

1.092462

1.092514

1.092540

1.092566

1.092592
1.092618

1.092644

1.092670

1.092696

1. 092722

1.092748

1.092774

1.092800

1.092826

1.002878

1. 092878

1.092930

1.092956

1.092983

1.093009

1.093061

1.093087

1.093113

1.093139

1.093191

1.093217

1.093243

1.093269

1.093321

1.093347

1.093373

1.093399
1.093425

1.093451 


0.0
0.1
0.2
0.3
0.4
0.5
0.6
0.7
0.8
0.9

$\begin{array}{llll}99.393 & 99.325 & 99.258 & 99.191 \\ 98.722 & 98.655 & 98.588 & 98.521 \\ 98.051 & 97.984 & 97.917 & 97.849 \\ 97.380 & 97.313 & 97.246 & 97.178 \\ 96.709 & 96.642 & 96.575 & 96.508 \\ 96.038 & 95.971 & 95.904 & 95.837 \\ 95.367 & 95.300 & 95.233 & 95.166 \\ 94.697 & 94.630 & 94.562 & 94.495 \\ 94.026 & 93.959 & 93.892 & 93.825 \\ 93.355 & 93.288 & 93.221 & 93.154\end{array}$

$\begin{array}{llllll}99.124 & 99.057 & 98.990 & 98.923 & 98.856 & 98.789 \\ 98.453 & 98.386 & 98.319 & 98.252 & 98.185 & 98.118\end{array}$

25892.685

92.68592 .618

$91.344 \quad 91.277$

$90.673 \quad 90.60$

$89.332 \quad 89.26$

$88.662 \quad 88.595-88.528$

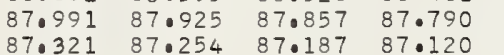

$86.651 \quad 86.584$

$97.782 \quad 97.715$

98.319
97.648

97.581

$\begin{array}{ll}98 \cdot 185 & 98.118 \\ 97.514 & 97.447\end{array}$

$\begin{array}{ll}97.112 & 97.044 \\ 96.441 & 96.374\end{array}$

$\begin{array}{rr}96.441 & 96.374 \\ 95.770 & 95.703\end{array}$

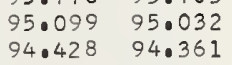

$96.307 \quad 96.240$

$95.636 \quad 95.56$

96.84

97.4476

$93.758 \quad 93.69$

$\begin{array}{llll}9.965 & 94.898 & 94.831 & 94.764\end{array}$

$\begin{array}{llll}93.624 & 93.557 & 93.490 & 93.422\end{array}$

0.283547

0.283546

0.283546

0.283545

0.283544

.283543

0.283542

0.28354

0.283540

0.28353

0.28353

0.283536

3862 .

$25885.980 \quad 85.913$

$85.846 \quad 85.780$

$87.053 \quad 86.986$

$88.260 \quad 88.193 \quad 88.126 \quad 88.050$

$\begin{array}{llll}87.589 & 87.522 & 87.455 & 87.388 \\ 86.919 & 86.852 & 86.785 & 86.718\end{array}$

0.83535

\begin{tabular}{llllllllll}
85.310 & 85.243 & 85.176 & 85.109 & 85.042 & 84.975 & 85.578 & 85.511 & 85.444 & 85.377 \\
\hline
\end{tabular}

$\begin{array}{llllllll}83.670 & 84.5405 & 84.238 & 84.171 & 84.104 & 84.037\end{array}$

$\begin{array}{llllllllll}83.970 & 83.13 & 83.836 & 83.769 & 83.702 & 83.635 & 83.568 & 83.501 & 83.434 & 83.367 \\ 83.300 & 83.233 & 83.166 & 83.099 & 83.032 & 82.965 & 82.898 & 82.83 .1 & 82.764 & 82.697\end{array}$

$82.630 \quad 82.563$

$81.959 \quad 81.893$

1023

$80.619 \quad 80.552$

(1.08

$82.429 \quad 82.362$

82.965

82.898
82.228

2.8

3863.0

3.

25879.280

$78.610 \quad 79 \cdot 21$

$\begin{array}{ll}77.940 & 77.873 \\ 77.270 & 77.203\end{array}$

$\begin{array}{ll}76.600 & 76.533 \\ 75.930 & 75.863\end{array}$

$\begin{array}{ll}75.930 & 75.863 \\ 75.261 & 75.194\end{array}$

$\begin{array}{ll}74.591 & 74.524 \\ 73.922 & 73.855\end{array}$

80.486
79.815

81.089
80.418

$81.692 \quad 81.62$

81.55

$\begin{array}{lll}82.160 & 82.094 & 82.027 \\ 81.490 & 81.424 & 81.356\end{array}$

$79.146 \quad 79.079 \quad 79.012 \quad 78.945$

$\begin{array}{llll}78.878 & 78.811 & 78.743 & 78.677 \\ 78.208 & 78.141 & 78.074 & 78.007\end{array}$

$\begin{array}{llllllll}77.806 & 77.739 & 78.342 & 78.275 & 78.208 & 78.141 & 78.074 & 78.007 \\ 77.672 & 77.605 & 77.538 & 77.471 & 77.404 & 77.337\end{array}$

$\begin{array}{llllllll}77.136 & 77.069 & 77.002 & 76.935 & 76.868 & 76.801 & 76.734 & 76.667 \\ 76.466 & 76.399 & 76.332 & 76.265 & 76.198 & 76.131 & 76.064 & 75.998\end{array}$

$75.796 \quad 75.72975 .66276 .265$

73.25273 .185

3864.0

4.0
$4 \cdot 1$
$4 \cdot 3$
$4 \bullet 4$
$4 \cdot 5$
4.6
4.7
4.9

$71.913 \quad 71.846$

$71.243 \quad 71.177$

$69.905 \quad 59.837$

69.23569 .168

$\begin{array}{ll}68.565 & 68.499 \\ 67.896 & 67.82\end{array}$

$\begin{array}{ll}67.227 & 67.160 \\ 66.558 & 66.491\end{array}$

75.060

3.78

$72.448 \quad 72.38$

74.993

$75 \cdot 595$
74.926

76.19
75.52

$75 \cdot 998$
75.328

$\begin{array}{llll}74.859 & 74.792 & 74.725 & 74.658\end{array}$

72.984

73.58
72.917

73.520

$\begin{array}{lll}73.453 & 74.056 & 73.989 \\ 73.386 & 73.319\end{array}$

$71.779 \quad 71.7$

$\begin{array}{ll}72.314 \\ 2 & 71.645 \\ 70.676\end{array}$

$72 \cdot 248$

72.181

$\begin{array}{lll}72.114 & 72.047 \quad 71.980\end{array}$

$\begin{array}{lllllll}71.042 & 70.976 & 70.908 & 70.842 & 70.774 & 70.708 & 70.641\end{array}$

$\begin{array}{llllllll}69.771 & 69.704 & 69.637 & 69.570 & 69.503 & 69.436 & 69.369 & 69.302\end{array}$

$\begin{array}{lllllllll}69.101 & 69.034 & 68.967 & 68.900 & 68.833 & 68.766 & 68.699 & 68.633\end{array}$

$68.365 \quad 68.29$

68.231
67.562

$\begin{array}{llll}68.164 & 68.097 & 68.030 & 67.963 \\ 67.495 & 67.428 & 67.361 & 67.294\end{array}$

$\begin{array}{llllllll}67.093 & 67.026 & 66.959 & 66.892 & 66.825 & 66.759 & 66.692 & 66.625\end{array}$

38650

5.
5.
5.
5.
5.5
5.0
50.7
5
5.

25865.888 65.21965 .821

$\begin{array}{ll}65.219 & 65.152 \\ 64.550 & 64.48\end{array}$

$\begin{array}{ll}63.881 & 63.814 \\ 63.212 & 63.145\end{array}$

$62.543 \quad 62.476$

$61.874 \quad 61.807$

$61.205 \quad 61.13$

$\begin{array}{ll}60.535 & 60.46 \\ 59.867 & 59.800\end{array}$

3866.0

6.

$58.529 \quad 58.462$

$57.860 \quad 57.793$

$57.191 \quad 57.125$

$55.854 \quad 56.456 \quad 56.3$

$\begin{array}{ll}55.854 & 55.787 \\ 55.186 & 55.118\end{array}$

$54.517 \quad 54.450$

$53.180 \quad 53.113$

$65.754 \quad 65.687$

6

0

$65.487 \quad 65.420 \quad 65 \cdot 353 \quad 65 \cdot 286$

$\begin{array}{lllllllll}65.085 & 65.018 & 64.951 & 64.885 & 64.818 & 64.751 & 64 \cdot 684 & 64.617\end{array}$

$\begin{array}{llllllll}63.747 & 63.680 & 63.613 & 63.546 & 63.479 & 63.412 & 63.345 & 63.279\end{array}$

$\begin{array}{lllllllll}63.078 & 63.011 & 62.944 & 62.877 & 62.810 & 62.743 & 62.676 & 62.610\end{array}$

$\begin{array}{llllllll}61.740 & 61.673 & 62.275 & 62.208 & 62.141 & 62.074 & 62.007 & 61.940 \\ & 61.606 & 61.539 & 61.472 & 61.405 & 61.338 & 61.271\end{array}$

$\begin{array}{llllllll}61.071 & 61.004 & 60.937 & 60.870 & 60.803 & 60.736 & 60.669 & 60.603\end{array}$

$\begin{array}{llllll}60.937 & 60.870 & 60.803 & 60.736 & 60.669 & 60.603 \\ 60.268 & 60.201 & 60.134 & 60.067 & 60.000 & 59.933\end{array}$

$59.733 \quad 59.666$

$\begin{array}{llllll}58.930 & 58.863 & 58.797 & 58.729 & 58.662 & 58.596\end{array}$

$\begin{array}{llllllll}8.395 & 58.328 & 58.261 & 58.195 & 58.128 & 58.061 & 57.994 & 57.927\end{array}$

$\begin{array}{lllllllll}57.058 & 56.991 & 56.924 & 56.857 & 56.790 & 56.724 & 56.657 & 56.590\end{array}$

$\begin{array}{llllllll}56.389 & 56.322 & 56.255 & 56.188 & 56.122 & 56.055 & 55.988 & 55.921\end{array}$

$\begin{array}{llllllll}55.720 & 55.654 & 55.587 & 55.520 & 55.453 & 55.386 & 55.319 & 55.252 \\ 55.052 & 54.985 & 54.918 & 54.851 & 54.784 & 54.717 & 54.651 & 54.584\end{array}$

$\begin{array}{llllllll}54.383 & 54.316 & 54.249 & 54.182 & 54.115 & 54.049 & 53.982 & 53.915\end{array}$

$\begin{array}{llllllll}4.383 & 54.316 & 54.249 & 54.182 & 54.115 & 54.049 & 53.982 & 53.915 \\ 3.714 & 53.647 & 53.581 & 53.514 & 53.447 & 53.380 & 53.313 & 53.246 \\ 3.046 & 52.979 & 52.912 & 52.845 & 52.779 & 52.712 & 52.645 & 52.578\end{array}$

$\begin{array}{llllllllll}5582.511 & 52.444 & 52.377 & 52.311 & 52.243 & 52.177 & 52.110 & 52.043 & 51.976 & 51.909\end{array}$

$51.843 \quad 51.776 \quad 51.709 \quad 51.642$

$\begin{array}{llllllllll}50.505 & 50.439 & 50.372 & 50.305 & 50.238 & 50.171 & 50.104 & 50.038 & 49.971 & 49.904\end{array}$

$\begin{array}{llll}49.837 & 49.770 \quad 49.703 \quad 49.637\end{array}$

$49.169 \quad 49.102 \quad 49.035 \quad 48.968$

$48.500 \quad 48.433 \quad 48.367 \quad 48.300$

$47.832 \quad 47.765$

$47.164 \quad 47.097 \quad 47.030 \quad 46.963$

$\begin{array}{rlll}45.827 & 45.760 \quad 45.694 \quad 45 \cdot 627\end{array}$

$45.159 \quad 45.092 \quad 45.025 \quad 44.958$

$44.491 \quad 44.424 \quad 44.357 \quad 44.291$

$43.823 \quad 43.756 \quad 43.689 \quad 43.622$

$42.487 \quad 42.420 \quad 42.353 \quad 42.286$

$41.819 \quad 41.752 \quad 41.685 \quad 41.618$

$41.151 \quad 41.084 \quad 41.017 \quad 40.950$

$\begin{array}{llll}40.483 & 40.417 & 40.350 & 40.283 \\ 39.815 & 39.749 & 39.682 & 39.615\end{array}$

49.57040 .503

$48.901 \quad 48.834$

$\begin{array}{lllllll}48.233 & 48.166 & 48.009 & 40.032 & 47.066 & 48.567\end{array}$

$\begin{array}{llllll}47.565 & 47.498 & 47.431 & 47.364 & 47.298 & 47.230\end{array}$

$\begin{array}{llllll}46.896 & 46.830 & 46.763 & 46.696 & 46.629 & 46.562 \\ 46.228 & 46.161 & 46.095 & 46.028 & 45.961 & 45.894\end{array}$

$\begin{array}{llllll}45.560 & 45.493 & 45.427 & 45.360 & 45.293 & 45.226\end{array}$

$\begin{array}{llllll}44.892 & 44.825 & 44.758 & 44 \cdot 691 & 44.625 & 44.558 \\ 44.224 & 44.157 & 44.090 & 44.023 & 43.957 & 43.890\end{array}$

$\begin{array}{llllll}44.224 & 44 \cdot 157 & 44.090 & 44 \cdot 023 & 43.957 & 43.890 \\ 43.556 & 43.489 & 43.422 & 43.355 & 43.288 & 43.221\end{array}$

$\begin{array}{llllll}42.887 & 42.821 & 42.754 & 42.687 & 42.620 & 42.554 \\ 42.220 & 42.153 & 42.086 & 42.019 & 41.952 & 41.885\end{array}$

$\begin{array}{llllll}42.220 & 42.153 & 42.086 & 42.019 & 41.952 & 41.885 \\ 41.552 & 41.485 & 41.418 & 41.351 & 41.284 & 41.218\end{array}$

$\begin{array}{llllll}41.552 & 41.485 & 41.418 & 41.351 & 41.284 & 41.218 \\ 40.884 & 40.817 & 40.750 & 40.683 & 40.617 & 40.550\end{array}$

$\begin{array}{lllllllllll}39.147 & 39.081 & 39.014 & 38.947 & 38.880 & 38.813 & 38.747 & 38.680 & 38.613 & 38.546\end{array}$

$\begin{array}{llllllllll}38.479 & 38.413 & 38.346 & 38.279 & 38.212 & 38.146 & 38.747 & 38.680 & 38.613 & 38.546\end{array}$

$\begin{array}{llllllllll}37.812 & 37.745 & 37.678 & 37.611 & 37.545 & 37.478 & 37.411 & 37.344 & 37.278 & 37.211\end{array}$

$\begin{array}{llllllllll}37.144 & 37.077 & 37.010 & 36.944 & 36.877 & 36.810 & 36.743 & 36.677 & 36.610 & 36.543\end{array}$

$\begin{array}{llllllllll}36.476 & 36.409 & 36.343 & 36.276 & 36.209 & 36.142 & 36.076 & 36.009 & 35.942 & 35.875\end{array}$

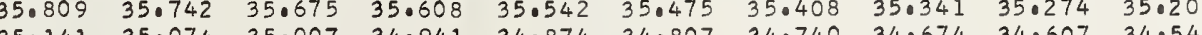

$35.141 \quad 35.074 \quad 35.00734 .94134 .874 \quad 34.807 \quad 34.740 \quad 3406740340607 \quad 34.540$

$34.473034 .40734 .340 \quad 34.273$ 34.206 $34.140 \quad 34.073 \quad 34.006 \quad 33.939073 .873$

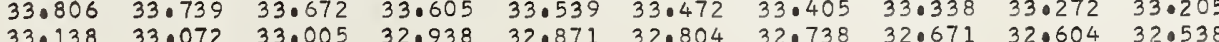

$\begin{array}{llll}.001 & .002 \quad .003 & .004 \quad .003\end{array}$

.004

.006

.007

$.604 \quad 32.538$

0.28353

0.28353

0.283531

0.28353
0.283530

0.283529

0.283528

0.283528
0.283527

0.283527

0.283526

0.283525
0.283525

0.283524

0.283523

0.283522

0.283521

0.283521
0.283520

0.283519

0.283518

0.283518

0.283517

0.283516

0.283516

0.283515
0.283515

0.283514

0.283513

0.283512
0.283512

0.283511

.283510

0.283509

0.283509

0.283508

0.283507

0.283506
0.283506

0.283505

0.283504

0.283503

0.283503

0.283502

0.283501

0.283500

0.283499

0.283498

0.283498

0.283497

0.283497

0.283496

0.283495

0.283494

0.283493

0.283492

0.283492

0.283491

0.283491
0.283490

0.283490

0.283489

0.283489

0.283488
0.283488

.094492

1.094518

1.094570

1.094622

1.094648

1.094700

1.094752

1.094778

1.094830

1.094882

1.0949

1.094934
1.094960

1.095012

1.095038

1.095090

1.095116

1.09516

1.095194
1.095220

1.095246

1.095273

1.095299
1.095325

1.095351

1.095377
1.095403

.095429

1.095481

1.095533 


$\begin{array}{rr}25832.471 & 32.404 \\ 31.803 & 31.736 \\ 31.136 & 31.069 \\ 30.468 & 30.402 \\ 29.801 & 29.734 \\ 29.134 & 29.067 \\ 28.466 & 28.399 \\ 27.799 & 27.732 \\ 27.132 & 27.065 \\ 26.465 & 26.398\end{array}$

32.337
31.670

$\begin{array}{lll}32.271 & 32.204 & 32.137 \\ 31.603 & 31.536 & 31.469\end{array}$

$\begin{array}{llll}32.070 & 32.003 & 31.937 & 31.870\end{array}$

$\begin{array}{llllllll}31.002 & 30.936 & 30.869 & 30.802 & 30.735 & 30.568 & 30.602 & 30.535\end{array}$

$\begin{array}{llllllll}30.335 & 30.268 & 30.201 & 30.135 & 30.068 & 30.001 & 29.934 & 29.867 \\ 29.667 & 29.601 & 29.534 & 29.467 & 29.401 & 29.334 & 29.267 & 29.200\end{array}$

$\begin{array}{llll}29.667 & 29.601 & 29.534 & 29.46\end{array}$

$29 \cdot 267$

29.200

0.6

0.8

3871.0

25825.797

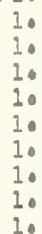

1.12
1.02
1.0

10.4

1.5
1.6
1.7

1. 8

3872 .

2.

2.3
2.4

2.4
2.5

2.6
2.7

2.8

3873.

3.1
3.2
3.3

3.3
3.4

3.5
3.5
3.7

3.8
3.9

3874

4.1
4.2
4.3

4.3
4.4

4.5

4.6

4.8
4.9

3875 .

5.1

5.3

5.4
5.5

5.7
5.8

5.

3876

6.1

6.3

6.5

6.6

6.7

6.9

3877

$7:$

$7 \cdot 3$

705

7.7
7.8

$25.730 \quad 25.730$

$\begin{array}{ll}23.796 & 23.730 \\ 23.129 & 23.063\end{array}$

$22.462 \quad 22.396$

$21.128 \quad 21.062$

$\begin{array}{ll}20.461 & 20.395 \\ 19.795 & 19.728\end{array}$

$25819.128 \quad 19.061$

$\begin{array}{ll}18.461 & 18.394 \\ 17.794 & 17.7\end{array}$

$\begin{array}{lll}17.127 & 17.051 & 17.651\end{array}$

$\begin{array}{lll}16.461 & 16.394 & 16.327 \\ 15.794 & 15.727 & 15.6\end{array}$

$\begin{array}{lll}15.128 & 15 \cdot 061 \\ 14.461 & 14.395\end{array}$

$\begin{array}{ll}13.794 & 13.728 \\ 13.128 & 13.061\end{array}$

$\begin{array}{llll}7.666 & 27.599 & 27.532 & 27.465\end{array}$

$\begin{array}{llll}28.066 & 27.999 & 27.933 & 27.866\end{array}$

$\begin{array}{llll}27.399 & 27.332 & 27.265 & 27.198 \\ 26.731 & 26.665 & 26.598 & 26.531\end{array}$

$\begin{array}{llll}26.331 & 26.264 & 26.198 & 26.13 \\ 25.564 & 25.597 & 25.531 & 25.46\end{array}$

25.397

25.998

$\begin{array}{llll}4.937 & 24.930 & 24.863 & 24.797 \\ 24.330 & 24.263 & 24.197 & 24.130\end{array}$

$\begin{array}{llll} & \end{array}$

$\begin{array}{llll}22.329 & 22.262 & 22.195 & 22.12 \\ 21.662 & 21.595 & 21.528 & 21.46\end{array}$

$\begin{array}{llll}20.995 & 21.595 & 21.528 & 21.462 \\ 20.928 & 20.862 & 20.795\end{array}$

24.730
24.063

$22.729 \quad 22.66$

$\begin{array}{llll}22.062 & 21.995 & 21.929 & 21.862 \\ 21.395 & 21.328 & 21.262 & 21.195\end{array}$

$\begin{array}{llll}20.728 & 20.661 & 20.595 & 20.528\end{array}$

$\begin{array}{ll}.328 & 20.261 \\ 9.661 & 19.595\end{array}$

$\begin{array}{ll}20.195 & 20.128 \\ 19.528 & 19.461\end{array}$

19.395

$\begin{array}{lll}19.328 & 19.261 & 19.195\end{array}$

$\begin{array}{llll}994 & 18.928 & 18.861 & 18.794\end{array}$

$18.728 \quad 18.66$

$18.594 \quad 18.528$

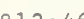

$11.795-12.39$

$\begin{array}{ll}11.128 & 11.06 \\ 10.462 & 10.396\end{array}$

$09.129 \quad 09.063$

$\begin{array}{lll}07.797 & 07.730\end{array}$

$\begin{array}{ll}07.131 & 07.064 \\ 06.465 & 06.398\end{array}$

25805.799

05.133

$03.801 \quad 03.400$

03.13503 .068

$\begin{array}{ll}02.469 & 02.402 \\ 01.803 & 01.736\end{array}$

$01.137 \quad 01.070$

00.47
25799.80

25799.13

99.073

$97.808 \quad 97.74$

$96.476 \quad 96.410$

$95.811 \quad 95.744$

$\begin{array}{ll}94.479 & 94.413 \\ 93.814 & 93.748 \\ 93.149 & 93.082\end{array}$

14.32

$16.927 \quad 17.528 \quad 17.461$

$\begin{array}{llll}7.394 & 17.328 & 17.261 & 17.194\end{array}$

$\begin{array}{llll}16.728 & 16.661 & 16.594 & 16.528 \\ 16.061 & 15.994 & 15.927 & 15.861\end{array}$

$\begin{array}{lll}15.594 & 15.527 & 15.46\end{array}$

$\begin{array}{llll}15.394 & 15.328 & 15.261 & 15.194\end{array}$

13.061
12.995

$14 \cdot 261$

$14.861 \quad 14.79$

$\begin{array}{llll}14.728 & 14.661 & 14.594 & 14.528\end{array}$

$12 \cdot 32$

$12 \cdot 26$

12.861

.461
.794

13.394
12.728

13.994

$13.261 \quad 13.195$

10.99

9.66209 .5

08.33
07.66

08.930
08.263

$11.528 \quad 12 \cdot 128$

12.062

11.995

12.595

12.528

$5792.483 \quad 92.417$

$\begin{array}{rl}91.818 & 91.7 \\ 91.152 & 91.086\end{array}$

$90.487 \quad 90.42$

$\begin{array}{llll}89.822 \quad 89.755 & 89.689 & 89.6 & \end{array}$

$\begin{array}{llll}89.157 & 89.090 \quad 89.024 & 88.95\end{array}$

$88.491 \quad 88.425$

$\begin{array}{ll}87.161 & 87.09 \\ 86.496 & 86.42\end{array}$

$\begin{array}{ll}88.358 & 88.292 \\ 87.693 & 87.627 \\ 87.028 & 86.961\end{array}$

785.83
85.16
84.5010

$84.501 \quad 84.099 \quad 85.033 \quad 84.96$

$\begin{array}{llll}83.836 & 83.769 & 83.703 & 84.30 \\ 83.73 .636\end{array}$

$\begin{array}{llll}82.506 & 82.104 & 83.038 & 82.971 \\ 82.373 & 82.306\end{array}$

$81.841 \quad 81.774 \quad 81.708 \quad 81.64$

$\begin{array}{lllll}80.511 & 80.445 & 80.378 & 80.312 & 80.24 \\ 79.846 & 79.780 & 79.713 & 79.647 & 79.580\end{array}$

3878.0

8.0
8.1
8.3
8.4
8.5
8.6
8.7
8.8
8.9

25779.18

78.51778 .917$.

$\begin{array}{llll}77.852 & 78.450 & 78.384 & 78.317\end{array}$

$\begin{array}{llll}77.187 & 77.121 & 77.054 & 76.98\end{array}$

$\begin{array}{llll}76.523 & 76.456 & 76.390 & 76.32 \\ 75.858 & 75.792 & 75.725 & 75.659\end{array}$

$\begin{array}{llll}75.194 & 75.127 & 75.061 & 74.994\end{array}$

$\begin{array}{llll}74.529 & 74.463 & 74.396 & 74.330 \\ 73.865 & 73.799 & 73.732 & 73.66 \\ 73.201 & 73.134 & 73.068 & 73.00\end{array}$

9.1
9.2
9.3
9.4
9.5
9.6
9.7
9.8
9.9

.2
.3
.4
.5
.6
.7
.88
.9

25772.

$\begin{array}{ll}72.536 & 72 \cdot 470 \\ 71.872 & 71 \cdot 805 \\ 71.207 & 71 \cdot 141\end{array}$

$\begin{array}{llll}71.014 & 71.739 & 71.672 & \\ 70.543 & 70.477 & 71.074 & 71.008\end{array}$

$\begin{array}{llll}69.879 & 69.812 & 70.410 & 70.34 \\ 69.746 & 69.679\end{array}$

$\begin{array}{llll}69.214 & 69.148 & 69.082 & 69.01 \\ 68.550 & 68.484 & 68.417 & 68.351\end{array}$

$67.886 \quad 67.820 \quad 67.753 \quad 67.687$

$\begin{array}{llll}67.222 & 67.156 & 67.089 & 67.022 \\ 66.558 & 66.491 & 66.425 & 66.359\end{array}$

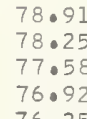

$8 \cdot 91$
$8 \cdot 25$
$7 \cdot 58$

$76.257-76.8550$

$\begin{array}{ll}75.592 & 75.52 \\ 74.928 & 74.86\end{array}$

$74.928 \quad 74 \cdot 861$

$\begin{array}{lll}3.599 & 73.533 & 74.1 \\ 73.566\end{array}$

$\begin{array}{lll}11.328 & 11.928 & 11.862\end{array}$

$1.262 \quad 11.195$

0.92010 .529

09.196

09.196
08.530

$\begin{array}{llll}.730 & 08.663 & 08.596 & 08.530 \\ .063 & 07.997 & 07.930 & 07.864 \\ 0.398 & 07.331 & 07.264 & 07.198\end{array}$

$\begin{array}{llll}07.398 & 07.331 & 07.264 & 07.198 \\ 06.731 & 06.565 & 06.598 & 06.531\end{array}$

05.399

05.99

05.932

5.86

0.283487

0.283486

0.283485

0.283484

0.283483

0.283483

0.283482

0.283481

0.283480

0.283479

0.283479

0.283478

0.283477

0.283476

0.283475

0.283474

0.283474

0.283473

0.283473

0.283471

0.283470

0.283469

0.283468

0.283468

0.283466

0.283464
0.283464

0.283463

0.283462

0.283462

0.283461

0.283461

0.283460

0.2845

0.283459

0.283458
0.283458

0.283457

0.283456

0.283456

0.283455
0.283455

0.283454

0.283454

0.283453

0.283452
0.283452

0.283451

0.283451

0.283450

0.283449

0.28344

0.283448

0.283447

0.283446

0.283446

0.283445

0.283445

0.283443

0.283443

0.283442

0.283442

0.283441

0.283440

0.283439

0.283439

0.283438

0.283437

0.283436

0.283436

0.283435

0.283434

0.283433

0.283433

0.283432

0.283431

0.283431

0.283430

0.283430

0.283429

0.283429

.010

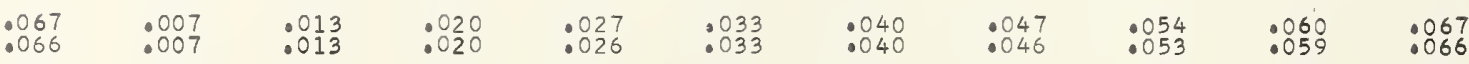




政

0.283421

0.283420
0.28341

0.28341

0.283417

$\begin{array}{ll}0.283415 & 1.100219 \\ 0.28315 & 1.10245 \\ 0.28314 & 1.100271 \\ 0.283414 & 1.100297 \\ 0.28313 & 1.100323 \\ 0.28313 & 1.100349 \\ 0.283412 & 1.100375 \\ 0.283111 & 1.100401 \\ 0.283411 & 1.100427 \\ 0.283410 & 1.100453\end{array}$

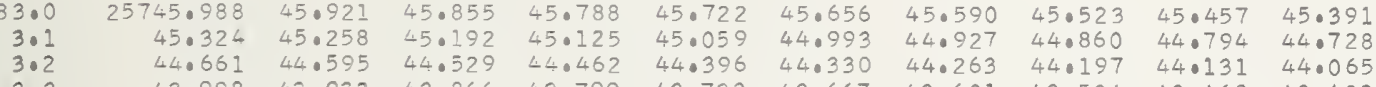

$\begin{array}{lllll}3.3 & 43.998 & 43.932 & 43.866 & 43.79\end{array}$

$\begin{array}{lllll}3.4 & 43.335 & 43.269 & 43.203 & 43.13 \\ 3.5 & 42.673 & 42.606 & 42.540 & 42.47\end{array}$

$\begin{array}{llll}3.5 & 42.673 & 42.606 & 42.540 \\ 3.6 & 42.010 & 41.943 & 41.87\end{array}$

3.7

$41.347 \quad 41.281$

$\begin{array}{llll}41.347 & 41.281 & 21.21 & 41.148 \\ 40.684 & 40.618 & 40.552 & 40.486 \\ 40.022 & 39.956 & 39.889 & 39.823\end{array}$

43.733

$43.070 \quad 43.000$

$\begin{array}{llll}44.263 & 44.197 & 44.131 & 44.065 \\ 43.501 & 43.534 & 43.468 & 43.402\end{array}$

$\begin{array}{llllll}42.407 & 42.341 & 42.275 & 42.208 & 42.142 & 42.076 \\ 41.745 & 41.678 & 41.612 & 41.546 & 41.479 & 410413\end{array}$

3884.0

40
402
40
40
40
40
40
40
40

3885.0

885.0

5.2
5.3
5.4

$5 \cdot 5$

5.6
5.7

5.7
5.8
5.9

$\begin{array}{rrrrrrrrrrr}3889.0 & 25706.267 & 06.201 & 06.135 & 06.069 & 06.003 & 05.937 & 05.871 & 05.805 & 05.739 & 05.672 \\ 9.1 & 05.606 & 05.540 & 05.474 & 05.408 & 05.342 & 05.276 & 05.210 & 05.144 & 05.078 & 05.011\end{array}$

$\begin{array}{lllllllllll}9.1 & 05.606 & 05.540 & 05.474 & 05.408 & 05.342 & 05.276 & 05.210 & 05.144 & 05.078 & 05.011 \\ 9.2 & 04.945 & 04.879 & 04.813 & 04.747 & 04.681 & 04.615 & 04.549 & 04.483 & 04.417 & 04.351\end{array}$

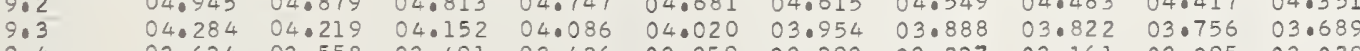

$\begin{array}{lllllllllll}9.4 & 03.624 & 03.558 & 03.491 & 03.426 & 03.359 & 03.293 & 03.227 & 03.161 & 03.095 & 03.029\end{array}$

$\begin{array}{lllllllllll}9.5 & 02.963 & 02.896 & 02.831 & 02.765 & 02.698 & 02.632 & 02.566 & 02.500 & 02.434 & 02.368\end{array}$

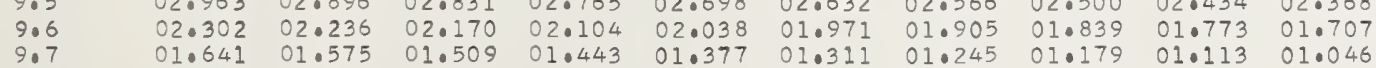

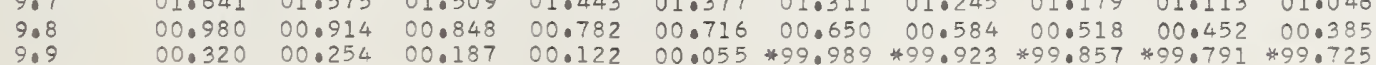

0.283409

0.283407

0.283407

0.028340

0.283405
0.283404

0.283404

0.283403
0.283402

0.283402

0.283401

0.283400

0.283399

0.283398

0.283397

0.283396

0.283395

0.283394

0.283393

0.283392

0.283391

0.283391
0.283390

0.283389

0.283389
0.283388

0.283388

0.283387
0.283386

0.283386

0.283385

0.283384

0.283384
0.283383

0.283382

0.28338

0.283380

0.283379

0.283378

0.283378
0.283377

0.283376

0.283376

0.283375

0.283374

0.283374

0.283372

0.283372

0.283371

0.283371
0.283370

0.283369
0.283369

1.100479
1.100505

1.100557

10100583

1.100635

1.100688

1.100740

1.100766

1.100792

1.100844

1.100896

1.100922

1.100948

1.101000

1.101026

1.101078

1.101130

1.101156

1.101182

1.101261

$1 \cdot 101287$

1.101313

1.101365

$1 \cdot 101391$

1.101443

1.101495

$1 \cdot 101521$

1.101573

1.101599

$1: 101625$

1.101677

1.101703

1.101755

1.101781 $1 \cdot 101807$

1.101860

1. 101886

$1 \cdot 101912$

1.101964

1.:101990

1.102042

1.102068
1.102094

1.102120

1.102146

1.102172

1. 102224

1.102250
1.102276

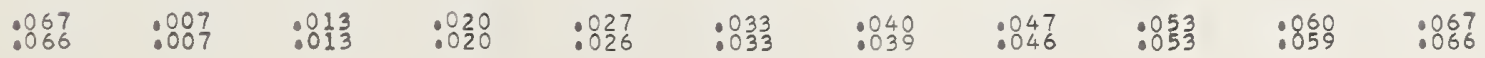




\subsection{1
0.2
0.3
0.4
0.5
0.6
0.7
0.8
0.9}

3891.

1.

3892.0

2.

2.3

2.4

2.6
2.7

2.8

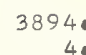

4.1
4.2
4.3
4.04

4.4
4.5

$4 \cdot 6$
$4 \cdot 7$

4.8
4.9

38950

5.2

$5 \cdot 3$

5.5

5.6

5.8

3896.0

6.1

$6 \cdot 2$

6.4

6.5

6.7

6.8
6.9

3897.0

$7 \cdot 2$

7.5

7.7
$7 \bullet 8$
7.9

3898 .

$8 \cdot 1$
8.2
8.3

8.8

3899.

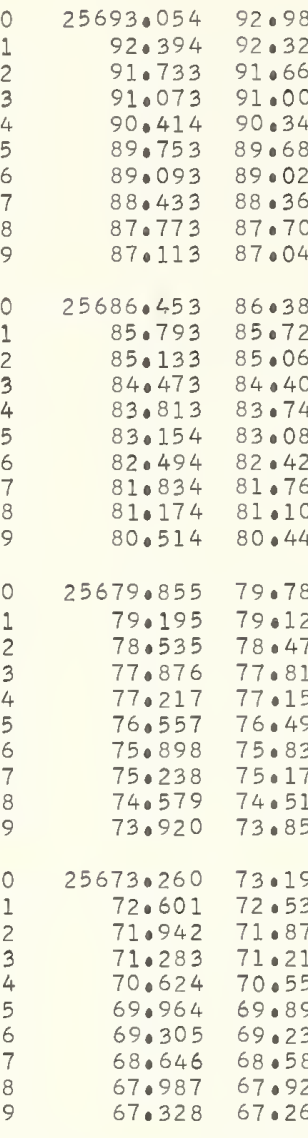

$\begin{array}{ll}98.998 & 98.932 \\ 98.338 & 98.272\end{array}$

$97.677 \quad 97.611$

$\begin{array}{ll}96.356 & 96.290 \\ 95.696 & 95.630\end{array}$

$95.035 \quad 94.969$

94.37594 .30

$98.866 \quad 98.46$

$98.206 \quad 98$.

96.88496 .81

$95.563 \quad 95.497$

94.903
94.243
93.58

94.837
94.177

92.922

292.856

91.60

90.94
90.28

89.621
88.961

92.196

90.875
90.216

90.216
89.555
88.895

88.301

88.235

$\begin{array}{lll}99.395 & 99.329 & 99.263 \\ 98.734 & 98.668 & 98.602\end{array}$

$\begin{array}{llllll}98.073 & 98.008 & 97.941 & 97.875 & 97.809 & 97.743 \\ 97.413 & 97.347 & 97.281 & 97.215 & 97.149 & 97.083\end{array}$

$\begin{array}{llllll}96.092 & 96.026 & 95.620 & 96.554 & 96.488 & 96.422\end{array}$

$\begin{array}{llllll}95.431 & 95.365 & 95.299 & 95.233 & 95.167 & 95.101\end{array}$

$\begin{array}{llllll}94.771 & 94.705 & 94.639 & 94.573 & 94.507 & 94.441\end{array}$

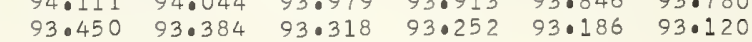

$\begin{array}{llllll}92.790 & 92.724 & 92.658 & 92.592 & 92.526 & 92.460\end{array}$

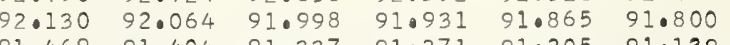

$\begin{array}{rlllll}90.810 & 91.404 & 91.337 & 91.271 & 91.205 & 91.139 \\ 90.744 & 90.677 & 90.612 & 90.545 & 90.479\end{array}$

$\begin{array}{llllll}90.149 & 90.083 & 90.018 & 89.951 & 89.885 & 89.819\end{array}$

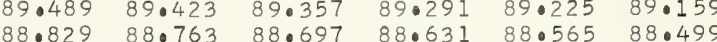

$88.829 \quad 88.763 \quad 88.697 \quad 88.631 \quad 88.565 \quad 88.499$

$\begin{array}{lll}87.509 & 87.443 & 87.377\end{array}$

$87.971 \quad 87.905 \quad 87.839$

86.321

186.255

$86 \cdot 189$

$\begin{array}{ll}85.661 & 85.595 \\ 85.001 & 84.935\end{array}$

$84.341 \quad 84.275$

83.022

82.362
81.702

82.956
82.296
81.636

$\begin{array}{ll}86.123 & 86.057 \\ 85.463 & 85.397\end{array}$

$\begin{array}{lll}84.869 & 84.803 & 85.397 \\ 84.209 & 84.143 & 84.737 \\ 83.077\end{array}$

$\begin{array}{lll}83.549 & 83.143 & 84.077 \\ 82.890 & 82.823 & 83.417\end{array}$

$\begin{array}{lll}82.890 & 82.823 & 82.758 \\ 82.230 & 82.164 & 82.09\end{array}$

$\begin{array}{lll}82.230 & 82.164 & 82.098 \\ 81.570 & 81.504 & 81.438\end{array}$

79.59179 .52

$79.723 \quad 79.65$

$\begin{array}{ll}79.063 & 78.997 \\ 78.404 & 78.338\end{array}$

$\begin{array}{lll}78.991 & 79.525 & 79.459\end{array}$

$\begin{array}{lll}78.931 & 78.865 & 78.800 \\ 78.272 & 78.206 & 78.140\end{array}$

$\begin{array}{ll}77.012 & 77.54 \\ 76.953 & 76.887\end{array}$

$\begin{array}{ll}76.293 & 76.22 \\ 75.634 & 75.56\end{array}$

74.974

74.50
74.90
74.249

$\begin{array}{llll}76.821 & 76.755 & 76.689 & 76.623\end{array}$

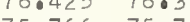

$106 \quad 75.040$

$\begin{array}{ll}74.447 & 74.381 \\ 73.788 & 73.722\end{array}$

73.65

$\begin{array}{ll}73.129 & 73.063 \\ 72.469 & 72.404 \\ 71.810 & 71.744\end{array}$

$\begin{array}{ll}72.0 \\ 4 & 72 \\ 4 & 7100 \\ 5 & 7100 \\ 67 & 70.3\end{array}$

72.
$71:$
71
70
69
69
68
67
67

72.93

72.93
72.27
71.61

70.492

69.17
68.51

$68.514 \quad 68.448$

$67.196 \quad 67 \cdot 130$

\begin{abstract}
166.406
\end{abstract}
970.953

70.294
69.635

68.976
68.317

67.65
66.99

.161

$\begin{array}{ll}61 & 76 \\ 02 & 75 \\ 43 & 74\end{array}$

$\begin{array}{lll}76.755 & 76.689 & 76.623\end{array}$

$75.370 \quad 75.304$

7.71174 .645

74.645
73.986
73.326

$72 \cdot 865$

$73 \cdot 45$

3.392

72.667

$\begin{array}{llll}.206 & 72.140 & 72.074 & 72.008\end{array}$

$\begin{array}{llll}70.887 & 70.821 & 70.755 & 70.689\end{array}$

$\begin{array}{llll}70.228 & 70.162 & 70.096 & 70.030\end{array}$

$\begin{array}{llll}68.910 & 68.844 & 68.778 & 68.712 \\ 68.251 & 68.185 & 68.119 & 68.053\end{array}$

$\begin{array}{ll}65.537 & 66.47 \\ 65.879 & 65.81 \\ 65.220 & 65.15\end{array}$

$\begin{array}{ll}65.747 \\ 4 & 65.08 \\ & 64.0429\end{array}$

$66 \cdot 340$
65.681

66.933

$\begin{array}{lll}67.526 & 67.460 & 67.394 \\ 66.867 & 66.801 & 66.735\end{array}$

$\begin{array}{ll}4.561 & 64.495 \\ 3.902 & 63.836\end{array}$

$\begin{array}{ll}63.243 & 63.17 \\ 62.584 & 62.51\end{array}$

64.42964 .363

66.27
65.61
64.956

$66 \cdot 20$

66.14

66.076

$66.549 \quad 65.483$
65.417

$\begin{array}{lll}4.890 & 64.824 & 64.758 \\ 4.231 & 64.165 & 64.099\end{array}$

$.506 \quad 63.441$

$\begin{array}{ll}1.584 & 62.51 \\ 1.926 & 61.86 \\ 1.267 & 61.20\end{array}$

$63.111 \quad 63.045 \quad 62.979$

$\begin{array}{ll}62.452 & 62.387 \\ 61.794 & 61.72\end{array}$

$\begin{array}{ll}60 & 61 \\ 01 & 61 \\ 42 & 60\end{array}$

$\begin{array}{ll}.794 & 61.72 \\ 1.135 & 61.06 \\ 0.476 & 60.4\end{array}$

$62.321 \quad 62 \cdot 255 \quad 62 \cdot 189 \quad 62 \cdot 123$

$60.608 \quad 60.542$

$59.818 \quad 59.75$

$61 \cdot 003$
60.345

$\begin{array}{lll}61.596 & 61.530 & 61.464 \\ 60.937 & 60.872 & 60.806\end{array}$

$\begin{array}{llllllll}59.291 & 59.225 & 59.159 & 59.093 & 59.028 & 58.962 & 58.896 & 58.830\end{array}$

$\begin{array}{llllllll}58.632 & 58.566 & 58.501 & 58.435 & 58.369 & 58.303 & 58.237 & 58.171\end{array}$

$\begin{array}{llllllll}57.974 & 57.908 & 57.842 & 57.776 & 57.710 & 57.645 & 57.579 & 57.513 \\ 57.315 & 57.250 & 57.184 & 57.118 & 57.052 & 56.987 & 56.921 & 56.855\end{array}$

$\begin{array}{llllllll}56.657 & 56.591 & 56.525 & 56.459 & 56.394 & 56.328 & 56.262 & 56.196 \\ 55.999 & 55.933 & 55.867 & 55.801 & 55.735 & 55.669 & 55.604 & 55.538\end{array}$

$\begin{array}{llllllll}5.940 & 55.933 & 55.867 & 55.801 & 55.735 & 55.669 & 55.604 & 55.538 \\ 55.340 & 55.274 & 55.209 & 55.143 & 55.077 & 55.011 & 54.945 & 54.879\end{array}$

$\begin{array}{llllllll}55.340 & 55.274 & 55.209 & 55.143 & 55.077 & 55.011 & 54.945 & 54.879 \\ 54.682 & 54.616 & 54.550 & 54.484 & 54.418 & 54.353 & 54.287 & 54.221 \\ 54.024 & 53.958 & 53.892 & 53.826 & 53.760 & 53.695 & 53.629 & 53.563\end{array}$

0.283368

0.283368

0.283366

0.283366

0.283365

.283365

0.283363

0.283363

0.28336

0.283362

0.283361

0.283360

0.283359

0.283359

0.283358
0.283358

0.283358
0.283357

0.283356

0.283356

0.283355

0.283354

0.283354

0.283353

0.283352

0.283352
0.283351

0.283351

0.283350

0.283349

0.283349
0.283348

0.283348

0.283347

0.283346

0.283346
0.283345

0.283345

0.283344

0.283343
0.283342

0.283342

0.283341

0.283341

0.283340
0.283339

0.283339

0.283338
0.283338

0.283337

0.283336

0.283336

0.283335
0.283335

0.283335
0.283334
0.0283334

0.283334
0.283334

0.283333

0.283332
0.283332

0.283332

0.283331

0.283331

0.283330

0.283329

0.283327

0.283327

0.283326

0.283324

0.283324

0.283323

0.283322
0.283322

0.283321

0.283321

0.283320

0.283320

0.283318

0.283318

0.283317

0.283317

0.283315

0.283315

0.283314

0.283314

0.283313

0.283312

0.283312

0.283311

0.283311
0.283310

.010

.066
.065

1.102302

$1: 102328$

1. 102380

1.102406

. 102459

1.102485

1.102511

1.102563

1.102589

1. 102641

1.102667

1.102693

$1 \cdot 102719$

1.102771

1.102823

$1 \cdot 102849$

1. 102901

$1 \cdot 102927$

- 102980

1.103006

1.103032
1.103058

1.103084

1.103110 
0.0
0.1
0.2
0.3
0.4
0.5
0.6
0.7
0.8
0.9

$\begin{array}{llllllllll}33.107 & 33.698 & 33.633 & 33.567 & 33.501 & 33.435 & 33.370 & 33.304 & 33.238 & 33.172 \\ 32.449 & 32.384 & 32.975 & 32.909 & 32.844 & 32.778 & 32.712 & 32.646 & 32.581 & 32.515\end{array}$ $\begin{array}{llllllllll}32.449 & 32.384 & 32.318 & 32.252 & 32.187 & 32.121 & 32.055 & 31.990 & 31.924 & 31.858 \\ 31.792 & 31.727 & 31.661 & 31.595 & 31.530 & 31.464 & 31.398 & 31.332 & 31.266 & 31.201\end{array}$ $\begin{array}{llllllllll}31.135 & 31.069 & 31.004 & 30.938 & 30.872 & 30.806 & 30.741 & 30.675 & 30.609 & 30.544 \\ 30.478 & 30.412 & 30.347 & 30.281 & 30.215 & 30.149 & 30.084 & 30.018 & 29.952 & 29.887\end{array}$ $\begin{array}{llllllllll}29.821 & 29.755 & 29.689 & 29.62 .4 & 29.5158 & 29.149 & 30.084 & 30.018 & 29.952 & 29.887 \\ & 29.492 & 29.427 & 29.361 & 29.295 & 29.229\end{array}$ $\begin{array}{llllllllll}29.821 & 29.755 & 29.689 & 29.62 .4 & 29.558 & 29.492 & 29.427 & 29.361 & 29.295 & 29.229 \\ 29.164 & 29.098 & 29.032 & 28.967 & 28.901 & 28.835 & 28.770 & 28.704 & 28.638 & 28.573\end{array}$ $\begin{array}{llllllllll}28.507 & 28.441 & 28.0375 & 28.967 & 28.901 & 28.835 & 28.770 & 28.704 & 28.638 & 28.573 \\ 28.310 & 28.244 & 28.178 & 28.113 & 28.047 & 27.981 & 27.916\end{array}$ 3901.0

0.283310

0.283308

0.283307

0.283306

0.283305

0.283304

0.283303
0.283303

0.283302
0.283301

0.283301
0.283300

0.283300

0.283299
0.283298

0.283298

0.283297

0.283296

0.283295

0.283294

0.283293

0.283292

0.283291

0.283290

0.283289

0.283289

0.283287
0.283287

0.283286

0.0 .283286

.283285

0.283284
0.283283

0.283283

0.283282
0.283281

0.283280

0.283280

0.283279

0.283278

0.283277
0.283276
0.283276

0.283276
0.283275

0.283275

0.283274
0.283273
0.283273

0.283273

0.283272

0.283271

0.283271

0.283270
0.283269

0.283269

0.283268

0.283268

0.283266

0.283266

0.28326

0.283264

0.283264

0.283263

0.283262

0.283261

0.283251

0.283260

0.283260
0.283259

0.283258

0.283257

0.283257

0.283256

0.283255

0.283254

0.283254

0.283253

0.283252

1.104907

1.104959

1.105012

1.105038

$1: 105090$

1.105142

2.105168

.105220

1.105272

1.105324

1.105376

1.105428

1.105481

1.105533

1.105585

1.105637

1.105689

1.105715

1.105767

1.105819

1.105871

1. 105923 
$\begin{array}{lllllllllll}3910.0 & 25568.206 & 68.141 & 68.075 & 68.010 & 67.944 & 67.879 & 67.813 & 67.748 & 67.683 & 67.617\end{array}$

$\begin{array}{lllllllllll}0.1 & 67.552 & 67.487 & 67.421 & 67.356 & 67.291 & 67.225 & 67.160 & 67.094 & 67.029 & 66.964 \\ 0.2 & 66.898 & 66.833 & 66.768 & 66.702 & 66.637 & 66.571 & 66.506 & 66.440 & 66.375 & 66.310\end{array}$

$\begin{array}{lllllllllll}0.3 & 66.244 & 66.179 & 66.114 & 66.048 & 65.983 & 65.917 & 65.852 & 65.787 & 65.721 & 65.656\end{array}$

0.5

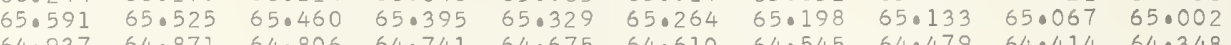
$\begin{array}{llllllllll}64.937 & 64.871 & 64.806 & 64.741 & 64.675 & 64.610 & 64.545 & 64.479 & 64.414 & 64.348 \\ 64.283 & 64.218 & 64.152 & 64.087 & 64.021 & 63.956 & 63.891 & 63.825 & 63.760 & 63.695\end{array}$

1
$1: 2$
1
1
1
1
1
10
2.
2
2
2
2
2
2
2
2

3
4

6

8

$$
\begin{array}{llllll}
61.015 & 60.949 & 60.884 & 60.819 & 60.753 & 60 \\
60.361 & 60.296 & 60.230 & 60.165 & 60.100 & 60 \\
59.708 & 59.643 & 59.577 & 59.512 & 59.447 & 59 . \\
59.054 & 58.989 & 58.924 & 58.858 & 58.793 & 58.7
\end{array}
$$

3917.0

$$
\begin{aligned}
& 7.1 \\
& 7.2 \\
& 7.3
\end{aligned}
$$

7.02

7.04

7067

3918.

8.1
8.2
8.9
8.4
8.5
8.6
8.7
8.9

3919.0

$9: 1$
$9: 2$
$9: 3$

9.03

9.5

9.6

9.8
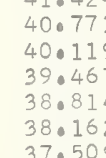

36.85
36.20

25535.552
34.900

34.248
33.596

32.944
32.292

31.640
30.98

30.33
29.68

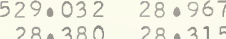

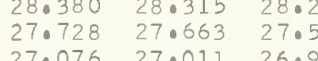

$\begin{array}{llll}26.424 & 27.011 & 26.946 & 26 \cdot \\ 26.359 & 26.024 & 26\end{array}$

$\begin{array}{lll}25.772 & 25.707 & 25.64 \\ 25.121 & 25.055 & 24.99 \\ 24.469 & 24.404 & 24.033\end{array}$

$$
46 \quad 41.881
$$$$
\begin{array}{ll}
81 \\
.81 \\
28 & 41.16 \\
.575 & 0.510
\end{array}
$$$$
\begin{array}{llllll}
41.815 & 41.750 & 41.685 & 41.620 & 41.554 & 41.489 \\
41.163 & 41.097 & 41.032 & 40.967 & 40.902 & 40.836
\end{array}
$$$$
\begin{array}{llllll}
40.510 & 40.445 & 40.380 & 40.314 & 40.249 & 40.184 \\
3.858 & 39.793 & 39.728 & 390662 & 30.597 & 30.532
\end{array}
$$

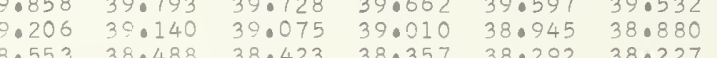$$
\begin{array}{llllll}
38.553 & 38.488 & 38.423 & 38.357 & 38.292 & 38.0227 \\
37.901 & 37.936 & 37.770 & 37.705 & 37.640 & 37.575
\end{array}
$$

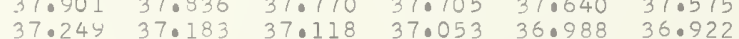$$
\begin{array}{llllll}
36.556 & 36.531 & 36.466 & 36.400 & 36.335 & 36.270
\end{array}
$$$$
\begin{array}{lllllll}
35.292 & 35.226 & 35.161 & 35.096 & 35.031 & 34.966 \\
3 & 34.920 & 34.574 & 34.500 & 34.0444 & 34.370 & 3.313
\end{array}
$$

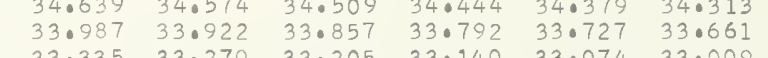$$
\begin{array}{llllll}
33.335 & 33.270 & 33.205 & 33.140 & 33.074 & 33.009 \\
32.683 & 32.618 & 32.553 & 32.487 & 32.022 & 32.357
\end{array}
$$

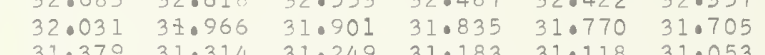$$
\begin{array}{llllll}
31.327 & 31.014 & 31.249 & 31.083 & 31.118 & 310.053 \\
30.727 & 30.662 & 30.596 & 30.531 & 30.466 & 300401
\end{array}
$$$$
\begin{array}{llllll}
30.075 & 30.010 & 29.944 & 29.879 & 29.814 & 29.0449 \\
29.423 & 29.358 & 29.292 & 29 \cdot 227 & 20.162 & 29.097
\end{array}
$$$$
23.166
$$

$25522.515 \quad 22.449$

$$
\begin{aligned}
& 21.863 \\
& 21.211 \\
& 20.560
\end{aligned}
$$$$
\begin{array}{llll}
20.560 & 20.495 & 21.081 & 21.016 \\
& 19.00 & 20.36
\end{array}
$$$$
19.909 \quad 19.84
$$$$
18.606 \quad 18.541
$$

17.95
17.30
16.65

25516.000 $516.000 \quad 15.935$

$\begin{array}{ll}15.349 & 15.026 \\ 14.698 & 14.66 \\ 14.047 & 13.98\end{array}$

12.74512 .679

$11.442 \quad 11.37$

$\begin{array}{ll}10.792 & 10.727 \\ 10.141 & 10.075\end{array}$

\section{$25509.490 \quad 09.425 \quad 09.360$}

08.83908 .773

$\begin{array}{lll}0.8188 & 08.123 \\ 07.537 & 07 & 0.1272\end{array}$

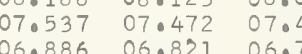

$06.235 \quad 06.170$

$05.585 \quad 05.520$

$04.934 \quad 04.86$
$04.284 \quad 04.21$

$03.633 \quad 03.021904: 1503$

\section{$\begin{array}{lll}36 & 28.771 & 28.706 \\ 84 & 28.119 & 28.054 \\ 532 & 28.067 & 27.402\end{array}$}

$\begin{array}{ll}27.467 & 27.0402 \\ 26.815 & 26.750\end{array}$

\subsection{0 .447}

24.860
24.208 24.79
24.14

24.143
23.492
22.840
28.641

$27 \cdot 337$

26.685 26.033 25.73
24.078 24.730
23.078
23.427 23.427 $\begin{array}{lll}28.575 & 28.510 & 28.445 \\ 27.923 & 27.858 & 27.793\end{array}$ $27 \cdot 272277 \cdot 207 \quad 27 \cdot 141$ $25.968 \quad 25.903 \quad 25 \cdot 838$ $\begin{array}{lll}25.316 & 25 \cdot 251 & 25.186 \\ 24.665 & 24.000 & 24.534\end{array}$ $24 \cdot 013 \quad 23 \cdot 948 \quad 23 \cdot 883$ $23 \cdot 361223 \cdot 296 \quad 23 \cdot 231$ $\begin{array}{llllll}2.254 & 22.189 & 22.124 & 22.059 & 21.993 & 21.928 \\ 1.602 & 21.537 & 21.472 & 21.407 & 21.342 & 21.277\end{array}$ $\begin{array}{llllll}21.602 & 21.537 & 21.472 & 21.407 & 21.342 & 21.277 \\ 20.951 & 20.886 & 20.821 & 20.756 & 20.690 & 20.625\end{array}$ $\begin{array}{llllll}20.299 & 20.234 & 20.069 & 20.104 & 20.039 & 19.974 \\ 19.648 & 19.583 & 19.518 & 19.452 & 19.387 & 19.322\end{array}$ $\begin{array}{llllll}18.997 & 18.931 & 18.866 & 18.801 & 18.736 & 18.671\end{array}$ $\begin{array}{llllll}17.694 & 18.280 & 18 \cdot 215 & 18 \cdot 150 & 18.085 & 18.020 \\ 17.029 & 17.563 & 17.499 & 17.433 & 17.368\end{array}$ $\begin{array}{llllll}17.042 & 16.977 & 16.912 & 16.847 & 16.782 & 16.717\end{array}$ $\begin{array}{lllllll}15.740 & 15.675 & 15.610 & 15.545 & 15.479 & 15.414 \\ 15.089 & 15.024 & 14.958 & 14.893 & 14.828 & 14.763\end{array}$ $\begin{array}{llllll}14.437 & 14.373 & 14.307 & 14.242 & 14.177 & 140112\end{array}$ $\begin{array}{llllll}13.135 & 13.070 & 13.005 & 12.940 & 12.875 & 12.810\end{array}$ $\begin{array}{llllll}12.484 & 12.419 & 12.354 & 12.289 & 12.224 & 12.159 \\ 11.833 & 11.768 & 11.703 & 11.0638 & 11.573 & 11.508\end{array}$ $\begin{array}{lllllll}11.182 & 11.117 & 11.052 & 10.987 & 10.922 & 10.857\end{array}$ $\begin{array}{llllll}0.531 & 10.466 & 10.401 & 10.336 & 10.271 & 10.206 \\ 9.880 & 09.815 & 09.750 & 09.685 & 09.620 & 09.555\end{array}$ $\begin{array}{llllll}09.229 & 09.164 & 09.099 & 09.034 & 08.969 & 08.904\end{array}$ $\begin{array}{llllll}08.578 & 08.513 & 08.448 & 08.383 & 08.318 & 08.253\end{array}$ $\begin{array}{lllllll}07.928 & 07.863 & 07.797 & 07.732 & 07.667 & 07.602 \\ 07.277 & 07.212 & 07.146 & 07.082 & 07.016 & 06.051\end{array}$ $\begin{array}{lllllll}06.626 & 06.561 & 06.496 & 06.431 & 06.366 & 06.301\end{array}$ $\begin{array}{llllll}05.976 & 05.910 & 05.845 & 05.780 & 05.715 & 05.650 \\ 05.325 & 05.260 & 05.195 & 05.130 & 05.065 & 05.000\end{array}$ $\begin{array}{lllllll}04.674 & 04.609 & 04.544 & 04.0479 & 04.414 & 04.3\end{array}$ $\begin{array}{llllll}4.023 & 03.958 & 03.893 & 03.828 & 03.763 & 03.698 \\ 0.373 & 03.308 & 03.243 & 03.178 & 03.113 & 03.048\end{array}$

$$
\begin{gathered}
.001 \quad .002 \\
.033056803 .00
\end{gathered}
$$$$
.002
$$

0.283251 0.283251 0.283250
0.283250 0.283249 0.283249 0.283248
0.283247 0.283247 0.283246

0.283246 0.283245 0.283244 0.283243 .283243 0.283242 0.283241 0.283241
0.283240

0.283240 0.283239 0.283239 0.283238 0.283237 0.283236 0.283236 0.283235

0.283234 0.283234 0.283233 0.283232
0.283232 0.283231 0.283231 0.283230 0.283229

\subsection{8} 0.283228 0.283227 0.283227 0.283226 0.283225 0.283224 0.283224

0.283223 0.283222 0.283221 0.283221 0.283220 0.283219 0.283219 0.283218

0.283217 0.283216 0.283215 0.283214
0.283214 0.283214 0.0283213 0.283213 0.283212

0.283211 0.283210 0.283210 0.283209 0.283208 0.283208 0.283207 0.283206 0.283205 0.283205 0.283204
0.283204 0.283203 0.283202 0.283202 0.283201
0.283201 0.283200

0.283200 0.283199
0.283198 0.283198 0.283197 0.283197
0.283196 0.283195 0.283195 0.283194

.010

1.107513 1.107539 $1: 107565$ 107617 1.107669 1.107695 


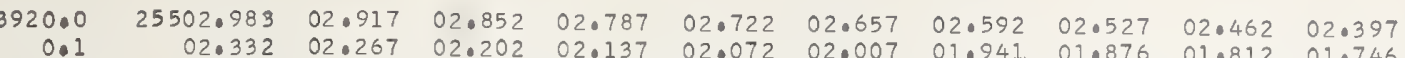

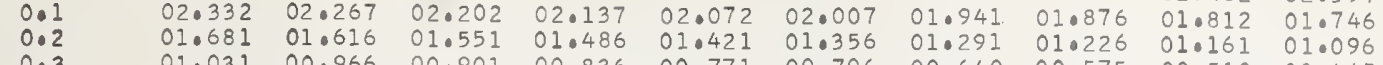

$\begin{array}{lllllllllll}0.2 & 0.031 & 00.966 & 00.901 & 00.836 & 00.771 & 00.706 & 00.640 & 01.226 & 01.161 & 01.096 \\ 0.4 & 00.380 & 00.315 & 00.250 & 00.185 & 00.120 & 00.055 & * 99.990 & 00.510 & 00.445 \\ 0.4 & 0.99 .925 & * 99.860 & * 99.795\end{array}$

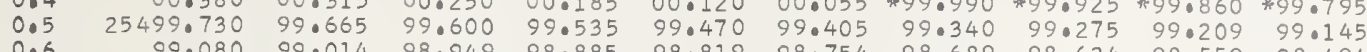

$\begin{array}{lllllllllll}0.6 & 99.080 & 99.014 & 98.949 & 98.885 & 98.819 & 98.754 & 98.689 & 98.624 & 98.559 & 98.494 \\ 0.7 & 98.429 & 99.364 & 98.299 & 98.234 & 98.169 & 98.104 & 98.039 & 07.974 & 97.909 & 97.044\end{array}$

$\begin{array}{lllllllllll}0.7 & 98.429 & 98.364 & 98.299 & 98.234 & 98.169 & 98.104 & 98.039 & 97.974 & 97.909 & 97.844 \\ 0.8 & 97.779 & 97.714 & 97.649 & 97.584 & 97.519 & 97.454 & 97.389 & 97.324 & 97.259 & 97.193\end{array}$

0.283193

0.283192

0.283190

0.28319

0.283189
0.283189

3921.

$25496.478 \quad 960413$

96.99896 .934

96.86

0.283188

$\begin{array}{lll}1.1 & 95.828 & 95.763 \\ 1.2 & 95.178 & 95.113\end{array}$

$\begin{array}{ll}95.178 & 95.113 \\ 94.528 & 94.463\end{array}$

$93.878 \quad 93.812$

$92.577 \quad 92.512$

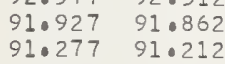

$95.698 \quad 95.633$

96.218

96.15
95.503

96.088

$\begin{array}{ll}94.397 & 94.333 \\ 93.747 & 93.682\end{array}$

$94.918 \quad 94.853$

$93.098 \quad 93.032$

$93.61793 .552 \quad 93.137$

$96.023 \quad 95.958 \quad 95.893$

0.283187

10

1.7
1.8
1.9

$90.627 \quad 90.562$

$92.448 \quad 92.382$

$\begin{array}{lll}92.967 & 92.902 & 92.83\end{array}$

$91.667 \quad 91.602$

$\begin{array}{llll}25489.977 & 89.912 & 89.847 & 89.78\end{array}$

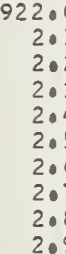

$91.017 \quad 90.952$

91.537

94.07
93.42

94.658
94.008

94.593

0.283186

0.283185

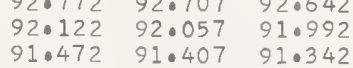

0.283183

0.283182

$\begin{array}{lllll}2.1 & 89.327 & 89.262 & 89.198 & 89.13 \\ 2.2 & 88.678 & 88.613 & 88.548 & 88.48\end{array}$

$\begin{array}{ll}89.718 & 89.65 \\ 89.068 & 89.00\end{array}$

$86.728 \quad 86.664$

$87.898 \quad 87.833$

$\begin{array}{lll}88.418 & 88.353 & 88.938\end{array}$

$\begin{array}{lll}90.822 & 90.757 & 90.692 \\ 90.172 & 90.107 & 90.042\end{array}$

1. 110172

$\begin{array}{lllll}87.010 & 87.248 & 87.183 & 87.118 & 87.053\end{array}$

$\begin{array}{llll}84.779 & 84.714 & 84.649 & 84.58 \\ 84.130 & 84.065 & 84.000 & 83.93\end{array}$

$\begin{array}{lll}89.522 & 89.457 & 89.392 \\ 88.873 & 88.808 & 88.743\end{array}$

0.28318

0.28318

3923.
3.
30
30
30
30
30
3.
30
3.

$25483.480 \quad 83.415$

$82.831 \quad 82.766$

$83.350 \quad 83.285$

85.16
84.52

85.104

85.039

$87.573-87.158 \quad 88.093$

0.283180

$86.274 \quad 86.209 \quad 86.144$

0.283179

0.283178

$\begin{array}{llll}82.181 & 82.116 & 82.051 & 81.98\end{array}$

$81.531 \quad 81.467$

80.233

$\begin{array}{lll}17 & 80.752 & 80.687\end{array}$

$\begin{array}{llll}80.233 & 80.168 & 80.103 & 80.038 \\ 79.583 & 79.518 & 79.453 & 79.388\end{array}$

78.284
77.635

78.86

5476.986

39240

40

78.155
77.505

83.220

83.80

$\begin{array}{lll}84.325 & 84.260 & 8.4 .195\end{array}$

0.28317

0.283176
0.283175

0.283174

0.283173

0.28317

0.283171

0.283170

.283169

0.283168

0.28316

$\begin{array}{lll}4.04 & 73.740 & 73.675 \\ 4.6 & 73.091 & 73.02 \\ 4.7 & 72.442 & 72.377\end{array}$

$\begin{array}{lll}4.8 & 71.793 & 71.72 \\ 4.9 & 71.144 & 71.07\end{array}$

72.961

71.66
71.014

3925.

5.0
5.1
5.2
5.3
5.4
5.5
5.6
5.7
5.8
5.9

25470.495

$\begin{array}{rrrrrrrrrrr}5.0 & 25470.495 & 70.430 & 70.366 & 70.301 & 70.236 & 70.171 & 70.106 & 70.041 & 69.976 & 69.911 \\ 5.1 & 69.846 & 69.781 & 69.717 & 69.652 & 69.587 & 69.522 & 69.457 & 69.392 & 69.327 & 69.262 \\ 5.2 & 69.198 & 69.133 & 69.068 & 69.003 & 68.938 & 68.873 & 68.808 & 68.743 & 68.678 & 68.614\end{array}$

$70.366 \quad 70.30$

72.18

72.766

$\begin{array}{rr}73.000 & 73.935 \\ 73.351 & 73.286 \\ 72.701 & 72 \cdot 636\end{array}$

73.870073080

$\begin{array}{ll}73.221 & 73 \cdot 156 \\ 72.572 & 72.507\end{array}$

1.110250

1.110302

1.110354

$1 \cdot 110380$

1.110432

$1 \cdot 110484$

68.54968 .484

$67.900 \quad 67.835$

$\begin{array}{ll}67.251 & 67.186 \\ 66.603 & 66.537\end{array}$

$\begin{array}{ll}68.419 & 68.354 \\ 67.770 & 67.705\end{array}$

67.121

$67.640 \quad 67.575$

$5.6 \quad 66.603$

$65.305 \quad 65.240$

$65.873 \quad 66.408$

66.34366 .27

67.511

$\begin{array}{lll}67.446 & 67.381 & 67.316\end{array}$

0.283165

0.283165

0.283163

0.283163

0.283162

0.283161

0.283160

0.283159

0.283159

0.28315

0.283157

0.283156

0.283155
0.283154

.110563

1.110641

$\begin{array}{lllllllllll}6.1 & 63.359 & 63.294 & 63.229 & 63.165 & 63.100 & 63.035 & 62.970 & 62.905 & 62.840 & 62.775\end{array}$

$\begin{array}{lllllllllll}6.3 & 62.062 & 61.997 & 61.932 & 61.867 & 61.803 & 61.738 & 61.673 & 61.608 & 61.543 & 61.478\end{array}$

$\begin{array}{lllllllllll}6.4 & 61.414 & 61.349 & 61.284 & 61.219 & 61.154 & 61.089 & 61.025 & 60.959 & 60.895 & 60.830 \\ 6.5 & 60.765 & 60.700 & 60.635 & 60.571 & 60.506 & 60.441 & 60.376 & 60.311 & 60.246 & 60.181\end{array}$

$\begin{array}{lllllllllll}6.6 & 60.117 & 60.052 & 59.987 & 59.922 & 59.857 & 59.792 & 59.728 & 59.663 & 59.598 & 59.533 \\ 6.7 & 59.468 & 59.404 & 59.339 & 59.274 & 59.209 & 59.144 & 59.079 & 59.015 & 58.950 & 58.885\end{array}$

$\begin{array}{lllllllllll}6.8 & 58.820 & 58.755 & 58.690 & 58.625 & 58.561 & 58.496 & 58.431 & 58.366 & 58.301 & 58.237 \\ 6.9 & 58.172 & 58.107 & 58.042 & 57.977 & 57.912 & 57.847 & 57.783 & 57.718 & 57.653 & 57.588\end{array}$

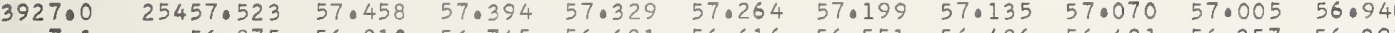

0.283154

0.283153

0.283153

0.283151

0.283151

0.283150

0.283149

0.283148

0.283147

0.283147
0.28314

0.283146

0.283145

0.28314

0.28314

0.283142

0.283142

0.283141

0.283140

0.283139

0.283139

0.283138

0.283138

0.283137

.110902

1.110928

1.110980

1.111058

1.11108

1.111136

1.11116

111214

111241

1.111293

1. 11137

1.111423

1.111475

1.111527

1.11157

1.11163

1.111684

1.111710

10111762

1.111814

1.111866

1.111918

$11-944$

1.111997

1.112049

1.112075

1.112127

1.112153

1.112205

1. 112225

1. 112283

1.112336

1.112362

$1 \cdot 112414$

1.112466

1. 112492

1. 112544

1.112570
1.112596

1. 112622

1. 112649

1.112701

.010

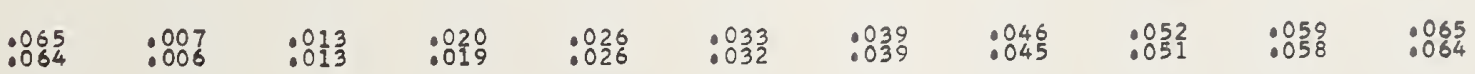




360

37.961
37.314
36.667
36.020

$\begin{array}{ll}37.897 & 37.832 \\ 37.249 & 37.185 \\ 36.602 & 36.538\end{array}$

$37 \cdot 767$
$37 \bullet 120$
$36 \cdot 473$

$\begin{array}{llll}37.703 & 37.638 & 37.573 & 37.509\end{array}$ $\begin{array}{llllllllll}36.149 & 36.084 & 36.020 & 35.955 & 35.890 & 35.825 & 35.761 & 35.696 & 35.631 & 35.567\end{array}$

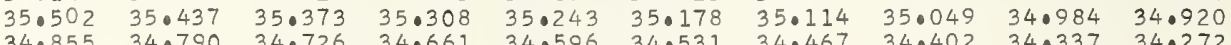
$\begin{array}{llllllllll}34.208 & 34.143 & 34.078 & 34.014 & 33.949 & 33.885 & 33.820 & 33.755 & 33.690 & 33.625\end{array}$ $\begin{array}{llllllllll}33.561 & 33.496 & 33.431 & 33.367 & 33.302 & 33.237 & 33.072 & 33.108 & 33.043 & 32.078\end{array}$ $\begin{array}{llllllllll}32.914 & 32.849 & 32.784 & 32.719 & 32.655 & 32.590 & 32.525 & 32.461 & 32.396 & 32.331\end{array}$

$$
\begin{array}{rl}
24.505 & 24.440 \\
23.859 & 23.794 \\
23.212 & 23.147 \\
22.566 & 22.501 \\
21.919 & 21.854 \\
21.273 & 21.208 \\
20.626 & 20.562 \\
19.980 & 19.916 \\
19.334 & 19.269
\end{array}
$$

0.283137

0.283136

0.283135

0.283134

0.283133

0.283133

0.283131

0.283131

0.283130

0.283130

0.283129

0.283128

0.283127

0.283127
0.283126

0.283126

0.283125

0.283125

0.283123

0.283122

0.283121

0.283121

0.283120

0.283119
0.283118
0.283118

0.283118

0.283117

0.283116

0.283115

0.283114

0.283114

0.283113

0.283112

0.283112

0.283111

0.283110

0.283109

0.283108

0.283108

0.283107
0.283106

0.283106

0.283105

0.283105

0.283104

0.283104

0.283102

0.283102

0.283101

0.283100

0.283100

0.283100

0.283099

0.283098
0.283097

0.283097

0.283096

0.283096

0.283095

0.283095

0.283093

0.283093

0.283092
0.283092

0.283091

0.283091
0.283090

0.283089

0.283089
0.283088

0.283088

0.283087

0.283087
0.283086

1.112727

1. 1127579

1. 112831

:.112883

1.112909

1.112935

1.112987 1.113014

- 113040

1.113092

1.113118

1.113170

1.113196
1.113222

1.113248

1.113274

1.113326

1.113353

1. 113379

1. 113431

1.113457
1.113483

1.113509

1.113535

1.113561
1.113587

1. 113613

1.113639

I. 113665

1.113718

1.113770

10113796 


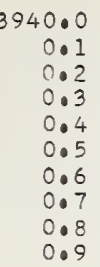

$\begin{array}{rrr}0.0 & 25373.529 & 73.464 \\ 0.1 & 72.885 & 72.820 \\ 0.2 & 72.240 & 72.176 \\ 0.3 & 71.596 & 71.532 \\ 0.4 & 70.953 & 70.888 \\ 0.5 & 70.309 & 70.245 \\ 0.6 & 69.665 & 69.601 \\ 0.7 & 69.021 & 68.957 \\ 0.8 & 68.378 & 68.313 \\ 0.9 & 67.734 & 67.670\end{array}$

73.400
72.756
72.112
71.468
70.824
70.180
69.537
68.893
68.249
67.605

73.335
72.691
72.047

72

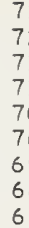

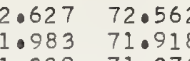

$3941 \cdot 0$

$1: 1$

1. 3

1.0

1.6

1. 8

66.962
66.318

80365.73

$64.516 \quad 64.451$

$63.873 \quad 63 \cdot 80$

$62.585 \quad 62.521$

$61.942 \quad 61.87$

65.674

$65.031 \quad 64.966$

$64.387 \quad 64.323$

$63.100 \quad 63.036$

$\begin{array}{ll}62.457 & 62.392 \\ 61.813 & 61.749\end{array}$

3942 .

$2 \cdot 1$

$2 \cdot 3$

2.4
2.5
2.6

2.8

3943.0
3.1
3.2
3.
3.4
3.5
3
3.7
3.8
3.9

3944
4
4
4
40
40
405
406
407
408
409

39450

$$
\begin{array}{r}
3945.0 \\
5 \bullet 1 \\
5 \bullet 2 \\
5: 3 \\
505 \\
5 \bullet 6 \\
507 \\
50 \\
5.9
\end{array}
$$

5.0
5.1
5.2
5.3
5.4
5.5
5.6
5.7
5.8
5.9

39460

$$
\begin{aligned}
& 3 \\
& 6 \\
& 60 \\
& 6.3 \\
& 60 \\
& 6.5 \\
& 6.6 \\
& 6.7 \\
& 6.8 \\
& 6.9
\end{aligned}
$$

3947

47.0
7.1
7.2
7.3
7.4
7.5
7.6
7.7
7.8
7.9

60.01260 .59

$59.369 \quad 59.304$

$58.725 \quad 58.66$

$\begin{array}{ll}57.439 & 57.375\end{array}$

$56.796 \quad 56.731$

$55.509 \quad 55.445$

$54.867 \quad 54.802$

$25354 \cdot 22$

$53.58+54 \cdot 15$

$53.517 \quad 53.45$

$52.295 \quad 52.231 \quad 52.167$

$\begin{array}{lll}51.652 & 51.588 & 51.5 \\ 51.009 & 50.945 & 50.8\end{array}$

$\begin{array}{lll}50.366 & 50.302 & 50.238\end{array}$

$49.081 \quad 49.017$

47.15
46.510

48.37

45.225

$4.582 \quad 44.51$

$42.655 \quad 42.59$

61.170

60.527
59.883

$.240-59.176$

$8.597 \quad 58.532$

$57.310 \quad 57.246$

$6.024 \quad 55.960$

$5.381 \quad 55.316$

25341.37

$40.728 \quad 41.306$

41.306
40.663
40.021
39.379

$\begin{array}{ll}39.443 & 39.37 \\ 38.801 & 38.73\end{array}$

$\begin{array}{lll}38.030 & 37.966\end{array}$

$\begin{array}{llll}38.516 & 37.452 & 37.388 & 37.324 \\ 36.874 & 36.810 & 36.746 & 36.68\end{array}$

$\begin{array}{llll}36.232 & 36.168 & 36.104 & 36.04\end{array}$

$35.591 \quad 35.526$

$\begin{array}{ll}6.104 & 36.040 \\ 5.462 & 35.398\end{array}$

25334.948

$$
\begin{aligned}
& 34.30 \\
& 33.66
\end{aligned}
$$

$34 \cdot 884$

$34.820 \quad 34.756$

$\begin{array}{llll}33.02 & 33.600 & 33.536 & 33.472\end{array}$

$\begin{array}{lll}32.958 & 32.894 & 32.830\end{array}$

$\begin{array}{llll}31.739 & 31.674 & 31.610 & 31.546\end{array}$

$\begin{array}{llll}31.097 & 31.032 & 30.968 & 30.904\end{array}$

$\begin{array}{llll}30.455 & 30.391 & 30.326 & 30.262 \\ 29.813 & 29.749 & 29.685 & 29.620\end{array}$

$29.171 \quad 29.107$

5328.530

$27.888 \quad 28.46$

$\begin{array}{lll}27.888 & 27.823 & 28.0 \\ 27.2460 & 27.780\end{array}$

$\begin{array}{llll}26.604 & 26.541 & 26.476 & 26.412\end{array}$

$25.963 \quad 25.899$

$25.322 \quad 25 \cdot 257$

$\begin{array}{ll}25.552 & 25.129\end{array}$

$\begin{array}{llll}23.038 & 23.974 & 23.910 & 23.846\end{array}$

$\begin{array}{ll}23.397 & 23.333 \\ 22.755 & 22.691\end{array}$

$23.910 \quad 23.846$

$\begin{array}{ll}23.269 & 23.204 \\ 22.627 & 22.563\end{array}$

$322.114 \quad 22.050$

$21.986 \quad 21.922$

3948

$\begin{array}{llll}21.473 & 21.408 & 21.344 & 21.280 \\ 20.831 & 20.767 & 20.703 & 20.639\end{array}$

$\begin{array}{llll}20.831 & 20.767 & 20.703 & 20.639\end{array}$

$\begin{array}{llll}20.190 & 20.126 & 20.062 & 19.99\end{array}$

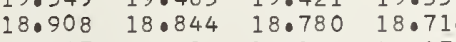

$\begin{array}{llll}18.267 & 18.202 & 18.138 & 18.07\end{array}$

$\begin{array}{llll}16.984 & 16.920 & 16.856 & 16.79\end{array}$

$16.343 \quad 16.279$

$\begin{array}{ll}16.856 & 16.792 \\ 16.215 & 16.151\end{array}$

49.0
9.1
9.0
9.4
9.5
9
9
9
9

$\begin{array}{ll}15.702 & 15.638\end{array}$

$15.574 \quad 15.510$

$\begin{array}{llll}14.420 & 14.356 & 14.292 & 14.22\end{array}$

$\begin{array}{llll}13.779 & 13.715 & 13.651 & 13.58 \\ 13.138 & 13.074 & 13.010 & 12.94\end{array}$

$12.497 \quad 12.433 \quad 12.369 \quad 12.305$

$\begin{array}{llll}11.856 & 11.792 & 11.728 & 11.66\end{array}$

$\begin{array}{llll}11.215 & 11.151 & 11.087 & 11.02 \\ 10.574 & 10.510 & 10.446 & 10.38\end{array}$

$09.934 \quad 09.870$

.001

.002

.003

.004

$\begin{array}{llllll}1.216 & 21.793 & 21.729 & 21.665 & 21.601 & 21.537 \\ & 21.152 & 21.088 & 21.024 & 20.959 & 20.895\end{array}$

$\begin{array}{llllll}20.575 & 20.511 & 20.447 & 20.383 & 20.318 & 20.254\end{array}$

$\begin{array}{llllll}19.934 & 19.869 & 19.805 & 19.741 & 19.677 & 19.613\end{array}$

$\begin{array}{llllll}18.651 & 18.587 & 18.523 & 18.459 & 18.395 & 18.331\end{array}$

$\begin{array}{llllll}18.010 & 17.946 & 17.882 & 17.818 & 17.754 & 17.690\end{array}$

$\begin{array}{llllll}16.087 & 16.022 & 15.958 & 15.895 & 15.830 & 15.766\end{array}$

$\begin{array}{llllll}15.446 & 15.381 & 15.317 & 15.253 & 15.189 & 15.125\end{array}$

$\begin{array}{llllll}14.804 & 14.740 & 14 \cdot 676 & 140612 & 14 \cdot 548 & 14 \cdot 484\end{array}$

$\begin{array}{llllll}13.523 & 13.459 & 13.394 & 13.330 & 13.266 & 13.202\end{array}$

$\begin{array}{llllll}12.882 & 12.818 & 12.754 & 12.689 & 12.625 & 12.561\end{array}$

$\begin{array}{llllll}12.241 & 12.177 & 12.113 & 12.048 & 11.984 & 11.920\end{array}$

$\begin{array}{llllll}11.600 & 11.536 & 11.472 & 11.408 & 11.344 & 11.280\end{array}$

$\begin{array}{lllllll}0.318 & 10.254 & 10.190 & 10.126 & 10.062 & 09.998\end{array}$

.005

09.550

09.485

$\begin{array}{ll}10.062 & 09.998 \\ 09.421 & 09.357\end{array}$

0.283080

0.283079

0.283078

0.283078

0.283076

0.283076

0.283075
0.283075

0.283074

0.283074

0.283073

0.283071

0.283071

0.283070

0.283069

0.283069

0.283068

0.283067
0.283067

0.283066

0.283066

0.283065

0.283064

0.283064

0.283063

0.283062
0.283062

0.283061

0.283061

0.283060

0.283059

0.283058
0.283058

0.283057

0.283057

0.283056
0.283056

0.283055

0.283054

0.283054

0.283053

0.283053
0.283052

0.283052

0.283051

0.283050

0.283049

0.283049

0.283048

0.283048

0.283047
0.283047

0.283046

0.283046
0.283045

0.283044

0.283044

0.283043

0.283042

0.283042

0.283040

0.283040

0.283039
0.283039

0.283038

0.283038

0.283037

0.283036
0.283035

0.283035

0.283034

0.283034
0.283033

0.283033

0.283033
0.283032

0.283031

0.283031

0.283030

0.283029

0.283029

0.283028
0.283028

0.283028
0.283027

0.283026

0.283026

0.283025

0.283025

1.115335

- 115387

- 115439

1.115491

1.115543

1.115595

1.115648

$1 \cdot 115674$

115752

115778

1. 115830

1.115856

$1 \cdot 115882$

- 115935

1.115961

1.116013

1.116065

.116091

1.116117

1.116143

-116195

1.116221

116248
1116274

1.116300

1.116352

1.116378

10116404

1.116456

. 116508

- 116535

1.116561

116613

1.116639

116665

- 116717

1.116769

1.116795

1.116821

1.116874

1.116900

10116926

1.116978

- 117030

1.117056

1. 117082

1.117134

$1 \cdot 117161$

1.117213

1.117239 


.05

.06

.07

.08

.09

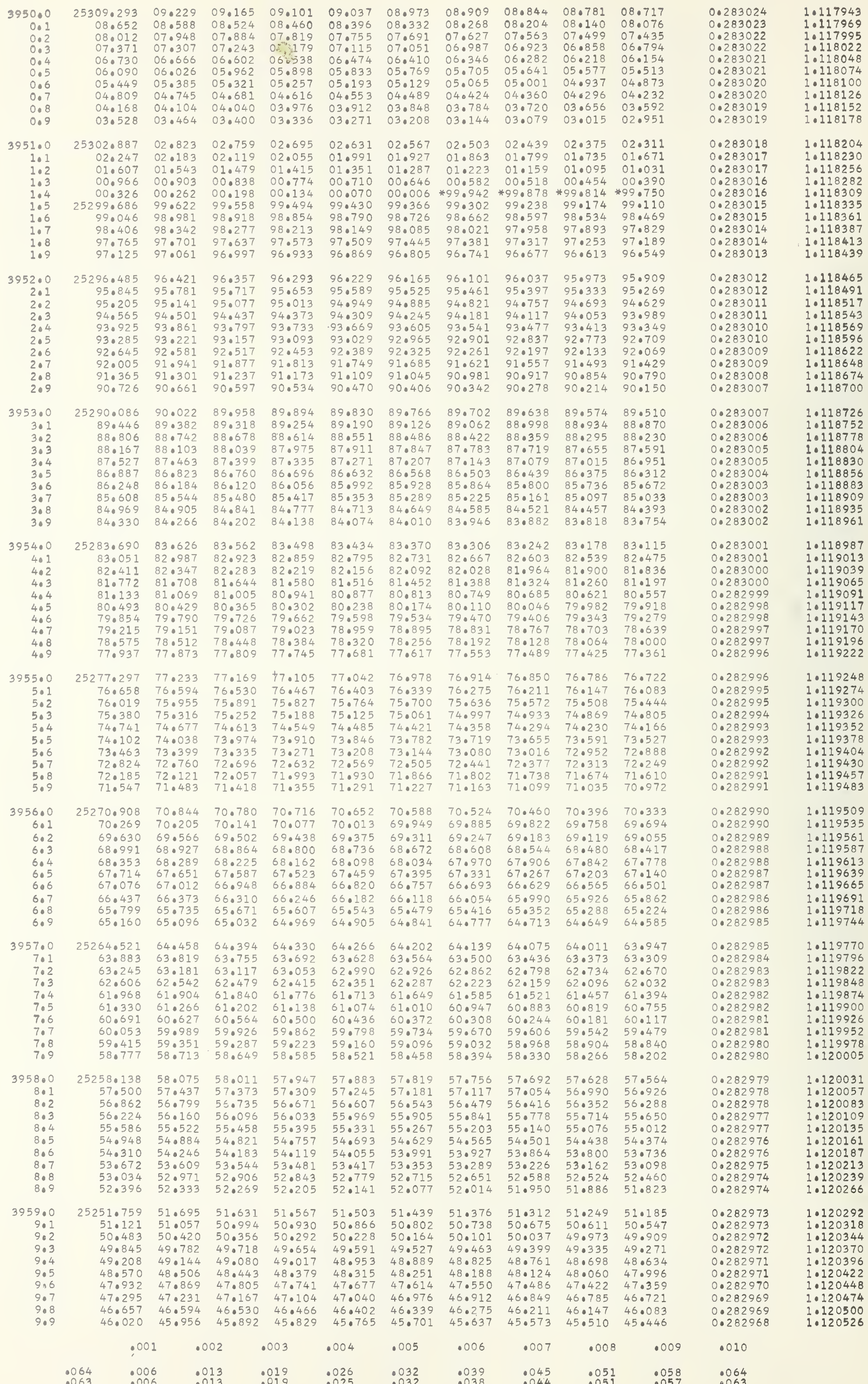




$\begin{array}{llll}44.745 & 44.681 & 44.617 & 44.553 \\ 44.107 & 44.044 & 43.980 & 43.916 \\ 43.470 & 43.406 & 43.343 & 43.278 \\ 42.833 & 42.769 & 42.705 & 42.641 \\ 42.195 & 42.131 & 42.068 & 42.004 \\ 41.558 & 41.494 & 41.430 & 41.367 \\ 40.920 & 40.857 & 40.793 & 40.729 \\ 40.283 & 40.219 & 40.156 & 40.092 \\ 39.646 & 39.582 & 39.518 & 39.455\end{array}$

两

$\begin{array}{llllll}44.490 & 44.426 & 44.000 & 44 \cdot 936 & 44 \cdot 872 & 44 \cdot 809 \\ 4 & 44.298 & 44.235 & 44 \cdot 171\end{array}$

$\begin{array}{llllll}43.852 & 43.789 & 43.725 & 43.661 & 43.597 & 43.534 \\ 43.215 & 43.151 & 43.087 & 43.024 & 42.960 & 42.896\end{array}$

$\begin{array}{llllll}42.577 & 42.514 & 42.450 & 42.386 & 42.323 & 42.259\end{array}$

$\begin{array}{llllll}41.940 & 41.876 & 41.813 & 41.749 & 41.685 & 41.622 \\ 41.303 & 41.239 & 41.175 & 41.112 & 41.048 & 40.084\end{array}$

$40.603 \quad 41.239 \quad 41.175$

$40.028 \quad 39.965$

40.538

$41 \cdot 112$

41.048

40.984
40.347

$\begin{array}{lllll}25239.009 & 38.945 & 38.881 & 38.818\end{array}$ $\begin{array}{llll}38.372 & 38.308 & 38.244 & 38.180 \\ 37.734 & 37.671 & 37.607 & 37.543\end{array}$ $\begin{array}{llll}37.734 & 37.671 & 37.607 & 37.543 \\ 37.097 & 37.033 & 36.970 & 36.906\end{array}$ $\begin{array}{llll}36.460 & 36.396 & 36.333 & 36.269 \\ 35.823 & 35.759 & 35.696 & 35.632\end{array}$ $\begin{array}{ll}35.186 & 35.123 \\ 34.549 & 34.486\end{array}$ $\begin{array}{ll}33.913 & 33.849 \\ 33.276 & 33.212\end{array}$

$\begin{array}{ll}35.696 & 35.632 \\ 35.059 & 34.995\end{array}$

$\begin{array}{ll}35.059 & 34.995 \\ 34.422 & 34.358 \\ 33.785 & 33.721\end{array}$

$\begin{array}{lllllll}38.754 & 38.690 & 38.626 & 38.563 & 38.499 & 38.435\end{array}$

$\begin{array}{llllll}38.117 & 38.053 & 37.989 & 37.926 & 37.862 & 37.798 \\ 37.480 & 37.416 & 37.352 & 37.289 & 37.225 & 37.161\end{array}$

$36.843 \quad 36.779$

$\begin{array}{lll}36.205 & 36.142 & 36.07\end{array}$

$\begin{array}{ll}35.568 & 35.505 \\ 34.931 & 34.868\end{array}$

36.078
35.441
34.804

36.651
36.01
35.377

$37 \cdot 225$

$\begin{array}{ll}33.658 & 33.594 \\ 33.021 & 32.957\end{array}$

$\begin{array}{ll}34.804 & 34.740\end{array}$

$35 \cdot 313$

36.524
35.887

$25232.639 \quad 32.575$

$32.512 \quad 32.448$

$32.384 \quad 32.320$

33.530
32.89

33.46
32.830

33.403
32.766

33.976

$\begin{array}{llll}32.002 & 31.938 & 31.875 & 31.811 \\ 31.365 & 31.302 & 31.238 & 31.174\end{array}$

$\begin{array}{ll}31.365 & 31.302 \\ 30.728 & 30.665\end{array}$

$30.092 \quad 30.028$

$29.455 \quad 29.391 \quad 29.328 \quad 29.264$

$\begin{array}{llll}28.818 & 28.754 & 28.691 & 28.627\end{array}$

$28.18128 \cdot 118$

$\begin{array}{ll}27.545 & 27 \cdot 481 \\ 26.908 & 26.844\end{array}$

$28.054 \quad 27.990$

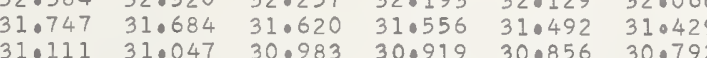

$\begin{array}{llllll}30.474 & 31.047 & 30.983 & 30.919 & 30.856 & 30.792\end{array}$

$\begin{array}{llllll}29.837 & 29.773 & 29.710 & 29.646 & 29.582 & 29.519 \\ 29.200 & 29.136 & 29.073 & 29.009 & 28.946 & 28.882\end{array}$

$\begin{array}{llllll}29.200 & 29.136 & 29.073 & 29.009 & 28.946 & 28.882 \\ 28.563 & 28.500 & 28.436 & 28.373 & 28.309 & 28.245 \\ 27.027 & 27.863 & 27.800 & 27.736 & 27.672 & 27.609\end{array}$

2.7
2.8
2.9

3963.0

$25226.272 \quad 26 \cdot 208$

$26.781 \quad 26.717$

$27.927 \quad 27.863$

$26.654 \quad 26.590$

26.526

26.463

$.036 \quad 26.972$

$\begin{array}{ll}26 \cdot 145 & 26 \cdot 081 \\ 25 \cdot 508 & 25.444 \\ 24.872 & 24.808\end{array}$

$24.999 \quad 24.93$

$24.362 \quad 24.299 \quad 24.235 \quad 24.171$

$23.726 \quad 23.662$

$23.089 \quad 23.026$

$\begin{array}{llllllll}23.599 & 23.535 & 23.471 & 23.407 & 23.344 & 23.280 & 23.217 & 23.153 \\ 22.962 & 22.899 & 22.835 & 22.771 & 22.708 & 22.644 & 22.580 & 22.517\end{array}$

$\begin{array}{llllll}26.017 & 25.953 & 25.890 & 25.826 & 25.762 & 25.699 \\ 25.381 & 25.317 & 25.253 & 25.190 & 25.126 & 25.062\end{array}$

$\begin{array}{llllll}24.744 & 24.680 & 24.617 & 24.553 & 24.490 & 24.426 \\ 24.108 & 24.044 & 23.980 & 23.917 & 23.853 & 23.789\end{array}$

$\begin{array}{llllllllll}22.453 & 22.389 & 22.326 & 22.262 & 22.198 & 22.135 & 22.071 & 22.008 & 21.944 & 21.880 \\ 21.817 & 21.753 & 21.689 & 21.626 & 21.562 & 21.499 & 21.435 & 21.371 & 21.308 & 21.244\end{array}$

$\begin{array}{ll}21.180 & 21.117 \\ 20.544 & 20.480\end{array}$

$\begin{array}{ll}21.053 & 20.990 \\ 20.417 & 20.353\end{array}$

$20.926 \quad 20.862$

21.435

$25219.908 \quad 19 \cdot 844$

3964.0

$4 \cdot 1$

$19.272 \quad 19.208$

19.78

19.717
19.0
18.045

$\begin{array}{ll}19.653 & 19.590 \\ 19.017 & 18.95\end{array}$

19.526

$\begin{array}{lll}20.735 & 20.671 & 20.608 \\ 20.099 & 20.035 & 19.971\end{array}$

$18.000 \quad 17.936$

$17.364 \quad 17.300$

$16.728 \quad 16.564$

$\begin{array}{ll}15.456 & 15.39 \\ 14.820 & 14.756\end{array}$

$14.184 \quad 14 \cdot 120$

17.872
17.236

$16.600 \quad 16.537$

$\begin{array}{ll}15.600 & 16.537 \\ 15.965 & 15.901\end{array}$

15.32
14.692

15.265

$\begin{array}{ll}18.381 & 18.31 \\ 17.745 & 17.681\end{array}$

18.890
18.254

$\begin{array}{lll}19.463 & 19.399 & 19.335 \\ 18.826 & 18.763 & 18.699\end{array}$

$\begin{array}{llllll}17.745 & 17.681 & 17.618 & 17.554 & 17.490 & 17.063 \\ 17.109 & 17.046 & 16.982 & 16.918 & 16.855 & 16.791\end{array}$

$\begin{array}{llllll}16.473 & 16.409 & 16.346 & 16.918 & 16.855 & 16.791 \\ 15.837 & 15.773 & 15.710 & 15.642 & 16.219 & 16.155 \\ 15.583 & 15.519\end{array}$

$\begin{array}{llllll}15.201 & 15.137 & 15.710 & 15.646 & 15.583 & 15.519 \\ & 15.074 & 15.010 & 14.947 & 14.883\end{array}$

$25213.548 \quad 13.484$

13.421

13.993

$\begin{array}{llllll}14.565 & 14.501 & 14.438 & 14.374 & 14.311 & 14.247 \\ 13.929 & 13.865 & 13.802 & 13.739 & 13.675 & 13.611\end{array}$

$\begin{array}{ll}12 \cdot 912 & 12 \cdot 84 \\ 12 \cdot 276 & 12 \cdot 212\end{array}$

12.78

$13 \cdot 357$
12.721

$11.640 \quad 11.577$

$10.368 \quad 10.305$

$09.097 \quad 09.033$

$11.513 \quad 11.449$

10.24

$\begin{array}{ll}08.461 & 08.398 \\ 07.826 & 07.762\end{array}$

$08.970 \quad 09.54$

$08.334 \quad 08.27$

13.293

$\begin{array}{lllll}13.230 & 13.166 & 13.103 & 13.039 & 12.975\end{array}$

$\begin{array}{llllll}12.022 & 11.958 & 11.895 & 11.831 & 11.767 & 11.704 \\ 11.386 & 11.322 & 11.259 & 11.195 & 11.131 & 11.068\end{array}$

$\begin{array}{llllll}10.750 & 10.687 & 10.623 & 10.559 & 10.496 & 10.432\end{array}$

09.47909 .415

$\begin{array}{llll}09.987 & 09.924 & 09.860 & 09.797 \\ 09.351 & 09.288 & 09.224 & 09.161\end{array}$

$\begin{array}{llll}09.351 & 09.288 & 09.224 & 09.161 \\ 08.716 & 08.652 & 08.589 & 08.525\end{array}$

$\begin{array}{llllll}08.843 & 08.779 & 08.716 & 08.652 & 08.589 & 08.525 \\ 08.207 & 08.144 & 08.080 & 08.017 & 07.953 & 07.889\end{array}$

3966.0

6
6
6
6
6
6
6
6
6

$\begin{array}{rl}207.190 & 07.127 \\ 06.555 & 06.491 \\ 05.919 & 05.856\end{array}$

$05.283 \quad 05.220$

$\begin{array}{llll}04.648 & 04.585 & 04.521 & 04.458 \\ 04.013 & 03.949 & 03.886 & 03.822\end{array}$

$07.063 \quad 07.000$

$06.936 \quad 06.872$

06.809

$\begin{array}{lll}06.745 & 06.682 & 06.618\end{array}$

$05.792 \quad 05.729$

$\begin{array}{llll}03.377 & 03.314 & 03.250 & 03.187\end{array}$

$\begin{array}{ll}02.742 & 02.678 \\ 02.106 & 02.043\end{array}$

$\begin{array}{ll}03.250 & 03.187 \\ 02.615 & 02.55\end{array}$

06.300
05.66

05.66505 .601

$04.394 \quad 04.331$

$\begin{array}{llllll}03.759 & 03.695 & 03.632 & 03.568 & 03.504 & 03.441 \\ 03.123 & 03.060 & 02.996 & 02.933 & 02.869 & 02.805\end{array}$

$06.173 \quad 06.110 \quad 06.046 \quad 05.983$

$\begin{array}{llll}05.538 & 05.474 & 05.411 & 05.347\end{array}$

$\begin{array}{llll}04.902 & 04.839 & 04.775 & 04.712\end{array}$

01.47101 .408

01.97

3967

$00.201-00.772$

$25199.566 \quad 99.502$

00.70900 .646

98.93198 .867

$98.296 \quad 98.232$

99.43

97.661197 .597

$96.390 \quad 96.32$

$\begin{array}{ll}95.755 & 95.692 \\ 95.120 & 95.05\end{array}$

98.16

97.53497 .470

$96.898 \quad 96.835$

$\begin{array}{ll}96.263 & 96.200 \\ 95.628 & 95.565\end{array}$

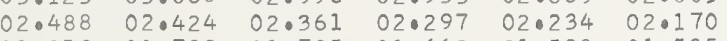

$\begin{array}{llllll}1.853 & 01.789 & 01.725 & 01.662 & 01.598 & 01.535\end{array}$

$\begin{array}{llllll}00.582 & 00.518 & 00.455 & 00.391 & 00.328 & 00.264\end{array}$

$\begin{array}{rrrrrr}9.947 & * 99.884 & * 99.820 & * 99.757 & * 99.693 & * 99.630 \\ 9.312 & 99.248 & 99.185 & 99.121 & 99.058 & 98.994\end{array}$

$\begin{array}{rlllll}9.677 & 98.613 & 98.550 & 98.486 & 98.423 & 98.359\end{array}$

$\begin{array}{llllll}97.406 & 97.343 & 97.280 & 97.216 & 97.152 & 97.089\end{array}$

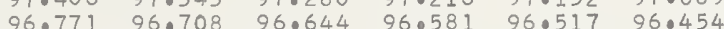

$\begin{array}{llllll}96.136 & 96.073 & 96.009 & 95.946 & 95.882 & 95.819\end{array}$

$\begin{array}{llllll}95.501 & 95.438 & 95.374 & 95.311 & 95.247 & 95.184 \\ 94.866 & 94.803 & 94.739 & 94.676 & 94.612 & 94.549\end{array}$

0.282968

1.120553

0.282967

.282966

0.282965

0.282964

0.282963
0.282963

0.282962

.282962

0.28296

0.28295

0.282958

0.282957

0.282956
.282956

0.282955

0.282953

.282953

0.282952

0.282951

0.282950

0.282950

0.282949

0.282948

0.282947

0.282946

0.282946

(1)

0.28294

0.282943

. .282942

0.282941

0.282940

0.282940

28293

0.282938

0.282937

0.282936
0.282935

0.282935

0.282934

(1)

0.282932

282931

0.282 .930

0.282929

0.282928

0.282928

0.282927

0.282926

0.282926

0.282925

0.282924

0.282923

0.282922

0.282922

0.282921

0.282920

0.282920

0.282919

0.282918

0.282917

0.282917

0.282916

0.282915

0.282915

0.282914

0.282913

1.20631

1.120683

1.120709

1. 120761

1.120814

.120866

1.120918

$1 \cdot 120944$

1.120996

I. 121048

1.121075
1.121101

10121153

1.121205

1.121283

$1 \cdot 121336$

1.121388

1.121414

1.121492

1.121518
1.121544

10121597

1.121623

10121649

- 121701

1. 121753

1.121805

1.121857

- 121910

.121962

1. 122014

1.122066

1.122119

1.122171

- 122223

1.122275

$1 \cdot 122327$

1.122380

1.122406

1.122458

1.122510

1.122562 


\subsection{2}

75.642

$73.550 \quad 73.487$

$\begin{array}{ll}72.916 & 72.853 \\ 72.282 & 72.219\end{array}$

$71.015 \quad 70.952$

$\begin{array}{ll}74.057 & 73.928\end{array}$

73.930

73.867

74.437
73.804

75.008
74.374
73.740

$74.945 \quad 74.881$

$\begin{array}{lll}70.381 & 70.318 \\ 69.747 & 69.684\end{array}$

$\begin{array}{llll}72.789 & 72.726 & 72.663 & 72.59 \\ 72.156 & 72.092 & 72.029 & 71.96\end{array}$

$\begin{array}{ll}71.522 & 71.458 \\ 70.888 & 70.82\end{array}$

71.395

71.965

73.170
72.536

71.902

$72 \cdot 47$

$\begin{array}{ll}73.677 & 73.614\end{array}$

$5169 \cdot 114$

$68.480 \quad 68.4$

69.6

70.19
69.55

70.12
69.49

70.06

70.63

$\begin{array}{lll}71.8205 & 71.775 & 71.012 \\ 710.142 & 710078\end{array}$

$\begin{array}{lll}67.846 & 67.783 \\ 670213 & 670149 & 67\end{array}$

66.57966 .516

$65.946 \quad 65.882$

$64.679 \quad 640616$

68.987
68.35
67.72
67.08
66.45
65.81
65.1
64.5
63.9
63.91

68.92
68.290

68.86

68.797

70.001
69.367

9.93

70.508

70.444

$63.413 \quad 63.349$

3973.0

$3 \cdot 1$

$5162.779 \quad 62.716$

$62.146 \quad 62.082$

61.512

$60.246 \quad 60.816$

$59.613 \quad 59.549$

3.5

3. 8

$\begin{array}{ll}58.346 & 58.283 \\ 57.713 & 57.650 \\ 57.080 & 57.017\end{array}$

62.65
62.01
61.38
60.75
60.11
59.48
58.853
58.220
57.587
56.95

67.65
67.02

67.59
66.95

68.163

68.10

68.670

69.240

69.17

0.282912

0.282911
0.282911
0.22290

0.282910

0.282910
0.282909

0.282909

0.282908
0.282908

0.282907

0.282906

0.282906

0.282905

0.282904

0.282904

0.282903

0.282902

0.282901

0.282900

0.282900

0.282899

0.282899

0.282898

0.282897

0.282897

0.282896

0.282895

0.282895

0.282894

0.282893

0.282893

0.282892

0.282892

3974.0

:

55.814
55.181
54.548
53.916

$56 \cdot 384$
$55 \cdot 751$

56.321

58.156
57.523
56.890

$\begin{array}{llllll}58.726 & 58.663 & 58.600 & 58.536 & 58.473 & 58.410\end{array}$

$\begin{array}{ll}57.460 & 57.0397 \\ 56.827 & 56.764\end{array}$

57.33
56.700

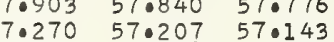

$\begin{array}{llllllll}56.194 & 56.131 & 56.067 & 560004 & 550041 & 550878\end{array}$

0.282890

0.282889

0.282888

0.282888

0.282887

0.282886

0.282886

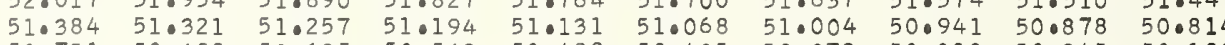

409

3975.

$5 \cdot 1$
$5 \cdot 2$
$5 \cdot 3$

$5 \cdot 3$
5.4

5.5

5.6

5.8

3976.0

:

$6 \cdot 2$
6.3

6.5

6.7
6.8

$49.486 \quad 50.05$

$48.853 \quad 48.790$

$47.588 \quad 47.525$

$\begin{array}{ll}46.956 & 46.892 \\ 46.323 & 46.250\end{array}$

$45.691 \quad 45.627$

$\begin{array}{ll}45.058 & 44.995 \\ 44.426 & 44.363\end{array}$

49.992

249.929

49.865

49.802

51.004
50.37

50.30

$43.793 \quad 43.730$

$\begin{array}{ll}43.161 & 43.098 \\ 42.529 & 42.466\end{array}$

$41.896 \quad 41.833$

$\begin{array}{ll}41.264 & 41.201 \\ 40.632 & 40.56\end{array}$

$40.000 \quad 39.936$

$\begin{array}{ll}39.367 & 39.304 \\ 38.735 & 38.672 \\ 38.103 & 38.040\end{array}$

48.727

48.09
47.46

46.829
46.197

45.564
44.932
44.0299

48.663

48.2350

$48.000 \quad 48.537$

46.766

46.133

$47.335 \quad 47.27$

$46.703 \quad 46.639$

$\begin{array}{ll}46.070 & 46.007 \\ 45.438 & 45.375\end{array}$

$\begin{array}{ll}45.438 & 45.375 \\ 44.805 & 44.742\end{array}$

49.739

48.47

47.84
47.20

$\begin{array}{lll}48.778 & 47.715 & 47.651\end{array}$

$45.944 \quad 45.880 \quad 45.817 \quad 45.754$

$45 \cdot 311$
44.679

45.24

$\begin{array}{ll}45.817 & 45.754 \\ 45.185 & 45.122\end{array}$

43.2

$44 \cdot 173 \quad 44 \cdot 109$

44.046

$\begin{array}{ll}44.552 & 44.489 \\ 43.920 & 43.857\end{array}$

0.282885

0.282884

0.282883

0.282882

0.282882

0.282881

0.282881

0.282880

0.282879

0.282878

0.282878

0.282877

0.282877

0.282876

0.282876

0.282875

$\begin{array}{lll}38.040 & 37.977 \quad 37.914\end{array}$

$$
\begin{aligned}
& 37.281 \\
& 36.64
\end{aligned}
$$

1.123267

1.123293

1.123319

1.123345
1.123371

1.123398

1.123424

1.123450

1.123476

1.123528

1.123554

1.123606

1.123632
1.123659

1. 123685

1.123711

1.123763

1.123789

1. 123815

1.123841

1. 123894

1.123894

1.123946

1.123972

1.123998

1. 124050

1.124076

1. 124102

1.124155 


$\begin{array}{rll}18.524 & 18.460 & 1 \\ 17.893 & 17.829 & 17 \\ 17.261 & 17.198 & 17 \\ 16.630 & 16.567 & 1 \\ 16.000 & 15.936 & 1 \\ 15.365 & 15.305 & 1 \\ 14.738 & 14.674 & 1 \\ 14.106 & 14.044 & 1 \\ 13.476 & 13.413 & 1 \\ 12.845 & 12.782 & 1\end{array}$

$\begin{array}{lll}18.397 & 18.334 \\ 17.766 & 17.703 \\ 17.135 & 17.072 & 17 \\ 16.504 & 16.441 & 160 \\ 15.873 & 15.810 & 150 \\ 15.242 & 15.179 & 15 \\ 14.611 & 14.548 & 14 \\ 13.981 & 13.918 & 130 \\ 13.350 & 13.287 & 130 \\ 12.719 & 12.656\end{array}$

$\begin{array}{lll}18.271 & 18.208 & 18 . \\ 17.640 & 17.577 & 17 . \\ 17.009 & 16.946 & 16 . \\ 16.378 & 16.315 & 16 . \\ 15.747 & 15.684 & 15 . \\ 15.116 & 15.053 & 140 \\ 14.485 & 14.422 & 140 \\ 13.855 & 13.792 & 13 . \\ 13.224 & 13.161 & 1 \\ 12.593 & 12.530 & 12\end{array}$

$\begin{array}{llll}18.145 & 18.082 & 18.019 & 17.956 \\ 17.514 & 17.451 & 17.388 & 17.324 \\ 16.883 & 16.820 & 16.757 & 16.693 \\ 16.252 & 16.189 & 16.125 & 16.062 \\ 15.621 & 15.558 & 15.495 & 15.432 \\ 14.990 & 14.927 & 14.864 & 14.801 \\ 14.359 & 14.296 & 14.233 & 14.170 \\ 13.729 & 13.665 & 13.602 & 13.539 \\ 13.097 & 13.035 & 12.971 & 12.908 \\ 12.467 & 12.404 & 12.341 & 12.277\end{array}$

482858

0.282857

0.282855

0.282855
0.282854

0.282853

$25099.605 \quad 99.542$

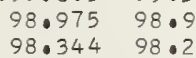

$97.714 \quad 97.651$

$97.084 \quad 97.021$

$96.455 \quad 96.392$

$95.195 \quad 95.13$

$\begin{array}{ll}94.564 & 94.502 \\ 93.935 & 93.872\end{array}$

25093.305

92.675

92.045

92.612

$89.526 \quad 89.463$

$88.267 \quad 88.204$

$87.638 \quad 87.575$

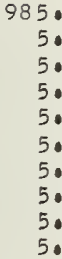

3986.

6.

6.4

6.5

6.

6.7

6.9

3987.0

7.

7.2

7.4

7.5
7.6

7.7
7.8
7.9

3988

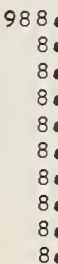

$25087.008 \quad 86.945$

$\begin{array}{ll}86.378 & 86.315 \\ 85.749 & 85.686\end{array}$

$85.119 \quad 85.057$

$4.490 \quad 84.427$

$\begin{array}{ll}83.861 & 83.79 \\ 83.231 & 83.16\end{array}$

$81.973 \quad 81.91$

$25080.714 \quad 80.6$

$\begin{array}{ll}80.085 & 80.02 \\ 79.456 & 79.39\end{array}$

$78.827 \quad 78.764$

$\begin{array}{ll}78.198 & 78 \cdot 135 \\ 77.569 & 77.506\end{array}$

$76.940 \quad 76.877$

$76.311 \quad 76.248$

$\begin{array}{ll}75.682 & 75.619 \\ 75.053 & 74.990\end{array}$

$0.739 \quad 00.676$

$00.109 \quad 00.046 * 99.683 \quad 00.550$

$99.479 \quad 99.416$

*9.857*99.794*99.731*99.668

$\begin{array}{llllll}99.353 & 99.290 & 99.227 & 99.164 & 99.100 & 99.038\end{array}$

$\begin{array}{lllllll}98.786 & 98.722 & 98.659 & 98.596 & 98.533 & 98.470 & 98.407\end{array}$

$\begin{array}{llllllll}97.588 & 97.525 & 97.462 & 97.399 & 97.336 & 97.273 & 97.210 & 97.147\end{array}$

96.95896 .895

$95.699 \quad 95.636$

5.069
95.006

$96.203 \quad 96.140$

$\begin{array}{ll}95.573 & 95.510 \\ 94.943 & 94.880\end{array}$

96.707

96.077

9600

96.58196 .518

93.809

$93 \cdot 179$

93.116

$\begin{array}{llllll}94.313 & 94.250 & 94.187 & 94.124 & 94.061 & 93.998 \\ 93.683 & 93.620 & 93.557 & 93.494 & 93.431 & 93.368\end{array}$

$\begin{array}{llllll}94.943 & 94.880 & 94.817 & 94.754 & 94.691 & 94.628 \\ 94.313 & 94.250 & 94.187 & 94.124 & 94.061 & 93.998 \\ 93.683 & 93.620 & 93.557 & 93.494 & 93.431 & 93.368\end{array}$

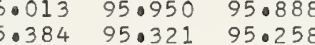

$\begin{array}{lll}.7754 & 95.321 & 95.258 \\ 94.691 & 94.628\end{array}$

$\begin{array}{lllllll}92.486 & 92.423 & 92.360 & 92.297 & 92.234 & 92.171 & 92.108\end{array}$

$\begin{array}{llllllll}91.290 & 91.227 & 91.793 & 91.730 & 91.667 & 91.604 & 91.542 & 91.479\end{array}$

$\begin{array}{llllllll}90.660 & 90.597 & 90.534 & 90.471 & 90.408 & 90.345 & 90.282 & 90.219\end{array}$

$\begin{array}{llllllll}89.401 & 89.338 & 89.275 & 89.212 & 89.148 & 89.085 & 89.023 & 88.960\end{array}$

$88.141 \quad 88.078$

$86.882 \quad 86.819$

$88.015 \quad 87.952 \quad 87.889 \quad 87.826 \quad 88.393 \quad 88.330$

$\begin{array}{llllll}87.386 & 87.323 & 87.260 & 87.197 & 87.134 & 87.071\end{array}$

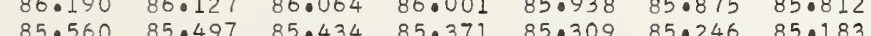

$\begin{array}{lllllllll}84.994 & 84.931 & 84.868 & 84.805 & 84.742 & 84.679 & 84.616 & 84.553\end{array}$

$\begin{array}{llllllll}84.364 & 84.301 & 84.238 & 84.175 & 84.113 & 84.050 & 83.987 & 83.924\end{array}$

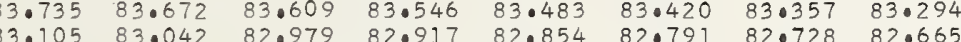

$\begin{array}{llllll} & \end{array}$

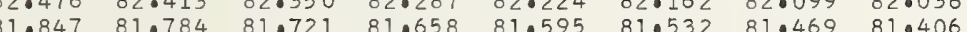

$81.218 \quad 81.155$

81.721

$80.589 \quad 80.526$

$\begin{array}{ll}79.959 & 79.896 \\ 79.330 & 79.268\end{array}$

78.701

77.44
76.81

78.638
78.009

77.380

$80.463-80.399$

80.96

81.53
80.90

79.83
79.205

$79 \cdot 205$
$78 \cdot 5$
77.9

77.946
77.31
76.68

79.77

80.33
79.708

80.27
79.645

80.84

81.406
80.777

$75.556 \quad 75.493$

75.43
74.80

78.513

$77 \cdot 88$
77.25

76.625
75.996

79.079
78.450

77.821

77.192
76.562

79.01

78.387
$77 \cdot 758$

$77 \cdot 758$
$77 \cdot 129$

76.500
75.87

$75 \cdot 24$
74.613

$25074 \cdot 424$

$\begin{array}{ll}73.795 & 73.73\end{array}$

74.298

74.235

74.172

$73.166 \quad 73.104$

$\begin{array}{ll}72.537 & 72.475 \\ 71.909 & 71.846\end{array}$

$\begin{array}{ll}71.280 & 71.217 \\ 70.651 & 70.588\end{array}$

$\begin{array}{ll}70.651 & 70.588 \\ 70.022 & 69.960\end{array}$

$\begin{array}{ll}69.394 & 69.331 \\ 68.765 & 68.702\end{array}$

73.04

72.412
71.783

$\begin{array}{ll}71.783 & 71.720\end{array}$

71.154
70.525

$\begin{array}{ll}70.525 & 70.463 \\ 69.897 & 69.834\end{array}$

$69.268 \quad 69.205$

$\begin{array}{llllll}73.543 & 73.481 & 73.418 & 73.355 & 73.292 & 73.229\end{array}$

$\begin{array}{llllll}72.915 & 72.852 & 72.789 & 72.726 & 72.663 & 72.600 \\ 72.286 & 72.223 & 72.160 & 72.097 & 72.034 & 71.971\end{array}$

$\begin{array}{llllll}72.286 & 72.223 & 72.160 & 72.097 & 72.034 & 71.971 \\ 71.657 & 71.594 & 71.531 & 71.469 & 71.406 & 71.343\end{array}$

$\begin{array}{llllll}71.028 & 70.966 & 70.903 & 70.840 & 70.777 & 70.714\end{array}$

$\begin{array}{ll}70.400 & 70.337 \\ 69.771 & 69.708 \\ 69.142 & 69.080\end{array}$

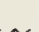

$\begin{array}{rr}8.0 & 2506 \\ 8.1 & 6 \\ 8.2 & 6 \\ 8.3 & 6 \\ 8.4 & 6 \\ 8.5 & 6 \\ 8.6 & 6 \\ 8.7 & 6 \\ 8.8 & 6 \\ 8.9 & 6\end{array}$

$67.508 \quad 67.47$

$\begin{array}{llll}66.879 & 66.817 & 66.754 & 66.691 \\ 66.251 & 66.188 & 66.125 & 66.062\end{array}$

$65.623 \quad 65.560 \quad 65.497 \quad 65.434$

64.99464 .93

$63.737 \quad 63.675$

$\begin{array}{ll}63.109 & 63 \cdot 046 \\ 62.480 & 62.418\end{array}$

$64.240 \quad 64.177$

63.612
62.983
62.35

63.549

67.88567 .822

70.274
60.641

$69.645 \quad 69.582 \quad 69.520 \quad 69.457$

$\begin{array}{llll}69.017 & 68.954 & 68.891 & 68.828\end{array}$

$\begin{array}{llllll}67.822 & 67.760 & 67.697 & 67.634 & 67.571\end{array}$

$\begin{array}{lllll}67.194 & 67.131 & 67.068 & 67.005 & 66.942 \\ 66.565 & 66.502 & 66.439 & 66.377 & 66.314\end{array}$

$\begin{array}{llllll}66.000 & 65.937 & 65.374 & 65.811 & 65.748 & 65.685\end{array}$

$\begin{array}{llllll}65.371 & 65.308 & 65.245 & 65 \cdot 183 & 65.120 & 65.057 \\ 64.742 & 64.680 & 64.617 & 64.554 & 64.491 & 64.428\end{array}$

$\begin{array}{llllll}64.742 & 64.680 & 64.617 & 64.554 & 64.491 & 64.428 \\ 64.114 & 64.051 & 63.989 & 63.926 & 63.863 & 63.800\end{array}$

\begin{tabular}{llllll}
6.114 & 64.051 & 63.989 & 63.926 & 63.863 & 63.800 \\
\hline 386 & 63.423 & 63.360 & 63.297 & 63.234 & 63.172
\end{tabular}

3989.0

9.1
9.2
9.3
9.4
9.5
9.6
9.7
9.8
9.9

25061

$\begin{array}{llll}61.223 & 61.790 & 61.727 & 61.664\end{array}$

$60.596 \quad 60.161 \quad 61.09961 .036$

$59.968 \quad 59.905$

$59.340 \quad 59.277 \quad 59.842$

$58.711 \quad 58.649 \quad 58.586$

$58.083 \quad 58.021$

$57.456 \quad 57.393$

$56.828 \quad 56.765$

$$
.001
$$

57.330
56.702
56.074 $\begin{array}{llll}60.408 & 60.973 & 60.910 & 6 \\ 60.345 & 60.282 & 6\end{array}$

\begin{tabular}{llllll}
59.717 & 59.654 & 59.591 & 50.156 & 60.094 & 60.031 \\
\hline
\end{tabular}

$\begin{array}{llllllll}57.267 & 57.204 & 57.141 & 57.079 & 57.016 & 56.953 & 56.890\end{array}$

56.011 $\begin{array}{lllllll}58.523 & 58.460 & 58.398 & 58.335 & 58.272 & 58.209 & 58.146 \\ 57.895 & 57.832 & 57.770 & 57.707 & 57.644 & 57.581 & 57.518\end{array}$ $\begin{array}{llllll}56.576 & 56.513 & 56.450 & 56.388 & 56.325 & 56.262 \\ 55.948 & 55.885 & 55.823 & 55.760 & 55.697 & 55.634\end{array}$
.006

.007
$.004 \quad .005$

0.282852

0.282850

0.282848

0.282848
0.282847

.282847

.282846
.282846

0.282845

0.282844

0.282843

. 282842

0.28284

0.282840

0.282840
0.282839

.282839

0.282838

0.282837

0.282836

0.282835
0.282835

0.282834

0.282834

0.282833

0.282832

0.282831

0.282830

0.282830

0.282829

0.282828

0.282828

.282827

0.282826

0.282825

0.282824

0.282824 
$\begin{array}{ll}5.509 & 5504 \\ 4.881 & 5408 \\ 4.253 & 5 \\ 3.625 & 53.1 \\ 2.097 & 5 \\ 2.369 & 52.9 \\ 1.741 & 51.6 \\ 1.114 & 51.0 \\ 50.486 & 50.4 \\ 4.88 & \end{array}$

\section{540}

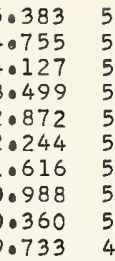

$\begin{array}{lll}55.320 & 55.258 & 5 \\ 54.692 & 54.629 & 5 \\ 54.064 & 54.001 & 5 \\ 53.437 & 53.374 & 5 \\ 52.809 & 52.746 & 5 \\ 52.0181 & 52.118 & 5 \\ 51.0553 & 51.490 & 5 \\ 50.026 & 50.863 & 5 \\ 50.298 & 50.235 & 50.1 \\ 49.670 & 49.607 & 4\end{array}$

.06

.07

.08

.09

$\lambda(n-1)$

$\begin{array}{llll}48.666 & 48.603 & 48.540 & 48.477 \\ 48.038 & 47.976 & 47.913 & 47.850\end{array}$

$\begin{array}{llll}47.411 & 47.348 & 47.285 & 47.222\end{array}$

$\begin{array}{rrrr}46.783 & 46.720 & 46.657 & 46.595 \\ 46.156 & 46.093 & 46.030 & 45.968\end{array}$

$\begin{array}{llll}45.528 & 45.465 & 45.403 & 45.340\end{array}$

$\begin{array}{llll}44.901 & 44.838 & 44.776 & 44.713\end{array}$

$44 \cdot 274$
43.646

25043.019

42.392
41.764

$41.137-41.702$

$\begin{array}{lllll}41.137 & 41.074 & 41.011 & 40.949\end{array}$

$\begin{array}{llll}40.510 & 40.447 & 40.384 & 40.322 \\ 39.883 & 39.820 & 39.757 & 39.694\end{array}$

$39.256 \quad 39.193 \quad 39.130 \quad 39.067$

$38.628 \quad 38.566$

$\begin{array}{llll}38.001 & 37.939 & 37.876 & 37.813 \\ 37.374 & 37.312 & 37.249 & 37.186\end{array}$

\section{$36.120 \quad 36.057$}

$\begin{array}{llll}350493 & 35.431 & 35.995 & 35.932\end{array}$

$34.866 \quad 34.803 \quad 34.741 \quad 34.678$

$34.239 \quad 34.177 \quad 34.114 \quad 34.051$

$32.986 \quad 32.923 \quad 32.860 \quad 32.798$

$\begin{array}{llll}32.986 & 32.923 & 32.860 & 32.798 \\ 32.359 & 32.296 & 32.233 & 32.171\end{array}$

$\begin{array}{llll}31.732 & 31.669 & 31.607 & 31.544 \\ 31.105 & 31.042 & 30.980 & 30.917\end{array}$

25030.479

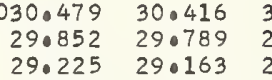

$28.599 \quad 28.536$

$\begin{array}{llll}27.972 & 27.909 & 28.473 & 28.411 \\ 27.847 & 27.785\end{array}$

$\begin{array}{llll}27.346 & 27.283 & 27.221 & 27.158 \\ 26.719 & 26.656 & 26.594 & 26.531 \\ 26.093 & 26.030 & 25.068 & 25.905\end{array}$

$\begin{array}{llll}26.093 & 26.030 & 25.968 & 25.905 \\ 25.466 & 25.404 & 25.341 & 25.278\end{array}$

$\begin{array}{llll}25.466 & 25.404 & 25 \cdot 341 & 25 \cdot 278 \\ 24.840 & 24.777 & 24.715 & 24.652\end{array}$

$$
\begin{array}{r}
50240.213 \\
23.58 \\
22.96
\end{array}
$$

22.96

$21.708 \quad 21.646$

21.08221 .019

19.830
19.204
19.7
19.577

18.577

25017.951

$$
\begin{aligned}
& 17.325 \\
& 16.699
\end{aligned}
$$

$15.047-16.010$

14082114.759

14.19514 .133

$\begin{array}{ll}13.569 & 13.507 \\ 12.944 & 12.8\end{array}$

12.318

25011.692

11.066

$09.815 \quad 10.378$

$09.190 \quad 09.127$

$\begin{array}{ll}0.50564 & 08.501 \\ 07.938 & 07.876\end{array}$

$07.313 \quad 07.25$

06.687
06.062

25005.436

$04.811 \quad 05.374$

$04.186 \quad 04.123$

03.560
02.935
020.49

$02.310 \quad 02.247$

$01.684 \quad 01.622$

$00.434 \quad 00.37$

249990809

24999.183

97.93

96.68

96.05896 .621

$95.433 \quad 95.971$

$94.808 \quad 940746 \quad 950308 \quad 95.246$

$\begin{array}{llll}940183 & 940121 & 94.058 & 93.996\end{array}$ $\begin{array}{lllllll}49.042 & 48.980 & 48.917 & 48.854 & 48.791 & 48.729\end{array}$ $\begin{array}{llllll}48.415 & 48.352 & 480289 & 48.226 & 480164 & 48.101\end{array}$ $\begin{array}{lllllll}47.160 & 47.724 & 47.662 & 47.599 & 470536 & 47.473 \\ 40097 & 47.034 & 46.971 & 460908 & 46.846\end{array}$ $\begin{array}{llllll}46.532 & 46.469 & 46 \cdot 406 & 46 \cdot 344 & 46 \cdot 281 & 46.219\end{array}$ $\begin{array}{lllllll}44.650 & 44.587 & 44.524 & 440462 & 44.399 & 44.336\end{array}$ $\begin{array}{llllll}44.023 & 43.960 & 43.897 & 430834 & 43.772 & 43.709 \\ 43.395 & 43.333 & 43.270 & 43.207 & 43.144 & 43.082\end{array}$

$\begin{array}{lllllll}42.768 & 42.705 & 42.643 & 42.580 & 42.517 & 42.454 \\ 42.141 & 42.078 & 42.015 & 41.952 & 41.890 & 41.827\end{array}$ $41.513 \quad 41.451 \quad 41.388 \quad 410325 \quad 41.263 \quad 410200$ $\begin{array}{lllllll}40.886 & 40.823 & 40.761 & 40.698 & 40.635 & 40.573\end{array}$ $\begin{array}{llllll}40.259 & 40.196 & 40.134 & 40.071 & 40.008 & 39.946\end{array}$ $\begin{array}{lllllll}39.004 & 38.942 & 38.879 & 38.816 & 38.754 & 38.691\end{array}$ $\begin{array}{llllll}38.377 & 38.315 & 38.252 & 38.189 & 38.127 & 38.064\end{array}$ $\begin{array}{llllll}37.123 & 37.061 & 37.625 & 37.562 & 37.500 & 37.437 \\ 36.998 & 36.935 & 36.873 & 36.810\end{array}$

$\begin{array}{llllll}36.496 & 36.434 & 36.371 & 36.308 & 36.245 & 36.183\end{array}$ $\begin{array}{llllll}35.869 & 35.807 & 35.744 & 350681 & 35.619 & 35.556 \\ 35.242 & 35.180 & 35.117 & 35.054 & 34.092 & 340920\end{array}$ $\begin{array}{lllllll}34.615 & 34.553 & 34.490 & 34.427 & 34.365 & 34.302\end{array}$ $\begin{array}{llllll}33.989 & 33.926 & 33.863 & 330801 & 33.738 & 33.675\end{array}$ $32.735 \quad 32.672 \quad 32.610 \quad 32.547 \quad 32.484 \quad 32.422$

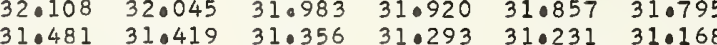
$\begin{array}{llllll}30.854 & 30.792 & 30.729 & 30.667 & 30.604 & 30.541\end{array}$

$\begin{array}{llllll}30.228 & 30.165 & 30.103 & 30.040 & 29.977 & 29.915\end{array}$

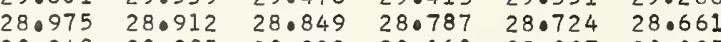
$\begin{array}{llllll}28.348 & 28.285 & 28 \cdot 222 & 28 \cdot 160 & 28.097 & 28.035 \\ 27 \cdot 722 & 27.659 & 27.596 & 27.534 & 27.471 & 27.408 \\ 27.095 & 27.03 & 26.970 & 26.907 & 26.044 & 26.782\end{array}$ $\begin{array}{lllllll}27.095 & 27.032 & 26.970 & 26.907 & 26.844 & 26.782 \\ 26.469 & 26.406 & 26.343 & 26.281 & 26.218 & 26.156\end{array}$ $\begin{array}{llllll}26.469 & 26.406 & 26.343 & 26.281 & 26.218 & 26.156 \\ 25.842 & 25.780 & 25.717 & 25.654 & 250592 & 25.529\end{array}$ $\begin{array}{llllll}25.216 & 25.153 & 25.091 & 25.028 & 24.965 & 24.902\end{array}$ $\begin{array}{lllllll}24.589 & 240527 & 240464 & 240402 & 240339 & 24 \cdot 276\end{array}$ $\begin{array}{ll}24.088 & 24.026 \\ 23.462 & 23.399 \\ 22.835 & 22.773\end{array}$ $\begin{array}{ll}22.209 & 22.146 \\ 21.583 & 21.520\end{array}$ 23.336 $22.710 \quad 22.648$ $22.084 \quad 22.021$ $23.838 \quad 23.775 \quad 23.712 \quad 23.650$ $\begin{array}{llll}22.585 & 22.522 & 22.460 & 22.397\end{array}$ $\begin{array}{llll}21.958 & 21.8996 & 21.833 & 21.771 \\ 21.0333 & 21.0270 & 21.0207 & 21.145\end{array}$ $\begin{array}{llll}21.333 & 21.270 & 21.207 & 21.145 \\ 20.706 & 20.644 & 20.581 & 20.51\end{array}$ $\begin{array}{llllllll}20.331 & 20.898 & 20.831 & 20.769 & 20.706 & 20.644 & 20.581 & 20.051\end{array}$ $\begin{array}{ll}9.078 & 19.016 \\ 8.452 & 18.390\end{array}$ 18.95
18.32 18.890 19.454 $\begin{array}{lll}19.329 & 19.266\end{array}$ $\begin{array}{llll}18.828 & 18.765 & 18.702 & 18.640 \\ 18.202 & 18.139 & 18.076 & 18.014\end{array}$ $\begin{array}{lllllll}17.701 & 17.638 & 17.576 & 17.513 & 17.450 & 17.388\end{array}$ $\begin{array}{llllllll}17.200 & 17.137 & 17.075 & 17.012 & 16.949 & 16.887 & 16.824 & 16.762\end{array}$ $\begin{array}{llllllll} & 16.44 & 16.386 & 16.323 & 16.261 & 16.198 & 16.135 \\ 15.948 & 15.885 & 15.823 & 15.760 & 15.698 & 15.635 & 15.573 & 15.510\end{array}$ $\begin{array}{llllllll}5.322 & 15.259 & 15.197 & 15.134 & 150072 & 150009 & 14.946 & 14.884\end{array}$ $\begin{array}{llllllll}14.070 & 14.633 & 14.571 & 14.508 & 14.446 & 140383 & 14 \cdot 321 & 140258 \\ 13.945 & 13.882 & 13.820 & 13.757 & 13.695 & 130632\end{array}$ $\begin{array}{lllllllll}13.444 & 13.382 & 13.319 & 13.257 & 13.194 & 13.131 & 13.069 & 13.006\end{array}$ $\begin{array}{lllllll}12.693 & 12.631 & 12.568 & 12.506 & 12.443 & 12.380 \\ 12.067 & 12.005 & 11.942 & 11.880 & 11.817 & 11.755\end{array}$ $\begin{array}{llllllll}1.567 & 11.504 & 11.442 & 11.379 & 11.317 & 11.254 & 11.191 & 110129\end{array}$ $\begin{array}{llllllll}10.941 & 10.879 & 10.816 & 10.753 & 10.691 & 10.628 & 10.566 & 10.503\end{array}$ $\begin{array}{llllllll}0.3190 & 10.253 & 10.191 & 10.128 & 10.065 & 10.003 & 09.940 & 09.878 \\ 09.690 & 09.627 & 0955 & 09.502 & 09.440 & 09.377 & 09.315 & 09.2552\end{array}$ $\begin{array}{lllllllll}09.064 & 09.002 & 08.939 & 08.877 & 08.814 & 08.751 & 08.689 & 08.626\end{array}$ $\begin{array}{llllllll}07.413 & 08.376 & 08 \cdot 314 & 08.251 & 08 \cdot 189 & 08 \cdot 126 & 08.063 & 08.001 \\ 07.813 & 07.751 & 07.688 & 07.626 & 07.563 & 07.500 & 070438 & 07.0375\end{array}$ $\begin{array}{lllllllll}07.188 & 07.125 & 07.063 & 07.000 & 06.937 & 06.875 & 06.812 & 06.750\end{array}$ $\begin{array}{llllllll}0.937 & 05.874 & 05.812 & 05.749 & 05.687 & 05.624 & 05.562 & 05.499\end{array}$ $\begin{array}{llllllll}05.311 & 05.249 & 05.186 & 05.124 & 05.061 & 04.999 & 04.936 & 04.874\end{array}$ $\begin{array}{llllllll}04.686 & 04.623 & 04.561 & 04 \cdot 498 & 04.436 & 04 \cdot 373 & 04 \cdot 311 & 04 \cdot 248 \\ 04.060 & 03.998 & 03.935 & 03.873 & 03.810 & 03.748 & 03.685 & 03.623\end{array}$ $\begin{array}{llllllll}03.435 & 03.372 & 03.310 & 03.247 & 03.185 & 03.122 & 03.060 & 02.997\end{array}$ $\begin{array}{llllllll}02.810 & 02.747 & 02.685 & 02.622 & 02.560 & 02.497 & 02.435 & 02.372\end{array}$ 1.55901 .497 $\begin{array}{lllllll}01.434 & 01.372 & 01.309 & 01.246 & 01.8184 & 01.7121\end{array}$ $\begin{array}{lllllll}0.809 & 00.746 & 00.684 & 00.621 & 00.559 & 00.496\end{array}$ $00.184 \quad 00.121 \quad 00.059 * 99.996 * 99.934 * 99.871$ $98.933 \quad 98.871 \quad 98.808 \quad 98.746 \quad 98.683 \quad 98.621$ $\begin{array}{llllll}98.308 & 98.246 & 98.183 & 98.121 & 98.058 & 97.996\end{array}$ $\begin{array}{llllll}97.683 & 97.621 & 97.558 & 97.496 & 97.433 & 97.371\end{array}$ $96.433 \quad 96.996 \quad 96.933 \quad 96.871 \quad 960808 \quad 96.746$ $\begin{array}{lllllll}95.808 & 95.746 & 95.683 & 95.621 & 95.558 & 95.496\end{array}$ $\begin{array}{llllll}95.183 & 95.121 & 95.058 & 94.996 & 94.933 & 94.871\end{array}$ $\begin{array}{llllll}94.558 & 94.496 & 94.433 & 940371 & 94.308 & 94 \cdot 246\end{array}$ $\begin{array}{llllll}93.933 & 93.871 & 93.808 & 93.746 & 93.683 & 93.621 \\ 93.309 & 93.246 & 93.184 & 93.121 & 93.059 & 92.997\end{array}$

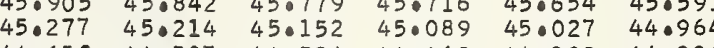

$\begin{array}{ll}0.282803 & 1.128385 \\ 0.282803 & 1.128411 \\ 0.282802 & 1.128437 \\ 0.282802 & 1.128463 \\ 0.282801 & 1.128489 \\ 0.282800 & 1.1228515 \\ 0.282800 & 1.128541 \\ 0.282799 & 1.128568 \\ 0.282799 & 1.128594 \\ 0.282798 & 1.128620\end{array}$

0.282798 0.282797 0.282797 0.282796 0.282795 0.282793

0.282792 0.282792 0.282790 0.282790 0.028789 0.282788

0.282787 0.282786 0.282786
0.282785 0.282785 0.282784 0.282784
0.282783 0.282783 0.282782

0.282782

0.282780

0.282780

0.282779

0.282778

0.282778

0.282777

0.282776

0.0282776

0.282775

0.282774

0.0 .282774

0.282772

0.282772
0.282771

0.282771

0.282770

0.282770

0.282769

0.282768

0.282767

0.282766

0.282765

0.282765

0.282763

0.282763

0.282762

0.282761

0.282760 0.0282759 0.282758 0.282758 0.282757 0.282757 0.282756 0.282755

0.282755 0.282754
0.282753 0.282753 0.282752 0.282751 0.282751 0.282750

1.128646 1.128672 1.128698 1.128750 10128776 


\begin{tabular}{|c|c|c|c|c|c|c|c|}
\hline$\lambda(A)$ & .00 & .01 & .02 & .03 & .04 & .05 & .06 \\
\hline 10.0 & 02300 & 92.872 & 92.809 & $92 \cdot 141$ & & 92.022 & 92.559 \\
\hline $\begin{array}{l}0.1 \\
0.2\end{array}$ & $\begin{array}{l}92.309 \\
91.684\end{array}$ & 92.247 & 92.184 & $92 \cdot 122$ & 92.059 & 91.997 & 91.934 \\
\hline $\begin{array}{l}0.2 \\
0.3\end{array}$ & $\begin{array}{l}91.684 \\
91.060\end{array}$ & $\begin{array}{l}91.622 \\
90.997\end{array}$ & $\begin{array}{l}91.560 \\
90.935\end{array}$ & $\begin{array}{l}91.497 \\
90.872\end{array}$ & $\begin{array}{l}91.435 \\
90.810\end{array}$ & 91.372 & $\begin{array}{l}91.309 \\
90.685\end{array}$ \\
\hline 0.4 & 91.060 & $\begin{array}{l}90.997 \\
90.372\end{array}$ & $\begin{array}{l}90.935 \\
90.310\end{array}$ & $\begin{array}{l}90.872 \\
90.248\end{array}$ & $\begin{array}{l}90.810 \\
90.185\end{array}$ & $\begin{array}{l}90.747 \\
90.123\end{array}$ & $\begin{array}{l}90.685 \\
90.060\end{array}$ \\
\hline 0.5 & 89.810 & 89.748 & 89.685 & 89.623 & 89.560 & 89.498 & 89.436 \\
\hline 0.6 & $89 \cdot 186$ & 89.123 & 89.061 & 88.998 & 88.936 & 88.873 & 88.811 \\
\hline 0.7 & 88.561 & 88.499 & 88.436 & 88.374 & 88.311 & 88.249 & 88.186 \\
\hline 0.8 & $\begin{array}{l}87.936 \\
87.312\end{array}$ & $\begin{array}{l}87.874 \\
87.249\end{array}$ & $\begin{array}{l}87.811 \\
87.187\end{array}$ & $\begin{array}{l}87 \cdot 749 \\
87.125\end{array}$ & $87: 6$ & $\begin{array}{l}87.624 \\
87.000\end{array}$ & $\begin{array}{l}87.562 \\
86.937\end{array}$ \\
\hline & & 87.249 & 87.187 & $870^{\circ}$ & 87.0 & & \\
\hline $\begin{array}{rl}4001 & \bullet 0 \\
1.1 & 1\end{array}$ & $\begin{array}{r}24986.687 \\
86.063\end{array}$ & $\begin{array}{l}86.625 \\
86.000\end{array}$ & $\begin{array}{l}86.562 \\
85.938\end{array}$ & $\begin{array}{l}86.500 \\
85.875\end{array}$ & $\begin{array}{l}86.437 \\
85.813\end{array}$ & $\begin{array}{l}85.375 \\
85.750\end{array}$ & $\begin{array}{l}86.312 \\
85.688\end{array}$ \\
\hline 1.2 & $\begin{array}{l}85.438 \\
85.48\end{array}$ & 85.376 & $\begin{array}{l}85.313 \\
85.313\end{array}$ & 85.251 & 85.188 & 85.126 & 85.063 \\
\hline 1.3 & 84.814 & 84.751 & 84.689 & 84.626 & 84.564 & 84.502 & 84.439 \\
\hline 1.4 & 84.189 & 84.127 & 840065 & 84.002 & 83.940 & 83.877 & 83.815 \\
\hline 1.5 & 83.565 & 83.503 & 83.440 & 83.378 & 83.315 & 83.253 & 83.190 \\
\hline 1.6 & 82.941 & 82.878 & .816 & 82.753 & 82.691 & 82.629 & 82.566 \\
\hline 1.7 & 82.316 & 82.254 & .192 & 82.129 & 82.067 & 82.004 & 81.942 \\
\hline $\begin{array}{l}1.8 \\
1.9\end{array}$ & & $\begin{array}{l}81.630 \\
81.005\end{array}$ & & 81.505 & 81.443 & $81 \cdot 380$ & 81.318 \\
\hline 1.9 & 81.068 & 81.005 & 80.943 & 80.881 & 80.818 & 80.756 & 80.694 \\
\hline $\begin{array}{r}002.0 \\
2.1\end{array}$ & $\begin{array}{r}24980.444 \\
79.819\end{array}$ & $\begin{array}{l}80.381 \\
79.757\end{array}$ & $\begin{array}{l}80.319 \\
79.695\end{array}$ & $\begin{array}{l}80.257 \\
79.632\end{array}$ & 80.194 & 80.132 & 80.069 \\
\hline $\begin{array}{l}2: 1 \\
2.2\end{array}$ & $\begin{array}{r}79.819 \\
79.196\end{array}$ & $\begin{array}{l}79.757 \\
79.133\end{array}$ & $\begin{array}{l}79.0655 \\
79.071\end{array}$ & $\begin{array}{l}79.632 \\
79.008\end{array}$ & $\begin{array}{l}79.550 \\
78.946\end{array}$ & $\begin{array}{l}79.508 \\
78.883\end{array}$ & $\begin{array}{l}79.445 \\
78.821\end{array}$ \\
\hline $2 \cdot 3$ & 78.572 & 78.509 & 78.446 & 78.384 & $\begin{array}{l}78.322 \\
78.322\end{array}$ & $\begin{array}{r}78.259 \\
78.259\end{array}$ & $78 \cdot 197$ \\
\hline $2 \cdot 4$ & 77.947 & $77 \cdot 885$ & $77 \cdot 822$ & 77.760 & 77.698 & 77.635 & 77.573 \\
\hline $2 \cdot 5$ & 77.323 & $77 \cdot 261$ & $77 \cdot 198$ & 77.136 & 77.073 & 77.011 & 76. \\
\hline 2.6 & 76.699 & 76.637 & 76.574 & 76.512 & 76.449 & 76.387 & $76 \cdot 325$ \\
\hline 2.7 & 76.075 & 76.013 & $\begin{array}{l}75.950 \\
75.327\end{array}$ & $\begin{array}{l}75 \cdot 888 \\
75\end{array}$ & $\begin{array}{l}75 \cdot 826 \\
75\end{array}$ & $\begin{array}{l}75.763 \\
75.70\end{array}$ & 75.701 \\
\hline $\begin{array}{l}2.8 \\
2.9\end{array}$ & $\begin{array}{l}75.452 \\
74.828\end{array}$ & $\begin{array}{l}75.389 \\
74.765\end{array}$ & $\begin{array}{l}75.327 \\
74.703\end{array}$ & $\begin{array}{l}75.264 \\
74.641\end{array}$ & $\begin{array}{l}75.202 \\
74.578\end{array}$ & $\begin{array}{l}75 \cdot 139 \\
74.516\end{array}$ & $\begin{array}{l}75.077 \\
74.453\end{array}$ \\
\hline & & & & 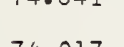 & & 730.802 & 73.830 \\
\hline $\begin{array}{r}03.0 \\
3.1\end{array}$ & $\begin{array}{r}24974.204 \\
73.580\end{array}$ & 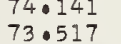 & $\begin{array}{l}74.079 \\
73.455\end{array}$ & $\begin{array}{l}74.017 \\
73.0393\end{array}$ & 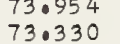 & $\begin{array}{l}73.892 \\
73.268\end{array}$ & $\begin{array}{l}73.830 \\
73.206\end{array}$ \\
\hline 3.2 & 72.956 & 72.894 & 72.831 & $\begin{array}{l}72.0769 \\
\end{array}$ & 72.707 & 72.644 & $\begin{array}{r}72.582 \\
72.582\end{array}$ \\
\hline 3.3 & 72.332 & 72.270 & 72.207 & 72.145 & 72.083 & 72.020 & 71.958 \\
\hline $0^{2}$ & 71.708 & 71.646 & 71.583 & 71.5 & 71.459 & 71.396 & 71.334 \\
\hline - & 71.084 & 71.022 & $70 \cdot 960$ & 70.897 & 70.835 & 70.773 & $70 \cdot 710$ \\
\hline$=$ & 70.461 & $70 \cdot 3$ & 70.336 & 70.274 & 70.211 & $70 \cdot 149$ & 70.087 \\
\hline 3 & 69.837 & $690^{\circ}$ & & 69.650 & 69.588 & 69.525 & 69.463 \\
\hline & & $\begin{array}{l}69.151 \\
68.528\end{array}$ & $\begin{array}{l}69.089 \\
68.465\end{array}$ & $\begin{array}{l}69.026 \\
68.403\end{array}$ & $\begin{array}{l}68.964 \\
68.341\end{array}$ & 68.902 & 68.839 \\
\hline 3.9 & 68. & 68.528 & 8.465 & 68.403 & 68.341 & $68 \cdot 278$ & $68 \cdot 216$ \\
\hline $4004 \cdot 0$ & $\begin{array}{r}24967.966 \\
67.343\end{array}$ & $\begin{array}{l}67.904 \\
67.281\end{array}$ & $\begin{array}{l}67.842 \\
67.218\end{array}$ & $\begin{array}{l}67.779 \\
67.156\end{array}$ & $\begin{array}{l}67.717 \\
67.0094\end{array}$ & 67.655 & 67.592 \\
\hline & $\begin{array}{l}67.343 \\
66.719\end{array}$ & $\begin{array}{l}77.281 \\
66.657\end{array}$ & & & $\begin{array}{l}67.094 \\
66.470\end{array}$ & $\begin{array}{l}031 \\
407\end{array}$ & \\
\hline 4.3 & 66.096 & 66.033 & $\begin{array}{l}66.595 \\
65.971\end{array}$ & $\begin{array}{l}66.0332 \\
65.909\end{array}$ & 65.846 & $\begin{array}{l}6.401 \\
65.784\end{array}$ & $\begin{array}{l}66.345 \\
65.721\end{array}$ \\
\hline 4.4 & 65.472 & 65.5 & 65.348 & 65.285 & 65.223 & 65.161 & 65.098 \\
\hline 4.5 & 64.849 & $64 \cdot 7$ & 64.724 & $64 \cdot$ & 64. & 640 & \\
\hline 4.6 & $64 \cdot 225$ & 64.163 & $640^{\circ}$ & 64. & 63. & 63. & \\
\hline 4.7 & 63.602 & $63 \cdot 5$ & 63.478 & 63.4 & 63. & $630^{\circ}$ & \\
\hline $4 \cdot 8$ & 62.979 & $\begin{array}{l}62.917 \\
62.293\end{array}$ & $\begin{array}{l}62.854 \\
62.233\end{array}$ & $\begin{array}{l}62.792 \\
62.768\end{array}$ & $\begin{array}{l}62.729 \\
62.706\end{array}$ & 62.567 & 62.605 \\
\hline 405 & 62.355 & $62 \cdot 293$ & 62.231 & 62.168 & 62.106 & 62.044 & 61.982 \\
\hline $\begin{array}{r}4005.0 \\
5.1\end{array}$ & $\begin{array}{r}24961.732 \\
61.109\end{array}$ & $\begin{array}{l}61.670 \\
61.047\end{array}$ & $\begin{array}{l}61.607 \\
60.984\end{array}$ & $\begin{array}{l}61.545 \\
60.922\end{array}$ & $\begin{array}{l}61.483 \\
60.860\end{array}$ & $\begin{array}{l}61.421 \\
60.797\end{array}$ & $\begin{array}{l}61.358 \\
60.735\end{array}$ \\
\hline 5.2 & 60.486 & 60.424 & 60.361 & 60.299 & 60. & 60. & 60. \\
\hline $5 \cdot 3$ & 3 & $590^{\circ}$ & 59.738 & 59. & 59.6 & 59. & 59. \\
\hline 5.4 & 59. & 59.1 & 59.115 & 59. & 58.990 & 58.928 & 58.865 \\
\hline 5.5 & 58.616 & 58.554 & 58.492 & 58.430 & 58.367 & 58.305 & 58.2 \\
\hline 5. & 57.993 & 57.931 & 57.869 & 57.807 & 57.7 & 57.6 & 57. \\
\hline 5. & 57.370 & 57. & 57.246 & 57.184 & 57.1 & 57.059 & 56.997 \\
\hline & & $\begin{array}{l}56.685 \\
56.062\end{array}$ & $\begin{array}{l}56.623 \\
56.000\end{array}$ & $\begin{array}{l}56.561 \\
55.937\end{array}$ & & 56.436 & 56.374 \\
\hline 5.9 & $56 \cdot 125$ & 56.062 & 6.000 & 55.937 & 5.875 & 55.813 & 55.751 \\
\hline 4006.0 & $\begin{array}{r}2495 \\
5\end{array}$ & 39 & 377 & 55 & 252 & $\begin{array}{l}190 \\
667\end{array}$ & $\begin{array}{l}55.128 \\
54.505\end{array}$ \\
\hline 6.2 & & & & & & & \\
\hline 6.3 & 53.633 & 53. & $\begin{array}{l}54.131 \\
53.508\end{array}$ & $\begin{array}{l}54.069 \\
53.446\end{array}$ & $\begin{array}{l}54.001 \\
53.384\end{array}$ & $\begin{array}{l}53.944 \\
53.321\end{array}$ & $\begin{array}{l}53 \\
53\end{array}$ \\
\hline 4 & 53.0 & 52. & 52.885 & 52. & 52.7 & 52.698 & 52. \\
\hline 5 & $52 \cdot 3$ & & 52 & 52. & 52 & 52. & 52. \\
\hline 6 & 51.7 & 51. & 51 & 51. & 51 & 51 & 51 \\
\hline 6.7 & 51.1 & $51 \cdot 0$ & 51.017 & 50. & 50 & 50 & 50. \\
\hline 6 & & 50. & $50 \cdot 3$ & 50. & & & 50. \\
\hline & & $49 \cdot 8$ & 49.771 & $490^{\circ}$ & $49 \bullet$ & ( & 49. \\
\hline .0 & 24949 & 49.211 & & & & 48.962 & \\
\hline $\begin{array}{l}7: 1 \\
702\end{array}$ & $\begin{array}{l}48 \cdot 6 \\
48.0\end{array}$ & $\frac{9}{6}$ & 47. & $\begin{array}{l}4 \varepsilon \\
47\end{array}$ & $\frac{2}{9}$ & & \\
\hline 2 & 47.4 & 4 & 47. & 47 & 47 & 4 & \\
\hline 4 & 46 & 1 & 9 & 46 & & & \\
\hline 7.5 & 46.161 & $46 \cdot c$ & 46.036 & & & & 45. \\
\hline & 45.538 & 45.476 & 45.414 & 1 & & & \\
\hline & & 44.854 & & $44^{\circ}$ & $44 \cdot 6$ & & \\
\hline & & $\begin{array}{l}44.231 \\
43.509\end{array}$ & 44.169 & 44.106 & $44 \cdot 0$ & 43. & 43. \\
\hline 7.9 & 43. & 43.609 & 43.546 & 43.484 & 43.422 & 43.360 & 43.298 \\
\hline & 2494 & 86 & 42.974 & & & 42.738 & 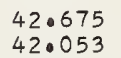 \\
\hline 8 & & & & & & & \\
\hline 8 & & & 4. & & & & \\
\hline 8 & & & & & & & \\
\hline 8 & & & 39 & & & & \\
\hline & & & 39 & & & & \\
\hline 8 & & & & & & & \\
\hline $\begin{array}{l}8.8 \\
8.9\end{array}$ & & & $37^{\circ}$ & & & & \\
\hline 8.9 & 37.449 & 37.387 & 37.325 & 37.263 & 37.200 & 37.138 & 37.076 \\
\hline & $\begin{array}{r}24936 \\
36\end{array}$ & & $\begin{array}{l}36.703 \\
36.081\end{array}$ & 41 & $\begin{array}{l}36.578 \\
35.956\end{array}$ & $\begin{array}{l}6 \\
4\end{array}$ & $\begin{array}{l}54 \\
32\end{array}$ \\
\hline 9 & 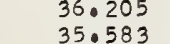 & & & & & & \\
\hline 9. & 34 & 34 & & & & & \\
\hline 9. & & & & & & & \\
\hline 9. & & & & & & & \\
\hline & & & & 32 & 32 & & \\
\hline 9. & 32.4 & 32.4 & $32 \cdot 3$ & 32.2 & 32. & & 32. \\
\hline 9.8 & 31.852 & 31.790 & 31.728 & 31.666 & 31. & 31.541 & 31.479 \\
\hline 9.9 & 31.230 & $31 \cdot 168$ & 31.106 & 31.044 & 30.982 & 30.919 & 30.857 \\
\hline
\end{tabular}

$\begin{array}{llllllllll}.001 & .002 & .003 & .004 & .005 & .006 & .007 & .008 & .009 & .010 \\ .006 & .012 & .019 & .025 & .031 & .037 & .044 & .050 & .056 & .862\end{array}$




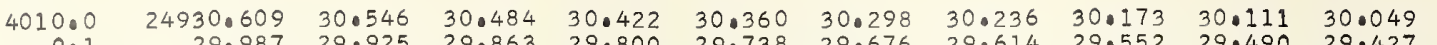

$\begin{array}{lllllllllll}0.1 & 29.987 & 29.925 & 29.863 & 29.800 & 29.738 & 29.676 & 29.614 & 29.552 & 29.490 & 29.427 \\ 0.2 & 29.365 & 29.303 & 29.241 & 29.179 & 29.717 & 29.054 & 28.092 & 28.930 & 28.868 & 28.0806\end{array}$

$\begin{array}{lllllllllll}0.2 & 29.365 & 29.303 & 29.241 & 29.179 & 29.117 & 29.054 & 28.992 & 28.930 & 28.868 & 28.806 \\ 0.3 & 28.744 & 28.681 & 28.619 & 28.557 & 28.495 & 28.433 & 28.371 & 28.300 & 28.246 & 28.184\end{array}$

$\begin{array}{lllllllllll}0.4 & 28.122 & 28.060 & 27.998 & 27.936 & 27.873 & 27.811 & 27.749 & 27.687 & 27.625 & 28.184 \\ 0.5 & 27.500 & 27.438 & 27.376 & 27.314 & 27.252 & 27.190 & 27.127 & 27.065 & 27.003 & 26.941\end{array}$

$\begin{array}{lllllllllll}0.5 & 27.500 & 27.438 & 27.376 & 27.314 & 27.252 & 27.190 & 27.127 & 27.065 & 27.003 & 26.941 \\ 0.6 & 26.879 & 26.817 & 26.755 & 26.592 & 26.630 & 26.568 & 26.506 & 26.444 & 26.382 & 26.320\end{array}$

$\begin{array}{lllllllllll}0.7 & 26.879 & 26.817 & 26.755 & 26.592 & 26.630 & 26.568 & 26.506 & 26.444 & 26.382 & 26.320 \\ 0.7 & 26.257 & 26.195 & 26.133 & 26.071 & 26.009 & 25.947 & 25.884 & 25.823 & 25.760 & 25.098\end{array}$

$\begin{array}{lllllllllll}0.8 & 25.636 & 25.574 & 25.512 & 25.449 & 25.387 & 25.325 & 25.263 & 25.201 & 25.139 & 25.076\end{array}$

$\begin{array}{lllllllllll}011.0 & 24924.393 & 24.331 & 24.269 & 24.207 & 24.145 & 24.082 & 24.020 & 23.958 & 23.896 & 23.834\end{array}$

$\begin{array}{lllllllllll}1.1 & 23.772 & 23.710 & 23.648 & 23.586 & 23.523 & 23.461 & 23.399 & 23.337 & 23.275 & 23.213 \\ 1.2 & 23.151 & 23.089 & 23.026 & 22.964 & 22.902 & 22.840 & 22.778 & 22.716 & 22.654 & 22.591\end{array}$

$\begin{array}{lllllllllll}1.3 & 22.529 & 22.467 & 22.405 & 22.343 & 22.281 & 22.219 & 22.156 & 22.094 & 22.032 & 21.970\end{array}$

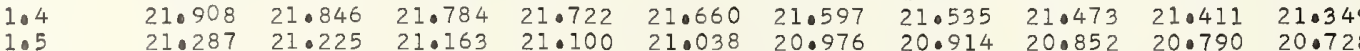

$\begin{array}{lllllllllll}1.6 & 20.666 & 20.603 & 20.541 & 20.479 & 20.417 & 20.355 & 20.293 & 20.231 & 20.169 & 20.106\end{array}$

$\begin{array}{lllllllllll}1.7 & 20.044 & 19.982 & 19.920 & 19.858 & 19.796 & 19.734 & 19.672 & 19.610 & 19.548 & 19.48 \\ 1.8 & 19.423 & 19.361 & 19.299 & 19.237 & 19.175 & 19.113 & 19.051 & 18.989 & 18.926 & 18.86\end{array}$

1.9

4012. 19.423

2
2
2
2
2
2
2
2
2
2

4013.

:

3.3

24918.181

$\begin{array}{lll}19.361 & 19.299 & 19.237 \\ 18.740 & 18.678 & 18.616\end{array}$

19.17
18.55

9.11

.610
.989
18.367

8.926

8.864
18.243

$2 \quad 16.939$

$18 \cdot 119$
17.498
16.877

16.318
15.697

$\begin{array}{ll}18.057 & 17.995\end{array}$

$17.932 \quad 17.870$

17.808

$17 \cdot 746$

$\begin{array}{ll}17.684 & 17.622 \\ 17.063 & 17.001\end{array}$

$\begin{array}{llllllllll}15.076 & 15.014 & 14.052 & 14.890 & 14.828 & 14.765 & 15.0324 & 15.262 & 15.200 & 15.138\end{array}$

$\begin{array}{llllllllll}14.455 & 14.393 & 14.331 & 14.269 & 14.207 & 14.145 & 14.082 & 14.020 & 13.958 & 13.896\end{array}$

$\begin{array}{llllllllll}13.834 & 13.772 & 13.710 & 13.648 & 13.586 & 13.524 & 13.462 & 13.399 & 13.337 & 13.275 \\ 13.213 & 13.151 & 13.089 & 13.027 & 12.965 & 12.903 & 12.841 & 12.779 & 12.716 & 12.654\end{array}$

12.592

$24911.971 \quad 11.909$

11.351

$10.110 \quad 10.047$

$\begin{array}{ll}09.489 & 09.42 \\ 08.868 & 08.80\end{array}$

$08.248 \quad 08.18$

$\begin{array}{ll}07.627 & 07.56 \\ 07.006 & 06.94\end{array}$

06.386

24905.766

$05.766 \quad 05.704$

04.525

$03.905-03.842$
03.8

$03.284 \quad 03.222$

02.043

$01.423 \quad 01.361$

4.7
4.9

4015.

00.183

01.361

13.08
12.46

12.96

11.847

$11.723 \quad 11.66$

$11.599 \quad 11.537 \quad 11.475 \quad 11.413$

$\begin{array}{llllllll}11.227 & 11.165 & 11.102 & 11.041 & 10.978 & 10.916 & 10.854 & 10.792\end{array}$

$\begin{array}{llllllll}10.606 & 10.544 & 10.482 & 10.420 & 10.358 & 10.296 & 10.234 & 10.171 \\ 09.985 & 09.923 & 09.861 & 09.799 & 09.737 & 09.675 & 09.613 & 09.551\end{array}$

$\begin{array}{llllllll}09.365 & 09.302 & 09.240 & 09.178 & 09.116 & 09.054 & 08.992 & 08.930 \\ 08.744 & 08.682 & 08.620 & 08.558 & 08.496 & 08.434 & 08.37 & 08.310\end{array}$

$\begin{array}{llllllll}0.744 & 08.682 & 08.620 & 08.558 & 08.496 & 08.434 & 08.371 & 08.310 \\ 08.124 & 08.061 & 07.999 & 07.937 & 07.875 & 07.813 & 07.751 & 07.689\end{array}$

$\begin{array}{llllllll}07.503 & 07.441 & 07.379 & 07.316 & 07.254 & 07.192 & 07.130 & 07.068\end{array}$

$\begin{array}{llllllll}06.882 & 06.820 & 06.758 & 06.696 & 06.634 & 06.572 & 06.510 & 06.448 \\ 06.262 & 06.200 & 06.138 & 06.076 & 06.014 & 05.952 & 05.890 & 05.828\end{array}$

0.282696

0.282695

0.282694

.282693

282693
0.282692

0.282692

0.282691

0.282690

.282690

0.282689

0.282688

282687

0.282687

0.282686

0.282685

0.282684
0.282684

0.282683

0.282683

0.282682

0.282681

0.282681

0.282680

0.282680

0.282679

0.282679

0.282678

0.282677

0.282676

0.282676

0.282675
0.282675

1.133609

1.133636
1.133662

1.133688

1.133740

1.133766

1.133792

1.133819

1.133871

1. 133923

1.133949

1. 134001

1.134028

1.134054

1.134106

1. 134132

1.134158

1.134210

1.134237

1.134263

1.134289

1.134341

1.134393

1.134420

1.134446

1.134498

1.134524

1.134550

1.134576

1.134602

0.282674

0.282674

0.282673

0.282673

0.282672

0.282671

0.282671

0.282670
0.282670

1.134655

1.134681

134707

1.134759

1.134785

$\begin{array}{llllllll}02.540 & 02.478 & 02.416 & 02.354 & 02.292 & 02.229 & 02.167 & 02.105\end{array}$

24899.562

5.

$5 \cdot 2$

5. 4

5.6
5.7

5.7
5.8

4016.

6.1

6.2
6.3

6.3
6.4
6.5

6.5

6.6
6.7

6.8
6.9

4017.

7.1
7.2
7.3

$7 \cdot 3$
$7 \cdot 4$

7.5
7.6

7.7
7.8

$\begin{array}{llllllllll}99.562 & 99.500 & 99.439 & 99.376 & 99.314 & 99.252 & 99.190 & 99.128 & 99.066 & 99.004 \\ 98.942 & 98.880 & 98.818 & 98.756 & 98.694 & 98.632 & 98.570 & 98.508 & 98.446 & 98.384\end{array}$

$\begin{array}{lllllllll}1.29 & 01.237 & 01.175 & 01.113 & 01.051 & 00.989 & 00.927 & 00.865\end{array}$

$\begin{array}{llllllllll}98.322 & 98.260 & 98.198 & 98.136 & 98.074 & 98.012 & 97.950 & 97.888 & 97.826 & 97.764\end{array}$

$\begin{array}{llllllllll}97.702 & 97.640 & 97.578 & 97.516 & 97.454 & 97.392 & 97.330 & 97.268 & 97.206 & 97.144\end{array}$

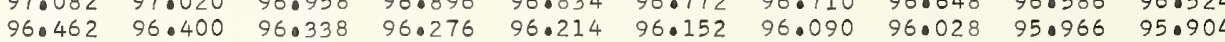

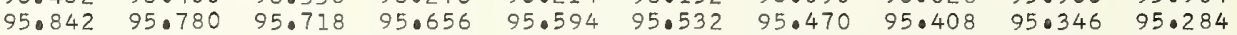

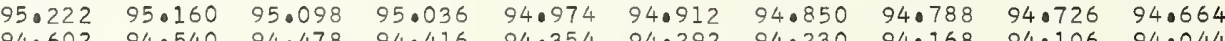

$\begin{array}{llllllllll}94.602 & 94.540 & 94.478 & 94.416 & 94.354 & 94.292 & 94.230 & 94.168 & 94.106 & 94.044 \\ 93.982 & 93.920 & 93.858 & 93.796 & 93.734 & 93.672 & 93.610 & 93.548 & 93.486 & 93.425\end{array}$

0.282669

0.282668

0.282667

0.282667

0.282666

0.282666

0.282666
0.282665

0.282665

1.134838

1.134864
1.134890

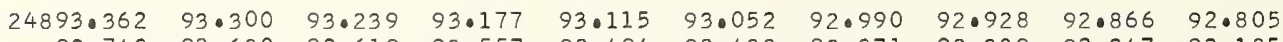

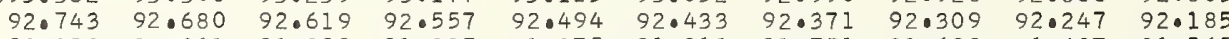
$\begin{array}{llllllllll}92.123 & 92.061 & 91.999 & 91.937 & 91.875 & 91.813 & 91.751 & 91.689 & 91.627 & 91.565\end{array}$

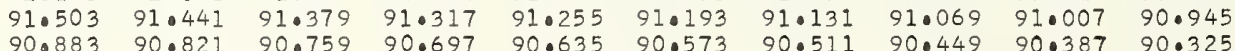
$\begin{array}{llllllllll}90.883 & 90.821 & 90.759 & 90.697 & 90.635 & 90.573 & 90.511 & 90.449 & 90.387 & 90.325 \\ 90.263 & 90.201 & 90.140 & 90.078 & 90.015 & 89.954 & 89.892 & 89.830 & 89.768 & 89.706\end{array}$

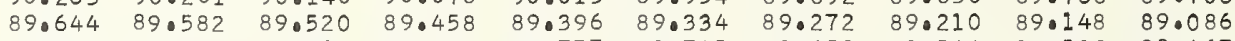
$89.024 \quad 8809338.901 \quad 88.839 \quad 88.777 \quad 88.715 \quad 88.653 \quad 88.591 .88 .52988 .467$ $\begin{array}{llllllllll}88.405 & 88.343 & 88.281 & 88.219 & 88.157 & 88.095 & 88.033 & 87.971 & 87.909 & 87.847\end{array}$

0.282664

0.282663

0.282663

0.282662

0.282662

0.282661

0.282661

0.282660

0.282659
0.282659

1.134916

1. 134942

I. 134994

1.135021

1.135047

1.135073

1. 135099

1.135125
1.135151

1. 135177

1.135204

1.135230

1.135256

1.135282

1.135334

1.135334

1.135387

0.282658

0.282658

0.282657

0.282657

0.282656

0.282656

0.282655

0.282655

0.282654

1.135413

4018.

8.
8.
8.
8.
8.
8.
8.7
8.8
8. $\begin{array}{llllllllll}80.353 & 80.291 & 80.229 & 80.167 & 80.105 & 80.043 & 79.981 & 79.919 & 79.857 & 79.795 \\ 79.733 & 79.672 & 79.610 & 79.548 & 79.486 & 79.424 & 79.362 & 79.300 & 79.238 & 79.176\end{array}$ $\begin{array}{llllllllll}79.114 & 79.052 & 78.990 & 78.928 & 78.867 & 78.805 & 78.743 & 78.681 & 78.619 & 78.557\end{array}$ $\begin{array}{lllllllllll}78.495 & 78.433 & 78.371 & 78.310 & 78.248 & 78.186 & 78.124 & 78.062 & 78.000 & 77.938\end{array}$ $\begin{array}{llllllllll}77.876 & 77.814 & 77.752 & 77.690 & 77.628 & 77.567 & 77.505 & 77.443 & 77.381 & 77.319 \\ 77.257 & 77.195 & 77.133 & 77.071 & 77.009 & 76.948 & 76.885 & 76.824 & 76.762 & 76.700\end{array}$ $\begin{array}{llllllllll}76.638 & 76.576 & 76.514 & 76.452 & 76.390 & 76.328 & 76.267 & 76.205 & 76.143 & 76.081\end{array}$ $\begin{array}{llllllllll}76.019 & 75.957 & 75.895 & 75.833 & 75.771 & 75.709 & 75.647 & 75.586 & 75.524 & 75.462 \\ 75.400 & 75.338 & 75.276 & 75.214 & 75.152 & 75.090 & 75.029 & 74.967 & 74.905 & 74.843\end{array}$

0.282653

0.282653

0.282652

0.282652

0.282650

0.282650

0.282649

0.282649

0.282648

0.282647

0.282647

0.282646

0.282646

0.282645

0.282645

0.282644

0.282644
0.282643

1. 135439

1.135465

1.135491

1.135547

1.135569

1.135596

1.135622

1.135648
1.135674

1.135700

1.135726

1.135752

1.135779

1. 135831

1. 135857

1.135883

1.135909
1.135935

1.135961

1.135988

1.136014

1.136066

1.136092

1.136118

1.136144

1.136197

.010

$: 062$ 


$$
\text { : }
$$$$
626.0
$$

0.282643

0.282642

0.282641

0.282640
0.282640
0.22835

0.282639

.282638

0.282638

0.282637

0.282636

0.282636

0.282635

0.282633

0.282632

0.022631

0.282630
0.282630

0.282629

0.282629

0.282629
0.282628
0.282628

0.282627

0.282627

0.282626

0.282625

0.282624

0.282623

0.282622

0.282621

0.282620

0.282620
0.282619

0.282619

0.282618

0.282617

0.282616

0.282615

0.282615
0.282614

0.282613

0.282612

0.282611

0.282611

0.282610

0.282610

0.282609

0.282608

0.282608

0.282607
0.282607

0.282606

0.282606

0.282605

0.282605
0.282604
0.282603

0.282603

0.282603
0.282602

0.282602

0.282601
0.282601

0.282600

0.282600

0.282599
0.282599

0.282598

0.282598

0.282597
0.282597

0.282596

0.282595

0.282595

0.282594
0.282593

0.282593

0.282592
0.282592

0.282591

0.282591
0.282590

.010

.062
1.136223

1.136275

1.136327

1.136354
1.136380

1.13640

1.136432
1.136458

1.136484

1.136510

1.136563

1.136615

1.136667

1.136693
1.136719

1.136746

10136772
1.136798

1.136824

1.136876

1.136929

1.136981

1.137059

1.137085

1.137138

1.137190

1.137216
1.137242

10137268

1.137321

1.137347
1.137373

1.137399

1. 137478

1.137530

1.137582

1.137634

1.137661

1.137713

10137739

1.137791

1.137843

1.137870

1. 137922

1.137948
1.137974

1.138000

1.138053

1.138079

1.138131

1.138183

1.138209

1.138262

1.138288

1.138340

10138366

1.138419
1.138445

1.138471

1. 138497

1.138523
1.138549

1.138575

1.138602
1.138628

1.138654

1.138680

1.138732

1. 138758

1.138785 
$\begin{array}{lllllllllll}4030.0 & 24806.886 & 06.824 & 06.763 & 06.701 & 06.640 & 06.578 & 06.517 & 06.455 & 06.394 & 06.332\end{array}$

$\begin{array}{lllllllllll}0.1 & 06.271 & 06.209 & 06.147 & 06.086 & 06.024 & 05.963 & 05.901 & 05.840 & 05.778 & 05.717 \\ 0.2 & 05.655 & 05.594 & 05.532 & 05.470 & 05.409 & 05.347 & 05.286 & 05.224 & 05.163 & 05.101\end{array}$

$\begin{array}{lllllllllll}0.2 & 05.655 & 05.594 & 05.532 & 05.470 & 05.409 & 05.347 & 05.286 & 05.224 & 05.163 & 05.101 \\ 0.3 & 05.040 & 04.978 & 04.917 & 0.4 \cdot 855 & 04.793 & 04.732 & 04.670 & 04.609 & 04.547 & 04.486\end{array}$

$\begin{array}{llllllllllll}0.4 & 04.424 & 04.363 & 04.301 & 04 \cdot 240 & 04 \cdot 178 & 04 \cdot 116 & 04.055 & 03.993 & 03.932 & 03.870 \\ 0.5 & 03.809 & 03.747 & 03.686 & 03.624 & 03.562 & 03.501 & 03.439 & 03.378 & 03.316 & 03.255\end{array}$

0.5

$0.7 \quad 02.578 \quad 02.516$

0.8

$\begin{array}{llllllllll}02.578 & 02.516 & 02.455 & 02.393 & 02.332 & 02.270 & 02.209 & 02.147 & 02.086 & 02.024 \\ 01.963 & 01.901 & 01.840 & 01.778 & 01.717 & 01.655 & 01.594 & 01.532 & 01.471 & 01.409 \\ 01.348 & 01.286 & 01.225 & 01.163 & 01.102 & 01.040 & 00.979 & 00.917 & 00.855 & 00.794\end{array}$

$\begin{array}{llll}03.070 & 03.624 & 03.562 & 03.501 \\ 03.009 & 02.947 & 02.886\end{array}$

$02.824 \quad 02.762 \quad 02.701 \quad 02.639$

$4032 \cdot 0$

$1: 1$

1.3

1.

1.6

1.7

4032 .

永:

2.2
2.3
2.4

2.5

2.6
2.7
2.8

2.9

4033.

3.1
3.2
3.3

3.3
3.4

3.5
3.6

3.7
3.8

4034.0

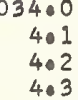

4.4
4.5

4.6
4.7

408
409

4035.

5.1
5.2
5.3
5.4

5.4
5.5

5.6
5.7

5.8

4036.0

6.1
6.2

6.3

6.4
6.5

6.6

6.6
607

6.8

4037.0

7.2

$7 \cdot 2$
$7 \cdot 3$

7.4

7.5

7.7
7.8

4038.0

038.0
8.1
8.2

$8 \cdot 2$

8.5

8.5
8.6

8.7

8.8

4039.

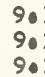

9.2

9.3

9.5

9.6

9.8
9.9
4800.732

4799.502

98.272

97.656

97.04296 .980

95.426

4794.581

93.352

$92 \cdot 737$
92.122

91.507

$90.278 \quad 90.216$

$89.048 \quad 88.987$

24.788 .434

87.819
87.204

$85.975 \quad 85.914$

$85.361 \quad 85.299$

$84.132 \quad 84.071$

$83.518 \quad 83.456$

782.280 4820289 81.675

$81.060-81.613$

80.385

79.832

79.21879 .156

$\begin{array}{ll}77.375 & 77.314 \\ 76.761 & 76.700\end{array}$

24776.147

$75.533 \quad 75.472$

$\begin{array}{ll}74.919 & 74 \cdot 858 \\ 74.305 & 74.244\end{array}$

$73.691 \quad 73.630$

$73.077 \quad 73.016$

$71.850 \quad 71.788$

$\begin{array}{ll}71.236 & 71.175 \\ 70.622 & 70.561\end{array}$

24770.008

69.395

$68.167 \quad 68.106$

$66.940 \quad 66.879$

$\begin{array}{ll}66.327 & 66.265 \\ 65.713 & 65.652\end{array}$

65.100

63.260

63.26063 .81

$62.646 \quad 62.585$

$62.033 \quad 61.972$

$60.806 \quad 60.745$

$60.193 \quad 60.132$

$59.580 \quad 50.132$

$58.967 \quad 58.90$

24757.740

57.12757 .67

$56.514 \quad 56.053$

$55.901 \quad 55.840 \quad 56.39$

$5.288 \quad 55.227 \quad 55.166 \quad 55.104$

$54.675 \quad 54.614 \quad 54.552 \quad 54.49$

$54.06254 .001 \quad 53.940 \quad 53.87$

52.83652 .775

$52.223 \quad 52.162$

$49.772 \quad 49.711$

$49.160 \quad 49.09$

$47.935 \quad 47.873$

$47.322 \quad 47.261$

$\begin{array}{ll}46.709 & 46.648 \\ 46.097 & 46.036\end{array}$
$00.609 * 0.54$
$99.994 * 99.933$
$96.303 \quad 96.242$

95.07395 .01

88.31188 .249

$82.166 \quad 82.105$

$80.323 \quad 80.262$

$79.095 \quad 79.033$

$\begin{array}{ll}78.867 & 77.805 \\ 77.252 & 77.191\end{array}$

76.577

$69.886 \quad 69.824$

$\begin{array}{llllllll}9.148 & 98.087 & 98.026 & 97.5794 & 98.518 & 98.456 & 98.395 & 98.333 \\ & 97.903 & 97.841 & 97.780 & 97.718\end{array}$

$\begin{array}{llllllll}97.534 & 97.472 & 97.410 & 97.349 & 97.287 & 97.226 & 97.164 & 97.103 \\ 96.918 & 96.857 & 96.795 & 96.734 & 96.672 & 96.611 & 96.550 & 96.488\end{array}$

$96.795 \quad 96.734$

$96.611 \quad 96.550 \quad 96.48$

$95.996 \quad 95.934 \quad 95.873$

95.565095 .504

5.442

$\begin{array}{lll}95 \cdot 381 & 95 \cdot 319 & 95 \cdot 258 \\ 94.766 & 94.704 & 94.643\end{array}$

$\begin{array}{llllllll} & 44.397 & 94.335 & 94.274 & 94 \cdot 213 & 94 \cdot 151 & 94 \cdot 089 & 94 \cdot 028\end{array}$

$\begin{array}{llllllll}3.229 & 93.167 & 93.106 & 93.044 & 92.983 & 92.921 & 92.860 & 92.798\end{array}$

$\begin{array}{llllllll} & \end{array}$

$\begin{array}{llllllll}1.384 & 91.323 & 91.261 & 91.200 & 91.138 & 91.077 & 91.015 & 90.954\end{array}$

$\begin{array}{llllllll}0.155 & 90.093 & 90.032 & 89.970 & 89.909 & 89.847 & 89.786 & 89.724 \\ 9.540 & 89.478 & 89.417 & 89.355 & 89.294 & 89.233 & 89.171 & 89.110\end{array}$

88.802

$89.355 \quad 89.294$

$\begin{array}{llllllll} & & & \end{array}$

$\begin{array}{lllllllll}.238 & 85.176 & 85.115 & 85.053 & 84.992 & 84.931 & 84.869 & 84.808\end{array}$

$\begin{array}{llllllll} & 84.500 & 84.439 & 84.378 & 84 \cdot 316 & 84.255 & 84.194\end{array}$

$\begin{array}{llllllll} & 83.825 & 83.763 & 83.702 & 83.641 & 83.579\end{array}$

$82.657 \quad 83.210$

83.149

3.08

$83.026 \quad 82.965$

$\begin{array}{llllll}82.043 & 81.982 & 81.920 & 81.859 & 81.797 & 81.736\end{array}$

$\begin{array}{llllllll} & 81.490 & 81.429 & 81.367 & 81.306 & 81.245 & 81.183 & 81.122\end{array}$

$80.200 \quad 80.139$

$\begin{array}{lll}79.586 & 79.525 & 79.463\end{array}$

$\begin{array}{ll}78.972 & 78.911 \\ 78.358 & 78.297\end{array}$

79.463

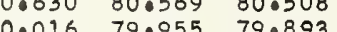

$\begin{array}{lll}80.016 & 79.955 & 79.893\end{array}$

$\begin{array}{lll}79.402 & 79.340 & 79.279\end{array}$

$\begin{array}{lll}78.788 & 78.726 & 78.665 \\ 78.174 & 78.112 & 78.051\end{array}$

$77.744 \quad 77.682$

77.621

77.56

$\begin{array}{ll}78.112 & 78.051 \\ 77.498 & 77.437\end{array}$

$76.516 \quad 76.454$

76.393

76.332

$76.884 \quad 76.823$

$\begin{array}{lllll}75 \cdot 779 & 75 \cdot 717 & 75.656 & 75.594\end{array}$

$\begin{array}{llllllll}75.410 & 75.349 & 75.287 & 75.226 & 75.165 & 75.103 & 75.042 & 74.981\end{array}$

$\begin{array}{llll}74.182 & 74.135 & 74.67 .4 & 74.612 \\ 74.060 & 73.998\end{array}$

$\begin{array}{llll}73.568 & 73.507 & 73.446 & 73.384\end{array}$

$73 \cdot 937$

$73 \cdot 323$

$\begin{array}{lll}750.490 & 74.428 \quad 740367\end{array}$

$73.875 \quad 73.814 \quad 73.753$

$72.095 \quad 72.038 \quad 72.586 \quad 72.525$

$\begin{array}{llllllll} & \end{array}$

$\begin{array}{llll}70.499 & 71.052 & 70.990 & 70.929 \\ 70.438 & 70.377 & 70.315\end{array}$

70.867

$70.806 \quad 70.745 \quad 70.683$

$69.763 \quad 69.702$

.282590

0.282589

0.282588

.282587

0.282587

0.282586

0.282585

0.282585

0.282584

0.282584

0.282582

0.282582

0.282581

.282580

0.282579

0.282579

. 282578

0.282577

0.282576

0.282575

0.282574

0.282574

0.282573

0.282573

0.282571

0.282571

0.282570

0.282570
0.282569

0.282569

0.282568

0.282568

0.282567
0.282567

0.282566

0.282566

0.282565

0.282564

0.282564

0.282563

0.282563

0.282562
0.282562

0.282561

0.282560

0.282560

0.282559

0.282558

0.282558

0.282557
0.282557

0.282556

0.282556

0.282555

0.282555

0.282554
0.282554

0.282553

0.282553

0.282552
0.282552

0.282551

0.282551

0.282550

0.282550

0.282549

0.282548

0.282547 


$.04 \quad .05$

.06

45.2

$\begin{array}{rrrrrr}4040.0 & 24745.484 & 45.423 & 45.362 & 45.301 & 4502 \\ 0.1 & 44.872 & 44.811 & 44.750 & 44.688 & 44.6 \\ 0.2 & 44.259 & 44.198 & 44.137 & 44.076 & 440 \\ 0.3 & 43.647 & 43.586 & 43.524 & 43.463 & 43.4 \\ 0.4 & 43.034 & 42.973 & 42.912 & 42.851 & 42.7 \\ 0.5 & 42.422 & 42.361 & 42.300 & 42.239 & 42 \\ 0.6 & 41.810 & 41.749 & 41.687 & 41.626 & 41.5 \\ 0.7 & 41.197 & 41.136 & 41.075 & 41.014 & 40.0 \\ 0.8 & 40.585 & 40.524 & 40.463 & 40.401 & 40.3 \\ 0.9 & 39.973 & 39.912 & 39.850 & 39.789 & 3907\end{array}$

$\begin{array}{rrrrr}24739.361 & 39.300 & 39.238 & 39.177 \\ 38.749 & 38.687 & 38.626 & 38.565 & 380\end{array}$

$\begin{array}{lllll}38.749 & 38.687 & 38.626 & 38.565 \\ 38.136 & 38.075 & 38.014 & 37.953 & 37 . \\ 37.524 & 37.463 & 37.402 & 37.341 & 37 . \\ 36.912 & 36.051 & 36.790 & 36.729\end{array}$

$\begin{array}{llll}36.912 & 36.851 & 36.790 & 36.729 \\ 36.300 & 36.239 & 36.178 & 36.116\end{array}$

$\begin{array}{llll}36.0100 & 36.239 & 36.178 & 36.116 \\ 350.688 & 35.627 & 35.566 & 35.504 \\ 35.076 & 35.015 & 34.954 & 34.892\end{array}$

$\begin{array}{llll}35.076 & 35.015 & 34.954 & 34.892 \\ 34.464 & 34.403 & 34.342 & 34.280 \\ 33.852 & 33.791 & 33.729 & 33.668\end{array}$

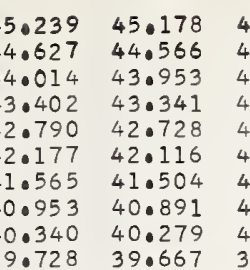

$\begin{array}{llll}45.117 & 45.055 & 44.9994 & 44.933 \\ 44.504 & 44.443 & 44.382 & 4.9321\end{array}$

$(n-1) \times 1000$

$\lambda(n-1)$

$\begin{array}{rrrrr}42.0 & 24733.240 & 33.179 & 33.118 & 33.057 \\ 2.1 & 32.628 & 32.567 & 32.506 & 32.445 \\ 2.2 & 32.016 & 31.955 & 31.894 & 31.833 \\ 2.3 & 31.405 & 31.344 & 31.282 & 31.221 \\ 2.4 & 30.793 & 30.732 & 30.671 & 30.010 \\ 2.4 & 30.181 & 30.120 & 30.059 & 29.998 \\ 2.5 & 29.570 & 29.509 & 29.448 & 29.0386 \\ 2.6 & 29.58 \\ 2.7 & 28.958 & 28.897 & 28.836 & 28.774 \\ 2.8 & 28.346 & 28.285 & 28.224 & 28.0163 \\ 2.9 & 27.735 & 27.673 & 27.612 & 27.551\end{array}$

$\begin{array}{lllllll}39.116 & 39.055 & 38.993 & 38.932 & 38.871 & 38.810\end{array}$

$\begin{array}{llllll}38.503 & 38.442 & 38.381 & 38 \cdot 320 & 38 \cdot 259 & 38 \cdot 198 \\ 37.892 & 37.830 & 37.769 & 37.708 & 37.647 & 37.585\end{array}$

$\begin{array}{llllll}37.280 & 37.218 & 37.157 & 37.096 & 37.034 & 36.973 \\ 36.667 & 36.606 & 36.545 & 36.484 & 36.422 & 36.361\end{array}$

$\begin{array}{llllll}36.055 & 35.994 & 35.933 & 35.872 & 35.810 & 35.749 \\ 35.443 & 35.382 & 35.321 & 35.260 & 35.198 & 35.137\end{array}$

$\begin{array}{llllll}34.831 & 34.780 & 35.321 & 35.260 & 35.198 & 35.137 \\ 34.099 & 34.648 & 34.586 & 34.525\end{array}$

$\begin{array}{llllll}34.219 & 34.158 & 34.097 & 34.036 & 33.975 & 33.913 \\ 33.607 & 33.546 & 33.485 & 33.424 & 33.363 & 33.302\end{array}$

0.282538

0.282537

0.282536

0.282535

0.282534

0.282534

0.282533

1.141452
1.141478

1.141504

1.141582

1.141635

0.282532

0.282531

0.282530

0.282529

0.282528

1.141687

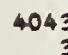

043.0
30
3
3
3
3
3
3
3
3.
3.0

$\begin{array}{rrrrrrrrrrr}.0 & 24727.123 & 27.062 & 27.001 & 26.939 & 26.878 & 26.817 & 26.756 & 26.695 & 26.634 & 26.573 \\ .1 & 26.511 & 26.450 & 26.389 & 26.328 & 26.267 & 26.206 & 26.145 & 26.083 & 26.022 & 25.961\end{array}$

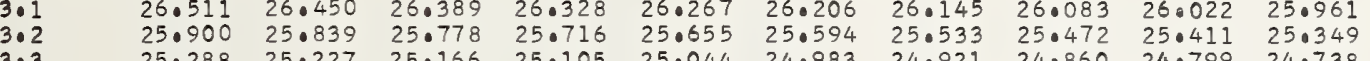

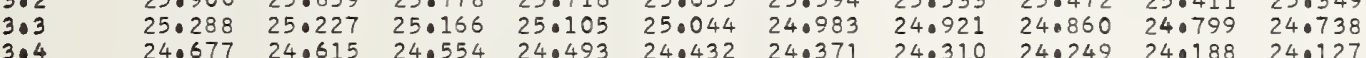

3.05

$\begin{array}{llll}24.065 & 24.004 & 23.943 & 23.882 \\ 23.454 & 23.0393 & 23.332 & 23.271\end{array}$

$22.843 \quad 22.781 \quad 22 \cdot 720 \quad 22.659$

$\begin{array}{lll}24.432 & 24.371 & 24.310 \\ 23.821 & 23.760 & 23.69\end{array}$

$24 \cdot 249 \quad 24 \cdot 188 \quad 24 \cdot 127$

3.7
3.8
3.9

$\begin{array}{ll}22.231 & 22.170 \\ 21.620 & 21.559\end{array}$

$\begin{array}{ll}22.109 & 22.048 \\ 21.498 & 21.437\end{array}$

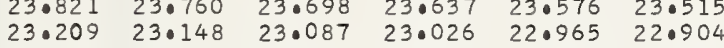

4044.
4.
4.
4.
4.
4.5
4.6
4.7
4.8
4.9

24721.009

$20.397 \quad 20.947$

21.498

$\begin{array}{llllll}22.598 & 22.537 & 22.476 & 22.415 & 22.354 & 22.292 \\ 21.987 & 21.925 & 21.864 & 21.803 & 21.742 & 21.681\end{array}$

$\begin{array}{llllll}21.375 & 21.314 & 21.253 & 21.192 & 21.131 & 21.070\end{array}$

$\begin{array}{llllllll}20.275 & 20.214 & 20.153 & 20.092 & 20.030 & 19.969 & 19.908 & 19.847\end{array}$

$\begin{array}{llllllllll}19.786 & 19.725 & 19.664 & 19.603 & 19.542 & 19.480 & 19.419 & 19.358 & 19.297 & 190236 \\ 19.175 & 19.114 & 19.052 & 18.991 & 18.930 & 18.869 & 18.808 & 18.747 & 18.686 & 18.625\end{array}$

$\begin{array}{llllllllll}18.563 & 18.502 & 18.441 & 18.380 & 18.319 & 18.258 & 18.197 & 18.136 & 18.074 & 18.013\end{array}$

$\begin{array}{llllllllll}17.952 & 17.891 & 17.830 & 17.069 & 17.708 & 17.647 & 17.586 & 17.525 & 17.463 & 17.402 \\ 17.3410 & 17.219 & 17.158 & 17.097 & 17.036 & 16.975 & 16.913 & 16.853 & 16.07910\end{array}$

$\begin{array}{llllllllll}16.730 & 16.669 & 16.608 & 16.547 & 16.486 & 16.425 & 16.364 & 16.302 & 16.241 & 16.180\end{array}$

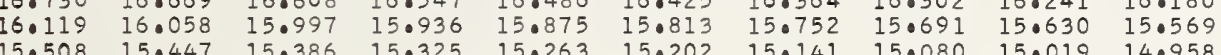

$\begin{array}{lllllllllll}404500 & 24714.897 & 14.836 & 14.775 & 14.714 & 14.653 & 14.592 & 14.530 & 14.469 & 140408 & 14.347\end{array}$

$\begin{array}{lllllllllll}3.1 & 14.286 & 14.225 & 14.164 & 14.103 & 14.042 & 13.981 & 13.920 & 13.859 & 13.798 & 13.737\end{array}$

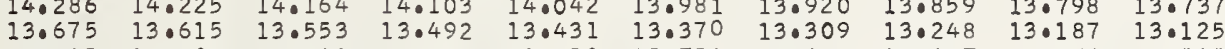

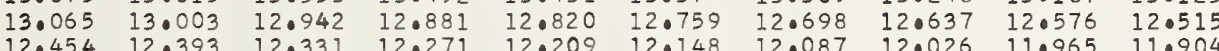

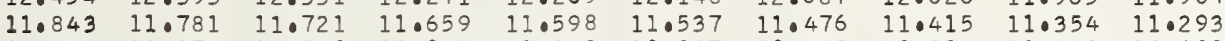

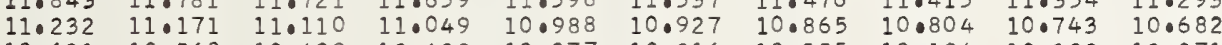

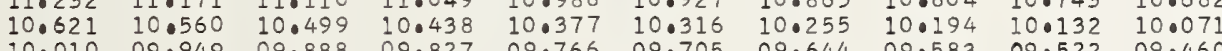

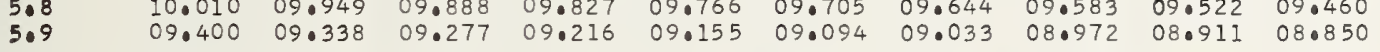

$\begin{array}{lllllllllll}4046.0 & 24708.789 & 08.728 & 08.667 & 08.606 & 08.544 & 08.484 & 08.423 & 08.361 & 08.300 & 08.239\end{array}$

$\begin{array}{lllllllllll}6.1 & 08.178 & 08.117 & 08.056 & 07.995 & 07.934 & 07.873 & 07.812 & 07.751 & 07.690 & 07.629\end{array}$

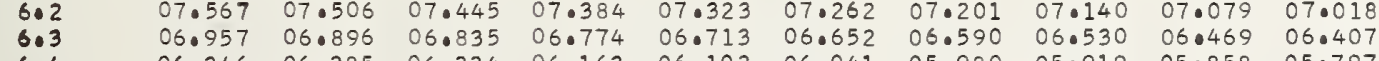
$\begin{array}{llllllllll}06 \cdot 346 & 06 \cdot 285 & 06 \cdot 224 & 06.163 & 06.102 & 06.041 & 05.980 & 05.919 & 05 \cdot 858 & 05.797 \\ 05.736 & 05.675 & 05.614 & 05.552 & 05.491 & 05.430 & 05.369 & 05.308 & 05.247 & 05.186\end{array}$ $\begin{array}{llllllllll}05.736 & 05.675 & 05.614 & 05.552 & 05.491 & 05.430 & 05.369 & 05.308 & 05.247 & 05 \cdot 186 \\ 05.125 & 05.064 & 05.003 & 04.042 & 04.881 & 04.820 & 04.759 & 04.698 & 04.637 & 04.576\end{array}$ $05.125 \quad 05.04405 .00304 .94204 .88104 .82004 .75904 .69804 .63704 .576$ $04.51504 .454 \quad 04.39304 .33204 .271004 .20904 .14804008704 .026 \quad 03.965$

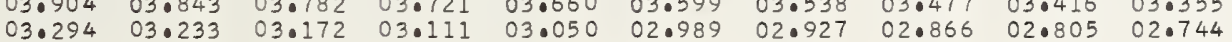
4702.68

4047.0 24702.68302 .622

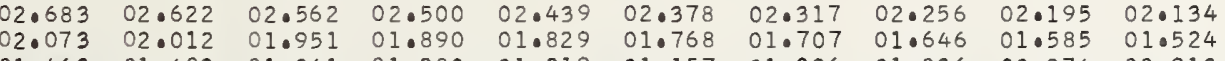
$\begin{array}{lllllllllll}01.463 & 01.402 & 01.341 & 01.280 & 01.219 & 01.157 & 01.096 & 01.036 & 00.974 & 00.913\end{array}$ $\begin{array}{llllllllll}00.852 & 00.791 & 00.730 & 00.669 & 00.608 & 00.547 & 00.486 & 00.425 & 00.364 & 00.303\end{array}$ $24699.632 \quad 99.571 \quad 99.510 \quad 90.459 * 99.998 * 99.937 * 99.876 * 99.815 * 99.754 * 99.693$

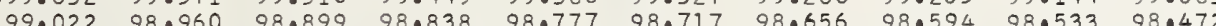

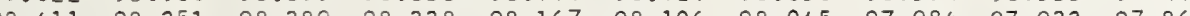

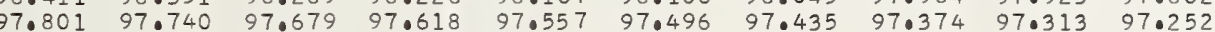

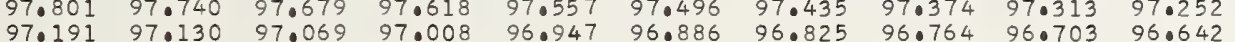

0.282521

0.282520

0.282520

(1)

0.282518

0.282518
0.282517

14171

1.141818

1.141870

0.282527

.141922
1.141948

0.282526

0.282525

(1)

0.0282523

1.141975

1.142027

1.142079

1.142132

1.142158

1.142210

0.282517

0.282516

0.282515
0.282515

0.282515

0.282514

0.282513

$1 \cdot 142236$

1. 142315

1.142341

1.142393

10142445

0.282512

0.282511

0.282510

0.282509

0.282509

0.282508

0.282507

0.282506

0.282506

0.282505

0.282504

0.282504

0.282503

0.282502

0.282501

0.282501

0.282500

0.282500

.282499

0.282498

0.282498

0.282497
0.282497

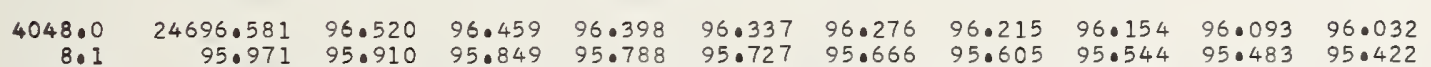

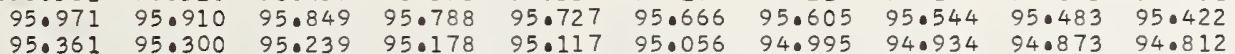

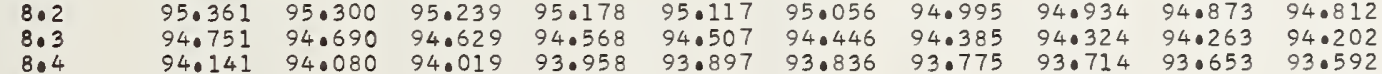

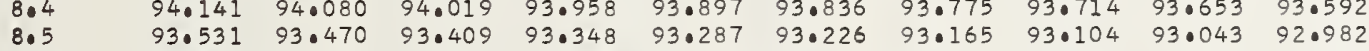

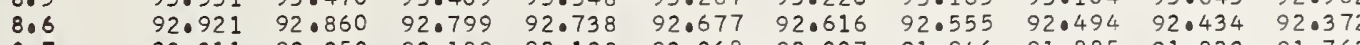

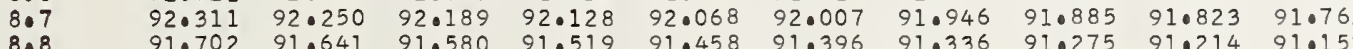

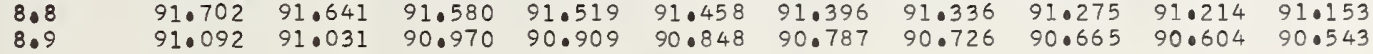

0.282496

0.282495

0.282495

0.282494

0.282493

0.282493

0.282492

0.282492

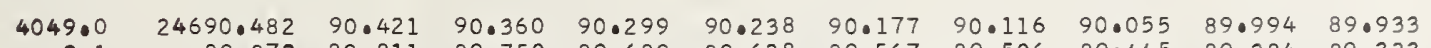

$\begin{array}{lllllllllll}9.1 & 89.872 & 89.811 & 89.750 & 89.689 & 89.628 & 89.567 & 89.506 & 89.445 & 89.384 & 89.323\end{array}$ $\begin{array}{lllllllllll}9.2 & 89.262 & 89.201 & 89.141 & 89.079 & 89.019 & 88.958 & 88.896 & 88.836 & 88.775 & 88.714 \\ 9.3 & 88.653 & 88.592 & 88.531 & 88.469 & 88.409 & 88.348 & 88.287 & 88.226 & 88.165 & 88.104 \\ 9.4 & 88.043 & 87.982 & 87.921 & 87.860 & 87.799 & 87.738 & 87.677 & 87.616 & 87.555 & 87.494\end{array}$ $\begin{array}{lllllllllll}88.043 & 87.982 & 87.921 & 87.860 & 87.799 & 87.738 & 87.677 & 87.616 & 87.555 & 87.494 \\ 87.433 & 87.372 & 87.312 & 87.250 & 87.189 & 87.128 & 87.067 & 87.007 & 86.946 & 86.885\end{array}$ $\begin{array}{llllllllll}87.433 & 87.372 & 87.312 & 87.250 & 87.189 & 87.128 & 87.067 & 87 \cdot 007 & 86.946 & 86.885 \\ 86.824 & 86.763 & 86.702 & 86.641 & 86.580 & 86.519 & 86.458 & 86.397 & 86.336 & 86.275\end{array}$ $\begin{array}{lllllllllll}86.824 & 86.763 & 86.702 & 86.641 & 86.580 & 86.519 & 86.458 & 86.397 & 86.336 & 86.275 \\ 86.214 & 86.153 & 86.092 & 86.031 & 85.970 & 85.909 & 85.848 & 85.787 & 85.726 & 85.665\end{array}$ $\begin{array}{llllllllll}86.214 & 86.153 & 86.092 & 86.031 & 85.970 & 85.909 & 85.848 & 85.787 & 85.726 & 85.665\end{array}$ $\begin{array}{llllllllll}85.604 & 85.544 & 85.483 & 85.422 & 85.361 & 85.300 & 85.239 & 85.178 & 85.117 & 85.056 \\ 84.995 & 84.934 & 84.873 & 84.812 & 84.751 & 84.690 & 84.629 & 84.568 & 84.507 & 84.447\end{array}$

0.282491

0.282490

0.282490

0.282489

0.282489

0.282488

0.282488

0.282487

0.282486

142498

1.142524

1.142576

1. 142628

1.142655

1. 142681

.142733

- 142759

1.142785

142838
.142864

1.142890

1.142942

1.142995

1.143021

.

.143099

1.143152

1.143178

1.143230

1.143282

.143308
.143335

1.143361

.143413

.143465

143518

1.143544

1143596

1.143622

.143675

1.143701

1.143753

1.143805

10143832

1.143884

1.143936

- 143962

1.143988

1.144015
1.144041

.010

.062
.060 
$74.638 \quad 74.577$

74.029
73.020 73.968

$\begin{array}{ll}76.343 & 76.282 \\ 75.734 & 75.673\end{array}$

75.125

$\begin{array}{lll}73.420 & 73.359 \\ 72.811 & 72.750\end{array}$

$$
\begin{array}{r}
467 \\
47 \\
46 \\
46 \\
45 \\
44 \\
44 \\
43 \\
43 \\
42
\end{array}
$$
$.001 \quad .002$ .003

$$
\text { . }
$$$$
\begin{array}{lll}
.049 & 77.988 & 770 \\
.440 & 77.379 & 770 \\
.831 & 76.770 & 760 \\
.221 & 76.160 & 760 \\
.612 & 75.551 & 750
\end{array}
$$$$
\begin{array}{rlll}
.612 & 75.551 & 75.490 & 750 \\
75.003 & 74.942 & 74.888 & 740.0
\end{array}
$$$$
\begin{array}{lll}
74.394 & 74.333 & 74.8 \\
73.785 & 73.024 & 7308
\end{array}
$$$$
73.176 \quad 7301
$$$$
\begin{array}{ll}
72.567 & 72.506 \\
71.958 & 71.898
\end{array}
$$

0.282472

0.282472

0.282471
0.282471

0.282470 0.282470 0.282469 0.282469 0.282468 0.282468 0.282467 0.282467 0.282466

0.282465 0.282465 0.282464 0.282464 0.282463 0.282462 0.282462 0.282461 0.282461
0.282460

0.282460 0.282459 0.282459
0.282458 0.282458
0.282458
0.282457

0.282458
0.282457
0.282457

0.282457

0.282457

0.282456

0.282455

0.282455

0.282454

0.282454

0.282453

0.282453

0.282452

0.282451

0.282451
0.282450

0.282450 0.282449 0.282449 0.282449 0.282448 0.282448 0.282447 0.282447 0.282446

0.282445

0.282444

0.282443

0.282443

0.282442

0.282442
0.282441

0.282441

0.282441
0.282440

0.282440

0.282439

0.282439

0.282438

0.282438
0.282437

0.282437
0.282437

0.282436

0.282436 0.282435
0.282435

1.144067 1. 144093 1.144145 1.144198 1. 144250 I. 144276

1.144329 1. 144355 1. 144407 1. 144433 1.144459 1. 144512 1.144538

10144590 1.144616 1.144642 10144695

1.144721
1.144747

1. 1447773

1.144773
1.144799 1.144826

1.144852 
$\begin{array}{llll}23.588 & 23.527 & 23.467 & 23.406\end{array}$

$\begin{array}{lllll}0.1 & 22.981 & 22.921 & 22.860 & 22.800 \\ 0 & 22.375 & 22.314 & 22.254 & 22.193\end{array}$

$\begin{array}{lll}0.2 & 22.375 & 22.0314 \\ 0.3 & 21.769 & 21.708 \\ 0.4 & 21.162 & 21.102\end{array}$

$\begin{array}{lll}0.4 & 21.162 & 21.102 \\ 0.5 & 20.556 & 20.495\end{array}$

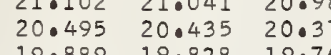

$19.343 \quad 10.283 \quad 19.228 \quad 19.76$

0.8

4061.

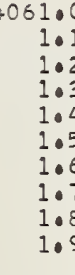$$
\begin{array}{r}
4062 \\
2 \\
2 \\
2 \\
2 \\
2 \\
2 \\
2 \\
2
\end{array}
$$

$$
4063
$$

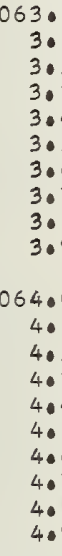

4065

4065.
5.
5.
5.
5.4
5.5
5.6
5.7
5

$\begin{array}{llll}18.737 & 18.676 & 18.616 & 18.55\end{array}$

$18.131 \quad 18.070$

24617.524

$\begin{array}{lll}16.918 & 17.464 & 17.40 \\ 16.858 & 16.797\end{array}$

$16.312 \quad 16.251 \quad 16.191 \quad 16.737$

$\begin{array}{lll}15.646 & 15.585 & 15.524\end{array}$

$14.484 \quad 14.040 \quad 14.979 \quad 14.918$

$\begin{array}{llll}13.888 & 13.827 & 13.767 & 13.706\end{array}$

$\begin{array}{llll}13.282 & 13.221 & 13.161 & 13.100\end{array}$

12.676
12.070

24611.464

$10.858 \quad 11.404$

10.252

09.5

$\begin{array}{llll}08.436 & 08.375 & 08.314 & 08.25 \\ 07.830 & 07.769 & 07.708 & 07.64\end{array}$

$07.224 \quad 07.16907 .708$

$06.618 \quad 06.558$

06.013

24605.407
04.802

$04.802 \quad 05.346$

$04.196 \quad 04.135$

$03.590 \quad 03.530$

02.985

02.379

$01.168 \quad 01.10$

90.563

02.924

$24599.353 \quad 99.292$

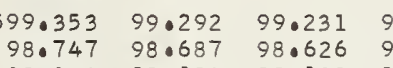

$\begin{array}{llll}98.142 & 98.082 & 98.021 & 97.960\end{array}$

$\begin{array}{llll}97.537 & 97.476 & 97.416 & 97.355\end{array}$

$96.932 \quad 96.871 \quad 96.81196 .750$

$\begin{array}{llll}96.726 & 96.266 & 96.206 & 96.145 \\ 95.721 & 95.661 & 95.600 & 95.540\end{array}$

$\begin{array}{llll}95.116 & 95.056 & 94.995 & 94.935 \\ 94.511 & 94.451 & 94.390 & 94.330\end{array}$

\begin{abstract}
$593.301 \quad 93.240$
\end{abstract}
$\begin{array}{llll}.041 & 94 \cdot 390 & 94.330 & 94.2\end{array}$ $90.882 \quad 90.821 \quad 90.760 \quad 90.700$ $90.277 \quad 90.216 \quad 90.156 \quad 90.095$ $89.672 \quad 89.61$ $\begin{array}{ll}88.462 & 88.402 \\ 87.858 & 87.797\end{array}$

$89.551 \quad 89.490$ 87.85

$\begin{array}{ll}88.341 & 88.281 \\ 87.737 & 87.676\end{array}$

$\begin{array}{llllll}23.345 & 23.285 & 23.224 & 23.163 & 23.103 & 23.042 \\ 22.739 & 22.678 & 22.618 & 22.557 & 22.496 & 22.436\end{array}$

$\begin{array}{llllll}22.133 & 22.072 & 22.011 & 21.951 & 21.890 & 21.829\end{array}$

$\begin{array}{llllll}20.920 & 20.859 & 21.405 & 21.344 & 21.283 & 21.223 \\ 4 & 20.738 & 20.677 & 20.616\end{array}$

$\begin{array}{llllll}20.313 & 20.253 & 20.192 & 20.131 & 20.071 & 20.010 \\ 19.707 & 19.646 & 19.586 & 19.525 & 19.465 & 19.0404\end{array}$

$\begin{array}{llllll}19.101 & 19.040 & 18.979 & 19.525 & 19.465 & 19.404\end{array}$

18.495
17.888

18.434

$\begin{array}{llll}18.979 & 18.919 & 18.858 & 18.798 \\ 18.373 & 18.313 & 18.252 & 18.191\end{array}$

$17.282 \quad 17 \cdot 22$

$\begin{array}{ll}16.676 & 16.615 \\ 16.070 & 16.009\end{array}$

$\begin{array}{ll}15.464 & 15.40 \\ 14.857 & 14.79\end{array}$

$14.251 \quad 14 \cdot 1$

13.58513 .52

$\begin{array}{llll}17.161 & 17.100 & 17.040 & 16.979 \\ 16.555 & 16.494 & 16.434 & 16.373\end{array}$

$\begin{array}{llll}15.948 & 15.888 & 15.827 & 15.767\end{array}$

$\begin{array}{llll}15.342 & 15.282 & 15.221 & 15.161\end{array}$

$\begin{array}{llll}4.130 & 14.070 & 14.000 & 14.9548\end{array}$

$\begin{array}{llll}2.918 & 12.858 & 12.797 & 12.737\end{array}$

$\begin{array}{llllll}12.434 & 12.373 & 12 \cdot 312 & 12.252 & 12 \cdot 191 & 12.130\end{array}$

11.222

11.161

11.101

$\begin{array}{lll}11.040 & 10.979 & 10.919\end{array}$

$\begin{array}{llllll}10.616 & 10.555 & 10.495 & 10.434 & 10.374 & 10.313 \\ 10.010 & 09.949 & 09.889 & 09.828 & 09.768 & 09.707\end{array}$

$\begin{array}{llllll}09.404 & 09.344 & 09.283 & 09.223 & 09.768 & 09.107 \\ \end{array}$

$\begin{array}{llllll}08.798 & 08.738 & 08.678 & 08.617 & 08.556 & 08.496 \\ 08.193 & 08.133 & 08.072 & 08.011 & 07.951 & 07.890\end{array}$

$\begin{array}{lll}08.011 & 07.951 & 07.890 \\ 07.406 & 07.345 & 07.284\end{array}$

$\begin{array}{llllll}07.587 & 07.527 & 07.466 & 07.406 & 07.345 & 07.284\end{array}$

$\begin{array}{llll}06.860 & 06.800 & 06.740 & 06.679\end{array}$

$\begin{array}{llll}06.255 & 06.194 & 06.134 & 06.073 \\ 05.649 & 05.589 & 05.528 & 05.468\end{array}$

$\begin{array}{ll}05.3770 & 06.315 \\ 05.710\end{array}$

$04.983 \quad 04.922 \quad 04.862$

$\begin{array}{llll}4.438 & 04.377 & 04.317 & 04.256\end{array}$

$\begin{array}{llll}03.833 & 03.772 & 03.711 & 03.651 \\ 03.227 & 03.167 & 03.106 & 03.045\end{array}$

$02.622 \quad 02.561 \quad 02.500 \quad 02.440$

$\begin{array}{llll}02.016 & 01.956 & 01.895 & 01.834 \\ 01.411 & 01.350 & 01.290 & 01.229\end{array}$

$\begin{array}{llll}01.411 & 01.350 & 01.290 & 01.229 \\ 00.805 & 00.745 & 00.684 & 00.624\end{array}$

$\begin{array}{llll}00.805 & 00.745 & 00.684 & 00.624 \\ 00.200 & 00.139 & 00.079 & 00.018\end{array}$

$\begin{array}{llllll}00.321 & 00.260 & 00.200 & 00.139 & 00.079 & 00.018 \\ 99.716 & 99.655 & 99.595 & 99.534 & 99.474 & 99.413 \\ 99.110 & 99.050 & 98.989 & 98.929 & 98.868 & 98.808\end{array}$

$\begin{array}{llllll}98.505 & 98.445 & 98.384 & 98.323 & 98.263 & 98.203 \\ 97.900 & 97.839 & 97.779 & 97.718 & 97.658 & 97.597\end{array}$

$\begin{array}{llllll}97.900 & 97.839 & 97.779 & 97.718 & 97.658 & 97.597 \\ 97.295 & 97.234 & 97.174 & 97.113 & 97.052 & 96.992\end{array}$

$\begin{array}{llllll}97.295 & 97.234 & 97.174 & 97.113 & 97.052 & 96.992 \\ 96.689 & 96.629 & 96.568 & 96.508 & 96.447 & 96.387\end{array}$

$\begin{array}{llllll}96.084 & 96.024 & 95.963 & 95.903 & 95.842 & 95.782\end{array}$

$\begin{array}{llllll}95.479 & 95.419 & 95.358 & 95.298 & 95.237 & 95.177 \\ 94.874 & 94.814 & 94.753 & 94.693 & 94.632 & 94.572\end{array}$

$\begin{array}{llllll}94.269 & 94 \cdot 208 & 94.148 & 94 \cdot 088 & 94.027 & 93.966 \\ 93.664 & 93.604 & 93.543 & 93.483 & 93.422 & 93.362\end{array}$

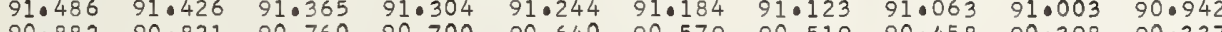

$\begin{array}{llllll}90.640 & 90.579 & 90.519 & 90.458 & 90.398 & 90.337\end{array}$

$\begin{array}{lllllll}90.035 & 89.974 & 89.914 & 89.853 & 89.793 & 89.732\end{array}$

4066.0

6.

$24587.253 \quad 87.192$

$89.430 \quad 89.36$

89.309

$89.249 \quad 89.188 \quad 89 \cdot 128$

$88.644 \quad 88.583 \quad 88.523$

$86.648 \quad 86.5$

$87.132 \quad 87.072$

$\begin{array}{ll}88.220 & 88.160 \\ 87.616 & 87.555\end{array}$

88.099
87.495

$\begin{array}{lll}88.039 & 87.979 & 87.918 \\ 87.434 & 87.374 & 87.313\end{array}$

6.4

6.5

6.6
6.7
6.8

6.8
6.9

4067.

7.

$7 \cdot 2$

7.

7.5

7.7
7.8
7.9

4068 .

$$
\begin{array}{r}
8 \\
8 . \\
8 \\
8 \\
8 \\
8 \\
8 \\
8 \\
8 \\
8
\end{array}
$$$$
86.043 \quad 85.983 \quad 85.923 \quad 85.862
$$

$84.834 \quad 84.778 \quad 85.318 \quad 85.257$

$\begin{array}{llll}84.230 & 84.169 & 84.713 & 84.653 \\ 84.109 & 84.048\end{array}$

83.62583 .564

$83.021 \quad 82.960 \quad 82.900 \quad 82.839$

$\begin{array}{llll}82.416 & 82.356 & 82.295 & 82.235 \\ 81.812 & 81.751 & 81.691 & 81.630\end{array}$

87.01

$\begin{array}{lllllll}85.802 & 85.741 & 85.28 & 86.225 & 86.164 & 86.104 \\ & 85.620 & 85.560 & 85.499\end{array}$

$\begin{array}{lllllll}85.197 & 85.136 & 85.076 & 85.016 & 84.955 & 84.895\end{array}$

$\begin{array}{llllll}84.593 & 84.532 & 84.472 & 84.411 & 84.351 & 84.290\end{array}$

$\begin{array}{lllllll}83.988 & 83.927 & 83.867 & 83.807 & 83.746 & 83.686\end{array}$

$\begin{array}{llllll}83.383 & 83.323 & 83.262 & 83.202 & 83.142 & 83.081\end{array}$

$\begin{array}{llllll}82.779 & 82.719 & 82.658 & 82.598 & 82.537 & 82.477 \\ 82.174 & 82.114 & 82.053 & 81.993 & 81.933 & 81.872\end{array}$

$24581 \cdot 207$

81.20781 .147

$\begin{array}{llll}78.790 & 78.729 & 78.669 & 78.609\end{array}$

$78.186 \quad 78.125 \quad 78.065 \quad 78.004$

$\begin{array}{llll}77.581 & 77.521 & 77.461 & 77.400\end{array}$

$\begin{array}{ll}76.977 & 76 \cdot 917 \\ 76.373 & 76.312\end{array}$

$75 \cdot 769 \quad 75: 708$

$76.856 \quad 76.796$

81.570

$4575.165 \quad 75 \cdot 104$

$\begin{array}{lllll}73.957 & 73.896 & 73.836 & 73.7775\end{array}$

$\begin{array}{llll}73.353 & 73.292 & 73.232 & 73.17\end{array}$

$72.749 \quad 72.688 \quad 72.628 \quad 72.568$

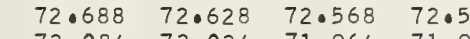

$71.541 \quad 71.480 \quad 71.420 \quad 71.360 \quad 71.903$

$\begin{array}{llllll}70.937 & 70.877 & 70.816 & 70.060 & 71.299 & 71.23\end{array}$

$\begin{array}{lllllll}70.333 & 70.273 & 70.212 & 70.152 & 70.092 & 70.031\end{array}$

$\begin{array}{lllll}.905 & 80.845 & 80.784 & 80.724 & 80.663\end{array}$

$80.361 \quad 80.301$

79.757

$78.548 \quad 78: 488$

$\begin{array}{ll}77.944 & 77.884 \\ 77.340 & 77.279\end{array}$

$\begin{array}{ll}76.736 & 75.675 \\ 76.131 & 76.071\end{array}$

76.615

75.406

74.923

74.802

.198

.594

$\begin{array}{llll}2.386 & 72.326 & 72.266 & 72.205\end{array}$

$\begin{array}{llll}71.782 & 71.722 & 71.662 & 71.601 \\ 71.178 & 71.118 & 71.058 & 70.997\end{array}$

$70.575 \quad 70.514 \quad 70.454 \quad 70.394$

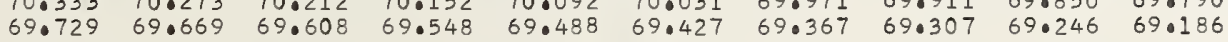

4069.0

68.125269 .065

69.00568 .044

$68.884 \quad 68.824 \quad 68.763 \quad 68.703 \quad 68.642 \quad 68.582$ $67.314 \quad 67.254 \quad 67.193 \quad 67.133 \quad 67.073 \quad 67.012 \quad 66.952 \quad 66.892 \quad 66.83166 .771$

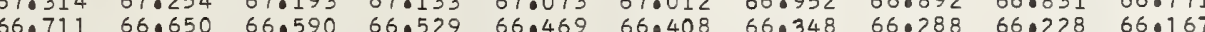
$\begin{array}{lllllllllll}66.707 & 60.046 & 650986 & 650.926 & 650865 & 650805 & 650745 & 65.684 & 650.624 & 65.563\end{array}$

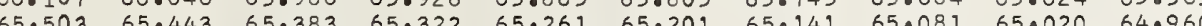

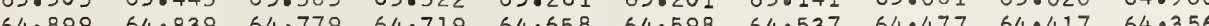
$\begin{array}{llllllllll}64.899 & 64.839 & 64.779 & 64.719 & 64.658 & 64.598 & 64.537 & 64.477 & 64.417 & 64.356\end{array}$

1.146683

0.282434
0.282433

0.282433

0.282432

0.282430

0.282430

0.282429

0.282429

0.282428

0.282427
0.282427

0.28242

0.282426

0.282425

0.282424

0.282423

0.282422

0.282422

. 28242

0.282420

0.282420
0.282419

0.282419

0.282418
0.282418

0.282417

0.282417

0.282416

. 282415

0.282415
0.282414

0.282414

0.282413

0.282413

0.282412

0.28241

0.28241

.282410

0.282409

0.282409

0.282408
0.282408

0.28240

0.282407

0.28240

0.28240

0.282405
0.282404

0.282404

0.282403

0.282403

0.282402

0.282401

0.282399

0.282398

0.282398

0.282397

0.282396

0.282396

.282395
.282395

0.282394

0.282394

0.282393

0.282393
0.282392

0.282392

0.282391

0.282391
0.282390

0

0.282390

0.282389
0.282389

0.282388

0.282388 
$\begin{array}{lllllllllll}4070.0 & 24563.089 & 63.029 & 62.968 & 62.908 & 62.847 & 62.787 & 62.727 & 62.666 & 62.606 & 62.546\end{array}$

$\begin{array}{lllllllllll}0.1 & 62.485 & 62.425 & 62.365 & 62.304 & 62.244 & 62.184 & 62.123 & 62.063 & 62.002 & 61.942 \\ 0.2 & 61.882 & 61.822 & 61.761 & 61.701 & 61.641 & 61.580 & 61.520 & 61.460 & 61.399 & 61.339\end{array}$

$\begin{array}{lllllllllll}0.2 & 61.882 & 61.822 & 61.761 & 61.701 & 61.641 & 61.580 & 61.520 & 61.460 & 61.399 & 61.339 \\ 0.3 & 61.279 & 61.218 & 61.158 & 61.097 & 61.037 & 60.977 & 60.916 & 60.856 & 60.796 & 60.735\end{array}$

0.4

60.675

60.615

$\begin{array}{llllllllll}59.468 & 59.408 & 59.348 & 59.287 & 59.227 & 59.167 & 59.106 & 59.046 & 58.986 & 58.925 \\ 58.865 & 58.805 & 58.744 & 58.684 & 58.624 & 58.563 & 58.503 & 58.443 & 58.382 & 58.322\end{array}$

$\begin{array}{llllllll}60.554 & 60.494 & 60.434 & 60.373 & 60.313 & 60.253 & 60.192 & 60.132\end{array}$

0.7

$\begin{array}{ll}58.262 & 58 \cdot 201 \\ 57.658 & 57.598\end{array}$

$\begin{array}{llllllll}5.134 & 59.287 & 59.227 & 59.167 & 59.106 & 59.046 & 58.986 & 58.925 \\ 58.744 & 58.684 & 58.624 & 58.563 & 58.503 & 58.443 & 58.382 & 58.322\end{array}$

4071.0

$\begin{array}{rrr}1.0 & 24557.055 & 56.995 \\ 1.1 & 56.452 & 56.392\end{array}$

$1 \cdot 3$

1.4

1.6

1.7

1.9

4072

2.3

2.4

2.6

2.8

$\begin{array}{ll}5.849 & 55.789 \\ 55.246 & 55.186\end{array}$

54.643
54.583

$53.437 \quad 53.376$

$\begin{array}{ll}52.833 & 52.773 \\ 52.231 & 52.170\end{array}$

$\begin{array}{ll}57.538 & 57.477\end{array}$

$\begin{array}{llllll}58.020 & 57.960 & 57.900 & 57.839 & 57.779 & 57.719 \\ 57.417 & 57.357 & 57.296 & 57.236 & 57.176 & 57.115\end{array}$

51.628

073.0

$$
\begin{array}{r}
3.0 \\
3 . \\
3 . \\
3 . \\
3.5 \\
3.5 \\
3.7 \\
3 . \\
3 .
\end{array}
$$

407400

400
40
4.0
40
40
40
40
40
40

4075.

5.0
5.0
5.0
5.0
5.0
5.07
5.8
5.9

4076.0

6.1
6.2
6.3

6.4

6.6

6.7

6.8

$$
\begin{array}{rllll}
4551.025 & 50.964 & 50.904 & 50.844 & 5 \\
50.422 & 50.362 & 50.301 & 50.241 & 50 \\
49.819 & 49.759 & 49.698 & 49.638 & 4 \\
49.216 & 49.156 & 49.096 & 49.035 & 48 \\
48.614 & 48.553 & 48.493 & 48.433 & 48 \\
48.010 & 47.950 & 47.890 & 47.830 & 47 \\
47.408 & 47.347 & 47.287 & 47.227 & 47 \\
46.805 & 46.745 & 46.685 & 46.624 & 46 \\
46.202 & 46.142 & 46.082 & 46.021 & 4 \\
45.600 & 45.539 & 45.479 & 45.419 & 4
\end{array}
$$

56.93
56.33
55.72
55.12
54.52
53.91
53.31
52.71
52.11
51.50
50.904
50.301
49.698
49.096
48.49
47.89
47.287
46.685
46.08
45.47

56.874
56.271

56.81
56.21
55.608

56.754

56.693

$\begin{array}{lll}56.633 & 56.573 & 56.512\end{array}$

55.065
54.462

55.608

55.548

$\begin{array}{ll}55.548 & 55.487 \\ 54.945 & 54.88\end{array}$

54.884
54.281

$\begin{array}{llll}53.859 & 53.799 & 53.739 & 53.678 \\ 53.256 & 53.196 & 53.135 & 53.075\end{array}$

52.653

52.050
51.447

51.990

51.929

52.472

55.427

54.82

$54.763 \quad 54.703$

$\begin{array}{lll}53.618 & 53.557 & 53.497\end{array}$

$\begin{array}{lll}53.015 & 52.955 & 52.894 \\ 52.412 & 52.351 & 52.291\end{array}$

$\begin{array}{ll}50.784 & 50.7 \\ 50.181 & 50.1\end{array}$

0.723
0.121
9.518

51.266

51.809
51.206

$1.748 \quad 51.688$

$48.975 \quad 48.915$

$\begin{array}{ll}48.372 & 48.312 \\ 47.770 & 47.709 \\ 47.167 & 47.107\end{array}$

$\begin{array}{ll}47.167 & 47.10 \\ 46.564 & 46.504\end{array}$

$\begin{array}{ll}45.961 & 45.901 \\ 45.359 & 45.298\end{array}$

50.060
49.457

48.854

48.252

47.046

4. 589

$\begin{array}{ll}46.444 & 46.383 \\ 45.841 & 45.781\end{array}$

4544.997

$44.394 \quad 44.334$

$43.189 \quad 43.129$

44.877
44.27
43.67

44.816

44.75

44.696

44.635

$45 \cdot 178$

$\begin{array}{ll}50.542 & 50.482 \\ 49.940 & 49.879\end{array}$

$49.337 \quad 49.276$

$48.734 \quad 48.674$

$\begin{array}{ll}48.131 & 48.071 \\ 47.528 & 47.468\end{array}$

$46.926 \quad 46.865$

$46.323 \quad 46.262$

$\begin{array}{ll}45.720 & 45.660 \\ 45.117 & 45.057\end{array}$

0.282383

0.282382

0.282381

0.282380

0.282380

0.282379

0.282378

0.282378

0.282377
0.282377

0.282376

0.282376

0.282375

0.282374
0.282374

0.282373

0.28237
0.28237

0.282372

0.282371
0.282370

0.282370

0.282369

0.282369

0.282368

0.282367

0.282367

0.282366

0.282366

0.282365

0.282364

0.282364

$\begin{array}{llllllllll}41.382 & 41.322 & 41.261 & 41.201 & 41.141 & 41.081 & 41.020 & 40.960 & 40.900 & 40.840\end{array}$

$\begin{array}{llllllllll}40.177 & 40.117 & 40.659 & 40.599 & 40.538 & 40.478 & 40.418 & 40.358 & 40.298 & 40.237\end{array}$

39.514

$39.454 \quad 39.394$

$39.334 \quad 39.273$

$\begin{array}{llll}39.213 & 39.153 & 39.093 & 39.032\end{array}$

0.282363

0.282363

0.282362

0.282361

0.282361

0.282360

0.282359

0.282358

0.282357

0.282357

0.282356

0.282356

0.282355

0.282354

0.282354
0.282353

0.282353

0.282352

0.282352

0.282351

0.282350

0.282350

0.282349

0.282349

$\begin{array}{llllllllll}23.322 & 23.262 & 23.202 & 23.142 & 23.081 & 23.021 & 22.961 & 22.901 & 22.841 & 22.781\end{array}$

$\begin{array}{llllllllll}22.119 & 22.059 & 21.999 & 21.938 & 21.878 & 21.818 & 21.758 & 21.698 & 21.638 & 21.577 \\ 21.518 & 21.457 & 21.397 & 21.337 & 21.277 & 21.217 & 21.157 & 21.096 & 21.036 & 20.976\end{array}$

4077.

7.1

7.3

7.4
7.5
7.6

7.7

$7 \cdot 8$

24520.91

20.254

$\begin{array}{ll}19.713 & 19.65 \\ 19.112 & 19.052\end{array}$

$18.511 \quad 18.451$

$17.910 \quad 17.849$

$16.707 \quad 16.647$

$15.505 \quad 15.445$

4078.0

8.

$8 \cdot 3$

8.4

8.5

8.6
8.7

8.8

4079.

$$
\begin{array}{r}
4079.0 \\
9.1 \\
9.2 \\
9.3 \\
9.4 \\
9.5 \\
9.6 \\
9.7 \\
9.0
\end{array}
$$

24514.903

14.302

$\begin{array}{ll}13.701 & 13.6 \\ 13.100 & 13.040\end{array}$

$12.499 \quad 12.439$

$\begin{array}{ll}11.898 & 11.838 \\ 11.297 & 11.237\end{array}$

$\begin{array}{ll}11.297 & 11.23 \\ 10.696 & 10.636\end{array}$

$10.095 \quad 10.035$

$20.796 \quad 20.7$

21.277

$\begin{array}{llll}20.555 & 20.495 & 20.435 & 20.375\end{array}$

0.282348 0.282347 0.282346 0.282346 0.282345 0.282345 0.282344 0.282344

0.282343 0.282342 0.282342
0.282341
0.282341 0.282341

0.282341

0.282340

0.282340

0.282339

0.282339

0.282338

0.282337

0.282337

0.282336

0.282335

0.282335

0.282334

0.282334 1.149300
$1=149326$
1.149352
$1 \cdot 149378$
1.149404
1.149430
1.149457
1.149483
1.149509
1.149535

1.149561

1.149614

1.149640

1.149666

1.149718

1.149744

10149771
1.149797

1.149823

1.149875

1.149901

1. 149928

1. 149954

1.149980
1.150006

1.150032

1.150032

1.150085

1.150111

1.150137

1.150163

1.150189

1.150216

1.150242

1.150294

1.150346

1.150373

1.150399

1.150451

1.150477

1. 150503

1.150556

1.150608

1.150634

1.150660

$1 \cdot 150687$

1.150713

1.150739

1.150791

1.150817

1.150870

1. 150896

1.150922

1.150948

1.150975

1. 151027

1.151053

1.15107 .9

1.151132

1.151158

1.151184 
$24496.883 \quad 96.823$ $96.282 \quad 96.222$

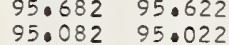
94.482 $93.882 \quad 93.822$ $93.281 \quad 93.221$ 92.68192 .622 91.481

4082.

$\begin{array}{rrr}2.0 & 24490.881 & 90.821 \\ 2.1 & 90.281 & 90.221\end{array}$

0.282333

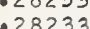

0.282331

0.282330

0.282330

0.282329

0.282328

.282327

0.282326

0.282325
0.282325
0.282324

0.282324

0.282323

0.282322

0.282322

0.282321

0.282320

0.282319

0.282318
0.282318

0.282317

0.282317

0.282316

0.282315

0.282314

0.282313
0.282313

0.282312

0.282312

0.28231

0.282311
0.282310

0.282310
0.282309

0.282309
0.282309

0.282308
0.282308

0.282307

0.282307
0.282306
0.282306

0.282306
0.282306
0.28235

0.282305

0.282305
0.282304

0.282304

0.282303
0.282303

0.282302

0.282302

0.282301

0.282300

0.282299

.282299

0.282298
0.282298

0.282297

0.282297

0.282296

0.282295

.282294

0.282294

0.282293

0.282292

0.282291

0.282291

0.022290

0.282289

0.282289

0.282288

0.282287 0.282287 0.282286

0.282285

0.282285

0.282284

0.282283
0.282283

.010

10151917

1.151969

1. 151995

1.152048

1.152074

1.152126

1.152179

1.15220

1. 152257

1.152283

1.152336

1. 152388

1.152440

l. 152493

1. 152519

I. 152571

1.152597

1.152650

1.152702

10152728

1.152781

1.152807

1.152859

1.152912

1.152964

1.152990

.153042

1. 153069

1.153121

1.153147

1.153199 


\section{$\begin{array}{llllll}42.381 & 42.321 & 42.261 & 42.202 & 42.142 & 42.680 \\ & 42.082\end{array}$}

$\begin{array}{llllll}41.186 & 41.126 & 41.066 & 41.006 & 40.947 & 40.887\end{array}$

$\begin{array}{llllll}40.588 & 40.528 & 40.469 & 40.409 & 40.349 & 40.289 \\ 39.991 & 39.931 & 39.871 & 39.812 & 39.752 & 39.692\end{array}$

$\begin{array}{llllll}39.393 & 39.333 & 39.274 & 39.214 & 39.154 & 39.094 \\ 38.796 & 38.736 & 38.676 & 38.616 & 38.557 & 38.497\end{array}$

$\begin{array}{llll}38.796 & 38.736 & 38.676 & 38.616\end{array}$

38.198
37.601

$\begin{array}{ll}37.959 & 37.900 \\ 37.362 & 37.302\end{array}$

$\begin{array}{llll}42.620 & 42.560 & 42.500 & 42.441 \\ 42.022 & 41.962 & 41.903 & 41.843\end{array}$

$41.425 \quad 41.365 \quad 41.305 \quad 41.245$

$40.230 \quad 40.170 \quad 40.1110 \quad 40.051$

$\begin{array}{llll}39.632 & 39.573 & 39.513 & 39.453\end{array}$

$39.035 \quad 38.975 \quad 38.915 \quad 38.856$

$\begin{array}{llll}38.437 & 38.378 & 38.318 & 38.258\end{array}$

24437.004

$\begin{array}{llll}37.004 & 36.944 & 36.884 & 36 . \\ 36.406 & 36.347 & 36.287 & 36 \\ 35.809 & 35.750 & 35.690 & 35\end{array}$

$\begin{array}{llll}35.212 & 35.750 & 35.690 & 35.630 \\ 35.152 & 35.092 & 35.032\end{array}$

$\begin{array}{llllll}35.212 & 35.152 & 35.092 & 35.032 & 34.973 & 34.913 \\ 34.615 & 34.555 & 34.495 & 34.436 & 34.376 & 34.316 \\ 34.017 & 33.958 & 33.898 & 33.838 & 33.779 & 33.719\end{array}$

$\begin{array}{lllllll}33.420 & 33.360 & 33.301 & 33.241 & 33.181 & 33.122\end{array}$

$32.226 \quad 32$

.763 320

$431.032 \quad 30.972$

30.435
29.838
29.241

$\begin{array}{ll}29.241 & 29.18 \\ 28.644 & 28.584\end{array}$

$\begin{array}{lll}28.044 & 28.584 & 28.525 \\ 28.047 & 27.988 & 27.928\end{array}$

$\begin{array}{llll}27.047 & 27.988 & 27.928 & 27.868 \\ 27.450 & 27.391 & 27.331 & 27.271\end{array}$

$\begin{array}{ll}26.854 & 26.794 \\ 26.257 & 26.197 \\ 25.660 & 25.600\end{array}$

24.466

25.003

26.134
26.137
25.541

26.07
25.048

$\begin{array}{ll}36.765 & 36.705 \\ 36.167 & 36.108 \\ 35.570 & 35.510 \\ 34.973 & 34.913 \\ 34.376 & 34.316 \\ 33.779 & 33.719 \\ 33.181 & 33.122 \\ 32.584 & 32.524 \\ 31.987 & 31.927\end{array}$

$\begin{array}{llll}36.645 & 36.585 & 36.526 & 36.466\end{array}$

$\begin{array}{llll}36.048 & 35.988 & 35.928 & 35.869 \\ 35.451 & 35.391 & 35.331 & 35.271\end{array}$

$\begin{array}{llll}35.451 & 35.391 & 35.331 & 35.271 \\ 34.853 & 34.794 & 34.734 & 34.674\end{array}$

$\begin{array}{llll}34.256 & 34.197 & 34.137 & 34.077 \\ 33.659 & 33.599 & 33.540 & 33.480\end{array}$

$\begin{array}{llll}33.062 & 33.002 & 32.942 & 32.88\end{array}$

$\begin{array}{llll}32.465 & 32.405 & 32.345 & 32.28\end{array}$

$\begin{array}{lll}3.106 & 32.047 & 3 \\ 1.509 & 31.450 & 31.0\end{array}$

31.987
31.390

31.92

$23.870 \quad 23.810$

$\begin{array}{ll}23.273 & 23.213 \\ 22.677 & 22.617\end{array}$

$24 \cdot 944$
$24 \cdot 347$

$24 \cdot 884$

30.793
30.196

30.734

31.27

$\begin{array}{lll}1.808 & 31.748 & 31.688 \\ 1.211 & 31.152 & 31.092\end{array}$

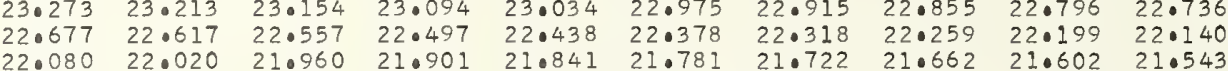

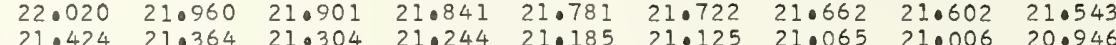

$\begin{array}{llllllll}20.767 & 20.708 & 20.648 & 20.588 & 20.529 & 20.469 & 20.409 & 20.350\end{array}$

$\begin{array}{ll}20.290 & 20.230 \\ 19.694 & 19.634\end{array}$

$20.767 \quad 20.708$

20.052

19.992

19.932

19.873

19.813

$24419.097 \quad 19.037$

18.500
17.900
17009

17.308

16.71116 .652

$18.978 \quad 18.918$

19.45519 .39

18.73

19.276

$19.216 \quad 19.257$

$\begin{array}{llllll}16.115 & 16.055 & 15.996 & 15.936 & 15.877 & 15.817 \\ 15.519 & 15.459 & 15.400 & 15.340 & 15.280 & 15.221\end{array}$

$\begin{array}{llllll}15.519 & 15.459 & 15.400 & 15.340 & 15.280 & 15.221 \\ 14.923 & 14.863 & 14.803 & 14.744 & 14.684 & 14.625\end{array}$

14.326
13.730

$24413.134 \quad 13.075$

$12.538 \quad 12.479$

14.207
13.611

14.147
13.552

14.088
13.492

14.028
13.432

$\begin{array}{llll}18.143 & 18.083 & 18.620 & 18.560\end{array}$

$\begin{array}{llll}17.546 & 17.487 & 17.427 & 17.367\end{array}$

$\begin{array}{llll}16.354 & 16.294 & 16.234 & 16.175\end{array}$

$\begin{array}{llll}5.757 & 15.698 & 15.638 & 15.579\end{array}$

$14.565 \quad 14.101 \quad 15.042 \quad 140982$

$\begin{array}{llll}14.565 & 14.505 & 14.446 & 14.386 \\ 13.969 & 13.909 & 13.850 & 13.790\end{array}$

$\begin{array}{ll}13.015 & 12.95 \\ 12.419 & 12.36\end{array}$

$12.896 \quad 12.836$

$\begin{array}{lllll}12.777 & 12.717 & 12.657 & 12.598\end{array}$

$\begin{array}{llllllllll}11.942 & 11.883 & 11.823 & 11.763 & 11.704 & 11.644 & 11.584 & 11.525 & 11.465 & 11.406\end{array}$

$\begin{array}{lllllllll}11.167 & 11.108 & 11.048 & 10.988 & 10.929 & 10.869 & 10.809\end{array}$

$\begin{array}{llllllllll}10.154 & 10.094 & 10.035 & 09.975 & 09.916 & 09.856 & 09.796 & 09.737 & 09.677 & 09.618\end{array}$

$\begin{array}{llllllllll}09.558 & 09.498 & 09.439 & 09.379 & 09.319 & 09.260 & 09.200 & 09.141 & 09.081 & 09.029\end{array}$

$\begin{array}{llllllllll}08.366 & 08.306 & 08.247 & 08.187 & 08.128 & 08.068 & 08.009 & 07.949 & 07.889 & 07.830 \\ 07.770 & 07.710 & 07.651 & 07.591 & 07.532 & 07.472 & 07.413 & 07.353 & 07.293 & 07.234\end{array}$

$\begin{array}{llll}0.174 & 07.114 & 07.055 & 06.995 \\ 06.578 & 06.519 & 06.459 & 06.400\end{array}$

$05.387 \quad 05.327 \quad 05.86305 .804$

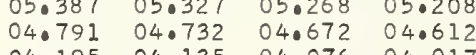

$\begin{array}{llll}04.195 & 04.135 & 04.076 & 04.017 \\ 03.600 & 03.540 & 03.480 & 03.42\end{array}$

$03.004 \quad 02.944 \quad 02.885 \quad 02.825$

$06.936 \quad 06.876$

06.817

06.757

$06.697 \quad 06.638$

$\begin{array}{llllll}05.740 & 060281 & 06.221 & 06.161 & 06.102 & 06.0638\end{array}$

$\begin{array}{lllllll}05.149 & 05.089 & 05.029 & 04.970 & 04.910 & 04.851\end{array}$

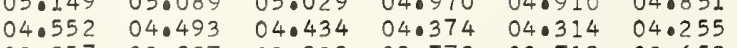

$\begin{array}{llllll}03.957 & 03.897 & 03.838 & 03.778 & 03.719 & 03.659\end{array}$

$\begin{array}{llllll}03.361 & 03.302 & 03.242 & 03.182 & 03.123 & 03.063\end{array}$

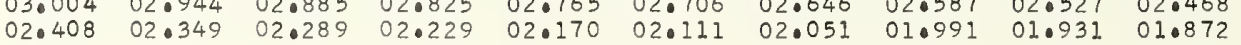

$\begin{array}{llllllllll}44401.217 & 01.157 & 01.098 & 01.039 & 00.979 & 00.919 & 00.860 & 00.800 & 00.740 & 00.681\end{array}$

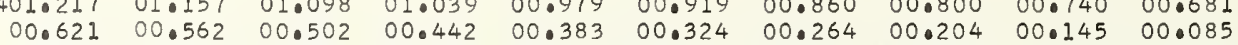
$00.026 * 99.967 * 99.907 * 99.847 * 99.788 * 99.728 * 99.668 * 99.609 * 99.550 * 99.490$

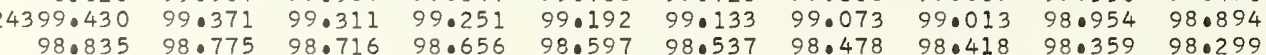
$\begin{array}{llllllllll}98.835 & 98.775 & 98.716 & 98.656 & 98.597 & 98.537 & 98.478 & 98.418 & 98.359 & 98.299 \\ 98.240 & 98.180 & 98.120 & 98.061 & 98.001 & 97.941 & 97.882 & 97.822 & 97.763 & 97.704\end{array}$

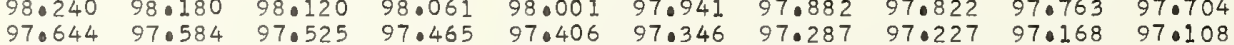
$\begin{array}{llllllllll}97.049 & 96.989 & 96.930 & 96.870 & 96.810 & 96.750 & 96.691 & 96.632 & 96.572 & 96.513\end{array}$ $\begin{array}{llllllllll}96.453 & 96.394 & 96.334 & 96.274 & 96.215 & 96.156 & 96.096 & 96.036 & 95.977 & 95.917 \\ 95.858 & 95.799 & 95.739 & 95.680 & 95.620 & 95.560 & 95.501 & 95.441 & 95.382 & 95.322\end{array}$

$24395.263 \quad 95.203$

94.66894 .608

$93.477 \quad 93.417$

$92.882 \quad 92.822$

$92.763 \quad 92.703$

$\begin{array}{llll}9.691 & 1.632 & 91.573 & 91.513\end{array}$

$90.501 \quad 90.037290 .978$ 90.918

$\begin{array}{llll}90.501 & 90.442 & 90.382 & 90.323 \\ 89.906 & 89.847 & 89.787 & 89.728\end{array}$

$88.716 \quad 89.252 \quad 89.19$

$\begin{array}{lllll}88.121 & 88.062 & 88.597 & 88.538\end{array}$

$\begin{array}{llll}87.526 & 87.467 & 87.407 & 87.348\end{array}$

$\begin{array}{llll}86.932 & 86.872 & 86.813 & 86.753 \\ 86.336 & 86.277 & 86.218 & 86.158\end{array}$

$\begin{array}{llll}85.742 & 85.682 & 85.623 & 85.563\end{array}$

$\begin{array}{llll}85.147 & 85.088 & 85.028 & 84.969\end{array}$

$\begin{array}{llll}83.958 & 83.898 & 83.838 & 83.779\end{array}$

95.02594 .965

$94.906 \quad 94.846 \quad 94.786 \quad 94.727$

$\begin{array}{llllll}940429 & 94.370 & 94 \cdot 311 & 94.251 & 94.191 & 94 \cdot 132 \\ 93.834 & 93.775 & 93.715 & 93.656 & 93.596 & 93.537\end{array}$

$\begin{array}{rlllll}93.834 & 93.775 & 93.715 & 93.656 & 93.596 & 93.537 \\ 93.239 & 93.180 & 93.120 & 93.061 & 93.001 & 92.941\end{array}$

$\begin{array}{lllllll}92.644 & 92.584 & 92.525 & 92.465 & 92.406 & 92.346\end{array}$

$\begin{array}{llllll}92.049 & 91.989 & 91.930 & 91.870 & 91.811 & 91.751 \\ 91.453 & 91.394 & 91.334 & 91.275 & 91.215 & 91.156\end{array}$

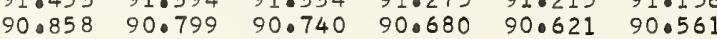

$\begin{array}{llllll}90.263 & 90.204 & 90.144 & 90.085 & 90.025 & 89.966 \\ 89.668 & 89.609 & 89.550 & 89.490 & 89.430 & 89.371\end{array}$

$\begin{array}{llllll}89.073 & 89.014 & 88.954 & 88.895 & 88.835 & 88.776 \\ 88.478 & 88.419 & 88.360 & 88.300 & 88.240 & 88.181\end{array}$

$\begin{array}{lllllll}87.884 & 87.824 & 87.764 & 87.705 & 87.646 & 87.586\end{array}$

$\begin{array}{llllll}87.289 & 87.229 & 87.169 & 87.110 & 87.051 & 86.991\end{array}$

$\begin{array}{llllll}86.694 & 86.634 & 86.575 & 86.515 & 86.456 & 86.396 \\ 86.099 & 86.039 & 85.980 & 85.920 & 85.861 & 85.802\end{array}$

$\begin{array}{lllllll}85.504 & 85.445 & 85.385 & 85.326 & 85.266 & 85.206\end{array}$

$\begin{array}{lllllll}84.909 & 84.849 & 84.790 & 84.731 & 84.671 & 84.612\end{array}$

$\begin{array}{llllll}84.314 & 84.255 & 84.196 & 84.136 & 84.076 & 84.017 \\ 83.719 & 83.660 & 83.601 & 83.541 & 83.482 & 83.422\end{array}$

0.282282

1.154535

.282281

0.282281

0.282280

0.282279

0.282279

0.282278

0.282277

0.282277

0.282276

0.282275
0.282275

0.282274

0.282274

0.282273

0.282272

0.282272

0.282271

0.282270

0.282270

0.282269

0.282268

0.282267

0.282267

0.282266

0.282265

0.282265

0.282284

0.282264

0.282263

0.282263

0.282262

0.282261

0.282261

0.282260

0.282260

0.282259

0.282259
0.282258

0.282258
0.282258

0.282257

0.282257

0.282256

0.282256

0.282255

0.282254

- 282254

0.282253

0.282252

0.282252

0.282251

0.282251

0.282250

0.282250

0.282249

0.282249

0.282248

0.282247

0.282247

0.282246

0.282246

0.282245

0.282245

0.282244

0.282244

0.282243
0.282243

0.282242

0.282242

0.282241

0.282240

0.282240

0.282239

0.282239

0.282238
0.282238

. 154587

1. 154613

1. 154666

1. 154692

1. 154744

1. 154770

1. 154797

1.154823

1. 154849

1. 154901

1. 154927

1.154954
1.154980

1.155006

1.155032

2.155058

1. 155085

1.155111

1.155163

1.155189

1.155215

1.155268

1. 155294

1.155320

- 155346

1.155399

1.155425

1.155451

1.155477

1. 155530

1.155582

1.155608

1.155634

1. 155661

1. 155713 
0.4

$\begin{array}{llll}81.519 & 81.460 & 81.995\end{array}$

$80.865 \quad 80.806$

$\begin{array}{llll}79.795 & 79.735 & 79.676 & 79.616\end{array}$

0.7

$\begin{array}{llll}79.200 & 79.141 & 79.082 & 79.022\end{array}$

$\begin{array}{llll}78.606 & 78.546 & 78.487 & 78.427 \\ 78.012 & 77.952 & 77.893 & 77.833\end{array}$

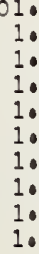

24377
76
76
750
750
740
730
730
720

4102
2
2
2
2
2
2
2
2
2
2

02.0
2.1
2.2
2.3
2.4
2.5
2.6
2.7
2.8
2.9

4103.0

3.1
3.2

3.3

3.4
3.5

3.7

3.9

4104

4.1

4.3

4.5

4.7

4.8
4.9

4105.

5.

5.3

5.5

5.7

5.7

4106

6.

$6 \cdot 1$

6.3

6.4

6.6

6.7
6.8

4107.0

7.

$7 \cdot 2$
7.3

7.4

70

7.6
7.7
7.8

7.8
7.9

410

$\begin{array}{rr}08.0 & 2433 \\ 8.1 & 3 \\ 8.2 & 340 \\ 8.3 & 340 \\ 8.4 & 330 \\ 8.5 & 320 \\ 8.5 & 320 \\ 8.7 & 310 \\ 8.8 & 310 \\ 8.9 & 300 \\ 09.0 & 2432 \\ 9.1 & 290 \\ 9.2 & 280 \\ 9.3 & 280 \\ 9.4 & 270 \\ 9.5 & 260 \\ 9.5 & 260 \\ 9.7 & 250 \\ 9.8 & 250 \\ 9.9 & 240\end{array}$

$77.417 \quad 77.358$

$\begin{array}{llll}76.823 & 76.764 & 76.704 & 76.645\end{array}$

$\begin{array}{lllll}76.823 & 76.764 & 76.704 & 76.0645\end{array}$

$\begin{array}{llll}75.040 & 74.980 & 74.921 & 74.861\end{array}$

$\begin{array}{llll}74.446 & 74.386 & 74.327 & 74.268 \\ 73.852 & 73.792 & 73.733 & 73.673\end{array}$

$73.257 \quad 73.198 \quad 73.138 \quad 73.079$

$\begin{array}{llll}72.663 & 72.604 & 72.544 & 72.485 \\ 72.069 & 72.009 & 71.950 & 71.890\end{array}$

24371.47

70.88071 .415

$\begin{array}{ll}70.880 & 70.821 \\ 70.286 & 70.227\end{array}$

69.692

$\begin{array}{ll}70.168 & 70.108 \\ 69.573 & 69.514\end{array}$

$\begin{array}{llll}68.504 & 68.445 & 68.979 & 68.920 \\ 68.38 & 68.326\end{array}$

$\begin{array}{llll}67.910 & 67.851 & 67.792 & 67.732\end{array}$

$\begin{array}{llll}67.316 & 67.257 & 67.198 & 67.138\end{array}$

$\begin{array}{llll}66.722 & 66.663 & 66.604 & 66.544 \\ 66.129 & 66.069 & 66.010 & 65.950\end{array}$

24365.534

365.534

$64 \cdot 941$
$64 \cdot 347$

65.475

650416

$\begin{array}{lll}64.288 & 64.228 & 64.169\end{array}$

$\begin{array}{llll}6.159 & 63.694 & 63.635 & 63.575 \\ 63.100 & 63.041 & 62.981\end{array}$

$\begin{array}{lllll}62.566 & 62.506 & 62.447 & 62.388\end{array}$

$61.972 \quad 61.913 \quad 61.853 \quad 61.794$

$\begin{array}{llll}60.785 & 60.725 & 60.666 & 60.607 \\ 60.191 & 60.132 & 60.073 & 60.013\end{array}$

\begin{abstract}
$59.004 \quad 58.945$
$\begin{array}{llll}58.411 & 58.352 & 58.886 & 58.826\end{array}$

$\begin{array}{llll}57.817 & 57.758 & 57.699 & 57.640\end{array}$

$\begin{array}{llll}57.224 & 57.165 & 57.105 & 57.046\end{array}$

$\begin{array}{llll}56.037 & 55.978 & 55.918 & 55.859\end{array}$

$\begin{array}{llll}55.444 & 55.385 & 55.325 & 55.266\end{array}$

$\begin{array}{llll}54.851 & 54.791 & 54.732 & 54.673 \\ 54.257 & 54.198 & 54.138 & 54.079\end{array}$
\end{abstract}

24353.66

53.07153 .011

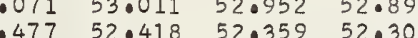

$51.884 \quad 51.825 \quad 51.76551 .706$

$50.698 \quad 50.632 \quad 51.172 \quad 51.113$

$\begin{array}{llll}50.105 & 50.045 & 49.986 & 49.927\end{array}$

49.512

48.918

48.453

49.393

49.334

24347.732

$47.732 \quad 47.673$

$46.546 \quad 46.488$

$45.954 \quad 45.895$

$44 \cdot 768 \quad 44 \cdot 70$

$44 \cdot 17544 \cdot 11$

$42.397 \quad 42.338$

$47.614 \quad 47.555$

47.014

$46.428 \quad 46.369$

$45.242 \quad 45 \cdot 183$

$\begin{array}{ll}44.650 & 44.590 \\ 44.057 & 43.997\end{array}$

$42 \cdot 87$

$\begin{array}{lll}41.753 & 41.687\end{array}$

$40.560 \quad 40.501$

$\begin{array}{lll}39.434 & 39.375 & 39.31\end{array}$

$38.240 \quad 38.100 \quad 38.131$

$37.597 \quad 37.538 \quad 38.071$

$\begin{array}{llll}37.064 & 37.005 & 36.946 & 36.88\end{array}$

36.472

37.00536 .946

$35.879 \quad 35.820$

228
35.168
35

$\begin{array}{llll}34.102 & 34.043 & 33.984 & 34.517 \\ & 34.924\end{array}$

$\begin{array}{llll}33.510 & 33.451 & 33.391 & 33.332\end{array}$

$\begin{array}{llll}32.917 & 32.858 & 32.799 & 32.740\end{array}$

$\begin{array}{llll}733 & 31.674 & 31.615 & 31.556\end{array}$

$\begin{array}{llll}31.141 & 31.082 & 31.022 & 30.963 \\ 30.549 & 30.490 & 30.430 & 30.371\end{array}$

$29.956 \quad 29.897$

$\begin{array}{ll}29.365 & 29.30 \\ 28.772 & 28.713\end{array}$

$28.654 \quad 28.59$

$27.589 \quad 27.530$

$26.405 \quad 26.345$

25.22125 .753

$26.286 \quad 26.227$

$26.286 \quad 26.227$

$\begin{array}{ll}25.221 & 25.161 \\ 24.629 & 24.570\end{array}$

25.102
24.510

24.451

$\begin{array}{llllll}83.125 & 83.065 & 83.006 & 82.947 & 82.887 & 82.828 \\ 82.530 & 82.471 & 82.411 & 82.352 & 82.292 & 82.233\end{array}$

$\begin{array}{llllll}11.341 & 81.876 & 81.816 & 81.757 & 81.698 & 81.638\end{array}$

$\begin{array}{llllll}80.746 & 80.687 & 80.627 & 80.568 & 80.509 & 80.449 \\ 80.152 & 80.092 & 80.032 & 79.973 & 70.014 & 79.854\end{array}$

$\begin{array}{rll}79.557 & 70.092 & 80.032\end{array}$

$78.368 \quad 78.309$

78.844

79.379

$78.784-79.31$

78.72

79.854
79.260

78.071

$\begin{array}{llllll}77.180 & 77.120 & 77.061 & 77.001 & 76.942 & 76.883 \\ 76.585 & 76.526 & 76.467 & 76.407 & 76.348 & 76.288\end{array}$

$75.397 \quad 75 \cdot 931$

$74.802 \quad 74.742 \quad 75.278$

$74.208 \quad 74.148 \quad 74.089$

$\begin{array}{lll}73.613 & 73.554 & 73.495 \\ 73.020 & 72.960 & 72.900\end{array}$

$\begin{array}{lll}72.425 & 72.366 & 72.30 \\ 71.831 & 71.771 & 71.71\end{array}$

$\begin{array}{lll}76.407 & 76 \cdot 348 & 76.288 \\ 75.813 & 75.753 & 75.694 \\ 75.218 & 75.159 & 75.099\end{array}$

$\begin{array}{lll}75.218 & 75.159 & 75.099 \\ 74.624 & 74.564 & 74.505\end{array}$

$74.030 \quad 73.970 \quad 73.911$

$\begin{array}{lll}72.841 & 72.782 & 72.722\end{array}$

$71.237 \quad 71.17$

71.11

$\begin{array}{ll}70.049 & 69.990\end{array}$

$\begin{array}{ll}69.455 & 69.395 \\ 68.861 & 68.801\end{array}$

$\begin{array}{ll}68.267 & 68.207 \\ 67.673 & 67.61\end{array}$

$67.079 \quad 67.01$

69.930

69.336

$\begin{array}{lll}69.336 & 69.276 & 69.217 \\ 68.742 & 68.683 & 68.623 \\ 68.148 & 68.088 & 68.029 \\ 67.554 & 67.495 & 67.435\end{array}$

66.960

66.901

0167.435

66.84

72.128
$\quad 71.534$

65.831

65.772

$\begin{array}{ll}65.297 & 65.23 \\ 64.703 & 64.644\end{array}$

65.178

$\begin{array}{lllll}64.044 & 64.584 & 64.525 & 64.466 & 64.406\end{array}$

$\begin{array}{lllll} & \end{array}$

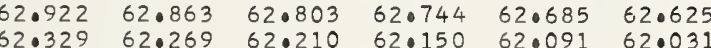

$\begin{array}{llllll}61.734 & 61.675 & 61.616 & 61.557 & 61.497 & 61.438\end{array}$

$\begin{array}{llllll}10.141 & 61.082 & 61.022 & 60.963 & 60.904 & 60.844\end{array}$

$\begin{array}{llllll}60.547 & 60.488 & 60.429 & 60.369 & 60.310 & 60.250 \\ 59.954 & 59.895 & 59.836 & 59.776 & 59.717 & 59.657\end{array}$

$\begin{array}{llllll}59.361 & 59.301 & 59.242 & 59.182 & 59.123 & 59.064\end{array}$

$\begin{array}{llllll}58.767 & 58.708 & 58.648 & 58.589 & 58.530 & 58.470 \\ 58.173 & 58.114 & 58.055 & 57.996 & 57.936 & 57.877\end{array}$

$\begin{array}{lllllll}57.580 & 57.521 & 57.461 & 57.402 & 57.343 & 57.283\end{array}$

$\begin{array}{llllll}56.986 & 56.927 & 56.868 & 56.809 & 56.749 & 56.690\end{array}$

$\begin{array}{lllllll}55.800 & 55.741 & 55.681 & 55.622 & 55.562 & 55.503\end{array}$

$\begin{array}{llllll}54.2013 & 55.147 & 55.088 & 55.029 & 54.969 & 54.910\end{array}$

$\begin{array}{llllll}54.020 & 53.960 & 53.901 & 53.842 & 53.782 & 53.723\end{array}$

$\begin{array}{llllll}53.427 & 53.367 & 53.308 & 53.249 & 53.190 & 53.130\end{array}$

$\begin{array}{llllll}52.240 & 52.181 & 52.121 & 52.062 & 52.003 & 51.944\end{array}$

$\begin{array}{llllll}51.647 & 51.588 & 51.528 & 51.469 & 51.409 & 51.350 \\ 51.054 & 50.094 & 50.035 & 50.876 & 50.817 & 50.757\end{array}$

$\begin{array}{llllll}50.460 & 50.401 & 50.342 & 50.282 & 50.223 & 50.164\end{array}$

$49.867 \quad 49.808$

49.274
48.682

49.215

50.342
$49 \cdot 749$

49.156

$49.097 \quad 49.037$

$48.503 \quad 48.444 \quad 48 \cdot 385$

$\begin{array}{llllll}46.902 & 46.844 & 46.784 & 46.724 & 46.665 & 46.606\end{array}$

$\begin{array}{llllll}46.310 & 46.250 & 46.191 & 46.132 & 46.073 & 46.013 \\ 45.717 & 45.657 & 45.598 & 45.539 & 45.479 & 45.420\end{array}$

$45.124 \quad 45.064 \quad 45.005 \quad 44.946 \quad 44.887 \quad 44.827$

$\begin{array}{llllll}44.531 & 44.472 & 44.412 & 44 \cdot 353 & 44.294 & 44.235 \\ 43.938 & 43.879 & 43.820 & 43.760 & 43.701 & 43.642\end{array}$

$\begin{array}{llllll}43.345 & 43.286 & 43.227 & 43.168 & 43.108 & 43.049\end{array}$

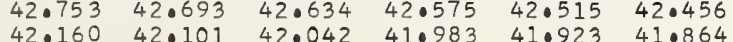

$\begin{array}{llllll}41.567 & 41.508 & 41.449 & 41.390 & 41.331 & 41.271\end{array}$

$\begin{array}{lllllll}40.975 & 40.916 & 40.856 & 40.797 & 40.738 & 40.678\end{array}$

$\begin{array}{llllll}40.382 & 40.323 & 40.263 & 40.205 & 40.145 & 40.086 \\ 39.790 & 39.730 & 39.671 & 39.612 & 39.552 & 39.493\end{array}$

$\begin{array}{lllllll}39.197 & 39.138 & 39.079 & 39.019 & 38.960 & 38.901\end{array}$

$\begin{array}{llllll}38.604 & 38.545 & 38.486 & 38.427 & 38.368 & 38.308\end{array}$

$\begin{array}{llllll}38.012 & 37.953 & 37.894 & 37.834 & 37.775 & 37.716 \\ 37.419 & 37.360 & 37.301 & 37.242 & 37.183 & 37.123\end{array}$

$\begin{array}{llllll}36.827 & 36.768 & 36.709 & 36.649 & 36.590 & 36.531\end{array}$

$\begin{array}{lllllll}35.642 & 35.583 & 35.524 & 35.465 & 35.406 & 35.346\end{array}$

$\begin{array}{llllll}35.050 & 34.991 & 34.931 & 34.872 & 34.813 & 34.753\end{array}$

$\begin{array}{llllll}34.458 & 34.398 & 34.339 & 34.280 & 34.221 & 34.162\end{array}$

$\begin{array}{llllll}33.273 & 33.214 & 33.747 & 33.687 & 33.628 & 33.569 \\ 33.155 & 33.095 & 33.036 & 32.977\end{array}$

$\begin{array}{llllll}32.273 & 33.214 & 33.155 & 33.095 & 33.036 & 32.977\end{array}$

$\begin{array}{llllll}32.088 & 32.029 & 31.970 & 31.911 & 31.852 & 31.792\end{array}$

$\begin{array}{llllll}31.496 & 31.437 & 31.378 & 31.319 & 31.259 & 31.200\end{array}$

$\begin{array}{llllll}30.904 & 30.845 & 30.786 & 30.726 & 30.667 & 30.608 \\ 30.312 & 30.253 & 30.194 & 30.135 & 30.075 & 30.016\end{array}$

$\begin{array}{lllllll}29.720 & 29.660 & 29.601 & 29.542 & 29.483 & 29.424\end{array}$

$\begin{array}{llllll}29.128 & 29.069 & 29.010 & 28.950 & 28.891 & 28.832 \\ 28.535 & 28.476 & 28.417 & 28.358 & 28.299 & 28.240\end{array}$

$\begin{array}{llllll}28.535 & 28.476 & 28.417 & 28.358 & 28.299 & 28.240 \\ 27.944 & 27.885 & 27.825 & 27.766 & 27.707 & 27.647\end{array}$

$\begin{array}{llllll}27.351 & 27.292 & 27.233 & 27.174 & 27.115 & 27.055\end{array}$

$\begin{array}{llllll}26.760 & 26.700 & 26.641 & 26.582 & 26.523 & 26.464 \\ 26.167 & 26.108 & 26.049 & 25.990 & 25.931 & 25.872\end{array}$

$\begin{array}{llllll}26.167 & 26.108 & 26.049 & 250990 & 25.931 & 25.872 \\ 25.576 & 25.517 & 25.457 & 25.398 & 25.339 & 25.280\end{array}$

$\begin{array}{llllll}4.984 & 24.925 & 24.865 & 24.806 & 24.747 & 24.688\end{array}$

$.004 \quad .005$

.007

.008

.009

$(n-1) \times 1000$

$\lambda(n-1)$

0.282232

0.282231

0.282231

0.282230

0.282229

0.282228

0.282227

0.282226

0.282225

. 282225

0.282224

0.282223

0.282222

0.282221

0.282221
0.282220

0.282220

0.282219

0.282218

0.282217

0.282216

0.282215

0.282214

0.282214

0.282213

0.282212

0.282212
0.282211

0.282211

0.282210

0.282209

0.282209
0.282208 
$\begin{array}{lllllllllll}110.0 & 24324.037 & 23.978 & 23.919 & 23.860 & 23.801 & 23.741 & 23 \cdot 682 & 23.623 & 23 \cdot 564 & 23.505\end{array}$

$\begin{array}{lllllllllll}0.1 & 23.445 & 23.386 & 23.327 & 23.268 & 23.208 & 23.150 & 23.090 & 23.031 & 22.972 & 22.913 \\ 0.2 & 22.854 & 22.795 & 22.736 & 22.676 & 22.617 & 22.558 & 22.499 & 22.440 & 22.380 & 22.321\end{array}$

$\begin{array}{lllllllllll}0.2 & 22.854 & 22.795 & 22.736 & 22.676 & 22.617 & 22.558 & 22.499 & 22.440 & 22.380 & 22.321 \\ 0.3 & 22.262 & 22.203 & 22.143 & 22.084 & 22.025 & 21.966 & 21.907 & 21.848 & 21.788 & 21.729\end{array}$

$\begin{array}{lllllllllll}0.4 & 21.670 & 21.611 & 21.552 & 21.493 & 21.434 & 21.374 & 21.315 & 21.256 & 21.197 & 21.138\end{array}$

$\begin{array}{lllllllllll}0.5 & 21.078 & 21.019 & 20.960 & 20.901 & 20.842 & 20.782 & 20.723 & 20.664 & 20.605 & 20.546\end{array}$

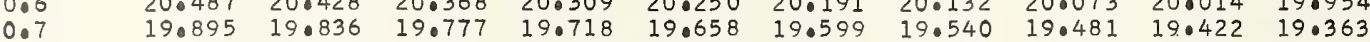

0.8

$19.303 \quad 19.244$

4111.0

$$
\begin{aligned}
& 1.3 \\
& 1.4 \\
& 1.5 \\
& 1.6 \\
& 1.7 \\
& 1.8
\end{aligned}
$$

1.1
1.2
1.3

1.9

4112.

24276.784

$\begin{array}{ll}4276.784 & 76.725 \\ 76.194 & 76.135 \\ 75.605 & 75.546 \\ 75.015 & 74.956\end{array}$

$75.015 \quad 74.956$

$74.426 \quad 74.367$

$73.836 \quad 73.777$

$\begin{array}{ll}73.247 & 73.188 \\ 72.658 & 72.59\end{array}$

$\begin{array}{lll}72.069 & 72.010 \\ 71.0479 & 71.421\end{array}$

$24270.890 \quad 70.831$ $\begin{array}{lll}70.301 & 70.231 & 70.7\end{array}$

$69.712 \quad 69.653 \quad 69.594 \quad 69.535$

$69.123 \quad 69.064 \quad 69.005 \quad 68.946$

$\begin{array}{llll}67.945 & 67.885 & 68.416 & 68.357\end{array}$

$\begin{array}{llll}67.355 & 67.296 & 67.238 & 67.178\end{array}$

$66.766 \quad 66.708 \quad 66.64966 .590$

$\begin{array}{llll}66.177 & 66.118 & 66.059 & 66.001 \\ 65.589 & 65.530 & 65.471 & 65.412\end{array}$

$\begin{array}{rr}74.308 & 740249 \\ 73.719 & 730660 \\ 72.5280 & 7\end{array}$

73.12973 .070

$1.951 \quad 71.892$
71.062

\begin{abstract}
$18.475 \quad 18.416$
18.949
\end{abstract}

$\begin{array}{ll}17.884 & 17.825 \\ 17.292 & 17.233 \\ 16.7010 & 116.642\end{array}$

$\begin{array}{lll}16.0110 & 16.042 \\ 16.051 & 16 \\ 15.518 & 15.459\end{array}$

15.518
14.027
14.0868

14.335

13.153
12.561
12.094

17.766

16.583
15.991

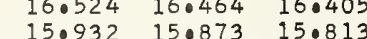

$\begin{array}{llll}15.400 & 15.341 & 15.281 & 15.222\end{array}$

$\begin{array}{llll}14.0217 & 140158 & 14.0999 & 14.631 \\ 140040\end{array}$

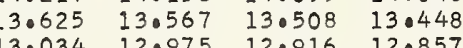

$\begin{array}{llll}12.443 & 12.384 & 12.325 & 12.266\end{array}$

$11.852 \quad 11.792 \quad 11.734 \quad 11.675$

$\begin{array}{llll}11.261 & 11.20202 & 11.1442 & 11.083\end{array}$

$\begin{array}{llll}10.078 & 10.019 & 090960 & 09.901\end{array}$

$\begin{array}{lllll}1008487 & 09.428 & 09.369 & 09.310\end{array}$

$\begin{array}{lllll}0.305 & 08.246 & 08.187 & 08.127\end{array}$

$\begin{array}{lllll}07.714 & 07.655 & 07.596 & 07.537\end{array}$

$\begin{array}{lllll}07.123 & 07.064 & 07.004 & 06.945\end{array}$

$\begin{array}{llllllll}06.178 & 06.119 & 06.060 & 06.000 & 05.941 & 05.882 & 05.823 & 05.764\end{array}$

$\begin{array}{lllllllll}04.996 & 04.937 & 04.878 & 04.819 & 04.759 & 04.701 & 04.641 & 04.582\end{array}$

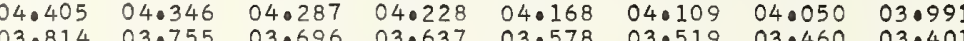

$\begin{array}{lllllllll}3.224 & 03.164 & 03.105 & 03.046 & 02.987 & 02.927 & 02.869 & 02.810\end{array}$

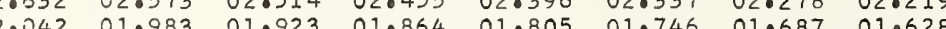

$\begin{array}{llllllllll}.451 & 01.392 & 01.0333 & 01.274 & 01.215 & 010156 & 010096 & 01028\end{array}$

$0.270 \quad 00.210$

$\begin{array}{rl}99.088 & 99.029 \\ 98.498 & 98.439 \\ 97.0917 & 97.028\end{array}$

97.907
97.3717
97.8258

9.13596 .076

$94.365 \quad 94.305$

93.18493 .125

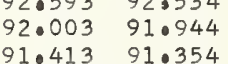

90.23290 .173

$\begin{array}{ll}89.052 & 88.993\end{array}$

$\begin{array}{lll}87.062 & 88.403 \\ 87.872 & 87.813 \\ 7.282 & 87.223 \\ 8.282 & 87.23\end{array}$

$86.102 \quad 86.043$

84.92284 .863

$\begin{array}{ll}3.0742 & 83.0683 \\ 3.153 & 83.094 \\ 3.153 & 8.094\end{array}$

82.563
81.973
81.383

$0.793 \quad 80.735$
0.735

99.61479 .555

780.457780376
77845777086
77056

$77.256 \quad 77.197$

$75.437 \quad 75.428$

00.151

99.56
980970

98.38
97.78

97.198

96.608
96.017
95.427

95.427
94.836

$94.246 \quad 94.187$

$94.246-940187$

93.066593 .597

92.475

$91.295 \quad 91.236$

90.11490 .646

89.524

90.055
89.465

$88.344 \quad 88.285$

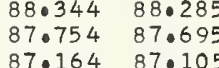

86.57488 .515

859844
85.394
85.3525

$84.804 \quad 840745$

$840214 \quad 840155$
$83.625 \quad 83.565$
$83.034 \quad 82.976$

$82.445 \quad 82.386$

$81.265 \quad 81.206$

$\begin{array}{lll}800676 & 80.617 \\ 80.085 & 80.026 \\ 70.006 & 78027\end{array}$

$\begin{array}{llll}790496 & 79.437 \\ 78.906 & 78.847 & 7 \\ 77.0728 & 77068 & 7\end{array}$

$78.317 \quad 78.258$

$\begin{array}{lll}77.728 & 77.668 \\ 77.137 & 77.079 & 7 \\ 760548 & 760489\end{array}$

$\begin{array}{ll}76.548 & 76.489 \\ 75.958 & 75.900\end{array}$

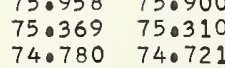

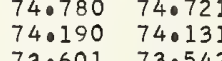

$\begin{array}{lll}73.601 & 73.542 \\ 73.011 & 72.053 & 7 \\ 71.023 & 71.074 & 7\end{array}$

$\begin{array}{llll}73.011 & 72.953 & 72.894\end{array}$

$\begin{array}{llll}71.833 & 71.774 & 72.304\end{array}$

$71.243 \quad 71.184 \quad 710126$

$70.654 \quad 70.505$

\begin{tabular}{llll}
70.065 & 70.007 \\
\hline
\end{tabular}

$69.466-69.417$

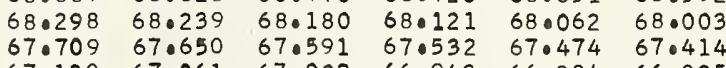

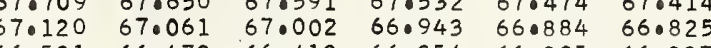

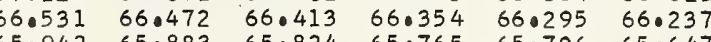

$\begin{array}{lllllll}65.942 & 65.883 & 65.824 & 65.765 & 65.0706 & 65.0647 \\ 65.353 & 65.294 & 65.235 & 65.176 & 65.117 & 65050\end{array}$

0.282183

0.282182

0.282181

0.282181

0.282180

0.282179

0.282178

0.282178

0.282177

0.282175

0.282175

0.282174

0.282173

0.282173

0.282172

0.282171

0.282171

0.282170

0.282169

0.282168

-1
-1

0.282167

0.282166

0.282166

0.282165

0.282165
0.282164

0.282164

0.282163

0.282163
0.282162
0

0.282162

0.282161

0.282160

0.0

0.282159
0.282159

0.282158

0.282158
0.282157

0.282157

0.282157

0.282156

0.282155
0.282154

0.282154

0.282153

0.282153

0.282152

0.282151

0.282150

0.282149

0.282149

0.282148

0.282147

0.282147

0.282146
0.282146

0.282146
0.282145

0.282145

0.282144 


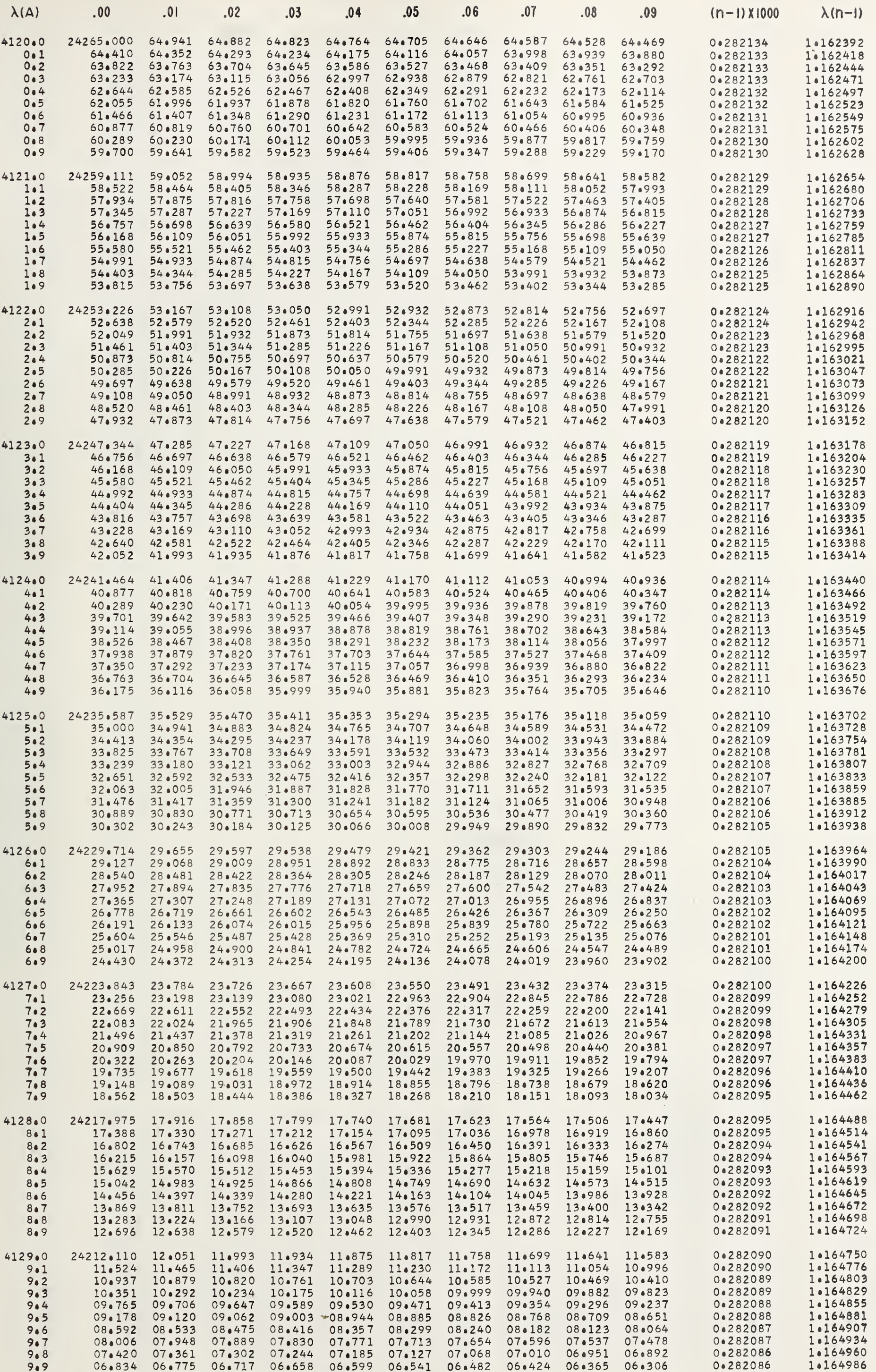


0.0282079

0.282079

0.282079

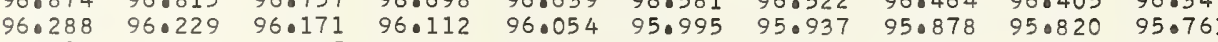

$\begin{array}{llllllllll}95.702 & 95.644 & 95.585 & 95.527 & 95.469 & 95.410 & 95.351 & 95.293 & 95.234 & 95.176 \\ 95.117 & 95.059 & 95.000 & 940941 & 94.883 & 94.824 & 94.766 & 94.707 & 94.648 & 94.590\end{array}$

0.282078

0.282077

0.282076

1.165274

1.165301

1.165353

1.165379

1.165405

10165432

1.165458

1.165484

0.282076 0.282075 0.282074 0.0078 0.282073 0.282072 0.282072

0.282071

0.282070

0.282069

0.282069

0.282068

0.282067

0.282067

0.282066

0.282055

0.282065

0.282064

0.282063

0.282063

0.282062

0.282062

0.282061

0.282061

0.282060

0.282059 0.282059 0.282058 0.282058 0.282057
0.282057

0.282056

0.282056

0.282055

0.282055
0.282054

0.282054

0.282053

0.282053

0.282052

1.165536 1.165563 10165615 1.165641 1. 1656694 1.165720 1.165746
1.165772

1.165825

10165851

1.165903

1.165930

1.165982

1. 166008

10166061

10166087

1.166113

1. 166165

1. 166218

1.166244

1.166270

1.166323

1.166349

1.166375

1.166401 
$\begin{array}{lllllllllll}4140.0 & 24147.779 & 47.721 & 47.663 & 47.604 & 47.546 & 47.488 & 47.429 & 47.371 & 47.313 & 47.255\end{array}$

$\begin{array}{llllllllllll}0.1 & 47.196 & 47.138 & 47.080 & 47.021 & 46.963 & 46.905 & 46.846 & 46.788 & 46.729 & 46.671 \\ 0.2 & 46.613 & 46.555 & 46.496 & 46.438 & 46.380 & 46.321 & 46.263 & 46.205 & 46.146 & 46.088\end{array}$

$\begin{array}{lllllllllll}0.3 & 46.613 & 46.555 & 46.496 & 46.438 & 46.380 & 46.321 & 46.263 & 46.205 & 46.146 & 46.088 \\ 0.3 & 46.030 & 45.971 & 45.913 & 45.855 & 45.797 & 45.738 & 45.680 & 45.621 & 45.563 & 45.504\end{array}$

$\begin{array}{llllllllllll}0.4 & 45.447 & 45.388 & 45.330 & 45.271 & 45.213 & 45.155 & 45.097 & 45.038 & 44 \cdot 980 & 44 \cdot 922 \\ 0.5 & 44.863 & 44.805 & 44.747 & 44.688 & 44.630 & 44.572 & 44.513 & 44.455 & 44.397 & 44.339\end{array}$

$\begin{array}{llllllllllll}0.6 & 44.281 & 44.222 & 44.164 & 44.105 & 44.047 & 43.989 & 43.931 & 43.872 & 43.814 & 43.756 \\ 0.7 & 43.697 & 43.639 & 43.581 & 43.523 & 43.464 & 43.406 & 43.348 & 43.290 & 43.231 & 43.173\end{array}$

$42.531 \quad 42.0573$

$42 \cdot 998$

42.939

$\begin{array}{lllllll}42.881 & 42.823 & 42.764 & 42.706 & 42.648 & 42.173\end{array}$

4141.0

$\begin{array}{rrr}1.0 & 24141.948 & 41.890 \\ 1.1 & 41.365 & 41.307\end{array}$

$\begin{array}{lll}1.2 & 40.782 & 40.724 \\ 1.3 & 40.199 & 40.141\end{array}$

$\begin{array}{lll}1.4 & 39.617 & 39.558 \\ 1.5 & 39.033 & 38.975\end{array}$

$\begin{array}{lll}1.6 & 38.451 & 38.393 \\ 1.7 & 37.868 & 37.810 \\ 1.8 & 37.285 & 37.227\end{array}$

$39.500 \quad 39.442$

$\begin{array}{ll}41.715 & 41.657\end{array}$

41.598

1.54

41.48

42.007

0.282037

0.282037

0.282036

0.282035

0.282034

0.282034

0.282033
0.282033

0.282032

0.282031

0.282030

0.282030

0.282029

0.282028

$\begin{array}{llllllllll}36.702 & 36.644 & 36.169 & 37.111 & 37.052 & 36.994 & 36.936 & 36.877 & 36.819 & 36.760\end{array}$

0.282027

$4142 \cdot 0$

$\begin{array}{rrr}2.0 & 24136.120 & 36.061 \\ 2.1 & 35.537 & 350.479\end{array}$

$340954 \quad 350479$

$34 \cdot 372 \quad 34 \cdot 313$

$36.003 \quad 35.945$

35.887

35.829

$35.770 \quad 35.71$

$35.654 \quad 35.596$

$\begin{array}{llllllll}34.255 & 34.197 & 34.139 & 34.080 & 34.022 & 330964 & 34.489 & 340430\end{array}$

$\begin{array}{llllllllll}33.78 & 33.731 & 33.673 & 33.614 & 33.556 & 33.498 & 33.440 & 33.382 & 33.323 & 33.265\end{array}$

$\begin{array}{llllllllll}32.624 & 32.566 & 32.507 & 32.449 & 32.391 & 32.333 & 32.275 & 32.216 & 32.158 & 32.100\end{array}$

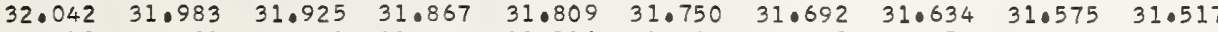

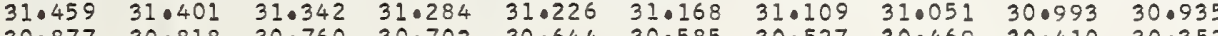

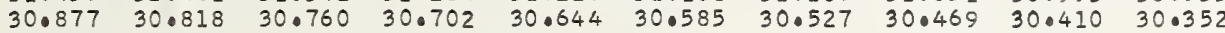

$\begin{array}{lllllllllll}4143.0 & 24130.294 & 30.236 & 30.177 & 30.119 & 30.061 & 30.003 & 29.945 & 29.886 & 29.828 & 29.770\end{array}$

$\begin{array}{rrrrrrrrrrr}3.1 & 29.712 & 29.653 & 29.595 & 29.537 & 29.479 & 29.421 & 29.362 & 29.304 & 29.246 & 29.187\end{array}$

$\begin{array}{lllllllllll}3.2 & 29.129 & 29.071 & 29.013 & 28.954 & 28.896 & 28.838 & 28.780 & 28.722 & 28.663 & 28.605 \\ 3.3 & 28.547 & 28.489 & 28.430 & 28.372 & 28.314 & 28.256 & 28.198 & 28.139 & 28.081 & 28.023\end{array}$

$\begin{array}{lllll}24124 \cdot 471 & 24 \cdot 413 & 24.355 & 24.297 & 240\end{array}$

24.995

25.403
24.821

$\begin{array}{llll}26.450 & 26.392 & 26.334 & 26.276\end{array}$

414400

$\begin{array}{lllllllllll}4.2 & 23.307 & 23.249 & 23.191 & 23.133 & 23.074 & 23.016 & 22.958 & 22.900 & 22.842 & 22.783\end{array}$

$\begin{array}{lllllllllll}403 & 22.725 & 22.667 & 22.608 & 22.551 & 22.492 & 22.434 & 22.376 & 22.318 & 22.259 & 22.201 \\ 4.4 & 22.143 & 22.085 & 22.027 & 21.969 & 21.910 & 21.852 & 21.794 & 21.736 & 21.677 & 21.619\end{array}$

$\begin{array}{lllllllllll}4.5 & 21.561 & 21.502 & 21.445 & 21.386 & 21.328 & 21.870 & 21.712 & 21.736 & 21.677 & 21.619 \\ 4 & 20.979 & 20.921 & 21.095 & 21.037\end{array}$

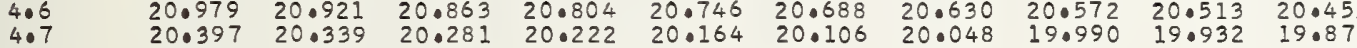

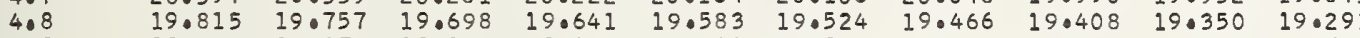

19.233

4145

$24118.651 \quad 18.59$

5.0
50
50
5
5
5
5
5
50
6
6.0
6.
6.
6.
6.
6.
6
6
6.7
6

$\begin{array}{ll}18.070 & 18.01 \\ 17.487 & 17.42\end{array}$

$16.324 \quad 16.266$

$\begin{array}{ll}15.742 & 15.684 \\ 15.160 & 15.102\end{array}$

$14.579 \quad 14.521$

$\begin{array}{ll}13.997 & 13.939 \\ 13.416 & 13.357\end{array}$

$19.117 \quad 19.058$

$\begin{array}{llllllllllll}4146.0 & 24112.834 & 12.775 & 12.718 & 12.659 & 12.601 & 12.543 & 12.485 & 12.427 & 12.369 & 12.311\end{array}$

18.535

$18.477 \quad 18.419$

18.360

18.88

$\begin{array}{llll}17.313 & 17.255 & 17.197\end{array}$

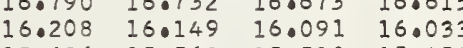

$\begin{array}{llll}15.626 & 15.568 & 15.510 & 15.452 \\ 15.044 & 14.986 & 14.928 & 14.870\end{array}$

$14.463 \quad 14.405$

$\begin{array}{ll}14 \cdot 928 & 14 \cdot 870 \\ 14.346 & 14 \cdot 28\end{array}$

$\begin{array}{llll}17.302 & 18.244 & 18.186 & 18.128 \\ 17.720 & 17.662 & 17.604 & 17.546\end{array}$

$\begin{array}{llll}17.138 & 17.081 & 17.022 & 16.964 \\ 16.557 & 16.498 & 16.440 & 16.382\end{array}$

$\begin{array}{llll}15.975 & 15.917 & 15.859 & 15.80\end{array}$

$\begin{array}{llll}15.393 & 15.335 & 15.277 & 15.219\end{array}$

$\begin{array}{llll}14.812 & 14.753 & 14.695 & 14.637 \\ 14.230 & 14.172 & 14.114 & 14.055\end{array}$

282027

0.28202

0.282026

0.282025

0.282024

0.282024

0.282023

.28202

282022

0.282021

0.282020

0.282019

.282019

0.282018

0.282017

0.282016

0.282015

0.282014

0.282013

0.282013

0.282012

0.282012

0.282011

0.282010

0.282009

0.282009

$\begin{array}{lllllllllll}6.1 & 12.252 & 12.194 & 12.136 & 12.078 & 12.020 & 11.962 & 11.904 & 11.845 & 11.787 & 11.729\end{array}$

0.282008

0.282008

0.282007

$\begin{array}{llllllllll}10.508 & 10.450 & 10.392 & 10.333 & 10.275 & 10.217 & 10.159 & 10.101 & 10.042 & 09.984\end{array}$

$\begin{array}{llllllllll}09.926 & 09.868 & 09.810 & 09.752 & 09.694 & 09.636 & 09.577 & 09.519 & 09.461 & 09.403\end{array}$

$\begin{array}{llllllllll}09.345 & 09.287 & 09.229 & 09.170 & 09.112 & 09.054 & 08.996 & 08.938 & 08.880 & 08.822\end{array}$

$\begin{array}{lllllllllll}08.763 & 08.705 & 08.647 & 08.589 & 08.531 & 08.473 & 08.415 & 08.357 & 08.299 & 08.240 \\ 08.183 & 08.124 & 08.066 & 08.008 & 07.950 & 07.892 & 07.834 & 07.775 & 07.717 & 07.659\end{array}$

$\begin{array}{llllllllll}08.183 & 08.124 & 08.066 & 08.008 & 07.950 & 07.892 & 07.834 & 07.775 & 07.717 & 07.659 \\ 07.601 & 07.543 & 07.485 & 07.427 & 07.368 & 07.310 & 07.252 & 07.194 & 07.136 & 07.078\end{array}$

0.282006

0.282005

0.282005

0.282004

$\begin{array}{lllllllllll}4147.0 & 24107.020 & 06.962 & 06.904 & 06.846 & 06.787 & 06.729 & 06.671 & 06.613 & 06.555 & 06.497\end{array}$

$\begin{array}{lllllllllll}7.1 & 06.438 & 06.380 & 06.322 & 06.264 & 06.206 & 06.148 & 06.090 & 06.031 & 05.973 & 05.915\end{array}$

$\begin{array}{llllllllll}05.857 & 05.799 & 05.741 & 05.683 & 05.625 & 05.567 & 05.509 & 05.451 & 05.393 & 05.334 \\ 05.276 & 05.218 & 05.159 & 05.102 & 05.043 & 04.985 & 040927 & 04.869 & 040811 & 04.753\end{array}$

$\begin{array}{lllllllllll}05.276 & 05.218 & 05.159 & 05.102 & 05.043 & 04.985 & 04.927 & 04.869 & 04 \cdot 811 & 04 \cdot 753 \\ 04.695 & 04.637 & 04.579 & 04.521 & 04.462 & 04.404 & 04.346 & 04.288 & 04.230 & 04 \cdot 172\end{array}$

$\begin{array}{lllllllllll}04.114 & 04.055 & 03.997 & 03.939 & 03.881 & 03.823 & 03.765 & 03.707 & 03.649 & 03.591\end{array}$

$\begin{array}{llllllllll}03.532 & 03.474 & 03.416 & 03.358 & 03.300 & 03.242 & 03.184 & 03.126 & 03.068 & 03.010\end{array}$

$\begin{array}{llllllllll}02.951 & 02.894 & 02.835 & 02.777 & 02.719 & 02.660 & 02.602 & 02.544 & 02.486 & 02.428\end{array}$

$\begin{array}{llllllllll}02.370 & 02.312 & 02.254 & 02.196 & 02.138 & 02.080 & 02.021 & 01.963 & 01.905 & 01.847 \\ 01.789 & 01.731 & 01.673 & 01.615 & 01.557 & 01.498 & 01.440 & 01.382 & 01.324 & 01.266\end{array}$

0.282003

0.282003

0.282002

0.282002

0.282001

0.282001

0.282000

0.282000

0.281999

0.281998

$\begin{array}{llllllllll}101.208 & 01.150 & 01.092 & 01.034 & 00.976 & 00.917 & 00.859 & 00.801 & 00.743 & 00.685\end{array}$

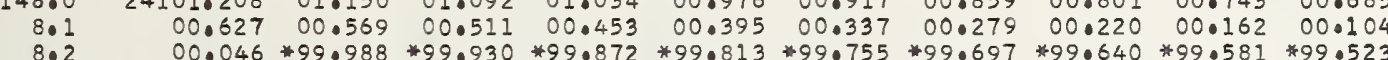

$\begin{array}{rlllllllll}24099.465 & 99.407 & 99.349 & 99.291 & 99.233 & 99.175 & 99.117 & 99.059 & 99.000 & 98.942\end{array}$ $\begin{array}{llllllllll}98.884 & 98.826 & 98.768 & 98.710 & 98.652 & 98.594 & 98.536 & 98.478 & 98.419 & 98.361\end{array}$ $\begin{array}{llllllllll}98.303 & 98.245 & 98.187 & 98.129 & 98.071 & 98.013 & 97.955 & 97.897 & 97.839 & 97.781\end{array}$ $\begin{array}{llllllllll}97.722 & 97.664 & 97.606 & 97.548 & 97.490 & 97.432 & 97.374 & 97.316 & 97.258 & 97.199\end{array}$

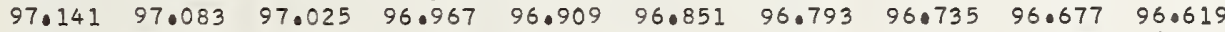
$\begin{array}{llllllllll}96.561 & 96.503 & 96.444 & 96.386 & 96.328 & 96.270 & 96.212 & 96.154 & 96.096 & 96.038\end{array}$

0.281997

0.281997

0.281996

0.281995

0.281995

0.281994

0.281993

0.281992

0.281992

0.281991

0.281991

0.281990

.167764

.167790

$1: 167843$

$1 \cdot 167895$

167922

.167974

168000

1. 168053

- 168079

1.168131

-168157

1.168184

1.168236

1.168262

1.168315

1.168341

1.168367

- 168420

1.168446

1.168498

10168524

1.168551

1.168603

168655

1.168682

1.168734

1.168760

1. 168813

1.168865

1.168891

$1 \cdot 168944$

1.168970

1.169023

1.169049

1.169101

1.169127

1.169180

1.169206

1.16958
1.16285
1
1

1.169311

10169337

1.169390

1.169442

1.169468

1.169494

1.169521

1.169573

.169625

10169652

10169704

1.169730

1.0169757

1.169809

1.169835

1.169888

1.169914

1.169966

1.169993

1.170045

1.170091

1.170124

1.170150

1.170202

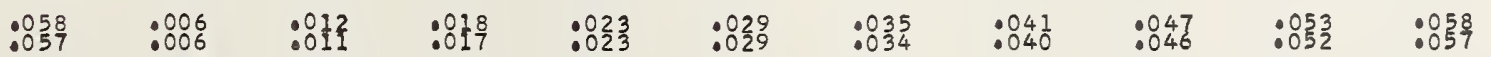


$(n-1) \times 1000 \quad \lambda(n-1)$

$\begin{array}{lllllllllll}4150.0 & 24089.593 & 89.535 & 89.478 & 89.419 & 89.361 & 89.303 & 89.245 & 89.187 & 89.129 & 89.071\end{array}$ $\begin{array}{lllllllllll}0.1 & 89.013 & 88.955 & 88.897 & 88.839 & 88.781 & 88.723 & 88.665 & 88.606 & 88.549 & 88.490 \\ 0.2 & 88.432 & 88.375 & 88.316 & 88.258 & 88.200 & 88.1142 & 88.084 & 88.026 & 87.068 & 87.910\end{array}$ $\begin{array}{llllllllllll}0.2 & 88.432 & 88.375 & 88.316 & 88.258 & 88.200 & 88.142 & 88.084 & 88.026 & 87.968 & 87.910 \\ 0.3 & 87.852 & 87.794 & 87.736 & 87.678 & 87.620 & 87.562 & 87.504 & 87.446 & 87.388 & 87.330\end{array}$ $\begin{array}{llllllllllll}0.4 & 87.272 & 87.214 & 87.156 & 87.098 & 87.040 & 86.981 & 86.924 & 86.866 & 86.808 & 86.350\end{array}$ $\begin{array}{llllllllllll}0.5 & 86.691 & 86.633 & 86.576 & 86.518 & 86.459 & 86.401 & 86.343 & 86.285 & 86.227 & 86.169\end{array}$ $\begin{array}{lllllllllll}86.111 & 86.053 & 85.995 & 85.937 & 85.879 & 85.821 & 85.763 & 85.705 & 85.647 & 85.589\end{array}$

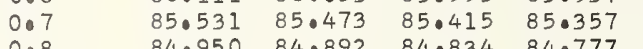

\subsection{830
76.250}

$75,670-75.1$

$75.090 \quad 75.032$

\subsection{8.8}

73.351
72.072

24072.192

\subsection{70.035}

$\begin{array}{llll}71.033 & 70.975 & 70.917 & 70.859 \\ 70.453 & 70.396 & 70.337 & 70.280 \\ 69.874 & 69.816 & 69.0758 & 69.700\end{array}$

$\begin{array}{llll}69.294 & 69.236 & 69.179 & 69.121 \\ 68.715 & 68.657 & 68.599 & 68.541\end{array}$

$\begin{array}{llll}68.135 & 68.078 & 68.020 & 67.962 \\ 67.556 & 67.498 & 67.440 & 67.382\end{array}$

$\begin{array}{lllll}67.556 & 67.498 & 67.440 & 67.382 \\ 66.977 & 66.919 & 66.861 & 66.803\end{array}$

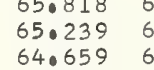

$\begin{array}{lll}64.080 & 64.601 \\ 64.080 & 64.022\end{array}$

63.501
62.922
62.032 .443
62.864

$62.342 \quad 62.284$

61.184

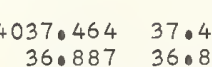

0.281989

0.281989

0.281988

0.281987

0.281986

0.281986

0.281985
0.281985

0.281984

0.281984

0.281983

0.281982

0.281982
0.281981

0.281981

0.281980
0.281980

0.281980

0.281979
0.281979

0.281978

0.281978

0.281977

0.281977

0.281976

0.281975

0.281974

0.281974
0.281973
0

0.281973

0.281972
0.281972
0.281971

0.281972

0.281971

0.281970

0.281970

0.281970
0.281969

0.281969

0.281968

0.281968

0.281967

0.281966

0.281965 0.281965
0.281964 0.281964 0.281963 0.281963 0.281962
0.281962 0.281961

0.281961

0.281960
0.281960

0.281959

0.281959

0.281958

0.281957

0.281956

0.281956

0.281955

0.281955

0.281954

0.281953

0.281953

0.281952

0.281951

0.281951 0.281950
0.281950 0.281949 0.281949 0.281948
0.281948 0.281947 0.281947

0.281946 0.281946 0.281945
0.281945
0 0.281944 0.281944

0.281943

0.281943

0.281942
0.281942

1.170255

1.170281

1.170333
1.170350

1. 1170386

1.170412
1.170438 


.02

.03

.04

.05

4160.0

$4031.687 \quad 31.629 \quad 310$ $\begin{array}{lll}31.572 & 31.514 & 31 \\ 30.993 & 30.936 & 30 \\ 30.416 & 30.358 & 30 \\ 29.838 & 29.781 & 2 \\ 29.261 & 29.203 & 2 \\ 28.683 & 28.625 & 2 \\ 28.106 & 28.048 & 270 \\ 27.528 & 27.471 & 27 \\ 26.950 & 26.893 & 2 \\ 26.373 & 26.316 & 26\end{array}$

$\begin{array}{llllll}1.456 & 31.398 & 31.340 & 31.282 & 31.225 & 31.167\end{array}$ $\begin{array}{llllllllll}31.109 & 31.051 & 30.993 & 30.936 & 30.878 & 30.820 & 30.762 & 30.705 & 30.647 & 30.589 \\ 30.531 & 30.474 & 30.416 & 30.358 & 30.301 & 30.243 & 30.185 & 30.127 & 30.070 & 30.012\end{array}$

$24025.911 \quad 25 \cdot 853$

$25.796 \quad 25.738$

$26.258 \quad 26.20$

$\begin{array}{llll}26.720 & 26.662 & 26.604 & 26.546 \\ 26.142 & 26.084 & 26.027 & 25.969\end{array}$

$\begin{array}{lllllll}25 \cdot 161 & 25.680 & 25 \cdot 623 & 25 \cdot 565 & 25 \cdot 507 & 25.450 & 25 \cdot 392 \\ 25.103 & 25.045 & 24.988 & 24.930 & 24.872 & 24.814\end{array}$

1.

24.756 .24 .6990

$24 \cdot 179 \quad 24 \cdot 122 \quad 24.641 \quad 24 \cdot 583$

$23.602 \quad 23.544 \quad 23.486 \quad 23.428$

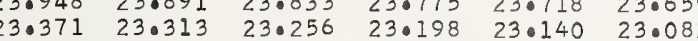

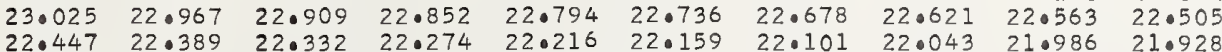

$\begin{array}{llllllll}22.332 & 22.274 & 22.216 & 22.159 & 22.101 & 22.043 & 21.986 & 21.928 \\ 21.755 & 21.697 & 21.639 & 21.582 & 21.524 & 21.466 & 21.409 & 21.351\end{array}$

$\begin{array}{ll}21.293 & 21 \cdot 235 \\ 20.716 & 20.658\end{array}$

$21.177 \quad 21.120$

21.63921 .582

24020.

$19.562 \quad 19$

18.98418 .927

$18.407 \quad 18.350$

$17.253 \quad 17.196$

$16.677 \quad 16.619$

$\begin{array}{ll}15.523 & 15.465 \\ 14.946 & 14.888\end{array}$

20.023

19.96

$19.908 \quad 19.850$

20.370

$\begin{array}{lll}20.889 & 20.831 & 20.773 \\ 20.312 & 20.254 & 20.197\end{array}$

$\begin{array}{llllllll}19.446 & 19.388 & 19.331 & 19.273 & 19.215 & 19.158 & 19.100 & 19.042\end{array}$

$\begin{array}{llllllll}18.869 & 18.812 & 18.754 & 18.696 & 18.638 & 18.581 & 18.523 & 18.465\end{array}$

$\begin{array}{llllllll}17.715 & 17.657 & 17.600 & 17.542 & 17.485 & 17.427 & 17.369 & 17.311\end{array}$

$\begin{array}{lllllllll}17.138 & 17.081 & 17.023 & 16.965 & 16.907 & 16.850 & 16.792 & 16.735\end{array}$

$\begin{array}{llllllll}16.561 & 16.504 & 16.446 & 16.388 & 16.331 & 16.273 & 16.215 & 16.157 \\ 15.984 & 15.927 & 15.869 & 15.811 & 15.753 & 15.696 & 15.638 & 15.581\end{array}$

$\begin{array}{llll}5.407 & 15.350 & 15.292 & 15.235 \\ 4.830 & 14.773 & 14.715 & 14.657\end{array}$

.177

15.581

2.8

4163.0

3.

$4.369 \quad 14 \cdot 311$

14.254

14.196
13.6

$14.138 \quad 14.08$

14.023

$13.215 \quad 13.158$

$\begin{array}{llll}2.639 & 12.581 & 12.523 & 12.466 \\ 2.062 & 12.004 & 11.947 & 11.889\end{array}$

$11.485 \quad 11.427$

$10.908 \quad 10.851$

$09.755 \quad 09.697$

$\begin{array}{ll}11.370 & 11.312 \\ 10.793 & 10.735\end{array}$

$09.179 \quad 09.121$

$10.217 \quad 10.159$

$\begin{array}{ll}11.831 & 11.77 \\ 11.255 & 11.197\end{array}$

$10.677 \quad 10.620$

10.101

09.467

13.446
12.869

$13 \cdot 96$

$13.908 \quad 13.850$

$\begin{array}{lll}.812 & 12.754 & 12.697\end{array}$

$\begin{array}{llll}11.716 & 11.658 & 11.601 & 11.543\end{array}$

$\begin{array}{llll}11.139 & 11.081 & 11.024 & 10.966\end{array}$

$\begin{array}{llll}10.562 & 10.505 & 10.447 & 10.389\end{array}$

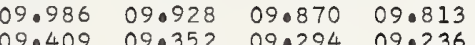

3.9

4164

4.1
4.2
4.3
4.45

4.4
4.5

4.6

4.7

$4008.602 \quad 08 \cdot 544$

$07.968 \quad 07 \cdot 487 \quad 08 \cdot 429$

08.371

08.31

08.833

\begin{abstract}
$08.718 \quad 08.659$
\end{abstract}
$\begin{array}{llllllllll}4.968 & 07.391 & 07.333 & 07.276 & 07.795 & 07.737 & 07.680 & 07.622 & 07.564 & 07.507\end{array}$

$\begin{array}{lllllllllll}06.296 & 06.239 & 06.180 & 06.123 & 06.065 & 06.007 & 05.950 & 05.897 & 06.811 & 06.354\end{array}$

$\begin{array}{llllllllll}05.719 & 05.662 & 05.604 & 05.547 & 05.489 & 05.431 & 05.374 & 05.316 & 05.259 & 05.201\end{array}$

$\begin{array}{llllllllll}04.566 & 04.509 & 04.451 & 04.394 & 04.336 & 04.278 & 04.221 & 04.163 & 04.106 & 04.048\end{array}$

$\begin{array}{llllllllll}04.566 & 04.509 & 04.451 & 04.394 & 04.336 & 04.278 & 04.221 & 04.163 & 04.106 & 04.048 \\ 03.990 & 03.933 & 03.875 & 03.818 & 03.760 & 03.702 & 03.644 & 03.587 & 03.529 & 03.471\end{array}$

4165.0

65
5.1
5.2
5.3
5.4
5.5
5.6
5.7
5.8
509 $\begin{array}{llll}02.838 & 02.780 & 02.723 & 02.665 \\ 02.261 & 02.204 & 02.146 & 02.088 \\ 01.685 & 01.628 & 01.570 & 0.10512\end{array}$ $\begin{array}{llll}0.685 & 01.628 & 01.570 & 01.512\end{array}$ $\begin{array}{llll}00.533 & 00.475 & 00.993 & 00.936\end{array}$ $\begin{array}{lllll}99.956 & 99.898 & 99.841 & 99.783\end{array}$

$\begin{array}{llll}99.380 & 99.323 & 99.265 & 99.208\end{array}$

$\begin{array}{llll}98.228 & 98.171 & 98.113 & 98.056\end{array}$

$97.653 \quad 97.595$

4166

66.0
60
6.2
6
60
6
6
6
6
6.7
6.9

4167.

767.

7.2

7.4

7.6

7.7
7.8
7.9

4168

168
8
8
8
8
8
8
8
8
8
8

4169.0
9.1
9.2
9.3
9.4
9.5
9.6
9.7
9.8
9.9

23997.076

95.92495 .443

$9.348 \quad 95.291$

$\begin{array}{ll}94 \cdot 772 & 94.71 \\ 94.197 & 94.13\end{array}$

93.62193 .56

$91.893 \quad 91.836$

97.537

$97 \cdot 480$

$03.183 \quad 03.125$

$\begin{array}{llll}03.068 & 03.010 & 02.953 & 02.895\end{array}$

$\begin{array}{llllll}02.607 & 02.550 & 02.492 & 02.434 & 02.376 & 02.319\end{array}$

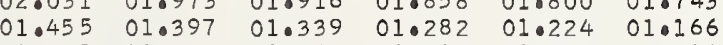

$\begin{array}{llllll}00.878 & 00.821 & 00.763 & 00.705 & 00.648 & 00.590\end{array}$

$\begin{array}{llllll}90.7026 & 00.244 & 00.187 & 00.129 & 00.072 & 00.014\end{array}$

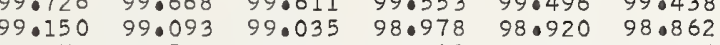

$\begin{array}{llllll}98.574 & 98.516 & 98.458 & 98.401 & 98.920 & 98.862 \\ 97.344 & 98.286\end{array}$

$\begin{array}{llllll}98.574 & 98.516 & 98.458 & 98.401 & 98.344 & 98.286 \\ 97.998 & 97.940 & 97.883 & 97.825 & 97.768 & 97.710\end{array}$

96.96196 .90

$96.846 \quad 96.78$

$97.307 \quad 97.24$

97.19197 .134

$90.742 \quad 90.684 \quad 90.626 \quad 90.569$

89.16090 .109

$89.590 \quad 89.533$

$88.439 \quad 88.381$

$\begin{array}{ll}87.864 & 87.80 \\ 87.288 & 87.230\end{array}$

$89.475 \quad 89.994$

$\begin{array}{ll}89.475 & 89.4 \\ 88.900 & 88.8 \\ 88.324\end{array}$

$\begin{array}{ll}88.324 & 88.266 \\ 87.749 & 87.691\end{array}$

$\begin{array}{ll}87.749 & 87.691 \\ 87.173 & 87.115\end{array}$

$\begin{array}{ll}86.712 & 86.655 \\ 86.137 & 86.079\end{array}$

6.597

$87 \cdot 115$
86.540
85.964

$\begin{array}{llll}96.731 & 96.673 & 96.616 & 96.558 \\ 96.155 & 96.097 & 96.039 & 95.982\end{array}$

$\begin{array}{llllll}95.694 & 95.636 & 95.579 & 95.521 & 95.464 & 95.406\end{array}$

$\begin{array}{lllllll}9 & 9518 & 95.061 & 95.003 & 94.945 & 94.887 & 94.830\end{array}$

$\begin{array}{llllll}94.542 & 94.484 & 94.427 & 94 \cdot 369 & 94.312 & 94 \cdot 254 \\ 93.966 & 93.909 & 93.851 & 93.793 & 93.736 & 93.678\end{array}$

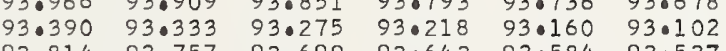

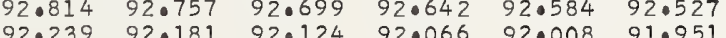

$\begin{array}{llllll}91.663 & 91.605 & 91.548 & 91.490 & 91.433 & 91.375\end{array}$

$\begin{array}{llllll}91.087 & 91.030 & 90.972 & 90.914 & 90.857 & 90.799\end{array}$

$\begin{array}{llllll}90.511 & 90.454 & 90.396 & 90.339 & 90.281 & 90.224\end{array}$

$\begin{array}{llllll}89.936 & 89.878 & 89.820 & 89.763 & 89.706 & 89.648 \\ 89.360 & 89.303 & 89.245 & 89.187 & 89.130 & 89.072\end{array}$

$\begin{array}{llllll}88.784 & 88.727 & 88.669 & 88.612 & 88.554 & 88.497\end{array}$

$\begin{array}{llllll}88.209 & 88.151 & 88.094 & 88.036 & 87.979 & 87.921 \\ 87.633 & 87.576 & 87.518 & 87.460 & 87.403 & 87.345\end{array}$

$\begin{array}{llllll}7.058 & 87.5000 & 87.518 & 87.460 & 87.403 & 87.345 \\ 86.942 & 86.885 & 86.828 & 86.770\end{array}$

$985.561-85050.0060 .8090$

$\begin{array}{lllllllllll}84.986 & 84.928 & 84.871 & 84.813 & 84.756 & 84.698 & 84.641 & 84.583 & 84.526 & 84.468\end{array}$

$\begin{array}{lllllllllll}84.410 & 84.353 & 84.296 & 84.238 & 84.180 & 84.123 & 84.065 & 84.008 & 83.950 & 83.893\end{array}$

$\begin{array}{lllllllllll}83.835 & 83.778 & 83.720 & 83.663 & 83.605 & 83.547 & 83.490 & 83.432 & 83.375 & 83.317 \\ 83.260 & 83.202 & 83.145 & 83.087 & 83.030 & 82.972 & 82.915 & 82.857 & 82.800 & 82.742\end{array}$

$\begin{array}{llllllllll}82.685 & 82.627 & 82.570 & 82.512 & 82.454 & 82.396 & 82.339 & 82.281 & 82.224 & 82.167\end{array}$

$\begin{array}{llllllllll}82.109 & 82.052 & 81.994 & 81.936 & 81.879 & 81.822 & 81.764 & 81.707 & 81.649 & 81.591\end{array}$

$\begin{array}{llllllllll}81.534 & 81.477 & 81.419 & 81.361 & 81.304 & 81.246 & 81.188 & 81.131 & 81.074 & 81.016\end{array}$

$\begin{array}{llllllllll}80.959 & 80.901 & 80.844 & 80.786 & 80.729 & 80.671 & 80.614 & 80.556 & 80.499 & 80.441 \\ 80.384 & 80.326 & 80.269 & 80.211 & 80.154 & 80.096 & 80.039 & 79.981 & 79.923 & 79.866\end{array}$

$\begin{array}{llllllllll}23979.808 & 79.751 & 79.693 & 79.636 & 79.578 & 79.521 & 79.463 & 79.406 & 79.348 & 79.291\end{array}$

$\begin{array}{llllllllll}79.233 & 79.176 & 79.118 & 79.061 & 79.003 & 78.946 & 78.888 & 78.831 & 78.773 & 78.715\end{array}$

$\begin{array}{llll}78.658 & 78.601 & 78.543 & 78.486\end{array}$

$\begin{array}{llll}78.083 & 78.025 & 77.968 & 77.911 \\ 77.508 & 77.450 & 77.393 & 77.335\end{array}$

$\begin{array}{llll}76.933 & 76.875 & 76.818 & 76.760\end{array}$

$\begin{array}{llll}76.358 & 76.301 & 76.243 & 76.18 \\ 75.782 & 75.725 & 75.668 & 75.610\end{array}$

$\begin{array}{lllll}75.782 & 75.725 & 75.668 & 75.610 & 75 \\ 75.208 & 75.150 & 75.093 & 75.036 & 746 \\ 74.633 & 74.575 & 74.518 & 74.460\end{array}$

$\begin{array}{lllllll}77.853 & 77.796 & 77.738 & 77.680 & 77.623 & 77.565\end{array}$

$\begin{array}{llllll}77.278 & 77.220 & 77.163 & 77.105 & 77.048 & 76.990\end{array}$

$\begin{array}{llllll}76.703 & 76.645 & 76.588 & 76.530 & 76.473 & 76.416 \\ 76.127 & 76.070 & 76.013 & 75.955 & 75.898 & 75.840\end{array}$

$\begin{array}{lllllll}75.553 & 75.495 & 75.438 & 75.381 & 75.323 & 75.265\end{array}$$$
.001
$$$$
.002
$$$$
.003
$$$$
.004
$$

74.920
74.345

74.86
74.28

$\begin{array}{lll}74 \cdot 805 & 74.748 & 74.690 \\ 74.230 & 74.173 & 74.115\end{array}$

$(n-1) \times 1000$

$\lambda(n-1)$

$0.281942 \quad 1.172877$

0.281941

0.281940

0.281940

.281938

0.281938

0.281937

0.281936

0.281935

0.281935

0.281934

0.281933

0.281933

0.281932

81932

0.281931

0.281930

0.281929

0.281929

0.281928

0.281927

0.281927

0.281926
0.281926

0.281925

0.281925

0.281924

0.281924
0.281923

0.281923

0.281922

0.281922
0.281921

0.281921

0.281920
0.281920

0.281919

0.281919

0.281918

0.281917

0.281917
0.281916

0.281916

0.281916

0.281915

0.281914
0.281914

0.281913

0.281913

0.281912
0.281912

0.281911

0.2819110

0.281910

0.281909
0.281909

0.281908

0.281908

0.281908

0.281907

0.281906

0.281906

0.281905

0.281904

0.281903

0.281903

0.281902

0.281902

0.281901

0.281900

0.281900

0.281899

0.281899

0.281898

0.281898

0.281897

0.281896
0.281895

0.281895

.010 


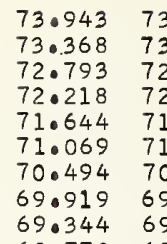

23968.310

$$
67 .
$$

$66.586 \quad 66.104$

$66.012 \quad 65.954$

$65.437 \quad 65.380$

$\begin{array}{ll}64.863 & 64.805 \\ 64.288 & 64.231 \\ 63.714 & 63.656\end{array}$

$\begin{array}{ll}63.714 & 63.656 \\ 63.140 & 63.082\end{array}$

61.

61.417
60.8
60.268

61.360

$\begin{array}{ll}60.268 & 60.211 \\ 59.694 & 59.636\end{array}$

$59.120 \quad 59.06$

$\begin{array}{ll}58.545 & 58.488 \\ 57.971 & 57.914 \\ 57.397 & 57.340\end{array}$

56.2

55.675
55.101

55.101
54.527 550043

$53.953 \quad 53.896$

$53.379 \quad 53.322 \quad 53.264$

$\begin{array}{lllll}52.805 & 52.748 & 52.6916 & 52.633\end{array}$

$\begin{array}{lllll}51.0658 & 510600 & 51.0543 & 52.059 \\ 51.485\end{array}$

50.510

$50.510 \quad 50.452$

$49.362 \quad 49.87949 .39 .248$

$\begin{array}{lllll}48.362 & 49.305 & 49.248 & 49.764 \\ 48.0789 & 48.739\end{array}$

$\begin{array}{lllll}480215 & 48.0157 & 48.0674 & 48.616\end{array}$

$\begin{array}{lllll}47.641 & 470584 & 47.526 & 47.469\end{array}$

$\begin{array}{lllll}47.067 & 47.010 & 46.953 & 46.896\end{array}$

$\begin{array}{llll}46.494 & 46.437 & 46.379 & 46.322 \\ 45.920 & 45.863 & 45.806 & 45.0748\end{array}$

$$
\begin{array}{r}
3945 . \\
44 . \\
44 .
\end{array}
$$$$
44.20044 .710
$$

$43.626 \quad 43.56$

$\begin{array}{ll}43.053 & 42.996 \\ 42.479 & 42.422\end{array}$

$41.906 \quad 41.849$

$\begin{array}{ll}41.333 & 41.276 \\ 40.760 & 40.702\end{array}$

40.18

0.231894

0.281894

0.281893

0.281892

0.281892

0.281891

0.281891

0.281890

0.281890

0.281889

0.281889

0.281888

0.281887

0.281886

0.281886

0.281885

0.281884

0.281884

0.281884
0.281883

0.281883

0.281882

0.281882

0.281881

0.281880

0.281880

0.281879

0.283878
0.281878
0.281879

0.281878
0.281877

0.281877

0.281876

0.281876

0.281875

0.281875

0.281874
0.281874

00281873

0.0281873

0.281872
0.281872

0.281872
0.281871

0.281871

0.281870
0.281870
0

0.281870
0.281869
0.2818

0.281869

0.281869

0.281868

0.281868
0.281867

0.281867

0.281866

0.281866
0.281865

0.281865

0.281864

0.281864

0.281863
0.281863

0.281862

0.281862

0.281862

0.281861
0.281861
0.28186

0.281861
0.281860

0.028185

0.281859

0.281858

0.281858
0.0281857

$1: 175499$
$1: 17526$
$1: 175526$
$1: 175578$
$1: 17504$
$1: 175631$
$1: 175657$
$1: 175683$
$1: 175090$
10175735
10175762

1.175762

1.175788
1.175814
1.17586

10175840

1.175867

1.175893

1.175945

1.175972
1.175998

1.176024

1.176050
1.176076

1.176103

1.176129

1.176181

1.176208

10176234

1.176286

10.176313

1.176365

1.176391

1.1176417

1.176470

1.176496

1.176549

10176575

1.1766017
1.176627
1.176650

1.176654

10176680

1.176706
1.176732
1.0176785

1.176758

$1 \cdot 176811$

1.176863

1.176890

1. 1.176916

1.176968

1.177025

1.177047

1.177073

10177100
1.177126
1017712

1.177152

1.177178

1.177204
1.177231

1.177257

1.177283
1.177309

1.177336

1.177362
1.177388

1.1777414

1.177441
1.177467

:0177493

1.177519

0.281857

0.281856

0.281856

0.281855

0.281855

0.281854

0.281854

0.281853

0.281852

0.281852

0.281851

0.281850

0.281850

0.281849

0.281849

0.281848

$\frac{1}{101777545}$

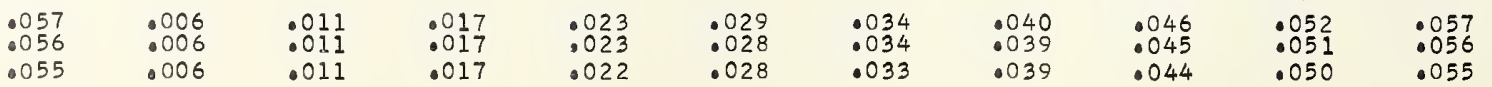




.0
01
0.2
0.3
0.4
0.5
06
07
0.8
0.9
.0
01
.2
.3
.3
.5
.6
.7
.8
.9
2.0
2.1
2.2
2.3
2.4
2.5
2.6
2.7
2.8
2.9

$\begin{array}{llllllllll}16.133 & 16.075 & 16.018 & 16.533 & 16.476 & 16.418 & 16.361 & 16.304 & 16.247 & 16.190 \\ 15.961 & 15.904 & 15.847 & 15.790 & 15.732 & 15.675 & 15.618\end{array}$ $\begin{array}{llllllllll}15.561 & 15.503 & 15.446 & 15.389 & 15.332 & 15.274 & 15.217 & 15.160 & 15.103 & 15.045\end{array}$ $\begin{array}{llllllllll}14.988 & 14.931 & 14.874 & 14.817 & 14.760 & 14.702 & 14.645 & 14.588 & 14.531 & 14.473 \\ 14.417 & 14.359 & 14.302 & 14.245 & 14.187 & 14.130 & 14.073 & 14.016 & 13.958 & 13.901\end{array}$ $\begin{array}{llllllllll}14.417 & 14.359 & 14.302 & 14.245 & 14.187 & 14.130 & 14.073 & 14.016 & 13.958 & 13.901 \\ 13.844 & 13.787 & 13.730 & 13.673 & 13.615 & 13.558 & 13.501 & 13.444 & 13.387 & 13.330\end{array}$ $\begin{array}{llllllllll}13.272 & 13.215 & 13.158 & 13.101 & 13.043 & 12.987 & 12.929 & 12.872 & 12.814 & 12.757 \\ 12.700 & 12.643 & 12.586 & 12.529 & 12.471 & 12.414 & 12.357 & 12.300 & 12.243 & 12.186\end{array}$ $\begin{array}{llllllllll}12.700 & 12.643 & 12.586 & 12.529 & 12.471 & 12.414 & 12.357 & 12.300 & 12.243 & 12.186 \\ 12.128 & 12.071 & 12.014 & 11.957 & 11.900 & 11.843 & 11.785 & 11.728 & 11.671 & 11.614 \\ 11.556 & 11.499 & 11.442 & 11.385 & 11.327 & 11.270 & 11.213 & 11.156 & 11.099 & 11.042\end{array}$

\section{$11.327 \quad 11.270$}

10.641 $910.984 \quad 10.927 \quad 10.870 \quad 10.81$ $\begin{array}{llll}10.413 & 10.355 & 10.298 & 10.24\end{array}$ $09.269 \quad 09.78$ $08.607 \quad 08.640$ $\begin{array}{lll}0.680 & 08.583\end{array}$ $07.554 \quad 07.068$ 06.58 $07.497,07.439$ $\begin{array}{llll}06.925 & 06.868 & 06.811\end{array}$ $\begin{array}{lll}06.410 & 06.353 & 06.296 \\ 05.839 & 05.782 & 05.725\end{array}$ $\begin{array}{lll}10.641 & 10.184 & 10.127 \\ 09.097 & 09.612 & 09.55\end{array}$ $\begin{array}{llll}10.012 & 09.955 & 09.898\end{array}$ 05.782 005.267 04.696040638 03.552 02.98103 .49 02.400020203 $01.838 \quad 01.781$ $00.695 \quad 00.638$ 05.153 06.239 $\begin{array}{lllllll}0.0468 & 08.911 & 08.926 & 08.868 & 08.811 & 08.754\end{array}$ $\begin{array}{lllllll}07.897 & 07.840 & 07.782 & 07.725 & 07.640 & 08.183\end{array}$ $\begin{array}{lllllll}07.325 & 07.268 & 07.211 & 07.154 & 07.096 & 07.039\end{array}$ $\begin{array}{lllllll}06.754 & 06.696 & 06.639 & 06.582 & 06.525 & 06.468\end{array}$ $\begin{array}{lllllll}06.182 & 06.125 & 06.067 & 06.010 & 05.953 & 05.896\end{array}$ $\begin{array}{llllllll}05.039 & 04.981 & 04.924 & 04.867 & 04.810 & 04.753\end{array}$

0.281848

0.281847

0.281846

0.281846
0.281845

0.281845

0.281844

0.281843

0.281842
0.281842

0.281841

0.281841
0.281841

0.281840

0.281840

0.281839
0.281839

0.281838

0.281838

0.281837

0.281836
0.281836

0.281835

0.281835
0.281834

0.281834

0.281834

0.281833

0.281832

0.281832

0.281831
0.281831

0.281830

0.281830

0.281829

0.281828

0.281828

0.281827

0.281827

0.281826

0.281825

0.281824

0.281824

0.281823

0.281822

0.281821

0.281821

0.281821
0.281820

0.281820

0.281819

0.281819

0.281818

0.281817

0.281817

0.281816

0.281815

0.281815

0.281814

0.281813

0.281813

0.281812

0.281812

0.281811

0.281810

0.281810

0.281809

0.281809

0.281808

0.281808

0.281807

0.281807
0.281806

0.281806

0.281805

0.281805

0.281804

0.281803

0.281803

0.281802

0.281802
0.281802

1.178123

1.178149
1.178175
1.17822

1.178201

1.178254

1.178280

1.178306
1.17833

1. 178385

1.178411
1.178437

10178464

1.178516

1.178569

1. 1.178621

1.178647

1.178674
1.178700
1.07875

1.178726

1.178752

1.178805

1.178831

1.178883

1.178910

1.178936
1.178962

1.178988

1.179015
1.179041

1.179067

10179093

1.179146

1.179172

10179198

.179251

1.179277

1.179329

1.179356

1.179408

1.179434

1.179461

1.179513

10179566 
$56.778-56.721$

$56.209 \quad 56.152$

$\begin{array}{ll}55.640 & 55.583 \\ 55.071 & 55.014 \\ 54.501 & 54.445\end{array}$

57.234

$57.177 \quad 57.120 \quad 57.06$

57.006

56.949

$56.892 \quad 56.835$

$58.932 \quad 53.875$

$\begin{array}{llll}55.526 & 55.469 & 55.412 & 55.355 \\ 54.957 & 54.900 & 54.843 & 54.78\end{array}$

54.388

53.363
52.794
52.225
51.656
51.087
50.518
49.949
49.380
48.812

53.306
52.738

53.819
53.249
52.681
52.111

\begin{abstract}
53.76
\end{abstract}
$54.274 \quad 54.217$

$55 \cdot 298$

$55 \cdot 81$
55.24

55.12

1.1
1.2
1.3
1.4
1.55
1.6
1.7
1.8
1.9
2.0

4192.

$2 \cdot 3$

$2 \cdot 3$

2.5

$2 \cdot 6$

2.8

419300

$$
\begin{array}{r}
193.0 \\
3.1 \\
3.2 \\
3 . \\
3 . \\
3.5 \\
3.0 \\
3 . \\
3.8 \\
3 .
\end{array}
$$

4194 .

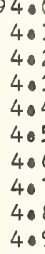

41950

5.

$5 \cdot 2$
$5 \cdot 3$
$5 \cdot 4$

5.4

5.6
5.7

5.8
5.9

4196.0

6.1

6.2

6.4

6.6

6.7

6.8

4197.

7.1
7.2
7.3

7.4

7.5
7.6

7.8

7.9

498.
8
8
8
8
8
8
8
8
8

\begin{abstract}
$23848 \cdot 242$
\end{abstract}
47.674
47.104

46.536
45.967

45.967
45.398

$45.398 \quad 45.341$

$44.830 \quad 44.772$

$\begin{array}{ll}44.260 & 44.204 \\ 43.692 & 43.635\end{array}$ 43.124

23842.555

41.986

$40.849-40.761$

$40.281 \quad 40.224$

$39.144 \quad 39.087$

$\begin{array}{ll}38.575 & 38.518 \\ 38.007 & 37.950\end{array}$

$3836.870 \quad 36.813$

36.30
35.73

$34.597 \quad 34.540$

$\begin{array}{ll}34.029 & 33.972 \\ 33.460 & 33.404\end{array}$

$32.892 \quad 32.836$

$\begin{array}{ll}32.324 & 32.267 \\ 31.756 & 31.699\end{array}$

23831.188

$30.620 \quad 30.5$

$30.052 \quad 29.995$

$\begin{array}{ll}28.916 & 28.42 \\ 28.85\end{array}$

$\begin{array}{ll}28.348 & 28.291 \\ 27.780 & 27.723\end{array}$

$\begin{array}{ll}27.212 & 27.155 \\ 26.644 & 26.587 \\ 26.076 & 26.020\end{array}$

$\begin{array}{rr}23825 \cdot 508 & 25.452 \\ 24.940 & 24.88\end{array}$

$\begin{array}{ll}24.940 & 24.8 \\ 24.373 & 24.3 \\ 23.805 & 23.7\end{array}$

$23.238 \quad 23.181$

$22.670 \quad 22.613$

$21.534 \quad 21.478$

$\begin{array}{ll}20.967 & 20.910 \\ 20.399 & 20.343\end{array}$

$23819.832 \quad 19.775$

$19.264 \quad 19.208$

$\begin{array}{ll}18.696 & 18.640 \\ 18.129 & 18.072\end{array}$

$\begin{array}{ll}17.562 & 17.505 \\ 16.994 & 16.937\end{array}$

$16.427 \quad 16.370$

$\begin{array}{ll}15.860 & 15.80 \\ 15.293 & 15.236\end{array}$

52.111

50.97450 .917

$\begin{array}{ll}50.404 & 50.347 \\ 49.836 & 49.779\end{array}$

49.266
48.698

$\begin{array}{ll}53.705 & 53.64 \\ 53.135 & 53.079\end{array}$

53.591

54.103

54.046

$48.129 \quad 48.07$

$\begin{array}{ll}47.560 & 47.503 \\ 46.991 & 46.934\end{array}$

$\begin{array}{ll}46.422 & 46.365 \\ 45.853 & 45.796\end{array}$

$45.285 \quad 45.228$

$44.716 \quad 44.658$

$\begin{array}{ll}44.147 & 44.090 \\ 43.578 & 43.52\end{array}$

$\begin{array}{llllll}53.135 & 53.079 & 53.022 & 52.965 & 52.908 & 52.851\end{array}$

$\begin{array}{llllll}51.998 & 51.941 & 52.453 & 52.396 & 52.339 & 52.282 \\ & 51.884 & 51.827 & 51.770 & 51.713\end{array}$

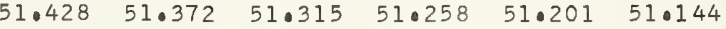

$\begin{array}{llllll}50.859 & 50.802 & 50.746 & 50.689 & 50.632 & 50.575\end{array}$

$\begin{array}{llllll}50.290 & 50.234 & 50.177 & 50.120 & 50.063 & 50.006\end{array}$

$\begin{array}{lllllll}49.153 & 49.096 & 49.039 & 48.982 & 48.925 & 48.868\end{array}$

$\begin{array}{llllll}48.584 & 48.527 & 48.470 & 48.413 & 48.356 & 48.299\end{array}$

$\begin{array}{llllll}48.015 & 47.958 & 47.901 & 47.844 & 47.787 & 47.730 \\ 47.446 & 47.389 & 47.332 & 47.275 & 47.218 & 47.161\end{array}$

$\begin{array}{llllll}46.877 & 46.820 & 46.763 & 46.707 & 46.650 & 46.593\end{array}$

$\begin{array}{llllll}46.308 & 46.251 & 46.195 & 46.138 & 46.081 & 46.023 \\ 45.739 & 45.682 & 45.626 & 45.569 & 45.512 & 45.455\end{array}$

$\begin{array}{llllll}45.171 & 45.114 & 45.057 & 45.000 & 44.943 & 44.886\end{array}$

$\begin{array}{lllllll}44.602 & 44.545 & 44.488 & 44.431 & 44.374 & 44.317\end{array}$

$43.010 \quad 42.953$

$43.465 \quad 43.40$

$\begin{array}{llll}43 \cdot 919 & 43.863 & 43.806 & 43.749 \\ 43.351 & 43.294 & 43.237 & 43.180\end{array}$

$42.441 \quad 42.384$

$\begin{array}{ll}41.872 & 41.81 \\ 41.304 & 41.24 \\ 40.735 & 40.67\end{array}$

40.735

$39.598-30.110$

$39.030 \quad 38.973$

37.89

38.40
$37 \cdot 83$

42.327

42.782

42.725

$41.190 \quad 41.133$

$40.053 \quad 39.996$

$39.484 \quad 39.42$

$38.916 \quad 38.859 \quad 38.802$

$\begin{array}{ll}38.347 & 38 \cdot 29 \\ 37.779 & 37.72\end{array}$

36.756

36.699

36.643

35.620

(1)

$33.915 \quad 33.85$

$\begin{array}{ll}32.779 & 32.722\end{array}$

$\begin{array}{ll}32.210 & 32.154 \\ 31.643 & 31.586\end{array}$

$31.074 \quad 31.01$

$\begin{array}{ll}30.506 & 30.449\end{array}$

$\begin{array}{ll}29.938 & 29.881 \\ 29.370 & 29.313 \\ 28.802 & 28.745\end{array}$

$\begin{array}{ll}28.802 & 28.745 \\ 28.234 & 28.177\end{array}$

$\begin{array}{ll}27.667 & 27.610 \\ 27.098 & 27.042\end{array}$

$\begin{array}{ll}26.531 & 26.474 \\ 25.963 & 25.906\end{array}$

$25.395 \quad 25 \cdot 338$

$\begin{array}{ll}24.827 & 24.770 \\ 24.260 & 24.20\end{array}$

$\begin{array}{ll}24.260 & 24.203 \\ 23.691 & 23.635\end{array}$

$\begin{array}{ll}23.124 & 23.067 \\ 22.556 & 22.499\end{array}$

$\begin{array}{ll}21.989 & 21.932 \\ 21.421 & 21.364\end{array}$

$\begin{array}{ll}21.421 & 21.364 \\ 20.853 & 20.797\end{array}$

19.718
19.1

19.15119 .09

$18.583 \quad 18.526$

$\begin{array}{ll}17.448 & 17.391\end{array}$

16.88
16.31

$16.313 \quad 16.257$

14.725

4.668

5.17
4.61

15.690
15.122

\section{5}

$\begin{array}{llllll}34.370 & 34.313 & 34.256 & 34.199 & 34.142 & 34.085 \\ 33.802 & 33.745 & 33.688 & 33.631 & 33.574 & 33.517\end{array}$

$33.233 \quad 33.177 \quad 33.120 \quad 33.063 \quad 33.006 \quad 32.949$

$\begin{array}{llllll}32.665 & 32.608 & 32.552 & 32.495 & 32.438 & 32.381\end{array}$

$\begin{array}{llllll}32.097 & 32.040 & 31.983 & 31.926 & 31.870 & 31.813 \\ 31.529 & 31.472 & 31.416 & 31.359 & 31.302 & 31.245\end{array}$

$\begin{array}{llllll}30.961 & 30.904 & 30.847 & 30.790 & 30.734 & 30.677 \\ 30.393 & 30.336 & 30.279 & 30.222 & 30.166 & 30.109\end{array}$

$\begin{array}{llllll}30.393 & 30.336 & 30.279 & 30.222 & 30.166 & 30.109 \\ 29.824 & 29.768 & 29.711 & 29.654 & 29.597 & 29.541\end{array}$

$\begin{array}{llllll}29.257 & 29.200 & 29.143 & 29.086 & 29.029 & 28.973\end{array}$

$\begin{array}{llllll}28.688 & 28.632 & 28.575 & 28.518 & 28.461 & 28.405 \\ 28.121 & 28.064 & 28.007 & 27.950 & 27.894 & 27.837\end{array}$

$\begin{array}{llllll}27.553 & 27.496 & 27.439 & 27.382 & 27.325 & 27.269\end{array}$

$\begin{array}{llllll}26.985 & 26.928 & 26.871 & 26.815 & 26.758 & 26.701\end{array}$

$\begin{array}{llllll}26.417 & 26.360 & 26.303 & 26.246 & 26.189 & 26.133 \\ 25.849 & 25.792 & 25.736 & 25.679 & 25.622 & 25.565\end{array}$

$\begin{array}{llllll}25.281 & 25.225 & 25.168 & 25.111 & 25.054 & 24.997 \\ 24.713 & 24.657 & 24.600 & 24.543 & 24.486 & 24.429\end{array}$

$\begin{array}{llllll}24.713 & 24.657 & 24.600 & 24.543 & 24.486 & 24.429 \\ 24.146 & 24.089 & 24.032 & 23.976 & 23.919 & 23.862\end{array}$

$\begin{array}{llllll}23.578 & 23.521 & 23.464 & 23.407 & 23.351 & 23.294\end{array}$

$\begin{array}{llllll}23.010 & 22.953 & 22.897 & 22.840 & 22.783 & 22.727 \\ 22.443 & 22.386 & 22.329 & 22.272 & 22.216 & 22.159\end{array}$

$\begin{array}{llllll}21.875 & 21.818 & 21.761 & 21.705 & 21.648 & 21.591\end{array}$

$\begin{array}{llllll}21.307 & 21.250 & 21.194 & 21.137 & 21.080 & 21.023\end{array}$

$\begin{array}{llllll}20.740 & 20.683 & 20.626 & 20.570 & 20.513 & 20.456 \\ 20.172 & 20.115 & 20.059 & 20.002 & 19.945 & 19.888\end{array}$

$\begin{array}{llllll}19.605 & 19.548 & 19.491 & 19.434 & 19.378 & 19.321\end{array}$

$\begin{array}{lllllll}19.037 & 18.981 & 18.924 & 18.867 & 18.810 & 18.753 \\ 18.469 & 18.413 & 18.356 & 18.300 & 18.243 & 18.186\end{array}$

$\begin{array}{llllll}17.902 & 17.845 & 17.789 & 17.732 & 17.675 & 17.618\end{array}$

$\begin{array}{llllll}17.334 & 17.278 & 17.221 & 17.165 & 17.108 & 17.051\end{array}$

$\begin{array}{llllll}16.200 & 16.711 & 16.654 & 16.597 & 16.541 & 16.484 \\ 16.208 & 16.087 & 16.030 & 15.973 & 15.917\end{array}$

$\begin{array}{llllll}15.633 & 15.576 & 15.519 & 15.463 & 15.406 & 15.349\end{array}$

$\begin{array}{llllll}15.065 & 15.009 & 14.952 & 14 \cdot 895 & 14 \cdot 838 & 14.782\end{array}$

$\begin{array}{ll}13.591 & 13.534 \\ 13.023 & 12.967\end{array}$

$\begin{array}{lll}13.023 & 12.967 & 12.910 \\ 12.456 & 12.399 & 12.343\end{array}$

$12.456 \quad 12.399 \quad 12.343$

11.77612 .286

$\begin{array}{llll}11.322 & 11.265 & 11.208 & 11.1\end{array}$

$\begin{array}{llll}10.187 & 10.131 & 10.074 & 10.017\end{array}$

$09.053 \quad 08.997$

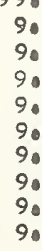

08.48608 .430

$\begin{array}{ll}07.920 & 07.863 \\ 07.352 & 07.296\end{array}$

$06.786 \quad 06.729$

$05.219 \quad 06.162$

04.518040462

$04.518 \quad 04.462$

03.951
03.385

\subsection{1 \\ 09.451
08.883}

08.940

13.931

$\begin{array}{lllll}14.441 & 14.385 & 14.328 & 14.271 & 14.215 \\ 13.874 & 13.817 & 13.760 & 13.704 & 13.647\end{array}$

$\begin{array}{llllll}13.364 & 13.307 & 13.250 & 13.194 & 13.137 & 13.080\end{array}$

$12.229 \quad 12.173 \quad 12.116 \quad 12.059 \quad 12.002 \quad 11.946$

$\begin{array}{llllll}11.662 & 11.605 & 11.549 & 11.492 & 11.435 & 11.378\end{array}$

$\begin{array}{llllll}10.528 & 10.471 & 10.415 & 10.358 & 10.301 & 10.244\end{array}$

$\begin{array}{llllll}09.394 & 09.337 & 09.281 & 09.224 & 09.167 & 09.110 \\ 08.826 & 08.770 & 08.713 & 08.657 & 08.600 & 08.543\end{array}$

$\begin{array}{llllll}08.260 & 08.203 & 08.146 & 08.090 & 08.033 & 07.977\end{array}$

$\begin{array}{llllllll}07.806 & 07.749 & 07.692 & 07.636 & 07.579 & 07.522 & 07.466 & 07.409\end{array}$

$\begin{array}{llllllll}07.239 & 07.183 & 07.126 & 07.069 & 07.012 & 06.956 & 06.899 & 06.843\end{array}$

$\begin{array}{llllllll}06.105 & 06.616 & 06.559 & 06.502 & 06.445 & 06.389 & 06.332 & 06.275 \\ 0.059 & 05.992 & 05.935 & 05.879 & 05.822 & 05.765 & 05.708\end{array}$

$\begin{array}{llllllll}05.539 & 05.482 & 05.425 & 05.368 & 05.312 & 05.255 & 05.198 & 05.142\end{array}$

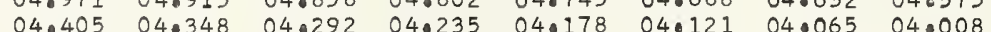

$\begin{array}{llllllll}04.405 & 04 \cdot 348 & 04.292 & 04 \cdot 235 & 04 \cdot 178 & 04 \cdot 121 & 04.065 & 04.008\end{array}$

$03 \cdot 725$

03.668

03.611

$03 \cdot 554$
$02 \cdot 988$

$\begin{array}{ll}03.498 & 03.441 \\ 02.931 & 02.874\end{array}$

$.001 \quad .002-.003$

0.281801

0.281800

0.281800

0.281799

0.281798

0.281798

0.281797

0.281796

0.281796

0.281795

0.281795

0.281794

0.281793

0.281793
0.281792

0.281792

0.281791

0.281790

0.281790

0.281790

0.281789

0.281788

0.281788

0.281787

0.281787

0.281786

0.281785

0.281785

0.28178

0.281784

0.281784
0.281783

0.281783

0.281782

0.281782

0.2878

0.281780 


.02

.03

400.0
0.0
0.0
0.0
0.0
0.07
0.07

$\begin{array}{ll}0.0 & 238 \\ 0.1 & \\ 0.2 & \\ 0.3 & \\ 0.4 & \\ 0.5 & \\ 0.6 & \\ 0.7 & \\ 0.8 & \\ 0.9 & \end{array}$

$\begin{array}{ll}02.818 & 02.761 \\ 02.251 & 02.195 \\ 01.684 & 01.628 \\ 01.118 & 01.061 \\ 00.551 & 00.495 \\ 99.984 & 99.928 \\ 99.418 & 99.361 \\ 98.851 & 98.795 \\ 98.285 & 98.228 \\ 97.719 & 97.662\end{array}$

$\begin{array}{llllllll}02.705 & 02.648 & 02.591 & 02.534 & 02.478 & 02.421 & 02.365 & 02.308\end{array}$ $\begin{array}{llllllll}02.138 & 02.081 & 02.024 & 01.968 & 01.911 & 01.854 & 01.798 & 01.741\end{array}$ $\begin{array}{llllllll}01.004 & 00.948 & 00.891 & 00.834 & 00.778 & 00.721 & 00.665 & 00.608\end{array}$ $\begin{array}{llllllll}00.438 & 00.381 & 00.324 & 00.268 & 00.211 & 00.155 & 00.098 & 00.041 \\ 99.871 & 99.815 & 99.758 & 99.701 & 99.645 & 99.588 & 90.531 & 99.475\end{array}$

\section{$23797.152 \quad 97.095$}

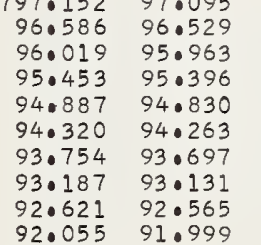

99.701

$99.078 \quad 99.021 \quad 98.965 \quad 98.908$

$98.172 \quad 98.115$

$\begin{array}{rlllll}98.625 & 98.568 & 98.511 & 98.455 & 98.398 & 98.342\end{array}$

$1: 1$
$1: 2$
$1: 3$
$1: 4$
$1: 5$
$1: 6$
$1: 7$
$1: 8$
1.9

4202.0
2.1
2.2
2.3
2.4
2.5
2.6
2.7
2.8
2.9

$23791.489 \quad 91.432$

$97.039 \quad 96.982$

$\begin{array}{rr}98.059 & 98.002 \\ 97.492 & 97.435\end{array}$

97.945

$\begin{array}{lll}97.888 & 97.832 & 97.775 \\ 97.322 & 97.266 & 97.209\end{array}$

$96.472 \quad 96.416$

9609
9603
9502
9406

$94.773 \quad 94.717$

93.64193 .584

$\begin{array}{ll}93.075 & 93.018 \\ 92.508 & 92.452 \\ 91.942 & 91.885\end{array}$

$\begin{array}{ll}96.926 & 96.869 \\ 96.359 & 96.302\end{array}$

96.81296 .756

$96.699 \quad 96.642$

$\begin{array}{llllll}95.793 & 95.736 & 95.679 & 95.623 & 95.566 & 95.510\end{array}$

$\begin{array}{llllll}95.226 & 95.170 & 95.113 & 95.056 & 95.000 & 94.943\end{array}$

$\begin{array}{llllll}94.094 & 94.037 & 93.980 & 93.924 & 93.867 & 93.811\end{array}$

$\begin{array}{llllll}93.527 & 93.471 & 93.414 & 93.358 & 93.301 & 93.244\end{array}$

4203.

3.
3.
3.
3.
3.
3.

$\begin{array}{llll}90.923 & 90.866 & 90.810 & 90.753 \\ 90.356 & 90.300 & 90.243 & 90.187 \\ 89.791 & 89.734 & 89.677 & 89.621\end{array}$

$91.376 \quad 91.319$

(1)

$\begin{array}{llll}92.848 & 92.791 & 92.735 & 92.678\end{array}$

$\begin{array}{llllll}91.828 & 91.772 & 92.282 & 92.225 & 92.168 & 92.112 \\ 91.715 & 91.659 & 91.602 & 91.545\end{array}$

$89.224 \quad 89.168 \quad 89.111 \quad 89.054$

$88.658 \quad 88.602$

$87.526 \quad 87.470$

$86.394 \quad 86.338$

$87 \cdot 413 \quad 87 \cdot 356$

(8)

90.69690 .640

$89.564 \quad 89.50$

$\begin{array}{llllll}0.508 & 89.451 & 89.394 & 89.337 & 89.281\end{array}$

$\begin{array}{llllll}88.432 & 88.375 & 88.885 & 88.828 & 88.771 & 88.715\end{array}$

$\begin{array}{lllllll}87.865 & 87.809 & 87.753 & 87.696 & 87.639 & 87.583\end{array}$

23785.82

$85.262 \quad 85.206$

85.715

85.65

87.18

87.130

$87.074 \quad 87.017$

$\begin{array}{llll}84.697 & 84.640 & 84.583 & 84.527\end{array}$

$84.131 \quad 84.074$

$82.999 \quad 82.942 \quad 82.886 \quad 82.829$

$81.867 \quad 81.811 \quad 81.754 \quad 81.698$

$\begin{array}{llll}81.302 & 81.245 & 81.188 & 81.132\end{array}$

$85.602 \quad 85.54$

85.489

85.998

$85.942 \quad 85.885$

$\begin{array}{lllllll}85.036 & 84.979 & 84.923 & 84.866 & 84.376 & 85.319 \\ 84.75 & 84.753\end{array}$

$\begin{array}{lllllll}84.470 & 84.413 & 84.357 & 84.301 & 84.244 & 34 \cdot 187\end{array}$

$\begin{array}{llllll}83.904 & 83.848 & 83.791 & 83.735 & 83.678 & 83.621 \\ 83.339 & 83.282 & 83.225 & 83.169 & 83.112 & 83.055\end{array}$

$\begin{array}{llllll}82.773 & 82.716 & 82.659 & 82.603 & 82.547 & 82.490\end{array}$

$\begin{array}{llllll}81.641 & 82.151 & 82.094 & 82.037 & 81.980 & 81.924\end{array}$

$\begin{array}{llllll}81.076 & 81.019 & 80.962 & 80.906 & 80.849 & 80.792\end{array}$

$23780.170 \quad 80.114$

$80.823 \quad 80.566$

20400

$\begin{array}{lrlll}4.1 & 23780.1605 & 79.548 & 79.492 & 79.435 \\ 4.2 & 79.039 & 78.983 & 78.927 & 78.870 \\ 4.3 & 78.474 & 78.417 & 78.361 & 78.304 \\ 4.4 & 77.908 & 77.852 & 77.795 & 77.739 \\ 4.5 & 77.343 & 77.286 & 77.230 & 77.173 \\ 4.6 & 76.777 & 76.721 & 76.664 & 76.607 \\ 4.7 & 76.212 & 76.156 & 76.099 & 76.042 \\ 4.8 & 75.646 & 75.590 & 75.533 & 75.477 \\ 4.9 & 75.081 & 75.024 & 74.968 & 74.911\end{array}$

$\begin{array}{llllll}.944 & 79.888 & 79.831 & 79.774 & 79.718 & 79.662\end{array}$

$\begin{array}{llllll}78.813 & 78.752 & 79.266 & 79.209 & 79.153 & 79.096 \\ 78.700 & 78.644 & 78.587 & 78.531\end{array}$

$\begin{array}{llllll}78.248 & 78.191 & 78.135 & 78.078 & 78.021 & 77.965 \\ 77.682 & 77.625 & 77.569 & 77.513 & 77.456 & 77.399\end{array}$

$\begin{array}{llllll}77.682 & 77.625 & 77.569 & 77.513 & 77.456 & 77.399 \\ 77.117 & 77.060 & 77.003 & 76.947 & 76.890 & 76.834\end{array}$

$\begin{array}{llllll}76.551 & 76.495 & 76.438 & 76.382 & 76.325 & 76.268\end{array}$

23774.515

$\begin{array}{llll}774.515 & 74.459 & 74.403 & 74.346 \\ 73.950 & 73.894 & 73.837 & 73.781 \\ 73.385 & 73.328 & 73.277 & 73.215\end{array}$

5.4

$72.820 \quad 72.763 \quad 72.706 \quad 72.650$

$72.254 \quad 72.198$

$71.689 \quad 71.63$

$\begin{array}{llll}71.124 & 71.067 & 71.011 & 70.95 \\ 70.558 & 70.502 & 70.446 & 70.38\end{array}$ $\begin{array}{ll}69.993 & 69 \cdot 937 \\ 69.428 & 69.372\end{array}$

$70.446 \quad 70.38$

$75 \cdot 420$

$75 \cdot 36$
$74 \cdot 798$

$\begin{array}{llll}75.872 & 75.816 & 75 \cdot 760 & 75.703 \\ 75.307 & 75.250 & 75.194 & 75.137\end{array}$

$\begin{array}{lllllll}74.289 & 74.233 & 74.176 & 74 \cdot 120 & 74.063 & 74.007\end{array}$

4206.

6.
6.
6.0
6.0
6.0
6.0
6.
6
6

23768.863

$\begin{array}{rlll}768 \cdot 863 & 68 \cdot 806 & 68.750 & 68.694 \\ 68.298 & 68.241 & 68.185 & 68 \cdot 128\end{array}$

$67.73367 .677 \quad 67.620 \quad 67.563$

$66.603 \quad 66.546 \quad 66.490 \quad 66.433$

$\begin{array}{llll}66.038 & 65.981 & 65.925 & 65.868\end{array}$

$\begin{array}{llll}65.473 & 65.416 & 65.360 & 65.303\end{array}$

$64.343 \quad 64.286$

$\begin{array}{ll}64.343 & 64 \cdot 286 \\ 63.778 & 63.722\end{array}$

4207.0

707

$\begin{array}{rllll}763.213 & 63.156 & 63.100 & 63.044 & 620 \\ 62.648 & 62.592 & 62.535 & 62.479 & 6\end{array}$

$\begin{array}{llll}62.648 & 62.592 & 62.535 & 62.479 \\ 62.083 & 62.027 & 61.971 & 61.914\end{array}$

$61.519 \quad 61.462$

$\begin{array}{llll}60.954 & 60.898 & 60.841 & 60.785\end{array}$

$\begin{array}{lllll}60.954 & 60.898 & 60.841 & 60.785 & 60.728 \\ 60.390 & 60.333 & 60.277 & 60.220 & 60.164 \\ 59.825 & 59.768 & 59.712 & 59.655 & 59.599\end{array}$

$\begin{array}{llll}59.260 & 59.204 & 59.147 & 59.091 \\ 58.695 & 58.639 & 58.583 & 58.526 \\ 58.131 & 58.074 & 58.018 & 57.962\end{array}$

4208.

88.0

23757.566

$\begin{array}{lll}57.566 & 57.510 & 57.453\end{array}$

$7.453 \quad 57.397$

$73.724 \quad 73.66$

$73.158 \quad 73.10$

72.594
72.028

$\begin{array}{llllll}.594 & 72.537 & 72.480 & 72.424 & 72.367 & 72.311 \\ .028 & 71.971 & 71.915 & 71.858 & 71.802 & 71.745 \\ .463 & 71.406 & 71.350 & 71.293 & 71.237 & 71.180\end{array}$

73.611

$\begin{array}{llll}7.045 & 72.989 & 72.933 & 72.876\end{array}$

$\begin{array}{lllllll}70.897 & 70.841 & 70.784 & 70.728 & 70.671 & 70.615\end{array}$

$\begin{array}{llllll}70.897 & 70.841 & 70.784 & 70.728 & 70.671 & 70.615 \\ 70.332 & 70.276 & 70.219 & 70.163 & 70.106 & 70.050\end{array}$

$\begin{array}{llllllllll}56.437 & 56.381 & 56.325 & 56.268 & 56.211 & 56.155 & 56.098 & 56.042 & 55.986 & 55.929\end{array}$

$\begin{array}{llllllllll}55.873 & 55.816 & 55.760 & 55.704 & 55.647 & 55.591 & 55.534 & 55.478 & 55.421 & 55.365 \\ 55.309 & 55.252 & 55.196 & 55.139 & 55.083 & 55.026 & 54.969 & 54.913 & 54.857 & 54.800\end{array}$

$\begin{array}{llllllllll}54.744 & 54.687 & 54.631 & 54.574 & 54.518 & 54.462 & 54.405 & 54.349 & 54.292 & 54.236\end{array}$

$\begin{array}{llllllllll}54.179 & 54.123 & 54.067 & 54.010 & 53.954 & 53.897 & 53.841 & 53.784 & 53.728 & 53.671\end{array}$

$\begin{array}{llllllllll}53.615 & 53.559 & 53.502 & 53.446 & 53.389 & 53.333 & 53.276 & 53.220 & 53.164 & 53.107 \\ 53.051 & 52.994 & 52.938 & 52.882 & 52.825 & 52.769 & 52.712 & 52.656 & 52.599 & 52.542\end{array}$

$\begin{array}{llllllllll}53.051 & 52.994 & 52.938 & 52.882 & 52.825 & 52.769 & 52.712 & 52.656 & 52.599 & 52.542 \\ 52.486 & 52.430 & 52.373 & 52.317 & 52.260 & 52.204 & 52.148 & 52.091 & 52.035 & 51.978\end{array}$

4209.0

9.000

23751.92251 .865

$\begin{array}{llllllllll}51.357 & 51.301 & 51.245 & 51.188 & 51.132 & 51.075 & 51.019 & 50.963 & 50.906 & 50.850 \\ 50.793 & 50.737 & 50.681 & 50.624 & 50.568 & 50.511 & 50.455 & 50.399 & 50.342 & 50.286\end{array}$

51.809

5
5
1 510

$\begin{array}{lllllllll}50.173 & 50.116 & 50.060 & 50.003 & 50.511 & 50.455 & 50.399 & 50.342 & 50.286\end{array}$

$\begin{array}{llllllllll}49.101 & 49.044 & 48.988 & 48.932 & 48.875 & 48.818 & 48.762 & 48.706 & 48.649 & 48.593\end{array}$

$\begin{array}{lllllllllll}48.537 & 48.480 & 48.424 & 48.367 & 48.311 & 48.255 & 48.198 & 48.142 & 48.085 & 48.029\end{array}$

$\begin{array}{llllllllll}47.972 & 47.916 & 47.860 & 47.803 & 47.747 & 47.690 & 47.634 & 47.577 & 47.521 & 47.465\end{array}$

$\begin{array}{llll}47.408 & 47.352 & 47.295 & 47.239 \\ 46.844 & 46.788 & 46.731 & 46.675\end{array}$

47.183

47.126

$\begin{array}{llll}47.07 .0 & 47.013 & 46.957 & 46.900\end{array}$

.001

.002

.003

.004

.005

.006

.007

$.008 \quad .009$

$\lambda(n-1)$

0.281755

0.281755

0.281754

0.281753

0.281752

0.281751
0.281751

0.281750

0.281750

0.28174

0.281749

81747

0.281747

0.281746

0.281745

0.281744

.281744

0.281743

0.281743

0.281742
0.281742

0.28174

0.281740

0.281740

0.281739

0.281738

0.281738
0.281738

0.281738
0.281737

0.281737

0.281736

0.281736

0.281735

0.281734

0.281733

0.281733

0.281732

.281732

0.281731

0.281730

0.281730

0.281729
0.281729
0.281728

0.281728

0.281727

0.281727

0.281727

0.281726

0.281725

0.281725

0.281724
0.281724

0.281723

0.281723

0.281722
0.281722

0.281722

0.281721

0.281721

0.281720

0.281719
0.281719

0.281718

0.281718

0.28171

0.281717
0.281716

0.281716

0.281715

0.281715
0.281714

-183371

1.183423

1.183450

1.183502

1.183528

1.183581

$1+183633$

1.183686

1.183738

10183765

1.183817

1.183869

1.183896

1.183922
1.183948

1.183974

1. 184001

1.184079

1.184106

1.184158

1.184184

1.184237

1.184263

1.184289

1. 184342

1. 184394

$1 \cdot 184421$

I. 184473

1.184526

1.184552

10184552

1.184604

$\because 184631$

$1 \cdot 184683$

184709

1.184762

1.18488

1.184841

1.184893

1. 184919

1.184946

1.184972

1. 184998

1.185051

1.185103

1.185129
1.185156

1.185182

1.185208

1.185234

1. 185261 


.02

.03

$\begin{array}{rrr}10.0 & 23746.280 & 46.223 \\ 0.1 & 45.716 & 45.660 \\ 0.2 & 45.152 & 45.096 \\ 0.3 & 44.588 & 44.532 \\ 0.4 & 44.024 & 43.968 \\ 0.5 & 43.460 & 43.404 \\ 0.6 & 42.896 & 42.840 \\ 0.7 & 42.333 & 42.277 \\ 0.8 & 41.769 & 41.713 \\ 0.9 & 41.205 & 41.149\end{array}$

$\begin{array}{lll}46.167 & 46.111 & 460 \\ 45.603 & 45.547 & 450 \\ 45.039 & 44.983 & 440 \\ 44.475 & 44.419 & 440 \\ 43.911 & 43.855 & 430 \\ 43.348 & 43.291 & 430 \\ 42.784 & 42.727 & 420 \\ 42.220 & 42.164 & 420 \\ 41.656 & 41.600 & 410 \\ 41.092 & 41.036 & 400\end{array}$

.04

.05

.06

$\begin{array}{lll}46.054 & 45.998 & 45.9 \\ 45.490 & 45.434 & 4503 \\ 44.926 & 44.870 & 440 \\ 440363 & 44.306 & 440 \\ 43.798 & 43.742 & 430 \\ 43.235 & 43.178 & 430 \\ 42.671 & 42.615 & 420 \\ 42.107 & 42.051 & 410 \\ 41.543 & 41.487 & 4104 \\ 40.979 & 40.923 & 40.8\end{array}$

$\begin{array}{llll}45.942 & 45.885 & 45 \cdot 829 & 45.773 \\ 45.378 & 45.322 & 45.265 & 45.208\end{array}$

.09

$(n-1) \times 1000$

$\lambda(n-1)$

$\begin{array}{rrr}411.0 & 23740.641 & 40.585 \\ 1.1 & 40.078 & 40.021 \\ 1.2 & 39.514 & 39.058 \\ 1.3 & 38.950 & 38.894 \\ 1.4 & 38.387 & 38.330 \\ 1.5 & 37.823 & 37.0786 \\ 1.6 & 37.259 & 37.203 \\ 1.7 & 36.696 & 36.639 \\ 1.8 & 36.132 & 36.076 \\ 1.9 & 35.569 & 35.512\end{array}$

$\begin{array}{lll}40.529 & 40.472 & 40 . \\ 39.965 & 39.908 & 39.8\end{array}$

$\begin{array}{llll}39.965 & 39.908 & 39.852 & 39.796\end{array}$

$\begin{array}{lll}38.837 & 38.781 & 380 \\ 38.274 & 38.218 & 380\end{array}$

$\begin{array}{llll}38.274 & 38.218 & 38.161 & 38.668 \\ 37.04\end{array}$

$\begin{array}{llll}37.710 & 37.654 & 37.597 & 37.541 \\ 37.146 & 37.090 & 37.034 & 36.978\end{array}$

35.512

2.1
2.2
20
20
207
20
2.0

4213.0

3.2

$3 \cdot 2$
$3 \cdot 3$
3.4

3.5

3.6

3.7

4214.0

4.1
4.2
4.3

4.4
4.5
406

4.6
4.7

4.8
4.9

4215.0

5.1

5.2
5.3
5.4

5.4
5.5

5.6
5.7

5.7
5.8
5.9

4216.0

6.1

6.2
6.3

6.4

6.5
6.6

6.6
6.7

6.8

4217.0

7.1
7.2

7.3

7.5

7.06

7.8
7.9

4218.

8.1
8.2
8.3

8.5

8.6

8.8

$\begin{array}{ll}3735.005 & 34.948 \\ 34.442 & 34.385 \\ 33.878 & 33.822 \\ 33.315 & 33.258 \\ 32.751 & 32.095 \\ 32.188 & 32.131 \\ 31.624 & 31.0568 \\ 31.061 & 31.005 \\ 30.498 & 30.441 \\ 29.935 & 29.878\end{array}$

23729.371

28.808

$28.245 \quad 28.189$

$27.681 \quad 27.625$

$26.555 \quad 26.048$

$250992 \quad 250936$

$\begin{array}{ll}25.429 & 25.373 \\ 24.866 & 24.810 \\ 24.303 & 24.247\end{array}$

24.303

$23723.740 \quad 23.684$

22.615

23.684

$22.052 \quad 21.995$

$20.926 \quad 20.870$

$\begin{array}{ll}20.363 & 20.307 \\ 19.800 & 19.744\end{array}$

$\begin{array}{ll}19.237 & 19.181 \\ 18.675 & 18.619\end{array}$

$36.583 \quad 36.526$

$36.470 \quad 36.414$

$35.456 \quad 35.399$

$23718.112 \quad 18.056$ $17.550 \quad 17.493$

$16.424 \quad 16.368$

$\begin{array}{ll}15.861 & 15.805 \\ 15.299 & 15.242\end{array}$

$14.737 \quad 14.680$

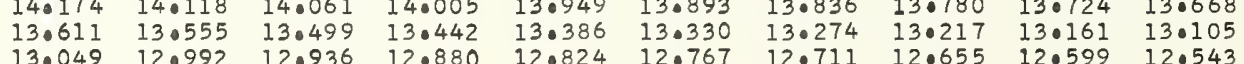

$\begin{array}{lll}34.892 & 34.836 \\ 34.329 & 34.272 & 340 \\ 33.765 & 33.709\end{array}$

$33.765 \quad 33.0709 \quad 33.216 \quad 340160$

$\begin{array}{llll}33.202 & 33.146 & 33.089 & 33.033 \\ 32.638 & 32.582 & 32.526 & 32.469 \\ 32.075 & 32.019 & 31.963 & 31.006\end{array}$

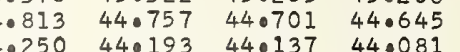

$\begin{array}{llll}40.250 & 440193 & 440137 & 44.081 \\ 3.0686 & 43.629 & 43.573 & 43.517\end{array}$

$43.122 \quad 43.065 \quad 43.009 \quad 42.053$

$\begin{array}{llll}41.994 & 42.502 & 42.446 & 42.389 \\ 41.938 & 41.882 & 41.825\end{array}$

$\begin{array}{llll}41.431 & 41.374 & 41.318 & 41.261 \\ 40.867 & 40.811 & 40.754 & 40.698\end{array}$

$\begin{array}{lllllll}31.399 & 31.343 & 31.850 & 31.793 & 31.737 & 31.681\end{array}$

$\begin{array}{lllllllll}30.948 & 30.892 & 30.836 & 30.779 & 30.723 & 30.067 & 30.611 & 30.0554\end{array}$

$\begin{array}{llllllll}30.385 & 30.329 & 30.272 & 30.216 & 30.160 & 30.103 & 30.047 & 29.990 \\ 29.822 & 29.765 & 29.709 & 29.653 & 29.597 & 29.540 & 29.484 & 29.428\end{array}$

$\begin{array}{llllllll}29.259 & 29.202 & 29.146 & 29.089 & 290033 & 28.977 & 280921 & 28.864\end{array}$

$\begin{array}{llllllll}28.695 & 28.639 & 28.583 & 28.527 & 28.470 & 28.414 & 28.357 & 28.301 \\ 28.132 & 28.076 & 28.019 & 27.963 & 27.906 & 27.851 & 27.794 & 27.738 \\ 27.569 & 27.513 & 27.457 & 27.000 & 27.344 & 27.287 & 27.036 & 27.175\end{array}$

$\begin{array}{lllllllll}27.569 & 27.513 & 27.457 & 27.400 & 27.344 & 27.287 & 27.231 & 27.175 \\ 27.006 & 26.950 & 26.893 & 26.837 & 26.781 & 26.724 & 26.658 & 26.612\end{array}$

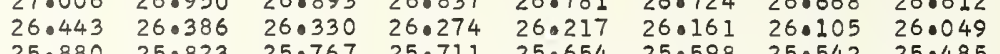

$\begin{array}{llllllll}25.880 & 25.823 & 25.767 & 25.711 & 25.654 & 25.598 & 250542 & 25.485 \\ 25.317 & 25.260 & 25.204 & 25.147 & 250091 & 25.035 & 240979 & 24.923 \\ 24.753 & 24.698 & 24.641 & 24.585 & 24.529 & 240472 & 240416 & 24.359\end{array}$

$\begin{array}{llllllll}24.753 & 24.698 & 24.641 & 24.585 & 24.529 & 24.472 & 240416 & 24 \cdot 359 \\ 24.191 & 24.135 & 24.078 & 24.022 & 23.966 & 230909 & 23.853 & 23.797\end{array}$

$23.628 \quad 23.572$

$23.515 \quad 23.459$

$23.403 \quad 23.346 \quad 23.290 \quad 23.234$

$\begin{array}{llllllll}23.065 & 23.008 & 22.952 & 22.896 & 22.840 & 22.783 & 22.727 & 22.671\end{array}$

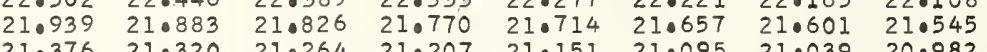

$\begin{array}{llllllll}21.376 & 21.320 & 21.264 & 21.207 & 21.151 & 21.095 & 21.039 & 20.982 \\ 20.814 & 20.757 & 20.701 & 20.644 & 20.588 & 20.0532 & 20.476 & 20.419\end{array}$

$\begin{array}{llllllll}20.250 & 20.194 & 20.138 & 20.082 & 20.025 & 19.969 & 19.913 & 19.856\end{array}$

$\begin{array}{llllllll}19.688 & 19.632 & 19.575 & 19.519 & 19.462 & 19.406 & 19.350 & 19.294 \\ 19.125 & 19.069 & 19.012 & 18.956 & 18.900 & 18.844 & 18.787 & 18.731\end{array}$

$\begin{array}{lllllllll}18.562 & 18.506 & 18.450 & 18.393 & 18.337 & 18.281 & 18.224 & 18.168\end{array}$

$\begin{array}{llllllll}17.437 & 17.381 & 17.324 & 17.268 & 17.712 & 17.718 & 17.662 & 17.606 \\ & 16.036 .099 & 17.043\end{array}$

$\begin{array}{lllllllll}16.874 & 16.818 & 16.761 & 16.705 & 16.649 & 16.593 & 16.537 & 16.480\end{array}$

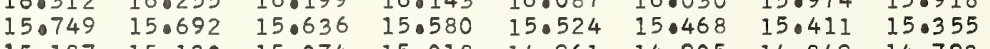

$\begin{array}{llllllll}15.187 & 15.130 & 15.074 & 15.018 & 14.961 & 14.905 & 14 \cdot 849 & 14.793 \\ 14.624 & 14.567 & 14.511 & 14.455 & 14.399 & 14.343 & 14.286 & 14.230\end{array}$

$\begin{array}{llllllll}14.624 & 14.567 & 14.511 & 14.455 & 14.399 & 14.343 & 14 \cdot 286 & 14 \cdot 230 \\ 14.061 & 14.005 & 13.949 & 13.893 & 13.836 & 13.780 & 13.724 & 13.668\end{array}$

$23712.486 \quad 12.430$

$\begin{array}{ll}11.924 & 11.868 \\ 11.361 & 11.305\end{array}$

$10.799 \quad 10.743$

$\begin{array}{lll}10.237 & 10.181 \\ 09.674 & 09.618\end{array}$

09.11209 .056

$\begin{array}{llllllllll}08.550 & 08.494 & 08.437 & 08 \cdot 381 & 08 \cdot 325 & 08 \cdot 269 & 08 \cdot 212 & 08 \cdot 156 & 08 \cdot 100 & 08 \cdot 044 \\ 07.988 & 07.931 & 07.875 & 07.819 & 07.763 & 07.707 & 07.650 & 07.594 & 07.538 & 07.482 \\ 07.426 & 07.369 & 07.313 & 07.257 & 07.200 & 07.144 & 07.088 & 07.032 & 06.976 & 06.919\end{array}$

$12.374 \quad 12.318$

$12.824 \quad 12.767$

$12.711 \quad 12.655 \quad 12.599 \quad 12.543$

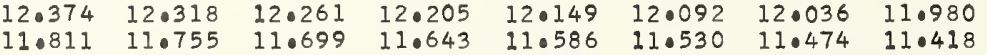

$\begin{array}{llllllll}11.249 & 11.193 & 11.137 & 11.080 & 11.024 & 10.968 & 10.912 & 11.418 \\ 10.855\end{array}$

$\begin{array}{llllllll}10.687 & 10.631 & 10.574 & 10.518 & 10.462 & 10.406 & 10.349 & 10.293 \\ 10.124 & 10.068 & 10.012 & 09.956 & 09.900 & 09.843 & 09.787 & 09.730\end{array}$

$\begin{array}{llllllll}09.562 & 09.506 & 09.449 & 09.393 & 09.337 & 09.281 & 09.225 & 09.168 \\ 09.000 & 08.943 & 08.887 & 08.831 & 08.775 & 08.719 & 08.662 & 08.606\end{array}$

$\begin{array}{lllllllll}09.000 & 08.943 & 08.887 & 08.831 & 08.775 & 08.719 & 08.662 & 08.606 \\ \end{array}$

$\begin{array}{llllllllll}23706.863 & 06.807 & 06.751 & 06.695 & 06.638 & 06.582 & 06.526 & 06.470 & 06.414 & 06.357\end{array}$ $\begin{array}{lllllllllll}06.301 & 06.245 & 06.189 & 06.132 & 06.076 & 06.020 & 05.964 & 05.907 & 05.852 & 05.795\end{array}$ $\begin{array}{lllllllllll}05.739 & 05.683 & 05.627 & 05.571 & 05.514 & 05.458 & 05.402 & 05.346 & 05.290 & 05.233\end{array}$ $\begin{array}{lllllllllll}05.177 & 05.121 & 05.065 & 05.009 & 04.953 & 04.896 & 04 \cdot 840 & 04.783 & 04 \cdot 727 & 04.671\end{array}$

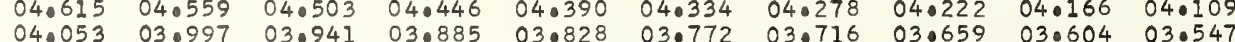
$\begin{array}{llllllllll}03.491 & 03.435 & 03.9478 & 03.885 & 03.828 & 03.772 & 03.716 & 03.659 & 03.604 & 03.547 \\ 03.266 & 03.210 & 03.154 & 03.098 & 03.042 & 02.985\end{array}$ $\begin{array}{llllllllllll}02.929 & 02.873 & 02.817 & 02.760 & 02.704 & 02.648 & 02.592 & 02.536 & 02.480 & 02.423\end{array}$

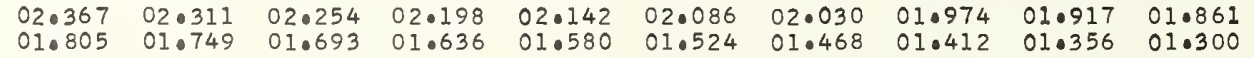

$\begin{array}{llllllllll}23701.243 & 01.187 & 01.131 & 01.075 & 01.018 & 00.962 & 00.906 & 00.850 & 00.794 & 00.738\end{array}$ $\begin{array}{llllllllll}00.681 & 00.625 & 00.569 & 00.513 & 00.457 & 00.401 & 00.344 & 00.288 & 00.232 & 00.176\end{array}$ \begin{tabular}{lllllll}
0 & 00.119 & 00.063 & 00.007 & $* 99.951 * 99.895 * 99.838 * 99.782 * 99.726 * 99.670 * 99.614$ \\
\hline
\end{tabular}

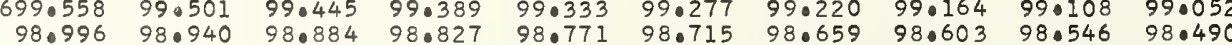

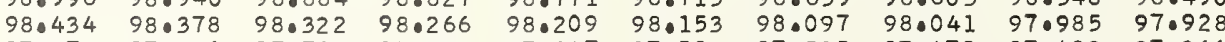

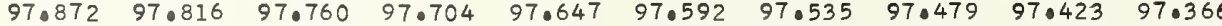

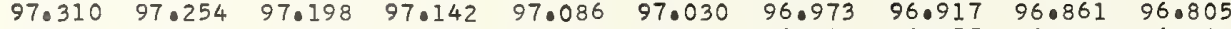
$\begin{array}{llllllllll}96.749 & 96.693 & 96.636 & 96.581 & 96.524 & 96.468 & 96.412 & 96.355 & 96.299 & 96.243 \\ 96.187 & 96.131 & 96.075 & 96.019 & 95.962 & 95.906 & 95.850 & 95.794 & 95.738 & 95.682\end{array}$

$23695.625 \quad 95 \cdot 569$

95.962950906

$95.289 \quad 950232 \quad 950177 \quad 950120$

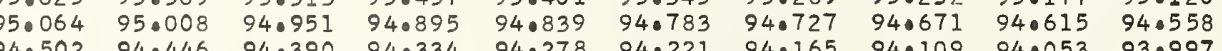
$\begin{array}{llllllllll}94 \cdot 502 & 94 \cdot 446 & 94 \cdot 390 & 94 \cdot 334 & 94 \cdot 278 & 94 \cdot 221 & 94 \cdot 165 & 94 \cdot 109 & 94 \cdot 053 & 93.997 \\ 93.941 & 93.884 & 93.828 & 93.772 & 93.716 & 93.660 & 93.604 & 93.547 & 93.491 & 93.435\end{array}$

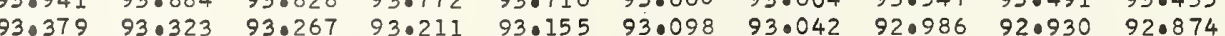

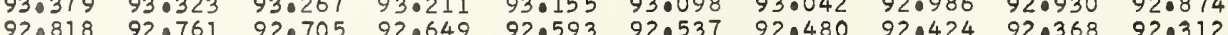

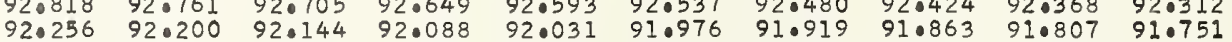

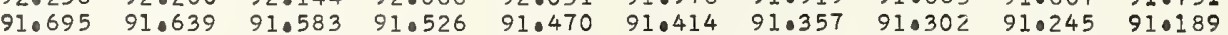

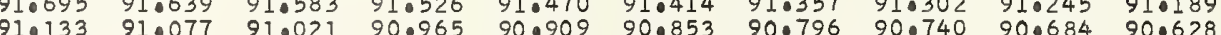
$90.572 \quad 90.516 \quad 90.460 \quad 90.403 \quad 90.347 \quad 90.291 \quad 90.235 \quad 90.179 \quad 90.123 \quad 90.066$ .001 .002

.003

.004

.005

.006
.00235

.007

$.008 \quad .009$

0.281709
0.281709

0.281708

0.281708
0.281707

0.281707

0.281706

0.281706

0.281706
0.281705

0.281705

0.281704

0.281704
0.281703

0.281703

0.281702

0.281702

0.281701

0.281701

0.281700

0.281700

0.281699

0.281698

0.281698

0.281697

0.281697

0.281696
0.281696

0.281696

0.281695

0.281695

0.281694

0.281693

0.281693

0.281692

0.281691

0.281691

0.281691

0.281690

0.281690

0.281689

0.281688

0.281688

0.281687
0.281687

0.281686

0.281686

0.281686

0.281685

0.281685

0.281684

0.281684

0.281683

0.281682

0.281682

0.281681

0.281681

0.281681

0.281680

0.281679

0.281679

0.281678
0.281678

0.281677

0.281677

0.281676

0.281676

0.281676

0.281675

0.281674

0.281674
0.281673

0.281673

0.281672

0.281672

0.281671

0.281671

0.281670

0.281670

0.281669
0.281669

0.281668

0.281668

0.281667

0.281667

0.281667

0.281666

0.281666
0.281665

0.281665

0.281665

.010

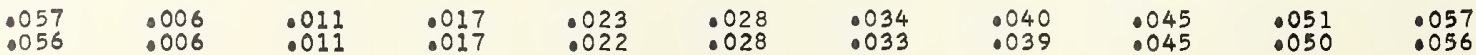

1.186022
1.186048

1.186074

1.186127

1.186153

1.186180

1.186206

10586258

10186284

1.186311

1.186363

1.186390

1.186416

1.186468

.186495

1.186521

.186573

1.186600

1.186626

1.186678

1.186705

1.186757

10186783

1.186836

1.186862

1.186888

1.186915

1.186941

1.186967

1.186993

1.187046

1.187072

1.187098

1.187151

1.187177

1.187203

1.187256

1.187308

10187335

1.187361

I.187387

I. 187440 
$\begin{array}{lllllllllll}4220.0 & 23690.010 & 89.954 & 89.898 & 89.842 & 89.786 & 89.730 & 89.674 & 89.617 & 89.562 & 89.505\end{array}$ $\begin{array}{lllllllllll}0.1 & 89.449 & 89.393 & 89.337 & 89.281 & 89.224 & 89.169 & 89.113 & 89.056 & 89.000 & 88.944 \\ 0.2 & 88.887 & 88.832 & 88.775 & 88.719 & 88.663 & 88.607 & 88.551 & 88.495 & 88.0439 & 88.383\end{array}$ $\begin{array}{lllllllllll}0.2 & 88.887 & 88.832 & 88.775 & 88.719 & 88.663 & 88.607 & 88.551 & 88.495 & 88.439 & 88.383 \\ 0.3 & 88.326 & 88.270 & 88.214 & 88.158 & 88.102 & 88.046 & 87.990 & 87.934 & 87.877 & 87.821\end{array}$ $\begin{array}{llllllllllll}0.4 & 87.765 & 87.709 & 87.653 & 87.597 & 87.540 & 87.484 & 87.428 & 87.373 & 87.316 & 87.821\end{array}$ $\begin{array}{lllllllllll}0.5 & 87.204 & 87.148 & 87.092 & 87.036 & 86.980 & 86.924 & 86.867 & 86.811 & 86.755 & 86.699\end{array}$ $\begin{array}{llllllllllll}0.6 & 86.643 & 86.587 & 86.531 & 86.474 & 86.418 & 86.362 & 86.306 & 86.250 & 86.194 & 86.138 \\ 0.7 & 86.082 & 86.026 & 85.969 & 85.913 & 85.857 & 85.801 & 85.745 & 85.689 & 85.633 & 85.577\end{array}$ $\begin{array}{lllllllllll}0.7 & 86.082 & 86.026 & 85.969 & 85.913 & 85.857 & 85.801 & 85.745 & 85.689 & 85.633 & 85.577 \\ 0.8 & 85.521 & 85.465 & 85.408 & 85.352 & 85.296 & 85.240 & 85.184 & 85.128 & 85.072 & 85.015\end{array}$ $84.959 \quad 84.903$

0.281661

0.281660

0.281659

0.281658

0.281658

0.281657

0.281657

$\begin{array}{llllllllll}82.154 & 82.098 & 82.042 & 81.986 & 81.930 & 81.874 & 81.818 & 81.762 & 81.705 & 81.649\end{array}$ $\begin{array}{llllllllll}81.593 & 81.537 & 81.481 & 81.425 & 81.369 & 81.312 & 81.256 & 81.200 & 81.145 & 81.088\end{array}$ $\begin{array}{llllllllll}80.471 & 80.415 & 80.920 & 80.864 & 80.808 & 80.752 & 80.696 & 80.640 & 80.583 & 80.527 \\ 80.359 & 80.303 & 80.247 & 80.191 & 80.135 & 80.079 & 80.022 & 79.966\end{array}$

$\begin{array}{ll}79.910 & 79.854 \\ 79.350 & 79.293\end{array}$

$\begin{array}{ll}80.359 & 80.303 \\ 79.798 & 79.742 \\ 79.237 & 79.181\end{array}$

$\begin{array}{llllll}80.247 & 80.191 & 80.135 & 80.079 & 80.022 & 79.966 \\ 79.686 & 79.630 & 79.574 & 79.518 & 79.462 & 79.406 \\ 79.125 & 79.069 & 79.013 & 78.957 & 78.901 & 78.844\end{array}$

4222.

22.0
2.1
2.2
2.3
2.4
2.5
2.6
2.7
2.8
2.9

$23678.788 \quad 78.732$

$\begin{array}{rllll}678.788 & 78.732 & 78.677 & 78.620 & 78 \\ 78.228 & 78.172 & 78.116 & 78.059 & 78 \\ 77.667 & 77.611 & 77.555 & 77.499 & 77.0 \\ 77.106 & 77.050 & 76.994 & 76.938 & 76 \\ 76.545 & 76.489 & 76.433 & 76.377 & 76 \\ 75.985 & 75.928 & 75.873 & 75.817 & 75 \\ 75.424 & 75.368 & 75.312 & 75.256 & 75 \\ 74.863 & 74.807 & 74.751 & 74.695 & 74 \\ 74.302 & 74.246 & 74.190 & 74.135 & 740 \\ 73.742 & 73.686 & 73.630 & 73.574 & 730\end{array}$

$78.564 \quad 78.508$

78.452

$\begin{array}{lll}78.396 & 78.340 & 78.284\end{array}$

2.9

4223.

3.

$23673.181 \quad 73.125$

$72.621 \quad 72.565$

$73.069 \quad 73.013$

$\begin{array}{lll}78.003 & 77.947 & 77.891 \\ 77.443 & 77.386 & 77.330\end{array}$

$75.760 \quad 75.704$

76.209
75.648

75.088
74.527

74.63974 .58

$74.078 \quad 74.02$

$\begin{array}{llll}73.966 & 73.910 & 73.854 & 73.798 \\ 73.406 & 73.350 & 73.294 & 73.238\end{array}$

75.03

74.47

$\begin{array}{ll}76.097 & 76.041 \\ 75.536 & 75.480\end{array}$

$\begin{array}{ll}74.975 & 74.919 \\ 74.415 & 74.359\end{array}$

0.281656

0.281656
0.281655

0.281655

0.281654

0.281654

0.281653

0.281653

0.281652

0.281651

0.281650

0.281650

0.281649

0.281649

3.3
3.4
3.5

$\begin{array}{llll}71.500 & 71.444 & 71.388 & 71.332\end{array}$

$70.379 \quad 70.323$

$69.819 \quad 69.762$

3.6

3.7

$\begin{array}{ll}69.258 & 69.202 \\ 68.698 & 68.642\end{array}$

$70.267 \quad 70.211$

$69.707 \quad 69.650$

$68.138 \quad 68.082$

$68.586 \quad 68.530$

$70.715 \quad 70.659$

$\begin{array}{ll}70.155 & 70.099 \\ 69.594 & 69.538\end{array}$

$\begin{array}{ll}69.034 & 68.978 \\ 68.474 & 68.418\end{array}$

$\begin{array}{llll}72.285 & 72.229 & 72.173 & 72.116 \\ 71.724 & 71.668 & 71.612 & 71.556 \\ 71.164 & 71.107 & 71.052 & 70.995\end{array}$

$\begin{array}{llll}70.603 & 70.547 & 70.491 & 70.435\end{array}$

$\begin{array}{llll}70.043 & 69.987 & 69.931 & 69.875\end{array}$

0.281648

0.281648

0.281647

$4224 \cdot 0$

23667

$67.577 \quad 67.521$

$67.466 \quad 67.40$

$67.913 \quad 67.857$

68.36

$68.866 \quad 68.810 \quad 68.754$

0.281647

0.281646

0.281645

0.281645
0.281644

0.281644

0.281643

$\begin{array}{llllllllll}65.336 & 65.280 & 65.224 & 65.168 & 65.112 & 65.056 & 65.000 & 64.944 & 64.8488 & 64.832 \\ 64.7776 & 64.720 & 64.664 & 64.608 & 64.552 & 64.496 & 64.440 & 64.384 & 64.328 & 64.272\end{array}$

$\begin{array}{llllllllll}64.776 & 64.720 & 64.664 & 64.608 & 64.552 & 64.496 & 64.440 & 64.384 & 64.328 & 64.272 \\ 64.216 & 64.160 & 64.104 & 64.048 & 63.992 & 63.936 & 63.880 & 63.824 & 63.768 & 63.712\end{array}$

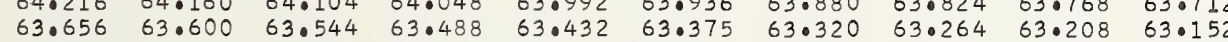

$\begin{array}{llllllllll}63.096 & 63.040 & 62.984 & 62.928 & 62.872 & 62.816 & 62.760 & 62.704 & 62.648 & 62.592 \\ 62.536 & 62.480 & 62.424 & 62.368 & 62.312 & 62.255 & 62.199 & 62.144 & 62.087 & 62.031\end{array}$

0.281643

0.281642
0.281642

23661.975

61.919

$61.864 \quad 61.808$

62.31262 .255

225
5
5
5
5
5
5
5
5

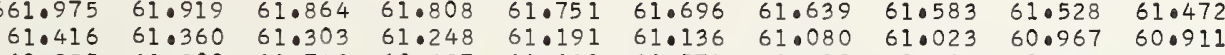

$60.855 \quad 60.800 \quad 60.743 \quad 60.687 \quad 60.631 \quad 60.575$

$50.240 \quad 60.184 \quad 60.128$

$59.176 \quad 59.120 \quad 59.064 \quad 59.008$

$58.016 \quad 58.560058 .504 \quad 58.448$

$57.496 \quad 57.440$

$58.952 \quad 58.896$

$\begin{array}{lllll}016 & 59.960 & 59.904 & 59.848 & 59.791 \\ .455 & 59.400 & 59.344 & 59.288 & 59.232\end{array}$

0.28164

0.281641

0.281640

0.281639

0.281639

0.281638

0.281638
0.281637

4226.

23656.376

6.

$55.817 \quad 56.321$

55.817
55.257

$54.697 \quad 54.201$

$54.138 \quad 54.082$

53.578

52.962
52.403

51.899
51.339

4227.

7.0
$7:$
$7: 3$
$7: 5$
$7: 0$
$7: 7$
709

23650.7

50.780
49.6
49.10

51.283

$56.265-56.209$

$\begin{array}{llll}57.720 & 57.664 & 57.608 & 57.552\end{array}$

0.28163

0.281637

0.281636
0.281636

0.281636

0.281635

0.281634

0.281634

0.281633

0.281633

0.281632

0.281632

0.281631

0.281630

0.281630

0.281630

0.281629

0.281628

$\begin{array}{lllllllllll}47.424 & 47.368 & 47.312 & 47.256 & 47.200 & 47.144 & 47.088 & 47.032 & 46.976 & 46.920\end{array}$

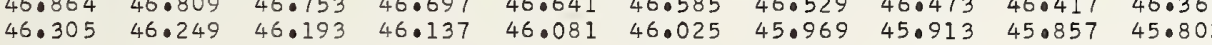

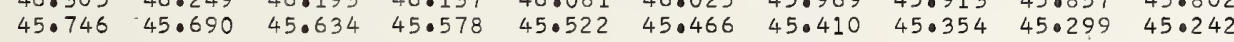

$45 \cdot 130$

$45.075 \quad 45.019$

$44.063 \quad 44.907$

$44.851 \quad 44 \cdot 795 \quad 44 \cdot 739 \quad 44 \cdot 683$

0.281628

0.281627

0.28162

0.281626

0.281625
0.281625

0.281625

0.281624

0.281623

0.281623

0.281622

0.281621

0.281621

0.281621
0.281620

0.281620

0.281619

1.188621

188647

1. 188700

$1 \cdot 188726$

1.188779

1. 188805

1.188831

1.188884

10188910

$1 \cdot 188963$

1.289015

1.189041

1.289068

1.189094

1.189146

1.189199

1.189225

1.189278

1.189330

1.189356

1.189409

1.189435

10189461

I.189514

1.189540

1.189567

1.189619

$1 \cdot 189672$

1.189698

1.189724

1.189777

1.189803

1.189855

10189882

1.189934

1.189960

10190013

1.190065

1.190092

1.190144

1.190197

1.190223

1.190276

1.190302

1.190328

1.190381

1.190407
1.190433

1.190459

1.190486

1.190538

1.190564

.190617

1.190643

1.190669
1.190696

1.190722

$1 \cdot 190748$

1. 190801

1.190853

1.190880

1.190932

190958

1.190985

1.191037

1.191063

1.191116

1.191142

1.191168

1.191195

.010

.056 
$\begin{array}{rrrrrrrrrrr}4230.0 & 23634.007 & 33.951 & 33.89 .5 & 33.839 & 33.783 & 33.727 & 33.671 & 33.615 & 33.560 & 33.504 \\ 0.1 & 33.448 & 33.392 & 33.336 & 33.280 & 33.224 & 33.169 & 33.113 & 33.057 & 33.001 & 32.945\end{array}$ $\begin{array}{lllllllllll}0.1 & 33.448 & 33.392 & 33.336 & 33.280 & 33.224 & 33.169 & 33.113 & 33.057 & 33.001 & 32.944 \\ 0.2 & 32.889 & 32.833 & 32.778 & 32.722 & 32.666 & 32.610 & 32.554 & 32.498 & 32.442 & 32.386\end{array}$ $\begin{array}{lllllllllll}0.3 & 32.331 & 32.275 & 32.219 & 32.163 & 32.107 & 32.052 & 31.996 & 31.940 & 31.884 & 31.828\end{array}$ 0.5 0.6 $31.772 \quad 31.716 \quad 31.660 \quad 31.605 \quad 31.549 \quad 31.493$ $\begin{array}{lllllll}30.655 & 30.599 & 30.543 & 30.487 & 30.431 & 30.376\end{array}$ 29.538
28.980

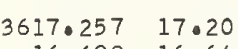

\begin{abstract}
.002
\end{abstract}

\section{$22.615 \quad 22.559$}

$\begin{array}{ll}22.056 & 22.000 \\ 21.498 & 21.0442 \\ 20.040 & 20.884\end{array}$

20.940

$20.382 \quad 20.326$

19.266

18.708
18.150
17.592

19.76

18.65

17.034

17.536

22.503

21.945

$\begin{array}{llll} & 20.0772 & 20.717 & 20.66\end{array}$

$\begin{array}{llll}20.271 & 20.215 & 20.159 & 20.103 \\ 19.712 & 19.656 & 19.601 & 19.545\end{array}$

$\begin{array}{lllll}19.154 & 19.099 & 19.043 & 18.987\end{array}$

$\begin{array}{llll}18.596 & 18.541 & 18.485 & 18.429\end{array}$

$\begin{array}{llll}18.038 & 17.982 & 170927 & 17 \cdot 871 \\ 17.481 & 17.425 & 17.369 & 17.313\end{array}$

$\begin{array}{llll}16.922 & 16.866 & 16.811 & 16.755\end{array}$

$\begin{array}{llllll}16.476 & 16.421 & 16.365 & 16.309 & 16.253 & 16.197 \\ 15.918 & 15.862 & 15.806 & 15.751 & 15.695 & 15.639\end{array}$

$\begin{array}{llllll}15.361 & 15.305 & 15.249 & 15.193 & 15.137 & 15.082\end{array}$

$\begin{array}{llllll}14.802 & 14.747 & 14.691 & 14.635 & 14.579 & 14.524\end{array}$

$\begin{array}{llllll}14.245 & 14.189 & 14.133 & 14.077 & 14.022 & 13.966 \\ 13.687 & 13.631 & 13.575 & 13.520 & 13.464 & 13.408\end{array}$

$\begin{array}{lllllll}13.130 & 13.074 & 13.018 & 12.962 & 12.907 & 12.851\end{array}$

$\begin{array}{llllll}12.572 & 12.516 & 12.460 & 12.404 & 12.349 & 12.293 \\ 12.014 & 11.958 & 11.903 & 11.847 & 11.791 & 11.735\end{array}$

$\begin{array}{llllll}11.457 & 11.401 & 11.345 & 11.289 & 11.233 & 110178\end{array}$

$\begin{array}{llllll}10.341 & 10.285 & 10.230 & 10.174 & 10.118 & 10.062\end{array}$

$\begin{array}{llllll}09.784 & 09.728 & 09.672 & 09.616 & 09.561 & 09.505\end{array}$

$\begin{array}{llllll}09.226 & 09.170 & 09.115 & 09.059 & 09.003 & 08.948 \\ 08.668 & 08.613 & 08.557 & 08.501 & 08.446 & 08.390\end{array}$

$\begin{array}{lllllll}08.111 & 08.055 & 08.000 & 07.944 & 07.888 & 07.832\end{array}$

$\begin{array}{llllll}07.553 & 07.498 & 07.442 & 07.386 & 07.331 & 07.275\end{array}$

$\begin{array}{llllll}06.996 & 06.940 & 06.885 & 06.829 & 06.773 & 06.717\end{array}$

$\begin{array}{lllllll}05.881 & 05.825 & 05.770 & 05.714 & 05.658 & 05.603\end{array}$

$\begin{array}{lllllll}05.324 & 05.268 & 05.212 & 05.156 & 05.101 & 05.045\end{array}$

$\begin{array}{lllllll}04.766 & 04.711 & 04.655 & 04.599 & 04.544 & 04.488\end{array}$

$\begin{array}{lllllll}04.209 & 04.154 & 04.098 & 04 \cdot 042 & 03.986 & 03.930 \\ 03.652 & 03.596 & 03.541 & 03.485 & 03.429 & 03.373\end{array}$

$\begin{array}{llllllll}03.095 & 03.039 & 02.983 & 02.927 & 02.872 & 02.816\end{array}$

$\begin{array}{lllllll}02.537 & 02.482 & 02.426 & 02.370 & 02.314 & 02.259\end{array}$

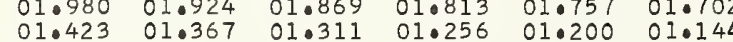

$\begin{array}{llllll}00.866 & 00.810 & 00.754 & 00.699 & 00.643 & 00.587\end{array}$

$\begin{array}{lllllll}00.309 & 00.253 & 00.197 & 00.141 & 00.086 & 00.030\end{array}$

$\begin{array}{lllllll}99.194 & 99.138 & 99.083 & 99.027 & 98.971 & 98.916\end{array}$

$\begin{array}{lllllll}98.637 & 98.582 & 98.526 & 98.470 & 98.415 & 98.359\end{array}$

$\begin{array}{lllllll}98.080 & 98.025 & 97.969 & 97.913 & 97.857 & 97.802\end{array}$

$96.966 \quad 96.911 \quad 96.85596 .799996 .743 \quad 96.687$

$\begin{array}{llllll}96.409 & 96.354 & 96.298 & 96.242 & 96.187 & 96.68131\end{array}$

$\begin{array}{llllll}95.853 & 95.797 & 95.741 & 95.685 & 95.630 & 95.574 \\ 95.295 & 95.240 & 95.184 & 95.128 & 95.073 & 95.017\end{array}$

$94.739 \quad 940683 \quad 94.628 \quad 940572 \quad 940516 \quad 94.461$

$\begin{array}{lllllll}94.182 & 94.126 & 94.071 & 94.015 & 93.959 & 93.904 \\ 93.625 & 93.570 & 93.514 & 93.458 & 93.403 & 93.347\end{array}$

$\begin{array}{llllll}93.625 & 93.570 & 93.514 & 93.458 & 93.403 & 93.347 \\ 93.068 & 93.013 & 92.957 & 92.901 & 92.845 & 92.790\end{array}$

$\begin{array}{lllllll}92.511 & 92.456 & 92.400 & 92.345 & 92.289 & 92.233\end{array}$

$\begin{array}{llllll}91.955 & 91.899 & 91.843 & 91.788 & 91.732 & 91.0677\end{array}$

$\begin{array}{llllll}91.398 & 91.343 & 91.287 & 91.231 & 91.176 & 91.120 \\ 90.842 & 90.786 & 90.730 & 90.675 & 90.619 & 90.563\end{array}$

$\begin{array}{lllllll}90.285 & 90.229 & 90.174 & 90.118 & 90.062 & 90.006 \\ 89.728 & 89.673 & 89.617 & 89.562 & 89.506 & 89.450\end{array}$

$\begin{array}{lllllll}89.172 & 89.116 & 89.060 & 89.004 & 88.949 & 88.893\end{array}$

$\begin{array}{llllll}88.615 & 88.560 & 88.504 & 88.448 & 88.392 & 88.337 \\ 88.058 & 88.003 & 87.947 & 87.892 & 87.836 & 87.780\end{array}$

$\begin{array}{lllllll}88.0502 & 88.003 & 87.947 & 87.892 & 87.836 & 87.780 \\ 87.5025 & 87.446 & 87.391 & 87.0335 & 87.279 & 87.224\end{array}$

$\begin{array}{llllll}86.945 & 86.889 & 86.834 & 86.778 & 86.723 & 86.667\end{array}$

$86.389 \quad 86.333 \quad 86.278 \quad 86.222 \quad 86.167 \quad 86.111$

$\begin{array}{llllll}85.872 & 85.777 & 85.721 & 85.665 & 85.610 & 85.554 \\ 85.276 & 85.220 & 85.165 & 85.109 & 85.053 & 84.098\end{array}$

$\begin{array}{llllll}84.720 & 84.664 & 84.608 & 84.552 & 84.497 & 84.441 \\ 84.163 & 84.107 & 84.052 & 83.996 & 83.941 & 83.885\end{array}$

$\begin{array}{lllllll}83.607 & 83.551 & 83.496 & 83.440 & 83.384 & 83.329\end{array}$

$\begin{array}{lllllll}83.050 & 82.995 & 82.939 & 82.884 & 82.828 & 82.772\end{array}$

$\begin{array}{llllll}82.494 & 82.439 & 82.383 & 82.328 & 82.272 & 82.216 \\ 81.938 & 81.882 & 81.827 & 81.771 & 81.015 & 81.660\end{array}$

$\begin{array}{llllll}81.382 & 81.326 & 81.271 & 81.215 & 81.159 & 81.104\end{array}$

$\begin{array}{lllllll}80.825 & 80.770 & 80.714 & 80.658 & 80.603 & 80.547\end{array}$

$\begin{array}{llllll}80.269 & 80.214 & 80.158 & 80.103 & 80.047 & 79.991 \\ 79.713 & 79.657 & 79.602 & 79.546 & 79.49 & 79.43\end{array}$

$\begin{array}{llllll}79.713 & 79.657 & 79.602 & 79.546 & 79.491 & 79.435 \\ 79.157 & 79.101 & 79.046 & 78.990 & 78.935 & 78.879\end{array}$

78.60178 .545

$(n-1) \times 1000$

$\lambda(n-1)$

0.281619

0.281618

0.281617

0.281617

0.281616

0.281616

0.281615

0.281614

0.281614

0.281613

0.281612

0.281612

.281611

0.281611
0.281610

0.281610

0.281609

0.281609
0.281608

0.281608

0.281607

0.281606

0.281605

0.281605

0.281604

0.281603

0.281603

0.281602

0.281601

0.281601

0.281600

.281599

0.281599

0.281598

0.281598

0.281597

0.281596

0.281596

0.281595

0.281595

0.281595

0.281594

0.281593

0.281592

0.281592

.281591

0.281591

0.281590

0.281589

0.281589

0.281588
0.281588

0.281587

0.281587

0.281587

0.281586

0.281585

0.281585

0.281584

0.281584
0.281583

0.281583

0.281582

0.281582

0.281581

0.281580

0.281580 
$\begin{array}{rrrrrrrrrrr}0.0 & 23578.267 & 78.211 & 78.156 & 78.100 & 78.045 & 77.989 & 77.933 & 77.878 & 77.823 & 77.767 \\ 0.1 & 77.711 & 77.656 & 77.600 & 77.544 & 77.489 & 77.433 & 77.377 & 77.322 & 77.266 & 77.210 \\ 0.0 & 77.155 & 77.099 & 77.044 & 76.980 & 76.933 & 76.077 & 76.821 & 76.765 & 76.710 & 76.655\end{array}$

$\begin{array}{lllllllllll}0.2 & 77.155 & 77.099 & 77.044 & 76.988 & 76.933 & 76.877 & 76.821 & 76.766 & 76.710 & 76.655 \\ 0.3 & 76.599 & 76.543 & 76.488 & 76.432 & 76.377 & 76.321 & 76.266 & 76.209 & 76.154 & 76.099\end{array}$

$\begin{array}{llllllllllll}0.4 & 76.043 & 75.988 & 75.932 & 75.876 & 75.821 & 75.765 & 75.710 & 75.654 & 75.599 & 75.543\end{array}$

$\begin{array}{llllllllllll}0.5 & 75.487 & 75.432 & 75.376 & 75.321 & 75.265 & 75.209 & 75.154 & 75.098 & 75.043 & 74.987 \\ 0.6 & 74.931 & 74.876 & 74.820 & 74.764 & 74.709 & 74.654 & 74.598 & 74.542 & 74.487 & 74.431\end{array}$

$\begin{array}{lllllllllll}0.7 & 74.375 & 74.320 & 74.264 & 74.209 & 74.153 & 74.098 & 74.042 & 73.987 & 73.931 & 73.875\end{array}$

$\begin{array}{lllllllllll}0.8 & 73.820 & 73.764 & 73.708 & 73.653 & 73.597 & 73.542 & 73.486 & 73.430 & 73.375 & 73.319 \\ 0.9 & 73.264 & 73.208 & 73.153 & 73.097 & 73.041 & 72.986 & 72.930 & 72.875 & 72.819 & 72.764\end{array}$

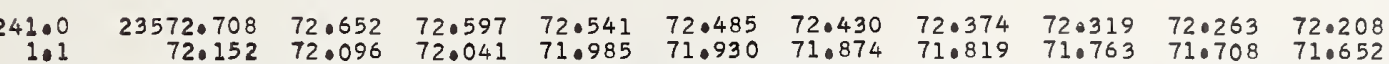

$\begin{array}{llllllllllll}1.1 & 72.152 & 72.096 & 72.041 & 71.985 & 71.930 & 71.874 & 71.819 & 71.763 & 71.708 & 71.652 \\ 1.2 & 71.596 & 71.541 & 71.485 & 71.430 & 71.374 & 71.318 & 71.262 & 71.207 & 71.152 & 71.096\end{array}$

$\begin{array}{lllllllllll}1.3 & 71.596 & 71.541 & 71.485 & 71.430 & 71.374 & 71.318 & 71.262 & 71.207 & 71.152 & 71.096 \\ 1.30 & 71.041 & 70.985 & 70.929 & 70.874 & 70.818 & 70.763 & 70.707 & 70.651 & 70.596 & 70.540\end{array}$

$\begin{array}{lllllllllllll}1.4 & 70.485 & 70.429 & 70.374 & 70.318 & 70.262 & 70.207 & 70.151 & 70.096 & 70.040 & 69.985\end{array}$

$\begin{array}{lllllllllll}1.5 & 69.929 & 69.873 & 69.818 & 69.762 & 69.707 & 69.651 & 69.596 & 69.540 & 69.485 & 69.429\end{array}$

\begin{tabular}{llllllllllll}
1.7 & 68.317 & 68.762 & 68.267 & 69.207 & 69.151 & 69.096 & 69.040 & 68.985 & 68.929 & 68.873 \\
\hline & 68.651 & 68.595 & 68.540 & 68.484 & 68.429 & 68.373 & 680318
\end{tabular}

$\begin{array}{lllllllllll}.8 & 68.262 & 68.207 & 68.151 & 68.096 & 68.040 & 67.984 & 67.929 & 67.873 & 67.818 & 67.762\end{array}$

$\begin{array}{llllllllllll}242.0 & 23567.151 & 67.095 & 67.040 & 66.984 & 66.929 & 66.873 & 66.818 & 66.762 & 66.707 & 66.651\end{array}$

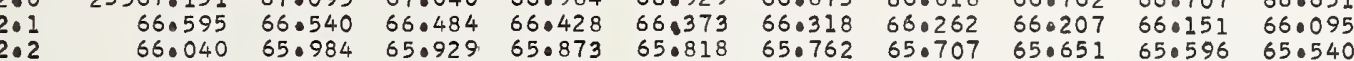

$\begin{array}{llllllllllll}2.2 & 66.040 & 65.984 & 65.929 & 65.873 & 65.818 & 65.762 & 65.707 & 65.651 & 65.596 & 65.540\end{array}$

$2 \cdot 4$

$65.484 \quad 65 \cdot 429 \quad 65 \cdot 373$

$64.374 \quad 64.31864 .818 \quad 64.76264 .707 \quad 64.651$

$\begin{array}{llllllllll}64.374 & 64.318 & 64.263 & 64.207 & 64.151 & 64.095 & 64.040 & 63.984 & 63.929 & 64.42\end{array}$

$\begin{array}{llllllll}63.063 & 63.429 & 63.374 & 63.318\end{array}$

$62.707 \quad 62.652 \quad 62.596 \quad 62.54162 .48562 .430 \quad 62.37462 .31862 .81860 .763$

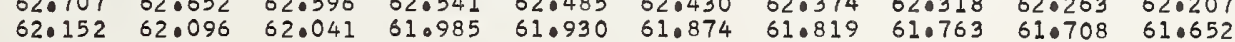

4243.

300
30
30
30
30
30
3
3.0

23561.596

$1.596 \quad 61.541$

$61.04160 .986 \quad 61.486$

$\begin{array}{lll}59.486 & 60.430 & 60.3 \\ 59.931 & 59.875 & 59.820\end{array}$

$59.376 \quad 59.320 \quad 59.264 \quad 59.764$

$\begin{array}{llll}58.820 & 58.765 & 58.709 & 58.654 \\ 58.265 & 58.210 & 58.154 & 58.098\end{array}$

$\begin{array}{llllll}58.265 & 58.210 & 58.154 & 58.098 & 58.043\end{array}$

$\begin{array}{lllllll}57.710 & 57.655 & 57.599 & 57.543 & 57.488 & 57.433\end{array}$

$\begin{array}{lllll}57.155 & 57.100 & 57.044 & 56.989 & 560 \\ 56.600 & 56.545 & 56.489 & 56.434 & 560\end{array}$

4244.

4.1
4.2
4.3

$4 \cdot 4$

4.7

$55.490 \quad 55.990$

$\begin{array}{llll}54.935 & 54.835 & 55.379 & 55.3 \\ 54.824 & 54.769\end{array}$

$\begin{array}{llll}54.380 & 54.324 & 54.269 & 54.21\end{array}$

53.825
3.270 $53.215 \quad 53.71453 .659$

$52.715 \quad 52.660 \quad 52.604 \quad 52.549$

$\begin{array}{llll}51.606 & 51.550 & 51.495 & 51.439 \\ 51.051 & 50.996 & 50.940 & 50.885\end{array}$

$55.823 \quad 55.768$

$\begin{array}{llll}56.822 & 56.76756 .711 \quad 56.656\end{array}$

550.

4245.

5.

49.941

49.38649 .886

$48.832 \quad 48.776$

$48.277 \quad 48 \cdot 22$

50.385
49.830

$\begin{array}{ll}50.330 \\ 49.775 \\ 276 & 49.220\end{array}$

$\begin{array}{ll}54.713 & 54.215 \\ 54.1 .658\end{array}$

$55.656 \quad 55.601 \quad 55.546$

$\begin{array}{llllll}54.158 & 54.103 & 54.602 & 54.547 & 54.491 & 54.436\end{array}$

$\begin{array}{llllll}53.603 & 53.548 & 53.492 & 53.437 & 53.381 & 53.326\end{array}$

$\begin{array}{llllll}53.048 & 52.993 & 52.937 & 52.882 & 52.826 & 52.771 \\ 52.493 & 52.438 & 52.383 & 52.327 & 52.271 & 52.216\end{array}$

$\begin{array}{llllll}51.938 & 51.883 & 51.827 & 51.772 & 51.717 & 51.661\end{array}$

$47.168 \quad 47.667 \quad 47.612$

$\begin{array}{lll}46.613 & 46.112 & 47.057\end{array}$

$\begin{array}{ll}46.059 & 46.003 \\ 45.504 & 45.449\end{array}$

49.220

$50.829 \quad 50.773$

$\begin{array}{ll}51.162 & 51.106 \\ 50.607 & 50.552\end{array}$

$\begin{array}{llllll}50.274 & 50.219 & 50.163 & 50.108 & 50.052 & 49.997 \\ 49.719 & 49.664 & 49.608 & 49.553 & 49.497 & 49.442\end{array}$

$\begin{array}{lllllll}49.165 & 49.109 & 49.053 & 48.998 & 48.943 & 48.887\end{array}$

$\begin{array}{lllllll}48.610 & 48.555 & 48.499 & 48.443 & 48.388 & 480332\end{array}$

$\begin{array}{llllllll}48.111 & 48.055 & 48.000 & 47.944 & 47.889 & 47.833 & 47.778\end{array}$

47.001

$\begin{array}{llllll}47.501 & 47.445 & 47.390 & 47.334 & 47 \cdot 279 & 47 \cdot 223\end{array}$

5.8

4246

6.

$4.349544 \cdot 894$

$\begin{array}{ll}45.948 & 45.892 \\ 45.393 & 45.338\end{array}$

$46.391 \quad 46.336 \quad 46.281 \quad 46.225 \quad 46.170 \quad 46.114$

$\begin{array}{llllll}45.837 & 45.781 & 45.726 & 45.670 & 45.615 & 45.559 \\ 45.282 & 45.227 & 45.172 & 45.116 & 45.061 & 450005\end{array}$

$\begin{array}{lllllllll}44.340 & 44.284 & 44.229 & 44.173 & 44.118 & 44.062 & 44.007 & 43.951 & 43.896\end{array}$

$\begin{array}{lllllllllll}43.841 & 43.785 & 43.730 & 43.674 & 43.619 & 43.563 & 43.508 & 43.452 & 43.397 & 43.342\end{array}$

$43.286 \quad 43.230 \quad 43.175 \quad 43.120 \quad 43.064$

$\begin{array}{llllllllll}42.732 & 42.676 & 42.621 & 42.565 & 42.510 & 42.454 & 42.399 & 42.344 & 42.288 & 42.233\end{array}$

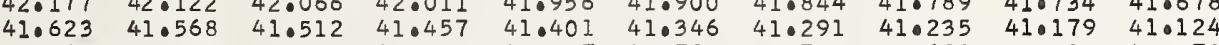

$\begin{array}{llllllllll}41.068 & 41.013 & 40.958 & 40.902 & 40.847 & 40.791 & 40.736 . & 40.681 & 40.625 & 40.570\end{array}$

$\begin{array}{llllllllll}40.514 & 40.459 & 40.403 & 40.348 & 40.293 & 40.237 & 40.182 & 40.126 & 40.071 & 40.015\end{array}$

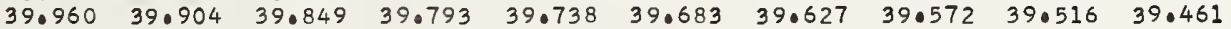

4247

7.0
77
7
7
7
7
70
70

39.40639 .35

$38.852 \quad 38.796 \quad 38.741 \quad 38.685$

\begin{tabular}{lllllllllll}
38.242 & 38.187 & 38.131 & 38.076 & 38.575 & 38.519 & 38.464 & 38.408 & 38.353 \\
\hline
\end{tabular}

$\begin{array}{llllllllll} & 37.633 & 37.577 & 37.521 & 37.466 & 37.411 & 37.355 & 37.300 & 37.244\end{array}$

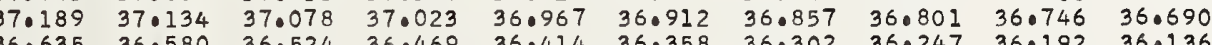

$\begin{array}{llllllllll}36.081 & 36.025 & 35.970 & 35.915 & 35.459 & 35.804 & 36.302 & 36.247 & 36.192 & 36.136\end{array}$

$\begin{array}{llllllllll}35.527 & 35.472 & 35.416 & 35.361 & 35.305 & 35.250 & 35.194 & 35.139 & 35.033 & 35.028\end{array}$

$\begin{array}{llllllllll}34.973 & 34.917 & 34.862 & 34.807 & 34.751 & 34.696 & 34.640 & 34.585 & 34.529 & 34.474 .\end{array}$

$\begin{array}{llllllllll}34.419 & 34.364 & 34.308 & 34.252 & 34.197 & 34.142 & 34.087 & 34.031 & 33.975 & 33.920\end{array}$

$\begin{array}{lllllllllll}4248.0 & 23533.865 & 33.809 & 33.754 & 33.698 & 33.643 & 33.588 & 33.532 & 33.477 & 33.422 & 33.366\end{array}$

$\begin{array}{lllllllllll}8.1 & 33.311 & 33.255 & 33.200 & 33.145 & 33.089 & 33.034 & 32.979 & 32.923 & 32.868 & 32.812\end{array}$

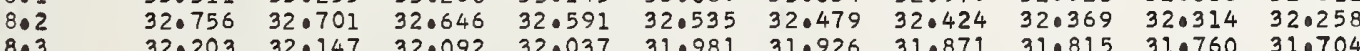

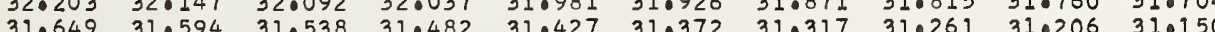

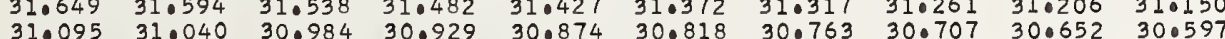

$\begin{array}{llllllllll}30.541 & 30.486 & 30.430 & 30.375 & 30.319 & 30.264 & 30.209 & 30.153 & 30.098 & 30.042\end{array}$

$\begin{array}{llllllllll}29.434 & 29.378 & 29.323 & 29.268 & 29.212 & 29.156 & 29.101 & 29.046 & 28.990 & 28.935 \\ 28.880 & 28.824 & 28.769 & 28.714 & 28.658 & 28.603 & 28.548 & 28.492 & 28.437 & 28.381\end{array}$

$\begin{array}{rrrrrrrrrrr}4249.0 & 23528.326 & 28.271 & 28.216 & 28.160 & 28.105 & 28.049 & 27.994 & 27.938 & 27.883 & 27.828 \\ 9.1 & 27.772 & 27.717 & 27.661 & 27.606 & 27.551 & 27.496 & 27.440 & 27.385 & 27.329 & 27.274\end{array}$

$\begin{array}{lllllllllll}9.1 & 27.772 & 27.717 & 27.661 & 27.606 & 27.551 & 27.496 & 27.440 & 27.385 & 27.329 & 27.274 \\ 9.2 & 27.219 & 27.163 & 27.108 & 27.052 & 26.997 & 26.942 & 26.886 & 26.831 & 26.776 & 26.720\end{array}$

$\begin{array}{lllllllllll}9.3 & 26.665 & 26.609 & 26.554 & 26.499 & 26.443 & 26.388 & 26.333 & 26.277 & 26.222 & 26.167 \\ 9.4 & 26.111 & 26.056 & 26.000 & 25.945 & 25.890 & 250834 & 25.779 & 25.724 & 25.668 & 25.613 \\ 9.5 & 25.557 & 25.502 & 25.447 & 25.392 & 25.336 & 25.281 & 25.225 & 25.170 & 25.115 & 25.060\end{array}$

$25.004 \quad 24.949 \quad 24.893 \quad 240838 \quad 240782 \quad 24.728 \quad 240672 \quad 240617 \quad 24.561240506$

$\begin{array}{llllllllll}24.450 & 24.396 & 24.340 & 24.838 & 24.782 & 24.728 & 24.672 & 24.617 & 24.561 & 24.506\end{array}$

$23.897 \quad 23.842 \quad 23.786 \quad 23.731 \quad 23.676 \quad 23.620 \quad 23.565 \quad 230510 \quad 230454 \quad 230399$

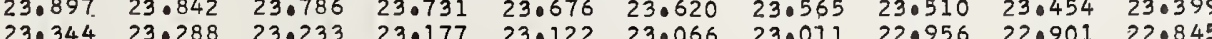

0.281574

.281574

281573

0.281572

281571

0.281571

0.281570

0.281570

0.281569
0.281568

0.281568

0.281567

0.281567

0.281566

0.281566

0.281565

0.281565

0.281564
0.281564

0.281563

0.281563

0.281562

0.281562

0.281561

0.281561

0.281560
0.281560

0.281559

0.281559

0.281558

0.281558

0.281557

0.281556

0.281556

0.281555

0.281554

0.281554

0.281554

0.281553

0.281553
0.281552

0.281552

.

1550

0.281550

0.281550

0.281549

0.281549

0.281548
0.281548

0.281547

0.281547

0.281546
0.281546

0.281546

0.281545
0.281545

0.281544

0.281544
0.281543

0.281543

0.281542

0.281542
0.281542

0.281542

0.281541

0.281541

0.281540
0.281540

0.281539

0.281538

0.281538

0.281538

0.281537

0.281536

0.281535

0.281535

0.281534

.281534

281532

0.281531

0.281531

1.193874

1.193900

1.193953

10193979

1.194031

1. 194084

1.194110

1.194136

1.194189

1.194215

1. 194268

1. 194294

1. 194320

1.194373

1.194399

1.194425

1.194452

1. 194504

1.194531

. 194583

1.194609

1.194662

1.194688

10194714

.194767

$1 \cdot 194793$

1.194846

1.194872

1.194925

1.194951

1.195003

1.195030

1. 195082

1.195108

1.195161

$1.195: 87$

1.195240

1.195266

1.195319

1.195371

1.195397
1.195424

- 195450 -195476 1.195503 1. 195555 1.195581 1. 195634

1.195660

1.195713 10195739 1.195792

1.195818

1.195844

1.195897

1.195923

1.195975

.196002

1.196028

1.196081

1. 196133

1.196159

1.196186

$1 \cdot 196238$

- 196264

1.196291

1.106343

1. 196370

1.196396

1. 196448

1. 196475

$\begin{array}{lllllllllll} & .001 & .002 & .003 & .004 & .005 & .006 & .007 & .008 & .009 & .010 \\ .055 & .006 & .011 & : 017 & .022 & .028 & .033 & .039 & .045 & : 050 & .056\end{array}$ 
0.281530

0.281529

0.281529

0.281528

0.281527

0.281527

0.281526

0.28152

0.28152

(

0.0281523

0.281523

0.281522

0.281522

0.281521

0.0281520

0.281519

0.281519

0.281518

0.281518

0.281517

0.281516

0.281516

0.281516

0.281515

0.281514

0.281514

0.281513

0.281513

0.281512

0.281512

0.281511

0.281511

0.001510

0.281510

0.281508
0.281508

0.281508

0.281507

0.281507

0.281506

0.281505

0.281505

0.281504

0.281504

0.281503

0.281503

0.281502

0.281501

0.281501

0.281501

0.281500

0.281499

0.281499

0.281498

0.281498

0.281497

0.281496

0.281495

0.281495

0.281494

0.281494

0.281493

0.281493

0.281492

0.281492
0.281491

0.281491

0.281490

0.281490

0.281489

0.281489

0.281488

0.281487

0.281487

0.281486
0.281486

10196501

1.196527

1.196580

1.196606

1.196632

1. 196685

1.196711
1.196737

1.196764

1.196790

1.196842 
3467.573 $67.573 \quad 67.518$ $\begin{array}{llll}67.022 & 66.967 & 66.912 & 66.857\end{array}$ $\begin{array}{llll}65.921 & 65.417 & 66.361 & 66.306 \\ 65 & 65.811 & 65.756\end{array}$ $\begin{array}{llll}65.370 & 65.315 & 65.260 & 65.205\end{array}$ $64.819 \quad 64.764 \quad 64.70964 .654$ $64.268 \quad 64 \cdot 213 \quad 64 \cdot 158 \quad 64 \cdot 103$ $\begin{array}{llll}63.718 & 63.663 & 63.608 & 63.553 \\ 63.167 & 63.112 & 63.057 & 63.002\end{array}$ 63.167
$62.617 \quad 62.112$ $\begin{array}{ll}63.057 & 63.002 \\ 62.507 & 62.451\end{array}$

234 $\begin{array}{llll}62.066 & 62.011 & 61.956 & 61.901 \\ 61.515 & 61.460 & 61.405 & 61.350 \\ 60.965 & 60.910 & 60.855 & 60.800\end{array}$

1.2

$1 \cdot 3$

1.5

1.6
1.7
1.8 $\begin{array}{llll}60.414 & 60.359 & 60.304 & 60.249 \\ 59.864 & 59.809 & 59.754 & 59.699\end{array}$ $\begin{array}{llll}59.313 & 59.258 & 59.203 & 59.148\end{array}$ $\begin{array}{lllll}58.763 & 58.708 & 58.653 & 58.598\end{array}$

1.9

$\begin{array}{llll}58.212 & 58.157 & 58.102 & 58.047 \\ 57.662 & 57.607 & 57.552 & 57.497 \\ 57.111 & 57.056 & 57.001 & 56.946\end{array}$

23456 $\begin{array}{rlll}546.561 & 56.506 & 56.451 & 56.396 \\ 56.011 & 55.956 & 55.900 & 55.845 \\ 55.460 & 55.406 & 55.350 & 55.295 \\ 54.910 & 54.855 & 54.800 & 54.745\end{array}$ $\begin{array}{llll}54.910 & 54.855 & 54.800 & 54.745\end{array}$ $\begin{array}{llll}54.360 & 54.305 & 54.250 & 54.195\end{array}$ $\begin{array}{llll}53.810 & 53.754 & 53.700 & 53.645\end{array}$ $\begin{array}{llll}52.709 & 52.654 & 52.599 & 52.544\end{array}$ $\begin{array}{llll}52.159 & 52.104 & 52.049 & 51.994 \\ 51.609 & 51.554 & 51.499 & 51.444\end{array}$

0.281473

0.281472

0.281472
0.281472
0.281471

0.281471

0.281470

0.281470

0.281469

0.281469
0.281468

0.281468

0.281468

0.281467

0.281466

0.281465

0.281465

0.281465

0.281464

0.281464

0.281463

0.281462

0.281461

0.28146

0.281460
0.28150

0.281460

0.281459

0.281459
0.281458
0.028445

0.281458

0.281458

0.281457

0.281456

0.281456
0.281455

0.281455

0.281455

0.281454

0.281454
0.281453
0.02834

0.281453

0.281452

0.281452

0.281451
0.281451

0.281451

0.281450

0.281450
0.281449

0.281449

0.281448

0.281448

0.281448

0.281447
0.281447

1.199129

10199181

$1: 199207$

1.199260

.199286

1.199339
1.199365

10199391

10.199444

1.199470

1.199523

1.199559

1.199602

1.199628

1. 199654

1.199707

.199733

1.199786

1.199812

10199864

10199917

1.199970

1.199996

1.200048

1.200075

1.200127

1.200180

1.200206

1.200259

1.200285

1.200311

1.200364

1.200390
1.200416

1.200443

1.200469

1.200521

1.200548

1.200600

1.200653

1.200705

1.200732

.200784

1.200811

1.200863

1.200889

1.200942

0.281446

0.281446

0.281445

0.281444

0.281444

0.281443

0.281443
0.281442

1.200968

$1 \cdot 200995$
1.201021

I. 201047

1.201073

1.201126

1.201152

1. 201231

1.201257

1.201310

1.201336

1..201389

1.201415

1.201468

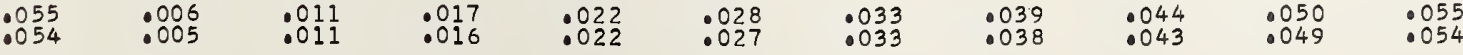

1.201494

1.201546

1.201573

.0201599

1.201652

1.201704
1.0201730

.010

1.201730 


.04
$\begin{array}{llll}401.654 & 01.600 & 01.545 & 01.490 \\ 01.107 & 01.052 & 00.997 & 00.942\end{array}$ $00.559 \quad 00.504 \quad 00.4$ 


\begin{tabular}{|c|c|c|c|c|c|c|c|c|c|c|c|c|}
\hline A) & .00 & .01 & .02 & .03 & .04 & .05 & .06 & .07 & .08 & .09 & 1000 & $n-1)$ \\
\hline $\begin{array}{l}80.0 \\
0.1 \\
0.2 \\
0.3 \\
0.4 \\
0.5 \\
0.5 \\
0.7 \\
0.8 \\
0.9\end{array}$ & $\begin{array}{l}357.914 \\
57.368 \\
56.822 \\
56.277 \\
55.731 \\
55.185 \\
54.640 \\
54.094 \\
53.549 \\
53.003\end{array}$ & $\begin{array}{l}57.859 \\
57.313 \\
56.768 \\
56.222 \\
55.676 \\
55.131 \\
54.585 \\
54.040 \\
53.494 \\
52.948\end{array}$ & $\begin{array}{l}57.805 \\
57.259 \\
56.713 \\
56.167 \\
55.622 \\
55.076 \\
54.530 \\
53.085 \\
53.439 \\
52.894\end{array}$ & $\begin{array}{l}57.750 \\
57.204 \\
56.658 \\
56.113 \\
55.567 \\
55.022 \\
54.476 \\
53.930 \\
53.385 \\
52.839\end{array}$ & $\begin{array}{l}57.695 \\
57.150 \\
56.604 \\
56.059 \\
55.512 \\
54.967 \\
54.421 \\
53.876 \\
53.330 \\
52.785\end{array}$ & $\begin{array}{l}57.641 \\
57.095 \\
56.549 \\
56.004 \\
55.458 \\
54.913 \\
54.367 \\
53.821 \\
53.276 \\
52.730\end{array}$ & $\begin{array}{l}57.586 \\
57.041 \\
56.495 \\
55.949 \\
55.404 \\
54.858 \\
54.312 \\
53.767 \\
53.221 \\
52.676\end{array}$ & $\begin{array}{l}57.531 . \\
56.986 \\
56.440 \\
55.894 \\
55.349 \\
54.803 \\
54.258 \\
53.712 \\
53.167 \\
52.621\end{array}$ & $\begin{array}{l}57.477 \\
56.931 \\
56.386 \\
55.840 \\
55.294 \\
54.749 \\
54.203 \\
53.658 \\
53.112 \\
52.567\end{array}$ & $\begin{array}{l}57.423 \\
56.877 \\
56.331 \\
55.785 \\
55.240 \\
54.694 \\
54.148 \\
53.603 \\
53.057 \\
52.512\end{array}$ & $\begin{array}{l}0.281398 \\
0.281398 \\
0.281398 \\
0.281397 \\
0.281397 \\
0.281396 \\
0.281396 \\
0.281395 \\
0.281395 \\
0.281395\end{array}$ & $\begin{array}{l}1.204383 \\
1.204412 \\
1.204438 \\
1.204464 \\
1.204491 \\
1.204517 \\
1.204543 \\
1.204570 \\
1.204596 \\
1.204622\end{array}$ \\
\hline $\begin{array}{l}281.0 \\
1.1 \\
1.2 \\
1.3 \\
1.4 \\
1.5 \\
1.6 \\
1.7 \\
1.8 \\
1.9\end{array}$ & $\begin{array}{l}352.458 \\
51.912 \\
51.367 \\
50.821 \\
50.276 \\
49.730 \\
49.186 \\
48.640 \\
48.095 \\
47.549\end{array}$ & $\begin{array}{l}52.403 \\
51.857 \\
51.312 \\
50.767 \\
50.222 \\
49.676 \\
49.131 \\
48.585 \\
48.040 \\
47.495\end{array}$ & $\begin{array}{l}52.348 \\
51.803 \\
51.258 \\
50.712 \\
50.167 \\
49.622 \\
49.076 \\
48.531 \\
47.986 \\
47.440\end{array}$ & $\begin{array}{l}52.294 \\
51.748 \\
51.203 \\
50.658 \\
50.113 \\
49.567 \\
49.022 \\
48.476 \\
47.931 \\
47.386\end{array}$ & $\begin{array}{l}52.239 \\
51.694 \\
51.149 \\
50.604 \\
50.058 \\
49.512 \\
48.967 \\
48.422 \\
47.877 \\
47.331\end{array}$ & $\begin{array}{l}52.185 \\
51.639 \\
51.094 \\
50.549 \\
50.003 \\
49.458 \\
48.913 \\
48.367 \\
47.822 \\
47.277\end{array}$ & $\begin{array}{l}52.130 \\
51.585 \\
51.039 \\
50.494 \\
49.949 \\
49.403 \\
48.858 \\
48.313 \\
47.768 \\
47.222\end{array}$ & $\begin{array}{l}52.075 \\
51.531 \\
50.985 \\
50.440 \\
49.894 \\
49.349 \\
48.804 \\
48.259 \\
47.713 \\
47.168\end{array}$ & $\begin{array}{l}52.021 \\
51.476 \\
50.931 \\
50.0385 \\
49.840 \\
49.295 \\
48.749 \\
48.204 \\
47.658 \\
47.113\end{array}$ & $\begin{array}{l}51.967 \\
51.421 \\
50.876 \\
50.331 \\
49.785 \\
49.240 \\
48.694 \\
48.149 \\
47.604 \\
47.059\end{array}$ & $\begin{array}{l}0.281394 \\
0.281394 \\
0.281393 \\
0.281393 \\
0.281392 \\
0.281392 \\
0.281392 \\
0.281391 \\
0.281391 \\
0.281390\end{array}$ & $\begin{array}{l}1.204648 \\
1.204675 \\
1.204701 \\
1.204727 \\
1.204754 \\
1.204780 \\
1.204806 \\
1.204832 \\
1.204859 \\
1.204885\end{array}$ \\
\hline $\begin{array}{r}82.0 \\
2.1 \\
2.2 \\
2.3 \\
2.4 \\
2.5 \\
2.6 \\
2.7 \\
2.8 \\
2.9\end{array}$ & $\begin{array}{r}3347.004 \\
46.459 \\
45.914 \\
45.369 \\
44.823 \\
44.278 \\
43.733 \\
43.188 \\
42.643 \\
42.098\end{array}$ & $\begin{array}{l}46.949 \\
46.405 \\
45.859 \\
45.314 \\
44.769 \\
44.224 \\
43.679 \\
43.134 \\
42.588 \\
42.044\end{array}$ & $\begin{array}{l}46.895 \\
46.350 \\
45.805 \\
45.260 \\
44.714 \\
44.170 \\
43.624 \\
43.079 \\
42.534 \\
41.989\end{array}$ & $\begin{array}{l}46.841 \\
46.295 \\
45.750 \\
45.205 \\
44.660 \\
44.115 \\
43.570 \\
43.025 \\
42.480 \\
41.935\end{array}$ & $\begin{array}{l}46.786 \\
46.241 \\
45.696 \\
45.150 \\
44.605 \\
44.061 \\
43.515 \\
42.970 \\
42.425 \\
41.880\end{array}$ & $\begin{array}{l}46.732 \\
46.186 \\
45.641 \\
45.096 \\
44.551 \\
44.006 \\
43.461 \\
42.916 \\
42.371 \\
41.826\end{array}$ & $\begin{array}{l}46.677 \\
46.132 \\
45.587 \\
45.042 \\
44.497 \\
43.951 \\
43.406 \\
42.861 \\
42.316 \\
41.771\end{array}$ & $\begin{array}{l}46.623 \\
46.077 \\
45.532 \\
440987 \\
44.442 \\
43.896 \\
43.352 \\
42.807 \\
42.261 \\
41.717\end{array}$ & $\begin{array}{l}46.568 \\
46.023 \\
45.478 \\
44.932 \\
44.387 \\
43.842 \\
43.297 \\
42.752 \\
42.207 \\
41.662\end{array}$ & $\begin{array}{l}46.514 \\
45.968 \\
45.423 \\
44.878 \\
44.333 \\
43.788 \\
43.243 \\
42.698 \\
42.153 \\
41.607\end{array}$ & $\begin{array}{l}0.281390 \\
0.281389 \\
0.281389 \\
0.281389 \\
0.281388 \\
0.281388 \\
0.281387 \\
0.281387 \\
0.281386 \\
0.281386\end{array}$ & $\begin{array}{l}1.204911 \\
1.204938 \\
1.204964 \\
1.204990 \\
1.205016 \\
1.205043 \\
1.205069 \\
1.205095 \\
1.205122 \\
1.205148\end{array}$ \\
\hline $\begin{array}{r}83.0 \\
3.1 \\
3.2 \\
3.3 \\
3.4 \\
3.5 \\
3.6 \\
3.7 \\
3.8 \\
3.9\end{array}$ & $\begin{array}{r}341.553 \\
41.008 \\
40.463 \\
39.918 \\
39.374 \\
38.828 \\
38.284 \\
37.739 \\
37.194 \\
36.649\end{array}$ & $\begin{array}{l}41.498 \\
40.954 \\
40.409 \\
39.864 \\
39.319 \\
38.774 \\
38.229 \\
37.685 \\
37.140 \\
36.595\end{array}$ & $\begin{array}{l}41.444 \\
40.899 \\
40.354 \\
39.809 \\
39.264 \\
38.720 \\
38.175 \\
37.630 \\
37.085 \\
36.540\end{array}$ & $\begin{array}{l}41.390 \\
40.845 \\
40.300 \\
39.755 \\
39.210 \\
38.665 \\
38.120 \\
37.575 \\
37.031 \\
36.486\end{array}$ & $\begin{array}{l}41.335 \\
40.790 \\
40.245 \\
39.700 \\
39.155 \\
38.611 \\
38.065 \\
37.521 \\
36.976 \\
36.431\end{array}$ & $\begin{array}{l}41.281 \\
40.736 \\
40.191 \\
39.646 \\
39.101 \\
38.556 \\
38.011 \\
37.466 \\
36.922 \\
36.377\end{array}$ & $\begin{array}{l}41.226 \\
40.681 \\
40.136 \\
39.592 \\
39.047 \\
38.502 \\
37.957 \\
37.412 \\
36.867 \\
36.323\end{array}$ & $\begin{array}{l}41.171 \\
40.627 \\
40.082 \\
39.537 \\
38.992 \\
38.447 \\
37.902 \\
37.358 \\
36.812 \\
36.268\end{array}$ & $\begin{array}{l}41.117 \\
40.572 \\
40.027 \\
39.482 \\
38.937 \\
38.393 \\
37.848 \\
37.303 \\
36.758 \\
36.214\end{array}$ & $\begin{array}{l}41.063 \\
40.518 \\
39.973 \\
39.428 \\
38.883 \\
38.338 \\
37.793 \\
37.249 \\
36.704 \\
36.159\end{array}$ & $\begin{array}{l}0.281386 \\
0.281385 \\
0.281385 \\
0.281384 \\
0.281384 \\
0.281383 \\
0.281383 \\
0.281383 \\
0.2813882 \\
0.281382\end{array}$ & $\begin{array}{l}1.205274 \\
1.205200 \\
1.205227 \\
1.205253 \\
1.205279 \\
1.205306 \\
1.205332 \\
1.205358 \\
1.205385 \\
1.205411\end{array}$ \\
\hline $\begin{array}{r}84.0 \\
4.1 \\
4.2 \\
4.3 \\
4.4 \\
405 \\
4 \cdot 6 \\
407 \\
4.8 \\
409\end{array}$ & $\begin{array}{l}336.104 \\
35.560 \\
35.015 \\
34.470 \\
33.926 \\
33.381 \\
32.837 \\
32.292 \\
31.748 \\
31.204\end{array}$ & $\begin{array}{l}36.050 \\
35.505 \\
34.961 \\
34.416 \\
33.872 \\
33.326 \\
32.782 \\
32.238 \\
31.693 \\
31.149\end{array}$ & $\begin{array}{l}35.996 \\
35.451 \\
34.906 \\
34.361 \\
33.817 \\
33.272 \\
32.728 \\
32.184 \\
31.639 \\
31.095\end{array}$ & $\begin{array}{l}35.941 \\
35.396 \\
34.852 \\
34.307 \\
33.762 \\
33.218 \\
32.674 \\
32.129 \\
31.585 \\
31.040\end{array}$ & $\begin{array}{l}35.887 \\
35.342 \\
34.797 \\
34.253 \\
33.708 \\
33.163 \\
32.619 \\
32.074 \\
31.530 \\
30.986\end{array}$ & $\begin{array}{l}35.832 \\
35.288 \\
34.743 \\
34.198 \\
33.654 \\
33.109 \\
32.565 \\
32.020 \\
31.476 \\
30.931\end{array}$ & $\begin{array}{l}35.778 \\
35.233 \\
34.688 \\
34.144 \\
33.599 \\
33.054 \\
32.510 \\
31.966 \\
31.421 \\
30.877\end{array}$ & $\begin{array}{l}35 \cdot 723 \\
35.178 \\
34.634 \\
34.089 \\
33.545 \\
33.000 \\
32.456 \\
31.911 \\
31.367 \\
30.822\end{array}$ & $\begin{array}{l}5.669 \\
5.124 \\
4.580 \\
4.035 \\
3.490 \\
2.946 \\
2.401 \\
1.857 \\
1.312 \\
0.768\end{array}$ & $\begin{array}{l}33.436 \\
32.891 \\
32.347 \\
31.802 \\
31.258 \\
30.713\end{array}$ & $\begin{array}{l}0.281381 \\
0.281381 \\
0.281380 \\
0.281380 \\
0.281379 \\
0.281379 \\
0.281379 \\
0.281378 \\
0.281378 \\
0.281377\end{array}$ & $\begin{array}{l}1.205437 \\
1.205463 \\
1.205490 \\
1.205516 \\
1.205542 \\
1.205569 \\
1.205595 \\
1.205621 \\
1.205647 \\
1.205674\end{array}$ \\
\hline $\begin{array}{r}285.0 \\
5.1 \\
5.2 \\
5.3 \\
5.4 \\
5.5 \\
5.6 \\
5.7 \\
5.8 \\
5.9\end{array}$ & $\begin{array}{l}330.659 \\
30.115 \\
29.570 \\
29.026 \\
28.481 \\
27.937 \\
27.392 \\
26.848 \\
26.304 \\
25.760\end{array}$ & $\begin{array}{l}30.604 \\
30.060 \\
29.516 \\
28.971 \\
28.427 \\
27.882 \\
27.338 \\
26.794 \\
26.250 \\
25.705\end{array}$ & $\begin{array}{l}30.550 \\
30.006 \\
29.461 \\
28.917 \\
28.372 \\
27.828 \\
27.283 \\
26.740 \\
26.195 \\
25.651\end{array}$ & & $\begin{array}{l}30.441 \\
29.897 \\
29.352 \\
28.808 \\
28.263 \\
27.719 \\
27.175 \\
26.631 \\
26.086 \\
25.542\end{array}$ & $\begin{array}{l}30.387 \\
29.843 \\
29.298 \\
28.754 \\
28.209 \\
27.665 \\
27.120 \\
26.576 \\
26.032 \\
25.488\end{array}$ & $\begin{array}{l}30.332 \\
29.788 \\
29.243 \\
28.699 \\
28.155 \\
27.610 \\
27.066 \\
26.522 \\
25.977 \\
25.433\end{array}$ & $\begin{array}{l}30 \cdot 278 \\
29.733 \\
29.189 \\
28.645 \\
28.100 \\
27.556 \\
27.011 \\
26.468 \\
25.923 \\
25.379\end{array}$ & & & & $\begin{array}{l}1.205700 \\
1.205726 \\
1.205753 \\
1.205779 \\
1.205805 \\
1.205831 \\
1.205858 \\
1.205884 \\
1.205910 \\
1.205937\end{array}$ \\
\hline $\begin{array}{l}286.0 \\
6.1 \\
6.2 \\
6.3 \\
6.4 \\
6.5 \\
6.6 \\
6.7 \\
6.8 \\
6.9\end{array}$ & $\begin{array}{l}325.216 \\
24.671 \\
24.127 \\
23.583 \\
23.039 \\
22.494 \\
21.951 \\
21.406 \\
20.863 \\
20.319\end{array}$ & $\begin{array}{l}25 \cdot 161 \\
24.617 \\
24.073 \\
23.528 \\
22.985 \\
22.440 \\
21.896 \\
21.352 \\
20.808 \\
20.264\end{array}$ & $\begin{array}{l}21.842 \\
21.298 \\
20.754 \\
20.210\end{array}$ & $\begin{array}{l}5.052 \\
4.508 \\
3.964 \\
3.420 \\
2.876 \\
2.332 \\
1.787 \\
1.243 \\
0.699 \\
0.155\end{array}$ & $\begin{array}{l}23.910 \\
23.365 \\
22.821 \\
22.277 \\
21.733 \\
21.189 \\
20.645 \\
20.101\end{array}$ & $\begin{array}{l}24.943 \\
24.399 \\
23.855 \\
23.311 \\
22.767 \\
22.223 \\
21.679 \\
21.135 \\
20.591 \\
20.046\end{array}$ & $\begin{array}{l}24.889 \\
24.345 \\
23.800 \\
23.256 \\
22.713 \\
22.168 \\
21.624 \\
21.080 \\
20.536 \\
19.992\end{array}$ & & & & $\begin{array}{l}0.081369 \\
0.281369\end{array}$ & $\begin{array}{l}1.205963 \\
1.205989 \\
1.206016 \\
1.206042 \\
1.206068 \\
1.206094 \\
1.206121 \\
1.206147 \\
1.206173 \\
1.206200\end{array}$ \\
\hline $\begin{array}{r}287.0 \\
7: 1 \\
7.2 \\
7: 3 \\
7: 4 \\
7.5 \\
7.6 \\
7: 7 \\
7: 8 \\
7.9\end{array}$ & $\begin{array}{r}319.774 \\
19.231 \\
18.687 \\
18.143 \\
17.599 \\
17.055 \\
16.511 \\
15.967 \\
15.424 \\
14.880\end{array}$ & $\begin{array}{l}19.720 \\
19.176 \\
18.632 \\
18.088 \\
17.544 \\
17.001 \\
16.457 \\
15.913 \\
15.369 \\
14.826\end{array}$ & $\begin{array}{l}19.666 \\
19.122 \\
18.578 \\
18.034 \\
17.490 \\
16.947 \\
16.402 \\
15.859 \\
15.315 \\
14.771\end{array}$ & & $\begin{array}{l}19.013 \\
18.469 \\
17.925 \\
17.381 \\
16.838 \\
16.293 \\
15.750 \\
15.206 \\
14.662\end{array}$ & & & & & & & $\begin{array}{l}1.206226 \\
1.206252 \\
1.206278 \\
1.206305 \\
1.206331 \\
1.206357 \\
1.206384 \\
1.206410 \\
1.206436 \\
1.206463\end{array}$ \\
\hline $\begin{array}{r}88.0 \\
8.1 \\
8.2 \\
8.3 \\
8.4 \\
8.5 \\
8.6 \\
8.7 \\
8.8 \\
8.9\end{array}$ & $\begin{array}{r}3314.336 \\
13.793 \\
13.249 \\
12.706 \\
12.162 \\
11.618 \\
11.075 \\
10.531 \\
09.988 \\
09.444\end{array}$ & $\begin{array}{l}12.108 \\
11.564 \\
11.021 \\
10.477 \\
09.933 \\
09.390\end{array}$ & $\begin{array}{l}12.053 \\
11.510 \\
10.966 \\
10.423 \\
09.879 \\
09.335\end{array}$ & & & & & & & & & $\begin{array}{l}1.206489 \\
1.206515 \\
1.206541 \\
1.206568 \\
1.206594 \\
1.206620 \\
1.206647 \\
1.206573 \\
1.206699 \\
1.206725\end{array}$ \\
\hline $\begin{array}{r}289.0 \\
9.1 \\
9.2 \\
9.3 \\
9.4 \\
9.5 \\
9.6 \\
9.7 \\
9.8 \\
9.9\end{array}$ & $\begin{array}{l}08.357 \\
07.814 \\
07.270 \\
06.727 \\
06.184 \\
05.640 \\
05.097 \\
04.554 \\
04.011\end{array}$ & $\begin{array}{l}05.586 \\
05.043 \\
04.500 \\
03.957\end{array}$ & $\begin{array}{l}04.445 \\
03.902\end{array}$ & $\begin{array}{l}07.107 \\
06.564 \\
06.021 \\
05.477 \\
04.934 \\
04.391 \\
03.848\end{array}$ & $\begin{array}{l}05.423 \\
04.880 \\
04.337 \\
03.793\end{array}$ & $\begin{array}{l}05.369 \\
04.825 \\
04.282 \\
03.739\end{array}$ & $\begin{array}{l}08.031 \\
07.0488 \\
06.944 \\
06.401 \\
05.858 \\
05.314 \\
04.777 \\
04.228 \\
03.685\end{array}$ & $\begin{array}{l}05.803 \\
05.260 \\
04.717 \\
04.174 \\
03.630\end{array}$ & $\begin{array}{l}07.922 \\
07.379 \\
06.836 \\
06.292 \\
05.749 \\
05.206 \\
04.663 \\
04 \cdot 119 \\
03.576\end{array}$ & $\begin{array}{l}06.238 \\
05.695 \\
05.151 \\
04.608 \\
04.065 \\
03.521\end{array}$ & $\begin{array}{l}0.281360 \\
0.281359 \\
0.281359 \\
0.281358 \\
0.281358 \\
0.281358 \\
0.281357 \\
0.281357 \\
0.281356 \\
0.281356\end{array}$ & $\begin{array}{l}1.20652 \\
1.206778 \\
1.206804 \\
1.206831 \\
1.206857 \\
1.206883 \\
1.206910 \\
1.206936 \\
1.206962 \\
1.206988\end{array}$ \\
\hline
\end{tabular}

.010

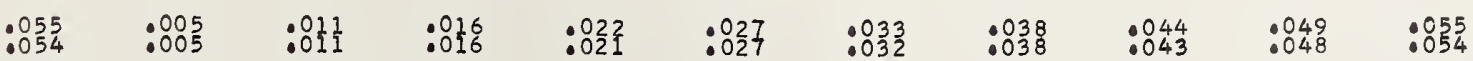


$\begin{array}{llllllllllll}4290.0 & 23303.467 & 03.413 & 03.359 & 03.304 & 03.250 & 03.196 & 03.141 & 03.087 & 03.033 & 02.979\end{array}$ $\begin{array}{lllllllllll}0.1 & 02.924 & 02.870 & 02.816 & 02.761 & 02.707 & 02.653 & 02.598 & 02.544 & 02.490 & 02.435 \\ 0.2 & 02.381 & 02.327 & 02.272 & 02.218 & 02.164 & 02.109 & 02.055 & 02.001 & 01.947 & 01.892\end{array}$ $\begin{array}{lllllllllll}0.3 & 01.838 & 01.783 & 01.729 & 01.675 & 01.621 & 01.566 & 01.512 & 01.458 & 01.403 & 01.349\end{array}$ $\begin{array}{lllllllllll}0.4 & 01.295 & 01.240 & 01.186 & 01.132 & 01.077 & 01.023 & 00.969 & 00.915 & 00.860 & 00.806\end{array}$ $00.752 \quad 00.697 \quad 00.643 \quad 00.589 \quad 00.53500 .480 \quad 00.426 \quad 00.372 \quad 00.318 \quad 00.263$ $00.20800 .154 \quad 00.100 \quad 00.045 * 99.991 * 99.937 * 99.883 * 99.828 * 99.774 * 99.720$

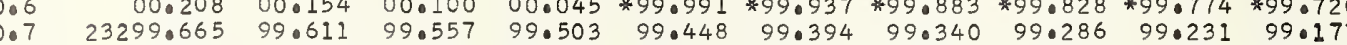
$\begin{array}{lrlllllllll}0.8 & 23.123 & 99.068 & 99.014 & 98.960 & 98.905 & 98.394 & 99.340 & 99.286 & 99.231 & 99.177\end{array}$ $\begin{array}{llllllllll}99.123 & 99.068 & 99.014 & 98.960 & 98.905 & 98.851 & 98.797 & 98.742 & 98.688 & 98.634 \\ 98.580 & 98.525 & 98.471 & 98.417 & 98.362 & 98.308 & 98.254 & 98.200 & 98.145 & 98.091\end{array}$

$\begin{array}{lll}97.656 & 97.602 & 97.548 \\ 97.114 & 97.059 & 97.005\end{array}$ 95.268

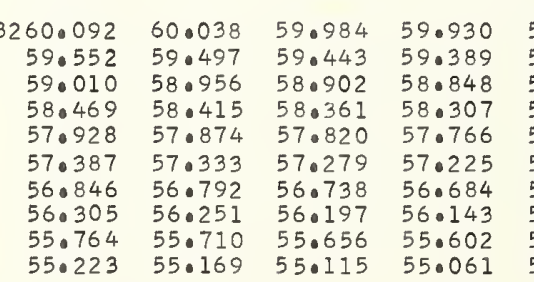

1.207541

1.207567
1.207593

1.207620

1.207646
1.207672 
23238.466$$
\begin{aligned}
& 338 \\
& 37 \\
& 37 \\
& 36 \\
& 36 \\
& 35 \\
& 35 \\
& 34 \\
& 34 \\
& 33 \\
& 34
\end{aligned}
$$

0.281291

0.28291

0.281290

0.281290

0.281289

0.281288

0.281288

1.210118

1.210170

1.210223

1.210276

1.210328

1. 210355

1.210433

1.210460

1.210512

1.210565

1.210591
1.210618

1.210644

1.210697

I. 210749

1.210775

1.210828

1.210881

1.210907
1.210933

0.281287

0.281287

0.281286

0.281285

0.281285

0.281284

0.281284

0.281283

0.281283

0.281282

0.281281

0.281280

0.281280

0.281280

1.210960

1012

1.211065

1.211091

1.21170

0.281279

0.281278

0.281278

0.281277

0.281277

0.281276

0.281275

1.211223

1.211275

1.211301

. 211380

1. 211407

1.211433

0.281274

0.281274

0.281274

0.281273

0.281272

0.281272

0.281271

1.0211486

1.211558

1.211591

1.211617

1.0211643

1.211696

.010

1.211749

1.211775

1. 211828

1. 211880

1.211933
1.211595
1.211985

1.212012

1.212064

1.212091

1.212143
1.212169

.212196

1.212248

$: 054$ 
$\begin{array}{lllllllllll}4310.0 & 23195.333 & 95.279 & 95.225 & 95.171 & 95.117 & 95.063 & 95.010 & 94.956 & 94 \cdot 902 & 94 \cdot 848\end{array}$

$\begin{array}{lllllllllll}0.2 & 94.795 & 94.741 & 94.687 & 94.633 & 94.579 & 94.526 & 94.472 & 94.418 & 94.364 & 94.310 \\ 0.2 & 94.256 & 94.203 & 94.149 & 94.095 & 94.041 & 93.987 & 93.933 & 93.880 & 93.826 & 93.772\end{array}$

$\begin{array}{lllllllllll}0.3 & 93.718 & 93.665 & 93.611 & 93.557 & 93.503 & 93.449 & 93.396 & 93.342 & 93.288 & 93.234\end{array}$

$\begin{array}{lllllllllll}0.4 & 93.180 & 93.126 & 93.073 & 93.019 & 92.965 & 92.911 & 92.857 & 92.803 & 92.750 & 92.696\end{array}$

$\begin{array}{lllllllllll}0.6 & 92.104 & 92.051 & 91.996 & 91.942 & 91.889 & 91.835 & 91.781 & 91.727 & 91.674 & 91.620\end{array}$

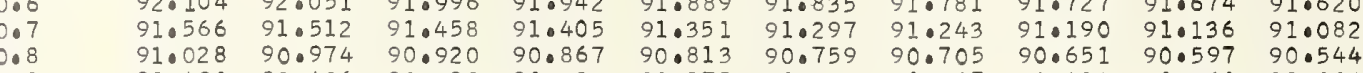

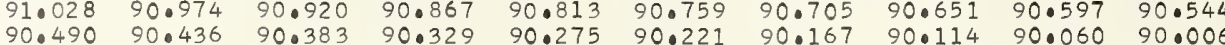

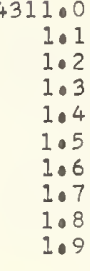

4312.0

2.0

$2 \cdot 3$

2.5
2.6

2.8

4313.

3.0
3.
3.
3.
3.
3.
3.
3.
3.

43140

$4 \cdot 1$
$4 \cdot 2$
4.3

$4 \cdot 3$
$4 \cdot 4$
$4 \cdot 5$

4.5
4.6
4.7

4.8

4315.

5.1
5.2

5. 3

5.5

5.7

5.9

4316.0

6.1

$6 \cdot 2$

6.4

6.5

6.7
6.8
6.9

4317.0

7.7 .12

.

7. 6

7.8
7.9

4318

8.

8.

8.4
8.5

8.6
8.7

8.8
8.9

4319.

9.1

9.3
9.4

9.4
9.5
9.6

9.7
9.8
9.9

$\begin{array}{rllll}23189.952 & 89.898 & 89.845 & 89.791 & 8 \\ 89.414 & 89.360 & 89.307 & 89.253 & 8\end{array}$

$\begin{array}{llll}89.414 & 89.360 & 89.307 & 89.253 \\ 88.876 & 88.823 & 88.769 & 88.715\end{array}$

$\begin{array}{llll}88.338 & 88.285 & 88.231 & 88.177\end{array}$

$87.801 \quad 87.747 \quad 87.693 \quad 87.639$

$\begin{array}{llll}86.725 & 86.671 & 86.617 & 86.564\end{array}$

$\begin{array}{llll}86.187 & 86.134 & 86.080 & 86.026 \\ 85.650 & 85.596 & 85.542 & 85.48\end{array}$

85.112

23184.574

84.03
83.499
82.961

$82.061-83.4457$

$82.424 \quad 82 \cdot 370$

81034

$80.349-81.295$

$80.274 \quad 80.220$

23179.199

78.662
78.124
77.5

$77.050-76.533$

76.512

$75.975 \quad 75.921$

$\begin{array}{ll}75.437 & 75.384 \\ 74.900 & 74.847 \\ 74.363 & 74.309\end{array}$

23173.826

73.28
72.75

73.772
73.235

72.215
71.677 71.161

$\begin{array}{llll}71.677 & 71.624 & 71.570 & 71.5 \\ 71.140 & 71.087 & 71.033 & 70.979\end{array}$

$\begin{array}{llll}71.603 & 70.550 & 70.496 & 70.442 \\ 70.066 & 70.013 & 69.959 & 69.906\end{array}$

$69.529 \quad 69.476$

$68.993 \quad 68.939$

69.959
69.422
68.885

69.906
69.368

23168.455

$67 \cdot 919$

$67.381 \quad 67.328$

66.308

65.771

65.235

64.161

23163.087

62.55163 .034

$62.551 \quad 62.497 \quad 62.44$

62.014

60.94160 .888

60.834

$\begin{array}{lll}59.868 & 59.814 & 59.7 \\ 59.332 & 59.278 & 59.22\end{array}$

$\begin{array}{ll}59.332 & 59.278 \\ 58.795 & 58.741\end{array}$

58.25

$23157.722 \quad 57.668$

$\begin{array}{lll}57.186 & 57.668 & 57.6\end{array}$

56.64

$\begin{array}{ll}56.113 & 56.0 \\ 55.577 & 55.5\end{array}$

$55.040 \quad 54.987$

$54.504 \quad 54.450 \quad 54.3$

53.91453 .86154 .34

$\begin{array}{ll}53.432 & 53.37 \\ 52.896 & 52.84\end{array}$

$51.823 \quad 51.769$

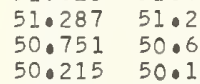

$\begin{array}{ll}50.215 & 50.11 \\ 49.678 & 49.6 \\ 40.143 & 49.089\end{array}$

49.143
48.606
48.05

$\begin{array}{ll}48 \cdot 071 & 48 \cdot 017 \\ 47.534 & 47.481\end{array}$

3146.099

46.99946 .945

$46.463 \quad 46.409$

$\begin{array}{llll}45.927 & 45.873 & 45.355 & 46.302\end{array}$

$\begin{array}{llll}45.391 & 45.337 & 45.284 & 45.230 \\ 44.855 & 44.802 & 44.748 & 44.6\end{array}$

$\begin{array}{llll}44.855 & 44.802 & 44.748 & 44.694 \\ 44.319 & 44.266 & 44.212 & 44.159\end{array}$

$43.783 \quad 43.730 \quad 43.676 \quad 43.623$

$\begin{array}{llll}43.248 & 43.195 & 43.141 & 43.087 \\ 42.712 & 42.658 & 42.605 & 42.552\end{array}$

$\begin{array}{llll}42.712 & 42.658 & 42.605 & 42.552 \\ 42.177 & 42.123 & 42.070 & 42.016\end{array}$

89.737
89.199
88.661

$88.124 \quad 88.070$

$87.048 \quad 86.994$

$86.510 \quad 86.456 \quad 86.940$

85.972

85.918

85.865

85.327

84.896

84.843

84.78

84.251

83.714
83.176
82.639

82.639

$82.208 \quad 82.155$

1.13481 .080

$\begin{array}{ll}80.596 & 80.54 \\ 0.059 & 80.005\end{array}$

81.02

79.951
79.414

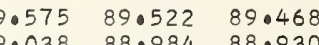

$88.500 \quad 88.446 \quad 88.392$

$\begin{array}{lll}87.962 & 87.908 & 87.854\end{array}$

$\begin{array}{lll}87.062 & 87.908 & 87.854 \\ 86.886 & 86.831 & 87.316\end{array}$

$\begin{array}{lll}86.349 & 86.295 & 86.241\end{array}$

$\begin{array}{lll}85.811 & 85.757 & 85.703\end{array}$

$\begin{array}{lll}85.273 & 85.219 & 85.166 \\ 84.736 & 84.682 & 84.628\end{array}$

$84 \cdot 198 \quad 84 \cdot 144 \quad 84.091$

83.552

$.585 \quad 82.531 \quad 82.477$

81.994
81.940

$80.436 \quad 80.382 \quad 80.328$

9.89

79.844

79.790

$\begin{array}{lllllll}78.984 & 78.930 & 78.876 & 78.823 & 78.769 & 78.715\end{array}$

$\begin{array}{llllll}78.447 & 78.393 & 78.339 & 78.285 & 78.232 & 78.178 \\ 77.909 & 77.855 & 77.802 & 77.748 & 77.694 & 77.641\end{array}$

7.372

7.835
76.297

75.760
5.223
74.686

77.318

77.802
77.264

77.264
76.727

$\begin{array}{ll}76.243 & 76.190 \\ 75.707 & 75.653\end{array}$

77.748
77.211

$\begin{array}{lll}77.217 & 77.157 & 77.103 \\ 76.673 & 76.620 & 76.566\end{array}$

$\begin{array}{llll}76.136 & 76.083 & 76.029\end{array}$

$\begin{array}{lll}75.599 & 75.545 & 75.491\end{array}$

$\begin{array}{lll}75.062 & 75.008 & 74.954\end{array}$

$\begin{array}{lll}74.524 & 74.471 & 74.417 \\ 73.987 & 73.933 & 73.880\end{array}$

.281270

0.281269

0.281269

0.281269

0.281268

0.281267

0.281266

0.281266

0.281266

0.281265

0.281265

0.281264

0.281264

0.281263

0.281263
0.281262

0.281262

0.281261

0.281261

0.281260

0.281260

0.281259

0.281258
0.281258

0.281258

0.281257

0.281257
0.281256

0.281256

0.281255

0.281255

0.281255

0.281254
0.281254

0.281253

0.281253

0.281253

0.281252

0.281251

0.281251

0.281250

0.281250

1.212275

1.212301

1.212354
1.212380

1. 212406

1.212433
1.212459

1.212485

1.212538

1.212564

I. 212590

1.212617

1.212669

1.212696

1.212748

1.212801

$1 \cdot 212827$

1.212853

1. 212880

. 212932

1.212959

1.212985

1.213011
1.213038

1.213064

1.213090

1. 213143

1.213169

1. 213195

1. 2132248

1.213274
1.213301

1.213327

1.213353

1.213380

1. 213432

1. 213459

1. 213485

1.213511

0.281249

0.281249

0.281248

0.281247

0.281247

0.281247

0.281246

0.281246

0.281245

0.281244

0.281244

0.281243
0.281243

0.281243

0.281242

0.281242

0.281241

0.281241

.281240

0.281240

0.281239

0.281239

0.281238

0.281238

0.281237

0.281237

0.281236

0.281235

0.281234

0.281234

0.281234

0.281233 


$.04 \quad .05$

.06

$$
\begin{array}{rrr}
141.641 & 41.587 & 4 \\
41.105 & 41.052 & 40 \\
40.570 & 40.516 & 4 \\
40.034 & 39.980 & 3
\end{array}
$$

$$
\begin{array}{r}
23098 . \\
98 \\
97 .
\end{array}
$$

0.281216

0.281215

0.281214

0.281213

0.281213

0.281212

0.281211

0.281211

0.281210

0.281209

0.281209

0.281208

0.281207

0.281206

0.281206

0.281206

0.281205

0.281204

0.281204
0.281203

0.281203

0.281203

0.281202

0.281201

0.281201

0.281200

0.281200

0.281199

0.281198

0.281198

0.281197
0.281196

0.281196

0.281195
0.281195

0.281195

0.281194

0.281193

0.281193

0.281192

0.281192

0.281191

0.281190

0.281190

0.281190

0.281189

0.281188

0.281188

0.281188

0.281187
0.281187

1.214906

1.214932
1.214958

1.214984
1.215011

1.215037

.215063

1.215090
1.215116
1.215142

1.215169
1.215195

1.215221

1.215274

1.215326

1.215379

1.215432

1.215458

1.215511

1.215563

1.215590

1.215642

1.215695

1. 215721

1. 215774

1. 215800

1.215826

1.215879

1.215905

1.215958

1. 216011

.216037

1. 216090

1.216116

1. 216168

1. 216221

1.216274

1.216300
1.216326

1.216353

1.216379

1.216432

1.216484

1.216511

1.216563

1.216616
1.216642

1.216642

1.216695

1.216747

1.216774

1.216826

1.216853

1.216905

1.216932

1.216958
1.216984

1.217010
1.217037

1.217063

1.217116

1.217168

1.217221

1.217274

1.217326

1.217353

1.217405

1.217432

1.217484

.010

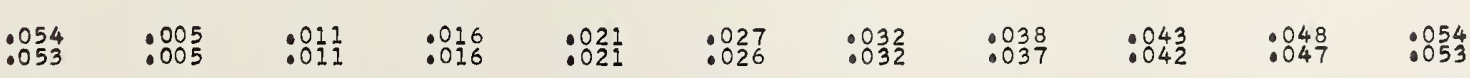




.04

.05

.06

3.1
3.2
3.3

3.04
3.4
3.5

30.5

$\begin{array}{ll}87.664 & 87.610 \\ 87.130 & 87.077 \\ 86.597 & 86.544 \\ 86.064 & 86.011 \\ 85.531 & 85.478 \\ 84.998 & 84.945 \\ 84.465 & 84.412 \\ 83.932 & 83.879 \\ 83.399 & 83.346\end{array}$

$\begin{array}{ll}88.090 & 88.037 \\ 87.557 & 87.503 \\ 87.023 & 86.970 \\ 86.490 & 86.437 \\ 85.958 & 85.905 \\ 85.425 & 85.371 \\ 84.892 & 84.838 \\ 84.358 & 84.305 \\ 83.825 & 83.772 \\ 83.292 & 83.239\end{array}$

3.39

$082.866 \quad 82.813$

82.333
81.800

$81.267 \quad 81.214$

$\begin{array}{llll}80.734 & 80.681 & 80.628 & 80.574\end{array}$

$\begin{array}{llll}80.202 & 80.148 & 80.095 & 80.042\end{array}$

$\begin{array}{llll}79.669 & 79.615 & 79.562 & 79.509\end{array}$ $\begin{array}{llll}79.136 & 79.083 & 79.030 & 78.976 \\ 78.603 & 78.550 & 78.496 & 78.443 \\ 78.071 & 78.017 & 77.964 & 77.911\end{array}$

077.537077 .484

$\begin{array}{rll}23077.537 & 77.484 & 77 . \\ 77.005 & 76.952 & 76 \\ 76.472 & 76.419 & 760 \\ 75.939 & 75.886 & 75 \\ 75.407 & 75.354 & 75 \\ 74.874 & 74.821 & 740 \\ 74.342 & 74.289 & 740 \\ 73.809 & 73.756 & 730 \\ 73.277 & 73.223 & 73 \\ 72.744 & 72.691 & 72\end{array}$

77.431
76.898
76.366

$\begin{array}{lll}77.378 & 770 \\ 8 & 76.845 & 760 \\ 76.312 & 76 .\end{array}$

$\begin{array}{ll}76.366 & 76.312 \\ 75.833 & 75.780\end{array}$

75.300
74.768

74.23
73.703

74.715

74.182
73.649

$23072.212 \quad 72 \cdot 158$

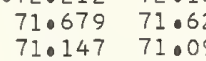

$70.614 \quad 70.561$

$69.549 \quad 69.496$

$69.017 \quad 68.964$

$\begin{array}{ll}68.485 & 68.432 \\ 67.953 & 67.899\end{array}$

67.421

66.356

65.82465 .771

$65.292 \quad 65.239$

$64 \cdot 228$

$64.228 \quad 64 \cdot 174$

$63.695 \quad 63.642$

$62.631 \quad 62.578$

23061.567 61.03561 .514

$60.503 \quad 60.450$

$\begin{array}{ll}59.971 & 59.918 \\ 59.440 & 59.386\end{array}$

$58.907 \quad 58.854$

$58.376 \quad 58.323 \quad 58.802$

$\begin{array}{llll}57.844 & 57.723 & 58.270 & 58.216\end{array}$

$\begin{array}{llll}57.312 & 57.259 & 57.206 & 57.153\end{array}$

23056.24

$55.717 \quad 56.19$

$55.185 \quad 55.664$

$54.654 \quad 54.601$

$54 \cdot 122 \quad 54.06$

$53.059 \quad 53.005$

$\begin{array}{ll}52.527 & 52.474 \\ 51.995 & 51.942\end{array}$

$\begin{array}{ll}51.995 & 51.942 \\ 51.464 & 51.411\end{array}$

50.401
49.869
49.338

$\begin{array}{llll}49.869 & 4.816 & 49.763 & 49.710 \\ 49.338 & 49.285 & 49.232 & 49.179\end{array}$

$\begin{array}{llll}48.807 & 48.753 & 48.700 & 48.647\end{array}$

$\begin{array}{llll}48.275 & 48.222 & 48.169 & 48.116 \\ 47.744 & 47.691 & 47.638 & 47.585\end{array}$

$\begin{array}{llll}47.213 & 47.160 & 47.107 & 47.054 \\ 46.682 & 46.629 & 46.575 & 46.523\end{array}$

$\begin{array}{lll}46.682 & 46.629 & 46.575 \\ 46.150 & 46.097 & 46.044\end{array}$

3045.619
45.088
440557.0

$\begin{array}{llll}45.557 & 44.504 & 44.951 & 44.928\end{array}$

$\begin{array}{lllll}44.025 & 43.972 & 43.919 & 43.866\end{array}$

$\begin{array}{llll}43.494 & 43.441 & 43.388 & 43.335 \\ 42.963 & 42.910 & 42.857 & 42.804\end{array}$

$\begin{array}{llll}42.432 & 42.379 & 42.326 & 42.273\end{array}$

$\begin{array}{llll}41.370 & 41.317 & 41.264 & 41.211 \\ 40.839 & 40.786 & 40.733 & 40.680\end{array}$

9.

$39.777 \quad 39.724$

$39.193 \quad 39.671 \quad 39.618$

$\begin{array}{llll}38.715 & 38.662 & 38.609 & 38.556\end{array}$

$\begin{array}{llll}38.184 & 38.131 & 38.078 & 38.025\end{array}$

$\begin{array}{llll}37.122 & 37.069 & 37.016 & 36.963\end{array}$

$\begin{array}{llll}36.591 & 36.539 & 36.485 & 36.432 \\ 36.061 & 36.007 & 35.954 & 35.90\end{array}$

$35.530 \quad 35.477 \quad 35.424$ $\begin{array}{llllll}87.983 & 87.930 & 87.876 & 87.823 & 87.770 & 87.717 \\ 87.450 & 87.397 & 87.344 & 87.290 & 87.237 & 87.184\end{array}$

$\begin{array}{llllll}86.917 & 86.367 & 87.344 & 87.290 & 87.237 & 87.184 \\ 86.810 & 86.757 & 86.704 & 86.650\end{array}$

$\begin{array}{llllll}86.384 & 86.331 & 86.278 & 86.224 & 86.171 & 86.117\end{array}$

$\begin{array}{llllll}85.811 & 85.797 & 85.744 & 85.691 & 85.638 & 85.584 \\ 85.265 & 85.211 & 85.158 & 85.105 & 85.052\end{array}$

$\begin{array}{llllll}84.785 & 84.732 & 84.678 & 84.625 & 84.572 & 84.518\end{array}$

$\begin{array}{llllll}84.252 & 84.198 & 84.145 & 84.092 & 84.039 & 83.985\end{array}$

$\begin{array}{llllll}83.719 & 83.666 & 83.612 & 83.559 & 83.505 & 83.452 \\ 83.186 & 83.132 & 83.079 & 83.026 & 82.973 & 82.919\end{array}$

$\begin{array}{llllll}82.653 & 82.600 & 82.546 & 82.493 & 82.440 & 82.387\end{array}$

$\begin{array}{llllll}82.120 & 82.067 & 82.013 & 81.960 & 81.907 & 81.853 \\ 81.587 & 81.534 & 81.480 & 81.427 & 81.374 & 81.321\end{array}$

$\begin{array}{llllll}81.587 & 81.534 & 81.480 & 81.427 & 81.374 & 81.321 \\ 81.054 & 81.001 & 80.948 & 80.894 & 80.841 & 80.788\end{array}$

$\begin{array}{llllll}80.521 & 80.468 & 80.415 & 80.362 & 80.308 & 80.255 \\ 79.988 & 70.935 & 79.882 & 79.828 & 79.775 & 79.722\end{array}$

$\begin{array}{llllll}79.486 & 79.935 & 79.882 & 79.828 & 79.775 & 79.722 \\ 79.402 & 79.349 & 79.296 & 79.242 & 79.189\end{array}$

$\begin{array}{lllllll}78.923 & 78.869 & 78.816 & 78.763 & 78.710 & 78.656\end{array}$

$\begin{array}{llllll}78.390 & 78.337 & 78.283 & 78.230 & 78.177 & 78.124 \\ 77.857 & 77.804 & 77.751 & 77.697 & 77.644 & 77.591\end{array}$

$\begin{array}{lllllll}77.324 & 77.271 & 77.218 & 77.165 & 77.112 & 77.058\end{array}$

$\begin{array}{lllllll}76.792 & 76.739 & 76.686 & 76.632 & 76.579 & 76.525 \\ 76.259 & 76.206 & 76.152 & 76.099 & 76.046 & 75.993\end{array}$

$\begin{array}{llllll}75.727 & 75.673 & 75.620 & 75.567 & 75.513 & 75.460\end{array}$

$\begin{array}{lllllll}75.194 & 75.140 & 75.087 & 75.034 & 74.981 & 74.927\end{array}$

$\begin{array}{llllll}74.129 & 74.075 & 74.022 & 73.969 & 73.916 & 73.862\end{array}$

$\begin{array}{lllllll}73.596 & 73.543 & 73.490 & 73.437 & 73.383 & 73.330\end{array}$

$\begin{array}{llllll}73.063 & 73.010 & 72.957 & 72.904 & 72.850 & 72.797 \\ 72.531 & 72.478 & 72.425 & 72.372 & 72.318 & 72.265\end{array}$

$\begin{array}{llllll}71.999 & 71.945 & 71.892 & 71.839 & 71.786 & 71.732\end{array}$

$\begin{array}{llllll}71.466 & 71.413 & 71.360 & 71.306 & 71.253 & 71.200 \\ 70.934 & 70.881 & 70.827 & 70.774 & 70.721 & 70.667\end{array}$

$\begin{array}{llllll}70.401 & 70.348 & 70.295 & 70.241 & 70.188 & 70.135\end{array}$

$\begin{array}{lllllll}69.869 & 69.816 & 69.763 & 69.709 & 69.656 & 69.603\end{array}$

$\begin{array}{llllll}69.336 & 69.283 & 69.230 & 69.177 & 69.124 & 69.071 \\ 68.804 & 68.751 & 68.698 & 68.645 & 68.591 & 68.538\end{array}$

$\begin{array}{llllll}68.272 & 68.219 & 68.698 & 68.645 & 68.591 & 68.538 \\ 68.165 & 68.112 & 68.059 & 68.006\end{array}$

$\begin{array}{llllll}68.272 & 68.219 & 68.165 & 68.112 & 68.059 & 68.006 \\ 67.740 & 67.687 & 67.633 & 67.580 & 67.527 & 67.474\end{array}$

$\begin{array}{llllll}66.676 & 66.622 & 66.569 & 66.516 & 66.463 & 66.410\end{array}$

$\begin{array}{lllllll}66.144 & 66.090 & 66.037 & 65.984 & 65.930 & 65.877\end{array}$

$\begin{array}{llllll}65.611 & 65.558 & 65.505 & 65.452 & 65.398 & 65.345\end{array}$

$\begin{array}{llllll}65.079 & 65.026 & 64 \cdot 973 & 64 \cdot 919 & 64 \cdot 866 & 64 \cdot 813\end{array}$

$\begin{array}{llllll}64.015 & 63.962 & 63.908 & 63.855 & 63.802 & 63.749\end{array}$

$\begin{array}{lllllll}63.483 & 63.429 & 63.376 & 63.323 & 63.270 & 63.217\end{array}$

$\begin{array}{lllllll}62.951 & 62.897 & 62.844 & 62.791 & 62.738 & 62.685\end{array}$

$\begin{array}{llllll}62.418 & 62.365 & 62.312 & 62.259 & 62.206 & 62.153 \\ 61.886 & 61.833 & 61.780 & 61.727 & 61.674 & 61.621\end{array}$

$\begin{array}{llllll}61.354 & 61.301 & 61.248 & 61.195 & 61.142 & 61.089\end{array}$

$\begin{array}{llllll}60.823 & 60.770 & 60.716 & 60.663 & 60.610 & 60.557\end{array}$

$\begin{array}{lllllll}59.759 & 59.706 & 59.652 & 59.599 & 59.546 & 59.493\end{array}$

$\begin{array}{lllllll}59.227 & 59.173 & 59.120 & 59.067 & 59.014 & 58.961\end{array}$

$\begin{array}{llllll}58.695 & 58.642 & 58.589 & 58.535 & 58.482 & 58.429\end{array}$

$\begin{array}{llllll}58.163 & 58.110 & 58.057 & 58.003 & 57.950 & 57.897 \\ 57.631 & 57.578 & 57.525 & 57.472 & 57.419 & 57.365\end{array}$

$\begin{array}{llllll}57.100 & 57.046 & 56.993 & 56.940 & 56.887 & 56.834\end{array}$

$\begin{array}{lllllll}56.036 & 55.983 & 55.930 & 55.876 & 55.823 & 55.770\end{array}$

$\begin{array}{llllll}55.504 & 55.451 & 55.398 & 55.345 & 55.292 & 55.238\end{array}$

$\begin{array}{llllll}54.973 & 54 \cdot 919 & 54.866 & 54.813 & 54.760 & 54 \cdot 707 \\ 54.441 & 54.388 & 54.334 & 54.281 & 54.228 & 54 \cdot 175\end{array}$

$\begin{array}{llllll}53.909 & 53.856 & 53.803 & 53.750 & 53.697 & 53.644\end{array}$

$\begin{array}{llllll}53.377 & 53.324 & 53.271 & 53.218 & 53.165 & 53.112 \\ 52.846 & 52.793 & 52.740 & 52.687 & 52.634 & 52.580\end{array}$

$\begin{array}{llllll}52.315 & 52.261 & 52.208 & 52.155 & 52.102 & 52.049\end{array}$

$\begin{array}{llllll}51.783 & 51.730 & 51.677 & 51.624 & 51.570 & 51.517 \\ 51.251 & 51.198 & 51.146 & 51.092 & 51.039 & 50.986\end{array}$

$\begin{array}{llllll}50.720 & 50.667 & 50.614 & 50.560 & 50.508 & 50.454\end{array}$

$\begin{array}{llllll}50.189 & 50.135 & 50.082 & 50.029 & 49.976 & 49.922\end{array}$

$\begin{array}{llllll}49.657 & 49.604 & 49.551 & 49.498 & 49.445 & 49.391 \\ 49.126 & 49.073 & 49.019 & 48.966 & 48.913 & 48.860\end{array}$

$\begin{array}{llllll}48.594 & 48.541 & 48.488 & 48.435 & 48.382 & 48.328\end{array}$

$\begin{array}{llllll}48.063 & 48.010 & 47.957 & 47.904 & 47.851 & 47.798 \\ 47.532 & 47.479 & 47.426 & 47.372 & 47.319 & 47.266\end{array}$

$\begin{array}{llllll}47.000 & 46.947 & 46.894 & 46.841 & 46.788 & 46.735\end{array}$

$\begin{array}{llllll}46.469 & 46.416 & 46.363 & 46.310 & 46.256 & 46.204 \\ 45.938 & 45.885 & 45.83 .2 & 45.779 & 45.725 & 45.672\end{array}$

$\begin{array}{llllll}45.407 & 45.354 & 45.301 & 45.247 & 45.194 & 45 \cdot 141\end{array}$

$\begin{array}{llllll}44.875 & 44.822 & 44.769 & 44 \cdot 716 & 44.663 & 44.610\end{array}$

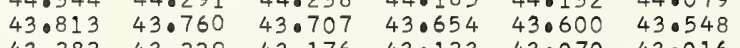

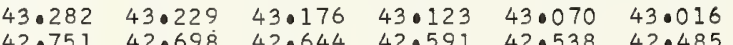

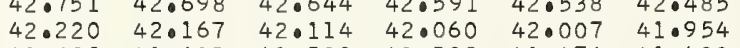

$\begin{array}{llllll}41.158 & 41.104 & 41.051 & 40.998 & 40.945 & 40.892 \\ 40.626 & 40.573 & 40.520 & 40.467 & 40.414 & 40.361\end{array}$

$\begin{array}{llllll}40.095 & 40.042 & 39.989 & 39.936 & 39.883 & 39.830\end{array}$

$\begin{array}{llllll}39.565 & 39.512 & 39.458 & 39.405 & 39.352 & 39.299\end{array}$

$\begin{array}{llllll}39.033 & 38.980 & 38.927 & 38.875 & 38.821 & 38.768 \\ 38.503 & 38.450 & 38.396 & 38.343 & 38.290 & 38.237\end{array}$

$\begin{array}{lllllll}37.971 & 37.918 & 37.865 & 37.812 & 37.759 & 37.706\end{array}$

$\begin{array}{llllll}36.910 & 36.857 & 36.804 & 36.751 & 36.698 & 36.645\end{array}$

$\begin{array}{llllll}36.379 & 36.326 & 36.273 & 36.220 & 36.167 & 36.114\end{array}$

$\begin{array}{lllllll}35.848 & 35.795 & 35.742 & 35.689 & 35.636 & 35.583 \\ 35.317 & 35.264 & 35.211 & 35.158 & 35.105 & 35.052\end{array}$

$(n-1) \times 1000$

$\lambda(n-1)$

$\begin{array}{ll}0.281186 & 1.217537 \\ 0.281186 & 1.217563 \\ 0.281186 & 1.217589 \\ 0.281185 & 1.217616 \\ 0.281185 & 1.217642 \\ 0.281184 & 1.217668 \\ 0.281184 & 1.217695 \\ 0.281183 & 1.217721 \\ 0.281183 & 1.217747 \\ 0.281183 & 1.217774\end{array}$

0.281182

0.281182

0.281181

0.281181

0.281180

0.281180

0.281179

0.281179

0.281178

0.281178

0.281177

0.281176

0.281176

0.281176

0.281175

0.281174

0.281174

0.281173

0.281173

0.281172

0.281172

0.281171

0.281171

0.281170

0.281169

0.281169

0.281168

0.281168

0.281167

0.281167

0.281166

0.281166

0.281165

0.281164

0.281164

0.281163

0.281163

0.281163
0.281162
0.281162

0.281161

0.281161

0.281161
0.281160
0.28160

0.281160
0.281160

0.281159

0.281159

0.281158

0.281158
0.281158

0.281157

0.281157

0.281156

0.281156

0.28115

0.281155

0.281154

0.281154

1.217800

1.217826
1.217853

1. 217879

1. 217905

1. 217932

1.217984

I. 218010

1.218063

1.218089

1.218116

1.218168

1.218195

1. 218221

1.218247
1.218274

1.218300

1.218326

1.218379

1.218405

1. 218432

1.218458

1.218484

1.218537

1.218537
1.218563

1.218589

1.218616
1.218642

1.218668

1.218695

1.218721

1.21874

1.218774
1.218800

1.218800

1. 218853

1.218879

1.218932

1.218932

1.218958 
1. 220695

i. 220748

1.220774
1.220800

1.220827
1.220853

1.220879
1.220906

1. 220958

1.220985
1.221011

1.221037
1.221063

1.221090
1.221116

1.221142
1.221169

1.221169
1.221195

1.0221221
1.221248

1.0221274
1.2221300
1
1.22109

1.221327

1.021339
1.222379

1.0221406
1.222432

.221458

1.221485

1. 2221511

1.021554
1.2221590

1.2211516
1.2221643
1.2216

1.0212669

1.0221722
1.021695

1.221748

10221744
+0221801

1.221127
1.221853

1.221880

1.221906
1.221932

1.221932
1.221958
1.221985

1.222011
1.222037

1.222064
1.222090

1.222116

1.222143
1.222169

1. 222195

1.222222
1.222248

1. 222274

1. 222301

1. 222353

I. 222406

1.222432
1.222459

1.222485

1.222538

1.222564

1.222590

1.222643

1.222669

1.222722

1.222748
1.222775

$\begin{array}{cccccccccc} & .001 & .002 & .003 & .004 & .005 & .006 & .007 & .008 & .009 \\ .053 & .005 & .011 & .016 & .021 & .026 & .032 & .037 & .042 & .048 \\ .052 & .005 & .010 & .016 & .021 & .026 & .031 & .036 & .042 & .024\end{array}$ 
$\begin{array}{lllllllllll}350.0 & 22982.046 & 81.993 & 81.941 & 81.888 & 81.835 & 81.782 & 81.729 & 81.676 & 81.624 & 81.571\end{array}$

$\begin{array}{lllllllllll}0.1 & 81.518 & 81.465 & 81.412 & 81.359 & 81.307 & 81.254 & 81.201 & 81.148 & 81.095 & 81.042 \\ 0.2 & 80.989 & 80.937 & 80.884 & 80.831 & 80.778 & 80.725 & 80.673 & 80.620 & 80.567 & 80.514\end{array}$

$\begin{array}{llllllllllll}0.3 & 80.461 & 80.408 & 80.355 & 80.303 & 80.250 & 80.197 & 80.144 & 80.091 & 80.039 & 79.986 \\ 0.4 & 79.933 & 79.880 & 79.827 & 79.774 & 79.722 & 79.669 & 79.616 & 79.563 & 79.510 & 79.457\end{array}$

$\begin{array}{llllllllllll}0.5 & 79.405 & 79.352 & 79.299 & 79.246 & 79.193 & 79.141 & 79.088 & 79.035 & 78.982 & 78.929\end{array}$

$\begin{array}{llllllllllll}0.6 & 78.877 & 78.824 & 78.771 & 78.718 & 78.666 & 78.613 & 78.560 & 78.507 & 78.454 & 78.401 \\ 0.7 & 78.348 & 78.296 & 78.243 & 78.190 & 78.137 & 78.084 & 78.031 & 77.979 & 77.926 & 77.873\end{array}$

$\begin{array}{lllllllllll}0.8 & 77.820 & 77.767 & 77.715 & 77.662 & 77.0609 & 77.556 & 77.503 & 77.451 & 77.398 & 77.0345 \\ 0 & 77.292 & 77.240 & 77.186 & 77.134 & 77.008 & 77.028 & 76.975 & 76.922 & 760870 & 76.817\end{array}$

$$
\text { itions }
$$

1.0
1.1
1.2
1.3
1.4
1.5
1.6
1.7
1.8
1.9

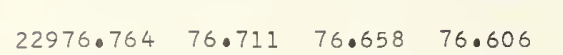

$\begin{array}{ll}76.764 & 76.7 \\ 76.236 & 76.18 \\ 75.708 & 75.6\end{array}$

76.658
76.1
75.602

$75.180 \quad 75.127 \quad 75.074 \quad 75.022$

$\begin{array}{llll}74.652 & 74.599 & 74.546 & 74.493\end{array}$

$\begin{array}{llll}74.124 & 74.071 & 74.019 & 73.966 \\ 73.596 & 73.543 & 73.490 & 73.437\end{array}$

$\begin{array}{llll}73.068 & 73.015 & 72.963 & 72.910 \\ 72.540 & 72.487 & 72.434 & 72.382\end{array}$

$\begin{array}{ll}72.540 & 72.487 \\ 72.012 & 71.959\end{array}$

4352.0

$2 \cdot 1$
$2 \cdot 2$
$2 \cdot 3$

$2 \cdot 3$
$2 \bullet 4$
$2 \cdot 5$

2.5
2.6

$\begin{array}{rr}22971.485 & 71.4 \\ 70.957 & 70.904\end{array}$

$\begin{array}{ll}70.957 & 70.904 \\ 70.429 & 70.377 \\ 69.901 & 69.8\end{array}$

$\begin{array}{llll}71.379 & 71.326 & 710 \\ 70.851 & 70.799 & 70 .\end{array}$

$\begin{array}{llllllllll}70.429 & 70.377 & 70.324 & 70.271 & 70.218 & 70.165 & 70.112 & 70.060 & 70.007 & 69.954 \\ 69.901 & 69.848 & 69.796 & 69.743 & 69.690 & 69.637 & 69.585 & 69.532 & 69.479 & 69.427 \\ 69.374 & 69.321 & 69.268 & 69.215 & 69.163 & 69.109 & 69.057 & 69.004 & 68.951 & 68.898 \\ 68.846 & 68.793 & 68.740 & 68.688 & 68.635 & 68.582 & 68.529 & 68.476 & 68.424 & 68.371\end{array}$

$\begin{array}{llllllllll}68.846 & 68.793 & 68.740 & 68.688 & 68.635 & 68.582 & 68.529 & 68.476 & 68.424 & 68.371 \\ 68.318 & 68.265 & 68.213 & 68.160 & 68.107 & 68.055 & 68.002 & 67.949 & 67.896 & 67.843\end{array}$

2.8

$3 \cdot \frac{1}{2}$

$3 \cdot 3$

$3 \cdot 5$

3.7

$\begin{array}{llll}67.790 & 67.738 & 67.685 & 67.632 \\ 67.263 & 67.210 & 67.157 & 67.105\end{array}$

$22966 \cdot 208$

$65.680 \quad 65 \cdot 627$

$\begin{array}{llll}65.680 & 65.627 & 65.574 & 65.5 \\ 65.152 & 65.100 & 65.047 & 64.994\end{array}$

$\begin{array}{llll}64.625 & 64.572 & 64.519 & 64.467\end{array}$

$\begin{array}{llll}64.097 & 64.045 & 63.992 & 63.939 \\ 63.570 & 63.517 & 63.465 & 63.412\end{array}$

$\begin{array}{llll}63.570 & 63.517 & 63.465 & 63.412 \\ 63.042 & 62.990 & 62.937 & 62.884\end{array}$

$\begin{array}{llll}62.515 & 62.463 & 62.410 & 62.357 \\ 61.988 & 61.935 & 61.882 & 61.830\end{array}$

4354.0

$4 \cdot 1$
402
403

$4 \cdot 4$
$4 \cdot 5$

4.6

$4 \cdot 7$

$4 \cdot 8$
4.9

435
5.
5
5.
5.
5.5
506
5
5
50

5.0
5.1
5.2
5.3
5.4
5.5
5.6
5.7
5.8
5.9

2960.933

60.406
59.8
59.35

$\begin{array}{llll}59.351 & 59.298 & 59.773 & 59.720\end{array}$

$\begin{array}{llll}58.824 & 58.771 & 58.718 & 58.665\end{array}$

$\begin{array}{llll}57.769 & 57.717 & 57.664 & 57.611\end{array}$

$\begin{array}{llll}57.242 & 57.189 & 57.137 & 57.084 \\ 56.715 & 56.662 & 56.609 & 56.557\end{array}$

22955.66

55.133
54.606

53.552

$53.025 \quad 52.072$

$52.498 \quad 52.446 \quad 52.393$

$\begin{array}{llll}51.972 & 51.919 & 51.866 & 52.340\end{array}$

$\begin{array}{ll}51.445 & 51.39 \\ 50.918 & 50.86\end{array}$

4356.0

6.1

6.3

6.5

6.6

6.8

4357.0
7.0
7.2
7.3
7.0
7.5
7.6
7.7
7.8
7.9

4358.0

$8 \cdot 1$
$8 \cdot 2$
8.3

$8 \cdot 3$
8.4

8.5

8.6

8.7
8.8
8.9

22950.39

$\begin{array}{rr}50.391 & 50.338 \\ 49.864 & 49.8\end{array}$

$\begin{array}{lll}49.337 & 49.812 & 49.75 \\ 48.811 & 48.758 & 49.232\end{array}$

$\begin{array}{llll}48.811 & 48.758 & 49.232 & 49.77\end{array}$

$\begin{array}{llll}48.284 & 48.231 & 48.705 & 48.65 \\ 47.28 & 48.12\end{array}$

$\begin{array}{llll}47.757 & 47.704 & 47.652 & 47.599\end{array}$

$\begin{array}{llll}46.703 & 46.651 & 46.598 & 46.546\end{array}$

$\begin{array}{llll}46.177 & 46.124 & 46.071 & 46.019 \\ 45.650 & 45.598 & 45.545 & 45.492\end{array}$

$22945.124 \quad 45.071 \quad 45.019 \quad 44.966$

$\begin{array}{llll}44 \cdot 597 & 44.544 & 44.491 & 44.439 \\ 44 \cdot 070 & 44.018 & 43.965 & 43.913\end{array}$

$43.017 \quad 42.965 \quad 42.912 \quad 42.859$

$42.490 \quad 42.438$

$41.964 \quad 41.912$

$\begin{array}{llll}40.911 & 40.859 & 40.806 & 40.754\end{array}$

$\begin{array}{llllll}6.553 & 76.500 & 76.447 & 76.394 & 76.342 & 76.289\end{array}$

$\begin{array}{llllll}75.497 & 75.972 & 75.919 & 75.866 & 75.813 & 75.760 \\ 75.444 & 75.391 & 75.338 & 75.286 & 75.233\end{array}$

$\begin{array}{llllll}74.969 & 74.916 & 74.863 & 74 \cdot 810 & 74.757 & 74.705 \\ 74.441 & 74.388 & 74.335 & 74.282 & 74.229 & 74.177\end{array}$

$\begin{array}{llllll}73.385 & 73.860 & 73.807 & 73.754 & 73.702 & 73.649 \\ 73.32 & 73.279 & 73.226 & 73.174 & 73.121\end{array}$

$\begin{array}{lllllll}72.857 & 72.804 & 72.751 & 72.699 & 72.646 & 72.593\end{array}$

$\begin{array}{llllll}72.329 & 72.276 & 72.223 & 72.171 & 72.118 & 72.065 \\ 71.801 & 71.748 & 71.696 & 71.643 & 71.590 & 71.537\end{array}$

$\begin{array}{llllll}1.274 & 71.221 & 71.168 & 71.115 & 71.062 & 71.010\end{array}$

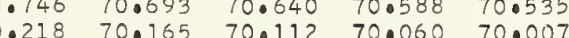

$\begin{array}{llllll}67.579 & 67.527 & 67.474 & 67.421 & 67.368 & 67.316 \\ 67.052 & 66.999 & 66.946 & 66.894 & 66.841 & 66.788\end{array}$

$\begin{array}{llllll}66.524 & 66.471 & 66.419 & 66.366 & 66.313 & 66.260\end{array}$

$\begin{array}{llllll}65.997 & 65.944 & 65.891 & 65.838 & 65 \cdot 786 & 65.733\end{array}$

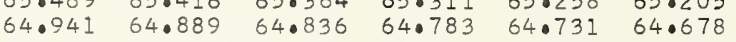

$\begin{array}{llllll}64.414 & 64.361 & 64.308 & 64.256 & 64.203 & 64 \cdot 150\end{array}$

$\begin{array}{lllllll}63.886 & 63.833 & 63.781 & 63.728 & 63.676 & 63.623 \\ 63.359 & 63.306 & 63.253 & 63.200 & 63.148 & 63.095\end{array}$

$\begin{array}{llllll}63.359 & 63.306 & 63.253 & 63.200 & 63.148 & 63.095 \\ 62.832 & 62.779 & 62.726 & 62.673 & 62.621 & 62.568\end{array}$

$62.304 \quad 62.251 \quad 62.198 \quad 62.146 \quad 62.093 \quad 62.040$

$\begin{array}{llllll}61.777 & 61.724 & 61.671 & 61.618 & 61.566 & 61.513 \\ 61.249 & 61.197 & 61.144 & 61.091 & 61.038 & 60.985\end{array}$

$\begin{array}{llllll}60.722 & 60.669 & 60.616 & 60.564 & 60.511 & 60.458 \\ 60.195 & 60.142 & 60.089 & 60.037 & 59.084 & 59.931\end{array}$

$\begin{array}{llllll}60.195 & 60.142 & 60.089 & 60.037 & 59.984 & 59.931 \\ 59.667 & 59.615 & 59.562 & 59.509 & 59.457 & 59.404\end{array}$

$\begin{array}{llllll}59.140 & 59.087 & 59.035 & 58.982 & 58.929 & 58.877\end{array}$

$\begin{array}{llllll}58.613 & 58.560 & 58.507 & 58.455 & 58.402 & 58.349 \\ 58.086 & 58.033 & 57.980 & 57.927 & 57.875 & 57.822\end{array}$

$\begin{array}{llllll}57.558 & 57.506 & 57.453 & 57.400 & 57.347 & 57.295\end{array}$

$\begin{array}{llllll}57.031 & 56.978 & 56.926 & 56.873 & 56.820 & 56.768\end{array}$

$\begin{array}{llllll}56.504 & 56.451 & 56.398 & 56.346 & 56.293 & 56.240 \\ 55.977 & 55.924 & 55.872 & 55.819 & 55.766 & 55.713\end{array}$

0.281104

0.281103

0.281102

0.281102

0.281101

0.281100
0.281100

0.281100

0.281099

0.281099

0.281098

0.281098

0.281097

0.281097

0.281096

0.281095

0.281095

0.281095

0.281094

0.281093

0.281093

0.281092

0.281092

0.281091

0.281091

0.28109

0.281090

0.281089

0.281089

0.28108

0.281088
0.281088

0.281087

0.281087

0.281086

0.281086

0.281085
0.281085

0.281084

0.281084
0.281084

0.281083

0.281083

0.281082
0.281082

0.281082

0.281081

0.28108 .

0.281080

0.281080

1.222801
1.222827

1.222854

1. 222906

1.222932

1.222985

1. 223011

1.223064

1.223117

1.223143

I. 223169

1.223222
1.223248

- 223275

1.223327

1.223354
1.223380

I. 223406

1.223433
1.223459

I. 223485

1. 223538

1. 223591

1.223617

1.223643

I. 223670

1. 223696

1. 223722

1. 223749

1.223801

1.223854

1.223880
1.223907

I. 223933

1. 223959

1.223986

1. 224038

1.224065
1.224091

1.224117

1.224144

1.224170
1.224196

1. 224222

I. 224249

I. 224275

1. 2243028

0.281079

0.281079

0.281078

0.281077

0.281077

0.281076

0.281076

1.224380

1.224407

1.224459

1.224486

1.224538

1.224565

1. 224591

0.281075

0.281074

0.281074

0.281073

0.281073

0.281073
0.281072

0.281072

1.224644

1.224670
1.224696

1.224723

1. 224749

1.224775

I. 224802

1. 224854

1. 224882

0.281071

0.281071

0.281070

0.281070

0.281069

0.281069

0.281068

0.281068
0.281068

0.281067

1. 224907

1. 224933

1.224960
1.224986

1.225012

1.225039

1.225065

I. 225118

$\begin{array}{llllllllll}35.648 & 35.595 & 35.543 & 35.490 & 35.438 & 35.385 & 35.333 & 35.280 & 35.227 & 35.175\end{array}$

0.281067

1.225170

0.281066

0.281066

0.281066

0.281065

0.281065

0.281064

0.281064

0.281064

1.225197

1.225223

1.225249
1.225276

1.225276
1.225302

1.225328

1.225355
1.225381

1.225407

$\begin{array}{llllllllll}30.914 & 30.861 & 30.809 & 30.756 & 30.703 & 30.651 & 30.598 & 30.546 & 30.493 & 30.440\end{array}$

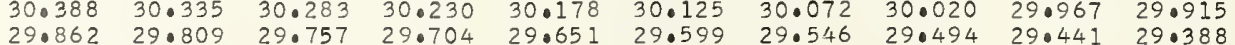

.010

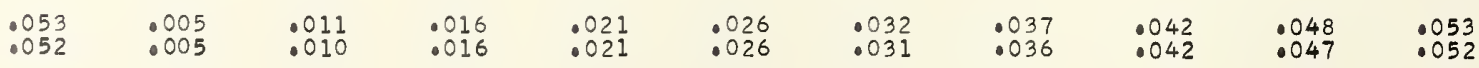


$\begin{array}{rrrrrrrrrrr}360.0 & 22929.336 & 29.283 & 29.231 & 29.178 & 29.126 & 29.073 & 29.021 & 28.968 & 28.915 & 28.863 \\ 0.1 & 28.810 & 28.757 & 28.705 & 28.652 & 28.600 & 28.547 & 28.495 & 28.442 & 28.389 & 28.337\end{array}$

$\begin{array}{lllllllllll}0.1 & 28.810 & 28.757 & 28.705 & 28.652 & 28.600 & 28.547 & 28.495 & 28.442 & 28.389 & 28.337 \\ 0.2 & 28.284 & 28.232 & 28.179 & 28.126 & 28.074 & 28.021 & 27.969 & 27.916 & 27.864 & 27.811\end{array}$

$\begin{array}{lllllllllll}0.3 & 27.758 & 27.706 & 27.653 & 27.601 & 27.548 & 27.495 & 27.443 & 27.390 & 27.338 & 27.285\end{array}$

$\begin{array}{lllllllllll}0.4 & 27.233 & 27 \cdot 180 & 27.127 & 27.075 & 27.022 & 26.969 & 25.917 & 26.865 & 26.812 & 26.760 \\ 0.5 & 26.707 & 26.654 & 26.602 & 26.549 & 26.496 & 26.444 & 26.391 & 26.339 & 26.286 & 26.234\end{array}$

$\begin{array}{lllllllllll}0.5 & 26.707 & 26.654 & 26.602 & 26.549 & 26.496 & 26.444 & 26.391 & 26.339 & 26.286 & 26.234 \\ 0.6 & 26.181 & 26.128 & 26.076 & 26.023 & 25.971 & 25.918 & 25.866 & 25.813 & 25.760 & 25.708\end{array}$

$\begin{array}{lllllllllll}0.7 & 25.655 & 25.603 & 25.550 & 25.497 & 25.445 & 25.392 & 25.340 & 25.287 & 25.235 & 25.182\end{array}$

$\begin{array}{lllllllllll}0.8 & 25.129 & 25.077 & 25.024 & 24.972 & 24 \cdot 919 & 24.867 & 24.814 & 24.761 & 24 \cdot 709 & 24 \cdot 657 \\ 0.9 & 24.604 & 24.552 & 24.499 & 24.446 & 24.394 & 24 \cdot 341 & 24.288 & 24 \cdot 236 & 24.183 & 24 \cdot 131\end{array}$

2924.078

$$
\begin{array}{r}
361.0 \\
1 . \\
1 . \\
10 \\
105 \\
107 \\
108
\end{array}
$$

$$
\begin{array}{rr}
924.078 & 24.02 \\
23.552 & 23.50
\end{array}
$$

$5 \quad 23.973 \quad 23.920$

$23.868 \quad 23 \cdot 815$

$23.027 \quad 22.974$

$\begin{array}{ll}22.501 & 22.449 \\ 21.976 & 21.923\end{array}$

$21.450 \quad 21.397 \quad 21.870 \quad 21.818$

$\begin{array}{lllll}20.925 & 20.872 & 20.345 & 21.293 & 21.240\end{array}$

19.874
19.348

4362.

2.
2.
2
2
2
2
2
2

22918.823

18.297
17.772

19.821

$\begin{array}{llll}.819 & 20.767 & 20.714 & 20.662 \\ .294 & 20.241 & 20.189 & 20.136\end{array}$

$8.770 \quad 18.718 \quad 18.665$

$\begin{array}{llll}17.194 & 17.141 & 17.615 & 17.568 \\ 17.089 & 17.037\end{array}$

$\begin{array}{llll}16.669 & 16.616 & 16.564 & 16.511\end{array}$

$\begin{array}{llll}16.196 & 16.143 & 16.091 & 16.038\end{array}$

$\begin{array}{llll}15.671 & 15.618 & 15.566 & 15.5 \\ 15.145 & 15.093 & 15.040 & 14.988\end{array}$

$4.988 \quad 14.935$

15.46
14.93
14.410

19.61
19.085

4363

63.0
3.1
3.2
3.3
3.5
3.5
3.6
3.7
3.8
3.9

22913.570

13.517

$13.465 \quad 13.413$

13.360

18.560

$\begin{array}{llll}23.763 & 23.710 & 23.658 & 23.605\end{array}$

$\begin{array}{llll}23.237 & 23 \cdot 184 & 23.132 & 23.079 \\ 22.711 & 22.659 & 22.606 & 22.554\end{array}$

21.660

20.60

$\begin{array}{lll}22.134 & 22.081 & 22.028 \\ 21.608 & 21.555 & 21.503\end{array}$

$\begin{array}{lll}21.082 & 21.030 & 20.977 \\ 20.557 & 20.504 & 20.451\end{array}$

$\begin{array}{lll}20.557 & 20.504 & 20.451 \\ 20.031 & 19.979 & 19.926\end{array}$

$\begin{array}{llll}9.558 & 19.506 & 19.453 & 19.401\end{array}$

$\begin{array}{lllll}18.507 & 18.455 & 18.402 & 18.350\end{array}$

$\begin{array}{lllll}18.035 & 17.982 & 17.930 & 17.877 & 17.824 \\ 17.509 & 17.457 & 17.404 & 17.352 & 17.299\end{array}$

$\begin{array}{lllll}16.984 & 16.931 & 16.879 & 16.826 & 16.774 \\ 16.458 & 16.406 & 16.354 & 16.301 & 16.248\end{array}$

$\begin{array}{lllll}15.933 & 15.881 & 15.828 & 15.776 & 15.723\end{array}$

15.408
1.4 .883

$\begin{array}{llll}15.356 & 15.303 & 15.250 & 15.198\end{array}$

14.830

14.778

$\begin{array}{ll}14 \cdot 725 & 14.673 \\ 14.200 & 14 \cdot 148 \\ 13.675 & 13.623\end{array}$

.281063

1.225434

0.28106

0.281061

0.281060

0.281060
0.281059

0.281059
0.281058

0.281058

.281057
.281057

0.281057

0.281056

0.281055
0.281055

0.281055

.281054

0.281053

0.281053

0.281052

0.281051
0.281051

1. 225486

.225539

. 225592

$1 \cdot 225644$
$1 \cdot 225671$

$\begin{array}{lllllllllll}13 & 13.045 & 12.992 & 12.940 & 12.887 & 12.835 & 12.782 & 13.255 & 13.202 & 13.150 & 13.098 \\ 0 & 12.520 & 12.467 & 12.415 & 12.362 & 12.310 & 12.257 & 12.205 & 12.577 & 12.625 & 12.572 \\ 3 & 1 & 12.052 & 12.100 & 12.047\end{array}$

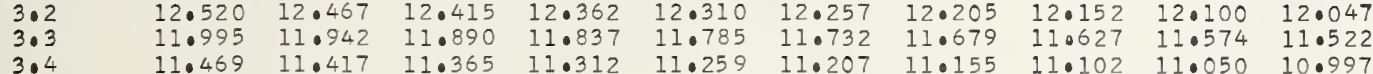

$10.945 \quad 10.892 \quad 10.840 \quad 10.787 \quad 10.735 \quad 10.682$

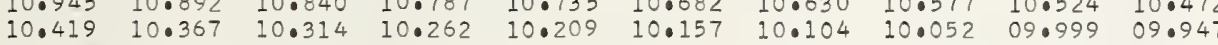

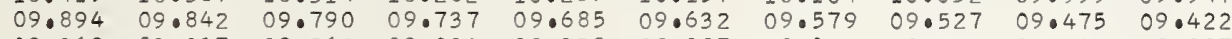

$\begin{array}{llll}09.369 & 09 \cdot 317 & 09.264 & 09.21 \\ 08.844 & 08.792 & 08.740 & 08.68\end{array}$

09.15

4364.0

40
40
40
40
40
40
40
40

22908.319

$07.795 \quad 07.742$

$\begin{array}{llll}07.270 & 07.218 & 07.689 & 07.637\end{array}$

$06.745 \quad 06.692$

$06 \cdot 220 \quad 06 \cdot 168$

$07.165 \quad 07.11$

08.109

09.107
08.582

$\begin{array}{llll}09.054 & 09.002 & 08.949 & 08.897 \\ 08.530 & 08.477 & 08.425 & 08.372\end{array}$

0.281050

0.281050

0.281049

0.281049

0.281048

0.281048

0.281047

1.225697

1.225723

1.22580

1.22588

I. 225934

$\begin{array}{llllllllll} & 5.642 & 05.590 & 05.538 & 05.485 & 05.433 & 05.380 & 05.328 & 05.275 & 05.223\end{array}$

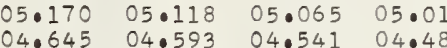

$04.121 \quad 04.06$

04.54104 .488

$\begin{array}{rrr}5.0 & 22903.071 & 03.019 \\ 5.1 & 02.547 & 02.49\end{array}$

03.543

03.49103 .43

4365.0

5,1
5.2
5.3
5.4
5.5 $02.022 \quad 01.970$ $\begin{array}{ll}01.498 & 01.445 \\ 00.973 & 00.9 \\ 00.448 & 00.396\end{array}$

5.5
5.6
5.7 $22899.924 \quad 99.871$ 99.819

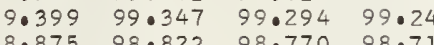

$98.350 \quad 98.298$

4366.0

$\begin{array}{rrrrlllllll}6.0 & 22897.825 & 97.773 & 97.721 & 97.668 & 97.616 & 97.563 & 97.511 & 97.458 & 97.406 & 97.354 \\ 6.1 & 97.301 & 97.249 & 97.196 & 97.144 & 97.092 & 97.039 & 96.987 & 96.934 & 96.881 & 96.829 \\ 6.2 & 96.776 & 96.724 & 96.672 & 96.619 & 96.567 & 96.514 & 96.462 & 96.410 & 96.357 & 96.305 \\ 6.3 & 96.252 & 96.200 & 96.147 & 96.095 & 96.043 & 95.990 & 95.938 & 95.885 & 95.833 & 95.780 \\ 6.4 & 95.728 & 95.675 & 95.623 & 95.570 & 95.518 & 95.466 & 95.413 & 95.361 & 95.308 & 95.256\end{array}$ $\begin{array}{llllllllll}95.728 & 95.675 & 95.623 & 95.570 & 95.518 & 95.466 & 95.413 & 95.361 & 95.308 & 95.256 \\ 95.203 & 95.151 & 95.099 & 95.046 & 94.994 & 94.941 & 94.889 & 94.836 & 94.784 & 94.732\end{array}$ $\begin{array}{llllllllll}95.203 & 95.151 & 95.099 & 95.046 & 94.994 & 94.941 & 94.889 & 94.836 & 94.784 & 94.732 \\ 94.679 & 94.627 & 94.574 & 94.522 & 94.470 & 94.417 & 94.365 & 94.312 & 94.260 & 94.208\end{array}$

$\begin{array}{llllllllll}94.679 & 94.627 & 94.574 & 94.522 & 94.470 & 94.417 & 94.365 & 94.312 & 94.260 & 94 \cdot 208 \\ 94.155 & 94.103 & 94.051 & 93.998 & 93.946 & 93.893 & 93.841 & 93.788 & 93.736 & 93.684\end{array}$

$6 \cdot 8$

$93.63193 .579 \quad 93.526 \quad 93.474$

4367

7.0
7.1
7.3
7.4
7.5
7.6
7.7
7.8
7

2289

$92.583 \quad 92.530$

$92.058 \quad 92.006 \quad 91.47835092 .426$

$\begin{array}{llll}91.534 & 91.482 & 81.429 & 91.37\end{array}$

$90.486 \quad 90.434 \quad 90.38190 .853$

$89.961 \quad 89.909 \quad 89.857 \quad 89.804$

$89.438 \quad 89.385 \quad 89.333 \quad 89.280$

$8.914 \quad 88.861$

$\begin{array}{ll}88.389 & 88 \cdot 337 \\ 87.866 & 87.813\end{array}$

4368.0

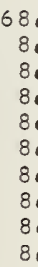

$\begin{array}{llll}87.341 & 87.289 & 87.237 & 87.184\end{array}$

$\begin{array}{llll}86.818 & 86.765 & 86.713 & 86.6\end{array}$

$\begin{array}{llll}86.293 & 86.241 & 86.189 & 86.136 \\ 85.770 & 85.717 & 85.665 & 85.613\end{array}$

$8.246 \quad 85.193$

\begin{tabular}{l}
85.08 \\
\hline
\end{tabular}

$\begin{array}{llll}84.722 & 84.669 & 84.617 & 84.565 \\ 84.198 & 84.146 & 84.093 & 84.041\end{array}$

$33.674-84.146$

$83.150 \quad 83.022 \quad 83.570 \quad 83.517$

$\begin{array}{llll}83.150 & 83.098 & 83.045 & 82.993 \\ 82.627 & 82.574 & 82.522 & 82.469\end{array}$

93.42

93.893
93.360

93.841

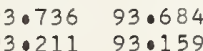

$\begin{array}{llllll}92.373 & 92.321 & 92.268 & 92.215 & 92.163 & 92.111\end{array}$

0.281046

0.281046

0.281045

0.281045

0.281044

0.281044

0.281043

0.281042

0.281041

$8 \div 041$

0.28104
0.28104

0.281039

0.281039

0.281038

0.28103

0.281038

.281037

0.281036

0.281036

0.28103

0.281034

0.281034

0.281033

0.281033

0.281032

0.281032

0.281031

0.281031
0.281031

0.281030
0.281030
0.281029

0.281030
0.281029

0.281029

0.281028

0.281028

0.281027

0.281027

.225960

1.226039

1. 226092

1.226145
1.22617

1.226224

1.226250

1. 226303

1.226329
1.226355

1. 226408

1.226434
1.226461

1.226487

1. 226540

1. 226566

1. 226619

1. 226645

1.226698

1.226750

1.226803

1. 226856

1.226882

1.226908

1.226961

1. 227014

1.227040
1.227066

1.227093

1.227145

1.227172

1.227224

1.227277

1.227303
1.227330
1.22750

1.0227356

1.227409

1. 2227435

1.227488

. 227514

1.227540

1.227593

1.227619

.0227672

0.227698
1.0227725
1.22751

1.227751
1.227777

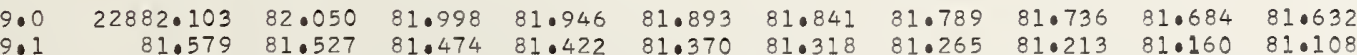
$\begin{array}{llllllllll}81.579 & 81.527 & 81.474 & 81.422 & 81.370 & 81.318 & 81.265 & 81.213 & 81.160 & 81.108 \\ 81.05 & 81.003 & 80.951 & 80.898 & 80.845 & 80.793 & 80.741 & 80.689 & 80.636 & 80.584\end{array}$ $\begin{array}{llllllllll}80.532 & 80.479 & 80.427 & 80.375 & 80.323 & 80.270 & 80.218 & 80.165 & 80.113 & 80.061\end{array}$ $\begin{array}{llllllllll}80.008 & 79.956 & 79.904 & 79.851 & 79.799 & 79.746 & 79.694 & 79.642 & 79.589 & 79.537\end{array}$ $\begin{array}{llllllllll}79.484 & 79.432 & 79.380 & 79.327 & 79.275 & 79.223 & 79.170 & 79.118 & 79.066 & 79.013\end{array}$ $\begin{array}{llllllllll}78.961 & 78.909 & 78.856 & 78.804 & 78.752 & 78.699 & 78.647 & 78.594 & 78.542 & 78.490\end{array}$ $\begin{array}{llllllllll}78.437 & 78.385 & 78.333 & 78.280 & 78.228 & 78.176 & 78.123 & 78.071 & 78.019 & 77.966\end{array}$ $\begin{array}{llllllllll}77.914 & 77.861 & 77.809 & 77.757 & 77.705 & 77.652 & 77.600 & 77.547 & 77.495 & 77.443 \\ 77.390 & 77.338 & 77.285 & 77.233 & 77.181 & 77.128 & 77.076 & 77.024 & 76.971 & 76.919\end{array}$

0.281026

0.281026

1.227804

0.281025

0.281025

0.281024

0.281024
0.281023

0.281023

1.227830
1.227856

1.227883

1.227909
1.227935

1. 227962

1.227988
1.228014

$$
.001
$$

.002

.003

.004

.005

.006

.007

$.008 \quad .009$

.010 
$\begin{array}{rrrrrrrrrrr}430.0 & 22876.867 & 76.814 & 76.762 & 76.710 & 76.657 & 76.605 & 76.553 & 76.500 & 76 \cdot 448 & 76.396 \\ 0.1 & 76.343 & 76.291 & 76.238 & 76.186 & 76.134 & 76.082 & 76.029 & 75.977 & 75.924 & 75.872\end{array}$

$\begin{array}{llllllllllll}0.2 & 75.820 & 75.768 & 75.715 & 75.663 & 75.610 & 75.558 & 75.506 & 75.454 & 75.401 & 75.349\end{array}$

$\begin{array}{llllllllllll}0.3 & 75.296 & 75.244 & 75.192 & 75.140 & 75.087 & 75.035 & 74.982 & 74.930 & 74.878 & 74.826\end{array}$

$\begin{array}{lllllllllll}0.4 & 74.773 & 74.721 & 74.669 & 74.616 & 74.564 & 74.511 & 74.459 & 74.407 & 74.355 & 74.302 \\ 0.5 & 74.250 & 74.198 & 74.146 & 74.093 & 74.041 & 73.988 & 73.936 & 73.883 & 73.831 & 73.779 \\ 0 & 73.727 & 73.574 & 73.622 & 73.569 & 73.517 & 73.465 & 73.413 & 73.360 & 73.308 & 73.255\end{array}$

$\begin{array}{llllllllllll}0.6 & 73.727 & 73.674 & 73.622 & 73.569 & 73.517 & 73.465 & 73.413 & 73.360 & 73.308 & 73.255\end{array}$

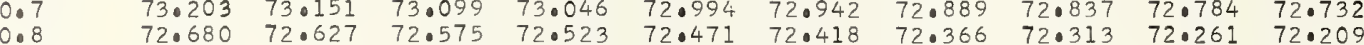

$\begin{array}{llllllllll}72.157 & 72.104 & 72.052 & 72.000 & 71.947 & 71.895 & 71.843 & 71.791 & 71.738 & 71.686\end{array}$

$\begin{array}{rrrrrrrrrrr}4371.0 & 22871.633 & 71.581 & 71.529 & 71.476 & 71.424 & 71.372 & 71.319 & 71.267 & 71.215 & 71.163\end{array}$

$\begin{array}{lllllllllll}1.1 & 71.110 & 71.058 & 71.005 & 70.953 & 70.901 & 70.849 & 70.796 & 70.744 & 70.692 & 70.639 \\ 1.2 & 70.586 & 70.534 & 70.482 & 70.430 & 70.377 & 70.325 & 70.273 & 70.221 & 70.168 & 70.116\end{array}$

$\begin{array}{lllllllllll}1.2 & 70.586 & 70.534 & 70.482 & 70.430 & 70.377 & 70.325 & 70.273 & 70.221 & 70.168 & 70.116 \\ 1.3 & 70.064 & 70.011 & 69.959 & 69.907 & 69.854 & 69.802 & 69.750 & 69.698 & 69.645 & 69.593\end{array}$

$69.54169 .488 \quad 69.436 \quad 69.383 \quad 69.331 \quad 60.279 \quad 69.227 \quad 69.174 \quad 69.12269 .593$

$\begin{array}{lllllllllll}1.4 & 69.017 & 68.965 & 68.913 & 68.861 & 68.808 & 68.756 & 68.703 & 68.651 & 68.599 & 68.547\end{array}$

$\begin{array}{llllllllll}68.494 & 68.442 & 68.390 & 68.337 & 68.285 & 68.233 & 68.180 & 68.128 & 68.599 & 68.547 \\ 6 & 68.076 & 68.023\end{array}$

$\begin{array}{lllllllllll}67.971 & 67.919 & 67.866 & 67.814 & 67.762 & 67.709 & 67.657 & 67.605 & 67.553 & 67.500\end{array}$

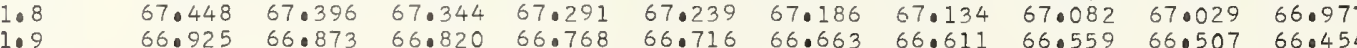

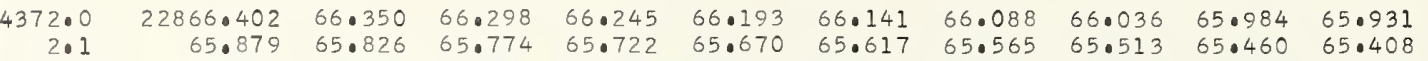

$\frac{2.2}{2: 2}$

$\frac{2.20}{2.3}$

2.45
2.5
0.5

2.0

2.8

4373.0

22861.1730 .0

$3 \cdot 2$

当.

畓,

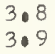

4374.0

$4 \cdot 1$
$4 \cdot 2$
$4 \cdot 3$

$4 \cdot 3$

$4 \cdot 5$

$4 \cdot 6$
$4 \cdot 7$
$4 \cdot 8$

4.8
4.9

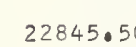

$\begin{array}{lllllllllll} & .001 & .002 & .003 & .004 & .005 & .006 & .007 & .008 & .009 & .010 \\ .052 & .005 & .010 & .016 & .021 & .026 & .031 & .037 & .042 & .047 & .052 \\ .051 & .005 & .010 & .015 & .021 & .026 & .031 & .036 & .041 & .046 & .051\end{array}$

1.228067

0.281022

0.281021

0.281021

0.281020

0.281019

0.281019

0.281018

0.281018

0.281017

0.281017

0.281016

0.281015

0.281015

0.281014

0.281014

0.281013

0.281012

0.281012

0.281011

0.281011

0.281010

0.281010

0.281009

0.281008

0.281008

0.281007

0.281007
0.281006

0.281006

0.281006

0.281005

0.281004

0.281004

0.281003

0.281002

0.281002

0.281002

0.281001

0.281000

0.281000

0.281000

0.280999
0.280998

0.280998

0.280998

0.280997

0.280996

0.280996

0.280995

0.280995

0.280994

0.280994

0.280994

0.280993

0.280992

0.280992

0.280992

0.280991

0.280990

0.280990

0.280990

0.280989

0.280988

0.280988 0.280988 0.280987 0.280986

0.280986

0.280986

0.280985

0.280985

0.280984

0.280984

0.280983

0.280983

1.228093
1.228120

I.228146

1.228172

I. 228225

l. 228278

1.228330

1.228357

1. 228409

I. 228436

1.228462

1.228488

1.228541

1.228594

1.228620

1.228646

1.228699

1.228725

1.228752

1. 228804

1.228857

1.228883

1.228936

1.228962

1.228989

1.229015

1.229041
1.229068

1.229094

1.229120 
$\begin{array}{lllllllllll}4380.0 & 22824 \cdot 637 & 24.585 & 24.533 & 24.481 & 24.429 & 24 \cdot 377 & 24.325 & 24.273 & 24 \cdot 221 & 24 \cdot 169\end{array}$

$\begin{array}{lllllllllll}0.1 & 24.116 & 24.064 & 24.012 & 23.960 & 23.908 & 23.856 & 23.804 & 23.751 & 23.699 & 23.647 \\ 0.2 & 23.595 & 23.543 & 23.491 & 23.439 & 23.387 & 23.335 & 23.282 & 23.231 & 23.179 & 23.126\end{array}$

$\begin{array}{lllllllllll}0.2 & 23.595 & 23.543 & 23.491 & 23.439 & 23.387 & 23.335 & 23.282 & 23.231 & 23.179 & 23.126 \\ 0.3 & 23.074 & 23.022 & 22.970 & 22.918 & 22.866 & 22.814 & 22.761 & 22.709 & 22.657 & 22.605\end{array}$

$\begin{array}{lllllllllll}0.4 & 22.553 & 22.501 & 22.449 & 22.397 & 22.345 & 22.292 & 22.241 & 22.189 & 22.136 & 22.084\end{array}$

$\begin{array}{lllllllllll}0.5 & 22.032 & 21.980 & 21.928 & 21.876 & 21.824 & 21.772 & 21.720 & 21.667 & 21.615 & 21.563 \\ 0.6 & 21.511 & 21.459 & 21.407 & 21.355 & 21.303 & 21.251 & 21.199 & 21.146 & 21.094 & 21.042 \\ 0.7 & 20.990 & 20.938 & 20.886 & 20.834 & 20.782 & 20.730 & 20.678 & 20.626 & 20.574 & 20.521\end{array}$

0.7

$\begin{array}{ll}20.469 & 20.417 \\ 19.948 & 19.896\end{array}$

$\begin{array}{ll}20.886 & 20.834 \\ 20.365 & 20.313\end{array}$

$\begin{array}{ll}21.303 & 21.25 \\ 20.782 & 20.730\end{array}$

$\begin{array}{llll}21.199 & 21.146 & 21.094 & 21.042 \\ 20.678 & 20.626 & 20.574 & 20.521\end{array}$

4381.0

81.0
1.1
1.2
1.3
1.4
1.5
1.6
1.7
1.8
1.9

22819.427

$\begin{array}{ll}19.427 & 19.375 \\ 18.907 & 18.855 \\ 18.386 & 18.334 \\ 17.865 & 17.813 \\ 17.344 & 17.293 \\ 16.824 & 16.771 \\ 16.303 & 16.251 \\ 15.782 & 15.730 \\ 15.262 & 15.210 \\ 14.741 & 14.689\end{array}$

$\begin{array}{lllll}19.323 & 19.271 & 19.219 & 19.167\end{array}$

19.63

$\begin{array}{lll}20.105 & 20.052 & 20.001 \\ 19.584 & 19.532 & 19.480\end{array}$

$\begin{array}{llll}19.115 & 19.063 & 19.011 & 18.959 \\ 18.594 & 18.542 & 18.490 & 18.438\end{array}$

$\begin{array}{llllllll}18.802 & 18.750 & 18.698 & 18.646 & 18.594 & 18.542 & 18.490 & 18.438 \\ 18.282 & 18.229 & 18.177 & 18.125 & 18.073 & 18.021 & 17.969 & 17.917\end{array}$

$\begin{array}{ll}8.282 & 18.229 \\ 7.761 & 17.709\end{array}$

$\begin{array}{llll}17.761 & 17.709 & 17.657 & 17.605 \\ 17.240 & 17.188 & 17.136 & 17.084\end{array}$

$16.720 \quad 16.668$

17.553

$\begin{array}{lllll}15.678 & 15.626 & 15.574 & 15.043 & 15.991 \\ 15.02 & 15.470\end{array}$

$\begin{array}{lll}17.500 & 17.448 & 17.396\end{array}$

$\begin{array}{lll}16.980 & 16.928 & 16.876 \\ 16.459 & 16.407 & 16.355\end{array}$

$\begin{array}{ll}15.262 & 15.210 \\ 14.741 & 14.689\end{array}$

$\begin{array}{ll}15.157 & 15.106 \\ 14.637 & 14.585\end{array}$

$15.574 \quad 15.522$

4382.

82.0
2.1
2.2
2.3
2.4
2.5
2.6
2.7
2.8
2.9

$13.700 \quad 14 \cdot 168$

$\begin{array}{llll}14.116 & 14.064 & 14.012 & 13.960\end{array}$

$\begin{array}{llll}15.470 & 15.418 & 15.886 & 15.834 \\ 15.366 & 15.314\end{array}$ $13.700 \quad 13.647$

$\begin{array}{ll}13.179 & 13.127 \\ 12.659 & 12.607\end{array}$

$\begin{array}{llll}12.138 & 12.0086 & 12.554 & 12.502\end{array}$

$\begin{array}{llll}12.034 & 11.982 & 11.930 & 11.87\end{array}$

$11.097 \quad 11.045$

$\begin{array}{llll}11.514 & 11.482 & 11.930 & 11.87 \\ 10.993 & 10.941 & 10.409 & 11.357 \\ 10.473 & 10.420 & 10.868 & 10.837\end{array}$

$\begin{array}{ll}10.576 & 10.525 \\ 10.056 & 10.004 \\ 09.536 & 09.484\end{array}$

$\begin{array}{llll}10.473 & 10.420 & 10.889 & 10.837 \\ 0.368 & 10.31\end{array}$

2.7
2.8
2.9

4383.0

3.1 0809.01508 .963 $\begin{array}{ll}08.495 & 08.4 \\ 07.974 & 07.922 \\ 07.454 & 07.402\end{array}$

$07.454 \quad 07.402$

$\begin{array}{ll}06.934 & 06.882 \\ 06.413 & 06.361\end{array}$

$05.893 \quad 05.841 \quad 05.7$.

$\begin{array}{ll}05.373 & 05.321 \\ 04.853 & 04.801 \\ 04.333 & 04.281\end{array}$

$09.432 \quad 09.380$

$08.911 \quad 08.859$

$\begin{array}{ll}09.848 & 09.796 \\ 09.327 & 09.275\end{array}$

4384

401
402
403
404
405
406
407
408
409 03.29203 .240

02.252 2. 02.200

$01.73201 .680 \quad 01.628$

$\begin{array}{lll}01.212 & 01.160 & 01.10 \\ 0.692 & 00.640 & 00.158\end{array}$

$\begin{array}{rrr}00.172 & 00.120 & 00.0 \\ 799.652 & 99.600 & 99.5\end{array}$

99.132

$99.080 \quad 99.02$

4385

5.
5.2
5.
5.
5.5
5.6
5.7
5.0
5.0

22798.612

$98.092 \quad 98.560$

$97.572 \quad 97.521 \quad 97.469$

$97.053 \quad 97.001 \quad 96.949$

$96.013 \quad 95.96$

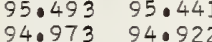

$94.454 \quad 94.402$

$95.909 \quad 95.857$

$\begin{array}{ll}95.389 & 95.337 \\ 94.870 & 94.818\end{array}$

93.93493 .882

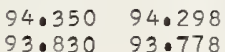

$\begin{array}{ll}8.807 & 08.75 \\ 8.287 & 08.23\end{array}$

$\begin{array}{lll}07.818 & 07.766 & 07.714 \\ 07.298 & 07.246 & 07.19\end{array}$

$\begin{array}{llll}06.778 & 06.726 & 06.673 & 06.622\end{array}$

05.737

$06.206 \quad 06.153$

$\begin{array}{ll}.685 & 05.633 \\ 5.165 & 05.113\end{array}$

05.581105 .529

$\begin{array}{lll}14 \cdot 897 & 14 \cdot 845 & 14.793 \\ 14.377 & 14.324 & 14.272\end{array}$

0.280982

1.230701

0.280981

.280981
.280980

0.280980

0.280979

0.280979
0.280978

0.280978

0.280977

0.280977

0.280976

0.280976

0.28097

0.280975
0.280974

1.230753

1. 230780

1. 230859

1.230921

0.280974

.280973
.280973

0.280973

0.280972
0.280972

0.280971

0.280971

0.280970

1.230964

1.230990
1.231017

1.231043

1.231069
1.231096

1.231148

1.231175
1.231201

0.280970

0.280969

0.280969

0.280968

0.280967

0.280967

0.280967

1. 231227

1. 231280

1. 231333

1.231386

1. 231438

.28096

0.280965

0.280965

0.280964

0.280964

0.280963

0.280962

0.280961

0.280961

0.280960

0.280959
0.280959

0.280959

4386.0

6.
6.
6.
6.
6.5
6.0
6.
6.
6.0

$92.895 \quad 92 \cdot 36$

93.31

93.258

$94.246 \quad 94.104$

95.181

$\begin{array}{lllll}96.793 & 96.741 & 96.689 & 96.636 & 96.585\end{array}$

$92.375 \quad 92.323$

$\begin{array}{llll}91.855 & 91.803 & 91.751 & 91.700\end{array}$

$90.284 \quad 91.232$

$\begin{array}{lll}90.816 & 90.764 & 90.712 \\ 90.297 & 90.245 & 90.193\end{array}$

$\begin{array}{llll}89.777 & 89.725 & 89.673 & 89.621\end{array}$

$\begin{array}{lllllllll}89.206 & 89.154 & 89.102 & 89.050 & 88.998 & 88.946 & 88.894 & 88.842 & 88.790\end{array}$

88.

4387

$$
\begin{array}{r}
387.0 \\
70 \\
70 \\
70 \\
70 \\
70 \\
70 \\
70 \\
70
\end{array}
$$

7.0
77.2
7.4
7
7.7
7.8

22788.2109

$88.219 \quad 88 \cdot 167$

$\begin{array}{llll}87.699 & 87.647 & 88.115 & 88.063 \\ 87.180 & 87.128 & 87.595 & 87.543\end{array}$

$\begin{array}{llll}86.660 & 86.608 & 87.076 & 87.024 \\ 86.557 & 86.505\end{array}$

$\begin{array}{lllll}86.141 & 86.089 & 86.037 & 85.985\end{array}$

$85.622 \quad 85.570 \quad 85.518085 .466$

$85.102 \quad 85.050 \quad 84.998-84.947$

$84.064 \quad 84.012 \quad 83.960 \quad 83.90$

$83.545 \quad 83.493$

$\begin{array}{ll}83.960 & 83.90 \\ 83.441 & 83.38\end{array}$

$93.206 \quad 93.154$

030100

$95.077 \quad 95.025$

$\begin{array}{ll}.038 & 93.986 \\ 3.518 & 93.466\end{array}$

0.280958

0.28095

0.280957

0.280956

0.280956

0.280955

0.280954

0.280954

0.280953

0.280953

0.280953

0.280952

0.280951

0.280950

0.280949

0.280949

0.280949

0.280948

0.280947

0.280947

0.280947

0.280946

$\begin{array}{llllllllll}79.391 & 79.340 & 79.288 & 79.236 & 79.184 & 79.132 & 79.080 & 79.028 & 78.976 & 78.924\end{array}$

$\begin{array}{llllllllll}78.873 & 78.821 & 78.769 & 78.717 & 78.665 & 78.613 & 78.562 & 78.509 & 78.457 & 78.406 \\ 78.354 & 78.302 & 78.250 & 78.198 & 78.146 & 78.094 & 78.042 & 77.990 & 77.938 & 77.887\end{array}$

0.280946

0.280945

0.280945

0.280944

0.280944

0.280943

0.280943

1.231491

1.231544

1.231596

1.231623

1.231675

1.231702
1.231728

1.231754

1. 231807

. 231833

1. 231886

1.231912

1.231965
1.231991

1.232018

1.232070

1.232097

-232123

1.232176

1. 232228

${ }_{1}^{1} .22322281$

I. 232334

.232387

1.232413
1.232439

1.232466
1.232492

1.232518

1.232545

.232597

1.232624

1. 232676

1.232703

.232755
.232782

1.232808

I. 232834

1.232861

.232913

1.232966

1.233019

1.233071

1.233098

$\begin{array}{llllllllll}76.797 & 76.745 & 76.693 & 76.641 & 76.589 & 76.537 & 76.485 & 76.434 & 76.382 & 76.330\end{array}$

$\begin{array}{llllllllll}75.759 & 75.707 & 75.655 & 75.603 & 75.552 & 75.0500 & 75.448 & 75.396 & 75.344 & 75.292\end{array}$

$\begin{array}{llllllllll}75.240 & 75.188 & 75.136 & 75.084 & 75.032 & 74.981 & 740929 & 74.877 & 74.825 & 74.773 \\ 74.721 & 74.669 & 74.617 & 74.566 & 74.514 & 74.462 & 74.910 & 74.358 & 74.306 & 74.0254\end{array}$

$\begin{array}{llllllllll}74.721 & 74.669 & 74.617 & 74.566 & 74.514 & 74.462 & 74.410 & 74.358 & 74.306 & 74.254 \\ 74.202 & 74.151 & 74.099 & 74.047 & 73.995 & 73.943 & 73.891 & 73.839 & 73.077 & 73.736\end{array}$

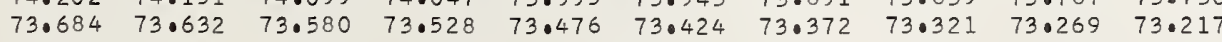

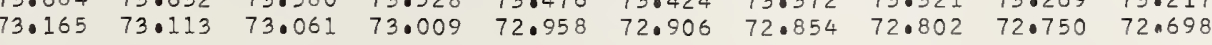

.020

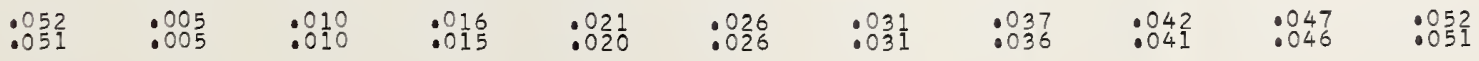


0.1

0.3

0.4
0.5

0.6
0.7
0.8
0.9

4391.

1.1
1.2

1.2
1.3

1.4
1.5

1.5
1.6

$1: 7$
$1: 8$
1.9

4392.0

$2 \cdot 1$
$2 \cdot 2$
$2 \cdot 3$

2.3

2.4
2.5

2.6
2.7
2.8

2.8
2.9

4393.

,

3.3
3.4

3.5
3.6

3.8
3.9

43940

401
4.2
40.3

4.22
4.3
4.4

4.5
4.6

4.7

4.8

4395.

$5 \cdot 1$

$5 \cdot 3$

$5 \cdot 5$

5.6
5.7

5.8
5.9

4396.

6.

6.2
6.3
60.4

6.4

6.6
6.7

6.7
6.8

6.

4397.

7.01
770.2
70.3
79.0

7.3
7.4

7.5
7.6

7.7
7.8

7.8
7.9

4398

8.1
8.2

8.3

8.5

8.6

8.8

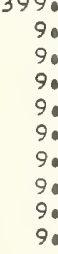

72.646
710.608
71009

$\begin{array}{llllllllll}69.534 & 69.482 & 69.430 & 69.378 & 69.327 & 69.275 & 69.223 & 69.171 & 69.119 & 69.067\end{array}$

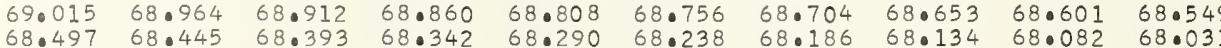

$\begin{array}{llllllllll}68.497 & 68.445 & 68.393 & 68.342 & 68.290 & 68.238 & 68.186 & 68.134 & 68.082 & 68.031 \\ 67.979 & 67.927 & 67.875 & 67.823 & 67.771 & 67.719 & 67.667 & 67.616 & 67.564 & 67.512\end{array}$

$22767.460 \quad 67 \cdot 408$

$\begin{array}{ll}66.941 & 66 \cdot 8 \\ 66.423 & 66 \cdot 3\end{array}$

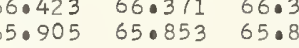

$65.386 \quad 65.334 \quad 65.282$

$\begin{array}{ll}64.867 & 64.81 \\ 64.349 & 64.29\end{array}$

$63.83164 .298 \quad 64.246$

63.313
62.795

22762.27

$61.758 \quad 62 \cdot 224$

$61.240 \quad 61.706$

$60.721 \quad 60.670$

$\begin{array}{ll}60.203 & 60.15 \\ 59.685 & 59.633\end{array}$

$\begin{array}{ll}59.167 & 59.11 \\ 58.649 & 58.597\end{array}$

$\begin{array}{ll}58.131 & 58.07 \\ 57.613 & 57.56\end{array}$

22757.095

56.577

$55.541 \quad 55.489$

$55.023 \quad 54.97$

$\begin{array}{lll}54.505 & 54.453 & 54.402\end{array}$

$\begin{array}{llll}5.987 & 53.936 & 53.884 & 53.832\end{array}$

$52.951 \quad 52 \cdot 900$

22751.9

$51.398 \quad 51.346$

$\begin{array}{llll}50.363 & 50.311 & 50.259 & 50.207\end{array}$

$48.292 \quad 48.240$

$\begin{array}{ll}47.774 & 47 \cdot 722 \\ 47.257 & 47.205\end{array}$

22746.739

$46.222 \quad 46.170$

45.704

$45 \cdot 187 \quad 45 \cdot 135$

$44.669 \quad 44.617$

$440151-440100 \quad 44.56$

$440100,44.048 \quad 43.096$

$\begin{array}{llll}43.116 & 43.065 & 43.013 & 42.96\end{array}$

$\begin{array}{lll}42.599 & 42.548 & 42.49\end{array}$

22741.56

40.5

40.01339 .961

$39.496 \quad 39.444$

$\begin{array}{lll}38.927 & 38.875\end{array}$

$\begin{array}{lll}37.893 & 37.841 & 37.789\end{array}$

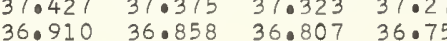

22736.393

$35.876 \quad 36.341$

$35.359 \quad 35.82$

$\begin{array}{ll}34.842 & 34.7790 \\ 34.325 & 34 \cdot 273\end{array}$

$33.808 \quad 33.75$

$33.291 \quad 33.239$

$\begin{array}{ll}32.257 & 32.205 \\ 31.740 & 31.688\end{array}$

36.2

35.77
35.25

36.238

36.721
55.204

3.687
4.169

$33.705 \quad 33.653$

$33 \cdot 187$

32.6

$22731.223 \quad 31.172$

30.706

$30.189 \quad 30.138$

$29.67329 .621 \quad 29$.

$\begin{array}{llll}29.156 & 29.104 & 29.053 & 29.001\end{array}$

$\begin{array}{llll}28.039-28.587 & 28.536 & 28.484\end{array}$

$\begin{array}{llll}28.123 & 28.071 & 28.019 & 27.968 \\ 27.605 & 27.554 & 27.502 & 27.451\end{array}$

$\begin{array}{llll}27.089 & 27.037 & 26.986 & 26.934 \\ 26.573 & 26.521 & 26.469 & 26.417\end{array}$

25.53925 .487

25.022
24.506
24.9

$\begin{array}{llll}23.990 & 23.938 & 23.886 & 23.834\end{array}$

$\begin{array}{llll}22.957 & 22.905 & 22.353 & 22.80\end{array}$

$\begin{array}{llll}22.440 & 22.389 & 22.337 & 22.28 \\ 21.924 & 21.872 & 21.820 & 21.76\end{array}$

$21.407 \quad 21.356 \quad 21.304 \quad 21.252$

$\begin{array}{lll}.001 & .002 \quad .003\end{array}$

\begin{abstract}
.003
\end{abstract}
.004

$51 \cdot 709$
51.191
50.673

.19151 .139

.657
.139
.621

$\begin{array}{ll}50.156 & 50.10 \\ 49.638 & 49.586\end{array}$

49.120
48.603

49.068

48.55
48.033

48.08
47.567
47.050

47.515
46.998

46.532

46.480

$45.497 \quad 45.445$

$44.980 \quad 44.92$

$44 \cdot 46$

$43.945 \quad 43.893$

$43 \cdot 427$

42.910
42.39

43.37

42.858

67.667

67.61

66.993

$\begin{array}{llll}66.630 & 66.579 & 66.527 & 66.475\end{array}$

$66.112 \quad 66.060 \quad 66.008 \quad 65.956$

$65.075 \quad 65.023 \quad 64.971 \quad 64.919$

$\begin{array}{lllll}64.557 & 64.505 & 64.453 & 64.401\end{array}$

$\begin{array}{llll}63.520 & 63.487 & 63.935 & 63.883 \\ 63.417 & 63.365\end{array}$

$\begin{array}{llll}63.002 & 62.950 & 62.898 & 62.846 \\ 62.483 & 62.432 & 62.380 & 62.328\end{array}$

$61.965 \quad 61.913 \quad 61.862 \quad 61.810$

$\begin{array}{llll}61.447 & 61.395 & 61.343 & 61.291 \\ 60.929 & 60.877 & 60.825 & 60.773\end{array}$

$\begin{array}{llll}60.410 & 60.358 & 60.307 & 60.255\end{array}$

$\begin{array}{llll}59.893 & 59.841 & 59.789 & 59.737 \\ 59.374 & 59.322 & 59.271 & 59.219\end{array}$

$\begin{array}{llll}58.856 & 58.805 & 59.271 & 59.219 \\ 58.753 & 58.701\end{array}$

$\begin{array}{llll}58.338 & 58.287 & 58.235 & 58.183\end{array}$

57.665
57.147

(

0.280942

0.280941
0.280941

0.280941

0.280940

0.280940

0.000

0.280938

0.280938

0.280938

0.280937

0.280936

0.280936

0.280936

0.280935

0.280935
0.280934

0.280934

0.280934

0.280933
0.280933

0.280932

0.280932

0.280932

0.280931

0.280931
0.280930

0.280930

0.280930

0.280929

0.280929

0.280928

0.280928

0.280927

0.280927

1.233335
1.233361

1. 233361

1.233414

1.233440
1.233467

1.233493

1.233546

1.233598

I. 233625

1.233651

1. 233704

1.233730

1.233756

1.233783
1.233809

1.233862

1. 233888

1. 233914

1. 233967

1. 233994

1.234020
1.234046

1. 234073

1.234125

1.234152

1. 234178

1.234204
1.234231

1.234257

1.234283

1. 234336

0.280926

0.280926

0.280925

0.280925

0.280924

0.280924
0.280924

0.280923

0.280923

0.28092

0.280922
0.280922

0.280921

0.280921
0.280920

0.280920

0.280920
0.280920

0.280920

0.280919

0.280918

0.280918

0.280918

0.280917

0.280917

0.280916

0.280916

0.280915

0.280915
0.280914

0.280914

0.280914

0.280913
0.280913

0.280913
0.280912

0.280912

0.280912

0.280911

0.280911
0.280910

0.280910

0.280910

0.280909

0.280909

0.280908

0.280908

0.280907

0.280907

. 234362 
$2710.568 \quad 10.516$

$\begin{array}{lll}12.013 & 12.477 & 12.426 \\ 12.961 & 11.909\end{array}$

12.374
11.858

12.838
12.323

$\begin{array}{lll}15.367 & 15.316 & 15.264 \\ 14.851 & 14.799 & 14.748\end{array}$

$\begin{array}{lll}14.851 & 14.799 & 14.748 \\ 14.335 & 14.284 & 14.232\end{array}$

$\begin{array}{lll}13.819 & 13.767 & 13.716 \\ 13.303 & 13.251 & 13.200\end{array}$

$\begin{array}{lll}12.787 & 12.735 & 12.684 \\ 12.271 & 12.219 & 12.168\end{array}$

$\begin{array}{lll}12.271 & 12.219 & 12.168 \\ 11.755 & 11.703 & 11.652\end{array}$

4402.0

2.0
2.2
2.0
2.5
2.0
2.7
2.0
2.9

$10.052 \quad 10.001$

10.929

09.02108 .969

$08.505 \quad 08.453$

$\begin{array}{llll}10.465 & 10.413 & 10.362 & 10.310 \\ 09.949 & 09.897 & 09.846 & 09.795\end{array}$

11.291
10.777

10.72

$\begin{array}{ll}11.187 & 11.136 \\ 10.671 & 10.620\end{array}$

$\begin{array}{llll}10.259 & 10.207 & 10.156 & 10.104 \\ 09.743 & 09.691 & 09.639 & 09.588\end{array}$ $\begin{array}{lll}07.989 & 07.937 \\ 07.473 & 07.421 & 07\end{array}$

$\begin{array}{lllll}09.433 & 09.382 & 09.330 & 09.27\end{array}$

09.227
08.71

$05.957 \quad 06.906$

$\begin{array}{lll}08.401 & 08.850 & 08.814 \\ 0.08 & 08.29\end{array}$

$\begin{array}{ll}06.442 & 06.390 \\ 05.926 & 05.874\end{array}$

07.370

07.8 .34
07.318

$\begin{array}{ll}07.783 & 07.7247 \\ 07.267 & 07.215\end{array}$

08.195

09.6917

09.639

$\begin{array}{ll}09 \cdot 124 & 09 \cdot 072 \\ 08.608 & 08.556\end{array}$

$\begin{array}{lll}07.628 & 08.092 & 08.041 \\ 07676 & 07.525\end{array}$

$\begin{array}{lllll}07.164 & 07.112 & 07.060 & 07.009 \\ 06.648 & 06.596 & 06.545 & 06.493\end{array}$

2270

4403

3.0
3.1
3.0
3.
30
3.
3.
3.7
3.0
3.9

$\begin{array}{ll}04.410 & 05.35 \\ 04.895 & 04.843\end{array}$

$04.379 \quad 04.328$

$03.348 \quad 03.296$

02.83202 .780

0.31702 .26502 .213

$01.285 \quad 01.750 \quad 01.698 \quad 01.646$

06.75106 .69

$\begin{array}{lll}6.338 & 06.287 & 06.23 \\ 5.823 & 05.771 & 05.71\end{array}$

06.184
05.668

05.617

$\begin{array}{lll}05.081 & 06.029 & 05.978 \\ 05.565 & 05.513 & 05.462\end{array}$

0.280902

0.280901

0.280901

0.280900

.28089

0.280899
0.280899

0.280898

0.280898
0.280897

0.280897

0.280896

0.280896

0.280895

0.280894

0.280894

0.280893

0.280893

0.280892

0.280892

0.280891

0.280890

0.280890

0.280890
0.280889

0.280889

0.280888

0.280888

.280887

0.280887

4404.0 $\begin{array}{ll}0.771 & 00.719\end{array}$

4.
40.
40
40.
40
40.6
40.7
40.8
409

$\begin{array}{ll}22700.255 & 00.2 \\ 22699.740 & 99.6\end{array}$

$99.224 \quad 99.173$

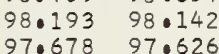

$97.163 \quad 97.111$

$\begin{array}{ll}96.647 & 96.596 \\ 96.132 & 96.080 \\ 95.617 & 95.565\end{array}$

$00.152 \quad 00.100$

01.079
00.564

$99.636 \quad 99.585$ 9 99.

$0.049 * 99.997$

$\begin{array}{llll}00.976 & 00.925 & 00.873 & 00.822 \\ 00.461 & 00.409 & 00.358 & 00.306\end{array}$

0.28088

0.280886

0.280886

0.280885

0.280884

0.280884

0.280883

0.280883

4405.
5.
5.
50
50
5.5
50
507
5.8
5.

$22695.102 \quad 95.050$

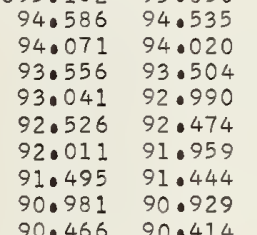

$\begin{array}{ll}94.999 & 94.947 \\ 94.483 & 94.432\end{array}$

$96.441 \quad 96.390$

$\begin{array}{llll}97.369 & 97.317 & 97.266 & 97.214 \\ 96.854 & 96.802 & 96.750 & 96.699\end{array}$

$97.059 \quad 97.00$

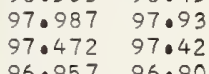

$\begin{array}{llllll}5.926 & 95.375 & 96.338 & 96.287 & 96.235 & 96.184 \\ 95.823 & 95.771 & 95.720 & 95.66\end{array}$

94.89

\begin{abstract}
94.844
\end{abstract}
94.79

$95.256 \quad 95.205 \quad 95.153$

0.280882

0.280882

0.280881

0.280881

0.280880

0.280880

0.280879
0.280879

4406.0

6.0
6.2
6.
6.4
6.5
6.6
6.7
6.
6.9

22689.951

$89.951 \quad 89.899$

$89.436 \quad 89.384 \quad 89.838$

$\begin{array}{lll}88.406 & 88.354 & 88.31 \\ 87.891 & 87.840 & 87.78\end{array}$

$\begin{array}{llll}87.891 & 87.840 & 87.788\end{array}$

$\begin{array}{lllll}87.376 & 87.324 & 87.273 \quad 87.222\end{array}$

$\begin{array}{llll}86.861 & 86.810 & 86.758 & 86.70 \\ 86.346 & 86.295 & 86.244 & 86.19\end{array}$

$\begin{array}{llll}86.346 & 86 \cdot 295 & 86.244 & 86.192 \\ 85.832 & 85.780 & 85.729 & 85.677\end{array}$

$85.317 \quad 85.265 \quad 85.214 \quad 85.162$

4407.0

$2684.802 \quad 84.750$

$\begin{array}{llll}84.257 & 84.236 & 84.699 & 84.6 \\ 84.0184 & 84.133\end{array}$

$\begin{array}{lllll}83.772 & 83.721 & 83.670 & 83.61 \\ 83.258 & 83.206 & 83.155 & 83.010\end{array}$

$\begin{array}{llll}82.758 & 83.206 & 83.155 & 83.104 \\ 82.692 & 82.640 & 82.58\end{array}$

$82.126 \quad 82.074$

$\begin{array}{llll}81.714 & 81.663 & 81.611 & 81.55\end{array}$

$80.685 \quad 80.634 \quad 80.582 \quad 80.531$

$\begin{array}{llll}80.171 & 80.119 & 80.068 & 80.016\end{array}$

$\begin{array}{llllll}92.320 & 92.268 & 92.217 & 92.165 & 92.114 & 92.062 \\ 91.805 & 91.753 & 91.702 & 91.650 & 91.599 & 91.547\end{array}$

$\begin{array}{llllll}. .290 & 91.238 & 91.182 & 91.6135 & 91.084 & 91.032\end{array}$

0.280878

0.280878

0.280877

0.280877

0.280876

0.280876

0.280875
0.280875

0.280875

0.280874

0.280874
0.280873

0.280873

0.280873

0.280872

0.280871

1.235970

1. 236022

236049
-236075

1.23610

1.236154

I. 236207

1.236233

.236286

I. 236312

.236365

.236391
.

136444
.236470

1.236497

1.236523

1.236576

1.236602
1.236628

1.236655

1.236681
1.236707

1.236734

1.236760

1. 236813

1. 236839

.
1.236892

1. 236918

I. 236971

.

1.237024

1.237050

1.237129

1. 237155

1. 237208

1.237234
1.237261

0.280871

1.237287

1. 237340

1.237366
1.237393

1.237419
1.237445

1.237472
1.237498

1.237551
1.237577

1.237603
1.237630

1.237656

.237682
. .237709

1. 237735

1. 237761

0.280871

0.280870

0.280869

0.280869

0.280869

0.280868

0.280867

1.237814
1.237841

1. 237867

1.237893

1.237946

1. 237972

1. 237999

1.238051

4408.0
8.
8.2
8.
8.
8.5
8.6
8.7
8
8 $\begin{array}{llllllllll}79.142 & 79.090 & 79.039 & 78.987 & 78.936 & 78.885 & 78.833 & 78.781 & 78.730 & 78.678 \\ 78.627 & 78.576 & 78.524 & 78.473 & 78.421 & 78.370 & 78.318 & 78.267 & 78.216 & 78.164\end{array}$

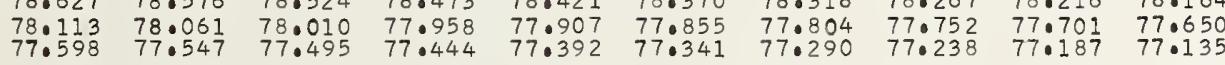
$\begin{array}{lllllllllll}77.084 & 77.032 & 76.981 & 76.929 & 76.878 & 76.826 & 76.775 & 76.724 & 76.672 & 76.621 \\ 76.0570 & 76.518 & 76.467 & 76.415 & 76.364 & 76.312 & 76.261 & 76.209 & 76.958 & 76.106\end{array}$ $\begin{array}{llllllllll}76.570 & 76.518 & 76.467 & 76.415 & 76.364 & 76 \cdot 312 & 76.261 & 76.209 & 76.158 & 76.106 \\ 76.055 & 76.004 & 75.952 & 75.901 & 75.849 & 75.798 & 75.746 & 75.695 & 75.644 & 75.592\end{array}$ $\begin{array}{llllllllll}75.541 & 75.489 & 75.438 & 75.387 & 75.335 & 75.284 & 75.232 & 75.181 & 75.129 & 75.07\end{array}$

0.280867

1.238078

0.280867

0.280866

0.280866

0.280866

0.280865

0.280864

0.280864

0.280864

$\frac{1.238104}{1.238130}$

$\frac{1}{1.238157}$

1.238209

1.238262

1.238289

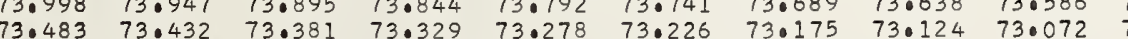

$\begin{array}{llllllllll}72.969 & 72.918 & 72.866 & 72.815 & 72.764 & 72.712 & 72.661 & 72.610 & 72.558 & 72.507\end{array}$

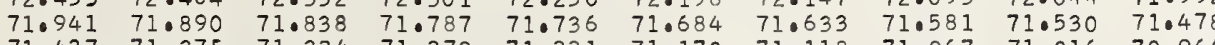

$\begin{array}{llllllllll}70.913 & 70.862 & 70.810 & 70.759 & 70.707 & 70.656 & 70.604 & 70.553 & 70.502 & 70.450\end{array}$

$\begin{array}{lllllllllll}70.399 & 70.347 & 70.296 & 70.244 & 70.193 & 70.142 & 70.090 & 70.039 & 69.987 & 69.936\end{array}$

$69.885 \quad 69.833 \quad 69.782 \quad 69.730 \quad 69.679 \quad 69.627$

6.576

$69.525 \quad 69.473 \quad 69.422$

1.238341

1.238394

1.238447

1.238473

1.238499

1.238552

.010

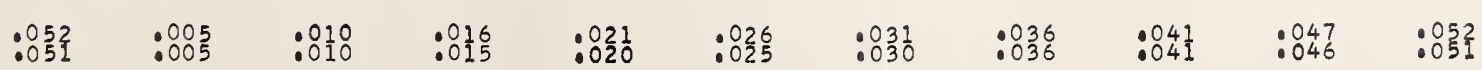


0.280859

0.280858

0.280858

0.280858
0.280857

0.280857
0.280857

0.280856

0.280856

0.280856
0.280855

0.280855

0.280855

0.0280854

0.280854

0.280853

0.280853

0.280852

0.0280851

0.280851

0.28085

0.280850

0.280850

0.280849

0.280849

0.280848

0.280847

0.280847

0.280847
0.280846

0.280846

0.280846

0.280845
0.280845

0.280845

0.280844

0.280844

0.280843
0.280843

0.280842

0.280842

0.280842

0.280841

0.280841

0.280840

0.280840
0.280840

0.280839

0.280839

0.280838

0.280838

0.280838
0.280837 0.280837
0.280837 0.280837 0.280836 0.280836

0.280835 0.280835
0.280835 0.280835
0.280834
0 0.280834 0.280833 0.280833 0.280833 0.280832
0.280832

0.280831 0.280831 0.280831
0.280830 0.280830 0.280829 0.280829 0.280829 0.280828
0.280828

0.280828 0.280827 0.280827 0.280826 0.280826
0.280826 0.280825 0.280825 0.280824
0.280824 .238631
.238657 1.238684 1.238737 1.238763 1.238816
1.238842

1.238868 1.238895 1.238921 1.238947 1.238974 1.239000 1.239026 1.239079
1.023907 


.02

$\begin{array}{llllllll}17.981 & 17.930 & 17.879 & 17.828 & 17.776 & 17.725 & 17.674 & 17.623 \\ 17.469 & 17.418 & 17.367 & 17.316 & 17.265 & 17.213 & 17.162 & 17.111\end{array}$

0.2

$16.548 \quad 16.009$

$16.958 \quad 16.906$

$\begin{array}{llllll}16.855 & 16.804 & 16.753 & 16.702 & 16.551 & 16.599\end{array}$

$16.037 \quad 15.986$

$16.446 \quad 16.395$

$\begin{array}{llllll}16.344 & 16.292 & 16.241 & 16.190 & 16.139 & 16.088\end{array}$

0.06

$\begin{array}{ll}15.013 & 14.962 \\ 14.502 & 14.451\end{array}$

$\begin{array}{ll}5.423 & 15.372 \\ 4.911 & 14.860\end{array}$

$\begin{array}{llllll}4.320 & 15.269 & 15.218 & 15.167 & 15.116 & 15.065 \\ 14.809 & 14.758 & 14.707 & 14.656 & 14.604 & 14.553 \\ 4.297 & 14.246 & 14.195 & 14.144 & 14.003 & 14.042\end{array}$

$\begin{array}{llllllllll}13.990 & 13.939 & 13.888 & 13.837 & 13.786 & 14.735 & 14.195 & 14.144 & 14.093 & 14.042\end{array}$

0.8

13.47

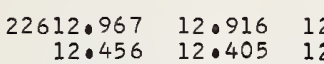

$\begin{array}{lllllllll}12.865 & 12.814 & 12.763 & 12.712 & 12.660 & 12.609 & 12.558 & 12.507 \\ 12.354 & 12.302 & 12.251 & 12.200 & 12.149 & 12.098 & 12.047 & 11.995\end{array}$

11.944311 .893 $\begin{array}{llllllllll}10.922 & 10.870 & 10.819 & 10.768 & 10.717 & 10.666 & 10.615 & 10.564 & 10.512 & 10.461\end{array}$ $\begin{array}{llllllllll}0.410 & 10.359 & 10.308 & 10.257 & 10.206 & 10.155 & 10.103 & 10.052 & 10.001 & 09.950\end{array}$

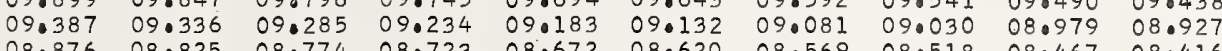
$\begin{array}{llllllllll}08.876 & 08.825 & 08.774 & 08.723 & 08.672 & 08.620 & 08.569 & 08.518 & 08.467 & 08.416 \\ 08.365 & 08.314 & 08.263 & 08.211 & 08.160 & 08.109 & 08.058 & 08.007 & 07.956 & 07.905\end{array}$

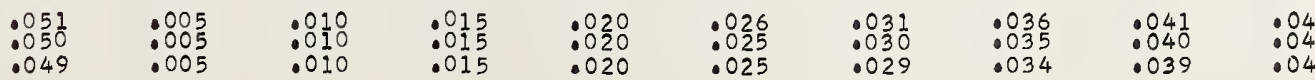

0.280823

0.280822

0.280822

0.280821

0.280821

0.280820

0.280819

0.280819

0.280818

0.280818

0.280817

0.280817
0.280816

0.280816

0.280815

0.280815

0.280814

0.280814

0.280813

0.280813

0.280812

0.280812

0.280811

0.280810

0.280810

0.280810

0.280809

0.280809

0.280808

0.280808

0.280807
0.280807

0.280807

0.280806

0.280806

0.280805
0.280805

0.280805

0.280804

0.280804
0.280803
0.280803

0.280803
0.280803

0.280803

0.280802
0.280802

0.280801

0.280801

0.280800

0.280800

0.280800

0.280799

0.280798

0.280798

0.280798

0.280797

0.280796

0.280796

0.280796
0.280795

0.280795

0.280794

0.280793
0.280793

0.280793

0.280792
0.280792

0.280792
0.080791
0

0.280791

0.280790

0.280790
0.280789

0.280789
0.280789

0.280789

0.280788

0.280788
0.280787 


.05

.06

.07

.08

.09

$(n-1) \times 1000$

$\lambda(n-1)$

\subsection{1
0.3
0.4
0.5
0.7
0.7
0.7}

\section{1}

$$
\begin{aligned}
& 31.0 \\
& 1.1 \\
& 1.2 \\
& 1.3 \\
& 1.4 \\
& 1.5 \\
& 1.6 \\
& 1.7 \\
& 1.8 \\
& 1.9
\end{aligned}
$$

$\begin{array}{ll}7 & 66 \\ 8 & 66 \\ 9 & 65 \\ 0 & 65 \\ 1 & 64 \\ 1 & 64 \\ 2 & 63 \\ 4 & 620\end{array}$

66.97
$65:$
65.

5.958

$\begin{array}{ll}7 & 6 \\ 8 & 6 \\ 8 & 6 \\ 9 & 6 \\ 0 & 6 \\ 1 & 6 \\ 2 & 6 \\ 2\end{array}$

$\begin{array}{ll}6.416 & 650 \\ 5.907 & 650 \\ 5.397 & 65 \\ 4.888 & 640 \\ 4.379 & 640 \\ 3.870 & 630 \\ 3.361 & 630 \\ 2.851 & 62 \\ 2.342 & 62\end{array}$

$\begin{array}{lll}66.875 & 66.824 & 66.7 \\ 60.365 & 66.314 & 66.2 \\ 65.856 & 65.805 & 65.7 \\ 65.346 & 65.295 & 65.2\end{array}$

66.773
65.263
65.754

$\begin{array}{llll}66.722 & 66.6711 & 66.620 & 66.569 \\ 66.212 & 66.161 & 66.110 & 66.060\end{array}$

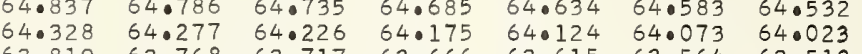

\section{.0 .819}

22561.935 61.426

60.407

59.89860 .356

59.38959 .338

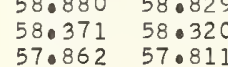

$\begin{array}{lll}57.862 & 57.811 \\ 57.353 & 57.302\end{array}$

22556.844

56.335
55.826
55.317

55.317
55.80
5.350

$54.300-54.249 \quad 54.707$

$\begin{array}{rl}53.791 & 53.740 \\ 53.282 & 5.720\end{array}$

$\begin{array}{lll}52.773 & 52.722 \\ 52.255 & 52.214 & 52\end{array}$

$22551.756 \quad 51.705$

$51.247 \quad 510196$

$50.738 \quad 50.687$

$\begin{array}{ll}50.230 & 50.179 \\ 49.721 & 49.670\end{array}$

$49.212 \quad 49.161$

$\begin{array}{ll}48.704 & 48.653 \\ 48.195 & 48.145 \\ 47.687 & 47.636\end{array}$

47.687
47.178

22546.670

46.161

$44.635-5.093540 .0077$

$44.127 \quad 44.077$

43.619

42.603

43.060
42.552

22541.58

$41.078 \quad 41.535$

$40.569 \quad 40.519$

$40.062 \quad 40.011$

$39.045 \quad 38.994$

$38.537 \quad 38.486$

$\begin{array}{ll}37.021 & 37.978 \\ 37.013 & 36.962\end{array}$

22536.505

35099

$\begin{array}{ll}35.489 & 35.43 \\ 34.980 & 34.933\end{array}$

$33.965 \quad 33.014$

$33.457 \quad 33.406$

$\begin{array}{ll}32.441 & 32.890 \\ 31.933 & 31.882\end{array}$

61.833
61.324
60.81
60.305
59.797
59.287
58.77
58.26
57.76
57.25

$\begin{array}{ll}10 & 63 \\ 01 & 62 \\ 91 & 62\end{array}$

63.208

63.666

63.615

63.564

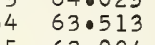

63.004
62.095

$\begin{array}{lllll}.782 & 61.731 & 61.680 & 6\end{array}$

$\begin{array}{lll}.782 & 61.73 \\ 3 & 61022 \\ 7 & 600.71 \\ 255 & 60.02\end{array}$

60.255
59.745
59.20
59.237

59.237
58.727
58.218

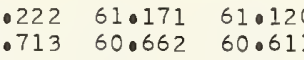

$\begin{array}{lll}0.694 \quad 59.643 & \\ .186 & 59.615 & 5\end{array}$

60.102
59.593

51.57
61.06

$62.037 \quad 61.986$

58.575

$61.018 \quad 60.067$

$60.051 \quad 60.000 \quad 50.0449$
50.05250

$59.542 \quad 590491 \quad 590440$

22531.

$\begin{array}{ll}30.017 & 31.310 \\ 30.867\end{array}$

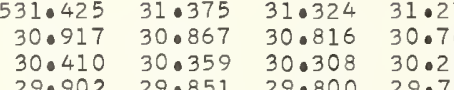

$\begin{array}{llll} & \\ 29.492 & 29.851 & 29.3000 & 30.258 \\ 29.750 & 29.750\end{array}$

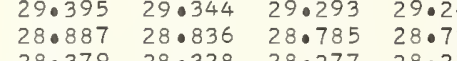

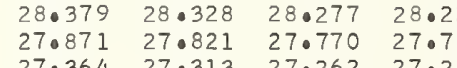

$\begin{array}{lll}27.364 & 27.313 \\ 26.856 & 26.805\end{array}$

27.262
26.755

$25.841 \quad 25: 090$

$\begin{array}{ll}25 \cdot 333 & 25.22 \\ 24.826 & 24.775\end{array}$

$24.319 \quad 24.26$

$\begin{array}{ll}26.247 & 26.1 \\ 25.740 & 2506\end{array}$

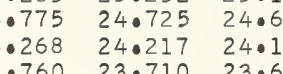

$\begin{array}{lll}230304 & 23.253 & 23.020\end{array}$

$\begin{array}{lllll}22.796 & 22.745 & 22.695 & 23.152 & 22.644 \\ 22 & 22\end{array}$

$\begin{array}{lll}22.0289 & 22.238 \\ 21.781 & 21.731 & 21\end{array}$

22521.274

$\begin{array}{rl}2521.274 & 21.22 \\ 20.767 & 20.076\end{array}$

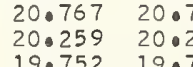

21.068

22.137
21.6220

$19.245 \quad 19.19$

$\begin{array}{ll}21.173 & 21.122 \\ 20.065 & 20.615 \\ 19065 & 20.607\end{array}$

(5700

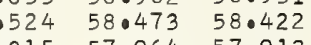

$\begin{array}{llllll}.167 & 58.116 & 58.065 & 58.015 & 57.964 & 57.913 \\ & 57.608 & 57.557 & 57.506 & 57.455 & 57.404\end{array}$

. 45557.404

$\begin{array}{lllllllll}56.742 & 56.692 & 56.641 & 56.590 & 56.539 & 56.488 & 56.437 & 56.386\end{array}$

5.8877
5.368

$\begin{array}{lllllll}.674 & 55.623 & 55.0572 & 55.521 & 55.470 & 55.419 & 55.368 \\ 5.165 & 55.114 & 55.063 & 55.012 & 54.961 & 540910 & 54.859\end{array}$

$\begin{array}{llllllll}.056 & 540605 & 54.554 & 54.503 & 54.452 & 54.402 & 54 \cdot 351 \\ .147 & 54.096 & 54.045 & 53.994 & 53.943 & 53.893 & 53.842\end{array}$

$\begin{array}{lllllll}.638 & 53.5877 & 53.537 & 53.486 & 53.435 & 53.384 & 53.333 \\ .129 & 53.078 & 53.027 & 52.977 & 52.026 & 52.875 & 52.824\end{array}$

$\begin{array}{lll}2.621 & 52.570 & 52.5 \\ 2.112 & 52.061 & 5200\end{array}$

-1
5

\begin{tabular}{l}
$51.959 \quad 51.908 \quad 51.857 \quad 51.806$ \\
\hline
\end{tabular}

$\begin{array}{lllllll}.093 & 51.552 & 51.501 & 51.450 & 51.399 & 51.349 & 51.298 \\ 51.044 & 50.993 & 50.942 & 50.891 & 50.840 & 50.789\end{array}$

$\begin{array}{lllllll}.586 & 50.535 & 50.484 & 50.433 & 50.382 & 50.332 & 50.281\end{array}$

$\begin{array}{lllllll}.568 & 49.517 & 49.467 & 49.416 & 49.8765 & 49.823 & 49.714 \\ 49.263\end{array}$

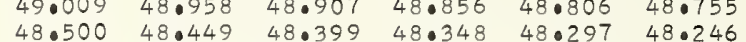

$\begin{array}{llll}48.399 & 48.348 & 48.297 & 48.246\end{array}$

$\begin{array}{lllllll}.043 & 47.992 & 47.941 & 47 \cdot 890 & 47.839 & 47.789 & 47.738 \\ 534 & 47.483 & 47.432 & 47.0381 & 47.331 & 47.280 & 47.229\end{array}$

$\begin{array}{llllll}47.483 & 47.432 & 47.381 & 47.331 & 47.280 & 47.229 \\ 46.975 & 46.924 & 46.873 & 46.822 & 46.771 & 46.720\end{array}$

$\begin{array}{llllll}46.466 & 46.415 & 46.364 & 46.313 & 46.263 & 46.212\end{array}$

$\begin{array}{llllll}45.449 & 45.907 & 45.856 & 45.805 & 45.754 & 45.703 \\ 45.398 & 45.347 & 45.297 & 45.246 & 45.195\end{array}$

$\begin{array}{lllllll}44.941 & 44.890 & 44.839 & 44.788 & 44.737 & 44.687\end{array}$

$43.924 \quad 43.874 \quad 43.823 \quad 43.772 \quad 43.721 \quad 43.670$

$\begin{array}{llllll}43.416 & 43.365 & 43.314 & 43.264 & 43.213 & 43.162\end{array}$

$\begin{array}{llllll}42.907 & 42.857 & 42.806 & 42.755 & 42.704 & 42.654 \\ 42.399 & 42.349 & 42.298 & 42.247 & 42.196 & 42.146\end{array}$

$\begin{array}{llllll}41.891 & 41.840 & 41.790 & 41.739 & 41.688 & 41.637\end{array}$

0.280785

1.243877

0.0280784

0.280784

0.280783

0.280782

0.280782

0.280781

1.243929

0.280781

0.280781

0.280780

0.280779

0.280779

0.280779

0.280778
0.280777

1.243956

.0244008
1.24035

1.244035
1.244061

1.244087
1.244114

0.280777

0.280776

0.280776

0.280776

0.280775

0.280774

0.280774

0.280774

0.280773

0.280772

0.280772

0.280772
0.280772

0.280771

0.280771

0.280770

0.280770
0.280770

0.280769

0.280769

0.280769

0.280768
0.280768

0.280767

0.280767

0.280767

0.280766
0.280766

1.244140

1.244167
1.244193

1.244219

1.244246

1.244298

1.244351
1.244377

1.244404

1.244430

1. 244483

1. 244509

1.244536

1.244562
1.244588

1.244615

1.244667

1.244694
1.244720

1.244720
1.244747

1.244747
1.244773

1.244799

1.244826

1.244852
1.244878

1.244905

0.280765

0.280765

0.280765
0.280764
0.280764

0.280764

0.280764
0.280763

0.280763

0.280762
0.280762

1.244931

1.244958

1.245010
1.245007

1.0245037

1.245063

11245089

1.245116
1.245142

1.245195

0.280762

0.280761

0.280761
0.280760

0.280760

0.280760

0.280759
0.280759
0.28059

0.280759
0.28075

0.280759

1.245221

1.245248

1.245274
1.245300

1.245300
1.245327
1.245379

1.245353

1.245379 
$\begin{array}{lrlllllllll}0 & 22516.202 & 16.151 & 16.100 & 16.050 & 15.99 .9 & 15.948 & 15.897 & 15.847 & 15.796 & 15.746 \\ 0.1 & 15.695 & 150644 & 15.593 & 15.542 & 15.492 & 15.441 & 15.390 & 15.340 & 150899 & 15.238\end{array}$ $\begin{array}{lllllllllll}0.2 & 15.187 & 15.137 & 15.086 & 15.035 & 14.985 & 14.934 & 140883 & 14 \cdot 833 & 14.782 & 14.731 \\ 0.3 & 14.681 & 14.630 & 14.579 & 14.529 & 14.478 & 14.427 & 140.376 & 14.326 & 14.0275 & 14.224\end{array}$ $\begin{array}{lllllllllll}0.4 & 14.174 & 14.123 & 14.072 & 14.021 & 13.970 & 13.920 & 13.869 & 13.819 & 13.768 & 13.717\end{array}$

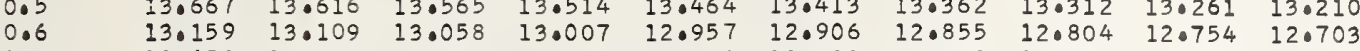
$\begin{array}{lllllllllll}0.7 & 12.652 & 12.602 & 12.551 & 12.500 & 12.450 & 12.399 & 12.348 & 12.298 & 12.247 & 12.196\end{array}$

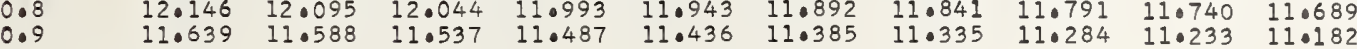

$22511.132 \quad 11.081 \quad 11.031 \quad 10.979$

10.929

$\begin{array}{lllll}1 & 10.625 & 10.574 & 110.523 & 10.479\end{array}$

$10.118 \quad 10.068 \quad 10.017 \quad 09.966 \quad 09.915$

$\begin{array}{llllllllll}09.611 & 09.560 & 09.510 & 09.459 & 09.408 & 09.358 & 09.307 & 09.256 & 09.206 & 09.155 \\ 09.104 & 09.054 & 09.003 & 08.952 & 08.902 & 08.851 & 08.801 & 08.750 & 08.699 & 08.648\end{array}$

$\begin{array}{lllll}10.372 & 10.321 & 10.270 & 10.219 & 10.169\end{array}$

$\begin{array}{lllllllll}08.496 & 08.446 & 08.395 & 08.344 & 08.293 & 08.243 & 08.192 & 08.142\end{array}$

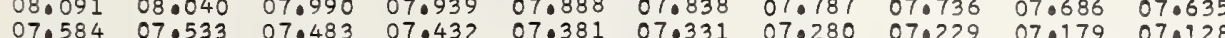

$\begin{array}{llllllllll}07.077 & 07.027 & 06.976 & 06.926 & 06.875 & 06.824 & 06.773 & 06.723 & 06.672 & 06.622\end{array}$

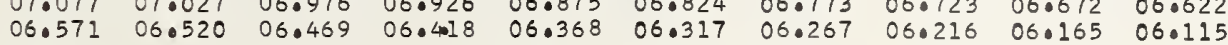

22506.06

2.1
2.2
2.3
2.4

4430
30
30
30
30
30
30
30
30
30
4440
40
40
40
40
40
40
40
40
40

$05.557 \quad 06.013 \quad 05.963 \quad 05.912$

$05.05105 .000 \quad 04.950 \quad 04.899$

$04.544 \quad 04.494$

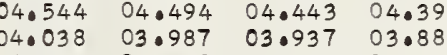

$03.531 \quad 03.480 \quad 03.430 \quad 03.379$

$02.518 \quad 02.468 \quad 02.423 \quad 02.873$

05.861

02.011

01.961

$02.417 \quad 02.36$

$05.355 \quad 05.30$

06.26

06.216

22500.999

$00.492 \quad 00.948$

$\begin{array}{ll}00.492 & 00.442 \\ 99.986 & 99.936\end{array}$

$99.479 \quad 99.436 \quad 99.885$

98.07939 .429 .

98.46798 .411

$\begin{array}{rr}97.961 & 97.910 \\ 97.454 & 97.404\end{array}$

$\begin{array}{ll}97.454 & 97.404 \\ 96.948 & 96.897\end{array}$

96.442

04.342

03.83504 .291

05.25
04.747

$04.747 \quad 04.697$

$\begin{array}{llllll}3.0329 & 03.278 & 03.227 & 03.176 & 03.126 & 03.075 \\ 2.822 & 02.771 & 02.721 & 02.670 & 02.619 & 02.569 \\ 0.316 & 02.265 & 02.214 & 02.164 & 02.113 & 02.062\end{array}$

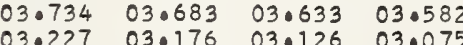

$22495.936 \quad 95.885 \quad 950$

$\begin{array}{lll}95.429 & 95.379 & 95 . \\ 94.923 & 94.873 & 94.0\end{array}$

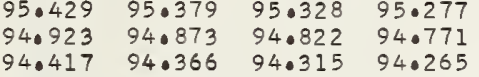

$93.911 \quad 93.860 \quad 93.810 \quad 93.759$

$\begin{array}{rrrr}93.405 & 93.354 & 93.304 & 93.253 \\ 92.899 & 92.848 & 92.797 & 92.747\end{array}$

$\begin{array}{llll}92.393 & 92.342 & 92.292 & 92.241 \\ 91.886 & 91.836 & 91.785 & 91.735\end{array}$

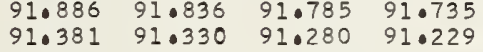

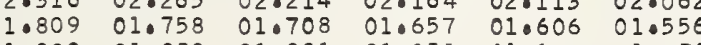

$\begin{array}{lllllll}00.796 & 00.745 & 00.695 & 00.644 & 00.594 & 00.543\end{array}$

$\begin{array}{llllll}.290 & 00.239 & 00.189 & 00.138 & 00.087 & 00.037 \\ .783 & 99.732 & 99.682 & 99.632 & 99.5811 & 99.530\end{array}$

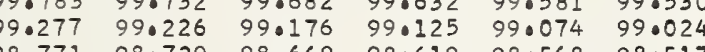

$\begin{array}{llllll}98.711 & 98.720 & 98.669 & 980619 & 98.568 & 98.517 \\ 98.264 & 98.214 & 98.163 & 98.112 & 98.062 & 98.011\end{array}$

$\begin{array}{llllll}97.758 & 97.708 & 97.657 & 97.606 & 97.555 & 97.505 \\ 97.252 & 97.201 & 97.150 & 97.100 & 97.049 & 96.999\end{array}$

$\begin{array}{llllll}97.252 & 97.201 & 97.150 & 97.100 & 97.049 & 96.999\end{array}$

$\begin{array}{llllll}96.746 & 96.695 & 96.644 & 96.594 & 96.543 & 96.492 \\ 96.239 & 96.188 & 96.138 & 96.087 & 96.037 & 95.986\end{array}$

$\begin{array}{lllllll}95.733 & 95.683 & 95.632 & 95.581 & 95.531 & 95.480 \\ 95.227 & 95.176 & 95.126 & 95.075 & 95.024 & 94.974\end{array}$

$\begin{array}{llllll}95.227 & 95.176 & 95.126 & 95.075 & 95.024 & 94.974 \\ 94.721 & 94.670 & 94.619 & 94.569 & 94.518 & 94.468\end{array}$

$\begin{array}{llllll}94.215 & 94.164 & 94.113 & 94.062 & 94.012 & 93.962 \\ 93.708 & 93.658 & 93.607 & 93.557 & 93.506 & 93.455\end{array}$

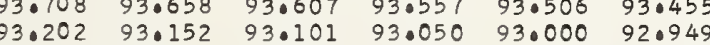

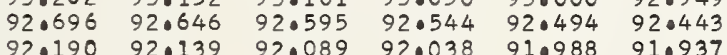

$92.190 \quad 92.139 \quad 92.08992 .038 \quad 91.988 \quad 91.937$

$\begin{array}{llllll}91.684 & 91.634 & 91.583 & 91.532 & 91.482 & 91.431 \\ 91.178 & 91.127 & 91.077 & 91.026 & 90.976 & 90.925\end{array}$

4445

4450
50
50
50
50
50
50
507
50
50

$5.0 \quad 22490.874$

$\begin{array}{rlll}2490.874 & 90.824 & 90.773 & 90.723 \\ 90.369 & 90.318 & 90.267 & 90.217 \\ 89.862 & 89.812 & 89.761 & 89.711\end{array}$

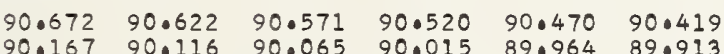

$89.660 \quad 89.610$

$88.851 \quad 88.800 \quad 88.750 \quad 88.699$

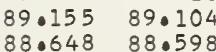

$90.065 \quad 90.015 \quad 89.964 \quad 89.913$

$\begin{array}{lllll}88.345 & 88.294 & 88.244 & 88.193\end{array}$

$88.143 \quad 88.092$

$87.333 \quad 87.283 \quad 87.738 \quad 87.687$

$\begin{array}{llll}86.828 & 86.777 & 86.726 & 86.676 \\ 86.322 & 86.271 & 86.220 & 86.170\end{array}$

$87.637 \quad 87.58$

$\begin{array}{llll}89.053 & 89.003 & 88.952 & 88.902 \\ 88.547 & 88.497 & 88.446 & 88.396\end{array}$

$\begin{array}{llll}88.042 & 87.991 & 87.940 & 87.890\end{array}$

$\begin{array}{llllll}86.625 & 86.574 & 86.524 & 86.473 & 86.423 & 86.372 \\ 86.119 & 86.069 & 86.018 & 85.968 & 85.917 & 85.866\end{array}$

4446

$\begin{array}{rrrrr}6.0 & 22485.816 & 85.765 & 85.715 & 85.664 \\ 6.1 & 85.310 & 85.260 & 85.209 & 85.159 \\ 6.2 & 84.805 & 84.754 & 84.704 & 84.653\end{array}$

$85.614 \quad 85.56$

85.51

$85.462 \quad 85.412 \quad 85.361$

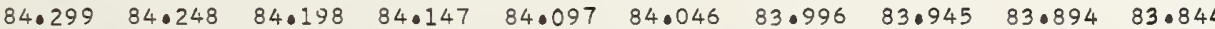

$\begin{array}{llllllllll}83.793 & 83.743 & 83.692 & 83.642 & 83.591 & 83.541 & 83.490 & 83.440 & 83.389 & 83.338\end{array}$

$\begin{array}{llllllllll}83.288 & 83.237 & 83.187 & 83.136 & 83.085 & 83.035 & 82.984 & 82.934 & 82.883 & 82.833\end{array}$

$\begin{array}{llllllllll}82.782 & 82.731 & 82.681 & 82.630 & 82.580 & 82.530 & 82.479 & 82.428 & 82.378 & 82.327\end{array}$

$\begin{array}{llllllllll}81.771 & 81.720 & 81.670 & 81.619 & 81.569 & 81.518 & 81.468 & 81.417 & 81.366 & 81.316 \\ 81.266 & 81.215 & 81.164 & 81.114 & 81.063 & 81.012 & 80.962 & 80.911 & 80.861 & 80.810\end{array}$

$\begin{array}{llllllllll}22480.750 & 80.709 & 80.659 & 80.608 & 80.558 & 80.507 & 80.457 & 80.406 & 80.356 & 80.305\end{array}$

$80.254 \quad 80.204 \quad 80.153 \quad 80.103$

$\begin{array}{llll}79.749 & 79.698 & 79.1548 & 79.103 \\ 79.043 & 79.193 & 79.142 & 79.092\end{array}$

$80.052 \quad 80.002 \quad 79.951 \quad 79.900 \quad 79.850 \quad 79.799$

$79.243 \quad 79 \cdot 193 \quad 79.142 \quad 79 \cdot 092$

$\begin{array}{llll}78.738 & 78.687 & 78.637 & 78.586 \\ 78.232 & 78.182 & 78.132 & 78.081 \\ 77.727 & 77.677 & 77.626 & 77.575\end{array}$

$79.547 \quad 79.496 \quad 79.445 \quad 79 \cdot 395 \quad 79 \cdot 344 \quad 79 \cdot 294$

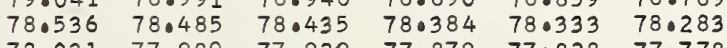

$\begin{array}{llllll}78.031 & 77.980 & 77.929 & 77.879 & 77.828 & 77.778\end{array}$

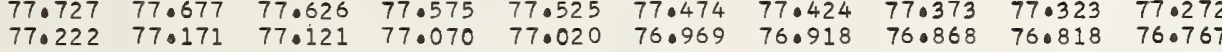

$\begin{array}{llllllllll}76.717 & 76.666 & 76.615 & 76.565 & 76.514 & 76.464 & 76.413 & 76.0363 & 76.312 & 76.262 \\ 76.211 & 76.161 & 76.110 & 76.059 & 76.009 & 75.958 & 75.908 & 75.857 & 75.807 & 75.756\end{array}$

$\begin{array}{rrrrrrrrrrr}4448.0 & 22475.706 & 75.655 & 75.605 & 75.554 & 75.503 & 75.453 & 75.402 & 75.352 & 75 \cdot 302 & 75.251 \\ 8.1 & 75.200 & 75.150 & 75.099 & 75.049 & 74.999 & 74.9488 & 74.897 & 74.847 & 74.796 & 74.746\end{array}$

$\begin{array}{llllllllll}75.200 & 75.150 & 75.099 & 75.049 & 74.999 & 74.948 & 74.897 & 74.847 & 74.796 & 74.746 \\ 74.695 & 74.0645 & 74.594 & 74.544 & 74.493 & 74.442 & 74.392 & 74.342 & 74.291 & 74.240\end{array}$

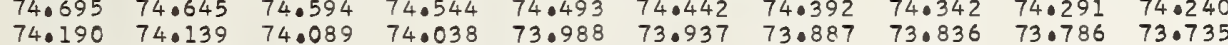

$\begin{array}{llllllllll}73.685 & 73.634 & 73.584 & 73.533 & 73.483 & 73.432 & 73.382 & 73.331 & 73.281 & 73.230\end{array}$

$\begin{array}{llllllllll}73.179 & 73.129 & 73.079 & 73.028 & 72.977 & 72.927 & 72.876 & 72.826 & 72.775 & 72.725 \\ 72.674 & 72.624 & 72.573 & 72.523 & 72.472 & 72.422 & 72.371 & 72.321 & 72.270 & 72.0219\end{array}$

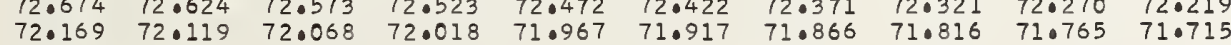

$\begin{array}{llllllllll}71.664 & 71.614 & 71.563 & 71.513 & 71.462 & 71.412 & 71.361 & 71.311 & 71.260 & 71.0210 \\ 71.159 & 71.108 & 71.058 & 71.007 & 70.957 & 70.906 & 70.856 & 70.805 & 70.755 & 70 \cdot 704\end{array}$

0.28074

0.280745

0.280745

.280744

0.280744

0.280743

0.280742

0.280742

280741

.280741

.

0.280739
0.280739

0.280739

0.280738

0.280737

0.280737

0.280736

0.280736
0.280735

0.280735

0.280735

0.280734

0.280734

0.280733

0.280732

0.280732

0.280732
0.280731

0.280731

0.280730

0.280730

0.280729

0.280729

28072

0.280728
0.280727

1.246724

0.280727

0.280727

.

0.280725

0.280725

0.280724

0.280724

1.246777

1.246803

1.246856

1.246882

1.246935

1.246961

.246988
.247014

1.247041

1.247067

1.247120

1.247172

1.247199

1.247251

1.247304

1.247331

1.247383

1.247410

1. 247462

1.247489
1.247515

1. 247542

0.280723

0.280723

0.280722

0.280722

0.280721

0.280721

0.280720

1.247568

1.247621

1.247647

1.247673
1.247700

1.247726

1.247779

0.280719

0.280719

0.280718

0.280718

0.280717
0.280717

0.280717

0.280716
0.280716

1.247832

1.247858

1.247911

1. 247937

1.247963
1.247990

1.248016

1.248069

0.280716

0.280715

0.280715

0.280714

0.280714

0.280713

0.280712

1.248095

1.248122

I. 248201

1. 248227

1.248254

1.248306
1.248333

1.248359

1.248385

1.248412

1.248464

1. 248491

1. 248544

1.248570

0.280712

.248623

1.248649

1.248702

1.248728

1.248755
1.248781

1.248807

.0248834

0.280712

1.248886

0.28071

1.248913
1.248939

0.280711

1.248966

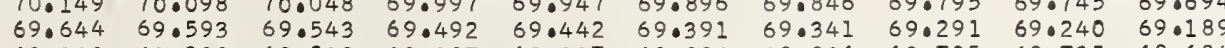

$\begin{array}{llllllllll}69.139 & 69.088 & 69.038 & 68.987 & 68.937 & 68.886 & 68.836 & 68.785 & 68.735 & 68.684\end{array}$

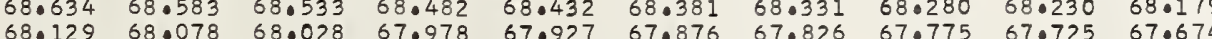

$\begin{array}{llllllllll}67.624 & 67.573 & 67.523 & 67.472 & 67.422 & 67.371 & 67.321 & 67.271 & 67.220 & 67.169\end{array}$

0.280710

0.280709

0.280709

1.248992

$\begin{array}{llllllllll} & \end{array}$

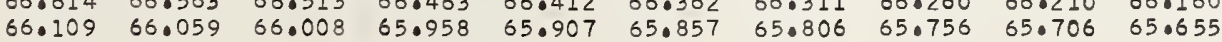

1.249045

1.249072

1.249124

$\begin{array}{lllllllllll} & .001 & .002 & .003 & .004 & .005 & .006 & .007 & .008 & .009 & .010 \\ .051 & .005 & .010 & .0015 & .020 & .025 & .030 & .036 & .0041 & .046 & .0055\end{array}$




.03

\section{5. \\ 5.3
5.4}

5.6
5.7

5.8
5.9

4456.

$$
\begin{aligned}
& 6.1 \\
& 6.2 \\
& 6.3
\end{aligned}
$$

6.3
6.4

6.5
6.5

6.7

7.3
7.4
7.5

7.5
7.6
7.7

7.7
7.8
7.9

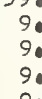

9.3

9.0

9.6

9.8

22465.604 65.100
64.595

64.090
63.586 63.081
62.576 62.576
62.071 61.567
61.062 22460.557 $\begin{array}{rll}460.557 & 60.507 & 60 . \\ 60.052 & 60.002 & 5 \\ 59.548 & 59.498 & 5 \\ 59.044 & 58.953 & 58\end{array}$ $59.044 \quad 58.993$ $\begin{array}{ll}58.539 & 58.489 \\ 58.034 & 57.984\end{array}$ $\begin{array}{lll}58.034 & 57.984 & 570 \\ 57.530 & 57.479 & 570 \\ 57.025 & 56.975 & 560\end{array}$ $\begin{array}{ll}57.025 & 56.975 \\ 56.521 & 56.470\end{array}$ 56.521
56.017

22455.512 55.008 54.503
53.999 $5.495 \quad 53.949$ $530495 \quad 530444$ $52.990-52.940$ $\begin{array}{ll}51.482 & 52.436 \\ 51.478 & 51.932\end{array}$ 51.478
50.974

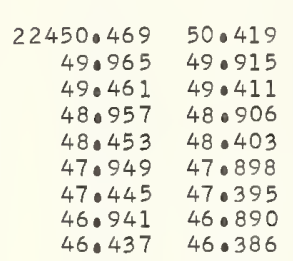
.05

\section{.06}

.07

.08

0.280704 0.280704 0.280703

0.280703

0.280702

0.280701

0.280701

0.280700

0.280700

0.280700

0.280699

0.280698
0.280698

0.280698

0.280697
0.280697

0.280696

0.280696

0.280695

0.280695

0.280695

0.280694
0.280694

0.280693

0.280693

0.280692

0.280692
0.280692

0.280691

0.280691

0.280690
0.280690

0.280690

0.280689

0.280688

0.280688

0.280688

0.280687

0.280687

0.280687

0.280686
0.280686

0.280685

0.280685

0.280685

0.280684

0.280683

0.280683

0.280682

0.280682

0.280681

0.280681

0.280681

0.280680

0.280679

0.280679

0.280678

0.280678

0.280677

0.280677

0.280677
0.280676

0.280676

0.280676

0.280675

0.280675

0.280674

1.249150
1.249177

1.249203

1.249229
1.249256

1.249282

1.249308
1.249335

1.249361
1.249388

1.249414

10249440

1.249467
1.249493

1.249519

1.249546
1.249572

1.249599

1.249625
1.249651

1.249678

1.249704

1. 249730

.249757
.249783

1.249810

1.249836

1.249862

1.249889
1.249915

1.249941

1.249968

1.250021

1.250047

1.250073

1.250126

1.250152

1.250205

1.250231

1.250284

1.250311

1.250337
1.250363

1.250363
1.250390

1.250390
1.250416

1.250469

1.250495

1.250522
1.250548

1.250548
1.250574

1.250601

1.250627

1.250654
1.250680

1.250706

1.250733

1.250759

1.250785
1.250812

1.250838

1.250865

1.250891

1.250944

1.250996

1.251023

1.251049

1. 251102

1.251128

1.251155

1.251207

1.251260

1.251287
1.251313

1.251339

1.251366
1.251392

1.251418

1. 251445

0.280674 0.280673 0.280673 0.280673 0.280672 0.280671 0.280671 0.280671

1.251524

1.251550 
$\begin{array}{rrrrrrrrrrr} & 22415.234 & 15.184 & 15.134 & 15.083 & 15.033 & 14.982 & 14.932 & 14.882 & 14.832 & 14.782 \\ 0.1 & 14.731 & 14.681 & 14.631 & 14.581 & 14.531 & 14.480 & 14.430 & 14.380 & 14.329 & 14.279\end{array}$

$\begin{array}{lllllllllll}0.2 & 14.229 & 14.179 & 14.128 & 14.078 & 14.028 & 13.978 & 13.927 & 13.877 & 13.827 & 13.776 \\ 0.3 & 13.726 & 13.676 & 13.626 & 13.576 & 13.525 & 13.475 & 13.425 & 13.375 & 13.324 & 13.274\end{array}$ $\begin{array}{llllllllll}13.726 & 13.676 & 13.626 & 13.576 & 13.525 & 13.475 & 13.425 & 13.375 & 13.324 & 13.274 \\ 13.224 & 13.174 & 13.123 & 13.073 & 13.023 & 12.972 & 12.923 & 12.872 & 12.822 & 12.771 \\ 12.721 & 12.671 & 12.621 & 12.571 & 12.520 & 12.470 & 12.420 & 12.369 & 12.320 & 12.269\end{array}$ $\begin{array}{lllllllllll}0.6 & 12.219 & 12.169 & 12.118 & 12.068 & 12.018 & 11.968 & 11.917 & 11.867 & 11.817 & 11.767 \\ 7 & 11.716 & 11.666 & 11.616 & 11.566 & 11.515 & 11.465 & 11.415 & 11.365 & 11.314 & 11.264\end{array}$ $\begin{array}{lllllllllll}0.8 & 11.214 & 11.164 & 11.114 & 11.063 & 11.013 & 10.963 & 10.913 & 10.862 & 10.812 & 10.762 \\ 0.9 & 10.712 & 10.662 & 10.611 & 10.561 & 10.510 & 10.460 & 10.410 & 10.360 & 10.310 & 10.260\end{array}$

0.280666

0.280665

0.280664

0.280663

0.280663

$4463.0 \quad 22400.167 \quad 00.117 \quad 00.067 \quad 00.016 * 99.966 * 99.916 * 99.866 * 99.816 * 99.766 * 99.715$ $\begin{array}{lllllllllll}3.1 & 22399.665 & 99.615 & 99.564 & 99.514 & 99.464 & 99.414 & 99.364 & 99.314 & 99.263 & 99.213\end{array}$ $\begin{array}{lllllllllll}3.2 & 99.163 & 99.113 & 99.063 & 99.013 & 98.962 & 98.912 & 98.862 & 98.812 & 98.762 & 98.712 \\ 3.3 & 98.661 & 98.611 & 98.561 & 98.511 & 98.460 & 98.410 & 98.360 & 98.310 & 98.260 & 98.210\end{array}$ $\begin{array}{lllllllllll}3.3 & 98.661 & 98.611 & 98.561 & 98.511 & 98.460 & 98.410 & 98.360 & 98.310 & 98.260 & 98.210 \\ 3.4 & 98.159 & 98.109 & 98.059 & 98.009 & 97.959 & 97.908 & 97.858 & 97.808 & 97.758 & 97.708\end{array}$

$\begin{array}{llllll}3.4 & 98.159 & 98.109 & 98.059 & 98.009 & 970 \\ 3.5 & 97.658 & 97.607 & 97.558 & 97.507 & 970\end{array}$

$\begin{array}{lllll}3.5 & 97.658 & 97.607 & 97.558 & 97.507 \\ 3.6 & 97.156 & 97.106 & 97.055 & 97.005\end{array}$

3.7 $\begin{array}{llllll}942 & 92.891 & 92.842 & 92.791 & 92.741 & 92.691\end{array}$

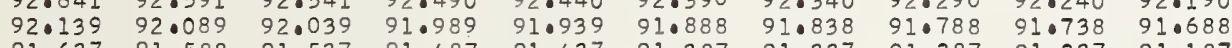

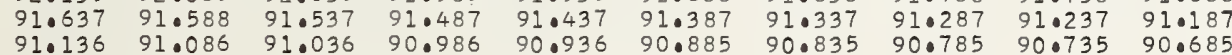

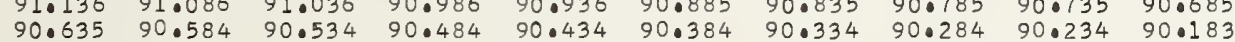

0.280662

0.280662

0.280661

0.280660

0.280660

0.280660

0.280659

0.280659

0.280658

0.280657

0.0280657

0.280656

0.280656
0.280656

0.280655

0.280655

0.280554

0.280554

0.280653

(1)

0.0280651

0.280651

0.280651

0.280650

0.280649

.280649

0.280649

0.280648

0.0280647

.280647

0.280646

.280646

0.280645

0.280645

0.280644
0.280644

0.280643

0.280643

0.280643
0.280642
0.2828

0.280642

0.280642
0.280641
0.283061

0.280641

0.280640
0.280640

0.280640

0.280639

0.280639

0.280639

0.280638

0.280637

0.280637

0.280637
0.280636

0.280636

0.280636

0.280635
0.280635

0.280634

.280634

0.280633

0.280633 $\begin{array}{llllllllll}67.591 & 67.541 & 67.491 & 67.441 & 67.390 & 67.340 & 67.290 & 67.240 & 67.190 & 67.140\end{array}$ $\begin{array}{llllllllll}67.090 & 67.040 & 66.990 & 66.940 & 66.891 & 66.841 & 66.791 & 66.740 & 66.690 & 66.640 \\ 66.590 & 66.540 & 66.490 & 66.440 & 66.390 & 66.340 & 66.290 & 66.240 & 66.190 & 66.140\end{array}$

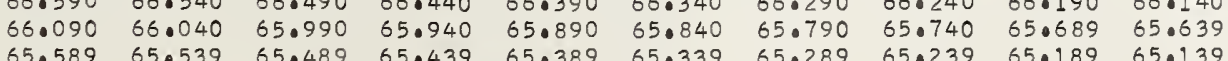

.0252553

1.252579
1.252605
1025265

1.252632
1.052658

1.252685

1.252737

1.252764
1.0252790

1.252816

1.252843

1.25282869
+1.252896

1.252922

1.252975

1.25301
1.253027
1.253027

1.253054
1.253080

1.253107

1.0253133
1.253159
1.253212

1.253186

1.253212
1.253238
1025329

1.253265
1.253291

1.253344

1.253370

1.253397
1.253423

1.253476

1.253502
1.253529

1.253555
1.253581

253634

1.253661

1.253713

1.253740
1.253766

1.253792
1.253819
1.25392

1.253845
1.253872

1.253898

1.253951

1.254004

1.254056

1.254083

1.254109
1.25135

$$
\begin{array}{lllllllll}
.001 & .002 & .003 & .004 & .005 & .006 & .007 & .008 & .009
\end{array}
$$

010

1. 254188

1.254241
1.254267

1.254294

1. 254346

1.254399

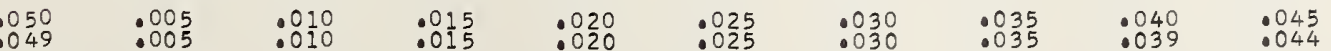


$(n-1) \times 1000$

$\lambda(n-1)$

$\begin{array}{lllllllllll}4470.0 & 22365.089 & 65.039 & 64 \cdot 989 & 64.939 & 64 \cdot 889 & 64 \cdot 839 & 64 \cdot 789 & 64 \cdot 739 & 64 \cdot 689 & 64 \cdot 639\end{array}$ $\begin{array}{lllllllllll}0.1 & 64.589 & 64.539 & 64.489 & 64.438 & 64.389 & 64.339 & 64.289 & 64.239 & 64.188 & 64.138 \\ 0.2 & 64.088 & 64.039 & 63.988 & 63.938 & 63.888 & 63.838 & 63.788 & 63.738 & 63.688 & 63.638\end{array}$ $\begin{array}{lllllllllll}0.3 & 63.588 & 63.538 & 63.488 & 63.438 & 63.388 & 63.338 & 63.288 & 63.238 & 63.188 & 63.138\end{array}$ $\begin{array}{lllllllllll}0.4 & 63.088 & 63.038 & 62.988 & 62.938 & 62.888 & 62.838 & 62.788 & 62.738 & 62.688 & 62.638\end{array}$ $\begin{array}{llllll}62.087 & 62.037 & 61.987 & 61.937 & 61.887 & 61.837\end{array}$ $61.53761 .087 \quad 61.437 \quad 61.387 \quad 61.037$ 60.587

4471

$\begin{array}{lr}1.0 & 22360.087 \\ 1.1 & 59.587 \\ 1.2 & 59.086 \\ 1.3 & 58.586 \\ 1.4 & 58.087 \\ 1.5 & 57.586 \\ 1.6 & 57.087 \\ 1.7 & 56.586 \\ 1.8 & 56.087 \\ 1.9 & 55.587\end{array}$

4472.0

$7 \cdot 2 \cdot 0$
$2 \cdot 2$

$2 \cdot 2$

$2 \cdot 4$

$2 \cdot 7$

2.8

4473.0

301

3.

3.

3.6

3.8
3.9

44740

40

40

405
4.6

4.7
4.8

4475.0

5.

5.2
5.3
5.4
5.5

5.5

5.6
5.7

5.8
5.9

4476.0

$$
\begin{aligned}
& 476.0 \\
& 60 \\
& 60 \\
& 60 \\
& 60 \\
& 60 \\
& 60 \\
& 60 \\
& 60 \\
& 60
\end{aligned}
$$

4477.0

447.0
7.1
7.2
7.3

7.4
7.5

7.5
7.6

7.7
7.8
7.9

4478 .

8.0
8.1
8.2
8.3

8.4

8.5

8.6
8.7

8.8

4479.

9.0

22355.087 54.587
54.087

$53.587 \quad 53.537$

$53.087 \quad 53.037 \quad 53.487$

$\begin{array}{llllll}52.587 & 52.537 & 52.488 & 52.937 & 52.887 & 52.837 \\ \end{array}$

$\begin{array}{llllll}52.088 & 52.038 & 51.988 & 51.938 & 51.888 & 51.838\end{array}$

$51.088 \quad 51.038$ 50.58

$22350.089 \quad 500$ $\begin{array}{lll}49.589 & 49.539 & 49.490 \\ 49.089 & 49.040 & 48.990\end{array}$ $48.590 \quad 48.540$ $48.091 \quad 48.041 \quad 47.990$

$\begin{array}{ll}47.591 & 47.54 \\ 47.092 & 47.042\end{array}$

$46.592 \quad 46.5$

46.093
45.593

22345.094

44.594
44.095
43.595
43.096
42.597
42.098
41.598
41.099
40.600

45.543

46.99

46.49246 .942

45.492
45.993
45.9043

$45 \cdot 943$
$45 \cdot 443$

44.994

44.944

44.544
44.045

5

4.995
43.945

$43.495 \quad 43.446$

42.996
42.497

8

41.998
41.498

42.946
42.447

41.948

22340.100

39.601
39.102

38.603

38.104
37.604

$37.105 \quad 37.055$

$\begin{array}{ll}36.606 & 36.557 \\ 36.107 & 36.057\end{array}$

35.608

22335.109

$34.610 \quad 35.059$

34.111

33.114

$31.617 \quad 31.567$

30.619

$22330 \cdot 120$

$29 \cdot 62$

28.62429 .073

$28.126 \quad 28.076$

$27.627 \quad 27 \cdot 577$

$26.630 \quad 26.580$

$\begin{array}{ll}26.131 & 26.081 \\ 25.633 & 25.58\end{array}$

$\begin{array}{ll}40.500 & 40.949 \\ 40.450\end{array}$

$61.787 \quad 61.737 \quad 610687 \quad 61.137$

$61.287 \quad 61.237 \quad 61.187 \quad 61.137$

$\begin{array}{llll}60.787 & 60.737 & 60.687 & 60.637\end{array}$

59.787

60.237

$60 \cdot 187$

60.137

$\begin{array}{llll}58.286 & 58.237 & 59.187 & 59.137 \\ 58.786 & 58.737 & 58.687 & 58.636\end{array}$

$\begin{array}{llll}58.287 & 58.237 & 58 \cdot 187 & 58.137\end{array}$

$\begin{array}{lllll}57.787 & 57.737 & 57.687 & 57.636\end{array}$

$\begin{array}{llll}56.786 & 56.736 & 56.586 & 56.536\end{array}$

$\begin{array}{llll}56.286 & 56.237 & 56.187 & 56.137\end{array}$

$\begin{array}{llll}55.786 & 55.736 & 55.687 & 55.637 \\ 55.287 & 55.237 & 55.187 & 55.137\end{array}$

54.787
54.287

$\begin{array}{lll}54.737 & 54.687 & 54.637\end{array}$

$\begin{array}{llll}53.787 & 53.737 & 53.687 & 53.637\end{array}$

$\begin{array}{llll}53.287 & 53.237 & 530187 & 53.137\end{array}$

$\begin{array}{llll}52.288 & 52.238 & 52.188 & 52.138\end{array}$

$\begin{array}{llll}51.788 & 51.738 & 51.688 & 51.638\end{array}$

$\begin{array}{llll}51.288 & 51.238 & 51.188 & 51.138\end{array}$

$\begin{array}{llllll}50.889 & 50.839 & 50.789 & 50.739 & 50.688 & 50.639 \\ 50.388 & 50.339 & 50.289 & 50.239 & 50.189 & 50.139\end{array}$

0.280632

0.280632

0.280631

0.280631

0.280630

0.280630

0.280629

0.280629

0.280628

0.280628

0.280628

0.280627

0.280626

0.280626

0.280626

0.280625

0.280625

0.280624

0.280624

0.280623

0.280623

0.280622

0.280622

0.280622

0.280621

0.280620

0.280620

0.280619

0.280619

0.280619

0.280618

0.280617

0.280617

0.280617

0.280616

0.280616

0.280615

0.280614

0.280614
0.280614

0.280613

0.280613

0.280613

0.280612

0.280612

0.280611

0.280611

0.280610

0.280610

0.280610

0.280609

0.280608

0.280607

0.280607

0.280607

0.280606

0.280606

0.280605

0.280605

0.280605

0.280604

0.280604

0.280603

0.280603
0.280602

0.280602

0.280602

0.280601
0.280601

0.280601

0.280600

0.280600

0.280600

0.280599

0.280598

0.280598

0.280598

0.280597

0.280597

0.280597

0.280596

0.280595

0.280595

1.254426

1. 254452

1.254478
1.254505

1.254531

1.254558

1.254584

1.254637

1.254689

1.254716

1.254742

1.254769

.254821

1. 254848

1.254874

1.254927

1.254953

1.254980

.255006
.255032

1.255059

1.255112

1.255138

1.255164
1.255191

1.255217

1.255243

1.255296

$1 \cdot 255323$

1. 255349

1.255402

1.255428
1.255455

1.255481

1.255534

1.255560

1. 255586

1.255613

1. 255639

1.255666

1.255692
1.255718

1.255745

1.255771

1.255824

1.255824
1.255850

1. 255877

1.255877
1.255903
1.255929

1. 255956

1.256009

1.256035

1.256061

1.256088

1.256114

1.256167

1. 256193

1.256246

1. 256272

1.256299

1.256325

1.256352

1. 256378

1.256404

1.256431

1.256457
1.256484

1.256510

1.256536

1. 256563

1.256589
1.256615

1.256642

1. 256668

1.256695

1. 256721

1.256747
.256774 


4890
9.1
9.2
9.4
9.5
9.6
9.7
9.0

0.280576

0.280576

0.280575
0.280575

0.280574

0.280574

0.280573

0.280572 0.280572

0.280571

0.280571

0.280570

0.280570

0.280569
0.280569

0.280569 0.280568 0.280567 0.280567 0.280567 0.280566 0.280566

0.280566

.257064

1. 257090

1.257143

1.257170

1.257222

1.257275

1.257328

1.257354

1. 257407

1.257433

1.257486

1.257539

1.257592

1.257618
1.257645

1. 257671

1.257697
1.257724

1.257776

1.257803

1.257856

1.257856
1.257882

1.257908

1.257962

1.257988

1.258014

1.258067

1.258120

1.258146

1.258199

1.258225

1.258278

1.258304
1.258331

1. 258383

1.258410
1.258436

1.258463

1.258489
1.258515

1. 258542

1.258594

1.258621

1.258647

1.258674
1.258700

1.258726

1.258779

1.258806

1.258858

1. 258911

1.258938

1.258990

1.259017

1.259069

1.259096

1.259122
1.259149

0.280565

0.280564

0.280564

0.280563

0.280563

0.280562
0.280562

0.280562

9201

1.259228

1.259254
1.259281

1.259307

1.259333
1.259360

1.259386

0.280561

0.280560

0.280560
0.280560

0.280560

0.280559

0.280558
0.280558

1.259439

.259465

1.259518

1.259545
1.259571

1. 259597

1.259624
1.259650 $\begin{array}{llllllllll}67.457 & 67.403 & 67.353 & 67.304 & 67.254 & 67.205 & 67.155 & 67.601 & 67.552 & 67.502\end{array}$ $\begin{array}{llllllllll}65.460 & 65.411 & 66.361 & 66.312 & 65.262 & 66.213 & 66.163 & 66.114 & 66.064 & 66.014\end{array}$

1.259676

$\begin{array}{lllllllllll} & .001 & .002 & .003 & .004 & .005 & .006 & .007 & .008 & .009 & .010 \\ .050 & .005 & .010 & .015 & .020 & .025 & .030 & .035 & .040 & .045 & .050 \\ 0045 & .010 & .015 & .020 & .024 & .029 & .034 & .039 & .044 & .049\end{array}$


0.280524

0.280524

0.280523

0.280523

0.280522

0.280522

0.280522

$\begin{array}{ll}0.280521 & 1.262289 \\ 0.280521 & 1.262316\end{array}$

1.260759
1.260785

1.260811

1.260864

1.260864
1.260890
1.260917

1.260917
1.260943

1.260970
1.260996

1.261022

1.261075

1.261102
1.261128

1.261154

1.261181

1.261234

1.261286

1.261313

1.261339
1.261366

1.261366
1.261392

1.261418

1.261445

1.261498

1.261550

1.261577
1.261603

1.261629

1.261656
1.261682

1.261709

1.261735
1.261761

1.261788

1.261814

1.261841
1.261867

1.261893
1.261920

1.261946

1.261973

1.262025

1.262078

1. 262105

1.262131

1.262184

1.262210

1.262263

.010 
$\begin{array}{rrrrrrr}0.0 & 2215.991 & 15.941 & 15.892 & 15.843 & 15.793 & 15.744 \\ 0.1 & 15.497 & 15.448 & 15.398 & 15.349 & 15.300 & 15.250 \\ 0.2 & 15.003 & 14.954 & 14.905 & 14.855 & 14.806 & 14.757 \\ 0.3 & 14.510 & 14.460 & 14.411 & 14.362 & 14.312 & 14.263 \\ 0.4 & 14.016 & 13.967 & 13.917 & 13.868 & 13.819 & 13.769\end{array}$

$\begin{array}{llllll}0.5 & 13.522 & 13.473 & 13.424 & 13.375 & 1 \\ 0.6 & 13.029 & 12.980 & 12.930 & 12.881 & 1 \\ 0.7 & 12.535 & 12.486 & 12.437 & 12.387 & 1\end{array}$

0.7
0.8
0.9

$\begin{array}{ll}12.042 & 11.992 \\ 11.549 & 11.499\end{array}$

4501.0

501.0
1.1
1.2
1.3
1.4
1.5
1.6
1.7
1.8
1.9

22211.055

$\begin{array}{ll}11.055 & 11.005 \\ 10.562 & 10.512 \\ 10.068 & 10.019 \\ 09.575 & 09.525 \\ 09.081 & 09.032 \\ 08.588 & 08.539 \\ 08.094 & 08.045 \\ 07.601 & 07.552 \\ 07.108 & 07.059 \\ 06.615 & 06.566\end{array}$

$\begin{array}{ll}2.437 & 12.387 \\ 1.943 & 11.894\end{array}$

$12.832 \quad 12.782$

12.338

12.782
12.289

$\begin{array}{llll}15.694 & 15.645 & 15.596 & 15.546 \\ 15.201 & 15.152 & 15.102 & 15.053 \\ 14.707 & 14.658 & 14.608 & 14.559\end{array}$

$\begin{array}{llll}14.7214 & 14.658 & 14.608 & 14.559\end{array}$

$\begin{array}{llll}13.720 & 13.671 & 13.621 & 13.572\end{array}$

$\begin{array}{llll}12.733 & 12.684 & 12.634 & 12.585\end{array}$

$11.746 \quad 11.607 \quad 12.141 \quad 12.091$

11.351

$\begin{array}{llll}11.746 & 11.697 & 11.647 & 11.598 \\ 11.252 & 11.203 & 11.154 & 11.104\end{array}$

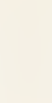

$(n-1) \times 1000$

$\lambda(n-1)$

1.5
1.6

202

2220

$\begin{array}{llll}06.122 & 06.072 & 06.023 & 05.974 \\ 05.628 & 05.579 & 05.530 & 05.480\end{array}$

$05.13505 .579 \quad 05.530 \quad 05.480$

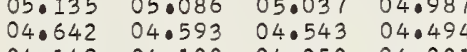

$04.149 \quad 04 \cdot 100$

$03.656 \quad 03.606 \quad 03.557 \quad 03.50$

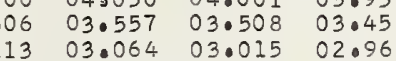

$\begin{array}{lllll}02.669 & 02.620 & 02.571 & 02.521 & 02.47\end{array}$

$\begin{array}{llll}02.176 & 02.127 & 02.078 & 02.029 \\ 01.684 & 01.634 & 01.584 & 01.535\end{array}$

4503.

$22201 \cdot 190$

$$
01.141 \quad 010
$$

$01.092 \quad 01.042$

01.979

$\begin{array}{llll}00.204 & 00.155 & 00.106 & 00.54 \\ 00.00\end{array}$

3.

$3 \cdot 3$
3.4
3.5

$99.218 \quad 99.169$

$99.120 \quad 99.070$

$\begin{array}{llll}98.725 & 98.676 & 98.627 & 98.578\end{array}$

$\begin{array}{llll}97.740 & 97.690 & 97.641 & 97.592\end{array}$

$\begin{array}{ll}97.247 & 97.197 \\ 96.754 & 96.705\end{array}$

$97.148 \quad 97.099$
96.0555

00.993

$00.007 * 99.958$

$99.514 \quad 99.465$

$98.528 \quad 98.479$

$\begin{array}{ll}98.035 & 97.986 \\ 97.542 & 97.493\end{array}$

$\begin{array}{llll}10.759 & 10.709 & 10.660 & 10.611 \\ 10.265 & 10.216 & 10.167 & 10.117\end{array}$

09.772

08.785

09.723

$09.229 \quad 09.180 \quad 09.131$

$\begin{array}{llll}08.292 & 08.242 & 08.193 & 08.144\end{array}$

$\begin{array}{llll}07.305 & 07.256 & 07.207 & 07.158\end{array}$

$\begin{array}{llll}06.812 & 06.763 & 06.713 & 06.664 \\ 06.319 & 06.270 & 06.220 & 06.171\end{array}$

0.280520

0.280520

0.280519

0.280519

0.280518

0.280518

0.280517

0.280517

0.280516
0.280516

0.280516

0.280515

0.280515

0.280514

0.280514

1.262342

1.262369

1.262421

1.262448

1.262500

1. 262553

1.262606

1. 262632

1.262659

1. 262712

1.262764
1.262791

1.262817

0.28051

0.28051

0.0280512

0.280512
0.0280512

0.28051

0.280511

0.280510
0.280510

1.262870

3.

4504

22196.26

$\begin{array}{lll}96.211 & 96.163 & 96.113\end{array}$

$\begin{array}{ll}97.050 & 97.000 \\ 96.557 & 96.507\end{array}$

$03.853 \quad 03.803 \quad 03.754 \quad 03.705$

$\begin{array}{llll}02.867 & 02.818 & 02.261 & 03.212\end{array}$

$\begin{array}{llll}02.374 & 02.324 & 02.275 & 02.226\end{array}$

0.280509

0.280509

0.280508

0.280508

0.280507

0.280507

0.280506

1.262896

1.262923

1.262976

1.263028

1.263055

1.263108

$\begin{array}{llllllll}96.163 & 96.113 & 96.064 & 96.015 & 95.965 & 95.916 & 95.867 & 95.818\end{array}$

$\begin{array}{lllllllllll}402 & 95.275 & 95.226 & 95.177 & 95.127 & 95.078 & 95.029 & 94.979 & 94.931 & 94.881 & 94.832\end{array}$

$\begin{array}{lllllllllll}4.3 & 94.783 & 94.733 & 94.684 & 94.635 & 94.586 & 94.536 & 94.487 & 94.438 & 94.388 & 94 \cdot 340 \\ 4.4 & 94.290 & 94.241 & 94.192 & 94.142 & 94.093 & 94.043 & 93.994 & 93.945 & 93.896 & 93.846\end{array}$

$\begin{array}{ll}4.4 & 94.290 \\ 4.5 & 93.797 \\ 4.6 & 93.305\end{array}$

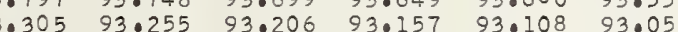

93.502

93.452

$93.403 \quad 93.354$

4.7
4.8
4.9

$92.319 \quad 92.270$

$92.713 \quad 92.664$

$92.615 \quad 92.565$

93.009

$92.959 \quad 92.910 \quad 92.861$

$91.827 \quad 91.777$

4505.

5.1
5.2
5.3
5.4
5.5
5.0
5.7
5.8
5.9

90.84190 .792

$91.236 \quad 91.187$

91.62991 .5

$\begin{array}{llll}91.024 & 91.974 & 91.925 & 91.876 \\ 91.531 & 91.482 & 91.433 & 91.383\end{array}$

0.28050

0.280505

0.280505

0.280504

0.28050

0.280503

0.280502

0.280502

0.280502

0.280501

0.280501

0.280500

0.280499

\begin{tabular}{llllllllll}
8.379 & 88.330 & 88.280 & 88.231 & 88.182 & 88.133 & 88.083 & 88.034 & 87.985 & 87.936 \\
\hline 7.037 & 87.037 & 87.788 & 87.739 & 87.690 & 87.641 & 87.591 & 87.542 & 87.493 & 87.443
\end{tabular}

$\begin{array}{llll}87.886 & 87.837 & 87.788 & 87.739 \\ 87.394 & 87.345 & 87.296 & 87.247\end{array}$

87.690

87.591

$86.902 \quad 86.853 \quad 86.803 \quad 86.754$

86.656

4506.

6.
60
6
6
6.
6.0
6.0
6.0
6.

22186.409

86.360

86.311

86.262
85.769

86.21

86.163

86.607

$\begin{array}{lll}87.050 & 87.000 & 86.951 \\ 86.557 & 86.508 & 86.458\end{array}$

0.280498

0.280498

0.280497

0.280497

0.280497

0.280496

0.280495

$\begin{array}{lllllllllll}82.963 & 82.914 & 82.865 & 82.816 & 82.767 & 82.717 & 82.668 & 82.619 & 82.570 & 82.521\end{array}$

$\begin{array}{llllllllll}82.471 & 82.422 & 82.373 & 82.324 & 82.275 & 82.225 & 82.176 & 82.126 & 82.077 & 82.028 \\ 81.979 & 81.930 & 81.881 & 81.831 & 81.782 & 81.733 & 81.684 & 81.635 & 81.585 & 81.536\end{array}$

0.280495

0.280494

0.280494

0.280494

0.280493

0.280493

0.280492

0.280492

0.280491

0.280491

0.280491

0.280490
0.280490

0.280490

0.280490

0.280489

0.280489

0.280489

0.280488

1.263134

1. 263160

1.263213

1. 263240

1.263266

1. 26331

1.263345
1.263372

1.263398

10263424

1.263477

1. 263504

1.263530

I. 263583

1.263609
1.263636

1.263688

1. 263741

1.263768
1.263794

1.263820

1.263847

1.263900

1.263926

1.263979

1.264005

1.264032

1.264058

1. 264111

1. 264163

1.264190

1.264216

1. 264243

1.264295

1.264322

1.264348

1.264401
1.264427

1. 264454

1. 264480

1.264533

1.264559

1.264586

1.264612

1.264639

1.264665
1.264691

0.280487

0.280487

1.264718

1.264744

0.280487

1. 264771

I. 264823

1. 264850

1.264876

1. 264903

0.280486

0.280485

0.280485

1.264929

.010

$.001 \quad .002$

.003

.004

.005

.006

.007

.008

.009

$: 048$ 
$\lambda(A)$

.00

.01

4510.0

$0.1 \quad 22166.732 \quad 66.683$

0.2

0.3

0.5
0.6

0.7

0.8

4511.0

1.

1.3

1.5

1.8

4512

2.

2.04

$2: 8$

513.0

3.2

3.2
3.3

3.3
3.4
3.5

3.5
3.6
3.7

3.7

30

$$
\begin{array}{r}
51400 \\
40.1 \\
402 \\
403 \\
404 \\
405 \\
406 \\
40.7 \\
40.8 \\
409
\end{array}
$$

4.3
4.4

$4 \cdot 5$
4.6
4.7

$4 \cdot 8$

4515.0

5.1

5.2

5.4

5.5
5.6
5.7

5.7
5.8

4516.0

6.1

6.2

6.4

6.5

6.6

6.7
6.8

6.9

4517.

$7 \circ 1$
$7 \circ 2$
7.3

7.5

7.6

7.8
7.9

4518.0

8.1
8.2
8.3
8.4
8.5
8.6
8.7
8.8
8.9

8.8
8.9

4519.0

9.1
9.2
9.3
9.4
9.5
9.6
9.7
9.8
9.9$$
\begin{array}{rlll}
48.071 & 48.022 & 47.973 & 47.924 \\
47.581 & 47.531 & 47.482 & 47.433 \\
22147.090 & 47.041 & 46.992 & 46.943 \\
46.599 & 46.550 & 46.501 & 46.452
\end{array}
$$$$
45.618 \quad 45.560
$$$$
45.128 \quad 45.079
$$$$
44.637 \quad 44.588
$$$$
43.656 \quad 43.607
$$$$
43.166 \quad 43.116
$$$$
45.520
$$$$
45.030 \quad 44.980
$$$$
44.048 \quad 43.999
$$

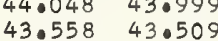$$
3.067
$$

42.135

$41.204 \quad 41.155$

$\begin{array}{ll}40.714 & 40.665 \\ 40.223 & 40.174\end{array}$

$39.733 \quad 39.684$

$39.243 \quad 39.194$

$\begin{array}{ll}38.262 & 38.213 \\ 37.772 & 37.723\end{array}$

$22137.282 \quad 37.233$

$\begin{array}{ll}36.792 & 36.742 \\ 36.301 & 36.253\end{array}$

$35.811 \quad 35.762$

$\begin{array}{ll}35.321 & 35 \cdot 272 \\ 34.831 & 34.782\end{array}$

$34.341 \quad 34.292$

$\begin{array}{ll}33.851 & 33.802 \\ 33.361 & 33.312\end{array}$

$\begin{array}{ll}33.361 & 33.312 \\ 32.871 & 32.822\end{array}$

$132 \cdot 38$

$\begin{array}{ll}31.401 & 31.352 \\ 30.911 & 30.862\end{array}$

$30.421 \quad 30.37$

$29.441 \quad 29.392$

$28.951 \quad 28.903$

$\begin{array}{ll}28.462 & 28.413 \\ 27.972 & 27.923\end{array}$

26.993

$26.993 \quad 26.944$

$26.013 \quad 25.964$

25.475

24.54424 .495

$\begin{array}{ll}24.054 & 24.00 \\ 23.565 & 23.51\end{array}$

$23.075 \quad 23.026$

22122.586

22.096

1.60721 .558

$21.117 \quad 21.06$

$20.138 \quad 20.090$

$19.649 \quad 19.600$

$2.577 \quad 42.528$

42.08

42.038
41.547

$1.106 \quad 41.057$

$40.125 \quad 40.076$

$39.635 \quad 39.586$

$39.145 \quad 39.095$

$\begin{array}{ll}38.164 & 38.115 \\ 37.674 & 37.625\end{array}$

37.184

36.69336 .135

$36.204 \quad 36.155$

$35.713 \quad 35.664$

$34.733 \quad 34.684$

$34.243 \quad 34.194$

$\begin{array}{ll}33.263 & 33.214 \\ 32.773 & 32.724\end{array}$

$\begin{array}{llll}32.773 & 32.724 & 32.675 & 320\end{array}$

$\begin{array}{llll}32.283 & 32.234 & 32.185 & 32.136\end{array}$

$31.303 \quad 31.254$

$30.323 \quad 30.274$

$29.833 \quad 29.784$

$28.854 \quad 28.80$

$\begin{array}{ll}31.597 \\ -156 & 31.107\end{array}$

$30.225 \quad 30.176$

$\begin{array}{ll}9.246 & 29.197 \\ 8.756 & 28.707\end{array}$

$\begin{array}{ll}8.266 & 28.217 \\ 27.776 & 27.727\end{array}$

29.147
28.658

28.658
28.16
27.678

$27.874 \quad 27.825$

27.23

27.188

$\begin{array}{ll}27.385 & 27.335 \\ 26.895 & 26.846\end{array}$

26.40526 .356

$\begin{array}{ll}25.915 & 25.866 \\ 25.426 & 25.377\end{array}$

$24.936 \quad 24.887$

$\begin{array}{ll}23.957 & 23.908\end{array}$

$\begin{array}{lll}26.797 & 26.748 & 26.699 \\ 26.307 & 26.258 & 26.209\end{array}$

$\begin{array}{llllll}25.328 & 25.279 & 25.230 & 25.181 & 25.132 & 25.083\end{array}$

$\begin{array}{lllllll}24.838 & 24.789 & 24.740 & 24.691 & 24.642 & 24.593\end{array}$

$\begin{array}{llllll}24.349 & 24.300 & 24.250 & 24.201 & 24.152 & 24.104\end{array}$

$\begin{array}{llllll}23.859 & 23.810 & 23.761 & 23.712 & 23.663 & 23.614\end{array}$

$\begin{array}{ll}23.467 & 23.4118 \\ 22.978 & 22.928\end{array}$

22.488

22.439

$\begin{array}{lll}22.879 & 22.831 & 22.782\end{array}$

22.73

$\begin{array}{ll}23.173 & 23.125 \\ 22.684 & 22.635\end{array}$

$\begin{array}{llllll}2.390 & 22.341 & 22.292 & 22.243 & 22.195 & 22.146\end{array}$

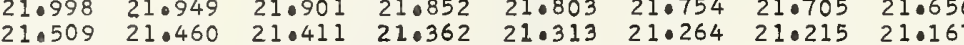

$\begin{array}{llllllll}21.019 & 20.970 & 20.922 & 20.873 & 20.823 & 20.775 & 20.726 & 20.677\end{array}$

$\begin{array}{llllllll}20.530 & 20.481 & 20.432 & 20.383 & 20.334 & 20.285 & 20.236 & 20.187\end{array}$

$\begin{array}{llllllll}20.041 & 19.991 & 19.943 & 19.894 & 19.845 & 19.796 & 19.747 & 19.698\end{array}$

$\begin{array}{llllllllll}19.160 & 19.111 & 19.062 & 19.013 & 18.964 & 18.915 & 18.866 & 18.817 & 18.768 & 18.719\end{array}$

$\begin{array}{llll}18.670 & 18.621 & 18.572 & 18.523 \\ 18.181 & 18.132 & 18.083 & 18.034\end{array}$

.001

.002

.003

.004

.005

17.887

.006

$(n-1) \times 1000 \quad \lambda(n-1)$

0.280484

0.280483
0.280483

0.280483

0.280482

0.280482

.280481

0.280480

0.280480

0.280480

0.280479

0.280479

0.280478

0.280478

0.280478

0.280477
0.280477

0.280476

0.280476

0.280475

0.280475

0.280474

0.280474

0.280474
0.280473

0.280473

0.280472

$8: 288473$

0.28047

0.280471

0.280470

0.280470

0.280469

0.280469

0.280468

0.280468

0.280468

0.280467

0.280467
0.280466

0.280466

0.280466

0.280465

0.280465

0.280464

0.280464

0.280463

0.280462

0.280462

0.280462

0.280461

0.280461

0.280460
0.280460

0.280460

0.280459

0.280459

0.280458

0.280458

0.280458

0.280457

0.280456

0.280456

0.280456

0.280455
0.280455

0.280455

0.280454

0.280454

0.280454

(

.

0.280452

0.280452

0.280451

1.264982

1.265008
1.265035

1.265061
1.265087

1.265114

1.265140

1.265193
1.265219

1.265246

1.265272

1.265299

.265325

1.265378

1.265404
1.265431

1.265457

265483

1.265510

1.265536

1.265589

1.265589
1.265615
1.265642

1.265668

1.265721

1.265774

1.265800

1:226583

1.265879

1.265932

1.265985

1.265985

1.266038

1.266064

1.266091
1.266117

1.266143

1.266170

1.266196

1.266223

1.266249
1.266275

1.266302

1.266328

I. 266355

1.266381

1.266407

1.266460 


\begin{tabular}{|c|c|c|c|c|c|c|c|c|c|c|c|c|}
\hline d) & .00 & DI & .02 & .03 & .04 & .05 & .06 & .07 & .08 & .09 & $(n-1) \times 1000$ & $\lambda(n-1)$ \\
\hline $\begin{array}{r}520.0 \\
0.1 \\
0.2 \\
0.3 \\
0.4 \\
0.5 \\
0.6 \\
0.7 \\
0.8 \\
0.5\end{array}$ & $\begin{array}{r}22117.691 \\
17.202 \\
16.713 \\
16.224 \\
15.734 \\
15.245 \\
14.756 \\
14.267 \\
13.778 \\
13.289\end{array}$ & $\begin{array}{l}17.642 \\
17.153 \\
16.664 \\
16.175 \\
15.685 \\
15.196 \\
14.707 \\
14 \cdot 218 \\
13.729 \\
13.240\end{array}$ & $\begin{array}{l}17.594 \\
17.104 \\
16.015 \\
16.126 \\
15.636 \\
15.147 \\
14.658 \\
14.169 \\
13.680 \\
13.191\end{array}$ & $\begin{array}{l}17.545 \\
17.055 \\
16.566 \\
16.077 \\
15.587 \\
15.0098 \\
14.609 \\
140.120 \\
13.631 \\
13.142\end{array}$ & $\begin{array}{l}17.496 \\
17.007 \\
16.517 \\
16.028 \\
15.539 \\
15.050 \\
14.560 \\
14.071 \\
13.582 \\
13.093\end{array}$ & $\begin{array}{l}17.447 \\
16.958 \\
16.468 \\
15.979 \\
15.0490 \\
15.000 \\
14.511 \\
14.022 \\
130.053 \\
13.044\end{array}$ & $\begin{array}{l}17.398 \\
16.909 \\
16.419 \\
15.930 \\
15.441 \\
14.952 \\
14.462 \\
13.973 \\
13.484 \\
12.995\end{array}$ & $\begin{array}{l}17.349 \\
16.860 \\
16.371 \\
15.881 \\
15.392 \\
14.903 \\
14.413 \\
13.925 \\
13.435 \\
12.946\end{array}$ & $\begin{array}{l}17.300 \\
16.811 \\
16.322 \\
15.832 \\
15.343 \\
14.854 \\
14.365 \\
13.875 \\
13.886 \\
12.897\end{array}$ & $\begin{array}{l}17.251 \\
16.762 \\
16.273 \\
15.784 \\
15.294 \\
14.805 \\
14.315 \\
13.827 \\
13.337 \\
12.848\end{array}$ & $\begin{array}{l}0.280447 \\
0.280447 \\
0.280447 \\
0.280446 \\
0.280446 \\
0.280446 \\
0.280445 \\
0.280445 \\
0.280444 \\
0.280444\end{array}$ & $\begin{array}{l}1.267622 \\
1.267648 \\
1.267675 \\
1.267701 \\
1.267728 \\
1.267754 \\
1.267780 \\
1.267807 \\
1.267833 \\
1.267860\end{array}$ \\
\hline $\begin{array}{l}521.0 \\
1.1 \\
1.2 \\
1.03 \\
1.4 \\
1.5 \\
1.6 \\
1.7 \\
1.8 \\
1.9\end{array}$ & $\begin{array}{r}112.799 \\
12.310 \\
11.821 \\
11.332 \\
10.843 \\
10.354 \\
09.865 \\
09.376 \\
08.887 \\
08.398\end{array}$ & $\begin{array}{l}12.750 \\
12.261 \\
11.772 \\
11.283 \\
10.794 \\
10.305 \\
09.816 \\
09.327 \\
08.838 \\
08.349\end{array}$ & $\begin{array}{l}12.702 \\
12.212 \\
11.723 \\
11.234 \\
10.745 \\
10.256 \\
09.767 \\
09.278 \\
08.789 \\
08.301\end{array}$ & $\begin{array}{l}12.653 \\
12.163 \\
11.675 \\
11.186 \\
10.696 \\
10.207 \\
09.718 \\
09.229 \\
08.740 \\
08.251\end{array}$ & $\begin{array}{l}12.604 \\
12.115 \\
11.625 \\
11.136 \\
10.647 \\
10.158 \\
09.670 \\
09.180 \\
08.692 \\
08.202\end{array}$ & $\begin{array}{l}12.555 \\
12.066 \\
11.0577 \\
11.088 \\
10.598 \\
10.0109 \\
09.621 \\
09.131 \\
08.643 \\
08.154\end{array}$ & $\begin{array}{l}12.506 \\
12.017 \\
11.528 \\
11.039 \\
10.550 \\
10.061 \\
09.572 \\
09.083 \\
08.594 \\
08.105\end{array}$ & $\begin{array}{l}12.457 \\
11.098 \\
11.479 \\
10.990 \\
10.501 \\
10.011 \\
09.0523 \\
09.034 \\
08.545 \\
08.056\end{array}$ & $\begin{array}{l}12.408 \\
11.919 \\
11.430 \\
10.941 \\
10.452 \\
09.963 \\
09.474 \\
08.985 \\
08.496 \\
08.007\end{array}$ & $\begin{array}{l}12.359 \\
11.870 \\
11.381 \\
10.892 \\
10.403 \\
09.914 \\
09.425 \\
08.936\end{array}$ & $\begin{array}{l}0.280444 \\
0.280443 \\
0.280443 \\
0.280443 \\
0.280442 \\
0.280442 \\
0.280442 \\
0.280441 \\
0.280441 \\
0.280440\end{array}$ & $\begin{array}{l}1.267886 \\
1.267912 \\
1.267939 \\
1.267965 \\
1.267992 \\
1.268018 \\
1.268044 \\
1.268071 \\
1.268097 \\
1.268124\end{array}$ \\
\hline $\begin{array}{l}22.0 \\
2.1 \\
2.2 \\
2.3 \\
2.4 \\
2.5 \\
2.6 \\
2.7 \\
2.8 \\
2.9\end{array}$ & $\begin{array}{r}107.909 \\
07.421 \\
06.932 \\
06.443 \\
05.954 \\
05.465 \\
04.977 \\
04.488 \\
03.999 \\
03.510\end{array}$ & $\begin{array}{l}07.860 \\
07.372 \\
06.883 \\
06.394 \\
05.905 \\
05.417 \\
04.927 \\
04.439 \\
03.950 \\
03.462\end{array}$ & $\begin{array}{l}07.812 \\
07.323 \\
06.834 \\
06.345 \\
05.856 \\
05.368 \\
04.879 \\
04.390 \\
03.901 \\
03.413\end{array}$ & $\begin{array}{l}07.763 \\
07.274 \\
06.785 \\
06.297 \\
05.807 \\
05.319 \\
04.830 \\
04.341 \\
03.853 \\
03.364\end{array}$ & $\begin{array}{l}07.714 \\
07.225 \\
06.736 \\
06.248 \\
05.759 \\
05.270 \\
04.781 \\
04.292 \\
03.804 \\
03.315\end{array}$ & $\begin{array}{l}07.665 \\
07.177 \\
06.0877 \\
06.199 \\
05.709 \\
05.221 \\
04.732 \\
04.243 \\
03.755 \\
03.266\end{array}$ & $\begin{array}{l}07.616 \\
07.128 \\
06.638 \\
06.150 \\
05.661 \\
05.172 \\
04.6883 \\
04.195 \\
03.706 \\
03.217\end{array}$ & $\begin{array}{l}07.567 \\
07.078 \\
06.590 \\
06.101 \\
05.612 \\
05.123 \\
04.635 \\
04.146 \\
03.657 \\
03.168\end{array}$ & $\begin{array}{l}07.519 \\
07.0 .30 \\
06.541 \\
06052 \\
05.5653 \\
05.0075 \\
04.585 \\
04.097 \\
03.008 \\
03.120\end{array}$ & $\begin{array}{l}07.470 \\
06.980 \\
06.492 \\
06.003 \\
05.514 \\
05.026 \\
04.0537 \\
04.048 \\
03.559\end{array}$ & $\begin{array}{l}0.280440 \\
0.280440 \\
0.280439 \\
0.280439 \\
0.280439 \\
0.280438 \\
0.280438 \\
0.280438 \\
0.280437 \\
0.280437\end{array}$ & $\begin{array}{l}.268150 \\
.268176 \\
.268203 \\
.268229 \\
.268256 \\
.268282 \\
.268309 \\
.268335 \\
.268361 \\
.268388\end{array}$ \\
\hline $\begin{array}{l}23.0 \\
3.1 \\
3.2 \\
3.3 \\
3.4 \\
3.5 \\
3.6 \\
3.7 \\
3.8 \\
3.9\end{array}$ & $\begin{array}{r}22103.022 \\
02.533 \\
02.044 \\
01.556 \\
01.067 \\
00.578 \\
00.090 \\
22099.601 \\
99.113 \\
98.625\end{array}$ & $\begin{array}{l}02.973 \\
02.484 \\
01.996 \\
01.0507 \\
01.018 \\
00.530 \\
00.041 \\
99.553 \\
99.064 \\
98.575\end{array}$ & $\begin{array}{r}02.924 \\
02.435 \\
01.947 \\
01.458 \\
00.969 \\
00.481 \\
* 99.992 \\
99.504 \\
99.015 \\
98.527\end{array}$ & $\begin{array}{r}02.875 \\
02.386 \\
01.898 \\
01.409 \\
00.921 \\
00.432 \\
* 99.943 \\
99.455 \\
98.967 \\
98.478\end{array}$ & $\begin{array}{r}02.826 \\
02.338 \\
01.849 \\
01.360 \\
00.872 \\
00.383 \\
* 99.895 \\
99.406 \\
98.918 \\
98.429\end{array}$ & $\begin{array}{r}02.777 \\
02.289 \\
01.800 \\
01.312 \\
00.823 \\
00.334 \\
* 99.846 \\
99.357 \\
98.869 \\
98.380\end{array}$ & $\begin{array}{r}02.728 \\
02.240 \\
01.751 \\
01.263 \\
00.774 \\
00.285 \\
* 99.797 \\
99.308 \\
98.820 \\
98.331\end{array}$ & $\begin{array}{l}02.679 \\
02.191 \\
01.702 \\
01.214 \\
00.725 \\
00.237 \\
* 99.748 \\
99.260 \\
98.771 \\
98.282\end{array}$ & $\begin{array}{r}02.631 \\
02.142 \\
01.654 \\
01.165 \\
00.676 \\
00.188 \\
* 99.699 \\
99.211 \\
98.722 \\
98.234\end{array}$ & $\begin{array}{l}02.582 \\
02.093 \\
01.604 \\
01.116 \\
00.627 \\
00.139 \\
* 99.650 \\
99.162 \\
98.674 \\
98.185\end{array}$ & $\begin{array}{l}0.280436 \\
0.280436 \\
0.280436 \\
0.280435 \\
0.280435 \\
0.280435 \\
0.280434 \\
0.280434 \\
0.280434 \\
0.280433\end{array}$ & $\begin{array}{l}.268414 \\
0268441 \\
0268467 \\
0268493 \\
268520 \\
268546 \\
268573\end{array}$ \\
\hline $\begin{array}{l}524.0 \\
4.1 \\
402 \\
4.3 \\
4.4 \\
405 \\
4.6 \\
4.7 \\
408 \\
4.9\end{array}$ & $\begin{array}{r}098.136 \\
97.648 \\
97.159 \\
96.671 \\
96.182 \\
95.694 \\
95.206 \\
94.717 \\
94.229 \\
93.741\end{array}$ & $\begin{array}{l}98.087 \\
97.599 \\
97.110 \\
96.622 \\
96.134 \\
95.645 \\
95.157 \\
94.669 \\
94.180 \\
93.692\end{array}$ & $\begin{array}{l}98.038 \\
97.550 \\
97.0062 \\
96.573 \\
96.084 \\
95.0596 \\
95.108 \\
94.620 \\
94.131 \\
93.643\end{array}$ & $\begin{array}{l}97.990 \\
97.501 \\
97.013 \\
96.524 \\
96.036 \\
95.0548 \\
95.059 \\
94.571 \\
94.083 \\
93.594\end{array}$ & $\begin{array}{l}97.941 \\
97.452 \\
96.964 \\
96.475 \\
95.987 \\
95.499 \\
95.010 \\
94.522 \\
94.034 \\
93.545\end{array}$ & $\begin{array}{l}97.892 \\
97.403 \\
96.915 \\
96.427 \\
95.938 \\
95.450 \\
94.961 \\
94.473 \\
93.985 \\
93.497\end{array}$ & $\begin{array}{l}97.843 \\
97.354 \\
96.866 \\
96.377 \\
95.889 \\
95.401 \\
94.013 \\
94.424 \\
93.936 \\
93.448\end{array}$ & $\begin{array}{l}97.794 \\
97.306 \\
96.817 \\
96.329 \\
95.841 \\
95.352 \\
94.864 \\
94.376 \\
93.887 \\
93.399\end{array}$ & & & & $\begin{array}{l}.268678 \\
026870 \\
.26873 \\
026875 \\
0268784 \\
0268810\end{array}$ \\
\hline $\begin{array}{l}25.0 \\
5.1 \\
5.2 \\
5.3 \\
5.4 \\
5.5 \\
5.6 \\
5.7 \\
5.8 \\
5.9\end{array}$ & $\begin{array}{r}093.252 \\
92.764 \\
92.276 \\
91.788 \\
91.300 \\
90.811 \\
90.323 \\
89.835 \\
89.347 \\
88.859\end{array}$ & $\begin{array}{l}93.203 \\
92.715 \\
92.227 \\
91.739 \\
91.251 \\
90.762 \\
90.275 \\
89.786 \\
89.298 \\
88.810\end{array}$ & $\begin{array}{l}93.155 \\
92.667 \\
92.178 \\
91.690 \\
91.202 \\
90.714 \\
90.226 \\
89.738 \\
89.250 \\
88.761\end{array}$ & $\begin{array}{l}93.106 \\
92.618 \\
92.129 \\
91.641 \\
91.153 \\
90.665 \\
90.177 \\
89.689 \\
89.201 \\
88.713\end{array}$ & $\begin{array}{l}93.057 \\
92.569 \\
92.081 \\
91.593 \\
91.104 \\
90.616 \\
90.128 \\
89.640 \\
89.152 \\
88.664\end{array}$ & $\begin{array}{l}93.008 \\
92.520 \\
92.032 \\
91.544 \\
91.055 \\
90.567 \\
90.079 \\
89.591 \\
89.103 \\
88.615\end{array}$ & $\begin{array}{l}92.959 \\
92.471 \\
91.983 \\
91.495 \\
91.007 \\
90.519 \\
90.030 \\
89.542 \\
89.054 \\
88.566\end{array}$ & & $\begin{array}{l}92.862 \\
92.374 \\
91.885 \\
91.397 \\
90.909 \\
90.421 \\
89.933 \\
89.445 \\
88.957 \\
88.469\end{array}$ & & $\begin{array}{l}0.280429 \\
0.280429 \\
0.280429 \\
0.280428 \\
0.280428 \\
0.280427 \\
0.280427 \\
0.280427 \\
0.280426 \\
0.280426\end{array}$ & $\begin{array}{l}1.268942 \\
1.26896 \\
1.26899 \\
1.26902 \\
1.26904 \\
1.26907 \\
1.26910 \\
1.26912 \\
1.26915 \\
1.26918\end{array}$ \\
\hline $\begin{array}{l}526.0 \\
6.1 \\
6.2 \\
6.3 \\
6.4 \\
6.5 \\
6.06 \\
6.7 \\
6.8 \\
6.9\end{array}$ & $\begin{array}{r}22088.371 \\
87.883 \\
87.395 \\
86.907 \\
86.419 \\
85.931 \\
85.444 \\
84.956 \\
84.468 \\
83.980\end{array}$ & $\begin{array}{l}88 \cdot 322 \\
87.834 \\
87.347 \\
86.859 \\
86.371 \\
85.883 \\
85.395 \\
84.907 \\
84.419 \\
83.931\end{array}$ & $\begin{array}{l}87.298 \\
86.810 \\
86.322 \\
85.834 \\
85.346 \\
84.858 \\
84.370 \\
83.882\end{array}$ & & $\begin{array}{l}88.176 \\
87.688 \\
87.200 \\
86.712 \\
86.224 \\
85.736 \\
85.249 \\
84.760 \\
84.273 \\
83.785\end{array}$ & $\begin{array}{l}88.127 \\
87.639 \\
87.151 \\
86.663 \\
86.175 \\
85.687 \\
85.200 \\
84.712 \\
84.224 \\
83.736\end{array}$ & $\begin{array}{l}88.078 \\
87.590 \\
87.103 \\
86.615 \\
86.127 \\
85.6638 \\
85.151 \\
84.663\end{array}$ & & & & & \\
\hline $\begin{array}{r}27: 0 \\
7: 1 \\
7: 2 \\
7: 3 \\
7: 4 \\
7: 5 \\
7: 6 \\
7: 7 \\
7: 8 \\
7: 9\end{array}$ & $\begin{array}{r}22083.492 \\
83.004 \\
82.516 \\
82.029 \\
81.541 \\
81.053 \\
80.566 \\
80.078 \\
79.590 \\
79.103\end{array}$ & $\begin{array}{l}83.443 \\
82.956 \\
82.468 \\
81.980 \\
81.492 \\
81.004 \\
80.517 \\
80.029 \\
79.542 \\
79.054\end{array}$ & $\begin{array}{l}83.395 \\
82.907 \\
82.419 \\
81.931 \\
81.443 \\
80.956 \\
80.468 \\
79.980 \\
79.493 \\
79.005\end{array}$ & $\begin{array}{l}83.346 \\
82.858 \\
82.370 \\
81.883 \\
81.395 \\
80.907 \\
80.419 \\
79.932 \\
79.444 \\
78.956\end{array}$ & $\begin{array}{l}83.297 \\
82.809 \\
82.321 \\
81.834 \\
81.346 \\
80.858 \\
80.371 \\
79.883 \\
79.396 \\
78.907\end{array}$ & $\begin{array}{l}83.248 \\
82.760 \\
82.272 \\
81.785 \\
81.297 \\
80.809 \\
80.322 \\
79.834 \\
79.346 \\
78.859\end{array}$ & $\begin{array}{l}83.199 \\
82.712 \\
82.224 \\
81.736 \\
81.248 \\
80.761 \\
80.273 \\
79.785 \\
79.298 \\
78.810\end{array}$ & & $\begin{array}{l}83 \cdot 102 \\
82.614 \\
82.126 \\
81.638 \\
81.151 \\
80.663 \\
80.175 \\
79.688 \\
79.200 \\
78.713\end{array}$ & & & $\begin{array}{l}1.26968 \\
1.26970\end{array}$ \\
\hline $\begin{array}{l}28 \cdot 0 \\
8.1 \\
8.2 \\
8.3 \\
8.4 \\
8.5 \\
8.6 \\
8.7 \\
8.8 \\
8.9\end{array}$ & $\begin{array}{r}22078.615 \\
78.127 \\
77.640 \\
77.152 \\
76.665 \\
76.177 \\
75.690 \\
75.202 \\
74.715 \\
74.228\end{array}$ & 74.179 & $\begin{array}{l}78.518 \\
78.030 \\
77.542 \\
77.055 \\
76.567 \\
76.080 \\
75.592 \\
75.105 \\
74.617 \\
74.130\end{array}$ & $\begin{array}{l}78.469 \\
77.981 \\
77.494 \\
77.006 \\
76.519 \\
76.031 \\
75.543 \\
75.056 \\
74.569 \\
74.081\end{array}$ & & $\begin{array}{l}77.396 \\
76.908 \\
76.421 \\
75.933 \\
75.446 \\
74.958 \\
74.471 \\
73.983\end{array}$ & & & & & & 1.26997 \\
\hline $\begin{array}{l}29.0 \\
9.1 \\
9.2 \\
9.3 \\
9.4 \\
9.5 \\
9.6 \\
9.7 \\
9.8 \\
9.9\end{array}$ & $\begin{array}{r}22073.740 \\
73.253 \\
72.765 \\
72.278 \\
71.791 \\
71.303 \\
70.816 \\
70.329 \\
69.842 \\
69.354\end{array}$ & $\begin{array}{l}72 \\
71 \\
71 \\
70\end{array}$ & $\begin{array}{l}73.643 \\
73.155 \\
72.668 \\
72.180 \\
71.693 \\
71.206 \\
70.719 \\
70.231 \\
69.744 \\
69.257\end{array}$ & $\begin{array}{l}73.106 \\
72.619 \\
72.132 \\
71.644 \\
71.157 \\
70.670 \\
70.183 \\
69.696 \\
69.208\end{array}$ & $\begin{array}{l}73.545 \\
73.058 \\
72.570 \\
72.083 \\
71.596 \\
71.109 \\
70.621 \\
70.134 \\
69.647 \\
69.159\end{array}$ & $\begin{array}{l}73.009 \\
72.521 \\
72.034 \\
71.547 \\
71.060 \\
70.573 \\
70.085 \\
69.598 \\
69.111\end{array}$ & $\begin{array}{l}0 \\
3 \\
6 \\
6 \\
8 \\
1 \\
4 \\
6\end{array}$ & $\begin{array}{l}72.911 \\
72.424 \\
71.937 \\
71.450 \\
70.962 \\
70.475 \\
69.988 \\
69.500 \\
69.014\end{array}$ & $\begin{array}{l}73 \cdot 350 \\
72.863 \\
72.375 \\
71.888 \\
71.401 \\
70.914 \\
70.426 \\
69.939 \\
69 \cdot 452 \\
68.965\end{array}$ & $\begin{array}{l}72.814 \\
72.327 \\
71.839 \\
71.352 \\
70.865 \\
70.377 \\
69.891 \\
69.403 \\
68.916\end{array}$ & $\begin{array}{l}0.280414 \\
0.280414 \\
0.280414 \\
0.280413 \\
0.280413 \\
0.280413 \\
0.280412 \\
0.280412 \\
0.280412\end{array}$ & 1.27023 \\
\hline
\end{tabular}
$\begin{array}{llllllllll} & \end{array}$

.010 
$4530.0 \quad 22068.867$ $68.380 \quad 68.819$ $68 \cdot 819$
68.331
67.844
67.357 67.406 $67 \cdot 844$
67.357 68 66.432 66.870
66.383 $\begin{array}{ll}65.945 & 65.896 \\ 65.458 & 65.409\end{array}$ $\begin{array}{ll}64.971 & 64.922 \\ 64.484 & 64.435\end{array}$

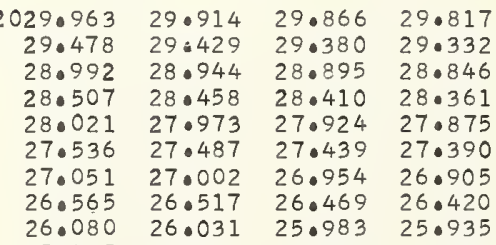

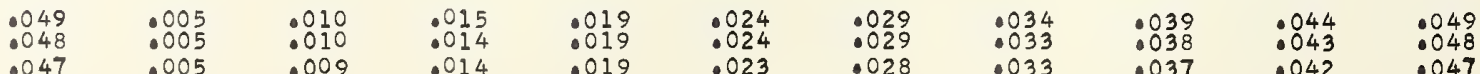

\section{.05}

06

.07

.08

.09

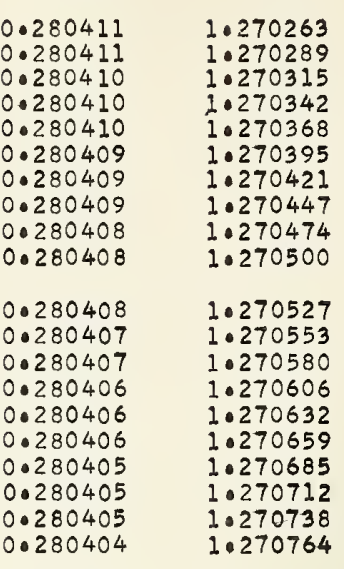

0.280404 0.280404 0.280403 0.280403 0.280402 0.280401 0.280401

0.280400 0.280400 0.280399 0.280399 0.280399 0.280398 0.280397

0.280397 0.280396 0.280396 0.280396 0.280395
0.280395 0.280394 0.280394

0.280393 0.280393 0.280392 0.280392 0.280392 0.280391 0.280391 0.280390
0.280390 0.280390 0.280389
0.280389 0.280389
0.280389 0.280389
0.280388 0.280388 0.280387
0.280387 0.280387
0.280387 0.280386

0.280386 0.280386 0.280385 0.280385 0.280385 0.280384 0.280383 0.280383
0.280383

1. 270791 1.270817 1.270870 1.270896 1.270923
1.270949 1.270976 1.271028 1. 271055 1. 271108 1.271134 1. 271160 1.271187
1.271213 1. 271213 1. 271266

1.271319 1.271345 1.271372 1.271425 1.271451
1.271477 1.271477
1.271504 1.271504
1.271530 1.271583 1.271609 1.271636
1.271662 1.271662 1.271689
1.271715 1.271741 1.271768
1.271794 1.271794
1.271821 1.271847 1.271874 1.271900
1.271926 1. 271953 1.271979
1.272006 1. 272032 1.272058
1.272085

1.272111 1.272138
1.272164 1.272164
1.272190 1. 272217 1.272243 1.272270
1.272296 1.272323
1.272349

0.280382 0.280382 0.280382 0.280381 0.280381 0.280380 0.280380 0.280380
3.280379 1.272375 1.272402 1.272428
1.272455 1. 272481 1.272507 1. 272534 .272587
1.272613

0.280379 0.280378 0.280378 0.280377

0.280377

0.280377

0.280376

0.280376
0.280376

1.272639 1.272666 1.272719 1.272745 1. 272772 1. 272824 1.272824 


\section{$22015.409 \quad 15.361 \quad 15.312 \quad 15.264$}

$\begin{array}{lll}5.215 & 15.167 & 15.118 \\ 4.731 & 14.682 & 14.634\end{array}$

$\begin{array}{lll}15.070 & 15 \cdot 021 & 14 \cdot 973 \\ 14.585 & 14.537 & 14.488\end{array}$ $\begin{array}{llll}14.439 & 14.391 & 14.343 & 14.294\end{array}$ $\begin{array}{llll}13.955 & 13.906 & 13.858 & 13.810\end{array}$ $\begin{array}{llll}13.470 & 13.422 & 13.373 & 13.324 \\ 12.985 & 12.937 & 12.889 & 12.840\end{array}$ $\begin{array}{llll}12.501 & 12.452 & 12.404 & 12.355 \\ 12.016 & 11.968 & 11.919 & 11.871\end{array}$

$\begin{array}{llllll}14.246 & 14.197 & 14.149 & 14.100 & 14.052 & 14.003\end{array}$ $\begin{array}{llllll}13.761 & 13.713 & 13.664 & 13.615 & 13.567 & 13.519\end{array}$

0.280368

0.280367

0.280367
0.280367

0.280366

0.280366

0.280365
0.280365

0.280365

0.280363

0.280363

0.280362

0.280362
0.280361

0.280361

.280361

0.280360
0.280360

0.280360

0.280359
0.280359

0.280358
0.280358

0.280357

0.280357
0.280357
0.28055

0.280356

0.280356

0.280355

0.280355

0.280354

0.280354

0.280353

0.280353
0.280353

0.280352

0.280352
0.280352
0.0235

.280351

0.280351

0.280350

0.280350

0.280350

0.280349
0.280349
0.28038

0.280348

0.280348

0.280348

0.280347
0.280347

1.272930

1.272956
1.272983

1.273036

1.273062

$\frac{1}{1.0273115}$

1.273168

1.273221

1.273273

1.273326

1.0273379

2.273432
1.273458

1.273485

1.273511
1.273538

1.273564
1.273590

1.0273617

1.0273696
1.273722

1.273749

1.0273775
1.273802

1.273828

1.273881

.273934

1.273960

1.273987

1. 0274039

1.274092

1.274145

1.274198

0.280347

0.280346

0.280346

0.280345

0.280345

0.280344

0.280343

1.274224

1.0274251
1.074277

1.274303

1.274356

1.274409

1.274436
1.274462

1.274488

1. 0274515

1.274568

1.274594
1.274620
1.027467

1.274647
1.274673
1.027472

1.274700
1.274726

1.274753

1.274779
1.274805

1.274832

1.274885

1.274911
1.274937

1.274964
1.0274990

0.280343

0.280343
0.280342

0.280342

0.280342

0.280341

0.280341

0.280340
0.280340

1.275017

1.275043
1.275070

1. 275096

.0275122
.225149

1.275275

1.275228
1.275254

1.275281
1.275307

1.0275334
1.275360
1.27531

2.275387

1.0275439

1.0275466
1.275492

1.275519

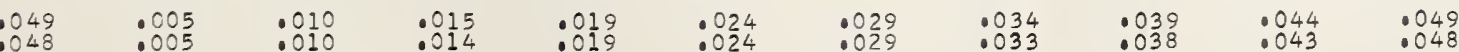


$4550.0 \quad 21971.863$

$\begin{array}{lll}0.1 & 21971.863 & 71.814\end{array}$

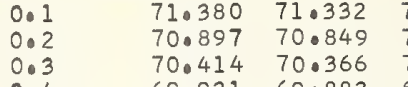
67.0518
66.552 66.987 $66.070 \quad 66.504$ $65.587 \quad 65.539$ $65.105 \quad 65.057$ $\begin{array}{ll}64.622 & 64.574 \\ 64.140 & 64.091\end{array}$ $63.657 \quad 63.609$ 63.174
62.692

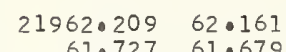

$\begin{array}{llllllll}71.766 & 71.718 & 71.670 & 71.621 & 71.573 & 71.525 & 71.477 & 71.428 \\ 71.283 & 71.235 & 71.187 & 71.139 & 71.091 & 71.042 & 70.993 & 70.945\end{array}$ $\begin{array}{llllllll}70.318 & 70.752 & 70.704 & 70.656 & 70.607 & 70.559 & 70.511 & 70.463\end{array}$ $69.035 \quad 69.786 \quad 69.738 \quad 69.690$ $68.869 \quad 68.821 \quad 68.773 \quad 68.725$

\section{$\begin{array}{ll}67.904 & 67.855 \\ 67.421 & 67.373\end{array}$}

$\begin{array}{lll}66.939 & 66.890 & 66 \\ 66.456 & 66.407 & 66\end{array}$

$\begin{array}{ll}65.974 & 65.925 \\ 65.490 & 65.44\end{array}$

$\begin{array}{ll}65.008 & 64.96 \\ 64.526 & 64.4777\end{array}$

$\begin{array}{lll}64.043 & 63.995 & 63.947 \\ 63.560 & 63.512 & 63.464\end{array}$

$\begin{array}{ll}63.078 & 63.030 \\ 62.596 & 62.547\end{array}$

\section{$\begin{array}{ll}61.631 & 61.582 \\ 61.148 & 61.100 \\ 60.666 & 60.618\end{array}$}

$\begin{array}{ll}60.666 & 60.618 \\ 60.183 & 60.135\end{array}$

$\begin{array}{ll}59.219 & 59.170 \\ 58.736 & 58.068 \\ 58.254 & 58.0206\end{array}$

$\begin{array}{ll}58.254 & 58.20 \\ 57.772 & 57.72 \\ 57.290 & 57.24\end{array}$

$\begin{array}{lll}56.807 & 56.759 \\ 56.325 & 56.277 & 560 \\ 55.043 & 55.795 & 550\end{array}$

$\begin{array}{ll}55.361 & 55.312 \\ 54.878 & 54.830\end{array}$

$\begin{array}{ll}54.396 & 54.348 \\ 53.914 & 53.866 \\ 53.432 & 53.384\end{array}$

67.290

68.242

69.642

69.159

68.193

69.594

68.628

69.545

69.063

$67.324 \quad 67.276$

67.228

67.662

67.671468 .049

67.566
67.083

$\begin{array}{lllll}6.829 & 65.780 & 65.732 & 65.684 & 65.635\end{array}$

$\begin{array}{llllll}65.394 & 65.346 & 65 \cdot 298 & 65 \cdot 250 & 65 \cdot 201 & 65 \cdot 153 \\ 64.912 & 64.863 & 64.815 & 64.767 & 64.719 & 64.670\end{array}$

$\begin{array}{llllll} & 64.043 & 64.284 & 64.236 & 64.188\end{array}$

.04

.05

.06

$(n-1) \times 1000$

$\lambda(n-1)$

0.280340

0.280339
0.280339

0.280339
0.280338

0.280338

0.280337

0.280337

0.280336

0.280336
0.280336

0.280336

0.280335

0.280335

0.280334

0.280334

0.280333

0.280332

0.0280332

0.280331

0.280331

0.280330

0.280330

0.280330
0.280329

0.280329

0.280329

0.280328

0.280327

0.280327

0.280326

0.280326

0.280325

0.280325

0.280325
0.280324

0.280324

0.280324

0.280323

0.280323

0.280322

0.28032

0.280321

0.280320

0.280320

0.280320

0.280319

0.280319

0.280318

0.280318

0.280318

0.280317

0.280317

0.280316

0.280315
0.280315

0.280315

0.280314

0.280314

0.280313

0.280313

0.280312

0.280312

0.280311

0.280311

0.280311

0.280310

0.280309

0.280309

0.280308

0.280308

0.280308

0.280307

0.280307

0.280306

0.280306

0.280306

0.280305

$\begin{array}{llllll}25.411 & 25.844 & 25 \cdot 796 & 25.748 & 25 \cdot 700 & 25.63 \\ 24.930 & 24.883 & 25.315 & 25.267 & 25.219 & 25.170 \\ 24.834 & 24.786 & 24.738 & 24.690\end{array}$

0.280305
0.280304

.010

1.275545

1.275571
1.275598

1.275624
1.275651

.0275677
.0275730

1.275704

1.275756

1.275809

1.275836

1.275862

1.275915

1.275941

1.275968

1.275994

1.276021
1.276047

1.276073

1.276100
1.276126

1. 276153

1.276279
1.276205

1.276232

1.276258

1.276285

1.276338

1.276364
1.276390

1.276390
1.276417

1.276443

1.276470
1.276496

1.276496

1.276549

1.276602

.276628

1.276689

1.276707
1.276734

1.276760

1.2767873

1.276839

1.276866 


\section{$\begin{array}{rlllll}21918.873 & 18.825 & 18.777 & 18.729 & 180 \\ 18.393 & 18.345 & 18.297 & 18.248 & 180\end{array}$}

$\begin{array}{lllllll}18.681 & 18.633 & 18.585 & 18.537 & 18.489 & 18.441\end{array}$

2 $\begin{array}{llll}18.393 & 18.345 & 18.297 & 18.248 \\ 17.912 & 17.864 & 17.816 & 17.768\end{array}$ $\begin{array}{llll}17.432 & 17.384 & 17.335 & 17.288 \\ 16.951 & 16.903 & 16.855 & 16.807\end{array}$ $16.470 \quad 16.423 \quad 16.375 \quad 16.327$

$\begin{array}{lllll}.6 & 15.990 & 15.942 & 15.894 & 15.846 \\ 1.7 & 15.510 & 15.462 & 15.414 & 15.366\end{array}$

1.8

$\begin{array}{llll}15.029 & 14.981 & 14 \bullet 933 & 14 \bullet 885 \\ 14.549 & 14.501 & 14.453 & 14.405\end{array}$

$\begin{array}{llllll}18.680 & 18.152 & 18.104 & 18.056 & 18.008 & 17.960\end{array}$

$\begin{array}{llllll}17.240 & 17.191 & 17.143 & 17.0576 & 17.528 & 17.480 \\ & 17.047 & 16.999\end{array}$

$\begin{array}{llllll}16.759 & 16.711 & 16.663 & 16.615 & 16.567 & 16.519\end{array}$

$\begin{array}{llllll}15.279 & 16.230 & 16.182 & 16.134 & 16.086 & 16.038 \\ 15.798 & 15.750 & 15.702 & 15.654 & 15.605 & 15.558\end{array}$

$\begin{array}{llllll}15.318 & 15.270 & 15.221 & 15.174 & 15.125 & 15.077\end{array}$

$21914.068 \quad 14.020 \quad 13.972 \quad 13.924$ $14.837 \quad 14.789$

$\begin{array}{llll}14.741 & 14.693 & 14.645 & 14.597 \\ 14.261 & 14.213 & 14.165 & 14.117\end{array}$

0.280301

1.278240

1.278266

1.278319

1.278345

1.278372

0.280301

0.280300

0.280300

0.280299

0.280299

.280298

0.280298
0.280297

1.278425

$\begin{array}{llllll}09.074 & 09.026 & 08.978 & 08.930 & 08.882 & 08.834\end{array}$ $\begin{array}{lllllllllll}07.826 & 07.777 & 07.729 & 07.682 & 07.634 & 07.585 & 07.537 & 07.490 & 07.441 & 07.394\end{array}$ $\begin{array}{llllllllll}07.346 & 07.298 & 07.250 & 07.201 & 07.154 & 07.106 & 07.058 & 07.010 & 06.962 & 06.914\end{array}$ $\begin{array}{llllllllll}06.865 & 06.817 & 06.770 & 06.721 & 06.673 & 06.625 & 06.577 & 06.529 & 06.481 & 06.433\end{array}$ $\begin{array}{llllllllll}06.385 & 06.337 & 06.289 & 06.241 & 06.194 & 06.146 & 06.097 & 06.050 & 06.001 & 05.953\end{array}$ $\begin{array}{llllllllll}05.906 & 05.858 & 05.810 & 05.761 & 05.714 & 05.665 & 05.517 & 05.569 & 05.521 & 05.474\end{array}$ $05.426 \quad 05.378 \quad 05.330 \quad 05.282$ $\begin{array}{llllll}0.714 & 05.665 & 05.617 & 05.569 & 05.521 & 05.474\end{array}$ $04.946 \quad 04.898 \quad 04.850 \quad 04.802$

$\begin{array}{llllll}05.234 & 05.186 & 05 \cdot 138 & 05.090 & 05.042 & 04 \cdot 994 \\ 04.754 & 04.706 & 04.658 & 04.610 & 04.562 & 04.514\end{array}$

456400<smiles>C=CC=C</smiles>

$$
\begin{array}{r}
1894 \\
94 \\
93 \\
93 \\
92 \\
92 \\
91 \\
91 \\
91 \\
90 \\
\\
21890 \\
89 \\
89 \\
88 \\
88 \\
87 \\
87 \\
86 \\
86 \\
85 \\
\hline
\end{array}
$$

0.280297

0.280297

0.280296

0.280295

0.280295

0.280294

0.280294

0.280294
0.280293

0.280293

0.280293

0.280292

0.280291

0.280291

0.280291
0.280290

0.280290

0.280290

0.280289

0.280289

0.280288
0.280288

0.280288

0.280287

0.280287

0.280286

0.280286

0.280285
0.280285

0.280285

0.280284

0.280284
0.280284

0.280283

0.280283

0.280283

0.280282

0.280282

0.280281

0.280281

0.280280
0.280280

0.280279

0.280279

0.280279
0.280278

0.280278

0.0280278

0.280277
0.280277

0.280277

0.280276

0.280276

0.280275
0.280275

0.280275

0.280274

0.280274

0.280274
0.280273

0.280272

0.280272
0.280272

0.280271

0.280271

0.280270

0.280270

0.280270

280269

1.278451
1.278478

1. 278504

1.278530

1.278583

11.278620

1.0278662
1.278689

1.278715
1.278742

1.278768

1.278795
1.278821

1.278847

1.278900

1.0278927
1.278953

- 278980

1.279006
1.279032

1.279059

1.279085
1.279112

1.279138

1.279164
1.279191

1.279244

1.279270

1.279297
1.279323

1.279349 
$\begin{array}{rrrrrrrrrrr}4570.0 & 21875.708 & 75.660 & 75.612 & 75.564 & 75.516 & 75.468 & 75.420 & 75 \cdot 373 & 75 \cdot 325 & 75.277 \\ 0.1 & 75.229 & 75.181 & 75.133 & 75.085 & 75.037 & 74.990 & 74.942 & 74.894 & 74 \cdot 846 & 74.798\end{array}$ $\begin{array}{llllllllllll}0.1 & 75.229 & 75.181 & 75.133 & 75.085 & 75.037 & 74.990 & 74.942 & 74.894 & 74.846 & 74.798 \\ 0.2 & 74.750 & 74.702 & 74.655 & 74.607 & 74.559 & 74.511 & 74.463 & 74.415 & 74.367 & 74.0320\end{array}$ $\begin{array}{llllllllllll}0.3 & 74.272 & 74.224 & 74.176 & 74.128 & 74.080 & 74.032 & 73.984 & 73.937 & 73.889 & 73 \cdot 841 \\ 0.4 & 73.793 & 73.745 & 73.697 & 73.649 & 73.602 & 73.554 & 73.506 & 73.458 & 73.410 & 73.362\end{array}$ $\begin{array}{llllllllllll}0.5 & 73.314 & 73.267 & 73.219 & 73.171 & 73.123 & 73.075 & 73.027 & 72.979 & 72.932 & 72.884 \\ 0.6 & 72.836 & 72.788 & 72.740 & 72.692 & 72.645 & 72.597 & 72.549 & 72.501 & 72.453 & 72.405 \\ 0.7 & 72.357 & 72.310 & 72.262 & 72.214 & 72.166 & 72.118 & 72.070 & 72.022 & 71.974 & 71.927\end{array}$

\subsection{622}

55.144
54.666

$540188 \quad 54.140$

53.71153 .663

52.75552 .70

21851.800

$$
\begin{aligned}
& 51.323 \\
& 50.845 \\
& 50.367 \\
& 49.890 \\
& 49.412 \\
& 48.935 \\
& 48.457 \\
& 47.979 \\
& 47.502
\end{aligned}
$$

$\begin{array}{cccccccccc} & .001 & .002 & .003 & .004 & .005 & .006 & .007 & .008 & .009 \\ .048 & .005 & .010 & .014 & .019 & .024 & .029 & .033 & .038 & .043 \\ .047 & .005 & .009 & .014 & .019 & .023 & .028 & .033 & .037 & .042\end{array}$


$\begin{array}{rrrrrrrrrrr}0.1 & 21827.945 & 27.897 & 27.849 & 27.802 & 27.754 & 27.706 & 27.659 & 27.611 & 27.563 & 27.516 \\ 0 & 27.468 & 27.420 & 27.373 & 27.325 & 27.278 & 27.230 & 27.182 & 27.135 & 27.087 & 27.039\end{array}$ $\begin{array}{lllllllllll}0.2 & 26.468 & 27.420 & 27.373 & 27.325 & 27.278 & 27.230 & 27.182 & 27.135 & 27.087 & 27.039 \\ 0 & 26.964 & 26.944 & 26.896 & 26.848 & 26.801 & 26.753 & 26.705 & 26.658 & 26.610 & 26.563\end{array}$ $\begin{array}{lllllllllll}0.3 & 26.515 & 26.467 & 26.420 & 26.372 & 26.324 & 26.277 & 26.229 & 26.181 & 26.134 & 26.086\end{array}$ $\begin{array}{lllllllllll}0.4 & 26.038 & 25.991 & 25.943 & 25.895 & 25.848 & 25.800 & 25.753 & 25.705 & 25.657 & 25.610 \\ 0.5 & 25.562 & 25.514 & 25.467 & 25.419 & 25.371 & 25.324 & 25.276 & 25.228 & 25.181 & 25.133\end{array}$ $\begin{array}{lllllllllll}0.6 & 25.562 & 25.514 & 25.467 & 25.419 & 25.371 & 25.324 & 25.276 & 25.228 & 25.181 & 25.133 \\ 0.6 & 25.086 & 25.038 & 24.990 & 24.942 & 24.895 & 24.847 & 24.800 & 24.752 & 24.704 & 24.656\end{array}$ $\begin{array}{lllllllllll}0.7 & 24.609 & 24.562 & 24.514 & 24.466 & 24.418 & 24.371 & 24.323 & 24.276 & 24.228 & 24.180\end{array}$ $\begin{array}{lllllllllll}0.8 & 24.133 & 24.085 & 24.038 & 23.990 & 23.943 & 23.895 & 23.847 & 23.799 & 23.751 & 23.704 \\ 0.9 & 23.656 & 23.609 & 23.561 & 23.513 & 23.466 & 23.418 & 23.371 & 23.323 & 23.275 & 23.228\end{array}$ $\begin{array}{ll}23.180 & 23.132 \\ 22.704 & 22.656 \\ 22.228 & 22.180 \\ 21.751 & 21.703 \\ 21.275 & 21.227 \\ 20.799 & 20.750 \\ 20.322 & 20.274 \\ 19.846 & 19.799 \\ 19.370 & 19.322 \\ 18.894 & 18.846\end{array}$ 23.085
22.608
22.132
21.656
21.179
20.703
20.227
19.751
19.274
18.798

$23.037 \quad 22.990 \quad 22.942$ 22.894<smiles>[141IH]</smiles>

$898.417 \quad 18.369$

0.280234
0.280233

0.280233

0.280232

0.280232

0.280231

0.280231

0.280230
0.280230

0.280230

.280229

0.280228

0.280228
0.280227

0.280227

0.280227
0.280226

0.280226

0.280225

0.280225

0.280224

0.280224

0.280224

0.280223

0.280223

0.280222

0.280222

0.280221

0.280221

0.280220

0.280220

0.280219
0.280219

0.280219

0.280218
0.280218

0.280218

0.280217

0.280217

0.280216

0.280215

0.280215

0.280214

0.280213

0.280213

0.280212
0.280212

0.280212

0.28021

0.280211

0.280210

0.280210

0.280209

0.280209

0.280208

0.280208

0.280207

0.280206

0.280206

0.280206

0.280205

0.280205

0.280204

0.280203

0.280203

0.280202

0.280202

0.280201

0.280201

0.280200

0.280200

1.283472

1.283498
1.283525

1.283551

1.283578
1.283604

1.283630

1.283657
-.283683

I. 283710

1.283736

1. 283789

1. 283815

.283842
.283868

1.283895

1.283948

283974

1.284000 
$\begin{array}{rrrrrrrrrrr}1 & 79.916 & 79.868 & 79.821 & 79.773 & 79.726 & 79.678 & 79.631 & 79.583 & 79.536 & 79.489\end{array}$

\begin{tabular}{llllllllllll}
0 & 78.441 & 79.394 & 79.346 & 79.299 & 79.251 & 79.204 & 79.156 & 79.109 & 79.062 & 79.014 \\
\hline & 78.967 & 78.919 & 78.872 & 78.824 & 78.777 & 78.729 & 78.682 & 78.635 & 78.587 & 78.540
\end{tabular}

$\begin{array}{llllllllll}78.018 & 77.970 & 77.923 & 77.875 & 77.828 & 77.781 & 77.733 & 77.686 & 77.638 & 77.591\end{array}$

$\begin{array}{llllllllll}77.543 & 77.496 & 77.923 & 77.875 & 77.828 & 77.781 & 77.733 & 77.686 & 77.638 & 77.0591\end{array}$

$\begin{array}{llllllllll}77.543 & 77.496 & 77.448 & 77.401 & 77.354 & 77.306 & 77.259 & 77.211 & 77.164 & 77.116 \\ 77.069 & 77.021 & 76.974 & 76.927 & 76.879 & 76.832 & 76.784 & 76.737 & 76.690 & 76.642\end{array}$

8

$\begin{array}{llll}76.595 & 76.547 & 76.500 & 76.45 \\ 76.121 & 76.073 & 76.026 & 75.978\end{array}$

\section{$\begin{array}{ll}76.690 & 76.642\end{array}$}

75.930

1
1
1
1
1
1
1
2
2
2
2
2
2
2
2
2

4593.0

3.5

3.6

$3 \cdot 8$
$3 \cdot 9$

4594.

$4 \cdot 4$
4.5

4.6
4.7
4.8

4.9

4595.0

5.1
5.2

$5 \cdot 2$
5.3
5.4

$5 \cdot 4$

5.6

5.8

4596.0

6.

6.2

6.4

6.6

6.7

4597.

7.1

7.4
7.5

7.6
7.7

$7 \cdot 8$
7.9

4598.0

8.1

8.2
8.3

8.4
8.5

8.7
8.8

8.8

4599.0

9.1

9.

9.4

9.6

9.8

775.646
75.172
74.698
74.223

$74.223 \quad 74.176 \quad 74.1128$

$73.701 \quad 73.654 \quad 73.607$

$\begin{array}{llll}72.801 & 72.753 & 72.706 & 72.658\end{array}$

$\begin{array}{llll}72.326 & 72.279 & 72.232 & 72.184\end{array}$

71.852
71.378

21770.90

70.430
69.956

69.482
69.008

68.53368 .486

$\begin{array}{ll}68.060 & 68.01 \\ 67.586 & 67.53\end{array}$

$67.586 \quad 67.538 \quad 67.491$

67.112

$21766 \cdot 164$

$65.690 \quad 65.643$

$65.216 \quad 65.643 \quad 65.59$

$64.742 \quad 64.695 \quad 64.122 \quad 65.074$

$64.269 \quad 64.221 \quad 64.174 \quad 64.126$

$63.795 \quad 63.747 \quad 63.700 \quad 63.653$

$63.321 \quad 63.273 \quad 63.226$

$62.374 \quad 62.326 \quad 62.279 \quad 62.232$

$61.900 \quad 61.853$

$21761 \cdot 426$

$60.953-60.905$

$60.47960 .432 \quad 60.858$

$59.532 \quad 59.48$

$58.585 \quad 58.537$

$\begin{array}{ll}58.111 & 58.06 \\ 57.637 & 57.590\end{array}$

57.164

21756.690

$56.217 \quad 56.169$

55.744

$54.797-54.749$

$54.323 \quad 54 \cdot 27$

$\begin{array}{lll}53.850 & 53.802 & 53.75\end{array}$

$52.903 \quad 52.856$

$1751.956 \quad 51.90$

$51.483 \quad 51.436 \quad 51.8$

$50.537 \quad 50.490$

50.063

49.590

$48 \cdot 171 \quad 48 \cdot 1$

$1747 \cdot 225$

46.752

46.752

$45.806 \quad 46.232$

$45.806 \quad 45.758 \quad 45.71$

$45.333-45.285$

$\begin{array}{lll}44.387 & 44.312 & 44.7 \\ 43.9 & 44.29\end{array}$

$43.387 \quad 44.339044 .292$

43.441
42.968

21742.495

42.023

41.077

$40.604 \quad 40.557 \quad 40.982 \quad 40.935$

$\begin{array}{llll}40.131 & 40.084 & 40.510 & 40.462 \\ 39.65 & 39.039\end{array}$

$\begin{array}{llll}39.659 & 39.611 & 39.564 & 39.517\end{array}$

$74.956 \quad 75.40$

75.36

75.78

5.267

75.693

$\begin{array}{lllllll}74.508 & 74.460 & 74.413 & 74.366 & 74.318 & 74.271\end{array}$

$\begin{array}{lllllll}74.034 & 73.986 & 73.939 & 73.891 & 73.844 & 73.271\end{array}$

$\begin{array}{llllll}73.559 & 73.512 & 73.465 & 73.417 & 73.370 & 73.322\end{array}$

72.61173 .038

72.01172 .563

$72 \cdot 990$

72.943

71.995

$72.896 \quad 72.848$

$72.421 \quad 72.374$

70.71

71.615
71.141

$71 \cdot 568$

71.520

$71 \cdot 473$

71.900

0.667

70.61

$70 \cdot 572$

$\begin{array}{ll}70.240 & 70.193 \\ 69.766 & 69.719\end{array}$

$60.766 \quad 69.71969 .671$

$68.818 \quad 68.77$

$68.344 \quad 68.297$

69.197
68.723

68.249
67.775

0

$67.396 \quad 67.349$

67.301

70.572
60.098

69.624
69.150

68.676

70.525

69.576

$69.103 \quad 69.529$

20268.628
68.155 68.581

$\begin{array}{ll}68.680 & 68.107\end{array}$

$\begin{array}{lll}67.254 & 67.207 & 67.15\end{array}$

66

66.40

.354

6.306

$\begin{array}{ll}66.733 & 66.685 \\ 66.259 & 66.21\end{array}$

$\begin{array}{llllll}65.974 & 65.927 & 65.880 & 65.832 & 65.785 & 65.738\end{array}$

$\begin{array}{lllllll}65.500 & 65.453 & 65.406 & 65.358 & 65.311 & 65.263\end{array}$

$64.553 \quad 64.505 \quad 64.45864$

$\begin{array}{lllllll}64.079 & 64.032 & 63.984 & 63.937 & 63.890 & 63.842\end{array}$

$\begin{array}{llllll}63.605 & 63.558 & 63.510 & 63.463 & 63.416 & 63.368\end{array}$

$\begin{array}{llllll}63.132 & 63.084 & 63.037 & 62.989 & 62.942 & 62.895\end{array}$

$\begin{array}{llllll}2.658 & 62.611 & 62.563 & 62.516 & 62.469 & 62.421 \\ 2.184 & 62.137 & 62.089 & 62.042 & 61.995 & 61.948\end{array}$

$61.521 \quad 61.474$

$\begin{array}{llllll}1.237 & 61.189 & 61.142 & 61.094 & 61.047 & 61.000\end{array}$

$\begin{array}{llllll}60.763 & 60.716 & 60.668 & 60.621 & 60.574 & 60.526\end{array}$

$\begin{array}{llllll}.289 & 60.242 & 60.195 & 60.147 & 60.100 & 60.053 \\ .816 & 59.769 & 59.721 & 59.674 & 59.626 & 59.579\end{array}$

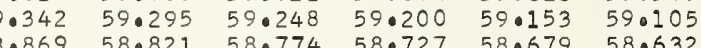

$\begin{array}{llllll}58.869 & 58.821 & 58.774 & 58.727 & 58.679 & 58.632\end{array}$

$\begin{array}{lllllll}57.921 & 57.874 & 57.827 & 57.780 & 57.732 & 57.685\end{array}$

$\begin{array}{llllll}57.448 & 57.401 & 57.354 & 57.306 & 57.258 & 57.211 \\ 56.974 & 56.927 & 56.880 & 56.833 & 56.785 & 56.738\end{array}$

$\begin{array}{llll}38.713 & 38.666 & 38.619 & 38.571 \\ 38.240 & 38.193 & 38.146 & 38.099\end{array}$

56.454

6.406

$6.312-56.264$

$\begin{array}{lllllll}55.081 & 55.033 & 54.986 & 54.938 & 54.891 & 54.844\end{array}$

$\begin{array}{lllllll}54.607 & 54.560 & 54.513 & 54.465 & 54.418 & 54.371\end{array}$

$\begin{array}{llllll}54.134 & 54.086 & 54.039 & 53.992 & 53.945 & 53.089\end{array}$

$\begin{array}{llllll}53.187 & 53.140 & 53.092 & 53.045 & 52.998 & 52.950\end{array}$

$\begin{array}{lllllll}52.714 & 52.667 & 52.619 & 52.572 & 52.524 & 52.477\end{array}$

$21737.768 \quad 37.720 \quad 37.674$

$\begin{array}{llll}37.295 & 37.248 & 37.200 & 37.15\end{array}$

$36.350 \quad 36.302$

$35.877 \quad 35.830$

$\begin{array}{llll}34.932 & 34.885 & 35.310\end{array}$

$34.460 \quad 34 \cdot 412 \quad 34 \cdot 365$

$\begin{array}{ll}33 \cdot 987 & 33 \cdot 940 \\ 33 \cdot 515 & 33 \cdot 468\end{array}$

.001

.002

.003

$51.578 \quad 51.531$

$\begin{array}{llllll}51.294 & 51.247 & 51.199 & 51.152 & 51.105 & 51.057\end{array}$

$\begin{array}{llllll}50.348 & 50.300 & 50.253 & 50.206 & 50.158 & 50.111\end{array}$

$\begin{array}{llllll}49.401 & 49.354 & 49.307 & 49.259 & 49.212 & 49.165\end{array}$

$\begin{array}{llllll}48.928 & 48.881 & 48.833 & 48.786 & 48.739 & 48.691\end{array}$

$\begin{array}{llllll}48.455 & 48.407 & 48.360 & 48.313 & 48.266 & 48.219\end{array}$

$\begin{array}{llllll}47.982 & 47.934 & 47.887 & 47.840 & 47.792 & 47.745 \\ 47.509 & 47.461 & 47.414 & 47.367 & 47.320 & 47.272\end{array}$

$\begin{array}{lllllll}47.036 & 46.988 & 46.941 & 46.894 & 46.846 & 46.799\end{array}$

$\begin{array}{llllll}46.563 & 46.515 & 46.468 & 46.421 & 46.373 & 46.326\end{array}$

$46.090 \quad 46.042 \quad 45 \cdot 995 \quad 45.948 \quad 45 \cdot 900 \quad 45.853$

$\begin{array}{llllll}45.616 & 45.569 & 45.522 & 45.475 & 45.427 & 45.380\end{array}$

$\begin{array}{lllllll}45.144 & 45.096 & 45.049 & 45.002 & 44.954 & 44.907 \\ 44.670 & 44.623 & 44.576 & 44.529 & 44.481 & 44.434\end{array}$

$\begin{array}{llllll}44.198 & 44.150 & 44.103 & 44.056 & 44.009 & 43.961\end{array}$

$43.725 \quad 43.677 \quad 43.630 \quad 43.583 \quad 43.535 \quad 43.488$

$\begin{array}{llllll}43.252 & 43.205 & 43.157 & 43.110 & 43.062 & 43.016 \\ 42.779 & 42.732 & 42.684 & 42.637 & 42.590 & 42.542\end{array}$

0.280199
0.280199

0.280199

0.280198

0.280198
0.280198

0.280197

0.07

0.280196

0.280196

0196

0.280195

0.280195

0.280194

0.280194

0.280193

0.280193
0.280193

0.280192

0.280192

0.280192

0.280191

0.280191

0.280190

0.280190

0.280189

0.280189

0.280189

0.280188

0.280188

0.280187

0.280187

0.280187

0.280186

0.280186

0.280185

0.280184

0.280184

0.280184

0.280183

0.280183

0.280183

0.280182

80182

0.280181

0.280181

0.280181

0.280180

0.280180

0.280179

0.28017 .9

0.280178

0.280178

. 280178

0.280177 


\begin{tabular}{|c|c|c|c|c|c|c|c|c|c|c|c|c|}
\hline (A) & .00 & .01 & .02 & .03 & .04 & .05 & .06 & .07 & .08 & .09 & $(n-1) \times 1000$ & $\lambda(n-1)$ \\
\hline $\begin{array}{r}400.0 \\
0.1 \\
0.2 \\
0.3 \\
0.4 \\
0.5 \\
0.6 \\
0.7 \\
0.8 \\
0.9\end{array}$ & $\begin{array}{r}733.042 \\
32.570 \\
32.097 \\
31.625 \\
31.153 \\
30.680 \\
30.208 \\
29.736 \\
29.263 \\
28.791\end{array}$ & $\begin{array}{l}32.995 \\
32.523 \\
32.050 \\
31.578 \\
31.105 \\
30.633 \\
30.160 \\
29.688 \\
29.216 \\
28.744\end{array}$ & $\begin{array}{l}32.948 \\
32.475 \\
32.003 \\
31.531 \\
31.058 \\
30.586 \\
30.113 \\
29.641 \\
29.168 \\
28.697\end{array}$ & $\begin{array}{l}32.901 \\
32.428 \\
31.956 \\
31.483 \\
31.011 \\
30.539 \\
30.066 \\
29.594 \\
29.122 \\
28.649\end{array}$ & $\begin{array}{l}32.853 \\
32.381 \\
31.908 \\
31.436 \\
30.963 \\
30.491 \\
30.019 \\
29.547 \\
29.074 \\
28.602\end{array}$ & $\begin{array}{l}32.806 \\
32.333 \\
31.861 \\
31.389 \\
30.917 \\
30.444 \\
29.972 \\
29.499 \\
29.027 \\
28.555\end{array}$ & $\begin{array}{l}32.759 \\
32.286 \\
31.814 \\
31.341 \\
30.869 \\
30.397 \\
29.924 \\
29.452 \\
28.980 \\
28.508\end{array}$ & $\begin{array}{l}32.711 \\
32.239 \\
31.767 \\
31.294 \\
30.822 \\
30.349 \\
29.877 \\
29.405 \\
28.932 \\
28.460\end{array}$ & $\begin{array}{l}32.664 \\
32.192 \\
31.719 \\
31.247 \\
30.775 \\
30.302 \\
29.830 \\
29.358 \\
28.885 \\
28.413\end{array}$ & $\begin{array}{l}32.617 \\
32.144 \\
31.672 \\
31.200 \\
30.727 \\
30.255 \\
29.783 \\
29.310 \\
28.838 \\
28.366\end{array}$ & $\begin{array}{l}0.280165 \\
0.280165 \\
0.280164 \\
0.280164 \\
0.280164 \\
0.280163 \\
0.280153 \\
0.280162 \\
0.280162 \\
0.280162\end{array}$ & $\begin{array}{l}1.288758 \\
1.288785 \\
1 \cdot 288811 \\
1.288838 \\
1.288864 \\
1.288891 \\
1.288917 \\
1.288943 \\
1.288970 \\
1.288996\end{array}$ \\
\hline $\begin{array}{r}4601.0 \\
1.1 \\
1.2 \\
1.3 \\
1.4 \\
1.5 \\
1.5 \\
1.7 \\
1.8 \\
109\end{array}$ & $\begin{array}{r}21728.319 \\
27.846 \\
27.375 \\
26.902 \\
26.430 \\
25.958 \\
25.486 \\
25.013 \\
24.541 \\
24.069\end{array}$ & $\begin{array}{l}28.271 \\
27.799 \\
27.327 \\
26.855 \\
26.383 \\
25.910 \\
25.438 \\
24.966 \\
24.494 \\
24.022\end{array}$ & $\begin{array}{l}28.224 \\
27.752 \\
27.280 \\
26.807 \\
26.335 \\
25.863 \\
25.8391 \\
24.919 \\
24.447 \\
23.975\end{array}$ & $\begin{array}{l}28 \cdot 177 \\
27.705 \\
27.232 \\
26.760 \\
26.288 \\
25.816 \\
25 \cdot 344 \\
24.872 \\
24.400 \\
23.927\end{array}$ & $\begin{array}{l}28.130 \\
27.658 \\
27.185 \\
26.713 \\
26.241 \\
25.769 \\
25.297 \\
24.824 \\
24.353 \\
23.880\end{array}$ & $\begin{array}{l}28.082 \\
27.610 \\
27.138 \\
26.666 \\
26.194 \\
25.721 \\
25.250 \\
24.777 \\
24.305 \\
23.833\end{array}$ & $\begin{array}{l}28.035 \\
27.563 \\
27.091 \\
26.619 \\
26.146 \\
25.674 \\
25.202 \\
24.730 \\
24.258 \\
23.786\end{array}$ & $\begin{array}{l}27.988 \\
27.516 \\
27.044 \\
26.572 \\
26.099 \\
25.627 \\
25.155 \\
24.6883 \\
24.211 \\
23.739\end{array}$ & $\begin{array}{l}27.941 \\
27.469 \\
26.996 \\
26.0524 \\
26.052 \\
25.580 \\
25.108 \\
24.636 \\
24.163 \\
23.692\end{array}$ & $\begin{array}{l}27.894 \\
27.421 \\
26.949 \\
26.477 \\
26.005 \\
25.533 \\
25.060 \\
24.589 \\
24.116 \\
23.644\end{array}$ & $\begin{array}{l}0.280161 \\
0.280161 \\
0.280161 \\
0.280160 \\
0.280160 \\
0.280160 \\
0.280159 \\
0.280159 \\
0.280159 \\
0.280158\end{array}$ & $\begin{array}{l}1.289023 \\
1.289049 \\
1.289076 \\
1.289102 \\
1.289129 \\
1.289155 \\
1.289181 \\
1.289208 \\
1.289234 \\
1.289261\end{array}$ \\
\hline $\begin{array}{r}4602.0 \\
2.1 \\
2.2 \\
2.3 \\
2.4 \\
2.5 \\
2.6 \\
2.7 \\
2.8 \\
2.9\end{array}$ & $\begin{array}{r}21723.597 \\
23.125 \\
22.653 \\
22.181 \\
21.709 \\
21.238 \\
20.765 \\
20.294 \\
19.822 \\
19.350\end{array}$ & $\begin{array}{l}23.550 \\
23.078 \\
22.606 \\
22.134 \\
21.662 \\
21.190 \\
20.718 \\
20.247 \\
19.774 \\
19.303\end{array}$ & $\begin{array}{l}23.503 \\
23.031 \\
22.559 \\
22.086 \\
21.615 \\
21.0143 \\
20.0711 \\
20.199 \\
19.727 \\
19.0256\end{array}$ & $\begin{array}{l}23.456 \\
22.983 \\
22.511 \\
22.040 \\
21.568 \\
21.096 \\
20.624 \\
20.152 \\
19.680 \\
19.0208\end{array}$ & $\begin{array}{l}23.408 \\
22.936 \\
22.464 \\
21.992 \\
21.521 \\
21.049 \\
20.577 \\
20.105 \\
19.633 \\
19.161\end{array}$ & $\begin{array}{l}23.361 \\
22.889 \\
22.417 \\
21.945 \\
21.474 \\
21.002 \\
20.530 \\
20.058 \\
19.586 \\
19.114\end{array}$ & $\begin{array}{l}23.314 \\
22.842 \\
22.370 \\
21.898 \\
21.426 \\
20.954 \\
20.482 \\
20.010 \\
19.539 \\
19.067\end{array}$ & $\begin{array}{l}23.267 \\
22.795 \\
22.323 \\
21.851 \\
21.0379 \\
20.907 \\
20.435 \\
19.964 \\
19.491 \\
19.020\end{array}$ & $\begin{array}{l}23.220 \\
22.0747 \\
22.276 \\
21.0803 \\
21.0332 \\
20.860 \\
20.388 \\
19.916 \\
19.444 \\
18.972\end{array}$ & $\begin{array}{l}23 \cdot 173 \\
22.700 \\
22.229 \\
21.757 \\
21.285 \\
20.813 \\
20.341 \\
19.869 \\
19.397 \\
18.925\end{array}$ & $\begin{array}{l}0.280158 \\
0.280158 \\
0.280157 \\
0.280157 \\
0.280157 \\
0.280156 \\
0.280156 \\
0.280156 \\
0.280155 \\
0.280155\end{array}$ & $\begin{array}{l}1.289287 \\
1.289314 \\
1.289340 \\
1.289366 \\
1.289393 \\
1.289419 \\
1.289446 \\
1.289472 \\
1.289499 \\
1.289525\end{array}$ \\
\hline $\begin{array}{r}4603.0 \\
3.1 \\
3.2 \\
3.3 \\
3.4 \\
3.5 \\
3.6 \\
3.7 \\
3.8 \\
3.9\end{array}$ & $\begin{array}{r}21718.878 \\
18.406 \\
17.935 \\
17.463 \\
16.991 \\
16.519 \\
16.047 \\
15.576 \\
15.104 \\
14.632\end{array}$ & $\begin{array}{l}18.831 \\
18.359 \\
17.887 \\
17.415 \\
16.944 \\
16.472 \\
16.000 \\
15.529 \\
15.057 \\
14.585\end{array}$ & $\begin{array}{l}18.784 \\
18.312 \\
17.840 \\
17.368 \\
16.896 \\
16.425 \\
15.953 \\
15.481 \\
15.010 \\
14.538\end{array}$ & $\begin{array}{l}18.736 \\
18.065 \\
17.793 \\
17.321 \\
16.849 \\
16.378 \\
15.906 \\
15.434 \\
14.963 \\
14.491\end{array}$ & $\begin{array}{l}18.689 \\
18.218 \\
17.746 \\
17.274 \\
16.802 \\
16.330 \\
15.859 \\
15.387 \\
14.916 \\
14.443\end{array}$ & $\begin{array}{l}18.642 \\
18.170 \\
17.698 \\
17.227 \\
16.755 \\
16.283 \\
15.812 \\
15.340 \\
14.868 \\
14.396\end{array}$ & $\begin{array}{l}18.595 \\
18.123 \\
17.651 \\
17.179 \\
16.708 \\
16.236 \\
15.764 \\
15.292 \\
14.821 \\
14.349\end{array}$ & $\begin{array}{l}18.548 \\
18.076 \\
17.0604 \\
17.132 \\
16.661 \\
16.189 \\
15.717 \\
15.246 \\
14.774 \\
14.0302\end{array}$ & $\begin{array}{l}18.501 \\
18.029 \\
17.557 \\
17.085 \\
16.613 \\
16.142 \\
15.670 \\
15.198 \\
140726 \\
14.255\end{array}$ & $\begin{array}{l}18.453 \\
17.982 \\
17.510 \\
17.038 \\
16.566 \\
16.095 \\
15.623 \\
15.151 \\
14.679 \\
14.208\end{array}$ & $\begin{array}{l}0.280155 \\
0.280154 \\
0.280154 \\
0.280154 \\
0.280153 \\
0.280153 \\
0.280153 \\
0.280152 \\
0.280152 \\
0.280152\end{array}$ & $\begin{array}{l}1.289552 \\
1.289578 \\
1028904 \\
1.289631 \\
10289657 \\
1028684 \\
0289710 \\
1.289737 \\
1.289763 \\
.0289790\end{array}$ \\
\hline $\begin{array}{r}4604.0 \\
4.1 \\
402 \\
403 \\
4.4 \\
4.5 \\
4.6 \\
407 \\
408 \\
409\end{array}$ & $\begin{array}{r}21714.161 \\
13.689 \\
13.218 \\
12.746 \\
12.274 \\
11.803 \\
11.331 \\
10.860 \\
10.388 \\
09.917\end{array}$ & $\begin{array}{l}14.113 \\
13.642 \\
13.170 \\
12.698 \\
12.227 \\
11.756 \\
11.284 \\
10.813 \\
10.341 \\
09.870\end{array}$ & $\begin{array}{l}14.066 \\
13.594 \\
13.123 \\
12.651 \\
12.180 \\
11.0708 \\
11.237 \\
10.766 \\
10.294 \\
09.823\end{array}$ & $\begin{array}{l}14.019 \\
13.547 \\
13.076 \\
12.604 \\
12.133 \\
11.661 \\
11.190 \\
10.718 \\
10.047 \\
09.775\end{array}$ & $\begin{array}{l}13.972 \\
13.500 \\
13.029 \\
12.557 \\
12.085 \\
11.614 \\
11.143 \\
10.671 \\
10.200 \\
09.728\end{array}$ & $\begin{array}{l}13.925 \\
13.453 \\
12.982 \\
12.510 \\
12.039 \\
11.567 \\
11.095 \\
10.624 \\
10.153 \\
09.681\end{array}$ & $\begin{array}{l}13.878 \\
13.406 \\
12.934 \\
12.463 \\
11.991 \\
11.520 \\
11.048 \\
10.576 \\
10.105 \\
09.634\end{array}$ & $\begin{array}{l}13.831 \\
13.359 \\
12.887 \\
12.416 \\
11.944 \\
11.472 \\
11.001 \\
10.530 \\
10.058 \\
09.587\end{array}$ & $\begin{array}{l}13.783 \\
13.312 \\
12.840 \\
12.0368 \\
11.897 \\
11.0426 \\
10.054 \\
10.482 \\
10.011 \\
09.540\end{array}$ & $\begin{array}{l}13.736 \\
13.264 \\
12.793 \\
12.322 \\
11.850 \\
11.378 \\
10.907 \\
10.435 \\
09.964 \\
09.492\end{array}$ & $\begin{array}{l}0.280151 \\
0.280151 \\
0.280150 \\
0.280150 \\
0.280150 \\
0.280149 \\
0.280149 \\
0.280149 \\
0.280148 \\
0.280148\end{array}$ & $\begin{array}{l}1.289816 \\
1.289842 \\
1.289869 \\
1.289895 \\
1.289922 \\
1.289948 \\
1.289975 \\
1.290001 \\
1.290027 \\
1.290054\end{array}$ \\
\hline $\begin{array}{r}4605.0 \\
5.1 \\
5.2 \\
5.3 \\
5.4 \\
5.5 \\
5.6 \\
507 \\
5.8 \\
5.9\end{array}$ & $\begin{array}{r}21709.445 \\
08.974 \\
08.502 \\
08.031 \\
07.560 \\
07.088 \\
06.617 \\
06.146 \\
05.675 \\
05.203\end{array}$ & $\begin{array}{l}09.398 \\
08.927 \\
08.455 \\
07.984 \\
07.512 \\
07.041 \\
06.570 \\
06.099 \\
05.627 \\
05.156\end{array}$ & $\begin{array}{l}09.351 \\
08.880 \\
08.408 \\
07.037 \\
07.465 \\
06.994 \\
06.523 \\
06.052 \\
05.580 \\
05.109\end{array}$ & $\begin{array}{l}09.304 \\
08.833 \\
08.361 \\
07.890 \\
07.418 \\
06.947 \\
06.475 \\
06.004 \\
05.533 \\
05.062\end{array}$ & $\begin{array}{l}09.257 \\
08.786 \\
08.314 \\
07.843 \\
07.371 \\
06.900 \\
06.428 \\
05.957 \\
05.486 \\
05.015\end{array}$ & $\begin{array}{l}09.209 \\
08.738 \\
08.267 \\
07.795 \\
07.324 \\
06.853 \\
06.381 \\
05.910 \\
05.439 \\
04.968\end{array}$ & $\begin{array}{l}09.162 \\
08.691 \\
08.219 \\
07.748 \\
07.277 \\
06.806 \\
06.334 \\
05.863 \\
05.392 \\
04.921\end{array}$ & $\begin{array}{l}09.115 \\
08.644 \\
08.173 \\
07.701 \\
07.230 \\
06.758 \\
06.287 \\
05.816 \\
05.344 \\
04.874\end{array}$ & & $\begin{array}{l}09.021 \\
08.549 \\
08.078 \\
07.607 \\
07.135 \\
06.664 \\
06.193 \\
05.722 \\
05.250 \\
04.779\end{array}$ & $\begin{array}{l}0.280148 \\
0.280147 \\
0.280147 \\
0.280147 \\
0.280146 \\
0.280146 \\
0.280146 \\
0.280145 \\
0.280145 \\
0.280145\end{array}$ & $\begin{array}{l}1.290080 \\
1.290107 \\
1.290133 \\
1.290160 \\
1.290186 \\
1.290213 \\
1.290239 \\
1.290265 \\
1.290292 \\
1.290318\end{array}$ \\
\hline $\begin{array}{r}4606.0 \\
6.1 \\
6.2 \\
6.3 \\
6.4 \\
6.5 \\
6.6 \\
6.7 \\
6.8 \\
6.9\end{array}$ & $\begin{array}{r}21704.732 \\
04.261 \\
03.790 \\
03.318 \\
02.847 \\
02.376 \\
01.905 \\
01.434 \\
00.963 \\
00.492\end{array}$ & $\begin{array}{l}04 \cdot 685 \\
04.214 \\
03.743 \\
03.271 \\
02.800 \\
02.329 \\
01.858 \\
01.387 \\
00.916 \\
00.445\end{array}$ & $\begin{array}{l}04.638 \\
04.167 \\
03.696 \\
03.224 \\
02.753 \\
02.282 \\
01.811 \\
01.340 \\
00.869 \\
00.398\end{array}$ & $\begin{array}{l}04.591 \\
04.119 \\
03.648 \\
03.177 \\
02.706 \\
02.235 \\
01.0764 \\
01.292 \\
00.822 \\
00.351\end{array}$ & $\begin{array}{l}04.543 \\
04.073 \\
03.601 \\
03.130 \\
02.659 \\
02.187 \\
01.717 \\
01.245 \\
00.775 \\
00.303\end{array}$ & $\begin{array}{l}04.496 \\
04.025 \\
03.554 \\
03.083 \\
02.612 \\
02.140 \\
01.670 \\
01.198 \\
00.728 \\
00.257\end{array}$ & $\begin{array}{l}04.449 \\
03.978 \\
03.507 \\
03.036 \\
02.565 \\
02.093 \\
01.623 \\
01.151 \\
00.680 \\
00.209\end{array}$ & $\begin{array}{l}04 \cdot 402 \\
03.931 \\
03.460 \\
02.989 \\
02.518 \\
02.046 \\
01.575 \\
01.104 \\
00.633 \\
00.162\end{array}$ & $\begin{array}{l}04.355 \\
03.884 \\
03.413 \\
02.941 \\
02.470 \\
01.999 \\
01.528 \\
01.057 \\
00.586 \\
00.115\end{array}$ & $\begin{array}{l}04.308 \\
03.837 \\
03.365 \\
02.895 \\
02.423 \\
01.952 \\
01.481 \\
01.010 \\
00.539 \\
00.068\end{array}$ & $\begin{array}{l}0.280144 \\
0.280144 \\
0.280144 \\
0.280143 \\
0.280143 \\
0.280143 \\
0.280142 \\
0.280142 \\
0.280142 \\
0.280141\end{array}$ & $\begin{array}{l}1.290345 \\
1.290371 \\
1.290398 \\
1.290424 \\
1.290450 \\
1.290477 \\
1.290503 \\
1.290530 \\
1.290555 \\
1.290583\end{array}$ \\
\hline $\begin{array}{r}4607.0 \\
7: 1 \\
7: 2 \\
7: 3 \\
7.4 \\
7: 5 \\
7: 6 \\
7: 07 \\
7.08 \\
7.9\end{array}$ & $\begin{array}{r}21700.021 \\
21699.550 \\
99.079 \\
98.608 \\
98.137 \\
97.666 \\
97.195 \\
96.725 \\
96.254 \\
95.783\end{array}$ & $\begin{array}{l}\text { *99.974 } \\
99.503 \\
99.032 \\
98.561 \\
98.090 \\
97.619 \\
97.148 \\
96.677 \\
96.206 \\
95.736\end{array}$ & $\begin{array}{r}* 99.927 \\
99.456 \\
98.985 \\
98.514 \\
98.043 \\
97.572 \\
97.101 \\
96.630 \\
96.159 \\
95.688\end{array}$ & $\begin{array}{r}* 99.880 \\
99.409 \\
98.938 \\
98.467 \\
97.996 \\
97.525 \\
97.054 \\
96.583 \\
96.112 \\
95.641\end{array}$ & $\begin{array}{l}* 99.833 \\
99.362 \\
98.891 \\
98.420 \\
97.948 \\
97.478 \\
97.007 \\
96.536 \\
96.065 \\
95.594\end{array}$ & $\begin{array}{l}99.785 \\
99.315 \\
98.844 \\
98.373 \\
97.902 \\
97.431 \\
96.960 \\
96.489 \\
96.018 \\
95.547\end{array}$ & $\begin{array}{l}\# 99.738 \\
99.267 \\
98.796 \\
98.326 \\
97.855 \\
97.384 \\
96.913 \\
96.442 \\
95.971 \\
95.500\end{array}$ & $\begin{array}{l}99.220 \\
98.750 \\
98.279 \\
97.808 \\
97.336 \\
96.866 \\
96.395 \\
95.924 \\
95.453\end{array}$ & $\begin{array}{r}* 99.644 \\
99.173 \\
98.702 \\
98.231 \\
97.760 \\
97.290 \\
96.819 \\
96.348 \\
95.877 \\
95.406\end{array}$ & & $\begin{array}{l}0.280141 \\
0.280141 \\
0.280140 \\
0.280140 \\
0.280140 \\
0.280139 \\
0.280139 \\
0.280139 \\
0.280138 \\
0.280138\end{array}$ & \\
\hline $\begin{array}{r}4608.0 \\
8.1 \\
8.2 \\
8.3 \\
8.4 \\
8.5 \\
8.6 \\
8.7 \\
8.8 \\
8.9\end{array}$ & $\begin{array}{r}21695.312 \\
94.841 \\
94.370 \\
93.899 \\
93.429 \\
92.958 \\
92.487 \\
92.017 \\
91.546 \\
91.075\end{array}$ & $\begin{array}{l}94.794 \\
94.323 \\
93.852 \\
93.382 \\
92.911 \\
92.440 \\
91.969 \\
91.499 \\
91.028\end{array}$ & $\begin{array}{l}95.218 \\
94.747 \\
94.276 \\
93.805 \\
93.335 \\
92.864 \\
92.393 \\
91.922 \\
91.452 \\
90.981\end{array}$ & $\begin{array}{l}95.170 \\
94.700 \\
94.229 \\
93.758 \\
93.288 \\
92.817 \\
92.346 \\
91.875 \\
91.405 \\
90.934\end{array}$ & $\begin{array}{l}95.123 \\
94.653 \\
94.182 \\
93.711 \\
93.240 \\
92.770 \\
92.299 \\
91.828 \\
91.0358 \\
90.887\end{array}$ & $\begin{array}{l}95.076 \\
94.606 \\
94.135 \\
93.664 \\
93.194 \\
92.723 \\
92.252 \\
91.781 \\
91.311 \\
90.840\end{array}$ & $\begin{array}{l}95.029 \\
94.559 \\
94.088 \\
93.617 \\
93.146 \\
92.676 \\
92.205 \\
91.734 \\
91.264 \\
90.793\end{array}$ & $\begin{array}{l}94.982 \\
94.511 \\
94.041 \\
93.570 \\
93.099 \\
92.628 \\
92.158 \\
91.687 \\
91.217 \\
90.746\end{array}$ & $\begin{array}{l}94.935 \\
94.464 \\
93.994 \\
93.523 \\
93.052 \\
92.582 \\
92.111 \\
91.640 \\
91.169 \\
90.699\end{array}$ & $\begin{array}{l}94.888 \\
94.417 \\
93.947 \\
93.476 \\
93.005 \\
92.534 \\
92.063 \\
91.593 \\
91.123 \\
90.652\end{array}$ & & $\begin{array}{l}1.290874 \\
1.290900 \\
1.290926 \\
1.290953 \\
1.290979 \\
1.291006 \\
1.291032 \\
1.291059 \\
1.291085 \\
1.291111\end{array}$ \\
\hline $\begin{array}{r}4609.0 \\
9.1 \\
9.02 \\
9.3 \\
9.4 \\
9.5 \\
9.6 \\
9.7 \\
9.8 \\
9.9\end{array}$ & $\begin{array}{r}21690.604 \\
90.134 \\
89.664 \\
89.193 \\
88.722 \\
88.252 \\
87.781 \\
87.311 \\
86.840 \\
86.370\end{array}$ & $\begin{array}{l}89.146 \\
88.675 \\
88.205 \\
87.734 \\
87.264 \\
86.793 \\
86.323\end{array}$ & $\begin{array}{l}90.040 \\
89.569 \\
89.099 \\
88.628 \\
88.158 \\
87.687 \\
87.217 \\
86.746 \\
86.276\end{array}$ & $\begin{array}{l}89.993 \\
89.522 \\
89.052 \\
88.581 \\
88.111 \\
87.640 \\
87.170 \\
86.699 \\
86.229\end{array}$ & $\begin{array}{l}89.946 \\
89.475 \\
89.005 \\
88.534 \\
88.064 \\
87.593 \\
87.123 \\
86.052 \\
86.182\end{array}$ & $\begin{array}{l}89.899 \\
89.428 \\
88.958 \\
88.487 \\
88.017 \\
87.546 \\
87.076 \\
86.605 \\
86.135\end{array}$ & $\begin{array}{l}89.852 \\
89.381 \\
88.910 \\
88.440 \\
87.969 \\
87.499 \\
87.029 \\
86.558 \\
86.088\end{array}$ & $\begin{array}{l}89.805 \\
89.334 \\
88.863 \\
88.393 \\
87.922 \\
87.452 \\
86.982 \\
86.511 \\
86.041\end{array}$ & $\begin{array}{l}88.346 \\
87.875 \\
87.405 \\
86.934 \\
86.464 \\
85.994\end{array}$ & $\begin{array}{l}89.240 \\
88.770 \\
88.299 \\
87.828 \\
87.358 \\
86.887 \\
86.417 \\
85.947\end{array}$ & $\begin{array}{l}0.280134 \\
0.280134 \\
0.280133 \\
0.280133 \\
0.280133 \\
0.280132 \\
0.280132 \\
0.280132 \\
0.280131 \\
0.280131\end{array}$ & $\begin{array}{r}0.01164 \\
.291191 \\
0291217 \\
0291244 \\
0291270 \\
.291297 \\
.291323 \\
.291349 \\
.0291376\end{array}$ \\
\hline
\end{tabular}


$0.0 \quad 21685.899$

0.2

0.6
0.7

0.9

4611.0

$1: 1$
1.2

1. 3

1.4

1.6
1.7

1.8
1.9

4612.

2.1

2.3

$2 \cdot 4$

2.6
2.7

2.8
2.9

46130

$3 \cdot 1$

$3 \cdot 2$
3.3
3.4

3.5

3.

3.9

4614.

4.1

$4 \cdot 3$

4.5

$4 \cdot 6$

$4 \cdot 7$
$4 \cdot 8$
$4 \cdot 9$

4615.0

5.

5.3

5.8

4616.

6.1

$6 \cdot 3$

6.4

6.6
6.7

608

4617.0

7.1
7.2
7.3

7.5

7.7

$7 \cdot 8$
$7 \cdot 9$

4618

8.1

8.3

8.8

619.0

9.1

9.3

9.4

9.6

9.8

1676.496

75.556 72.267

71
70
70
6
69
68

21667.100

65.22

64.752

662.405

1657.71

57.2
56.774
56.305

$\begin{array}{llllllllll}85.429 & 85.382 & 85.805 & 85.758 & 85.711 & 85.664 & 85.617 & 85.570 & 85.523 & 85.476 \\ 85.35 & 85.288 & 85.241 & 85.194 & 85.147 & 85.100 & 85.053 & 85.006\end{array}$ $\begin{array}{lllllllllll}84.488 & 84.912 & 84.865 & 84 \cdot 818 & 84.771 & 84.723 & 84.676 & 84.630 & 84.583 & 84.535\end{array}$

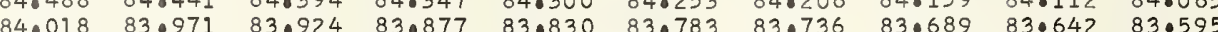
$\begin{array}{llllllllll}83.548 & 83.500 & 83.454 & 83.407 & 83.360 & 83.312 & 83.266 & 83.219 & 83.172 & 83.125\end{array}$ $\begin{array}{lllllllllll}8.078 & 83.031 & 82.983 & 82.936 & 82.890 & 82.842 & 82.795 & 82.748 & 82.701 & 82.654\end{array}$

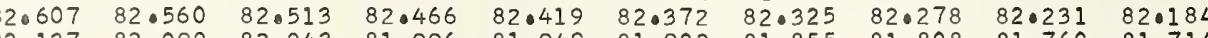

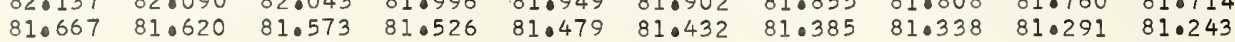

$21681.197 \quad 81.149$ $80.726 \quad 80.679$ $\begin{array}{ll}80.726 & 80.679 \\ 80.257 & 80.209\end{array}$

$\begin{array}{ll}79.786 & 79.739 \\ 79.316 & 79.269\end{array}$

$78.846 \quad 78.799$

$\begin{array}{ll}78.376 & 78 \cdot 329 \\ 77.906 & 77.859\end{array}$

$\begin{array}{ll}77.436 & 77.389 \\ 76.966 & 76.919\end{array}$

$81.103 \quad 81.056$

$80.162 \quad 80.11$

79.69
79.22

78.72279 .175

$\begin{array}{ll}78.282 & 78.235\end{array}$

77.34
76.872

77.295

$\begin{array}{ll}80.539 & 80.49 \\ 80.068 & 80.02\end{array}$

$\begin{array}{ll}80.068 & 80.02 \\ 79.598 & 79.55\end{array}$

$79 \cdot 12$

$\begin{array}{ll}78.658 & 78.611 \\ 78.188 & 78.141\end{array}$

77.71

78.141

$76.096 \quad 76.448$

75.086750 .03900

74.61674 .56

73.67673 .629

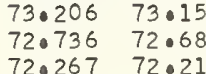

$76.402 \quad 76.355$

76.77

77.201

80.914

80.445
79.974

79.504
79.034

78.564
78.094

77

$\begin{array}{ll}78.564 & 78.517 \\ 78.094 & 78.047 \\ 77.624 & 77.577 \\ 77.154 & 77.107\end{array}$

$\begin{array}{ll}75.932 & 75088 \\ 75.462 & 75.41\end{array}$

$\begin{array}{ll}74.992 & 74.945 \\ 74.522 & 74.475\end{array}$

$\begin{array}{ll}74.052 & 74.005 \\ 73.582 & 73.535\end{array}$

$75 \cdot 838$

75.368
74.898

$74 \cdot 428$
73.958

73.488
73.018

75.79

$75 \cdot 32$

74.38
73.91

73.441
72.971

71.327
70.857
70.387
69.918
69.448
68.978
68.509
68.039
67.570

71.750

$72.642 \quad 72.596$

72.54

72.501

$\begin{array}{llll}76.214 & 76.167 & 76.120 & 76.073 \\ 75.0744 & 75.697 & 75.650 & 75.603\end{array}$

$75.744 \quad 75.697 \quad 75.650 \quad 75.603$

$\begin{array}{llll}74.274 & 75 \cdot 227 & 75 \cdot 180 & 75.133\end{array}$

$74.33474 .287 \quad 74 \cdot 240 \quad 74 \cdot 193$

$\begin{array}{llll}73.864 & 73.817 & 73 \cdot 770 & 73.723\end{array}$

$\begin{array}{llll}73.394 & 73.347 & 73.300 & 73.253 \\ 72.924 & 72.877 & 72 \cdot 831 & 72.783\end{array}$

$72.454 \quad 72.407-72.360$

$\begin{array}{llllllll}71.703 & 71.656 & 71.609 & 71.562 & 71.515 & 71.468 & 71.421 & 71.374\end{array}$

$\begin{array}{lllll}71.280 & 71.233 & 71.186 & 71.139 & 71.09 \\ 70.810 & 70.763 & 70.716 & 70.669 & 70.622\end{array}$

71.045

$70 \cdot 998$

70.29370 .247

69.871

69.82469 .777

70.19

70.622
70.153

70.105

70.05

$70.951 \quad 70.904$

70.48270 .434

2

$\begin{array}{lllll}68.884 & 68.837 & 68.791 & 68.744\end{array}$

$\begin{array}{llll}69.636 & 69.589 & 69.542 & 69.495\end{array}$

67.945
67.476

$68 \cdot 368$

68.32

68.744

69.166

$69.119 \quad 69.072 \quad 69.025$

$66.630 \quad 66.583$

66.16166 .114

67.006

666.959

67.851
67.38

$67 \cdot 804$
67.335

$68.227 \quad 68.180 \quad 68.133 \quad 68.086$

$\begin{array}{llll}67.757 & 67.710 & 67.663 & 67.616\end{array}$

63.81364 .236

63.34463 .297

$61.936 \quad 61.888$

$61.466 \quad 61.41$

$60.528 \quad 60.481$

$60.058 \quad 60.011$

$59.589 \quad 59.542$

$58.651 \quad 58.604$

$58.18258 \cdot 13$

$56.305-56.727$

$55.836 \quad 55.78$

54.42954 .382

$53.959 \quad 53 \cdot 91$

$66.067 \quad 66.020$

66.912

66.86

66.81

$66.771 \quad 66.724 \quad 66.677$

$65.128 \quad 65.081$

65.973
65.503

65.457
64.987

65.457
64.987

65.879

$65 \cdot 879$
65.409

$66 \cdot 30$

6.832
5.363

66.254

65.315

65.738

$\begin{array}{ll}64.658 & 64 \cdot 61 \\ 64 \cdot 188 & 64 \cdot 142\end{array}$

64.0564
64.095

64.095
63.625

64.517
64.048
63.578

64.470

63.53

$64 \cdot 42$

63.954

$64 \cdot 846$
$64 \cdot 377$

63.907

63.860

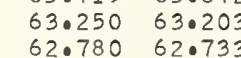

63.156
62.68

62.640

62.593

3.015

$62 \cdot 968$
62.499

63.391

$62.311 \quad 62.264$

62.217
61.748

62.17

$62.123 \quad 62.076 \quad 62.029 \quad 61.982$

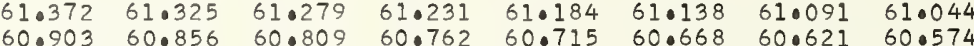

$\begin{array}{llllllll}60.434 & 60.387 & 60.340 & 60.293 & 60.246 & 60.199 & 60.152 & 60.105 \\ 59.965 & 59.918 & 59.871 & 59.824 & 59.777 & 59.730 & 59.683 & 59.636\end{array}$

$59.777 \quad 59.730 \quad 59.683 \quad 59.636$

$\begin{array}{llllllll}59.495 & 59.448 & 59.402 & 59.355 & 59.308 & 59.261 & 59.214 & 59.167 \\ 59.026 & 58.979 & 58.932 & 58.885 & 58.838 & 58.792 & 58.745 & 58.698\end{array}$

$58.557 \quad 58.510$

58.932

$57.619 \quad 57.572$

57.994

57.947

$\begin{array}{llll}58.369 & 58.322 & 58.275 & 58.229\end{array}$

$57.149 \quad 57.102$

56.21

56.164
55.695

$57.056 \quad 57.4$

$\begin{array}{ll}57.056 & 57.00 \\ 56.586 & 56.53\end{array}$

57.431

570384

55.27

$54.803 \quad 54.757$

56.117

56.070

$\begin{array}{llll}57.431 & 570384 & 57.337 & 57.290\end{array}$

$\begin{array}{llll}56.492 & 56.446 & 56.399 & 56.352\end{array}$

$56.023 \quad 55.976 \quad 55.929 \quad 55.883$

$\begin{array}{llll}55.085 & 55.507 & 55.460 & 55.414\end{array}$

$\begin{array}{llllll}55.179 & 55.132 & 50085 & 55.038 & 54.992 & 54.944\end{array}$

$\begin{array}{llllll}54.710 & 54.663 & 54.616 & 54.569 & 54.522 & 54.475 \\ 54.241 & 54.194 & 54.147 & 54.100 & 54.053 & 54.007\end{array}$

$53.490 \quad 53.444$

$52.552 \quad 52.506$

$51.615 \quad 51.568$

$51.146 \quad 51.099$

$\begin{array}{ll}50.677 & 50.630 \\ 50.208 & 50.16\end{array}$

$53 \cdot 865$
$53 \cdot 397$

52.927

53.772

54.194

$\begin{array}{ll}49.739 & 49.692 \\ 49.270 & 49.223 \\ 48.801 & 48.754\end{array}$

52.834

53.256

$\begin{array}{llll}53.209 & 53.162 & 53.115 & 53.068\end{array}$

51.521

51.052

50.58350 .536

$\begin{array}{lllllll}52.834 & 52.787 & 52.740 & 52.693 & 52.646 & 52.599 \\ 2 & 52.365 & 52.318 & 52.271 & 52.224 & 52.177 & 52.130 \\ & 51.896 & 51.849 & 51.802 & 51.755 & 51.708 & 51.661\end{array}$

$\begin{array}{llllll}51.427 & 51.849 & 51.802 & 51.755 & 51.708 & 51.661\end{array}$

$\begin{array}{llllll}51.427 & 51.380 & 51.333 & 51.286 & 51.239 & 51.193 \\ 50.958 & 50.911 & 50.864 & 50.817 & 50.771 & 50.724\end{array}$

$\begin{array}{lllllll}50.489 & 50.442 & 50.395 & 50.348 & 50.302 & 50.255\end{array}$

$\begin{array}{llllll}50.021 & 49.974 & 49.927 & 49.880 & 49.833 & 49.786 \\ 49.552 & 49.504 & 49.458 & 49.411 & 49.364 & 49.317\end{array}$

$\begin{array}{llllllll}49.645 & 49.598 & 49.552 & 49.504 & 49.458 & 49.411 & 49.364 & 49.317 \\ 49.176 & 49.130 & 49.083 & 49.036 & 48.989 & 48.942 & 48.895 & 48.848\end{array}$ 
$\begin{array}{rrrrrrrrrrr}0.0 & 21638.961 & 38.914 & 38.868 & 38.821 & 38.774 & 38.727 & 38.680 & 38.634 & 38.587 & 38.540 \\ 0.1 & 38.493 & 38.446 & 38.399 & 38.352 & 38.306 & 38.259 & 38.212 & 38.165 & 38.118 & 38.071\end{array}$

$\begin{array}{lllllllllll}0.2 & 38.025 & 37.978 & 37.931 & 37.884 & 37.837 & 37.791 & 37.744 & 37.697 & 37.650 & 37.603\end{array}$

$\begin{array}{lllllllllll}0.3 & 37.556 & 37.510 & 37.462 & 37.416 & 37.369 & 37.322 & 37.275 & 37.228 & 37.181 & 37.135 \\ 0.4 & 37.088 & 37.041 & 36.994 & 36.948 & 36.901 & 36.854 & 36.807 & 36.760 & 36.713 & 36.667\end{array}$

$\begin{array}{lllllllllll}0.5 & 36.620 & 36.573 & 36.526 & 36.479 & 36.432 & 36.385 & 36.339 & 36.292 & 36.245 & 36.198\end{array}$

$\begin{array}{llllllllllll}0.6 & 36.151 & 36.104 & 36.058 & 36.011 & 35.964 & 35.917 & 35.871 & 35.824 & 35.777 & 35.730\end{array}$

$\begin{array}{llllllllll}35.683 & 35.636 & 35.590 & 35.543 & 35.496 & 35.449 & 35.402 & 35.355 & 35.309 & 35.262\end{array}$

$(n-1) \times 1000$

$\lambda(n-1)$

0.280097

0.2880096

0.280096

.280095

0.280095

0.280094

0.280094
0.280094

0.280093

0.0003

.280092

0.280092

0.280091

0.280091

0.280090

0.280090

0.280090

0.280089

0.280089

0.280088

0.280088

0.280087

0.280087

0.280086

0.280086

0.280085

0.280085

0.280084

0.280083

0.280083

0.280083

0.280082

0.280082
0.280082
0.2832

0.280081

0.28008

0.280080

0.280080

0.280079

0.280079

0.280078

0.280078

0.280077

0.280077

0.280076

0.280076

0.280076

0.280075

0.280075

0.280074

0.280074

0.280073

0.280073

0.280073

0.280072

0.280072

0.280072

0.280071

0.280071

0.280070
0.280070

0.280070

0.280069

0.280069

0.280069

0.280068

0.280068

0.280067

0.280067

0.280066

0.280066

0.280066

0.280065

0.280065

0.280064

0.280064

0.280063
$1 \cdot 294047$

1.294073

.294126

1.294152

1.294205

1.294258
1.294285

1.294312

.294338

1.294390

.294443

1.294470
1.294496

1.294523

.294549

. 294628

1.294655

1.294708

. 294734

. 294761

1. 2947874

- 294840 .294866
.294893

1.294919

1.294946

1.294999

1.295025

1.295078

.295104

1.295131

1.295184

1.295237

. 295263

1.295290

1.295343

- 295448

- 295501

1.295528

. 295581

2.295633

1. 295660

1.295686

1.295739

1.295766

1.295819

1.295845
1.295871

1.295898

1.295924

1.295977

1. 296004

1. 296030

1. 296083

1.296209

1.296162

1.296189

1. 296215

1.296268

.296295

I. 296348

1.296374
1.296400

1.296427

.296453
.296480

1.296506

. 296559

1.296586

. 296612

1.296665
1.295369

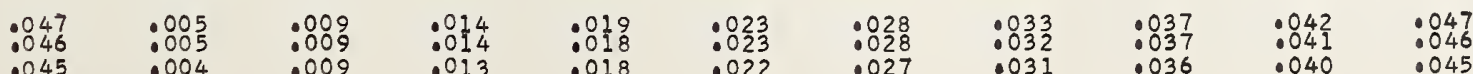


$\begin{array}{rrrrrrrrrrr}4630.0 & 21592.225 & 92.179 & 92.132 & 92.086 & 92.039 & 91.992 & 91.946 & 91.899 & 91.853 & 91.806 \\ 0.1 & 91.759 & 91.713 & 91.666 & 91.619 & 91.573 & 91.526 & 91.479 & 91.433 & 91.386 & 91.339\end{array}$

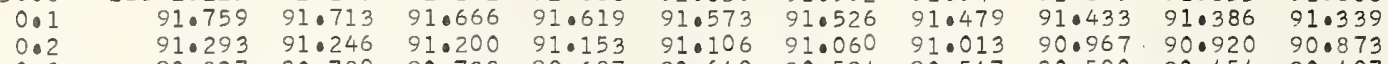

$\begin{array}{lllllllllll}0.3 & 90.827 & 90.780 & 90.733 & 90.687 & 90.640 & 90.594 & 90.547 & 90.500 & 90.454 & 90.407\end{array}$

$\begin{array}{lllllllllll}0.4 & 90.360 & 90.314 & 90.267 & 90.220 & 90.174 & 90.127 & 90.081 & 90.034 & 89.987 & 89.941 \\ 0.5 & 89.894 & 89.847 & 89.801 & 89.754 & 89.708 & 89.661 & 89.614 & 89.568 & 89.521 & 89.475\end{array}$

$\begin{array}{lllllllllll}0.5 & 89.894 & 89.847 & 89.801 & 89.754 & 89.708 & 89.661 & 89.614 & 89.568 & 89.521 & 89.475 \\ 0.6 & 89.428 & 89.381 & 89.334 & 89.288 & 89.241 & 89.195 & 89.148 & 89.101 & 89.055 & 89.008 \\ 0.6 & 88.962 & 88.815 & 88.868 & 88.822 & 88.775 & 88.729 & 88.682 & 88.635 & 88.589 & 88.542\end{array}$

$0.7 \quad 88.962 \quad 88.915$

0.8
0.9

$\begin{array}{ll}88.495 & 88.449 \\ 88.029 & 87.983\end{array}$

$8.868 \quad 88.822$

$\begin{array}{ll}89.241 & 89.195 \\ 88.775 & 88.729\end{array}$

89.008
88.542

4631.0

1.1
1.2
1.3

$1: 3$
1.4

1.5

1.6

1.8 \begin{tabular}{llllllllll}
87.097 & 87.050 & 87.004 & 86.957 & 87.377 & 87.330 & 87.283 & 87.237 & 87.190 & 87.144 \\
\hline
\end{tabular} $\begin{array}{llllllllll}86.631 & 86.584 & 86.538 & 86.491 & 86.444 & 86.398 & 86.351 & 86.304 & 86.258 & 86.211 \\ 86.165 & 86.118 & 86.071 & 86.025 & 85.978 & 85.932 & 85.885 & 85.838 & 85.792 & 85.745\end{array}$ $\begin{array}{llllllllll}85.699 & 85.652 & 85.605 & 85.559 & 85.512 & 85.466 & 85.419 & 85.373 & 85.326 & 85.279 \\ 85.232 & 85.186 & 85.139 & 85.093 & 85.046 & 85.000 & 84.953 & 84.906 & 84.860 & 84.813\end{array}$ $\begin{array}{llllllllll}85.232 & 85.186 & 85.139 & 85.093 & 85.046 & 85.000 & 84.953 & 84.906 & 84.860 & 84.813\end{array}$ $\begin{array}{llllllllll}84.701 & 84.254 & 84.673 & 84.627 & 84.580 & 84.534 & 84.487 & 84.440 & 84.394 & 84.347 \\ 84.301 & 84.25 & 84.161 & 84.114 & 84.067 & 84.021 & 83.974 & 83.928 & 83.881\end{array}$ $\begin{array}{llllllllll}83.834 & 83.788 & 83.741 & 83.695 & 83.648 & 83.602 & 83.555 & 83.508 & 83.462 & 83.415 \\ 83.369 & 83.322 & 83.275 & 83.229 & 83.182 & 83.135 & 83.089 & 83.042 & 82.996 & 82.949\end{array}$

0.280060

0.280059

0.280059

0.280058
0.280058

0.280058

0.280057

0.280057

1.296744

1.2296797

I. 296850

1.296876

1.296903
1.296929

$2 \cdot 9$

$\begin{array}{rr}21582.902 & 82.856 \\ 82.437 & 82.390 \\ 81.971 & 81.924\end{array}$

$\begin{array}{llllllll}82.809 & 82.763 & 82.716 & 82.669 & 82.623 & 82.576 & 82.530 & 82.483\end{array}$

0.280056

0.280056

0.280056

0.280055 $\begin{array}{llllllllll}81.039 & 80.992 & 80.946 & 80.899 & 80.852 & 80.806 & 80.760 & 80.713 & 80.666 & 80.620\end{array}$ $\begin{array}{llllllllll}80.573 & 80.526 & 80.480 & 80.433 & 80.387 & 80.340 & 80.293 & 80.247 & 80.200 & 80.154 \\ 80.107 & 80.061 & 80.014 & 79.967 & 79.92 & 79.874 & 79.828 & 79.781 & 79.734 & 79.688\end{array}$ $\begin{array}{llllllllll}79.642 & 79.595 & 79.548 & 79.502 & 79.455 & 79.408 & 79.362 & 79.315 & 79.269 & 79.222\end{array}$ $\begin{array}{llllllllll}79.175 & 79.129 & 79.082 & 79.036 & 78.989 & 78.943 & 78.896 & 78.849 & 78.803 & 78.756 \\ 78.710 & 78.663 & 78.617 & 78.570 & 78.523 & 78.477 & 78.430 & 78.384 & 78.337 & 78.291\end{array}$

0.280054

0.280054

1.296956

1.296982

1.297035

1.297062

1.297115

1.0297141

1.297167
1.297194

78.10

\title{
$\begin{array}{llll}78.058 & 78.011 & 77.96\end{array}$
}

\begin{abstract}
77.91
\end{abstract}
77.872

$\begin{array}{ll}77.778 & 77.732 \\ 77.313 & 77.266 \\ 76.847 & 76.801\end{array}$

$\begin{array}{ll}76.847 & 76.801 \\ 75.382 & 76.335\end{array}$

$\begin{array}{ll}75.916 & 75.869 \\ 75.450 & 75.404\end{array}$

$74.985 \quad 74.938$

$\begin{array}{ll}77.220 & 77.173 \\ 76.754 & 76.708\end{array}$

$\begin{array}{ll}76.288 & 76.24\end{array}$

$\begin{array}{ll}77.592 & 77.546 \\ 77.127 & 77.080\end{array}$

$\begin{array}{lll}76.661 & 76.614 & 76.56\end{array}$

$\begin{array}{lll}76.195 & 76.149 & 76.102\end{array}$

76.987

$\begin{array}{ll}75.823 & 75.776 \\ 75.357 & 75.311\end{array}$

$\begin{array}{ll}74.519 & 74 \cdot 472 \\ 74.053 & 74.007\end{array}$

4634.0

401

$4 \cdot 3$

4.4

$4 \cdot 5$

4.7

4.8

4635.0

$5 \cdot 1$
5.2

$5 \cdot 2$

5.5

506

5.8

4636.0

$6 \cdot 1$

6.3

6.4

6.6

6.7

6.8
6.9

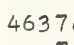

7.0

7.3

7.6

7.8

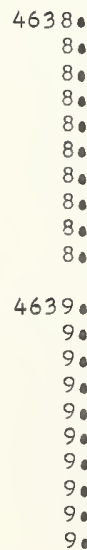
73.12

$72.657 \quad 72.610$

$71.726 \quad 71.679$

$71.260 \quad 71.214$

$70.330 \quad 70.283$

$\begin{array}{ll}69.864 & 69.817 \\ 69.399 & 69.352\end{array}$

21568.93

68.468

$67.072 \quad 67.026$

66.607

$65.677 \quad 65.630$

$65.211 \quad 65 \cdot 165$

$21564 \cdot 281$

$63.816 \quad 64.23$

$63.351 \quad 63.304$

$62.885 \quad 62.83$

$\begin{array}{ll}62.420 & 62.374 \\ 61.955 & 61.909\end{array}$

$61.490 \quad 61.44$

$61.025 \quad 60.979$

60.560

60.095

74.42
73.960

74.845
74.379

$\begin{array}{ll}75.264 & 75.218\end{array}$

$\begin{array}{ll}74.798 & 74.752\end{array}$

75.636
75.171

76.056

75.590
75.124

74.65

$\begin{array}{ll}77.406 & 77.825 \\ 76.359\end{array}$

$76.940 \quad 76.894$

$\begin{array}{ll}76.475 & 76.428\end{array}$

$75.543 \quad 75.497$

$\begin{array}{ll}75.078 & 75.031 \\ 74.612 & 74.565\end{array}$

73.495

$73 \cdot 448$
72.9

\subsection{3 .82}

$74 \cdot 240$
73.774

73.728

73.681

\section{$\begin{array}{ll}72.564 & 72.517 \\ 72.098 & 72.05\end{array}$}

71.63371 .58

$\begin{array}{ll}71.167 & 71.12 \\ 70.702 & 70.65\end{array}$

$72.936 \quad 72.88$

$73 \cdot 30$
72.84

$73 \cdot 26$
72.79

$73 \cdot 216$

$\begin{array}{lll}72.470 & 72.424 & 72.377 \\ 72.005 & 71.958 & 71.912\end{array}$

$\begin{array}{llll}71.865 & 71.819 & 71.772\end{array}$

$\begin{array}{llllll}71.074 & 71.028 & 70.981 & 70.934 & 70.888 & 70.841\end{array}$

$\begin{array}{lllllllll}70.237 & 70.190 & 70.143 & 70.097 & 70.050 & 70.004 & 69.957 & 69.910\end{array}$

$\begin{array}{ll}69.771 & 69.724 \\ 69.306 & 69.259\end{array}$

$69.212 \quad 69.165 \quad 69.58569 .538 \quad 69.492 \quad 69 \cdot 445$

0.28005

0.280052

0.280052

0.28005

0.280051

0.280051

0.280050

0.280049

0.280049

0.280048

0.280048

0.280048

0.280047

0.280047

0.280046

0.280046

0.280046

0.280045

0.280045

0.280044

0.280044

0.280044

0.280043
0.280043

1.297220

1.297247

1.297300

1.297326

1. 297379

1.297405

1. 297432

$1 \cdot 297485$

1.29751.

1.297564

1.297591

1.297617

1.297644
1.297670

I. 297696

.297723

1.297749
1.297776

1.297776

1. 297829

1.297855
1.297882

1.297882
1.297908

1.297908

1.297935

1.298014

I. 298040

1.298067

I. 298120

1.298146

I. 298173

1.298199

0.280043

0.280042

0.280042

0.280042

0.280041

0.280041

0.280040

0.280040

0.280039

0.280039

0.280039

0.280038

0.280038

0.280037

0.280037

0.280037

$\begin{array}{llllllllll}56.842 & 56.795 & 56.749 & 56.702 & 56.656 & 56.609 & 56.562 & 56.516 & 56.469 & 56.428\end{array}$

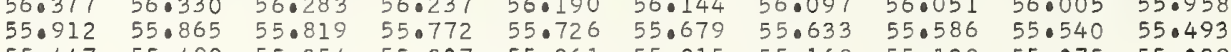

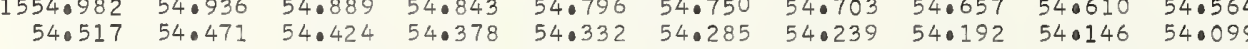

$\begin{array}{lllllllllll}0 & 54.053 & 54.006 & 53.960 & 53.913 & 53.867 & 53.820 & 53.774 & 53.728 & 53.681 & 53.635\end{array}$

$\begin{array}{llllllllll}53.588 & 53.541 & 53.495 & 53.449 & 53.402 & 53.356 & 53.309 & 53.263 & 53.216 & 53.170\end{array}$

$\begin{array}{llllllllll}53.124 & 53.077 & 53.031 & 52.984 & 52.937 & 52.891 & 52.845 & 52.798 & 52.752 & 52.705\end{array}$

$\begin{array}{llllllllll}52.194 & 52.147 & 52.101 & 52.055 & 52.008 & 51.962 & 51.915 & 51.869 & 51.823 & 51.776\end{array}$

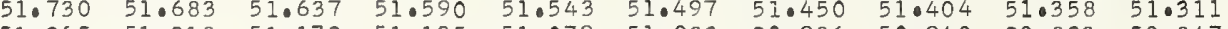

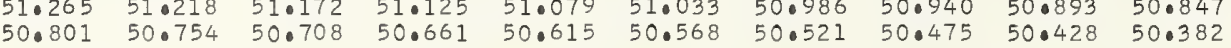

0.280036

0.280036

0.280035

0.280035

0.280034

0.280034

0.280034

0.280033

1.298252

1.298278

1.298305

1.298331

1.298358

1.298411 


$\begin{array}{llll}.00 & .01 & .02 & .03\end{array}$

$.04 \quad .05$

$\begin{array}{rllll}21545.691 & 45.645 & 45.599 & 45.552 & 45 \\ 45.227 & 45.180 & 45.134 & 45.087 & 450 \\ 44.763 & 44.716 & 44.670 & 44.623 & 44 \\ 44.298 & 44.252 & 44.205 & 44.159 & 44 \\ 43.834 & 43.788 & 43.741 & 43.695 & 43.6 \\ 43.370 & 43.323 & 43.277 & 43.230 & 430 \\ 42.906 & 42.859 & 42.813 & 42.766 & 42.7 \\ 42.441 & 42.395 & 42.348 & 42.302 & 42 \\ 41.977 & 41.931 & 41.884 & 41.838 & 41 . \\ 41.513 & 41.467 & 41.420 & 41.374 & 41.3\end{array}$

$45.506 \quad 45.459$

.06

$(n-1) \times 1000$

$\lambda(n-1)$

$\begin{array}{rlll}21541.049 & 41.002 & 40.956 & 40.910 \\ 40.585 & 40.538 & 40.492 & 40.446 \\ 40.121 & 40.074 & 40.028 & 39.981 \\ 39.656 & 39.610 & 39.563 & 39.517 \\ 39.192 & 39.146 & 39.099 & 39.053 \\ 38.728 & 38.682 & 38.636 & 38.589 \\ 38.264 & 38.218 & 38.171 & 38.125 \\ 37.800 & 37.754 & 37.708 & 37.661 \\ 37.336 & 37.290 & 37.243 & 37.197 \\ 36.872 & 36.826 & 36.780 & 36.733\end{array}$

$\begin{array}{llllll}.041 & 44.995 & 45.412 & 45.366 & 45.320 & 45.273 \\ 4.948 & 44.902 & 44.855 & 44.809\end{array}$

$\begin{array}{llllll}44.577 & 44.531 & 44.484 & 44.437 & 44.391 & 44.345\end{array}$

$43.648 \quad 43.602 \quad 43.556 \quad 43.509 \quad 43.462 \quad 43.416$

$\begin{array}{llllll}41.792 & 41.2095 & 42.163 & 42.116 & 42.070 & 42.023 \\ 41.6999 & 41.652 & 41.006 & 41.560\end{array}$

$\begin{array}{llllll}40.863 & 40.817 & 40.770 & 40.724 & 40.678 & 40.631\end{array}$

$\begin{array}{llllll}40.399 & 40.353 & 40.306 & 40.260 & 40.613 & 40.167\end{array}$

$\begin{array}{llllll}39.935 & 39.888 & 39 \cdot 842 & 39.796 & 39.749 & 39.703 \\ 39.471 & 390424 & 39.378 & 39.331 & 390285 & 39.239\end{array}$

$\begin{array}{llllll}39.007 & 38.960 & 38.914 & 38.868 & 38.821 & 38.0775\end{array}$

$\begin{array}{lllllll}38.543 & 38.496 & 38.450 & 38.403 & 38.357 & 38.311 \\ 38.079 & 38.032 & 37.985 & 37.939 & 37.893 & 37.847\end{array}$

4642.0

$2 \cdot 1$

21536.408

$35.945 \quad 35$

$35.481 \quad 35.498 \quad 35.852 \quad 35.805$

$\begin{array}{ll}37.151 & 37.560 \\ 36.687 & 36.640\end{array}$

37.522

37.476

37642

37.847

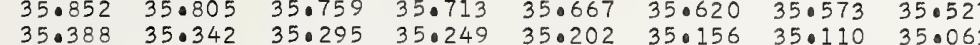

$\begin{array}{lllllllllll}35.017 & 34.970 & 34.924 & 34.878 & 34.831 & 34.785 & 34.739 & 340692 & 34.646 & 34.600\end{array}$

$\begin{array}{llllllllll}34.553 & 34.507 & 34.460 & 34.414 & 34.367 & 34.321 & 340.275 & 34.228 & 34 \cdot 182 & 34 \cdot 135 \\ 34.089 & 34.042 & 33.996 & 33.950 & 33.904 & 33.857 & 33.811 & 33.764 & 33.718 & 33.672\end{array}$

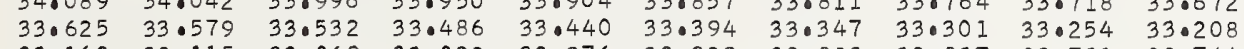

$\begin{array}{llllllllll}33.162 & 33.115 & 33.069 & 33.022 & 32.976 & 32.929 & 32.883 & 32.837 & 32.791 & 32.744 \\ 32.698 & 32.651 & 32.605 & 32.559 & 32.512 & 32.466 & 32.419 & 32.373 & 32.037 & 32.281\end{array}$

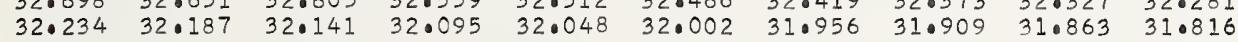

$\begin{array}{llllllllll}21531.770 & 31.724 & 31.677 & 31.631 & 31.585 & 31.538 & 31.492 & 31.446 & 31.399 & 31.353\end{array}$ $\begin{array}{llllllllll}31.307 & 31.260 & 31.214 & 31.167 & 31.121 & 31.074 & 31.028 & 30.982 & 30.935 & 30.889 \\ 30.843 & 30.796 & 30.750 & 30.704 & 30.657 & 30.611 & 30.564 & 30.518 & 30.472 & 30.426\end{array}$

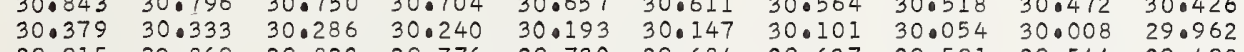
$\begin{array}{llllllllll}29.915 & 29.869 & 29.823 & 29.776 & 29.730 & 29.684 & 29.637 & 29.591 & 29.544 & 29.498\end{array}$

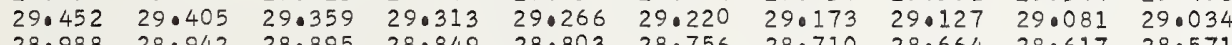

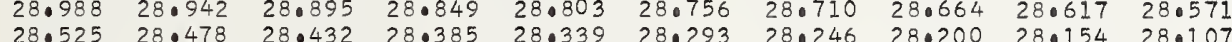

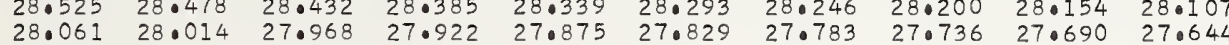

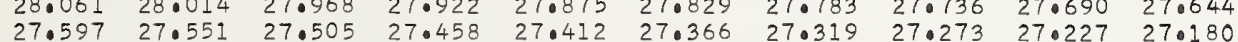

4644.0 $21527.134 \quad 27 \cdot 0$

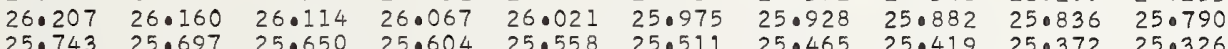

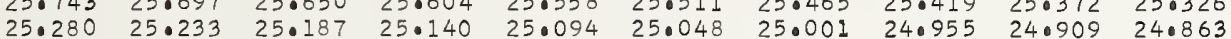
$\begin{array}{llllllllll}24.816 & 24.770 & 24.724 & 24.677 & 24.631 & 24.584 & 24.538 & 24.492 & 240446 & 24.399\end{array}$

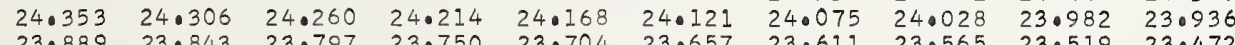

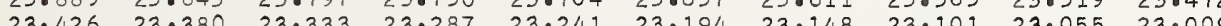

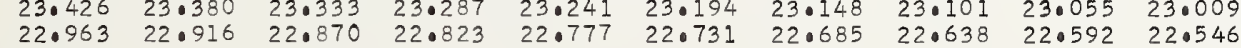

21522

45.0
5.0
5.0
5.0
50
5.5
5.0
5.0
5.0
5.

4646.0

46.0
6.1
6.2
6.3
6.4
6.5
6.6
6.7
6.8
6.9

6.5

6.6

6.7
6.8
6.9

4647.0

70
$7: 0$
$7: 0$
$7: 0$
$7: 0$
$7: 0$
$7: 0$

$22.499 \quad 22.453$

$22.036 \quad 21.990$

$21.109 \quad 21.06$

$20.646 \quad 20.600$

$19.719 \quad 19.673$

$18.793 \quad 18.747$

22.407

22.360

22.314

$4 \quad 22.26$

22.221

$\begin{array}{lll}22.638 & 22.592 & 22.546 \\ 22.075 & 22.129 & 22.082\end{array}$

$\begin{array}{llllllll} & & \end{array}$

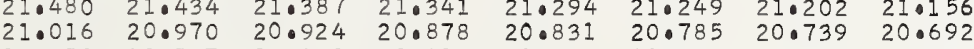

$\begin{array}{llllllll}20.553 & 20.507 & 20.461 & 20.415 & 20.368 & 20.322 & 20.275 & 20.229\end{array}$

$\begin{array}{llllllll}20.090 & 20.044 & 19.997 & 19 \cdot 951 & 19.905 & 19.858 & 19.812 & 19.766\end{array}$

21517.866

$1517.866 \quad 17.820$

$\begin{array}{ll}17.404 & 17.357 \\ 16.940 & 16.8\end{array}$

$16.477 \quad 16.431$

$16.014 \quad 15.968 \quad 15.385 \quad 16.339$

$\begin{array}{llll}15.551 & 15.505 & 15.459 & 15.813\end{array}$

$15.089615 .042 \quad 14.996 \quad 14.950$

$\begin{array}{llll}14.625 & 14.579 & 14.533 & 14.48 \\ 14.163 & 14.116 & 14.070 & 14.02\end{array}$

$13.699 \quad 13.653$

$\begin{array}{ll}4.070 & 14.02 \\ 3.607 & 13.56\end{array}$

21513.237

13.190

$13.144 \quad 13.098$

$\begin{array}{rrr}513.237 & 13.190 & 13.1 \\ 12.773 & 12.727 & 12.6\end{array}$

$\begin{array}{llll}12.311 & 12.265 & 12.218 & 12.17\end{array}$

$\begin{array}{llll}11.848 & 11.801 & 11.755 & 11.709\end{array}$

$10.922 \quad 10.876 \quad 10.830 \quad 110.783$

$\begin{array}{llll}10.459 & 10.413 & 10.367 & 10.32\end{array}$

$\begin{array}{llll}09.997 & 09.950 & 09.904 & 09.857 \\ 09.533 & 09.487 & 09.441 & 09.395\end{array}$

$09.071 \quad 09.025$

$\begin{array}{lll}09.441 & 09.395 \\ 08.978 & 08.932\end{array}$

$\begin{array}{ll}11.200 & 11.15 \\ 10.737 & 10.690 \\ 10.274 & 10.228 \\ 09.811 & 09.765 \\ 0.0349 & 09.302\end{array}$

$\begin{array}{ll}09.349 & 09.302 \\ 08.886 & 08.83\end{array}$

4648.0

8.1

21508.608

$08.146 \quad 08.099$

$07.683 \quad 07.636 \quad 08.05$

08.469

$\begin{array}{llllllll}08.423 & 08.377 & 08.330 & 08.284 & 08.238 & 08.192\end{array}$

$\begin{array}{llllllllll}07.220 & 07.174 & 07.127 & 07.081 & 07.035 & 06.989 & 06.942 & 06.896 & 06.850 & 06.803 \\ 06.757 & 06.711 & 06.665 & 06.618 & 06.572 & 06.526 & 06.480 & 06.433 & 06.387 & 06.341\end{array}$

$\begin{array}{lllllllllll}06.294 & 06.248 & 06.202 & 06.156 & 06.110 & 06.063 & 06.017 & 05.971 & 05.925 & 05.878\end{array}$ $\begin{array}{lllllllllll}05.832 & 05.786 & 05.739 & 05.693 & 05.647 & 05.601 & 05.554 & 05.508 & 05.462 & 05.416\end{array}$ $\begin{array}{lllllllllll}05.369 & 05.323 & 05.277 & 05.230 & 05.184 & 05.138 & 05.092 & 05.046 & 05.000 & 04.953\end{array}$ $\begin{array}{llllllllll}04.907 & 04.861 & 04.814 & 04.768 & 04.722 & 04.675 & 04 \cdot 629 & 04.583 & 04.536 & 04.490 \\ 04.444 & 04.398 & 04.352 & 04.305 & 04.259 & 04.213 & 04.167 & 04.120 & 04.074 & 04.028\end{array}$

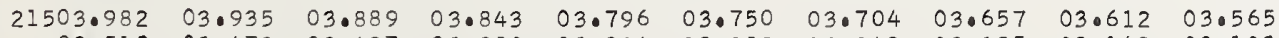
$\begin{array}{llllllllll}03.519 & 03.473 & 03.427 & 03.380 & 03.334 & 03.288 & 03.242 & 03.195 & 03.149 & 03.103\end{array}$ $\begin{array}{llllllllll}03.057 & 03.010 & 02.964 & 02.918 & 02.872 & 02.825 & 02.779 & 02.733 & 02.687 & 02.640\end{array}$ $01093 \quad 01.947 \quad 02.301 \quad 020316 \quad 02.27002 .224 \quad 02017$

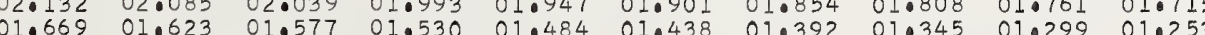

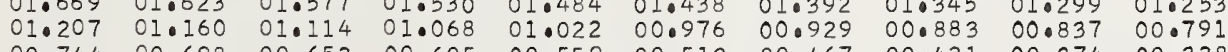

$\begin{array}{llllllllll}00.744 & 00.698 & 00.652 & 00.605 & 00.559 & 00.513 & 00.467 & 00.421 & 00.374 & 00.328 \\ 00.282 & 00.236 & 00.189 & 00.143 & 00.097 & 00.051 & 00.004 & * 99.958 & * 99.912 & * 99.866\end{array}$

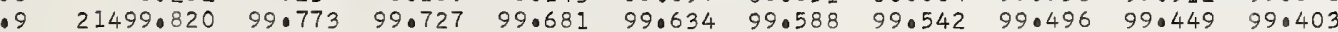

0.280029

0.280029

0.280028

0.280028

0.280027

0.280027
0.280026

0.280026

0.280026

0.280025

0.280024
0.280024

0.280024

0.280023

0.280023

0.280022

0.280022

0.280021

0.280021

0.280020

0.280020

0.280019

0.280019

0.280018

(1)

0.280018

0.28017

0.280017

0.280016

0.280016

0.280015

0.280015

0.280015

0.280014

0.280014

0.280013
0.280013

0.280013

0.280012
0.280012

0.280012

0.280011

0.280011

0.280010

0.280010

0.280009

0.280009

0.280009

0.280008

0.280008

0.280008
0.280007

0.280007

0.280007
0.280006

0.280006

0.280006

0.280005

0.280005

0.280005

0.280004

0.280004

0.280004

0.280003
0.280003

0.280003

0.280002

0.280002

0.280001
0.280001

0.280000

0.280000

0.279999

0.279999

0.279998

0.279998

0.279998

0.279997
0.279997
0.279997

0.279997

0.279996

.010

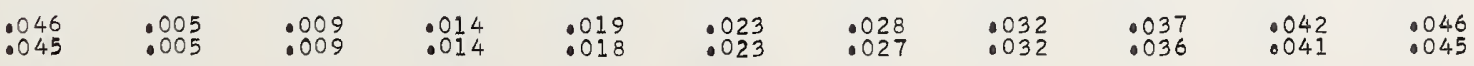

299336

.299363

1.299416

.299442

1.299495

1.299522

1.299548
1.299575

1.299601

.299654

1.299680

1.299733

1.299760
1.299786

1.299813

1.299866

1.299892

1.299918

1.299971

.300024

$1 \cdot 300051$

1.300104

1.300130

1.300183

1.300209

1.300262

. 300289

1.300315

1.300368

1.300395

1.300421

1.300448
1.300474

1.300500

1.300527
1.300553

1.300580

1.300633

1.300659

1.300686

.300739

1.300765

1.300818

1.300844

1.300897

1.300924

1. 300950

1.301003

1.301030

1.301082

1. 301109

1.301135
.0301162

10301188

1.301215
1.0301241

1.301268

1.301294

1. 301321

1.301373

1.301400

1.301453

1.301479

1.301532

1.301585

1.301638

1.301664

1.301717

1.301744

1.301797

1.301823

1.301876

1.301903

1.301929
1.301955 
$\lambda(A)$ .00 .01 .02 .03

4650.0 0.1

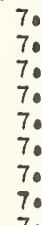

$\begin{array}{rrr}21499.357 & 99.311 & 990 \\ 98.895 & 98.849 & 98 \\ 98.433 & 98.386 & 980 \\ 97.970 & 97.924 & 97 . \\ 97.508 & 97.462 & 970 \\ 97.045 & 96.999 & 96 \\ 96.583 & 96.537 & 96 \\ 96.121 & 96.075 & 96 \\ 95.659 & 95.613 & 95 \\ 95.197 & 95.151 & 95\end{array}$

21494.734 94.27

$93.348 \quad 93.302$

$92.886 \quad 92.840$

91.962

$91.500 \quad 91.454$

91.038
90.576

21490.114

$$
89.653
$$

89.606

$88.267 \quad 88.220$

$87.343 \quad 87.297$

$86.881 \quad 86.835$

$\begin{array}{ll}86.419 & 86.0373 \\ 85.058 & 85.911\end{array}$

21485.496

85.034

84.111

$83.649 \quad 83.604$

$83.187 \quad 83.141$

82.26482

81.80281 .756

80.417
79.996

79.49479 .910

$79.033 \quad 78.987$

$78.572 \quad 78.526$

78.110
78.0649
77.064

$\begin{array}{lll}77.187 & 77.141 \\ 76.726 & 760680\end{array}$

21476.26

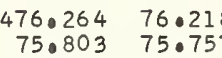

$75.342 \quad 75.296$

$74.419 \quad 74.373$

$73.958 \quad 73.912$

73.49773 .451

$\begin{array}{ll}72.575 & 72.529 \\ 72.114 & 72.067\end{array}$

$471.652 \quad 71.6606$
$71.191 \quad 71.015$
$70.730 \quad 70.664$

70.26970 .022

$\begin{array}{llll}70.8080 & 69.0262 & 70.176 & 69.71\end{array}$

$\begin{array}{llll}69.347 & 69.301 & 69.25\end{array}$

$670964 \quad 670917$

$\begin{array}{lll}67.503 & 670457\end{array}$

21467.04$$
66.5
$$

$\begin{array}{lll}65.120 & 66.074\end{array}$

$65.198 \quad 65.152$

$\begin{array}{ll}64.737 & 64.691 \\ 64.276 & 64.230\end{array}$

$63.816 \quad 63.770$

$\begin{array}{ll}63.355 & 63 \cdot 309 \\ 62.894 & 62.848\end{array}$

\subsection{7}

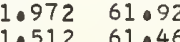

61.05161 .005

60.12960 .083

59.60859 .623

$\begin{array}{rl}58.748 & 58.701 \\ 58.287 & 58.02415\end{array}$

58.28

$457.826 \quad 57.780$

$57.366 \quad 57.320$

$56.906 \quad 56.859$

$\begin{array}{ll}56.445 & 56.39 \\ 55.984 & 55.938\end{array}$

$\begin{array}{lll}55.524 & 55.438 & 55.89\end{array}$

$55.063 \quad 55.017 \quad 54.971$

54.55754 .511

$\begin{array}{llll}54.142 & 54.096 & 54.050 & 54.004 \\ 53.682 & 53.636 & 53.590 & 53.544\end{array}$

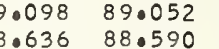

$79.864-79.279$

79.941
78.895

$\begin{array}{ll}78.018 \quad 77.972 \\ 77.557 & 77.510\end{array}$

$\begin{array}{ll}77.095 & 77.004 \\ 76.634 & 76.58\end{array}$
.04

05

.06

.07

.08

.09

$(n-1) \times 1000$

$\lambda(n-1)$

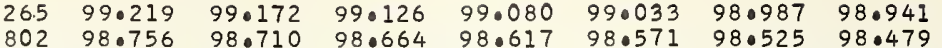

$\begin{array}{llllllll} & 98.240 & 98.248 & 98.201 & 98.155 & 98 \cdot 109 & 98.063 & 98.016 \\ 97.878 & 97.832 & 97.785 & 97.739 & 97.693 & 97.646 & 97.600 & 97.554\end{array}$

$\begin{array}{llllllll}97.415 & 97.369 & 97.323 & 97.277 & 97.230 & 97.184 & 97.138 & 97.092 \\ 96.953 & 96.907 & 96.861 & 96.814 & 96.768 & 96.722 & 96.676 & 96.629\end{array}$

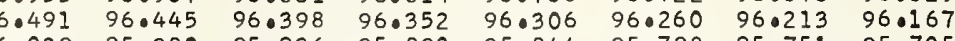

$\begin{array}{lllllll} & 95.890 & 95.844 & 95.798 & 95.751 & 95.705 \\ \end{array}$

$94.643994 .596 \quad 94.550 \quad 94.504 \quad 940458 \quad 940411940.365940319$

$\begin{array}{llllllll}94.180 & 94.134 & 94.088 & 94.042 & 93.996 & 93.949 & 93.903 & 93.857\end{array}$

$\begin{array}{llllllll} & 92.748 & 92.702 & 92.656 & 92.609 & 92.563 & 92.517 & 92.470\end{array}$

$\begin{array}{rr}90.946 & 90.900 \\ 90.484 & 90.437\end{array}$

$90.022 \quad 89.976$

\begin{tabular}{r|r|}
8.174 & 88.128 \\
7.713 & 87.667 \\
87.250
\end{tabular}

$\begin{array}{lll}87.250 & 87.204 \\ 6.789 & 86.743\end{array}$

$\begin{array}{rl}8.327 & 86.281 \\ 5.865 & 85.819\end{array}$

.31591 .269

$90.854 \quad 90.807$

91.223

$91.177 \quad 91.131 \quad 91.084$

$\begin{array}{llllll}.930 & 89.883 & 89.837 & 89.791 & 89.745 & 89.699\end{array}$

$\begin{array}{llllll}9.006 & 88.959 & 88.913 & 88.867 & 88.821 & 88.775\end{array}$

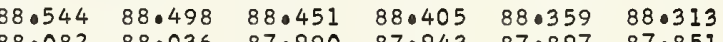

$\begin{array}{lllllll}88.082 & 88.036 & 87.990 & 87.943 & 87.897 & 87.851 \\ 87.620 & 87.574 & 87.528 & 87.0481 & 87.435 & 87.389\end{array}$

$\begin{array}{lllllll}87.158 & 87.112 & 87.066 & 87.020 & 86.973 & 86.927\end{array}$

$\begin{array}{lllllll}86.697 & 86.650 & 86.604 & 86.558 & 86.512 & 86.465\end{array}$

$\begin{array}{llllll}86.235 & 86.188 & 86.142 & 86.096 & 86.050 & 86.004 \\ 85.773 & 85.727 & 85.681 & 85.635 & 85.588 & 85.542\end{array}$

$\begin{array}{llllllll}8.403 & 85.357 & 85.311 & 85.265 & 85.219 & 85.172 & 85.126 & 85.080\end{array}$

$\begin{array}{lllllllll} & 84.942 & 84.896 & 84.850 & 84.803 & 84.757 & 84.711 & 84.665 & 84.618 \\ 84.480 & 84.434 & 84.387 & 84.341 & 840295 & 84.249 & 84.203 & 84.157\end{array}$

$\begin{array}{lllllllll}84.018 & 83.972 & 83.926 & 83.880 & 83.834 & 83.787 & 83.741 & 83.695\end{array}$

$\begin{array}{lllllllll}.633 & 82.587 & 82.541 & 82.495 & 82.448 & 82.402 & 82.356 & 82.310\end{array}$

$\begin{array}{lllllllll} & 82.125 & 82.079 & 82.033 & 81.987 & 81.941 & 81.895 & 81.849\end{array}$

$\begin{array}{lllllllll}80.787 & 80.741 & 80.695 & 80.648 & 80.602 & 80.556 & 80.510 & 80.464\end{array}$

$80.233 \quad 80.648$

$\begin{array}{lllllll}79.771 & 79.725 & 79.679 & 79.633 & 79.587 & 79.541\end{array}$

$\begin{array}{llllll}78.848 & 78.802 & 79.218 & 79.171 & 79.125 & 79.019 \\ 78.078 & 78.710 & 78.664 & 78.618\end{array}$

$\begin{array}{lllllll}78.387 & 78 \cdot 341 & 78.295 & 78 \cdot 249 & 78.203 & 78 \cdot 156 \\ 77.926 & 77.880 & 77.833 & 77.787 & 77.741 & 77.095\end{array}$

$\begin{array}{llllll}77.926 & 77.880 & 77.833 & 77.787 & 77.741 & 77.695 \\ 77.464 & 77.418 & 77.372 & 77.326 & 77.280 & 77.233\end{array}$

$\begin{array}{llllll}77.0464 & 77.418 & 77.372 & 77.326 & 77.280 & 77.233 \\ 77.003 & 76.957 & 76.911 & 76.865 & 76.818 & 76.772\end{array}$

$\begin{array}{lllllllll}76.172 & 76.126 & 76.080 & 76.034 & 75.988 & 75.942 & 750896 & 75.850\end{array}$

$\begin{array}{llllllll}75.250 & 75.204 & 75.6157 & 75.0711 & 75.025 & 75.480 & 75.434 & 75.388 \\ 740973 & 74.927\end{array}$

$\begin{array}{llllllll}74.08 & 74.742 & 74.696 & 74.650 & 74.604 & 74.558 & 74.512 & 74.466\end{array}$

$\begin{array}{lllllllll}74.866 & 73.820 & 73.774 & 73.728 & 73.682 & 73.635 & 73.590 & 73.543\end{array}$

$\begin{array}{llllllll}2.094 & 73.359 & 73.313 & 73.267 & 73.220 & 73.174 & 73.128 & 73.082 \\ 72.897 & 72.851 & 72.805 & 72.759 & 72.713 & 72.667 & 72.621\end{array}$

$\begin{array}{llllllll}72.482 & 72.437 & 72.390 & 72.344 & 72.298 & 72.252 & 72.206 & 72.160 \\ 72.021 & 71.975 & 71.929 & 71.883 & 71.837 & 71.791 & 71.745 & 71.698\end{array}$

$\begin{array}{lllllllll}1.560 & 71.514 & 71.468 & 71.422 & 71.376 & 71.330 & 71.283 & 71.237\end{array}$ $\begin{array}{llllllll}71.053 & 71.007 & 70.961 & 70.915 & 70.868 & 70.822 & 70.776 \\ 70.592 & 70.546 & 70.500 & 70.453 & 70.407 & 70.361 & 70.315\end{array}$ $\begin{array}{lllllll}70.131 & 70.084 & 70.038 & 69.992 & 69.946 & 69 \cdot 900 & 69.854 \\ 69.669 & 69.623 & 69.578 & 69.531 & 69.485 & 69.439 & 69.393\end{array}$

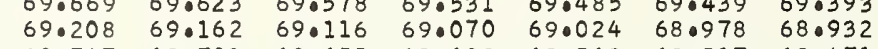
$\begin{array}{llllllll}68.793 & 68.747 & 68.701 & 68.655 & 68.609 & 68.563 & 68.517 & 68.471 \\ 68.33 & 68.286 & 68.240 & 68.194 & 68.148 & 68.102 & 68.056 & 68.010\end{array}$ $\begin{array}{llllllll}67.871 & 67.825 & 67.779 & 67.733 & 67.687 & 67.641 & 67.595 & 67.549 \\ 67.411 & 67.365 & 67.318 & 67.272 & 67.226 & 67.180 & 67.134 & 67.088\end{array}$

$\begin{array}{llllllll}66.950 & 66.904 & 66.857 & 66.811 & 66.765 & 66.719 & 660673 & 66.627\end{array}$ $\begin{array}{llllllll} & 66.442 & 66.397 & 66.351 & 66.304 & 66.258 & 66.212 & 66.166\end{array}$ $\begin{array}{lllllllll}65.567 & 65.521 & 65.475 & 65.429 & 65.383 & 65.336 & 65.290 & 65.244\end{array}$ $\begin{array}{llllllll}.0406 & 65.060 & 65.013 & 64.968 & 64.922 & 640875 & 64.829 & 64.783\end{array}$ $\begin{array}{lllllll}64.599 & 64.553 & 64.507 & 64.461 & 640415 & 64 \cdot 369 & 64 \cdot 323\end{array}$ $\begin{array}{lllllllll} & 63.723 & 63.677 & 63.631 & 63.585 & 63.539 & 630493 & 63.447 & 63.401\end{array}$

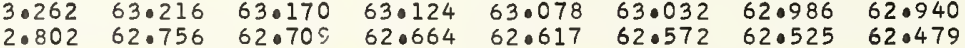

$62.341 \quad 62.295 \quad 62.24962 .203 \quad 62.156 \quad 62.110 \quad 62.064 \quad 62.018$ $60.958 \quad 60.913 \quad 60.867 \quad 60.821 \quad 60.774 \quad 60.728 \quad 60.682 \quad 60.636$ $\begin{array}{llllllll}60.498 & 60.452 & .60 .406 & 60.360 & 60.314 & 60.268 & 60.221 & 60.176 \\ 60.037 & 59.991 & 59.945 & 59.899 & 59.853 & 59.807 & 59.761 & 59.715\end{array}$ $\begin{array}{llllllll}59.577 & 59.531 & 59.485 & 59.439 & 59.393 & 59.346 & 59.301 & 59.254\end{array}$ $\begin{array}{llllllll}59.116 & 59.070 & 59.024 & 58.978 & 58.932 & 58.886 & 58.840 & 58.794 \\ 58.655 & 58.610 & 58.563 & 58.517 & 58.471 & 58.425 & 58.379 & 58.333\end{array}$ $\begin{array}{lllllllll}57.734 & 57.688 & 57.642 & 57.596 & 57.550 & 57.504 & 57.458 & 57.412\end{array}$

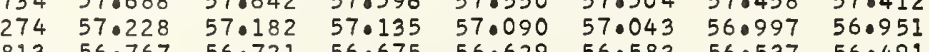
.003

54.41
53.958
53.498 $\begin{array}{lllll}56.675 & 56.629 & 56.583 & 56.537 & 56.491\end{array}$

$\begin{array}{lllll}55.754 & 55.708 & 55.662 & 55.616 & 55.570\end{array}$

$54.833 \quad 54.787 \quad 54.741 \quad 540156550109$

$\begin{array}{lllll}54.373 & 54.327 & 54.281 & 54.235 & 54 \cdot 188\end{array}$

$\begin{array}{ll}0.279996 & 1.301982 \\ 0.279996 & 1.302008 \\ 0.279995 & 1.302035 \\ 0.279995 & 1.302061 \\ 0.279995 & 1.302088 \\ 0.279994 & 1.302114 \\ 0.279994 & 1.302141 \\ 0.279994 & 1.302167 \\ 0.279993 & 1.302194 \\ 0.279993 & 1.302220\end{array}$

0.279993 0.279992

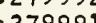
0.279991 0.279990 0.279990
0.279990

\subsection{7} 1.302299 1.302326 1.302352 1.302379 1.302405 1.302432 1.302458

0.279989 0.279989 0.279989 0.279988 0.279988 0.279988

0.279987

0.279986 0.279986 0.279986 0.279985

0.279985
0.279985

0.279984

0.279984
0.279984
0.279983

0.279984
0.279983

0.279983

0.279982

0.279981

0.279981

0.279980

0.279980

0.279980

0.279979
0.279979

0.27997

0.279978
0.279978

0.279978

0.279977

0.279977
0.279977

0.279976

0.279976

0.279975

0.279975

0.279974 
$\begin{array}{rlllllllll}1453.221 & 53.176 & 53.130 & 53.084 & 53.038 & 52.992 & 52.946 & 52.900 & 52.854 & 52.808 \\ 52.762 & 52.716 & 52.669 & 52.624 & 52.578 & 52.532 & 52.486 & 52.439 & 52.394 & 52.347\end{array}$ $\begin{array}{llllllllll}52.302 & 52.256 & 52.209 & 52.163 & 52.117 & 52.071 & 52.025 & 51.979 & 51.933 & 51.887\end{array}$ $\begin{array}{llllllllll}51.841 & 51.795 & 51.749 & 51.703 & 51.657 & 51.611 & 51.565 & 51.519 & 51.473 & 51.427\end{array}$ $\begin{array}{llllllllll}51.381 & 51.335 & 51.289 & 51.243 & 51.197 & 51.151 & 51.105 & 51.058 & 51.012 & 50.966\end{array}$ $\begin{array}{llllllllll}50.920 & 50.874 & 50.828 & 50.782 & 50.736 & 50.690 & 50.644 & 50.598 & 50.552 & 50.506 \\ 50.460 & 50.414 & 50.368 & 50.322 & 50.276 & 50.230 & 50.184 & 50.138 & 50.092 & 50.046\end{array}$ $\begin{array}{llllllllll}50.000 & 49.954 & 49.908 & 49.862 & 49.816 & 49.770 & 49.724 & 49.678 & 49.632 & 49.586\end{array}$ $\begin{array}{llllllllll}49.080 & 49.033 & 48.987 & 48.941 & 48.895 & 48.850 & 48.803 & 48.757 & 48.711 & 48.665\end{array}$

$\begin{array}{lllll}48.343 & 48.297 & 48.251 & 48.205\end{array}$

$\begin{array}{llllll}47.975 & 47.929 & 47.883 & 47.837 & 47.791 & 47.745\end{array}$

$\begin{array}{llllll}47.055 & 47.009 & 46.963 & 46.917 & 46.871 & 46.825\end{array}$

$\begin{array}{llllll}46.595 & 46.549 & 46.503 & 46.457 & 46.411 & 46.365 \\ 46.135 & 46.089 & 46.042 & 45.996 & 45.951 & 45.905\end{array}$

$\begin{array}{lllllll}46.135 & 46.089 & 46.042 & 45.996 & 45.951 & 45.905 \\ 45.675 & 45.629 & 45.583 & 45.537 & 45.491 & 45.445\end{array}$

$\begin{array}{llllll}45.215 & 45.169 & 45.123 & 45.077 & 45.031 & 440985 \\ 44.755 & 44.708 & 44.663 & 440616 & 44.571 & 44.525\end{array}$

0.279963

0.279963

0.279962
0.279962

0.279962

0.279961
0.279961

0.279961

0.279960
0.279960

0.279960

0.279959
0.279959

0.279959

0.279958

0.279958

0.279957

1.8
1.9

4662

2.3

$\begin{array}{rllll}214440018 & 43.972 & 43.927 & 43.881 & 430 \\ 43.559 & 43.513 & 43.467 & 43.421 & 430\end{array}$ $\begin{array}{llll}43.559 & 43.513 & 43.467 & 43.421 \\ 43.099 & 43.053 & 43.007 & 42.961\end{array}$ $\begin{array}{llll}43.099 & 43.053 & 43.007 & 42.961 \\ 42.639 & 42.593 & 42.547 & 42.501 \\ 42.179 & 42.133 & 42.087 & 42.041\end{array}$ $\begin{array}{llll}42.179 & 42.133 & 42.087 & 42.041 \\ 41.719 & 41.673 & 41.627 & 41.581\end{array}$ $\begin{array}{llll}41.719 & 41.673 & 41.627 & 41.581 \\ 41.259 & 41.213 & 41.167 & 41.121\end{array}$ $\begin{array}{llll}41.259 & 41.213 & 41.167 & 41.121 \\ 40.799 & 40.753 & 40.707 & 40.661 \\ 40.340 & 40.293 & 40.248 & 40.202\end{array}$ $\begin{array}{llll}40.340 & 40.293 & 40.248 & 40.202 \\ 39.880 & 39.834 & 39.788 & 39.742\end{array}$

$43.834 \quad 43.789$ 44.20

$\begin{array}{llllll}43.375 & 43.329 & 43.283 & 43.237 & 43.191 & 43.145\end{array}$ $\begin{array}{llllll} & 43.737 & 42.731 & 42.685\end{array}$ $\begin{array}{llllll}41.095 & 41.049 & 410903 & 42.317 & 42.271 & 42.225\end{array}$ $\begin{array}{llllll}41.535 & 41.489 & 41.443 & 41.397 & 41.351 & 41.305\end{array}$ $\begin{array}{llllll}41.075 & 41.029 & 40.983 & 40.937 & 40.891 & 40.845\end{array}$ $\begin{array}{llll}39.880 & 39.834 & 39.788 & 39.742\end{array}$ $\begin{array}{rllll}21439.420 & 39.374 & 39.328 & 39.282 & 39 \\ 38.960 & 38.914 & 38.868 & 38.822 & 38 \\ 38.500 & 38.455 & 38.408 & 38.363 & 38\end{array}$ $\begin{array}{llll}38.041 & 37.994 & 37.948 & 37.903\end{array}$ $\begin{array}{llll}37.581 & 37.535 & 37.489 & 37.443\end{array}$ $\begin{array}{llll}37.121 & 37.075 & 37.029 & 36.983\end{array}$ $36.662 \quad 36.615 \quad 36.570 \quad 36.523$ $\begin{array}{llll}36.202 & 36.156 & 36.110 & 36.064 \\ 35.742 & 35.696 & 35.650 & 35.604\end{array}$ $\begin{array}{llll}35.742 & 35.696 & 35.650 & 35.604 \\ 35.283 & 35.237 & 35.191 & 35.145\end{array}$

$\begin{array}{llllll}40.615 & 40.569 & 40.523 & 40.478 & 40.431 & 40.385\end{array}$ $\begin{array}{llllll}40.156 & 40.110 & 40.064 & 40.017 & 39.971 & 39.926 \\ 39.696 & 39.650 & 39.604 & 39.558 & 39.512 & 39.466\end{array}$

$\begin{array}{lllllll}39.236 & 39.190 & 39.144 & 39.098 & 39.052 & 39.006\end{array}$ $\begin{array}{lllllll}38.776 & 38.730 & 38.684 & 38.638 & 38.592 & 38.546 \\ 38.316 & 38.271 & 38.224 & 38.179 & 38.133 & 38.087\end{array}$ $\begin{array}{lllllll}37.857 & 37.811 & 37.765 & 37.719 & 37.673 & 37.627\end{array}$ $\begin{array}{llllll}36.937 & 36.351 & 37.305 & 37.259 & 37.213 & 37.167 \\ 36.891 & 36.845 & 36.799 & 36.754 & 36.708\end{array}$ $\begin{array}{llllll}36.478 & 36.432 & 36.386 & 36.390 & 36.754 & 36.708\end{array}$

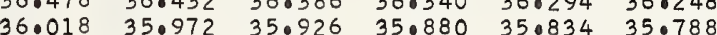
$\begin{array}{llllll}35.559 & 35.512 & 35.467 & 35.420 & 35.375 & 35.329 \\ 35.099 & 35.053 & 35.007 & 34.961 & 34.915 & 34.869\end{array}$

$\begin{array}{lllll}21434.823 & 34.777 & 34.731 & 34.685\end{array}$ $\begin{array}{llll}34.364 & 34.318 & 34.272 & 34.226 \\ 33.904 & 33.858 & 33.812 & 33.766\end{array}$ $\begin{array}{llll}33.444 & 33.398 & 33.353 & 33.307\end{array}$ $\begin{array}{llll}32.985 & 32.939 & 32.893 & 32.847 \\ 32.525 & 32.479 & 32.434 & 32.388\end{array}$ $\begin{array}{llll}32.525 & 32.479 & 32.434 & 32.388 \\ 32.066 & 32.021 & 31.974 & 31.928\end{array}$ $\begin{array}{llll}32.066 & 32.021 & 31.974 & 31.928 \\ 31.607 & 31.561 & 31.515 & 31.469\end{array}$ $\begin{array}{llll}31.147 & 31.102 & 31.055 & 31.010 \\ 30.688 & 30.642 & 30.596 & 30.550\end{array}$

$\begin{array}{lll}34.639 & 34.593 & 34.5 \\ 34.180 & 34.134 & 34.0\end{array}$

$\begin{array}{llllll}34.180 & 34.134 & 34.088 & 34.042 & 34.456 & 34.410 \\ & 33.996 & 330950\end{array}$ $\begin{array}{llllll}33.720 & 33.674 & 33.628 & 33.582 & 33.536 & 33.490\end{array}$ $\begin{array}{llllll}32.801 & 32.755 & 32.709 & 32.123 & 33.077 & 33.031 \\ 32.063 & 32.617 & 32.571\end{array}$ $\begin{array}{llllll}32.342 & 32.296 & 32.250 & 32.204 & 32.158 & 32.112 \\ 31.883 & 31.836 & 31.791 & 31.745 & 31.698 & 31.653\end{array}$ 405 4.8
4.9

$\begin{array}{rrrr}21430.229 & 30.183 & 30.137 & 30.091\end{array}$ $\begin{array}{llll}29.769 & 29.723 & 29.677 & 29.631\end{array}$

5.1 $29.310 \quad 29.264$ $28.850 \quad 28.804 \quad 28.759 \quad 28.713$ $\begin{array}{llll}28.9 & 28.345 & 28.299 & 28.253 \\ 27.932 & 27.886 & 27.840 & 27.794\end{array}$ $27.473 \quad 27.427 \quad 27.38$ $\begin{array}{llll}27.014 & 26.968 & 26.922 & 26.875\end{array}$ $\begin{array}{llll}26.554 & 26.508 & 26.462 & 26.417 \\ 26.095 & 26.049 & 26.003 & 25.957\end{array}$ $\begin{array}{llllll}31.423 & 31.377 & 31.331 & 31.285 & 31.239 & 31.193\end{array}$ $\begin{array}{llllll}30.964 & 30.918 & 30.872 & 30.826 & 30.780 & 30.734 \\ 30.504 & 30.458 & 30.412 & 30.366 & 30.321 & 30.274\end{array}$

0.279956

0.279956 0.279955 0.279955 0.279955
0.279955 0.279954 0.279954
0.279954

0.279953 0.279953 0.279953 0.279952
0.279952 0.279952 0.279951 0.279951 0.279950

0.279950 0.279950
0.279949 0.279949 0.279949 0.279948 0.279948 0.279947
0.279947

$1 \cdot 304628$ 1.304681 1.304734 1.304760 1.304787 I. 304840

1.304892 1.304919 1.304945 I. 304998 1.305025 1.305078 1.305104

1.305157 1.305184 1. 305236 1.305263 1. 305316 1.305342 1.305369

1. 305422 1.305448 1.305475 1.305501 1.305528 1.305554 1.305580 1.305607 1.305660

1.305686 1.305713 1.305766 1.305792 1.305819 1.305845 1. 305872 1.305924

0.279947 0.279946 0.279945 0.279945 0.279945 0.279944 0.279944
0.279944 $1 \cdot 305951$ 1. 306004 1.306030 1.306083 1. 306110 $\begin{array}{llllll}28.208 & 28.162 & 28.116 & 28.070 & 28.024 & 27.978 \\ 27.748 & 27.702 & 27.656 & 27.610 & 27.564 & 27.519\end{array}$ $\begin{array}{llllll}27.289 & 27.243 & 27.197 & 27.151 & 27.105 & 27.059\end{array}$

0.279943 0.279943 0.279942 0.279942 0.279942 0.279941 0.279941 0.279940 $\begin{array}{llllllllll}24.718 & 24 \cdot 671 & 24.625 & 24 \cdot 580 & 24 \cdot 534 & 24.488 & 24 \cdot 442 & 24 \cdot 396 & 24 \cdot 350 & 24 \cdot 304 \\ 24.258 & 24.212 & 24.166 & 24.121 & 24.075 & 24.029 & 23.983 & 23.937 & 23.891 & 23.845\end{array}$ $\begin{array}{llllllllll}23.799 & 23.753 & 23.707 & 23.661 & 23.615 & 23.570 & 23.524 & 23.478 & 23.432 & 23.386\end{array}$ $\begin{array}{llllllllll}23.340 & 23.294 & 23.248 & 23.202 & 23.156 & 23.111 & 23.065 & 23.019 & 22.973 & 22.927\end{array}$

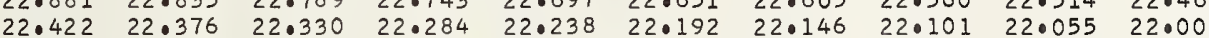
$\begin{array}{llllllllll}21.963 & 21.917 & 21.871 & 21.825 & 21.779 & 21.733 & 21.687 & 21.641 & 21.595 & 21.550\end{array}$

0.279940 0.279940 0.279939 0.279939 0.279938 0.279938 0.279937

0.279937 0.279936 0.279936 0.279935 0.279935 0.279 0.279934 0.279934 1.306163 1. 306189

1.306216 1.306268 1.306295 1. 306348 1.306374 1.306427

$1 \cdot 306480$ 1.306507 1.306560 1.306586 1.306613 1.306639 1.306692 1.306792

1.306745 1.306771 1.306824 1.306851 1.306877 1.306904 1.306930 1.306957 0.279933 0.279933 0.279933 0.279932 0.279932 0.279932 0.279931 0.279931 .306983

4669.
9
9
9.
9.
9.5
9.6
9.7
9.8
9.9

$\begin{array}{llllllllll}411.869 & 11.823 & 11.777 & 11.731 & 11.686 & 11.640 & 11.594 & 11.548 & 11.502 & 11.456\end{array}$

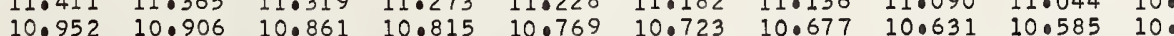
$\begin{array}{llllllllll}10.493 & 10.448 & 10.402 & 10.356 & 10.310 & 10.264 & 10.219 & 10.173 & 10.127 & 10.081\end{array}$

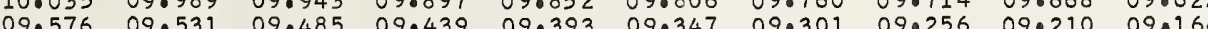
$\begin{array}{llllllllll}09.118 & 09.072 & 09.026 & 08.980 & 08.935 & 08.889 & 08.843 & 08.797 & 08.751 & 08.705\end{array}$ $\begin{array}{llllllllll}08.660 & 08.614 & 08.568 & 08.522 & 08.476 & 08.430 & 08.384 & 08.339 & 08.293 & 08.247\end{array}$ $\begin{array}{llllllllll}08.201 & 08.155 & 08.109 & 08.064 & 08.018 & 07.972 & 07.926 & 07.880 & 07.834 & 07.789\end{array}$

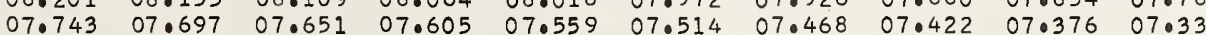

$\begin{array}{lllllllllll} & .001 & .002 & .003 & .004 & .005 & .006 & .007 & .008 & .009 & .010 \\ : 845 & : 885 & : 889 & : 814 & : 818 & : 823 & : 828 & : 832 & : 837 & : 849 & : 845 \\ .044 & .004 & .009 & .013 & .018 & .022 & .026 & .031 & .035 & .040 & .044\end{array}$

.307009 . 307062 1.07115 - 307142 1.307195 1. 307221 1. 307248 
$\begin{array}{lllllllllll}670.0 & 21407.284 & 07.238 & 07.193 & 07.147 & 07.101 & 07.055 & 07.009 & 06.963 & 06.918 & 06.872\end{array}$ $\begin{array}{lllllllllll}0.1 & 06.826 & 06.780 & 06.734 & 06.688 & 06.643 & 06.597 & 06.551 & 06.505 & 06.459 & 06.413 \\ 0.2 & 06.368 & 06.322 & 06.276 & 06.230 & 06.184 & 06.138 & 06.093 & 06.047 & 06.001 & 05.955\end{array}$ $\begin{array}{lllllllllll}0.3 & 06.368 & 06.322 & 06.276 & 06.230 & 06.184 & 06.138 & 06.093 & 06.047 & 06.001 & 05.955 \\ 0.3 & 05.909 & 05.864 & 05.818 & 05.772 & 05.726 & 05.680 & 05.634 & 05.588 & 05.542 & 05.497\end{array}$ $\begin{array}{lllllllllll}0.4 & 05.451 & 05.405 & 05.359 & 05.313 & 05.267 & 05.222 & 05.176 & 05.130 & 05.084 & 05.038\end{array}$

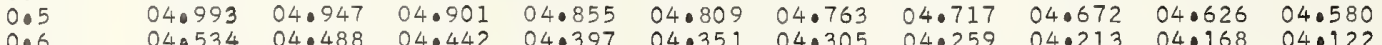

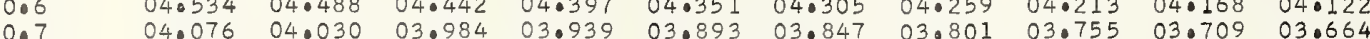
$0.8 \quad 03.618 \quad 03.572 \quad 03.526 \quad 03.480 \quad 03.43503 .8403 .801 \quad 03.75503 .70903 .664$ 0.9 $\begin{array}{llllllllll}03.618 & 03.572 & 03.526 & 03.480 & 03.435 & 03.389 & 03.343 & 03.297 & 03.251 & 03.206 \\ 03.160 & 03.114 & 03.068 & 03.022 & 02.976 & 02.931 & 02.885 & 02.839 & 02.793 & 02.747\end{array}$

$\begin{array}{lllllllllll}1.0 & 21402.701 & 02.655 & 02.610 & 02.564 & 02.518 & 02.472 & 02.426 & 02.380 & 02.335 & 02.289\end{array}$ $\begin{array}{lllllllllll}1.1 & 02.243 & 02.197 & 02.151 & 02.105 & 02.060 & 02.014 & 01.968 & 01.922 & 01.877 & 01.831\end{array}$ $\begin{array}{lllllllllll}1.2 & 01.785 & 01.739 & 01.693 & 01.647 & 01.602 & 01.556 & 01.510 & 01.464 & 01.418 & 01.373 \\ 1.3 & 01.327 & 01.281 & 01.235 & 01.189 & 01.144 & 01.098 & 01.052 & 01.006 & 00.960 & 00.915\end{array}$ $\begin{array}{lllllllllll}1.4 & 00.869 & 00.823 & 0.777 & 0.731 & 0.0 .685 & 0.098 & 01.052 & 01.006 & 00.960 & 0.915\end{array}$ $\begin{array}{lrlllllllll}1.5 & 00.410 & 00.365 & 00.319 & 00.273 & 00.227 & 00.181 & 00.136 & 00.090 & 00.044 & \$ 99.998\end{array}$

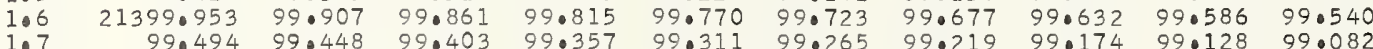
$\begin{array}{lllllllllll}1.8 & 99.494 & 99.448 & 99.403 & 99.357 & 99.311 & 99.265 & 99.219 & 99.174 & 99.128 & 99.082 \\ 1.8 & 99.036 & 98.990 & 98.945 & 98.899 & 98.853 & 98.807 & 98.762 & 98.716 & 98.670 & 98.624\end{array}$ $\begin{array}{lllllllllll}672.0 & 21398 \cdot 120 & 98.074 & 98.029 & 97.983 & 97.937 & 97.891 & 97.845 & 97.800 & 97.754 & 97.708\end{array}$ $\begin{array}{lllllllllll}2.1 & 97.662 & 97.616 & 97.571 & 97.525 & 97.479 & 97.433 & 97.387 & 97.342 & 97.296 & 97.250\end{array}$ $\begin{array}{lllllllllll}2.2 & 97.204 & 97.159 & 97.113 & 97.067 & 97.021 & 96.975 & 96.929 & 96.884 & 96.838 & 96.792\end{array}$

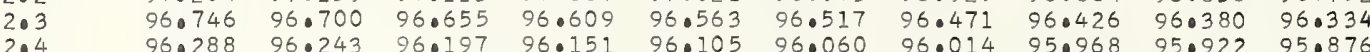
$\begin{array}{llllllllll}96.288 & 96.243 & 96.197 & 96.151 & 96.105 & 96.060 & 96.014 & 95 \cdot 968 & 95.922 & 95.876\end{array}$ $\begin{array}{llllllllll}95.831 & 95.785 & 95.739 & 95.693 & 95.647 & 95.601 & 95.556 & 95.510 & 95.464 & 95.418\end{array}$

$\begin{array}{llllllllll}95.373 & 95.327 & 95.281 & 95.235 & 95.189 & 95.144 & 95.098 & 95.052 & 95.006 & 94.960 \\ 94.915 & 94.869 & 94.823 & 94.777 & 94.731 & 94.686 & 94.640 & 94.594 & 94.548 & 94.502\end{array}$ $\begin{array}{ll}94.457 & 94.411 \\ 93.999 & 93.953\end{array}$

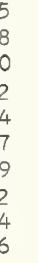

$93.450 \quad 93.404$

$94.274 \quad 94.228$

94.640

94.502
94.045
93.587

$21388.964 \quad 88.918$

$88.507 \quad 88.461$

$87.591 \quad 87.546$

87.134
86.677
86.630

$86.219 \quad 86.173$

$\begin{array}{ll}85.762 & 85.716 \\ 85.304 & 85.258\end{array}$

84.847

$21384.389 \quad 84 \cdot 343$

$83.932 \quad 83.88$

$83.474 \quad 83.429 \quad 83.383$

$\begin{array}{llll}83.017 & 82.971 & 82.926 & 82.837\end{array}$

$\begin{array}{ll}82.514 \quad 8288 & 82.422\end{array}$

$81.188 \quad 81.142$

$\begin{array}{ll}80.730 & 80.685 \\ 80.273 & 80.228\end{array}$

4676.0

6.12

6.2

6.4

6.5

6.7

6.8
6.9

4677.0

$7 \cdot 1$
7.2
7.3

7.3

7.5

$7 \cdot 6$
7.7

7.8

4678.

8.1

8.3

8.4

8.6

8.8

4679.0

9.1
9.2
9.3

9.5

9.6

9.8

9.9

21379.816

$\begin{array}{ll}79.359 & 79.31 \\ 78.902 & 78.856\end{array}$

78.90278 .856

$77.987 \quad 77.942$

$\begin{array}{ll}77.530 & 77.484 \\ 77.073 & 77.027\end{array}$

$76.616 \quad 76.570$

$\begin{array}{ll}76.159 & 76.113 \\ 75.702 & 75.656\end{array}$

$74.788 \quad 74.742$

$\begin{array}{ll}74.331 & 74.285 \\ 73.874 & 73.82\end{array}$

$\begin{array}{ll}73.417 & 73.37 \\ 72.960 & 72.91\end{array}$

$\begin{array}{ll}72.503 & 72.457 \\ 72.046 & 72.000\end{array}$

$\begin{array}{ll}71.589 & 71.543 \\ 71.132 & 71.087\end{array}$

21370.675

70.21

69.762
69.305

$68.305 \quad 69.260$

$68.392 \quad 68.346$

$67.935 \quad 67.889$

$67.021 \quad 66.976$

81.55

$2.534 \quad 92.488$

93.35

93.312

93.724

3.678

93.22

$93.175 \quad 93.129$

$\begin{array}{llll}92.809 & 92.763 & 92.717 & 92.671\end{array}$

$1.618 \quad 91.573$

$92.442 \quad 92.396$

$9.351 \quad 92.30$

92.26

92.214

$\begin{array}{ll}0.703 & 90.657 \\ 0.246 & 90.200\end{array}$

91.52

91.481

1.43691 .390

.34491 .298

$\begin{array}{ll}9.788 & 89.742 \\ 9.330 & 89.285\end{array}$

90.154

91.023
90.566

$90.978 \quad 90.93$

90.886

90.841

88.873

88.827

89.239

89.193

$90.062 \quad 90.017 \quad 890971 \quad 89.926$

$8.605 \quad 89.559 \quad 89.513 \quad 89.46$

$88.781 \quad 88.736$

88.690

89.102

.042
6.58 .997

87.866

87.408

88.278
87.820

88.232
87.775

88.64
88.186
87.72

$88 \cdot 598$

89.010

86.08
$.670 \quad 85.624$

$\begin{array}{ll}86.493 & 86.448 \\ 86.036 & 85.990\end{array}$

87.317

86.402

$87.271 \quad 87.225 \quad 87.180$

$86.814 \quad 86.768 \quad 86.722$

$\begin{array}{lll}86.356 & 86.311 & 86.265\end{array}$

$85.487 \quad 85.441 \quad 85.396 \quad 85.350$

85.030

84.984

8.03

84.893

84.664

84.61

$84 \cdot 115$

84.069

84.023

84.435

$83.749 \quad 83.703$

83.65

$83 \cdot 611$
$83 \cdot 154$

$82.834 \quad 82.78$

$\begin{array}{ll}82.376 & 82.33 \\ 81.919 & 81.87\end{array}$

$82 \cdot 74$

$82.697 \quad 82.651 \quad 82.605$

$828 \quad 81.782 \quad 81.737$
82.148

$\begin{array}{lllllll}1.965 & 81.919 & 81.874 & 81.828 & 81.782 & 81.737 & 81.691 \\ 1.508 & 81.462 & 81.416 & 81.371 & 81.325 & 81.279 & 81.233\end{array}$

$80.639 \quad 80.593$

$81.005 \quad 80.95$

80.913

$\begin{array}{rrr}.547 & 80.502 & 80.456 \\ 80.090 & 80.045 & 79.099\end{array}$

80.410
79.953

79.725

79.679

79.633

79.587

79.542

79.496

80.365

80.776
80.319

78.81079 .22

78.353
77.896

77.43

78.307
77.850

79.176
78.719

$76.951 \quad 76.936$

$76.524 \quad 76.47$

$78.261 \quad 78.673$

78.627

79.039
78.58

79.45

79.862

75.610

76.890

77.759

78.124
78.076 78.490

$\begin{array}{lllll}77.713 & 77.667 & 77.621 & 77.03 & \end{array}$

$\begin{array}{llll}77.256 & 77.210 & 77.165 & 77.119\end{array}$

$\begin{array}{llll}76.799 & 76.753 & 76.707 & 76.661 \\ 76.341 & 76.296 & 76.250 & 76.205\end{array}$

75.153

75.564

75.51

$\begin{array}{ll}74.696 & 74.650 \\ 74.239 & 74.19\end{array}$

$73.325 \quad 73.280$

72.86972 .82

$\begin{array}{ll}72.411 & 72.366 \\ 71.955 & 71.909\end{array}$

75.06

74.970

$75 \cdot 382$

$75 \cdot 7$

75.748

75.748
750290

$\begin{array}{llllll} & \end{array}$

$\begin{array}{llllll}73.234 & 73.645 & 73.599 & 73.554 & 73.508 & 73.462 \\ 73.188 & 73.143 & 73.097 & 73.051 & 73.005\end{array}$

$\begin{array}{lllllll}72.777 & 72.731 & 72.686 & 72.640 & 72.594 & 72.549\end{array}$

$\begin{array}{llllll}72.320 & 72.274 & 72.229 & 72.183 & 72.137 & 72.092 \\ 71.863 & 71.818 & 71.772 & 71.726 & 71.680 & 71.635\end{array}$

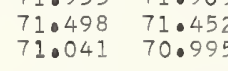

$71.680 \quad 71.635$

$\begin{array}{llllll}71.406 & 71.361 & 71.315 & 71.269 & 71.223 & 71.178 \\ 70.949 & 70.904 & 70.858 & 70.812 & 70.767 & 70.721\end{array}$

0.279930

0.279930
0.279930

0.279929
0.279929

0.279929

0.27998

0.279928

0.279927

0.279927

0.279927

0.279926

0.279926
0.279926

0.279925

0.279925
0.279925

0.279924
0.279924

0.279924

0.279923
0.279923

0.279923

0.279922

0.279922

0.279922

0.279921
0.279921

0.279920

0.279920

0.279919

0.279919

0.279919
0.279918

0.279918

0.279918
0.279917

0.279917

0.279916

0.279916 


$$
\begin{array}{rlllllllll}
361.543 & 61.497 & 61.452 & 61.406 & 61.360 & 61.315 & 61.269 & 61.223 & 61.178 & 61.132 \\
61.086 & 61.041 & 60.995 & 60.949 & 60.904 & 60.858 & 60.813 & 60.767 & 60.721 & 60.676
\end{array}
$$

$\begin{array}{lllllllllll}0.1 & 61.086 & 61.041 & 60.995 & 60.949 & 60.904 & 60.858 & 60.813 & 60.767 & 60.721 & 60.676\end{array}$

0.0

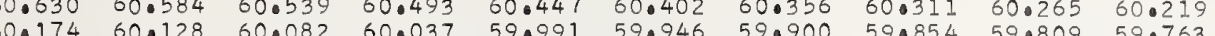
$\begin{array}{llllllllll}59.718 & 59.672 & 59.626 & 59.580 & 59.534 & 59.489 & 59.443 & 59.398 & 59.352 & 59.306\end{array}$ $\begin{array}{llllllllll}59.261 & 59.215 & 59.170 & 59.124 & 59.078 & 59.033 & 58.987 & 58.941 & 58.896 & 58.850\end{array}$ $\begin{array}{llllllllll}58.805 & 58.759 & 58.713 & 58.668 & 58.622 & 58.576 & 58.531 & 58.485 & 58.439 & 58.394\end{array}$ $\begin{array}{llllllllll}58.348 & 58.303 & 58.257 & 58.211 & 58.166 & 58.120 & 58.074 & 58.029 & 57.983 & 57.938\end{array}$ $\begin{array}{llllllllll}57.892 & 57.846 & 57.801 & 57.755 & 57.710 & 57.664 & 57.618 & 57.572 & 57.527 & 57.481 \\ 57.436 & 57.390 & 57.344 & 57.299 & 57.253 & 57.208 & 57.162 & 57.116 & 57.071 & 57.025\end{array}$

4681.0

21356 56.97956350 .93

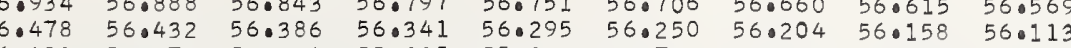
$\begin{array}{lllllllllll}55.611 & 55.565 & 55.519 & 55.474 & 55.428 & 55.383 & 55.337 & 55.291 & 55.246 & 55.200\end{array}$

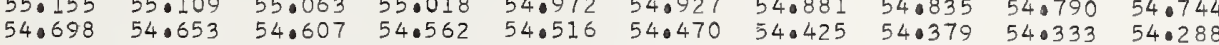
$\begin{array}{lllllllllll}54.242 & 54.197 & 54.151 & 54.105 & 54.060 & 54.014 & 53.969 & 53.923 & 53.877 & 53.832\end{array}$ $53.786 \quad 53.741 \quad 53.695 \quad 53.649 \quad 53.604 \quad 53.558 \quad 53.512 \quad 53.467 \quad 53.421 \quad 53.376$ $\begin{array}{llllllllll}53.330 & 53.284 & 53.239 & 53.193 & 53.148 & 53.102 & 53.056 & 53.011 & 52.965 & 52.920\end{array}$

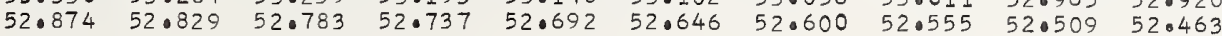

$52.418 \quad 52.372$

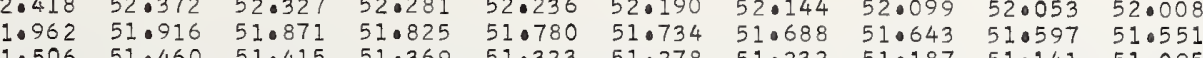

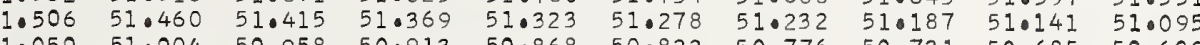

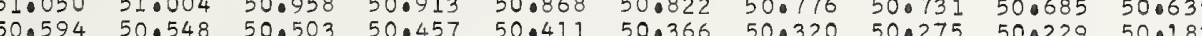
$\begin{array}{llllllllll}50.138 & 50.092 & 50.047 & 50.001 & 40.4156 & 50.366 & 50.376 & 50.73 & 50.0685 & 50.639\end{array}$ $\begin{array}{llllllllll}49.682 & 49.636 & 49.591 & 49.545 & 49.500 & 49.454 & 49.408 & 49.363 & 49.317 & 49.271\end{array}$ $\begin{array}{llllllllll}49.226 & 49.180 & 49.135 & 49.089 & 49.044 & 48.998 & 48.952 & 48.907 & 48.862 & 48.816\end{array}$ $\begin{array}{llllllllll}48.770 & 48.725 & 48.679 & 48.634 & 48.588 & 48.543 & 48.497 & 48.451 & 48.406 & 48.360\end{array}$ $\begin{array}{llllllllll}48.314 & 48.269 & 48.223 & 48.178 & 48.132 & 48.087 & 48.041 & 47.996 & 47.950 & 47.904\end{array}$ $47.859 \quad 47.81$

$\begin{array}{lllllllllll}46.947 & 46.357 & 47.312 & 47.266 & 47.220 & 47.175 & 47.129 & 47.084 & 47.038 & 46.992\end{array}$ $\begin{array}{lllllllllll}46.491 & 46.445 & 46.400 & 46.354 & 46.309 & 46.263 & 46.218 & 46.172 & 46.126 & 46.081\end{array}$ $\begin{array}{lllllllllll}46.035 & 45.990 & 45.944 & 45.899 & 45.853 & 45.808 & 45.762 & 45.717 & 45.671 & 45.625\end{array}$ $\begin{array}{llllllllll}45.580 & 45.534 & 45.489 & 45.443 & 45.397 & 45.352 & 45.306 & 45.260 & 45.215 & 45.169\end{array}$

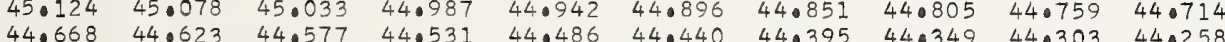

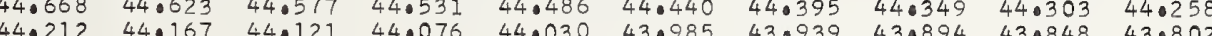
$\begin{array}{llllllllll}44.212 & 44.167 & 44.121 & 44.076 & 44.030 & 43.985 & 43.939 & 43 \cdot 894 & 43.848 & 43.802 \\ 43.757 & 43.711 & 43.666 & 43.620 & 43.574 & 43.529 & 43.483 & 43.438 & 43.392 & 43.346\end{array}$

$\begin{array}{rlllllllll}21343.301 & 43.255 & 43.210 & 43.164 & 43.119 & 43.073 & 43.028 & 42.982 & 42.937 & 42.891 \\ 42.845 & 42.800 & 42.754 & 42.709 & 42.663 & 42.618 & 42.572 & 42.526 & 42.481 & 42.435\end{array}$

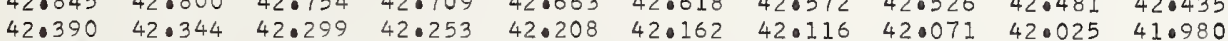

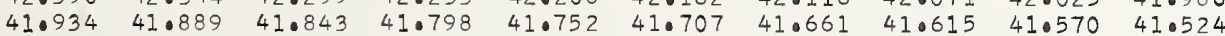
$\begin{array}{llllllllll}1.479 & 41.433 & 41.387 & 41.342 & 41.296 & 41.251 & 41.205 & 41.160 & 41.114 & 41.069\end{array}$ $41.023 \quad 40.977 \quad 40.932 \quad 40.886 \quad 40.841$ $\begin{array}{llllllllll}40.568 & 40.522 & 40.476 & 40.431 & 40.385 & 40.340 & 40.294 & 40.249 & 40.203 & 40.157\end{array}$ $\begin{array}{llllllllll}40.112 & 40.066 & 40.021 & 39.975 & 39.930 & 39.884 & 39.839 & 39.793 & 39.748 & 39.702\end{array}$ $\begin{array}{llllllllll}39.656 & 39.611 & 39.565 & 39.520 & 39.474 & 39.428 & 39.383 & 39.337 & 39.292 & 39.247 \\ 39.201 & 39.155 & 39.110 & 39.064 & 39.019 & 38.973 & 38.928 & 38.882 & 38.837 & 38.791\end{array}$ 6850

4686 86
6
6
6
6
6
6
6
6
6

7.0

4688.0

8.
8
8
8
8
8
8
8
8
689
9
9
9
9
9
9
9
9
9
9.6
$\begin{array}{llll}338.745 & 38.700 & 38.655 & 38.609 \\ 38.290 & 38.244 & 38.199 & 38.153\end{array}$ $\begin{array}{lllllllllll}37.835 & 37.789 & 37.744 & 37.653 & 38.108 & 38.062 & 38.017 & 37.971 & 37.926 & 37.880\end{array}$ $\begin{array}{llllllllll} & \end{array}$ $\begin{array}{lllllllll} & \end{array}$

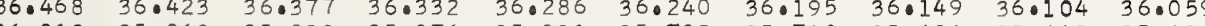

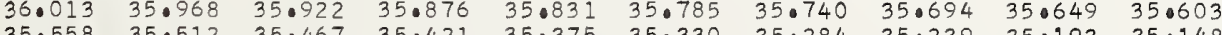
$\begin{array}{llllllllll}35.558 & 35.512 & 35.467 & 35.421 & 35.375 & 35.330 & 35.284 & 35.239 & 35.193 & 35.148\end{array}$ $\begin{array}{llllllllll}35.102 & 35.057 & 35.011 & 34.966 & 34.920 & 34.875 & 34.829 & 34.784 & 34.738 & 34.693 \\ 34.647 & 34.601 & 34.556 & 34.510 & 34.465 & 34.419 & 34.374 & 34.328 & 34.283 & 34.237\end{array}$

$\begin{array}{llllllllll}21334.192 & 34.146 & 34.101 & 34.055 & 34.010 & 33.964 & 33.918 & 33.873 & 33.828 & 33.782\end{array}$ $\begin{array}{llllllllll}33.737 & 33.691 & 33.646 & 33.600 & 33.554 & 33.509 & 33.463 & 33.418 & 33.372 & 33.327\end{array}$ $\begin{array}{llllllllll}33.281 & 33.236 & 33.190 & 33.145 & 33.099 & 33.053 & 33.008 & 32.963 & 32.917 & 32.872 \\ 32.826 & 32.781 & 32.735 & 32.690 & 32.644 & 32.598 & 32.553 & 32.507 & 32.462 & 32.416\end{array}$ $\begin{array}{llllllllll}32.371 & 32.325 & 32.280 & 32.234 & 32.188 & 32.143 & 32.098 & 32.052 & 32.007 & 31.961\end{array}$

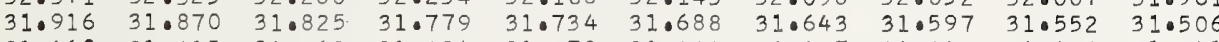
$\begin{array}{llllllllll}31.460 & 31.415 & 31.369 & 31.324 & 31.278 & 31.233 & 31.187 & 31.142 & 31.096 & 31.051\end{array}$ $\begin{array}{llllllllll}31.005 & 30.960 & 30.914 & 30.869 & 30.823 & 30.778 & 30.732 & 30.687 & 30.641 & 30.595\end{array}$

$\begin{array}{lllllllllll}6.8 & 30.550 & 30.504 & 30.459 & 30.414 & 30.368 & 30.323 & 30.277 & 30.231 & 30.186 & 30.141 \\ 6.9 & 30.095 & 30.050 & 30.004 & 29.958 & 29.913 & 29.868 & 29.822 & 29.777 & 29.731 & 29.686\end{array}$ $29.18529 \cdot 13900$ $28.730 \quad 28.685 \quad 29.094 \quad 29.048$ $\begin{array}{lllllllll}28.229 & 28.639 & 28.593 & 28.548 & 28.502 & 28.457 & 28.411 & 28.366 & 28.320\end{array}$

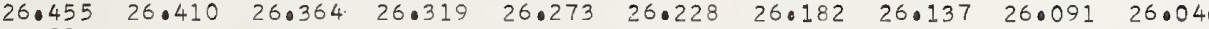

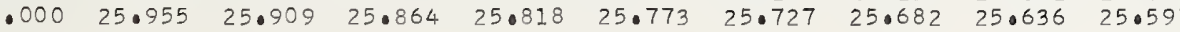

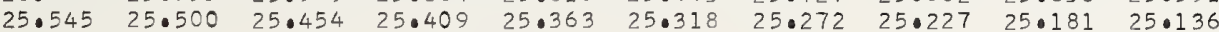
$\begin{array}{llllllllll}24.636 & 24.590 & 24.545 & 24.499 & 24.454 & 24.408 & 24.363 & 24.317 & 24.27 .1 & 24.226\end{array}$

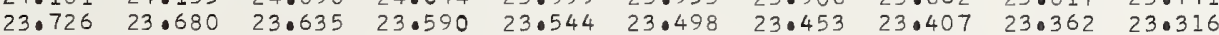

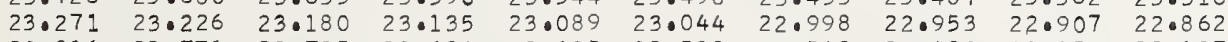
$\begin{array}{llllllllll}22.816 & 22.771 & 22.725 & 22.680 & 22.635 & 22.589 & 22.543 & 22.498 & 22.452 & 22.407\end{array}$

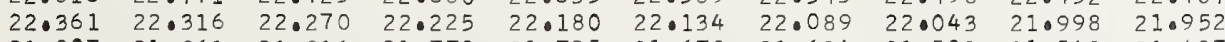

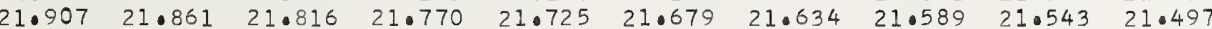

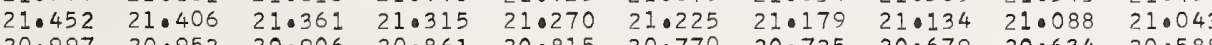

$\begin{array}{llllllllll}21320.542 & 20.497 & 20.452 & 20.406 & 20.361 & 20.315 & 20.270 & 20.224 & 20.179 & 20.133\end{array}$ $\begin{array}{llllllllll}20.088 & 20.042 & 19.997 & 19.951 & 19.906 & 19.861 & 19.815 & 19.770 & 19.724 & 19.679\end{array}$ $\begin{array}{llllllllll}19.633 & 19.588 & 19.542 & 19.497 & 19.451 & 19.406 & 19.360 & 19.315 & 19.270 & 19.224\end{array}$ $\begin{array}{llllllllll}18.178 & 19.133 & 19.087 & 19.042 & 18.997 & 18.951 & 18.906 & 18.860 & 18.815 & 18.770 \\ 18.724 & 18.678 & 18.633 & 18.588 & 18.542 & 18.497 & 18.451 & 18.406 & 18.360 & 18.315\end{array}$ $\begin{array}{llllllllll}18.269 & 18.224 & 18.178 & 18.133 & 18.087 & 18.042 & 17.997 & 17.951 & 17.906 & 17.860\end{array}$ $\begin{array}{llllllllll}17.815 & 17.769 & 17.724 & 17.678 & 17.633 & 17.587 & 17.542 & 17.496 & 17.451 & 17.405\end{array}$ $\begin{array}{llllllllll}17.360 & 17.315 & 17.269 & 17.224 & 17.6378 & 17.133 & 17.087 & 17.04 & 17.959 & 17.905\end{array}$

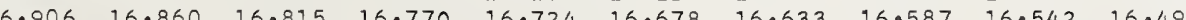

.279898 0.279897

0.279897

0.279896

0.279895

0.279895

0.279894

0.279894

.279893

.279893

0.279892

0.270891

0.279891

0.279890

.279890

0.279890

0.279889

0.279889

0.279888

0.279888

0.279888

0.279887

79887

279886

0.279886

.279885

0.279885

0.279884

0.279884

0.279883

0.279883

0.279882

0.279882
0.279882

0.279881

0.279881
0.279880

.279880

. 279880

0.279879
0.279878

0.279878

0.279877

0.279876

0.279875

0.279875

0.279874

0.279874
.279874
0.279873

0.279873

0.279873

0.279872

0.279872

0.27987

0.279871
0.279871

0.279870
0.279870

0.279870

0.279869

0.279869

0.279868

0.279868

0.279867

0.279867

0.279867

0.279867

0.279866

.279866

1.309921

1.309974

- 310027

.

1. 310106

1. 310133

1. 310185

1.310238

-310265

1. 310318

- 310344

.310397
.310424

1. 310450

1.310503

1310556

1310582

. 310635

1. 310662

1.310715

1. 310741

- 310794

1. 310821

$1 \cdot 310847$

1.310900

1.310927
1.310953

1.310980

1.311032

1.311059

1. 311112

1.311138

1. 311165

1.311244

1.311271

.311324

. 311377

1. 311403

1. 311456

1.311509

1.311535
1.311562

1.311588

1.311641

1. 311694

1.311721

1.311774

1. 311827

1.311880

1.311906
1.311932

1. 311959

1.311985

$1 \cdot 312038$

1.312065
1.312091

1. 312118

1. 312171

1. 312224

1. 312250

1.312303

1.312330
1.312356

1. 312382

1. 312409

1. 312462

1.312515

1. 312541 


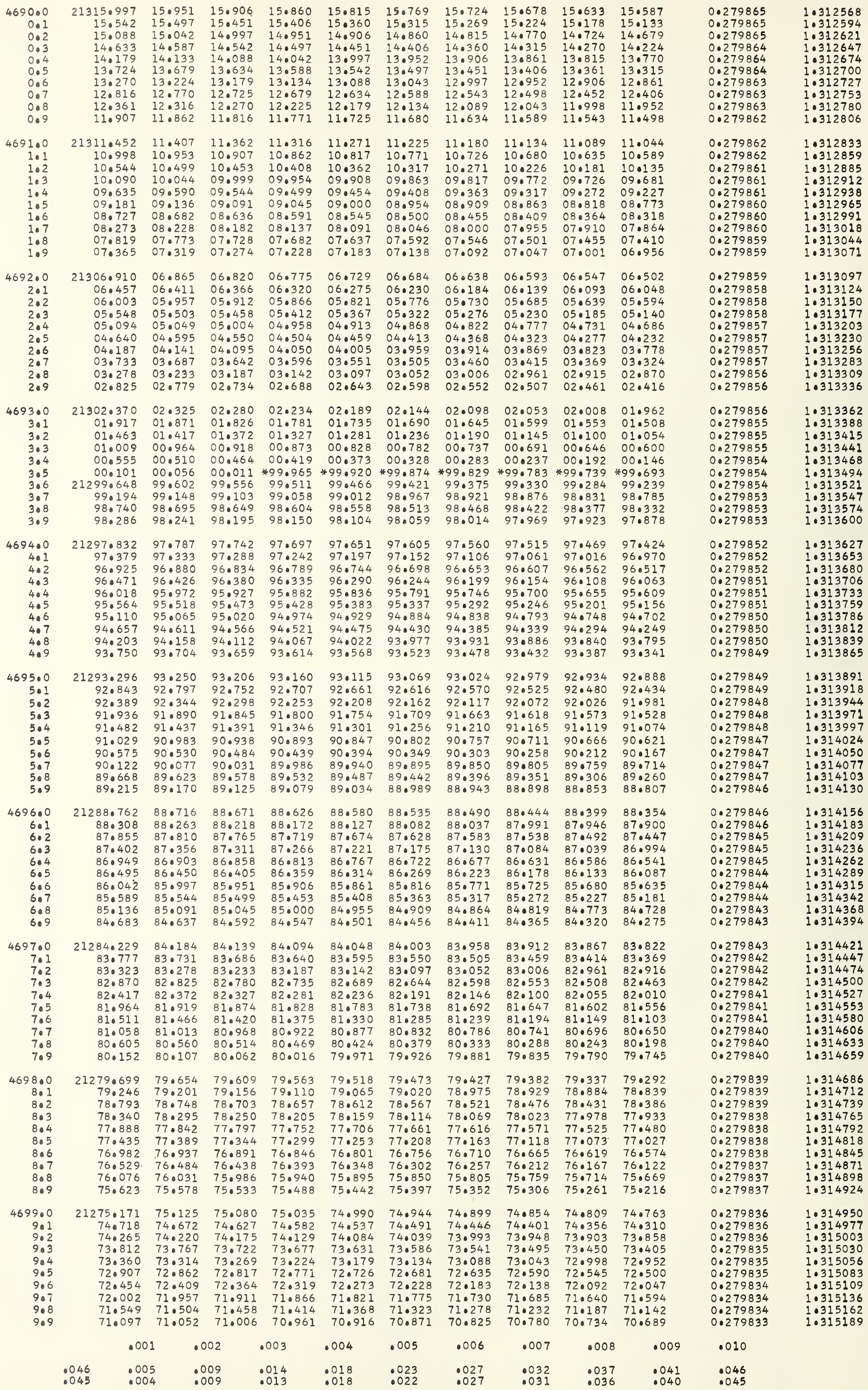




$62.049 \quad 62.004$ \\ $\begin{array}{ll}3.315 & 63.270 \\ 2.863 & 62.818 \\ 6\end{array}$}

63.129647 .084

64.49

$\begin{array}{lll}64.898 & 64.853 & 64.807\end{array}$

21261.51

2.
2.
2.
2.
2.0
2.0
2.0

$\begin{array}{lll}61.597 & 61.551 & 61 . \\ 61.145 & 61.099 & 6\end{array}$

$60.693 \quad 60.647$

$59.788 \quad 59.743$

$\begin{array}{ll}59.336 & 59.291 \\ 58.884 & 58.839\end{array}$

$\begin{array}{ll}58.884 & 58.839 \\ 58.432 & 58.387 \\ 57.980 & 57.035\end{array}$

$61.506 \quad 61.46$

62.320

63.180
62.727

63.586

63.994

$\begin{array}{ll}64.401 & 64.355 \\ 63.948 & 63.903\end{array}$

$\begin{array}{ll}57.980 & 57.935 \\ 57.528 & 57.483\end{array}$

$60.002 \quad 60.557$

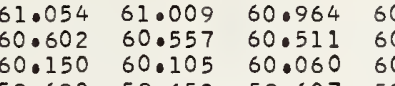

$\begin{array}{lllll}59.698 & 59.652 & 59.600 & 59.562 \\ 59.246 & 59.201 & 59.155 & 59.110 \\ 58.793 & 58.748 & 58.703 & 58.658\end{array}$

-10
5.342

58.748
58.296
57.84

$\begin{array}{lll}59.155 & 59.110 & 59.517 \\ 59.06\end{array}$

63.089
62.637

63.496
63.044

63.451
62.999
620546

21257.0

4703

3.1
3.2
3.3
3.4

3.4
3.5

3.6
3.7

3.8
3.9

4704.0

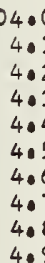

$56.076 \quad 57.031$

$56.624 \quad 56.579$

$55.720 \quad 55.675$

$\begin{array}{ll}55.268 & 55.223 \\ 54.816 & 54.771\end{array}$

$\begin{array}{ll}54.816 & 54.771 \\ 54.365 & 54.319\end{array}$

$53.913 \quad 53.867$

$\begin{array}{ll}53.461 & 53.415 \\ 53.009 & 52.964\end{array}$

$56.986 \quad 56.940$ 52.557
52.105 52.512

52.105

52.060
51.608

$51.202 \quad 51.156$

$\begin{array}{ll}50.750 & 50.705 \\ 50.298 & 50.253 \\ 49.846 & 49.801\end{array}$

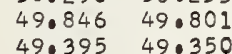

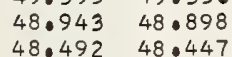

56.082

$55.629 \quad 55.584$

$\begin{array}{ll}55.178 & 55.133 \\ 54.726 & 54.681\end{array}$

$\begin{array}{ll}54.274 & 54.229 \\ 53.822 & 53.777\end{array}$

3.370
53.325
2.919
52.87

248.040

4705.0

5.1
5.2
5.3
5.4
50
5.
5.7
5.
5.

47.58

47.995

52.467

\subsection{2}

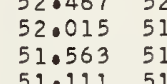

$\begin{array}{ll}51.111 & 51.066 \\ 50.660 & 50.614\end{array}$

$\begin{array}{ll}50.208 & 50.163 \\ 49.756 & 49.711 \\ 49.305 & 49.260\end{array}$

$\begin{array}{ll}49.305 & 49.260 \\ 48.853 & 48.808\end{array}$

$\begin{array}{lll}58.251 & 58.658 & 58.613 \\ & 58.206 & 58.161\end{array}$

61.732

$61.687 \quad 61.642$

46.68

47.543
47.092

47.950 48.356

47.498
47.047

47.905
47.453
47.001

$$
\begin{array}{ll} 
& 47 \\
3 & 47 \\
0 & 46 \\
1 & 46 \\
0 & 46
\end{array}
$$

$45.782 \quad 45.737$

45.331
44.879

44.428

45.286

46.144

46.550
46.098

45.240

45.195

$43.976 \quad 43.931$

$\begin{array}{ll}44.789 & 44.744 \\ 44.337 & 44.292 \\ 43.886 & 43.841\end{array}$

$\begin{array}{ll}45.602 & 45.556 \\ 45.150 & 45.105\end{array}$

$44.698 \quad 44.653$

$\begin{array}{ll}44.247 & 44.202 \\ 43.796 & 43.751\end{array}$

4706.0

6.1
6.2
6.3

6.4

6.5

6.6

6.8

1243.525

$43.074 \quad 43.480$

$42.623 \quad 42.577$

43.435
42.98

43.390

$43.345 \quad 43.300$

$42.171 \quad 42.126$

$\begin{array}{lllll}41.268 & 41.023 & 41.178 & 41.133\end{array}$

$\begin{array}{llll}40.817 & 40.772 & 40.727 & 40.682\end{array}$

$39.914 \quad 39.869$

$40.276 \quad 40.230$

$42.442 \quad 42.397$

$\begin{array}{ll}41.991 & 41.946 \\ 41.539 & 41.494\end{array}$

$41.088 \quad 41.043$

$\begin{array}{ll}40.637 & 40.592 \\ 40.185 & 40.140\end{array}$

$39.463 \quad 39.418$

4707.0

7.0

21239.012

$\begin{array}{ll}38.561 & 38.967 \\ 38.516\end{array}$

$\begin{array}{lllll}37.658 & 38.0613 & 38.020 & 37.974\end{array}$

$\begin{array}{lllll}37.208 & 37.162 & 37.117 & 37.07\end{array}$

$36.305 \quad 36.260$

(35.854 35.80

$\begin{array}{ll}36.666 & 36.621 \\ 36.215 & 36.170\end{array}$

$\begin{array}{ll}35.403 & 35.358 \\ 34.952 & 34.907\end{array}$

35.76
35.31

35.71
35.268

$\begin{array}{ll}39.734 & 39.689 \\ 39.283 & 39.238\end{array}$

$38.832 \quad 38.78$

$\begin{array}{ll}37.929 & 37.884 \\ 37.478 & 37.433\end{array}$

$37.027 \quad 36.982$

$\begin{array}{ll}36.576 & 36.531 \\ 36.125 & 36.080\end{array}$

$36.125 \quad 36.080 \quad 36.035$

234.501

4708.0

8.1
8.2
8.3
8.4
8.5
8.6
8.7
8.8
8.9

4709.0

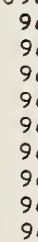

$$
\begin{aligned}
& 234 . \\
& 34 . \\
& 33 . \\
& 33 . \\
& 32 \\
& 32 . \\
& 31 . \\
& 31 . \\
& 30 \\
& 30 .
\end{aligned}
$$

.001

.002

.003

.004

$\begin{array}{ll}61.235 & 61.190 \\ 60.783 & 60.738\end{array}$

60.33160 .286

$\begin{array}{lll}59.924 & 59.879 & 59.834 \\ 590472 & 59.427 & 59.381\end{array}$

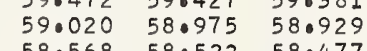

$\begin{array}{lll}58.568 & 58.522 & 58.477 \\ 58.116 & 58.071 & 58.025\end{array}$

$\begin{array}{lll}57.663 & 57.618 & 57.573 \\ 57.212 & 57.167 & 57.121\end{array}$

0.279833

0.279833

0.279832

0.279832

0.279831

0.279831

0.279830
0.279830

0.279830

.279830

0.279829

0.279829

0.279828

0.279827

0.279827

0.279827

0.279826
0.279826
0.279826

0.279826

0.279825
0.279825

0.279825

0.279824
0.279824

0.279824

0.279823

0.279823

0.279822

0.279822

0.279822

0.279821

0.279821

0.279820

0.279820

0.279819

0.279819

0.279818

0.279818

0.279817

0.279817

0.279816

0.279816

0.279816

0.279815
0.279815

0.279815

0.279814
0.279814

0.279814

0.279814

0.279813

0.279813
0.279812

0.0279812

0.279812 
0.0
0.1
0.2
0.3
0.14
0.5
0.16
0.7
0.8
0.0

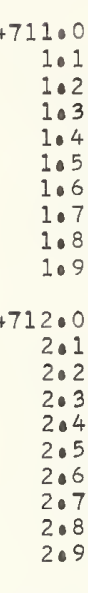

4713

3.2

3.3
3.4
3.5 $\begin{array}{ll}225.484 & 25.439 \\ 25.033 & 24.988\end{array}$

24.583
24.132
23.682

23.231

22.331

21.429

21220.979

20.528
20.078

19.177

$\begin{array}{ll}18.727 & 18.682 \\ 18.277 & 18.231 \\ 18.23 & \end{array}$

$\begin{array}{ll}17.826 & 17.781 \\ 17.376 & 17.331 \\ 16.36 & 16.01\end{array}$

16.926

21216.475

$16.025 \quad 16.430$

$15.575 \quad 15.530$

$14.674 \quad 14.629$

14.224

13.324 13.

12.874
12.424

21211.973

11.523

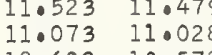

$10.173 \quad 10.0128$

$09.723 \quad 09.678$

08.82309 .228

$\begin{array}{lll}08.374 & 08.328 \\ 07.924 & 07.879\end{array}$

07.024
06.574
06.124

$06.574 \quad 06.529$

$05.675 \quad 050629$

$05.224 \quad 05.179$

$04.325 \quad 04.280$

$\begin{array}{ll}03.875 & 03.830 \\ 03.426 & 03.381\end{array}$

$$
\begin{aligned}
& 202.976 \\
& 02.526 \\
& 02.077
\end{aligned}
$$

02.077
01.627

$00.728 \quad 00.683$

$21199.829 \quad 99.784$

99.379
$98.930 \quad 99.0334$
98.885

$21198.480 \quad 98.435$

97.582

$97.132 \quad 97.087$

96.683960637

$95.784 \quad 96.188$

$\begin{array}{ll}95.334 & 95.289 \\ 94.885 & 94.840\end{array}$

$\begin{array}{rr}94.8855 & 94.840 \\ 94.435 & 94.390\end{array}$

21193.986 93.537 93.08

$92.189 \quad 92.144$

91074091.695

90.84290 .797

$\begin{array}{llll}900.392 & 90.347 \\ 89.943 & 89.898 & 8\end{array}$

$89.045 \quad 89.000$

$88.147 \quad 88.10$

$87.698 \quad 87.653$

87.24987 .204

860351860305

$\begin{array}{ll}85.902 & 85.857 \\ 85.453 & 85.408\end{array}$

$1185.004 \quad 84.959$

$84.555 \quad 84.510$

$\begin{array}{ll}84.106 & 84.061 \\ 83.657 & 83.612\end{array}$

$\begin{array}{ll}83.208 & 83.163 \\ 82.759 & 82.714\end{array}$

$\begin{array}{ll}82.759 & 82.714 \\ 82.311 & 82.266\end{array}$

$\begin{array}{ll}81.862 & 81.817 \\ 81.413 & 81.368 \\ 80.964 & 80.919\end{array}$

$\begin{array}{ll}25.394 & 25.349 \\ 24.943 & 24.089 \\ 240493 & 24.04 \\ 24.042 & 2.097\end{array}$

$\begin{array}{lll}24.042 & 23.997 & 24.40 \\ 23.95\end{array}$

$\begin{array}{llll}23.592 & 23.546 & 23.501 & 23.045\end{array}$

$\begin{array}{llll}22.090 & 23.096 & 23.051 & 23.00 \\ 22.646 & 22.601 & 22.556\end{array}$

$\begin{array}{llll}22 \cdot 240 & 22.195 & 22.0150 & 22.10 \\ 21.790 & 21.745 & 21.700 & 21.65\end{array}$

$\begin{array}{lll}21.339 & 21.294 & 21.24\end{array}$

$20.889 \quad 20.844$

$\begin{array}{lll}20.438 & 20.393 & 20.34 \\ 19.988 & 19.943 & 19.898\end{array}$

$\begin{array}{lll}19.537 & 19.493 & 19.448\end{array}$

$18.087 \quad 19.042$

$\begin{array}{llll}18.187 & 18.592 & 18.547 & 18.50 \\ 18.01 & 18.096 & 18.051\end{array}$

$\begin{array}{llll}17.736 & 17.691 & 17.646 & 17.60 \\ 17.286 & 17.241 & 17.196 & 17.15\end{array}$

$\begin{array}{lll}16.835 & 16.790 & 16.745\end{array}$

$16.385 \quad 16.340$

$\begin{array}{ll}15.935 & 15.889 \\ 15.485 & 150440\end{array}$

$\begin{array}{lll}15.30 & 16.295 & 16.250\end{array}$

$\begin{array}{llll}14.584 & 14.539 & 14.494 & 14.0449\end{array}$

$\begin{array}{llll}13.684 & 13.639 & 13.594 & 130549\end{array}$

$13.234 \quad 13.189$

12.334

$11.884 \quad 11.839$

$\begin{array}{ll}11.434 & 11.038 \\ 10.983 & 10.93\end{array}$

10.53310 .489

$09.634-09.589$

$08.734 \quad 09.138$

$0.0283 \quad 08.23$

$07.384 \quad 07.339$

$06.934 \quad 06.889$

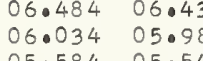

05.584
$05.135 \quad 05.50$
0.5000

$\begin{array}{lll}040235 & 04.640 \\ 03.705 & 0319\end{array}$

03.75
03.335

$02.886 \quad 02.84$

$\begin{array}{ll}02.886 & 02.841 \\ 02.436 & 02.391 \\ 01.987 & 01.912\end{array}$

01.537

01.08801 .042

00.638
00.188
09.739

$99.739 \quad 90.13$

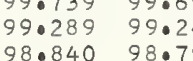

$98.390 \quad 98.345$

97.491

$97.042 \quad 96.997$

96.14396 .548

95014396.096

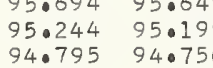

3.144

13.099
12.649
12.198

11.793

11.749

11.344

$10.893 \quad 10.84$

$\begin{array}{lll}09.993 \quad 00.94 & 0.94\end{array}$

$\begin{array}{lll}09.094 & 09.049 & 09.003 \\ 08.644 & 08.598 & 08.55\end{array}$

07.6

066

$06.394 \quad 06.799$

$\begin{array}{lll}05.944 & 05.349 & 0599 \\ 05.494 & 05.450\end{array}$

05.404
$05045 \quad 0505000$

04.595
04.550
$04.145 \quad 04.10$

03.6

04.650
04100
03.651

02.796

02.75

$\begin{array}{ll}02.796 & 02.751 \\ 02.346 & 02.30 \\ 01.097 & 01.85\end{array}$

$\begin{array}{lll}01.897 & 01.852 & 01.807\end{array}$

01.44
00099

$00.548 \quad 00.95$

$000548 \quad 0050$
$000099 \quad 00054$

$99 \cdot 649.99 \cdot 604$
990199.990155

98.750

98.300

97.401
96.952

$96.952 \quad 06.356$

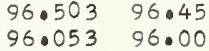

96.053
95.604
95.055

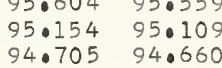

$94.345 \quad 940301$

94.256

94.211

$\begin{array}{lll}93.896 & 93.852 & 93.8 \\ 93.447 & 93.402 & 93.3\end{array}$

92.54992 .503

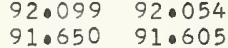

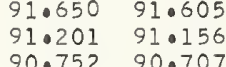

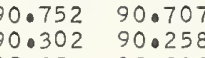

93.806
93.35
92.90

$92.009-92.414$

$91.560-91.065$

91.11191 .066

90.66290 .617

89.763

$89.404 \quad 89.35$

88.055
88.506
88.98
80.012

$88.057 \quad 88.01$
87.608
87.565

$\begin{array}{ll}87.159 & 87.114 \\ 86.710 & 86.665 \\ 8606 & \end{array}$

$\begin{array}{ll}86.710 & 86.665 \\ 86.261 & 86.216 \\ 86.216\end{array}$

$89.314 \quad 89.269$

$\begin{array}{ll}88.865 & 88.821 \\ 88.416 & 88.371\end{array}$

87.96
87.518

87.518

86.620
86.171

87.922
87.47

87.024
86.575

$\begin{array}{ll}85.812 & 85.76 \\ 85.363 & 85.31\end{array}$

85.722

84.9

$84.465 \quad 84.460$

84.016
83.0567
8305
83.05

(3).

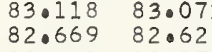

$82.221 \quad 82.176$

$\begin{array}{lllllll}84.824 & 84.779 & 84.734 & 84.689 & 84.645 & 84.600 \\ 84.0375 & 84.330 & 84.285 & 84.240 & 84.696 & 84.151\end{array}$

$\begin{array}{llllll}84.375 & 84 \cdot 330 & 84 \cdot 285 & 84 \cdot 240 & 84 \cdot 196 & 84 \cdot 151 \\ 83.0227 & 830882 & 83.837 & 83.792 & 83.747 & 830702\end{array}$

$\begin{array}{llllll}83.478 & 83.0433 & 83.0388 & 83.343 & 83.298 & 83.253\end{array}$

$\begin{array}{lllllll}83.029 & 82.984 & 82.939 & 82.894 & 82.0449 & 82.804 \\ 82.580 & 82.535 & 82.490 & 82.445 & 820400 & 82.355\end{array}$

$\begin{array}{lllllll}82.580 & 82.535 & 82.490 & 82.445 & 82.400 & 82.355 \\ 82.131 & 82.086 & 82.041 & 81.096 & 81.051 & 81.906\end{array}$

$\begin{array}{llllll}82.131 & 82.086 & 82.041 & 81.0996 & 81.951 & 81.906 \\ 81.682 & 81.037 & 81.0992 & 81.0548 & 81.0503 & 81.0458\end{array}$

$\begin{array}{llll}1.323 & 81.0727 & 81.062 & 82.0 \\ 1.32 & 81.278 & 81.233 & 810\end{array}$

10.188
0.740

.144
8.695

$80.65080 .605 \quad 80.560$

0.279801

0.279800

0.279800

0.279799

0.279799

0.279799

0.279798

0.279798

0.279797
0.279797
0.27979

0.279797

0.279796

0.279796

0.279795

0.279795

0.27979

0.279794
0.279794
0.279793

0.279793

0.279793

0.279792

0.279792
0.279792

0.279792

0.279791

0.279791
0.279791
0.27979

0.279790

0.279790

0.279790
0.279789
0.27978

0.279789

0.279789

0.279788

0.279788

0.279788

0.279787

0.279787
0.279787
0.279786

0.279786

0.279786

0.279786
0.279785

0.279785

0.279785 
$\begin{array}{rrrrrrrrrrr}4720.0 & 21180.515 & 80.470 & 80.426 & 80.381 & 80.336 & 80.291 & 80.246 & 80.201 & 80.157 & 80.112\end{array}$

$\begin{array}{lllllllllll}0.1 & 80.067 & 80.022 & 79.977 & 79.932 & 79.888 & 79.843 & 79.798 & 79.753 & 79.708 & 79.663 \\ 0.2 & 79.618 & 79.573 & 79.529 & 79.484 & 79.439 & 79.394 & 79.349 & 79.304 & 79.259 & 79.214\end{array}$

$\begin{array}{lllllllllll}0.2 & 79.618 & 79.573 & 79.529 & 79.484 & 79.439 & 79.394 & 79.349 & 79.304 & 79.259 & 79.214 \\ 0.3 & 79.169 & 79.125 & 79.080 & 79.035 & 78.990 & 78.945 & 78.900 & 78.855 & 78.811 & 78.766\end{array}$

$\begin{array}{llllllllllll}0.4 & 78.721 & 78.676 & 78.631 & 78.586 & 78.541 & 78.497 & 78.452 & 78.407 & 78.362 & 78.317 \\ 0.5 & 78.272 & 78.227 & 78.183 & 78.138 & 78.093 & 78.048 & 78.003 & 77.958 & 77.914 & 77.869\end{array}$

$\begin{array}{llllllllllll}0.5 & 78.272 & 78.227 & 78.183 & 78.138 & 78.093 & 78.048 & 78.003 & 77.958 & 77.914 & 77.869 \\ 0.6 & 77.824 & 77.779 & 77.734 & 77.689 & 77.644 & 77.599 & 77.554 & 77.510 & 77.465 & 77.420\end{array}$

$\begin{array}{lllllllllll}0.7 & 77.375 & 77.330 & 77.285 & 77.240 & 77.196 & 77.151 & 77.106 & 77.061 & 77.016 & 76.971\end{array}$

$\begin{array}{lll}76.927 & 76.882 & 76 \\ 76.478 & 76.433 & 76\end{array}$

$4721: 0$

21176

$\begin{array}{lll}176.029 & 75.984 & 7 \\ 75.581 & 75.536 & 7 \\ 75.132 & 75.087 & 7 \\ 74.684 & 74.639 & 7 \\ 74.235 & 74.190 & 7 \\ 73.787 & 73.742 & 730 \\ 73.338 & 73.293 & 730 \\ 72.890 & 72.845 & 7 \\ 72.441 & 72.396 & 7 \\ 71.993 & 71.948 & 7\end{array}$

76.38876 .343

$\begin{array}{ll}76.747 & 76.702 \\ 76.254\end{array}$

76.657
76.209

$\begin{array}{lll}76.612 & 76.567 & 76.523 \\ 76.164 & 76.119 & 76.074\end{array}$

4722

$2:$
$2:$
$2:$
$2:$
$2:$
$2: 0$
$2: 0$
$2: 0$

21171.54

$\begin{array}{ll}71.545 & 71.500 \\ 71.096 & 71.052\end{array}$

$70.548 \quad 71.052 \quad 71.007$

$\begin{array}{lll}710.0503 & 70.558 \quad 70.513\end{array}$

69.751

69.303 .69 .258

68.85568 .810

$\begin{array}{ll}70.110 & 70.06 \\ 69.662 & 69.617\end{array}$

75.850
75.40
74.95

75.805

75.760

75.715

$\begin{array}{ll}75.670 & 75.625 \\ 75.222 & 75.177\end{array}$

5.04274 .99

74.953
74.504
74.056

$74.908 \quad 74.863$

$\begin{array}{lll}74.818 & 74.774 & 74.729\end{array}$

$68 \cdot 310$

$69.214 \quad 69.16$

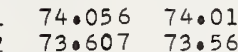

$73 \cdot 96$

$74 \cdot 370 \quad 74 \cdot 325-74 \cdot 280$

73.652

$\begin{array}{ll}73.607 & 73.562 \\ 73.159 & 73.114\end{array}$

$\begin{array}{llll}73.518 & 73.473 & 73.876 & 73.832 \\ 73.428 & 73.383\end{array}$

$\begin{array}{llll}73.069 & 73.024 & 72.979 & 72.935\end{array}$

67.958
67.510

4723.

3.1
3.2
3.3

21167.062

$67.062 \quad 67.0$

$66.614 \quad 66.569 \quad 66.973$

$66.166 \quad 66.121$

$\begin{array}{ll}65.718 & 65.673 \\ 65.270 & 65.225 \\ 64.821 & 64.776\end{array}$

65.270

$66.524 \quad 66.479$

$72 \cdot 262$

72.666
72.217

$72 \cdot 621$

72.576

$72 \cdot 979$

$72 \cdot 935$

$\begin{array}{lll}6.180 & 65.135 \\ 776 & 64.732 & 64.687\end{array}$

3.6

3.7

$63.925 \quad 63.329 \quad 64.284$

$\begin{array}{llll}63.477 & 63.432 & 63.836 & 63.791 \\ 63.388 & 63.343\end{array}$

71.27

71.23

71.634

71.589

0.27976

0.279769

0.279769

0.279768

0.279767

0.279767

0.279767
0.279766

0.279766

0.279766

0.279766
0.279765

0.27976

0.279765
0.279764

0.279764

0.279764
0.279763

0.279763

0.279763
0.279762

0.27976

0.279761

0.27976

0.279760

0.279760

0.279760

0.279760
0.279750
0.279759

0.279759

0.279759
0.279758

0.279758

0.279758

0.279757

4724.0

4.
4.
4.
4.
4.
4.
4.7
4.0
4.9

62.134

62.08

62.49262 .8

$61.238 \quad 61.193$

60.7942
59.894

60.745

59.84

58.999

59.401
58.954

62.044
61.596
61.148

$4 \quad 61.999$

$7 \quad 62.40$

$\begin{array}{lll}63.701 & 63.6 \\ 63.253 & 63.2\end{array}$

$\begin{array}{llll}05 & 64.060 & 64.463 & 64.418 \\ .015 & 63.970\end{array}$

158.103

4725.

(2)

5.3
5.4
5.5

5.4
5.5
5.6
5.7
5.8

5.8
5.9

4726.0

6.
6.
6.
6.
6.
6.
6.0
6.
6.

21153

$\begin{array}{ll}58.103 & 58 \cdot 05 \\ 57.655 & 57.61\end{array}$

$\begin{array}{lll}57.208 & 57.610 & 57.56\end{array}$

$56.759 \quad 56.715$

$56.312 \quad 56.267 \quad 56.222$

$\begin{array}{llll}55.864 & 55.819 & 55.775\end{array}$

$54.969 \quad 54.924$

54.521

54.074

54.476
54.029

54.879

61.103

.95461 .9

$\begin{array}{lll}63.164 & 63.119 & 63.074\end{array}$

0.279757

0.279756

0.279756
0.279756

0.279755
0.279755

0.279755

0.279754

0.279754
0.279754

0.279754

0.279753

0.279753
0.279753

0.279752

0.279752
0.279752

0.279751

0.279751
0.279751

0.279750

0.279750

0.27974

0.27974
0.27974

0.279748
0.279748

0.279748 $\begin{array}{llllllllll}51.388 & 51.343 & 51.299 & 51.254 & 51.209 & 51.164 & 51.119 & 51.074 & 51.030 & 50.985 \\ 50.940 & 50.896 & 50.851 & 50.806 & 50.762 & 50.717 & 50.672 & 50.627 & 50.583 & 50.538\end{array}$ $\begin{array}{llllllllll}50.940 & 50.896 & 50.851 & 50.806 & 50.762 & 50.717 & 50.672 & 50.627 & 50.583 & 50.538 \\ 50.493 & 50.448 & 50.404 & 50.359 & 50.314 & 50.269 & 50.225 & 50.180 & 50.135 & 50.090\end{array}$ $\begin{array}{llllllllll}50.045 & 50.001 & 49.956 & 49.911 & 49.867 & 49.822 & 49.777 & 49.732 & 49.687 & 49.643\end{array}$

0.279748

4727.0

21149.151 $48.703 \quad 48 \cdot 1$ $\begin{array}{lllll}4.703 & 48.659 & 48.061 & 49.01\end{array}$

$47.800 \quad 48.211 \quad 48.167 \quad 48.12$

$47.361 \quad 47.317$

$46.914 \quad 46.869$

$46.467 \quad 46.422$

$46.377 \quad 46.33$

$\begin{array}{llll}46.019 & 45.975 & 45.930 & 45.885\end{array}$

45.125

45.527
45.080

45.48
45.035

48.

248.927

$\begin{array}{llll}48.882 & 48.837 & 48.793 & 48.748\end{array}$

0.279747

0.279747

0.279747

0.279746

0.279746

0.279745

0.279745

0.279744

4728.0

8.2

211440

$44.230 \quad 44.633$

$\begin{array}{llll}44.230 & 44.186 & 44.588 & 44.543 \\ 43.783 & 43.739 & 43.694 & 43.096\end{array}$

$43.694 \quad 43.649$

$42.889 \quad 42.844$

$\begin{array}{ll}42.442 & 42.397 \\ 41.995 & 41.950\end{array}$

$41.995 \quad 41.950$

$\begin{array}{ll}43.246 & 43.20 \\ 42.799 & 42.75\end{array}$

$\begin{array}{ll}42.799 & 42.755 \\ 42.353 & 42.308\end{array}$

$46.288 \quad 46.243$

$\begin{array}{llll}46.198 & 46.153 & 46.109 & 46.06\end{array}$

$44.946 \quad 44.901$

0.279744

0.279744

0.279743

0.279743

0.279742

0.279742

$\begin{array}{llllllllll}41.100 & 41.056 & 41.011 & 40.966 & 40.922 & 40.877 & 40.832 & 40.787 & 40.743 & 41.145\end{array}$

$\begin{array}{lllll}41.100 & 41.056 & 41.011 & 40.966 & 40 \\ 40.654 & 40.609 & 40.564 & 40.519 & 40\end{array}$

4729

$\begin{array}{ll}40.206 & 40.161 \\ 39.759 & 39.715\end{array}$

40.117

$40.475 \quad 40.430$

$\begin{array}{llll}40.832 & 40.787 & 40.743 & 40.698 \\ 40.385 & 40.340 & 40.296 & 40.251\end{array}$

0.279741

0.279741

0.279740

0.279740

0.279739

0.279739

0.279738

$\begin{array}{llllllllll}38.418 & 38.374 & 38.329 & 38.284 & 38.239 & 38.195 & 38.150 & 38.106 & 38.061 & 38.016\end{array}$

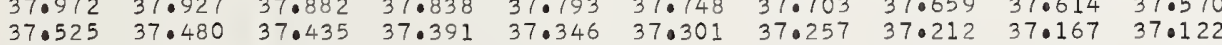

$\begin{array}{llllllllll}37.078 & 37.033 & 36.989 & 36.944 & 36.899 & 36.854 & 36.810 & 36.765 & 36.720 & 36.676\end{array}$

$\begin{array}{llllllllll}36.631 & 36.586 & 36.542 & 36.497 & 36.452 & 36.408 & 36.363 & 36.318 & 36.273 & 36.229\end{array}$

$\begin{array}{llll}36.184 & 36.139 & 36.095 & 36.0\end{array}$

.005

$.007 \quad .008 \quad .009$

.010

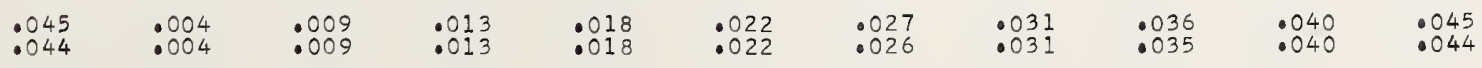

1.320564

1.320591

.320644

1.320670

1.320723

1.320776

1.320802

1.320855

1.320882

1. 320935

1. 320968

1.321041

1.321067
1.321094

1.321120

1.321173

1. 321226

1.321253
1.321279

1.321306

1.321332
1.321359

1. 321385

1.321412
1.321438

1.321465

1.321491

1.321518
1.321544

1. 321571

1.321597
1.321624

1. 321650

1.321676
1.321703

1. 321729

1.321782
1.321809

$1 \cdot 321835$

1. 321868

1.321915

1. 321941

1. 321968

1. 322021

1.322047
1.322074

1.322100

1. 322153

1.322180
1.322206

1. 322233

1.322259
1.322286 


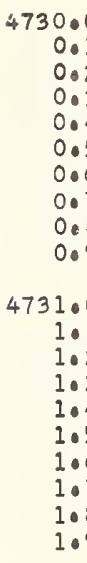

4732
2
2
2
2
2.
2.
2
2.
2.
4733.
3.
3.
3.
3.4
3.5
3.6
3.7
3.
3.

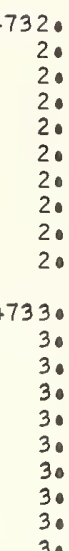

4734.

$$
\begin{array}{r}
734.0 \\
4 \cdot 1 \\
4 \cdot 2 \\
4.3 \\
4.4 \\
4.5 \\
4.6 \\
4 \bullet 7 \\
4.8 \\
4.9
\end{array}
$$

4735.0

$$
\begin{aligned}
& 5.1 \\
& 5.2
\end{aligned}
$$

$5 \cdot 2$
5.3

5.3
5.4

5.5
5.6

5.6
5.7
5.8

5.8
5.9

4736.0

6.1
6.2
6.3

6.4
6.5
6.6
6.7

6.6
6.7

6.8
6.9

4737.

7.1
7.2

7.3
7.4

7.5

7.6
7.7

7.8
7.9

4738.0

8.1
8.2
8.3

8.3

8.4

8.6

8.7
8.8
8.9

4739.0

9.1
9.2
9.3
9.4
9.5
9.6
9.7
9.8

$\begin{array}{ll}35.290 & 35.246 \\ 34.844 & 34.799\end{array}$

$34.397 \quad 34 \cdot 352$

$33.503 \quad 33.458$

$33.056 \quad 33.012$

$\begin{array}{ll}32.610 & 32.565 \\ 32.163 & 32.118\end{array}$

31.717

$32 \cdot 118$
31.672

$\begin{array}{llll}35.648 & 35.603 & 35.559 & .35 .51 \\ 35.201 & 35.156 & 35.112 & 35.067\end{array}$

$\begin{array}{lllll} & 35.02\end{array}$

$\begin{array}{llll}34.307 & 34.263 & 34.218 & 34.173\end{array}$

$33.414 \quad 33.369 \quad 33.324$

$\begin{array}{llll}32.967 & 32.922 & 32.878 & 32.833\end{array}$

$\begin{array}{llll}32.521 & 32.476 & 32.431 & 32.38 \\ 32.073 & 32.029 & 31.984 & 31.940\end{array}$

$34.129 \quad 34.084 \quad 34.039 \quad 33.995$

$\begin{array}{llll}33.235 & 33.190 & 33.146 & 33.101\end{array}$

$\begin{array}{llll}32.789 & 32.744 & 32.699 & 32.655\end{array}$

$21131.270 \quad 31.225$

31.180

$\begin{array}{lll}31.583 & 31.538 & 31.493\end{array}$

31.895

32.297

$\begin{array}{ll}32.252 & 32.208 \\ 31.806 & 31.761\end{array}$

$\begin{array}{ll}30.823 & 30.779 \\ 30.376 & 30.332\end{array}$

29.930

30.332
$29 \cdot 885$

$29.037 \quad 28.992$

$\begin{array}{ll}28.590 & 28.545 \\ 28.144 & 28.099\end{array}$

$\begin{array}{ll}27.697 & 27.653 \\ 27.251 & 27.206\end{array}$

$30.734 \quad 31.136$

$\begin{array}{llll}30.287 & 30.242 & 30.645 & 30.60 \\ 20.198 & 30.15\end{array}$

$\begin{array}{llll} & \end{array}$

$\begin{array}{llll}29.394 & 29.349 & 29.304 & 29.260\end{array}$

$\begin{array}{llll}28.948 & 28.903 & 28.858 & 28.813 \\ 28.501 & 28.456 & 28.412 & 28.36\end{array}$

$\begin{array}{llll}31.002 & 30.957 & 30.913 & 30.868 \\ 30.555 & 30.510 & 30.466 & 30.421\end{array}$

$\begin{array}{llll}30.108 & 30.064 & 30.019 & 29.975\end{array}$

$\begin{array}{llll}29.0662 & 29.617 & 29.573 & 29.528\end{array}$

$28.322 \quad 28.278 \quad 28.233 \quad 28.188$

27.251

21126.804

26.358

26.760

27.60

$\begin{array}{llll}28.010 & 27.965 & 27.920 & 27.876\end{array}$

$25.465 \quad 25.420$

$\begin{array}{ll}25.019 & 24.974 \\ 24.572 & 24.527\end{array}$

$24.126 \quad 24.081$

26.71526 .670

26.268 25.822

$\begin{array}{llll}25.375 & 25.737 & 25.733 & 25.688\end{array}$

$\begin{array}{llll}24.929 & 24.885 & 24.840 & 24.795\end{array}$

24.483

$\begin{array}{lll}24.438 & 24.393 & 24.349\end{array}$

$\begin{array}{ll}23.233 & 23.188 \\ 22.787 & 22.742\end{array}$

23.590

$21.894 \quad 21.850$

$\begin{array}{ll}21.448 & 21.403 \\ 21.002 & 20.957\end{array}$

20.55520 .511

$\begin{array}{ll}20.109 & 20.064 \\ 19.663 & 19.618\end{array}$

$\begin{array}{ll}19.217 & 19.172 \\ 18.771 & 18.726\end{array}$

22.697

$\begin{array}{ll}23.501 & 23.456 \\ 23.055 & 23.010\end{array}$

$27.429 \quad 27.385 \quad 27.340 \quad 27.29$

$18.325 \quad 18.280$

21.359

22.207

22.608

$17.432 \quad 17.388$

16.987

$16.095 \quad 16.050$

$15.203 \quad 15.158$

$\begin{array}{ll}14 \cdot 757 & 14 \cdot 712 \\ 14.311 & 14.266\end{array}$

$20.912 \quad 20.868$

$20.020 \quad 19.976$

$\begin{array}{ll}19.128 & 19.083 \\ 18.681 & 18.637\end{array}$

$\begin{array}{ll}21.716 & 22.117 \\ 21.671\end{array}$

$\begin{array}{llll}26.536 & 26.491 & 26.447 & 26.402\end{array}$

$\begin{array}{llll}26.090 & 26.045 & 26.000 & 25.956\end{array}$

$25.197 \quad 25.152 \quad 25.108 \quad 25.063$

$\begin{array}{llll}24.751 & 24.706 & 24.661 & 24.616 \\ 24.304 & 24.260 & 24.215 & 24.170\end{array}$

$\begin{array}{llll}24.304 & 24.260 & 24.215 & 24.170 \\ 23.858 & 23.813 & 23.769 & 23.724\end{array}$

$\begin{array}{llll}23.411 & 23.367 & 23.322 & 23.278\end{array}$

$\begin{array}{llll}22.965 & 22.921 & 22.876 & 22.832 \\ 22.519 & 22.474 & 22.430 & 22.385\end{array}$

$\begin{array}{llll}22.073 & 22.028 & 21.984 & 21.939\end{array}$

$\begin{array}{llll}21.626 & 21.582 & 21.537 & 21.492\end{array}$

$\begin{array}{llll}.180 & 21.136 & 21.091 & 21.046 \\ .734 & 20.689 & 20.645 & 20.600 \\ .288 & 20.243 & 20.198 & 20.154\end{array}$

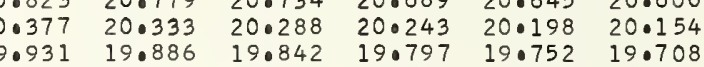

$\begin{array}{llll}19.574 & 19.529 & 19.485 & 19.440 \\ 19.128 & 19.083 & 19.039 & 18.994 \\ 18.681 & 18.637 & 18.592 & 18.548 \\ 18.235 & 18.191 & 18.146 & 18.102\end{array}$

17.789

17.7
17.2

$\begin{array}{llll}19.395 & 19.351 & 19.306 & 19.261\end{array}$

$\begin{array}{llll}18.503 & 18.458 & 18.414 & 18.369\end{array}$

$13.865 \quad 13.820$ $12.973 \quad 12.928$

$12.527 \quad 12.483$

$11.635 \quad 11.591$

$11.190 \quad 11.145$

$10.744 \quad 10.69$

$09.852 \quad 09.808$

16.451

$16.006 \quad 15.961$

17.700
17.254

17.656
17.209

$\begin{array}{llll}17.611 & 17.566 & 17.522 & 17.477\end{array}$

$15.916 \quad 15.872$

$\begin{array}{llll}15.114 & 15.069 & 15.024 & 14.980 \\ 14.667 & 14.623 & 14.578 & 14.534\end{array}$

14.622
13.0775

$\begin{array}{ll}14.177 \\ 5 & 13.731\end{array}$

$\begin{array}{llll}13.330 & 13.285 & 13.240 & 13.196\end{array}$

$\begin{array}{llll}16.719 & 16.675 & 16.630 & 16.585\end{array}$

$\begin{array}{llll}16.273 & 16.229 & 16.184 & 16.139\end{array}$

$15.827 \quad 15.783 \quad 15.738 \quad 15.693$

$\begin{array}{llll}14.935 & 14.891 & 14.846 & 14.801\end{array}$

$\begin{array}{llll}14.489 & 14.445 & 14.400 & 14.355\end{array}$

$\begin{array}{lll}13.999 & 13.954 & 13.910 \\ 13.553 & 13.508 & 13.463\end{array}$

1108.96

$08.070 \quad 08.02$

$07.178 \quad 07.134$

$\begin{array}{ll}06.732 & 06.688 \\ 06.287 & 06.242\end{array}$

$05.841 \quad 05.797$

$\begin{array}{ll}05.396 & 05.351 \\ 04.950 & 04.906\end{array}$

$2.884 \quad 12.839$

$13 \cdot 240$

12.750

$13 \cdot 151$

$13.107 \quad 13.062 \quad 13.018$

11.99211 .948

$12.349 \quad 12.30$

12.705

$13 \cdot 107$
12.661

$\begin{array}{ll}11.546 & 11.502 \\ 11.101 & 11.056\end{array}$

$\begin{array}{lll}11.903 & 11.859 & 11.814 \\ 11.457 & 11.413 & 11.368\end{array}$

$\begin{array}{lll}12.215 & 12.171 & 12.126\end{array}$

$\begin{array}{llll}0.655 & 10.610 & 10.566 & 10.5\end{array}$

$\begin{array}{llll}11.368 & 11.323 & 11.279 & 11.234\end{array}$

$\begin{array}{lll}11.323 & 11.279 & 11.234 \\ 10.878 & 10.833 & 10.788\end{array}$

$\begin{array}{lllll}10.521 & 10.476 & 10.432 & 10.387 & 10.343\end{array}$

$\begin{array}{llll}10.031 & 09.986 & 09.942 & 09.897 \\ 09.585 & 09.540 & 09.496 & 09.451\end{array}$

09.31709 .719

$10.120 \quad 10.075$

09.585

09.540

08.87208 .827

08.782

08.738

08.693

08.649

$09.050 \quad 09.006$

$07.980 \quad 07.936$

$\begin{array}{ll}07.534 & 07.490 \\ 07.089 & 07.044\end{array}$

$\begin{array}{ll}06.644 & 06.599 \\ 06.198 & 06.153\end{array}$

$07.891 \quad 07.846$

$\begin{array}{lllll}0.084 & 08.248 & 08.203 & 08.159 & 08.114\end{array}$

$\begin{array}{llllll}07.401 & 07.356 & 07.312 & 07.267 & 07.223\end{array}$

$\begin{array}{llllll}07.000 & 06.955 & 06.911 & 06.866 & 06.822 & 06.777\end{array}$

.75205 .708

$5.307 \quad 05.262$

$06.109 \quad 06.064 \quad 06.020 \quad 05.975 \quad 05.930 \quad 05.886$

$05.663 \quad 05.618 \quad 05.574 \quad 05.530 \quad 05.485 \quad 05.440$

$\begin{array}{llll}04.059 & 04.014 & 03.970 & 03.925 \\ 03.614 & 03.569 & 03.525 & 03.4 \\ 03.168 & 03.124 & 03.079 & 03.034\end{array}$

$\begin{array}{llll}03.168 & 03.124 & 03.079 & 03.034\end{array}$

$\begin{array}{lllllllllll} & 02.634 & 02.589 & 02.544 & 02.500 & 02.456 & 02.456 & 02.812 & 02.767 \\ 0.723 & 02.678 & 02.634 & 02.51 & 02.366 & 02.322\end{array}$

$\begin{array}{llllllllll}02.233 & 02.188 & 02.144 & 02.099 & 02.054 & 02.010 & 01.965 & 01.921 & 01.876\end{array}$

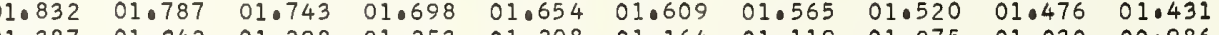

$\begin{array}{llllllllll}01.387 & 01.342 & 01.298 & 01.253 & 01.208 & 01.164 & 01.119 & 01.075 & 01.030 & 00.986\end{array}$

$\begin{array}{llllllllll}00.941 & 00.896 & 00.852 & 00.808 & 00.763 & 00.719 & 00.674 & 00.629 & 00.585 & 00.540 \\ 00.496 & 00.451 & 00.407 & 00.362 & 00.318 & 00.273 & 00.229 & 00.184 & 00.139 & 00.095\end{array}$

$21100.050 \quad 00.006 * 99.961 * 99.917 * 99.872 * 99.828 * 99.783 * 99.739 * 99.694 * 99.650$

$\begin{array}{llllllllll}21099.605 & 99.561 & 99.516 & 99.471 & 99.427 & 99.383 & 99.338 & 99.293 & 99.249 & 99.204\end{array}$

$\begin{array}{llllllllll}99.160 & 99.115 & 99.071 & 99.026 & 98.981 & 98.937 & 98.892 & 98.848 & 98.803 & 98.759 \\ 98.714 & 98.670 & 98.625 & 98.581 & 98.536 & 98.492 & 98.447 & 98.403 & 98.358 & 98.314\end{array}$

$\begin{array}{llllllllll}98.269 & 98.225 & 98.180 & 98.135 & 98.091 & 98.047 & 98.002 & 97.958 & 97.913 & 97.868\end{array}$

$\begin{array}{llllllllll}97.824 & 97.779 & 97.735 & 97.690 & 97.646 & 97.601 & 97.557 & 97.512 & 97.468 & 97.423\end{array}$

$\begin{array}{llllllllll}97.379 & 97.334 & 97.290 & 97.245 & 97.201 & 97.156 & 97.112 & 97.067 & 97.022 & 96.978\end{array}$

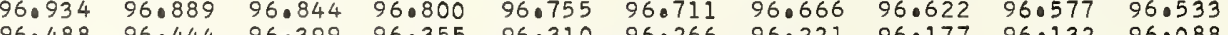

$\begin{array}{llllllllll}96.488 & 96.444 & 96.399 & 96.355 & 96.310 & 96.266 & 96.221 & 96.177 & 96.132 & 96.088 \\ 96.043 & 95.999 & 95.954 & 95.909 & 95.865 & 95.821 & 95.776 & 95.731 & 95.687 & 95.643\end{array}$

$\begin{array}{rlllllllll}21095.598 & 95.554 & 95.509 & 95.465 & 95.420 & 95.376 & 95.331 & 95.287 & 95.242 & 95.198 \\ 95.153 & 95.108 & 95.064 & 95.019 & 94.975 & 94.931 & 94.886 & 94.842 & 94.797 & 94.752\end{array}$

$95.153 \quad 95.108 \quad 95.064 \quad 95.019$

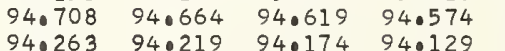

$93.818 \quad 93.773 \quad 93.729 \quad 93.684$

$93.373 \quad 93.328 \quad 93.28493 .240$

$\begin{array}{llll}2.928 & 92.883 & 92.839 & 92.794 \\ 92.483 & 92.438 & 92.394 & 92.349\end{array}$

$92.038 \quad 91.993 \quad 91.948 \quad 91.904$

$\begin{array}{rlllll}9.085 & 94.040 & 94.441 & 94.396 & 94.352 & 94.308 \\ & 93.996 & 93.951 & 93.907 & 93.862\end{array}$

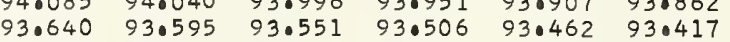

$\begin{array}{lllllll}93.195 & 93.150 & 93.105 & 93.061 & 93.017 & 92.972 \\ 93.750 & 92.705 & 92.661 & 92.616 & 92.572 & 92.527\end{array}$

$\begin{array}{llllll}2.305 & 92.260 & 92.215 & 92.171 & 92.127 & 92.082\end{array}$

.001

.002

.003

91.815

$\begin{array}{llll}91.771 & 91.726 & 91.682 & 91.637 \\ 91.326 & 91.281 & 91.237 & 91.192\end{array}$

0.279738

0.279737

0.279737

0.279736

0.279736

0.279735

0.279735

0.279735

0.279734
0.279734

0.279734

0.279733

0.279733

0.279732

0.279732
0.279732

0.279732

0.279731

0.279731

0.279730

0.279730

0.279730
0.279729

0.279729

0.279729

0.279728

0.279728

0.279728
0.279727

0.279727

0.279727

0.279726

0.279726
0.279726

0.279726

0.279725

0.279725

0.279724

0.279724

0.279724
0.279723

0.279723 


.07

.08

.09

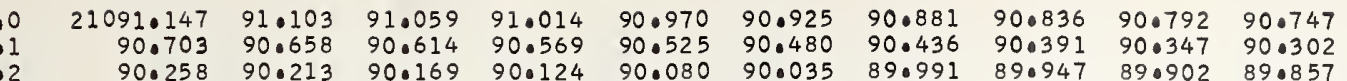
$\begin{array}{lllllllllll}90.258 & 90.213 & 90.169 & 90.124 & 90.080 & 90.035 & 89.991 & 89.947 & 890902 & 89.857\end{array}$ $\begin{array}{lllllllllll}89.368 & 89.768 & 89.724 & 89.680 & 89.635 & 89.591 & 89.546 & 89.501 & 89.457 & 89.413 \\ 89.279 & 89.234 & 89.190 & 89.146 & 89.101 & 89.057 & 89.012 & 88.968\end{array}$ $\begin{array}{lllllllllll}88.923 & 88.878 & 88.834 & 88.790 & 88.745 & 88.701 & 88.656 & 88.612 & 88.567 & 88.523\end{array}$ $\begin{array}{lllllllllll}88.479 & 88.434 & 88.389 & 88.344 & 88.300 & 88.256 & 88.211 & 88.167 & 88.122 & 88.078\end{array}$ $\begin{array}{lllllllllllll}0.7 & 88.033 & 87.989 & 87.945 & 87.900 & 87.855 & 87.811 & 87.766 & 87.722 & 87.678 & 87.633\end{array}$ $\begin{array}{llllllllllll}0.8 & 87.589 & 87.544 & 87.500 & 87.455 & 87.411 & 87.366 & 87.322 & 87.277 & 87.233 & 87.188 \\ 0.9 & 87.144 & 87.099 & 87.055 & 87.010 & 86.966 & 86.922 & 86.877 & 86.833 & 86.788 & 86.743\end{array}$

0.279682 0.279681 0.279681 0.279680 0.279680 0.279680 0.279679

0.279678 0.279678
0.279678 0.279678 0.279677 0.279677 0.279677 0.279676 0.279676

1.326021

1.326074

1.326200

1.326127

1. 326206

1.326232

1.326285

1.326338

1.326365

1.326418

1.32644

1. 326497

1.326524
1.326550

1.326550

1.326603

1.326656

1.326683

1.326736

16326762

1.326789
1.326815

1.326842

1.326868

1.326895

1.326921

1.326974

1.327001

1.327027

1.327080

1.327133

1.327160

1.327213

1. 327266

1.327292

1. 327319

1.327372

1.327398

1.327425
1.327451

1.327478

1.327504
1.327531

1.327557

1.327584
1.327610

1.327637

1.327663

1.327690

1.327743

1.327769
1.327796

1. 327822

1.327848
1.327875

1. 327901

1. 327928

1.327954
1.327981

1. 328007

1.328034
1.328060

1.328087

1. 328113

1.328140
1.328166

1.328193

1.328219
1.328246

1. 328272

1.328299

1.328325

1.328352

.328405
.328432

.010

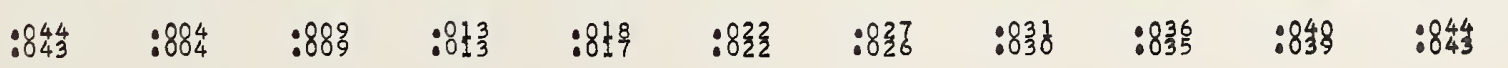


$\begin{array}{lllllllllll}4750.0 & 21046.746 & 46.701 & 46.657 & 46.613 & 46.569 & 46.524 & 46.480 & 46.436 & 46 \cdot 391 & 46.347\end{array}$

$\begin{array}{llllllllllll}0.1 & 46.303 & 46.258 & 46.214 & 46.170 & 46.126 & 46.081 & 46.037 & 45.993 & 45.948 & 450904 \\ 0 & 45.860 & 45.816 & 45.771 & 45.727 & 45.683 & 45.638 & 45.594 & 45.550 & 45.506 & 450461\end{array}$

$\begin{array}{llllllllllll}0.3 & 45.417 & 45.372 & 45.328 & 45.284 & 45.240 & 45.195 & 45.151 & 45.106 & 45.062 & 45.018\end{array}$

$\begin{array}{lllllllllll}44.974 & 44.929 & 44.885 & 44.841 & 44.796 & 44.752 & 44.708 & 44.664 & 44.619 & 44.575\end{array}$

$\begin{array}{llllllllllll}0.5 & 44.531 & 44.486 & 44.442 & 44.398 & 44.354 & 44.309 & 44.265 & 44.220 & 44.176 & 44.132 \\ 0.6 & 44.088 & 44.043 & 43.999 & 43.955 & 43.911 & 43.866 & 43.822 & 43.778 & 43.733 & 43.689\end{array}$

$\begin{array}{lllllllllll}0.7 & 43.645 & 43.601 & 43.556 & 43.512 & 43.467 & 43.423 & 43.379 & 43.335 & 43.290 & 43.246\end{array}$

0.9

$42.759 \quad 42 \cdot 715$

$\begin{array}{ll}43.113 & 43.069 \\ 42.670 & 42.626\end{array}$

$43.025 \quad 42.980$

42.936

42.892

4751.0

1.1
1.02
1.03

$42 \cdot 271$

$\begin{array}{ll}41.430 & 41.386 \\ 40.987 & 40.943\end{array}$

40.544

$\begin{array}{ll}40.544 & 40.500 \\ 40.102 & 40.057\end{array}$

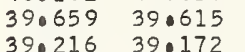

$\begin{array}{lll}42.228 & 42.183 & 420 \\ 41.784 & 41.740 & 4\end{array}$

$42.582 \quad 42.537$

38.773
38.331

38.729

$41.342 \quad 41.297$

$\begin{array}{ll}40.456 & 40.412\end{array}$

$41.696 \quad 42.094$

42.050

$41.253 \quad 41.209$

$\begin{array}{ll}40.816 & 40.766 \\ 40.367 & 40.323\end{array}$

$\begin{array}{ll}39.570 & 39.526 \\ 39.128 & 39.083\end{array}$

$\begin{array}{ll}39.925 & 39.880 \\ 39.482 & 39.437\end{array}$

$\begin{array}{ll}39.482 & 39.437 \\ 39.039 & 38.995\end{array}$

$41.607 \quad 41.563$

$41.164 \quad 41.120$

40.722
40.279

$39.836 \quad 40.235$

$\begin{array}{llll}39.393 & 39.349 & 39.304 & 39.260 \\ 38.950 & 38.906 & 38.862 & 38.818 \\ 38.508 & 38.463 & 38.419 & 38.375\end{array}$

1.7
1.8
1.9

4752.

2.1
2.2
2.3
2.4
2.5
2.6
2.7
2.8
2.9

21037.888

$37.445,37.844$

$\begin{array}{ll}38.685 & 38.640 \\ 38.242 & 38.198\end{array}$

$\begin{array}{ll}38.596 & 38.55 \\ 38.153 & 38.10\end{array}$

$\begin{array}{ll}38.419 & 38.375\end{array}$

$\begin{array}{ll}7.003 & 36.958\end{array}$

36.560

$36.117 \quad 36.073$

$35.232 \quad 350188$

$\begin{array}{ll}34 \cdot 789 & 34 \cdot 745 \\ 34.347 & 34.302\end{array}$

$\begin{array}{ll}37.800 & 37.755 \\ 37.356 & 37.312\end{array}$

$37.711 \quad 37.66$

37.622

38.021

$1.962 \quad 41.917$

$36.914 \quad 36.870$

$\begin{array}{ll}37.268 & 37.224 \\ 36.825 & 36.78\end{array}$

37.180
36.737

$37.578 \quad 37.534 \quad 37.490$

$\begin{array}{llllllll}36.427 & 36.383 & 36.338 & 36.294 & 36.250 & 36.206 & 36.162\end{array}$

$\begin{array}{llllllll}35.586 & 35.542 & 35.940 & 35 \cdot 896 & 35 \cdot 852 & 35.807 & 35.763 & 35.719\end{array}$

2.8

33.904

4753

3.

$33.019 \quad 33.417$

32.577
32.134

$31.250 \quad 31.205$

$30.807 \quad 30.763$

$\begin{array}{ll}29.922 & 29.878 \\ 29.480 & 29.436\end{array}$

$35.497 \quad 35.453$

$\begin{array}{llll}35.409 & 35.365 & 35.321 & 35.276 \\ 34.967 & 34.922 & 34.878 & 34.833\end{array}$

$\begin{array}{llll}34.967 & 34.922 & 34.878 & 34 \cdot 833 \\ 34.524 & 34.479 & 34.435 & 34.391\end{array}$

$\begin{array}{llllll}34.612 & 34.568 & 34.524 & 34.479 & 34.435 & 34.391 \\ 34.170 & 34.125 & 34.081 & 34.037 & 33.993 & 33.949\end{array}$

0.279675

$1 \cdot 328458$

0.279675
0.279675

0.279674

0.279674

0.279673

0.279673

0.279673

$1: 328484$

1.328537

1.328590

1.328617

1.328643

1.328696

0.279672

1.328723

0.279672

0.279671

0.279671

0.279671
0.279670

0.279670

0.279670

0.279669

0.279669

0.279669

0.279668

0.279667
0.279666

1.328876

1.328829

1.328855
1.328882

1.328908

1.328935

1.328988

1.329014

1.329041
1.329067

1.329094

1.329094

1.329120

1. 329173

1. 329200

0.279666

1.329253

0.279666

0.279655

0.279665

0.279665

0.279665

0.279664

0.07964

0.279664

1.329306

1.329332

1.329359

1.329385

1.329412
1.329438

1. 329465

0.279663

4754.0
4.1
4.2
4.3
4.4
4.5
4.5
4.7
4.8
4.9

$21029.038 \quad 28.993$

$\begin{array}{ll}28.595 & 28.551 \\ 28.153 & 28.109\end{array}$

$28.949 \quad 28.905$

$28.861-28.816$

$\begin{array}{llll}28.772 & 28.728 & 28.684 & 28.639\end{array}$

0.279663

0.279662

0.279662

0.279661

0.279661

0.279660

0.279660

1.329518

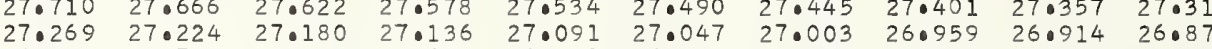

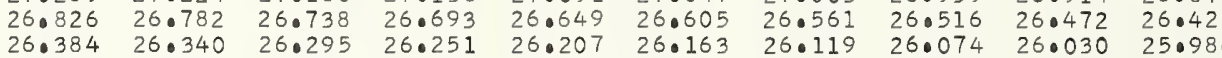

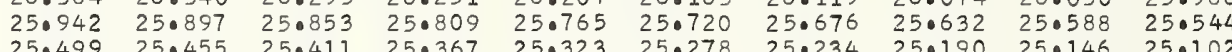
$\begin{array}{llllllllll}25.499 & 25 \cdot 455 & 25.411 & 25 \bullet 367 & 25 \cdot 323 & 25 \cdot 278 & 25 \cdot 234 & 25 \cdot 190 & 25 \cdot 146 & 25 \cdot 102 \\ 25.057 & 25 \cdot 013 & 24.969 & 24 \cdot 924 & 24 \cdot 880 & 24 \cdot 836 & 24.792 & 24 \cdot 748 & 24.703 & 24.0659\end{array}$

0.279660

0.279660

0.279659

0.279659

0.279658

0.279658

0.279657

1.329571

1.329597

1.329624
1.329650

1.329677

1.329703

1.329730
1.329756

755
5.1
5.2
5.3
5.4
5.5
5.7
50
5.9

4756.

56.0
6.1
6.2

$6 \cdot 2$

6.4

6.5
6.6

6.7
6.8

6.9

4757.

$7: 1$

$7 \cdot 3$
$7 \cdot 4$

7.4
7.5

7.6
7.7
7.8

7.8
7.9

4758.

8.1
8.2
8.3

8.4
8.5

8.5
8.6

8.6
8.7
8.8

8.8
8.9

4759.0

9.1
9.2
9.3

9.3
9.4
9.5

9.5
9.6

9.6
9.7
9.8

22.405
21.962

21.078
20.636

21.476
21.034

$\begin{array}{ll}22.316 & 22.27 \\ 21.874 & 21.83\end{array}$

$\begin{array}{ll}22.228 & 22.62 \\ 22.18\end{array}$

$22.581 \quad 22.537 \quad 22.935 \quad 22.091$

$\begin{array}{llll}22.139 & 22.095 & 22.051 & 22.007\end{array}$

$\begin{array}{llll}21.697 & 21.653 & 21.609 & 21.564 \\ 21.255 & 21.211 & 21.167 & 21.123\end{array}$

1020.194

$20.592 \quad 20.548$

20.946
20.504

$\begin{array}{llll}20.813 & 20.769 & 20.725 & 20.681 \\ 20.371 & 20.327 & 20.283 & 20.239\end{array}$

0.279657

0.279656

0.279656

0.279656

0.279655

0.279655

0.279655

0.279654

1.329783

1.329809

1.329836
1.329862

1. 329889

1.329915

1.329942

1. 329968

1.330021

$\begin{array}{llllllllll}18.868 & 18.824 & 18.780 & 18.736 & 18.692 & 18.648 & 18.604 & 18.559 & 18.515 & 18.471\end{array}$

$\begin{array}{llllllllll}17.985 & 17.940 & 17.896 & 17.852 & 17.808 & 17.764 & 17.719 & 17.675 & 17.631 & 17.587 \\ 17.543 & 17.499 & 17.455 & 17.410 & 17.366 & 17.322 & 17.278 & 17.233 & 17.189 & 17.145\end{array}$

$\begin{array}{llllllllll}17.101 & 17.057 & 17.013 & 16.969 & 16.924 & 16.880 & 16.836 & 16.792 & 16.748 & 16.703 \\ 16.659 & 16.615 & 16.571 & 16.527 & 16.483 & 16.438 & 16.394 & 16.350 & 16.305 & 16.261\end{array}$

$\begin{array}{llllllllll}16.217 & 16.173 & 16.129 & 16.085 & 16.041 & 15.997 & 15.952 & 15.908 & 15.864 & 15.820\end{array}$

0.279654

0.279653

0.279653

0.279652

0.279652

0.279652

0.279651

$\begin{array}{llllllllll}13.125 & 13.081 & 13.037 & 12.993 & 12.949 & 12.905 & 12.860 & 12.816 & 12.772 & 12.728\end{array}$

$\begin{array}{llllllllll}12.242 & 12.198 & 12.153 & 12.109 & 12.065 & 12.021 & 11.977 & 11.933 & 11.888 & 11.844\end{array}$

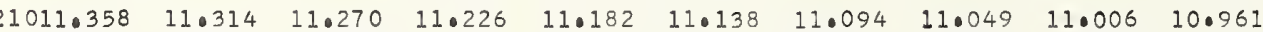

$\begin{array}{llllllllll}10.917 & 10.873 & 10.829 & 10.785 & 10.741 & 110.697 & 10.652 & 110.608 & 110.564 & 10.961\end{array}$

$\begin{array}{llllllllll}10.476 & 10.432 & 10.388 & 10.343 & 10.299 & 10.255 & 10.211 & 10.167 & 10.123 & 10.078\end{array}$

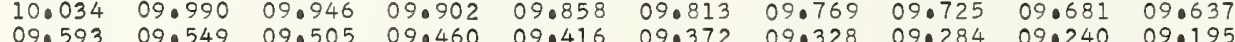

$\begin{array}{llllllllll}0.151 & 09.107 & 09.063 & 09.019 & 08.975 & 08.930 & 08.886 & 08.842 & 08.798 & 08.754\end{array}$

$\begin{array}{llllllllll}08.710 & 08.666 & 08.621 & 08.577 & 08.533 & 08.489 & 08.445 & 08.401 & 08.356 & 08.312\end{array}$

$\begin{array}{llllllllll}08.268 & 08 \cdot 224 & 08.180 & 08 \cdot 136 & 08 \cdot 092 & 08.047 & 08.003 & 07.959 & 07.915 & 07.871\end{array}$

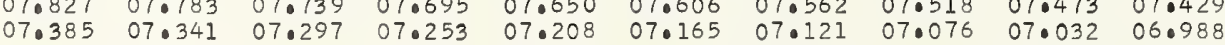

0.279651

0.279650

0.279649

0.279649

0.279648

0.279648

1.330048

1.330074

1.330127

1.330154

1.330207

I. 330260

1. 330286

1.330339

1.330366

1.330392

1. 330445

1.330445
1.330472

1.330472
1.330498

1.330525
1.330551

1. 330578

1.330604

1. 330631

1.330657
1.330684

1.330684
1.330710 


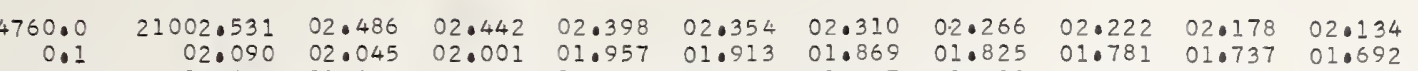
$\begin{array}{lllllllllll}0.1 & 02.090 & 02.045 & 02.001 & 01.957 & 01.913 & 01.869 & 01.825 & 01.781 & 01.737 & 01.692 \\ 0.2 & 01.648 & 01.604 & 01.560 & 01.516 & 01.472 & 01.427 & 01.383 & 01.340 & 01.295 & 01.251\end{array}$ $\begin{array}{lllllllllll}0.3 & 01.207 & 01.163 & 0.1119 & 01.075 & 0.1 .031 & 00.987 & 00.942 & 00.898 & 00.854 & 00.810 \\ 0.4 & 00.766 & 00.722 & 00.677 & 00.633 & 00.589 & 00.545 & 00.501 & 00.457 & 00.413 & 00.36\end{array}$

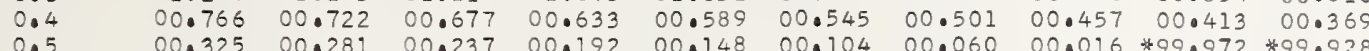

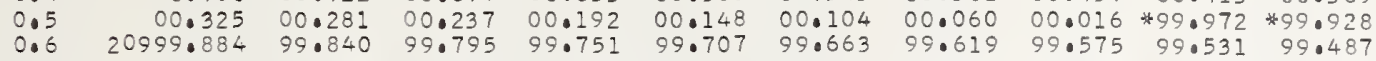
$\begin{array}{lllllllllll}0.7 & 99.443 & 99.398 & 99.354 & 99.310 & 99.266 & 99.222 & 99.178 & 99.134 & 99.090 & 99.046\end{array}$ $\begin{array}{lllllllllll}0.8 & 99.001 & 98.957 & 98.913 & 98.869 & 98.825 & 98.781 & 98.737 & 98.693 & 98.648 & 98.604 \\ 0.9 & 98.560 & 98.516 & 98.472 & 98.428 & 98.384 & 98.340 & 98.296 & 98.252 & 98.208 & 98.163\end{array}$

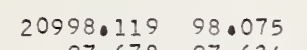

0.279644

1.331107

0.279644

0.279643

0.279643

0.279642

0.27964
0.27964
0.279641

0.279641

0.279641
0.279640

0.279640

0.279639

0.279639

0.279638
0.279638

0.279638

0.279637

0.279637

0.27936

0.279636
0.279636

0.279635

0.279635
0.2776535
0
0

0.279634
0.2779634
0.274

0.279634

0.279633

0.279633

0.279632

0.279632

0.279631

.279631

0.279630
0.279630
0.227962

0.279630
0.279629

0.279629

0.279629
0.27928
0.27928

0.279628

0.279628

0.279627

0.279627

0.279626

0.279626
0.279625
0.27965

0.279625
0.279625
0.279625

0.279624

0.279624

0.279624
0.279624

0.279623

0.279623

0.279623

0.279622
0.279622
0.27962

0.279622
0.279621
0.027921

.279621

0.279621

0.279620
0.279620

.331160
.331187

1.331213

10331266

1. 331319

1.331372

1. 10331399

1.331452
1.331478

王 33151505

1.331558
1.331584

1.331637

1.331664

1.331717
1.331743

${ }_{1}^{1} .331731700$

1.331823

1.331902

1. 0331955

$+331982$

1.332035

1.332061

1. 332114

1.332167

1.0332194
.33220

1.0332220
1.032247

1.332300

1.0332326
1.33253

1.0332379

0.279620

0.279620

0.279619
0.279619

0.279618

0.279618

0.279617

1.332432

0.279617

0.279616

0.279616

0.279615

0.279615
0.279615

0.279614

1.332459

1.332512

1.332565

10332618

1.332671
1.03264

1.332697

1.332724
1.332750

1.332803

1.332830
1.332856

I. 332883 


.02

.03
58.061
57.622

$\begin{array}{llllll}58.325 & 58.281 & 58.237 & 58.193 & 58.150 & 58.105 \\ 57.886 & 57.842 & 57.798 & 57.754 & 57.710 & 57.666\end{array}$

\section{2}

2.1

2

2.5

$2 \cdot 6$
2.7

$2 \cdot 8$

4773.0

3.1
3.2

3.3

3.4

3.6

3.7

3.8
3.9

47740

$4 \cdot 1$

$4 \cdot 3$

405

406

4.8

$4775 \cdot 0$

5.1

$5 \cdot 2$
5.3

$5 \cdot 4$
5.5

$5 \cdot 5$

5.7
5.8

5.8
5.9

4776.

6.1

6.3

6.4
6.5

6.6

6.8

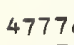

7.1

7.3

7.4
7.5
7.6

7.7
7.8
7.9
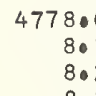

8.2

0.279614

0.279613

0.079613

0.279612

0.279612

0.279611

0.279611

0.279611

0.279610

0.279610

0.279609

0.279609

0.279609

0.279608

0.279608

0.279608

0.279607

0.279607
0.279607
0.279606

0.279606

0.279606

0.279605

0.279605

0.279605

0.279604

0.279604
0.279604

0.279603

0.279603

0.279603

0.279602

0.279602

0.279602

0.279601

0.279601

0.279600

0.279600

0.279600

0.279599
0.279599

0.279599

0.279598

0.279598

0.279598

0.279598

0.279597
0.279597
0.279597

0.279597
0.279597

0.279596

0.279596
0.279596

0.279595

0.279595

0.279594

0.279594
0.279594

0.279594

0.279593

0.279593

0.279592

0.279592

0.279592

0.27959

0.27959

0.279591

0.279590

0.279589

0.279589

0.27958

0.279588

0.279588

0.279587
0.279587
0.279587

0.279587

0.279586

0.279586

0.279586
0.279585

0.279585
0.279585

0.279584

0.279584
0.279584 
$\begin{array}{rrrrrrrrrrr}0.0 & 20914.655 & 14.611 & 14.568 & 14.524 & 14.480 & 14.436 & 14.393 & 14.349 & 14.305 & 14.261 \\ 0.1 & 14.218 & 14.174 & 14.130 & 14.086 & 14.043 & 13.999 & 13.955 & 13.912 & 13.868 & 13.824 \\ 0.2 & 13.780 & 13.736 & 13.693 & 13.649 & 13.605 & 13.561 & 13.518 & 13.474 & 13.430 & 13.386\end{array}$

$\begin{array}{lllllllllll}0.2 & 13.780 & 13.736 & 13.693 & 13.649 & 13.605 & 13.561 & 13.518 & 13.474 & 13.430 & 13.386 \\ 0.3 & 13.343 & 13.299 & 13.255 & 13.212 & 13.168 & 13.124 & 13.080 & 13.036 & 12.993 & 12.949\end{array}$

$\begin{array}{lllllllllll}0.4 & 12.905 & 12.862 & 12.818 & 12.774 & 12.730 & 12.687 & 12.643 & 12.599 & 12.555 & 12.511 \\ 0.5 & 12.468 & 12.424 & 12.380 & 12.337 & 12.293 & 12.249 & 12.205 & 12.161 & 12.118 & 12.074\end{array}$

$\begin{array}{lllllllllll}0.5 & 12.468 & 12.424 & 12.380 & 12.337 & 12.293 & 12.249 & 12.205 & 12.161 & 12.118 & 12.074 \\ 0.6 & 12.031 & 11.987 & 11.943 & 11.899 & 11.855 & 11.812 & 11.768 & 11.724 & 11.680 & 11.636\end{array}$

$\begin{array}{lllllllllll}0.7 & 11.593 & 11.549 & 11.505 & 11.462 & 11.418 & 11.374 & 11.330 & 11.287 & 11.243 & 11.199 \\ 0.8 & 11.156 & 11.112 & 11.068 & 11.024 & 10.981 & 10.937 & 10.893 & 10.849 & 10.805 & 10.762\end{array}$

$\begin{array}{llllllllll}11.156 & 11.112 & 11.068 & 11.024 & 10.981 & 10.937 & 10.893 & 10.849 & 10.805 & 10.762 \\ 10.718 & 10.674 & 10.631 & 10.587 & 10.543 & 10.500 & 10.456 & 10.412 & 10.368 & 10.324\end{array}$

0.279583

0.279583

0.279582

0.279582

.279581

$20910.281 \quad 10.237$ $\begin{array}{lll}09.843 & 09.800 & 09.756 \\ 09.406 & 09.362 & 09.319 \\ 0.090\end{array}$

$08.969 \quad 08.925$

$08.531 \quad 08.488 \quad 08.444$

$\begin{array}{ll}08.094 & 08.050 \\ 07.657 & 07.613\end{array}$

$\begin{array}{ll}07.220 & 07.176 \\ 06.782 & 06.739\end{array}$

$08.444 \quad 08.400 \quad 08$

$06.345 \quad 06.302$

$\begin{array}{llll}0.956 & 08.31 \\ 07.963 & 07.919 & 07.875\end{array}$

07.569
07.132
06.695

.526
7.088
6.651

4782.0

$\begin{array}{rr}82.0 & 2090 \\ 2.12 & \\ 2.2 & \\ 2.3 & \\ 2.4 & \\ 2.5 & \\ 2.6 & \\ 2.7 & \\ 2.0 & \end{array}$

$905.908 \quad 05.864 \quad 05.821$

$\begin{array}{llll}0.471 & 05.427 & 05.383 & 05.7 \\ 0503\end{array}$

$\begin{array}{lllll}04.596 & 04.553 & 04.946 & 04.903\end{array}$

$\begin{array}{lll}0.159 & 04.116\end{array}$

$\begin{array}{lll}0.722 & 03.678 \\ 03.286 & 03.242 & 0\end{array}$

$04.072 \quad 04.028$

$02.849 \quad 02.805$

$03.198 \quad 03.155$

$01.974 \quad 01.931$

$\begin{array}{ll}02.761 & 02.71 \\ 02.324 & 0.2 .28\end{array}$

$10.106 \quad 10.062$

10.018

09.974
090537

$09.931 \quad 09.887$

0.27958

0.279580

0.279580

0.279579

0.279579

0.279578

0.279578

0.279577

0.279577

0.0 .279577

0.279576

0.279575

2.9

20901.537

01.494

01.450

01.406

03.11103 .504

04.897
03.460

$\begin{array}{llll}04.291 & 04.247 & 04.203\end{array}$

$\begin{array}{ll}01.100 & 01.057 \\ 00.664 & 00.620\end{array}$

3.

$00.226 \quad 00.183$

$\begin{array}{rr}20899.790 & 99.746 \\ 99.353 & 99.309\end{array}$

$\begin{array}{ll}99.353 & 99.309 \\ 98.916 & 98.872\end{array}$

$\begin{array}{lll}01.013 & 00.969 & 00.92 \\ 00.576 & 00.532 & 00.48 \\ 00.139 & 00.095 & 00.05\end{array}$

$98.479 \quad 98.435$

99.26

00.095
99.658

00.052
99.615

98.785
98.348

99.17
98.741

$\begin{array}{ll}98.042 & 97.998 \\ 97.605 & 97.562\end{array}$

4784

84.0
40
40
40
40
405
406
407
408
409

20897.16

$99.168 \quad 97.125$

97.955

97.911

98.304
97.867

97.08197 .037

97.430

.630
2.193

3.023
2.586

$\begin{array}{llll}03.417 & 03.373 & 03.329\end{array}$

$\begin{array}{ll}96.732 & 96.688 \\ 96.295 & 96.251\end{array}$

$\begin{array}{ll}95.858 & 95.814 \\ 95.421 & 95.377\end{array}$

$94.984 \quad 94.941$

$\begin{array}{ll}94.548 & 94.504 \\ 94.111 & 94.068\end{array}$

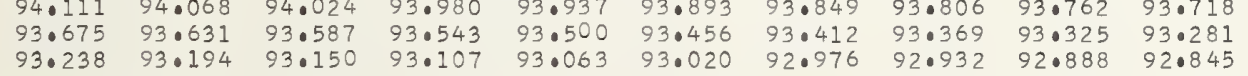

$\begin{array}{ll}96.644 & 96.601 \\ 96.208 & 96.164\end{array}$

$\begin{array}{ll}95.771 & 95.727 \\ 95.334 & 95.290 \\ 94.897 & 94.85\end{array}$

94.897
94.460
94.854

$96.994 \quad 96.950$

01.319
00.882

01.71

$96.120 \quad 96.013 \quad 96.470 \quad 96.426 \quad 96.382 \quad 96.338$

$\begin{array}{llllll}95.683 & 95.076 & 96.032 & 95.989 & 95.945 & 95.902 \\ 95.596 & 95.552 & 95.508 & 95.465\end{array}$

$\begin{array}{llllll}95.246 & 95.203 & 95.159 & 95.115 & 95.072 & 95.028 \\ 94.810 & 94.766 & 94.722 & 94.679 & 94.635 & 94.592\end{array}$

$\begin{array}{lllllllll}94.024 & 93.980 & 93.937 & 94 \cdot 330 & 94 \cdot 286 & 94 \cdot 242 & 94 \cdot 198 & 94 \cdot 155 \\ 93.893 & 93.849 & 93.806 & 93.762 & 93.718\end{array}$

4785.0

4.0
5.0
5.1
50
5.0
5.4
50
50.
5.7
5
50

$20892.801 \quad 92.758$

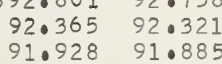

$91.928 \quad 91.885 \quad 91.277 \quad 92.233$

$\begin{array}{llll}91.491 & 91.448 & 91.404 & 91.36 \\ 91.055 & 91.011 & 90.968 & 90.924\end{array}$

$90.618 \quad 90.574$

$90.182 \quad 90.138$

$89.745 \quad 89.701$

$88.872 \quad 88.828$

90.531

$89.094 \quad 90.05$

5.8
5.9

4786.

6.

$88.000 \quad 87.956$

$87.563 \quad 87.519$

$87.126 \quad 87.083$

$86.254 \quad 86.210$

$85.381 \quad 85.338$

$84.945 \quad 84.901$

$\begin{array}{ll}89.221 & 89.178 \\ 88.785 & 88.741\end{array}$

92.62
92.19
91.75
91.31
90.88
90.44
90.00
89.57
89.13
88.698

92.58

$\begin{array}{llll}92.539 & 92.495 & 92.452 \quad 92.408\end{array}$

$\begin{array}{llllll}.190 & 92.146 & 92.103 & 92.059 & 92.015 & 91.971 \\ .753 & 91.710 & 91.666 & 91.622 & 91.579 & 91.535\end{array}$

$\begin{array}{llllll}.317 & 91.273 & 91.229 & 91.186 & 91.142 & 91.099 \\ 880 & 90.837 & 90.793 & 90.749 & 90.705 & 90.062\end{array}$

$\begin{array}{llllll}0.444 & 90.400 & 90.356 & 90.312 & 90.269 & 90.225\end{array}$

\begin{tabular}{llllll}
.571 & 89.964 & 89.920 & 89.876 & 89.833 & 89.789 \\
\hline & 89.527 & 89.483 & 89.440 & 89.396 & 89.352
\end{tabular}

$88.349 \quad 88.305$

(2.698

$\begin{array}{llll}89.047 & 89.003 & 88.959 & 88.916 \\ 88.610 & 88.567 & 88.523 & 88.479\end{array}$

$\begin{array}{ll}87.912 & 87.868 \\ 87.476 & 87.432 \\ 07.039 & 06.996\end{array}$

88.26
87.82
87.38

$88 \cdot 21$
87.78

$\begin{array}{llll}88.174 & 88.130 & 88.087 & 88.043\end{array}$

$86.603 \quad 86.559$

$85.730 \quad 85.686$

$\begin{array}{ll}85.294 & 85.250 \\ 84.857 & 84.814\end{array}$

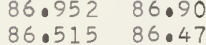

87.301

$\begin{array}{rll}87.258 & 87.214 & 87.170\end{array}$

$\begin{array}{llllll}86.079 & 86.036 & 85.992 & 86.385 & 86.341 & 86 \cdot 297\end{array}$

$\begin{array}{lllllll}85.643 & 85.599 & 85.556 & 85.512 & 85.468 & 85.425\end{array}$

$\begin{array}{llllll}85.207 & 85.163 & 85.119 & 85.076 & 85.032 & 84.988\end{array}$

$84.509 \quad 84.465$

$84.421 \quad 84.377$

$84.334 \quad 84.291$

84.683
84.247

84.203

4787

7.01
7.0
7.03
7.04
7.0
7.07
7.08
709

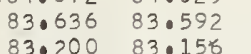

$\begin{array}{ll}83.200 & 83.156 \\ 82.763 & 82.720 \\ 8.0327 & 82.28\end{array}$

$82.327 \quad 82.284$

$81.455 \quad 81.412$

$81.019 \quad 80.975$

$80.147 \quad 80.103$

$\begin{array}{ll}3.985 & 83.941 \\ 3.549 & 83.505\end{array}$

83.898

83.854

$\begin{array}{llll}83.810 & 83.767 & 83.723 & 83.680\end{array}$

$\begin{array}{llll} & \end{array}$

$\begin{array}{lllllllll}82.676 & 82.633 & 82.589 & 82.545 & 82.502 & 82.458 & 82.415 & 82.87\end{array}$

$\begin{array}{llllllll}82.240 & 82.197 & 82.153 & 82.110 & 82.066 & 82.022 & 81.979 & 81.935\end{array}$

$\begin{array}{llllllll}81.804 & 81.760 & 81.717 & 81.673 & 81.630 & 81.586 & 81.542 & 81.499\end{array}$

$\begin{array}{llllllll}81.368 & 81.324 & 81.281 & 81.237 & 81.194 & 81.150 & 81.106 & 81.06 \\ 80.932 & 80.888 & 80.844 & 80.801 & 80.758 & 80.714 & 80.670 & 80.626\end{array}$

$\begin{array}{llllllll}0.496 & 80.452 & 80.409 & 80.365 & 80.321 & 80.714 & 80.670 & 80.626 \\ 0\end{array}$

$0879 \cdot 711 \quad 79.667$

$80.060 \quad 80.016$

4788

8.0
8.1
8.2
8.0
8.4
8
8.6
8.0
8.0
8.9

$79.275 \quad 79 \cdot 231$

$\begin{array}{llll}78.839 & 78.795 & 79.187 & 79.140 \\ 78.403 & 78.359 & 78.315 & 78.7072\end{array}$

$78.403 \quad 78.359$

$\begin{array}{ll}77.967 & 77.923 \\ 77.531 & 77.487\end{array}$

$\begin{array}{ll}77.094 & 77.05 \\ 76.659 & 76.615\end{array}$

$\begin{array}{ll}76.659 & 76.61 \\ 76.222 & 76.17 \\ 75.787 & 75.74\end{array}$

$78.751 \quad 78 \cdot 708$

$\begin{array}{ll}78.315 & 78.272 \\ 77.0879 & 77.836\end{array}$

$\begin{array}{ll}77.444 & 77.400 \\ 77.0007 & 76.96\end{array}$

$76.572-76.528$

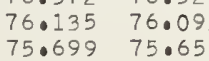

79.536
79.100

$6 \quad 79.493$

79.885

$\begin{array}{lll}79.842 & 79.798 \quad 79.754\end{array}$

$\begin{array}{lllllll}78.664 & 78.621 & 78.577 & 78.533 & 78.490 & 78.446\end{array}$

$\begin{array}{lllllll}78.228 & 78.184 & 78.141 & 78.097 & 78.053 & 78.010 \\ 77.792 & 77.749 & 77.705 & 77.661 & 77.618 & 77.574\end{array}$

$\begin{array}{llllll}77.356 & 77.313 & 77.705 & 77 \cdot 661 & 77 \cdot 618 & 77.574 \\ 76.225 & 77 \cdot 182 & 77.138\end{array}$

$\begin{array}{lllllll}76.920 & 76.877 & 76.833 & 76.789 & 76.746 & 76.702 \\ 76.484 & 76.441 & 76.397 & 76.354 & 76.310 & 76.266\end{array}$

$\begin{array}{lll}76.354 & 76.310 & 76.266 \\ 75.917 & 75.874 & 75.830\end{array}$

$\begin{array}{llllll}76.048 & 76.005 & 75 \cdot 961 & 75.917 & 75.874 & 75.830 \\ 75.612 & 75.569 & 75.525 & 75.482 & 75.438 & 75.395\end{array}$

4789.0

99.0
9.1
9.2
9.4
9.5
9.6
9.7
9.8

0.279574

0.279573

.279573

0.0279572

.279572

0.279571

0.279571
0.279570
0.279570

0.279570

.27956

0.279569

0.279568

0.279568

(1)

.0279566

0.279566

0.279565

0.279565

.279564

0.279563

0.279563

0.279562

0.279562

0.279562

0.279561
0.279561

0.279561

0.279560

0.279560

0.279559

0.279558

0.279558

0.279557

0.279557

0.279557

0.279556

0.279556

0.279555

0.279555

0.279554

0.279554

0.279554

.336408

1.336434

1.336487

1.336514

1.336540
1.336567

1.336620
1.336646

1.336673

1.336726

1.336752
1.336779

1.33680

1. 336858

1.336885
1.336911

1.336938

1.336991

1.337017

1.337070 
0.279553

(1)

0.279552

0.279552

0.279551

0.279551

0.279551

0.279550

0.279550

0.279549

0.279549

0.279548

0.279548

0.279547
0.279547

0.279547

0.279547

0.279546
0.279546
0.27546

0.279546

0.279545
0.027955
0.2755

0.279545

0.279544
0.279544

0.279544

0.279544

0.279543
0.279543
0.27954

0.279543

0.279542
0.279542

0.279542

0.279541
0.279541

0.27954

0.279541

0.279540

0.279540
0.279539

0.279539

0.279539

0.279538
0.279538

0.279538

0.279538
0.279537
0.279597

0.279537

0.279537

0.279536

0.279536

0.279536
0.279535
0.279555

0.279535

0.279535

0.279535

0.279534
0.279534
0.279534

0.279534

0.279533
0.279533

0.0279533

0.279532

0.279532

0.279532

0.279531

0.279531
0.279531
0.279530

0.279530

0.279530

0.279529
0.279529

0.279529

0.279529

0.279528
0.279528

0.279528

0.279527
0.279527
0.27527

0.279527

0.279526
0.279526

0.279526

0.279526

0.279525

0.279525

0.279524
0.279524
0.279524

0.279524

0.279523
0.279523

.010

1.339059

1.339112

1.339136

1. 339191

1.339218

1.0339271

1.339324

1.339350

1.339377
1.339403

1.339430

1.339456

1.339483

1.339536

1.339589 1.339615 1.339642 1.3339668 1.0339695 10339721 1.339748 1.339774 1.339801
1.339827

1.339854 1.339880 1.0339907
1.339933 1.339960

1.339986

1.340013

1.3400039
1.340066

1.340092
1.34006

1.340119 $1 \cdot 340145$ 1.340172
1.340198 1. 340225 1.340251
1.340278 1. 340304 1.340331
1.340357

$1 \cdot 340384$ 1.340411 1.340464 1.340490 1. 340517 1. 340543 1.340570
1.340596 1.340623

1.340649 1.340676 $\frac{1}{1 \cdot 340702}$ 1.340755 1.340782
1.340808 


$$
1.0
$$

1.2
1.3
1.4

1.4

1.5

1.7
1.8
1.9

4802

02.0
2.1
2.2
2.3
2.4
2.5
2.6
2.7
2.8
2.9

2.5

2.6
2.7

2.9

4803.0

3.3

3.4
3.5

3.6
3.7

3.8
3.9

48040

$\begin{array}{ll}04.0 & 208 \\ 4.1 & \\ 4.2 & \\ 4.3 & \\ 4.4 & \\ 4.5 & \\ 4.6 & \\ 4.7 & \\ 4.8 & \\ 4.9 & \end{array}$

$\begin{array}{ll}23.174 & 23.131 \\ 22.740 & 22.697\end{array}$

$23.087 \quad 23.044$ $22.307 \quad 22.263$ $\begin{array}{ll}21.873 & 21.829 \\ 21.439 & 21.0396\end{array}$ $\begin{array}{ll}21.439 & 21.396 \\ 21.006 & 20.062\end{array}$ $20.572 \quad 20.52$ $\begin{array}{ll}20.138 & 20.095 \\ 19.705 & 19.661\end{array}$ $\begin{array}{ll}19.705 & 19.661 \\ 19.271 & 19.228\end{array}$

\title{
$22.220 \quad 22.177$
}

$\begin{array}{ll}21.786 & 21.743 \\ 21.353 & 21.309\end{array}$

$\begin{array}{ll}21.353 & 21.309 \\ 20.919 & 20.875\end{array}$

$\begin{array}{ll}20.485 & 20.845 \\ 20.052 & 20.008\end{array}$

$20818.837 \quad 18.794$ $\begin{array}{ll}18.404 & 18.361 \\ 17.970 & 17.9 \\ 17.537 & 17.494 \\ 17.0104 & 17.0061\end{array}$

$\begin{array}{ll}17.537 & 17.494 \\ 17.104 & 17.066\end{array}$

$\begin{array}{ll}17.104 & 17.061 \\ 16.670 & 16.627\end{array}$

$16.237 \quad 16.194$

$\begin{array}{ll}15.803 & 15.760 \\ 15.370 & 15.327 \\ 14.937 & 14.893\end{array}$

$\begin{array}{ll}20.652 & 19.575 \\ 19.6185 & 19.141\end{array}$

$18.751 \quad 18.708$

$\begin{array}{ll}18.317 & 18.274 \\ 17.884 & 17.840 \\ 17.450 & 17.407\end{array}$

$\begin{array}{ll}17.450 & 17.407 \\ 17.017 & 16.974 \\ 16.584 & 16.540\end{array}$

$\begin{array}{ll}16.584 & 16.974 \\ 16.50 & 16.540\end{array}$

$\begin{array}{llll}16.150 & 16.107 & 16.064 & 16.454\end{array}$

$14.070 \quad 14.027$

$13.203 \quad 13.160$

$12.770 \quad 12.727$

$15.283 \quad 15.240$

$12.337-1294$

$14.417 \quad 14.374$

$15.630 \quad 15.587$

$11.903 \quad 11.860$

$13.983 \quad 13.940$

$\begin{array}{ll}13.550 & 13.507 \\ 13.116 & 13.073 \\ 12.683 & 12.640\end{array}$

14.330

$4.330 \quad 14.287$

$\begin{array}{ll}12.683 & 12.640 \\ 12.250 & 12.207\end{array}$

(1)

$\begin{array}{llll}11.037 & 10.993 & 10.950 & 10.907 \\ 10.604 & 10.561 & 10.517 & 10.474\end{array}$

$\begin{array}{ll}13.463 & 13.420 \\ 13.030 & 12.987\end{array}$

$\begin{array}{lll}12.597 & 12.987 & 12.9443\end{array}$

(1.730

12.12012 .077

12.510
12.077
11.644
11.0210

$\begin{array}{ll}10.864 & 10.820 \\ 10.430 & 10.387\end{array}$

11.217
10.0777
10.344

$\begin{array}{ll}09.997 & 09.954 \\ 09.564 & 09.521\end{array}$

$09 \cdot 911$

$\begin{array}{llll}0.170 & 10.127 & 10.084 & 10.041 \\ 09.738 & 09.694 & 09.651 & 09.607\end{array}$

$09.304 \quad 09.261 \quad 09.218 \quad 09.174$

$\begin{array}{llll}0.871 & 08.828 & 08.784 & 08.741\end{array}$

$\begin{array}{llll}0.005 & 07.962 & 07.918 & 07.875\end{array}$

$\begin{array}{llll}07.572 & 07.529 & 07.485 & 07.442\end{array}$

$\begin{array}{llll}06.706 & 06.662 & 06.619 & 06.576\end{array}$

06.273

48050

5.0
50
5
5
5
5
5
5
50

20805.

$05.840 \quad 05.797$

$04.4074 \quad 04.963$

$04.541 \quad 04.939$

04.108

$03.675 \quad 03.0632$

03.24203 .199

02.80

$\begin{array}{lll}03.632 & 03.588 & 03.545\end{array}$

$02.376 \quad 02.333 \quad 02.290 \quad 02.246$

$09.131 \quad 09.088$

$08.698 \quad 08.655$

$07.832 \quad 07.788$

$\begin{array}{lll}07.3996 & 07.355 \\ 06.966 & 06.922\end{array}$

09.04

8.611

$05.753 \quad 05.710$

$\begin{array}{ll}06.532 & 06.48 \\ 06.099 & 06.056\end{array}$

07.745

07.312

06.446

0

$05.667 \quad 05.623$

05.580

$04.887 \quad 04.844$

$04.801 \quad 04.757$

$\begin{array}{lll}04.367 & 04.324 & 04.281 \\ 03.935 & 03.892 & 03.284\end{array}$

$03.502 \quad 03.458 \quad 03.415$

03.06903 .02

03.415
02.082

$02.203 \quad 02.16$

02.549

$01.770 \quad 01.72$

4806.0

6.
6.
6.
6.
6.5
6.6
6.0
6.0
6.9

4807.0

807
7
7
7
7
7
7
7
70
70
70

4808.0

808.0
8.1
8
8,2
8
8.5
8.6
8.7
8.8
8.9

$01.510 \quad 01.467$

$01.078 \quad 01.034 \quad 01.424 \quad 01.381$

$00.212 \quad 00.169 \quad 00.558 \quad 00.51$

$\begin{array}{llll}20799.779 & 99.736 & 99.693 & 99.649\end{array}$

$99.346 \quad 99.303 \quad 99.260 \quad 99.217$

$98.914 \quad 98.870 \quad 98.827 \quad 98.78$

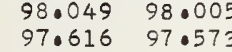

98.39
97.962
97.52

98.784
97.019

$01.337 \quad 01.294 \quad 01.251$

$00.00 .000 .295 \quad 00.255$

$99.60699 .563 \quad 99.520 \quad 99.477 \quad 990433 \quad 990390$

$\begin{array}{lllllll}99.174 & 99.130 & 99.087 & 99.044 & 99.001 & 98.957\end{array}$

$9797.183 \quad 97.140 \quad 97.097 \quad 97.053$

$96.750096 .707 \quad 96.664 \quad 96.621$

$\begin{array}{llll}96.318 & 96.275 & 96.231 & 96.188 \\ 95.885 & 95.842 & 95.799 & 95.756\end{array}$

$95.453 \quad 95.410 \quad 95.366 \quad 95.323$

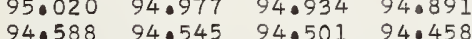

$94.588 \quad 94.545 \quad 94.501 \quad 94.458$

$\begin{array}{llll}94.156 & 94.112 & 94.069 & 94.026 \\ 93.723 & 93.679 & 93.636 & 93.593\end{array}$

$93.291 \quad 93.247$

98.08 .69

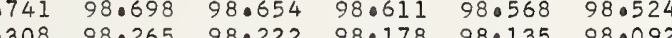

$\begin{array}{llllll}97.875 & 97.832 & 97.789 & 97.746 & 970702 & 97.659\end{array}$

$\begin{array}{lllllll}97.010 & 96.957 & 96.923 & 96.880 & 960837 & 96.794\end{array}$

$\begin{array}{lllllll}96.578 & 96.534 & 96.491 & 96.448 & 96.405 & 96.361\end{array}$

$\begin{array}{llllll}96.145 & 96.101 & 96.058 & 96.015 & 950972 & 950929\end{array}$

$\begin{array}{llllll}95.280 & 95.237 & 95.194 & 950150 & 950107 & 95.064\end{array}$

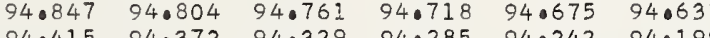

$\begin{array}{llllll}94.415 & 94.372 & 94 \cdot 329 & 94 \cdot 285 & 94 \cdot 242 & 94 \cdot 199 \\ 93.982 & 93.9399 & 93.896 & 93.853 & 93.809 & 93.766\end{array}$

$0792.858 \quad 92.815 \quad 92.771 \quad 92.728$

$\begin{array}{lllllll}93.550 & 93.507 & 93.463 & 93.420 & 93.377 & 93.334 \\ 93.117 & 93.074 & 93.031 & 92.988 & 92.944 & 92.901\end{array}$

92.426
91.9993
91.382

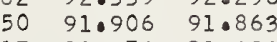

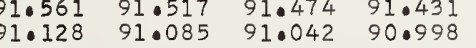

$90.696 \quad 90.653 \quad 90.610 \quad 90.566$

90.26390 .220

$89.831 \quad 89.788 \quad 89.745 \quad 89.701$

$\begin{array}{llll}89.399 & 89.355 & 89 \cdot 312 & 89.269 \\ 88.967 & 88.923 & 88.880 & 88.837\end{array}$

$\begin{array}{llllll}92.685 & 92.642 & 92.598 & 92.555 & 92.512 & 92.469\end{array}$

$\begin{array}{llllll}92.253 & 92.209 & 92.166 & 92.123 & 92.079 & 92.036 \\ 91.820 & 91.777 & 91.734 & 91.690 & 91.647 & 91.604\end{array}$

$\begin{array}{llllll}91.328 & 91.777 & 91.734 & 91.690 & 91.647 & 91.604 \\ 91.388 & 91.0344 & 91.301 & 91.258 & 91.214 & 91.171\end{array}$

$\begin{array}{llllll}90.955 & 90.912 & 90.869 & 90.826 & 90.782 & 90.739\end{array}$

$\begin{array}{llllll}90.523 & 90.480 & 90.437 & 90.393 & 90.350 & 90.307\end{array}$

$\begin{array}{llllll}90.091 & 90.047 & 90.004 & 89 \cdot 961 & 89.917 & 89.874\end{array}$

$\begin{array}{llllll}89.658 & 89.615 & 89.572 & 89.529 & 89.485 & 89.442 \\ 89.226 & 89.183 & 89.139 & 89.096 & 89.053 & 89.010\end{array}$

4809

09.0
901
9.9
9.4
9.6
9.7
9.8

$\begin{array}{rllll}88.967 & 88.923 & 88.880 & 88.837 \\ 88.534 & 88.491 & 88.448 & 88.405\end{array}$

$\begin{array}{lllllll}88.361 & 88.318 & 88.275 & 88.231 & 88.188 & 88.145\end{array}$

$\begin{array}{llll}88.102 & 88.059 & 88.015 & 87.972 \\ 87.670 & 87.627 & 87.583 & 87.540\end{array}$

$87.237 \quad 87.194 \quad 87.151 \quad 87.108$

$\begin{array}{llll}86.805 & 86.762 & 86.719 & 86.676 \\ 86.373 & 86.330 & 86.287 & 86.243\end{array}$

$85.941 \quad 85.898 \quad 85.854 \quad 85.811$

$85.509 \quad 85.465 \quad 85.422 \quad 85.379$

$\begin{array}{llllll}88.361 & 88.318 & 88.275 & 88.231 & 88.188 & 88.145 \\ 87.497 & 87.456 & 87.843 & 87.799 & 87.756 & 87.713 \\ 87.410 & 87.367 & 87.324 & 87.281\end{array}$

$87.021 \quad 86.978 \quad 87.0367 \quad 870324 \quad 87.0281$

$\begin{array}{lllllll}86.0632 & 86.589 & 86.546 & 86.503 & 86.459 & 86.416 \\ 86.200 & 86.157 & 86.114 & 86.070 & 86.027 & 85.984\end{array}$

$\begin{array}{llllll}86.208 & 86.157 & 86.114 & 86.070 & 86.027 & 85.984 \\ 85.768 & 85.725 & 85.682 & 85.638 & 85.595 & 85.552\end{array}$

$\begin{array}{llll}85.076 & 85.033 & 84.990 & 84.947 \\ 84.644 & 84.601 & 84.558 & 84.515\end{array}$

$85.638 \quad 85.595 \quad 85.552$

0001

.002

.003

.004

.005

85.250
84.817
84.0385

$.206 \quad 85.163 \quad 85.120$

1.001

$: 023$

.006

.007

\begin{abstract}
$.299 \quad 84.255$
\end{abstract}
0.279523

0.279522

0.279522

0.279521

0.279521

0.279520

0.279520
0.279520

0.279519

0.279519

0.279518

0.0279518

0.279517
0.279517

1.341736

1.341763
1.341789

I. 341842

1.341895

1.341948

0.27957

0.279516

0.279516
0.279515
0.27515

0.0279525

0.279515

0.279514

1.341975

1. 342028

1.342054

1.342107

1.342160

1.342213

0.279514

0.279514
0.279513

0.279513

0.279512

0.279512

0.279512

0.279511

1.342240

1.342266
1.342293

1.342346

1.342372
1.342399

1. 342452

0.279511
0.279511

0.279510

0.279510

0.279509

0.279509
0.279509

0.279508

0.279508

0.279508
0.279508

0.279507
0.279507
0.279507

0.279507
0.279507

0.279506

0.279506

0.279506
0.279505

0.279505

0.279505

0.279505
0.279504

0.279504

0.279504
0.279503

0.279503

0.279503

0.279502

0.279502 
1.344626 $\begin{array}{llllllllll} & \end{array}$ $\begin{array}{llllllllll}78.165 & 78.122 & 78.510 & 78.467 & 78.424 & 78.381 & 78.337 & 78.294 & 78.251 & 78.208\end{array}$ $\begin{array}{lllllllllll}77.633 & 77.690 & 77.646 & 77.603 & 77.560 & 77.517 & 77.474 & 77.862 & 77.819 & 77.776\end{array}$ $\begin{array}{llllllllll}77.301 & 77.258 & 77.215 & 77.171 & 77.128 & 77.085 & 77.042 & 76.999 & 76.955 & 76.912\end{array}$ $\begin{array}{llllllllll}76.869 & 76.826 & 76.783 & 76.740 & 76.696 & 76.653 & 76.610 & 76.567 & 76.524 & 76.480\end{array}$ $\begin{array}{llllllllll}76.437 & 76.394 & 76.351 & 76.308 & 76.265 & 76.221 & 76.178 & 76.135 & 76.092 & 76.049 \\ 76.006 & 75.962 & 75.919 & 75.876 & 75.833 & 75.790 & 75.747 & 75.703 & 75.660 & 75.617\end{array}$

0.279490

0.279489

0.279489

0.279488

0.279488
0.279487

1.344653
1.344679

1.344706

$1 \cdot 344732$

1.344785

1. 344812

1.344865

0.279487

0.279487
0.279486

0.279486

0.279486

0.279485

0.279485

0.279485

$1 \cdot 344891$ $\begin{array}{llllllllll}74.710 & 74.667 & 74.624 & 74.581 & 74.538 & 74.494 & 74.451 & 74.408 & 74.365 & 74.322\end{array}$ $\begin{array}{llllllllll}73.847 & 73.804 & 73.761 & 73.718 & 73.675 & 73.632 & 73.588 & 73.545 & 73.502 & 73.459\end{array}$ $\begin{array}{llllllllll}72.984 & 72.973 & 73.329 & 73.286 & 73.243 & 73.200 & 73.156 & 73.113 & 73.070 & 73.027 \\ 72.897 & 72.854 & 72.811 & 72.768 & 72.725 & 72.682 & 72.639 & 72.595\end{array}$ $\begin{array}{llllllllll}72.552 & 72.509 & 72.466 & 72.423 & 72.380 & 72.336 & 72.293 & 72.250 & 72.207 & 72.164\end{array}$ $\begin{array}{llllllllll}72.121 & 72.077 & 72.034 & 71.991 & 71.948 & 71.905 & 71.862 & 71.819 & 71.775 & 71.732 \\ 71.689 & 71.646 & 71.603 & 71.560 & 71.516 & 71.473 & 71.430 & 71.387 & 71.344 & 71.301\end{array}$

0.279484 0.279484 $\begin{array}{llllllllll}70.826 & 70.783 & 70.740 & 70.697 & 70.654 & 70.610 & 70.567 & 70.524 & 70.481 & 70.437\end{array}$ $\begin{array}{llllllllll}70.395 & 70.351 & 70.308 & 70.265 & 70.222 & 70.178 & 70.135 & 70.092 & 70.049 & 70.006\end{array}$ $\begin{array}{llllllllll}69.963 & 69.920 & 69.876 & 69.833 & 69.790 & 69.747 & 69.704 & 69.661 & 69.618 & 69.575 \\ 69.531 & 69.488 & 69.445 & 69.402 & 69.359 & 69.316 & 69.272 & 69.229 & 69.186 & 69.143\end{array}$

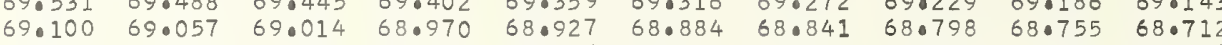
$\begin{array}{llllllllll}68.668 & 68.625 & 68.582 & 68.539 & 68.496 & 68.453 & 68.841 & 68.798 & 68.755 & 68.712 \\ 6\end{array}$ $\begin{array}{llllllllll}68.237 & 68.194 & 68.151 & 68.107 & 68.064 & 68.021 & 68.409 & 68.366 & 68.323 & 68.280 \\ 67.98 & 67.935 & 67.892 & 67.849\end{array}$ $\begin{array}{llllllllll}67.806 & 67.762 & 67.719 & 67.676 & 67.633 & 67.590 & 67.547 & 67.503 & 67.460 & 67.417 \\ 67.374 & 67.331 & 67.288 & 67.245 & 67.201 & 67.158 & 67.115 & 67.072 & 67.029 & 66.986\end{array}$

0.279483

0.279483

0.279483

0.279482

0.279482

$1 \cdot 344918$

1344971

1.344997

1.345024

1.345077

$1 \cdot 345103$

$\begin{array}{llllllllll}20766.943 & 66.900 & 66.857 & 66 \cdot 813 & 66.770 & 66.727 & 66.684 & 66.641 & 66.598 & 66.554\end{array}$

0.27948

0.279481 $\begin{array}{llllllllll}65.649 & 65.605 & 65.562 & 65.519 & 65.476 & 65.433 & 65.390 & 65.347 & 65.303 & 65.260\end{array}$ $-64.743 \quad 64.700 \quad 64 \cdot 656$

$61.681-61.069$

$60.905-60.862-61.250 \quad 61.207$

60.47460 .86260 .819

$60.043 \quad 60.431 \quad 60.388 \quad 60.34$

$\begin{array}{llll}59.612 & 59.569 & 59.526 & 59.482\end{array}$

$\begin{array}{llll}59.181 & 59.138 & 59.094 & 59.05 \\ 58.750 & 58.707 & 58.663 & 58.62\end{array}$

62.45

63.70
63.277

63.66

$\begin{array}{lll}63.622 & 63.578 & 63.535 \\ 63.190 & 63.147 & 63.104\end{array}$

0.279480

0.279480

0.279470

0.279479

.0279479

1.345156

1.345209

1.345236

1.345289

1.345316

1.345342

1.345369

1.345422

1.345448

1.345475

1.345528

1.345554

1.345581

1.345634

0.279478

0.279478

0.279477

0.279477

0.279476

0.279476

0.279476
0.279475

1.345687

1.345713

1.345766

1.345793

1.345819

1.345846

1.345872

1.345925

4816

6. 57.887
57.457
57.025

$58.276 \quad 58.233 \quad 58.189$

59.008
58.577
58.05

$59.353 \quad 59.310 \quad 59.698 \quad 590655$

58.577

8.534

8.49

$\begin{array}{lll}57.025 & 56.982 & 56.93\end{array}$

57.327
56.89

57.715
57.28

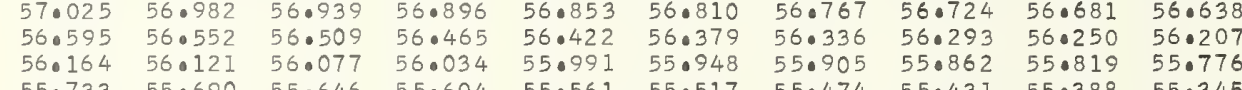

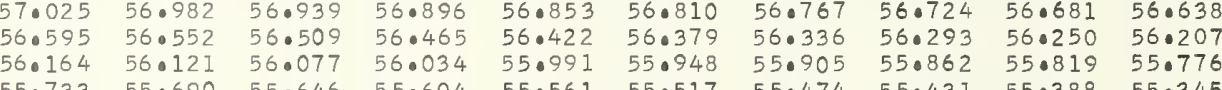

6.5

6.7

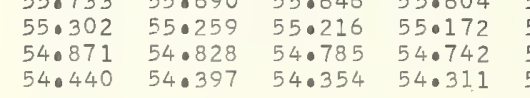

7.1
7.2
7.3
7.4
7.5
7.6
7.7
7.8
7.9

20754.009

$$
\begin{array}{rllll} 
& & & & \\
53.009 & 53.966 & 53.923 & 53.880 & 53 \\
53.578 & 53.535 & 53.492 & 53.4499 & 53 \\
53.148 & 53.104 & 53.061 & 53.018 & 52 \\
52.717 & 52.674 & 52.631 & 52.588 & 52 \\
52.286 & 52.243 & 52.200 & 52.157 & 52 \\
51.855 & 51.812 & 51.770 & 51.726 & 51 \\
51.425 & 51.382 & 51.338 & 51.205 & 51.2
\end{array}
$$

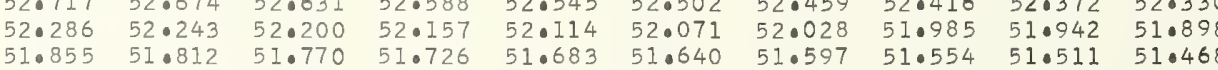

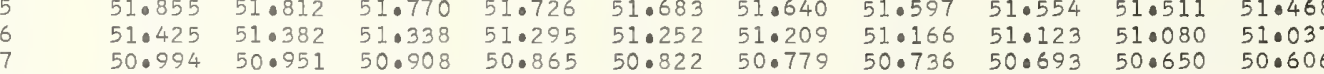
$\begin{array}{llllllllll}50.994 & 50.951 & 50.908 & 50.865 & 50.822 & 50.779 & 50.736 & 50.693 & 50.650 & 50.606 \\ 50.563 & 50.520 & 50.477 & 50.434 & 50.391 & 50.348 & 50.305 & 50.262 & 50.219 & 50.176 \\ 50.133 & 50.090 & 50.046 & 50.003 & 49.960 & 49.917 & 49.874 & 49.831 & 49.788 & 49.745\end{array}$

0.279475

1.345952 0.279474 0.279474 0.279474

0.279473

0.279473

0.279473
0.279472

1.345978
1.346005

1.346032

1.346058
1.346085

1.346111

1.346138

1.346191

0.279472

1.346217

0.279472

0.279471

.279471

0.279470

0.279470
0.279469

1.346270

1.346297

1.346323

1.346350

1.346403

1.346456

0.279469

1.346482

0.279469

0.279468

0.279468

0.279468
0.279467

0.279467

0.279467

1.346509
1.346535

1.346562

1.346588

1.346615
1.346641

1.346668

1.346694
1.346721

$\begin{array}{llllllllll}46.688 & 46.645 & 46.602 & 46.558 & 46.515 & 46.472 & 46.429 & 46.386 & 46.343 & 46.300 \\ 46.257 & 46.214 & 46.171 & 46.128 & 46.085 & 46.042 & 45.999 & 45.956 & 45.913 & 45.870\end{array}$

0.279466

1.346748

$\begin{array}{rrrrrrrrrrr}4819.0 & 20745.396 & 45.353 & 45 \cdot 310 & 45.267 & 45.224 & 45.181 & 45 \cdot 138 & 45 \cdot 095 & 45 \cdot 052 & 45 \cdot 009 \\ 9.1 & 44.966 & 44.923 & 44.880 & 44.836 & 44.794 & 44.750 & 44.707 & 44.664 & 44.629 & 44.578\end{array}$

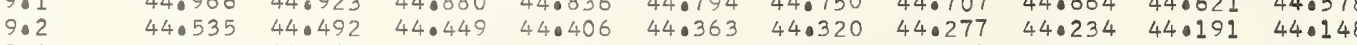

1.346774

0.279466

279465
.279465

0.279465

0.279465

1.346801

1.346854

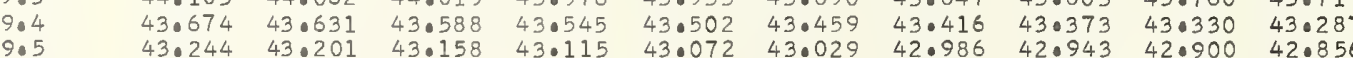

$\begin{array}{lllllllllll}9.5 & 43.244 & 43.201 & 43.158 & 43.115 & 43.072 & 43.029 & 42.986 & 42.943 & 42.900 & 42.856 \\ 9.6 & 42.813 & 42.770 & 42.727 & 42.684 & 42.641 & 42.598 & 42.555 & 42.512 & 42.469 & 42.426\end{array}$

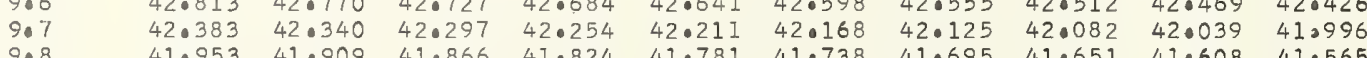

0.279464

0.279464

1.346880

1.346933

1.346960

.010

$\begin{array}{lllllllllll} & .001 & .002 & .003 & .004 & .005 & .006 & .007 & .008 & .009 & .010 \\ .043 & .004 & .009 & .013 & .017 & .021 & .026 & .030 & .034 & .039 & .043 \\ .042 & .004 & .008 & .013 & .017 & .021 & .025 & .029 & .034 & .038 & .042 \\ .041 & .004 & .008 & .012 & .016 & .020 & .025 & .029 & .033 & .037 & .041\end{array}$


4820.0
0.12
0.02
0.3
0.04
0.5
0.06
0.07
0.8
0.9

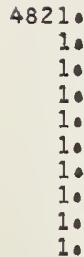

1.9
100
10
1.0
1.9
1.0

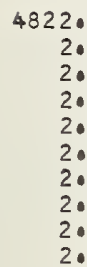

22

4823.

$$
\begin{array}{r}
823.0 \\
3.1 \\
3.2 \\
3.3 \\
3.4 \\
3.5 \\
3.6 \\
3.7 \\
3.8 \\
3.9
\end{array}
$$$$
4824.0
$$$$
\begin{array}{r}
824 . \\
4 . \\
4 . \\
4 . \\
4 . \\
4.5 \\
40.6 \\
4.8 \\
4.9
\end{array}
$$

4825.

5.0
5.1
5.
5.0
5.0
50

4826.0

$$
826.0
$$$$
\begin{array}{rl}
40.662 & 40.619 \\
40.232 & 40.189 \\
39.801 & 39.758 \\
39.371 & 39.328 \\
38.941 & 38.898 \\
38.510 & 38.468 \\
38.080 & 38.037 \\
37.650 & 37.607 \\
37.220 & 37.177
\end{array}
$$$$
\begin{aligned}
& 41.006 \\
& 40.576 \\
& 40.146
\end{aligned}
$$$$
\begin{array}{llllll}
40.920 & 40.877 & 40.834 & 40.791 & 40.748 & 40.705
\end{array}
$$$$
\begin{array}{lllllll}
40.490 & 40.447 & 40.404 & 40.361 & 40.318 & 40.274 \\
40.059 & 40.016 & 39.973 & 39.930 & 39.887 & 39.844
\end{array}
$$$$
\begin{array}{llllll}
40.059 & 40.016 & 39.973 & 39.930 & 39.887 & 39.844 \\
39.629 & 39.586 & 39.543 & 39.500 & 39.457 & 39.414
\end{array}
$$$$
\begin{array}{llllllll}
39.285 & 39.242 & 39.199 & 39.156 & 39.113 & 39.070 & 39.027 & 38.984 \\
38.855 & 38.812 & 38.769 & 38.726 & 38.683 & 38.639 & 38.597 & 38.554
\end{array}
$$$$
\begin{array}{lllllllll}
38.425 & 38.381 & 38.339 & 38.296 & 38.252 & 38.209 & 38.166 & 38.123 \\
37.994 & 37.951 & 37.908 & 37.865 & 37.822 & 37.779 & 37.736 & 37.693
\end{array}
$$

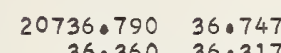

0.279463 0.279463

0.279462

0.279462

0.279461

.279461

0.279461

0.279460

0.279460

0.279459

0.279459

0.279458

0.279458

0.279457

0.279457

0.279456
0.279456

0.279456

0.279456

0.279455

0.279454

0.279454

0.279453

0.279453

0.279453

0.279452

0.279452
0.279452

0.279451

0.279451

(

0.27950
0.279450

0.279450
0.279449
0.2794

0.279449

0.279448

0.279448

0.279448

0.279447
0.279447
0.279476

0.279447

0.279446
0.279446

0.279446

0.279445

0.279445
0.279445
0.27945

0.279445
0.279444
0.27944

0.279444

0.279444
0.279443
0.27943

0.279443
0.279443

0.279443

0.279442
0.279442

0.279442

0.279441

0.279441

0.279440

0.279440

0.279440

0.279439

0.279439

0.279438

0.279438

0.279438

0.279438
0.279437

0.279437

0.279437

0.279436

0.279436

0.279435

0.279435

0.279435

0.279434

.010

1.349108 


.02

.03

4830

$$
\begin{array}{r}
830.0 \\
0.1 \\
0.2 \\
0.3 \\
0.4 \\
0.5 \\
0.6 \\
0.7 \\
0.8 \\
0.9
\end{array}
$$

$$
\begin{array}{rr}
676.746 & 76.704 \\
76.319 & 76.276 \\
75.891 & 75.848 \\
75.463 & 75.421 \\
75.036 & 74.993
\end{array}
$$

0.279431
0.279430
0.027930

0.279430

0.279430

0.279429

0.279429
0.279429
0.27928

0.279428

0.279428

1.349930

1.349957

1.349983
1.350010

1.350036
1.350063

1.350089

1.350116
1.350142

1.350169

$0.279428 \quad 1.350195$

0.279428
0.279428
0.279427

0.279427

0.279427

0.0279426

0.279426

0.279425

1.350222

1.350248
1.350275

1.350301

1.350354

1.350381
3.350407

1.350434

0.279425

0.279425
0.279425
0.279424

0.279424

0.279423

0.279423
0.279423
0.279423

0.0279423
0.279423

0.279422
0.0279422

$1 \cdot 350460$

1. 1350514

1.350540

1.350567
1.350593

1.350593
1.350620

1.350646

1.350673

0.279422

0.279421

0.279421

0.279420

0.279420

0.279420

2.350726

1.350752

1.350779

1.35085
1.35032

1.350858

0.279420
0.279419

1.350911

1.350938

0.279419

1.350991

0.279419
0.279418
0.279418

0.279418
0.279418

0.279418

0.279417
0.279417

0.279417
0.279417

1.351017

1.351044
1.351071

1.351097

1.351124
1.351150

0.279416

0.279416

0.279416
0.279416

0.279415

0.279415
0.279415
0.27945

0.279414

0.279414
0.279414

1.351177

1.351203
1.351230

1.351256

1.351283
1.351300

1.351336

1.351362

1.351389
1.351415

1.351442

$\begin{array}{ll}0.279413 & 1.351468 \\ 0.351495\end{array}$

$0.279413 \quad 1.351521$

$0.279413 \quad 1.351548$

$\begin{array}{ll}0.279413 & 1.351574 \\ 0.279412 & 1.351601 \\ 0.027912 & 1.35162\end{array}$

0.279412

0.279412

0.279411

0.0279411

1.351628

1.351681

0.279411

1.351707
1.351734
1.351760

0.279410

1.351787

0.279409

0.279409

0.279408

0.279408

0.279408

1.351813

1.351840
1.351866

1.351893

1
1
1
1 3551951962

0.279407

0.279407

0.279407

0.279406
0.279406
0.279406

0.279406
0.279406
0.027906

0.279406

0.0279405

0.279405
0.279405

1.352052

1.352078

1.352132

1.352185

1.35221

1
1.03522264
3.352929

.010

1.352291 


5
5
540
5
530
5
520
5
510

$\begin{array}{ll}55.386 & 55.344 \\ 54.959 & 54.917 \\ 54.533 & 54.490 \\ 54.106 & 54.063 \\ 53.679 & 53.637 \\ 53.252 & 53.210 \\ 52.826 & 52.783 \\ 52.400 & 52.357 \\ 51.973 & 51.930 \\ 51.546 & 51.504\end{array}$

$\begin{array}{ll}55.301 & 55 . \\ 54.874 & 54 . \\ 54.448 & 540 \\ 54.021 & 530 \\ 53.594 & 530 \\ 53.167 & 530 \\ 52.741 & 52 . \\ 52.314 \\ 51.887 \\ 51.461\end{array}$

$\begin{array}{lllllll}55.259 & 55.216 & 55.173 & 55.130 & 55.087 & 55.045 & 55.002 \\ 54.831 & 54.789 & 54.746 & 54.704 & 54.661 & 54.618 & 54.575\end{array}$

206

\begin{abstract}
$\begin{array}{rllll}651.119 & 51.077 & 51.034 & 50.992 & 50 . \\ 50.693 & 50.650 & 50.608 & 50.565 & 50 .\end{array}$
\end{abstract}
841.
$1:$
$1:$
10
10
10
10
10

50.26750 .224

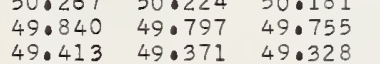

$48.987 \quad 49.371 \quad 49.328 \quad 49.285$

$\begin{array}{llll}48.987 & 48.944 & 48.902 & 48.85 \\ 48.560 & 48.518 & 48.475 & 48.43\end{array}$

$\begin{array}{llll}48.134 & 48.091 & 48.049 & 48.006 \\ 47.707 & 47.065 & 47.622 & 47.580\end{array}$

$\begin{array}{ll}47 \cdot 707 & 47 \cdot 665 \\ 47.281 & 47 \cdot 238\end{array}$

4842.0

2
2.
2.
2.
2.0
2.0
2
2.0

$20646.854 \quad 46.812 \quad 46.769 \quad 46.727 \quad 46.0$

$\begin{array}{llllllllll}46.428 & 46.385 & 46.343 & 46.300 & 46.258 & 46.215 & 46.172 & 46.130 & 46.087 & 46.044 \\ 46.002 & 45.959 & 45.917 & 45.874 & 45.831 & 45.788 & 45.746 & 45.703 & 45.661 & 45.618 \\ 45.575 & 45.533 & 45.490 & 45.448 & 45.405 & 45.362 & 45.320 & 45.277 & 45.234 & 45.192\end{array}$

$\begin{array}{llllllllll}45.149 & 45.106 & 45.064 & 45.021 & 44.979 & 44.936 & 44.893 & 44.851 & 44.2308 & 45.192 \\ 4\end{array}$

$\begin{array}{llllllllll}44.723 & 44.680 & 44.637 & 44.595 & 44.552 & 44.510 & 44.467 & 44.424 & 44.382 & 44.339\end{array}$

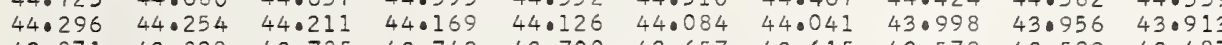

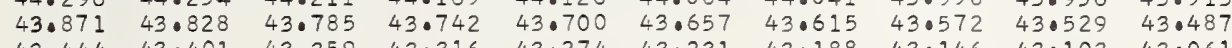

$\begin{array}{llllllllll}43.444 & 43.401 & 43.359 & 43.316 & 43.274 & 43.231 & 43.188 & 43.146 & 43.103 & 43.061 \\ 43.018 & 42.975 & 42.933 & 42.890 & 42.847 & 42.805 & 42.762 & 42.719 & 42.677 & 42.634\end{array}$

4843.

3.1
3.
3.
3.
3.
3.
3.0
3.0

$20642.592 \quad 42.549$

$42.166 \quad 42.123 \quad 42.506 \quad 42.464$

$\begin{array}{llllll}42.421 & 42.378 & 42.336 & 42.293 & 42.251 & 42.208\end{array}$

$\begin{array}{llllllllll}41.739 & 41.697 & 41.654 & 41.611 & 41.569 & 41.526 & 41.410 & 41.867 & 41.824 & 41.782 \\ 41.31 .41 & 41.398 & 41.356\end{array}$

$\begin{array}{llllllllll}41.313 & 41.270 & 41.228 & 41.185 & 41.143 & 41.100 & 41.057 & 41.014 & 40.972 & 40.929\end{array}$

$\begin{array}{llllllllll}40.887 & 40.844 & 40.802 & 40.759 & 40.716 & 40.674 & 40.631 & 40.589 & 40.546 & 40.503\end{array}$

$\begin{array}{llllllllll}40.034 & 39.992 & 39.949 & 39.906 & 39.864 & 39.822 & 39.779 & 39.736 & 39.694 & 39.651\end{array}$

$\begin{array}{llllllllll}39.609 & 39.566 & 39.523 & 39.481 & 39.438 & 39.395 & 39.353 & 39.310 & 39.268 & 39.225\end{array}$

$\begin{array}{llllllllll}39.182 & 39.139 & 39.097 & 39.054 & 39.012 & 38.969 & 38.927 & 38.884 & 38.841 & 38.799 \\ 38.756 & 38.714 & 38.671 & 38.628 & 38.586 & 38.543 & 38.501 & 38.458 & 38.416 & 38.373\end{array}$

4844.

4.1
4.2
4
4.
4.5
4.6
4.7
40
40

0638.

$38.330 \quad 38.28$

$37.478 \quad 37.436$

$37.052 \quad 37.009$

$36.626 \quad 36.583$

$\begin{array}{ll}36.200 & 36.157 \\ 35.774 & 35.731\end{array}$

$35.348 \quad 35 \cdot 30$

$\begin{array}{ll}34 \cdot 922 & 34.880 \\ 34.496 & 34.454\end{array}$

4845

5.

5.3

5.5

5.6
5.7
5.8

33.645

$33.645 \quad 33.602$

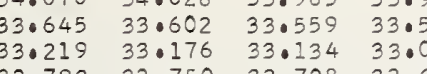

$\begin{array}{llll}32.793 & 32.750 & 32.708 & 32.6 \\ 32.367 & 32.324 & 32.282 & 32.2\end{array}$

$31.941 \quad 31.899 \quad 31.856 \quad 31.81$

$\begin{array}{llll}31.515 & 31.473 & 31.430 & 31.38\end{array}$

30.66430 .621

5

484

6
6
6
6
6
6
6
6
6

20629.8

$$
\begin{array}{rr}
0629.812 & 29.7 \\
29.387 & 29.3 \\
28.961 & 28.9 \\
28.535 & 28.4 \\
28.1110 & 28.0 \\
27.684 & 27.6 \\
27.259 & 27.2 \\
26.833 & 26.7 \\
26.407 & 26.3 \\
25.982 & 25.9 \\
& \\
0625.556 & 25.5 \\
25.131 & 25.0 \\
24.705 & 24.6 \\
24.280 & 24.237 \\
23.854 & 23.8 \\
23.429 & 23.3 \\
23.003 & 22.961 \\
22.578 & 22.536 \\
22.153 & 22.1 \\
21.728 & 21.6 \\
&
\end{array}
$$

$28.110 \quad 28.067 \quad 28.450$

$27.259 \quad 27.216 \quad 27.174$

$\begin{array}{lll}26.407 & 26.365 & 26.32\end{array}$

4847

$7 \cdot 1$

7.3

7.4

$7 \cdot 6$

7.8

$20625 \cdot 556$

0.279404

0.279404

. 279403

0.279403

0.27940

0.279402
0.279402

0.27940
0.27940

0.279401

0.27940

0.279400

0.279399

0.279399
0.279399

0.279399

0.079998
0.279398
0.627989

0.279398
0.2739397
0.279

0.279397

0.279397

0.279396
0.279396

0.279396

0.279395

.279395

0.279394
0.279394

0.279394

0.279393
0.279393

.279393

0.279392

0.279392

0.279391

0.279391

0.279390

0.279390
0.279390

0.279390
0.279389

0.279389

0.279388

0.279388

0.279387

0.279387

0.27937

0.279386

0.279386

0.279385

0.279385

.279384

0.279384

0.279383

0.279383

0.279383

0.279382

0.279382

0.279381

0.279381
0.279380

0.279380

0.279380
0.279380

0.279379
0.279379

0.279379

0.279378

0.279378

0.279378
0.279377

0.279377
0.279377

0.279376

0.279376

0.279376

.0352317

1.352370
1.352397

1.352423
1.352450

1.352476

1.352503
1.352529

1.352582
1.352609

1.352636
1.352662

1.352689

1.352715
1.352742

1. 352795

1.352821

1.0352874

10352927

.8352984
.352980

1.353007

.0353033
1.353060
1.3500

.353086

1.353113

1.0353166
1.353193

1.353219
1.353246

1.353272

1.353325

1.353378

1.353405

1. 353458

1. 353511

1.353554

1.0353617
0.3351

1.353644

1.353670
1.356679

1.353723
1.353750
1.35370

1.353776

10353803
1.353829

1.353856
1.353882

1.353909

1.353935

1.353988

1. 354015

1.354068

1.354121

1. 354174

1.35227

1. 3525254

.354307

1.354360

.354386

1.354439

1.354492

1.354519

1.354546

1.354599

1.354652

1.354705

1. 354758

1. 354811

1.354837

1.354864
1.354890

1.354917
1.354943

.010

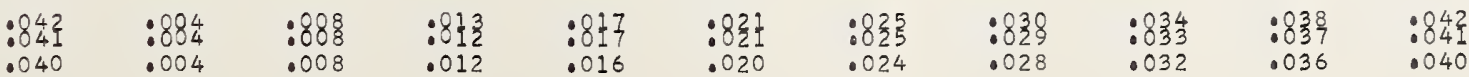




.04

.05

.06

$\begin{array}{ll}12.374 & 12.331 \\ 11.948 & 11.906 \\ 11.523 & 11.481 \\ 11.099 & 11.056 \\ 10.674 & 10.631 \\ 10.249 & 10.206 \\ 09.824 & 09.781 \\ 09.399 & 09.356 \\ 08.974 & 08.932\end{array}$

$\begin{array}{lllll}12.714 & 12.671 & 12.628 & 12.586 & 12 \\ 12.289 & 12.246 & 12.204 & 12.161 & \\ 11.864 & 11.821 & 11.779 & 11.736 & \\ 11.438 & 11.396 & 11.354 & 11.311 & \\ 11.013 & 10.971 & 10.928 & 10.886 & \\ 10.589 & 10.546 & 10.504 & 10.461 & \\ 10.164 & 10.121 & 10.079 & 10.036 & \\ 09.739 & 09.697 & 09.654 & 09.611 & \\ 09.314 & 09.272 & 09.229 & 09.187 & \\ 08.889 & 08.847 & 08.804 & 08.762 & 08\end{array}$

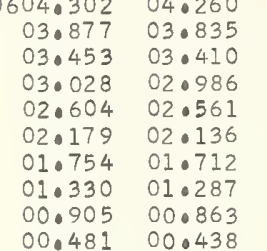

20600.056

99.20

00.014

07.615

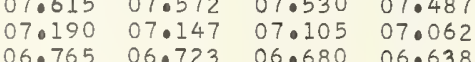

$\begin{array}{llll}06.765 & 06.723 & 06.680 & 06.638\end{array}$

$\begin{array}{llll}06.340 & 06.298 & 06.255 & 06.213 \\ 05.916 & 05.873 & 05.831 & 05.78\end{array}$

$05.491 \quad 05.448$

$\begin{array}{ll}05.406 & 05.364\end{array}$

04.0642

98.359

99.59

98.35998 .716

$\begin{array}{ll}97.934 & 97.892 \\ 97.510 & 97.468\end{array}$

$97.086 \quad 97.043898 \%$

96.661
96.237

20595.812

$\begin{array}{rr}595.812 & 95.7 \\ 95.388 & 95.346\end{array}$

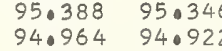

$94.540 \quad 94.922$

$\begin{array}{llll}94.115 & 94.073 & 94.031 & 93.988\end{array}$

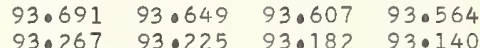

$\begin{array}{llll}93.267 & 93.225 & 93.182 & 93 \cdot 140 \\ 92.843 & 92.801 & 92.758 & 92.716\end{array}$

$\begin{array}{llll}92.419 & 92.376 & 92.334 & 92.292 \\ 91.995 & 91.952 & 91.910 & 91.867\end{array}$

20591.570

\begin{abstract}
$91.570 \quad 91.52$
\end{abstract}
90.72291 .106

$\begin{array}{ll}90.298 & 90.256 \\ 89.874 & 89.832\end{array}$

$89.450 \quad 89.408$

$89.026 \quad 88 \cdot 984$

$88.178 \quad 88.135$

20587.330 $\begin{array}{ll}86.906 & 86.864 \\ 86.482 & 86.440\end{array}$ $86.058 \quad 86.016$ $\begin{array}{llll}85.634 & 85.592 & 85.550 & 85.507 \\ 85.210 & 85.168 & 85.126 & 85.083\end{array}$ $\begin{array}{llll}84.786 & 84.744 & 84.702 & 85.083\end{array}$ $\begin{array}{llll}84.363 & 84.321 & 84.278 & 84.236\end{array}$ $\begin{array}{llll}83.939 & 83.896 & 83.854 & 83.812 \\ 83.515 & 83.473 & 83.430 & 83.388\end{array}$ 20583.09183 .049 $\begin{array}{ll}82.667 & 82.625 \\ 82.244 & 82.202 \\ 81.820 & 81.778\end{array}$ $\begin{array}{lll}81.778 & 81.735\end{array}$ $81.396 \quad 81.354 \quad 81.312$ $\begin{array}{llll}80.549 & 80.507 & 80.488 & 80.845\end{array}$

$\begin{array}{llll}80.125 & 80.083 & 80.041 & 79.998\end{array}$ $\begin{array}{llll}79.702 & 79.659 & 79.617 & 79.575 \\ 79.278 & 79.236 & 79.193 & 79.151\end{array}$

$\begin{array}{rrrr}20578.854 & 78.812 & 78.770 & 78.728 \\ 78.431 & 78.389 & 78.346 & 78.304\end{array}$

$\begin{array}{llll}78.431 & 78.389 & 78.346 & 78.304 \\ 78.008 & 77.965 & 77.923 & 77.880\end{array}$

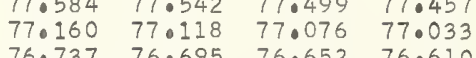

$\begin{array}{llll}76.737 & 76.6595 & 76.652 & 76.610 \\ 76.313 & 76.271 & 76.229 & 76.186\end{array}$

$\begin{array}{lllll}75.890 & 75.848 & 75 \cdot 0205 & 76 \cdot 180 \\ 75 & 75063\end{array}$

$\begin{array}{llll}75.0466 & 75.424 & 750381 & 75.339 \\ 75.043 & 750000 & 740958 & 740916\end{array}$

$\begin{array}{ll}04.556 & 04.514 \\ 04.132 & 04.090\end{array}$

\begin{abstract}
04.13
\end{abstract}
04.090

$\begin{array}{ll}3.665 & 0 \\ 3.240 & 030 \\ .816 & 020\end{array}$

$\begin{array}{ll}02.858 & 02.816 \\ 02.433 & 02.391\end{array}$

$\begin{array}{ll}02.009 & 01.967 \\ 01.584 & 01.542\end{array}$

$\begin{array}{ll}01.584 & 01.542 \\ 01.160 & 01.117 \\ 00.735 & 00.693\end{array}$

00.735
00.311 $\begin{array}{lll}12.501 & 12.459 & 12.416 \\ 12.076 & 12.034 & 11.099\end{array}$ $\begin{array}{lll}11.651 & 11.609 & 11.0566 \\ 1.0226 & 110184 & 11.141\end{array}$ $0.801 \quad 10.759 \quad 10.716$ $\begin{array}{lll}090951 & 100334 & 10.0292 \\ 090909 & 09.866\end{array}$ $0.527 \quad 09.484 \quad 09.442$ $\begin{array}{llll}09.1027 & 090059 & 09.017 \\ 08.677 & 080634 & 08.592\end{array}$

$\begin{array}{lllll}08.294 & 08.252 & 08.209 & 08.167 \\ 07.870 & 07.827 & 07.785 & 07.742\end{array}$ $\begin{array}{llll}07.870 & 070827 & 07.785 & 07.742 \\ 07.445 & 07.403 & 07.360 & 070317\end{array}$ $\begin{array}{llll}07.020 & 06.978 & 06.9935 & 06.893 \\ 06.595 & 06.553 & 06.510 & 06.468\end{array}$ $\begin{array}{lllll}06 \cdot 170 & 06 \cdot 128 & 060086 & 06.043\end{array}$ $\begin{array}{lllll}0.06 & 0.7746 & 06.703 & 05.661 & 05.618\end{array}$ $\begin{array}{llll}5.321 & 050279 & 050236 & 050194 \\ 04.806 & 04.854 & 04.812 & 04.760\end{array}$ $\begin{array}{lllll}04.047 & 04.005 & 040387 & 04.0344\end{array}$
0.279375 0.279375 0.279374
0.279374
0.27934 0.279374 0.279374
0.279373
0.27373 0.279373 0.279373

0.279372 0.279372
0.279372 0.279371 0.279371 0.279371 0.279370 0.279370

0.279369 0.279369
0.279369 0.279369 0.279368 0.279368 0.279367 0.279367

0.279367 0.279366 0.279366
0.279365
0.279365 0.279365 0.279365 0.279364 0.279364

0.279364 0.279363 0.279363 0.279362 0.279362 0.279362 0.279362 0.279361

0.279361 0.279360
0.279360 0.279360 0.279360 0.279359
0.279359 0.27935 0.279358
0.279358

0.279358 0.279358
0.279357 0.279357 0.279357
0.279356 0.279356 0.279356 0.279356
0.279355

0.279355 0.279355 0.279354 0.279354 0.279354 0.279353 0.279353
0.279353 0.279352

0.279352 0.279352
0.279352 0.279351 0.279351 0.279351 0.279350 0.279350

0.279349 0.279349 0.279349
0.279348 0.279348 0.279348
0.279347 0.279347
0.279347 0.279347

0.279347

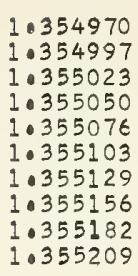

1.355235 1.355262 1.355315

1.355341

1.355368

1.355394

1.355448

1.355502 1.355527 1.355580 1.355607 1.355633 1.355686 1.355713 1.355766 1.355792
1.355819 1.355845 1.355872 1.355899

1.355925

1.355952

1.355978
1.356005

1.356031

1.356058
1.356084

1.356084
1.356111

1.356111
1.356137

1.356164 1.356190 1.356243 1.356270 1.356296 1.356323 1.356350
1.356376 1.356403 1.356429 1.356456 1.356482
1.356509 1.356509
1.356535

1.356562 1.356588 1.356615 1.356641
1.356668 1.356694 1.356721 1.356748 1.356774
1.356801

1.356827 1.356854 1.356880
1.356907 1.356933 1.356960 1.356986 1.357013 1.357039
1.357066 1.357092 1.357119 1.357172 1. 357225 1. 357278 1.357305

1.357358 
$\begin{array}{llllllllll}0.386 & 70.344 & 70.302 & 70.259 & 70.217 & 70.174 & 70.132 & 70.090 & 70.048 & 70.005 \\ 9.963 & 69.920 & 69.878 & 69.835 & 69.793 & 69.751 & 69.709 & 69.667 & 69.624 & 69.582\end{array}$ $\begin{array}{llllllllll}69.540 & 69.497 & 69.455 & 69.413 & 69.370 & 69.328 & 69.286 & 69.243 & 69.201 & 69.159\end{array}$ $\begin{array}{llllllllll}68.693 & 68.651 & 68.608 & 68.566 & 68.524 & 68.482 & 68.439 & 68.397 & 68.778 & 68.73\end{array}$ $\begin{array}{llllllllll}68.270 & 68.228 & 68.186 & 68.143 & 68.101 & 68.058 & 68.016 & 67.973 & 67.931 & 67.889\end{array}$ $\begin{array}{llllllllll}67.847 & 67.804 & 67.762 & 67.720 & 67.677 & 67.635 & 67.593 & 67.551 & 67.508 & 67.846\end{array}$ $\begin{array}{llllll}67.424 & 67.381 & 67.339 & 67.297 & 67.254 & 67.212\end{array}$ $\begin{array}{llllll}66.577 & 66.958 & 66.916 & 66.874 & 66.831 & 66.789 \\ 6 & 66.493 & 66.450 & 66.408 & 66.366\end{array}$ $\begin{array}{rlllllllll}566.154 & 66 \cdot 112 & 66.070 & 66.027 & 65.985 & 65.943 & 65 \cdot 900 & 65.858 & 65.816 & 65.773\end{array}$ $\begin{array}{llllllllll}65.308 & 65.266 & 65.223 & 65.181 & 65.139 & 65.096 & 65.054 & 65.012 & 64.970 & 64.927\end{array}$

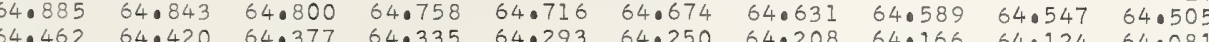
$\begin{array}{llllllllll}64.039 & 63.997 & 63.955 & 63.912 & 63.870 & 63.828 & 63.785 & 63.743 & 63.701 & 63.658\end{array}$ $\begin{array}{llllllllll}63.616 & 63.574 & 63.531 & 63.489 & 63.447 & 63.405 & 63.362 & 63.320 & 63.278 & 63.23\end{array}$ $\begin{array}{llllllllll}62.770 & 62.728 & 62.686 & 62.644 & 62.609 & 62.550 & 62.516 & 62.897 & 62.855 & 62.812\end{array}$

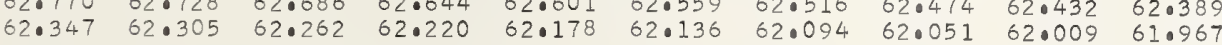

0.279346 0.279346 0.279345 0.279345 0.279345 0.279344 0.279344

0.279343

0.279343

0.279342

0.279342
0.279342

0.279341

$4862 \cdot ?$

20561.92

$61.840 \quad 61.798 \quad 61.755 \quad 61.713$

60.656060 .613

$60.233 \quad 60.190$

$\begin{array}{ll}59.810 & 59.76 \\ 59.387 & 59.345\end{array}$

$\begin{array}{ll}59.387 & 59.345 \\ 58.965 & 58.92\end{array}$

$61.417 \quad 61.374 \quad 61.332$

$58.542 \quad 58.49$

$0.571 \quad 60.529 \quad 60.487$

$\begin{array}{ll}60.148 & 60.106 \\ 59.725 & 59.68\end{array}$

$\begin{array}{lll}59.302 & 59.260 & 59.21\end{array}$

61.290
60.867

$61.671 \quad 61.628 \quad 61.586 \quad 61.544$

4863

3.
3.
3.
3.
3.
3.
3.
3.

20557.696

56.85

57.231

8.45

55.583000

$56.386-56.764$

$55.583 \quad 55.541$

$55.160 \quad 55 \cdot 11$

$54.315 \quad 54.27$

53.89

4864

$4 \cdot 1$

4.3

4.4

$4 \cdot 5$
$4 \cdot 6$

4.7

$4 \cdot 8$
4.9

4865

5.1

$5 \cdot 2$

504

5.5

$5 \cdot 7$
5.8

20553.47

$\begin{array}{ll}53.047 & 53.005 \\ 52.625 & 52.583\end{array}$

53.428

$51.780 \quad 51.738$

51.35

50.893
50.470

50.090
49.668

$549 \cdot 245$

50.048
49.625

57.612

58.337

$59.218 \quad 59.17$

$\begin{array}{llll}60.825 & 60.783 & 60.740 & 60.698\end{array}$

0.279341

0.279340
0.279340

0.279340

0.279339

0.279339

0.279338

0.279338

0.279337

0.279337

0.279336

9336

0.279336

0.2279336
0.279335

0.279335

0.279335
0.279334

0.279334

0.279334

0.279333

0.279333

0.279332

$1 \cdot 357623$

48.823
48.400

49.203
48.781
48.35

50.005
49.583

$47.978 \quad 47.936$

$47.133 \quad 47.091$

46.71

$46.289 \quad 46.247$

$45 \cdot 867$
45.444

46.247
45.824
45.402

$49.161 \quad 49.11$

9.118
48.696
8.274

$\begin{array}{ll}48.316 & 48.274 \\ 7.894 & 47.852 \\ 7.471 & 47.429\end{array}$

$\begin{array}{ll}47.049 & 47.007 \\ 46.626 & 46.584\end{array}$

$\begin{array}{ll}6.626 & 46.584 \\ 46.204 & 46.16\end{array}$

47.004
46.162
45.740

4866.

44.980 45.36

6
6
6
6
6.5
6
6
6
6
60

$\begin{array}{ll}44 \cdot 600 & 44 \cdot 558 \\ 44 \cdot 178 & 44 \cdot 135 \\ 43 \cdot 755 & 43 \cdot 713\end{array}$

$43.333 \quad 43.29$

42.911

$42 \cdot 869$
42.447

44.51

844.896

85.27
4

..076 49.0

$\begin{array}{ll}48.654 & 48.612\end{array}$

$\begin{array}{ll}47.809 & 47.76 \\ 47.386 & 47.34\end{array}$

$46.965 \quad 46.922$

$\begin{array}{ll}.0542 & 46.50 \\ 6.120 & 46.078\end{array}$

$\begin{array}{llllllllll}42.489 & 42.447 & 42.405 & 42.362 & 42.320 & 42.278 & 42.236 & 42.194 & 42.151 & 42.109 \\ 42.067 & 42.025 & 41.982 & 41.940 & 41.898 & 41.856 & 41.814 & 41.771 & 41.729 & 41.687 \\ 41.645 & 41.603 & 41.560 & 41.518 & 41.476 & 41.434 & 41.392 & 41.349 & 41.307 & 41.265\end{array}$

$43.671 \quad 43.62$

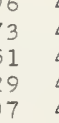

$44.853 \quad 44.811$

$\begin{array}{llll}46.036 & 45.993 & 45.951 & 45.909\end{array}$

0.279332

0.279332

0.279331

0.279330

0.279330

0.279330

0.279329

$1 \cdot 357650$

1.357703

1.357756

1357809

1.357835
1.357862

1.357888

1.357915

1.357968

1.358021

1.358048

1.358101
1.358127

1.358154

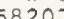

I. 358260

1. 358313

1.358366

1.358419

1.358446
1.358472

1.358499
1.358525

. 358552

1.358605

1.358631
1.358658

$\begin{array}{llllllllll}41.223 & 41.180 & 41.138 & 41.096 & 41.054 & 41.012 & 40.969 & 40.927 & 40.885 & 40.843\end{array}$

$\begin{array}{lllllllllll}4867.0 & 20540.801 & 40.759 & 40.717 & 40.674 & 40.632 & 40.590 & 40.548 & 40.505 & 40.463 & 40.421\end{array}$

$\begin{array}{llllllllll}40.379 & 40.337 & 40.294 & 40.252 & 40.210 & 40.168 & 40.125 & 40.083 & 40.041 & 39.999\end{array}$

$\begin{array}{llllllllll}39.957 & 39.915 & 39.872 & 39.830 & 39.788 & 39.746 & 39.704 & 39.661 & 39.619 & 39.577 \\ 39.535 & 39.492 & 39.450 & 39.408 & 39.366 & 39.323 & 39.281 & 39.239 & 39.197 & 39.155\end{array}$

$\begin{array}{lllllllllll}39.113 & 39.071 & 39.028 & 38.986 & 38.944 & 38.902 & 38.860 & 38.817 & 38.775 & 38.733\end{array}$

$\begin{array}{llllllllll}38.691 & 38.649 & 38.606 & 38.564 & 38.522 & 38.480 & 38.438 & 38.395 & 38.353 & 38.311\end{array}$

$\begin{array}{llllllllll}38.269 & 38.227 & 38.184 & 38.142 & 38.100 & 38.058 & 38.016 & 37.973 & 37.931 & 37.889\end{array}$

$\begin{array}{lllllllllll}37.847 & 37.805 & 37.763 & 37.720 & 37.678 & 37.636 & 37.594 & 37.552 & 37.510 & 37.467\end{array}$

$\begin{array}{llllllllll}37.425 & 37.383 & 37.340 & 37.298 & 37.256 & 37.214 & 37.172 & 37.130 & 37.087 & 37.045 \\ 37.003 & 36.96 & 36.919 & 36.876 & 36.834 & 36.792 & 36.750 & 36.708 & 36.666 & 36.624\end{array}$

0.279329

0.279329

0.279328

0.279328

0.279328

0.279327

0.2279327
0.279326

1. 35868

1.358711
1.358737

1.358764
$? .358791$

1. 358817

I. 358844

1.358870
1.358897

1.358923

0.279326

1.358950
1.358976

1.359003

1.359029

1. 359082

1.359109

0.279326

0.279326
0.279325

0.279325

0.279325
0.279324

0.279324

0.279324

1. 359189

$\begin{array}{rrrrrrrrrrr}4868.0 & 20536.581 & 36.539 & 36.497 & 36.455 & 36.412 & 36.370 & 36.328 & 36.286 & 36 \cdot 244 & 36 \cdot 202\end{array}$

$\begin{array}{llllllllllll}8.1 & 36.159 & 36.117 & 36.075 & 36.033 & 35.991 & 35.948 & 35.906 & 35.864 & 35.822 & 35.780\end{array}$ $\begin{array}{llllllllll}35.316 & 35.273 & 35.231 & 35.189 & 35.569 & 35.526 & 35.484 & 35.442 & 35.400 & 35.358 \\ 35.147 & 35.105 & 35.062 & 35.020 & 34.979 & 34.937\end{array}$ $\begin{array}{llllllllll}35.316 & 35.273 & 35.231 & 35.189 & 35.147 & 35.105 & 35.062 & 35.020 & 34.979 & 34.937 \\ 34.894 & 34.852 & 34.810 & 34.768 & 34.725 & 34.684 & 34.641 & 34.599 & 34.557 & 34.514\end{array}$ $\begin{array}{llllllllll}34.472 & 34.430 & 34.388 & 34.346 & 34.304 & 34.261 & 34.219 & 34.177 & 34.135 & 34.093\end{array}$ $\begin{array}{llllllllll}34.059 & 34.009 & 33.966 & 33.924 & 33.882 & 33.840 & 33.798 & 33.755 & 33.713 & 33.671\end{array}$ $\begin{array}{llllllllll}33.629 & 33.587 & 33.544 & 33.502 & 33.460 & 33.418 & 33.376 & 33.334 & 33.292 & 33.249 \\ 33.207 & 33.165 & 33.123 & 33.081 & 33.039 & 32.996 & 32.954 & 32.912 & 32.870 & 32.828\end{array}$

$\begin{array}{lllllllllll}8.8 & 33.207 & 33.165 & 33.123 & 33.081 & 33.039 & 32.996 & 32.954 & 32.912 & 32.870 & 32.828 \\ 8.9 & 32.786 & 32.743 & 32.701 & 32.659 & 32.616 & 32.574 & 32.532 & 32.490 & 32.448 & 32.406\end{array}$

0.279323

0.279323

0.279322

0.279322

0.279322

0.279321

0.279321

$\begin{array}{rrrrrrrrrrr}4869.0 & 20532.364 & 32.322 & 32.280 & 32.237 & 32.195 & 32.153 & 32.111 & 32.068 & 32.027 & 31.984 \\ 9.1 & 31.942 & 31.900 & 31.858 & 31.815 & 31.773 & 31.731 & 31.689 & 31.647 & 31.604 & 31.562\end{array}$

$\begin{array}{lllllllllll}9.1 & 31.942 & 31.900 & 31.858 & 31.815 & 31.773 & 31.731 & 31.689 & 31.647 & 31.604 & 31.562 \\ 9.2 & 31.521 & 31.478 & 31.436 & 31.394 & 31.352 & 31.309 & 31.268 & 31.225 & 31.183 & 31.141\end{array}$ $\begin{array}{llllllllll}31.099 & 31.056 & 31.014 & 30.972 & 30.930 & 30.888 & 30.845 & 30.303 & 30.761 & 30.719\end{array}$ $\begin{array}{llllllllll} & \end{array}$ $\begin{array}{llllllllll}30.255 & 30.213 & 30.171 & 30.129 & 30.087 & 30.045 & 30.002 & 29.960 & 29.918 & 29.876\end{array}$

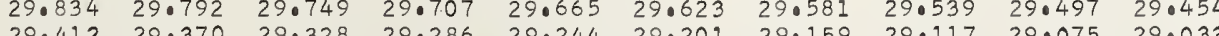

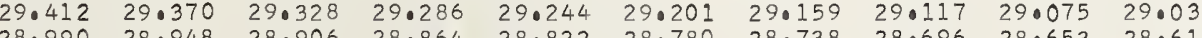

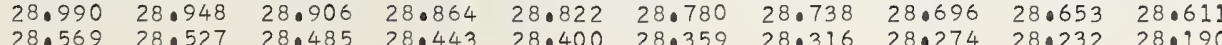

0.279320

0.279320

0.279320

0.279319

0.279319

0.279319

0.279318
0.279318

0.279318

. 359215

1.359268

1.359295
1.359321

I. 359348

1.359374
1.359401

1.359427
1.359454

1.359480

1.359507

1.359560

1.359587
1.359613

1.359640

1.359666

1.359693
1.359719

$$
.001
$$

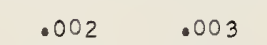

.005

.006

.007

.008

.009

.010

1.359746 
$\begin{array}{rrrrrrrrrrr}4870.0 & 20528 \cdot 148 & 28 \cdot 105 & 28.063 & 28.021 & 27.979 & 27.937 & 27.895 & 27 \cdot 852 & 27 \cdot 811 & 27 \cdot 768 \\ 0.1 & 27.726 & 27.684 & 27.642 & 27.600 & 27.558 & 27.515 & 27.473 & 27.431 & 27.389 & 27.347\end{array}$

$\begin{array}{llllllllll}27.305 & 27.263 & 27.220 & 27.178 & 27.136 & 27.094 & 27.052 & 27.010 & 26.967 & 26.925\end{array}$

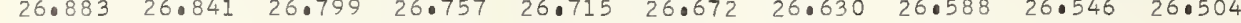
$\begin{array}{llllllllll}26.462 & 26.420 & 26.377 & 26.335 & 26.293 & 26.251 & 26.209 & 26.167 & 26.124 & 26.082\end{array}$

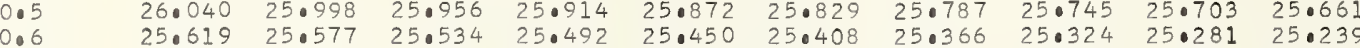
$\begin{array}{llllllllll}25.198 & 25.155 & 25.113 & 25.071 & 25.029 & 24.987 & 24.945 & 24.902 & 24.860 & 24.818 \\ 24.776 & 24.734 & 24.692 & 24.650 & 24.608 & 24.565 & 24.523 & 24.481 & 24.439 & 24.397\end{array}$

3.0

3.2
3.3
3.
3.
3.
3.
3.
3.9

4874 .

40.2

40.3
4.45

4.5
4.6

4.7
4.8
4.9

4875

50.

5.04

505

5.6

5.8
5.9

4876
6
6
6
6
6
6
6
6

76.0
6.1
6.2
6.3
6.4
6.5
6.6
6.7
6.8
6.9

70

77.2

$7:$

7.07
7.7
7.9

$8 \cdot 1$
8.2
8.3

8.3
8.4
8.5

8.5
8.6

8.9

4879.

9.0
9.1
9.2
9.3
9.4
9.5
9.6
9.7
9.8
9.9

\begin{abstract}
$23.512 \quad 23.470$
23.091

22.669
22.248

$21.827 \quad 21.785$

$21.406 \quad 21.363$

20.984
20.563
\end{abstract}

20.142

519.7
19.300
18.8
18.457
18.
17.615

$18.457 \quad 18.41$

$17.615 \quad 17.573$

$\begin{array}{ll}17.194 & 17.152 \\ 16.773 & 16.731 \\ 16.352 & 16.310 \\ 15.931 & 15.889\end{array}$

20515.510

15.089

$14.247 \quad 14.626$

$13.826 \quad 13.78$

$\begin{array}{ll}13.405 & 13.363 \\ 12.984 & 12.942\end{array}$

$\begin{array}{ll}12.563 & 12.52 \\ 12.142 & 12.100\end{array}$

20511.30

10.880
10.459
10.038
09.618

09.61809 .996

$\begin{array}{ll}09.197 & 09.155 \\ 08.776 & 08.734\end{array}$

$\begin{array}{ll}08.776 & 08.734 \\ 08.355 & 08.313\end{array}$

$\begin{array}{ll}07.935 & 07.893 \\ 07.514 & 07.472\end{array}$

20507.093

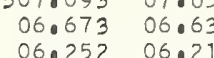

$\begin{array}{ll}05.831 & 05.210 \\ 05.841 & 05.36\end{array}$

$\begin{array}{ll}05.411 & 05.369 \\ 04.990 & 04.948\end{array}$

$\begin{array}{ll}04.990 & 04.948 \\ 04.570 & 04.528\end{array}$

$\begin{array}{ll}04.149 & 04.107 \\ 03.729 & 03.687\end{array}$

$\begin{array}{ll}03.729 & 03.687 \\ 03.308 & 03.266\end{array}$

$2050.2 \cdot 887$ $02.467 \quad 02.846$

$02.047 \quad 02.005$

01.62601 .58401 .54

$\begin{array}{ll}01.206 & 01.164 \\ 00.785 & 00.744\end{array}$

$00.365 \quad 00.323$

$20499.945 \quad 99.903$

$99.104 \quad 99.062$

$20498.684 \quad 98.642$

97.843

$97.423 \quad 97.381$

$97.003 \quad 96.961$

$96.162 \quad 96.120$

$95.742 \quad 95.700$

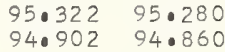

$20494 \cdot 481$

494. 981

93.64194 .01

$\begin{array}{llll}93.221 & 93.179 & 93.137 & 93.09 \\ 92.801 & 92.759 & 92.717 & 92.67\end{array}$

$\begin{array}{llll}2.381 & 92.339 & 92.297 & 92.25\end{array}$

91.96191 .919

$\begin{array}{ll}91.121 & 91.07 \\ 90.701 & 90.65\end{array}$

91.877
91.457

490.28

90.239

89.441

$89.021-88.975$

$88.560-88.937-88.89$

$88.181 \quad 88.140 \quad 88.098 \quad 88.05$

$\begin{array}{llll}87.342 & 87.300 & 87.258 & 87.216\end{array}$

$\begin{array}{llll}86.922 & 86.880 & 86.838 & 86.79 \\ 86.502 & 86.460 & 86.418 & 86.376\end{array}$

$5.426 \quad 15.384$

$1.217 \quad 11.175$

\subsection{8 .229}

\section{$\begin{array}{rr}179 & 98.137 \\ .759 & 97.717\end{array}$}

4.608624 .10

3.765

$23.343 \quad 2301$

$.922 \quad 22.880$

$\begin{array}{ll}.079 & 22.038 \\ 1.658 & 21.61\end{array}$

$1.237 \quad 21.195$

20.352

$24 \cdot 102$

24.060

24.018

$\begin{array}{llll}838 & 22.796 & 22.754 & 22.711\end{array}$

$\begin{array}{llll}22.416 & 22.374 & 22.332 & 22.290 \\ 21.995 & 21.953 & 21.911 & 21.869\end{array}$

$\begin{array}{llll}21.574 & 21.531 & 21.490 & 21.448 \\ 21.153 & 21.111 & 21.068 & 21.026\end{array}$

$\begin{array}{llll}21.153 & 21.111 & 21.068 & 21.026 \\ 20.731 & 20.689 & 20.647 & 20.605\end{array}$

$\begin{array}{llllll}19.552 & 19.510 & 19.468 & 19.426 & 19.384 & 19.342\end{array}$

$\begin{array}{llll}9.468 & 19.426 & 19.384 & 19.342 \\ 9.047 & 19.005 & 18.963 & 18.920\end{array}$

$\begin{array}{llllllll}18.752 & 18.710 & 18.667 & 18.626 & 18.583 & 18.542 & 18.499\end{array}$

$\begin{array}{lllllll}17.909 & 18.289 & 18.247 & 18.205 & 18.162 & 18.120 & 18.078 \\ 17.867 & 17.825 & 17.783 & 17.741 & 17.699 & 17.657\end{array}$

$\begin{array}{lll}17.447 & 17.404\end{array}$

$\begin{array}{llll}17.362 & 17.320 & 17.278 & 17.236\end{array}$

$\begin{array}{llll}16.941 & 16.320 & 17.278 & 17.236 \\ 16.89 & 16.857 & 16.815\end{array}$

$\begin{array}{llll}16.941 & 16.899 & 16.857 & 16.815\end{array}$

$\begin{array}{llllll}6.604 & 16.562 & 16.520 & 16.478 & 16.436 & 16.394 \\ 6.184 & 16.141 & 16.099 & 16.057 & 16.015 & 15.973 \\ 5.762 & 15.720 & 15.678 & 15.636 & 15.594 & 15.552\end{array}$

15.341

15.299

15.257

15.215

$\begin{array}{ll}15 \cdot 173 & 15 \cdot 131 \\ 14 \cdot 752 & 14 \cdot 710\end{array}$

$\begin{array}{llllll}14.499 & 14.457 & 14.836 & 14.794 & 14.752 & 14.710 \\ 14.415 & 14.373 & 14.331 & 14.289\end{array}$

$\begin{array}{lllllll}14.078 & 14.036 & 13.994 & 13.952 & 13.910 & 13.868\end{array}$

$\begin{array}{llllllll}3.321 & 13.699 & 13.657 & 13.615 & 13.573 & 13.531 & 13.489 & 13.447 \\ 13.236 & 13.194 & 13.152 & 13.110 & 13.069 & 13.026\end{array}$

$\begin{array}{lllllll}12.858 & 12.816 & 12.774 & 12.732 & 12.690 & 12.647 & 12.605 \\ 12.437 & 12.395 & 12.353 & 12.311 & 12.269 & 12.227 & 12.185\end{array}$

$.058 \quad 12.016 \quad 11.974$

$$
11.132
$$

11.890

12.26

$11.806 \quad 11.764$

$\begin{array}{llllll}1.132 & 11.090 & 11.048 & 11.006 & 10.964 & 10.922 \\ 0.112 & 10.670 & 10.628 & 10.585 & 10.543 & 10.501\end{array}$

$\begin{array}{llllll}10.291 & 10.249 & 10.207 & 10.165 & 10.123 & 10.081 \\ 09.870 & 09.828 & 09.786 & 09.744 & 09.702 & 09.660\end{array}$

$\begin{array}{llllll}09.449 & 09.407 & 09.365 & 09.323 & 09.281 & 09.239 \\ 09.029 & 08.987 & 08.944 & 08.902 & 08.860 & 08.818\end{array}$

$\begin{array}{llllll}09.029 & 08.987 & 08.944 & 08.902 & 08.860 & 08.818 \\ 08.608 & 08.566 & 08.524 & 08.481 & 08.439 & 08.397\end{array}$

$\begin{array}{llllll}08.187 & 08.145 & 08.103 & 08.061 & 08.019 & 07.977\end{array}$

07.767

8.145
7.725
7.304

07.556
07.135

$\begin{array}{llllllll}07.010 & 06.967 & 06.925 & 06.883 & 06.841 & 06.799 & 06.757 & 06.715 \\ 06.588 & 06.546 & 06.505 & 06.462 & 06.420 & 06.378 & 06.336 & 06.294\end{array}$ $\begin{array}{llllllll}0.168 & 06.546 & 06.505 & 06.462 & 06.420 & 06.378 & 06.336 & 06.294 \\ 0.126 & 06.084 & 06.042 & 06.000 & 05.958 & 05.916 & 05.874\end{array}$ $\begin{array}{llllllll}5.327 & 05.285 & 05.243 & 05.201 & 05.579 & 05.537 & 05.495 & 05.453 \\ 0.159 & 05.117 & 05.074 & 05.032\end{array}$ $\begin{array}{lllllll} & 04.798 & 0.738 & 04.696 & 04.654 & 04.612\end{array}$ $\begin{array}{llllllll} & 4.444 & 04.402 & 04.360 & 04.317 & 04.275 & 04.233 & 04.191 \\ 04.065 & 04.023 & 03.981 & 03.939 & 03.897 & 03.855 & 03.813 & 03.771\end{array}$ $\begin{array}{lllllllll}.245 & 03.603 & 03.561 & 03.519 & 03.476 & 03.434 & 03.392 & 03.750 \\ 0.224 & 03.182 & 03.140 & 03.098 & 03.056 & 03.014 & 02.972 & 02.930\end{array}$ $\begin{array}{llllllll}02.804 & 02.761 & 02.719 & 02.677 & 02.635 & 02.593 & 02.552 & 02.509\end{array}$ $\begin{array}{lllllll}01.500 & 01.458 & 01.416 & 01.374 & 01.332 & 01.290 & 01.248\end{array}$ $\begin{array}{llllllll}0.281 & 00.239 & 00.617 & 00.575 & 00.533 & 00.491 & 00.449 & 00.407 \\ 0.197 & 00.155 & 00.113 & 00.071 & 00.029 & * 99.987\end{array}$ $\begin{array}{llllllll}.861 & 99.819 & 99.777 & 99.734 & 99.693 & 99.651 & 99.609 & 99.566\end{array}$

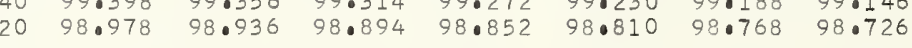

898.516

698.473

8.38

$98.347 \quad 98.305$

$\begin{array}{llllll}9.675 & 97.633 & 98.011 & 97.969 & 97.927 & 97.885 \\ 97.591 & 97.549 & 97.507 & 97.465\end{array}$ $\begin{array}{llllll}97.255 & 97.213 & 97.171 & 97.129 & 97.086 & 97.045\end{array}$ $\begin{array}{llllll}96.834 & 96.793 & 96.750 & 96.708 & 96.667 & 96.624\end{array}$ $\begin{array}{llllll}96.414 & 96.372 & 96.330 & 96.288 & 96.246 & 96.204 \\ 95.994 & 95.952 & 95.910 & 95.868 & 95.826 & 95.784\end{array}$ $\begin{array}{llllll}95.574 & 95.532 & 95.490 & 95.448 & 95.406 & 95.364\end{array}$

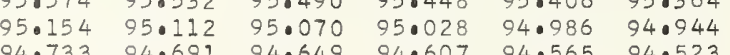

0.279318 0.279317 0.279316 0.279316

0.279316

.279325

0.279315

0.279314

0.279314

0.279313

0.279313
0.279313

0.279313
0.279312

0.279312

0.279312

0.279311

0.279311

0.279310

0.279310

0.279310

0.279310

0.279309

0.279309

0.279308

0.279308
0.279308

0.279308

0.279307

0.279307

0.279306

0.279306

0.279306

0.279306
0.279305

0.279305

0.279305

0.279304

0.279304

0.279304

0.279303

0.279303
0.279303

0.279302

0.279302

0.279302

0.279301

0.279301
0.279301

0.279300

0.279300

0.279300

0.27929

0.279299

0.279298

0.279298
0.279298

0.279298

0.279297

0.279297

0.279296

0.279296

0.279296

0.279296

0.279295

0.279295

0.279294

0.279294
0.279294

0.279294

0.279293

0.279293
0.279292

0.279292

0.279292

0.279292

0.279291

0.279291
0.279291

0.279290

0.279290

0.279290
0.279289

1.360277

1.360303 


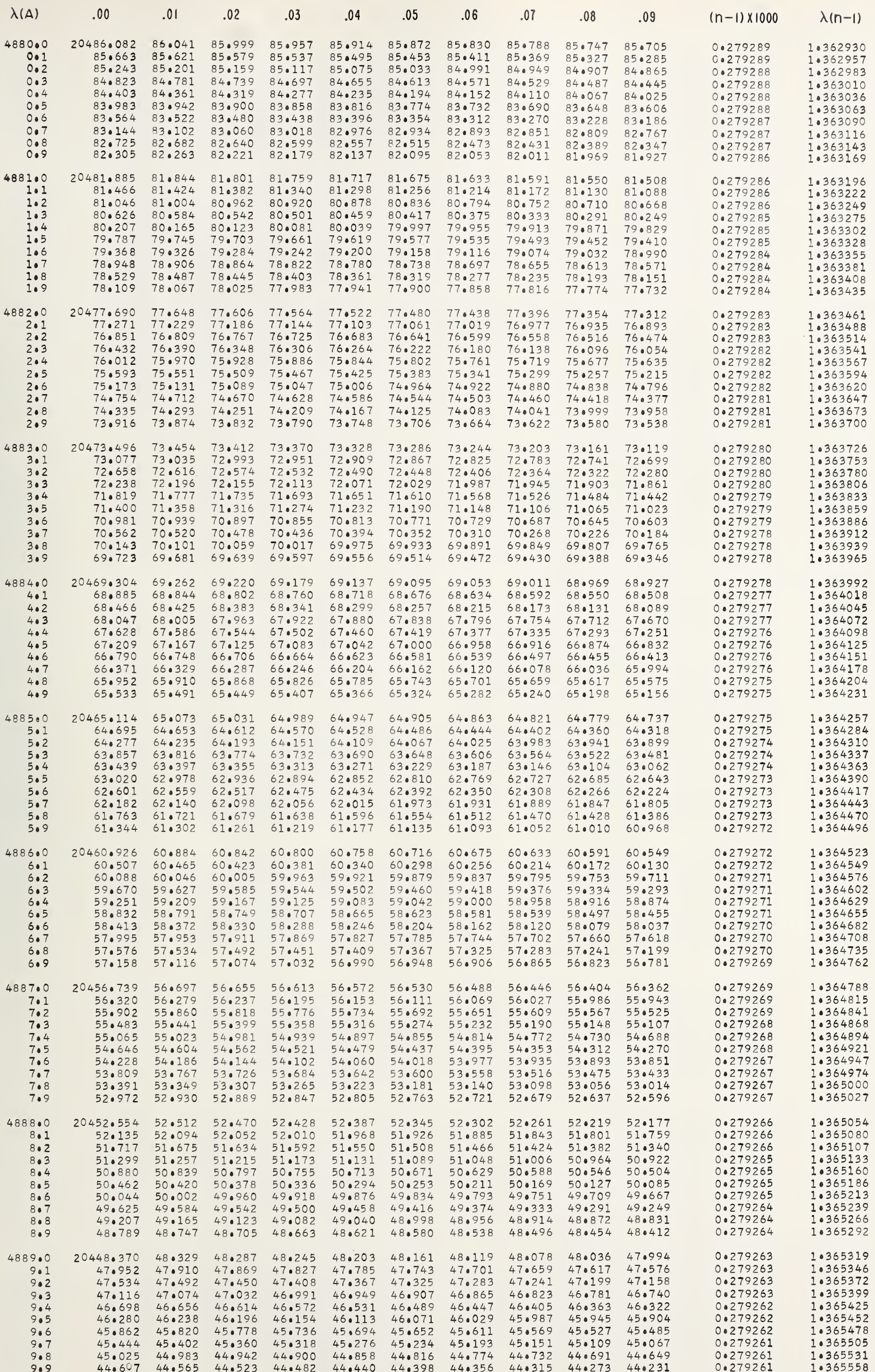


$39.173 \quad 39.132$

$\begin{array}{ll}38.338 & 38.296\end{array}$

$\begin{array}{ll}37.502 & 37.460 \\ 37.084 & 37.042\end{array}$

36.667
36.249

20435.831

$35.413 \quad 35.379$

34.578

$34 \cdot 160$
33.742

$33.325 \quad 33.70$

32.907
32.490

33.283

20431.654

$31.237 \quad 31.613$

30.819
30.402

$29.984 \quad 20.042$

$\begin{array}{lll}29.567 & 29.525 \\ 29.149 & 29.107\end{array}$

28.732
28.314
28.6990
27.0772 27.897

20427.47927 .438

$\begin{array}{ll}27.062 & 27.020 \\ 26.645 & 26.003\end{array}$

$\begin{array}{ll}26.227 & 26.186 \\ 25.810 & 25.769\end{array}$

25.393
25.036
24.0351
24.934

$\begin{array}{ll}24.976 & 24.934 \\ 24.0558 & 24.517 \\ 24.541 & 24.099\end{array}$

24.141
23.724

20423.307

22.890
22.472
22.05

$22.055 \quad 22.013$

$21.638 \quad 21.596$

$\begin{array}{ll}20.803 & 20.762 \\ 20.387 & 20.345\end{array}$

$\begin{array}{ll}190969 & 190927 \\ 19.552 & 19.511\end{array}$

39.926
39.50

40.302

41.848
41.430

42.224

$\begin{array}{ll}420600 & 42.55 \\ 42.183 & 42.141\end{array}$

0.279260

0.279260

0.279259

0.279259
0.27959
0.27259

0.279259

0.279258
0.279258

0.279258

0.279258
0.279257
0.27957

0.279257

0.279257
0.279256
0.27956

0.279256

0.279256

0.279255

0.279255

0.279254

0.279254
0.279254
0.27925

0.279254

0.279253

0.279253
0.279253

0.279252

0.279252

0.279252

$\begin{array}{lllllllll}31.571 & 31.529 & 31.487 & 31.446 & 31.404 & 31.362 & 310321 & 31.0279 \\ 31.153 & 310111 & 31.070 & 31.026 & 30.986 & 30.944 & 30.003 & 30.861\end{array}$

$\begin{array}{lllllllll}30.736 & 30.694 & 30.652 & 30.0610 & 300.569 & 30.5527 & 30.485 & 30.444 \\ 30.318 & 30.277 & 30.235 & 30.193 & 30.151 & 30.109 & 30.068 & 30.026\end{array}$

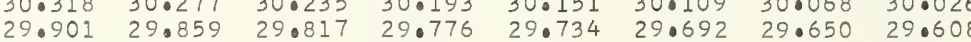

$\begin{array}{llllllll}29.483 & 29 \cdot 442 & 29 \cdot 400 & 29 \cdot 358 & 29 \cdot 316 & 29 \cdot 274 & 29 \cdot 233 & 29 \cdot 191\end{array}$

$\begin{array}{llllllll}29.066 & 29.024 & 28.082 & 28.940 & 28.899 & 28.857 & 28.815 & 28.773 \\ 28.648 & 28.607 & 28.565 & 28.523 & 28.481 & 28.440 & 28 \cdot 398 & 28.356\end{array}$

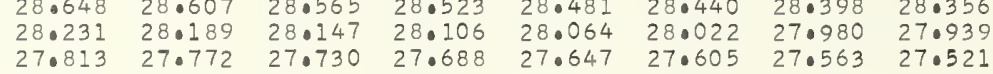

0.27925

0.027925

0.279251

0.279250

0.279250

0.279250

1.365584

1.3 .65637

1.355664

1.365717

1.365744

1.365797

.365823

1.365850

1.365876

1.365929

1.365956

1.365983
1.366009

1.366036

1.366062
1.365089

1.366115

1.366142

1.366168

$1 \cdot 366195$

1.366221
1.0366248
1.06270

1.366248
1.366275

1.366301

1.366328

1.366381

1.366407

1.366434

1.366460

1.366487
1.366513
1.366586

1.366540

1.366566

1.366593
1.366620

0.279249

$\begin{array}{llllllll}27.396 & 27.354 & 27.312 & 27.271 & 27.229 & 27.187 & 27 \cdot 146 & 27 \cdot 104 \\ 26.079 & 26.937 & 26.895 & 26.854 & 26.812 & 26.770 & 26.728 & 26.687\end{array}$

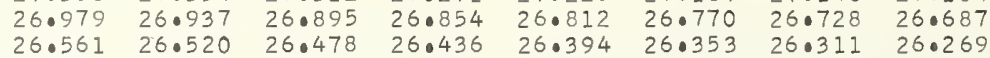

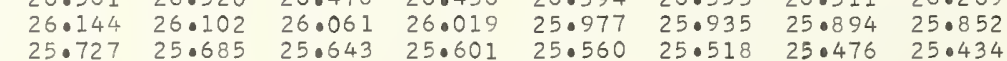

0.279249

1.366646

0.27248

0.279248

0.279248

0.279248

0.279247

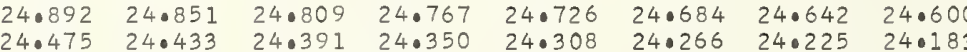

0.279247

$\frac{1}{1.366673}$

1.366726

1.366752

1.366779

1.366805

1.366832

1.366858
1.368885

0.279246

0.279246
0.279246
0.279246

0.279246
0.279246
0.279245

0.279245

0.279245

0.279245

0.279245
0.279244
0.279244

0.279244

1.366912

1.366938

1. 0.3669655

1.367018

1.367044

1.367071

1.367097

0.279244

0.279243

0.279243

0.279243

0.279242

0.279242

0.279242

0.279241

$\begin{array}{llllllllll}16.216 & 16.175 & 16.133 & 16.091 & 16.049 & 16.008 & 15.966 & 150925 & 15.883 & 15.841\end{array}$

$\begin{array}{lllllllllll}15.799 & 15.758 & 15.716 & 15.674 & 150633 & 15.591 & 15.549 & 15.508 & 150466 & 15.424 \\ 15.382 & 150341 & 150299 & 150257 & 150216 & 150174 & 15.132 & 150091 & 15.049 & 15.007\end{array}$

0.279241

$204140965 \quad 140924$

14.88

14.84

$14.799 \quad 14.757$

14.715

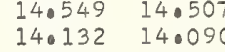

$13.715 \quad 13.673$

$\begin{array}{llllllll} & \end{array}$

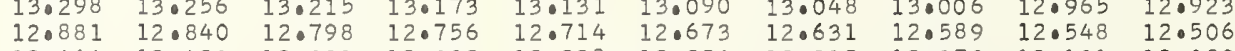

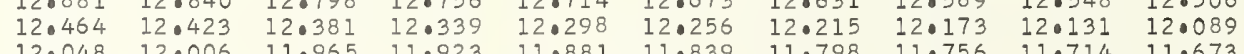

$\begin{array}{llllllllll}12.048 & 12.006 & 11.955 & 11.923 & 11.881 & 11.839 & 11.798 & 11.756 & 11.714 & 11.673 \\ 11.631 & 11.589 & 11.547 & 11.506 & 11.464 & 11.423 & 11.381 & 11.339 & 11.298 & 11.256\end{array}$

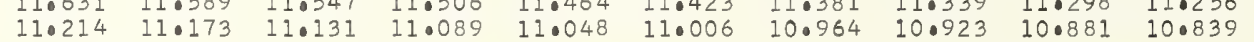

0.279241

0.279240

0.279239

0.279239

0.279239

0.279239

$\begin{array}{llllllllll}20410.797 & 10.756 & 10.714 & 10.672 & 10.631 & 10.589 & 10.547 & 10.506 & 10.464 & 10.423\end{array}$

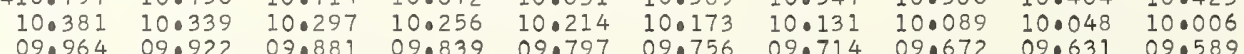
$\begin{array}{llllllllll}09.547 & 09.506 & 09.464 & 09.423 & 09.381 & 09.339 & 09.297 & 09.256 & 09.214 & 09.173\end{array}$ $\begin{array}{llllllllll}09.131 & 09.089 & 09.047 & 09.006 & 08.964 & 08.923 & 08.881 & 08.839 & 08.797 & 08.756\end{array}$ $\begin{array}{llllllllll}08.714 & 08.673 & 08.631 & 08 \cdot 589 & 08.548 & 08 \cdot 506 & 08.464 & 08.422 & 08 \cdot 381 & 08.339 \\ 08.298 & 08.256 & 08.214 & 08.173 & 08.131 & 08.089 & 08.047 & 08.006 & 07.964 & 07.922\end{array}$ $\begin{array}{llllllllll}08.298 & 08.256 & 08.214 & 08.173 & 08.131 & 08.089 & 08.047 & 08.006 & 07.964 & 07.922 \\ 07.881 & 07.839 & 07.798 & 07.756 & 07.714 & 07.673 & 07.631 & 07.589 & 07.548 & 07.506\end{array}$ $\begin{array}{llllllllll}07.881 & 07.839 & 07.798 & 07.756 & 07.714 & 07.673 & 07.631 & 07.589 & 07.548 & 07.506 \\ 07.464 & 07.423 & 07.381 & 07.340 & 07.298 & 07.256 & 07.214 & 07.173 & 07.131 & 07.089\end{array}$ $\begin{array}{llllllllll}07.048 & 07.006 & 06.964 & 06.923 & 06.881 & 06.840 & 06.798 & 06.756 & 06.715 & 06.673\end{array}$

0.279238 0.279238

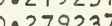
0.279237 0.279237 0.279236 0.279236 1.367150

1.367177 $\frac{1}{1.36767204}$ 1.367257 1.367283 1.367310 1.367336 1.367363 1.367389

$\begin{array}{rlllllllll}20406.631 & 06.590 & 06.548 & 06.506 & 06.465 & 06.423 & 06.381 & 06.339 & 06.298 & 06.256 \\ 06.215 & 06.173 & 06.131 & 06.090 & 06.048 & 06.006 & 05.965 & 05.923 & 05.881 & 05.840\end{array}$

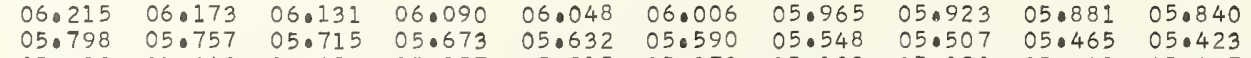

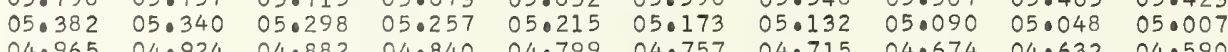

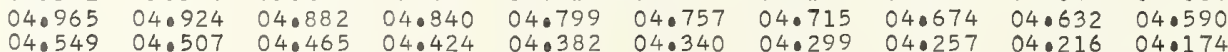

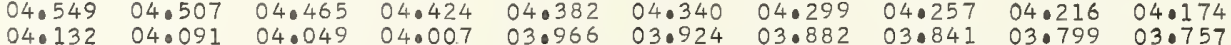
$\begin{array}{llllllllll}03.716 & 03.674 & 03.0633 & 03.591 & 03.549 & 03.507 & 03.466 & 03.424 & 03.383 & 03.341\end{array}$

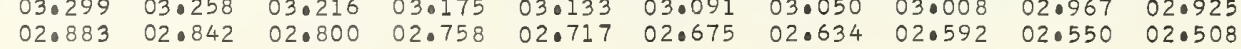

1.367442

1.367469

1.367496

1.367522
1.367549
1.3675602

1.367575

1. 1367602

1.367655 0.279236

1.367708 
$\lambda(A)$ .00 .01 .02 .03

4900.

0.2

0.3

0.5

0.7

0.9

4901.

$\begin{array}{rrr}1.0 & 20398.304 & 98.262 \\ 1.1 & 97.888 & 97.846\end{array}$

1.

1.0

1.05
1.07
1.8

1.8

4902.0

2.

2.3
2.4

2.5
2.6

2.6
$2 \bullet 7$

2.8
2.9

4903

3.1
3.2
3.3
3.4
3.5
3.6
3.7
3.8
3.9

3.8

4904.0

4905

5.0
5.
5.
5.
5.
5.0
5.0
5

4906

06.0
6.1
6.2
6.3
6.4
6.5
6.6
6.7
6.8
6.9

6.2
6.3
6.4

6.5

6.6

4907.

7.
7
7
7
7
7
7.0
7.0
7

4908.

8.

4909

9.1
9.0
9.
9.
9.
9.
9.

9.1
9.2
9.3
9.4
9.5
9.6
9.7
9.8
9.9

9.1
9.2
9.3
9.4
9.5
9.6
9.7
9.8
9.9

$\begin{array}{ll}402.467 & 02.425 \\ 02.051 & 02.009 \\ 01.634 & 01.593 \\ 01.218 & 01.176 \\ 00.802 & 00.760 \\ 00.385 & 00.344 \\ 99.969 & 99.927 \\ 99.553 & 99.511 \\ 99.136 & 99.095 \\ 98.720 & 98.678\end{array}$

$02.384 \quad 02.34$

$\begin{array}{ll}97.472 & 97.430 \\ 97.055 & 97.014\end{array}$

$96.639 \quad 96.598$

$96.223 \quad 96.182$

$95.391 \quad 95.350$

94.559

$20394.143 \quad 94 \cdot 101$

$93.727 \quad 93.6$

$92.895 \quad 92.853$

$91.231 \quad 91.189$

$90.399 \quad 90.357$

20389.983 89.567

$89.567 \quad 89.526$

$89.152 \quad 89.110$

$88.320 \quad 88.278$

$87.904 \quad 87.863$

$87.073 \quad 87.031$

$86.241 \quad 86.200$

20385.825

$85.410 \quad 85.784$

$84.994 \quad 84.952$

$84.163 \quad 84.121$

$83.747 \quad 83.70$

83.33183 .290

82.500
82.085

$82 \cdot 458$

99.46999 .842

98.22198 .179

$96.972 \quad 96.931$

$96.140 \quad 96.098$

$95.308 \quad 95.266$

94.892
94.476 94.850

$94.060 \quad 94.018$

93.22893 .186

$92.812 \quad 92.770$

$91.980 \quad 91.938$

$91.148 \quad 91.106$

$90.316 \quad 90.274$

$89.900 \quad 89.859$

$\begin{array}{ll}89.068 & 89.027 \\ 88.652 & 88.611\end{array}$

$\begin{array}{ll}88.237 & 88.195 \\ 87.821 & 87.779\end{array}$

$\begin{array}{ll}87.821 & 87.779 \\ 87.405 & 87.364\end{array}$

$\begin{array}{ll}86.989 & 86.948 \\ 86.573 & 86.532\end{array}$

$85.742 \quad 85.701$

$84.911 \quad 84.869$

$\begin{array}{ll}84.495 & 84.454 \\ 84.080 & 84.038\end{array}$

$\begin{array}{ll}83.664 & 83.623 \\ 83.248 & 83.207 \\ 82.833 & 82.791\end{array}$

$20381.669 \quad 81.62$

$\begin{array}{ll}81.254 & 81.212 \\ 80.839 & 80.797\end{array}$

$80.423 \quad 80.381$

78.76178 .720

$\begin{array}{ll}82.417 & 82.376 \\ 82.002 & 81.960\end{array}$

$81.586 \quad 81.54$

$80.756 \quad 80.71$

79.925
79.88

$78.761 \quad 78.720 \quad 78.678 \quad 78.636$

$\begin{array}{ll}78.346 & 78 \cdot 304 \\ 77.931 & 77.889\end{array}$

$\begin{array}{ll}78.263 & 78.221 \\ 77.847 & 77.806\end{array}$

$\begin{array}{llll}77.515 & 77.474 & 77.432 & 77.39 \\ 77.100 & 77.058 & 77.017 & 76.97 \\ 76.585 & 76.643 & 76.601 & 76.560\end{array}$

$\begin{array}{llll}76.685 & 76.643 & 76.601 & 76.560 \\ 76.269 & 76.228 & 76.186 & 76.1\end{array}$

$75.854 \quad 75.81$

$\begin{array}{llll}75.023 & 74.982 & 74.356 & 75.31\end{array}$

$\begin{array}{llll} & 74.940 & 74.898 \\ 4.608 & 74.567 & 74.525 & 74.48\end{array}$

$\begin{array}{ll}74 \cdot 193 & 74.151 \\ 73.778 & 73.736\end{array}$

74.110

$\begin{array}{rr}20373.362 & 73.32 \\ 72.947 & 72.906 \\ 72.532 & 72.491 \\ 72.117 & 72.075\end{array}$

73.280

$3.280 \quad 73.238$

$\begin{array}{llll}1.551 & 01.926 & 01.884 & 01.84 \\ 0.509 & 01.468 & 01.42\end{array}$

$\begin{array}{lll}0.135 & 01.093 & 010 \\ 00.718 & 00.677 & 00 .\end{array}$

$\begin{array}{lll}0.000 & 0.039\end{array}$

$99.803 \quad 99.76$

98.

$\begin{array}{ll}99.386 & 99.34 \\ 98.970 & 98.928\end{array}$

98.13798 .096

$\begin{array}{llll}97.388 & 97.347 & 97.721 & 97.68 \\ .05 & 97.26\end{array}$

$96.473 \quad 96.431$

95.64195 .599

$95.224 \quad 95.183$

$94 \cdot 808$
94.392

$94 \cdot 351$

$93.976 \quad 93.935$

$9.144 \quad 93.10$

$92.312 \quad 92.271$

$91.896 \quad 91.855$

$91.480 \quad 91.439$

$90.649 \quad 90.60$

90.233

$89.817 \quad 89.775$

$\begin{array}{ll}89.401 & 89.359 \\ 88.985 & 88.944\end{array}$

$88.569 \quad 88.528$

$87.738 \quad 87.696$

$87.322 \quad 87.281$

$86.006 \quad 86.281 \quad 87.239$

$\begin{array}{lll}86.906 & 86.865 & 86.82 \\ 86.491 & 86.449 & 86.407\end{array}$

$\begin{array}{llll}17 & 02.175 & 02.134 & 02.092 \\ 01 & 01.759 & 01.718 & 01.676\end{array}$

$\begin{array}{llll}01.801 & 01.759 & 01.718 & 01.676 \\ 01.385 & 01.343 & 01.301 & 01.260\end{array}$

$\begin{array}{llll}0.968 & 00.927 & 00.885 & 00.843\end{array}$

$\begin{array}{llll}00.552 & 00.510 & 00.469 & 00.427 \\ 00.135 & 00.094 & 00.052 & 00.011\end{array}$

$\begin{array}{llll}99.719 & 99.677 & 99.636 & 99.594\end{array}$

$\begin{array}{llll}9.303 & 99.261 & 99.220 & 99.178 \\ 98.887 & 98.845 & 98.803 & 98.762\end{array}$

$98.470 \quad 98.429 \quad 98.387 \quad 98.345$

$\begin{array}{llll}98.054 & 98.013 & 97.971 & 97.929 \\ 97.638 & 97.596 & 97.555 & 97.513\end{array}$

$\begin{array}{llll}97.222 & 97.180 & 97.139 & 97.097\end{array}$

$\begin{array}{llll}96.806 & 96.764 & 96.722 & 96.681\end{array}$

$\begin{array}{llll}95.973 & 95.932 & 95.890 & 95.849\end{array}$

$\begin{array}{llll}95.557 & 95.516 & 95.474 & 95.433\end{array}$

94.725

$\begin{array}{ll}95.058 & 95.016 \\ 94.642 & 94.601\end{array}$

$\begin{array}{llll}93.893 & 93.851 & 93.810 & 93.768\end{array}$

93.06

92.229

$91 \cdot 813$

90.981

89.733

88.9182

8.486

.071

$\begin{array}{lll}88.029 & 88.403 & 88.362 \\ 87.987 & 87.946\end{array}$

$\begin{array}{lll}87.613 & 87.572 & 87.530\end{array}$

$\begin{array}{lll}87.197 & 87.156 & 87.114\end{array}$

$\begin{array}{lll}86.781 & 86.740 & 86.698 \\ 86.366 & 86.324 & 86.283\end{array}$

$86.075 \quad 86.03$

85.99

$5.950 \quad 85.908 \quad 85.867$

$85.659 \quad 85.617$

84

$\begin{array}{lll}85.534 & 85.493 & 85.451\end{array}$

$\begin{array}{lll}85.119 & 85.077 & 85.035 \\ 84.703 & 84.662 & 84.620\end{array}$

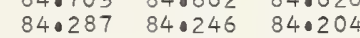

$83.996 \quad 83.955$

84.32

$\begin{array}{lll}83.581 & 83.539 & 83.49 \\ 83.165 & 83.124 & 83.08\end{array}$

$\begin{array}{lll}83.872 & 33.830 & 83.789\end{array}$

$\begin{array}{lll}83.456 & 83.415 & 83.373 \\ 83.041 & 82.999 & 82.957\end{array}$

$82.625 \quad 82.583 \quad 82.542$
82.209

$\begin{array}{lll}82.750 & 82.708 & 82.6\end{array}$

81.918

81.503

81.461

82.25
81.836

$82 \cdot 20$

81.75

81.711

80.67
80.25
79.84
79.426

81.046

81.420

$81 \cdot 37$

$\begin{array}{ll}81.337 & 81.295 \\ 80.922 & 80.880\end{array}$

$\begin{array}{llll}8.589 & 80.963 & 80.922 & 80.880 \\ 0.548 & 80.506 & 80.465\end{array}$

79.800

$\begin{array}{llllllll}79.094 & 79.052 & 79.011 & 78.384 & 79.343 & 79.301 & 79.260 & 79.218\end{array}$

78.59

78.553

8.927

$\begin{array}{lll}78.886 & 78.844 & 78.80\end{array}$

$\begin{array}{rrr}78.055 & 78.013 & 77.972\end{array}$

$\begin{array}{llllll}77.764 & 77.723 & 77.0981 & 78.055 & 78.013 & 77.972 \\ & 77.640 & 77.598 & 77.557\end{array}$

$77.349 \quad 77.307$

$77.266 \quad 77.224 \quad 77.183 \quad 77.141$

$76.934 \quad 76.892$

$\begin{array}{lll}76.518 & 76.492 & 76.851\end{array}$

$76 \cdot 103$
75.687
75.072

75.27

$\begin{array}{lllll}76.062 & 76.020 & 76.394 & 76.352 & 76.311 \\ 75.978 & 75.937 & 75.895\end{array}$

$\begin{array}{lllll}75.646 & 75.605 & 75.563 & 75.521 & 75.480\end{array}$

$\begin{array}{llllll}75.231 & 75.189 & 75.148 & 75.106 & 75.065 \\ 74.816 & 74.774 & 74.733 & 74.691 & 74.649\end{array}$

$\begin{array}{lllll}74 \cdot 816 & 74 \cdot 774 & 74 \cdot 733 & 74 \cdot 691 & 74 \cdot 649 \\ 74.400 & 74.359 & 74.318 & 74.276 & 74.234\end{array}$

$\begin{array}{llllll}74.442 & 74.400 & 74.359 & 74.318 & 74.276 & 74.234 \\ 74.027 & 73.985 & 73.944 & 73.902 & 73.860 & 73.819 \\ 73.611 & 73.570 & 73.529 & 73.487 & 73.446 & 73.404\end{array}$

$(n-1) \times 1000$

$\lambda(n-1)$

0.279232

0.279232

0.279231

0.279231

0.279230
0.279230

0.279230

0.279229

0.279229

0.279229
0.279228

0.279228
0.279228

0.279228

0.279227
0.279227

0.279227

0.279226

0.279226

0.279225

0.279225

0.279225

0.279224

0.0279224
0.272223
0.27222

0.279223

0.279223

0.279222

0.279222

0.279222
0.279221

0.279221

0.279221

0.279221

0.279220

0.279220
0.279220

.279219

0.279219
0.279219

0.279218

0.279218

0.279218

0.279217

0.279217

0.279216

0.279216

0.079279
0.279225

0.27921

0.0279214
0.279214

0.279214
0.279214
0.279213

0.279213
0.279213

0.279213

0.279213

0.279212
0.279212

0.279212

0.279211
0.279211

0.279211

0.279210

0.279210

0.279210
0.279209

0.279209 
$4910.0 \quad 20360.914 \quad 60.873$

$0.1 \quad 60.500 \quad 60.458$

$\begin{array}{lll}0.2 & 60.085 & 60.044 \\ 0.3 & 59.670 & 59.629\end{array}$

$\begin{array}{lll}0.4 & 59.256 & 59.214 \\ 0.5 & 58.841 & 58.800\end{array}$

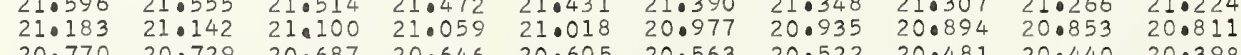
$\begin{array}{llllllllll}20.770 & 20.729 & 20.687 & 20.646 & 20.605 & 20.563 & 20.522 & 20.481 & 20 \cdot 440 & 20.0398\end{array}$ $\begin{array}{llllllllll}20.357 & 20.315 & 20.274 & 20.233 & 20.192 & 20.150 & 20.109 & 20.068 & 20.026 & 19.985 \\ 19.944 & 19.903 & 19.861 & 19.820 & 19.779 & 19.738 & 19.696 & 19.655 & 19.614 & 19.572\end{array}$

$(n-1) \times 1000$

$\lambda(n-1)$

0.279204 0.279204
0.279204
0 0.0279204
0.279203
0.279203 0.279203 0.279223
0.279202 0.279202
0.279202
0.279202 0.279202

0.279202 0.279201
0.279201
0.27921

0.279201

0.279200
0.279200
0.27920

0.279200

0.279200

0.279199
0.279199

0.279199
0.279199

0.279199
0.279198
0.279198

0.279198
0.279198
0

0.279197

0.279197

0.279197

0.279196

0.279196

0.279195

0.279195

0.279195
0.279195

0.279194

0.279194
0.279194
0.27904

0.279193

0.279193

0.279192

0.279192

0.279192

0.279191
0.279191

0.279191

0.279190

0.279190

0.279190

0.279189

0.279189

0.279189

0.279189
0.279188

0.279188

0.279188

0.279187
0.279187
0.2797

0.279187 0.279186 0.279186 0.279185
0.279185

0.279185

0.279185
0.279184
0.279184

0.279184

0.279184
0.279183

0.279183

0.279183

0.279183
0.279182

0.279182

0.079182

.279182

0.279181
0.279181

0.279181
0.279180
0.27980

0.279180

0.279180
0.279180

1.370894
1.370920

1.370920
1.370947

1.370973
1.371000

1. 371026

1.371079

1.371106
1.371132

1.371159

1.371186

1.371239

1.371265

1.371292
1.371318

1.371345

10371398

1.371425

1. 371478

1.371504

1.371557

1.371584
1.371610

1.3716637
1.371663

1.371690

1.371717

1.0371770

1.371796

1.371823
1.371849

1. 371876

1.3711902
1.371929

1.371956

1.372009

.0372035
1.372062

1.372062
1.372088

1.372115

1.372141
1.3721168

1.372221

1.372248

1.372301

1. 372354

1.372354

1.372380

1.372433

1.372487

1.372513

1.372540

1.372566
1.372593

1.372619

1.372646

1.372699

1.372752

1.372779

1.372805
1.372832

1.372858

1.372885
1.372911

1.372938

1.372964
1.372991

0.279179

0.279179
0.279179
0.279798

0.279179

0.279178

0.279177

0.279177

1.373018
1.373044

1.073071

1.373097
1.373124

1.373150
1.373177

1.0373203

1
1.303732250
1.3732

10373283

1. 373310

1.373363

1.373389 

$\begin{array}{rrr}20319.531 & 19.490 \\ 19.118 & 19.077\end{array}$

0.1

0.2

$\begin{array}{ll}18.705 & 18.6 \\ 18.292 & 18.250\end{array}$

$\begin{array}{llllllll}19.448 & 19.407 & 19.366 & 19.324 & 19.283 & 19.242 & 19.201 & 19.159 \\ 19.035 & 18.994 & 18.953 & 18.912 & 18.870 & 18.829 & 18.788 & 18.746\end{array}$

$\begin{array}{llllllll}0.4 & 17.879 & 17.838 & 17.797 & 17.755 & 17.714 & 17.673\end{array}$

0.5

$\left.\begin{array}{llllll}17.466 & 17.425 & 17.384 & 17.342 & 17.301 & 17.260\end{array}\right]$

0.7

$\begin{array}{llllllllll}17.053 & 17.012 & 16.971 & 16.929 & 16.888 & 16.847 & 16.806 & 17.177 & 17.136 & 17.095\end{array}$

0.8

$\begin{array}{ll}16.228 & 16.186 \\ 15.814 & 15.773\end{array}$

4921.0

1.0
1.1
1.2
1.3
1.4
1.5
1.6
1.7
1.8
1.9

\begin{tabular}{|c|c|c|c|c|c|}
\hline 15.402 & 15.361 & 15.319 & 15.278 & 15.237 & 15.195 \\
\hline 989 & $14 \cdot 948$ & 14.906 & 14.865 & $14 \cdot 824$ & 14.782 \\
\hline 14.576 & 14.535 & 14.494 & 14.453 & 14.411 & 14.370 \\
\hline 14.164 & $14 \cdot 122$ & 14.081 & 14.040 & 13.999 & 13.958 \\
\hline 751 & 13.709 & 13.668 & 13.627 & 13.586 & 13.545 \\
\hline 338 & 13.297 & 13.256 & 13.214 & 13.173 & $13 \cdot 132$ \\
\hline & 12.884 & 12.843 & 12.802 & 12.760 & 12.719 \\
\hline 13 & 12.471 & 12.430 & 12.389 & 12.348 & 12.306 \\
\hline & 12.059 & 12.017 & 11.976 & 11.935 & 1.894 \\
\hline & 11.646 & 11.605 & 1.563 & 11.522 & 1.1 .481 \\
\hline
\end{tabular}

4922

2.
2.
2.
2.
2.
2.0
2.07
2
2.0

$20311.275 \quad 11.234$

10.86

$10.037 \quad 09.495$

$09.624 \quad 09.583$

$08.799 \quad 08.758 \quad 08.716$

$\begin{array}{ll}08.386 & 08 \cdot 345 \\ 07.974 & 07.933 \\ 07.561 & 07.520\end{array}$

$11.192 \quad 11.151$

$11.109 \quad 11.068$

$\begin{array}{llll}16.806 & 16.764 & 16.723 & 16.681\end{array}$

307.149

4923.0

3.

3.

06.737

$06.737 \quad 06.69$

05.91105 .870

$05.086 \quad 05.045$

$04.262 \quad 04.221$

$03.437 \quad 03.396$

20303 .

4924.0

$4 \cdot 1$

02.

02.61202 .571

$\begin{array}{ll}02.200 & 02.159 \\ 01.788 & 01.747\end{array}$

$01.376 \quad 01.334$

$\begin{array}{ll}00.963 & 00.922 \\ 00.551 & 00.510\end{array}$

$\begin{array}{lll}00.551 & 00.510 & 00.469 \\ 00.139 & 00.098 & 00.0556\end{array}$

20299.727

99.68

20298.90

4925

5.2

5.2

$5 \cdot 4$

5.6
5.7
5.8

$5 \cdot 8$

4926

6
6
6
6
6
6
6
6
6

4927

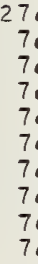

98.49098.

$98.078 \quad 98.037$

$97.666 \quad 97.62$

$96.842 \quad 96.801$

$9.430 \quad 96.38$

$95.605 \quad 95.56$

$95.194 \quad 95.152$

$\begin{array}{ll}10.738 \\ 10.367 & 10.326\end{array}$

$\begin{array}{ll}0.542 & 09.500\end{array}$

$\begin{array}{ll}10.697 & 10.656 \\ 10.284 & 10.243\end{array}$

$09.872 \quad 09.830$

$\begin{array}{ll}09.459 & 09.41 \\ 09.046 & 09.005\end{array}$

$\begin{array}{llll}15.980 & 15.938 & 15.897 & 15.856 \\ 15.567 & 15.526 & 15.484 & 15.443\end{array}$

$15.154 \quad 15.113 \quad 15.072 \quad 15.031$

$\begin{array}{llll}14.741 & 14.700 & 14.659 & 14.617 \\ 14.329 & 14.288 & 14.246 & 14.20\end{array}$

$\begin{array}{llll}13.916 & 13.875 & 13.833 & 13.792\end{array}$

$\begin{array}{llll}13.503 & 13.462 & 13.421 & 13.379 \\ 13.091 & 13.049 & 13.008 & 12.967\end{array}$

$\begin{array}{llll}12.678 & 12.636 & 12.595 & 12.554\end{array}$

$\lambda(n-1)$

0.279177

0.279176

0.279176

0.279174
0.279174

0.279174

0.0279173

0.279173

0.279172

0.27917

0.279171

0.279171
0.279171

0.279170

0.279170

0.279170

0.27916

0.279169
0.279169

1.373549

1.373575

1.373628

1.373655
1.373681

1.373708

1.373761
1.373788

1.373814

1.373841
1.373867

1.373894

1.3373920
1.373947

$1 \cdot 373973$

1.374027

1.374080

1.374106

1.374159

1.374186

.374239

1.374266

1.374292
1.374319

0.279168

0.0279168

1.374345

0.279167

0.279167
0.279167
0.279167

1.374398

1.374425

1.374451

1.374505

1.374531

1.374558
1.374584

0.279166

0.279165

0.279165

1.374611

1.374664

1.374690
.374717

0.279164

0.279164
0.279164

0.279164

0.279163

1.374744

1.374797

. 374823

0.279163

0.279162

1.374876

0.279162
0.279162

0.279161

0.279161

0.279160

1.374903

1.374929

1.374956

1.374983
1.375009

$97.08997 .048 \quad 97.007 \quad 96.965 \quad 96.924 \quad 96.883$

$96.759 \quad 96.718 \quad 96.67796 .63596 .594 \quad 96.553 \quad 96.512 \quad 96.471$

0294.78

9.93595 .894

$95.853 \quad 95.811 \quad 95.770 \quad 95 \cdot 729 \quad 950688 \quad 950647$

0.279160

1.375036

1.375089

0.279160

0.279160

$93.793 \quad 93.751 \quad 93.710 \quad 93.66993 .628 \quad 93.587$

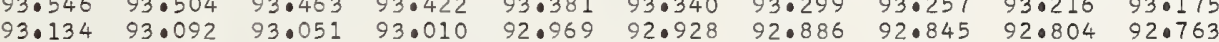

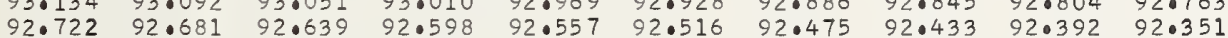

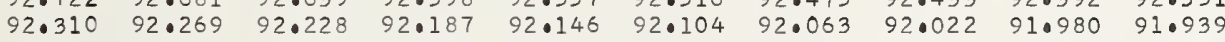

$\begin{array}{lllllllll} & \end{array}$

$\begin{array}{llllllllll}91.486 & 91.445 & 91.404 & 91.363 & 91.322 & 91.281 & 91.239 & 91.198 & 91.157 & 91.116 \\ 91.074 & 91.033 & 90.992 & 90.951 & 90.910 & 90.869 & 90.827 & 90.786 & 90.745 & 90.704\end{array}$

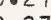

0.279159

0.279158

0.279158

0.279158

1.375142

1.375168

1.375221

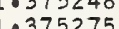

.375301

1.375328

0.279157

0.279157

$\begin{array}{rlllllllll}90.251 & 90.622 & 90.581 & 90.539 & 90.498 & 90.457 & 90.416 & 90.375 & 90.333 & 90.292 \\ 90.209 & 90.168 & 90.127 & 90.086 & 90.045 & 90.004 & 89.963 & 89.921 & 89.880 \\ 89.839 & 89.798 & 89.757 & 89.816 & 89.674 & 89.633 & 89.592 & 89.551 & 89.510 & 89.460\end{array}$

$90.251 \quad 90.209 \quad 90.168 \quad 90.127$

$\begin{array}{llll}89.427 & 89.386 & 89.755 & 89.304\end{array}$

$89.016 \quad 88.974$

$88.604 \quad 88.563 \quad 88.522 \quad 88.480$

\begin{tabular}{llllll}
89.262 & 89.0321 & 89.592 & 89.551 & 89.510 & 89.4 \\
\hline & 890 & 89.139 & 89.098 & 89.057
\end{tabular}

$\begin{array}{llllllll} & \end{array}$

$\begin{array}{llllllllll}87.368 & 87.327 & 87.286 & 87.657 & 87.616 & 87.574 & 87.533 & 87.492 & 87.451 & 87.410\end{array}$

$\begin{array}{llllllllll}87.368 & 87 \cdot 327 & 87.286 & 87 \cdot 245 & 87.204 & 87 \cdot 163 & 87 \cdot 122 & 87 \cdot 080 & 87 \cdot 039 & 86 \cdot 998 \\ 86.957 & 86.916 & 86.875 & 86.833 & 86.792 & 86.751 & 86.710 & 86.669 & 86.627 & 86.586\end{array}$

$\begin{array}{lllllllllll}4928.0 & 20286.545 & 86.504 & 86.463 & 86.422 & 86.381 & 86.339 & 86.298 & 86.257 & 86.216 & 86.175\end{array}$ $\begin{array}{lllllllllll}86.134 & 86.093 & 86.051 & 86.010 & 85.969 & 85.928 & 85.887 & 85.845 & 85.804 & 85.763 \\ 85.722 & 85.681 & 85.640 & 85.598 & 85.557 & 85.516 & 85.475 & 85.434 & 85.0393 & 85.352\end{array}$ $\begin{array}{llllllllll}85.722 & 85.681 & 85.640 & 85.5998 & 85.557 & 85.516 & 85.475 & 85.434 & 85.393 & 85.352 \\ 85.310 & 85.269 & 85.228 & 85.078 & 85.146 & 85.05 & 85.053 & 85.022 & 84.981 & 84.940\end{array}$ $\begin{array}{llllllllll}85.310 & 85.269 & 85.228 & 85.187 & 85.146 & 85.105 & 85.053 & 85.022 & 84.981 & 84.940 \\ 84.899 & 84.857 & 84.816 & 84.775 & 84.734 & 84.693 & 84.652 & 84.611 & 84.570 & 84.528\end{array}$ $\begin{array}{llllllllll}84.899 & 84 \cdot 857 & 84 \cdot 816 & 84.775 & 84.734 & 84.693 & 84.652 & 84 \cdot 611 & 84.570 & 84.528 \\ 84.487 & 84.446 & 84.405 & 84.364 & 84.323 & 84.281 & 84.240 & 84.199 & 84.158 & 84.117\end{array}$ $\begin{array}{llllllllll}84.076 & 84.035 & 83.993 & 83.952 & 83.911 & 83.870 & 84 \cdot 240 & 84.199 & 84.158 & 84.117 \\ 83.787 & 83.746 & 83.705\end{array}$ $\begin{array}{llllllllll}83.664 & 83.623 & 83.582 & 83.541 & 83.500 & 83.458 & 83.417 & 83.376 & 83.335 & 83.294\end{array}$ $\begin{array}{lllllllllll}83.253 & 83.211 & 83.170 & 83.129 & 83.088 & 83.047 & 83.006 & 82.964 & 82.923 & 82.882 \\ 82.841 & 82.800 & 82.759 & 82.718 & 82.676 & 82.635 & 82.594 & 82.553 & 82.512 & 82.471\end{array}$

0.279157

0.279156

0.279156

0.279155

0.279155

1.375381

0.279154

0.279154

0.279154

0.279153

0.279153

0.279152

1.375407

1.375434

1.375487

1.375514

1.375567

1.375593

1.375646

0.279152

1.375673

1.375699

1.375753
1.375779

1.375806

1.375832

1.375885

0.279152

0.279151

1.375938

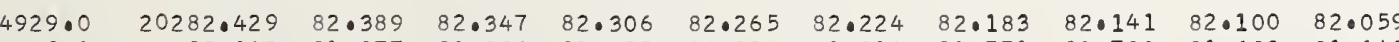
$\begin{array}{llllllllll}82.018 & 81.977 & 81.936 & 81.895 & 81.854 & 81.812 & 81.771 & 81.730 & 81.689 & 81.648\end{array}$ $\begin{array}{llllllllll}81.607 & 81.565 & 81.524 & 81.483 & 81.442 & 81.401 & 81.360 & 81.319 & 81.278 & 81.236 \\ 81.195 & 81.154 & 81.113 & 81.072 & 81.031 & 80.989 & 80.948 & 80.907 & 80.866 & 80.825\end{array}$

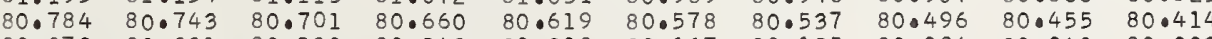
$\begin{array}{lllllllllll}80.372 & 80.331 & 80.290 & 80.249 & 80.208 & 80.167 & 80.125 & 80.084 & 80.043 & 80.002\end{array}$ $\begin{array}{lllllllllll}79.961 & 79.920 & 79.879 & 79.837 & 79.796 & 79.755 & 79.714 & 79 \cdot 673 & 79 \cdot 632 & 79 \cdot 591\end{array}$ $\begin{array}{llllllllll}79.550 & 79.509 & 79.467 & 79.426 & 79.385 & 79.344 & 79.303 & 79.261 & 79.220 & 79.179\end{array}$

$\begin{array}{llllllllll}79.138 & 79.097 & 79.056 & 79.015 & 78.974 & 78.932 & 78.891 & 78.850 & 78.809 & 78.768 \\ 78.727 & 78.686 & 78.645 & 78.604 & 78.562 & 78.521 & 78.480 & 78.439 & 78.398 & 78.356\end{array}$

0.279151

0.279151

0.279150

0.279150

0.279149
0.279149

1.375965

1.375992
1.376018

1.376045

1.376071

1.376098

1.376151
1.376177

.010

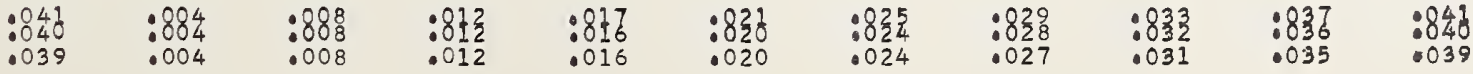


$4930.0 \quad 20278.315$

0.2

0.5

0.8
0.9

$4931.0 \quad 20274.203$

$1: 2$

$1.3 \quad 73.381$

1.7

4932.

2.1

2.3

2.5

2.6
2.7

2.8

4933.

3.1
3.2
3.3

3.3

3.5

3.7
3.8
3.9

401

4. 2

4.5

$4 \cdot 6$

4.9

4935.

$5 \cdot 2$

5.3

5.4
5.5

5.6
5.7

5.7
5.8

4936.0

6.1

6.3

6.5

6.6

6. 8

4937.

$7 \cdot 1$

$7 \cdot 3$

7.5
7.6

7.7

7.8
7.9

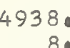

8.1
8.2

8.3
8.4

8.5

8.8

77.082
76.670

76.259

75.025
74.614

20274.203
73.792

72.969
72.559

20270.093

68.860

20265.983

261.876

61.066

56.12

55.718

$54 \cdot 897$
54.487

20253.666

20245.46
$75.848 \quad 75.807$

$71.736 \quad 71.695$

70.914
70.503

69.682

68.449
68.038

$68.038 \quad 67.99$

67.216
66.805

66.805
66.394

65.573
65.162

$64 \cdot 751$

63.929

63.108
62.698

60.64460 .01014

$60.234 \quad 60.192$

$59.412 \quad 59: 310$

$\begin{array}{ll}58.591 & 58.550 \\ 58.181 & 58.140\end{array}$

$20257.770 \quad 57.729$

$57.360 \quad 57 \cdot 31$

$56.539 \quad 56.498$

55.308

$52.846 \quad 52.80$

$52.435 \quad 52.394$

$\begin{array}{ll}51.943 & 51.9 \\ 51.533 & 51.9492\end{array}$

$51.205 \quad 51.164 \quad 51.123$

$50.794-50.753 \quad 50.71250 .0$

$\begin{array}{ll}50.384 & 50.343 \\ 49.974 & 49.933\end{array}$

$49.154 \quad 49.113 \quad 49.4$

$48.333 \quad 48.702$

$47.924 \quad 47.88$

$47.513 \quad 47.473$

$\begin{array}{ll}47.104 & 47.062 \\ 46.693 & 46.65\end{array}$

$46.283 \quad 46.242$ 46.283
45.873

$4.463 \quad 45.423$ $45.053 \quad 45.012 \quad 44.971$ $\begin{array}{lll}44.603 & 44.562 & 44.53\end{array}$ $44.233 \quad 44.192 \quad 44.151 \quad 44.111$ $\begin{array}{llll}43.823 & 43.782 & 43.741 & 43.700\end{array}$ $\begin{array}{llll}43.414 & 43.373 & 43.332 & 43.291 \\ 43.004 & 42.963 & 42.922 & 42.881\end{array}$ $42.594 \quad 42.553 \quad 42.512 \quad 42.471$ $\begin{array}{lll}42.184 & 42.143 & 42.102 \\ 41.774 & 41.733 & 41.692\end{array}$

$20241.364 \quad 41.323 \quad 41.282 \quad 41.24$ $40.954 \quad 40.913$

$\begin{array}{lll}40.545 & 40.504 & 40.87\end{array}$

$\begin{array}{llll}40.135 & 40.094 & 40.053 & 40.01\end{array}$

$39.725 \quad 39.684 \quad 39.643 \quad 39.60$

$\begin{array}{lll}39.315 & 39.274 & 39.23\end{array}$

$38.865-38.824$
38.783

$\begin{array}{llll}38.496 & 38.455 & 38.414 & 38.373 \\ 38.086 & 38.045 & 38.004 & 37.063\end{array}$

$38 \cdot 783$
38.373
$37 \cdot 963$

$37.594 \quad 37.5$
.003

$\begin{array}{ll}78.151 & 78.110 \\ 77.740 & 77.69 \\ 77.328 & 77.28 \\ 76.917 & 76.87 \\ 76.506 & 76.46\end{array}$

$\begin{array}{llll}78.069 & 78.027 & 77.987 & 77.945\end{array}$

$\begin{array}{lllll}77.246 & 77.0165 & 77.575 & 77.534\end{array}$

$\begin{array}{llll}76.835 & 76.794 & 76.752 & 76.711\end{array}$

$\begin{array}{lllll}76.012 & 75.971 & 75.930 & 75.889\end{array}$

$\begin{array}{lllll}75.601 & 75.560 & 75.519 & 75.478\end{array}$

$75.683 \quad 75.642$

$75.272 \quad 75.231$

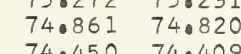

$74 \cdot 779$

$\begin{array}{lll}75.149 & 75.108 & 75.067 \\ 74.737 & 74.696 & 74.655\end{array}$

$\begin{array}{lll}74.326 & 74.285 & 74.244\end{array}$

$\begin{array}{lllll}73.956 & 73.915 & 73.874 & 73.833\end{array}$

$\begin{array}{llll}73.545 & 73.504 & 73.463 & 73.422\end{array}$

$\begin{array}{llll}72.723 & 72.682 & 72.641 & 72.600\end{array}$

$\begin{array}{llll}72.312 & 72.271 & 72.229 & 72.188\end{array}$

$\begin{array}{llll}71.901 & 71.860 & 71.819 & 71.778\end{array}$

$\begin{array}{lllll}71.099 & 71.038 & 70.908 & 71.366\end{array}$

70.668

71.038

70.627

0.58

69.846

69.805

69.394

68.572

68.161

67.339

66.929

66.107

$.764 \quad 69.723$

$69.353-69.312$

68.53268 .901

$6.120 \quad 68.070$

$\begin{array}{ll}67.709 & 67.668\end{array}$

$66.887 \quad 66.846$

$\begin{array}{ll}66.641 & 66.600 \\ 66.230 & 66.189\end{array}$

66.148

65.696

$6.066 \quad 66.025$

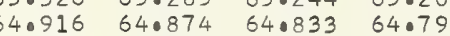

$\begin{array}{llllll}64.587 & 64.546 & 64.505 & 64.463 & 64.422 & 64.382 \\ 64.176 & 64.135 & 64.094 & 64.053 & 64.012 & 63.970 \\ 63.765 & 63.724 & 63.683 & 63.642 & 63.601 & 63.560\end{array}$

$\begin{array}{llllll}64.176 & 64.135 & 64.094 & 64.053 & 64.012 & 63.970 \\ 63.765 & 63.724 & 63.683 & 63.642 & 63.601 & 63.560\end{array}$

$\begin{array}{llllll}63.355 & 63.314 & 63.272 & 63.231 & 63.190 & 63.149\end{array}$

$62.944 \quad 62.903 \quad 62.862 \quad 62.821 \quad 62.780 \quad 62.739$

$\begin{array}{llll}62.451 & 62.410 & 62.369 & 62.328 \\ 62.040 & 61.999 & 61.958 & 61.917\end{array}$

$62.122 \quad 62.082$

$\begin{array}{llllll}61.712 & 61.671 & 61.630 & 61.589 & 61.548 & 61.507 \\ 61.301 & 61.260 & 61.219 & 61.178 & 61.137 & 61.096\end{array}$

1.58

1.548

$\begin{array}{llllll}61.712 & 61.671 & 61.630 & 61.589 & 61.548 & 61.507 \\ 61.301 & 61.260 & 61.219 & 61.178 & 61.137 & 61.096\end{array}$

$\begin{array}{llllll}60.890 & 60.849 & 60.809 & 60.768 & 60.726 & 60.685\end{array}$

$\begin{array}{llllll}60.480 & 60.439 & 60.398 & 60.357 & 60.315 & 60.27\end{array}$

$\begin{array}{lllllll}59.659 & 59.618 & 59.577 & 59.536 & 59.495 & 59.453\end{array}$

$\begin{array}{llllll}59.248 & 59.207 & 59.166 & 59.125 & 59.084 & 59.043 \\ 58.838 & 58.797 & 58.756 & 58.715 & 58.674 & 58.533\end{array}$

58.427

58.386

58.756

$58 \cdot 304$
$57 \cdot 894$

$58 \cdot 263$

8.222

$\begin{array}{llll}57.524 & 57.483 & 57.442 & 57.401\end{array}$

$\begin{array}{llll}57.114 & 57.073 & 57.031 & 56.990\end{array}$

$\begin{array}{llll}56.293 & 56.252 & 56.210 & 56.170\end{array}$

$\begin{array}{llll}55.882 & 55.841 & 55.800 & 55.759\end{array}$

$\begin{array}{llll}55.472 & 55.431 & 55.390 & 55.349\end{array}$

$\begin{array}{llllll}55.144 & 55.103 & 55.062 & 55.020 & 54.979 & 54.938 \\ 54.733 & 54.692 & 54.651 & 54.610 & 54.569 & 54.528 \\ 54.323 & 54.282 & 54.241 & 54.200 & 54.159 & 54.118 \\ 53.912 & 53.872 & 53.830 & 53.789 & 53.748 & 53.707\end{array}$

$\begin{array}{llllll}54.733 & 54.692 & 54.651 & 54.610 & 54.569 & 54.528 \\ 54.323 & 54.282 & 54.241 & 54.200 & 54.159 & 54.118 \\ 53.912 & 53.872 & 53.830 & 53.789 & 53.748 & 53.707\end{array}$

$\begin{array}{llllll}53.502 & 53.461 & 53.420 & 53.379 & 53.338 & 53.297\end{array}$

$\begin{array}{llllll}53.092 & 53.051 & 53.010 & 52.969 & 52.927 & 52.886\end{array}$

$\begin{array}{llllll}52.271 & 52.230 & 52.189 & 52.148 & 52.107 & 52.066\end{array}$

$\begin{array}{llllll}51.861 & 51.820 & 51.779 & 51.738 & 51.697 & 51.656\end{array}$

$\begin{array}{llllll}51.451 & 51.410 & 51.368 & 51.327 & 51.287 & 51.246 \\ 51.041 & 51.000 & 50.958 & 50.917 & 50.876 & 50.835\end{array}$

$\begin{array}{llllll}51.041 & 51.000 & 50.958 & 50.917 & 50.876 & 50.835 \\ 50.630 & 50.589 & 50.549 & 50.507 & 50.466 & 50.425\end{array}$

$\begin{array}{llllll}50.220 & 50.179 & 50.138 & 50.097 & 50.056 & 50.015\end{array}$

$\begin{array}{llllll}49.400 & 49.359 & 49.318 & 49.277 & 49.236 & 49.195 \\ 48.990 & 48.949 & 48.908 & 48.867 & 48.826 & 48.785\end{array}$

$\begin{array}{llllll}48.990 & 48.949 & 48.908 & 48.867 & 48.826 & 48.785 \\ 48.579 & 48.538 & 48.498 & 48.457 & 48.416 & 48.375\end{array}$

$\begin{array}{llllll}48.169 & 48.128 & 48.087 & 48.046 & 48.005 & 47.965\end{array}$

$\begin{array}{llllll}47.760 & 47.719 & 47.678 & 47.636 & 47.595 & 47.554 \\ 47.349 & 47.308 & 47.267 & 47.226 & 47.186 & 47.145\end{array}$

$\begin{array}{llllll}46.940 & 46.899 & 46.858 & 46.817 & 46.775 & 46.734\end{array}$

$\begin{array}{llllll}46.529 & 46.488 & 46.448 & 46.406 & 46.365 & 46.324\end{array}$

$\begin{array}{llllll}46.119 & 46.078 & 46.037 & 45.996 & 45.955 & 45.915 \\ 45.709 & 45.668 & 45.627 & 45.586 & 45.545 & 45.504\end{array}$

$\begin{array}{lllllll}45.299 & 45.258 & 45.217 & 45.176 & 45.135 & 45.094\end{array}$

$\begin{array}{llllll}44.889 & 44.848 & 44.807 & 44.766 & 44 \cdot 725 & 44 \cdot 684\end{array}$

$\begin{array}{llllll}44.069 & 44.028 & 43.987 & 43.946 & 43.905 & 43.865\end{array}$

$\begin{array}{lllllll}43.659 & 43.619 & 43.578 & 43.537 & 43.496 & 43.455\end{array}$

$\begin{array}{lllllll}43.250 & 43.209 & 43.167 & 43.126 & 43.086 & 43.045\end{array}$

$\begin{array}{llllll}42.840 & 42.799 & 42.758 & 42.717 & 42.676 & 42.635 \\ 42.430 & 42.389 & 42.348 & 42.307 & 42.266 & 42.22\end{array}$

$\begin{array}{llllll}42.020 & 41.979 & 41.938 & 41.897 & 41.856 & 41.815 \\ 41.610 & 41.569 & 41.528 & 41.487 & 41.446 & 41.405\end{array}$

0.279149

0.279149

0.279148

0.279148

0.279148

0.279147

0.279146

0.279146

0.279146

0.279146

0.279145

0.279145

0.279144

0.279144

0.279143

0.279143

0.279143

0.279143

0.279142

0.279142

0.279141

0.279141
0.279141

0.279141

0.279140

0.279140

0.279140

0.279139

0.279139

0.279139

0.279138
0.279138

0.279138

0.279138

0.279137

0.279137

0.279137
0.279136

0.279136

0.279136

0.279135

0.279135

0.279134

0.279134

0.279134

0.279133

0.279133
0.279133

0.279132

0.279132

0.279132
0.279132

0.279131

0.279131

0.279130

0.279130

0.279130

0.279129

0.279129
0.279129

0.279129

0.279128 
.05

4940.0
0.1
0.2
0.3
0.4
0.5
0.6
0.7
0.9

$4941: 0$
$1:$
1
1
1
1
1
$1:$
1
1

$\begin{array}{llllllll}37.185 & 37.144 & 37.103 & 37.062 & 37.021 & 36.980 & 36.939 & 36.898\end{array}$ $\begin{array}{llllllll}36.775 & 36.734 & 36.693 & 36.652 & 36.611 & 36.570 & 36.529 & 36.488 \\ 36.366 & 36.325 & 36.284 & 36.243 & 36.202 & 36.161 & 36.120 & 36.079\end{array}$ $\begin{array}{llllllll}35.546 & 35.915 & 35 \cdot 874 & 35.833 & 35.792 & 35.751 & 35.710 & 35.669 \\ 3505 & 35.064 & 35.424 & 35.383 & 35.342 & 35.301 & 35.260\end{array}$ $\begin{array}{llllllll}35.137 & 35.096 & 35.055 & 35.014 & 34.973 & 34.932 & 34.891 & 34.850 \\ 34.727 & 34.686 & 34.046 & 34.604 & 34.563 & 34.527 & 34.481 & 34.440\end{array}$ $\begin{array}{llllllll}3.4 .318 & 34.686 & 34.046 & 34.604 & 34.563 & 34.522 & 34.481 & 34.440 \\ 34.236 & 34.195 & 34.154 & 34.113 & 34.072 & 34.031\end{array}$

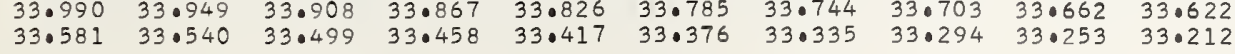

0.279110

0.279110

0.279110

0.279109

.279109

0.279109

0.279108
0.279108

0.279108

0.279107

0.279107

0.279107
0.279107

0.279106

0.279106

0.279106

0.279105

0.279104

0.279104
0.279104

0.279103
0.279103

0.279103
0.279103

0.279102

0.279102

0.279101

0.279101
0.279101

0.279101

0.279100

0.279100
0.279100

0.279100

0.279099

0.279099

0.279098

0.279098

0.279098

0.279097

0.279097

0.279097

0.279096

0.279096 0.279095 0.279095 0.279095
0.279094

.378886

$1 \cdot 378939$

1.373993

.379046

1.379099

1.379125

1.379152

1.379205
1.379232

.379258
.379285

1.379311

1.379364

1.379391

1.379444

1.379497

1.379524
1.379550

1.379577
1.379603

1.379630

10379657

1.379711

1.379736
1.379763

1.379789

1.379816
1.379842

1.379869
1.379896

1.379922

1.379949
1.379975

1.380002

.380028 
$\begin{array}{llllllllll}96.384 & 96.344 & 96.302 & 96.261 & 96.221 & 96.180 & 96.139 & 96.098 & 96.058 & 96.017 \\ 95.976 & 95.935 & 95.894 & 95.854 & 95.813 & 95.772 & 95.731 & 95.690 & 95.650 & 95.609\end{array}$

$\begin{array}{lllllllllll}0.1 & 95.976 & 95.935 & 95.894 & 95.854 & 95.813 & 95.772 & 95.731 & 95.690 & 95.650 & 95.609 \\ 0.2 & 95.568 & 95.527 & 95.487 & 95.446 & 95.405 & 95.364 & 95.323 & 95.282 & 95.242 & 95.201 \\ 0.3 & 95.160 & 95.119 & 95.078 & 95.038 & 94.997 & 94.956 & 94.915 & 94.875 & 94.834 & 94.793\end{array}$

$\begin{array}{lllllllllll}0.4 & 94.752 & 94.711 & 94.671 & 94.630 & 94.589 & 94.548 & 94.507 & 94.467 & 94.426 & 94.385 \\ 0.5 & 94.344 & 94.303 & 94.263 & 94.222 & 94.181 & 94.140 & 94.099 & 94.059 & 94.018 & 93.977\end{array}$

$\begin{array}{lllllllllll}0.5 & 94.344 & 94.303 & 94.263 & 94.222 & 94.181 & 94.140 & 94.099 & 94.059 & 94.018 & 93.977 \\ 0.6 & 93.936 & 93.896 & 93.855 & 93.814 & 93.773 & 93.732 & 93.692 & 93.651 & 93.610 & 93.569\end{array}$

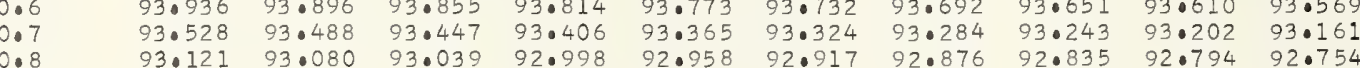

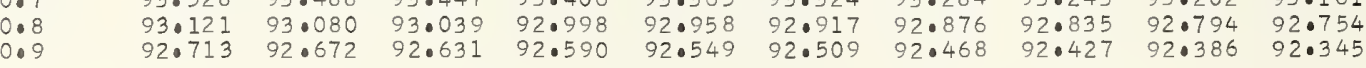

0.279094

1.381516

$0.279094 \quad 1.381542$

$\begin{array}{ll}0.279093 & 1.381595 \\ 0.279093 & 1.381622\end{array}$

0.279092

0.279092

0.279092

1.381649

1.381675
1.381702

1.381728
1.381755

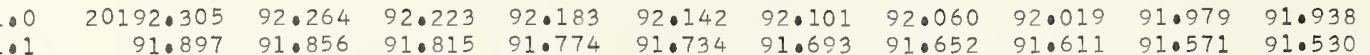

$\begin{array}{lllllllllll}1.1 & 91.897 & 91.856 & 91.815 & 91.774 & 91.734 & 91.693 & 91.652 & 91.611 & 91.571 & 91.530 \\ 1.2 & 91.489 & 91.448 & 91.408 & 91.367 & 91.326 & 91.295 & 91.245 & 91.204 & 91.163 & 91.122\end{array}$ $\begin{array}{llllllllll}91.081 & 91.041 & 91.000 & 90.959 & 90.918 & 90.877 & 90.837 & 90.796 & 90.755 & 90.714\end{array}$

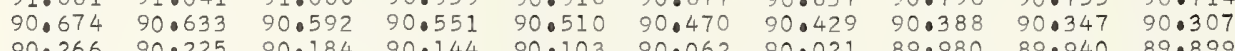

0.279091

1.381781

0.279091

0.279091

0.279090

0.279090
0.279090

0.279089

0.279089
0.279089

1.381808
1.381834

1.381861

1.381888

1.381914

1.381967

1.381994
1.382020

0.279089 0.279088
0.279088
0.279088 0.279088 0.279088
0.279087 0.279087 0.279087 0.279086

1.382047 $\begin{array}{llllllllll}84.966 & 84.333 & 85.292 & 85.659 & 85.619 & 85.578 & 85.537 & 85.496 & 85.455 & 85.41 \\ 84.926 & 84.885 & 84.844 & 84.81 & 85.170 & 85.129 & 85.089 & 85.048 & 85.007\end{array}$ $0184.151 \quad 84.111$

84.070

84.844
84.436

84.803
84.396

84

4953.

3.2
3.3

3.3
3.4

3.6

3.8

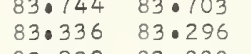

$82.929 \quad 82.888$

$\begin{array}{ll}82.521 & 82.481 \\ 82.114 & 82.073 \\ 81.707 & 81.666\end{array}$

3.9 $\begin{array}{ll}81.299 & 81.259 \\ 80.892 & 80.851\end{array}$

$\begin{array}{rr}80.485 & 80.444 \\ 780.077 & 80.036\end{array}$

\section{2}

$4 \cdot 3$
4.4

4.5
4.6

4.7
4.8
4.9

4955.0

5.1
5.2
5.3

5.4
5.5

5.5
5.6
5.7

5.7
5.8 $\begin{array}{rlllll}20180.077 & 80.036 & 79.996 & 79.955 & 79.914 & 79.874 \\ 79.670 & 79.629 & 79.588 & 79.548 & 79.507 & 79.466 \\ 79.263 & 79.222 & 79.181 & 79.140 & 79.099 & 79.059\end{array}$

$83.662 \quad 83.621$

83.98

83.948

83.907

84.273

84.640
84.233

84.192 $78.855 \quad 78.814$
78.448 78.407 $\begin{array}{ll}78.448 & 78.407 \\ 78.041 & 78.000\end{array}$ $77.634 \quad 77.593$ $\begin{array}{ll}77.226 & 77.186 \\ 76.819 & 76.778 \\ 76.412 & 76.371\end{array}$

. $847 \quad 82.807$

$83.173 \quad 83.133$

83.49

83.86

$83.825 \quad 83.784$

0.279086

0.279086

0.279085
0.279085

0.279085

0.279085

0.279084

0.279083

0.279083

0.279083

0.279083

0.279082

0.279082

0.279082

0.279081
0.279081

1.382074

1.382127

1.382153
1.382180

1.382206

1.382233

1.382286

$20176.004 \quad 75.964$

$\begin{array}{ll}75.597 & 75.557 \\ 75.190 & 75.150 \\ 74.783 & 74.742\end{array}$

$\begin{array}{ll}74.783 & 74.742 \\ 74.0376 & 74.33\end{array}$

$\begin{array}{lll}73.969 & 73.928 & 73.88\end{array}$

$\begin{array}{llll}73.962 & 73.521 & 73.480 & 73.43 \\ 73.155 & 73.0114 & 73.073 & 73.033\end{array}$

$72.748 \quad 72.707 \quad 72.666$

495600

6.0
6.12
6.2
6.3

6.4
6.5
6.6

6.7

6.8
6.9

$0171.933 \quad 71.893$

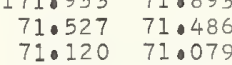

$\begin{array}{ll}70.712 & 70.672 \\ 70.306 & 70.265\end{array}$

$\begin{array}{ll}70.306 & 70.265 \\ 69.898 & 69.858\end{array}$

$69.492 \quad 69.451$

$\begin{array}{ll}69.085 & 69.044 \\ 68.678 & 68.637\end{array}$

$\begin{array}{ll}68.678 & 68.637 \\ 68.271 & 68.230\end{array}$

$20163.796 \quad 63.756$

$$
\begin{array}{rll}
63.390 & 63.349 & 63.3 \\
62.983 & 62.042 & 62.902 \\
62.576 & 62.536 & 62.4 \\
62.170 & 62.129 & 62.0 \\
61.763 & 61.723 & 61.6 \\
61.356 & 61.316 & 61.2 \\
60.950 & 60.909 & 60.8 \\
60.543 & 60.503 & 60.4 \\
60.137 & 60.096 & 60.0
\end{array}
$$$$
\begin{aligned}
& 63.390 \\
& 62.983 \\
& 62.93
\end{aligned}
$$$$
62.170 \quad 62.129 \quad 62.00
$$

$61.356 \quad 61.316$

$60.950 \quad 60.909$

71.852

$71.445 \quad 71.012$

$70.631 \quad 70.59$

$\begin{array}{ll}70.224 & 70.18 \\ 69.817 & 69.777\end{array}$

$69.410 \quad 69.36$

$\begin{array}{ll}69.003 & 68.96 \\ 68.596 & 68.556\end{array}$ $\begin{array}{ll}68.596 & 68.556 \\ 68.190 & 68.14\end{array}$

$67.783 \quad 67.742$

$\begin{array}{ll}67.376 & 67.33 \\ 86.969 & 66.92\end{array}$

6.742
.335
66.928 $\begin{array}{ll}66.562 & 66.522 \\ 66.156 & 66.115 \\ 65.740 & 65.708\end{array}$

$65.342 \quad 65.301$

$\begin{array}{ll}64.935 & 64.895 \\ 64.528 & 64.488\end{array}$

1
95
88
81

$$
\begin{array}{ll}
08 & 65 \\
01 & 65 \\
95 & 64 \\
88 & 64 \\
81 & 64
\end{array}
$$$$
\begin{aligned}
& 75.842 \\
& 75.027 \\
& 74.020
\end{aligned}
$$$$
\begin{array}{ll}
5 & 75.394 \\
7 & 74.987 \\
020 & 74.579
\end{array}
$$$$
76.982
$$$$
\begin{array}{lll}
77.0348 & 77.307 & 77.267
\end{array}
$$$$
76.127 \quad 76.086 \quad 76.045
$$

0.279081

0.2790

0.279080

0.279079

0.279079

0.279079

0.279079
0.279078
0.279078

0.279078

1.382313

1.382366

1.382392

1.382419

1.382472

1.382499

1.382552

0.279078

0.279078

0.279077

0.279077

0.279076

0.279076

0.279076

0.279075

1.382578

1.382605

1.382631
1.382658

1.382685

1. 382711

1.382738

1.382791

0.279075

0.279075

0.279075

0.279074

0.279074

0.279073

0.279073

1.382844

10382870

1.382897
1.382924

1.382924
1.382950

1.382977

1.383003

1.383030

1.383083

1.383110

1.383136

1.383163
1.383189

1.383216

1. 383242

1.383269
1.383295

1.383322

1.383349

1.383375

1.383402

1.383428
1.383455

1.383481

1.383508

I. 383535

1.383561

1.383588
1.383614

0.279072

1.383641
1.383667

1.383694

0.279072

0.279071

0.279071

0.279070

0.279070
0.279070

1.383721
1.383747

1.383774

1.383800

1.383853

0.279070

0.279069

0.279069

0.279069

0.279068
0.279068
0.279068

0.279068
0.279068

1.383880

$$
\begin{array}{lllll}
59.324 & 59.283 & 59.242 & 59.202 & 5 \\
58.117 & 58.877 & 58.836 & 58.795 & 5 \\
58.511 & 58.470 & 58.430 & 58.389 & 5
\end{array}
$$

$\begin{array}{llllllllll}58.105 & 58.064 & 58.023 & 58.389 & 58 \cdot 348 & 58 \cdot 308 & 58 \cdot 267 & 58 \cdot 227 & 58 \cdot 186 & 58 \cdot 145 \\ 570.083 & 57.942 & 57.002 & 57.861 & 57.820 & 57.780 & 57.739\end{array}$ 


$$
\begin{aligned}
& 155 \\
& 55 \\
& 54 \\
& 54 \\
& 54 \\
& 53 \\
& 53 \\
& 52 \\
& 52 \\
& 52
\end{aligned}
$$

$\begin{array}{llllllllll}55.666 & 55.625 & 55.585 & 55.544 & 55.504 & 55.463 & 55.422 & 55.382 & 55.341 & 55.301 \\ 55.260 & 55.219 & 55.178 & 55.138 & 55.097 & 55.057 & 55.016 & 54.975 & 54.935 & 54.894\end{array}$ $\begin{array}{llllllllll}54.854 & 54.813 & 54.772 & 54.731 & 54.691 & 54.650 & 54.610 & 54 \cdot 569 & 54 \cdot 528 & 54.488 \\ 54.447 & 54.406 & 54.366 & 54.325 & 54.285 & 54.244 & 54.203 & 54.163 & 54.122 & 54.082\end{array}$

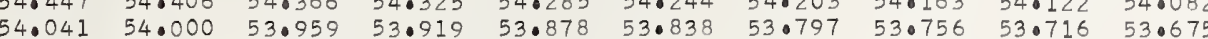

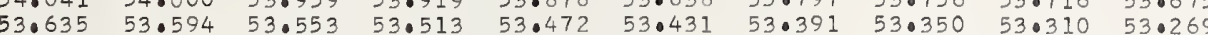
$\begin{array}{llllllllll}53.228 & 53.187 & 53.147 & 53.106 & 53.066 & 53.025 & 52.984 & 52.944 & 52.903 & 52.863\end{array}$ $\begin{array}{llllllllll}52.822 & 52.781 & 52.741 & 52.700 & 52.659 & 52.619 & 52.578 & 52.538 & 52.497 & 52.457\end{array}$

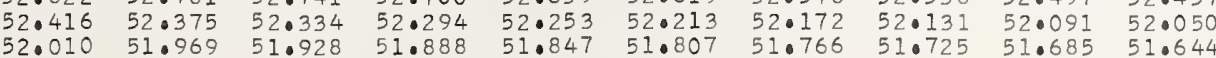

20151

100

4962.0

20147

51.60351 .563

$\begin{array}{llll}51.197 & 51.156 & 51.116 & 51.482 \\ 51.075\end{array}$

$\begin{array}{llllllllll}50.385 & 50.344 & 50.303 & 50.263 & 50.222 & 50.588 & 50.548 & 50.507 & 50.466 & 50.425\end{array}$

$\begin{array}{llllllllll}49.979 & 49.938 & 49.897 & 49.857 & 49.816 & 49.776 & 49.735 & 49.695 & 49.654 & 49.513\end{array}$

$\begin{array}{llllllllll}49.572 & 49.532 & 49.491 & 49.451 & 49.410 & 49.369 & 49.329 & 49.288 & 49.248 & 49.207\end{array}$

$\begin{array}{llllllllll}49.167 & 49.126 & 49.085 & 49.044 & 49.004 & 48.963 & 48.923 & 48.882 & 48.842 & 48.801\end{array}$

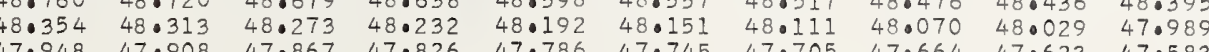

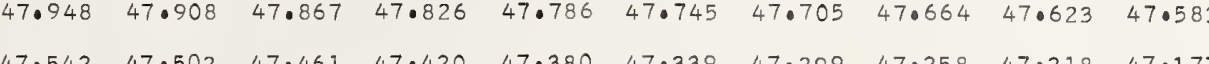

2.1

$47.136 \quad 47.095 \quad 47.055 \quad 47.014 \quad 46$

$46.730 \quad 46.689 \quad 46.649 \quad 46.608 \quad 46$

$\begin{array}{llllll}6.568 & 46.527 & 46.487 & 46.446 & 46.405 & 46.365\end{array}$

$\begin{array}{llllllllll}45.512 & 45.472 & 45.431 & 45.390 & 45.350 & 45.309 & 45.269 & 45.228 & 45.187 & 45.147\end{array}$

$\begin{array}{llllllllll}45.106 & 45.065 & 45.025 & 44.984 & 44.944 & 44.903 & 44.863 & 44.822 & 44.781 & 44.741\end{array}$

$\begin{array}{llllllllll}44.700 & 44.660 & 44.619 & 44.579 & 44.538 & 44.497 & 44.457 & 44.416 & 44.376 & 44.335\end{array}$

$\begin{array}{llllllllll}44.294 & 44.254 & 44.213 & 44.173 & 44.132 & 44.091 & 44.051 & 44.010 & 43.969 & 43.929 \\ 43.888 & 43.848 & 43.807 & 43.767 & 43.726 & 43.686 & 43.645 & 43.604 & 43.564 & 43.523\end{array}$

$\begin{array}{ll}2 & 7 \\ 2 & 8 \\ 2 & 9\end{array}$

4963.0

20143.

$$
\begin{aligned}
& 43.0 \\
& 42 \\
& 42 \\
& 41 \\
& 41 \\
& 41 . \\
& 40 . \\
& 40 .
\end{aligned}
$$

$\begin{array}{llllllllll}43.077 & 43.442 & 43.401 & 43.361 & 43.320 & 43.280 & 43.239 & 43.198 & 43.158 & 43.117\end{array}$ $\begin{array}{llllllllll}42.671 & 42.630 & 42.590 & 42.549 & 42.508 & 42.468 & 42.837 & 42.793 & 42.752 & 42.711 \\ 4 & .387 & 42.346 & 42.306\end{array}$

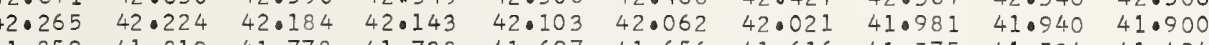
$41.097-41.656 \quad 41.516 \quad 41.575 \quad 41.534 \quad 41.494$

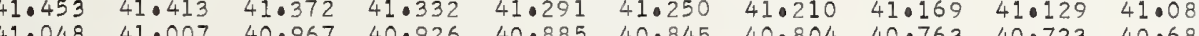

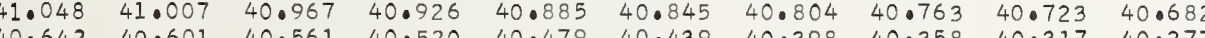
$\begin{array}{llllllllll}40.236 & 40.196 & 40.155 & 40.115 & 40.074 & 40.033 & 40.398 & 40.358 & 40.317 & 40.277\end{array}$

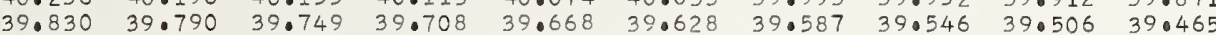

6400
401
402
403
404
405
407
408
409

20139.42

38.61338 .0783

$\begin{array}{llll}38.06 & 38.126 & 38.08\end{array}$

$\begin{array}{llll}7.396 & 37.356 & 37.315 & 37.275\end{array}$

$36.909-36.860$

$35 \cdot 774 \quad 36 \cdot 139$

6.50436 .464

135

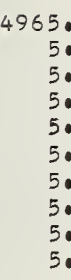

$\begin{array}{ll}5.1 & \\ 5.2 & \\ 5.3 & \\ 5.4 & 3 \\ 5.5 & \\ 5.6 & 33 \\ 5.7 & \\ 5.8 & \\ 5.9 & \end{array}$

34.96334 .92

$34.517 \quad 34.47$

$33.747 \quad 33.706 \quad 33.076$

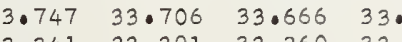

$32.936 \quad 32.895$

$32.530 \quad 32.490$

32.854

$31.720 \quad 31.679$

4966

6.

0131.314

$31 \cdot 274$

32.04

$30.909 \quad 30.868 \quad 31.233 \quad 31.19$

$\begin{array}{llll}30.503 & 30.463 & 30.422 & 30.78 \\ 30.098 & 30.057 & 30.017 & 29.97\end{array}$

$\begin{array}{llll}30.098 & 30.057 & 30.017 & 29.97 \\ 29.693 & 29.652 & 29.612 & 29.57\end{array}$

$29.287 \quad 29.247 \quad 29.207 \quad 29 \cdot 166$

$28.882 \quad 28.841 \quad 28 \cdot 801$

$28.477 \quad 28 \cdot 436 \quad 28 \cdot 396 \quad 28 \cdot 350$

$\begin{array}{llll}28.071 & 28.031 & 27.990 & 27.950 \\ 27.666 & 27.626 & 27.585 & 27.545\end{array}$

6.8

4967.0

$20127 \cdot 26$ $26.856 \quad 26.815$

$26.45126 .410 \quad 26.369$

$25.640 \quad 25.600 \quad 25.559 \quad 25 \cdot 519$

$\begin{array}{llll}25.235 & 25.195 & 25.154 & 25.114\end{array}$

$\begin{array}{llll}24.830 & 24.790 & 24.749 & 24.708\end{array}$

$\begin{array}{llllllllll}24.020 & 23.979 & 23.939 & 23.898 & 23.858 & 23.817 & 23.777 & 23.736 & 23.696 & 23.655 \\ 23.615 & 23.574 & 23.534 & 23.493 & 23.453 & 23.412 & 23.372 & 23.331 & 23.291 & 23.250\end{array}$

$39.262 \quad 39.222$

39.18

$39 \cdot 141 \quad 39 \cdot 100 \quad 39 \cdot 060$

$\begin{array}{llllll}38.451 & 38.410 & 38.370 & 38.735 & 38.694 & 38.654 \\ 38.029 & 38.289 & 38.248\end{array}$

$\begin{array}{llllll}38.045 & 38.005 & 37.964 & 37.924 & 37.883 & 37.843\end{array}$

$\begin{array}{llllll}37.234 & 37.193 & 37.153 & 37.0118 & 37.478 & 37.437 \\ & 37.112 & 37.072 & 37.031\end{array}$

$\begin{array}{llllll}36.829 & 36.788 & 36.747 & 36.707 & 36.666 & 36.625\end{array}$

$\begin{array}{llllll}36.423 & 36.382 & 36.342 & 36.301 & 36.260 & 36.220\end{array}$

$\begin{array}{ll}36.018 & 35.977 \\ 35.612 & 35.57\end{array}$

35.93
35.53

$35 \cdot 815$
$35 \cdot 409$

$\begin{array}{llllll}35.206 & 35.166 & 35.125 & 35.085 & 35.044 & 35.004 \\ 34.801 & 34.760 & 34.720 & 34.679 & 34.639 & 34.598\end{array}$

$\begin{array}{llllll}34.801 & 34.760 & 34.720 & 34.679 & 34.639 & 34.598 \\ 34.396 & 34.355 & 34.314 & 34.274 & 34.233 & 34.193\end{array}$

$\begin{array}{llllll}33.990 & 33.949 & 33.909 & 33.868 & 33.828 & 33.787\end{array}$

$\begin{array}{llllll}33.584 & 33.544 & 33.503 & 33.463 & 33.422 & 33.382\end{array}$

$\begin{array}{llllll}32.774 & 32.733 & 32.693 & 32.652 & 32.611 & 32.571\end{array}$

$\begin{array}{llllll}32.368 & 32.327 & 32 \cdot 287 & 32.247 & 32 \cdot 206 & 32.165 \\ 31.963 & 31.922 & 31.882 & 31.841 & 31.801 & 31.760\end{array}$

$\begin{array}{llllll}31.963 & 31.922 & 31.882 & 31.841 & 31.801 & 31.760 \\ 31.557 & 31.517 & 31.476 & 31.436 & 31.395 & 31.354\end{array}$

0.279067
0.279067

.279066

.279066

0.279065

0.279065

0.279065

.27906

0.279064

0.27906

0.279062

0.279062

0.27906

0.279061

0.279060

0.279060

0.059

0.279059
0.27905

0.279058

0.279058

.279058

0.279057

0.279057
0.279057
0.279056

0.279056

0.279056
0.279056

0.279055

0.279055

0.279054

0.279053

0.279053
0.279053

0.279053
0.279052

0.279052

0.279052
0.279052

0.279051
0.279051

0.279051

0.279050
0.279050

0.279050

0.279050
0.279049

0.279049

0.279049

0.279048

$1 \cdot 384172$
1.384199

1.384225

1.384278

1. 384331

1.384385

$1 \cdot 384438$

84464

1. 384517

384597

1.384650

$1 \cdot 384703$

1.384730
1.384757

$1 \cdot 384783$

1.384836

1. 384889

1.384969

1.384996

1.385049

1. 385102

1.385155

1.385182
1.385208

1.385235

$1 \cdot 385261$

1.385314

$1 \cdot 385341$

1.385368
1.385394

1.385421
1.385447

1.385500

$1 \cdot 385527$

1.385580

1.385607
1.385633

1.385660

$1 \cdot 385686$

1.385713
1.385739

$\begin{array}{lllllllllll}4968.0 & 20123.209 & 23.169 & 23.129 & 23.088 & 23.048 & 23.007 & 22.967 & 22.926 & 22.886 & 22.845\end{array}$ $\begin{array}{llllllllll}22.804 & 22.764 & 22.723 & 22.683 & 22.643 & 22.602 & 22.562 & 22.521 & 22.480 & 22.440 \\ 22.400 & 22.359 & 22.319 & 22.278 & 22.238 & 22.197 & 22.157 & 22.116 & 22.076 & 22.035\end{array}$

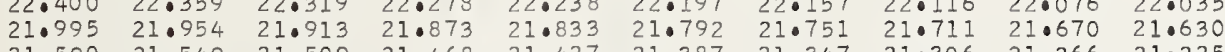

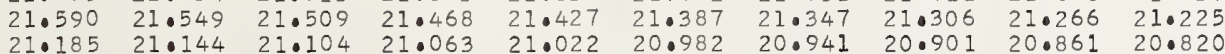
$\begin{array}{llllllllll}20.780 & 20.739 & 20.698 & 20.658 & 20.618 & 20.577 & 20.537 & 20.496 & 20.456 & 20.415\end{array}$ $\begin{array}{llllllllll}20.375 & 20.334 & 20.294 & 20.253 & 20.213 & 20.172 & 20.132 & 20.091 & 20.051 & 20.010\end{array}$

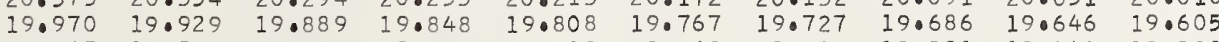

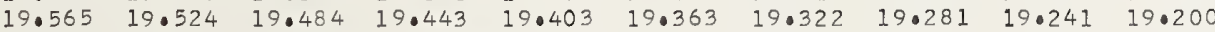

$\begin{array}{llllllllll}20119.160 & 19.119 & 19.079 & 19.038 & 18.998 & 18.957 & 18.917 & 18.876 & 18.836 & 18.796\end{array}$ $\begin{array}{llllllllll}18.755 & 18.715 & 18.674 & 18.634 & 18.593 & 18.553 & 18.512 & 18.472 & 18.431 & 18.390\end{array}$ $\begin{array}{llllllllll}18.350 & 18.310 & 18.269 & 18.229 & 18.188 & 18.147 & 18.107 & 18.067 & 18.026 & 17.986 \\ 17.945 & 17.905 & 17.864 & 17.824 & 17.783 & 17.743 & 17.702 & 17.662 & 17.621 & 17.581\end{array}$ $\begin{array}{llllllllll}17.945 & 17.905 & 17.864 & 17.824 & 17.783 & 17.743 & 17.702 & 17.662 & 17.621 & 17.581 \\ 17.541 & 17.500 & 17.459 & 17.419 & 17.378 & 17.338 & 17.298 & 17.257 & 17.217 & 17.176\end{array}$ $\begin{array}{llllllllll}17.135 & 17.095 & 17.055 & 17.014 & 16.974 & 16.933 & 16.893 & 16.852 & 16.812 & 16.771\end{array}$ $\begin{array}{llllllllll}16.731 & 16.690 & 16.650 & 16.609 & 16.569 & 16.528 & 16.488 & 16.448 & 16.407 & 16.366\end{array}$ $\begin{array}{llllllllll}16.326 & 16.286 & 16.245 & 16.205 & 16.164 & 16.124 & 16.083 & 16.043 & 16.002 & 15.962\end{array}$

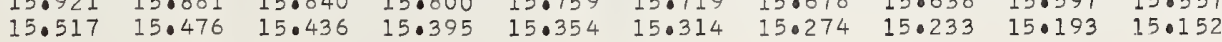

0.279048

0.279047

0.279047

.279047

0.279046

0.279046

1.385766

1.385793
1.385819

1.385846

1.385899

1.385925

$1 \cdot 385952$

1.386005

0.279045

0.279045
0.279045

0.279044

0.279044

0.279043

0.279043

$1 \cdot 386032$

1.386111

1.386138

1.386191
1.386218

1.386244

0.279043
0.279042

0.279042

0.279042
0.279042

0.279042

0.279041
0.279041

0.279041

0.279041

1.386297

1.386324
1.386351

1.386377

1.386430

1. 386457

1. 386510

. 386536

- 386563

1.386590

1.386643

1.386669

1.386722

I. 386749

.386776

.010

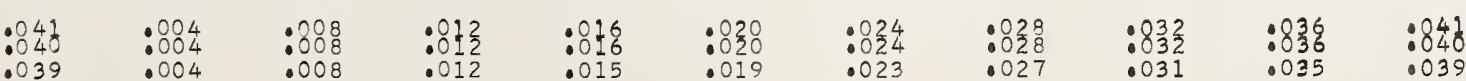




\subsection{7 \\ 13.493 \\ 12.280 \\ 11.470}

13.08913 .048

20111.065

$10.661 \quad 10.621$

$10.257 \quad 10.216$

$\begin{array}{lll}09.448 & 09.407 \\ 09.043 & 09000 & 0\end{array}$

08.63908 .598

$\begin{array}{lll}08.234 & 08.194 \\ 07.830 & 07.789 & 0\end{array}$

$07.425 \quad 07.385$

20107.021

$06.616 \quad 06.980$

$\begin{array}{lll}06.0216 & 06.576 \\ 06.212 & 06.17\end{array}$

05.807
05.403

$05.403 \quad 05.363$

04.594

$04.190-04.554$

03.78
03.38

20102.977

02.57
02.16

01.76
01.361

01003010

$00.552 \quad 00.512$

$20099.148 \quad 00 \cdot 108$

20098.936

$98.532 \quad 98.49$
0809
08728

97.72498 .087

$97.320 \quad 970270$

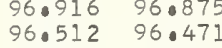

$\begin{array}{ll}96.108 & 96.0 \\ 95.704 & 95.653\end{array}$

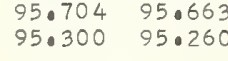

$20094.896 \quad 94.856$

94.49

$94.088 \quad 94.048$

$93.280 \quad 93.644$

$92.876 \quad 92.836$

$92.069 \quad 92.020$

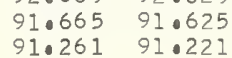

20090.858

90.45
90.05
89.646

$8.243 \quad 89.20$

$88.436 \quad 88.395$

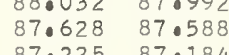

20086.821

86.417

86.014

8061085.570

$85 \cdot 207$
84.8030
84.0767

$\begin{array}{lll}84.803 & 84.763 \\ 840400 & 84.350\end{array}$

$830996 \quad 83.3596$

$\begin{array}{ll}83.593 & 83.552 \\ 83.189 & 83.149\end{array}$

20082.786

81.97988 .342

81.57681 .535

$\begin{array}{lll}81.172 & 81.132 \\ 80.769 & 80.729\end{array}$

$\begin{array}{llll}79.962 & 70.922 & 80.285 & 80.245\end{array}$

$\begin{array}{llll}79.559 & 79.519 & 79.478 & 79.438\end{array}$

$20078.752 \quad 78.712$

78.34978 .780 .309

77.946
77.543
77.90962

$\begin{array}{lllll}77.543 & 77.502 & 71.085 & 770825 \\ 77.462 & 77.822\end{array}$

76.736 77.0696 $76.059 \quad 77.019$

$\begin{array}{llll}76.333 & 76.293 & 76.252 & 76.212\end{array}$

$\begin{array}{lllll}75.930 & 75.890 & 75.849 & 75.80\end{array}$

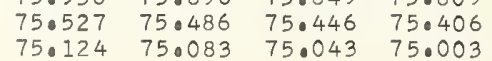

$.001 \quad .002$

\begin{abstract}
.003
\end{abstract}

\section{$: 00$}

$\begin{array}{ll}.950 & 14.90 \\ .545 & 14.50\end{array}$

$\begin{array}{ll}.141 & 14.100\end{array}$

$13.331 \quad 13.291$

12.522

12.482

1.71

11.672
11.268

10.90

10.86

0.459

.054

$.690 \quad 09.650$

$\begin{array}{ll}08.881 & 08.841 \\ 08.477 & 08.436\end{array}$

$\begin{array}{ll}08.477 & 08.436 \\ 08.072 & 08.032\end{array}$

07.66

07.62

06.85

06.81

$\begin{array}{llll}4.869 & 14.828 & 14 \cdot 788 & 14 \cdot 748 \\ 4.464 & 14.424 & 14.383 & 14 \cdot 343\end{array}$

$\begin{array}{llll}14.060 & 14.019 & 13.979 & 13.938\end{array}$

$13.250 \quad 13.210 \quad 13.170 \quad 13.129$

$\begin{array}{llll}12.846 & 12.805 & 12.765 & 12.724\end{array}$

$\begin{array}{llll}12.037 & 11.996 & 11.956 & 11.915\end{array}$

$\begin{array}{llll}11.632 & 11.592 & 11.551 & 11.511\end{array}$

$\begin{array}{llll}10.823 & 10.782 & 10.742 & 10.701\end{array}$

$\begin{array}{llll}10.418 & 10.378 & 10.337 & 10.297\end{array}$

$\begin{array}{llll}09.609 & 09.569 & 09.528 & 09.488\end{array}$

$09.205 \quad 09.164 \quad 09 \cdot 124 \quad 09 \cdot 083$

$\begin{array}{llll}0.0396 & 080355 & 08 \cdot 315 & 08.274\end{array}$

$\begin{array}{llll}07.587 & 07.546 & 07.911 & 07.870\end{array}$

$\begin{array}{llll}07.587 & 07.546 & 07.506 & 07.466\end{array}$

$\begin{array}{llll}06.778 & 06.738 & 06.697 & 06.657\end{array}$

$\begin{array}{lllllll}0.50646 & 050605 & 050565 & 05.524 & 0558484 & 05.444\end{array}$

$\begin{array}{llllll}05.241 & 05.201 & 05.161 & 050120 & 05080 & 050039\end{array}$

$\begin{array}{lllllll}04.433 & 04.393 & 04.352 & 04.312 & 040271 & 040231\end{array}$

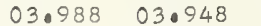

$\begin{array}{llll}03.948 & 03.907 & 03.867 & 03.826 \\ 03.543 & 03.503 & 03.463 & 03.422 \\ 03.139 & 03.099 & 03.058 & 03.018\end{array}$

\section{$03.220 \quad 03.180$}

02.735

$02.694 \quad 02.654 \quad 02.614$

$\begin{array}{llllll}.412 & 02.371 & 02.331 & 02.290 & 02.0250 & 02.209\end{array}$

$\begin{array}{lllll}0 & 01.927 & 01.886 & 01.846 & 01.805\end{array}$

$\begin{array}{llllll} & 01.018\end{array}$

$\begin{array}{llllllll}00.876 & 00.835 & 00.795 & 00.754 & 00.714 & 00.674 & 00.0633 & 00.593 \\ 0.0 .471 & 00.431 & 00.391 & 00.350 & 00.310 & 00.269 & 00.229 & 00.188\end{array}$

$\begin{array}{lll}0.067 & 00.027 * 99.987 * 9.9046 * 99.906 * 99.865 * 99.825 * 99.785\end{array}$

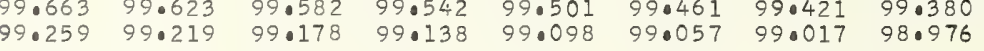

$\begin{array}{llllll}98.774 & 98.734 & 98.693 & 98.653 & 98.613 & 98.572 \\ 98.370 & 98.330 & 98.289 & 98.249 & 98.208 & 98.168\end{array}$

$\begin{array}{lllllll}97.966 & 97.926 & 97.885 & 97.845 & 97.804 & 97.764\end{array}$

$\begin{array}{llllll}97.562 & 97.522 & 97.481 & 97.441 & 97.400 & 97.360 \\ 97.158 & 97.118 & 97.077 & 97.037 & 96.996 & 96.956\end{array}$

$96.754 \quad 96.714 \quad 96.673 \quad 96.633 \quad 96.593 \quad 96.552$

$\begin{array}{llllll}96.350 & 96.310 & 96.269 & 96.229 & 96.188 & 96.148\end{array}$

$95.946 \quad 95.906$

$95.865 \quad 95.825 \quad 95.785 \quad 95.744$

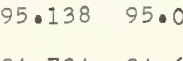

94.73494 .694

95.057

$\begin{array}{lll}95.421 & 95.381 & 95 \cdot 340 \\ 95.017 & 94.977 & 94.936\end{array}$

$\begin{array}{llllll}93.927 & 93.886 & 93.846 & 93.805 & 93.765 & 93.725\end{array}$

$\begin{array}{llllll}93.523 & 93.482 & 93.442 & 93.401 & 93.361 & 93.321\end{array}$

$\begin{array}{llllll}92.715 & 92.675 & 92.634 & 92.594 & 92.553 & 92.513\end{array}$

$\begin{array}{llllll}92.311 & 92.271 & 92.230 & 92.190 & 92.150 & 92.109\end{array}$

$\begin{array}{llllll}91.503 & 91.463 & 91.81 .423 & 91.786 & 91.746 & 91.706 \\ 91.100 & 91.060 & 91.019 & 90.979 & 91.342 & 91.302\end{array}$

$\begin{array}{llllll}90.697 & 90.656 & 90.615 & 90.575 & 90.535 & 90.494\end{array}$

$\begin{array}{llllll}90.293 & 90.252 & 90.212 & 90.171 & 90.131 & 90.091\end{array}$

$\begin{array}{llllll}89.889 & 89 \cdot 848 & 89.808 & 89.768 & 89.727 & 89.687 \\ 89.485 & 89.445 & 89.404 & 89.364 & 89.323 & 89.283\end{array}$

$\begin{array}{llllll}89.081 & 89.041 & 89.001 & 88.960 & 88.920 & 88.880 \\ 88.678 & 88.637 & 88.597 & 88.557 & 88.516 & 88.476\end{array}$

$88.274 \quad 88.234 \quad 88.193 \quad 88.153 \quad 88.113 \quad 88.072$

$\begin{array}{llllll}87.467 & 87.427 & 87.386 & 87.346 & 87.305 & 87.265\end{array}$

$\begin{array}{lllllll}87.063 & 87.023 & 86.982 & 86.942 & 86.902 & 86.861\end{array}$

$\begin{array}{llllll}86.256 & 86.216 & 86.175 & 86.135 & 86.094 & 86.054\end{array}$

$\begin{array}{llllll}85.853 & 85.812 & 85.772 & 85.731 & 85.691 & 85.651 \\ 85.449 & 85.409 & 85.368 & 85.328 & 85.287 & 85.247\end{array}$

$\begin{array}{lllllll}85.045 & 85.005 & 84.965 & 84.924 & 84.884 & 84.844\end{array}$

$\begin{array}{llllll}84.642 & 84.602 & 84.561 & 84.521 & 84.481 & 84.440\end{array}$

$\begin{array}{lllllll}84.239 & 84.198 & 84 \cdot 158 & 84.117 & 84.077 & 84.037\end{array}$

$\begin{array}{lllllll}83.835 & 83.795 & 83.754 & 83.714 & 83.674 & 83.633 \\ 83.431 & 83.391 & 83.351 & 83.310 & 83.270 & 83.230\end{array}$

$\begin{array}{llllll}83.431 & 83.391 & 83.351 & 83.310 & 83.270 & 83.230 \\ 83.028 & 82.988 & 82.948 & 82.907 & 82.867 & 82.826\end{array}$

$\begin{array}{llllll}82.625 & 82.584 & 82.544 & 82.503 & 82.463 & 82.423\end{array}$

$\begin{array}{lllllll}82.221 & 82.181 & 82.141 & 82.100 & 82.060 & 82.020 \\ 81.818 & 81.777 & 81.737, & 81.697 & 81.656 & 81.616\end{array}$

$\begin{array}{llllll}81.414 & 81.0774 & 81.737_{4} & 81.697 & 81.656 & 81.616 \\ & 81.334 & 81.293 & 81.253 & 81.213\end{array}$

$\begin{array}{lllllll}81.011 & 80.971 & 80.930 & 80.890 & 80.850 & 80.809\end{array}$

$\begin{array}{llllll}80.608 & 80.567 & 80.527 & 80.487 & 80.447 & 80.406\end{array}$

$\begin{array}{llllll}80.205 & 80.164 & 80.124 & 80.083 & 80.043 & 80.002\end{array}$

$\begin{array}{llllll}79.398 & 79.357 & 79.317 & 79.680 & 79.640 & 79.599 \\ 79.277 & 79.236 & 79.196\end{array}$

$\begin{array}{lllllll}78.591 & 78.551 & 78.510 & 78.470 & 78.430 & 78.390\end{array}$

$\begin{array}{llllll}78.188 & 78.147 & 78.5107 & 78.067 & 78.430 & 78.390 \\ 78.027 & 77.986\end{array}$

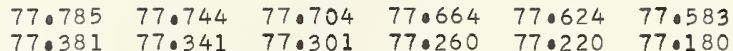

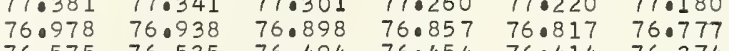

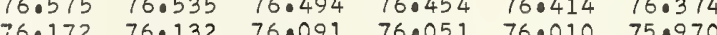

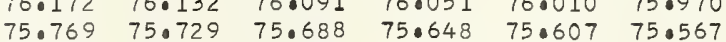

75.365
74.962

$75.325,75.688$

$\begin{array}{lll}75 \cdot 648 & 75 \cdot 607 & 75.567 \\ 75.245 & 75.204 & 75.164\end{array}$

$\begin{array}{lll}75 \cdot 245 & 75 \cdot 204 & 75 \cdot 164 \\ 74.842 & 74.801 & 74.761\end{array}$

$.004 \quad .005 \quad .006$

0.279039

0.279039

.279039

279038

279038

0.279037

.279037

0.279036

0.279036

. 279035

0.279035

0.279035

0.279034

(1)

0.279032

0.279032

790

.279030

(1)

0.279029

.279029

.279028

.279028

0.279027
0.279027

0.279027
0.279027

0.279027

0.279026
0.279026

源 279026

.279025

0.279025

0.279024

0.279024

.279023

.279023

.279022

0.279022

0.279021

年

0.279019

279018
279018
0.279018

279017 


$\begin{array}{ll}.0 & 20 \\ .1 & \\ .2 & \\ .3 & \\ .5 & \\ .6 & \\ .7 & \\ .8 & \\ .9 & \end{array}$

$\begin{array}{rlll}074.720 & 74.680 & 74.640 & 74.600 \\ 74.317 & 74.277 & 74.237 & 74.197 \\ 73.915 & 73.874 & 73.834 & 73.793 \\ 73.511 & 73.471 & 73.431 & 73.391 \\ 73.108 & 73.068 & 73.028 & 72.988 \\ 72.705 & 72.665 & 72.625 & 72.584 \\ 72.302 & 72.262 & 72.222 & 72.181 \\ 71.899 & 71.859 & 71.819 & 71.778 \\ 71.496 & 71.456 & 71.416 & 71.375 \\ 71.093 & 71.053 & 71.013 & 70.972\end{array}$

$\begin{array}{ll}7.559 & 74.519 \\ 4.156 & 74.116 \\ 73.753 & 73.713\end{array}$

$\begin{array}{llll}74.479 & 74.438 & 74 \cdot 398 & 74.358 \\ 74.076 & 74.035 & 73.995 & 73.955\end{array}$

0.279013
0.279013

0.279013

0.279012
0.279012

$\begin{array}{lllllll}.738 & 71.698 & 71.657 & 71.617 & 71.577 & 71.537\end{array}$

0.279012

0.279011
0.279011

\begin{tabular}{rrrrrrrrrrr}
0.1 & 20070.690 & 70.650 & 70.610 & 70.570 & 70.529 & 70.489 & 70.448 & $70 \cdot 408$ & 70.368 & 70.328 \\
\hline & 70.287 & 70.247 & 70.207 & 70.166 & 70.126 & 70.086 & 70.046 & 70.005 & 69.965 & 69.925
\end{tabular}

1.2

1.4

1.6
1.7

$69.885 \quad 69.844 \quad 69.804 \quad 69.764$

$\begin{array}{lllllll}69.079 & 69.038 & 68.998 & 68.958 & 68.917 & 69.2877\end{array}$

$68.676 \quad 68.636 \quad 680596 \quad 68.555 \quad 68$

$68.273 \quad 68.233 \quad 68.193 \quad 68.152$

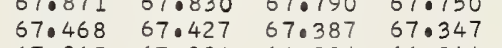

$68.515 \quad 68.475$

$68.112 \quad 68.072$

$67.065 \quad 67.024$

67.266

$69.643 \quad 69.603 \quad 69.562 \quad 69.522$

$\begin{array}{llll}69.240 & 69.199 & 690159 & 69.119\end{array}$

$\begin{array}{llll}68.837 & 68.797 & 68.757 & 68.716 \\ 68.434 & 68.394 & 68.354 & 68.313\end{array}$

$\begin{array}{llll}68.031 & 67.991 & 67.051 & 67.911 \\ 67.629 & 67.5899 & 67.548 & 67.508\end{array}$

$\begin{array}{llll}67.226 & 67.186 & 67.145 & 67.105 \\ 66.823 & 66.783 & 66.0743 & 66.702\end{array}$

0.279011

0.279010
0.279010

0.279009
0.279009

0.2279009
0.279009

0.279008
0.279008

4982

20066.662

66.25966 .028

66.622

$66.581 \quad 66.541$

66.90466 .864

$66.420-66.380-66.340 \quad 66.300$

$\begin{array}{llllllll}650776 & 65.736 & 66.098 & 66.058 & 66.018 & 650977 & 65.937 & 65.897\end{array}$

$\begin{array}{lllllllll}65.373 & 65.333 & 65.293 & 65.252 & 65.212 & 65.172 & 65.131 & 650091\end{array}$

$\begin{array}{llllllllll}65.051 & 65.011 & 64.970 & 64.930 & 64.890 & 64.850 & 64.809 & 64.769 & 64.729 & 64.688\end{array}$

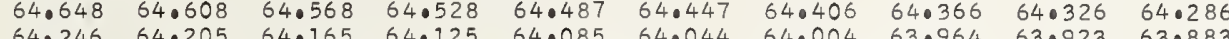

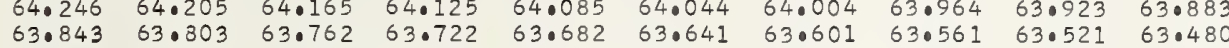

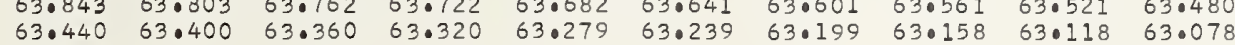

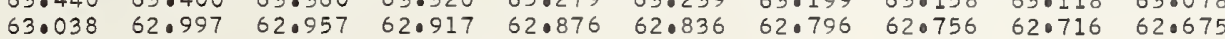

0.279008

0.279008

0.279007

0.279007

0.279006

0.279006

$20062.635 \quad 62.595$

$62.635 \quad 62.595 \quad 62.554 \quad 62.514$

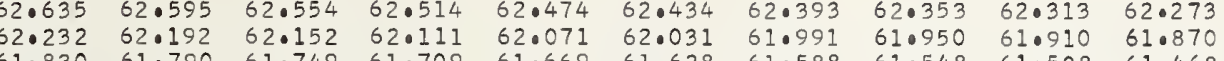

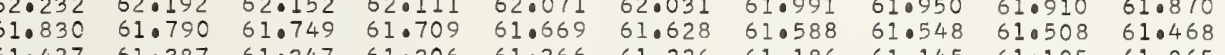

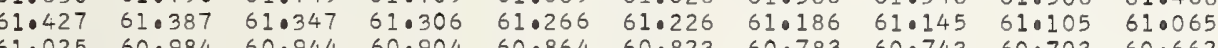

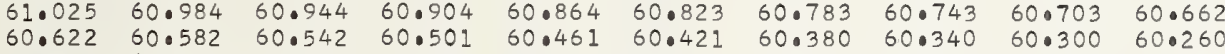

$\begin{array}{llllllllll}60.622 & 60.582 & 60.542 & 60.501 & 60.461 & 60.421 & 60.380 & 60.340 & 60.300 & 60.260 \\ 60.219 & 60.179 & 60.139 & 60.099 & 60.059 & 60.018 & 59.978 & 59.938 & 59.897 & 59.8557\end{array}$

$\begin{array}{llllllllll}60.219 & 60.179 & 60.139 & 60.099 & 60.059 & 60.018 & 59 \cdot 978 & 59.938 & 59.897 & 59.857 \\ 59.817 & 59.777 & 59.737 & 59.696 & 59.656 & 59.616 & 59.576 & 59.535 & 59.495 & 59.455\end{array}$

$\begin{array}{llllllllll}59 \cdot 414 & 59.374 & 59.334 & 59.294 & 59 \cdot 253 & 59.213 & 59.173 & 59 \cdot 133 & 59 \cdot 093 & 59 \cdot 052\end{array}$

0.279005

0.279005

0.279004

0.279004

0.279003

0.279003

$5058.00958 .569-58.5290580 .489$

$\begin{array}{llllll}58.448 & 58.408 & 58.368 & 58.328 & 58.288 & 58.247\end{array}$

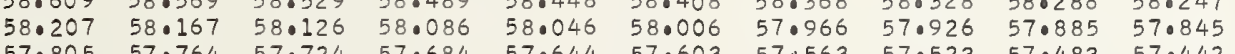

$\begin{array}{llllllllll}57.805 & 57.764 & 57.724 & 57.684 & 57.644 & 57.603 & 57.563 & 57.523 & 57.483 & 57.442\end{array}$

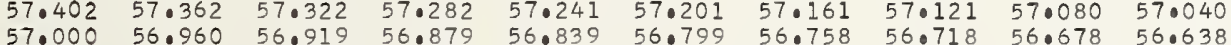

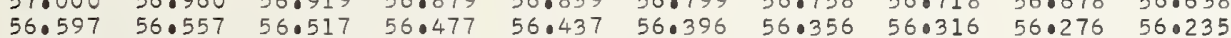

$\begin{array}{llllllllll}56.195 & 56.155 & 56.115 & 56.074 & 56.034 & 550994 & 550954 & 55.913 & 55.873 & 550833\end{array}$

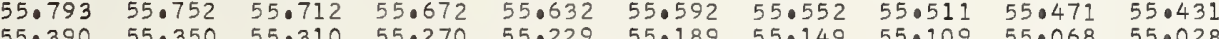

$\begin{array}{llllllllll}55 \cdot 390 & 55.350 & 55 \cdot 310 & 55.270 & 55.229 & 55.189 & 55.149 & 55.109 & 55 \cdot 068 & 55.028 \\ 54.988 & 54.948 & 54.907 & 54.867 & 54.827 & 54.787 & 54.747 & 54.707 & 54.666 & 54.626\end{array}$

0.279003

0.279002

0.279002

0.279001

0.279001

0.279001

0.279000

1.389486

1.389539
1.389565

1.389592

1.389645

1.389698

1.389751

1.389805

1.389831

1.389884

1.389911

1.389991

1.390017

1.390044

.390097

1.390150

1.390203

1.390230
1.390256

1.390283

1.390309

1.390363

1.390416

. 390469

1.390495

1.390549

1.390575

1.390628

1.390681

1.390735

1.390761

498500

409
5.0
50
50
50
5.04
50
50
5
50
50

$\begin{array}{rll}54.586 & 54 \cdot 546 & 54.50 \\ 54.183 & 54.143 & 54.103\end{array}$

54.465

$\begin{array}{llllll}54.425 & 54.385 & 54 \cdot 344 & 54 \cdot 304 & 54.264 & 54 \cdot 224 \\ 54.023 & 53.982 & 53.942 & 530902 & 53.862 & 53.821\end{array}$

$\begin{array}{llllllllll}53.781 & 53.741 & 53.701 & 53.661 & 53.620 & 53.580 & 53.540 & 53.500 & 53.459 & 53.419\end{array}$

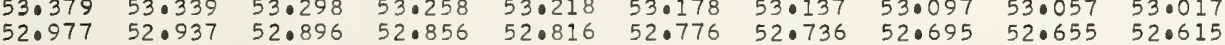

$\begin{array}{lllllllllll}52.574 & 52.534 & 52.494 & 52.454 & 52.414 & 52.373 & 52.333 & 52.293 & 52.253 & 52.212 \\ 52.177 & 52.132 & 52.092 & 52.052 & 52.013 & 51.971 & 51.931 & 51.891 & 51.851 & 51.810\end{array}$

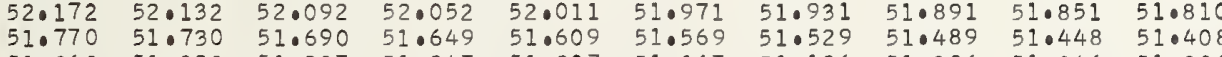

$\begin{array}{llllllllll}51.368 & 51.328 & 51.287 & 51.247 & 51.207 & 51.167 & 51.126 & 51.086 & 51.046 & 51.006 \\ 50.966 & 50.926 & 50.885 & 50.845 & 50.805 & 50.765 & 50.724 & 50.684 & 50 \cdot 644 & 50 \cdot 604\end{array}$

0.279000

0.279000

0.278999

0.278999

0.278998

0.278998

0.278997

1.39081

1.390867

1.390894

1.390947

1.390974

1.391027

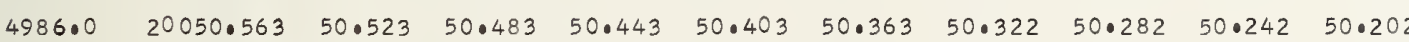

$\begin{array}{lllllllllll}6.1 & 50.162 & 50.121 & 50.081 & 50.041 & 50.001 & 49.960 & 49.920 & 49.880 & 49.840 & 49.799\end{array}$

$\begin{array}{lllllllllll}6.2 & 49.759 & 49.719 & 49.079 & 49.639 & 49.598 & 49.558 & 49.518 & 49.8878 & 49.440 & 49.799 \\ 6.3 & 49.357 & 49.317 & 49.277 & 49.237 & 49.197 & 49.156 & 49.116 & 49.076 & 49.036 & 49.397\end{array}$

$\begin{array}{lllllllllll}6.3 & 49.357 & 49 \cdot 317 & 49.277 & 49.237 & 49 \cdot 197 & 49.156 & 49.116 & 49.076 & 49.036 & 48.995 \\ 6.4 & 48.955 & 48.915 & 48.875 & 48.834 & 48.794 & 48.754 & 48.714 & 48.674 & 48.634 & 48.593\end{array}$

$48.553 \quad 48.513 \quad 48.473 \quad 48.433$

$48.151 \quad 48.111 \quad 48.071$

$\begin{array}{lllllllllll}6.7 & 47.749 & 47.709 & 47.669 & 47.628 & 47.588 & 47.548 & 47.508 & 47 \cdot 468 & 47.427 & 47 \cdot 387 \\ 6.8 & 47.347 & 47.307 & 47.267 & 47.226 & 47.186 & 47.146 & 47: 106 & 47.065 & 47.025 & 46.985\end{array}$

$48.392 \quad 48.352 \quad 48.312 \quad 48.272 \quad 48.232 \quad 48.191$

0.278997

1.391080

0.278997

0.278996

0.278996

0.278996

0.278995

0.278995

.0391107

1.391160

391186

1.391239

$\begin{array}{lllllllllll}6.8 & 47.347 & 47.307 & 47.267 & 47.226 & 47.186 & 47.146 & 47 \cdot 106 & 47.065 & 47 \cdot 025 & 46.985 \\ 6.9 & 46.945 & 46.905 & 46.865 & 46.824 & 46.784 & 46.744 & 46.704 & 46.664 & 46.624 & 46.583\end{array}$

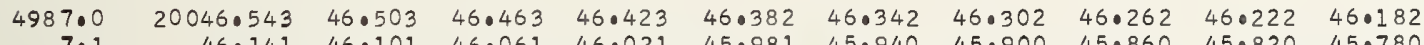

$\begin{array}{llllllllll}46.141 & 46.101 & 46.061 & 46.021 & 45 \cdot 981 & 45.940 & 45.900 & 45.860 & 45 \cdot 820 & 45.780\end{array}$

$\begin{array}{llllllllll}45.740 & 45.699 & 45.659 & 45.619 & 45.579 & 45.538 & 45.498 & 450458 & 450418 & 450378\end{array}$

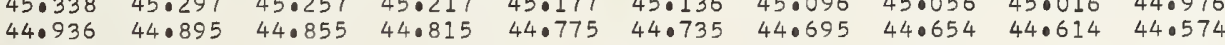

$\begin{array}{llllllllll}44.534 & 44.494 & 44.453 & 44.413 & 44.373 & 44.333 & 44.292 & 44.252 & 44.212 & 44.172\end{array}$

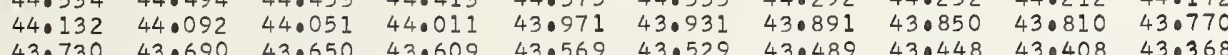

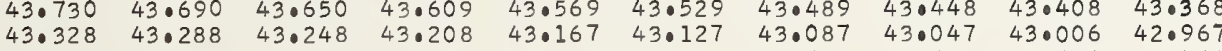

$\begin{array}{llllllllll}42.926 & 42.886 & 42.846 & 42.806 & 42.765 & 42.726 & 42.685 & 42.645 & 42.604 & 42.564\end{array}$

0.278995

0.0278994

0.27894

0.278993

0.278993

0.278993

0.278993

0.278992

.0391293

91346

. .391322
.391399

. 391452

1.391479

1.391532

1.391558

0.278992

1.391612
1.391638

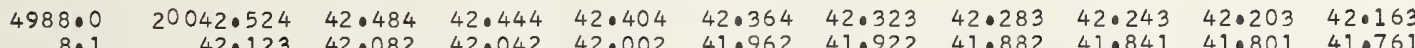

$\begin{array}{lllllllllll}8.1 & 42.123 & 42.082 & 42.042 & 42.002 & 41.962 & 41.922 & 41.882 & 41.841 & 41.801 & 41.761\end{array}$

$\begin{array}{lllllllllll}8.2 & 41.721 & 41.681 & 41.640 & 41.600 & 41.560 & 41.520 & 41.480 & 41.439 & 41.399 & 41.359 \\ 8.3 & 41.319 & 41.279 & 41.239 & 41.198 & 41.158 & 41.118 & 41.078 & 41.038 & 40.998 & 40.958\end{array}$

$\begin{array}{lllllllllll}8.3 & 41.319 & 41.279 & 41.239 & 41.198 & 41.0158 & 41.118 & 41.078 & 41.038 & 40.998 & 40.958 \\ 8.4 & 40.917 & 40.877 & 40.837 & 40.797 & 40.756 & 40.716 & 40.676 & 40.636 & 40.596 & 40.556\end{array}$

$\begin{array}{lllllllllll}8.5 & 40.515 & 40.475 & 40.435 & 40.395 & 40.355 & 40.315 & 40.274 & 40.234 & 40.194 & 40.154\end{array}$

$\begin{array}{lllllllllll}8.6 & 40.114 & 40.074 & 40.033 & 39.993 & 39.953 & 39.913 & 39.873 & 39.833 & 39.792 & 39.752\end{array}$

$\begin{array}{lllllllllll}8.7 & 39.712 & 39.672 & 39.632 & 39.592 & 39.551 & 39.511 & 39.471 & 39.431 & 39.391 & 39.351 \\ 8.8 & 39.310 & 39.270 & 39.230 & 39.190 & 39.150 & 39.109 & 39.069 & 39.029 & 38.989 & 38.0449\end{array}$

0.278991

0.278991

0.278991

0.278990

0.278990

$\begin{array}{llllllllll}38.909 & 38.868 & 38.828 & 38.788 & 38.748 & 38.708 & 38.668 & 38.627 & 38.587 & 38.547\end{array}$

0.278989

0.278989

0.278989

0.278988

0.278988
0.278988

0.278988

0.278988
0.278987
0.278987

0.278987

0.278987

1.391665

1.391718

. 391744

1.391798

1.391824

$\begin{array}{rrrrrrrrrrr}989.0 & 20038.507 & 38.467 & 38.427 & 38.387 & 38.346 & 38.306 & 38.266 & 38.226 & 38 \cdot 186 & 38.146 \\ 9.1 & 38.105 & 38.065 & 38.025 & 37.985 & 37.945 & 37.905 & 37.865 & 37.824 & 37.784 & 37.744 \\ 9.12 & 37.704 & 37.654 & 37.024 & 37.583 & 37.543 & 37.503 & 37.463 & 370423 & 37.382 & 37.342\end{array}$

$\begin{array}{llllllllll}37.704 & 37.664 & 37.624 & 37.583 & 37.543 & 37.503 & 37.463 & 37.423 & 37.382 & 37.342\end{array}$

$\begin{array}{llllllllll}36.901 & 36.860 & 36.820 & 36.780 & 36.740 & 36.700 & 36.060 & 36.620 & 36.579 & 36.53\end{array}$

$\begin{array}{lllllllllll}36.097 & 36.057 & 36.017 & 35.977 & 350937 & 35.897 & 35.856 & 35.816 & 35.776 & 35.736\end{array}$

$\begin{array}{llllllllll}350696 & 35.656 & 35.615 & 35.575 & 35.535 & 35.495 & 350455 & 35.415 & 35.375 & 35.334\end{array}$

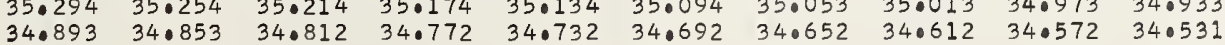

.010

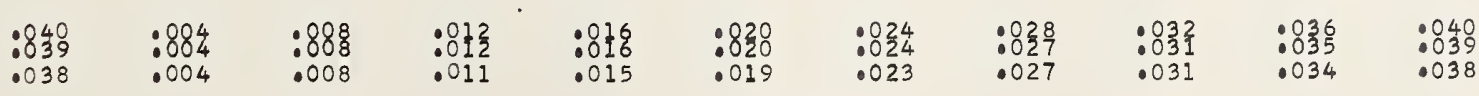

1.391957

1.392010

1.392037

1.392063

1.392090 


\subsection{1
0.2
0.3
0.4
0.5
0.6
0.7
0.8
0.9}

4991.0

1.01
1.0
1.04
1.0
1.07
1.0

4992.0

$2 \cdot 1$
$2 \cdot 2$
$2 \cdot 3$

$2 \cdot 3$
2.4

2.4

2.7

2. 8

4993.

3.1
3.2
3.3

3.3
3.4

3.5
3.6

3.7
3.9

4994.

4.0
40
4.0
4.0
4.04
4.5
4.0
40
4.0
4.0

5.

5.3

5.4
5.5

5.6

5.8

4996.0

6.

6.3

6.5

6.6

6.8
6.9

4997.

7.

7.3

7.5

7.7

4998 .

9.1

9.3
9.4

9.5

9.7
9.8
9.9

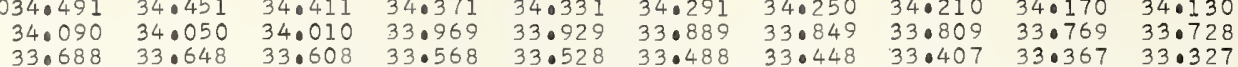

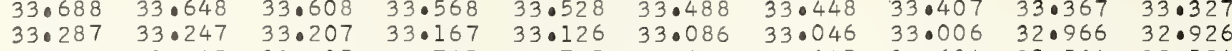
$\begin{array}{llllllllll}32.885 & 32.845 & 32.805 & 32.765 & 32.725 & 32.685 & 32.645 & 32.604 & 32.564 & 32.524\end{array}$

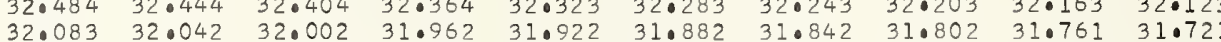
$\begin{array}{llllllllll}31.681 & 31.641 & 31.601 & 31.561 & 31.521 & 31.480 & 31.441 & 31.400 & 31.360 & 31.320\end{array}$ $\begin{array}{llllllllll}31.280 & 31.240 & 31.199 & 31.159 & 31.119 & 31.079 & 31.039 & 30.999 & 30.958 & 30.919 \\ 30.878 & 30.838 & 30.798 & 30.758 & 30.718 & 30.678 & 30.638 & 30.598 & 30.557 & 30.517\end{array}$

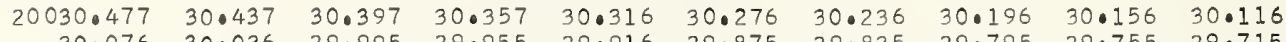
$\begin{array}{llllllllll}30.076 & 30.036 & 29.995 & 29.955 & 29.916 & 29.875 & 29.835 & 29.795 & 29.755 & 29.715\end{array}$ $\begin{array}{llllllllll}29.675 & 29.635 & 29.594 & 29.554 & 29.514 & 29.474 & 29.434 & 29.394 & 29.354 & 29.313\end{array}$ $\begin{array}{llllllllll}29.273 & 29.233 & 29.193 & 29.153 & 29.113 & 29 \cdot 073 & 29.032 & 28.992 & 28.952 & 28.912\end{array}$ $\begin{array}{llllllllll}28.470 & 28.431 & 28.390 & 28.350 & 28.310 & 28.270 & 28.230 & 28.190 & 28.150 & 28.110\end{array}$ $\begin{array}{llllllllll}28.070 & 28.029 & 27.989 & 27.949 & 27.909 & 27.869 & 27.829 & 27.789 & 27.749 & 27.708\end{array}$ $\begin{array}{llllllllll}27.668 & 27.628 & 27.588 & 27.548 & 27.508 & 27.468 & 27.427 & 27.387 & 27.347 & 27.307\end{array}$ $\begin{array}{llllllllll}27.267 & 27.227 & 27.187 & 27.147 & 27.107 & 27.066 & 27.026 & 26.986 & 26.946 & 26.906 \\ 26.866 & 26.826 & 26.785 & 26.745 & 26.705 & 26.665 & 26.625 & 26.585 & 26.545 & 26.505\end{array}$

$20026.465 \quad 26.425$ $26.063 \quad 26.023$ $25.662 \quad 25.622$ 25.261125 .221 $24.459 \quad 24.419$ $\begin{array}{ll}24.058 & 24.419 \\ 24.018\end{array}$ $\begin{array}{ll}23.657 & 23.617 \\ 23.256 & 23.216\end{array}$ $\begin{array}{ll}23.256 & 23 \cdot 216 \\ 22.855 & 22 \cdot 815\end{array}$

$26 \cdot 385 \quad 26 \cdot 344$

$\begin{array}{llll}0.983 & 25.943 & 25.3003 & 26.26\end{array}$ $\begin{array}{llll}25.542 & 25.502 & 25.462\end{array}$ $\begin{array}{ll}25.181 & 25 \cdot 1 \\ 24.780 & 24.7\end{array}$ $\begin{array}{ll}24.780 & 24.740 \\ 24.379 & 24.33 \\ 23.978 & 23.93\end{array}$ 23.577
23.17
22.0775

$20022 \cdot 454 \quad 22 \cdot 414$

$\begin{array}{ll}22.053 & 22.013 \\ 21.652 & 21.612 \\ 21.251 & 21.211\end{array}$

$\begin{array}{ll}21.251 & 21.211 \\ 20.850 & 20.810\end{array}$

$\begin{array}{ll}20.449 & 20.409 \\ 20.048 & 20.008\end{array}$

$19.647 \quad 19.607$

$\begin{array}{ll}19.246 & 19.206 \\ 18.846 & 18.806\end{array}$

$22.374 \quad 22 \cdot 334$

$21.973 \quad 21.933 \quad 21.893 \quad 22.253$

$21.572 \quad 21.532$

20.770

$20.369 \quad 20.329$

19.069

$20018.445 \quad 18.405$

$\begin{array}{ll}18.044 & 18.004 \\ 17.643 & 17.603\end{array}$

$\begin{array}{ll}17.242 & 17.202 \\ 16.842 & 16.801\end{array}$

$16.441 \quad 16.401$

$16.040 \quad 16.00$

$15.238 \quad 15.198$

14.83 $\begin{array}{ll}14.036 & 13.99 \\ 13.636 & 13.59\end{array}$ $\begin{array}{ll}13.235 & 13.195 \\ 12.834 & 12.794\end{array}$ $12.434 \quad 12.394$ $\begin{array}{ll}12.033 & 11.993 \\ 11.633 & 11.593\end{array}$ $\begin{array}{ll}11.232 & 11.192 \\ 10.832 & 10.791\end{array}$ $20010.431 \quad 10.391$

$\begin{array}{ll}10.031 & 09.990 \\ 09.630 & 09.590 \\ 09.229 & 09.189 \\ 08.829 & 08.789 \\ 08.428 & 08.389 \\ 08.028 & 07.988 \\ 07.628 & 07.588 \\ 07.227 & 07.187 \\ 06.827 & 06.787\end{array}$

20006.426 $06.026 \quad 05.986$ $05.626 \quad 05.586$ $\begin{array}{ll}0.225 & 05.18 \\ 04.825 & 04.78\end{array}$ $04.425 \quad 04.385$ $\begin{array}{ll}04.025 & 03.98 \\ 03.624 & 03.58\end{array}$ $\begin{array}{ll}03.224 & 03.184 \\ 02.824 & 02.784\end{array}$

$0002.424 \quad 02.384$

02.023

02.023
01.623

$01.623 \quad 01.583$

$\begin{array}{ll}0.10223 & 01.183 \\ 00.823 & 00.783\end{array}$

00.42300 .383

$00.023 * 0.383 \quad 00.343 \quad 00.303$

$19999.623 * 99.583$

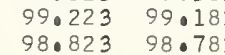

18.36

17.964

17.16217 .122

16.361
15.960
150.321

$15.559 \quad 15.51$

$25 \cdot 10$
24.69
24.29

$24.699 \quad 24.66$

.224
.823
.422
.021
.01
. .21

250

$26 \cdot 184 \quad 26 \cdot 144 \quad 26 \cdot 104$

$\begin{array}{lll}25.382 & 25.342 & 25.301\end{array}$

$\begin{array}{lll}24 \cdot 980 & 24.940 & 24.900 \\ 24.579 & 24.539 & 24.499\end{array}$

$24 \cdot 178 \quad 24 \cdot 138 \quad 24 \cdot 098$

$\begin{array}{lll}.777 & 23.737 & 23.697\end{array}$

$\begin{array}{llllll}3.497 & 23.457 & 23.417 & 23.376 & 23.336 & 23.296 \\ 23.096 & 23.055 & 23.015 & 22.975 & 22.935 & 22.895\end{array}$

$\begin{array}{lll}23.096 & 23.055 \\ 22.695 & 22.655\end{array}$

22.615

22.574

22.534

2.494

$\begin{array}{lllllll}21.091 & 21.051 & 21.010 & 20.970 & 20.930 & 20.890\end{array}$

$\begin{array}{ll}20.930 & 20.890 \\ 20.530 & 20.489\end{array}$

$\begin{array}{lll}.570 & 20.530 & 20.489 \\ .168 & 20.128 & 20.088\end{array}$

$\begin{array}{ll}4.758 & 15 \cdot 11 \\ & 14.718\end{array}$

$4.357 \quad 14 \cdot 31$

$13.556 \quad 13.516$

$\begin{array}{ll}3.155 & 13.115\end{array}$

$1.953 \quad 11.913$

$1.552 \quad 11.512$

10.75

$10.351 \quad 10.311$

$09.550 \quad 09.510$

$09.109 \quad 09.470$

$\begin{array}{ll}08.749 & 08.70 \\ 08.349 & 08.309\end{array}$

$\begin{array}{ll}07.948 & 07.908 \\ 07.548 & 07.508\end{array}$

$\begin{array}{ll}07.147 & 07.107 \\ 06.747 & 06.707\end{array}$

$\begin{array}{ll}06.346 & 06.306 \\ 05.946 & 05.906\end{array}$

$05.546 \quad 05.506$

$\begin{array}{ll}05.145 & 05.10 \\ 05.145 & 5.10 \\ 04.745 & 04.705\end{array}$

$04.745 \quad 04.705 \quad 04.665$

289.24

$\begin{array}{lll}.888 & 19.848 & 19.808\end{array}$

$\begin{array}{ll}19.086 & 19.046 \\ 18.685 & 18.64\end{array}$

19.006
18.605

$\begin{array}{lll}19.768 & 19.728 & 19.687\end{array}$

$18.966^{\circ} 18.926 \quad 18.886$

$8.284 \quad 18.244$

$17.483 \quad 17.444$

$\begin{array}{lll}17.082 & 17.042 & 17.000\end{array}$

$16.281 \quad 16.240$

$\begin{array}{ll}15.840 & 15.800\end{array}$

5.078

15.43
15.038

$14 \cdot 277$

\subsection{7}

18.204
17.803
17.403
17.002
16.601
16.200
15.800
15.399
14.998
14.597

$\begin{array}{lll}18.164 & 18.124 & 18.084 \\ 17.763 & 17.723 & 17.683\end{array}$

$\begin{array}{lll}17.763 & 17.723 & 17.683 \\ 17.363 & 17.323 & 17.282\end{array}$

$16.961 \quad 16.921 \quad 16.882$

$\begin{array}{lll}16.160 & 16.120 & 16.481 \\ 16.080\end{array}$

$\begin{array}{lll}15.759 & 15.719 & 15.679\end{array}$

$\begin{array}{lll}14.958 & 14.918 & 14.878\end{array}$

$14 \cdot 477$

$\begin{array}{llllll}.875 & 13.836 & 13.796 & 13.756 & 13.716 & 14.076 \\ 13.676\end{array}$

$\begin{array}{llllll}12.674 & 12.634 & 12.594 & 12.554 & 12.514 & 12.474 \\ 12.273 & 12.233 & 12.193 & 12.153 & 12.114 & 12.073\end{array}$

$\begin{array}{llllll}11.873 & 11.833 & 11.793 & 11.753 & 11.713 & 11.672\end{array}$

$\begin{array}{llllll}1.072 & 11.032 & 10.992 & 10.952 & 10.912 & 10.872\end{array}$

$\begin{array}{llllll}10.271 & 10.231 & 10.191 & 10.151 & 10.111 & 10.071\end{array}$

$\begin{array}{llllll}09.870 & 09.830 & 09.790 & 09.750 & 09.710 & 09.670\end{array}$

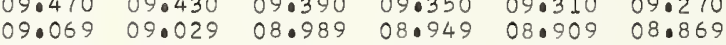

$\begin{array}{llllll}08.669 & 08.629 & 08.589 & 08.549 & 08.509 & 08.469\end{array}$

$\begin{array}{llllll}08.268 & 08.228 & 08.188 & 08.148 & 08.108 & 08.068\end{array}$

$\begin{array}{llllll}07.468 & 07.427 & 07.388 & 07.347 & 07.708 & 07.668\end{array}$

$\begin{array}{llllll}07.067 & 07.027 & 06.987 & 06.947 & 06.907 & 06.867 \\ 06.667 & 06.627 & 06.587 & 06.547 & 06.507 & 06.466\end{array}$

$\begin{array}{llllll}06.266 & 06.226 & 06.186 & 06.146 & 06.106 & 06.066\end{array}$

$\begin{array}{llllll}05.866 & 05.826 & 05.786 & 05.746 & 05.706 & 05.666\end{array}$

$\begin{array}{llllll}.466 & 05.426 & 05.385 & 05 \cdot 345 & 05.305 & 05 \cdot 265\end{array}$

$\begin{array}{llllll} & \end{array}$

$\begin{array}{lllllllll} & 04.265 & 04 \cdot 225 & 04 \cdot 185 & 04.145 & 04.105 & 04.065 \\ 03.945 & 03.905 & 03.865 & 03.824 & 03.784 & 03.744 & 03.704 & 03.664\end{array}$

$\begin{array}{llllllll}03.544 & 03.504 & 03.464 & 03.424 & 03.384 & 03.344 & 03.304 & 03.264\end{array}$

$\begin{array}{llllllll}02.744 & 02.704 & 02.664 & 02.624 & 02.584 & 02.544 & 02.504 & 02.464\end{array}$

998.42398 .383

98.02298 .383 .070

97.62397 .583

$96.823 \quad 96.783 \quad 97.14297 .103$

$96.42296 .383 \quad 96.343 \quad 96.302$

$96.023 \quad 95.983 \quad 95.943 \quad 95 \cdot 903$

$\begin{array}{llll}95.623 & 95.583 & 95.543 & 95.50 \\ 95.223 & 95.183 & 95.143 & 95.10\end{array}$

$\begin{array}{lllll}02.224 & 02.183 & 02.143 & 02.103 & 02.063\end{array}$

$\begin{array}{llllll}1.863 & 01.823 & 01.783 & 01.743 & 01.703 & 01.663\end{array}$

$\begin{array}{llllll}01.463 & 01.423 & 01.383 & 01.343 & 01.303 & 01.263\end{array}$ $6063-00.223 \quad 00.183 \quad 00.143 \quad 00.103 \quad 00.063$ . $00.863 * 0.023 * 0.183 * 0.0143 * 00.703 * 00.063$

940823

0.278987 0.278986
0.278986 0.278986 0.278986
0.278985 0.278985 0.278985 0.22789884
0.278984

0.278984 0.278984
0.278983 0.278983 0.278983 0.278983 0.278982

0.278982

0.278982
0.278982

0.278981

0.278981
0.278981

0.2789810

0.278980

0.278980

0.27898

0.278979

0.278979

0.278979

0.278978 0.278978 0.278978 0.278977 0.278977 0.278977 0.278977
0.278976

0.278976

0.278976

0.278975

0.278975

0.278975

0.278974

0.278974

0.2278974
0.278974

0.278973

0.278973
0.278973

0.278973

0.278972

0.278972

0.278972

0.278971
0.278971

0.278971
0.278971

0.278971

0.278970

0.278970

0.278969

0.278969

0.278969

0.278968

0.278968

0.278968
0.278967

0.278967

0.278967

0.278966

0.278966
0.278966

0.278966
0.278966 
$\begin{array}{lllllllllll}5000 \cdot 0 & 19994.423 & 94.383 & 94.343 & 94.303 & 94.263 & 94.223 & 94 \cdot 183 & 94 \cdot 143 & 94 \cdot 103 & 94 \cdot 063\end{array}$

$\begin{array}{lllllllllll}0.1 & 94.023 & 93.983 & 93.943 & 93.903 & 93.863 & 93.823 & 93.783 & 93.743 & 93.703 & 93.663\end{array}$

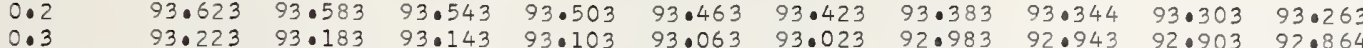

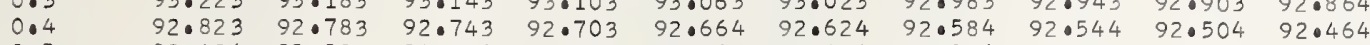

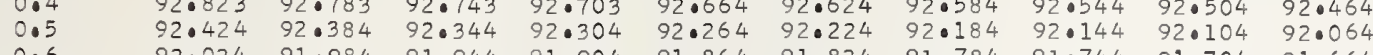

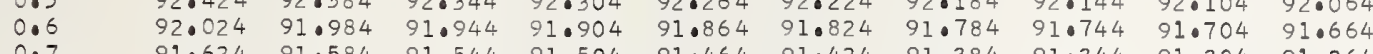

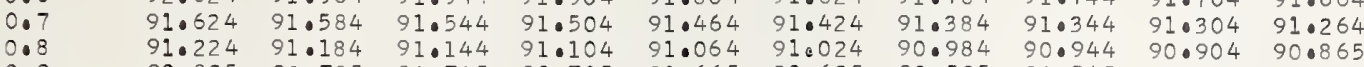

$90.825 \quad 90.785 \quad 90.745 \quad 90.705$

5001.0

19990

$\begin{array}{rlll}990.425 & 90.385 & 90.345 & 90.305 \\ 90.025 & 89.985 & 89.945 & 89.905 \\ 89.625 & 89.585 & 89.545 & 89.505 \\ 89.226 & 89.186 & 89.146 & 89.106\end{array}$

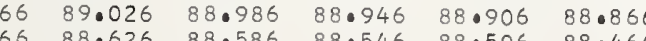

$\begin{array}{lllll}88.426 & 88.386 & 88.346 & 88.307\end{array}$

$88.027 \quad 87 \cdot 987 \quad 87.947 \quad 87 \cdot 906$

$\begin{array}{llllllllll}87.627 & 87.587 & 87.547 & 87.507 & 87.467 & 87.427 & 87.387 & 87.347 & 87.308 & 87.268 \\ 87.228 & 87.187 & 87.147 & 87.108 & 87.068 & 87.028 & 86.988 & 86.948 & 86.908 & 86.868\end{array}$

5002.0

2.019986 .4

$2 \cdot 1$

$2 \cdot 3$

$2 \cdot 4$

2.6

$2 \cdot 7$

$6.428 \quad 86.388$

$\begin{array}{llll}8.029 & 85.989 & 85.949 & 86.309 \\ 85.629 & 85.589 & 85.549 & 8509\end{array}$

$\begin{array}{llll}85.629 & 85.589 & 85.549 & 85.510 \\ 85.229 & 85.189 & 85.150 & 85.110\end{array}$

$\begin{array}{llll}85.229 & 85.189 & 85.150 & 85.110 \\ 84.830 & 84.790 & 84.750 & 84.710 \\ 84.431 & 84.391 & 84.351 & 84.311\end{array}$

$\begin{array}{llll}84.431 & 84.391 & 84.351 & 84.311 \\ 84.031 & 83.991 & 83.951 & 83.911\end{array}$

$\begin{array}{llll}83.632 & 83.592 & 83.552 & 83.512\end{array}$

$\begin{array}{llll}83.232 & 83.192 & 83.152 & 83.113 \\ 82.833 & 82.793 & 82.753 & 82.713\end{array}$

5003.

$\begin{array}{ll}82.433 & 82.394 \\ 82.034 & 81.994 \\ 81.635 & 81.595\end{array}$

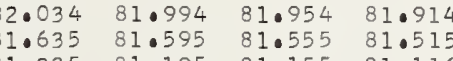

$\begin{array}{llll}81.235 & 81.195 & 81.155 & 81.116 \\ 80.836 & 80.796 & 80.756 & 80.716\end{array}$

$80.037 \quad 79.997$

$\begin{array}{llll}80.037 & 79.997 & 79.957 & 79.917 \\ 79.638 & 79.598 & 79.558 & 79.518\end{array}$

$79.239 \quad 79.199$

$\begin{array}{ll}86.269 & 86.229 \\ 85.869 & 85.829\end{array}$

$\begin{array}{ll}85.869 & 85.829 \\ 85.469 & 85.429 \\ 85.070 & 85.030\end{array}$

$\begin{array}{ll}85.070 & 85.030 \\ 84.670 & 84.631\end{array}$

$84 \cdot 271$
83.87
83.472

84.631
84.231
83.832

83.472
83.073
82.673

83.432
83.033

85.78

$\begin{array}{lll}86.148 & 86.109 & 86.069 \\ 85.749 & 85.709 & 85.669\end{array}$

$\begin{array}{llll}84.990 & 85.350 & 85.310 & 85.270\end{array}$

$\begin{array}{llll}84.591 & 84.551 & 84.511 & 84.471\end{array}$

$78.440 \quad 78.401$

5004

4.
4.
4
4
4
4
4
4
4

5005

5.
5.
5.
5.
5.5
5.6
5.7
5

$\begin{array}{ll}78.041 & 78.00 \\ 77.642 & 77.60\end{array}$

$77.243 \quad 77.203$

$\begin{array}{ll}76.844 & 76.804 \\ 76.444 & 76.405\end{array}$

$76.045 \quad 76.005$

$75.646 \quad 75.606$

$\begin{array}{ll}75.247 & 75 \cdot 207 \\ 74.848 & 74.808\end{array}$

82.274

$82 \cdot 234$

83.392

$\begin{array}{lll}84 \cdot 151 & 84 \cdot 111 & 84.071 \\ 83.752 & 83.7112 & 83.672\end{array}$

$\begin{array}{llll}83.352 & 83.312 & 83.272\end{array}$

$\begin{array}{llllll}81.076 & 81.036 & 81.395 & 81.355 & 81.315 & 81.275 \\ & 80.996 & 80.956 & 80.916 & 80.876\end{array}$

$\begin{array}{llllll}80.277 & 80.636 & 80.596 & 80.556 & 80.516 & 80.477\end{array}$

$\begin{array}{llllll}79.878 & 79.838 & 80.197 & 80.157 & 80.117 & 80.077 \\ 79.798 & 79.758 & 79.718 & 79.678\end{array}$

$\begin{array}{llllll}79.878 & 79.838 & 79.798 & 79.758 & 79.718 & 79.678 \\ 79.478 & 79.438 & 79.399 & 79.359 & 79.319 & 79.279\end{array}$

$8.760 \quad 78.719$

79.079
78.680

$79 \cdot 359$

$\begin{array}{ll}78.361 & 78.32 \\ 77.961 & 77.921 \\ 77.552 & 77.52\end{array}$

78.28
77.88

78.241

78.201

$78 \cdot 56$

$78.520 \quad 78.480$

0.278960

0.278960

0.278959

0.278959

0.278959

0.278958

0.278958

0.278957

0.278957

0.278957

0.278956

0.278956
0.278956

0.278955
0.278955

0.278955

0.278955
0.278954

0.278954
0.278954

0.278954

0.278953
0.278953

0.278953
0.278952

0.278952

0.278952
0.278952

0.278951

0.278951

0.278951

0.278950

0.278950

0.278950

0.278949
0.278949

0.278949

$\begin{array}{llllllll}77.552 & 77.522 & 77.482 & 77.442 & 77.403 & 77.0363 & 77.722 & 77.682 \\ 77.163 & 77.123 & 77.083 & 77.043 & 77.003 & 76.963 & 76.923 & 77.283 \\ 76.764 & 76.724 & 76.684 & 76.644 & 76.604 & 76.564 & 76.524 & 76.484\end{array}$

$\begin{array}{ll}76.764 & 76.72\end{array}$

$75.96575 \bullet 925$

$\begin{array}{ll}76.285 & 76.245 \\ 75.886 & 75.846\end{array}$

76.604

76
06 75

$\begin{array}{rrr}564 & 76.923 & 76.884 \\ 76.48\end{array}$

$\begin{array}{lllllllll}75.566 & 75.526 & 75.486 & 75.446 & 75.407 & 75.367 & 75.327 & 75.287\end{array}$

0.278948

0.278948

0.278948

0.278947

0.278947
0.278947

0.278946

0.278946

0.278946

0.278945

0.278945
0.278945

$\begin{array}{llllllllll}72.055 & 72.015 & 71.975 & 71.935 & 71.895 & 71.855 & 71.815 & 71.775 & 71.735 & 71.695 \\ 71.656 & 71.616 & 71.576 & 71.536 & 71.496 & 71.456 & 71.016 & 71.376 & 71.336 & 71.296\end{array}$ $\begin{array}{llllllllll}71.656 & 71.616 & 71.576 & 71.536 & 71.496 & 71.456 & 71.416 & 71.376 & 71.336 & 71.296 \\ 71.257 & 71.217 & 71.177 & 71.137 & 71.097 & 71.057 & 71.017 & 70.977 & 70.937 & 70.897\end{array}$ $\begin{array}{llllllllll}71.257 & 71.217 & 71.177 & 71.137 & 71.097 & 71.057 & 71.017 & 70.977 & 70.937 & 70.897 \\ 70.858 & 70.818 & 70.778 & 70.738 & 70.698 & 70.658 & 70.618 & 70.578 & 70.539 & 70.499\end{array}$

5006.0 $\begin{array}{rlllllllll}19970.458 & 70.419 & 70.379 & 70.339 & 70.299 & 70.259 & 70.219 & 70.179 & 70.139 & 70.100 \\ 70.060 & 70.020 & 69.980 & 69.940 & 69.900 & 69.860 & 69.820 & 69.781 & 69.740 & 69.701\end{array}$ $\begin{array}{llllllllll}69.661 & 69.621 & 69.581 & 69.541 & 69.501 & 69.461 & 69.422 & 69.382 & 69.342 & 69.302 \\ 69.262 & 69.222 & 69.182 & 69.142 & 69.102 & 69.062 & 69.022 & 68.983 & 68.943 & 68.903\end{array}$

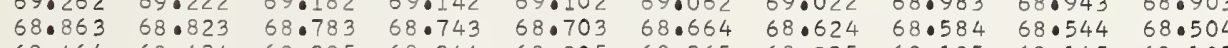
$\begin{array}{llllllllll}68.464 & 68.424 & 68.385 & 68.344 & 68.305 & 68.265 & 68 \cdot 225 & 68 \cdot 185 & 68.145 & 68.105\end{array}$ $\begin{array}{llllllllll}68.065 & 68.025 & 67.986 & 67.946 & 67.906 & 67.866 & 67.826 & 67.786 & 67.746 & 67.706\end{array}$ $\begin{array}{lllllllllll}67.268 & 67.228 & 67.188 & 67.148 & 67.108 & 67.068 & 67.029 & 66.989 & 66.949 & 66.909\end{array}$ $\begin{array}{llllllllll}66.869 & 66.829 & 66.789 & 66.749 & 66.709 & 66.669 & 66.630 & 66.590 & 66.550 & 66.510\end{array}$

19966.470 $66.470 \quad 66.430$ $65.673 \quad 65.031 \quad 65.992$ $65.274 \quad 65.234 \quad 65.193$ $64.875 \quad 64.835 \quad 64.795$ $\begin{array}{lllllll}64.078 & 64.038 & 63.998 & 63.958 & 63.918 & 63.878 & 63.8\end{array}$

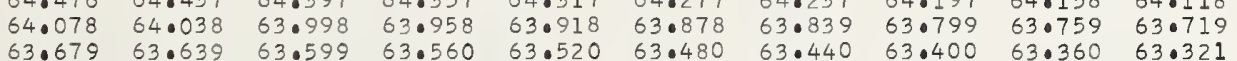
$\begin{array}{llllllllll}63.281 & 63.240 & 63.200 & 63.161 & 63.121 & 63.081 & 63.041 & 63.400 & 63.360 & 63.321\end{array}$ $\begin{array}{llllllllll}62.882 & 62.842 & 62.802 & 62.762 & 62.722 & 62.683 & 62.643 & 62.603 & 62.563 & 62.523\end{array}$

0.278944

0.278944
0.278944

0.278944
0.278944

0.278943
0.278943

0.278943

0.278942
0.278942

0.278942

0.278942
0.278941

0.278941

0.278941
0.278941

0.278941

0.278940

0.278940

0.278940

0.278939

0.278939

0.278939

0.278938
0.278938

0.278938

0.278937
0.278937

0.278937

$\begin{array}{llllllllll}60.092 & 60.052 & 60.012 & 59.972 & 59.933 & 59.893 & 59.853 & 59.813 & 59.773 & 59.73\end{array}$

$\begin{array}{llllllllll}59.693 & 59.654 & 59.614 & 59.574 & 59.534 & 59.494 & 59.454 & 59.415 & 59.375 & 59.335 \\ 59.295 & 59.255 & 59.215 & 59.176 & 59.135 & 59.096 & 59.056 & 59.016 & 58.976 & 58.937\end{array}$

$\begin{array}{llllllllll}58.896 & 58.856 & 58.817 & 58.777 & 58.737 & 58.697 & 58.657 & 58.617 & 58.578 & 58.538\end{array}$

0.278936

0.278936

0.278936

0.278936
0.278935

0.278935

0.278935

0.278934

0.278934
0.278934

.394801

.394827

- 394880

1.394907

1.394960

1. 395013

1.395066

1.395093

1.395146

1.395199

1.395226

1.395279

1. 395332

1.395359

1.395412

1. 395465

. 395492

1.395518

1.395571

1.395598

1.395624
.395651

1.395678

1.395731

1.395757

1. 395811

1.395864

1.395890

1.395943

1.395970

1.396023

1.396050

1.396076
1.396103

1.396129

1.396156

.396183
.396209

1.396236

1.396262

1.396316

1.396342
1.396369

1.396395

1.396422

1.396475

1.396502
1.396528

1.396555

1.396581

1.396634

1.396661

1.396688

1.396714

1.396767

1.396794

1.396821
1.396847

1.396874

1.396927

1.396953

1.396980
1.397007

1.397033

1.397060

1.397113

1.397139

1.397193

. 397246

1.397246
1.397272

1.397272
1.397299

1.397326

1.397352
1.397379

1. 397405

.010

.040 
$\begin{array}{lllllllll}54.435 & 54 \cdot 395 & 54 \cdot 355 & 54 \cdot 315 & 54 \cdot 275 & 54 \cdot 235 & 54 \cdot 196 & 54 \cdot 156 \\ 54.036 & 53.997 & 53.957 & 53.917 & 53.877 & 53.837 & 53.798 & 53.758\end{array}$ $\begin{array}{llllllllll}53.718 & 53.678 & 53.638 & 53.598 & 53.559 & 53.519 & 53.479 & 53.439 & 53.399 & 53.359\end{array}$

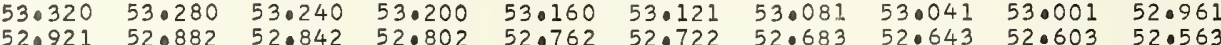

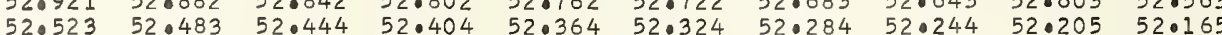
0.5 0.6

$51.727-51.687$

$51 \cdot 329$

5011.0

1.

$1 \cdot 2$

1.4

1.5
1.6

1.8

1.8
1.9

5012.0

2.1

2.3

2.4

2.6
2.7

2.8
2.9

5013.

3.1

$3 \cdot 3$

3.4
3.5

3.6
3.7

3.8
3.9

5014.0

4.1

$4 \cdot 3$
$4 \cdot 4$

$4 \cdot 4$
$4 \cdot 5$

4.6
4.7

4.8
4.9

5015.0

$5 \cdot 1$
$5 \cdot 2$
$5 \cdot 3$

$5 \cdot 3$

5.5

$5 \cdot 6$
5.7

5.8
5.9

$\begin{array}{rrrr}9950.532 & 50.493 & 50.453 & 50.413 \\ 50.134 & 50.094 & 50.055 & 50.015\end{array}$

$\begin{array}{llll}50.736 & 49.696 & 49.656 & 49.617\end{array}$

$49.338 \quad 49.298 \quad 49$

$\begin{array}{llll}48.940 & 48.900 & 48.860 & 48.820\end{array}$

$\begin{array}{llll}48.542 & 48.502 & 48.462 & 48.423 \\ 48.144 & 48.104 & 48.064 & 48.024\end{array}$

$47.746 \quad 47.706$

$\begin{array}{ll}47.348 & 47.308 \\ 46.950 & 46.910\end{array}$

$\begin{array}{ll}48.064 & 48.024 \\ 47.666 & 47.626\end{array}$

$9946.552 \quad 46.512$

$\begin{array}{llll}46.52 & 46.512 & 46.472 & 46.432\end{array}$

$\begin{array}{llll}45.756 & 45.716 & 46.074 & 46.034\end{array}$

$45.358 \quad 45.318 \quad 45.278 \quad 45.239$

$\begin{array}{llll}44.960 & 44.920 & 44.880 & 44 \cdot 84 \\ 44.562 & 44.522 & 44.482 & 44.44\end{array}$

$\begin{array}{llll}43.766 & 43.727 & 44.085 & 44.045\end{array}$

$\begin{array}{llll}43.368 & 43.329 & 43.289 & 43.24\end{array}$

$9942.573 \quad 42.533 \quad 42.493 \quad 42.454$

$\begin{array}{ll}42.175 & 42.135 \\ 41.777 & 41.738\end{array}$

$41.379 \quad 41.340$

$\begin{array}{ll}40.982 & 40.942 \\ 40.584 & 40.544\end{array}$

40.186

$39.789 \quad 39.749$

$\begin{array}{ll}39.391 & 39.351 \\ 38.993 & 38.953\end{array}$

$41.698 \quad 41.658$

$\begin{array}{ll}41.300 & 41.260 \\ 40.902 & 40.862\end{array}$

$\begin{array}{ll}40.505 & 40.465 \\ 40.106 & 40.067\end{array}$

$39.709 \quad 39.669$

19938.595

38.198

38.556

37.403

37.005
36.607

$35.812 \quad 35.772$

$\begin{array}{ll}35.415 & 35.375 \\ 35.017 & 34.977\end{array}$

$38.516 \quad 38.476$

51.96651 .926

$\begin{array}{llll}51.488 & 51.448 & 51.408 & 51.368\end{array}$

$\begin{array}{llllll}51.169 & 51.130 & 51.090 & 51.050 & 51.010 & 50.970 \\ 50.771 & 50.731 & 50.692 & 50.652 & 50.612 & 50.572\end{array}$

$\begin{array}{llllll}50.373 & 50.333 & 50.293 & 50.254 & 50.214 & 50.174 \\ 49.975 & 49.935 & 49.895 & 49.855 & 49.816 & 49.776\end{array}$

$\begin{array}{llllll}49.577 & 49.537 & 49.497 & 49.458 & 49.418 & 49.378\end{array}$

$\begin{array}{lllllll}49.179 & 49.139 & 49.099 & 49.059 & 49.019 & 48.980\end{array}$

$\begin{array}{lllllll}48.781 & 48.741 & 48.701 & 48.661 & 48.622 & 48.582\end{array}$

$\begin{array}{llllll}47.383 & 48.343 & 48.303 & 48.263 & 48.223 & 48.184 \\ 4.985 & 47.945 & 47.905 & 47.865 & 47.825 & 47.785\end{array}$

$\begin{array}{lllllll}47.587 & 47.547 & 47.507 & 47.467 & 47.427 & 47.388\end{array}$

$\begin{array}{llllll}47.188 & 47.149 & 47.109 & 47.069 & 47.029 & 46.990\end{array}$

0.278934

(1)

0.278933

0.278933

0.278933

0.278932

0.278932

0.278931

0.278931

0.278931

0.278930

0.278930

0.278930
0.278930

0.278930

0.278929

0.278929

0.278929

0.278928

0.278928

0.278928

0.278927

0.078

0.278926

0.278926

0.278926

0.278926
0.278925

0.278925

0.278925

0.278925

0.278924

0.278924

0.278924
0.278924

0.278923

0.278923

0.278923
0.278923

0.278922

0.278922

0.278922

0.278922

0.278921

$3.4 \cdot 222$

$33.825 \quad 33.785$

$33.427 \quad 33.387$

$\begin{array}{lll}32.990 & 33.348 & 33.30\end{array}$

$\begin{array}{llll}32.633 & 32.593 & 32.553 & 32.51\end{array}$

$\begin{array}{llll}32.235 & 32.195 & 32.156 & 32.1 \\ 31.838 & 31.798 & 31.758 & 31.7\end{array}$

$\begin{array}{llll}31.440 & 31.401 & 31.361 & 31.32 \\ 31.043 & 31.003 & 30.964 & 30.924\end{array}$

5016.0

6.1

$30.248 \quad 30.209$

$\begin{array}{llll}29.851 & 29.812 & 30.169 & 30.1\end{array}$

$\begin{array}{lllll}29.454 & 29.414 & 29.375 & 29.33\end{array}$

$29.057 \quad 29.017$

$28.65928 .620 \quad 28.580$

$\begin{array}{lll}28.262 & 28.222 & 28.18 \\ 27.865 & 27.825 & 27.785\end{array}$

$\begin{array}{lll}27.468 & 27.428 & 27.3 \\ 27.070 & 27.031 & 26.99\end{array}$

19926.673

7.

7.2

$7 \cdot 3$

$7 \cdot 5$

7.6

7.8

5018.0

8.1
8.2
8.3

8.3

8.6

8.6

8.8
8.9

5019.

9.1
9.2
9.3

9.4

9.6

9.7

\begin{abstract}
$26.276 \quad 26.236$
\end{abstract}
$25.879 \quad 26.236 \quad 26.196$

$\begin{array}{lllllll}25.839 & 25.799 & 25.760 & 25.720 & 25.680\end{array}$

$\begin{array}{llllll}25.084 & 25.045 & 25.005 & 24.965 & 24.926 & 24.886\end{array}$

$\begin{array}{llllll}24.687 & 24.648 & 24.608 & 24.568 & 24.528 & 24.48 \\ 24.290 & 24.250 & 24.211 & 24.171 & 24.132 & 24.092\end{array}$

$\begin{array}{llllll}24.290 & 24.250 & 24.211 & 24.171 & 24.132 & 24.09 \\ 23.893 & 23.854 & 23.814 & 23.774 & 23.734 & 23.60\end{array}$

$\begin{array}{llllll}23.496 & 23.456 & 23.417 & 23.377 & 23.337 & 23.298 \\ 23.099 & 23.060 & 23.020 & 22.980 & 22.940 & 22.901\end{array}$

$922.702 \quad 22.662 \quad 22.623 \quad 22.583$

$\begin{array}{llll}22 \cdot 305 & 22 \cdot 265 & 22 \cdot 226 & 22 \cdot 1 \\ 21.908 & 21.868 & 21.829 & 21.7\end{array}$

$\begin{array}{llllll}21.868 & 21.829 & 21.789 & 21.746 & 22.10\end{array}$

$\begin{array}{llllll}21.114 & 21.074 & 21.032 & 21.392 & 21.352 & 21.313\end{array}$

$\begin{array}{llllll}20.717 & 20.677 & 20.638 & 20.598 & 20.558 & 20.51\end{array}$

$\begin{array}{llllll}20.320 & 20.281 & 20.241 & 20.201 & 20.161 & 20.122\end{array}$

$\begin{array}{lll}19.844 & 19.804\end{array}$

$19.129 \quad 19.48$

$19918.733 \quad 18.693$

$18.693 \quad 18.653$

$18.336 \quad 18.296$

$\begin{array}{lllllll}178.018 & 17.979\end{array}$

$\begin{array}{llllllll}17.463 & 17.423 & 17.383 & 17.344 & 17.304 & 17.264 & 17.225 & 17.185\end{array}$

$\begin{array}{llllllllll}16.76 .068 & 17.026 & 16.987 & 16.947 & 16.907 & 16.868 & 16.828 & 16.788\end{array}$

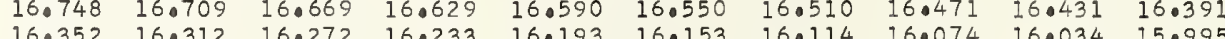

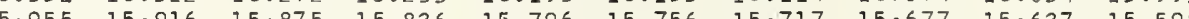

$15.036 \quad 15.796 \quad 15.756 \quad 15.717 \quad 150677 \quad 15.637 \quad 15.598$

$\begin{array}{llll}15.558 & 15.518 & 15.479 & 15.439 \\ 15.162 & 15.122 & 15.082 & 15.042\end{array}$

15.400
15.002

15.002

.005

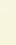

0.278921

0.278920

0.278920

0.278920

0.278920

0.278919

0.278919

0.278918

0.278918

0.278917

0.278917

0.278917

0.278917

0.278916

0.278916
0.278916

0.278916

0.278915

0.278915

0.278915

0.278914

0.278914

0.278914

0.278913

0.278913

0.278913

0.278913

0.278912

0.278912

0.278911

0.278911

0.278910

0.278910

0.278910

0.278910

0.278909

0.278909

0.278908

0.278908

.010

1.397458
1.397485

1.397512

1.397565

1.397618

1.397644

1.397671
1.397698

1.397724

1.397777

1.397804

1.397857

1.397884

1.397937

1.397963

1.397990

.398017

1.398043

. 398096

- 398123

1.398176

1.398203

1.398229

1.398256

- 398282

1.398309

1.398336
1.398362

. 398389

1.398415

$1 \cdot 398442$

1.398468
1.398495

1.398522

1. 398548

1.398575
1.398601

1. 398628

1.398655

1.398681

1. 398708

1.398734
1.398761 
$\begin{array}{rrrrrrrrrrr}0.0 & 19914.765 & 14.725 & 14.686 & 14.646 & 14.606 & 14.566 & 14.527 & 14.487 & 14.448 & 14.408 \\ 0.1 & 14.068 & 14.328 & 14.289 & 14.249 & 14.209 & 14.170 & 14.130 & 140090 & 14.051 & 14.011\end{array}$

$\begin{array}{llllllllllll}0.2 & 13.971 & 13.932 & 13.892 & 13.852 & 13.812 & 13.773 & 13.733 & 13.694 & 13.654 & 13.614 \\ 0.3 & 13.575 & 13.535 & 13.496 & 13.456 & 13.416 & 13.376 & 13.337 & 13.297 & 13.257 & 13.218\end{array}$

$\begin{array}{llllllllllll}0.4 & 13.178 & 13.138 & 13.099 & 13.059 & 13.019 & 12.980 & 12.940 & 12.900 & 12.861 & 13.218 \\ 0.5 & 12.781 & 12.742 & 12.702 & 12.663 & 12.623 & 12.583 & 12.543 & 12.504 & 12.464 & 12.425\end{array}$

$\begin{array}{lllllllllll}0.6 & 12.385 & 12.345 & 12.305 & 12.266 & 12.226 & 12.187 & 12.147 & 12.504 & 12.464 & 12.0425 \\ 0.0 & 11.988 & 11.948 & 11.900 & 11.869 & 12.067 & 12.028\end{array}$

$\begin{array}{lllllllllll}0.7 & 11.988 & 11.948 & 11.909 & 11.869 & 11.830 & 11.790 & 11.750 & 11.711 & 11.671 & 11.0631\end{array}$

$\begin{array}{lllllllllll}0.8 & 11.592 & 11.552 & 11.512 & 11.473 & 11.433 & 11.393 & 11.354 & 11.314 & 11.274 & 11.235 \\ 0.9 & 11.195 & 11.155 & 11.116 & 11.076 & 11.036 & 10.997 & 10.957 & 10.917 & 10.878 & 10.838\end{array}$

$\begin{array}{rrrrrrrrrrr}5021.0 & 19910.798 & 10.759 & 10.719 & 10.680 & 10.640 & 10.601 & 10.561 & 10.521 & 10.481 & 10.442\end{array}$

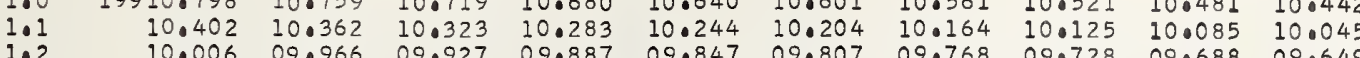

$\begin{array}{lllllllllll}1.2 & 10.006 & 09.966 & 09.927 & 09.887 & 09.847 & 09.807 & 09.768 & 09.728 & 09.0688 & 09.649 \\ 1.3 & 09.609 & 09.569 & 09.530 & 09.490 & 09.450 & 09.411 & 09.371 & 09.332 & 09.292 & 09.252\end{array}$

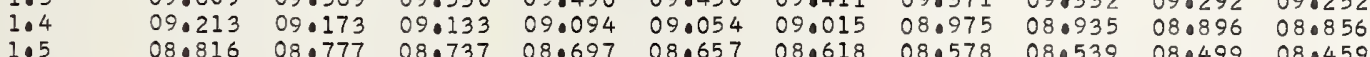

$\begin{array}{llllllllllll}1.5 & 08.816 & 08 \cdot 777 & 08.737 & 08.697 & 08.657 & 08.618 & 08.578 & 08.539 & 08.499 & 08.459 \\ 1.6 & 08.420 & 08.380 & 08.340 & 08.301 & 08.261 & 08.222 & 08.182 & 08.142 & 08.103 & 08.063\end{array}$

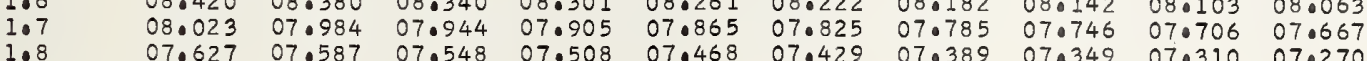

$\begin{array}{llllllllllll}1.8 & 07.627 & 07.587 & 07.548 & 07.508 & 07.468 & 07.429 & 07.389 & 07.349 & 07.310 & 07.270 \\ 1.9 & 07.230 & 07.191 & 07.151 & 07.112 & 07.072 & 07.032 & 06.992 & 06.953 & 06.913 & 06.874\end{array}$

$\begin{array}{llllllllllll}5022.0 & 19906 \cdot 834 & 06.794 & 06.755 & 06.715 & 06.676 & 06.636 & 06.596 & 06.557 & 06.517 & 06.477\end{array}$

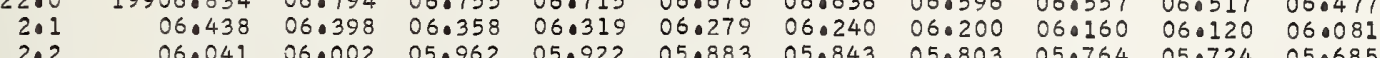

$\begin{array}{llllllllllll}2.2 & 06.041 & 06.002 & 05.962 & 05.922 & 05.883 & 05.843 & 05.803 & 05.764 & 05.724 & 05.6885 \\ 2.3 & 05.645 & 05.605 & 05.566 & 05.526 & 05.487 & 05.447 & 05.407 & 05.367 & 05.328 & 05.288\end{array}$

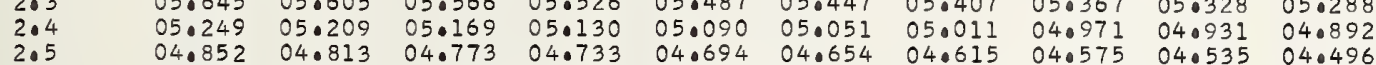

$\begin{array}{lllllllllll}2.6 & 04.456 & 04 \cdot 417 & 04.376 & 04 \cdot 337 & 04 \cdot 297 & 04 \cdot 258 & 04 \cdot 218 & 04 \cdot 178 & 04 \cdot 139 & 04.099\end{array}$

$\begin{array}{llllllllllll}2.7 & 04.060 & 04.020 & 03.980 & 03.941 & 03.901 & 03.862 & 03.822 & 04.1782 & 04.139 & 04.0343 & 03.0903 \\ 2.8 & 03.663 & 03.624 & 03.584 & 03.545 & 03.505 & 03.465 & 03.426 & 03.386 & 03.346 & 03.307\end{array}$

$\begin{array}{lllllllllll}2.9 & 03.267 & 03.228 & 03.188 & 03.148 & 03.109 & 03.069 & 03.030 & 02.990 & 02.950 & 02.910\end{array}$

$\begin{array}{lllllllllll}5023.0 & 19902.871 & 02.832 & 02.792 & 02.752 & 02.712 & 02.673 & 02.633 & 02.594 & 02.554 & 02.514\end{array}$

$\begin{array}{lllllllllll}3.1 & 02.475 & 02.435 & 02.395 & 02.356 & 02.316 & 02.277 & 02.237 & 02.197 & 02.158 & 02.118 \\ 3.2 & 02.079 & 02.039 & 01099 & 01.960 & 01.920 & 01.880 & 010841 & 01.801 & 01.761 & 01.722\end{array}$

$\begin{array}{lllllllllll}3.2 & 02.079 & 02.039 & 01.0903 & 01.960 & 01.920 & 01.880 & 01.841 & 01.801 & 01.761 & 01.722 \\ 3.3 & 01.682 & 01.643 & 01.603 & 01.563 & 01.524 & 01.484 & 01.445 & 01.0405 & 01.365 & 01.326\end{array}$

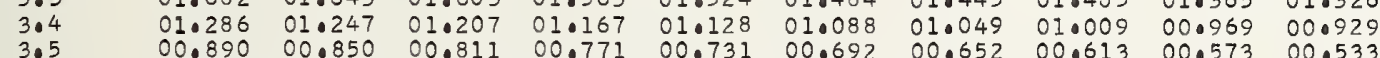

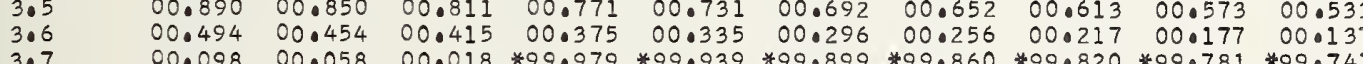

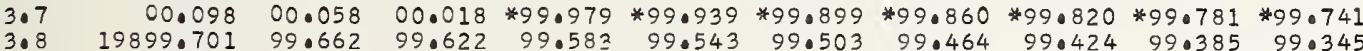

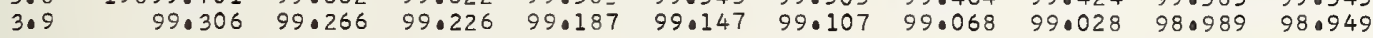

$\begin{array}{lllllllllll}5024.0 & 19898.909 & 98.870 & 98.830 & 98.791 & 98.751 & 98.711 & 98.672 & 98.632 & 98.593 & 98.553\end{array}$

$\begin{array}{lllllllllll}4 \cdot 1 & 98.513 & 98.474 & 98.434 & 98.395 & 98.355 & 98.315 & 98.276 & 98.236 & 98.196 & 98.157\end{array}$

$\begin{array}{lllllllllll}4.2 & 98.117 & 98.078 & 98.038 & 97.998 & 97.959 & 97.919 & 97.880 & 97.840 & 97.801 & 97.761 \\ 4.3 & 97.721 & 97.682 & 97.642 & 97.603 & 97.563 & 97.523 & 97.484 & 97.444 & 97.404 & 97.365\end{array}$

$\begin{array}{lllllllllll}4.3 & 97.721 & 97.682 & 97.642 & 97.603 & 97.563 & 97.523 & 97.484 & 97.444 & 97.404 & 97.365 \\ 4.4 & 97.325 & 97.285 & 97.246 & 97.206 & 97.167 & 97.127 & 97.088 & 97.048 & 97.008 & 96.969\end{array}$

$\begin{array}{lllllllllll}4.4 & 97.325 & 97.285 & 97.246 & 97.206 & 97.167 & 97.127 & 97.088 & 97.048 & 97.008 & 96.969 \\ 4.5 & 96.929 & 96.890 & 96.850 & 96.811 & 96.771 & 96.731 & 96.692 & 96.652 & 96.613 & 96.573\end{array}$

$\begin{array}{lllllllllll}4.6 & 96.533 & 96.493 & 96.454 & 96.414 & 96.375 & 96.335 & 96.296 & 96.256 & 96.216 & 96.177 \\ 4.7 & 96.137 & 96.098 & 96.058 & 96.018 & 95.979 & 95.939 & 95.900 & 95.860 & 95.821 & 95.78\end{array}$

$\begin{array}{lllllllllll}4.7 & 96.137 & 96.098 & 96.058 & 96.018 & 95.979 & 95.939 & 95.900 & 95.860 & 95.821 & 95.781 \\ 4.8 & 95.741 & 95.701 & 95.662 & 95.622 & 95.583 & 95.543 & 95.504 & 95.464 & 95.424 & 95.385\end{array}$

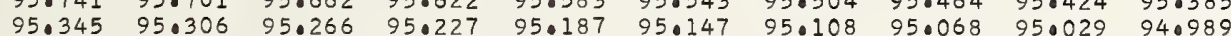

$\begin{array}{llllllllll}19894.949 & 94 \cdot 910 & 94.870 & 94 \cdot 831 & 94 \cdot 791 & 94.751 & 94 \cdot 712 & 94.672 & 94 \cdot 633 & 94.593\end{array}$

$\begin{array}{lllllllllll}5.1 & 94.553 & 94.514 & 94.474 & 94.435 & 94.395 & 94.355 & 94.316 & 94.276 & 94.237 & 94 \cdot 197 \\ 5.2 & 94.158 & 94.118 & 94.078 & 94.039 & 93.999 & 93.959 & 93.920 & 93.880 & 93.841 & 93.801 \\ 5.3 & 93.761 & 93.722 & 93.683 & 93.643 & 93.603 & 93.564 & 93.524 & 93.485 & 93.445 & 93.406\end{array}$

5.

$93.761 \quad 93.722$

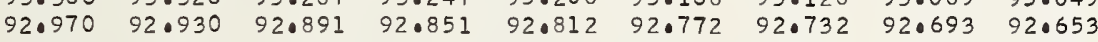

$92.574-92.534-92.891 \quad 92.851$

$92.178 \quad 92.139 \quad 92.099 \quad 92.060$

$91.782 \quad 91.743$

26
6.
6
6
60
6
6
6
6
6

19890.991

$990.991 \quad 90.9$

$\begin{array}{llll}90.595 & 90.556 & 90.912 & 90.872\end{array}$

$90.160 \quad 90.120 \quad 90.081$

$88.617 \quad 88.577$

$89.329 \quad 89.289$

$\begin{array}{ll}89.329 & 89.289 \\ 8.933 & 88.894\end{array}$

$\begin{array}{lllll}88.221 & 88.182 & 88.142 & 88.102\end{array}$

$\begin{array}{llll}87.826 & 87.786 & 87.747 & 87.707 \\ 87.430 & 87.390 & 87.351 & 87.311\end{array}$

$92.416 \quad 92.376$

$92.732 \quad 92.693 \quad 92.653 \quad 92.614$

0.278908

0.278907

0.278907

0.278907

0.278906

.

0.278905

0.278905

0.278905

0.278904

0.278904

0.278904

0.278903

0.278903

1.400117

.400143
.400170

1.400196

1.400223
1.400250

1.400276

1.400303

1.400356

0.278902

8902
8902

0.278902

0.278901

0.278901

0.278901

0.278900

1.400382

1.400409

1.400462

1.400489

1.400542

1.400569

1.400622

278900

0.278899

0.278899

0.278899

0.278898

0.278898

0.278898
0.278898

.400648

1.400701

1.400755

1.400808

1.400861

0.278897

0.278897

0.278897

.278896

0.278896

0.278895

0.278895

0.278895

0.278894

0.278894
0.278894

0.278894

0.278893

0.278893

8893

0.278892

0.278892

0.278892
0.278892

0.278891

0.27889

0.278891

0.278890

0.278890
0.278890

5027

70

19887.034

$\begin{array}{llllllllll}87.034 & 86.995 & 86.956 & 86.916 & 86.876 & 86.836 & 86.797 & 86.758 & 86.718 & 86.678 \\ 86.639 & 86.599 & 86.560 & 86.520 & 86.481 & 86.441 & 86.401 & 86.362 & 86.322 & 86.283\end{array}$

$\begin{array}{lllllllllll}86.243 & 86.204 & 86.164 & 86.125 & 86.085 & 86.045 & 86.006 & 85.966 & 85.927 & 85.887\end{array}$

$\begin{array}{llll}850452 & 85.413 & 85.373 & 85.333\end{array}$

$85.056 \quad 85.017$

$84.661 \quad 84.622 \quad 84.582 \quad 84.542$

$83.870 \quad 83.830 \quad 83.791 \quad 83.751$

\begin{tabular}{lllllll}
85.294 & 85.255 & 85.215 & 85.571 & 85.531 & 85.492 \\
\hline
\end{tabular}

$\begin{array}{llllll}84.898 & 84.859 & 84.819 & 84.780 & 84.740 & 84 \cdot 701\end{array}$

$\begin{array}{llllll}84.503 & 84.463 & 84.424 & 84.384 & 84.345 & 84 \cdot 305 \\ 84.107 & 84.068 & 84.028 & 83.989 & 83.949 & 83.910\end{array}$

$83.475 \quad 83.435$

83.71284 .068

0.278889

0.278889

0.278889

0.278889

0.278888

0.278888

0.278888

0.278887

5028.

8.0
8.0
8.0
8.0
8.5
8.0
8.7
8.8
8.9
29.0
9.0
9.2
9.3
9.4
9.6
9.7
9.8
9.9

$\begin{array}{llllllllll}19883.079 & 83.040 & 83.000 & 82.960 & 82.921 & 82.881 & 82.842 & 82.802 & 82.763 & 82.723\end{array}$ $\begin{array}{llllllllll}82.684 & 82.644 & 82.605 & 82.565 & 82.525 & 82.486 & 82.446 & 82.407 & 82.367 & 82.328 \\ 82.288 & 82.249 & 82.209 & 82.170 & 82.130 & 82.091 & 82.051 & 82.011 & 81.972 & 81.932\end{array}$ $\begin{array}{llllllllll}81.893 & 81.853 & 81.814 & 81.774 & 81.735 & 81.695 & 81.656 & 81.616 & 81.576 & 81.537 \\ 81.498 & 81.458 & 81.418 & 81.379 & 81.339 & 81.300 & 81.260 & 81.221 & 81.181 & 81.142\end{array}$ $\begin{array}{lllllllllll}81.102 & 81.063 & 81.023 & 80.984 & 80.944 & 80.905 & 80.865 & 80.826 & 80.786 & 80.746\end{array}$

0.278887

0.278887

0.278886

0.278886

0.278885

.278885 $\begin{array}{llllllllll}80.312 & 80.272 & 80.232 & 80.193 & 80.153 & 80.114 & 80.074 & 80.035 & 79.995 & 79.956\end{array}$ $\begin{array}{llllllllll}79.916 & 79.876 & 79.837 & 79.797 & 79.758 & 79.718 & 79.679 & 79.639 & 79.600 & 79.560 \\ 79.521 & 79.481 & 79.442 & 79.402 & 79.363 & 79.323 & 79.284 & 79.244 & 79.205 & 79.165\end{array}$

0.278885

1.400914

1.400941

1.400994

1.401020

1.401074

1.401100

1.401127

1.401180

1.401207

1.401260

.401286

1.401313

1.401366

10401419

$1 \cdot 401446$

1.401472

1.401526

1.401579

1.401605

1.401632

1.401685

1.401712

10401765

1.401791

1.401818

1.401845

1.401898

1.401924

1. 401978

1.402004

1.402031

1.402057

1.402110

1.402137

1.402190

1.402243

1.402270

1.402323

1.402376

1.402403

1.402429

1.402483

$\begin{array}{llllllllllll}5029.0 & 19879.125 & 79.086 & 79.046 & 79.007 & 78.967 & 78.928 & 78.888 & 78.849 & 78.809 & 78.770\end{array}$

$\begin{array}{llllllllllll}9.1 & 78.730 & 78.691 & 78.651 & 78.612 & 78.572 & 78.533 & 78.493 & 78.454 & 78.414 & 78.375 \\ 9.2 & 78.335 & 78.296 & 78.256 & 78.216 & 78.177 & 78.137 & 78.098 & 78.058 & 78.019 & 77.979\end{array}$

0.278884

1.402509

.278884

0.278884 $\begin{array}{llllllllll}77.939 & 77.900 & 77.861 & 77.821 & 77.781 & 77.742 & 77.702 & 77.663 & 77.623 & 77.584 \\ 77.544 & 77.505 & 77.465 & 77.426 & 77.386 & 77.347 & 77.307 & 77.268 & 77.228 & 77.189\end{array}$ $\begin{array}{lllllllllll}77.149 & 77.110 & 77.070 & 77.031 & 76.991 & 76.952 & 76.912 & 76.873 & 76.833 & 76.794\end{array}$ $\begin{array}{lllllllllll}76.754 & 76.715 & 76.675 & 76.635 & 76.596 & 76.557 & 76.517 & 76.477 & 76.438 & 76.398\end{array}$

.278883

0.278883

0.278882

1.402536
1.402562

1. 402589

1.402616

1.402669

1.402695

1.402722
1.402748

$\begin{array}{lllllllllll}75.964 & 75.924 & 75.885 & 75.845 & 75.806 & 75.766 & 75.727 & 75.687 & 75.647 & 75.608 \\ 75.568 & 75.529 & 75.489 & 75.450 & 75.410 & 75.371 & 75.332 & 75.292 & 75.252 & 75.213\end{array}$

.010

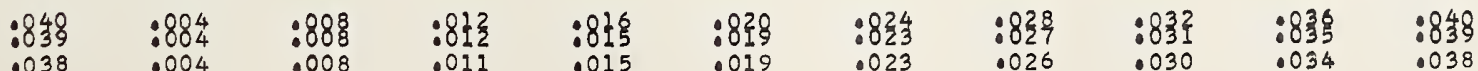


31.0

$1: 2$
$1: 0$
$1: 0$
$1: 0$

5032.

2.

2.3
2.4

2.5

2.6

2.8

5033.0

$3 \cdot 1$

3.4

3.5

3.6
3.7
3.8

5034.0

\section{4.}

4.2
4.3

$4 \cdot 4$

$4 \cdot 6$

4.8
4.9

5035.

5.

$5 \cdot 3$
5.4

5.5
5.6

5.6

5.8
5.9

5036.0

6.1
6.2
6.3

6.3

$6 \cdot 4$

6.6
6.7

6.8

\subsection{038}

$69.643 \quad 69.604$

$69.248 \quad 69.209$

$\begin{array}{ll}68.853 & 68.814 \\ 68.458 & 68.419 \\ 68.063 & 68.024\end{array}$

$\begin{array}{ll}68.063 & 68.024 \\ 67.669 & 67.629\end{array}$

$$
\begin{aligned}
& 867.274 \\
& 66.879 \\
& 66.484 \\
& 66.089 \\
& 65.695 \\
& 65.300 \\
& 64.906 \\
& 64.511 \\
& 64.116 \\
& 63.74
\end{aligned}
$$

19863.326 62.93
62.538 (62. $61.748 \quad 61.709$ $61.354 \quad 61.314$ $\begin{array}{ll}60.959 & 60.920 \\ 60.564 & 60.525\end{array}$ $60.170 \quad 60.130$ $\begin{array}{ll}58.986 & 59.3 \\ 58.98\end{array}$

$$
\begin{aligned}
& 58.592 \\
& 58.19
\end{aligned}
$$

$\begin{array}{ll}74.936 & 740 \\ 74.541 & 740 \\ 74.146 & 740 \\ 73.751 & 730 \\ 73.0556 & 730 \\ 72.961 & 720 \\ 72.5566 & 720 \\ 72.171 & 720 \\ 71.7776 & 7 \\ 71.0381 & 710\end{array}$

$$
\begin{aligned}
& 74 \\
& 74 \\
& 74 \\
& 73 \\
& 73 \\
& 72 \\
& 72 \\
& 72 \\
& 71 \\
& 71 \\
& 71
\end{aligned}
$$

.08

.09

$(n-1) \times 1000$

$\lambda(n-1)$

$0.278882-1.402775$

$\begin{array}{ll}0.278881 & 1.402802 \\ 0.278881 & 1.402828\end{array}$

$.278881-1.402855$

$0.278881 \quad 1.402881$

0.278880

$0.278880 \quad 1.402961$

$0.278879 \quad \begin{aligned} & 1.4029814 \\ & 0.027880\end{aligned}$

$0.278879 \quad 1.403041$

$0.278879 \quad 1.403094$

$0.278878 \quad 1.403121$

$0.278878 \quad 1.403147$

$0.278878-1.403200$

$0.278877 \quad 1.403227$

$\begin{array}{ll}0.278877 & 1.403254 \\ 0.278877 & 1.403280\end{array}$

0.278877

0.278876

0.278876

0.278876

0.278875

0.278875

0.278874

0.278874

0.278874

0.278873

0.278873

0.278873

0.278872

0.278872

0.27887

0.278871

0.278871

0.278871

0.278870

0.278870

0.278870
0.278869
0.278869

0.278869

1.403307

1.403360

1.403387

1.403413

1.403466

1. 403493

1.403519

1.403573

1.403626

1.403626
1.403652

1.403679

.403706

1.403732
1.403759

1.403785

1. 403812

0.278869

0.278868

0.278868
0.2788688

0.278868

0.278867

0.278867

0.278867
0.278866

1. 403839

1.403865

1.403892
1.403918

1.403945

1.403971

1.403998

1.404025
1.404051

1.404078

0.278866

0.278866

0.278866

0.278865
0.278865

0.278865

0.278865

0.278864

0.278864
0.278864

1.404104

1.404131

1.404184

1.404211

1.404237

I. 404291

1.404317
1.404344

1.404370

1.404397

1.404423

1.404477

1.404503

1.404530

.404556

1.404583
1.404610

0.278864

0.278863

0.278863

0.278862

0.278862
0.278862

0.278862
0.278861

1.404636

1.404663
1.404689

1.404716

1.404743
1.404769

$45.346 \quad 45.307 \quad 45.268 \quad 45.22$

$\begin{array}{llll}44.952 & 44.913 & 44 \cdot 874 & 44 \cdot 834 \\ 44.559 & 44.519 & 44.480 & 44.440\end{array}$

$\begin{array}{lllll}44.165 & 44.125 & 44.086 & 44 \cdot 047 \\ 43.771 & 43.731 & 43.692 & 43.653\end{array}$

1.404796

1.404849

0.278861

0.278861

0.278861

0.278860

0.278860

0.278860

0.278859

0.278859
0.278859

1.404902

1.404929

1.404955

1.404982

1.405035

1.405062 
19823.939 23.93923 .900 23.153 23 1114

$\begin{array}{ll}23.861 & 23.821 \\ 23.467 & 23.42\end{array}$

$\begin{array}{llllll}23.782 & 23.743 & 23.703 & 23.664 & 23.625 & 23.585\end{array}$ $\begin{array}{llllllllll}22.367 & 22.327 & 22 \cdot 288 & 22.249 & 22.209 & 22.170 & 22.131 & 22.092 & 22.052 & 22.013\end{array}$

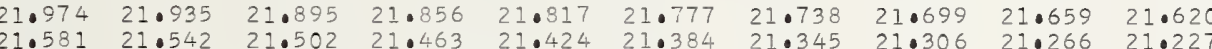

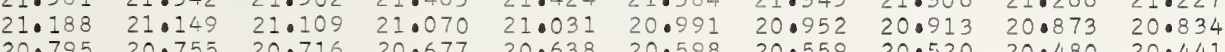

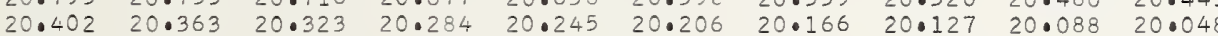

0.278833 0.278833 0.278832 0.278832 0.278832 0.278831 0.278831 0.278831

1.406418

1.406471

1.406497
1.406524

1.406551

1.406577

1.406604
1.406630

1.406657

1.406710
1.406737

1.406763

1.406790

1.406843

1.406896

1.406949

1.407003

1.407029

1.407056
1.407082

1.407109
1.407136

1.407162
1.407189

1.407215

1.407295

1.407322
1.407348

1.407375
1.407402

1.407428

1.407481

1.407508
1.407534

1.407561

1.407588
1.407614

1.407641
1.407667

1.407694

1.407721

1.407774

1.407827

1.407854
1.407880 1.407907 1.407933
1.407960 1.407987 1.408013 1.408040 
9796.46 $96.069 \quad 96.030$ $95.638 \quad 95.5$
95.0779 $94.893 \quad 94.854 \quad 94.207 \quad 95.167$ $\begin{array}{llll}94.501 & 94.462 & 94.423 & 94.384\end{array}$ $93.717 \quad 93.678 \quad 93.63993 .600$ $93.325 \quad 93.286 \quad 93.247 \quad 93.208$

19792.542 $92.150 \quad 92.503$ 92.150 $91 \cdot 758$ 91.719 90.97490 .935 90.19190 .152

89.407

89.760

89.016

19788
88
87
870
870
86
86
850

88.23288 .585

$\begin{array}{ll}88.232 & 88.193 \\ 87.841 & 87.801\end{array}$

$\begin{array}{ll}87.449 & 87.410 \\ 87.057 & 87.018\end{array}$

$86.666 \quad 86.626$

$\begin{array}{ll}86.274 & 86.235 \\ 85.882 & 85.843\end{array}$

$\begin{array}{ll}85.491 & 85.452 \\ 85.099 & 85.060\end{array}$

$19784.708 \quad 84066$ $84 \cdot 316 \quad 84 \cdot 277$

$83.533 \quad 83.494$

$83.103 \quad 83.063 \quad 83.024$

$\begin{array}{llll}82.750 & 82.711 & 82.672 & 82.633\end{array}$

$\begin{array}{llll}81.968 & 81.928 & 81.889 & 81.850\end{array}$

$\begin{array}{ll}81.576 & 81.53 \\ 81.185 & 81.14\end{array}$

406

4. 8

5055.0

501
502
503
504
505
506
507
50.
50

505600

6.1

6.3

6.4

6.5
6.6

6.

6.8
6.9

5057.0

$7 \cdot 1$
$7 \cdot 2$
$7 \cdot 3$

$7 \cdot 3$

7.5

7.6
7.7

7.8
7.9

5058.

8.1
8.2
8.3

8.3
8.4
8.5

8.6
8.7

8.8
8.9

5059.

9.1

9.3

9.4

9.7
9.8
9.9
19780. 80.40280 .36

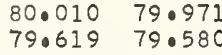

$79.228 \quad 79.188$

$78.054 \quad 78015$

$\begin{array}{lll}77.662 & 770623 \\ 77.271 & 77.232\end{array}$

776.88
76.489

$\begin{array}{lll}76.489 & 76.449 & 76.410 \\ 76.098 & 76.058 & 76.01\end{array}$

$\begin{array}{lll}75.706 & 75.667 & 75.628\end{array}$

$\begin{array}{llll}75.315 & 75.276 & 75.237 & 75.5 \\ 75.198\end{array}$

$\begin{array}{lll}74.533 & 74.494 & 74.455 \\ 74.142 & 74.103 & 74.063\end{array}$

$\begin{array}{lllll}74.142 & 74.103 & 74.063 & 74.024\end{array}$

$\begin{array}{llll}73.751 & 73.712 & 73.673 & 73.634 \\ 73.360 & 73.321 & 73.281 & 73.242\end{array}$

19772.969

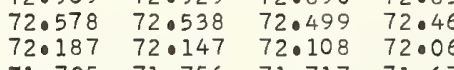

$\begin{array}{llll}71.095 & 71.0756 & 71.717 & 71.678\end{array}$

$71 \cdot 405 \quad 71 \cdot 365$

$70.23170 .192 \quad 70.153 \quad 70.114$

$\begin{array}{llll}69.841 & 69.801 & 69.762 & 69.723\end{array}$
$78.836 \quad 78.79$
78.445
78.406

$\begin{array}{llll}74.924 & 74.885 & 74.846 & 74.807\end{array}$

$\begin{array}{llll}70.613 & 70.583 & 70.935 & 70.896\end{array}$

$68.668 \quad 69.020$

$\begin{array}{ll}68.668 & 68.628 \\ 68.277 & 68.238\end{array}$

$\begin{array}{ll}67.886 & 67.847 \\ 67.495 & 67.456\end{array}$

$\begin{array}{lll}67.104 & 67.065 & 67.026\end{array}$

$66.713 \quad 66.674 \quad 66.635 \quad 66.98$

$\begin{array}{llll}66.323 & 66.284 & 66.244 & 66.205 \\ 65.932 & 65.893 & 65.854 & 65.81\end{array}$

$\begin{array}{llll}65.932 & 65.893 & 65.854 & 65.814 \\ 65.541 & 65.502 & 65.463 & 65.424\end{array}$

$64.750 \quad 65 \cdot 111$

$64.760 \quad 64.720$

65.07
64.68
64.291

$63.978 \quad 63.939$

$\begin{array}{llll}63.196 & 63.157 & 63.509 & 63.470 \\ 63.118 & 63.079\end{array}$

$\begin{array}{llll}62.806 & 62.767 & 62.728 & 62.68 \\ 62.415 & 62.376 & 62.337 & 62.29\end{array}$

$\begin{array}{llll}62.024 & 61.985 & 61.946 & 61.907 \\ 61.634 & 61.595 & 61.556 & 61.517\end{array}$

$$
\begin{aligned}
& 60 \\
& 60 \\
& 60 \\
& 59 \\
& 59 \\
& 58 \\
& 58 \\
& 58
\end{aligned}
$$

$92.777 \quad 92.738$

$\begin{array}{llllll}91.993 & 91.954 & 91.915 & 91.875 & 91.836 & 91.797\end{array}$

$91.20991 .170 \quad 91.131091 .09201 .05291 .014$

$90.818 \quad 90.77900 .740 \quad 90.700 \quad 90.66190 .622$

$\begin{array}{llllll}90.426 & 90.386 & 90.347 & 90.308 & 90.269 & 90.230\end{array}$

$89.642 \quad 89.603 \quad 89.564 \quad 89.525 \quad 89.486 \quad 89.446$

$\begin{array}{llllll}88.859 & 88.820 & 88.781 & 88.741 & 88.702 & 88.663\end{array}$

$87.566 \quad 87.527 \quad 87.488$
87.575

$86.900 \quad 86.061 \quad 86.822 \quad 86.783 \quad 86.744 \quad 86.705$

86.50986 .470

$85.726 \quad 85.687$

$86.431 \quad 86.392 \quad 86.353 \quad 86.313$

$\begin{array}{llll}.039 & 86.000 & 85.960 & 85.921 \\ .647 & 85.608 & 85.569 & 85.530\end{array}$

1387

0.278830

0.278830
0.278830

0.278830

0.278829

0.278829

0.278828

0.278828
0.278828

1.408093

0.278828

0.278827

0.278827

0.278827

0.278826

0.278826

0.278826

0.278825

0.278825
0.278825

0.278824

0.278824
0.278824

0.278824

0.278824
0.278823

0.278823

0.278823

1.408119

1.408199

1.408252

1.408306

1.408332

0.278823

0.278822

0.278822

0.278822

0.278821

0.278821

0.278821
0.278820

1.408359

1.408385

1.408412

1.408465

1.408492

1.408518

1.408545

1.408598

1.408625

1.408651
1.408678

1.408705

1.408731
1.408758

1.408784

1.408811
1.408838

1.408838
1.408864

1.408891

1.408917

1.408944

1.408997

1.409024

1.409077

1.409130

0.278820
0.27882

0.278820

0.27881

0.27881

0.278819

0.278818

0.278818
0.278818

1.409157

1. 409210

1.409236

1.409263

1.409290

1.409343

1.409369

0.278818

0.278817

0.278817

0.278817

0.278816
0.278816

0.278816

0.278816
0.278815

0.278815
0.278815

0.278815

0.27881

0.278814

0.278814

0.278814

0.278814

0.27881

0.278813
0.278813

1.409396

1.409423
1.409449

1.409449
1.409476

1.409476

1.409502
1.409529

1.409529

1.409556

1.409582

1.409635

0.278812

0.278812

0.278812

0.27881

0.27881

0.27881

0.278811

0.278810
0.278810

1.409689

1.409715

1.409742

1.409768

1.409821

1.409848

1.409875

1.409901

1.409954

1.409981

1.410008

1.410061

1.410087

1.410114

1.410141

1.410167
1.410194

0.278810

1.410220

0.27880

1.410247

0.27880

1.410274

$0.278809 \quad 1.410300$

$0.278809 \quad 1.41035$

$0.278808 \quad 1.410380$

$0.278808 \quad 1.41040$

$\begin{array}{ll}0.278808 & 1.410433 \\ 0.278808 & 1.410460\end{array}$

0.278807

$1 \cdot 410486$

0.278807

0.278807

0.278807 


\begin{tabular}{|c|c|c|c|c|c|c|c|}
\hline$\lambda(A)$ & .00 & .01 & .02 & .03 & .04 & .05 & .06 \\
\hline . & 7.338 & 30099 & 57.260 & 57.221 & 57.182 & 57.143 & 57.104 \\
\hline 0.1 & 56.948 & 56.908 & 56.869 & 56.830 & 56.791 & 56.752 & 56.713 \\
\hline 0.2 & 56.557 & 56.518 & 56.479 & 56.440 & 56.401 & $56 \cdot 36 ?$ & 56.323 \\
\hline 0.3 & 56.167 & 56.127 & 56.089 & 56.050 & 56.010 & 55.971 & 55.932 \\
\hline 0.4 & 55.776 & 55.737 & 55.698 & 55.659 & 55.620 & 55.581 & 55.542 \\
\hline 0.5 & $55 \cdot 386$ & $55 \cdot 347$ & 55.308 & 55.269 & 55.230 & 55.191 & $55 \cdot 152$ \\
\hline 0.6 & 54.995 & $54 \cdot 956$ & 54.917 & 54.878 & 54.839 & $54 \cdot 800$ & 54.761 \\
\hline 0.7 & 54.605 & $54 \cdot 566$ & 54.527 & 54.488 & 54.449 & 54.410 & $54 \cdot 371$ \\
\hline $\begin{array}{l}0.8 \\
0.9\end{array}$ & $\begin{array}{l}54.214 \\
53.824\end{array}$ & $\begin{array}{l}54.176 \\
53.785\end{array}$ & $\begin{array}{l}54.136 \\
53.746\end{array}$ & $\begin{array}{l}54.097 \\
53.707\end{array}$ & $\begin{array}{l}54.059 \\
53.668\end{array}$ & $\begin{array}{l}54.020 \\
53.629\end{array}$ & $\begin{array}{l}53.980 \\
53.590\end{array}$ \\
\hline & & & & & & & \\
\hline 1.1 & 44 & 53.005 & 52.966 & 52.927 & 52.888 & 52.849 & 52.810 \\
\hline 1.2 & 52.654 & 52.615 & 52.575 & 52.536 & 52.497 & 52.458 & 52.419 \\
\hline 1.3 & $52 \cdot 263$ & 52.224 & 52.185 & 52.146 & 52.107 & 52.068 & 52.029 \\
\hline 1.4 & 51.873 & 51.834 & 51.795 & 51.756 & $51.7 \cdot 17$ & 51.678 & 51.639 \\
\hline & $\begin{array}{l}51.482 \\
51.0093\end{array}$ & $\begin{array}{l}51.444 \\
51.0553\end{array}$ & $\begin{array}{r}51.405 \\
51.0115\end{array}$ & $\begin{array}{l}51.365 \\
50.976\end{array}$ & $\begin{array}{l}51.326 \\
50.937\end{array}$ & 51.288 & 51.249 \\
\hline & $\begin{array}{l}51.093 \\
50.703\end{array}$ & $\begin{array}{l}51.053 \\
50.663\end{array}$ & $\begin{array}{l}51.0115 \\
50.624\end{array}$ & $\begin{array}{l}50.976 \\
50.058\end{array}$ & $\begin{array}{l}50.937 \\
50.546\end{array}$ & 50.898 & 50.859 \\
\hline 1.8 & $\begin{array}{l}50.703 \\
50.312\end{array}$ & $\begin{array}{l}50.663 \\
50.273\end{array}$ & $\begin{array}{l}50.024 \\
50.234\end{array}$ & $\begin{array}{l}50.0585 \\
50.195\end{array}$ & $\begin{array}{l}50.546 \\
50.156\end{array}$ & $\begin{array}{l}50.507 \\
50.117\end{array}$ & $\begin{array}{l}50.469 \\
50.078\end{array}$ \\
\hline $\begin{array}{l}1.8 \\
1.9\end{array}$ & 49.922 & 49.883 & $\begin{array}{l}50.234 \\
49.844\end{array}$ & 49.805 & $\begin{array}{l}50.156 \\
49.766\end{array}$ & $\begin{array}{l}50.117 \\
49.727\end{array}$ & $\begin{array}{l}50.078 \\
49.688\end{array}$ \\
\hline 52.0 & 749.532 & 49.493 & 49.454 & 49.415 & 49.376 & 49.337 & 49.298 \\
\hline & $49 \cdot 142$ & 49.103 & 49.064 & 40.025 & 48.986 & 48.947 & 48.008 \\
\hline $2 \cdot 2$ & 48.752 & 48.713 & 48.674 & 48.635 & 48.595 & 48.557 & 48.518 \\
\hline 2.3 & 48.362 & $48 \cdot 323$ & 48.284 & 48.245 & 48.206 & 48.167 & 48.128 \\
\hline 2.4 & $\begin{array}{l}47.971 \\
47\end{array}$ & 47.932 & $\begin{array}{r}47.893 \\
4\end{array}$ & 47.854 & $\begin{array}{r}47.815 \\
47\end{array}$ & 47.777 & 47.738 \\
\hline 2.5 & $\begin{array}{l}47.5811 \\
47\end{array}$ & $\begin{array}{l}47.542 \\
47.52\end{array}$ & $\begin{array}{l}47.503 \\
472\end{array}$ & $\begin{array}{l}47.464 \\
47.074\end{array}$ & $\begin{array}{l}47.426 \\
47.035\end{array}$ & 47.386 & $\begin{array}{l}47.347 \\
46.957\end{array}$ \\
\hline $\begin{array}{l}2.6 \\
2.7\end{array}$ & $\begin{array}{l}47.191 \\
46.801\end{array}$ & $\begin{array}{l}4 \cdot 1.122 \\
46 \cdot 762\end{array}$ & $\begin{array}{l}4.1133 \\
46.723\end{array}$ & $\begin{array}{l}1.014 \\
46.6884\end{array}$ & $\begin{array}{l}4.0335 \\
46.645\end{array}$ & $\begin{array}{l}46.9966 \\
46.606\end{array}$ & $\begin{array}{l}46.957 \\
46.567\end{array}$ \\
\hline 2.8 & 46.411 & 46.372 & 46.333 & 46.294 & 46.255 & 46.216 & 46. \\
\hline 2.9 & 46.021 & $45 \cdot 982$ & 45.943 & 45.904 & 45.865 & 45.826 & 45.787 \\
\hline & 19745.631 & 45.593 & 45.553 & 45.514 & 45.475 & 45.436 & 45.397 \\
\hline 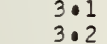 & $\begin{array}{l}45.241 \\
44.8551\end{array}$ & $\begin{array}{l}45.202 \\
44.812\end{array}$ & 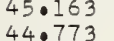 & $\begin{array}{l}45.124 \\
44.734\end{array}$ & $\begin{array}{l}45.085 \\
44.695\end{array}$ & $\begin{array}{l}45.046 \\
44.656\end{array}$ & $\begin{array}{l}45 \cdot 007 \\
44.617\end{array}$ \\
\hline 3.3 & 44.461 & $44 \cdot 422$ & 44.383 & $44 \cdot 344$ & 44.305 & $44^{\circ}$ & $44 \cdot 227$ \\
\hline 3.4 & 44.072 & 44.032 & 43.993 & 43.954 & 43.915 & 43.876 & 43.838 \\
\hline 3.5 & 43.681 & 43.643 & 43.604 & 43.564 & 43.525 & 43.486 & 43.447 \\
\hline 3 & 43.292 & 43.252 & $43 \cdot 213$ & 43.175 & 43.136 & & 43.058 \\
\hline 3 & 42.902 & 42.863 & 42.823 & 42.785 & 42.746 & 42 & 42.668 \\
\hline $3 \cdot 8$ & 42.512 & 42.473 & 42.434 & 42.395 & 42.356 & $42 \cdot 317$ & 42.278 \\
\hline 3.9 & $42 \cdot 122$ & 42.083 & 42.044 & 42.005 & 41.966 & 41.927 & 41.888 \\
\hline $54 \cdot 0$ & 741.732 & 41.693 & 41.654 & 41.615 & 41.576 & 41.537 & 41.498 \\
\hline & $41 \cdot 342$ & 41.203 & & $41 \cdot 225$ & 41.186 & 41.147 & \\
\hline $4 \cdot 2$ & 40.952 & 40.913 & 40.875 & 40.835 & 40.796 & 40.757 & 40.719 \\
\hline $4 \cdot 3$ & 40.562 & 40.524 & 40.485 & 40.446 & 40.406 & 40.367 & 40.329 \\
\hline 4.4 & 40.173 & 40.134 & 40.095 & 40.056 & 40.017 & 39.978 & 39.939 \\
\hline 4.5 & 39.783 & $39 \cdot 744$ & $39 \cdot 705$ & 39.666 & 39.627 & 39.588 & 39.549 \\
\hline 4.6 & $39 \cdot 3$ & 39.354 & $39 \cdot$ & 39.276 & 39.237 & 39.198 & $39^{\circ}$ \\
\hline 4.7 & 39.004 & 38 : & 38.926 & 38. & 38. & 38. & $388^{\circ}$ \\
\hline $\begin{array}{l}4.8 \\
4.9\end{array}$ & $\begin{array}{l}38.614 \\
38.224\end{array}$ & $\begin{array}{l}38{ }^{\circ} \\
38\end{array}$ & $\begin{array}{l}38: \\
38:\end{array}$ & $\begin{array}{l}38 . \\
38 .\end{array}$ & $\begin{array}{l}38.0 \\
38.0\end{array}$ & $\begin{array}{l}38 . \\
38 .\end{array}$ & $\begin{array}{l}38 . \\
37\end{array}$ \\
\hline & & & & 38. & 38. & $38 \bullet$ & \\
\hline & 37. & 37.406 & $\begin{array}{l}37 \\
37\end{array}$ & 8 & $370^{\circ}$ & 0 & 1 \\
\hline & 37 & 37. & 36. & 36. & 36 & 36 & \\
\hline 3 & 68 & 36 . & & & & & \\
\hline 5.4 & 36.276 & 36. & & & & & \\
\hline 5.5 & 35.886 & $35{ }^{\circ}$ & 35. & & 35. & & \\
\hline $\begin{array}{l}5.6 \\
5.9\end{array}$ & $\begin{array}{l}35.497 \\
35.07\end{array}$ & 35. & 35.4 & & & & \\
\hline $\begin{array}{l}5.7 \\
5.8\end{array}$ & $\begin{array}{l}35.107 \\
34.717\end{array}$ & $\begin{array}{l}35.0 \\
34.0\end{array}$ & $\begin{array}{l}\begin{array}{l}35.029 \\
34.6440\end{array}\end{array}$ & $\begin{array}{l}34.990 \\
340601\end{array}$ & 34.951 & $34^{\circ}$ & \\
\hline 5.9 & 34.328 & $34 \cdot 289$ & 34.250 & $\begin{array}{l}\begin{array}{l}34.601 \\
34.211\end{array} \\
34.03\end{array}$ & $\begin{array}{l}34.562 \\
34.172\end{array}$ & $\begin{array}{l}34.523 \\
34.133\end{array}$ & $\begin{array}{l}34.484 \\
34.094\end{array}$ \\
\hline 5066.0 & 38 & 3 & 60 & 33.822 & 3.782 & 33.743 & .705 \\
\hline & & & & & & & \\
\hline 6.2 & & 33. & 33. & & $330^{\circ}$ & 32. & \\
\hline 6 & & 32. & 32. & & 32. & 32. & \\
\hline 6.4 & & 32 & 32 . & 32 & 32 & 32. & \\
\hline 6. & & 31. & 31. & 31. & 31. & 31. & 31 \\
\hline 6.6 & 3 & 31. & 31. & 31. & 31. & 6 & \\
\hline 6.7 & & 31 . & $31 \cdot$ & 31. & & 31. & \\
\hline 6. & & 30 & & & & & \\
\hline & & & & & & & \\
\hline & 43 & & & $\begin{array}{l}29.927 \\
29.537\end{array}$ & $\begin{array}{l}29 \cdot 888 \\
29 \cdot 499\end{array}$ & $\begin{array}{l}29.849 \\
29.460\end{array}$ & $\begin{array}{l}29.810 \\
29.421\end{array}$ \\
\hline 7.2 & & 29 & & 29. & 2 & 0 & 1 \\
\hline & & 28 & 28. & $28 \cdot 7$ & & 28 & \\
\hline & & 28.4 & & & & & \\
\hline & & 28 & 28. & & & & \\
\hline $7: 6$ & 8 & 27 & $27^{\circ}$ & & & & \\
\hline 7. & 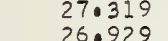 & & & & & & \\
\hline $70.8-80$ & $\begin{array}{l}26.929 \\
26.540\end{array}$ & $\begin{array}{l}26.890 \\
26.501\end{array}$ & $\begin{array}{l}26 \cdot 852 \\
26.462\end{array}$ & $\begin{array}{l}26 \cdot 813 \\
26.423\end{array}$ & & $\begin{array}{l}26.735 \\
26.345\end{array}$ & $260^{\circ}$ \\
\hline & & & & & & 200345 & coosor \\
\hline & & & $\begin{array}{l}3 \\
34\end{array}$ & $\begin{array}{l}26.034 \\
25.645\end{array}$ & $\begin{array}{l}25.995 \\
25.606\end{array}$ & $\begin{array}{l}25.956 \\
25.567\end{array}$ & \\
\hline 8. & & & & & & & \\
\hline 8. & & & & & & & \\
\hline 8 & & & & & & & \\
\hline 8 & & & & & & & \\
\hline & 2. & & & & & & \\
\hline & & & & & & & \\
\hline $8 \cdot 8$ & 23.037 & 22 & & & 22. & & \\
\hline 80 & 2.648 & 22.610 & & 22.532 & 22.493 & 2.2 .454 & $22 \cdot 415$ \\
\hline $9 \cdot 0$ & 19722.259 & & & & & 65 & 5 \\
\hline & & & & & & & \\
\hline & & & & & & & \\
\hline $9 \cdot$ & 210 & & & & & & \\
\hline 9.5 & $\begin{array}{l}20.703 \\
20.314\end{array}$ & $\begin{array}{l}20.664 \\
20.275\end{array}$ & $\begin{array}{l}200^{\circ} \\
20\end{array}$ & $\begin{array}{l}20 . \\
20\end{array}$ & $\begin{array}{l}20 \\
20\end{array}$ & 20. & $\begin{array}{l}200^{\circ} \\
20 .\end{array}$ \\
\hline 9. & 19.925 & 19.886 & 19.847 & & 19.770 & 19.730 & 19.692 \\
\hline & 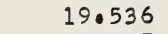 & 19.497 & 19.458 & & 10.380 & 10 & 19.303 \\
\hline 9.8 & .147 & $19 \cdot 108$ & 19.070 & 19.031 & 8.992 & 18.953 & 18.914 \\
\hline
\end{tabular}




.02

.03

5070.0
0.0
0.0
0.0
0.0
0.07
0.0

70.0
0.1
0.2
0.3
0.14
0.5
0.0
0.7
0.0
0.9

$$
\text { (1) }
$$

3.2

3.4
3.5

3.5
3.7
3.8

\title{
$19714 \cdot 481 \quad 14 \cdot 442 \quad 14 \bullet 403$
} $\begin{array}{lll}14.092 & 14.053 & 14.0 \\ 13.703 & 13.565 & 13.0625\end{array}$

$\begin{array}{ll}13.703 & 13.665 \\ 13.314 & 13.276\end{array}$

$\begin{array}{ll}12.926 & 12.887 \\ 12.537 & 12.499\end{array}$

$12.149 \quad 12.110 \quad 12.071$

$\begin{array}{llllll}11.760 & 11.721 & 11.682 & 11.643 & 11.993 & 11.954 \\ 11.064 & 11.565\end{array}$

$\begin{array}{lllllll}11.371 & 11.332 & 11.294 & 11.255 & 11.216 & 11.177 & 1 \\ 10.982 & 10.944 & 10.905 & 10.866 & 10.827 & 10.788 & 100\end{array}$

$\begin{array}{ll}110.594 & 10.55 \\ 10.205 & 10.166 \\ 09.817 & 09.778\end{array}$

$\begin{array}{llll}0.817 & 09.778 & 09.739 & 09.700 \\ 0.428 & 09.389 & 09.351 & 09.312\end{array}$

$09.040 \quad 09.001$

$\begin{array}{llllll}09.040 & 09.001 & 08.962 & 08.923 & 08.884 & 08.845 \\ 08.651 & 08.612 & 08.573 & 08.534 & 08.496 & 08.457 \\ 08.262 & 08.224 & 08.185 & 08.146 & 08.107 & 08.068\end{array}$

$\begin{array}{lllll}07.874 & 07.835 & 07.796 & 07.757 & 07 . \\ 07.485 & 07.447 & 07.408 & 07.369 & 07 \\ 07.097 & 07.058 & 07.019 & 06.980 & 068\end{array}$

06.320

05.932 05.8

$\begin{array}{lll}05.155 & 05.11 \\ 04.767 & 04.7\end{array}$

$\begin{array}{lll}04.378 & 04.330 \\ 03.990 & 03.0914\end{array}$

$03.602 \quad 03.563$

19702.825

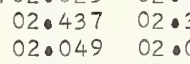

$\begin{array}{lll}01.6650 & 01.6210 \\ 01.272 & 01.223\end{array}$

$\begin{array}{lll}01.272 & 01.233 \\ 000884 & 000845 & 0.0\end{array}$

$\begin{array}{lll}00.495 & 00.457 \\ 00.107 & 00.069\end{array}$

19699.719

99.680

\begin{abstract}
06.63106 .592
\end{abstract}
$07.330 \quad 07.291$

$\begin{array}{ll}07.330 & 07.291 \\ 06.941 & 06.903\end{array}$

$98.942 \quad 98 \cdot 904$

$\begin{array}{ll}98.554 & 98.516 \\ 98.166 & 98 \cdot 127 \\ 97.778 & 97.739\end{array}$

$\begin{array}{ll}97.778 & 97.739 \\ 97.390 & 97.351\end{array}$

$\begin{array}{ll}97.002 & 96.963 \\ 96.614 & 96.575\end{array}$

$\begin{array}{llll}95.838 & 95.799 & 95.760 & 95.72\end{array}$

19695.06

$\begin{array}{llll}94.674 & 94.635 & 94.596 & 94.557 \\ 94.286 & 94.247 & 94.208 & 94.169 \\ 93.898 & 93.859 & 93.820 & 93.781\end{array}$

$\begin{array}{llll}93.510 & 93.471 & 93.432 & 93.3 \\ 93.122 & 93.083 & 93.044 & 93.006\end{array}$

$\begin{array}{llll}92.734 & 92.695 & 92.656 & 92.618 \\ 92.346 & 92.307 & 92.269 & 92.230\end{array}$

$\begin{array}{llll}92.346 & 92.307 & 92.269 & 92.23 \\ 91.958 & 91.919 & 91.881 & 91.84 \\ 91.571 & 91.532 & 91.493 & 91.45\end{array}$

19691.18291 .14

$\begin{array}{ll}90.795 & 90.7 \\ 90.407 & 90.368\end{array}$

$\begin{array}{ll}90.019 & 89.98 \\ 89.631 & 89.593\end{array}$

$\begin{array}{ll}89.243 & 89.20 \\ 88.856 & 88.817\end{array}$

$88.468 \quad 88.42$

91.105

87.69

$\begin{array}{ll}6 & 90.717 \\ 8 & 90.329\end{array}$

$19687.305 \quad 87.266$

$\begin{array}{llll}86.305 & 87.266 & 87.227 & 87.18 \\ 86.917 & 86.878 & 86.840 & 86.801 \\ 86.530 & 86.491 & 86.452 & 86.413 \\ 86.142 & 86.103 & 86.064 & 86.026\end{array}$

$\begin{array}{llll}85.142 & 86.103 & 86.064 & 86.026 \\ 85.754 & 85.716 & 85.677 & 85.638\end{array}$

$\begin{array}{llll}85.366 & 85.328 & 85.289 & 85.250 \\ 84.979 & 84.940 & 84.901 & 84.863\end{array}$

$\begin{array}{llll}84.979 & 84.940 & 84.901 & 84.863 \\ 84.591 & 84.552 & 84.514 & 84.475 \\ 84.204 & 84.165 & 84.126 & 84.088 \\ 83.816 & 83.777 & 83.739 & 83.700\end{array}$

5079.

$9 \cdot 1$

9.3
9.5

9.5

$$
\begin{array}{r}
19683 \\
83 \\
82 \\
82 \\
81 \\
81 \\
81 \\
80 \\
80 \\
79
\end{array}
$$

$83.428 \quad 83.390$

$33.041 \quad 83.00$
83.045

\begin{abstract}
83.35
\end{abstract}
83.312

06.553
06.165
05.776

$\begin{array}{ll}3 & 06.51 \\ 5 & 06.126\end{array}$

$\begin{array}{llllllll}854 & 05.815 & 05.776 & 05.737 & 05.699 & 05.660 & 05.621 & 05.582 \\ .66 & 05.427 & 05.388 & 05.349 & 05.310 & 05.271 & 05.232 & 05.194 \\ .077 & 05.038 & 05.000 & 04.961 & 04.922 & 04.883 & 04.844 & 04.805\end{array}$

78

$\begin{array}{lll}834 & 03.796 \\ .447 & 03.407\end{array}$

$\begin{array}{llll}8.654 & 82.615 & 82.576 & 82.5 \\ 82.266 & 82.227 & 82.189 & 82.150\end{array}$

$81.879 \quad 81.840 \quad 81.801 \quad 81.762$

$\begin{array}{llllllllll}81.491 & 81.453 & 81.414 & 81.375 & 81.336 & 81.298 & 81.259 & 81.220 & 81.182 & 81.143 \\ 81.104 & 81.065 & 81.026 & 80.988 & 80.949 & 80.910 & 80.871 & 80.833 & 80.794 & 80.755 \\ 80.717 & 80.678 & 80.639 & 80.600 & 80.562 & 80.523 & 80.484 & 80.445 & 80.406 & 80.368\end{array}$

02.670 $\begin{array}{llllllllll}80.717 & 80.678 & 80.639 & 80.600 & 80.562 & 80.523 & 80.484 & 80.445 & 80.406 & 80.368 \\ 80.329 & 80.290 & 80.251 & 80.213 & 80.174 & 80.135 & 80.096 & 80.058 & 80.019 & 79.980 \\ 79.942 & 79.903 & 79.864 & 79.825 & 79.787 & 79.748 & 79.709 & 79.670 & 79.632 & 79.593\end{array}$

$126 \quad 06.475$

.087060

$\begin{array}{lll}06.359 \\ 0.048 & 06.009 & 05.970\end{array}$

$\begin{array}{lll}.660 & 05.621 & 05.582\end{array}$

04.805

$\begin{array}{llllll}04.611 & 04.573 & 04.534 & 04 \cdot 495 & 04.456 & 04.417 \\ 04.223 & 04.184 & 04.145 & 04.106 & 04.067 & 04.029\end{array}$

3.757

04.718

03.679

03.640

$\begin{array}{lllllll}.058 & 03.019 & 02.980 & 02.941 & 02.903 & 02.864\end{array}$

02.631

02.59

02.55

$02.514 \quad 02.475$

$\begin{array}{llllll}1.893 & 01.854 & 01.816 & 01.777 & 01.738 & 01.0699\end{array}$

$\begin{array}{llllll}.505 & 01.466 & 01.427 & 01.388 & 01.349 & 01.311\end{array}$

$\begin{array}{llllll} & 01.0100 & 0.961 & 00.922\end{array}$

$\begin{array}{rrrrrr}0.340 & 00.301 & 00.262 & 00.224 & 00.185 & 00.146\end{array}$

$\begin{array}{rrrrrr}.564 & 99.525 & 99.486 & 99.447 & 99.408 & 99.370\end{array}$

$\begin{array}{llllll}8.787 & 98.749 & 98.710 & 98.671 & 98.632 & 98.593\end{array}$

$\begin{array}{lllllll}8.399 & 98.361 & 98.322 & 98.283 & 98.244 & 98.205\end{array}$

$\begin{array}{llllll}8.011 & 97.972 & 97.934 & 97.895 & 97.856 & 97.817\end{array}$

$\begin{array}{llllll}. .235 & 97.196 & 97.157 & 97.118 & 97.080 & 97.041\end{array}$

$\begin{array}{cccccc}6.459 & 96.420 & 96.381 & 96.342 & 96.303 & 96.265\end{array}$

$\begin{array}{lllllll}96.071 & 96.032 & 95.993 & 95.954 & 95.916 & 95.877\end{array}$

$\begin{array}{rlllll}9.683 & 95.644 & 95.605 & 95.566 & 95.527 & 95.489\end{array}$

$\begin{array}{llllll}4.907 & 94.868 & 94.829 & 94 \cdot 790 & 94.751 & 94.713\end{array}$

$\begin{array}{llllll}94.519 & 94.480 & 94.441 & 94.402 & 94.364 & 94.324 \\ 94.131 & 94.092 & 94.053 & 94.014 & 93.975 & 93.937\end{array}$

$93.743 \quad 93.704 \quad 93.66593 .626 \quad 93.58793 .549$

$\begin{array}{llllll}2.579 & 92.540 & 92.501 & 92.463 & 92.424 & 92.385\end{array}$

$\begin{array}{llllll}192.152 & 92.114 & 92.075 & 92.036 & 91.997\end{array}$

$\begin{array}{llllll}1.803 & 91.764 & 91.726 & 91.687 & 91.648 & 91.609 \\ 1.415 & 91.376 & 91.338 & 91.299 & 91.260 & 91.221\end{array}$

.005

.006

006

.008

.009

$(n-1) \times 1000 \quad \lambda(n-1)$

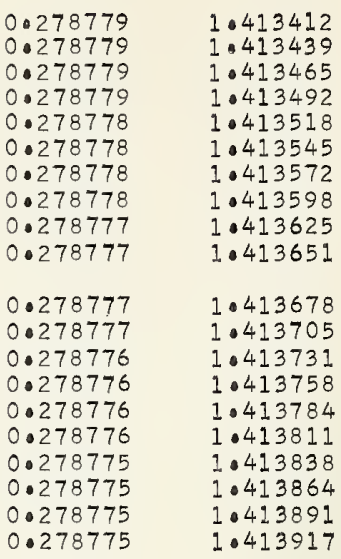

0.02707

0.278774
0.278744
0.227874

0.0278774
0.278774
0.0278773

0.278773
0.278773
0.27879

0.278773
0.278773

0.278773

0.278772

1.413970

1.413997

1.414050
1.414077

1.414103

1.414130
1.414157

0.278771

1.414210

0.278771

0.278771
0.278771

0.278770

0.278770

0.278770
0.278770

0.278769

0.278769

0.278769
0.278769

0.278768

0.278768
0.278768

0.278768

0.278767

0.278767

0.278767
0.278767
0.278766

0.278767

0.278766

0.278766

0.278765

0.278765
0.278765

0.278765
0.278765

0.278764

0.278764
0.278764

0.27876

0.278763

0.27876

0.278762
0.278762

1.414263

1.414290

1. 414343

1.414369

1.414423

1.414476

1.414502

1.4145556

1.414582

1.414609

1.414662

1.414689

1.414742
1.414768

1.414795

1.414822

1.414848

1.414875
1.414901

1.414928

1.414955
1.414981

0.278762

0.278762
0.278761

0.278761
0.278761

0.278761

0.278761

0.278760

0.278760

0.278760
0.278760

0.278759

0.278759

0.278759

0.278759
0.278758

0.278758

0.278758

0.278758

0.278757
0.27875

1.415008

1.415034

1.415088

1.415114
1.415141

1.415167

1.415221

1.415274

1.415300

1.415327
1.415354

. 415380

1.415407

1.415433

1.415460

1.415487
1.415513

1.415540

1.415566

1.415593
1.415620

. 415646

1.415673

1.415726

1.415753
1.415779

0.278757

0.278757
0.278756

0.278756

0.278756

0.278756

0.278755

0.278755
0.278755

1.415806

1.415832

1.415886

1.415912
1.415939

1.415965

1.415992

1.416019

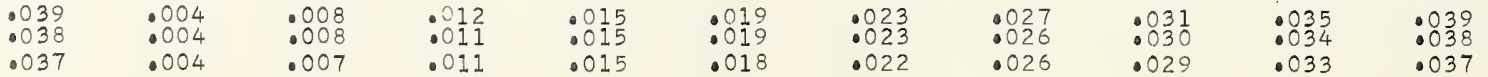


$\begin{array}{llllllllll}79.554 & 79.516 & 79.477 & 79.438 & 79.399 & 79.360 & 79.322 & 79 \cdot 283 & 79 \cdot 244 & 79 \cdot 206 \\ 79.167 & 79.128 & 79.089 & 79.051 & 79.012 & 78.973 & 78.934 & 78.896 & 78.857 & 78.818\end{array}$

$\begin{array}{lllllllllll}0.2 & 78.780 & 78.741 & 78.702 & 78.663 & 78.625 & 78.586 & 78.547 & 78.508 & 78.8569 & 78.818 \\ 0.2 & 78.392 & 78.353 & 78.315 & 78.276 & 78.237 & 78.198 & 78.160 & 78.121 & 78.082 & 78.044 \\ 0.4 & 78.005 & 77.966 & 77.927 & 77.889 & 77.850 & 77.811 & 77.772 & 77.734 & 77.695 & 77.656\end{array}$

$\begin{array}{lllllllllll}0.5 & 77.617 & 77.579 & 77.540 & 77.501 & 77.462 & 77.424 & 77.385 & 77.0446 & 77.308 & 77.6269\end{array}$

$\begin{array}{llllllllllll}0.6 & 77.230 & 77.191 & 77.153 & 77.114 & 77.075 & 77.037 & 76.998 & 76.959 & 76 \cdot 920 & 76.882\end{array}$

$\begin{array}{lllllllllll}0.8 & 76.456 & 76.417 & 76.378 & 76.339 & 76.301 & 76.262 & 76.223 & 76.185 & 76.146 & 76.107 \\ 0.9 & 76.068 & 76.030 & 75.991 & 75.952 & 75.913 & 75.875 & 75.836 & 75.797 & 75.758 & 75.720\end{array}$

0.278754

1.416072

0.278754

0.278753

0.278753

0.278753

0.278752
0.278752

1.416125

5081.0

$9675.681 \quad 75.642$

$\begin{array}{ll}75.294 & 75.255 \\ 74.907 & 74.868\end{array}$

$\begin{array}{ll}75.604 & 75.56 \\ 75.216 & 75.178\end{array}$

$75.526 \quad 75.487$

$\begin{array}{lllll}75.449 & 75.410 & 75.371 & 75.333\end{array}$

$\begin{array}{ll}74.519 & 74.481 \\ 74.132 & 74.094\end{array}$

$73.745 \quad 73.707$

$\begin{array}{llll}73.358 & 73.319 & 73.280 & 73.24 \\ 72.971 & 72.932 & 72.893 & 72.855\end{array}$

$\begin{array}{ll}75.139 & 75.100 \\ 74.752 & 74.713 \\ 74.365 & 74.026\end{array}$

$\begin{array}{ll}74.365 & 74.326 \\ 73.977 & 73.939 \\ 73.590 & 73.55\end{array}$

$\begin{array}{ll}72.583 & 72 \cdot 545 \\ 72.197 & 72 \cdot 158\end{array}$

$73.203 \quad 73.164$

$\begin{array}{lllll}74.674 & 74.0636 & 74.0597 & 74.0558\end{array}$

$\begin{array}{llll}74.287 & 74.248 & 74.209 & 74.171 \\ 73.900 & 73.861 & 73.823 & 73.784\end{array}$

0.278752
0.278752

0.278751

0.278751

0.278751
0.278750
0.0278750

0.278750

0.278750

5082.0

$\begin{array}{lrl}2.0 & 19671.809 & 71.771\end{array}$

$\begin{array}{ll}71.0422 & 71.384 \\ 71.035 & 70.997 \\ 70.0648 & 70.609\end{array}$

$71.732 \quad 71.693$

72.429
72.39
$72.042 \quad 72.00$

2.3

2.4

$69.874 \quad 69.835$

$69.487 \quad 69.448$

2.7

$69.100 \quad 69.062$

$\begin{array}{ll}71.345 & 71.306 \\ 70.958 & 70.919 \\ 70.571 & 70.532\end{array}$

$\begin{array}{ll}71.655 & 71.616 \\ 71.268 & 71.229\end{array}$

$\begin{array}{lllll}73.1259 & 73.087 & 73.048 & 73.009\end{array}$

68.713
68.326

5083.0

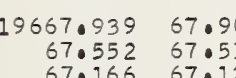

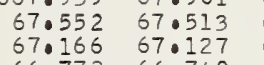

$66.392-66.35$

$\begin{array}{ll}70.571 & 70.532 \\ 60.184 & 70.14\end{array}$

$\begin{array}{ll}69.797 & 69.758 \\ 69.410 & 69.371\end{array}$

$\begin{array}{ll}71.268 & 71.226 \\ 70.880 & 70.842 \\ 70.493 & 70.455\end{array}$

71.577

$\begin{array}{llll}73.08 & 73.048 & 73.000\end{array}$

72.235
71.848

0.278749

0.278749

0.278749

0.278748

0.278748

0.278747
0.278747

.416178

1.416205

1.416231

1.416311

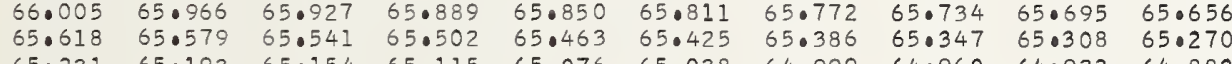

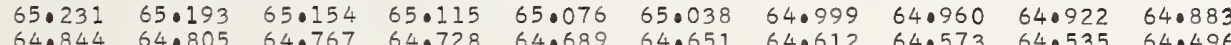

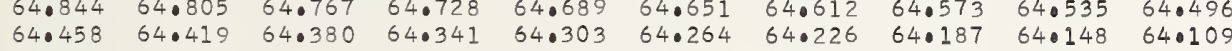

0.278747

0.278747

0.278746

0.278746

0.278746
0.278745
0.278745

0.278745

0.278745

19664.071
63.584
63.03
63.032

$63.993 \quad 63.955$

63.916

63.877

$63.838 \quad 63.800 \quad 63.761 \quad 63.723$

$\begin{array}{llllllllll}63.684 & 63.645 & 63.606 & 63.568 & 63.529 & 63.491 & 63.452 & 63.413 & 63.375 & 63.336\end{array}$

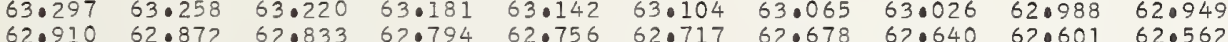

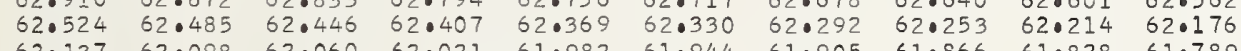

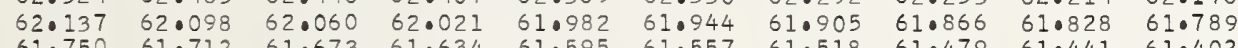

$\begin{array}{llllllllll}61.750 & 61.712 & 61.673 & 61.634 & 61.595 & 61.557 & 61.518 & 61.479 & 61.441 & 61.402\end{array}$

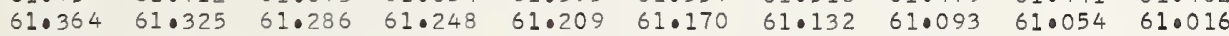

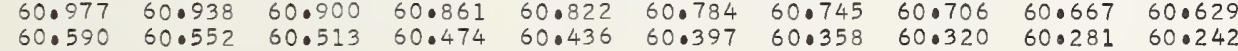

0.278744

0.278744
0.278744

0.278744

0.278743

0.278743

0.278743

0.278742

4.8
4.9

5085.0

5.0
5.
50
50
5.
50
5.7
50
50

19660.204

$59.817 \quad 60.165$

$60.165 \quad 60.126 \quad 60.0$

60.049

$60.010 \quad 59.972 \quad 59.933 \quad 59.894 \quad 59.855$

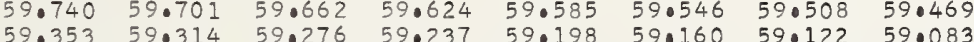

$\begin{array}{llllllllll}59.044 & 59.005 & 58.967 & 58.928 & 58.890 & 58.851 & 58.812 & 58.773 & 58.735 & 58.6960\end{array}$

$\begin{array}{llllllllll}58.657 & 58.619 & 58.580 & 58.542 & 58.503 & 58.464 & 58.426 & 58.387 & 58.348 & 58.310\end{array}$

$\begin{array}{llllllllll}58.271 & 58.232 & 58.194 & 58.155 & 58.116 & 58.078 & 58.039 & 58 \cdot 000 & 57.962 & 57.923 \\ 57.884 & 57.846 & 57.807 & 57.768 & 57.730 & 57.691 & 57.0652 & 57.614 & 57.575 & 57.536\end{array}$

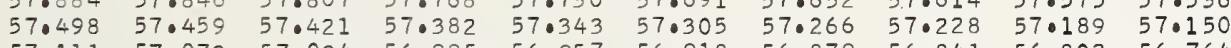

$\begin{array}{llllllllll}57.111 & 57.073 & 57.034 & 56.995 & 56.957 & 56.918 & 56.879 & 56.841 & 56.802 & 56.764 \\ 56.725 & 56.686 & 56.647 & 56.609 & 56.570 & 56.532 & 56.493 & 56.454 & 56.416 & 56.377\end{array}$

0.27874

0.278742

0.278741

0.278741

0.278741

0.278740

0.278740

1.416338

1.416364

1.416418

1.416471

1.416497
1.416524

1.416551
1.416577

1.416604

1.416630

1.416684

1.416737

1.416763

1.416817

1.416870

1. 416923

1.416976

1.417003

. .417056

1.417083

1.417136

1.417163
1.417189

1.417216

1.417242
1.417269

1.417296

1.417322

1.417349

0.278740

5086.0

6.0
6.
6.
6.0
6.0
6.7
6.
6.9

19656.0338

$\begin{array}{llll}56 \cdot 338 & 56 \cdot 300 & 56.261 & 56 \cdot 222 \\ 55.952 & 55.913 & 55.875 & 55.836 \\ 55.566 & 55.527 & 55.488 & 55.449\end{array}$

$55.024 \quad 54.986 \quad 54.947 \quad 54.908 \quad 54 \cdot 870 \quad 54.831$

$\begin{array}{llllllllll}54.406 & 54.368 & 54.329 & 54.290 & 54.251 & 54.213 & 54.561 & 54.522 & 54.483 & 54.445 \\ & 54.176 & 54.097 & 54.058\end{array}$

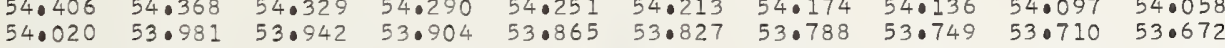

$\begin{array}{llllllllll}53.633 & 53.595 & 53.556 & 53.517 & 53.479 & 53.440 & 53.402 & 53.363 & 53.324 & 53.286\end{array}$

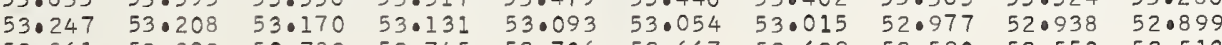

0.278739

0.278739

0.278739
0.278739

0.278738

0.278738

0.278738

0.278737

1.417402

1.417429

1.417482

.417508

1.417562

1.417588

1.417641

5087.0

19652.

$\begin{array}{ll}52.474 & 52 \\ 52.088 & 52 \\ 51.702 & 51 \\ 51.315 & 51 \\ 50.929 & 50 \\ 50.543 & 50 \\ 50.156 & 50 \\ 49.771 & 49 \\ 49.384 & 49 \\ 48.998 & 48\end{array}$

$52.397 \quad 52.358$

$\begin{array}{llllll}52.706 & 52.667 & 52.629 & 52.590 & 52.552 & 52.513 \\ 52.320 & 52.281 & 52.242 & 52.204 & 52.166 & 52.127\end{array}$

0.278737

0.278736

0.278736

0.278736

0.00278735

0.278735

0.278735

1.417668

1.417695

1.017721

1.417774

1.417828

1.417881

0.278734

0.278734

$\begin{array}{rrrrrrrrrrrr}5088.0 & 19648.612 & 48.573 & 48.535 & 48.496 & 48.457 & 48.419 & 48.380 & 48.342 & 48.303 & 48.264 \\ 8.0 & 48.226 & 48.187 & 48.148 & 48.110 & 48.071 & 48.033 & 47.994 & 47.955 & 47.917 & 47.878\end{array}$ $\begin{array}{lllllllllll}48.226 & 48.187 & 48.148 & 48.110 & 48.071 & 48 \cdot 033 & 47.994 & 47.955 & 47 \cdot 917 & 47.878 \\ 47.839 & 47.801 & 47.762 & 47.724 & 47.685 & 47.646 & 47.6008 & 47.569 & 47.531 & 47.492\end{array}$

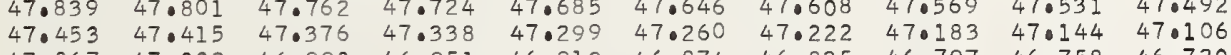
$\begin{array}{llllllllll}47.067 & 47.029 & 46.990 & 46.951 & 46.913 & 46.874 & 46.835 & 46.797 & 46.758 & 46.720\end{array}$ $\begin{array}{llllllllll}46.681 & 46.643 & 46.604 & 46.565 & 46.527 & 46.488 & 46.449 & 46.411 & 46.372 & 46.334 \\ 46.205 & 46.256 & 46.218 & 46.179 & 46.145 & 46.102 & 46.063 & 46.025 & 45.986 & 45.947\end{array}$

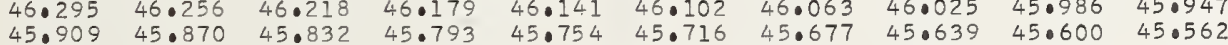

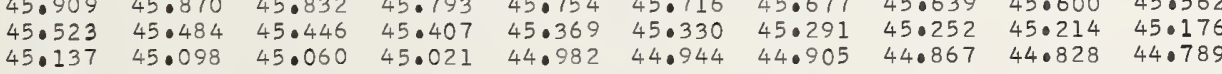

0.278734

0.278733

0.278733

0.278733

0.278732

1.417934

1.417961

1.418014

1.418040

1.418067

.0418120

1.418147

1.418200

(1)

1.418280

1.418306

.0418360

0418386

1.418413

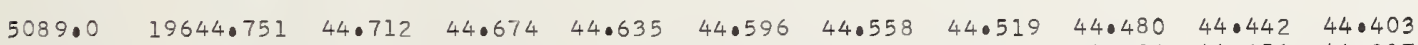
$\begin{array}{llllllllll}44 \cdot 365 & 44 \cdot 326 & 44 \cdot 287 & 44 \cdot 249 & 44 \cdot 210 & 44 \cdot 172 & 44 \cdot 133 & 44 \cdot 094 & 44 \cdot 056 & 44 \cdot 017 \\ 43.979 & 43.940 & 43.902 & 43.863 & 43 \cdot 824 & 43.786 & 43.747 & 43.709 & 43.670 & 43.631\end{array}$ $\begin{array}{llllllllll}43.593 & 43.554 & 43.516 & 43.477 & 43.438 & 43.400 & 43.361 & 43.323 & 43.284 & 43.246\end{array}$ $\begin{array}{llllllllll}43.207 & 43.168 & 43.130 & 43.091 & 43.052 & 43.014 & 42.975 & 42.937 & 42.898 & 42.860\end{array}$ $\begin{array}{llllllllll}42.821 & 42.782 & 42.744 & 42.705 & 42.667 & 42.628 & 42.589 & 42.551 & 42.512 & 42.474\end{array}$

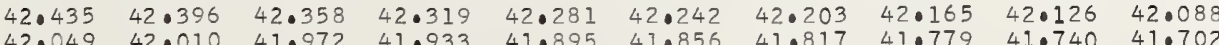
$\begin{array}{llllllllll}42.049 & 42.010 & 41.972 & 41.933 & 41.895 & 41.856 & 41.817 & 41.779 & 41.740 & 41.702\end{array}$ $\begin{array}{llllllllll}41.663 & 41.624 & 41.586 & 41.547 & 41.509 & 41.470 & 41.432 & 41.393 & 41.354 & 41.316 \\ 41.277 & 41.239 & 41.200 & 41.161 & 41.123 & 41.084 & 41.046 & 41.007 & 40.969 & 40.930\end{array}$

0.278732

1.418466

0.278732

0.278731

0.278731

0.278730

0.278730

0.278730

1.418493

1.418546

1.418572

1.418599

1.418626

1.418652

1.418679 


.05

\section{.06}

.07

$\begin{array}{llllllll}40.814 & 40.776 & 40.737 & 40.698 & 40.660 & 40.621 & 40.583 & 40.544 \\ 40.428 & 40.390 & 40.351 & 40.3113 & 40.274 & 40.235 & 40.197 & 40.158\end{array}$

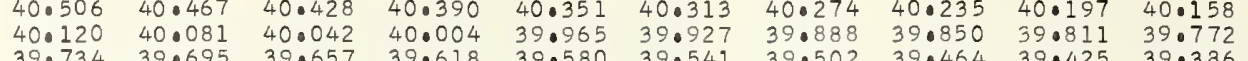

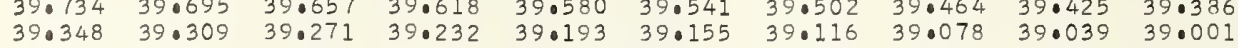
$\begin{array}{llllllllll}38.962 & 38.924 & 38.885 & 38.846 & 38.808 & 38.769 & 38.731 & 38.692 & 38.654 & 38.615\end{array}$ $\begin{array}{llllllllll}38.576 & 38.538 & 38.499 & 38.460 & 38.422 & 38.384 & 38.345 & 38.306 & 38.268 & 38.229\end{array}$ $\begin{array}{llllllllll}38.191 & 38.152 & 38.114 & 38.075 & 38.036 & 37.998 & 37.959 & 37.921 & 37.882 & 37.844\end{array}$

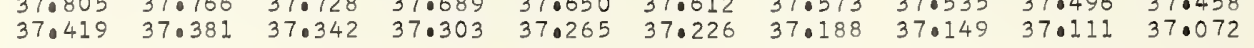
$\begin{array}{ll}36.648 & 36.609 \\ 36.262 & 36.223\end{array}$ $\begin{array}{ll}35.877 & 35.838 \\ 35.491 & 35.452\end{array}$ $\begin{array}{ll}35.491 & 35.452 \\ 35.105 & 35.067\end{array}$ $34.719 \quad 34.681$ $\begin{array}{ll}34.334 & 34.296 \\ 33.948 & 33.010\end{array}$ $\begin{array}{lll}33.948 & 33.910 \\ 33.563 & 33.524\end{array}$

36.056
36.570
36.185

36.91

$36.879 \quad 36.840$

36.302

36.763

$\begin{array}{ll}37.112 & 37.072 \\ 36.725 & 36.686\end{array}$

1.6

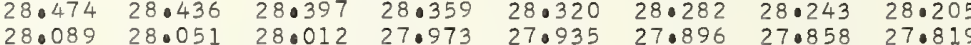

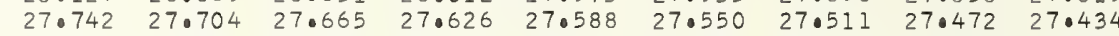
$\begin{array}{llllllllll}27.395 & 27.357 & 27.318 & 27.280 & 27.241 & 27.203 & 27.164 & 27.126 & 27.087 & 27.049\end{array}$ $\begin{array}{llllllllll}27 \cdot 010 & 26 \cdot 971 & 26 \cdot 933 & 26 \cdot 894 & 26 \cdot 856 & 26 \cdot 817 & 26 \cdot 779 & 26 \cdot 740 & 26 \cdot 702 & 26 \cdot 663\end{array}$

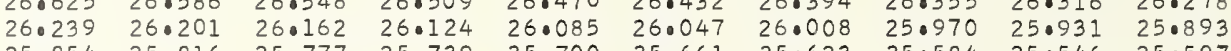

$\begin{array}{lllllllllll}509400 & 196250469 & 25.430 & 25.392 & 25 \cdot 353 & 25 \cdot 315 & 25.276 & 25 \cdot 238 & 250199 & 250161 & 25 \cdot 122\end{array}$ $\begin{array}{lllllllllll}4 \cdot 1 & 25.084 & 25.045 & 25.007 & 24.968 & 24.930 & 24.891 & 24.852 & 240814 & 24.775 & 24.737\end{array}$ $4 \cdot 3$ 21.579 $20.847 \quad 20.808 \quad 20.77$ $\begin{array}{lll}20.461 & 20.423 & 20.38 \\ 20.077 & 20.03 & 20.000\end{array}$

$20.077 \quad 20.038$

$\begin{array}{lll}19.307 & 19.268 & 19.615\end{array}$ $13.533 \quad 13.879$ 13.533 $12.763 \quad 13.110 \quad 13.071$

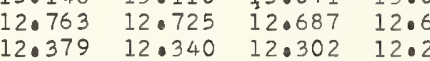
$\begin{array}{llll}11.994 & 11.956 & 12.302 & 12.26 \\ 11.917 & 11.87\end{array}$

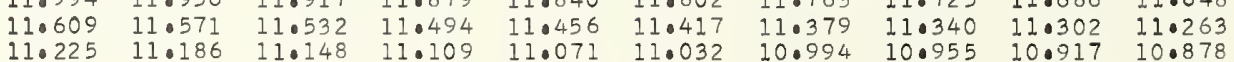
$\begin{array}{llllllllll}10.840 & 10.801 & 10.763 & 10.725 & 10.686 & 100.648 & 10.609 & 10.571 & 10.532 & 10.494 \\ 10.455 & 10.417 & 10.378 & 10.340 & 10.301 & 10.263 & 10.224 & 10.186 & 10.147 & 10.109\end{array}$

$\begin{array}{lllll}610.070 & 10.032 & 09.994 & 09.955 & 0 \\ 09.686 & 09.647 & 09.0009 & 09.571 & 0 \\ 09.301 & 09.263 & 09.224 & 09.186 & 0 \\ 08.917 & 08.878 & 08.840 & 08.802 & 0 \\ 08.532 & 08.493 & 08.455 & 08.417 & 0 \\ 08.147 & 08.109 & 08.071 & 08.032 & 07 . \\ 07.763 & 07.724 & 07.686 & 07.647 & 07.6 \\ 07.378 & 07.340 & 07.302 & 07.263 & 07.2 \\ 06.994 & 06.955 & 06.917 & 06.878 & 06.8 \\ 06.609 & 06.571 & 06.532 & 06.494 & 06.4\end{array}$
$\begin{array}{lllllllllll}06.225 & 06.187 & 06.148 & 06.110 & 06.071 & 06.032 & 05.994 & 05.956 & 05.917 & 05.879 \\ 05.840 & 05.802 & 05.763 & 05.725 & 05.687 & 05.648 & 05.610 & 05.571 & 05.532 & 05.494\end{array}$ $\begin{array}{llllllllll}05.456 & 05.417 & 05.379 & 05.340 & 05 \cdot 302 & 05.263 & 05 \cdot 225 & 05 \cdot 187 & 05 \cdot 148 & 05.110 \\ 05.071 & 05.033 & 04.994 & 04.956 & 04.917 & 04.879 & 04.841 & 04.802 & 04.764 & 04.725\end{array}$ $\begin{array}{lllllllllll}04.687 & 04.648 & 04.610 & 04.572 & 04.533 & 04.495 & 04.456 & 04.417 & 04.379 & 04.341\end{array}$ $\begin{array}{lllllllllll}04.302 & 04.264 & 04.225 & 04.187 & 04.148 & 04.110 & 04.072 & 04 \cdot 033 & 03.995 & 03.956 \\ 03.918 & 03.879 & 03.841 & 03.802 & 03.764 & 03.726 & 03.687 & 03.649 & 03.610 & 03.572\end{array}$ $\begin{array}{lllllllllll}03.533 & 03.495 & 03.457 & 03.418 & 03.380 & 03.341 & 03.303 & 03.264 & 03.226 & 03.187\end{array}$ $\begin{array}{lllllllllll}03.149 & 03.111 & 03.072 & 03.034 & 022.995 & 02.957 & 02.918 & 02.880 & 02.842 & 02.803\end{array}$

$\begin{array}{ll}0.278729 & 1.418732 \\ 0.278729 & 1.418759 \\ 0.278729 & 1.418785 \\ 0.278729 & 1.418812 \\ 0.278728 & 1.418839 \\ 0.278728 & 1.418865 \\ 0.278728 & 1.418892 \\ 0.278728 & 1.418918 \\ 0.278727 & 1.418945 \\ 0.278727 & 1.418972\end{array}$

0.278727

0.278727

0.278726

0.278726

0.278725

0.278725

0.278725

1.418998 1.419025 1.419078 1.419105 1.419131 .419158
.019184 1.419211 $0.278724 \quad 1.419264$ 0.278724 0.00278724 0.278723 0.278723 0.278723 0.278722 1.419291 1.419344 1.419371 1.419397
1.419424 1.419450 1.419477

0.278722 1.419530 0.278722 0.278721 0.278721 0.278721 0.278720 0.278720 0.278720

0.278719

0.278719

0.278719

0.278718

0.278718

0.278718

0.278717

0.278717

1.419557 1.419610 1.419637 1.419663
1.419690 1.419690 1.419743

0.278717 0.278717 0.278716 0.278716 0.278716 0.278715 $\begin{array}{ll}0.278715 & 1.420275 \\ 0.278715 & 1.420302\end{array}$ 1.419796 1.419823 1.419876 1.419903
1.419929 1.419956 1.419982
1.420009 1.420009

1.420062 1.420089 1.420116 1.420169 1.420195 1.420222 1.420249

0.278714 0.278714 0.278714 0.278713 0.278713 0.278713 0.278713 1.420328 1.420355 1.420382
1.420408 1.420435 1.420461 1.420488 1.420515
1.420541 $0.278712 \quad 1.420568$

0.278712 1.420594 0.278711 0.27871 0.27871 0.278711 0.278710 0.278710 0.278710
0.278710

1.420621
1.420648 1.420674 1.420701 1.420727 1.420754 1.420781 0.278709 0.278709 0.278709 0.278709 0.278708 0.278708 0.278708 0.278707
0.278707

1.420860 1.420887 1.420914 1.420940 1.420994 1.421020 1.421073

0.278707 0.278706 0.278706 0.278706 0.278706 0.278705
0.278705
0.278705 0.278705 1.421127 1.421180 1.421206 1.421233 
$\begin{array}{lllllllllll}5100.0 & 19602.380 & 02.342 & 02.303 & 02.265 & 02.227 & 02.188 & 02.150 & 02.112 & 02.073 & 02.035\end{array}$ $\begin{array}{lllllllllll}0.12 & 01.996 & 01.958 & 01.919 & 01.880 & 01.842 & 01.804 & 01.765 & 01.727 & 01.688 & 01.650 \\ 0.2 & 0.612 & 01.573 & 01.535 & 01.496 & 0.1 .458 & 01.419 & 01.381 & 01.343 & 01.304 & 01.266\end{array}$ $\begin{array}{lllllllllll}0.3 & 01.227 & 01.189 & 01.151 & 01.112 & 01.074 & 01.035 & 00.997 & 00.958 & 00.920 & 00.882 \\ 0.4 & 00.843 & 00.804 & 00.766 & 00.728 & 00.689 & 00.651 & 00.613 & 00.574 & 00.536 & 00.497\end{array}$

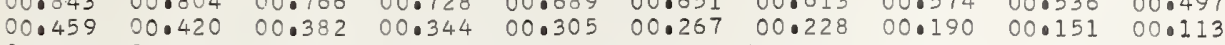

$0.6 \quad 00.07400 .036 * 99.998 * 99.959 * 99.921 * 99.882 * 99.844 * 99.805 * 99.767 * 99.729$

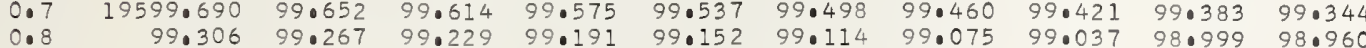
$\begin{array}{lllllllllll}0.8 & 99.306 & 99.267 & 99.229 & 99.191 & 99.152 & 99.114 & 99.075 & 99.037 & 98.999 & 98.960 \\ 0.9 & 98.922 & 98.883 & 98.845 & 98.806 & 98.768 & 98.730 & 98.691 & 98.653 & 98.615 & 98.576\end{array}$

$\begin{array}{ll}98.230 & 98.192 \\ 97.846 & 97.808\end{array}$

0.278702

0.278702

0.278702

0.27870

0.278701

.278700

0.278700
0.278700

0.278699
0.278699

0.278699

0.278698

0.278698
0.278698
0.278698

.278698

0.278697

0.278697

.278697
0.278697

0.278696

0.278696

0.278696

0.278695

0.278695

0.278695

0.0278694

0.278694

0.278693

0.278693

0.278693
0.278692

0.278692

0.278692

0.278691

0.278691

0.278691

0.278690

0.278690

0.278690

0.0278689

0.278689

.278689

0.278688

0.278688

0.278688

0.278687

0.278687

0.278687
0.278686

0.278686
0.278686

0.278685
0.278685

0.278685

0.278684

0.278684

0.278683
0.278683

0.278683

0.278683

0.278682

0.278682
0.278682

0.278682

0.278681

0.278681

0.278681

0.278680

0.278680

.421446

1.421499

1.421552

1.421579
1.421605

1.421659

1.421685
1.421712

1.421739

1.421765
1.421792

1. 421818

1.421845

1.421898

10421925

1.421951
1.421978

1.422005

1.422031
.422058

1.422084

1.422138

1.422164

1.422191

1.422217
1.422244

1.422271
1.422297

1.422324
1.422350 
$\begin{array}{lllllllllll}110.0 & 19564.020 & 63.982 & 63.944 & 63.905 & 63.867 & 63.829 & 63.790 & 63.752 & 63.714 & 63.676\end{array}$

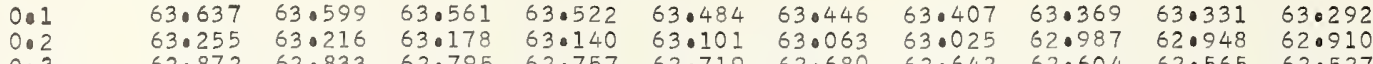
$\begin{array}{llllllllll}62.833 & 62.795 & 62.757 & 62.719 & 62.680 & 62.642 & 62.604 & 62.565 & 62.527\end{array}$ $\begin{array}{lllllllllll}0.4 & 62.489 & 62.450 & 62.412 & 62.374 & 62.336 & 62.298 & 62.259 & 62.221 & 62.183 & 62.144 \\ 0.5 & 62.106 & 62.068 & 62.030 & 61.991 & 61.953 & 61.915 & 61.876 & 61.838 & 61.800 & 61.761\end{array}$

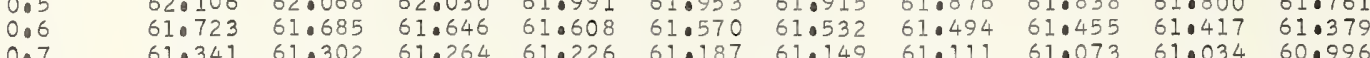
$\begin{array}{lllllllllll}0.7 & 61.341 & 61.302 & 61.264 & 61.226 & 61.187 & 61.149 & 61.111 & 61.073 & 61.034 & 60.996 \\ 0.8 & 60.958 & 60.919 & 60.881 & 60.843 & 60.805 & 60.766 & 60.728 & 60.690 & 60.651 & 60.613\end{array}$ $\begin{array}{lllllllllll}0.8 & 60.958 & 60.919 & 60.881 & 60.843 & 60.805 & 60.766 & 60.728 & 60.690 & 60.651 & 60.613 \\ 0.9 & 60.575 & 60.537 & 60.499 & 60.460 & 60.422 & 60.384 & 60.345 & 60.307 & 60.269 & 60.230\end{array}$

1.2

1.4

1.5
1.6

1.7
1.8

5112

2

2.3
2.4

2.5
2.6

2.6
2.7
2.8

2.8
2.9

5113.

3.1
3.2

3.3
3.4

3.5

3.6
3.7

3.8
3.9

5114.0

4. 1

4.3
4.4

406

4.8
4.9

5115.

5.

$5 \cdot 3$

5.4
5.5

5.6

5.8

5116.0

$$
\begin{aligned}
& 6.1 \\
& 6.2 \\
& 6.3 \\
& 6.14 \\
& 6.5 \\
& 6.6
\end{aligned}
$$

\section{4}

6.7
6.8

6.8
6.9

5117.

$7 \cdot 3$
$7 \cdot 4$

7.5
7.6

7.7
7.8
7.9

5118.

8.

8.4

8.

8.8
8.9

5119

9.

19560.192

59.427
59.044

$59.044 \quad 59.006$

$57.896 \quad 57.858$

$\begin{array}{ll}57.131 & 57.093\end{array}$

9556.366

55.983
55.601

55.218
54.836

54.453
54.071

53.689
53.306

53.306
52.924

19552.541

52.159
51.776

51.394

$50.629 \quad 50.591$

50.24750 .208

49.482
49.100

19548.718

48.335
47.953
47.571

$47 \cdot 189 \quad 47 \cdot 151$

$\begin{array}{llll}46.806 & 46.769 & 46.730 & 46.6\end{array}$

$\begin{array}{llll}46.042 & 46.004 & 45.3566 & 46.3 \\ 45.927\end{array}$

45.660
45.278

19544.896

44.514
44.132
43.750

43.368

42.986
42.604

42.222

41.458

19541.076

40.694
40.312

40.312
39.930

$\begin{array}{llll}39.930 & 39.892 & 39.854 & 39.8 \\ 39.548 & 39.510 & 39.472 & 39.4 \\ 39.166 & 39.128 & 39.090 & 39.0\end{array}$

$\begin{array}{llll}38.784 & 38.746 & 38.708 & 38.0570\end{array}$

$\begin{array}{llll}38.403 & 38.365 & 38.326 & 38.28\end{array}$

$\begin{array}{llll}38.021 & 37.982 & 37.944 & 37.90 \\ 37.639 & 37.601 & 37.562 & 37.52\end{array}$

19537.257

$537.257 \quad 37.219$

36.493

$\begin{array}{lllll}36.0112 & 36.073 & 36.417 & 36.379\end{array}$

$\begin{array}{llll}35.348 & 35.310 & 35.654 & 35.61 \\ 35.272 & 35.23\end{array}$

$\begin{array}{llll}34.966 & 34.928 & 34.890 & 34.852\end{array}$

$\begin{array}{llll}34.203 & 34.165 & 34.127 & 34.08 \\ 33.821 & 33.783 & 33.745 & 33.707\end{array}$

19533.440

33.058
32.677

33.402
33.020
32.638

33.364

$32.295 \quad 32.256,32.600 \quad 32.562$

$\begin{array}{llll}31.913 & 31.875 & 31.837 & 31.79\end{array}$

$31.150 \quad 31.112 \quad 31.074 \quad 31.03$

$30.768 \quad 30.730$

30.387
30.005

9529.624

29.242

28.86

30.34
$29 \cdot 96$

30.69230 .654

60.03960 .001

59.963

59.925

59.886

$59 \cdot 848$

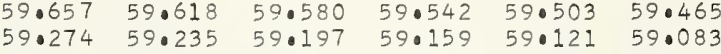

$\begin{array}{lllllll}58.891 & 58.853 & 58.815 & 58.776 & 58.738 & 58.700\end{array}$

$\begin{array}{llllll}58.126 & 58.088 & 58.049 & 58.011 & 57.973 & 57.935\end{array}$

$\begin{array}{lllllll}58.126 & 58.088 & 58.049 & 58.011 & 57.973 & 57.935 \\ 57.743 & 57.705 & 57.667 & 57.628 & 57.590 & 57.552\end{array}$

$57.361 \quad 57.32$

$\begin{array}{ll}57.667 & 57.628 \\ 57.284 & 57.246\end{array}$

57.0990
57.208

56.825

57.552
57.169

57.787
56.404

56.213

56.557

56.901
56.519

56.48

$\begin{array}{ll}56.060 & 56.022 \\ 55.677 & 55.630\end{array}$

6.022
5.639
5.257

$\begin{array}{llllll}.448 & 55.410 & 55.372 & 55.333 & 55.295 & 55.257 \\ .065 & 55.027 & 54.989 & 54.950 & 54.912 & 54.874\end{array}$

.065350 .027

.918

$4 \cdot 262$

54.606

54.568

54.912

54.530

54.492

54.109

5.765253 .727

$3.382 \quad 53.344$

53.153
52.770

11

53.45

53.42

3.00

52.579

$\begin{array}{llllll}.388 & 52.350 & 52.312 & 52.274 & 52.235 & 52.197 \\ 2.006 & 51.968 & 51.929 & 51.891 & 51.853 & 51.814\end{array}$

$\begin{array}{llllll}.623 & 51.585 & 51.547 & 51.509 & 51.470 & 51.432 \\ .241 & 51.203 & 51.165 & 51.126 & 51.088 & 51.050\end{array}$

$\begin{array}{llllll}50.858 & 50.821 & 50.782 & 50.744 & 50.706 & 50.667 \\ 0.476 & 50.438 & 50.400 & 50.362 & 50.323 & 50.285\end{array}$

$\begin{array}{llllll}50.094 & 50.056 & 50.018 & 49.979 & 49.941 & 49.903\end{array}$

$\begin{array}{llll}50.018 & 49.979 & 49.941 & 49.903 \\ 9.635 & 49.597 & 49.559 & 49.521\end{array}$

$\begin{array}{llllll}49.329 & 49.291 & 49.253 & 49.215 & 49.176 & 49.138 \\ 48.947 & 48.909 & 48.871 & 48.833 & 48.794 & 48.756\end{array}$

$\begin{array}{lllllll}48.565 & 48.527 & 48.488 & 48.450 & 48.412 & 48.374\end{array}$

$\begin{array}{lllllll}48.183 & 48.145 & 48.106 & 48.068 & 48.030 & 47.991\end{array}$

$\begin{array}{llllll}47.801 & 47.762 & 47.724 & 47.686 & 47.647 & 47.609 \\ 47.418 & 47.380 & 47.342 & 47.303 & 47.265 & 47.227\end{array}$

$\begin{array}{llllll}47.036 & 46.998 & 46.960 & 46.921 & 46.883 & 46.845 \\ 46.654 & 46.615 & 46.577 & 46.539 & 46.501 & 46.463\end{array}$

$\begin{array}{lllllll}46.272 & 46.234 & 46.195 & 46.157 & 46.119 & 46.080\end{array}$

$\begin{array}{llllll}45.889 & 45.851 & 45.813 & 45.775 & 45.737 & 45.698\end{array}$

$\begin{array}{llllll}.507 & 45.469 & 45.431 & 45.393 & 45.354 & 45.316\end{array}$

$\begin{array}{llllll}44.743 & 44.705 & 44.667 & 44.629 & 44.590 & 44.552\end{array}$

$\begin{array}{llll}4.667 & 44.629 & 44.590 & 44.55 \\ 4.284 & 44.246 & 44.208 & 44.170 \\ 4.903 & 43.865 & 43.826 & 43.788\end{array}$

$\begin{array}{lllllll}44.361 & 44.323 & 44.284 & 44.865 & 44.826 & 43.78 \\ 43.979 & 43.941 & 43.903 & 43.865 & 43.826 & 43.788 \\ 43.597 & 43.559 & 43.521 & 43.482 & 43.444 & 43.406\end{array}$

$\begin{array}{lllllll}43.215 & 43.177 & 43.139 & 43.100 & 43.062 & 43.024\end{array}$

$\begin{array}{llllll}42.833 & 42.795 & 42.757 & 42.719 & 42.680 & 42.642\end{array}$

$\begin{array}{llllll}42.451 & 42.413 & 42.375 & 42.336 & 42.298 & 42.260 \\ 42.069 & 42.031 & 41.993 & 41.955 & 41.916 & 41.878\end{array}$

$42.069 \quad 42.031$

$\begin{array}{llll}41.993 & 41.955 & 41.916 & 41.878 \\ 41.611 & 41.572 & 41.534 & 41.496\end{array}$

$\begin{array}{llllll}41.305 & 41.267 & 41.229 & 41.190 & 41.152 & 41.114\end{array}$

$\begin{array}{llllll}40.541 & 40.503 & 40.465 & 40.427 & 40.388 & 40.350\end{array}$

$\begin{array}{llllll}40.159 & 40.121 & 40.083 & 40.045 & 40.006 & 39.968\end{array}$

$\begin{array}{llllll}39.777 & 39.739 & 39.701 & 39.663 & 39.625 & 39.586\end{array}$

$\begin{array}{llllll}39.013 & 38.975 & 38.037 & 38.899 & 38.861 & 39.205\end{array}$

$\begin{array}{llllll}38.632 & 38.594 & 38.555 & 38.517 & 38.479 & 38.441\end{array}$

$\begin{array}{llllll}38.250 & 38.211 & 38.173 & 38.135 & 38.097 & 38.059\end{array}$

$\begin{array}{llllll}.868 & 37.830 & 37.792 & 37.753 & 37.715 & 37.677\end{array}$

$\begin{array}{llllll}37.104 & 37.066 & 37.028 & 36.990 & 36.952 & 36.914\end{array}$

$\begin{array}{llllll}36.723 & 36.685 & 36.646 & 36.608 & 36.570 & 36.531\end{array}$

$\begin{array}{llllll}36.341 & 36.302 & 36.264 & 36.226 & 36.188 & 36.150\end{array}$

$\begin{array}{llllll}35.577 & 35.539 & 35.501 & 35.463 & 35.425 & 35.386\end{array}$

$\begin{array}{llllll}35.196 & 35.157 & 35.119 & 35.081 & 35.043 & 35.005\end{array}$

$\begin{array}{lllllll}34.814 & 34.776 & 34.737 & 34.699 & 34.661 & 34.623\end{array}$

$34.050 \quad 34.012 \quad 34.356 \quad 34.318034 .280 \quad 34 \cdot 241$

$33.669 \quad 33.631$

33.974
33.593

33.936

33.897

$33.287 \quad 33.249 \quad 33.210$

33.173

$\begin{array}{lll}32.524 & 32.485 & 32.829\end{array}$

$32.142 \quad 32.104 \quad 32.066 \quad 32.028$

$\begin{array}{lll}31.379 & 31.341 & 31.302\end{array}$

$\begin{array}{lll}30.998 & 30.959 & 30.92 \\ 30.616 & 30.577 & 30.54\end{array}$

31.646
31.265

31.265
30.88
30.501

$33.134 \quad 33.096$

$32.753 \quad 32.715$

$\begin{array}{ll}32.371 & 32.333 \\ 31.989 & 31.951\end{array}$

$1.608 \quad 31.570$

$\begin{array}{ll}1.226 & 31.188 \\ 30.845 & 30.806\end{array}$

$\begin{array}{ll}30.845 & 30.806 \\ 30.463 & 30.425\end{array}$

$\begin{array}{lll}30.234 & 30.196 & 30.158 \\ 29.853 & 29.815 & 29.776\end{array}$

30.044

$29.357 \quad 29 \cdot 319 \quad 29 \cdot 281$

$\begin{array}{lllllllll}28.823 & 28.784 & 28.746 & 28.708 & 28.670 & 28.632 & 28.594 & 28.556 & 28.518 \\ 28.441 & 28.403 & 28.365 & 28.327 & 28.289 & 28.250 & 28.212 & 28.174 & 28.136\end{array}$

$\begin{array}{llllllllll}28.098 & 28.060 & 28.021 & 28.365 & 28.327 & 28.289 & 28.250 & 28.212 & 28.174 & 28.136 \\ & 28.983 & 27.945 & 27.907 & 27.869 & 27.831 & 27.793 & 27.755\end{array}$

$\begin{array}{llll}27.716 & 27.678 & 27.640 & 27.602\end{array}$

$26.954 \quad 26.916 \quad 26.877 \quad 26.83$

$27.564 \quad 27.526 \quad 27.48$

$\begin{array}{llllll}27.182 & 27.144 & 27.106 & 27.068 & 27.411 & 27.373\end{array}$

$\begin{array}{llll}26.572 & 26.534 & 26.496 & 26.458 \\ 26.191 & 26.153 & 26.115 & 26.076\end{array}$

26.763

$26.420 \quad 26.381$

$\begin{array}{llll}27.106 & 27.068 & 27.030 & 26.992 \\ 26.725 & 26.687 & 26.649 & 26.610\end{array}$

.001

.002

.003

.004

.005

.007

$\begin{array}{ll}5.886 & 25.848\end{array}$

0.278680

$0.278679 \quad 1.424080$

$0.278679 \quad 1.424107$

$0.278679 \quad 1.424160$

$0.278678 \quad 1.424213$

$0.278678 \quad 1.424240$

$\begin{array}{ll}0.278678 & 1.424266 \\ 0.278678 & 1.424293\end{array}$

$0.278677 \quad 1.424320$

0.278677

0.278677

0.278676

0.278676

0.278676

0.278675

0.278675

.278675

0.278674

0.278674

0.278674

0.278673

0.278673

0.278673

0.278672

0.278672

0.278672
0.278672

0.278671

0.278671

0.278671

0.278671
0.278670

0.278670

1.424320

1.424373

1.424426

1.424453

1.424506

1. 424532

1.424586 
$\begin{array}{rrrrrrrrrrr}5120.0 & 19525.809 & 25.771 & 25.733 & 25.695 & 25.657 & 25.619 & 25.581 & 25.542 & 25.504 & 25.466 \\ 0.1 & 25.428 & 25.390 & 25.352 & 25.313 & 25.276 & 25.238 & 25.199 & 25.161 & 25.123 & 25.085\end{array}$

$\begin{array}{lllllllllll}0.2 & 25.428 & 25.390 & 25.352 & 25.313 & 25.276 & 25.238 & 25.199 & 25.161 & 25.123 & 25.085 \\ 0.047 & 25.0400 & 24.970 & 24.932 & 24.894 & 24.856 & 24.818 & 24.780 & 24.742 & 24.703\end{array}$

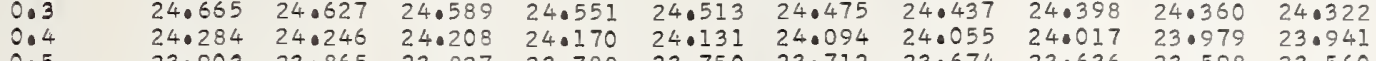

$\begin{array}{lllllllllll}0.5 & 23.903 & 23.865 & 23.827 & 23.788 & 23.750 & 23.712 & 23.674 & 23.636 & 23.598 & 23.560 \\ 0.6 & 23.521 & 23.483 & 23.445 & 23.407 & 23.369 & 23.331 & 23.293 & 23.254 & 23.2 .16 & 23.178\end{array}$

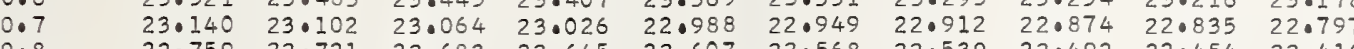

0.9

22.759 . 378 22

5121.0

19521096 $21.996 \quad 21.958 \quad 2109$

21.615421 .577

$\begin{array}{llll}21.615 & 21.577 & 21.539 & 21.501 \\ 21.234 & 21.196 & 21.158 & 21.120 \\ 20.853 & 20.815 & 20.777 & 20.739 \\ 20.472 & 20.434 & 20.396 & 20.358\end{array}$

$20.091 \quad 20.053$

$\begin{array}{llll}19.329 & 19.291 & 19.252 & 19.21\end{array}$

$\begin{array}{ll}22.607 & 22.568 \\ 22.225 & 22 \cdot 187\end{array}$

$\begin{array}{llll}22.530 & 22.492 & 22.454 & 22.416 \\ 22.149 & 22.111 & 22.073 & 22.035\end{array}$

$\begin{array}{llllll}21.844 & 21.806 & 21.768 & 21.730 & 21.692 & 21.654 \\ 21.463 & 21.425 & 21.386 & 21.348 & 21.310 & 21.272\end{array}$

$\begin{array}{llllll}21.463 & 21.425 & 21.386 & 21.348 & 21.310 & 21.272 \\ 21.082 & 21.043 & 21.006 & 20.968 & 20.929 & 20.891\end{array}$

$\begin{array}{llllll}20.700 & 20.662 & 20.624 & 20.586 & 20.548 & 20.510\end{array}$

$\begin{array}{llllll}20.320 & 20.281 & 20.243 & 20.205 & 20.167 & 20.129 \\ 19.938 & 19.900 & 19.862 & 19.824 & 19.786 & 19.748\end{array}$

$\begin{array}{lllllll}19.214 & 19.557 & 19.519 & 19.481 & 19.443 & 19.405 & 19.367 \\ 19.138 & 19.100 & 19.062 & 19.024 & 18.986\end{array}$

$18.566 \quad 18.4$

5122
2
2
2
2
2
2
2
2
2

$19518 \cdot 185 \quad 18 \cdot 147 \quad 18.1$

$18.109 \quad 18.071$

$18.795 \quad 18.757$

$18.719 \quad 18.681 \quad 18.643 \quad 18.605$

$\begin{array}{lll}17.804 & 170 \\ 17.424 & 170 \\ 17.042 & 170\end{array}$

$\begin{array}{ll}17.042 & 17.004 \\ 16.661 & 16.623\end{array}$

$\begin{array}{ll}16.280 & 16.242 \\ 15.899 & 15.861\end{array}$

$15.899 \quad 15.861$

15.518

$17.347 \quad 17.309$

$\begin{array}{llllll}18.033 & 17.995 & 17.957 & 17.919 & 17.881 & 17.843 \\ 17.652 & 17.614 & 17.576 & 17.538 & 17.500 & 17.461\end{array}$

$\begin{array}{ll}15.137 & 15.099 \\ 14.757 & 14.718\end{array}$

6.585 16.547

$\begin{array}{ll}16.204 & 16.166 \\ 15.823 & 15.785\end{array}$

$\begin{array}{llllll}17.271 & 17.233 & 17.195 & 17.156 & 17.118 & 17.080\end{array}$

$\begin{array}{llllll}16.890 & 16.852 & 16.814 & 16.776 & 16.737 & 16.699 \\ 16.509 & 16.471 & 16.433 & 16.395 & 16.356 & 16.318\end{array}$

$\begin{array}{llllll}16.509 & 16.471 & 16.433 & 16.395 & 16.356 & 16.318 \\ 16.128 & 16.090 & 16.052 & 16.014 & 15.976 & 15.937\end{array}$

$\begin{array}{llllllll}15.442 & 15.404 & 15.366 & 15.328 & 15.290 & 15.252 & 15.214 & 15.176\end{array}$

5123

1951403

3
3
3
3
3
3
3
3
3
3

$13.375 \quad 14.337$

$14.680 \quad 14.642$

$14 \cdot 985 \quad 14 \cdot 947$

$\begin{array}{llll}15.290 & 15.252 & 15 \cdot 214 & 15.176 \\ 14.909 & 14.871 & 14.833 & 14.795 \\ 14.528 & 14.490 & 14.452 & 14.414\end{array}$

$\begin{array}{ll}13.995 & 13.957 \\ 13.614 & 13.576\end{array}$

$13.918 \quad 13.880$

$14.223 \quad 14.185$

$14 \cdot 147 \quad 14.109 \quad 14.071 \quad 14.033$

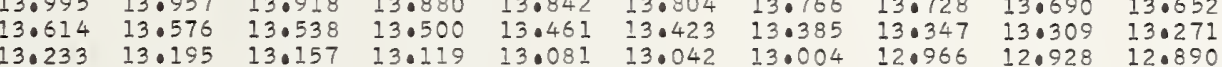

$\begin{array}{llllllllll}12.852 & 12.814 & 12.776 & 12.738 & 13.081 & 13.042 & 13.004 & 12.966 & 12.928 & 12.890 \\ \end{array}$

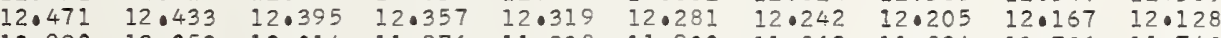

$\begin{array}{llllllllll}12.090 & 12.052 & 12.014 & 11.976 & 11.938 & 11.900 & 11.862 & 11.824 & 11.786 & 11.748\end{array}$

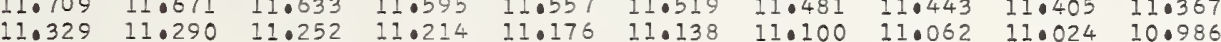

$\begin{array}{llllllllll}10.948 & 10.910 & 11.252 & 11.214 & 11.176 & 11.138 & 11.100 & 11.062 & 11.024 & 10.986 \\ 10.872 & 10.833 & 10.795 & 10.758 & 10.719 & 10.681 & 10.643 & 10.605\end{array}$

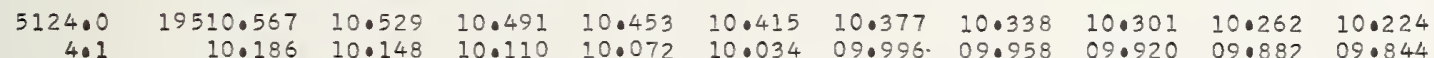

$\begin{array}{lllllllllll}4.1 & 10.186 & 10.148 & 10.110 & 10.072 & 10.034 & 09.996 & 09.958 & 09.920 & 09.882 & 09.844 \\ 4.2 & 09.806 & 09.768 & 09.729 & 09.691 & 09.653 & 09.615 & 09.577 & 09.539 & 09.501 & 09.463\end{array}$

4.3

$09.425 \quad 09.387 \quad 09.349 \quad 09.311$

$\begin{array}{llllllllll}09.044 & 09.006 & 08.968 & 08.930 & 08.892 & 08.854 & 08.816 & 0.1778 & 08.740 & 08.701\end{array}$

$\begin{array}{lllllllllll}08.663 & 08.625 & 08.587 & 08.549 & 08.511 & 08.473 & 08.435 & 08.397 & 08.359 & 08.321\end{array}$

$\begin{array}{llllllllll}08.283 & 08.245 & 08.207 & 08.168 & 08.131 & 08.093 & 08.054 & 08.016 & 07.978 & 07.940\end{array}$

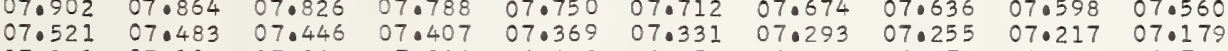

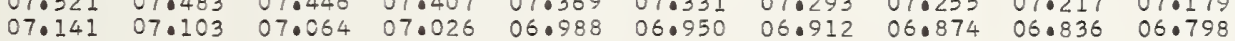

0.278655

1.426714

0.278655

0.278654

.278653

0.278653
0.278653

0.278653

0.278652

0.278652

0.278652
0.278651

0.27865

0.278651

0.278650
0.278650

0.278650

0.278649

0.278649

0.278649

0.278648
0.278648

1.426741

0.278649

0.278648
0.278647
0.278647

0.278647

0.278647

0.278647

0.278646

0.278645

0.278645

0.278645

(

0.278644

0.278644

0.278643

1.426794
1.426821

1.426848

1.426901

1.426954

4.8
4.9

5125

5.1
5.2
5.3

06.76006 .722

$06.684 \quad 06.54$

$06.608 \quad 06.570 \quad 06.532 \quad 06.494 \quad 06.456 \quad 06.418$

0.278643

0.278642

$\begin{array}{lllllllllll}05.999 & 05.961 & 05.923 & 05.885 & 05.847 & 05.809 & 05.771 & 05.733 & 05.695 & 05.656\end{array}$ $\begin{array}{llllllllll}05.618 & 05.580 & 05.542 & 05.504 & 05.466 & 05.428 & 05.390 & 05.352 & 05.314 & 05.276\end{array}$ $\begin{array}{lllllllllll}04.857 & 04.819 & 04.781 & 04.743 & 04.705 & 04.667 & 04.629 & 04.591 & 04.553 & 04.515\end{array}$ $\begin{array}{llllllllll}04.477 & 04.438 & 04.400 & 04.362 & 04.324 & 04.286 & 04.248 & 04 \cdot 210 & 04.172 & 04.134\end{array}$

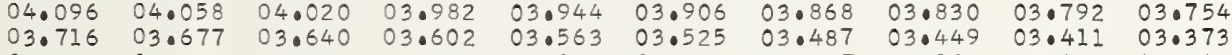
$\begin{array}{llllllllll}03.335 & 03.297 & 03.259 & 03.221 & 03.183 & 03.145 & 03.107 & 03.069 & 03.031 & 02.993\end{array}$

0.278642

0.278642

0.278641

0.278641

0.278641

$5126 \cdot 0$

$19502.955 \quad 02.917 \quad 02.879 \quad 02.841$

$\begin{array}{llllll}02.802 & 02.764 & 02.726 & 02.688 & 02.650 & 02.612\end{array}$

02.536

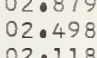

2.460

$\begin{array}{lllllll}02.802 & 02.764 & 02.726 & 02.688 & 02.650 & 02.612 \\ 0.2422 & 02.384 & 02.346 & 02.308 & 02.270 & 02.0232\end{array}$

$\begin{array}{llllllllll}01.813 & 01.775 & 01.737 & 01.699 & 01.661 & 01.623 & 01.966 & 01.927 & 01.889 & 01.851 \\ \end{array}$

$\begin{array}{llllllllll}01.433 & 01.395 & 01.357 & 01.319 & 01.281 & 01.243 & 01.205 & 01.167 & 01.128 & 01.091\end{array}$

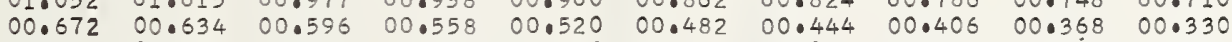

$\begin{array}{llllllllll}00.672 & 00.634 & 00.596 & 00.558 & 00.520 & 00.482 & 00.444 & 00.406 & 00.368 & 00.330 \\ 00.292 & 00.254 & 00.216 & 00.178 & 00.140 & 00.102 & 00.064 & 00.026 & * 99.988 & * 99.949\end{array}$

$19499.911 \quad 99.873 \quad 99.835 \quad 09.797$

$99.531 \quad 99.493$

$00.064^{\circ} 00.026 * 99.988 * 99.949$

6.9

99.113

$99.455 \quad 99.417$

5127. 98.771009

$7: 1$

$\begin{array}{llll}98.770 & 98.732 & 98.694 & 98.65 \\ 98.390 & 98.352 & 98.314 & 98.27 \\ 98.010 & 97.972 & 97.934 & 97.89\end{array}$

$97.630 \quad 97.592$

$96.869 \quad 96.83$

$96.109 \quad 96.071 \quad 96.033 \quad 95.99$

$\begin{array}{llllll}98.999 & 98.961 & 98.923 & 98.885 & 98.846 & 98.808\end{array}$

0.27864

0.278640

0.278640

0.278639

0.278639

0.278639

0.278638

0.278638

0.278638

0.27863

0.278637

0.278636

0.278636

1.426981

1.427007

1.427060
1.427087

- 427114

1.427140

1.427194

1.427247

427273

1.427327
1.427353

1.427380

1.427433

1.427460
1.427486

1.427513

1.427593

1.427646

1.427673

1.427726
1.427752

1.427779

10427806

1.427859

1.427885

1.427912

1.427965
1.427992

1.428045

1.428072

1.428098

i. 428152

1.428178
1.428205

1.428231

1.428285

1.428311

1.428364

1.428391

1.428418

1.428471

1.42852

1.428577

1.428604

1.428657

1.428684

1.428710
1.428737

1.428737

1. 428817

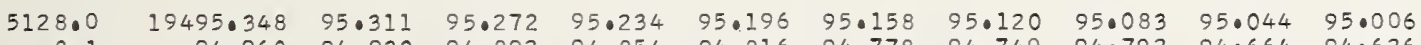

$\begin{array}{lllllllllll}8 \cdot 1 & 94 \cdot 968 & 94.930 & 94 \cdot 892 & 94 \cdot 854 & 94 \cdot 816 & 94 \cdot 778 & 94 \cdot 740 & 94 \cdot 702 & 94 \cdot 664 & 94 \cdot 626\end{array}$

$\begin{array}{lllllllllll}8.2 & 94.588 & 94.550 & 94.512 & 94.474 & 94.436 & 94 \cdot 398 & 94.360 & 94.322 & 94.284 & 94.246 \\ 8.3 & 94.208 & 94.170 & 94.132 & 94.094 & 94.056 & 94.018 & 93.980 & 93.942 & 93.904 & 93.866\end{array}$

$\begin{array}{lllllllllll}8.4 & 93.828 & 93.790 & 93.752 & 93.714 & 93.676 & 93.638 & 93.600 & 93.562 & 93.524 & 93.486 \\ 8.5 & 93.448 & 93.410 & 93.372 & 93.334 & 93.296 & 93.258 & 93.220 & 93.182 & 93.144 & 93.106\end{array}$

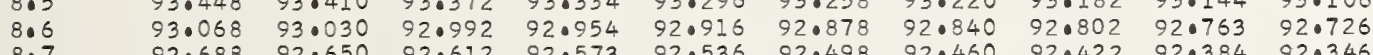

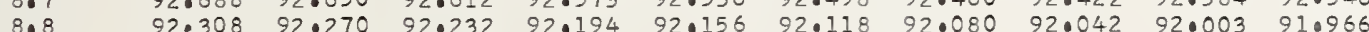

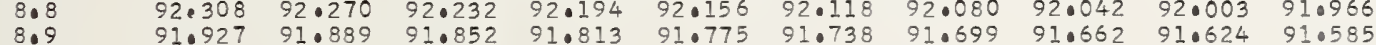

0.278636

0.278635

.278635

0.278635

0.278634

278634

0.278634

0.278633

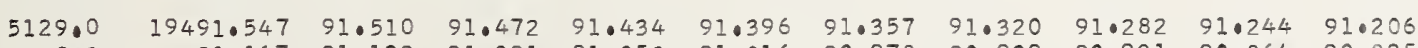

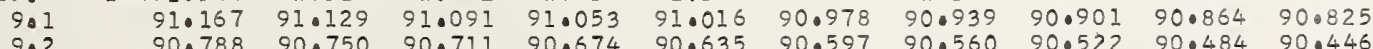

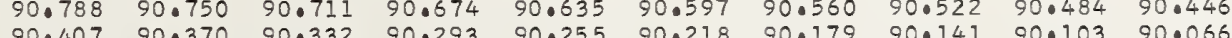

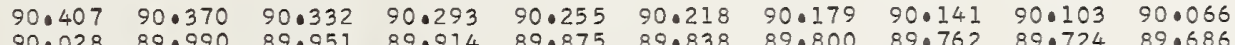

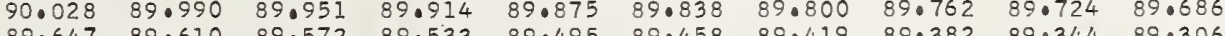

$\begin{array}{llllllllll}89.647 & 89.610 & 89.572 & 89.533 & 89.495 & 89.458 & 89.419 & 89.382 & 89.344 & 89.306\end{array}$

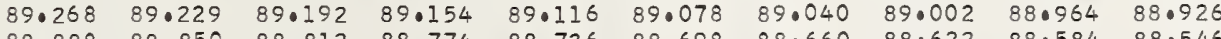

$\begin{array}{llllllllll}88.888 & 88.850 & 88.812 & 88.774 & 88.736 & 88.698 & 88.660 & 88.622 & 88.584 & 88.546\end{array}$

$\begin{array}{llllllllll}88.508 & 88.470 & 88.432 & 88.394 & 88.356 & 88.318 & 88.280 & 88.242 & 88.204 & 88.166\end{array}$

0.278633

0.278632

0.278632

0.278631

1.428844

1.428870

1.428923

1.428950

1.429003

1.429030

1.429056
1.429083

1.429110

1.429136

1.429190

1.429216
1.429243

1.429243

1.429269

1.429296

1.429323
1.429349

$\begin{array}{lllllllllll} & .001 & .002 & .003 & .004 & .005 & .006 & .007 & .008 & .009 & .010 \\ .038 & .004 & .008 & .011 & .015 & .019 & .023 & .027 & .030 & .034 & .038 \\ .037 & .004 & .007 & .011 & .015 & .019 & .022 & .026 & .030 & .033 & .037\end{array}$ 


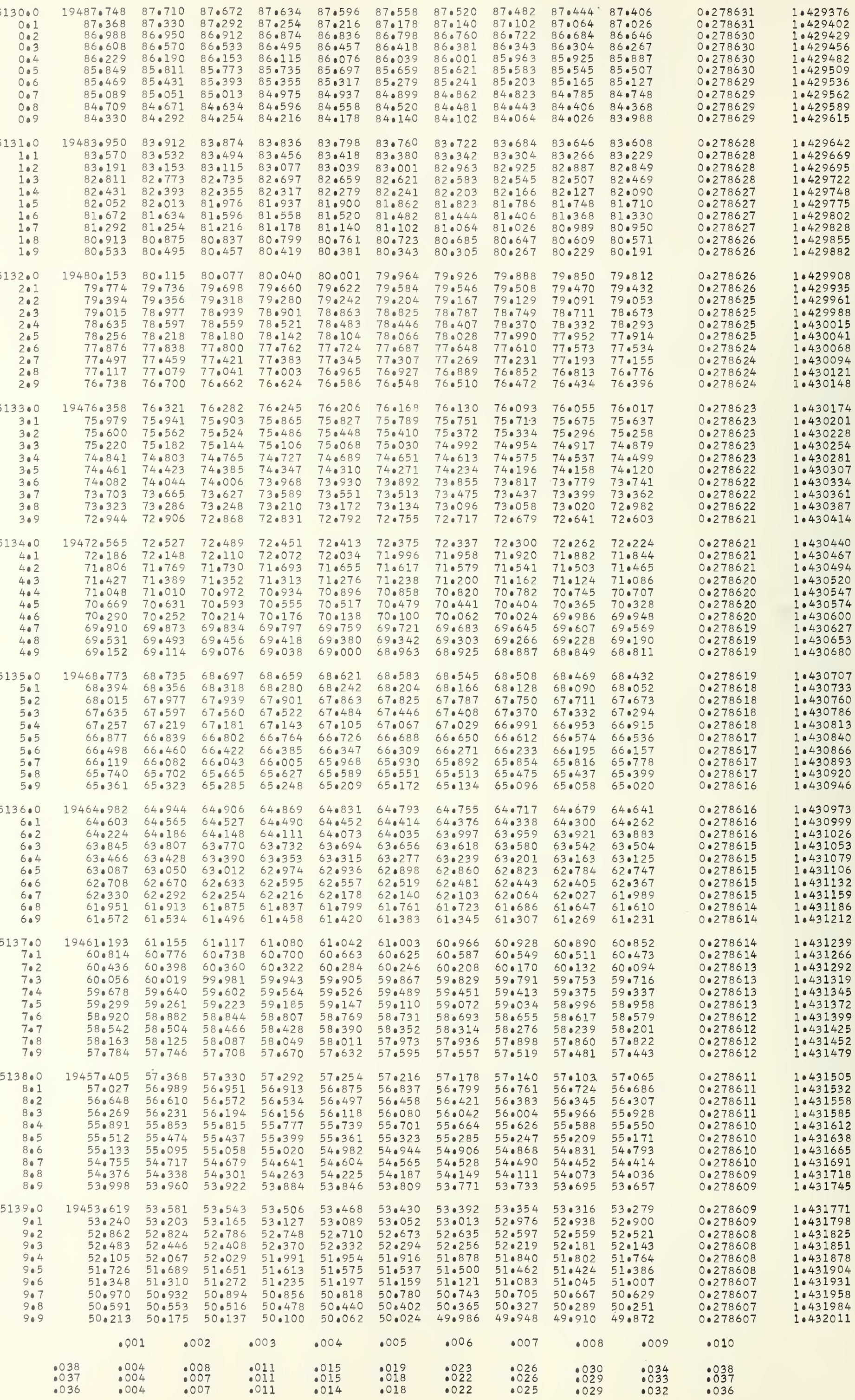




0.0
0.1
0.2
0.3
0.4
0.5
0.6
0.7
0.8
0.9

$\begin{array}{rllll}949.834 & 49.797 & 49.75 .9 & 49.721 & 4906 \\ 49.456 & 49.418 & 49.381 & 49.343 & 490 \\ 49.078 & 49.040 & 49.002 & 48.964 & 480 \\ 48.699 & 48.662 & 48.624 & 48.586 & 480 \\ 48.321 & 48.283 & 48.245 & 48.208 & 48.1 \\ 47.943 & 47.905 & 47.867 & 47.829 & 470 \\ 47.564 & 47.527 & 47.489 & 47.451 & 47 \\ 47.186 & 47.148 & 47.111 & 47.073 & 47 \\ 46.808 & 46.770 & 46.732 & 46.694 & 4606 \\ 46.430 & 46.392 & 46.354 & 46.316 & 460\end{array}$

$49.305 \quad 49.267$

$\begin{array}{llll}49.608 & 49.570 & 49.532 & 49.494\end{array}$

$\begin{array}{llllll}48.927 & 48.889 & 48.851 & 48.813 & 48.775 & 48.737\end{array}$

$\begin{array}{llllll}48.548 & 48.510 & 48.473 & 48.435 & 48.397 & 48 \cdot 359 \\ 48.170 & 48.132 & 48.094 & 48.056 & 48.019 & 47.981\end{array}$

$\begin{array}{llllll}47.792 & 47.754 & 47.716 & 47.678 & 47.640 & 47.603\end{array}$

$\begin{array}{lllllllllll} & 47.073 & 47.035 & 46.997 & 46.959 & 46.922 & 46.884 & 46.846\end{array}$

$\begin{array}{llllllllll}46.430 & 46.392 & 46.354 & 46.316 & 46.278 & 46.619 & 46.581 & 46.543 & 46.505 & 46.468 \\ & 46.241 & 46.203 & 46.165 & 46.127 & 46.089\end{array}$

5141.0

$1: 1$
1.03

1.2
1.3
2.4

1.5

1.5

$1: 7$
$1: 8$

$45.073 \frac{1}{46.0} \quad 45.63$

$\begin{array}{llll}45.295 & 45.635 & 45.597 & 45.560\end{array}$

$44.917 \quad 44.879 \quad 44.841 \quad 44.803$

$\begin{array}{llll}44.539 & 44.501 & 44.463 & 44.425\end{array}$

$\begin{array}{llll}44.160 & 44.123 & 44.085 & 44.047 \\ 43.782 & 43.744 & 43.707 & 43.669\end{array}$

$\begin{array}{llll}43.404 & 43.366 & 43.328 & 43.291\end{array}$

$\begin{array}{llll}43.026 & 42.988 & 42.950 & 42.913 \\ 42.648 & 42.610 & 42.572 & 42.534\end{array}$

$\begin{array}{llllll}45.900 & 45.862 & 45.824 & 45.787 & 45.749 & 45.711 \\ 45.522 & 45.484 & 45.446 & 45.408 & 45.371 & 45.333\end{array}$

$\begin{array}{llllll}45.522 & 45.484 & 45.44,6 & 45.408 & 45.371 & 45.333 \\ 45.144 & 45.106 & 45.068 & 45.030 & 44.992 & 44.954\end{array}$

$\begin{array}{llllll}44.765 & 44.728 & 440690 & 44.652 & 44.614 & 44.576\end{array}$

$\begin{array}{llllll}44 \cdot 387 & 44.350 & 44.312 & 44.274 & 44.236 & 44.198 \\ 44.009 & 43.971 & 43.933 & 43.896 & 43.858 & 43.820\end{array}$

$\begin{array}{llllll}43.631 & 43.593 & 43.555 & 43.518 & 43.480 & 43.442\end{array}$

$\begin{array}{llllll}43.253 & 43.215 & 43.177 & 43.139 & 43.102 & 43.064 \\ 42.875 & 42.837 & 42.799 & 42.761 & 42.723 & 42.686\end{array}$

$19442.270 \quad 42.232 \quad 42.194 \quad 42.156$

$\begin{array}{llllll}42.496 & 42.459 & 42.421 & 42.383 & 42.345 & 42.307 \\ 42.118 & 42.081 & 42.043 & 42.005 & 41.967 & 41.929\end{array}$

142

$2 \cdot 1$
$2 \cdot 2$
$2 \cdot 3$

2.3

2.5

2.6
2.7
2.8

$\begin{array}{llll}41.892 & 41.854 & 41.816 & 41.778 \\ 41.513 & 41.476 & 41.438 & 41.400\end{array}$

$\begin{array}{llll}41.135 & 41.097 & 41.060 & 41.022\end{array}$

$\begin{array}{llll}40.757 & 40.719 & 40.682 & 40.644 \\ 40.379 & 40.342 & 40.304 & 40.266\end{array}$

$\begin{array}{llll}40.001 & 39.963 & 39.926 & 39.888\end{array}$

$\begin{array}{llll}39.623 & 39.585 & 39.548 & 39.510 \\ 39.245 & 39.207 & 39.170 & 39.132\end{array}$

$41.740 \quad 41.702$

$41.362 \quad 41.324 \quad 41.665$

42.005

41.967
41.589

41.929
41.551

$\begin{array}{llllll}40.628 & 40.568 & 40.531 & 40.493 & 40.455 & 40.417\end{array}$

$\begin{array}{llllll}40.228 & 40.190 & 40.152 & 40.115 & 40.077 & 40.039 \\ 39.850 & 39.812 & 39.774 & 39.737 & 39.699 & 39.661\end{array}$

38.867

$39 \cdot 207$
$38 \cdot 829$

5143

3.

19438.

$38.111 \quad 38.451$

$\begin{array}{llll}38.111 & 38.073 & 38.036 & 37.998 \\ 37.734 & 37.696 & 37.658 & 37.620\end{array}$

38.41

$39.472 \quad 39.434$

39.69

39.661
39.283

$36.978 \quad 36.318 \quad 37.280 \quad 37 \cdot 242$

$\begin{array}{llll}36.599 & 36.562 & 36.524 & 36.486\end{array}$

$36.222 \quad 36.184 \quad 36.146 \quad 36.108$

$\begin{array}{llll}35.844 & 35.806 & 35.768 & 35.730 \\ 35.466 & 35.428 & 35.391 & 35.353\end{array}$

$\begin{array}{llll}35.466 & 35.428 & 35.391 & 35.353 \\ 35.088 & 35.050 & 35.012 & 34.975\end{array}$

$\begin{array}{lllllll}38.338 & 38.300 & 38.262 & 38.225 & 38.187 & 38.149\end{array}$

$\begin{array}{llllll}37.960 & 37.922 & 37.885 & 37.847 & 37.809 & 37.771 \\ 37.582 & 37.544 & 37.507 & 37.469 & 37.431 & 37.393\end{array}$

$\begin{array}{lllllll}37.204 & 37.167 & 37.129 & 37.091 & 37.053 & 37.015 \\ 36.826 & 36.789 & 36.751 & 36.713 & 36.675 & 36.637\end{array}$

$\begin{array}{llllll}36.448 & 36.411 & 36.373 & 36.335 & 36.297 & 36.260\end{array}$

$\begin{array}{lllllll}36.071 & 36.033 & 35.995 & 35.957 & 35.919 & 35.882\end{array}$

5144

$4 \cdot 1$

$4 \cdot 2$
$4 \cdot 3$

4.4

$4 \cdot 5$
$4 \cdot 6$

$4 \cdot 6$
$4 \cdot 7$
$4 \cdot 8$

$4 \cdot 8$

5145

4.0
50
50
50
50
50
50
50
50
50

5146.

6.1

6.3

6.4

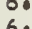

6.7

6.8

5147

7.0
7
70
70
7
70
70
70
70

$\begin{array}{rr}9434.710 & 34 \cdot 673 \\ 34.333 & 34.295\end{array}$

$33.955 \quad 33.917$

$\begin{array}{llll}33.579 & 33.539 & 33.8501 & 33.842\end{array}$

$\begin{array}{llll}33.199 & 33.161 & 33.124 & 33.086\end{array}$

$\begin{array}{llll}32.822 & 32.784 & 32.746 & 32.708 \\ 32.444 & 32.406 & 32.368 & 32.330\end{array}$

$\begin{array}{llll}32.066 & 32.028 & 31.990 & 31.953\end{array}$

$\begin{array}{llll}31.688 & 31.650 & 31.613 & 31.575 \\ 31.311 & 31.273 & 31.235 & 31.197\end{array}$

$19430.933 \quad 30.895$ $\begin{array}{llll}30.555 & 30.518 & 30.480 & 30.442\end{array}$

$\begin{array}{llll}30.178 & 30.140 & 30.102 & 30.064\end{array}$

$\begin{array}{llll}29.800 & 29.762 & 29.725 & 29.687\end{array}$

$\begin{array}{llll}29.045 & 29.007 & 28.969 & 28.932\end{array}$

$28.667 \quad 28.630 \quad 28.592$

$\begin{array}{llll}28.290 & 28.252 & 28.214 & 28.176\end{array}$

27.535

$27 \cdot 497$

26.78026 .742

$\begin{array}{llll}26.402 & 26.742 & 26.704 & 26.666\end{array}$

$\begin{array}{llll}25.270 & 25.232 & 25 \cdot 195 & 25.157\end{array}$

$\begin{array}{llll}24.892 & 24.855 & 24.817 & 24.779 \\ 24.515 & 24.477 & 24.440 & 24.402\end{array}$

$\begin{array}{llll}24.137 & 24.100 & 24.062 & 24.024\end{array}$

19423.383

$23 \cdot 345$

23.685

$23.006 \quad 22.968 \quad 22.930$

$22.628 \quad 22.591 \quad 22.553 \quad 220.51$

$22.251 \quad 22.213 \quad 22.176 \quad 22.138$

$\begin{array}{llll}21.874 & 21.836 & 21.798 & 21.760\end{array}$

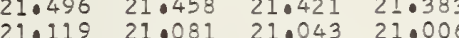

$\begin{array}{llll}20.742 & 20.704 & 20.666 & 20.628\end{array}$

$\begin{array}{llll}20.364 & 20.327 & 20.289 & 20.251 \\ 19.987 & 19.949 & 19.912 & 19.874\end{array}$

5148

$19.534 \quad 19.497$

$\begin{array}{llll}18.855 & 19.195 & 19.157 & 19.11\end{array}$

$\begin{array}{llll}18.478 & 18.441 & 18.403 & 18.365\end{array}$

$\begin{array}{llll}18.101 & 18.063 & 18.026 & 17.988\end{array}$

$\begin{array}{llll}17.724 & 17.687 & 17.049 & 17.611 \\ 16.37 & 17.309 & 17.271 & 17.233\end{array}$

$\begin{array}{llll}16.593 & 16.555 & 16.517 & 16.47\end{array}$

$16.216 \quad 16.178 \quad 16.140 \quad 16.102$

5149

9.4

$\begin{array}{llll}15.084 & 15.424 & 15.386 & 15.348\end{array}$

$14.707 \quad 14.669 \quad 14.632 \quad 14.594$

$14.330 \quad 14.292 \quad 14.255 \quad 14.217$

$\begin{array}{llll}13.953 & 13.916 & 13.878 & 13.840 \\ 13.576 & 13.539 & 13.501 & 13.463\end{array}$

$\begin{array}{llll}13.199 & 13.161 & 13.124 & 13.086\end{array}$

$\begin{array}{llll}12.822 & 12.784 & 12.747 & 12.709 \\ 12.445 & 12.407 & 12.370 & 12.332\end{array}$

34.937

35.277 350

$\begin{array}{llllll}34.559 & 34.521 & 34.484 & 34.446 & 34.408 & 34.371 \\ 34.181 & 34.144 & 34.106 & 34.068 & 34.030 & 33.992\end{array}$

$\begin{array}{llllll}33.804 & 33.766 & 33.728 & 33.690 & 33.653 & 33.615\end{array}$

$\begin{array}{llllll}33.048 & 33.010 & 33.350 & 33.312 & 33.275 & 33.237 \\ 32.973 & 32.935 & 32.897 & 32.859\end{array}$

$\begin{array}{llllll}32.670 & 32.633 & 32.595 & 32.557 & 32.519 & 32.481 \\ 32.293 & 32.255 & 32.217 & 32.179 & 32.142 & 32.104\end{array}$

$\begin{array}{llllll}31.915 & 31.877 & 31.839 & 31.802 & 31.764 & 31.726\end{array}$

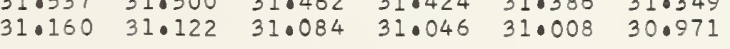

$\begin{array}{llllll}30.782 & 30.744 & 30.706 & 30.669 & 30.631 & 30.593\end{array}$

$\begin{array}{llllll}30.404 & 30.367 & 30.329 & 30.291 & 30.253 & 30.215\end{array}$

$\begin{array}{llllll}29.649 & 29.611 & 29.573 & 29.913 & 29.875 & 29.838 \\ 29.536 & 29.498 & 29.460\end{array}$

$\begin{array}{llllll}29.271 & 29.234 & 29.196 & 29.158 & 29.120 & 29.083 \\ 28.894 & 28.856 & 28.818 & 28.781 & 28.743 & 28.705\end{array}$

$\begin{array}{llllll}28.516 & 28.479 & 28.441 & 28.403 & 28.365 & 28.327\end{array}$

$\begin{array}{llllll}28.139 & 28.101 & 28.063 & 28.025 & 27 \cdot 988 & 27 \cdot 950 \\ 27.761 & 27.723 & 27.686 & 27.648 & 27.610 & 27.572 \\ 27.384 & 27.346 & 27.308 & 27.270 & 27.233 & 27.195\end{array}$

$\begin{array}{llllll}27.006 & 26.969 & 26.931 & 26.893 & 26.855 & 26.818\end{array}$

$\begin{array}{llllll}26.529 & 26.591 & 26.553 & 26.515 & 26.478 & 26.440 \\ 26.251 & 26.214 & 26.176 & 26.138 & 26.100 & 26.063\end{array}$

$\begin{array}{llllll}25.874 & 25.836 & 25.798 & 25.760 & 25.723 & 25.685\end{array}$

$\begin{array}{llllll}25.496 & 25.459 & 25.421 & 25.383 & 25.345 & 25.308\end{array}$

$\begin{array}{llllll}24.741 & 24.704 & 24.666 & 24.628 & 24.591 & 24.553\end{array}$

$\begin{array}{llllll}24.364 & 24.326 & 24.289 & 24 \cdot 251 & 24.213 & 24 \cdot 175 \\ 23.987 & 23.949 & 23.911 & 23.873 & 23.836 & 23.798\end{array}$

$\begin{array}{llllll}23.609 & 23.572 & 23.534 & 23.496 & 23.458 & 23.421\end{array}$

$\begin{array}{llllll}23.232 & 23.194 & 23.156 & 23.119 & 23.081 & 23.043 \\ 22.855 & 22.817 & 22.779 & 22.741 & 22.704 & 22.666\end{array}$

$\begin{array}{llllll}22.477 & 22.439 & 22.402 & 22.364 & 22.326 & 22.289\end{array}$

$\begin{array}{llllll}22.100 & 22.062 & 22.024 & 21.987 & 21.949 & 21.911 \\ 21.723 & 21.685 & 21.647 & 21.609 & 21.572 & 21.534\end{array}$

$\begin{array}{llllll}21.345 & 21.308 & 21.270 & 21.232 & 21.195 & 21.157 \\ 20.968 & 20.930 & 20.893 & 20.855 & 20.817 & 20.779\end{array}$

$\begin{array}{llllll}20.591 & 20.553 & 20.515 & 20.478 & 20.440 & 20.402\end{array}$

$\begin{array}{llllll}20.214 & 20.176 & 20.138 & 20.100 & 20.062 & 20.025 \\ 19.836 & 19.799 & 19.761 & 19.723 & 19.685 & 19.647\end{array}$

$\begin{array}{llllll}19.459 & 19.421 & 19.384 & 19.346 & 19.308 & 19.271\end{array}$

$\begin{array}{llllll}18.705 & 18.667 & 18.529 & \mathbf{1 8 . 5 9 2} & 18.554 & 18.516\end{array}$

$\begin{array}{llllll}18.327 & 18.290 & 18 \cdot 252 & 18 \cdot 214 & 18.176 & 18.139 \\ 17.950 & 17.913 & 17.875 & 17.837 & 17.799 & 17.762\end{array}$

$\begin{array}{llllll}17.573 & 17.535 & 17.498 & 17.460 & 17.422 & 17.385 \\ 17.196 & 17.158 & 17.121 & 17.083 & 17.045 & 17.007\end{array}$

$\begin{array}{llllll}16.819 & 16.781 & 16.743 & 16.706 & 16.668 & 16.630\end{array}$

$\begin{array}{llllll}16.442 & 16.404 & 16.366 & 16.329 & 16.291 & 16.253\end{array}$

$\begin{array}{llllll}15.687 & 15.650 & 15.612 & 15.574 & 15.537 & 15.499\end{array}$

$\begin{array}{llllll}15.311 & 15.273 & 15.235 & 15.198 & 15.160 & 15.122 \\ 14.033 & 14.896 & 14.858 & 14.820 & 14.782 & 14.745\end{array}$

$\begin{array}{llllll}14.556 & 14.519 & 14.481 & 14.443 & 14.406 & 14.368\end{array}$

$\begin{array}{llllll}14.179 & 14.142 & 14.104 & 14.066 & 14.029 & 13.991\end{array}$

$\begin{array}{llllll}13.802 & 13.765 & 13.727 & 13.689 & 13.652 & 13.614\end{array}$

$\begin{array}{llllll}13.048 & 13.010 & 12.973 & 12.935 & 12.898 & 12.860\end{array}$

$.001 \quad .002 \quad .003$

12.29

0
12.025

12.21

$\begin{array}{ll}12.521 & 12.0483 \\ 12.144 & 12.106\end{array}$

0.278607

0.278606

.278606

0.278606

0.278605

0.278605

0.278604

78604

278603

. 278603

278602

0.278602
0.278602

0.27860

0.278601

0.278601

0.278600

0.278600
0.278600

0.278600

0.278599

0.278599
0.278599

0.278599

0.278598
0.278598

0.278598

0.278598

0.278597

0.278597

0.278597

0.278596
0.278596

0.278596

0.278596

0.278595

0.278595
0.278595

0.278594

0.278594

0.278594

0.278593

0.278593
0.278593

0.278593

0.278593
0.278592

0.278592

0.278592

0.278592

0.278591

0.278591

0.278590
0.278590

0.278590

0.278590

0.278589

0.278589

0.278589
0.278588

0.278588

0.278588

0.278588

0.278587

0.278587

0.278587
0.278586

0.278586

0.278586

0.278586

0.278585

0.278585

0.278585

0.278584

0.278584

. 278584

0.278583

0.278583

0.278583

. 432037

1. 432091

1.432144
1.432179

.432197
. .432224

1.432250

1.432304

. 432357

1.432410

1.432463

$\frac{1}{1} \cdot 432517$

1.432570

1.432623

1.432676

1.432730

$1 \cdot 432783$

1.432836

1.432863
1.432889

1.432916

1.432969

1.433022 


.02

.03

.04

.05

.06

.07

.08

.09

$(n-1) \times 1000$

$\lambda(n-1)$

$\begin{array}{rrrrrrrrrrr}5150.0 & 19412.068 & 12.031 & 11.993 & 11.955 & 11.917 & 11.880 & 11.842 & 11.805 & 11.767 & 11.729 \\ 0.1 & 11.691 & 11.654 & 11.616 & 11.578 & 11.541 & 11.503 & 11.465 & 11.427 & 11.390 & 11.352\end{array}$

$\begin{array}{lllllllllll}0.1 & 11.691 & 11.654 & 11.616 & 11.578 & 11.541 & 11.503 & 11.465 & 11.427 & 11.390 & 11.352 \\ 0.2 & 11.314 & 11.277 & 11.239 & 11.201 & 11.164 & 11.126 & 11.088 & 11.051 & 11.013 & 10.095\end{array}$

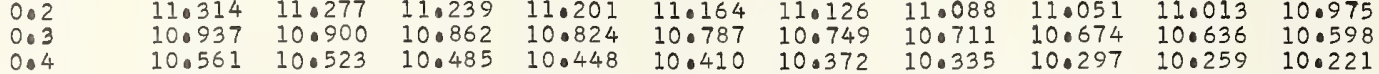

$\begin{array}{lllllllllll}0.4 & 10.561 & 10.523 & 10.485 & 10.448 & 10.410 & 10.372 & 10.335 & 10.297 & 10.259 & 10.221 \\ 0.5 & 10.184 & 10.146 & 10.108 & 10.071 & 10.033 & 0.995 & 0.9095 & 0.920 & 09.882 & 0.0 .045\end{array}$

$\begin{array}{llllllllllll}0.5 & 10.184 & 10.146 & 10.108 & 10.071 & 10.033 & 09.995 & 09.958 & 09.920 & 09.882 & 09.845 \\ 0.6 & 09.807 & 0.9 .769 & 09.731 & 09.694 & 09.656 & 09.619 & 09.581 & 09.543 & 09.505 & 09.468\end{array}$

$\begin{array}{llll}0.7 & 09.430 & 09.393 & 09 . \\ 0.8 & 09.053 & 09.015 & 0.08 \\ 0.9 & 08.677 & 08.639 & 0.60\end{array}$

$09.355 \quad 09.317$

$09.279 \quad 09.241$

$\begin{array}{llll}09.204 & 09.166 & 09.129 & 09.091\end{array}$

5151.0

1.0
$1: 1$
$1: 3$
1.4
1.5
1.6
1.7
1.8
1.9

$9408.300 \quad 08 \cdot 262$

$\begin{array}{ll}07.923 & 07.885 \\ 07.546 & 07.509\end{array}$

$08.224 \quad 08.187 \quad 08$

08.488

$\begin{array}{lll}08.790 & 08.752 & 08.714 \\ 08.413 & 08.375 & 08.337\end{array}$

$\begin{array}{llllllll}07.848 & 7.810 & 07.772 & 07.735 & 07.697 & 07.659 & 07.621 & 07.584\end{array}$

$\begin{array}{lllllllllll} & 07.094 & 07.056 & 07.019 & 06.981 & 06.943 & 06.906 & 06.868 & 06.830\end{array}$

$\begin{array}{llllllllll}0.792 & 06.755 & 06.717 & 06.679 & 06.642 & 06.604 & 06.567 & 06.529 & 06.491 & 06.454\end{array}$

$\begin{array}{llllllllll}06.039 & 06.001 & 05.964 & 05.926 & 05.888 & 05.851 & 05.813 & 05.775 & 05.738 & 05.700\end{array}$

$\begin{array}{llllllllll}05.663 & 05.625 & 05.587 & 05.550 & 05.512 & 05.474 & 05.437 & 05.399 & 05.361 & 05.323\end{array}$

$\begin{array}{ll}05.286 & 05.248 \\ 04.909 & 04.872\end{array}$

5152.0

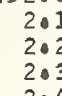

$2 \cdot 4$

2.6

2.8

5153.

3.1

$3 \cdot 3$

3.5

3.5
3.6
3.7

3.7
3.8

5400

4.

$4 \cdot 1$
$4 \cdot 2$
$4 \cdot 3$

$4 \cdot 3$
$4 \cdot 4$

4.5

406

4.8

5155.0

5.1
5.2
5.3

5.4

5.6

5.8 $04.532 \quad 04.495$ $\begin{array}{ll}04.156 & 04.118 \\ 03.780 & 03.742\end{array}$ $\begin{array}{ll}03.403 & 03.365 \\ 03.026 & 02.989\end{array}$ $02.650 \quad 02.612$ $\begin{array}{ll}02.273 & 02.236 \\ 01.897 & 01.859\end{array}$

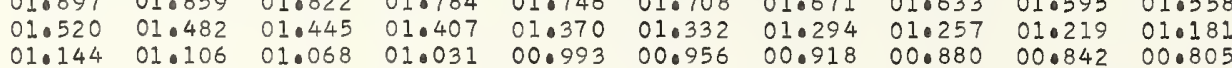

$\begin{array}{ll}05.211 & 05.173 \\ 04.834 & 04.796\end{array}$

$\begin{array}{llll}05.437 & 05.399 & 05.361 & 05.323 \\ 05.060 & 05.022 & 04.984 & 04.947 \\ 04.683 & 04.646 & 04.608 & 04.570\end{array}$

$\begin{array}{llllllll}04 \cdot 457 & 04 \cdot 420 & 04 \cdot 382 & 04 \cdot 344 & 04 \cdot 306 & 04 \cdot 269 & 04 \cdot 231 & 04 \cdot 194\end{array}$

$\begin{array}{lllllllll}04.081 & 04.043 & 04.005 & 03.968 & 03.930 & 03.892 & 03.855 & 03.817 \\ 03.704 & 03.667 & 03.629 & 03.591 & 03.554 & 03.5516 & 03.479 & 03.441\end{array}$

$\begin{array}{llllllll}03.328 & 03.290 & 03.629 & 03.591 & 03.554 & 03.516 & 03.479 & 03.441 \\ 0 & 03.215 & 03.177 & 03.139 & 03.102 & 03.064\end{array}$

$\begin{array}{llllllll}02.951 & 02.913 & 02.876 & 02.838 & 02.801 & 02.763 & 02.725 & 02.687\end{array}$

$\begin{array}{llllllll}02.198 & 02.160 & 02.123 & 02.085 & 02.047 & 02.010 & 01.972 & 01.934\end{array}$

$\begin{array}{llllllllll}19400.767 & 00.729 & 00.692 & 00.654 & 00.616 & 00.579 & 00.541 & 00.504 & 00.466 & 00.428\end{array}$

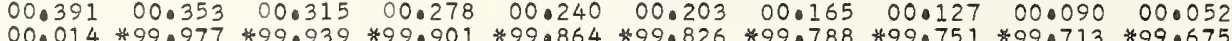

$\begin{array}{llllllllll}19399.638 & 99.600 & 99.562 & 99.525 & 99.487 & 99.449 & 990412 & 990374 & 99.337 & 99.299\end{array}$ $\begin{array}{llllllllll}99.261 & 99.224 & 99.186 & 99.148 & 99.111 & 99.073 & 99.035 & 98.998 & 98.960 & 98.922\end{array}$ $\begin{array}{llllllllll}98.509 & 98.471 & 98.433 & 98.396 & 98.358 & 98.320 & 98.282 & 98.245 & 98.584 & 98.546 \\ & 98.207 & 98.169\end{array}$ $\begin{array}{llllllllll}98.132 & 98.094 & 98.057 & 98.019 & 97.981 & 97.944 & 97.906 & 97.869 & 97.831 & 97.793\end{array}$

$\begin{array}{llllllllll}97.756 & 97.718 & 97.681 & 97.643 & 97.605 & 97.568 & 97.530 & 97.492 & 97.454 & 97.417 \\ 97.379 & 97.342 & 97.304 & 97.266 & 97.229 & 97.191 & 97.154 & 97.116 & 97.078 & 97.041\end{array}$

$19397.003 \quad 96.966$

96.62696 .589

$96.250 \quad 96.213$

$95.498 \quad 95.460$

$95.121 \quad 95.084$

94.36994 .331

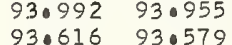

$96.928 \quad 96.890$

$96.175 \quad 96.137$

$\begin{array}{llll}95.799 & 95.761 & 95.723 & 95.686 \\ 95.422 & 95.385 & 95.347 & 95.310 \\ 95.046 & 95.009 & 94.971 & 94.933\end{array}$

$\begin{array}{ll}94.670 & 94.632 \\ 94.294 & 94.256\end{array}$

$\begin{array}{llllll}95.347 & 95.310 & 95.272 & 95.234 & 95.197 & 95.159 \\ 94.971 & 94.933 & 940896 & 940858 & 940820 & 94.783\end{array}$

$92.864 \quad 93.203$

$92.488 \quad 92.450$

$92.112 \quad 92.074$

$91.359 \quad 91.322$

$90.983 \quad 90.946$

$90.231 \quad 90.193$

93.16593 .127

$\begin{array}{ll}92.789 & 92.75 \\ 92.413 & 92.37\end{array}$

$\begin{array}{ll}92.037 & 91.99 \\ 91.660 & 91.623\end{array}$

91.28

$0.908 \quad 90.870$

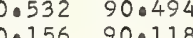

$89.855 \quad 89.817$

5156.0

6.1

6.2

6.4

6.5

6.6

6.7
6.8

6.9

5157.0

$7 \cdot 1$
$7 \cdot 2$
7.3

7.3

$7 \cdot 5$

7.6

7.8

5158.0

8.1

8.4

8.7

8.9

5159.0

9.1

9.3

9.5

9.6

9.7
9.9

89.441

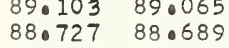

$\begin{array}{ll}88.351 & 88.313 \\ 87.975 & 87.937\end{array}$

$87.599 \quad 87.561$

$87.223 \quad 87.185$

$\begin{array}{ll}86.471 & 86.433 \\ 86.095 & 86.057\end{array}$

89.780

89.742

$\begin{array}{llllll}94.218 & 94.181 & 94.143 & 94.105 & 94.068 & 94.406\end{array}$

$93.842 \quad 93.804 \quad 93.767 \quad 93.729 \quad 93.692 \quad 94 \cdot 030$

$\begin{array}{llllll}93.466 & 93.428 & 93.391 & 93.353 & 93.315 & 93.278\end{array}$

$89.404 \quad 89.366$

$\begin{array}{ll}89.028 & 88.990 \\ 88.652 & 88.61 \\ 88.276 & 88.238\end{array}$

$\begin{array}{ll}88.276 & 88.238 \\ 87.900 & 87.862\end{array}$

$\begin{array}{ll}87.524 & 87.486 \\ 87.147 & 87 \cdot 110\end{array}$

$\begin{array}{ll}87.147 & 87.110 \\ 86.771 & 86.734\end{array}$

$\begin{array}{llllll}93.090 & 93.052 & 93.014 & 92.977 & 92.939 & 92.902 \\ 92.714 & 92.676 & 92.638 & 92.601 & 92.563 & 92.525\end{array}$

$\begin{array}{llllll}92.337 & 92.300 & 92.262 & 92.225 & 92.187 & 92.149\end{array}$

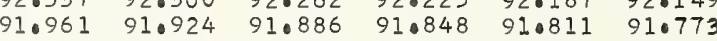

$\begin{array}{llllll}91.585 & 91.547 & 91.510 & 91.472 & 91.435 & 91.397\end{array}$

$\begin{array}{llllll}90.833 & 91.171 & 91.134 & 91.096 & 91.059 & 91.021 \\ 90.795 & 90.758 & 90.720 & 90.682 & 90.645\end{array}$

$\begin{array}{llllll}90.457 & 90.795 & 90.758 & 90.720 & 90.682 & 90.645\end{array}$

$\begin{array}{llllll}90.451 & 90.419 & 90.382 & 90.344 & 90.306 & 90.269 \\ 90.043 & 90.005 & 89.968 & 89.930 & 89.893\end{array}$

$\begin{array}{llllll}89.667 & 89.629 & 89.592 & 89.554 & 89.517\end{array}$

09586.05

9385.71

85.682

$\begin{array}{llll}85.343 & 85.306 & 85.268 & 85.606 \\ 85.230\end{array}$

$84.591 \quad 84 \cdot 930 \quad 84 \bullet 892 \quad 84 \cdot 854$

$84.216 \quad 84.178 \quad 84.140 \quad 84 \cdot 10$

$\begin{array}{llll}83.840 & 83.802 & 83.765 & 83.7 \\ 83.464 & 83.426 & 83.388 & 83.35\end{array}$

$83.088 \quad 83.051 \quad 83.013$

$\begin{array}{llllllllll}83.088 & 83.051 & 83.013 & 82.975 & 82.938 & 82.900 & 82.863 & 82.825 & 82.788 & 82.750 \\ 82.712 & 82.675 & 82.637 & 82.600 & 82.562 & 82.524 & 82.487 & 82.449 & 82.411 & 82.374 \\ 82.336 & 82.299 & 82.261 & 82.224 & 82.186 & 82.149 & 82.111 & 82.073 & 82.036 & 81.998\end{array}$

$88.952 \quad 89.291 \quad 89.253 \quad 89.216 \quad 89.178 \quad 89.140$

$\begin{array}{llllll}88.952 & 88.915 & 88.877 & 88.840 & 88.802 & 88.764 \\ 88.576 & 88.539 & 88.501 & 88.464 & 88.426 & 88.388\end{array}$

88.2000 .539

$87.824 \quad 87.787$

$87.073 \quad 87.035$

$\begin{array}{llll}87.749 & 87.712 & 87.674 & 87.636 \\ 87.373 & 87.336 & 87.298 & 87.260\end{array}$

$86.997 \quad 86.960 \quad 86.922 \quad 86.885$

$\begin{array}{lllllll}86.321 & 86.283 & 86.245 & 86.208 & 86.170 & 86.133\end{array}$

$\begin{array}{lllllll}85.569 & 85.531 & 85.493 & 850456 & 850418 & 85.381\end{array}$

$\begin{array}{llllll}85.193 & 85.155 & 85.117 & 85.080 & 85.042 & 85.005\end{array}$

$\begin{array}{lllllll}84.817 & 84 \cdot 779 & 84 \cdot 742 & 84.704 & 84 \cdot 667 & 84.629 \\ 84.441 & 84.404 & 84.366 & 84.328 & 84.291 & 84.253\end{array}$

$\begin{array}{lllllll}84.065 & 84.028 & 83.990 & 83.952 & 83.915 & 83.877\end{array}$

$\begin{array}{lllllll}83.689 & 83.652 & 83.614 & 83.577 & 83.539 & 83.501\end{array}$

$\begin{array}{llllllllll}19381.961 & 81.923 & 81.885 & 81.848 & 81.810 & 81.773 & 81.735 & 81.698 & 81.860 & 81.623\end{array}$

$\begin{array}{llllllllll}81.585 & 81.547 & 81.510 & 81.472 & 81.435 & 81.397 & 81.360 & 81.322 & 81.284 & 81.247\end{array}$

$\begin{array}{llllllllll}81.209 & 81.172 & 81.134 & 81.096 & 81.059 & 81.021 & 80.984 & 80.946 & 80.908 & 80.871\end{array}$

$\begin{array}{llllllllll}80.458 & 80.420 & 80.758 & 80.721 & 80.683 & 80.646 & 80.608 & 80.570 & 80.533 & 80.495 \\ 80.345 & 80.308 & 80.270 & 80.233 & 80.195 & 80.157 & 80.120\end{array}$

$\begin{array}{llllllllll}80.082 & 80.045 & 80.007 & 79.969 & 79.932 & 79.894 & 79.857 & 79.819 & 79.782 & 79.744\end{array}$

$\begin{array}{lllllllllll}79.707 & 79.669 & 79.631 & 79.594 & 79.556 & 79.519 & 79.481 & 79.444 & 79.406 & 79.368\end{array}$

$\begin{array}{llllllllll}79.331 & 79.293 & 79.256 & 79.218 & 79.180 & 79.143 & 79.105 & 79.068 & 79.031 & 78.993 \\ 78.955 & 78.918 & 78.880 & 78.843 & 78.805 & 78.768 & 78.730 & 78.692 & 78.655 & 78.617\end{array}$

$\begin{array}{llllllllll}78.580 & 78.542 & 78.505 & 78.467 & 78.429 & 78.392 & 78.354 & 78.317 & 78.279 & 78.241\end{array}$

$\begin{array}{rlllllllll}19378.204 & 78.167 & 78.129 & 78.091 & 78.054 & 78.016 & 77.979 & 77.941 & 77.904 & 77.866\end{array}$

$\begin{array}{llllllllll}77.453 & 77.415 & 77.378 & 77.340 & 77.302 & 77.265 & 77.228 & 77.190 & 77.152 & 77.115\end{array}$

$\begin{array}{lllllllllll}77.077 & 77.040 & 77.002 & 76.965 & 76.927 & 76.890 & 76.852 & 76.814 & 76.777 & 76.739\end{array}$

$\begin{array}{lllllllllll}76.702 & 76.664 & 76.626 & 76.589 & 76.551 & 76.514 & 76.476 & 76.439 & 76.401 & 76.364\end{array}$

$\begin{array}{llllllllll}75.951 & 75.913 & 75.875 & 75.214 & 76.176 & 76.138 & 76.101 & 76.063 & 76.026 & 75.98 \\ 75.80 & 75.800 & 75.763 & 75.725 & 75.688 & 75.650 & 75.613\end{array}$

$\begin{array}{lllllllllll}75.575 & 75.538 & 75.500 & 75.462 & 75.425 & 75.387 & 75.350 & 75.312 & 75.275 & 75.237\end{array}$

$\begin{array}{llllll}75.200 & 75.162 & 75.125 & 75.087 & 75.049 & 75.012 \\ 74.824 & 74.786 & 74.749 & 74.711 & 74.674 & 74.636\end{array}$

$\begin{array}{llll}74.974 & 74.937 & 74.275 & 750237 \\ 74.590 & 74.862\end{array}$

$\begin{array}{ll}0.278582 & 1.434699 \\ 0.278582 & 1.434726 \\ 0.278582 & 1.434753 \\ 0.278582 & 1.434779 \\ 0.278581 & 1.434806 \\ 0.278581 & 1.434832 \\ 0.278581 & 1.434859 \\ 0.278581 & 1.434886 \\ 0.278580 & 1.434912 \\ 0.278580 & 1.434939\end{array}$

0.278580

0.278580

.278580
.278579

0.278579

0.278579

0.278578

0.278578

0.278578

0.278577
0.278577

0.278577

0.2785576
0.278576

0.278576
0.278575

0.278575

0.278575

0.278574

0.278574

0.278574

0.278574

0.278573
0.278573

0.278573

0.278573

0.278572

0.278572

0.278572

.278571

0.278571

0.278571

0.278570

0.278570

0.278570

0.278569

0.278569

0.278569

0.278569

0.278568

1.434966

1.434992

.435019

I. 435072

1.435099

1.435152

1.0435179
1.435205

1.435232

1.435285

1.435312

1.435338

1.435392

1.435428

1.435445
1.435471

1.435498

1.435525

1.435578

1.435604

1.435658

1.435684

1.435711

1.435764

1.435791

10435817

1. 435871

1.435897

1.435924
1.435951

1.435977

1.436030

1.436057

1.436084

1.436137

1.436164

1.436190

1.436217

1.436270

0.278568

0.278568
0.278568

0.278567

0.278567

0.278567
0.278567

0.278566

0.278566
0.278566

1.436297

1.436323

1.436350

1.436403

1.436430

1.436456

1.436510

0.278566

0.278565 


.06

160.0
0.1

0.1

0.2
0.3
0.4

0.4

0.5
0.6
0.7

0.7
0.7
0.9

51610

5162.0

62
2
2
2
2
2
2
2
2

5163.0
3.1
3.2
3.3
3.4
3.5
3.6
3.7
3.8
3.9

51640

40
40
40
40
40
40
407
408
409

5165.0

65.0
5.1
5.
5.
5.4
5.5
5.0
5.7
5.8
5.9

5166.0

66.0
6.
6.
6.0
6.4
60
6.0
6.7
6
6.

5167.0

167.0
7.1
7.2
7.3

7.4
7.5

7.6
7.7

7.8
7.9

5168.

8.

8.1
8.2
8.3

8.3

8.6

8.7
8.8
8.9

5169.0

90
90
90
90
90
9.0
9.0
9.0
90

$\begin{array}{llllll}374.448 & 74.411 & 74.374 & 74.336 & 74.299 & 74 \\ 74.073 & 74.035 & 73.998 & 73.960 & 73.923 & 73 \\ 73.698 & 73.660 & 73.623 & 73.585 & 73.548 & 73 \\ 73.322 & 73.284 & 73.247 & 73.210 & 73.172 & 73 \\ 72.947 & 72.909 & 72.872 & 72.834 & 72.797 & 72 \\ 72.571 & 72.534 & 72.496 & 72.459 & 72.421 & 72 \\ 72.196 & 72.158 & 72.121 & 72.083 & 72.046 & 72 \\ 71.821 & 71.783 & 71.745 & 71.708 & 71.670 & 71 \\ 71.445 & 71.408 & 71.370 & 71.333 & 71.295 & 71 \\ 71.070 & 71.032 & 70.995 & 70.957 & 70.920 & 70\end{array}$

$9370.694 \quad 70.657$

70.319

69.944
69.569

$69.193 \quad 69.156$

$\begin{array}{ll}68.818 & 68.781 \\ 68.443 & 68.405\end{array}$

$68.068 \quad 68.030$

$\begin{array}{ll}67.692 & 67.655 \\ 67.317 & 67.280\end{array}$

66.567

$66.192 \quad 66.529$

$65.816 \quad 65.779$

$65.441 \quad 65.404$

64.691

$64.316 \quad 64.279$

63.566

19363.191

62.81

$62.066 \quad 62.028$

$61.691 \quad 61.653$

$61.316 \quad 61.279$

$60.566 \quad 60.529$

60.191
59.816

359.441

$59.066 \quad 59.029$

58.69258 .654

$58.317 \quad 58.279$

$\begin{array}{lll}57.942 & 57.905 & 57.867\end{array}$

$57.192 \quad 57.155 \quad 57.117$

$\begin{array}{llll}56.818 & 56.780 & 56.743 & 56.705\end{array}$

$56.443 \quad 56.405 \quad 56.36$

19355.693

$55.319 \quad 55.6$

$\begin{array}{llll}54.944 & 54.906 & 55.244 & 55.20\end{array}$

$\begin{array}{lllll}54.569 & 54.532 & 54.494 & 54.457\end{array}$

54.152

$3.820 \quad 53.782$

$3.445 \quad 53.407$

$52.696 \quad 52.65$

$52.321 \quad 52.284$

54.11954 .08

52.996
52.621
52.5

193510

31.947
51.572 51.534

$51.198 \quad 51.160 \quad 51.49$

$50.82350 .785 \quad 50.748$

50.448

$\begin{array}{ll}50.073 & 50.036 \\ 49.699 & 49.66\end{array}$

$49.325 \quad 49.287$

48.576

19348.20

47.827

$\begin{array}{ll}47.827 & 47.790 \\ 47.452 & 47.415 \\ 47.078 & 47.041\end{array}$

$46.704 \quad 46.666$

$\begin{array}{ll}45.955 & 45.917 \\ 45.581 & 45.543\end{array}$

$\begin{array}{ll}45.206 & 45.168 \\ 44.832 & 44.794\end{array}$

$9344.457 \quad 44.420$

$\begin{array}{ll}44.083 & 44.046\end{array}$

$43.334 \quad 43.297$

$42.960 \quad 42.923$

$42.212 \quad 42.175$

$41.838 \quad 41.800$

$\begin{array}{ll}41.463 & 41.426 \\ 41.089 & 41.052\end{array}$

9340

40.34140 .30

39.96739 .929

$39.593 \quad 39.555$

$38.844 \quad 38.807$

$\begin{array}{lll}38.433 & 38.396 & 38.358\end{array}$

$\begin{array}{llll}38.096 & 38.059 & 38.021 & 37.98 \\ 37.722 & 37.685 & 37.647 & 37.61 \\ 37.348 & 37.311 & 37.273 & 37.23\end{array}$

$\begin{array}{ll}.261 & 740 \\ .885 & 730\end{array}$

$510 \quad 73.848$

73.473
73.097

71.0083

69.04369 .006

68.631
68.255

7

8.291559.

.87251 .834

52.50

$49.999 \quad 49.961$

$49.250 \quad 49.212$

48.875
48.501

48.126
47.752

47.003

$46.629 \quad 46.591$

$\begin{array}{ll}45.880 & 45.842 \\ 45.506 & 45.458\end{array}$

$\begin{array}{ll}45.131 & 45.094\end{array}$

44.6

$49.550 \quad 49.512$

$49.175 \quad 49.137$

$\begin{array}{ll}48.801 & 48.76 \\ 48.426 & 48.38\end{array}$

$\begin{array}{ll}3.634 & 43.596 \\ 3.260 & 43.222\end{array}$
53.370
52.93 .33
52.95

$73.135 \quad 73.097$
73.059

72.384

72.346

$71.971 \quad 71.933$

$182 \quad 71.520 \quad 71.483$
71.145

$\begin{array}{lll}71.807 & 70.140 & 71.108 \\ 70.732\end{array}$

$\begin{array}{lllll}0.507 & 70.469 & 70.432 & 70.395 & 70.357\end{array}$

$\begin{array}{llll}70.094 & 70.056 & 70.019 & 69.981 \\ 69.719 & 69.681 & 69.644 & 69.606\end{array}$

$\begin{array}{llll}69.343 & 69.306 & 69.268 & 69.231\end{array}$

$\begin{array}{llll}68.968 & 68.931 & 68.893 & 68.856\end{array}$

$\begin{array}{llll}68.593 & 68.556 & 68.518 & 68.480 \\ 68.218 & 68.180 & 68.143 & 68.105\end{array}$

$\begin{array}{lllll}.880 & 67.843 & 67.805 & 67.768 & 67.730\end{array}$

$\begin{array}{llllll}67.542 & 67.505 & 67.467 & 67.430 & 67.392 & 67.355 \\ 67.167 & 67.130 & 67.092 & 67.055 & 67.017 & 66.979\end{array}$

$\begin{array}{lllllll}66.792 & 66.754 & 66.717 & 66.679 & 66.642 & 66.604\end{array}$

$\begin{array}{llllll}66.417 & 66.379 & 66.342 & 66.304 & 66.267 & 66.229 \\ 66.042 & 66.004 & 65.967 & 65.929 & 65.892 & 65.854\end{array}$

$\begin{array}{lllllll}65.667 & 65.629 & 65.591 & 65.554 & 65.516 & 65.479 \\ 65.291 & 65.254 & 65.216 & 65.179 & 65.141 & 65.104\end{array}$

$\begin{array}{lllllll}640916 & 640879 & 64 \cdot 841 & 64.804 & 64.766 & 64.729\end{array}$

$\begin{array}{llllll}64.504 & 64.466 & 64.429 & 64.391 & 640353\end{array}$

$64.091 \quad 64.053 \quad 640016 \quad 63.979$

$\begin{array}{llll}63.716 & 63.678 & 63.641 & 63.604 \\ 63.341 & 63.303 & 63.266 & 63.228\end{array}$

$\begin{array}{llllll}63.041 & 63.003 & 62.966 & 62.928 & 62.891 & 62.854\end{array}$

$\begin{array}{llllll}2.666 & 62.628 & 62.591 & 62.553 & 62.516 & 62.478\end{array}$

$\begin{array}{llllll}.916 & 61.878 & 61.841 & 61.803 & 61.766 & 61.729\end{array}$

$\begin{array}{llllll}.541 & 61.503 & 61.466 & 61.428 & 61.391 & 61.353\end{array}$

$\begin{array}{llllll}60.791 & 60.753 & 60.716 & 60.678 & 60.641 & 60.604 \\ 60.416 & 60.378 & 60.341 & 60.303 & 60.266 & 60.229\end{array}$

$\begin{array}{llllll}60.041 & 60.004 & 59.966 & 59.928 & 59.891 & 59.854\end{array}$

$\begin{array}{lllll}.254 & 59.216 & 59.179 & 59 \cdot 141 & 59.104\end{array}$

$\begin{array}{lllll}.504 & 58.467 & 58.429 & 58.392 & 58.354\end{array}$

$\begin{array}{lllll}.129 & 58.092 & 58.054 & 58.017 & 57.979 \\ .754 & 57.717 & 57.679 & 57.642 & 57.604\end{array}$

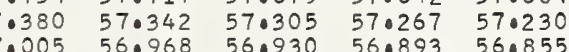

$\begin{array}{lllllll}.043 & 57.005 & 56.968 & 56.930 & 56.893 & 56.855\end{array}$

$\begin{array}{llllll}.668 & 56.630 & 56.593 & 56.555 & 56.518 & 56.480 \\ 5.293 & 56.256 & 56.218 & 56.180 & 56.143 & 56.106\end{array}$

$\begin{array}{llllll}55.918 & 55.881 & 55.843 & 55.806 & 55.768 & 55.731\end{array}$

$\begin{array}{lllllll}55.543 & 55.506 & 55.469 & 55.431 & 55.394 & 55.356\end{array}$

$\begin{array}{llllll}54.419 & 54.382 & 54.344 & 54.307 & 54.269 & 54.232\end{array}$

$\begin{array}{llllll}53.670 & 53.633 & 53.595 & 53.558 & 53.520 & 53.482\end{array}$

$\begin{array}{llll}53.595 & 53.558 & 53.520 & 53.482 \\ 53.220 & 53.183 & 53.145 & 53.108\end{array}$

$\begin{array}{lllllll}.921 & 52.883 & 52.846 & 52.183 & 53.145 & 53.108 \\ 52.771 & 52.733\end{array}$

$\begin{array}{llll}52.471 & 52.434 & 52.396 & 52.359 \\ 52.096 & 52.059 & 52.021 & 51.984\end{array}$

$\begin{array}{llll}51.722 & 51.684 & 51.647 & 51.609\end{array}$

$47.752 \quad 47.714$

$44.383 \quad 44.345$

$0.224 \quad 50.18$

49.849
49.475
49.812

$\begin{array}{llll}49.475 & 49.437 & 49.399 & 49.36 \\ 49.100 & 49.063 & 49.025 & 48.98\end{array}$

$48.726 \quad 48.688 \quad 48.0651 \quad 48.614$

$\begin{array}{llll}48.351 & 48.314 & 48.276 & 48.239\end{array}$

$\begin{array}{llllll}48.052 & 48.014 & 47.977 & 47.939 & 47.902 & 47.865 \\ 47.677 & 47.640 & 47.602 & 47.565 & 47.527 & 47.490\end{array}$

$\begin{array}{llllll}47.677 & 47.640 & 47.602 & 47.565 & 47.527 & 47.490\end{array}$

$\begin{array}{llllll}47.302 & 47.265 & 47.228 & 47.190 & 47.153 & 47.115 \\ 46.928 & 46.891 & 46.853 & 46.816 & 46.778 & 46.741\end{array}$

$\begin{array}{llllll}46.554 & 46.517 & 46.479 & 46.442 & 46.404 & 46.367\end{array}$

$\begin{array}{llllll}46.179 & 46.142 & 46.104 & 46.067 & 46.030 & 45.992\end{array}$

$\begin{array}{llllll}45.805 & 45.768 & 45.730 & 45.693 & 45.655 & 45.618 \\ 45.431 & 45.393 & 45.356 & 45.319 & 45.281 & 45.243\end{array}$

$\begin{array}{lllllll}45.056 & 45.019 & 44.981 & 44.944 & 440906 & 44.869 \\ 4.682 & 44.645 & 44.607 & 44.570 & 44.532 & 44.495\end{array}$$$
0001
$$

$44.308 \quad 44.270 \quad 44.233 \quad 44 \cdot 196 \quad 44 \cdot 158 \quad 44 \cdot 121$

$43.934 \quad 43.896 \quad 43.859 \quad 430821 \quad 43.784 \quad 43.7 .46$

$\begin{array}{llllll}43.559 & 43.521 & 43.484 & 43.447 & 43.409 & 43.372\end{array}$

$\begin{array}{llllll}43.185 & 43.147 & 43.110 & 43.073 & 43.035 & 42.998 \\ 42.810 & 42.773 & 42.736 & 42.698 & 42.661 & 42.623\end{array}$

$42.436 \quad 42.399 \quad 42.362 \quad 42.324 \quad 42.287 \quad 42.249$

$\begin{array}{llllllll}42.511 & 42.474 & 42.436 & 42.39 & 42.362 & 42.324 & 42.287 & 42.249\end{array}$

$\begin{array}{llllllll}1.763 & 41.725 & 41.688 & 41.650 & 41.613 & 41.576 & 41.538 & 41.501\end{array}$

$\begin{array}{llllllll}1.389 & 41.351 & 41.314 & 41.276 & 41.239 & 41.201 & 41.164 & 41.127 \\ 1.014 & 40.977 & 40.939 & 40.902 & 40.865 & 40.827 & 40.790 & 40.752\end{array}$

$(n-1) \times 1000$

$\lambda(n-1)$

0.278558

0.278558
0.278558

0.278558

0.278557
0.278557

0.278557
0.278557

0.278557
0.278556

0.278556

0.278556
0.278556

0.278555
0.278555

0.278555
0.278555

0.278554

0.278554
0.278554

0.278554

0.278553
0.278553

0.278553

0.278552

0.278552
.278552

0.278552

0.27855
0.27855

0.278551

0.278550

0.278550

0.278550

0.278549

0.278549

.27854

0.278548
0.278548

0.278548

0.278548
0.278547

0.278547

0.278547

0.278547

0.278546

0.278546
0.278546

0.278546

0.278545
0.278545

0.278545

0.278545
0.278544

0.278544

0.278544

0.278544

0.278543

0.278543

0.278543

0.278542
0.278542

0.278542

0.278542

0.278542

0.278541

0.278541

0.278541

0.278540

0.278540

0.278540
0.278540

0.278539

0.278539
0.278539

0.278539

0.278538
0.278538

0.278538

0.278538

0.278537
0.278537

0.278537

0.278537

0.278537

0.278536
0.278536

0.278536

0.278536

0.278535

0.278535
0.278535

.437362
.437388

1.437415

. 437468

1.437495 
$\begin{array}{rrrrrrrrrrr}0.936 .974 & 36.937 & 36.899 & 36.862 & 36.824 & 36.787 & 36.750 & 36.712 & 36.675 & 36.637 \\ 1 & 36.600 & 36.583 & 36.525 & 36.488 & 36.451 & 36.413 & 36.376 & 36.338 & 36.301 & 36.263\end{array}$ $\begin{array}{llllllllllll}0.2 & 36.226 & 36.189 & 36.151 & 36.114 & 36.451 & 36.076 & 36.039 & 36.002 & 35.964 & 35.927 & 35.889\end{array}$ $\begin{array}{lllllllllll}0.4 & 35.478 & 35.441 & 35.403 & 35.366 & 35.328 & 35.291 & 35.254 & 35.216 & 35.179 & 35.142\end{array}$ $\begin{array}{lllllllllll}35.104 & 35.067 & 35.030 & 34.992 & 34.955 & 34.917 & 34 \cdot 880 & 34.843 & 340805 & 34 \cdot 768\end{array}$ $\begin{array}{lllllllllll}34.730 & 34.693 & 34.655 & 34.618 & 34.581 & 34.543 & 34.506 & 34.469 & 340431 & 34.394\end{array}$

$33.160 \quad 33.123$

33.459

33.795
33.42

$34 \cdot 13$

34.095

32.113

32.450

32.786
32.412 32.74

33.085

33.048

31.366

$30.618 \quad 30.581$

$\begin{array}{lll}32.039 & 32.001 & 31.064\end{array}$

32.300
31.926

33.010

33.34

$33 \cdot 683$

33.646
33.272

30.244
29.871

5172

2.1
2.2
2.3

2.3
2.4

2.4
2.5

2.6

2. 7

2.9

5173.0

3.1
3.2
3.3

3.3

3.5

3.6
3.7

3.7
3.8

517400

40

$4 \cdot 2$

4.5

4.7

4.8

5175.0

5.1
5.2

5.3

5.4

5.5

507

5.8
5.9

5176.0

6.1

$6 \cdot 2$

604

6.6

6.8
6.9

5177.

7.1
7.2
7.3

7.3

7.5
7.6

7.7
7.8
7.9

5178.

8.1
8.2
8.3

8.3
8.4
8.5
8.6

8.6
8.7

8.8
8.9

$9329.497 \quad 29.459$

$29.123 \quad 29.086$

$28.376 \quad 28.338$

$\begin{array}{ll}28.002 & 27.965 \\ 27.628 & 27.591\end{array}$

$27.255 \quad 27.217$

26.881

26.134

$26 \cdot 844$
$26 \cdot 470$

$\begin{array}{llll}31.665 & 31.627 & 31.590 & 31.553\end{array}$

$\begin{array}{llll}31.254 & 31.216 & 31.179 & 31.14\end{array}$

$30.543 \quad 30.50$

$30.843 \quad 30.805$

32.263

$32.599 \quad 32.562 \quad 32.524$

$32.226 \quad 32 \cdot 188 \quad 32 \cdot 151$

$31.478 \quad 31.440 \quad 31.403$

$\begin{array}{llll}310.768 & 30.730 & 30.693 & 30.656\end{array}$

86

$\begin{array}{llllllll}29.422 & 29.385 & 29.347 & 29.310 & 29.272 & 29.235 & 29.198 & 29.160 \\ 29.048 & 29.011 & 28.974 & 28.936 & 28.899 & 28.862 & 28.824 & 28.787\end{array}$

$30.095 \quad 30.057$

$\begin{array}{llllllll}29.048 & 29.011 & 28.974 & 28.936 & 28.899 & 28.862 & 28.824 & 28.787 \\ 28.675 & 28.637 & 28.600 & 28.562 & 28.525 & 28.488 & 28.450 & 28.413\end{array}$

$\begin{array}{llllllll}28.675 & 28.637 & 28.600 & 28.562 & 28.525 & 28.488 & 28.450 & 28.413 \\ 28.301 & 28.264 & 28.226 & 28.189 & 28.151 & 28.114 & 28.077 & 28.040\end{array}$

$\begin{array}{llllllll}27.927 & 27.890 & 27.852 & 27.815 & 27.778 & 27.740 & 27.703 & 27.666\end{array}$

$\begin{array}{llllllll}27.554 & 27.516 & 27.479 & 27.441 & 27.404 & 27.367 & 27.330 & 27.292 \\ 27.180 & 27.143 & 27.105 & 27.068 & 27.031 & 26.993 & 26.956 & 26.918\end{array}$

$\begin{array}{llllllll}27.180 & 27.143 & 27.105 & 27.068 & 27.031 & 26.993 & 26.956 & 26.918 \\ 26.806 & 26.769 & 26.731 & 26.694 & 26.657 & 26.620 & 26.582 & 26.545 \\ \end{array}$

$19325.760 \quad 25 \cdot 723$

$\begin{array}{ll}25.386 & 25.34 \\ 25.013 & 24.976\end{array}$

$24.640 \quad 24.602$

$23.892 \quad 23 \cdot 855$

$23 \cdot 519 \quad 23 \cdot 481$

$\begin{array}{ll}22.772 & 22 \cdot 734 \\ 22.399 & 22 \cdot 361\end{array}$

25.68
25.31
24.93
24.56
24.19
23.8
23.4
23.0
22.69
22.3

\begin{tabular}{lll}
26.396 \\
\hline & 26.022
\end{tabular}

$\begin{array}{llll}26.283 & 26.246 & 26.208 & 26.171 \\ 25.910 & 25.872 & 25.835 & 25.798\end{array}$

0.278535

0.278534

0.278534

0.278534

0.278533

0.278533

0.278533

0.278532

0.278532

0.278532

0.278531

0.278531

0.278531

0.278531

0.278530
0.278530

0.278530

0.278530

0.278529
0.278529

0.278529

0.278529

0.278528
0.278528

0.278528

0.278528

0.278528

0.278527

0.278527
0.278527
0.278527

0.278527

0.278526

0.278526

0.278526

0.278525

$19322.025 \quad 21.988$

21.652
21.0278
21.06

$\begin{array}{ll}8 & 21.950 \\ 4 & 21.577 \\ 1 & 21.203\end{array}$

$20.905 \quad 20.867$

20.15

$19.785 \quad 19.747$

$\begin{array}{lll}19.411 & 19.374 & 19.337\end{array}$

$\begin{array}{ll}19.038 & 19.001 \\ 18.665 & 18.627\end{array}$

$19318.291 \quad 18 \cdot 254$

$17.918 \quad 17.88$

$17.171 \quad 17.134$

$16.425 \quad 16.388$

$\begin{array}{ll}16.425 & 16.388 \\ 16.052 & 16.014\end{array}$

$\begin{array}{ll}15.679 & 15.641 \\ 15.305 & 15.268\end{array}$

$\begin{array}{ll}15.305 & 15.268 \\ 14.932 & 14.895\end{array}$

$14.186 \quad 14.522$

$13.813 \quad 13.775$ 13.13

$\begin{array}{llll}13.402 & 13.365 & 13.3\end{array}$

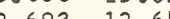

$12.320 \quad 12.283$

$11.574 \quad 11.537$

12.61

$11.201 \quad 11.164$

$11.873-1208$

$19310.828 \quad 10.791$

$\begin{array}{lll}10.455 & 10.418 & 10.754\end{array}$

$\begin{array}{llll}10.083 & 10.045 & 10.381 & 10.3\end{array}$

$\begin{array}{llll}0.7337 & 09.672 & 09.635 & 09.59\end{array}$

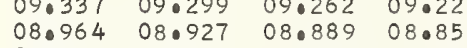

$\begin{array}{llll}08.591 & 08.553 & 08.516 & 08.47\end{array}$

$\begin{array}{llll}08.218 & 08.181 & 08.143 & 08.10 \\ 07.845 & 07.807 & 07.770 & 07.73\end{array}$

$07.472 \quad 07.43$

19307.099

$06.726 \quad 06.06$

$06.353 \quad 06.316$

$\begin{array}{ll}05.980 & 05.943 \\ 05.608 & 05.570\end{array}$

$\begin{array}{ll}05.235 & 05.198 \\ 04.862 & 04.825\end{array}$

$\begin{array}{ll}04.862 & 04.82 \\ 04.490 & 04.45\end{array}$

$\begin{array}{ll}04.117 & 04.07 \\ 03.744 & 03.70\end{array}$

07.397

$7 \cdot 733$

$\begin{array}{lllllllllll}5179.0 & 19303.371 & 03.334 & 03.297 & 03.260 & 03.222 & 03.185 & 03.147 & 03.110 & 03.073 & 03.036\end{array}$

$\begin{array}{ll}07.024 & 06.987 \\ 06.652 & 06.614\end{array}$

6.98
6.614
6.2
5.869

$0.0 .906 \quad 05.869$

$05.533 \quad 05.496$

04.788 04.750

$\begin{array}{lll}04.377 & 040340 & 04.676\end{array}$

$24.789 \quad 24.752 \quad 24 \cdot 714 \quad 240$

$\begin{array}{llll}24.042 & 24.005 & 23.967 & 23.93\end{array}$

$23.295 \quad 23.258 \quad 23.220 \quad 23.183$

$\begin{array}{llll}22.921 & 22.884 & 22.847 & 22.809\end{array}$

0.278525

0.278525

0.278524

0.278524

0.278524

0.278523

0.278523
0.278523

0.278523

0.278523

0.278522

0.278522

0.278522

0.27852

0.278521

0.278521
0.278521

0.278520

0.278520

0.278520

0.278520

0.278519

0.278519

0.278519

0.278518

0.278518

0.278517

0.278517

0.278517

0.278517

0.278516

0.278516

0.278516

0.27851

0.278515

0.278515

0.278514

0.278514
0.278514

0.278514

0.278514

$\begin{array}{lllllllllll}9.1 & 02.998 & 02.961 & 02.924 & 02.886 & 02.849 & 02.812 & 02.775 & 02.738 & 02.700 & 02.663 \\ 9.2 & 02.626 & 02.589 & 02.551 & 02.514 & 02.477 & 02.439 & 02.402 & 02.365 & 02.328 & 02.290\end{array}$

9.3

9.5

$\begin{array}{llllllllll}02.253 & 02.216 & 02.178 & 02.141 & 02.104 & 02.067 & 02.029 & 01.992 & 01.955 & 01.918 \\ 01.880 & 01.843 & 01.806 & 01.769 & 01.731 & 01.694 & 01.657 & 01.620 & 01.582 & 01.545\end{array}$

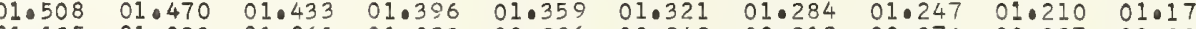

9.7

9.9

$\begin{array}{llllllllll}0.763 & 00.725 & 00.688 & 00.650 & 00.613 & 00.576 & 00.539 & 00.501 & 00.464 & 00.427\end{array}$

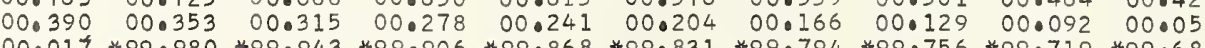

0.278513

0.278513

0.27851

0.27851

0.278512
0.278512

0.278512

0.278511

1.440024

1.440051
1.440077

1.440131

1.440184

1.440210
1.440237

1.440264

1.440290

1.440344

1.440370

1.440397

1.440423

1.440477

1.440503
1.440530

1.440557

1.440583

1.440610

1.440663

1.440690

10440716

1.440743

1.440770
1.440796 


$\begin{array}{rlll}9299.645 & 99.607 & 99.570 & 99.533 \\ 99.272 & 99.235 & 99.198 & 99.160 \\ 98.899 & 98.862 & 98.825 & 98.788 \\ 98.527 & 98.490 & 98.453 & 98.415 \\ 98.154 & 98.117 & 98.080 & 98.042 \\ 97.782 & 97.745 & 97.708 & 97.670 \\ 97.409 & 97.372 & 97.335 & 97.297 \\ 97.037 & 97.000 & 96.962 & 96.925 \\ 96.665 & 96.627 & 96.590 & 96.553 \\ 96.292 & 96.255 & 96.218 & 96.180\end{array}$

$\begin{array}{llllll}99.496 & 99.458 & 99.421 & 99.384 & 99.347 & 99.309 \\ 99.123 & 99.086 & 99.048 & 99.011 & 98.974 & 98.937\end{array}$

$5182 \cdot 0$

$2 \bullet \frac{1}{2}$

2.3

2.5

2.6
2.7
2.8

$2 \cdot 8$

5183.0

$3 \cdot 1$

3.3

3.5

3.6

3.8

19292.196 91.824 $\begin{array}{llll}1.079 & 91.042 & 91.005 & 90.968\end{array}$ $\begin{array}{cccc}90.334 & 90.670 & 90.632 & 90.595 \\ 90.298 & 90.260 & 90.223\end{array}$ $89.962 \quad 89.925 \quad 89.888 \quad 89.851$ $\begin{array}{llll}89.590 & 89.553 & 89.516 & 89.479\end{array}$ $\begin{array}{llll}89.218 & 89.181 & 89.144 & 89.106 \\ 88.846 & 88.809 & 88.771 & 88.734\end{array}$

$\begin{array}{llllll}95.771 & 95.733 & 95.696 & 95.659 & 95.622 & 95.584\end{array}$ $\begin{array}{llllll}95.398 & 95.361 & 95.324 & 95 \cdot 286 & 95 \cdot 249 & 95.212 \\ 95.026 & 94.989 & 94.951 & 94.914 & 94.877 & 94.839\end{array}$ $\begin{array}{llllll}94.653 & 94.616 & 94.579 & 94.542 & 94.877 & 94.839 \\ \end{array}$ $\begin{array}{llllll}94.281 & 94.244 & 94.207 & 94.169 & 94.132 & 94.095 \\ 93.908 & 93.871 & 93.834 & 93.797 & 93.760 & 93.722\end{array}$ $\begin{array}{llllll}93.536 & 93.499 & 93.462 & 93.425 & 93.387 & 93.350 \\ 93.164 & 93.126 & 93.090 & 93.052 & 93.015 & 92.978\end{array}$

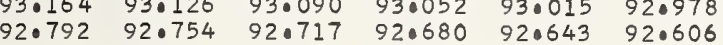
$\begin{array}{llllll}92.419 & 92.382 & 92.345 & 92.308 & 92.270 & 92.233\end{array}$

0.278511

1.442687

0.278510

0.278510

0.278510

0.278520

0.278509

0.278509

0.278508

0.278508

0.278508

0.278507

0.278507

0.278507

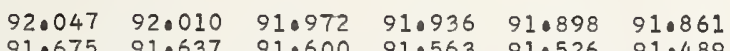

$\begin{array}{llllll}91.675 & 91.637 & 91.600 & 91.563 & 91.526 & 91.489\end{array}$

$\begin{array}{llllll}90.930 & 90.893 & 90.855 & 90.818 & 90.781 & 90.744\end{array}$

$\begin{array}{llllll}90.558 & 90.521 & 90.484 & 90.446 & 90.409 & 90.372\end{array}$

$\begin{array}{llllll}89.813 & 89.776 & 89.739 & 90.074 & 90.037 & 90.000 \\ & 89.702 & 89.665 & 89.627\end{array}$

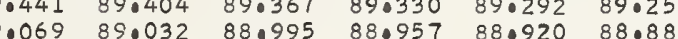

$\begin{array}{llll}19288.474 & 88.437 & 88.399 & 88.362\end{array}$ $\begin{array}{llll}88.102 & 88.064 & 88.027 & 87.990 \\ 87.729 & 87.692 & 87.655 & 87.618\end{array}$ $\begin{array}{llll}87.357 & 87.320 & 87.283 & 87.246 \\ 86.985 & 86.948 & 86.911 & 86.874\end{array}$ $86.241 \quad 86.204 \quad 86.16786 .502$ $\begin{array}{llll}85.869 & 85.832 & 85.795 & 85.758\end{array}$ $\begin{array}{llll}85.497 & 85.460 & 85.423 & 85.386 \\ 85.125 & 85.088 & 85.051 & 85.014\end{array}$

$88.325 \quad 88 \cdot 288$ 88.623

$\begin{array}{lll}88.957 & 88.920 & 88.883 \\ 88.585 & 88.548 & 88.511\end{array}$

0.278506

0.278506

0.278506

0.278505

0.278505

0.278504
0.278504

0.278504

0.278504

0.278503
0.278503

0.278503

0.278502

0.278502

0.278502

5184.0

19284.753

$84.753 \quad 84.716$

$\begin{array}{ll}84.679 & 84.642 \\ 84.307 & 84.270\end{array}$

$84.009 \quad 83.972 \quad 83.935 \quad 83.897$

$83.600 \quad 83.563 \quad 83.526$

$83.265 \quad 83.228 \quad 83.191 \quad 830$

$82.893 \quad 82.856 \quad 82.819 \quad 82.782$

$82.521 \quad 82.484 \quad 82.447 \quad 82.782$

$\begin{array}{llll}82.150 & 82.112 & 82.075 & 82.038\end{array}$

$81.406 \quad 81.369 \quad 81.331 \quad 81.294$

$881.034 \quad 80.997$

5.1

$\begin{array}{llll}80.290 & 80.253 & 80.216 & 80.179\end{array}$

$\begin{array}{llll}79.547 & 79.510 & 79.472 & 79.435\end{array}$

$\begin{array}{llll}79.175 & 79.138 & 79.100 & 79.063\end{array}$

$\begin{array}{llll}78.803 & 78.766 & 78.729 & 78.69\end{array}$

$\begin{array}{llll}78.059 & 78.022 & 77.985 & 77.948 \\ 77.688 & 77.651 & 77.613 & 77.576\end{array}$

5186

6.

6.3

6.4

6.6

6.7
6.8
6.9

5187

7.0

$7 \cdot 3$

7.5

$7 \cdot 6$
$7 \cdot 7$
7.8

7.8
7.9

5188

8.1
8
8
8
8
8
8
8
8
8
80

19277.31

$\begin{array}{lll}77.279 & 77.242 & 77.20\end{array}$

$\begin{array}{llll}76.573 & 76.535 & 76.498 & 76.461\end{array}$

$75.829 \quad 75.792 \quad 75.755 \quad 75.718$

$\begin{array}{lllll}75.458 & 75.421 & 75.383 & 75.34\end{array}$

$\begin{array}{lllll}75.086 & 75.049 & 75.011 & 74.974 \\ 74.714 & 74.677 & 74.640 & 74.603\end{array}$

$\begin{array}{llll}74.343 & 74.305 & 74.268 & 74.23\end{array}$

$73.971 \quad 73.934 \quad 73.897$

$\begin{array}{rlll}19273.600 & 73.562 & 73.525 & 73.4 \\ 73.228 & 73.191 & 73.154 & 73.1\end{array}$

$\begin{array}{llll}73.228 & 73.191 & 73.154 & 73.11 \\ 72.856 & 72.819 & 72.782 & 72.74\end{array}$

$\begin{array}{llll}72.485 & 72.448 & 72.411 & 72.374 \\ 72.114 & 72.076 & 72.039 & 72.002\end{array}$

$\begin{array}{llll}72.114 & 72.076 & 72.039 & 72.002 \\ 71.742 & 71.705 & 71.667 & 71.630\end{array}$

$\begin{array}{llll}71.370 & 71.333 & 71.296 & 71.25\end{array}$

$\begin{array}{llll}70.999 & 70.962 & 70.925 & 70.887 \\ 70.627 & 70.590 & 70.553 & 70.516\end{array}$

$\begin{array}{llll}70.627 & 70.590 & 70.553 & 70.516 \\ 70.256 & 70.219 & 70.181 & 70.144\end{array}$

$\begin{array}{rlll}19269.884 & 69.847 & 69.810 & 69.773 \\ 69.513 & 69.476 & 69.438 & 69.401\end{array}$

$\begin{array}{llll}69.513 & 69.476 & 69.438 & 69.401 \\ 69.142 & 69.104 & 69.067 & 69.030\end{array}$

$\begin{array}{llll}68.770 & 68.733 & 68.696 & 68.659 \\ 68.399 & 68.362 & 68.324 & 68.287\end{array}$

$\begin{array}{llll}68.399 & 68.362 & 68.324 & 68.287 \\ 68.027 & 67.990 & 67.953 & 67.916\end{array}$

$67.656 \quad 67.619 \quad 67.582 \quad 67.545$

$\begin{array}{llll}67.285 & 67.248 & 67.211 & 67.17\end{array}$

$\begin{array}{lll}66.913 & 66.876 & 66.839 \\ 66.542 & 66.505 & 66.468\end{array}$

66.802

5189.0

19266

$\begin{array}{llll}65.800 & 65.762 & 65.725 & 65.688\end{array}$

$65.428 \quad 65.391 \quad 65.354 \quad 65.317$

$\begin{array}{llll}65.057 & 65.020 & 64.983 & 64.946\end{array}$

$64.314 \quad 64.278 \quad 64.240 \quad 64.203$

$63.943 \quad 63.906 \quad 63.86963 .832$

$\begin{array}{llll}63.201 & 63.164 & 63.127 & 63.090 \\ 62.830 & 62.793 & 62.756 & 62.719\end{array}$

\begin{abstract}
.001
\end{abstract}

$$
.002
$$$$
.003
$$

$\begin{array}{lllllll}77.167 & 77.130 & 77.093 & 77.056 & 77.019 & 76.981\end{array}$

$\begin{array}{llllll}76.796 & 76.758 & 76.721 & 76.684 & 76.647 & 76.610 \\ 76.424 & 76.387 & 76.350 & 76.312 & 76.275 & 76.238\end{array}$

$\begin{array}{lllllll}76.052 & 76.015 & 75.978 & 75.940 & 75.903 & 75.866\end{array}$

$\begin{array}{llllll}75.680 & 75.644 & 75.606 & 75.569 & 75.532 & 75.495 \\ 75.309 & 75.272 & 75.235 & 75.198 & 75.160 & 75.123\end{array}$

$\begin{array}{llllll}74.937 & 74.900 & 74.863 & 74.826 & 74.789 & 74.751\end{array}$

$\begin{array}{lllllll}74.566 & 74.529 & 74.491 & 74.454 & 74.417 & 74.380\end{array}$

$\begin{array}{llllll}74.194 & 74.157 & 74.120 & 74.083 & 74.045 & 74.008 \\ 73.822 & 73.785 & 73.748 & 73.711 & 73.674 & 73.637\end{array}$

$\begin{array}{lllllll}73.451 & 73.414 & 73.376 & 73.339 & 73.302 & 73.265 \\ 73.079 & 73.042 & 73.005 & 72.968 & 72.931 & 72.894\end{array}$

$\begin{array}{lllllll}73.079 & 73.042 & 73.005 & 72.968 & 72.931 & 72.894 \\ 72.708 & 72.670 & 72.634 & 72.596 & 72.559 & 72.522\end{array}$

$\begin{array}{llllll}72.336 & 72.0299 & 72.634 & 72.596 & 72.559 & 72.522 \\ 72.225 & 72.187 & 72.151\end{array}$

$\begin{array}{llllll}71.965 & 71.927 & 71.890 & 71.853 & 71.816 & 71.779\end{array}$

$\begin{array}{llllll}71.593 & 71.556 & 71.519 & 71.482 & 71.445 & 71.407 \\ 71.222 & 71.185 & 71.147 & 71.110 & 71.073 & 71.036\end{array}$

$\begin{array}{llllll}70.850 & 70.813 & 70.776 & 70.739 & 70.702 & 70.665\end{array}$

$\begin{array}{llllll}70.479 & 70.442 & 70.405 & 70.367 & 70.330 & 70.293 \\ 70.107 & 70.070 & 70.033 & 69.996 & 69.959 & 69.922\end{array}$

$\begin{array}{llllll}69.736 & 69.699 & 69.662 & 69.625 & 69.587 & 69.550\end{array}$

$\begin{array}{llllll}69.365 & 69.327 & 69.290 & 69.253 & 69.216 & 69.179\end{array}$

$\begin{array}{llllll}68.993 & 68.956 & 68.919 & 68 \cdot 882 & 68.844 & 68.807 \\ 68.622 & 68.584 & 68.547 & 68.510 & 68.473 & 68.436\end{array}$

$\begin{array}{llllll}68.250 & 68.213 & 68.176 & 68.139 & 68.102 & 68.065 \\ 67.879 & 67.842 & 67.804 & 67.768 & 67.730 & 67.693\end{array}$

$\begin{array}{llllll}67.879 & 67.842 & 67.804 & 67.768 & 67.730 & 67.693 \\ 67.508 & 67.470 & 67.433 & 67.396 & 67.359 & 67.322\end{array}$

$\begin{array}{lllllll}67.136 & 67.099 & 67.062 & 67.025 & 66.988 & 66.950\end{array}$

$\begin{array}{llllll}66.765 & 66.728 & 66.691 & 66.654 & 66.616 & 66.579 \\ 66.394 & 66.357 & 66.320 & 66.282 & 66.245 & 66.208\end{array}$

$\begin{array}{lllllll}66.022 & 65.985 & 65.948 & 65.911 & 65.874 & 65.837\end{array}$

$\begin{array}{llllll}65.651 & 65.614 & 65.577 & 65.540 & 65.503 & 65.465 \\ 65.280 & 65.242 & 65.206 & 65.168 & 65.131 & 65.094\end{array}$

$\begin{array}{llllll}65.280 & 65.242 & 65.206 & 65.168 & 65.131 & 65.094 \\ 64.909 & 64.872 & 64.834 & 64.797 & 64.760 & 64.723\end{array}$

$\begin{array}{lllllll}64.537 & 64.500 & 64.463 & 64.426 & 64.389 & 64.352\end{array}$

$\begin{array}{llllll}64.166 & 64.129 & 64.092 & 64.055 & 64.018 & 63.981 \\ 63.795 & 63.758 & 63.720 & 63.683 & 63.646 & 63.609\end{array}$

$\begin{array}{llllll}63.424 & 63.386 & 63.350 & 63.312 & 63.275 & 63.238\end{array}$

$04 \quad .005$

005

.006

.007

53362.496

0.278501

0.278501

0.278501
0.278501

0.278501

0.278500

0.278500

0.278500
0.278499

0.278499

0.278499

0.278499
0.278498

0.278498

0.278498
0.278498

0.278498
0.278498

0.278498
0.278498

0.278497

0.278497

0.27849

0.278496
0.278496

0.278496

0.278496

0.278495

0.278495

0.278495

0.278494

0.278494

0.278494

0.278494

0.278494
0.278493

0.278493

0.278493

0.278493
0.278492

0.278492

0.278492

0.278492

0.278491

0.278491
0.278491

0.278491

0.278490

0.278490
0.278490

0.278490

0.278490

0.278489

0.278489

0.278489
0.278489

0.278488

0.278488

0.278488
0.278488

.442740

1.442767
1.442793

1.442820

1.442847

1.442900

.0442953

1.442980

1.443033

1.443060

1.443113

1.443139

1. 443163

1.443219

1.443246
1.443273

1.443299

1.443326
1.443352

1.443379
1.443406 
$\begin{array}{rrlllllllll}190.0 & 19262.459 & 62.422 & 62.385 & 62.348 & 62.311 & 62.273 & 62.236 & 62.199 & 62.162 & 62.125\end{array}$

$\begin{array}{lllllllllll}0.1 & 62.088 & 62.051 & 62.014 & 61.977 & 61.939 & 61.902 & 61.865 & 61.828 & 61.791 & 61.754\end{array}$

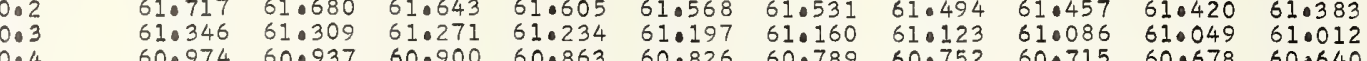
$\begin{array}{lllllllllll}0.4 & 60.974 & 60.937 & 60.900 & 60.863 & 60.826 & 60.789 & 60.752 & 60.715 & 60.678 & 60.640 \\ 0.5 & 60.603 & 60.566 & 60.529 & 60.492 & 60.455 & 60.418 & 60.381 & 60.344 & 60.307 & 60.269\end{array}$ $\begin{array}{lllllllllll}0.6 & 60.232 & 60.195 & 60.529 & 60.492 & 60.455 & 60.418 & 60.381 & 60.344 & 60.307 & 60.269\end{array}$ $0.7 \quad 50.861 \quad 59.824 \quad 59.787 \quad 59.750 \quad 59.713 \quad 59.676 \quad 59.639 \quad 59.602 \quad 59.565 \quad 59.528$

$50490 \quad 59.453 \quad 59.416 \quad 59.379 \quad 59.342 \quad 59.305 \quad 59036859.230259 .5650 .528$ 59.490

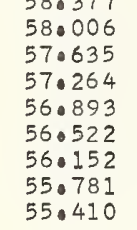

0.278480

0.278480
0.278480

0.278480

0.278479
0.278479

0.278479

0.278479

0.278479

0.278478 0.278477 0.278477 0.278477 0.278476

0.278476
0.278476

0.278476

0.278475

0.278475

0.278475
0.278475

0.278475

0.278474

0.278474

0.278473

0.278473

0.278473

0.278473
0.278472

0.278472

0.278472

0.278472
0.278472

0.278471

0.278471

0.278471

0.278470

0.278470

0.278470

0.278469
0.278469

0.278469

0.278469

0.278468

0.278468
0.278468
0

0.278468

0.278468

0.278467
0.278467
0.278667

0.278467

0.278466

0.278466

0.278466
0.278466

0.278455

0.278465

0.278465
0.278465

0.278465
0.278465

0.278464

1.445350

1.445376
1.445403

1. 445430

1.445456

1.445510

1.445536
1.445563

1.445616

1.445643
1.445669

1.445696

1.445723
1.445749

1.445776

1.445802

1.445856

1.445882

1.445909
1.445936

1.445962

1.445989
1.446016

1.446042

1.446069

1.446095
1.446122

1.446149

1. 446175 


.02

.03

.04

.05

.06

.07

.08

$(n-1) \times 1000$

$\begin{array}{rrrrrrrrrrr}200.0 & 19225.416 & 25 \cdot 379 & 25.342 & 25 \cdot 305 & 25 \cdot 268 & 25 \cdot 231 & 25 \cdot 194 & 25 \cdot 157 & 25 \cdot 120 & 25 \cdot 083 \\ 0.1 & 25.046 & 25.009 & 24.972 & 24.935 & 24.898 & 24.862 & 24.824 & 24.788 & 24.750 & 24.714\end{array}$

$\begin{array}{lllllllllll}0.2 & 24.677 & 24.640 & 24.603 & 24.566 & 24.529 & 24.492 & 24.455 & 24.418 & 24.381 & 24.0344 \\ 0.3 & 24.307 & 24.270 & 24.033 & 24.0196 & 24.559 & 24.122 & 24.085 & 24.048 & 24011 & 23.074\end{array}$

$\begin{array}{llllllllllll}0.3 & 24.307 & 24.270 & 24.233 & 24.196 & 24.159 & 24.122 & 24.085 & 24.048 & 24 \cdot 011 & 24.974 \\ 0.4 & 23.937 & 23.900 & 23.063 & 23.026 & 23.089 & 23.753 & 230716 & 23.679 & 23.642 & 23.605\end{array}$

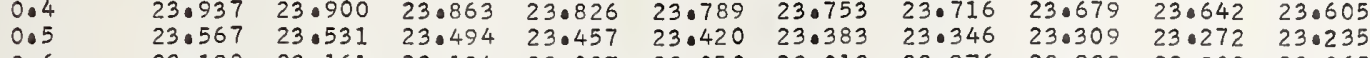

$\begin{array}{lllllllllll}0.6 & 23.198 & 23.161 & 23.124 & 23.087 & 23.050 & 23.013 & 22.976 & 22.939 & 22.902 & 22.865 \\ 0.7 & 23.829 & 22.792 & 22.054 & 22.717 & 22.000 & 22.043 & 22.007 & 22.570 & 22.533 & 220496\end{array}$

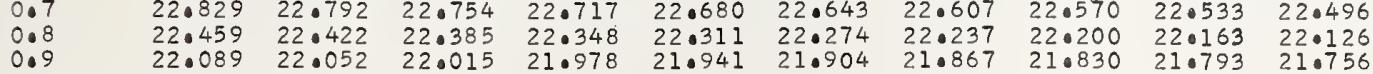

5201.0

1.0
10
103
10
100
107
100
109

19221.719

21.3502190683

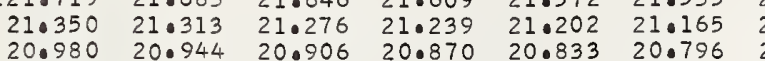

$\begin{array}{lllllllll}20.944 & 20.906 & 20.870 & 20.833 & 20.796 & 20.759 & 20.722 & 210.054 & 21.017 \\ 20.085 & 20.648\end{array}$

$\begin{array}{llllllllll}20.611 & 20.574 & 20.537 & 20.500 & 20.463 & 20.426 & 20.389 & 20.352 & 20.315 & 20.678\end{array}$

$\begin{array}{llllllllll}20.241 & 20.204 & 20.167 & 20.130 & 20.094 & 20.057 & 20.020 & 19.983 & 19.946 & 19.909 \\ 19.872 & 19.835 & 19.798 & 19.761 & 19.724 & 19.687 & 19.650 & 190614 & 19.576 & 19.540\end{array}$

$\begin{array}{llllllllll}19.502 & 19.465 & 19.428 & 19.391 & 19.354 & 19.318 & 19.281 & 19.244 & 190207 & 19.570\end{array}$

$\begin{array}{lllllllllll}19.133 & 19.096 & 19 \cdot 059 & 19 \cdot 022 & 18.985 & 18.948 & 18 \cdot 911 & 18.874 & 18.837 & 18.1701\end{array}$

$\begin{array}{llllllllll}18.763 & 18.727 & 18.689 & 18.653 & 18.615 & 18.579 & 18.542 & 18.505 & 18.468 & 18.431 \\ 18.394 & 18.357 & 18.320 & 18.283 & 18.246 & 18.209 & 18.172 & 18.135 & 18.098 & 18.062\end{array}$

5202.0

19218.02

2.0
2.2
2.0
2.
206
2.7
2.0
2.9

17.

17.988

$17.877 \quad 17.840$

$17.803 \quad 17.766 \quad 17.729 \quad 17.692$

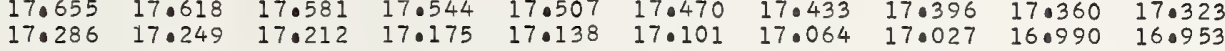

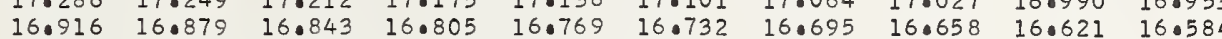

$\begin{array}{llllllllll}16.547 & 16.510 & 16.473 & 16.436 & 16.399 & 16.362 & 16.325 & 16.289 & 16.251 & 16.214\end{array}$

$\begin{array}{llllllllll}16.177 & 16.141 & 16.104 & 16.067 & 16.030 & 15.993 & 15.956 & 15.919 & 15.882 & 150845 \\ 15.808 & 15.771 & 15.734 & 15.698 & 15.061 & 15.624 & 15.587 & 15.550 & 15.513 & 15.476\end{array}$

$\begin{array}{llllllllll}15.808 & 15.771 & 15.734 & 15.698 & 15.661 & 15.624 & 15.587 & 15.550 & 15.513 & 15.476 \\ 15.439 & 15.402 & 15.365 & 15.328 & 15.292 & 15.254 & 15.218 & 150.181 & 15.144 & 15.107\end{array}$

$\begin{array}{llllllllll}15.070 & 15.033 & 14.996 & 14.959 & 14.922 & 14.885 & 14.848 & 14.811 & 14.774 & 14.73\end{array}$

5203.0

$192140331 \quad 140294 \quad 140257-140220-140183 \quad 140146$

$13.962 \quad 13.925$

13.962 13.925

$\begin{array}{llll}3.257 & 140220 & 14.183 & 14.146 \\ 3.888 & 13.851 & 13.814 & 13.777 \\ 13.5150 & 13.482 & 13.445 & 13.408\end{array}$

$\begin{array}{llll}14 \cdot 109 & 14 \cdot 073 & 14.036 & 13.999 \\ 13.740 & 13.703 & 13.667 & 13.629\end{array}$

$13.223 \quad 13.186 \quad 13.150 \quad 13.113 \quad 13.076 \quad 13.039$

$\begin{array}{llllll}12.854 & 12.817 & 12.780 & 12.743 & 12.706 & 12.669\end{array}$

$12.485 \quad 12.44$

$12.0747 \quad 12.709$

$\begin{array}{llll}12.411 & 12.374 & 12.337 & 12.300 \\ 12.042 & 12.005 & 11.0968 & 11.931\end{array}$

$13.371 \quad 13.334 \quad 13.297 \quad 13.260$

3.

3.6
3.7

3.7
3.8
3.9

5204.0

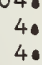

$\begin{array}{ll}11.377 & 11.340 \\ 11.008 & 10.971\end{array}$

$11.673 \quad 11.636$

$19210.639 \quad 10.602$

$\begin{array}{ll}10.270 & 10.233 \\ 09.901 & 09.864\end{array}$

09.901109 .864

$\begin{array}{ll}09.163 & 09.125 \\ 08.793 & 08.756\end{array}$

$\begin{array}{ll}10.565 & 10.528 \\ 10.196 & 10.159\end{array}$

$\begin{array}{llll}2.633 & 12.596 & 12.559 & 12.522\end{array}$

$\begin{array}{llll}12.263 & 12.227 & 12.190 & 12.153 \\ 11.894 & 11.857 & 11.820 & 11.783\end{array}$

08.42408 .0387

09.82

09.458 09.790

09.089

08.05508 .019

$\begin{array}{ll}07.686 & 07.649 \\ 07.317 & 07.280\end{array}$

08.683

$\begin{array}{ll}08.350 & 08.31 \\ 07.981 & 07.94\end{array}$

$\begin{array}{lll}07.613 & 07.575 \\ 07.243 & 07.207 & 0\end{array}$

1.23011 .193

$11.525 \quad 11.488 \quad 11.451 \quad 11.414$

$\begin{array}{llll}11.156 & 11.119 & 11.082 & 11.045 \\ 10.787 & 10.750 & 10.713 & 10.676\end{array}$

0.278464
0.278464

0.278464

40

0.278463

0.278463

0.278462

0.278462
0.278462

0.278462

0.27846

0.278461

0.278461

0.278460

0.278460

0.278460

0.278459

0.278459

0.278459

.0278458

0.078458

0.278458

0.278458

0.278457

0.278457

0.278457

0.278456

0.278456

0.278455

0.27845

0.278455

0.278454

0.278454

.278454

0.278454

0.278453

0.278453

0.278453

5205.0

5.0
5.0
5.0
50
5.0
5.0
50
5.0
5

19206.948

$\begin{array}{lll}206.948 & 06.911 & 06.874 \\ 06.579 & 06.542 & 06.5 \\ 06.210 & 06.173 & 06.1\end{array}$

$05.841 \quad 05.173 \quad 06.136$

$05.472 \quad 05.435$

$05.103 \quad 05.066$

$\begin{array}{ll}04.734 & 04.697 \\ 04.365 & 04.329\end{array}$

$\begin{array}{ll}03.997 & 03.960 \\ 03.628 & 03.591\end{array}$

05.76805 .731

$05.030 \quad 04.993$

$\begin{array}{ll}4.660 & 04.624 \\ 0 . .292 & 04.255\end{array}$

-.625
0.258
0.886

$\begin{array}{ll}3.923 & 03.88 \\ 3.554 & 03.517\end{array}$

5206.0

6.1
6.2
6.3

$19203.259 \quad 03.222$

$\begin{array}{lll}03.259 & 03.222 & 03.185\end{array}$

$02.521 \quad 02.484$

$01.783 \quad 01.747$

$01.414 \quad 01.378$

$\begin{array}{ll}01.046 & 01.009 \\ 00.677 & 00.640\end{array}$

6.9

$\begin{array}{rlll}00.308 & 00.271 & 00.235 & 00.198 \\ 199.940 & 99.903 & 99.866 & 99.829\end{array}$

5207.0
7.1
7.2
7.3
7.4
7.6
7.7
7
70

\begin{tabular}{|c|c|c|c|}
\hline & & & \\
\hline & •165 & -4 & 99.092 \\
\hline & 98.796 & 98.760 & 98.723 \\
\hline 46 & 98.428 & 98.391 & 0 \\
\hline 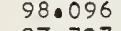 & 98.059 & 98.022 & \\
\hline 7 & $97 \cdot 691$ & 97.654 & 97.617 \\
\hline 3. & .322 & 97.285 & 7.248 \\
\hline 1990 & 96.953 & -91 & \\
\hline & 584 & 96.548 & 96.511 \\
\hline
\end{tabular}

$99.423 \quad 99.38$

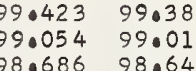

$\begin{array}{llllll}98.686 & 98.649 & 98.612 & 98.575 & 98.539 & 98.501\end{array}$

$\begin{array}{llllll}97.948 & 97.281 & 98.243 & 98.206 & 980169 & 980133\end{array}$

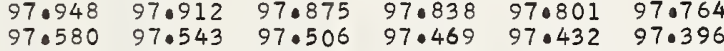

$\begin{array}{lllllll}97.211 & 97.174 & 97.137 & 97.101 & 97.064 & 97.027\end{array}$

$96.253 \quad 96.216$

$\begin{array}{llllll}96.843 & 96.806 & 96.769 & 96.732 & 96.695 & 96.658 \\ 96.474 & 96.437 & 96.400 & 96.363 & 96.326 & 96.290\end{array}$

0.278452

0.278452
0.278452

0.278452

0.278451

0.278451

0.278451

0.278451

0.278450

0.278450

0.278450

0.278450
0.278449

0.278449

0.278449

0.278449

0.278448

0.278448
0.278448

0.278448

0.0278448

0.278447

0.278447
0.278447
0.0278447

0.278447
0.0278447

0.278446

0.278446

0.278446
0.278446

$\begin{array}{rrrrrrrrrrr}5208.0 & 19195.884 & 95.847 & 95.811 & 95.774 & 95.737 & 95.700 & 95.663 & 95.626 & 95.589 & 95.552 \\ 8.1 & 95.516 & 95.479 & 95.442 & 95.405 & 95.368 & 95.332 & 95.295 & 95.258 & 95.221 & 95.184\end{array}$

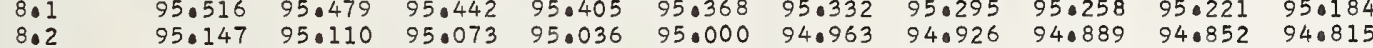

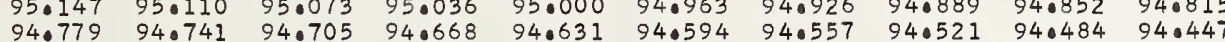

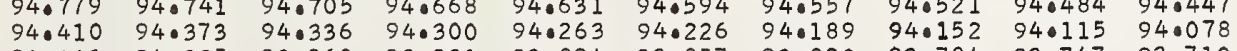

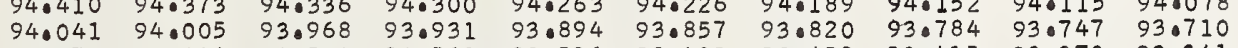

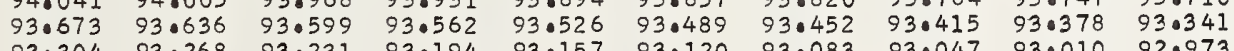

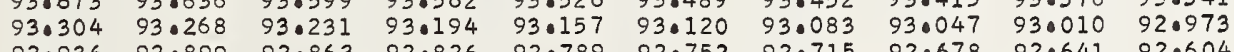

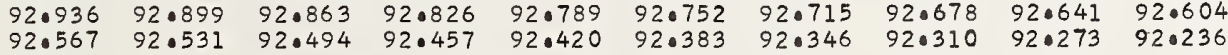

0.278445

0.278445

0.278445

0.278445

0.278444

0.278444

0.278444

0.278443

0.278443

0.278443

0.278443

0.278442

0.278442

0.278442

0.278441

0.278441

\begin{tabular}{llllllllll}
89.621 & 89.584 & 89.547 & 89.510 & 89.473 & 89.436 & 89.400 & 89.363 & 89.326 & 89.289 \\
\hline
\end{tabular}

$\begin{array}{llllllllll}89.252 & 89.216 & 89.179 & 89.142 & 89 \cdot 105 & 89.068 & 89 \cdot 031 & 88.994 & 88.958 & 88.921 \\ 88.884 & 88.847 & 88.810 & 88.773 & 88.737 & 88.700 & 88.663 & 88.626 & 88.589 & 88.552\end{array}$

$\begin{array}{lllllllllll} & .001 & .002 & .003 & .004 & .005 & .006 & .007 & .008 & .009 & .010 \\ .837 & : 884 & .887 & .811 & .815 & .818 & .822 & .826 & .832 & .8332 & .833 \\ .035 & .003 & .007 & .010 & .014 & .017 & .021 & .024 & .028 & .031 & .035\end{array}$

1.448040

1.448066

1.448093

1.448246

1.448173
1.048199

1.448226

1.448279

1.448306

1.448359

1.448386

1.448439

.448466

1.448519

.448546

1.448572

1.448626
1.448652

1.448652

1.448705

1.448732

1.448785

.448812

1.448865

.448892

1.448919

.448972

1.449025

1.449052

1.449078

1. 0449105

.449158

1.449185

1.449238

1.449265

1.449318

1.449345

1.449371

1.449425

10449451

2.0449505

1.449531

1.449584

1.449611

1.449638

1.449664

10449718

1.449744

1.449798

1.449824

1.449877

1.449904

1.449957

1. 449984

1.450011

1.450037

1.450064

1.450117

1.450244

.450170
.450197

1.450224

1.450250
1.450277

1.450304

1.450330

1.450357
1.450384

1.450437

1.450490

1.450490

1.450543

1.450570

1.450623
1.450650

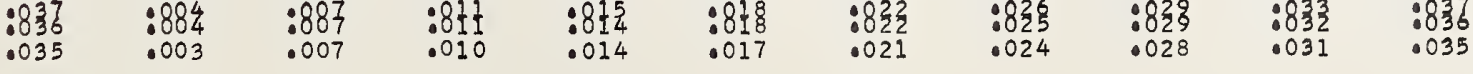


$\begin{array}{lllllllllll}5210.0 & 19188.516 & 88.479 & 88.442 & 88.405 & 88.368 & 88.331 & 88.294 & 88.258 & 88.221 & 88.184\end{array}$ $\begin{array}{llllllllllll}0.1 & 88.147 & 88.110 & 88.073 & 88.037 & 88.000 & 87.963 & 87.927 & 87.890 & 87.853 & 87.816\end{array}$ $\begin{array}{llllllllllll}0.3 & 87.411 & 87.374 & 87.337 & 87.300 & 87.263 & 87.227 & 87.190 & 87.153 & 87.116 & 87.080\end{array}$ $\begin{array}{llllllllllll}0.4 & 87.043 & 87.006 & 86.969 & 86.932 & 86.895 & 86.859 & 86.822 & 86.785 & 86.748 & 86.711\end{array}$

19184.833$$
\begin{array}{r}
9184.8 \\
84.4 \\
84.09
\end{array}
$$ 


.07

.08

.09

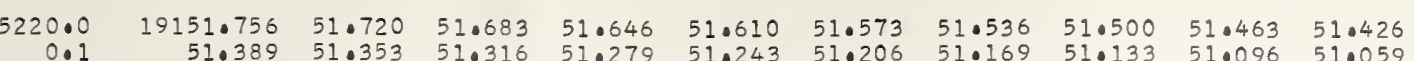

$\begin{array}{lllllllllll}0.1 & 51.389 & 51.353 & 51.316 & 51.279 & 51.243 & 51.206 & 51.169 & 51.133 & 51.096 & 51.059 \\ 0.2 & 51.022 & 50.986 & 50.949 & 50.912 & 50.876 & 50.839 & 50.802 & 50.766 & 50.729 & 50.692\end{array}$

$\begin{array}{lllllllllll}0.2 & 51.022 & 50.986 & 50.949 & 50.912 & 50.876 & 50.839 & 50.802 & 50.766 & 50.729 & 50.692 \\ 0.3 & 50.656 & 50.619 & 50.583 & 50.546 & 50.509 & 50.472 & 50.436 & 50.399 & 50.362 & 50.326\end{array}$

0.278399

0.278399
0.278399

0.278399

0.278398

0.278398
0.278398

0.278397

0.278397

0.278397

0.278396

0.278396

0.278395

0.278395
0.278395

1.453340
1.453367
1.453394
1.453420
1.453447
1.453474
1.453500
1.453527
1.453553
1.453580

1.453607
1.453633

1.453660
1.453687

1.453713

1.453767

1.453820
1.453846

1.453873

1.453900

1.453953

1.454006

1.454033

1.454086

1.454139

1.454166

1.454219

1.454273

1.0454299

1.454353 


.02

.03

.04

.05

.06

$\begin{array}{lcc}.07 & .08 & .09 \\ 14 \cdot 882 & 14.845 & 14.809 \\ 14.517 & 14.480 & 14.443 \\ 14.151 & 140115 & 14.078 \\ 13.786 & 13.749 & 13.713 \\ 13.420 & 130384 & 13.347 \\ 13.055 & 13.018 & 12.982 \\ 12.689 & 12.653 & 12.616 \\ 12.324 & 12.288 & 12.251 \\ 11.958 & 110.922 & 11.885 \\ 11.5993 & 11.557 & 11.520\end{array}$

$\begin{array}{lrllllll}30.0 & 19115.138 & 15.101 & 15.065 & 15.028 & 14.992 & 14.955 & 140 \\ 0.1 & 14.772 & 14.736 & 14.699 & 14.663 & 14.626 & 14.590 & 1 \\ 0.2 & 14.407 & 14.370 & 14.334 & 14.297 & 14.261 & 14.224 & 140 \\ 0.3 & 14.042 & 14.005 & 13.969 & 13.932 & 13.895 & 13.859 & 130 \\ 0.4 & 13.676 & 13.639 & 13.603 & 13.566 & 13.530 & 13.493 & 130 \\ 0.5 & 13.311 & 13.274 & 13.238 & 13.201 & 13.165 & 13.128 & 130 \\ 0.6 & 12.945 & 12.909 & 12.872 & 12.835 & 12.799 & 12.762 & 120 \\ 0.7 & 12.580 & 12.543 & 12.507 & 12.470 & 12.434 & 12.397 & 1 \\ 0.8 & 12.214 & 12.178 & 12.142 & 12.105 & 12.068 & 12.031 & 110 \\ 0.9 & 11.849 & 11.812 & 11.776 & 11.739 & 11.703 & 11.667 & 1\end{array}$

3.0
1.1
1.2
1.3
1.4
1.5
1.6
1.7
1.8
1.9

111.484
11.118
10.753
10.387
10.022
09.657
09.292
08.927
08.561
08.196

11.447
11.082
10.717
10.351
09.986
09.621
09.255
08.890
08.525
08.160

$\begin{array}{llll}11.411 & 11.374 & 11.338 & 11.301 \\ 11.045 & 11.009 & 10.972 & 10.936\end{array}$

$$
\begin{array}{ll}
1 & 1 \\
36 & 1 \\
70 & 1 \\
05 & 1
\end{array}
$$

$\begin{array}{llll}1.264 & 11.228 & 11.191 & 11.155\end{array}$

$\begin{array}{lllllllll}10.680 & 10.644 & 10.607 & 10.570 & 10.534 & 10.497 & 10.461 & 10.424\end{array}$

$\begin{array}{llllllll}09.584 & 09.547 & 09.511 & 09.474 & 09.438 & 09.401 & 09.365 & 09.328\end{array}$

9107.83107 .794

07.466

$07.101 \quad 07.064$

$\begin{array}{ll}06.735 & 06.699 \\ 06.370 & 06.333\end{array}$

$06.005 \quad 05.969$

$\begin{array}{ll}05.640 & 05.603 \\ 05.275 & 05.23\end{array}$

$\begin{array}{ll}04.910 & 04.873 \\ 04.544 & 04.508\end{array}$

$19104 \cdot 17904 \cdot 143$

03.44903 .413

03.08403 .048

$\begin{array}{ll}02.719 & 02.683 \\ 02.354 & 02.318\end{array}$

$\begin{array}{ll}02.354 & 02 \cdot 318 \\ 01.989 & 01.95\end{array}$

$\begin{array}{ll}01.624 & 01.588 \\ 01.259 & 01.223\end{array}$

$\begin{array}{ll}01.259 & 01.223 \\ 00.894 & 00.858\end{array}$

$19100.529 \quad 00.493$ 19099.800 $99.435 \quad 99.763$

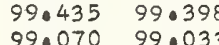
$99.070 \quad 99.033$ $98.340 \quad 98.303$

$97.610 \quad 97.574$

9096.88 $96.152 \quad 96.11$ $95.787 \quad 95 \cdot 750$ $95.057 \quad 95.021$ $94.693 \quad 94.656$ $94.328 \quad 94 \cdot 292$ 93.963

.21909 .18

$\begin{array}{llll}0.854 & 08.817 & 08.780 & 08.74\end{array}$

09.073

09.036

09.000

08.963

$08.123 \quad 08.086$

$\begin{array}{lll}08.415 & 08.379 & 080 \\ 08.050 & 08.013 & 070\end{array}$

8.342
0.977

$\begin{array}{lll}.671 & 08.634 & 08.598\end{array}$

$\begin{array}{llllllll}07.758 & 07.721 & 07.685 & 07.648 & 07.612 & 07.575 & 07.539 & 07.502\end{array}$

$\begin{array}{llllllll}07.393 & 07.356 & 07.320 & 07.283 & 07.246 & 07.210 & 07.173 & 07.137\end{array}$

$\begin{array}{llllllll}06.662 & 06.626 & 06.589 & 06.553 & 06.516 & 06.479 & 06.443 & 06.407\end{array}$

$\begin{array}{llllllll}06.297 & 06.260 & 06.224 & 06.187 & 06.151 & 06.115 & 06.078 & 06.042\end{array}$

05.93205 .896

$\begin{array}{ll}.567 & 05.530 \\ 0.202 & 05.165\end{array}$

04.837 04.800

$05.859 \quad 05.823 \quad 05.786$

05.750

05.713

06.042

$\begin{array}{lll}.494 & 05.457 & 050 \\ 0.129 & 05.092 & 050\end{array}$

$.056 \quad 0500$

$\begin{array}{lll}384 & 05.348 & 05.311\end{array}$

$\begin{array}{ll}4.107 & 04.070\end{array}$

$04.398 \quad 040362$

04.326

04.289

04.617

04.946

$\begin{array}{llllllll}03.741 & 03.705 & 03.668 & 03.632 & 03.595 & 03.524 & 03.887 & 03.851 \\ 03.522 & 03.486\end{array}$

$\begin{array}{llllllll} & 03.303 & 03.267 & 03.230 & 03.194 & 03.157 & 03.121\end{array}$

$\begin{array}{llllllll}0.011 & 02.975 & 02.938 & 02.902 & 02.865 & 02.829 & 02.792 & 02.756 \\ 2.646 & 02.610 & 02.573 & 02.537 & 02.500 & 02.464 & 02.427 & 02.391\end{array}$

$\begin{array}{llllllll}02.281 & 02.245 & 02.208 & 02.172 & 02.135 & 02.099 & 02.062 & 02.026\end{array}$

$\begin{array}{llllllll}1.916 & 01.880 & 01.844 & 01.807 & 01.770 & 01.734 & 01.697 & 01.661\end{array}$

1.187 01.150 010

$00.457 \quad 00.420 \quad 00$

$00.748 \quad 00.712 \quad 00.675 \quad 00.63900 .602 \quad 00.566$

$99.727 \quad 99.690$

$\begin{array}{ll}99.362 & 99.325 \\ 98.997 & 98.960\end{array}$

$98.632 \quad 98.596$

$98.267 \quad 98.230$

7.53

$97 \cdot 866$
97.501
97.136

(6)

$\begin{array}{ll}96.443 & 96.407 \\ 96.079 & 96.042\end{array}$

$\begin{array}{ll}95.714 & 95.677 \\ 95.349 & 95.312\end{array}$

$\begin{array}{ll}95.349 & 95.312 \\ 94.984 & 94.948\end{array}$

$\begin{array}{ll}94.620 & 94.583 \\ 94.255 & 94.218\end{array}$

03059

$19093.234 \quad 93.1$

92.869

$92.140 \quad 92.46$

$91.775 \quad 91.739$

91.41

$\begin{array}{llll}91.046 & 91.010 & 90.973 & 90.937 \\ 90.682 & 90.645 & 90.609 & 90.572\end{array}$

$\begin{array}{llll}90.317 & 90.281 & 90.244 & 90.208 \\ 89.953 & 89.916 & 89.880 & 89.843\end{array}$

19089.58

89.223

$88.859 \quad 88.823$

$\begin{array}{llll}88.130 & 88.094 & 88.057 & 88.021\end{array}$

$\begin{array}{lllll}87.401 & 87.365 & 87.328 & 87.656\end{array}$

$\begin{array}{llll}87.037 & 87.000 & 86.964 & 86.927\end{array}$

$\begin{array}{ll}86.672 & 86.636 \\ 86.308 & 86.271\end{array}$

$\begin{array}{ll}86.600 & 86.563 \\ 86.235 & 86.198\end{array}$

5238.0

$$
\begin{array}{r}
85 . \\
85 . \\
84 .
\end{array}
$$

$\begin{array}{llll}85.579 & 85.543 & 85.871 & 85.834 \\ 8506 & 85.470\end{array}$

$\begin{array}{llll}85.215 & 85.178 & 85.142 & 85.105 \\ 84.851 & 84.814 & 84.778 & 84.741\end{array}$

$\begin{array}{llll}84.486 & 84.450 & 84.413 & 84.377\end{array}$

$83.758 \quad 83.721 \quad 83.685 \quad 83.648$

$\begin{array}{llll}83.393 & 83.357 & 83.321 & 83.284 \\ 83.029 & 82.992 & 82.956 & 82.920\end{array}$

$\begin{array}{llll}82.665 & 82.628 & 82.592 & 82.555\end{array}$

82.264

82.228

82.191

$\begin{array}{llll}81.572 & 81.536 & 81.499 & 81.827 \\ & 81.463\end{array}$

$81.208 \quad 81.171 \quad 81.135 \quad 81.099$

$\begin{array}{llll}80.844 & 80.807 & 80.771 & 80.734 \\ 80.479 & 80.443 & 80.407 & 80.370\end{array}$

$\begin{array}{lllll}80.115 & 80.079 & 80.042 & 80.006\end{array}$

$\begin{array}{llll}79.751 & 79.715 & 79.678 & 79.642\end{array}$

$\begin{array}{ll}79.387 & 79.351 \\ 79.023 & 78.987\end{array}$

$\begin{array}{ll}79.678 & 79.642 \\ 79.314 & 79.278 \\ 78.950 & 78.914\end{array}$

.001

.002

.003

$00.019 * 99.982 * 9.000 .347$

年

$9.289 \quad 99.252 \quad 99.216 \quad 99.179 \quad 99.143 \quad 99.106$

$\begin{array}{lllllll}9.924 & 98.887 & 98.851 & 98.814 & 98.778 & 98.741\end{array}$

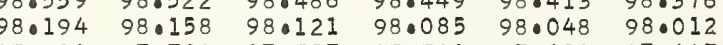

$\begin{array}{llllll}97.829 & 97.793 & 97.757 & 97.720 & 97.683 & 97.647\end{array}$

$\begin{array}{llllll}97.100 & 97.063 & 97.027 & 96.990 & 96.954 & 96.917\end{array}$

$\begin{array}{llllll}96.735 & 96.699 & 96.662 & 96.626 & 96.589 & 96.553\end{array}$

$\begin{array}{llllll}96.006 & 96.334 & 96.297 & 96.261 & 96.224 & 96.188\end{array}$

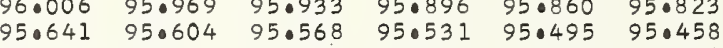

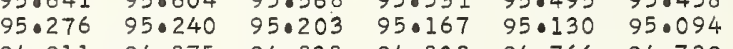

$\begin{array}{llllll}94.911 & 94.875 & 94.838 & 94.802 & 94.766 & 94.729\end{array}$

$\begin{array}{llllll}94 \cdot 547 & 94 \cdot 510 & 94.474 & 94 \cdot 437 & 94 \cdot 401 & 94.364\end{array}$

$\begin{array}{llllll}93.1817 & 94.145 & 94 \cdot 109 & 94 \cdot 073 & 94.036 & 94 \cdot 000 \\ 93.781 & 93.744 & 93.708 & 93.671 & 93.635\end{array}$

$\begin{array}{llllll}93.817 & 93.7816 & 93.744 & 93.708 & 93.671 & 93.635 \\ 93.452 & 93.416 & 93.380 & 93.343 & 93.307 & 93.270\end{array}$

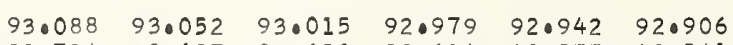

$\begin{array}{llllll}92.724 & 92.687 & 92.650 & 92.614 & 92.577 & 92.541 \\ 92.359 & 92.322 & 92.286 & 92.250 & 92.213 & 92.177\end{array}$

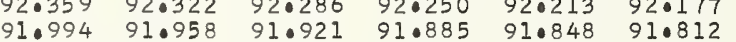

$\begin{array}{llllll}91.629 & 91.593 & 91.557 & 91.520 & 91.484 & 91.447\end{array}$

$\begin{array}{llllll}91.265 & 91.229 & 91.192 & 91.156 & 91.119 & 91.083 \\ 90.900 & 90.864 & 90.827 & 90.791 & 90.754 & 90.718\end{array}$

$90.536 \quad 90.499 \quad 90.463 \quad 90.427 \quad 90.390 \quad 90.354$

$\begin{array}{llllll}90.171 & 90.135 & 90.098 & 90.062 & 90.025 & 89.989 \\ 89.807 & 89.771 & 89.734 & 89.698 & 89.661 & 89.625\end{array}$

0.278395

0.278394

0.278394

0.278394

0.278394

0.278393

0.278393

0.278393

0.278392

0.278392
0.278392

0.278392

0.278392

0.27839

0.278391

0.278391
0.278390

0.278390

0.278390

0.278389

0.278389

0.278389

0.278389

0.278389
0.278388

0.278388
0.278388

0.278388

0.278388
0.278387

0.278387

0.278387

0.278387

0.278386

0.278386
0.278386

0.278386
0.278386

0.278386

0.278385

0.278385

0.278385

0.278384

0.278384

0.278384

0.278384
0.278384

0.278383

0.278383

0.278383

0.278383

0.278382

0.278382

0.278382

0.278381

0.278381

0.278381

0.278381
0.278380

0.278380

0.278380

0.278380
0.278379

0.278379

0.278379

0.278379

0.278378

0.278378
0.278378

0.278378

0.278378

0.278377

0.278377

0.278377
0.278377

0.278376

0.278376

0.278376

0.278376

0.278375

0.278375

0.278375
0.278374

1.456004

1.456058

1.456084

1.456138

10456164

1.456217
1.456244

1.456271

1.456297
1.456324

1.456352

1.456404

1.456431
1.456457

1.456484
1.456511

1.456537

1.456564

1.456617

1.456644

1.456697 


.02

.03

5240. 0.1

$\begin{array}{lll}78.659 & 78.623 & 78.58 \\ 78.295 & 78.258 & 78.22\end{array}$

$\begin{array}{lll}77.931 & 77.894 & 77.858 \\ 77.567 & 77.530 & 77.494\end{array}$

$\begin{array}{lllll}77.203 & 77.166 & 77.130 & 77.457\end{array}$

$\begin{array}{llll}76.839 & 76.802 & 76.766 & 76.729\end{array}$

$\begin{array}{llll}76.475 & 76.438 & 76.402 & 76.365\end{array}$

0.7

0.8

5241.0

1.

$1: 1$
$1: 2$
$1 \bullet 3$

1.4

$1: 6$
1.7
1.8

1.8

5242
2
2
2
2
2
$2 \bullet$
$2 \bullet$
$2 \bullet 7$
2.8
2.9

$\begin{array}{lllll}75.746 & 75.710 & 75.674 & 75.637 \\ 75.383 & 75.346 & 75.310 & 75.273\end{array}$

$\begin{array}{lll}74.655 & 74.618 & 74.58\end{array}$

$\begin{array}{lll}74 \cdot 291 & 74 \cdot 254 & 74 \cdot 218 \\ 73.927 & 73.890 & 73.854\end{array}$

$73.563 \quad 73.527 \quad 73.890 \quad 73.818$

$73.199 \quad 73.163 \quad 73.126 \quad 73.090$

$\begin{array}{llll}72.835 & 72.799 & 72.762 & 72.726\end{array}$

$\begin{array}{llll}72.108 & 72.071 & 72.035 & 71.999 \\ 71.744 & 71.708 & 71.671 & 71.63\end{array}$

071.380

$$
\begin{array}{rr}
9071.380 & 71 \\
71.016 & 70 \\
70.652 & 70 \\
70.289 & 70 \\
69.925 & 69 \\
69.561 & 69 \\
69.197 & 69 \\
68.834 & 68 \\
68.470 & 68 \\
68.106 & 68
\end{array}
$$$$
71 \cdot 34
$$$$
71.30
$$$$
71.27
$$$$
2
$$$$
5243.0
$$$$
3.1
$$$$
3 .
$$$$
\begin{aligned}
& 3.4 \\
& 3.5 \\
& 3.6
\end{aligned}
$$$$
3.6
$$$$
\begin{aligned}
& 3.8 \\
& 3.9
\end{aligned}
$$$$
5244 \bullet
$$$$
4 .
$$$$
4 \cdot 2
$$$$
\begin{aligned}
& 4 \cdot 3 \\
& 4 \cdot 4 \\
& 4 \cdot 5
\end{aligned}
$$$$
4.5
$$$$
\text { s.t. }
$$

5245.0

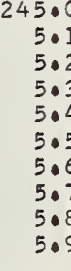

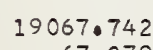

0.278372

0.278372

0.278371

0.278371

0.278371

0.278370

0.278370

0.278369

0.278389

0.278369

0.278368

0.278368

0.278368
0.278368

0.278367

0.278367

0.278367

0.278366

0.278366

0.278365

0.278365

0.278365

0.278364

0.278364

0.278364

0.278363

0.278363

0.278363

0.278363

0.278362

0.278362

0.278362

0.27836

0.278361

0.278361

0.278360

0.278360

0.278360

0.278359
0.278359

0.278359
0.278359

0.278359

0.278358

0.278358

0.278358
0.278358
0.027855

0.278357

.278357

0.278357
0.278357
0.278356

0.278356

0.278356

.278356

0.278356

0.0278355

0.278355

0.278355
0.278355

.278354

0.278354

0.278353
0.278353

0.278353

0.278353
0.278353

.278352

0.278352
0.278352
0.278352

0.278352 


$\begin{array}{rrr}5250.0 & 19042.319 & \\ 0.1 & 41.956 & \\ 0.2 & 41.594 & \\ 0.3 & 41.231 & 410 \\ 0.4 & 40.868 & \\ 0.5 & 40.506 & \\ 0.6 & 40.143 & 40 \\ 0.7 & 39.781 & 3 \\ 0.8 & 39.418 & 39 \\ 0.9 & 39.055 & 39\end{array}$

$41 \cdot 283$
41.558
41.195
40.832
40.470
40.107
39.744
39.382
$39 \cdot 019$

$\begin{array}{lll}42.247 & 42.210 & 4 \\ 41.884 & 41.848 & 4 \\ 41.521 & 41.485 & 4 \\ 41.158 & 41.122 & 4 \\ 40.796 & 40.760 & 40 \\ 40.433 & 40.397 & 40 \\ 40.071 & 40.034 & 39 \\ 39.708 & 39.672 & 39 \\ 39.345 & 39.309 & 39 \\ 38.983 & 38.947 & 38\end{array}$

\title{
$\begin{array}{lll}42.174 & 42 \cdot 138 & 42 \cdot 102 \\ 41.811 & 41.775 & 41.739\end{array}$
}

4200
4107
4
400
400
400
3908
390
390

$\begin{array}{ll}420029 & 410993 \\ 41.0666 & 410630\end{array}$ $\begin{array}{llllll}41.086 & 41.012 & 41.376 & 41.340 & 41.304 & 41.267\end{array}$ $\begin{array}{lllllll}40.723 & 40.687 & 40.651 & 40.615 & 40.578 & 40.542\end{array}$ $\begin{array}{llllll}40.361 & 40.324 & 40.288 & 40.252 & 40.216 & 40.179\end{array}$ $\begin{array}{llllll}39.635 & 39.962 & 39.926 & 39.8897 & 39.853 & 39.817\end{array}$

5251.0 1.1 1.2

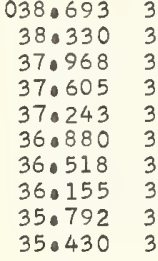$$
.001
$$$$
.002
$$$$
.003
$$

\begin{abstract}
06.334
\end{abstract}

\begin{abstract}
.06 .29
\end{abstract}$$
.006
$$$$
.007
$$

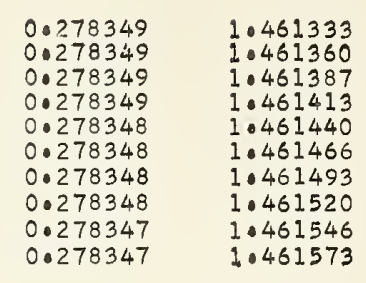

0.278347

0.278347
0.278346
0.277346

0.278346

0.278346

0.278346

0.278345

0.278345
0.278345

1.461600

1.461626

1.461680

1.461706

1.461733
1.461760

1.461786

1.461813
1.461840

0.278345

0.278344
0.278344

0.278344

0.278344

0.278344

0.278343

0.278343
0.278343

1.461866

1.461893

1.461946

1.461973

1.462026

1.462053

1.462106

0.278342

0.278342

0.278342

0.278342

0.278341

0.278341
0.278341

0.278341

0.278340

0.278340
0.278340
0.0278339

0.278340
0.278339

0.278339

0.278339
0.278339
0.278339

0.278339

0.278338

0.278338

0.278338

0.278338

0.278337
0.278337

0.278337

0.278337

0.278336
0.278336

0.278336

0.278336

0.278335

0.278335
0.278335

0.278335
0.278335

0.278335

0.278334

0.278334

0.278334

1.462133

1.462159

1.462213

1.462239

1.462266

1.462293
1.462319

1.462346
1.462372

1.462399

1.462426
1.462452

1.462452
1.462479

1.462479

1.462506
1.462532

1.462559
1.462586

1. 462586

1.462666

1.4626962

1.462719

1.462746

1.462799

1.462825

1.462852
1.462879

1.462905

0.278333

0.278333

0.278333

0.278332

0.278332

0.278332

0.278332

0.278332
0.278331

1.462932

1.462959

1. 462985

1.463039

1.463065
1.463092

1.463119

1.463145
1.463172

1.463199

1.463225

1.463252

1.463279
1.463305

1.463305
1.463332

1.463358

1.463385

1.463412
1.463438

0.278331

0.278331

0.278330

0.278330

0.278330

0.278330

0.278329
0.278329

1.463465

1.463492

1.463518

1.463572

1.463598
1.463625

1.463652

1.463678
1.463705

0.278329

0.278328

0.278328

0.278328

0.278328

0.278327

0.278327
0.278327

1.463732
1.463758
1.463785
1.463822
1.463838
1.463865
1.463891
1.463918
1.463945
1.463971

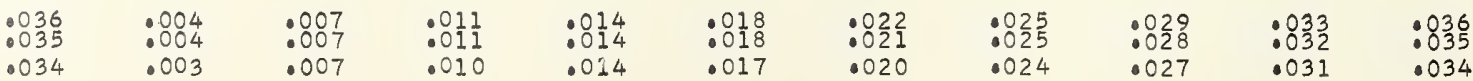


$\begin{array}{lllllllllll}5260.0 & 19006.117 & 06.081 & 06.045 & 06.009 & 05.973 & 05.937 & 05.900 & 05.865 & 05.828 & 05.792\end{array}$

0.278327 $\begin{array}{lllllllllll}0.1 & 05.756 & 05.720 & 05.684 & 05.648 & 05.612 & 05.575 & 05.539 & 05.503 & 05.467 & 05.431 \\ 0.2 & 05.395 & 05.359 & 05.323 & 05.286 & 05.250 & 05.214 & 05.178 & 05.142 & 05.105 & 05.069\end{array}$ $\begin{array}{lllllllllll}0.3 & 05.033 & 04.997 & 04.961 & 04.925 & 04.889 & 04.853 & 04.817 & 04.781 & 04.744 & 04.708\end{array}$ $\begin{array}{lllllllllll}0.4 & 0.0672 & 04.636 & 04.600 & 04.564 & 04.528 & 04.492 & 04.455 & 04.419 & 04.383 & 04.347 \\ 0.5 & 04.311 & 04.275 & 04.239 & 04.202 & 04.0466 & 04.130 & 04.094 & 04.058 & 04.022 & 03.986\end{array}$

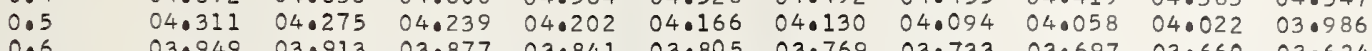
$\begin{array}{llllllllllll}0.6 & 03.949 & 03.913 & 03.877 & 03.841 & 03.805 & 03.769 & 03.733 & 03.697 & 03.650 & 03.624 \\ 0.7 & 03.588 & 03.552 & 03.516 & 03.480 & 03.444 & 03.407 & 03.372 & 03.335 & 03.299 & 03.265\end{array}$ $\begin{array}{lllllllllll}0.7 & 03.588 & 03.552 & 03.516 & 03.480 & 03.444 & 03.407 & 03.372 & 03.335 & 03.299 & 03.263 \\ 0.8 & 03.227 & 03.191 & 03.155 & 03.119 & 03.083 & 03.047 & 03.010 & 02.974 & 02.938 & 02.902 \\ 0.9 & 02.866 & 02.830 & 02.793 & 02.757 & 02.721 & 02.685 & 02.649 & 02.613 & 02.577 & 02.541\end{array}$ 0.278326
0.278326
0.278326 0.278326 0.278325 0.278325 0.278325
0.278325

0.278324

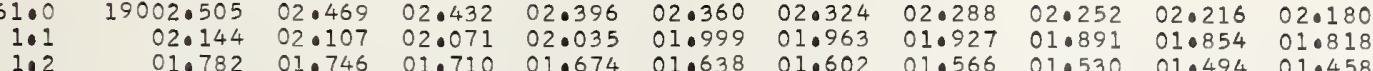

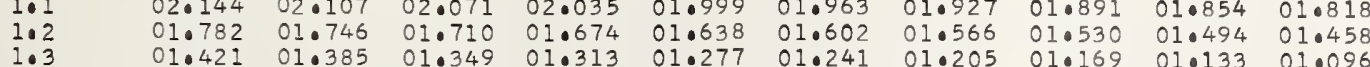

$\begin{array}{lllllllllll}1.3 & 01.421 & 01.385 & 01.349 & 01.313 & 01.277 & 01.241 & 01.205 & 01.169 & 01.133 & 01.096 \\ 1.4 & 01.060 & 01.024 & 0.088 & 00.952 & 00.916 & 00.880 & 00.844 & 00.807 & 00.771 & 00.735\end{array}$

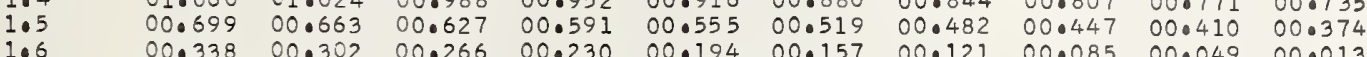

$\begin{array}{lllllllllll}1.6 & 00.338 & 00.302 & 00.266 & 00.230 & 00.194 & 00.157 & 00.121 & 00.085 & 00.049 & 00.013 \\ 1.7 & 99.977 & 99.941 & 99.905 & 99.869 & 99.833 & 99.796 & 99.760 & 99.724 & 99.688 & 99.652\end{array}$

$\begin{array}{lllllllllll}1.8 & 99.616 & 99.580 & 99.544 & 99.508 & 99.471 & 99.435 & 99.399 & 99.363 & 99.327 & 99.0291 \\ 1.8 & 99.255 & 99.219 & 99.182 & 99.146 & 99.110 & 99.074 & 99.038 & 99.002 & 98.966 & 98.930\end{array}$

0.278324

0.278324

0.278323
0.278323
0.278323

0.278323

0.278323

5262.0

\title{
2.0
2.0
2.03
2.4
2.5
2
2
2
2.8
}

$\begin{array}{rr}0 & 1899 \\ 1 & 980 \\ 2 & 980 \\ 3 & 970 \\ 4 & 970 \\ 5 & 9700 \\ 6 & 960 \\ 7 & 960 \\ 8 & 950\end{array}$

$98.532 \quad 98.858$

$98.172 \quad 98.135$

$97.450 \quad 97.414$

$96.728 \quad 95.059$

$\begin{array}{ll}98.822 & 98.7 \\ 98.460 & 98.4 \\ 98.09 & 98.063\end{array}$

$280^{2}$

$98.749 \quad 98.713 \quad 98.677 \quad 98.641 \quad 98.60598 .569$

0.278322

0.278322

0.278322

$\begin{array}{llllllll}97.738 & 97.702 & 97.666 & 97.630 & 97.594 & 97.558 & 97.0532 & 97.87 .486\end{array}$

$96.367 \quad 96.331$

$97.377 \quad 97 \cdot 341$

$97.305 \quad 97.26$

$96.944 \quad 96.908 \quad 97.233 \quad 97.197 \quad 97 \cdot 161 \quad 97.125$

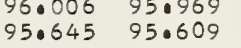

6.65596 .619

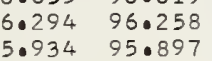

$\begin{array}{llllll}96.583 & 96.547 & 96.511 & 96.475 & 96.439 & 96.403\end{array}$

5263.0

$\begin{array}{rrrl}63.0 & 18995.284 & 95.248 & 9 \\ 3.1 & 94.923 & 94.887 & 9 \\ 3.2 & 94.562 & 94.526 & 9 \\ 3.3 & 94.201 & 94.165 & 9 \\ 3.4 & 93.840 & 93.804 & 93.7 \\ 3.5 & 93.479 & 93.443 & 9 \\ 3.6 & 93.118 & 93.082 & 9 \\ 3.7 & 92.758 & 92.722 & 9206 \\ 3.8 & 92.397 & 92.361 & 9 \\ 3.9 & 92.036 & 92.000 & 9109\end{array}$

$95.212 \quad 950176$

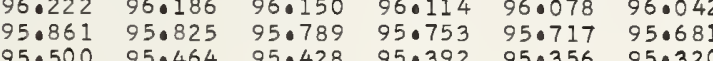

0.278321

0.278321

0.278321

0.278320

0.278320

0.278320

0.278319

0.278329

0.278319

0.278318

0.278318
0.278318

5264.0

$18991.675 \quad 91.639$

$91.675 \quad 91.639$

$91.314 \quad 911.278$

$\begin{array}{ll}90.593 & 90.557 \\ 90.232 & 90.196\end{array}$

$\begin{array}{ll}90.232 & 90.196 \\ 89.871 & 89.835\end{array}$

89.51189 .475

$\begin{array}{ll}89.150 & 89.11 \\ 88.789 & 88.753\end{array}$

$88.429 \quad 88.393$

$91.242 \quad 91.567$

$91.242 \quad 91.206$

90.52190 .485

$\begin{array}{ll}90.160 & 90.124 \\ 89.799 & 89.763\end{array}$

$\begin{array}{ll}89.439 & 89.403 \\ 89.078 & 89.042\end{array}$

$\begin{array}{ll}89.078 & 89.042 \\ 88.717 & 88.681\end{array}$

$18988.068 \quad 88.032$

$88.356 \quad 88.320$

5265.0 $87.0708 \quad 88.032$

$87.996 \quad 87.960$

$87.347 \quad 87.31$

$87.275 \quad 87.239$

86.62586 .590

$\begin{array}{ll}86.914 & 86.878 \\ 86.553 & 86.517\end{array}$

$\begin{array}{ll}86.265 & 86.229 \\ 85.904 & 85.868\end{array}$

86.19306 .157

$\begin{array}{lllll}85.544 & 85.508 & 85.472 & 85.436\end{array}$

$\begin{array}{lll}85.183 & 85.147 \\ 84.823 & 84.787\end{array}$

$\begin{array}{ll}5.472 & 85.436 \\ 5.111 & 85.075\end{array}$

$\begin{array}{ll}85.111 & 85.075 \\ 84.751 & 84.715\end{array}$

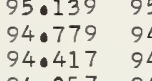

$94.057 \quad 94.021$

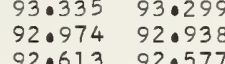

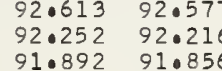

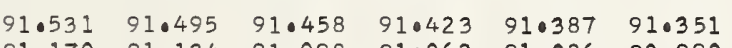

$\begin{array}{llllll}90.809 & 90.773 & 91.098 & 91.062 & 91.026 & 90.990 \\ & 90.737 & 90.701 & 90.665 & 90.629\end{array}$

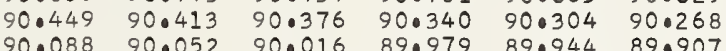

$\begin{array}{llllll}90.088 & 90.052 & 90.016 & 89.979 & 89.944 & 89.907 \\ 89.727 & 89.691 & 89.655 & 89.619 & 89.583 & 89.547\end{array}$

$\begin{array}{lllllll}89.367 & 89.331 & 89.294 & 89.258 & 89.222 & 89.186\end{array}$

$\begin{array}{llllll}89.006 & 88.969 & 88.934 & 88.898 & 88.862 & 88.825 \\ 88.645 & 88.509 & 88.573 & 88.537 & 88.501 & 88.465\end{array}$

$\begin{array}{llllll}88.284 & 88.249 & 88.212 & 88.176 & 88.140 & 88.104\end{array}$

0.27831

0.278317

0.278317

0.278316

0.278316

0.278316

0.278315

$\begin{array}{lllllll}87.924 & 87.888 & 87.852 & 87.816 & 87 \cdot 780 & 87.744 \\ 87.563 & 87.527 & 87.491 & 87.455 & 87.419 & 87.383\end{array}$

$\begin{array}{llllll}87.563 & 87.527 & 87.491 & 87.455 & 87.419 & 87.383 \\ 87.202 & 87.167 & 87.131 & 87.094 & 87.058 & 87.022\end{array}$

$\begin{array}{lllllll}86.842 & 86.806 & 86.770 & 86.734 & 86.698 & 86.662\end{array}$

$\begin{array}{llllll}86.481 & 86.445 & 86.409 & 86.373 & 86.337 & 86.301 \\ 86.121 & 86.085 & 86.049 & 86.013 & 85.977 & 85.940\end{array}$

$\begin{array}{lllllll}85.760 & 85.724 & 85.0488 & 86.0132 & 85.977 & 85.95 \\ 85.652 & 85.616 & 85.580\end{array}$

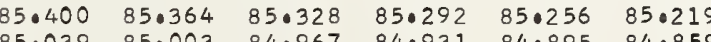

5.8
5.9

5266.0

66.0
6.1
6.2
6.3
6.4
6.5
6.6
6.7
6.0
6.0

18984.462

84.462
84.102 84.426

$84.390 \quad 84.354$

$\begin{array}{llll}84.678 & 84.643 & 84.607\end{array}$

$\begin{array}{lll}84 \cdot 931 & 84 \cdot 895 & 84.859 \\ 84.571 & 84.534 & 84.498\end{array}$

$\begin{array}{lllllll}84.318 & 84.282 & 84.246 & 84.210 & 84.174 & 84.138 \\ 83.958 & 83.922 & 83.885 & 83.849 & 83.813 & 83.777\end{array}$

$83.741 \quad 83.705 \quad 83.669 \quad 83.633$

$\begin{array}{llll}83.381 & 83.345 & 83.309 & 83.273 \\ 83.021 & 82.984 & 82.948 & 82.912\end{array}$

$\begin{array}{llll}83.021 & 82.984 & 82.948 & 82.912 \\ 82.660 & 82.524 & 82.588 & 82.552\end{array}$

$\begin{array}{lllll}82.300 & 82.263 & 82.227 & 82.192\end{array}$

$\begin{array}{llll}81.939 & 81.903 & 81.867 & 81.831 \\ 81.579 & 81.542 & 81.507 & 81.471\end{array}$

$\begin{array}{llll}81.579 & 81.542 & 81.507 & 81.471 \\ 81.218 & 81.182 & 81.146 & 81.110\end{array}$

5267.0

67.0
7.0
702
703
704
705
7.6
7.07
709

$\begin{array}{rrrr}18980.858 & 80.822 & 80.786 & 80.750 \\ 80.498 & 80.461 & 80.425 & 80.389\end{array}$

$\begin{array}{llll}80.137 & 80.101 & 80.425 & 80.389 \\ 79.777 & 79.06 & 80.029 \\ 79.417 & 79.005 & 790.669\end{array}$

$\begin{array}{lllll}79.7477 & 79.741 & 79.705 & 79.669 \\ 79.417 & 79.380 & 79.344 & 79.308\end{array}$

$\begin{array}{llll}79.056 & 79.020 & 78.984 & 78.948 \\ 78.596 & 78.660 & 78.624 & 78.588\end{array}$

$\begin{array}{llll}78 \cdot 336 & 78 \cdot 300 & 78 \cdot 264 & 78 \cdot 228 \\ 77.975 & 77.0939 & 77.903 & 77.867 \\ 77.615 & 77.579 & 77.543 & 77.507\end{array}$

\begin{tabular}{llllll} 
& 83.922 & 83.885 & 83.849 & 83.813 & 83.777 \\
\hline 3.597 & 83.567 & 83.525 & 83.489 & 83.453 & 83.417
\end{tabular}

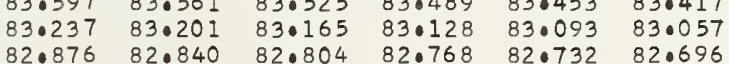

$\begin{array}{llllll}82.876 & 82.840 & 82.804 & 82.768 & 82.732 & 82.696 \\ 82.516 & 82.480 & 82.444 & 82.408 & 82.372 & 82.336\end{array}$

$\begin{array}{lllllll}82.156 & 82.119 & 82.083 & 82.047 & 82.011 & 81.975 \\ 81.795 & 81.759 & 81.723 & 81.687 & 81.651 & 81.615\end{array}$

$\begin{array}{llllll}81.795 & 81.759 & 81.723 & 81.687 & 81.651 & 81.615 \\ 81.435 & 81.398 & 81.363 & 81.326 & 81.291 & 81.254 \\ 81.074 & 81.038 & 81.002 & 80.966 & 80.930 & 80.894\end{array}$

0.278315

0.278315

0.278314

0.278314

0.278314
0.278313

0.278313

0.278313

0.278313

0.278312

0.278312

0.278312

0.278311

0.278311

0.278311

0.278310

0.278310
0.278310

0.278310

0.278310

0.278309

0.278309

$\begin{array}{lllllllllll}5268.0 & 18977.255 & 77.219 & 77.183 & 77.147 & 77.111 & 77.075 & 77.039 & 77.003 & 76.967 & 76.931\end{array}$

$\begin{array}{lllllllllll}76.895 & 76.859 & 76.823 & 76.787 & 76.751 & 76.715 & 76.679 & 76.643 & 76.607 & 76.571\end{array}$

$\begin{array}{llllllllll}76.535 & 76.499 & 76.463 & 76.427 & 76.391 & 76.354 & 76.0719 & 76.282 & 76.246 & 76.210\end{array}$

$\begin{array}{llllllllll}76 \cdot 174 & 76 \cdot 138 & 76 \cdot 103 & 76 \cdot 066 & 76 \cdot 030 & 75 \cdot 994 & 75 \cdot 958 & 75 \cdot 922 & 75 \cdot 886 & 75 \cdot 850 \\ 75.814 & 75.778 & 75.742 & 75.706 & 750670 & 75.634 & 75.598 & 75.562 & 75.526 & 75 \cdot 490\end{array}$

$\begin{array}{llllllllll}75.454 & 75.418 & 75.382 & 75.346 & 75.310 & 75.274 & 75.238 & 75.202 & 75.166 & 75.130\end{array}$

$\begin{array}{lllllllllll}75.094 & 75.058 & 75.022 & 74.986 & 74.950 & 74.914 & 74.878 & 74.842 & 740806 & 74.770\end{array}$

$\begin{array}{llllllllll}74.734 & 74.698 & 74.662 & 74.626 & 74.590 & 74.553 & 74.518 & 74.482 & 740.446 & 74.410\end{array}$

$\begin{array}{lllllllllll}74.374 & 74.338 & 74.302 & 74.266 & 74.230 & 74 \cdot 194 & 74 \cdot 158 & 740122 & 74 \cdot 086 & 74 \cdot 050 \\ 74.014 & 73.978 & 73.941 & 73.905 & 73.869 & 73.833 & 73.797 & 73.761 & 73.725 & 73.689\end{array}$

0.278309

0.278308

0.278308
0.278308

0.278308

0.278307

0.278307

0.278307
0.278307

1.464051

1.464078

1.464131

1.464158

1.464211
1.464238

1.064263
1.064291

1.464318

1.464371

1. 464398

1.464424
1.464451

1.464478

1.464531

1.464558

1.464611

1.464638

1.464664
1.464691

1.464718

1.464744
1.464771

1.464824

1.464878

1.464904

1.464931

1.464984

1.465011

1.465064

1.465091

1.465117

1.465171

1.465197

1.465224

1.465277

1.465331

1.465357
1.465384

1.465411

1.465437

1.465464

1.465517
1.465544

1.465570

.465597

1.465624

1.465650

.0465704

1.465730

1.465784

.0465810

1.465864

1.465890

1.465917

1.465944
1.065970

1.465997

.466023
.466050

1.466077

1.466130

1.466157

1.466210

1.466263

1.466317

1.466343

$\begin{array}{lllllllllll}5269.0 & 18973.653 & 73.617 & 73.582 & 73.545 & 73.509 & 73.473 & 73.437 & 73.402 & 73 \cdot 365 & 73.329\end{array}$

$\begin{array}{llllllllllll}9.1 & 73.293 & 73.257 & 73.221 & 73.186 & 73.149 & 73.113 & 73.077 & 73.041 & 73.005 & 72.969\end{array}$

0.278306

0.278306

0.278306

0.278306

0.278305

0.278305

0.278305

0.278305
0.278304

1.465397

1.466450

1.466477

1.466503
1.466530

1.466557

1.466583

1.466610

.010

.036

70.41370 .3

\begin{abstract}
$\begin{array}{lll}70.341 \quad 70 \\ .002 & .003\end{array}$
\end{abstract}
.004

.005

.006

.007

.009

.036 

$66.814 \quad 66.778 \quad 66.742$

$$
\begin{array}{r}
1.1 \\
1.2 \\
1.3 \\
1.4 \\
1.5 \\
1.5 \\
1.7 \\
1.8 \\
1.9 \\
5272.0 \\
2.1 \\
2.2 \\
2.3 \\
2.4 \\
2.5 \\
2.5 \\
2.7 \\
2.8 \\
2.0
\end{array}
$$

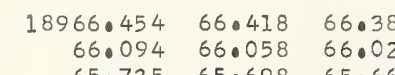

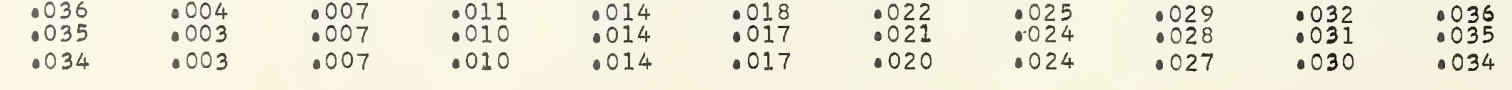

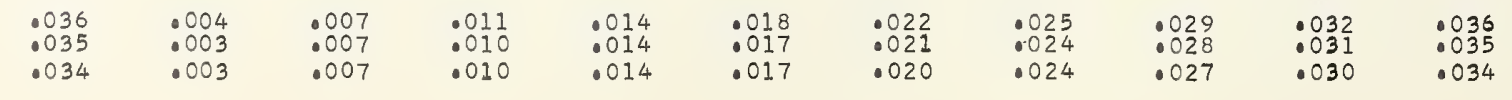

.010 


\begin{tabular}{|c|c|c|c|c|c|c|c|c|}
\hline$\lambda(A)$ & .00 & .01 & .02 & .03 & .04 & .05 & .06 & .07 \\
\hline 5280.0 & $18934 \cdot 125$ & 34.089 & 34.053 & 34.018 & 33. & 33.946 & 33.910 & 33.874 \\
\hline $\begin{array}{l}0.1 \\
0.2\end{array}$ & $\begin{array}{l}33.767 \\
33.408\end{array}$ & 3.731 & $\begin{array}{l}33.695 \\
33.336\end{array}$ & $\begin{array}{l}33.659 \\
33.301\end{array}$ & $\begin{array}{l}33.623 \\
33.265\end{array}$ & $\begin{array}{l}33.587 \\
33.279\end{array}$ & 33.552 & \\
\hline 0.3 & $\begin{array}{l}33.408 \\
33.050\end{array}$ & $\begin{array}{l}33.372 \\
33.014\end{array}$ & $\begin{array}{l}33.336 \\
32.078\end{array}$ & $\begin{array}{l}\begin{array}{l}33.301 \\
32.942\end{array}\end{array}$ & $\begin{array}{l}33.265 \\
32.906\end{array}$ & $\begin{array}{l}33.229 \\
32.870\end{array}$ & $\begin{array}{l}33.193 \\
33.834\end{array}$ & $\begin{array}{l}33.157 \\
33.799\end{array}$ \\
\hline 0.4 & 32.691 & $\begin{array}{l}32.014 \\
32.655\end{array}$ & 32.619 & 32.583 & 32.547 & 32.512 & $\begin{array}{l}\begin{array}{l}32.834 \\
32.476\end{array} \\
32\end{array}$ & $\begin{array}{l}\begin{array}{l}32.999 \\
32.440\end{array} \\
32.04\end{array}$ \\
\hline 0.5 & 32.332 & 32.297 & 32.261 & 32.225 & 32.189 & 32.153 & 32.117 & 32.082 \\
\hline 0.6 & 31.974 & 31.938 & 31.902 & 31.866 & 31.831 & 31.795 & 31.759 & 31.723 \\
\hline 0.7 & $31 \cdot 615$ & 31.580 & 31.544 & 31.508 & 31.472 & 31.436 & 31.400 & $31 \cdot 365$ \\
\hline $\begin{array}{l}0.8 \\
0.9\end{array}$ & $\begin{array}{l}31.257 \\
30.898\end{array}$ & $\begin{array}{l}31.221 \\
30.863\end{array}$ & $\begin{array}{l}31.185 \\
30.827\end{array}$ & & $\begin{array}{l}31.114 \\
30.755\end{array}$ & $\begin{array}{l}31.078 \\
30.719\end{array}$ & $\begin{array}{l}31.042 \\
30.083\end{array}$ & $\begin{array}{l}31.006 \\
30.0647\end{array}$ \\
\hline & & 30.504 & 30004 & & 30.13 & 300119 & 30.083 & 30.041 \\
\hline 1.1 & $\begin{array}{r}18930.181 \\
30.184\end{array}$ & $\begin{array}{l}30.146 \\
30.146\end{array}$ & 30.110 & $\begin{array}{l}30.433 \\
30.074\end{array}$ & $\begin{array}{l}30.397 \\
30.038\end{array}$ & 30.002 & $\begin{array}{l}30.325 \\
29.966\end{array}$ & $\begin{array}{l}30.289 \\
29.931\end{array}$ \\
\hline $1 \cdot 2$ & 29.823 & $29 \cdot 787$ & 29.751 & $29 \cdot 716$ & 29.680 & 29.644 & 29.608 & 29.573 \\
\hline 103 & 29.465 & 29.429 & 29.393 & $29 \cdot 357$ & $29 \cdot 322$ & 29.286 & 29.250 & 29.214 \\
\hline $\begin{array}{l}1.4 \\
1.5\end{array}$ & $\begin{array}{l}29.106 \\
28.748\end{array}$ & 29.071 & 29.035 & 28.999 & 28.963 & 28.927 & 28.892 & 28.856 \\
\hline $\begin{array}{l}1.5 \\
1.6\end{array}$ & $\begin{array}{l}28.748 \\
28.390\end{array}$ & $28 \cdot 712$ & 28.677 & 28.641 & 28.605 & 28.569 & 28.533 & 28.497 \\
\hline $\begin{array}{l}1.6 \\
1.7\end{array}$ & $\begin{array}{l}28.390 \\
28.031\end{array}$ & $28 \cdot 354$ & 28.318 & $28 \cdot 282$ & 28.246 & 28.210 & 28.175 & 28.139 \\
\hline 1.8 & $\begin{array}{l}28.031 \\
27.673\end{array}$ & $\begin{array}{l}27.996 \\
27.037\end{array}$ & $\begin{array}{l}27.960 \\
27.601\end{array}$ & $\begin{array}{l}27.924 \\
27.565\end{array}$ & $\begin{array}{l}27 \cdot 888 \\
27.530\end{array}$ & $\begin{array}{l}27.852 \\
27.494\end{array}$ & $\begin{array}{l}27 \cdot 816 \\
27.458\end{array}$ & $\begin{array}{l}27.780 \\
27.427\end{array}$ \\
\hline 1.9 & 27.315 & $\begin{array}{l}27.279 \\
\end{array}$ & 27.243 & 27.207 & 27.171 & 27.135 & 27.100 & 27.064 \\
\hline $\begin{array}{l}32.0 \\
2.1\end{array}$ & 18926.956 & . 920 & 26.885 & 26.849 & 26.813 & 26.777 & 26.741 & 26.706 \\
\hline & & & & & & 26.419 & & 347 \\
\hline $\begin{array}{l}2.2 \\
2.3\end{array}$ & $\begin{array}{l}26.240 \\
25.881\end{array}$ & $26 \cdot 204$ & 26.168 & $26 \cdot 132$ & 26.096 & 26.060 & 26.025 & $25 \cdot 989$ \\
\hline 2.4 & $\begin{array}{l}25.881 \\
25.523\end{array}$ & $\begin{array}{l}25.845 \\
25.487\end{array}$ & $\begin{array}{l}25.810 \\
25.451\end{array}$ & $\begin{array}{l}25.774 \\
25.415\end{array}$ & $\begin{array}{l}25.738 \\
25.380\end{array}$ & $\begin{array}{l}25.722 \\
25.344\end{array}$ & $\begin{array}{l}25.666 \\
25.308\end{array}$ & $\begin{array}{l}25.631 \\
25.272\end{array}$ \\
\hline 2.5 & 25.165 & 25.129 & 25.093 & 25.057 & 25.021 & 24.986 & & 24.914 \\
\hline 2.6 & $24 \cdot 807$ & 24.771 & 24.735 & 24.699 & 24.663 & 24.627 & 24.592 & 24.556 \\
\hline 2.7 & $24 \cdot 448$ & 24.412 & 24.377 & $24 \cdot 341$ & & 24.269 & 24.233 & 24.198 \\
\hline $\begin{array}{l}2.8 \\
2.9\end{array}$ & $\begin{array}{l}24.090 \\
23.732\end{array}$ & $\begin{array}{l}24.054 \\
23.696\end{array}$ & $\begin{array}{l}24.019 \\
23.660\end{array}$ & $\begin{array}{l}23.983 \\
23.624\end{array}$ & $\begin{array}{l}23.947 \\
23.588\end{array}$ & $\begin{array}{l}23.911 \\
23.553\end{array}$ & $\begin{array}{l}23.875 \\
23.517\end{array}$ & $\begin{array}{l}23.839 \\
23.481\end{array}$ \\
\hline 52 & & & 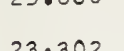 & & & 230 & 23.517 & 23.481 \\
\hline 302 & 15 & 22.979 & $\begin{array}{l}23.302 \\
22.944\end{array}$ & $\begin{array}{l}23.266 \\
22.908\end{array}$ & $\begin{array}{l}23.230 \\
22.872\end{array}$ & $\begin{array}{l}23.195 \\
22.836\end{array}$ & $\begin{array}{l}23.159 \\
22.801\end{array}$ & $\begin{array}{l}23.123 \\
22.765\end{array}$ \\
\hline $\begin{array}{l}3 \cdot 2 \\
3 \cdot 3\end{array}$ & 22.657 & 22.622 & 22.586 & 22.550 & 22.514 & 22.478 & 22.443 & 22.407 \\
\hline $\begin{array}{l}3 \cdot 3 \\
3 \cdot 4\end{array}$ & 22.299 & $\begin{array}{l}22.263 \\
21005\end{array}$ & 22.228 & 22.192 & 22.156 & 22.120 & 22.084 & 22.048 \\
\hline $\begin{array}{l}3.4 \\
3.5\end{array}$ & $\begin{array}{l}21.941 \\
21.5833\end{array}$ & 21.905 & 21.869 & $\begin{array}{l}21.833 \\
21.475\end{array}$ & $\begin{array}{l}21.798 \\
21.439\end{array}$ & 21.762 & 21.726 & $\begin{array}{l}21.690 \\
21.332\end{array}$ \\
\hline $\begin{array}{l}3.0 \\
3.6\end{array}$ & 21.225 & 21.189 & $\begin{array}{l}21.011 \\
21.153\end{array}$ & $\begin{array}{l}21.415 \\
21.117\end{array}$ & $\begin{array}{l}21.439 \\
21.082\end{array}$ & & $21 \cdot 368$ & $\begin{array}{l}21.332 \\
20.974\end{array}$ \\
\hline 3.7 & 20.867 & 20.831 & 20.795 & 20.759 & 20.723 & 20.687 & 20.652 & 20.616 \\
\hline 3.8 & $20 \cdot 508$ & $20 \cdot 473$ & 20.437 & $20 \cdot 401$ & 20.365 & 20.330 & 20.294 & 20.258 \\
\hline 3.9 & $20 \cdot 151$ & 20.115 & 20.079 & 20.043 & 20.007 & $19 \cdot 972$ & 19.936 & 19.900 \\
\hline $\begin{array}{r}5284.0 \\
4.1\end{array}$ & $\begin{array}{r}18919.792 \\
19.434\end{array}$ & $\begin{array}{l}19.757 \\
19.398\end{array}$ & $\begin{array}{l}19.721 \\
19.363\end{array}$ & $\begin{array}{l}19.685 \\
19.327\end{array}$ & $\begin{array}{l}19.649 \\
19.291\end{array}$ & $\begin{array}{l}19.613 \\
19.255\end{array}$ & $\begin{array}{l}19.577 \\
19.219\end{array}$ & $\begin{array}{l}19.542 \\
19.184\end{array}$ \\
\hline 4.2 & 19.076 & 19.041 & $\begin{array}{l}19.005 \\
\end{array}$ & $\begin{array}{l}18.969 \\
1896\end{array}$ & 18.933 & 18.897 & 18.862 & 18.826 \\
\hline $4 \cdot 3$ & 18.718 & 18.682 & 18.647 & 18.611 & 18.575 & 18.539 & 18.503 & 18 \\
\hline $4 \cdot 4$ & 18.360 & $18 \cdot 324$ & 18.289 & $18 \cdot 253$ & 18.217 & $18 \cdot 181$ & 18.146 & $18 \cdot 110$ \\
\hline 405 & 18.002 & $17 \cdot 967$ & 17.931 & $17 \cdot 895$ & 17.859 & 17.823 & 17.787 & 17.752 \\
\hline $4 \cdot 6$ & 17.644 & 17.609 & 17.573 & 17.537 & 17.501 & 17.465 & 17.429 & 17.394 \\
\hline 4.7 & 17.286 & $17 \cdot 250$ & 17.215 & $17 \cdot 179$ & $17 \cdot 143$ & 17.107 & 17.072 & 17.036 \\
\hline $\begin{array}{l}4.8 \\
4.9\end{array}$ & $\begin{array}{l}16.928 \\
16.570\end{array}$ & & $\begin{array}{l}16.857 \\
16.499\end{array}$ & $\begin{array}{l}16.821 \\
16.463\end{array}$ & $16 \cdot 785$ & 16.749 & 16.713 & 16.678 \\
\hline $4 \cdot 9$ & 16. & 16.535 & 16.499 & 16.463 & 16.427 & 16.392 & 16.356 & $16 \cdot 320$ \\
\hline $\begin{array}{r}5285.0 \\
5.1\end{array}$ & $\begin{array}{r}18916.212 \\
15.854\end{array}$ & $\begin{array}{l}16.177 \\
15.819\end{array}$ & $\begin{array}{l}16.141 \\
15.783\end{array}$ & & $\begin{array}{l}16.069 \\
15.711\end{array}$ & $\begin{array}{l}16.033 \\
15.676\end{array}$ & & \\
\hline $\begin{array}{l}5.1 \\
5.2\end{array}$ & 15.497 & 15.461 & 15.425 & 15.389 & 15.354 & $\begin{array}{l}15.018 \\
15.318\end{array}$ & 15.282 & \\
\hline 5.3 & $15 \cdot:$ & $15 \cdot 103$ & $15 \cdot 0$ & $15 \bullet$ & & & & \\
\hline 5.4 & 14.781 & $14 \cdot 745$ & 14.709 & $140^{\circ}$ & 14. & 14. & & \\
\hline 5.5 & 14.423 & 14.387 & $14 \cdot 351$ & 14. & 14. & 14. & 140 & 3 \\
\hline 5.6 & 14.065 & 14.029 & 13. & 13 • & 13. & 13. & 13 . & \\
\hline 5.7 & 13.708 & 13.672 & 13. & & & 13. & & \\
\hline $\begin{array}{l}5.8 \\
5.9\end{array}$ & $\begin{array}{l}13.349 \\
12.992\end{array}$ & $13 \cdot 314$ & 13.278 & 13.242 & 13.207 & $13 \cdot 171$ & $13 \cdot 135$ & \\
\hline & 12.992 & $12 \cdot 956$ & 12.920 & $12 \cdot 885$ & $12 \cdot 848$ & 12.813 & 12.777 & 12.741 \\
\hline $\begin{array}{r}5286.0 \\
6.1\end{array}$ & $\begin{array}{r}18912.634 \\
12.276\end{array}$ & $\begin{array}{l}12.598 \\
12.240\end{array}$ & 12.562 & 12.527 & 12.491 & 12.455 & 12.419 & 12.384 \\
\hline $\begin{array}{l}6.1 \\
6.2\end{array}$ & $\begin{array}{l}12.210 \\
11.918\end{array}$ & 11.883 & 120 & $\begin{array}{l}122: \\
11 .\end{array}$ & 110 & $\begin{array}{l}12 \\
11\end{array}$ & $12:$ & 120 \\
\hline 6.3 & 11.561 & 11.525 & 11 & 11 . & 11 & 11. & 11 \% & 11. \\
\hline 6.4 & 11.203 & 11.167 & 11.131 & 11. & 11. & 11 . & & 10. \\
\hline 6.5 & 10.845 & 10.810 & 10.7 & 10. & 10. & 10 & 10. & \\
\hline 6.6 & 10.487 & 10.451 & $10 \cdot 4$ & 10. & 10. & 10. & 10. & 10 \\
\hline 6.7 & $10 \cdot 130$ & 10.094 & 10.0 & 10. & 09. & 09. & 09. & 09 \\
\hline 0.8 & 09.772 & 09.736 & 09. & & 09. & 09 & & 09 \\
\hline 6.9 & 09.414 & 09.379 & 09.343 & 09.307 & 09.271 & 09.236 & 09.200 & 09.164 \\
\hline .0 & 909.057 & 09.021 & .985 & 49 & $8 \cdot 914$ & 08.878 & 08.842 & 8.806 \\
\hline & & & & & & & & \\
\hline $7 \cdot 2$ & 08 & 08 & 08 & 4 & 08 & 08 & & \\
\hline $7 \cdot 3$ & 4 & 07. & & & & & & \\
\hline $7 \cdot 4$ & 6 & $07^{\circ}$ & & & & & & \\
\hline $7 \cdot 5$ & 9 & 07 & & & 07. & & & \\
\hline $7 \cdot 6$ & 06. & 06.875 & & & 06. & 060 & 06 & \\
\hline $7 \cdot 7$ & 3 & $06^{\circ}$ & 06 & & $060^{\circ}$ & & 05. & 06. \\
\hline $\begin{array}{l}7: 8 \\
7: 9\end{array}$ & $\begin{array}{l}06.196 \\
05.839\end{array}$ & $\begin{array}{l}06 \cdot 160 \\
05.802\end{array}$ & $\begin{array}{l}06.125 \\
05.767\end{array}$ & $\begin{array}{l}06.089 \\
05.731\end{array}$ & $\begin{array}{l}06.053 \\
05.695\end{array}$ & $\begin{array}{l}06.017 \\
05.660\end{array}$ & $\begin{array}{l}05.981 \\
05.624\end{array}$ & $\begin{array}{l}05.946 \\
05.589\end{array}$ \\
\hline & & & & & & & & \\
\hline & $\begin{array}{r}18905.481 \\
05.124\end{array}$ & $\begin{array}{l}05.445 \\
05.088\end{array}$ & $\begin{array}{l}05.410 \\
05.052\end{array}$ & $\begin{array}{l}05.374 \\
05.017\end{array}$ & $\begin{array}{l}05.338 \\
04.981\end{array}$ & $\begin{array}{l}05.302 \\
04.945\end{array}$ & $\begin{array}{l}05.267 \\
04.909\end{array}$ & $\begin{array}{l}05.231 \\
04.874\end{array}$ \\
\hline & & & & & & & & \\
\hline & 04.409 & 04.373 & 04.3 & 2 & 04. & & 040 & \\
\hline 8. & 04.051 & 04.015 & 03.9 & 4 & 03. & 0 & 03. & \\
\hline 8. & 03.694 & 03.658 & 03.6 & 6 & & & 03. & \\
\hline 8 & & 03.301 & 03.2 & 0 & 03. & 03. & 03.1 & \\
\hline 8. & & 02.943 & 02. & 72 & 02. & 02.800 & 02.7 & 02. \\
\hline 8.8 & 02.622 & 02.586 & 02.550 & 02.514 & 02.479 & 02.443 & 02.407 & \\
\hline 8.9 & 02.264 & 02.228 & 02.193 & 02.157 & 02.121 & 02.085 & 02.050 & 02.014 \\
\hline & & & & & & & & \\
\hline & & & & & & & & \\
\hline & & & & & & & & \\
\hline & & & & & & & & \\
\hline & $\begin{array}{l}7 \\
0\end{array}$ & & & & & & & \\
\hline & $\begin{array}{l}00.120 \\
99.763\end{array}$ & $\begin{array}{l}00.084 \\
99.727\end{array}$ & $\begin{array}{l}00.048 \\
99.691\end{array}$ & $\begin{array}{l}00.013 \\
99.656\end{array}$ & *99. & $\begin{array}{r}* 99.941 \\
99.584\end{array}$ & $\begin{array}{r}* 99.906 \\
99.548\end{array}$ & $\begin{array}{r}* 99.870 \\
99.512\end{array}$ \\
\hline 9.7 & $\begin{array}{l}99.163 \\
99.406\end{array}$ & 99.370 & 99.334 & 9.298 & 99.262 & 99.227 & 99.191 & 99.155 \\
\hline 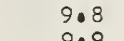 & $\begin{array}{r}99.048 \\
98.0691\end{array}$ & 99.012 & 98.619 & 98.584 & 08.548 & 98.869 & 98.834 & 98.798 \\
\hline & & & & & & & & 98.441 \\
\hline
\end{tabular}




.01

.02

.03

5290.

0.1

0.4

0.7

0.9

529100

1.0

103

1.4

1.6

1. 8

5292.0

201

202

2.4

206

2.8

5293.0

3.2

3.3

3.5

3.7

3.8
3.9

52940

$4 \cdot 2$

403

4.4

4.6

4.7
4.8

5295

55

5.3

5.6

5.7
5.8
5.9

5296

6.1
6.2
6.3
6.4
6.5
6.6
6.7
6.8
6.9

297

29700
701
702
7.3
7.4
7.5
7.5
7.7
7.8
709

5298.0

8.1
8.2
8.3
8.4
8.5
8.6
8.7
8.8
8.9

5299.0

9.1
9.2
9.3

9.4

9.6

9.8
9.9

$\begin{array}{rllll}889.333 & 98.298 & 98.262 & 98.226 & 98 . \\ 97.976 & 97.941 & 97.905 & 97.869 & 970 \\ 97.619 & 97.583 & 97.548 & 97.512 & 970 \\ 97.262 & 97.226 & 97.191 & 97.155 & 970 \\ 96.905 & 96.869 & 96.833 & 96.797 & 96 \\ 96.547 & 96.512 & 96.476 & 96.440 & 960 \\ 96.190 & 96.155 & 96.119 & 96.083 & 960 \\ 95.833 & 95.797 & 95.762 & 95.726 & 95 \\ 95.476 & 95.440 & 95.405 & 95.369 & 95 \\ 95.119 & 95.083 & 95.047 & 95.012 & 94\end{array}$

$\begin{array}{rr}894.762 & 94.726 \\ 94.405 & 94.369 \\ 94.048 & 94.012 \\ 93.690 & 93.655 \\ 93.333 & 93.298 \\ 92.976 & 92.941 \\ 92.619 & 92.583 \\ 92.262 & 92.227 \\ 91.905 & 91.869 \\ 91.548 & 91.513\end{array}$

94.69

94.655

$\begin{array}{ll}94.333 & 94.298 \\ 93.976 & 93.940\end{array}$

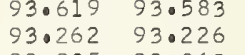

$92.905 \quad 92.869$

92.19192 .155

91.834
91.477

$18891 \cdot 191$

$90.834 \quad 90.79$

90.47790 .442

$89.763 \quad 89.728$

$89.406 \quad 89.371$

$88.693 \quad 88.657$

$\begin{array}{ll}88.336 & 88.300 \\ 87.979 & 87.943\end{array}$

$18887.622 \quad 87.587$

$\begin{array}{ll}87.265 & 87.230 \\ 86.909 & 86.873\end{array}$

86.55286 .51

86.195
85.838
85.150

$\begin{array}{ll}85.481 & 85.446 \\ 85.125 & 85.08\end{array}$

$\begin{array}{ll}84.768 & 84.732 \\ 84.411 & 84.375\end{array}$

8884.054

$83.698 \quad 83.66$

$\begin{array}{ll}83.341 & 83.305 \\ 82.984 & 82.949\end{array}$

$82.628 \quad 82.592$

$82.271 \quad 82.23$

$81.558 \quad 81.522$

$\begin{array}{ll}81.202 & 81.166 \\ 80.845 & 80.809\end{array}$

18880.488

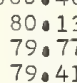

$79.418 \quad 79.383$

$79.062 \quad 79.027$

$78.706 \quad 78.670 \quad 78.6$

$\begin{array}{llll}78.313 & 78.278 & 78.242\end{array}$

$\begin{array}{ll}77.636 & 77.601 \\ 77.280 & 77.244\end{array}$

$91.120 \quad 91.084$

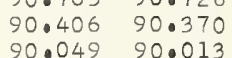

$\begin{array}{ll}89.692 & 89.656 \\ 89.335 & 89.300\end{array}$

$\begin{array}{ll}88.978 & 88.943 \\ 88.622 & 88.586\end{array}$

$\begin{array}{ll}88.265 & 88.229 \\ 87.908 & 87.872\end{array}$

$87.551 \quad 87.515 \quad 87.479$

$86.837 \quad 86.802$

$86.124 \quad 86.088$

$\begin{array}{ll}85.767 & 85.731 \\ 85.410 & 85.375\end{array}$

$\begin{array}{ll}85.053 & 85.018 \\ 84.697 & 84.661\end{array}$

$83.983 \quad 83.94$

$\begin{array}{ll}83.270 & 83.234 \\ 82.913 & 82.878\end{array}$

$\begin{array}{ll}82.556 & 82.521 \\ 82.200 & 82.164\end{array}$

$81.843 \quad 81.808$

$81.130 \quad 81.095$

$87.123 \quad 87.444$

$86.766 \quad 86.730$

$86.409 \quad 86.373$

$86.052 \quad 86.017 \quad 85.981$

$\begin{array}{lll}85.695 & 85.660 & 85.624\end{array}$

$84.982 \quad 84.946$

$\begin{array}{lll}84.625 & 84.590 & 84.55\end{array}$

$83.912 \quad 83.876$

83.84

$83.555 \quad 83.51$

$\begin{array}{lll}83.198 & 83.163 & 83.127\end{array}$

$\begin{array}{ll}82.485 & 82.449 \\ 82.128 & 82.093\end{array}$

$81.772 \quad 81.736 \quad 81.700$
$81.0416 \quad 81.380 \quad 81.344$

$\begin{array}{lll}1.416 & 81.380 & 81.344 \\ 81.059 & 81.023 & 80.988\end{array}$

\section{$80.417 \quad 80.3$}

80.70

\begin{abstract}
80.346
\end{abstract}
780.631

0.63677 .601

18876.923

$$
\begin{aligned}
& 76.5 \\
& 76.2 \\
& 75.8 \\
& 75.4 \\
& 75.1 \\
& 74.7 \\
& 74.4 \\
& 74.07 \\
& 73.7
\end{aligned}
$$

$\begin{array}{ll}76.567 & 76.531 \\ 76.210 & 76.175\end{array}$

76.175
76.13

7.4987 .462

$\begin{array}{ll}74.749 \\ 7.429 & 74.393\end{array}$

$\begin{array}{ll}74.072 & 74.036 \\ 73.716 & 73.680\end{array}$

18873.360

73.00372 .968

$\begin{array}{ll}72.647 & 72.6 \\ 72.291 & 72.25\end{array}$

$71.93572 .255 \quad 72.21$

$\begin{array}{lll}71.578 & 71.543 & 71.507 \\ 71.222 & 71.187 & 71.151\end{array}$

$\begin{array}{lll}71.222 & 71.187 & 71.15 \\ 70.866 & 70.830 & 70.79 \\ 70.510 & 70.474 & 70.43\end{array}$

$\begin{array}{ll}70.510 & 70.474 \\ 70.154 & 70.118\end{array}$

$18869.797 \quad 69.762$

$\begin{array}{ll}69.441 & 69.4 \\ 69.085 & 69.0\end{array}$

$68.729 \quad 68.693$

$\begin{array}{ll}68.373 & 68.33 \\ 68.017 & 67.98\end{array}$

$67.660 \quad 67.625$

$\begin{array}{ll}67.304 & 67.269 \\ 66.948 & 66.913\end{array}$

$\begin{array}{ll}66.948 & 66.911 \\ 66.592 & 66.557\end{array}$

$77.921 \quad 77.886$

$77 \cdot 565 \quad 77 \cdot 529$

$\begin{array}{llllll}79.989 & 79.954 & 79.918 & 79.882 & 79.846 & 79.811 \\ 79.633 & 79.597 & 79.562 & 79.526 & 79.490 & 79.454 \\ 79.276 & 79.240 & 79.205 & 79.169 & 79.134 & 79.098 \\ 78.919 & 78.884 & 78.848 & 78.813 & 78.777 & 78.741\end{array}$

$\begin{array}{llllll}78.919 & 78.884 & 78.848 & 78.813 & 78.777 & 78.741 \\ 78.563 & 78.527 & 78.492 & 78.456 & 78.420 & 78.385\end{array}$

$\begin{array}{lllllll}78.207 & 78.171 & 78.135 & 78.100 & 78.064 & 78.028\end{array}$

$\begin{array}{lllllll}77.850 & 77.814 & 77.779 & 77.743 & 77.708 & 77.672\end{array}$

$\begin{array}{llllll}77.494 & 77.458 & 77.422 & 77.387 & 77.351 & 77.315 \\ 77.137 & 77.102 & 77.066 & 77.030 & 76.995 & 76.959\end{array}$

$\begin{array}{lllllllll} & & & \end{array}$

$\begin{array}{llllllllll}65.524 & 65.489 & 65.453 & 65.417 & 65.382 & 65.346 & 65.311 & 65.275 & 65.239 & 65.204\end{array}$

$\begin{array}{llllllllll}65.168 & 65.133 & 65.097 & 65.062 & 65.026 & 64.990 & 64.955 & 64.919 & 64.884 & 64.848\end{array}$

$\begin{array}{llllllllll}64 \cdot 812 & 64 \cdot 777 & 64 \cdot 741 & 64 \cdot 706 & 64 \cdot 670 & 64 \cdot 634 & 64 \cdot 599 & 64 \cdot 563 & 64 \cdot 527 & 64 \cdot 492 \\ 64.456 & 64.421 & 64.385 & 64.349 & 64.314 & 64.278 & 64 \cdot 243 & 64 \cdot 207 & 64 \cdot 172 & 64.136\end{array}$

$\begin{array}{llllllllll}64.456 & 64.421 & 64.385 & 64 \cdot 349 & 64.314 & 64.278 & 64 \cdot 243 & 64 \cdot 207 & 64 \cdot 172 & 64 \cdot 136 \\ 64.100 & 64.065 & 64.029 & 63.994 & 63.958 & 63.922 & 63.887 & 63.851 & 63.815 & 63.780\end{array}$

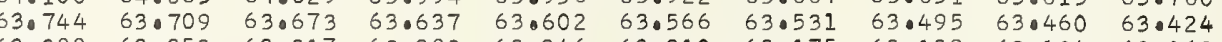

$\begin{array}{llllllllll}63.032 & 62.997 & 62.961 & 62.926 & 62.890 & 62.854 & 62.819 & 62.783 & 62.748 & 62.068\end{array}$

$(n-1) \times 1000 \quad \lambda(n-1)$

$\begin{array}{ll}0.278260 & 1.471994 \\ 0.278260 & 1.472021 \\ 0.278259 & 1.472047 \\ 0.278259 & 1.472074 \\ 0.278259 & 1.472101 \\ 0.278259 & 1.472127 \\ 0.278258 & 1.472154 \\ 0.278258 & 1.472181 \\ 0.278258 & 1.472207 \\ 0.278258 & 1.472234\end{array}$

0.278258

0.278257

0.278257

0.278257

0.278256

0.278256

0.278256

0.278255

0.278255

0.278255

0.278254
0.278254

0.278254

0.278254

0.278254

0.278253

0.278253

0.278253

0.278252

0.278252

0.278252

0.278252

0.278251

0.278251
0.278251

0.278251

0.278251

0.278250

0.278250
0.278250

0.278250

0.278250

0.278249

0.278249
0.278249

0.278249

0.278248
0.278248

0.278248

0.278248

0.278248

0.278247

0.278247

0.278247
0.278247

1.472262

1.472287

1.472341

1.472367

1. 472421

1.472447
1.472474

1. 472501

10472527

1.472580

1.472607
1.472634

1.472634
1.472660

1.472660
1.472687

1.472714

1.472740
1.472767

1.472794

1.472820

1.472847
1.072874

1.472874

1.472900
1.472927

10472954

1.472980
1.473007

1.473034

1.473060

1.473087
1.473114

1.473140

1.473167

1.473194

1.473220
1.473247

1.473247
1.473274

1.473327

1.473354

1.473380
1.473407

1.473434

1.473460

I. 473487

1.473514

1.473540
1.473567

0.278247

0.278246
0.278246

0.278246

0.278246

0.278245

0.278245

0.278245

0.278245

1.473594

1.473620
1.473647

1.473674

1.473700

1.473727

1.473753

1.473780

1.473807
1.473833

0.278244

0.278244

0.278244

0.278243

0.278243

0.278243
0.278243

0.278243
0.278243

0.278243
0.278243

0.278242

0.278242

0.278242

0.278241

0.278241

0.278241

0.278241

0.278240

0.278240

0.278240

0.278239 


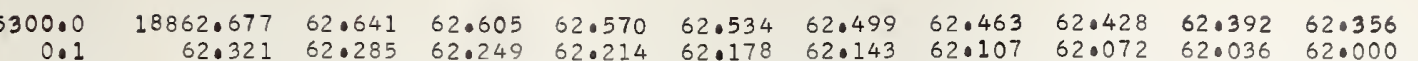
$\begin{array}{lllllllllll}0.1 & 62.321 & 62.285 & 62.249 & 62.214 & 62.178 & 62.143 & 62.107 & 62.072 & 62.036 & 62.000 \\ 0.2 & 61.965 & 61.929 & 61.894 & 61.858 & 61.823 & 61.787 & 61.751 & 61.716 & 61.680 & 61.645\end{array}$ $\begin{array}{lllllllllll}0.2 & 61.965 & 61.929 & 61.894 & 61.858 & 61.823 & 61.787 & 61.751 & 61.716 & 61.680 & 61.645 \\ 0.3 & 61.609 & 61.573 & 61.538 & 61.502 & 61.467 & 61.431 & 61.395 & 61.360 & 61.324 & 61.289\end{array}$ $\begin{array}{lllllllllll}0.4 & 61.253 & 61.218 & 61.182 & 61.146 & 61.111 & 61.075 & 61.040 & 61.004 & 60.969 & 60.933 \\ 0.5 & 60.897 & 60.862 & 60.826 & 60.791 & 60.755 & 60.719 & 60.684 & 60.648 & 60.613 & 60.577\end{array}$ $\begin{array}{lllllllllll}0.5 & 60.897 & 60.862 & 60.826 & 60.791 & 60.755 & 60.719 & 60.684 & 60.648 & 60.613 & 60.577 \\ 0.6 & 60.541 & 60.506 & 60.470 & 60.435 & 60.399 & 60.364 & 60.328 & 60.292 & 60.257 & 60.221\end{array}$ $\begin{array}{llllllllllll}0.7 & 60.186 & 60.150 & 60.115 & 60.079 & 60.043 & 60.008 & 59.972 & 59.937 & 59.901 & 59.865\end{array}$ $\begin{array}{lllllllllll}0.8 & 59.830 & 59.794 & 59.759 & 59.723 & 59.687 & 59.652 & 59.616 & 59.581 & 59.545 & 59.510 \\ 0.9 & 59.474 & 59.438 & 59.403 & 59.367 & 59.332 & 59.296 & 59.261 & 59.225 & 59.189 & 59.154\end{array}$

$\begin{array}{lllllllllll}5301.0 & 18859.118 & 59.083 & 59.047 & 59.011 & 58.976 & 58.940 & 58.905 & 58.869 & 58.834 & 58.798\end{array}$ $\begin{array}{llllllllllll}1.1 & 58.762 & 58.727 & 58.691 & 58.656 & 58.620 & 58.585 & 58.549 & 58.513 & 58.478 & 58.442\end{array}$ $\begin{array}{llllllllllll}1.2 & 58.407 & 58.371 & 58.335 & 58.300 & 58.264 & 58.229 & 58.193 & 58.158 & 58.122 & 58.087 \\ 1.3 & 58.051 & 58.015 & 57.980 & 57.944 & 57.909 & 57.873 & 57.838 & 57.802 & 57.767 & 57.731\end{array}$ $\begin{array}{lllllllllll}1.3 & 58.051 & 58.015 & 57.980 & 57.944 & 57.909 & 57.873 & 57.838 & 57.802 & 57.767 & 57.731 \\ 1.4 & 57.695 & 57.660 & 57.624 & 57.588 & 57.553 & 57.517 & 57.482 & 57.446 & 57.411 & 57.375\end{array}$ $\begin{array}{lllllllllll}1.4 & 57.695 & 57.660 & 57.624 & 57.588 & 57.553 & 57.517 & 57.482 & 57.446 & 57.411 & 57.375 \\ 1.5 & 57.340 & 57.304 & 57.269 & 57.233 & 57.198 & 57.162 & 57.126 & 57.091 & 57.055 & 57.020\end{array}$ $\begin{array}{lllllllllll}1.6 & 56.984 & 56.948 & 56.913 & 56.878 & 56.842 & 56.806 & 56.771 & 56.735 & 56.700 & 56.664 \\ 1.7 & 56.628 & 56.593 & 56.557 & 56.522 & 56.486 & 56.450 & 56.415 & 56.380 & 56.344 & 56.308\end{array}$ $\begin{array}{lllllllllll}1.7 & 56.628 & 56.593 & 56.557 & 56.522 & 56.486 & 56.450 & 56.415 & 56.380 & 56.344 & 56.308 \\ 1.8 & 56.273 & 56.237 & 56.202 & 56.166 & 56.131 & 56.095 & 56.060 & 56.024 & 55.989 & 55.953 \\ 1.9 & 55.917 & 55.882 & 55.846 & 55.810 & 55.775 & 55.739 & 55.704 & 55.668 & 55.633 & 55.597\end{array}$

0.278238

0.278237

0.278237

0.278236

0.278236

0.278236

0.278236

0.0278235
0.278235

0.278225
0.278235

0.278234

0.278234
0.278234

0.078234
0.278234

$\begin{array}{rrrrrrrrrrr}5302.0 & 18855.562 & 55.526 & 55.490 & 55.455 & 55.419 & 55.384 & 55.348 & 55.313 & 55.277 & 55.242 \\ 211 & 55.206 & 55.170 & 55.135 & 55.099 & 55.064 & 55.028 & 54.992 & 54.957 & 54.921 & 54.886\end{array}$

$\begin{array}{lllllllllll}2.1 & 55.206 & 55.170 & 55.135 & 55.099 & 55.064 & 55.028 & 54.992 & 54.957 & 54.921 & 54.886 \\ 2.2 & 54.850 & 54.815 & 54.779 & 54.744 & 54.708 & 54.672 & 54.637 & 54.602 & 54.566 & 54.530\end{array}$

$\begin{array}{lllllllllll}2.2 & 54 \cdot 850 & 54 \cdot 815 & 54.779 & 54 \cdot 744 & 54 \cdot 708 & 54 \cdot 672 & 54 \cdot 637 & 54 \cdot 602 & 54.566 & 54 \cdot 530 \\ 2.3 & 54.495 & 54.459 & 54.424 & 54.388 & 54.353 & 54.317 & 54 \cdot 281 & 54.246 & 54 \cdot 210 & 54 \cdot 175\end{array}$

$\begin{array}{lllllllllll}2.4 & 54.139 & 54.104 & 54.068 & 54.032 & 53.997 & 53.961 & 53.926 & 53.890 & 53.855 & 53.819 \\ 2.5 & 53.783 & 53.748 & 53.713 & 53.677 & 53.641 & 53.606 & 53.570 & 53.535 & 53.499 & 53.463\end{array}$

$\begin{array}{llllllllllll}2.6 & 53.428 & 53.392 & 53.357 & 53.321 & 53.286 & 53.250 & 53.215 & 53.179 & 53.144 & 53.108\end{array}$

$\begin{array}{lllllllllll}2.7 & 53.073 & 53.037 & 53.001 & 52.966 & 52.930 & 52.895 & 52.859 & 52.824 & 52.788 & 52.753\end{array}$

$\begin{array}{lllllllllll}2.8 & 52.717 & 52.681 & 52.646 & 52.610 & 52.575 & 52.539 & 52.503 & 52.468 & 52.433 & 52.397 \\ 2.9 & 52.361 & 52.326 & 52.290 & 52.255 & 52.219 & 52.184 & 52.148 & 52.113 & 52.077 & 52.042\end{array}$

$\begin{array}{lllllllllll}5303.0 & 18852.006 & 51.970 & 51.935 & 51.899 & 51.864 & 51.828 & 51.792 & 51.757 & 51.721 & 51.686\end{array}$

$\begin{array}{lllllllllll}3.1 & 51.650 & 51.615 & 51.579 & 51.544 & 51.508 & 51.473 & 51.437 & 51.402 & 51.366 & 51.331 \\ 3.2 & 51.295 & 51.260 & 51.224 & 51.188 & 51.153 & 51.117 & 51.082 & 51.046 & 51.010 & 50.975\end{array}$

$\begin{array}{lllllllllll}3.2 & 51.295 & 51.260 & 51.224 & 51.188 & 51.153 & 51.117 & 51.082 & 51.046 & 51.010 & 50.975 \\ 3.3 & 50.939 & 50.904 & 50.868 & 50.833 & 50.797 & 50.762 & 50.726 & 50.691 & 50.655 & 50.620\end{array}$

$\begin{array}{lllllllllll}3.4 & 50.584 & 50.549 & 50.513 & 50.477 & 50.442 & 50.406 & 50.371 & 50.335 & 50.300 & 50.264 \\ 3.5 & 50.229 & 50.193 & 50.157 & 50.122 & 50.036 & 50.051 & 50.015 & 49.980 & 49.944 & 490.909\end{array}$

$\begin{array}{lllllllllll}3.4 & 50.229 & 50.193 & 50.157 & 50.122 & 50.086 & 50.051 & 50.015 & 49.980 & 49.944 & 49.909 \\ 3.5 & 49.873 & 49.838 & 49.802 & 49.767 & 49.731 & 49.696 & 49.660 & 49.625 & 49.589 & 49.553\end{array}$

$\begin{array}{lllllllllll}3.6 & 49.873 & 49.838 & 49.802 & 49.767 & 49.731 & 49.696 & 49.660 & 49.625 & 49.589 & 49.553 \\ 3.7 & 49.518 & 49.482 & 49.447 & 49.411 & 49.375 & 49.340 & 49.305 & 49.269 & 49.233 & 49.198\end{array}$

$\begin{array}{llllllllllll}3.8 & 49.162 & 49.127 & 49.091 & 49.056 & 49.020 & 48.985 & 48.949 & 48.914 & 48.878 & 48.843\end{array}$

$\begin{array}{lllllllllll}3.8 & 49.162 & 49.127 & 49.091 & 49.056 & 49.020 & 48.985 & 48.949 & 48.914 & 48.878 & 48.843 \\ 3.9 & 48.807 & 48.771 & 48.736 & 48.700 & 48.665 & 48.629 & 48.594 & 48.558 & 48.523 & 48.487\end{array}$

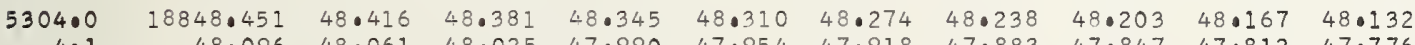

$\begin{array}{llllllllllll}4.1 & 48.096 & 48.061 & 48.025 & 47.990 & 47.954 & 47.918 & 47.883 & 47.847 & 47.812 & 47.776\end{array}$

$\begin{array}{lllllllllll}4 \cdot 2 & 47.741 & 47.705 & 47.670 & 47.634 & 47.599 & 47.563 & 47.528 & 47.492 & 47.457 & 47.421 \\ 4.3 & 47.385 & 47.350 & 47.315 & 47.279 & 47.243 & 47.208 & 47.172 & 47.137 & 47.101 & 47.066\end{array}$

$\begin{array}{lllllllllll}4.3 & 47.385 & 47.350 & 47.315 & 47.279 & 47.243 & 47.208 & 47.172 & 47.137 & 47.101 & 47.066 \\ 4.4 & 47.030 & 46.995 & 46.959 & 46.924 & 46.888 & 46.853 & 46.817 & 46.781 & 46.746 & 46.710\end{array}$

$\begin{array}{lllllllllll}4 \cdot 5 & 46.675 & 46.640 & 46.604 & 46.569 & 46.533 & 46.497 & 46.462 & 46.426 & 46.391 & 46.355 \\ 4.6 & 46.320 & 46.284 & 46.249 & 46.213 & 46.178 & 46.142 & 46.106 & 46.071 & 46.035 & 46.000\end{array}$

$\begin{array}{lllllllllll}4.8 & 46.32 & 46.284 & 46.249 & 46.213 & 46.178 & 46.142 & 46.106 & 46.071 & 46.035 & 46.000 \\ 4.7 & 45.965 & 45.929 & 45.893 & 45.858 & 45.822 & 45.787 & 45.751 & 45.716 & 45.680 & 45.645 \\ 4.8 & 45.609 & 45.573 & 45.538 & 45.503 & 45.467 & 45.431 & 45.396 & 45.360 & 45.325 & 45.290\end{array}$

4.8

$45.254 \quad 45.219 \quad 45 \cdot 18$

$45 \cdot 503$

$\begin{array}{lllll}45.787 & 45.751 & 45.716 & 45.680 & 45.645 \\ 45.431 & 45.396 & 45.360 & 45.325 & 45.290 \\ 45.076 & 45.041 & 45.005 & 44.970 & 44.934\end{array}$

5305.

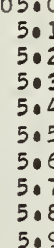

$18844.898 \quad 44 \cdot 863$

$44.543 \quad 44.508 \quad 44.82$

$44 \cdot 792$
44.437

44.75

$\begin{array}{lllll}44.721 & 44 \cdot 685 & 44.650 & 44.615 & 44 \cdot 579\end{array}$

5.2

5.4

5.5

5.6

5.8

$\begin{array}{ll}3.833 & 43.797 \quad 43.76\end{array}$

$\begin{array}{llll}4.478 & 43.442 & 43.407 & 43.371\end{array}$

$43.123 \quad 43.087 \quad 43.052$

$\begin{array}{llll}42.758 & 42.732 & 42.697 & 42.661\end{array}$

$\begin{array}{llll}42.412 & 42.377 & 42.341 & 42.306\end{array}$

$41.702 \quad 41.667$

5

306.0
6.1
6.2
6.3
6.4
6.5
6.5
6.7
6.8
6.9

$6.0 \quad 18841.347 \quad 41.31$

5307.0
7
7
7
7.5
7.5
7.6
7.7
7.8
7.9 $\begin{array}{ll}40.992 & 40.956 \\ 40.637 & 40.601\end{array}$

$40.282 \quad 40.24$

$39.927 \quad 39.891$

$39.217 \quad 39.181 \quad 39.501$

$\begin{array}{ll}38.862 & 38.82 \\ 38.507 & 38.47\end{array}$

$38.152 \quad 38.116$

41.276

41.240

$\begin{array}{ll}44.0401 & 44.36 \\ 44.046 & 44.01\end{array}$

$\begin{array}{llll}44 \cdot 685 & 44 \cdot 650 & 44 \cdot 615 & 44 \cdot 579 \\ 44.330 & 44.295 & 44 \cdot 259 & 44.224 \\ 43.975 & 43.940 & 43.904 & 43.868\end{array}$

$\begin{array}{llllll}43.691 & 43.656 & 43.620 & 43.584 & 43.549 & 43.513 \\ 43.336 & 43.300 & 43.265 & 43.229 & 43.194 & 43.158\end{array}$

$\begin{array}{llllll}42.981 & 42.945 & 42.909 & 42.874 & 42.839 & 42.803\end{array}$

$\begin{array}{llllll}42.626 & 42.590 & 42.554 & 42.519 & 42.483 & 42.448 \\ 42.270 & 42.235 & 42.199 & 42.164 & 42.128 & 42.093\end{array}$

42.270
41.915 $\begin{array}{llllll}41.560 & 41.525 & 41.489 & 41.454 & 41.419 & 41.383\end{array}$

0.278233

0.278233

0.278233

0.278232

.278232

0.278232

0.278231

0.278231

0.278231
0.278231

0.278230

0.278230

0.278230

0.278229

0.278229

0.278229
0.278229

0.278228

0.278228

0.278228

0.278227
0.278227

.278227

0.278227

0.278226

.278226
.272225

0.278226

0.278225

0.278225

0.278225

0.278225

0.278224

.278224

0.278224
0.278223

.278223

.278223

0.278223
0.278223

0.278222

0.278222
0.278222

0.278222

0.278222

0.278221

0.278221
0.278220

0.278220

0.278220

0.278220
0.278220

0.278219

0.278219

0.278219

0.278218

0.278218

0.278218
0.278218

0.278218
0.278217

0.278217

0.278216

0.278216

0.278216

10474660

1.474689
1.474713

1.474713

1.474767

1.474753

1.474846

474873
.474900

1.474926

1.474953
1.474980

1.475006

1.475060

1.475086

1.475113

1.475166

1.475193

1.475220

1.475273

1.475300

1.475353

1.475380

1.475433

1.475460

1.4754686
1.475523

1.475540

1.475565
1.475593

1.475620

1.475673
1.475700

1.475726

1.475753

1.475806

1.475833

1.475886

1.475913

1.475940

1.475993

1.476020

1. 476073

1.476100

1.476153

1.476180

1.476206

1.476260

1.0476286

1.0476339
1.043939

1.0476366

10476393

1.476446

1.476473

1.476526

1.0476553

1.476606

1.476633

1.476686

1.476713

1.476766

1.476793

1.476819

1.476873

1476926

1.476953

1.477006

1.477059

1.477113

1.4771139
1.477166

1.477193

1.477246

1.477273
1.477299

.010

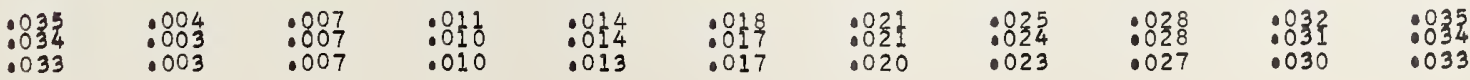




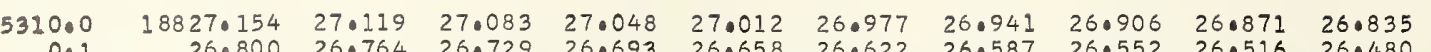
$\begin{array}{lllllllllll}0.1 & 26.800 & 26.764 & 26.729 & 26.693 & 26.658 & 26.622 & 26.587 & 26.552 & 26.516 & 26.480\end{array}$

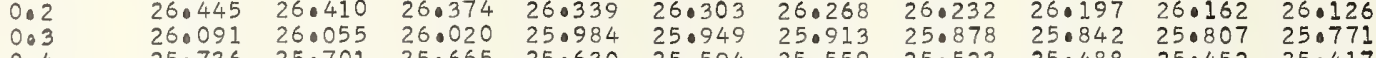
$\begin{array}{lllllllll}25.701 & 25.665 & 25.630 & 25.594 & 25.559 & 25.523 & 25.488 & 25.452 & 25.417\end{array}$

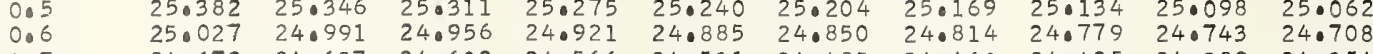
$\begin{array}{lllllllllll}24.673 & 24.637 & 24.602 & 24.566 & 24.531 & 24.495 & 24.460 & 24.425 & 24.389 & 24.354\end{array}$

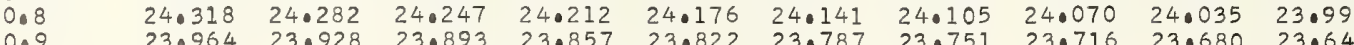

$1.0 \quad 18823.609$

1.2

1.4

1.5
1.6
1.7

1.8

5312.

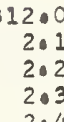

2

2.5

2.

5313.

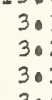

3.4
3.5
3.6

3.7

3.8
3.9

53140

$4 \cdot 1$
$4 \cdot 2$
$4 \cdot 3$

4.5

4.6
4.7

4.8
4.9

5315.0

5.

5.3

5.4

5.6

5.8
5.9

5316.0

6.1

6.3
6.4

6.5

6.6
6.7

6.8
6.9

5317.

701

7.3
7.4

7.

7.6
7.7

7.8
7.9

5318

8.1
8.2
8.3

8.3

8.4
8.5

8.6
8.7
8.8

8.8
8.9

823.609
23.255 23.574

$\begin{array}{llll}23.255 & 23.219 & 23.1838 & 23.503 \\ 23.18 & 23.149\end{array}$

$22.546 \quad 22.510$

$22.192 \quad 22.156$

$\begin{array}{llllll}21.483 & 21.448 & 21.412 & 21.377 & 21.341 & 21.306 \\ 21.129 & 21.093 & 21.058 & 21.022 & 20.987 & 20.951\end{array}$

$\begin{array}{ll}20.774 & 20.739 \\ 20.420 & 20.385\end{array}$

$18820.066 \quad 200$

19.71

$\begin{array}{llll}19.357 & 19.322 & 19.286 & 19.251 \\ 19.003 & 18.967 & 18.932 & 18.896\end{array}$

$0.030 \quad 19.995 \quad 19.959$

$\begin{array}{lllllll}18.649 & 18.613 & 18.578 & 18.542 & 18.507 & 18.472\end{array}$

$\begin{array}{llllllllll}18.294 & 18.259 & 18.223 & 18.188 & 18.153 & 18.117 & 18.082 & 18.046 & 18.011 & 17.976 \\ 17.940 & 17.905 & 17.869 & 17.834 & 17.799 & 17.763 & 17.728 & 17.692 & 17.657 & 17.621 \\ 17.586 & 17.551 & 17.515 & 17.480 & 17.444 & 17.409 & 17.374 & 17.338 & 17.302 & 17.267\end{array}$

$\begin{array}{llllllll} & \end{array}$

$\begin{array}{llllll}18816.523 & 16.488 & 16.453 & 16.417 & 16.382 & 16.34\end{array}$

$\begin{array}{llllll}16.169 & 16.134 & 16.098 & 16.063 & 16.028 & 15.992 \\ 15.815 & 15.780 & 15.744 & 15.709 & 15.673 & 15.638 \\ 15.461 & 15.426 & 15.390 & 15.355 & 15.319 & 15.284\end{array}$

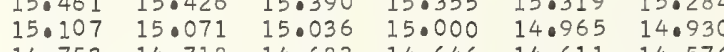

$\begin{array}{llllll}14.753 & 14.718 & 14.682 & 14.646 & 14.611 & 14.576 \\ 14.399 & 14.363 & 14.328 & 14.292 & 14.257 & 14.222\end{array}$

$\begin{array}{llllll}14.045 & 14.009 & 13.974 & 13.938 & 13.903 & 13.867\end{array}$

13.336

$18812.982 \quad 12.947$

$12.628 \quad 12.5$

$12.912 \quad 12.876$

13.19

13.160

$11.920 \quad 11.885$

$\begin{array}{ll}11.566 & 11.5 \\ 11.212 & 11.17\end{array}$

$\begin{array}{ll}10.859 & 10.823 \\ 10.505 & 10.469\end{array}$

$\begin{array}{ll}10.151 & 10.11 \\ 09.797 & 09.76\end{array}$

18809.443

09.08909 .407

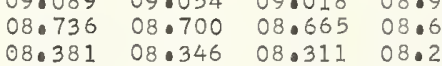

$08.028 \quad 07.992 \quad 07.957 \quad 07.2728$

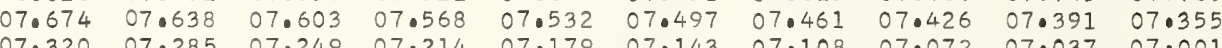

$\begin{array}{llllllllll}06.966 & 06.931 & 06.896 & 06.860 & 06.825 & 06.789 & 06.754 & 06.719 & 06.683 & 06.0648\end{array}$

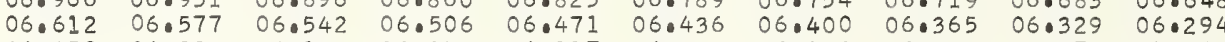

$\begin{array}{llllllllll}05.551 & 05.516 & 05.480 & 05.445 & 05.410 & 05.374 & 05.339 & 05.303 & 05.268 & 05.233 \\ 05.198 & 05.162 & 05.127 & 05.091 & 05.056 & 05.021 & 04.985 & 04.950 & 04.915 & 04.879 \\ 04.844 & 04.808 & 04.773 & 04.738 & 04.702 & 04.667 & 04.631 & 04.596 & 04.561 & 04.525\end{array}$

$\begin{array}{llllllll}04.419 & 04.384 & 04.348 & 04.313 & 04 \cdot 278 & 04 \cdot 242 & 04 \cdot 207 & 04 \cdot 172\end{array}$

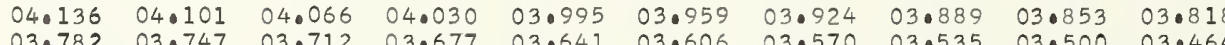

$03.42903 .39403 .358 \quad 03.323 \quad 03.287 \quad 03.252 \quad 03.517 \quad 03.181 \quad 03.146 \quad 03.464$

$03.07503 .040 \quad 03.005 \quad 02.96902 .034 \quad 02.898 \quad 02.863 \quad 02.828 \quad 02.792 \quad 02.757$

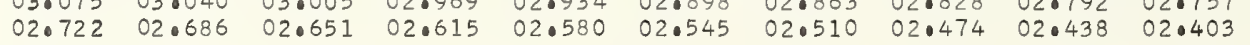

$\begin{array}{llllllllll}18802.368 & 02.333 & 02.297 & 02.262 & 02.226 & 02.191 & 02.156 & 02.121 & 02.085 & 02.050\end{array}$

$\begin{array}{llllllllll}02.014 & 01.979 & 01.944 & 01.908 & 01.873 & 01.838 & 01.802 & 01.767 & 01.731 & 01.696\end{array}$

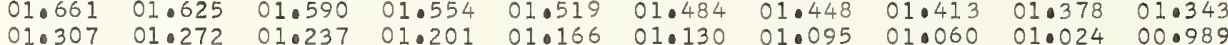

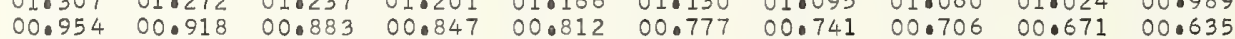

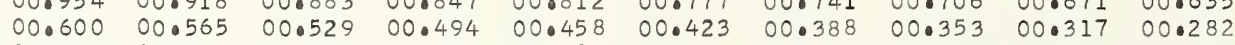

$\begin{array}{llllllll}18799.893 & 90.211 & 00.176 & 00.140 & 00.105 & 00.070 & 00.034 & * 99.999 * 99.963 * 99.928\end{array}$

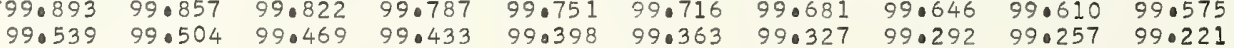
$\begin{array}{llllllllll}99.539 & 99.504 & 99.469 & 99.433 & 99.398 & 99.363 & 99.327 & 99.292 & 99.257 & 99.221 \\ 99.186 & 99.150 & 99.115 & 99.080 & 99.044 & 99.009 & 98.974 & 98.938 & 98.903 & 98.868\end{array}$

$\begin{array}{llllllllll}18798.832 & 98.797 & 98.762 & 98.726 & 98.691 & 98.656 & 98.620 & 98.585 & 98.550 & 98.514\end{array}$ $\begin{array}{llllllllll}98.479 & 98.443 & 98.408 & 98.373 & 98.337 & 98.302 & 98.267 & 98.231 & 98.196 & 98.161 \\ 98.125 & 98.090 & 98.055 & 98.019 & 97.984 & 97.949 & 97.914 & 97.878 & 97.843 & 97.807\end{array}$ $\begin{array}{llllllllll}98.125 & 98.090 & 98.055 & 98.019 & 97.984 & 97.949 & 97.914 & 97.878 & 97.843 & 97.807 \\ 97.772 & 97.736 & 97.701 & 97.666 & 97.631 & 97.595 & 97.560 & 97.524 & 97.489 & 97.454\end{array}$ $\begin{array}{llllllllll}97.418 & 97.383 & 97.348 & 97.312 & 97.277 & 97.242 & 97.207 & 97.171 & 97.136 & 97.100\end{array}$

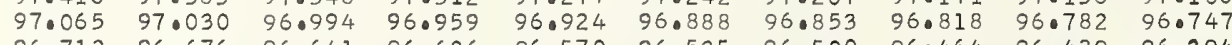

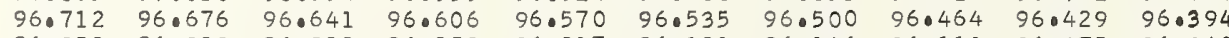
$\begin{array}{llllllllll}96.358 & 96.323 & 96.288 & 96.252 & 96.217 & 96.181 & 96.146 & 96.111 & 96.075 & 96.040 \\ 96.005 & 95.969 & 95.934 & 95.899 & 95.864 & 95.828 & 95.793 & 95.757 & 95.722 & 95.687\end{array}$

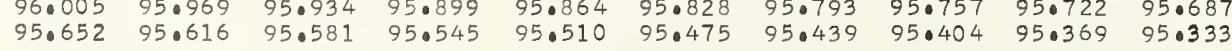

$\begin{array}{lllllll}95.157 & 95.121 & 95.086 & 95.051 & 95.015 & 94.980\end{array}$ $\begin{array}{llll}94.945 & 94 \cdot 909 & 94.874 & 94.839 \\ 94.591 & 94.556 & 94.521 & 94.485\end{array}$

$\begin{array}{llll}94.238 & 94.203 & 94.167 & 94.132 \\ 93.885 & 93.849 & 93.814 & 93.779\end{array}$

$94.450 \quad 94 \cdot 768$

$\begin{array}{llll}95.086 & 95.051 & 95.015 & 94.980 \\ 94.733 & 94.697 & 94.662 & 94.626\end{array}$

93.88593 .84903 .81493 .77

$94.097 \quad 94.062 \quad 94.026 \quad 93.991 \quad 93.956 \quad 93.920$

$\begin{array}{llll}93.531 & 93.496 & 93.461 & 93.426 \\ 93.178 & 93.143 & 93.107 & 93.072\end{array}$

$93.390 \quad 93.35$

$93.673 \quad 93.637 \quad 93.602 \quad 93.567$

9.6

9.8

$\begin{array}{llll}.825 & 92.790 & 92.754 & 92.719\end{array}$

93.001

$\begin{array}{llll}93.319 & 93.284 & 93.249 & 93.214 \\ 92.966 & 92.931 & 92.896 & 92.860\end{array}$

9.9

$92.118 \quad 92.083 \quad 92.048$

$\begin{array}{llllll}92.684 & 92.648 & 92.613 & 92.578 & 92.542 & 92.507\end{array}$

.002

.003

\begin{abstract}
.004
\end{abstract}
.005

$\begin{array}{llll}92.260 & 92.224 & 92.189 & 92.154 \\ 91.906 & 91.871 & 91.836 & 91.801\end{array}$

$(n-1) \times 1000$

1.477326

0.278216

0.278216
0.278215

.278215

0.278215

0.278215

0.278214

0.278214
0.278214

0.278214

0.278213
0.278213

0.278213

0.278213
0.278213

0.278212

0.278212
0.278212

0.278212

1.477353
1.477379

1.477406

1.477459
1.477486

1.477486

1.477539
.0477566

0.278211

0.278211

0.278211

0.278211
0.278210

0.278210

0.278210

0.278210
0.278209

1.477593

1.477619

1.477646

1.477699

1.477726
1.477753

1.477779
1.047806

1.477859

1.477886
1.477913

1.477939

1.477966

1.478019

1.478046

.478073
1.478099

0.278209

0.278209

1.478126

0.078209

0.278208

0.278208

0.278208

0.278208
0.278207

1.478152

1.478206

1.478232

1.478286

1.478312

1.478339
1.478366

0.278207

0.278207

0.278206

0.278206

0.278206
0.278206

0.278206
0.278206

0.278205

0.278205

0.278205
0.278205

0.278205
0.278204

0.278204

0.278204

0.278204

0.278204

0.278203

0.278203

1.478392
1.478419

1.478446

1.478472

1.478499

1.478526

1.478552
1.478579

1.478606

1.478659

1.478686

1.478712
1.478739

1.478766

1.478766

1.478792

1.478819

1.478872

0.278203

0.278203

0.278202

0.278202

0.278202

0.278201
0.278201

0.278201

1.478926

1.478952

1.478979

1.479032

1.479059

1.479086

0.278201

1.479139
1.479166

0.278201

1.479192

. 278200

0.278200

0.278200

0.278199

0.278199

0.278199
0.278199

1.479219

1.479246
1.479272

1.479299

1.479326
1.479352

1.479379

1.479406

0.278198

0.278198
0.278198

0.278198

0.278198

0.278197

0.278197

10479459

1.479486

1.479512
1.479539

1.479566

1.479592

1.479619

1.479646

1.479672

0.278196

10479726

278196

0.278196 


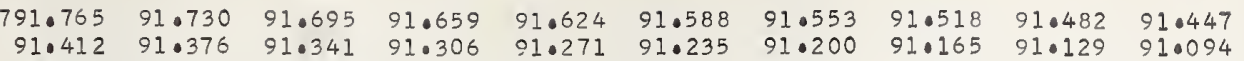

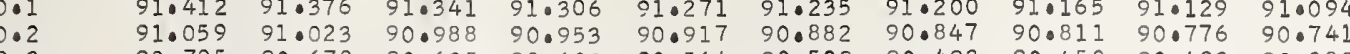

$\begin{array}{lllllllllll}0.2 & 91.059 & 91.023 & 90.988 & 90.953 & 90.917 & 90.882 & 90.847 & 90.811 & 90.776 & 90.741 \\ 0.3 & 90.705 & 90.670 & 90.635 & 90.600 & 90.564 & 90.529 & 90.493 & 90.458 & 90.423 & 90.388\end{array}$

$\begin{array}{lllllllllll}0.4 & 90.352 & 90.317 & 90.282 & 90.246 & 90.211 & 90.176 & 90.141 & 90.105 & 90.070 & 90.034 \\ 0.5 & 89.999 & 89.964 & 89.928 & 89.893 & 89.858 & 89.823 & 89.787 & 89.752 & 89.717 & 89.681\end{array}$

$\begin{array}{lllllllllll}0.6 & 89.646 & 89.611 & 89.575 & 89.540 & 89.505 & 89.469 & 89.434 & 89.399 & 89.364 & 89.328\end{array}$

$\begin{array}{lllllllllll}0.7 & 89.293 & 89.258 & 89.222 & 89.187 & 89.151 & 89.116 & 89.081 & 89.046 & 89.010 & 88.975 \\ 0.8 & 88.940 & 88.904 & 88.869 & 88.834 & 88.799 & 88.763 & 88.728 & 88.692 & 88.657 & 88.622\end{array}$

$\begin{array}{llllllllll}88.940 & 88.904 & 88.869 & 88.834 & 88.799 & 88.763 & 88.728 & 88.692 & 88.657 & 88.622 \\ 88.587 & 88.551 & 88.516 & 88.480 & 88.445 & 88.410 & 88.375 & 88.339 & 88.304 & 88.269\end{array}$

$\begin{array}{rrrrrrrrrrr}5321.0 & 18788.233 & 88.198 & 88.163 & 88.128 & 88.092 & 88.057 & 88.021 & 87.987 & 87.951 & 87.916 \\ 1.1 & 87.880 & 87.845 & 87.810 & 87.775 & 87.739 & 87.704 & 87.668 & 87.633 & 87.598 & 87.562 \\ 1.2 & 87.527 & 87.492 & 87.457 & 87.421 & 87.386 & 87.351 & 87.316 & 87.280 & 87.245 & 87.209\end{array}$

$\begin{array}{lllllllllll}1.2 & 87.527 & 87.492 & 87.457 & 87.421 & 87.386 & 87.351 & 87.316 & 87.280 & 87.245 & 87.209 \\ 1.3 & 87.174 & 87.139 & 87.104 & 87.068 & 87.033 & 86.998 & 86.962 & 86.927 & 86.892 & 86.856\end{array}$

1.4

$86.821 \quad 86.786 \quad 86.750 \quad 86.715$

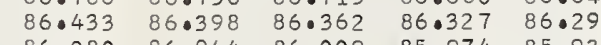

$85.762 \quad 85.727 \quad 85.692 \quad 85.656 \quad 85.674 \quad 85.939$

1.7
1.8
1.9

$8.409 \quad 85.374 \quad 85.339$

85.656
85.303

$\begin{array}{llll}86.609 & 86.574 & 86.539 & 86.503\end{array}$

$85.056 \quad 85.021 \quad 84.986$

$85.903 \quad 85.868 \quad 85.833 \quad 85.797$

5322.0

2

$84.350 \quad 84.315 \quad 84.280$

$\begin{array}{llll}83.998 & 83.962 & 83.927 & 83.892\end{array}$

$82.233-82.551$

$81.880 \quad 81.845 \quad 82.163$

$515 \quad 82.480$

532300

3.1

18781.17

$81.174 \quad 81.13$

$80.822 \quad 80.786 \quad 81.1$

$\begin{array}{lll}80.469 & 80.434 & 80.39\end{array}$

$\begin{array}{llll}80.116 & 80.081 & 80.046 \quad 80.010\end{array}$

$\begin{array}{llll}80.116 & 80.081 & 80.046 & 80.010\end{array}$

$79.058 \quad 79.375$

3.5

3.6

$\begin{array}{ll}78.705 & 78.022 \\ 78.070\end{array}$

$\begin{array}{lll}78.352 & 78.317 & 78.2\end{array}$

.987
78.952

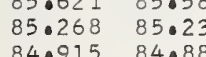

85.55

$\begin{array}{lll}85.868 & 85.833 & 85.797 \\ 85.515 & 85.480 & 85.445\end{array}$

$\begin{array}{lll}85.162 & 85.127 & 85.092\end{array}$

$78.000 \quad 77.964$

53240$$
\begin{array}{rr}
18777.647 & 77.6 \\
77.294 & 77.259
\end{array}
$$$$
\begin{array}{ll}
77.294 & 77.259 \\
76.942 & 76.906 \\
76.589 & 76.5
\end{array}
$$$$
\begin{array}{llll}
76.589 & 76.506 & 76.871 & 76.8 \\
76.553 & 76.518 & 76.483
\end{array}
$$

$\begin{array}{llll}76.236 & 76.201 & 76.166 & 76.130\end{array}$

$\begin{array}{llll}75.531 & 75.496 & 75.460 & 75.42\end{array}$

$75.178 \quad 75 \cdot 143$

$\begin{array}{ll}74 \cdot 826 & 74 \cdot 790 \\ 74.473 & 74.438\end{array}$

$75 \cdot 10$
74.75

75.07
74.72
74.367

$\begin{array}{ll}84.562 & 84.527 \\ 84.209 & 84.574\end{array}$

84.492

84.457

$\begin{array}{ll}84 \cdot 421 & 84.386 \\ 84.068 & 84.033\end{array}$

$\begin{array}{llllll}83.856 & 83.821 & 83.786 & 83.751 & 83.715 & 83.680\end{array}$

$\begin{array}{llllll}83.503 & 83.468 & 83.433 & 83.397 & 83.362 & 83.327 \\ 83.150 & 83.115 & 83.080 & 83.045 & 83.010 & 82.974\end{array}$

$\begin{array}{lllllll}82.798 & 82.762 & 82.727 & 82.692 & 82.656 & 82.621\end{array}$

$\begin{array}{llllll}.445 & 82.409 & 82.374 & 82.339 & 82.304 & 82.268 \\ 2.092 & 82.056 & 82.021 & 81.986 & 81.951 & 81.915\end{array}$

774.120

5325.

5.
5.2
5.
5.
5.
5.
5
5
5.0

$$
\begin{array}{lll}
73.768 & 73.733 & 73.6 \\
73.416 & 73.380 & 73.3 \\
73.063 & 73.028 & 72.9 \\
72.710 & 72.675 & 72.6 \\
72.358 & 72.323 & 72.2
\end{array}
$$$$
73.416 \quad 73.38
$$$$
72.710 \quad 72.675 \quad 72.640
$$$$
\begin{array}{lll}
72.005 & 71.970 & 71.935
\end{array}
$$

71.30171 .265

5326.0

18770.59

6.1
6.2
6.3
6.4
6.5
6.6
6.7
6.8

6.7

6.8
6.9

5327.

7.0
7.1
7.2
7.3
7.4
7.5
7.6
7.7
7.8
7.9

5328

8.0
8.2
8.4
8.5
8.6
8.7
8.8
8.9

5329

29.0
9.1
9.2
9.3
9.4
9.5
9.6
9.7
9.8
9.9 $767.072 \quad 67.037$ $66.720 \quad 66.684 \quad 67.001$ 66.33266 .297 $\begin{array}{lll}65.563 & 65.080 & 65.945\end{array}$

$64.958 \quad 64.923 \quad 64.88$

$64.606 \quad 64.571-64.536$

64.25464 .219

$18763.550 \quad 63.514$

63.19763 .162

$62.845 \quad 62.810 \quad 62.7$

$62 \cdot 141 \quad 62 \cdot 106$

$61.437 \quad 61.402$

$60.733 \quad 60.697$

$60.381 \quad 60.346$

18760.029

59.64259 .60

$58.073 \quad 59.290 \quad 59.254$

$\begin{array}{ll}58.254 & 59.219 \\ 58.867 & 5\end{array}$

$\begin{array}{llll}58.234 & 58.198 & 58.163\end{array}$

81.386

8

.6688

986 
$\begin{array}{lllllllllll}5330.0 & 18756.509 & 56.474 & 56.439 & 56.404 & 56.368 & 56.333 & 56.298 & 56.263 & 56.228 & 56.192\end{array}$

$\begin{array}{lllllllllll}0.1 & 56.157 & 56.122 & 56.087 & 56.052 & 56.016 & 55.981 & 55.046 & 55.911 & 55.876 & 55.840 \\ 0.1 & 55.805 & 55.770 & 55.0735 & 55.700 & 55.065 & 55.629 & 55.594 & 55.559 & 55.524 & 55.489\end{array}$

$\begin{array}{lllllllllll}0.2 & 55.805 & 55.770 & 55.735 & 55.700 & 55.665 & 55.629 & 55.594 & 55.559 & 55.524 & 55.489 \\ 0.3 & 55.453 & 55.418 & 55.383 & 55.348 & 55.313 & 55.277 & 55.242 & 55.207 & 55.172 & 55.137\end{array}$

$\begin{array}{lllllllllll}0.3 & 55.453 & 55.418 & 55.383 & 55.348 & 55.313 & 55.277 & 55.242 & 55.207 & 55.172 & 55.137 \\ 0.4 & 55.102 & 55.066 & 55.031 & 54.996 & 54.961 & 54.926 & 54.891 & 54.855 & 54.820 & 54.785 \\ 0.5 & 54.750 & 54.715 & 54.679 & 54.644 & 54.609 & 54.574 & 54.539 & 54.503 & 54.468 & 54.433\end{array}$

0.6

0.8

54.750

$\begin{array}{llll}54.398 & 54.363 & 54.327 & 54.292 \\ 54.046 & 54.011 & 53.976 & 53.940\end{array}$

$54.609 \quad 54.574$

$53.694 \quad 53.659$

$\begin{array}{ll}53.976 & 53.940 \\ 53.624 & 53.589 \\ 53.272 & 53.237\end{array}$

$\begin{array}{ll}54.257 & 54.222 \\ 53.905 & 53.870\end{array}$

54.187

54.503

54.468
54.433

$5331 \cdot 0$

$\begin{array}{rrrr}8752.990 & 52.956 & 52.920 & 520 \\ 52.639 & 52.604 & 52.569 & 520\end{array}$

53.553
53.202
53.167

53.835

$\begin{array}{lll}53.800 & 53.765 & 53.729\end{array}$

$\begin{array}{lll}53.448 & 53.413 & 53.378 \\ 53.096 & 53.061 & 53.026\end{array}$

0.27817

0.278172

0.278172

0.278171

0.278171

0.278171

0.278170

0.278170

$1 \cdot 2$

$2.287 \quad 52.252 \quad 52.217 \quad 52.182$

5

$52.498 \quad 52.463 \quad 52.428 \quad 52.393 \quad 52.357 \quad 52.322$

0.278170

0.278170

$\begin{array}{llllllllll}51.584 & 51.549 & 51.513 & 51.478 & 51.443 & 51.408 & 51.373 & 51.337 & 51.302 & 51.267 \\ 51.232 & 51.197 & 51.162 & 51.126 & 51.091 & 51.056 & 51.021 & 50.986 & 50.951 & 50.915\end{array}$

1.5

1.8

50.177

5332.

2.1
2.2
2.3

50.142

$50.810 \quad 50.775$

$51.091 \quad 51.056$

$\begin{array}{lllllll}50.388 & 50.704 & 50.669 & 50.634 & 50.599 & 50.564\end{array}$

0.278169

0.278168

0.278168

0.278168

0.278167

0.278167

0.278166

1.482659

1.482712

1. 482766

1.482792

1.482846

1.482872
1.482899

$47.715 \quad 47.680$

$47.364 \quad 47 \cdot 329$

2.8

46.661
46.309

5333.0

3.1
3.2
3.3

$18745 \cdot 958$

45.255

$45 \cdot 923$
45.571

44.903
44.552

$44 \cdot 868$

. 45.8

4.200

44.517
44.166

44.833

45.149

$\begin{array}{ll}44.482 & 44.447 \\ 44.130 & 44.095\end{array}$

3.5
3.6

3.7
3.8

$43.498 \quad 43.463$

43.146
42.795

5334.0

18742.443

43.463
43.111
42.760

43.727

$\begin{array}{ll}9 & 43.744 \\ 7 & 43.392 \\ 6 & 43.041 \\ 5 & 42.689\end{array}$

$\begin{array}{lllllll}47.224 & 47.188 & 47.153 & 47.118 & 47.083 & 47.047\end{array}$

$\begin{array}{lllllll}46.872 & 46.837 & 46.802 & 46.766 & 46.731 & 46.696\end{array}$

$\begin{array}{llllll}46.169 & 46.485 & 46.450 & 46.415 & 46.380 & 46.345 \\ 46.134 & 46.098 & 46.063 & 46.028 & 45.993\end{array}$

0.278166

0.278166

0.278166

0.278165

0.278165

0.278165
0.278164

0.278164

1.482926

1.482952

1.483006

1.483032

.483059

1.483086

1.483139

1.483166

4.2

42.092

$2.408 \quad 42$.

$2.373 \quad 420$

$2.338 \quad 420$

$\begin{array}{llllll} & 43.673 & 43.638 & 43.603 & 43.568 & 43.533\end{array}$

$\begin{array}{llllll} & & \end{array}$

0.278164

1.483192

1.483246

1.483272
1.483299

1.483326

1.483352

1.483406

1.483406

1.483459

1. 483486

1.483512

1.483539
1.483566

1.483592

1.483619

1.483646

1.483672
1.483699

0.278164

0.278164

0.278163

0.278163

0.278163

$\begin{array}{llllllllll}41.038 & 41.003 & 40.968 & 40.933 & 40.897 & 40.862 & 40.827 & 40.792 & 40.757 & 40.722\end{array}$

4.5

$\begin{array}{llllllllll}39.633 & 39.598 & 39.563 & 39.528 & 39.492 & 39.457 & 39.422 & 39.387 & 39.352 & 39.317\end{array}$

4.9

5335.0

5.1
5.2
5.3

5.4

5.5
5.6

5.7

5.8

5336.0

3.1
6.2
6.3

6.4

6.5

6.6

6.7
6.8
6.9

$38.579 \quad 38.544$

39.21139 .176

$39.141 \quad 39.106$

$\begin{array}{llll}39.422 & 39.387 & 39.352 & 39.317 \\ 39.071 & 39.036 & 39.000 & 38.965\end{array}$

0.278162

0.278162

0.278162
0.278162

1.483726

1.483752

1.483779

1.483806

1.483859

.483886

1.483912

1.483966

0.278162

0.278161

0.278161

0.278161

$\begin{array}{lllllllllll}37.877 & 37.842 & 37.806 & 37.771 & 37.736 & 37.701 & 37.666 & 37.631 & 37.596 & 37.561\end{array}$

$\begin{array}{llllllllll}37.525 & 37.490 & 37.455 & 37.420 & 37.385 & 37.350 & 37.315 & 37.280 & 37.245 & 37.209\end{array}$

$\begin{array}{llllllllll}37.174 & 37.139 & 37.104 & 37.069 & 37.034 & 36.999 & 36.963 & 36.928 & 36.893 & 36.858 \\ 36.823 & 36.788 & 36.753 & 36.718 & 36.683 & 36.647 & 36.612 & 36.577 & 36.542 & 36.507\end{array}$

$\begin{array}{llllllllll}36.472 & 36.437 & 36.402 & 36.367 & 36.332 & 36.296 & 36.261 & 36.226 & 36.191 & 36.156\end{array}$

$\begin{array}{llllllllll}36.121 & 36.086 & 36.051 & 36.016 & 35.980 & 35.945 & 35.910 & 35.875 & 35.840 & 35.805 \\ 35.770 & 35.735 & 35.700 & 35.065 & 35.529 & 35.594 & 35.559 & 35.524 & 35.489 & 35.454\end{array}$

0.278161

0.278160

0.278160

0.278160

0.278159

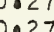

0.278159

0.278159

0.278158

0.278158

0.278158

$\begin{array}{lllllllllll}33.312 & 33.277 & 33.242 & 33.207 & 33.172 & 33.137 & 33.102 & 33.067 & 33.031 & 32.996\end{array}$

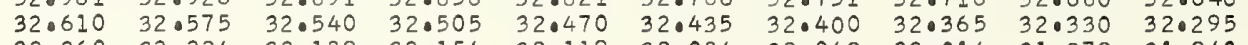

$\begin{array}{llllllllll}32.260 & 32.224 & 32.189 & 32.154 & 32.119 & 32.084 & 32.049 & 32.014 & 31.979 & 31.943\end{array}$

$\begin{array}{lllllllllll}3337.0 & 18731.908 & 31.873 & 31.838 & 31.803 & 31.768 & 31.733 & 31.698 & 31.663 & 31.628 & 31.593\end{array}$

$\begin{array}{lllllllllll}7.1 & 31.557 & 31.522 & 31.487 & 31.452 & 31.417 & 31.382 & 31.347 & 31.312 & 31.276 & 31.241\end{array}$

$\begin{array}{lllllllllll}7.2 & 31.207 & 31.171 & 31.136 & 31.101 & 31.066 & 31.031 & 30.996 & 30.961 & 30.926 & 30.891\end{array}$

704

$7 \cdot 6$

7.8

30.504 30.820

$\begin{array}{llllllllll}30.154 & 30.119 & 30.083 & 30.049 & 30.364 & 30.329 & 30.294 & 30.259 & 30.224 & 30.189 \\ & 30.013 & 29.978 & 29.943 & 29.908 & 29.873 & 29.838\end{array}$

$\begin{array}{llllllllll}29.802 & 29.768 & 29.732 & 29.698 & 29.662 & 29.627 & 29.592 & 29.557 & 29.522 & 29.487\end{array}$

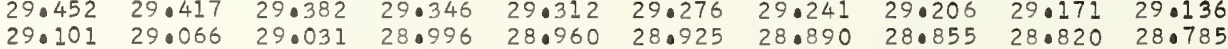

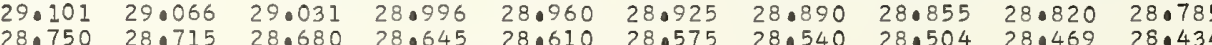

0.278157

0.278157

0.278157

0.278

0.278156

0.278156

0.278156

0.278156

1.483992

1.484019
1.484046

1.484046

1.484099

1.484126

1.484152
1.484179

1.484206

1.484232

1.484259

1.484286

1.484312
1.484339

1.484366

1.484392

1.484419

1.484446
1.484472

1.484472
1.484499

0.278155

78155

0.278155

0.278154

0.278154

0.278154

0.278154

0.278153

1.484526

1.484552

1.484579
1.484606

1.484632

1.484659

1.484686

.484739

1.484792

1.484819

1.484846

1.484872

1.484926

1.484952

1.484979
1.485006

0.278153

1.485032

533900

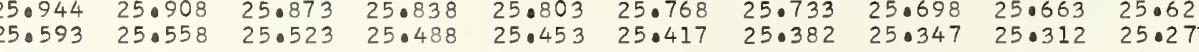

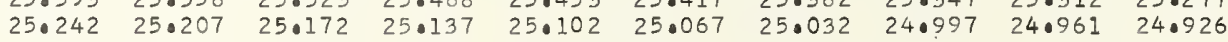

1.485059

0.278153

0.278152

0.278152

0.278152

0.278152

0.278151

1.485086

1.485112
1.485139

1.485166

1.485192

1.485246

1.485272
1.485299

.010

.035

.001 
$18.230 \quad 18.195$

$\begin{array}{ll}15.076 & 15.041 \\ 14.726 & 14.691\end{array}$

$15.006 \quad 15.322$

$15.987 \quad 150952$

$16.969 \quad 16.934 \quad 16.898 \quad 16.863$

534200

2.0
2.2
2.0
2.4
2.0
2
2
2.8

18714.375

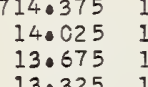

14.341
13.990

14.306

$15.287 \quad 15.25$ $16.268 \quad 16.233 \quad 16 \cdot 198 \quad 16.163$ $\begin{array}{llll}15.567 & 15.532 & 15.847 & 15.812 \\ 15.217 & 15.181 & 15.497 & 15.462\end{array}$

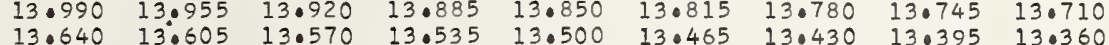

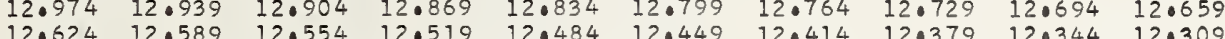

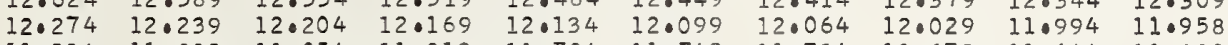

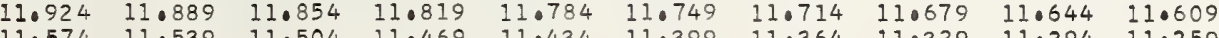

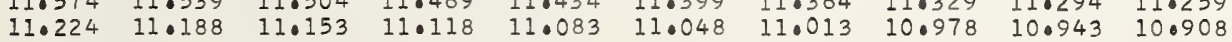

$\begin{array}{lllllllllll}5343.0 & 18710.873 & 10.838 & 10.803 & 10.768 & 10.733 & 10.698 & 10.663 & 10.628 & 10.593 & 10.558\end{array}$

$\begin{array}{lllllllllll}3.1 & 10.523 & 10.488 & 10.453 & 10.418 & 10.383 & 10.348 & 10.313 & 10.278 & 10.243 & 10.208\end{array}$

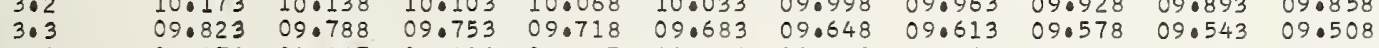

0.278151

0.278150

0.278150

0.278150

0.278149

0.278149

0.278149

0.278149

0.278148

0.278148

0.278147

0.278147

0.278147

0.278146

0.278146

0.278146

0.278145
0.278145

0.278145

0.278144

0.278144

0.27814

0.278144

0.278143

0.278143

0.278143
0.278143

0.278142

0.278142

0.278142

0.278141

0.278141

0.278141

0.278140

0.278140

0.278140

0.278140

0.278139

0.278139

0.278139

0.278138
0.278138

0.278138

0.278138

0.278137

0.278137

0.278137

0.278137

0.278136

0.278136

0.278136

0.278135

0.278135

0.278135

0.278134

0.278134

0.278134

0.278134

0.278133

0.278133

0.278133

0.278132

0.278132

0.278132

0.278132

0.278131

0.27813

0.278132

0.278131

0.278130

0.278130

1.485326 1.485352

1.485406

.485432

1.485486

1.485512
1.485539

1.485539
1.485566

1.485592

1.485646

1. 4885672

1.485726

1.485779

1.485832

1.485859

1.485922

1.485966

1.485992

1.486019

1.486072

1.486126

1.486152

1.486206 
5350.0 0.1
0.2
0.3 0.3 0.5 0.6
0.7 0.7
0.8
0.9

1.2
1.0
1.4

1.5

2.3

2.4
2.5

2.6

2.7

2.9
$86.043 \quad 86.008$

$\begin{array}{lll}85.694 & 86.008 & 85.973 \\ 85.659 & 85.624\end{array}$

$85.344 \quad 85.309$

$84.646 \quad 84.611$

$\begin{array}{lll}84.297 & 84.262 & 84.576\end{array}$

$83.948 \quad 83.913$ $\begin{array}{ll}83.598 & 83.563 \\ 83.249 & 83.214\end{array}$ 82.551

$82.551 \quad 82.516$

$81.853 \quad 81.818$

$81.503 \quad 81.469$

$80.805 \quad 80.770$

$\begin{array}{ll}80.456 & 80.421 \\ 80.107 & 80.072 \\ 79.758 & 79.723\end{array}$

$18679.409 \quad 79.374$

$\begin{array}{ll}79.060 & 79.025 \\ 78.711 & 78.676\end{array}$

$\begin{array}{ll}78.362 & 78.327 \\ 78.013 & 77.978\end{array}$

$\begin{array}{ll}77.664 & 77.629 \\ 77.315 & 77.281\end{array}$

$76.966 \quad 76.931$

$\begin{array}{ll}76.617 & 76.583 \\ 76.269 & 76.234\end{array}$

$18675.920 \quad 75.885$

$\begin{array}{ll}75.571 & 75.536 \\ 75.222 & 75.187\end{array}$

$74.873 \quad 74.838$

$\begin{array}{ll}74.524 & 74.489\end{array}$

$\begin{array}{ll}74.175 & 74.140 \\ 73.826 & 73.792\end{array}$

$\begin{array}{ll}73.478 & 73.443 \\ 73.129 & 73.094\end{array}$

72.78

0.386
0.037
9.688

$\begin{aligned} & 79.33979 . \\ & 78.990 \\ & 78.641\end{aligned} 78$. $\begin{array}{rr}672.431 & 72.3 \\ 72.083 & 72.0\end{array}$

$\begin{array}{ll}72.083 & 72.048 \\ 71.734 & 71.699\end{array}$

$\begin{array}{llll}71.385 & 71.350 & 71.664 & 71.62\end{array}$

$\begin{array}{lllll}71.036 & 71.001 & 70.967 & 70.932\end{array}$

$\begin{array}{llll}70.688 & 70.653 & 70.618 & 70.583\end{array}$

$60.939 \quad 60.956 \quad 70.269 \quad 70.235$

$\begin{array}{llll}69.642 & 69.607 & 69.572 & 69.53 \\ 69.293 & 69.258 & 69.223 & 69.18\end{array}$

18668.94

68.596
68.24

67.898

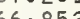

66.505

$66.156-66.469$

65.80

$18665.459 \quad 65.424$

65.110
64.76
64.413

$64.413 \quad 64 \cdot 379$

64.065

63.68

$63.020 \quad 62.98$

62.672
$62.323 \quad 62.63$

18661.97

$61.626 \quad 61.940$

$\begin{array}{llll}61.626 & 61.592 & 61.557 & 61.522 \\ 61.278 & 61.243 & 61.208 & 61.174 \\ 60.930 & 60.895 & 60.860 & 60.825\end{array}$

$60.58260 .547 \quad 60.512 \quad 60.477$

50.23360 .198

$\begin{array}{ll}59.537 & 59.502 \\ 59.188 & 59.153\end{array}$

$\begin{array}{ll}59 \cdot 188 & 59 \cdot 15 \\ 58.840 & 58.80\end{array}$

$8658 \cdot 492 \quad 58 \cdot 457$

$\begin{array}{ll}58.144 & 58 \cdot 10 \\ 57.795 & 57.760 \\ 57.447 & 57.41\end{array}$

$57.099 \quad 57.06$

$56.403 \quad 56.368$

$\begin{array}{ll}55.706 & 55.672 \\ 55.358 & 55.323\end{array}$

$55.358 \quad 55.323$

54.66

54.31254 .627

$\begin{array}{ll}54.314 & 54.27 \\ 53.966 & 53.93 \\ 53.618 & 53.583\end{array}$

$\begin{array}{ll}53.618 & 53.58 \\ 53.270 & 53.235\end{array}$

$52.922 \quad 52.887$

$\begin{array}{ll}52.574 & 52.53 \\ 52.226 & 52.191\end{array}$

$\begin{array}{lll}52.226 & 52.191 & 52.156 \\ 51.878 & 51.843 & 51.808\end{array}$

\section{.938}

$\begin{array}{lll}8.252 & 86.217 & 86.182 \\ 5.903 & 85.868 & 85.833 \\ 5.554 & 85.519 & 85.484\end{array}$

$\begin{array}{ll}.554 & 85.519 \\ 5.205 & 85.170\end{array}$

$\begin{array}{ll}8.855 & 84.821 \\ 4.506 & 84.471 \\ 8.157 & 84.122\end{array}$

$\begin{array}{ll}.157 & 84.122 \\ 3.808 & 83.773\end{array}$

85.135

84.786
84.436
84.087

84.087
83.738

$\begin{array}{ll}3.459 & 83.424 \\ 3.109 & 83.075\end{array}$

83.389
83.040

8.798
8.449

$85 \cdot 100$
84.750

84.402
84.052

83.703

83.354

\section{.41182 .376}

82.690
82.341
81.992

82.656

.306
.958
.608
.259

2.271
1.923

$\begin{array}{llllllll}81.748 & 81.713 & 81.678 & 81.643 & 81.608 & 81.573 & 81.538\end{array}$

$\begin{array}{llllllll}81.399 & 81.364 & 81.329 & 81.294 & 81.259 & 81.224 & 81.189 \\ 81.050 & 81.015 & 80.980 & 80.945 & 80.910 & 80.875 & 80.840 \\ 80.701 & 80.666 & 80.631 & 80.596 & 80.561 & 80.526 & 80.491\end{array}$

0.701280

.654

$\begin{array}{lll}.561 & 80.526 & 80.491 \\ .212 & 80.177 & 80.142 \\ .863 & 79.828 & 79.793\end{array}$

.270 79.235

79.247

.863

$79.200 \quad 79.165 \quad 79.130 \quad 79.095$

$\begin{array}{llllll} & 78.886 & 78.851 & 78.816 & 78.781 & 78.746 \\ & 78.537 & 78.502 & 78.467 & 78.432 & 78.397\end{array}$

78.606

77

79
78
78
78
77
77
77
76
76
76

$\begin{array}{lllllll}8.223 & 78.188 & 78.153 & 78.118 & 78.083 & 78.048\end{array}$

$\begin{array}{llllll}77.874 & 77.839 & 77.804 & 77.769 & 77.734 & 77.699 \\ 77.525 & 77.490 & 77.455 & 77.420 & 77.385 & 77.350\end{array}$

$\begin{array}{lllllll}.176 & 77.141 & 77.106 & 77.071 & 77.036 & 77.001 \\ \end{array}$

$\begin{array}{llll}76.478 & 76.443 & 76.408 & 76.0 \\ 76.129 & 76.094 & 76.059 & 76.0\end{array}$

$\begin{array}{lll}76.0273 & 76.338 & 76.303 \\ 75.024 & 75.99 & 75.955\end{array}$

$\begin{array}{llllll}75.780 & 75.745 & 75.710 & 75.675 & 75.640 & 75.605\end{array}$

$\begin{array}{llllll}75.431 & 75.396 & 75.361 & 75.326 & 75.292 & 75.257 \\ 75.082 & 75.047 & 75.013 & 74.978 & 74.943 & 74.908\end{array}$

$\begin{array}{lll}74.733 & 74.698 & 74.664 \\ 74.385 & 74.350 & 74.315\end{array}$

$\begin{array}{lll}74 \cdot 978 & 74 \cdot 943 & 74 \cdot 908 \\ 74.629 & 74 \cdot 594 & 74.559\end{array}$

$\begin{array}{lll}74.280 & 74.245 & 74.210\end{array}$

$\begin{array}{lllllll}74.036 & 74.001 & 73.966 & 73.931 & 73.896 & 73.861 \\ 73.687 & 73.652 & 73.617 & 73.582 & 73.548 & 73.513\end{array}$

$\begin{array}{llllll}73.338 & 73.303 & 73.269 & 73.234 & 73.199 & 73.164\end{array}$

$\begin{array}{llllll}72.990 & 72.955 & 72.920 & 72.885 & 72.850 & 72.815 \\ 72.641 & 72.606 & 72.571 & 72.536 & 72.501 & 72.466\end{array}$

0.278129
0.278129

0.278129

0.278129
0.278129

0.278128
0.278128
0

0.278128

0.278128
0.278128

0.278127

0.278127

0.278127

0.278127

0.278126

0.278126

0.278126
0.278125

0.278125

0.278125

0.278125

0.278124

0.278124

0.278124

0.278124

0.278123

0.278123

0.278122

0.278122

0.278122

0.278122

0.278121

0.278121

0.278121

0.278121

0.278120

0.278120

0.278120

0.278119

0.278119

0.278119

0.278119
0.278118

0.278118

0.278118

0.278118
0.278118

0.278117

0.278117
0.278117

0.278117

0.278117
0.278116

0.278116

0.278116

0.278115

0.278115

0.278115
0.278115

0.278115

0.278114

0.278114

0.278114

0.278114

0.278113

0.278113

0.278113
0.278113

.487993

1.488019

1.488073

1.488099
1.488126

1.488126

1.488179

1.488206

1.488259

1.488286

.0488313

48339
.88366

.488393

1.488420

1.488473

1.488500

1.488526

.488580

1.488606

1.488633

1.488660

1.488713

1.488740

1.488766

1.488793

.488820
.488846

I. 488873

1.488900

1.488926

1.488953
1.488980

1.488980

1.489006 


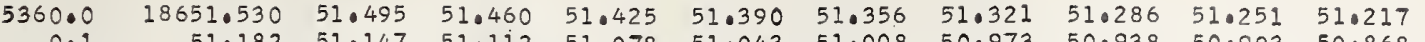
$\begin{array}{lllllllllll}0.1 & 51.182 & 51.147 & 51.112 & 51.078 & 51.043 & 51.008 & 50.973 & 50.938 & 50.903 & 50.868\end{array}$ $\begin{array}{lllllllllll}0.2 & 50.834 & 50.799 & 50.764 & 50.729 & 50.695 & 50.660 & 50.625 & 50.590 & 50.555 & 50.521 \\ 0.3 & 50.486 & 50.451 & 50.417 & 50.382 & 50.347 & 50.312 & 50.277 & 50.242 & 50.208 & 50.173\end{array}$ $\begin{array}{lllllllllll}0.3 & 50.486 & 50.451 & 50.417 & 50.382 & 50.347 & 50.312 & 50.277 & 50.242 & 50.208 & 50.173 \\ 0.4 & 50.138 & 50.103 & 50.068 & 50.033 & 49.999 & 49.964 & 49.929 & 49.894 & 49.860 & 49.825\end{array}$ $\begin{array}{llllllllllll}0.4 & 50.138 & 50.103 & 50.068 & 50.033 & 49.999 & 49.964 & 49.929 & 49.894 & 49.860 & 49.825 \\ 0.5 & 49.790 & 49.755 & 49.720 & 49.686 & 49.651 & 49.616 & 49.581 & 49.547 & 49.512 & 49.477\end{array}$

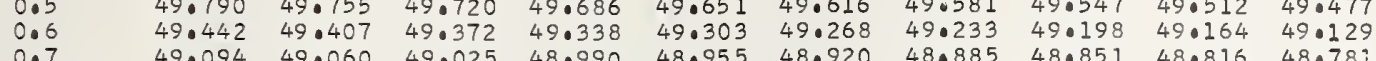
$\begin{array}{lllllllllll}0.7 & 49.094 & 49.060 & 49.025 & 48.990 & 48.955 & 48.920 & 48.885 & 48.851 & 48.816 & 48.781 \\ 0.8 & 48.746 & 48.711 & 48.677 & 48.642 & 48.607 & 48.572 & 48.538 & 48.503 & 48.468 & 48.433\end{array}$ $\begin{array}{lllllllllll}0.8 & 48.746 & 48.711 & 48.677 & 48.642 & 48.607 & 48.572 & 48.538 & 48.503 & 48.468 & 48.433 \\ 0.9 & 48.398 & 48.364 & 48.329 & 48.294 & 48.259 & 48.225 & 48.190 & 48.155 & 48.120 & 48.085\end{array}$

0.278108

.278108

0.278108

0.278107

0.278107

0.278107

0.278106

5361.0

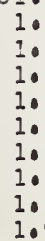

18648

$48.051 \quad 48.016$ $4.703 \quad 47.668$ $47.355 \quad 47 \cdot 320$ $46.659 \quad 46.625$ $46.311 \quad 46.277$ $45.964 \quad 45.929$ $45.616 \quad 45.581$ $45.268 \quad 45.233$

47.981
47.633

47.946

$\begin{array}{llll}47.842 & 47.807 & 47.772 & 47.738\end{array}$

1.

I. 5

1.6
1.7
1.8

44.921

5362.0

186440

$44.225 \quad 44.538$

$\begin{array}{ll}44.225 & 44.190\end{array}$

$43.530 \quad 43.495$

$43.182 \quad 43.147$

$42.487 \quad 42.452$

$\begin{array}{ll}42.139 & 42.104 \\ 41.791 & 41.757\end{array}$

41.444

5363.0

3.2

3.3

3.5
3.6

3.6
3.7

3.7
3.8
3.9

5364

4.
4.
40
40
4.5
40
4.7
40
4.0

5365

5.0
5.2
5.0
5.
5.
50
5
5
50

18641.096

$40.749 \quad 41.062$

$40.401 \quad 40.3$

$39.706 \quad 39.671$

$39.358 \quad 39.32$

$\begin{array}{ll}39.011 & 38.976 \\ 38.664 & 38.529\end{array}$

$38.316 \quad 38.281$

$\begin{array}{ll}47.937 & 47.25 \\ 46.937 & 46.903\end{array}$

$46.590 \quad 46.503$

$\begin{array}{ll}46.242 & 46.207\end{array}$

$\begin{array}{ll}45.894 & 45.860 \\ 45.546 & 45.511\end{array}$

$\begin{array}{lllllll}47.564 & 47.529 & 47.494 & 47.459 & 47.425 & 47.390 \\ 47.216 & 47.181 & 47.146 & 47.111 & 47.077 & 47.042\end{array}$

$\begin{array}{ll}47 \cdot 216 & 47 \cdot 181 \\ 46.868 & 46.833\end{array}$

$46.520 \quad 46.486$

$46 \cdot 172 \quad 46 \cdot 137$

$\begin{array}{llll}46.798 & 46.764 & 45.729 & 46.69\end{array}$

$\begin{array}{llll}46.451 & 46.416 & 46.381 & 46.346\end{array}$

$\begin{array}{llllll}45.825 & 45.790 & 45.755 & 45.720 & 45.686 & 45.651 \\ 45.477 & 45.442 & 45.407 & 45.373 & 45.338 & 45.303\end{array}$

$\begin{array}{ll}45.199 & 45.164 \\ 44.851 & 44.816\end{array}$

$\begin{array}{ll}45.477 & 45.442 \\ 45.129 & 45.094\end{array}$

$45 \cdot 407$

$\begin{array}{ll}45.686 & 45.651 \\ 45.338 & 45.303\end{array}$

$44.503 \quad 44.469 \quad 440$

$4.434 \quad 44.399$

44.712

44.677

44.642

4.607

$$
\begin{array}{lll}
43.808 & 43.773 \\
43.460 & 43.426
\end{array}
$$

$\begin{array}{ll}43.460 & 43.426 \\ 43.112 & 43.078 \\ 42.765 & 42.730\end{array}$

$\begin{array}{llllll}43.391 & 43.356 & 43.321 & 43.286 & 43.251 & 43.217\end{array}$

$\begin{array}{llllll}43.043 & 43.008 & 42.973 & 42.939 & 42.904 & 42.869\end{array}$

$\begin{array}{lll}42.417 & 42.383 \\ 42.070 & 42.035\end{array}$

. $348 \quad 42.661$

$42 \cdot 93$

$42.556 \quad 42.52$

$41.031 \quad 41.243 \quad 42.208 \quad 42.174$

$\begin{array}{llllll}2.000 & 41.965 & 41.931 & 41.896 & 41.861 & 41.826 \\ 1.652 & 41.618 & 41.583 & 41.548 & 41.513 & 41.479 \\ 1.305 & 41.270 & 41.235 & 41.201 & 41.166 & 41.131\end{array}$

$41.027 \quad 40.992 \quad 40.0$

$40.957 \quad 40.92$

40.887

40.853

$40.818 \quad 40 \cdot 783$

$\begin{array}{ll}40.332 & 40.297 \\ 39.984 & 30.949\end{array}$

39.984

$39.636 \quad 39.602$

38.941
38.594

39.254
38.907

40.61040 .57

$39.915 \quad 39.880$

$\begin{array}{ll}39.567 & 39.532 \\ 39.219 & 39.185\end{array}$

40.193

39.84
39.49

$39.150 \quad 39.463$

38.80

38.108

$\begin{array}{ll}39.428 & 39.393\end{array}$

$\begin{array}{ll}38.872 & 38.83 \\ 38.525 & 38.490\end{array}$

8637.62

$37.021 \quad 37.587$

37.89

38.212
37.865

$38.177 \quad 38.143$

$37.482 \quad 37.44$

37.413

38.420

9.0

8.73

38.698

$36.2727 \quad 37.239$

$36.579 \quad 36.544$

36.23136 .197

$35.884 \quad 35.850$

$\begin{array}{ll}35.587 & 35.502 \\ 35.189 & 35.155\end{array}$

$\begin{array}{ll}34.842 & 34.807 \\ 34.495 & 34.460\end{array}$

$37.204 \quad 37.170$

$36.510 \quad 36.822$

36.16

36.475
36.127

$\begin{array}{ll}37.135 & 37.100 \\ 36.787 & 36.753\end{array}$

$36.440 \quad 36.40$

36.71

36.37

$\begin{array}{ll}38.038 & 38.004 \\ 37.691 & 37.656\end{array}$

$35.467 \quad 35.433$

$\begin{array}{ll}36.093 & 36.05 \\ 35.745 & 35.710\end{array}$

$\begin{array}{llllll}6.093 & 36.058 & 36.023 & 35.988 & 35.954 & 35.919 \\ 5.745 & 35.710 & 35.676 & 35.641 & 35.506 & 35.572 \\ 35.398 & 35.363 & 35.328 & 35.293 & 35.259 & 35.224\end{array}$

33.800

34.1 .73

$33.105 \quad 33.07$

$32.758 \quad 32.723$

$31.717 \quad 31.682$

$\begin{array}{ll}31.369 & 31.334 \\ 31.022 & 30.987\end{array}$

$34 \cdot 773$

35.085
34.73
34.390

35.05

35.016

35.29

$\begin{array}{ll}5.259 & 35.224\end{array}$

$\begin{array}{ll}3 & 34.07 \\ 5 & 33.730\end{array}$

34.043
33.696

$34.009 \quad 33.974$

$\begin{array}{llll}34.634 & 34.599 & 34.564 & 34.530\end{array}$

$33.030 \quad 33.004 \quad 33.070 \quad 33.835$

$\begin{array}{llllllll}33.383 & 33.349 & 33.661 & 33.626 & 33.592 & 33.557 & 33.522 & 33.487\end{array}$

$\begin{array}{lllllll}33.001 & 32.967 & 32.932 & 32.847 & 33.210 & 33.175 & 33.140\end{array}$

$\begin{array}{llllllll}32.689 & 32.654 & 32.619 & 32.585 & 32.550 & 32.515 & 32.480 & 32.446 \\ 32.341 & 32.307 & 32.272 & 32.237 & 32.202 & 32.168 & 32.133 & 32.098\end{array}$

5
5
5
5
5

5366.0

6
6
6
6
6
6
6
6
6
6

18630.675

30.67530 .640

$29.980 \quad 29.946$

$29.63329 .598,29.911$

$29.286 \quad 29.251$

$28.592 \quad 28.557$

$28.245 \quad 28.210$

$27.551-27.516$

5367.0

7.1

$627.203 \quad 27 \cdot 169$

$26.85626 .822 \quad 26.134$

$\begin{array}{llll}26.50 & 26.475 & 26.440 & 26.40\end{array}$

$25.815 \quad 25.781 \quad 25.746 \quad 25.71$

$\begin{array}{llll}25.468 & 25.434 & 25.399 & 25.36\end{array}$

$\begin{array}{llll}25.121 & 25.086 & 25.052 & 25.017\end{array}$

24.77424 .740

$240427 \quad 240393 \quad 24.358$

$24.081 \quad 24.045$

536800

$$
\begin{array}{r}
368 . \\
8 . \\
8 . \\
8 . \\
8 . \\
8 . \\
8 . \\
8 .
\end{array}
$$

536900

$$
\begin{array}{r}
3690 \\
9.1 \\
9.2 \\
9.3 \\
904 \\
905 \\
9.6 \\
90 \\
90
\end{array}
$$
623.733
23.386
23.6 $\begin{array}{llll}23.386 & 23.352 & 23.664 & 23.6\end{array}$ $22.970 \quad 22.935$ $22.693 \quad 22.65$

21.964

$21.2760-22.241$

$21.305 \quad 21.271$

$\begin{array}{ll}20.958 & 20.923 \\ 20.612 & 20.577\end{array}$

$\begin{array}{llll}31.855 & 31.821 & 31.786 & 31.751\end{array}$

$\begin{array}{llll}31.508 & 31.473 & 31.439 & 31.404\end{array}$

$\begin{array}{llll}30.814 & 30.779 & 30.744 & 30.709\end{array}$

0.27810

0.278106

0.278105

0.27810

0.278105

0.278104

0.278104

0.278104

0.278103

.278103

0.278103

0.278102

0.278102

0.278102

0.278101

0.278101

0.278101

0.278100

0.278100

0.278100

0.278100
0.278099

0.27809

0.278099

0.278098

0.278098

0.278098
0.278098

0.278098

0.278097
0.278097

0.278097

0.278097

0.278097
0.278096

0.278096

0.278096

0.278096

0.278095

0.278095
0.278095

0.278095

0.278094

0.278094
0.278094

0.278094

0.278093

0.278093

278093

0.278092

0.278092

0.278092

0.278092

0.278091

0.278091

0.278091

0.278091

0.278090

0.278090

0.278090

0.278090

0.278089

0.278089

0.278089
0.278089

0.278088

0.278088

0.278088
0.278088

0.278088

0.278087 
0.278086

0.278086
0.278086

0.278086

0.278085
0.278085

1.493381

1.493408

1.493434

1.493488

1.493514

0.278085

0.278085

0.278084

0.278084

0.278084

0.278083

0.278083

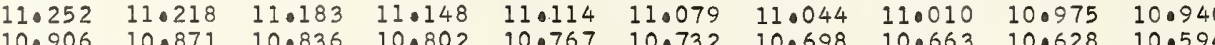

$\begin{array}{lllllllllll}10 & 10.559 & 10.524 & 10.490 & 10.455 & 10.421 & 10.386 & 10.351 & 10.317 & 10.028 & 10.594 \\ 10.00 .282 & 10.248\end{array}$

1.493594

1.0493621

1.493674

1.0493701

1.493754

1.493781

1.493834

$\begin{array}{lllllllllll}5372.0 & 18609 \cdot 866 & 09 \cdot 832 & 09.797 & 090762 & 09.728 & 090693 & 090558 & 09.624 & 09 \cdot 589 & 09 \cdot 555\end{array}$

$\begin{array}{lllllllllll}2.2 & 09.174 & 09.139 & 09.104 & 09.070 & 09.035 & 09.000 & 08.966 & 08.931 & 08.896 & 08.862\end{array}$

2.3

2.4

2.6

$\begin{array}{llllll}08.827 & 08.792 & 08.758 & 08.723 & 08.689 & 08.654 \\ 08.481 & 08.446 & 08.411 & 08.377 & 08.342 & 08.308\end{array}$

08.619 08.584 $08.550 \quad 08.515$

$\begin{array}{llllllllll}08.481 & 08.446 & 08.411 & 08.377 & 08.342 & 08.308 & 08.273 & 08.238 & 08.204 & 08.169 \\ 08.134 & 08.100 & 08.065 & 08.031 & 07.996 & 07.961 & 07.927 & 07.892 & 07.857 & 07.823\end{array}$

$\begin{array}{llllllllll}07.788 & 07.753 & 07.719 & 07.684 & 07.650 & 07.615 & 07.928 & 07.892 & 07.857 & 07.823 \\ 0.546 & 07.511 & 07.476\end{array}$

2.7

$07.442 \quad 07.407 \quad 07.373 \quad 07.338 \quad 07.303 \quad 07.26907$

$07.234 \quad 07.199 \quad 070165 \quad 070.130$

$\begin{array}{llll}07.095 & 07.061 & 07.026 & 06.991 \\ 06.749 & 06.714 & 06.680 & 06.645\end{array}$

$\begin{array}{lll}06.957 & 06.922 & 0 \\ 0611 & 06.576 & 0\end{array}$

06.887

06.853

$\begin{array}{lll}06.818 & 06.784 \\ 06.472 & 06.437\end{array}$

0.278083

0.278082

0.278082

0.278082

0.278082

0.278081

0.278081

10493861

1.493914

1.493941
1.493968

1.493905

1.494021

1.494048

1.494075
1.494101

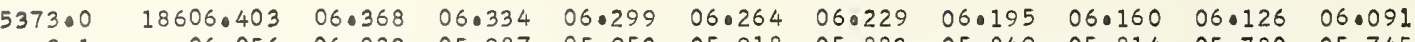

$3 \cdot 1$
3.2
3.3 $06.056 \quad 06.022 \quad 05.987 \quad 050953 \quad 050$

$\begin{array}{lllllllll} & \end{array}$

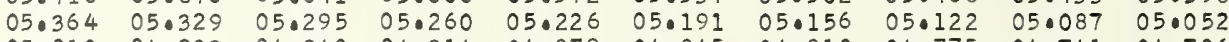

$\begin{array}{lllllllllll}05.018 & 04.983 & 04.948 & 040914 & 04.879 & 04.845 & 04.810 & 04.775 & 04.741 & 04.706\end{array}$

$\begin{array}{llllllllll}040325 & 04.291 & 04.256 & 04.221 & 04 \cdot 187 & 04.152 & 04 \cdot 118 & 04.083 & 04.048 & 04.013\end{array}$

$\begin{array}{lllllllllll}03.973 & 03.944 & 03.910 & 03.875 & 03.841 & 03.806 & 03.771 & 03.737 & 03.702 & 03.667\end{array}$

$\begin{array}{llllllllll}03.633 & 03.598 & 03.564 & 03.529 & 03.494 & 03.460 & 03.425 & 03.391 & 03.356 & 03.322 \\ 03.287 & 03.252 & 03.217 & 03.183 & 03.148 & 03.114 & 03.079 & 03.044 & 03.010 & 02.975\end{array}$

0.278081

0.278081

0.278080

0.278080

0.278080

0.278079

0.278079

1.494128

$\begin{array}{rlllllllll}18602.940 & 02.906 & 02.871 & 02.837 & 02.802 & 02.767 & 02.733 & 02.698 & 02.664 & 02.629 \\ 02.594 & 02.560 & 02.525 & 02.490 & 02.456 & 02.421 & 02.386 & 02.352 & 02.317 & 02.283\end{array}$

537400

4.3

$02.594 \quad 02.560$

$\begin{array}{llllllllll}01.902 & 01.867 & 02.179 & 02.144 & 02.110 & 02.075 & 02.041 & 020006 & 01.971 & 01.937\end{array}$

$\begin{array}{llllllllll}01.556 & 01.521 & 01.487 & 01.452 & 01.417 & 01.383 & 01.348 & 01.314 & 01.279 & 01.244\end{array}$

4.5

$\begin{array}{llllllllll}01.210 & 01.175 & 01.141 & 01.106 & 01.072 & 01.037 & 01.002 & 00.968 & 00.933 & 00.898 \\ 00.864 & 00.829 & 00.794 & 00.760 & 00.725 & 00.691 & 00.656 & 00.621 & 00.587 & 00.552\end{array}$

$\begin{array}{llllllllll}00.518 & 00.483 & 00.448 & 00.414 & 00.379 & 00.344 & 00.310 & 00.276 & 00.241 & 00.206\end{array}$

4.8

53750.0

375.0
5.1
5.2
5.3
5.4
5.5
5.6
5.7
5.8
5.9 18599.826

5.4

18599.479

99.445

$99.134 \quad 99.099$

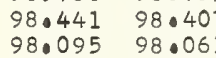

$97.749 \quad 97.715 \quad 97 \cdot 680 \quad 97.646$

$\begin{array}{llll}97.404 & 97.369 & 97.334 & 97.300 \\ 97.058 & 97.023 & 96.988 & 96.954 \\ 96.712 & 96.677 & 96.643 & 96.008\end{array}$

$\begin{array}{ll}96.712 & 96.677 \\ 96.366 & 96.33\end{array}$

5376.0

6.1

6.5

6.6

6.7
6.8

$18596.020 \quad 95.985$

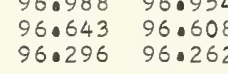

$00.033 * 99.999 * 99.964 * 99.929 * 99.895 * 99.860$

0.27807

0.278079

0.278078

0.278078

0.278078

0.278077

0.278077
0.278077

1.494158

1.494181

1.494208

1.494261

1.494288

1.494341

1.494395

1.494421

1.494448

1.494475

1.494528

1.094555

1.494508

0.278077

0.278076

0.278076

0.278076

0.278076

0.278075

0.278075

0.278075

10494661

1.494661

1.494715

1.0494741

1.494768

1.494795

1.494822

$\begin{array}{lllllll}97.265 & 97.231 & 97.196 & 97.161 & 97.126 & 97.092\end{array}$

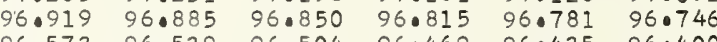

1.494875
1.494902

0.278074

0.278074
0.278074

0.278074

0.278074

0.278073

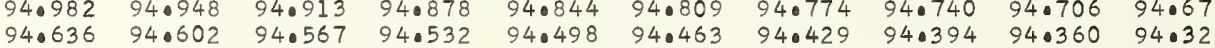

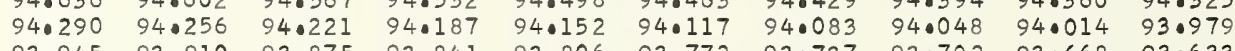

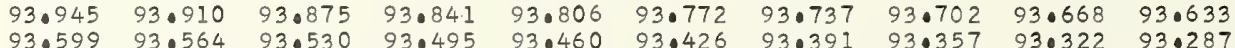

0.278073

0.278073

1.494928

1.494955

1.095008

1.495035

1.495088

1.495115

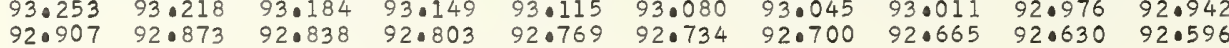

1.0495142
1.045168

5377.0

701

$7 \cdot 2$

$7 \cdot 5$

7.6

7.8

$18592.561 \quad 92.527$

$92.492 \quad 92.458$

$92.423 \quad 92.388 \quad 92.354 \quad 92.319 \quad 92.285 \quad 92.250$

0.278072

1.495193

0.278072

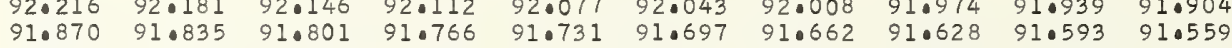

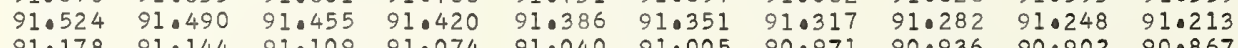

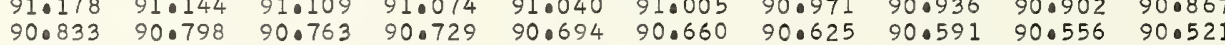

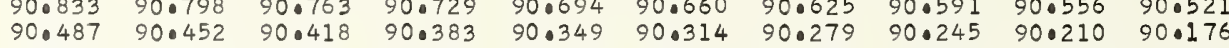

$\begin{array}{llllllllll}90.141 & 90.107 & 90.072 & 90.037 & 90.003 & 89.968 & 89.934 & 89.899 & 89.865 & 89.830\end{array}$

$\begin{array}{llllllllll}89.795 & 89.761 & 89.727 & 89.692 & 89.657 & 89.623 & 89.588 & 89.554 & 89.519 & 89.485 \\ 89.450 & 89.416 & 89.381 & 89.0346 & 89.312 & 89.277 & 89.243 & 89.208 & 89.174 & 89.1139\end{array}$

0.278072

0.278071

0.278071

0.278071

0.278071
0.278070

1.495248

1.495275

1.495302

1.495328

1.495355

1.495382

1.495408
1.495435

$\begin{array}{lllllllllll}5378.0 & 18589.104 & 89.070 & 89.035 & 89.001 & 88.966 & 88.932 & 88.897 & 88.863 & 88.828 & 88.793\end{array}$

0.278070

0.278070

0.278070

0.278070

0.278069
0.278069

0.278069
0.278069

0.278069
0.278069

0.278069

1.495462

1.495488

1.495515
1.495542

1.495542
1.495569

$\begin{array}{lllllllllll}87.722 & 87.687 & 87.653 & 87.618 & 87.583 & 87.549 & 87.515 & 87.480 & 87.446 & 87.411\end{array}$

$\begin{array}{lllllllllll}8.5 & 87.376 & 87.342 & 87.307 & 87.273 & 87.238 & 87.204 & 87.169 & 87.135 & 87.100 & 87.065 \\ 8.6 & 87.031 & 86.996 & 86.961 & 86.927 & 86.893 & 86.858 & 86.823 & 86.789 & 86.754 & 86.720\end{array}$

$\begin{array}{lllllllllll}8.7 & 86.685 & 86.651 & 86.616 & 86.582 & 86.547 & 86.512 & 86.478 & 86.443 & 86.409 & 86.374\end{array}$

$\begin{array}{lllllllllll}8.8 & 86.340 & 86.305 & 86.271 & 86.236 & 86.201 & 86.167 & 86.132 & 86.098 & 86.063 & 86.029 \\ 8.9 & 85.994 & 85.959 & 85.925 & 85.890 & 85.856 & 85.822 & 85.787 & 85.752 & 85.718 & 85.683\end{array}$

0.278068

0.278068

0.278068

0.278068

0.278067
0.278067

0.278067
0.278067

0.278067

0.278066

1.495595
1.495622

1.495649

1.495675
1.495702

$\begin{array}{lllllllllll}18585.649 & 85.614 & 85.579 & 85.545 & 85.510 & 85.476 & 85.441 & 85.407 & 85.372 & 85.338\end{array}$

$\begin{array}{llllllllllll}9.2 & 84.958 & 84.923 & 84.889 & 84.854 & 84.819 & 84.785 & 84.750 & 84.716 & 84.681 & 84 \cdot 646 \\ 9.3 & 84.612 & 84.577 & 84.543 & 84.509 & 84.474 & 84.439 & 84.405 & 84.370 & 84.336 & 84.301\end{array}$

$\begin{array}{llllllllllll}9.4 & 84.267 & 84.232 & 84.198 & 84.163 & 84.128 & 84.094 & 84.059 & 84.025 & 83.990 & 83.956\end{array}$

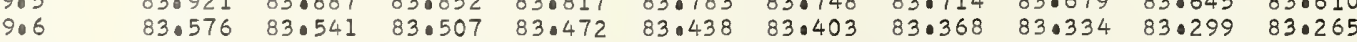

$\begin{array}{llllllllll}83.230 & 83.196 & 83.161 & 83.126 & 83.092 & 83.057 & 83.023 & 82.989 & 82.954 & 82.919\end{array}$

$\begin{array}{lllllllllll}908 & 82.885 & 82.850 & 82.816 & 82.781 & 82.747 & 82.712 & 82.677 & 82.643 & 82.609 & 82.574\end{array}$

1.495729

1.495755
1.495782

1.495782

1.495835
1.495862

1.495862

1.495889

1.495915
1.495942

1.495969

$\begin{array}{lllllllllll} & .001 & .002 & .003 & .004 & .005 & .006 & .007 & .008 & .009 & .010 \\ .034 & .003 & .007 & .010 & .014 & .017 & .021 & .024 & .028 & .031 & .034 \\ .033 & .003 & .007 & .010 & .013 & .017 & .020 & .023 & .027 & .030 & .033 \\ .032 & .003 & .006 & .010 & .013 & .016 & .019 & .023 & .026 & .029 & .032\end{array}$




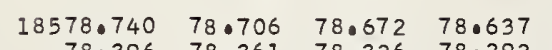

.010

.003

.007

.010

.014

.017

.021

.024

.027

.031

.034 
0.278043

0.278043

0.278043

0.278042

0.278042

0.278042

0.278042

0.278041 $\begin{array}{lllllllll}41.149 & 41.114 & 41.080 & 41.045 & 41.011 & 40.977 & 40.942 & 40.908 & 40.874\end{array}$

$\begin{array}{rlllllllll}18540.839 & 40.805 & 40.771 & 40.736 & 40.702 & 40.667 & 40.633 & 40.599 & 40.564 & 40.530 \\ 40.495 & 40.461 & 40.427 & 40.393 & 40.358 & 40.324 & 40.289 & 40.255 & 40.220 & 40.186\end{array}$ $\begin{array}{lllllllllll}40.152 & 40.117 & 40.083 & 40.049 & 40.014 & 39.980 & 39.946 & 39.911 & 39.877 & 39.843\end{array}$

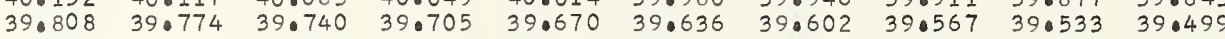
$\begin{array}{llllllllll}39.464 & 39.430 & 39.395 & 39.361 & 39.327 & 39.292 & 39.258 & 39.224 & 39.189 & 39.155\end{array}$ $\begin{array}{llllllllll}39.120 & 39.086 & 39.052 & 39.017 & 38.983 & 38.948 & 38.914 & 38.880 & 38.845 & 38.811\end{array}$ $\begin{array}{lllllllllll}38.777 & 38.742 & 38.708 & 38.674 & 38.639 & 38.605 & 38.570 & 38.536 & 38.501 & 38.467\end{array}$ $\begin{array}{lllllllllll}38.433 & 38.398 & 38.364 & 38.330 & 38.295 & 38.261 & 38.227 & 38.192 & 38.158 & 38.123\end{array}$ $\begin{array}{llllllllll}37.745 & 37.711 & 37.677 & 37.642 & 37.608 & 37.573 & 37.539 & 37.505 & 37.470 & 37.436\end{array}$ $\begin{array}{rrrrrrrrrrr}5393.0 & 18537.401 & 37.367 & 37.333 & 37.298 & 37.264 & 37.229 & 37.195 & 37.161 & 37.127 & 37.092 \\ 3.1 & 37.058 & 37.023 & 36.989 & 36.955 & 36.920 & 36.886 & 36.852 & 36.817 & 36.783 & 36.749\end{array}$

3.1

$3 \cdot 2$

3.4

3.6

3.6
3.7

539400

36.714

36.027

35.683

$35.339 \quad 35.64$

34.996
34.652

34.652
34.309

18533.965

4.1
4.2
4.3

4.5

4.6

4.8

5395.

$$
\begin{aligned}
& 395.0 \\
& 5.1 \\
& 5.2 \\
& 5.3 \\
& 5.4 \\
& 5.5 \\
& 5.6 \\
& 5.7 \\
& 5.8
\end{aligned}
$$

6.1
6.2
6.3

6.3
6.4

6.5
6.6

6.6
6.7

6.8
6.9

5397.

0.278041

0.27804

0.278040

0.278040

0.278040

0.278040

0.278039

0.278039

0.278039

0.278038

0.278038

0.278038
0.278038
0.27037

0.278037

0.278037

0.278037

0.278036

0.27836

0.278036

.

0.278035

0.278035

0.278035

0.2780275
0.278034

.278034

.

0.278034

0.278034
0.278033
0.027803

0.278033

1.498717
1.0498743

10498770

10.498797

1.498850

1.498877
1.0498904

1.498930

1.0498957

1.0499010

1.0499037

1.499064

10499127

1.499170

1.499197

1.0499250

1.. 499304

1.499330

1.499384

1.499410

1.499464

1.499490
1.499517

10499544

0.499571
1.0499597

1.499624

10499651

1.4499677
1.499704

1.499731

1.499757

1.0499811

1.499837

1.499864

1.499891
1.0499917

1.499944

1.499997

1.500024

1.500051

1.500078
1.500104

1.500104
1.500131

1.500158

1.500184

1.500238

0.278033

0.278032
0.278032
0.2278032

1.500264

0.27803

0.278032
0.278032

0.278031

0.278031

0.278031

1.500291

1.500344

1.500371

1.500398

1.500424

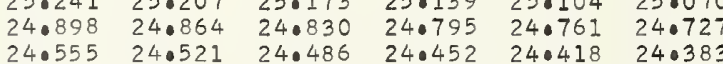

$\begin{array}{lllllll}24.5555 & 24.521 & 24.486 & 24.452 & 240418 & 240383 \\ 24.212 & 24.177 & 24.143 & 24.409 & 24074 & 24.040\end{array}$

0.278031

1.500504

.0278030

0.278030

0.278030

.278030

0.278029

0.278029
0.278029

1.500531

1.500558

1.500584

1.500638

1.500665

1.500691

$\frac{1}{10500745}$

0.278029

1.500798 0.278028 0.278028 0.278028 0.278027 0.278027 0.278027

0.278027

.5500851

1.500878

1.500905

1.500931

1.0500985

1.501011

0.278026

0.278026
0.278026
0.27826

0.278026

0.278026

0.278025
0.278025
0.2725

0.278025
0.278025
0.27025

0.278025
0.278025

1.501065

1.501091

10501145 


\section{.}

5402

2
2
2
2
2
2
2
2
2

5403

03.0
3.0
3.0
30
3.0
3.6
3.67
3.9
3.9

5404.0

404.0
4.1
4.2
403
4.4
405
406
407
4.8
409

\author{
5405
}

4050
50
50
50
50
50
50
507
50
50
4060

5406.0

406.0
6.1
6.2
60
6.4
6.5
6.0
60
60
6.

5407.0

707.0
70
$7:$
$7:$
7.5
7.6
707
7.9

$7.1 \quad 18489.40$

$\begin{array}{rlll}89.404 & 89.370 & 89.336 & 89.302 \\ 89.062 & 89.028 & 88.994 & 88.960\end{array}$

$\begin{array}{llll}89.062 & 89.028 & 88.994 & 88.960 \\ 88.720 & 88.686 & 88.652 & 88.618\end{array}$

$\begin{array}{llll}88.379 & 88.0344 & 88.310 & 88.276 \\ 88.037 & 88.002 & 87.968 & 87.0934\end{array}$

$\begin{array}{llll}87.695 & 87.661 & 87.626 & 87.592 \\ 87.353 & 87.319 & 87.284 & 87.250\end{array}$

$\begin{array}{llll}87.353 & 87.319 & 87.284 & 87.250 \\ 87.011 & 86.977 & 86.943 & 86.908 \\ 86.669 & 86.635 & 86.001 & 86.567\end{array}$

$\begin{array}{llll}86.669 & 86.635 & 86.601 & 86.567 \\ 86.327 & 86.293 & 86.259 & 86.225\end{array}$

5408.0

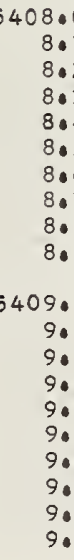

$\begin{array}{lllll}18485.985 & 85 \cdot 951 & 85.917 & 85.883\end{array}$ $\begin{array}{llll}85.644 & 85.609 & 85.575 & 85.541 \\ 85.302 & 85.268 & 85.234 & 85.199\end{array}$ $\begin{array}{llll}85.302 & 85.268 & 85.234 & 85.199 \\ 84.960 & 84.926 & 84.892 & 84.858\end{array}$ $\begin{array}{llll}84.960 & 84.926 & 84.892 & 84.858 \\ 84.618 & 84.584 & 84.550 & 84.516\end{array}$ $\begin{array}{llll}84.618 & 84.584 & 84.5550 & 84.516 \\ 84.276 & 84.242 & 84.0208 & 84.174\end{array}$ $\begin{array}{llll}83.935 & 83.901 & 83.866 & 83.832\end{array}$ $\begin{array}{llll}83.593 & 83.559 & 83.525 & 83.490 \\ 83.251 & 83.217 & 83.183 & 83.149\end{array}$

$\begin{array}{llll}82.910 & 82.875 & 82.841 & 82.807\end{array}$

$\begin{array}{lllll}79.835 & 79.801 & 79.766 \quad 79.732\end{array}$

$\begin{array}{llllll}13.235 & 13.200 & 13.166 & 13.132 & 13.098 & 13.063 \\ 12.892 & 12.858 & 12.823 & 12.789 & 12.755 & 12.720\end{array}$ $\begin{array}{lllllll}12.549 & 12.515 & 12.481 & 12.446 & 12.412 & 12.378\end{array}$ $\begin{array}{llllll}12.206 & 12.172 & 12.138 & 12.103 & 12.069 & 12.035 \\ 11.864 & 11.829 & 11.795 & 11.761 & 11.726 & 11.692\end{array}$ $\begin{array}{llllll}11.521 & 11.486 & 11.452 & 11.418 & 11.384 & 11.349\end{array}$

$\begin{array}{lllllll}11.178 & 11.144 & 11.109 & 11.075 & 11.041 & 11.007 \\ 10.835 & 10.801 & 10.767 & 10.732 & 10.698 & 10.664\end{array}$ $\begin{array}{ll}10.492 & 10.458 \\ 10.150 & 10.116\end{array}$

$\begin{array}{lllll}458 & 10.424 & 10.390 & 10.355 & 10.321 \\ 0.116 & 10.081 & 10.047 & 10.012 & 09.978\end{array}$

10.390

0.698

0.278024

0.278024

0.278024

0.278024

0.278023

0.278023

0.278023

0.278022

0.078022

0.278022

0.278021

0.00278021

0.278021

0.278021

0.278020

0.278020
0.278020

0.278020

0.278019

.278019

0.278019
0.278019

0.278018

0.278018

0.278018
0.278018

0.278018

0.278017

0.278017

0.278017

0.278016

0.278016

0.278016

0.278015

0.278015

0.278015

0.278015
0.278015

0.278014
0.278014

0.278014

0.278014

0.278013

0.278013

0.278012

0.278012

10.501332

1.501358
1.501385

1.501412

1.501465

1.501492

1.501545

1.501598

1.501625

1.501652

1.501732

1.501785

1.501812

1.501865

1.501892

1.501945

1.501999

1.502025

1.502079

1.502132

1.502159

1.502212

1.502239

1.502292

1.502319

1.502372

1.502399

1.502426

1.502479

.502506
1.502532

1.502559

.502586

1.502639

0.278012

0.278011

0.278011

0.278011

0.278010

1.502666

. .502693

1.502746

1.502799

1.502826

1.502853

1.502906

.502933

.502959

1.503013

1.503066

1.503093

1.503119

1.503173

0.278010

0.278010

.503200

$\begin{array}{llllll}.268 & 89.233 & 89.199 & 89.165 & 89.131 & 89.097 \\ 8.926 & 88.892 & 88.857 & 88.823 & 88.789 & 88.755\end{array}$

$\begin{array}{lllllll}88.584 & 88.550 & 88.515 & 88.481 & 88.447 & 88.413\end{array}$

$\begin{array}{llllll}88.242 & 88.208 & 88.174 & 88.139 & 88.105 & 88.071\end{array}$

$\begin{array}{lllllll}87.558 & 87.524 & 87.490 & 87.456 & 87.421 & 87.387\end{array}$

$\begin{array}{llllll}87.216 & 87.182 & 87 \cdot 148 & 87.114 & 87 \cdot 079 & 87 \cdot 045\end{array}$

$\begin{array}{llllll}86.532 & 86.498 & 86.464 & 86.430 & 86.396 & 86.362\end{array}$

0.278009

0.278009

0.278009

0.278008

0.278008

1.503253

.503280

1.503333

.503360

1.503413

0.278008

0.278008

0.278007

0.278007

0.278007

0.278006

0.278006

$\begin{array}{lllllllllll}18482.568 & 82.534 & 82.500 & 82.465 & 82.431 & 82.397 & 82.363 & 82.329 & 82.295 & 82.260\end{array}$

$\begin{array}{llllllllll}82.226 & 82.192 & 82.158 & 82.124 & 82.090 & 82.055 & 82.021 & 81.987 & 81.953 & 81.918\end{array}$

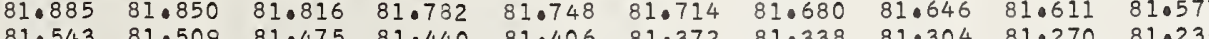

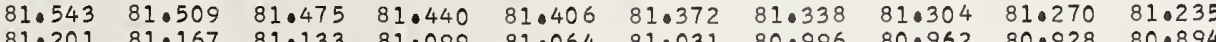

$\begin{array}{llllllllll}81.201 & 81.167 & 81.133 & 81.099 & 81.064 & 81.031 & 80.996 & 80.962 & 80.928 & 80.894 \\ 80.859 & 80.825 & 80.791 & 80.757 & 80.723 & 80.689 & 80.655 & 80.621 & 80.586 & 80.552\end{array}$

$\begin{array}{llllllllll}80.518 & 80.484 & 80.449 & 80.416 & 80.381 & 80.347 & 80.313 & 80.279 & 80.245 & 80.210\end{array}$

$\begin{array}{llllllllll}80.176 & 80.142 & 80.108 & 80.014 & 80.381 & 80.347 & 80.313 & 80.279 & 80.245 & 80.2210 \\ 70.0005 & 79.971 & 79.937 & 79.903 & 79.86\end{array}$

79.971

$79.937 \quad 79.903 \quad 79.869$

0.278006

0.278006

0.278005

0.278005

0.278005

0.278005

0.278005

0.278004

0.278004
0.278004

1.503466

1.503520

1.503546

1.503600

1.503627

1.503653
1.503680

1.503680
1.503707

1.503733

1.503760

1.503787

1.503840

1.503867

1.503920

1.503947
1.503973

.010

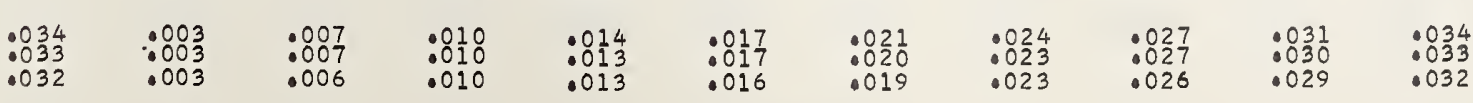




.03
0.1
0.2
0.0
0.4
0.6
0.7
0.0

$$
\begin{array}{r}
54110 \\
10 \\
10 \\
10 \\
10 \\
10 \\
10 \\
1.9
\end{array}
$$

5412.

$$
\begin{aligned}
& 2 \\
& 2 \\
& 2 \\
& 2 . \\
& 2 . \\
& 2 . \\
& 2 . \\
& 2 . \\
& 2 .
\end{aligned}
$$

$2 \cdot 1$
2.2
2.3
2.4
2.5
2.6
2.7
2.8
2.9

5413.0

3.1
3.2
3.3

3.3
3.4

3.5
3.6

3.6

3.8
3.9

5414.

40

4.2
4.3

4.4
4.5

$4 \cdot 6$
4.7

4.8
4.9

5415.

5.

5.3

5.5

5.6

5.8

5416

6.2

6.2

6.5

6.6

6.8

5417

7.

7.3

7.5
7.7
7.8

7.

5418

8.1

8.2

8.4
8.5

8.5
8.6
8.7

8.7
8.8

8.9

5419.

9.1

9.3
9.4
9.5
9.6

9.6
9.7
9.8
9.9

18479.151

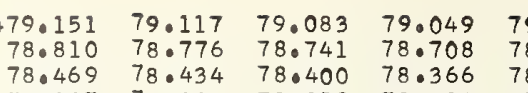

$\begin{array}{lllll}78.127 & 78.093 & 78.059 & 78.024\end{array}$

77.785

$\begin{array}{llll}77.444 & 77.410 & 77.375 & 77.341 \\ 77.102 & 77.068 & 77.034 & 77.000\end{array}$

$\begin{array}{lllll}76.761 & 76.727 & 76.692 & 76.658\end{array}$

$\begin{array}{ll}76.419 & 76.385 \\ 76.078 & 76.044\end{array}$

18475.736

75.395
75.053
74.712

75.019
74.678

74.029

73.995

$73.347 \quad 73.312$

$\begin{array}{ll}73.005 & 72.971 \\ 72.664 & 72.630\end{array}$

18472.323

71.981

$71.299 \quad 71.264$

$70.616 \quad 70.582$

$\begin{array}{ll}70.275 & 70.241 \\ 69.934 & 69.899\end{array}$

$69.592 \quad 69.558$

69.251

18468.910

$68.569 \quad 68.534$

68.19468 .159

$\begin{array}{lll}67.545 & 67.852 & 67.818 \\ 67.511 & 67.477 & 67\end{array}$

67.20467 .170

$66.522 \quad 66.82966 .79$

$\begin{array}{llll}66.181 & 66.147 & 66.113 & 66.079\end{array}$

$65.158 \quad 65.465$

64.81

$\begin{array}{lllll}6.135 & 64.101 & 64.067 & 64.032\end{array}$

$63.793 \quad 63.760 \quad 63.726 \quad 63.691$

$\begin{array}{llll}63.112 & 63.078 & 63.043 & 63.009\end{array}$

$\begin{array}{llll}62.771 & 62.737 & 62.703 & 62.668\end{array}$

61.748
61.407

62.055

61.066

$60.725-60.69$

$60.384-60.350$

$\begin{array}{llll}59.703 & 59.668 & 59.635 & 59.600\end{array}$

$\begin{array}{llll}59.362 & 59.328 & 59.293 & 59.260 \\ 59.021 & 58.987 & 58.953 & 58.918\end{array}$

458.680

$58.339 \quad 58.646$

$\begin{array}{llll}57.939 & 58.305 & 58.271 & 58.237 \\ 57.964 & 57.930 & 57.896\end{array}$

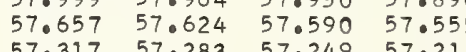

$\begin{array}{llll}56.976 & 56.942 & 56.908 & 56.874\end{array}$

$\begin{array}{llll}56.635 & 56.601 & 56.567 & 56.533 \\ 56.295 & 56.260 & 56.226 & 56.19\end{array}$

$\begin{array}{llll}55.954 & 55.920 & 55.886 & 55.852 \\ 55.613 & 55.579 & 55.545 & 55.511\end{array}$

$\begin{array}{lllll}18455.272 & 55.239 & 55.204 & 55.170\end{array}$

$\begin{array}{llll}54.932 & 54.898 & 54.864 & 54.830 \\ 54.591 & 54.557 & 54.523 & 54.489\end{array}$

$\begin{array}{llll}54.250 & 54.216 & 54.183 & 54.148\end{array}$

$\begin{array}{llll}53.569 & 53.535 & 53.501 & 53.407\end{array}$

$\begin{array}{llll}53.229 & 53.194 & 53.160 & 53.126\end{array}$

$\begin{array}{llll}52.888 & 52.854 & 52.820 & 52.786 \\ 52.547 & 52.513 & 52.479 & 52.445 \\ 52.207 & 52.173 & 52.139 & 52.104\end{array}$

8451.866

$\begin{array}{llll}51.526 & 51.491 & 51.458 & 51.764\end{array}$

$\begin{array}{llll}51.185 & 51.151 & 51.117 & 51.083 \\ 50.844 & 50.810 & 50.777 & 50.742\end{array}$

$\begin{array}{llll}50.504 & 50.470 & 50.436 & 50.402\end{array}$

$\begin{array}{llll}50.163 & 50.130 & 50.095 & 50.061\end{array}$

$\begin{array}{llll}49.823 & 49.789 & 49.755 & 49.72 \\ 49.483 & 49.448 & 49.414 & 49.38\end{array}$

$\begin{array}{llll}49.483 & 49.448 & 49.414 & 49.380 \\ 49.142 & 49.108 & 49.074 & 49.040\end{array}$

$48.802 \quad 48.768 \quad 48.733 \quad 48.699$

$18448.461 \quad 48.427 \quad 48.393 \quad 48.359$

$47.780 \quad 47.746 \quad 47.712 \quad 47.019$

$\begin{array}{llll}47.440 & 47.406 & 47.372 & 47.338\end{array}$

$\begin{array}{llll}47.100 & 47.065 & 47.031 & 46.997 \\ 46.759 & 46.725 & 46.691 & 46.65\end{array}$

$\begin{array}{llll}46.759 & 46.725 & 46.691 & 46.657 \\ 46.419 & 46.385 & 46.351 & 46.317\end{array}$

$\begin{array}{llll}46.079 & 46.044 & 46.010 & 45.976 \\ 45.738 & 45.704 & 45.670 & 45.636\end{array}$

$\begin{array}{llll}45.738 & 45.704 & 45.670 & 45.636 \\ 45.398 & 45.364 & 45.330 & 45.296\end{array}$ $\begin{array}{llllll}.015 & 78.980 & 78.946 & 78.912 & 78.878 & 78.844 \\ & 78.905 & 78.571 & 78.537 & 78.502\end{array}$

$\begin{array}{llllll}78.673 & 78.639 & 78.605 & 78.571 & 78.537 & 78.502 \\ 78.332 & 78.298 & 78.263 & 78.229 & 78.195 & 78.161\end{array}$

$\begin{array}{llllll}77.990 & 77.956 & 77.922 & 77.888 & 77.854 & 77.820 \\ 77.649 & 77.615 & 77.581 & 77.546 & 77.512 & 77.478\end{array}$

$\begin{array}{llllll}77.307 & 77.273 & 77.239 & 77.205 & 77.171 & 77.136\end{array}$

$\begin{array}{lllllll}76.966 & 76.932 & 76.897 & 76.863 & 76.829 & 76.795\end{array}$

$\begin{array}{llllll}76.024 & 76.590 & 76.556 & 76.522 & 76.488 & 76.453\end{array}$

$\begin{array}{llllll}75.941 & 75.249 & 76.214 & 76.180 & 76.146 & 76.112 \\ 75.873 & 75.839 & 75.805 & 75.771\end{array}$

$\begin{array}{llllll}75.600 & 75.566 & 75.531 & 75.498 & 75.463 & 75.429\end{array}$

$\begin{array}{lllllll}74.917 & 74.883 & 74.849 & 74.815 & 740781 & 74.746\end{array}$

$\begin{array}{lllllll}74.576 & 74.541 & 74.507 & 74.473 & 74.439 & 74.405\end{array}$

$\begin{array}{llllll}74.234 & 74.200 & 74.166 & 74.132 & 74.098 & 74.063 \\ 73.893 & 73.859 & 73.824 & 73.790 & 73.756 & 73.722\end{array}$

$\begin{array}{lllllll}73.552 & 73.517 & 73.483 & 73.449 & 73.415 & 73.381\end{array}$

$\begin{array}{llllll}73.210 & 73.176 & 73.142 & 73.108 & 73.073 & 73.039\end{array}$

$\begin{array}{llllll}72.527 & 72.493 & 72.459 & 72.425 & 72.391 & 72.357\end{array}$

$\begin{array}{llllll}72.186 & 72.152 & 72.118 & 72.084 & 72.050 & 72.015 \\ 71.845 & 71.811 & 71.777 & 71.742 & 71.708 & 71.674\end{array}$

$\begin{array}{llllll}71.503 & 71.469 & 71.435 & 71.401 & 71.367 & 71.333\end{array}$

$\begin{array}{llllll}71.162 & 71.128 & 71.094 & 71.060 & 71.026 & 70.992 \\ 70.821 & 70.787 & 70.752 & 70.719 & 70.684 & 70.650\end{array}$

$\begin{array}{llllll}70.479 & 70.445 & 70.411 & 70.377 & 70.343 & 70.309\end{array}$

$\begin{array}{lllllll}70.138 & 70.104 & 70.070 & 70.036 & 70.002 & 69.968\end{array}$

$\begin{array}{llllll}69.456 & 69.422 & 69.388 & 69.354 & 69.320 & 69.285\end{array}$

$\begin{array}{lllllll}68.773 & 68.739 & 68.705 & 68.671 & 68.637 & 68.603\end{array}$

$\begin{array}{llllll}68.432 & 68.398 & 68.364 & 68.330 & 68.296 & 68.261\end{array}$

$\begin{array}{llllll}68.091 & 68.057 & 68.023 & 67.989 & 67.955 & 67.921 \\ 67.750 & 67.716 & 67.682 & 67.647 & 67.614 & 67.579\end{array}$

$\begin{array}{lllllll}67.409 & 67.375 & 67.341 & 67.307 & 67.272 & 67.238\end{array}$

$\begin{array}{llllll}66.727 & 66.692 & 66.658 & 66.624 & 66.590 & 66.556\end{array}$

$\begin{array}{llllll}66.386 & 66.352 & 66.318 & 66.283 & 66.249 & 66.215\end{array}$

$\begin{array}{llllll}66.045 & 66.010 & 65.976 & 65.942 & 65.908 & 65.874\end{array}$

$\begin{array}{llllll}65.363 & 65.328 & 65.294 & 65.260 & 65.226 & 65.192\end{array}$

$\begin{array}{llllll}65.021 & 64.987 & 64.953 & 64.919 & 64.885 & 64.851 \\ 64.680 & 64.646 & 64.612 & 64.578 & 64.544 & 64.510\end{array}$

$\begin{array}{llllll}64.339 & 64.305 & 64.271 & 64.237 & 64.203 & 64.169\end{array}$

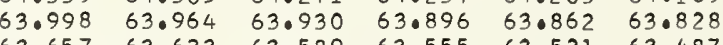

$\begin{array}{llllll}63.316 & 63.623 & 63.589 & 63.555 & 63.521 & 63.487 \\ & 63.282 & 63.248 & 63.214 & 63.180 & 63.146\end{array}$

$62.975 \quad 62.941 \quad 62.907 \quad 62.87365 .83960 .805$

$\begin{array}{llllll}62.635 & 62.600 & 62.566 & 62.532 & 62.498 & 62.464 \\ 62.293 & 62.259 & 62.225 & 62.191 & 62.157 & 62.123\end{array}$

$\begin{array}{llllll}61.952 & 61.918 & 61.884 & 61.850 & 61.816 & 61.782\end{array}$

$\begin{array}{llllll}61.612 & 61.578 & 61.543 & 61.509 & 61.475 & 61.441 \\ 61.271 & 61.236 & 61.203 & 61.168 & 61.134 & 61.100\end{array}$

$\begin{array}{llllll}61.273 & 61.236 & 61.203 & 61.168 & 61.134 & 61.100 \\ 60.930 & 60.896 & 60.862 & 60.827 & 60.793 & 60.759\end{array}$

$\begin{array}{llllll}60.589 & 60.555 & 60.521 & 60.487 & 60.452 & 60.418\end{array}$

$\begin{array}{llllll}60.248 & 60.214 & 60.180 & 60.146 & 60.112 & 60.078 \\ 59.907 & 59.873 & 59.839 & 59.805 & 59.771 & 59.737\end{array}$

$\begin{array}{llllll}59.566 & 59.532 & 59.498 & 59.464 & 59.430 & 59.396\end{array}$

$\begin{array}{llllll}59.225 & 59.191 & 59.157 & 59.123 & 59.089 & 59.055 \\ 58.885 & 58.851 & 58.816 & 58.782 & 58.748 & 58.714\end{array}$

$\begin{array}{lllllll}58.544 & 58.510 & 58.475 & 58.441 & 58.407 & 58.373\end{array}$

$\begin{array}{lllllll}58.203 & 58.169 & 58.135 & 58.101 & 58.067 & 58.032 \\ 57.862 & 57.828 & 57.794 & 57.760 & 57.726 & 57.692\end{array}$

$\begin{array}{lllllll}57.181 & 57.147 & 57.113 & 57.078 & 57.044 & 57.010 \\ 56.840 & 56.806 & 56.771 & 56.738 & 56.704 & 56.669\end{array}$

$\begin{array}{llllll}56.499 & 56.465 & 56.431 & 56.397 & 56.363 & 56.329\end{array}$

$\begin{array}{llllll}56.158 & 56.124 & 56.090 & 56.056 & 56.022 & 55.988\end{array}$

$\begin{array}{llllll}55.818 & 55.784 & 55.750 & 55.715 & 55.681 & 55.647 \\ 55.477 & 55.443 & 55.409 & 55.375 & 55.341 & 55.306\end{array}$

$\begin{array}{llllll}55.136 & 55.102 & 55.068 & 55.034 & 55.000 & 54.966 \\ 54.795 & 54.761 & 54.727 & 54.693 & 54.659 & 54.625\end{array}$

$\begin{array}{lllllll}54.795 & 54.761 & 54.727 & 54.0693 & 54.659 & 54.625 \\ 54.455 & 54.421 & 54.387 & 54.353 & 54.319 & 54.285\end{array}$

$\begin{array}{llllll}54.114 & 54.080 & 54.046 & 54.012 & 53.978 & 53.044\end{array}$

$\begin{array}{lllllll}53.773 & 53.740 & 53.706 & 53.671 & 53.637 & 53.603\end{array}$

$53.092 \quad 53.058 \quad 53.365023 .331053 .297 \quad 53.263$

$\begin{array}{llllll}52.718 & 52.584 & 52.650 & 52.616 & 52.581\end{array}$

$\begin{array}{llllll}52.411 & 52.377 & 52.343 & 52.309 & 52.275 & 52.241 \\ 52.071 & 52.037 & 52.002 & 51.969 & 51.934 & 51.900\end{array}$

$\begin{array}{llllll}51.730 & 51.696 & 51.662 & 51.628 & 51.594 & 51.560\end{array}$

$\begin{array}{llllll}51.389 & 51.355 & 51.321 & 51.287 & 51.253 & 51.219\end{array}$

$\begin{array}{llllll}51.049 & 51.015 & 50.981 & 50.947 & 50.913 & 50.879 \\ 50.708 & 50.674 & 50.640 & 50.606 & 50.572 & 50.538\end{array}$

$\begin{array}{llllll}50.368 & 50.334 & 50.300 & 50.266 & 50.231 & 50.198\end{array}$

$\begin{array}{llllll}50.027 & 49.993 & 49.959 & 49.925 & 49.891 & 49.857\end{array}$

$\begin{array}{llllll}49.387 & 49.653 & 49.619 & 49.584 & 49.551 & 49.516 \\ 49.312 & 49.278 & 49.244 & 49.210 & 49.176\end{array}$

$\begin{array}{llllll}49.006 & 48.972 & 48.938 & 48.904 & 48.870 & 48.836\end{array}$

$\begin{array}{llllll}48.325 & 48.291 & 48.257 & 48.223 & 48.189 & 48.155\end{array}$

$\begin{array}{lllllll}47.985 & 47.950 & 47.917 & 47.882 & 47.848 & 47.814\end{array}$

$\begin{array}{llllll}47.644 & 47.610 & 47.576 & 47.542 & 47.508 & 47.474 \\ 47.304 & 47.270 & 47.236 & 47.201 & 47.168 & 47.134\end{array}$

$\begin{array}{llllll}46.963 & 46.929 & 46.895 & 46.861 & 46.827 & 46.793\end{array}$

$\begin{array}{lllllll}46.623 & 46.589 & 46.555 & 46.521 & 46.487 & 46.453\end{array}$

$\begin{array}{lllllll}46.283 & 46.249 & 46.215 & 46.180 & 46.146 & 46.112 \\ 45.942 & 45.908 & 45.874 & 45.840 & 45.806 & 45.772\end{array}$

$\begin{array}{lllllll}45.602 & 45.568 & 45.534 & 45.500 & 45.466 & 45.772\end{array}$

$\begin{array}{llllll}45.261 & 45.228 & 45.194 & 45.160 & 45.125 & 45.091\end{array}$

$\begin{array}{ll}0.278004 & 1.504000 \\ 0.278004 & 1.504027 \\ 0.278003 & 1.504053 \\ 0.278003 & 1.504080 \\ 0.278003 & 1.504107 \\ 0.278003 & 1.504134 \\ 0.278002 & 1.504160 \\ 0.278002 & 1.504187 \\ 0.278002 & 1.504214 \\ 0.278002 & 1.504240\end{array}$

$0.278002 \quad 1.504267$

0.278001

0.278001

0.278001

0.278000

.278000

0.278000

0.278000

0.277999

0.277999

0.277999

0.277999

0.277998

0.277998

0.277998

0.277997

0.277997

0.277997

0.277996

0.277996

0.277996

0.277995

0.277995

0.277995

0.277994

0.277994

0.277994

0.277903

0.277993
0.277993

0.277993

0.277993
0.277992

0.277992

0.277992

0.277992
0.277992

0.277991

0.277991

0.277001

0.27799

0.277990

0.277990

0.277990
0.277990

0.277989

0.277989

0.277989

0.27798

0.27798

0.27708

0.277988
0.277988

0.277987

0.277987

0.277987
0.277987

0.277986

0.277986

0.277986

0.277986

0.277985

0.277985

0.277985

0.277984

0.277984

0.27798

0.277984

.504294

1.504320
1.504347

1.504374

1.504427

1.504454

1.504480
1.504507

1.504534

.504561
.0504587

1.504587
1.504614

1.504614

1.504641

1.504694

1. 504721

1.504747

1.504801

1.504827

1.504854

1.504881 


\begin{tabular}{|c|c|c|c|c|c|c|}
\hline$\lambda(A)$ & .00 & .01 & .02 & .03 & .04 & .05 \\
\hline 5420.0 & $\begin{array}{r}18445.057 \\
44.717\end{array}$ & $\begin{array}{l}45.023 \\
44.683\end{array}$ & $\begin{array}{l}44.989 \\
44.649\end{array}$ & 44.955 & 44.921 & 44.887 \\
\hline $\begin{array}{l}0.1 \\
0.2\end{array}$ & $\begin{array}{l}44.717 \\
44.377\end{array}$ & $\begin{array}{l}44.683 \\
44.343\end{array}$ & $\begin{array}{l}44.649 \\
44.309\end{array}$ & 44.615 & 44.581 & $\begin{array}{l}44.547 \\
44.207\end{array}$ \\
\hline 0.3 & $\begin{array}{l}44.377 \\
44.036\end{array}$ & 44.002 & $\begin{array}{l}44.309 \\
43.969\end{array}$ & $\begin{array}{l}44.275 \\
43.935\end{array}$ & $\begin{array}{l}44.24 .0 \\
43.900\end{array}$ & $\begin{array}{l}44.207 \\
43.866\end{array}$ \\
\hline 0.4 & 43.696 & 43.662 & 43.628 & 43.594 & 43.560 & 43.526 \\
\hline 0.5 & 43.356 & $43 \cdot 322$ & 43.288 & 43.254 & 43.220 & $43 \cdot 186$ \\
\hline 0.6 & 43.016 & 42.982 & 42.948 & 42.914 & 42.880 & $42 \cdot 845$ \\
\hline 0.7 & 42.676 & 42.642 & 42.607 & 42.573 & 42.539 & 42.505 \\
\hline 0.8 & $\begin{array}{l}42.335 \\
41.995\end{array}$ & $\begin{array}{l}42.301 \\
41.961\end{array}$ & 42.267 & 42.233 & 42.199 & 42.165 \\
\hline 0.9 & 41.995 & 41.961 & 41.927 & 41.893 & 41.859 & 41.825 \\
\hline $\begin{array}{l}1.0 \\
1.1\end{array}$ & $\begin{array}{r}18441.655 \\
41.315\end{array}$ & $\begin{array}{l}41.621 \\
41.281\end{array}$ & 41.587 & 41.553 & 41.519 & 41.485 \\
\hline & $\begin{array}{l}41.315 \\
40.975\end{array}$ & $\begin{array}{l}41.281 \\
40.941\end{array}$ & 41.247 & $\begin{array}{l}41.213 \\
40.873\end{array}$ & $\begin{array}{l}41.179 \\
40.839\end{array}$ & $\begin{array}{l}41.145 \\
40.805\end{array}$ \\
\hline $\begin{array}{l}1.2 \\
1.3\end{array}$ & $\begin{array}{l}\begin{array}{l}40.975 \\
40.635\end{array}\end{array}$ & $\begin{array}{l}40.941 \\
40.601\end{array}$ & $\begin{array}{l}40.907 \\
40.567\end{array}$ & $\begin{array}{l}40.813 \\
40.533\end{array}$ & $\begin{array}{l}40.839 \\
40.499\end{array}$ & $\begin{array}{l}40.805 \\
40.465\end{array}$ \\
\hline 1.2 & 40.294 & 40.260 & 40.226 & 40.192 & 40.158 & 40.125 \\
\hline 1.5 & 39.954 & 39.920 & 39.886 & 39.852 & 39.818 & 39.784 \\
\hline 1.6 & 39.614 & 39.580 & 39.546 & 39.512 & 39.478 & 39.444 \\
\hline 1.7 & 39.274 & 39.240 & 39.206 & 39.172 & 39.138 & $39 \cdot 104$ \\
\hline 1. & 38.934 & 38.900 & 38.866 & 38.832 & 38.798 & 38.764 \\
\hline 1.9 & 38.594 & 38.560 & 38.526 & 38.492 & 38.458 & 38.424 \\
\hline 422.0 & 18438.254 & $\begin{array}{l}38 \cdot 220 \\
37 \cdot 880\end{array}$ & 38.186 & 38.152 & 38 & 38.084 \\
\hline $\begin{array}{l}2.1 \\
2.2\end{array}$ & $\begin{array}{l}37.914 \\
37.574\end{array}$ & $\begin{array}{l}37.880 \\
37.540\end{array}$ & $\begin{array}{l}37.846 \\
37.506\end{array}$ & $\begin{array}{l}37.812 \\
37.472\end{array}$ & $\begin{array}{l}37.778 \\
37.438\end{array}$ & $\begin{array}{l}37.744 \\
37.404\end{array}$ \\
\hline 2.3 & 37.234 & 37.200 & 37.166 & 37.132 & $\begin{array}{l}37.098 \\
37.098\end{array}$ & 37.064 \\
\hline 2.4 & 36.894 & 36.860 & 36.826 & 36.792 & 36.758 & 36.724 \\
\hline 2.5 & 36.553 & 36.520 & 36.486 & 36.452 & 36.418 & 36.384 \\
\hline 2.6 & 36.214 & 36.180 & 36.146 & 36.112 & 36.078 & 36.044 \\
\hline 2.7 & 35.874 & 35.840 & 35.806 & 35.772 & 35.738 & 35.704 \\
\hline $\begin{array}{l}2.8 \\
2.9\end{array}$ & $\begin{array}{l}35.534 \\
35.194\end{array}$ & $\begin{array}{l}35.500 \\
35.160\end{array}$ & $\begin{array}{l}35.466 \\
35.126\end{array}$ & $\begin{array}{l}35.432 \\
35.092\end{array}$ & $\begin{array}{l}35.398 \\
35.058\end{array}$ & $\begin{array}{l}35.364 \\
35.024\end{array}$ \\
\hline 3.0 & 18 & 34.820 & 34.786 & 34.752 & 32 & 34.684 \\
\hline & .514 & 34.480 & 34.446 & 34.412 & 34.378 & 34.344 \\
\hline 3.2 & $34 \cdot 174$ & $34 \cdot 140$ & 34.106 & 34.072 & 34.038 & 34.004 \\
\hline $3 \cdot 3$ & 33.834 & 33.800 & 33.766 & 33.732 & $32 \cdot 6$ & 33.664 \\
\hline 3.4 & 33.494 & 33.460 & 33.426 & 33.392 & 33.358 & 33.324 \\
\hline 3.5 & 33.154 & $33 \cdot 121$ & 33.086 & 33.052 & 33.019 & 32.984 \\
\hline $\begin{array}{l}3.6 \\
3.7\end{array}$ & 32.814 & 32.780 & 32.746 & 32.713 & 32.678 & 32.645 \\
\hline $\begin{array}{l}3.7 \\
3.8\end{array}$ & $\begin{array}{l}32.475 \\
32.135\end{array}$ & $\begin{array}{l}32.441 \\
32.101\end{array}$ & $\begin{array}{l}32.407 \\
32.067\end{array}$ & 32.373 & $\begin{array}{r}32.339 \\
31.999\end{array}$ & $\begin{array}{l}32.305 \\
31.965\end{array}$ \\
\hline $\begin{array}{l}3.8 \\
3.9\end{array}$ & $\begin{array}{l}32.135 \\
31.795\end{array}$ & 31.761 & 31.727 & 31.693 & 31.659 & 31.625 \\
\hline 5424.0 & 18431.455 & 31.421 & 31.387 & 31.353 & 31.319 & 31.285 \\
\hline & 31.115 & & 31. & 31. & & \\
\hline $4 \cdot 2$ & 30.776 & 30.742 & 30.708 & 30.674 & 30.639 & 30.605 \\
\hline $\begin{array}{l}4.3 \\
4.4\end{array}$ & $\begin{array}{l}30.436 \\
30.096\end{array}$ & $\begin{array}{l}30.402 \\
30.0622\end{array}$ & 30.368 & 30.334 & $30 \cdot 300$ & 30.266 \\
\hline $\begin{array}{l}4.04 \\
4.5\end{array}$ & 29.756 & $\begin{array}{l}30.062 \\
29.722\end{array}$ & $\begin{array}{l}30.028 \\
29.688\end{array}$ & $\begin{array}{l}29.994 \\
29.654\end{array}$ & $\begin{array}{l}29.960 \\
29.620\end{array}$ & $\begin{array}{l}29.926 \\
29.586\end{array}$ \\
\hline 4.6 & 29.417 & 29.383 & 29.349 & 29.315 & 29.281 & 29.247 \\
\hline 4.7 & 29.077 & 29.043 & 29.009 & 28.975 & & \\
\hline 4.8 & 28.737 & 28.703 & 28.669 & 28.635 & 28.601 & 28.567 \\
\hline $4 \cdot 9$ & 28.397 & $28 \cdot 363$ & 28.329 & 28.295 & 28.261 & 28.228 \\
\hline 25.0 & $\begin{array}{r}18428.058 \\
27.718\end{array}$ & 28.024 & 27.990 & 27.956 & 22 & 27.888 \\
\hline & $27 \cdot 718$ & 27.684 & 27.650 & 27.616 & & \\
\hline$c^{2}$ & 27.378 & $27 \cdot 344$ & 27.310 & 27.276 & 42 & 27. \\
\hline $5 \cdot 3$ & 27.039 & 27.005 & 26.971 & 26.937 & 3 & \\
\hline 5 & 26.6 & 26.665 & 26.631 & 26. & 3 & \\
\hline $5 \cdot 5$ & 26.359 & $26 \cdot 325$ & $26 \cdot 2$ & $26 \cdot 3$ & 4 & \\
\hline $\begin{array}{l}5.6 \\
5.7\end{array}$ & $\begin{array}{l}26.020 \\
25.680\end{array}$ & $\begin{array}{l}25.986 \\
25.646\end{array}$ & $\begin{array}{l}250^{\circ} \\
250^{\circ}\end{array}$ & $\begin{array}{l}250^{\circ} \\
250^{\circ}\end{array}$ & 4 & \\
\hline 5.8 & 25.340 & $\begin{array}{l}25.046 \\
25.306\end{array}$ & $\begin{array}{l}25.612 \\
25.273\end{array}$ & 25.239 & $\begin{array}{l}25.544 \\
25.205\end{array}$ & 25.171 \\
\hline 5.9 & 25.001 & 24.967 & 24.933 & 24.899 & $24 \cdot 865$ & 24.831 \\
\hline & 18424.661 & $\begin{array}{l}24.627 \\
24.0288\end{array}$ & $\begin{array}{l}24.594 \\
24.254\end{array}$ & $\begin{array}{l}24.560 \\
24.220\end{array}$ & $\begin{array}{l}24.525 \\
24.186\end{array}$ & 24.491 \\
\hline 6. & $\begin{array}{l}24.322 \\
23.982\end{array}$ & $\begin{array}{l}24 \cdot 2 \\
23.9\end{array}$ & $\begin{array}{l}240^{\circ} \\
23 .\end{array}$ & $\begin{array}{l}240^{\circ} \\
230^{\circ}\end{array}$ & 6 & $\begin{array}{l}24.152 \\
23.812\end{array}$ \\
\hline 6. & 20 & 23.6 & 23 . & 23. & 7 & 23. \\
\hline 6. & 23.3 & 23.2 & 23 . & 23. & 23. & 23. \\
\hline 6.5 & 22.964 & 22.930 & 22.896 & 22.862 & 22 . & 22 \\
\hline 6.6 & 22.624 & 22.590 & 22.556 & 22.522 & 22. & 22 \\
\hline $\begin{array}{l}6.7 \\
6.8\end{array}$ & & $22 \cdot 251$ & 22. & 22.1 & & \\
\hline 6.9 & $\begin{array}{l}21.945 \\
21.506\end{array}$ & $\begin{array}{l}21.911 \\
21.572\end{array}$ & $\begin{array}{l}21.877 \\
21.538\end{array}$ & $\begin{array}{l}21.844 \\
21.504\end{array}$ & $\begin{array}{l}21.810 \\
21.470\end{array}$ & $\begin{array}{l}21.776 \\
21.436\end{array}$ \\
\hline 5427.0 & 6 & 21 & 98 & 2 & 1 & 77 \\
\hline & & & & & & \\
\hline 7.2 & 20 & 20 & 20 & & & \\
\hline 7 & 20 & 20 & & & & \\
\hline 7 & 19 & 19. & 19 & 19 & & \\
\hline 5 & 19 & 19 & 19. & 19 & & \\
\hline & & 19.1 & 19 & 19 & & \\
\hline 7 & 18 & 18. & & & & \\
\hline$\because 0$ & 18 & 18. & & & & \\
\hline 7.9 & 18.212 & $18 \cdot 1$ & 18.144 & $18 \cdot 110$ & 76 & $188^{\circ}$ \\
\hline & 18417.873 & 17.839 & 17.805 & $17^{\circ}$ & 17 & 17 \\
\hline & & & & & & \\
\hline 80 & 17. & $\begin{array}{l}176^{\circ} \\
160^{\prime}\end{array}$ & $176^{\circ}$ & $170^{\circ}$ & & \\
\hline 8. & 16.516 & 16.4 & $\begin{array}{l}160^{\circ} \\
16 .\end{array}$ & 16. & 16 & \\
\hline 8. & 16.176 & 16.143 & 16. & 16. & & \\
\hline 8. & 15.837 & 15.803 & & 15. & & \\
\hline 8. & 15. & $150^{\circ}$ & & & & \\
\hline $\begin{array}{l}8.8 \\
8.9\end{array}$ & $\begin{array}{l}15.159 \\
14.820\end{array}$ & $\begin{array}{l}15.125 \\
14.786\end{array}$ & $\begin{array}{l}15.091 \\
14.752\end{array}$ & $\begin{array}{l}15.057 \\
14.718\end{array}$ & & \\
\hline & & & & & 14.684 & 14. \\
\hline & & 7 & 14.413 & $\begin{array}{l}14.379 \\
14.040\end{array}$ & $\begin{array}{l}14.345 \\
14.006\end{array}$ & \\
\hline & 802 & & & & & \\
\hline 9 & 13.463 & 13.429 & 13.3 & 13. & & \\
\hline 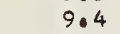 & & .090 & & & & \\
\hline 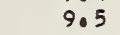 & & & & & & \\
\hline 0 & 12.445 & 12.411 & $12 . ?$ & & & \\
\hline 0 & & 1207 & & & & \\
\hline tר & 11.767 & 11.733 & 11.699 & 11.666 & 11.632 & 11.598 \\
\hline 0 & 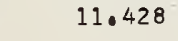 & 11.39 & 11.360 & 11.326 & 11.292 & 11.259 \\
\hline & & & & .003 & .004 & .005 \\
\hline & .00 & & 007 & .010 & .013 & .017 \\
\hline
\end{tabular}




.03

\title{
0.3
}

$\begin{array}{rlll}8411.089 & 11.055 & 11.021 & 10.987 \\ 10.750 & 10.716 & 10.682 & 10.648\end{array}$

$\begin{array}{llllllllll}10.750 & 10.716 & 10.682 & 10.648 & 10.515 & 10.581 & 10.547 & 10.513 & 10.479 & 10.445 \\ 10.411 & 10.377 & 10.343 & 10.309 & 10.275 & 10.241 & 10.208 & 10.174 & 10.140 & 10.106 \\ 10.072 & 10.038 & 10.004 & 09.970 & 09.937 & 09.903 & 09.869 & 09.835 & 09.801 & 09.767\end{array}$

$\begin{array}{llllllllll}09.733 & 09.699 & 09.665 & 09.631 & 09.937 & 09.903 & 09.869 & 09.835 & 09.801 & 09.767 \\ & 09.563 & 09.530 & 09.496 & 09.462 & 09.428\end{array}$

$\begin{array}{llllllllll}09.394 & 09.360 & 09.326 & 09.292 & 09.258 & 09.224 & 09.190 & 09.157 & 09.123 & 09.089\end{array}$

$\begin{array}{llllllllllll}0.6 & 09.055 & 09.021 & 08.987 & 08.953 & 08.920 & 08.886 & 08.852 & 08.818 & 08.784 & 08.750 \\ 0.7 & 08.716 & 08.682 & 08.648 & 08.614 & 08.580 & 08.546 & 08.513 & 08.479 & 08.445 & 08.411\end{array}$

$\begin{array}{lllllllllll}0.7 & 08.716 & 08.682 & 08.648 & 08.614 & 08.580 & 08.546 & 08.513 & 08.479 & 08.445 & 08.411 \\ 0.8 & 08.377 & 08.343 & 08.309 & 08.275 & 08.241 & 08.208 & 08.174 & 08.140 & 08.106 & 08.072\end{array}$

$\begin{array}{llllllllll}08.038 & 08.004 & 07.970 & 07.936 & 07.902 & 07.869 & 07.835 & 07.801 & 07.767 & 07.733\end{array}$

\begin{abstract}
18407.6990
\end{abstract} $\begin{array}{rrr}07.699 & 07.665 & 07 . \\ 07.360 & 07.326 & 07 .\end{array}$

$\begin{array}{llllllllll}07.360 & 07.326 & 07.292 & 07.259 & 07.225 & 07.191 & 07.157 & 07.123 & 07.089 & 07.055\end{array}$

$\begin{array}{llllllllll}07.021 & 06.988 & 06.954 & 06.920 & 06.886 & 06.852 & 06.818 & 06.784 & 06.750 & 06.716\end{array}$

$\begin{array}{llllllllll}06.344 & 06.648 & 06.615 & 06.581 & 06.547 & 06.513 & 06.479 & 06.445 & 06.411 & 06.377\end{array}$

$\begin{array}{llllllllll}06.005 & 05.971 & 05.937 & 05.903 & 05.208 & 06.174 & 06.140 & 06.106 & 06.073 & 06.0539 \\ 0.8535 & 05.801 & 05.767 & 05.733 & 05.700\end{array}$

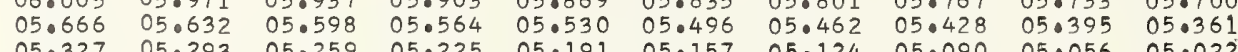

\begin{tabular}{llllllllll}
05.327 & 05.293 & 05.259 & 05.225 & 05.19 .1 & 05.157 & 05.124 & 05.090 & 05.056 & 05.022 \\
\hline
\end{tabular}

$\begin{array}{llllllllll}04.988 & 04.954 & 04.920 & 04.886 & 04.853 & 04.819 & 04.785 & 04.751 & 04.717 & 04.683 \\ 04.649 & 04.615 & 04.582 & 04.548 & 04.514 & 04.480 & 04.446 & 04.412 & 04.378 & 04.344\end{array}$

$\begin{array}{llllllllll}18404.310 & 04.277 & 04.243 & 04.209 & 04.175 & 04.141 & 04.107 & 04.073 & 04.039 & 04.006\end{array}$ $\begin{array}{llllllllll}03.972 & 03.938 & 03.904 & 03.870 & 03.836 & 03.802 & 03.768 & 03.734 & 03.701 & 03.667\end{array}$ $\begin{array}{llllllllll}03.633 & 03.599 & 03.565 & 03.531 & 03.497 & 03.463 & 03.430 & 03.396 & 03.362 & 03.328\end{array}$ $\begin{array}{llllllllll}03.294 & 03.260 & 03.226 & 03.192 & 03.158 & 03.125 & 03.091 & 03.057 & 03.023 & 02.989\end{array}$ $\begin{array}{llllllllll}02.955 & 02.921 & 02.887 & 02.854 & 02.820 & 02.786 & 02.752 & 02.718 & 02.684 & 02.650\end{array}$ $\begin{array}{llllllllll}02.616 & 02.583 & 02.549 & 02.515 & 02.481 & 02.447 & 02.413 & 02.379 & 02.346 & 02.312\end{array}$ $\begin{array}{llllllllll}02.278 & 02.244 & 02.210 & 02.176 & 02.142 & 02.108 & 02.074 & 02.041 & 02.007 & 01.973\end{array}$ $\begin{array}{llllllllll}01.939 & 01.905 & 01.871 & 01.837 & 01.803 & 01.770 & 01.736 & 01.702 & 01.668 & 01.634\end{array}$ $\begin{array}{llllllllll}01.261 & 01.228 & 01.533 & 01.499 & 01.465 & 01.431 & 01.397 & 01.363 & 01.329 & 01.295 \\ 01.194 & 01.160 & 01.126 & 01.092 & 01.058 & 01.024 & 00.991 & 00.957\end{array}$

$\begin{array}{llllllllll}18400.923 & 00.889 & 00.855 & 00.821 & 00.787 & 00.754 & 00.720 & 00.686 & 00.652 & 00.618\end{array}$ $\begin{array}{llllllllll}00.584 & 00.550 & 00.516 & 00.483 & 00.449 & 00.415 & 00.381 & 00.347 & 00.313 & 00.279\end{array}$

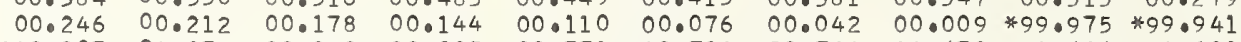

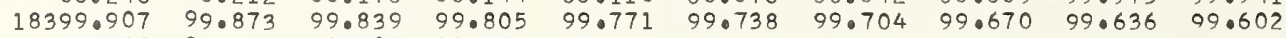

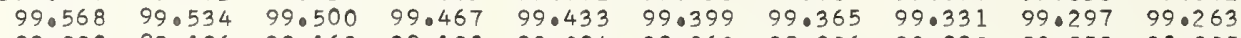

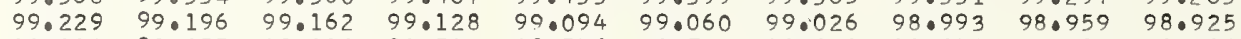

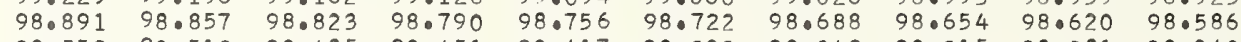
$\begin{array}{llllllllll}98.552 & 98.519 & 98.485 & 98.451 & 98.417 & 98.383 & 98.349 & 98.315 & 98.281 & 98.248\end{array}$

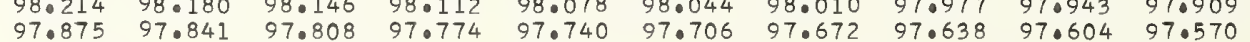

$\begin{array}{llllll}87.250 & 87.217 & 87.183 & 87.149 & 87.115 & 87.081 \\ 86.912 & 86.878 & 86.844 & 86.811 & 86.777 & 86.743\end{array}$

$\begin{array}{llllll}86.574 & 86.540 & 86.507 & 86.473 & 86.439 & 86.405\end{array}$ $\begin{array}{lllllll}85.898 & 85.864 & 85.830 & 85.796 & 85.762 & 85.729\end{array}$ $\begin{array}{llllll}85.560 & 85.526 & 85.492 & 85.458 & 85.424 & 85.390 \\ 85.221 & 85.188 & 85.154 & 85.120 & 85.086 & 85.052\end{array}$ $\begin{array}{llllll}84.883 & 84.850 & 84.816 & 84.782 & 84.748 & 84.714 \\ 84.545 & 84.511 & 84.478 & 84.444 & 84.0410 & 84.0776\end{array}$ $\begin{array}{llllll}84.207 & 84.174 & 84.140 & 84.106 & 84.072 & 84.0738\end{array}$

$\begin{array}{lllllll}3.8699 & 83.835 & 83.801 & 83.768 & 83.734 & 83.700 \\ 83.531 & 83.497 & 83.864 & 83.030 & 83.0305 & 83.362\end{array}$ $\begin{array}{lllllll}3.193 & 83.159 & 83.125 & 83.092 & 83.058 & 83.024\end{array}$ $\begin{array}{llllll}82.855 & 82.821 & 82.787 & 82.754 & 82.720 & 82.0686 \\ 82.517 & 82.0483 & 82.049 & 82.0416 & 82.0382 & 82.348\end{array}$ $\begin{array}{llllll}82.179 & 82.145 & 82.111 & 82.078 & 82.044 & 82.010\end{array}$

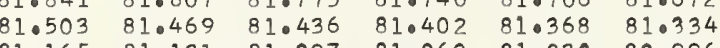
\begin{tabular}{llllll}
\hline .165 & 81.131 & 81.097 & 81.063 & 81.030 & 80.996
\end{tabular} $\begin{array}{llllll}0.489 & 80.455 & 80.422 & 80.388 & 80.354 & 80.320\end{array}$ 


.04

.05

$$
\begin{array}{r}
440.0 \\
0.1 \\
0.2 \\
0.3 \\
0.4 \\
0.5 \\
0.6 \\
0.7 \\
0.8 \\
0.9 \\
441.0 \\
1.1 \\
1.2 \\
1.3 \\
1.4 \\
1.5 \\
1.6 \\
1.7 \\
1.8 \\
1.9 \\
542.0
\end{array}
$$

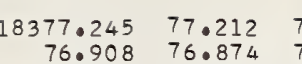
$\begin{array}{lll}76.908 & 76.874 & 76 \\ 76.570 & 76.536 & 76.0\end{array}$ $\begin{array}{ll}77.178 & 77 \\ 76.840 & 76 \\ 76.502 & 76.46 \\ 76.165 & 76.1 \\ 75.827 & 75.7 \\ 75.489 & 75.46 \\ 75.151 & 75.1 \\ 74.813 & 74.7 \\ 74.476 & 74.4 \\ 74.138 & 74.1\end{array}$ $75.894 \quad 75.861$ $75.556 \quad 75.523$ $75.219 \quad 75.185$ $74.881 \quad 74.847$

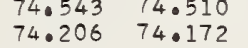

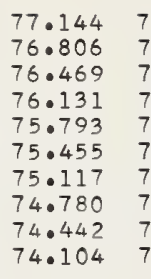

$\begin{array}{llllll}77.110 & 77.077 & 77.043 & 77.009 & 76.977 & 76.941 \\ 76.773 & 7.6 .739 & 76.705 & 76.671 & 76.637 & 76.604\end{array}$ $\begin{array}{lllllll}76.435 & 76.401 & 76.367 & 76.333 & 76.300 & 76.266\end{array}$ $\begin{array}{llllll}76.097 & 76.063 & 76.030 & 75.996 & 75.962 & 75.928 \\ 75.759 & 75.726 & 75.692 & 75.658 & 75.624 & 75.590\end{array}$ $\begin{array}{lllllll}75.421 & 75.388 & 75.354 & 75.320 & 75.287 & 75.253\end{array}$ $\begin{array}{llllll}75.084 & 75.050 & 75.016 & 74.982 & 74.948 & 74.915 \\ 74.746 & 74.712 & 74.678 & 74.645 & 74.611 & 74.577\end{array}$ $\begin{array}{llllll}74.746 & 74.712 & 74.678 & 74.645 & 74.611 & 74.577 \\ 74.408 & 74.375 & 74.0341 & 74.0307 & 74.273 & 74.040\end{array}$ $18373.868 \quad 73.834 \quad 73$. 73.801
73.463
73.125
72.787 $\begin{array}{ll}73.193 & 73.159 \\ 72.855 & 72.821\end{array}$ $72.517 \quad 72.484$ $72.179 \quad 72.146$ $\begin{array}{lll}71.842 & 71.808 \\ 71.505 & 71.471\end{array}$ 72.450
72.112

年
$\begin{array}{llll}.001 & .002 \quad .003 \quad .004\end{array}$

$\begin{array}{lllllll}50.125 & 50.092 & 50.058 & 50.024 & 49.991 & 49.957\end{array}$

$\begin{array}{llllll}49.789 & 50.092 & 50.058 & 50.024 & 49.991 & 49.957 \\ 49.452 & 49.455 & 49.721 & 49.687 & 49.654 & 49.620\end{array}$

$\begin{array}{llllll}49.452 & 49.418 & 49.385 & 49.351 & 49.317 & 49.283 \\ 49.115 & 49.081 & 49.048 & 49.014 & 48.980 & 48.947\end{array}$

$\begin{array}{lllllll}49.115 & 49.081 & 49.048 & 49.014 & 48.980 & 48.947 \\ 48.778 & 48.745 & 48.711 & 48.677 & 48.644 & 48.610\end{array}$

$\begin{array}{lllllll}48.441 & 48.408 & 48.374 & 48.341 & 48.307 & 48.273 \\ 48.105 & 48.071 & 48.037 & 48.004 & 47.970 & 47.936\end{array}$

$\begin{array}{lllllll}47.768 & 47.734 & 47.701 & 47.067 & 47.633 & 47.600 \\ 47.431 & 47.397 & 47.364 & 47.330 & 47.207 & 47.263\end{array}$

$\begin{array}{llllll}47.431 & 47.397 & 47.364 & 47.330 & 47.297 & 47.263 \\ 47.094 & 47.061 & 47.027 & 46.994 & 46.960 & 46.926\end{array}$

$\begin{array}{llllll}46.758 & 46.724 & 46.690 & 46.657 & 46.623 & 46.589\end{array}$

$\begin{array}{lllllll}46.084 & 46.051 & 46.017 & 45.983 & 45.950 & 45.016\end{array}$

$\begin{array}{llllll}45.748 & 45.714 & 45.680 & 45.647 & 45.613 & 45.580 \\ 45.411 & 45.378 & 45.344 & 45.310 & 45.276 & 45.243\end{array}$

$\begin{array}{lllllll}45.074 & 45.041 & 45.007 & 44.974 & 44.940 & 44.906\end{array}$

$\begin{array}{llllll}44.738 & 44.704 & 44.671 & 44.637 & 44.603 & 44.570\end{array}$

$\begin{array}{llllll}44.401 & 44.367 & 44.334 & 44.300 & 44.267 & 44.233 \\ 44.065 & 44.031 & 43.997 & 43.964 & 43.930 & 43.896\end{array}$

9.7
9.8
9.9

.004

.005

.006

43.627

$.008 \quad .009$

$(n-1) \times 1000$

$\lambda(n-1)$

0.277942

0.277942
0.277942

0.277942

0.277941

0.277941

0.277941

0.277940

0.277940
0.277940
0.277940

0.277940
0.277939

0.277939

0.277939
0.277939

0.277938

0.277938

0.277938

0.277937

0.277937

0.277937
0.277937

0.277036

0.277936

0.277936
0.277936

0.277935

0.277935

0.277935

0.277934

0.277934

0.277934

0.277933

0.277933

0.277933
0.277933

0.277932

0.277932
0.277932

0.277932

0.277931
0.277931

0.27793

0.277930

0.277930
0.277030
0.277930

0.277930

0.277930
0.277920
0.277920

0.277929
0.277920
0.277929

0.277929

0.277929

0.277928

0.277928
0.277928

0.277928
0.277928
0.277928

0.277928

0.277927

0.277927

0.277927
0.277926

0.277926

0.277926
0.277926

0.277976

0.277925

0.27792

0.277925

0.277925
0.277924

$\begin{array}{ll}0.277924 & 1.514409 \\ 0.277924 & 1.514436 \\ 0.277924 & 1.514463 \\ 0.277024 & 1.514489 \\ 0.777973 & 1.514516 \\ 0.277923 & 1.514543 \\ 0.277923 & 1.514570 \\ 0.277923 & 1.514596 \\ 0.277923 & 1.514623 \\ 0.277922 & 1.514650\end{array}$

1.513876

1.513929

1.513958

1.514009
1.514036

1.514062
1.514089

1.514142

1.514169

1.514223

1.514249
1.514276

1.514303

1.514356

.514409

.0514436

.514489
.514516

.514543
.514570
.514596

.514623
.514650

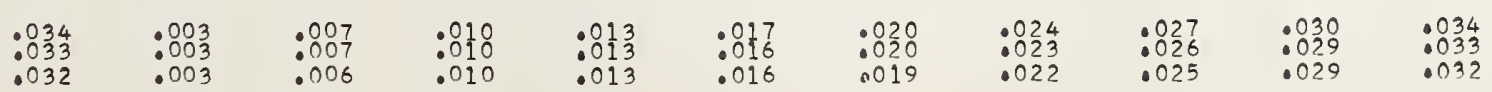




.04

.05

.06

.07

.08

.09

$\begin{array}{rrr}5450.0 & 18343.526 & 43.492 \\ 0.1 & 43.189 & 43.156 \\ 0.2 & 42.853 & 42.819 \\ 0.3 & 42.516 & 42.483 \\ 0.4 & 42.180 & 42.146 \\ 0.5 & 41.844 & 41.810 \\ 0.6 & 41.507 & 41.473 \\ 0.7 & 41.171 & 41.137 \\ 0.8 & 40.834 & 40.801 \\ 0.9 & 40.498 & 40.464\end{array}$

$\begin{array}{lll}3.459 & 43.425 & 4 \\ 3.122 & 43.089 & 430 \\ 2.786 & 42.752 & 4 \\ 2.449 & 42.416 & 420 \\ 2.113 & 42.079 & 42 . \\ 1.776 & 41.743 & 4 \\ 1.440 & 41.406 & 4 \\ 1.103 & 41.070 & 410 \\ 0.767 & 40.733 & 40 \\ 0.430 & 40.396 & 4\end{array}$

$\begin{array}{llllll}43.391 & 43.358 & 43.324 & 43.291 & 43.257 & 43.223 \\ 43.055 & 43.021 & 42.988 & 42.954 & 42.920 & 42.886\end{array}$ $\begin{array}{llllll}43.055 & 43.021 & 42.988 & 42.954 & 42.920 & 42.886 \\ 42.718 & 42.685 & 42.651 & 42.617 & 42.584 & 42.550\end{array}$ $\begin{array}{llllll}42.382 & 42.348 & 42.314 & 42.281 & 42.248 & 42.214\end{array}$ $\begin{array}{llllll}42.045 & 42.012 & 41.978 & 41.945 & 41.911 & 41.877\end{array}$

$$
\begin{array}{r}
8313 \\
12 \\
12 \\
12 \\
11 \\
11 \\
11 \\
10
\end{array}
$$
$\begin{array}{llllllllll}12.949 & 12.915 & 13.218 & 13.184 & 13.150 & 13.117 & 13.083 & 13.050 & 13.016^{\prime} & 12.982 \\ 12.848 & 12.815 & 12.781 & 12.748 & 12.714 & 12.681 & 12.647\end{array}$ $\begin{array}{lllllllllll}12.278 & 12.580 & 12.547 & 12.513 & 12.479 & 12.446 & 12.413 & 12.379 & 12.0345 & 12.312 \\ 12.211 & 12.177 & 12.144 & 12.110 & 12.077 & 12.043 & 12.010 & 11.976\end{array}$

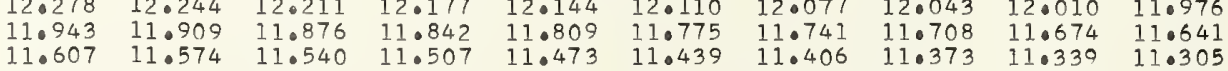

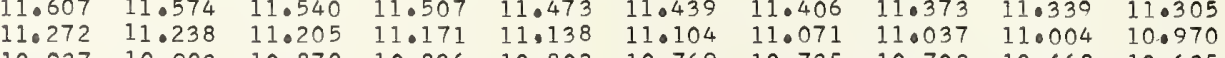

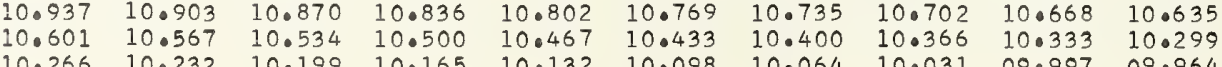
$\begin{array}{llllllllll}10.266 & 10.232 & 10.199 & 10.165 & 10.132 & 10.098 & 10.064 & 10.031 & 09.997 & 09.964\end{array}$

$\begin{array}{llllllllll} & .001 & .002 & .003 & .004 & .005 & .006 & .007 & .008 & .009 \\ .833 & : 883 & .883 & .818 & .813 & .817 & .838 & .823 & .827 & .8338 \\ .031 & .003 & .006 & .009 & .013 & .016 & .019 & .022 & .025 & .028\end{array}$

\subsection{2 \\ 0.277922 \\ 0.277921 \\ 0.277921 \\ 0.277921 \\ .514703 \\ 1.514730
1.514756 \\ 1.514783 \\ 1.514810
1.514837 \\ 1.514863 \\ . 514917}

514970 .514997 .515050
.515077 5

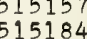

515210 50.515264 515290
515317

515344
515370 515451

0.277916

277914

0.277914

277913

0.277013

0.277912

0.277912

0.27791

.516278

0.277910

0.27790

0.277908

0.277904

0.277004

0.277903

0.277903

0.277903
0.277902

1.517106

1.517132

1.517186

$1.517 \% 12$ 
$\begin{array}{llllllllll}18306.578 & 06.544 & 06.511 & 06.477 & 06.444 & 06.410 & 05.376 & 06.343 & 06.300 & 06.276\end{array}$ $\begin{array}{lllll}06.242 & 06.209 & 06.175 & 06.142 & 06.1 \\ 05.907 & 05.874 & 05.940 & 05.807 & 0507\end{array}$ $05.907 \quad 05.874 \quad 05.840 \quad 05.807 \quad 05$ 05.572205 .538 $05.23705 .203 \quad 05.170 \quad 05.136$ $\begin{array}{lll}04.901 & 04.868 \\ 04.566 & 04.533\end{array}$

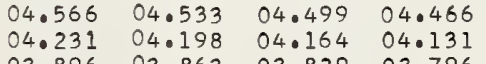
$\begin{array}{llllllllll}03.896 & 03.863 & 03.829 & 03.796 & 03.762 & 03.729 & 03.695 & 03.662 & 03.628 & 03.595 \\ 03.561 & 03.528 & 03.494 & 03.460 & 03.427 & 03.394 & 03.360 & 03.326 & 03.293 & 03.259\end{array}$

$\begin{array}{lllllll}06.108 & 06.075 & 06.041 & 06.008 & 05.074 & 06.276\end{array}$ $05.773 \quad 05.740 \quad 05.706 \quad 05.672 \quad 05.639 \quad 05.605$ $05.438 \quad 05.404 \quad 05.371 \quad 05.337 \quad 05.304 \quad 05.270$ $\begin{array}{llllll}05.103 & 05.069 & 05.036 & 05.002 & 04.969 & 04.935 \\ 04.7688 & 04.734 & 04.700 & 04.667 & 04.634 & 04.600\end{array}$ $\begin{array}{llllll}04.768 & 04.734 & 04.700 & 04.667 & 04.634 & 04.600 \\ 04.432 & 04.399 & 04.365 & 04.332 & 04.298 & 04.265\end{array}$ $\begin{array}{llllll}04.097 & 04.399 & 04.365 & 04.332 & 04.298 & 04.265 \\ 04.097 & 04.063 & 04.030 & 03.997 & 03.963 & 03.930\end{array}$

0.277900

0.277900

0.277900

0.277899

0.277899

0.277899

0.277898

$\begin{array}{rlllllllll}00.545 & 00.512 & 00.479 & 00.445 & 00.411 & 00.378 & 00.344 & 00.311 & 00.278 & 00.244 \\ 00.210 & 00.177 & 00.144 & 00.110 & 00.076 & 00.043 & 00.010 & * 99.976 & * 99.943 & * 99.909\end{array}$

0.277898

0.277898

0.277898

0.777897

0.277897

0.277896

5463.0 $\begin{array}{rlllllllll}18299.875 & 99.842 & 99.809 & 99.775 & 90.741 & 99.708 & 99.674 & 99.641 & 99.608 & 99.574 \\ 99.541 & 99.507 & 99.473 & 99.440 & 99.407 & 99.373 & 99.340 & 99.306 & 99.272 & 99.239 \\ 99.206 & 99.172 & 99.139 & 99.105 & 99.072 & 99.038 & 99.005 & 98.971 & 98.037 & 98.904\end{array}$

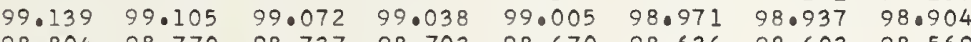

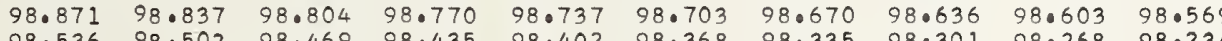

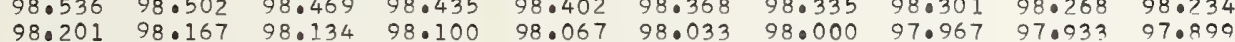
$\begin{array}{llllllllll}97.866 & 97.832 & 97.799 & 97.766 & 97.732 & 97.698 & 97.655 & 970632 & 97.598 & 97.564\end{array}$ $\begin{array}{llllllllll}97.531 & 97.498 & 97.464 & 97.430 & 97.397 & 97.364 & 97.330 & 97.297 & 97.263 & 97.220\end{array}$ $\begin{array}{llllllllll}97.196 & 97.163 & 97.129 & 97.096 & 97.062 & 97.029 & 96.995 & 96.962 & 96.928 & 96.895 \\ 96.861 & 96.828 & 96.794 & 96.761 & 96.727 & 96.694 & 96.660 & 96.627 & 96.593 & 96.560\end{array}$

0.277896

0.277896

0.277896

0.277895

0.277895

51758

.0517613

.517666

1.517720

0.277894

5464.0
4.1
4.2
4.3
4.4
4.5
4.6
4.7
4.8
4.9

18296.5

$\begin{array}{llll}96.526 & 96.493 & 96.459 & 96.426 \\ 96.192 & 96.158 & 96.124 & 96.091 \\ 95.857 & 95.823 & 95.790 & 95.756 \\ 95.522 & 95.488 & 95.455 & 95.422 \\ 95.187 & 95.154 & 95.120 & 95.086 \\ 94.852 & 94.819 & 94.785 & 94.752 \\ 94.517 & 94.484 & 94.450 & 94.417 \\ 94.183 & 94.149 & 94.116 & 94.082 \\ 93.848 & 93.814 & 93.781 & 93.748 \\ 93.513 & 93.480 & 93.446 & 93.413\end{array}$

$96.392 \quad 96.359 \quad 96.325 \quad 96.292 \quad 96.259 \quad 96.225$

5465.0

$\begin{array}{llll}18293.178 & 93.145 & 93.111 & 93.078\end{array}$ $\begin{array}{rrrr}92.844 & 92.810 & 92.777 & 92.0743 \\ 92.509 & 92.476 & 92.442 & 92.408\end{array}$ $92.174 \quad 92.141 \quad 92.108 \quad 92.074$

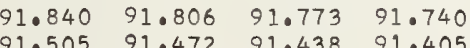
$91.505 \quad 91.472 \quad 91.438 \quad 91.405$ $91.170 \quad 91.137 \quad 91.104 \quad 91.070$ $\begin{array}{rlll}90.836 & 90.802 & 90.769 & 90.735 \\ 90.501 & 90.468 & 90.434 & 90.401\end{array}$ $90.167 \quad 90.133$

$\begin{array}{rr}90.434 & 90.401 \\ 90.100 & 90.066\end{array}$

95.058 96.024

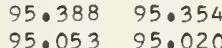

$94.719 \quad 94.685$

$94.049 \quad 94.015$

$\begin{array}{llll}95.990 & 95.957 & 95.924 & 95.890 \\ 95.656 & 95.622 & 95.589 & 95.555\end{array}$

$\begin{array}{rllll}9.95321 & 95.287 & 95.254 & 95.220\end{array}$

$\begin{array}{llll}94.986 & 94.953 & 94.919 & 94.986 \\ 94.651 & 04.618 & 94.584 & 94.551\end{array}$

$\begin{array}{llllll}93.714 & 93.680 & 93.647 & 93.614 & 93.580 & 93.547 \\ 93.379 & 93.346 & 93.312 & 93.279 & 93.245 & 93.212\end{array}$

0.277894

0.277894

0.277894
0.277894

0.277893

0.277893

0.277893

0.277893
0.277892

1.517800

1.517827

1.517880

1.517933

1.517960

1.518013

1.518040

1.518094

0.277892

$\begin{array}{llllll}93.044 & 93.011 & 92.978 & 92.944 & 92.911 & 92.877\end{array}$

$\begin{array}{llllll}92.710 & 92.677 & 92.643 & 92.609 & 92.576 & 92.542 \\ 92.375 & 92.342 & 92.309 & 92.275 & 92.242 & 92.208\end{array}$

$\begin{array}{llllll}92.041 & 92.007 & 91.974 & 91.940 & 91.907 & 91.873\end{array}$

0.277892

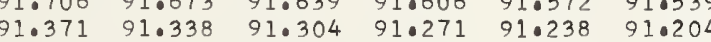

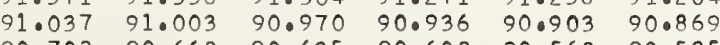

5.7

$\begin{array}{llllll}90.702 & 90.668 & 90.635 & 90.602 & 90.568 & 90.535 \\ 90.367 & 90.334 & 90.301 & 90.267 & 90.234 & 90.200\end{array}$

0.277891

0.277891

0.277891

0.277890

1.518147

1.518174

1.518227

.518280

1.518307

1.518361

18289.832 $\begin{array}{llll}89.832 & 89.799 & 89.765 & 89.732 \\ 89.497 & 89.464 & 89.430 & 89.397 \\ 89.163 & 89.129 & 89.096 & 89.062\end{array}$

$\begin{array}{llllll}89.698 & 89.665 & 89.631 & 89.598 & 89.564 & 89.531\end{array}$

0.277890

0.277890

0.277890

0.277889 $\begin{array}{llllllllll}88.494 & 88.460 & 88.427 & 88.393 & 88.360 & 88.326 & 88.293 & 88.260 & 88.226 & 88.192\end{array}$ $\begin{array}{llllllllll}88.159 & 88.126 & 88.092 & 88.059 & 88.025 & 87.992 & 87.958 & 87.925 & 87.892 & 87.858\end{array}$ $\begin{array}{lllllllllll}87.825 & 87.791 & 87.758 & 87.724 & 87.691 & 87.657 & 87.624 & 87.590 & 87.557 & 87.523\end{array}$ $\begin{array}{llll}87.490 & 87.457 & 87.423 & 87.390\end{array}$

$\begin{array}{llll}86.821 & 86.788 & 86.754 & 86.720\end{array}$

$87.356 \quad 87.323$

$87.289 \quad 87.256 \quad 87.222 \quad 87.189$

0.27788

0.277888

$\begin{array}{llll}18286.486 & 86.453 & 86.420 & 86.386 \\ 86.152 & 86.118 & 86.085 & 86.052\end{array}$ $\begin{array}{llll}85.818 & 85.784 & 85.751 & 85.717\end{array}$ $85.483 \quad 85.449 \quad 85.416 \quad 85.383$ $85.149 \quad 85.115 \quad 85.082 \quad 85.04$

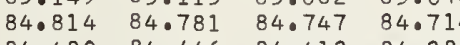
$\begin{array}{lllll}4.480 & 84.446 & 84.413 & 84.38\end{array}$ $\begin{array}{llll}84.146 & 84.112 & 84.078 & 84.04 \\ 83.811 & 83.777 & 83.744 & 83.71\end{array}$

$\begin{array}{llllll}86.353 & 86.319 & 86.286 & 86.252 & 86.219 & 86.185\end{array}$

0.27788
0.07788
0.27788

0.277888

0.277888

0.277887

0.277887
0.277887
0.277887

0.277887

0.277887

$\begin{array}{llllllllllll}7.8 & 83.811 & 83.7777 & 83.744 & 83.711 & 82.677 & 83.644 & 83.610 & 83.577 & 83.544 & 83.510 \\ 7.9 & 83.477 & 83.443 & 83.410 & 83.376 & 83.343 & 83.309 & 83.276 & 83.242 & 83.209 & 83.176\end{array}$

$\begin{array}{llllll}84.346 & 84.647 & 84.614 & 84.580 & 84.547 & 84.0513\end{array}$

$\begin{array}{llllll}84.346 & 84.313 & 84.279 & 84.246 & 84.212 & 84.179 \\ 84.011 & 83.978 & 83.945 & 83.911 & 83.878 & 83.844\end{array}$

$\begin{array}{lllllllllll}5468.0 & 18283.142 & 83.109 & 83.075 & 83.042 & 83.009 & 82.975 & 82.941 & 82.908 & 82.875 & 82.841\end{array}$

$\begin{array}{llllllllllll}8.1 & 82.808 & 82.774 & 82.741 & 82.708 & 82.674 & 82.641 & 82.607 & 82.574 & 82.540 & 82.507\end{array}$

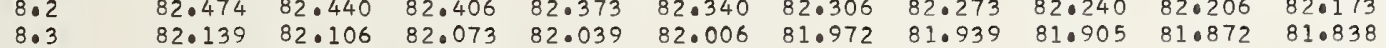

$\begin{array}{llllllllllll}8.4 & 81.805 & 81.771 & 81.738 & 81.704 & 81.671 & 81.638 & 81.604 & 81.571 & 81.537 & 81.504\end{array}$

$\begin{array}{lllllllllll}8.5 & 81.470 & 81.437 & 81.404 & 81.370 & 81.337 & 81.303 & 81.270 & 81.237 & 81.203 & 81.170\end{array}$

$\begin{array}{lllllllllll}8.6 & 81.136 & 81.103 & 81.069 & 81.036 & 81.002 & 80.969 & 80.936 & 80.902 & 80.869 & 80.835 \\ 8.7 & 80.802 & 80.769 & 80.735 & 80.702 & 80.668 & 80.635 & 80.602 & 80.568 & 80.535 & 80.501\end{array}$

$\begin{array}{lllllllllll}8.8 & 80.802 & 80.769 & 80.735 & 80.702 & 80.668 & 80.635 & 80.602 & 80.568 & 80.535 & 80.501 \\ 8.8 & 80.468 & 80.434 & 80.401 & 80.367 & 80.334 & 80.301 & 80.267 & 80.234 & 80.200 & 80.167\end{array}$

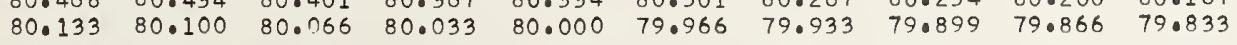

0.27788

0.277886

0.277886

0.0 .007785

0.277885

.518414

1.518441

.0518494

1.518521

1.518574

1.518601

1.518681

$\begin{array}{rrrrrrrrrrr}5469.0 & 18279.799 & 79.766 & 79.732 & 79.699 & 79.665 & 79.632 & 79.598 & 79.565 & 79.532 & 79.498 \\ 9.1 & 79.465 & 79.431 & 79.398 & 79.365 & 79.331 & 79.298 & 79.264 & 79.031 & 79.198 & 79.164\end{array}$

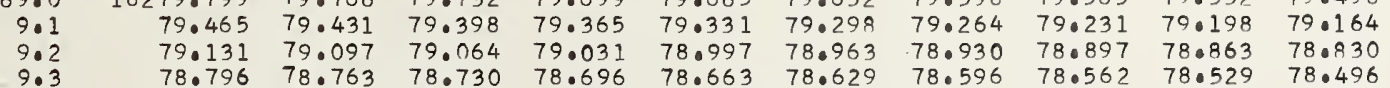

$\begin{array}{lllllllllll}9.3 & 78.796 & 78.763 & 78.730 & 78.696 & 78.653 & 78.629 & 78.556 & 78.562 & 78.529 & 78.496 \\ 9.4 & 78.462 & 78.429 & 78.396 & 78.362 & 78.0329 & 78.295 & 78.262 & 78.228 & 78.195 & 78.161 \\ 9.5 & 78.128 & 78.095 & 78.061 & 78.028 & 77.094 & 77.961 & 77.027 & 77.894 & 77.061 & 77.027\end{array}$

$\begin{array}{llllllllllll}9.5 & 78.128 & 78.095 & 78.061 & 78.028 & 77.094 & 77.961 & 77.927 & 77.894 & 77.861 & 77.827 \\ 9.6 & 77.094 & 77.760 & 77.727 & 77.694 & 77.660 & 77.627 & 77.594 & 77.560 & 77.527 & 77.493\end{array}$

$\begin{array}{lllllllllll}9.6 & 77.794 & 77.760 & 77.727 & 77.694 & 77.660 & 77.627 & 77.594 & 77.560 & 77.527 & 777.493 \\ 9.7 & 77.460 & 77.426 & 77.393 & 77.359 & 77.0326 & 77.292 & 77.259 & 77.226 & 77.192 & 77.159\end{array}$ $\begin{array}{lllllllllll}9.8 & 77.125 & 77.092 & 77.059 & 77.025 & 76.992 & 76.958 & 76.925 & 76.892 & 76.858 & 76.825 \\ 9.9 & 76.791 & 76.758 & 76.725 & 76.691 & 76.658 & 76.625 & 76.591 & 76.558 & 76.524 & 76.491\end{array}$

$\begin{array}{llll}.006 & .007 & .008 & .00\end{array}$

0.277884

. .518708

1.518761

1.518788

1.518841

1.518894
1.518921

0.277884

0.277884

0.277884
0.277883
0.277883

0.277883

0.277883

0.277883

0.277883
0.277882

1.518948

1.519001

1.519055

.519081

1.519135

1.519188

1.519215

1.519268

1.519322

1.519375

1.519402
1.519428

1.519482

1.519509

1.519562

1.519615

1.519669

1.519695
1.519722

1. 519749

1.519776
1.519802

1.519829

1.519856
1.519882

1.519909

1.519936

.010 
$\begin{array}{llllllllllll}0.8 & 73.785 & 73.751 & 73.718 & 73.685 & 73.651 & 73.618 & 73.584 & 73.551 & 73.518 & 73.484\end{array}$

.277882

0.27788

0.277881

0.277881

0.277881
0.277880

1.520016 73.451

$$
\begin{aligned}
& 576.0 \\
& 6.1 \\
& 6.2 \\
& 6 . \\
& 6 . \\
& 6 . \\
& 6 . \\
& 6 . \\
& 6 . \\
& 6 .
\end{aligned}
$$

0.277880 0.277880 0.277879

0.277879

0.277879

0.277879
0.277878

0.277878

0.277878

0.277878

0.277877

0.277877

0.277877
0.277876

0.277876
0.277876

0.277876

0.277876

0.277876
0.277875
0.277875

0.277875

0.277875

0.277875
0.277874

0.277874

0.277874

0.277874

0.277874

0.277873

0.277873

0.277873

0.277873
0.277873

0.277872

0.277872
0.277872

0.277872

0.277872

0.277871

0.277871

0.277871
0.277871

0.277870

0.277870

0.277870

0.277869

0.277869

0.277869 1.520069 1.520096
1.520123

1.520149

1.520176

1.520229
1.520256

1.520283

1.520310

1.520363

1.520416

1.520443

1.520470

1.520496

1.520550

1.520577

1.520630

1.520657

1.520683
1.520710

1.520737

1.520763
1.520790

1.520817

1.520844
1.520870

1.520870

1.520897
1.520924

1.520950

1.520977

1.521004

1.521030
1.521057

1.521084

1.521111
1.521137

. 521164

1.521191
1.521217

1.521244

1.521271
1.521297

1.521324

1.521351
1.521378

1.521378
1.521404

1.521431

1.521458
1.521484

1.521511

1.521538

1.521564
1.521591

1.521618

1.521645

1.521698

1.521725
1.521751

1.521778

1.521805

$0.277868 \quad 1.521885$

0.277868
0.277868

1.521912

0.277868

0.277868

0.277867

0.277867

0.277867
0.277867
0.277867

0.277867

1.521938

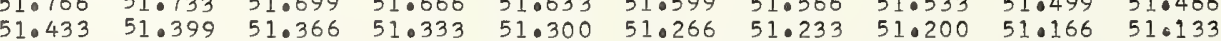

$\begin{array}{llllllllll}51.100 & 51.066 & 51.033 & 51.000 & 50.967 & 50.933 & 50.900 & 50.866 & 50.833 & 50.800 \\ 50.766 & 50.733 & 50.700 & 50.666 & 50.633 & 50.600 & 50.567 & 50.533 & 50.500 & 50.467\end{array}$

$\begin{array}{llllllllll}50.433 & 50.400 & 50.367 & 50.333 & 50.300 & 50.267 & 50.233 & 50.200 & 50.167 & 50.133 \\ 50.100 & 50.067 & 50.033 & 50.000 & 49.967 & 49.934 & 49.900 & 49.867 & 49.833 & 49.800\end{array}$

0.27786

0.277866

0.277866
0.277866
0.277866

0.277866

0.277865

0.277865

0.277865

1.521992

1.522018

1.522072

1.522125

$\begin{array}{lllllllllll}5478.0 & 18249.767 & 49.734 & 49.700 & 49.667 & 49.634 & 49.600 & 49.567 & 49.534 & 49.500 & 49.467\end{array}$

$\begin{array}{lllllllllll}8.1 & 49.434 & 49.400 & 49.367 & 49.334 & 49.301 & 49.267 & 49.234 & 49.200 & 49 \cdot 167 & 49.134 \\ 8.2 & 49.101 & 49.067 & 49.034 & 49.001 & 48.967 & 48.934 & 48.901 & 48.867 & 48.834 & 48.801\end{array}$

$\begin{array}{lllllllllll}8.4 & 48.768 & 48.734 & 48.701 & 48.667 & 48.634 & 48.601 & 48.568 & 48.534 & 48.501 & 48.468 \\ 8.5 & 48.434 & 48.011 & 48.368 & 48.334 & 48.301 & 48.268 & 48.235 & 48.201 & 48.168 & 48.035\end{array}$

$\begin{array}{lllllllllll}8.5 & 48.101 & 48.068 & 48.035 & 48.001 & 47.968 & 47.935 & 47.901 & 47.868 & 47.835 & 47.802 \\ 8.6 & 47.768 & 47.735 & 47.701 & 47.668 & 47.635 & 47.602 & 47.568 & 47.535 & 47.502 & 47.460\end{array}$

$\begin{array}{lllllllllll}8.7 & 47.435 & 47.402 & 47.369 & 47.335 & 47.302 & 47.269 & 47.235 & 47.202 & 47.169 & 47.135\end{array}$

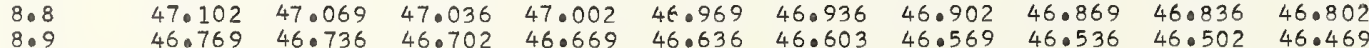

0.277864

0.277864
0.277864

0.277864
0.277864
0.277864

0.277864

0.277864

0.277863

0.277863

0.277863

1.522152

1.522179
1.522205

1.522232

1.522285

1.522312
1.522339

1.522365

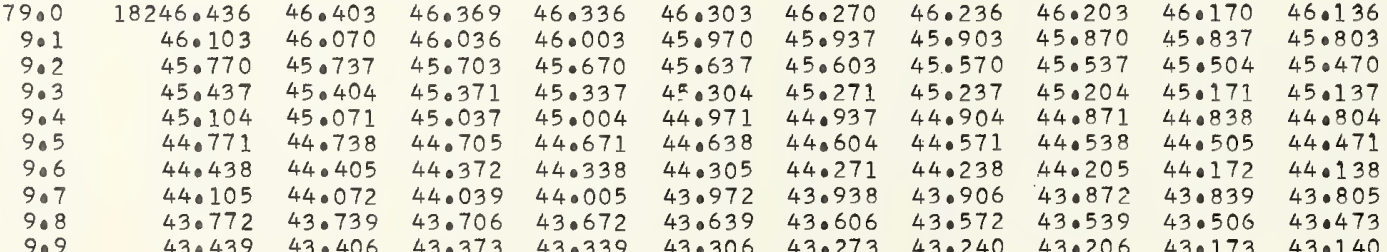

1.522419

1.522446

1.522499
1.552526

1.522526

$0.277863 \quad 1.522659$

\begin{tabular}{|c|c|c|c|c|c|c|c|c|c|c|}
\hline & .001 & .002 & .003 & .004 & .005 & .006 & .007 & .008 & .009 & .010 \\
\hline 233 & $\begin{array}{l}: 883 \\
.003\end{array}$ & $\begin{array}{l}: 887 \\
: 006\end{array}$ & $\begin{array}{l}: 818 \\
.009\end{array}$ & $\begin{array}{l}: 813 \\
813 \\
0012\end{array}$ & $\begin{array}{l}: 816 \\
: 016\end{array}$ & $: 839$ & $: 833$ & $: 837$ & $\begin{array}{r}8339 \\
: 028\end{array}$ & : $83 \overline{3}$ \\
\hline
\end{tabular}




$.04 \quad .05$

5480

$\begin{array}{rrr}0.1 & 18243.106 & 43.073 \\ 0.2 & 42.773 & 42.740 \\ 0.3 & 42.441 & 42.407\end{array}$

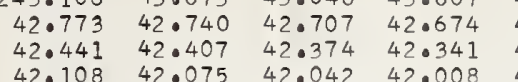

$\begin{array}{lllll}0.3 & 42.1775 & 41.742 & 41.708 & 41.675 \\ 0.4 & 1.71 .442 & 41.409 & 41.376 & 41.343 \\ 0.5 & 41.410 \\ 0.6 & 1.109 & 41.076 & 4.043\end{array}$

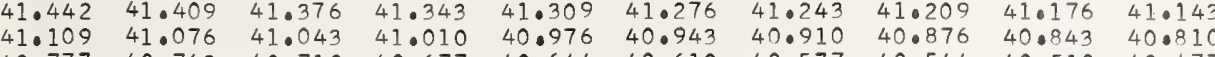

$\begin{array}{lll}40.777 & 40.743 \\ 40.444 & 40.411\end{array}$

$\begin{array}{ll}40.444 & 40.411 \\ 40.111 & 40.078\end{array}$

1.0
$1: 1$
$1: 2$
$1: 3$
$1: 4$
$1: 5$
$1: 7$
1.

$18239.778 \quad 39.745$

$\begin{array}{ll}39.445 & 39.412 \\ 39.113 & 39.080\end{array}$

$\begin{array}{lll}38.780 & 38.747\end{array}$

$\begin{array}{ll}38.447 & 38.414 \\ 38.114 & 38.081 \\ 37.782 & 37.749\end{array}$

$\begin{array}{ll}37.782 & 37.749 \\ 37.449 & 37.416\end{array}$

$\begin{array}{ll}37.116 & 37.083 \\ 36.784 & 36.750\end{array}$

40.710
40.377

$\begin{array}{ll}0.677 & 40.0 \\ 0.344 & 0.00\end{array}$

$\begin{array}{llllll}42.973 & 42.940 & 42.907 & 42.874 & 42.840 & 42.807 \\ 42.640 & 42.607 & 42.574 & 42.541 & 42.507 & 42.474 \\ 42.308 & 42.274 & 42.241 & 42.208 & 42.175 & 42.141 \\ 41.975 & 41.942 & 41.908 & 41.875 & 41.842 & 41.808 \\ 41.642 & 41.609 & 41.575 & 41.542 & 41.509 & 41.476 \\ 41.309 & 41.276 & 41.243 & 41.209 & 41.176 & 41.143 \\ 40.976 & 40.943 & 40.910 & 40.876 & 40.843 & 40.810 \\ 40.644 & 40.610 & 40.577 & 40.544 & 40.510 & 40.477 \\ 40.311 & 40.277 & 40.244 & 40.211 & 40.178 & 40.144 \\ 39.978 & 39.945 & 39.911 & 39.878 & 39.845 & 39.812\end{array}$

$(n-1) \times 1000$

$\lambda(n-1)$

5482

2

2.

$2 \cdot 7$
2.9

5483.0

3.1

3.2

3.4

3.5
3.6
3.7

3.6
3.7
3.88

3.9

5484.0

4.1
4.2
4.3
4.4
4.5
4.6
4.7
4.8
4.9

4.5

4.6
4.7
4.8

4.8
4.9

5485

5.1
502
5.3
5.4
50
5
5
5.7
50

5486

86.0
6
6
6
6
6.
6.
6
6.0
6

5487

7.0
7.2
7.3
7.4
7.5
7.9
7.9
7.9

5488
8
8
8
8
8
8
8
8
8
5489
9
9
9
9
9
9
9
9

$36.118 \quad 36.0$

$35.453 \quad 35.420$

$34.788 \quad 34.755$

34.455

$34.123 \quad 34.090$

$\begin{array}{ll}33.790 & 33.757 \\ 33.458 & 33.424\end{array}$

32.79

32.46

32.127

31.462

$30.798 \quad 30.764$

30.133

8229.800
29.468

$29.135 \quad 29.102$

$28.471 \quad 28.437$

28.105

$\begin{array}{ll}27.806 & 27.773 \\ 27.474 & 27.440\end{array}$

$27.141 \quad 27.108$

$8226.477 \quad 26.44$

$\begin{array}{ll}26.144 & 26 \cdot 11 \\ 25.812 & 25.77\end{array}$

$\begin{array}{ll}25.480 & 25.447 \\ 25.148 & 25.115\end{array}$

$24.815 \quad 24.782$

$24.483 \quad 24.450$

$\begin{array}{ll}24.151 & 24.118 \\ 23.819 & 23.785\end{array}$

23.48

18223

$22.490 \quad 22.78$

$22.158 \quad 22.125$

$21.826 \quad 21.79$

$\begin{array}{ll}21.494 & 21.460 \\ 21.161 & 21.128\end{array}$

$21.161 \quad 21.128$

$\begin{array}{ll}39.712 & 39.678 \\ 39.379 & 39.346 \\ 39.046 & 39.013 \\ 38.713 & 38.680 \\ 38.381 & 38.347 \\ 38.048 & 38.015 \\ 37.715 & 37.682 \\ 37.383 & 37.349 \\ 37.050 & 37.017 \\ 36.717 & 36.684\end{array}$

39.64
39.312
38.98
38.64
38.31
37.98
37.64
37.31
36.98
36.65

39.61

$39.578 \quad 39.545 \quad 39.512 \quad 39.479$

$\begin{array}{lllll}39.279 & 39.246 & 39.212 & 39.179 & 39.146 \\ 38.946 & 38.913 & 38.880 & 38.846 & 38.813\end{array}$

$\begin{array}{llllll}38.614 & 38.580 & 38.547 & 38.514 & 38.480\end{array}$

$\begin{array}{llllll}38.281 & 38.248 & 38.214 & 38.181 & 38.148\end{array}$

$\begin{array}{lllll}37.615 & 37.582 & 37.882 & 37.848 & 37.815 \\ 37.549 & 37.516 & 37.482\end{array}$

37.25

$7 \cdot 549$

37.183

37.150

$\begin{array}{llllllll}36.385 & 36.351 & 36.318 & 36.285 & 36.251 & 36.218 & 36.185 & 36.152\end{array}$

$\begin{array}{llllllll}36.052 & 36.019 & 35.985 & 35.952 & 35.919 & 35.885 & 35.85 ? & 35.819\end{array}$

$\begin{array}{llllllll}35.719 & 35.686 & 35.653 & 35.619 & 35.586 & 35.553 & 35.520 & 35.486\end{array}$

$\begin{array}{llllllll}35.054 & 35.021 & 34.988 & 34.954 & 34.921 & 34.888 & 34.854 & 34.821\end{array}$

$\begin{array}{llllllll}34.721 & 34.688 & 34.655 & 34.622 & 34.588 & 34.555 & 34.522 & 34.489\end{array}$

$\begin{array}{llllllll}34.389 & 34.355 & 34.322 & 34.289 & 34.256 & 34 \cdot 222 & 34.189 & 34.156\end{array}$

$3.724 \quad 33.690$

$\begin{array}{ll}33.657 & 33.624 \\ 33.325 & 33.292\end{array}$

33.923

33.890

3.857

33.823
33.491

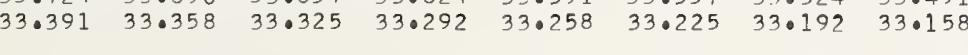

$\begin{array}{llllllll}33.059 & 33.025 & 32.992 & 32.959 & 32.925 & 32.892 & 32.859 & 32.826\end{array}$

$\begin{array}{llllllll}32.79 .4 & 32.693 & 32.660 & 32.626 & 32.593 & 32.560 & 32.526 & 32.493 \\ 32.360 & 32.327 & 32.293 & 32.260 & 32.227 & 32.194 & 32.161\end{array}$

$\begin{array}{lllllllll}32.061 & 32.028 & 31.994 & 31.961 & 31.928 & 31.895 & 31.862 & 31.828 \\ 31.729 & 31.695 & 31.662 & 31.629 & 31.595 & 31.562 & 31.529 & 31.496\end{array}$

$\begin{array}{llllllll}31.396 & 31.363 & 31.329 & 31.296 & 31.263 & 31.230 & 31.197 & 31.163\end{array}$

$31.063 \quad 31.031$

$\begin{array}{ll}30.731 & 30.698 \\ 30.399 & 30.365\end{array}$

$30.066 \quad 30.033$

30.99730 .964

$30.665 \quad 30.631$

$\begin{array}{llll}30.931 & 30.897 & 30.864 & 30.831\end{array}$

$\begin{array}{llll}30.598 & 30.565 & 30.531 & 30.498\end{array}$

$\begin{array}{llll}30.266 & 30.232 & 30.199 & 30.166 \\ 29.933 & 29.900 & 29.867 & 29.833\end{array}$

$29.734 \quad 29.700$

29.66

29.634

$\begin{array}{llll}29.601 & 29.568 & 29.534 & 29.501\end{array}$

$\begin{array}{llllllll}29.069 & 29.036 & 29.002 & 28.969 & 28.936 & 28.903 & 28.870 & 28.836\end{array}$

$\begin{array}{llllllll}28.737 & 28.703 & 28.670 & 28.637 & 28.604 & 28.570 & 28.537 & 28.504 \\ 28.404 & 28.371 & 28.338 & 28.305 & 28.271 & 28.238 & 28.205 & 28.172\end{array}$

$\begin{array}{llllllll}28.072 & 28.039 & 28.005 & 27.972 & 27.939 & 27.906 & 27.872 & 27.839\end{array}$

$\begin{array}{llllllll}27.739 & 27.706 & 27.673 & 27.640 & 27.606 & 27.573 & 27.540 & 27.507\end{array}$

$\begin{array}{llllllll}27.407 & 27.374 & 27.341 & 27.307 & 27.274 & 27.241 & 27.208 & 27.174\end{array}$

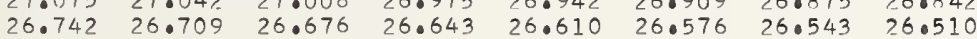

$\begin{array}{llllllll}26.410 & 26.377 & 26.344 & 26.311 & 26.277 & 26.244 & 26.211 & 26.178\end{array}$

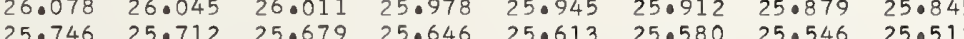

$\begin{array}{llllllll}25.414 & 25.380 & 25.347 & 25.314 & 25.281 & 25.247 & 25.214 & 25.181\end{array}$

$\begin{array}{llllllll}25.081 & 25.048 & 25.015 & 24.981 & 24 \cdot 948 & 24 \cdot 915 & 24 \cdot 882 & 24 \cdot 848 \\ 24.749 & 24.716 & 24.682 & 24.649 & 24.616 & 24.583 & 24.550 & 24.516\end{array}$

24.74924 .716

24.0.08 $24.384-24.350$

$24 \cdot 649$
$24 \cdot 317$

$\begin{array}{lll}24.616 & 24.583 & 24.550\end{array}$

$24 \cdot 516$

$23.752 \quad 23.719$

$24.018 \quad 23.985$

$23.952 \quad 23.918 \quad 23.885 \quad 23.852$

$23.088 \quad 23.055$

23.35

23.32

$\begin{array}{llll}23.619 & 23.586 & 23.553 & 23.520\end{array}$

$\begin{array}{llll}22.955 & 22.922 & 22.889 & 22.855\end{array}$

$2.424 \quad 22.390$

$22.091 \quad 22.058$

11.427

$21.095 \quad 21.06$

22.689
22.35

22.357
22.025

21.693
21.361

22.656
22.324

22.324

$\begin{array}{llll}22.523 & 22.590 & 22.556 & 22.523 \\ 22.291 & 22.258 & 22.224 & 22.191\end{array}$

$\begin{array}{llll}22.291 & 22.258 & 22.224 & 22.191 \\ 21.958 & 21.925 & 21.892 & 21.859\end{array}$

$\begin{array}{ll}20.497 & 20.464 \\ 20.165 & 20.132\end{array}$

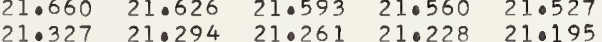

$\begin{array}{lllll}21.327 & 21.294 & 21.261 & 21.228 & 21.195 \\ 20.995 & 20.962 & 20.929 & 20.896 & 20.863\end{array}$

$\begin{array}{lllll}20.663 & 20.962 & 20.929 & 20.896 & 20.863 \\ 20.630 & 20.597 & 20.564 & 20.531\end{array}$

20.36520 .331

$\begin{array}{llll}20.298 & 20.265 & 20.232 & 20.198 \\ 19.966 & 19.933 & 19.899 & 19.866\end{array}$

$\begin{array}{rr}18219.833 & 19.800 \\ 19.501 & 19.468\end{array}$

$19.767 \quad 19.733$

$19.700 \quad 19.66$

$\begin{array}{llll}19.634 & 19.601 & 19.568 & 19.534\end{array}$

$\begin{array}{llll}19.169 & 19.136 & 19.103 & 19.069 \\ 18.837 & 18.804 & 18.771 & 18.738\end{array}$

$18.505 \quad 18.472 \quad 18.438 \quad 18.405$

$18.173 \quad 18.140 \quad 18.107 \quad 18.073$

$17.841 \quad 17.808$

$\begin{array}{lll}17.509 & 17.476 & 17.443\end{array}$

$\begin{array}{ll}17.177 & 17 \cdot 144 \\ 16.845 & 16.812\end{array}$

$17.741 \quad 17.708$

$19.036 \quad 19.003$

$\begin{array}{ll}8.372 & 18.339\end{array}$

$\begin{array}{ll}17.708 & 17.675\end{array}$

$\begin{array}{llll}19.302 & 19.269 & 19.236 & 19.202\end{array}$

$\begin{array}{llll}18.970 & 18.937 & 18.904 & 18.870 \\ 18.638 & 18.605 & 18.572 & 18.538\end{array}$

$\begin{array}{llll}18.306 & 18.273 & 18.239 & 18.206\end{array}$

$\begin{array}{llll}17.974 & 17.941 & 17.907 & 17.874\end{array}$

$\begin{array}{llll}17.642 & 17.609 & 17.575 & 17.542\end{array}$

8216

16.18

16.480

$16.447 \quad 16.414$

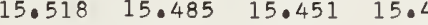

$15.186 \quad 15.153 \quad 15.119 \quad 15.086$

$\begin{array}{llll}14.854 & 14.821 & 14.788 & 14.754\end{array}$

$14.522 \quad 14.489$

$\begin{array}{ll}14 \cdot 190 & 14.157 \\ 13.858 & 13.825\end{array}$

$13.527 \quad 13.493$

14.456

$14.124 \quad 14.09$

$\begin{array}{ll}13.792 & 13.759 \\ 13.460 & 13.427\end{array}$

$15.717 \quad 15.684$

$15.385 \quad 15.352$

$15.053 \quad 15.020$

$\begin{array}{ll}14.721 & 14.688 \\ 16.389 & 14.356\end{array}$

$4.058 \quad 14.024$

$\begin{array}{ll}3.726 & 13.692 \\ 3.394 & 13.36\end{array}$

$\begin{array}{llll}16.314 & 16.281 & 16.248 & 16.215\end{array}$

$\begin{array}{llll}15.982 & 15.949 & 15.916 & 15.883\end{array}$

$\begin{array}{llll}15.318 & 15.285 & 15.252 & 15.219\end{array}$

$\begin{array}{llll}14.655 & 14.622 & 14.588 & 14.555\end{array}$

$\begin{array}{llll}14.323 & 14.290 & 14.257 & 14.224\end{array}$

$\begin{array}{llll}13.659 & 13.958 & 13.925 & 13.892 \\ 13.626 & 13.593 & 13.560\end{array}$

$\begin{array}{rlllllllll}18213.195 & 13.162 & 13.128 & 13.095 & 13.062 & 13.029 & 12.996 & 12.963 & 12.929 & 17.896 \\ 12.863 & 12.830 & 12.796 & 12.763 & 12.730 & 12.697 & 12.664 & 12.631 & 12.597 & 12.564\end{array}$

$12.863 \quad 12.830 \quad 12$.

$12.199 \quad 12.166$

$11.868 \quad 11.834$

$11.536 \quad 11.503 \quad 11.469$

$10.872 \quad 10.839$

$\begin{array}{ll}10.541 & 10.507 \\ 10.209 & 10.176\end{array}$

$.001 \quad .002$

10.806
10.47
10.143

12.432

$\begin{array}{lllllll}12.730 & 12.697 & 12.664 & 12.631 & 12.597 & 12.564 \\ 12.398 & 12.365 & 12.332 & 12.299 & 12.266 & 12.032\end{array}$

$\begin{array}{llllll}12.398 & 12.365 & 12.332 & 12.299 & 12.266 & 12.032 \\ 12.067 & 12.033 & 12.000 & 11.967 & 11.934 & 11.901\end{array}$

$\begin{array}{llllll}11.735 & 11.702 & 11.068 & 11.967 & 11.934 & 11.901 \\ & 11.635 & 11.602 & 11.569\end{array}$

$\begin{array}{llllll}11.403 & 11.370 & 11.337 & 11.304 & 11.271 & 11.237 \\ 11.072 & 11.038 & 11.005 & 10.972 & 10.938 & 10.906\end{array}$

$\begin{array}{llllll}11.072 & 11.038 & 11.005 & 10.972 & 10.938 & 10.906 \\ 10.740 & 10.706 & 10.673 & 10.640 & 10.607 & 10.574\end{array}$

$\begin{array}{llllll}10.408 & 10.375 & 10.342 & 10.308 & 10.275 & 10.242 \\ 10.076 & 10.043 & 10.010 & 09.977 & 09.944 & 09.910\end{array}$

.008

.009

1.522686

0.277862

0.277862

0.277861

0.277861
0.277861

0.277861
0.277861

0.277860

.277860
.277860

0.2778600
.277860
0.277859

0.277859

0.2777859

0.2778559
0.277859

0.27785

.277858
.277858

0.777857
.277857
0.077857

0.077857

0.277857
0.277857
0.277857

0.277856
0.27785

0.277856

0.277856

0.277855

0.2777855

0.277854

0.277854

0.2778554
0.277854

0.277854

0.27785

0.277853

0.277853
0.277853

0.277859

0.277852
0.277852

0.277852

0.2778552
0.277852

0.277851

0.277851
0.277851

0.27785
0.277850
0.277850

0.277850
0.277850

0.277850

0.277850

0.277849

0.277849

0.277849
0.277849

0.277849 


\begin{tabular}{|c|c|c|c|c|c|c|c|c|c|c|c|c|}
\hline $\begin{array}{l}0.0 \\
0.1 \\
0.2 \\
0.3 \\
0.3 \\
0.4 \\
0.5 \\
0.6 \\
0.7 \\
0.8 \\
0.9\end{array}$ & $\begin{array}{r}209.877 \\
09.546 \\
09.214 \\
08.882 \\
08.551 \\
08.219 \\
07.887 \\
07.556 \\
07.224 \\
06.893\end{array}$ & $\begin{array}{l}09.844 \\
09.512 \\
09.181 \\
08.849 \\
08.517 \\
08.186 \\
07.854 \\
07.523 \\
07.191 \\
06.859\end{array}$ & $\begin{array}{l}09.811 \\
09.479 \\
09.147 \\
08.816 \\
08.484 \\
08.153 \\
07.821 \\
07.490 \\
07.158 \\
06.826\end{array}$ & $\begin{array}{l}09.778 \\
09.446 \\
09.114 \\
08.783 \\
08.451 \\
08.120 \\
07.788 \\
07.456 \\
07.125 \\
06.793\end{array}$ & $\begin{array}{l}09.745 \\
00.413 \\
09.081 \\
08.750 \\
08.418 \\
08.086 \\
07.755 \\
07.423 \\
07.092 \\
06.760\end{array}$ & $\begin{array}{l}09.711 \\
09.380 \\
09.048 \\
08.716 \\
08.385 \\
08.053 \\
07.721 \\
07.090 \\
07.058 \\
06.727\end{array}$ & $\begin{array}{l}09.678 \\
09.346 \\
09.015 \\
08.683 \\
08.352 \\
08.020 \\
07.688 \\
07.357 \\
07.025 \\
06.694\end{array}$ & $\begin{array}{l}09.645 \\
09.313 \\
08.982 \\
08.650 \\
08.0318 \\
07.987 \\
07.655 \\
07.324 \\
06.992 \\
06.660\end{array}$ & $\begin{array}{l}09.612 . \\
09.280 \\
08.949 \\
08.617 \\
08.285 \\
07.954 \\
07.622 \\
07.290 \\
06.959 \\
06.627\end{array}$ & $\begin{array}{l}09.579 \\
09.247 \\
08.916 \\
08.584 \\
08.252 \\
07.920 \\
07.589 \\
07.257 \\
06.926 \\
06.594\end{array}$ & $\begin{array}{l}0.277843 \\
0.277842 \\
0.277842 \\
0.277842 \\
0.277842 \\
0.277842 \\
0.277841 \\
0.277841 \\
0.277841 \\
0.277841\end{array}$ & $\begin{array}{l}1.525356 \\
1.525383 \\
1.525410 \\
1.525436 \\
1.525463 \\
1.525490 \\
1.525516 \\
1.525543 \\
1.525570 \\
1.525597\end{array}$ \\
\hline $\begin{array}{l}1.0 \\
1.1 \\
1.2 \\
1.03 \\
1.4 \\
1.05 \\
1.6 \\
1.7 \\
1.8 \\
1.9\end{array}$ & $\begin{array}{r}18206.561 \\
06.229 \\
05.898 \\
05.566 \\
05.235 \\
04.903 \\
04.572 \\
04.240 \\
03.909 \\
03.577\end{array}$ & $\begin{array}{l}06.528 \\
0.52 .196 \\
05.865 \\
05.533 \\
05.202 \\
04.870 \\
04.539 \\
04.207 \\
0.875 \\
03.544\end{array}$ & $\begin{array}{l}06.495 \\
06.163 \\
05.831 \\
05.500 \\
05.168 \\
04.837 \\
04.505 \\
04.174 \\
03.843 \\
03.511\end{array}$ & $\begin{array}{l}06.461 \\
0.130 \\
05.798 \\
05.467 \\
05.135 \\
04.804 \\
04.472 \\
04.141 \\
03.809 \\
03.478\end{array}$ & $\begin{array}{l}06.428 \\
06.097 \\
05.765 \\
05.434 \\
05.102 \\
04.771 \\
04.439 \\
04.108 \\
03.776 \\
03.445\end{array}$ & $\begin{array}{l}06.395 \\
06.064 \\
05.732 \\
05.000 \\
05.069 \\
04.737 \\
04.0406 \\
04.074 \\
03.7443 \\
03.412\end{array}$ & $\begin{array}{l}06.362 \\
06.031 \\
05.699 \\
05.367 \\
05.036 \\
04.704 \\
04.0373 \\
04.042 \\
03.710 \\
03.378\end{array}$ & $\begin{array}{l}06.329 \\
05.997 \\
05.666 \\
05.334 \\
05.003 \\
04.671 \\
04.340 \\
04.008 \\
03.677 \\
03.345\end{array}$ & $\begin{array}{l}06.296 \\
05.964 \\
05.633 \\
05.301 \\
04.969 \\
04.638 \\
04.306 \\
03.975 \\
03.644 \\
03.312\end{array}$ & $\begin{array}{l}06.262 \\
05.931 \\
05.599 \\
05.268 \\
04.936 \\
04.605 \\
04.273 \\
03.942 \\
03.610 \\
03.279\end{array}$ & $\begin{array}{l}0.277841 \\
0.277784 \\
0.277840 \\
0.277840 \\
0.277840 \\
0.277840 \\
0.277840 \\
0.277839 \\
0.277839 \\
0.277839\end{array}$ & $\begin{array}{l}1.525623 \\
1.575650 \\
1.525677 \\
1.525703 \\
1.525730 \\
1.525759 \\
1.525783 \\
1.525810 \\
1.525837 \\
1.525864\end{array}$ \\
\hline $\begin{array}{l}92 \cdot 0 \\
2 \bullet 1 \\
2.2 \\
2.3 \\
2.4 \\
2.5 \\
2.6 \\
2.7 \\
2.8 \\
2.9\end{array}$ & $\begin{array}{l}203.246 \\
02.914 \\
02.583 \\
02.251 \\
01.920 \\
01.589 \\
01.257 \\
00.926 \\
00.594 \\
00.263\end{array}$ & $\begin{array}{l}03.213 \\
02.881 \\
02.550 \\
02.218 \\
01.887 \\
01.556 \\
01.224 \\
00.893 \\
00.561 \\
00.230\end{array}$ & $\begin{array}{l}03.180 \\
02.848 \\
02.517 \\
02.185 \\
01.854 \\
01.522 \\
01.191 \\
00.860 \\
00.528 \\
00.197\end{array}$ & $\begin{array}{l}03.146 \\
02.815 \\
02.483 \\
02.152 \\
01.821 \\
01.489 \\
01.158 \\
00.827 \\
00.495 \\
00.164\end{array}$ & $\begin{array}{l}03.113 \\
02.782 \\
02.450 \\
02.119 \\
01.788 \\
01.456 \\
01.125 \\
00.793 \\
00.462 \\
00.131\end{array}$ & $\begin{array}{l}03.080 \\
02.749 \\
02.4117 \\
02.086 \\
01.754 \\
01.423 \\
01.092 \\
00.760 \\
00.429 \\
00.098\end{array}$ & $\begin{array}{l}03.047 \\
02.7116 \\
02.384 \\
02.052 \\
01.721 \\
01.390 \\
01.059 \\
00.727 \\
00.396 \\
00.065\end{array}$ & $\begin{array}{l}03.014 \\
02.682 \\
02.351 \\
02.019 \\
01.688 \\
01.357 \\
01.025 \\
00.694 \\
00.363 \\
00.031 *\end{array}$ & $\begin{array}{l}02.981 \\
02.649 \\
02.318 \\
01.986 \\
01.655 \\
01.323 \\
00.992 \\
00.651 \\
00.330 \\
* 99.998 \text { * }\end{array}$ & $\begin{array}{l}02.948 \\
02.616 \\
02.285 \\
01.953 \\
01.622 \\
01.291 \\
00.959 \\
00.628 \\
00.296 \\
* 99.965\end{array}$ & $\begin{array}{l}0.277839 \\
0.277839 \\
0.2777838 \\
0.277838 \\
0.277838 \\
0.277838 \\
0.277838 \\
0.277837 \\
0.277837 \\
0.277837\end{array}$ & $\begin{array}{l}1.525890 \\
1.525917 \\
1.525944 \\
1.525970 \\
1.525997 \\
1.556024 \\
1.526051 \\
1.526077 \\
1.526104\end{array}$ \\
\hline $\begin{array}{l}93.0 \\
3.1 \\
3.2 \\
3.3 \\
3.4 \\
3.5 \\
3.6 \\
3.7 \\
3.8 \\
3.9\end{array}$ & $\begin{array}{r}199.932 \\
99.601 \\
99.269 \\
98.938 \\
98.607 \\
98.275 \\
97.944 \\
97.613 \\
97.282 \\
96.950\end{array}$ & $\begin{array}{l}99.899 \\
99.567 \\
99.236 \\
98.905 \\
98.573 \\
98.242 \\
97.911 \\
97.580 \\
97.249 \\
96.917\end{array}$ & $\begin{array}{l}99.866 \\
99.534 \\
99.203 \\
98.872 \\
98.540 \\
98.209 \\
97.878 \\
97.547 \\
97.216 \\
96.884\end{array}$ & $\begin{array}{l}99.833 \\
99.501 \\
99.170 \\
98.839 \\
98.507 \\
98.176 \\
97.845 \\
97.513 \\
97.182 \\
96.851\end{array}$ & $\begin{array}{l}99.799 \\
99.468 \\
99.137 \\
98.805 \\
98.474 \\
98.143 \\
97.8112 \\
97.480 \\
97.149 \\
96.818\end{array}$ & $\begin{array}{l}99.766 \\
99.435 \\
99.104 \\
98.772 \\
98.441 \\
98.110 \\
97.779 \\
97.447 \\
97.1116 \\
96.785\end{array}$ & $\begin{array}{l}99.733 \\
99.402 \\
99.071 \\
98.739 \\
98.408 \\
98.077 \\
97.745 \\
97.414 \\
97.083 \\
96.752\end{array}$ & $\begin{array}{l}99.700 \\
99.369 \\
99.037 \\
98.706 \\
98.375 \\
98.044 \\
97.712 \\
97.381 \\
97.050 \\
96.719\end{array}$ & $\begin{array}{l}99.667 \\
99.335 \\
99.004 \\
98.673 \\
98.342 \\
98.010 \\
97.679 \\
97.348 \\
97.017 \\
96.686\end{array}$ & $\begin{array}{l}99.634 \\
99.302 \\
98.971 \\
98.640 \\
98.308 \\
97.977 \\
97.646 \\
97.315 \\
96.984 \\
96.652\end{array}$ & $\begin{array}{l}0.277837 \\
0.2777837 \\
0.277836 \\
0.277836 \\
0.277836 \\
0.277836 \\
0.277836 \\
0.277835 \\
0.277835 \\
0.277835\end{array}$ & $\begin{array}{l}.526157 \\
.526184 \\
.526211 \\
.526237 \\
.526264 \\
.526291 \\
.526318 \\
.526344 \\
.526371 \\
.526398\end{array}$ \\
\hline $\begin{array}{r}494.0 \\
4.1 \\
4.2 \\
4.3 \\
4.4 \\
4.5 \\
4.6 \\
4.7 \\
4.8 \\
4.9\end{array}$ & $\begin{array}{r}18196.619 \\
96.288 \\
95.957 \\
95.625 \\
95.294 \\
94.963 \\
94.632 \\
94.301 \\
93.970 \\
93.639\end{array}$ & $\begin{array}{l}96.586 \\
96.255 \\
95.924 \\
95.592 \\
95.261 \\
94.930 \\
94.599 \\
94.268 \\
93.937 \\
93.606\end{array}$ & $\begin{array}{l}96.553 \\
96.222 \\
95.891 \\
95.559 \\
95.228 \\
94.897 \\
94.566 \\
94.235 \\
93.904 \\
93.573\end{array}$ & $\begin{array}{l}96.520 \\
96.189 \\
95.857 \\
95.526 \\
95.195 \\
94.864 \\
94.533 \\
94.202 \\
93.871 \\
93.540\end{array}$ & $\begin{array}{l}96.487 \\
96.156 \\
95.824 \\
95.493 \\
95.162 \\
94.831 \\
94.500 \\
94.168 \\
93.837 \\
93.507\end{array}$ & $\begin{array}{l}96.454 \\
96.122 \\
95.791 \\
95.460 \\
95.129 \\
94.798 \\
94.467 \\
94.135 \\
93.804 \\
93.473\end{array}$ & $\begin{array}{l}96.420 \\
96.089 \\
95.758 \\
95.427 \\
95.096 \\
94.764 \\
94.434 \\
94.102 \\
93.771 \\
93.440\end{array}$ & $\begin{array}{l}96.387 \\
96.056 \\
95.725 \\
95.394 \\
95.063 \\
94.732 \\
94.400 \\
94.069 \\
93.738 \\
93.407\end{array}$ & $\begin{array}{l}96.354 \\
96.023 \\
95.692 \\
95.361 \\
95.030 \\
94.0698 \\
94.0367 \\
94.036 \\
93.705 \\
93.374\end{array}$ & $\begin{array}{l}94.003 \\
93.672 \\
93.341\end{array}$ & $\begin{array}{l}0.277835 \\
0.2777835 \\
0.2777834 \\
0.277834 \\
0.277834 \\
0.277834 \\
0.277834 \\
0.277833 \\
0.277833 \\
0.277833\end{array}$ & \\
\hline $\begin{array}{l}95.0 \\
5.1 \\
5.2 \\
5.3 \\
5.4 \\
5.5 \\
5.6 \\
5.7 \\
5.8 \\
5.9\end{array}$ & $\begin{array}{r}18193.308 \\
92.977 \\
92.646 \\
92.314 \\
91.984 \\
91.653 \\
91.322 \\
90.991 \\
90.650 \\
90.329\end{array}$ & $\begin{array}{l}93.275 \\
92.944 \\
92.613 \\
92.281 \\
91.951 \\
91.620 \\
91.289 \\
90.958 \\
90.526 \\
90.295\end{array}$ & $\begin{array}{l}93.241 \\
92.910 \\
92.559 \\
92.249 \\
91.917 \\
91.586 \\
91.255 \\
90.094 \\
90.594 \\
90.262\end{array}$ & $\begin{array}{l}93.208 \\
92.877 \\
92.546 \\
92.215 \\
91.885 \\
91.553 \\
91.223 \\
90.891 \\
90.551 \\
90.229\end{array}$ & $\begin{array}{l}93.175 \\
92.844 \\
92.513 \\
92.182 \\
91.852 \\
91.520 \\
91.189 \\
90.858 \\
90.527 \\
90.196\end{array}$ & $\begin{array}{l}93.142 \\
92.811 \\
92.480 \\
92.149 \\
91.818 \\
91.487 \\
91.156 \\
90.825 \\
90.494 \\
90.163\end{array}$ & $\begin{array}{l}93.109 \\
92.7778 \\
92.447 \\
92.116 \\
91.785 \\
91.454 \\
91.123 \\
90.792 \\
90.461 \\
90.130\end{array}$ & $\begin{array}{l}93.076 \\
92.0745 \\
92.414 \\
92.083 \\
91.752 \\
91.0421 \\
91.090 \\
90.759 \\
90.428 \\
90.097\end{array}$ & $\begin{array}{l}93.043 \\
92.712 \\
92.381 \\
92.050 \\
91.719 \\
91.0388 \\
91.057 \\
90.726 \\
90.395 \\
90.064\end{array}$ & $\begin{array}{l}93.010 \\
92.679 \\
92.348 \\
92.017 \\
91.686 \\
91.355 \\
91.024 \\
90.693 \\
90.362 \\
90.031\end{array}$ & $\begin{array}{l}0.277833 \\
0.277833 \\
0.277832 \\
0.277832 \\
0.277832 \\
0.277832 \\
0.277832 \\
0.277831 \\
0.277831 \\
0.277831\end{array}$ & $\begin{array}{l}1.526691 \\
1.526718 \\
1.526745 \\
1.026772 \\
1.526798 \\
1.0526825 \\
1.526852\end{array}$ \\
\hline $\begin{array}{l}96.0 \\
6.1 \\
6.2 \\
6.3 \\
6.4 \\
6.5 \\
6.6 \\
6.7 \\
6.8 \\
6.9\end{array}$ & $\begin{array}{r}18189.998 \\
89.567 \\
89.336 \\
89.005 \\
88.674 \\
88.343 \\
88.012 \\
87.681 \\
87.350 \\
87.020\end{array}$ & $\begin{array}{l}89.965 \\
89.634 \\
89.303 \\
88.972 \\
88.641 \\
88.310 \\
87.979 \\
87.648 \\
87.317 \\
86.986\end{array}$ & $\begin{array}{l}89.932 \\
89.500 \\
89.270 \\
88.939 \\
88.608 \\
88.277 \\
87.946 \\
87.615 \\
87.284 \\
86.953\end{array}$ & $\begin{array}{l}89.898 \\
89.567 \\
89.237 \\
88.906 \\
88.575 \\
88.244 \\
87.913 \\
87.582 \\
87.251 \\
86.920\end{array}$ & $\begin{array}{l}80.865 \\
89.534 \\
89.203 \\
88.872 \\
88.542 \\
88.211 \\
87.880 \\
87.549 \\
87.218 \\
86.887\end{array}$ & $\begin{array}{l}89.832 \\
89.501 \\
89.170 \\
88.839 \\
88.509 \\
88.178 \\
87.847 \\
87.516 \\
87.185 \\
86.854\end{array}$ & $\begin{array}{l}89.799 \\
89.468 \\
89.137 \\
88.806 \\
88.475 \\
88.144 \\
87.813 \\
87.483 \\
87.152 \\
86.821\end{array}$ & $\begin{array}{l}89.766 \\
89.435 \\
89.104 \\
88.773 \\
88.442 \\
88.111 \\
87.781 \\
87.450 \\
87.119 \\
86.788\end{array}$ & $\begin{array}{l}89.733 \\
89.402 \\
89.071 \\
88.740 \\
88.409 \\
88.078 \\
87.747 \\
87.417 \\
87.086 \\
86.755\end{array}$ & $\begin{array}{l}87.383 \\
87.053 \\
86.722\end{array}$ & $\begin{array}{l}.277831 \\
.277831 \\
.277830 \\
.277830 \\
.277830 \\
.277830 \\
.277830 \\
.277830 \\
.777879 \\
.277829\end{array}$ & 1.52719 \\
\hline $\begin{array}{r}497.0 \\
7.1 \\
7.2 \\
7.3 \\
7.4 \\
7.5 \\
7.6 \\
7.7 \\
7.8 \\
7.9\end{array}$ & $\begin{array}{r}18186.688 \\
86.358 \\
86.027 \\
85.696 \\
85.365 \\
85.034 \\
84.704 \\
84.373 \\
84.042 \\
83.711\end{array}$ & $\begin{array}{l}86.656 \\
86.325 \\
85.994 \\
85.663 \\
85.332 \\
85.001 \\
84.671 \\
84.340 \\
84.009 \\
83.678\end{array}$ & $\begin{array}{l}86.623 \\
86.292 \\
85.061 \\
85.630 \\
85.299 \\
84.969 \\
84.638 \\
84.307 \\
83.976 \\
83.645\end{array}$ & $\begin{array}{l}85.597 \\
85.266 \\
84.935 \\
84.605 \\
84.274 \\
83.943 \\
83.612\end{array}$ & $\begin{array}{l}86.556 \\
86.226 \\
85.895 \\
85.564 \\
85.233 \\
84.902 \\
84.572 \\
84.241 \\
83.910 \\
83.579\end{array}$ & $\begin{array}{l}86.192 \\
85.861 \\
85.531 \\
85.200 \\
84.869 \\
84.539 \\
84.208 \\
83.877 \\
83.546\end{array}$ & $\begin{array}{l}86.490 \\
86.159 \\
85.829 \\
85.498 \\
85.167 \\
84.836 \\
84.505 \\
84.175 \\
83.844 \\
83.513\end{array}$ & $\begin{array}{l}86.457 \\
86.126 \\
85.795 \\
85.465 \\
85.134 \\
84.803 \\
84.472 \\
84.142 \\
83.811 \\
83.480\end{array}$ & $\begin{array}{l}86.42 .4 \\
86.093 \\
85.762 \\
85.432 \\
85.101 \\
84.770 \\
84.439 \\
84.108 \\
83.778 \\
83.447\end{array}$ & $\begin{array}{l}86.391 \\
86.060 \\
85.729 \\
85.398 \\
85.068 \\
84.737 \\
84.406 \\
84.075 \\
83.745 \\
83.414\end{array}$ & & \\
\hline $\begin{array}{l}98.0 \\
8.1 \\
8.2 \\
8.3 \\
8.4 \\
8.5 \\
8.6 \\
8.7 \\
8.8 \\
8.9\end{array}$ & $\begin{array}{r}8183.381 \\
83.050 \\
82.719 \\
82.389 \\
82.058 \\
81.727 \\
81.396 \\
81.066 \\
80.735 \\
80.405\end{array}$ & $\begin{array}{l}83.348 \\
83.017 \\
82.686 \\
82.355 \\
82.025 \\
81.694 \\
81.364 \\
81.033 \\
80.702 \\
80.372\end{array}$ & $\begin{array}{l}83.315 \\
82.984 \\
82.653 \\
82.323 \\
81.992 \\
81.661 \\
81.330 \\
81.000 \\
80.669 \\
80.339\end{array}$ & $\begin{array}{l}82.289 \\
81.959 \\
81.628 \\
81.298 \\
80.967 \\
80.636 \\
80.305\end{array}$ & $\begin{array}{l}82.918 \\
82.587 \\
82.256 \\
81.926 \\
81.595 \\
81.264 \\
80.934 \\
80.603 \\
80.273\end{array}$ & $\begin{array}{l}81.893 \\
81.562 \\
81.231 \\
80.901 \\
80.570 \\
80.240\end{array}$ & & $\begin{array}{l}81.826 \\
81.496 \\
81.165 \\
80.834 \\
80.504 \\
80.173\end{array}$ & $\begin{array}{l}83.116 \\
82.785 \\
82.455 \\
82.124 \\
81.793 \\
81.463 \\
81.132 \\
80.802 \\
80.471 \\
80.140\end{array}$ & & & \\
\hline $\begin{array}{l}99.0 \\
9.1 \\
9.2 \\
9.3 \\
9.4 \\
9.5 \\
9.6 \\
9.7 \\
9.8 \\
9.9\end{array}$ & $\begin{array}{r}18180.074 \\
79.743 \\
79.413 \\
79.082 \\
78.752 \\
78.421 \\
78.091 \\
77.760 \\
77.430 \\
77.099\end{array}$ & $\begin{array}{l}80.041 \\
79.710 \\
79.380 \\
79.049 \\
78.719 \\
78.388 \\
78.058 \\
77.0727 \\
77.0396 \\
77.066\end{array}$ & $\begin{array}{l}80.008 \\
79.677 \\
79.347 \\
79.016 \\
78.686 \\
78.355 \\
78.025 \\
77.0294 \\
77.364 \\
77.033\end{array}$ & $\begin{array}{l}79.975 \\
79.645 \\
79.314 \\
78.983 \\
78.052 \\
78.322 \\
77.0992 \\
77.661 \\
77.331 \\
77.000\end{array}$ & $\begin{array}{l}78.289 \\
77.958 \\
77.628 \\
77.0298 \\
76.967\end{array}$ & $\begin{array}{l}78.586 \\
78.256 \\
77.925 \\
77.595 \\
77.264 \\
76.934\end{array}$ & $\begin{array}{l}77.231 \\
76.901\end{array}$ & $\begin{array}{l}78.190 \\
77.859 \\
77.529 \\
77.198 \\
76.868\end{array}$ & $\begin{array}{l}79.810 \\
79.479 \\
79.148 \\
78.818 \\
78.487 \\
78.157 \\
77.826 \\
77.496 \\
77.165 \\
76.835\end{array}$ & $\begin{array}{l}79.777 \\
79.446 \\
79.115 \\
78.785 \\
78.454 \\
78.124 \\
77.793 \\
77.463 \\
77.132 \\
76.802\end{array}$ & & $1.5 ? .800$ \\
\hline & \multicolumn{2}{|c|}{.001} & & 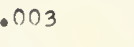 & 4 & . & 年 & . & 年 & . & 10 & \\
\hline & $\begin{array}{l}: 00 \\
: 00 \\
.00\end{array}$ & & & & & 015 & .019 & $\begin{array}{r}.022 \\
.022\end{array}$ & .025 & & .031 & \\
\hline
\end{tabular}


$\begin{array}{llllllllll}76.438 & 76.436 & 76.703 & 76.670 & 76.636 & 76.604 & 76.570 & 76.538 & 76.504 & 76.471 \\ 76.372 & 76.339 & 76.306 & 76.273 & 76.240 & 76.207 & 76.174 & 76.141\end{array}$

$\begin{array}{lllllllllll}76.108 & 76.075 & 76.042 & 76.009 & 75.976 & 75.942 & 75.910 & 75.876 & 75.844 & 75.810\end{array}$

$\begin{array}{lllllllllll}75.777 & 75.744 & 75.711 & 75.678 & 75.645 & 75.612 & 75.579 & 75.546 & 75.513 & 75.480\end{array}$

$\begin{array}{lllllllll}75.414 & 75.381 & 75.348 & 75.315 & 75.282 & 75.249 & 75 \cdot 216 & 75 \cdot 182 & 75.149\end{array}$

$\begin{array}{llllllllll}74.786 & 74.753 & 75.050 & 75.017 & 74.984 & 74.951 & 74 \cdot 918 & 74 \cdot 885 & 74.852 & 74.819 \\ 74.050 & 74.687 & 74.654 & 74.621 & 74.588 & 74.555 & 74.521 & 74.489\end{array}$

$\begin{array}{lllllllllll}74.456 & 74.423 & 74.390 & 74.356 & 74.323 & 74.290 & 74.257 & 74.224 & 74.191 & 74.158\end{array}$

$\begin{array}{llllllllll}74.125 & 74.092 & 74.059 & 74.026 & 73.993 & 73.960 & 73.927 & 73.894 & 73.861 & 73.828 \\ 73.795 & 73.762 & 73.729 & 73.696 & 73.663 & 73.630 & 73.596 & 73.563 & 73.530 & 73.497\end{array}$

0.277893

1816 66.530066 .86 $\begin{array}{lll}66.827 & 66.794 & 66.760 \\ 66.497 & 66.463 & 66.431\end{array}$ $66.200 \quad 66.167 \quad 66.134 \quad 66.100$ $65.869 \quad 65.836$ $\begin{array}{llll}64.879 & 64.846 & 64.813 & 64.780\end{array}$ $64.549 \quad 64.516 \quad 640483$ $64.219 \quad 64.186 \quad 64.153 \quad 64.120$

$\begin{array}{ll}67.388 & 67.355 \\ 67.058 & 67.024\end{array}$

67.652

$\begin{array}{lll}67.949 & 67.916 & 67.883 \\ 67.619 & 67.586 & 67.553\end{array}$

0.277819

0.277819

0.277819
0.277819
0.27719

0.277818

0.277818

0.277818

0.277817

0.277817

0.277817

0.277817

0.277816

0.277816

0.277815

5504.0

18163

$\begin{array}{rlll}163.559 & 63.526 & 63.493 & 63.460 \\ 63.229 & 63.196 & 63.163 & 63.130 \\ 62.899 & 62.866 & 62.833 & 62.800 \\ 62.569 & 62.536 & 62.503 & 62.470\end{array}$

$\begin{array}{llll}62.239 & 62.206 & 62.173 & 62.140 \\ 61.909 & 61.876 & 61.843 & 61.810\end{array}$

$61.579 \quad 61.546 \quad 61.513 \quad 61.480$

$\begin{array}{llll}61.250 & 61.216 & 61.183 & 61.150 \\ 60.919 & 60.886 & 60.854 & 60.820\end{array}$

$60.590 \quad 60.886$

$60.854 \quad 60.820$
$60.523 \quad 60.490$

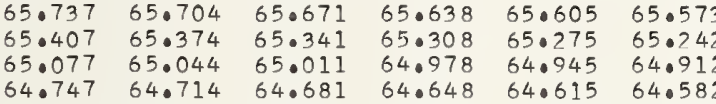

$\begin{array}{lllllll}64.4417 & 64.384 & 64 \cdot 351 & 64 \cdot 318 & 640285 & 64 \cdot 252 \\ 64.087 & 64.054 & 64.021 & 63.988 & 63.055 & 63.022\end{array}$

0.277815

$0.2778,5$

0.077815

0.277814

0.277814
0.277814
0.2774

0.277814

18160

$\begin{array}{lllll}59.600 & 59.567 & 59.564 & 59.83 & \end{array}$

$\begin{array}{lllll}58.610 & 58.577 & 58.544 & 58.51\end{array}$

$\begin{array}{llll}58.281 & 58.248 & 58.215 & 58.182\end{array}$

$\begin{array}{llll}57.051 & 57.918 & 57.885 & 57.852 \\ 57.621 & 57.588 & 57.555 & 57.522 \\ 57.291 & 57.258 & 57.225 & 57.192\end{array}$ 56.63 56.30
55.97

56.92

$\begin{array}{ll}56.896 & 56.863 \\ 56.565 & 56.533 \\ 56.236 & 56.203\end{array}$

$\begin{array}{llll}55.609 & 55.576 & 55.543\end{array}$

$54.983 \quad 54.950 \quad 54.917 \quad 54.884$

$\begin{array}{lllll}54.653 & 54.620 & 54.587 & 54.554\end{array}$

$\begin{array}{llll}54.323 & 54.291 & 54.258 & 54.225 \\ 53.994 & 53.961 & 53.928 & 53.895\end{array}$

5507.0

18153.664

$53.335 \quad 53.631$

$53.005 \quad 52.972$

$\begin{array}{ll}52.675 & 52.642 \\ 52.346 & 52.313\end{array}$

$52.016 \quad 51.983$

$51.357 \quad 51.324$

50.698

50.665

53.598

53.565
53.236

$\begin{array}{ll}52.939 & 52.90 \\ 52.610 & 52.577\end{array}$

$52.280 \quad 52.247$

$51.621 \quad 51.588$

$51.291 \quad 51.25$

18150.368

5508.0

8.1
$8 \cdot 2$

$8 \cdot 2$
8.3

8.3
8.4
8.5

8.5
8.6

8.7

8.8
8.9

5509

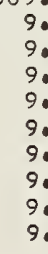

$$
\begin{array}{ll}
50.039 & 50 \\
49.709 & 49
\end{array}
$$

$49.380 \quad 49.677$

$49.050 \quad 49.017$

$48.721 \quad 48.688$

$\begin{array}{ll}48.391 & 48.358 \\ 48.062 & 48.029\end{array}$

$47.732 \quad 47.699$

$50.632 \quad 50.599$

47.403

50.302

$49.973 \quad 49.940$

$49.644 \quad 49.611$

48.984

$48.655 \quad 48.622$

48.622
48.293

48.293
47.963

63.097
62.0367
62.064
62.734
62.037
62.074

$\begin{array}{lll}62.107 & 62.074 \\ 61.777 & 61.0744 \\ 61 & \end{array}$

$\begin{array}{lll}61.047 & 61.044 \\ 6 ! .117 & 61.084 & 0\end{array}$

$\begin{array}{ll}60.787 & 60.754 \\ 60.458 & 60.425\end{array}$

$\begin{array}{lll}60.127 & 60.094 & 60.0 \\ 59.798 & 59.765 & 59.9\end{array}$

$\begin{array}{lll}60.127 & 50.094 & 00.002 \\ 50.468 & 59.765 & 59.732 \\ 50.435 & 59.002\end{array}$

59.138
58.808

58.47
58.14
57.819

58.775

58.445
58.115

57.489
57.159

57.786
57.456
57.126

$56 \cdot 829$
56.500

56.170
55.840

$\begin{array}{llllllll}55.510 & 55.807 & 55.774 & 55.741 & 55.0708 & 55.675\end{array}$

$\begin{array}{llllll}55.181 & 55.478 & 55.445 & 55.412 & 55.379 & 55.346 \\ 55.148 & 55.115 & 55.082 & 55.049 & 55.016\end{array}$

$\begin{array}{llllll}54.851 & 54.818 & 54.785 & 54.752 & 54.019 & 54.686 \\ 54.521 & 54.0488 & 54.455 & 54.422 & 54.300 & 54.356\end{array}$

$\begin{array}{llllll}54.521 & 54.488 & 54.455 & 54.422 & 54.339 & 54.356 \\ 54.192 & 54.159 & 54.126 & 54.093 & 54.000 & 54.027\end{array}$

$\begin{array}{llllll}53.532 & 53.499 & 53.796 & 53.763 & 53.730 & 53.697 \\ 03.466 & 53.434 & 53.401 & 53.368\end{array}$

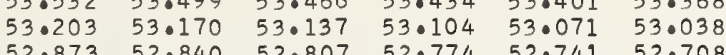

$\begin{array}{llllll}52.873 & 52.840 & 52.807 & 52.774 & 52.741 & 52.708 \\ 52.543 & 52.510 & 52.478 & 52.445 & 52.412 & 52.379\end{array}$

$\begin{array}{llllll}52.214 & 52.181 & 52.148 & 52.115 & 52.002 & 52.049\end{array}$

$\begin{array}{llllll}51.884 & 51.851 & 51.818 & 51.786 & 51.753 & 51.720\end{array}$

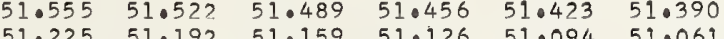

$\begin{array}{llllll}51.225 & 51.192 & 51.159 & 51.126 & 51.094 & 51.061 \\ 50.896 & 50.863 & 50.830 & 50.797 & 50.764 & 50.721\end{array}$

$\begin{array}{lllllll}50.566 & 50.533 & 50.500 & 50.467 & 50.434 & 50.401\end{array}$

$\begin{array}{llllll}50.237 & 50.204 & 50.170 & 50.138 & 50.105 & 50.072 \\ 40.907 & 49.874 & 49.841 & 49.808 & 49.775 & 49.742\end{array}$

$\begin{array}{lllllll}40.578 & 49.545 & 49.512 & 49.479 & 49.446 & 49.413\end{array}$

$\begin{array}{llllll}49.248 & 49.215 & 49.182 & 49.149 & 490116 & 49.083\end{array}$

$48.019 \quad 48.886 \quad 48.853348 .820 \quad 48.787 \quad 48.754$

$\begin{array}{llllll}48.260 & 48.5256 & 48.523 & 48.490 & 480457 & 48.424 \\ 48.2600 & 48.194 & 48.161 & 48.0128 & 48.095\end{array}$

$\begin{array}{llllll}47.930 & 47.897 & 47.8864 & 47.831 & 47.0798 & 47.0765\end{array}$

$\begin{array}{llllll}47.271 & 47.238 & 47.205 & 47.172 & 47.139 & 47.106\end{array}$

$\begin{array}{llllllllll}18147.073 & 47.041 & 47.008 & 46.975 & 46.942 & 46.909 & 46.876 & 46.843 & 46.810 & 46.777\end{array}$ $\begin{array}{llllllllll}46.744 & 46.711 & 46.678 & 46.646 & 46.613 & 46.580 & 46.547 & 46.514 & 46.481 & 46.448\end{array}$

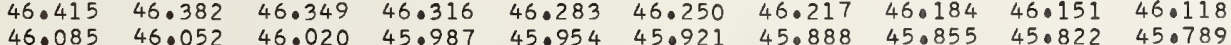

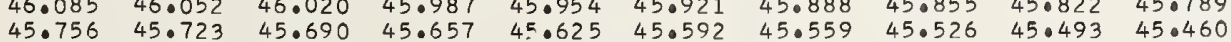
$\begin{array}{llllllllllll}45.427 & 45.394 & 45.361 & 45.328 & 45.295 & 45.262 & 45.229 & 45.197 & 45.164 & 45.131\end{array}$ $\begin{array}{llllllllllll}45.097 & 45.064 & 45.031 & 44.999 & 44.966 & 44.933 & 44.900 & 44.867 & 44.834 & 44.801\end{array}$ $\begin{array}{llllllllll}44.768 & 44.735 & 44.702 & 44.669 & 44.636 & 44.604 & 44.571 & 44.538 & 44.505 & 44.472\end{array}$

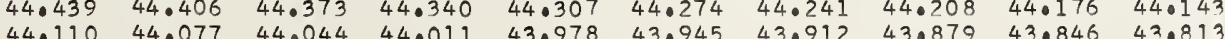

9.8

$.004 \quad .005$

$: 807$

0010
$: 010$
009

$: 012$

\begin{abstract}
.006
\end{abstract}


$\begin{array}{rrrrrrrrrrr}5510.0 & 18143.780 & 43.748 & 43.715 & 43.682 & 43.648 & 43.615 & 43.583 & 43.550 & 43.517 & 43.484 \\ 0.1 & 43.451 & 43.418 & 43.385 & 43.352 & 43.319 & 43.286 & 43.253 & 43.220 & 43.187 & 43.155\end{array}$

$\begin{array}{lllllllllll}0.1 & 43.451 & 43.418 & 43.385 & 43.352 & 43.319 & 43.286 & 43.253 & 43.220 & 43.187 & 43.155 \\ 0.2 & 43.122 & 43.089 & 43.056 & 43.023 & 42.990 & 42.957 & 42.924 & 42.891 & 42.858 & 42.825\end{array}$

$\begin{array}{lllllllllll}0.2 & 43.122 & 43.089 & 43.056 & 43.023 & 42.990 & 42.957 & 42.924 & 42.891 & 42.858 & 42.825 \\ 0.3 & 42.792 & 42.759 & 42.727 & 42.694 & 42.661 & 42.628 & 42.595 & 42.562 & 42.529 & 42.496\end{array}$

0.4

$42.463 \quad 42.430 \quad 42.397 \quad 42.364$

0.6

$42.134 \quad 42.101 \quad 42.068 \quad 42.035$

$\begin{array}{llllll}42.332 & 42.299 & 42.266 & 42.233 & 42.200 & 42.167\end{array}$

$\begin{array}{lllllll}42.002 & 41.969 & 41.936 & 41.904 & 41.871 & 41.838\end{array}$

0.7

$41.476 \quad 41.443 \quad 41.410 \quad 41.377$

$\begin{array}{llll}41.146 & 41.114 & 41.081 & 41.048 \\ 40.817 & 40.784 & 40.751 & 40.719\end{array}$

$\begin{array}{lllllll}41.673 & 41.640 & 41.607 & 41.574 & 41.542 & 41.509\end{array}$

$\begin{array}{llllll}41.344 & 41.311 & 41.278 & 41.245 & 41.212 & 41.179 \\ 41.015 & 40.982 & 40.949 & 40.916 & 40.883 & 40.850\end{array}$

5511.

$$
\begin{aligned}
& 1.1 \\
& 1.2 \\
& 1.3 \\
& 1.4 \\
& 1.5 \\
& 1.6 \\
& 1.07 \\
& 1.8
\end{aligned}
$$

$3 \cdot 1$

$3 \cdot 2$
$3 \cdot 3$
3.4

3.5

3.6

3.8
3.9

$\begin{array}{llllllllllll}9.2 & 13.537 & 13.504 & 13.471 & 13.438 & 13.405 & 13.373 & 13.340 & 13.307 & 13.274 & 13.241 \\ 9.3 & 13.208 & 13.176 & 13.143 & 13.110 & 13.077 & 13.044 & 13.012 & 12.979 & 12.946 & 12.913\end{array}$

$\begin{array}{lllllllllll}9.4 & 12.880 & 12.848 & 12.815 & 13.782 & 12.749 & 12.716 & 12.683 & 12.651 & 12.618 & 12.585\end{array}$

$\begin{array}{lllllllllll}.5 & 12.552 & 12.520 & 12.487 & 12.454 & 12.421 & 12.388 & 12.355 & 12.323 & 12.290 & 12.257 \\ .6 & 12.224 & 12.191 & 12.158 & 12.126 & 12.093 & 12.060 & 12.027 & 11.994 & 11.961 & 11.920\end{array}$

$\begin{array}{llllllllll}11.896 & 11.863 & 11.830 & 11.797 & 11.765 & 11.732 & 11.699 & 11.666 & 11.634 & 11.601 .\end{array}$

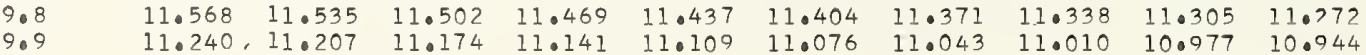

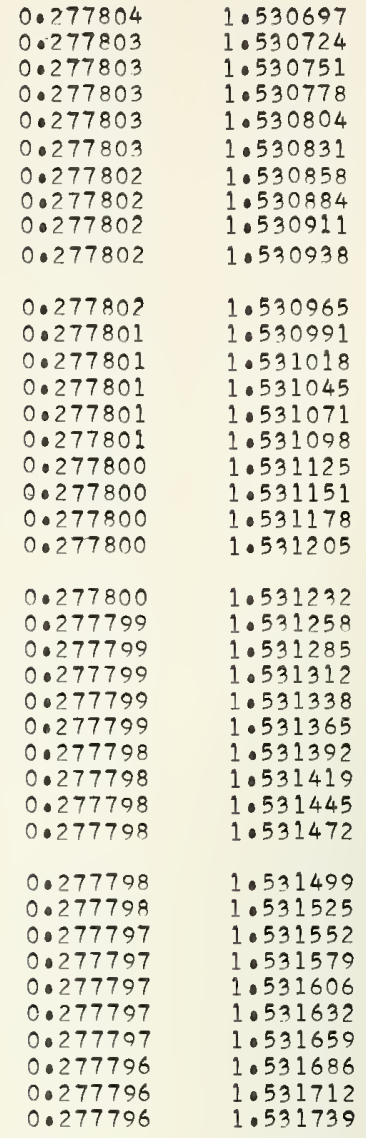

\subsection{0}

0.2777906
0.277795
0.277795

0.277795

0.277795

0.277795

0.277794

0.277794

0.277794
0.277794
0.277703

0.277703

0.277703

0.277793

0.277792

0.277792

0.277792

0.277792
0.277791

0.2777901
0.277791

0.2777791
0.2777991

0.277799
0.27779

0.2777791
0.277790

0.2777790
0.277790

0.277790

0.277790

0.277789

0.777789

0.277789

0.277788

0.277788

0.277788
0.0777788

0.277787

0.277787
0.0777787
0.077797

0.27778

0.777787

0.0277786
0.277786

0.277786
0.277786

0.277786

0.277786

0.27778

0.277785

$0 .>77785$

0.277784

1.531766 1.521793
1.531819 1.521846 1.531873 1.531926 1.531953 1.531980

1. 532033

1.532060

1.532086
.532113

0.532140

1. 0.5321632193

1.5322200
1.532247

1.532247
1.532273

1.532300

1.532327

1.532353
1.532380
1.53250

1.522407

1.522434
1.537460

10.532487
1.532514
1.0532540 
$\begin{array}{lllllllllll}18107.631 & 07.598 & 07.566 & 07.533 & 07.500 & 07.467 & 07.434 & 07.402 & 07.369 & 07.336\end{array}$ $\begin{array}{lllllllllll}07.303 & 07.271 & 07.238 & 07.205 & 07.172 & 07.139 & 07.106 & 07.074 & 07.041 & 07.008\end{array}$ $\begin{array}{llllllllll}06.975 & 06.942 & 06.910 & 06.877 & 06.844 & 06.811 & 06.779 & 06.746 & 06.713 & 06.680 \\ 06.647 & 06.615 & 06.582 & 06.549 & 06.516 & 06.483 & 06.451 & 06.418 & 06.385 & 06.352\end{array}$ $\begin{array}{llllllllll}06.647 & 06.615 & 06.582 & 06.549 & 06.516 & 06.483 & 06.451 & 06.418 & 06.385 & 06.352 \\ 06.319 & 06.287 & 06.254 & 06.221 . & 06.188 & 06.156 & 06.123 & 06.090 & 06.057 & 06.024\end{array}$ $\begin{array}{llllllllll}05.991 & 05.959 & 05.926 & 05.893 & 05.860 & 05.827 & 05.795 & 05.762 & 05.729 & 05.697 \\ 05.664 & 05.631 & 05.598 & 05.565 & 05.532 & 05.500 & 05.467 & 05.434 & 05.401 & 05.368\end{array}$ $\begin{array}{llllllllll}05.664 & 05.631 & 05.598 & 05.565 & 05.532 & 05.500 & 05.467 & 05.434 & 05.401 & 05.36\end{array}$ $\begin{array}{llllllllll}05.336 & 05.303 & 05.270 & 05.237 & 05.204 & 05.172 & 05.139 & 05.106 & 05.073 & 05.041 \\ 05.008 & 04.975 & 04.942 & 04.910 & 04.876 & 04.844 & 04.811 & 04.778 & 04.746 & 04.713\end{array}$ $\begin{array}{llllllllll}05.008 & 04.975 & 04.942 & 04.910 & 04.876 & 04.844 & 04.811 & 04.778 & 04.746 & 04.713 \\ 04.680 & 04.647 & 04.614 & 04.582 & 04.549 & 04.516 & 04.483 & 04.450 & 04.418 & 04.385\end{array}$

0.277782

0.277782

0.277782

0.27778

0.27778

0.277781

1.533582 $\begin{array}{rlllllll}104.352 & 04.319 & 04.287 & 04.254 & 04.221 & 04.188 & 0 \\ 04.024 & 03.991 & 03.958 & 03.926 & 03.893 & 03.860 & 03.1 \\ 03.697 & 03.664 & 03.631 & 03.598 & 03.565 & 03.532 & 03\end{array}$ $\begin{array}{llllllllll}03.368 & 03.336 & 03.303 & 03.270 & 03.237 & 03.532 & 3.500 & 03.467 & 03.434 & 03.401\end{array}$ $\begin{array}{lllllllllll}03.041 & 03.008 & 02.975 & 02.942 & 02.910 & 02.877 & 02.844 & 02.811 & 02.779 & 02.0746\end{array}$ $\begin{array}{lllllllllll}02.713 & 02.680 & 02.647 & 02.615 & 07.582 & 02.549 & 02.516 & 02.483 & 02.451 & 02.418\end{array}$ $\begin{array}{llllllllll}02.385 & 02.352 & 02.320 & 02.287 & 02.254 & 02.221 & 02.188 & 02.156 & 02.123 & 02.090\end{array}$

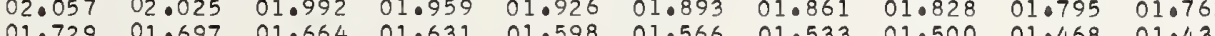
$\begin{array}{llllllllll}01.729 & 01.697 & 01.664 & 01.631 & 01.598 & 01.566 & 01.533 & 01.500 & 01.468 & 01.435 \\ 01.402 & 01.369 & 01.336 & 01.303 & 01.271 & 01.238 & 01.205 & 01.172 & 01.139 & 01.107\end{array}$ $\begin{array}{llllllllll}18101.074 & 01.041 & 01.009 & 00.976 & 00.943 & 00.910 & 00.877 & 00.845 & 00.812 & 00.779\end{array}$

0.277778

0.277778

0.277778

0.277777

0.277777

1.533636

1.533662

1.533716

1.533769

1.533822

1.533849

0.277776

0.277776

0.2777766

0.277775

0.277775

0.277774

0.2777774

0.277774

0.277774

0.277773

0.2777773
0.277773

1.533903

1.533929
1.533956

1.533983

1.534036

1.534063
1.534090

1.534116

0.277772

0.277772

0.277772

0.277771

0.277771

1.534170

1.5341906
1.534223

1.534250

1.534303

1.534357
1.534383

1.534437

1.535212

0.277770

0.277770

0.277770

0.277769

0.277769

0.277769
0.277769

0.2777669
0.277768

0.277768

0.277768
0.277767
0.277767

0.277767

0.277767

0.277767

0.277766

0.277766

0.277766

0.277765

.534464
.534490

1. .534544

1. 534597

1.534651

1.534704

1.534757

1.534811

1.534864

1.534918
1.534944

1.534971
1.534998

1.535025
1.535051

.535078
. .535105

1.535158

1.535238
1.535265

1.535292

1.535318

1.535372

1.535398

1.535452
1.535479

1.535505

1.535532
1.535559

1.535585
1.535612

1.535639
1.535666

1.535692
1.535719

0.277765

1.535772
1.535799
1.535826
1.535853
1.535879
1.535906
1.535933
1.535959
1.535986
1.536013

.010

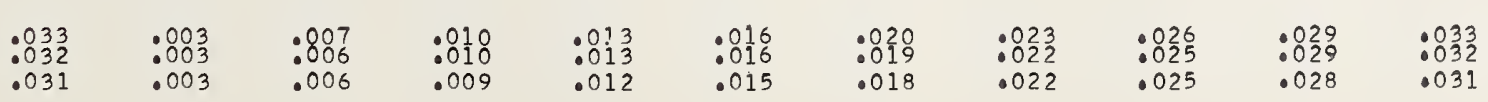


$\begin{array}{llllllllllll}5530.0 & 18078.162 & 78.129 & 78.096 & 78.063 & 78.031 & 77.998 & 77.965 & 77.933 & 77.900 & 77.867\end{array}$

8074.893

1.0
1.1
1.2
1.3
1.4
1.5
1.6
1.7
1.8
1.9

$$
\begin{array}{llll}
74.893 & 74.860 & 74.828 & 74.795 \\
74.566 & 74.534 & 74.501 & 74.469 \\
74.240 & 74.207 & 74.174 & 74.141 \\
73.913 & 73.880 & 73.847 & 73.815 \\
73.586 & 73.553 & 73.521 & 73.488 \\
73.259 & 73.227 & 73.194 & 73.161
\end{array}
$$

$72.606 \quad 72.573$

72.279
71.952

$\begin{array}{ll}75.089 & 75.056\end{array}$

75.351
75.024

$75.645 \quad 750612 \quad 75.579$

$\begin{array}{lllllll}74.762 & 74.730 & 74.697 & 74.664 & 74.632 & 74.599\end{array}$

$\begin{array}{lllllll}74.0436 & 74.403 & 74.370 & 74.337 & 74.305 & 74.272 \\ 74.109 & 74.076 & 74.043 & 74.011 & 73.978 & 73.945\end{array}$

$\begin{array}{lllllll}73.782 & 73.750 & 73.717 & 73.684 & 73.651 & 73.619\end{array}$

$\begin{array}{lllllll}73.455 & 73.423 & 73.390 & 73.357 & 73.324 & 73.292 \\ 73.129 & 73.096 & 73.063 & 73.031 & 72.998 & 72.965\end{array}$

$\begin{array}{llllll}72.802 & 72.096 & 73.063 & 73.031 & 72.998 & 72.969 \\ 72.736 & 72.704 & 72.671 & 72.639\end{array}$

$\begin{array}{llllll}72.475 & 72.442 & 72.410 & 72.377 & 72.344 & 72.312\end{array}$

$\begin{array}{llllll}72 \cdot 148 & 72.116 & 72.083 & 72.050 & 72.018 & 71.985 \\ 71.822 & 71.789 & 71.756 & 71.724 & 71.691 & 71.658\end{array}$

$\begin{array}{lllllll}71.495 & 71.462 & 71.429 & 71.397 & 71.365 & 71.332\end{array}$

$\begin{array}{lllllll}71.168 & 71.136 & 71.103 & 71.070 & 71.038 & 71.005 \\ 70.842 & 70.809 & 70.776 & 70.744 & 70.711 & 70.678\end{array}$

$\begin{array}{llllll}70.515 & 70.482 & 70.450 & 70.417 & 70.385 & 70.6752\end{array}$

$\begin{array}{llllll}70.189 & 70.156 & 70.123 & 70.090 & 70.058 & 70.025 \\ 69.862 & 69.829 & 69.796 & 69.764 & 69.731 & 69.698\end{array}$

$\begin{array}{llllll}69.535 & 69.503 & 69 \cdot 796 & 69.764 & 69 \cdot 731 & 69.698 \\ 69.470 & 69.437 & 69.405 & 69.372\end{array}$

$\begin{array}{llllll}69.208 & 69.176 & 69.143 & 69.111 & 69.078 & 69.045\end{array}$

$\begin{array}{lllllll}68.882 & 68.849 & 68.817 & 68.784 & 68.752 & 68.719 \\ 68.555 & 68.523 & 68.490 & 68.458 & 68.425 & 68.392\end{array}$

$\begin{array}{lllllll}68.229 & 68.196 & 68.164 & 68.131 & 68.098 & 68.066\end{array}$ $\begin{array}{llllll}67.902 & 67.870 & 67.837 & 67.804 & 67.772 & 67.739\end{array}$ $\begin{array}{llllll}67.576 & 67.543 & 67.511 & 67.478 & 67.445 & 67.413 \\ 67.249 & 67.217 & 67.184 & 67.151 & 67.119 & 67.086\end{array}$ $\begin{array}{llllll}66.923 & 66.890 & 66.858 & 66.825 & 66.792 & 66.760 \\ 66.596 & 66.564 & 66.531 & 66.498 & 66.466 & 66.433\end{array}$ $\begin{array}{llllll}66.596 & 66.564 & 66.531 & 66.498 & 66.466 & 66.433 \\ 66.270 & 66.237 & 66.205 & 66.172 & 66.139 & 66.109\end{array}$ $\begin{array}{lllllll}65.943 & 65.911 & 65.878 & 65.846 & 65.813 & 65.781\end{array}$ $\begin{array}{llllll}65.617 & 65.585 & 65.552 & 65.519 & 65.487 & 65.454 \\ 65.291 & 65.258 & 65.226 & 65.193 & 65.160 & 65.127\end{array}$

$\begin{array}{llllll}64.964 & 64.932 & 64.899 & 64.866 & 64.834 & 64 \cdot 801\end{array}$

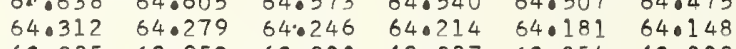
$\begin{array}{llllll}63.985 & 63.952 & 63.920 & 63.887 & 63.854 & 63.822\end{array}$ $\begin{array}{llllll}63.632 & 63.626 & 63.594 & 63.561 & 63.528 & 63.495 \\ 63.300 & 63.267 & 63.234 & 63.202 & 63.169\end{array}$ $\begin{array}{lllllll}63.006 & 62.973 & 62.941 & 62.908 & 62.875 & 62.843\end{array}$ $\begin{array}{llllll}62.679 & 62.647 & 62.614 & 62.582 & 62.549 & 62.516 \\ 62.353 & 62.321 & 62.288 & 62.255 & 62.223 & 62.190\end{array}$ $\begin{array}{lllllll}62.027 & 61.994 & 61.961 & 61.929 & 61.896 & 61.864\end{array}$ $\begin{array}{llllll}61.700 & 61.668 & 61.535 & 61.603 & 61.570 & 61.537\end{array}$ $61.048 \quad 61.015 \quad 60.983 \quad 60.950 \quad 60.917 \quad 600885$

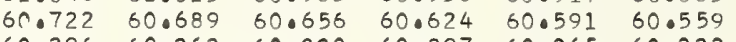
$\begin{array}{llllll}60.396 & 60.363 & 60.330 & 60.297 & 60.265 & 60.232 \\ 60.069 & 60.036 & 60.004 & 59.971 & 59.939 & 59.0006\end{array}$ $\begin{array}{lllllll}59.743 & 59.710 & 59.677 & 59.645 & 59.612 & 59.580\end{array}$ $\begin{array}{llllll}59.417 & 59.384 & 59.352 & 59.319 & 59.286 & 59.254 \\ 59.090 & 59.058 & 59.025 & 58.992 & 58.960 & 58.927\end{array}$ 0.277765 0.277765
0.277765
0.277764 0.277764 0.277764 0.277764 0.277764
0.277763
0.277763

0.277763

0.077763

0.27776 .3

0.277762

0.277762

0.277762
0.277762

0.279762

0.277761
0.277761

0.27776
0.27776

0.277761
0.277760
0.277760

0.277760
0.277760

0.277760
0.277760
0.277760

0.277760

0.277759
0.277759

0.277759

0.277759

0.000

0.277758

0.277758

0.277758

0.277757

0.277757

0.277756

0.277756
0.277756

0.277756

0.277756

0.277755

0.277755

0.277755

0.277754

0.277754

0.277754

0.277754

0.277753

$\begin{array}{lllllll}58.438 & 58.405 & 58.373 & 58.340 & 58.307 & 58.275\end{array}$

0.277753

0.777753

0.0277753

0.277752

0.277752

0.277752

0.277751
0.277751

$\begin{array}{lllllll}55.177 & 55.144 & 55.111 & 55.079 & 55.046 & 55.014 \\ 54.851 & 54.818 & 54.785 & 54.753 & 54.720 & 54.687\end{array}$ $\begin{array}{llllll}54.524 & 54.818 & 54.785 & 54.753 & 54.720 & 54.087 \\ 54.492 & 54.459 & 54.427 & 54.394 & 54.361\end{array}$ $\begin{array}{lllllll}54.198 & 54.166 & 54.133 & 54 \cdot 100 & 54.068 & 54.035\end{array}$ $\begin{array}{llllll}53.872 & 53.840 & 53.807 & 53.775 & 53.742 & 53.709 \\ 53.546 & 53.514 & 53.481 & 53.449 & 53.016 & 53.283\end{array}$ $53.220 \quad 53.188 \quad 53.155 \quad 53.123 \quad 53.090 \quad 53.057$ $\begin{array}{lllllll}52.894 & 52.862 & 52.829 & 52.797 & 52.764 & 52.731\end{array}$

0.27775

0.27775

0.277750

0.277750
0.277750
0.277750

0.277750

0.277750 $\begin{array}{llllll}51.916 & 51.884 & 51.851 & 51.819 & 51.786 & 51.753\end{array}$ $\begin{array}{llllll}51.591 & 51.558 & 51.525 & 51.493 & 51.460 & 51.427\end{array}$ $\begin{array}{llllll}5 ! .264 & 51.232 & 51.199 & 51.167 & 51.134 & 51.101 \\ 50.938 & 50.906 & 50.873 & 50.841 & 50.808 & 50.776\end{array}$ $\begin{array}{lllllll}50.613 & 50.580 & 50.548 & 50.515 & 50.482 & 50.449\end{array}$ $\begin{array}{llllll}50.287 & 50.254 & 50.221 & 50.189 & 50.156 & 50.124\end{array}$ $\begin{array}{lllllll}49.961 & 49.928 & 49.896 & 49.863 & 49.831 & 49.798\end{array}$ $\begin{array}{llllll}49.635 & 49.602 & 49.570 & 49.537 & 49.505 & 49.472\end{array}$ $\begin{array}{llllll}49.309 & 49.277 & 49.244 & 49.211 & 49.179 & 49.146 \\ 48.983 & 48.951 & 48.918 & 48.885 & 48.853 & 48.820\end{array}$

0.277749 0.27774 0.277749 0.277749 0.277748 0.277748
0.277748
0.277748 1.536040 1.536066 1.536093
1.536120 1.536146 1.536173 1.536200
1.536227 1.536253

1.536307 1.536333 1.536360
1.536387 1.536414 1.536440
1.536467 1.536467 1.536494
1.536520 .536547

1.536574 1.536601
1.536677 1.536654 1.536681 1.536734 1.536761 1.536788
1.536814

1.536841 1.536868 1.536921 1.536948 1.536975 1.537001 1.537055 1.537108
1.537135 1.537162 1.537188 1.537215 1.537242 1.537268
1.537295 1.537322 1.537349

1.537375 1.537402 1.537429
1.537455 1.537455
1.537482 1.537509 1.537536
1.537562 1.537589 1.537616

1.537642 1.537669
1.537696 1.537723 1.537749 1.537776 1.537803 1.537829
1.537856 1.537883

1.537910 1.537936
1.537963 1.537990 1.538016 


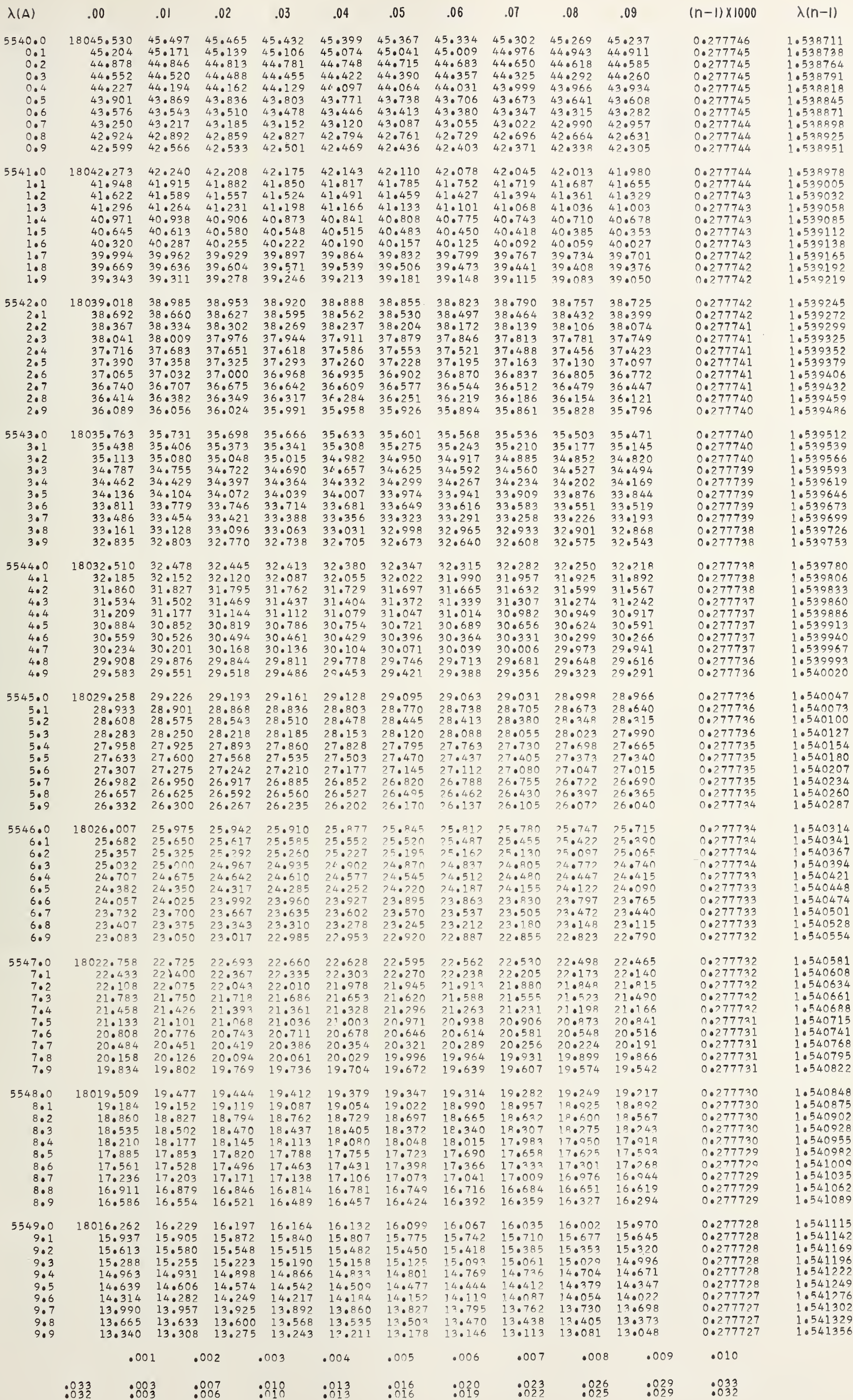




\begin{tabular}{|c|c|c|c|c|c|c|c|}
\hline$\lambda(A)$ & .00 & .01 & .02 & .03 & .04 & .05 & .06 \\
\hline $\begin{aligned} 50.0 \\
0.1\end{aligned}$ & $\begin{array}{r}18013.016 \\
12.691\end{array}$ & $\begin{array}{l}12.983 \\
12.659\end{array}$ & $\begin{array}{l}12.951 \\
12.626\end{array}$ & $\begin{array}{l}12.918 \\
12.594\end{array}$ & $\begin{array}{l}12.886 \\
12.562\end{array}$ & 12.854 & 12.821 \\
\hline 0.12 & $\begin{array}{l}12.691 \\
12.367\end{array}$ & $\begin{array}{l}12.659 \\
12.334\end{array}$ & $\begin{array}{l}12.626 \\
12.302\end{array}$ & $\begin{array}{l}12.594 \\
12.270\end{array}$ & $\begin{array}{l}12.562 \\
12.237\end{array}$ & $\begin{array}{l}12.529 \\
12.204\end{array}$ & $\begin{array}{l}12.497 \\
12.172\end{array}$ \\
\hline 0.3 & 12.042 & 12.010 & 11.977 & 11.945 & 11.912 & $\begin{array}{l}12.204 \\
11.880\end{array}$ & 11.847 \\
\hline $\begin{array}{l}0.4 \\
0.5\end{array}$ & 11.718 & 11.685 & 11.653 & 11.620 & 11.588 & 11.556 & 11.523 \\
\hline $\begin{array}{l}0.5 \\
0.6\end{array}$ & 11.393 & 11.361 & 11.328 & 11.296 & 11.263 & 11.231 & 11.198 \\
\hline $\begin{array}{l}0.6 \\
0.7\end{array}$ & 11.069 & 11.036 & 11.004 & 10.971 & 10.939 & 10.906 & 10.874 \\
\hline $\begin{array}{l}0.7 \\
0.8\end{array}$ & $\begin{array}{l}10.744 \\
10.420\end{array}$ & $\begin{array}{l}10.712 \\
10.387\end{array}$ & $\begin{array}{l}10.679 \\
10.355\end{array}$ & $\begin{array}{l}10.647 \\
10.323\end{array}$ & $\begin{array}{l}10.614 \\
10.290\end{array}$ & $\begin{array}{l}10.582 \\
10.258\end{array}$ & $\begin{array}{l}10.550 \\
10.225\end{array}$ \\
\hline 0.9 & 10.095 & 10.063 & 10.031 & 09.998 & 09.966 & 09.933 & 09.901 \\
\hline $\begin{aligned} 51.0 \\
1.1\end{aligned}$ & 18009.771 & 09.739 & 09.706 & 09.674 & 09.641 & 09.609 & 09.576 \\
\hline & 09.447 & 09.414 & 09.382 & $09 \cdot 349$ & 09.317 & $09 \cdot 284$ & 09.252 \\
\hline $\begin{array}{l}1.2 \\
1.3\end{array}$ & 09.122 & $\begin{array}{l}09.090 \\
087765\end{array}$ & 09.057 & 09.025 & 08.992 & 08.960 & 08.927 \\
\hline $\begin{array}{l}1.3 \\
1.4\end{array}$ & $\begin{array}{l}08.798 \\
08.473\end{array}$ & $\begin{array}{l}08.765 \\
08.441\end{array}$ & $\begin{array}{l}08.733 \\
08.408\end{array}$ & $\begin{array}{l}08.700 \\
08.376\end{array}$ & $\begin{array}{l}08.668 \\
08.344\end{array}$ & $\begin{array}{l}08.635 \\
08.311\end{array}$ & $\begin{array}{l}08.603 \\
08.279\end{array}$ \\
\hline 1.5 & 08.149 & 08.116 & $\begin{array}{l}08.408 \\
08.084\end{array}$ & $\begin{array}{l}08.316 \\
08.052\end{array}$ & $\begin{array}{l}08.344 \\
08.019\end{array}$ & $\begin{array}{l}08.311 \\
07.987\end{array}$ & 07.954 \\
\hline $\begin{array}{l}1.6 \\
1.7\end{array}$ & 07.824 & 07.792 & 07.759 & 07.727 & 07.695 & 07.662 & 07.630 \\
\hline $\begin{array}{l}1.7 \\
1.8\end{array}$ & $\begin{array}{l}07.500 \\
07.176\end{array}$ & 07.468 & 07.435 & 07.403 & 07.370 & 07.338 & 07.306 \\
\hline $\begin{array}{l}1.8 \\
1.9\end{array}$ & $\begin{array}{l}07.176 \\
06.851\end{array}$ & $\begin{array}{l}07.143 \\
06.819\end{array}$ & $\begin{array}{l}07.111 \\
06.786\end{array}$ & $\begin{array}{l}07.078 \\
06.754\end{array}$ & $\begin{array}{l}07.046 \\
06.722\end{array}$ & $\begin{array}{l}07.013 \\
06.689\end{array}$ & $\begin{array}{l}06.981 \\
06.657\end{array}$ \\
\hline & 18006 & & & & & & \\
\hline 2.1 & 06.203 & 06.170 & $\begin{array}{l}06.462 \\
06.138\end{array}$ & $\begin{array}{l}06.430 \\
06.105\end{array}$ & 06.073 & $\begin{array}{l}06.035 \\
06.041\end{array}$ & $\begin{array}{l}06.332 \\
06.008\end{array}$ \\
\hline 1. & 05.878 & 05.846 & 05.813 & 05.781 & 05.749 & 05.716 & 05.684 \\
\hline 2. & 05.554 & 05.521 & 05.489 & 05.457 & 05.424 & 05.392 & 05.359 \\
\hline 2 & 05.230 & 05.198 & 05.165 & 05.133 & 05.100 & 05.068 & 05.035 \\
\hline $\begin{array}{l}2.5 \\
2.6\end{array}$ & 04.905 & .873 & .841 & 04.808 & 04.776 & 04.743 & 04.711 \\
\hline $\begin{array}{l}2.6 \\
2.7\end{array}$ & 04.581 & 04.549 & .0516 & $4 \cdot 484$ & 04.452 & 04.419 & 04.387 \\
\hline $\begin{array}{l}2.7 \\
2.8\end{array}$ & $\begin{array}{l}04.257 \\
023032\end{array}$ & 04.225 & $\cdot .192$ & 4.160 & $04 \cdot 127$ & 04.095 & 04.062 \\
\hline $\begin{array}{l}2.8 \\
2.9\end{array}$ & $\begin{array}{l}03.933 \\
03.609\end{array}$ & $\begin{array}{l}03.900 \\
03.576\end{array}$ & $\begin{array}{l}03.868 \\
03.543\end{array}$ & $\begin{array}{l}03.836 \\
03.511\end{array}$ & $\begin{array}{l}03.803 \\
03.479\end{array}$ & $\begin{array}{l}03.771 \\
03.447\end{array}$ & $\begin{array}{l}03.738 \\
03.414\end{array}$ \\
\hline 5553.0 & 18003.284 & 03.252 & 03.219 & 03.187 & 03.155 & 03.122 & 03.090 \\
\hline $\begin{array}{l}3.1 \\
3.2\end{array}$ & $\begin{array}{l}02.960 \\
02.636\end{array}$ & 02.928 & 02.895 & 02.863 & 02.830 & 02.798 & 02.766 \\
\hline $\begin{array}{l}3.2 \\
3.3\end{array}$ & $\begin{array}{l}02.636 \\
02.312\end{array}$ & 02.604 & 02.571 & 02.539 & 02.506 & 02.474 & 02.441 \\
\hline $\begin{array}{l}3.3 \\
3.4\end{array}$ & $\begin{array}{l}02.312 \\
01.988\end{array}$ & $\begin{array}{l}02.279 \\
01.955\end{array}$ & $\begin{array}{l}02.247 \\
01.923\end{array}$ & $\begin{array}{l}02.215 \\
01.890\end{array}$ & $\begin{array}{l}02.182 \\
01.858\end{array}$ & $\begin{array}{l}02.150 \\
01.826\end{array}$ & $\begin{array}{l}02.117 \\
01.793\end{array}$ \\
\hline 3.5 & 01.663 & 01.631 & 01.599 & 01.566 & 01.534 & 01.501 & 01.469 \\
\hline 3.6 & 01.339 & 01.307 & 01.274 & 01.242 & 01.210 & 01.177 & 01.145 \\
\hline 3.7 & 01.015 & 00.983 & 00.950 & 00.918 & 00.885 & 00. & 00.821 \\
\hline $\begin{array}{l}3.8 \\
3.9\end{array}$ & $\begin{array}{l}00.691 \\
00.367\end{array}$ & $\begin{array}{l}00.658 \\
00.334\end{array}$ & 00.626 & $\begin{array}{l}00.594 \\
00.270\end{array}$ & 00.561 & $\begin{array}{l}00.529 \\
00.205\end{array}$ & 00.497 \\
\hline & & 00010 & 00.302 & & $\begin{array}{r}00.238 \\
* 00.013 *\end{array}$ & & 00.173 \\
\hline $\begin{array}{r}54.0 \\
4.1\end{array}$ & $\begin{array}{l}18000.043 \\
17999.719\end{array}$ & $\begin{array}{l}00.010 \\
99.686\end{array}$ & $\begin{array}{c}* 99.978 \\
99.654\end{array}$ & $\begin{array}{r}* 99.946 \\
99.622\end{array}$ & $\begin{array}{c}* 99.913 * \\
99.589\end{array}$ & $\begin{array}{r}* 99.881 \\
99.557\end{array}$ & $\begin{array}{r}* 99.848 \\
99.524\end{array}$ \\
\hline 4.2 & $99^{\circ}$ & 99.362 & $99^{\circ}$. & 99. & 99.265 & 99.232 & 99. \\
\hline 40 & $99 \cdot 0$ & 99.038 & 99. & $98^{\circ}$ & 98.941 & $980^{\circ}$ & 98. \\
\hline $\begin{array}{l}4.4 \\
4.5\end{array}$ & 98.747 & 98.714 & 98.682 & & 98.617 & & 98. \\
\hline $\begin{array}{l}4.5 \\
4.6\end{array}$ & $\begin{array}{l}98.422 \\
98.099\end{array}$ & $\begin{array}{r}98.390 \\
98.066\end{array}$ & 98.358 & $\begin{array}{l}98.325 \\
98.001\end{array}$ & $\begin{array}{l}98.293 \\
97.069\end{array}$ & $\begin{array}{l}98.260 \\
07\end{array}$ & 98.228 \\
\hline 4.7 & 97.774 & 97.742 & 97.710 & 97.677 & 97.645 & 97.612 & 97.580 \\
\hline 4. & 97.450 & 97.418 & 97.386 & 97. & 97.321 & 97. & 97. \\
\hline 409 & 97.126 & 97.094 & 97.062 & 97.029 & 96.997 & 96.965 & 96.932 \\
\hline 55.0 & $\begin{array}{r}17996.802 \\
96.479\end{array}$ & $\begin{array}{l}96.770 \\
96.746\end{array}$ & & $\begin{array}{l}96.705 \\
96.7881\end{array}$ & 96. & $\begin{array}{l}41 \\
16\end{array}$ & 8 \\
\hline $\begin{array}{l}5.1 \\
5.2\end{array}$ & $\begin{array}{l}96.479 \\
96.155\end{array}$ & $\begin{array}{l}6.446 \\
6.122\end{array}$ & $\begin{array}{l}960^{\circ} \\
96 .\end{array}$ & $\begin{array}{l}96.381 \\
96.057\end{array}$ & 96. & $\begin{array}{l}96.316 \\
95.992\end{array}$ & \\
\hline 5.3 & 95.831 & .798 & 95.766 & 95.733 & 95.701 & 95.668 & 95.636 \\
\hline 5.4 & 95.507 & 95.474 & 95.442 & 95. & 95.377 & 95. & 95.312 \\
\hline 5.5 & 95.183 & 95.151 & 95.118 & 95.086 & 95.053 & 95.021 & 94.988 \\
\hline 5.6 & 94.859 & 94.826 & 94.794 & 94.762 & 94.729 & 94.697 & 94.665 \\
\hline 5.7 & 94.535 & 94.503 & 94.470 & 94.438 & 94.406 & 94.373 & 94.341 \\
\hline 5.8 & 94.211 & 94.178 & 94.146 & 94.114 & 94.082 & 94.049 & 94.017 \\
\hline 5.9 & 93.887 & 93.855 & 93.823 & 93.790 & 93.758 & 93.725 & 93.693 \\
\hline 56.0 & 993.563 & 93.531 & 99 & 93.466 & 93.434 & 93.401 & 93.369 \\
\hline & & & & & & & \\
\hline 60 & 92 & 92.883 & 92. & 92 & 92. & & \\
\hline $6 \cdot 3$ & 92 & 92.559 & 92. & & & & \\
\hline & 8 & 92.236 & 92. & 92 & 92. & 92 & \\
\hline 5 & 91 & 91.9 & 91. & 91.8 & 91 . & & 91. \\
\hline 6.6 & $\begin{array}{l}0 \\
7\end{array}$ & 91 & & $91 \cdot 5$ & & & \\
\hline 6.7 & $91 \cdot 2$ & 91 . & 91. & 91 。 & & & \\
\hline 6.8 & 3 & $90 \cdot 940$ & 90. & 90. & & & \\
\hline 6.9 & 90.649 & 90.617 & 90.5 & 90.552 & $90 \cdot 5$ & 90. & 90. \\
\hline $\begin{array}{r}5557.0 \\
7.1\end{array}$ & $\begin{array}{r}17990.325 \\
90.001\end{array}$ & $\begin{array}{l}90.293 \\
89.969\end{array}$ & $\begin{array}{l}90.261 \\
89.0337\end{array}$ & $\begin{array}{l}90.228 \\
89.905\end{array}$ & $\begin{array}{l}90.196 \\
89.872\end{array}$ & $\begin{array}{l}90.164 \\
89.840\end{array}$ & $\begin{array}{l}90.131 \\
89.807\end{array}$ \\
\hline 101 & $\frac{1}{8}$ & 89 & 3 & $\begin{array}{l}5 \\
1\end{array}$ & & 6 & \\
\hline 7.3 & $89 . ?$ & 89. & 89.290 & 89. & 89.225 & 89. & 89. \\
\hline 7.4 & 1 & 88.998 & 88.966 & 88. & 88.9 & 88. & 88. \\
\hline 7.5 & 88.707 & 88.675 & & 0 & 88. & 88. & 88 . \\
\hline 7 & 4 & 88.351 & 88.318 & 6 & 88.254 & & \\
\hline 7. & & 88.0 & & & 87. & 8 & 87. \\
\hline 7.8 & 87.736 & 87.704 & 87.671 & & 87.606 & 74 & 87.542 \\
\hline 7.9 & 87.412 & 87.380 & 87.348 & 87.315 & 87.283 & 87.251 & 87.218 \\
\hline 8 & $1-7$ & 87.057 & 87.024 & .992 & 86.959 & 86.927 & 86.895 \\
\hline & & & & & & & \\
\hline & & & & & & & \\
\hline 8 & & & & & & & \\
\hline & & & & & & & \\
\hline 8 & & & & & & & \\
\hline & & & & & & & \\
\hline 8 & & & & & & & \\
\hline $8 \cdot$ & 00 & $84 \cdot 4$ & & & & & \\
\hline 8.9 & 84.177 & $84 \cdot 144$ & $84 \cdot 112$ & 84.079 & 84.047 & 84.015 & 83.982 \\
\hline 59.0 & 53 & .821 & 83. & 83.756 & 4 & 1 & 9 \\
\hline & & & & & & & \\
\hline 9. & 6 & 3.174 & 83. & & & & \\
\hline 9 & $\begin{array}{l}3 \\
0\end{array}$ & & & & & & \\
\hline 9. & 82. & 82.527 & 82.494 & & & & \\
\hline & $\begin{array}{l}82.2 \\
81.9\end{array}$ & 13 & 71 & $\frac{9}{5}$ & 6 & $\begin{array}{l}74 \\
50\end{array}$ & $\begin{array}{l}+2 \\
18 \\
18\end{array}$ \\
\hline 9.7 & 81.589 & 81.557 & $\begin{array}{l}81.841 \\
81.524\end{array}$ & $\begin{array}{l}1.813 \\
1.492\end{array}$ & 81. & 81. & 81. \\
\hline 9.8 & 81.265 & 81.233 & 81.201 & 81.168 & 81.136 & 81.10 & 81.071 \\
\hline 9.9 & 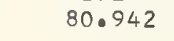 & 80.910 & 80.877 & 80.845 & 80.813 & 80.780 & .748 \\
\hline & .00 & & 002 & .003 & .004 & .005 & .006 \\
\hline
\end{tabular}




.06

$\begin{array}{rr}5560.0 & 17980.6 \\ 0.1 & 80.2 \\ 0.2 & 79.2 \\ 0.3 & 7 \\ 0.4 & 79.6 \\ 0.5 & 7 \\ 0.6 & 78.0 \\ 0.7 & 78.3 \\ 0.8 & 78.0 \\ 0.9 & 77.7\end{array}$

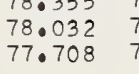

$\begin{array}{rr}0.619 & 80.586\end{array}$

$\begin{array}{ll}79.2952 & 80.263 \\ 79.940 \\ 79.648 & 79.616\end{array}$

$\begin{array}{llll}7 . .648 & 79.616 & 79.584 & 79.552\end{array}$

$\begin{array}{lll}79.002 & 78.060 & 78\end{array}$

5561.0
1.1
1.2
1.
1.
1.0
1.0
1.0
1.9

$\begin{array}{ll}61.0 & 179 \\ 1.11 & \\ 1.2 & \\ 1.3 & \\ 1.04 & \\ 1.5 & \\ 1.6 & \\ 1.7 & \\ 1.8 & \\ 1.9 & \end{array}$

$\begin{array}{rl}77.708 & 77.676 \\ 977.385 & 77.353 \\ 77.062 & 77.030 \\ 76.739 & 76.706 \\ 76.416 & 76.383\end{array}$

76.416760

$76.092 \quad 76.060$

$\begin{array}{ll}75.769 & 75.737 \\ 75.446 & 75.413\end{array}$

$\begin{array}{ll}75.123 & 75.090 \\ 74.799 & 74.767 \\ 74.476 & 74.444\end{array}$

$76.028 \quad 75.99$

$\begin{array}{lll}75.705 & 75.672 & 75.640\end{array}$

$\begin{array}{lll}75.381 & 75.349 & 75.317 \\ 75.058 & 75.026 & 74.093\end{array}$

5562.

2.0
2.2
2.
2.
2.5
2.6
2.7
2.8

$17974.153 \quad 74 \cdot 121$

$\begin{array}{ll}73.830 & 73.798 \\ 73.507 & 73.475 \\ 73.184 & 73.151\end{array}$

$\begin{array}{ll}73.184 & 73.475 \\ 72.861 & 72.828 \\ 72.537 & 72.505\end{array}$

$72.214 \quad 72 \cdot 182$

$\begin{array}{ll}71.891 & 71.859 \\ 71.568 & 71.536\end{array}$

$\begin{array}{ll}74.735 & 74.702 \\ 74.412 & 74.379\end{array}$

74.670
74.347

71.24

$\begin{array}{ll}74.088 & 74.05 \\ 73.0765 & 73.03\end{array}$

74.02
73.701

$\begin{array}{ll}73.442 & 73.410 \\ 73.119 & 73.087 \\ 72.796 & 72.07\end{array}$

73.37
73.05
72.731

$\begin{array}{lllll}72.796 & 72.764 & 72.731 & 72.699 \\ 72.473 & 72.440 & 72.408 & 72.036\end{array}$

$\begin{array}{lll}72.473 & 72.440 & 72.408 \\ 72.150 & 72.118 & 72.085\end{array}$

.085
7.762
7.439

72.053

71.213

5563.

3.
3.
3.
3.
3.5
3.0
3.7
3.0
3.

$\begin{array}{ll}70.922 & 70.890 \\ 70.599 & 70.567 \\ 70.276 & 70.244\end{array}$

$69.953 \quad 69.921$

$\begin{array}{llll}69.9530 & 69.921 & 69.888 & 70.179\end{array}$

$69.307 \quad 69.275 \quad 69.565 \quad 69.533$

$\begin{array}{llll}68.984 & 68.2752 & 69.242 & 69.210 \\ 68.982 & 68.919 & 68.887\end{array}$

$68.661 \quad 68.629 \quad 68.596 \quad 68.564$

$\begin{array}{llll}68.338 & 68.306 & 68.273 & 68.241 \\ 68.015 & 67.983 & 67.950 & 67.918\end{array}$

$\begin{array}{ll}71.439 & 71.407 \\ 71.116 & 71.083\end{array}$

80.42
80.10
79
79.47
7
78.13
78.48
78.16
77.83
77.5
7

$\begin{array}{llll}80.424 & 80.392 & 80.360 & 80.328 \\ 80.101 & 80.069 & 80.036 & 80.004 \\ 79.778 & 79.745 & 79.713 & 79.681\end{array}$

$\begin{array}{lll}79.422 & 79.013 & 79 \cdot 681 \\ 70.099 & 79006 & 79.358\end{array}$

$\begin{array}{llll}79.131 & 79.099 & 79.066 & 79.034 \\ 78.808 & 78.776 & 78.743 & 78.711\end{array}$

$\begin{array}{lll}78.776 & 78.743 & 78.711 \\ 78.452 & 78.420 & 78.387\end{array}$

$\begin{array}{lll}78.452 & 78.420 & 78.387 \\ 78.129 & 78.096 & 78.064\end{array}$

0.79

70.760

$\begin{array}{ll}70.470 & 70.433 \\ 70.147 & 70.115\end{array}$

$\begin{array}{lll}70.470 & 70.437 & 70.405\end{array}$

69.501
69.178

69.46

$\begin{array}{ll}68.855 & 68.823 \\ 68.532 & 68.500\end{array}$

69.113

68.1
680

$17967.692 \quad 67.660$

67.

67.0

$67.628 \quad 67.59$

67.563

67.854

$67.822 \quad 67.789 \quad 67.757 \quad 67.724$

$\begin{array}{llllllllll} & \end{array}$

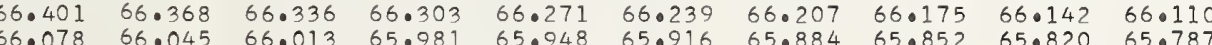
$\begin{array}{llllllllll}65.755 & 65.723 & 65.690 & 65.658 & 65.626 & 65.593 & 65.561 & 65.529 & 65.496 & 65.464\end{array}$ $\begin{array}{llllllllll}65.432 & 65.400 & 65.367 & 65.335 & 65.303 & 65.271 & 65.238 & 65.206 & 65.174 & 65.141 \\ 65.109 & 65.077 & 65.045 & 65.012 & 64.080 & 64.048 & 64.915 & 64.883 & 64.851 & 64.019\end{array}$ $\begin{array}{llllllllll}65.786 & 64.754 & 64.722 & 64.689 & 64.657 & 64.625 & 64.593 & 64.560 & 64.578 & 64.0496\end{array}$

$1964.463 \quad 64.431$

5565.0

5. 63.8180 63.81863 .786

64.39964 .367

64.65764 .625

$64 \cdot 270 \quad 64 \cdot 238 \quad 64 \cdot 205 \quad 64 \cdot 173$ $\begin{array}{llllllllll}0 & 63.754 & 63.721 & 63.689 & 63.657 & 63.625 & 63.592 & 63.560 & 63.578\end{array}$

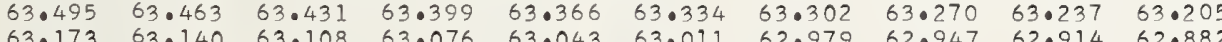
$\begin{array}{llllllllll}62.850 & 62.818 & 62.785 & 62.753 & 62.721 & 62.688 & 62.656 & 62.624 & 62.592 & 62.560\end{array}$ $\begin{array}{llllllllll}62.527 & 62.495 & 62.462 & 62.430 & 62.398 & 62.366 & 62.333 & 62.301 & 62.260 & 62.337\end{array}$

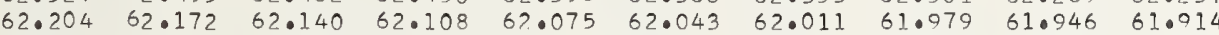

$\begin{array}{llllllllll}61.882 & 61.849 & 61.817 & 61.785 & 61.752 & 61.720 & 61.688 & 61.6556 & 61.624 & 61.591 \\ 61.559 & 61.527 & 61.494 & 61.462 & 61.430 & 61.398 & 61.365 & 61.333 & 61.301 & 61.969\end{array}$

17961.236

5566 $6 \cdot 1$
$6 \cdot 2$
6.3

6.4
6.5
6.5

6.6

6.7
6.8
6.9

6.8
6.9

5567.0

7.1
$7 \cdot 2$
7.3

7.3
7.4

7.5

7.6

7.8
7.9

60.59160 .881

$60.268 \quad 60.236$

59.62359 .591

$59.300 \quad 59.268$

58.978 58.94

58.333

$\begin{array}{ll}59.236 & 59.204 \\ 58.913 & 58.881\end{array}$

$\begin{array}{ll}58.913 & 58.881 \\ 58.591 & 58.558 \\ 58.268 & 58.236\end{array}$

$\begin{array}{llll}57.010 & 57.978 & 57.945 & 57.913\end{array}$

$\begin{array}{lllll}57.687 & 57.655 & 57.623 & 57.591\end{array}$

$\begin{aligned} & 57.687 \quad 57.655 \\ & 57.042\end{aligned} 57.333-57.300$

$\begin{array}{llll}57.042 & 57.010 & 56.978 & 57.946\end{array}$

$56.397 \quad 56.365 \quad 56.333 \quad 56.30$

$\begin{array}{llll}56.074 & 56.042 & 56.010 & 55.978 \\ 55.752 & 55.720 & 55.687 & 55.055\end{array}$

$\begin{array}{llll}55.752 & 55.720 & 55.687 & 55.65 \\ 55.429 & 55.397 & 55.365 & 55.33\end{array}$

$\begin{array}{llll}55.429 & 55.397 & 55.365 & 55.333 \\ 55.107 & 55.075 & 55.042 & 55.010\end{array}$

$\begin{array}{lllllll}61.107 & 61.075 & 61.042 & 61.010 & 60.978 & 60.946\end{array}$

$\begin{array}{llllll}60.784 & 60.752 & 60.720 & 60.688 & 60.655 & 60.623 \\ 60.462 & 60.420 & 60.397 & 60.365 & 60.333 & 60.300\end{array}$

$60.13960 .107 \quad 60.074 \quad 60.042 \quad 60.010 \quad 59.978$

$\begin{array}{llllll}59.814 & 59.784 & 59.752 & 59.720 & 59 \cdot 687 & 59.655 \\ 59.494 & 59.461 & 59.429 & 59.397 & 59 \cdot 365 & 59.333\end{array}$

$\begin{array}{lllllll}59.171 & 59.139 & 59.107 & 59.074 & 59.042 & 59.010\end{array}$

$\begin{array}{lllllll}58.848 & 58.816 & 58.784 & 58.752 & 58.719 & 58.687 \\ 58.526 & 58.494 & 58.461 & 58.429 & 58.397 & 58.365\end{array}$

$\begin{array}{llllll}58.526 & 58.494 & 58.461 & 58.429 & 58.397 & 58.0865 \\ 58.203 & 58.171 & 58.139 & 58.107 & 58.074 & 58.042\end{array}$

$\begin{array}{llllll}57.881 & 57.849 & 57.816 & 57.784 & 57.752 & 57.720 \\ 57.558 & 57.526 & 57.404 & 57.461 & 57.479 & 57.397\end{array}$

$\begin{array}{llllll}57.558 & 57.526 & 57.494 & 57.461 & 57.429 & 57.720 \\ 57.236 & 57.203 & 57.171 & 57.720 & 57.107 & 57.074\end{array}$

$\begin{array}{lllllll}56.913 & 56.881 & 56.848 & 56.816 & 56.784 & 56.752\end{array}$

$\begin{array}{llllll}56.591 & 56.558 & 56.526 & 56.494 & 56.462 & 56.429 \\ 56.268 & 56.236 & 56.204 & 56.172 & 56.139 & 56.107\end{array}$

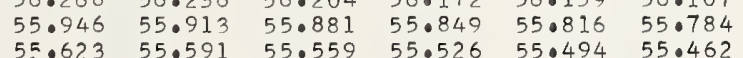

$\begin{array}{lllllll}55.623 & 55.591 & 55.559 & 55.526 & 55.494 & 55.462 \\ 55.301 & 55.268 & 55.236 & 55.204 & 55.172 & 55.130\end{array}$

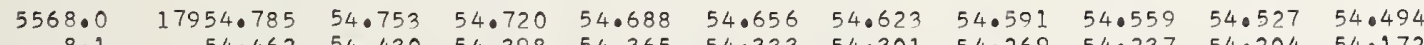

$\begin{array}{lllllllllll}8.1 & 54.462 & 54.430 & 54.398 & 54.365 & 54.333 & 54.301 & 54.269 & 54.237 & 54.204 & 54 \cdot 172 \\ 8.2 & 54.140 & 54.108 & 54.075 & 54.043 & 54.010 & 53.978 & 53.946 & 53.914 & 53.887 & 53.840\end{array}$

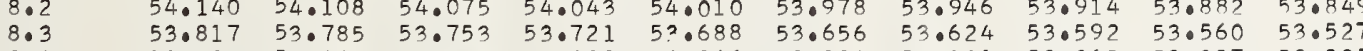

$\begin{array}{llllllllllll}8.4 & 53.495 & 53.463 & 53.430 & 53.398 & 53.366 & 53.334 & 53.301 & 53.269 & 53.237 & 53.205\end{array}$

$\begin{array}{lllllllllll}8.5 & 53.172 & 53.140 & 53.108 & 53.076 & 53.043 & 53.011 & 52.979 & 52.947 & 52.915 & 52.882\end{array}$

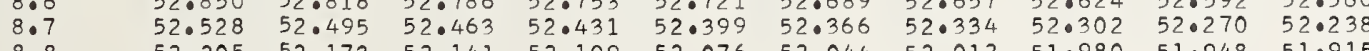

$\begin{array}{lllllllllll}8.8 & 52.205 & 52.173 & 52.141 & 52.109 & 52.076 & 52.044 & 52.012 & 51.980 & 51.948 & 51.915 \\ 8.9 & 51.883 & 51.851 & 51.818 & 51.786 & 51.754 & 51.722 & 51.689 & 51.657 & 51.625 & 51.593\end{array}$

$\begin{array}{llllllllll}51.561 & 51.528 & 51.496 & 51.464 & 51.432 & 51.399 & 51.367 & 51.335 & 51.303 & 51.071\end{array}$

556900

$\begin{array}{rlllllllll}951.561 & 51.528 & 51.496 & 51.464 & 51.432 & 51.399 & 51.367 & 51.335 & 51.303 & 51.271 \\ 51.238 & 51.206 & 51.174 & 51.142 & 51.109 & 51.077 & 51.045 & 51.012 & 50.980 & 50.048\end{array}$ $\begin{array}{lllllllllll}50.916 & 50.884 & 50.852 & 50.819 & 50.787 & 50.755 & 50.723 & 50.690 & 50.658 & 50.626\end{array}$ $\begin{array}{lllllllllll}50.594 & 50.561 & 50.529 & 50.497 & 50.465 & 50.432 & 50.400 & 50.368 & 50.336 & 50.303\end{array}$

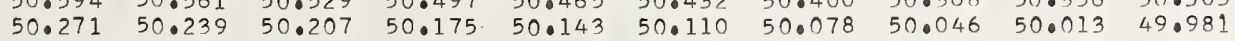
$\begin{array}{llllllllll}49.949 & 49.917 & 49.885 & 49.852 & 49.820 & 49.788 & 49.755 & 49.723 & 49.691 & 49.659\end{array}$ $\begin{array}{lllllllllll}49.627 & 49.594 & 49.562 & 49.530 & 49.498 & 49.466 & 49.433 . & 49.401 & 49.369 & 49.337\end{array}$ $\begin{array}{lllllllllll}49.304 & 49.272 & 49.240 & 49.208 & 49.176 & 49.143 & 49.111 & 49.079 & 49.047 & 49.014\end{array}$

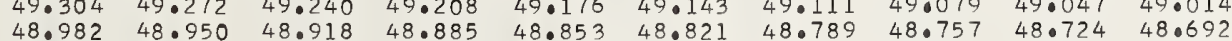
$\begin{array}{llllllllll}48.660 & 48.628 & 48.595 & 48.563 & 48.531 & 48.499 & 48.467 & 48.434 & 48.402 & 48.370\end{array}$

.007

.008

.009

$(n-1) \times 1000$

$\lambda(n-1)$

$\begin{array}{ll}0.277708 & 1.544054 \\ 0.277707 & 1.544081 \\ 0.277707 & 1.544108 \\ 0.277707 & 1.544135 \\ 0.277707 & 1.544161 \\ 0.277707 & 1.544188 \\ 0.277706 & 1.544715 \\ 0.277706 & 1.544741 \\ 0.2777006 & 1.544268 \\ 0.277706 & 1.544295\end{array}$

$\begin{array}{ll}0.277706 & 1.544322 \\ 0.277706 & 1.544348 \\ 0.277705 & 1.544375 \\ 0.277705 & 1.544402 \\ 0.277705 & 1.544428 \\ 0.277705 & 1.544455 \\ 0.277705 & 1.544482 \\ 0.277704 & 1.544509 \\ 0.277704 & 1.544535 \\ 0.277704 & 1.544562\end{array}$

0.277704

0.277703

0.277703

0.277703
.0277703

0.2777703
0.277702
0.277702

0.2777020

0.277702

0.27770

0.277701
0.277701

0.277701
0.277700

0.277700

0.277700

0.277700
0.277699

0.27769

0.277699
0.277699

0.277699

0.277608

0.277698

0.277697
0.277697
0.277697

0.277697

0.277697

0.277697
0.277696

0.277696

0.277696
0.277696

0.277696

0.277695

0.277695

0.277695

0.277604

0.2777694
0.277694

0.277694

0.277694
0.277694
0.277693

0.277693

0.277693

0.277693

0.077692

0.277602

0.277692

0.27769

0.277691

0.277691
0.277691

0.277691

0.277690

0.277690

0.277690

0.277690

0.27768

0.277689

0.277689

.010

.032
1.544589

1.544642

1.544696

1.544696
1.544749

1.544776

0.544820

1.544856
1.544883

1.544909

1.544963

1.544990

1.545016

.545043
1.545070

1.545123

1.545150

1.545203

1.545230
1.55257

1.545283

1.545310

.0545364

1.545390

1.545444

1.545471
1.545497

.

1.545577

.545604
.0545631

1.545658

1.545684
1.545711

1.545738
1.545764

1.545791

1.545845

1.545871
1.545898

1.545925 1.545952
1.545978 1.546005 1.546032 1.546058
1.546085 1.546112 1.546139
1.546165

1.546192

1.546245

1.546272
1.546299

1.546326

1.546352
1.546379

1.546406
1.546432

1.546459

1. 546486

1.546529

1.546593

1.546620

1.546646
1.546673 


.04

$17945.116 \quad 45.084$ 44.794
44.472

44.150
43.828

$\begin{array}{ll}43.505 & 43.473 \\ 43.183 & 43.151\end{array}$

$42.862 \quad 42.829$

42.218

17941.895

41.573
41.251
40.929

$40.929 \quad 40.897$

$40.608 \quad 40.575$

$\begin{array}{ll}40.285 & 40.253 \\ 39.964 & 39.931\end{array}$

$\begin{array}{ll}39.964 & 39.931 \\ 39.642 & 39.609\end{array}$

$\begin{array}{ll}39.320 & 39.288 \\ 38.998 & 38.966\end{array}$

17938.676

$38.354 \quad 38.322$

$37.710 \quad 37.678$

$\begin{array}{ll}37.389 & 37.35\end{array}$

$36.745 \quad 36.713$

$36.102 \quad 36.069$

35.78

$17935.458 \quad 35.426$

$35.136 \quad 35.104$

$34.492 \quad 34.460$

$33.849 \quad 33.817$

$33.528 \quad 33.495$

$\begin{array}{ll}32.884 & 32.852 \\ 32.562 & 32.530\end{array}$

$17932.241 \quad 32.209$

$\begin{array}{ll}31.919 & 31.887 \\ 31.597 & 31.565\end{array}$

$\begin{array}{ll}31.276 & 31.24 \\ 30.954 & 30.92\end{array}$

$30.633 \quad 30.60$

$\begin{array}{ll}30.311 & 30.27 \\ 29.990 & 29.95\end{array}$

$29.346 \quad 29.314$

28.703

$28.382 \quad 28.671$

$28.060 \quad 28.028$

$\begin{array}{ll}27.739 & 27.70 \\ 27.417 & 27.38\end{array}$

$27.096 \quad 27.064$

$26.453 \quad 26.421$

$925 \cdot 810$
$25 \cdot 489$

25.489
25.167

25.135

$24.524 \quad 24.492$

$23.882 \quad 23.849$

$23.560 \quad 23.52$

$\begin{array}{ll}23.239 & 23.207 \\ 22.918 & 22.885\end{array}$

5578.0

1.547261

1.547288
1.547314

1.547314
1.547341

1.547368
1.547394

1.547394
1.547421

1.547448

1.547475
1.547501 
$\begin{array}{rrrr}17916.172 & 16.140 & 16.108 & 16.076 \\ 15.851 & 15.819 & 15.787 & 15.755\end{array}$ 0.1
0.1
0.4
0.6
0.7
0.8 $\begin{array}{llll}15.851 & 15.819 & 15.787 & 15.755 \\ 15.530 & 15.498 & 15.466 & 15.434 \\ 15.209 & 15.177 & 15.145 & 15.113\end{array}$ $\begin{array}{lllll}.3 & 15.209 & 15.177 & 15.145 & 15.113 \\ .4 & 14.888 & 14.856 & 14.824 & 14.792 \\ 05 & 14.567 & 14.535 & 14.503 & 14.471\end{array}$ $\begin{array}{lllll}0.5 & 14.567 & 14.535 & 14.503 & 14.471 \\ 0.6 & 14.246 & 14.214 & 14.182 & 14.150\end{array}$ $\begin{array}{lllll}0.6 & 14.246 & 14.214 & 14.182 & 14.150 \\ 0.7 & 13.925 & 13.893 & 13.861 & 13.829\end{array}$ $\begin{array}{lllll}0.8 & 13.604 & 13.572 & 13.540 & 13.508 \\ 0.9 & 13.283 & 13.251 & 13.219 & 13.187\end{array}$

$.04 \quad .05$

.06

.07

$\begin{array}{llllll}16.044 & 16.012 & 15.980 & 15.948 & 15.916 & 15.884 \\ 15.723 & 15.691 & 15.659 & 15.627 & 15.594 & 15.562 \\ 15.402 & 15.370 & 15.338 & 15.306 & 15.273 & 15.241 \\ 15.081 & 15.049 & 15.017 & 14.985 & 14.953 & 14.920 \\ 14.760 & 14.728 & 14.696 & 14.664 & 14.631 & 14.599 \\ 14.439 & 14.407 & 14.375 & 14.343 & 14.311 & 14.278 \\ 14.118 & 14.086 & 14.053 & 14.021 & 13.989 & 13.957 \\ 13.797 & 13.765 & 13.733 & 13.701 & 13.668 & 13.636 \\ 13.476 & 13.444 & 13.411 & 13.379 & 13.347 & 13.315 \\ 12.155 & 13.123 & 13.091 & 13.059 & 13.027 & 12.995\end{array}$

1.
1.
1
1
1
1
1.
2.
2.
2
2
2
2
2
2
2

17912.962

$\begin{array}{ll}912.962 & 12.930 \\ 12.642 & 12.610 \\ 12.321 & 12.289 \\ 12.000 & 11.968 \\ 11.679 & 11.647 \\ 11.358 & 11.326 \\ 11.037 & 11.005 \\ 10.716 & 10.684 \\ 10.395 & 10.363 \\ 10.074 & 10.042\end{array}$

$\begin{array}{ll}12.898 & 12.866 \\ 12.577 & 12.545\end{array}$

$\begin{array}{llllll}12.834 & 12.802 & 12.770 & 12.738 & 12.706 & 12.674\end{array}$

$\begin{array}{ll}12.256 & 12.224 \\ 11.936 & 11.904\end{array}$

$\begin{array}{llllll}12.192 & 12.160 & 12.128 & 12.096 & 12.385 & 12.353 \\ & 12.064 & 12.032\end{array}$

$\begin{array}{ll}11.936 & 11.904 \\ 11.615 & 11.582\end{array}$

$\begin{array}{llllll}11.551 & 11.518 & 11.486 & 11.454 & 11.422 & 11.390\end{array}$

$\begin{array}{llllll}11.229 & 11.198 & 11.165 & 11.133 & 11.101 & 11.069\end{array}$

$\begin{array}{llllllll}10.973 & 10.941 & 10.909 & 10.876 & 10.844 & 10.812 & 10.780 & 10.748\end{array}$

$\begin{array}{llllll}10.588 & 10.556 & 10.524 & 10.491 & 10.459 & 10.427\end{array}$

$09.946 \quad 09.914 \quad 09.882 \quad 09.850 \quad 09.818 \quad 09.786$

$\begin{array}{llll}17909.753 & 09.721 & 09.689 & 09.657\end{array}$

09.43309 .400

$\begin{array}{ll}09.689 & 09.657 \\ 09.368 & 09.336\end{array}$

09.62509 .593

09.56

09.529

$09.497 \quad 09 \cdot 465$

$\begin{array}{llllllllll}09.112 & 09.080 & 09.048 & 09.016 & 08.983 & 08.951 & 08.919 & 08.887 & 08.855 & 08.823\end{array}$

$\begin{array}{lllllllllll}08.791 & 08.759 & 08.727 & 08.695 & 08.663 & 08.631 & 08.598 & 08.566 & 08.534 & 08.502\end{array}$

$\begin{array}{llllllllll}08.438 & 08.406 & 08.374 & 08.342 & 08.310 & 08.278 & 08.246 & 08.213 & 08.181\end{array}$

$\begin{array}{llllllllll}07.829 & 07.796 & 07.085 & 08.053 & 08.021 & 07.989 & 07.957 & 07.925 & 07.893 & 07.86 \\ 0764 & 07.732 & 07.700 & 07.668 & 07.636 & 07.604 & 07.572 & 07.540\end{array}$

$\begin{array}{llllllllll}07.508 & 07.476 & 07.444 & 07.412 & 07.379 & 07.347 & 07.315 & 07.283 & 07.251 & 07.219\end{array}$

$\begin{array}{llllllllll}07.187 & 07.155 & 07.123 & 07.091 & 07.059 & 07.027 & 06.995 & 06.962 & 06.931 & 06.898 \\ 06.866 & 06.834 & 06.802 & 06.770 & 06.738 & 06.706 & 06.674 & 06.642 & 06.610 & 06.578\end{array}$

06.674

06.642

$\begin{array}{llll}06.225 & 06.193 & 06.160 & 06.129\end{array}$

$\begin{array}{llll}05.904 & 05.872 & 05.840 & 05.808\end{array}$

$04.942 \quad 04.910$

$\begin{array}{llll}04.621 & 04.910 & 04.878 & 04.846\end{array}$

$\begin{array}{llll}04.301 & 04.269 & 04.557 & 04.525\end{array}$

$\begin{array}{llll}03.980 & 03.948 & 03.916 & 03.884\end{array}$

03.65903 .627

$03.595 \quad 03.563$

6.417

06.385

06.353

06.321

$06.289 \quad 06.257$

$\begin{array}{lllllll}0.776 & 05.744 & 05.712 & 05.680 & 05.648 & 05.615\end{array}$

$\begin{array}{lllllll}05.135 & 05.103 & 05.070 & 05.038 & 05.006 & 04.974\end{array}$

$\begin{array}{lllllll}04.814 & 04.782 & 04.750 & 04.718 & 04.686 & 04.653\end{array}$

$\begin{array}{llllll}04.493 & 04.461 & 04.429 & 04.397 & 04.365 & 04.333\end{array}$

$\begin{array}{llllll}04.172 & 04.140 & 04.108 & 04.076 & 04.044 & 04.012 \\ 03.852 & 03.820 & 03.788 & 03.756 & 03.724 & 03.692\end{array}$

$17903.339 \quad 03.307$

$\begin{array}{ll}03.018 & 02.986 \\ 02.698 & 02.666\end{array}$

$\begin{array}{ll}03.275 & 03.243 \\ 02.954 & 02.922\end{array}$

$03.467 \quad 03.435 \quad 03.403 \quad 03.371$

5584

$4 \cdot 3$

$02.056 \quad 02.02401 .092 \quad 01.060$

$\begin{array}{llll}01.736 & 01.704 & 01.672 & 01.640\end{array}$

$\begin{array}{llll}01.415 & 01.383 & 01.351 & 01.319\end{array}$

$\begin{array}{llll}01.075 & 01.063 & 01.031 & 00.999\end{array}$

00.454

0.422

5585.0

$\begin{array}{llll}17900.133 & 00.101 & 00.069 & 00.037\end{array}$

$99.172 \quad 99.140$

$\begin{array}{ll}99.749 & 99.717 \\ 99.428 & 99.396\end{array}$

$\begin{array}{llll}98.851 & 9.819 & 98.787 & 98.755\end{array}$

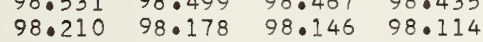

$97.890 \quad 97.858$

$97.249 \quad 97.217$

97.50
97.18

5586.0

86
6
6
6
6
6
6
6
6
6
6.9

$96.928 \quad 96.897$

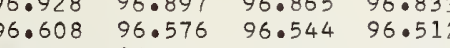

$96.288 \quad 96.256 \quad 96.224 \quad 96.192$

$95.647 \quad 95.615 \quad 95.583 \quad 95.551$

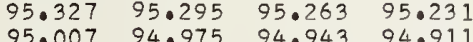

94.0685 94.95494 .94304 .911

$\begin{array}{llll}94.366 & 94.334 & 94.302 & 94.270 \\ 94.046 & 94.014 & 93.981 & 93.949\end{array}$

$\begin{array}{llllll}03.210 & 03.178 & 03.146 & 03.115 & 03.082 & 03.050\end{array}$

$\begin{array}{llllll}02.569 & 02.537 & 02.505 & 02.473 & 02.441 & 02.409\end{array}$

$\begin{array}{llllll}02.249 & 02.217 & 02.185 & 02.153 & 02.121 & 02.089\end{array}$

$\begin{array}{llllll}01.608 & 01.575 & 01.543 & 01.511 & 01.479 & 01.448\end{array}$

$\begin{array}{llllll}01.287 & 01.255 & 01.223 & 01.191 & 01.159 & 01.127 \\ 00.967 & 00.934 & 00.903 & 00.870 & 00.838 & 00.806\end{array}$

$\begin{array}{llllll}00.646 & 00.614 & 00.582 & 00.550 & 00.518 & 00.486\end{array}$

$00.005 * 99.973 * 09.941 * 99.909 * 99.877 * 99.845$

$99.364 \quad 99.332 \quad 99.300 \quad 99.268 \quad 99.236 \quad 99.204$

$\begin{array}{rlllll}99.043 & 99.011 & 98.979 & 98.947 & 98.915 & 98.883 \\ 98.723 & 98.691 & 08.659 & 98.627 & 98.595 & 98.563\end{array}$

$\begin{array}{llllll}98.403 & 98.370 & 98.338 & 98.306 & 98.274 & 98.242\end{array}$

$\begin{array}{llllll}.082 & 98.050 & 98.018 & 97.986 & 97.954 & 97.922\end{array}$

$\begin{array}{llllll}97.441 & 97.409 & 97.698 & 97.666 & 97.634 & 97 \cdot 602 \\ 97.121 & 97.089 & 97.057 & 97.345 & 97.313 & 97.281\end{array}$

$97.12197 .089 \quad 97.057 \quad 97.025 \quad 96.993 \quad 96.961$

$\begin{array}{llllll}96.801 & 96.769 & 96.736 & 96.705 & 96.672 & 96.640\end{array}$

$\begin{array}{llllll}96.480 & 96.448 & 96.416 & 96.384 & 96.352 & 96.320 \\ 96.160 & 96.128 & 96.096 & 96.064 & 96.032 & 96.000\end{array}$

$\begin{array}{llllll}96.160 & 96.128 & 96.096 & 96.064 & 96.032 & 96.000 \\ 95.840 & 95.807 & 95.775 & 95.743 & 95.711 & 95.679\end{array}$

$\begin{array}{llllll}95.519 & 95.487 & 95.455 & 95.423 & 95.391 & 95.359\end{array}$

$\begin{array}{llllll}95.199 & 95.167 & 95.135 & 95.103 & 95.071 & 95.039 \\ 94.878 & 94.846 & 94.814 & 94.782 & 94.750 & 94.718\end{array}$

$94.558 \quad 94.526 \quad 94.494 \quad 94.462 \quad 94.430 \quad 94.398$

$\begin{array}{llllll}94.238 & 94.206 & 94.174 & 94.142 & 94 \cdot 110 & 94 \cdot 078 \\ 93.918 & 93.885 & 93.854 & 93.822 & 93.790 & 93.757\end{array}$

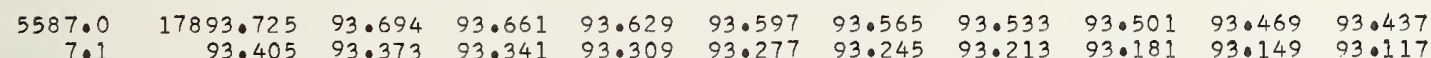
$\begin{array}{llllllllll}93.405 & 93.373 & 93.341 & 93.309 & 93.277 & 93.245 & 93.213 & 93.181 & 93.149 & 93.117\end{array}$ $\begin{array}{llllllllll}93.085 & 93.053 & 93.021 & 92.989 & 92.957 & 92.925 & 92.893 & 92.861 & 92.829 & 92.797\end{array}$

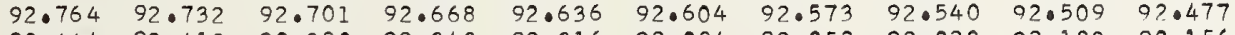

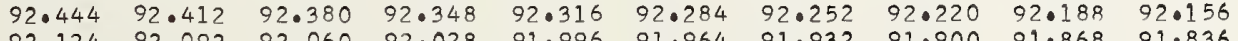

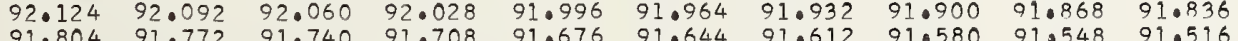

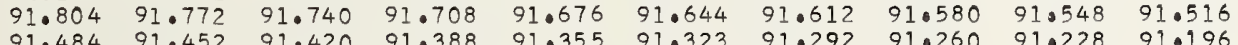

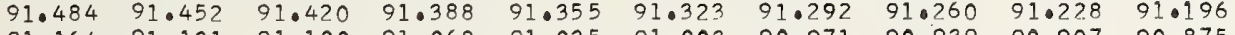
$\begin{array}{llllllllll}91.164 & 91.131 & 91.100 & 91.068 & 91.035 & 91.003 & 90.971 & 90.939 & 90.907 & 90.875 \\ 90.844 & 90.812 & 90.779 & 90.747 & 90.716 & 90.684 & 90.651 & 90.619 & 90.587 & 90.555\end{array}$

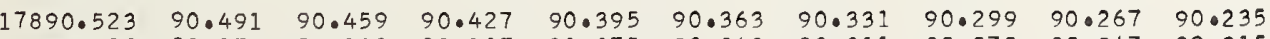
$\begin{array}{llll}90.203 & 90.171 & 90.139 & 90.107 \\ 80.138 & 80.171 & 89.819 & 89.787\end{array}$ $89.563 \quad 89.531 \quad 89.499 \quad 89.467$ $89.243 \quad 89.211 \quad 89.178 \quad 89.146$ $\begin{array}{llll}88.923 & 88.891 & 88.859 & 88.827\end{array}$ $88.603 \quad 88.571 \quad 88.538 \quad 88.506$ $88.282 \quad 88.250 \quad 88.218 \quad 88.186$

$\begin{array}{llll}87.962 & 87.930 & 87.898 & 87.866\end{array}$

$\begin{array}{llll}7887.322 & 87.291 & 87.259 & 87.227\end{array}$

$\begin{array}{llll}87.002 & 86.970 & 86.938 & 86.906 \\ 86.682 & 86.650 & 86.618 & 86.586\end{array}$

$\begin{array}{lllll}86.682 & 86.650 & 86.618 & 86.586 \\ 86.362 & 86.330 & 86.299 & 86.267\end{array}$

$\begin{array}{lll}86.362 & 86.330 & 86.299 \\ 86.042 & 86.010 & 85.978\end{array}$

$\begin{array}{llll}85.722 & 85.690 & 85.678 & 85.946\end{array}$

$\begin{array}{llll}85.722 & 85.690 & 85.658 & 85.626 \\ 85.402 & 85.370 & 85.338 & 85.306\end{array}$

$\begin{array}{lllll}85.083 & 85.051 & 85.019 & 84.987\end{array}$

$\begin{array}{llll}84.762 & 84.730 & 84.698 & 84.667\end{array}$

001

.002

.003

.004

$\begin{array}{lll}.075 & 90.043 & 90.011 \\ 8.755 & 89.723 & 89.691\end{array}$

$\begin{array}{lllllll}89.115 & 89.083 & 89.051 & 89.019 & 88.987 & 88.955\end{array}$

$\begin{array}{lllllll}.794 & 88.762 & 88.730 & 88.699 & 88.667 & 88.635\end{array}$

$\begin{array}{lllllll}88.474 & 88.442 & 88.410 & 88.378 & 88.346 & 88.314 \\ 88.154 & 88.122 & 88.091 & 88.058 & 88.026 & 87.994\end{array}$

$\begin{array}{llllll}7.834 & 87.802 & 87.770 & 87.738 & 87.706 & 87.674 \\ 87.514 & 87.482 & 87.450 & 87.418 & 87.386 & 87.354\end{array}$

$\begin{array}{llllll}87.194 & 87.162 & 87.130 & 87.099 & 87.067 & 87.034\end{array}$

$\begin{array}{llllll}87.875 & 86.842 & 86.810 & 86.778 & 86.746 & 86.714 \\ 86.554 & 86.522 & 86.490 & 86.458 & 86.427 & 86.395\end{array}$

$\begin{array}{lllllll}86.234 & 86.202 & 86.170 & 86.138 & 86.106 & 86.074\end{array}$

$\begin{array}{lllllll}85.915 & 85.882 & 85.850 & 85.818 & 85.786 & 85.754\end{array}$

$\begin{array}{lllllll}85.594 & 85.562 & 85.531 & 85.499 & 85.466 & 85.434 \\ 85.274 & 85.242 & 85.210 & 85.178 & 85.146 & 85.115\end{array}$

$\begin{array}{llllll}84.954 & 84.242 & 85.210 & 85.178 & 85.146 & 85.115 \\ 84.891 & 84.859 & 84.827 & 84.794\end{array}$

$\begin{array}{llllll}84.954 & 84.922 & 84.891 & 84.859 & 84.827 & 84.794 \\ 84.635 & 84.603 & 84.570 & 84.538 & 84.507 & 84.475\end{array}$

$(n-1) \times 1000$

$\lambda(n-1)$

0.277670
0.277670
0.277670

.277670
0.277669

0.277669

0.277669

0.2776689
0.277668

0.277668

(1)

0.277668

0.277667

0.277667

0.277667

0.277666

0.277666

0.277666

0.277665

0.277665

0.277665
0.277665

0.277664
0.277664

0.277664

0.27766

0.277663

0.277663

0.277663

0.277663
0.277662
0.277662

0.277662

0.27766
0.27766
0.077662

0.277662

0.277661

0.277661

0.277661

0.277660

0.277660
0.277660
0.277660

0.277660

0.277660

0.277659

0.277659

0.277659

0.2776599
0.277658
0.277658

0.277658

0.277658
0.277658
0.277658

0.277658

0.277658
0.377657
0.277657

0.277657

0.277657

0.277657

0.277657

0.277656

0.277656

0.277655

0.27765

0.27765

0.277655

0.277654

0.277654

0.277654

0.277653

0.277653

0.27765

0.277652

0.277652

0.277652

1.549399
1.549425

1.549452

1.549479

1.549532

1.549559

1.549612

.549666

.549693

1.549746

1.549800

1.549853

1.549906

1.549933

1.549987

1.550013

1.550067
.550093

1.550120

.550200

1.550227

.
1.550281

1.550334

1.550361
1.550387

1.550414

1. 550468

1.550494

1.550548

1.550501

.550628
1.550655

1.550681
1.550708

1.550735

1.550788

1.550815
.550842

.550868
1.550895

1.550922

1.550975

1.551002

551056

1.551082

1.551136

1.551162
1.551189

1.551216
1.551243

1.551269

1.551296
1.551323

1.551350

1.551403

1.551456

1.551483
1.551510

1. 551537

1.551563

1.551617

1.551670

1.551750

1. 55180

1.551831
1.551857

1.551884

1.551937

1.551991

1.552044

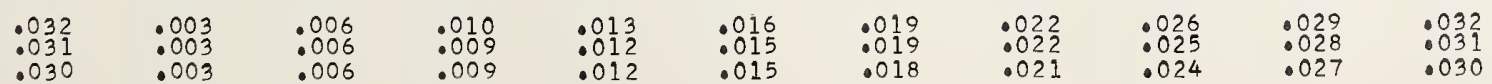




\title{
$17880.924 \quad 80.892$
}

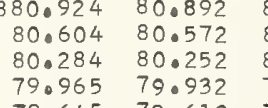

1.3

79.645

1.5
1.6
1.7

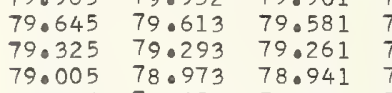
$\begin{array}{lllll}79.325 & 79.093 & 78.941 & 79.229 & 79.909\end{array}$ $\begin{array}{llll}78.686 & 78.654 & 78.622 & 78.0 \\ 78.365 & 78.333 & 78.302 & 78.0 \\ 78.046 & 78.014 & 77.982\end{array}$

78.590
78.270
77.950

$\begin{array}{llll}83.930 & 83.899 & 83.867 & 83.835 \\ 83.611 & 83.579 & 83.547 & 83.515 \\ 83.291 & 83.259 & 83.227 & 83.195 \\ 82.971 & 82.939 & 82.907 & 82.875 \\ 82.651 & 82.619 & 82.587 & 82.555 \\ 82.331 & 82.299 & 82.267 & 82.235 \\ 82.011 & 81.979 & 81.947 & 81.915 \\ 81.691 & 81.659 & 81.627 & 81.595 \\ 81.372 & 81.340 & 81.308 & 81.276 \\ 81.052 & 81.020 & 80.988 & 80.956\end{array}$

0.277651

0.0277651

0.0277651

0.277650

0.277650

0.277650

0.277650

0.277649
0.277649
0.027649

0.277649

0.277649
0.277649

0.277648

0.277648

0.277648

\begin{tabular}{|c|c|c|c|}
\hline 77 & 77.694 & & \\
\hline & 77.375 & 77.343 & \\
\hline & 77.055 & 77.023 & \\
\hline 76 & 76.735 & 76.703 & 67 \\
\hline 44 & 76.416 & 76.384 & 35 \\
\hline 12 & 76.096 & 76.064 & \\
\hline 80 & 75.7776 & 75.744 & \\
\hline & 57 & 425 & 39 \\
\hline $75 \cdot 169$ & 75.137 & 75.105 & .073 \\
\hline
\end{tabular}

$$
\begin{array}{ll}
78.238 & 78.206 \\
77.918 & 77.886
\end{array}
$$

17874.530

$$
\begin{array}{r}
874.530 \\
74.21 \\
73.89
\end{array}
$$

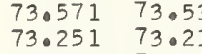

$72.932 \quad 72.900$

72.613 71.0973
71.0654

17871.334<smiles>[C+]1=C[CH+]C1</smiles>
70.696
70.375
69.6797 70.05
70.05
69.737 $69.737 \quad 69.705$ $\begin{array}{lll}69.099 & 69.067 \\ 68.779 & 68.0747\end{array}$ 68.460

17868.140

$$
\begin{aligned}
& 67.821 \\
& 67.502 \\
& 67.182
\end{aligned}
$$

67.18
66.85

66.863
66.544
65.924

66.22
65.90

65.905
65.586
65.567

65.267

$17864 \cdot 947$

864.947
64.62
64.30

63.990

63.570
63.35
63.032

63.03
62.71

72.081
71.261

71.041
71.0622

74.466

74.434

$\begin{array}{ll}77.598 & 77.566 \\ 77.279 & 770247 \\ 76.059 & 76.067\end{array}$

16.639 76.607

$76.000 \quad 75.968$

$75.681 \quad 75.648$
75.36175
75.329

75.361
75.041
74.0722
74.0099

\subsection{2}

\begin{abstract}
74.370
\end{abstract}
$73.827 \quad 73.7957$

74.08
73.076

$\begin{array}{llll}73.188 & 73.156 \\ 72.868 & 72.836\end{array}$

72.549
72.517

$\begin{array}{ll}72.0229 & 72.197 \\ 71.910 & 71.87 \\ 71.5900 & 71859\end{array}$

$73.443 \quad 73.0731$

$73.124 \quad 730.092$
$72.804 \quad 720772$
72.065

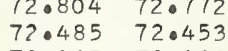

72.48
72.165

71.846
71.526

72.133
71.81
71.094

$71.271 \quad 71.239$

70.95170 .919

70.632

$69.993 \quad 69.961$

71.0207

71.175

$77.568 \quad 70.536$

70.249
69.929
69.217
69.897

$69.610 \quad 69.579 \quad 69.865$

$69.354 \quad 69.322$

$\begin{array}{lll}69.290 & 69.258 & 69.226\end{array}$

69.226
68.907
68.587

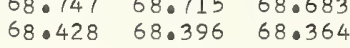

\begin{abstract}
68.109
57.789
68.077
\end{abstract}
$\begin{array}{ll}57.789 & 67.757 \\ 67.470 & 67.438 \\ 67 & 67\end{array}$

$\begin{array}{lll}67.150 & 67.118 \\ 66.831 & 66.799 \\ 66.112 & 66.160\end{array}$

66.512

$66.192 \quad 66.160$

$65.554 \quad 65.522$

65.25

62.075

5597.0

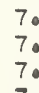

7.0

7.5

77.6

7.9

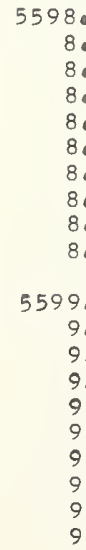

$17861.756 \quad 61.724$ $\begin{array}{ll}61.437 & 61.0425 \\ 61.117 & 61.006\end{array}$ $60.798 \quad 60.76$ $60.479 \quad 60.447$

$\begin{array}{llll}59.841 & 59.809 & 60.096 & 60.064\end{array}$

$\begin{array}{lllll}59.522 & 59.490 & 59.458 & 59074 \\ 5 & 50.427 & \end{array}$

59.203
58.884

58.171
.852$$
\begin{aligned}
& 58.246 \quad 58.2314 \\
& 53.207
\end{aligned}
$$$$
57.608 \quad 57.576
$$

$57.289 \quad 57.257$

$56.970 \quad 56.938$

$56.651 \quad 56.619$

56.332

56.01
55.659
68.04
67.72
67.40
67.086

67.086
66.767
66.448

66.448

65.809
65.49
65.171

65.171

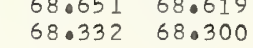

68.013

67.981

68.268

67.699
67.037
6.035

67.05567 .34023

\begin{tabular}{ll}
66.415 & 66.703 \\
66.416 & 66.384 \\
\hline
\end{tabular}

66.097

$65.777,65.745$

67.652
67.31
.0631

$\begin{array}{llll}66.672 & 66.640 & 66.608 & 66.576\end{array}$

$\begin{array}{llll}66.352 & 66.320 & 66.288 & 660256 \\ 66.033 & 65.001 & 65.969 & 65.937\end{array}$

$\begin{array}{llll}66.033 & 66.001 & 65.969 & 65.937 \\ 65.714 & 65.682 & 65.650 & 65.018\end{array}$

$\begin{array}{lllll}65.714 & 65.682 & 65.650 & 65.618 \\ 65.304 & 65.362 & 65.331 & 65.299\end{array}$

$\begin{array}{llllll}65.05 & 65.107 & 65.075 & 65.043 & 650011 & 64.979\end{array}$

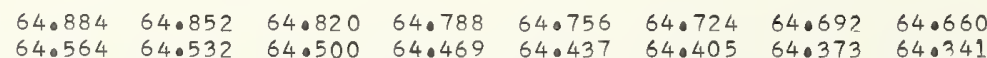

$\begin{array}{llllllll}64.564 & 64.532 & 64.500 & 64.4469 & 64.437 & 64.405 & 64.373 & 64 \cdot 0341 \\ 64.0245 & 64.213 & 64.181 & 64.149 & 64.117 & 64.085 & 64053 & 640021\end{array}$

$\begin{array}{llllllll}64.245 & 64.213 & 64.181 & 64.149 & 64.117 & 64.085 & 64.053 & 64 \cdot 021 \\ 63.026 & 63.894 & 63.862 & 63.030 & 63.798 & 63.766 & 63.0734 & 63.0702\end{array}$

$\begin{array}{lllllllll}63.606 & 63.574 & 63.543 & 63.511 & 63.479 & 63.4447 & 63.415 & 63.383 \\ 63.288 & 63.256 & 63.224 & 63.192 & 63.160 & 63.128 & 63.096 & 630064\end{array}$

$\begin{array}{llllllll}62.068 & 62.036 & 62.004 & 62.873 & 62.841 & 62.809 & 62.0777 & 62.0445\end{array}$

$$
\begin{array}{lll}
62.049 & 62.017 & 62 \\
62.330 & 62.0298 & 6 \\
62.011 & 61.0979 & 6 \\
6 & 0
\end{array}
$$

$62.585 \quad 62.553 \quad 62.521 \quad 62.490 \quad 62.458 \quad 62.426$

0.277648

0.0277647

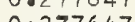

0.277647

0.277647

0.276

0.0277646

1.552071

1.552125

1.552151

1.552205

1.552231
1.552258

1.552285
1.0552312

1.552338

$\frac{1}{1.552365}$

1.552419

1.552445
10552472

1.552449

1.552552

1.552579

0.277646

0.2777646
0.277645
0.277645

0.277645

0.277645

0.277645

0.277644

0.277644
0.277644

1.552606

10.552632
1.0552569

1.552686

1.552713
1.552730

1.552766

1.552793

1.552819
1.552846

0.277644

0.277644

0.277644

0.277643

0.277643

0.277643

0.277643
0.277642

0.277642

1.552873
1.552900

1.552926

1.552953

1.553007

1.553033

1.553060

10553087
1.553113

0.277642

0.277642

0.277642

0.277641

0.277641

0.277641

0.277641

0.277640

1.553140

10.053167

1.553220

1.553247

1.553274

1.553354
1.553381

0.277640

0.277640

0.277640
0.277640

0.277639

0.277639
0.277639

0.277639

0.277639

0.277638 
$\begin{array}{lllllllllll}5600.0 & 17852.187 & 52.155 & 52.123 & 52.091 & 52.059 & 52.027 & 51.996 & 51.964 & 51.932 & 51.900\end{array}$ $\begin{array}{lllllllllll}0.1 & 51.868 & 51.836 & 51.804 & 51.773 & 51.741 & 51.709 & 51.677 & 51.645 & 51.613 & 51.582 \\ 0.2 & 51.550 & 51.517 & 51.486 & 51.454 & 51.422 & 51.390 & 51.358 & 51.326 & 51.294 & 51.262\end{array}$

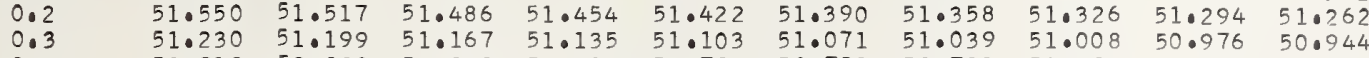
$\begin{array}{lllllllllll}0.4 & 50.912 & 50.880 & 50.848 & 50.816 & 50.784 & 50.752 & 50.721 & 50.689 & 50.657 & 50.944 \\ 0.5 & 50.593 & 50.561 & 50.529 & 50.498 & 50.466 & 50.434 & 50.402 & 50.030 & 50.338 & 50.306\end{array}$ $\begin{array}{lllllllllll}0.6 & 50.593 & 50.561 & 50.529 & 50.498 & 50.466 & 50.434 & 50.402 & 50.370 & 50.338 & 50.306 \\ 0.6 & .50 .274 & 50.242 & 50.211 & 50.179 & 50.147 & 50.115 & 50.083 & 50.051 & 50.019 & 49.988\end{array}$ $\begin{array}{llllllllllll}0.7 & 49.956 & 49.924 & 49.892 & 49.860 & 49.828 & 49.796 & 49.765 & 49.733 & 49.701 & 49.669\end{array}$ $\begin{array}{lllllllllll}0.8 & 49.637 & 49.605 & 49.573 & 49.542 & 49.510 & 49.478 & 49.446 & 49.414 & 49.382 & 49.350 \\ 0.9 & 49.318 & 49.286 & 49.254 & 49.223 & 49.191 & 49.159 & 49.127 & 49.095 & 49.063 & 49.031\end{array}$

0.277633
0.277633
0.27763

0.277632
0.277632

0.277632

.277632

0.277631

1.554744

0.077631

.27763

0.277630

.277630

.0 .277630

0.277629

5602.

$17845.813 \quad 45.781$

$$
\begin{array}{ll}
45.750 & 45.718 \\
45.431 & 45.399
\end{array}
$$

$\begin{array}{lllllll}45.686 & 45.654 & 45.622 & 45.591 & 45.559 & 45.577\end{array}$ $\begin{array}{llll}45.495 & 45.463 & 45.431 & 45.399 \\ 45.176 & 45.145 & 45.113 & 45.081\end{array}$

$44.858 \quad 44.826$

$44.539 \quad 44.507 \quad 44.475$

$44.221 \quad 44.189$

$\begin{array}{ll}43.902 & 43.870 \\ 43.584 & 43.552\end{array}$

$\begin{array}{ll}43.265 & 43.233 \\ 42.947 & 42.915\end{array}$

44.157
43.839

44.762
44.444

$\begin{array}{llllll}45.368 & 45.336 & 45.304 & 45.272 & 45.240 & 45 \cdot 208 \\ 45.049 & 45.017 & 44.985 & 44.953 & 44.921 & 44.090\end{array}$

0.777690

0.277629

0.277628

0.277628

0.277628

0.277628
0.277627

.55479

5603.0

2.9
3.0
3.
3.
3.
30
3.0
3.7
3.0
3.9

17842.628 $42.310 \quad 42.278$

$\begin{array}{ll}43.202 & 43.488 \\ 2.883 & 42.851\end{array}$

$44.093 \quad 44.062 \quad 44.030 \quad 43.998 \quad 43.966 \quad 43.934$

$\begin{array}{lllllll}43.775 & 43.743 & 43.711 & 43.679 & 43.647 & 43.616 \\ 43.456 & 43.425 & 43.393 & 43.361 & 43.329 & 43.297\end{array}$

$\begin{array}{llllll}43.138 & 43.106 & 43.074 & 43.042 & 43.010 & 42.979 \\ 42.820 & 42.788 & 42.756 & 42.724 & 42.692 & 42.660\end{array}$

0.277627

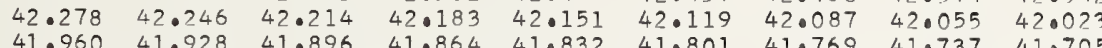

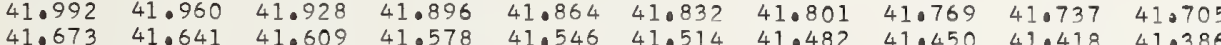

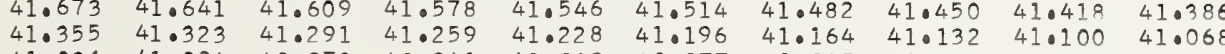

$\begin{array}{llllllllll}41.036 & 41.004 & 40.973 & 40.941 & 40.909 & 40.877 & 40.845 & 40.813 & 40.781 & 40.750 \\ 40.718 & 40.686 & 40.654 & 40.623 & 40.591 & 40.559 & 40.527 & 40.495 & 40.463 & 40.432\end{array}$

$\begin{array}{llllllllll}40.718 & 40.686 & 40.654 & 40.623 & 40.591 & 40.559 & 40.527 & 40.495 & 40.463 & 40.432\end{array}$

$\begin{array}{llllllllll}40.400 & 40.368 & 40.336 & 40.304 & 40.272 & 40.240 & 40.208 & 40.177 & 40.145 & 40.113 \\ 40.081 & 40.049 & 40.018 & 39.986 & 39.954 & 39.922 & 39.890 & 39.858 & 39.827 & 39.795\end{array}$

$\begin{array}{llllllllll}39.763 & 39.731 & 39.699 & 39.667 & 39.636 & 39.604 & 39.572 & 39.540 & 39.508 & 39.476\end{array}$

5604.0

4.0
$4:$
$4: 2$
$4:$
40
40
$4:$
40
4.9

17839.444

$39.126 \quad 39.413$

39.381

39.349

$38.808 \quad 38.776 \quad 38.744 \quad 38.712$

$38.171 \quad 38.139038 .426 \quad 38.394$

$37.853 \quad 37.821$

$\begin{array}{llll}37.535 & 37.503 & 37.471 & 37.439\end{array}$

$\begin{array}{llll}36.898 & 36.866 & 37.153 & 37.121 \\ 36.835 & 36.803\end{array}$

39.317
38.999
38.680
38.362
38.04
37.072
37.407
37.08
36.771
36.45

39.285

$\begin{array}{llll}39.253 & 39.222 & 39.190 & 39.158\end{array}$

$36.580 \quad 36.548$

560500

5.1
5.2
5.3
5.4
5.5
5.6
5.7
5.8
5.9

$36.262 \quad 36.230$

$35.625 \quad 35.912 \quad 35.880 \quad 35.848$

$\begin{array}{lll}35.594 & 35.562 & 35.530\end{array}$

$34.989 \quad 34.957 \quad 34.926 \quad 34.894$

$\begin{array}{llll}34.671 & 34.639 & 34.607 & 34.576\end{array}$

$34.353 \quad 34.32$

$\begin{array}{llll}33.716 & 33.685 & 33.653 & 33.621 \\ 33.398 & 33.367 & 33.335 & 33.303\end{array}$

$35.816 \quad 36 \cdot 103$

$35.498 \quad 35.466$

$\begin{array}{ll}34.862 & 34.830 \\ 34.544 & 34.512\end{array}$

$\begin{array}{ll}34.544 & 34.512 \\ 34.226 & 34 \cdot 194 \\ 33.0 & \end{array}$

$\begin{array}{ll}33.907 & 33.875 \\ 32.589 & 33.55\end{array}$

$\begin{array}{llll}38.935 & 38.903 & 38.871 & 38.840 \\ 38.617 & 38.585 & 38.553 & 38.521\end{array}$

$33.271 \quad 33.240$

5606

6.1

$17833.080 \quad 33.0$

$33.017 \quad 32.985$

$\begin{array}{lllllll}32.953 & 32.921 & 32.889 & 32.858 & 32.826 & 32.794 \\ 32.635 & 32.603 & 32.571 & 32.540 & 32.508 & 32.476\end{array}$

$\begin{array}{llll}38.299 & 38.267 & 38 \cdot 235 & 38 \cdot \bullet 20 \\ 37.980 & 37.948 & 37.917 & 37.885\end{array}$

$\begin{array}{llll}37.662 & 37.630 & 37.598 & 37.567 \\ 37.344 & 37.312 & 37.280 & 37.248\end{array}$

$\begin{array}{llll}37.026 & 36.994 & 36.280 & 37.248 \\ 36.020 & 36.930\end{array}$

$\begin{array}{llll}36.707 & 36.675 & 36.644 & 36.612 \\ 36.389 & 36.357 & 36.325 & 36.293\end{array}$

0.0277627

0.0277626

1.554851

.0554904

.0554958

0.277626

1.555011

1.555064

.555118

1.55517

.55522

0.277629

.55530

1.555358

1.555385

1.555485

1.555519

$\begin{array}{lllll}32.285 & 32.253 \quad 32.221 & 32.190 & 32.158\end{array}$

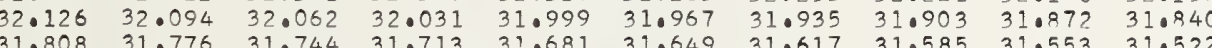

$\begin{array}{llllllll} & \end{array}$

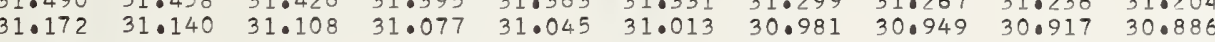

$\begin{array}{llllllllll}30.854 & 30.822 & 30.790 & 30.758 & 30.727 & 30.695 & 30.663 & 30.631 & 30.599 & 30.568\end{array}$

$\begin{array}{lllllllllll}6.8 & 30.536 & 30.504 & 30.472 & 30.440 & 30.409 & 30.377 & 30.345 & 30.313 & 30.281 & 30.250 \\ 6.9 & 30.218 & 30.186 & 30.154 & 30.122 & 30.091 & 30.059 & 30.027 & 29.995 & 29.963 & 29.932\end{array}$

17829.900

$29.582 \quad 29.868 \quad 29.836$

$29.264 \quad 29.55029 .518 \quad 29.487$

$28.946 \quad 28.91428 .28329 .168$

$28.628 \quad 28.596 \quad 28.564 \quad 28.532$

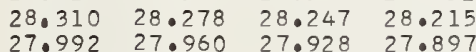

$27.992 \quad 27.960-27.928$

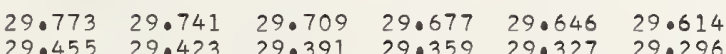

$\begin{array}{llllll}29.455 & 29.423 & 29.391 & 29.359 & 29.327 & 29.296 \\ 29.137 & 29.105 & 29.073 & 29.041 & 29.010 & 28.978\end{array}$

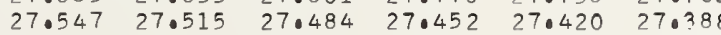

$\begin{array}{llll}27.356 & 27.324 & 27.293 & 27.261 \\ 27.038 & 27.007 & 26.975 & 26.943\end{array}$

$\begin{array}{llllll}27.229 & 27.197 & 27.166 & 27.134 & 27.102 & 27.070 \\ 26.911 & 26.880 & 26.848 & 26.816 & 26.784 & 26.752\end{array}$

5608.0

$\begin{array}{rlll}17826.720 & 26.689 & 26.657 & 26.625 \\ 26.0085 & 26.071 & 26.339\end{array}$

$\begin{array}{llllllllll}26.403 & 26.371 & 26.339 & 26.307 & 26.276 & 26.044 & 26.212 & 26.180 & 26.148 & 26.117 \\ 26.085 & 26.053 & 26.021 & 25.989 & 25.958 & 25.926 & 25.894 & 25.862 & 25.830 & 25.799\end{array}$

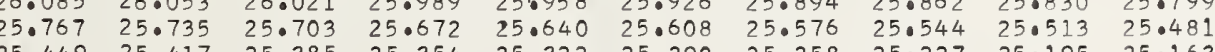

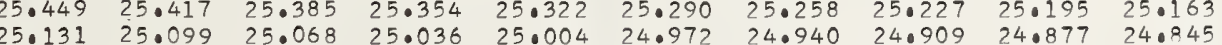

$\begin{array}{llllllllll}24.813 & 24.782 & 24.750 & 24.718 & 24.686 & 24.654 & 24.623 & 24.591 & 24.559 & 24.527\end{array}$

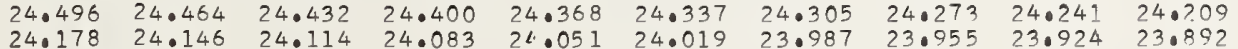

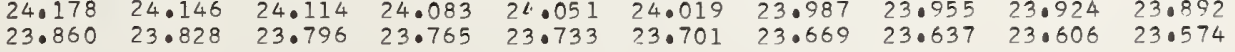

.02776

0.0777625

0.277624

1.555546

1.555599

1.055626

0.555679

10555733

0

1.555813

1.055866

.555920

.0555973

1.556027

0.277624
0.277623

0.077623

1.556080

$0.277673-1.556187$

$0.277623 \quad 1.556214$

$0.277622 \quad 1.556267$

$\begin{array}{ll}0.2277622 & 1.556294 \\ 0.277622 & 1.556321\end{array}$

0.277622
0.27762
0.27762
0.27762
0.27762
0.27762
0.27762
0.27762
0.277620
0.22776

1.556347

0.277620

0.277620

0.277620
0.277620
0.277610

0.777619

0.277619

0.277619

0.277619

0.277618

0.277618
0.277618

0.277618

0.277617

0.277617

0.777617

0.277617

1.556401

0.277616

0.277616

0.277616

0.277615

0.277615

0.277615

0.277615

.556454

1.556508

.0556561

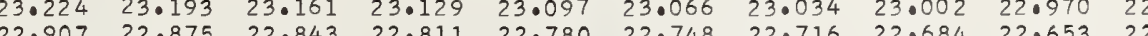

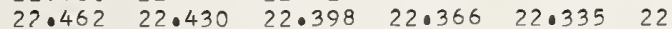

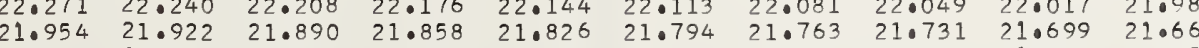

$\begin{array}{llllllllll}21.636 & 21.604 & 21.572 & 21.541 & 21.509 & 21.477 & 21.445 & 21.413 & 21.38 ? & 21.350 \\ 21.318 & 21.286 & 21.255 & 21.223 & 21.191 & 21.159 & 21.127 & 21.096 & 21.064 & 21.032\end{array}$

$\begin{array}{llllllllll}21.000 & 20.969 & 20.937 & 20.905 & 20.873 & 20.842 & 20.810 & 20.778 & 20.746 & 20.715 \\ 20.683 & 20.651 & 20.619 & 20.587 & 20.556 & 20.524 & 20.492 & 20.460 & 20.428 & 20.397\end{array}$

.010

1.556615

.056668

1.556695

1.556748

1.556775

1.556829
1.556855

.0556882

1.556909

.556962
.055690

1.556989

1.557042

1.557069

1.557123

.0557149

1.557203

1.557230

1.557283

1.557310

.557363
.557390

.003

.004

.005

.006

.007

$.008 \quad .009$

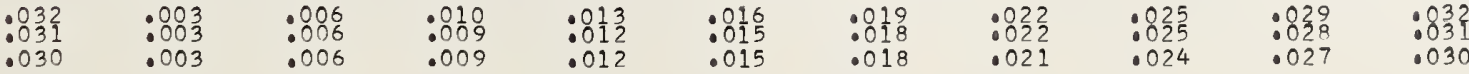




.03

.04

5610.0

0.1
0.2
0.3
0.4
0.5
0.6
0.7
0.8
0.9

5611.0

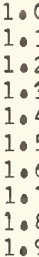
20.04720 .016 $\begin{array}{llll}19.730 & 19.698 & 19.984 & 19.952 \\ 19.412 & 19.380 & 19.349 & 19.635\end{array}$ $\begin{array}{llll}19.094 & 19.063 & 19.349 & 19.317 \\ 18.031 & 18.999\end{array}$ $\begin{array}{lllll}18.777 & 18.745 & 18.714 & 18.682\end{array}$ $18.428 \quad 18.396-18.364$ $\begin{array}{llll}18.142 & 18.110 & 18.078 & 18.047 \\ 17.824 & 17.792 & 17.761 & 17.729 \\ 17.507 & 17.475 & 17.443 & 17.411\end{array}$

$\begin{array}{llllll}20.238 & 20.206 & 20.174 & 20.143 & 20.111 & 20.079 \\ 19.920 & 19.889 & 19.857 & 19.825 & 19.793 & 19.762\end{array}$ $\begin{array}{llllll}19.603 & 19.571 & 19.539 & 19.508 & 19.476 & 19.444\end{array}$ $\begin{array}{llllll}10.285 & 19.253 & 19.222 & 19.190 & 19.158 & 19.126 \\ 18.968 & 18.936 & 18.904 & 18.872 & 18.841 & 18.800\end{array}$ $\begin{array}{llllll}18.650 & 18.618 & 18.586 & 18.872 & 18.841 & 18.809 \\ 4.555 & 18.523 & 18.491\end{array}$ $\begin{array}{llllll}18.332 & 18.301 & 18.269 & 18.237 & 18.205 & 18.174\end{array}$

$\begin{array}{lllllll}18.015 & 17.983 & 17.951 & 17.920 & 17.898 & 17.856\end{array}$

$\begin{array}{rlll}17817.189 & 17.157 & 17.126 & 17.094 \\ 16.872 & 16.840 & 16.808 & 16.776\end{array}$

$\begin{array}{lllllll}17.062 & 17.031 & 16.999 & 16.967 & 16.935 & 16.903\end{array}$

1.2

1.3
1.4
1.5

1.6

1.8

$\begin{array}{llll}16.554 & 16.522 & 16.491 & 16.459 \\ 16.236 & 16.205 & 16.173 & 16.141\end{array}$

$\begin{array}{llll}16.236 & 16.205 & 16.173 & 16.141 \\ 15.919 & 15.887 & 15.855 & 15.824\end{array}$

$\begin{array}{llll}15.601 & 15.570 & 15.538 & 15.506\end{array}$

$\begin{array}{llll}15.284 & 15.252 & 15.220 & 15.189 \\ 14.967 & 14.935 & 14.903 & 14.871\end{array}$

$\begin{array}{llll}14.649 & 14.617 & 14.586 & 14.554 \\ 14.332 & 14.300 & 14.268 & 14.237\end{array}$

$\begin{array}{lllllll}16.427 & 16.3135 & 16.681 & 16.649 & 16.617 & 16.586 \\ 16.364 & 16.332 & 16.300 & 16.268\end{array}$

$\begin{array}{lllllll}16.110 & 16.078 & 16.046 & 16.014 & 15.983 & 15.951\end{array}$

$\begin{array}{llllll}15.475 & 15.760 & 15.729 & 15.697 & 15.665 & 15.633 \\ 15.411 & 15.411 & 15.379 & 15.348 & 15.316\end{array}$

$15.157 \quad 15.125$

$15.094 \quad 15.062 \quad 15.348 \quad 15.316$

$\begin{array}{llllll} & 14.776 & 14.744 & 14.713 & 14.681\end{array}$

5612.

2.

13.697

13.983

$13.951 \quad 13.910$

$14.205 \quad 14 \cdot 173$

$14.141 \quad 14.109 \quad 14.078 \quad 14.046$

$2 \cdot 3$

2. 6

2.8

5613.0

$3 \cdot 5$

3.6
3.7

3.9

5614.0

$4 \cdot 1$
$4 \cdot 2$
$4 \cdot 3$

$4 \cdot 3$

$4 \cdot 4$
$4 \cdot 5$

$4 \cdot 6$
$4 \cdot 7$

4.8
4.9

$\begin{array}{llll}13.062 & 13.348 & 13.316 & 13.284\end{array}$

$12.745 \quad 12.713$

$12.427 \quad 12.396$

$\begin{array}{ll}11.793 & 11.761 \\ 11.475 & 11.444\end{array}$

$\begin{array}{llll}12.681 & 12.649 & 12.935 & 12.903\end{array}$

$17810.841 \quad 10.809$

10.523

$9.889 \quad 00.175$

$09.254 \quad 09.223 \quad 09.191$

$\begin{array}{lll}08.620 & 08.588-08.557 & 08.525\end{array}$

08.302

17807.668

07.351
07.03
06.717

06.717
06.400

$05.448 \quad 05.417$

$\begin{array}{ll}05.131 & 05.099 \\ 04.814 & 04.782\end{array}$

$2.046 \quad 12.015$

$\begin{array}{ll}12.300 & 12.269\end{array}$

$\begin{array}{llll}3.824 & 13.792 & 13.760 & 13.729\end{array}$

$\begin{array}{llll}3.189 & 13.157 & 13.125 & 13.094\end{array}$

$12.554 \quad 12.522 \quad 12.491 \quad 12.459$

$\begin{array}{llll}12.237 & 12.205 & 12.174 & 12.142\end{array}$

$\begin{array}{llll}11.919 & 11.888 & 11.856 & 11.824\end{array}$

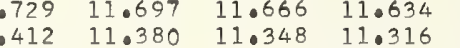

$11.285 \quad 11.253 \quad 11.221 \quad 11.190$

$\begin{array}{llllllll}10.777 & 10.746 & 10.714 & 10.682 & 10.650 & 10.618 & 10.587 & 10.555 \\ 10.460 & 10.428 & 10.397 & 10.365 & 10.333 & 10.301 & 10.270 & 10.238\end{array}$

$\begin{array}{llll}10.016 & 09.984 & 09.952 & 09.92\end{array}$

$09.381 \quad 09.350 \quad 09.318 \quad 09.286$

15.0

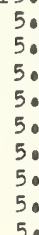

5.1

$5 \cdot 3$

5.6

5.8

5616.0

6.1
6.
6.
6.
6.6
6.7
6.8

$\begin{array}{rr}17801.326 & 01.295 \\ 01.010 & 00.978\end{array}$

$00.059 \quad 00.027 * 99.995 * 99.963 * 99.932 * 99.900 * 99.869 * 99.837 * 99.805 * 99.773$

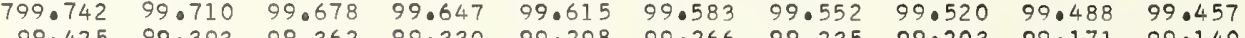

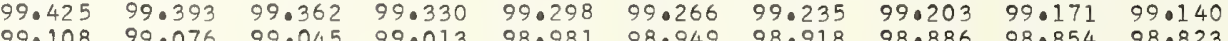

$\begin{array}{llllllllll}99.108 & 99.076 & 99.045 & 99.013 & 98.981 & 98.949 & 98.918 & 98.886 & 98.854 & 98.823\end{array}$

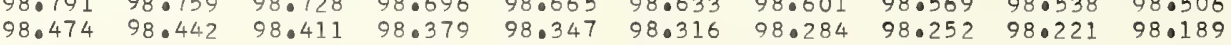

$\begin{array}{lllllllllll}5617.0 & 17798.157 & 98.126 & 98.094 & 98.062 & 98.031 & 97.999 & 97.967 & 97.936 & 97.904 & 97.872\end{array}$

$\begin{array}{lllllllllll}7.2 & 97.524 & 97.492 & 97.460 & 97.429 & 97.397 & 97.365 & 97.334 & 97.302 & 97.270 & 97.239\end{array}$

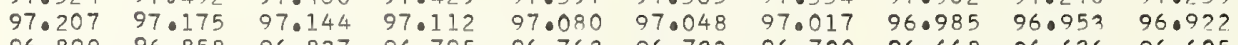
$\begin{array}{llllllllll}96.890 & 96.858 & 96.827 & 96.795 & 96.763 & 96.732 & 96.700 & 96.668 & 96.636 & 96.605\end{array}$ $\begin{array}{llllllllll}96.573 & 96.542 & 96.510 & 96.478 & 96.446 & 96.415 & 96.383 & 96.351 & 96.320 & 96.288\end{array}$

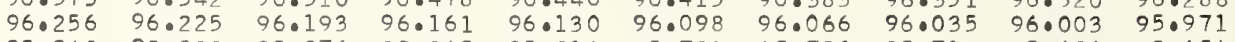
$\begin{array}{llllllllll}95.940 & 95.908 & 95.876 & 95.845 & 95.813 & 95.781 & 95.750 & 95.718 & 95.686 & 95.654\end{array}$

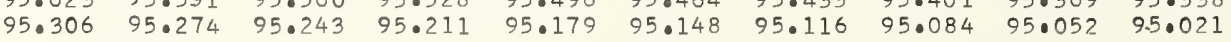

$\begin{array}{lrlllllllll}5618.0 & 17794 \cdot 989 & 94.958 & 94.926 & 94 \cdot 894 & 94 \cdot 863 & 94 \cdot 831 & 94 \cdot 799 & 94 \cdot 768 & 94.736 & 94 \cdot 704\end{array}$ $\begin{array}{lllllllllll}8.1 & 94.673 & 94.641 & 94.609 & 94.578 & 94.546 & 94.514 & 94 \cdot 483 & 94.451 & 94.419 & 94.387\end{array}$ $\begin{array}{lllllllllll}8.2 & 94.356 & 94.324 & 94.292 & 94.261 & 94.229 & 94.197 & 94.166 & 94.134 & 94.103 & 94.071 \\ 8.3 & 94.039 & 94.007 & 93.976 & 93.944 & 93.912 & 93.881 & 93.849 & 93.817 & 93.786 & 93.754\end{array}$

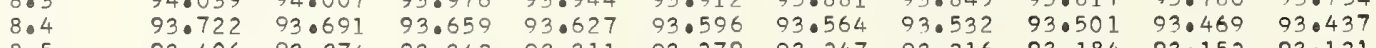
$\begin{array}{llllllllll}93.406 & 93.374 & 93.342 & 93.311 & 93.279 & 93.247 & 93.216 & 93.184 & 93.152 & 93.121\end{array}$

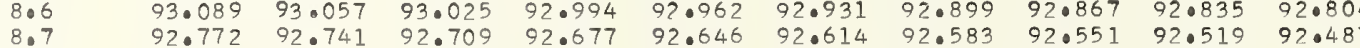

$\begin{array}{llllllllll}92.456 & 92.424 & 92.393 & 92.361 & 92.329 & 92.297 & 92.266 & 92.234 & 92.519 & 92.487\end{array}$

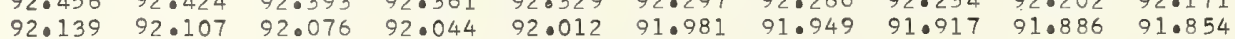

791.82291 .791

$\begin{array}{llllll}91.696 & 91.664 & 91.632 & 91.601 & 91.569 & 01.537\end{array}$

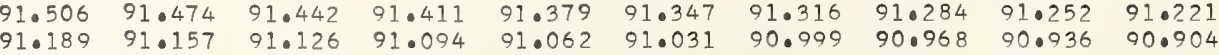

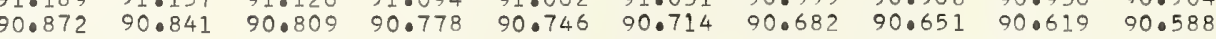

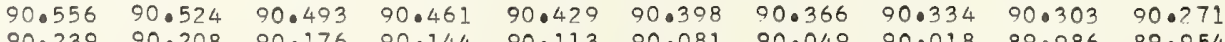

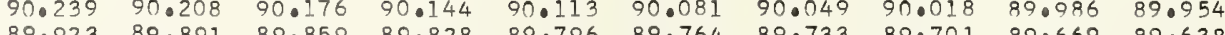
$89.606 \quad 89.575 \quad 89.543 \quad 89.511-89.479 \quad 89.448 \quad 80.416 \quad 89.385 \quad 89.3538 .0032$

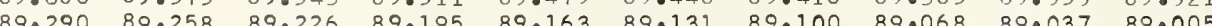

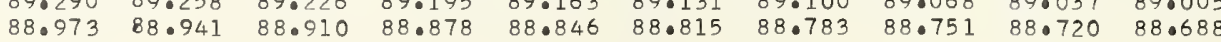

\begin{tabular}{|c|c|c|c|c|c|c|c|c|c|c|}
\hline & .001 & .002 & .003 & .004 & .005 & .006 & .007 & .008 & .009 & .010 \\
\hline$: 833$ & $: 883$ & $: 888$ & $: 818$ & $: 813$ & $: 816$ & $: 818$ & $: 832$ & $: 825$ & $: 832$ & $: 832$ \\
\hline 0 & .003 & .006 & .009 & .012 & .015 & .018 & .021 & .024 & .027 & .030 \\
\hline
\end{tabular}

$(n-1) \times 1000 \quad \lambda(n-1)$

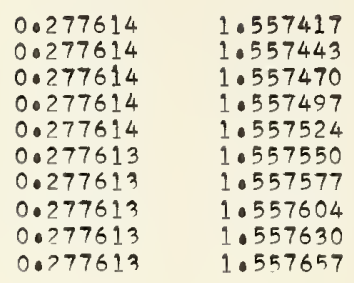

0.277613

0.277612

0.277612

0.277612

0.277611

0.277611

0.277611

0.277611
0.277610

0.277610

0.277610

0.277610

0.2777609
0.277609

0.277609

0.277609
0.277608

0.277608

0.277608

0.277608
0.277607

0.277607

0.277607

0.2777607
0.277607

0.277606

0.277606

0.2777606
0.277606

0.277606
0.277606

0.277605

0.277605

0.277605
0.277605

0.277605

0.277604

0.277604

0.277604

0.277604
0.277604

0.277603

0.277603

0.277603

0.277602

0.277602

0.277602

0.277602

0.277601

0.277601

0.277601

0.277600

0.277600

0.277600

0.277600

0.277600
0.277590

0.277590

0.277599

0.277599

0.27759

0.277598
0.277598

0.277598

0.27759

0.2775597
0.277597
0.277597

0.277507

277507

0.277597

0.277597

0.277596

.557684
.557711

1.557737

1.557764
1.557791

1.557818

1.557844

1.557898

1.557951

1.557978

1.558005
1.558031

1.558058

1.558058
1.558085

1.558112

1.558165

1.558165
1.558192

1.558219

1.558245
1.558272

1.558272

. 558325

1.558352

1.558379

1.558432

1.558486

1.558513

1.558539

1.558566
1.558593

1. 558619

1.558646

1.558673

1.558726

1. 558753

1. 558780

1.558807
1.558833

1. 558860

1.558887

1.558914
1.558940

1.558967

1. 558994

1. 559020

1. 55907

. 559101

1.559154

1. 559181

10559208

1.0559261

1. 559288

1.559314
1.559341

I. 559368

1.559395
1.559421

1.559421
1.559448

1.0559475
1.5550502

1.559528

1. 559555

1.559582

1.5596035

1.559662
1.559689

1. 559715

1. 559742

1.559795

1.559822

1.559849

1.55990

1.55992

1.559956

1.559983

1.560009
1.560036

1.560063

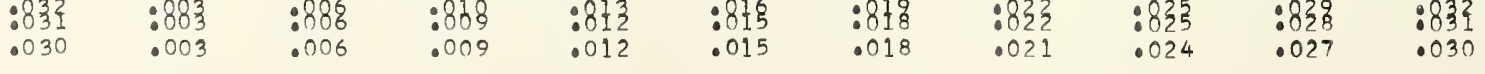


$\begin{array}{rrrrrrrrrrr}0.0 & 17788.656 & 88.625 & 88.593 & 88.562 & 88.530 & 88.498 & 88.467 & 88.435 & 88.403 & 88.372 \\ 0.1 & 88.340 & 88.308 & 88.277 & 88.245 & 88.214 & 88.182 & 88.150 & 88.118 & 88.087 & 88.055\end{array}$

$\begin{array}{lllllllllllll}0.2 & 88.023 & 87.992 & 87.960 & 87.928 & 87.897 & 87.865 & 87.834 & 87.802 & 87.770 & 87.739\end{array}$

$\begin{array}{llllllllllll}0.3 & 87.707 & 87.675 & 87.644 & 87.612 & 87.581 & 87.549 & 87.517 & 87.486 & 87.454 & 87.422\end{array}$

$\begin{array}{lllllllllll}0.4 & 87.390 & 87.359 & 87.327 & 87.295 & 87.264 & 87.232 & 87.201 & 87.169 & 87.137 & 87.106 \\ 0.5 & 87.074 & 87.042 & 87.011 & 86.979 & 86.948 & 86.916 & 86.884 & 86.853 & 86.821 & 86.789\end{array}$

$\begin{array}{llllllllllll}0.6 & 86.758 & 86.726 & 86.694 & 86.663 & 86.631 & 86.599 & 86.568 & 86.536 & 86.504 & 86.473 \\ 0.7 & 86.441 & 86.409 & 86.378 & 86.346 & 86.314 & 86.283 & 86.251 & 86.220 & 86.188 & 86.156\end{array}$

$\begin{array}{lllllllllll}0.8 & 86.125 & 86.093 & 86.062 & 86.030 & 85.998 & 85.966 & 85.935 & 85.903 & 85.872 & 85.840 \\ 0.9 & 85.808 & 85.777 & 85.745 & 85.713 & 85.682 & 85.650 & 85.618 & 85.587 & 85.555 & 85.523\end{array}$

0.277596

$\begin{array}{llllll}85.682 & 85.650 & 85.618 & 85.587 & 85.555 & 85.523\end{array}$

$\begin{array}{rrrrrrrrrrr}1.0 & 17785.492 & 85.460 & 85.429 & 85.397 & 85.365 & 85.333 & 85.302 & 85.271 & 85.239 & 85.207 \\ 1.1 & 85.175 & 85.144 & 85.112 & 85.081 & 85.049 & 85.017 & 84.986 & 84.954 & 84.922 & 84.891 \\ 1.2 & 84.859 & 84.828 & 84.796 & 84.764 & 84.732 & 84.701 & 84.669 & 84.638 & 84.606 & 84.575\end{array}$

$\begin{array}{lllllllllll}1.2 & 84.859 & 84.828 & 84.796 & 84.764 & 84.732 & 84.701 & 84.669 & 84.638 & 84.606 & 84.575 \\ 1.3 & 84.543 & 84.511 & 84.480 & 84.448 & 84.416 & 84.385 & 84.353 & 84.321 & 84.290 & 84.258\end{array}$

$\begin{array}{llllllllllll}1.4 & 84.227 & 84.195 & 84.163 & 84.132 & 84.100 & 84.068 & 84.037 & 84.005 & 83.973 & 83.942\end{array}$

$\begin{array}{llllllllllll}1.5 & 83.594 & 83.562 & 83.531 & 83.499 & 83.467 & 83.436 & 83.404 & 83.372 & 83.341 & 83.309\end{array}$

$\begin{array}{llllllllllll}1.7 & 83.278 & 83.246 & 83.214 & 83.183 & 83.151 & 83.1 .19 & 83.088 & 83.056 & 83.024 & 82.993 \\ 1.8 & 82.961 & 82.929 & 82.898 & 82.866 & 82.835 & 82.803 & 82.771 & 82.740 & 82.708 & 82.677\end{array}$

$\begin{array}{llllllllll}82.645 & 82.613 & 82.582 & 82.550 & 82.519 & 82.487 & 82.455 & 82.424 & 82.392 & 82.360\end{array}$

277596

1.560116

0.277595

0.277595

0.277595

0.277595

- 560170

.560197
1.560223

1.560250

.560304

$\begin{array}{lllll}17782.328 & 82.297 & 82.265 & 82.234 & 820\end{array}$

$\begin{array}{llll}82.012 & 81.981 & 81.949 & 81.917 \\ 81.696 & 81.665 & 81.633 & 81.601\end{array}$

$\begin{array}{lllll}81.854 & 81.823 & 81.791 & 81.759 & 81.728 \\ 81.538 & 81.506 & 81.475 & 81.443 & 81.411\end{array}$

2.

2.4

2.5

2.6
2.7
2.8

$\begin{array}{llll}.063 & 81.032 & 81.000 & 80.969\end{array}$

$\begin{array}{llll}80.747 & 80.716 & 80.684 & 80.652\end{array}$

$\begin{array}{llll}80.115 & 80.083 & 80.052 & 80.020 \\ 79.799 & 79.767 & 79.735 & 79.704\end{array}$

0.277594

0.277594

0.277594

0.277593

0.277593

.277593

0.277592

0.277592

0.277592

0.277591

0.27759

0.27759

$79.482 \quad 79.451$

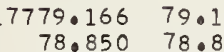

79.10379 .1

$\begin{array}{ll}78.850 & 78.8 \\ 78.534 & 78.502\end{array}$

$78.218 \quad 78.186$

$77.902 \quad 77.870$

$78.471-78.755$

$\begin{array}{ll}79.356 & 79.641 \\ 79.324\end{array}$

79.609
79.293

$77.269 \quad 77.23$

78.15

78.439

$\begin{array}{ll}70.040 & 79.008 \\ 78.723 & 78.692 \\ 78.407 & 78.376\end{array}$

$\begin{array}{lllll}78.976 \quad 78.945 & 78.913 \quad 78.982\end{array}$

0.27759

0.0277590

0.277590

0.277590

0.277589

0.277589
0.277589
0.277589

$\begin{array}{ll}76.637 & 76.605 \\ 76.321 & 76.289\end{array}$

$77.206 \quad 77.175$

$77.775 \quad 77.743$

$\begin{array}{lllll}78.028 & 77.996 & 77.965 & 77.93\end{array}$

$776.005 \quad 75.973$

$\begin{array}{ll}76.574 & 76.542 \\ 76.258 & 76.226\end{array}$

$76.827 \quad 76.795$

77.080

$\begin{array}{llll}77.364 & 77.333 & 77.30\end{array}$

5624.0

$\begin{array}{ll}75.689 & 75.657 \\ 75.373 & 75.341 \\ 75.057 & 75.025\end{array}$

$\begin{array}{ll}75.057 & 75.025 \\ 74.741 & 74.0700 \\ 74.425 & 74.0393\end{array}$

$74.425 \quad 74.393$

$75.942 \quad 75.910$

76.19

0.2775

1.560357

1.560384

1.560410

1.560491

1.560544

1.560598

1.560624

1.560678

1.560705

1.560731

1.560785

1.560838

4.5

$4 \cdot 6$

$\begin{array}{llll}74.109 & 74.077 & 74.045 & 74.014 \\ 73.793 & 73.761 & 73.729 & 73.698\end{array}$

$75.309 \quad 75.278$

$\begin{array}{ll}74.994 & 74.962 \\ 74.677 & 74.646\end{array}$

$\begin{array}{ll}73.477 & 73.445 \\ 73.161 & 73.129\end{array}$

$\begin{array}{ll}73.729 & 73.698 \\ 3.414 & 73.382\end{array}$

0.277589

0.0277589
0.277588

0.277588

0.277588
0.277588
0.2758

0.277587

0.277587

5625.

25.0
5.1
50
50
50
50
50
50
50
5.0

$\begin{array}{ll}72.529 & 72.813 \\ 72.213 & 72.181\end{array}$

$\begin{array}{ll}72.781 & 72.750 \\ 72.465 & 72.434 \\ 72.150 & 72.118\end{array}$

$\begin{array}{llll}71.897 & 71.865 & 71.834 & 71.802\end{array}$

$71.581 \quad 71.549$

$71.518 \quad 71.486$

10.265971 .234

$70.886 \quad 70.854$

$\begin{array}{ll}70.317 & 70.286 \\ 70.001 & 69.970\end{array}$

$70.570 \quad 70.539$

$74.614 \quad 74.583$

$\begin{array}{ll}73.982 & 73.950 \\ 73.666 & 73.635\end{array}$

$\begin{array}{llll}74.235 & 74.204 & 74.172 & 74.140\end{array}$

$\begin{array}{rrrr}74.919 & 73.887 & 73.856 & 73.824 \\ 73.603 & 73.572 & 73.540 & 73.50\end{array}$

$\begin{array}{llllll}73.350 & 73.319 & 73.287 & 73.255 & 73.224 & 73.192 \\ 73.034 & 73.003 & 72.971 & 72.939 & 72.908 & 72.876\end{array}$

0.277587

$\begin{array}{llllll}72.718 & 72.687 & 72.655 & 72.624 & 72.592 & 72.560 \\ 72.402 & 72.371 & 72.339 & 72.308 & 72.276 & 72.244\end{array}$

$\begin{array}{llllll}72.086 & 72.055 & 72.023 & 71.992 & 71.960 & 71.928\end{array}$

$\begin{array}{llllll}71.455 & 71.423 & 71.391 & 71.360 & 71.328 & 71.297\end{array}$

$\begin{array}{lllllll}71.138 & 71.107 & 71.075 & 71.044 & 71.012 & 70.981 \\ 70.823 & 70.791 & 70.760 & 70.728 & 70.696 & 70.665\end{array}$

5.7
5.8
5.9

626
6
6
6
6
6
6
6
6
6

$17769.686 \quad 69.654$ $\begin{array}{ll}70.254 & 70.223 \\ 69.938 & 69.907\end{array}$

$\begin{array}{llllll}70.507 & 70.475 & 70.444 & 70.412 & 70.380 & 70.349\end{array}$

$\begin{array}{llllll}70.191 & 70.159 & 70.128 & 70.096 & 70.065 & 70.033 \\ 69.875 & 69.844 & 69.812 & 69.780 & 69.749 & 69.717\end{array}$

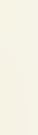

0.277586
0.27586

0.277586

0.277586

0.277586
0.277585

0.277585

0.277585

0.277585
0.277585
0.0277584

0.277584

0.277584
0.277584

0.277584

0.277584
0.277583 $\begin{array}{llllllllll} & \end{array}$ $\begin{array}{llllllllll}68.106 & 68.075 & 68.043 & 68.012 & 67.980 & 67.948 & 67.917 & 67.885 & 67.854 & 67.823 \\ 67.791 & 67.759 & 67.727 & 67.696 & 67.664 & 67.633 & 67.601 & 67.570 & 67.538 & 67.507\end{array}$ $\begin{array}{llllllllll}67.475 & 67.443 & 67.412 & 67.380 & 67.349 & 67.317 & 67.286 & 67.254 & 67.222 & 67.191\end{array}$ $\begin{array}{llllllllll}66.844 & 66.812 & 66.780 & 66.749 & 66.717 & 66.686 & 66.654 & 66.622 & 66.591 & 66.559\end{array}$

$\begin{array}{lllllllllll}5627.0 & 17766.528 & 66.496 & 66.465 & 66.433 & 66.401 & 66.370 & 66.338 & 66.307 & 66.275 & 66 . ? 43\end{array}$ $\begin{array}{llllllllll}66.212 & 66.180 & 66.149 & 66.117 & 66.086 & 66.054 & 66.022 & 65.991 & 65.959 & 65.978\end{array}$ $\begin{array}{lllllllllll}65.896 & 65.865 & 65.833 & 65.802 & 65.770 & 65.738 & 65.707 & 65.675 & 65.644 & 65.612\end{array}$ $\begin{array}{llllllllll}65.580 & 65.549 & 65.517 & 65.486 & 65.454 & 65.423 & 65.391 & 65.359 & 65.328 & 65.296\end{array}$ $\begin{array}{llllllllll}65.265 & 65.233 & 65.202 & 65.170 & 65.139 & 65.107 & 65.075 & 65.044 & 65.012 & 64.981\end{array}$ $\begin{array}{lllllllllll}64.949 & 64.917 & 64.886 & 64.854 & 64.823 & 64.791 & 64.760 & 64.728 & 64.697 & 64.665\end{array}$ $\begin{array}{llllllllll}64.634 & 64.602 & 64.570 & 64.539 & 64.507 & 64.476 & 64.444 & 64.413 & 64.381 & 64.350\end{array}$ $\begin{array}{llllllllll}64.318 & 64.286 & 64.255 & 64.223 & 64.191 & 64.160 & 64.128 & 64.097 & 64.065 & 64.034 \\ 64.002 & 63.970 & 63.939 & 63.907 & 63.876 & 63.844 & 63.813 & 63.781 & 63.750 & 63.718\end{array}$

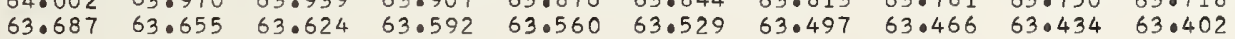

0.277583

0.277583

0.277583
0.277583

0.277583

0.277582

0.277582

0.277582

1.560892

1.560918

1.560945
1.560972

1.560999

1.561052

1.561079
1.561105

1.561132

1.561159

1.561186
1.561212

1.561239

1.561293

1.561319

1.561346

1.561400

0.277581

0.277581

0.277588
0.27758

0.277581

0.277581

0.277580

0.277580

1.561426

1.561453
1.561480

1. 561506

1.561560

1.581587

1.561640

,

1.561720

.561747
.561774

1.561827

1.561854

1.561908

1.561961

1.562014

1.562041

1. 562068

1.562095
1.562121

1.562148

1.562175
1.562202

0.277580

0.277579

0.277579
0.277579

0.277579
0.277579

0.277579

0.277579

0.277578
0.277578

1.562228

1.562255
1.582282

1.562308
1.562335

1.562362

1.562415

1.562442

1.562496

1.562522

1.562549
1.562576

1.562603

1.562656 $\begin{array}{llllllllll}58.638 & 58.607 & 58.575 & 58.543 & 58.512 & 58.480 & 58.448 & 58.417 & 58.386 & 58.354\end{array}$ $\begin{array}{llllllllll}58.323 & 58.291 & 58.259 & 58.228 & 58.197 & 58.165 & 58.133 & 58.102 & 58.070 & 58.039 \\ 58.007 & 57.976 & 57.944 & 57.913 & 57.881 & 57.849 & 57.818 & 57.786 & 57.755 & 57.773\end{array}$

$57.692 \quad 57.660 \quad 57.629 \quad 57.597 \quad 57.565 \quad 57.534 \quad 57.502 \quad 57.471 \quad 57.439 \quad 57.408$

$\begin{array}{llllllllll}57.692 & 57.660 & 57.629 & 57.597 & 57.565 & 57.534 & 57.502 & 57.471 & 57.439 & 57.408 \\ 57.376 & 57.345 & 57.313 & 57.282 & 57.250 & 57.219 & 57.187 & 57.156 & 57.124 & 57.093\end{array}$

1.562683

9.8

\begin{tabular}{|c|c|c|c|c|c|c|c|c|}
\hline .001 & .002 & .003 & .004 & .005 & .006 & .007 & .008 & .009 \\
\hline $\begin{array}{l}: 083 \\
: 083 \\
.003\end{array}$ & $\begin{array}{l}: 086 \\
: 006\end{array}$ & $\begin{array}{l}.809 \\
.009 \\
.009\end{array}$ & $\begin{array}{l}013 \\
012 \\
012\end{array}$ & $\begin{array}{l}: 816 \\
: 015\end{array}$ & $\begin{array}{l}: 819 \\
018 \\
0018\end{array}$ & $\begin{array}{l}: 832 \\
: 821 \\
.021\end{array}$ & $\begin{array}{l}: 825 \\
8024 \\
0024\end{array}$ & $\begin{array}{l}: 828 \\
.827\end{array}$ \\
\hline
\end{tabular}


$\begin{array}{lllllllllll}5630.0 & 17757.061 & 57.029 & 56.998 & 56.966 & 56.935 & 56.903 & 56.872 & 56.840 & 56.809 & 56.777\end{array}$ $\begin{array}{lllllllllll}0.1 & 56.745 & 56.714 & 56.682 & 56.651 & 56.619 & 56.588 & 56.556 & 56.525 & 56.493 & 56.462\end{array}$ $\begin{array}{lllllllllll}0.2 & 56.430 & 56.399 & 56.367 & 56.335 & 56.304 & 56.272 & 56.241 & 56.209 & 56.178 & 56.146 \\ 0.3 & 56.115 & 56.083 & 56.052 & 56.020 & 55.989 & 55.957 & 55.926 & 55.894 & 55.863 & 55.831\end{array}$ $\begin{array}{llllllllllll}0.4 & 55.800 & 55.768 & 55.736 & 55.705 & 55.673 & 55.642 & 55.610 & 55.579 & 55.547 & 55.515 \\ 0.5 & 55.484 & 55.453 & 55.421 & 55.389 & 55.358 & 55.326 & 55.295 & 55.263 & 55.232 & 55.200\end{array}$ $\begin{array}{lllllllllll}0.5 & 55.484 & 55.453 & 55.421 & 55.389 & 55.358 & 55.326 & 55.295 & 55.263 & 55.232 & 55.200 \\ 0.6 & 55.169 & 55.137 & 55.106 & 55.074 & 55.043 & 55.011 & 54.979 & 54.948 & 54.916 & 54.885\end{array}$ $\begin{array}{lllllllllll}0.7 & 54.853 & 54.822 & 54.790 & 54.759 & 54.727 & 54.696 & 54.664 & 54.633 & 54.601 & 54.570\end{array}$ $\begin{array}{lllllllllll}0.8 & 54.538 & 54.506 & 54.475 & 54.444 & 54.412 & 54.380 & 54.349 & 54.317 & 54 \cdot 286 & 54.254 \\ 0.9 & 54.223 & 54.191 & 54.160 & 54.128 & 54.097 & 54.065 & 54.033 & 54.002 & 53.970 & 53.939\end{array}$

$\begin{array}{llllllllllll}5631.0 & 17753.907 & 53.876 & 53.844 & 53.813 & 53.781 & 53.750 & 53 \cdot 718 & 53.687 & 53.655 & 53.624\end{array}$ $\begin{array}{llllllllllll}1.1 & 53.592 & 53.561 & 53.529 & 53.498 & 5 ? .466 & 53.435 & 53.403 & 53.371 & 53.340 & 53.309\end{array}$ $\begin{array}{llllllllllll}1.2 & 53.277 & 53.245 & 53.214 & 53.182 & 53.151 & 53.119 & 53.088 & 53.056 & 53.025 & 52.993 \\ 1.3 & 52.962 & 52.930 & 52.898 & 52.867 & 52.835 & 52.804 & 52.772 & 52.741 & 52.709 & 52.678\end{array}$

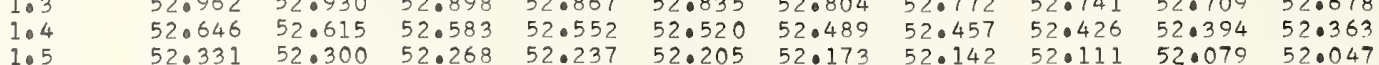
$\begin{array}{lllllllllll}1.6 & 52.016 & 51.984 & 51.953 & 51.921 & 51.890 & 51.858 & 51.827 & 51.795 & 51.764 & 51.732\end{array}$ $\begin{array}{llllllllllll}1.7 & 51.701 & 51.669 & 51.638 & 51.606 & 59.575 & 51.543 & 51.511 & 51.480 & 51.448 & 51.417 \\ 1.8 & 51.385 & 51.354 & 51.323 & 51.291 & 51.260 & 51.228 & 51.196 & 51.165 & 51.134 & 51.102\end{array}$ $\begin{array}{lllllllllll}1.8 & 51.385 & 51.354 & 51.323 & 51.291 & 51.260 & 51.228 & 51.196 & 51.165 & 51.134 & 51.102 \\ 1.9 & 51.070 & 51.039 & 51.007 & 50.976 & 50.944 & 50.913 & 50.881 & 50.850 & 50.818 & 50.786\end{array}$

$\begin{array}{lllllllllll}5632.0 & 17750.755 & 50.724 & 50.692 & 50.660 & 50.629 & 50.597 & 50.566 & 50.535 & 50.503 & 50.471\end{array}$ $\begin{array}{lllllllllll}2.1 & 50.440 & 50.408 & 50.377 & 50.345 & 50.314 & 50.282 & 50.251 & 50.219 & 50.188 & 50.156 \\ 2.2 & 50.125 & 50.093 & 50.062 & 50.030 & 49.999 & 49.967 & 49.936 & 49.904 & 49.873 & 49.841\end{array}$ $\begin{array}{lllllllllll}2.2 & 50.125 & 50.093 & 50.062 & 50.030 & 49.999 & 49.967 & 49.936 & 49.904 & 49.873 & 49.841\end{array}$ $\begin{array}{lllllllllll}2.3 & 49.810 & 49.778 & 49.747 & 49.715 & 40.684 & 49.652 & 49.621 & 49.589 & 49.558 & 49.526 \\ 2.4 & 49.495 & 49.463 & 49.431 & 49.400 & 49.368 & 49.337 & 49.305 & 49.274 & 49.242 & 49.211\end{array}$ $\begin{array}{lllllllllll}2.5 & 49.179 & 49.148 & 49.116 & 49.085 & 49.053 & 49.022 & 48.990 & 48.959 & 48.927 & 48.896\end{array}$ $\begin{array}{llllllllllll}2.6 & 48.864 & 48.833 & 48.801 & 48.770 & 48.738 & 48.707 & 48.675 & 48.644 & 48.612 & 48.581 \\ 2.7 & 48.549 & 48.518 & 48.486 & 48.455 & 48.423 & 48.397 & 48.360 & 48.329 & 48.297 & 48.266\end{array}$

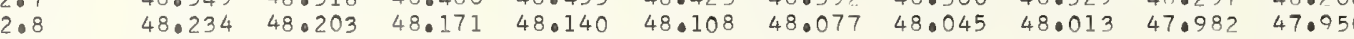
$\begin{array}{llllllllll}48.234 & 48.203 & 48.171 & 48.140 & 48.108 & 48.077 & 48.045 & 48.013 & 47.982 & 47.950 \\ 47.919 & 47.887 & 47.856 & 47.824 & 47.793 & 47.761 & 47.730 & 47.698 & 47.667 & 47.635\end{array}$

$$
\begin{array}{ll}
47.289 & 47.257 \\
46.974 & 46.942 \\
46.659 & 46.527
\end{array}
$$$$
46.344 \quad 46.312
$$$$
\begin{array}{ll}
46.029 & 45.997 \\
45.714 & 45.682
\end{array}
$$$$
\begin{array}{ll}
45.399 & 45.367
\end{array}
$$

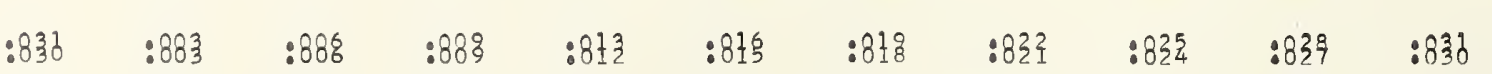


$\begin{array}{lllllllllll}5640.0 & 17725 \cdot 577 & 25.546 & 25.514 & 25 \cdot 483 & 25 \cdot 451 & 25 \cdot 420 & 25 \cdot 388 & 25 \cdot 357 & 25 \cdot 326 & 25 \cdot 294\end{array}$ $\begin{array}{lllllllllll}0.1 & 25.263 & 25.231 & 25.200 & 25.168 & 25.137 & 25.106 & 25.074 & 25.043 & 25 \cdot 011 & 24 \cdot 980 \\ 0.2 & 24.948 & 24.917 & 24.885 & 24.854 & 24.823 & 24.791 & 24.760 & 24.729 & 24.697 & 24.666 \\ 0.3 & 24.634 & 24.503 & 24.572 & 24.540 & 24.509 & 24.477 & 24.446 & 24.414 & 24.383 & 24.352\end{array}$

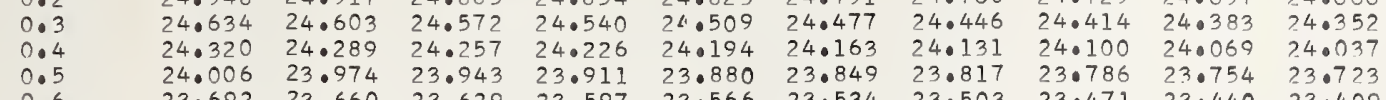
$\begin{array}{lllllllllll}0.6 & 23.692 & 23.660 & 23.629 & 23.597 & 23.566 & 23.534 & 23.503 & 23.471 & 23.440 & 23.409 \\ 0.7 & 23.377 & 23.346 & 23.314 & 23.283 & 23.251 & 23.220 & 23.189 & 23.757 & 23.126 & 23.094\end{array}$ $\begin{array}{lllllllllll}0.7 & 23.377 & 23.346 & 23.314 & 23.283 & 23.251 & 23.220 & 23.189 & 23.157 & 23.126 & 23.094 \\ 0.8 & 23.063 & 23.032 & 23.000 & 22.969 & 22.937 & 22.906 & 22.875 & 22.843 & 22.812 & 22.780\end{array}$ 0.9 $\begin{array}{llll}23.063 & 23.032 & 23.000 & 22.969 \\ 22.749 & 22.718 & 22.686 & 22.655\end{array}$

$$
\begin{array}{rlll}
7722.435 & 22.403 & 22.372 & 22.341 \\
22.120 & 22.089 & 22.058 & 22.026
\end{array}
$$

$\begin{array}{llll}21.806 & 21.775 & 21.744 & 21.712 \\ 21.492 & 21.461 & 21.429 & 21.398\end{array}$

$\begin{array}{llll}21.178 & 21.147 & 21.115 & 21.084 \\ 20.864 & 20.833 & 20.801 & 20.770\end{array}$

$\begin{array}{llll}20.864 & 20.833 & 20.801 & 20.770 \\ 20.550 & 20.518 & 20.487 & 20.456\end{array}$

19.92

5642.
2.
2.
2
2.
2
2
2
2
2

17719.293$$
19.293 \quad 19.262
$$

18.351

$18.037 \quad 18.006$

$\begin{array}{ll}17.409 & 17.378\end{array}$

$17.095 \quad 17.064$

16.468

5643

3.

3.

3.4
3.5

3.6

3.8

5644

4.0
4.
4.
4.
4.4
4.5
4.6
4.7
4.8
4.9

$17716.154 \quad 16 \cdot 122$

$15.840 \quad 15.808$

$15.212 \quad 15.180$

$\begin{array}{ll}14.898 & 14.866 \\ 14.584 & 14.552\end{array}$

14.584

$\begin{array}{ll}14.270 & 14.239 \\ 3.956 & 13.925\end{array}$

$\begin{array}{ll}13.642 & 13.611 \\ 13.329 & 13.297\end{array}$

$20.173 \quad 20.14$

22.937
22.623

22.906
22.592

$\begin{array}{llll}22.875 & 22.843 & 22.812 & 22.780 \\ 22.560 & 22.529 & 22.498 & 22.466\end{array}$

$\begin{array}{llllll}22.309 & 22.278 & 22.246 & 22.215 & 22.183 & 22.152 \\ 21.995 & 21.963 & 21.932 & 21.901 & 21.869 & 21.838\end{array}$

$\begin{array}{llllll}21.681 & 21.649 & 21.618 & 21.587 & 21.555 & 21.524 \\ 21.366 & 21.335 & 21.304 & 21.272 & 21.241 & 21.209\end{array}$

$\begin{array}{llllll}21.052 & 21.021 & 20.990 & 20.958 & 20.927 & 20.896\end{array}$

$\begin{array}{llllll}20.738 & 20.707 & 20.675 & 20.644 & 20.613 & 20.581 \\ 20.424 & 20.393 & 20.362 & 20.330 & 20.299 & 20.267\end{array}$

$\begin{array}{llllll}20.110 & 20.079 & 20.047 & 20.016 & 19.984 & 19.953\end{array}$

$17713.014 \quad 12.983$

$\begin{array}{ll}713 \cdot 014 & 12 \cdot 98 \\ 12 \cdot 701 & 12 \cdot 66 \\ 12.387 & 12 \cdot 35 \\ 12.073 & 12.04\end{array}$

$11.759 \quad 11.728$

11.13211 .100

$9.231 \quad 19.199$

19.796

0.07
9.76

20.04
19.73

20.016
19.7
19.3

19.671

19.639
19.325

$\begin{array}{ll}10.818 & 10.787\end{array}$

$\begin{array}{ll}10.504 & 10.473 \\ 10.190 & 10.159\end{array}$

5645.0

5.

17709.877

$09.877 \quad 09.8$

$\begin{array}{ll}09.563 & 09.531 \\ 09.250 & 09.218\end{array}$

$08.936 \quad 08.904$

$08.622 \quad 08.591$

$\begin{array}{lll}07.995 & 07.963 & 07.93 \\ 07.681 & 07.649 & 07.618\end{array}$

$\begin{array}{ll}07.367 & 07.336 \\ 07.054 & 07.022\end{array}$

$\begin{array}{ll}8.603 & 18.571\end{array}$

$19.168 \quad 19.136$

19.10

19.074

$19.042 \quad 19.011$

$\begin{array}{llllllll}8.603 & 18.571 & 18.540 & 18.508 & 18.477 & 18.446 & 18.414 & 18.383 \\ 8.289 & 18.257 & 18.226 & 18.195 & 18.163 & 18.132 & 18.100 & 18.069 \\ 1.975 & 17.943 & 17.912 & 17.880 & 17.849 & 17.818 & 17.786 & 17.755\end{array}$

$\begin{array}{ll}17.661 & 17.629 \\ 17.346 & 17.315\end{array}$

$\begin{array}{llll}17.535 & 17.504 & 17.477 & 17.441 \\ 17.221 & 17.189 & 17.158 & 17.127\end{array}$

$\begin{array}{llll}17.221 & 17.189 & 17.158 & 17.127 \\ 16.907 & 16.876 & 16.844 & 16.813\end{array}$

16.719 16.687

17.284
6.252

16.938

$\begin{array}{lll}16.091 & 16.059\end{array}$

16.342

15.997

16.593

6.876

$\begin{array}{llll}15.965 & 15.934 & 15.902 & 15.871\end{array}$

$\begin{array}{llllllll}15.463 & 15.431 & 15.400 & 15.369 & 15.337 & 15.620 & 15.588 & 15.557 \\ & 1506 & 15.274 & 15.243\end{array}$

$14.835 \quad 14.804$

$14.207 \quad 14.176$

15.086

$\begin{array}{llllll}14.772 & 14.741 & 14.709 & 14.678 & 14.647 & 14.615\end{array}$

$\begin{array}{llllll}14.458 & 14.427 & 14.396 & 14.364 & 14.333 & 14.302 \\ 14.145 & 14.113 & 14.082 & 14.050 & 14.019 & 13.988\end{array}$

$13.580 \quad 13.548$

$13.831 \quad 13.799$

$13.768 \quad 13.736 \quad 13.705 \quad 13.674$

$12.952 \quad 12.920$

$1 ? .203 \quad 130$

$\begin{array}{lllll}13.171 & 13.454 & 13.423 & 13.391 & 13.360 \\ 13.109 & 13.077 & 13.046\end{array}$

$\begin{array}{llllllll}2.638 & 12.920 & 12.889 & 12.858 & 12.826 & 12.795 & 12.764 & 12.732 \\ 12.575 & 12.544 & 12.512 & 12.481 & 12.449 & 12.418\end{array}$

$\begin{array}{llllllll}12.324 & 12.293 & 12.261 & 12.230 & 12.199 & 12.167 & 12.136 & 12.104 \\ 12.010 & 11.979 & 11.948 & 11.916 & 11.885 & 11.853 & 11.822 & 11.791\end{array}$

$\begin{array}{llllllll}1.697 & 11.665 & 11.634 & 11.603 & 11.571 & 11.540 & 11.508 & 11.477\end{array}$

$\begin{array}{llll}.383 & 11.351 & 1 ? .320 & 11.289\end{array}$

$11.257 \quad 11.226 \quad 11.195 \quad 11.163$

$\begin{array}{llllllll}10.755 & 10.724 & 10.692 & 10.661 & 10.630 & 10.598 & 10.567 & 10.536\end{array}$

$\begin{array}{llllllll}10.441 & 10.410 & 10.379 & 10.347 & 10.316 & 10.284 & 10.253 & 10.222 \\ 10.128 & 10.096 & 10.065 & 10.034 & 10.002 & 09.971 & 09.939 & 09.908\end{array}$

$\begin{array}{llllllll}0.814 & 09.782 & 09.751 & 09.720 & 09.688 & 09.657 & 09.626 & 09.594\end{array}$

$\begin{array}{llllllll}09.500 & 09.469 & 09.437 & 09.406 & 09.375 & 09.344 & 09.312 & 09.281\end{array}$

$\begin{array}{llllllll}.187 & 09.155 & 09.124 & 09.092 & 09.061 & 09.030 & 08.998 & 08.967 \\ 8.873 & 08.842 & 08.810 & 08.779 & 08.747 & 08.716 & 08.685 & 08.653\end{array}$

5.5

5.7

5.9

5646.0

6
6
6
6
6
6
6
6
6

17706.740

$06.427 \quad 06.395$

$06.113 \quad 06.08$

$05.486 \quad 05.45$

04.85904 .827

04.54504 .514

$03.918 \quad 03.887$

$08.810 \quad 08.779$

$\begin{array}{llll}08.747 & 08.716 & 08.685 & 08.653 \\ 08.434 & 08.402 & 08.371 & 08.34\end{array}$

$\begin{array}{lllllll}08.183 & 08 \cdot 151 & 08 \cdot 120 & 08.089 & 08.057 & 08.026 \\ 07.869 & 07.838 & 07.806 & 07.775 & 07.744 & 07.712\end{array}$

$\begin{array}{lllllll}07.555 & 07.524 & 07.493 & 07.461 & 07.430 & 07.399\end{array}$

$\begin{array}{llll}07.179 & 07.148 & 07.116 & 07.085\end{array}$

5647.0

17703

03.29103 .260

$02.978 \quad 02.260 \quad 03.22$

$02.664 \quad 02.633$

$02.351 \quad 02.319$

$01.724 \quad 01.69$

01.41101 .379

$01.411 \quad 01.37901 .348 \quad 01.31$

$00.784 \quad 00.752$

06.6

06.960

$06.552 \quad 06.521 \quad 06.490 \quad 06.458$

$\begin{array}{lllllll}06.301 & 06.270 & 06.239 & 06.207 & 06.176 & 06.145\end{array}$

$06.050 \quad 06.019$

$05.423 \quad 05.392$

$0.110 \quad 05.078$

$\begin{array}{llllll}05.988 & 05.956 & 05.925 & 05.894 & 05.862 & 05.831\end{array}$

$\begin{array}{llllll}05.674 & 05.643 & 05.611 & 05.580 & 05.549 & 05.517 \\ 05.361 & 05.329 & 05.298 & 05.266 & 05.235 & 05.20\end{array}$

$\begin{array}{llllll}05.047 & 05.016 & 04.984 & 04.953 & 04.922 & 04.890\end{array}$

$\begin{array}{llllll}04.734 & 04.702 & 04.671 & 04.639 & 04.608 & 04.577\end{array}$

$\begin{array}{ll}0.482 & 04.451 \\ 0.169 & 04.138\end{array}$

$04.420 \quad 04.388$

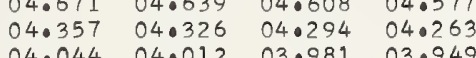

$\begin{array}{llllll}04.106 & 04.075 & 04.044 & 04.012 & 03.981 & 03.949 \\ 0 ? .793 & 03.761 & 03.730 & 03.699 & 03.667 & 03.636\end{array}$

.77755

0.277559

0.077559

0.777559

277558

0.27755

0.27755
0.27755

0.77755

0.277557

0.277556

0.0777556

0.277556

0.27755

0.277555

0.277555

77755

0.277554

0.27755

0.277554

0.277554

0.27755

0.277553
0.277553
0.277553

0.277553

0.27755

0.0277552

0.277552

0.2775

0.2775

0.27755

0.277550

0.277550

0.277550
0.277550
0.277550

0.277550

0.277549

0.277549

0.277549
0.2775

0.277548

0.277548

0.277548

0.277548

0.277547

0.277547
0.277547

0.277547

0.277546

0.277546

0.277546
0.277546

0.277546

0.777545

0.277545

0.277545

0.277544
0.277544

0.277544

0.277544

0.277544

0.077543

0.077543

0.27754

0.277543

0.277542

$\begin{array}{lllllllllll} & .001 & .002 & .003 & .004 & .005 & .006 & .007 & .008 & .009 & .010 \\ .031 & .003 & .006 & .009 & .012 & .016 & .019 & .022 & .025 & .028 & .0219 \\ .030 & .003 & .006 & .009 & .012 & .015 & .018 & .021 & .024 & .027 & .0213 \\ .029 & .003 & .006 & .009 & .012 & .015 & .018 & .020 & .023 & .026 & .029\end{array}$

1.565918
1.565944

1.565971

1.566025

1.566105

.566158
1.566185

1.566238

1. 566292

1.566345

1.566399

1.566426

1.566452
1.566479

1.566506

1.566533
1.566559

1.566613

1.566640

. 5666693

1.566720
1.566747

1. 566773

1.566800
1.566827

1.566853

.566880
.566907

1.566960

.566989
.5667014

1.567041

1.567094
. .567121

.567148
.567174

.567201
.567228

.567254
.567281

.567308
1.567335

1.567361
1.567388

1.567415
1.567442

1.567468

1.567522

.567575

- 567629

1.567682

1.567736

1.567789

$\begin{array}{rrrllllllll}5649.0 & 17697.337 & 97.306 & 97.274 & 97.243 & 97.212 & 97.180 & 97.149 & 97.118 & 97.086 & 97.055\end{array}$

$\begin{array}{llllllllll}96.710 & 96.679 & 96.548 & 96.616 & 96.585 & 96.554 & 96.527 & 96.491 & 96.460 & 96.428\end{array}$

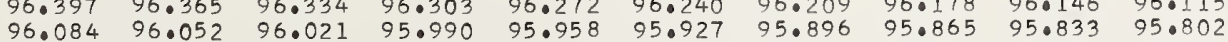

$\begin{array}{llllllllll}95.771 & 95.740 & 95.708 & 95.677 & 95.645 & 95.614 & 95.583 & 95.551 & 95.520 & 95.489\end{array}$

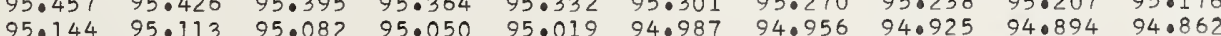

$95.14495 .113 \quad 95.08295 .050 \quad 95.019 \quad 94.987 \quad 94.956 \quad 94.925 \quad 94.894 \quad 94.862$

$94.83194 .800 \quad 94.768 \quad 94.737 \quad 94.706 \quad 94.674 \quad 94.64304 .612 \quad 94.581294$

9.8

.006

000

.0 .2


$\begin{array}{rrrrrrrrrrr}0.1 & 17694.204 & 94.173 & 94.142 & 94.111 & 94.079 & 94.048 & 94.017 & 93.985 & 93.954 & 93.923 \\ 03.891 & 93.860 & 93.829 & 93.798 & 93.766 & 93.735 & 93.704 & 93.672 & 93.641 & 93.610 \\ 0.2 & 93.578 & 93.547 & 93.516 & 93.484 & 93.453 & 93.422 & 93.390 & 93.359 & 93.328 & 93.296\end{array}$ $\begin{array}{lllllllllll}0.2 & 93.578 & 93.547 & 93.516 & 93.484 & 93.453 & 93.422 & 93.390 & 93.359 & 93.328 & 93.296 \\ 0.3 & 93.265 & 93.234 & 93.203 & 93.171 & 93.140 & 93.109 & 93.077 & 93.046 & 93.015 & 92.983\end{array}$ $\begin{array}{llllllllll}92.952 & 92.921 & 92.889 & 92.858 & 92.827 & 92.795 & 92.764 & 92.733 & 92.701 & 92.670\end{array}$

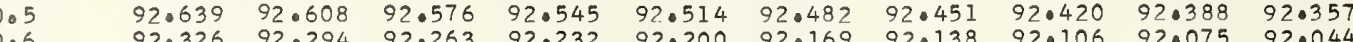
$\begin{array}{lllllllllll}0.6 & 92.326 & 92.294 & 92.263 & 92.232 & 92.200 & 92.169 & 92.138 & 92.106 & 92.075 & 92.044 \\ 0.7 & 92.013 & 91.981 & 91.950 & 91.919 & 91.887 & 91.856 & 91.825 & 91.793 & 91.762 & 91.731\end{array}$

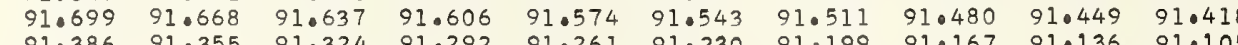

$\begin{array}{rrrrrrrrrrr}551.0 & 17691.073 & 91.042 & 91.011 & 90.979 & 90.948 & 90.917 & 90.885 & 90.854 & 90.823 & 90.792 \\ 1.1 & 90.760 & 90.729 & 90.698 & 90.667 & 90.635 & 90.604 & 90.573 & 90.541 & 90.510 & 90.479\end{array}$

$\begin{array}{lllllllllll}1.2 & 90.447 & 90.416 & 90.385 & 90.354 & 90.322 & 90.291 & 90.260 & 90.228 & 90.197 & 90.166\end{array}$

$\begin{array}{lllllllllll}89.821 & 89.790 & 89.759 & 89.727 & 89.696 & 89.665 & 89.634 & 89.602 & 89.571 & 89.540\end{array}$

.009

.004

.005




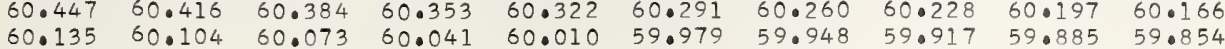

0.277508

0.277507
0.277507

0.277507
0.277507

0.277507
0.277507

0.277506

0.277506
0.277506

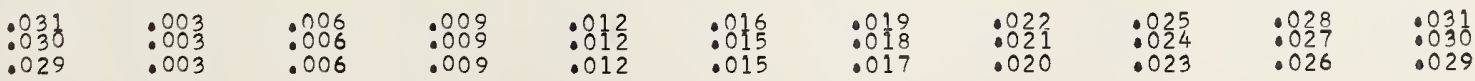


$\begin{array}{lllllllllll}5670.0 & 17631.792 & 31.760 & 31.729 & 31.698 & 31.667 & 31.636 & 31.605 & 31.574 & 31.543 & 31.512\end{array}$ $\begin{array}{lllllllllll}0.1 & 31.481 & 31.450 & 31.418 & 31.388 & 31.356 & 31.325 & 31.294 & 31.263 & 31.232 & 31.201 \\ 0.2 & 31.170 & 31.139 & 31.107 & 31.076 & 31.04 & 31.014 & 30.983 & 30.952 & 30.921 & 30.890\end{array}$ $\begin{array}{llllllllllll}0.3 & 30.859 & 30.828 & 30.797 & 30.766 & 30.735 & 30.703 & 30.672 & 30.641 & 30.610 & 30.579\end{array}$ $\begin{array}{lllllllllll}0.4 & 30.548 & 30.517 & 30.486 & 30.455 & 30.424 & 30.393 & 30.361 & 30.330 & 30.299 & 30.268\end{array}$ $\begin{array}{lllllllllll}0.5 & 30.237 & 30.206 & 30.175 & 30.144 & 30.113 & 30.082 & 30.051 & 30.020 & 29.988 & 29.957\end{array}$

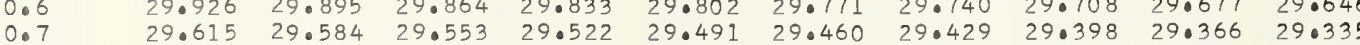
$29.30429 .273 \quad 29.242 \quad 29.211 \quad 29.180 \quad 20.149 \quad 29.118 \quad 29087 \quad 29.056 \quad 290025$ 0.9 $28.372 \quad 28.341$ $28.621 \quad 28.590$ $\begin{array}{llllllllll}28.061 & 28.030 & 27.999 & 27.968 & 27.937 & 27.906 & 27.875 & 27.844 & 27.812 & 27.781 \\ 27.750 & 27.719 & 27.688 & 27.657 & 27.626 & 27.595 & 27.564 & 27.532 & 27.502 & 27.470\end{array}$ $\begin{array}{llll}28.310 & 28.279 & 28.559 & 28.527 \\ 28.248 & 28.217\end{array}$

$28.496 \quad 28.465 \quad 28.434 \quad 28.403$ $\begin{array}{lllllllll}27.408 & 27.377 & 27.346 & 27.315 & 27.284 & 27.564 & 27.532 & 27.502 & 27.470\end{array}$ $\begin{array}{llllllllll}27.129 & 27.098 & 27.067 & 27.035 & 27.004 & 26.973 & 26.942 & 26.911 & 26.880 & 26.849\end{array}$ $\begin{array}{lll}.6 & 26.818 & 26.787\end{array}$ $25.885 \quad 25.854$

2.1
2.2
2.32

2.4

2.5

2.7

2.8

$17625.575 \quad 25.544$ $26.134 \quad 26.103$

$26: 694 \quad 26.663$

$26.631 \quad 26.600 \quad 26.569 \quad 26.538$

25.264

$\begin{array}{ll}25.264 & 25 \cdot 233 \\ 24.953 & 24.922\end{array}$

25.51

25.481

$26.072-26.041$

$\begin{array}{llll}26.321 & 26.290 & 26.258 & 26.227\end{array}$

24.64324 .611

$24.021 \quad 23.990$

$\begin{array}{llllllllll}24.021 & 23.990 & 23.959 & 23.928 & 23.897 & 23.866 & 23.835 & 23.804 & 23.773 & 23.742 \\ 23.710 & 23.679 & 23.648 & 23.617 & 23.586 & 23.555 & 23.524 & 23.493 & 23.462 & 23.431\end{array}$

24.891

24.860

$25.450 \quad 25.419$

$25.699 \quad 25.668 \quad 25.637 \quad 25.606$

0.277506

0.277505

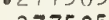

0.277505

0.277504

0.277504

1.573458

$\begin{array}{lllllllll}23.369 & 23.338 & 23.307 & 23.275 & 23.244 & 23.214 & 23.182 & 23.151 & 23.120\end{array}$

673.0

3.1

17622.468

3.2

$3 \cdot 3$

3.5

3.7

3.8

622.468

22.437

23.027
22.716

22.685

$\begin{array}{ll}22.965 & 22.934 \\ 22.654 & 22.623\end{array}$

$\begin{array}{llll}22.903 & 22.872 & 22.841 & 22.810\end{array}$

0.277504

0.277504

0.277504

0.277503

0.277503

0.277503

0.277502

1.573485

1.573538

1.573592

1.573618

1.573645
1.573672

1.573699

74.0

$\begin{array}{rrrrr}674.0 & 17619.362 & 19.331 & 19.300 & 19.269 \\ 4.1 & 19.052 & 19.021 & 18.990 & 18.958 \\ 4.2 & 18.741 & 18.710 & 18.679 & 18.648 \\ 4.3 & 18.430 & 18.399 & 18.368 & 18.337 \\ 4.4 & 18.120 & 18.089 & 18.058 & 18.027 \\ 4.5 & 17.809 & 17.779 & 17.748 & 17.716 \\ 4.6 & 17.499 & 17.468 & 17.437 & 17.406 \\ 4.7 & 17.189 & 17.157 & 17.126 & 17.095 \\ 4.8 & 16.878 & 16.847 & 16.816 & 16.785 \\ 4.9 & 16.568 & 16.537 & 16.506 & 16.475\end{array}$

5675

5.1
5.2
5.03

5.3
5.4
5.5

5.5
5.6

5.8

$\begin{array}{lllll}21.847 & 21.816 & 21.784 & 21.753 \\ 21.536 & 21.505 & 21.474 & 21.443\end{array}$

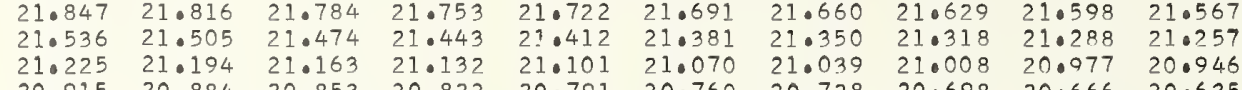

$\begin{array}{llllll}2.344 & 22.312 & 22.281 & 22.250 & 22.219 & 22.188\end{array}$ $\begin{array}{llllllllll} & 20.81 & 20.977 & 20.946 \\ \end{array}$ $\begin{array}{llllllllll}20.294 & 20.263 & 20.232 & 20.200 & 20.169 & 20.138 & 20.107 & 20.076 & 20.045 & 20.014 \\ 19.983 & 19.952 & 19.921 & 19.890 & 19.859 & 19.828 & 19.797 & 19.766 & 19.735 & 19.704\end{array}$ $\begin{array}{llllllllll}19.983 & 19.952 & 19.921 & 19.890 & 19.859 & 19.828 & 19.797 & 19.766 & 19.735 & 19.704 \\ 19.673 & 19.642 & 19.611 & 19.579 & 19.549 & 19.517 & 19.486 & 19.455 & 19.424 & 19.393\end{array}$

$17616.257 \quad 16.226 \quad 16.195 \quad 16.164$

$\begin{array}{llllll}19.238 & 19.207 & 19.176 & 19.145 & 19.114 & 19.083\end{array}$

$\begin{array}{llllll}18.617 & 18.586 & 18.555 & 18.524 & 18.493 & 18.461\end{array}$

$\begin{array}{llllll}18.306 & 18.275 & 18.244 & 18.213 & 18.182 & 18.151 \\ 17.996 & 17.965 & 17.934 & 17.903 & 17.872 & 17.841\end{array}$

$\begin{array}{llllll}17.685 & 17.654 & 17.623 & 17.903 & 17.872 & 17.841 \\ 17.575 & 17.6344 & 17.313 & 17.592 & 17.561 & 17.530\end{array}$

$\begin{array}{llllll}17.375 & 17.344 & 17.313 & 17.282 & 17.250 & 17.220 \\ 17.064 & 17.033 & 17.002 & 16.971 & 16.940 & 16.909\end{array}$

$\begin{array}{llllll}16.754 & 16.723 & 16.692 & 16.661 & 16.630 & 16.599\end{array}$

0.277502

0.277502
0.277502

0.277502

0.277501

0.277501

0.277501

1. 573725

1.573752
1.573779

1.573806
1.573832

1.573859

1.573886
1.573913

1.573939
1.573966

0.277500

0.277500

0.277500
0.277500

0.277500

0.277500

0.777499

0.277499

1.573993

1.574020

1. 594073

1.574100
1.574127

1.574153

1.574180

1.574207
1.574234

1.574260

1.574314

1.574341

1. 574367

1.574394

1.574394
1.574421

1.574474

0.277499

0.277499

0.27749

0.277498

0.2774498
0.277498

0.277498

0.277497

1.574501

0.277497

1.574528

1.574554

1.574581
1.574608

1.574635

1.574661
1.574688

1.574715
1.574742

$0.277497 \quad 1.574795$

0.277497

0.277497

0.277496
0.277496

0.277496
0.277496
0.277406

0.277406

0.277496

0.277496
C. 277405

1.574822

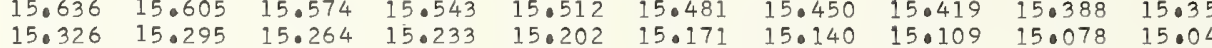

$\begin{array}{llllllllll}15.016 & 14.985 & 14.954 & 14.923 & 14.892 & 14.861 & 14.830 & 14.799 & 14.768 & 14.736\end{array}$

$\begin{array}{llllllllll}14.395 & 14.364 & 14.333 & 14.302 & 14.271 & 14.240 & 14.209 & 14.178 & 14.147 & 14.116\end{array}$

$\begin{array}{llllllllll}13.774 & 13.743 & 13.712 & 13.681 & 13.650 & 13.619 & 13.898 & 13.867 & 13.836 & 13.805 \\ 13.464 & 13.433 & 13.402 & 13.371 & 13.340 & 13.309 & 13.588 & 13.557 & 13.526 & 13.495\end{array}$

5676.0

6.1
6.2
6.3

6.4

6.6

6.8

$17613.154 \quad 13.123 \quad 13.092$

$12.844 \quad 12.812 \quad 13.092 \quad 13.061$

$\begin{array}{llllllllll}12.844 & 12.812 & 12.781 & 12.750 & 12.719 & 12.688 & 12.657 & 12.626 & 12.595 & 12.564 \\ 12.533 & 12.502 & 12.471 & 12.440 & 12.409 & 12.378 & 12.347 & 12.316 & 12.285 & 12.254 \\ 12.223 & 12.192 & 12.161 & 12.130 & 12.099 & 12.068 & 12.037 & 12.006 & 11.975 & 11.944\end{array}$

$\begin{array}{lllllllll} & 12.161 & 12.130 & 17.099 & 12.068 & 12.037 & 12.006 & 11.975 & 11.944\end{array}$

$\begin{array}{llllllllll}11.912 & 11.881 & 11.850 & 11.819 & 11.789 & 11.757 & 11.726 & 11.695 & 11.664 & 11.633 \\ 11.602 & 11.571 & 11.540 & 11.509 & 11.478 & 11.447 & 11.416 & 11.385 & 11.354 & 11.323\end{array}$

$\begin{array}{llllllllll}11.292 & 11.261 & 11.230 & 11.199 & 11.168 & 11.137 & 11.106 & 11.075 & 11.044 & 11.013\end{array}$

$\begin{array}{llllllllll}10.672 & 10.641 & 10.609 & 10.578 & 10.547 & 10.827 & 10.796 & 10.765 & 10.734 & 10.703 \\ & 10.516 & 10.485 & 10.454 & 10.423 & 10.392\end{array}$

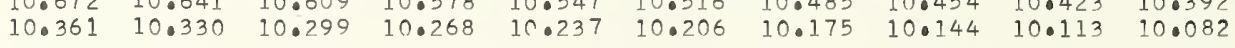

0.277495

0.277495

0.277495

0.277495
0.277494

0.2774904

0.277494
0.277404

0.27749

$0 . ? 77494$

1.574849
1.574875

1.574902

1. 574929

1. 574956

1.574982
1.575009

1.575063

1.57508

1.575116

1.575143
1.575170

1.575170
1.575196

1.57522 ?

1.575250
1.575277

$\begin{array}{lllllllllll}5677.0 & 17610.051 & 10.020 & 09.989 & 09.958 & 09.927 & 09.896 & 09.865 & 09.834 & 09.803 & 09.772\end{array}$

$\begin{array}{lllllllllll}7.1 & 09.741 & 09.710 & 09.679 & 09.648 & 09.617 & 09.586 & 09.555 & 09.524 & 09.493 & 09.462 \\ 7.2 & 09.431 & 09.400 & 09.369 & 09.338 & 09.307 & 09.276 & 09.245 & 09.214 & 09.183 & 09.152\end{array}$

$\begin{array}{lllllllllll}7.3 & 09.431 & 09.400 & 09.369 & 09.338 & 09.307 & 09.276 & 09.245 & 09.214 & 09.183 & 09.152 \\ 7 & 09.089 & 09.059 & 09.028 & 08.997 & 08.966 & 08.934 & 08.903 & 08.873 & 08.842 \\ 7 & 08.81 & 08.780 & 08.748 & 08.717 & 08.687 & 08.656 & 08.625 & 08.594 & 08.562 & 08.531\end{array}$

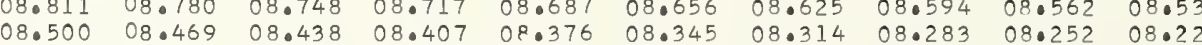

7.6

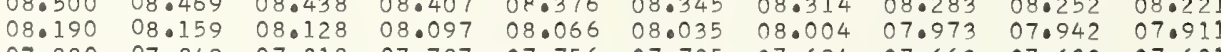

7.8
7.9

$07.570 \quad 07.549 \quad 07 \cdot 818 \quad 07 \cdot 787$

$\begin{array}{llllll}07.756 & 07.725 & 07.694 & 07.663 & 07.632 & 07.601\end{array}$

$\begin{array}{llllllllll}07.570 & 07.539 & 07.508 & 07.477 & 07.446 & 07.415 & 07.384 & 07.353 & 07.322 & 07.291 \\ 07.260 & 07.229 & 07.198 & 07.167 & 07.136 & 07.105 & 07.074 & 07.043 & 07.012 & 06.980\end{array}$

0.27749

0.277493

0.27749

0.277493

0.277493

0.277492

0.277492

0.277492

1.575330

1.575330
1.575357

1.575383
1.575410

1.575437

1.575464
1.575490

1.575517

$\begin{array}{llllllllllll}5678.0 & 17606.949 & 06.919 & 06.888 & 06.857 & 06.826 & 06.795 & 06.764 & 06.733 & 06.702 & 06.671\end{array}$

$\begin{array}{lllllllllll}8.1 & 06.640 & 06.609 & 06.578 & 06.547 & 06.516 & 06.484 & 06.453 & 06.422 & 06.391 & 06.361\end{array}$

$\begin{array}{lllllllllll}8.3 & 06.020 & 05.989 & 05.958 & 05.927 & 05.896 & 05.865 & 05.833 & 05.802 & 05.771 & 05.740\end{array}$

$\begin{array}{llllllllll}04.159 & 04.128 & 04.097 & 04.066 & 04.035 & 04.004 & 03.973 & 04.252 & 04.221 & 04.190 \\ 0.942 & 03.911 & 03.880\end{array}$

0.27749

1.575597

$0.277491 \quad 1.575651$

0.277491

0.27749

0.27749

0.277490

0.277490

1.575704

1.575758

1.575785

0.277490

1.575838

$\begin{array}{lllllllllll}5679.0 & 17603.849 & 03.818 & 03.787 & 03.756 & 03.725 & 03.694 & 03.663 & 03.632 & 03.601 & 03.570\end{array}$

$\begin{array}{lllllllllll}9.1 & 03.539 & 03.508 & 03.477 & 03.447 & 03.415 & 03.384 & 03.353 & 03.322 & 03.291 & 03.260 \\ 9.2 & 03.229 & 03.198 & 03.167 & 03.136 & 03.105 & 03.074 & 03.044 & 03.013 & 02.982 & 02.951\end{array}$

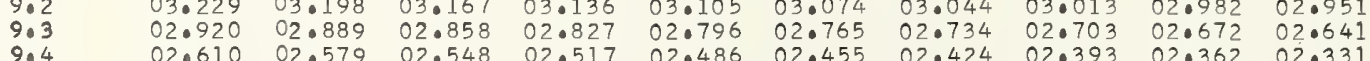

9.4

9.5

$\begin{array}{llllllllll}02.300 & 02.579 & 02.548 & 02.517 & 02.486 & 02.455 & 02.424 & 02.393 & 02.362 & 02.331 \\ 02.238 & 02.207 & 02.176 & 02.145 & 02.114 & 02.083 & 02.052 & 02.021\end{array}$

$\begin{array}{lllllllllll}9.6 & 01.990 & 01.959 & 01.928 & 01.897 & 01.866 & 01.835 & 01.804 & 01.773 & 01.742 & 01.711 \\ 9.7 & 01.680 & 01.649 & 01.618 & 01.587 & 01.556 & 01.525 & 01.494 & 01.463 & 01.432 & 01.401\end{array}$

9.9

$01.370 \quad 01.33901 .308 \quad 01.277$

$1.246 \quad 01.215$

$\begin{array}{llll}01.494 & 01.463 & 01.432 & 01.401\end{array}$

$.001 \quad .002$

.003

.004

.005

00.87

$0.843 \quad 00.812 \quad 00.781$

0.277490

0.277489
0.277489

0.27748

0.277489

0.277489

1.575865
1.575892

1.575892
1.575918

1.575945

1.575999

1.576025

$0.277488 \quad 1.576079$

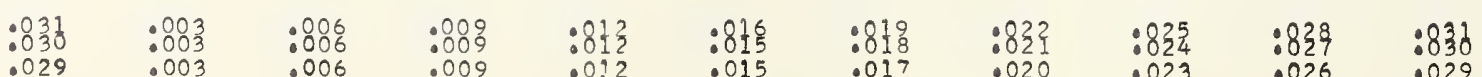


$\begin{array}{rrrrrrrrrrr}0.1 & 00.440 & 00.419 & 00.688 & 00.657 & 00.626 & 00.595 & 00.564 & 00.533 & 00.507 & 00.471 \\ 0.1 & 00.478 & 00.348 & 00.347 & 00.317 & 00.286 & 00.255 & 00.224 & 00.193 & 00.162\end{array}$

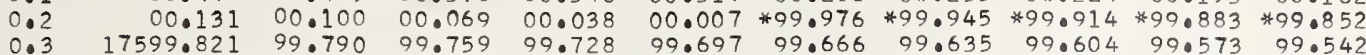

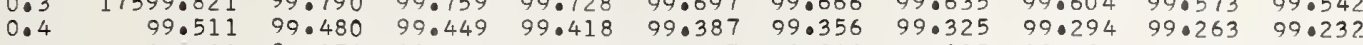

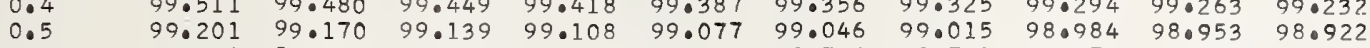
$\begin{array}{lllllllllll}0.6 & 98.891 & 98.860 & 98.829 & 98.799 & 98.768 & 98.736 & 98.705 & 98.674 & 98.643 & 98.613\end{array}$

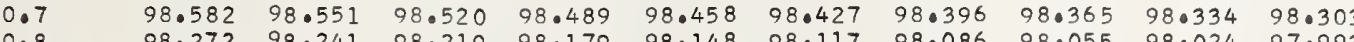
$\begin{array}{lllllllllll}0.8 & 98.272 & 98.241 & 98.210 & 98.179 & 98.148 & 98.117 & 98.086 & 98.055 & 98.024 & 97.993\end{array}$

.277488

0.277488

0.277488

0.277487

0.277487

0.277487

0.277486

5681.0

$17597.652 \quad 97.621$

$97.342 \quad 97 \cdot 311$

$96.723 \quad 96.692$

$96.104 \quad 96.073$

95.79495 .763

$\begin{array}{ll}95.484 & 95.453 \\ 95.174 & 95.143\end{array}$

97.590
97.280
96.971
96.561
96.351
96.042
95.732
95.422
95.113
94.803

97.559
97.250

$\begin{array}{llllll}97.528 & 97.497 & 97.466 & 97.436 & 97.405 & 97.373 \\ 97.219 & 97.187 & 97.156 & 97.125 & 97.094 & 97.064\end{array}$

$94.865 \quad 94.834 \quad 94.803 \quad 94.772$

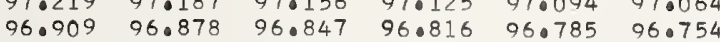

$\begin{array}{llllll}96.599 & 96.568 & 96.537 & 96.506 & 96.475 & 96.444\end{array}$

$\begin{array}{llllll}97.289 & 96.258 & 96.227 & 96.196 & 96.166 & 96.135 \\ 95.979 & 95.948 & 95.917 & 95.887 & 95.856 & 95.825\end{array}$

$\begin{array}{rlllll}95.670 & 95.639 & 95.608 & 95.577 & 95.546 & 95.515\end{array}$

$\begin{array}{llllll}95.360 & 95.329 & 95.298 & 95.267 & 95.236 & 95.205\end{array}$

1.9

5682.

$$
\begin{array}{r}
82.0 \\
2.1 \\
2.2 \\
2.3 \\
2.4 \\
2.5 \\
2.6 \\
2.7 \\
2.8 \\
2.9
\end{array}
$$

$17594.555 \quad 94.524 \quad 94$

$94.245 \quad 94.214 \quad 94.183 \quad 94.153 \quad 940$

$93.936 \quad 93.905$

$93.316 \quad 93.285$

$92.697 \quad 92.666$

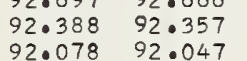

$93.874 \quad 93.843$

$\begin{array}{ll}.564 & 93.533 \\ 3.254 & 93.223\end{array}$

$\begin{array}{llllll}94.741 & 94.0710 & 94.979 & 94.958 & 94.927 & 94.8896 \\ & & & & 94.617 & 94.586\end{array}$

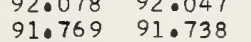

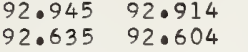

$\begin{array}{ll}2.635 & 92.604 \\ 2.326 & 92.295 \\ 2.016 & 91.985\end{array}$

$94.122 \quad 94.4001$

94.369

$\begin{array}{lll}94.338 & 94.307 & 94.276\end{array}$

$\begin{array}{llllll}9.812 & 93.781 & 93.750 & 93.719 & 93.688 & 93.657\end{array}$

$\begin{array}{llllll}93.502 & 93.471 & 93.440 & 93.409 & 93.379 & 93.348\end{array}$

$\begin{array}{llllll}92.883 & 92.852 & 92.821 & 92.790 & 92.759 & 92.728\end{array}$

$\begin{array}{llllll}92.573 & 92.542 & 92.511 & 92.480 & 92.449 & 92.419\end{array}$

5683.0

3.
$3:$
$3:$
$3:$
$3:$
$3:$
3.

$91.459 \quad 91.428$

$91.149 \quad 91.118 \quad 91.087 \quad 91.057$

$\begin{array}{llll}90.530 & 90.809 & 90.778 & 90.747 \\ 90.499 & 90.469 & 90.437\end{array}$

$\begin{array}{llll}90.221 & 90.190 & 90.159 & 90.128 \\ 89.911 & 89.880 & 89.850 & 89.819\end{array}$

$89.911 \quad 89.88$

$\begin{array}{llll}89.602 & 89.571 & 89.540 \quad 89.509\end{array}$

$88.983 \quad 88.952$

$\begin{array}{ll}89.540 & 89.509 \\ 89.230 & 89.199\end{array}$

$88.674 \quad 88.643$

5684.0

$\begin{array}{rr}588.364 & 88.3 \\ 88.055 & 88.02 \\ 87.745 & 87.714\end{array}$

$\begin{array}{llllllllll}87.745 & 87.714 & 87.683 & 87.652 & 87.621 & 87.591 & 87.560 & 87.529 & 87.498 & 87.467 \\ 87.436 & 87.405 & 87.374 & 87.343 & 87.312 & 87.281 & 87.250 & 87.219 & 87.188 & 87.157\end{array}$

88.612

89.447

.168
89.138
8.859
88.828

92.202
91.892

$92.171 \quad 92.140 \quad 92.109$

.277486
.277486

-1
-77486

0.277486

0.277486

0.277485

0.277485

0.277485

0.277485

0.277484

0.277484

0.277484

0.277483

0.277483

0.277483

0.277483

0.277483

0.277482

0.277482

0.277482

0.277482

0.277481

0.277481

0.277481

$\begin{array}{llllllllll}87.126 & 87.095 & 87.064 & 87.033 & 87.003 & 86.972 & 86.941 & 86.910 & 86.870 & 86.848\end{array}$

$86.817 \quad 86.786-86.755 \quad 86.724$

$86.508 \quad 86.477 \quad 86.446 \quad 86.415$

$\begin{array}{llll}86.198 & 86 \cdot 167 & 86.136 & 86.105 \\ 85.889 & 85.858 & 85.827 & 85.796\end{array}$

$85.580 \quad 85.549$

5685.0

$5 \cdot 1$

17585

$\begin{array}{llll}85.270 & 85.240 & 85.208 & 85.177 \\ 84.961 & 84.930 & 84.899 & 84.868\end{array}$

$84.652 \quad 84.621 \quad 84.590 \quad 84.559$

$84.342 \quad 84.311$

$83.724 \quad 83.693$

$82.796 \quad 82.765 \quad 83.734 \quad 82.703$

$\begin{array}{ll}82.796 & 82.765 \\ 82.487 & 82.456\end{array}$

$82.734 \quad 82.703$

$\begin{array}{llllll}86.684 & 86.662 & 86.631 & 86.601 & 86.570 & 86.539\end{array}$

$\begin{array}{llllll}86.074 & 86.044 & 86.013 & 85.982 & 85.951 & 85.920\end{array}$

0.277480

0.277480

0.277480

0.277480

1.576132

1.576186

.576239
1.576266

1.576293

1.576346

1.576400

.576480

.576533
.576560

1.576587

1.576640

.576667

1.576721

1.576774

.576801

1.576854

1.576881

1.576935

1.576961

1.577015

1. 577068

1.577068
1.577095
1.577122

1.577149

0.277479

0.2774779
0.277479
0.277479

0.277479

0.277478

0.277478
0.277478

0.277478

0.277477
0.277477

5686

6.

$\begin{array}{rr}81.868 & 81.8 \\ 81.559 & 81.528\end{array}$

$82.116 \quad 82.085$

$\begin{array}{llllll}.800 & 83.569 & 83.538 & 83.507 & 83.476 & 83.446\end{array}$

$\begin{array}{llllll}.981 & 82.950 & 82.920 & 82.889 & 82.858 & 82.827\end{array}$

$82.054 \quad 82.023 \quad 81.992 \quad 81.961 \quad 81.930 \quad 81.899$

$\begin{array}{llllllllll}81.868 & 81.837 & 81.807 & 81.776 & 81.745 & 81.714 & 81.683 & 81.652 & 81.621 & 81.590 \\ 81.559 & 81.528 & 81.497 & 81.466 & 81.435 & 81.405 & 81.374 & 81.343 & 81.312 & 81.281 \\ 81.250 & 81.219 & 81.188 & 81.157 & 81.126 & 81.095 & 81.064 & 81.033 & 81.003 & 80.972\end{array}$

$\begin{array}{llllllllll} & \end{array}$

$\begin{array}{llllllllll}80.632 & 80.601 & 80.570 & 80.539 & 80.508 & 80.477 & 80.446 & 80.415 & 80.384 & 80.353\end{array}$

$\begin{array}{llllllllll}80.322 & 80.292 & 80.260 & 80.230 & 80.199 & 80.168 & 80.137 & 80.106 & 80.075 & 80.044 \\ 80.013 & 79.982 & 79.951 & 79.921 & 79.890 & 79.859 & 79.828 & 79.797 & 79.766 & 79.735\end{array}$

$\begin{array}{llllllllll}79.704 & 79.673 & 79.642 & 79.611 & 79.581 & 79.550 & 79.519 & 79.488 & 79.457 & 79.426 \\ 79.395 & 79.364 & 79.333 & 79.302 & 79.271 & 79.240 & 79.210 & 79.179 & 79.148 & 79.117\end{array}$

6.8

5687.0

$\begin{array}{lllllll}78.962 & 78.931 & 78.900 & 78.870 & 78.839 & 78.808\end{array}$

$\begin{array}{lllllllllll}78.468 & 78.437 & 78.406 & 78.375 & 78.344 & 78.313 & 78.282 & 78.251 & 78.220 & 78.189\end{array}$

$\begin{array}{llllllllll}78.850 & 77.128 & 78.097 & 78.066 & 78.035 & 78.004 & 77.973 & 77.942 & 77.911 & 77.881 \\ 77.788 & 77.757 & 77.726 & 77.695 & 77.664 & 77.633 & 77.602 & 77.571\end{array}$

$\begin{array}{lllllllllll}77.540 & 77.510 & 77.479 & 77.448 & 77.417 & 77.386 & 77.355 & 77.324 & 77.293 & 77.262\end{array}$

$\begin{array}{llllllllll}77.231 & 77.200 & 77.170 & 77.139 & 77.108 & 77.077 & 77.046 & 77.015 & 76.984 & 76.953\end{array}$

$\begin{array}{llllllllll}76.923 & 76.892 & 76.861 & 76.830 & 76.799 & 76.768 & 76.737 & 76.706 & 76.675 & 76.645 \\ 76.014 & 76.583 & 76.552 & 76.521 & 76.490 & 76.459 & 76.428 & 76.397 & 76.366 & 76.336\end{array}$

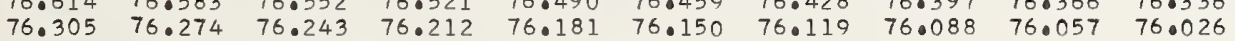

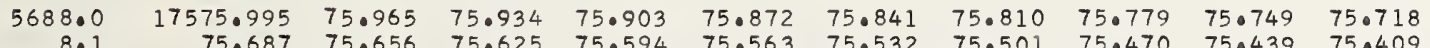

$\begin{array}{llllllllllll}8.1 & 75.687 & 75.656 & 75.625 & 75.594 & 75.563 & 75.532 & 75.501 & 75.470 & 75.439 & 75.409 \\ 8.2 & 75.378 & 75.347 & 75.316 & 75.285 & 75.254 & 75.223 & 75.192 & 75.161 & 75.130 & 75.100\end{array}$

$\begin{array}{llllllllllll}8.3 & 75.069 & 75.038 & 75.007 & 74.976 & 74.945 & 74.914 & 74.883 & 74.852 & 74.822 & 74.791\end{array}$

$\begin{array}{llllllllllll}8.4 & 74.760 & 74.729 & 74.698 & 74.667 & 74.636 & 74.605 & 74.574 & 74.543 & 74.512 & 74.481 \\ 8.5 & 74.451 & 74.420 & 74.389 & 74.358 & 74.327 & 74.296 & 74.265 & 74.235 & 74.204 & 74.173\end{array}$

$\begin{array}{lllllllllll}8.5 & 74.451 & 74.420 & 74.389 & 74.358 & 74.327 & 74.296 & 74.265 & 74.235 & 74.204 & 74.173 \\ 8.6 & 74.142 & 74.111 & 74.080 & 74.049 & 74.018 & 73.987 & 73.956 & 73.926 & 73.895 & 73.864\end{array}$

$\begin{array}{lllllllllll}8.7 & 73.833 & 73.802 & 73.771 & 73.740 & 73.709 & 73.678 & 73.648 & 73.617 & 73.586 & 73.555 \\ 8.8 & 73.524 & 73.493 & 73.462 & 73.431 & 73.400 & 73.370 & 73.339 & 73.308 & 73.277 & 73.046\end{array}$

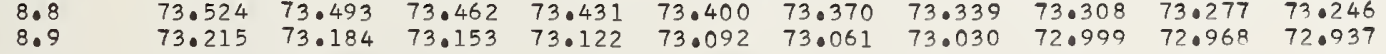

$\begin{array}{lllllllllll}5689.0 & 17572.906 & 72.875 & 72.844 & 72.813 & 72.783 & 72.752 & 72.721 & 72.690 & 72.659 & 72.628\end{array}$

$\begin{array}{lllllllllll}9.1 & 72.597 & 72.566 & 72.535 & 72.505 & 72.474 & 72.443 & 72.412 & 72.381 & 72.350 & 72.319 \\ 9.2 & 72.289 & 72.258 & 72.227 & 72.196 & 72.165 & 72.134 & 72.103 & 72.072 & 72.042 & 72.010\end{array}$

$\begin{array}{lllllllllll}9.2 & 72.289 & 72.258 & 72.227 & 72.196 & 72.165 & 72.134 & 72.103 & 72.072 & 72.042 & 72.010 \\ 9.3 & 71.979 & 71.948 & 71.918 & 71.887 & 71.856 & 71.825 & 71.794 & 71.763 & 71.732 & 71.702\end{array}$

$\begin{array}{lllllllllll}9.4 & 71.671 & 71.640 & 71.609 & 71.578 & 71.547 & 71.516 & 71.485 & 71.455 & 71.424 & 71.393 \\ 9.5 & 71.362 & 71.331 & 71.300 & 71.269 & 71.238 & 71.207 & 71.176 & 71.146 & 71.115 & 71.084\end{array}$

$\begin{array}{lllllllllll}9.5 & 71.362 & 71.331 & 71.300 & 71.269 & 71.238 & 71.207 & 71.176 & 7.146 & 71.115 & 71.084 \\ 9.6 & 71.053 & 71.022 & 70.991 & 70.960 & 70.929 & 70.899 & 70.868 & 70.837 & 70.806 & 70.775\end{array}$

$\begin{array}{llllllllllll}9.7 & 70.744 & 70.713 & 70.682 & 70 & 552 & 70.521 & 70.590 & 70.559 & 70.528 & 70.497 & 70.466\end{array}$

$\begin{array}{llllllllllll}9.8 & 70.435 & 70.404 & 70.374 & 70.343 & 70.312 & 70.281 & 70.250 & 70.219 & 70.188 & 70.157\end{array}$

0.277477

0.277477

0.277477
0.277476

0.277476

0.277476
0.277476

1.577202
1.577229

1.597256

.0577309

1.577363

1.5773689
1.577416

0.277476

0.277476

0.277475
0.277475

0.277475

0.2774755

0.277475
0.277474

0.277474
0.277474

.577470

1.577496

1.577550

1.577576
1.577603

1.577630
1.577657

1.577683

0.277474

0.277474
0.277474

0.277474

0.277473

0.277473
0.277473

0.277473

0.277473
0.277472

1.577737

.577790

1.577817
1.577844

. 577871

1.577897

1.577951
1.577978

0.277472

0.2774472
0.277472

0.277472

0.277471

0.27747

0.277471
0.277471

1.578004

1.578031
1.578058

1.578085

1.578111
1.578138

1.578165

1.578192
1.578218

1.578272
1.578299

1.578325

1.578352
1.578379

1.578406

1.578432
1.578459

1. 578486

1. 578539

1.578566
1.578593

1.578620
1.578646

1.578673
1.578700

1.578727
1.578753

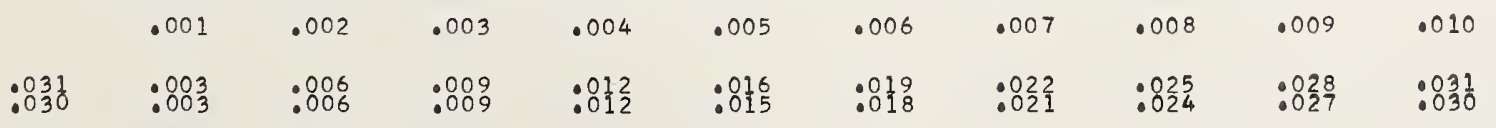


0.277470

0.277470

0.277469

0.277469

0.277469

1.578834

1.578860
1.578887

1.578914

1.578941
1.578967

1.579021

0.277469 $\begin{array}{rlllllllll}7566.730 & 66.700 & 66.669 & 66.638 & 66.607 & 66.576 & 66.545 & 66.514 & 66.483 & 66.453 \\ 66.422 & 66.391 & 66.360 & 66.329 & 66.298 & 66.268 & 66.237 & 66.206 & 66.175 & 66.144\end{array}$ $\begin{array}{llllllllll}66.113 & 66.082 & 66.052 & 66.021 & 65.990 & 65.959 & 65.928 & 65.897 & 65.866 & 65.835\end{array}$ $\begin{array}{lllllllllll}65.804 & 65.773 & 65.743 & 65.712 & 65.681 & 65.650 & 65.619 & 65.588 & 65.558 & 65.527\end{array}$ $\begin{array}{llllllllll}65.496 & 65.465 & 65.434 & 65.403 & 65.373 & 65.342 & 65.311 & 65.280 & 65.249 & 65.218 \\ 65.187 & 65.156 & 65.125 & 65.094 & 65.064 & 65.033 & 65.002 & 64.971 & 64.940 & 64.909\end{array}$ $64.879 \quad 64.848 \quad 64.817 \quad 64.786$

$$
\begin{array}{r}
7563.6 \\
63.3 \\
63.0 \\
62.7 \\
62.4 \\
62.1 \\
61.7 \\
61.4 \\
61.1 \\
60.8
\end{array}
$$$$
2
$$$$
\begin{array}{r}
5693 \\
3 \\
30 \\
30 \\
30 \\
305 \\
306 \\
307
\end{array}
$$

3.01
302
303
304
305
306
30.7
30.8
3.9

$$
\begin{array}{rll}
17560.559 & 60.528 & 60 . \\
60.251 & 60.220 & 60 \\
59.042 & 59.911 & 5 \\
59.634 & 59.603 & 5 \\
59.325 & 59.295 & 5 \\
59.017 & 58.986 & 58 \\
58.708 & 58.678 & 58 \\
58.400 & 58.369 & 58 \\
58.092 & 58.061 & 58
\end{array}
$$

.2
.3
.4

4.5
4.6
4.7

$$
\begin{array}{llll}
56.550 & 56.519 & 56 \\
56.242 & 56.211 & 58.1 \\
55.243 & 55 & 503 & 55.8
\end{array}
$$$$
\begin{array}{ll}
56.242 & 56.211 \\
55.933 & 55.903 \\
55.625 & 55.594
\end{array}
$$$$
55.317 \quad 55.286
$$

550009
54.700

17554.392
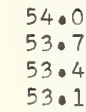

$53.159 \quad 53.128$

$\begin{array}{lll}52.543 & 52.052 \\ 52.522\end{array}$

$$
\begin{array}{lll}
52.543 & 52.012 & 52.048 \\
52.235 & 52.204 & 52.173 \\
51.027 & 51.806 & 51.065 \\
511028 & 51.807 & 51.057
\end{array}
$$

$$
\begin{aligned}
& 47.922 \\
& 47.614 \\
& 47.306
\end{aligned}
$$

$44.534 \quad 44.503$

$\begin{array}{lll}44.226 & 44.19 \\ 43.918 & 43.887\end{array}$

$$
\begin{array}{ll}
43.610 & 43.580 \\
43.303 & 43.272 \\
42.005 & 42.064
\end{array}
$$

1. 580144 1.580171 1.580198 1.580224
1.580251 1.580278 1.580305
1.580331 1. 580358 1.580412 1.580438 1.580465
1.580492 1.580519 1.580545
1.580572 1.580572
1.580599 1.580626
1.580652

1.580679

1.580706 1.580733
1.580759 1.580786 1.580813
1.580839 1.580839 1.580866
1.580893
1.580920 1.580946 1.580973
1.581000 1.581027 1.581080 1.581080
1.581107 1.581107
1.581134
1.581160 1.581187

1.581214 1.581241
1.581267 1.581267
1.581294 1.581321
1.581348 1.581348
1.581374 1.581374 1.581401
1.581428

.010

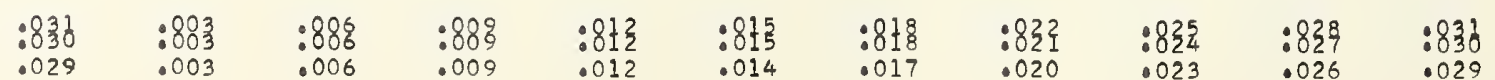




\section{$\begin{array}{ll}35.610 & 35.579 \\ 35.302 & 35.27\end{array}$}

$\begin{array}{ll}35.302 & 35.271 \\ 34.994 & 34.964\end{array}$

$\begin{array}{ll}34.687 & 34.656\end{array}$

$\begin{array}{ll}34.379 & 34.349 \\ 34.072 & 34.041\end{array}$

$\begin{array}{ll}35.241 & 35.210 \\ 34.933 & 34.902\end{array}$

$\begin{array}{ll}34.933 & 34.902 \\ 34.625 & 34.595 \\ 34.318 & 34.287\end{array}$

35.763
35.794

35.733

35.702

$35.671 \quad 35.640$

$\begin{array}{ll}33.765 & 33.734 \\ 33.457 & 33.426\end{array}$

$\begin{array}{ll}34.010 & 33.980\end{array}$

$33.149 \quad 33.119$

5.179

$34.841 \quad 35.118$

$\begin{array}{lll}34.841 & 34.810 & 34.087\end{array}$

$4.256 \quad 34.226$

34.503
34.195
139

33.887

$.779 \quad 340749 \quad 350.718$

$340749 \quad 340718$
34.0414
34.010

0.277451

0.27745

0.277450

0.277450

0.277450

0.277450

$17532.842 \quad 32.811$

\subsection{2
2
2
2} 32.524
32.227
32.52
310.019

$\begin{array}{ll}32.781 & 32.750\end{array}$

$\begin{array}{ll}33.334 & 33.30\end{array}$

33.272
32.965

33.54
33.242

$33.826 \quad 33.795$

31.91931 .889

$\begin{array}{ll}31.612 & 31.581 \\ 31.305 & 31.274\end{array}$

$30.997 \quad 30.966$

$\begin{array}{ll}30.690 & 30.659 \\ 30.382 & 30.352 \\ 30.075 & 30.044\end{array}$

$32.166 \quad 32.135$

32.71

32.688
32.381

32.65
32.35

$32.627 \quad 32.596 \quad 32.565$

$\begin{array}{llll}31.551 & 31.827 & 31.797 & 31.766\end{array}$

$\begin{array}{llll}31.243 & 31.212 & 31.182 & 31.151\end{array}$

31.735

$32 . ?$
31.98

$529.768 \quad 29.737$

$30.628 \quad 30.598$

703.0

3.

$3 \cdot 2$

3.4

$3 \cdot 5$

3.7 $29.460 \quad 29.4$ $28.845 \quad 28.81$ $28.538 \quad 28.50$

$\begin{array}{ll}28.231 & 28.200 \\ 27.924 & 27.893\end{array}$

$27.616 \quad 27.585$ $-27.002$

5704.0

4.

17526.

26.69426.
26.387
26.35

$\begin{array}{ll}26.387 & 26.35 \\ 26.080 & 26.0\end{array}$

$\begin{array}{ll}25.773 & 25.742 \\ 25.465 & 25.435\end{array}$

$25.158 \quad 25.127$

$30.321 \quad 30.29$

$30.874 \quad 30.844$

$\begin{array}{lll}31.397 & 31.366 & 31.643\end{array}$

$24.851 \quad 24.820$

$29.706 \quad 29.675$

$30.259 \quad 30.22$

$\begin{array}{llll}31.00 & 31.02\end{array}$

$\begin{array}{llll}30.505 & 30.475 & 30.444 & 30.413\end{array}$

$30.198 \quad 30.167 \quad 30.136 \quad 30.106$

$\begin{array}{llllllll}29.092 & 29.061 & 29.030 & 28.999 & 28.969 & 28.938 & 28.907 & 28.876 \\ 28.784 & 28.753 & 28.723 & 28.692 & 28.661 & 28.630 & 28.600 & 23.569\end{array}$

$29.583 \quad 29.552 \quad 29.522 \quad 29.491$

$\begin{array}{llllllll}28.169 & 28.139 & 28.108 & 28.077 & 28.046 & 28.016 & 27.985 & 27.954 \\ 27.862 & 27.832 & 27.801 & 27.770 & 27.739 & 27.708 & 27.678 & 27.647\end{array}$

$24.544 \quad 24.513$

$\begin{array}{ll}24.237 & 24.206 \\ 23.930 & 23.899\end{array}$

$27.801 \quad 27.770$

$27.248 \quad 27.217$

$\begin{array}{ll}27.186 & 27.155 \\ 26.879 & 26.84\end{array}$

27.43
27.12

$26.633 \quad 26.602$

26.57

26.54

26.5102604

0.277449

0.277449

0.27744

0.277448

0.277448

0.27744

0.27744
0.27744

0.2777447
0.27744

0.277447

0.277446

0.277446
0.277446

0.277446

0.2777446

0.277445

$\begin{array}{lllllll} & 25.926 & 25.896 & 25 \cdot 865 & 25 \cdot 834 & 25.803\end{array}$

$5.404 \quad 25.373$

$25.343 \quad 25619$

$\begin{array}{lllll}25.588 & 25.557 & 25.527 & 25.496 \\ 25.281 & 25.250 & 25.019 & 25.189\end{array}$

$\begin{array}{ll} & \end{array}$

25.03525 .00

$\begin{array}{llll}24.974 & 24.943 & 24.912 & 24.882\end{array}$

$\begin{array}{lll}24.482 & 24.452 \\ & \end{array}$

4.8

5705

5.2

17523.62

$23.623 \quad 23.59$

$23.315 \quad 23.28423 .561$

.86823 .837

$\begin{array}{llllll}24.114 & 24.083 & 24.052 & 24.022 & 23.991 & 23.950\end{array}$

0.277445

0.277445
0.277445

0.277444

0.277444

0.277444

$\begin{array}{llllllllll}23.008 & 22.978 & 22.947 & 22.223 & 23.192 & 23.162 & 23.131 & 23.100 & 23.070 & 23.039 \\ 22.838 & 22.855 & 22.824 & 22.793 & 22.762 & 27.732\end{array}$

$22.394 \quad 22.363 \quad 22.333 \quad 22.302$

(1.780 21.749 21.718 21.687

$\begin{array}{ll}1.749 & 21.71\end{array}$

21.687

$22.578 \quad 22.547$

$\begin{array}{llllll}22.271 & 22.240 & 22.510 & 22.179 & 22.148 & 22.1 .17\end{array}$

21.16521 .13521 .104

1.104
0.797

5706

$\begin{array}{llll}0.552 & 20.521 & 20.490 & 20.4 \\ 0.244 & 20.214 & 20.183 & 20.1\end{array}$

6.

6.3

$19.630 \quad 19.906 \quad 19.876$

$\begin{array}{llll}9.323 & 19.293 & 19.262 & 19.23\end{array}$

$\begin{array}{llll}19.016 & 18.986 & 18.955 & 18.92 \\ 8.709 & 18.678 & 18.648 & 18.611\end{array}$

$\begin{array}{llll}18.402 & 18.372 & 18.341 & 18.310\end{array}$

$\begin{array}{llll}18.095 & 18.064 & 18.034 & 18.003 \\ 17.788 & 17.758 & 17.727 & 17.696\end{array}$

$\begin{array}{llllll}21.657 & 21.626 & 21.595 & 21.565 & 21.534 & 21.503\end{array}$

0.27744

0.277443

0.277443

0.277443

0.277443
0.277443

0.277442

0.277442

0.277442

0.27744 ?

0.277441

0.277441

0.277441

0.277441

0.277440

0.277440

0.277440

0.277440

0.277439

0.2774439
0.277439

0.277439

0.277439

0.277439

0.277438

$0 . ? 77438$

0.277438

0.277438

0.277437

0.277437

0.277436

0.277436

0.277436

58156

1.581588

1.581669
1.581695

58172

.58174
.58177

.581802
.581229

. 581856

.581883
1581909

. 581936

1.581963

.582016

. 582043

582097

. 582150

582204

1.582230

. 582284

1. 582311

1.582364

- 582418

.582471

1.582498

1. 582551

1.58260 .5

1. 582658

1. 582712

1.582765

1.582819

1.582846

1.582899

1.582926
. .582953

1.582979
1.583006

.583033
.583060

1.583086

1.583113
1.583140

1.583167
1.583193

- 583220

1.583274

1.583300
1.583327

1.583354

1.583381
1.583407

1. 583434

1.583461
.583488

1.583514

1.583558
1.583595

1.583621

1.583648
1.583675

1.583702

1. 583755

1.583809

1.583835
1.583862

1.583889

1. 583916

1. 583969

1.583996
1.584023 $\begin{array}{llllllllll}10.118 & 10.087 & 10.056 & 10.026 & 09.995 & 09.965 & 09.934 & 09.903 & 09.872 & 09.842\end{array}$

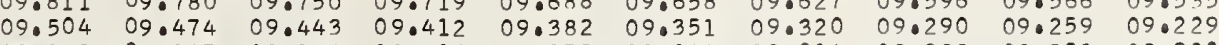
$\begin{array}{llllllllll}09.198 & 09.167 & 09.136 & 09.106 & 09.075 & 09.044 & 09.014 & 08.983 & 08.952 & 08.922\end{array}$ $\begin{array}{llllllllll}08.891 & 08.860 & 08.830 & 08.799 & 08.768 & 08.738 & 08.707 & 08.676 & 08.646 & 08.615 \\ 08.584 & 08.554 & 08.523 & 08.492 & 0 . .462 & 08.431 & 08.400 & 08.370 & 08.339 & 08.308\end{array}$

1.584049

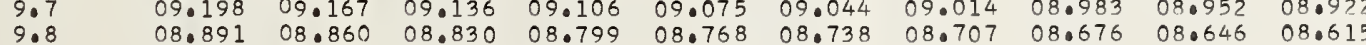
9.9

$\begin{array}{cccccccccc} & .001 & .002 & .003 & .004 & .005 & .006 & .007 & .008 & .009 \\ .031 & .003 & .006 & .009 & .012 & .015 & .018 & .022 & .025 & .028 \\ .030 & .003 & .006 & .009 & .012 & .015 & .018 & .021 & .024 & .027 \\ & .003 & .006 & .009 & .012 & .014 & .017 & .020 & .023 & .026\end{array}$

.010 


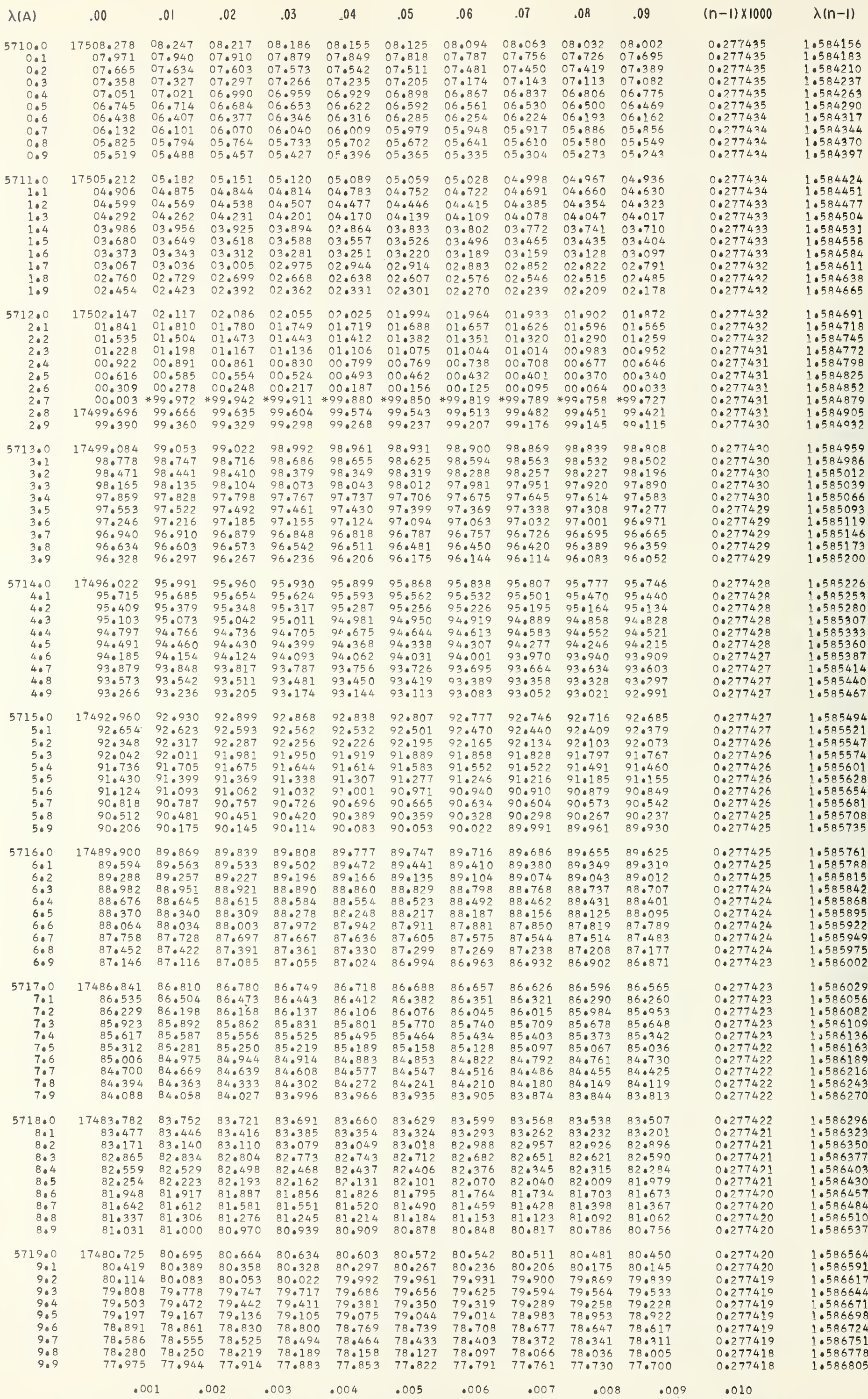

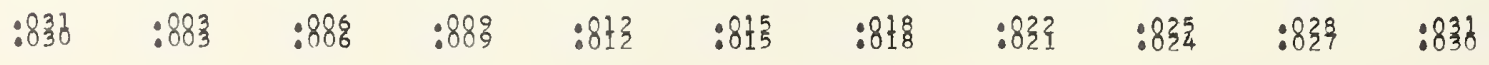




\begin{tabular}{|c|c|c|c|c|c|c|c|c|c|c|c|c|}
\hline A) & .00 & 1 & .02 & .03 & .04 & .05 & .06 & .07 & .08 & .09 & 100 & $(n-1)$ \\
\hline $\begin{array}{l}20.0 \\
0.1 \\
0.2 \\
0.3 \\
0.4 \\
0.5 \\
0.6 \\
0.7 \\
0.8 \\
0.9\end{array}$ & $\begin{array}{r}17477.669 \\
77.0364 \\
77.058 \\
76.052 \\
76.447 \\
76.142 \\
75.836 \\
75.531 \\
75.225 \\
74.920\end{array}$ & $\begin{array}{l}77.639 \\
77.0333 \\
77.028 \\
76.0222 \\
76.417 \\
76.111 \\
75.805 \\
75.500 \\
75.194 \\
74.889\end{array}$ & $\begin{array}{l}77.608 \\
77.302 \\
76.997 \\
76.692 \\
76.386 \\
76.081 \\
75.775 \\
75.469 \\
75.164 \\
74.858\end{array}$ & $\begin{array}{l}77.577 \\
77.072 \\
76.966 \\
76.661 \\
76.355 \\
76.050 \\
75.744 \\
75.439 \\
75.133 \\
74.828\end{array}$ & $\begin{array}{l}77.547 \\
77.241 \\
76.936 \\
76.630 \\
76.325 \\
76.019 \\
75.714 \\
75.408 \\
75.103 \\
74.798\end{array}$ & $\begin{array}{l}77.516 \\
77.211 \\
76.906 \\
76.600 \\
76.294 \\
75.989 \\
75.683 \\
75.378 \\
75.072 \\
74.767\end{array}$ & $\begin{array}{l}77.486 \\
77.180 \\
76.875 \\
76.569 \\
76.264 \\
75.958 \\
75.653 \\
75.0347 \\
75.042 \\
74.736\end{array}$ & $\begin{array}{l}77.455 \\
77.150 \\
76.844 \\
76.539 \\
76.233 \\
75.928 \\
75.622 \\
75.0317 \\
75.011 \\
74.706\end{array}$ & $\begin{array}{l}77.425 \\
77.119 \\
76.814 \\
76.508 \\
76.203 \\
755.897 \\
750599 \\
75.286 \\
74.981 \\
74.675\end{array}$ & $\begin{array}{l}77.394 \\
77.089 \\
76.783 \\
76.478 \\
76.172 \\
75.866 \\
75.561 \\
75.256 \\
74.950 \\
74.645\end{array}$ & $\begin{array}{l}0.277418 \\
0.277418 \\
0.277418 \\
0.277418 \\
0.277417 \\
0.277417 \\
0.277417 \\
0.277417 \\
0.277417 \\
0.277417\end{array}$ & $\begin{array}{l}586831 \\
586858 \\
586885 \\
586912 \\
586938 \\
586965 \\
586992 \\
587019 \\
587045 \\
587072\end{array}$ \\
\hline $\begin{aligned} 721.0 \\
1: 1 \\
1.2 \\
1.3 \\
1.4 \\
1.5 \\
1.6 \\
1.7 \\
1.8 \\
1.9\end{aligned}$ & $\begin{array}{r}17474.614 \\
74.309 \\
74.003 \\
73.698 \\
73.393 \\
73.087 \\
72.782 \\
72.476 \\
72.171 \\
71.866\end{array}$ & $\begin{array}{l}74.584 \\
74.278 \\
73.973 \\
73.067 \\
73.0362 \\
73.057 \\
72.751 \\
72.446 \\
72.140 \\
71.835\end{array}$ & $\begin{array}{l}74.553 \\
74.248 \\
73.942 \\
73.637 \\
73.331 \\
73.026 \\
72.720 \\
72.415 \\
72.110 \\
71.805\end{array}$ & $\begin{array}{l}74.522 \\
74.217 \\
73.912 \\
73.606 \\
73.301 \\
72.995 \\
72.690 \\
72.385 \\
72.079 \\
71.774\end{array}$ & $\begin{array}{l}74.492 \\
74.187 \\
73.881 \\
73.576 \\
73.271 \\
72.965 \\
72.0660 \\
72.054 \\
72.049 \\
71.0744\end{array}$ & $\begin{array}{l}74.461 \\
74.156 \\
73.851 \\
73.545 \\
73.240 \\
72.934 \\
72.629 \\
72.324 \\
72.019 \\
71.713\end{array}$ & $\begin{array}{l}74.431 \\
74.125 \\
73.820 \\
73.515 \\
73.209 \\
72.904 \\
72.598 \\
72.293 \\
71.988 \\
71.083\end{array}$ & $\begin{array}{l}74.400 \\
74.095 \\
73.090 \\
73.484 \\
73.179 \\
72.873 \\
72.568 \\
72.262 \\
71.057 \\
71.652\end{array}$ & $\begin{array}{l}74.370 \\
74.064 \\
73.759 \\
73.454 \\
73.148 \\
72.843 \\
72.537 \\
72.232 \\
71.927 \\
71.622\end{array}$ & $\begin{array}{l}74.339 \\
74.034 \\
73.728 \\
73.423 \\
73.117 \\
72.812 \\
72.507 \\
72.201 \\
71.896 \\
71.591\end{array}$ & $\begin{array}{l}0.277416 \\
0.277416 \\
0.277416 \\
0.277416 \\
0.277416 \\
0.277415 \\
0.277415 \\
0.277415 \\
0.277415 \\
0.277415\end{array}$ & $\begin{array}{l}1.587099 \\
1.587126 \\
1.587152 \\
1.587179 \\
1.587206 \\
1.587233 \\
1.587259 \\
1.587286 \\
1.587313 \\
1.587340\end{array}$ \\
\hline $\begin{array}{r}722.0 \\
2.1 \\
2.2 \\
2.3 \\
2.4 \\
2.5 \\
2.6 \\
2.7 \\
2.8 \\
2.9\end{array}$ & $\begin{array}{r}17471.561 \\
71.255 \\
70.950 \\
70.645 \\
70.339 \\
70.034 \\
69.729 \\
69.423 \\
69.118 \\
68.813\end{array}$ & $\begin{array}{l}71.530 \\
71.225 \\
70.919 \\
70.614 \\
70.309 \\
70.003 \\
69.698 \\
69.393 \\
69.088 \\
68.782\end{array}$ & $\begin{array}{l}71.499 \\
71.194 \\
70.889 \\
70.583 \\
70.278 \\
69.973 \\
69.667 \\
69.362 \\
69.057 \\
68.752\end{array}$ & $\begin{array}{l}71.469 \\
71.164 \\
70.858 \\
70.553 \\
70.248 \\
69.942 \\
69.637 \\
69.332 \\
69.027 \\
68.0721\end{array}$ & $\begin{array}{l}71.438 \\
71.133 \\
70.828 \\
70.522 \\
70.217 \\
69.012 \\
69.0607 \\
69.001 \\
68.906 \\
68.691\end{array}$ & $\begin{array}{l}71.408 \\
71.103 \\
70.797 \\
70.492 \\
70.187 \\
69.881 \\
69.576 \\
69.271 \\
68.966 \\
68.660\end{array}$ & $\begin{array}{l}71.377 \\
71.072 \\
70.767 \\
70.461 \\
70.156 \\
69.851 \\
69.545 \\
69.240 \\
68.935 \\
68.630\end{array}$ & $\begin{array}{l}71.347 \\
71.042 \\
70.736 \\
700.431 \\
70.125 \\
69.820 \\
69.515 \\
69.010 \\
68.905 \\
68.599\end{array}$ & $\begin{array}{l}71.316 \\
71.011 \\
70.706 \\
700400 \\
70.095 \\
69.790 \\
69.484 \\
69.179 \\
68.874 \\
68.569\end{array}$ & $\begin{array}{l}71.286 \\
70.980 \\
70.675 \\
70.370 \\
70.064 \\
69.759 \\
69.454 \\
69.149 \\
68.843 \\
68.538\end{array}$ & $\begin{array}{l}0.277415 \\
0.277414 \\
0.277414 \\
0.277714 \\
0.277414 \\
0.277414 \\
0.277414 \\
0.277413 \\
0.277413 \\
0.277413\end{array}$ & $\begin{array}{l}1.587366 \\
1.587393 \\
1.587420 \\
1.587447 \\
1.587473 \\
1.587500 \\
1.587527 \\
1.557554 \\
1.557580 \\
1.587607\end{array}$ \\
\hline $\begin{array}{l}23.0 \\
3.1 \\
3.2 \\
3.3 \\
3.4 \\
3.5 \\
3.6 \\
3.7 \\
3.8 \\
3.9\end{array}$ & $\begin{array}{r}17468.508 \\
68.202 \\
67.897 \\
67.592 \\
67.287 \\
66.982 \\
66.676 \\
66.371 \\
66.066 \\
65.761\end{array}$ & $\begin{array}{l}68.477 \\
68.172 \\
67.867 \\
67.562 \\
67.256 \\
66.951 \\
66.646 \\
66.341 \\
66.035 \\
65.730\end{array}$ & $\begin{array}{l}68.447 \\
68.141 \\
67.836 \\
67.531 \\
67.226 \\
66.921 \\
66.615 \\
66.310 \\
66.005 \\
65.700\end{array}$ & $\begin{array}{l}68.416 \\
68.111 \\
67.800 \\
67.500 \\
67.1195 \\
66.890 \\
66.585 \\
66.280 \\
65.975 \\
65.669\end{array}$ & $\begin{array}{l}68.385 \\
68: 080 \\
67.775 \\
67.470 \\
67.165 \\
66.859 \\
66.554 \\
66.249 \\
65.944 \\
65.639\end{array}$ & $\begin{array}{l}68.355 \\
68.050 \\
67.745 \\
67.439 \\
67.134 \\
66.829 \\
66.524 \\
66.219 \\
65.914 \\
65.608\end{array}$ & $\begin{array}{l}68.324 \\
68.019 \\
67.714 \\
67.409 \\
67.104 \\
66.798 \\
66.493 \\
66.188 \\
65.883 \\
65.578\end{array}$ & $\begin{array}{l}68.294 \\
67.9899 \\
67.684 \\
67.0378 \\
67.073 \\
66.0768 \\
66.463 \\
66.158 \\
65.853 \\
65.547\end{array}$ & $\begin{array}{l}68.264 \\
67.958 \\
67.653 \\
67.348 \\
67.043 \\
66.738 \\
66.432 \\
66.127 \\
65.822 \\
65.517\end{array}$ & $\begin{array}{l}68.933 \\
67.928 \\
67.623 \\
67.317 \\
67.012 \\
66.707 \\
66.402 \\
66.096 \\
65.792 \\
65.486\end{array}$ & $\begin{array}{l}0.277413 \\
0.277413 \\
0.277413 \\
0.277412 \\
0.277412 \\
0.277412 \\
0.277412 \\
0.277412 \\
0.277411 \\
0.277411\end{array}$ & $\begin{array}{l}1.587634 \\
1.587661 \\
1587687 \\
.587714 \\
.587741 \\
.587768 \\
.587794 \\
.5587821\end{array}$ \\
\hline $\begin{array}{l}24.0 \\
4.1 \\
4.2 \\
4.3 \\
4.4 \\
4.5 \\
4.6 \\
4.7 \\
4.8 \\
4.9\end{array}$ & $\begin{array}{r}17465.456 \\
65.151 \\
64.845 \\
64.541 \\
64.236 \\
63.930 \\
63.625 \\
63.320 \\
63.015 \\
62.710\end{array}$ & $\begin{array}{l}65.425 \\
65.120 \\
64.815 \\
64.510 \\
64.205 \\
63.900 \\
63.595 \\
63.290 \\
62.985 \\
62.679\end{array}$ & $\begin{array}{l}65.395 \\
65.090 \\
64.784 \\
64.479 \\
64.174 \\
63.869 \\
63.564 \\
63.259 \\
62.954 \\
62.649\end{array}$ & $\begin{array}{l}65.364 \\
65.059 \\
64.754 \\
64.449 \\
64.144 \\
63.839 \\
63.534 \\
63.229 \\
62.924 \\
62.618\end{array}$ & $\begin{array}{l}65.334 \\
65.029 \\
64.723 \\
64.418 \\
64.113 \\
63.808 \\
63.503 \\
63.198 \\
62.893 \\
62.588\end{array}$ & $\begin{array}{l}65.303 \\
64.998 \\
64.693 \\
64.388 \\
64.083 \\
63.778 \\
63.473 \\
63.168 \\
62.863 \\
62.558\end{array}$ & $\begin{array}{l}65.273 \\
64.968 \\
64.663 \\
64.0557 \\
64.052 \\
63.747 \\
63.442 \\
63.137 \\
62.832 \\
62.527\end{array}$ & $\begin{array}{l}65.247 \\
64.037 \\
64.632 \\
64.327 \\
64.022 \\
63.717 \\
63.412 \\
63.107 \\
62.802 \\
62.497\end{array}$ & $\begin{array}{l}65.212 \\
640.907 \\
64.602 \\
640.297 \\
630.991 \\
63.686 \\
630381 \\
63.076 \\
62.0771 \\
62.466\end{array}$ & $\begin{array}{l}65 \cdot 181 \\
64.876 \\
64.571 \\
64.266 \\
63.961 \\
63.656 \\
63.351 \\
63.046 \\
62.741 \\
62.436\end{array}$ & $\begin{array}{l}.277411 \\
.277411 \\
.277411 \\
0277411 \\
.277410 \\
.277410 \\
.277410 \\
.277410 \\
.277410 \\
.277410\end{array}$ & $\begin{array}{l}1.58803 \\
1.58806 \\
1.58808 \\
1.58811 \\
1.58814\end{array}$ \\
\hline $\begin{array}{r}725.0 \\
5.1 \\
5.2 \\
5.3 \\
5.4 \\
5.5 \\
5.6 \\
5.7 \\
5.8 \\
5.9\end{array}$ & $\begin{array}{r}17462.405 \\
62.100 \\
61.795 \\
61.490 \\
61.185 \\
60.880 \\
60.575 \\
60.270 \\
59.965 \\
59.660\end{array}$ & $\begin{array}{l}62.375 \\
62.070 \\
61.765 \\
61.459 \\
61.155 \\
60.850 \\
60.545 \\
60.240 \\
59.935 \\
59.630\end{array}$ & $\begin{array}{l}62.344 \\
62.039 \\
61.0734 \\
61.429 \\
61.124 \\
60.819 \\
60.5114 \\
60.209 \\
59.904 \\
59.599\end{array}$ & $\begin{array}{l}62.314 \\
62.009 \\
61.704 \\
61.398 \\
61.094 \\
60.789 \\
60.484 \\
60.179 \\
59.874 \\
59.569\end{array}$ & $\begin{array}{l}62.283 \\
61.978 \\
61.673 \\
61.368 \\
61.063 \\
60.758 \\
60.453 \\
60.148 \\
59.843 \\
59.539\end{array}$ & $\begin{array}{l}62.253 \\
61.948 \\
61.643 \\
61.337 \\
61.033 \\
60.728 \\
60.423 \\
60.118 \\
59.813 \\
59.508\end{array}$ & $\begin{array}{l}62.222 \\
61.917 \\
61.612 \\
61.307 \\
61.002 \\
60.697 \\
60.392 \\
60.087 \\
59.782 \\
59.477\end{array}$ & $\begin{array}{l}62.192 \\
61.886 \\
61.582 \\
61.276 \\
60.972 \\
60.667 \\
60.362 \\
60.057 \\
59.0752 \\
59.447\end{array}$ & $\begin{array}{l}62.161 \\
61.856 \\
61.551 \\
61.046 \\
60.941 \\
60.036 \\
60.331 \\
60.026 \\
59.021 \\
59.416\end{array}$ & $\begin{array}{l}62.131 \\
61.826 \\
61.571 \\
61.716 \\
60.911 \\
60.606 \\
60.301 \\
59.996 \\
59.691 \\
59.386\end{array}$ & $\begin{array}{l}0.277409 \\
0.277409 \\
0.077409 \\
0.277409 \\
0.277409 \\
0.277409 \\
0.277408\end{array}$ & $\begin{array}{l}1.58838 \\
1.58841\end{array}$ \\
\hline $\begin{array}{l}26.0 \\
6.1 \\
6.2 \\
6.3 \\
6.4 \\
6.5 \\
6.6 \\
6.7 \\
6.8 \\
6.9\end{array}$ & $\begin{array}{r}17459.355 \\
59.051 \\
58.746 \\
58.441 \\
58.136 \\
57.831 \\
57.526 \\
57.221 \\
56.917 \\
56.612\end{array}$ & $\begin{array}{l}59.325 \\
59.020 \\
58.715 \\
58.410 \\
58.105 \\
57.801 \\
57.496 \\
57.191 \\
56.886 \\
56.581\end{array}$ & $\begin{array}{l}59.294 \\
58.990 \\
58.685 \\
58.380 \\
58.075 \\
57.0770 \\
57.465 \\
57.160 \\
56.856 \\
56.551\end{array}$ & $\begin{array}{l}59.264 \\
58.959 \\
58.654 \\
58.349 \\
58.044 \\
57.740 \\
57.435 \\
57.130 \\
56.825 \\
56.520\end{array}$ & $\begin{array}{l}59.233 \\
58.929 \\
58.624 \\
58.319 \\
58.014 \\
57.709 \\
57.404 \\
57.099 \\
56.794 \\
56.490\end{array}$ & $\begin{array}{l}59.203 \\
58.898 \\
58.593 \\
58.288 \\
57.983 \\
57.678 \\
57.374 \\
57.069 \\
56.764 \\
56.459\end{array}$ & $\begin{array}{l}59.172 \\
58.868 \\
58.563 \\
58.258 \\
57.953 \\
57.648 \\
57.343 \\
57.039 \\
56.733 \\
56.429\end{array}$ & $\begin{array}{l}59.142 \\
58.837 \\
58.532 \\
58.227 \\
57.922 \\
57.618 \\
57.313 \\
57.008 \\
56.703 \\
56.398\end{array}$ & $\begin{array}{l}59.112 \\
58.006 \\
58.502 \\
58.197 \\
57.892 \\
57.587 \\
57.082 \\
56.978 \\
56.073 \\
56.368\end{array}$ & $\begin{array}{l}59.081 \\
58.776 \\
58.471 \\
58.167 \\
57.861 \\
57.557 \\
57.252 \\
56.947 \\
56.642 \\
56.337\end{array}$ & $\begin{array}{l}0.277408 \\
0.277408 \\
0.277407 \\
0.277407 \\
0.277407 \\
0.277407 \\
0.277407 \\
0.277406 \\
0.277406 \\
0.277406\end{array}$ & 1.5886 \\
\hline $\begin{array}{r}727.0 \\
7.1 \\
7.2 \\
7.3 \\
7.4 \\
7.5 \\
7.6 \\
7.7 \\
7.8 \\
7.9\end{array}$ & $\begin{array}{r}17456.307 \\
56.002 \\
55.697 \\
55.392 \\
55.088 \\
54.783 \\
54.478 \\
54.174 \\
53.869 \\
53.564\end{array}$ & $\begin{array}{l}56.276 \\
55.971 \\
55.667 \\
55.362 \\
55.057 \\
54.752 \\
54.448 \\
54.143 \\
53.838 \\
53.534\end{array}$ & $\begin{array}{l}56.246 \\
55.941 \\
55.636 \\
55.332 \\
55.027 \\
54.722 \\
54.417 \\
54.112 \\
53.808 \\
53.503\end{array}$ & $\begin{array}{l}56.215 \\
55.911 \\
55.606 \\
55.301 \\
54.996 \\
54.691 \\
54.387 \\
54.082 \\
53.777 \\
53.473\end{array}$ & $\begin{array}{l}56.185 \\
55.880 \\
55.575 \\
55.271 \\
54.966 \\
54.661 \\
54.356 \\
54.052 \\
52.747 \\
53.442\end{array}$ & $\begin{array}{l}56.155 \\
55.850 \\
55.545 \\
55.240 \\
54.935 \\
54.630 \\
54.326 \\
54.021 \\
53.716 \\
53.412\end{array}$ & $\begin{array}{l}56.124 \\
55.819 \\
55.514 \\
55.209 \\
54.905 \\
54.600 \\
54.295 \\
53.990 \\
53.686 \\
53.381\end{array}$ & $\begin{array}{l}56.094 \\
55.0789 \\
55.484 \\
55.179 \\
54.875 \\
54.570 \\
54.265 \\
53.960 \\
53.655 \\
53.351\end{array}$ & & $\begin{array}{l}56.032 \\
55.728 \\
55.423 \\
55.118 \\
54.813 \\
54.509 \\
54.204 \\
53.899 \\
53.594 \\
53.290\end{array}$ & & - 588 \\
\hline $\begin{array}{l}728.0 \\
8.1 \\
8.2 \\
8.3 \\
8.4 \\
8.5 \\
8.6 \\
8.7 \\
8.8 \\
8.9\end{array}$ & $\begin{array}{r}17453.259 \\
52.955 \\
52.650 \\
52.345 \\
52.041 \\
51.736 \\
51.431 \\
51.127 \\
50.822 \\
50.517\end{array}$ & $\begin{array}{l}53.229 \\
52.924 \\
52.619 \\
52.315 \\
52.010 \\
51.706 \\
51.4011 \\
51.096 \\
50.792 \\
50.487\end{array}$ & $\begin{array}{l}53.198 \\
52.894 \\
52.589 \\
52.284 \\
51.979 \\
51.675 \\
51.370 \\
51.066 \\
50.761 \\
50.457\end{array}$ & $\begin{array}{l}53.168 \\
52.863 \\
52.558 \\
52.254 \\
51.049 \\
51.645 \\
51.340 \\
51.035 \\
50.730 \\
50.426\end{array}$ & & & & & & & & $\begin{array}{l}1.5891 \\
1.5892\end{array}$ \\
\hline $\begin{array}{l}29.0 \\
9.1 \\
9.2 \\
9.3 \\
9.4 \\
9.5 \\
9.6 \\
9.7 \\
9.8 \\
9.9\end{array}$ & $\begin{array}{r}17450.213 \\
49.908 \\
49.604 \\
49.299 \\
48.995 \\
48.690 \\
48.385 \\
48.081 \\
47.776 \\
47.472\end{array}$ & $\begin{array}{l}50.182 \\
49.878 \\
49.573 \\
49.269 \\
48.964 \\
48.659 \\
48.355 \\
48.050 \\
47.746 \\
47.441\end{array}$ & $\begin{array}{l}50.152 \\
49.847 \\
49.543 \\
49.238 \\
48.934 \\
48.629 \\
48.324 \\
48.020 \\
47.716 \\
47.411\end{array}$ & $\begin{array}{l}50.122 \\
49.817 \\
49.512 \\
49.208 \\
48.903 \\
48.599 \\
48.294 \\
47.990 \\
47.685 \\
47.380\end{array}$ & $\begin{array}{l}50.091 \\
49.786 \\
49.482 \\
49.177 \\
48.873 \\
48.568 \\
48.264 \\
47.959 \\
47.655 \\
47.350\end{array}$ & $\begin{array}{l}50.060 \\
49.756 \\
49.451 \\
49.147 \\
48.842 \\
48.538 \\
48.233 \\
47.929 \\
47.624 \\
47.320\end{array}$ & $\begin{array}{l}50.030 \\
49.726 \\
49.421 \\
49.116 \\
48.812 \\
48.507 \\
48.203 \\
47.898 \\
47.594 \\
47.289\end{array}$ & $\begin{array}{l}5 \\
5 \\
0 \\
6 \\
1 \\
1 \\
7 \\
2 \\
8\end{array}$ & $\begin{array}{l}49.360 \\
49.055 \\
48.751 \\
48.446 \\
48.142 \\
47.837 \\
47.533 \\
47.228\end{array}$ & $\begin{array}{l}49.329 \\
49.025 \\
48.720 \\
48.416 \\
48.112 \\
47.807 \\
47.502 \\
47.198\end{array}$ & $\begin{array}{l}.277402 \\
.277402 \\
.277402 \\
.277402 \\
.277402 \\
.277401 \\
.277401 \\
.277401 \\
.277401 \\
.277401\end{array}$ & $\begin{array}{r}.05894 \\
.5894 \\
.5594\end{array}$ \\
\hline & \multicolumn{2}{|c|}{.001} & .002 & .000 & 0.04 & 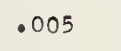 & 年 & & .008 & & .010 & \\
\hline & & & & $\begin{array}{r}.009 \\
.009\end{array}$ & $\begin{array}{l}.012 \\
.011\end{array}$ & .014 & & .02 & & .0 & .029 & \\
\hline
\end{tabular}




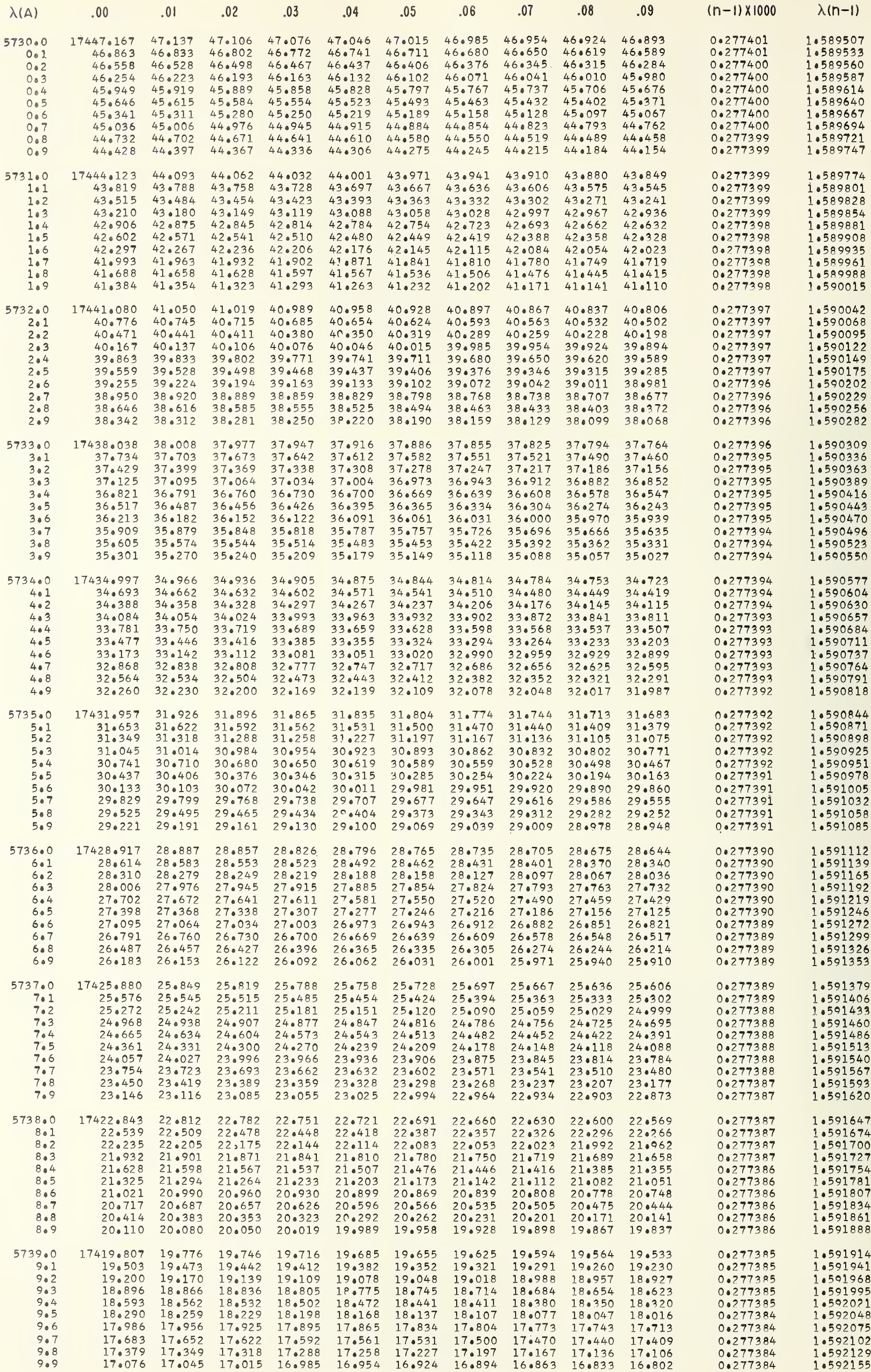

0.277399 1.589828 1.589854
1.589881 589908
589935 . 589961 0042 590095 590149 .590202 (50.2029. 590282 590309 590363 590389 590443 1.590470 590523
590550 590577 590630 590684 590737 .590764
.590791 .590844 1.590871
1.590898 .590925 .590951
.590978 .591005 591058 .591112 .599165 591219 . 591246 591299 591326
591353 591379 .591406
.501433 .501433
.591460
.591486 .591513 .591540 . 591593 591647 .591674 591727 591781 .591834
.591861 591914 .501968 .591995 592048 1.592102 $0.277384 \quad 1.592155$

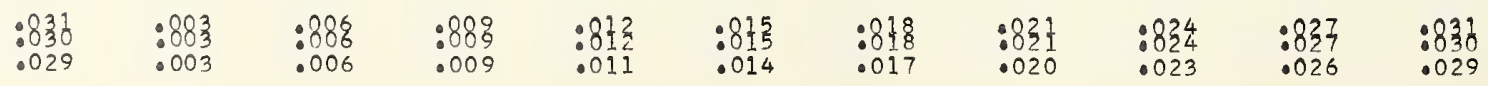


$\begin{array}{rrrrrrrrrrr}5740.0 & 17416.772 & 16.742 & 16.711 & 16.681 & 16.651 & 16.620 & 16.590 & 16.560 & 16.530 & 16.499 \\ 0.1 & 16.469 & 16.438 & 16.408 & 16.378 & 16.347 & 16.317 & 16.287 & 16.256 & 16.226 & 16.196\end{array}$ $\begin{array}{lllllllllll}0.2 & 16.469 & 16.438 & 16.408 & 16.378 & 16.347 & 16.317 & 16.287 & 16.256 & 16.226 & 16.196 \\ 0.166 & 16.135 & 16.104 & 16.074 & 16.044 & 16.014 & 15.983 & 15.953 & 15.923 & 15.892\end{array}$ $\begin{array}{lllllllllll}0.3 & 15.862 & 15.832 & 15.801 & 15.771 & 15.740 & 15.710 & 15.680 & 15.649 & 15.619 & 15.589 \\ 0.4 & 15.559 & 15.528 & 15.498 & 15.467 & 15.437 & 15.407 & 15.376 & 15.346 & 15.316 & 15.785\end{array}$ $\begin{array}{lllllllllll}0.5 & 15.255 & 15.225 & 15.195 & 15.164 & 15.134 & 15.104 & 15.073 & 15.043 & 15.012 & 14.982 \\ 0.6 & 14.952 & 14.921 & 14.891 & 14.861 & 14.831 & 14.800 & 14.770 & 14.739 & 14.709 & 14.679\end{array}$

$\begin{array}{lllllllllll}0.7 & 14.548 & 14.618 & 14.588 & 14.557 & 14.527 & 14.497 & 14.467 & 14.436 & 14.406 & 14.375 \\ 0.8 & 14.345 & 14.315 & 14.284 & 14.254 & 14.224 & 14.193 & 14.163 & 14.133 & 14.102 & 14.072\end{array}$ 0.9 $14 \cdot 345$
14.042

$17413.739 \quad 13.708 \quad 13.67$

14.254
13.951

$14 \cdot 224$
12.920

$\begin{array}{llllll}13.617 & 13.587 & 13.556 & 13.526 & 13.496 & 13.465 \\ 13.314 & 13.283 & 13.253 & 13.223 & 13.192 & 13.162\end{array}$

$\begin{array}{lllllllllll}13.435 & 13.405 & 13.374 & 13.344 & 13.314 & 13.283 & 13.253 & 13.223 & 13.192 & 13.162 \\ 13.132 & 13.102 & 13.071 & 13.041 & 13.010 & 12.980 & 12.950 & 12.919 & 12.889 & 12.859\end{array}$

$\begin{array}{lllllllllll}13 & 12.829 & 12.798 & 12.768 & 12.738 & 12.707 & 12.677 & 12.646 & 12.616 & 12.586 & 12.555 \\ 1 & 12.525 & 12.495 & 12.465 & 12.434 & 12.404 & 12.374 & 12.343 & 12.313 & 12.282 & 12.252\end{array}$

$\begin{array}{lllllllllll}1.5 & 12.222 & 12.192 & 12.161 & 12.131 & 12.101 & 12.070 & 12.040 & 12.010 & 11.979 & 11.949\end{array}$

$\begin{array}{lllllllllll}1.6 & 11.919 & 11.888 & 11.858 & 11.828 & 11.797 & 11.767 & 11.737 & 11.706 & 11.676 & 11.646\end{array}$

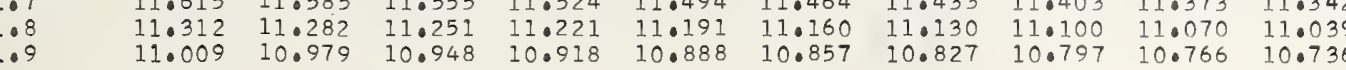

742.
2.
2.
2.
2.
2.0
2.0
2.

74.0
3.1
3.2
3.3
3.4
3.5
3.6
3.7
3.8
3.9

$\begin{array}{llll}7410.706 & 10.675 & 10.645 & 10.615\end{array}$

$10.403 \quad 10.372$

10.099

09.496309 .766

$09.493-09.462$

$08.887 \quad 08.159$

08.280
07.977

$8.553 \quad 08.250$

$\begin{array}{ll}0.342 & 10.312 \\ 10.039 & 10.008\end{array}$

$0.584 \quad 10.554 \quad 10.524$

$\begin{array}{llllll}10.584 & 10.554 & 10.524 & 10.493 & 10.463 & 10.433 \\ 10.281 & 10.251 & 10.221 & 10.190 & 10.160 & 10.130\end{array}$

$\begin{array}{llllllll}0.736 & 09.705 & 09.675 & 09.645 & 09.614 & 09.584 & 09.554 & 09.523\end{array}$

$\begin{array}{llllllll}0.42 & 09.402 & 0.90372 & 09.341 & 09.311 & 09.281 & 09.250 & 09.220 \\ 09.129 & 09.099 & 09.068 & 09.038 & 09.008 & 08.978 & 08.947 & 08.917\end{array}$

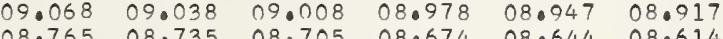

$\begin{array}{lllllllll}8.523 & 08.492 & 08.462 & 08.432 & 08.402 & 08.371 & 08.341 & 08.311\end{array}$

17407.674

$07.674 \quad 07.644$

$\begin{array}{llll}07.917 & 07.886 & 07\end{array}$

$08.159 \quad 08.129$

$\begin{array}{llll}08.098 & 08.0068 & 08.038 & 08.31 \\ 07.795 & 07.0765 & 07.735 & 07.008 \\ 0704\end{array}$

$\begin{array}{llllll}07.553 & 07.522 & 07.492 & 07.462 & 07.432 & 07.401\end{array}$

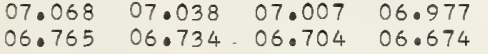
06.46206 .431 06.15906 .128

$\begin{array}{ll}05.553 & 05.522 \\ 05.250 & 05.219 \\ 04.947 & 04.916\end{array}$

$06.704 \quad 06.674$

06.94706 .917

06.886

$\begin{array}{llllll}06.644 & 06.613 & 06.583 & 06.552 & 06.522 & 06.492\end{array}$

$\begin{array}{llllllll}06.401 & 06.371 & 06.341 & 06.310 & 06 \cdot 280 & 06 \cdot 250 & 06.219 & 06.189\end{array}$

$\begin{array}{llllllll}06.098 & 06.068 & 06.037 & 06.007 & 05.977 & 05.947 & 05.916 & 05.886\end{array}$

4.
$40^{\circ}$
$40^{\circ}$
$40^{\circ}$
4.5
4.7
4.

$\begin{array}{rrrrrrrrrrr}.0 & 17404.644 & 04.613 & 04.583 & 04.552 & 04.522 & 04.492 & 04.462 & 04.431 & 04.401 & 04.371 \\ .1 & 04.341 & 04.310 & 04.280 & 04.250 & 04.219 & 04.189 & 04.159 & 04.128 & 04.098 & 04.068\end{array}$

05.189050 .152

05.734 105.704

$\begin{array}{llll}05.674 & 05.644 & 05.613 & 05.583\end{array}$

$\begin{array}{llllll}05.128 & 05.098 & 05.068 & 05.340 & 05.310 & 05.280 \\ 04.825 & 04.795 & 04.765 & 04.734 & 05.007 & 04.977 \\ 0\end{array}$

0.277384
0.277383
0.277383
0.277383
0.277383
0.277383
0.277383
0.277382
0.277382
0.277382

1.592182

0.277382

0.277382

0.27738

0.277381

0.277381
0.277381

0.277380

0.277380

0.277380
0.277380

0.277380

0.277380
0.277379

0.277379
0.277379

0.277379
0.277379

0.277378

0.277378

0.277378

0.277378

0.277377

0.277377

.592236

(

.592343

1.592396

$03.734 \quad 03.704$

$\begin{array}{ll}04.280 & 04.2 \\ 03.977 & 03.947\end{array}$

$\begin{array}{ll}04.219 & 04.189 \\ 03.916 & 03.88\end{array}$

$\begin{array}{llll}04.159 & 04.128 & 04.098 & 04.068\end{array}$

0.277377

0.277376

$\begin{array}{lllllllll}03.401 & 03.371 & 03.341 & 03.310 & 03.280 & 03.250 & 03.219 & 03.189 & 03.159\end{array}$

$\begin{array}{lllllllllll}03.129 & 03.098 & 03.068 & 03.038 & 03.007 & 02.977 & 02.947 & 02.917 & 02.886 & 02.856 \\ 02.826 & 02.795 & 02.765 & 02.735 & 02.704 & 02.674 & 02.644 & 02.614 & 02.583 & 02.553\end{array}$

02.52302 .79

$01.917 \quad 01.886$

02.159 1 02.12

02.09

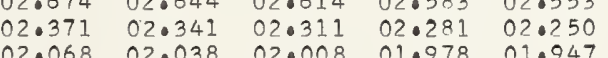

5745.0

5.2

01.311

01.58

$01.553 \quad 01.523$

$0 ? .19930190$

$1.402 \quad 01.37 ? \quad 01.341$

$\begin{array}{llllllllll}01.008 & 00.978 & 00.948 & 00.917 & 0.0887 & 00.857 & 00.877 & 00.796 & 00.766 & 0.0135\end{array}$

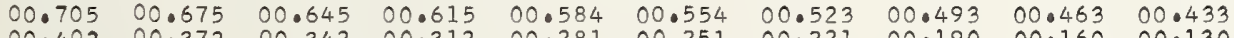

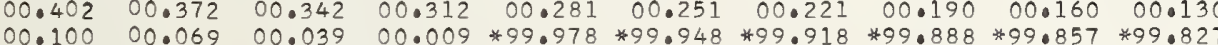

$17399.797 \quad 99.766$

$99.494 \quad 99.464 \quad 99.433 \quad 99.706$

$99.191 \quad 99.161$

99.43313199 .403

$99.676 \quad 99.645 \quad 99.615 \quad 99.585 \quad 99.554 \quad 99.524$

98.888

8.858

5746.0

6.

17398.

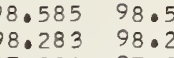

98.52598 .495

$99.070 \quad 99.040$

$\begin{array}{llll}.312 & 99.282 & 99.252 & 99.221 \\ .009 & 98.979 & 98.949 & 98.919\end{array}$

$\begin{array}{llll}97.980 & 97.950 & 97.919 & 97.889\end{array}$

$\begin{array}{llll}97.677 & 97.647 & 97.617 & 97.586 \\ 97.374 & 97.344 & 97.314 & 97.283\end{array}$

$\begin{array}{llll}97.072 & 97.042 & 97.011 & 96.981 \\ 96.769 & 96.739 & 96.708 & 96.678\end{array}$

$\begin{array}{llll}96.769 & 96.739 & 96.708 & 96.678 \\ 96.466 & 96.436 & 96.406 & 96.375\end{array}$

96.16496 .13

$96.103 \quad 96.375$

$98.464 \quad 98.434 \quad 98.404 \quad 98.374 \quad 98.343 \quad 98.313$

$\begin{array}{llllll}98.162 & 98.131 & 98.101 & 98.071 & 98.040 & 98.010 \\ 97.85 .9 & 97.829 & 97.798 & 97.768 & 97.738 & 97.708\end{array}$

$\begin{array}{llllll}97.556 & 97.526 & 97.496 & 97.465 & 97.435 & 97.405\end{array}$

$\begin{array}{llllll}97.253 & 97.223 & 97.193 & 97.162 & 97.132 & 97.102 \\ 96.950 & 96.920 & 96.890 & 96.860 & 96.830 & 96.799\end{array}$

$\begin{array}{llllll}96.648 & 96.617 & 96.587 & 96.557 & 96.527 & 96.497\end{array}$

6.7

95.86195 .831

$\begin{array}{llllll}96.345 & 96.315 & 96.285 & 96.254 & 96.224 & 96.194 \\ 96.042 & 96.012 & 95.982 & 95.951 & 95.921 & 95.891\end{array}$

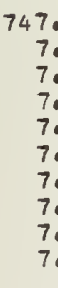

$\begin{array}{rrrrlllllll}7.0 & 17395.558 & 95.528 & 95.498 & 95.467 & 95.437 & 95.406 & 95.376 & 95.346 & 95.316 & 95.28 \\ 7.1 & 95.255 & 95.225 & 95.195 & 95.165 & 95.134 & 95.104 & 95.074 & 95.043 & 95.013 & 94.98 \\ 7.2 & 94.953 & 94.923 & 94.892 & 94.862 & 94.832 & 94.802 & 94.771 & 94.741 & 94.710 & 94.68 \\ .3 & 94.650 & 94.620 & 94.590 & 94.559 & 94.529 & 94.499 & 94.469 & 94.438 & 94.408 & 94.37 \\ 7.4 & 94.347 & 94.317 & 94.287 & 94.257 & 96.227 & 94.196 & 94.166 & 94.135 & 94.105 & 94.07 \\ 7.5 & 94.045 & 94.014 & 93.984 & 93.954 & 93.924 & 93.893 & 93.863 & 93.833 & 93.803 & 93.77\end{array}$

$\begin{array}{llllllllll}94.045 & 94.014 & 93.984 & 93.954 & 93.924 & 93.893 & 93.863 & 93.833 & 93.803 & 93.772\end{array}$

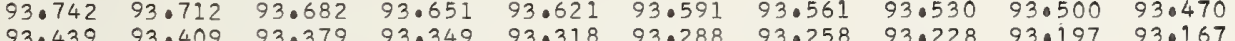

$93.137 \quad 93.106 \quad 93.076 \quad 93.046$

$93.318 \quad 93.288 \quad 93.258 \quad 93.228 \quad 93.197 \quad 93.167$

$92.834 \quad 92.804 \quad 92.774 \quad 92.744$

$92.71492 .683 \quad 92.653 \quad 92.623 \quad 92.593 \quad 92.562$

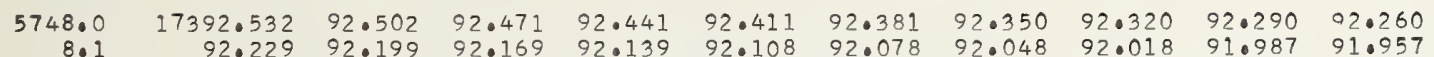

$\begin{array}{lllllllllll}8.1 & 92.229 & 92.199 & 92.169 & 92.139 & 92.108 & 92.078 & 92.048 & 92.018 & 91.987 & 91.957 \\ 8.2 & 91.927 & 91.897 & 91.866 & 91.836 & 91.806 & 91.776 & 91.745 & 91.715 & 91.685 & 91.655\end{array}$

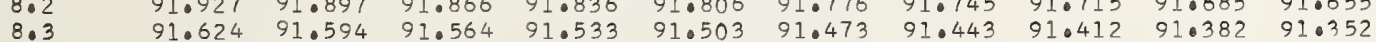

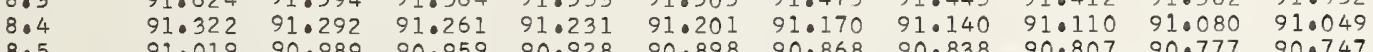

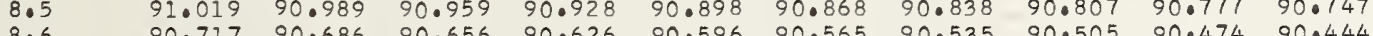

$\begin{array}{lllllllllll}8.6 & 90.717 & 90.686 & 90.656 & 90.626 & 90.596 & 90.565 & 90.535 & 90.505 & 90.474 & 90.444 \\ 8.7 & 90.414 & 90.384 & 90.354 & 90.323 & 90.293 & 90.263 & 90.233 & 90.202 & 90.172 & 90.142\end{array}$

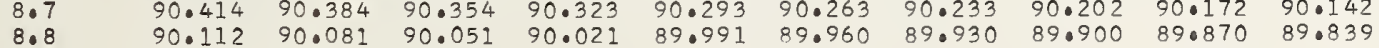

$\begin{array}{lllllllllll}8.8 & 90.112 & 90.081 & 90.051 & 90.021 & 89.991 & 89.960 & 89.930 & 89.900 & 89.870 & 89.839 \\ 8.9 & 89.809 & 89.779 & 89.749 & 89.718 & 89.688 & 89.658 & 89.628 & 89.597 & 89.567 & 89.537\end{array}$

$\begin{array}{rrrrrrrrrrr}5749.0 & 17389.507 & 89.477 & 89.446 & 89.416 & 89.386 & 89.355 & 89.325 & 89.295 & 89.265 & 89.234 \\ 9.1 & 89.204 & 89.174 & 89.144 & 89.114 & 89.083 & 89.053 & 89.023 & 88.992 & 88.962 & 88.932\end{array}$

$\begin{array}{lrlllllllll}9.1 & 89.204 & 89.174 & 89.144 & 89.114 & 89.083 & 89.053 & 89.023 & 88.992 & 88.962 & 88.932 \\ 9.2 & 88.902 & 88.872 & 88.847 & 88.811 & 88.781 & 88.750 & 88.720 & 88.690 & 88.660 & 88.630\end{array}$

$\begin{array}{llllllllllll}9.2 & 88.902 & 88.872 & 88.841 & 88.811 & 88.781 & 88.750 & 88.720 & 88.690 & 88.660 & 88.630 \\ 9.3 & 88.599 & 88.569 & 88.539 & 88.509 & 88.478 & 88.448 & 88.418 & 88.387 & 88.357 & 88.327\end{array}$

$\begin{array}{llllllllllll}9.4 & 88.297 & 88.267 & 88.236 & 88.206 & 88.176 & 88.146 & 88.115 & 88.085 & 88.055 & 88.025 \\ 9.5 & 87.925 & 87.964 & 87.934 & 87.904 & 87.874 & 87.843 & 87.813 & 87.783 & 87.752 & 87.722\end{array}$

$\begin{array}{llllllllllll}9.5 & 87.995 & 87.964 & 87.934 & 87.904 & 87.874 & 87.843 & 87.813 & 87.783 & 87.752 & 87.722 \\ 9.6 & 87.692 & 87.662 & 87.631 & 87.601 & 87.571 & 87.541 & 87.510 & 87.480 & 87.450 & 87.420\end{array}$

$\begin{array}{llllllllllll}9.7 & 87.390 & 87.359 & 87.329 & 87.299 & 87.269 & 87.239 & 87.208 & 87.178 & 87.147 & 87.117\end{array}$

$\begin{array}{lllllllllll}9.8 & 87.087 & 87.057 & 87.027 & 86.996 & 86.966 & 86.936 & 86.906 & 86.875 & 86.845 & 86.815 \\ 9.9 & 86.785 & 86.755 & 86.724 & 86.694 & 86.664 & 86.634 & 86.604 & 86.573 & 86.543 & 86.512\end{array}$

9.9

$\begin{array}{lllllll}86.966 & 86.936 & 86.906 & 86.875 & 86.845 & 86.815 \\ 86.664 & 86.634 & 86.604 & 86.573 & 86.543 & 86.512\end{array}$

0.277376

0.277376
0.277375

1.592450

1.592503

1.592530
1.592557

592583

$9.50 ? .610$

1.592 .664

1.592717

1.592791

1.592824

1.592851
.592878

1.592904
1.592931

1.592985

1.593011

1.593065

1. 593092

1.503145

1.593172

1.593226

0.277375
0.277375
0.2777375

0.277375

0.277374

0.277374
0.277374
0.277374

1.593252

1.593279
1.593306

1.593333
1.593359

1.593386

0.277374
0.277374

$0: 27737$

0.277373

0.0277373

0.277372

0.277732

0.277372
0.277372

0.27737

0.27737
0.27737

0.27737
0.0277371

0.277371

0.0277377
0.277370

0.277370

1.593440

1.593466

0.277370
0.277370

0.27737
0.27737
0.077736
0.2736

0.27736

0.277369
0.277369

0.2775

0.277369
0.277368

1.593520
1.593547

0.277368

0.277368
0.0777368

0.27736

0.277368
0.277367

0.277367
0.27367

0.277656
0.0277367
0.27767

1.59362

1.593680

1.5593707
1.593734

. 593787

1.593814

${ }_{1}^{1.55993841}$

1.5593894

1.593948

10593975
1.594001

1.5594001
1.594028

1.594055
1.594082

1.594082

1.594135
1.594162

1.594189

1.594215
1.594242
1.59228

1.594269
1.594296

$$
.001 \quad .002
$$

.003

.004

.005

.006

.007

.008

.009

.010

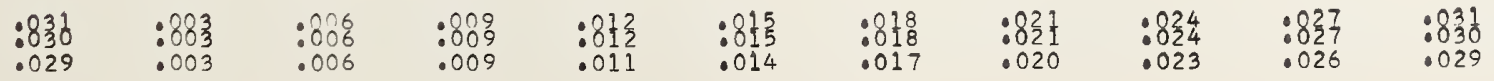




$\begin{array}{ll}0.277367 & 1.594858 \\ 0.277366 & 1.594884 \\ 0.277366 & 1.594911 \\ 0.277366 & 1.594938 \\ 0.277366 & 1.594965 \\ 0.277366 & 1.594991 \\ 0.277366 & 1.595018 \\ 0.277365 & 1.595045 \\ 0.277365 & 1.595072 \\ 0.277365 & 1.595098\end{array}$

0.277365

0.277365

0.277364

0.277364

.0277364

0.277364

0.277363

1.595125

1.595152
1.595179

1.595206

1.595259

1.595286

0.0277363

0.277362

0.277362

0.277362
0.277362
0.277362
0.277362

0.277362

0.27736

0.277361

0.277361
0.277361
0.277361

0.277361

0.277360

0.277360

0.277360

0.277360

0.277359

0.277359

0.277359

0.277359

0.277358

0.277358

0.277358
0.277358

0.277358

0.277357

0.277357

0.277357

0.277357

0.277356

0.277356

0.277356
0.277356

0.277356
0.277355

0.277355

0.277355

0.277355

1.595393

1.505446

1.595473

1.595500
1.595527

1.595553

1.595580
1.595607
1.595634

0.277355

0.277354

0.277354

0.277354

0.277354
0.27735
0.277353

0.277353

1.595660 1.595687 1.595714
1.595741 1.595767 1.595794 1.595821
.0595848 1.595874

1.595901

1.595928

1.595955
1.595981

1.595981

1.596035

1.596062

1.596089

1.596142

0.277353

1.596196

1.596222

1.596249

1.596276

1.596303
1.596329

1.596356

1.596383

1.596410
1.596436

1.596463

1.596490

1.596517
1.596543

1.596570

1.596597

1.596624

1.596650

1.596677
1.596704

0.277353

0.277352

0.277352

0.277352

0.277352

0.277351

1.596731

0.277351

0.277351

0.277351

0.277350

0.277350

0.277350

0.277350

1.596757 


.06

$$
\begin{array}{r}
760 . \\
0 . \\
0 . \\
0 . \\
0 . \\
0 .
\end{array}
$$

$17356.298 \quad 56.268$

$$
\begin{array}{rlll}
7356.298 & 56.268 & 56.238 & 56 . \\
55.996 & 55.966 & 55.936 & 550 \\
55.695 & 55.665 & 55.635 & 550
\end{array}
$$$$
\begin{array}{llll}
55.394 & 55.364 & 55.334 & 55.305
\end{array}
$$$$
\begin{array}{llll}
55.093 & 55.062 & 55.032 & 55.002
\end{array}
$$$$
\begin{array}{llll}
54.791 & 54.761 & 54.731 & 54.701
\end{array}
$$$$
54.490 \quad 54.460 \quad 54.430 \quad 54.400
$$

\section{$\begin{array}{lllllll}56.177 & 56.147 & 56.117 & 56.087 & 56.057 & 56.027 \\ 55.976 & 55.846 & 55.816 & 55.786 & 55.755 & 55.725\end{array}$} $\begin{array}{llllll}55.376 & 55.846 & 55.816 & 55.786 & 55.755 & 55.725 \\ 55.574 & 55.544 & 55.514 & 55.484 & 55.454 & 55.424\end{array}$ $\begin{array}{llllll}55.273 & 55.243 & 55.213 & 55.183 & 55.153 & 55.123\end{array}$ $\begin{array}{llllll}54.972 & 54.942 & 54.912 & 54.882 & 54.852 & 54.821 \\ 54.671 & 54.641 & 54.610 & 54.581 & 54.550 & 54.520\end{array}$ $\begin{array}{llllll}54.671 & 54.641 & 54.610 & 54.581 & 54.550 & 54.520 \\ 54.369 & 54.339 & 54.300 & 54.270 & 54.249 & 54.219\end{array}$ $\begin{array}{llllll}54.369 & 54.339 & 54.309 & 54.279 & 54.249 & 54.219 \\ 54.068 & 54.038 & 54.008 & 53.978 & 53.948 & 53.918\end{array}$ $\begin{array}{llllll}53.767 & 53.737 & 53.707 & 53.677 & 53.646 & 53.616 \\ 53.466 & 53.436 & 53.406 & 53.375 & 53.345 & 53.315\end{array}$

53.165
$53.863 \quad 52.18$
52.83

53.10
52.80
52.502

$\begin{array}{lll}53.074 & 53.044 & 53.014 \\ 52.773 & 52.743 & 52.713\end{array}$

$\begin{array}{llllll}52.562 & 52.532 & 52.502 & 52.472 & 52.442 & 52.412\end{array}$

$\begin{array}{llllll}51.960 & 51.930 & 51.900 & 51.869 & 51.839 & 51.809\end{array}$

$\begin{array}{llllll}51.658 & 51.628 & 51.598 & 51.568 & 51.538 & 51.508 \\ 51.357 & 51.327 & 51.297 & 51.267 & 51.237 & 51.207\end{array}$

$\begin{array}{llllll}5 ! .056 & 51.026 & 50.996 & 50.966 & 50.936 & 50.906 \\ 50.755 & 50.725 & 50.695 & 50.665 & 50.635 & 50.505\end{array}$

$\begin{array}{llllll}50.454 & 50.424 & 50.394 & 50.364 & 50.333 & 50.303\end{array}$

$\begin{array}{llllll}50.153 & 50.123 & 50.093 & 50.063 & 50.03 ? & 50.002\end{array}$

$\begin{array}{llllll}49.551 & 49.521 & 49.490 & 49.460 & 49.430 & 49.400\end{array}$

$\begin{array}{llllll}40.250 & 49.219 & 49.189 & 49.159 & 49.129 & 49.099 \\ 48.948 & 48.918 & 48.888 & 48.858 & 48.828 & 48.799\end{array}$

$\begin{array}{lllllll}48.647 & 48.617 & 48.587 & 48.557 & 48.527 & 48.497\end{array}$

$\begin{array}{llllll}48.346 & 48.316 & 48.286 & 48 \cdot 256 & 48.226 & 48 \cdot 196\end{array}$

$\begin{array}{llllll}48.045 & 48.015 & 47.985 & 47.955 & 47.925 & 47.895 \\ 47.744 & 47.714 & 47.684 & 47.654 & 47.624 & 47.594\end{array}$

$\begin{array}{llllll}47.443 & 47.413 & 47.383 & 47.353 & 47 \cdot 323 & 47.293\end{array}$

$\begin{array}{llllll}47.142 & 47.112 & 47.082 & 47.052 & 47.022 & 46.992 \\ 46.841 & 46.811 & 46.781 & 46.751 & 46.721 & 46.691\end{array}$

$46.540 \quad 46.510 \quad 46.480 \quad 46.450 \quad 46.420 \quad 46.390$

$\begin{array}{llllll}46.239 & 46.209 & 46.179 & 46.149 & 46.110 & 46.089\end{array}$

$\begin{array}{lllllll}45.637 & 45.607 & 45.577 & 45.547 & 45.517 & 45.487\end{array}$

$\begin{array}{lllllll}45.336 & 45.306 & 45.276 & 45.246 & 45.216 & 45.186\end{array}$

$\begin{array}{llllll}45.035 & 45.005 & 44.975 & 44 \cdot 945 & 44 \cdot 915 & 44 \cdot 885 \\ 44.735 & 44.705 & 44.674 & 440644 & 44.614 & 44.584\end{array}$

$\begin{array}{llllll}44.735 & 44.0705 & 44.674 & 44.644 & 44.614 & 44.584 \\ 44.434 & 44.404 & 44.374 & 44.343 & 44.313 & 44.283\end{array}$

$\begin{array}{llllll}44 \cdot 133 & 44.103 & 44.073 & 44.042 & 44.012 & 43.982\end{array}$

$\begin{array}{llllll}43.832 & 43.802 & 43.771 & 43.741 & 43.711 & 43.681 \\ 43.531 & 43.501 & 43.471 & 43.441 & 43.411 & 43.381\end{array}$

$\begin{array}{llllll}43.230 & 43.200 & 43.170 & 43.140 & 43.110 & 43.080\end{array}$

$\begin{array}{llllll}42.628 & 42.598 & 42.568 & 42.538 & 42.508 & 42.478\end{array}$

$\begin{array}{llllll}42.328 & 42.297 & 42.267 & 42.237 & 42.207 & 42.177 \\ 42.027 & 4.997 & 41.967 & 41.937 & 41.906 & 41.876\end{array}$

$\begin{array}{llllll}41.726 & 41.696 & 41.666 & 41.635 & 41.606 & 41.575 \\ 41.425 & 41.395 & 41.365 & 41.335 & 41.305 & 41.275\end{array}$

$\begin{array}{lllllll}41.124 & 41.094 & 41.064 & 41.034 & 41.004 & 40.974\end{array}$

$\begin{array}{llllll}40.823 & 40.793 & 40.763 & 40.733 & 40.703 & 40.673\end{array}$

$\begin{array}{llllll}40.222 & 40.192 & 40.162 & 40.132 & 40.102 & 40.072\end{array}$

$\begin{array}{llllll}40.222 & 40.192 & 40.162 & 40.132 & 40.102 & 40.072 \\ 39.921 & 39.891 & 39.861 & 39.831 & 39.801 & 39.771\end{array}$

$\begin{array}{llllll}39.621 & 39.591 & 39.561 & 39.531 & 39.500 & 39.470\end{array}$

$\begin{array}{llllll}39.320 & 39.290 & 39.260 & 39.230 & 39.199 & 39.170 \\ 39.019 & 38.989 & 38.959 & 38.929 & 38.899 & 38.869\end{array}$

$\begin{array}{llllll}38.719 & 38.688 & 38.658 & 38.628 & 38.598 & 38.568 \\ 38.418 & 38.388 & 38.358 & 38.328 & 38.298 & 38.267\end{array}$

$\begin{array}{lllllll}38.117 & 38.087 & 38.057 & 38.027 & 37.997 & 37.967\end{array}$

$\begin{array}{llllll}37.816 & 37.786 & 37.756 & 37.726 & 37.696 & 37.6666 \\ 37.516 & 37.486 & 37.456 & 37.426 & 37.396 & 37.365\end{array}$

$\begin{array}{llllll}37.516 & 37.486 & 37.456 & 37.426 & 37.396 & 37.365 \\ 37.215 & 37.185 & 37.155 & 37.125 & 37.095 & 37.065\end{array}$

$\begin{array}{lllllll}36.915 & 36.884 & 36.854 & 36.824 & 36.794 & 36.764 \\ 36.614 & 36.583 & 36.553 & 36.524 & 36.404 & 36.463\end{array}$

$\begin{array}{llllll}36.614 & 36.583 & 36.553 & 36.524 & 36.494 & 36.463 \\ 36.313 & 36.283 & 36.253 & 36.223 & 36.193 & 36.163\end{array}$

$\begin{array}{llllll}36.012 & 35.982 & 35.952 & 35.922 & 35.892 & 35.862\end{array}$

$\begin{array}{llllll}35.712 & 35.682 & 35.652 & 35.622 & 35.592 & 35.562 \\ 35.411 & 35.381 & 35.351 & 35.321 & 35.291 & 35.261\end{array}$

$\begin{array}{lllllll}35.111 & 35.081 & 35.051 & 35.021 & 34.990 & 34.960\end{array}$

$\begin{array}{llllll}34.810 & 34.780 & 34.750 & 34.720 & 34.690 & 34.660 \\ 34.510 & 34.479 & 34.449 & 34.419 & 34.389 & 34.359\end{array}$

$\begin{array}{llllll}34.510 & 34.479 & 34.449 & 34.419 & 34.389 & 34.359 \\ 34.209 & 34.179 & 34.149 & 34.119 & 34.089 & 34.059\end{array}$

$\begin{array}{llllll}33.908 & 33.878 & 33.848 & 33.818 & 33.788 & 33.758\end{array}$

$\begin{array}{llllll}33.608 & 33.578 & 330.548 & 33.518 & 33.488 & 33.458\end{array}$

$\begin{array}{lllllll}33.307 & 33.277 & 33.247 & 33.217 & 33.187 & 33.157\end{array}$

$\begin{array}{llllll}33.007 & 32.977 & 32.947 & 32.917 & 32.886 & 32.856\end{array}$

$\begin{array}{llllll}32.406 & 32.376 & 32.346 & 32.316 & 32.286 & 32.255\end{array}$

$\begin{array}{llllll}32.105 & 32.075 & 32.045 & 32.015 & 31.985 & 31.955\end{array}$

$\begin{array}{llllll}31.805 & 31.775 & 31.745 & 31.715 & 31.685 & 31.655\end{array}$

$\begin{array}{llllll}31.504 & 31.474 & 31.444 & 31.414 & 31.384 & 31.354 \\ 31.204 & 31.174 & 31.144 & 31.114 & 31.084 & 31.054\end{array}$

$\begin{array}{llllll}30.903 & 30.873 & 30.843 & 30.813 & 30.783 & 30.753\end{array}$

$\begin{array}{llllll}30.603 & 30.573 & 30.543 & 30.513 & 30.483 & 30.453\end{array}$

$\begin{array}{llllll}30.303 & 30.272 & 30.242 & 30.212 & 30.182 & 30.152 \\ 30.002 & 29.972 & 20.942 & 29.912 & 29.882 & 29.852\end{array}$

$\begin{array}{llllll}20.702 & 29.672 & 29.642 & 29.611 & 29.582 & 29.552 \\ 29.401 & 29.371 & 29.341 & 29.311 & 29.281 & 29.751\end{array}$

$\begin{array}{llllll}29.101 & 29.071 & 29.041 & 29.011 & 28.981 & 28.951\end{array}$

$\begin{array}{llllll}28.801 & 28.771 & 28.740 & 28.710 & 28.680 & 28.650\end{array}$

$\begin{array}{llllll}28.500 & 28.470 & 28.440 & 28.410 & 28.380 & 28.350\end{array}$

$\begin{array}{llllll}28.200 & 28.170 & 28.140 & 28.110 & 28.080 & 28.050 \\ 27.900 & 27.870 & 27.840 & 27.810 & 27.779 & 27.0749\end{array}$

$\begin{array}{llllll}27.599 & 27.870 & 27.840 & 28.110 & 28.080 & 28.050 \\ 27.569 & 27.539 & 27.509 & 27.479 & 27.7449\end{array}$

$\begin{array}{llllll}27.299 & 27.269 & 27.239 & 27.209 & 27.179 & 27.149\end{array}$

$\begin{array}{llllll}26.999 & 26.969 & 26.938 & 26.908 & 26.878 & 26.848\end{array}$

$\begin{array}{llllll}26.698 & 26.9668 & 26.938 & 26.908 & 26.878 & 26.848 \\ 26.578 & 26.548\end{array}$

$\begin{array}{lllllll}26.698 & 26.668 & 26.638 & 26.608 & 26.5778 & 26.548 \\ 26.398 & 26.368 & 26.338 & 26.308 & 26.278 & 26.748\end{array}$

.277350

0.277349

0.277349

0.277349

0.277348

0.277348
0.277348

0.277348

0.277347

0.277347

0.277347

0.277346

0.277346

0.277346

0.277346

0.277345

0.277345

0.277345

0.277344

0.277344

0.277344

0.277344

. 277343

0.277343

0.277343

0.277343
0.277343
0.277342

0.277342

0.277342

0.277342

0.277342

0.277341

0.277341

0.277341

0.277340

0.277340

0.277340
0.277340
0.277340

0.277340

0.277339

0.277339
0.277339
0

0.277339

0.277339
0.277339
0

0.277338

0.277338

0.277338
0.277338

0.277338

0.277338

0.277337
0.277337
0.277397

0.0277337

0.277337

0.077337

0.277336
0.277336

0.277336

0.277336

0.277336
0.277336

0.277335

0.27733

0.277335

0.277335

0.277334 
0.0

0.4

0.7

0.8

71.
1.0
1.0
1.5
1.6
1.8

5772

$$
\begin{array}{r}
2.0 \\
2.1 \\
2.2 \\
2.3 \\
2.4 \\
2.5 \\
2.6 \\
2.7 \\
2.8 \\
2.9
\end{array}
$$$$
5773.0
$$$$
\begin{aligned}
& 3.0 \\
& 3.2 \\
& 3.04
\end{aligned}
$$

$$
\begin{aligned}
& 3 . \\
& 3 . \\
& 3.6 \\
& 3.0
\end{aligned}
$$$$
\begin{aligned}
& 3.5 \\
& 3.6 \\
& 3.7 \\
& 3.8 \\
& 3.9
\end{aligned}
$$$$
5774.0
$$$$
40
$$$$
\begin{aligned}
& 4.2 \\
& 4.3 \\
& 4.4
\end{aligned}
$$

4.5
4.6

4.7
4.8

$$
5775 .
$$$$
575.0
$$$$
\begin{aligned}
& 5.2 \\
& 5.3 \\
& 5.4
\end{aligned}
$$$$
5.5
$$$$
5.7
$$$$
5776.0
$$$$
\begin{array}{r}
7.0 \\
6.0 \\
6.0 \\
6.0 \\
6.0 \\
6.5 \\
6.6 \\
6.7 \\
6.8 \\
6.9
\end{array}
$$

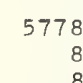

$\begin{array}{rr}17323.216 & 23.186 \\ 22.915 & 22.885\end{array}$ $\begin{array}{rrr}22.915 & 22.885 & 22 \\ 22.615 & 22.585 & 220 \\ 22.315 & 22.285 & 220\end{array}$ $\begin{array}{ll}22.015 & 21.985 \\ 21.715 & 21.685\end{array}$ $\begin{array}{ll}21.715 & 21.685 \\ 21.415 & 21.385\end{array}$ $\begin{array}{ll}21.115 & 21.084 \\ 20.814 & 20.784 \\ 20.514 & 20.484\end{array}$

$3.156 \quad 23.125$ $\begin{array}{ll}22.855 & 22.825 \\ 22.555 & 22.525 \\ 22.255 & 22.225\end{array}$ $\begin{array}{ll}22.255 & 22.225 \\ 21.955 & 21.925\end{array}$ $\begin{array}{ll}21.054 & 21.024 \\ 20.754 & 20.724 \\ 20.454 & 20.424\end{array}$ $\begin{array}{ll}19.914 & 19.184 \\ 19.614\end{array}$ $\begin{array}{ll}19.614 & 19.584 \\ 19.314 & 19.284\end{array}$ $19.014 \quad 18.984$ $\begin{array}{ll}18.714 & 18.684 \\ 18.414 & 18.384\end{array}$

$20.154 \quad 20.124$

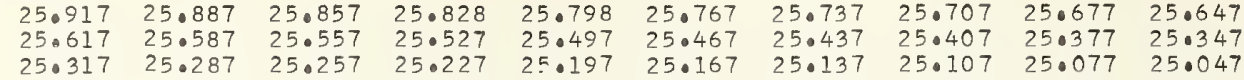
$\begin{array}{llllllllll}25.017 & 24.987 & 24.957 & 24.927 & 24.897 & 24.867 & 24.837 & 24.807 & 24.776 & 24.746\end{array}$ $\begin{array}{llllllllll}24.717 & 24.687 & 24.656 & 24.626 & 24.596 & 24.566 & 24.536 & 24.506 & 24.476 & 24.446 \\ 24.416 & 24.386 & 24.356 & 24.326 & 24.296 & 24.266 & 24.236 & 24.206 & 24.176 & 24.146\end{array}$

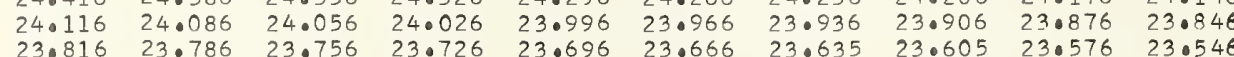

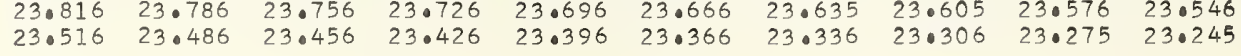
$21.655 \quad 21.625 \quad 21.895$ $21.354 \quad 21.325 \quad 21.594 \quad 21.564$

$23.095 \quad 23.065$

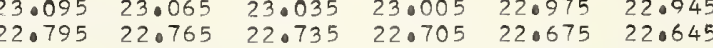
$22.495-22.465 \quad 22.435 \quad 22.405 \quad 22 \cdot 375 \quad 22 \cdot 345$

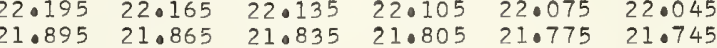

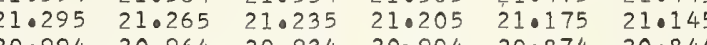
$\begin{array}{llllll}20.994 & 20.964 & 20.934 & 20.904 & 20.874 & 20.844\end{array}$ $\begin{array}{llllll}20.694 & 20.664 & 20.634 & 20.604 & 20.574 & 20.544 \\ 20.395 & 20.364 & 20.334 & 20.304 & 20.274 & 20.244\end{array}$

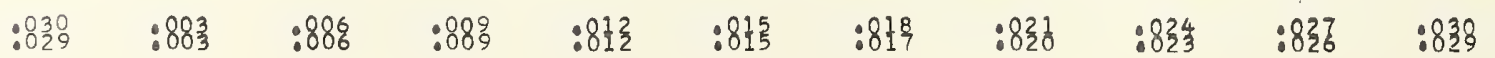




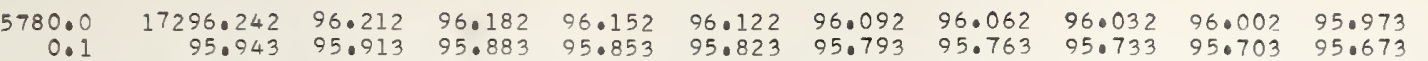

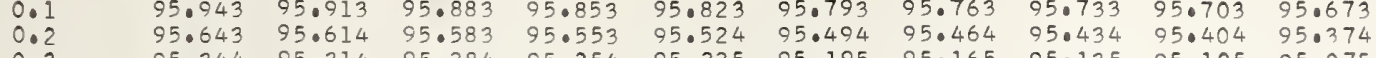

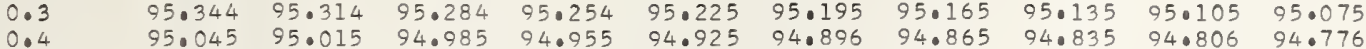

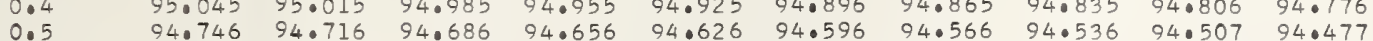
$0.6 \quad 94.447 \quad 94.417 \quad 94.387 \quad 94.357 \quad 94.3$

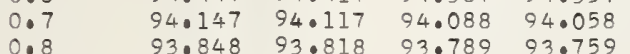

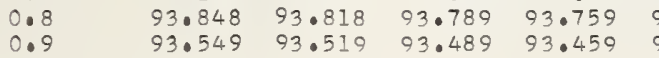

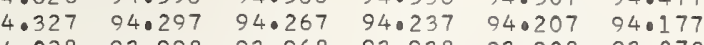
$94.028 \quad 93.998 \quad 93.968 \quad 93.938 \quad 93.908 \quad 93.878$

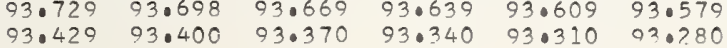

$\begin{array}{ll}0.277316 & 1.602886 \\ 0.277316 & 1.602912 \\ 0.277316 & 1.602939 \\ 0.277315 & 1.602966 \\ 0.277315 & 1.602993 \\ 0.277315 & 1.603019 \\ 0.277315 & 1.603046 \\ 0.277315 & 1.603073 \\ 0.277315 & 1.603100 \\ 0.277314 & 1.602127\end{array}$

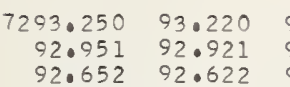

$\begin{array}{lll}1.1 & 92.951 & 92.921 \\ 1.2 & 92.652 & 92.622 \\ 1.3 & 92.353 & 92.323\end{array}$

$\begin{array}{lll}1.3 & 92.353 & 92.323 \\ 1.4 & 92.053 & 92.024 \\ 1.5 & 91.755 & 91.724\end{array}$

$\begin{array}{lll}1.6 & 91.455 & 91.425 \\ 1.7 & 91.156 & 91.126\end{array}$

$\begin{array}{lll}1.8 & 90.857 & 90.126 \\ 1.8 & 90.857 & 90.827\end{array}$

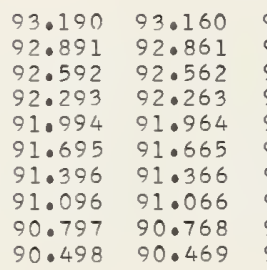

$93.130 \quad 93.100$

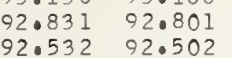

$\begin{array}{ll}92.233 & 92.203 \\ 91.934 & 91.904 \\ 91.635 & 01.605\end{array}$

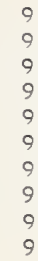

$\begin{array}{llll}93.071 & 93.041 & 93.010 & 97.981 \\ 92.771 & 92.741 & 92.711 & 92.682 \\ 92.472 & 92.442 & 92.413 & 92.382\end{array}$

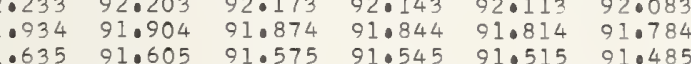

$\begin{array}{llllll}91.336 & 91.306 & 91.276 & 91.246 & 91.216 & 91.186\end{array}$

5782.0

\section{$\begin{array}{llll}17290.259 & 90.229 & 90.199 & 90 .\end{array}$}

$\begin{array}{ll}90.259 & 90.229 \\ 89.960 & 89.930 \\ 89.661 & 89.631\end{array}$

$\begin{array}{lll}89.362 & 89.332 & 89.302 \\ 89.063 & 89.033 & 89.003\end{array}$

$\begin{array}{lll}88.764 & 88.734 & 88.704 \\ 88.465 & 88.435 & 88.405\end{array}$

$88.166 \quad 88.136 \quad 88.106 \quad 88.076$

$\begin{array}{llll}87.867 & 87.837 & 87.808 & 87.777 \\ 87.568 & 87.538 & 87.508 & 87.479\end{array}$

5783.0

17287.2690

$87.269 \quad 87.240$

$87.209 \quad 87.180 \quad 87$.

$\begin{array}{llll}86.970 & 86.940 & 86.910 & 86.881 \\ 86.672 & 86.642 & 86.612 & 86.582\end{array}$

$\begin{array}{llll}86.373 & 86.343 & 86.313 & 86.283\end{array}$

$85.775 \quad 85.745-85.715 \quad 85.685$

$85.476 \quad 85.446 \quad 85.416 \quad 85.386$

$\begin{array}{lllll}84.878 & 84.848 & 84.819 & 84.789\end{array}$

$\begin{array}{llll}84.580 & 84.550 & 84.520 & 84.490\end{array}$

5784.0

4.0
4.0
4.0
4.0
4.5
4.7
4.8

$\begin{array}{rlll}17284.281 & 84.251 & 84.221 & 84.191 \\ 83.982 & 83.952 & 83.922 & 83.892\end{array}$

$83.683 \quad 83.653 \quad 83.623$

$\begin{array}{lllll}83.384 & 83.354 & 83.324 & 83.295\end{array}$

$83.085 \quad 83.05$

$82.787 \quad 82.757 \quad 82.727$

$\begin{array}{llll}82.189 & 82.159 & 82.129 & 82.009\end{array}$

$\begin{array}{llll}81.890 & 81.860 & 81.831 & 81.801 \\ 81.592 & 81.562 & 81.532 & 81.502\end{array}$

$\begin{array}{ll}90.738 & 90.708 \\ 90.439 & 90.409\end{array}$

$\begin{array}{ccccc}0.678 & 90.048 & 90.917 & 90.887\end{array}$

$\begin{array}{lllllll}90.139 & 90.110 & 90.080 & 90.050 & 00.020 & 89.090\end{array}$

0.977314

0.27731
0.27731

0.277314

0.277313

0.277313

1.60318

1.603234

1.603287

1.603341

1.603394

0.277312
0.077312

0.277312

0.277312
0.277312

0.277311

0.277311

$\begin{array}{llllll}89.242 & 89.213 & 89.183 & 89.153 & 89.123 & 89.093\end{array}$

$\begin{array}{llllll}88.645 & 88.615 & 88.8845 & 88.854 & 88.824 & 88.794 \\ 88.555 & 88.525 & 88.495\end{array}$

$\begin{array}{lllllll}88.045 & 88.0115 & 88.286 & 88.256 & 88.226 & 88.196 \\ 88.046 & 88.017 & 87.987 & 87.957 & 87.927 & 87.897\end{array}$

$\begin{array}{llllll}87.748 & 87.718 & 87.688 & 87.658 & 87.628 & 87.598 \\ 87.449 & 87.419 & 87.389 & 87.359 & 87.329 & 87.2 .99\end{array}$

0.27731

0.27731

0.277310

$\begin{array}{lllll} & \end{array}$

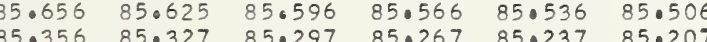

\begin{tabular}{llllll}
85.058 & 85.327 & 85.297 & 85.267 & 85.237 & 85.207 \\
\hline & 85.028 & 84.998 & 84.968 & 84.038 & 84.908
\end{tabular}

0.277310
0.277310
0.277309

0.277309

.063501

1.603555

1.603608

1.603635

$281.293 \quad 81.263$

5.1
5.2

5.3

5.5

5.6
5.7

$\begin{array}{llll}80.696 & 80.666 & 80.636 & 80.606 \\ 80.397 & 80.367 & 80.337 & 80.307\end{array}$

$\begin{array}{llll}80.098 & 80.068 & 80.30 .038 & 80.30 .008\end{array}$

$\begin{array}{llll}79.800 & 79.770 & 79.740 & 79.710\end{array}$

$79.202 \quad 79.172$

$78.903 \quad 78.874$

$79.142 \quad 79.113$

$84.460 \quad 84.430$

\begin{tabular}{llll}
84.400 & 84.669 & 84.639 & 84.609 \\
\hline 470 & 84.341 & 84.311
\end{tabular}

0.277309
0.277309
0.277309

1.603689

5.8
5.9

$78.605 \quad 78.575$

$\begin{array}{llllll}8.161 & 84.131 & 84.101 & 84.072 & 84.042 & 84.012\end{array}$

$\begin{array}{llllll}3.563 & 83.534 & 83.504 & 83.474 & 83.444 & 82.414\end{array}$

$\begin{array}{lllllll}82.966 & 82.936 & 82.906 & 82.876 & 82.846 & 82.816\end{array}$

$\begin{array}{llllll}82.667 & 82.637 & 82.607 & 82.578 & 82.548 & 82.518\end{array}$

$\begin{array}{llllll}82.070 & 82.040 & 82.010 & 81.980 & 81.950 & 81.920\end{array}$

0.0277309

0.277308

0.277308

0.277308
0.277308

1.603742

1.603796

1.603849

1.603903

5786.0

6.0
6.2
6.3
6.
6.5
6.6
6.7
6.8
6.9

$\begin{array}{rlll}7278.306 & 78.276 & 78.246 & 78.217 \\ 78.008 & 77.978 & 77.948 & 77.918\end{array}$

$\begin{array}{lllll}77.709 & 77.679 & 77.649 & 77.619\end{array}$

$\begin{array}{llll}77.410 & 77.380 & 77.351 & 777.321 \\ 77.112 & 77.082 & 77.052 & 77.022\end{array}$

$\begin{array}{llll}76.813 & 76.783 & 76.753 & 76.724 \\ 76.515 & 76.485 & 76.555 & 76.425\end{array}$

$\begin{array}{llll}76.216 & 76.186 & 76.455 & 76.425 \\ 75.156 & 76.126\end{array}$

$\begin{array}{llll}75.917 & 75.888 & 75.858 & 75 \cdot 828 \\ 75.619 & 75.589 & 75.559 & 75.529\end{array}$

$\begin{array}{llllll}81.173 & 81.144 & 81.114 & 81.084 & 81.054 & 81.024\end{array}$

$\begin{array}{llllll}80.875 & 80.845 & 80.815 & 80.785 & 80.755 & 80.725 \\ 80.576 & 80.546 & 80.516 & 80.487 & 80.457 & 80.427\end{array}$

$\begin{array}{llllll}80.277 & 80.247 & 80.218 & 80.187 & 80.158 & 80.128\end{array}$

$\begin{array}{llllll}70.979 & 79.949 & 79.919 & 79.889 & 79.859 & 79.829 \\ 79.680 & 79.650 & 79.620 & 79.590 & 79.561 & 79.531\end{array}$

$\begin{array}{llllll}79.381 & 79.351 & 79.322 & 79.292 & 79.262 & 79.232\end{array}$

$\begin{array}{lllllll}78.784 & 78.754 & 78.724 & 78.694 & 78.665 & 78.635 \\ 78.486 & 78.456 & 78.426 & 78.396 & 78.366 & 78.336\end{array}$

0.277307

0.277307

0.277307

0.277307

0.277306

0.277306

0.277306

0.277306

$\begin{array}{lllllll}77.888 & 77.858 & 78.127 & 78.097 & 78.067 & 78.037 \\ 77.828 & 77.799 & 77.769 & 77.739\end{array}$

$\begin{array}{lllllll}77.589 & 77.560 & 77.530 & 77.500 & 77.470 & 77.440\end{array}$

$\begin{array}{lllllll}76.992 & 76.962 & 76.933 & 76.903 & 76.873 & 76.843\end{array}$

$\begin{array}{lllllll}76.694 & 76.664 & 76.634 & 76.604 & 76.574 & 76.544 \\ 76.305 & 76.365 & 76.335 & 76.305 & 76.276 & 76.246\end{array}$

0.277305

0.277305

0.277305

0.277305

$\begin{array}{llllll}74.097 & 76.067 & 76.037 & 76.007 & 75.977 & 75.947 \\ 75.798 & 75.768 & 75.739 & 75.708 & 75.679 & 75.649\end{array}$

0.277304

5787

17275.32100

$\begin{array}{rr}7.0 & 17275.3 \\ 7: 1 & 75.0 \\ 7: 2 & 74.07 \\ 7.3 & 74.4 \\ 7: 4 & 74.0\end{array}$

$\begin{array}{lllllllllll} & & & \end{array}$

$\begin{array}{llllllllll}74.425 & 74.395 & 74.365 & 74.335 & 74.305 & 74.276 & 74.246 & 74.216 & 74.186 & 74.156\end{array}$

$\begin{array}{llllllllll}74.126 & 74.097 & 74.067 & 74.037 & 74.007 & 73.977 & 73.948 & 73.917 & 730888 & 72.858\end{array}$

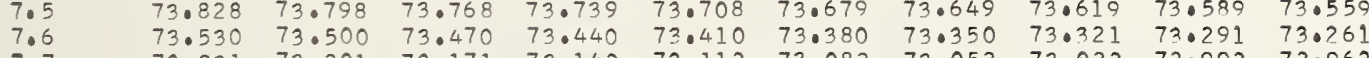

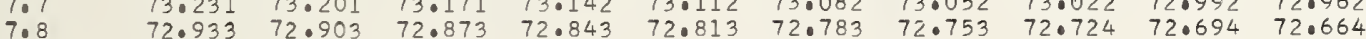

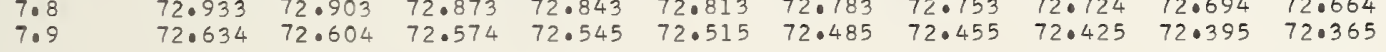

0.277304

0.277304

0.277304

0.277303

0.277303

0.277303

0.277302

0.277302

0.277302

0.277302

0.277302
0.277301
0.277301

0.27730
0.277301

0.277301

0.277301

0.277301

0.277300
0.277300
0.277300

0.277300

0.277300
0.277300
0.277300

0.277300

0.277209
0.277299

1.603956

.6603983
.0604010

1.604036

1.604063

1.604090
1.604117

1.604144

1.604170

1.604224

1.604251

.604321

1.604358

1.604384

1.604438
1.604465

1.604491

1.604518

1.604545
1.604572

1.604599

1.604625

1.604652

1.604706

1.604759

1.604813

1.604813

1.604866

1.604893

1.604946

1.605000

1.605027

1.605054

1.605107

1.605134

1.605187

1.605241

1.605294

1.605321

1.605348
1.605375

1.605401 $\begin{array}{llllllllll}68.159 & 68.129 & 68.099 & 68.069 & 68.330 & 68.308 & 68.278 & 68.248 & 68.219 & 68.189 \\ & 68.010 & 67.980 & 67.950 & 67.920 & 67.891\end{array}$ $\begin{array}{lllllllllll}67.861 & 67.831 & 67.801 & 67.771 & 67.741 & 67.711 & 67.682 & 67.652 & 67.622 & 67.592\end{array}$

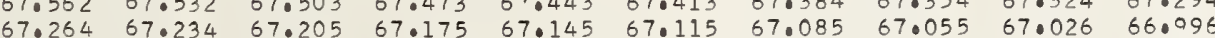
$\begin{array}{llllllllll}66.966 & 66.936 & 66.906 & 66.876 & 66.847 & 66.817 & 66.787 & 66.757 & 66.728 & 66.698 \\ 66.568 & 66.638 & 66.608 & 66.578 & 66.549 & 66.519 & 66.489 & 66.459 & 66.429 & 66.399\end{array}$

1.605535 


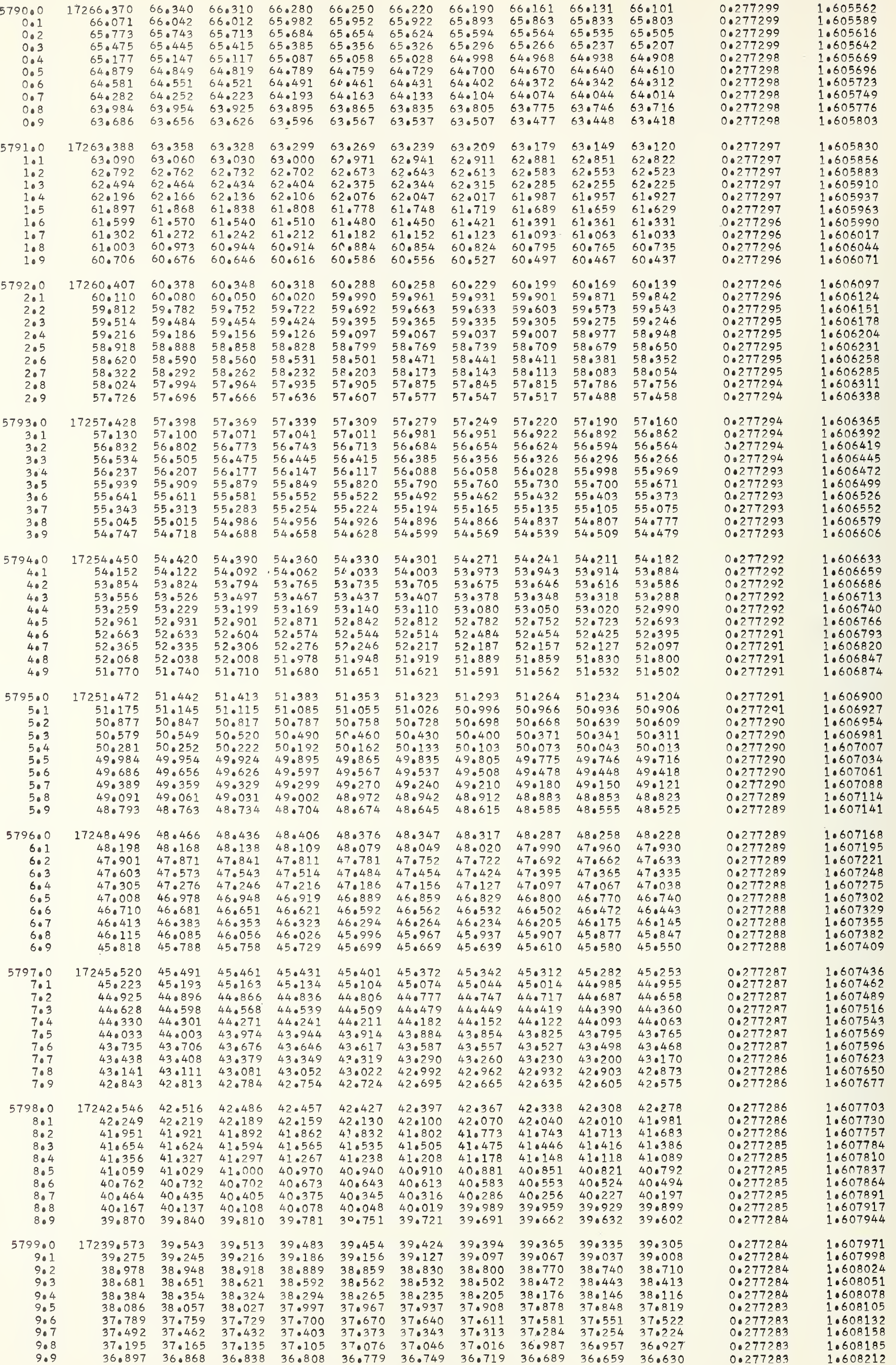


$\begin{array}{llllllllll}36.303 & 36.273 & 36.244 & 36.511 & 36.481 & 36.451 & 36.422 & 36.392 & 36.363 & 36.333 \\ 36.006 & 35.976 & 35.946 & 35.917 & 36.184 & 36.155 & 36.125 & 36.095 & 36.065 & 36.036 \\ & 35.887 & 35.857 & 35.828 & 35.798 & 35.768 & 35.738\end{array}$

$\begin{array}{llllllllllll}3 & 35.709 & 35.679 & 35.649 & 35.620 & 35.590 & 35.560 & 35.531 & 35.501 & 35.471 & 35.441\end{array}$

$\begin{array}{lllllllllll}35 \cdot 41.1 & 35 \cdot 382 & 35.352 & 35 \cdot 322 & 35 \cdot 293 & 35 \cdot 263 & 35 \cdot 233 & 35 \cdot 204 & 35 \cdot 174 & 35 \cdot 144\end{array}$

$\begin{array}{llll}35.115 & 35.085 & 35.055 & 35.025\end{array}$

34.996834 .966

$34.520 \quad 34.490 \quad 34.461 \quad 34.431$

$34.698 \quad 34.66$

34.639

34.609

$34 \cdot 877$
34.579

34.550
34.253

33.926

34.193
33.896

17233.629

$33.332 \quad 33.30$

$\begin{array}{ll}33.035 & 33.0 \\ 32.738 & 32.7\end{array}$

32.441

$32.144 \quad 32.114$

$31.550 \quad 31.520$

$\begin{array}{ll}31.253 & 31.223 \\ 30.956 & 30.926\end{array}$

$\begin{array}{lll}33.570 & 33.540 & 3 \\ 33.273 & 33.243 & \\ 32.976 & 32.946 & \\ 32.679 & 32.649 & 32 \\ 32.381 & 32.352 & 32 \\ 32.084 & 32.055 & 32 \\ 31.787 & 31.758 & 31 \\ 31.490 & 31.461 & 31 \\ 31.193 & 31.164 & 31 \\ 30.896 & 30.867 & 30\end{array}$

$\begin{array}{ll}34.104 & 34.07 \\ 33.807 & 33.77\end{array}$

34.04
33.74

34.015
33.718

33.985
33.68

33.956
33.659

$33.213 \quad 33.18$

$\begin{array}{llll}33.451 & 33.421 & 33.39 ? & 33.362 \\ 33.154 & 33.124 & 33.094 & 33.065\end{array}$

$\begin{array}{llllll}32.886 & 32.857 & 32.827 & 32.797 & 32.768\end{array}$

$\begin{array}{llllll}32.322 & 32.292 & 32.263 & 32.233 & 32.203 & 32.174\end{array}$

$\begin{array}{llllll} & \end{array}$

$\begin{array}{llllll}31.431 & 31.401 & 31.372 & 31.342 & 31.312 & 31.282\end{array}$

$\begin{array}{llllll}31.134 & 31.104 & 31.074 & 31.045 & 31.015 & 30.986 \\ 30.837 & 30.807 & 30.778 & 30.748 & 30.718 & 30.688\end{array}$

17230.659

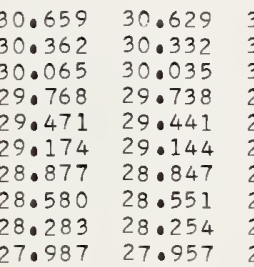

$30.600 \quad 30.570$

$30.540 \quad 30.51$

$\begin{array}{llll}30.480 & 30.451 & 30.421 & 30.392\end{array}$

$5803 \cdot$
$3 \bullet$
$3 \cdot$
$3 \cdot$
$3 \cdot$
$3 \bullet$
$3 \bullet$
$3 \bullet$
3.

17227.690

$$
227.690 \quad 27.660
$$

$30.006 \quad 29.976$

$\begin{array}{ll}30.243 & 30.213 \\ 29.946 & 29.917\end{array}$

$29.412 \quad 29.382$

$29.649 \quad 29.61$

$\begin{array}{lllllll}29.352 & 29.323 & 29.590 & 29.560 & 29.531 & 29.501\end{array}$

$\begin{array}{llllll}29.055 & 29.026 & 29.293 & 29.263 & 29.233 & 29.204 \\ \end{array}$

$28.818 \quad 28.78$

$28.759 \quad 28.72$

$\begin{array}{llll}28.996 & 28.966 & 28.937 & 28.907\end{array}$

$\begin{array}{llllll}28.461 & 28.432 & 28.402 & 28.372 & 28.343 & 28.313\end{array}$

$\begin{array}{llllllll}28.224 & 28.194 & 28.165 & 28.135 & 28.105 & 28.075 & 28.046 & 28.016 \\ 27.927 & 27.897 & 27.868 & 27.838 & 27.808 & 27.779 & 27.749 & 27.719\end{array}$

0.277283
0.277282
0.277282
0.277282
0.277282
0.277282
0.277282
0.277281
0.277281
0.277281

1.608239

0.27728

0.27778
0.27728
0.27728
0.0277280

0.0777280
0.277280
0.27728

0.277280

0.0277280

0.277280
0.277279

0.277279

0.0777279

0.277279

0.277278
0.277278

0.277278

0.277278

1.608319

1.608372

1.609453

1.608479

$\begin{array}{lllllllllll}.1 & 27.393 & 27.363 & 27.330 & 27.601 & 27.571 & 27.541 & 27.511 & 27.482 & 27.452 & 27 \cdot 422 \\ .2 & 27.096 & 27.066 & 27.036 & 27.304 & 27.274 & 27.244 & 27.215 & 27.185 & 27.155 & 27.125 \\ 3 & 26.007 & 26.077 & 26.948 & 26.918 & 26.88 & 26.858 & 260829\end{array}$

0.277278

0.277277
$0.277 ? 77$

0.277277

$\begin{array}{llllllllll}26.769 & 26.740 & 26.710 & 26.680 & 26.650 & 26.621 & 26.591 & 26.56 ? & 26.532\end{array}$

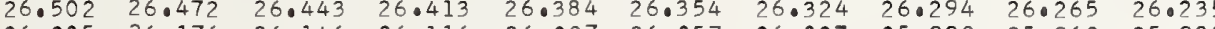

$\begin{array}{llllllllll}26.205 & 26.176 & 26.146 & 26.116 & 26.087 & 26.057 & 26.027 & 25.998 & 25.968 & 25.938 \\ 25.908 & 25.879 & 25.849 & 25.820 & 25.790 & 25.760 & 25.730 & 25.901 & 25.671 & 25.641\end{array}$

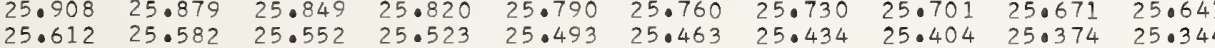

$\begin{array}{lllllllll}25.285 & 25.256 & 25.226 & 25.196 & 25.167 & 25.137 & 25 \cdot 107 & 25.077 & 25.048\end{array}$

0.277277

0.277276

1.608506

1.608533

1.60858

1.608613

.608667

1.608694

1.608720

.609794

1.608801

1.608854

1.608881

1.608935

1.608961

1.609015

5804.

4.0
$4 \cdot$
$4 \cdot$
$4 \cdot 4$
$4 \cdot 5$
$4 \cdot 6$
4.7
4.9

17224.721

$24 \cdot 989$

$24.959 \quad 24.929$

24.89

24.870

$24.840 \quad 24.810 \quad 24.781 \quad 24.751$

0.277276

.609042

1.609095

1.609122

1.609175

1.609202

1.609256

0.277779

1.609309

0.277276

.609336

0.277275

.6009390

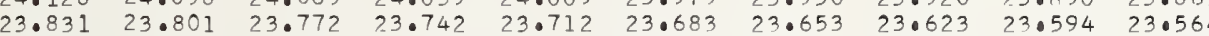

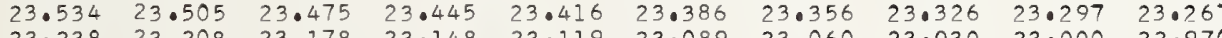

$\begin{array}{llllllllll}23.238 & 23.208 & 23.178 & 23.148 & 23.119 & 23.089 & 23.060 & 23.030 & 23.000 & 22.970 \\ 22.941 & 22.911 & 22.882 & 22.852 & 22.822 & 22.792 & 22.763 & 22.733 & 22.703 & 22.674\end{array}$

$\begin{array}{llllllllll}22.644 & 22.615 & 22.585 & 22.555 & 22.525 & 22.496 & 22.466 & 22.437 & 22.407 & 22.377\end{array}$

$\begin{array}{llllllllll}22.347 & 22.318 & 22.288 & 22.259 & 22.229 & 22.199 & 22.169 & 22.140 & 22.110 & 22.080\end{array}$

1.609443

0.0277275
0.2777275

1.609523

1.60577

5805.0

17221.754

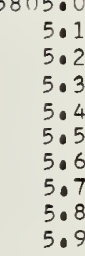

5806.0

506.0
6.1
6.2
6.3
6.4
6.5
6.5
6.7
6.8
6.9

5807.0

07.0
7.1
7.2
7.3

7.4

7.5
7.6
7.7

7.8

5808

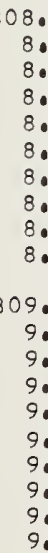

$21.458 \quad 21.428$

21.695

21.665

$\begin{array}{llllll}21.635 & 21.606 & 21.576 & 21.547 & 21.517 & 21.487\end{array}$

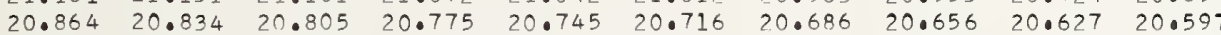
$\begin{array}{llllllllll}20.567 & 20.538 & 20.508 & 20.479 & 20.449 & 20.419 & 20.390 & 20.360 & 20.330 & 20.301\end{array}$

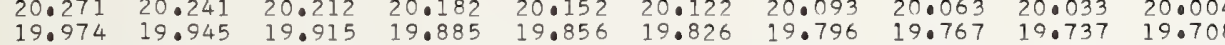
$\begin{array}{llllllllll}19.381 & 19.351 & 19.322 & 19.292 & 19.262 & 19.233 & 19.203 & 19.173 & 19.144 & 19.114\end{array}$

$\begin{array}{llllllllll}17218.788 & 18.758 & 18.729 & 18.699 & 18.669 & 18.639 & 18.610 & 18.580 & 18.551 & 18.521\end{array}$ $\begin{array}{llllllllll}18.491 & 18.462 & 18.432 & 18.402 & 18.373 & 18.343 & 18.313 & 18.284 & 18.254 & 18.225\end{array}$

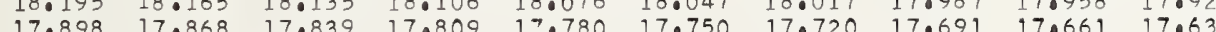
$\begin{array}{llllllllll}17.602 & 17.572 & 17.542 & 17.513 & 17.483 & 17.453 & 17.424 & 17.394 & 17.365 & 17.235\end{array}$ $\begin{array}{llllllllll}17.305 & 17.276 & 17.246 & 17.216 & 17.187 & 17.157 & 17.127 & 17.098 & 17.068 & 17.038\end{array}$ $\begin{array}{llllllllll}17.009 & 16.979 & 16.949 & 16.920 & 16.890 & 16.860 & 16.831 & 16.801 & 16.771 & 16.742\end{array}$

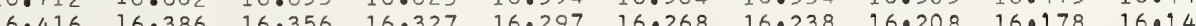
$\begin{array}{llllllllll}16.416 & 16.386 & 16.356 & 16.327 & 16.297 & 16.268 & 16.238 & 16.208 & 16.178 & 16.149 \\ 16.119 & 16.089 & 16.060 & 16.030 & 16.001 & 15.971 & 15.941 & 15.912 & 15.882 & 15.852\end{array}$

$17215.823 \quad 15.793$

14.93314 .904

$14.637 \quad 14.607$

$14.04414 .014 \quad 13.985$

$13.451 \quad 13.42$

13.688113 .659

13.15513 .125

3.096

$\begin{array}{rrrrrrrrrrr}.0 & 17212.859 & 12.829 & 12.799 & 12.770 & 12.740 & 12.710 & 12.681 & 12.651 & 12.622 & 12.592 \\ 8.1 & 12.562 & 12.532 & 12.503 & 12.473 & 12.444 & 12.414 & 12.385 & 12.355 & 12.325 & 12.295 \\ 8.2 & 12.266 & 12.236 & 12.207 & 12.177 & 12.147 & 12.118 & 12.088 & 12.058 & 12.029 & 11.999\end{array}$ $\begin{array}{llllllllll}11.969 & 11.940 & 11.910 & 11.881 & 11.851 & 12.118 & 12.088 & 12.058 & 12.029 & 11.999 \\ \end{array}$ $\begin{array}{llllllllll}11.673 & 11.644 & 11.614 & 11.584 & 11.555 & 11.525 & 11.495 & 11.466 & 11.733 & 11.703 \\ \end{array}$

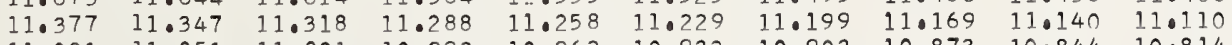
$\begin{array}{llllllllll}11.081 & 11.051 & 11.021 & 10.992 & 10.962 & 10.932 & 10.903 & 10.873 & 10.844 & 10.814\end{array}$ $\begin{array}{llllllllll}10.784 & 10.755 & 10.725 & 10.695 & 10.666 & 10.636 & 10.606 & 10.577 & 10.547 & 10.518\end{array}$ $\begin{array}{llllllllll}10.488 & 10.458 & 10.429 & 10.399 & 10.370 & 10.340 & 10.310 & 10.281 & 10.251 & 10.221 \\ 10.192 & 10.162 & 10.132 & 10.103 & 10.073 & 10.044 & 10.014 & 09.984 & 09.955 & 09.925\end{array}$

$\begin{array}{llllllllll}17209.896 & 09.866 & 09.836 & 09.807 & 09.777 & 09.747 & 09.718 & 09.688 & 09.658 & 09.629\end{array}$

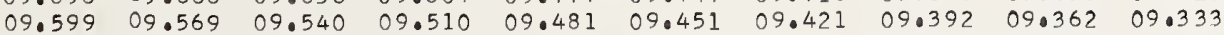
$\begin{array}{llllllllll}09.303 & 09.273 & 09.244 & 09.214 & 09.184 & 09.155 & 09.125 & 09.096 & 09.066 & 09.036\end{array}$ $\begin{array}{llllllllll}09.007 & 08.977 & 08.948 & 08.918 & 08.888 & 08.858 & 08.829 & 08.799 & 08.770 & 08.740\end{array}$ $\begin{array}{llllllllll}08.710 & 08.681 & 08.651 & 08.622 & 08.592 & 08.562 & 08.533 & 08.503 & 08.473 & 08.444\end{array}$ $\begin{array}{llllllllll}08.414 & 08.385 & 08.355 & 08.325 & 08.296 & 08.266 & 08.236 & 08.207 & 08.177 & 08.148\end{array}$ $\begin{array}{lllllllllll}08.118 & 08.088 & 08.059 & 08.029 & 08.000 & 07.970 & 07.940 & 07.911 & 07.881 & 07.852\end{array}$ $\begin{array}{llllllllll}07.822 & 07.792 & 07.763 & 07.733 & 07.703 & 07.674 & 07.644 & 07.615 & 07.585 & 07.555\end{array}$ $\begin{array}{llllllllll}07.526 & 07.496 & 07.467 & 07.437 & 07.407 & 07.377 & 07.348 & 07.318 & 07.289 & 07.259\end{array}$ $\begin{array}{llllllllll}07.229 & 07.200 & 07.170 & 07.141 & 07.111 & 07.081 & 07.052 & 07.022 & 06.997 & 06.963\end{array}$

0.277272

0.077274

0.0277774

0.27777

0.02777273
0.0277273

0.277273

0.0777272

0.277272

0.0277772

0.277271
0.277271

0.277271
0.2277271

0.227727
0.277277
0.22727

0.277270

0.277770

0.277770

0.0277270
0.27727

0.277269

0.2777269
0.27769

0.277269

0.277769

0.077268

0.77758

0.0277268
0.0277268

0.277268

0.277267
0.277267
0.277267

0.277267
0.277267

0.277267

0.2777967

0.277966

0.277766

.609604

1.609630
1.609657

1.609684

1.609711

. 609764

1.609818

$\{.609845$

1.609871

1.609925

.609952

1.609978

1.610005

.610059

1.610112

1.610166

1.610193

1.610219

1.610273

1.610300

1.610380

1.610407

1.610460

1.610487

1.610541

1.61 .0567
1.610594

1.610621

1.610648

1.610674
1.610701

1.610728

1.610755

1.610782
1.610808

1.610835

1.610862
.610899

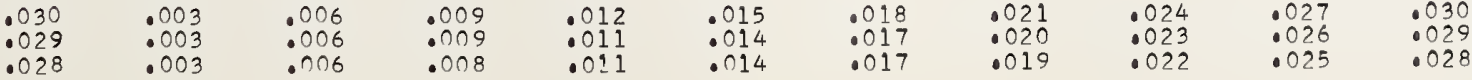


$\begin{array}{lllllllllll}5810.0 & 17206.933 & 06.904 & 06.874 & 06.844 & 06.815 & 06.785 & 06.756 & 06.726 & 06.697 & 06.667\end{array}$ $\begin{array}{llllllllllll}0.1 & 06.637 & 06.608 & 06.578 & 06.549 & 06.519 & 06.489 & 06.460 & 06.430 & 06.400 & 06.371 \\ 0.2 & 06.341 & 06.312 & 06.282 & 06.252 & 06.223 & 06.193 & 06.164 & 06.134 & 06.104 & 06.075\end{array}$ $\begin{array}{lllllllllll}0.3 & 06.345 & 06.015 & 05.986 & 05.255 & 0.05 .927 & 06.193 & 06.164 & 06.134 & 06.104 & 06.075\end{array}$ $0.4 \quad 05.74905 .71905 .690 \quad 05.660 \quad 05.63105 .60105 .572 \quad 05.542 \quad 05.512 \quad 05.482$ $\begin{array}{lllllllllll}0.5 & 05.453 & 05.423 & 05.394 & 05.364 & 05.334 & 05.305 & 05.275 & 05.246 & 05.216 & 05.186\end{array}$

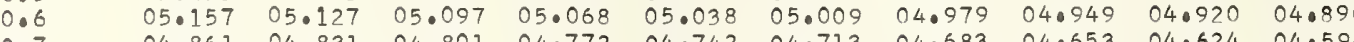
$\begin{array}{lllllllllll}0.7 & 04.864 & 04.831 & 04.801 & 04.772 & 04.742 & 04.713 & 04.683 & 04.653 & 04.824 & 04.594\end{array}$ 0.9

5811.

$$
\begin{aligned}
& 03.677 \\
& 03.380 \\
& 03.084 \\
& 02.788 \\
& 02.492 \\
& 02.196 \\
& 01.900 \\
& 01.604 \\
& 01.308
\end{aligned}
$$

0.277266

0.277266

0.277265

0.277265

0.277265
0.277265

0.777265

0.277265

0.277264

0.277264

0.277264
0.277264

0.277264
0.277264

0.277264
0.277263

0.277263

0.277263
0.277263

0.27726

0.277263
0.277262

0.277262

0.277262

0.277262

0.277262

0.277261

1.610915

1.610942
1.610969

1.610996

1.611049

1.611076

1.611129

1. 611183

1.611210
1.611237

1.611263

.611290
.611317

1.011344

1.611370

1.611424

$\begin{array}{ll}0.277261 & 1.611718 \\ 0.277261 & 1.611745 \\ 0.277261 & 1.611772 \\ 0.277261 & 1.611799 \\ 0.277260 & 1.611825 \\ 0.277260 & 1.611852 \\ 0.277260 & 1.611879 \\ 0.277260 & 1.611906 \\ 0.277260 & 1.611933 \\ 0.277260 & 1.611959\end{array}$

0.277259

0.277259

0.277259

0.277259

0.277258

0.277258
0.277258
0.277258

0.277258

0.277258

0.277758

0.2777257
0.277257
0.277257

0.277257

0.277257
0.277257
0.277257

0.277257

0.277256
0.277256

0.277256

0.277256
0.277256

0.277256
0.277256

0.27725

0.277255
0.277255

0.27725

0.277255
0.277255

0.277254
0.277254

0.2777254
0.277254
0.277254

0.277254

0.277254
0.277253

0.277253
0.2777253

0.277253

1.611451
.611479

1.611504

1.611531
1.611558

1.611585

1.611611

1.611638

1.611665
1.611692

$\begin{array}{ll}0.277253 & 1.613057 \\ 0.277253 & 1.613084 \\ 0.277252 & 1.613110 \\ 0.277752 & 1.613137 \\ 0.277752 & 1.613164 \\ 0.277752 & 1.613191 \\ 0.277252 & 1.613219 \\ 0.277252 & 1.613244 \\ 0.277252 & 1.613271 \\ 0.277251 & 1.613298 \\ 0.277251 & 1.613325 \\ 0.277251 & 1.613351 \\ 0.277251 & 1.613378 \\ 0.277251 & 1.0613405 \\ 0.277251 & 1.613432 \\ 0.277250 & 1.613458 \\ 0.277250 & 1.613485 \\ 0.277250 & 1.613512 \\ 0.277250 & 1.613539 \\ 0.277250 & 1.613566\end{array}$

1.611986

1.612040

1.612066

1.612120

1.612147

1.612173

1.612254

1.612281

1.612307

1.612361

1.612388

1.612441

1.612521

1.612548

1.612575
1.612602

1.612629

1.612655

1.612682

1.612736

1.612789

1. 612816

1.61 .2869

1.612896

1.612923
1.612950

1.612977 


.02

.03

.04

$\begin{array}{lll}17177.369 & 77.339 & 770\end{array}$

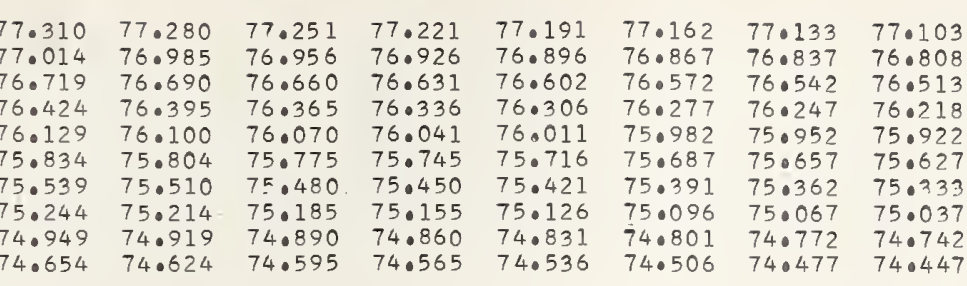
$\begin{array}{ll}76.779 & 76.749 \\ 76.483 & 76.454\end{array}$ $76.188 \quad 76.159$ $\begin{array}{ll}75.893 & 75.864 \\ 75.598 & 75.568\end{array}$ $75.303 \quad 75.273$ $\begin{array}{ll}75.008 & 74.978 \\ 74.713 & 74.683\end{array}$

17174.418 $74 \cdot 418 \quad 74.388$

$73.828 \quad 73.798$

$73.238 \quad 73.208$

$72.943 \quad 72.913$

$72.353 \quad 72.323$

74.35
74.06
73.76
73.474
73.178
72.88
72.58
72.2
71.9
71.704

74.32

74.300

74.270

74.241

73.739

72.709

73.680
73.38

73.65
73.356

$\begin{array}{lll}74.211 & 74 \cdot 182 & 74.152 \\ 73.916 & 73.886 & 73.857\end{array}$

$\begin{array}{lll}73.149 & 73.120 & 73.090 \\ 72.854 & 72.825 & 72.795\end{array}$

73.061

$\begin{array}{lll}73.621 & 73.592 & 73.562\end{array}$

$\begin{array}{ll}72.058 & 72.028 \\ 71.763 & 71.733\end{array}$

3822.

20

17171.468

$1.468 \quad 71.438$

71.409

$\begin{array}{lll}72.559 & 72.530 & 72.500\end{array}$

72.47

$\begin{array}{lll}73.031 & 73.002 & 72.972 \\ 72.736 & 72.907 & 72.677\end{array}$

$70.878 \quad 70.849$

$\begin{array}{ll}70.583 & 70.553 \\ 70.288 & 70.259\end{array}$

$69.993 \quad 69.964$

$69.698 \quad 69.66$

$\begin{array}{ll}69.109 & 69.079 \\ 68.814 & 68.784\end{array}$

71.114
70.819

70.524
70.229

69.934

9.639

71.969
71.67

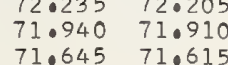

71.881
71.586

71.08
70.79

$71.350 \quad 71.320$

$71.291-71.261-71.232$

$\begin{array}{rrr}71.790 & 70.760 & 70.730\end{array}$

$\begin{array}{lll}70.495 & 70.465 & 70.436 \\ 70.200 & 70.170 & 70.141\end{array}$

70.701

$\begin{array}{llll}0.701 & 70.671 & 70.642 & 70.612\end{array}$

$\begin{array}{lllllll}70.170 & 70.141 & 70.111 & 70.082 & 70.052 & 70.022\end{array}$

5823.0

3.2

7168.

$68.224 \quad 68.195$

$\begin{array}{lll}67.929 & 67.195 & 68.16\end{array}$

$67.635 \quad 67.605$

$67.045 \quad 67.310$

66.720

66.160

66.131

65.866

5824.0

65.27

65.542

64.687

64.097

63.803

$65 \cdot 247$
64.952

64.657

64.363

64.068

63.213

$\begin{array}{lll}63.744 & 63.715\end{array}$

62.919

63.184
62.889

3825.

$5 \cdot 1$

$5 \cdot 2$
$5 \cdot 3$

$5 \cdot 4$

5.6

5.8
5.7

5.8
5.9

3826

6.

6.2

$6 \cdot 4$

6.5

6.7 62.595 $62.330 \quad 62.300$ $61.740 \quad 61.711$

$61.446 \quad 61.416$

$60.856 \quad 60.827$

$\begin{array}{ll}60.267 & 60.238 \\ 59.973 & 59.943\end{array}$

$60.503 \quad 60.474$

17159 59.38459 .64 $50.354 \quad 59.32$ $\begin{array}{lll}58.795 & 58.765 & 58.736\end{array}$ $58.500 \quad 58.471$

$58.206 \quad 58.176$

$57.617 \quad 57.587$

$\begin{array}{ll}57.022 & 57.293 \\ 56.998\end{array}$

3827.

7
7.01
7.3

17156.7

$156.733 \quad 56.7$

$56.439 \quad 56.409 \quad 56.38$

$\begin{array}{llll}55.556 & 55.526 & 55.497 & 55.467\end{array}$

54.967

$\begin{array}{ll}54.908 & 54.879 \\ 54.614 & 54.584\end{array}$

54.378
54.084

$\begin{array}{ll}.937 & 54.908 \\ .643 & 54.61\end{array}$

$69.581 \quad 69.551 \quad 69.521$

69.22

69.197

69.46

69.433

69.138

$\begin{array}{lllllll}68.991 & 68.961 & 68.932 & 68.902 & 68.873 & 68.843 \\ 68.696 & 68.666 & 68.637 & 68.607 & 68.578 & 68.548\end{array}$

$\begin{array}{llllll}68.401 & 68.371 & 68.342 & 68.312 & 68.283 & 68.254\end{array}$

$\begin{array}{ll}67.811 & 67.782 \\ 67.517 & 67.487\end{array}$

$67.752 \quad 67.723$

$67.163 \quad 67.13367 .399$

$66.868 \quad 66.838 \quad 67 \cdot 104$

$\begin{array}{ll}67.222 & 67 \cdot 192 \\ 66.927 & 66.897\end{array}$

$66.632 \quad 66.603$

$\begin{array}{ll}66.573 & 66.544 \\ 66.514 & 66.485\end{array}$

$\begin{array}{llllll}66.042 & 66.013 & 65.984 & 65.954 & 65.925 & 65.895\end{array}$

65.601

$\begin{array}{llllll}65.453 & 65.424 & 65.394 & 65.365 & 65.335 & 65.306\end{array}$

$\begin{array}{lllllll}64.864 & 64.834 & 64.805 & 64.775 & 64.746 & 64.716\end{array}$

$\begin{array}{llllll}64.569 & 64.540 & 64.510 & 64.480 & 64.451 & 64.422 \\ 64.274 & 64.245 & 64.215 & 64.186 & 64.156 & 64.127\end{array}$

$\begin{array}{llllll}63.979 & 63.950 & 63.921 & 63.891 & 63.862 & 63.832\end{array}$

$\begin{array}{llllll}63.685 & 63.656 & 63.626 & 63.596 & 63.567 & 63.538\end{array}$

$\begin{array}{llllll}63.096 & 63.066 & 63.037 & 63.007 & 62.978 & 62.948\end{array}$

$\begin{array}{lllllll}62.506 & 62.477 & 62.447 & 62.418 & 62.388 & 62.359\end{array}$

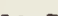

.05454 .02

5828.0

$\begin{array}{rrr}153.790 & 53.760 & 53.731 \\ 53.495 & 53.466 & 53.436\end{array}$

54.290
53.996

8.

$\begin{array}{llll}53.201 & 53.466 & 53.436 & 53.407\end{array}$

$\begin{array}{llll}52.907 & 52.877 & 52.848 & 52.81\end{array}$

$\begin{array}{llll}52.613 & 52.583 & 52.554 & 52.52 \\ 52.318 & 52.280 & 52.259 & 52.230\end{array}$

$\begin{array}{llll} & \end{array}$

$51.730 \quad 51.700 \quad 51.671 \quad 51.641$

$\begin{array}{llll}51.435 & 51.406 & 51.377 & 51.347 \\ 51.141 & 51.112 & 51.082 & 51.053\end{array}$

7150.8
50.5
50.25

$\begin{array}{llll}50.553 & 50.523 & 50.494 & 50.465 \\ 50.259 & 50.229 & 50.200 & 50.170 \\ 49.964 & 49.935 & 49.906 & 49.876\end{array}$

$\begin{array}{llll} & \end{array}$

$\begin{array}{llll}49.670 & 49.641 & 49.611 & 49.582\end{array}$

49.376
49.082

$49.347 \quad 49.317 \quad 49.288$

$\begin{array}{lll}49.052 & 49.023 & 48.99\end{array}$

$\begin{array}{llll}48.788 & 48.758 & 48.729 & 48.699 \\ 48.493 & 48.464 & 48.435 & 48.405\end{array}$

$48.199 \quad 480$

.001

.002

.003

.004

50.729
50.435
50.141

$50.141 \quad 50.112$

$\begin{array}{llll}49.788 & 49.758 & 49.729 & 49.699\end{array}$

$\begin{array}{llllll}49.49 & 49.494 & 49.464 & 49.435 & 49.405\end{array}$

$\begin{array}{llllll}48.670 & 48.641 & 48.611 & 48.582 & -48.552 & 48.523\end{array}$

.004

.005

48.317
48.023

$\begin{array}{lll}48.582 & 48 \cdot 552 & 48.523 \\ 48.287 & 48.258 & 48.229\end{array}$

$\begin{array}{rrr}.007 & .008 \quad .009\end{array}$

$0.277250 \quad 1.613592$

$\lambda(n-1)$

0.277249

0.2777249
0.2777249

0.377249

0.277248

0.277248
0.277248

0.277248

0.277248

0.277247

0.277247

0.277247

1.613619

1.613673

1.613699

1.613753
1.613780

1.613806
1.613833

0.277246

1.613860

1.613914

1.613967

1.613994

1.614047

0.277246
0.277246

0.277246

0.277246

0.277245
0.277245

0.277245

0.277245
0.277245

0.27724
0.27724

0.277244

0.277244

0.277244

0.277244

0.277243
0.277243

0.277243

0.277243

0.277242

0.277242
0.277242

0.277242

0.277242
0.277242

0.277241

0.277241

0.277241

0.277241

0.277240

0.277240

0.2777240
0.277240

0.277240

0.2777240
0.277239

0.277239
0.277239

0.277239

0.277239

0.277238

0.5777238

0.277238

0.2777238
0.277738

0.277237

0.277237

0.277237
0.277237
0.277237

0.277237

0.277236

0.277236
0.277236

0.277236
0.277236

0.277236

0.277235

0.27723
0.27723

0.277235

0.277235

0.27723

0.277234

0.277234

0.277234

0.277234

0.277234
0.277233

.614101

1.614128

1.614181

1.614208

1.614262

1. 614315

1.614342
1.614369

1.614395
1.614422

1.614449

1.614476

1.614529

1.614556

1.614610

1.614663

1.614690
1.614717

1.614743

1.614797

1.614850 
147.905
47.611
47.317

0.1
0.2

0.2
0.3
0.4

0.4
0.5
0.6

0.5
0.7
0.8

0.8
0.9

46.729

47.582
47.288

$\begin{array}{ll}46.435 & 46.699 \\ 46.405\end{array}$

$\begin{array}{ll}46.141 & 46.111 \\ 45.847 & 45.817\end{array}$

45.552
45.259

5831.

1.01
1.2
1.03
1.04
1.5
1.06
1.07
1.8

1.9

5832.0

2.1

$2 \cdot 3$

2.4

2.6

2.7
2.8
2.9

5833.

:

3.2
3.3
3.4

3.4

3.6

3.8
3.9

5834.0

4.2

$4 \cdot 3$

$4 \cdot 4$
$4 \cdot 5$

4.6
4.7

4.8
4.9

5835.

5.

$5 \cdot 3$

5.5

5.6

5.8
5.9

5836

6.1
6.2
6.3
6.4
6.5
6.5
6.7
6.8
6.9

$17144.964 \quad 44.935$

44.670
44.376
44.082
43.788
43.494
43.200
42.906
42.612
42.318

44.641

44.6

42.025

41.730

41.437

41.14341 .113

$40.849 \quad 40.820$

$40.261 \quad 40.526$

$\begin{array}{ll}39.967 & 39.938 \\ 39.673 & 39.644\end{array}$

39.673
39.380

17139.086

$\begin{array}{rlll}139.086 & 39.056 & 39.027 & 38.998 \\ 38.792 & 38.762 & 38.733 & 38.704\end{array}$

$\begin{array}{llll}38.204 & 38.175 & 38.439 & 38.410\end{array}$

$\begin{array}{llll}37.910 & 37.881 & 37.852 & 37.116\end{array}$

$37.617 \quad 37.587$

$37.323 \quad 37.293$

$36.735 \quad 36.706$

37.55

$37.264 \quad 37.235$

7136.148

35.85436 .11

$35.561 \quad 35.531$

$\begin{array}{ll}35.267 & 35.237 \\ 34.973 & 34.944\end{array}$

$34.679 \quad 34.650$

$\begin{array}{ll}34.386 & 34.356 \\ 34.092 & 34.063\end{array}$

$33.798 \quad 33.76$

$17133.211 \quad 33.18$

$\begin{array}{ll}32.917 & 32.888 \\ 32.624 & 32.59\end{array}$

$32.330 \quad 32.30$

$\begin{array}{ll}32.037 & 32.007 \\ 31.743 & 31.71\end{array}$

$31.449 \quad 31.420$

$\begin{array}{ll}31.156 & 31.12 \\ 30.862 & 30.83\end{array}$

36.677

36.94
36.647

$36.089 \quad 36.060$

$\begin{array}{ll}35.795 & 35.766 \\ 35.502 & 35.472\end{array}$

35.208

34.621

35.179
34.885

$34.327-34.29$

$33.740 \quad 33.004$

33.446

$33.152 \quad 33.123$

$\begin{array}{ll}32.859 & 32.829 \\ 32.565 & 32.536\end{array}$

32.272

$31.978 \quad 31.948$

$\begin{array}{ll}31.685 & 31.655 \\ 31.391 & 31.362\end{array}$

$31.097 \quad 31.068$

30.804
30.510

30.774

470

$\begin{array}{llllll}47.493 & 47.464 & 47.435 & 47.405 & 47.376 & 47.346\end{array}$

$\begin{array}{llllll}47.199 & 47.170 & 47.141 & 47.111 & 47.082 & 47.052\end{array}$

$46.611 \quad 46.582$

$46.023 \quad 45.99$

$45.729 \quad 45.69$

46.552

46.258
45.964

$46.523 \quad 46.493 \quad 46.464$

$\begin{array}{lll}46.229 & 46.199 & 46.170 \\ 45.935 & 45.905 & 45.876\end{array}$

$\begin{array}{lllllll}44.847 & 44.817 & 44.788 & 440759 & 44.729 & 44.700\end{array}$

$\begin{array}{lllllll}44.553 & 44.523 & 44.494 & 44.464 & 44.435 & 44.406\end{array}$

$\begin{array}{lllllll}44.259 & 44.229 & 44.200 & 44.170 & 44.141 & 44.112\end{array}$

$\begin{array}{llllll}43.965 & 43.935 & 43.906 & 43.876 & 43.847 & 43.818 \\ 43.671 & 43.641 & 43.612 & 43.583 & 43.553 & 43.524\end{array}$

$\begin{array}{llllll}43.377 & 43.347 & 43.318 & 43.289 & 43.259 & 43.230\end{array}$

$\begin{array}{lllllll}43.083 & 43.053 & 43.024 & 42.994 & 42.965 & 42.936\end{array}$

$\begin{array}{llllll}42.789 & 42.760 & 42.730 & 42.701 & 42.671 & 42.642\end{array}$

$\begin{array}{llllll}42.495 & 42.465 & 42.436 & 42.406 & 42.377 & 42.348 \\ 42.201 & 42.172 & 42.142 & 42.113 & 42.083 & 42.054\end{array}$

$\begin{array}{llllll}41.907 & 41.877 & 41.848 & 41.819 & 41.789 & 41.760\end{array}$

$\begin{array}{llllll}41.613 & 41.584 & 41.554 & 41.525 & 41.495 & 41.466\end{array}$

$\begin{array}{lllllll}41.025 & 40.996 & 40.966 & 40.937 & 40.908 & 40.878\end{array}$

$\begin{array}{llllll}40.731 & 40.702 & 40.673 & 40.643 & 40.614 & 40.584\end{array}$

$\begin{array}{llllll}40.437 & 40.408 & 40.379 & 40.349 & 40.320 & 40.291\end{array}$

$\begin{array}{llllll}40.144 & 40.114 & 40.085 & 40.055 & 40.026 & 39.997 \\ 39.850 & 39.820 & 39.791 & 39.761 & 39.732 & 39.703\end{array}$

$\begin{array}{llllll}30.556 & 39.527 & 39.497 & 39.468 & 39.438 & 0.39 .409 \\ 39.262 & 39.233 & 39.203 & 39.174 & 39.145 & 39.115\end{array}$

$\begin{array}{llllll}38.968 & 38.939 & 38.909 & 38.880 & 38.851 & 38.821\end{array}$

$\begin{array}{llllll}38.674 & 38.645 & 38.615 & 38.586 & 38.557 & 38.528 \\ 38.380 & 38.351 & 38.322 & 38.292 & 38.263 & 38.234\end{array}$

$\begin{array}{lllllll}38.087 & 38.057 & 38.028 & 37.999 & 37.969 & 37.940\end{array}$

$\begin{array}{lllllll}37.793 & 37.764 & 37.734 & 37.705 & 37.676 & 37.646\end{array}$

$\begin{array}{llllll}37.205 & 37.176 & 37.147 & 37.117 & 37.088 & 37.059\end{array}$

$\begin{array}{llllll}36.912 & 36.882 & 36.853 & 36.824 & 36.794 & 36.765\end{array}$

$\begin{array}{llllll}36.518 & 36.588 & 36.559 & 36.530 & 36.500 & 36.471 \\ 36.324 & 36.295 & 36.265 & 36.236 & 36.207 & 36.177\end{array}$

$\begin{array}{lllllll}36.030 & 36.001 & 35.971 & 35.942 & 35.913 & 35.884\end{array}$

$\begin{array}{llllll}35.737 & 35.707 & 35.678 & 35.649 & 35.619 & 35.590\end{array}$

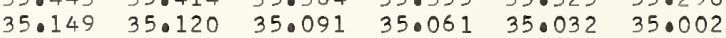

$\begin{array}{lllllll}34.856 & 34.826 & 34.797 & 34.767 & 34.738 & 34.709\end{array}$

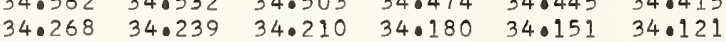

$33.975 \quad 33.945 \quad 33.916 \quad 33.886 \quad 33.857 \quad 33.828$

$\begin{array}{llllll}33.681 & 33.652 & 33.622 & 33.593 & 33.564 & 33.534 \\ 33.387 & 33.358 & 33.329 & 33.299 & 33.270 & 33.240\end{array}$

$\begin{array}{lllllll}33.094 & 33.064 & 33.035 & 33.006 & 32.976 & 32.949\end{array}$

$\begin{array}{llllll}32.800 & 32.771 & 32.741 & 32.712 & 32.683 & 32.653 \\ 32.506 & 32.477 & 32.448 & 32.418 & 32.389 & 32.360\end{array}$

$\begin{array}{llllll}32.213 & 32.183 & 32.154 & 32.418 & 32.389 & 32.360 \\ 32.125 & 32.095 & 32.066\end{array}$

$\begin{array}{llllll}31.919 & 31.890 & 31.861 & 31.831 & 31.802 & 31.772 \\ 31.626 & 31.596 & 31.567 & 31.538 & 31.508 & 31.479\end{array}$

$\begin{array}{llllll}31.332 & 31.303 & 31.273 & 31.244 & 31.215 & 31.186\end{array}$

$\begin{array}{llllll}31.039 & 31.009 & 30.980 & 30.950 & 30.921 & 30.892\end{array}$

$\begin{array}{llllll}30.745 & 30.716 & 30.686 & 30.657 & 30.628 & 30.598 \\ 30.452 & 30.422 & 30.393 & 30.364 & 30.334 & 30.304\end{array}$

.2

$\begin{array}{rrrr}130.275 & 30.246 & 30.217 & 30.187 \\ 29.982 & 29.952 & 29.923 & 29.894\end{array}$

$\begin{array}{llll}29.688 & 29.659 & 29.630 & 29.600\end{array}$

$\begin{array}{llll}29.395 & 29.365 & 29.336 & 29.30\end{array}$

$\begin{array}{llll}28.808 & 28.779 & 28.749 & 28.720\end{array}$

$28.514 \quad 28.485 \quad 28.456 \quad 28.427$

$\begin{array}{llll}27.927 & 27.898 & 27.869 & 27.840 \\ 27.634 & 27.004 & 27.575 & 27.546\end{array}$

$\begin{array}{llllll}30.158 & 30.128 & 30.099 & 30.070 & 30.041 & 30.011 \\ 29.865 & 29.835 & 29.806 & 29.776 & 29.747 & 29.718\end{array}$

$\begin{array}{llllll}29.865 & 29.835 & 29.806 & 29.776 & 29.747 & 29.718\end{array}$

$\begin{array}{llllll}20.277 & 29.248 & 29.219 & 29.189 & 29.160 & 29.131 \\ 28.984 & 28.955 & 28.925 & 28.896 & 28.866 & 28.837\end{array}$

$\begin{array}{llllll}28.690 & 28.661 & 28.632 & 28.603 & 28.573 & 28.544\end{array}$

$\begin{array}{llllll}28.397 & 28.368 & 28.338 & 28.309 & 28.280 & 28.250 \\ 28.104 & 28.074 & 28.045 & 28.016 & 27.986 & 27.957\end{array}$

5837
7
7
7
7
7
7
7
7
7

$27.047 \quad 27.01$

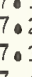

$26.46026 .431 \quad 26.402^{2} 26.372$

$26.167 \quad 26.138 \quad 26.108 \quad 26.079$

$\begin{array}{llll}25.581 & 25.844 & 25.815 & 25.78 \\ 25.551 & 25.522 & 25.49\end{array}$

$\begin{array}{llll}25.287 & 25.258 & 25.229 & 25.19 \\ 24.994 & 24.064 & 24.935 & 24.906\end{array}$

$24.700 \quad 24.671 \quad 24.642 \quad 24.612$

$27.810 \quad 27.781$

$\begin{array}{llllll}27.810 & 27.781 & 27.751 & 27.722 & 27.693 & 27.663 \\ 27.517 & 27.487 & 27.458 & 27.429 & 27.399 & 27.370\end{array}$

$\begin{array}{llllll}27.223 & 27.194 & 27.165 & 27.135 & 27.106 & 27.076\end{array}$

$\begin{array}{llllll}26.930 & 26.900 & 26.871 & 26.842 & 26.812 & 26.783 \\ 26.636 & 26.607 & 26.578 & 26.548 & 26.519 & 26.490\end{array}$

$\begin{array}{llllll}26.343 & 26.313 & 26.284 & 26.255 & 26.226 & 26.197\end{array}$

$\begin{array}{llllll}26.050 & 26.021 & 25.991 & 25.962 & 25.932 & 25.903\end{array}$

$\begin{array}{llllll}25.757 & 25.727 & 25.698 & 25.668 & 25.639 & 25.610 \\ 25.463 & 25.434 & 25.404 & 25.375 & 25.346 & 25.316\end{array}$

$\begin{array}{lllllll}25.170 & 25.141 & 25.111 & 25.082 & 25.052 & 25.023\end{array}$

$\begin{array}{llllll}24.876 & 24 \cdot 847 & 24.818 & 24.788 & 24 \cdot 759 & 24 \cdot 730 \\ 24.583 & 24.554 & 24.524 & 24.495 & 24.466 & 24.436\end{array}$

$\begin{array}{lllllllllll}5838.0 & 17124.407 & 24.378 & 24.348 & 24.319 & 24.290 & 24.260 & 24.231 & 24.202 & 24.172 & 24.143\end{array}$

$\begin{array}{lllllllllll}8.1 & 24.114 & 24.084 & 24.055 & 24.026 & 23.996 & 23.967 & 23.938 & 23.908 & 23.879 & 23.850 \\ 8.2 & 23.821 & 23.791 & 23.762 & 23.732 & 23.703 & 23.674 & 23.645 & 23.615 & 23.586 & 23.556\end{array}$

$\begin{array}{lllllllllll}8.2 & 23.821 & 23.791 & 23.762 & 23.732 & 23.703 & 23.674 & 23.645 & 23.615 & 23.586 & 23.556 \\ 8.3 & 23.527 & 23.498 & 23.469 & 23.439 & 23.410 & 23.380 & 23.351 & 23.322 & 23.299 & 23.263 \\ 8.4 & 23.234 & 23.205 & 23.175 & 23.146 & 23.117 & 23.087 & 23.058 & 23.029 & 22.999 & 22.970\end{array}$

$8 \cdot 5$

8.6

8.7
8.8
8.9

$\begin{array}{llllllllll}23.234 & 23.205 & 23.175 & 23.146 & 23.117 & 23.087 & 23.058 & 23.029 & 22.999 & 22.970\end{array}$

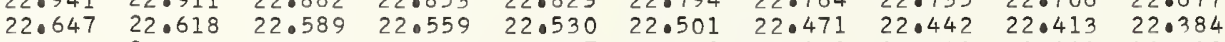

$\begin{array}{llllllllll}22.354 & 22.325 & 22.295 & 22.266 & 22.237 & 22.208 & 22.178 & 22.149 & 22.119 & 22.090\end{array}$

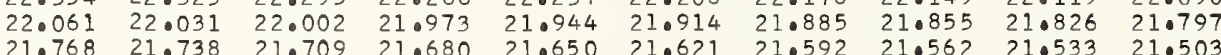

$\begin{array}{lllllllllll}5839.0 & 17121.474 & 21.445 & 21.416 & 21.386 & 21.357 & 21.328 & 21.298 & 21.269 & 21.240 & 21.210\end{array}$

$\begin{array}{lllllllllll}9.1 & 21.181 & 21.152 & 21.122 & 21.093 & 21.064 & 21.035 & 21.005 & 20.976 & 20.946 & 20.917 \\ 9.2 & 20.888 & 20.859 & 20.829 & 20.800 & 20.771 & 20.741 & 20.712 & 20.683 & 20.653 & 20.624 \\ 9.3 & 20.595 & 20.565 & 20.536 & 20.507 & 20.478 & 20.448 & 20.419 & 20.389 & 20.360 & 20.331\end{array}$

$9 \cdot 3$

9.4

9.5

9.7

$\begin{array}{llllllllll}20.302 & 20.272 & 20.243 & 20.213 & 20.184 & 20.155 & 20.125 & 20.096 & 20.067 & 20.038 \\ 20.008 & 19.979 & 19.950 & 19.920 & 19.891 & 19.862 & 19.832 & 19.803 & 19.774 & 10.745\end{array}$

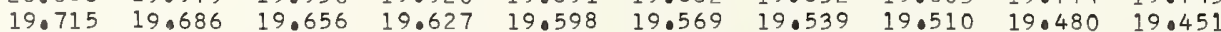

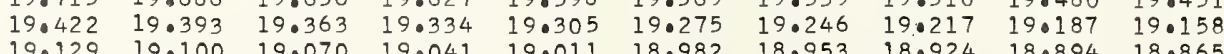

$19.129 \quad 19.100 \quad 19.070 \quad 19.041$

$19.011 \quad 18.982$

$8.83618 .806 \quad 18.7$

18.748

$18.719 \quad 18.689$

$\begin{array}{ll}18.719 & 18.689 \\ .004 & .005\end{array}$

18.660

$: 830$

$: 883$

.886

$: 812 \quad: 815$

$: 818$

$: 823 \quad: 834 \quad: 823$

\section{$(n-1) \times 1000$}

$\lambda(n-1)$

$0.277233 \quad 1.616269$

0.277233

0.007273

0.277233

0.277232

(1)

.277232

1.616296

1.616323

1.616376

1.616403

1.616457

1.616484
1.616510

.616537

.616591

616644

.616698

.616751

.616805

.616858

.616912

.616939

.616992

.617046

617073

617126

617180

. 617206

617260

.617314

.617367

.0617421

.617474

.617501

617554

.0617608

.617635
.617662

.617688

.6177152
.617769

.617795

.617822
.617849

.617876

.617929

.617956

618010

.618036

.618090
.618117

.618143

.618197

.618224

.618277

.618304

618358
.618384

.618411

.618465

.618492

618545

.618599

.618625
.618652

.618679

.618732

.618786

.618840

.618893

.618920 


.02

5840.0

0.1

0.3

0.4
0.5

0.6

0.8
0.9

5841.

1:

5842

2.1
2.2

2.3

2.5

2.6

2.8
2.9

5843.

3.

3.3

3.5

3.6

3.8
3.9

5844

4.2

4.

4.4

4.6

4.7

4.8
4.9

5845

5.1
5.2

5.3

5.4

5.6
5.7

5.8

5846.

6
6
6
6
6
6
6
6
6
60

6.1

6.4
6.5

6.6

6.8

5847

$7: 2$

77.3

7.5
7.6

7.60

7.8
7.9

5848

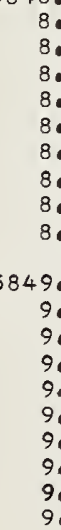

8.1
8.2
8.3
8.4
8.5
8.6
8.7
8.8
8.9
49.0
9.1
9.2
9.
9.
9.5
9.6
9.7
9.9

$\begin{array}{rl}10.339 & 10.3 \\ 10.046 & 10.01 \\ 17109.753 & 09.7 \\ 09.460 & 09.43 \\ 09.168 & 09.13\end{array}$

$09.460 \quad 09.431$

$08.875 \quad 08.845$

08.28908 .260

$07.704 \quad 07.67$

$\begin{array}{ll}07.118 & 07.382\end{array}$

06.53

06.53306 .50

$05.947 \quad 05.918$

$05.655 \quad 05.625$

05.069

05.333
05.040

$04.777 \quad 04 \cdot 747$

04.19104 .162

$17103.899 \quad 03.870$ $03.314 \quad 03.284$ 03.02102 .992 02.72802 .69 $02.436 \quad 02.407$ 02.85101 .822

$01.558 \quad 01.52$

$01.266 \quad 01.236$

17100.973 00.68000. $00.388 \quad 00.359$

$17099.803 \quad 99.774$ $99.510 \quad 99.48$

98.92698 .897

$\begin{array}{ll}98.633 & 98.604 \\ 98.341 & 98.312\end{array}$

17098.04

$098.049 \quad 98.01$

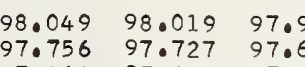

$97.464 \quad 97.43497 .40$

$96.879 \quad 96.850$

$96.587 \quad 96.557$

$96.294 \quad 96.265$

$\begin{array}{ll}95.709 & 95.680 \\ 95.417 & 95.388\end{array}$

17095.125

$90.125 \quad 9500$

$94.833 \quad 94.803$

$94.248 \quad 94.21$

$93.66493 .634 \quad 93.605 \quad 93.576$

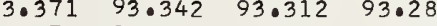

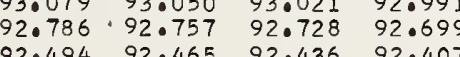

92.494

$17092.202 \quad 92.173$

$91.910 \quad 91.881$

$91.618 \quad 91.588$

$\begin{array}{llll}91.033 & 91.004 & 90.975 & 90.946\end{array}$

$90.741 \quad 90.712$

$\begin{array}{llll}90.157 & 90.127 & 90.098 & 90.069\end{array}$

$\begin{array}{llll}89.865 & 89.835 & 89.806 & 89.777 \\ 89.573 & 89.543 & 89.514 & 89.485\end{array}$

.001

.002

.003

.004

.004

$\begin{array}{llllll}.029 & .003 & .006 & .009 & .012 & .015 \\ .028 & .003 & .006 & .008 & .011 & .014 \\ .027 & .003 & .005 & .008 & .011 & .014\end{array}$

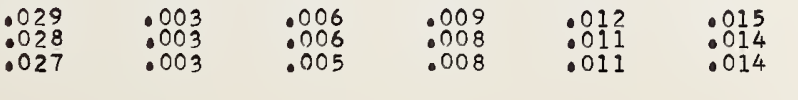

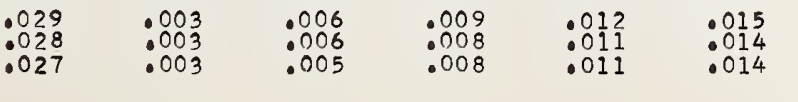




$.02 \quad .03$

.04

.05

6.1

6.4$$
5857 .
$$$$
\begin{aligned}
& 7: 1 \\
& 7: 2 \\
& 7.3
\end{aligned}
$$$$
\begin{aligned}
& 7.2 \\
& 7.3 \\
& 7.4 \\
& 7.06
\end{aligned}
$$$$
7.5
$$$$
\begin{aligned}
& 7.6 \\
& 7.7 \\
& 7.8 \\
& 7.9
\end{aligned}
$$$$
7.9
$$$$
5858 .
$$$$
\begin{aligned}
& 8.1 \\
& 8.2 \\
& 8.3
\end{aligned}
$$$$
\begin{aligned}
& 8.3 \\
& 8.4 \\
& 8.5
\end{aligned}
$$$$
\begin{aligned}
& 8.5 \\
& 8.6
\end{aligned}
$$$$
\begin{aligned}
& 8.6 \\
& 8.7 \\
& 8.8
\end{aligned}
$$$$
\begin{aligned}
& 8.8 \\
& 8.9
\end{aligned}
$$

5859.

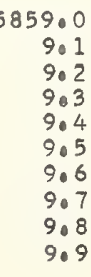
$\begin{array}{rlll}086.360 & 86.330 & 86.301 & 86.272 \\ 86.068 & 86.038 & 86.009 & 85.980 \\ 85.776 & 85.746 & 85.717 & 85.688\end{array}$ $\begin{array}{llll}85.484 & 85.454 & 85.425 & 85.688 \\ 85.396\end{array}$ $\begin{array}{llll}85.191 & 85.162 & 85.133 & 85.104\end{array}$ $\begin{array}{llll}84.900 & 84.870 & 84.841 & 84.812\end{array}$ $\begin{array}{llll}84.316 & 84.286 & 84.257 & 84.228\end{array}$ $\begin{array}{llll}84.024 & 83.994 & 83.965 & 83.936 \\ 83.732 & 83.703 & 83.673 & 83.644\end{array}$

$\begin{array}{rrrr}17083.440 & 83.411 & 83.382 & 83.352 \\ 83.148 & 83.119 & 83.089 & 83.060\end{array}$ $\begin{array}{llll}82.856 & 82.827 & 82.798 & 82.769\end{array}$ $\begin{array}{llll}82.564 & 82.535 & 82.506 & 82.477\end{array}$ $\begin{array}{llll}82.272 & 82.243 & 82.214 & 82.185 \\ 81.980 & 81.951 & 81.922 & 81.893\end{array}$ $\begin{array}{llll}81.980 & 81.951 & 81.922 & 81.893 \\ 81.688 & 81.659 & 81.630 & 81.601\end{array}$ $\begin{array}{llll}81.688 & 81.659 & 81.630 & 81.601 \\ 81.396 & 81.367 & 81.338 & 81.309 \\ 81.105 & 81.075 & 81.046 & 81.017\end{array}$

$\begin{array}{llll}81.105 & 81.075 & 81.046 & 81.017 \\ 80.813 & 80.784 & 80.754 & 80.725\end{array}$ 7080.521 $\begin{array}{llll}79.937 & 70.908 & 80.171 \\ 79.879 & 79\end{array}$ $\begin{array}{llll}79.646 & 79.616 & 79.879 & 79.850\end{array}$ $79.354 \quad 79.325 \quad 79.295$ $\begin{array}{lll}79.062 & 79.033 & 79.004\end{array}$ $\begin{array}{lll}78.770 & 78.741 & 78.712\end{array}$ $78,187,70.0159$ 77.895

$17077.604 \quad 77 \cdot 574$

$\begin{array}{lll}77.312 & 77.274 \\ 77.020 & 76.0991 \\ 76.728 & 76.999\end{array}$

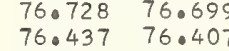

$76.145 \quad 76.11$

$\begin{array}{llll}75 & 0.053 & 75.824 & 75.75\end{array}$

75.270750241

78.12

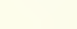

74.08957 .74 .657

$\begin{array}{ll}74.103 & 74.366 \\ 74.074 \\ 73.812 & 73.0782\end{array}$

\begin{tabular}{ll}
73.812 & 73.782 \\
730520 & 73.0491 \\
\hline 73029 & 73.90
\end{tabular}

73.029
72.937
73.090
72.908

$\begin{array}{ll}72.646 & 72.616 \\ 72.354 & 72.325 \\ 72.062 & 72.033\end{array}$

$77.545 \quad 77.516$

77.253
76.962

72.062$$
\begin{aligned}
& 7071.771 \\
& 71.479 \\
& 71.118 \\
& 70.896 \\
& 70.665 \\
& 70.0314 \\
& 70.002 \\
& 69.871 \\
& 69.849 \\
& 69.14
\end{aligned}
$$

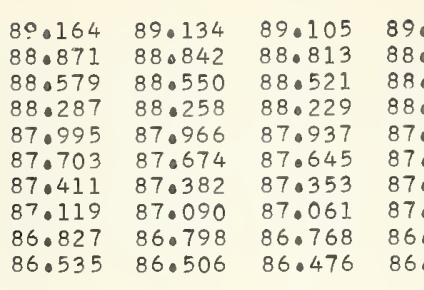

$\begin{array}{ll}86.243 & 86.214 \\ 85.051 & 85.921\end{array}$

$85.659 \quad 85.630 \quad 85.600$

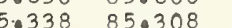

$85.075 \quad 85.046 \quad 85.016$

$\begin{array}{lll}88.462 & 84.0432 & 84.0403 \\ 84.170 & 84.141 & 84.111 \\ 8\end{array}$

8

$83.323 \quad 83.294$

83.031
82.0739
82.002

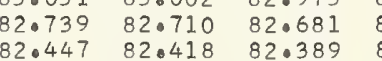

$\begin{array}{llll}0.447 & 82.418 & 82.389 & 82.052\end{array}$

$\begin{array}{lllll}81.864 & 81.834 & 82.097 & 82.068 & 81.0776\end{array}$

\begin{tabular}{llllll}
.572 & 81.543 & 81.513 & 81.484 & 81.0747 & 81.0718 \\
\hline
\end{tabular}

$\begin{array}{lllllll}1.0280 & 81.251 & 81.0221 & 81.192 & 81.0163 & 81.134\end{array}$

$\begin{array}{llllll}80.988 & 80.959 & 80.930 & 80.900 & 80.871 & 80.842 \\ 80.696 & 80.667 & 80.638 & 80.009 & 80.579 & 80.550\end{array}$

$\begin{array}{lllllll}80.404 & 80.375 & 80.346 & 80.317 & 80.288 & 80.259\end{array}$

790.558

79.558
79.266
78.975

78.683

$80.113 \quad 80.083$

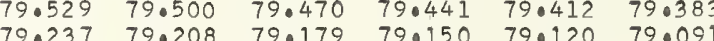

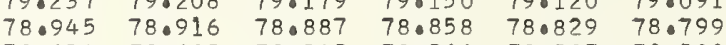

$\begin{array}{llllllll}78.654 & 78.625 & 78.595 & 78.566 & 78.537 & 78.508\end{array}$

$\begin{array}{lllllll}78.070 & 78.041 & 78 \cdot 012 & 770982 & 77.953 & 77.924 \\ 770779 & 77.749 & 77.0720 & 77.691 & 770662 & 77.6633\end{array}$

$\begin{array}{lllllll}77.487 & 77.457 & 77.428 & 77.399 & 77 \cdot 370 & 77 \cdot 341\end{array}$

$\begin{array}{llllll}77.195 & 77.166 & 77.137 & 77.107 & 77.078 & 77 \cdot 049 \\ 76.003 & 76.874 & 76.845 & 76.816 & 76.086 & 76.0757\end{array}$

$\begin{array}{lllllll}76.612 & 76.582 & 76.553 & 76.524 & 76.495 & 76.466\end{array}$

$\begin{array}{llllll}76.320 & 76.291 & 76.261 & 76.232 & 76.203 & 76.174\end{array}$

$\begin{array}{llllll}76 \cdot 028 & 75.999 & 75 \cdot 970 & 75.941 & 750912 & 75.882 \\ 75.0737 & 75.708 & 750678 & 750649 & 750620 & 750591\end{array}$

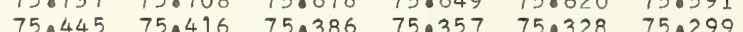

$\begin{array}{lllllll}75.153 & 75.124 & 75.005 & 750066 & 750037 & 750007\end{array}$

$\begin{array}{lllllll}74.570 & 74.541 & 74.511 & 74.483 & 740453 & 74.424\end{array}$

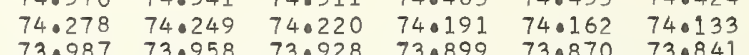

$\begin{array}{llllll}73.987 & 73.958 & 73.928 & 73.899 & 73.870 & 73.841 \\ 73.065 & 730666 & 730637 & 730607 & 73.579 & 73.549\end{array}$

$\begin{array}{llllll}73.0404 & 73.375 & 73.0345 & 730316 & 73.0287 & 73.258\end{array}$

$\begin{array}{llllll}73.112 & 73.083 & 73.053 & 73.024 & 72.995 & 72.966\end{array}$

$\begin{array}{llllll}72.820 & 72.791 & 72.0762 & 720733 & 72.0704 & 72.6665 \\ 72.529 & 72500 & 720471 & 72.441 & 720412 & 72.383\end{array}$

$\begin{array}{llllll}72.529 & 72.500 & 72.0471 & 72.441 & 72.412 & 72.0383 \\ 72.238 & 72.208 & 72.179 & 72.150 & 72.121 & 72.092\end{array}$

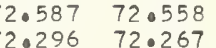

$71.046 \quad 71.017$

$\begin{array}{lllll}72.0179 & 72.150 & 72.0121 & 72.0092 \\ 71.888 & 71.859 & 71.829 & 71.800\end{array}$

$\begin{array}{lllllll}71.655 & 71.625 & 71.596 & 71.567 & 71.538 & 71.509\end{array}$

$\begin{array}{llllll}71.363 & 71.0334 & 71.305 & 71.275 & 71.0246 & 71.217\end{array}$

$70.780 \quad 70.751 \quad 70.721 \quad 70.692 \quad 70.663 \quad 70.634$

$\begin{array}{lllllll} & \end{array}$

$\begin{array}{llllllllll}70.022 & 69.993 & 69.964 & 69.935 & 60.906 & 69.876 & 69.847 & 69.818 & 69 \cdot 789 & 69.760 \\ 6.731 & 69.702 & 69.672 & 69.643 & 69.614 & 69.585 & 69.556 & 69.527 & 69.497 & 69.468\end{array}$

$\begin{array}{llllllllll}69.439 & 69.410 & 69 \cdot 381 & 69.352 & 69.323 & 69.293 & 69 \cdot 264 & 69 \cdot 235 & 69 \cdot 206 & 69 \cdot 177\end{array}$

$\begin{array}{llllllllll}17068.856 & 68.827 & 68.798 & 68.769 & 68.740 & 68.710 & 68.681 & 68.652 & 68.623 & 68.594\end{array}$

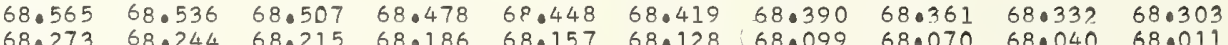

$\begin{array}{llllllllll}68.293 & 68.244 & 68.215 & 68 \cdot 186 & 68 \cdot 157 & 68.128 & 68.099 & 68 \cdot 070 & 68.040 & 68 \cdot 011 \\ 67.982 & 67.953 & 67.924 & 67.895 & 67.865 & 67.836 & 67.807 & 67.778 & 67.749 & 67.720\end{array}$

$\begin{array}{llllllllllll}67.691 & 67.661 & 67.632 & 67.603 & 67.574 & 67.545 & 67.516 & 67.487 & 67.458 & 67.428\end{array}$

$\begin{array}{llllllllllll}67.399 & 67.370 & 67.341 & 67.312 & 67.283 & 67.254 & 67.224 & 67.196 & 67.166 & 67.137\end{array}$

$\begin{array}{llllllllll}67.108 & 67.079 & 67.050 & 67.021 & 66.991 & 66.962 & 66.933 & 66.904 & 66.875 & 66.846\end{array}$

$\begin{array}{llllll}66.700 & 66.671 & 66.642 & 66.613 & 66.583 & 66.554\end{array}$

$\begin{array}{llllllllll}66.234 & 66.496 & 66.467 & 66.438 & 66.409 & 66.379 & 66.350 & 66.321 & 66.292 & 66.263 \\ 66.176 & 66.146 & 66.117 & 66.088 & 66.059 & 66.030 & 66.001 & 65.972\end{array}$

$\begin{array}{llllllllll}17065.943 & 65.914 & 65.884 & 65.855 & 65.826 & 65.797 & 65.768 & 65.739 & 65.709 & 65.680\end{array}$ $\begin{array}{lllllllllll}65.651 & 65.622 & 65.593 & 65.564 & 65.535 & 65.506 & 65.476 & 65.447 & 65.418 & 65.389\end{array}$ $\begin{array}{llllllllll}65.360 & 65.331 & 65.302 & 65.272 & 65.243 & 65.214 & 65.185 & 65 \cdot 156 & 65.127 & 65.098\end{array}$ $\begin{array}{llllllllll}65.068 & 65.039 & 65.010 & 64.981 & 64.952 & 64.923 & 64.894 & 64.865 & 64.836 & 64.8 .06\end{array}$ $\begin{array}{llllllllll}64.777 & 64.748 & 64.719 & 64.690 & 64.661 & 64.632 & 64.603 & 64.573 & 64.544 & 64.515\end{array}$ $\begin{array}{llllllllll}64.486 & 64.457 & 64.428 & 64.399 & 64.369 & 64 \cdot 340 & 64 \cdot 311 & 64 \cdot 282 & 64 \cdot 253 & 64 \cdot 224 \\ 64.195 & 64.166 & 64.136 & 64.107 & 64.078 & 64.049 & 64.020 & 63.991 & 63.962 & 63.033\end{array}$

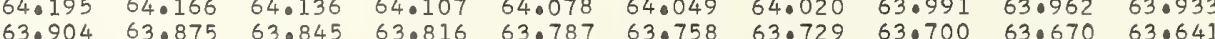
$\begin{array}{llllllllll}63.9612 & 63.583 & 63.845 & 63.816 & 63.787 & 63.758 & 63.729 & 63.700 & 63.670 & 63.641 \\ 63.525 & 63.496 & 63.467 & 63.437 & 63.408 & 63.379 & 63.0350\end{array}$ $\begin{array}{lllllllllll}63.321 & 63.292 & 63.263 & 63.234 & 63.205 & 63.175 & 63.146 & 63.117 & 63.088 & 63.059\end{array}$

$\begin{array}{llllllllll}17063.030 & 63.001 & 62.971 & 62.942 & 62.913 & 62.884 & 62.855 & 62.826 & 62.797 & 62.768\end{array}$

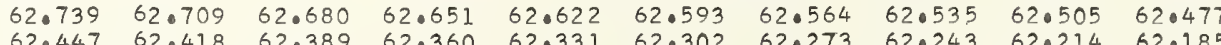

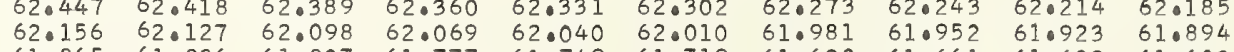
$\begin{array}{llllllllll}61.865 & 61.836 & 61.807 & 61.777 & 61.749 & 61.719 & 61.0890 & 61.661 & 61.032 & 61.0603 \\ 61.574 & 61.545 & 61.516 & 61.486 & 61.457 & 61.428 & 61.399 & 61.370 & 61.341 & 61.312\end{array}$

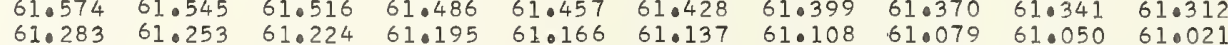

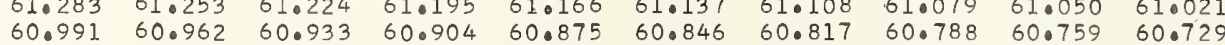
$\begin{array}{lllllllllll}60.700 & 60.671 & 60.642 & 60.613 & 60.584 & 60.555 & 60.525 & 60.496 & 60.467 & 60.729\end{array}$ $60.409 \quad 60.380 \quad 60.351 \quad 60.322 \quad 60.293 \quad 60.264 \quad 60.234 \quad 60.205 \quad 60.176 \quad 60.147$

$(n-1) \times 1000 \quad \lambda(n-1)$

\begin{tabular}{|c|}
\hline 0.277201 \\
\hline $\begin{array}{l}0.277201 \\
0.277200\end{array}$ \\
\hline $\begin{array}{l}0.2777200 \\
0.277200\end{array}$ \\
\hline $\begin{array}{l}77200 \\
77200\end{array}$ \\
\hline $\begin{array}{l}77200 \\
77199\end{array}$ \\
\hline 77199 \\
\hline
\end{tabular}

10621892

0.27719

0.277199

0.277199

0.277198
0.277198

0.277198

0.277198

0.277198
0.277198

0.277197

0.277197

0.277197

0.27797

0.277196

0.277196
0.277196

0.277196

0.277196

0.277195

0.277195

0.277195

0.277195

0.277195

0.277194

0.277194

0.277194

0.277194

0.277193

0.277193
0.277193

0.277193

0.277193

0.277192

0.277192
0.277192
0.277192

0.277192

0.277192

0.277192

0.277191

0.277191

0.277191

0.277191

0.277190

0.277190

0.277190

0.277190

.021945

1.621972

$\{.621999$

1.622053

1.0622106

1.622160

1.622186

1.622240

1.622267

1.622320

.0622320
1.622347

1.632374

1.622427

1.622454
1.622489

1.622481

1.622508
1.622535

1.622535

1.622561

1.822588

1.622642

1.622695

1.062749

1.622749
1.622776

1.622802

1.622829

1.622856

1.672883
1.622909

1.622936

1.622963

1.622990

1.623017
1.623043

1.623070

1.623097

1.623124

1.623150

1.623177

1.623231

1.623257

1.623284
1.623311

1.623338

1.623365
1.623391

1.623418

1.623445
1.623472

$0.277189 \quad 1.623498$

$0.277189 \quad 1.623525$

$0.277189 \quad 1.623579$

$0.277189 \quad 1.623606$

$0.277188-1.673659$

$0.277188 \quad 1.823686$

$\begin{array}{ll}0.277188 & 1.623713 \\ 0.277188 & 1.623739\end{array}$

$0.277188 \quad 1.623766$

$\begin{array}{ll}0.277188 & 1.623796 \\ 0.277188 & 1.623820 \\ 0.277187 & 1.623849\end{array}$

$\begin{array}{ll}0.277188 & 1.623820 \\ 0.277187 & 1.623847\end{array}$

$0.277187 \quad 1.623873$

$0.277187 \quad 1.623900$

$0.277187 \quad 1.62395$

$0.277187 \quad 1.623980$

$0.277186 \quad 9.624034$

$0.277186 \quad 1.624061$

$0.277186 \quad 1.624088$

$0.277186 \quad 1.624114$

$0.277185 \quad 1.624168$

0.277185

$0.277185 \quad 1.624248$

$0.277185 \quad 1.624275$ 
$\begin{array}{rrrrrrrrrrr}5860.0 & 17060.118 & 60.089 & 60.060 & 60.031 & 60.002 & 59.972 & 59.943 & 59.914 & 59.885 & 59.856 \\ 0.1 & 59.827 & 59.798 & 59.769 & 59.740 & 59.710 & 59.681 & 59.652 & 59.623 & 59.594 & 59.565\end{array}$ $\begin{array}{lllllllllll}0.1 & 59.827 & 59.798 & 59.769 & 59.740 & 59.710 & 59.681 & 59.652 & 59.623 & 59.594 & 59.565 \\ 0.2 & 59.536 & 59.507 & 59.478 & 59.448 & 59.419 & 59.390 & 59.361 & 59.332 & 59.303 & 59.274\end{array}$ $\begin{array}{llllllllllll}0.3 & 59.245 & 59.215 & 59.187 & 59.157 & 59.128 & 59.099 & 59.070 & 59.041 & 59.012 & 58.983 \\ 0.4 & 58.954 & 58.925 & 58.885 & 58.866 & 58.837 & 58.808 & 58.779 & 58.0750 & 58.721 & 58.691\end{array}$ $\begin{array}{lllllllllll}0.4 & 58.954 & 58.925 & 58.895 & 58.866 & 58.837 & 58.808 & 58.779 & 58.750 & 58 \cdot 721 & 58.691 \\ 0.5 & 58.663 & 58.633 & 58.604 & 58.575 & 58.546 & 58.517 & 58.488 & 58.459 & 58.430 & 58.400\end{array}$ $\begin{array}{lllllllllll}0.6 & 58.371 & 58.342 & 58.313 & 58.575 & 58.546 & 58.517 & 58.488 & 58.459 & 58.430 & 58.400 \\ 0.0255 & 58.226 & 58.197 & 58.168 & 58.138 & 58.110\end{array}$ $\begin{array}{llllllllllll}0.7 & 58.081 & 58.051 & 58.022 & 57.993 & 57.964 & 57.935 & 57.906 & 57.876 & 57.847 & 57.818\end{array}$ $\begin{array}{lllllllllll}0.8 & 57.789 & 57.760 & 57.731 & 57.702 & 57.673 & 57.644 & 57.615 & 57.585 & 57.557 & 57.527 \\ 0.9 & 57.498 & 57.469 & 57.440 & 57.411 & 57.382 & 57.353 & 57.323 & 57.294 & 57.265 & 57.236\end{array}$

$\begin{array}{llllllllllll}5861.0 & 17057.207 & 57.178 & 57.149 & 57.120 & 57.091 & 57.062 & 57.032 & 57.004 & 56.974 & 56.945\end{array}$

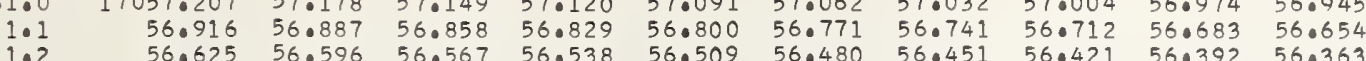

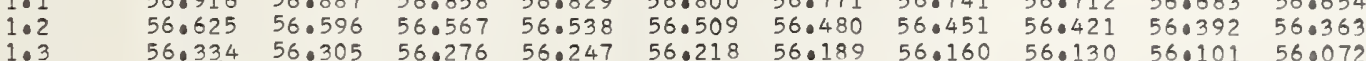
$\begin{array}{lllllllllll}1.3 & 56.33 .4 & 56.305 & 56.276 & 56.247 & 56.218 & 56.189 & 56.160 & 56.130 & 56.101 & 56.072 \\ 1.4 & 56.043 & 56.014 & 55.985 & 55.956 & 55.927 & 55.898 & 55.869 & 55.839 & 55.810 & 55.781\end{array}$

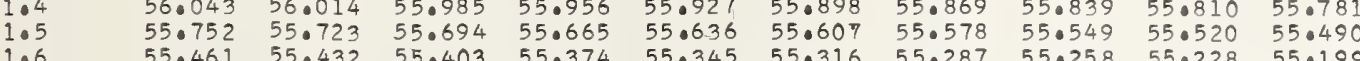
$\begin{array}{llllllllllll}1.6 & 55.461 & 55.432 & 55.403 & 55.374 & 55.345 & 55.316 & 55.287 & 55.258 & 55.228 & 55.199 \\ 1.7 & 55.170 & 55.141 & 55.112 & 55.083 & 55.054 & 55.025 & 54.996 & 54.967 & 54.937 & 54.908\end{array}$

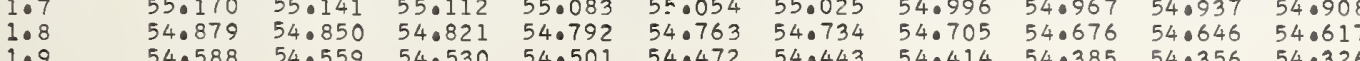
5862.0 2.0 $\begin{array}{rllll}17054.298 & 54.269 & 54.239 & 54.210 & 54 . \\ 54.006 & 53.977 & 53.948 & 53.919 & 530 \\ 53.716 & 53.687 & 53.657 & 53.628 & 530\end{array}$ $54.181 \quad 54.152 \quad 54.123 \quad 54.094 \quad 54.065 \quad 54.036$

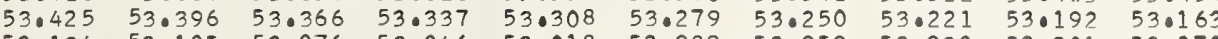
$\begin{array}{llllllllll}53.134 & 53.105 & 53.076 & 53.046 & 53.018 & 52.989 & 52.959 & 52.930 & 52.901 & 52.872\end{array}$ $\begin{array}{llllllllll}52.843 & 52.814 & 52.785 & 52.756 & 52.727 & 52.697 & 52.668 & 52.639 & 52.610 & 52.581 \\ 52.552 & 52.523 & 52.494 & 52.465 & 52.436 & 52.407 & 52.377 & 52.348 & 52.319 & 52.290\end{array}$ $\begin{array}{llllllllll}52.552 & 52.523 & 52.494 & 52.465 & 52.436 & 52.407 & 52.377 & 52.348 & 52.319 & 52.290 \\ 52.261 & 52.232 & 52.203 & 52.174 & 52.145 & 52.116 & 52.087 & 52.058 & 52.029 & 51.999\end{array}$ $\begin{array}{lllllllllll}2.7 & 52.261 & 52.232 & 52.203 & 52.174 & 52.145 & 52.116 & 52.087 & 52.058 & 52.029 & 51.999\end{array}$ $\begin{array}{lllllllllll}2.8 & 51.970 & 51.941 & 51.912 & 51.883 & 51.854 & 51.825 & 51.796 & 51.767 & 51.738 & 51.709 \\ 2.9 & 51.679 & 51.650 & 51.621 & 51.592 & 51.563 & 51.534 & 51.505 & 51.476 & 51.447 & 51.418\end{array}$

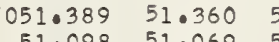

$51.272 \quad 51.243$ $51.214 \quad 51.185 \quad 51.156 \quad 51.127$ $\begin{array}{llllllllll}51.098 & 51.069 & 51.040 & 51.011 & 50.981 & 50.952 & 50.923 & 50.894 & 50.865 & 50.836\end{array}$ $\begin{array}{llllllllll}50.807 & 50.778 & 50.749 & 50.720 & 50.691 & 50.662 & 50.633 & 50.604 & 50.574 & 50.545\end{array}$ $\begin{array}{llllllllll}50.516 & 50.487 & 50.458 & 50.429 & 50.400 & 50.371 & 50.342 & 50.312 & 50.283 & 50.254 \\ 50.225 & 50.196 & 50.167 & 50.138 & 50.100 & 50.080 & 50.0510 & 50.022 & 49.993 & 49.964\end{array}$

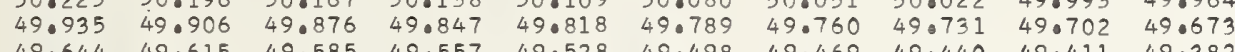
$\begin{array}{lllllllllll}49.644 & 49.615 & 49.585 & 49.557 & 49.528 & 49.498 & 49.469 & 49.440 & 49.411 & 49.382\end{array}$ $\begin{array}{llllllllll}49.062 & 49.033 & 49.004 & 48.975 & 48.046 & 48.917 & 48.888 & 48.859 & 48.830 & 48.801 \\ 48.771 & 48.742 & 48.713 & 48.684 & 48.655 & 48.626 & 48.597 & 48.568 & 48.539 & 48.510\end{array}$

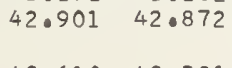

0.2777170
0.277170

0.277170
0.277170

0.277169
0.277169

0.27716

0.277169
0.277169

1.624302

1.624355

1.624382
1.624409

1.624436
1.624462

1.624489
1.624516

1.624570

1.624590
1.624623

.624650
.694677
1.62470

.624703
.624730

1.62478

1.624837

1.624864

1.624918

1.624971

1.625025

1.625052
1.625078

1.625105

1.625132
1.625159

1.625185

1.625239

1.625266
1.625293
1.625319

1.625319
1.625346

1.625400
1.625426

1.625453

1.6254807

1.625534
1.625560
1.625587

1.625641

.625667

1.625694

1.625748

1.625801

1.625828
1.625855

1.625908

1.6259352

.0625989
.0626016

1.626042

1.626069
1.626096

1.626123

1.626176

1.626230

1.626257
1.626283

1.626310

1.626337

1.626390

1.626444

1.626471
1.626498

1.626524
1.626551

1.626578
1.626605

1.626631

1.626712

1.626739
1.626765

1.626792
1.626819

1.626846
1.626872 


.04
$\begin{array}{rlll}17025.254 & 25.225 & 25.196 & 25.167\end{array}$ $24.675 \quad 24.646 \quad 24.616 \quad 24.587$ $24.384-24.355-24.326 \quad 24.588$ $24.094 \quad 24.066 \quad 24.037 \quad 24.008$ 23.80523 .776 $23.225 \quad 23.196$ 22.645

$\begin{array}{ll}23.747 & 23.008 \\ 23.457 & 23.428 \\ 23.067 & 23.138\end{array}$ $17022.355 \quad 22.326$ $21.776 \quad 21.747$ $21.486 \quad 21.457$ $20.906 \quad 20.877$ $\begin{array}{ll}20.616 & 20.587 \\ 20.327 & 20.298\end{array}$ $\begin{array}{ll}20.037 & 20.008 \\ 19.747 & 19.718\end{array}$ $17019.458 \quad 19.428$

$\begin{array}{lllllllllll} & .001 & .002 & .003 & .004 & .005 & .006 & .007 & .008 & .009 & .010 \\ .0328 & : 083 & : 886 & : 888 & .812 & : 815 & .817 & .838 & : 833 & : 836 & .838\end{array}$


$\begin{array}{llllllllll}17002.091 & 02.062 & 02.033 & 02.004 & 01.975 & 01.946 & 01.917 & 01.888 & 01.860 & 01.831 \\ 01.802 & 01.773 & 01.744 & 01.715 & 01.686 & 01.657 & 01.628 & 01.599 & 01.570 & 01.542\end{array}$

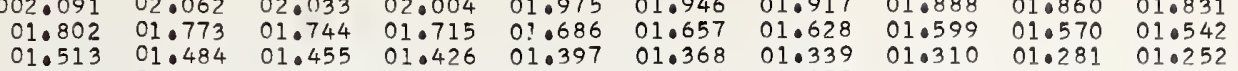
$\begin{array}{lllllllllll}.2 & 01.513 & 01.484 & 01.455 & 01.426 & 01.397 & 01.368 & 01.339 & 01.310 & 01.281 & 01.252 \\ .3 & 01.223 & 01.194 & 01.166 & 01.137 & 01.108 & 01.079 & 01.050 & 01.021 & 00.992 & 00.963 \\ 0.3 & 00.934 & 00.906 & 00.876 & 00.848 & 00.819 & 00.790 & 00.761 & 00.732 & 00.703 & 00.674\end{array}$ $\begin{array}{lllllllllll}0.3 & 00.934 & 00.906 & 00.876 & 00.848 & 01.80 .819 & 00.790 & 00.761 & 00.732 & 00.703 & 00.674 \\ 0.4 & 00.645 & 00.616 & 00.587 & 00.558 & 00.530 & 00.500 & 00.472 & 00.443 & 00.414 & 00.385 \\ 0.5 & 00.656 & 00.327 & 00.298 & 00.270 & 00.240 & 00.212 & 00.183 & 00.154 & 00.125 & 00.096\end{array}$

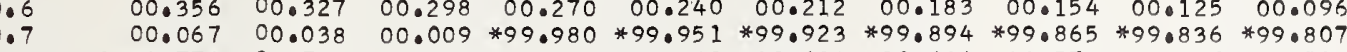
$\begin{array}{rrrrrrrrrrr}0.8 & 16999.778 & 99.749 & 99.720 & 99.691 & 99.662 & 99.634 & 99.604 & 99.576 & 99.547 & 99.518 \\ 0.9 & 99.489 & 99.460 & 99.431 & 99.402 & 99.373 & 99.344 & 99.315 & 99.287 & 99.258 & 99.229\end{array}$

$\begin{array}{llllllllll} & .001 & .002 & .003 & .004 & .005 & .006 & .007 & .008 & .009 \\ .029 & .003 & .006 & .009 & .0012 & .015 & .017 & .020 & .023 & .026 \\ 0.028 & .003 & .006 & .008 & .011 & .014 & .017 & .020 & .022 & .025\end{array}$

$\begin{array}{ll}0.277153 & 1.6296 .58 \\ 0.277153 & 1.629684 \\ 0.277152 & 1.629711 \\ 0.277152 & 1.629738 \\ 0.277152 & 1.629765 \\ 0.277152 & 1.629792 \\ 0.277152 & 1.629818 \\ 0.277152 & 1.629845 \\ 0.277151 & 1.629872 \\ 0.277151 & 1.629899\end{array}$

$0.277151-1.62992$

$0.277151 \quad 1.63000$

$\begin{array}{ll}0.277150 & 1.63003 \\ 0.277150 & 1.63005\end{array}$

0.277150

$0.077750 \quad 1.630113$

$0.277150 \quad 1.630166$

0.277149

0.0277714

0.277149

0.277149

0.297149

0.277148
0.277148

1.630193

0.277148
0.277148
0.277148

0.277148

0.277147

0.277147

0.277147

0.277147

0.277146

0.277146

0.277146

0.277146

0.277145

0.277145

0.277145
0.277145

0.277144

0.277144

0.277144

0.277144

0.277144
0.277143

0.277143

0.277143

0.277143

0.277143

0.277143
0.277142

0.277142

0.277142

0.277142

0.277142

0.277141

0.277141

0.277141

0.277141
0.277140
0.277140

0.277140

0.277140

0.277140
0.277140

0.277139

0.277139

0.277139

0.277139

0.277139
0.277139

630247

1.630274

1.630327

1.630381

1.630407
1.630434

1.630461

1.630488

1.630541

1.630568

1.630595
. .630522

1.630649

1.630675
1.630702

.630729

1.630756

1.630809

1.630836
1.630863

1.630890

1.630916

.630970

$0.277138 \quad 1.632068$

$0.277138 \quad 1.632095$

$\begin{array}{ll}0.277138 & 1.632148 \\ 0.277138 & 1.632175\end{array}$

$\begin{array}{ll}0.277138 & 1.632202 \\ 0.277137 & 1.632229\end{array}$

$0.277137 \quad 1.632255$

$\begin{array}{ll}0.277137 & 1.632282 \\ 0.277137 & 1.632309\end{array}$

.010

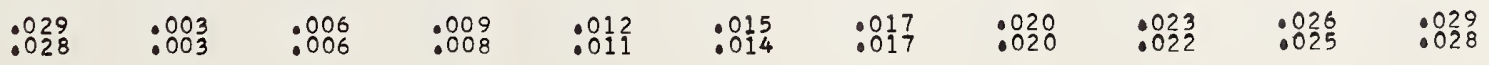




.02

.03

.04

.05

.06

.07

\author{
.08
}

.09

5893.0

$$
\begin{array}{r}
93.0 \\
3.1 \\
3.2 \\
3.3 \\
3.4 \\
3.5 \\
3.6 \\
3.7 \\
3.8 \\
3.9
\end{array}
$$

73.225
72.037
72.649
72.361
72.073
71.784
71.096
71.208
70.920
70.632

73.196
72.908
72.620

$73.167 \quad 73.13$

\section{$\begin{array}{lll}72.879 & 72.851 & 730 . \\ 72.591 & 72.562 & 720 \\ 72.0303 & 72.274 & 720\end{array}$}

$\begin{array}{lllll}72.303 & 72.274 & 72.533 & 72.505 \\ 2.3245 & 72.217\end{array}$

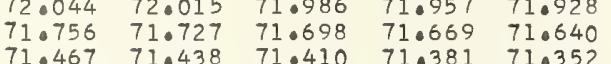

71.179

$\begin{array}{lll}71.438 & 71.410 & 71.0381 \\ 71.151 & 71.122 & 71.093\end{array}$ 70.632

$$
\begin{aligned}
& 70.863 \\
& 70.574 \quad 70.8
\end{aligned}
$$

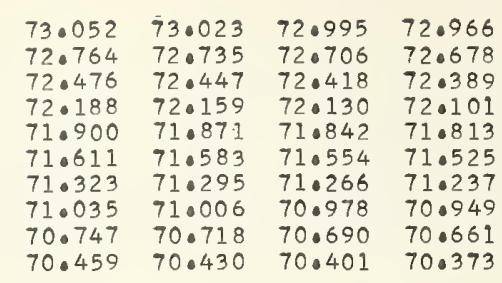

70.517

$$
\begin{array}{ll}
690.344 & 70.315 \\
70.056 & 70.027 \\
69.768 & 69.739 \\
69.480 & 69.451 \\
69.192 & 69.163 \\
68.904 & 68.875 \\
68.616 & 68.587 \\
68.328 & 68.299 \\
68.040 & 68.011 \\
67.752 & 67.723
\end{array}
$$

16967.464

$$
\begin{aligned}
& 67.176 \\
& 66.888
\end{aligned}
$$

66.600

66.312

66.024

$65.736 \quad 65.707$

$65.160 \quad 65 \cdot 131$

69.998 .710

70.258

\begin{abstract}
$70.229 \quad 70.200$
\end{abstract}
70.171

$\begin{array}{lll}70.142 & 70.114 & 70.085\end{array}$

$\begin{array}{llllllll}69.422 & 69.393 & 69.365 & 69.336 & 69.307 & 69.278 & 69.250 & 69.220\end{array}$ $\begin{array}{llllllll}68.846 & 69.105 & 69.076 & 69.048 & 69.019 & 68.990 & 68.961 & 68.932 \\ 68.817 & 68.788 & 68.760 & 68.731 & 68.702 & 68.673 & 68.645\end{array}$

$\begin{array}{lllllllll}68.558 & 68.529 & 68.500 & 68.472 & 68.443 & 68.414 & 68.385 & 68.356\end{array}$

$\begin{array}{llllllll}8.270 & 68.241 & 68.212 & 68.184 & 68.155 & 68.126 & 68.097 & 68.068\end{array}$ $\begin{array}{lll}67.723 & 67.694 & 67.665\end{array}$

64.297

64.00

64.556

$63.721 \quad 63.692$

63.43363 .405

$62.858 \quad 62.829$

$\begin{array}{lll}62.058 & 62.829 & 62.800\end{array}$

$\begin{array}{ll}62.052 & 62.512 \quad 62.483\end{array}$

62.092

61.13161 .102

$60.555 \quad 60.527$

$60.268 \quad 60.239 \quad 60.21060 .469$

$\begin{array}{llll}59.980 & 59.951 & 59.922 & 59.894\end{array}$

$\begin{array}{llll}59.404 & 59.375 & 59.3347 & 59.306\end{array}$

59.117

$16958.829 \quad 58.800$ $\begin{array}{ll}58.541 & 58.512 \\ 58.254 & 58.225\end{array}$

$57.956 \quad 57.225$

57.678

57.39

$57.103-57.074$

56.52
56.240

16955.953

55.665
55.378

$5.378 \quad 55.349$

$55.090 \quad 55.061$

54.802

54.198

$53.652 \quad 53.624$

53.365

16953.077

52.790
52.503

$52.215 \quad 52.186$

$51.927 \quad 51.899 \quad 52.157$

$51.61151 .583 \quad 51.554$

$\begin{array}{llll}51.353 & 51.324 & 51.295 & 51.267 \\ 51.065 & 51.036 & 51.008 & 50.97\end{array}$

$\begin{array}{llll}50.778 & 50.749 & 50.720 & 50.692 \\ 50.490 & 50.462 & 50.433 & 50.404\end{array}$

6950.203
49.916

$\begin{array}{lll}49.916 & 49.174 & 50.146\end{array}$

$\begin{array}{llll}49.628 & 49.600 & 49.571 & 49.542\end{array}$

$\begin{array}{llll}49.341 & 49.312 & 49.283 & 49.25\end{array}$

$\begin{array}{lllll}48.766 & 48.738 & 48.709 & 48.680\end{array}$

$\begin{array}{llll}48.479 & 48.450 & 48.421 & 48.393\end{array}$

$\begin{array}{llll}47.904 & 47.875 & 47.847 & 47.818\end{array}$

6947.330

$47.042 \quad 47.301$

$\begin{array}{llll}46.755 & 46.014 & 46.985 & 46.95\end{array}$

$\begin{array}{llll} & 0.698 & 46.669\end{array}$

$\begin{array}{llll}46.181 & 46.152 & 46.123 & 46.094\end{array}$

$\begin{array}{llll}45.606 & 45.577 & 45.549 & 45.520\end{array}$

$\begin{array}{llll}45.319 & 45.290 & 45.261 & 45.233\end{array}$

$\begin{array}{llll}45.031 & 45.003 & 44.974 & 44.946 \\ 44.744 & 44.716 & 44.687 & 44.658\end{array}$

$\begin{array}{llllll}67.924 & 67.896 & 67.867 & 67.838 & 67.809 & 67.781 \\ 67.636 & 67.608 & 67.579 & 67.550 & 67.521 & 67.492\end{array}$

0.27713

0.277137
0.277137
0.277136

1.632336

0.277136

0.277136

0.277136

0.277136

1.632389

1.632416

1.632443

1.632496

1.632523
1.632550

$0.279135 \quad 1.632604$

0.277135

0.277135

0.277135

0.277134

0.277134

0.277134

0.277134

1.63263 .0

1.632684

1.632711

1.632764

1.632791
1.632818

0.277134

0.277133

0.277133

0.277133

0.277133

0.277132

.632845

0.277132

0.277132

0.279132
0.277131

0.279131

0.277131

0.277131

0.277131

0.277130

0.2771130
0.277130

0.2779130

0.277130

0.277130

0.277129

1.632871
1.632898

1.632925

1.632952
1.632979

1.633005

1.633059

1.633086

1.633139

1.633166

1.633220

1.633246
1.633273

1.633273

1.633300
1.633327

1.633327
1.633354

1.633407

1.633434

1.633461
1.633487

$\begin{array}{llllll}60.440 & 60.412 & 60.670 & 60.642 & 60.613 & 60.584\end{array}$

$\begin{array}{lllllll}60.153 & 60.124 & 60.095 & 60.066 & 60.037 & 60.009\end{array}$

0.277129

1.633541

1.633568

1.633621

0.277129

0.279129

1.633675

0.277128

0.277128
0.277128

0.277128

0.277128
0.277128

0.277127

0.277127
0.277127

0.277127

0.277127

0.277127
0.277127

0.277126

0.277126

0.277126
0.277126

1.633702

1.633729

1.633755
1.633782

1.6337809

1.633836

1.633862

1.633916

0.279126

0.277125

0.277125

0.277125

0.277125

0.277125

1.633943

1.633970

9.633996

1.634050

1.634077

1.634103

1.634130
1.634157

1.634184

1.634211

9.634237

1.634291

1.634318

1.634371

1.634398
1.634425

0.2771241 .0634452

0.277124
0.277124
0.277124

$\{.634478$

$0.277124 \quad 1.634532$

$0.277124 \quad 1.634586$

$0.277123 \quad 1.634612$

$0.277123 \quad 1.634639$

$0.277123 \quad 1.634666$

$\begin{array}{ll}0.277123 & 1.634693 \\ 0.277123 & 1.634720\end{array}$

$\begin{array}{ll}0.277123 & 1.634746 \\ 0.2771122 & 1.634773\end{array}$

0.277122
0.277122
0.279122

$0.277122 \quad 0.634827$

$0.277122 \quad 1.634853$

$0.277122 \quad 0.0348807$

$\begin{array}{ll}0.2771222 & 1.634961 \\ 0.277121 & 9.634961 \\ 0.277121 & 1.634987\end{array}$ 


.04

.05

.06

$\begin{array}{rrrr}16944.457 & 44.428 & 44.400 & 44.371\end{array}$

$\begin{array}{rrrrrr}0.1 & 44.170 & 44.141 & 44.112 & 44.084 \\ 0.2 & 43.883 & 43.854 & 43.825 & 43.797\end{array}$

$\begin{array}{lll}0.3 & 43.883 & 43.854 \\ 0.595 & 43.567\end{array}$

$\begin{array}{lll}0.4 & 43.309 & 43.280 \\ 0.5 & 43.021 & 42.993 \\ 0.6 & 42.7334 & 42.705\end{array}$

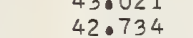

$0.7 \quad 42.447 \quad 42.418$

$\begin{array}{lll}0.8 & 42.160 & 42.131 \\ 0.9 & 41.873 & 41.844\end{array}$

$3.251 \quad 43.222$

$\begin{array}{ll}42.964 & 42.935 \\ 42.677 & 42.648\end{array}$

$42.390 \quad 42.361$

$\begin{array}{llllll}44.055 & 44.026 & 43.285 & 44.256 & 44.227 & 44.199 \\ 43.998 & 43.969 & 43.940 & 43.912\end{array}$

$\begin{array}{llllll}43.768 & 43.739 & 43.711 & 43.682 & 43.653 & 43.625\end{array}$

$\begin{array}{llllll}43.194 & 43.452 & 43.423 & 43.395 & 43.366 & 43.337\end{array}$

$\begin{array}{llllll}42.906 & 42.878 & 42.849 & 42.820 & 42.792 & 42.763\end{array}$

$\begin{array}{llllll}42.619 & 42.591 & 42.562 & 42.533 & 42.504 & 42.476 \\ 42.332 & 42.303 & 42.275 & 42.246 & 42.217 & 42.188\end{array}$

$41.873 \quad 41.844 \quad 41.815 \quad 41.787$

$\begin{array}{llllll}42.045 & 42.016 & 41.988 & 41.959 & 41.930 & 41.902 \\ 41.758 & 41.729 & 41.700 & 41.672 & 41.643 & 41.614\end{array}$

1:

$\begin{array}{r}169 \\ 4 \\ 4 \\ 4 \\ 4 \\ 4 \\ 3 \\ 3 \\ 390 \\ 390 \\ 3900 \\ \hline\end{array}$

41.299
41.011
40.724
40.437
40.150
39.863
39.576
39.289
39.002

$\begin{array}{ll}41.557 & 410 \\ 41.270 & 410 \\ 40.983 & 40\end{array}$

$41.528 \quad 41.500$

$\begin{array}{llllll}41.471 & 41.442 & 41.413 & 41.385 & 41.356 & 41.327\end{array}$

$\begin{array}{lll}40.983 & 40.954 & 40.925 \\ 40.696 & 40.667 & 40.638\end{array}$

$\begin{array}{lll}40.409 & 40.380 & 40.351 \\ 40.122 & 40.093 & 40.064\end{array}$

$41 \cdot 184 \quad 41.155$

$\begin{array}{ll}40.897 & 40.86 \\ 40.610 & 40.58\end{array}$

$\begin{array}{llllll}40.323 & 40.581 & 40.552 & 40.523 & 40.495 & 40.466\end{array}$

$\begin{array}{llllll}40.036 & 40.007 & 40.265 & 40.236 & 40.208 & 40.179\end{array}$

$\begin{array}{llllll}39.749 & 39.720 & 39.691 & 39.662 & 39.634 & 39.605\end{array}$

$39.806 \quad 39.777$

39.260

5902.

2.1
2
2
2
2
2
2

$16938.715 \quad 38.687$

$\begin{array}{ll}38.428 & 38.399 \\ 38.141 & 38.113\end{array}$

$\begin{array}{ll}37.854 & 37.825 \\ 37.567 & 37.539\end{array}$

$37.280 \quad 37.252$

$36.993 \quad 36.965$

$36.707 \quad 36.678$

36.133

5903.0

3.
3.
3.
3.
3.
3.0
3.07
3.0
3.9

16935.846

$$
\begin{array}{ll}
35.846 & 35.8 \\
35.559 & 35.5
\end{array}
$$

$$
35.272
$$

$34.985 \quad 34.957$

$34.698 \quad 34 \cdot 670$

$\begin{array}{ll}34.412 & 34.383 \\ 34.125 & 34.096\end{array}$

33.838

$33.551 \quad 33.529$

33.264

5904.0

16932.978 $\begin{array}{ll}32.978 & 32.949 \\ 32.691 & 32.662\end{array}$

4.0

$32.404 \quad 32.375$

31.83031 .88

31.540
31.544

$31.257 \quad 31.228$

$\begin{array}{ll}30.970 & 30.941 \\ 30.683 & 30.655\end{array}$

$30.396 \quad 30.368$

5905.

$\begin{array}{rr}930.110 & 30.0 \\ 29.823 & 29.794\end{array}$

$29.537 \quad 29.508$

$29.250 \quad 29.22$

$\begin{array}{ll}28.963 & 28.93 \\ 28.677 & 28.64\end{array}$

$28.390 \quad 28.361$

.

$27.816 \quad 27.78$

5906

6.1

6.2

6.3

6.5

6.6

6.7

6.8
6.9

5907.0

7.1

$7 \cdot 2$
$7 \cdot 3$

7.4

$7 \cdot 6$

7.7
7.8
7.9

26.24327 .215 $26.957 \quad 26.928$

26.38426 .355

$26.097 \quad 26.068$

$25.524 \quad 25.49$

$25.237 \quad 25.209$

$\begin{array}{ll}24.951 & 24.922 \\ 24.664 & 24.635\end{array}$

$16924.378 \quad 24 \cdot 349$

$\begin{array}{ll}24.091 & 24.06 \\ 23.805 & 23.77\end{array}$

$\begin{array}{llll}23.518 & 23.776 & 23.747 & 23.719\end{array}$

$\begin{array}{llll}23.232 & 23.203 & 23.461 & 23.432\end{array}$

$22.945 \quad 22.917 \quad 22.888 \quad 22.859$

$\begin{array}{llll}22.659 & 22.630 & 22.602 & 22.573\end{array}$

$\begin{array}{llll}22.086 & 22.057 & 22.029 & 22.000 \\ 21.799 & 21.771 & 21.742 & 21.713\end{array}$

5908

.007

.008

$(n-1) \times 1000$

$\lambda(n-1)$

$\begin{array}{ll}0.277121 & 1.635014 \\ 0.277121 & 1.635041 \\ 0.277121 & 1.635068 \\ 0.277121 & 1.635094 \\ 0.277120 & 1.635121 \\ 0.277120 & 1.635148 \\ 0.277120 & 1.635175 \\ 0.277120 & 1.635202 \\ 0.277120 & 1.635228 \\ 0.277120 & 1.635255\end{array}$

0.27711

0.277119

0.277119

0.277119

0.277118
0.277118

0.277118

0.277118

0.277117

0.0277117

0.277117

0.277117
0.277116

0.277116
0.277116
0.27716

.0277116

0.277116
0.077116
0.27116

0.27116
0.27115
0.27115
0.27115

0.277115
0.277115

0.277115
0.0277115
0

0.277115
0.277114

0.277114
0.277714
0

0.077114
0.277114
0.27714

0.027714
0.27714
0.277113

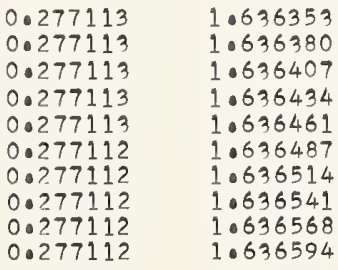

0.277112

0.27711

0.27711
0.27711

0.27711
0.027711
0.27711

0.277111
0.277110

0.277110

0.277110
0.277110
0.22710

0.277110

0.277110
0.077109
0

0.277109

0.277109

0.277108

0.277108

0.277108
0.277108

0.27710

0.277108

0.277107

0.277107

1.636621

1.636648

1.636702

1.636755

1.0636782
1.636809

1.636836
1.6368862

0.277107

0.277107

0.277106

0.277106

0.277106

0.277106

0.277106

.636889

4..6.3.9212

1.63596909

1.: 1.60 .692

1.637050

1.637077
1.637103

1.637157

1.637184

1.637237

1.637264
1.637291

1.637318

1.637344
1.637371

1.637425

1.637452

1.637505

1.637559

1.637586
1.637612

1.637639
1.637666

.010

$: 0228$ 


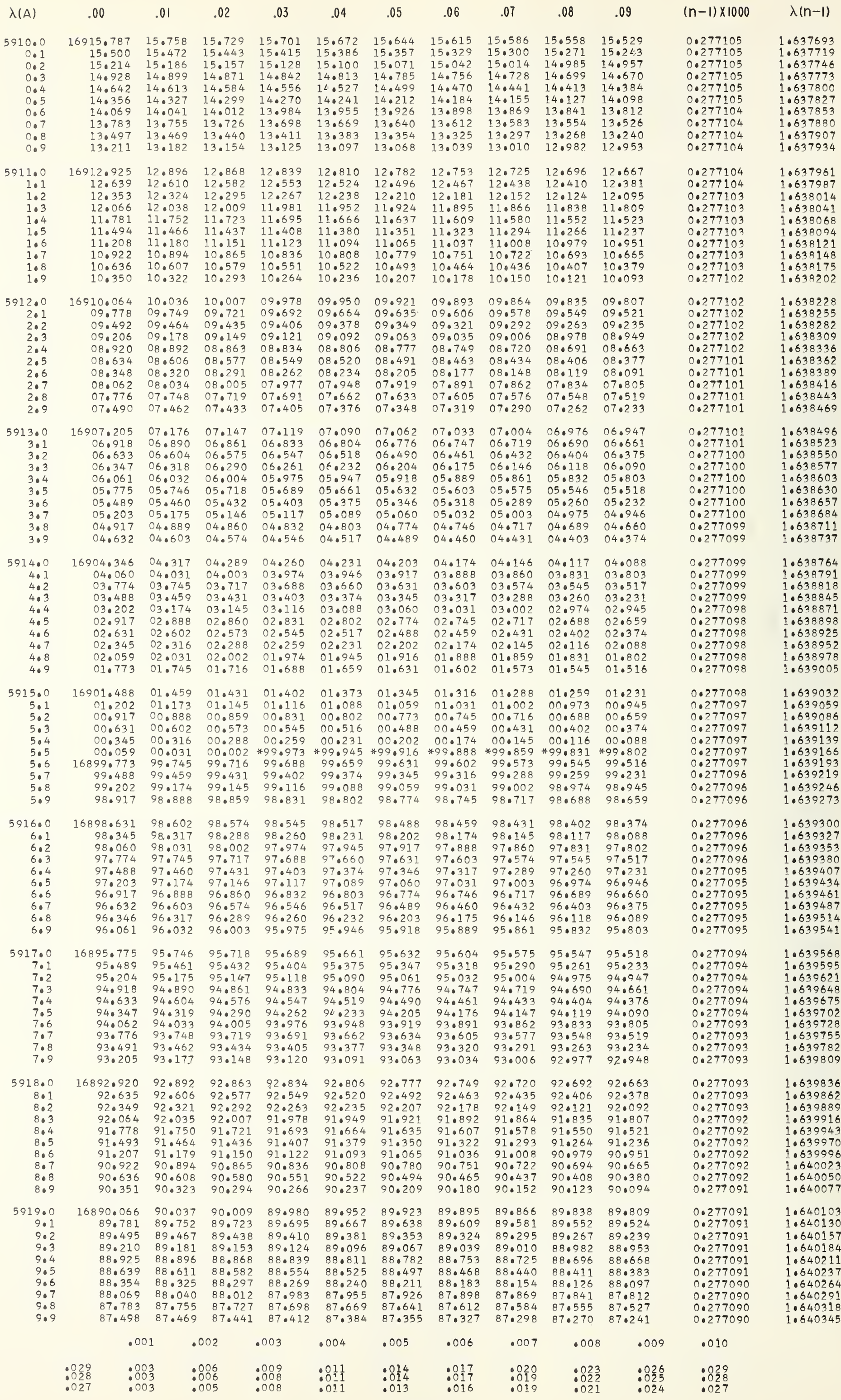




.04

.05

.09

$(n-1) \times 1000$

$\lambda(n-1)$

0.277089 $\begin{array}{lllllllllll}84.076 & 84.047 & 84.019 & 83.990 & 83.962 & 83.933 & 83.905 & 83.876 & 83.848 & 83.819 \\ 83.791 & 83.762 & 83.733 & 83.705 & 83.575 & 83.548 & 83.639 & 83.591 & 83.562 & 83.534\end{array}$ $\begin{array}{lllllllllll}83.505 & 83.477 & 83.448 & 83.420 & 83.391 & 83.363 & 83.334 & 83.306 & 83.277 & 83.249\end{array}$ $\begin{array}{lllllllllll}83.220 & 83.192 & 83.163 & 83.135 & 83.106 & 83.078 & 83.049 & 83.021 & 82.092 & 82.964\end{array}$ $\begin{array}{lllllllllll}82.935 & 82.907 & 82.878 & 82.850 & 82.821 & 82.792 & 82.764 & 82.736 & 82.707 & 82.678\end{array}$ $\begin{array}{lllllllllll}82.650 & 82.622 & 82.593 & 82.565 & 82.536 & 82.507 & 82.479 & 82.450 & 82.422 & 82.394\end{array}$ $\begin{array}{llllllllll}82.365 & 82.336 & 82.308 & 82.280 & 82.251 & 82.223 & 82.194 & 82.166 & 82.137 & 82.108\end{array}$ $\begin{array}{llllllllll}82.080 & 82.052 & 82.023 & 81.995 & 81.966 & 81.937 & 81.909 & 81.880 & 81.852 & 81.823 \\ 81.795 & 81.767 & 81.738 & 81.709 & 81.681 & 81.653 & 81.624 & 81.595 & 81.567 & 81.538\end{array}$

$\begin{array}{lllllllllll}5922.0 & 16881.510 & 81.481 & 81.453 & 81.424 & 81.396 & 81.367 & 81.339 & 81.311 & 81.282 & 81.253\end{array}$ $\begin{array}{lllllllllll}2.1 & 81.225 & 81.196 & 81.168 & 81.139 & 81.111 & 81.083 & 81.054 & 81.025 & 80.997 & 80.968 \\ 2.2 & 80.940 & 80.911 & 80.883 & 80.854 & 80.826 & 80.797 & 80.769 & 80.740 & 80.712 & 80.683\end{array}$ $\begin{array}{lllllllllll}2.1 & 81.225 & 81.196 & 81.168 & 81.139 & 81.111 & 81.083 & 81.054 & 81.025 & 80.997 & 80.968 \\ 2.2 & 80.940 & 80.911 & 80.883 & 80.854 & 80.826 & 80.797 & 80.769^{-} & 80.740 & 80.712 & 80.683 \\ 2.3 & 80.655 & 80.626 & 80.598 & 80.569 & 80.541 & 80.512 & 80.484 & 80.455 & 80.427 & 80.398\end{array}$ $\begin{array}{lllllllllll}2.4 & 80.370 & 80.341 & 80.313 & 80.284 & 80.256 & 80.227 & 80.199 & 80.170 & 80.142 & 80.113 \\ 2.5 & 80.085 & 80.056 & 80.028 & 79.999 & 79.97 & 79.942 & 70.914 & 79.885 & 79.857 & 79.028\end{array}$ $\begin{array}{lllllllllll}2.5 & 80.085 & 80.056 & 80.028 & 79.999 & 79.971 & 79.942 & 79.914 & 79.885 & 79.857 & 79.828 \\ 2.6 & 79.800 & 79.771 & 79.743 & 79.714 & 79.686 & 79.657 & 79.629 & 79.600 & 79.572 & 79.543\end{array}$ $\begin{array}{lllllllllll}2.6 & 79.800 & 79.771 & 79.743 & 79.714 & 79.686 & 79.657 & 79.629 & 79.600 & 79.572 & 79.543 \\ 2.7 & 79.515 & 79.486 & 79.458 & 79.429 & 79.401 & 79.372 & 79.344 & 79.315 & 79.287 & 79.258\end{array}$ $\begin{array}{lllllllllll}2.8 & 79.230 & 79.201 & 79.173 & 79.144 & 79.116 & 79.378 & 79.344 & 79.315 & 79.287 & 79.258 \\ 2.9 & 78.945 & 78.916 & 78.888 & 78.859 & 78.831 & 78.802 & 78.774 & 79.030 & 79.002 & 78.973\end{array}$ $\begin{array}{llllllllll}78.945 & 78.916 & 78.888 & 78.859 & 78.831 & 78.802 & 78.774 & 78.745 & 78.717 & 78.688\end{array}$ $\begin{array}{rlllllllll}16878.660 & 78.631 & 78.603 & 78.574 & 78.546 & 78.517 & 78.489 & 78.460 & 78.432 & 78.403\end{array}$ $\begin{array}{llllllllll}78.375 & 78.346 & 78.318 & 78.289 & 78.261 & 78.232 & 78.204 & 78.175 & 78.147 & 78.118 \\ 78.090 & 78.062 & 78.033 & 78.004 & 77.976 & 77.948 & 77.919 & 77.890 & 77.862 & 77.833\end{array}$ $\begin{array}{llllllllll}77.805 & 77.776 & 77.748 & 77.719 & 77.691 & 77.662 & 77.634 & 77.605 & 77.577 & 77.549\end{array}$ $\begin{array}{llllllllll}77.520 & 77.491 & 77.463 & 77.435 & 77.406 & 77.378 & 77.349 & 77.321 & 77.292 & 77.264\end{array}$ $\begin{array}{llllllllll}77.235 & 77.207 & 77.178 & 77.149 & 77.121 & 77.093 & 77.064 & 77.036 & 77.007 & 76.979\end{array}$ $\begin{array}{lllllllllll}76.950 & 76.922 & 76.893 & 76.865 & 76.836 & 76.808 & 76.779 & 76.751 & 76.722 & 76.694\end{array}$

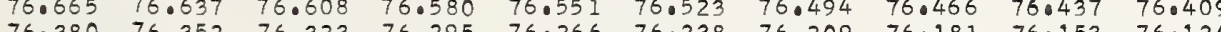
$\begin{array}{llllllllll}76.380 & 76.352 & 76.323 & 76.295 & 76.266 & 76.238 & 76.209 & 76.181 & 76.153 & 76.124 \\ 76.095 & 76.067 & 76.039 & 76.010 & 75.981 & 75.953 & 75.925 & 75.896 & 75.867 & 75.839\end{array}$

0.27708

0.277088

0.277088

0.277088
0.277087

0.277087

0.277087

0.277087

0.277086

0.277086

.277086

0.277086

0.277086

0.277085

0.277085

0.277085

0.277084

0.2770

0.277084

0.277084

0.277084

5924.0

$75.811 \quad 75.7$

$\begin{array}{ll}75.754 \quad 75.725 \\ 75.469 & 75.440\end{array}$

$\begin{array}{llllll}75.697 & 75.668 & 75.640 & 75.611 & 75.583 & 75.554 \\ 75.412 & 75.383 & 75.355 & 75.326 & 75.298 & 75.269\end{array}$

$75.241 \quad 75.212 \quad 75.18475 .155$

$\begin{array}{llll}74.956 & 74.927 & 74.899 & 74.871\end{array}$

$\begin{array}{llll}74.386 & 74.358 & 74.329 & 74.301\end{array}$

$\begin{array}{llll}74.101 & 74.073 & 74.044 & 74.016 \\ 73.817 & 73.788 & 73.760 & 73.731\end{array}$

$\begin{array}{llll}73.532 & 73.503 & 73.475 & 73.447\end{array}$

$\begin{array}{llllll}75.127 & 75.098 & 75.070 & 75.042 & 75.013 & 74.984\end{array}$

$\begin{array}{llllll}74.557 & 74.529 & 74.500 & 74.472 & 74.443 & 74.415\end{array}$

$\begin{array}{llllll}74.272 & 74.244 & 74.215 & 74.187 & 74.159 & 74.130\end{array}$

$\begin{array}{llllll}73.988 & 73.959 & 73.931 & 73.902 & 73.874 & 73.845 \\ 73.703 & 73.674 & 73.646 & 73.617 & 73.589 & 73.560\end{array}$

$73.247 \quad 73.21$

5925

5.
5.
5.

$72.962 \quad 72.934$

73.190

$73.617 \quad 73.589 \quad 73.560$

$72.393 \quad 72.365$

$72.906 \quad 72.877$

72.848

73.105

73.076

$73.048 \quad 73.019 \quad 72.991$

0.277084

0.277083

0.277083

0.277083

0.277083

0.277083

0.277082

0.27708 ?

0.277082
0.277082

$\begin{array}{llll}71.823 & 71.795 & 71.766 & 71.738 \\ 71.539 & 71.510 & 71.482 & 71.453\end{array}$

$\begin{array}{llllll}72.564 & 72.535 & 72.507 & 72.478 & 72.450 & 72.421 \\ 72.279 & 72.250 & 72.222 & 72.193 & 72.165 & 72.136\end{array}$

1.25471 .22

$71.197 \quad 71: 168$

$\begin{array}{llllll}71.994 & 71.966 & 71.937 & 71.909 & 71.880 & 71.852\end{array}$

$\begin{array}{llllll}71.709 & 71.681 & 71.653 & 71.624 & 71.595 & 71.567 \\ 71.425 & 71.396 & 71.368 & 71.339 & 71.311 & 71.282\end{array}$

5.5
5.6
5.7

5.8

$\begin{array}{llll}70.684 & 70.656 & 70.628 & 70.599 \\ 70.400 & 70.371 & 70.343 & 70.314\end{array}$

$\begin{array}{llllll}71.140 & 71.112 & 71.083 & 71.055 & 71.026 & 70.998\end{array}$

$\begin{array}{llllll}70.855 & 70.827 & 70.798 & 70.770 & 70.741 & 70.713 \\ 70.571 & 70.542 & 70.514 & 70.485 & 70.457 & 70.428\end{array}$

$70.400=10$

5926

6.

$69.830 \quad 70.087$

$\begin{array}{ll}70.058 & 70.030 \\ 69.773 & 69.745\end{array}$

70.286

$\begin{array}{llll}70.514 & 70.485 & 70.457 & 70.428 \\ 70.229 & 70.200 & 70.172 & 70.143\end{array}$

0.277082

0.277081
0.277081
0.0277081

0.277081

0.277081

0.277081

0.277080

0.2777080
0.277080

0.277080
0.277080
0.277080

0.277080

0.277080

0.277079

0.277079
0.277079

$\begin{array}{llllllllll}68.407 & 68.379 & 68.350 & 68.322 & 68.293 & 68.265 & 68.236 & 68.208 & 68.179 & 68.1151 \\ 68.123 & 68.094 & 68.066 & 68.037 & 68.009 & 67.080 & 67.952 & 67.923 & 67.895 & 67.866\end{array}$

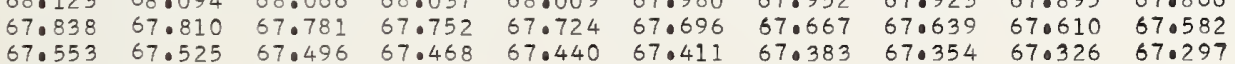

6.8

5927.0
7
7
7
7
7
7
7
70
70

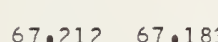

$\begin{array}{llllll}67.155 & 67.126 & 67.098 & 67.070 & 67.041 & 67.013\end{array}$

0.277079

0.277079

0.277079

0.277078

0.277078

0.277078

0.277077 .640452 1.640479 1.640505 1.640559

1.640586

1.640639

1.640666
1.640693

1.640720

1.640746

1.640800

. 640827

.640880

1.640907

1.640961

1.640988

1.641041

1.641068

1.641121

1.641175

1.641202

1.641255

1.641282

1.641309

1.641336
1.641363

1.641389
1.641416

1.641443

1.641470

1.641496

1.641550

1.641577

1.641630

1.641684

$\begin{array}{llll}66.529 & 66.500 & 66.472 & 66.443 \\ 66.244 & 66.216 & 66.187 & 66.159\end{array}$

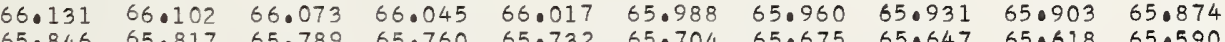
$\begin{array}{llllllllll}65.846 & 65.817 & 65.789 & 65.760 & 65.732 & 65.704 & 65.675 & 65.647 & 65.618 & 65.590 \\ 65.562 & 65.533 & 65.504 & 65.476 & 65.448 & 65.419 & 65.391 & 65.362 & 65.334 & 65.305 \\ 65.277 & 55.24 & 55.220 & 55.191 & 65.163 & 65.135 & 65.106 & 65.078 & 65.049 & 65.021\end{array}$ $\begin{array}{llllllllll}65.277 & 65.248 & 65.220 & 65.191 & 65.163 & 65.135 & 65.106 & 65.078 & 65.049 & 65.021 \\ 64.992 & 64.964 & 64.936 & 64.907 & 64.879 & 64.850 & 64.822 & 64.793 & 64.765 & 64.736\end{array}$

$\begin{array}{llllllllll}64.708 & 64.679 & 64.651 & 64.622 & 64.594 & 64.566 & 64.537 & 64.509 & 64.480 & 64.452\end{array}$

0.277077

0.277077

0.277077

0.27707

0.277076

0.277076

0.277076

1.641711

1.641764

1.641818

1.641845

1.641871

1.641925
1.641952

1.641979

1.642005

1.642032

1.642086

1.642113
1.642139

1.642166

1.642193

1.642247

1. 642273

1.642300
1.642327

1.642354
1.642381

1.642407

1.642434

1.642488

0.277076

0.297076

0.277075
0.27707

0.277075

0.277075
0.277075
0.277075

0.277075

0.277075
0.277074

10642514

1.642568

1.0642595
1.642622

1.642648

1.642675

1.642702
1.642729

1.642756

1.642782

1.642809

1.642853

1.642889

1.647916

1.642970

1.642997

$\begin{array}{llllllllll}59.588 & 59.560 & 59.531 & 59.503 & 50.475 & 59.446 & 59.418 & 59.389 & 59.361 & 59.333\end{array}$

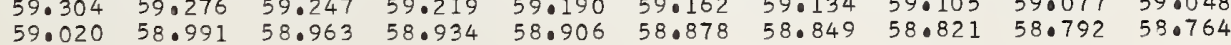

.010

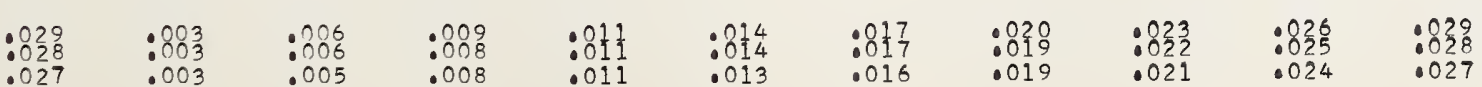


1.643131

1.643157

0.277073

1.643219

.643265

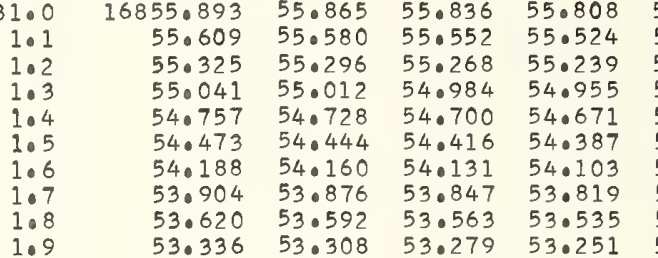

55.779
55.495
550.211
55.21
54.927
54.643
54.359
54.075
53.791
53.506
53.222

55.751 5 $550.467 \quad 5504$

$\begin{array}{llll}55.723 & 55.694 & 550666 & 55.637 \\ 5.438 & 55.410 & 55.382 & 55.353\end{array}$

0.277073

0.277072

0.277072

$0.2770 \% 2$

0.277072

0.277072

$\begin{array}{lllllllllll}5932.0 & 16853.052 & 53.023 & 52.995 & 52.967 & 52.938 & 52.910 & 52.881 & 52.853 & 52.824 & 52.796\end{array}$

$\begin{array}{lllllllllll}2.1 & 52.768 & 52.739 & 52.711 & 52.683 & 52.654 & 52.626 & 52.597 & 52.569 & 52.541 & 52.512 \\ 2.2 & 52.484 & 52.455 & 52.427 & 52.088 & 52.370 & 52.342 & 52.313 & 52.285 & 52.256 & 52.228\end{array}$

2

2.4

$52.199 \quad 52.171$

$51.916 \quad 51.887$

$52.143 \quad 52.114$

$\begin{array}{ll}51.632 & 51.603 \\ 51.347 & 51.319\end{array}$

$\begin{array}{ll}51.859 & 51.830 \\ 51.575 & 51.546\end{array}$

$51.063 \quad 51.035$

51.29151 .262

2.8
2.9

5933.0

$50.495 \quad 50.467$

$\begin{array}{ll}50.007 & 50.978 \\ 50.723 & 50.694\end{array}$ $49.927 \quad 50.18$

$49.643 \quad 49.61$

$50.155 \quad 50.126$

49.35

49.615
49.331

49.586

48.792

49.047

$49.302 \quad 49.274$

3.6

3.8
3.9

$\begin{array}{lllll}48.224 & 48.195 & 48.167 & 48.138\end{array}$

47.939
47.656

48.195
47.911

$\begin{array}{ll}48.167 & 48.138 \\ 47.883 & 47.854 \\ 47.589 & 47.550\end{array}$

5934.0

$4 \cdot 1$
4.2
4.3

4.3

4.4

4.7
4.8

4.9

5935.0

5.1
5.2
5.03
5.4

16847.372

$47.088 \quad 47.343$

$\begin{array}{ll}46.088 & 47.059 \\ 46.804 & 46.775\end{array}$

$46.520 \quad 46.492$

$\begin{array}{ll}45.236 & 46.208 \\ 45.952 & 45.924\end{array}$

$\begin{array}{lllll}4.668 & 45.640 & 45.896 & 45.867\end{array}$

$\begin{array}{llll}45.385 & 45.356 & 45.611 & 45.583 \\ 4.328 & 45.299\end{array}$

$\begin{array}{llll}45.101 & 45.073 & 45.044 & 45.015 \\ 44.817 & 44.788 & 44.760 & 44.732\end{array}$

$52.370 \quad 52.342$

$52.086 \quad 52.058 \quad 52.029$

$\begin{array}{lll}51.802 & 51.773 & 51.745 \\ 51.518 & 51.489 & 51.46\end{array}$

52.285

52.00152 .256

51.972
51.688

$\begin{array}{llllll}51.234 & 51.205 & 51.177 & 51.148 & 51.120 & 51.092\end{array}$

$\begin{array}{llllll}50.666 & 50.637 & 50.609 & 50.580 & 50.552 & 50.524\end{array}$

0.27707

0.27707
0.27707
0.027079

0.277071

0.277071

0.277071

0.277070

0.277070

0.277070

0.277070

$\begin{array}{lllllll}50.098 & 50.069 & 50.041 & 50.012 & 49.984 & 49.956\end{array}$

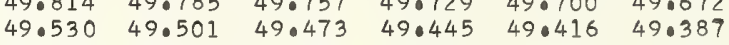

$\begin{array}{llllll}49.246 & 49.217 & 49.189 & 49.160 & 49.132 & 49.104\end{array}$

$\begin{array}{llllll}48.678 & 48.933 & 48.905 & 48.876 & 48.848 & 48.820 \\ 48.68 & 48.621 & 48.593 & 48.564 & 48.536\end{array}$

$\begin{array}{llllll}48.6394 & 48.649 & 48.6217 & 48.593 & 48.564 & 48.536 \\ 4 & 48.365 & 48.337 & 48.309 & 48.280 & 48.252\end{array}$

$\begin{array}{lllllll}48.110 & 48.082 & 48.053 & 48.025 & 47.996 & 47.068\end{array}$

$\begin{array}{llllll}47.826 & 47.798 & 47.769 & 47.741 & 47.712 & 47.684 \\ 47.542 & 47.514 & 47.485 & 47.457 & 47.428 & 47.400\end{array}$

$47.315 \quad 47.286$

$\begin{array}{lllllll}47.258 & 47.230 & 47.201 & 47.173 & 47.145 & 47.116\end{array}$

$\begin{array}{llllll}46.974 & 46.946 & 46.917 & 46.889 & 46.860 & 46.832 \\ 46.690 & 46.662 & 46.634 & 46.605 & 46.577 & 46.548\end{array}$

$\begin{array}{llllll}46.690 & 46.662 & 46.634 & 46.605 & 46.577 & 46.548 \\ 46.406 & 46.378 & 46.350 & 46.321 & 46.293 & 46.264\end{array}$

$\begin{array}{llllll}46.123 & 46.094 & 46.066 & 46.037 & 46.009 & 45.980\end{array}$

$\begin{array}{llllll}45.839 & 45.810 & 45.782 & 45.754 & 45.725 & 45.697 \\ 45.555 & 45.526 & 45.498 & 45.469 & 45.441 & 45.413\end{array}$

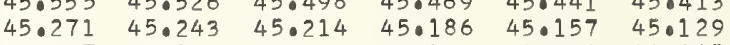

0.277069

0.277069

0.277069

0.277069

0.277068

0.277068

0.277068

0.277068

0.277067
0.277067

0.277067

0.277067
0.277067
0.277067

0.277067

0.277067

$\begin{array}{lllllll}44.419 & 44.391 & 44.363 & 44.334 & 44.306 & 44.278\end{array}$ $\begin{array}{llllllllll}44.249 & 44.221 & 44.192 & 44.164 & 44.136 & 44.107 & 44.079 & 44.051 & 44.022 & 43.994\end{array}$

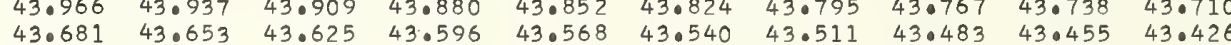

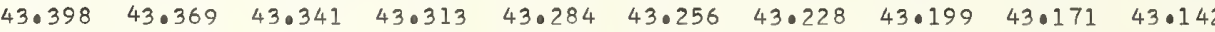
$\begin{array}{lllllllllll}43.114 & 43.086 & 43.057 & 43.029 & 43.000 & 42.972 & 42.944 & 42.916 & 42.887 & 42.859\end{array}$

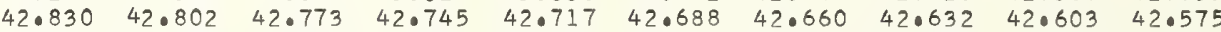
$\begin{array}{llllllllll}42.547 & 42.518 & 42.490 & 42.461 & 42.433 & 42.405 & 42.376 & 42.348 & 42.320 & 42.291\end{array}$

$\begin{array}{llllllllll}42.263 & 42.234 & 42.206 & 42.178 & 42.149 & 42.121 & 42.093 & 42.064 & 42.036 & 42 \cdot 008 \\ 41.979 & 41.951 & 41.922 & 41.894 & 41.865 & 41.837 & 41.809 & 41.780 & 41.752 & 41.724\end{array}$

1.644122

1.644149

1.644202

1.644229

1.644256

1.644309

1.644336

1.644390

1.644417
1.644443

1.644470

1.644497
1.644524

1.644524
1.644550

1.6445577
1.644604

1.644604

1.644658

1.644711

1.644738

1.644765
1.644792

1.644792

1.644818
1.644845

1.644872 
$\begin{array}{rrrrrrrrrrr}5940.0 & 16830.354 & 30.326 & 30.297 & 30.269 & 30.241 & 30.212 & 30.184 & 30.156 & 30.127 & 30.099 \\ 0.1 & 30.071 & 30.042 & 30.014 & 29.986 & 29.95 .8 & 29.929 & 29.901 & 29.872 & 29.844 & 29.816\end{array}$ $\begin{array}{lllllllllll}0.1 & 30.071 & 30.042 & 30.014 & 29.986 & 29.95 .8 & 29.929 & 29.901 & 29.872 & 29.844 & 29.816 \\ 0.2 & 29.787 & 29.759 & 29.731 & 29.702 & 29.674 & 29.646 & 29.617 & 29.589 & 29.561 & 29.532\end{array}$ $\begin{array}{lllllllllll}0.3 & 29.504 & 29.476 & 29.448 & 29.419 & 29.391 & 29.362 & 29.334 & 29.306 & 29.278 & 29.249 \\ 0.4 & 29.221 & 29.192 & 29.164 & 29.136 & 29.108 & 29.079 & 29.051 & 29.022 & 28.994 & 28.0966\end{array}$ $\begin{array}{lllllllllll}0.4 & 29.221 & 29.192 & 29.164 & 29.136 & 29.108 & 29.079 & 29.051 & 29.022 & 28.994 & 28.966 \\ 0.5 & 28.938 & 28.909 & 28.881 & 28.853 & 28.824 & 28.796 & 28.768 & 28.739 & 28.711 & 28.683\end{array}$ $\begin{array}{lllllllllll}0.6 & 28.654 & 28.626 & 28.597 & 28.569 & 28.541 & 28.513 & 28.484 & 28.456 & 28.427 & 28.399\end{array}$ $\begin{array}{lllllllllll}0.7 & 28.371 & 28.343 & 28.314 & 28.286 & 28.258 & 28.229 & 28.201 & 28.173 & 28.144 & 28.116 \\ 0.8 & 28.088 & 28.059 & 28.031 & 28.003 & 27.974 & 27.946 & 27.918 & 27.889 & 27.861 & 27.833\end{array}$ $\begin{array}{lllllllllll}0.8 & 28.088 & 28.059 & 28.031 & 28.003 & 27.974 & 27.946 & 27.918 & 27.889 & 27.861 & 27.833 \\ 0.9 & 27.804 & 27.776 & 27.748 & 27.719 & 27.691 & 27.663 & 27.635 & 27.606 & 27.578 & 27.550\end{array}$

0.277045
0.277045

0.277045
0.0277045
0.277045

0.277044

0.277044
0.0777044

0.0277044

0.277044
0.277044

1.647337
1.647364

1.647390

1.647417

1.6647471

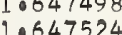

1.647551

1.647605

1.647631

1.647685

1.647712
1.647739

1.647765
1.647792

1.647819
1.647846

1.647873

1.647899
1.6647926
1.64796

1.649953
1.6449890

.

还 1.648039

1.668889
1.644114

1.648141

1.648167
1.648194

1.648221
1.648248

1.648275

1.648301
1.648328

$.001 \quad .002$

.003

.004

\begin{abstract}
.005
\end{abstract}

\begin{abstract}
.007
\end{abstract}
$.008 \quad .009$

.010

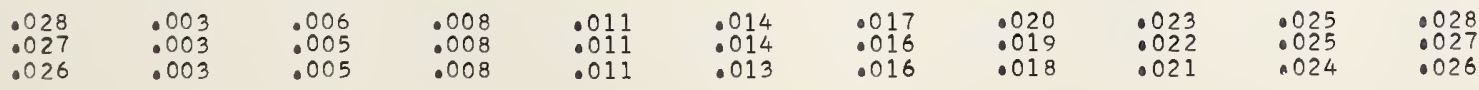


$\lambda(n-1)$

$\begin{array}{rrrrrrrrrrr}5950.0 & 16802.068 & 02.040 & 02.011 & 01.983 & 01.955 & 01.927 & 01.899 & 01.870 & 01.842 & 01.814\end{array}$ $\begin{array}{lllllllllll}0.1 & 01.786 & 01.757 & 01.729 & 01.701 & 01.673 & 01.644 & 01.616 & 01.588 & 01.560 & 01.531 \\ 0.2 & 01.503 & 01.475 & 01.447 & 01.418 & 01.390 & 01.362 & 01.334 & 01.306 & 01.277 & 01.249\end{array}$ $\begin{array}{llllllllllll}0.3 & 01.221 & 01.193 & 01.165 & 01.136 & 01.108 & 01.080 & 01.051 & 01.023 & 00.995 & 00.967\end{array}$ $\begin{array}{llllllllllll}0.4 & 00.938 & 00.910 & 00.882 & 00.854 & 00.826 & 00.797 & 00.769 & 00.741 & 00.713 & 00.684 \\ 0.5 & 00.656 & 00.528 & 00.500 & 00.572 & 00.543 & 00.515 & 00.487 & 00.458 & 00.430 & 00.402\end{array}$

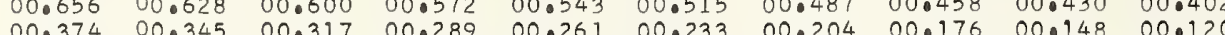
$0.7 \quad 00.0020 .00 .120$

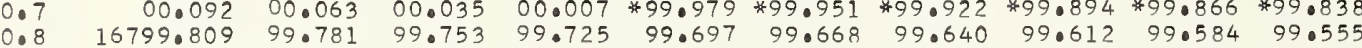

$1 \cdot 1$
1.2
1.3

1.3
1.4
1.5

1.6

1.8

$98.963 \quad 98.934$

$98.398 \quad 98.652$

$98.116 \quad 98.087$

$97.551 \quad 97.523$

$97.269 \quad 97.241$

$\begin{array}{ll}96.987 & 96.959 \\ 26.705 & 96.677\end{array}$

$99.188 \quad 99.160$

96.42
96.1
95.8

96.394

$95.294 \quad 95.266$

$\begin{array}{llll}95.012 & 94.266 & 95.237 & 95.209\end{array}$

$\begin{array}{llll}94.729 & 94.701 & 94.673 & 94.645\end{array}$

$\begin{array}{llll}94.447 & 94.419 & 94.391 & 94.363 \\ 94.165 & 94.137 & 94.109 & 94.081 \\ 93.883 & 93.855 & 93.826 & 93.798\end{array}$

6793.60

$$
\begin{aligned}
& 93.3 \\
& 93.037
\end{aligned}
$$

$5954 \cdot 0$

$4 \cdot 1$
$4 \cdot 2$
$4 \cdot 3$

$4 \cdot 3$

4.5
4.6
4.7
4.8

$4 \cdot 8$
4.9

5955.0

5.
5.
5.
5.
5.
5.6
5.7
5.8
5.9

5956.

56.0
6.1
6.2
6.3

6.4

6.5

6.7

6.8

16790.780

$90.498 \quad 90.470$

$90.216 \quad 90.188$

$\begin{array}{llll}89.934 & 89.906 & 89.878 & 80.132\end{array}$

$\begin{array}{llll}89.653 & 89.624 & 89.596 & 89.568\end{array}$

$\begin{array}{lllll}89.371 & 89.342 & 89.314 & 89.286\end{array}$

$\begin{array}{llll}89.089 & 89.060 & 89.032 & 89.004 \\ 88.807 & 88.778 & 88.750 & 88.722\end{array}$

$\begin{array}{llll}88.525 & 88.497 & 88.468 & 88.440 \\ 88.243 & 88.214 & 88.186 & 88.158\end{array}$

$16787.961 \quad 87.933$ $\begin{array}{llll}87.679 & 87.651 & 87.622 & 87.594 \\ 87.397 & 87.369 & 87.341 & 87.312 \\ 87.115 & 87.087 & 87.059 & 87.031\end{array}$

$\begin{array}{llll}87.115 & 87.087 & 87.059 & 87.031 \\ 86.833 & 86.805 & 86.777 & 86.749\end{array}$

$\begin{array}{llll}86.833 & 86.805 & 86.777 & 86.749 \\ 86.552 & 86.523 & 86.495 & 86.467\end{array}$

$\begin{array}{llll}86.269 & 86.241 & 86.213 & 86.185\end{array}$

$\begin{array}{llll}85.988 & 85.959 & 85.931 & 85.903 \\ 85.706 & 85.678 & 85.649 & 85.621\end{array}$

$85.424 \quad 85.396$

$16785.142 \quad 85.114$

$84.860 \quad 84.832$

$\begin{array}{ll}84.578 & 84.550 \\ 84.297 & 84.269\end{array}$

$\begin{array}{ll}84.015 & 83.987 \\ 83.733 & 83.705\end{array}$

$\begin{array}{ll}83.733 & 83.705 \\ 83.451 & 83.423\end{array}$

$\begin{array}{ll}83.170 & 83.14 \\ 82.888 & 82.86\end{array}$

$\begin{array}{ll}82.888 & 82.860 \\ 82.606 & 82.578\end{array}$

85.36

$85.086 \quad 85.058$

$\begin{array}{ll}84.804 & 84.776 \\ 84.522 & 84.494\end{array}$

$\begin{array}{ll}84.240 & 84.212 \\ 83.958 & 83.930\end{array}$

$\begin{array}{ll}83.958 & 83.930 \\ 83.677 & 83.649\end{array}$

$\begin{array}{ll}83.395 & 83.367 \\ 83.113 & 83.085\end{array}$

$\begin{array}{ll}83.113 & 83.085 \\ 82.832 & 82.803\end{array}$

99.69799 .668

$\begin{array}{lll}99.612 & 99.584 & 99.555 \\ 99.330 & 99.301 & 99.273\end{array}$

$99.132 \quad 99.104 \quad 99.076 \quad 99.047 \quad 99.019 \quad 98.991$

$\begin{array}{llllll}98.850 & 98.821 & 98.793 & 98.765 & 98.737 & 98.70\end{array}$

$\begin{array}{llllll}98.567 & 98.539 & 98.511 & 98.483 & 98.455 & 98.426\end{array}$

$\begin{array}{lllllll}98.003 & 97.975 & 97.947 & 97.918 & 97.890 & 97.862\end{array}$

$\begin{array}{llllll}97.721 & 97.692 & 97.664 & 97.636 & 97.608 & 97.580\end{array}$

$\begin{array}{llllll}97.438 & 97.410 & 97.382 & 97.354 & 97.0325 & 97.297 \\ 97.156 & 97.128 & 97.100 & 97.072 & 97.043 & 97.015\end{array}$

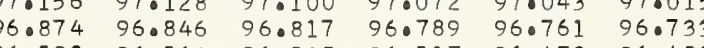

$\begin{array}{llllll}96.592 & 96.564 & 96.5335 & 96.507 & 96.479 & 96.450\end{array}$

0.277043

0.277043
0.277043

0.277043

0.277043

0.277043

0.277042

0.277042

0.277042

0.277042

0.27704

0.27704

0.27704

0.277041
0.277041

0.277040

$\begin{array}{llllll}96.310 & 96.281 & 96.253 & 96.225 & 96.197 & 96.168\end{array}$

$\begin{array}{llllll}96.027 & 95.999 & 95.971 & 95.943 & 95.915 & 95.886 \\ 95.745 & 95.717 & 95.689 & 95.660 & 95.632 & 95.60\end{array}$

$\begin{array}{llllll}95.463 & 95.435 & 95.406 & 95.378 & 95.350 & 95.322\end{array}$

$\begin{array}{llllll}5.181 & 95.153 & 95.124 & 95.096 & 95.068 & 95.040\end{array}$

$\begin{array}{llllll}94.617 & 94.588 & 94.560 & 94.532 & 94.504 & 94.476\end{array}$

$\begin{array}{llllll}4.334 & 94.306 & 94.278 & 94.250 & 94.222 & 94.193\end{array}$

$\begin{array}{llllll}93.770 & 94.024 & 93.996 & 93.968 & 93.939 & 93.911 \\ 93.742 & 93.714 & 93.686 & 93.657 & 93.629\end{array}$

0.277040
0.277040
0.277040

0.277040

0.277040

0.277040
0.277039
0.277039

0.277039

0.277039
0.277039

0.277039

0.277039

0.277039

0.277038
0.277038

0.277038

0.277038

0.277038

0.277037

0.277037

0.277037

0.277037
0.277037
0.277036

0.277036

0.277036

0.277036

0.277036

0.277035

0.277035

0.277035

0.277035

0.277035

0.277034

0.277034

0.277034
0.277034

0.277034

0.277034

0.277033

0.277033

0.277033

$\begin{array}{lllllllllll}7.1 & 82.042 & 82.014 & 81.986 & 81.958 & 81.212 & 82.184 & 82.155 & 82.127 & 82.099 & 82.071 \\ 7.1 & 81.761 & 81.733 & 1.905 & 81.657 & 81.902 & 81.874 & 81.845 & 81.817 & 81.789\end{array}$

$\begin{array}{llllllllllll}7.2 & 81.761 & 81.733 & 81.705 & 81.677 & 81.648 & 81.620 & 81.592 & 81.564 & 81.535 & 81.507\end{array}$

7.

$\begin{array}{llllllllll}81.198 & 81.169 & 81.141 & 81.113 & 81.085 & 81.338 & 81.310 & 81.282 & 81.254 & 81.226 \\ 81.029 & 81.000 & 80.972 & 80.944\end{array}$

$\begin{array}{lllllllllll}80.916 & 80.888 & 80.859 & 80.831 & 80.803 & 80.775 & 80.747 & 80.719 & 80.690 & 80.662\end{array}$

$\begin{array}{lllllllllll}80.634 & 80.606 & 80.578 & 80.550 & 80.521 & 80.493 & 80.465 & 80.437 & 80.409 & 80.381\end{array}$

$\begin{array}{lllllllllll}7.7 & 80.353 & 80.324 & 80.296 & 80.268 & 80.240 & 80.212 & 80.184 & 80.155 & 80.127 & 80.099 \\ 7.8 & 80.071 & 80.043 & 80.015 & 79.986 & 79.958 & 79.930 & 79.902 & 79.874 & 79.846 & 79.817 \\ 7.9 & 79.789 & 79.761 & 79.733 & 79.705 & 79.677 & 79.648 & 79.620 & 79.592 & 79.564 & 79.536\end{array}$

0.277033

0.27703

0.277032

0.27703

0.277032

0.277031

.648408

9.648462

.648516

.648542

1.648596

1.648676

1.648703

1.648730

1.648757
.6648784
.6648810

1.648810

1.648837

1.648891

1.648944

1.648971
1.648998

1.649025

1.649052

1.649078

1.649105

1.649132

1.649185

1.649212

1.649239
1.649266

1.649293

1.649319

1.649346
1.649373

1.649400

1.649427
9.649453

1.649480

1.649507

1.649534
1.649561

1.649561
1.649587

1.649614

1.649641

1.649641

1.649695

1.649748

1.649775

1.649802

1.649829

1.649882

1.649909

1.649936
1.649963

1.650016

1.650043

1.650070

1.650096
1.650123

1.650150

1.650177

1.650204

1.650230
1.650257

$\begin{array}{rrrrrrrrrrr}5958.0 & 16779.508 & 79.479 & 79.451 & 79.423 & 79.395 & 79.367 & 79.339 & 79.311 & 79.282 & 79.254 \\ 8.1 & 79.226 & 79.198 & 79.170 & 79.142 & 79.114 & 79.085 & 79.057 & 79.029 & 79.000 & 78.972\end{array}$

$\begin{array}{lllllllllll}8.1 & 79.226 & 79.198 & 79.170 & 79.142 & 79.114 & 79.085 & 79.057 & 79.029 & 79.000 & 78.972 \\ 8.2 & 78.944 & 78.916 & 78.888 & 78.860 & 78.832 & 78.804 & 78.775 & 78.747 & 78.719 & 78.691\end{array}$

$\begin{array}{llllllllllll}8.3 & 78.663 & 78.635 & 78.606 & 78.578 & 78.550 & 78.522 & 78.494 & 78.466 & 78.437 & 78.409 \\ 8 & 78.381 & 78.353 & 78.325 & 78.297 & 78.269 & 78.240 & 78.212 & 78.184 & 78.156 & 78.128\end{array}$

$\begin{array}{llllllllllll}8.4 & 78.381 & 78.353 & 78.325 & 78.297 & 78.269 & 78.240 & 78.212 & 78.184 & 78.156 & 78.128 \\ 8.5 & 78.100 & 78.072 & 78.043 & 78.015 & 77.987 & 77.959 & 77.931 & 77.903 & 77.8 .75 & 77.846\end{array}$

$\begin{array}{lllllllllllll}8.6 & 77.818 & 77.790 & 77.761 & 77.734 & 77.705 & 77.677 & 77.649 & 77.621 & 77.593 & 77.565\end{array}$

$\begin{array}{lllllllllll}8.7 & 77.536 & 77.508 & 77.480 & 77.452 & 77.424 & 77.396 & 77.368 & 77.339 & 77.311 & 77.283\end{array}$

$\begin{array}{lllllllllll}8.8 & 77.255 & 77.227 & 77.198 & 77.170 & 77.142 & 77.114 & 77.086 & 77.058 & 77.030 & 77.001\end{array}$

0.27703

0.277031

0.27703

0.277031

0.277030

0.277030

0.277030

1.650284

1.650311

1.650338

1.650364
1.650391

1.650418

1.650445

1.650472

1.650498

1.650552

1.650579

1.650632

1.650659

1.650686

1.650740

1.650766

$\begin{array}{rrrrrrrrrrr}5959.0 & 16776.692 & 76.664 & 76.635 & 76.607 & 76.579 & 76.551 & 76.523 & 76.495 & 76 \cdot 467 & 76.438 \\ 9.1 & 76.410 & 76.382 & 76.354 & 76.326 & 76.298 & 76.270 & 76.241 & 76.213 & 76.185 & 76.157\end{array}$

$\begin{array}{llllllllllll}9.1 & 76.410 & 76.382 & 76.354 & 76.326 & 76.298 & 76.270 & 76.241 & 76.213 & 76.185 & 76.157 \\ 9.2 & 76.129 & 76.101 & 76.073 & 76.044 & 76.016 & 75.988 & 75.960 & 75.932 & 75.903 & 75.875\end{array}$

$\begin{array}{llllllllllll}9.3 & 75.847 & 75.819 & 75.791 & 75.763 & 75.735 & 75.706 & 75.678 & 75.650 & 75.622 & 75.594 \\ 9 & 75.566 & 75.538 & 75.510 & 75.481 & 75.05 & 75.425 & 75.397 & 75.369 & 75.341 & 75.312\end{array}$

$\begin{array}{lllllllllll}75.566 & 75.538 & 75.510 & 75.481 & 75.453 & 75.425 & 75.397 & 75.369 & 75.341 & 75.312\end{array}$

$\begin{array}{llllllllll}75.284 & 75.256 & 75.228 & 75.200 & 75.172 & 75.143 & 75.115 & 75.087 & 75.059 & 75.031 \\ 75.003 & 74.975 & 74.946 & 74.918 & 74.890 & 74.862 & 74.834 & 74.806 & 74.778 & 74.750\end{array}$

$\begin{array}{llllllllll}74.721 & 74.693 & 74.665 & 74.637 & 74.609 & 74.581 & 74.552 & 74.524 & 74.496 & 74.468\end{array}$

$\begin{array}{llllllllll}74.440 & 74.412 & 74.384 & 74.355 & 74.327 & 74.299 & 74 \cdot 271 & 74 \cdot 243 & 74 \cdot 215 & 74 \cdot 187\end{array}$

0.277030

1.650820

0.277030

1.650847

0.27702

0.277029

0.277029

0.277079

$0.2770 ? 8$

1.650874

1.650927

1.650954

1.651007

1.651034

.010 


\begin{tabular}{|c|c|c|c|c|c|c|c|c|c|c|c|c|}
\hline $\begin{array}{r}960.0 \\
0.1 \\
0.2 \\
0.3 \\
0.4 \\
0.5 \\
0.6 \\
0.7 \\
0.8 \\
0.9\end{array}$ & $\begin{array}{r}16773.877 \\
73.595 \\
73.314 \\
73.032 \\
72.751 \\
72.470 \\
72.189 \\
71.907 \\
71.626 \\
71.345\end{array}$ & $\begin{array}{l}73.849 \\
73.567 \\
73.286 \\
73.005 \\
72.723 \\
72.442 \\
72.160 \\
71.879 \\
71.598 \\
71.316\end{array}$ & $\begin{array}{l}73.821 \\
73.539 \\
73.258 \\
72.977 \\
72.695 \\
72.414 \\
72.132 \\
71.851 \\
71.570 \\
71.288\end{array}$ & $\begin{array}{l}73.792 \\
73.511 \\
73.229 \\
72.948 \\
72.667 \\
72.385 \\
72.104 \\
71.823 \\
71.542 \\
71.260\end{array}$ & $\begin{array}{l}73.764 \\
73.483 \\
73.201 \\
72.920 \\
72.639 \\
72.357 \\
72.076 \\
71.795 \\
71.513 \\
71.232\end{array}$ & $\begin{array}{l}73.736 \\
73.455 \\
73.173 \\
72.892 \\
72.611 \\
72.329 \\
72.048 \\
71.767 \\
71.485 \\
71.204\end{array}$ & $\begin{array}{l}73 \cdot 708 \\
73 \cdot 427 \\
73 \cdot 145 \\
72 \cdot 864 \\
72 \cdot 582 \\
72 \cdot 301 \\
72 \cdot 020 \\
71.739 \\
71.457 \\
71.176\end{array}$ & $\begin{array}{l}73 \cdot 680 \\
73.398 \\
73.117 \\
72.835 \\
72.554 \\
72.273 \\
71.992 \\
71.710 \\
71.429 \\
71.147\end{array}$ & $\begin{array}{l}73.652 \\
73.370 \\
73.089 \\
72.807 \\
72.526 \\
72.245 \\
71.964 \\
71.682 \\
71.401 \\
71.119\end{array}$ & $\begin{array}{l}73.624 \\
73.342 \\
73.061 \\
72.779 \\
72.498 \\
72.217 \\
71.935 \\
71.654 \\
71.373 \\
71.091\end{array}$ & $\begin{array}{l}0.277028 \\
0.277028 \\
0.277028 \\
0.277028 \\
0.277028 \\
0.277027 \\
0.277027 \\
0.277027 \\
0.277027 \\
0.277027\end{array}$ & $\begin{array}{l}1.651088 \\
1.651115 \\
1.651141 \\
1.651168 \\
1.651195 \\
1.651222 \\
1.651249 \\
1.651275 \\
1.651302 \\
1.651329\end{array}$ \\
\hline $\begin{array}{r}5961.0 \\
1.1 \\
1.2 \\
1.3 \\
1.4 \\
1.5 \\
1.6 \\
1.7 \\
1.8 \\
1.9\end{array}$ & $\begin{array}{r}16771.063 \\
70.782 \\
70.500 \\
70.219 \\
69.938 \\
69.657 \\
69.375 \\
69.094 \\
68.812 \\
68.531\end{array}$ & $\begin{array}{l}71.035 \\
70.754 \\
70.472 \\
70.191 \\
69.910 \\
69.629 \\
69.347 \\
69.066 \\
68.785 \\
68.503\end{array}$ & $\begin{array}{l}71.007 \\
70.726 \\
70.444 \\
70.163 \\
69.882 \\
69.600 \\
69.319 \\
69.038 \\
68.757 \\
68.475\end{array}$ & $\begin{array}{l}70.979 \\
70.698 \\
70.416 \\
70.135 \\
69.854 \\
69.572 \\
69.291 \\
69.010 \\
68.728 \\
68.447\end{array}$ & $\begin{array}{l}70.951 \\
70.669 \\
70.388 \\
70.107 \\
69.825 \\
69.544 \\
60.263 \\
68.981 \\
68.700 \\
68.419\end{array}$ & $\begin{array}{l}70.923 \\
70.641 \\
70.360 \\
70.078 \\
69.797 \\
69.516 \\
69.235 \\
68.954 \\
68.672 \\
68.391\end{array}$ & $\begin{array}{l}70.895 \\
70.613 \\
70.332 \\
70.050 \\
69.769 \\
69.488 \\
69.207 \\
68.925 \\
68.644 \\
68.363\end{array}$ & $\begin{array}{l}70.866 \\
70.585 \\
70.304 \\
70.022 \\
69.741 \\
69.460 \\
69.178 \\
68.897 \\
68.616 \\
68.335\end{array}$ & $\begin{array}{l}70.838 \\
70.557 \\
70.27 .5 \\
69.994 \\
69.713 \\
69.431 \\
69.150 \\
68.869 \\
68.588 \\
68.306\end{array}$ & $\begin{array}{l}70.810 \\
70.529 \\
70.247 \\
69.966 \\
69.685 \\
69.403 \\
69.122 \\
68.841 \\
68.560 \\
68.278\end{array}$ & $\begin{array}{l}0.277027 \\
0.277026 \\
0.277026 \\
0.277026 \\
0.277026 \\
0.277026 \\
0.277026 \\
0.277026 \\
0.277025 \\
0.277025\end{array}$ & $\begin{array}{l}1.651356 \\
1.651383 \\
1.651409 \\
1.651436 \\
1.651463 \\
1.651490 \\
1.651517 \\
1.659543 \\
1.651570 \\
1.651597\end{array}$ \\
\hline $\begin{array}{r}5962.0 \\
2.1 \\
2.2 \\
2.3 \\
2.4 \\
2.5 \\
2.5 \\
2.7 \\
2.8 \\
2.9\end{array}$ & $\begin{array}{r}16768.250 \\
67.969 \\
67.688 \\
67.406 \\
67.125 \\
66.844 \\
66.563 \\
66.282 \\
66.000 \\
65.719\end{array}$ & $\begin{array}{l}68 \cdot 222 \\
67 \cdot 941 \\
67 \cdot 660 \\
67 \cdot 378 \\
67 \cdot 097 \\
66 \cdot 816 \\
66 \cdot 535 \\
66 \cdot 253 \\
65 \cdot 972 \\
65.691\end{array}$ & $\begin{array}{l}68.194 \\
67.913 \\
67.632 \\
67.350 \\
67.069 \\
66.788 \\
66.507 \\
66.225 \\
65.944 \\
65.663\end{array}$ & $\begin{array}{l}68 \cdot 166 \\
67.885 \\
67.603 \\
67.322 \\
67.041 \\
66.760 \\
66.479 \\
66.197 \\
65.916 \\
65.635\end{array}$ & $\begin{array}{l}68.138 \\
67.856 \\
67.575 \\
67.294 \\
67.013 \\
66.731 \\
66.450 \\
66.169 \\
65.888 \\
65.607\end{array}$ & $\begin{array}{l}68 \cdot 109 \\
67 \cdot 828 \\
67 \cdot 547 \\
67 \cdot 266 \\
66.985 \\
66.703 \\
66.422 \\
66.141 \\
65.860 \\
65.579\end{array}$ & $\begin{array}{l}68.082 \\
67.800 \\
67.519 \\
67.238 \\
66.957 \\
66.676 \\
66.394 \\
66.113 \\
65.832 \\
65.551\end{array}$ & $\begin{array}{l}68.053 \\
67.772 \\
67.491 \\
67.209 \\
66.928 \\
66.647 \\
66.366 \\
66.085 \\
65.804 \\
65.522\end{array}$ & $\begin{array}{l}68.025 \\
67.744 \\
67.463 \\
67.182 \\
66.900 \\
66.619 \\
66.338 \\
66.057 \\
65.776 \\
65.494\end{array}$ & $\begin{array}{l}67.997 \\
67.716 \\
67.435 \\
67.154 \\
66.872 \\
66.591 \\
66.310 \\
66.029 \\
65.747 \\
65.466\end{array}$ & $\begin{array}{l}0.277025 \\
0.277025 \\
0.277025 \\
0.277025 \\
0.277025 \\
0.277024 \\
0.277024 \\
0.277024 \\
0.277024 \\
0.277024\end{array}$ & $\begin{array}{l}1.651624 \\
9.651659 \\
1.651677 \\
1.651704 \\
1.651731 \\
1.651758 \\
1.651785 \\
1.651811 \\
1.651838 \\
1.651865\end{array}$ \\
\hline $\begin{array}{r}5963.0 \\
3.1 \\
3.2 \\
3.3 \\
3.4 \\
3.5 \\
3.6 \\
3.7 \\
3.8 \\
3.9\end{array}$ & $\begin{array}{r}16765.438 \\
65.157 \\
64.876 \\
64.595 \\
64.313 \\
64.033 \\
63.751 \\
63.470 \\
63.189 \\
62.908\end{array}$ & $\begin{array}{l}65 \cdot 410 \\
65 \cdot 129 \\
64 \cdot 848 \\
64 \cdot 567 \\
64 \cdot 285 \\
64 \cdot 004 \\
63 \cdot 723 \\
63 \cdot 442 \\
63 \cdot 161 \\
62.880\end{array}$ & $\begin{array}{l}65.382 \\
65.101 \\
64.820 \\
64.539 \\
64.257 \\
63.976 \\
63.695 \\
63.414 \\
63.133 \\
62.852\end{array}$ & $\begin{array}{l}65.354 \\
65.073 \\
64 \cdot 792 \\
64.510 \\
64.229 \\
63.948 \\
63.667 \\
63.386 \\
63.105 \\
62.824\end{array}$ & $\begin{array}{l}65.326 \\
65.044 \\
64.763 \\
64.482 \\
64.201 \\
63.920 \\
62.639 \\
63.358 \\
63.077 \\
62.796\end{array}$ & $\begin{array}{l}65.298 \\
65.016 \\
64.735 \\
64.454 \\
64.173 \\
63.892 \\
63.611 \\
63.330 \\
63.049 \\
62.768\end{array}$ & $\begin{array}{l}65 \cdot 270 \\
64 \cdot 988 \\
64 \cdot 707 \\
64.426 \\
64 \cdot 145 \\
63.864 \\
63.583 \\
63.302 \\
63.021 \\
62.740\end{array}$ & $\begin{array}{l}65.241 \\
64.960 \\
64.679 \\
64.398 \\
64.117 \\
63.836 \\
63.555 \\
63.273 \\
62.992 \\
62.711\end{array}$ & $\begin{array}{l}65.213 \\
64.932 \\
64.651 \\
64.370 \\
64.089 \\
63.808 \\
63.526 \\
63.245 \\
62.964 \\
62.683\end{array}$ & $\begin{array}{l}65.185 \\
64.904 \\
64.623 \\
64.342 \\
64.061 \\
63.780 \\
63.499 \\
63.217 \\
62.936 \\
62.655\end{array}$ & $\begin{array}{l}0.277024 \\
0.277023 \\
0.277023 \\
0.277023 \\
0.777073 \\
0.277023 \\
0.277023 \\
0.277023 \\
0.277022 \\
0.277022\end{array}$ & $\begin{array}{l}1.651892 \\
1.651919 \\
1.651945 \\
1.651972 \\
1.651999 \\
1.652026 \\
1.652052 \\
1.652079 \\
1.652106 \\
1.652133\end{array}$ \\
\hline $\begin{array}{r}5964.0 \\
4.1 \\
4.2 \\
4.3 \\
4.4 \\
4.5 \\
4.6 \\
4.7 \\
4.8 \\
4.9\end{array}$ & $\begin{array}{r}16762.627 \\
62.346 \\
62.065 \\
61.784 \\
61.503 \\
61.222 \\
60.941 \\
60.660 \\
60.379 \\
60.098\end{array}$ & $\begin{array}{l}62.599 \\
62.318 \\
62.037 \\
61.756 \\
61.475 \\
61.194 \\
60.913 \\
60.632 \\
60.351 \\
60.070\end{array}$ & $\begin{array}{l}62.571 \\
62.290 \\
62.009 \\
61.728 \\
61.447 \\
61.166 \\
60.885 \\
60.604 \\
60.323 \\
60.042\end{array}$ & $\begin{array}{l}62.543 \\
62.262 \\
61.980 \\
61.700 \\
61.418 \\
61.137 \\
60.857 \\
60.575 \\
60.295 \\
60.013\end{array}$ & $\begin{array}{l}62.515 \\
62.234 \\
61.952 \\
61.672 \\
61.390 \\
61.109 \\
60.829 \\
60.547 \\
60.267 \\
59.986\end{array}$ & $\begin{array}{l}62.486 \\
62.206 \\
61.925 \\
61.643 \\
61.362 \\
61.081 \\
60.800 \\
60.520 \\
60.239 \\
59.958\end{array}$ & $\begin{array}{l}62.458 \\
62.177 \\
61.896 \\
61.615 \\
61.334 \\
61.053 \\
60.772 \\
60.491 \\
60.210 \\
59.929\end{array}$ & $\begin{array}{l}62.430 \\
62.149 \\
61.868 \\
61.587 \\
61.306 \\
61.025 \\
60.744 \\
60.463 \\
60.182 \\
59.901\end{array}$ & $\begin{array}{l}62.402 \\
62.121 \\
61.840 \\
61.559 \\
61.278 \\
60.997 \\
60.716 \\
60.435 \\
60.154 \\
59.873\end{array}$ & $\begin{array}{l}62.374 \\
62.093 \\
61.812 \\
61.531 \\
61.250 \\
60.969 \\
60.688 \\
60.407 \\
60.126 \\
59.845\end{array}$ & $\begin{array}{l}0.277022 \\
0.277022 \\
0.277022 \\
0.277022 \\
0.277021 \\
0.277021 \\
0.277021 \\
0.277021 \\
0.277021 \\
0.277021\end{array}$ & $\begin{array}{l}1.652160 \\
1.652186 \\
1.652213 \\
1.652240 \\
1.652267 \\
1.652294 \\
1.652320 \\
1.652347 \\
1.652374 \\
1.652401\end{array}$ \\
\hline $\begin{array}{r}5965.0 \\
5.1 \\
5.2 \\
5.3 \\
5.4 \\
5.5 \\
5.6 \\
5.7 \\
5.8 \\
5.9\end{array}$ & $\begin{array}{r}16759.817 \\
59.536 \\
59.255 \\
58.974 \\
58.693 \\
58.412 \\
58.131 \\
57.850 \\
57.569 \\
57.289\end{array}$ & $\begin{array}{l}59.789 \\
59.508 \\
59.227 \\
58.946 \\
58.665 \\
58.384 \\
58.103 \\
57.822 \\
57.542 \\
57.260\end{array}$ & $\begin{array}{l}59.761 \\
59.479 \\
59.199 \\
58.918 \\
58.537 \\
58.356 \\
58.075 \\
57.794 \\
57.513 \\
57.232\end{array}$ & $\begin{array}{l}59.733 \\
59.452 \\
59.171 \\
58.890 \\
58.609 \\
58.328 \\
58.047 \\
57.766 \\
57.485 \\
57.204\end{array}$ & $\begin{array}{l}59.705 \\
59.424 \\
59.143 \\
58.862 \\
58.581 \\
58.300 \\
58.019 \\
57.738 \\
57.457 \\
57.176\end{array}$ & $\begin{array}{l}59.677 \\
59.396 \\
59.115 \\
58.833 \\
58.553 \\
58.271 \\
57.991 \\
57.710 \\
57.429 \\
57.148\end{array}$ & $\begin{array}{l}59.648 \\
59.367 \\
59.086 \\
58.805 \\
58.525 \\
58.244 \\
57.963 \\
57.682 \\
57.401 \\
57.120\end{array}$ & $\begin{array}{l}59.620 \\
59.339 \\
59.058 \\
58.777 \\
58.497 \\
58.216 \\
57.935 \\
57.654 \\
57.373 \\
57.092\end{array}$ & $\begin{array}{l}59.592 \\
59.311 \\
59.030 \\
58.749 \\
58.468 \\
58.187 \\
57.906 \\
57.625 \\
57.345 \\
57.064\end{array}$ & $\begin{array}{l}59.564 \\
59.283 \\
59.002 \\
58.721 \\
58.440 \\
58.159 \\
57.879 \\
57.597 \\
57.317 \\
57.036\end{array}$ & $\begin{array}{l}0.277021 \\
0.277020 \\
0.277020 \\
0.277020 \\
0.277020 \\
0.277020 \\
0.277020 \\
0.277020 \\
0.277019 \\
0.277019\end{array}$ & $\begin{array}{l}1.652428 \\
1.652454 \\
1.652481 \\
1.652508 \\
1.652535 \\
1.652562 \\
1.652588 \\
1.652615 \\
1.652642 \\
1.652669\end{array}$ \\
\hline $\begin{array}{r}966.0 \\
6.1 \\
6.2 \\
6.3 \\
6.4 \\
6.5 \\
6.6 \\
6.7 \\
6.8 \\
6.9\end{array}$ & $\begin{array}{r}16757.008 \\
56.727 \\
56.446 \\
56.165 \\
55.884 \\
55.604 \\
55.323 \\
55.042 \\
54.761 \\
54.480\end{array}$ & $\begin{array}{l}56.979 \\
56.699 \\
56.418 \\
56.137 \\
55.856 \\
55.575 \\
55.294 \\
55.014 \\
54.733 \\
54.452\end{array}$ & $\begin{array}{l}56.951 \\
56.671 \\
56.390 \\
56.109 \\
55.828 \\
55.547 \\
55.266 \\
54.986 \\
54.705 \\
54.424\end{array}$ & $\begin{array}{l}56.923 \\
56.643 \\
56.362 \\
56.081 \\
55.800 \\
55.519 \\
55.239 \\
54.958 \\
54.677 \\
54.396\end{array}$ & $\begin{array}{l}56.895 \\
56.615 \\
56.333 \\
56.053 \\
55.772 \\
55.491 \\
55.210 \\
54.929 \\
54.649 \\
54.368\end{array}$ & $\begin{array}{l}56.867 \\
56.586 \\
56.306 \\
56.025 \\
55.744 \\
55.463 \\
55 \cdot 182 \\
54 \cdot 901 \\
54.621 \\
54.340\end{array}$ & $\begin{array}{l}56.839 \\
56.558 \\
56.277 \\
55.997 \\
55.716 \\
55.435 \\
55.154 \\
54.873 \\
54.592 \\
54.312\end{array}$ & $\begin{array}{l}56.811 \\
56.530 \\
56.249 \\
55.969 \\
55.687 \\
55.407 \\
55.126 \\
54.845 \\
54.564 \\
54.284\end{array}$ & $\begin{array}{l}56.783 \\
56.502 \\
56.221 \\
55.940 \\
55.659 \\
55.379 \\
55.098 \\
54.817 \\
54.536 \\
54.256\end{array}$ & $\begin{array}{l}56.755 \\
56.474 \\
56.193 \\
55.912 \\
55.631 \\
55.351 \\
55.070 \\
54.789 \\
54.508 \\
54.228\end{array}$ & $\begin{array}{l}0.277019 \\
0.277019 \\
0.277019 \\
0.277019 \\
0.277018 \\
0.277018 \\
0.277018 \\
0.277018 \\
0.277018 \\
0.277018\end{array}$ & $\begin{array}{l}1.652696 \\
1.652722 \\
1.652749 \\
1.652776 \\
1.652803 \\
1.652830 \\
1.652856 \\
1.652883 \\
1.652910 \\
1.652937\end{array}$ \\
\hline $\begin{array}{r}5967.0 \\
7.1 \\
7.2 \\
7.3 \\
7.4 \\
7.5 \\
7.6 \\
7.7 \\
7.8 \\
7.9\end{array}$ & $\begin{array}{r}16754.199 \\
53.918 \\
53.638 \\
53.357 \\
53.076 \\
52.796 \\
52.515 \\
52.234 \\
51.953 \\
51.673\end{array}$ & $\begin{array}{l}54 \cdot 171 \\
53 \cdot 890 \\
53 \cdot 610 \\
53 \cdot 329 \\
53.048 \\
52.768 \\
52.487 \\
52.206 \\
51.926 \\
51.645\end{array}$ & $\begin{array}{l}54.143 \\
53.862 \\
53.582 \\
53.301 \\
53.020 \\
52.740 \\
52.459 \\
52.178 \\
51.897 \\
51.617\end{array}$ & $\begin{array}{l}54.115 \\
53.834 \\
53.554 \\
53.273 \\
52.992 \\
52.711 \\
52.431 \\
52.150 \\
51.869 \\
51.589\end{array}$ & $\begin{array}{l}54.087 \\
5 ? .806 \\
53.526 \\
53.245 \\
52.964 \\
52.683 \\
52.403 \\
52.122 \\
51.841 \\
51.561\end{array}$ & $\begin{array}{l}54.059 \\
53.778 \\
53.498 \\
53.217 \\
52.936 \\
52.655 \\
52.375 \\
52.094 \\
51.813 \\
51.532\end{array}$ & $\begin{array}{l}54.031 \\
53.750 \\
53.469 \\
53.188 \\
52.908 \\
52.627 \\
52.346 \\
52.066 \\
51.785 \\
51.504\end{array}$ & $\begin{array}{l}54.003 \\
53.722 \\
53.441 \\
53.160 \\
52.880 \\
52.599 \\
52.318 \\
52.038 \\
51.757 \\
51.476\end{array}$ & $\begin{array}{l}53.975 \\
53.694 \\
53.413 \\
53.133 \\
52.852 \\
52.571 \\
52.290 \\
52.010 \\
51.729 \\
51.448\end{array}$ & $\begin{array}{l}53.947 \\
53.666 \\
53.385 \\
53.104 \\
52.824 \\
52.543 \\
52.262 \\
51.981 \\
51.701 \\
51.420\end{array}$ & $\begin{array}{l}0.277018 \\
0.277017 \\
0.277017 \\
0.277017 \\
0.277017 \\
0.277017 \\
0.277017 \\
0.277016 \\
0.277016 \\
0.277016\end{array}$ & $\begin{array}{l}1.652964 \\
1.652990 \\
1.653017 \\
1.653044 \\
1.653071 \\
1.653097 \\
1.653124 \\
1.653151 \\
1.653178 \\
1.653205\end{array}$ \\
\hline $\begin{array}{r}5968.0 \\
8.1 \\
8.2 \\
8.3 \\
8.4 \\
8.5 \\
8.6 \\
8.7 \\
8.8 \\
8.9\end{array}$ & $\begin{array}{r}16751.392 \\
51.111 \\
50.831 \\
50.550 \\
50.269 \\
49.989 \\
49.708 \\
49.427 \\
49.147 \\
48.866\end{array}$ & $\begin{array}{l}51.364 \\
51.083 \\
50.802 \\
50.522 \\
50.241 \\
49.961 \\
49.680 \\
49.399 \\
49.119 \\
48.838\end{array}$ & $\begin{array}{l}51.336 \\
51.055 \\
50.774 \\
50.494 \\
50.213 \\
49.933 \\
49.652 \\
49.371 \\
49.091 \\
48.810\end{array}$ & $\begin{array}{l}51.308 \\
51.027 \\
50.746 \\
50.466 \\
50.185 \\
49.905 \\
49.624 \\
49.343 \\
49.063 \\
48.782\end{array}$ & $\begin{array}{l}51.280 \\
50.999 \\
50.718 \\
50.438 \\
50.157 \\
49.876 \\
49.596 \\
40.315 \\
49.034 \\
48.754\end{array}$ & $\begin{array}{l}51.252 \\
50.971 \\
50.690 \\
50.410 \\
50.129 \\
49.848 \\
49.568 \\
49.287 \\
49.006 \\
48.726\end{array}$ & $\begin{array}{l}51.224 \\
50.943 \\
50.562 \\
50.382 \\
50.101 \\
49.821 \\
49.540 \\
49.259 \\
48.978 \\
48.698\end{array}$ & $\begin{array}{l}51.196 \\
50.915 \\
50.634 \\
50.354 \\
50.073 \\
49.792 \\
49.511 \\
49.231 \\
48.950 \\
48.670\end{array}$ & $\begin{array}{l}51.167 \\
50.887 \\
50.606 \\
50.326 \\
50.045 \\
49.764 \\
49.483 \\
49.203 \\
48.922 \\
48.642\end{array}$ & $\begin{array}{l}51.139 \\
50.859 \\
50.578 \\
50.298 \\
50.017 \\
49.736 \\
49.456 \\
49.175 \\
48.894 \\
48.614\end{array}$ & $\begin{array}{l}0.277016 \\
0.277016 \\
0.277016 \\
0.277016 \\
0.277015 \\
0.277015 \\
0.277015 \\
0.277015 \\
0.277015 \\
0.277015\end{array}$ & $\begin{array}{l}1.653231 \\
1.653258 \\
1.653285 \\
1.653312 \\
1.653339 \\
1.653365 \\
1.653392 \\
1.653419 \\
1.653446 \\
1.653473\end{array}$ \\
\hline $\begin{array}{r}969.0 \\
9.1 \\
9.2 \\
9.3 \\
9.4 \\
9.5 \\
9.6 \\
9.7 \\
9.8 \\
9.9\end{array}$ & $\begin{array}{r}16748.586 \\
48.305 \\
48.025 \\
47.744 \\
47.463 \\
47.183 \\
46.902 \\
46.622 \\
46.341 \\
46.061\end{array}$ & $\begin{array}{l}48.558 \\
48 \cdot 277 \\
47.997 \\
47.716 \\
47.435 \\
47.155 \\
46.874 \\
46.594 \\
46.313 \\
46.033\end{array}$ & $\begin{array}{l}48.530 \\
48.249 \\
47.969 \\
47.688 \\
47.407 \\
47.127 \\
46.846 \\
46.565 \\
46.285 \\
46.005\end{array}$ & $\begin{array}{l}48.501 \\
48.221 \\
47.940 \\
47.660 \\
47.379 \\
47.099 \\
46.818 \\
46.537 \\
46.257 \\
45.977\end{array}$ & $\begin{array}{l}48.473 \\
48.193 \\
47.912 \\
47.632 \\
47.351 \\
47.071 \\
46.790 \\
46.509 \\
46.229 \\
45.948\end{array}$ & $\begin{array}{l}48.445 \\
48.165 \\
47.884 \\
47.604 \\
47.323 \\
47.042 \\
46.762 \\
46.481 \\
46.201 \\
45.920\end{array}$ & $\begin{array}{l}48.417 \\
48.137 \\
47.856 \\
47.575 \\
47.295 \\
47.015 \\
46.734 \\
46.453 \\
46.173 \\
45.892\end{array}$ & $\begin{array}{l}48.389 \\
48.109 \\
47.828 \\
47.547 \\
47.267 \\
46.987 \\
46.706 \\
46.425 \\
46.145 \\
45.864\end{array}$ & $\begin{array}{l}48.361 \\
48.081 \\
47.800 \\
47.520 \\
47.239 \\
46.958 \\
46.678 \\
46.397 \\
46.117 \\
45.836\end{array}$ & $\begin{array}{l}48.333 \\
48.053 \\
47.772 \\
47.491 \\
47.211 \\
46.930 \\
46.650 \\
46.369 \\
46.089 \\
45.808\end{array}$ & $\begin{array}{l}0.277014 \\
0.277014 \\
0.2777014 \\
0.277014 \\
0.277014 \\
0.277014 \\
0.277014 \\
0.277013 \\
0.277013 \\
0.277013\end{array}$ & $\begin{array}{l}1.653499 \\
1.653526 \\
1.653553 \\
1.653580 \\
1.653607 \\
1.653633 \\
1.653660 \\
1.653687 \\
1.653714 \\
1.653741\end{array}$ \\
\hline
\end{tabular}


$\begin{array}{lllllllllll}5970.0 & 16745.780 & 45.752 & 45.724 & 45.696 & 45.668 & 45.640 & 45.612 & 45.584 & 45.556 & 45.528\end{array}$ $\begin{array}{lllllllllll}0.1 & 45.500 & 45.472 & 45.444 & 45.416 & 45.388 & 45.360 & 45.331 & 45.303 & 45.275 & 45.247 \\ 0.2 & 45.219 & 45.191 & 45.163 & 45.135 & 45.107 & 45.079 & 45.051 & 45.023 & 44.905 & 44.067\end{array}$ $\begin{array}{lllllllllll}0.2 & 45.219 & 45.191 & 45.163 & 45.135 & 45.107 & 45.079 & 45.051 & 45.023 & 44.995 & 44.967 \\ 0.3 & 44.939 & 44.911 & 44.883 & 44.855 & 44.827 & 44.799 & 44.771 & 44.743 & 44.715 & 44.687\end{array}$ $\begin{array}{lllllllllll}0.3 & 44.939 & 44.911 & 44.883 & 44.855 & 44.827 & 44.799 & 44.771 & 44.743 & 44.715 & 44.687 \\ 0.4 & 44.658 & 44.631 & 44.603 & 44.574 & 44.546 & 44.518 & 44.490 & 44.462 & 44.434 & 44.406\end{array}$ $\begin{array}{lllllllllll}0.4 & 44.658 & 44.631 & 44.603 & 44.574 & 44.546 & 44.518 & 44.490 & 44.462 & 44.434 & 44.406 \\ 0.5 & 44.378 & 44.350 & 44.322 & 44.294 & 44.266 & 44.238 & 44.210 & 44.182 & 44.154 & 44.126\end{array}$

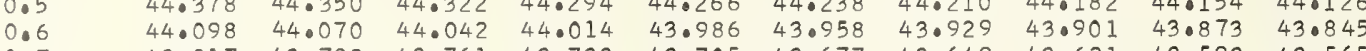
$\begin{array}{llllllllllll}0.7 & 43.817 & 43.789 & 43.761 & 43.733 & 43.705 & 43.677 & 43.649 & 43.621 & 43.593 & 43.565\end{array}$

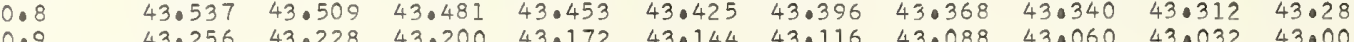

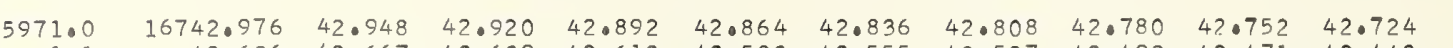

$\begin{array}{lllllllllll}1.1 & 42.696 & 42.667 & 42.639 & 42.612 & 42.583 & 42.555 & 42.527 & 42.499 & 42.471 & 42.443 \\ 1.2 & 42.415 & 42.387 & 42.359 & 42.331 & 42.303 & 42.275 & 42.247 & 42.219 & 42.191 & 42.163\end{array}$

$\begin{array}{lllllllllll}1.2 & 42.415 & 42.387 & 42.359 & 42.331 & 42.303 & 42.275 & 42.247 & 42.219 & 42.191 & 42.163 \\ 1.3 & 42.135 & 42.107 & 42.079 & 42.051 & 42.023 & 41.995 & 41.966 & 41.938 & 41.910 & 41.882\end{array}$

$\begin{array}{llllllllll}41.854 & 41.826 & 41.798 & 41.770 & 41.742 & 41.714 & 41.686 & 41.658 & 41.630 & 41.602\end{array}$

$1.5 \quad 41.574 \quad 41.546$

$\begin{array}{lll}1.6 & 41.293 & 41.266 \\ 1.7 & 41.013 & 40.985\end{array}$

1.8

5972.0

\begin{tabular}{|c|c|}
\hline $\begin{array}{l}0.277013 \\
0.27013 \\
0.277013 \\
0.0277012 \\
0.027012 \\
0.027012 \\
0.277012 \\
0.0277012 \\
0.277012\end{array}$ & $\begin{array}{l}1.653757 \\
1.653794 \\
1.653821 \\
1.653848 \\
1.65385 \\
1.653901 \\
1.653928 \\
1.653955 \\
1.653982 \\
1.654009\end{array}$ \\
\hline $\begin{array}{l}0.277011 \\
0.277011 \\
0.077011 \\
0.277011 \\
0.077011 \\
0.277011 \\
0.077011 \\
0.077010 \\
0.077010 \\
0.277010\end{array}$ & 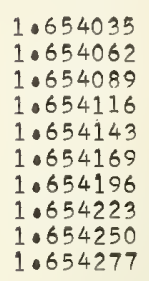 \\
\hline $\begin{array}{l}0.277010 \\
0.277010 \\
0.0277010 \\
0.277009 \\
0.077009 \\
0.277009 \\
0.0777009 \\
0.277009 \\
0.277009 \\
0.277009\end{array}$ & 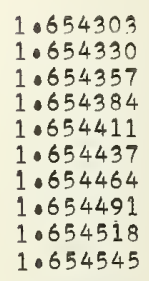 \\
\hline
\end{tabular}

0.277008

0.277008

0.277008

0.277008

0.277008

0.277007

0.277007
0.277007

0.277007

0.277007

0.277007

0.277006

0.277006

0.277006

0.277006
0.277006

0.277005

0.277005

0.277005

0.277005
0.277005

0.277005

0.277004

0.2777004
0.277004

0.277004

0.277004

0.277004

0.277004
0.277003

0.277003

0.277003
0.277003

0.277003

0.277003
0.277003

0.277002
0.277002

0.277002
0.277002

0.277002

0.277002
0.277002

0.27700
0.27700

0.277001
0.277001

1.654571

1.654598

1.654652

1.654705

1.654732

1.654759

1.654786

1.654839

1.654866

1.654893

1.654920

1.654946

10655000

1.655054

1.655107
1.655134

1.655134

1.655188

1.655214

1.655241

1.655268

1.655322

1.655375

1.655402

1.655429
1.655456

1.655482

1.655509
1.655536

1.655563
1.655590

1.655616

0.27700
0.277001
0.277001

0.277001

0.277000

0.277000

0.277000

0.277000

0.277000

1.655643

1.655670
1.655697

1.655724

1.655750
1.655777

1.655804

1.655831

1.655858
1.655884

0.276999

0.276999

0.27699

0.27699

0.27699

0.27699

0.276998

1.655911

1.655938

1.655992

1.656018

1.656072

1.656090
1.656126

1.656179

1.656206

1.656233

1.656260

1.6553313
1.656340

1.656367

106556394
1.6656420

.010

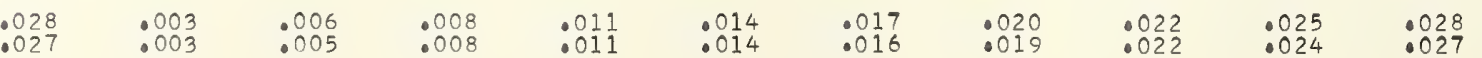


$\begin{array}{rlllllllll}17.498 & 17.750 & 17.721 & 17.694 & 17.666 & 17.638 & 17.610 & 17.582 & 17.554 & 17.526 \\ 17.219 & 17.191 & 17.442 & 17.414 & 17.386 & 17.358 & 17.330 & 17.302 & 17.274 & 17.247 \\ 17.135 & 17.107 & 17.079 & 17.051 & 17.023 & 16.995 & 16.967\end{array}$ $\begin{array}{llllllllll}16.939 & 16.911 & 16.883 & 16.855 & 16.827 & 16.799 & 16.771 & 16.743 & 16.716 & 16.687\end{array}$ $\begin{array}{llllllllll}16.660 & 16.632 & 16.604 & 16.576 & 16.548 & 16.520 & 16.492 & 16.464 & 16.436 & 16.408 \\ 16.380 & 16.352 & 16.324 & 16.296 & 16.268 & 16.240 & 16.212 & 16.184 & 16.156 & 16.128\end{array}$ $\begin{array}{llllllllll}16.380 & 16.352 & 16.324 & 16.296 & 16.268 & 16.240 & 16.212 & 16.184 & 16.156 & 16.128 \\ 16.101 & 16.073 & 16.044 & 16.017 & 15.989 & 15.961 & 15.933 & 15.905 & 15.877 & 15.849\end{array}$ $\begin{array}{llllllllll}16.101 & 16.073 & 16.044 & 16.017 & 15.989 & 15.961 & 15.933 & 15.905 & 15.877 & 15.849 \\ 15.821 & 15.793 & 15.765 & 15.737 & 15.709 & 15.681 & 15.653 & 15.625 & 15.597 & 15.569\end{array}$ $\begin{array}{llllllllll}15.821 & 15.793 & 15.765 & 15.737 & 15.709 & 15.681 & 15.653 & 15.625 & 15.597 & 15.569 \\ 15.542 & 15.514 & 15.486 & 15.458 & 15.430 & 15.402 & 15.374 & 15.346 & 15.318 & 15.290\end{array}$ $\begin{array}{llllllllll}15.542 & 15.514 & 15.486 & 15.458 & 15.430 & 15.402 & 15.374 & 15.346 & 15.318 & 15.290 \\ 15.262 & 15.234 & 15.206 & 15.178 & 15.150 & 15.122 & 15.094 & 15.066 & 15.038 & 15.010\end{array}$

16714.983

1.0
1.1
1.2
1.3
1.4
1.5
1.6
1.7

$\begin{array}{lllll}14.703 & 14.955 & 14.927 & 14.899 & 140 \\ 14.675 & 14.647 & 14.619 & 140\end{array}$

$\begin{array}{llllll}14.703 & 14.675 & 14.647 & 14.619 & 14.592 & 14.843\end{array}$

$\begin{array}{llllll}14.144 & 14.115 & 14.368 & 14.340 & 14.312 & 14.284 \\ 14.088 & 14.061 & 14.032 & 14.005\end{array}$

$\begin{array}{llllll}13.865 & 13.837 & 13.809 & 13.781 & 13.753 & 13.725\end{array}$

$\begin{array}{llll}13.585 & 13.557 & 13.530 & 13.501\end{array}$

$13.306 \quad 13.278$

$\begin{array}{llll}13.530 & 13.501 & 12.474 & 13.446 \\ 13.250 & 13.222 & 13.194 & 13.166\end{array}$

13.027
12.747
12.468

$12.999 \quad 12.971 \quad 12.943$

$13.194 \quad 13.166$

$\begin{array}{llll}14.815 & 14.787 & 14.759 & 14.731 \\ 14.535 & 14.507 & 14.479 & 14.452\end{array}$

$\begin{array}{llll}14.535 & 14.507 & 14.479 & 14.452 \\ 14.256 & 14.228 & 14.200 & 14.172\end{array}$

$\begin{array}{llll}3.697 & 13.648 & 13.9 .21 & 13.893 \\ 13.669 & 13.641 & 13.613\end{array}$

$\begin{array}{llll}13.418 & 13.390 & 13.362 & 13.334\end{array}$

$\begin{array}{llll}13.138 & 13.110 & 13.082 & 13.054 \\ 12.859 & 12.831 & 12.803 & 12.775\end{array}$

$16712.188 \quad 12.161$

$$
\begin{array}{rrr}
712.188 & 12.161 \\
11.909 & 11.881 \\
11.630 & 11.602
\end{array}
$$

$\begin{array}{ll}11.630 & 11.602 \\ 11.350 & 11.32\end{array}$

$\begin{array}{ll}11.071 & 11.043 \\ 10.792 & 10.764\end{array}$

$10.512 \quad 10.484$

10.233
09.954

$\begin{array}{ll}0.205 & 10.456 \\ 0.177\end{array}$

09.675

9.926

12.133
11.853
11.574
11.294
11.015
10.736
10.456
10.177
09.898
09.618

12.384

12.356

$3 \cdot 1$
3.2
3.3 16709.39509 .367

$$
09.339090
$$

$\begin{array}{llll}12.105 & 12.076 & 12.049 & 120 \\ 11.825 & 11.797 & 11.769 & 110\end{array}$

$\begin{array}{llll}12.579 & 12.552 & 12.524 & 12.496 \\ 12.300 & 12.272 & 12.244 & 12.216\end{array}$

$\begin{array}{llll}12.021 & 11.993 & 11.965 & 11.937 \\ 11.741 & 11.713 & 11.686 & 11.658\end{array}$

$\begin{array}{llll}11.741 & 11.713 & 11.686 & 11.658 \\ 11.462 & 11.434 & 11.406 & 11.378 \\ 11.183 & 11.155 & 11.127 & 11.099\end{array}$

$\begin{array}{lllllll}11.266 & 11.239 & 11.210 & 11.183 & 11.155 & 11.127 & 11.099 \\ 10.987 & 10.959 & 10.931 & 10.903 & 10.875 & 10.847 & 10.819\end{array}$

$10.708 \quad 10.680 \quad 10.652$

$\begin{array}{llll}10.624 & 10.596 & 10.568 & 10.540\end{array}$

$\begin{array}{lllllll}10.149 & 10.121 & 10.093 & 10.065 & 10.037 & 10.010 & 09.981\end{array}$

$\begin{array}{lll}09.116 & 09.088 & 09.060 \\ 08.836 & 08.809 & 08.781\end{array}$

$08.557 \quad 08.530 \quad 08.501 \quad 08.474$

$08.278 \quad 08.250$

$07.999 \quad 07.971 \quad 07.943$

$07.440 \quad 07.412$

$\begin{array}{llll}07.161 & 07.133 & 07.385 & 07.3 \\ 06.88 & 06.854 & 06.826 & 07.077\end{array}$

$06.882 \quad 06.854 \quad 06.826$

5984.0

.60306 .575

$\begin{array}{lll}06.044 & 06.017 & 05.98\end{array}$

$05.765 \quad 05.737$

$05.207 \quad 05.179$

$04.649 \quad 04.621$

$04.091 \quad 04.062$

5985.0

16703.

$03.532 \quad 03.504$

$\begin{array}{ll}03.253 & 03.2 \\ 02.974 & 02.946\end{array}$

$02.695 \quad 02.667$

$02.416 \quad 02.38$

$02.137 \quad 02.109$

$01.579 \quad 01.551$

06.547

$\begin{array}{ll}0.961 \\ 0.709 & 05.681\end{array}$

09.84209 .814

$\begin{array}{llll}09.786 & 09.758 & 09.730 & 09.702 \\ 09.507 & 09.479 & 09.451 & 09.423\end{array}$

0.276998

0.276998
0.276998

0.276997

0.276907

276997

0.276997

0.276996

0.276996

0.276996

.276996

0.276995

0.276995

0.276995
0.276995

0.276995

0.276995

0.276994

0.276994

0.276994

.276994

0.276993

1.656447

1.656474

1.656554

.656581

1.656608

1.656662

1.656715

.656742

.656796

1.656822

.656876

1.656903

.655629
.656956

0.276993

0.276993
0.076903
0
0.27693

0.276993

0.0276993

0.276992

0.0276992

0.276992

1.656983

1.657010
1.657037

1.657063
1.657090

1.657117

1.657171

1.6557224

0.276997

0.276992
0.276992

0.27699

0.07699

0.276991

$\begin{array}{llllllll}04.872 & 04.844 & 04.816 & 04 \cdot 788 & 04.760 & 04 \cdot 732 & 04 \cdot 705 & 04.677 \\ 04.593 & 04.565 & 04.537 & 04.509 & 04.481 & 04.453 & 04.425 & 04.397\end{array}$

$\begin{array}{llllllll}04.314 & 04.286 & 04.258 & 04.230 & 04.202 & 04 \cdot 174 & 04.146 & 04.118 \\ 04.034 & 04.007 & 03.979 & 03.951 & 03.923 & 03.895 & 03.867 & 03.839\end{array}$

0.276991

1.657251

.657278

1.657331

1.657385

1.657412

1.657465

0.276990

0.276990
0.276990

0.276990

0.276990

0.276990

0.276989
0.276989

0.276989

$\begin{array}{rrrrrrrrrrr}5986.0 & 16701.021 & 00.993 & 00.965 & 00.937 & 00.909 & 00.881 & 00.854 & 00.826 & 00.798 & 00.770 \\ 6.1 & 00.742 & 00.714 & 00.686 & 00.658 & 00.630 & 00.602 & 00.574 & 00.547 & 00.519 & 00.491\end{array}$

$\begin{array}{llllllllllll}6.1 & 00.742 & 0.714 & 0.0886 & 00.658 & 0 & .6330 & 00.602 & 00.574 & 00.547 & 00.519 & 00.491 \\ 6.2 & 00.463 & 00.435 & 00.407 & 00.379 & 00.351 & 00.323 & 00.295 & 00.268 & 00.240 & 00.212\end{array}$

$\begin{array}{rrrrrrrrrrr}6.3 & 00.184 & 00.156 & 00.128 & 00.100 & 00.072 & 00.044 & 00.016 & * 99.989 & * 99.961 & * 99.933\end{array}$

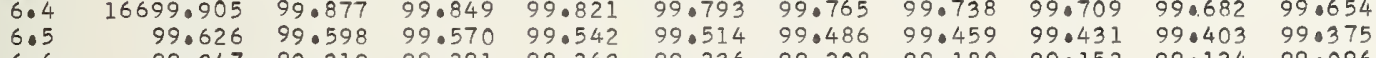

$\begin{array}{lllllllllll}6.6 & 99.347 & 99.319 & 99.291 & 99.263 & 99.236 & 99.208 & 99.180 & 99.152 & 99.124 & 99.096\end{array}$

$\begin{array}{lllllllllll}6.7 & 99.068 & 99.040 & 99.012 & 98.984 & 98.956 & 98.929 & 98.901 & 98.873 & 98.845 & 98.817 \\ 6.8 & 98.789 & 98.761 & 98.733 & 98.706 & 98.677 & 98.650 & 98.622 & 98.594 & 98.566 & 98.538\end{array}$

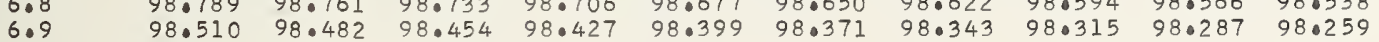

0.276989

0.276989

0.276988

0.276988

0.276988

0.276988

0.276988

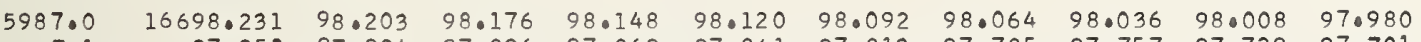

$\begin{array}{llllllllllll}7.1 & 97.952 & 97.924 & 97.896 & 97.869 & 97.841 & 97.813 & 97.785 & 97.757 & 97.729 & 97.701 \\ 7.2 & 97.674 & 97.646 & 97.618 & 97.590 & 97.566 & 97.534 & 97.506 & 970478 & 970450 & 970423\end{array}$

$\begin{array}{lllllllllll}7.2 & 97.674 & 97.646 & 97.618 & 97.590 & 97.562 & 97.534 & 97.506 & 97.478 & 97.450 & 97.423 \\ 7.3 & 97.395 & 97.367 & 97.339 & 97.311 & 97.283 & 97.255 & 97.227 & 97.199 & 97.172 & 97.144\end{array}$

$\begin{array}{lllllllllll}7.4 & 97.116 & 97.088 & 97.060 & 97.032 & 97.004 & 96.976 & 96.948 & 96.921 & 96.893 & 96.865\end{array}$ $\begin{array}{lllllllllll}96.837 & 96.809 & 96.781 & 96.753 & 96.725 & 96.697 & 96.670 & 96.642 & 96.614 & 96.586\end{array}$

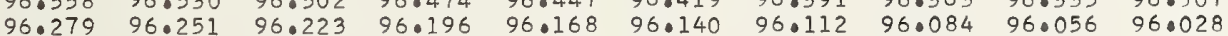

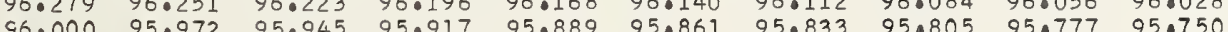

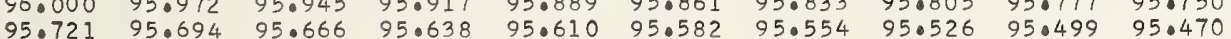

0.276987

0.276987
0.276987
0.276987

0.276987

0.276987

0.276986

0.276986

0657510

1.657546

1.657573
1.657599

.657653

1.657680
1.657707

1.657733
1.657760

1.657787

1.657814
1.657841

.657867
.657894

.657921
.657948

1.657975

1.658001
1.658028

0.276986

0.276986

0.27698

0.276985

0.27698

0.27698

0.27698

0.276985

1.658055

1.658109

1.658109
1.658135

1.658162

1.658216

1.658243

1.658269
1.658296

0.276984

0.27698

0.276984

0.276984

0.276984

0.27698

0.276983

1.658323

1.658350
1.658377

1.658403

1.658430

1.658484

1.658511
1.658537

1.658564

1.658591

1.658618

1.658671

1.658698

1.658752

1.658779
1.658805

1.658850

1.658886

1.658913

1.658939

1.658993

1.659020

1.659047

.010

1.659100

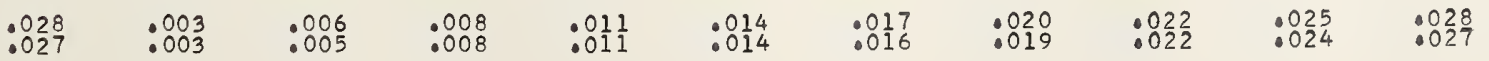


$\begin{array}{lllllllllll}5990.0 & 16689.868 & 89.840 & 89.812 & 89.785 & 89.757 & 89.729 & 89.701 & 89.674 & 89.646 & 89.618\end{array}$ $\begin{array}{lllllllllll}0.1 & 89.590 & 89.562 & 89.534 & 89.506 & 80.479 & 89.450 & 89.423 & 89.395 & 89.367 & 89.339\end{array}$ $\begin{array}{lllllllllll}0.3 & 89.032 & 89.005 & 89.257 & 89.228 & 89.200 & 89.172 & 89.144 & 89.116 & 89.088 & 89.061 \\ 0.38 & 89.949 & 88.921 & 88.893 & 88.865 & 88.837 & 88.810 & 88.782\end{array}$ $\begin{array}{llllllllllll}88.754 & 88.726 & 88.698 & 88.670 & 88.643 & 88.615 & 88.587 & 88.559 & 88.531 & 88.503\end{array}$ $\begin{array}{llllllllllll}0.5 & 88.476 & 88.448 & 88.420 & 88.392 & 88.364 & 88.336 & 88.308 & 88.281 & 88.253 & 88.503\end{array}$ $\begin{array}{lllllllllllll}0.6 & 88.197 & 88.169 & 88.141 & 88.113 & 88.085 & 88.058 & 88.030 & 88.002 & 87.974 & 87.946\end{array}$ $\begin{array}{lllllllllll}0.7 & 87.918 & 87.891 & 87.863 & 87.835 & 87.807 & 87.779 & 87.751 & 87.723 & 87.695 & 87.667\end{array}$ $\begin{array}{lllllllllll}0.8 & 87.640 & 87.612 & 87.584 & 87.556 & 87.528 & 87.500 & 87.473 & 87.445 & 87.417 & 87.389\end{array}$

1.

1.3$$
70.38770 .35
$$$$
\begin{array}{ll}
70.109 & 70.082 \\
69.831 & 69.803
\end{array}
$$$$
69.553 \quad 69.526
$$$$
\begin{array}{rr}
69.498 & 69.748 \\
69.470
\end{array}
$$

$0.276983 \quad 1.659127$ .276083

0.276983

0.276982

0.276982

0.276982

0.276982
0.276981

0.276981

0.276981

0.27698

0.276981
0.276981

0.276980

0.276980
0.276980

0.276980

0.276980

0.276980

0.276980

.0276979

0.276979

0.276979

0.276979
0.276978

0.276978

0.276078

0.276978

0.276978

0.276978

0.276977

0.276977
0.0276977

0.276977

0.276977
0.0276977
0.276976

0.276976

0.276976
0.0276976

0.276976

0.276976

0.276975

0.276975

0.0276975

0.276975

0.276975

0.276975
0.276974

0.276974

0.276974
0.276974

0.276974

0.276974
0.0276974

0.276973

0.076973
0.076973
0.076973

0.276973

0.276973

0.276973
0.276972

0.276972
0.276972

0.276972
0.276972

0.276972

0.276972
0.276972
0.076971

0.276971

0.0276971

0.276971
0.276971

0.276971

0.276971
0.276971

0.276970

0.276970

0.276970

0.276970
0.276970

0.276970
0.276969

0.276969

0.0276969

0.276969

0.276969

0.27606

0.276968

0.276968
0.276968

.659154

1.659181
1.659207

1.659234

1.659261
1.659288

659315

1.659341

1.659395

1.659422

1.659475

1.659502

1.659556

1.659583

1.659636

1.659663

1.659690
1.659717

1.659743

1.659770

.0659797
.659824

1.659851

1.659877
1.659904

1.659931

1.659958
1.659985

1.660011
1.660038

1.560065
1.660092

1.0600119

1.0660145
1.660172

1.660199

1.660226

1.660253
1.660279

1.660279

1.660333 
$\begin{array}{llllllllll}61.497 & 61.469 & 61.441 & 61.414 & 61.386 & 61.358 & 61.330 & 61.302 & 61.275 & 61.247\end{array}$

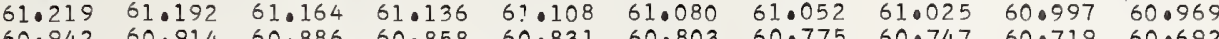
$\begin{array}{llllllllll}60.942 & 60.914 & 60.886 & 60.858 & 60.831 & 60.803 & 60.775 & 60.747 & 60.719 & 60.692\end{array}$ $60.664 \quad 60.636 \quad 60.608 \quad 60.581 \quad 60.553 \quad 60.525 \quad 60.497 \quad 60.46960 .44260 .414$ $\begin{array}{llllllllll}60.386 & 60.358 & 60.331 & 60.303 & 60.275 & 60.248 & 60.220 & 60.192 & 60.164 & 60.136\end{array}$

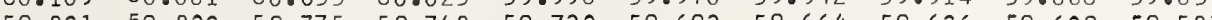

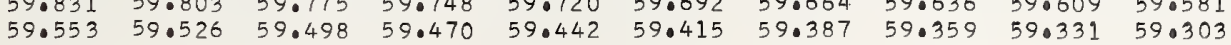

(1)

76967

0.276967
0.276967

$\begin{array}{rrr}16659.276 & 59.248 & 59.2 \\ 58.998 & 58.970\end{array} 58.0$

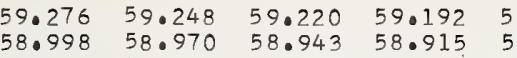

$\begin{array}{llllll}59.165 & 59.137 & 59.109 & 59.082 & 59.054 & 59.026\end{array}$ $\begin{array}{llll}58.720 & 58.693 & 58.665 & 58.637\end{array}$ $\begin{array}{llll}58.443 & 58.415 & 58.387 & 58.360 \\ 58.166 & 58.138 & 58.110 & 58.082\end{array}$ $57.888 \quad 57.860 \quad 57.832 \quad 57.804$ $\begin{array}{llll}57.610 & 57.583 & 57.555 & 57.527 \\ 57.333 & 57.305 & 57.277 & 57.250\end{array}$ $\begin{array}{llll}57.055 & 57.028 & 57.000 & 56.972 \\ 56.778 & 56.750 & 56.722 & 56.694\end{array}$

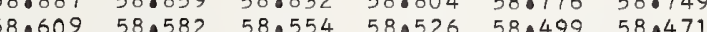
$\begin{array}{llllll}58.332 & 58.582 & 58.554 & 58.526 & 58.499 & 58.471 \\ 58.304 & 58.276 & 58.249 & 58.221 & 58.193\end{array}$ $\begin{array}{lllllll}58.054 & 58.027 & 57.999 & 57.971 & 57.943 & 57.916\end{array}$ $\begin{array}{lllllll}57.777 & 57.749 & 57.721 & 57.694 & 57.666 & 57.638 \\ 57.499 & 57.471 & 57.444 & 57.416 & 57.388 & 57.361\end{array}$ $\begin{array}{llllll}57.422 & 57.471 & 57.444 & 57.416 & 57.388 & 57.361 \\ 57.222 & 57.194 & 57.166 & 57.138 & 57.111 & 57.083\end{array}$ $656.500 \quad 56.472$

$\begin{array}{llllll}56.944 & 56.917 & 56.888 & 56.861 & 56.833 & 56.805 \\ 56.667 & 56.639 & 56.611 & 56.583 & 56.556 & 56.528\end{array}$

$0.276966-1.662075$

$0.276966 \quad 1.662102$

0.276966

0.276966

0.276966

0.276965

0.276965

0.276965

0.27696
0.276965

0.276964

0.276964

0.276964
0.276964

0.276964

.661887

1.661914

1.661968

1.662021

$0.276963-1.66261$

$0.276963-1.662638$

$0.276963 \quad 1.662669$

$0.276963-1.662718$

$\begin{array}{ll}0.276962 & 1.662745 \\ 0.662772\end{array}$

$0.276962 \quad 1.662799$

$\begin{array}{ll}0.0276962 & 1.662826 \\ 0.276962 & 1.662852\end{array}$

$0.276962 \quad 1.662879$

0.276962

0.276962

0.27696

0.276961

0.27696

0.276961

0.276960

0.276950
0.0276960
0.2760

0.0276960

0.0276960
0.0276960
0.27600

0.276960

0.276959
0.276959
0.227959

0.27659
0.276959

0.276959

0.276959

0.276958

0.0276958

0.276958

0.276958

0.276958
0.276958

0.276957

0.276957
0.276957

0.276957

0.276957
0.276957
0.276957

0.276957

0.276956
0.276956

0.276956

0.276956
0.276956

0.276956
0.276956

0.276955
0.276955
0.27695

0.276955

0.276955

0.276955

0.276954

0.276954

0.276954

0.276954

0.276954
0.276954

0.276953

0.276953
0.276953

.662906

1.662960

1.662986

1.663040

1.663067
1.663094

10663147

1.663201

1.663254

1.663281

1.663335

1.663388

1.663415

1.663442
1.663469

1.663496

1.663549

1.663576

1.663630

1.663683

1.663710

1.663764

1.663790
1.663817

1.663844

1.663898

1.663951

1.663978 


$\begin{array}{rrrr}10.0 & 16634.329 & 34.301 & 34 . \\ 0.1 & 34.052 & 34.024 & 330 \\ 0.2 & 33.775 & 33.748 & 330 \\ 0.3 & 33.498 & 33.471 & 330 \\ 0.4 & 33.222 & 33.194 & \\ 0.5 & 32.945 & 32.917 & 320 \\ 0.6 & 32.668 & 32.640 & 320 \\ 0.7 & 32.392 & 32.364 & 320 \\ 0.8 & 32.115 & 32.087 & 320 \\ 0.9 & 31.838 & 31.810 & 310\end{array}$

$\begin{array}{ll}34.273 & 34.246 \\ 33.996 & 33.969 \\ 33.720 & 33.692 \\ 33.443 & 33.416 \\ 33.166 & 33.138 \\ 32.890 & 32.862 \\ 32.613 & 32.585 \\ 32.336 & 32.308 \\ 32.059 & 32.032 \\ 31.783 & 31.755\end{array}$

\section{0}

$\begin{array}{llllll}33.941 & 34.190 & 34.163 & 34.135 & 34.107 & 34.080 \\ 33.913 & 33.886 & 33.858 & 33.830 & 33.803\end{array}$

$\begin{array}{lllllll}33.664 & 33.637 & 33.609 & 33.582 & 33.554 & 33.526\end{array}$

$\begin{array}{llllll}33.111 & 33.083 & 33.056 & 33.028 & 33.000 & 32.972\end{array}$

$\begin{array}{lllllll}32.557 & 32.807 & 32.779 & 32.751 & 32.723 & 32.696\end{array}$

$31.838 \quad 31.81$

$\begin{array}{llllll}32.281 & 32.253 & 32.226 & 32.198 & 32.170 & 32.142\end{array}$

$$
2012
$$

$$
\begin{array}{r}
3 . \\
3 . \\
3 . \\
3 . \\
3 . \\
3 . \\
3 . \\
3 . \\
3 .
\end{array}
$$

6015.0

$\begin{array}{rrrr}15.0 & 16620.501 & 20.474 & 2 \\ 5.1 & 20.225 & 20.197 & 2 \\ 5.2 & 19.949 & 19.921 & 1 \\ 5.3 & 19.672 & 19.645 & 1 \\ 5.4 & 19.396 & 19.368 & 1 \\ 5.5 & 19.120 & 19.092 & 1 \\ 5.6 & 18.844 & 18.816 & 1 \\ 5.7 & 18.567 & 18.540 & 1 \\ 5.8 & 18.291 & 18.264 & 1 \\ 5.9 & 18.015 & 17.987 & 1\end{array}$

$\begin{array}{lllll}6016.0 & 16617.739 & 17.711 & 17.683 & 17.656\end{array}$

6.1
6.2
6.3

6.3

6.5
6.6
6.7

6.8
6.9

6017.

7:

7.03

70

7.8

6018.0

$\begin{array}{rrrrr}8.0 & 16612.216 & 12.188 & 12.161 & 12.133 \\ 8.1 & 11.940 & 11.912 & 11.885 & 11.857 \\ 8.2 & 11.664 & 11.636 & 11.609 & 11.581 \\ 8.3 & 11.388 & 11.360 & 11.333 & 11.305 \\ 8.4 & 11.112 & 11.084 & 11.057 & 11.029 \\ 8.5 & 10.836 & 10.808 & 10.781 & 10.753 \\ 8.6 & 10.560 & 10.532 & 10.505 & 10.477 \\ 8.7 & 10.284 & 10.256 & 10.229 & 10.201 \\ 8.8 & 10.008 & 09.980 & 09.953 & 09.925 \\ 8.9 & 09.732 & 09.704 & 09.677 & 09.649\end{array}$

6019.0

\section{(1) \\ 9.3}

9.1
9.2
9.3

9.5

9.7

9.8
9.9
$16631.561 \quad 31.534$

$31.008 \quad 30.980$

31.506

31.478

$30.731 \quad 30.70$

$\begin{array}{lll}30.455 & 30.427 \quad 30.39\end{array}$

$29.901 \quad 29.874$

$\begin{array}{ll}29.625 & 29.597 \\ 29.348 & 29.32\end{array}$

30.372

$29.846 \quad 29.819$

29.07 $\begin{array}{llll}17.186 & 17.158 & 17.131 & 17.10 \\ 16.910 & 16.882 & 16.855 & 16.827\end{array}$ $16.910 \quad 16.882$ $\begin{array}{llll}16.358 & 16.330 & 16.302 & 16.275\end{array}$ $\begin{array}{llll}16.081 & 16.054 & 16.026 & 15.99\end{array}$ $\begin{array}{ll}15.529 & 15.501 \\ 15.253 & 15.22\end{array}$

6614.077

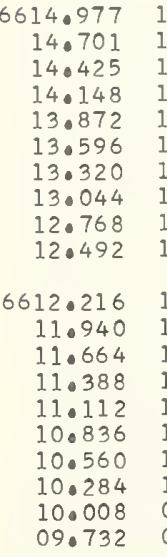

$\begin{array}{llllll}31.451 & 31.423 & 31.395 & 31.368 & 31.340 & 31.312\end{array}$

$\begin{array}{llllll}31.174 & 31.146 & 31.119 & 31.091 & 31.063 & 31.036\end{array}$

$\begin{array}{llllll}30.621 & 30.593 & 30.565 & 30.538 & 30.510 & 30.482\end{array}$

$\begin{array}{llllll}30.344 & 30.316 & 30.289 & 30.261 & 30.233 & 30.206\end{array}$

$\begin{array}{llllll}29.791 & 29.763 & 29.735 & 29.708 & 29.680 & 29.652\end{array}$

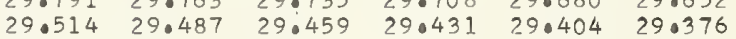

$\begin{array}{llllll}29.238 & 29.210 & 29.182 & 29.155 & 29.127 & 29.099\end{array}$

$\begin{array}{lllllll}28.684 & 28.657 & 28.629 & 28.602 & 28.574 & 28.546\end{array}$

$\begin{array}{llllll}28.408 & 28.380 & 28.352 & 28.325 & 28.297 & 28.270 \\ 28.131 & 28.104 & 28.076 & 28.048 & 28.021 & 27.993\end{array}$

$\begin{array}{llllll}27.854 & 27.827 & 27.799 & 27.771 & 27.744 & 27.716\end{array}$

$\begin{array}{llllll}27.578 & 27.551 & 27.523 & 27.495 & 27.467 & 27.440 \\ 27.301 & 27.274 & 27.246 & 27.219 & 27.191 & 27.163\end{array}$

$\begin{array}{llllll}27.025 & 26.997 & 26.970 & 26.942 & 26.914 & 26.887\end{array}$

$\begin{array}{llllll}26.748 & 26.721 & 26.693 & 26.665 & 26.638 & 26.610\end{array}$

$\begin{array}{llllll}26.472 & 26.444 & 26.417 & 26.389 & 26.361 & 26.334 \\ 26.196 & 26.168 & 26.140 & 26.113 & 26.085 & 26.057\end{array}$

$\begin{array}{llllll}25.919 & 25.891 & 25.864 & 25.83 .6 & 25.808 & 25.781 \\ 25.642 & 25.615 & 25.587 & 25.560 & 25.532 & 25.504\end{array}$

$\begin{array}{llllll}25.642 & 25.615 & 25.587 & 25.560 & 25.532 & 25.504 \\ 25.366 & 25.338 & 25.311 & 25.283 & 25.255 & 25.228\end{array}$

$\begin{array}{llllll}25.366 & 25.338 & 25.311 & 25.283 & 25.255 & 25.228 \\ 25.089 & 25.062 & 25.034 & 25.006 & 24.979 & 24.951\end{array}$

$\begin{array}{llllll}24.813 & 24.785 & 24.758 & 24.730 & 24.702 & 24.675 \\ 24.536 & 24.509 & 24.481 & 24.454 & 24.426 & 24.398\end{array}$

$\begin{array}{llllll}24.260 & 24.232 & 24.205 & 24.177 & 24.149 & 24.122\end{array}$

$\begin{array}{llllll}23.984 & 23.956 & 23.928 & 23.901 & 23.873 & 23.845\end{array}$

$\begin{array}{llllll}23.707 & 23.680 & 23.652 & 23.624 & 23.597 & 23.569 \\ 23.431 & 23.403 & 23.375 & 23.348 & 23.320 & 23.292\end{array}$

$\begin{array}{llllll}23.154 & 23.127 & 23.099 & 23.072 & 23.044 & 23.016\end{array}$

$\begin{array}{lllllll}22.602 & 22.574 & 22.546 & 22.519 & 22.491 & 22.463\end{array}$

$\begin{array}{llllll}22.436 & 22.408 & 22.380 & 22.353 & 22.325 & 22.297 \\ 22.159 & 22.132 & 22.104 & 22.076 & 22.049 & 22.021 \\ 21.883 & 21.855 & 21.828 & 21.800 & 21.772 & 21.745\end{array}$

$\begin{array}{llllll}21.607 & 21.579 & 21.551 & 21.524 & 21.496 & 21.469 \\ 21.330 & 21.303 & 21.275 & 21.247 & 21.219 & 21.192\end{array}$

$\begin{array}{llll}22.270 & 22.242 & 22.215 & 22 \cdot 187\end{array}$

$\begin{array}{llll}21.994 & 21.966 & 21.938 & 21.911\end{array}$

$\begin{array}{llll}21.441 & 21.413 & 21.385 & 21.358\end{array}$

$21.165 \quad 21.137 \quad 21.109 \quad 21.082$

$\begin{array}{llll}20.888 & 20.860 & 20.833 & 20.805 \\ 20.612 & 20.584 & 20.556 & 20.529\end{array}$

$\begin{array}{llllll}20.391 & 20.363 & 20.335 & 20.308 & 20.280 & 20.253\end{array}$

$\begin{array}{llllll}20.115 & 20.087 & 20.059 & 20.031 & 20.004 & 19.976\end{array}$

$\begin{array}{llllll}19.838 & 19.811 & 19.783 & 19.755 & 19.728 & 19.700 \\ 19.562 & 19.534 & 19.507 & 19.479 & 19.451 & 19.424\end{array}$

$\begin{array}{llllll}19.562 & 19.534 & 19.507 & 19.479 & 19.451 & 19.424 \\ 19.286 & 19.258 & 19.230 & 19.203 & 19.175 & 19.147\end{array}$

$\begin{array}{lllllll}19.009 & 18.982 & 18.954 & 18.927 & 18.899 & 18.871 \\ 18.733 & 18.705 & 18.678 & 18.650 & 18.622 & 18.595\end{array}$

$\begin{array}{llllll}18.457 & 18.429 & 18.402 & 18.650 & 18.622 & 18.595 \\ 18.374 & 18.346 & 18.319\end{array}$

$\begin{array}{llllll}18.181 & 18.153 & 18.125 & 18.097 & 18.346 & 18.319 \\ 17.904 & 17.877 & 17.849 & 17.822 & 17.704 & 18.042\end{array}$

$\begin{array}{llllll}17.628 & 17.601 & 17.573 & 17.545 & 17.518 & 17.490\end{array}$

$\begin{array}{llllll}17.352 & 17.324 & 17.297 & 17.269 & 17.241 & 17.214\end{array}$

$\begin{array}{llllll}17.076 & 17.048 & 17.021 & 16.993 & 16.965 & 16.937 \\ 16.799 & 16.772 & 16.744 & 16.717 & 16.689 & 16.661\end{array}$

$\begin{array}{llllll}16.523 & 16.496 & 16.468 & 16.440 & 16.413 & 16.385 \\ 16.247 & 16.219 & 16.192 & 16.164 & 16.137 & 16.109\end{array}$

$\begin{array}{llllll}16.247 & 16.219 & 16.192 & 16.164 & 16.137 & 16.109 \\ 15.971 & 15.943 & 15.916 & 15.888 & 15.860 & 15.833\end{array}$

$\begin{array}{llllll}15.971 & 15.943 & 15.916 & 15.888 & 15.860 & 15.833 \\ 15.695 & 15.667 & 15.639 & 15.612 & 15.584 & 15.557\end{array}$

$\begin{array}{lllllll}15.419 & 15.391 & 15.363 & 15.336 & 15.308 & 15.281\end{array}$

$\begin{array}{lllllll}15.143 & 15.115 & 15.087 & 15.060 & 15.032 & 15.004\end{array}$

$\begin{array}{llllll}14.866 & 14.839 & 14.811 & 14.783 & 14.756 & 14.728\end{array}$

$\begin{array}{lllllll}14.314 & 14.287 & 14.5259 & 14.507 & 14.479 & 14.452 \\ 14.231 & 14.204 & 14.176\end{array}$

$\begin{array}{llllll}14.038 & 14.010 & 13.983 & 13.955 & 13.928 & 13.900 \\ 13.762 & 13.734 & 13.707 & 13.679 & 13.651 & 13.624\end{array}$

$\begin{array}{llllll}13.762 & 1.3 .734 & 13.707 & 13.679 & 13.651 & 13.624 \\ 13.486 & 13.458 & 13.431 & 13.403 & 13.375 & 13.348\end{array}$

$\begin{array}{llllll}12.210 & 13.182 & 13.155 & 13.127 & 13.099 & 13.072 \\ 12.934 & 12.906 & 12.878 & 12.851 & 12.823 & 12.796\end{array}$

$\begin{array}{llllll}12.934 & 12.906 & 12.878 & 12.851 & 12.823 & 12.796 \\ 12.657 & 12.630 & 12.602 & 12.575 & 12.547 & 12.520\end{array}$

$\begin{array}{llllll}12.657 & 12.630 & 12.602 & 12.575 & 12.547 & 12.520 \\ 12.382 & 12.354 & 12.326 & 12.299 & 12.271 & 12.243\end{array}$

$\begin{array}{llllll}12.105 & 12.078 & 12.050 & 12.023 & 11.995 & 11.967 \\ 11.829 & 11.802 & 11.774 & 11.747 & 11.719 & 11.691\end{array}$

$\begin{array}{llllll}11.829 & 11.802 & 11.774 & 11.747 & 11.719 & 11.691 \\ 11.553 & 11.526 & 11.498 & 11.470 & 11.443 & 11.415\end{array}$

$\begin{array}{llllll}11.277 & 11.526 & 11.498 & 11.470 & 11.443 & 11.415 \\ 11.250 & 11.222 & 11.195 & 11.167 & 11.139\end{array}$

$\begin{array}{llllll}11.001 & 10.974 & 10.946 & 10.919 & 10.891 & 10.863 \\ 10.725 & 10.698 & 10.670 & 10.643 & 10.615 & 10.587\end{array}$

$\begin{array}{llllll}10.725 & 10.698 & 10.670 & 10.643 & 10.615 & 10.587 \\ 10.449 & 10.422 & 10.394 & 10.367 & 10.339 & 10.312\end{array}$

$\begin{array}{llllll}10.173 & 10.146 & 10.118 & 10.091 & 10.063 & 10.035\end{array}$

$\begin{array}{llllll}09.897 & 09.870 & 09.842 & 09.815 & 09.787 & 09.760 \\ 09.622 & 09.594 & 09.566 & 09.539 & 09.511 & 09.483\end{array}$

$\begin{array}{llllll}0.0 .345 & 09.318 & 09.291 & 09.263 & 09.235 & 09.208\end{array}$

$\begin{array}{llllll}09.070 & 09.042 & 09.014 & 08.987 & 08.959 & 08.932\end{array}$

$\begin{array}{llllll}08.794 & 08.766 & 08.739 & 08.711 & 08.683 & 08.656\end{array}$

$\begin{array}{llllllllll}08.628 & 08.601 & 08.573 & 08.545 & 08.794 & 08.766 & 08.739 & 08.711 & 08.683 & 08.656 \\ 08.352 & 08.324 & 08.297 & 08.269 & 08.242 & 08.490 & 08.463 & 08.435 & 08.407 & 08.380 \\ 08.076 & 08.049 & 08.021 & 07.994 & 0.08 .187 & 08.159 & 08.131 & 08.104 \\ 0.076 & 07.938 & 07.911 & 07.883 & 07.856 & 07.828\end{array}$

$\begin{array}{lllllllllll}08.076 & 08.049 & 08.021 & 07.994 & 07.966 & 07.938 & 07.911 & 07.883 & 07.856 & 07.828 \\ 07.800 & 07.773 & 07.745 & 07.718 & 07.690 & 07.662 & 07.635 & 07.607 & 07.580 & 07.552\end{array}$

$\begin{array}{llllllllll}07.525 & 07.497 & 07.469 & 07.442 & 07.414 & 07.387 & 07.359 & 07.332 & 07.304 & 07.276\end{array}$

$\begin{array}{llllllllll}07.249 & 07.221 & 07.193 & 07.166 & 07.138 & 07.111 & 07.083 & 07.055 & 07.028 & 07.000 \\ 06.973 & 06.945 & 06.917 & 06.890 & 06.863 & 06.835 & 06.807 & 06.780 & 06.752 & 06.724\end{array}$
0.276953

0.276953

0.276053

0.276952

0.276952

0.276952

0.276952

0.276952

0.276951

0.276951

27695

0.276951

0.27695

0.276950

0.276950
0.276950

0.276950

0.276950

0.276950
0.276950

0.27694

0.276949

0.276949

0.276949
0.276949

0.276949

0.276948

0.276948

0.276948
0.276948

0.276948

0.276948

0.276947

0.276947

0.276947

0.276947

0.276947
0.27694

0.276946

0.276946

0.276946

0.276946

0.276946
0.276946

0.276946

0.276945

0.276945

0.276945

0.276945
0.276945

0.276945
0.276945
0.276944

0.276944

0.276944

0.276944

0.276944

0.276944

0.276943

0.276943

0.276943

0.276943

0.276943

0.276943

0.276942

0.276942

0.276942

0.276942

0.276942

0.276042

0.276941

0.27694

0.276941

0.276941

0.276941
0.276941

0.276940

0.276940

0.276940

0.276940
0.276940

0.276940

0.276939

0.276939

0.276939

0.276939

0.276939

0.276939

0.276938
0.276938
1.664487

1.664514

1.664541
1.664568

.664594

.664621

1.664675

1.664798

1.664755

1.664782

1.664809

1.664862

1.664889

1.664916

1. 664970

1.665023

1.665050

1.665077
1.665104

1.665131

1.665157

1.665184
1.665211

1.665238

1.665291

1.665318

1.665345

1.66539

1.665425

1.665452

1.665479

1.665506
1.655533

1.665559

1.665586

1.665640

1.665667

1.665693

1.665747

1.665774

1.665827

1.665854

1.6658808

1.665908
1.665935

1.665961

1.666015

1.666042

1.666095

1.666122

1.666170

1.666203

1.666229

1.666256

1.666256
1.666283

1.666310

1.666363

1.666390

1.666417

1.666471

1.666498

1.666578

1.666632

1.666658

1.666685

1.666712

1.366739

1.666792

1.666819

1.666873

.1 .666900

1.666926
1.666953

1.666980

1.667007

1.667060

1.667087
1.667114
1.667141 

$\begin{array}{llllllllll}03.663 & 03.635 & 03.608 & 03.581 & 0.2 .553 & 03.525 & 03.498 & 03.470 & 03.443 & 03.415\end{array}$

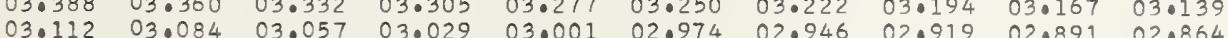
$\begin{array}{llllllllll}02.836 & 02.808 & 02.781 & 02.753 & 02.726 & 02.698 & 02.670 & 02.643 & 02.8915 & 02.864 \\ \end{array}$ $\begin{array}{llllllllll}02.560 & 02.533 & 02.505 & 02.478 & 02.450 & 02.422 & 02.670 & 02.643 & 02.615 & 02.588 \\ 0\end{array}$

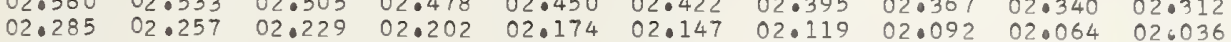
$\begin{array}{llllllllll}02.009 & 01.981 & 01.954 & 01.202 & 02.174 & 02.147 & 02.119 & 02.092 & 02.064 & 02.036 \\ & 01.898 & 01.871 & 01.844 & 01.816 & 01.788 & 01.761\end{array}$ $\begin{array}{llllllllll}01.733 & 01.706 & 01.678 & 01.650 & 0.1 .623 & 01.595 & 01.568 & 01.540 & 01.513 & 01.485 \\ 01.457 & 01.430 & 01.402 & 01.375 & 01.347 & 01.320 & 01.292 & 01.264 & 01.237 & 01.209\end{array}$

0.276937
0.276937

0.276937

0.276937

0.276937

0.276936

0.276936

0.276936

76036

0.276935
0.276935

$16601.182 \quad 01.154$

$01.127 \quad 01.099$

01.34701 .320

0.276935 $\begin{array}{llllllllll}00.906 & 00.879 & 00.851 & 00.823 & 00.796 & 00.768 & 00.741 & 00.713 & 00.686 & 00.658\end{array}$ $\begin{array}{llllllllll}00.630 & 00.603 & 00.575 & 00.548 & 00.520 & 00.493 & 00.465 & 00.437 & 00.410 & 00.382\end{array}$ $\begin{array}{rlllllllll}00.355 & 00.327 & 00.300 & 00.272 & 00.244 & 00.217 & 00.189 & 00.162 & 00.134 & 00.107 \\ 00.079 & 00.052 & 00.024 & * 99.996 & * 99.969 & * 99.941 & * 99.914 & * 99.886 & * 99.859 & * 99.831\end{array}$

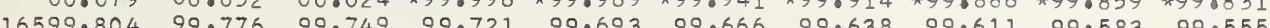

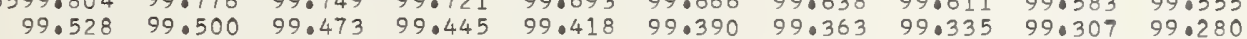

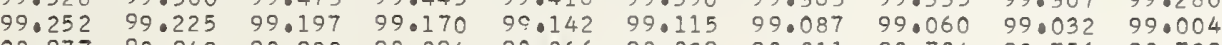
$\begin{array}{llllllllll}98.977 & 98.949 & 98.922 & 98.894 & 98.866 & 98.839 & 98.811 & 98.784 & 98.756 & 98.729 \\ 98.701 & 98.674 & 98.646 & 98.618 & 98.591 & 98.563 & 98.536 & 98.508 & 98.481 & 98.453\end{array}$ $\begin{array}{rlllllllll}16598.426 & 98.398 & 98.370 & 98.343 & 98.315 & 98.288 & 98.260 & 98.233 & 98.205 & 98.177 \\ 98.150 & 98.122 & 98.095 & 98.067 & 98.040 & 98.012 & 97.985 & 97.957 & 97.929 & 97.902\end{array}$ $\begin{array}{llll}98.150 & 98.122 & 98.095 & 98.067 \\ 97.875 & 97.847 & 97.819 & 97.792\end{array}$ $97.599 \quad 97.571 \quad 97.544 \quad 97.516$ 97.59907 .571 $97.544 \quad 97.516$ $97.048 \quad 97.020 \quad 96.993 \quad 96.965$ $96.772 \quad 96.745 \quad 96.717 \quad 96.690$ 96.49796 .469 96.44196 .414 97.489

97.213 97.461

$\begin{array}{llllll}96.937 & 96.910 & 96.883 & 96.855 & 96.827 & 96.800 \\ 96.662 & 96.635 & 96.607 & 96.579 & 96.552 & 96.524\end{array}$ $\begin{array}{ll}96.221 & 96.194 \\ 95.946 & 95.918\end{array}$ $\begin{array}{llll}97.433 & 97.406 & 97.378 & 97.351 \\ 97.158 & 97.130 & 97.103 & 97.075 \\ 96.883 & 96.855 & 96.827 & 96.800\end{array}$

60240 $16595.670 \quad 95.643950$ $5.890 \quad 95.86$

\section{$96.111 \quad 96.083$}

$96.33196 .304 \quad 96.276 \quad 96.249$

$\begin{array}{llll}96.056 & 96.028 & 96.001 & 95.973 \\ 95.780 & 95.753 & 95.725 & 95.698\end{array}$ $\begin{array}{llll}95.395 & 95.367 & 95.615 & 95.587 \\ 953 & 95.312\end{array}$

95.00994 .98

$94.458 \quad 94.430$

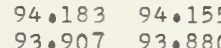

$92.632 \quad 93.604$

95.505
95.229

94.994

$\begin{array}{lll}95.477 & 95.450 & 95.422 \\ 95.202 & 95.174 & 95.147\end{array}$

$\begin{array}{llll}94.678 & 94.651 & 94.899 & 94.871 \\ 94.403 & 94.375 & 94.623 & 94.596\end{array}$

$\begin{array}{llll}94.127 & 94.100 & 94.072 & 94.045\end{array}$ 93.13693 .108

16540.16

90.960
90.685

91.20891 .18

$91.704 \quad 91.677$

92.200

$92.723 \quad 92.695 \quad 92.668$

90.135 90.658
90.382

90.905
90.630

$91.153 \quad 91.126$

91.374

$92.172 \quad 92.145 \quad 92.117$ 89.006189 .3033 88.786 88.510 $88.235 \quad 88.208$

87.960
87.685

6027.0

16587.40 87.134

$87.134 \quad 87.382$

$86.859 \quad 86.832$

$86.309 \quad 86.281$

$85.758 \quad 85.731$

$85.483 \quad 85.456$

$85.208 \quad 85.181$

$90.107 \quad 90.080$

90.603

90.850

90.823

91.02191 .86991 .842

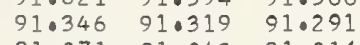

$84.933 \quad 84.905$

$89.832 \quad 89.80$

$\begin{array}{ll}89.556 & 89.52 \\ 89.281 & 89.25\end{array}$

$89.006 \quad 88.978$

$\begin{array}{ll}88.731 & 88.703 \\ 88.455 & 88.428\end{array}$

$\begin{array}{ll}88.455 & 88.428 \\ 88.180 & 88.153\end{array}$

90.05
8.9 .777

$\begin{array}{llllll}.052 & 90.024 & 89.997 & 89.969 & 89.942 & 89.914 \\ .777 & 89.749 & 89.721 & 89.694 & 89.667 & 89.639\end{array}$

90.272

$\begin{array}{lll}90.795 & 90.768 & 90.740\end{array}$

$\begin{array}{lll}0.520 & 90.492 & 90.465 \\ 0.245 & 90.217 & 90.189\end{array}$

$88.676 \quad 88.923$

$88.400 \quad 88.373$

88.125

87.82

$87.630 \quad 87.602$

$87.575 \quad 87.547$

$87.079 \quad 87.052$

$860^{\circ}$

$\begin{array}{ll}86.529 & 86.501 \\ 86.253 & 86.226 \\ 85.979 & 85.951\end{array}$

$\begin{array}{ll}85.979 & 85.951 \\ 85.703 & 85.676\end{array}$

$\begin{array}{ll}85.428 & 85.401 \\ 85.153 & 85.125\end{array}$

$86.749 \quad 86.721$

$\begin{array}{ll}86.474 & 86.446 \\ 86.198 & 86.171\end{array}$

$\begin{array}{ll}85.923 & 85.89 \\ 85.648 & 85.621\end{array}$

$85.648 \quad 85.621 \quad 85.593$

$\begin{array}{ll}85.373 & 85.34 \\ 85.098 & 85.070\end{array}$

89.446

89.171

88.621
88.345

88.070

$89.419 \quad 89.391 \quad 89 \cdot 364$

$88.068 \quad 88.841 \quad 88.813$

$\begin{array}{lll}88.593 \quad 88.565 & 88.538\end{array}$

$\begin{array}{lll}88.318 & 88.290 & 88.263 \\ 88.042 & 88.015 & 87.0987\end{array}$

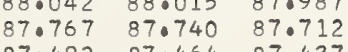

$87.244 \quad 87.217 \quad 87.189 \quad 87.162$ $\begin{array}{llll}86.969 & 86.942 & 86.914 & 86.986\end{array}$

$\begin{array}{llll}86.694 & 86.667 & 86.639 & 86.611\end{array}$

$\begin{array}{llll}86.144 & 86.116 & 86.088 & 86.061 \\ 85.868 & 85.841 & 85.813 & 85.786\end{array}$

$\begin{array}{llll}85.593 & 85.566 & 85.538 & 85.511 \\ 85.318 & 85.291 & 85.263 & 85.236\end{array}$

$65840658=840630 \quad 8406030840575$

6028.

$8 \cdot 1$ $84.383 \quad 84.355$

$83.832 \quad 83.805$

$\begin{array}{ll}83.557 & 83.530 \\ 83.282 & 83.255\end{array}$

$83.007 \quad 82.979$

$\begin{array}{ll}82.732 & 82.705 \\ 82.457 & 82.429\end{array}$

$82.182 \quad 82.155$

9.

$581.907 \quad 81.879$

$\begin{array}{ll}81.632 & 81.604 \\ 81.357 & 81.329\end{array}$

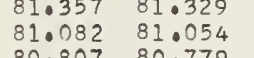

$\begin{array}{ll}80.807 & 80.779 \\ 80.532 & 80.504\end{array}$

$\begin{array}{llll}80.257 & 80.229 & 80.202 & 80.174\end{array}$

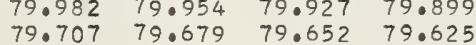

$\begin{array}{llll}79.432 & 79.0704 & 79.652 & 79.625 \\ 79.377 & 79.349\end{array}$

84.327
84.052
84.0300
84.025

83.777
83.502
83.750
83.0475

83.22783 .200

82.677
82.402
82.649

$\begin{array}{lll}8.402 & 82.0375 \\ 2.127 & 82.099\end{array}$

$84.548 \quad 84.520$

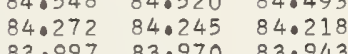

$83.722 \quad 83.695 \quad 83.667$

$\begin{array}{lll}83.447 & 83.420 & 83.39 \\ 83.172 & 83.145 & 83.117\end{array}$

$83.090 \quad 83.062$
83.03

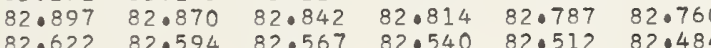

$\begin{array}{llllll}82.347 & 82.319 & 82.292 & 82.264 & 82.237 & 82.20\end{array}$

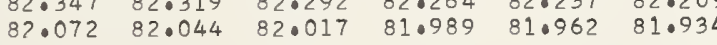

$\begin{array}{lllllll}81.797 & 81.769 & 81.742 & 81.714 & 81.687 & 81.659\end{array}$

$\begin{array}{llllll}81.522 & 81.494 & 81.467 & 81.0439 & 81.412 & 81.384 \\ 81.247 & 81.219 & 81.192 & 81.164 & 81.137 & 810100\end{array}$

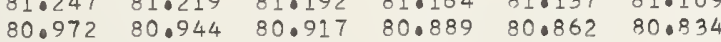

$\begin{array}{lllllll}80.697 & 80.669 & 80.642 & 80.614 & 80.587 & 80.55\end{array}$

$\begin{array}{llllll}80.422 & 80.394 & 80.367 & 80.339 & 80.312 & 80.284 \\ 80.147 & 80.1110 & 80.092 & 80.064 & 800.037 & 80.010\end{array}$

$\begin{array}{llllll}80.147 & 80.119 & 80.092 & 80.064 & 80.037 & 80.010 \\ 79.0772 & 79.844 & 79.817 & 70.790 & 70.762 & 79.734\end{array}$

$\begin{array}{llllll}79.872 & 79.844 & 79.817 & 790790 & 790.062 & 79.0734 \\ 79.597 & 790569 & 79.542 & 790514 & 790487 & 79.45\end{array}$ $\begin{array}{llllll}79.597 & 79.569 & 79.542 & 79.514 & 79.487 & 79.459 \\ 79.322 & 79.294 & 79 \cdot 267 & 79.240 & 79.212 & 79.18\end{array}$

1.667168

.667221

677275

.667328

.067382

1.667436

.66748

1.667543

1.667597

1.667650

1.667704

1.667731

-276935
26935
0

0.27693

0.276934

0.276934

0.276934
0.276934

0.276934

0.076934

0.276933
0.276933

.0276933

0.276933

0.276932

0.276932

0.276932

0.276932

0.276931

0.276931

0.276931
0.276931

0.276931

0.276930

0.276930

0.276930

0.276930

0.276929

0.076929

0.276929
0.276929
0.276929

0.276929 
$\begin{array}{rrrrrrrrrrr}030.0 & 16579.157 & 79.130 & 79.102 & 79.074 & 79.047 & 79.020 & 78.992 & 78.965 & 78.937 & 78.909 \\ 0.01 & 78.882 & 78.854 & 78.827 & 78.800 & 78.772 & 78.745 & 78.717 & 78.689 & 78.662 & 78.635\end{array}$

$\begin{array}{llllllllllll}0.1 & 78.882 & 78 \cdot 854 & 78.827 & 78.800 & 78.772 & 78.745 & 78.717 & 78.689 & 78.662 & 78.635\end{array}$

$\begin{array}{llllllllllll}0.0 & 78.607 & 78.580 & 78.552 & 78.525 & 78.497 & 78.470 & 78.442 & 78.415 & 78.387 & 78.360\end{array}$

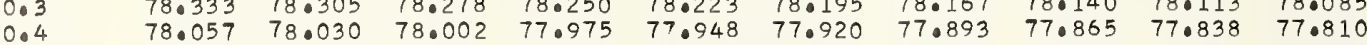

$\begin{array}{lllllllllll}0.5 & 77.783 & 77.755 & 77.728 & 77.700 & 77.673 & 77.645 & 77.618 & 77.590 & 77.563 & 77.535\end{array}$

$\begin{array}{llllllllllll}0.6 & 77.508 & 77.480 & 77.453 & 77.425 & 77.398 & 77.370 & 77.343 & 77.315 & 77.288 & 77.260\end{array}$

$\begin{array}{lllllllllll}0.07 & 77.233 & 77.205 & 77.178 & 77.150 & 77.123 & 77.095 & 77.068 & 77.041 & 77.013 & 76.986 \\ 0.8 & 76.958 & 76.931 & 76.903 & 76.875 & 76.0848 & 76.821 & 76.793 & 76.065 & 76.738 & 76.711\end{array}$

0.9 $\begin{array}{lll}76.958 & 76.931 & 760 \\ 76.683 & 76.656 & 760\end{array}$

6031.0

$\begin{array}{lrlll}1.0 & 16576.408 & 76.381 & 76.0\end{array}$ $\begin{array}{ll}76.408 & 76.381 \\ 76.133 & 76.106 \\ 75.859 & 75.831 \\ 75.584 & 75.556\end{array}$ $75.309 \quad 75.281$ $\begin{array}{lll}75.034 & 75.007 \\ 74.759 & 74.732\end{array}$ 74.48474 .457 $\begin{array}{ll}74.210 & 74.182 \\ 73.935 & 73.907\end{array}$

$\begin{array}{ll}76.353 & 76.326 \\ 76.078 & 76.051 \\ 75.804 & 75.776 \\ 75.529 & 75.501 \\ 75.254 & 75.227 \\ 74.0979 & 74.952 \\ 74.0704 & 74.677 \\ 74.029 & 74.402 \\ 74.155 & 74.127 \\ 73.880 & 73.852\end{array}$

$76.848 \quad 76.821$

$\begin{array}{llll}76.793 & 76.765 & 76.738 & 76.711 \\ 76.518 & 76.491 & 76.463 & 76.436\end{array}$

$16573.660 \quad 73.633$

76.573

6032

$\begin{array}{ll}73.111 & 73.083 \\ 72.836 & 72.809 \\ 72.561 & 72.534\end{array}$

72.56172 .534

$72.012 \quad 71.984$

$71.737 \quad 71.710$

73.605
73.0331
73.05
72.08
72.50
72.023
71.0957
71.0682
71.407
71.0733

73.57
73.303

$\begin{array}{ll}76.298 & 76.271 \\ 76.023 & 75.996 \\ 75.749 & 75.921 \\ 75.75\end{array}$

$71.188 \quad 71.160$

$\begin{array}{lllll}76.243 & 76.216 & 76.188 & 76.161\end{array}$ $\begin{array}{ll}74.100 & 74.072 \\ 73.825 & 73.798\end{array}$

$\begin{array}{lllll}75.694 & 75.666 & 75.639 & 75.611\end{array}$

$\begin{array}{lllll}75.419 & 75.391 & 75.364 & 75.336\end{array}$

$\begin{array}{lllll}74.869 & 74.842 & 740814 & 74.787\end{array}$

$\begin{array}{lllll}74.594 & 74.567 & 74.540 & 74.512\end{array}$

$74.320 \quad 74.292 \quad 74 \cdot 265 \quad 74.237$

0.276923

0.276923

0.276923

0.276923

0.276923
0.276923
0.276922

0.276922

0.276922
0.276922

1.669848 1.669875 1.669929 1.669982 1.6700036

1.670063
1.670089

0.276922

1.670116

0.276922

0.276922

0.276921

0.276921

0.276921

0.276921

1.670143

1.670170

1.670223

1.670250

1.670277

1.670331

0.276920

0.276920

0.276920

0.276920

$\begin{array}{llllllll}72.754 & 72.726 & 72.699 & 72.671 & 72.644 & 72.616 & 72.589\end{array}$

$\begin{array}{lllllll}72.479 & 72.451 & 72.424 & 72.396 & 72.369 & 72.341 & 72.314 \\ 72.204 & 72.177 & 72.149 & 72.122 & 72.094 & 72.067 & 72.039\end{array}$

0.276920

0.276919
0.276919

0.276919

1.670384

1.670411

1.670438

1.670492

1.670518

1.670572

1.670626

0.276919

0.276919

0.276919

0.276918

0.276918

0.276918

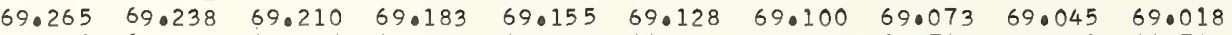

$\begin{array}{llllllllll}68.990 & 68.963 & 68.936 & 68.908 & 68.881 & 68.853 & 68.826 & 68.798 & 68.771 & 68.743\end{array}$

$\begin{array}{llllllllll}68.716 & 68.688 & 68.661 & 68.634 & 68.506 & 68.579 & 68.551 & 68.524 & 68.496 & 68.469 \\ 68.441 & 68.414 & 68.386 & 68.359 & 68.332 & 68.304 & 68.277 & 68.249 & 68.222 & 68.194\end{array}$

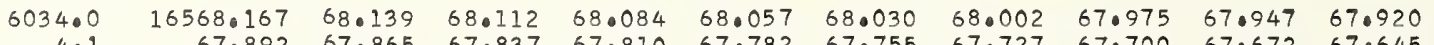

$\begin{array}{llllllllllll}4.1 & 67.892 & 67.865 & 67.837 & 67.810 & 67.782 & 67.755 & 67.727 & 67.700 & 67.672 & 67.645\end{array}$

$\begin{array}{llllllllllll}4.3 & 67.343 & 67.316 & 67.288 & 67.261 & 67.233 & 67.206 & 67.178 & 67.151 & 67.124 & 67.096\end{array}$

405

406

$67.068 \quad 67.041$

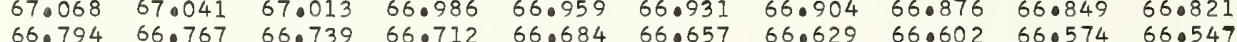

4.8

$66.519 \quad 66.492 \quad 66.464 \quad 66.437$

409

$\begin{array}{lllll}65.970 & 65.943 & 65.916 & 65.8\end{array}$

$66.410 \quad 66.382$

$\begin{array}{lllll}66.0355 & 66.327 & 66.300 & 66.272\end{array}$

6035

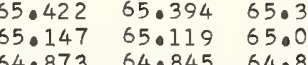

$64.598 \quad 64.571 \quad 64.818 \quad 640790$

$\begin{array}{llll}64.598 & 64.571 & 64.518\end{array}$

504

$64.049 \quad 64.022 \quad 63.0$

5.6

$63.500 \quad 63.473 \quad 63.445$

5.8
5.9

6036.0

$63.226 \quad 63.198 \quad 63.1710$

63.967

0

6.2

$\begin{array}{lll}62.0403 & 62.650 & 62.622 \\ 62.375 & 62.348\end{array}$

$62.128 \quad 62.101 \quad 62.348 \quad 62.320$

$\begin{array}{llll}61.854 & 61.826 & 61.799 & 61.771\end{array}$

61.57961 .552

61.52

61.497
61.223

61.30561 .278

60.976

60.948
60.674

$60.757 \quad 60.729$

60.702

60.674
60.400

$65.312 \quad 65 \cdot 284$

65.257

$65.229 \quad 65.202 \quad 65.174$

0.276918

0.276918
0.276917

0.276917

0.276917

0.276917

0.276917

0.276917

0.276916

1.670652

1.670706

1.670733

1.670786

1.670813

1.670867

1.670920

1.670947

1.670974
1.671001

1.671028

1.671054

1.671054
1.671081

0.276916

1.671108

0.276916

0.276916

0.276916
0.276916

0.276915

0.276915

0.276915

0.276915

1.671162

6.8

60.208

6037.0

7.1
7.2
7.3

$16559.933 \quad 50$

$\begin{array}{llll}59.659 & 59.906 & 59.879 & 59.851\end{array}$

$\begin{array}{llll}59.385 & 59.632 & 59.604 & 59.57 \\ 59.357 & 59.330 & 59.30\end{array}$

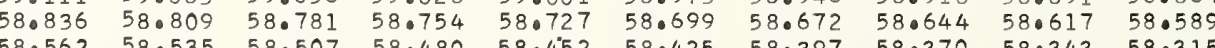

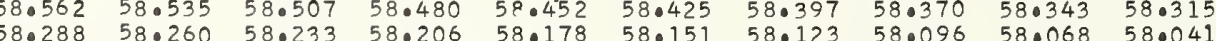

$\begin{array}{lllllllllll}7.6 & 58.288 & 58.260 & 58.233 & 58.206 & 58.178 & 58.151 & 58.123 & 58.096 & 58.068 & 58.041 \\ 7.7 & 58.013 & 57.986 & 57.959 & 57.931 & 57.904 & 57.876 & 57.849 & 57.822 & 57.794 & 57.767\end{array}$

$\begin{array}{llllllllllll}7.8 & 57.739 & 57.77 .2 & 57.685 & 57.657 & 57.630 & 57.602 & 57.575 & 57.547 & 57.520 & 57.0492\end{array}$

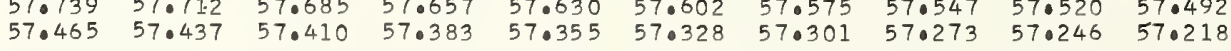

0.27691

0.276914

0.276914

0.276914

0.276914

0.276914

0.276914

1.671188

1.671215

1.671242

1.671268
1.671296

1.671323

1.671349

1.671403

$\begin{array}{rrrrrrrrrrr}038.0 & 16557.191 & 57.164 & 57.136 & 57.109 & 57.081 & 57.054 & 57.026 & 56.999 & 56.971 & 56.944 \\ 8.1 & 56.917 & 56.889 & 56.862 & 56.834 & 56.807 & 56.780 & 56.752 & 56.725 & 56.697 & 56.670\end{array}$

$\begin{array}{lllllllllll}8.1 & 56.917 & 56.889 & 56.862 & 56.834 & 56.807 & 56.780 & 56.752 & 56.725 & 56.697 & 56.670 \\ 8.2 & 56.642 & 56.615 & 56.588 & 56.560 & 56.533 & 56.505 & 56.478 & 56.450 & 56.423 & 56.396\end{array}$

$\begin{array}{lllllllllll}8.2 & 56.642 & 56.615 & 56.588 & 56.560 & 56.533 & 56.505 & 56.478 & 56.450 & 56.423 & 56.396 \\ 8.3 & 56.368 & 56.341 & 56.313 & 56.286 & 56.259 & 56.231 & 56.204 & 56.176 & 56.149 & 56.121\end{array}$

8.4

$\begin{array}{llllllllll}56.094 & 56.067 & 56.039 & 56.012 & 55.084 & 55.237 & 56.204 & 56.176 & 56.149 & 56.121 \\ 55.820 & 55.092 & 55.765 & 55.738 & 55.710 & 55.583 & 55.655 & 55.902 & 55.875 & 55.847\end{array}$

$\begin{array}{lllllllllll}55.820 & 55.792 & 55.765 & 55.738 & 55.710 & 55.683 & 55.655 & 55.628 & 55.601 & 55.573 \\ 55.546 & 55.518 & 55.491 & 55.463 & 55.436 & 55.409 & 55.387 & 55.354 & 55.326 & 55.209\end{array}$

8.6

$\begin{array}{llllllllll}55.546 & 55.518 & 55.491 & 55.463 & 55.436 & 55.409 & 55.381 & 55.354 & 55.326 & 55.299\end{array}$

$\begin{array}{lllllllllll}8.8 & 54.997 & 54.970 & 54.943 & 54.915 & 54.888 & 54.860 & 54.833 & 54.805 & 54.778 & 54.751 \\ 8.9 & 54.723 & 54.696 & 54.668 & 54.641 & 54.614 & 54.586 & 54.559 & 54.531 & 54.504 & 54.476\end{array}$

0.276913

1.671457

1.671483

1.671539

1.671564

1.671591

1.671644

1.671671
1.671698

0.276913

0.276913

0.276913

0.276913

0.27691

0.276912

0.276912

0.276912
0.276912

1.671725

1.671751
1.671778

1.671805

1.671832

1.671859

1.671886

1.671912

1.671939
1.671966

$0.276912 \quad 1.671993$

0.276912

1.672020

$0.276911 \quad 1.0672046$

$0.276911 \quad 1.672100$

$0.276911 \quad 1.672127$

0.276911

0.276911

0.276910

1.672154

1.672207

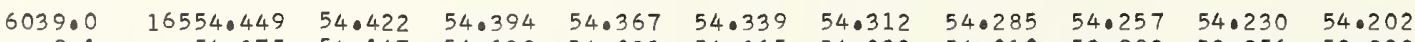

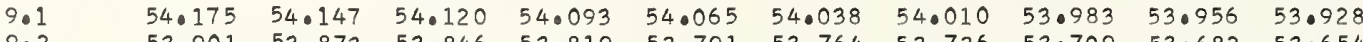

$\begin{array}{lllllllllll}53.901 & 53.873 & 53.846 & 53.819 & 53.791 & 53.764 & 53.736 & 53.709 & 53.682 & 53.654\end{array}$

$\begin{array}{llllllllll}53.627 & 53.599 & 53.572 & 53.545 & 53.517 & 53.490 & 53.462 & 53.435 & 53.408 & 53.380 \\ 53.353 & 53.325 & 53.298 & 53.270 & 53.243 & 53.216 & 53.188 & 53.161 & 53.133 & 53.106\end{array}$

$\begin{array}{lllllllllll}53.079 & 53.051 & 53.024 & 52.996 & 52.969 & 52.941 & 52.914 & 52.887 & 52.859 & 52.832\end{array}$

$\begin{array}{llllllllll}52.804 & 52.777 & 52.750 & 52.722 & 52.695 & 52.667 & 52.640 & 52.613 & 52.585 & 52.558\end{array}$

$\begin{array}{llllllllll}52.531 & 52.503 & 52.476 & 52.448 & 52.421 & 52.394 & 52.366 & 52.339 & 52.311 & 52.284\end{array}$

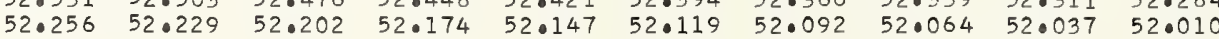

0.27691

1.67226

0.276910

0.276910
0.276910

0.276909

0.276909
0.276909

0.276909

0.276909

1.672288

1.672314

1.672368

1.672395

1.672448

9.8

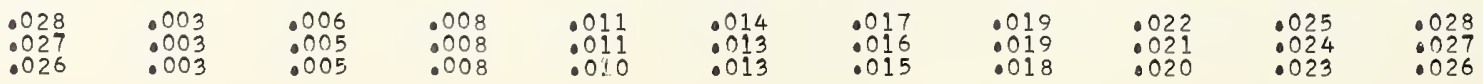




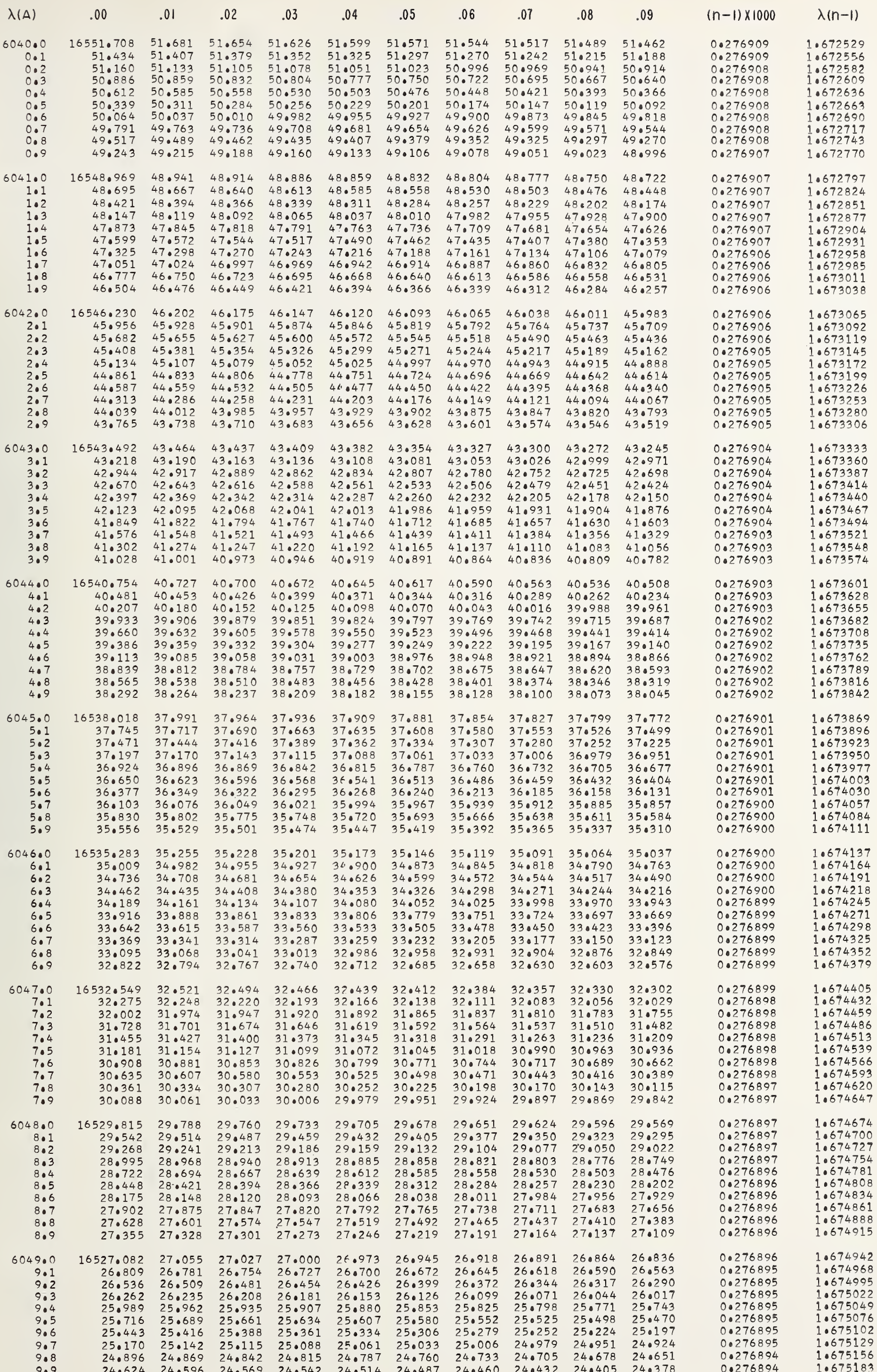


$\begin{array}{rrrrrrrrrrr}0.1 & 16524.350 & 24.323 & 24.296 & 24.269 & 24.0241 & 24.214 & 24.187 & 24.159 & 24.132 & 24.105 \\ 0.14 & 24.077 & 24.050 & 24.022 & 23.995 & 23.968 & 23.941 & 23.013 & 23.886 & 23.859 & 23.832 \\ 0.2 & 23.804 & 23.777 & 23.750 & 23.722 & 23.0595 & 23.668 & 23.640 & 23.613 & 23.586 & 23.558\end{array}$

$\begin{array}{lllllllllll}0.2 & 23.804 & 23.777 & 23.750 & 23.722 & 23.695 & 23.668 & 23.640 & 23.613 & 23.586 & 23.558 \\ 0.3 & 23.531 & 23.504 & 23.476 & 23.449 & 23.422 & 23.394 & 23.367 & 23.340 & 23.31 ? & 23.285\end{array}$

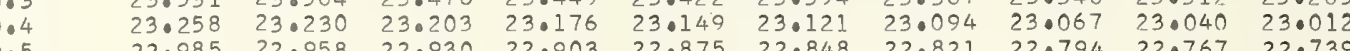

$\begin{array}{llllllllll}22.985 & 22.958 & 22.930 & 22.903 & 22.875 & 22.848 & 22.821 & 22.794 & 22.767 & 22.739\end{array}$

$\begin{array}{lllllllllll}0.6 & 22.712 & 22.685 & 22.657 & 22.630 & 22.603 & 22.575 & 22.548 & 22.521 & 22.493 & 22.466 \\ 0.7 & 22.439 & 22.412 & 22.384 & 22.357 & 22.330 & 22.302 & 22.275 & 22.248 & 22.220 & 22.193\end{array}$

$$
\begin{array}{r}
1: 0 \\
1: 1 \\
1: 2 \\
1: 3 \\
1: 4 \\
1.5 \\
1.6 \\
1.7 \\
1.8 \\
1.9
\end{array}
$$

6052.

2.2
2.3

2.4

6054.0

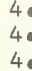

4.

4.7

4.8
4.9

6055

5.1
5.2
5.3

5.3

5.6

5.8
5.9

6056.

6.1
6.2

6.3

605

6.6

6.8

6057

7.2

7.4

7.6

7.8

6058.

8.1
8.2
8.3

8.3
8.4

8.5

8.7

8.8

9.10 13.16013 .405 $\begin{array}{ll}12.887 & 12.860 \\ 12.614 & 12.587\end{array}$ $12.342 \quad 12.31$ $11.796 \quad 11.769$ $11.523 \quad 11.496$ 10.978

$16510.706 \quad 10.678$ $10.433 \quad 10.405$ $09.887 \quad 09.860$ $09.615 \quad 09.587$ $\begin{array}{ll}09.342 & 09.315 \\ 09.069 & 09.042\end{array}$ $08.797 \quad 08.770$ $\begin{array}{ll}08.524 & 08.497 \\ 08.252 & 08.224\end{array}$ $\begin{array}{ll}21.565 & 21.538 \\ 21.292 & 21.26\end{array}$ $\begin{array}{lll}21.292 & 21.265 & 21.238 \\ 21.019 & 20.992 & 20.964\end{array}$ $\begin{array}{llll}746 & 20.719 & 20.691 & 20.00664\end{array}$ $20.473 \quad 20.446 \quad 20.418$ $\begin{array}{llll}19.927 & 20.173 & 20.145 & 20.118\end{array}$ $\begin{array}{llll}19.654 & 19.627 & 19.600 & 19.57\end{array}$ $\begin{array}{llll}19.108 & 19.081 & 19.054 & 19.026\end{array}$ $\begin{array}{ll}18.835 & 18.808 \\ 18.562 & 18.535\end{array}$ $\begin{array}{llll}18.289 & 18.535 & 18.508 & 18.480\end{array}$ $\begin{array}{llll}18.017 & 17.989 & 17.962 & 17.935\end{array}$ $\begin{array}{llll}17.743 & 17.716 & 17.689 & 17.662 \\ 17.471 & 17.443 & 17.416 & 17.389\end{array}$ $\begin{array}{llll}17.198 & 17.170 & 17.143 & 17.116\end{array}$ $\begin{array}{llll}16.925 & 16.897 & 16.870 & 16.843 \\ 16.652 & 16.625 & 16.597 & 16.570\end{array}$

21.456 21.428

1.674

1.647

$\begin{array}{llll}6.106 & 16.079 & 16.052 & 16.024\end{array}$

$\begin{array}{llll}15.561 & 15.533 & 15.506 & 15.479\end{array}$

$\begin{array}{llll}15.288 & 15.260 & 15.233 & 15.206 \\ 15.015 & 14.988 & 14.960 & 14.93\end{array}$ $\begin{array}{llll}14.742 & 14.715 & 14.687 & 14.660 \\ 14.469 & 14.442 & 14.415 & 14.387 \\ 14.197 & 14.169 & 14.142 & 14.115\end{array}$

$\begin{array}{llllllll}14.197 & 14.169 & 14.142 & 14.115 & 14.087 & 14.060 & 14.033 & 14.005 \\ 13.924 & 13.896 & 13.869 & 13.842 & 13.814 & 13.787 & 13.760 & 13.733 \\ 13.651 & 13.624 & 13.596 & 13.569 & 13.542 & 13.514 & 13.487 & 13.460\end{array}$ $14 \cdot 442$

20.910

$21.156 \quad 21.128 \quad 21.101$

$\begin{array}{llll}20.364 & 20.337 & 20.309 & 20.282\end{array}$

$\begin{array}{llll}20.091 & 20.063 & 20.036 & 20.009\end{array}$

$\begin{array}{llll}19.545 & 19.518 & 19.490 & 19.463\end{array}$

$\begin{array}{llll}19.272 & 19.245 & 19.218 & 19.190\end{array}$

$\begin{array}{llll}18.726 & 18.699 & 18.671 & 18.644\end{array}$

$\begin{array}{llll}18.453 & 18.426 & 18.398 & 18.371\end{array}$

$\begin{array}{llll}18.180 & 18.153 & 18.125 & 18.098\end{array}$

$\begin{array}{llll}17.6074 & 17.8807 & 17.853 & 17.825 \\ 17.580 & 17.552\end{array}$

$\begin{array}{llll}17.362 & 17.334 & 17.307 & 17.280\end{array}$

$\begin{array}{llll}16.816 & 17.061 & 17.034 & 17.007\end{array}$

$\begin{array}{llll}16.816 & 16.788 & 16.761 & 16.734 \\ 16.543 & 16.515 & 16.488 & 16.461\end{array}$

$\begin{array}{llll}15.997 & 15.970 & 15.942 & 15.915\end{array}$

$\begin{array}{llll}15.724 & 15.697 & 15.670 & 15.642 \\ 15.451 & 15.424 & 15.397 & 15.369\end{array}$

$\begin{array}{llll}15.178 & 15.151 & 15.124 & 15.097\end{array}$

$\begin{array}{llll}14.906 & 14.878 & 14.851 & 14.824\end{array}$

$\begin{array}{llll}14.633 & 14.606 & 14.578 & 14.551 \\ 14.360 & 14.333 & 14.305 & 14.278\end{array}$

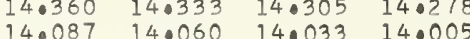

$\begin{array}{llllllll}13.378 & 13.351 & 13.323 & 13.296 & 13.269 & 13.242 & 13.214 & 13.187\end{array}$

$\begin{array}{llllllll}13.105 & 13.078 & 12.051 & 13.024 & 12.996 & 12.969 & 12.941 & 12.914\end{array}$

$\begin{array}{llllllll}12.833 & 12.805 & 12.778 & 12.751 & 12.723 & 12.696 & 12.669 & 12.642\end{array}$

$\begin{array}{llllllll}12.287 & 12.260 & 12.233 & 12.205 & 12.178 & 12.151 & 12.123 & 12.096\end{array}$

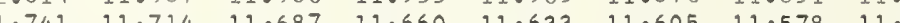

1.469

11.714

11.687

11.66

11.63
11.36

11.50
11.33

$1.578 \quad 11.551$ 10.924

$\begin{array}{ll}6507.979 & 07.95\end{array}$ $\begin{array}{ll}07.707 & 07.679 \\ 07.434 & 07.406\end{array}$

$07.161 \quad 07.134$

$06.889 \quad 06.86$

10.378 10.3 10.0

10.596

11.114
10.842

10.814

$09.833 \quad 09.806$

09.560

09.01509 .260

$\begin{array}{ll}0.015 & 08.988 \\ 08.742 & 08.715\end{array}$

$\begin{array}{ll}08.470 & 08.442 \\ 08.197 & 08.170\end{array}$

$10.324 \quad 10.296$

10.54
10.269

10.78

11.033

11.278

$\begin{array}{llllllllll}0.071 & 06.044 & 06.017 & 05.989 & 05.962 & 05.935 & 05.908 & 05.880 & 05.853 & 05.826\end{array}$

$\begin{array}{llllllllll}05.799 & 05.771 & 05.744 & 05.717 & 05.689 & 05.662 & 05.635 & 05.608 & 05.581 & 05.553 \\ 05.526 & 05.499 & 05.472 & 05.444 & 05.417 & 05.390 & 05.363 & 05.335 & 05.308 & 05.281\end{array}$

$\begin{array}{rlllllllll}16505.254 & 05.227 & 05.199 & 05.172 & 05.145 & 05.117 & 05.090 & 05.063 & 05.036 & 05.008 \\ 04.981 & 04.954 & 04.927 & 04.899 & 04.872 & 04.845 & 04.818 & 04.790 & 04.763 & 04.736\end{array}$ $\begin{array}{lllllllllll}04.709 & 04.681 & 04.654 & 04.627 & 04.600 & 04.573 & 04.545 & 04.518 & 04.490 & 04.463\end{array}$ $\begin{array}{llllllllll}04.436 & 04.409 & 04.382 & 04 \cdot 354 & 04.327 & 04.300 & 04.273 & 04.245 & 04.218 & 04.191\end{array}$ $\begin{array}{lllllllllll}04.164 & 04.136 & 04.109 & 04.082 & 04.055 & 04.028 & 04.000 & 03.973 & 03.946 & 03.918\end{array}$ $\begin{array}{lllllllllll}03.891 & 03.864 & 03.837 & 03.810 & 03.782 & 03.755 & 03.728 & 03.700 & 03.673 & 03.646\end{array}$ $\begin{array}{llllllllll}03.346 & 03.319 & 03.5292 & 03.537 & 03.510 & 03.483 & 03.455 & 03.428 & 03.401 & 03.374 \\ 0.237 & 03.237 & 03.210 & 03.183 & 03.156 & 03.128 & 03.101\end{array}$ $\begin{array}{llllllllll}03.074 & 03.047 & 03.020 & 02.992 & 02.965 & 02.938 & 02.910 & 02.883 & 02.856 & 02.829\end{array}$ $\begin{array}{llllllllll}02.802 & 02.774 & 02.747 & 02.720 & 02.693 & 02.665 & 02.638 & 02.611 & 02.583 & 02.556\end{array}$

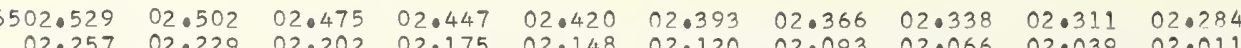
$\begin{array}{llllllllll}01.258 & 02.229 & 02.202 & 02.175 & 02.148 & 02.120 & 02.01821 & 01.0194 & 01.766 & 01.739\end{array}$ $\begin{array}{llllllllll}01.712 & 01.685 & 01.657 & 01.630 & 0 ? .503 & 01.576 & 01.548 & 01.521 & 01.494 & 01.467\end{array}$ $\begin{array}{llllllllll}0.439 & 01.412 & 01.385 & 01.358 & 01.331 & 01.303 & 01.276 & 01.249 & 01.222 & 01.194\end{array}$ $\begin{array}{llllllllll}01.167 & 1.140 & 01.113 & 01.085 & 01.058 & 01.031 & 01.004 & 00.977 & 00.949 & 00.922\end{array}$ $\begin{array}{llllllllll}0.623 & 00.595 & 00.568 & 00.541 & 00.513 & 00.486 & 00.459 & 00.432 & 00.405 & 00.377\end{array}$

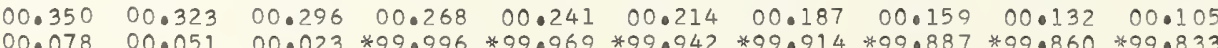

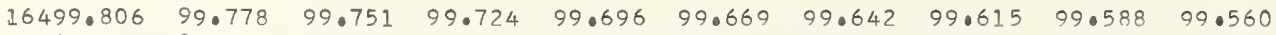

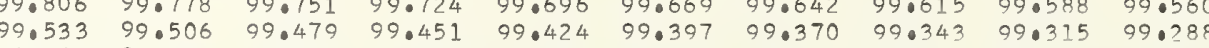

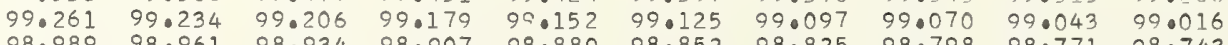
$98.716 \quad 98.689 \quad 98.962 \quad 08.63598 .88098 .852 \quad 98.825 \quad 98.798$ 98.771 98.743

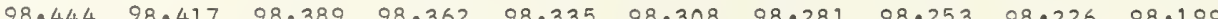
$98.17298 .145 \quad 08.11798 .090 \quad 98.063 \quad 08036 \quad 98.008 \quad 97.081-970054 \quad 07.027$ $\begin{array}{lllllllllll}97.809 & 97.872 & 97.845 & 97.818 & 97.791 & 07.763 & 97.736 & 07.700 & 07.6832 & 97.654\end{array}$

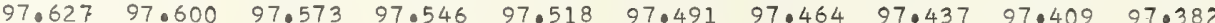
$97.355 \quad 97.328 \quad 97.300 \quad 97.273 \quad 97.246 \quad 97.21907 .192 \quad 97.164 \quad 97040997.382$

$\begin{array}{ll}0.276894 & 1.675210 \\ 0.276894 & 1.675237 \\ 0.276894 & 1.675263 \\ 0.276894 & 1.675290 \\ 0.276894 & 1.675317 \\ 0.276893 & 1.675344 \\ 0.276893 & 1.675371 \\ 0.276893 & 1.675397 \\ 0.276893 & 1.675424 \\ 0.276893 & 1.675451\end{array}$

0.276893 0.276893 0.276892 0.276892 0.276892 0.276892

0.276891

1.675478 1.675505 1.675558 1.675585 1.675639 1.675665 0.276891 0.276891 0.276891
0.276891
0.27691 0.276891 0.276890 0.276890
0.276890
0.276890 0.276890

0.276890 0.276890
0.276890 0.276890 0.276889 0.276889 0.276889 0.276889 0.276889
0.276889

0.276888 0.276888 0.276888 0.276888 0.276887 0.276887 0.776887 0.276887 0.276887 0.276887 0.276886
0.276886 0.276886 0.276886
0.276886 0.276886 0.276886

0.276885 0.276885
0.276885 0.276885 0.276885 0.276885 0.276885 0.27688 0.276884 0.276884 0.276884 0.276883 0.276883 0.27688 0.276883

0.276893 0.77688 0.276882 0.276882 0.276882 0.276882 0.27688

0.276881 0.276881 0.276881 0.276881 0.276880 0.276880 0.276880 0.276880

1.675746 1.675800 1.675826
1.695853 1.675880 1.675907
1.675934 1.675960

1.676014 1.676041
1.676068 1.676068 1.676121 1.676148 1.676148 1.676175
1.676202 1.676228 1. 676282 6309 1.676336 1.676389 10676443 

$\begin{array}{llll}96.811 & 96.783 & 96.756 & 96.729 \\ 96.538 & 96.511 & 96.484 & 96.457\end{array}$ $\begin{array}{llll}96.266 & 96.239 & 96.212 & 96.185 \\ 95.994 & 95.967 & 95.939 & 95.912\end{array}$ $\begin{array}{llll}95.722 & 95.695 & 95.667 & 95.640 \\ 95.449 & 95.422 & 95.395 & 95.368 \\ 95.177 & 95.150 & 95.123 & 95.096\end{array}$ $\begin{array}{llll}95.177 & 95.150 & 95.123 & 95.096\end{array}$ $\begin{array}{llll}94.905 & 94.878 & 94.851 & 94.823 \\ 94.633 & 94.606 & 94.579 & 94.552\end{array}$

0.276877
0.276877

0.276877
0.276877
0.276876

0.276878

0.276876

0.276876

0.276876

0.276875

0.276875

0.276875

0.276875
0.276875
0.276874

0.276874

0.276874
0.276874

$0.276874 \quad 1.678936$

0.27687

0.276874

0.276874

0.27687

0.276873

0.276873
0.276873

0.276873

0.276872
0.276872
0.2679

0.276872
0.076872

0.276872

0.0276872
0.27872

0.276871
0.0276871

0.276871

$\begin{array}{ll}0.276871 & 1.679499 \\ 0.276871 & 1.679526 \\ 0.276871 & 1.679553 \\ 0.276871 & 1.679580 \\ 0.276870 & 1.679607 \\ 0.276870 & 1.679633 \\ 0.276870 & 1.679660 \\ 0.276870 & 1.679687 \\ 0.276870 & 1.679714 \\ 0.276870 & 1.679741\end{array}$

$0.276870 \quad 1.679768$

$\begin{array}{ll}0.276869 & 1.679794 \\ 0.276869 & 1.679821\end{array}$

$\begin{array}{ll}0.276869 & 1.679848 \\ 0.276869 & 1.679875\end{array}$

0.276869

$\begin{array}{ll}0.2776869 & 1.679928\end{array}$

$0.276868 \quad 1.670982$

$0.276868 \quad 1.680009$

$\begin{array}{ll}0.276868 & 1.680036 \\ 0.276868 & 1.680062 \\ 0.276868 & 1.680089 \\ 0.276868 & 1.680116 \\ 0.276868 & 1.680143 \\ 0.276867 & 1.680170 \\ 0.276867 & 1.680197 \\ 0.276867 & 1.680223 \\ 0.276867 & 1.680250 \\ 0.276867 & 1.680277\end{array}$

$0.276867 \quad 1.680304$

1.680304
1.680331

$0.276866 \quad 1.680384$

$\begin{array}{ll}0.276866 & 1.680411 \\ 0.276866 & 1.680438\end{array}$

$0.276866 \quad 1.680465$

$\begin{array}{ll}0.276866 & 1.680491 \\ 0.276866 & 1.680518\end{array}$

$\begin{array}{ll}0.276866 & 1.680518 \\ 0.276865 & 1.680545\end{array}$

\begin{tabular}{|c|c|c|c|c|c|c|c|c|c|c|}
\hline & .001 & .002 & .003 & .004 & .005 & .006 & .007 & .008 & .009 & .010 \\
\hline$: 827$ & $: 88 \frac{3}{3}$ & $: 835$ & $: 888$ & $: 811$ & $: 81 \frac{4}{3}$ & $: 816$ & $: 818$ & $: 832$ & $: 83 \frac{5}{4}$ & $: 83$ \\
\hline
\end{tabular}




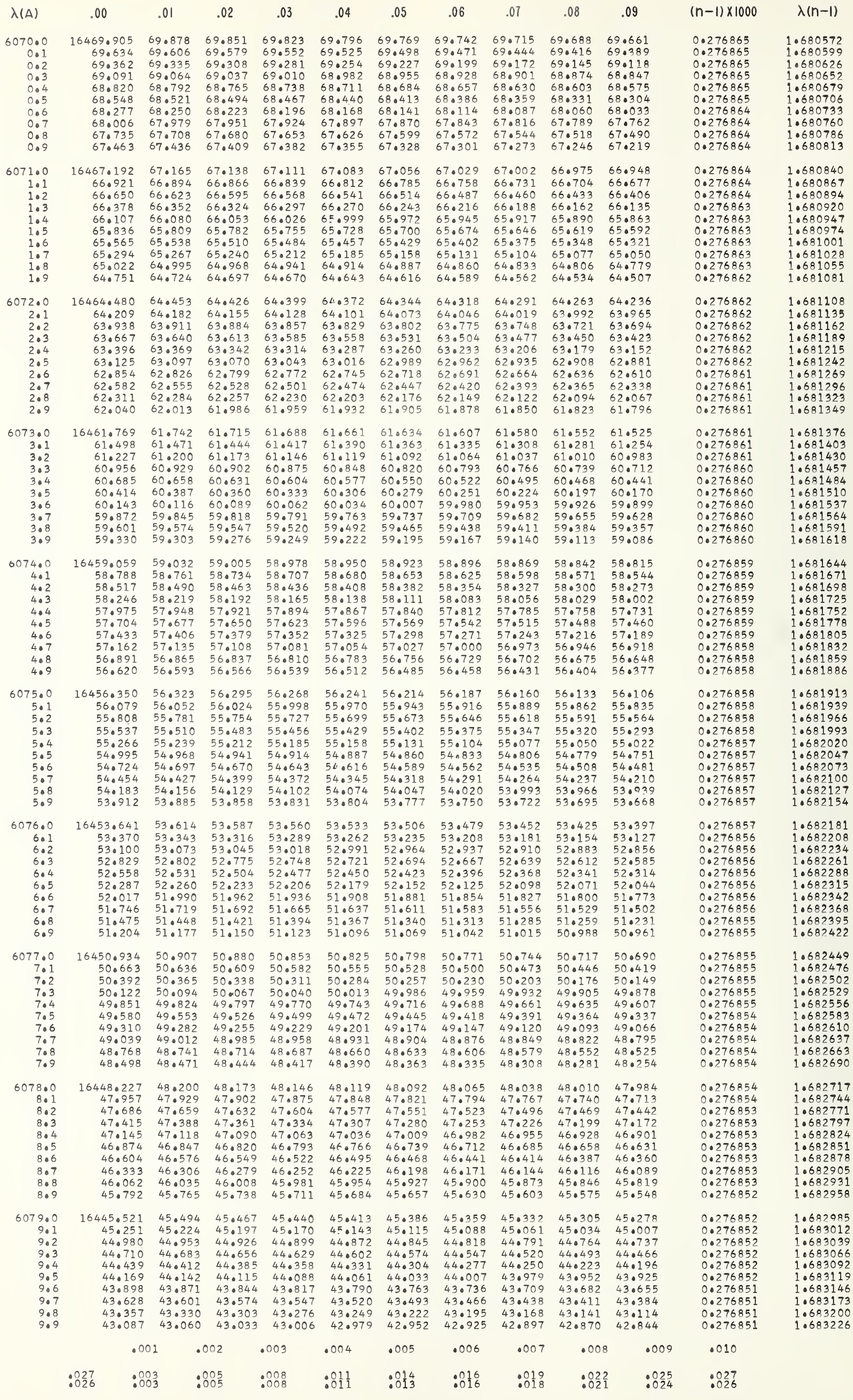


$\lambda(A)$

.00

.01

0.

0.2

0.4
0.5
0.6

0.6

0.8
0.9

6081.

6082.0

$$
\begin{array}{r}
6083.0 \\
3.1 \\
3.2 \\
3.3 \\
3.4 \\
3.5 \\
3.6 \\
3.7 \\
3.8 \\
3.9
\end{array}
$$

6084.0

$$
\begin{array}{r}
6084 . \\
4 . \\
4 . \\
4 . \\
4 . \\
4 . \\
4 . \\
4 . \\
4 . \\
4 .
\end{array}
$$$$
\begin{array}{r}
6085 \\
5 . \\
5 \\
5 .
\end{array}
$$$$
\begin{aligned}
& 85.0 \\
& 5.1 \\
& 5.2 \\
& 5.3 \\
& 5.4 \\
& 5.5 \\
& 5.6 \\
& 5 \\
& 5 \\
& 5.8
\end{aligned}
$$$$
\begin{array}{r}
6086 \\
6 \\
6 \\
6 \\
6 \\
6 \\
6 \\
6 \\
6 \\
6
\end{array}
$$

$(n-1) \times 1000$

$\lambda(n-1)$

$\begin{array}{ll}0.276851 & 1.683253 \\ 0.276851 & 1.683280 \\ 0.276851 & 1.683307 \\ 0.276850 & 1.683334 \\ 0.276850 & 1.683361 \\ 0.776850 & 1.683387 \\ 0.276850 & 1.683414 \\ 0.276850 & 1.683441 \\ 0.276850 & 1.683468 \\ 0.276850 & 1.683495\end{array}$

0.276849

0.276849

0.276849

0.276849

0.276849

0.276848

0.276848
0.276848

0.276848

0.276848

0.276847

0.276847

0.276847

0.276847

0.276847

0.276846

0.275846

0.276846

0.276846

0.276846

0.276845
0.276845

0.276845

0.276845

0.276844

0.276844

0.276844

0.276844
0.276844

0.276844

0.276844
0.276843
0.276843

0.276843

0.278843

0.276843

0.276843
0.276843
0.276842

0.27684 ?

0.276842

0.276842

0.276842

0.276842
0.276842

0.276842

0.276841
0.276841

0.276841
0.276841
0.276841

0.276841

1.683521

1.0683548
1.683575

1.683602

1.683629
1.683655

1.683682

.683709
.683736
1.6837763

1.683736
1.683763

1.683790

.683816
.0683843

1.683870

1.6833924

1.683950

1.683977

1.688031

.684058

1.684111

1.684138

1.684192

.6884219

1.684245
1.684272

1.684326

1.684353

1.684406

1.684433

1.684487

1.684514
1.684540

1.684594

1.684621
1.684648

.684674

1.684701

1.684755

1.684782
1.684800

1.684835

0.276841

0.276841
0.276841

0.276840

0.276840

0.276840
0.276840
0.276840

0.276840
0.276840
0.275840

0.276840
0.276840

0.276840

1.684862

1.684889

1.684916
1.684943

1.684969

1.684996

1.685023
1.685050

1.685077
1.685103

1.685130

1.685157

1.685211

1.685238

1.685264

1.685318

1.685345
1.685372

0.276839

0.276839

0.276839

0.276839

0.27683

0.276839

0.276838

0.276838
0.276838

1.685398

1.685425

1.685479

1.685506

1.685533

1.685586

0.276838
0.276838
0.276838

0.27683

0.276837

0.276837

0.276837

0.276837

1.685667
1.685693
1.685720
1.685747
1.685774
1.685801
1.685827
1.685854
1.685881
1.685908

.010

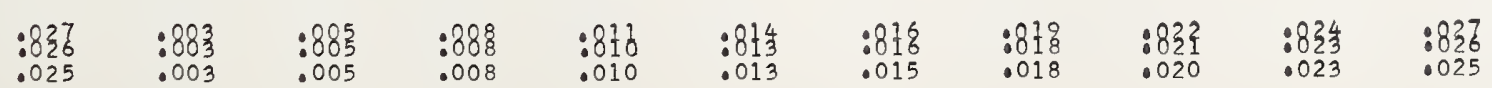


$\begin{array}{rrrrrrrrrrr}6090.0 & 16415.817 & 15.790 & 15.763 & 15.736 & 15.709 & 15.682 & 15.655 & 15.628 & 15.601 & 15.574 \\ 0.5150 & 15.547 & 15.521 & 15.493 & 15.467 & 15.440 & 15.413 & 15.386 & 15.359 & 15.332 & 15.305\end{array}$ $\begin{array}{lllllllllll}0.1 & 15.547 & 15.521 & 15.493 & 15.467 & 15.440 & 15.413 & 15.386 & 15.359 & 15.332 & 15.305 \\ 0.2 & 15.278 & 15.251 & 15.224 & 15.197 & 15.170 & 15.143 & 15.116 & 15.089 & 15.062 & 15.035\end{array}$ $\begin{array}{llllllllllll}0.3 & 15.008 & 14.981 & 14.955 & 14.927 & 14.901 & 14.874 & 14.847 & 14.820 & 14.793 & 14.766 \\ 0.4 & 14.739 & 14.712 & 14.685 & 14.658 & 14.631 & 14.604 & 14.577 & 14.550 & 14.523 & 14.496\end{array}$ $\begin{array}{lllllllllll}0.5 & 14.469 & 14.442 & 14.416 & 14.388 & 14.362 & 14.334 & 14.308 & 14.281 & 14.254 & 14.227\end{array}$ $\begin{array}{llllllllllll}0.6 & 14.200 & 14.173 & 14.146 & 14.119 & 14.092 & 14.065 & 14.038 & 14.011 & 13.984 & 13.957\end{array}$

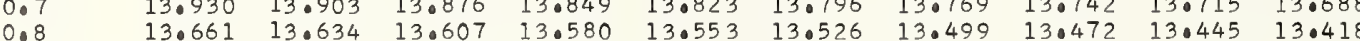
$\begin{array}{lllllllllll}0.8 & 13.661 & 13.634 & 13.607 & 13.580 & 13.553 & 13.526 & 13.499 & 13.472 & 13.445 & 13.418 \\ 0.9 & 13.391 & 13.364 & 13.337 & 13.311 & 13.284 & 13.257 & 13.230 & 13.203 & 13.176 & 13.149\end{array}$

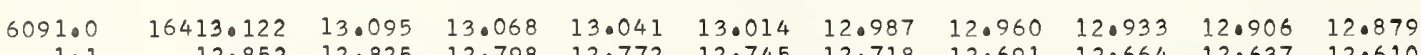
$\begin{array}{rrrrrrrrrrr}1.1 & 12.852 & 12.825 & 12.798 & 12.772 & 12.745 & 12.718 & 12.691 & 12.664 & 12.637 & 12.610 \\ 1.2 & 12.583 & 12.556 & 12.529 & 12.502 & 12.475 & 12.448 & 12.421 & 12.395 & 12.367 & 12.341\end{array}$ $\begin{array}{lllllllllll}1.2 & 12.313 & 12.287 & 12.260 & 12.233 & 12.206 & 12.179 & 12.421 & 12.395 & 12.367 & 12.341 \\ 1.3 & 12.044 & 12.017 & 12.090 & 11.963 & 12.05 & 12.098 & 12.071\end{array}$ $\begin{array}{lllllllllll}1.4 & 12.044 & 12.017 & 11.990 & 11.963 & 11.937 & 11.909 & 11.883 & 11.855 & 11.829 & 11.802 \\ 1.5 & 11.775 & 11.748 & 11.721 & 11.694 & 11.667 & 11.640 & 11.613 & 11.586 & 11.559 & 11.532\end{array}$ $\begin{array}{lllllllllll}1.6 & 11.505 & 11.478 & 11.451 & 11.425 & 11.397 & 11.371 & 11.344 & 11.317 & 11.290 & 11.263\end{array}$ $\begin{array}{lllllllllll}1.7 & 11.236 & 11.209 & 11.182 & 11.155 & 11.128 & 11.101 & 11.074 & 11.047 & 11.020 & 10.993 \\ 1.8 & 10.966 & 10.940 & 10.913 & 10.886 & 10.859 & 10.832 & 10.805 & 10.778 & 10.751 & 10.724\end{array}$ $\begin{array}{lllllllllll}1.8 & 10.966 & 10.940 & 10.913 & 10.886 & 10.859 & 10.832 & 10.805 & 10.778 & 10.751 & 10.724 \\ 1.9 & 10.697 & 10.670 & 10.643 & 10.616 & 10.589 & 10.562 & 10.536 & 10.509 & 10.481 & 10.455\end{array}$

$\begin{array}{lll}10.616 & 10.589 & 10.562 \\ 10.347 & 10.320 & 10.293\end{array}$

$\begin{array}{llll}10.266 & 10.240 & 10.212 & 10.186\end{array}$ $\begin{array}{llllllllll}10.158 & 10.132 & 10.104 & 10.078 & 10.051 & 10.024 & 09.997 & 09.970 & 09.943 & 09.916\end{array}$ $\begin{array}{llllllllll}09.889 & 09.862 & 09.835 & 09.808 & 0 . .781 & 09.755 & 09.728 & 09.701 & 09.674 & 09.647\end{array}$ $\begin{array}{llllllllll}09.620 & 09.593 & 09.566 & 09.539 & 09.512 & 09.485 & 09.458 & 09.431 & 09.405 & 09.377\end{array}$ $\begin{array}{llllllllll}09.081 & 09.054 & 09.027 & 09.000 & 08.973 & 08.946 & 08.920 & 08.893 & 08.866 & 08.839\end{array}$ $\begin{array}{lllllllllll}08.812 & 08.785 & 08.758 & 08.731 & 08.704 & 08.677 & 08.650 & 08.623 & 08.596 & 08.570\end{array}$ $\begin{array}{lllllllllll}0.543 & 08.516 & 08.489 & 08.462 & 08.435 & 08.408 & 08.381 & 08.354 & 08.327 & 08.300\end{array}$

0.276837 0.276836 0.276836 0.276836 0.276836 0.276836 0.276835
0.276835

0.276835 0.276835 0.276835
0.276835
0.276835 0.276835 0.276834 0.276834 0.276834
0.276834
0.276834 0.276834

0.276834 0.276834
0.276833 0.276833 0.276833
0.276832

0.276832 0.276832 0.276832 0.278832 0.27683 0.276831
0.276831

0.276831

0.276831 0.276831 0.276830 0.276830 0.276830 0.276830

0.276830

0.276829 0.276829 0.276829
0.276829
0.276829 0.276829
0.276829 0.276829 0.276828 0.276828
0.276828

0.276828

0.276828
0.276828
0.276828 0.276828 0.276827 0.276827 0.276827
0.276827 0.276827

0.276827 0.276826
0.276826
0.276826

0.276826
0.276826

0.276826

0.276826
0.276826

0.276826
0.276825

0.276825

0.276825 0.276825

0.276825
0.276825

0.276825

0.276824

0.276824

0.276824

0.276824 0.276824 0.276823
0.276823 0.276823 0.276823 0.276823 0.276823 .685935 1.685962 1.686015 1.686042 1.686096 1.686149 1.686176

1.688203 1.686230 1.686283 1.686310

1.686337
1.686364

1.686391

1.686417
1.686444

1.6886471 1.686498
1.686525 1.686552 1.686605 1.6866559 1.686686
1.686712

1.686739 1.686766
1.686793 1.686820 1.686846 1.686873 1.686900 1.686954
1.6869981

1.687007 1.687034
1.687061 1.687088 1.687115 1.687141 1.687168 1.687195
1.687222 1.687249

1.687276 1.687302 1.687356 1.687383 1.687410
1.687436 1.687490 1.687544 1.687571
1.687597 1.687597
1.687624 1.687651 1.687678
1.687705 1.687731 1.687758
1.687785 1.687812 1.687839
1.687865 1.687892 1.687919 1.687946 1.687973 1.688000 1.688026
1.688053

1.688080 1.688107 1.688134
1.688161 1.688187 1.688214 1.688241 1.688268 1.688321

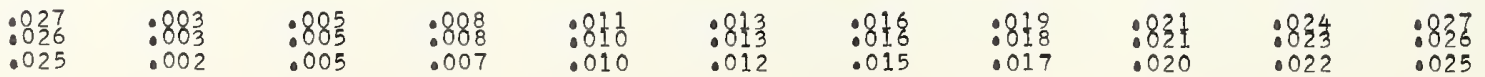


$\lambda(A)$ .00 .01 .02 .03

.04

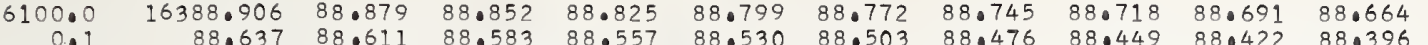

$\begin{array}{lllllllllll}0.1 & 88.637 & 88.611 & 88.583 & 88.557 & 88.530 & 88.503 & 88.476 & 88.449 & 88.422 & 88.396 \\ 0.2 & 88.369 & 88.342 & 88.315 & 88.288 & 88.261 & 88.234 & 88.208 & 88.181 & 88.154 & 88.127\end{array}$

$\begin{array}{llllllllllll}0.2 & 88.369 & 88.342 & 88.315 & 88.288 & 88.261 & 88.234 & 88.208 & 88.181 & 88.154 & 88.127 \\ 0.3 & 88.100 & 88.073 & 88.046 & 88.020 & 87.993 & 87.966 & 87.939 & 87.912 & 87.885 & 87.858\end{array}$

$\begin{array}{llllllllllll}0.4 & 88.1032 & 87.805 & 87.778 & 87.751 & 87.724 & 87.697 & 87.670 & 87.643 & 87.616 & 87.590\end{array}$

$\begin{array}{llllllllllll}0.5 & 87.563 & 87.536 & 87.509 & 87.482 & 87.455 & 87.428 & 87.402 & 87.375 & 87.348 & 87.321 \\ 0.5 & 87.294 & 87.267 & 87.240 & 87.214 & 87.187 & 87.160 & 87.133 & 87.106 & 87.079 & 87.052\end{array}$

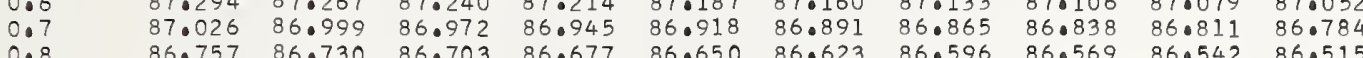

$\begin{array}{lllllllllll}0.8 & 86.757 & 86.730 & 86.703 & 86.677 & 86.650 & 86.623 & 86.596 & 86.569 & 86.542 & 86.515 \\ 0.9 & 86.488 & 86.461 & 86.435 & 86.408 & 86.381 & 86.354 & 86.327 & 86.300 & 86.273 & 86.247\end{array}$

0.276822

0.276822

0.276822

0.276822

0.276821

$\begin{array}{llllll}86.112 & 86.085 & 86.059 & 86.032 & 86.005 & 85.978\end{array}$

6386.

85.95185 .924

$.924 \quad 85.897 \quad 85.871$

$\begin{array}{lllll}85.683 & 85.656 & 85.629 & 85.602 \\ 85.414 & 85.387 & 85.361 & 85.334\end{array}$

$\begin{array}{llll}85.4146 & 85.387 & 85.361 & 85.334 \\ 85.146 & 85.092 & 85.065 \\ 84.077 & 84.050 & 85.823 & 8.0796\end{array}$

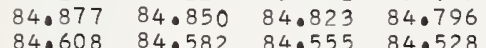

$\begin{array}{llll}84.608 & 84.582 & 84.555 & 84.528 \\ 84.340 & 84.313 & 84.286 & 84.260\end{array}$

$\begin{array}{llll}84.071 & 84.045 & 84.018 & 83.991 \\ 83.803 & 83.776 & 83.749 & 83.722\end{array}$

$\begin{array}{lllllll}55.844 & 85.817 & 85.790 & 85.763 & 85.736 & 85.709\end{array}$

$\begin{array}{lllllll}85.575 & 85.549 & 85.521 & 85.495 & 85.468 & 85.441\end{array}$

$\begin{array}{llllll}85.307 & 85.280 & 85.253 & 85.226 & 85.199 & 85 \cdot 172 \\ 85.038 & 85.011 & 84.984 & 84.958 & 84.937 & 84.004\end{array}$

$\begin{array}{llllll}85.038 & 85.011 & 84.984 & 84.958 & 84.931 & 84.904 \\ 84.770 & 84.743 & 84.716 & 84.689 & 84.662 & 84.635\end{array}$

$84.501 \quad 84.474 \quad 84.447 \quad 84.420 \quad 84.394 \quad 84.367$

83.964

$\begin{array}{llll}84.447 & 84.420 & 84.394 & 84.367 \\ 84.179 & 84.152 & 84.125 & 84.009\end{array}$

$16383.534 \quad 83.508 \quad 83.481 \quad 83.454 \quad 83$.

$\begin{array}{llll}83.266 & 83.239 & 83.212 & 83.186 \\ 82.998 & 82.971 & 82.944 & 82.917\end{array}$

$83.427 \quad 83.400 \quad 83.373 \quad 83.347 \quad 83.320 \quad 83.293$

$\begin{array}{lllllllll}82.944 & 82.917 & 82.890 & 83.132 & 83.105 & 83.078 & 83.051 & 83.025 \\ & 82.863 & 82.836 & 82.810 & 82.783 & 83.756\end{array}$

$\begin{array}{llllllll}82.52 & 82.595 & 82.568 & 82.541 & 82.514 & 82.488\end{array}$

$\begin{array}{lllllllllll}82.193 & 82.166 & 82.139 & 82.112 & 82.085 & 82.058 & 82.031 & 82.004 & 81.978 & 81.951\end{array}$

$\begin{array}{llllllllll}81.924 & 81.897 & 81.870 & 81.843 & 81.817 & 81.790 & 81.763 & 81.736 & 81.709 & 81.682\end{array}$

$\begin{array}{llllllllll}81.656 & 81.629 & 81.602 & 81.575 & 81.548 & 81.521 & 81.495 & 81.468 & 81.441 & 81.414\end{array}$

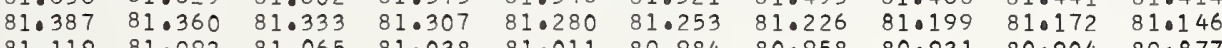

2.8

6103

16380

3.0
3.0
3.0
3.4
3.0
3
3.0
3.0

$380.850 \quad 80.823$

$\begin{array}{llll}80.582 & 80.555 & 80.797 & 80.770 \\ 00.528 & 80.501\end{array}$

$\begin{array}{llll}80.045 & 80.286 & 80.260 & 80.233 \\ 70.018 & 79.991 & 79.965\end{array}$

$99.777 \quad 79.750$

79.04
79.240 $79.481 \quad 79.455$

$78.972-78.945$

$79.186 \quad 79.160$

$78.435 \quad 78.408$

78.650

78.623

$\begin{array}{lllllll}80.743 & 80.716 & 80.689 & 80.662 & 80.635 & 80.609 \\ 80.474 & 80.448 & 80.421 & 80.394 & 80.367 & 80.340\end{array}$

$\begin{array}{llllll}80.206 & 80.179 & 80.152 & 80.125 & 80.099 & 80.072\end{array}$

$\begin{array}{llllll}79.938 & 79.911 & 79.884 & 79.857 & 79.830 & 79.804\end{array}$

$\begin{array}{lllllll}79.401 & 79.0374 & 79.347 & 79.321 & 79.294 & 79.0267\end{array}$

$\begin{array}{lllllll}79.133 & 79.106 & 79.079 & 79.052 & 79.025 & 78.998\end{array}$

$\begin{array}{llllll}78.596 & 78.569 & 78.542 & 78.515 & 78.757 & 78.730\end{array}$

6104.0

4.1
4.2
4.3

$78 \cdot 140$

$78.113 \quad 78.086$

$78.328 \quad 78.301$

$\begin{array}{llll}78.542 & 78.515 & 78.489 & 78.462 \\ 78.274 & 78.247 & 78.220 & 78.193\end{array}$

$77.630 \quad 77.603$

$77.362 \quad 77.335 \quad 77.308 \quad 77.281$

$\begin{array}{llll}76.825 & 76.067 & 77.040 & 77.013 \\ 76.772 & 76.745\end{array}$

$\begin{array}{llll}76.557 & 76.530 & 76.503 & 76.476 \\ 76.289 & 76.262 & 76.235 & 76.208\end{array}$

$\begin{array}{llll}76.289 & 76.262 & 76.235 & 76.208 \\ 76.020 & 75.994 & 75.0967 & 75.940 \\ 75.752 & 75.725 & 75.0698 & 75.672\end{array}$

$\begin{array}{lllllll}78.059 & 78.032 & 78.006 & 77.979 & 77.952 & 77.925 \\ 77.091 & 77.764 & 77.737 & 77.710 & 77.6884 & 77.6557\end{array}$

$\begin{array}{llllll}77.791 & 77.764 & 77.737 & 77.710 & 77.684 & 77.657 \\ 77.523 & 77.496 & 77.469 & 77.442 & 77.415 & 77.0389\end{array}$

$\begin{array}{lllllll}77.254 & 77.227 & 77.201 & 77.174 & 77.147 & 77 \cdot 120 \\ 76.986 & 76.959 & 76.932 & 76.906 & 76.879 & 76.852\end{array}$

$\begin{array}{llllll}76.718 & 76.9591 & 76.932 & 76.906 & 76.879 & 76.852 \\ 76.664 & 76.637 & 76.610 & 76.584\end{array}$

$\begin{array}{lllllll}76.450 & 76.423 & 76.396 & 76.369 & 76.342 & 76.316 \\ 76.181 & 76.155 & 76.128 & 76.101 & 76.074 & 76.047\end{array}$

4.7

6105

$\begin{array}{rrrrr}16375.484 & 75.457 & 75.430 & 75.403\end{array}$

$\begin{array}{lll}75.913 & 75.886 & 75.0 \\ 75.645 & 75.618\end{array}$

$\begin{array}{llll}.128 & 76.101 & 76.074 & 76.047 \\ .859 & 75.833 & 75.806 & 75.779\end{array}$ $\begin{array}{llll}75.216 & 75.189 & 75.162 & 75.13 \\ 74.947 & 74.921 & 74.894 & 74.867\end{array}$ $74.679 \quad 74.652 \quad 74.626 \quad 74.59$

$\begin{array}{lllll}74.411 & 74.384 & 74.357 & 74.330\end{array}$

$74.143 \quad 74.116 \quad 74.089 \quad 74.062$

$73.875 \quad 73.848$

$\begin{array}{llll}73.606 & 73.580 & 73.553 & 73.526\end{array}$

$75.376 \quad 75.350$

$75.323 \quad 75.296 \quad 75.269 \quad 75.242$

$\begin{array}{llllll}75.108 & 75.082 & 75.055 & 75.028 & 75.001 & 74.974 \\ 74.840 & 74.813 & 74.786 & 74.760 & 74.733 & 74.706\end{array}$

$\begin{array}{lllllll}74.572 & 74.545 & 74.518 & 74.491 & 740465 & 74.438\end{array}$

$\begin{array}{llllll}74.304 & 74.277 & 74.250 & 74.223 & 74.196 & 74.170 \\ 74.036 & 74.009 & 73.982 & 73.955 & 73.978 & 73.901\end{array}$

5.8

73.338
73.070 73.043

6106.0

72.77

$\begin{array}{ll}73.285 & 73.25 \\ 73.016 & 72.99\end{array}$

73.231

73.204

73.177

$\begin{array}{lll}73.150 & 73.124 & 73.097 \\ 72.882 & 72.856 & 72.829\end{array}$

0.27682

0.276821

0.276821

0.276820

0.276820

0.276820

0.276820

0.276820

0.276819

0.276819

0.276819

0.276819

0.276818
0.276818

0.276818

0.276818

0.276918

0.276817

0.276817

0.276897

0.276817

0.276817

0.276817

0.276816

0.276816

0.276816

0.276816

0.276816
0.276815

0.276815

0.276815

0.276815

0.276815

0.276815

0.276814

0.276814

1.688616

1.688643
1.688670

1.688697

1.688724
1.688750

1.688777

1.688831
1.688858

1.688885

1.683911

1.088938

.688992

1.689019

.689072

1.689099

1.689153

1.689180

1.689733

1.689260

.689314

1.689340

1.689367

1.689421

1.689448

1.689475
1.689501
1.69952

.689528

1.689582

1.689609
1.689635

1.689689

1.689716

1.689743

1.689770

1.689823

1.689850

1.689877

1.689930

1.689957

1.689984

1.690038

1.690065

1.690091

1.690118

$\begin{array}{llllllllll}72.266 & 72.239 & 72.212 & 72.185 & 72.158 & 72.132 & 72.105 & 72.078 & 72.051 & 72.024\end{array}$

$\begin{array}{llllllllll}71.997 & 71.971 & 71.944 & 71.917 & 71.890 & 71.864 & 71.837 & 71.810 & 71.783 & 71.756\end{array}$

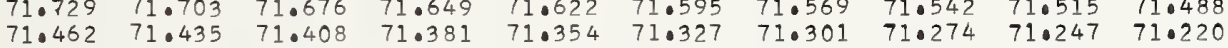

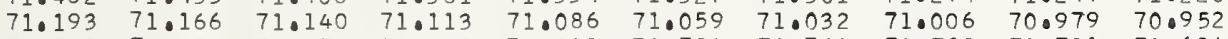

$\begin{array}{llllllllll}70.925 & 70.898 & 70.872 & 70.845 & 70.818 & 70.791 & 70.764 & 70.738 & 70.711 & 70.6844\end{array}$

$\begin{array}{llllllllll}70.657 & 70.630 & 70.604 & 70.577 & 70.550 & 70.523 & 70.496 & 70.469 & 70.443 & 70.416 \\ 70.389 & 70.362 & 70.335 & 70.309 & 70.282 & 70.255 & 70.228 & 70.201 & 70.175 & 70.148\end{array}$

0.276814

0.276814

0.276813

0.276813

0.776813

0.276813

0.276813

1.690225

1.690252

1.690306

1.690333

1.690360

1.690413

1.690440
1.690467

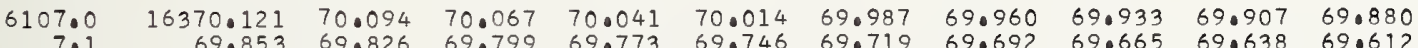

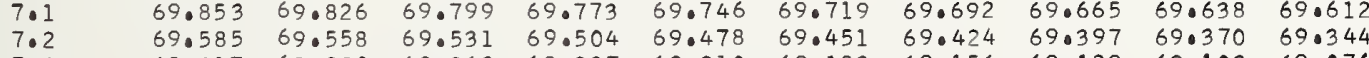

$\begin{array}{lllllllllll}7.2 & 69.585 & 69.558 & 69.531 & 69.504 & 69.478 & 69.451 & 69.424 & 69.397 & 69.370 & 69.344 \\ 7.3 & 69.317 & 69.290 & 69.263 & 69.237 & 69.210 & 69.183 & 69.156 & 69.129 & 69.103 & 69.076 \\ 7.4 & 69.049 & 69.022 & 69.095 & 68.968 & 68.942 & 68.915 & 68.888 & 68.851 & 68.834 & 68.808\end{array}$

$\begin{array}{llllllllll}69.049 & 69.022 & 68.995 & 68.968 & 68.942 & 68.915 & 68.888 & 68.861 & 68.834 & 68.808 \\ 68.781 & 68.754 & 68.0727 & 68.700 & 68.674 & 68.0647 & 68.620 & 68.593 & 68.567 & 68.540\end{array}$ $\begin{array}{llllllllll}68.781 & 68.754 & 68.727 & 68.700 & 68.674 & 68.647 & 68.620 & 68.593 & 68.567 & 68.540 \\ 68.513 & 68.486 & 68.459 & 68.432 & 68.406 & 68.379 & 68.352 & 68.325 & 68.298 & 68.072\end{array}$

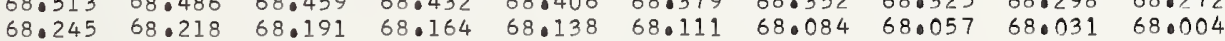

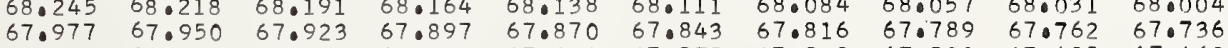

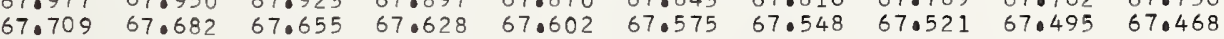

0.276812

1.690494

0.276812

1.690520

1.690547

0.276812

0.276812

0.276812

0.276811

0.276811

1.690601

1.690628

1.690655

1.690681

$\begin{array}{rrrrrrrrrrr}6108.0 & 16367.441 & 67.414 & 67.387 & 67.361 & 67.334 & 67.307 & 67.280 & 67.253 & 67.226 & 67.200 \\ 8.01 & 67.173 & 67.146 & 67.119 & 67.093 & 67.066 & 67.039 & 67.012 & 66.985 & 66.958 & 66.932\end{array}$

$\begin{array}{lllllllllll}8.1 & 67.173 & 67.146 & 67.119 & 67.093 & 67.066 & 67.039 & 67.012 & 66.985 & 66.958 & 66.932 \\ 8.2 & 66.905 & 66.878 & 66.851 & 66.825 & 66.798 & 66.771 & 66.744 & 66.718 & 66.691 & 66.564\end{array}$

$\begin{array}{lllllllllll}8.2 & 66.905 & 66.878 & 66.851 & 66.825 & 66.798 & 66.771 & 66.744 & 66.718 & 66.691 & 66.664 \\ 8.3 & 66.637 & 66.610 & 66.583 & 66.557 & 66.530 & 66.503 & 66.476 & 66.449 & 66.423 & 66.395\end{array}$

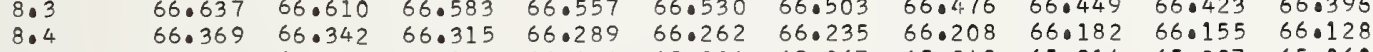

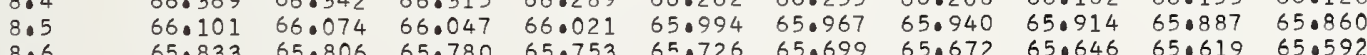

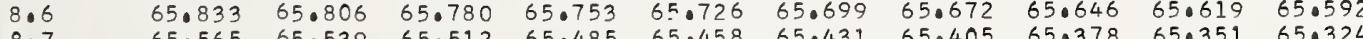

$\begin{array}{llllllllll}65.507 & 65.539 & 65.512 & 65.485 & 65.458 & 65.431 & 65.405 & 65.378 & 65.351 & 65.324\end{array}$

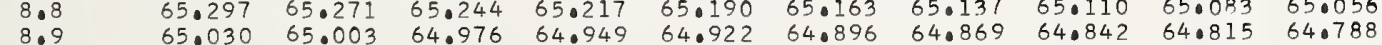

\begin{tabular}{rrrrrrrrrrr}
6109.0 & 16364.762 & 64.735 & 64.708 & 64.681 & 64.654 & 64.628 & 64.601 & 64.574 & 64.547 & 64.521 \\
\hline & 64.494 & 64.467 & 64.040 & 64.414 & 64.387 & 640360 & 64.333 & 64.306 & 64.279 & 64.253
\end{tabular}

$\begin{array}{llllllllllll}9.1 & 64.494 & 64.467 & 64.440 & 64.414 & 64.387 & 64.360 & 64.333 & 64.306 & 64.279 & 64.253\end{array}$

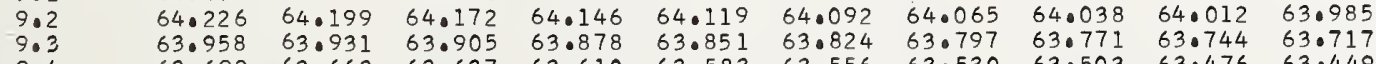

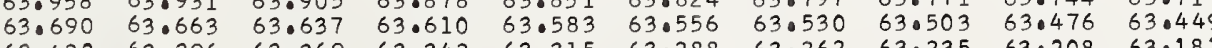
$\begin{array}{llllllllll}63.422 & 63.396 & 63.369 & 63.342 & 63.315 & 63.288 & 63.262 & 63.235 & 63.208 & 63.181 \\ 63.155 & 63.128 & 63.101 & 63.074 & 63.047 & 63.021 & 62.994 & 62.967 & 62.940 & 62.914\end{array}$ $\begin{array}{llllllllll}63.155 & 63.128 & 63.101 & 63.074 & 63.047 & 63.021 & 62.994 & 62.967 & 62.940 & 62.914 \\ 62.887 & 62.860 & 62.833 & 62.806 & 62.780 & 62.753 & 62.726 & 62.699 & 62.672 & 62.646\end{array}$

$\begin{array}{lllllllllll}9.7 & 62.887 & 62.860 & 62.833 & 62.806 & 62.780 & 62.753 & 62.726 & 62.699 & 62.672 & 62.646 \\ 9.8 & 62.619 & 62.592 & 62.565 & 62.538 & 62.512 & 62.485 & 62.458 & 62.431 & 62.405 & 62.378 \\ 9.9 & 62.351 & 62.324 & 62.297 & 62.271 & 62.244 & 62.217 & 62.190 & 62.164 & 62.137 & 62.110\end{array}$

0.27681

0.276811

0.276811

0.276810

0.276810

0.276810

0.276810

0.276810

0.276809

0.276809

0.276809

0.276809

0.27680

0.276809

0.276808

1.690762

1.690815

1.690842

1.690869

1.690896

1.690950

1.690976

1.691030

1.691084

1.691110

1.691164

1.691191

1.691218

1.691245

1.601271

$\begin{array}{lllllllllll} & .001 & .002 & .003 & .004 & .005 & .006 & .007 & .008 & .009 & .010 \\ .027 & .003 & .005 & .008 & .011 & .013 & .016 & .019 & .021 & .024 & .027 \\ 0026 & .003 & .005 & .008 & .010 & .013 & .016 & .018 & .021 & .023 & .026\end{array}$ 


.04

.05

.06

6110.0
0.1
0.0
0.0
0.0
0.0
0.0

0.0
0.1
0.2
0.3
0.4
0.5
0.6
0.7
0.8
0.9

6111.0

$$
\begin{array}{r}
11.0 \\
1.1 \\
1.2 \\
1.3 \\
1.4 \\
1.5 \\
1.6 \\
1.7 \\
1.8 \\
1.9
\end{array}
$$

$$
\begin{array}{r}
12.0 \\
2.1 \\
2.2 \\
2.3 \\
2.4 \\
2.5 \\
2.6 \\
2.7 \\
2.8 \\
2.9
\end{array}
$$$$
6113 .
$$

$$
\begin{array}{r}
6113.0 \\
3.1 \\
3.2 \\
3.3 \\
3.4 \\
3 . \\
3 . \\
3.7 \\
3 . \\
3 .
\end{array}
$$$$
6114
$$

4.

4.3

4.5

4.5
4.6
4.7

4.8
4.9

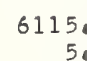

150
5.0
50
50
50
50
50
50
5
50

6116.

6.1
6.2
6.3

6.4

6.5
6.6

6.7
6.8

6117.

$17: 0$
$7: 1$
7.2
7.3

7.3
7.4
7.5

7.5
7.6
7.7

7.7
7.8
7.9

6118.0

18.0
8.1
8.3

8.3
8.4

8.5

8.6
8.7

8.8
8.9

6119.0

9.

9.2
9.3
9.4

9.3
9.4
9.5
9.6

9.5
9.6
9.7

9.7
9.8
9.9
362.083
61.815
61.548
61.280
61.012
60.745
60.477
60.209
59.941
59.674

16359.406

59.138

58.870
58.603

58.335

$58.068 \quad 58.041$

$\begin{array}{ll}57.800 & 57.773 \\ 57.532 & 57.505\end{array}$

$\begin{array}{ll}57.265 & 57.238 \\ 56.997 & 56.970\end{array}$

16356.720 $56.462 \quad 56.703$

$56.194 \quad 56.167$

$55.926 \quad 55.900$

$\begin{array}{ll}55.659 & 55.632 \\ 55.391 & 55.365\end{array}$

$55.124 \quad 55.097$

$54.856 \quad 540.829$

54.58
54.32

16354.05

53.78
53.51

52.98

52.716

52.449

51.914
51.646

16351.37

51.111
50.844

50.577

$50.309 \quad 50.58$

$50.042 \quad 50.01$

$\begin{array}{ll}49.774 & 49.748 \\ 49.507 & 49.48\end{array}$

$\begin{array}{ll}49.240 & 49.48 \\ 48.972 & 48.213\end{array}$

$48.405 \quad 48.678$

$48.170 \quad 48.144$

$47.903 \quad 47.876$

$\begin{array}{lllll}47.636 & 47.6009 & 47.58\end{array}$

$\begin{array}{llll}47.368 & 47.342 & 47.31\end{array}$

$47.101 \quad 47.074$

$46.834 \quad 46.807$

16346.032 45.765

$45.497 \quad 45.471$

$44.963 \quad 44.936$

$44.696 \quad 44.669$

$44.428 \quad 44.401$

$\begin{array}{ll}44.161 & 44.135 \\ 43.0894 & 43.867\end{array}$

43.627

43.867
43.600

46.78

$46.780-46.753$

$46.245 \quad 46.219$

$45.978 \quad 450952$

$45.711 \quad 450684$

$45.444 \quad 45.417$

45.177
44.909 45.150

$44.642 \quad 44.615$

\begin{tabular}{ll}
$44 \cdot 375$ & 44.348 \\
44.108 & 44.081 \\
43.840 & 43.814 \\
\hline
\end{tabular}

6343.360

$\begin{array}{ll}43.360 & 43.333 \\ 43.092 & 43.066\end{array}$

$\begin{array}{llll}43.092 & 43.066 & 43.006 & 43.279\end{array}$

$\begin{array}{llll}43.09 & 43.798 & 42.77 .2 & 42.745\end{array}$

$\begin{array}{llll}42.291 & 42.264 & 42.238 & 42.21\end{array}$

$\begin{array}{llll}42.024 & 41.9997 & 41.970 & 41.94\end{array}$

$41.757 \quad 41.730 \quad 41.703 \quad 41.677$

$\begin{array}{llll}41.222 & 41.196 & 41.169 & 41.142 \\ 40.955 & 40.928 & 40.902 & 40.875\end{array}$

$16340.688 \quad 40.662$

$\begin{array}{lll}40.421 & 40.394 & 40.635\end{array}$

$\begin{array}{llll}39.353 & 39.326 & 39.300 & 39.273\end{array}$

$\begin{array}{llll}38.552 & 38.525 & 38.4498 & 38.477\end{array}$

38.285

$16338.018 \quad 37.991$

$37.991 \quad 37.96$
.018

$\begin{array}{lllll}37.751 & 37.724 & 37.9697 & 37.938\end{array}$

$\begin{array}{llll}37.484 & 37.457 & 37.430 & 37.404\end{array}$

$\begin{array}{llll}36.950 & 36.923 & 36.896 & 36.870\end{array}$

$\begin{array}{llll}36.683 & 36.656 & 36.629 & 36.603\end{array}$

$\begin{array}{llll}36.416 & 36.389 & 36.362 & 36.336 \\ 36.149 & 36.122 & 36.095 & 36.069\end{array}$

$36.149 \quad 36.122 \quad 36.095 \quad 36.069$

$\begin{array}{lll}35.882 & 35.855 & 35.829 \\ 35.615 & 35.588 & 35.562\end{array}$

35.802
53.519
53.251

$46.299 \quad 46.272$

$39.620 \quad 39.593 \quad 39.566 \quad 30.540$

$\begin{array}{llll}39.086 & 39.059 & 39.032 & 39.00\end{array}$ $\begin{array}{lllllll}61.976 & 61.949 & 61.923 & 61.896 & 61.869 & 61.842\end{array}$ $\begin{array}{llllll}61.708 & 61.682 & 61.655 & 61.628 & 61.601 & 61.575 \\ 61.441 & 61.414 & 61.387 & 61.360 & 61.333 & 61.307\end{array}$ $61.173 \quad 61.146 \quad 61.119 \quad 61.092 \quad 61.066 \quad 61.039$

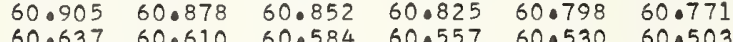
$\begin{array}{lllllll}60.370 & 60.610 & 60.584 & 60.557 & 60.530 & 60.503 \\ 60.316 & 60.289 & 60.262 & 60.236\end{array}$

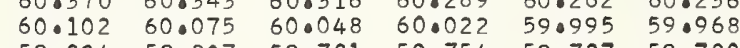
$\begin{array}{llllll}59.834 & 59.807 & 59.781 & 59.754 & 59.727 & 59.700 \\ 59.566 & 59.540 & 59.513 & 59.486 & 59.459 & 59.432\end{array}$

$\begin{array}{llllll}59.299 & 59.272 & 59.245 & 59.219 & 59.192 & 59.165\end{array}$

$\begin{array}{llllll}50.031 & 59.004 & 58.977 & 58.951 & 58.924 & 58.897\end{array}$

$\begin{array}{llllll}58.763 & 58.737 & 58.710 & 58.683 & 58.656 & 58.630\end{array}$

$\begin{array}{llllll}58.496 & 58.469 & 58.442 & 58.415 & 58.389 & 58.36 \\ 58.228 & 58.201 & 58.174 & 58.148 & 58.121 & 58.094\end{array}$

$\begin{array}{lllllll}57.960 & 57.934 & 57.907 & 57.880 & 57.853 & 57.826\end{array}$

$\begin{array}{lllllll}57.693 & 57.666 & 57.639 & 57.612 & 57.586 & 57.559\end{array}$

$\begin{array}{llllll}57.425 & 57.398 & 57.372 & 57.345 & 57.318 & 57.291 \\ 57.157 & 57.131 & 57.104 & 57.077 & 57.050 & 57.024\end{array}$

$\begin{array}{llllll}57.159 & 57.131 & 57.104 & 57.077 & 57.050 & 57.024 \\ 56.890 & 56.863 & 56.836 & 56.810 & 56.783 & 56.756\end{array}$

$\begin{array}{lllllll}56.622 & 56.595 & 56.569 & 56.542 & 56.515 & 56.488\end{array}$

$\begin{array}{llllll}56.355 & 56.328 & 56.301 & 56.274 & 56.247 & 56.221\end{array}$

$\begin{array}{lllllll}55.819 & 55.793 & 55.766 & 55.739 & 55.712 & 55.686\end{array}$

$\begin{array}{lllllll}55.552 & 55.525 & 55.498 & 55.471 & 55.445 & 55.418\end{array}$

$\begin{array}{lllllll}55.017 & 54.990 & 54.963 & 54.936 & 54.910 & 54.883\end{array}$

$\begin{array}{llllll}54.749 & 54.722 & 54.696 & 54.669 & 54.642 & 54.0615\end{array}$

$\begin{array}{llllll}54.482 & 54.455 & 54.428 & 54.6401 & 54.642 & 54.615 \\ 54.214 & 54.187 & 54.161 & 54.134 & 54.3107 & 54.348\end{array}$

$\begin{array}{lllllll}53.947 & 53.920 & 53.893 & 53.866 & 53.840 & 53.813 \\ 53.679 & 53.652 & 53.626 & 53.599 & 53.572 & 53.546\end{array}$

$\begin{array}{llllll}53.411 & 53.385 & 53.358 & 53.331 & 53.305 & 53.278\end{array}$

$\begin{array}{llllll}53.147 & 53.117 & 53.091 & 53.064 & 53.037 & 53.010 \\ 52.850 & 52.823 & 52.796 & 52.770 & 52.0433\end{array}$

$\begin{array}{llllll}52.609 & 52.582 & 52.556 & 52.529 & 52.502 & 52.475\end{array}$

$\begin{array}{llllll}52.342 & 52.315 & 52.288 & 52.261 & 52.235 & 52.208 \\ 52.074 & 52.048 & 52.021 & 51.994 & 51.967 & 51.940\end{array}$

$\begin{array}{lllllll}52.074 & 52.048 & 52.021 & 51.994 & 51.967 & 51.940\end{array}$

$\begin{array}{llllll}51.807 & 51.780 & 51.753 & 51.727 & 51.700 & 51.673 \\ 51.539 & 51.513 & 51.486 & 51.459 & 51.432 & 51.406\end{array}$

$\begin{array}{lllllll}51.272 & 51.245 & 51.219 & 51.192 & 51.165 & 51.138 \\ 51.004 & 50.978 & 500.951 & 50.924 & 50.897 & 50.871\end{array}$

$\begin{array}{llllll}51.004 & 50.978 & 50.951 & 50.924 & 50.897 & 50.871 \\ 50.737 & 50.710 & 50.684 & 50.657 & 50.630 & 50.603\end{array}$

$\begin{array}{llllll}50.470 & 50.443 & 50.416 & 50.0389 & 50.630 & 50.0603 \\ & 50.363 & 50.036\end{array}$

$\begin{array}{lllllll}50.202 & 50.176 & 50.149 & 50.122 & 50.095 & 50.068 \\ 49.935 & 49.908 & 49.881 & 49.855 & 49.828 & 49.801\end{array}$

$\begin{array}{llllll}49.935 & 49.908 & 49.881 & 49.855 & 49.828 & 49.801 \\ 49.667 & 49.641 & 49.614 & 49.587 & 49.560 & 49.534\end{array}$

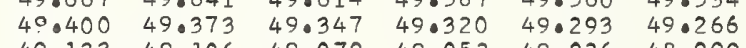

$\begin{array}{llllll}49.133 & 49.106 & 49.079 & 49.052 & 49.026 & 48.999 \\ 48.865 & 48.839 & 48.812 & 48.785 & 48.758 & 48.732\end{array}$

$\begin{array}{lllllll}48.598 & 48.571 & 48.545 & 48.518 & 48.491 & 48.464\end{array}$

$\begin{array}{llllll}48.331 & 48 \cdot 304 & 48.277 & 48 \cdot 250 & 48.224 & 48.197 \\ 48.063 & 48.036 & 48.010 & 47.983 & 47.056 & 470030\end{array}$

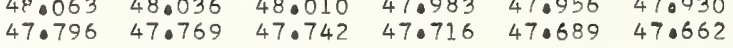

$\begin{array}{llllll}47.529 & 47.502 & 47.475 & 47.448 & 47.422 & 47.395\end{array}$

$\begin{array}{lllllll}47.261 & 47.234 & 47.208 & 47.181 & 47.154 & 47.128\end{array}$

$\begin{array}{llllll}46.727 & 46.967 & 46.941 & 46.914 & 460887 & 46.860 \\ 46.673 & 46.046 & 46.520 & 46.593\end{array}$

$\begin{array}{llllll}46.459 & 46.433 & 46.406 & 46.379 & 46.353 & 46.326 \\ 46.192 & 46.165 & 46.139 & 46.112 & 46.085 & 46.058\end{array}$

$\begin{array}{lllllll}45.925 & 45.898 & 45.872 & 450845 & 45.818 & 45.791\end{array}$

$\begin{array}{lllllll}45.658 & 45.631 & 45.604 & 45.577 & 45.551 & 45.524\end{array}$

$\begin{array}{llllll}45.390 & 45.364 & 45.337 & 45.310 & 45.284 & 45.257\end{array}$

$\begin{array}{lllllll}44.856 & 44.829 & 44.802 & 44.776 & 44.749 & 44.722\end{array}$

$\begin{array}{llllll}44.589 & 44.562 & 44.535 & 44.509 & 44.482 & 44.455\end{array}$

$\begin{array}{llllll}44.3222 & 44.295 & 44.268 & 44.241 & 44.214 & 44.188 \\ 44.054 & 44.028 & 44.001 & 43.974 & 43.047 & 43.921\end{array}$

$\begin{array}{llllll}43.787 & 43.760 & 43.734 & 43.707 & 43.680 & 43.654 \\ 43.520 & 43.493 & 43.467 & 43.440 & 43.413 & 43.385\end{array}$

$\begin{array}{lllllll}43.253 & 43.226 & 43.199 & 43.173 & 43.146 & 43.119\end{array}$ $\begin{array}{llllll}42.986 & 42.959 & 42.932 & 42.905 & 42.879 & 42.852 \\ 42.718 & 42.692 & 42.665 & 42.638 & 42.611 & 42.585\end{array}$ $\begin{array}{lllllll}42.451 & 42.424 & 42.398 & 42.371 & 42.344 & 42.318\end{array}$ $\begin{array}{llllll}42.184 & 42.157 & 42.131 & 42.104 & 42.077 & 42.050 \\ 41.917 & 41.890 & 41.864 & 41.837 & 41.810 & 41.783\end{array}$ $41.650 \quad 41.623 \quad 41.596 \quad 41.570 \quad 41.543 \quad 41.516$ $\begin{array}{llllll}41.383 & 41.356 & 41.329 & 41.303 & 41.276 & 41.249\end{array}$ $\begin{array}{llllll}41.116 & 41.089 & 41.062 & 41.035 & 41.009 & 40.982 \\ 40.849 & 40.822 & 40.795 & 40.768 & 40.742 & 40.715\end{array}$ $\begin{array}{lllllll}40.581 & 40.555 & 40.528 & 40.501 & 40.475 & 40.448\end{array}$ $\begin{array}{llllll}40.314 & 40.288 & 40.261 & 40.234 & 40.207 & 40.181 \\ 40.047 & 40.021 & 39.994 & 39.967 & 39.940 & 39.914\end{array}$ $\begin{array}{llllll}39.780 & 39.753 & 39.727 & 39.700 & 39.673 & 39.647\end{array}$ $\begin{array}{llllll}39.513 & 39.486 & 39.460 & 39.433 & 39.406 & 39.380\end{array}$ $\begin{array}{llllll}39.246 & 39.219 & 39.193 & 39.166 & 39.139 & 39.112\end{array}$ $38.712 \quad 38.952 \quad 38.926 \quad 38.899 \quad 38.872 \quad 38.846$ $\begin{array}{llllll}38.445 & 38.418 & 38.391 & 38.365 & 38.338 & 38.312\end{array}$

$\begin{array}{llllll}37.884 & 37.858 & 37.831 & 37.804 & 37.777\end{array}$ $\begin{array}{llllll}37.377 & 37.350 & 37.324 & 37.564 & 37.537 & 37.511 \\ 37.297 & 37.270 & 37.243\end{array}$ $\begin{array}{lllllll}37.110 & 37.083 & 37.057 & 37.030 & 37.0003 & 36.977\end{array}$ $\begin{array}{llllll} & 36.790 & 36.763 & 36.736 & 36.709\end{array}$ $\begin{array}{llllll}36.5760 & 36.549 & 36.523 & 36.496 & 36.469 & 36.443 \\ 36.309 & 36.282 & 36.256 & 36.229 & 36.202 & 36.176\end{array}$ $36.042 \quad 36.016 \quad 35.989 \quad 35.962 \quad 35.935 \quad 35.909$ $\begin{array}{llllll}35.775 & 35.749 & 35.722 & 35.655 & 35.668 & 35.0442 \\ 35.508 & 35.482 & 35.455 & 35.428 & 35.401 & 35.0375\end{array}$ $(n-1) \times 1000 \quad \lambda(n-1)$

$\begin{array}{ll}0.276808 & 1.691298 \\ 0.275808 & 1.691325 \\ 0.276808 & 1.691352 \\ 0.276808 & 1.691379 \\ 0.276808 & 1.691405 \\ 0.276808 & 1.691432 \\ 0.276807 & 1.691459 \\ 0.276807 & 1.691488 \\ 0.276807 & 1.691513 \\ 0.276807 & 1.691540\end{array}$

0.276807

0.276807

0.276807

0.276806

0.276806

0.276806

0.276806

0.276806

0.276805

0.276805

0.276805

0.276805

0.276805

0.276805

0.276804

0.276804

0.276804

0.276804

0.276804
0.276803

0.276803

0.276803
0.276803

0.276803

0.276803

0.276802

0.276802

0.276802
0.276802

0.276802

0.276802

0.276802

0.276801

0.276801

0.276801

0.276801

0.276801

0.276800

0.276800

0.276800
0.276800
0.276800

0.276800

0.276800

0.276800

0.276799
0.276799
0.276790

0.276799
0.276799
0.076799

0.276799

0.276799

0.276799
0.276790

0.276799

0.276798

0.276798
0.276798

0.276798

0.276798
0.276798

0.276798

0.276797

0.276797
0.276797

0.276797

0.276797

0.276797

0.276796

0.276796

0.276796
0.276796

0.276796
0.276796

0.276796

0.276795

0.276795

0.276795

0.276795

0.276795

0.276795

0.276794

.010

1.691566

1.691620

.0691647

1.691700

1.691727

1.691781

1.691808

1.691835 
$\begin{array}{rrrrrrrrrrr}6120.0 & 16335.348 & 35.322 & 35.295 & 35.268 & 35.241 & 35.215 & 35.188 & 35.161 & 35 \cdot 135 & 35.108 \\ 0 & 35.081 & 35.054 & 35.028 & 35.001 & 34.974 & 34.948 & 34.921 & 34.894 & 34.858 & 34.841\end{array}$ $\begin{array}{llllllllllll}0.2 & 34.814 & 34.788 & 34.761 & 34.734 & 34.708 & 34.681 & 34.654 & 34.628 & 34.601 & 34.574\end{array}$ 0.276794

0.276794 1.693980

121.0
1.1
1.2
1.3
1.4
1.5
1.6
1.7
1.8
1.9 $\begin{array}{lllllllllll}34.547 & 34.521 & 34.494 & 34.467 & 34.441 & 34.414 & 34.387 & 34.360 & 34.334 & 34.307\end{array}$

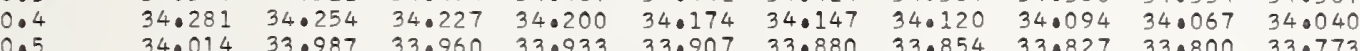
$\begin{array}{llllllllllll}0.5 & 34.014 & 33.987 & 33.960 & 33.933 & 33.907 & 33.880 & 33.854 & 33.827 & 33.800 & 33.773 \\ 0.6 & 33.747 & 33.720 & 33.693 & 33.667 & 33.640 & 33.613 & 33.587 & 33.560 & 33.533 & 33.507\end{array}$ $\begin{array}{lllllllllll}0.7 & 33.480 & 33.453 & 33.427 & 33.400 & 33.373 & 33.346 & 33.320 & 33.293 & 33.266 & 33.240\end{array}$ $\begin{array}{lllllllllll}0.8 & 33.213 & 33.186 & 33.160 & 33.133 & 33.106 & 33.080 & 33.053 & 33.026 & 33.000 & 32.973 \\ 0.9 & 32.946 & 32.920 & 32.893 & 32.866 & 32.840 & 32.813 & 32.786 & 32.759 & 32.733 & 32.706\end{array}$

\section{$\begin{array}{llllll}32.840 & 32.813 & 32.786 & 32.759 & 32.733 & 32.706\end{array}$} $\begin{array}{rllll}16332.679 & 32.653 & 32.626 & 32.599 & 32 . \\ 32.413 & 32.386 & 32.359 & 32.333 & 32\end{array}$

$32.146 \quad 32.119 \quad 32.092 \quad 32.066$

$31.879 \quad 31.852 \quad 31.826 \quad 31.799$

$\begin{array}{llllll}1.4 & 31.612 & 31.585 & 31.559 & 31.532 \\ 1.5 & 31.345 & 31.319 & 31.292 & 31.265\end{array}$

$\begin{array}{llll}31.079 & 31.052 & 31.025 & 30.999 \\ 30.812 & 30.785 & 30.758 & 30.732\end{array}$

$\begin{array}{llll}30.545 & 30.518 & 30.492 & 30.465\end{array}$

32.039632 .012

$\begin{array}{llllll}31.772 & 31.745 & 31.719 & 31.952 & 31.932 & 31.906\end{array}$

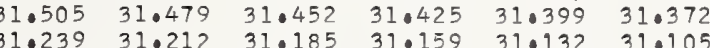

$\begin{array}{llllll}30.972 & 30.945 & 30.918 & 30.892 & 30.865 & 30.839\end{array}$

$\begin{array}{llllll}30.705 & 30.678 & 30.652 & 30.625 & 30.598 & 30.572\end{array}$
30.278

6122
2
20
20
204
205
206
207
208

2.
2.
2.
2.
2.0
2.
2.

6123.0

3.1
3.
3.
3.4
3.5
3.6
3.7
3.

6124.

$\begin{array}{rl}612 & 4 \cdot 0 \\ 4 & \cdot 1 \\ 4 & \cdot 2 \\ 4 \cdot 0 & \end{array}$

4.4

4.5
4.6

4.7
4.8

4.9

6125

5.1
5.2
5.3
5.4
5.5
5.5
5.7
5.8
5.9

$6 ! 26.0$

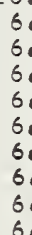

6127.

127.0
7.1
7.2
7.3
7.4
7.5
7.6
7.7
7.8
7.9

$\begin{array}{rlll}330.012 & 29.985 & 29.958 & 29.932 \\ 29.745 & 29.718 & 29.691 & 29.655\end{array}$

$29.211 \quad 29.185 \quad 29.158 \quad 29.13$

28.678 28.65 28.89128 .865

$28.385028 .358 \quad 28.531$

27.878

16327.344

27.078

$26.278-26.251$

26.01125 .98

$25.749 \quad 25.45$

25.212

16324.679

$24.412 \quad 24.652$

$24.146 \quad 24.11$

$23.879 \quad 23.85$

23.012

$\begin{array}{ll}22.546 & 22.520 \\ 22.280 & 22.253\end{array}$

16322.01

21.747

21.48721 .720

$21.214 \quad 21.187$

$20.948 \quad 20.92$

20.1150 .20 .38

$\begin{array}{ll}19.882 & 19.85 \\ 19.615 & 19.58\end{array}$

20.335

$30.172 \quad 30.41$

$30 \cdot 385$

$29.905 \quad 29.87$

$\begin{array}{ll}29.638 & 29.61 \\ 29.371 & 29.34\end{array}$

$28.838 \quad 28.81$

$\begin{array}{ll}28.571 & 28.54 \\ 28.305 & 28.27\end{array}$

$28.038 \quad 28.01$

$\begin{array}{ll}28.038 & 28.01 \\ 27.771 & 27.74 \\ 27.505 & 27.478\end{array}$

$\begin{array}{llll}29.851 & 29.825 & 29.798 & 29.771 \\ 29.585 & 29.558 & 29.531 & 29.505\end{array}$

$\begin{array}{llll}29.318 & 29.291 & 29.265 & 29.238\end{array}$

$\begin{array}{llll}28.785 & 28.758 & 28.731 & 28.705\end{array}$

$\begin{array}{llll}28.518 & 28.491 & 28.465 & 28.438\end{array}$

$\begin{array}{llll}28.251 & 28.224 & 28.198 & 28.171\end{array}$

$\begin{array}{llll}27.718 & 27.691 & 27.655 & 27.638\end{array}$

$27.238 \quad 27.211$

$\begin{array}{llll}27.185 & 27.158 & 27.131 & 27.104\end{array}$

$27.291 \quad 27 \cdot 26$

$\begin{array}{ll}26.758 & 26.731 \\ 26.491 & 26.465\end{array}$

26.22426 .198

$26.704 \quad 26.678$

26.438

26.171
25.905

26.411

26.985

25.638

25.61

26.385

$\begin{array}{lll}26.625 & 26.598 & 26.571 \\ 26.358 & 26.331 & 26.305\end{array}$

$25.159 \quad 25.132$

25.10
24.83

25.34
25.07

24.625

24.599

24.57

24.545

25.58

$\begin{array}{lll}26.091 & 26.065 & 26.038 \\ 25.825 & 25.798 & 25.771\end{array}$

$\begin{array}{lll}25 \cdot 825 & 25 \cdot 798 & 25.771\end{array}$

$\begin{array}{lll}25.292 & 25.265 & 25.238\end{array}$

24.519

24.498

24.46

24.705

24.092

23.55
23.29

24.065
23.799

24.039

(1)

22.239

24.01
23.74

23.746
23.479

23.98
23.71

23.71
23.45

$23 \cdot 45$
$23 \cdot 18$

22

$22.760 \quad 22.733$

$22.706 \quad 22.580$

$22 \cdot 173$

$22 \cdot 14$

$\begin{array}{llll}22.386 & 22.360 & 22.333 & 22.307 \\ 22.120 & 22.093 & 22.067 & 22.040\end{array}$

$21.960 \quad 21.93$

$21.907 \quad 21.880$

$\begin{array}{llll}21.854 & 21.827 & 21.800 & 21.774 \\ 21.587 & 21.560 & 21.534 & 21.507\end{array}$

$\begin{array}{llllll}21.640 & 21.614 & 21.587 & 21.560 & 21.534 & 21.507 \\ 21.374 & 21.347 & 21.321 & 21.294 & 21.267 & 21.240\end{array}$

$\begin{array}{llll}1.161 & 21.134 & 21.107 & 21.08\end{array}$

$\begin{array}{llll}21.054 & 21.027 & 21.001 & 20.974\end{array}$

$\begin{array}{llllll}20.841 & 20.814 & 20.788 & 20.761 & 20.734 & 20.708 \\ 20.574 & 20.548 & 20.521 & 20.495 & 20.468 & 20.441\end{array}$

$\begin{array}{llllll}20.308 & 20.281 & 20.255 & 20.228 & 20.202 & 20.175\end{array}$

$\begin{array}{llllll}20.042 & 20.015 & 19.988 & 19.962 & 19.935 & 19.90\end{array}$

$19.509 \quad 19.48$

$\begin{array}{llll}19.722 & 19.695 & 19.669 & 19.642 \\ 19.456 & 19.429 & 19.402 & 19.375\end{array}$

$\begin{array}{rrr}16319.349 & 19.322 & 19.296 \\ 19.083 & 19.056 & 19.029\end{array}$

$\begin{array}{lll}18.816 & 18.790 & 18.76 \\ 18.550 & 18.523 & 18.497\end{array}$

$\begin{array}{llll}18.283 & 18.257 & 18.230 & 18.20 \\ 18.017 & 17.991 & 17.964 & 17.937\end{array}$

$\begin{array}{llll}17.751 & 17.724 & 17.697 & 17.67\end{array}$

$\begin{array}{llll}17.218 & 17.192 & 17.165 & 17.138 \\ 16.952 & 16.925 & 16.898 & 16.872\end{array}$

$15.620 \quad 15.594 \quad 15.8367$

$15.354 \quad 15.327 \quad 15.301$

$15.088 \quad 15.061$

$\begin{array}{llll}14.555 & 14.529 & 14.502 & 14.475\end{array}$

$19.242 \quad 19.216$

$19.163 \quad 19.136 \quad 19.109$

$\begin{array}{llllll}18.976 & 18.949 & 18.923 & 18.896 & 18.869 & 18.843\end{array}$

$\begin{array}{llllll}18.443 & 18.417 & 18.390 & 18.363 & 18.337 & 18.310\end{array}$

$\begin{array}{llllll}18 \cdot 177 & 18 \cdot 150 & 18 \cdot 124 & 18 \cdot 097 & 18 \cdot 070 & 18 \cdot 044\end{array}$

$\begin{array}{llllll}17.644 & 17.618 & 17.591 & 17.564 & 17.538 & 17.511\end{array}$

$\begin{array}{llllll}17.378 & 17.351 & 17.325 & 17.298 & 17.271 & 17.245\end{array}$

$\begin{array}{llllll}17.112 & 17.085 & 17.058 & 17.032 & 17.005 & 16.978 \\ 16.845 & 16.819 & 16.792 & 16.765 & 16.739 & 16.712\end{array}$

6128.0

28
8
8
8
8
8
8
8
8
8129
9
9
9
9
9
9
9
9
9
9.6

$\begin{array}{rrrrrrrrrrr}8.1 & 13.023 & 13.996 & 13.970 & 13.943 & 12.916 & 13.890 & 13.863 & 13.837 & 13.810 & 13.783 \\ & 13.757 & 13.730 & 13.703 & 13.677 & 13.650 & 13.623 & 13.597 & 13.570 & 13.544 & 13.517\end{array}$

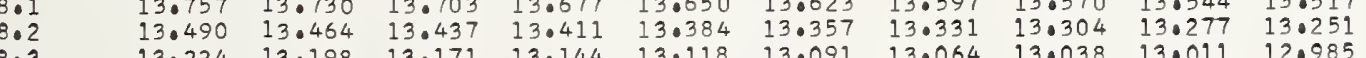

$\begin{array}{lllllllllll}83 & 13.224 & 13.198 & 13.171 & 13.144 & 13.118 & 13.091 & 13.064 & 13.038 & 13.011 & 12.985 \\ 8.4 & 12.958 & 12.931 & 12.905 & 12.878 & 12.852 & 12.825 & 12.798 & 12.772 & 12.745 & 12.718\end{array}$

$\begin{array}{lllllllllll}8.4 & 12.958 & 12.931 & 12.905 & 12.878 & 12.852 & 12.825 & 12.798 & 12.772 & 12.745 & 12.718 \\ 8.5 & 12.692 & 12.665 & 12.639 & 12.612 & 12.585 & 12.559 & 12.532 & 12.505 & 12.479 & 12.452\end{array}$

$\begin{array}{lllllllllll}8.6 & 12.426 & 12.399 & 12.372 & 12.346 & 12.319 & 12.293 & 12.266 & 12.239 & 12.213 & 12.186\end{array}$

$\begin{array}{llllllllll}12.160 & 12.133 & 12.106 & 12.080 & 12.053 & 12.026 & 12.000 & 11.973 & 11.947 & 11.920\end{array}$

$\begin{array}{lllllllllll}8.8 & 11.893 & 11.867 & 11.840 & 11.813 & 11.787 & 11.760 & 11.734 & 11.707 & 11.680 & 11.654 \\ 8.9 & 11.627 & 11.601 & 11.574 & 11.547 & 11.521 & 11.494 & 11.468 & 11.441 & 11.414 & 11.388\end{array}$

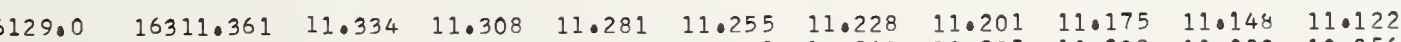

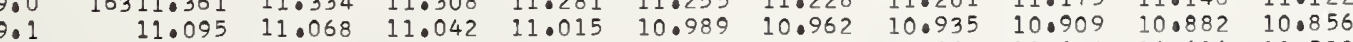

$\begin{array}{lllllllllll}9.2 & 10.829 & 10.802 & 10.776 & 10.749 & 10.722 & 10.696 & 10.669 & 10.642 & 10.616 & 10.589\end{array}$

$\begin{array}{llllllllllll}0.3 & 10.563 & 10.536 & 10.510 & 10.483 & 10.456 & 10.430 & 10.403 & 10.376 & 10.350 & 10.323\end{array}$

$\begin{array}{llllllllllll}9.4 & 10.297 & 10.270 & 10.243 & 10.217 & 10.190 & 10.163 & 10.137 & 10.110 & 10.084 & 10.057 \\ 9.5 & 10.031 & 10.004 & 09.977 & 09.951 & 09.924 & 09.897 & 09.871 & 09.844 & 09.818 & 09.791\end{array}$ $\begin{array}{llllllllll}09.764 & 09.738 & 09.711 & 09.685 & 09.658 & 09.631 & 09.605 & 09.578 & 09.551 & 09.525\end{array}$

$09.232 \quad 09.206 \quad 09.179 \quad 09.152$

$08.966 \quad 08.939 \quad 08.913 \quad 08.886$

08.860
$29.478-29.451 \quad 29.425 \quad 29.665$

2.81322 .786

20.681520 .654

$25.691 \quad 25.066$
25.425
25.309

27.158 16.41916 .392

$16.153 \quad 16.12616 .10$

$14.822 \quad 14.795 \quad 15.76$

0.276794

0.276794

0.276793

0.27679

0.276793
0.276793

0.276793

0.276792

0.276792

7679

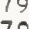

276792

0.27679

0.27679

0.27679

0.27679

0.276791

.276790

0.276790
0.276790

0.276790

0.276790
0.276790
0.276790

0.276700

0.276789

0.276789

0.276789

0.276789

0.276789

0.276789

0.276788
0.276788

0.276788

0.276788

0.276788

0.276788

0.276787

0.276787

0.276787

0.276787
0.276787
0.2767

0.276787

0.27678

0.276786

0.276786

0.276786

0.276786

0.276786

0.276785
0.276785

0.276785

0.276785

0.276785

0.276785
0.276785

0.276784

0.276784

0.276784

0.276784

0.276784
0.276784

0.776784

0.276783

0.276783

.276783

0.276783

0.276783

0.276783

0.276782

0.276782

0.276782

0.276782

0.276782

0.276781

0.276781
0.276781

0.276781

0.276781
0.276781

0.276781
0.276781

0.276780

.010

$\begin{array}{lllllllll}.001 & .002 & .003 & .004 & .005 & .006 & .007 & .008 & .009\end{array}$

.027

1.694034

1.694061
1.694087 
$\begin{array}{llllllllll}08.434 & 08.674 & 08.647 & 08.620 & 08.594 & 08.567 & 08.541 & 08.514 & 08.487 & 08.461 \\ 08.381 & 08.354 & 08.328 & 08.301 & 08.274 & 08.248 & 08.221 & 08.195\end{array}$

$\begin{array}{lllllllllll}08.168 & 08.141 & 08.115 & 08.088 & 08.062 & 08.035 & 08.009 & 07.982 & 07.955 & 07.929\end{array}$ $\begin{array}{lllllllllll}07.902 & 07.876 & 07.849 & 07.822 & 07.796 & 07.769 & 07.742 & 07.716 & 07.689 & 07.663 \\ 07.636 & 07.609 & 07.583 & 07.556 & 07.530 & 07.503 & 07.476 & 07.450 & 07.423 & 07.397\end{array}$ $\begin{array}{llllllllll}07.636 & 07.609 & 07.583 & 07.556 & 07.530 & 07.503 & 07.476 & 07.450 & 07.423 & 07.397 \\ 07.370 & 07.344 & 07.317 & 07.290 & 07.264 & 07.237 & 07.210 & 07.184 & 07.157 & 07.131\end{array}$ $\begin{array}{llllllllll}07.104 & 07.077 & 07.051 & 07.024 & 06.998 & 06.971 & 06.944 & 06.918 & 06.891 & 06.865\end{array}$ $\begin{array}{llllllllll}06.838 & 06.812 & 06.785 & 06.758 & 06.732 & 06.705 & 06.679 & 06.652 & 06.625 & 06.599 \\ 06.572 & 06.546 & 06.519 & 06.492 & 06.466 & 06.439 & 06.412 & 06.386 & 06.359 & 06.333\end{array}$ $\begin{array}{llllllllll}06.572 & 06.546 & 06.519 & 06.492 & 06.466 & 06.439 & 06.412 & 06.386 & 06.359 & 06.333 \\ 06.306 & 06.280 & 06.253 & 06.226 & 06.200 & 06.173 & 06.147 & 06.120 & 06.093 & 06.067\end{array}$

0.276780

1.696662 0.276780 0.276780

0.276780
0.276779

0.276779

0.276779
0.276799

0.276779
0.276779

1.696689

1.696743

1.696770
1.696796

1.696823

1.696850
1.696877

$\begin{array}{llllllllll}16306.040 & 06.014 & 05.987 & 05.960 & 05.934 & 05.907 & 05.881 & 05.854 & 05.827 & 05.801\end{array}$

0.276779

0.276778

0.276778

0.276778

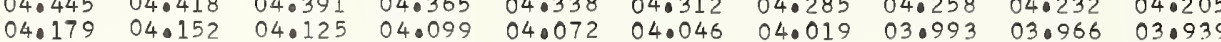

$\begin{array}{llllllllll}03.913 & 03.886 & 03.860 & 03.833 & 03.806 & 03.780 & 03.753 & 03.727 & 03.700 & 03.673 \\ 03.647 & 03.620 & 03.594 & 03.567 & 03.541 & 03.514 & 03.487 & 03.461 & 03.434 & 03.407\end{array}$

0.276778

0.276778

1.6996930

$\begin{array}{lllllllllll}16303.381 & 03.354 & 03.328 & 03.301 & 03.275 & 03.248 & 03.222 & 03.195 & 03.168 & 03.142\end{array}$

$\begin{array}{lllllllllll}02.849 & 02.823 & 02.796 & 02.769 & 02.743 & 02.716 & 02.690 & 02.653 & 02.637 & 02.610\end{array}$

$2 \cdot 2$

1.78601 .750

$\begin{array}{lll}01.999 & 01.972 & 01 \\ 01.733 & 01.706 & 01\end{array}$

02.21102 .185

$02.424 \quad 02.397 \quad 02.371 \quad 02.344$

$\begin{array}{lll}01.520 & 01.494 & 01.467 \\ 01.254 & 01.228 & 01.201\end{array}$

00.988

6133.0 00.696

$\begin{array}{llll}00.457 & 00.430 & 00.669\end{array}$

$3 \cdot 3$

$00.191 \quad 00.164$

3.4
3.5

3.6

3.7
3.8

$\begin{array}{lllll}99.660 & 99.633 & 99.606 & 99.846\end{array}$

$99.128 \quad 99.102 \quad 99.341$

$98.852 \quad 98.036$

$98.597 \quad 98.570$

99.075
98.809

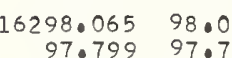

6134.0

4.1
4.2
4.3
4.4

4.4
4.5

4.6
4.07

4.8
4.9

6135.0

5.1
5.2
5.3

5.3
5.4
5.5

5.6

$5 \cdot 7$
5.8

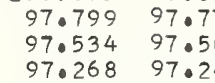

$97.268 \quad 97.242$

$96.737 \quad 96.711$

$\begin{array}{ll}96.471 & 96.445 \\ 96.206 & 96.179\end{array}$

98.544
98.278

99.314

99.048

$\begin{array}{lll}01.680 & 01.653 \\ 01.414 & 01.387\end{array}$

02.158

$02.131 \quad 02.105 \quad 02.078$

$950940 \quad 95.914$

$98.012 \quad 97.985$

$\begin{array}{ll}97.746 & 97.720 \\ 97.481 & 97.454\end{array}$

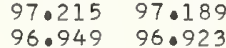

$\begin{array}{ll}96.949 & 96.923 \\ 96.684 & 96.657\end{array}$

$96.418 \quad 96.392$

$95.674 \quad 95.648$

$96.153 \quad 96.12$

16295.409

$95.143 \quad 95.117$

95.62

$94.612 \quad 94.586$

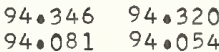

$93.815 \quad 93.78$

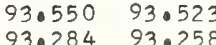

$95.356 \quad 95.329$

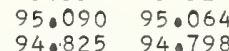

94.55994 .532

$\begin{array}{ll}94.293 & 94.267 \\ 94.028 & 94.001\end{array}$

$93.497 \quad 93.470$
93.07

$\begin{array}{llll}93.284 & 93.258 & 93.231 & 93.205 \\ 93.019 & 92.992 & 92.966 & 92.939\end{array}$

6136.

6.1

$92.753 \quad 92.727$

$92.700 \quad 92.673$

$\begin{array}{llll}92.488 & 92.461 & 92.434 & 92.408\end{array}$

$\begin{array}{llll}91.222 & 92.196 & 92.169 & 92.142 \\ 91.691 & 91.930 & 91.904 & 91.877\end{array}$

$\begin{array}{llll}91.691 & 91.664 & 91.638 & 91.61 \\ 91.426 & 91.399 & 91.373 & 91.34\end{array}$

$91.160 \quad 91.134 \quad 91.107 \quad 91.080$

$\begin{array}{llll}90.895 & 90.868 & 90.842 & 90.815\end{array}$

$90.364 \quad 90.337$

90.31190 .284

6.9

$\begin{array}{rrrr}16290.098 & 90.072 & 90.045 & 90.019 \\ 89.833 & 89.806 & 89.780 & 89.753\end{array}$

$7: 1$

$89.568 \quad 89.541 \quad 89.514 \quad 89.488$

$89.302 \quad 89.276 \quad 89.249 \quad 89.222$

$88.771 \quad 88.745$

88.98
88.71

$88.506 \quad 88.479 \quad 88.453$

$\begin{array}{llll}87.975 & 87.949 & 87.922 & 87.896 \\ 87.710 & 87.683 & 87.557 & 87.630\end{array}$

$00.882 \quad 00.856$

01.626

$\begin{array}{lll}01.866 & 01.839 & 01.812 \\ 01.600 & 01.573 & 01.547\end{array}$

$01.334 \quad 01.307 \quad 01.281$

$01.095 \quad 01.068 \quad 01.042 \quad 01.015$

0.276777

0.276777
0.276777

0.276777
0.276777

0.276777

0.276776

0.276776

0.276776

0.276776

0.276776

0.276775

0.276775

0.276775
0.276775

0.276775

0.276774

0.276774

0.276774

0.276774

$\begin{array}{lllllll}96.83 & 96.870 & 96.843 & 96.817 & 96.790 & 96.764\end{array}$

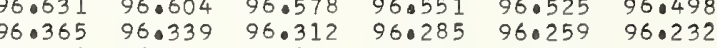

0.276774

0.276774

0.276773

0.276773

$\begin{array}{llllll}95.303 & 95.276 & 95.250 & 95.223 & 95.196 & 95.170 \\ 95.037 & 95.010 & 94.984 & 94.957 & 94.931 & 94.904\end{array}$

$\begin{array}{llllll}95.037 & 95.010 & 94.984 & 94.957 & 94.931 & 94.904 \\ 94.771 & 94.745 & 940718 & 94.692 & 94.665 & 94.639\end{array}$

$\begin{array}{llllll}94.506 & 94.745 & 94.718 & 94.692 & 94.665 & 94.6039 \\ 94.479 & 94.453 & 94.426 & 94.400 & 94.373\end{array}$

$\begin{array}{llllll}94.240 & 94 \cdot 214 & 94 \cdot 187 & 94 \cdot 161 & 94 \cdot 134 & 94 \cdot 107 \\ 92.975 & 93.948 & 93.922 & 93.895 & 93.868 & 93.842\end{array}$

$\begin{array}{llllll}93.709 & 93.683 & 93.656 & 93.629 & 93.503 & 93.576\end{array}$

$\begin{array}{lllllll}93.443 & 93.417 & 93.390 & 93.364 & 93.337 & 93.311\end{array}$

0.276793

0.276773

0.276773

0.276772

0.276772

0.276772
0.276772

$\begin{array}{llllll}92.647 & 92.620 & 92.594 \quad 92.567 & 92.541 & 92.514\end{array}$

0.276772

$\begin{array}{llllll}92.381 & 92.355 & 92.328 & 92.302 & 92.275 & 92.249\end{array}$

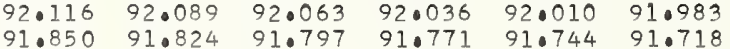

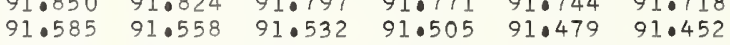

$\begin{array}{llllll}91.319 & 91.293 & 91.266 & 91.240 & 91.213 & 91.187\end{array}$

$\begin{array}{llllll}91.054 & 91.027 & 91.001 & 90.974 & 90.948 & 90.921 \\ 90.788 & 90.762 & 90.735 & 90.709 & 90.682 & 90.656\end{array}$

$\begin{array}{llllll}90.523 & 90.496 & 90.40 .470 & 90.4443 & 90.417 & 90.390 \\ 90.258 & 90.231 & 00.204 & 90.178 & 90.151 & 90.125\end{array}$

0.276772

0.276771

0.27677

0.276771

0.276771
0.276771

.696984

1.697011

1.697065

1.697091

1.697118

1.697172

1.697199

1.697226

1.697279

1.697306

1.6697333
1.697360

1.697386

1.697413

1.697467

1.697494

1.697521

1.697574

1.697601

1.697628
1.697655

1.697682

1.697735

1.697762

1.697789
1.697816

1.697842

1.697869

1.697896

1.697923

1.697977

1.698003

1.698030

1.698057

1.698084
1.698111

1.698137

1.698164

1.698191

1.698218
1.698245

1.6988272

1.698298

1.698352

1.698379

1.698406

1.698459

1.698486

0.276770

0.276770
0.276770

1.698540

0.276770

0.276770

0.276770

0.276769

0.276769

1.698593

1.698620

1.698647

1.698674

1.698701

1.698754

0.276769

0.276769

1.698808

$\begin{array}{lllllllllll}6138.0 & 16287.444 & 87.418 & 87.391 & 87.365 & 87.338 & 87.312 & 87.285 & 87.259 & 87.232 & 87 \cdot 206\end{array}$

$\begin{array}{lllllllllll}8.1 & 87.179 & 87.152 & 87.126 & 87.099 & 87.073 & 87.046 & 87.020 & 86.993 & 86.967 & 86.940 \\ 8.2 & 86.914 & 86.887 & 86.861 & 86.834 & 86.807 & 86.781 & 86.755 & 86.728 & 86.701 & 86.675\end{array}$

$\begin{array}{lllllllllll}8.2 & 86.914 & 86.887 & 86.861 & 86.834 & 86.807 & 86.781 & 86.755 & 86.728 & 86.701 & 86.675 \\ 8.3 & 86.648 & 86.622 & 86.595 & 86.569 & 86.542 & 86.516 & 86.489 & 86.463 & 86.436 & 86.410\end{array}$

$\begin{array}{llllllllllll}8.4 & 86.383 & 86.356 & 86.330 & 86.303 & 86.277 & 86.250 & 86.224 & 86.197 & 86.171 & 86.144\end{array}$

$\begin{array}{lllllllllll}8.5 & 86.118 & 86.091 & 86.065 & 86.038 & 86.012 & 85.985 & 85.959 & 85.932 & 85.906 & 85.879 \\ 8.6 & 85.852 & 85.826 & 85.799 & 85.773 & 85.746 & 85.720 & 85.693 & 85.657 & 85.640 & 85.614\end{array}$

$\begin{array}{lllllllllll}8.6 & 85.852 & 85.826 & 85.799 & 85.773 & 85.746 & 85.720 & 85.693 & 85.667 & 85.640 & 85.614 \\ 8.7 & 85.587 & 85.561 & 85.534 & 85.507 & 85.481 & 85.455 & 85.428 & 85.401 & 85.375 & 85.348\end{array}$

$\begin{array}{lllllllllll}8.8 & 85.322 & 85.295 & 85.269 & 85.242 & 85.216 & 85.189 & 85.162 & 85.136 & 85.110 & 85.083\end{array}$

0.276768

776768

0.276768

0.276768
0.276768

$\begin{array}{llllllllll}85.057 & 85.030 & 85.003 & 84.977 & 84.950 & 84.924 & 84.897 & 84.871 & 84.844 & 840818\end{array}$

0.276768

1.698835

1.698889

1.698915

1.698942

1.698969

1.698996

0.276768

1.699040

$\begin{array}{lllllllllll}6139.0 & 16284.791 & 84.765 & 84.738 & 84.712 & 84.685 & 84.658 & 84.632 & 84.606 & 84.579 & 84.552\end{array}$

$\begin{array}{llllllllllll}9.1 & 84.526 & 84.499 & 84.473 & 84.446 & 84.420 & 84.393 & 84.367 & 84.340 & 84.314 & 84.287 \\ 9.2 & 84.261 & 84.234 & 84.208 & 84.181 & 84.155 & 84.128 & 84.102 & 84.075 & 84.048 & 84.022\end{array}$

$\begin{array}{llllllllllll}9.3 & 83.995 & 83.969 & 83.942 & 83.916 & 83.889 & 83.863 & 83.836 & 83.810 & 83.783 & 83.757\end{array}$

$\begin{array}{llllllllllll}9.4 & 83.730 & 83.704 & 83.677 & 83.651 & 83.624 & 83.598 & 83.571 & 83.545 & 83.518 & 83.491 \\ 9.5 & 83.455 & 83.438 & 83.412 & 83.385 & 83.359 & 83.332 & 83.306 & 83.279 & 83.253 & 83.226\end{array}$

9.6

$\begin{array}{lllllllllll}83.465 & 83.438 & 83.412 & 83.385 & 83.359 & 83.332 & 83.306 & 83.279 & 83.253 & 83.226\end{array}$

$\begin{array}{lllllllllll}9.7 & 82.935 & 82.908 & 82.881 & 82.855 & 82.828 & 82.802 & 82.776 & 82.749 & 82.722 & 82.961 \\ 9 & 82.659 & 82.643 & 82.616 & 82.590 & 82.563 & 82.0537 & 82.510 & 82.484 & 82.457 & 82.431\end{array}$

9.8 
0.276766

0.276766
0.276766
0.276766

0.276766

0.276765

0.276765

0.276765

0.276765

0.276765

0.276764

0.276764

0.276764

0.276764

0.27676

0.276763

0.276763

0.276763

0.276762

0.276762

0.276762

0.276762

0.276762

0.27676

0.276761
0.276761

0.276761

0.276761
0.276761

0.276761

0.27676
0.276760

0.276760

0.276760
0.276760

0.276760

0.276760
0.276760
0.276750

0.276759

276759

0.276759
0.276759

0.276759
0.276759
0.276759

0.276758
0.276758

0.276758
0.276758

0.276758

0.276758

0.276758
0.276757
0.276757

0.276757

0.276757

0.276757

0.276757

0.276757

0.276757
0.276756

0.276756

0.276756
0.276756

0.276756

0.276758

0.276755

0.276755

0.276755

0.276755
0.276755
0.276754

0.276754

0.276754

0.276754
0.276754

0.276754

0.276754

0.276753

0.276753

0.27675

0.276753

0.276753
0.276752
1.699345 1.699371
1.699398
1.69945 1.699425 1.699452

1.699505

1.699532

1.699613

1.699640

1.699693

1.699720

1.699774

1.699801

1.699854

1.69988

1.699935

1069996

1.700015

1.700069

1.700122

$1: 700149$

1.700203

1.700230

1.700283

1.700310

1.700364

1.700417

1.700444

1.700498

1.700525

1.700578

1.700632

1.700632
1.700659

1.700686

1.700739

1.700766

.700793
1.700820

1.700847

1.700873
1.700900

1.700954

1.700981

.701008
1.701034

1.701061
1.701088

1.701115

1.701169

1.701222

1.701249
1.701276

1.701303

1.701330

1.701383

1.701410
1.701437

1.701490

1.701517

1.701544

1.701598
1.701625

1.701651

.701678
.701705

1.701759

1.701812

1.701866

1.701920

1.701946

1.701973

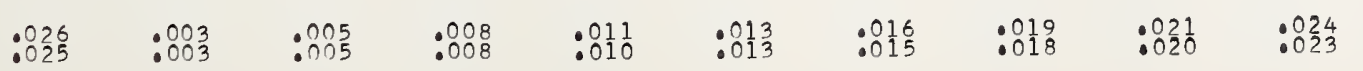



$\begin{array}{llll}55.400 & 55.638 & 55.611 & 55.585 \\ 55.136 & 55.109 & 55.347 & 55.321 \\ 55.083 & 55.056\end{array}$ $\begin{array}{llllll} & 54.871 & 54.845 & 54.818 & 54.792\end{array}$ $\begin{array}{lllllllllll} & 54.607 & 54.580 & 54.554 & 54.528 & 54.501 & 54.475 & 54.448 & 54.422 & 54.396 & 54.369 \\ 0 & 54.343 & 54.316 & 54.290 & 54.263 & 54.237 & 54.211 & 54.184 & 54.158 & 54.131 & 54.105\end{array}$ $\begin{array}{llllllllllll} & 53.550 & 53.524 & 53.497 & 53.471 & 53.444 & 53.418 & 53.391 & 53.365 & 53.339 & 53.312\end{array}$

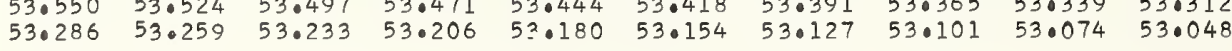

$\begin{array}{ll}0.276752 & 1.702027 \\ 0.276752 & 1.702054 \\ 0.276752 & 1.702081 \\ 0.276752 & 1.702107 \\ 0.276752 & 1.702134 \\ 0.276752 & 1.702161 \\ 0.276752 & 1.702188 \\ 0.276751 & 1.702215 \\ 0.276751 & 1.702242 \\ 0.276751 & 1.702268\end{array}$

$$
\begin{array}{r}
152.0 \\
2.1 \\
2.2 \\
2.3 \\
2.4 \\
2.5 \\
2.6 \\
2.7 \\
2.8 \\
2.9
\end{array}
$$$$
3.1
$$$$
\begin{aligned}
& 3.3 \\
& 3.4
\end{aligned}
$$

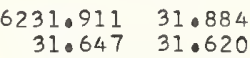

$\begin{array}{llll}31.647 & 31.620 & 31.594 & 31.831 \\ 31.58 & 31.568\end{array}$

$31.120 \quad 31.094 \quad 31.331 \quad 31.304$

$\begin{array}{llll}30.856 & 30.830 & 30.804 & 30.77\end{array}$

$\begin{array}{ll}30.593 \quad 30.567 \quad 30.5 \\ 30.329 & 30.303\end{array}$

$\begin{array}{llll}30.329 & 30.303 & 30.277 & 30.250\end{array}$

$\begin{array}{llll}30.066 & 30.040 & 30.013 & 29.98 \\ 29.802 & 29.776 & 29.750 & 29.72\end{array}$

$\begin{array}{llll}29.8539 & 29.776 & 29.750 & 29.723 \\ 29.512 & 29.486 & 29.460\end{array}$

$\begin{array}{lllllll}52.916 & 52.889 & 52.863 & 52.836 & 52.810 & 52.784\end{array}$

$\begin{array}{llllll}52.651 & 52.625 & 52.599 & 52.572 & 52.546 & 52.520 \\ 52.387 & 52.361 & 52.335 & 52.308 & 52.281 & 52.255\end{array}$

$\begin{array}{lllllll}52.123 & 52.097 & 52.070 & 52.044 & 52.017 & 51.991\end{array}$

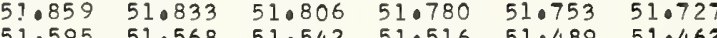

$\begin{array}{llllll}51.331 & 51.568 & 51.542 & 51.516 & 51.489 & 51.463 \\ 51.278 & 51.251 & 51.225 & 51.190\end{array}$

$\begin{array}{llllll}51.066 & 51.040 & 51.014 & 50.987 & 50.961 & 50.934\end{array}$

$\begin{array}{llllll}50.802 & 50.776 & 50.749 & 50.723 & 50.697 & 50.670 \\ 50.538 & 50.512 & 50.485 & 50.459 & 50.432 & 50.406\end{array}$

$\begin{array}{llllll}50.274 & 50.247 & 50.221 & 50.195 & 50.168 & 50.142\end{array}$

$\begin{array}{llllll}50.010 & 49.983 & 49.957 & 49.930 & 49.904 & 49.878\end{array}$

$\begin{array}{llllll}49.745 & 49.719 & 49.693 & 49.666 & 49.640 & 49.614\end{array}$

$\begin{array}{llllll}49.482 & 49.455 & 49.429 & 49.402 & 49.376 & 49.349 \\ 49.217 & 49.191 & 49.165 & 49.138 & 49.112 & 49.085\end{array}$

$\begin{array}{lllllll}48.953 & 48.927 & 48.901 & 48.874 & 48.848 & 48.821\end{array}$

$\begin{array}{llllll}48.689 & 48.663 & 48.636 & 48.610 & 48.583 & 48.557\end{array}$

$\begin{array}{llllll}48.425 & 48.399 & 48.372 & 48.346 & 48.319 & 48.293\end{array}$

$\begin{array}{lllllll}47.897 & 47.871 & 47.844 & 470818 & 47.791 & 47.765\end{array}$

$\begin{array}{lllllll}47.633 & 47.606 & 47.580 & 47.554 & 47.527 & 47.501\end{array}$

$\begin{array}{llllll}47.369 & 47.342 & 47.316 & 47.290 & 47.263 & 47.237\end{array}$

$\begin{array}{llllll}47.105 & 47.078 & 47.052 & 47.026 & 46.999 & 46.973 \\ 46.841 & 46.814 & 46.788 & 46.761 & 46.735 & 46.709\end{array}$

$\begin{array}{llllll}46.577 & 46.550 & 46.524 & 46.498 & 46.471 & 46.445\end{array}$

$\begin{array}{llllll}46.313 & 46.286 & 46.260 & 46.234 & 46.207 & 46.181 \\ 46.049 & 46.022 & 45.996 & 45.969 & 45.943 & 45.917\end{array}$

$\begin{array}{lllllll}45.785 & 45.758 & 45.732 & 45.705 & 45.679 & 45.653\end{array}$

$\begin{array}{lllllll}45.521 & 45.494 & 45.468 & 45.441 & 45.415 & 45.389\end{array}$

$44.993 \quad 44.966 \quad 44.940 \quad 44.914 \quad 44.887 \quad 44.861$

$\begin{array}{llllll}44.729 & 44.702 & 44.676 & 44.649 & 44.623 & 44.597 \\ 44.465 & 44.438 & 44.412 & 44.386 & 44.359 & 44.333\end{array}$

$\begin{array}{lllllll}44.201 & 44.174 & 44.148 & 44.121 & 44.095 & 44.069\end{array}$

$\begin{array}{llllll}42.937 & 43.911 & 43.884 & 43.858 & 43.831 & 43.805 \\ 43.673 & 43.647 & 43.620 & 43.594 & 43.558 & 43.541\end{array}$

$\begin{array}{lllllll}43.409 & 43.383 & 43.356 & 43.330 & 43.303 & 43.277\end{array}$

$\begin{array}{lllllll}43.145 & 43.119 & 43.092 & 43.066 & 43.040 & 43.013 \\ 42.881 & 42.855 & 42.828 & 42.802 & 42.776 & 42.740\end{array}$

$\begin{array}{lllllll}42.617 & 42.591 & 42.565 & 42.538 & 42.512 & 42.485\end{array}$

$\begin{array}{lllllll}42.353 & 42.327 & 42.301 & 42 \cdot 274 & 42.248 & 42.221\end{array}$

$\begin{array}{lllllll}42.090 & 42.063 & 42.037 & 42.010 & 41.984 & 41.958 \\ 41.026 & 41.799 & 41.773 & 41.746 & 41.720 & 41.0694\end{array}$

$\begin{array}{llllll}41.826 & 41.799 & 41.773 & 41.746 & 41.720 & 41.694 \\ 41.562 & 41.535 & 41.509 & 41.483 & 41.456 & 41.430\end{array}$

$\begin{array}{llllll}41.298 & 41.272 & 41.245 & 41.219 & 41.192 & 41.166 \\ 41.034 & 41.008 & 40.981 & 40.955 & 40.029 & 40.902\end{array}$

$\begin{array}{lllllll}40.770 & 40.744 & 40.718 & 40.691 & 40.0655 & 40.638\end{array}$

$\begin{array}{lllllll}40.506 & 40.480 & 40.454 & 40.427 & 40.401 & 40.375\end{array}$

$\begin{array}{llllll}40.243 & 40.216 & 40.190 & 40.164 & 40.137 & 40.111 \\ 39.979 & 39.953 & 39.926 & 39.900 & 39.874 & 39.847\end{array}$

0.27675

0.276751

0.276751

0.276750

0.276750

0.276750

0.276750

0.276750

0.276749

0.276749

0.276749

0.276749

0.276748

0.276748

0.276748

0.276748

0.276748
0.276748
0.0276747

0.276747

0.276747

0.276747
0.276747

0.276747

0.276747

0.276746

0.276746

0.276746

0.276746

0.276746
0.276746

0.276745

0.276745

0.276745
0.276745

0.276745

0.276745
0.276745

0.276744

0.276744
0.276744

0.276744

$\begin{array}{lllllll}39.715 & 39.689 & 39.662 & 39.636 & 39.610 & 39.583 \\ 39.451 & 39.425 & 39.399 & 39.372 & 39.346 & 39.320\end{array}$

$\begin{array}{llllll}39.451 & 39.425 & 39.399 & 39.372 & 39.346 & 39.320\end{array}$

$\begin{array}{llllll}39.188 & 39.161 & 39.135 & 39.108 & 39.082 & 39.056 \\ 38.924 & 38.897 & 38.871 & 38.845 & 38.818 & 38.792\end{array}$

$\begin{array}{lllllll}38.660 & 38.634 & 38.607 & 38.581 & 38.554 & 38.528\end{array}$

$\begin{array}{llllll}38.396 & 38.370 & 38.344 & 38.317 & 38.291 & 38.264\end{array}$

$\begin{array}{llllll}37.869 & 37.843 & 37.816 & 37.790 & 37.763 & 37.737\end{array}$

$\begin{array}{llllll}37.605 & 37.579 & 37.552 & 37.526 & 37.500 & 37.473 \\ 37.341 & 37.315 & 37.289 & 37.262 & 37.236 & 37.209\end{array}$

0.276744

0.276744

0.276743

0.276743

0.276743

1.702295

1.702322

1.702376

1.702429

1.702456

1.702510
1.702537

1.702563

1.702590

1.702644

1.702698

1.702724

1.702778

1.702832

1.702885

1.702912

1.702939

1.702966

1.703019

1.703046

1.903100

1.703127

1.703180

1.703207

1.703261

1.703288

1.703368

1.703395

1.703422
1.703449
1.979502

1.703476

1.703502

1.703529

1.703556

1.703583
1.703610

1.703636

1.703663
1.703690

1.703917

1.703744

1.0703741
1.703799

1.703824

1.703905

$\begin{array}{llllll}37.078 & 37.051 & 37.025 & 36.999 & 36.972 & 36.946 \\ 36.814 & 36.787 & 36.761 & 36.735 & 36.708 & 36.682\end{array}$

$\begin{array}{llllll}36.550 & 36.524 & 36.498 & 36.471 & 36.445 & 36.418\end{array}$

$\begin{array}{llllll}36.287 & 36.260 & 36.234 & 36.207 & 36.181 & 36.155\end{array}$

$\begin{array}{lllllll}35.0759 & 35.733 & 35.707 & 350680 & 350654 & 350627\end{array}$

$\begin{array}{lllllll}35.495 & 35.469 & 35.443 & 35.416 & 350390 & 35.364\end{array}$

$\begin{array}{lllllll}35.232 & 35.206 & 35.179 & 35.153 & 35.126 & 35.100 \\ 34.968 & 34.942 & 34.915 & 34.889 & 34.863 & 34.836\end{array}$

$\begin{array}{llllll}34.705 & 34.0788 & 34.052 & 34.625 & 34.0599 & 34.573\end{array}$

0.276743

0.276742

0.276742

0.276742

0.276742

0.276742

0.276742

1.703932

1.703958

1.704012

1.704039

1.704066

10704119
1.9704146

0.276741

0.276741
0.276741
0.276741

1.904173

0.276741

0.276741

0.276740
0.27674

0.276740

0.276740
0.276740

1.704200

10.704253

1.704280
1.904307

1.0704334
1.704364 


.07

.08

0.276736

0.276736

6162.

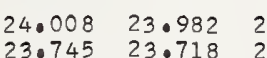

2.1
2.2
2
2
2.
2.7
2.0
2.9

$\begin{array}{lll}23.745 & 23.718 \\ 23.481 & 23.455 & 230\end{array}$

23.481123 .455

$22.955 \quad 22.928$

$22.692 \quad 22.665$

$22.165 \quad 22.139$

$21.639 \quad 21.612$

$\begin{array}{ll}23.955 & 23.929 \\ 23.692 & 23.666\end{array}$

$23.902 \quad 23.876$

$24.113 \quad 24.087$

$23.797 \quad 23.771$

$23.429 \quad 23.402 \quad 23.376 .23 .350$

$\begin{array}{llll}23.165 & 23.139 & 23.113 & 23.086 \\ 22.902 & 22.876 & 22.849 & 22.823\end{array}$

$22.639 \quad 22.613 \quad 22.586 \quad 22.560$

22.376

22.349

$22.323 \quad 22.297$

$\begin{array}{ll}23.587 & 23.560 \\ 23.323 & 23.297\end{array}$

$\begin{array}{llll}23.323 & 23.297 & 23.271 & 2 \cdot 3.244 \\ 23.060 & 23.034 & 23.008 & 22.981\end{array}$

$\begin{array}{llll}22.797 & 22.770 & 22.744 & 22.718 \\ 22.534 & 22.507 & 22.481 & 22.455\end{array}$

$\begin{array}{llll}22.534 & 22.507 & 22.481 & 22.455 \\ 22.270 & 22.244 & 22.218 & 22.191\end{array}$

$\begin{array}{llll}22.007 & 22.244 & 22.218 & 22.191 \\ 21.981 & 21.954 & 21.928\end{array}$

$16221.375 \quad 21.349$

163.0
3.0
3
3.04
3.05
3.07

3.1
3.1
3.3
3.4
3.5
3.0
3.7
3.0
3.0

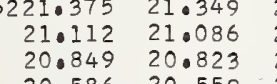

$21.586 \quad 21.560$

$\begin{array}{llllll}21.797 & 21.770 & 21.744 & 21.718 & 21.691 & 21.665 \\ 21.533 & 21.507 & 21.481 & 21.454 & 21.0428 & 21.402\end{array}$

$\begin{array}{ll}20.586 & 20.559 \\ 20.323 & 20.296\end{array}$

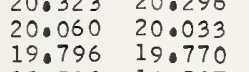

$19.533 \quad 19.507$

$\begin{array}{lll}1.323 & 21.296 & 210 \\ 21.000 & 21.033 & 210\end{array}$

$23.270 \quad 21.24$

$\begin{array}{llll}21.218 & 21.191 & 21.165 & 21.138 \\ 20.954 & 20.928 & 20.901 & 20.875\end{array}$

$\begin{array}{ll}19.270 & 19.244 \\ 19.007 & 18.981\end{array}$

$20.533 \quad 20.507$

$20.270 \quad 20.244$

$20.744 \quad 20.981$

20.954

0.276736

0.276736

0.276735

0.276735
0.276735

0.276735

0.276735

0.276734

0.276734

0.276734

0.276734

0.276734

0.276733

0.276733
0.276733

$\begin{array}{rrlllllllll}6164.0 & 16218.744 & 18.717 & 18.691 & 18.665 & 18.638 & 18.612 & 18.586 & 18.560 & 18.533 & 18.507\end{array}$

$\begin{array}{rrrrrrrrrrrr}6164.0 & 16218.744 & 18.717 & 18.691 & 18.665 & 18.638 & 18.612 & 18.586 & 18.560 & 18.533 & 18.507\end{array}$

$\begin{array}{llll}19.744 & 19.717 & 19.691 & 19.665 \\ 19.481 & 19.454 & 19.0428 & 19.402\end{array}$

$\begin{array}{llll}20.165 & 20.138 & 20.112 & 20.086\end{array}$

$\begin{array}{llll}19.902 & 19.875 & 19.849 & 1908823 \\ 19.638 & 19.612 & 19.586 & 19.560\end{array}$

$\begin{array}{llll}19.375 & 19.349 & 19.323 & 19.296\end{array}$ $\begin{array}{llllllllll}18.481 & 18.454 & 18.428 & 18.402 & 18.375 & 18.349 & 18.323 & 18.297 & 18.270 & 18.244\end{array}$

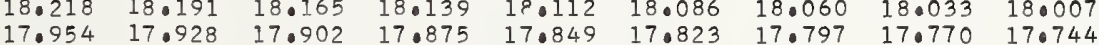

0.276733

0.276733

0.276733

0.276733

0.276732

0.0276732

$\begin{array}{llllllllll}17.428 & 17.402 & 17.376 & 17.349 & 17.323 & 17.297 & 17.271 & 17.244 & 17.218 & 17.192\end{array}$

$\begin{array}{llllllllll}17.165 & 17.139 & 17.113 & 17.086 & 17.060 & 17.034 & 17.007 & 16.981 & 16.955 & 16.928\end{array}$

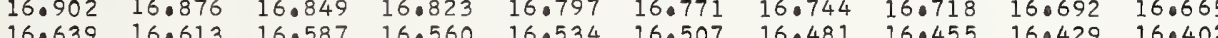

0.276732

$16.376 \quad 16.350$

$\begin{array}{ll}16.587 & 16.560 \\ 16.323 & 16.297\end{array}$

$\begin{array}{ll}16.534 & 16.507 \\ 16.271 & 16.245\end{array}$

16.481
16.218

6165.0

5.0
5.0
5.0
5.04
5.5
5.0
5.0
50
5.0

$16216.113 \quad 16.0$

16.060

$\begin{array}{lll}16.034 & 16.008 & 15.981\end{array}$

$\begin{array}{lllll}15.955 & 15.929 & 150902 & 150876\end{array}$

$15.587 \quad 15.561$

$\begin{array}{llll}15.534 & 15.508 & 15.482 & 15.45\end{array}$

$15.061 \quad 15.03$

$15.271 \quad 15.24$

$\begin{array}{ll}14.798 & 14.772 \\ 14.535 & 14.509\end{array}$

$\begin{array}{llll}14.745 & 14.982 & 14.956 & 14.92 \\ 14.019 & 14.693 & 14.0666\end{array}$

$14.595 \quad 14.509$

$14.482 \quad 14.456$

$14.009 \quad 13.983$

$\begin{array}{ll}14.219 & 14.193 \\ 13.956 & 13.930\end{array}$

$\begin{array}{ll}14.693 & 14.666 \\ 14.430 & 14.403\end{array}$

$\begin{array}{llll}15.692 & 15.666 & 150639 & 15.613\end{array}$

$\begin{array}{llll}15.166 & 15.140 & 15.377 & 15.350 \\ 15.114 & 15.087\end{array}$

$14.903 \quad 14.877 \quad 14.850 \quad 14.824$

$14.640 \quad 14.614 \quad 14.588 \quad 14.561$

$\begin{array}{llll}14.377 & 14.351 & 14.324 & 14.298 \\ 14.114 & 14.088 & 14.062 & 14.035\end{array}$

$6213.483 \quad 13.457$

$\begin{array}{ll}13.430 & 13.40 \\ 13.168 & 13.14 \\ 12.905 & 12.87\end{array}$

$14.167 \quad 14.140$

13.85

$\begin{array}{lll}14.088 & 14.062 & 14.035 \\ 13.825 & 13.799 & 13.777\end{array}$

6166.0

66.0
6.1
6.2
6.3
6.4
6.5
6.6
6.8
6.9

13.220

13.37

13.351

13.325

$12.957 \quad 12.931$

$\begin{array}{ll}12.642 & 12.615 \\ 12.379 & 12.352\end{array}$

$12.431 \quad 12.405$

$\begin{array}{ll}12.379 & 12.352 \\ 12.116 & 12.08\end{array}$

$11.906 \quad 11.879$

$11.643 \quad 11.617 \quad 11.590 \quad 11.564$

$\begin{array}{llll}11.380 & 11.354 & 11.327 & 11.301 \\ 11.117 & 11.091 & 11.065 & 11.038\end{array}$

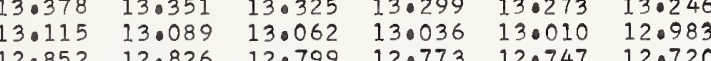

$\begin{array}{llllll}12.852 & 12.826 & 12.799 & 12.773 & 12.747 & 12.720 \\ 12.589 & 12.563 & 12.536 & 12.510 & 12.484 & 12.458\end{array}$

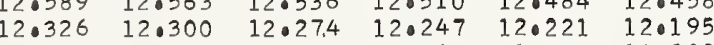

$\begin{array}{llllll}12.063 & 12.037 & 12.011 & 11.984 & 11.958 & 11.932 \\ 11.801 & 11.0774 & 11.748 & 11.722 & 11.695 & 11.6699\end{array}$

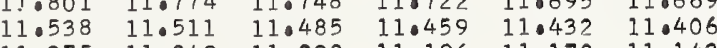

0.276732

0.276732

0.276731

0.276731

0.276731

0.27673

0.276730

0.276730

0.276730

.0276730

0.276730

0.276730

0.276729

0.276729

6167.0

67.0
7
$7: 0$
$7: 3$
$7: 4$
$7: 5$
$7: 6$
$7: 8$
$7: 9$

$16210.854 \quad 10.828$

$10.802 \quad 10.775$

10.749

0.276729

0.276729

0.276729

$\begin{array}{lllllllllll}10.328 & 10.302 & 10.276 & 10.250 & 10.223 & 10.197 & 10.171 & 10.145 & 10.118 & 10.092\end{array}$

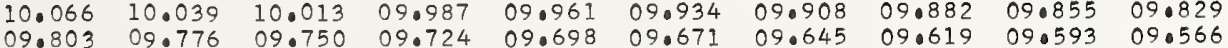

$\begin{array}{llllllllll}09.540 & 09.514 & 09.487 & 09.461 & 09.435 & 09.409 & 09.382 & 09.356 & 09.330 & 09.303\end{array}$

$\begin{array}{llllllllll}09.277 & 09.251 & 09.225 & 09.198 & 09.172 & 09.146 & 09.119 & 09.093 & 09.067 & 09.041\end{array}$

$\begin{array}{llllllllll}0.014 & 8.988 & 08.962 & 08.936 & 08.969 & 08.883 & 08.857 & 088.830 & 08.804 & 08.778 \\ 08.752 & 08.725 & 08.699 & 08.673 & 08.646 & 08.620 & 08.594 & 08.568 & 08.541 & 08.515\end{array}$

$\begin{array}{lllllllllll}08.489 & 08.462 & 08.436 & 08.410 & 08.384 & 08.357 & 08.331 & 08.305 & 08.279 & 08.252\end{array}$

0.276728

0.276798

0.276728

0.276728

$\begin{array}{llllllllllll}6168.0 & 16208.226 & 08.200 & 08.173 & 08.147 & 08.121 & 08.094 & 08.068 & 08.042 & 08.016 & 07.989\end{array}$

$\begin{array}{lllllllllll}07.963 & 07.937 & 07.911 & 07.884 & 07.858 & 07.832 & 07.806 & 07.779 & 07.753 & 07.727\end{array}$

$\begin{array}{llllllllllll}8.1 & 07.701 & 07.674 & 07.648 & 07.622 & 07.595 & 07.569 & 07.543 & 07.516 & 07.490 & 07.464\end{array}$

$\begin{array}{llllllllllll}07.438 & 07.411 & 07.385 & 07.359 & 07.333 & 07.306 & 077.280 & 07.254 & 07 \cdot 228 & 07.201 \\ 07.175 & 07.149 & 07.122 & 07.096 & 07.070 & 07.044 & 07.017 & 06.991 & 06.965 & 06.938\end{array}$

$\begin{array}{lllllllllll}07.175 & 07.149 & 07.122 & 07.096 & 07.070 & 07.044 & 07.017 & 06.991 & 06.965 & 06.938\end{array}$

$\begin{array}{llllllllllll}06.649 & 06.623 & 06.597 & 06.571 & 06.544 & 06.518 & 06.492 & 06.466 & 06.439 & 06.413\end{array}$

$\begin{array}{lllllllllll}8.6 & 06.649 & 06.623 & 06.597 & 06.571 & 06.544 & 06.518 & 06.492 & 06.466 & 06.439 & 06.413 \\ 8.7 & 06.387 & 06.360 & 06.334 & 06.308 & 06.281 & 06.255 & 06.229 & 06.203 & 06.177 & 06.150 \\ 8.8 & 00.124 & 06.098 & 06.077 & 06.045 & 06.019 & 05.993 & 05.966 & 05.940 & 05.914 & 05.888\end{array}$

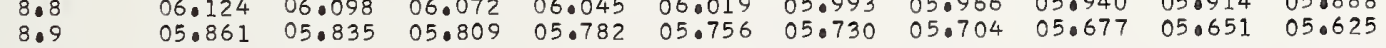

0.276728

0.276727

0.276727

0.276727

0.276727

0.276727

0.276726

$\begin{array}{lllllllllll}6169.0 & 16205.599 & 05.572 & 05.546 & 05.520 & 05.494 & 05.467 & 05.441 & 05.415 & 05.389 & 05.362\end{array}$

$\begin{array}{lllllllllll}9.1 & 05.336 & 05.310 & 05.284 & 05.257 & 05.231 & 05.204 & 05.178 & 05.152 & 05.126 & 05.099 \\ 9.2 & 05.073 & 05.047 & 05.021 & 04.994 & 04.968 & 04.942 & 04.916 & 04.889 & 04.863 & 04.837\end{array}$

$\begin{array}{lllllllllll}9.2 & 05.073 & 0.047 & 05.021 & 04.994 & 04.968 & 04.942 & 04.916 & 04.827 & 04.600 & 04.837 \\ 9.3 & 04.811 & 04.784 & 04.758 & 04.732 & 04.706 & 04.679 & 04.653 & 04.627 & 04.600 & 04.574\end{array}$

$\begin{array}{lllllllllll}9.3 & 04.811 & 04.784 & 04.758 & 04.732 & 04.0406 & 04.642 & 04.0453 & 04.627 & 04.0630 & 04.574 \\ 9.4 & 04.548 & 04.522 & 04.495 & 04.469 & 04.443 & 04.417 & 04.390 & 04.364 & 04.338 & 04.312\end{array}$

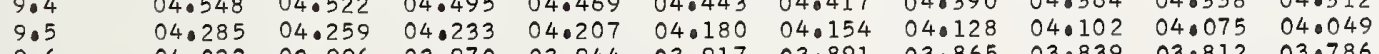

$\begin{array}{llllllllllll}9.6 & 04.022 & 03.996 & 03.970 & 03.944 & 03.917 & 03.891 & 03.865 & 03.839 & 03.812 & 03.786\end{array}$

$\begin{array}{lllllllllll}9.7 & 03.760 & 03.734 & 03.707 & 03.681 & 03.655 & 03.629 & 03.602 & 03.576 & 03.550 & 03.524 \\ 9.8 & 03.497 & 03.471 & 03.445 & 03.418 & 03.392 & 03.366 & 03.340 & 03.314 & 03.287 & 03.261\end{array}$

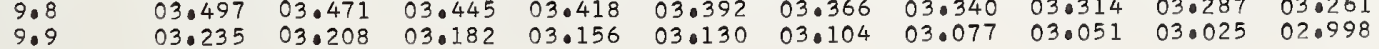

0.276726

0.276726
0.276726

0.27672

0.276726

0.276725

0.276725
0.276725

1.704710
1.704736

1.704763

1.704817

1.704844

1.704897

1.704951

704978

(7) 500

1.705058

(

1.705139

1. 705166

1.705219

1.705246

0.705273

.705327

1.705380

705407
.705434

1.705461

.705514

1.705541
1.705568

.705595
1.705622

.7.705648

1.705575

.0705729

1.705783

.705809
1.705836

.705863

1.705890
1.705917

.705944

1.706051

1.706078
1.706105

1.706131

1.706185

1.706212

1.706265

1.706319

1.706346

1.706400

1.706426

.706480

1.706534

1.706587

1.706614

1.706668

1.706695

1.706748

1.706775
1.706802

1.706856

1.906883

1.706936

1.706963

1.707017

1.707043
1.707070

1.707124

1.707151
1.707178

1.707231

1.707258

1.707312

$\begin{array}{llllllllll}.235 & 03.208 & 03.182 & 03.156 & 03.130 & 03.104 & 03.077 & 03.051 & 03.025 & 02.98\end{array}$

.010 
$\begin{array}{lllllllllll}6170.0 & 16202.972 & 02.946 & 02.920 & 02.893 & 02.867 & 02.841 & 02.815 & 02.788 & 02.762 & 02.736\end{array}$

$\begin{array}{lllllllllll}0.1 & 02.709 & 02.683 & 02.657 & 02.631 & 02.604 & 02.578 & 02.552 & 02.526 & 02.499 & 02.473 \\ 0.2 & 02.447 & 02.421 & 02.394 & 02.368 & 02.342 & 02.316 & 02.289 & 02.263 & 02.237 & 02.210\end{array}$

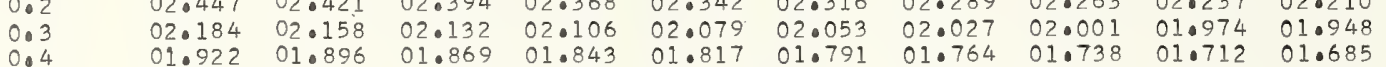

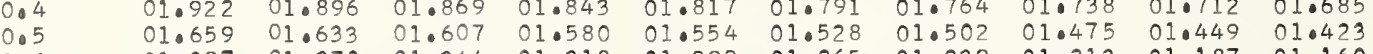

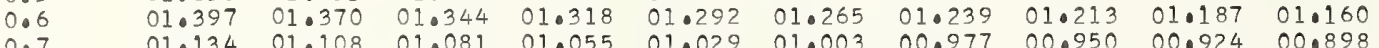

$\begin{array}{lllllllllll}0.77 & 01.134 & 01.108 & 01.081 & 01.055 & 01.029 & 01.003 & 00.977 & 00.950 & 00.924 & 00.898\end{array}$

$\begin{array}{llllllllll}00.871 & 00.845 & 00.819 & 00.793 & 00.766 & 00.740 & 00.714 & 00.688 & 00.662 & 00.635 \\ 00.609 & 00.583 & 00.556 & 00.530 & 00.504 & 00.478 & 00.451 & 00.425 & 00.399 & 00.373\end{array}$

16200.346

\subsection{0}

00.556

$\begin{array}{rr}16199.821 & 99.058 \\ 99.559 & 99.533\end{array}$

$99.296 \quad 99.270$

99.03499 .00

00.032
99.769
99.506

00.268

$98.771 \quad 98 \cdot 745$

99.244

99.743

00.24100 .2

$00.215 \quad 00.189 \quad 00.163 \quad 00.136 \quad 00.110$

98.24698 .220

$98.981-98.955$

$99.454 \quad 99.428$

$99.926 * 99.900 * 99 \cdot 874 * 99 \cdot 848$

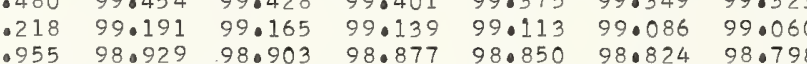

9.984

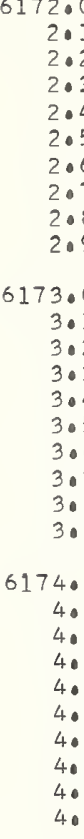

$\begin{array}{ll}2.0 & 161 \\ 2.1 & \\ 2.2 & \\ 2.3 & \\ 2.4 & \\ 2.5 & \\ 2 & \end{array}$

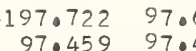

$97.197 \quad 97.17$

96.93496 .908

$96.410 \quad 96.38$

$96.147 \quad 96.12$

$95.885 \quad 95 \cdot 859$

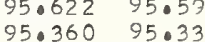

98.430

98.66798 .640

$98.404 \quad 98.378$

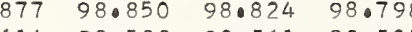

98.168

97.669

97.643
97.380

$97.144 \quad 97.118$

96.62096 .593

96.35796 .331

$96.095 \quad 96.068$

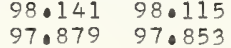

$98.614 \quad 98.588 \quad 98.561 \quad 98.535$

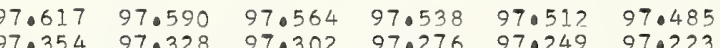

$\begin{array}{llllll}97.092 & 97.066 & 97.039 & 97.013 & 96.987 & 96.961\end{array}$

$\begin{array}{llllll}96.829 & 96.803 & 96.777 & 96.751 & 96.724 & 96.698\end{array}$

$\begin{array}{llllll}96.305 & 96.278 & 96.252 & 96.226 & 96.200 & 96.173\end{array}$

$96.042 \quad 96.016 \quad 95.990 \quad 95.964 \quad 95.937 \quad 95.911$

$\begin{array}{llllll}95.740 & 95.754 & 95.727 & 95.701 & 95.675 & 95.649 \\ 95.517 & 95.491 & 05.465 & 95.439 & 95.413 & 95.386\end{array}$

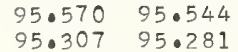

$95.517 \quad 95.491$

95.727 . 950

6173.0

$3 \cdot 1$

3.4

3.6 94.835 $94.311-94.547$

$95.045 \quad 95.019$

94.993

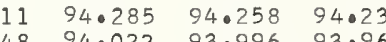

$93.786 \quad 93.760 \quad 93.734 \quad 93.707$

$93.524 \quad 93.497 \quad 93.471 \quad 93.445$

$93.261-93.235$

92.999
92.737

93.235

93.209993 .183

94.46

94.966

996049

93.94394 .179

93.68193 .655

93.41

6192.474

740
4.0
4.0
40
40
40
40
40
40
40

6175.0

5.1

5.2
5.3
5.4

5.4
5.5

5.6
5.7

5.8

6176.

6.1

6.2
6.3

6.5

6.5
6.6
6.7

6.7
6.8

6177.0

7.1

$7: 2$

7.3

7.5
7.6

7.8

6178.0

178.0
8.1
8.2
8.3

8.3

8.5

8.6
8.7
8.8

8.8
8.9

6179.0

9.1
$9: 2$
90
9.5
$9: 6$
$9: 7$
9.8

$$
\begin{aligned}
& \begin{array}{l}
92.212 \\
91.950
\end{array} \\
& \begin{array}{l}
91.688 \\
91.426
\end{array} \\
& 91.426 \quad 91.662 \\
& 90.639
\end{aligned}
$$$$
91.163 \quad 91.137
$$

90.61
90.351
90.08

$92.422 \quad 92.39$

92.89

93.130

4.179
593
130

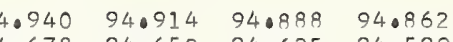

$\begin{array}{llll}94.416 & 94.389 & 94.363 & 94.337\end{array}$

$94.153 \quad 940127 \quad 94010194.075$

6189.852

$89.590 \quad 89.826 \quad 89$.

$89.328 \quad 89.302$

$\begin{array}{ll}89.066 & 89.040 \\ 88.804 & 88.777\end{array}$

$88.542 \quad 88.515$

$88.279-88.253 \quad 88.227$

$\begin{array}{ll}87.755 & 87.729 \\ 87.493 & 87.467\end{array}$

87.965

87.703
87.441

$16187.231 \quad 87.205$ 86.969

86.707

86.943
86.680

$\begin{array}{ll}87.178 & 87.152 \\ 86.917 & 86.890\end{array}$

92.370

$86.445 \quad 86.418$

$85.921 \quad 85.894$

$85.658 \quad 85.632$

$\begin{array}{ll}85.396 & 85.370 \\ 85.134 & 85.108\end{array}$

$86.130 \quad 86.104$

$85.868 \quad 85.842$

$84.872 \quad 84.846$

85.344
85.082

85.318

$16184.610 \quad 840584$ $84.348 \quad 84.322$

$\begin{array}{ll}84.086 & 84.060 \\ 83.824 & 83.798\end{array}$

83.56283 .536

$\begin{array}{ll}83.300 & 83.274 \\ 83.039 & 83.012\end{array}$

$82.777 \quad 82.750$

$\begin{array}{ll}82.515 & 82.489 \\ 82.253 & 82.227\end{array}$

84.5 .5

84.794

$92.370 \quad 92.343$

92.343

\begin{tabular}{l}
$9.366 \quad 93.340 \quad 93.314 \quad 93.288$ \\
\hline
\end{tabular}

$\begin{array}{llll}3.104 & 93.078 & 93.052 & 93.025\end{array}$

$83.772 \quad 83.746$

$83.510 \quad 83.484$

$\begin{array}{ll}83.248 & 83.222 \\ 82.986 & 82.960 \\ 82.724 & 82.098\end{array}$

$91.583 \quad 91.819$

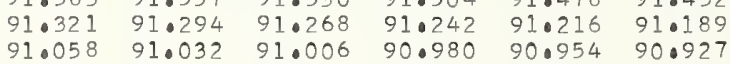

$\begin{array}{llllll}90.796 & 90.770 & 90.744 & 90.717 & 90.691 & 90.665\end{array}$

$\begin{array}{llllll}90.534 & 90.508 & 90.482 & 90.455 & 90.429 & 90.403\end{array}$

$\begin{array}{llllll}90.272 & 90.246 & 90.219 & 90.193 & 90.167 & 90.141 \\ 90.010 & 89.983 & 89.957 & 89.931 & 89.905 & 89.878\end{array}$

$89.747 \quad 89.721 \quad 89.695 \quad 89.669 \quad 89.643 \quad 89.616$

$\begin{array}{llllll}89.485 & 89.459 & 89.433 & 89.406 & 89.380 & 89.354 \\ 80.223 & 89.197 & 89.171 & 89.145 & 89.118 & 89.092\end{array}$

$\begin{array}{lllllll}88.961 & 88.935 & 88.908 & 88.882 & 88.856 & 88.830\end{array}$

$\begin{array}{llllllll}88.699 & 88.673 & 88.646 & 88.620 & 88.594 & 88.568\end{array}$

$\begin{array}{llllll}88.437 & 88.410 & 88.384 & 88.358 & 88.332 & 88.306\end{array}$

$\begin{array}{llllll}88.175 & 88.148 & 88.122 & 88.096 & 88.070 & 88.043\end{array}$

$\begin{array}{lllllll}7.650 & 87.886 & 87.860 & 87.834 & 870807 & 87.781\end{array}$

$\begin{array}{lllllll}87.126 & 87.100 & 87.074 & 87.047 & 87.021 & 86.995\end{array}$

$\begin{array}{lllllll}86.864 & 86.838 & 86.812 & 86.785 & 86.759 & 86.733\end{array}$

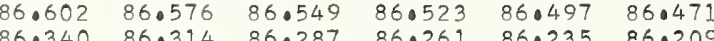

$\begin{array}{llllll}86 \cdot 340 & 86 \cdot 314 & 86 \cdot 287 & 86 \cdot 261 & 86 \cdot 235 & 86 \cdot 209 \\ 86.078 & 86.052 & 86.025 & 85.999 & 85.073 & 85.947\end{array}$

$\begin{array}{lllllll}85.816 & 85.789 & 85.763 & 85.737 & 85.711 & 85.68\end{array}$

$85.554 \quad 850527 \quad 85.501 \quad 85.475 \quad 85.449 \quad 850423$

$\begin{array}{llllll}85.292 & 85.265 & 85.239 & 85.213 & 85.187 & 85.161 \\ 85.030 & 85.003 & 84.977 & 84.051 & 84.025 & 84.898\end{array}$

$\begin{array}{llllll}84.768 & 84.741 & 84.715 & 84.689 & 84.663 & 84.636\end{array}$

$\begin{array}{lllllll}84.505 & 84.479 & 84.453 & 84.427 & 840401 & 84.374 \\ 84.244 & 84.217 & 84.191 & 84.165 & 84.139 & 84.113\end{array}$

$\begin{array}{llllll}84.981 & 84.217 & 84 \cdot 191 & 84.165 & 84.139 & 84.113 \\ 83.985 & 83.929 & 83.903 & 83.877 & 83.851\end{array}$

$\begin{array}{llllll}83.719 & 83.693 & 83.667 & 83.641 & 83.615 & 83.589\end{array}$

$\begin{array}{llllll}83.4196 & 83.170 & 83.144 & 83.117 & 83.091 & 83.065\end{array}$

$\begin{array}{llllll}83.196 & 83.170 & 83.144 & 83 \cdot 117 & 83.091 & 83.065 \\ 82.934 & 82.908 & 82.881 & 82.855 & 82.829 & 82.803\end{array}$

82.672

$\begin{array}{lllll}82.646 & 82.620 & 82.593 & 82.567 & 82.541\end{array}$

$\begin{array}{rlllllllll}16181.991 & 81.965 & 81.938 & 81.912 & 81.886 & 81.860 & 81.834 & 81.808 & 81.781 & 81.755 \\ 81.729 & 81.903 & 81.677 & 81.650 & 81.624 & 81.598 & 81.572 & 81.546 & 81.519 & 81.493\end{array}$ $81.467 \quad 81.441$ $81.205 \quad 81.179$ $\begin{array}{ll}80.943 & 80.917 \\ 80.681 & 80.655\end{array}$

$\begin{array}{ll}80.681 & 80.655 \\ 80.419 & 80.393 \\ 80.158 & 80.113\end{array}$

$\begin{array}{ll}80.158 & 80.131 \\ 79.896 & 79.870 \\ 79.634 & 79.608\end{array}$

81.677
81.415

$81.415 \quad 81.388$

81.624

$80.809-81.126$

$81.100 \quad 81.07$

$81.572 \quad 81.546 \quad 81.510 \quad 89.493$

$79.634 \quad 79.608$

$80.367 \quad 80.341$

$\begin{array}{llll}80.048 & 81.022 & 80.996 & 80.96\end{array}$

$80.576 \quad 80.550 \quad 80.524 \quad 80.498 \quad 80.472 \quad 80.446$

$\begin{array}{lllllllll}31 & 80.105 & 80.079 & 80.053 & 80.288 & 80.262 & 80.236 & 80.210 & 80.184 \\ 70.027 & 80.000 & 79.974 & 79.948 & 79.92 \\ 79.843 & 79.817 & 70.791 & 79.765 & 79.739 & 79.712 & 79.686 & 79.660\end{array}$

$\begin{array}{lllllll}79.555 & 79.529 & 79.503 & 79.477 & 79 \cdot 450 & 79 \cdot 424 & 79 \cdot 39\end{array}$

$\begin{array}{llllllllll}79.110 & 79.346 & 79.320 & 79.293 & 79.267 & 79.241 & 79.215 & 79.189 & 79 \cdot 162 & 79.136 \\ 79.085 & 79.032 & 79.005 & 78.979 & 78.953 & 78.927 & 78.901 & 78.875\end{array}$

$\begin{array}{llllllllll}78.848 & 78.822 & 78.796 & 78.770 & 78.743 & 78.717 & 78.591 & 78.665 & 78.639 & 78.613\end{array}$

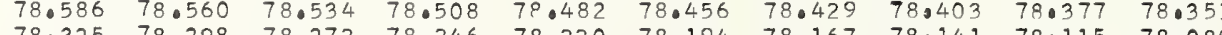

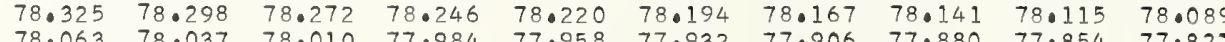

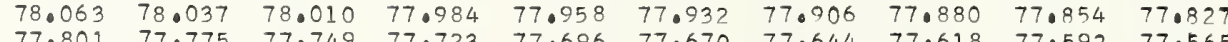

$77.539 \quad 77.513 \quad 77.487 \quad 77.723$

$77.696 \quad 77.670$

$77.644 \quad 77.618 \quad 77.592 \quad 77.565$

$\begin{array}{llll}777.539 & 77.513 & 77.487 & 77.46 \\ 77.277 & 77.251 & 77.225 & 77.19 \\ 77.016 & 76.990 & 76.963 & 76.937\end{array}$

77.173

77.408
77.146
76.885

77.382

$\begin{array}{lll}77.0356 & 77.0330 & 77.0304 \\ 77.004 & 77.068 & 77.0042\end{array}$

0.276725
0.276725

0.276725
0.276725
0.276725

0.276724

0.276724

0.276724
0.276724

0.276724

0.276794
0.276724

0.276723

0.276723

0.276723
0.276723
0.276723

0.276723

0.276723

0.276722

0.276722

0.276722

0.276722

0.276721

0.27672

0.276721

0.276721

0.27679

0.276720

0.276720

0.276720

0.276720
0.276720

0.276720
0.276720

0.276719

0.276719

0.276719

0.276719

0.276719

0.276718

0.276718

0.276718

0.276718

0.276718
0.276718
0.276718

0.276717

0.276719 


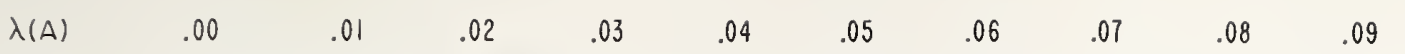

$(n-1) \times 1000 \quad \lambda(n-1)$

6180.
0.1
0.2
0.0
0.0
0.5
0.7
0
0
6181
1
1
1
1
1
1
1
1
1

$2 \cdot 1$

$2 \cdot 3$

2.6
2.7
2.8

2.8

6183.0

3.1
3.2
3.3

3.3

3.5

3.6

3.8

6184.0

4.1
4.2
4.3
4.4

4.4
4.5

$4 \cdot 6$
4.7

4.8
4.9

$6185 \circ$

5.1
5.2
5.3

5.3
5.4

5.4

5.6
5.7
5.8
5.9

5.8
5.9

6186.

6.

6.

6.4
6.5
6.6

6.

6.

6187

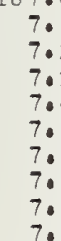

6188.

$$
\begin{array}{r}
6188 \\
8 \\
8 \\
8 \\
8 \\
8 \\
8 \\
8 \\
8 \\
8 \\
8 \\
8 \\
6189 \\
9 \\
9 \\
9 \\
9 \\
9 \\
9 \\
9 \\
9 \\
9
\end{array}
$$

$\begin{array}{llllll}76.649 & 76.623 & 76.597 & 76.571 & 76.544 & 76.518 \\ 76.387 & 76.361 & 76.335 & 76.309 & 76.283 & 76.257\end{array}$ $\begin{array}{llllll}76.387 & 76.361 & 76.335 & 76 \cdot 309 & 76.283 & 76.257 \\ 76.126 & 76.100 & 76.073 & 76.047 & 76.021 & 75.095\end{array}$ $75 \cdot 864$ 75.340 75.079 75.838 $75 \cdot 31$ 75.812 75.786
75.524 75.262

75.759
75.498
75.236
$7.236 \quad 75.471$ $\begin{array}{llllll}75.053 & 75.288 & 75.2620 & 75.0236 & 75.210\end{array}$ $\begin{array}{llllllllll}74.660 & 74.634 & 74.608 & 74.582 & 74.555 & 74.529 & 74.503 & 74.477 & 74.451 & 74.425 \\ 74.398 & 74.372 & 74.346 & 74.320 & 74.0294 & 74.268 & 74.241 & 74.715 & 74.180 & 74.162\end{array}$

$\begin{array}{rlllllllll}16174.137 & 74.111 & 74.084 & 74.058 & 74.032 & 74.006 & 73.980 & 73.954 & 73.927 & 73.901 \\ 73.875 & 73.849 & 73.823 & 73.797 & 73.771 & 73.744 & 73.718 & 73.0632 & 73.666 & 73.06378\end{array}$ $\begin{array}{llllllllll}73.613 & 73.587 & 73.561 & 73.535 & 73.509 & 73.483 & 73.456 & 73.430 & 73.404 & 73.378\end{array}$

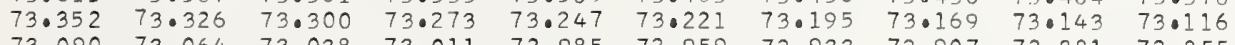

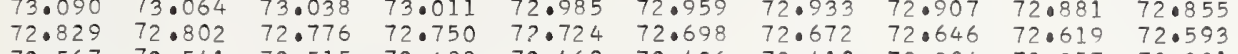

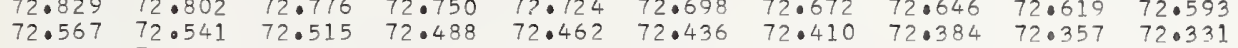

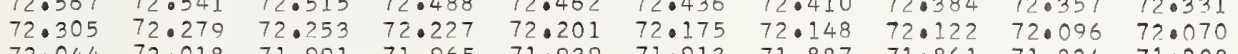

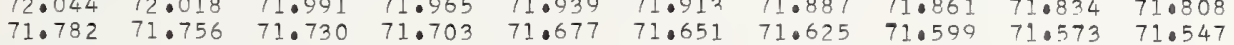
$\begin{array}{rrrr}16171.521 & 71.494 & 71.468 & 71.4 \\ 71.259 & 71.233 & 71.207 & 71.1\end{array}$ $70.997 \quad 70.233 \quad 71.207$

$70.736 \quad 70.710 \quad 70.683 \quad 70.657$

$70.474 \quad 70.448 \quad 70.422 \quad 70.396$

$70.213 \quad 70.186$

69.95169 .925

$69.428 \quad 69.402$

70.422

70.134

69.16

16168.90 $68.005 \quad 68.879$

68.38

$68.120-68.35$

$67.859 \quad 67.83$

67.598

$67.336 \quad 67.310$

$\begin{array}{ll}67.075 & 67.048 \\ 66.813 & 66.787\end{array}$

66.552

16166.290

66.029

65.768

65.245
64.983

64.983
64.722

$64.461 \quad 64.434$

64.199
63.938

66.26

66.00
65.74

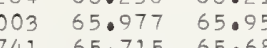

$\begin{array}{ll}65.977 & 65.95 \\ 65.715 & 65.689 \\ 65.454 & 65.042\end{array}$

$\begin{array}{ll}65.454 & 65.428 \\ 65.192 & 65.166\end{array}$

$64.931 \quad 64.905$

$64.608 \quad 64.382$

71.390

$\begin{array}{lllll}71.364 & 71.337 & 71 \cdot 311 & 71.985\end{array}$ $\begin{array}{llllll}70.893 & 70.867 & 70.840 & 70.814 & 70.788 & 71.0742\end{array}$

$\begin{array}{llllll}70.631 & 70.605 & 70.579 & 70.553 & 70.526 & 70.500\end{array}$

$\begin{array}{lllllll}70.108 & 70.082 & 70.056 & 70.030 & 70.003 & 69.977\end{array}$ $\begin{array}{llllll}69.845 & 69.820 & 69.794 & 69.768 & 69.742 & 69.716\end{array}$ 6163.677 $63.475 \quad 63.650$

$63.25-63.38$

$62.893 \quad 62.867$

$62.631 \quad 62.605$

$62.370 \quad 62.344 \quad 62.318$

$62.109 \quad 62.082 \quad 62.056$

$61.84761 .821 \quad 61.795 \quad 62.030$

$\begin{array}{ll}61.586 & 61.560 \\ 61.325 & 61.29\end{array}$

16161.064

60.80

61.038

61.53
61.27

60.541
60.280

60.019

$59.496 \quad 59.470$

$59.235 \quad 59 \cdot 20$

58.974

$59.209 \quad 59.183$

61.011
60.750
60.489
60.228
59.966
59.705
59.444
59.183
58.922
58.060

60.98
60.724

60.985
60.724
60.463
60.202

60.202
59.94

59.679
59.418

59.15
58.896

58.896
58.634

16158.452

$58.452 \quad 58.425$

$58.190 \quad 58.16$

58.39
58.138

58.373

$\begin{array}{llll}57.929 & 57.903 & 57.877 & 57.851\end{array}$

$\begin{array}{llll}57.668 & 57.542 & 57.516 & 57.590\end{array}$

$\begin{array}{ll}57.407 & 57.38 \\ 57.146 & 57.120\end{array}$

57.146
56.885
56.6264 .85

$\begin{array}{ll}56.624 & 56.597 \\ 56.362 & 56.336\end{array}$

$\begin{array}{ll}57.355 & 57.32 \\ 57.094 & 57.068\end{array}$

$56.832 \quad 56.806$

$\begin{array}{ll}56.832 & 56.806 \\ 56.571 & 56.545 \\ 56.310 & 56.28\end{array}$

56.101

16155.840

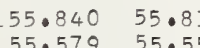

$\begin{array}{llll}55.579 & 55.553 & 55.788 & 55.7 \\ 5 & 52.527 & 55.501\end{array}$

$\begin{array}{lllll}55.318 & 55.292 & 55.266 & 55.240\end{array}$

55.05

$54.796 \quad 54.770$

$\begin{array}{lllll}54.535 & 54.500 & 54.483 & 54.718\end{array}$

$\begin{array}{llllll}54.0374 & 54.048 & 54.023 & 54.457\end{array}$

$53.752 \quad 53.726$

$52.969-53.204 \quad 53.178$

$52.708 \quad 52.943 \quad 52.917$

52.408752 .682

$51.925 \quad 51.890$

52.39552 .630

69.323
69.062

60.207

$\begin{array}{llll}69.533 & 69.506 & 69.480 & 69.454 \\ 69.271 & 69.245 & 69.219 & 69.193\end{array}$

$\begin{array}{lllllll}68.800 & 68.774 & 68.748 & 68.722 & 68.696 & 68.670\end{array}$

$\begin{array}{llllll}68.539 & 68.513 & 68.486 & 68.460 & 68.434 & 68.408\end{array}$

$\begin{array}{llllll}68.016 & 67.2590 & 68.225 & 68.199 & 68.173 & 68.147 \\ 67.964 & 67.938 & 57.911 & 67.885\end{array}$

$\begin{array}{llllll}67.754 & 67.728 & 67.702 & 67.676 & 67.650 & 67.624\end{array}$

$67.231-67.205 \quad 67.179 \quad 67.153 \quad 67.38867 .362$

$66.970 \quad 66.944$

66.447

66.682
66.421

66.918

66.892

$.865 \quad 66.839$

$66.604 \quad 66.578$

$\begin{array}{llllll}66.186 & 66.159 & 66.133 & 66.107 & 66.081 & 66.055\end{array}$

$65.024 \quad 65.898$

65.401
65.140

64.617
64.35

64.853
64.59
64.33

$\begin{array}{llll}65.872 & 65.846 & 65.820 & 65.794 \\ 65.611 & 65.584 & 65.558 & 65.537\end{array}$

$\begin{array}{lllll}65.349 & 65.323 & 65.297 & 65.071\end{array}$

$65.088 \quad 65.062 \quad 65.036 \quad 65.009$

$\begin{array}{llll}64.827 & 64 \cdot 800 & 64 \cdot 774 & 64 \cdot 748 \\ 64.565 & 64.539 & 64.513 & 64 \cdot 0487\end{array}$

$\begin{array}{llllll}64.095 & 64.069 & 64.042 & 64.016 & 63.990 & 63.064\end{array}$

0.276711

0.27671

0.07671

0.276711

0.276710

0.776710

0.276710

0.276710

0.276709

0.276709

0.276709

0.776709

0.276708

0.276708
0.276708
0.276708

0.276708

0.276708

0.276708

0.276707

0.276707

0.276707
0.276707
0.276707

0.276707

0.276707

0.276706

0.276706

0.276706

0.27670

0.27670

0.276705

0.276705

0.27670

0.276704
0.2767
0.276704

0.276704

0.27670

0.276704

0.276703

0.276703
0.276703

0.276703

$60.95960 .933 \quad 60.907 \quad 60.881 \quad 60.855 \quad 60.828$

$\begin{array}{llllll}60.698 & 50.672 & 60.646 & 60.620 & 60.593 & 60.567 \\ 60.437 & 60.411 & 60.384 & 60.358 & 60.332 & 60.306\end{array}$

$\begin{array}{llllll}60.175 & 60.149 & 60.123 & 60.097 & 60.071 & 60.045 \\ 50.014 & 50.888 & 50.862 & 50.836 & 50.811 & 50.783\end{array}$

$\begin{array}{lllllll}59.653 & 59.627 & 59.601 & 59.575 & 59.548 & 59.5 ? 2\end{array}$

$\begin{array}{llllll}5.392 & 59.366 & 59.340 & 59.313 & 59.287 & 59.261\end{array}$

$\begin{array}{llllll}59.130 & 59.104 & 59.078 & 59.052 & 59.026 & 59.000 \\ 58.869 & 58.843 & 58.817 & 58.791 & 55.765 & 58.739\end{array}$

$58.608 \quad 58.582 \quad 58.556 \quad 58.530 \quad 58.504 \quad 58.478$

51.66451 .638

$58.347 \quad 58.32$

$58.086 \quad 58.06$
57.825
57.79

$\begin{array}{llllllll}57.041 & 57.015 & 56.989 & 56.963 & 56.937 & 56.911\end{array}$

$\begin{array}{llllll}56.780 & 56.754 & 56.728 & 56.702 & 56.676 & 56.650\end{array}$

$\begin{array}{lllllll}56.519 & 56.493 & 56.467 & 56.441 & 56.415 & 56.388\end{array}$

$\begin{array}{llllll}56.258 & 56 \cdot 232 & 56 \cdot 206 & 56 \cdot 180 & 56.154 & 56.127 \\ 55.997 & 55.971 & 55.945 & 55.919 & 55.892 & 55.866\end{array}$

$\begin{array}{lllllll}55.736 & 55.710 & 55.684 & 55.657 & 55.631 & 55.605\end{array}$

$\begin{array}{lllllll}55.475 & 55.449 & 55.422 & 55.396 & 55.370 & 55.344\end{array}$

$\begin{array}{llllll}55.214 & 55.187 & 55.161 & 55 \cdot 135 & 55 \cdot 109 & 55 \cdot 083 \\ 54.953 & 54.927 & 54.900 & 54.874 & 54.848 & 54.82 ?\end{array}$

$\begin{array}{llllll}54.953 & 54.927 & 54.900 & 54.874 & 540848 & 54.8822 \\ 54.692 & 54.665 & 54.639 & 54.613 & 54.0577 & 54.561\end{array}$

$\begin{array}{lllllll}54.431 & 54.405 & 54.379 & 54.352 & 54.326 & 54.300\end{array}$

$\begin{array}{lllllll}54.170 & 54.144 & 54.117 & 54.091 & 54.065 & 54.039\end{array}$

$\begin{array}{lllll}53.883 & 53.857 & 53.830 & 53.804 & 53.778\end{array}$

$\begin{array}{llllll}53.648 & 53.621 & 53.595 & 53.569 & 53.543 & 53.517 \\ 53.387 & 53.361 & 53.334 & 53.308 & 53.282 & 53.256\end{array}$

$\begin{array}{lllllll}53.126 & 53.099 & 53.073 & 53.047 & 53.021 & 52.995 \\ 52.865 & 52.839 & 52.812 & 52.786 & 52.760 & 52.734\end{array}$

$\begin{array}{llllll}52.604 & 52.578 & 52.552 & 52.525 & 52.499 & 52.473\end{array}$

$\begin{array}{llllll}52.343 & 52.317 & 52.291 & 52.265 & 52.238 & 52.012\end{array}$

$51.821 \quad 51.705 \quad 51.760 \quad 51.743 \quad 51.9716 \quad 510951$

$51.82151 .795 \quad 51.7690951 .743 \quad 51.716 \quad 51.690$

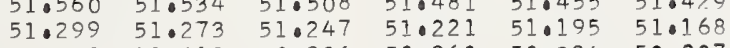

$51.142 \quad 51.116 \quad 51.090 \quad 51.064$

50.777
.004

.005

$50.725 \quad 50.960 \quad 50.0$
50.699

\begin{tabular}{|c|c|c|c|c|c|c|c|c|c|c|}
\hline & .001 & .002 & .003 & .004 & .005 & .006 & .007 & .008 & .009 & .010 \\
\hline $\begin{array}{r}026 \\
0225 \\
.024\end{array}$ & $\begin{array}{l}: 003 \\
: 003 \\
.002\end{array}$ & $\begin{array}{l}: 005 \\
.005 \\
005\end{array}$ & $\begin{array}{l}: 008 \\
0008 \\
.007\end{array}$ & $\begin{array}{r}810 \\
810 \\
010\end{array}$ & $\begin{array}{l}.013 \\
: 013 \\
.012\end{array}$ & $\begin{array}{r}: 016 \\
: 015 \\
.014\end{array}$ & $\begin{array}{r}018 \\
0018 \\
.017\end{array}$ & $\begin{array}{r}.021 \\
: 020 \\
.019\end{array}$ & $\begin{array}{l}: 024 \\
: 023 \\
0222\end{array}$ & $\begin{array}{l}.026 \\
.025 \\
.024\end{array}$ \\
\hline
\end{tabular}

1.710075
1.7101 .02
1.710129
1.710156
1.710182
1.710209
1.710236
1.710263
1.710290
1.710317

1.710343

1.710370
1.710397

1.710451

1.710478

1.710558

1.710612

1.710665

1.710719

$1: 710746$

1.710826

1.710880

1.710934

1.710987

1.711014

1.711095

1.711148

1.711202

1.711256

1.711309

1. 711363

1.711417

1.711440 


.03

$$
\begin{aligned}
& 90.0 \\
& 0.1 \\
& 0.2 \\
& 0.3 \\
& 0.4 \\
& 0.5 \\
& 0.6 \\
& 0.7 \\
& 0.8 \\
& 0.9
\end{aligned}
$$

6191.0

1.

1.2
1.3

1.3
1.04
1.5$$
1.6
$$$$
\begin{aligned}
& 2.1 \\
& 2.2 \\
& 2.3
\end{aligned}
$$

3.1
3.3
3.4
3.5

3.6
3.7

3.8
3.9

6194.0

94.0
4.1
4.2
4.3
4.4
4.5
4.6
4.7
4.8
4.9

6195

5.1
5.2
5.3
5.4

5.5

5.6
5.7
5.8

6196

$$
\begin{array}{r}
6196 . \\
6 . \\
6 . \\
6 . \\
6 . \\
6 . \\
6 . \\
6 . \\
6.0 \\
6 .
\end{array}
$$

6197.

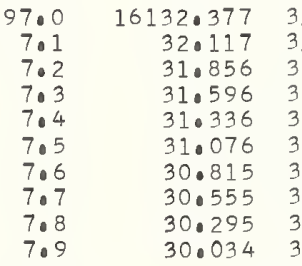

$6198.0 \quad 16129.774 \quad 29.748$

16148.01

$$
\begin{aligned}
& 47.751 \\
& 47.490 \\
& 47.229 \\
& 46.969 \\
& 46.708 \\
& 46.447 \\
& 46.186 \\
& 45.925 \\
& 45.665
\end{aligned}
$$

16145.404

45.143
44.882

44.622

$44.361-44.596$

$44.100 \quad 44.074$

$43.839 \quad 43.813$

43.318

16142.79$$
\begin{aligned}
& 42.536 \\
& 42.276 \\
& 42.015
\end{aligned}
$$

$41.754 \quad 41.72$

$41.233 \quad 41.207$

40.71240.

40.451

$4 \cdot 2$
4.3

40.7
4.8
4.9

.016137 .585 37.585
37.325
37.0559

$\begin{array}{ll}36.804 & 36.77 \\ 36.543 & 36.517\end{array}$

$36.283 \quad 36.257$

$\begin{array}{ll}35.762 & 35.736\end{array}$

$16134.981 \quad 34.95$

340.720
34.460

34.199

33.67933 .65

33.158

$\begin{array}{ll}33.158 & 33.132 \\ 32.898 & 32.872\end{array}$

32.63
150.621
50.360
50.099
49.838
49.577
49.316
49.055
48.794
48.533
48.273

$37.064 \quad 37.03$

$\begin{array}{ll}35.502 & 35.476 \\ 35.241 & 35.215\end{array}$

$.872 \quad 32.1066$

32.820

$\begin{array}{lll}32.351 & 32.325 & 32.299 \\ 32.091 & 32.065 & 32.039 \\ 31.830 & 31.004 & 31.778\end{array}$

31.830
31.510
31.050

31.050

$\begin{array}{ll}31.544 & 31.51 \\ 31.284 & 31.25\end{array}$

$\begin{array}{ll}31.284 & 31.258 \\ 31.024 & 30.998\end{array}$

$\begin{array}{ll}30.763 & 30.737 \\ 30.503 & 30.477\end{array}$

$\begin{array}{ll}30.243 & 30.477 \\ 20.282 & 20.217\end{array}$

$129.774 \quad 29.748$

$\begin{array}{ll}29.514 & 29.488 \\ 29.254 & 29.228\end{array}$

$\begin{array}{ll}29.722 & 29.696 \\ 29.462 & 29.436 \\ 29.202 & 29.176\end{array}$

$\begin{array}{llll}28.993 & 28.968 & 28.942 & 28.916 \\ 28.733 & 28.707 & 28.681 & 28.65 \\ 28.473 & 28.447 & 28.431 & 28.395\end{array}$

$\begin{array}{ll}28.473 & 28.447 \\ 28.213 & 28.187\end{array}$

$\begin{array}{llll}28.213 & 28.187 & 28.161 & 28.13 \\ 27.953 & 27.927 & 27.901 & 27.075\end{array}$

$\begin{array}{llll}27.693 & 27.667 & 27.901 & 27.847 \\ 27.432 & 27.406 & 27.0480 & 27.015 \\ 27.354\end{array}$

$\begin{array}{lll}.04 & .05\end{array}$

50
50
59
49
49
49
48
48
48
48
47
47

50.516
5.25
49.99

50.490
50.229
49.968

.06

.07

.08

.09

$(n-1) \times 1000$

$\lambda(n-1)$

$\begin{array}{ll}0.276698 & 1.712758 \\ 0.276697 & 1.712785 \\ 0.276697 & 1.712812 \\ 0.276697 & 1.712839 \\ 0.276697 & 1.712865 \\ 0.276697 & 1.712892 \\ 0.276697 & 1.712919 \\ 0.276697 & 1.712946 \\ 0.276697 & 1.712973 \\ 0.276696 & 1.713000\end{array}$

0.276696 0.276696 0.276696
0.276696 0.276696 0.276696 0.276695

0.276695

0.276695

0.276695
0.276695

0.0276695

0.276694

0.276694

0.276694

0.276604

0.276694

0.276693

0.276693

0.276693

0.276693

0.276693

0.276693
0.276692

0.276692
0.276692

0.276692

0.276692

0.276692
0.276692

0.276692

0.276692

0.276691

0.276691
0.276691

1.713026

1.713080

1.713107

1.713134

1.713187

.713214
1.713241

1.713268

1.713295
1.713322

1.713348

1.713375
1.713402

1.713429

1.713456
1.713483

1.713509

1.713563

1.713590
1.713617

1.713644

1.713670

1.713697
1.713724

1.713751
1.713778

1.713831

1.713858

1.713912

1.713939
1.713966

1.713966

0.2766

0.276691
0.2766
0.2766

0.276690

0.276690
0.276690
0.276690

0.276690

0.276690

0.276690
0.276690

1.714100

1.714127

1.714180
1.714207

1.714234

1.714261

$\begin{array}{llllll}36.179 & 36.153 & 36.127 & 36.101 & 36.075 & 36.049 \\ 35.918 & 35.892 & 35.866 & 35.840 & 35.814 & 35.788\end{array}$

$\begin{array}{lllllll}35.658 & 35.632 & 35.606 & 35.580 & 35.554 & 350528\end{array}$

$\begin{array}{llllll}35.397 & 35.371 & 35 \cdot 345 & 35 \cdot 319 & 35.293 & 35.267 \\ 35.137 & 35.111 & 35.085 & 35.059 & 350033 & 350007\end{array}$

0.276689

0.276689

0.076689

0.276689

0.276689

0.276689

0.276688

0.276688

0.276688

0.276688

0.776688

0.276688
0.276687

0.276687

0.276687

0.276687

1.714314

1.714368

1.714395

1.714422

1.714475

1.714502
1.714529

1.714556

1.714583

1.714636

179690

1.714717

1.714770

1.714797

$\begin{array}{llllll}30.711 & 30.685 & 30.659 & 30.633 & 30.607 & 30.581\end{array}$

$\begin{array}{llllll}30.451 & 30.425 & 30.399 & 30.373 & 30.347 & 30.321 \\ 30.191 & 30.165 & 30.139 & 30.113 & 30.087 & 30.061\end{array}$

0.276687

1,714851

$0.276687 \quad 1.714905$

$\begin{array}{ll}0.276687 & 1.714031 \\ 0.276687 & 1.714958 \\ 0.276686 & 1.714985\end{array}$

$0.276686 \quad 1.714985$

$\begin{array}{ll}0.276686 & 1.715012 \\ 0.276686 & 1.715030 \\ 0.276686 & 1.715066\end{array}$

$0.776686 \quad 1.715066$

$\begin{array}{ll}0.276686 & 1.715092 \\ 0.276686 & 1.715119\end{array}$

$0.276685 \quad 1.715173$

$0.276685 \quad 1.715200$

$\begin{array}{ll}0.776685 & 1.0715227 \\ 0.276685 & 9.715253\end{array}$

$0.276685 \quad \frac{1}{1.7115280}$

0.10715307

0.276684

0.276684

1715361

1.715388

$\begin{array}{lllllllllll}9.7 & 25.352 & 25.586 & 25.560 & 25.534 & 25.508 & 25.482 & 25.456 & 25.430 & 25 \cdot 404 & 25.378 \\ 9 & 25.3500 & 25.273 & 25.247 & 25.222 & 25.196 & 25 \cdot 170 & 25.143 & 25.117\end{array}$

$\begin{array}{llll}25.091 & 25.066 & 25.040 & 25.014 \\ 24.832 & 24.805 & 24.779 & 24.753\end{array}$

$\begin{array}{llllllllll} & .001 & .002 & .003 & .004 & .005 & .006 & .007 & .008 & .009 \\ .026 & .003 & .005 & .008 & .010 & .013 & .016 & .018 & .021 & .024 \\ .025 & .003 & .005 & .008 & .010 & .013 & .015 & .018 & .020 & .023\end{array}$

.010

.026 


$.01 \quad .02$

.03

.04

.05

.06

.07

.08

.09

$(n-1) \times 1000$

$\lambda(n-1)$

6200.0
0.12
0.2
0.3
0.4
0.5
0.6
0.7
0.8
0.9

$\begin{array}{ll}0.1 & 1612 \\ 0.2 & 24.0 \\ 0.3 & 23.7 \\ 0.4 & 23.5 \\ 0.5 & 23.2 \\ 0.6 & 23.0 \\ 0.7 & 22.7 \\ 0.8 & 22.4 \\ 0.9 & 22.02\end{array}$

$24 \cdot 31$
$24 \cdot 05$
$23 \cdot 7$
$23 \cdot 531$
$23 \cdot 27$
$23 \cdot 01$
22.751
22.491
22.231

$\begin{array}{lll}24.545 & 24.519 & 24 \\ 24.285 & 24.259 & 24 \\ 24.025 & 23.999 & 23 \\ 23.765 & 23.739 & 23 \\ 23.505 & 23.479 & 23 \\ 23.245 & 23.219 & 23 \\ 22.985 & 22.959 & 22 \\ 22.725 & 22.699 & 22 \\ 22.465 & 22.439 & 22 \\ 22.205 & 22.179 & 22\end{array}$

3
3
3
3
3

$\begin{array}{ll}24.467 & 24.441 \\ 24.207 & 24.181 \\ 23.947 & 23.921 \\ 23.687 & 23.661 \\ 23.427 & 23.401 \\ 23.167 & 23.141 \\ 22.907 & 22.881 \\ 22.647 & 22.621 \\ 22.387 & 22.361 \\ 22.127 & 22.101\end{array}$

$\begin{array}{llll}24.415 & 24.389 & 24 \cdot 363 & 24.337 \\ 24.155 & 24.129 & 24.103 & 24.077\end{array}$

$\begin{array}{llll}23.895 & 23.869 & 23.843 & 23.817\end{array}$

$\begin{array}{llll}23.635 & 23.609 & 23.583 & 23.557 \\ 23.375 & 23.349 & 23.323 & 23.297\end{array}$

$\begin{array}{llll}23.115 & 23.089 & 23.063 & 23.037\end{array}$

$\begin{array}{llll}22.855 & 22.829 & 22.803 & 22.777 \\ 22.595 & 22.569 & 22.543 & 22.517\end{array}$

6201.0

$1: 1$
$1: 2$
$1: 3$
$1: 5$
$1: 0$
$1: 7$
109

$16121.971 \quad 21.945$

$21.919 \quad 21.893$

$21.867 \quad 21.841$

$\begin{array}{llll}22.335 & 22.309 & 22.283 & 22.257 \\ 22.075 & 22.049 & 22.023 & 21.997\end{array}$

0.276684

0.276684

0.276684

0.276683

0.276683

0.276683

0.276683

$\begin{array}{llll}21.711 & 21.685 & 21.659 & 21.6333 \\ 21.451 & 21.425 & 21.399 & 21.373\end{array}$

$\begin{array}{llll}21.191 & 21.165 & 21.139 & 21.113 \\ 20.931 & 20.905 & 20.879 & 20.853\end{array}$

$\begin{array}{llll}20.671 & 20.645 & 20.619 & 20.593\end{array}$

$\begin{array}{llll}20.411 & 20.385 & 20.359 & 20.333\end{array}$

$19.891 \quad 19.865$

19.632

$21.607 \quad 21.58$

$\begin{array}{llll}21.815 & 21.789 & 21.763 & 21.737\end{array}$

$\begin{array}{llllll}20.827 & 20.801 & 20.775 & 20.749 & 20.723 & 20.697\end{array}$

$\begin{array}{llllll}20.567 & 20.541 & 20.515 & 20.489 & 20.463 & 20.437 \\ 20.307 & 20.281 & 20.255 & 20.229 & 20.203 & 20.177\end{array}$

0.276683

0.276682

0.276682

0.276682

0.276682

0.27668

6202.0

16119.372

19.346

$19.579 \quad 19.553$

$\begin{array}{llllll}19.787 & 19.761 & 19.735 & 19.710 & 19.684 & 19.658 \\ 19.527 & 19.501 & 19.475 & 19.449 & 19.423 & 19.397\end{array}$

0.276681

0.276681

0.276681

$\begin{array}{llllllllll}18.852 & 18.826 & 18.800 & 18.774 & 18.748 & 18.722 & 18.696 & 18.670 & 18.644 & 18.618\end{array}$

$\begin{array}{llllllllll}18.592 & 18.566 & 18.540 & 18.514 & 18.488 & 18.462 & 18.436 & 18.410 & 18.384 & 18.358\end{array}$

$\begin{array}{llllllllll}18.332 & 18.306 & 18.280 & 18.254 & 18.228 & 18.202 & 18.176 & 18.150 & 18.124 & 18.098\end{array}$

$\begin{array}{llllllllll}17.812 & 17.786 & 17.780 & 17.734 & 17.708 & 17.682 & 17.656 & 17.630 & 17.604 & 17.578\end{array}$

$\begin{array}{llllllllll}17.552 & 17.526 & 17.500 & 17.474 & 17.448 & 17.423 & 17.397 & 17.371 & 17.345 & 17.319 \\ 17.292 & 17.267 & 17.241 & 17.215 & 17.189 & 17.163 & 17.137 & 17.111 & 17.085 & 17.059\end{array}$

0.276681

0.276680

0.276680

6203.

$\begin{array}{lll}16.747 & 16.721 & 16.695\end{array}$

16.92916 .903

$\begin{array}{lllll}16.617 & 16.591 & 16.565 & 16.539\end{array}$

3

$\begin{array}{ll}16.513 & 16.747 \\ 16.253 & 16.487\end{array}$

$\begin{array}{llll}16.253 & 16.227 & 16.461 & 16.435\end{array}$

$\begin{array}{ll}16.669 & 16.643 \\ 16.409 & 16.38\end{array}$

0.276680

0.276680

0.276680

0.276679

$\begin{array}{llllllllll}15.734 & 15.708 & 15.682 & 15.656 & 15.630 & 15.604 & 15.578 & 15.552 & 15.526 & 15.500\end{array}$

$\begin{array}{llllllllll}15.474 & 15.448 & 15.422 & 15.396 & 15.370 & 15.344 & 15.318 & 15.292 & 15.266 & 15.240\end{array}$

$\begin{array}{llllllllll}14.954 & 14.928 & 14.902 & 14.876 & 14.850 & 14.824 & 14.798 & 14.773 & 14.747 & 14.721\end{array}$

$\begin{array}{llllllllll}14.695 & 14.669 & 14.643 & 14.617 & 14.591 & 14.565 & 14.539 & 14.513 & 14.487 & 14.461\end{array}$

0.276679

0.276679

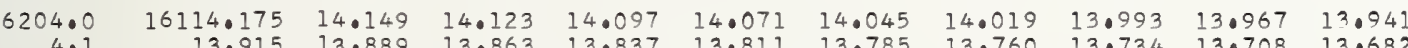

$\begin{array}{lllllllllll}4.1 & 13.915 & 13.889 & 13.863 & 13.837 & 13.811 & 13.785 & 13.760 & 13.734 & 13.708 & 13.682 \\ 4.2 & 13.656 & 13.630 & 13.604 & 13.578 & 13.552 & 13.526 & 13.500 & 13.474 & 13.448 & 13.422\end{array}$

$\begin{array}{lllllllllll}4.2 & 13.656 & 13.630 & 13.604 & 13.578 & 13.552 & 13.526 & 13.500 & 13.474 & 13.448 & 13.422 \\ 4.3 & 13.396 & 13.370 & 13.344 & 13.318 & 13.292 & 13.266 & 13.240 & 13.214 & 13.188 & 13.162\end{array}$

$\begin{array}{lllllllllll}4.4 & 13.136 & 13.110 & 13.084 & 13.058 & 13.032 & 13.006 & 12.980 & 12.954 & 12.928 & 12.90 \\ 4.5 & 12.877 & 12.851 & 12.825 & 12.799 & 12.773 & 12.747 & 12.721 & 12.695 & 12.669 & 12.643\end{array}$

$\begin{array}{lllllllllll}4.6 & 12.617 & 12.591 & 12.565 & 12.539 & 12.513 & 12.487 & 12.461 & 12.435 & 12.409 & 12.643 \\ 4.7 & 12.357 & 12.331 & 12.305 & 12.579 & 12.553 & 12.027 & 12.201 & 12.175 & 120149 & 12.123\end{array}$

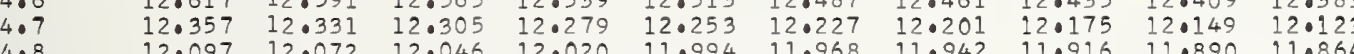

4.9

12.097
11.838

12.072

6205.

5.1
5.2
5.3

16111.578

$\begin{array}{rr}111.578 & 11.5 \\ 11.318 & 11.2 \\ 11.059 & 11.0\end{array}$

$\begin{array}{llll}10.799 & 10.773 & 11.007 & 10.98 \\ 10.747 & 10.721\end{array}$

$\begin{array}{llll}10.540 & 10.514 & 10.488 & 10.462\end{array}$

$10.280 \quad 10.254$

$09.761 \quad 09.735$

$\begin{array}{ll}09.501 & 09.475 \\ 09.242 & 09.216\end{array}$

$00.969 \quad 0.202$

$\begin{array}{ll}.969 & 09.943 \\ 0.709 & 09.683\end{array}$

5.7

5.8
5.9

6206.

6.0
6.1
6.3
6.5
6.6
6.7
6.8
6.9

16108.982

$\begin{array}{ll}08.982 & 08.996 \\ 08.723 & 08.696\end{array}$

$\begin{array}{ll}08.723 & 08.696 \\ 08.463 & 08.437\end{array}$

$08.203 \quad 08.177$

$\begin{array}{lll}07.944 & 07.918 & 07.892\end{array}$

$07.684 \quad 07.658$

$\begin{array}{lll}07.425 & 07.399 & 07.373\end{array}$

$\begin{array}{llll}07.165 & 07.139 & 07.113 & 07.347\end{array}$

$\begin{array}{llll}06.906 & 06.880 & 06.854 & 06.828 \\ 06.646 & 06.620 & 06.594 & 06.568\end{array}$

11.994
11.734

11.942

$\begin{array}{lll}11.916 & 11.890 & 11.864 \\ 11.656 & 11.630 & 11.604\end{array}$

0.27667

0.276679

0.276678

0.276678

.276678

0.276678

0.276677

0.276677

0.276677

0.276677

0.276677

0.276677

0.276676

0.276676

0.276676

0.276676

0.276675

0.276675

0.276675

0.276675

$\begin{array}{lllllllllll}6207.0 & 16106.387 & 06.361 & 06.335 & 06.309 & 06.283 & 06.257 & 06.231 & 06.205 & 06.179 & 06.153\end{array}$

$\begin{array}{lllllllllll}7.1 & 06.127 & 06.101 & 06.075 & 06.049 & 06.024 & 05.998 & 05.972 & 05.946 & 05.920 & 05.894 \\ 7.2 & 05.868 & 05.842 & 05.816 & 05.790 & 05.764 & 05.738 & 05.712 & 05.686 & 05.660 & 05.634\end{array}$

7.

$05.608 \quad 05.582 \quad 05.556 \quad 05.531$

$\begin{array}{lllllllllll}0.349 & 05.323 & 05.297 & 05.271 & 05.245 & 05.479 & 05.453 & 05.427 & 05.401 & 05.375\end{array}$

$\begin{array}{lllllllllll}05.089 & 05.063 & 05.037 & 05.011 & 04.986 & 05.219 & 05.193 & 05.167 & 05.141 & 05.115\end{array}$

$\begin{array}{lllllllllll}04.830 & 04.804 & 04.778 & 04.752 & 04.726 & 04.700 & 04.674 & 04.648 & 04.622 & 04.596\end{array}$

$\begin{array}{llllllllll}04.571 & 04.545 & 04.519 & 04.493 & 04.467 & 04.441 & 04.415 & 04.389 & 04.363 & 04.337\end{array}$

$\begin{array}{llllllllll}04.311 & 04.285 & 04.259 & 04.233 & 04.207 & 04.181 & 04.155 & 04.130 & 04.104 & 04.078 \\ 04.052 & 04.026 & 04.000 & 03.974 & 03.948 & 03.922 & 03.896 & 03.870 & 03.844 & 03.818\end{array}$

0.276675

0.276675

0.276674
0.276674

0.276674

0.276674

0.276674

0.276674
0.276673

.7715441

1.715495

1.715549

1.715602

1.7156296

1.715710
1.715736

1.715763

1.795817

1.715871

1.715924

1.715978

1.716032

1.716058
1.716085

1.716112

1.716166

1.716246

1.716273

1.716300
1.716327

1.716354

.716407

1.716461

1.716515

1.716541

1.716595

1.716649

1.716676
1.716702

1.716729

1.916783

1.716837

1.716890

1.716917

1.716971
1.716998

1.917051

1.7171105
1.711132

1.717159

1.717212

1.017256
1.0717293

1.717320

10717373

1071727

1.717481

10.717507

$0.276673 \quad 1.717588$

$\begin{array}{llllllllllll}6208.0 & 16103.792 & 03.766 & 03.740 & 03.714 & 03.688 & 03.663 & 03.637 & 03.611 & 03.585 & 03.559\end{array}$

$\begin{array}{llllllllllll}8.1 & 03.533 & 03.507 & 03.481 & 03.455 & 03.429 & 03.403 & 03.377 & 03.351 & 03.325 & 03.299 \\ 8.2 & 03.274 & 03.248 & 03.222 & 03.196 & 03.170 & 03.144 & 03.118 & 03.092 & 03.066 & 03.040\end{array}$

$\begin{array}{lllllllllll}8.3 & 03.014 & 02.988 & 02.962 & 02.936 & 02.910 & 02.884 & 02.858 & 02.833 & 02.807 & 02.781\end{array}$ $\begin{array}{llllllllll}02.755 & 02.729 & 02.703 & 02.677 & 02.651 & 02.625 & 02.599 & 02.573 & 02.547 & 02.521\end{array}$ $\begin{array}{llllllllll}02.236 & 02.210 & 02.444 & 02.417 & 02.391 & 02.365 & 02.340 & 02.314 & 02.288 & 02.262 \\ 0.158 & 02.132 & 02.106 & 02.080 & 02.054 & 02.028 & 02.003\end{array}$

$\begin{array}{llllllllll}01.977 & 01.951 & 01.925 & 01.899 & 01.873 & 01.847 & 01.821 & 01.795 & 01.769 & 01.743\end{array}$

$\begin{array}{llllllllll}01.717 & 01.691 & 01.665 & 01.640 & 01.614 & 01.588 & 01.562 & 01.536 & 01.510 & 01.484 \\ 01.458 & 01.432 & 01.406 & 01.380 & 01.354 & 01.328 & 01.302 & 01.276 & 01.250 & 01.224\end{array}$

0.276673
0.276673
0.27653

0.0276673

0.276673

0.276673
0.276672
0.27672

0.276572

0.0276672

0.0276572
0.27672

0.0276672

0.27667

0.276671

0.276671

0.276671

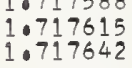

1.0717668

1.071722

1. 0717776

1.717856

1.717910

10717939

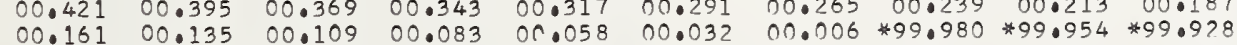

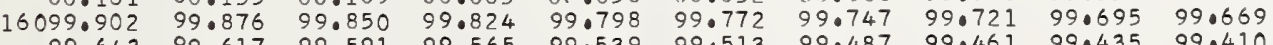

$\begin{array}{llllllllll}99.643 & 99.617 & 99.591 & 99.565 & 99.539 & 99.513 & 99.487 & 99.461 & 99.435 & 99.410 \\ 99.384 & 99.358 & 99.332 & 99.306 & 99.280 & 99.254 & 99.228 & 99.202 & 99.176 & 99.150\end{array}$

$\begin{array}{llllllllll}99.124 & 99.099 & 99.073 & 99.047 & 99.021 & 98.995 & 98.969 & 98.943 & 98.917 & 98.891 \\ 98.865 & 98.839 & 98.813 & 98.787 & 98.761 & 98.735 & 98.710 & 98.684 & 98.658 & 98.632\end{array}$

$\begin{array}{lllllll}.001 & .002 & .003 & .004 & .005 & .006 & .007\end{array}$

.010

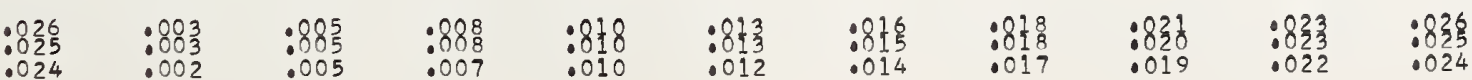




.04

.580 7.828

3.12

$3 \cdot 3$

3.5

3.6 3. 8

5.1
5.2
50
5.4
5.5
50.6
5.7
5.8 $16085.655 \quad 85.629$ 85.396 $85.137 \quad 85.11$ $\begin{array}{ll}84.878 & 84.85 \\ 84.620 & 84.594\end{array}$ $84.361 \quad 84.335$ $84.102 \quad 84.07$ $83.843 \quad 83.817$ $\begin{array}{llll}83.584 & 83.559 & 83.533 & 83.507 \\ 83.326 & 83.300 & 83.274 & 83.248\end{array}$ 86.120
85.862

90.78190 .755

90.263
90.260 .237 $\begin{array}{ll}89.745 & 89.719 \\ 89.486 & 89.460\end{array}$ $89.227 \quad 89.201$

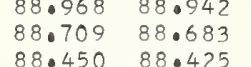
$\begin{array}{llllll}98.502 & 98.476 & 98.450 & 98.425 & 98.398 & 98.372 \\ 98.243 & 98.217 & 98.191 & 98.165 & 98.139 & 98.113\end{array}$ $\begin{array}{llllll}98.243 & 98.217 & 98.191 & 98.165 & 98.139 & 98.113\end{array}$

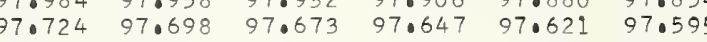

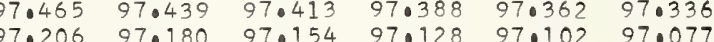

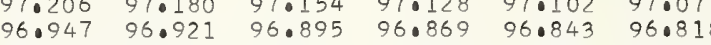

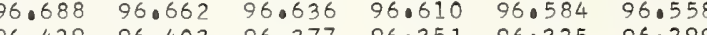
$\begin{array}{llllll}96.170 & 96.403 & 96.377 & 96.351 & 96.325 & 96.29 \\ 96.144 & 96.118 & 96.092 & 96.066 & 96.040\end{array}$

$\begin{array}{llllll}95.911 & 95.885 & 95.859 & 95.833 & 95 \cdot 807 & 95.781\end{array}$ $95.651 \quad 95.625 \quad 95.599 \quad 95.573 \quad 95.548 \quad 95.522$ $\begin{array}{llllll}95.392 & 95.366 & 95.340 & 95.315 & 95.289 & 95.263 \\ 95.133 & 95.107 & 95.081 & 95.055 & 95.029 & 95.004\end{array}$ $\begin{array}{llllll}94.874 & 94.848 & 94.822 & 94.796 & 94.770 & 94.744\end{array}$ $\begin{array}{lllllll}94.615 & 94.589 & 94.563 & 94.537 & 94.511 & 94.485\end{array}$ $\begin{array}{llllll}94.356 & 94.330 & 94.304 & 94.278 & 94.252 & 94.226\end{array}$ $\begin{array}{lllllll}94.096 & 94.071 & 94.045 & 94.019 & 93.993 & 93.967\end{array}$

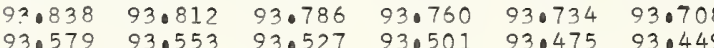
$93.319 \quad 93.293 \quad 93.268 \quad 93.242 \quad 93.216 \quad 93.190$ $\begin{array}{llllll}93.060 & 93.035 & 93.009 & 92.983 & 92.957 & 92.931\end{array}$ $92.801992 .775 \quad 92.750 \quad 92.724 \quad 92 \cdot 698 \quad 92.672$ $\begin{array}{llllll}92.283 & 92.257 & 92.231 & 92.205 & 92.180 & 92.154\end{array}$ $\begin{array}{llllll}92.024 & 91.998 & 91.973 & 91.947 & 91.921 & 91.895\end{array}$ $\begin{array}{llllll}91.765 & 91.739 & 91.713 & 91.687 & 91.661 & 91.636\end{array}$

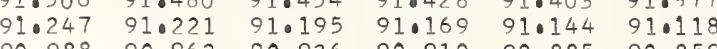
$\begin{array}{llllll}90.729 & 90.703 & 90.577 & 90.651 & 90.625 & 90.600\end{array}$

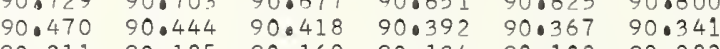
$\begin{array}{llllll}90.211 & 90.185 & 90.160 & 90.134 & 90.108 & 90.08\end{array}$ $\begin{array}{llllll}89.693 & 89.926 & 89.900 & 89.875 & 89.849 & 89.823\end{array}$ $\begin{array}{lllllll}89.434 & 89.408 & 89.383 & 89.357 & 89.331 & 89.305\end{array}$ $\begin{array}{lllllll}89.175 & 89.150 & 89.124 & 89.098 & 89.072 & 89.046\end{array}$ $\begin{array}{llllll}88.916 & 88.891 & 88.865 & 88.839 & 88.813 & 88.787 \\ 88.658 & 88.632 & 88.606 & 88.580 & 88.554 & 88.528\end{array}$ $\begin{array}{llllll}88.658 & 88.632 & 88.606 & 88.580 & 88.554 & 88.528 \\ 88.399 & 88.373 & 88.347 & 88.321 & 88.295 & 88.269\end{array}$ $\begin{array}{llllll}88.140 & 88.114 & 88.088 & 88.06 ? & 88.036 & 88.010 \\ 87.881 & 87.855 & 87.829 & 87.803 & 87.0777 & 87.751\end{array}$ $\begin{array}{llllll}87.881 & 87.855 & 87.829 & 87.803 & 87.777 & 87.751 \\ 87.622 & 87.596 & 87.570 & 87.544 & 87.518 & 87.492\end{array}$ $\begin{array}{llllll}87.363 & 87.337 & 87 \cdot 311 & 87.286 & 87.260 & 87.234\end{array}$ \begin{tabular}{llllll}
86.845 & 86.819 & 86.794 & 87.026 & 87.001 & 86.768 \\
86.586 & 86.561 & 86.535 & 86.509 & 86.742 & 86.716 \\
\hline
\end{tabular} $\begin{array}{llllll}86.328 & 86.561 & 86.535 & 86.509 & 86.483 & 86.7167 \\ 86.302 & 86.276 & 86.250 & 86.224 & 86.198\end{array}$ $\begin{array}{lllllll}86.069 & 86.043 & 86.017 & 85.991 & 85.965 & 85.939 \\ 85.810 & 85.784 & 85.758 & 85.732 & 85.706 & 85.581\end{array}$

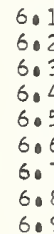

6.3

6.3
6.4
6.5

6.5

6.7

6.9

6217.0 $7: 1$

$7: 3$

7.6
7.7
7.8

7.8
7.9

621800<smiles>C1C2CC1C2</smiles>

8.2
8.3

8.4
8.5

8.6
8.7

8.8 82.808

83.04
82.782

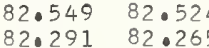
$82.032 \quad 82.006$ $81.515 \quad 81.489$ $81.256 \quad 81.230$ $80.997 \quad 80.971$

83.01
82.75 82.498 82.239 $81.980 \quad 81.954$ \begin{tabular}{lll}
81.204 & 81.437 \\
\hline 1.178
\end{tabular} $6080.480 \quad 80.45$ $\begin{array}{ll}80.221 & 80.19 \\ 79.963 & 70.937\end{array}$ $\begin{array}{ll}79.963 & 79.93 \\ 79.704 & 79.678\end{array}$ $\begin{array}{llll}79.187 & 79.420 & 79.394 & 79.36\end{array}$ $79.18779 .161279 .135 \quad 79 \cdot 109$ $\begin{array}{llll}78.928 & 78.902 & 78.877 & 78.85 \\ 78.670 & 78.644 & 78.618 & 78.59 \\ 78.411 & 78.385 & 78.359 & 78.33\end{array}$ $\begin{array}{ll}78.411 & 78.385 \\ 78.152 & 78.126\end{array}$ 78.359
78.101 $16077.894 \quad 77.868$ $\begin{array}{ll}77.635 & 77.60 \\ 77.377 & 77.35 \\ 77.118 & 77.09\end{array}$

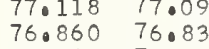
$\begin{array}{ll}76.860 & 76.83 \\ 76.601 & 76.575\end{array}$ 77.842
77.58

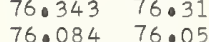
77.32
77.067

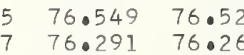
$76.058 \quad 76.032 \quad 76.006$ $\begin{array}{ll}75.825 & 75.800 \\ 75.567 & 75.541\end{array}$

6219. 9.1
9.2
9.3
9.4
9.5
9.6
907
908
9.9 9.4 9.8

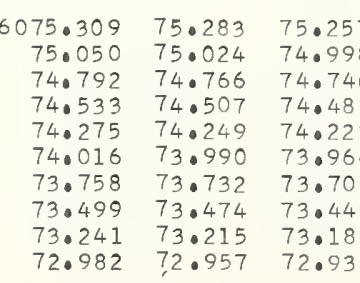

\section{$(n-1) \times 1000 \quad \lambda(n-1)$}

$\begin{array}{ll}0.276671 & 1.718125 \\ 0.276671 & 1.718151 \\ 0.276670 & 1.718178 \\ 0.276670 & 1.718205 \\ 0.276670 & 1.718233 \\ 0.276670 & 1.798259 \\ 0.276670 & 1.7798286 \\ 0.276670 & 1.7183112 \\ 0.276670 & 1.718339 \\ 0.276669 & 1.718366\end{array}$

0.27666

0.0276669

0.276669

0.276669

0.276669

0.276668

0.276668

0.276668

0.276668

0.276668

0.276667

0.276667

0.276667
0.276667

0.276667

0.276666
0.276666

0.276666

0.276666

0.276666

0.276666
0.276666

0.276665

0.276565

0.276665
0.276665

0.276665
0.276665

0.276665
0.276664
0.276564

0.276664

0.276664
0.276664

0.276664

0.2766644
0.276664

0.276664

0.276663

0.276663

0.276663

0.276663 


.05

.06

.07

.08

\begin{tabular}{|c|c|c|c|c|c|c|c|c|c|c|c|c|}
\hline $\begin{array}{r}20.0 \\
0.1 \\
0.2 \\
0.3 \\
0.4 \\
0.5 \\
0.6 \\
0.7 \\
0.8 \\
0.9\end{array}$ & $\begin{array}{r}6072.724 \\
72.466 \\
72.207 \\
71.949 \\
71.691 \\
71.432 \\
71.174 \\
70.916 \\
70.657 \\
70.399\end{array}$ & $\begin{array}{l}72.698 \\
72.440 \\
72.181 \\
71.923 \\
71.665 \\
71.406 \\
71.148 \\
70.890 \\
70.631 \\
70.373\end{array}$ & $\begin{array}{l}72.672 \\
72.414 \\
72.156 \\
71.897 \\
71.639 \\
71.381 \\
71.122 \\
70.864 \\
70.605 \\
70.347\end{array}$ & $\begin{array}{l}72.647 \\
72.388 \\
72.130 \\
71.871 \\
71.613 \\
71.355 \\
71.096 \\
70.838 \\
70.580 \\
70.321\end{array}$ & $\begin{array}{l}72.621 \\
72.362 \\
72.104 \\
71.845 \\
79.587 \\
71.329 \\
71.070 \\
70.812 \\
70.554 \\
70.296\end{array}$ & $\begin{array}{l}72.595 \\
72.336 \\
72.078 \\
71.820 \\
71.561 \\
71.303 \\
71.045 \\
70.786 \\
70.528 \\
70.270\end{array}$ & $\begin{array}{l}72.569 \\
72.311 \\
72.052 \\
71.794 \\
71.536 \\
71.277 \\
71.019 \\
70.761 \\
70.502 \\
70.244\end{array}$ & $\begin{array}{l}72.543 \\
72.285 \\
72.026 \\
71.768 \\
71.510 \\
71.251 \\
70.993 \\
70.735 \\
70.476 \\
70.218\end{array}$ & $\begin{array}{l}72.517 \\
72.259 \\
72.001 \\
71.742 \\
71.484 \\
71.225 \\
70.967 \\
70.709 \\
70.451 \\
70.192\end{array}$ & $\begin{array}{l}72.492 \\
72.233 \\
71.975 \\
71.716 \\
71.458 \\
71.200 \\
70.941 \\
70.683 \\
70.425 \\
70.166\end{array}$ & $\begin{array}{l}0.276657 \\
0.276657 \\
0.276657 \\
0.276657 \\
0.276657 \\
0.276657 \\
0.276656 \\
0.276656 \\
0.276656 \\
0.276656\end{array}$ & $\begin{array}{l}1.720808 \\
1.720835 \\
1.720862 \\
1.720889 \\
1.720915 \\
1.720942 \\
1.720969 \\
1.720906 \\
1.771023 \\
1.721050\end{array}$ \\
\hline $\begin{array}{l}21.0 \\
1: 1 \\
1: 2 \\
1.3 \\
1.4 \\
1.5 \\
1.6 \\
1.7 \\
1.8 \\
1.9\end{array}$ & $\begin{array}{r}670.141 \\
69.882 \\
69.624 \\
69.365 \\
69.107 \\
68.849 \\
68.591 \\
68.332 \\
68.074 \\
67.816\end{array}$ & $\begin{array}{l}70.115 \\
69.856 \\
69.598 \\
69.340 \\
69.081 \\
68.823 \\
68.565 \\
68.307 \\
68.049 \\
67.790\end{array}$ & $\begin{array}{l}70.089 \\
69.831 \\
69.572 \\
69.314 \\
69.056 \\
68.797 \\
68.539 \\
68.281 \\
68.023 \\
67.765\end{array}$ & $\begin{array}{l}70.063 \\
69.805 \\
69.546 \\
69.288 \\
69.030 \\
68.771 \\
68.513 \\
68.255 \\
67.997 \\
67.739\end{array}$ & $\begin{array}{l}70.037 \\
69.779 \\
69.520 \\
69.262 \\
69.004 \\
68.746 \\
68.487 \\
68.229 \\
67.971 \\
67.713\end{array}$ & $\begin{array}{l}70.011 \\
69.753 \\
69.495 \\
69.236 \\
68.978 \\
68.720 \\
68.462 \\
68.204 \\
67.945 \\
67.687\end{array}$ & $\begin{array}{l}69.985 \\
69.727 \\
69.469 \\
69.211 \\
68.952 \\
68.694 \\
68.436 \\
68.178 \\
67.919 \\
67.661\end{array}$ & $\begin{array}{l}69.960 \\
69.701 \\
69.443 \\
69.185 \\
68.926 \\
68.668 \\
68.410 \\
68.152 \\
67.894 \\
67.635\end{array}$ & $\begin{array}{l}69.934 \\
69.676 \\
69.417 \\
69.159 \\
68.901 \\
68.642 \\
68.384 \\
68.126 \\
67.868 \\
67.610\end{array}$ & $\begin{array}{l}69.908 \\
69.650 \\
69.391 \\
69.133 \\
68.875 \\
68.617 \\
68.358 \\
68.100 \\
67.842 \\
67.584\end{array}$ & $\begin{array}{l}0.276656 \\
0.276656 \\
0.276656 \\
0.276656 \\
0.276655 \\
0.276655 \\
0.276655 \\
0.276655 \\
0.276655 \\
0.276655\end{array}$ & $\begin{array}{l}1.721076 \\
1.721103 \\
1.721130 \\
1.721157 \\
1.721184 \\
1.721211 \\
1.721237 \\
1.721264 \\
1.791291 \\
1.771318\end{array}$ \\
\hline $\begin{array}{r}222.0 \\
2.1 \\
2.2 \\
2.3 \\
2.4 \\
2.5 \\
2.6 \\
2.7 \\
2.8 \\
2.9\end{array}$ & $\begin{array}{r}6067.558 \\
67.300 \\
67.042 \\
66.783 \\
66.525 \\
66.267 \\
66.009 \\
65.750 \\
65.492 \\
65.234\end{array}$ & $\begin{array}{l}67.532 \\
67.274 \\
67.016 \\
66.757 \\
66.499 \\
66.241 \\
65.983 \\
65.725 \\
65.467 \\
65.208\end{array}$ & $\begin{array}{l}67.506 \\
67.248 \\
66.990 \\
66.732 \\
66.473 \\
66.215 \\
65.957 \\
65.699 \\
65.441 \\
65.182\end{array}$ & $\begin{array}{l}67.480 \\
67.222 \\
66.964 \\
66.706 \\
66.448 \\
66.189 \\
65.931 \\
65.673 \\
65.415 \\
65.156\end{array}$ & $\begin{array}{l}67.455 \\
67.196 \\
66.938 \\
66.680 \\
66.422 \\
66.163 \\
65.905 \\
65.647 \\
65.389 \\
65.131\end{array}$ & $\begin{array}{l}67.429 \\
67.171 \\
66.912 \\
66.654 \\
66.396 \\
66.138 \\
65.880 \\
65.621 \\
65.363 \\
65.105\end{array}$ & $\begin{array}{l}67.403 \\
67.145 \\
66.886 \\
66.628 \\
66.370 \\
66.112 \\
65.854 \\
65.596 \\
65.337 \\
65.079\end{array}$ & $\begin{array}{l}67.377 \\
67.119 \\
66.861 \\
66.603 \\
66.344 \\
66.086 \\
65.828 \\
65.570 \\
65.312 \\
65.053\end{array}$ & $\begin{array}{l}67.351 \\
67.093 \\
66.835 \\
66.577 \\
66.318 \\
66.060 \\
65.802 \\
65.544 \\
65.286 \\
65.028\end{array}$ & $\begin{array}{l}67.325 \\
67.067 \\
66.809 \\
66.551 \\
66.292 \\
66.034 \\
65.776 \\
65.518 \\
65.260 \\
65.002\end{array}$ & $\begin{array}{l}0.276655 \\
0.276654 \\
0.276654 \\
0.276654 \\
0.276654 \\
0.276654 \\
0.276654 \\
0.276654 \\
0.276654 \\
0.276653\end{array}$ & $\begin{array}{l}1.721345 \\
1.721372 \\
1.721398 \\
1.721425 \\
1.721452 \\
1.721479 \\
1.721506 \\
1.721533 \\
1.721559 \\
1.791586\end{array}$ \\
\hline $\begin{array}{l}23.0 \\
3.1 \\
3.2 \\
3.3 \\
3.4 \\
3.5 \\
3.6 \\
3.7 \\
3.8 \\
3.9\end{array}$ & $\begin{array}{r}064.976 \\
64.718 \\
64.460 \\
64.202 \\
63.943 \\
63.685 \\
63.427 \\
63.169 \\
62.911 \\
62.653\end{array}$ & $\begin{array}{l}64.950 \\
64.692 \\
64.434 \\
64.176 \\
63.918 \\
63.660 \\
63.401 \\
63.143 \\
62.885 \\
62.627\end{array}$ & $\begin{array}{l}64.924 \\
64.666 \\
64.408 \\
64 \cdot 150 \\
63.892 \\
63.634 \\
63.376 \\
63.117 \\
62.859 \\
62.601\end{array}$ & $\begin{array}{l}64.899 \\
64.640 \\
64.382 \\
64.124 \\
63.866 \\
63.608 \\
63.350 \\
63.092 \\
62.833 \\
62.575\end{array}$ & $\begin{array}{l}64.873 \\
64.615 \\
64.356 \\
64.098 \\
63.840 \\
63.582 \\
63.324 \\
63.066 \\
62.808 \\
62.550\end{array}$ & $\begin{array}{l}64.847 \\
64.589 \\
64.331 \\
64.072 \\
63.814 \\
63.556 \\
63.298 \\
63.040 \\
62.782 \\
62.524\end{array}$ & $\begin{array}{l}64.821 \\
64.563 \\
64.305 \\
64.047 \\
63.789 \\
63.530 \\
63.272 \\
63.014 \\
62.756 \\
62.498\end{array}$ & $\begin{array}{l}64.795 \\
64.537 \\
64.279 \\
64.021 \\
63.763 \\
63.505 \\
63.246 \\
62.988 \\
62.730 \\
62.472\end{array}$ & $\begin{array}{l}64.770 \\
64.511 \\
64.253 \\
63.995 \\
63.737 \\
63.479 \\
63.221 \\
62.963 \\
62.705 \\
62.446\end{array}$ & $\begin{array}{l}64 \cdot 744 \\
64.485 \\
64 \cdot 227 \\
63.969 \\
63.711 \\
63.453 \\
63.195 \\
62.937 \\
62.679 \\
62.421\end{array}$ & $\begin{array}{l}0.276653 \\
0.276653 \\
0.276653 \\
0.276653 \\
0.276653 \\
0.276653 \\
0.276652 \\
0.276652 \\
0.276652 \\
0.276652\end{array}$ & $\begin{array}{l}1.721613 \\
1.721640 \\
1.721667 \\
1.721694 \\
1.721720 \\
1.721747 \\
1.721774 \\
1.721801 \\
1.721828 \\
1.721855\end{array}$ \\
\hline $\begin{array}{r}224 \cdot 0 \\
4 \cdot 1 \\
4 \cdot 2 \\
4 \cdot 3 \\
4.4 \\
4.5 \\
4.6 \\
4.7 \\
4.8 \\
4.9\end{array}$ & $\begin{array}{r}6062.395 \\
62.137 \\
61.879 \\
61.621 \\
61.363 \\
61.105 \\
60.847 \\
60.589 \\
60.330 \\
60.073\end{array}$ & $\begin{array}{l}62.369 \\
62.111 \\
61.853 \\
61.595 \\
61.337 \\
61.079 \\
60.821 \\
60.563 \\
60.305 \\
60.047\end{array}$ & $\begin{array}{l}62.343 \\
62.085 \\
61.827 \\
61.569 \\
61.311 \\
61.053 \\
60.795 \\
60.537 \\
60.279 \\
60.021\end{array}$ & $\begin{array}{l}62.317 \\
62.059 \\
61.801 \\
61.543 \\
61.285 \\
61.027 \\
60.769 \\
60.511 \\
60.253 \\
59.995\end{array}$ & $\begin{array}{l}62.292 \\
62.034 \\
61.775 \\
61.517 \\
61.259 \\
61.001 \\
60.743 \\
60.485 \\
60.227 \\
59.969\end{array}$ & $\begin{array}{l}62.266 \\
62.008 \\
61.750 \\
61.492 \\
61.234 \\
60.975 \\
60.717 \\
60.460 \\
60.202 \\
59.943\end{array}$ & $\begin{array}{l}62.240 \\
61.982 \\
61.724 \\
61.466 \\
61.208 \\
60.950 \\
60.692 \\
60.434 \\
60.176 \\
59.918\end{array}$ & $\begin{array}{l}62.214 \\
61.956 \\
61.698 \\
61.440 \\
61.182 \\
60.924 \\
60.666 \\
60.408 \\
60.150 \\
59.892\end{array}$ & $\begin{array}{l}62.188 \\
61.930 \\
61.672 \\
61.414 \\
61.156 \\
60.898 \\
60.640 \\
60.382 \\
60.124 \\
59.866\end{array}$ & $\begin{array}{l}62.163 \\
61.905 \\
61.646 \\
61.388 \\
61.130 \\
60.872 \\
60.614 \\
60.356 \\
60.098 \\
59.840\end{array}$ & $\begin{array}{l}0.276652 \\
0.776652 \\
0.276652 \\
0.276652 \\
0.276651 \\
0.276651 \\
0.276651 \\
0.276651 \\
0.276651 \\
0.276651\end{array}$ & $\begin{array}{l}1.721881 \\
1.721908 \\
1.721935 \\
1.721962 \\
1.721989 \\
1.722016 \\
1.722043 \\
1.722069 \\
1.722096 \\
1.722123\end{array}$ \\
\hline $\begin{array}{r}6225.0 \\
5.1 \\
5.2 \\
5.3 \\
5.4 \\
5.5 \\
5.6 \\
5.7 \\
5.8 \\
5.9\end{array}$ & $\begin{array}{r}16059.815 \\
59.556 \\
59.299 \\
59.041 \\
58.783 \\
58.525 \\
58.267 \\
58.009 \\
57.751 \\
57.493\end{array}$ & $\begin{array}{l}59.789 \\
59.531 \\
59.273 \\
59.015 \\
58.757 \\
58.499 \\
58.241 \\
57.983 \\
57.725 \\
57.467\end{array}$ & $\begin{array}{l}59.763 \\
59.505 \\
59.247 \\
58.989 \\
58.731 \\
58.473 \\
58.215 \\
57.957 \\
57.699 \\
57.441\end{array}$ & $\begin{array}{l}59.737 \\
59.479 \\
59.221 \\
58.963 \\
58.705 \\
58.447 \\
58.189 \\
57.931 \\
57.673 \\
57.416\end{array}$ & $\begin{array}{l}59.711 \\
59.453 \\
59.195 \\
58.937 \\
58.680 \\
58.421 \\
58.164 \\
57.906 \\
57.648 \\
57.390\end{array}$ & $\begin{array}{l}59.686 \\
59.427 \\
59.170 \\
58.911 \\
58.654 \\
58.396 \\
58.138 \\
57.880 \\
57.622 \\
57.364\end{array}$ & $\begin{array}{l}59.660 \\
59.402 \\
59.144 \\
58.886 \\
58.628 \\
58.370 \\
58.112 \\
57.854 \\
57.596 \\
57.338\end{array}$ & $\begin{array}{l}59.634 \\
59.376 \\
59.118 \\
58.860 \\
58.602 \\
58.344 \\
58.086 \\
57.828 \\
57.570 \\
57.312\end{array}$ & $\begin{array}{l}59.608 \\
59.350 \\
59.092 \\
58.834 \\
58.576 \\
58.318 \\
58.060 \\
57.802 \\
57.545 \\
57.286\end{array}$ & $\begin{array}{l}59.582 \\
59.324 \\
59.066 \\
58.808 \\
58.550 \\
58.292 \\
58.035 \\
57.777 \\
57.519 \\
57.261\end{array}$ & $\begin{array}{l}0.276651 \\
0.276650 \\
0.276650 \\
0.276650 \\
0.276650 \\
0.276650 \\
0.276650 \\
0.276650 \\
0.276650 \\
0.276649\end{array}$ & $\begin{array}{l}1.722150 \\
1.722177 \\
1.722204 \\
1.722230 \\
1.722257 \\
1.722284 \\
1.722311 \\
1.722338 \\
1.722365 \\
1.722391\end{array}$ \\
\hline $\begin{array}{r}26.0 \\
6.1 \\
6.2 \\
6.3 \\
6.4 \\
6.5 \\
6.6 \\
6.7 \\
6.8 \\
6.9\end{array}$ & $\begin{array}{r}16057.235 \\
56.977 \\
56.719 \\
56.461 \\
56.203 \\
55.946 \\
55.688 \\
55.430 \\
55.172 \\
54.914\end{array}$ & $\begin{array}{l}57.209 \\
56.951 \\
56.693 \\
56.436 \\
56.178 \\
55.920 \\
55.662 \\
55.404 \\
55.146 \\
54.888\end{array}$ & $\begin{array}{l}57.183 \\
56.926 \\
56.668 \\
56.410 \\
56.152 \\
55.894 \\
55.636 \\
55.378 \\
55.121 \\
54.863\end{array}$ & $\begin{array}{l}57.158 \\
56.900 \\
56.642 \\
56.384 \\
56.126 \\
55.868 \\
55.610 \\
55.353 \\
55.095 \\
54.837\end{array}$ & $\begin{array}{l}57.132 \\
56.874 \\
56.616 \\
56.358 \\
56.100 \\
55.842 \\
55.585 \\
55.327 \\
55.069 \\
54.011\end{array}$ & $\begin{array}{l}57.106 \\
56.848 \\
56.590 \\
56.332 \\
56.075 \\
55.817 \\
55.559 \\
55.301 \\
55.043 \\
54.785\end{array}$ & $\begin{array}{l}57.080 \\
56.822 \\
56.565 \\
56.307 \\
56.049 \\
55.791 \\
55.533 \\
55.275 \\
55.017 \\
54.760\end{array}$ & $\begin{array}{l}57.055 \\
56.797 \\
56.539 \\
56.281 \\
56.023 \\
55.765 \\
55.507 \\
55.249 \\
54.992 \\
54.734\end{array}$ & $\begin{array}{l}57.029 \\
56.771 \\
56.513 \\
56.255 \\
55.997 \\
55.739 \\
55.481 \\
55.224 \\
54.966 \\
54.708\end{array}$ & $\begin{array}{l}57.003 \\
56.745 \\
56.487 \\
56.229 \\
55.971 \\
55.714 \\
55.456 \\
55.198 \\
54.940 \\
54.682\end{array}$ & $\begin{array}{l}0.276649 \\
0.276649 \\
0.276649 \\
0.276649 \\
0.276649 \\
0.276649 \\
0.276648 \\
0.276648 \\
0.276648 \\
0.276648\end{array}$ & $\begin{array}{l}1.722418 \\
1.722445 \\
1.722472 \\
1.722499 \\
1.722526 \\
1.722552 \\
1.722579 \\
1.722606 \\
1.722633 \\
1.722660\end{array}$ \\
\hline $\begin{array}{r}227.0 \\
7.1 \\
7.2 \\
7.3 \\
7.4 \\
7.5 \\
7.6 \\
7.7 \\
7.8 \\
7.9\end{array}$ & $\begin{array}{r}16054.656 \\
54.398 \\
54.141 \\
53.883 \\
53.625 \\
53.368 \\
53.109 \\
52.852 \\
52.594 \\
52.336\end{array}$ & $\begin{array}{l}54.631 \\
54.373 \\
54.115 \\
53.857 \\
53.599 \\
53.342 \\
53.084 \\
52.826 \\
52.568 \\
52.311\end{array}$ & $\begin{array}{l}54.605 \\
54.347 \\
54.089 \\
53.831 \\
53.574 \\
53.316 \\
53.058 \\
52.800 \\
52.543 \\
52.285\end{array}$ & $\begin{array}{l}54.579 \\
54.321 \\
54.063 \\
53.806 \\
53.548 \\
53.290 \\
53.032 \\
52.774 \\
52.517 \\
52.259\end{array}$ & $\begin{array}{l}54.553 \\
54.295 \\
54.038 \\
53.780 \\
53.522 \\
52.264 \\
53.006 \\
52.749 \\
52.491 \\
52.233\end{array}$ & $\begin{array}{l}54.527 \\
54.270 \\
54.012 \\
53.754 \\
53.496 \\
53.238 \\
52.981 \\
52.723 \\
52.465 \\
52.207\end{array}$ & $\begin{array}{l}54.502 \\
54.244 \\
53.986 \\
53.728 \\
53.471 \\
53.213 \\
52.955 \\
52.697 \\
52.439 \\
52.182\end{array}$ & $\begin{array}{l}54.476 \\
54.218 \\
53.960 \\
53.703 \\
53.445 \\
53.187 \\
52.929 \\
52.671 \\
52.414 \\
52.156\end{array}$ & $\begin{array}{l}54.450 \\
54.192 \\
52.935 \\
53.677 \\
53.419 \\
53.161 \\
52.903 \\
52.646 \\
52.388 \\
52.130\end{array}$ & $\begin{array}{l}54.424 \\
54.167 \\
53.909 \\
53.651 \\
53.393 \\
53.135 \\
52.878 \\
52.620 \\
52.362 \\
52.104\end{array}$ & $\begin{array}{l}0.276648 \\
0.276648 \\
0.276648 \\
0.276648 \\
0.276647 \\
0.276647 \\
0.276647 \\
0.276647 \\
0.276647 \\
0.276647\end{array}$ & $\begin{array}{l}1.722687 \\
1.792713 \\
1.722740 \\
1: 722767 \\
1.722794 \\
1.722821 \\
1.722848 \\
1.722874 \\
1.722901 \\
1.722928\end{array}$ \\
\hline $\begin{array}{r}228.0 \\
8.1 \\
8.2 \\
8.3 \\
8.4 \\
8.5 \\
8.6 \\
8.7 \\
8.8 \\
8.9\end{array}$ & $\begin{array}{r}16052.079 \\
51.821 \\
51.563 \\
51.305 \\
51.048 \\
50.790 \\
50.532 \\
50.275 \\
50.017 \\
49.759\end{array}$ & $\begin{array}{l}52.053 \\
51.795 \\
51.537 \\
51.280 \\
51.022 \\
50.764 \\
50.506 \\
50.249 \\
49.991 \\
49.733\end{array}$ & $\begin{array}{l}52.027 \\
51.769 \\
51.511 \\
51.254 \\
50.996 \\
50.738 \\
50.481 \\
50.223 \\
49.965 \\
49.708\end{array}$ & $\begin{array}{l}52.001 \\
51.744 \\
51.486 \\
51.228 \\
50.970 \\
50.713 \\
50.455 \\
50.197 \\
49.940 \\
49.682\end{array}$ & $\begin{array}{l}51.975 \\
51.718 \\
51.460 \\
51.202 \\
50.945 \\
50.687 \\
50.429 \\
50.172 \\
49.914 \\
49.656\end{array}$ & $\begin{array}{l}51.950 \\
51.692 \\
51.434 \\
51.177 \\
50.919 \\
50.661 \\
50.403 \\
50.146 \\
49.888 \\
49.630\end{array}$ & $\begin{array}{l}51.924 \\
51.666 \\
51.408 \\
51.151 \\
50.893 \\
50.635 \\
50.378 \\
50.120 \\
49.862 \\
49.605\end{array}$ & $\begin{array}{l}51.898 \\
51.641 \\
51.383 \\
51.125 \\
50.867 \\
50.610 \\
50.352 \\
50.094 \\
49.837 \\
49.579\end{array}$ & $\begin{array}{l}51.872 \\
51.615 \\
51.357 \\
51.099 \\
50.841 \\
50.584 \\
50.326 \\
50.068 \\
49.811 \\
49.553\end{array}$ & $\begin{array}{l}51.847 \\
51.589 \\
51.331 \\
51.073 \\
50.816 \\
50.558 \\
50.300 \\
50.043 \\
49.785 \\
49.527\end{array}$ & $\begin{array}{l}0.276647 \\
0.276646 \\
0.276646 \\
0.276646 \\
0.276646 \\
0.276646 \\
0.276646 \\
0.276646 \\
0.276646 \\
0.276645\end{array}$ & $\begin{array}{l}1.722955 \\
1.722982 \\
1.723009 \\
1.723035 \\
1.723062 \\
1.773089 \\
1.723116 \\
1.723143 \\
1.723170 \\
1.723196\end{array}$ \\
\hline $\begin{array}{l}29.0 \\
9.1 \\
9.2 \\
9.3 \\
9.4 \\
9.5 \\
9.6 \\
9.7 \\
9.8 \\
9.9\end{array}$ & $\begin{array}{r}049.502 \\
49.244 \\
48.986 \\
48.729 \\
48.471 \\
48.213 \\
47.956 \\
47.698 \\
47.441 \\
47.183\end{array}$ & $\begin{array}{l}49.476 \\
49.218 \\
48.961 \\
48.703 \\
48.445 \\
48.188 \\
47.930 \\
47.672 \\
47.415 \\
47.157\end{array}$ & $\begin{array}{l}49.450 \\
49.192 \\
48.935 \\
48.677 \\
48.419 \\
48.162 \\
47.904 \\
47.647 \\
47.389 \\
47.131\end{array}$ & $\begin{array}{l}49.424 \\
49.167 \\
48.909 \\
48.651 \\
48.394 \\
48.136 \\
47.879 \\
47.621 \\
47.363 \\
47.106\end{array}$ & $\begin{array}{l}49.399 \\
49.141 \\
48.883 \\
48.626 \\
48.368 \\
48.110 \\
47.853 \\
47.595 \\
47.338 \\
47.080\end{array}$ & $\begin{array}{l}49.373 \\
49.115 \\
48.858 \\
48.600 \\
48.342 \\
48.084 \\
47.827 \\
47.569 \\
47.312 \\
47.054\end{array}$ & $\begin{array}{l}49.347 \\
49.089 \\
48.832 \\
48.574 \\
48.317 \\
48.059 \\
47.801 \\
47.544 \\
47.286 \\
47.028\end{array}$ & $\begin{array}{l}49.321 \\
49.063 \\
48.806 \\
48.548 \\
48.291 \\
48.033 \\
47.776 \\
47.518 \\
47.260 \\
47.003\end{array}$ & $\begin{array}{l}49.295 \\
49.038 \\
48.780 \\
48.523 \\
48.265 \\
48.007 \\
47.750 \\
47.492 \\
47.235 \\
46.977\end{array}$ & $\begin{array}{l}49.012 \\
48.754 \\
48.497 \\
48.239 \\
47.982 \\
47.724 \\
47.466 \\
47.209 \\
46.951\end{array}$ & $\begin{array}{l}0.276645 \\
0.276645 \\
0.276645 \\
0.276645 \\
0.276645 \\
0.276645 \\
0.276644 \\
0.276644 \\
0.276644 \\
0.276644\end{array}$ & $\begin{array}{l}1.723223 \\
1.723250 \\
1.723277 \\
1.723304 \\
1.723331 \\
1.723357 \\
1.723384 \\
1.723411 \\
1.723438 \\
1.723465\end{array}$ \\
\hline
\end{tabular}


$\begin{array}{lllllllllll}6230.0 & 16046.925 & 46.900 & 46.874 & 46.848 & 46.822 & 46.797 & 46.771 & 46.745 & 46.719 & 46.694\end{array}$

$\begin{array}{llllllllllll}0.1 & 46.668 & 46.642 & 46.616 & 46.591 & 46.565 & 46.539 & 46.513 & 46.487 & 46.462 & 46.436 \\ 0.2 & 46.410 & 46.385 & 46.359 & 46.333 & 46.307 & 46.281 & 46.256 & 46.230 & 46.204 & 46.178\end{array}$

$\begin{array}{lllllllllll}0.3 & 46.153 & 46.127 & 46.101 & 46.076 & 46.050 & 46.024 & 45.998 & 45.973 & 45.947 & 45.921 \\ 0.4 & 45.895 & 45.869 & 45.844 & 45.818 & 45.792 & 45.766 & 45.741 & 45.715 & 45.689 & 45.663\end{array}$

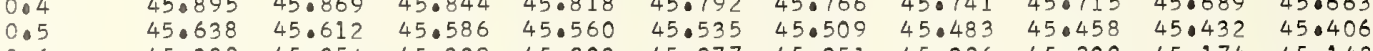

$\begin{array}{llllllllllll}0.6 & 45.380 & 45.354 & 45.329 & 45.303 & 45.277 & 45.251 & 45.226 & 45.200 & 45.174 & 45.148\end{array}$

$\begin{array}{lllllllllll}0.8 & 44.865 & 44.839 & 44.814 & 44.788 & 44.762 & 44.736 & 44.710 & 44.685 & 44.659 & 44.633\end{array}$

$\begin{array}{llllllllll}44.608 & 44.582 & 44.556 & 44.530 & 44.505 & 44.479 & 44.453 & 44.427 & 44.402 & 44.376\end{array}$

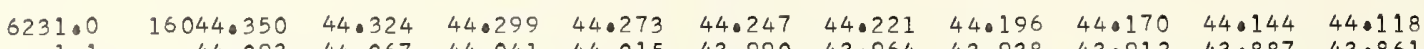

$\begin{array}{llllllllllll}1.1 & 44.093 & 44.067 & 44.041 & 44.015 & 43.990 & 43.964 & 43.938 & 43.912 & 43.887 & 43.861 \\ 1.2 & 43.835 & 43.809 & 43.784 & 43.758 & 43.732 & 43.707 & 43.681 & 43.655 & 43.629 & 43.603\end{array}$

$\begin{array}{lllllllllll}1.2 & 43.835 & 43.809 & 43.784 & 43.758 & 43.732 & 43.707 & 43.681 & 43.655 & 43.629 & 43.603 \\ 1.3 & 43.578 & 43.552 & 43.526 & 43.500 & 43.475 & 43.449 & 43.423 & 43.397 & 43.372 & 43.346\end{array}$

$\begin{array}{llllllllllll}1.4 & 43.320 & 43.294 & 43.269 & 43.243 & 42.217 & 43.192 & 43.166 & 43.140 & 43.114 & 43.088\end{array}$

$\begin{array}{llllllllllll}1.5 & 43.063 & 43.037 & 43.011 & 42.985 & 42.960 & 42.934 & 42.908 & 42.883 & 42.857 & 42.831 \\ 1.6 & 42.805 & 42.780 & 42.754 & 42.728 & 42.702 & 42.677 & 42.651 & 42.625 & 42.599 & 42.574\end{array}$

$\begin{array}{lllllllllll}1.6 & 42.805 & 42.780 & 42.754 & 42.728 & 42.702 & 42.677 & 42.651 & 42.625 & 42.599 & 42.574 \\ 1.7 & 42.548 & 42.522 & 42.496 & 42.470 & 42.445 & 42.419 & 42.393 & 42.368 & 42.342 & 42.316\end{array}$

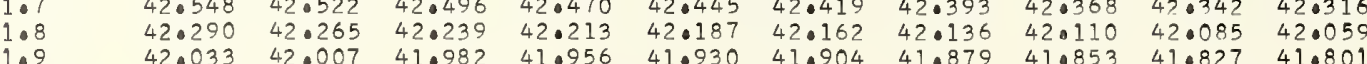

$\begin{array}{rrrrrrrrrrr}6232.0 & 16041.776 & 41.750 & 41.724 & 41.698 & 41.673 & 41.647 & 41.621 & 41.595 & 41.570 & 41.544 \\ 2 & 41.518 & 41.492 & 41.467 & 41.441 & 41.415 & 41.389 & 41.364 & 41.338 & 41.312 & 41.286\end{array}$

$\begin{array}{lllllllllll}2.1 & 41.518 & 41.492 & 41.467 & 41.441 & 41.415 & 41.389 & 41.364 & 41.338 & 41.312 & 41.546 \\ 2.2 & 41.261 & 41.235 & 41.209 & 41.183 & 41.158 & 41.132 & 41.106 & 41.081 & 41.055 & 41.029\end{array}$

$\begin{array}{lllllllllll}2.2 & 41.261 & 41.235 & 41.209 & 41.183 & 41.158 & 41.132 & 41.106 & 41.081 & 41.055 & 41.029 \\ 2.3 & 41.003 & 40.978 & 40.952 & 40.926 & 40.901 & 40.875 & 40.849 & 40.823 & 40.797 & 40.772\end{array}$

$\begin{array}{llllllllllll}2.4 & 40.746 & 40.720 & 40.694 & 40.669 & 40.643 & 40.617 & 40.592 & 40.566 & 40.540 & 40.514\end{array}$

$\begin{array}{llllllllllll}2.5 & 40.489 & 40.463 & 40.437 & 40.411 & 40.386 & 40.360 & 40.334 & 40.309 & 40.283 & 40.257\end{array}$

$\begin{array}{lllllllllll}2.6 & 40.231 & 40.205 & 40.180 & 40.154 & 40.128 & 40.103 & 40.077 & 40.051 & 40.025 & 40.000\end{array}$

$\begin{array}{lllllllllll}2.7 & 39.974 & 39.948 & 39.922 & 39.897 & 39.871 & 39.845 & 39.820 & 39.794 & 39.768 & 39.742\end{array}$

2.8

$\begin{array}{llllllllll}39.717 & 39.691 & 39.665 & 39.639 & 39.614 & 39.588 & 39.562 & 39.536 & 39.511 & 39.485 \\ 39.459 & 39.433 & 39.408 & 39.382 & 39.357 & 39.331 & 39.305 & 39.279 & 39.254 & 39.228\end{array}$

6233.0

:

$3 \cdot 2$

$3 \cdot 5$

$3 \cdot 7$

3.8

6234.0

$\begin{array}{lrr}4.1 & 16036.629 & 36.604\end{array}$

$4 \cdot 2$

$4 \cdot 2$
$4 \cdot 4$

4.4
$4 \bullet 5$
$4 \bullet 6$
$4 \cdot 7$

4.7

4. 8

6235.0

5.

$5 \cdot 2$
5.3
5.4

$5 \cdot 4$

$16039.202 \quad 39 \cdot 176$

$38.945 \quad 38.919$

$\begin{array}{ll}38.687 & 38.662 \\ 38.430 & 38.405\end{array}$

$38.173 \quad 38.1$

$\begin{array}{ll}37.916 & 37.890 \\ 37.658 & 37.632\end{array}$

$\begin{array}{ll}37.401 & 37.375 \\ 37.144 & 37.118\end{array}$

$39.151 \quad 39.125$

$39.099 \quad 39.073$

$39.048 \quad 39.022 \quad 38.996 \quad 38.971$

$\begin{array}{llllllll}38.893 & 38.868 & 38.842 & 38.816 & 38.790 & 38.765 & 38.739 & 38.713 \\ 38.636 & 38.610 & 38.584 & 38.559 & 38.533 & 38.507 & 38.482 & 38.456\end{array}$

$\begin{array}{llllllll}38.379 & 38.353 & 38.327 & 38.302 & 38.276 & 38.250 & 38.224 & 38.199\end{array}$

$\begin{array}{lllllllll}38.121 & 38.096 & 38.070 & 38.044 & 38.019 & 37.993 & 37.967 & 37.941 \\ 37.864 & 37.838 & 37.813 & 37.079 & 37.76 & 37.036 & 37.710 & 37.584\end{array}$

\begin{tabular}{llllllll}
37.864 & 37.838 & 37.813 & 37.787 & 37.761 & 37.736 & 37.710 & 37.684 \\
37.607 & 37.581 & 37.555 & 37.530 & 37.504 & 37.478 & 37.452 & 37.427 \\
\hline 7.350 & 37.324 & 37.298 & 37.272 & 37.247 & 37.221 & 37.195 & 37.170
\end{tabular}

$\begin{array}{ll}7.350 & 37.324 \\ 37.092 & 37.067\end{array}$

37.298 37.27

$36.886 \quad 36.861$

$\begin{array}{ll}37.092 & 37.067 \\ 36.835 & 36.809\end{array}$

$\begin{array}{ll}37.041 & 37.015 \\ 36.784 & 36.758\end{array}$

$\begin{array}{llll}36.989 & 36.964 & 36.938 & 36.912 \\ 36.732 & 36.706 & 36.681 & 36.055\end{array}$

$\begin{array}{ll}36.372 & 36.346 \\ 36.115 & 36.089\end{array}$

36.5
36.321
36.0

$36 \cdot 552$
36.295

$\begin{array}{ll}35.857 & 35.832 \\ 35.600 & 35.575 \\ 35.343 & 35.317\end{array}$

$35.343 \quad 35.317$

$\begin{array}{ll}34.086 & 35.060 \\ 34.829 & 34.803 \\ 34.572 & 34.546\end{array}$

$35.806 \quad 35.780$

$\begin{array}{ll}35.292 & 35.266 \\ 35.035 & 35.009\end{array}$

$\begin{array}{ll}35.035 & 35.009 \\ 34.777 & 34.751\end{array}$

$34 \cdot 572$
34.314

34.520
34.263

34.495
34.237

$\begin{array}{ll}6.526 & 36.500 \\ 36.269 & 36.24\end{array}$

$36.012 \quad 35.986$

$\begin{array}{ll}35.755 & 35.729 \\ 35.498 & 35.47\end{array}$

$\begin{array}{llllll}34.983 & 34.957 & 35.189 & 35.163 & 35.137 & 35.112\end{array}$

$\begin{array}{lllllll}34.726 & 34.700 & 34.674 & 34.649 & 34.623 & 34.597\end{array}$

$16034.057 \quad 34.031$

$34.006 \quad 33.980$

34.469

34.677

$\begin{array}{lll}34.649 & 34.623 & 34.597 \\ 34.392 & 34.366 & 34.340\end{array}$

$33.954 \quad 33.929 \quad 33.903 \quad 33.877 \quad 33.852 \quad 33.826$

$\begin{array}{llll}33.800 & 33.774 & 33.749 & 33.723 \\ 33.543 & 33.517 & 33.491 & 33.466\end{array}$

$33.286 \quad 33.260$

$33.029 \quad 33.003 \quad 32.977 \quad 32.95$

$32.772 \quad 32.746 \quad 32.720 \quad 32.694$

$\begin{array}{llllllllll}32.514 & 32.489 & 32.463 & 32.437 & 32.411 & 32.386 & 32.360 & 32.334 & 32.309 & 32.283 \\ 32.257 & 32.232 & 32.206 & 32.180 & 32.154 & 32.129 & 32.103 & 32.077 & 32.052 & 32.026\end{array}$

$33.697 \quad 33.671$

33.903
33.646

$32.096 \quad 32.000 \quad 32.874 \quad 33.106 \quad 33.080 \quad 33.054$

$\begin{array}{llllll}32.976 & 32.900 & 32.874 & 32.849 & 32.823 & 32.797 \\ 39.669 & 32.643 & 32.617 & 32.592 & 32.566 & 32.540\end{array}$

6236.0

36.
6.
6
6.3
6.5
6.6
6.7
6.0

6237.

37.0
7.1
7.2
7.3
7.4

7.5
7.6

7.6

7.8

6238

238.0
8.1
8.2
8.3
8.4

8.4

8.6
8.7
8.8

$31.743 \quad 31.71$

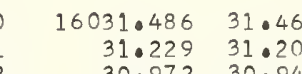

$\begin{array}{ll}31.229 & 31.20 \\ 30.972 & 30.946\end{array}$

$30.715 \quad 30.68$

$\begin{array}{ll}30.458 & 30.432 \\ 30.20 .1 & 30.175\end{array}$

$\begin{array}{ll}29.944 & 29.918 \\ 29.687 & 29.661\end{array}$

$\begin{array}{ll}29.430 & 29.404 \\ 29.173 & 29.147\end{array}$

$16028.916 \quad 28.890$

$\begin{array}{ll}28.659 & 28.63 \\ 28.402 & 28.37\end{array}$

$\begin{array}{ll}28.145 & 28.119 \\ 27.888 & 27.86\end{array}$

$27.631 \quad 27.605$

$\begin{array}{ll}27.374 & 27.34 \\ 27.117 & 27.09\end{array}$

$\begin{array}{ll}26.860 & 26.834 \\ 26.603 & 26.577\end{array}$

31.69

$31.435 \quad 31.40$

$31.178 \quad 31.152$

$\begin{array}{ll}30.663 & 30.63 \\ 30.406 & 30.38\end{array}$

$\begin{array}{ll}30.406 & 30.381 \\ 30.149 & 30.124\end{array}$

$\begin{array}{ll}29.892 & 29.86 \\ 29.635 & 29.60\end{array}$

$32.154 \quad 32.129$

$\begin{array}{llll}32.360 & 32.334 & 32.309 & 32.283 \\ 32.103 & 32.077 & 32.052 & 32.026\end{array}$

$31.383 \quad 31.357$

$\begin{array}{llllll}3 ! .126 & 31.100 & 31.332 & 31.306 & 31.280 & 31.255 \\ 31.075 & 31.049 & 31.023 & 30.998\end{array}$

$\begin{array}{llllll}30.869 & 30.843 & 30.818 & 30.792 & 30.766 & 30.740 \\ 30.512 & 30.586 & 30.561 & 30.535 & 30.509 & 30.484\end{array}$

$\begin{array}{llllll}30.355 & 30.329 & 30.303 & 30.278 & 30.252 & 30.226\end{array}$

$\begin{array}{llllll}30.098 & 30.072 & 30.047 & 30.021 & 29.995 & 29.969\end{array}$

$\begin{array}{llllll}29.841 & 29.815 & 29.790 & 29.764 & 29.738 & 29.712 \\ 29.584 & 29.558 & 29.532 & 29.507 & 29.481 & 29.455\end{array}$

$\begin{array}{ll}29.378 & 29.353 \\ 29.121 & 29.095\end{array}$

$29.327 \quad 29 \cdot 301$

$\begin{array}{llll}29.532 & 29.507 & 29.481 & 29.455 \\ 29.275 & 29.250 & 29.224 & 29.198\end{array}$

$\begin{array}{lllllllll}28.864 & 28.839 & 28.813 & 28.787 & 28.762 & 28.736 & 28.710 & 28.684\end{array}$

$\begin{array}{llllllll}28.607 & 28.582 & 28.556 & 28.530 & 28.504 & 28.479 & 28.453 & 28.427\end{array}$

$\begin{array}{llllllll}28.350 & 28.325 & 28.299 & 28.273 & 28.248 & 28.222 & 28.196 & 28.170 \\ 28.093 & 28.068 & 28.042 & 28.016 & 27.990 & 27.965 & 27.939 & 27.913\end{array}$

$\begin{array}{llllllll}27.836 & 27.811 & 27.785 & 27.759 & 27.734 & 27.708 & 27.682 & 27.656 \\ 27.579 & 27.554 & 27.528 & 27.502 & 27.477 & 27.451 & 27.425 & 27.399\end{array}$

$\begin{array}{llllllll}27.323 & 27.297 & 27.271 & 27.245 & 27.220 & 27.194 & 27.168 & 27.143 \\ 27.065 & 27.040 & 27.014 & 26.989 & 26.963 & 26.937 & 26.911 & 26.885\end{array}$

8.9

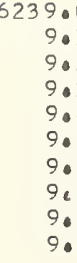

9.0
9.1
9.2
9.3
9.4
9.5
9.6
9.7
9.8
9.9

$26.089 \quad 26.063$

$\begin{array}{ll}25.832 & 25.807 \\ 25.575 & 25.550\end{array}$

$\begin{array}{ll}25.318 & 25.29 \\ 25.062 & 25.036\end{array}$

$24.805 \quad 24.779$

$\begin{array}{llll}24.548 & 24.522 & 24.754 & 24.7\end{array}$

$\begin{array}{ll}24.291 & 24.265 \\ 24.034 & 24.008\end{array}$

$\begin{array}{ll}24.496 & 24.72 \\ 24.240 & 24.21\end{array}$

$\begin{array}{llllll}26.757 & 26.731 & 26.706 & 26.680 & 26.654 & 26.629\end{array}$

$\begin{array}{llllllll}26.808 & 26.783 & 26.757 & 26.731 & 26.706 & 26.680 & 26.654 & 26.629 \\ 26.552 & 26.526 & 26.500 & 26.475 & 26.449 & 26.423 & 26.397 & 26.372\end{array}$

0.276644

$0.276644 \quad 1.723545$

$0.276643 \quad 1.723599$

$\begin{array}{ll}0.276643 & 1.723626 \\ 0.276643 & 1.723653\end{array}$

$0.276643 \quad 1.723653$

$0.276643 \quad 1.773733$

0.27664

0.27664

0.276642

0.276642

0.27664

0.276642

0.276641

1.723760

1.723814

1.723841

1.723867
1.723894

1.723921

1.723975

$0.276641 \quad 1.724028$

0.276641

0.276641

0.27664

0.27664

0.276640

0.276640

1.724055

1.724082
1.724109

1.724136

1.724163
1.724189

1.724216

0.276640
0.276640

0.276640

0.276640

0.276639

0.276639

0.276639

0.276639

1.724243
1.724270

0.276639

0.276638

0.276638

0.276638
0.276638
0.276638

0.276638

0.276638

0.276638
0.276638

0.276638
0.276637

1. 724299

0.276637

0.276637

0.276637
0.276637

0.276637
0.276637

0.276636
0.276636

0.2766636
0.276636

0.276636

0.276636
0.276636

0.276636

0.276635
0.276635

0.27663

0.276635
0.276635

0.276635

.724324
.724350

1.724350

1.724404

1.724458

1.724485

1.724512

0.276635

0.276635
0.276634

0.276634

0.276634

0.276634
0.276634

0.27663

0.276634
0.276633

1.724565

1.724592
1.724619

1.724619

1.724699

1.724726

1.724753
1.724780

1.724780
1.724807

1.724834

1.724860
1.724887

1.724887

1.724914

1.724968

1.724995

1.725048

1.725102

0.276633

0.276633
0.276633

0.276633
0.276633

0.27663

0.276632

0.276632
0.276632

1.0775129

1.0725182

1.0725236

1.725263

1.0725317

1.725370

1. 0725399

10725424

1.725478

1.725504
1.725531

1.725558

1.725612

0.27663

0.27663

0.276632

0.276632

0.276631

0.276631

0.276631

0.276631

1.725639

1.725666
1.725692

1. 725719

1.725746

1.725773 


.02

.03

$$
\begin{array}{r}
6240.0 \\
0.1 \\
0.2 \\
0.3 \\
0.4 \\
0.5 \\
0.6 \\
0.7 \\
0.8 \\
0.9 \\
6241.0 \\
1.1 \\
1.2 \\
1.3 \\
1.4 \\
1.5 \\
1.6 \\
1.7 \\
1.8 \\
1.9 \\
6242.0 \\
2.1 \\
2.2 \\
2.3 \\
2.4 \\
2.5 \\
2.6 \\
2.7 \\
2.8 \\
2.9 \\
6243
\end{array}
$$

$$
\begin{array}{r}
16021.20 \\
20.95 \\
20.69 \\
20.43 \\
20.18 \\
19.92 \\
19.66 \\
19.41 \\
19.15 \\
18.89
\end{array}
$$

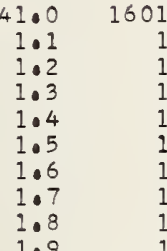

$6018.642 \quad 18.617$

$(n-1) \times 1000$

$\lambda(n-1)$

$\begin{array}{ll}0.276631 & 1.726175 \\ 0.276631 & 1.726202 \\ 0.276630 & 1.726229 \\ 0.276630 & 1.726256 \\ 0.276630 & 1.726283 \\ 0.276630 & 1.726310 \\ 0.276630 & 1.726336 \\ 0.276630 & 1.726363 \\ 0.276630 & 1.726390 \\ 0.766629 & 1.726417\end{array}$

0.276629

0.276629

0.276629
0.276629
0.0276629

0.276629

0.276629

0.276628
0.276678
0.276628

0.276628

0.276628

0.276628

0.276628
.0276628

0.276827
0.276627
0.276627

0.276627

0.276527
0.276677

0.276627

0.276626

0.0275626

0.276626

0.276526

0.276626

0.276626

0.276625

0.276625

0.276625

0.276625
0.276625

0.276624
0.276624

0.276624

0.276624
0.276624

0.276624
0.276624
0.276624

0.276624

0.276624
0.276623

0.276623

0.276623
0.276623

0.276623

0.276623

0.276623

0.276622
0.276622
0.276622

0.276622

0.276622
0.276622

0.276622
0.276622

0.27662

0.27669

0.276621

0.276621
0.276621

0.276621
0.276621

0.276621
0.276620

0.276620

0.276620

0.276620

0.276630

0.276620

0.276619

0.276619

0.276619

0.276619

0.276619
0.276619

0.276619

0.276618

0.276618

0.276618

0.276618

.010
1.726444

1.726497

1.726551

1.726605

1.726632
1.726659

1.726685

1.726712
1.726730
1.026756

1.726766

1.726820

1.726846

1.726900

1.726927

1.726981

1.727034

1.727088

1.727115
1.727142

1.727195

1.727249

1.727303

1.727330
1.727356

1.727383
1.727410

1.727464

1.727517

1.727544
1.727571

1.727625
1.727652

1.727705
1.727732

1.727786

1.727813
1.727839

1.727866

1.727920

1.727947
1.727974

1.728000
1.728027

1.728054

1.728081
1.728108

1.728135

1.728188
1.728215

1.728242
1.728269

1.728296

1.728323

1.728349

1.728403

1.728430
1.728457

1.728484
1.728510

1.728537
1.728564

1.728591

1.728618

1.728645

1.728698

1.728725

1.728779

1.728806
1.728833

$\begin{array}{lllllllllll} & .001 & .002 & .003 & .004 & .005 & .006 & .007 & .008 & .009 & .010 \\ .026 & .003 & .005 & .008 & .010 & .013 & .015 & .018 & .021 & .023 & .026 \\ .0025 & .005 & .007 & .010 & .012 & .015 & .017 & .020 & .022 & .025\end{array}$


$\begin{array}{lllllllllll}95.064 & 95.038 & 95.013 & 94.987 & 94.962 & 94.936 & 95.166 & 95.141 & 95.115 & 95.090 \\ 0.910 & 94.885 & 94.859 & 94.833\end{array}$

$\begin{array}{llllllllll}94.808 & 94 \cdot 782 & 94.757 & 94 \cdot 731 & 94.706 & 94 \cdot 680 & 94 \cdot 654 & 94 \cdot 629 & 94.603 & 94.578\end{array}$

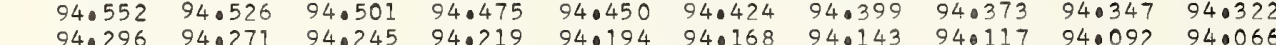

$\begin{array}{lllllllllll}0 & 94.296 & 94.271 & 94.245 & 94.219 & 94.194 & 94.168 & 94.143 & 94.1117 & 94.092 & 94 \cdot 066 \\ 0 & 94.040 & 94.015 & 93.989 & 93.964 & 93.938 & 93.912 & 93.887 & 93.861 & 93.836 & 93.810\end{array}$

$\begin{array}{llll}93.784 & 93.759 & 93.733 & 93.708 \\ 0 & 93.528 & 93.503 & 93.477\end{array}$

$93.273 \quad 93.247 \quad 93.221 \quad 93.196$

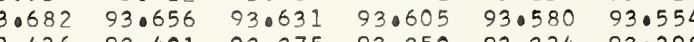

$\begin{array}{llllll}93.426 & 93.401 & 93.375 & 93.350 & 93.324 & 93.298 \\ 93.170 & 93.145 & 93.119 & 93.094 & 93.068 & 93.042\end{array}$

0.276617

0.276617

0.276617

0.276617

0.276617

0.2766917

0.276616

0.276616

1.728859 1.728913

1.728940

1.728994

1.729020

1.729047
1.729074

0.276616

$1: 0$

6252

$2 \cdot 1$
$2 \cdot 2$
$2 \cdot 3$

$2 \cdot 3$

2.5

2.6

2.8

6253.

3.1
3.2
3.3

3.4

3.6

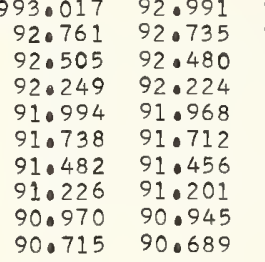

$\begin{array}{lll}92.480 & 92.454 & 92.684\end{array}$

$\begin{array}{ll}1.942 & 91.917 \\ 1.687 & 91.661\end{array}$

$\begin{array}{llllll}92.914 & 92.889 & 92.863 & 92.838 & 92.812 & 92.787\end{array}$

$\begin{array}{rr}1.175 & 91.149 \\ 90.919 & 90.894\end{array}$

$90.203 \quad 90.177$

$\begin{array}{ll}89.947 & 89.922 \\ 89.691 & 89.666\end{array}$

$89.436 \quad 89.410$

$\begin{array}{llll}88.924 & 88.899 & 88.873 & 88.103\end{array}$

$\begin{array}{llll}88.669 & 88.643 & 88.617 & 88.592\end{array}$

$\begin{array}{llll}88.413 & 88.387 & 88.362 & 88.336\end{array}$

5987.902

$87.646 \quad 87.676$

$\begin{array}{lll}87.569 \\ 87.595 & 87.595 & 87.569\end{array}$

$\begin{array}{llll}87.135 & 87.109 & 87.083 & 87.058\end{array}$

$86.879 \quad 86.853 \quad 86.828 \quad 86.802$

$86.623 \quad 86.598 \quad 86.572 \quad 86.547$

$\begin{array}{lllll}86.368 & 86.342 & 86.317 & 86.291\end{array}$

$\begin{array}{llll}86.112 & 86.086 & 86.061 & 86.035 \\ 85.856 & 85.831 & 85.805 & 85.780\end{array}$

$\begin{array}{ll}.403 & 92.377\end{array}$

$92.607 \quad 92.582 \quad 92.556 \quad 92.531$

.276616

0.276616

0.276615

0.276615

0.276615
0.276615

1.0729128
1.722155

1.729181

1.729235

1.729262

1.729289

1.0729316

0.276615

0.276615
0.276615

0.276615
0.276614

0.276614

0.276614

0.276614

0.276614

0.276614

0.276613
0.276613

0.276613

0.276613

0.276613

0.276613

0.276613

$85.601 \quad 85.575 \quad 85.550 \quad 85.524$

$\begin{array}{llllll}86.010 & 85.984 & 85.959 & 85.933 & 85.907 & 85.882\end{array}$

$\begin{array}{lllll}15985.345 & 85.319 & 85.294 & 85.268\end{array}$

$$
6254 .
$$

4.2

$4 \cdot 3$

$4 \cdot 4$

$4 \cdot 6$
4.7

$\begin{array}{llll}83.301 & 83.275 & 83.250 & 83.224\end{array}$

$$
\begin{array}{r}
6255.0 \\
5.1 \\
5.2 \\
5.3
\end{array}
$$

15982.790

$$
\begin{array}{rr}
982.790 & 82.764 \\
82.534 & 82.508
\end{array}
$$

$82.534 \quad 82.50$

$82.023 \quad 81.998$

$\begin{array}{ll}81.767 & 81.742 \\ 81.512 & 81.487\end{array}$

$\begin{array}{llll}81.257 & 81.231 & 81.206 & 81.180\end{array}$

$\begin{array}{llll}80.746 & 80.720 & 80.695 & 80.669\end{array}$

$\begin{array}{ll}80.746 & 80.720 \\ 80.490 & 80.465\end{array}$

$15980.235 \quad 80.20$

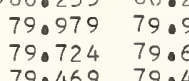

$\begin{array}{llll}79.469 & 79.698 & 79.673 & 79.647\end{array}$

$\begin{array}{llll}79.213 & 79.188 & 79.162 & 79.137\end{array}$

$\begin{array}{llll}78.958 & 78.932 & 78.907 & 78.881\end{array}$

$78.447 \quad 78.422 \quad 78.396 \quad 78.370$

$\begin{array}{llll}78.192 & 78.166 & 78.141 & 78.115 \\ 77.936 & 77.911 & 77.885 & 77.860\end{array}$

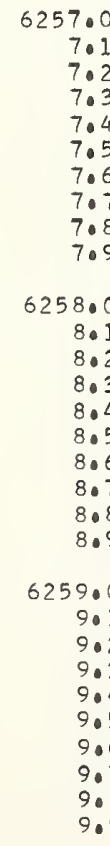

$\begin{array}{rlll}15977.681 & 77.655 & 77.630 & 77.604 \\ 77.426 & 77.400 & 77.375 & 77.349 \\ 77.170 & 77.145 & 77.119 & 77.094 \\ 76.915 & 76.889 & 76.864 & 76.838 \\ 76.660 & 76.634 & 76.609 & 76.583 \\ 76.404 & 76.379 & 76.353 & 76.328 \\ 76.149 & 76.123 & 76.098 & 76.073 \\ 75.894 & 75.868 & 75.843 & 75.817 \\ 75.638 & 75.613 & 75.587 & 75.562 \\ 75.383 & 75.357 & 75.332 & 75.306\end{array}$

$85.243 \quad 85 \cdot 217$

85.703

$85.677 \quad 85.652 \quad 85.626$

0.276612

0.276612

0.276612

0.076612

0.276612

0.276612

0.27661

0.276611

0.276611

.729369

0.27661

0.2766

0.27661

0.276610

0.276610

0.276610

0.276610

0.276610

.729396

1.729423

1.729477

1.729503

1.729557

1.729611

1.729665

1.729718

1.729718

1.729772

1.729799

1.729826

1.729879

1.729933

1.729960
1.729987

1.730013

1.730040

1.730067

1.730094

1.730121

0.27661

0.276609

0.276609

0.276609

0.276609

0.276609

0.276609

0.276608

1.730201

1.730255

1.730282

1.730309

1.730336

1.730389

1.730443

0.276608

1.730470

$\begin{array}{llllll}79.622 & 79.596 & 79.571 & 79.545 & 79.520 & 79.494\end{array}$

$\begin{array}{llllll}78.856 & 78.830 & 79.060 & 79.034 & 79.009 & 78.983 \\ 78.805 & 78.779 & 78.754 & 78.728\end{array}$

$\begin{array}{llllll}78.345 & 78.319 & 78.5294 & 78.268 & 78.243 & 78.217\end{array}$

$\begin{array}{llll}78.038 & 78.013 & 77.987 & 77.962 \\ 77.783 & 77.758 & 77.732 & 77.706\end{array}$

1.730523

1.730550

1.730604

1.730631

1.730684
1.730711

0.27660

1.730738

0.276608

0.276608

0.276608

0.276608

0.276607

0.276607

1.730792

1.730819

1.730845

1.730899

1.730926

$\begin{array}{lllllll}76.047 & 76.021 & 75.996 & 75.970 & 75.945 & 75.919\end{array}$

$\begin{array}{llllll}75.792 & 750766 & 75.740 & 75.715 & 75 \cdot 689 & 75.064 \\ 75.536 & 75.511 & 75.485 & 750460 & 75.434 & 750409\end{array}$

$\begin{array}{llll}75.485 & 75.460 & 75.434 & 75.409 \\ 75.230 & 75.204 & 75.179 & 75.153\end{array}$

0.276607

0.276607

0.276607

0.276606

0.276606

0.276606

0.276606

1.730980

0.276606

0.276606

0.276605

0.276605

0.276605

0.276605

0.276605

1.731007
1.731033

1.721060

1.731114

1.731168

1.731194

1.731248

$\frac{1.731275}{1.731302}$

1.731329

1.721355

1.731409

1.731436

1.731463

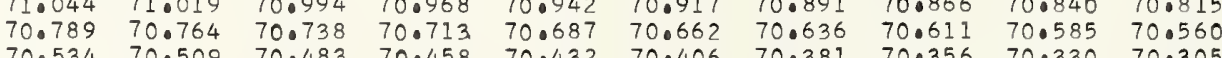

$\begin{array}{llllllllll}70.534 & 70.509 & 70.483 & 70.458 & 70.432 & 70.406 & 70.381 & 70.356 & 70.330 & 70.305 \\ 70.279 & 70.253 & 70.228 & 70.202 & 70.177 & 70.151 & 70.126 & 70.100 & 70.075 & 70.049\end{array}$

.010

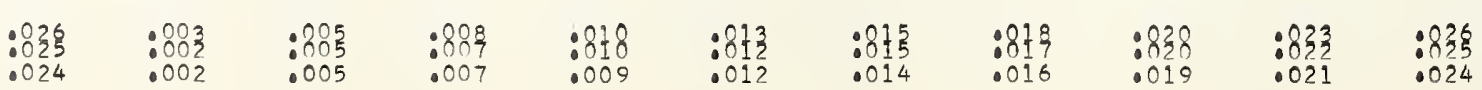


$\begin{array}{llllllll}9.973 & 69.947 & 69.922 & 69.896 & 69.871 & 69.845 & 69.820 & 69.794\end{array}$

$\begin{array}{lllllll}0.4 & 69.004 & 68.978 & 68.208 & 69.182 & 69.156 & 69.131 \\ 0 & 69.749 & 68.927 & 68.902 & 68.876\end{array}$

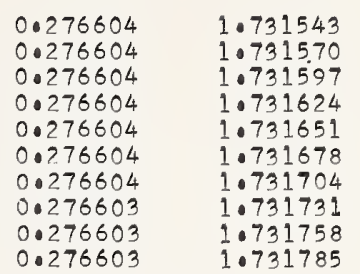

0.276603

0.276603

0.276603

0.276603

0.076602

0.276602

0.276602

1.971812

1.731839

1.731892

1.731946

1.032000

0.276602

0.276602

0.276602
0.27601

0.276501

0.276601
0.276001
0.27661

0.0276001

0.276601

0.276600

0.0276600
0.276600
0.27600

0.276600
.027600

0.276600
0.276500
0.27660

0.276600

0.276600
0.276599

0.276599

0.0276599
0.276599

0.0276599

0.276599

0.276599
0.0276598

0.276598

0.276598
0.276598

0.276598

0.276598
0.276598
0.276598

0.276598
0.276598
0.2769

0.276597

0.0276597
0.275977

0.276597

0.276597

0.0276596
0.276596

0.276596
0.276596
0.276596

0.276596

0.276596

0.276596
0.276596
0.2275995

0.276595

0.276595

0.276595

0.276595
0.276595

0.276595

0.276595
0.276594
0.276544

0.276594

0.276594
0.27654
0.276594

1.732080

1.732107

1.0732161

10732188

1.0732241

1.732228
1.73225
1
1 732322

1.732349

1.732402

1.732456

1.732510

$1: 732563$

0.27659

0.2775594
0.276594

0.276594

0.276593

0.276593

0.276593

0.276593
0.276593

10732617

1.732671

1.732724

. 732751

1.732805

1.732832

1.732885

$\frac{1}{1.0732912}$

1.732966

1.732993
1.0733020

10733046

$\frac{1}{10} .733100$

0.276593

0.276592

0.276592
0.276592

0.276592

0.276592
0.276592

0.276592

0.276592
0.276591

1.733154

1. 07333181

1.733234
1.733261

10.733288

1.733342

1.733395

1.733422

1
1.7333449
1.733476
1.733530

10.733503
1.0733530

1.733557
1.0733583
1.735637

1.0733610
1.0733637

1.733691

10.733718

10.733771

1.733825
1.733852
1.773909

1.0733879
1.733905

1.733959

1.734013

1.734066

10.734009

1.734147

1.734201

.010

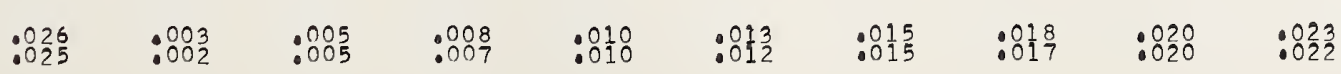

$: 836$ 


\begin{tabular}{|c|c|}
\hline$\lambda(A)$ & .00 \\
\hline 6270.0 & 159440554 \\
\hline 0.1 & 44.299 \\
\hline 0.2 & $\begin{array}{l}44.045 \\
43.791\end{array}$ \\
\hline $\begin{array}{l}0.3 \\
0.4\end{array}$ & $\begin{array}{l}43.791 \\
43.536\end{array}$ \\
\hline 0.5 & $\begin{array}{l}43.536 \\
43.282\end{array}$ \\
\hline 0.6 & $\begin{array}{l}43.282 \\
43.028\end{array}$ \\
\hline 0.7 & $\begin{array}{l}42.774 \\
\end{array}$ \\
\hline 0.8 & 42.519 \\
\hline 0.9 & 42.265 \\
\hline 6271.0 & 15942.011 \\
\hline 101 & $\begin{array}{l}41.757 \\
41.503\end{array}$ \\
\hline 1.2 & $\begin{array}{l}41.503 \\
41.248\end{array}$ \\
\hline $\begin{array}{l}1.3 \\
1.4\end{array}$ & $\begin{array}{l}41.248 \\
40.994\end{array}$ \\
\hline $\begin{array}{l}1.4 \\
1.5\end{array}$ & $\begin{array}{l}40.994 \\
40.740\end{array}$ \\
\hline $\begin{array}{l}1.5 \\
1.6\end{array}$ & $\begin{array}{l}40.740 \\
40.486\end{array}$ \\
\hline $\begin{array}{l}1.6 \\
1.7\end{array}$ & $\begin{array}{l}40.486 \\
40.232\end{array}$ \\
\hline $\begin{array}{l}1.7 \\
1.8\end{array}$ & 40.232 \\
\hline $\begin{array}{l}1.8 \\
1.9\end{array}$ & $\begin{array}{l}39.978 \\
39.723\end{array}$ \\
\hline 1.9 & 39.723 \\
\hline $\begin{array}{r}6272.0 \\
2.1\end{array}$ & $\begin{array}{r}15939.469 \\
39.215\end{array}$ \\
\hline $\begin{array}{l}2.1 \\
2.2\end{array}$ & $\begin{array}{l}39.215 \\
38.961\end{array}$ \\
\hline 2.3 & $\begin{array}{l}380.901 \\
38,707\end{array}$ \\
\hline 2.3 & $\begin{array}{l}38.453 \\
38.45\end{array}$ \\
\hline 2.5 & $\begin{array}{l}30.433 \\
38.199\end{array}$ \\
\hline 2.06 & $\begin{array}{l}37.945 \\
37.945\end{array}$ \\
\hline & $\begin{array}{l}37.691 \\
37.691\end{array}$ \\
\hline 2.8 & \\
\hline 2.9 & 37.182 \\
\hline 6273.0 & $\begin{array}{r}15936.928 \\
36.674\end{array}$ \\
\hline & $\begin{array}{l}36.674 \\
36.420\end{array}$ \\
\hline $\begin{array}{l}3.2 \\
3.3\end{array}$ & $\begin{array}{l}36.420 \\
36.166\end{array}$ \\
\hline $\begin{array}{l}3.3 \\
3.4\end{array}$ & $\begin{array}{l}36.166 \\
35.912\end{array}$ \\
\hline $\begin{array}{l}3.4 \\
3.5\end{array}$ & 35.658 \\
\hline $\begin{array}{l}3.5 \\
3.6\end{array}$ & 35.404 \\
\hline $\begin{array}{l}3.6 \\
3.7\end{array}$ & 35.150 \\
\hline $\begin{array}{l}3.7 \\
3.8\end{array}$ & 34.896 \\
\hline $\begin{array}{l}3.8 \\
3.9\end{array}$ & 34.642 \\
\hline & \\
\hline $\begin{array}{r}6274.0 \\
4.1\end{array}$ & $\begin{array}{r}5934.388 \\
34.134\end{array}$ \\
\hline 4.2 & 33.880 \\
\hline $4 \cdot 3$ & 33.626 \\
\hline $4 \cdot 4$ & 33.372 \\
\hline 4.5 & 33.119 \\
\hline $4 \cdot 6$ & 32.864 \\
\hline 4.7 & 32.611 \\
\hline 4.8 & 32.356 \\
\hline 4.9 & 32.103 \\
\hline & 15931.849 \\
\hline 5.1 & 31.595 \\
\hline $\begin{array}{l}5.2 \\
5.3\end{array}$ & 31.341 \\
\hline $\begin{array}{l}203 \\
5,4\end{array}$ & $\begin{array}{l}31.087 \\
30.833\end{array}$ \\
\hline $\begin{array}{l}504 \\
5.5\end{array}$ & $\begin{array}{l}30.833 \\
30.579\end{array}$ \\
\hline 5.6 & 30.326 \\
\hline 5.7 & 30.072 \\
\hline 5.8 & 29.818 \\
\hline 5.9 & 29.564 \\
\hline 6276.0 & 15929.310 \\
\hline 6.1 & 9.056 \\
\hline $\begin{array}{l}0 \\
6\end{array}$ & $\begin{array}{l}28.003 \\
28.803\end{array}$ \\
\hline 6. & 28.549 \\
\hline 6 & $\begin{array}{l}28.295 \\
28.295\end{array}$ \\
\hline 6 & 28.041 \\
\hline 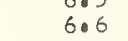 & $\begin{array}{l}27.787 \\
27.787\end{array}$ \\
\hline 6. & 27.5 \\
\hline 6 & $\begin{array}{l}27.280 \\
27.026\end{array}$ \\
\hline 6.9 & 27.026 \\
\hline 77.0 & 15926.773 \\
\hline & 26.519 \\
\hline 7.2 & 26.265 \\
\hline $7 \cdot 3$ & 26.011 \\
\hline 7.4 & 25.758 \\
\hline 7.5 & 25.504 \\
\hline 7.6 & 25.250 \\
\hline 7.7 & 24.997 \\
\hline $\begin{array}{l}7: 8 \\
7.9\end{array}$ & $\begin{array}{l}24.743 \\
24.489\end{array}$ \\
\hline & \\
\hline & $\begin{array}{r}15924.236 \\
23.982\end{array}$ \\
\hline 1 & 2 \\
\hline - & 23.475 \\
\hline 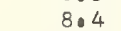 & $20=$ \\
\hline$=$ & 22.968 \\
\hline 8.6 & 22.7 \\
\hline 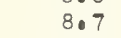 & 22.461 \\
\hline 8.8 & 22.207 \\
\hline 8.9 & 21.953 \\
\hline & 15921 \\
\hline & \\
\hline 3 & \\
\hline $9 \cdot 3$ & 9 \\
\hline $\begin{array}{l}9.4 \\
9.5\end{array}$ & $\begin{array}{l}20.686 \\
20.432\end{array}$ \\
\hline 9.6 & 20.178 \\
\hline 0 & 19.9 \\
\hline 90 & \\
\hline 9. & 19.418 \\
\hline & .08 \\
\hline & 825 \\
\hline
\end{tabular}




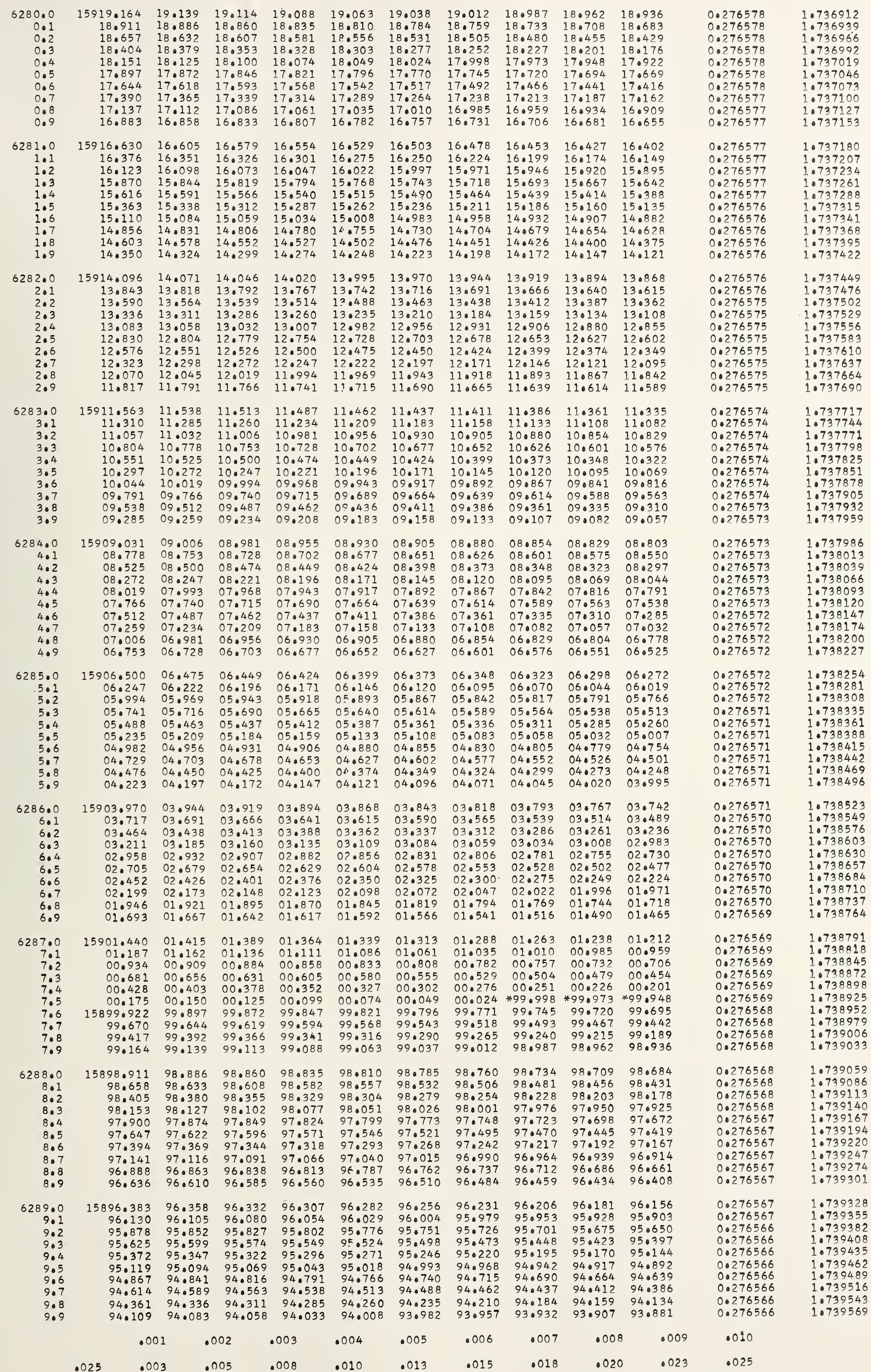


$\begin{array}{rrrrrrrrrrr}0.0 & 15893.856 & 93.831 & 93.805 & 93.780 & 93.755 & 93.730 & 93.70 .4 & 93.679 & 93.654 & 93.629 \\ 0.1 & 93.603 & 93.578 & 93.553 & 93.528 & 93.502 & 93.477 & 93.452 & 93.426 & 93.401 & 93.376 \\ 0.2 & 93.351 & 93.325 & 93.300 & 93.275 & 93.250 & 93.224 & 93.199 & 93.174 & 93.148 & 93.123\end{array}$ $\begin{array}{lllllllllll}0.2 & 93.351 & 93.325 & 93.300 & 93.275 & 93.250 & 93.224 & 93.199 & 93.174 & 93.148 & 93.123 \\ 0.3 & 93.098 & 93.073 & 93.047 & 93.022 & 92.997 & 92.972 & 92.946 & 92.921 & 92.896 & 92.871\end{array}$

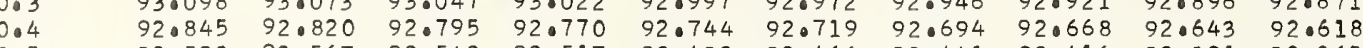
$\begin{array}{lllllllllll}0.5 & 92.593 & 92.567 & 92.542 & 92.517 & 92.492 & 92.466 & 92.441 & 92.416 & 92.391 & 92.365\end{array}$

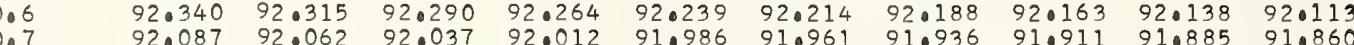

$\begin{array}{llll}90.824 & 90.799 & 91.026 & 91.001\end{array}$

$\begin{array}{llll}90.572 & 90.547 & 90.521 & 90.496\end{array}$

$90.319 \quad 90.294$

$\begin{array}{llll}90.067 & 90.042 & 90.016 & 89.991 \\ 89.814 & 89.789 & 89.764 & 89.738\end{array}$

$\begin{array}{llll}89.814 & 89.789 & 89.764 & 89.738 \\ 89.562 & 89.536 & 89.511 & 89.486\end{array}$

89.309
89.057

\begin{abstract}
$15888.804 \quad 88.779$
\end{abstract}
88.551

$88.299 \quad 88.274$

$\begin{array}{ll}88.046 & 88.021 \\ 87.794 & 87.0769\end{array}$

$87.541 \quad 87.516$

$87.036 \quad 87.011$

$86.531 \quad 86.506$

$15886.279 \quad 86.254$

86.026

$86.026 \quad 86.001$

$\begin{array}{llll}85.774 & 85.749 & 85.724 & 85.951 \\ 85.522 & 85.0497 & 85.471 & 85.446\end{array}$

$\begin{array}{llll}85.522 & 85.497 & 85.471 & 85.446\end{array}$

$\begin{array}{llll}85.269 & 85.244 & 85.219 & 85.194 \\ 85.017 & 84.992 & 84.967 & 84.941\end{array}$

$\begin{array}{llll}85.017 & 84.992 & 84.967 & 84.941 \\ 84.765 & 84.739 & 84.714 & 84.689 \\ 84.512 & 84.487 & 84.462 & 84.437\end{array}$

$\begin{array}{llll}84.512 & 84.487 & 84.462 & 84.437 \\ 84.260 & 84.235 & 84.209 & 84.184\end{array}$

84.007

6294.

$4 \cdot 1$
$4 \cdot 2$
$4 \cdot 3$
$4 \cdot 4$

$4 \cdot 4$

4.6
4.7

$4 \cdot 8$
$4 \cdot 9$

$\begin{array}{lllllllllll}6298.0 & 15873.667 & 73.642 & 73.616 & 73.591 & 73.566 & 73.541 & 73.516 & 73.491 & 73.465 & 73.440\end{array}$ $\begin{array}{lllllllllll}8.1 & 73.415 & 73.390 & 73.365 & 73.339 & 73.314 & 73.289 & 73.264 & 73.238 & 73.213 & 73.188 \\ 8.2 & 73.163 & 73.138 & 73.112 & 73.087 & 73.062 & 73.037 & 73.012 & 72.986 & 72.961 & 72.936\end{array}$ $\begin{array}{lllllllllll}8.2 & 73.163 & 73.138 & 73.112 & 73.087 & 73.062 & 73.037 & 73.012 & 72.986 & 72.961 & 72.936 \\ 8.3 & 72.911 & 72.886 & 72.860 & 72.835 & 72.810 & 72.785 & 72.760 & 72.734 & 72.709 & 72.684 \\ 8.4 & 72.659 & 72.634 & 72.608 & 72.583 & 72.558 & 72.533 & 72.508 & 72.482 & 72.457 & 72.432\end{array}$ $\begin{array}{lllllllllll}8.4 & 72.659 & 72.634 & 72.608 & 72.583 & 72.558 & 72.533 & 72.508 & 72.482 & 72.457 & 72.432 \\ 8.5 & 72.407 & 72.382 & 72.356 & 72.331 & 72.306 & 72.281 & 72.256 & 72.230 & 72.205 & 72.180\end{array}$ $\begin{array}{lllllllllll}8.6 & 72.155 & 72.130 & 72.104 & 72.079 & 72.054 & 72.029 & 72.004 & 71.978 & 71.953 & 71.928 \\ 8.7 & 71.903 & 71.878 & 71.852 & 71.827 & 71.802 & 71.777 & 71.0752 & 71.726 & 71.701 & 71.676\end{array}$ $\begin{array}{lllllllllll}8.7 & 71.903 & 71.878 & 71.852 & 71.827 & 71.802 & 71.777 & 71.752 & 71.726 & 71.701 & 71.676 \\ 8.8 & 71.651 & 71.626 & 71.601 & 71.575 & 71.550 & 71.525 & 71.500 & 71.474 & 71.449 & 71.424\end{array}$

$\begin{array}{lllllllllll}8.8 & 71.651 & 71.626 & 71.601 & 71.575 & 71.550 & 71.525 & 71.500 & 71.474 & 71.449 & 71.424 \\ 8.9 & 71.399 & 71.374 & 71.348 & 71.323 & 71.298 & 71.273 & 71.248 & 71.223 & 71.197 & 71.172\end{array}$

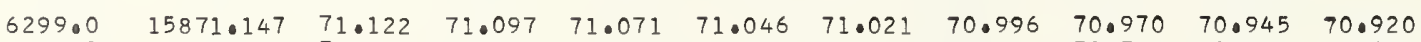

$\begin{array}{lllllllllll}9.1 & 70.895 & 70.870 & 70.845 & 70.819 & 70.794 & 70.769 & 70.744 & 70.719 & 70.693 & 70.668 \\ 9.2 & 70.643 & 70.018 & 70.593 & 70.567 & 70.542 & 70.517 & 70.492 & 70.467 & 70.441 & 70.416\end{array}$

$\begin{array}{lllllllllll}9.2 & 70.643 & 70.618 & 70.593 & 70.567 & 70.542 & 70.517 & 70.492 & 70.467 & 70.441 & 70.416 \\ 9.3 & 70.391 & 70.366 & 70.341 & 70.315 & 70.290 & 70.265 & 70.240 & 70.215 & 70.190 & 70.164\end{array}$

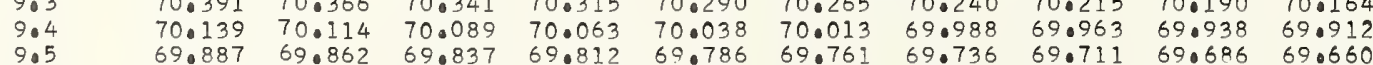

$\begin{array}{lllllllllll}9.6 & 69.887 & 69.862 & 69.837 & 69.812 & 69.786 & 69.761 & 69.736 & 69.711 & 69.686 & 69.660 \\ 9.6 & 69.635 & 69.610 & 69.585 & 69.560 & 69.535 & 69.509 & 69.484 & 69.459 & 69.434 & 69.409\end{array}$

$\begin{array}{lllllllllll}9.7 & 69.383 & 69.358 & 69.333 & 69.308 & 69.282 & 69.257 & 69.232 & 69.207 & 69.182 & 69.157\end{array}$

$\begin{array}{lllllllllll}9.8 & 69.131 & 69.106 & 69.081 & 69.056 & 69.031 & 69.005 & 68.980 & 68.955 & 68.930 & 68.905 \\ 9.9 & 68.880 & 68.854 & 68.829 & 68.804 & 68.779 & 68.754 & 68.728 & 68.703 & 68.678 & 68.653\end{array}$ $\begin{array}{llllllllll}68.880 & 68.854 & 68.829 & 68.804 & 68.779 & 68.754 & 68.728 & 68.703 & 68.678 & 68.653\end{array}$

$\begin{array}{ll}0.276565 & 1.739596 \\ 0.276565 & 1.739623 \\ 0.276565 & 1.739650 \\ 0.276565 & 1.739677 \\ 0.276565 & 1.739704 \\ 0.276565 & 1.739731 \\ 0.276565 & 1.739757 \\ 0.276565 & 1.739784 \\ 0.776564 & 1.739811 \\ 0.276564 & 1.739838\end{array}$

0.276564

0.27656

0.276564
0.276564
0.27654

0.276564
0.276563
0.27653

0.0276563

0.276563
0.276563

1.739865

1.739919

1.739945

10.739972
1.0739999

.740026

1.740080

0.276563

0.276563

0.276562

0.0276562

0.276562
0.276562

0.276562

0.276562

0.276562

0.276561

0.0276561

0.276561
0.276561

0.276561

0.276561

0.27656

0.276560

0.0276560
0.276560
0

0.276560

0.276560
0.276560
0.276590

0.27655

0.276559
0.276559
0.27559

0.276559
0.276559

0.276559

0.276559
00276559

0.0276559
0.276559

0.076558
0.276558

0.276558
0.276558
0.027655

0.276558

0.276558
0.276558

.740106

0.276558

0.276558

0.276557

0.276557

0.276557

0.276557

0.276557
0.276557

.740133
.740160

1.740187

1.740241

1.740268

1.740321

1.740348
1.740375

1.740402

1.740455

1.740482

1.740509
1.740536

1.740563

1.740616

1.740670

1.740697
1.740724
1.740751

1.740778

1.740804
1.740831

1.740858

1.740912

1.740939

1.740965
1.740992

1.741019

1.741046
1.741073

1.741100

1.741127

1.741153
1.741180

0.276556

0.276556

0.276556
0.276556
0.276556

0.276556

0.276556

0.276556
0.276555
0.27655

0.0276555

1.741207

1.741234
1.741261

1.741288

1.741314
1.741341

1.741368

1.741395

0.276555

0.276555
0.276555

0.027655
0.076555
0.27655

0.276555

0.27655
0.276554

0.0276554
0.276554
0.27654

0.276554
0.276554

1.741476

1.741502
1.741529

1.741556

1.741610

1.741637

1.741690
1.741717

0.276554
0.276554

0.276554
0.276553

0.276553
0.276553

0.27655

0.276553

0.276553

1.741744

1.741771

1.741825

1.741851

1.741905

1.741959

$\begin{array}{ll}0.276553 & 1.742227 \\ & 1.742254\end{array}$

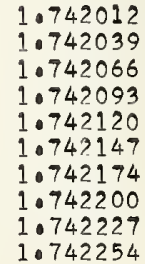

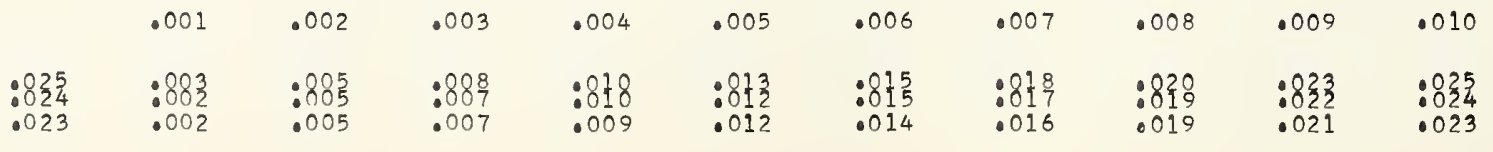



63.844

$$
\begin{array}{rlll}
863.592 & 63.567 & 63.542 & 63.516 \\
63.340 & 63.315 & 63.290 & 63.265 \\
63.089 & 63.063 & 63.038 & 63.013
\end{array}
$$

15861.075 $60.823 \quad 60.798$ $\begin{array}{llll}60.320 & 60.295 & 60.270 & 60.245\end{array}$ $60.068 \quad 60.043 \quad 60.018 \quad 59.993$ $59.565 \quad 59.540 \quad 59.515 \quad 59.490$ $59.314 \quad 59.289$

$\begin{array}{lllll}59.062 & 59.037 & 59.012 & 58.987\end{array}$

6304.0

15858

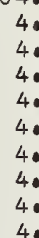

0.276553

0.276552

0.276552

0.276552

0.276552

0.276552
0.276551

$\begin{array}{ll}0.276551 & 1.742549 \\ 0.276551 & 1.742576 \\ 0.276551 & 1.742603 \\ 0.276551 & 1.742630 \\ 0.276551 & 1.742657 \\ 0.276551 & 1.742684 \\ 0.276550 & 1.742711 \\ 0.276550 & 1.742737 \\ 0.276550 & 1.742764 \\ 0.276550 & 1.742791\end{array}$

0.27655
0.27655
0.27550

0.0276550

0.276550
0.276549
0.27650

0.276549

0.276549

0.276549
0.276549

0.276549

0.276549
0.276549

0.276548

0.0276548

0.276548
0.0276548
0.27658

0.276548

0.0276548
0.0276548

0.276548

0.276547

0.276547
0.276547

0.276547

0.276547
0.276547

0.276547

0.276547
0.276546

0.276546

0.276546
0.276546

0.276546
0.276546

0.276546

0.276546
0.276545

0.276545
0.276545

0.276545
0.276545

0.276545
0.276545

0.276545

0.276545
0.276545

0.276545
0.276544

0.276544

0.276544

0.276544

0.276544

0.276544

0.276544

0.276543
0.276543

0.276543
0.276543

0.276543

0.276543

0.276543
0.276543

0.276543
0.276543
0.276542

1.742818

1.742845

1.742898

1.742952

1.743006

.743080

1.743086

1.743140

1.743167

1.743221

1.743247

1.743301

0.276542

0.276542
0.276542

0.0277542

0.276542
0.276542

0.276541

0.276541
0.276541

1.743355

1.743409

1.743462

10743489

1.743543
1.743570

1.743596

1.743623

1.743650
1.743677

1.743704

1.743758

1.743784
1.743811
1.743838

0.276541
0.276541 
6310.<smiles>C1[As][As]=[As]1</smiles>

0.3
0.4
0.5

0.6

0.7
0.8
0.9

6311.0

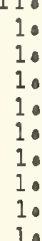

6312.0

$$
\begin{array}{r}
612 \\
2 \\
2 \\
2 \\
2 \\
2 . \\
2 . \\
20 \\
2 . \\
2
\end{array}
$$$$
6313.0
$$$$
3 .
$$

3.2
3.3
3.4

3.4
3.5

3.6
3.7

3.8
3.9

63140
40
40
403
404
405
406
407
408

6315.<smiles></smiles>

631600

316.0
6.1
6.2

6.12
6.2
6.3

6.4
6.5

6.6

6.8
6.9

$6317: 0$
$7: 1$
$7: 2$
$7: 3$
$7: 4$
$7: 5$
$7: 6$
$7: 07$
$7: 09$

$6318 \cdot 0$
8.1
8.2
8.03
8.4
8.5
8.6
8.7
8.8
8.9

\section{9.}

$$
\begin{array}{r}
319.0 \\
9.1 \\
9.2 \\
9.3 \\
9.4 \\
9.5 \\
9.6 \\
9.7 \\
9.8 \\
9.9
\end{array}
$$

8.3

8.5
8.6
8.7

8.7

9.4

9.6

9.8

9.9 $\begin{array}{rll}843.479 & 43.454 & 43 . \\ 43.228 & 43.203 & 430 \\ 42.977 & 42.952 & 42 . \\ 42.726 & 42.701 & 4 \\ 42.475 & 42.450 & 42 . \\ 42.224 & 42.199 & 420 \\ 41.973 & 41.948 & 410 \\ 41.722 & 41.697 & 410 \\ 41.471 & 41.446 & 410 \\ 41.220 & 41.195 & 410\end{array}$ $\begin{array}{rr}5840.969 & 40.944\end{array}$ $40.216 \quad 40.191$ $39.965 \quad 39.940$ $\begin{array}{ll}39.714 & 39.689 \\ 39.463 & 39.438\end{array}$ $\begin{array}{ll}39.212 & 39.18 \\ 38.961 & 38.936\end{array}$ $\begin{array}{ll}38.961 & 38.936 \\ 38.710 & 38.685\end{array}$

$$
\begin{array}{r}
5838.459 \\
38.208
\end{array}
$$$$
\begin{aligned}
& 38.208 \\
& 37.958 \\
& 37.707
\end{aligned}
$$$$
37.958 \quad 37.932
$$$$
37.707 \quad 37.682
$$$$
37.205 \quad 37.180
$$$$
36.954 \quad 36.929
$$$$
36.703 \quad 36.67
$$$$
36.201 \quad 36.17
$$

15835.951 35.700

35.449

34094

$340697 \quad 34.922$

$34.446 \quad 34.421$

$\begin{array}{ll}340195 & 34.170 \\ 33.944 & 33.919\end{array}$

33.69

15833.44

$32.941 \quad 32.916$

$\begin{array}{ll}32.690 & 32.66 \\ 32.440 & 32.415\end{array}$

32.18

$31.938 \quad 31.913$

31.588 310.062 31.8887

31.43
31.18

15830.93

$30.685 \quad 30.910$

30.434

$30.183 \quad 30.15$

$29.933 \quad 29.90$

$\begin{array}{ll}29.682 & 29.657 \\ 29.432 & 29.406\end{array}$

29.181

28.930
28.680

29.156
28.905

28.905
28.654

15828.429

$28.178 \quad 28.40$

$\begin{array}{ll}27.928 & 28.153 \\ 27.677 & 27.903\end{array}$

$\begin{array}{ll}27.677 & 27.652 \\ 27.427 & 27.040\end{array}$

$27.176 \quad 27.15$

$\begin{array}{ll}26.925 & 26.900 \\ 26.675 & 26.650\end{array}$

$\begin{array}{ll}26.424 & 26.399 \\ 26.174 & 26.149\end{array}$

$15825.923 \quad 25.898$

$$
\begin{array}{rll}
825.923 & 25.898 & 2 \\
25.673 & 25.648 & 250 \\
25.422 & 25.397 & 250 \\
25.172 & 25.147 & 250 \\
24.921 & 24.896 & 2 \\
24.671 & 24.646 & 240 \\
24.420 & 24.395 & 240 \\
24.170 & 24.145 & 240 \\
23.919 & 23.894 & 2 \\
23.669 & 23.644 & 230
\end{array}
$$

15823.418

8.8
8.9

$\begin{array}{llll}22.917 & 22.892 & 23.1187 \\ 22.667 & 22.052 & 22.617\end{array}$

$15820.914 \quad 20.889$ $\begin{array}{ll}40.718 & 40.69 \\ 40.467 & 40.442\end{array}$

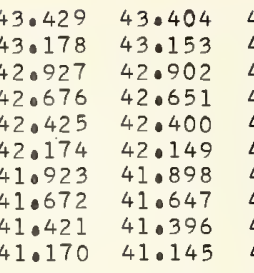

43.379
43.128
42.877
42.626
42.375
42.124
41.873
41.622
41.371
41.120

43.354

$\begin{array}{lllll}43.329 & 43.304 & 43.279 & 43.254\end{array}$ $\begin{array}{lllll}42.852 & 42.827 & 42.802 & 42.0776 & 42.751\end{array}$ 42.601

42.099

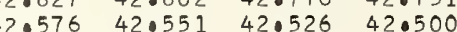

$42.325 \quad 42.290 \quad 420274 \quad 42.249$

$42.074 \quad 42.049 \quad 42.023 \quad 41.998$

$41.822 \quad 41.797 \quad 41.772 \quad 41.747$

$40.919 \quad 40.894$

$\begin{array}{ll}40.668 & 40.643 \\ 40.417 & 40.392\end{array}$

40.166

39.890

39.639

$\begin{array}{ll}39.413 & 39.388 \\ 39.162 & 39.137\end{array}$

38.911
38.660

38.409
38.158

38.886
38.635

$\begin{array}{ll}40.869 & 40.8 \\ 40.618 & 40.8\end{array}$

$\begin{array}{lllllll}40.367 & 40.342 & 40.317 & 40.291 & 40.266 & 40.241\end{array}$

$\begin{array}{lllllll}40.1116 & 40.090 & 40.065 & 40.040 & 40.015 & 39.990\end{array}$

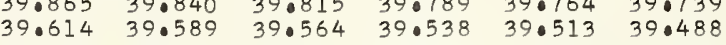

$\begin{array}{llllll}39.363 & 39.338 & 39.313 & 39.287 & 39.262 & 39.237\end{array}$

$\begin{array}{lllllll}30.112 & 39.087 & 39.062 & 39.036 & 39.011 & 38.986\end{array}$

$\begin{array}{llllll}38.861 & 38.836 & 38.811 & 38.786 & 38.761 & 38.735 \\ 38.610 & 38.585 & 38.560 & 38.535 & 38.510 & 38.484\end{array}$

38.384
38.133

$38.359 \quad 38.334$

$\begin{array}{llll}38.309 & 38.284 & 38.259 & 38.234 \\ 38.058 & 38.033 & 38.008 & 37.983\end{array}$

$\begin{array}{llllll}38.108 & 38.083 & 38.058 & 38.033 & 38.008 & 37.983\end{array}$

$37.656 \quad 37.631$

$\begin{array}{ll}37.406 & 37.380 \\ 37.155 & 37.130 \\ 36.004 & 36.879\end{array}$

36.904

36.879

$37.606-37.581$

$\begin{array}{lllllll}37.355 & 37.330 & 37.305 & 37.280 & 37.255 & 37.430\end{array}$

$\begin{array}{lllllll}37.104 & 37.079 & 37.054 & 37.029 & 37.004 & 36.979\end{array}$

$\begin{array}{llllll}36.854 & 36.828 & 36.803 & 36.778 & 36.753 & 36.728\end{array}$$$
\begin{array}{ll}
36.352 & 36.327 \\
36.101 & 36.076
\end{array}
$$

$\begin{array}{llll}36.553 & 36.528 & 36.502 & 36.477 \\ 36.302 & 36.277 & 36.25 ? & 36.226\end{array}$

$36.051 \quad 36.026 \quad 36.001 \quad 35.976$

$\begin{array}{lllllll}35.850 & 35.825 & 35.800 & 35.775 & 35.750 & 35.725\end{array}$

$\begin{array}{llllll}35.349 & 35.324 & 35.299 & 35.274 & 35.248 & 35.223\end{array}$

$\begin{array}{lllllll}35.098 & 35.073 & 35.048 & 35.023 & 34.998 & 34.973\end{array}$

$\begin{array}{llllll}34.847 & 34.822 & 34.797 & 34.772 & 34.747 & 34.722\end{array}$

$\begin{array}{llllll}34.596 & 34.571 & 34.546 & 34.521 & 34.496 & 34.471 \\ 34.345 & 34.320 & 34.0205 & 34.270 & 34.245 & 34.220\end{array}$

$\begin{array}{llllll}34.095 & 34.070 & 34.045 & 34.020 & 34.245 & 34.220 \\ 33.844 & 33.819 & 33.794 & 33.769 & 33.994 & 33.969 \\ 330.044 & 33.719\end{array}$

$34.396 \quad 34.37$

$\begin{array}{ll}34.145 & 34.120 \\ 33.894 & 33.869\end{array}$

$33.844 \quad 33.819$

$\begin{array}{llllll}33.342 & 33.317 & 33.292 & 33.267 & 33.242 & 33.217\end{array}$

$33.393 \quad 33.368$

$\begin{array}{ll}33.342 & 33.317 \\ 33.092 & 33.067 \\ 32.841 & 32.816\end{array}$

$\begin{array}{ll}32.841 & 32.816 \\ 32.590 & 32.565\end{array}$

$\begin{array}{ll}32.590 & 32.565 \\ 32.339 & 32.314 \\ 32.03\end{array}$

32.838

$31.838 \quad 31.81$

$33.042 \quad 33.016 \quad 32.991 \quad 32.966$

$\begin{array}{llll}32.791 & 32.766 & 32.741 & 32.715\end{array}$

$\begin{array}{llll}32.540 & 32.515 & 32.490 & 32.465 \\ 32.289 & 32.264 & 32.239 & 32.214\end{array}$

$32.039 \quad 32.013 \quad 31.098 \quad 31.963$
31.098

$31.788 \quad 31.763 \quad 31.738 \quad 31.713$

$\begin{array}{llllll}31.337 & 31.0311 & 31.286 & 31.512 & 31.487 & 31.462 \\ 31.086 & 31.051 & 31.036 & 31.010 & 31.236 & 31.211\end{array}$

$\begin{array}{llllll}30.835 & 30.810 & 30.785 & 30.760 & 30.735 & 30.710\end{array}$

$\begin{array}{llllll}30.585 & 30.559 & 30.534 & 30.509 & 30.484 & 30.459 \\ 30.3344 & 30.309 & 30.284 & 30.259 & 30.234 & 30.208\end{array}$

$\begin{array}{llllll}30.083 & 30.058 & 30.033 & 30.008 & 29.983 & 29.958\end{array}$

$\begin{array}{llllll}29.833 & 29.807 & 29.782 & 29.757 & 29.732 & 29.707\end{array}$

$\begin{array}{llllll}29.582 & 29.557 & 29.532 & 29.507 & 79.482 & 29.457 \\ 29.331 & 29.306 & 29.281 & 29.256 & 29.231 & 29.206\end{array}$

$29.381 \quad 29.35$

29.13129 .106

$29.080 \quad 29.056$

$28.830 \quad 28.805$

$29.031 \quad 29.256 \quad 29.231 \quad 29.206$

$28.780 \quad 28.755 \quad 28.730 \quad 28.705$

$28.629 \quad 28.604$

28.329

$\begin{array}{llll}28.128 & 28.354 & 28.329 & 28.304 \\ 27.878 & 27.0353 & 28.078 & 28.05\end{array}$

$\begin{array}{llll}27.878 & 27.853 & 27.078 & 28.05 \\ 27.627 & 27.602 & 27.577 & 27.80 \\ 27.376 & 27.351 & 27.326 & 27.552\end{array}$

$27.376 \quad 27.35$

$\begin{array}{ll}27.326 & 27.0301 \\ 27.0776 & 27.05\end{array}$

$26.825 \quad 26.800$

26.875 26.850

$\begin{array}{ll}26.625 & 26.600 \\ 26.374 & 26.34 \\ 26.124 & 26.09\end{array}$

$\begin{array}{ll}26.575 & 26.550 \\ 26.0324 & 26.299 \\ 26.074 & 26.048\end{array}$

$25.873 \quad 25.84$

$\begin{array}{ll}25.623 & 25.59 \\ 25.372 & 25.34\end{array}$

$25.823 \quad 25.79$

$\begin{array}{llll}25.122 & 25.097 & 25.322 & 25.297 \\ 24.072 & 25.047\end{array}$

$\begin{array}{llll}24.621 & 24.596 & 24.821 & 24.79 \\ 24.571 & 24.545\end{array}$

$\begin{array}{llll}24.370 & 24.345 & 24.320 & 24.295 \\ 24.120 & 24.095 & 24.069 & 24.045\end{array}$

$\begin{array}{lllll}28.279 & 28.254 & 28.228 & 28.203\end{array}$

$\begin{array}{llll}28.028 & 28.003 & 27.978 & 27.953 \\ 27.0777 & 27.752 & 27.727 & 27.702\end{array}$

$\begin{array}{llll}27.777 & 27 \cdot 752 & 27 \cdot 727 & 27 \cdot 902 \\ 27.527 & 27.502 & 27.477 & 27.452\end{array}$

$\begin{array}{llll}27.276 & 27.251 & 27.226 & 27.201 \\ 27.026 & 27.001 & 26.976 & 26.050\end{array}$

$\begin{array}{llll}26.775 & 26.750 & 26.725 & 26.700\end{array}$

$\begin{array}{llll}26.525 & 26.500 & 26.474 & 26.449\end{array}$

$\begin{array}{llll}26.023 & 25.949 & 26.224 & 26.199 \\ 25.973 & 25.948\end{array}$

$\begin{array}{lllll}25.773 & 25.748 & 250723 & 25.698\end{array}$

$\begin{array}{llll}25.522 & 25.497 & 25.472 & 25.447 \\ 25.272 & 25.247 & 25.222 & 25.197\end{array}$

$\begin{array}{llll}25.021 & 24.996 & 24.971 & 24.946\end{array}$

$24.771 \quad 24.746 \quad 24 \cdot 721 \quad 24.696$

$24.270 \quad 24.245 \quad 24.220 \quad 24.195$

$24.020 \quad 23.995 \quad 230969 \quad 23.944$

$\begin{array}{llll}23.769 & 23.744 & 23.719 & 23.694 \\ 23.519 & 23.494 & 33.468 & 23.443\end{array}$

$23.168 \quad 23.393 \quad 23.368$

$\begin{array}{lllll} & 23.0168 & 23.143 & 23.118 & 23.093 \\ 22.667 & 22.642 & 22.617 & 22.0592\end{array}$

$\begin{array}{llll}22.417 & 22.392 & 22.367 & 22.34\end{array}$

$\begin{array}{llll}21.916 & 21.891 & 21.866 & 21.841\end{array}$

$21.415 \quad 21.390 \quad 21.365 \quad 21.340$

$\begin{array}{llll}20.914 & 20.889 & 20.864 & 20.839 \\ 20.664 & 20.639 & 20.614 & 20.589 \\ 20.414 & 20.388 & 20.363 & 20.338\end{array}$

$\begin{array}{llll}20.163 & 20.138 & 20.363 & 20.338\end{array}$

$\begin{array}{lllll}19.913 & 19.888 & 19.863 & 19.0838\end{array}$

$\begin{array}{llll}19.663 & 19.638 & 19.612 & 19.587 \\ 19.412 & 19.387 & 19.362 & 19.337\end{array}$

$\begin{array}{llll}19.162 & 19.137 & 19.112 & 19.087\end{array}$

$\begin{array}{llll}19.161 & 19.137 & 19.112 & 19.087 \\ 18.911 & 18.886 & 18.861 & 18.836\end{array}$

$\begin{array}{ll}23.819 & 23.794 \\ 23.559 & 23.544\end{array}$

$\begin{array}{llll}23.268 & 23.243 & 23.218 & 23.103\end{array}$

$\begin{array}{ll}23.318 & 23.293 \\ 23.068 & 23.043\end{array}$

23.068

23.043
22.792
22.542

$\begin{array}{llll}23.018 & 22.993 & 22.958 & 22.943 \\ 22.767 & 22.742 & 22.717 & 22.692 \\ 22.517 & 22.492 & 22.067 & 22.0442\end{array}$

$\begin{array}{llllll}22.317 & 22.292 & 22.0266 & 22.492 & 22.467 & 22.442\end{array}$

$\begin{array}{llllll}22.066 & 22.041 & 22.016 & 21.991 & 21.966 & 21.941\end{array}$

$\begin{array}{llllll}21.816 & 21.791 & 21.766 & 21.740 & 21.715 & 21.6691\end{array}$

$\begin{array}{llllll}21.565 & 21.540 & 21.515 & 21.490 & 21.465 & 21.440 \\ 21.315 & 21.290 & 21.265 & 21.240 & 21.215 & 21.190\end{array}$

$\begin{array}{llllll}21.315 & 21.290 & 21.265 & 21.240 & 21.215 & 21.190 \\ 21.064 & 21.039 & 21.014 & 20.989 & 20.964 & 20.939\end{array}$

$\begin{array}{lllllll}20.814 & 20.789 & 20.764 & 20.739 & 20.714 & 20.689\end{array}$

$\begin{array}{llllll}20.564 & 20.539 & 20.514 & 20.489 & 20.464 & 20.439 \\ 20.313 & 20.288 & 20.263 & 20.238 & 20.213 & 20.188\end{array}$

$\begin{array}{llllll}20.063 & 20.038 & 20.013 & 20.0238 & 20.213 & 20.0188 \\ 10.813 & 19.878 & 19.763 & 19.988 & 19.963 & 19.938 \\ 10.968 & 10.713 & 10.087\end{array}$

$\begin{array}{llllll}19.562 & 19.537 & 19.763 & 19.738 & 19.713 & 19.6687 \\ 19.512 & 19.487 & 19.462 & 19.437\end{array}$

$\begin{array}{llllll}19.562 & 19.537 & 19.512 & 19.487 & 19.462 & 19.437 \\ 19.312 & 19.287 & 19.262 & 19.237 & 19.212 & 19.187\end{array}$

$\begin{array}{llllll}19.062 & 19.037 & 19.262 & 19.237 & 19.212 & 19.187 \\ 19.012 & 18.987 & 18.962 & 18.937\end{array}$

$\begin{array}{lllll}18.661 & 18.636 & 18.611 & 18.586\end{array}$

$\begin{array}{ll}0.276540 & 1.744966 \\ 0.276540 & 1.744993 \\ 0.276539 & 1.745019 \\ 0.276539 & 1.745046 \\ 0.276539 & 1.745073 \\ 0.276539 & 1.745100 \\ 0.276539 & 1.745127 \\ 0.276539 & 1.745154 \\ 0.276539 & 1.745180 \\ 0.276539 & 1.745207\end{array}$

0.276538

0.276538

0.276538

0.276538

0.276538

0.00276538

0.276537

1.745234

1.745288

1.745368

1.745395

1.745449

0.276537

0.276537

0.276537

0.276537

0.276536

0.276536

0.276536

0.276536

0.276536

0.276536

0.276535

0.276535

0.276535

0.276535
0.276535
0.276535

0.276535
0.276535

0.276535

0.276535 


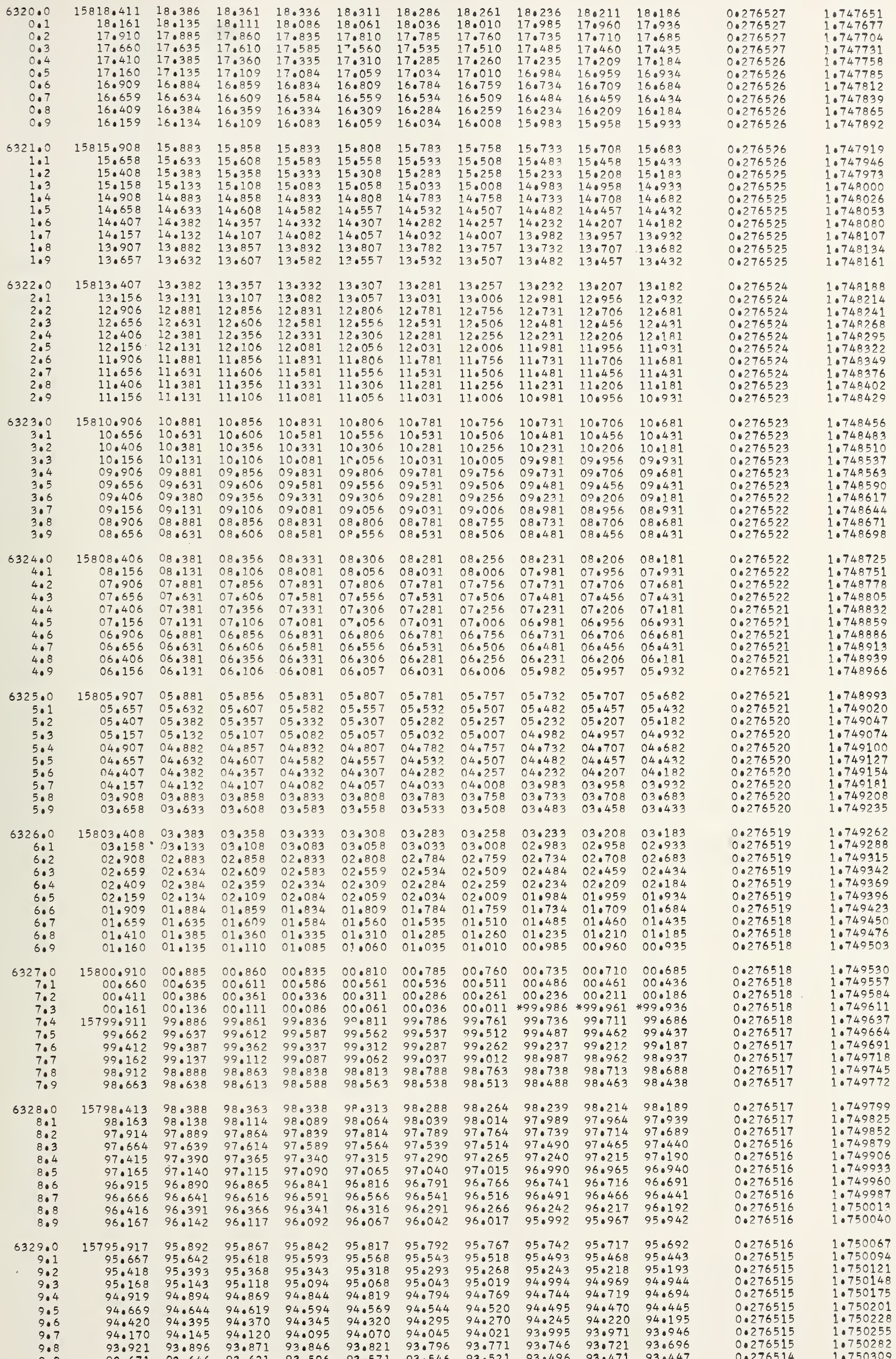

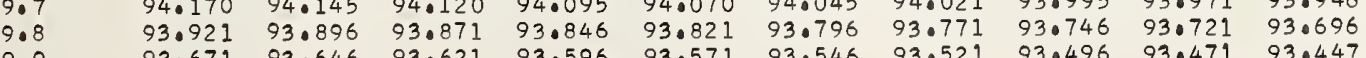
0.276514 1.750309

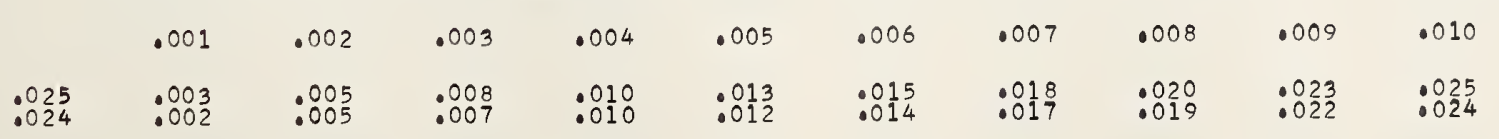




\section{0.
0.0
0.0
0.0
0
0
0}

$\begin{array}{rlll}793.422 & 93.397 & 93.372 & 93.347 \\ 93.172 & 93.147 & 93.122 & 93.097 \\ 92.923 & 92.898 & 92.873 & 92.848\end{array}$ $92.673 \quad 92.648 \quad 92.623 \quad 92.598$ 2.17402 .149020124 $91.925 \quad 91.900 \quad 91.87$ (1.850 $91.426 \quad 91.401 \quad 91.376 \quad 91.351$

$91.176 \quad 91.151 \quad 91.126 \quad 91.102$

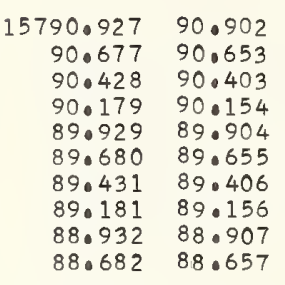

0.276513

0.276513

0.276513

0.276513

0.276512

0.276512

0.276512

0.276512

0.276512

0.276511

0.276511

0.276511

0.276511

0.276511

0.276510

0.276510

0.276510

0.276510

0.276510

0.276510
0.276509

0.276509

0.276

0.27650
0.276500

0.276509

0.276508

0.276508

0.276508
0.276508

0.276508
0.276508

0.276507
0.276507

0.276507

0.276507
0.276507

0.276507
0.276507

0.276507

0.276507

0.276506
0.276506

0.276506

0.276506
0.276506

0.276506

0.276506
0.276506

1.750336

1.750362
1.750389

10750416

1.750443
1.750470

1.750497
1.750524

1.750550

1.950604

1.750631
1.750658

1.750685

1.750738

1.750765

1.750819

.750846

1.750893

1.750899

1.750953

1.750980
1.751007

1.751034

1.751061

1.751114

1.751141

1.751168

1.751222

1.751249

1.751275
1.751302

1.751329

1.751356
1.751383

0.276505

0.276505
0.276505

0.276505

0.276505

0.276505

0.276505
0.276505

0.276504
0.276504

1.751410

1.751437
1.751463

1.751490

1.751517
1.751544

1.751571

1.751624
1.751651

1.751678

1.751705
1.751732

1.751759

1.751786
1.751812 


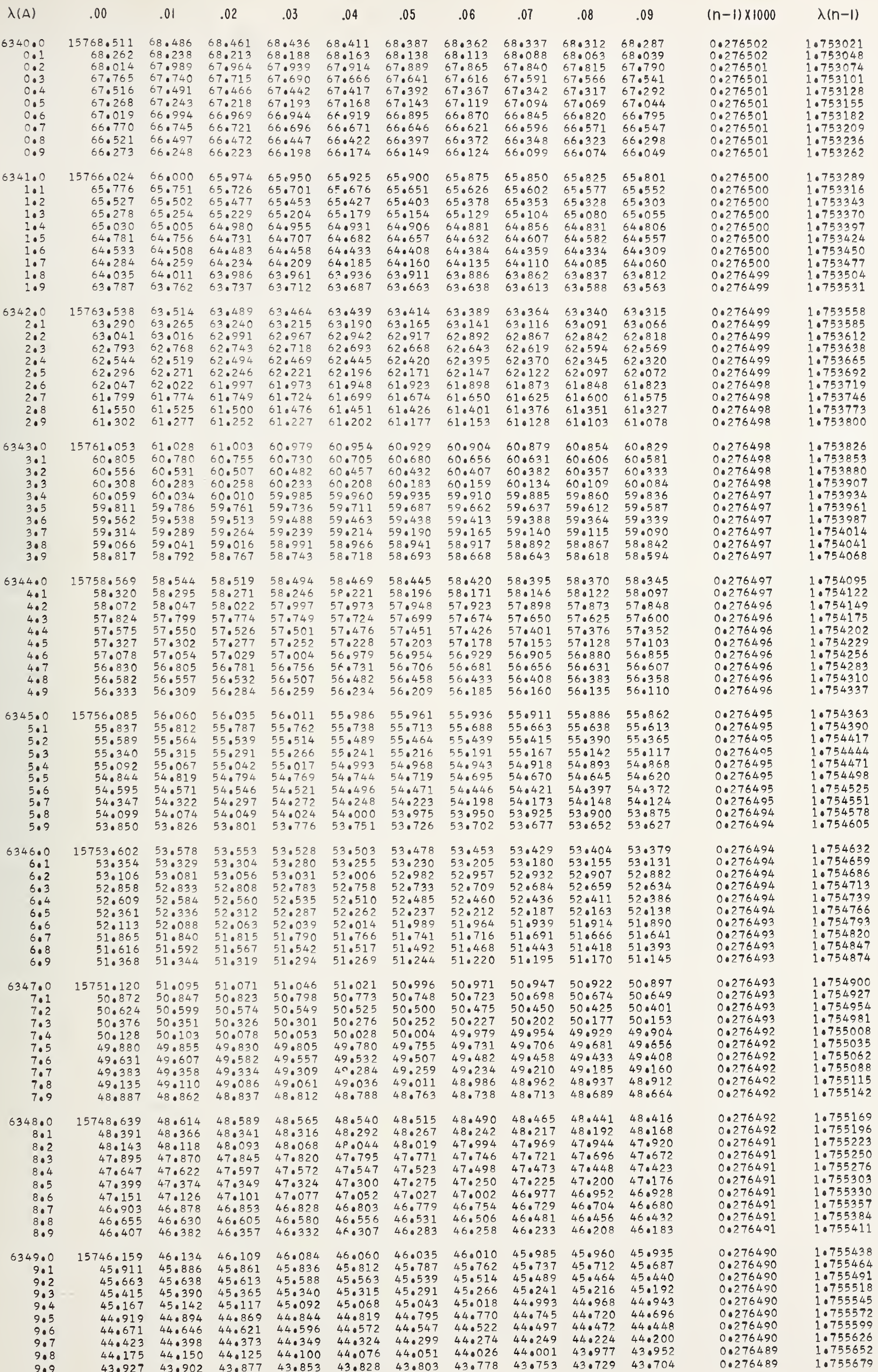


1.756512

1.756565
1.756592
1.756619

1.756619
1.756646

1.756673

1.756700
1.756727

1.756780

1.756807

1.756834
1.756861

1.756888

1.756914
1.756941

1.756968

1.757022

1.757049
1.757076

1.757102

1.757129
1.757156

1.7571
1.757183
1.757210

1.757237

1.757264
1.757290

1.757317

1.7573147
1.757371
1.757398

1.757398
1.757425

1.757452
1.757478

1.757478
1.757505

1.757532
1.757559

1.757586

1.757613

1.757640

1.757666
1.757693

1.7577920
1.0757747

1.757747

1.757801
1.757828

1.757854

1.757881
1.757908

1.757935
1.757962

1.757989

1.7580162
1.758069

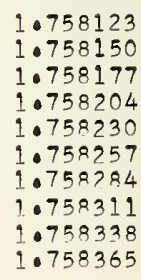

$: 82 \frac{25}{84}: 882 \quad: 885 \quad: 887 \quad: 818 \quad: 813 \quad: 815 \quad: 817 \quad: 818 \quad: 8321 \% \quad: 825$ 
$\lambda(A)$ .00

.01

.02

.03

.04

.05

.07

.08

.09

$(n-1) \times 1000$

$\lambda(n-1)$

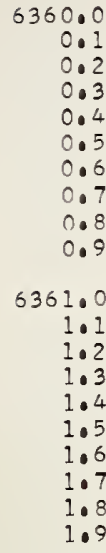

0.1
0.1
0.3
0.4
0.5
0.6
0.7
0.8
0.9

$\begin{array}{rl}718.925 & 18 \\ 18.678 & 18 \\ 18.431 & 18 \\ 18.183 & 18 \\ 17.936 & 17 \\ 17.689 & 17 \\ 17.442 & 17 \\ 17.195 & 17 \\ 16.948 & 16 \\ 16.701 & 16\end{array}$

15

$\begin{array}{rllllllllll}716.454 & 16.429 & 16.404 & 16.380 & 16.355 & 16.330 & 16.306 & 16.281 & 16.256 & 16.232\end{array}$

$\begin{array}{llllllllll}15.960 & 15.935 & 15.910 & 16.133 & 16.108 & 16.083 & 16.058 & 16.034 & 16.009 & 15.984 \\ 15.96 & 15.861 & 15.836 & 15.812 & 15.787 & 15.762 & 15.739\end{array}$

$\begin{array}{llllllllll}15.713 & 15.688 & 15.663 & 15.639 & 15.614 & 15.589 & 15.564 & 15.540 & 15.515 & 15.490\end{array}$

$\begin{array}{lllllllllll}15.466 & 15.441 & 15.416 & 15.391 & 15.367 & 15.342 & 15.317 & 15.293 & 15.268 & 15.243 \\ 15.219 & 15.194 & 15.169 & 15.145 & 15.120 & 15.095 & 15.071 & 15.046 & 15.021 & 14.996\end{array}$

$\begin{array}{llllllllll}14.971 & 14.947 & 14.922 & 14.897 & 14.873 & 14.848 & 14.823 & 14.799 & 14.774 & 14.749\end{array}$

$\begin{array}{llllllllll}14.725 & 14.700 & 14.675 & 14.650 & 14.626 & 14.601 & 14.576 & 14.552 & 14.527 & 14.502\end{array}$

$\begin{array}{llllllllll}14.477 & 14.453 & 14.428 & 14.403 & 14.379 & 14.354 & 14.329 & 14.305 & 14.280 & 14.255 \\ 14.230 & 14.206 & 14.181 & 14.156 & 14.132 & 14.107 & 14.082 & 14.058 & 14.033 & 14.008\end{array}$

6362.

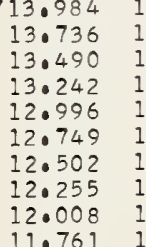

13.959213 .712 13.0

$3.934 \quad 13.909$

$\begin{array}{llllll}13.885 & 13.860 & 13.835 & 13.811 & 13.786 & 13.761\end{array}$

2.1

$2 \cdot 3$

2.6

2.8

12.008
11.761

$\begin{array}{rrrrrrrrrrr}11.0411 .514 & 11.489 & 11.465 & 11.440 & 11.415 & 11.390 & 11.366 & 11.341 & 11.316 & 91.392 \\ 3.1 & 111.267 & 11.242 & 11.218 & 11.193 & 11.168 & 11.144 & 11.119 & 11.094 & 11.069 & 11.045\end{array}$

$13.465 \quad 13.440 \quad 13.416$

$\begin{array}{lllllll}12.027 & 13.144 & 13.119 & 13.094 & 13.070 & 13.045 & 13.020\end{array}$

$\begin{array}{lllllllll}12.724 & 12.699 & 12.675 & 12.650 & 12.625 & 12.600 & 12.576 & 12.551 & 12.526\end{array}$

$\begin{array}{lllllllll}2.230 & 12.205 & 12.428 & 12.403 & 12.378 & 12.354 & 12.329 & 12.304 & 12.279 \\ 12.156 & 12.131 & 12.107 & 12.082 & 12.057 & 12.032\end{array}$

$\begin{array}{rrrrrrrrrrr}363.0 & 15711.514 & 11.489 & 11.465 & 11.440 & 11.415 & 11.390 & 11.366 & 11.341 & 11.316 & 91.992 \\ 3.1 & 11.267 & 11.242 & 11.218 & 11.193 & 11.168 & 11.144 & 11.119 & 11.094 & 11.069 & 11.045 \\ 3.1 & 11.020 & 10.095 & 10.971 & 10.946 & 10.921 & 10.897 & 10.872 & 10.847 & 10.823 & 10.998\end{array}$

$\begin{array}{rrrrrrrrrrr}11.411 .514 & 11.489 & 11.465 & 11.440 & 11.415 & 11.390 & 11.366 & 11.341 & 11.316 & 91.992 \\ 3.1 & 11.267 & 11.242 & 11.218 & 11.193 & 11.168 & 11.144 & 11.119 & 11.094 & 11.069 & 11.045 \\ 3.2 & 11.020 & 10.995 & 10.971 & 10.946 & 10.921 & 10.897 & 10.872 & 10.847 & 10.823 & 10.798\end{array}$

$\begin{array}{rrrrrrrrrrr}11.411 .514 & 11.489 & 11.465 & 11.440 & 11.415 & 11.390 & 11.366 & 11.341 & 11.316 & 91.992 \\ 3.1 & 11.267 & 11.242 & 11.218 & 11.193 & 11.168 & 11.144 & 11.119 & 11.094 & 11.069 & 11.045 \\ 3.2 & 11.020 & 10.995 & 10.971 & 10.946 & 10.921 & 10.897 & 10.872 & 10.847 & 10.823 & 10.798\end{array}$

$\begin{array}{llllll}11.909 & 11.884 & 11.860 & 11.835 & 11.810 & 11.786 \\ 11.662 & 11.637 & 11.613 & 11.588 & 11.563 & 11.539\end{array}$

0.276477

1.758391
1.75841 .8

3.3

$\begin{array}{llllllllll}10.773 & 10.749 & 10.971 & 10.946 & 10.921 & 10.897 & 10.872 & 10.847 & 10.823 & 10.798\end{array}$

$\begin{array}{llllllllll}10.526 & 10.502 & 10.477 & 10.452 & 10.428 & 10.403 & 10.378 & 10.354 & 10.329 & 10.304\end{array}$

$\begin{array}{llllllllll}10.280 & 10.255 & 10.230 & 10.205 & 10.181 & 10.156 & 10.131 & 10.107 & 10.082 & 10.057 \\ 10.032 & 10.008 & 09.983 & 09.958 & 09.934 & 09.909 & 09.884 & 09.860 & 09.835 & 09.810\end{array}$

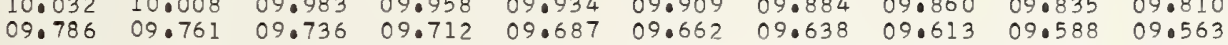

$\begin{array}{llllllllll}09.539 & 09.514 & 09.490 & 09.465 & 09.440 & 09.415 & 09.391 & 09.366 & 09.341 & 09.317 \\ 09.292 & 09.267 & 09.243 & 09.218 & 09.193 & 09.169 & 09.144 & 09.119 & 09.094 & 09.070\end{array}$

3.8

4.1
4.2
4.3

$4 \cdot 3$

$08.798 \quad 08.774$

08.996

9.21

$\begin{array}{llllll}0.193 & 09.169 & 09.144 & 09.119 & 09.094 & 09.070\end{array}$ $\begin{array}{lllllllllll}08.752 & 08.774 & 08.749 & 08.724 & 08.700 & 08.675 & 08.650 & 08.625 & 08.601 & 08.576 \\ 08.527 & 08.502 & 08.477 & 08.453 & 08.428 & 08.403 & 08.379 & 08.354 & 08.329\end{array}$ $\begin{array}{llllllllll} & 08.280 & 08.255 & 08.231 & 08.206 & 08.181 & 08.156 & 08.132 & 08.107 & 08.083\end{array}$ $\begin{array}{llllllllll}07.811 & 07.786 & 07.762 & 07.737 & 07.712 & 07.687 & 07.663 & 07.638 & 07.614 & 07.589\end{array}$ $\begin{array}{llllllllll}07.564 & 07.540 & 07.515 & 07.490 & 07.466 & 07.441 & 07.416 & 07.391 & 07.367 & 07.342\end{array}$

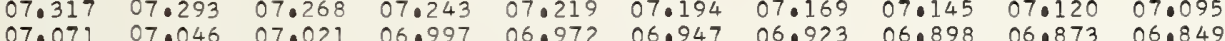
$\begin{array}{llllllllll}07.071 & 07.046 & 07.021 & 06.997 & 06.972 & 06.947 & 06.923 & 06.898 & 06.873 & 06.849 \\ 06.824 & 06.799 & 06.774 & 06.750 & 06.725 & 06.700 & 06.676 & 06.651 & 06.626 & 06.602\end{array}$

0.276476

0.276475

0.276475

0.276475

0.276475

0.276474

0.276474

0.276474

0.276474
0.276474

0.276474

0.276473

0.276473
0.276473

0.776472
0.276473

0.276473

0.276473

0.276472

0.276472
0.276472

0.276472

0.276472

0.27647
0.27647

0.27647

0.276471

0.27647
0.27647

0.276471
0.276471

0.276470
0.276470

0.276470
0.276470

0.276470
0.276470

0.276470

0.276469

0.276469

0.276469

0.276469
0.276469
0.27696

0.27646

0.0796469

.276468

0.276468
0.276468

0.276468

0.276468
0.276468

0.276468

0.276467
0.276467
0.076467

0.276467
0.076467
0

0.0276467
0.0276467

0.276467

0.276467

0.276467

0.276466
0.276466

0.276466

0.276466

0.276466

0.276466
0.276466

0.276465

0.276465
0.276465

0.276465
0.276465

0.276465

0.276465

0.0276464
0.276464

7758499

.758526
.758553

1.758606

1
1.758741
10758767
10
7

1075821

0758875

1.758929

10758982

10759036
1.0759063

1759090

.759143
.759170

10759199

1.759278

1.759331

1.759385

1.759439

$\frac{7}{759466}$

.759519

1.759573

1.759627

1.759681

1.759734

1.759788

1.759842

1. 759895

1.759922
1.759949

1.760003

.76005

.760110

1.760164

1.960218

1.760271
1.760298

1.760325

1.760379

10760433

1.760459

1.760540

1.760567

1.760621

.760647

1.760701

.760728
1.760755

1.760809

1.760835

1.7608362
1.760899

.1760943

1.760970

1.761023

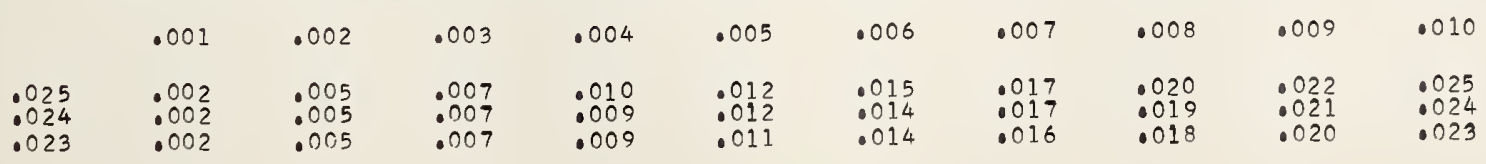


$\begin{array}{lllllllllll}0.8 & 92.278 & 92.253 & 92.229 & 92.204 & 92.179 & 92.155 & 92.130 & 92.105 & 92.081 & 92.056 \\ 0.9 & 92.031 & 92.007 & 91.982 & 91.958 & 91.933 & 91.908 & 91.884 & 91.859 & 91.834 & 91.810\end{array}$

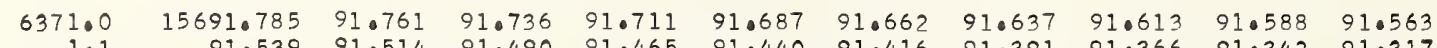

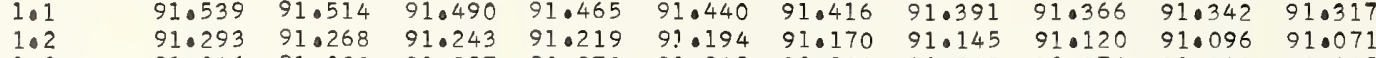

$\begin{array}{lllllllllll}1.2 & 91.293 & 91.268 & 91.243 & 91.219 & 91.194 & 91.170 & 91.145 & 91.120 & 91.096 & 91.071 \\ 1.3 & 91.046 & 91.022 & 90.997 & 90.972 & 90.948 & 90.923 & 90.898 & 90.874 & 90.849 & 90.825\end{array}$

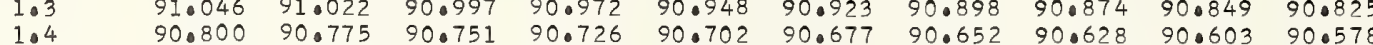

1.5

1.6

$90.800 \quad 90.775 \quad 90.751 \quad 90.726$

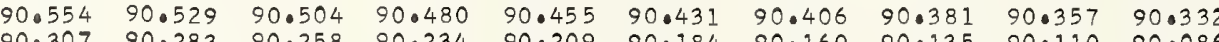

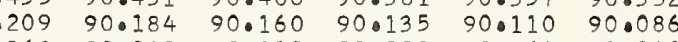

$\begin{array}{llllll}9.963 & 89.938 & 89.913 & 89.889 & 89.864 & 89.840\end{array}$

6372.0

2.4

2.6

2.8

6373.0

$3:$

3.3

3.4

3.6
3.7
3.8

3.8

63740

4.1
4.2
4.3

4.3
4.4

4.5
4.6

4.7
4.8

4.9

6375.

5.1
5.2

5.2

5.4

5.5

5.7

5.8
5.9

6376.0

6.1
6.2
6.3

6.3
6.4

6.4
6.5

6.6

6.8
6.9

6377.

70

7.3
7.4

7.5
7.6

7.7
7.8
7.9

6378

8.1

8.3

8.4
8.5

8.6

8.7
8.8

6379.

9.1

9.2

9.4
9.5

9.6
9.7

9.8
9.9 $\begin{array}{ll}88.830 & 88.80 \\ 88.584 & 88.55 \\ 88.338 & 88.313\end{array}$

$88.092 \quad 88.067$

$87.845 \quad 87.821$

$\begin{array}{ll}87.599 & 87.575 \\ 87.353 & 87.329\end{array}$

87.107

15686.86

86.61
86.36

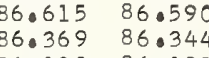

$86.122 \quad 86.098$

$85.630 \quad 85.0605$

$85.384 \quad 85.360$

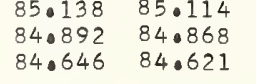

$\begin{array}{ll}84 \cdot 154 & 84.129 \\ 830908 & 83.083\end{array}$

$83.661 \quad 83.637$

$\begin{array}{ll}83.416 & 83.391 \\ 83.170 & 83.145\end{array}$

$82.924 \quad 82.899$

$\begin{array}{ll}82.678 & 82.653 \\ 82.432 & 82.407\end{array}$ 82.186

$15681.940 \quad 81.915$

$\begin{array}{ll}81.694 & 81.66 \\ 81.448 & 81.423\end{array}$

$81.202 \quad 81.177$

$80.710 \quad 80.685$

$80.464 \quad 80.439$

$\begin{array}{rr}79.972 & 79.947 \\ 79.726 & 79.701\end{array}$

$79.480 \quad 79.456$

$\begin{array}{ll}78.988 & 78.964 \\ 78.742 & 78.718\end{array}$

$\begin{array}{ll}78.742 & 78.718 \\ 78.496 & 78.472\end{array}$

$78.250 \quad 78.226$

$\begin{array}{ll}78.005 & 77.980 \\ 77.759 & 77.734\end{array}$

$\begin{array}{ll}77.0759 & 77.0734 \\ 77.513 & 77.488 \\ 77.267 & 77.243\end{array}$

$\begin{array}{rr}15677.021 & 76.9 \\ 76.775 & 76.751\end{array}$

$76.530 \quad 76.50$

$76.038 \quad 76.013$

$\begin{array}{ll}75.792 & 75.76 \\ 75.546 & 75.52\end{array}$

$75.301 \quad 75.522,750497$

$\begin{array}{ll}75.055 & 75.030 \\ 74.809 & 74.78\end{array}$

$15674.563 \quad 74.539$

$\begin{array}{ll}74.318 & 74.293 \\ 74.072 & 74.047\end{array}$

73.826
73.580 7302

$\begin{array}{ll}73.580 & 73.55 \\ 73.335 & 73.310\end{array}$

73.08973 .06

$72.843 \quad 72.818 \quad 73.040$

$\begin{array}{ll}72.597 & 72.57 \\ 72.352 & 72.32\end{array}$

$15672.106 \quad 72.082$

$\begin{array}{ll}71.860 & 71.836 \\ 71.615 & 71.590\end{array}$

$71.369 \quad 71.34$

$\begin{array}{ll}71.123 & 71.09 \\ 70.878 & 70: 85\end{array}$

$70.632 \quad 70.607$

$\begin{array}{llll}70.386 & 70.362 & 70.583 & 70.5 \\ 70.141 & 70.116 & 70.092 & 70.0067\end{array}$

$70.337 \quad 70.313$

$\begin{array}{llll}70.141 & 70.116 & 70.092 & 70.06\end{array}$ $\begin{array}{llllll}89.224 & 89.199 & 89.175 & 89.150 & 89.126 & 89.101 \\ 82.978 & 88.953 & 88.929 & 88.904 & 88.879 & 88.855\end{array}$

$88.732 \quad 88.707 \quad 88.682 \quad 88.658 \quad 88.679 \quad 88.855$

$\begin{array}{lllllll}88.485 & 88.461 & 88.436 & 88.412 & 88.387 & 88.362\end{array}$

$\begin{array}{llllll}88.240 & 88.215 & 88.190 & 88.166 & 88.141 & 88.116\end{array}$

$\begin{array}{lllllll}87.993 & 87.969 & 87.944 & 87.919 & 87.895 & 87.870\end{array}$

$\begin{array}{llllll}87.501 & 87.476 & 87.698 & 87.673 & 87.649 & 87.624\end{array}$

$\begin{array}{lllllll}87.255 & 87.230 & 87.205 & 87.181 & 87.156 & 87.132\end{array}$

$\begin{array}{lllllll}87.009 & 86.984 & 86.959 & 86.935 & 86.910 & 86.885\end{array}$

$\begin{array}{llllll}86.762 & 86.738 & 86.713 & 86.689 & 86.664 & 86.639\end{array}$

$\begin{array}{llllll}86.516 & 86.492 & 86.467 & 86.443 & 86.418 & 86.393 \\ 86.270 & 86.246 & 86.221 & 86.196 & 86.172 & 86.147\end{array}$

$\begin{array}{lllllll}86.270 & 86.246 & 86.221 & 86.196 & 86.172 & 86.147\end{array}$

$\begin{array}{lllllll}85.778 & 85.753 & 85.729 & 85.704 & 85.679 & 85.655\end{array}$

$\begin{array}{llllll}85.532 & 85.507 & 85.483 & 85.458 & 85.433 & 85.409\end{array}$

$\begin{array}{llllll}85.286 & 85.261 & 85.236 & 85.212 & 85.187 & 85.163 \\ 85.040 & 85.015 & 84.990 & 84.966 & 84.941 & 84.917\end{array}$

$\begin{array}{llllll}84.0493 & 85.0169 & 84.990 & 84.966 & 84.941 & 84.917 \\ 84.547 & 84.523 & 84.498 & 84.720 & 84.695 & 84.671 \\ 84.47 & 84.449 & 84.424\end{array}$

$\begin{array}{llllll}84.301 & 84.277 & 84.252 & 84.228 & 84.203 & 84.178\end{array}$

$\begin{array}{lllllll}84.055 & 84.031 & 84.006 & 83.981 & 83.957 & 83.932\end{array}$

$\begin{array}{lllllll}83.803 & 83.785 & 83.760 & 83.736 & 83.711 & 83.686 \\ 83.563 & 83.539 & 83.514 & 83.490 & 83.465 & 83.440\end{array}$

$\begin{array}{llllll}83.317 & 83.293 & 83.268 & 83.243 & 83.219 & 83.194\end{array}$

$\begin{array}{llllll}83.071 & 83.047 & 83.022 & 82.997 & 82.973 & 82.948 \\ 82.825 & 82.801 & 82.776 & 82.751 & 82.727 & 82.702\end{array}$

$\begin{array}{lllllll}82.579 & 82.555 & 82.530 & 82.505 & 82.481 & 82.456\end{array}$

$\begin{array}{llllll}82.333 & 82.308 & 82.284 & 82.259 & 82.235 & 82.210 \\ 82.087 & 82.062 & 82.038 & 82.013 & 81.989 & 81.964\end{array}$

$\begin{array}{lllllll}81.841 & 81.817 & 81.792 & 81.767 & 81.743 & 81.718\end{array}$

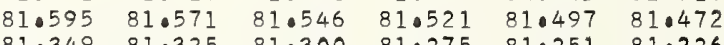

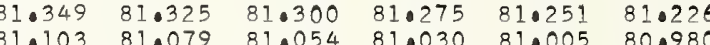

$\begin{array}{llllll}80.857 & 80.833 & 80.808 & 80.783 & 80.759 & 80.734\end{array}$

$\begin{array}{llllll}80.611 & 80.587 & 80.562 & 80.538 & 80.513 & 80.488\end{array}$

$\begin{array}{llllllll}80.119 & 80.095 & 80.070 & 80.046 & 80.021 & 79.996\end{array}$

$\begin{array}{llllll}80.119 & 80.095 & 80.070 & 80.046 & 80.021 & 79.996 \\ 79.873 & 79.849 & 79.824 & 79.800 & 79.775 & 79.750\end{array}$

$\begin{array}{llllll}79.628 & 79.603 & 79.578 & 79.554 & 79.529 & 79.505\end{array}$

$\begin{array}{llllllll}79.431 & 79.406 & 79.382 & 79.357 & 79.333 & 79.308 & 79.283 & 79.259 \\ 79.185 & 79.160 & 79.136 & 79.111 & 79.087 & 79.062 & 79.037 & 79.013\end{array}$

$\begin{array}{lllllllll}78.939 & 78.914 & 78.890 & 78.865 & 78.841 & 78.816 & 78.791 & 78.767 \\ 78.693 & 78.669 & 78.644 & 78.619 & 78.595 & 78.570 & 78.546 & 78.521\end{array}$

$\begin{array}{llllllll}78.447 & 78.423 & 78.398 & 78.374 & 78.349 & 78.324 & 78.300 & 78.275\end{array}$

$\begin{array}{llllllll}77.956 & 77.931 & 77.906 & 77.882 & 77.857 & 77.833 & 77.808 & 77.984\end{array}$

$\begin{array}{llllllll}7.610 & 77.685 & 77.660 & 77.636 & 77.611 & 77.587 & 77.562 & 77.537\end{array}$

$\begin{array}{llllll}77.169 & 77.144 & 77.120 & 77.095 & 77.070 & 77.046\end{array}$

$\begin{array}{llllll}76.923 & 76.898 & 76.874 & 76.849 & 76.825 & 76.800\end{array}$

$\begin{array}{llllll}76.431 & 76.407 & 76.382 & 76.358 & 76.333 & 76.508\end{array}$

$\begin{array}{llllll}76.186 & 76.161 & 76.136 & 76.112 & 76.087 & 76.062\end{array}$

$\begin{array}{lllllll}75.940 & 75.915 & 75.891 & 75.866 & 75.841 & 75.817\end{array}$

$\begin{array}{llllll}75.448 & 75.423 & 75.399 & 75.374 & 75.350 & 75.325\end{array}$

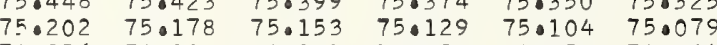

$\begin{array}{lllllll}74.956 & 74.932 & 74.907 & 74.883 & 74.858 & 74.834\end{array}$

$\begin{array}{lllllll}74.465 & 74.440 & 74.416 & 74.391 & 74.367 & 74.342\end{array}$

$\begin{array}{llllll}74.019 & 74.440 & 74.416 & 74.391 & 74.367 & 74.342 \\ 74.170 & 74.146 & 740121 & 740096\end{array}$

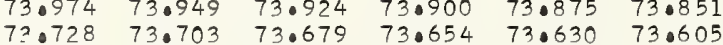

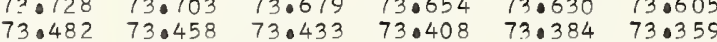

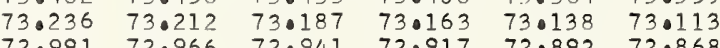

$\begin{array}{llllll}72.091 & 72.0966 & 72.941 & 720917 & 72.892 & 72.0868\end{array}$

$\begin{array}{llllll}72.745 & 72.720 & 72.696 & 72.671 & 72.6447 & 72.622\end{array}$

$\begin{array}{llllll}72.499 & 72.475 & 72.450 & 72.426 & 72.401 & 72.376 \\ 72.253 & 72.229 & 72.204 & 72.180 & 72.155 & 72.130\end{array}$

$\begin{array}{lllllll}72.008 & 71.983 & 71.959 & 71.934 & 71.910 & 71.885\end{array}$

$\begin{array}{llllll}71.762 & 71.0738 & 71.713 & 71.0688 & 71.064 & 71.639\end{array}$

$\begin{array}{llllll}71.516 & 71.492 & 71.0467 & 71.443 & 71.418 & 71.394 \\ 71.0271 & 71.246 & 71.022 & 71.197 & 71.172 & 71.148\end{array}$

$71.025 \quad 71.001 \quad 70.076 \quad 70.951 \quad 70.027 \quad 70.002$

$\begin{array}{llllll}70.780 & 70.755 & 70.730 & 70.706 & 70.681 & 70.657 \\ 70.534 & 70.509 & 70.485 & 70.460 & 70.436 & 70.411\end{array}$

$\begin{array}{lllllll}70.288 & 70.264 & 70.239 & 70.215 & 70.190 & 70.165\end{array}$

$\begin{array}{llllll}70.043 & 70.018 & 69.993 & 69.969 & 69.944 & 69.920 \\ 69.797 & 69.772 & 69.748 & 69.723 & 69.699 & 69.674\end{array}$

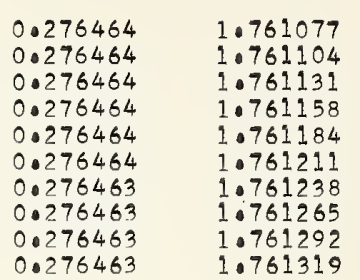

$0.276463 \quad 1.761346$

$0.276463 \quad 1.761373$

$0.296463 \quad 1.761426$

$\begin{array}{ll}1.761453 \\ 0.276462 & 1.761480\end{array}$

$0.276462 \quad 1.761507$

$\begin{array}{ll}0.276462 & 1.761534 \\ 0.276462 & 1.761561\end{array}$

$\begin{array}{ll}0.276462 . & 1.761561 \\ 0.276462 & 1.761587\end{array}$

0.276462

0.276462

0.276461

0.27646
0.27646
0.2764

0.276461

0.276461
0.276461

1.761614

0.27646

0.276460
0.276460
0.027660

0.276460

.276460

0.276460
0.276460
0.27606

0.276460
0.276460
0.27640

0.276460

0.276459

1.761668

1.761695

1.761749

1.761775

1.761829

1.761883

0.276459

0.276459
0.276459
0.276459

0.276459

.276459

0.276459

0.276458

0.276458
0.276458

0.276458

0.276458

0.276458

0.276458

0.276457

0.276457

0.276457

0.276457

0.276457

0.276457

0.276457

0.276456

0.276456

0.0276456

0.276456
0.276456
0.276456

0.276456

1.761937

10.761963

1.762017

1.762044

1.762098

1.762125

0.276456

0.027645
0.27645

0.276455

0.276455

0.276454

.762151

1.762178

1.762232

1.762259

1.762313

1.762339
1.762366

1.762393

1.762420

1.762447

1.762500

1.762527

1.762554

.0762581

1.762635

1.762688

1.762715

1.782742
1.762769

1.762769 


.04

6382 2
2
2
2
2
2
2
2
2
2

6383

$$
\begin{array}{r}
383 \\
3 \\
3 \\
3 \\
3 . \\
3 . \\
3 . \\
3 . \\
3 . \\
3 .
\end{array}
$$

6384.

4.1
4.
4.
4.
4.6
4.0
4.0

6385.0

5.

5.4

5.7

5.8

6386.

386
6
6
6
6
6
6
60
60
608

6
6
6
6
6
6
6
6
6
6
6

6387.0

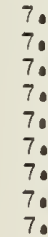

6388

38
8
8
8
8
8
8
8
8
8
8

6389

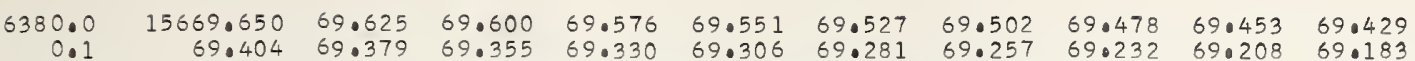

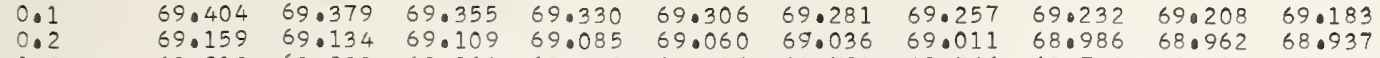
$\begin{array}{lllllllllll}0.3 & 68.913 & 68.888 & 68.864 & 68.839 & 68.815 & 68.790 & 68.766 & 68.741 & 68.716 & 68.692\end{array}$ $\begin{array}{lllllllllll}0.4 & 68.667 & 68.643 & 68.618 & 68.594 & 68.569 & 68.545 & 68.520 & 68.495 & 68.471 & 68.446\end{array}$ $\begin{array}{lllllllllll}0.5 & 68.422 & 68.397 & 68.373 & 68.348 & 68.323 & 68.299 & 68.274 & 68 \cdot 250 & 68 \cdot 225 & 68 \cdot 201 \\ 0.6 & 68.176 & 68.151 & 68.127 & 68.103 & 68.078 & 68.053 & 68.029 & 68.004 & 67.980 & 67.955\end{array}$ $\begin{array}{lllllllllll}0.7 & 67.931 & 67.906 & 67.881 & 67.857 & 67.832 & 67.808 & 67.783 & 67.759 & 67.734 & 67.710 \\ 0.8 & 67.685 & 67.661 & 67.630 & 67.611 & 67.587 & 67.562 & 67.538 & 67.513 & 67.489 & 67.464\end{array}$ $\begin{array}{lllllllllll}0.8 & 67.685 & 67.661 & 67.636 & 67.611 & 67.587 & 67.562 & 67.538 & 67.513 & 67.489 & 67.464 \\ 0.9 & 67.440 & 67.415 & 67.390 & 67.366 & 67.341 & 67.317 & 67.292 & 67.268 & 67.243 & 67.218\end{array}$

$\begin{array}{rrrrrrrrrrr}6381.0 & 15667.194 & 67.169 & 67.145 & 67.120 & 67.096 & 67.071 & 67.047 & 67.022 & 66.998 & 66.973 \\ 1.11 & 66.948 & 66.924 & 66.099 & 66.875 & 66.850 & 66.0726 & 66.801 & 66.776 & 66.752 & 66.728\end{array}$

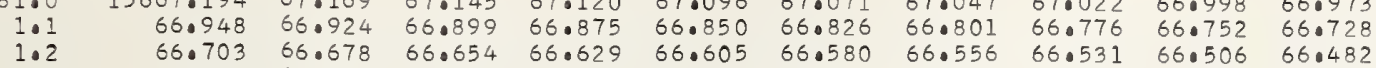
$\begin{array}{lllllllllll}1.2 & 66.703 & 66.678 & 66.654 & 66.629 & 66.505 & 66.580 & 66.556 & 66.531 & 66.506 & 66.482 \\ 1.3 & 66.457 & 66.433 & 66.408 & 66.384 & 66.359 & 66.335 & 66.310 & 66.286 & 66.261 & 66.236\end{array}$ $\begin{array}{lllllllllll}1.4 & 66.212 & 66.187 & 66.163 & 66.138 & 66.1114 & 66.089 & 66.065 & 66.040 & 66.016 & 65.0991 \\ 1.5 & 65.967 & 65.942 & 65.917 & 65.893 & 65.868 & 65.844 & 65.819 & 65.795 & 65.770 & 65.744\end{array}$ $\begin{array}{llllllllllll}1.6 & 65.721 & 65.696 & 65.6772 & 65.647 & 65.623 & 65.598 & 65.574 & 65.549 & 65.524 & 65.500 \\ 1.7 & 65.475 & 65.451 & 65.026 & 65.402 & 65.377 & 65.353 & 65.328 & 65.304 & 65.279 & 65054\end{array}$

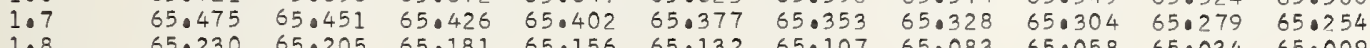
$\begin{array}{lllllllllll}1.8 & 65.230 & 65.205 & 65.181 & 65.156 & 65.132 & 65.107 & 65.083 & 65.058 & 65.034 & 65.009 \\ 1.9 & 64.984 & 64.960 & 64.935 & 64.911 & 64.886 & 64.862 & 64.837 & 64.813 & 64.788 & 64.764\end{array}$

15664.739 64.494 .248 64.248 63.75763 .733 $63.512 \quad 63.487$ $63.021 \quad 62.996$ $62.776 \quad 62.75$

15662.285 62.046 $62.040 \quad 62.260 \quad 62.236$ 61.54961 .770 $61.303 \quad 61.279$ $60.813 \quad 60.7$ $60.568 \quad 60.543$ 60.322
60.077

15659.83 $59.586 \quad 59.568$ $\begin{array}{ll}59.341 & 59.317 \\ 59.096 & 59.071\end{array}$ $58.850 \quad 58.82$ $58.605 \quad 58.58$ $58.115 \quad 58.090$

$57.624 \quad 57.600$

$15657.379 \quad 57.35$ 57.134

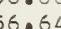
56.619 56.153 55.908

55.172

15654.927 54.68 54.682
54.437
54.192

53.947

53.702

53.21253 .187

$\begin{array}{ll}52.966 & 52.942 \\ 52.721 & 52.697\end{array}$

15652.476

$52.476 \quad 52.452$

$51.986 \quad 51.96$

$51.496 \quad 51.472$

$51.251 \quad 51.227$

$50.76150 .736 \quad 50.0$

50.51

50.271

15650
49

49.781
49.536

49.536
49.291

$49.291 \quad 49.267$

$\begin{array}{ll}49.046 & 49.022 \\ 48.801 & 48.777\end{array}$

$48.556 \quad 48.532$

$48.311 \quad 48.287$

$\begin{array}{ll}48.066 & 48.04 \\ 47.821 & 47.79\end{array}$

$64.690 \quad 64.665$

64.64

64.61

$\begin{array}{llll}64.592 & 64.567 & 64.543 & 64.518\end{array}$

$64.396 \quad 64 \cdot 371 \quad 64 \cdot 346 \quad 64 \cdot 322 \quad 64 \cdot 297 \quad 64 \cdot 273$

$\begin{array}{llllllll}64.199 & 64.174 & 6.1150 & 64.125 & 64.101 & 64.076 & 64.052 & 64.027 \\ 63.954 & 63.929 & 63.905 & 63.880 & 63.855 & 63.831 & 63.807 & 63.782\end{array}$

$\begin{array}{lllllllll}3.708 & 63.684 & 63.659 & 63.635 & 63.610 & 63.585 & 63.561 & 63.536\end{array}$

$\begin{array}{llllllll}6.218 & 63.193 & 63.168 & 63.389 & 63.365 & 63.340 & 63.316 & 63.291 \\ 63.119 & 63.095 & 63.070 & 63.046\end{array}$

$62.923 \quad 62.898 \quad 62.874 \quad 62.849 \quad 62.825 \quad 62.800$

$\begin{array}{llllllll}62.727 & 62.702 & 6 ? .678 & 62.653 & 62.628 & 62.604 & 62.579 & 62.555 \\ 62.481 & 62.457 & 62.432 & 62.408 & 62.383 & 62.359 & 62.334 & 62.309\end{array}$

$\begin{array}{llllllll}2.236 & 62.211 & 62.187 & 62.162 & 62.138 & 62.113 & 62.089 & 62.064\end{array}$

$\begin{array}{llllllll}61.745 & 61.721 & 61.696 & 61.672 & 61.647 & 61.622 & 61.598 & 61.573\end{array}$

$\begin{array}{llllllll}61.500 & 61.475 & 61.451 & 61.426 & 61.401 & 61.377 & 61.353 & 61.32 \\ 61.254 & 61.230 & 61.205 & 61.181 & 61.156 & 61.132 & 61.107 & 61.08\end{array}$

$\begin{array}{llllllll}1.009 & 60.985 & 60.960 & 60.935 & 60.911 & 60.886 & 60.862 & 60.837\end{array}$

$\begin{array}{llll}60.911 & 60.886 & 60.862 & 60.837 \\ 60.666 & 60.641 & 60.617 & 60.592\end{array}$

$\begin{array}{llllll}60.469 & 60.445 & 60.420 & 60.396 & 60.371 & 60.347 \\ 0.224 & 60.190 & 60.175 & 60.151 & 60.126 & 60.10\end{array}$

$\begin{array}{ll}60.273 & 60.2 \\ 60.028 & 60.00\end{array}$

$\begin{array}{ll}60.224 & 60.19 \\ 59.979 & 59.954\end{array}$

$59.930 \quad 59.905 \quad 59.881 \quad 59.856$

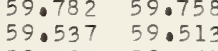

59.73
59.48
$59 \cdot 243$

59.709
59.464

$\begin{array}{llll}59.684 & 59.660 & 59.635 & 59.611 \\ 59.439 & 59.415 & 59.390 & 59.366\end{array}$

$59.047 \quad 59.022$

$\begin{array}{ll}58.801 & 58.777 \\ 58.556 & 58.532\end{array}$

52.998

58.75258 .728

$\begin{array}{llll}59.194 & 59.169 & 59.145 & 59.120\end{array}$

$\begin{array}{llllll}58.507 & 58.483 & 58.703 & 58.679 & 58.654 & 58.630\end{array}$

$\begin{array}{llllll}58.262 & 58.238 & 58.213 & 58.188 & 58.164 & 58.140\end{array}$

$\begin{array}{ll}8.066 & 58.041 \\ 7.821 & 57.79\end{array}$

58.017

57.992
57.747

5700

57.72
57.47

57

$\begin{array}{llllll}57.281 & 57.256 & 57.232 & 57.208 & 57.183 & 57.158\end{array}$ 7.085
57.060

57.036
56.791 56.01

$\begin{array}{llll}56.987 & 56.962 & 56.038 & 56.913\end{array}$ $\begin{array}{llllll}56.546 & 56.521 & 56.496 & 56.472 & 56.448 & 56.423\end{array}$ $\begin{array}{llllll}56.300 & 56.276 & 56.251 & 56.227 & 56.202 & 56.178\end{array}$ $\begin{array}{llllll}5.810 & 55.786 & 55.761 & 55.736 & 55.712 & 55.687\end{array}$ $55.074 \quad 55.050$

550

$55.025 \quad 55.001 \quad 54.976 \quad 54.952$

$\begin{array}{llllll}54.829 & 54.805 & 54.780 & 54.756 & 54.731 & 54.707\end{array}$

$\begin{array}{llllll}4.339 & 54.315 & 54.290 & 54.266 & 54.241 & 54.216\end{array}$ $\begin{array}{lllllll}56.094 & 54.069 & 54.045 & 54.020 & 53.996 & 53.971\end{array}$ $\begin{array}{llllll} & 53.824 & 53.800 & 53.775 & 53.751 & 53.726\end{array}$ $\begin{array}{llllll}53.604 & 53.579 & 53.555 & 53.530 & 53.506 & 53.481 \\ 53.359 & 53.334 & 53.310 & 53.285 & 53.261 & 53.236\end{array}$ $\begin{array}{llllll}53.114 & 53.089 & 53.065 & 53.040 & 53.015 & 52.991\end{array}$ $52.623 \quad 52.599 \quad 52.574 \quad 52.550 \quad 52.525 \quad 52.501$ $\begin{array}{llllll}52.378 & 52.354 & 52.329 & 52.305 & 52.280 & 52.256\end{array}$ $\begin{array}{llllll}51.888 & 51.864 & 51.839 & 51.815 & 51.790 & 51.766\end{array}$ $\begin{array}{llllll}51.888 & 51.864 & 51.839 & 51.815 & 51.790 & 51.766 \\ 51.643 & 51.619 & 51.594 & 51.570 & 51.545 & 51.521\end{array}$ $\begin{array}{llllll}51.398 & 51.374 & 51.349 & 51.324 & 51.300 & 51.276\end{array}$

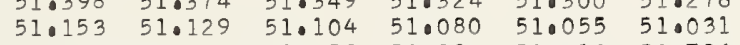
$\begin{array}{llllll}50.908 & 50.883 & 50.859 & 50.834 & 50.810 & 50.786\end{array}$ $\begin{array}{lllllll}50.663 & 50.639 & 50.614 & 50.589 & 50.565 & 50.541\end{array}$ $\begin{array}{llllll}50.418 & 50.394 & 50.369 & 50.345 & 50.320 & 50.295 \\ 50.173 & 50.149 & 50.124 & 50.099 & 50.075 & 50.050\end{array}$ $\begin{array}{lllllll}49.928 & 49.903 & 49.879 & 49.855 & 49.830 & 49.806\end{array}$ $\begin{array}{llllll}49.683 & 49.658 & 49.634 & 49.609 & 49.585 & 49.561\end{array}$ $49.438 \quad 49.414 \quad 49.389 \quad 49.365 \quad 49.340 \quad 49.316$ $49.193 \quad 49.168 \quad 49.144 \quad 49.120 \quad 49.095 \quad 49.071$ $\begin{array}{llllll}48.948 & 48.924 & 48.899 & 48.875 & 48.850 & 48.826 \\ 48.703 & 48.679 & 48.654 & 48.630 & 48.605 & 48.581\end{array}$ $\begin{array}{lllllll}48.703 & 48.649 & 48.454 & 48.409 & 48.385 & 48.360 & 48.336\end{array}$ $\begin{array}{llllll}48.213 & 48.189 & 48.164 & 48.140 & 48.115 & 48.091\end{array}$ $\begin{array}{llllll}47.968 & 47.944 & 47.919 & 47.895 & 47.870 & 47.846 \\ 47.724 & 47.699 & 47.675 & 47.650 & 47.625 & 47.601\end{array}$ $\begin{array}{lllllll}47.478 & 47.454 & 47.430 & 47.405 & 47.381 & 47.356\end{array}$ $\begin{array}{llllllllll}47.332 & 47.307 & 47.283 & 47.258 & 47.234 & 47.209 & 47.185 & 47.160 & 47.136 & 47.111 \\ 47.087 & 47.062 & 47.038 & 47.013 & 46.989 & 46.964 & 46.940 & 46.915 & 46.891 & 46.866 \\ 46.842 & 46.817 & 46.793 & 46.768 & 46.744 & 46.719 & 46.695 & 46.670 & 46.646 & 46.621 \\ 46.597 & 46.572 & 46.548 & 46.523 & 46.499 & 46.474 & 46.450 & 46.425 & 46.401 & 46.376 \\ 46.352 & 46.328 & 46.303 & 46.279 & 46.254 & 46.229 & 46.205 & 46.181 & 46.156 & 46.132 \\ 46.107 & 46.083 & 46.058 & 46.034 & 46.009 & 45.985 & 45.960 & 45.936 & 45.911 & 45.887 \\ 45.862 & 45.838 & 45.813 & 45.789 & 45.764 & 45.740 & 45.715 & 45.691 & 45.666 & 45.642 \\ 45.617 & 45.593 & 45.568 & 45.544 & 45.520 & 45.495 & 45.470 & 45.446 & 45.422 & 45.397 \\ 45.373 & 45.348 & 45.323 & 45.299 & 45.275 & 45.250 & 45.226 & 45.201 & 45.177 & 45.152\end{array}$ $\begin{array}{llllllllll}47.332 & 47.307 & 47.283 & 47.258 & 47.234 & 47.209 & 47.185 & 47.160 & 47.136 & 47.111 \\ 47.087 & 47.062 & 47.038 & 47.013 & 46.989 & 46.964 & 46.940 & 46.915 & 46.891 & 46.866 \\ 46.842 & 46.817 & 46.793 & 46.768 & 46.744 & 46.719 & 46.695 & 46.670 & 46.646 & 46.621 \\ 46.597 & 46.572 & 46.548 & 46.523 & 46.499 & 46.474 & 46.450 & 46.425 & 46.401 & 46.376 \\ 46.352 & 46.328 & 46.303 & 46.279 & 46.254 & 46.229 & 46.205 & 46.181 & 46.156 & 46.132 \\ 46.107 & 46.083 & 46.058 & 46.034 & 46.009 & 45.985 & 45.960 & 45.936 & 45.911 & 45.887 \\ 45.862 & 45.838 & 45.813 & 45.789 & 45.764 & 45.740 & 45.715 & 45.691 & 45.666 & 45.642 \\ 45.617 & 45.593 & 45.568 & 45.544 & 45.520 & 45.495 & 45.470 & 45.446 & 45.422 & 45.397 \\ 45.373 & 45.348 & 45.323 & 45.299 & 45.275 & 45.250 & 45.226 & 45.201 & 45.177 & 45.152\end{array}$ $\begin{array}{llllllllll}47.332 & 47.307 & 47.283 & 47.258 & 47.234 & 47.209 & 47.185 & 47.160 & 47.136 & 47.111 \\ 47.087 & 47.062 & 47.038 & 47.013 & 46.989 & 46.964 & 46.940 & 46.915 & 46.891 & 46.866 \\ 46.842 & 46.817 & 46.793 & 46.768 & 46.744 & 46.719 & 46.695 & 46.670 & 46.646 & 46.621 \\ 46.597 & 46.572 & 46.548 & 46.523 & 46.499 & 46.474 & 46.450 & 46.425 & 46.401 & 46.376 \\ 46.352 & 46.328 & 46.303 & 46.279 & 46.254 & 46.229 & 46.205 & 46.181 & 46.156 & 46.132 \\ 46.107 & 46.083 & 46.058 & 46.034 & 46.009 & 45.985 & 45.960 & 45.936 & 45.911 & 45.887 \\ 45.862 & 45.838 & 45.813 & 45.789 & 45.764 & 45.740 & 45.715 & 45.691 & 45.666 & 45.642 \\ 45.617 & 45.593 & 45.568 & 45.544 & 45.520 & 45.495 & 45.470 & 45.446 & 45.422 & 45.397 \\ 45.373 & 45.348 & 45.323 & 45.299 & 45.275 & 45.250 & 45.226 & 45.201 & 45.177 & 45.152\end{array}$ $\begin{array}{llllllllll}47.332 & 47.307 & 47.283 & 47.258 & 47.234 & 47.209 & 47.185 & 47.160 & 47.136 & 47.111 \\ 47.087 & 47.062 & 47.038 & 47.013 & 46.989 & 46.964 & 46.940 & 46.915 & 46.891 & 46.866 \\ 46.842 & 46.817 & 46.793 & 46.768 & 46.744 & 46.719 & 46.695 & 46.670 & 46.646 & 46.621 \\ 46.597 & 46.572 & 46.548 & 46.523 & 46.499 & 46.474 & 46.450 & 46.425 & 46.401 & 46.376 \\ 46.352 & 46.328 & 46.303 & 46.279 & 46.254 & 46.229 & 46.205 & 46.181 & 46.156 & 46.132 \\ 46.107 & 46.083 & 46.058 & 46.034 & 46.009 & 45.985 & 45.960 & 45.936 & 45.911 & 45.887 \\ 45.862 & 45.838 & 45.813 & 45.789 & 45.764 & 45.740 & 45.715 & 45.691 & 45.666 & 45.642 \\ 45.617 & 45.593 & 45.568 & 45.544 & 45.520 & 45.495 & 45.470 & 45.446 & 45.422 & 45.397 \\ 45.373 & 45.348 & 45.323 & 45.299 & 45.275 & 45.250 & 45.226 & 45.201 & 45.177 & 45.152\end{array}$ $\begin{array}{llllllllll}47.332 & 47.307 & 47.283 & 47.258 & 47.234 & 47.209 & 47.185 & 47.160 & 47.136 & 47.111 \\ 47.087 & 47.062 & 47.038 & 47.013 & 46.989 & 46.964 & 46.940 & 46.915 & 46.891 & 46.866 \\ 46.842 & 46.817 & 46.793 & 46.768 & 46.744 & 46.719 & 46.695 & 46.670 & 46.646 & 46.621 \\ 46.597 & 46.572 & 46.548 & 46.523 & 46.499 & 46.474 & 46.450 & 46.425 & 46.401 & 46.376 \\ 46.352 & 46.328 & 46.303 & 46.279 & 46.254 & 46.229 & 46.205 & 46.181 & 46.156 & 46.132 \\ 46.107 & 46.083 & 46.058 & 46.034 & 46.009 & 45.985 & 45.960 & 45.936 & 45.911 & 45.887 \\ 45.862 & 45.838 & 45.813 & 45.789 & 45.764 & 45.740 & 45.715 & 45.691 & 45.666 & 45.642 \\ 45.617 & 45.593 & 45.568 & 45.544 & 45.520 & 45.495 & 45.470 & 45.446 & 45.422 & 45.397 \\ 45.373 & 45.348 & 45.323 & 45.299 & 45.275 & 45.250 & 45.226 & 45.201 & 45.177 & 45.152\end{array}$ $\begin{array}{llllllllll}47.332 & 47.307 & 47.283 & 47.258 & 47.234 & 47.209 & 47.185 & 47.160 & 47.136 & 47.111 \\ 47.087 & 47.062 & 47.038 & 47.013 & 46.989 & 46.964 & 46.940 & 46.915 & 46.891 & 46.866 \\ 46.842 & 46.817 & 46.793 & 46.768 & 46.744 & 46.719 & 46.695 & 46.670 & 46.646 & 46.621 \\ 46.597 & 46.572 & 46.548 & 46.523 & 46.499 & 46.474 & 46.450 & 46.425 & 46.401 & 46.376 \\ 46.352 & 46.328 & 46.303 & 46.279 & 46.254 & 46.229 & 46.205 & 46.181 & 46.156 & 46.132 \\ 46.107 & 46.083 & 46.058 & 46.034 & 46.009 & 45.985 & 45.960 & 45.936 & 45.911 & 45.887 \\ 45.862 & 45.838 & 45.813 & 45.789 & 45.764 & 45.740 & 45.715 & 45.691 & 45.666 & 45.642 \\ 45.617 & 45.593 & 45.568 & 45.544 & 45.520 & 45.495 & 45.470 & 45.446 & 45.422 & 45.397 \\ 45.373 & 45.348 & 45.323 & 45.299 & 45.275 & 45.250 & 45.226 & 45.201 & 45.177 & 45.152\end{array}$ $\begin{array}{llllllllll}47.332 & 47.307 & 47.283 & 47.258 & 47.234 & 47.209 & 47.185 & 47.160 & 47.136 & 47.111 \\ 47.087 & 47.062 & 47.038 & 47.013 & 46.989 & 46.964 & 46.940 & 46.915 & 46.891 & 46.866 \\ 46.842 & 46.817 & 46.793 & 46.768 & 46.744 & 46.719 & 46.695 & 46.670 & 46.646 & 46.621 \\ 46.597 & 46.572 & 46.548 & 46.523 & 46.499 & 46.474 & 46.450 & 46.425 & 46.401 & 46.376 \\ 46.352 & 46.328 & 46.303 & 46.279 & 46.254 & 46.229 & 46.205 & 46.181 & 46.156 & 46.132 \\ 46.107 & 46.083 & 46.058 & 46.034 & 46.009 & 45.985 & 45.960 & 45.936 & 45.911 & 45.887 \\ 45.862 & 45.838 & 45.813 & 45.789 & 45.764 & 45.740 & 45.715 & 45.691 & 45.666 & 45.642 \\ 45.617 & 45.593 & 45.568 & 45.544 & 45.520 & 45.495 & 45.470 & 45.446 & 45.422 & 45.397 \\ 45.373 & 45.348 & 45.323 & 45.299 & 45.275 & 45.250 & 45.226 & 45.201 & 45.177 & 45.152\end{array}$ $\begin{array}{llllllllll}47.332 & 47.307 & 47.283 & 47.258 & 47.234 & 47.209 & 47.185 & 47.160 & 47.136 & 47.111 \\ 47.087 & 47.062 & 47.038 & 47.013 & 46.989 & 46.964 & 46.940 & 46.915 & 46.891 & 46.866 \\ 46.842 & 46.817 & 46.793 & 46.768 & 46.744 & 46.719 & 46.695 & 46.670 & 46.646 & 46.621 \\ 46.597 & 46.572 & 46.548 & 46.523 & 46.499 & 46.474 & 46.450 & 46.425 & 46.401 & 46.376 \\ 46.352 & 46.328 & 46.303 & 46.279 & 46.254 & 46.229 & 46.205 & 46.181 & 46.156 & 46.132 \\ 46.107 & 46.083 & 46.058 & 46.034 & 46.009 & 45.985 & 45.960 & 45.936 & 45.911 & 45.887 \\ 45.862 & 45.838 & 45.813 & 45.789 & 45.764 & 45.740 & 45.715 & 45.691 & 45.666 & 45.642 \\ 45.617 & 45.593 & 45.568 & 45.544 & 45.520 & 45.495 & 45.470 & 45.446 & 45.422 & 45.397 \\ 45.373 & 45.348 & 45.323 & 45.299 & 45.275 & 45.250 & 45.226 & 45.201 & 45.177 & 45.152\end{array}$

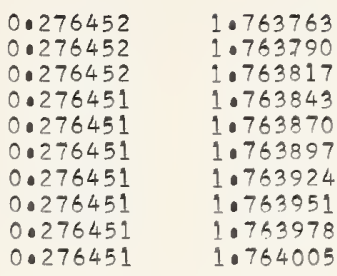

0.27645 0.276450

0.276450

.276450

0.276450

0.276450

0.276450

0.276449

0.27644

76449

0.27644

0.276448

1.76403

0.276448

0.276448

0.27644

. 276448

0.276447

0.276447

0.276447
0.276447
0.276447

0.276447

0.276446

0.276446

0.276446
0.276466

0.776446

0.276446

0.276446

0.276445

0.276445

0.0276445

0.276445

0.276445
0.276445

0.276444

0.276444

0.276444

0.276444

0.276444

0.276444

0.276443

0.276443

0.276443

0.276443
0.276443

0.276443

0.276443
0.276442
0.276442

0.276442

0.276442

0.276442

0.276442

0.276442

0.0276441

0.27644

0.27644

0.276441

0.27644

0.276440

0.276440

0.276440

0.276440

0.276440

0.276440

.010

$: 825$ 


\section{0.0
0.0
0.0
0
0
0
0
0
0.08}

0.1
0.2
0.3
0.4
0.5
0.6
0.7
0.8
0.9

6392.0

$2 \cdot 1$
$2 \cdot 2$
$2 \cdot 3$

2.3
2.4

2.5

2.6
2.7

2. 8

6393.0

3.1
3.2
3.3

3.3
3.4
3.5

3.6

3.7
3.9

6394.0

401
40.2
40.6

4.3
4.4
4.55

4.6
4.7

4.8

6395.

5.1
5.2
5.3
5.4

5.4
5.5

5.6

5.7
5.8
5.9

6396.0

6.1

6.2
6.3
6.4

6.4
6.5

6.6
6.7

6.8
6.9

6397.

7

7.3

7.5
7.6

7.7

6398.0

8.1
8.2

8.

8.4
8.5

8.6
8.7

8.7
8.8

8.9

6399.

9.

9.2
9.3
9.4

9.4
9.5

9.6
9.7

9.8 $\begin{array}{llllllllll}44.883 & 45.103 & 45.079 & 45.054 & 45.030 & 45.005 & 44.981 & 44.956 & 44.932 & 44.907 \\ \end{array}$ $\begin{array}{llllllllll}44.638 & 44.614 & 44.589 & 44.565 & 44.540 & 44.516 & 44.491 & 44.467 & 44.442 & 44.418\end{array}$ $\begin{array}{lllllllllll}44.393 & 44.369 & 44.344 & 44.320 & 44.295 & 44.271 & 44.246 & 44.222 & 44.197 & 44.173\end{array}$ $\begin{array}{llllllllll}44.148 & 44.124 & 44.099 & 44.075 & 44.051 & 44.026 & 44.002 & 43.977 & 43.953 & 43.928\end{array}$ $\begin{array}{lllllllllll}43.659 & 43.634 & 43.610 & 43.585 & 43.561 & 43.536 & 43.512 & 43.487 & 43.463 & 43.439\end{array}$ $\begin{array}{llllllllll}43.414 & 43.390 & 43.365 & 43.341 & 43.31 \epsilon & 43.292 & 43.267 & 43.243 & 43.218 & 43.194\end{array}$ $\begin{array}{llllllllll}430169 & 43.145 & 43.120 & 43.096 & 43.071 & 43.047 & 43.022 & 42.998 & 42.974 & 42.049\end{array}$

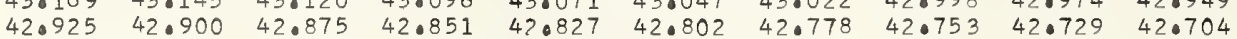
$\begin{array}{llll}42.435 & 42.411 & 42.386 & 42.362\end{array}$ $42.190 \quad 42.166 \quad 42.141 \quad 42.117$ $\begin{array}{llll}41.945 & 41.921 & 41.897 & 41.872 \\ 41.701 & 41.676 & 41.652 & 41.627\end{array}$ $\begin{array}{llll}41.701 & 41.676 & 41.652 & 41.627 \\ 41.456 & 41.432 & 41.407 & 41.383\end{array}$ $41.211 \quad 41.187 \quad 41.162 \quad 41.138$ $40.967 \quad 40.942 \quad 40.918 \quad 40.893$ $40.722 \quad 40.698 \quad 40.673 \quad 40.649$

$42.582 \quad 42.557$

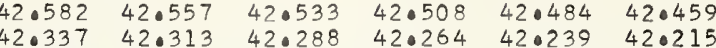
$\begin{array}{llllll}42.092 & 42.068 & 42.043 & 42.019 & 41.994 & 41.970\end{array}$ $\begin{array}{llllll}41.848 & 41.823 & 41.799 & 41.774 & 41.750 & 41.725\end{array}$ $\begin{array}{llllll}41.358 & 41.334 & 41.554 & 41.529 & 41.505 & 41.480 \\ & 41.309 & 41.285 & 41.260 & 41.236\end{array}$ $41.113 \quad 41.089 \quad 41.064 \quad 41.040 \quad 41.016 \quad 40.991$ $40.869 \quad 40.844 \quad 40.820 \quad 40.795 \quad 40.779 \quad 40.746$ $40.624 \quad 40.599 \quad 40.575 \quad 40.551 \quad 40.526 \quad 40.502$ $\begin{array}{llllll}40.379 & 40.355 & 40.330 & 40.306 & 40.281 & 40.257\end{array}$ $15640.233 \quad 40.208 \quad 40.184 \quad 40.159$ $39.743 \quad 39.963$ $\begin{array}{llll}39.743 & 39.719 & 39.694 & 39.670 \\ 39.498 & 39.474 & 39.450 & 39.425\end{array}$ $39.254 \quad 39.229 \quad 39.205 \quad 39.181$ $\begin{array}{lll}38.985 & 38.960 & 38.936\end{array}$ 38.740 $\begin{array}{llll}38.495 & 38.471 & 38.446\end{array}$ $\begin{array}{ll}38.275 & 38.25 \\ 38.031 & 38.006\end{array}$

$\begin{array}{ll}38.226 & 38.20 \\ 37.982 & 37.95\end{array}$

\section{$\begin{array}{ll}40.135 & 40.110 \\ 39.890 & 39.865\end{array}$}

39.890
39.645
39.621

$\begin{array}{ll}39.401 & 39.376 \\ 39.156 & 39.132\end{array}$

$38.911 \quad 38.887$

$\begin{array}{ll}38.667 & 38.642 \\ 38.422 & 38.398\end{array}$

$\begin{array}{ll}38.177 & 38.153 \\ 37.933 & 37.908\end{array}$

$\begin{array}{llll}40.086 & 40.061 & 40.037 & 40.012 \\ 39.841 & 39.817 & 39.792 & 39.768\end{array}$ $\begin{array}{llll}39.841 & 39.817 & 39.792 & 39.768 \\ 39.596 & 39.572 & 39.547 & 39.523\end{array}$ $39.352 \quad 39.327 \quad 39.303 \quad 39.278$ $\begin{array}{llll}39.107 & 39.083 & 39.058 & 39.034\end{array}$ $\begin{array}{llll}38.862 & 38.838 & 38.813 & 38.789\end{array}$ $\begin{array}{llll}38.618 & 38.593 & 38.569 & 38.544 \\ 38.373 & 38.349 & 38.324 & 38.300\end{array}$ $15637.786 \quad 37.762$ $\begin{array}{ll}37.541 & 37.517 \\ 37.297 & 37.27 \\ 37.052 & 37.028\end{array}$ $\begin{array}{llll}36.808 & 36.783 & 36.759 & 36.734 \\ 36.563 & 36.539 & 36.514 & 36.490\end{array}$ $\begin{array}{llll}36.319 & 36.294 & 36.270 & 36.24\end{array}$ $\begin{array}{llll}36.074 & 36.050 & 36.025 & 36.00 \\ 35.829 & 35.805 & 35.781 & 35.75\end{array}$ $35.585 \quad 35.560$

$\begin{array}{ll}35.536 & 35.512\end{array}$

$15635.340 \quad 35.316$

$\begin{array}{ll}35.096 & 35.071 \\ 34.851 & 34.827 \\ 34.607 & 34.582 \\ 34.362 & 34.338 \\ 34.118 & 34.093 \\ 33.873 & 33.849 \\ 33.629 & 33.604 \\ 33.384 & 33.360 \\ 33.140 & 33.115\end{array}$

$35.292 \quad 35.26$

$\begin{array}{ll}35.047 & 35.02 \\ 34.802 & 34.77\end{array}$

$\begin{array}{ll}34.558 & 34.533 \\ 34.313 & 34.28\end{array}$

$\begin{array}{ll}34.069 & 34.044 \\ 33.824 & 33.800\end{array}$

$33.140 \quad 33.115$

$15632.895 \quad 32.871$

$32.651 \quad 32.626$

$32.162 \quad 32.138$

$1.918 \quad 31.893 \quad 31.869$

$\begin{array}{lll}31.673 & 31.649 & 31.624\end{array}$

$31.429 \quad 31.404 \quad 31.380 \quad 31.355$

$\begin{array}{llll}31.1940 & 30.916 & 31.135 & 31.11 \\ 30.948 & 30.891 & 30.867\end{array}$

30.696

15630.451

29.96329 .938

$29.7174-29.0642-29.65$

$29.274-29.449-29.425$

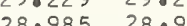

$28.741-28.717-28.937$

$28.497 \quad 28.472$

$5628.008 \quad 27.984$

$27.764 \quad 27.739 \quad 27.959$

$\begin{array}{ll}27.520 & 27.49 \\ 27.275 & 27.251\end{array}$

$27.031 \quad 27.006$

$\begin{array}{ll}26.787 & 26.762 \\ 26.542 & 26.518\end{array}$

$26.298 \quad 26.274$

$\begin{array}{ll}26.054 & 26.030 \\ 25.810 & 25.785\end{array}$

$15625.565 \quad 25.541$

$\begin{array}{llll}25.321 & 25.297 & 25.272 & 25.2 \\ 25.077 & 25.052 & 25.028 & 25.004\end{array}$

$\begin{array}{llll}24.833 & 24.808 & 24.784 & 24.760\end{array}$

$\begin{array}{llllll} & 24.711 & 24.686 & 24.662 & 24.637 & 24.613\end{array}$

$\begin{array}{llllllllll}24.340 & 24.320 & 24.296 & 24.271 & 24.0247 & 24.222 & 24.198 & 24.4174 & 24.393 & 24.369 \\ 24.100 & 24.076 & 24.051 & 24.027 & 24.003 & 23.97 & 24.125\end{array}$

$\begin{array}{llllllllll}23.856 & 24.076 & 24.051 & 24.027 & 24.003 & 23.978 & 23.754 & 23.929 & 23.905 & 23.880 \\ 23.832 & 23.807 & 23.783 & 23.758 & 23.734 & 23.710 & 23.585 & 23.661 & 23.636\end{array}$

$\begin{array}{llllllllll}23.612 & 23.588 & 23.563 & 23.539 & 23.514 & 23.490 & 23.465 & 23.441 & 23.417 & 23.392 \\ 23.368 & 23.343 & 23.319 & 23.295 & 23.270 & 23.246 & 23.221 & 23.197 & 23.172 & 23.148\end{array}$

$\begin{array}{llllllllll}15623.124 & 23.099 & 23.075 & 23.050 & 23.026 & 23.001 & 22.977 & 22.953 & 22.928 & 22.904\end{array}$ $\begin{array}{llllllllll}22.879 & 22.855 & 22.831 & 22.806 & 22.782 & 22.757 & 22.733 & 22.708 & 22.584 & 22.650 \\ 22.535 & 22.511 & 22.586 & 22.562 & 22.538 & 22.513 & 22.489 & 22.464 & 22.440 & 22.41\end{array}$ $\begin{array}{llllllllll}22.635 & 22.511 & 22.586 & 22.562 & 22.538 & 22.513 & 22.489 & 22.464 & 22.440 & 22.415 \\ 22.391 & 22.367 & 22.342 & 22.318 & 22.293 & 22.269 & 22.245 & 22.220 & 22.196 & 22.172\end{array}$ $\begin{array}{llllllllll}22.147 & 22.123 & 22.098 & 22.074 & 22.049 & 22.025 & 22.001 & 21.976 & 21.952 & 21.927 \\ 21.903 & 21.878 & 21.854 & 21.830 & 21.805 & 21.781 & 21.756 & 21.732 & 21.708 & 21.683\end{array}$ $\begin{array}{llllllllll}21.659 & 21.878 & 21.854 & 21.830 & 21.805 & 21.781 & 21.756 & 21.732 & 21.708 & 21.683 \\ 21.659 & 21.634 & 21.610 & 21.586 & 21.561 & 21.537 & 21.512 & 21.488 & 21.464 & 21.439\end{array}$

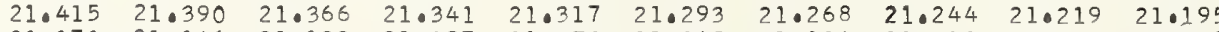

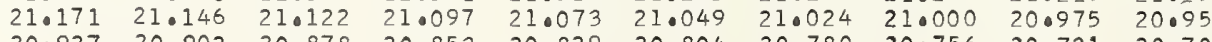

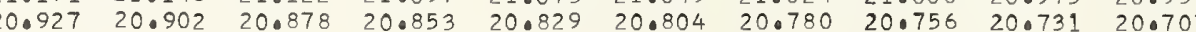

0.276440

0.276430

0.276439

0.276439

0.276439

0.276438

0.276438

0.276438

0.276438

0.276438

0.276438

0.276438

0.276438
0.276437
0.276437

0.276437

0.276437

0.276437

0.0276437

0.0276436

0.276436

0.276436

0.276436

0.276436

0.276436

0.276435

0.276435

0.276435

0.276435

0.276435

0.276434

0.276434
0.276434

0.276434

0.276434
0.276434

0.276434

0.276433

0.276433

0.276433

0.276433
0.276433

0.276433

0.276433

0.276433
0.276432

0.276432

0.276432

0.276432

0.276432

0.276432

0.276432

0.27643

0.27643

0.276431
0.276431

0.276431

0.276431

0.276431
0.276431

0.276430

0.276430

0.276430

0.276430

0.276430

0.276430

0.276430
0.276429
0.276429

0.276429

0.276429
0.276429

0.276429

0.276429
0.276429

0.276429

0.276429

0.276428

.276428

0.276428

0.276428

0.276428

0.276428

0.276428
0.276427

1.766449

1.766502

1.766529

1.766556

1.766610

1.766664

1.766690

1.766717

1. 766771

1.766798

1.766825

1.766878

1.766905

1.766959

1.766986

1.767013
1.767040

1.767066
1.767093

1.767120

1.767147

1.787174

1.767228

1.767254

1.767281

1.767335

1.767389

1.767416

1.767442

1.767469

1.767523

1.767550

1.767604

1.767630

1.767684

1.767711
1.0767738

.0767765

1.767792

1.767818

1.767872

1.767899

1.767926

1.767980

.768006

1.768060

1.768087

1.768114

1.768141

1.768195

1.768221 


.05

.06

.07

.08

.09

$(n-1) \times 1000$

$\lambda(n-1)$

6400.0
0.1
0.2
0.
0.
0.7
0.7
0.9

$\begin{array}{rrrrrrrrrrr}0.0 & 15620.682 & 20.658 & 20.634 & 20.609 & 20.585 & 20.560 & 20.536 & 20.512 & 20.487 & 20.463 \\ 0.1 & 20.438 & 20.414 & 20.390 & 20.365 & 20.341 & 20.316 & 20.292 & 20.267 & 20.243 & 20.219\end{array}$

$\begin{array}{lllllllllll}0.2 & 20.194 & 20.170 & 20.146 & 20.121 & 20.097 & 20.072 & 20.048 & 20.023 & 19.999 & 19.975 \\ 0.3 & 19.950 & 19.926 & 19.901 & 19.877 & 19.853 & 19.828 & 19.804 & 19.779 & 19.755 & 19.731\end{array}$

$\begin{array}{llllllllll}19.706 & 19.682 & 19.657 & 19.633 & 19.609 & 19.584 & 19.560 & 19.535 & 1.9 .511 & 19.487 \\ 19.462 & 19.438 & 19.413 & 19.389 & 19.365 & 19.340 & 19.316 & 19.292 & 19.267 & 19.242\end{array}$

$\begin{array}{llllllllll}19.218 & 19.194 & 19.169 & 19.145 & 19.120 & 19.096 & 19.072 & 19.047 & 19.023 & 19.242\end{array}$

$\begin{array}{llllllllll}18.974 & 18.950 & 18.925 & 18.901 & 18.876 & 18.852 & 18.828 & 18.803 & 18.779 & 18.755\end{array}$

$\begin{array}{llllllllll}18.486 & 18.462 & 18.437 & 18.413 & 18.389 & 18.364 & 18.540 & 18.559 & 18.535 & 18.510 \\ & 18.315 & 18.291 & 18.266\end{array}$ $\begin{array}{ll}18.242 & 18.21 \\ 17.998 & 17.97 \\ 17.754 & 17.7 \\ 17.510 & 17 . \\ 17.266 & 17.2 \\ 17.022 & 16.9 \\ 16.778 & 16.7 \\ 16.534 & 16.5 \\ 16.290 & 16.266 \\ 16.047 & 16.02\end{array}$

$\begin{array}{ll}18 & 18 \\ 74 & 170 \\ 30 & 1707 \\ 86 & 1704 \\ 42 & 1702 \\ 98 & 11 \\ 54 & 1 \\ 10 & 1 \\ 66 & 1 \\ 22 & 150\end{array}$

$18.193 \quad 18.169$

18.144

18.120

$\begin{array}{llll}18.096 & 18.071 & 18.047 & 18.022\end{array}$

$1:$
$1:$
$1: 5$
$1: 5$
1.8
1.9

6402

2.

15615.802

$15.802 \quad 15.778$

$15.315 \quad 15.234$

$15.071 \quad 15.0$

$\begin{array}{lllll}14.827 & 14.802 & 14.778 & 14.754 & 14.7729\end{array}$

$\begin{array}{llllll}14.339 & 14.515 & 14.534 & 14.510 & 14.485 & 14.461\end{array}$

$\begin{array}{lllllll}14.095 & 14.071 & 14.047 & 14.022 & 13.998 & 13.973\end{array}$

$13.608 \quad 13.583$

$\begin{array}{ll}13.803 & 13.77 \\ 13.559 & 13.534\end{array}$

13.75
13.510

$13 \cdot 729$
13.486

6403.0

3.
3.
3.0
3.0
3.0
30
30
3.0
3.0

$13.364 \quad 13.339$

$\begin{array}{ll}12.876 & 12.8 \\ 12.632 & 12.608\end{array}$

$\begin{array}{llll}13.315 & 13.290 & 12.266 & 13.242 \\ 13.071 & 13.047 & 13.022 & 12.998\end{array}$

$12.388 \quad 12.364$

$\begin{array}{ll}12.145 & 12.120 \\ 11.901 & 11.876\end{array}$

11.9017911 .876

$\begin{array}{lll}12.827 & 12.803 & 12.77 \\ 12.583 & 12.559 & 12.535\end{array}$

$12.340 \quad 12.315$

$12.535 \quad 12.510$

$\begin{array}{llll}12.096 & 12.071 & 12.047 & 12.023 \\ 11.852 & 11.828 & 1 ? .803 & 11.779\end{array}$

$\begin{array}{llll}17.852 & 17.827 & 17.803 & 17.779 \\ 17.608 & 17.583 & 17.550 & 17.534\end{array}$

$11.413 \quad 11.38$

$11.608 \quad 11.584$

$\begin{array}{ll}1 ? .803 & 11.779 \\ 11.559 & 11.535\end{array}$

$\begin{array}{llll}17.364 & 17.339 & 17.315 & 17.291\end{array}$

$\begin{array}{llll}16.876 & 16.851 & 16.827 & 16.803\end{array}$

$\begin{array}{llll}16.632 & 16.608 & 16.583 & 16.559\end{array}$

$\begin{array}{llll}16.388 & 16.364 & 16.339 & 16.315 \\ 16.144 & 16.120 & 16.095 & 16.071\end{array}$

0.276427
0.276427

0.276427

0.276426

0.2764 ?

0.276426

0.27642

0.276475

0.276425

0.276425

0.276425
0.276425

$\begin{array}{llll}15.656 & 15.632 & 15.607 & 15.583 \\ 15.412 & 15.388 & 15.364 & 15.339\end{array}$

$\begin{array}{llll}15.168 & 15.144 & 15.120 & 15.095\end{array}$

$\begin{array}{llll}14.681 & 14.656 & 14.632 & 14.607\end{array}$

$14.437 \quad 14.412 \quad 14.388 \quad 14.363$

$\begin{array}{llll}14 \cdot 193 & 14 \cdot 168 & 14 \cdot 144 & 14 \cdot 120 \\ 13.949 & 13.925 & 13.900 & 13.876\end{array}$

$\begin{array}{llll}13.705 & 13.681 & 13.656 & 13.637 \\ 13.461 & 13.437 & 13.41 .2 & 13.388\end{array}$

0.276425

0.276424

0.276424

0.276424

0.2764 ?

$13.217 \quad 13.193 \quad 13.169 \quad 13.144$

0.27642
0.027642

0.27642
0.0276422
0.27623

$12.486 \quad 12.462 \quad 12.437 \quad 12.413$

$\begin{array}{llll}12.242 & 12.218 & 12.193 & 12.169 \\ 11.998 & 11.974 & 11.950 & 11.925\end{array}$

0.276423

0.27649

0.776423

6404.0

15610.926

$\begin{array}{ll}10.926 & 10.901 \\ 10.682 & 10.657\end{array}$

$10.877 \quad 10.853$

$11.072 \quad 11.047$

$\begin{array}{llll}11.267 & 11.243 & 11.218 & 11.194 \\ 11.023 & 10.999 & 10.974 & 10.950\end{array}$

0.276422
0.27642

$\begin{array}{llllllllll}10.438 & 10.414 & 10.389 & 10.365 & 10.584 & 10.560 & 10.536 & 10.511 & 10.487 & 10.463\end{array}$

$\begin{array}{llllllllll}10.194 & 10.170 & 10.146 & 10.121 & 10.097 & 10.072 & 10.048 & 10.024 & 09.999 & 09.975 \\ 09.951 & 09.926 & 09.902 & 09.878 & 09.853 & 09.829 & 09.804 & 09.780 & 09.756 & 09.731\end{array}$

$\begin{array}{llllll}09.907 & 0.926 & 09.902 & 09.878 & 09.853 & 09.82 \\ 09.709 .658 & 09.634 & 09.609 & 09.585\end{array}$

$09.463 \quad 09.439 \quad 09.414 \quad 09.390 \quad 09.366 \quad 09.341$

$\begin{array}{llll}0.317 & 09.292 & 09.268 & 09.20244\end{array}$

$\begin{array}{llllllllll}08.976 & 08.951 & 08.927 & 08.903 & 08.878 & 08.854 & 08.829 & 08.805 & 08.781 & 08.756\end{array}$

$08.732 \quad 08.708 \quad 08.683$

$\begin{array}{ll}0.878 & 08.85 \\ 08.535 & 08.610\end{array}$

$\begin{array}{llll}08.829 & 08.805 & 08.781 & 08.756 \\ 08.586 & 08.561 & 08.537 & 08.513\end{array}$

6405.

$\begin{array}{rlllllllll}15608.488 & 08.464 & 08.440 & 08.415 & 08.391 & 08.366 & 08.342 & 08.318 & 08.293 & 08.769 \\ 08.245 & 08.220 & 08.196 & 08.172 & 08.147 & 08.123 & 08.098 & 08.074 & 08.050 & 08.025 \\ 08.001 & 07.977 & 07.952 & 07.028 & 07.903 & 07.879 & 07.855 & 07.830 & 07.806 & 07.782\end{array}$

$\begin{array}{llllllllll}08.001 & 07.977 & 07.952 & 07.928 & 07.903 & 07.879 & 07.855 & 07.830 & 07.806 & 07.782 \\ 07.757 & 07.733 & 07.909 & 07.684 & 07.660 & 07.635 & 07.611 & 07.587 & 07.562 & 07.538\end{array}$

$\begin{array}{llllllllll}07.757 & 07.733 & 07.709 & 07.684 & 07.660 & 07.635 & 07.611 & 07.587 & 07.562 & 07.538 \\ 07.514 & 07.489 & 07.465 & 07.441 & 07.416 & 07.392 & 07.367 & 07.343 & 07.319 & 07.294\end{array}$

$\begin{array}{llllllllll}07.270 & 07.246 & 07.221 & 07.197 & 07.172 & 07.148 & 07.124 & 07.099 & 07.075 & 07.051 \\ 07.025 & 07.002 & 06.978 & 05.053 & 06.929 & 06.005 & 06.880 & 06.856 & 06.831 & 06.807\end{array}$

$\begin{array}{llllllllll}06.783 & 06.758 & 06.734 & 06.709 & 06.685 & 06.661 & 06.636 & 06.612 & 06.588 & 06.563\end{array}$

$\begin{array}{llllllllll}06.539 & 06.515 & 06.490 & 06.466 & 06.442 & 06.417 & 06.393 & 06.369 & 06.344 & 06.320\end{array}$

$\begin{array}{llllllllll}06.295 & 06.271 & 06.247 & 06.222 & 06.198 & 06.174 & 06.149 & 06.125 & 06.100 & 06.076\end{array}$

$\begin{array}{rrrrrrrrrrr}6406.0 & 15606.052 & 06.027 & 06.003 & 05.979 & 05.954 & 05.930 & 05.906 & 05.881 & 05.857 & 05.833 \\ 6.1 & 05.808 & 05.784 & 05.759 & 05.735 & 05.711 & 05.686 & 05.662 & 05.638 & 05.613 & 05.589\end{array}$

$\begin{array}{llllllllll}05.808 & 05.784 & 05.759 & 05.735 & 05.711 & 05.686 & 05.662 & 05.638 & 05.613 & 05.589 \\ 05.565 & 05.540 & 05.516 & 05.491 & 05.467 & 05.443 & 05.418 & 05.394 & 05.370 & 05.345\end{array}$

$05.565 \quad 05.540$

$\begin{array}{ll}0.321 & 05.297 \\ 05.077 & 05.053\end{array}$

$\begin{array}{ll}04.834 & 04.809 \\ 04.590 & 04.566\end{array}$

05.27205 .24

$05.467 \quad 05.443$

$\begin{array}{llll}05.418 & 05.394 & 05.370 & 05.345 \\ 05.175 & 05.151 & 05.126 & 05.102\end{array}$

$\begin{array}{llllllllll}04.785 & 04.761 & 04.736 & 04.712 & 04.688 & 04.663 & 04.639 & 04.615\end{array}$

$\begin{array}{llllllllll}04.590 & 04.566 & 04.542 & 04.517 & 04.493 & 04.468 & 04.444 & 04.420 & 04 \cdot 395 & 04.371 \\ 04.347 & 04.322 & 04.298 & 04.274 & 04.249 & 04.225 & 04.201 & 04.176 & 04 \cdot 152 & 04.127\end{array}$

$\begin{array}{ll}04.103 & 04.079 \\ 03.859 & 03.835\end{array}$

04.127

0.276422

0.276422

0.776421

0.27642
0.27642

0.27642
0.27642

0.276421

0.0276420

0.276420

0.276420

0.276420

0.0276420

0.276419

0.276419

0.276419

0.276419

.769135
1.769162

.769188

.76926

.76932

.760350
.760376

1.769403

176945

1.769511

1.769564

1.760618

1.769672
1.769699

1.769726

.769779
1.769806

1.769833

1.769887

1.769940

1.769967

1.770021

1.770075

1.770128
1.770155

0.27641

0.276419

0.276418
0.276418

0.276418

0.276418
0.276418

0.0276418
0.276418

0.276418

$\begin{array}{llllllllll}01.911 & 01.887 & 01.863 & 01.838 & 01.814 & 01.790 & 01.765 & 01.741 & 01.717 & 01.692\end{array}$

$\begin{array}{llllllllll}01.668 & 01.644 & 01.619 & 01.595 & 0 ? .571 & 01.546 & 01.522 & 01.497 & 01.473 & 01.449 \\ 01.424 & 01.400 & 01.376 & 01.351 & 01.327 & 01.303 & 01.278 & 01.254 & 01.230 & 01.205\end{array}$

$\begin{array}{lllllllllll}6408.0 & 15601.181 & 01.157 & 01.132 & 01.108 & 01.084 & 01.059 & 01.035 & 01.011 & 00.985 & 00.962\end{array}$

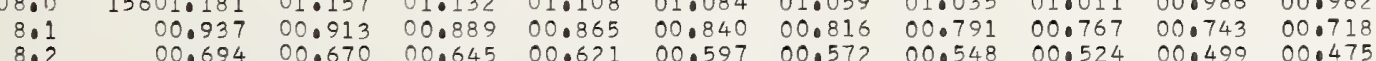
$\begin{array}{llllllllll}00.451 & 00.426 & 00.402 & 00.378 & 00.353 & 00.329 & 00.304 & 00.280 & 00.256 & 00.232\end{array}$ $\begin{array}{rlllllllll}00.207 & 00.183 & 00.158 & 00.134 & 00.110 & 00.085 & 00.061 & 00.037 & 00.012 & * 99.988\end{array}$ $\begin{array}{rlllllllll}99.964 & 99.939 & 99.915 & 99.891 & 99.866 & 99.842 & 99.818 & 99.793 & 99.769 & 99.745 \\ 99.720 & 99.696 & 99.672 & 99.647 & 99.623 & 99.599 & 99.574 & 99.550 & 99.526 & 99.501\end{array}$

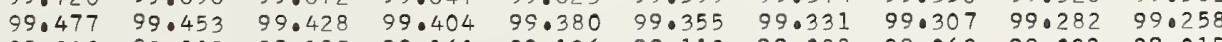
$\begin{array}{llllllllll}99.233 & 99.209 & 99.185 & 99.161 & 99.136 & 99.112 & 99.088 & 99.063 & 99.039 & 99.015 \\ 98.990 & 98.966 & 98.942 & 98.917 & 98.893 & 98.869 & 98.844 & 98.820 & 98.796 & 98.771\end{array}$

0.276418

0.276417
0.276417
0.276417

0.276417

0.276417
0.276417

0.276417

0.27641 ?

0.276417
0.276416

1.770209

1.770290
1.770316

1.770343
1.770370

1.770424

1.770478

1.770531

.770585
1.770612

1.770666
1.770693

1.770746

1.790800

.770854
.770881

.770934

.770988

0.276416
0.276416

0.276416

0.276416
0.276416

0.276416

0.276416
0.276415

0.276415

0.276415

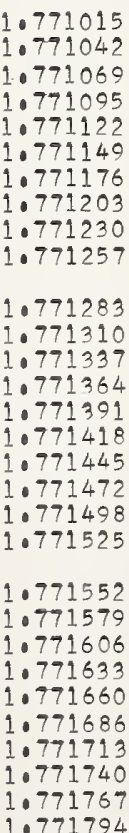

$\begin{array}{llllllllll}97.043 & 97.019 & 96.995 & 96.970 & 96.946 & 96.922 & 96.897 & 96.873 & 96.849 & 96.824 \\ \end{array}$

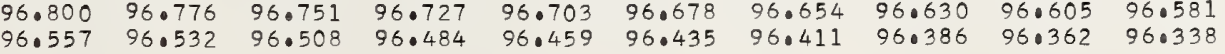

.010

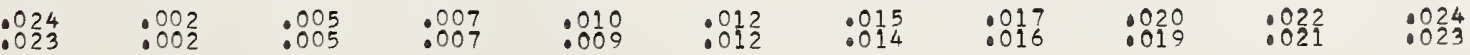




0.0
0.1
0.2
0.3
0.4
0.5
0.6
0.7
0.8
0.9

$\begin{array}{rrr}596.313 & 96.289 & 9 \\ 96.070 & 96.046 & 9 \\ 95.827 & 95.802 & 9 \\ 95.583 & 95.559 & 950 \\ 95.340 & 95.316 & 950 \\ 95.097 & 95.073 & 9 \\ 94.854 & 94.829 & 940 \\ 94.610 & 94.586 & 9 \\ 94.367 & 94.343 & 940 \\ 94.124 & 94.099 & 94\end{array}$

$\begin{array}{lll}96.265 & 96.240 & 9 \\ 96.022 & 95.997 & 9 \\ 95.778 & 95.754 & 9 \\ 95.535 & 95.511 & 950 \\ 95.292 & 95.267 & 9 \\ 95.048 & 95.024 & 950 \\ 94.805 & 94.781 & 940 \\ 94.562 & 94.537 & 94 . \\ 94.319 & 94.294 & 940 \\ 94.075 & 94.051 & 94\end{array}$

$95.973 \quad 95.94$

$\begin{array}{llll}96.167 & 96.143 & 96.119 & 96.094\end{array}$

6411.0

$1: 0$
$1: 2$
$1: 3$
$1: 5$
$1: 6$
$1: 7$
$1: 8$ $\begin{array}{ll}93.637 & 93.613 \\ 93.394 & 93.370\end{array}$ 93.15193 .127 $\begin{array}{llll}93.151 & 93.127 & 93.102 & 93.078 \\ 92.908 & 92.883 & 92.859 & 92.835 \\ 92.665 & 92.640 & 92.616 & 92.592\end{array}$ $\begin{array}{ll}92.178 & 92.154 \\ 91.935 & 91.911\end{array}$ 93.832
93.58
3.34
3.102
92.85
92.616
92.37
92.130
91.88
91.643

93.808 91.69291 .668

92.349 $591 \cdot 449 \cdot 91 \cdot 424$ $91.206 \quad 91.181$ $\begin{array}{ll}90.962 & 90.938 \\ 90.719 & 90.695\end{array}$ $90.476 \quad 90.452$ 90.23390 .209 $89.990 \quad 89.966$ $\begin{array}{ll}89.504 & 89.479 \\ 89.260 & 89.236\end{array}$ $91.400 \quad 91.376$

.862

95.462 05.437 95.656
95.413 $95.389 \quad 95.365$ $.756 \quad 94.732$ $94.513 \quad 94.48$ $\begin{array}{llll}95.194 & 95 \cdot 170 & 95.146 & 95.121\end{array}$ $\begin{array}{llll}94.908 & 94.627 & 94.902 & 94.878\end{array}$ $94.027 \quad 94.002$

$\begin{array}{llllll}93.783 & 93.759 & 93.735 & 93.711 & 93.686 & 93.662\end{array}$

6413.0

3.1

3.2

3.4

$3 \cdot 5$

3.7 $84.886 \quad 84.862 \quad 84.0838 \quad 85.056$

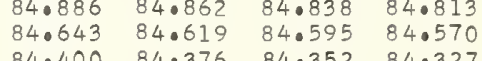

15584.157

$$
\begin{array}{rr}
584.157 & 84.13 \\
83.914 & 83.89 \\
83.672 & 83.647 \\
83.428 & 83.40 \\
83.186 & 83.16
\end{array}
$$$$
83 .
$$

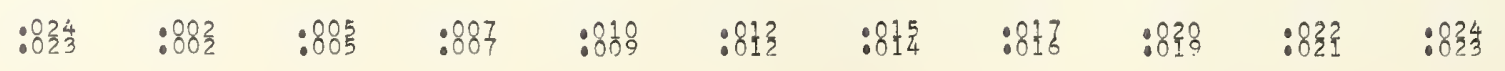




.03

.04

.05

.06

.07

.08

.09

$(n-1) \times 1000$

$\lambda(n-1)$

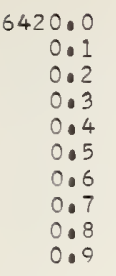

$\begin{array}{rr}0.0 & 15572.020 \\ 0.1 & 71.778 \\ 0.2 & 71.535 \\ 0.3 & 71.292 \\ 0.4 & 71.050 \\ 0.5 & 70.807 \\ 0.6 & 70.565 \\ 0.7 & 70.322 \\ 0.8 & 70.080 \\ 0.9 & 69.837\end{array}$

1.996
1.753
1.511
1.268
1.026
0.783
0.541
0.298
0.056
9.813

$\begin{array}{lll}.972 & 71.947 & 71.0 \\ .729 & 71.705 & 71 \\ .486 & 71.462 & 71.0\end{array}$

$\begin{array}{llllll}71.923 & 71.899 & 71.875 & 71.850 & 71.826 & 71.802 \\ 71.681 & 71.656 & 71.632 & 71.608 & 71.583 & 71.559\end{array}$

$\begin{array}{llll}71.390 & 71.365 & 71.341 & 71.317\end{array}$

$\begin{array}{llllll}71.196 & 71.171 & 71.147 & 71.123 & 71.098 & 71.074 \\ 70.953 & 70.929 & 70.904 & 70.880 & 70.856 & 70.832\end{array}$

$\begin{array}{llllllll}71.001 & 70.977 & 70.953 & 70.929 & 70.904 & 70.880 & 70.856 & 70.832 \\ 70.759 & 70.735 & 70.710 & 70.686 & 70.662 & 70.638 & 70.613 & 70.589\end{array}$

$\begin{array}{llllllll}70.516 & 70.492 & 70.468 & 70.444 & 70.419 & 70.395 & 70.371 & 70.347 \\ 70.274 & 70.250 & 70.225 & 70.201 & 70.177 & 70.153 & 70.128 & 70.104\end{array}$

$\begin{array}{lll}70.153 & 70.128 & 70.104 \\ 69.910 & 69.886 & 69.862 \\ 69.668 & 69.643 & 69.619\end{array}$

6421.

$1: 0$
$1: 1$
$1: 2$
$1: 3$
$1: 4$
$1: 5$
$1: 6$
$1: 7$
$1: 8$
1.9

$15569.595 \quad 69.571$

69.78969 .765

69.98369 .959

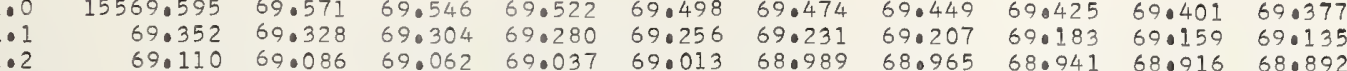

$\begin{array}{lllllllllll}1.2 & 69.110 & 69.086 & 69.062 & 69.037 & 69.013 & 68.989 & 68.965 & 68.941 & 68.916 & 68.892 \\ 1.3 & 68.868 & 68.844 & 68.819 & 68.795 & 68.771 & 68.747 & 68.722 & 68.698 & 68.674 & 68.650\end{array}$

$\begin{array}{lllllllllll}1.4 & 68.625 & 68.601 & 68.577 & 68.553 & 68.528 & 68.504 & 68.480 & 68.456 & 68.431 & 68.407\end{array}$

$\begin{array}{lllllllllll}1.5 & 68.383 & 68.359 & 68.334 & 68.310 & 68.286 & 68.262 & 68.238 & 68.213 & 68.189 & 68.165 \\ 1.6 & 68.140 & 68.116 & 68.092 & 68.068 & 68.043 & 68.019 & 67.995 & 67.971 & 67.947 & 67.922\end{array}$

$\begin{array}{llllllllllll}1.7 & 67.898 & 67.874 & 67.849 & 67.825 & 67.801 & 67.777 & 67.753 & 67.728 & 67.704 & 67.680 \\ 1.8 & 67.656 & 67.631 & 67.607 & 67.583 & 67.559 & 67.534 & 67.510 & 67.486 & 67.462 & 67.437\end{array}$

67.656

6422
2
2
2
2
2
$2 \bullet$
2
2
2
2
2

15567.171

$67 \cdot 17$
66.92
66.6
66.443

67.147

$\begin{array}{llll}67.607 & 67.58 \\ 9 & 67.365 & 67.34\end{array}$

$\begin{array}{ll}67.801 & 67.777 \\ 67.516 & 67.534\end{array}$

67.48

67.437
67.195

$\begin{array}{ll}0.276403 & 1.774507 \\ 0.276403 & 1.774534 \\ 0.776403 & 1.774561 \\ 0.276403 & 1.774588 \\ 0.276402 & 1.774614 \\ 0.276402 & 1.774641 \\ 0.276402 & 1.774668 \\ 0.276402 & 1.774695 \\ 0.276402 & 1.774722 \\ 0.276402 & 1.774749\end{array}$

0.276402

0.276402

0.27640

0.27640

0.276401

0.276401

1.774776

.7774829

1.77488

1.774937

10774964

0.27640
0.276400

0.276400

.276400

0.276400

$\begin{array}{llllllllll}66.201 & 66.177 & 66.153 & 66.129 & 66.104 & 66.080 & 66.056 & 66.031 & 66.007 & 65.983\end{array}$

$\begin{array}{llllllllll}65.959 & 65.935 & 65.910 & 65.886 & 65.862 & 65.838 & 65.813 & 65.789 & 65.765 & 65.741 \\ 65.716 & 65.692 & 65.668 & 65.644 & 65.620 & 65.595 & 65.571 & 65.547 & 65.523 & 65.40\end{array}$

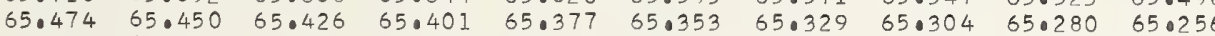

$\begin{array}{llllllllll}65.232 & 65.208 & 65.183 & 65.159 & 65.135 & 65.111 & 65.086 & 65.062 & 65.038 & 65.014\end{array}$

0.276400

0.276400

$\begin{array}{rrrrrrrrrrr}6423.0 & 15564.747 & 64.723 & 64.699 & 64 \cdot 674 & 64.650 & 64.626 & 64 \cdot 602 & 64 \cdot 578 & 64 \cdot 553 & 64 \cdot 529 \\ 3.1 & 64.505 & 64.481 & 64.456 & 64.432 & 64.408 & 64.384 & 64 \cdot 359 & 64.335 & 64 \cdot 311 & 64.287\end{array}$

$\begin{array}{llllllllllll}3.2 & 64.262 & 64.238 & 64.214 & 64.190 & 64.165 & 64.141 & 64.117 & 64.093 & 64.069 & 64.044 \\ 3.3 & 64.020 & 63.096 & 63.972 & 63.948 & 63.023 & 63.890 & 63.875 & 63.851 & 63.826 & 63.802\end{array}$

3.4

$\begin{array}{llllllllll}63.778 & 63.754 & 63.720 & 63.705 & 63.681 & 63.857 & 63.875 & 63.851 & 63.826 & 63.802 \\ 63.632 & 63.608 & 63.584 & 63.560\end{array}$

$\begin{array}{llllllllll}63.536 & 63.511 & 63.487 & 63.463 & 63.439 & 63.414 & 63.390 & 63.366 & 63.342 & 63.317\end{array}$

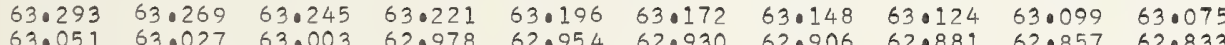

$62.80963 .027 \quad 63.003 \quad 62.978 \quad 620$

$62.954 \quad 62.930 \quad 62.906 \quad 62.881 \quad 62.857 \quad 62.833$

$\begin{array}{llllllllll}62.566 & 62.542 & 62.518 & 62.494 & 62.470 & 62.445 & 62.421 & 62.6399 & 62.615 & 62.591 \\ & 62.373 & 62.348\end{array}$

0.276399

0.276399

0.276399

0.276399

0.276399

0.276398

0.276398

6424.0

$\begin{array}{llllllllll}15562.324 & 62.300 & 62.276 & 62.251 & 62.227 & 62.203 & 62.179 & 62.155 & 62.130 & 62.106\end{array}$

$\begin{array}{llllllllll}62.082 & 62.058 & 62.034 & 62.009 & 61.985 & 61.961 & 61.937 & 61.912 & 61.888 & 61.864\end{array}$

$\begin{array}{llllllllll}61.597 & 61.573 & 61.549 & 61.525 & 61.501 & 61.476 & 61.452 & 61.428 & 61.404 & 61.380\end{array}$

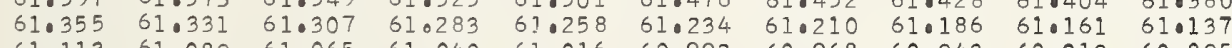

$\begin{array}{llllllllll}61.113 & 61.089 & 61.065 & 61.040 & 61.016 & 60.992 & 60.968 & 60.943 & 60.919 & 60.895\end{array}$

$\begin{array}{llllllllll}60.871 & 60.847 & 60.823 & 60.798 & 60.774 & 60.750 & 60.725 & 60.701 & 60.677 & 60.653\end{array}$

$\begin{array}{llllllllll}60.629 & 60.604 & 60.580 & 60.556 & 60.532 & 60.508 & 60.483 & 60.459 & 60.435 & 60.411 \\ 60.386 & 60.362 & 60.338 & 60.314 & 60.290 & 60.265 & 60.241 & 60.217 & 60.103 & 60.169\end{array}$

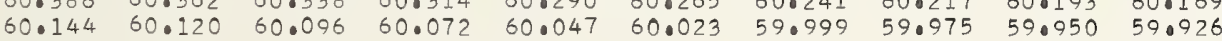

0.27639

0.276398
0.276398

0.276398

0.276398
0.276398

0.276398

0.276397

0.276397
0.276397

6425.

$$
\begin{aligned}
& 5.1 \\
& 5.2 \\
& 5.3 \\
& 5.4 \\
& 5.5 \\
& 5.6 \\
& 5.7 \\
& 5.8 \\
& 5.9
\end{aligned}
$$

.015559 .902

$\begin{array}{llllllllll} & 59.854 & 59.829 & 50.805 & 59.781 & 59.757 & 59.733 & 59.708 & 59.684\end{array}$

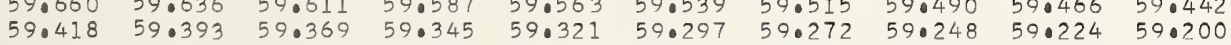
$\begin{array}{llllllllll}59.176 & 59.151 & 59.127 & 59.103 & 59.079 & 59.054 & 59.030 & 59.006 & 58.982 & 58.958\end{array}$ $\begin{array}{llllllllll}58.933 & 58.909 & 58.885 & 58.861 & 58.837 & 58.812 & 58.788 & 58.764 & 58.740 & 58.715 \\ 58.691 & 58.667 & 58.643 & 58.619 & 58.594 & 58.570 & 58.546 & 58.522 & 58.497 & 58.473\end{array}$ $\begin{array}{llllllllll}58.691 & 58.667 & 58.643 & 58.619 & 58.594 & 58.570 & 58.546 & 58.522 & 58.497 & 58.473 \\ 58.449 & 58.425 & 58.401 & 58.376 & 58.352 & 58.328 & 58.304 & 58.280 & 58.255 & 58.231\end{array}$ $\begin{array}{llllllllll}58.207 & 58.183 & 58.159 & 58.134 & 58.110 & 58.086 & 58.062 & 58.038 & 58.013 & 57.989\end{array}$ $\begin{array}{llllllllll}57.965 & 57.941 & 57.916 & 57.892 & 57.868 & 57.844 & 57.819 & 57.795 & 57.771 & 57.747\end{array}$

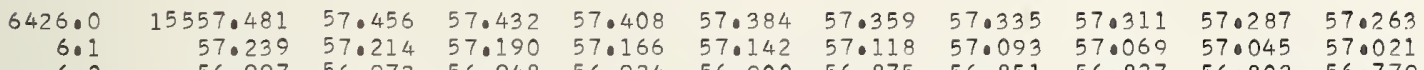
$\begin{array}{lllllllllll}6.2 & 56.997 & 56.972 & 56.948 & 56.924 & 56.900 & 56.875 & 56.851 & 56.827 & 560803 & 56.779\end{array}$ 604 6.5

$\begin{array}{lllllllll} & 56.464 & 56.440 & 56.416 & 56.391 & 56.367 & 56.343 & 560318 & 56.294\end{array}$ $\begin{array}{lllllllllll}56.028 & 56.004 & 55.980 & 55.956 & 55.931 & 55.907 & 55.883 & 55.859 & 55.834 & 550810\end{array}$ $\begin{array}{lllllllllll}55.786 & 55.762 & 55.738 & 55.713 & 55.689 & 55.665 & 55.041 & 55.617 & 55.592 & 55.0568\end{array}$ $\begin{array}{llllllllll}55.544 & 55.520 & 55.496 & 55.472 & 55.447 & 55.423 & 55.399 & 55.375 & 55.351 & 55.326\end{array}$

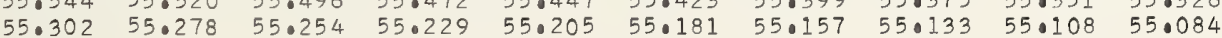

0.276397

0.276396

0.276396

0.0276396

.0276396

0.276396

0.276396

0.276395

0.076305

0.276395

0.276395

0.276395

$\begin{array}{lllllllllll}6427.0 & 15555.060 & 55.036 & 55.012 & 54.987 & 54.963 & 54.939 & 54.915 & 54 \cdot 891 & 54 \cdot 866 & 54 \cdot 842\end{array}$

$\begin{array}{llllllllllll}7.1 & 54.818 & 54.794 & 54.770 & 54.745 & 54.721 & 54.697 & 54.673 & 54.648 & 54.624 & 54.600 \\ 7.2 & 54.576 & 54.552 & 54.528 & 54.503 & 54.479 & 54.455 & 54.431 & 54.407 & 54.382 & 54.358\end{array}$

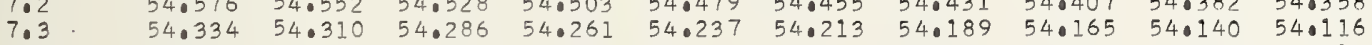

$\begin{array}{lllllllllll}7.4 & 54.092 & 54.068 & 54.043 & 54.019 & 52.995 & 53.971 & 53.947 & 53.923 & 53.898 & 53.874\end{array}$

$\begin{array}{llllllllllll}7.6 & 53.608 & 53.584 & 53.560 & 53.535 & 53.511 & 53.487 & 53.463 & 53.439 & 53.414 & 53.390\end{array}$

$\begin{array}{lllllllllll}7.7 & 53.366 & 53.342 & 53.318 & 53.293 & 53.269 & 53.245 & 53.221 & 53.197 & 53.172 & 53.148\end{array}$

$\begin{array}{lllllllllll}7.8 & 53.124 & 53.100 & 53.076 & 53.051 & 53.027 & 53.003 & 52.979 & 52.955 & 52.931 & 52.906 \\ 7.9 & 52.882 & 52.858 & 52.834 & 52.810 & 52.785 & 52.761 & 52.737 & 52.713 & 52.688 & 52.664\end{array}$

$\begin{array}{lrlllllllll}6428.0 & 15552.640 & 52.616 & 52.592 & 52.568 & 52.543 & 52.519 & 52.495 & 52.471 & 52.447 & 52.422\end{array}$

$\begin{array}{lllllllllll}8.1 & 52.398 & 52.374 & 52.350 & 52.326 & 52.301 & 52.277 & 52.253 & 52.229 & 52.205 & 52.181 \\ 8.2 & 52.156 & 52.132 & 52.108 & 52.083 & 52.059 & 52.035 & 52.011 & 51.987 & 51.963 & 51.938\end{array}$

$\begin{array}{lllllllllll}8.2 & 52.156 & 52.132 & 52.108 & 52.083 & 52.059 & 52.035 & 52.011 & 51.987 & 51.963 & 51.938 \\ 8.3 & 51.914 & 51.890 & 51.866 & 51.842 & 51.818 & 51.793 & 51.769 & 51.745 & 51.721 & 51.697\end{array}$

$\begin{array}{lllllllllll}8.4 & 51.672 & 51.648 & 51.624 & 51.600 & 51.576 & 51.551 & 51.527 & 51.503 & 51.479 & 51.454 \\ 8.5 & 51.430 & 51.406 & 51.382 & 51.358 & 51.334 & 51.309 & 51.285 & 51.261 & 51.237 & 51.213\end{array}$

$\begin{array}{lllllllllll}8.5 & 51.430 & 51.406 & 51.382 & 51.358 & 51.334 & 51.309 & 51.285 & 51.261 & 51.237 & 51.213 \\ 8.6 & 51.188 & 51.164 & 51.140 & 51.116 & 51.092 & 51.068 & 51.043 & 51.019 & 50.995 & 50.971\end{array}$

$\begin{array}{lllllllllll}8.7 & 50.947 & 50.922 & 50.898 & 50.874 & 50.850 & 50.826 & 50.802 & 50.777 & 50.753 & 50.729\end{array}$

$\begin{array}{lllllllllll}8.8 & 50.705 & 50.681 & 50.656 & 50.632 & 50.608 & 50.584 & 50.560 & 50.536 & 50.511 & 50.487 \\ 8.9 & 50.463 & 50.439 & 50.414 & 50.390 & 50.366 & 50.342 & 50.318 & 50.293 & 50.269 & 50.245\end{array}$

$\begin{array}{lllllllllll}6429.0 & 15550.221 & 50.197 & 50.173 & 50.148 & 50.124 & 50.100 & 50.076 & 50.052 & 50.028 & 50.003\end{array}$

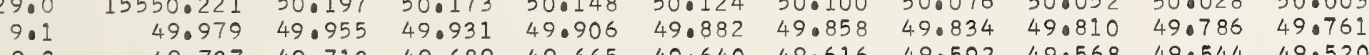

$\begin{array}{lllllllllll}9.2 & 49.737 & 49.713 & 49.689 & 49.665 & 49.640 & 49.616 & 49.592 & 49.568 & 49.544 & 49.520 \\ 9.3 & 49.495 & 49.471 & 49.447 & 49.423 & 49.399 & 49.374 & 49.350 & 49.326 & 49.302 & 49.278\end{array}$

$\begin{array}{lllllllllll}9.3 & 49.495 & 49.471 & 49.447 & 49.423 & 49.399 & 49.374 & 49.350 & 49.326 & 49.302 & 49.278 \\ 9.4 & 49.254 & 49.229 & 49.205 & 49.181 & 49.157 & 49.133 & 49.108 & 49.084 & 49.060 & 49.036\end{array}$

$\begin{array}{llllllllllll}9.5 & 49.012 & 48.988 & 48.963 & 48.939 & 48.915 & 48.891 & 48.867 & 48.842 & 48.818 & 48.794 \\ 9.6 & 48.770 & 48.746 & 48.722 & 48.697 & 48.673 & 48.649 & 48.625 & 48.601 & 48.576 & 48.552\end{array}$

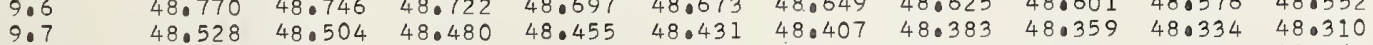

$\begin{array}{llllllllllll}9.8 & 48.286 & 48.262 & 48.238 & 48.214 & 48.189 & 48.165 & 48.141 & 48.117 & 48.093 & 48.069\end{array}$

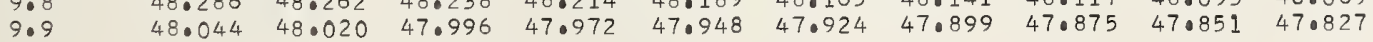

0.276394

0.276394

0.276394

0.276394

0.276394

0.276394

0.276393

0.276393

0.276393

0.0276393
0.276393

0.0276393

0.276399

0.276393
0.276392

0.276392

0.276392

0.276392

0.276392

0.276392
0.276392

0.276391

0.276391

0.276391
0.276391

0.276391

1.775044
1.775071
1.775098
1.775125
1.775152
1.775179
1.775205
1.775232
1.775259
1.775286

1.775313

1.775367

1.775420

1.775447
1.775474

1.775501
1.775528

1.775581

1.775608

1.7795662

1.775689
1.775716

1.775743

1.775770
1.775796

1.775850

1.775877
1.775904

1.775931

1.775984

1.776011

.776065

1.776119

1.776146
1.776173

1.776199

1.776253

1.776280

1.776334$$
.001
$$

.002

.003

.004

.005

.006

.007

$.008 \quad .009$

.010

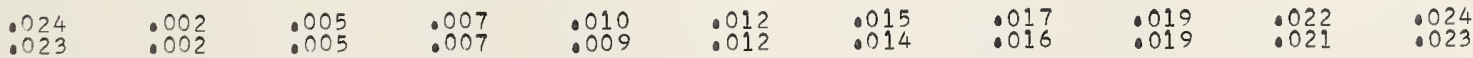

1.776387

1.776441

1.776495

1.776549

1.776602

1.776656

1.776683
1.776710

1.776763

1.776790

1.776844

1.776925
1.776952
1.776978
1.777005
1.777032
9.777059
1.777086
1.777113
1.777140
1.777166 


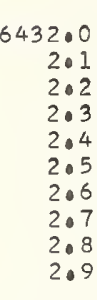

$\begin{array}{rr}33.0 & 1554 \\ 3.1 & 400 \\ 3.2 & 400 \\ 3.3 & 3 \\ 3.4 & 3 \\ 3.5 & 390 \\ 3.6 & 390 \\ 3.7 & 380 \\ 3.8 & 380\end{array}$

$\begin{array}{llllllllll}47.563 & 47.778 & 47.754 & 47.730 & 47.706 & 47.682 & 47.658 & 47.633 & 47.609 & 47.585\end{array}$ $\begin{array}{llllllllll}47.319 & 47.295 & 47.271 & 47.246 & 47.222 & 47.198 & 47.174 & 47.150 & 47.125 & 47.101\end{array}$ $\begin{array}{lllllllllll}47.077 & 47.053 & 47.029 & 47.005 & 46.980 & 46.956 & 46.932 & 46.908 & 46.884 & 46.860\end{array}$ $\begin{array}{llllllllll}46.594 & 46.569 & 46.545 & 46.521 & 46.497 & 46.473 & 46.449 & 46.425 & 46.400 & 46.376\end{array}$ $\begin{array}{llllllllll}46.352 & 46.328 & 46.304 & 46.280 & 46.255 & 46.231 & 46.207 & 46.183 & 46.159 & 46.134\end{array}$ $\begin{array}{llllllllll}46.110 & 46.086 & 46.062 & 46.038 & 46.013 & 45.989 & 45.965 & 45.941 & 45.917 & 45.893\end{array}$ $\begin{array}{lllllllllll}45.868 & 45.844 & 45.820 & 45.796 & 45.772 & 45.748 & 45.723 & 45.699 & 45.675 & 45.651\end{array}$ $\begin{array}{llllllllll}15545.385 & 45.361 & 45.337 & 45.312 & 45.288 & 45.264 & 45.240 & 45.216 & 45.192 & 45.167\end{array}$ 1.2 1.4

$\begin{array}{rll}4.0877 & 44.853 \quad 44.829\end{array}$$$
44.418
$$

$44 \cdot 177$

$43.693 \quad 43.669$

$\begin{array}{ll}43.451 & 43.427 \\ 43.210 & 43.186\end{array}$

$44.611 \quad 44.5 .87$

$\begin{array}{ll}44.370 & 44.346 \\ 44.128 & 44.104\end{array}$

$\begin{array}{ll}43.886 & 43.862 \\ 43.645 & 43.621\end{array}$

$15542.968 \quad 42.944$

42.726

2.2

2.4

2.6

$\begin{array}{ll}42.243 & 42.219 \\ 42.002 & 41.977\end{array}$

$41.760 \quad 41.736$

41.518

$\begin{array}{ll}41.277 & 41.253 \\ 41.035 & 41.011\end{array}$

$40.793 \quad 40.769$

6434.

4.1
4.0
4.
4.5
4.6
4
4.7
4.9 $40.310 \quad 40.28$

40.069
39.827

39.586

$38.620 \quad 38.837$

43.403

43.621
43.379
43.137

$45.047 \quad 45.022$

$\begin{array}{ll}44.805 & 44.781 \\ 44.563 & 44.539\end{array}$

$\begin{array}{ll}44.563 & 44.539 \\ 44.322 & 44.297\end{array}$

$\begin{array}{ll}44.080 & 44.055 \\ 43.838 & 43.814\end{array}$

$43.596 \quad 43.572$

$\begin{array}{ll}43.355 & 43.331 \\ 43.113 & 43.089\end{array}$

$\begin{array}{llll}44.998 & 44.974 & 44.950 & 44.926 \\ 440757 & 44.732 & 44.708 & 44.684\end{array}$

$\begin{array}{llll}44.757 & 44.732 & 44.708 & 44.684\end{array}$

$44.273 \quad 44.249 \quad 44.225 \quad 44.201$

$44.031 \quad 44.007 \quad 43.983 \quad 43.959$

$\begin{array}{llll}43.790 & 43.766 & 43.741 & 43.717\end{array}$

$43.306 \quad 43.282 \quad 43.258 \quad 43.234$

$42.920 \quad 42.896$

$42.871 \quad 42.847 \quad 420$

$42.436 \quad 42.412$

$\begin{array}{ll}42.630 & 42.606 \\ 42.388 & 42.364\end{array}$

42.823
42.581
42.340

$43.041 \quad 430016 \quad 42.992$

$41.953 \quad 41.929$

$42.146 \quad 42.122$

$42.340 \quad 42.557 \quad 42.533 \quad 42.509$

$\begin{array}{llllll}41.905 & 41.08 & 42.098 & 42.074 & 42.050 & 42.026\end{array}$

$\begin{array}{ll}41.712 & 41.687 \\ 41.470 & 41.446\end{array}$

$\begin{array}{llllll}41.663 & 41.639 & 41.615 & 41.591 & 41.567 & 41.542\end{array}$

$\begin{array}{llllll}41.422 & 41.397 & 41.373 & 41.349 & 41.325 & 41.301\end{array}$

$15538.137 \quad 38 \cdot 113$

$37.895 \quad 37.871$

$37.654 \quad 37.630$

37.17

$37 \cdot 388$

36.92

36.905

$36.688 \quad 36.664$

$\begin{array}{ll}1.228 & 41.204 \\ 0.987 & 40.963\end{array}$

$41.180 \quad 41.156$

$41.132 \quad 41.108 \quad 41.083 \quad 41.059$

$36.205 \quad 36.181$

\begin{abstract}
$40.504 \quad 40.479$
\end{abstract}
$40.697 \quad 40.673$

$\begin{array}{llll}40.890 & 40.866 & 40.842 & 40.818 \\ 40.649 & 40.624 & 40.600 & 40.576\end{array}$

$\begin{array}{llllll}40.455 & 40.431 & 40.407 & 40.383 & 40.359 & 40.334\end{array}$

$\begin{array}{lllllll}40.214 & 40.190 & 40.165 & 40.141 & 40.117 & 40.093 \\ 39.972 & 39.948 & 39.924 & 39.900 & 39.876 & 39.851\end{array}$

$40.021 \quad 39.996$

39.537

$39.296-39.27$

$\begin{array}{ll}39.055 & 39.031 \\ 38.813 & 38.789\end{array}$

$39.489 \quad 39.706$

$\begin{array}{llll}9.0441 & 39.417 & 39.393 \quad 39.36\end{array}$

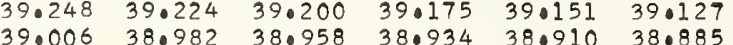

$\begin{array}{lllllll}38.765 & 38.741 & 38.716 & 38.692 & 38.668 & 38.644\end{array}$

$\begin{array}{lllllll}38.523 & 38.499 & 38.475 & 38.451 & 38.427 & 38.402\end{array}$

$38.330 \quad 38.306$

6435

5.1

5.3

504

5.6

5.8

6436.

6.1
6.2
6.3

6.4

6.6

6.7

6.8

6437

7.1
7.2
7.3

7.2
7.3
7.5

7.5

7.7
7.8

$35.481 \quad 35.457$

$34.998 \quad 34.215$

34.75734 .732

$34.515 \quad 34.491$

$\begin{array}{llll}34.079 & 34.008 & 33.984 & 33.960\end{array}$

$33.550 \quad 33.525$

$33.067 \quad 33.284$

$32.826 \quad 32.80$

$32.343 \quad 32.31$

$\begin{array}{ll}32.102 & 32.077 \\ 31.860 & 31.836\end{array}$

$31.619 \quad 31.595$

$\begin{array}{ll}31.378 & 31.354 \\ 31.136 & 31.112\end{array}$

38.089

$37.605 \quad 37.581$

$\begin{array}{ll}37.364 & 37.340 \\ 37.123 & 37.099\end{array}$

$36.881 \quad 36.857$

$\begin{array}{ll}36.640 & 36.615 \\ 36.398 & 36.374\end{array}$

38.28238 .258

$\begin{array}{llll}38.233 & 38.209 & 38.185 & 38.161\end{array}$

$\begin{array}{lll}38.040 & 38.016 & 37 \\ 37.799 & 37.775 \\ 37.557 & 37.533 & 37 \\ 37.316 & 37.592 & 37\end{array}$

$\begin{array}{llllll}37.074 & 37.050 & 37.026 & 37.002 & 36.978 & 36.953\end{array}$

$\begin{array}{llllll}36.833 & 36.808 & 36.785 & 36.760 & 36.736 & 36.712\end{array}$

$\begin{array}{lllllll}36.591 & 36.567 & 36.543 & 36.519 & 36.495 & 36.471 \\ 36.350 & 36.326 & 36.302 & 36.277 & 36.253 & 36.229\end{array}$

$\begin{array}{lllllll}36.108 & 36.084 & 36.060 & 36.036 & 36.012 & 35.988\end{array}$

$35.674 \quad 35.650$

$35.625 \quad 35.601$

$35.819 \quad 35.794 \quad 35.770 \quad 35.746$

$\begin{array}{llllll}35.384 & 35.360 & 35.577 & 35.553 & 35.529 & 35.505 \\ 35.312 & 35.288 & 35.263\end{array}$

$34.901-34.877 \quad 35.094 \quad 35.070 \quad 35.046 \quad 35.022$

$\begin{array}{llllll}34.660 & 34.636 & 34.612 & 34.588 & 34.563 & 34.539\end{array}$

$\begin{array}{llllll}34.419 & 34.394 & 34.370 & 34.346 & 34.322 & 34.298\end{array}$

$\begin{array}{llllll}34.177 & 34.153 & 34 \cdot 129 & 34 \cdot 105 & 34 \cdot 081 & 34.057 \\ 33.936 & 33.912 & 33.888 & 33.863 & 33.839 & 33.815\end{array}$

$\begin{array}{llllll}33.936 & 33.912 & 33.888 & 33.863 & 33.839 & 33.815 \\ 33.694 & 33.670 & 33.646 & 33.622 & 33.598 & 33.574\end{array}$

$\begin{array}{llllll}33.453 & 33.429 & 33.405 & 33.381 & 33.357 & 33.332\end{array}$

$33.260 \quad 33.236$

$33.212 \quad 33.188$

$33.164 \quad 33.139 \quad 33.115 \quad 33.091$

$\begin{array}{llllll}32.729 & 32.705 & 32.922 & 32.898 & 32.874 & 32.850 \\ 32.681 & 32.657 & 32.633 & 32.608\end{array}$

$\begin{array}{llllll}32.488 & 32.464 & 32.439 & 32.415 & 32.391 & 32.367 \\ 32.246 & 32.222 & 32.198 & 32.174 & 32.150 & 32.126\end{array}$

$\begin{array}{llllll}32.005 & 31.981 & 31.957 & 31.933 & 31.909 & 31.884\end{array}$

$39.764 \quad 31.740 \quad 31.716 \quad 31.691 \quad 31.667 \quad 31.643$

$\begin{array}{llllll}31.522 & 31.498 & 31.474 & 31.450 & 31.426 & 31.402\end{array}$

.81231 .78

$31.571 \quad 31.547$

$31.088 \quad 31.064$

$\begin{array}{llll}530.895 & 30.871 & 30.847 & 30.823 \\ 30.654 & 30.630 & 30.606 & 30.558\end{array}$

$\begin{array}{llll}31.233 & 31.209 & 31.185 & 31.161 \\ 30.992 & 30.967 & 30.943 & 30.919\end{array}$

$\begin{array}{llllllll} & \end{array}$

$\begin{array}{llllllllll}30.413 & 30.388 & 30.364 & 30.340 & 30.316 & 30.292 & 30.268 & 30.244 & 30.220 & 30.195\end{array}$

$\begin{array}{llllllllll}30.171 & 30.147 & 30.123 & 30.099 & 30.075 & 30.051 & 30.027 & 30.003 & 29.979 & 29.954 \\ 29.930 & 29.906 & 29.882 & 29.858 & 29.834 & 29.809 & 29.785 & 29.761 & 29.737 & 29.713\end{array}$

$\begin{array}{llllllllll}29.689 & 29.665 & 29.641 & 29.616 & 29.592 & 29.568 & 29.544 & 29.520 & 29.496 & 29.472\end{array}$

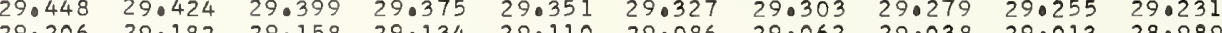

$\begin{array}{llllllllll}29.206 & 29.182 & 29.158 & 29.134 & 29.110 & 29.086 & 29.062 & 29.038 & 29.013 & 28.989\end{array}$

$\begin{array}{llllllllll}28.724 & 28.700 & 28.676 & 28.652 & 28.628 & 28.603 & 28.579 & 28.555 & 28.531 & 28.507\end{array}$

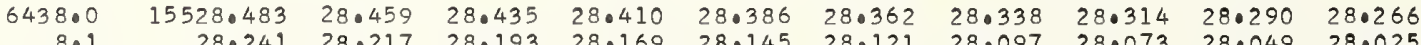

$\begin{array}{llllllllllll}8.1 & 28.241 & 28.217 & 28.193 & 28.169 & 28.145 & 28.121 & 28.097 & 28.073 & 28.049 & 28.025\end{array}$

$\begin{array}{lllllllllll}8.2 & 28.000 & 27.976 & 27.952 & 27.928 & 27.904 & 27.880 & 27.856 & 27.832 & 27.807 & 27.783 \\ 8.3 & 27.759 & 27.735 & 27.71 & 27.687 & 27.663 & 27.639 & 27.614 & 27.590 & 27.566 & 27.542\end{array}$

$\begin{array}{lllllllllll}8.4 & 27.518 & 27.494 & 27.470 & 27.446 & 27.422 & 27.397 & 27.373 & 27.349 & 27.325 & 27.301\end{array}$

\begin{tabular}{lllllllllll}
8.5 & 27.277 & 27.253 & 27.229 & 27.204 & 27.180 & 27.156 & 27.132 & 27.108 & 27.084 & 27.060 \\
\hline & 27.036 & 27.011 & 26.988 & 26.963 & 26.939 & 26.915 & 26.891 & 26.867 & 26.843 & 26.819
\end{tabular}

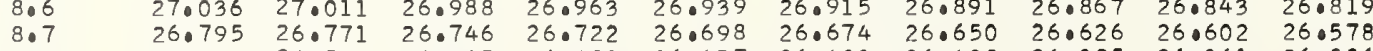

$\begin{array}{lllllllllll}8.8 & 26.553 & 26.529 & 26.505 & 26.481 & 26.457 & 26.433 & 26.409 & 26.385 & 26.361 & 26.336 \\ 8.9 & 26.312 & 26.288 & 26.264 & 26.240 & 26.216 & 26.192 & 26.167 & 26.143 & 26.119 & 26.095\end{array}$

25.830

25.830

25.0406 $25.782 \quad 25079$

$25.348-25.324 \quad 25.300$

$25.107-25.083 \quad 25.058$

24.86624 .842

24.62524 .600

$24.142 \quad 24.118$ 24. 24.094

$23.901 \quad 23.877 \quad 23.853$

$.001 \quad .002$

.003

25.97525 .951

$\begin{array}{llll}25.927 & 25.902 & 25.878 & 25.854\end{array}$

$\begin{array}{lll}25.902 & 25.878 & 25.854 \\ 25.661 & 25.637 & 25.613\end{array}$

$\begin{array}{llllll}25.492 & 25.468 & 25.444 & 25.420 & 25.396 & 25.372\end{array}$

$\begin{array}{lllllll}25.251 & 25.227 & 25.203 & 25.179 & 25.155 & 25.131 \\ 25.010 & 24.986 & 24.962 & 24.938 & 24.914 & 24.890\end{array}$

$\begin{array}{llllllll}4.793 & 24.769 & 24.745 & 24.721 & 24 \cdot 697 & 24.673 & 24.649\end{array}$

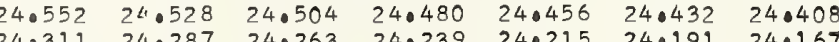

$\begin{array}{llllll}24.287 & 24.263 & 24.239 & 24.215 & 24.191 & 24.167\end{array}$

$24.046 \quad 24.022$

$\begin{array}{ll}0.276391 & 1.777193 \\ 0.276391 & 1.777220 \\ 0.276391 & 1.777247 \\ 0.276391 & 1.777274 \\ 0.276390 & 1.777301 \\ 0.276390 & 1.777328 \\ 0.276390 & 1.777355 \\ 0.276390 & 1.777381 \\ 0.276390 & 1.777408 \\ 0.276390 & 1.777435\end{array}$

0.276390

1.777462

0.276390

0.276390

0.276389

0.276389

0.276389

0.276389

0.276389

0.276388

0.276388

0.276388
0.276388

0.276388

0.276388
0.276388

0.276388

0.276388
0.276387

1.777489
1.777516

1.777543
1.777569

1.777596
1.777623

1.777650

1.777679

0.276387

0.276387

0.276387

0.276387
0.276387
0.2276387

0.276387

0.276387

0.276386

0.276386
0.276386

0.276386

0.276386

0.276386
0.276386

0.276386

0.276385

0.276385

0.276385
0.276385

0.276385

1.777731

1.777784

1.777811
1.777838

1.777865
1.777892

1.777919

1.7779946
1.777972

0.276385

0.276385

0.276385

0.276385

0.27638

0.27638

0.276384
0.276384

0.276384

1.777999

1.778053

1.778080

1.778107
1.778134

1.778160

1.778187

1.778241

0.276384

0.27638

0.276383

0.276383
0.276383
0.27638

0.27638

0.276383

0.276383

0.276383

0.276382

0.276382 
15521.250

$\begin{array}{rl}521.250 & 21.226 \\ 21.009 & 20.985 \\ 20.768 & 20.744 \\ 20.527 & 20.503 \\ 20.286 & 20.262 \\ 20.045 & 20.021 \\ 19.804 & 19.780 \\ 19.563 & 19.539 \\ 19.323 & 19.298 \\ 19.082 & 19.057\end{array}$

21.684
21.443

7.0

70.3

7.5

$7: 8$

6448.0

48.0
8.1
8.2
8.3
8.
8.5
8.6
8.7
8.
8.

6449

$\begin{array}{rlllllllll}15509.211 & 09.187 & 09.163 & 09.139 & 09.115 & 09.091 & 09.067 & 09.043 & 09.018 & 08.994 \\ 08.970 & 08.946 & 08.922 & 08.898 & 08.874 & 08.850 & 08.826 & 08.802 & 08.778 & 08.754\end{array}$ $\begin{array}{lllllllllll}08.730 & 08.706 & 08.682 & 08.657 & 08.633 & 08.609 & 08.585 & 08.561 & 08.537 & 08.513\end{array}$ $\begin{array}{llllllllll}0.429 & 08.465 & 08.441 & 08.417 & 08.393 & 08.369 & 08.345 & 08.321 & 08.297 & 08.273\end{array}$

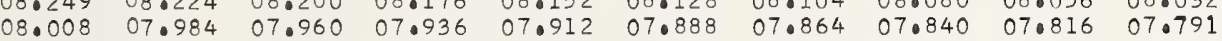
$\begin{array}{llllllllllll}07.767 & 07.743 & 07.0719 & 07.695 & 07.071 & 07.647 & 07.623 & 07.599 & 07.575 & 07.551\end{array}$ $\begin{array}{lllllllllll}07.527 & 07.503 & 07.479 & 07.455 & 07.431 & 07.407 & 07.383 & 07.359 & 07.334 & 07.310\end{array}$ $\begin{array}{lllllllllll}07.286 & 07.262 & 07.238 & 07.214 & 07.190 & 07.166 & 07.142 & 070118 & 07.094 & 07.070\end{array}$

$15506.805 \quad 06.78$

$\begin{array}{lllll}06.565 & 06.541 & 06.757 & 06.733\end{array}$

$06.324 \quad 06.3000$

06.084

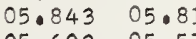

05.362

$04.881 \quad 04.857$

5504.400 04.160
0.3049

03.160
03.979
03.699

03.439

02.958

02.958 . 027 02.477
02.237

5501.996

$\begin{array}{llllllllll}01.996 & 01.972 & 01.948 & 01.924 & 01.900 & 01.876 & 01.852 & 01.828 & 01.804 & 01.780 \\ 01.756 & 01.732 & 01.708 & 01.684 & 01.660 & 01.636 & 01.612 & 01.588 & 01.564 & 01.540\end{array}$

$06.517 \quad 06.49$

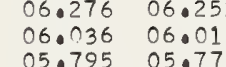

05.795
05.555
0505.0531

$05.314 \quad 05.290$
$0.074 \quad 05.050$

04.833
04.593

04.809

06.95

06.926

$\begin{array}{lllll}07.901 & 06.877 & 06.853 & 06.829\end{array}$ $\begin{array}{lllllll}06.228 & 06.444 & 06.420 & 060396 & 06.372 & 06.348 \\ 06.2204 & 06.180 & 06.156 & 06.132 & 06.108\end{array}$ $\begin{array}{llllll}05.988 & 05.963 & 05.939 & 05.015 & 05.891 & 05.867\end{array}$ $\begin{array}{lllllll}05.506 & 05.482 & 05.458 & 05.645 & 05.6510 & 05.627\end{array}$ $\begin{array}{llllll}05.266 & 05.242 & 05.218 & 05.194 & 05.170 & 05.146\end{array}$

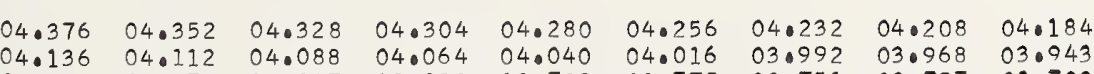

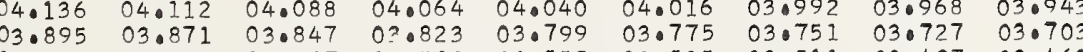

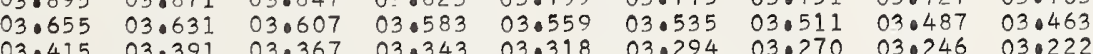

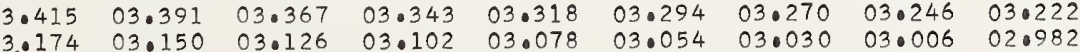

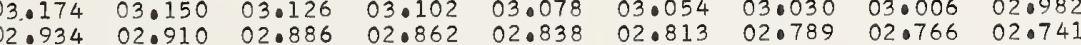

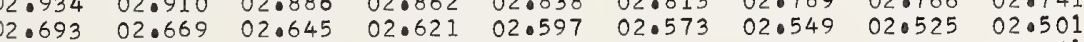

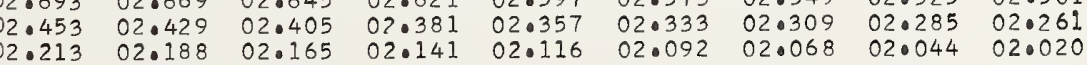
$\begin{array}{lllllllllll}9.2 & 01.516 & 01.0491 & 01.708 & 01.684 & 01.0660 & 01.0636 & 01.612 & 01.588 & 01.564 & 01.540\end{array}$

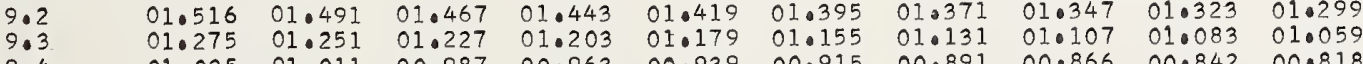
$\begin{array}{llllllllll}01.035 & 01.011 & 00.987 & 00.963 & 00.939 & 00.915 & 00.891 & 000866 & 00.842 & 00.818\end{array}$ $\begin{array}{llllllllll}00.794 & 00.770 & 00.746 & 00.722 & 00.698 & 00.674 & 00.650 & 00.626 & 00.602 & 00.578\end{array}$

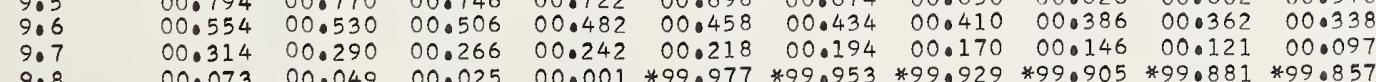

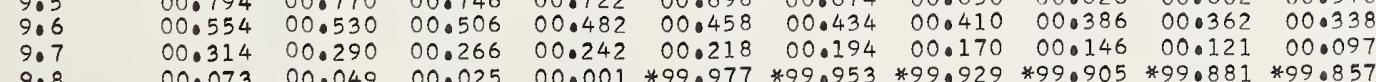

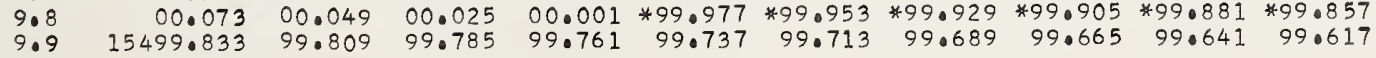

0.276379

.276379

.276378

0.276378

0.027678

0.276378
0.276378

0.27637

0.276378
0.276377
0.27637

0.276377

0.276377
0.276377

0.276377

0.276377
0.076377

0.276376

0.276376
0.276376
0.027676

0.276376

0.276376

0.276376
0.276375

0.276375

0.276375
0.276375
0.27635

0.276375

0.276375
0.276375
0.276375

0.0276375

0.276374

0.276374
0.276374

0.276374

0.0276374

0.276374
0.276374
0.276373

0.276373

0.276373
0.276373
0.276373

0.276373

0.276373

0.276373

0.276373
0.276373
0.2276372

0.276372

0.276372

0.276372

0.276372
0.276372

0.276372

0.276371

0.27637

0.276371

0.276371
0.276371
0

0.276371

0.276370

0.276370

0.276370

0.276370

0.276370
.0276370

0.276370

0.276369

0.276369

0.076369

0.276369

0.276369
0.276368
0.2768

0.27636

0.276368 0.27636

0.276367

0.0276367

0.276367
0.276367

1.0779880

.0779934

10779960

1.780014

1.780041

1.780095

1.780148

1.780175

1.780229

.0780256
1.780283

1.780310

1.780363

1.780417

10.780444

1.780498

1.780525

1.780578

1.780605

1.780659

1.780686

1.780713

1.780766

1.780820

1.780847

1.780894
1.0780901

1.780954

10780982

1.781035

1.0781062
1.0781089

$1: 781116$
1.781143

10781169

1.781223

1.781279

10781304

10781357

1.781411

1.0781438
1.781465

1. 781492

1.781546

1.781572

1.781626

1.781653

1.781709

1.781760

1.0781814

0.781841
1.781868

10781895

1.781922
1.781949
1.781975

1.782029

1.782056

10.782110

1.782163

1.782190

10.782244 
$\lambda(n-1)$

\begin{tabular}{|c|c|c|c|c|c|c|c|c|c|c|c|c|}
\hline $\begin{array}{l}50.0 \\
0.1 \\
0.2 \\
0.3 \\
0.4 \\
0.5 \\
0.6 \\
0.7 \\
0.8 \\
0.9\end{array}$ & $\begin{array}{r}499.593 \\
99.353 \\
99.112 \\
98.872 \\
98.632 \\
98.391 \\
98.151 \\
97.911 \\
97.671 \\
97.430\end{array}$ & $\begin{array}{l}99.569 \\
99.328 \\
99.088 \\
98.848 \\
98.608 \\
98.367 \\
98.127 \\
97.887 \\
97.647 \\
97.406\end{array}$ & $\begin{array}{l}99.545 \\
99.304 \\
99.064 \\
98.824 \\
98.583 \\
98.343 \\
98.103 \\
97.863 \\
97.623 \\
97.382\end{array}$ & $\begin{array}{l}99.521 \\
99.280 \\
99.040 \\
98.800 \\
98.560 \\
98.319 \\
98.079 \\
97.839 \\
97.599 \\
97.358\end{array}$ & $\begin{array}{l}99.497 \\
99.256 \\
99.016 \\
98.776 \\
98.536 \\
98.295 \\
98.055 \\
97.815 \\
97.574 \\
97.334\end{array}$ & $\begin{array}{l}99.473 \\
99.232 \\
98.992 \\
98.752 \\
98.512 \\
98.271 \\
98.031 \\
97.791 \\
97.550 \\
97.310\end{array}$ & $\begin{array}{l}99.449 \\
99.208 \\
98.968 \\
98.728 \\
98.488 \\
98.247 \\
98.007 \\
97.767 \\
97.526 \\
97.286\end{array}$ & $\begin{array}{l}99.425 \\
99.184 \\
98.944 \\
98.704 \\
98.464 \\
98.223 \\
97.983 \\
97.743 \\
97.502 \\
97.262\end{array}$ & $\begin{array}{l}99.401 \\
99.160 \\
98.920 \\
98.680 \\
98.439 \\
98.199 \\
97.959 \\
97.719 \\
97.479 \\
97.238\end{array}$ & $\begin{array}{l}99.377 \\
99.136 \\
98.896 \\
98.656 \\
98.415 \\
98.175 \\
97.935 \\
97.695 \\
97.454 \\
97.214\end{array}$ & $\begin{array}{l}0.276367 \\
0.276367 \\
0.276367 \\
0.276367 \\
0.276366 \\
0.276366 \\
0.276366 \\
0.276366 \\
0.276366 \\
0.276366\end{array}$ & $\begin{array}{l}1.782566 \\
1.782593 \\
1.782620 \\
1.782647 \\
1.782674 \\
1.782701 \\
1.782728 \\
1.782755 \\
1.782781 \\
1.782808\end{array}$ \\
\hline $\begin{array}{r}6451.0 \\
1.1 \\
1.2 \\
1.3 \\
1.4 \\
1.5 \\
1.6 \\
1.7 \\
1.8 \\
1.9\end{array}$ & $\begin{array}{r}15497.190 \\
96.950 \\
96.710 \\
96.469 \\
96.229 \\
95.989 \\
95.749 \\
95.509 \\
95.269 \\
95.028\end{array}$ & $\begin{array}{l}97.166 \\
96.926 \\
96.686 \\
96.446 \\
96.205 \\
95.965 \\
95.725 \\
95.485 \\
95.245 \\
95.004\end{array}$ & $\begin{array}{l}97.142 \\
96.902 \\
96.661 \\
96.422 \\
96.181 \\
95.941 \\
95.701 \\
95.461 \\
95.221 \\
94.980\end{array}$ & $\begin{array}{l}97.118 \\
96.878 \\
96.638 \\
96.397 \\
96.157 \\
95.917 \\
95.677 \\
95.437 \\
95.197 \\
94.956\end{array}$ & $\begin{array}{l}97.094 \\
96.854 \\
96.614 \\
96.373 \\
96.133 \\
95.893 \\
95.653 \\
95.413 \\
95.172 \\
94.932\end{array}$ & $\begin{array}{l}97.070 \\
96.830 \\
96.590 \\
96.349 \\
96.109 \\
95.869 \\
95.629 \\
95.389 \\
95.148 \\
94.908\end{array}$ & $\begin{array}{l}97.046 \\
96.806 \\
96.566 \\
96.325 \\
96.085 \\
95.845 \\
95.605 \\
95.365 \\
95.124 \\
94.884\end{array}$ & $\begin{array}{l}97.022 \\
96.782 \\
96.542 \\
96.301 \\
96.061 \\
95.821 \\
95.581 \\
95.341 \\
95.101 \\
94.860\end{array}$ & $\begin{array}{l}96.998 \\
96.758 \\
96.517 \\
96.277 \\
96.037 \\
95.797 \\
95.557 \\
95.317 \\
95.076 \\
94.836\end{array}$ & $\begin{array}{l}96.974 \\
96.734 \\
96.493 \\
96.253 \\
96.013 \\
95.773 \\
95.533 \\
95.292 \\
95.052 \\
94.812\end{array}$ & $\begin{array}{l}0.276366 \\
0.276366 \\
0.276365 \\
0.276365 \\
0.276365 \\
0.276365 \\
0.276365 \\
0.276365 \\
0.276365 \\
0.276365\end{array}$ & $\begin{array}{l}1.782835 \\
1.782862 \\
1.782889 \\
1.782916 \\
1.782943 \\
1.782969 \\
1.782996 \\
1.783023 \\
1.783050 \\
1.783077\end{array}$ \\
\hline $\begin{array}{r}452.0 \\
2.1 \\
2.2 \\
2.3 \\
2.4 \\
2.5 \\
2.6 \\
2.7 \\
2.8 \\
2.9\end{array}$ & $\begin{array}{r}15494.788 \\
94.548 \\
94.308 \\
94.068 \\
93.828 \\
93.588 \\
93.347 \\
93.107 \\
92.867 \\
92.627\end{array}$ & $\begin{array}{l}94 \cdot 764 \\
94 \cdot 524 \\
94.284 \\
94.044 \\
93.804 \\
93.564 \\
93.323 \\
93.083 \\
92.843 \\
92.603\end{array}$ & $\begin{array}{l}94.740 \\
94.500 \\
94.260 \\
94.020 \\
93.780 \\
93.540 \\
93.299 \\
93.059 \\
92.819 \\
92.579\end{array}$ & $\begin{array}{l}94.716 \\
94.476 \\
94.236 \\
93.996 \\
93.756 \\
93.516 \\
93.275 \\
93.035 \\
92.795 \\
92.555\end{array}$ & $\begin{array}{l}94.692 \\
94.452 \\
94.212 \\
93.972 \\
93.732 \\
93.491 \\
93.251 \\
93.011 \\
92.771 \\
92.531\end{array}$ & $\begin{array}{l}94.668 \\
94.428 \\
94.188 \\
93.948 \\
93.708 \\
93.467 \\
93.227 \\
92.987 \\
92.747 \\
92.507\end{array}$ & $\begin{array}{l}94.644 \\
94.404 \\
94.164 \\
93.924 \\
93.684 \\
93.443 \\
93.203 \\
92.963 \\
92.723 \\
92.483\end{array}$ & $\begin{array}{l}94.620 \\
94.380 \\
94.140 \\
93.900 \\
93.660 \\
93.419 \\
93.179 \\
92.939 \\
92.699 \\
92.459\end{array}$ & $\begin{array}{l}94 \cdot 596 \\
94 \cdot 356 \\
94 \cdot 116 \\
93.876 \\
93.635 \\
93.395 \\
93.155 \\
92.915 \\
92.675 \\
92.435\end{array}$ & $\begin{array}{l}94.572 \\
94.332 \\
94.092 \\
93.852 \\
93.612 \\
93.371 \\
93.131 \\
92.891 \\
92.651 \\
92.411\end{array}$ & $\begin{array}{l}0.276365 \\
0.276364 \\
0.276364 \\
0.276364 \\
0.276364 \\
0.276364 \\
0.276364 \\
0.276364 \\
0.276364 \\
0.276363\end{array}$ & $\begin{array}{l}1.783104 \\
1.783131 \\
1.783158 \\
1.783184 \\
1.783211 \\
1.783238 \\
1.783265 \\
1.783292 \\
1.783319 \\
1.783346\end{array}$ \\
\hline $\begin{array}{r}6453.0 \\
3.1 \\
3.2 \\
3.3 \\
3.4 \\
3.5 \\
3.6 \\
3.7 \\
3.8 \\
3.9\end{array}$ & $\begin{array}{r}5492.387 \\
92.147 \\
91.907 \\
91.667 \\
91.427 \\
91.187 \\
90.947 \\
90.707 \\
90.467 \\
90.227\end{array}$ & $\begin{array}{l}92.363 \\
92.123 \\
91.883 \\
91.643 \\
91.403 \\
91.163 \\
90.923 \\
90.683 \\
90.443 \\
90.203\end{array}$ & $\begin{array}{l}92.339 \\
92.099 \\
91.859 \\
91.619 \\
91.379 \\
91.139 \\
90.899 \\
90.659 \\
90.419 \\
90.179\end{array}$ & $\begin{array}{l}92.315 \\
92.075 \\
91.835 \\
91.595 \\
91.355 \\
91.115 \\
90.875 \\
90.635 \\
90.395 \\
90.155\end{array}$ & $\begin{array}{l}92.291 \\
92.051 \\
91.811 \\
9 ? .571 \\
91.331 \\
91.091 \\
90.851 \\
90.611 \\
90.371 \\
90.131\end{array}$ & $\begin{array}{l}92.267 \\
92.027 \\
91.787 \\
91.547 \\
91.307 \\
91.067 \\
90.827 \\
90.587 \\
90.347 \\
90.107\end{array}$ & $\begin{array}{l}92.243 \\
92.003 \\
91.763 \\
91.523 \\
91.283 \\
91.043 \\
90.803 \\
90.563 \\
90.323 \\
90.083\end{array}$ & $\begin{array}{l}92.219 \\
91.979 \\
91.739 \\
91.499 \\
91.259 \\
91.019 \\
90.779 \\
90.539 \\
90.299 \\
90.059\end{array}$ & $\begin{array}{l}92.195 \\
91.955 \\
91.715 \\
91.475 \\
91.235 \\
90.995 \\
90.755 \\
90.515 \\
90.275 \\
90.035\end{array}$ & $\begin{array}{l}92.171 \\
91.931 \\
91.691 \\
91.451 \\
91.211 \\
90.971 \\
90.731 \\
90.491 \\
90.251 \\
90.010\end{array}$ & $\begin{array}{l}0.276363 \\
0.276363 \\
0.276363 \\
0.276363 \\
0.276363 \\
0.276363 \\
0.276363 \\
0.276362 \\
0.276362 \\
0.276362\end{array}$ & $\begin{array}{l}1.783372 \\
1.783399 \\
1.783426 \\
1.783453 \\
1.783480 \\
1.783507 \\
1.783534 \\
1.783561 \\
1.783587 \\
1.783614\end{array}$ \\
\hline $\begin{array}{r}454 \cdot 0 \\
4.1 \\
4 \cdot 2 \\
4 \cdot 3 \\
4.4 \\
4.5 \\
4.6 \\
4.7 \\
4.8 \\
4.9\end{array}$ & $\begin{array}{r}15489.987 \\
89.746 \\
89.507 \\
89.267 \\
89.027 \\
88.787 \\
88.547 \\
88.307 \\
88.067 \\
87.827\end{array}$ & $\begin{array}{l}89.963 \\
89.723 \\
89.483 \\
89.243 \\
89.003 \\
88.763 \\
88.523 \\
88.283 \\
88.043 \\
87.803\end{array}$ & $\begin{array}{l}89.939 \\
89.699 \\
89.459 \\
89.219 \\
88.979 \\
88.739 \\
88.499 \\
88.259 \\
88.019 \\
87.779\end{array}$ & $\begin{array}{l}89.915 \\
89.675 \\
89.435 \\
89.195 \\
88.955 \\
88.715 \\
88.475 \\
88.235 \\
87.995 \\
87.755\end{array}$ & $\begin{array}{l}89.891 \\
89.651 \\
89.411 \\
89.171 \\
88.931 \\
88.691 \\
88.451 \\
88.211 \\
87.971 \\
87.731\end{array}$ & $\begin{array}{l}89.867 \\
89.627 \\
89.387 \\
89.147 \\
88.907 \\
88.667 \\
88.427 \\
88.187 \\
87.947 \\
87.707\end{array}$ & $\begin{array}{l}89.843 \\
89.603 \\
89.363 \\
89.123 \\
88.883 \\
88.643 \\
88.403 \\
88.163 \\
87.923 \\
87.683\end{array}$ & $\begin{array}{l}89.819 \\
89.578 \\
89.339 \\
89.099 \\
88.859 \\
88.619 \\
88.379 \\
88.139 \\
87.899 \\
87.659\end{array}$ & $\begin{array}{l}89.795 \\
89.555 \\
89.315 \\
89.075 \\
88.835 \\
88.595 \\
88.355 \\
88.115 \\
87.875 \\
87.635\end{array}$ & $\begin{array}{l}89.771 \\
89.531 \\
89.291 \\
89.051 \\
88.811 \\
88.571 \\
88.331 \\
88.091 \\
87.851 \\
87.611\end{array}$ & $\begin{array}{l}0.276362 \\
0.276362 \\
0.276362 \\
0.276362 \\
0.276362 \\
0.276362 \\
0.276361 \\
0.276361 \\
0.276361 \\
0.276361\end{array}$ & $\begin{array}{l}1.783641 \\
1.783668 \\
1.783695 \\
1.783722 \\
1.783749 \\
1.783776 \\
1.783802 \\
1.783829 \\
1.783856 \\
1.783883\end{array}$ \\
\hline $\begin{array}{r}455.0 \\
5.1 \\
5.2 \\
5.3 \\
5.4 \\
5.5 \\
5.6 \\
5.7 \\
5.8 \\
5.9\end{array}$ & $\begin{array}{r}15487.587 \\
87.347 \\
87.10 .7 \\
86.867 \\
86.627 \\
86.387 \\
86.147 \\
85.908 \\
85.668 \\
85.428\end{array}$ & $\begin{array}{l}87.563 \\
87.323 \\
87.083 \\
86.843 \\
86.603 \\
86.363 \\
86.124 \\
85.884 \\
85.644 \\
85.404\end{array}$ & $\begin{array}{l}87.539 \\
87.299 \\
87.059 \\
86.819 \\
86.579 \\
86.339 \\
86.100 \\
85.860 \\
85.620 \\
85.380\end{array}$ & $\begin{array}{l}87.515 \\
87.275 \\
87.035 \\
86.795 \\
86.555 \\
86.315 \\
86.075 \\
85.836 \\
85.596 \\
85.356\end{array}$ & $\begin{array}{l}87.491 \\
87.251 \\
87.011 \\
86.771 \\
86.531 \\
86.291 \\
86.052 \\
85.812 \\
85.572 \\
85.332\end{array}$ & $\begin{array}{l}87.467 \\
87.227 \\
86.987 \\
86.747 \\
86.507 \\
86.267 \\
86.027 \\
85.788 \\
85.548 \\
85.308\end{array}$ & $\begin{array}{l}87.443 \\
87.203 \\
86.963 \\
86.723 \\
86.483 \\
86.244 \\
86.003 \\
85.764 \\
85.524 \\
85.284\end{array}$ & $\begin{array}{l}87.419 \\
87.179 \\
86.939 \\
86.699 \\
86.459 \\
86.219 \\
85.979 \\
85.740 \\
85.500 \\
85.260\end{array}$ & $\begin{array}{l}87.395 \\
87.155 \\
86.915 \\
86.675 \\
86.435 \\
86.195 \\
85.956 \\
85.716 \\
85.476 \\
85.236\end{array}$ & $\begin{array}{l}87.371 \\
87.131 \\
86.891 \\
86.651 \\
86.411 \\
86.172 \\
85.932 \\
85.692 \\
85.452 \\
85.212\end{array}$ & $\begin{array}{l}0.276361 \\
0.276361 \\
0.276361 \\
0.276361 \\
0.276360 \\
0.276360 \\
0.276360 \\
0.276360 \\
0.276360 \\
0.276360\end{array}$ & $\begin{array}{l}1.783910 \\
1.783937 \\
1.783964 \\
1.783990 \\
1.784017 \\
1.784044 \\
1.784071 \\
1.784098 \\
1.784125 \\
1.784152\end{array}$ \\
\hline $\begin{array}{r}456.0 \\
6.1 \\
6.2 \\
6.3 \\
6.4 \\
6.5 \\
6.6 \\
6.7 \\
6.8 \\
6.9\end{array}$ & $\begin{array}{r}15485.188 \\
84.948 \\
84.708 \\
84.468 \\
84.229 \\
83.989 \\
83.749 \\
83.509 \\
83.269 \\
83.030\end{array}$ & $\begin{array}{l}85 \cdot 164 \\
84 \cdot 924 \\
84.684 \\
84 \cdot 444 \\
84 \cdot 205 \\
83 \cdot 965 \\
83 \cdot 725 \\
83 \cdot 485 \\
83 \cdot 245 \\
83 \cdot 006\end{array}$ & $\begin{array}{l}85.140 \\
84.900 \\
84.660 \\
84.420 \\
84.181 \\
83.941 \\
83.701 \\
83.461 \\
83.221 \\
82.982\end{array}$ & $\begin{array}{l}85.116 \\
84.876 \\
84.636 \\
84.396 \\
84.157 \\
83.917 \\
83.677 \\
83.437 \\
83.197 \\
82.958\end{array}$ & $\begin{array}{l}85.092 \\
84.852 \\
84.612 \\
84.372 \\
84.133 \\
83.893 \\
83.653 \\
83.413 \\
83.173 \\
82.934\end{array}$ & $\begin{array}{l}85.068 \\
84.828 \\
84.589 \\
84.349 \\
84.109 \\
83.869 \\
83.629 \\
83.389 \\
83.149 \\
82.910\end{array}$ & $\begin{array}{l}85.044 \\
84.804 \\
84.564 \\
84.324 \\
84.085 \\
83.845 \\
83.605 \\
83.365 \\
83.125 \\
82.886\end{array}$ & $\begin{array}{l}85.020 \\
84.780 \\
84.540 \\
84.301 \\
84.061 \\
83.821 \\
83.581 \\
83.341 \\
83.102 \\
82.862\end{array}$ & $\begin{array}{l}84.996 \\
84.756 \\
84.516 \\
84.277 \\
84.037 \\
83.797 \\
83.557 \\
83.317 \\
83.078 \\
82.838\end{array}$ & $\begin{array}{l}84.972 \\
84.732 \\
84.492 \\
84.253 \\
84.013 \\
83.773 \\
83.533 \\
83.293 \\
83.054 \\
82.814\end{array}$ & $\begin{array}{l}0.276360 \\
0.276360 \\
0.276360 \\
0.276359 \\
0.276359 \\
0.276359 \\
0.276359 \\
0.276359 \\
0.276359 \\
0.276359\end{array}$ & $\begin{array}{l}1.784179 \\
1.784205 \\
1.784232 \\
1.784259 \\
1.784286 \\
1.784313 \\
1.784340 \\
1.784367 \\
1.784393 \\
1.784420\end{array}$ \\
\hline $\begin{array}{r}457.0 \\
7.1 \\
7.2 \\
7.3 \\
7.4 \\
7.5 \\
7.6 \\
7.7 \\
7.8 \\
7.9\end{array}$ & $\begin{array}{r}15482.790 \\
82.550 \\
82.310 \\
82.070 \\
81.831 \\
81.591 \\
81.351 \\
81.111 \\
80.872 \\
80.632\end{array}$ & $\begin{array}{l}82.766 \\
82.526 \\
82.286 \\
82.047 \\
81.807 \\
81.567 \\
81.327 \\
81.088 \\
80.848 \\
80.608\end{array}$ & $\begin{array}{l}82.742 \\
82.502 \\
82.262 \\
82.023 \\
81.783 \\
81.543 \\
81.303 \\
81.063 \\
80.824 \\
80.584\end{array}$ & $\begin{array}{l}82.718 \\
82.478 \\
82.238 \\
81.999 \\
81.759 \\
81.519 \\
81.279 \\
81.040 \\
80.800 \\
80.560\end{array}$ & $\begin{array}{l}82.694 \\
82.454 \\
82.214 \\
81.975 \\
8 ? .735 \\
81.495 \\
81.255 \\
81.016 \\
80.776 \\
80.536\end{array}$ & $\begin{array}{l}82.670 \\
82.430 \\
82.190 \\
81.951 \\
81.711 \\
81.471 \\
81.231 \\
80.992 \\
80.752 \\
80.512\end{array}$ & $\begin{array}{l}82.646 \\
82.406 \\
82.166 \\
81.927 \\
81.687 \\
81.447 \\
81.207 \\
80.968 \\
80.728 \\
80.488\end{array}$ & $\begin{array}{l}82.622 \\
82.382 \\
82.142 \\
81.903 \\
81.663 \\
81.423 \\
81.183 \\
80.944 \\
80.704 \\
80.464\end{array}$ & $\begin{array}{l}82.598 \\
82.358 \\
82.118 \\
81.879 \\
81.639 \\
81.399 \\
81.159 \\
80.920 \\
80.680 \\
80.440\end{array}$ & $\begin{array}{l}82.574 \\
82.334 \\
82.094 \\
81.855 \\
81.615 \\
81.375 \\
81.135 \\
80.896 \\
80.656 \\
80.416\end{array}$ & $\begin{array}{l}0.276359 \\
0.276358 \\
0.276358 \\
0.276358 \\
0.276358 \\
0.276358 \\
0.276358 \\
0.276358 \\
0.276358 \\
0.276357\end{array}$ & $\begin{array}{l}1.784447 \\
1.784474 \\
1.784501 \\
1.784528 \\
1.784555 \\
1.784582 \\
1.784608 \\
1.784635 \\
1.784662 \\
1.784689\end{array}$ \\
\hline $\begin{array}{r}6458.0 \\
8.1 \\
8.2 \\
8.3 \\
8.4 \\
8.5 \\
8.6 \\
8.7 \\
8.8 \\
8.9\end{array}$ & $\begin{array}{r}15480.392 \\
80.153 \\
79.913 \\
79.673 \\
79.434 \\
79.194 \\
78.954 \\
78.715 \\
78.475 \\
78.235\end{array}$ & $\begin{array}{l}80.368 \\
80.129 \\
79.889 \\
79.649 \\
79.410 \\
79.170 \\
78.930 \\
78.691 \\
78.451 \\
78.211\end{array}$ & $\begin{array}{l}80.344 \\
80.105 \\
79.865 \\
79.625 \\
79.386 \\
79.146 \\
78.907 \\
78.667 \\
78.427 \\
78.187\end{array}$ & $\begin{array}{l}80.320 \\
80.081 \\
79.841 \\
79.601 \\
79.362 \\
79.122 \\
78.882 \\
78.643 \\
78.403 \\
78.164\end{array}$ & $\begin{array}{l}80.297 \\
80.057 \\
79.817 \\
79.577 \\
79.338 \\
79.098 \\
78.859 \\
78.619 \\
78.379 \\
78.140\end{array}$ & $\begin{array}{l}80.272 \\
80.033 \\
79.793 \\
79.553 \\
79.314 \\
79.074 \\
78.834 \\
78.595 \\
78.355 \\
78.116\end{array}$ & $\begin{array}{l}80.249 \\
80.009 \\
79.769 \\
79.529 \\
79.290 \\
79.050 \\
78.811 \\
78.571 \\
78.331 \\
78.092\end{array}$ & $\begin{array}{l}80.224 \\
79.985 \\
79.745 \\
79.505 \\
79.266 \\
79.026 \\
78.787 \\
78.547 \\
78.307 \\
78.068\end{array}$ & $\begin{array}{l}80.201 \\
79.961 \\
79.721 \\
79.482 \\
79.242 \\
79.002 \\
78.763 \\
78.523 \\
78.283 \\
78.044\end{array}$ & $\begin{array}{l}80.177 \\
79.937 \\
79.697 \\
79.458 \\
79.218 \\
78.978 \\
78.739 \\
78.499 \\
78.259 \\
78.020\end{array}$ & $\begin{array}{l}0.276357 \\
0.276357 \\
0.276357 \\
0.276357 \\
0.276357 \\
0.276357 \\
0.276357 \\
0.276357 \\
0.276356 \\
0.276356\end{array}$ & $\begin{array}{l}1.784716 \\
1.784743 \\
1.784770 \\
1.784796 \\
1.784823 \\
1.784850 \\
1.784877 \\
1.784904 \\
1.784931 \\
1.784958\end{array}$ \\
\hline $\begin{array}{r}459.0 \\
9.1 \\
9.2 \\
9.3 \\
9.4 \\
9.5 \\
9.6 \\
9.7 \\
9.8 \\
9.9\end{array}$ & $\begin{array}{r}577.996 \\
77.756 \\
77.517 \\
77.277 \\
77.037 \\
76.798 \\
76.558 \\
76.319 \\
76.079 \\
75.839\end{array}$ & $\begin{array}{l}77.972 \\
77.0732 \\
77.493 \\
77.253 \\
77.013 \\
76.0774 \\
76.534 \\
76.295 \\
76.055 \\
75.815\end{array}$ & $\begin{array}{l}77.948 \\
77.708 \\
77.469 \\
77.229 \\
76.989 \\
76.750 \\
76.510 \\
76.271 \\
76.031 \\
75.792\end{array}$ & $\begin{array}{l}77.924 \\
77.684 \\
77.445 \\
77.205 \\
76.966 \\
76.726 \\
76.486 \\
76.247 \\
76.007 \\
75.768\end{array}$ & $\begin{array}{l}77.900 \\
77.660 \\
77.421 \\
77.181 \\
76.942 \\
76.702 \\
76.462 \\
76.223 \\
75.983 \\
75.744\end{array}$ & $\begin{array}{l}77.876 \\
77.636 \\
77.397 \\
77.157 \\
76.918 \\
76.678 \\
76.438 \\
76.199 \\
75.959 \\
75.720\end{array}$ & $\begin{array}{l}77.852 \\
77.612 \\
77.373 \\
77.133 \\
76.894 \\
76.654 \\
76.414 \\
76.175 \\
75.935 \\
75.696\end{array}$ & $\begin{array}{l}77.828 \\
77.588 \\
77.349 \\
77.109 \\
76.870 \\
76.630 \\
76.390 \\
76.151 \\
75.911 \\
75.672\end{array}$ & $\begin{array}{l}77.804 \\
77.565 \\
77.325 \\
77.085 \\
76.846 \\
76.606 \\
76.367 \\
76.127 \\
75.887 \\
75.648\end{array}$ & $\begin{array}{l}77.780 \\
77.541 \\
77.301 \\
77.061 \\
76.822 \\
76.582 \\
76.343 \\
76.103 \\
75.863 \\
75.624\end{array}$ & $\begin{array}{l}0.276356 \\
0.276356 \\
0.276356 \\
0.276356 \\
0.276356 \\
0.276356 \\
0.276355 \\
0.276355 \\
0.276355 \\
0.276355\end{array}$ & $\begin{array}{r}1.784985 \\
1.785011 \\
1.785038 \\
1.785065 \\
1.785092 \\
1.785119 \\
1.785146 \\
1.785173 \\
1.785200 \\
1.785226\end{array}$ \\
\hline
\end{tabular}
$\begin{array}{llllllllll} & & & \end{array}$ 


\begin{abstract}
.01
\end{abstract}
6460 .

460.0
0.1
0.2

0.1
0.2
0.3
0.4

0.4

0.6
0.6
0.8

0.7
0.8
0.9

6461.

$1: 0$
1.1
$1: 2$
$1: 3$

1.4
1.5

1.6

1.6
1.7
1.9

6462.

2.1
2.2
2.3
2.4
2.5
2.6
2.07
2.8
2.9

6463.0

3.3

3.5

3.6

3.8
3.9

6464.0

4.1
4.2
4.3
4.4
4.5
4.6
4.7
4.8
4.9

4.9

6465.0

5.1

5.3

5.4

5.6
5.7
5.8

5.8
5.9

6466

66.0
6.1
6.2
6.3
6.4
6.5
6.6
6.7
6.8
6.9

6.4
6.5

6.7
6.8
6.9

6467

70

7.04

7.4
7.5
7.6

705
707
708
7.9

6468

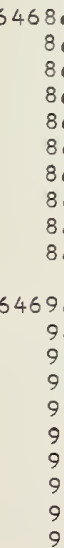

$72.486 \quad 72.46$

$72.247 \quad 72.223$

71.768 71.744

71.528
71.289
71.050

15470.810

70.571
70.331

$69.852 \quad 69.828$

15468.417 $67.698 \quad 67.674$

$66.980 \quad 66.957$

15466.02

65.78

65.306

$65.066 \quad 65.042$

$64.588 \quad 64.56$

$64.349 \quad 64.325$

63.870

64.086
63.846

63.392

$2.913 \quad 62.890$

$62.674 \quad 62.651$

$62.196 \quad 62.172$

61.479 61.00060 .216 60.76160 .737

$9.805 \quad 59.78$

59.303

$458.849 \quad 58.82$

$\begin{array}{ll}58.610 & 58.586 \\ 58.371 & 58.347\end{array}$

56.698

15456.45

$56.259 \quad 56.435$

55.742

15454.070

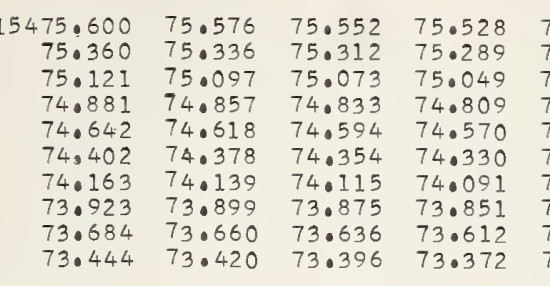

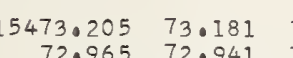

$\begin{array}{ll}72.965 & 72.941 \\ 72.726 & 72.702\end{array}$

70.33170 .547

69.61369 .589

69.134
68.895
68.871
68.656
68.632 $\begin{array}{ll}68.177 & 68.153 \\ 67.938 & 67.914\end{array}$ $67.459067 .435 \quad 67.411$

$\begin{array}{lll}67.220 & 67.196 & 67.17\end{array}$

$\begin{array}{lll}6.741 & 66.717 & 66.693\end{array}$

$\begin{array}{lll}66.502 & 66.478 & 66.45 \\ 66.263 & 66.239 & 66.215\end{array}$

$61.718 \quad 61.0394$

61.655

65.975

$\begin{array}{ll}0.736 & 65.7 \\ 65.497 & 65.473\end{array}$

$\begin{array}{rr}6.258 & 65.234\end{array}$

$65.018 \quad 64.995$

64.77964 .755

4.301

64.516
64.277

63.082

$50.08859 .064 \quad 59.040 \quad 59.016$

$58.132 \quad 58.3108 \quad 58.323$

$\begin{array}{lll}57.893 \quad 57.869 & 57.845\end{array}$

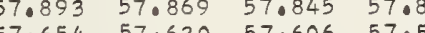

$\begin{array}{llllll}57.893 & 57.869 & 57.845 & 57.821\end{array}$

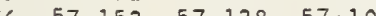

$56.937 \quad 56.913 \quad 56.889 \quad 56.865$

$\begin{array}{ll}56.220 & 56.196 \\ 55.981 & 55.957\end{array}$

$\begin{array}{llll}5 & 0.967 \\ 55.718 & 55.933 & 55.909\end{array}$

$\begin{array}{lllll}5 & 5.4003 & 55.479 & 55.455 & 55.43\end{array}$

$\begin{array}{llll}55.254 & 55.240 & 55.216 \quad 550192\end{array}$

$\begin{array}{llll}55.025 & 55.001 & 54.977 & 54.953\end{array}$

$\begin{array}{llll}54.786 & 54.762 & 54.738 & 54.714 \\ 54.547 & 54.523 & 54.499 & 54.475 \\ 54.308 & 54.284 & 54.260 & 54.237\end{array}$

$4.022 \quad 53.99$

$\begin{array}{lllll}53.830 & 53.807 & 53.783 & 53.75\end{array}$

$\begin{array}{llll}53.592 & 53.568 & 53.544 & 53.52 \\ 53.353 & 53.329 & 53.305 & 53.28\end{array}$

$53.114 \quad 53.090 \quad 53.066 \quad 53.042$

$\begin{array}{lllll}52.875 & 52.851 & 52.827 & 52.80\end{array}$

$\begin{array}{llll}52.636 & 52.612 & 52.589 & 52.56\end{array}$

$\begin{array}{llll}52.158 & 52.135 & 52.111 & 52.087 \\ 51.920 & 51.896 & 51.872 & 51.848\end{array}$
$50.504 \quad 75.480$

$\begin{array}{llllll}75.265 & 75.241 & 75.456 & 75.432 & 75.408 & 75.384 \\ 75.217 & 75.193 & 75.169 & 75.145\end{array}$

$\begin{array}{llllll}75.025 & 75.001 & 74.977 & 74.953 & 74.929 & 74.905\end{array}$

$74.546 \quad 74.522$

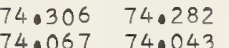

$\begin{array}{llll}74.03067 & 74.028 & 74.0498 & 74 \\ 73.043 & 74.019\end{array}$

$73.588 \quad 73.564$

$\begin{array}{lllll} & \\ 4.043 & 74.019 & 73.995 & 73.971 & 73.1847 \\ 3.803 & 73.779 & 73.755 & 73.732 & 73.708 \\ 3.564 & 73.540 & 73.516 & 73.492 & 73.468\end{array}$

$\begin{array}{llll}73.300 & 73.276 & 73.252 & 73.229\end{array}$

$\begin{array}{lllllll}73.109 & 73.085 & 73.061 & 73.037 & 73.013 & 72.989\end{array}$

$\begin{array}{llllll}72.869 & 72.845 & 72.821 & 72.797 & 72.774 & 72.750\end{array}$

$\begin{array}{llllll}72.630 & 72.606 & 72.582 & 72.558 & 72.534 & 72.510 \\ 72.390 & 72.366 & 72.342 & 72.319 & 72.295 & 72.271\end{array}$

$\begin{array}{lllllll}72.151 & 72.127 & 72.103 & 72.079 & 72.055 & 72.031\end{array}$

$\begin{array}{ll}71.911 & 71.887 \\ 71.672 & 71.048 \\ 71.432 & 71.040\end{array}$

71.864

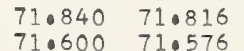

71.792

$\begin{array}{lllllll}71.432 & 71.409 & 71.385 & 71.361 & 71.337 & 71.313\end{array}$

$\begin{array}{llll}71.0145 & 71.121 & 71.098 & 71.073 \\ 70.906 & 70.882 & 70.858 & 70.834\end{array}$

$\begin{array}{lllllll}70.714 & 70.690 & 70.667 & 70.643 & 70.619 & 70.595\end{array}$

$\begin{array}{llllll}70.475 & 70.451 & 70.427 & 70.403 & 70.379 & 70.355\end{array}$

$\begin{array}{llllll}69.996 & 69.972 & 69.9848 & 69.164 & 70.140 & 70.116 \\ 69.901 & 69.901 & 69.876\end{array}$

$69.757 \quad 69.733 \quad 6907096990685 \quad 690661169.637$

$69.278 \quad 69.254 \quad 69.230 \quad 69.206 \quad 69 \cdot 182 \quad 69.158$

$69.039 \quad 69.015 \quad 68.991 \quad 68.967 \quad 68.943 \quad 68.919$

$\begin{array}{llllll}68.799 & 68.775 & 68.751 & 68.728 & 68.704 & 68.680 \\ 68.560 & 68.536 & 68.512 & 68.488 & 68.464 & 68.440\end{array}$

$\begin{array}{lllllll}68.321 & 68.297 & 68.273 & 68.249 & 68.225 & 68.201\end{array}$

$\begin{array}{llllll}68.081 & 68.057 & 68.033 & 68.010 & 67.986 & 67.962\end{array}$

$\begin{array}{lllllll}67.003 & 67.579 & 67.055 & 67.531 & 670507 & 67.483\end{array}$

$\begin{array}{lllllll}67.363 & 67.339 & 67.316 & 67.292 & 67.268 & 67.244\end{array}$

$67.124 \quad 67 \cdot 100 \quad 67.076 \quad 67.052 \quad 67 \cdot 028 \quad 67.004$

$\begin{array}{llllll}66.645 & 66.622 & 66.598 & 66.574 & 66.550 & 66.526\end{array}$

$\begin{array}{llllll}66.406 & 66.382 & 66.358 & 66.334 & 66.311 & 66.287 \\ 66.167 & 66.143 & 66.119 & 66.095 & 66.071 & 66.047\end{array}$

$\begin{array}{llllll}65.928 & 65.904 & 65.880 & 65.856 & 65.832 & 65.808\end{array}$

$\begin{array}{llllll}65.688 & 65.664 & 65.641 & 65.617 & 65.593 & 65.569 \\ 65.449 & 65.425 & 65.401 & 65.377 & 65.354 & 65.329\end{array}$

$\begin{array}{lllllll}65.210 & 65.186 & 65.162 & 65.138 & 65.114 & 65.090\end{array}$

$\begin{array}{llllll}64.971 & 64.947 & 64.923 & 64.899 & 64.875 & 64.851 \\ 64.731 & 64.708 & 64.684 & 64.660 & 64.0336 & 64.612\end{array}$

$64.492 \quad 64.468 \quad 64.444 \quad 640420 \quad 640397 \quad 64.373$

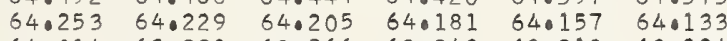

$\begin{array}{llllll}64.014 & 63.990 & 63.966 & 63.942 & 63.918 & 63.894 \\ 63.775 & 63.751 & 63.727 & 63.703 & 63.679 & 63.655\end{array}$

$\begin{array}{lllllll}63.535 & 63.511 & 63.488 & 63.464 & 63.440 & 63.416\end{array}$

$\begin{array}{llllll}63.296 & 63.272 & 63.248 & 63.224 & 63.201 & 63.177\end{array}$

$\begin{array}{lllllll}62.818 & 62.794 & 62.770 & 62.746 & 62.722 & 62.698\end{array}$

$\begin{array}{llllll}62.579 & 62.555 & 62.531 & 62.507 & 62.483 & 62.459\end{array}$

$\begin{array}{llllll}62.339 & 62.316 & 62.292 & 62.268 & 62.244 & 62.220\end{array}$

$\begin{array}{llllll}62.100 & 62.077 & 62.053 & 62.029 & 62.005 & 61.981 \\ 61.861 & 61.837 & 61.813 & 61.790 & 61.766 & 61.742\end{array}$ $\begin{array}{lllllll}61.622 & 61.598 & 61.574 & 61.551 & 61.527 & 61.503\end{array}$

$\begin{array}{llllll}61.144 & 61.120 & 61.096 & 61.072 & 61.048 & 61.024\end{array}$

$\begin{array}{llllll}60.881 & 60.857 & 60.833 & 60.809 & 60.785\end{array}$

$\begin{array}{llllll}60.666 & 60.642 & 60.618 & 60.594 & 60.570 & 60.546 \\ 60.427 & 60.403 & 60.379 & 60.355 & 60.331 & 60.307\end{array}$

$\begin{array}{llllll}60.187 & 60.164 & 60.140 & 60.116 & 60.092 & 60.068 \\ 50.948 & 59.925 & 59.0 .01 & 59.177 & 59.853 & 59.829\end{array}$

$\begin{array}{llllll}59.948 & 59.925 & 59.9 .01 & 59.877 & 59.853 & 59.829 \\ 59.709 & 59.685 & 59.661 & 59.638 & 59.614 & 59.590\end{array}$

$\begin{array}{lllllll}59.470 & 59.447 & 59.423 & 59.399 & 59.375 & 59.351\end{array}$

$\begin{array}{lllllll}59.231 & 59.207 & 59.183 & 59.160 & 59.136 & 59.112\end{array}$

$\begin{array}{lllllll}58.753 & 58.729 & 58.705 & 58.681 & 58.657 & 58.634\end{array}$

$\begin{array}{llllll}58.275 & 58.251 & 58.227 & 58.203 & 58.179 & 58.156\end{array}$

$\begin{array}{lllllll}58.036 & 58.012 & 57.988 & 57.964 & 57.941 & 57.917\end{array}$

$\begin{array}{llllll}57.558 & 57.773 & 57.749 & 57.725 & 57.701 & 57.677\end{array}$

$\begin{array}{lllllll}57.319 & 57.295 & 57.271 & 57.247 & 57.224 & 57.200\end{array}$

$\begin{array}{llllll}57.080 & 57.056 & 57.032 & 57.008 & 56.984 & 56.961\end{array}$

$\begin{array}{lllllll}56.841 & 56.817 & 56.793 & 56.770 & 56.746 & 56.722\end{array}$

$\begin{array}{llllll}56.363 & 56.339 & 56.315 & 56.292 & 56.268 & 56.244\end{array}$

$\begin{array}{llllll}56.124 & 56.100 & 56.076 & 56.052 & 56.029 & 56.005\end{array}$

$\begin{array}{llllll}55.885 & 55.861 & 55.838 & 55.814 & 55.790 & 55.766 \\ 55.646 & 55.622 & 55.598 & 55.575 & 55.551 & 55.527\end{array}$

$\begin{array}{lllllll}55.407 & 55.383 & 55.359 & 55.336 & 55.31 .2 & 55.288\end{array}$

$\begin{array}{lllllll}55.168 & 55.145 & 55.121 & 55.097 & 550073 & 55.049\end{array}$

$\begin{array}{llllll}54.929 & 54.906 & 54.882 & 54.858 & 54.834 & 54.810 \\ 54.691 & 54.667 & 54.643 & 54.619 & 54.595 & 54.571\end{array}$

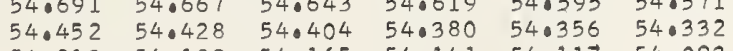

$\begin{array}{lllllll}53.974 & 53.950 & 53.926 & 53.902 & 53.878 & 53.854\end{array}$

$\begin{array}{llllll}53.735 & 53.711 & 53.687 & 53.663 & 53.640 & 53.616\end{array}$

$\begin{array}{llllll}53.496 & 53.472 & 53.448 & 53.424 & 53.401 & 53.377 \\ 53.257 & 53.233 & 53.209 & 53.186 & 53.162 & 53.138\end{array}$

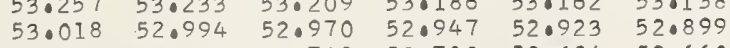

$\begin{array}{llllll}52.779 & 52.755 & 52.732 & 52.708 & 52.0684 & 52.660\end{array}$

$\begin{array}{llllll}52.541 & 52.517 & 52.493 & 52.469 & 52.445 & 52.421\end{array}$

$\begin{array}{llllll} & \end{array}$

$\begin{array}{llllll}2.063 & 52.039 & 52.015 & 51.991 & 51.958 & 51.944 \\ 1.824 & 51.800 & 51.776 & 51.752 & 51.729 & 51.705\end{array}$

$.004-.005$

.005

.006

.007

$(n-1) \times 1000$

$\lambda(n-1)$

0.276355

0.276355

0.276355

0.276354

0.276354

0.276354
0.276354

0.276354

0.276354

0.276353

0.276353

.276353

0.276353
0.276353

0.276353

0.276353
0.276352

0.276352

(

0.0275352

0.276352
0.276352

0.27635

0.276351

0.27635

0.27635

0.27635

0.276351

0.276350

0.276350
0.276350
0.276350

0.276350

0.276350

0.276350

0.276349

0.276349

0.276349

0.276349

0.276349

0.276348

0.276348

0.276348
0.276348

0.276348

0.276348
0.276348

0.276348

0.276347
0.276347
0.276347

0.276347

0.276347
0.276347

0.276347
0.276347

0.276347

0.27634

0.276346

0.276346

0.276346

0.276346

0.276346

0.276346

0.276346
0.276345

0.276345

0.276345

0.276345 
$\begin{array}{llllllllll}51.442 & 51.657 & 51.633 & 51.609 & 51.585 & 51.561 & 51.538 & 51.514 & 51.490 & 51.466 \\ 51.418 & 51.394 & 51.370 & 51.346 & 51.323 & 51.299 & 51.275 & 51.251 & 51.227\end{array}$

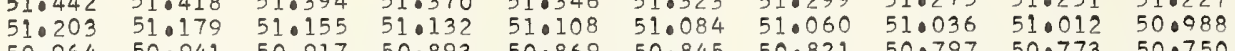
$\begin{array}{lllllllllll}50.964 & 50.941 & 50.917 & 50.893 & 50.869 & 50.845 & 50.821 & 50.797 & 50.773 & 50.750 \\ 50.726 & 50.702 & 50.678 & 50.654 & 50.530 & 50.606 & 50.582 & 50.558 & 50.535 & 50.511\end{array}$ $\begin{array}{llllllllll}50.487 & 50.463 & 50.439 & 50.415 & 50.391 & 50.367 & 50.344 & 50.320 & 50.296 & 50.272\end{array}$ $\begin{array}{llllllllll}50.487 & 50.463 & 50.439 & 50.415 & 50.391 & 50.367 & 50.344 & 50.320 & 50.296 & 50.272 \\ 50.248 & 50.224 & 50.200 & 50.176 & 50.153 & 50.129 & 50.105 & 50.081 & 50.057 & 50.033\end{array}$

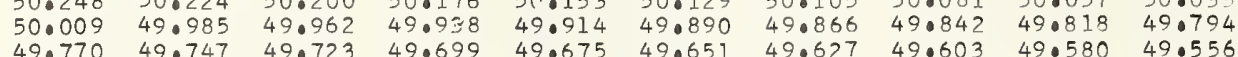
$\begin{array}{llllllllll}49.532 & 49.508 & 49.484 & 49.460 & 49.436 & 49.412 & 49.389 & 49.365 & 49.341 & 49.317\end{array}$

$\begin{array}{llllllllll}15449.293 & 49.269 & 49.245 & 49.222 & 49 \cdot 198 & 49.174 & 49.150 & 49 \cdot 126 & 49.102 & 49 \cdot 078\end{array}$ $\begin{array}{llllllllllll}1 & 49.055 & 49.031 & 49.007 & 48.983 & 48.959 & 48.935 & 48.911 & 48.887 & 48.864 & 48.840\end{array}$ $\begin{array}{lllllllllll}.2 & 48.816 & 48.792 & 48.768 & 48.744 & 48.720 & 48.696 & 48.673 & 48.649 & 48.625 & 48.601\end{array}$ $\begin{array}{lllllllllll}.3 & 48.577 & 48.553 & 48.529 & 48.505 & 48.482 & 48.458 & 48.434 & 48.410 & 48.386 & 48.362 \\ 1.4 & 48.338 & 48.314 & 48.291 & 48.267 & 48.243 & 48.219 & 48.195 & 48.171 & 48.147 & 48.123\end{array}$ $\begin{array}{llllllllll}48.100 & 48.076 & 48.052 & 48.028 & 48.004 & 47.980 & 47.957 & 47.932 & 47.909 & 47.885\end{array}$ $\begin{array}{lllllllllll}.6 & 47.861 & 47.837 & 47.813 & 47.789 & 47.765 & 47.742 & 47.718 & 47.694 & 47.670 & 47.646\end{array}$

$\begin{array}{llllllllll}47.622 & 47.598 & 47.574 & 47.551 & 47.527 & 47.503 & 47.479 & 47.455 & 47.431 & 47.407 \\ 47.383 & 47.360 & 47.336 & 47.312 & 47.288 & 47.264 & 47.240 & 47.216 & 47.193 & 47.169\end{array}$

$15446.006 \quad 46.882$ $\begin{array}{ll}47.336 & 47.312 \\ 47.097 & 47.073\end{array}$

$47.288 \quad 47.26$

47.479
47.240

47.169
46.930 $\begin{array}{lllll}46.667 & 46.644 & 46.858 & 46.834 & 460 \\ 46.420 & 46.596 & 460\end{array}$ $\begin{array}{llll}46.429 & 46.405 & 46.381 & 46.357\end{array}$ $\begin{array}{llll}46.190 & 46.166 & 46.142 & 46.119 \\ 45.952 & 45.928 & 45.904 & 45.880 \\ 45.713 & 45.688 & 45.565 & 45.641\end{array}$ $\begin{array}{llll}45.713 & 45.689 & 45.665 & 45.641 \\ 45.474 & 45.450 & 45.427 & 45.403 \\ 45.236 & 45.212 & 45.188 & 45.164\end{array}$ $\begin{array}{llll}45.236 & 45.212 & 45.188 & 45.164 \\ 44.997 & 44.973 & 44.949 & 44.925\end{array}$

$46.811 \quad 46.787$

$\begin{array}{llll}46.763 & 46.739 & 46.715 & 46.691\end{array}$ $\begin{array}{llllll}46.333 & 46.309 & 46.286 & 46.262 & 46.238 & 46.214\end{array}$ $\begin{array}{llllll}46.095 & 46.071 & 46.047 & 46.023 & 45.999 & 45.975 \\ 45.856 & 45.832 & 45.808 & 45.784 & 45.760 & 45.737\end{array}$ $\begin{array}{llllll}45.856 & 45.832 & 45.808 & 45.784 & 45.760 & 45.737 \\ 45.617 & 45.594 & 45.570 & 45.546 & 45.527 & 45.498\end{array}$ 44.758

$\begin{array}{rlll}15444.520 & 44.496 & 44.472 & 44.448 \\ 44.281 & 44.257 & 44.234 & 44.210 \\ 44.043 & 44.019 & 43.995 & 43.971 \\ 43.804 & 43.780 & 43.756 & 43.733 \\ 43.565 & 43.542 & 43.518 & 43.494 \\ 43.327 & 43.303 & 43.279 & 43.255 \\ 43.088 & 43.064 & 43.041 & 43.017 \\ 42.850 & 42.826 & 42.802 & 42.778 \\ 42.611 & 42.587 & 42.563 & 42.540 \\ 42.373 & 42.349 & 42.325 & 42.301\end{array}$
$\begin{array}{lllllll}45.379 & 45.355 & 45.331 & 45.307 & 45.283 & 45.260\end{array}$

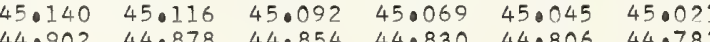
$\begin{array}{llllll}44.902 & 44.878 & 44.854 & 44.830 & 44.806 & 44.782 \\ 44.663 & 44.639 & 44.615 & 44.591 & 44.567 & 44.544\end{array}$ $\begin{array}{lllllll}44.424 & 44.400 & 44.377 & 44.353 & 44.329 & 44.305\end{array}$ 15442.134 41.896
41.0657 $\begin{array}{llll}42.110 & 42.086 & 42.062\end{array}$ $41.180 \quad 41.395 \quad 41 \cdot 371 \quad 41.347$ $40.942 \quad 40.018 \quad 40.894 \quad 40.870$ $\begin{array}{llll}40.703 & 40.0679 & 40.656 & 40.632 \\ 40.455 & 40.417 & 40.417 & 40.635\end{array}$ $\begin{array}{llll}40.465 & 40.441 & 40.417 & 40.393 \\ 40.226 & 40.202 & 40.179 & 40.155 \\ 39.988 & 30.964 & 39.940 & 39.916\end{array}$

$\begin{array}{llllll}43.947 & 43.923 & 43.900 & 43.876 & 43.852 & 43.828\end{array}$ $\begin{array}{llllll}43.708 & 43.685 & 43.661 & 43.637 & 43.613 & 43.589\end{array}$ $43.470 \quad 43.446 \quad 43.422 \quad 43.398 \quad 43.375 \quad 43.351$ $\begin{array}{llllll}43.231 & 43.208 & 43.184 & 43.160 & 43.136 & 43.112\end{array}$ $\begin{array}{llllll}42.953 & 42.969 & 42.945 & 42.921 & 42.898 & 42.874\end{array}$ $42.516 \quad 42.492 \quad 42.468 \quad 42.444 \quad 42.420 \quad 42.397$ $\begin{array}{lllllll}42.039 & 42.015 & 41.991 & 41.967 & 41.943 & 41.919\end{array}$ $\begin{array}{llllll}4 ! .800 & 41.776 & 41.753 & 41.729 & 41.705 & 41.681 \\ 41.562 & 41.538 & 41.514 & 41.490 & 41.466 & 41.442\end{array}$ $\begin{array}{llllll}41.562 & 41.538 & 41.514 & 41.490 & 41.466 & 41.442 \\ 41.323 & 41.299 & 41.276 & 41.252 & 41.228 & 41.204\end{array}$ $\begin{array}{llllll}41.085 & 41.061 & 41.037 & 41.013 & 40.989 & 40.965 \\ 40.846 & 40.822 & 40.799 & 40.775 & 40.751 & 40.727\end{array}$ $\begin{array}{llllll}40.846 & 40.822 & 40.799 & 40.775 & 40.751 & 40.727 \\ 40.608 & 40.584 & 40.560 & 40.536 & 40.519 & 40.489\end{array}$

$$
\begin{array}{r}
575 \\
5.0 \\
5.2 \\
50 \\
5.4 \\
5.5 \\
5.6 \\
5.7 \\
50
\end{array}
$$

34.98
34.74
34.505 $\begin{array}{llll}34.743 & 34.719 & 34.696 & 34.672 \\ 34.505 & 34.481 & 34.457 & 34.434 \\ 34.267 & 34.243 & 34.210 & 34.195\end{array}$ $34.029 \quad 34.243 \quad 34.21$ ब 34.195 $33.790 \quad 33.767 \quad 33.743 \quad 33.719$ $\begin{array}{llll}33.552 & 33.528 & 33.504 & 33.48\end{array}$ $33.075 \quad 33.052 \quad 33.028 \quad 330.004$

$\begin{array}{lll}40.369 & 40.345 \\ 40.131 & 40.107 & 40\end{array}$

$\begin{array}{llll}40.0322 & 40.038 & 40.074 & 40.050\end{array}$

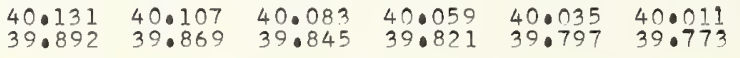

0.276343 0.0276343 0.076343 0.276343 0.276343 0.276342
0.276342 0.276342

0.276342

0.276342

0.276342

0.076341

0.27634

0.276341

.276341

0.27634

0.276341

0.276341

0.276340

0.276340

0.276340

0.276340

0.276340
0.276339

0.276339

0.276339

0.276339

0.276330
0.776330

0.276339

0.276338

0.276338
0.276338

0.276338

0.276338

0.276338

0.276327

0.276337

1.787940

1.787967
.0787994

1.788021
1.788048

1.788074

10788101

1.788182

1.788209

1.788236

1.788289

1.788216
.0788343

1.788370
1.788397

.788424

1.788478

1.788504

1.788558

1.788585

1.788639

10788692

1.788746

1.788773

1.788827

1.788854

1.788907

1.788934

1.788988

0.276337

$\begin{array}{llllll}39.654 & 39.630 & 39.606 & 39.582 & 39.559 & 39.535 \\ 39.415 & 39.392 & 39.368 & 39.344 & 39.320 & 39.096\end{array}$

$\begin{array}{llllll}39.177 & 39.153 & 39.129 & 39.105 & 39 \cdot 082 & 39 \cdot 058\end{array}$

\begin{tabular}{llllll}
38.700 & 38.576 & 38.891 & 38.867 & 38.843 & 38.819 \\
\hline
\end{tabular}

0.276337

0.276337

0.276337

$\begin{array}{llllll}38.223 & 38.199 & 38.176 & 38.152 & 38.128 & 38.104\end{array}$

0.276336

1.789015

1.789042

1. 1789096

1.789149

1.789176

10789230

1.789284

1.789311

1.789337

1.789391

1.789418

1.789472

0.276336

0.276336

0.276336

0.276336

0.276336

0.276335

0.276335

0.276335

$\begin{array}{llllll}35.363 & 35.578 & 35.554 & 35.530 & 35.506 & 35.482\end{array}$

0.276325

0.0276335

0.0276335

0.27633

0.0276334

0.276334

0.276334

0.276334
0.276334

$\begin{array}{llllll}32.080 & 32.956 & 32.932 & 32.909 & 32.885 & 32.861\end{array}$

0.276334
0.276334

0.276333
0.276333
0.276333

0.276333

0.276333

1.789499

1.789552

1.789579

10789633

1.789660

1.789687

1.989714

1.789767

1.789821

19789848

1.0789875

1.789929

1.789982

1.789002

1.790036

1.790090

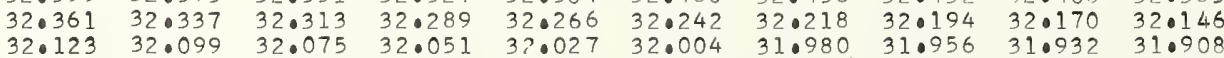
$\begin{array}{llllllllll}31.884 & 31.861 & 31.837 & 31.813 & 31.789 & 31.765 & 31.741 & 31.718 & 31.0694 & 310670\end{array}$ $\begin{array}{llllllllll}31.0408 & 31.034 & 31.360 & 31.337 & 31.313 & 31.289 & 31.265 & 31.241 & 31.217 & 31.194\end{array}$

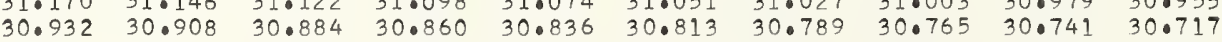
$\begin{array}{lllllllllll}30.693 & 30.670 & 30.646 & 30.0222 & 30.598 & 30.574 & 30.550 & 30.527 & 30.503 & 30.479 \\ 30.455 & 30.431 & 30.408 & 30.384 & 30.360 & 30.336 & 30.312 & 30 \cdot 289 & 30.265 & 30.241\end{array}$

0.276333

10790117

1.790170

10790197

1.790251

10790278

$\begin{array}{ll}0.076333 \\ 0.076332 & 10.790258 \\ 0.0790385\end{array}$

$0.276332 \quad 1.0790412$

$\begin{array}{ll}0.276332 \\ 0.276332 & 1.0790439 \\ 0.270490466\end{array}$

$0.276332 \quad 1.790493$

$0.276332 \quad 1.790520$

$0.276332 \quad 1.790547$

$0.276332 \quad 1.790573$

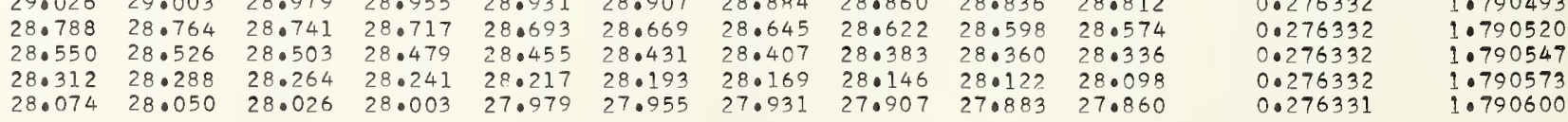

$\begin{array}{lllllllllll} & .001 & .002 & .003 & .004 & .005 & .006 & .007 & .008 & .009 & .010 \\ .834 & : 883 & : 885 & : 887 & : 888 & : 812 & : 814 & : 817 & : 818 & .832 & : 8324\end{array}$ 
$\begin{array}{rrrrrrrrrrr}0.1 & 15427.836 & 27.812 & 27.788 & 27.764 & 27.741 & 27.717 & 27.693 & 27.669 & 27.645 & 27.622 \\ 0.2 & 27.598 & 27.574 & 27.550 & 27.526 & 27.503 & 27.479 & 27.455 & 27.431 & 27.0407 & 27.384 \\ 0.2 & 27.360 & 27.336 & 27.312 & 27.288 & 27.264 & 27.241 & 27.217 & 27.193 & 37.169 & 27.145\end{array}$ $\begin{array}{lllllllllll}0.3 & 27.122 & 27.098 & 27.074 & 27.288 & 27.264 & 27.241 & 27.217 & 27.193 & 27.169 & 27.145 \\ 0.4 & 26.884 & 26.860 & 26.836 & 26.812 & 27.026 & 27.003 & 26.979 & 26.955 & 26.931 & 2.6 .907 \\ 0.4 & 26.68 & 26.765 & 26.741 & 26.717 & 26.693 & 26.669\end{array}$ $\begin{array}{lllllllllll}0.5 & 26.646 & 26.622 & 26.598 & 26.574 & 26.550 & 26.526 & 26.503 & 26.479 & 26.455 & 26.431\end{array}$ $\begin{array}{lllllllllll}0.6 & 26.408 & 26.384 & 26.360 & 26.336 & 26.312 & 26.288 & 26.265 & 26.241 & 26.217 & 26.193\end{array}$ $\begin{array}{lllllllllll}0.8 & 25.931 & 25.908 & 25.884 & 26.098 & 26.074 & 26.051 & 26.027 & 26.003 & 25.979 & 25.955 \\ 0 & 25.693 & 25.9570 & 25.845 & 25.0622 & 25.836 & 25.812 & 25.789 & 25.765 & 25.741 & 25.0717\end{array}$ 481.0 $15425.455 \quad 25.432$

$\begin{array}{llllll}25.360 & 25.336 & 25.313 & 25.289 & 25.265 & 25.241\end{array}$ $\begin{array}{llllll}25.122 & 25.098 & 25.075 & 25.051 & 25.027 & 25.003 \\ 24.884 & 24.860 & 24.837 & 24.813 & 24.789 & 24.765\end{array}$ $\begin{array}{llllll}24.884 & 24.860 & 24.837 & 24.813 & 24.789 & 24.765 \\ 24.646 & 24.622 & 24.599 & 24.575 & 24.551 & 24.527\end{array}$ $\begin{array}{llllllll}24.218 & 24.194 & 24.408 & 24.385 & 24.361 & 24.337 & 24.313 & 24.289\end{array}$

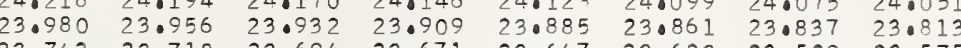

6487

7

$\begin{array}{rrrrrrrrrrr}6489.0 & 15406.438 & 06.415 & 06.391 & 06.367 & 06.343 & 06.320 & 06.296 & 06.272 & 06.248 & 06.225 \\ 9.1 & 06.201 & 06.177 & 06.153 & 06.130 & 06.106 & 06.082 & 06.058 & 06.035 & 06.011 & 05.987\end{array}$

$\begin{array}{lllllllllll}9.1 & 06.201 & 06.177 & 06.153 & 06.130 & 06.106 & 06.082 & 06.058 & 06.035 & 06.011 & 05.987 \\ 9.2 & 05.063 & 05.940 & 05.016 & 05.892 & 05.868 & 05.845 & 05.821 & 05.797 & 05.774 & 05.750\end{array}$

$\begin{array}{lllllllllll}9.2 & 05.963 & 05.940 & 05.916 & 05.892 & 05.868 & 05.845 & 05.821 & 05.797 & 05.774 & 05.750 \\ 9.3 & 05.726 & 05.702 & 05.679 & 05.655 & 05.631 & 05.607 & 05.584 & 05.560 & 05.0536 & 05.512\end{array}$

0.276331
0.076331
0.276331
0.076331
0.276331
0.275331
0.276331
0.276331
0.276330
0.27633

0.276330

0.276330

年

.076330

0.27632

0.276329

0.276329

0.276329

.27632

0.276378

0.276328
0.276328

0.276328

0.276328

0.276327

0.0776327

0.776327

.0276327
.076397

0.276327

0.276327
0.276326

0.27636

0.276326
0.076326

0.276336
0.376336

0.27632

0.2763

0.27632

0.276325

0.27632

0.276325
0.276225
0.27624

0.276324

0.27633
0.27632

0.276324

0.276324

0.276324

0.276324
0.276322
0

0.276323

0.276323

0.276329
0.276323

0.276323

0.0276322

0.276322
0.276322

0.2763

0.276322
0.276322

0.276322

0.276321
0.276321

0.276321

0.276321
0.276321

0.276321
0.276321

0.276321
0.276321

0.276320
0.276320

0.276320

0.276320

0.276320

.010

1.790869

1.790896

10790923

1.791003

.791057

1.79111

1.791165

1:791191

1.791272

1.091326

$1: 791353$

1.791433

1.791460
1.791487
10.791947

1.791514

1.791568

10791621
10791648
1.079675

10791702

1.091756

1.0791809

1.7918862

1.791890
1.791917
1.791944

$1: 791971$ 
$\begin{array}{lllllllllll}6490.0 & 15404.065 & 04.041 & 04.017 & 03.993 & 03.969 & 03.946 & 03.922 & 03.898 & 03.875 & 03.851\end{array}$

$\begin{array}{llllllllllll}0.1 & 03.827 & 03.803 & 03.780 & 03.756 & 03.732 & 03.708 & 03.685 & 03.661 & 03.637 & 03.614 \\ 0.2 & 03.590 & 03.566 & 03.542 & 03.519 & 03.495 & 03.471 & 03.447 & 03.424 & 03.400 & 03.376\end{array}$

$\begin{array}{lllllllllll}0.3 & 03.352 & 03.329 & 03.305 & 03.281 & 03.257 & 03.234 & 03.210 & 03.186 & 03.163 & 03.139 \\ 0.4 & 03.115 & 03.091 & 03.068 & 03.044 & 03.020 & 02.996 & 02.973 & 02.949 & 02.925 & 02.901\end{array}$

0.5

$\begin{array}{llllllllll}03.115 & 03.091 & 03.068 & 03.044 & 03.020 & 02.996 & 02.973 & 02.949 & 02.925 & 02.901\end{array}$

$\begin{array}{llllllllll}02.878 & 02.854 & 02.830 & 02.807 & 02.783 & 02.759 & 02.735 & 02.712 & 02.688 & 02.664 \\ 02.640 & 02.617 & 02.593 & 02.569 & 02.546 & 02.522 & 02.498 & 02.474 & 02.451 & 02.427\end{array}$

$\begin{array}{llllllllll}02.403 & 02.379 & 02.356 & 02.332 & 02.308 & 02.285 & 02.261 & 02.237 & 02.213 & 02.190\end{array}$

0.8

02.166

6491.0

1.1
1.2
1.3

1.4

1.6

1.8

$15401.69101 .668 \quad 01.644$

$\begin{array}{llll}01.454 & 01.430 & 01.407 & 01.620\end{array}$

$\begin{array}{llll}0.1217 & 01.193 & 01.169 & 01.146 \\ 00.979 & 00.956 & 00.032 & 00.908\end{array}$

$\begin{array}{llllllllll}00.979 & 00.956 & 00.932 & 00.908 & 00.885 & 00.861 & 00.837 & 00.813 & 00.790 & 00.766 \\ 00.742 & 00.718 & 00.695 & 00.671 & 00.647 & 00.624 & 00.600 & 00.576 & 00.552 & 00.529 \\ 00.505 & 00.481 & 00.458 & 00.434 & 00.410 & 00.386 & 00.363 & 00.339 & 00.315 & 00.291\end{array}$

$\begin{array}{llllllllll}0.268 & 00.244 & 00.220 & 00.197 & 00.173 & 00.149 & 00.363 & 00.339 & 00.315 & 00.291 \\ \end{array}$

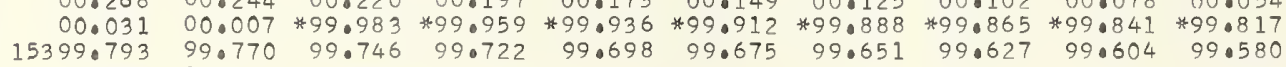

$\begin{array}{rlllllllll}399.793 & 99.770 & 99.746 & 99.722 & 99.698 & 99.675 & 99.651 & 99.627 & 99.604 & 99.580 \\ 99.556 & 99.532 & 99.509 & 99.485 & 99.461 & 99.437 & 99.414 & 99.390 & 99.366 & 99.343\end{array}$

$\begin{array}{rlllllllll}15399.319 & 99.295 & 99.271 & 99.248 & 99.224 & 99.200 & 99.177 & 99.153 & 99.129 & 99.105 \\ 99.082 & 99.058 & 99.034 & 99.010 & 98.987 & 98.963 & 98.939 & 98.916 & 98.892 & 98.868\end{array}$ $\begin{array}{llllllllll}99.082 & 99.058 & 99.034 & 99.010 & 98.987 & 98.963 & 98.939 & 98.916 & 98.892 & 98.868 \\ 98.844 & 98.821 & 98.797 & 98.773 & 98.749 & 98.726 & 98.702 & 98.678 & 98.655 & 98.631\end{array}$ $\begin{array}{llllllllll}98.607 & 98.584 & 98.560 & 98.536 & 98.512 & 98.489 & 98.465 & 98.441 & 98.418 & 98.394\end{array}$ $\begin{array}{llllllllll}98.370 & 98.346 & 98.323 & 98.299 & 98.275 & 98.252 & 98.228 & 98.204 & 98.180 & 98.156\end{array}$ $\begin{array}{llllllllll}98.133 & 98.109 & 98.085 & 98.062 & 98.038 & 98.014 & 97.991 & 97.967 & 97.943 & 97.919\end{array}$ $\begin{array}{llllllllll}97.659 & 97.635 & 97.611 & 97.587 & 97.564 & 97.540 & 97.516 & 97.493 & 97.469 & 97.445\end{array}$ $\begin{array}{llllllllll}97.421 & 97.398 & 97.374 & 97.350 & 97.327 & 97.303 & 97.279 & 97.256 & 97.232 & 97.208 \\ 97.184 & 97.161 & 97.137 & 97.113 & 97.089 & 97.066 & 97.042 & 97.018 & 96.995 & 96.971\end{array}$ 96.94796 .923 $96.710 \quad 96.686 \quad 96.663$ $96.473 \quad 96.449 \quad 96.426 \quad 96.402$ $\begin{array}{llll}96.236 & 96.212 & 96.188 & 96.165\end{array}$ $95.762 \quad 95.738 \quad 95.714 \quad 95.691$ $\begin{array}{llll}95.524 & 95.501 & 95.477 & 95.453\end{array}$

$95.050 \quad 95.027 \quad 95.003$

95.216

5394.576

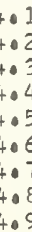

6495.0

5.1

5.3

5.6

5.8

$\begin{array}{ll}9.552 & 94.529\end{array}$

94.102

$93.628 \quad 93.641 \quad 93.81$

$93.391 \quad 93.367 \quad 93.344$

93.154

92.680
92.443

$93.130 \quad 93.107$

92.656

5392.206

$92 \cdot 182$

$91.732 \quad 91.708$

$91.495 \quad 91.472 \quad 91.448 \quad 91.64$

$91.258 \quad 91.234 \quad 91.211 \quad 91.187$

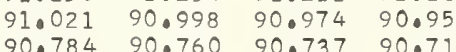

$90.547 \quad 90.524 \quad 90.500 \quad 90.47$

$\begin{array}{llll}90.310 & 90.287 & 90.263 & 90.239 \\ 90.073 & 90.050 & 90.026 & 90.002\end{array}$

6496.0

$6 \cdot 1$

6.3

6.5

6.6

6.7

89.813

$89.600 \quad 89.573 \quad 89.789 \quad 89.765$

$89.363 \quad 89.339 \quad 89.315 \quad 89.29$

$\begin{array}{llll}89.126 & 89 \cdot 102 & 89.078 & 89.05 \\ 88.889 & 88.865 & 88.842 & 88.81\end{array}$

$\begin{array}{llll}88.652 & 88.629 & 88.605 & 88.581 \\ 88.415 & 88.392 & 88.368 & 88.34\end{array}$

$88.415 \quad 88.392 \quad 88.368 \quad 88.344$

$\begin{array}{llllll}96 \cdot 852 & 96.829 & 96.805 & 96.781 & 96 \cdot 758 & 96.734 \\ 96.615 & 96.591 & 96.568 & 96.544 & 96.520 & 96.497\end{array}$

$\begin{array}{llllll}96.378 & 96.354 & 96.331 & 96.307 & 96.283 & 96.260\end{array}$

$\begin{array}{llllll}96.141 & 96.117 & 96.093 & 96.070 & 96.046 & 96.022\end{array}$

$\begin{array}{llllll}95.904 & 95.880 & 95.856 & 95.833 & 95.809 & 95.785 \\ 95.567 & 05.642 & 95.520 & 95.506 & 95.572 & 95.548\end{array}$

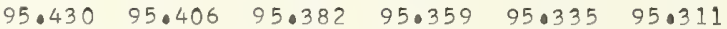

$\begin{array}{llllll}95.193 & 95.169 & 95.145 & 95.122 & 95.098 & 95.074\end{array}$

$94.955 \quad 94.932 \quad 94.908 \quad 94.884 \quad 94.861 \quad 94.837$

$\begin{array}{llll}88.179 & 88.155 & 88.131 & 88.107 \\ 87.942 & 87.918 & 87.894 & 87.871\end{array}$

6497.0

$\begin{array}{llll}5387.468 & 87.444 & 87.421 & 87.397\end{array}$

$7: 1$
$7: 2$
7.3

7.4

7.6
7.07
7.8

7.8

6498.

8.1
8.2
8.3
8.4

8.5

8.6
8.7
8.8

8.8

6499

$\begin{array}{llll}87.231 & 87.207 & 87.184 & 87.160 \\ 86.994 & 86.971 & 86.947 & 86.923 \\ 86.757 & 86.734 & 86.710 & 86.687 \\ 86.521 & 86.497 & 86.473 & 86.450 \\ 86.284 & 86.260 & 86.236 & 86.213 \\ 86.047 & 86.023 & 86.000 & 85.976 \\ 85.810 & 85.787 & 85.763 & 85.739 \\ 85.573 & 85.550 & 85.526 & 85.503 \\ 85.337 & 85.313 & 85.289 & 85.266\end{array}$

$\begin{array}{llll}85.573 & 85.550 & 85.526 & 85.503 \\ 85.337 & 85.313 & 85.289 & 85.266\end{array}$

$94 \cdot 481 \quad 94 \cdot 458$

$\begin{array}{llll}94.434 & 94.410 & 94.387 & 94.363\end{array}$

$\begin{array}{llllll}94.007 & 93.984 & 94.197 & 94.173 & 94.150 & 94.126 \\ 93.960 & 93.936 & 93.912 & 93.889\end{array}$

$\begin{array}{llllll}3.770 & 93.747 & 93.723 & 93.699 & 93.676 & 93.652\end{array}$

$\begin{array}{llllll}93.533 & 93.510 & 93.486 & 93.462 & 93.438 & 93.415 \\ 93.296 & 93.272 & 93.249 & 93.225 & 93.201 & 93.178\end{array}$

$\begin{array}{llllll}93.059 & 93.036 & 93.012 & 92.988 & 92.964 & 92.941\end{array}$

$\begin{array}{llllll}92.822 & 92.799 & 92.775 & 92.751 & 92.727 & 92.704 \\ 92.585 & 92.562 & 92.538 & 92.514 & 92.490 & 92.467\end{array}$

$92.11192 .088 \quad 92.064 \quad 92.040 \quad 92.016 \quad 91.993$

$\begin{array}{llllll}91.874 & 91.850 & 91.827 & 91.803 & 91.780 & 91.756\end{array}$

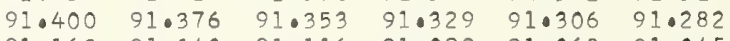

$\begin{array}{llllll}91.163 & 91.140 & 91.116 & 91.092 & 91.068 & 91.045\end{array}$

$\begin{array}{llllll}90.689 & 90.666 & 90.642 & 90.618 & 90.595 & 90.571\end{array}$

$\begin{array}{llllll}90.453 & 90.429 & 90.405 & 90.381 & 90.358 & 90.334\end{array}$

$\begin{array}{llllll}90.216 & 90.192 & 90.168 & 90.145 & 90.121 & 90.097 \\ 89.979 & 89.955 & 89.931 & 89.908 & 89.884 & 89.860\end{array}$

$\begin{array}{llllll}89.742 & 89.718 & 89.694 & 89.671 & 89.647 & 89.623\end{array}$

$\begin{array}{llllll}89.268 & 89.244 & 89.221 & 89.434 & 89.410 & 89.386 \\ & 89.197 & 89.173 & 89.149\end{array}$

$89.031 \quad 89.007 \quad 88.984 \quad 88.960 \quad 88.937 \quad 88.913$

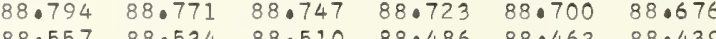

$88.57 \quad 88.534 \quad 88.510-88.486 \quad 88.463-88.439$

$\begin{array}{lll}88.5321 \quad 88.297 \quad 88.273 \quad 88.250 & 88.226 & 88.202\end{array}$

$\begin{array}{llllll}87.847 & 88.060 & 88.036 & 88.013 & 87.989 & 87.965\end{array}$

$\begin{array}{lllll}87.586 & 87.563 & 87.539 & 87.515 & 87.492\end{array}$

$\begin{array}{llllll}87.373 & 87.349 & 87.326 & 87.302 & 87.279 & 87.255\end{array}$

$\begin{array}{llllll}87.136 & 87.113 & 87.089 & 87.065 & 87.042 & 87.018 \\ 86.899 & 86.876 & 86.852 & 86.828 & 86.805 & 86.781\end{array}$

$\begin{array}{llllll}86.899 & 86.876 & 86.852 & 86.828 & 86.805 & 86.781 \\ 86.663 & 86.639 & 86.615 & 86.592 & 86.568 & 86.544\end{array}$

$86.426 \quad 86.402 \quad 86.379 \quad 86.355 \quad 86.331 \quad 86.307$

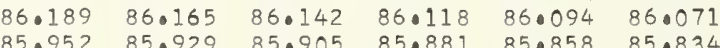

$\begin{array}{llllll}85.952 & 85.929 & 85.905 & 85.881 & 85.858 & 85.834 \\ 85.715 & 85.692 & 85.668 & 85.645 & 85.621 & 85.597\end{array}$

$\begin{array}{llllll}85.479 & 85.455 & 85.431 & 85.408 & 85.384 & 85.260 \\ 85.242 & 85.218 & 85.195 & 85.171 & 85.147 & 85.124\end{array}$

$\begin{array}{llllllllll} & 54.005 & 84.982 & 84.958 & 84.934 & 84.911 & 84.887\end{array}$ $\begin{array}{lllllllllll}84.863 & 84.839 & 84.816 & 84.792 & 84.768 & 84.745 & 84.721 & 84.697 & 84.674 & 84.650\end{array}$ $\begin{array}{llllllllll}84.626 & 84.603 & 84.579 & 84.555 & 84.532 & 84.508 & 84.484 & 84.461 & 84.437 & 84.413 \\ 84.390 & 84.366 & 84.342 & 84.319 & 84.295 & 84.271 & 84.248 & 84.224 & 84.200 & 84.177\end{array}$ $\begin{array}{llllllllll}84.153 & 84.129 & 84.106 & 84.082 & 84.058 & 84.035 & 84.011 & 83.987 & 83.964 & 83.940\end{array}$ $\begin{array}{llllllllll}83.916 & 83.893 & 83.869 & 83.845 & 82.822 & 83.798 & 83.774 & 83.750 & 83.727 & 83.703\end{array}$ $\begin{array}{llllllllll}83.679 & 83.656 & 83.632 & 83.609 & 83.585 & 83.561 & 83.537 & 83.514 & 83.490 & 83.467\end{array}$ $\begin{array}{llllllllll}83.443 & 83.419 & 83.395 & 83.372 & 83.348 & 83.324 & 83.301 & 83.277 & 83.253 & 83.230\end{array}$ $\begin{array}{llllllllll}83.206 & 83.182 & 83.159 & 83.135 & 83.111 & 83.088 & 83.064 & 83.040 & 83.017 & 82.993 \\ 82.969 & 82.946 & 82.922 & 82.898 & 82.875 & 82.851 & 82.827 & 82.804 & 82.780 & 82.756\end{array}$

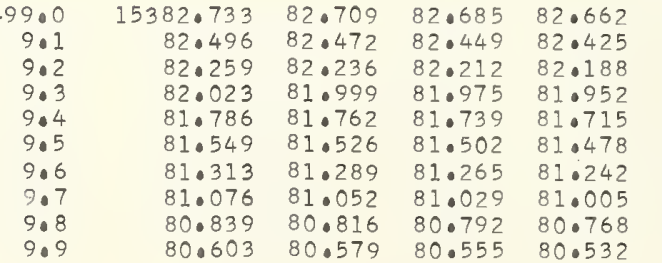

$82.638 \quad 82.614 \quad 82.591 \quad 82.567 \quad 82.543 \quad 82.520$

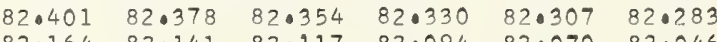

$\begin{array}{lllllll}82.164 & 82.141 & 82.117 & 82.094 & 82.070 & 82.046 \\ 81.928 & 81.904 & 81.881 & 81.857 & 81.833 & 81.810\end{array}$

$\begin{array}{llllll}81.691 & 81.668 & 81.644 & 81.620 & 81.597 & 81.573\end{array}$

$\begin{array}{llllll}81.218 & 81.194 & 81.407 & 81.384 & 81.360 & 81.336 \\ \end{array}$

$\begin{array}{llllll}80.981 & 80.958 & 80.934 & 80.910 & 80.887 & 80.863\end{array}$

$\begin{array}{lll}80.745 & 80.721 & 80.697 \\ 80.508 & 80.484 & 80.461\end{array}$

$80.674 \quad 80.650 \quad 80.626$

$\begin{array}{ll}0.276320 & 1.793314 \\ 0.276320 & 1.793341 \\ 0.276319 & 1.793368 \\ 0.276319 & 1.793395 \\ 0.276319 & 1.793499 \\ 0.276319 & 1.793449 \\ 0.276319 & 1.793476 \\ 0.276319 & 1.793502 \\ 0.276319 & 1.793529 \\ 0.276319 & 1.793556\end{array}$

0.276318

0.276318

0.276318
0.276318

0.276318

0.276318

0.276318

0.276318
0.276317

0.276317

0.276317
0.276317
0.0276317

0.276317

0.276317
0.276317

0.276316

1.793583

1.793610

1.793637

1.793691

1.993744

1.793771

1.793825

1.793852

1.793879

1.793932

1.793959

1.793986

1.794013
1.794040

1.794094

0.276316

0.276316
0.276316

0.276316

0.276316

0.276315

0.276315

0.276315
0.276315

1.794120

1.794174

1.794201

1.794255

1.794282

1.794309

0.276315

0.276315
0.276315

0.276315

0.276314
0.276314

0.276314

0.0276314

1.794362

1.794389

1.794416

1.794470

1.794497

1.794550

1.794579

$1: 794664$

0.276314

0.276314
0.276314
0.276313

0.276313

0.276313

0.27631.

0.276313
0.276313

1.794658

1.794685

1.794739

1.794765

1.704810

0.276313

0.276312
0.276312

0.27631

0.276312

0.276312

0.276312

0.276312
0.276312
0.276312

0.276311

0.276311
0.276311

0.276311

0.276311
0.276311

0.276311

0.276311

0.276310

0.276310

0.276310
0.276310
0.276310

0.276310

0.276310
0.276310

0.276310

0.276309

0.276309

0.276309

0.276309

0.276309

0.276309

0.276309

0.276308

0.276308

0.276308
0.276308

1.794927

1.794954

10794980

1.795034

1.795061

1.795088

1.795115

1.795195

1.795222

1.795249

1.795276

1.795330

1.795383

1.795410
1.795437

1.995464

1.795491

1.795545

1.795572

1.795598

1.795652

1.795679
1.795706

$$
.001 \quad .002
$$

$$
.003
$$

.004

.005

.006

.007

.008

.009 


.04

6500.0

0.0

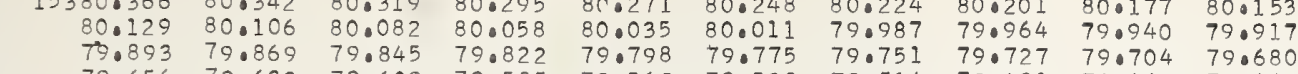

$80.319 \quad 80.29$

80.27

.05

.06

.07

.08

.09

$(n-1) \times 1000$

$\lambda(n-1)$

\begin{tabular}{llllllllll}
79.656 & 79.633 & 79.609 & 79.585 & 79.562 & 79.538 & 79.514 & 79.491 & 79.467 & 790.443 \\
\hline
\end{tabular}

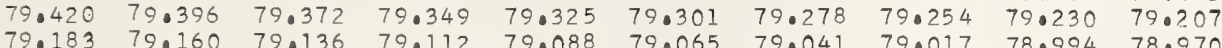

$\begin{array}{llllllllll}79.183 & 79.160 & 79.136 & 79.112 & 79.088 & 79.065 & 79.041 & 79.017 & 78.994 & 78 \cdot 970 \\ 78.946 & 78.923 & 78.899 & 78.875 & 78.852 & 78.828 & 78.805 & 78.781 & 78.757 & 78.734\end{array}$

$\begin{array}{llllllllll}78.710 & 78.686 & 78.663 & 78.639 & 78.615 & 78.592 & 78.568 & 78.544 & 78.521 & 78.497 \\ 78.473 & 78.450 & 78.426 & 78.402 & 78.379 & 78.055 & 78.331 & 78.308 & 78.284 & 78.260\end{array}$

$\begin{array}{llllllllll}78.473 & 78.450 & 78.426 & 78.402 & 78.379 & 78.355 & 78 \cdot 331 & 78.308 & 78 \cdot 284 & 78 \cdot 260 \\ 78.237 & 78.213 & 78.189 & 78.166 & 78.142 & 78.119 & 78.095 & 78.071 & 78.048 & 78.024\end{array}$

6501.0

$1: 0$
$1:$
$1:$
$1:$
$1: 0$
$1:$
$1:$

$15378.000 \quad 77.977$

$\begin{array}{lllllllll}77.953 & 77.929 & 77.906 & 77.882 & 77.858 & 77.835 & 77.811 & 77.787\end{array}$

$\begin{array}{llllllllll}77.764 & 77.740 & 77.716 & 77.693 & 77.669 & 77.646 & 77.622 & 77.598 & 77.575 & 77.551 \\ 77.527 & 77.0503 & 77.480 & 77.456 & 77.432 & 77.409 & 77.385 & 77.362 & 77.338 & 77.314\end{array}$

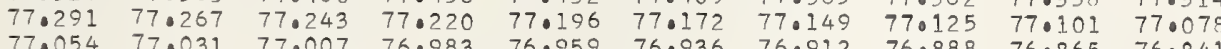

$\begin{array}{llllllllll}776.054 & 77.031 & 77.007 & 76.983 & 76.959 & 76.936 & 76.912 & 76.888 & 76 \cdot 865 & 76.841 \\ 76.818 & 76.794 & 76.770 & 76.747 & 76.723 & 76.699 & 76.676 & 76.652 & 76.628 & 76.605\end{array}$

$\begin{array}{llllllllll}76.581 & 76.557 & 76.534 & 76.510 & 76.487 & 7.6 .463 & 76.439 & 76.415 & 76.392 & 76.368\end{array}$

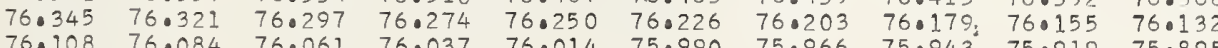

$\begin{array}{llllllllll}76.108 & 76.084 & 76.061 & 76.037 & 76.014 & 75.990 & 75.966 & 75.943 & 75.919 & 75.895 \\ 75.872 & 75.848 & 75.824 & 75.801 & 75.777 & 75.753 & 75.730 & 75.706 & 75.682 & 75.659\end{array}$

6502.0

1.0
2.
2.
2.
2.
2.
2.
2.

$15375.635 \quad 75.612$

$75.399 \quad 75.375$

$\begin{array}{lllllllll}75.588 & 75.564 & 75.541 & 75.517 & 75.493 & 75.470 & 75.446 & 75.422\end{array}$

75.16275 .13

$75.115 \quad 75.091$

74.68974 .666

74.453374 .429

$\begin{array}{ll}73.980 & 73.956 \\ 73.743 & 73.720\end{array}$

74.64274 .618

$\begin{array}{llll}74.406 & 74.382 & 74.595 & 74.57\end{array}$

$\begin{array}{llll}75.020 & 74.997 & 74.973 & 74.949\end{array}$

$\begin{array}{ll}73.743 & 73.720 \\ 73.507 & 73.484\end{array}$

$\begin{array}{llllllll}73.933 & 73.909 & 73.885 & 73.862 & 73.838 & 73.814 & 73.791 & 73.767 \\ 73.696 & 73.673 & 73.649 & 73.625 & 73.602 & 73.578 & 73.554 & 73.531\end{array}$

74.146

74.035874 .334

$74.547 \quad 74.524 \quad 74 \cdot 500 \quad 74 \cdot 476$

$74031174.287 \quad 74 \cdot 264 \quad 740240$

6503.0

$3 \cdot 1$
3.2
3.3
3.4

$15373.271 \quad 73.247$

73.22

73.200

$73.413 \quad 73.389$

$\begin{array}{lllll}73.129 & 73.105 & 73.082 & 73.058\end{array}$

$\begin{array}{llllllllll}73.034 & 73.011 & 72.987 & 72.964 & 72.940 & 72.916 & 72.892 & 72.869 & 72.845 & 72.822 \\ 72.798 & 72.774 & 72.751 & 72.727 & 72.703 & 72.680 & 72.656 & 72.632 & 72.609 & 72.585\end{array}$

$\begin{array}{llllllllll}72.562 & 72.538 & 72.514 & 72.491 & 72.467 & 72.443 & 72.420 & 72.396 & 72.373 & 72.340\end{array}$

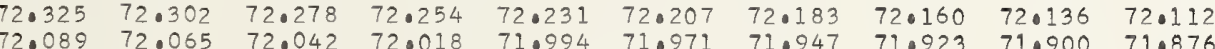

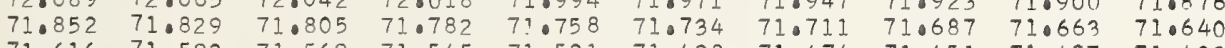

$\begin{array}{llllllllll}71.616 & 71.592 & 71.569 & 71.545 & 71.521 & 71.498 & 71.474 & 71.451 & 71.0427 & 71.403\end{array}$

$\begin{array}{llllllllll}71.380 & 71.356 & 71.333 & 71.309 & 71.285 & 71.262 & 71.238 & 71.214 & 71.191 & 71.167 \\ 71.143 & 71.120 & 71.096 & 71.073 & 71.049 & 71.025 & 71.002 & 70.978 & 70.954 & 70.931\end{array}$

15370.007

70.67170 .804

70.671
70.434
70.198

$70.198 \quad 70.411$

$70.860 \quad 70.836$

$\begin{array}{llllll}70.812 & 70.789 & 70.765 & 70.742 & 70.718 & 70.694 \\ 70.576 & 70.552 & 70.529 & 70.505 & 70.482 & 70.458\end{array}$

$99.962 \quad 69.938$

$69.726 \quad 69.702$

$69.253 \quad 69.229$

$70.387-70.364$

70.5
70.340

$\begin{array}{rl}69.017 & 68.993 \\ 68.780 & 68.757\end{array}$

$69.915-69.891$

$69.442 \quad 69.418$

$70.104 \quad 70.080$

\begin{tabular}{l}
$69.867 \quad 69.844 \quad 69.820 \quad 69.796 \quad 690.773 \quad 69.985$ \\
\hline
\end{tabular}

$\begin{array}{llllll}69.631 & 69.607 & 69.584 & 69.560 & 69.536 & 69.513\end{array}$

$\begin{array}{llllll}69.395 & 69 \cdot 371 & 69 \cdot 347 & 69 \cdot 324 & 69 \cdot 300 & 69.277\end{array}$

6505.0

5.1

$68.308 \quad 68.22$

$68.922 \quad 68.898$ 68.

6

0.276308

1.796002

0.276308

0.276307

0.276307

0.276307

0.276307
0.276307

1.796055

.796082

1.796136

0.276307

.796190

.276307
.276307

.0276306
.0276306

0.276306

0.276306
0.276306

1.796243

0.27630

0.0776305

0.276305

0.276305
0.276305
0.276305

0.276305

0.276305
0.276305

1.796270

1.796324

1.796351
1.096378

1.796405

1.796458

0.276304

0.276304

0.276304
0.276304

0.276304

0.276304

0.276304
0.276303

1.796539

0.276303
0.276303
0.0276303

0.276303

0.276303

0.276303
0.276303

0.276302

0.276302

1.796566

1.796620

1.796673

1.796727
1.796754
1.796781

$\begin{array}{lllllllll}6.284 & 68.261 & 68.237 & 68.213 & 68.190 & 68.166 & 68.142 & 68.119 & 68.095\end{array}$ $\begin{array}{llllllllll}67.835 & 68.048 & 68.024 & 68.001 & 67.977 & 67.953 & 67.930 & 67.906 & 67.883 & 67.859\end{array}$ $\begin{array}{llllllll}67.98 & 67.0765 & 67.0741 & 67.0717 & 67.094 & 67.006 & 67.0846 & 67.623\end{array}$ $\begin{array}{llllllllll}67.363 & 67.339 & 67.316 & 67.292 & 67.268 & 67.245 & 67.221 & 67.198 & 67.174 & 67 \cdot 150\end{array}$ $\begin{array}{llllllllll}67.127 & 67.103 & 67.079 & 67.056 & 67.032 & 67.009 & 66.985 & 66.961 & 66.938 & 66.914\end{array}$

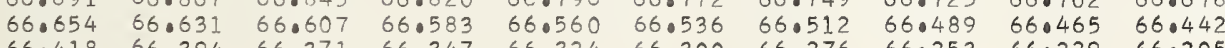

0.276302

0.276302

0.276302

0.276302

0.276301

0.276301

0.276301

6506.0

366.18266 .158

$\begin{array}{llllllll}66.135 & 66.111 & 66.087 & 66.064 & 66.040 & 66.017 & 65.993 & 65.969\end{array}$

$\begin{array}{lllllllllll}6.1 & 65.946 & 65.922 & 65.899 & 65.875 & 65.851 & 65.828 & 65.804 & 65.780 & 65.757 & 65.733 \\ 6.2 & 65.710 & 65.686 & 65.662 & 65.639 & 65.615 & 65.592 & 65.5688 & 65.544 & 65.521 & 65.497\end{array}$

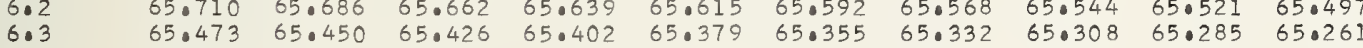

6.4

6.4

6.6

$65.237 \quad 65.214$

65.001 64. 6477

65.42665 .402

$\begin{array}{llllll}65.379 & 65.355 & 65.332 & 65.308 & 65.285 & 65.261 \\ 65.143 & 65.119 & 65.096 & 65.072 & 65.048 & 65.025\end{array}$

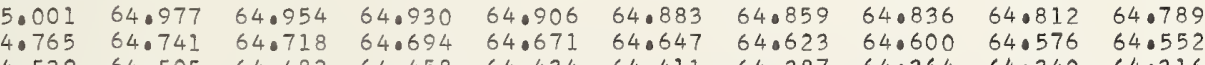

$64.529 \quad 64.505 \quad 64.482 \quad 64.458 \quad 64.434 \quad 640411 \quad 640387 \quad 640364 \quad 640340 \quad 64.316$

$\begin{array}{llllllllll}64.293 & 64.269 & 64.0245 & 64.222 & 64.198 & 64.0175 & 64.151 & 64 \cdot 127 & 64.104 & 64 \cdot 080\end{array}$

0.276301

0.276301

0.276301

0.276300

0.276300

0.276300

0.276300

6.9

$\begin{array}{rrrrrrrrrrr}6507.0 & 15363.820 & 63.797 & 63.773 & 63.750 & 63.726 & 63.702 & 63.679 & 63.655 & 63.632 & 63.608 \\ 7.1 & 63.584 & 63.561 & 63.537 & 63.514 & 62.490 & 63.466 & 63.443 & 63.419 & 63.395 & 63.372\end{array}$

$\begin{array}{rrrrrrrrrrr}6507.0 & 15363.820 & 63.797 & 63.773 & 63.750 & 63.726 & 63.702 & 63.679 & 63.655 & 63.632 & 63.608 \\ 7.1 & 63.584 & 63.561 & 63.537 & 63.514 & 62.490 & 63.466 & 63.443 & 63.419 & 63.395 & 63.372\end{array}$

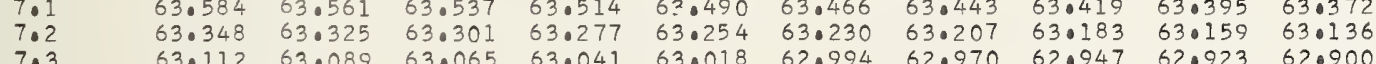

$\begin{array}{lllllllllll}7.3 & 63.112 & 63.089 & 63.065 & 63.041 & 63.018 & 62.994 & 62.970 & 62.947 & 62.923 & 62.900 \\ 7.4 & 62.876 & 62.852 & 62.829 & 62.805 & 62.782 & 62.758 & 62.734 & 62.711 & 62.687 & 62.663\end{array}$

$\begin{array}{lllllllllll}7.5 & 62.640 & 62.616 & 62.593 & 62.569 & 62.546 & 62.522 & 62.498 & 62.475 & 62.451 & 62.427\end{array}$

$\begin{array}{lllllllllll}7.6 & 62.404 & 62.380 & 62.357 & 62.333 & 62.309 & 62.286 & 62.262 & 62.239 & 62.215 & 62.191 \\ 7.7 & 62.168 & 62.144 & 62.121 & 62.097 & 62073 & 62.050 & 62.026 & 62.003 & 61.979 & 61.055\end{array}$

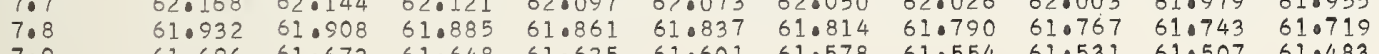

$\begin{array}{llllllllll}61.696 & 61.672 & 61.648 & 61.625 & 61.601 & 61.578 & 61.554 & 61.531 & 61.507 & 61.483\end{array}$

0.276300

0.276300
0.276300

0.276299

0.276299

0.276299

0.276299

0.276299

0.276799

0.276299

0.276298
0.276298

0.276298

0.276298

0.276298

0.276298

1.796808

1.796862

1.796888

1.796942

1.796969

1.796996
1.797023

1.797077

1.797103
1.7997130
1.90759

1.997157

1.797211

1.797265
1.797292

1.797372

1.797426

1.797453
1.997480

1.797507

1.797560

1.797614

1.797641
1.797668

1.797695

1.797722
1.0797748

1.797775

1.797829

1.797883

1.797936

1.797963

1.797990

1.798044

1.798098

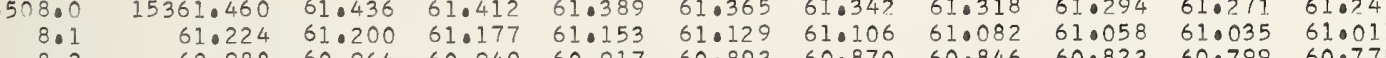
$\begin{array}{llllllllll}60.988 & 60.964 & 60.940 & 60.917 & 60.893 & 60.870 & 60.846 & 60.823 & 60.799 & 60.775 \\ 60.751 & 60.728 & 60.704 & 60.681 & 60.657 & 60.634 & 60.610 & 60.586 & 60.563 & 60.539\end{array}$ $\begin{array}{lllllllllll}60.516 & 60.492 & 60.468 & 60.445 & 60.421 & 60.398 & 60.374 & 60.350 & 60.327 & 60.303\end{array}$ $\begin{array}{llllllllll}60.280 & 60.256 & 60.232 & 60.209 & 60.185 & 60.161 & 60.138 & 60.114 & 60.091 & 60.067\end{array}$ $\begin{array}{llllllllll}60.044 & 60.020 & 59.996 & 59.973 & 59.949 & 59.926 & 59.902 & 59.878 & 59.855 & 59.831 \\ 59.808 & 59.784 & 59.760 & 59.737 & 59.713 & 59.690 & 59.666 & 59.642 & 59.619 & 59.595\end{array}$

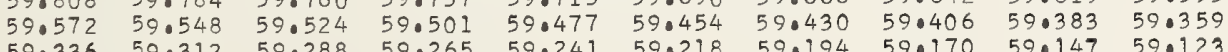
$\begin{array}{llllllllll}59.336 & 59.312 & 59.288 & 59.265 & 59.241 & 59.218 & 59.194 & 59.170 & 59.147 & 59.123\end{array}$

0.276297

0.276297

0.276297

0.276297

0.276297

0.276297

0.276297

1.798151

1.798205

1.798232

1.798286

1.798313

.798367

$\begin{array}{rrrllllllll}6509.0 & 15359.100 & 59.076 & 59.052 & 59.029 & 59.005 & 58.987 & 58.958 & 58.934 & 58.911 & 58.887 \\ 9.1 & 58.864 & 58.840 & 58.817 & 58.793 & 58.770 & 58.746 & 58.722 & 58.699 & 58.675 & 58.652 \\ 9.2 & 58.628 & 58.604 & 58.581 & 58.557 & 58.534 & 58.510 & 58.486 & 58.463 & 58.439 & 58.416 \\ 9.3 & 58.392 & 58.368 & 58.345 & 58.321 & 58.298 & 58.274 & 58.250 & 58.227 & 58.203 & 58.180 \\ 9.4 & 58.156 & 58.132 & 58.109 & 58.085 & 58.062 & 58.038 & 58.015 & 57.991 & 57.967 & 57.944 \\ 9.5 & 57.920 & 57.896 & 57.873 & 57.849 & 57.826 & 57.802 & 57.779 & 57.755 & 57.731 & 57.708 \\ 9.6 & 57.684 & 57.661 & 57.637 & 57.613 & 57.590 & 57.566 & 57.543 & 57.519 & 57.496 & 57.472 \\ 9.7 & 57.448 & 57.425 & 57.401 & 57.377 & 57.354 & 57.330 & 57.307 & 57.283 & 57.260 & 57.236 \\ 9.8 & 57.212 & 57.189 & 57.165 & 57.142 & 57.118 & 57.094 & 57.071 & 57.047 & 57.024 & 57.000 \\ 9.9 & 56.976 & 56.953 & 56.929 & 56.906 & 56.882 & 56.858 & 56.835 & 56.811 & 56.788 & 56.764\end{array}$

1.798420

1.798474

1.798501

1.798555

1.798581

1.798608
1.798635

.010

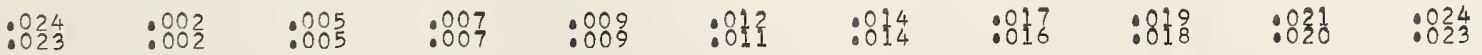


56.670 $\begin{array}{llllll}56.646 & 56.623 & 56.599 & 56.575 & 56.552 & 56.528 \\ 56.410 & 56.387 & 56.363 & 56.339 & 56.316 & 56.292\end{array}$ 0.276296 0.276296 0.276296 $\begin{array}{llllllllll}56.033 & 56.009 & 55.986 & 55.962 & 55.939 & 55.915 & 55.891 & 55.868 & 55.844 & 55.821\end{array}$ $54.382 \quad 54.359$ $53.910 \quad 53.887$ $\begin{array}{llll}5.674 & 53.651 & 53.863 & 53.840\end{array}$ $\begin{array}{llll}53.439 & 53.415 & 53.392 & 53.368\end{array}$ $\begin{array}{llll}53.203 & 53.179 & 53.156 & 53.132\end{array}$ $\begin{array}{llll}52.731 & 52.708 & 52.684 & 52.661\end{array}$ $\begin{array}{llll}52.495 & 52.472 & 52.448 & 52.425 \\ 52.260 & 52.236 & 52.213 & 52.189\end{array}$

$\begin{array}{llllll}5 & 50.207 & 55.184 & 55.160 & 55.137 & 55.113\end{array}$

$$
\begin{array}{rl}
5349.667 & 49 . \\
49.431 & 49 . \\
49.196 & 49 .
\end{array}
$$

42.81

$$
\begin{array}{rr}
5342.600 & 42 \\
42.365 & 42 \\
42.129 & 42 \\
41.894 & 41 \\
41.658 & 41 \\
41.423 & 41 \\
41.187 & 41 \\
40.952 & 40 \\
40.716 & 40 \\
40.481 & 40
\end{array}
$$

0.276295

0.276295

0.276295

0.276295

0.276295

0.276294

0.276294
0.276294
0.276294

0.276294

0.276294

0.276294
0.276294
0.276294

0.276294

0.276293

0.276293

0.276793

0.296293

1.798689
1.798716
1.798743
1.798770
1.798796
1.798823
1.798850
1.798877
1.798904
1.798931

0.276293

0.276293

0.276292

0.276292

0.276292

0.276292

0.276292

0.276292

0.276292

0.0276291

0.276291

0.276291

0.276291
0.276291

0.276291

0.276291

1.798958

1.798985
1.799011

1.799038

1.799065

1.799119

1.799146

0.276291

0.276290

0.276290
0.276290
0.076290

0.2762290

0.276290

0.276290

0.276290

0.276289

0.276289

0.276289
0.276280
0.27628

0.276289
0.276280
0.276289

0.276289

0.276289
0.276289

0.276289
0.276289
0.276288

0.276288

0.276288

0.276988

0.276288
0.276288

0.276288

0.276288
0.276288

0.276288

0.276287
0.276287

0.276287

0.276287

0.276287
0.276287

0.276287

0.276287
0.276286

0.276286

0.276286

0.276286

1.799226

1.799253

1.799307

1.799334
1.79936

1.799388

1.799415
1.799441

1.799468

1.799495

1.799549

1.799603

1.799630

1.799656

1.799710
1.799737

1.7999764 
$\begin{array}{rrrrrrrrrrr}6520.0 & 15333.187 & 33.164 & 33.140 & 33.117 & 33.093 & 33.070 & 33.046 & 33.023 & 32.999 & 32.976 \\ 0.1 & 32.952 & 32.028 & 32.905 & 32.882 & 33.858 & 32.834 & 32.811 & 32.787 & 32.764 & 32.740\end{array}$ $\begin{array}{llllllllll}32.952 & 32.928 & 32.905 & 32.882 & 32.858 & 32.834 & 32.811 & 32.787 & 32.764 & 32.740 \\ 32.717 & 32.693 & 32.670 & 32.646 & 32.623 & 32.599 & 32.576 & 32.552 & 32.529 & 32.505\end{array}$

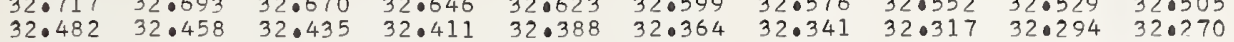

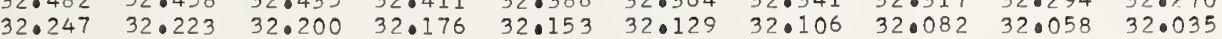
$\begin{array}{llllllllll}32.012 & 31.988 & 31.964 & 31.941 & 31.917 & 31.894 & 31.870 & 31.847 & 31.823 & 31.800\end{array}$

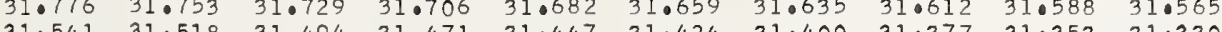

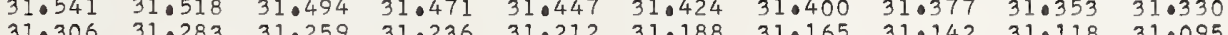

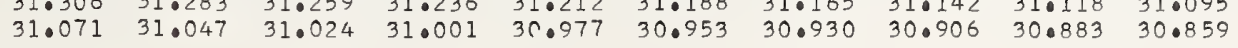
$\begin{array}{rrr}5330.836 & 30.812 \quad 30.7 \\ 30.601 & 30.577 & 30.0\end{array}$ $30.601 \quad 30.577 \quad 30.789 \quad 30.765$ $\begin{array}{llll}30.366 & 30.5772 & 30.554 & 30.530 \\ 30.319 & 30.295\end{array}$ $30.131 \quad 30.107$ $\begin{array}{ll}29.896 \quad 29.872 \\ 29.661 & 29.637\end{array}$ $\begin{array}{ll}29.661 & 29.637 \\ 29.425 & 29.402\end{array}$ $\begin{array}{ll}29.425 & 29.402 \\ 29.190 & 29.167 \\ 28.1955 & 28.932\end{array}$ $\begin{array}{ll}28.955 & 28.932 \\ 28.720 & 28.697\end{array}$

$\begin{array}{lll}30.084 & 30.060 \\ 29.849 & 29.825\end{array}$

$\begin{array}{ll}30.742 & 30.718 \\ 30.507 & 30.483\end{array}$

$\begin{array}{llll}30.695 & 30.671 & 30.648 & 30.624 \\ 30.460 & 30.436 & 30.413 & 30.389\end{array}$

5323.786

4.1
4.2
4.3
4.4
4.5
4.6
4.7
4.8
4.9

0.276284

0.276283

0.27628

0.276283

0.276283

0.276283

0.276282

0.276282

0.276282

0.276282

0.278282

0.276282

0.276281

0.276281

0.276281

0.276281

0.276281

0.276281

0.276280
0.276280

0.276280

0.276280

0.276280

0.276280

0.276279

0.076279

0.276279

0.276279

0.276279

0.276279

0.276278

0.276278

0.276278
0.276778

0.276278

0.276278

0.276277

0.276277

0.276277

0.276277

0.276277

0.276276

0.276276

0.276276

0.276276
0.276276

0.276276

0.276276

0.276275

0.276275
0.276275

0.276275
0.276275
0.276275

0.276275

0.276275

0.276275
0.276274

0.276274

0.276274
0.276274

0.276274

0.276274

0.276274

0.276274

0.276273

1.801377

..801430

1.801484

1.801511

1.801565

1.801618

1.801645

1.801672

1.801726

1.801780

1.801807

1.801833

1.801914

1.801941

1.801995

1.802022

1.802075

1.802102
1.802129

1.802183

1.802210

1.80226

1.802317

1.802344

1.802398
1.802425

1.802452

1.802478

1.802532

1.802559

1.802586

1.802640

1.802693

1.802720

1.802747
1.802774

1.802801

1.802828

1.802882

1. 802908

1.802935
1.802962

1.802989

1.803016

1.803070

1.803097
1.803123

1.803150

1.803177
1.803204

1.803258

1.803312

1.803338
1.803365

1.803365
1.803392

1.803419

1.803473

1.803527

1.803554 


\section{1 \\ 0.5 \\ 0.}

0.3

6531.

1.1
1.2

1. 3

1.5

1.7

1.9

$15307.362 \quad 07.33$ $\begin{array}{ll}07.128 & 07.104 \\ 06.893 & 06.870\end{array}$ $06.659 \quad 06.636$ $06.425 \quad 06.401$ $05.956 \quad 05.93$ $\begin{array}{ll}05.722 & 05.69 \\ 05.487 & 05.46 \\ 05.253 & 05.23\end{array}$

15305.01 05.01904 .995 $\begin{array}{ll}04.784 & 04.76 \\ 04.550 & 04.52\end{array}$ $\begin{array}{ll}04.316 & 04.29 \\ 04.082 & 04.05\end{array}$ $03.847 \quad 03.82$

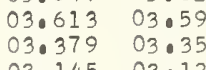

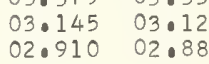

15302.67

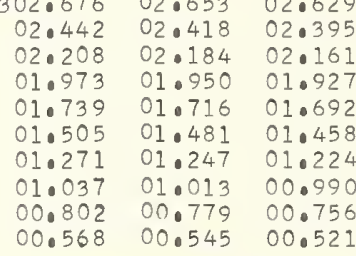

15300.334 00.10
15299.866

00.31$$
\begin{aligned}
& 99.63 \\
& 990397
\end{aligned}
$$

$0.397 \quad 99.609$
90.1734

$99.163 \quad 99.140$
98.929
98.906

98.695
98.461 98.672 98.227

$$
\begin{array}{r}
5297.993 \\
97.75
\end{array}
$$

97.759
97.525
97.291 97.29197 .501 $97.057 \quad 97.033$

96.589
06.354 96.565

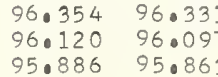

15295.652

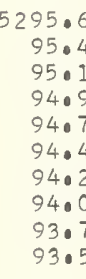

$$
\begin{array}{r}
5293.312 \\
93.079 \\
03.845
\end{array}
$$

$93.079 \quad 93.289$

$92.845 \quad 92.821$

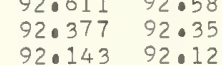

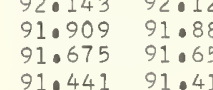

$91.441 \quad 91.041$
$910207 \quad 91.18$

15290.97

90.739
90.506
90.272

$\begin{array}{lll}90.739 & 90.950 & 90.927 \\ 90.506 & 90.716 & 90.093\end{array}$

$90.506 \quad 90.46$
$90.272 \quad 90.22$

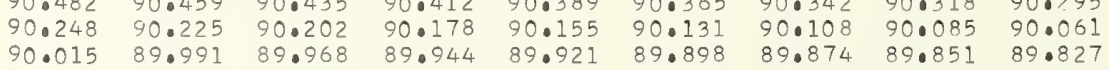
$\begin{array}{llllllllll}89.804 & 89.781 & 89.757 & 89.734 & 89.710 & 89.687 & 89.664 & 89.640 & 89.617 & 89.594\end{array}$

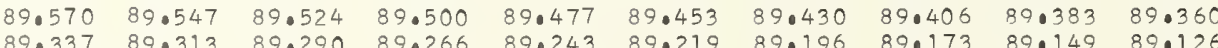
$\begin{array}{llllllllll}89 \cdot 337 & 89 \cdot 313 & 89 \cdot 290 & 89 \cdot 266 & 89 \cdot 243 & 89 \cdot 219 & 89 \cdot 196 & 89 \cdot 173 & 89 \cdot 149 & 89 \cdot 126 \\ 89.103 & 89.079 & 89.056 & 89 \cdot 032 & 89 \cdot 009 & 88.986 & 88.962 & 88.939 & 88.016 & 88.892\end{array}$

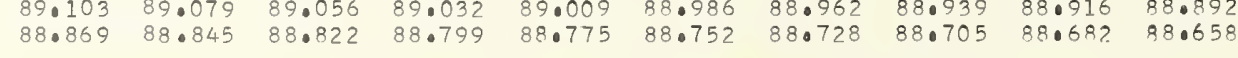

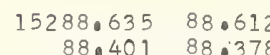

$\begin{array}{lll}88.635 & 88.612 & 88.588 \\ 88.401 & 88.378 & 88.354\end{array}$

$\begin{array}{llll}88.167 & 88.378 & 88.354 & 88.34 \\ 87.144 & 88.121 & 88.097\end{array}$

87.093387 .910

$\begin{array}{lllll}87.000 & 87.676 & 87.653 & 87.0630 \\ 87.066 & 87.443 & 87.010 & 87.306\end{array}$

$\begin{array}{llll}87.232 & 87.209 & 87.47186 & 87.396 \\ 86.162 & 87.162 \\ 86.999 & 8.975 & 86.052 & 86.028\end{array}$

$\begin{array}{llll}86.999 & 86.975 & 86.952 & 86.928 \\ 86.765 & 86.741 & 86.718 & 86.695 \\ 86.531 & 86.508 & 86.484 & 86.461\end{array}$

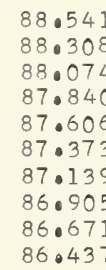

\begin{abstract}
88.518
\end{abstract}
$88.495 \quad 88.471 \quad 88.448 \quad 88.425$

$\begin{array}{lllll}88.284 & 88.261 & 88.237 & 88.214 & 88.191\end{array}$

$\begin{array}{llllll}87.817 & 87.793 & 87.770 & 87.746 & 87.723\end{array}$

$\begin{array}{lllll}87.583 & 87.559 & 87.536 & 87.513 & 87.489 \\ 87.349 & 87.326 & 87.302 & 87.279 & 87.256\end{array}$

$\begin{array}{llllll}87.115 & 87.092 & 87.068 & 87.045 & 87.022\end{array}$

$\begin{array}{lllll}86.882 & 86.858 & 86.835 & 86.812 & 86.788\end{array}$

$\begin{array}{llllll}86.648 & 86.624 & 86.601 & 86.578 & 86.554 \\ 86.414 & 86.391 & 86.367 & 86.344 & 86.321\end{array}$

0.276273

0.276273

0.027627

0.276273

0.276273

0.276272

0.276272

0.276272

0.276272

0.0276772

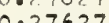

0.27627

0.276271

0.276271

0.276271

0.276271

0.276271

0.276270

0.276270

0.276270

0.276270

0.276270

0.276269

0.276769

0.776269
0.276269

0.276269

0.276269
0.276268

0.276268

0.276268

0.276268
0.276268

0.276268

0.0276268

0.276267

0.276267

0.276267

0.276267

0.276267

0.276267

0.276267

0.276266

0.276266
0.276266

0.276266

0.276266

0.2762 .66
0.276266

0.276266

0.276265
0.276265

$0.276 ? 65$

0.276265
0.276265

0.276265

0.276265
0.276265

0.276265

0.276264

0.276264
0.776264

0.276764

0.276264

0.276264
0.276264

0.276264

0.276263

0.276263

0.276263

0.276263
0.276263

1.804064

1.804118

1.804145

1.804172
1.804199

1.804225

1.804279

1.804306

1.804333

1.804360

1.804387

1.804414

1.804469

1. 804494

1.804521

1.804575

1.804602

1.804629

1.804655

1.804682
1.804709

1.804736

1.804763

1.804790

1.804844

1. 804870

1.804897

1.804924

1.804951
1.804978

1.805005

1.805032

ใ. 205059

$\frac{1}{10}: 80505112$

1.805139

1. 18051606

1.805220

1.805247

1.005301

1.80532

1.805381

1.805408

10805435

1.805462
1.805489

1.805516

1.805542

1.005569

1.805623

1.805677

1.805704
1.805731

1.805757

1.005784

1.805838

1.805865

1. 10.905892

1.0905946

10805972

1.806026

1.806053
1.806080
1.80610

1.806107

10.806134

1.006187

0.07762 .63

0.276263

0.276263
0.276263
0.276256

0.276262
0.276262
0.27622

0.276262

0.276262

0.276262
0.276262

1.806214

1.0906241
1.006268

1.806295

1.806322

1.806349

1.806376

1.0906429

1.906483

1.0806510
10806537

1.906564

10.806591

1.006644

10906671

1.806725

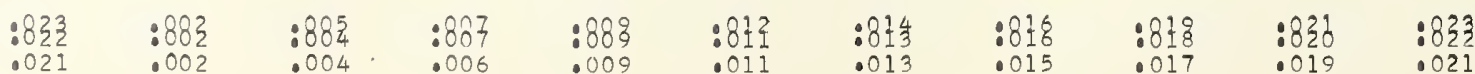


$\begin{array}{rrrrrrrrrrr}0.0 & 15286.297 & 86.274 & 86.251 & 86.227 & 86.204 & 86 \cdot 180 & 86.157 & 86.134 & 86 \cdot 110 & 86.087 \\ 1 & 86.063 & 86.040 & 86.017 & 85.993 & 85.970 & 85.947 & 85.923 & 85.900 & 85.877 & 85.853\end{array}$

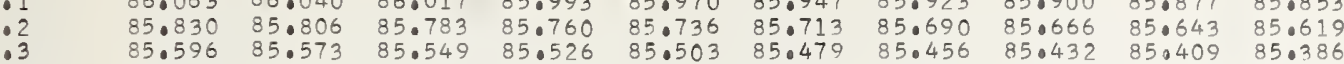
$\begin{array}{lllllllllll} & 85.362 & 85.339 & 85.316 & 85.292 & 85.269 & 85.246 & 85.222 & 85.199 & 85.175 & 85.386\end{array}$ $\begin{array}{llllllllllll}0.5 & 85.129 & 85.105 & 85.082 & 85.058 & 85.035 & 85.012 & 84.989 & 84.965 & 84.942 & 84.918\end{array}$ $\begin{array}{llllllllll}84.661 & 84.638 & 84.615 & 84.591 & 84.568 & 84.544 & 84.521 & 84.498 & 84.474 & 84.0651\end{array}$

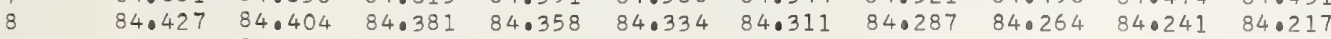
$\begin{array}{llllllllll}84.427 & 84.404 & 84.381 & 84.358 & 84.334 & 84.311 & 84.287 & 84.264 & 84.241 & 84.217 \\ 84.194 & 84.171 & 84.147 & 84.124 & 84.100 & 84.077 & 84.054 & 84.030 & 84.007 & 83.984\end{array}$

6543. 3.0
30
30
30
30
30
30
30
30
3

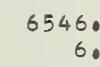$$
\begin{array}{r}
546.0 \\
6.1 \\
6.2 \\
6.3 \\
6.4 \\
6.5 \\
6.6 \\
6.7 \\
6.8 \\
6.9
\end{array}
$$$$
\begin{array}{r}
6547.0 \\
7 \\
7.2
\end{array}
$$$$
7:
$$$$
\begin{aligned}
& 7.3 \\
& 7.4 \\
& 7.5
\end{aligned}
$$$$
\begin{aligned}
& 7.5 \\
& 7.6 \\
& 7.7 \\
& 7.8
\end{aligned}
$$$$
\begin{aligned}
& 7.8 \\
& 7.9
\end{aligned}
$$$$
6548
$$$$
8 .
$$$$
\begin{aligned}
& 8.3 \\
& 8.4
\end{aligned}
$$$$
\begin{aligned}
& 8.4 \\
& 8.5
\end{aligned}
$$$$
\begin{array}{r}
8.5 \\
8.6
\end{array}
$$$$
\begin{aligned}
& 8.6 \\
& 8.7 \\
& 8.8
\end{aligned}
$$$$
\begin{aligned}
& 8.8 \\
& 8.9
\end{aligned}
$$$$
6549
$$$$
\begin{array}{r}
6549.0 \\
9.1 \\
9.2 \\
9.3 \\
9.4
\end{array}
$$$$
9.4
$$$$
\begin{aligned}
& 9.5 \\
& 9.6
\end{aligned}
$$$$
\begin{aligned}
& 9.7 \\
& 9.8 \\
& 9.9
\end{aligned}
$$

$\begin{array}{llllllllllll}41.0 & 15283.960 & 83.937 & 83.913 & 83.890 & 83.867 & 83.843 & 83.820 & 83.797 & 83.773 & 83.750\end{array}$ $\begin{array}{llllllllllll}1.1 & 83.727 & 83.703 & 83.680 & 83.657 & 83.633 & 83.610 & 83.586 & 83.563 & 83.540 & 83.516 \\ 1.2 & 83.493 & 83.469 & 83.446 & 83.423 & 83.399 & 83.376 & 83.353 & 83.329 & 83.006 & 83.283\end{array}$ $\begin{array}{lllllllllll}1.3 & 83.495 & 83.469 & 83.446 & 83.423 & 83.399 & 83.376 & 83.353 & 83.329 & 83.306 & 83.283 \\ 1.3 & 83.259 & 83.236 & 83.213 & 83.189 & 83.166 & 83.142 & 83.119 & 83.096 & 83.072 & 83.049\end{array}$ $\begin{array}{llllllllllll}1.4 & 83.026 & 83.002 & 82.979 & 82.956 & 82.932 & 82.909 & 82.885 & 82.862 & 82.839 & 82.815\end{array}$ $\begin{array}{lllllllllll}1.6 & 82.792 & 82.769 & 82.745 & 82.722 & 82.699 & 82.675 & 82.652 & 82.629 & 82.605 & 82.582 \\ 1.6 & 82.558 & 82.535 & 82.512 & 82.488 & 82.465 & 82.442 & 82.418 & 82.395 & 82.372 & 82.348\end{array}$ $\begin{array}{lllllllllll}1.7 & 82.325 & 82.301 & 82.278 & 82.255 & 82.231 & 82.208 & 82.185 & 82.161 & 82.138 & 82.115 \\ 1.8 & 82.091 & 82.068 & 82.044 & 82.021 & 81.998 & 81.974 & 81.951 & 81.928 & 81.904 & 81.881\end{array}$

$\begin{array}{lllllllllll}42.0 & 15281.624 & 81.601 & 81.577 & 81.554 & 81.530 & 81.507 & 81.484 & 81.460 & 81.437 & 81.414\end{array}$ $\begin{array}{lllllllllll}2.1 & 81.390 & 81.367 & 81.344 & 81.320 & 81.297 & 81.274 & 81.250 & 81.227 & 81.204 & 81.180\end{array}$ $\begin{array}{llllllllllll}2.2 & 81.157 & 81.133 & 81.110 & 81.087 & 81.063 & 81.040 & 81.017 & 80.993 & 80.970 & 80.947\end{array}$ $\begin{array}{lllll}2.3 & 80.923 & 80.900 & 80.876 & 80.853\end{array}$ $\begin{array}{lllll}.05 & 80.690 & 80.666 & 80.643 & 80.620 \\ 20.456 & 80.433 & 80.409 & 80.386\end{array}$ $\begin{array}{lllll}80.6 & 80.223 & 80.199 & 80.176 & 80.153\end{array}$

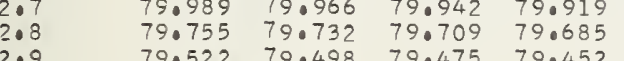
$80.596 \quad 80.573 \quad 80.550 \quad 80.526 \quad 80.503 \quad 80.0479$ $\begin{array}{llllll}80.363 & 80.339 & 80.316 & 80.293 & 80.269 & 80.246 \\ 80.129 & 80.106 & 80.082 & 80.059 & 80.036 & 80.012\end{array}$ $\begin{array}{llllll}80.129 & 80.106 & 80.082 & 80.059 & 80.036 & 80.012 \\ 79.896 & 79.872 & 79.849 & 79.826 & 79.802 & 79.779\end{array}$ $\begin{array}{llllllllll}79.755 & 79.732 & 79.709 & 79.685 & 79.662 & 79.639 & 790.615 & 79.592 & 79.569 & 79.545 \\ 79.522 & 79.498 & 79.475 & 79.452 & 70.428 & 79.405 & 79.382 & 79.358 & 79.335 & 79.312\end{array}$

$$
15279.288 \quad 79.265
$$

0.276261

0.276260

0.276760

0.276260
0.276260
0.276260

0.276260
0.276260

0.276260

0.27625
0.27625

0.276259

0.276259

0.276259

0.276259
0.276259

0.276258

0.276258
0.276258
0.076258

0.276258

0.276258

0.276258

0.276257

0.276257

0.276257

0.276257

0.276257

0.276256
0.276256

0.276256

0.276256

0.27625

0.276255

0.276255

0.276255
0.276255
0.276255

0.27625

0.276254

0.276254
0.276254

0.276254

0.276254

0.276254

0.276253

0.276253

0.276253

0.276253

0.276253

0.0276253
0.0276252

0.276252

0.276252

0.276252

0.276252

0.276252

0.276251
0.276251

0.276251
0.276251

0.276251

0.276251
0.276251

0.276251

0.276250

1.806752

1.806806

1.806833

1.8068913

1.806967

1.807021

1.807048

1.807101
1.807128

1.807182
1.807200

1.807236
1.807263

1.807289

1.807316

1.807370

.807424

.807478
.807505

1.807531

1.807558

1.807612

1.807639

1.807603

1.807746

1.807800

1.807827

1.807854
1.807881

1.807908

1.807961

1.808015

1.808069

808096

1.808150

1.808203

1.808230 
$(n-1) \times 1000$

$\begin{array}{rrrrrrrrrrr}6550.0 & 15262.960 & 62.936 & 62.913 & 62.890 & 62.866 & 62.843 & 62.820 & 62.797 & 62.773 & 62.750\end{array}$

$\begin{array}{lllllllllll}0.1 & 62.727 & 62.703 & 62.680 & 62.657 & 62.633 & 62.610 & 62.587 & 62.563 & 62.540 & 62.517 \\ 0.2 & 62.494 & 62.470 & 62.447 & 62.424 & 62.400 & 62.377 & 62.354 & 62.331 & 62.307 & 62.784\end{array}$

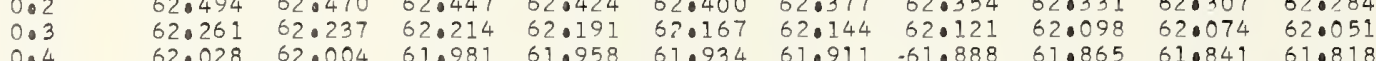

$\begin{array}{llllllllllll}0.4 & 62.028 & 62.004 & 61.981 & 61.958 & 61.934 & 61.911 & -61.888 & 61.865 & 61.841 & 61.818 \\ 0.5 & 61.795 & 61.771 & 61.748 & 61.725 & 61.701 & 61.678 & 61.655 & 61.631 & 61.608 & 61.0585\end{array}$

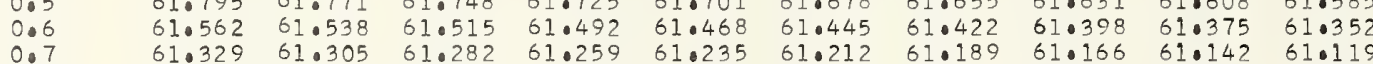

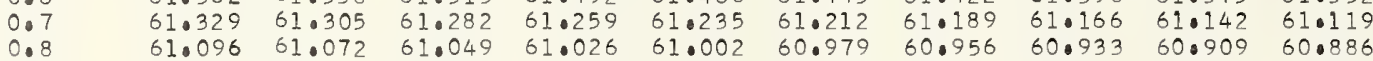

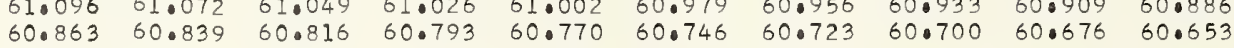

$\begin{array}{lllllllllll}6551.0 & 15260.630 & 60.606 & 60.583 & 60.560 & 60.536 & 60.513 & 60.490 & 60.467 & 60.443 & 60.420\end{array}$

$\begin{array}{lllllllllll}1.1 & 60.397 & 60.373 & 60.350 & 60.327 & 60.304 & 60.280 & 60.257 & 60.234 & 60.211 & 60.187\end{array}$

$\begin{array}{lllllllllll}1.2 & 60.164 & 60.141 & 60.117 & 60.094 & 60.071 & 60.047 & 60.024 & 60.001 & 59.977 & 59.954 \\ 1.3 & 59.931 & 59.908 & 59.884 & 59.861 & 59.838 & 59.814 & 59.791 & 59.768 & 59.745 & 59.721\end{array}$

$\begin{array}{llllllllllll}1.4 & 59.698 & 59.675 & 59.651 & 59.628 & 59.605 & 59.582 & 59.558 & 59.535 & 59.512 & 590488\end{array}$

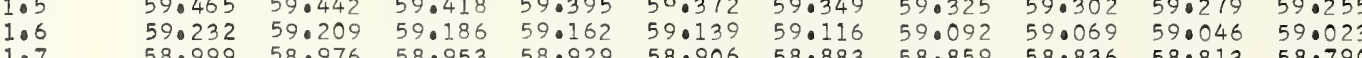

1.9

$\begin{array}{ll}58.766 & 58.743 \\ 58.533 & 5.8 .510\end{array}$

6552.0

2.1
2.2
2.3

$\begin{array}{llllllllll}15258.301 & 58.277 & 58.254 & 58.231 & 58.207 & 58.184 & 58.161 & 58.138 & 58.114 & 58.091\end{array}$

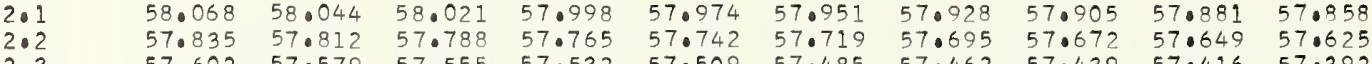

$\begin{array}{lllllllllll}2.3 & 57.602 & 57.579 & 57.555 & 57.532 & 57.509 & 57.485 & 57.462 & 57.439 & 57.416 & 57.392\end{array}$

2.5

2.6

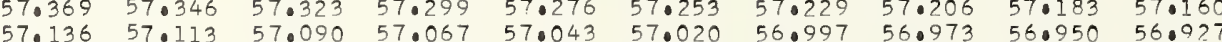
$\begin{array}{llllllllll}56.903 & 56.880 & 56.857 & 56.834 & 56.810 & 56.787 & 56.764 & 56.740 & 56.717 & 56.0694\end{array}$

$\begin{array}{lll}56.671 & 56.647 & 560 \\ 56.438 & 56.415 & 560\end{array}$

6553.0

$\begin{array}{llllll}56.810 & 56.787 & 56.764 & 56.740 & 56.717 & 56.694\end{array}$

$\begin{array}{llll}55.949 & 55.926 \quad 55.902\end{array}$

$56 \cdot 345$

56.32

$\begin{array}{llll}56.531 & 56.508 & 56.484 & 56.461 \\ 56.298 & 56.275 & 56.252 & 56.228\end{array}$

$\begin{array}{lllll}55.739 & 55.716 & 55.693 & 55.902 \\ 55.507 & 55.483 & 55.6070 & 55.437\end{array}$

55

$\begin{array}{lllll}55.274 & 55.250 & 55.227 & 55.20 \\ 55.047 & 55.018 & 54.294 & 54.071\end{array}$

3.5
3.6

3.8

$54.808-54.785$

$54.575 \quad 54.785 \quad 54.762$

54.971
54073

$\begin{array}{lllllll} & 5.856 & 55.833 & 55.809 & 55.786 & 55.763\end{array}$

$\begin{array}{lllllll}55.413 & 55.390 & 55.367 & 55.344 & 550370 & 55.297\end{array}$ $\begin{array}{llllllll} & 54.625 & 54.661 & 54.645 & 54.622 & 54.599\end{array}$

$54.110 \quad 54.087$

6554.0

4.1
4.2
4.3

53.854

$\begin{array}{ll}54.063 & 54.27 \\ 53.031 & 53.0407\end{array}$

54.250

54.45

54.436

54.412

$54.389 \quad 54.366$

4.4
4.5

4.06

4.6
4.8

$53.179 \quad 53.156$

5
5.156 $53.132 \quad 53.100$

$\begin{array}{ll}52.714 & 52.6 \\ 52.481 & 52.458\end{array}$

$52.248 \quad 52.225$

555.0

5.1
5.2
5.3

5.4

5.5

5.7

$\begin{array}{ll}52.016 & 51.992 \\ 51.783 & 51.760\end{array}$

52.667
52.6064

$\begin{array}{ll}52.434 & 52.41 \\ 52.202 & 52.178\end{array}$

54.017
52.78

53.994
53.761

53.970
53.738

53.947

$4.156 \quad 54.133$

51.550

5.9

6556.0

6.1
6.2
6.3
6.4
6.5
6.6
6.7
6.8
6.9

6557.0

7.2
7.3

7.04

$7: 6$

$7: 8$

\begin{abstract}
51.31751 .294
\end{abstract}
$\begin{array}{ll}51.085 & 51.061 \\ 50.852 & 50.8\end{array}$

$\begin{array}{llll}50.619 & 50.529 & 50.805\end{array}$

$\begin{array}{lll}50.387 & 50.364 & 50.573 \\ 50.340\end{array}$

$\begin{array}{lllll}50.154 & 50.131 & 50.3408 & 50.31\end{array}$

$49.922 \quad 49.898 \quad 49.875 \quad 49.852$

$\begin{array}{ll}49.689 & 49.666 \\ 49.456 & 49.433\end{array}$

$\begin{array}{ll}49.456 & 49.433 \\ 49.224 & 49.200\end{array}$

$\begin{array}{ll}49.642 & 49.61 \\ 49.410 & 49.387\end{array}$

$\begin{array}{lllllll}53.551 & 53.528 & 53.505 & 53.482 & 53.458 & 53.435 \\ 53.319 & 53.295 & 53.272 & 53.249 & 53.226 & 53.202\end{array}$

15248.991 $48.758 \quad 48.735$ $\begin{array}{llll}48.526 & 48.735 & 48.712 & 48.6 \\ 48.293 & 48.270 & 48.47 & 48\end{array}$

$48.061 \quad 48.037$

$47.828 \quad 47.805$

$\begin{array}{rl}47.596 & 47.572 \\ 47.363 & 47.340\end{array}$

48.24

48.456
48.224

53.08
52.85

52.85
52.620

53.063

53.27
53.03

53.24

$\begin{array}{ll}47.130 & 47.107 \\ 46.898 & 46.875\end{array}$

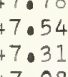

47.991
47.758

(5.

5246.666

46.433
46.200

46.200

46.642

$47.084 \quad 47.06$

51.92

$52.597 \quad 52.57$

$\begin{array}{lll}53.0163 & 52.093 & 52.969 \\ 52.783 & 52.760 & 52.737\end{array}$

$\begin{array}{llll}45.968 & 45.945 & 46.154 & 46.131 \\ 45.22 & 45.898\end{array}$

$\begin{array}{llll}45.735 & 45.712 & 45.689 & 45.666\end{array}$

$45.27 \% 45.480$

$45.038 \quad 45.015$

$45.456 \quad 45.433$

$45.224 \quad 45.201$

44.805
44.573

6558.0

8.1

$44 \cdot 341 \quad 44 \cdot 317$

$43.876 \quad 43.852$

$43.411 \quad 43.388$

$43.178 \quad 43.155$

$\begin{array}{ll}42.946 & 42.923 \\ 42.714 & 42.690\end{array}$

$\begin{array}{ll}44.759 & 44.736 \\ 44.526 & 44.503\end{array}$

$5 ! \cdot 224$

52.132

$52 \cdot 341$
52.109

52.55

52.760
52.527
52.504

$\begin{array}{llll}.341 & 52.318 & 52.295 & 52.271 \\ .109 & 52.085 & 52.062 & 52.039 \\ .876 & 51.853 & 51.829 & 51.006\end{array}$

0.276250
0.276250
0.276250
0.276250
0.276250
0.276250
0.276250
0.276250
0.276249
0.276249

1.809440

1.809467

1.809494

1.809547

1.809574

1.809628

1.809655
1.809682

0.276249

0.276249

0.276249
0.276249
0.276749

0.276249

(1)

0.276249

0.276248

1.809709

1.809736

.809789

1.809816

.809843

1.809897

.809924
+.809951

0.276248

0.27624

1.809977

0.276248

0.276248

0.276248
0.776248

0.276247

0.276247

0.276247

1.810004

1.810031

1.810085

1.810139

1.810166

1.810192

0.276247

0.276247

0.276247

0.276246

0.276246

0.276246

0.276246
0.276246

1.810246

1.810273

1.810327

1.810354
1.810381

1.810408

1.810434

0.276246

0.276246

0.276246
0.276245
0.276245

0.276245

0.276245

0.276745

0.276245

1.810488

0.276245

0.276245

0.276244

0.276244
0.276244

0.276244

0.276244

0.276244

0.276244
0.276244

1.810515

1.810542

1.810569
1.810596

1.810623

1.810676

1.810703

1.810730
1.810757

0.276244

0.276243

0.276243

0.276243

0.276243

0.276243

0.276243

1.810784

1.810811

1.810838

1. 810891

1.810918

1.810945

1.810972

1.810999
1.811026

8.6

$42.481 \quad 42.458$

$\begin{array}{ll}44.294 & 44.271 \\ 44.062 & 44.038 \\ 43.829 & 43.806 \\ 43.597 & 43.573\end{array}$

$\begin{array}{ll}43.597 & 43.573 \\ 43.364 & 43.341\end{array}$

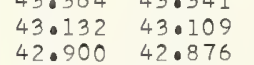

$\begin{array}{llllll}48.433 & 48.410 & 48.386 & 48.363 & 48.340 & 48.317\end{array}$

$\begin{array}{llllll}47.968 & 47.944 & 47.921 & 47.898 & 47.875 & 47.851\end{array}$

8.8
8.9

$42.249 \quad 42.226$

$\begin{array}{ll}42.667 & 42.644 \\ 42.435 & 42.411\end{array}$

0.276243

1.811053

1.811080

1.811133

1.811160

1.811214

1.811241

0.276242

0.276242

0.276242

0.276242

0.276242

0.276242

0.2776242

0.276242

1.811295

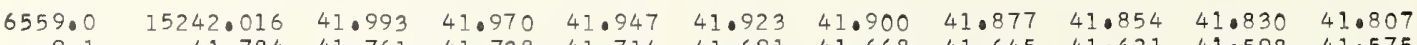

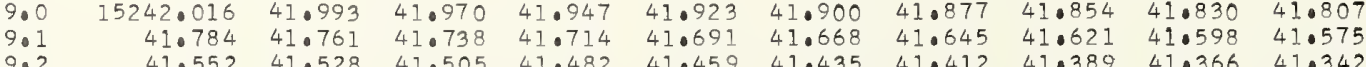

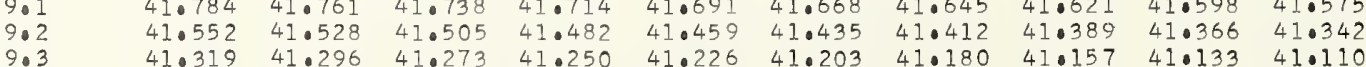

$\begin{array}{llllllll} & \end{array}$

$\begin{array}{llllllllll}40.855 & 40.831 & 40.808 & 40.785 & 40.762 & 40.738 & 40.715 & 40.692 & 40.669 & 40.878\end{array}$

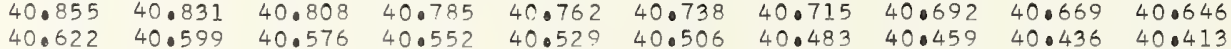

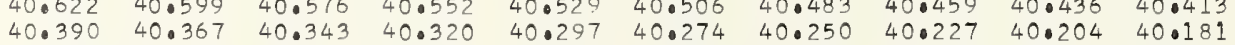

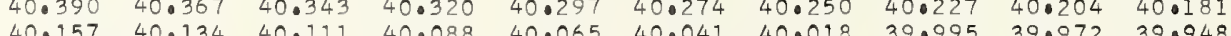

9.8

$\begin{array}{ll}40.157 & 40.134 \\ 39.925 & 39.902\end{array}$

40.111
39.870

40.088
39.856

40.065
39.832

$\begin{array}{ll}40.041 & 40.018 \\ 39.809 & 39.786\end{array}$

0.276241 


$.02 \quad .03$

.04

.05
$\begin{array}{rllllllllll}237.370 & 37.347 & 37.324 & 37.300 & 37.277 & 37.254 & 37.231 & 37.208 & 37.184 & 37.161 \\ 37.138 & 37.115 & 37.092 & 37.068 & 37.045 & 37.022 & 36.999 & 36.975 & 36.952 & 36.929\end{array}$

$\begin{array}{lllll}39.577 & 39.553 & 39.530 & 39.507 & 39.484 \\ 39.344 & 39.321 & 39.298 & 39.275 & 39.252\end{array}$ $\begin{array}{lllll}39.112 & 39.089 & 39.066 & 39.042 & 39.019 \\ 38.880 & 38.857 & 38.833 & 38.810 & 38.787\end{array}$ $\begin{array}{lllll}38.848 & 38.857 & 38.833 & 38.810 & 38.787 \\ 38.642 & 38.601 & 38.578 & 38.555\end{array}$ $\begin{array}{lllll}38.415 & 38.392 & 38.369 & 38.346 & 38.322\end{array}$ $\begin{array}{lllll}38.183 & 38.160 & 38.137 & 38.113 & 38.090\end{array}$ $\begin{array}{lllll}37.9719 & 37.927 & 37.904 & 37.881 & 37.858 \\ 37.695 & 37.672 & 37.649 & 37.626\end{array}$ $\begin{array}{lllllllllll}36.906 & 36.883 & 36.859 & 36.836 & 36.813 & 36.790 & 36.767 & 36.743 & 36.720 & 36.697\end{array}$ $\begin{array}{llllllllll}36.441 & 36.418 & 36.627 & 36.604 & 36.581 & 36.557 & 36.534 & 36.511 & 36.488 & 36.465 \\ & 36.372 & 36.349 & 36.325 & 36.302 & 36.279 & 36.256 & 36.232\end{array}$ $\begin{array}{llllllllll}36.209 & 36.186 & 36.163 & 36.140 & 36.116 & 36.093 & 36.070 & 36.047 & 36.023 & 36.000\end{array}$ $\begin{array}{lllllllllll}35.977 & 35.954 & 35.931 & 35.907 & 35.884 & 35.861 & 35.838 & 35.814 & 35.791 & 35.768\end{array}$ $\begin{array}{llllllllll}35.745 & 35.722 & 35.698 & 35.675 & 35.652 & 35.629 & 35.605 & 35.582 & 35.559 & 35.536\end{array}$ $\begin{array}{llllllllll}35.513 & 35.490 & 35.466 & 35.443 & 35.420 & 35.396 & 35.373 & 35.350 & 35.327 & 35.304 \\ 35.281 & 35.257 & 35.234 & 35.211 & 35.188 & 35.164 & 35.141 & 35.118 & 35.095 & 35.071\end{array}$

$0.276239 \quad 1.812128$

0.276239
0.276239 $\quad 9.812155$

0.276239

0.276238

0.276238

0.276238

0.276238

0.276238

0.276238

0.276238

0.276237
0.276237
0.276237

0.276237

0.276237
0.276237

0.276237

0.276237

0.276236

0.276236

0.276236

0.276236

0.276236
0.276235
0.027625

0.276235

0.27623

0.027623

0.0276235

0.276235

1.812209

1.812262

1.812289

1.812343

1.812397

1.812424

$\frac{1}{1.812477}$

1.812531

1. 812585

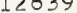

0.276234

0.276234

0.276234

0.276234
0.276234

0.276234

0.276234
0.276233

0.276233

0.276233

0.276233

0.276233

0.276232

0.276232

0.276232

0.276232

0.276232

0.276232

0.276231

0.276231

0.27623

0.27623

0.276231

0.276231

0.276231
0.276230

0.276230
0.276230

0.276230
0.276230

0.276230

0.276230

0.276230
0.276229

0.276229

0.276229

0.276229

1.812665
1.812692

1.812719

1.812773

1.812827

1. 812881

1.812934

1.812961

1.813015
1.813042

1.813069

1. 813122

1.813149
1.813176

0.276229

0.276229
0.276229

0.276228

0.276 .228

0.276228

0.276228
0.276228

0.276228

.813203

.813230

1.813284

1.813311

1.813364
1.813391

1.813418
1.813445

1.813472

1.813499

1.813553

1.813579
1.813606

1.813606

1.813660

.813768

1.813794
1.813821

1.813848

1.813902

1.813956

1. 814010

1.814036 
$\begin{array}{lllllllllll}6570.0 & 15216.497 & 16.474 & 16.451 & 16.428 & 16.405 & 16.381 & 16.358 & 16.335 & 16.31 ? & 16.789\end{array}$ $\begin{array}{llllllllllll}0.2 & 16.266 & 16.242 & 16.219 & 16.196 & 16.173 & 16.150 & 16.127 & 16.103 & 16.080 & 16.057 \\ 0.26 & 16.034 & 16.011 & 15.988 & 15.964 & 15.941 & 15.918 & 15.895 & 15.872 & 15.849 & 15.826\end{array}$ $\begin{array}{lllllllllll}0.3 & 15.802 & 15.779 & 15.756 & 15.733 & 15.710 & 15.687 & 15.663 & 15.640 & 15.617 & 15.594\end{array}$ $\begin{array}{lllllllllll}0.4 & 15.571 & 15.548 & 15.525 & 15.501 & 15.478 & 15.455 & 15.432 & 15.409 & 15.386 & 15.362 \\ 0.5 & 15.339 & 15.316 & 15.293 & 15.270 & 15.247 & 15.224 & 15.200 & 95.177 & 15.154 & 15.131 \\ 0.6 & 15.108 & 15.084 & 15.061 & 15.038 & 15.015 & 14.992 & 14.969 & 14.946 & 14.923 & 14.999\end{array}$

0.8

6571.0

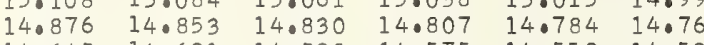
$14.413 \quad 14.390$

$$
\begin{aligned}
& 1.1 \\
& 1: 2 \\
& 1.3 \\
& 1.4 \\
& 1.5 \\
& 1.6 \\
& 1.7 \\
& 1.8 \\
& 1.9
\end{aligned}
$$

$\begin{array}{rl}15214.182 & 14.158 \\ 13.950 & 13.927 \\ 13.719 & 13.695 \\ 13.487 & 13.464 \\ 13.255 & 13.232 \\ 13.024 & 13.001 \\ 12.792 & 12.769 \\ 12.561 & 12.538 \\ 12.329 & 12.306 \\ 12.098 & 12.075\end{array}$

$15211.867 \quad 11.843$ 11.635
11.404 $11.172 \quad 11.149$ $\begin{array}{ll}10.941 & 10.918 \\ 10.709 & 10.686\end{array}$ $10.478 \quad 10.45$ $\begin{array}{ll}10.246 & 10.223 \\ 10.015 & 09.992 \\ 09.784 & 09.750\end{array}$ $\begin{array}{ll}14.598 & 14.575 \\ 14.367 & 14.344\end{array}$

$\begin{array}{llll}14.135 & 14.112 & 14.089 & 14.066 \\ 13.904 & 13.881 & 12.857 & 13.834\end{array}$

$\begin{array}{llll}13.904 & 13.881 & 13.857 & 13.834 \\ 13.672 & 13.649 & 13.626 & 13.603 \\ 13.441 & 13.417 & 13.394 & 13.371\end{array}$

$\begin{array}{llll}13.441 & 13.417 & 13.394 & 13.371 \\ 13.209 & 13.186 & 13.163 & 13.140 \\ 12.078 & 12.054 & 12.031 & 12.908\end{array}$

$\begin{array}{llll}12.978 & 12.954 & 12.931 & 12.908 \\ 12.746 & 12.723 & 12.700 & 12.677\end{array}$

$\begin{array}{llll}12.746 & 12.723 & 12.700 & 12.677 \\ 12.515 & 12.491 & 19.468 & 12.445 \\ 12.283 & 12.260 & 12.237 & 12.214\end{array}$ $\begin{array}{llll}12.283 & 12.260 & 12.237 & 12.214 \\ 12.052 & 12.029 & 12.005 & 11.982\end{array}$

$15209.552 \quad 09.529$

09.3

09.090
08.858

$08.627-08.60$

$08.395 \quad 08.37$

$07.933 \quad 07.910$

07.701

15207.23

07.007

$06.545 \quad 06.52$

$06.082 \quad 06.059$

$05.851 \quad 05.82$

$05.388 \quad 05.365$

$11.820 \quad 11.797$

$11.774 \quad 11.751$

$\begin{array}{llll}11.357 & 11.334 & 11.311 & 11.288 \\ 11.126 & 11.103 & 1 ? .079 & 11.056\end{array}$

$\begin{array}{llll}10.894 & 10.871 & 10.848 & 10.825\end{array}$

$\begin{array}{llll}10.663 & 10.640 & 10.617 & 10.594 \\ 10.432 & 10.408 & 10.385 & 10.362\end{array}$

$\begin{array}{llll}10.200 & 10.177 & 10.154 & 10.131 \\ 09.969 & 09.946 & 09.922 & 09.899\end{array}$

14.969

$\begin{array}{lll}150177 & 15.154 & 15.131\end{array}$

$\begin{array}{llll}14.274 & 14.251 & 14.228 & 14.205\end{array}$

$\begin{array}{llll}14.043 & 14.020 & 13.996 & 13.973\end{array}$

$\begin{array}{llll}13.811 & 13.788 & 13.765 & 13.742 \\ 13.580 & 13.556 & 13.533 & 13.510\end{array}$

$\begin{array}{llll}13.348 & 13.325 & 13.302 & 13.27\end{array}$

$\begin{array}{llll}13.116 & 13.093 & 13.070 & 13.047\end{array}$

$\begin{array}{llll}12.654 & 12.862 & 12.839 & 12.816 \\ 12.630 & 12.607 & 12.584\end{array}$

$12.422 \quad 12.399$

$\begin{array}{llll}12.191 & 12.168 & 12.144 & 12.121 \\ 11.959 & 11.936 & 11.913 & 11.890\end{array}$

$11.728 \quad 11.705 \quad 11.681 \quad 11.658$

$11.496 \quad 11.473 \quad 11.450 \quad 11.4 ? 7$

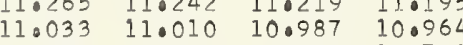

$\begin{array}{llll}10.802 & 10.779 & 10.756 & 10.732\end{array}$

$\begin{array}{llll}10.570 & 10.547 & 10.524 & 10.501 \\ 10.339 & 10.316 & 10.293 & 10.270\end{array}$

$\begin{array}{llll}10.108 & 10.085 & 10.061 & 10.038\end{array}$

$\begin{array}{llll}09.645 & 09.622 & 09.599 & 09.575\end{array}$

$\begin{array}{llllllll}09.506 & 09.483 & 09.460 & 09.436 & 09.413 & 09.390 & 09 \cdot 367 & 09.344\end{array}$

$\begin{array}{llllllll}09.275 & 09.251 & 09.228 & 09.205 & 09.182 & 09.159 & 09.136 & 09.113\end{array}$

$\begin{array}{llllllll}0.812 & 08.789 & 08.766 & 08.742 & 08.719 & 08.696 & 08.673 & 08.650\end{array}$

$\begin{array}{llllllll}08.580 & 08.557 & 08.534 & 08.511 & 08.488 & 08.465 & 08.442 & 08.418\end{array}$

$\begin{array}{llllllll}0.349 & 08.326 & 08.303 & 08.280 & 08.257 & 08.234 & 08.210 & 08.187\end{array}$

$\begin{array}{llllllll}0.085 & 08.072 & 08.048 & 08.025 & 08.002 & 07.9979 & 07.956\end{array}$

$\begin{array}{llllllll}07.655 & 07.632 & 07.609 & 07.586 & 07.562 & 07.540 & 07.516 & 07.493 \\ 07.424 & 07.401 & 07.377 & 07.354 & 07.331 & 07.308 & 07.285 & 07.262\end{array}$

$15204.926 \quad 04.903$

04.695
04.464 04.672

04.23204 .209

$\begin{array}{ll}04.001 & 03.97 \\ 03.770 & 03.747\end{array}$

03.53903 .51503 .72

$\begin{array}{ll}03.307 & 03.28 \\ 03.076 & 03.05\end{array}$

07.192

07.169

$07.146 \quad 07.123$

$07.100-07.077 \quad 07.054-07.031$

$\begin{array}{llllllll}06.730 & 06.707 & 06.683 & 06.660 & 06.637 & 06.614 & 06.591 & 06.568 \\ 06.499 & 06.475 & 06.452 & 06.429 & 06.406 & 06.383 & 06.360 & 06.337\end{array}$

$\begin{array}{llllllll}06.267 & 06.244 & 06.221 & 06.198 & 06.175 & 06.15 ? & 06.129 & 06.105\end{array}$

$06.036 \quad 06.013 \quad 05.990 \quad 05.967$

$05.805 \quad 05.782$

$\begin{array}{ll}05.342 & 05.31 \\ 05.111 & 05.08\end{array}$

$05.527 \quad 05.504$

$05.944 \quad 05.921$

$\begin{array}{llll}05.712 & 05.921 & 05.897 & 05.874\end{array}$

$05.48105 .458 \quad 05.435 \quad 05.412$

$05.250 \quad 05.227 \quad 05.204 \quad 05.180$

$\begin{array}{llllllll}04.880 & 04.857 & 04.833 & 04.810 & 04.787 & 04.764 & 04.741 & 04.718\end{array}$ $\begin{array}{ll}04.649 & 04.6 \\ 04.417 & 04.394\end{array}$

04.833

\begin{tabular}{ll}
$04 \cdot 8$ \\
2 & 04.5 \\
\hline & 049
\end{tabular}

02.84

15202.61

02.59

$02.151 \quad 02.12$

$01.920 \quad 01.897$

01.45801 .435

01.227

$00.965 \quad 00.77$

15200.302

$\begin{array}{rr}15200.302 & 00.279 \\ 00.071 & 00.048\end{array}$

04.18

04.394
04.163

04.37
04.140

04.348
04.117

04.556
04.325

$\begin{array}{lll}04.533 & 04 \cdot 510 & 04.487 \\ 04.302 & 04.279 & 04.255\end{array}$

03.49203 .700

$\begin{array}{ll}03.909 & 03.88 \\ 03.677 & 03.65\end{array}$

$\begin{array}{llll}04.093 & 04.070 & 04.047 & 04.024 \\ 03.862 & 03.839 & 03.816 & 03.793\end{array}$

$\begin{array}{llll}03.862 & 03.839 & 03.816 & 03.793 \\ 03.631 & 03.608 & 03.585 & 03.562\end{array}$

$\begin{array}{llll}03.400 & 03.377 & 03.354 & 03.331\end{array}$

03.030

03.238

03.445

03.215
02.984
02.75

03.654
03.423
03.192
02.961

03.169

03.377
03.146

$03 \cdot 122 \quad 03.09$

$02.568 \quad 02.544$

$02.521 \quad 02.498$

02.70

$\begin{array}{lll}02.683 & 02.891 & 02.868\end{array}$

$\begin{array}{llllllll}02.336 & 02.313 & 02.290 & 02.267 & 02.475 & 02.452 & 02.429 & 02.406\end{array}$

$\begin{array}{lllllllll}02.082 & 02.059 & 02.036 & 02.013 & 01.990 & 01.966 & 01.943\end{array}$

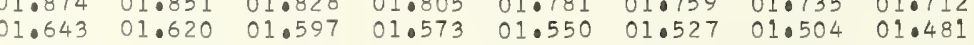

$\begin{array}{llllllll}01.412 & 01.389 & 01.365 & 01.342 & 01.319 & 01.296 & 01.273 & 01.250 \\ 01.181 & 01.158 & 01.134 & 01.111 & 01.088 & 01.065 & 01.042 & 01.019\end{array}$

0.949

1.158

$01.088 \quad 01.065 \quad 01.042 \quad 01.019$

\subsection{8}

00.695

$0.672 \quad 00.649$

0.857

.834
0.603

$\begin{array}{ll}.811 & 00.788\end{array}$

$\begin{array}{lll}9.840 & 99.817 & 00.025\end{array}$

$99.609 \quad 99.586 \quad 99.5$

$99.378 \quad 99.355 \quad 99.332$

$98.916 \quad 98.893$

$\begin{array}{ll}98.685 & 98.66 \\ 98.453 & 98.431 \\ 98.223 & 98.19\end{array}$

$\begin{array}{ll}99.101 & 99.309 \\ 9.10 & 907\end{array}$

$\begin{array}{llllllll}0.233 & 00.210 & 00.187 & 00.164 & 00.141 & 00.118 & 00.094\end{array}$

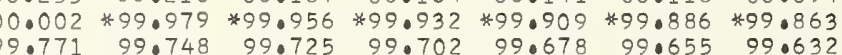

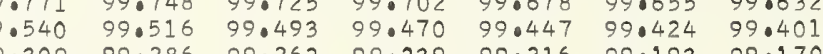

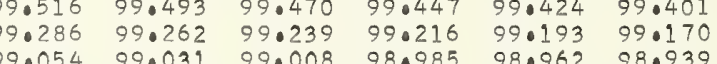

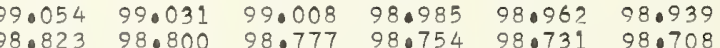

$\begin{array}{lllllllll}98.639 & 98.615 & 98.592 & 98.569 & 98.546 & 98.523 & 98.500 & 98.477 \\ 31 & 98.407 & 98.384 & 98.361 & 98.338 & 98.315 & 98.292 & 98.269 & 98.246\end{array}$

6578.

8.1
8.2
8.3

97.7760
97.5530

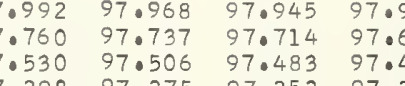

$\begin{array}{llll}97.298 & 97.275 & 97.252 & 97.22 \\ 97.068 & 97.044 & 97.021 & 96.99\end{array}$

$\begin{array}{llll}96.836 & 96.813 & 96.790 & 96.76\end{array}$

8.5

8.6

$96.605 \quad 96.582 \quad 96.559$

96.536

$\begin{array}{llll}96.374 & 96.351 & 96.328 & 96.30 \\ 96.143 & 96.120 & 96.097 & 96.07 \\ 95.912 & 95.889 & 95.866 & 95.84\end{array}$

$\begin{array}{ll}98.361 & 98.338 \\ 98.130 & 98.107\end{array}$

8.9

6579.0

95.451

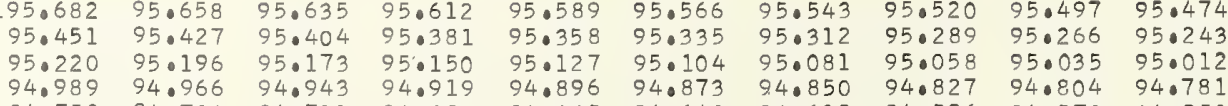

$95.658 \quad 95.635$

95.61

97.668

97.876

$\begin{array}{llllll}97.437 & 97.414 & 97.391 & 97.368 & 97.345 & 97.322\end{array}$

$97.206 \quad 97.183 \quad 97.160 \quad 97.137 \quad 97.114 \quad 97.091$

$\begin{array}{llllll}96.975 & 96.952 & 96.929 & 96.906 & 96.883 & 96.859 \\ 96.744 & 96.721 & 06.698 & 06.675 & 96.652 & 96.629\end{array}$

$\begin{array}{llllll}96.513 & 96.490 & 96.6988 & 96.675 & 96.652 & 96.629 \\ & 96.467 & 96.444 & 96.421 & 96.397\end{array}$

$\begin{array}{llllll}96.282 & 96.259 & 96.236 & 96.213 & 96.190 & 96.167\end{array}$

$\begin{array}{llllll}96.051 & 96.028 & 96.005 & 95.982 & 95.959 & 95.936 \\ 95.820 & 95.797 & 95.774 & 95.751 & 95.728 & 95.704\end{array}$

$\begin{array}{llllllllll}94.758 & 94.966 & 94.943 & 94.919 & 94.896 & 94.873 & 94.850 & 94.827 & 94.804 & 94.781\end{array}$

$\begin{array}{llllllllll}94.527 & 94.504 & 94.481 & 94.458 & 94.434 & 94.411 & 94.388 & 94.565 & 94.573 & 94.550 \\ & 94.342 & 94.319\end{array}$

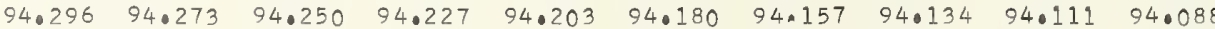

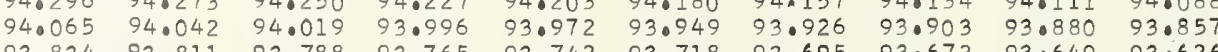

9.8

$93.834 \quad 93.811$

93.788

93.76540

$3.972 \quad 93.94$

93.9
93.6

9

0.276228

0.276228

0.0276227

0.276227

0.276227

0.076

0.276227

0.276227

0.276797

0.7762 .26
0.276226

0.276226

0.276226
0.276226

0.276226

0.276226
0.276226

0.276226

0.276275

$0.2767,75$

0.276725

0.276225

0.276225

0.276225

0.276224

0.276224

0.2762224
$0.276 ? 94$

0.276224

0.276224

0.276224

0.276224

0.276223
0.276223

0.276223

0.276223
0.276223

0.276223

0.276223

$0.2762 ? 3$
0.276223

0.276222

0.276222

0.276222

0.276222

0.276222

0.276222

0.27622

0.27622

0.276221
0.276221

0.276221
0.276221

0.276221

0.276221

0.276221

0.27622

0.276220

$0.276 ? 20$

0.2762220
0.276220

0.276220

0.276220

0.276220 
1.818311

1.818365

1.818391

$\frac{1}{1.818445}$

1.818499

1.818553

1.818580

1.818606

.818660

1.818687
1.818714

1.818941
1.818768

10818795

1.818848

1.818875
1.818902

1.818929

1.818956
1.818983

1.819010

1.819037

1.819117

1.819144

1.819198

1.819252

1.819305

1.819359

1.819386

1. 1.819413

10819467
1.819494

1.819521

1.819574
1.819601

1.819655

1.819682
1.819709

10.819736

1.819789

1.819816

1.819870
1.819897

1.819924

1.819978

1.820004

1.820058
1.820085

1.820112

1.820139

.010

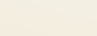

.023
.022 
$\begin{array}{lllllllllll}6590.0 & 15170.317 & 70.294 & 70.271 & 70.248 & 70.225 & 70.202 & 70.179 & 70.156 & 70.133 & 70.110\end{array}$ $\begin{array}{lllllllllll}0.1 & 70.087 & 70.064 & 70.041 & 70.018 & 69.995 & 69.972 & 69.949 & 69.926 & 69.903 & 69.880 \\ 0.2 & 69.857 & 69.834 & 69.811 & 69.788 & 69.765 & 69.742 & 69.719 & 69.696 & 69.673 & 69.649\end{array}$

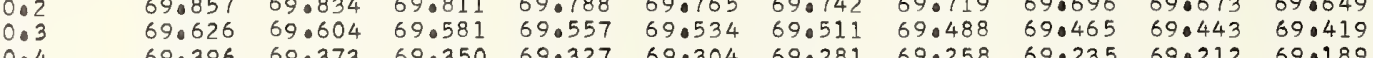
$\begin{array}{lllllllllll}0.4 & 69.396 & 69.373 & 69.350 & 69.327 & 69.304 & 69.281 & 69.258 & 69.235 & 69.212 & 69.189\end{array}$ $\begin{array}{llllllllll}69.166 & 69.143 & 69.120 & 69.097 & 69.074 & 69.051 & 69.028 & 69.005 & 68.982 & 68.959\end{array}$ $\begin{array}{llllllllll}68.936 & 68.913 & 68.890 & 68.867 & 68.844 & 68.821 & 68.798 & 68.775 & 68.752 & 68.729\end{array}$

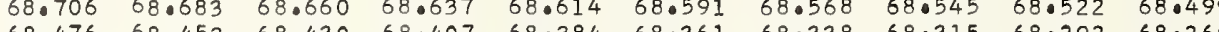

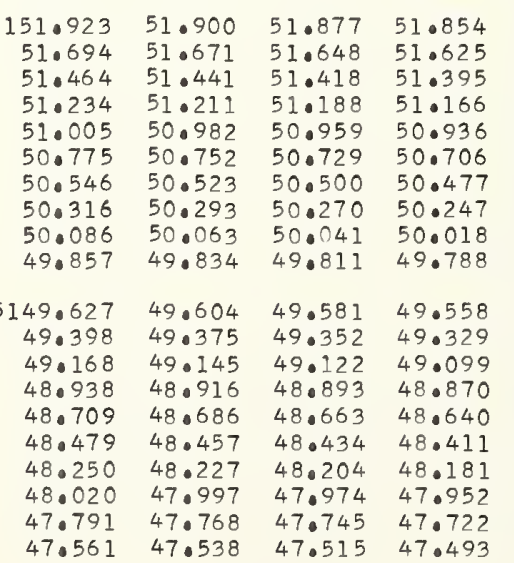

0.276205

0.276205
0.276205
0.276205

0.276205

0.276205

0.276205
0.276204

0.276204

$\frac{1}{1.820193}$

1.820246

1.820273

1.820327

1.820354

$\begin{array}{ll}0.276204 & 1.820408 \\ & 1.820435\end{array}$

0.276204

0.276204
0.276204

0.276204

0.276204
0.276204

0.276203

0.276203
0.276203
0.276203

0.276203

0.276203
0.276203
0.276203

0.276203
0.276203
0.0276203

0.276203

0.276202
0.276202

0.276202

0.276202
0.276202

1.820462 1.820488
1.820515

1.820542

1.820569
1.820596

1.820623

1.820677

1.820730

1.820757
1.820784

1.820811

1.820838

1.820865
1.820892

1.820919

1.820945
1.820972

0.276202

0.276202

0.2762 .02

0.276201

0.276201

0.276201
0.276201
0.276201

0.276201

1.820999

1.821026
1.821053

1.821080

1.821107

1.821134

1.821187

$0.276201-1.821268$

0.276201
0.276201
0.276200

0.276201
0.276200

0.276200

0.276200
0.276200

0.276200

0.276200

1.821295

1.0821322
1.821349

1.821376

1.821402
1.821429

1.821456

1.821483
1.821510

0.276200

0.276200
0.276190
0.276199

0.276199

0.276199

0.276199

0.276199

0.276199
0.276199

1.821537

1.821564

1.821618

1.821644

1.821671

1.821698
1.821725

1.821752

0.276199

0.276198

0.276198
0.276198

0.276198

0.276198
0.276198

0.276198
0.276198

0.276198
0.276198

1.821806

0.276197

0.276197
0.276197

0.276197
0.276197

0.276197
0.276197

0.276197
0.276197

0.276197

0.276197
0.276196

1.821833
1.821860

1.821886

1.821913
1.821940

1.821967
1.821994
1.822021

0.276196

0.276196
0.276196

0.276196
0.276196

0.276196

0.276196
0.276196

0.276196
0.276195
0.276195

1.822075

1.822101

1.822128
1.822155

1.822182

1.822236

1.822263
1.822290

1.822317

0.276195
0.276195

0.276195

0.276195
0.276195
0.276195

0.276195

0.276195

0.276194

1.822343
1.822370

1.822397

1.822424
1.822459

1. 822478

1.822505

$\frac{1}{1.822532}$ 


\begin{tabular}{|c|c|c|c|c|c|c|c|c|c|c|c|c|}
\hline A) & .00 & 1 & 2 & .03 & .04 & .05 & .06 & .07 & .08 & 9 & 00 & 1) \\
\hline $\begin{array}{l}00.0 \\
0.1 \\
0.2 \\
0.3 \\
0.4 \\
0.5 \\
0.6 \\
0.7 \\
0.8 \\
0.9\end{array}$ & $\begin{array}{r}15147.332 \\
47.102 \\
46.873 \\
46.643 \\
46.41 .4 \\
46.184 \\
45.955 \\
45.725 \\
45.496 \\
45.266\end{array}$ & $\begin{array}{l}47.309 \\
47.079 \\
46.850 \\
46.620 \\
46.391 \\
46.161 \\
45.932 \\
45.702 \\
450473 \\
45.244\end{array}$ & $\begin{array}{l}47.286 \\
47.057 \\
46.827 \\
46.597 \\
46.368 \\
46.138 \\
45.909 \\
45.679 \\
45.450 \\
45.221\end{array}$ & $\begin{array}{l}47.263 \\
47.033 \\
46.804 \\
46.574 \\
46.345 \\
46.115 \\
45.886 \\
45.656 \\
45.427 \\
45.198\end{array}$ & $\begin{array}{l}47.240 \\
47.010 \\
46.781 \\
46.552 \\
46.322 \\
46.093 \\
45.863 \\
45.634 \\
45.404 \\
45.175\end{array}$ & $\begin{array}{l}47.217 \\
46.988 \\
46.758 \\
46.529 \\
46.299 \\
46.070 \\
45.840 \\
45.611 \\
450381 \\
45.152\end{array}$ & $\begin{array}{l}47.194 \\
46.965 \\
46.735 \\
46.506 \\
46.276 \\
46.047 \\
45.817 \\
45.588 \\
45.358 \\
45.129\end{array}$ & $\begin{array}{l}47.171 \\
46.942 \\
46.712 \\
46.483 \\
46.253 \\
46.024 \\
45.794 \\
45.565 \\
45.335 \\
45.106\end{array}$ & $\begin{array}{l}47.148 \\
46.919 \\
46.689 \\
46.460 \\
46.230 \\
46.001 \\
450.771 \\
45.542 \\
45.312 \\
45.083\end{array}$ & $\begin{array}{l}47.125 \\
46.896 \\
46.666 \\
46.437 \\
46.207 \\
45.978 \\
45.748 \\
45.519 \\
45.290 \\
45.060\end{array}$ & $\begin{array}{l}0.276194 \\
0.276194 \\
0.276194 \\
0.276194 \\
0.276194 \\
0.276194 \\
0.276193 \\
0.276193 \\
0.276193 \\
0.276193\end{array}$ & $\begin{array}{l}1.822881 \\
1.822908 \\
1.822935 \\
1.822962 \\
1.822989 \\
1.823016 \\
1.823043 \\
1.823069 \\
1.823096\end{array}$ \\
\hline $\begin{array}{l}601.0 \\
1.1 \\
1.2 \\
1.3 \\
1.4 \\
1.5 \\
1.6 \\
1.7 \\
1.8 \\
1.9\end{array}$ & $\begin{array}{r}15145.037 \\
44.808 \\
44.578 \\
44.349 \\
44.120 \\
43.890 \\
43.661 \\
43.431 \\
43.202 \\
42.973\end{array}$ & $\begin{array}{l}45.015 \\
44.785 \\
44.556 \\
44.326 \\
44.097 \\
43.867 \\
430638 \\
43.408 \\
43.179 \\
42.950\end{array}$ & $\begin{array}{l}44.991 \\
44.762 \\
44.533 \\
44.303 \\
44.074 \\
43.844 \\
43.615 \\
43.385 \\
43.156 \\
42.927\end{array}$ & $\begin{array}{l}44.968 \\
44.739 \\
44.510 \\
44.280 \\
44.051 \\
43.821 \\
43.592 \\
43.363 \\
43.133 \\
42.904\end{array}$ & $\begin{array}{l}44 \cdot 945 \\
44.716 \\
44 \cdot 487 \\
44 \cdot 257 \\
44 \cdot 028 \\
43.798 \\
43 \cdot 569 \\
43 \cdot 340 \\
42.110 \\
42.881\end{array}$ & $\begin{array}{l}44.922 \\
44.093 \\
44.464 \\
44.034 \\
44.005 \\
43.076 \\
43.546 \\
43.317 \\
43.087 \\
42.858\end{array}$ & $\begin{array}{l}44.900 \\
44.670 \\
44.441 \\
44.211 \\
43.982 \\
43.753 \\
43.523 \\
43.294 \\
43.064 \\
42.835\end{array}$ & $\begin{array}{l}44.877 \\
44.647 \\
44.418 \\
44.188 \\
43.959 \\
43.730 \\
43.500 \\
43.271 \\
43.042 \\
42.812\end{array}$ & $\begin{array}{l}44.854 \\
44.624 \\
44.395 \\
44.166 \\
430.936 \\
43.0707 \\
430477 \\
43.248 \\
43.019 \\
420789\end{array}$ & $\begin{array}{l}44.831 \\
44.601 \\
44 \cdot 372 \\
440143 \\
43.913 \\
430684 \\
430454 \\
43.225 \\
42.996 \\
42.766\end{array}$ & $\begin{array}{l}0.276193 \\
0.276193 \\
0.276193 \\
0.276193 \\
0.276193 \\
0.276192 \\
0.276192 \\
0.276192 \\
0.276192 \\
0.276192\end{array}$ & $\begin{array}{l}1.823150 \\
1.823177 \\
1.823204 \\
1.823231 \\
1.823258 \\
1.823284 \\
1.823311 \\
1.823338 \\
1.823365 \\
1.823392\end{array}$ \\
\hline $\begin{array}{r}602.0 \\
2.1 \\
2.2 \\
2.3 \\
2.4 \\
2.5 \\
2.6 \\
2.7 \\
2.8 \\
2.9\end{array}$ & $\begin{array}{r}15142.743 \\
42.514 \\
42.285 \\
42.055 \\
41.826 \\
41.597 \\
41.367 \\
41.138 \\
40.908 \\
40.679\end{array}$ & $\begin{array}{l}42.720 \\
42.491 \\
42.262 \\
42.032 \\
41.803 \\
41.574 \\
41.344 \\
41.115 \\
40.886 \\
40.656\end{array}$ & $\begin{array}{l}42.698 \\
42.468 \\
42.239 \\
42.010 \\
41.780 \\
41.551 \\
41.321 \\
41.092 \\
40.863 \\
40.633\end{array}$ & $\begin{array}{l}42.674 \\
42.445 \\
42.216 \\
41.987 \\
41.757 \\
41.528 \\
41.298 \\
41.069 \\
40.840 \\
40.611\end{array}$ & $\begin{array}{l}42.651 \\
42.422 \\
42.193 \\
41.964 \\
41.734 \\
41.505 \\
41.276 \\
41.046 \\
40.817 \\
40.588\end{array}$ & $\begin{array}{l}42.629 \\
42.399 \\
42.170 \\
41.941 \\
41.711 \\
41.482 \\
41.253 \\
41.023 \\
40.0794 \\
40.565\end{array}$ & $\begin{array}{l}42.606 \\
42.376 \\
42.147 \\
41.917 \\
41.688 \\
41.459 \\
41.230 \\
41.000 \\
40.771 \\
40.542\end{array}$ & $\begin{array}{l}42.583 \\
42.353 \\
42.124 \\
41.895 \\
41.665 \\
41.436 \\
41.207 \\
40.977 \\
40.748 \\
40.519\end{array}$ & $\begin{array}{l}42.560 \\
42.330 \\
42.101 \\
41.872 \\
41.642 \\
41.4113 \\
41.184 \\
40.954 \\
40.725 \\
40.496\end{array}$ & $\begin{array}{l}42.537 \\
42.307 \\
42.078 \\
41.849 \\
41.620 \\
41.390 \\
41.161 \\
40.932 \\
40.702 \\
40.473\end{array}$ & $\begin{array}{l}0.276192 \\
0.276192 \\
0.276192 \\
0.276199 \\
0.276191 \\
0.276191 \\
0.276191 \\
0.276191 \\
0.276191 \\
0.276191\end{array}$ & $\begin{array}{l}1.823419 \\
1.823446 \\
1.823473 \\
1.823500 \\
1.823526 \\
1.823553 \\
1.823580 \\
1.823607 \\
1.823634 \\
1.823661\end{array}$ \\
\hline $\begin{array}{r}6603.0 \\
3.1 \\
3.2 \\
3.3 \\
3.4 \\
3.5 \\
3.5 \\
3.7 \\
3.8 \\
3.9\end{array}$ & $\begin{array}{r}15140.450 \\
40.221 \\
39.991 \\
39.762 \\
39.533 \\
39.304 \\
39.074 \\
38.845 \\
38.616 \\
38.387\end{array}$ & $\begin{array}{l}40.427 \\
40.198 \\
39.969 \\
39.739 \\
39.510 \\
39.281 \\
39.051 \\
38.822 \\
38.593 \\
38.364\end{array}$ & $\begin{array}{l}40.404 \\
40.175 \\
39.946 \\
39.716 \\
39.487 \\
39.258 \\
39.029 \\
38.799 \\
38.570 \\
38.341\end{array}$ & $\begin{array}{l}40.381 \\
40.152 \\
39.923 \\
39.693 \\
39.464 \\
39.235 \\
39.006 \\
38.776 \\
38.547 \\
38.318\end{array}$ & $\begin{array}{l}40 \cdot 358 \\
40.129 \\
39.900 \\
39.670 \\
39.441 \\
39.212 \\
38.983 \\
38.753 \\
38.524 \\
38.295\end{array}$ & $\begin{array}{l}40.335 \\
40.106 \\
39.877 \\
39.047 \\
39.418 \\
39.189 \\
38.960 \\
38.730 \\
38.501 \\
38.272\end{array}$ & $\begin{array}{l}40.312 \\
40.083 \\
39.854 \\
39.625 \\
39.395 \\
39.166 \\
38.937 \\
38.708 \\
38.478 \\
38.249\end{array}$ & $\begin{array}{l}40.290 \\
40.060 \\
39.831 \\
39.602 \\
39.372 \\
39.143 \\
38.914 \\
38.685 \\
38.455 \\
38.226\end{array}$ & $\begin{array}{l}40.267 \\
40.037 \\
39.808 \\
39.5579 \\
39.349 \\
39.120 \\
38.891 \\
38.662 \\
38.433 \\
38.203\end{array}$ & $\begin{array}{l}40.244 \\
40.014 \\
39.785 \\
39.555 \\
39.326 \\
39.007 \\
38.886 \\
38.639 \\
38.010 \\
38.180\end{array}$ & $\begin{array}{l}0.276191 \\
0.276191 \\
0.276191 \\
0.276190 \\
0.276190 \\
0.276190 \\
0.276190 \\
0.276190 \\
0.276190 \\
0.276190\end{array}$ & $\begin{array}{l}823688 \\
883715 \\
833742 \\
823768 \\
823795 \\
8823822 \\
823849 \\
823876 \\
823903 \\
823930\end{array}$ \\
\hline $\begin{array}{r}04 \cdot 0 \\
4 \cdot 1 \\
4.2 \\
4.3 \\
4.4 \\
4.5 \\
4.6 \\
4.7 \\
4.8 \\
4.9\end{array}$ & $\begin{array}{r}138.157 \\
37.928 \\
37.699 \\
37.470 \\
37.240 \\
37.011 \\
36.782 \\
36.553 \\
36.324 \\
36.095\end{array}$ & $\begin{array}{l}38.135 \\
37.905 \\
37.076 \\
37.447 \\
37.218 \\
36.989 \\
36.759 \\
36.530 \\
36.301 \\
36.072\end{array}$ & $\begin{array}{l}38.112 \\
37.882 \\
37.653 \\
37.424 \\
37.195 \\
36.966 \\
36.736 \\
36.507 \\
36.278 \\
36.049\end{array}$ & $\begin{array}{l}38.089 \\
37.859 \\
37.630 \\
37.401 \\
37.172 \\
36.943 \\
36.713 \\
36.484 \\
36.255 \\
36.026\end{array}$ & $\begin{array}{l}38.066 \\
37.0836 \\
37.007 \\
37.0078 \\
37.0149 \\
36.920 \\
36.690 \\
36.061 \\
36.232 \\
36.003\end{array}$ & $\begin{array}{l}38.043 \\
37.813 \\
37.584 \\
37.055 \\
37.126 \\
36.897 \\
36.067 \\
36.438 \\
36.209 \\
35.980\end{array}$ & $\begin{array}{l}38.020 \\
37.791 \\
37.562 \\
37.332 \\
37.103 \\
36.874 \\
36.045 \\
36.416 \\
36.186 \\
35.957\end{array}$ & $\begin{array}{l}37.0997 \\
37.768 \\
37.539 \\
37.309 \\
37.080 \\
36.851 \\
36.622 \\
36.393 \\
36.163 \\
35.934\end{array}$ & $\begin{array}{l}37.974 \\
37.0745 \\
37.516 \\
37.286 \\
37.057 \\
36.0828 \\
36.0599 \\
36.370 \\
36.141 \\
35.911\end{array}$ & $\begin{array}{l}37.051 \\
37.0522 \\
37.493 \\
37.263 \\
37.034 \\
36.805 \\
36.576 \\
36.347 \\
36.118 \\
35.888\end{array}$ & & $\begin{array}{l}.823984 \\
.824010 \\
.824037 \\
.824064 \\
.824091 \\
.824118 \\
.824145 \\
.824172 \\
.824199\end{array}$ \\
\hline $\begin{array}{r}605.0 \\
5.1 \\
5.2 \\
5.3 \\
5.4 \\
5.5 \\
5.6 \\
5.7 \\
5.8 \\
5.9\end{array}$ & $\begin{array}{r}135.866 \\
35.836 \\
35.407 \\
35.178 \\
34.949 \\
34.720 \\
34.491 \\
34.261 \\
34.032 \\
33.803\end{array}$ & $\begin{array}{l}35 \cdot 843 \\
35.613 \\
35.384 \\
35.155 \\
34.926 \\
34.697 \\
34.468 \\
34.239 \\
34.010 \\
33.780\end{array}$ & $\begin{array}{l}35.820 \\
35.591 \\
35.361 \\
35.132 \\
34.903 \\
34.674 \\
34.445 \\
34.216 \\
33.987 \\
33.757\end{array}$ & $\begin{array}{l}35.338 \\
35.109 \\
34.880 \\
34.651 \\
34.022 \\
34.193 \\
33.064 \\
33.735\end{array}$ & $\begin{array}{l}35.774 \\
35.0545 \\
35.315 \\
35.086 \\
34.857 \\
34.0628 \\
34.0399 \\
34.170 \\
33.941 \\
33.712\end{array}$ & $\begin{array}{l}35.751 \\
35.522 \\
35.293 \\
35.063 \\
34.834 \\
34.605 \\
34.376 \\
34.147 \\
33.918 \\
33.689\end{array}$ & & $\begin{array}{l}35.705 \\
35.476 \\
35.247 \\
35.018 \\
34.788 \\
34.559 \\
34.330 \\
34.101 \\
33.872 \\
33.643\end{array}$ & $\begin{array}{l}35.682 \\
35.453 \\
35.224 \\
34.995 \\
34.766 \\
34.056 \\
34.0307 \\
34.078 \\
330849 \\
33.620\end{array}$ & & & \\
\hline $\begin{array}{l}606.0 \\
6.1 \\
6.2 \\
6.3 \\
6.4 \\
6.5 \\
6.0 \\
6.7 \\
6.8 \\
6.9\end{array}$ & $\begin{array}{r}5133.574 \\
33.345 \\
33.116 \\
32.887 \\
32.658 \\
32.429 \\
32.200 \\
31.971 \\
31.742 \\
31.513\end{array}$ & $\begin{array}{l}33.551 \\
33.0322 \\
33.093 \\
32.864 \\
32.635 \\
32.406 \\
32.177 \\
31.048 \\
31.719 \\
31.0490\end{array}$ & $\begin{array}{l}33.528 \\
33.299 \\
33.070 \\
32.841 \\
32.011 \\
32.383 \\
32.154 \\
31.025 \\
31.096 \\
31.467\end{array}$ & $\begin{array}{l}33.505 \\
33.276 \\
33.047 \\
32.818 \\
32.589 \\
32.360 \\
32.131 \\
31.902 \\
31.673 \\
31.444\end{array}$ & $\begin{array}{l}33.024 \\
32.795 \\
32.566 \\
32.337 \\
32.108 \\
31.879 \\
31.650 \\
31.421\end{array}$ & $\begin{array}{l}33.460 \\
33.231 \\
33.002 \\
32.772 \\
32.543 \\
32.314 \\
32.085 \\
31.856 \\
31.627 \\
31.398\end{array}$ & $\begin{array}{l}32.521 \\
32.291 \\
32.062 \\
31.833 \\
31.604 \\
31.375\end{array}$ & & & & & \\
\hline $\begin{array}{r}5607.0 \\
7.1 \\
7.2 \\
7.3 \\
7.4 \\
7.5 \\
7.6 \\
7.7 \\
7.8 \\
7.9\end{array}$ & $\begin{array}{l}131.284 \\
31.055 \\
30.826 \\
30.597 \\
30.368 \\
30.139 \\
29.910 \\
29.681 \\
29.452 \\
29.223\end{array}$ & $\begin{array}{l}31.261 \\
31.032 \\
30.803 \\
30.574 \\
30.345 \\
30.116 \\
29.887 \\
29.658 \\
29.429 \\
29.200\end{array}$ & $\begin{array}{l}31.009 \\
30.780 \\
30.551 \\
30.322 \\
30.093 \\
29.864 \\
29.635 \\
29.406 \\
29.177\end{array}$ & $\begin{array}{l}31.215 \\
30.986 \\
30.757 \\
30.528 \\
30.299 \\
30.070 \\
29.841 \\
29.612 \\
29.383 \\
29.154\end{array}$ & & $\begin{array}{l}31.169 \\
30.940 \\
30.711 \\
30.482 \\
30.253 \\
30.024 \\
29.795 \\
29.566 \\
29.337 \\
29.108\end{array}$ & & & & & & \\
\hline $\begin{array}{l}8.1 \\
8.2 \\
8.3 \\
8.4 \\
8.5 \\
8.6 \\
8.7 \\
8.8 \\
8.9\end{array}$ & $\begin{array}{l}28.765 \\
28.536 \\
28.307 \\
28.078 \\
27.849 \\
27.620 \\
27.391 \\
27.162 \\
26.934\end{array}$ & & $\begin{array}{l}28.032 \\
27.80 \\
27.57 \\
27.034 \\
27.117 \\
26.888\end{array}$ & & & & & & & & & \\
\hline $\begin{array}{l}9.1 \\
9.2 \\
9.3 \\
9.4 \\
9.5 \\
9.6 \\
9.7 \\
9.8 \\
9.9\end{array}$ & $\begin{array}{l}26.476 \\
26.247 \\
26.018 \\
25.789 \\
25.560 \\
25.332 \\
25.103 \\
24.874 \\
24.645\end{array}$ & $\begin{array}{l}25.766 \\
25.537 \\
25.309 \\
25.080 \\
24.851 \\
24.622\end{array}$ & $\begin{array}{l}25.972 \\
25.744 \\
25.515 \\
25.286 \\
25.057 \\
24.828 \\
24.599\end{array}$ & $\begin{array}{l}25.949 \\
25.721 \\
25.492 \\
25.263 \\
25.034 \\
24.805 \\
24.576\end{array}$ & $\begin{array}{l}26.384 \\
26.155 \\
25.927 \\
25.698 \\
25.469 \\
25.240 \\
25.011 \\
24.782 \\
24.554\end{array}$ & $\begin{array}{l}26.361 \\
26.361 \\
25.0904 \\
25.675 \\
25.446 \\
25.217 \\
24.988 \\
24.0760 \\
24.531\end{array}$ & $\begin{array}{l}26.110 \\
25.881 \\
25.652 \\
25.423 \\
25.194 \\
24.965 \\
24.737 \\
24.508\end{array}$ & $\begin{array}{l}26.545 \\
26.316 \\
26.087 \\
250858 \\
250629 \\
250400 \\
250171 \\
240943 \\
24.714 \\
240485\end{array}$ & $\begin{array}{l}26.522 \\
26.293 \\
26.064 \\
25.835 \\
25.606 \\
25.377 \\
25.148 \\
24.920 \\
24.691 \\
24.462\end{array}$ & $\begin{array}{l}26.270 \\
26.041 \\
25.812 \\
25.583 \\
25.354 \\
25.126 \\
24.897 \\
24.658 \\
24.439\end{array}$ & $\begin{array}{l}0.276184 \\
0.276183 \\
0.276183 \\
0.276183 \\
0.276183\end{array}$ & $\begin{array}{l}8.82551 \\
1.8255\end{array}$ \\
\hline
\end{tabular}

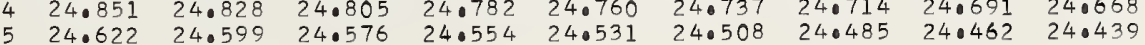

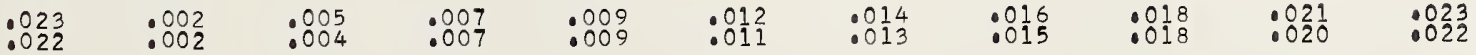




.05

.07

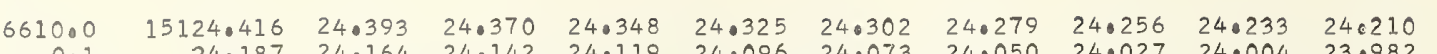

$\begin{array}{llllllllllll}0.1 & 24.187 & 24.164 & 24.142 & 24.119 & 24.096 & 24.073 & 24.050 & 24.027 & 24.004 & 23.982 \\ 0.2 & 23.959 & 23.936 & 23.913 & 23.890 & 23.867 & 23.844 & 23.821 & 23.799 & 23.776 & 23.753\end{array}$

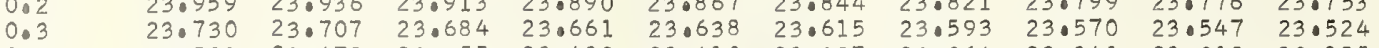

$\begin{array}{lllllllllll}0.4 & 23.501 & 23.478 & 23.455 & 23.432 & 23.410 & 23.387 & 23.364 & 23.341 & 23.318 & 23.295\end{array}$

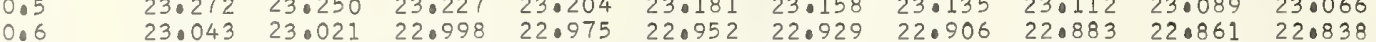

$\begin{array}{lllllllllll}0.7 & 22.815 & 22.792 & 22.769 & 22.746 & 22.723 & 22.700 & 22.677 & 22.655 & 22.632 & 22.609\end{array}$

$\begin{array}{lllllllllll}0.8 & 22.586 & 22.563 & 22.540 & 22.517 & 22.495 & 22.472 & 22.449 & 22.426 & 22.403 & 22.380 \\ 0.9 & 22.357 & 22.334 & 22.312 & 22.289 & 22.266 & 22.243 & 22.220 & 22.197 & 22.174 & 22.151\end{array}$

$\begin{array}{lllllllllll}6611.0 & 15122.128 & 22.106 & 22.083 & 22.060 & 22.037 & 22.014 & 21.991 & 21.968 & 21.946 & 21.923\end{array}$

$\begin{array}{lllllllllll}1.1 & 21.900 & 21.877 & 21.854 & 21.831 & 21.808 & 21.785 & 21.763 & 21.740 & 21.717 & 21.694 \\ 1.2 & 21.671 & 21.648 & 21.625 & 21.602 & 21.580 & 21.557 & 21.534 & 21.511 & 21.488 & 21.465\end{array}$

$\begin{array}{lllllllllll}1.2 & 21.671 & 21.648 & 21.625 & 21.602 & 21.580 & 21.557 & 21.534 & 21.511 & 21.488 & 21.465 \\ 1.3 & 21.442 & 21.419 & 21.397 & 21.374 & 21.351 & 21.328 & 21.305 & 21.282 & 21.259 & 21.237\end{array}$

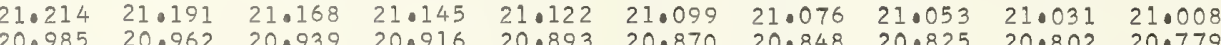
$\begin{array}{llllllllll}20.985 & 20.962 & 20.939 & 20.916 & 20.893 & 20.870 & 20.848 & 20.825 & 20.802 & 20.779 \\ 20.756 & 20.733 & 20.711 & 20.688 & 20.665 & 20.642 & 20.619 & 20.596 & 20.573 & 20.550\end{array}$ $\begin{array}{llllllllll}20.756 & 20.733 & 20.711 & 20.688 & 20.665 & 20.642 & 20.619 & 20.596 & 20.573 & 20.550 \\ 20.527 & 20.505 & 20.482 & 20.459 & 20.436 & 20.413 & 20.390 & 20.367 & 20.344 & 20.322\end{array}$

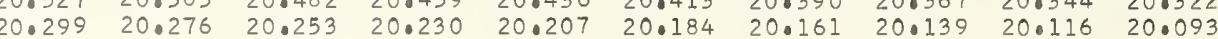

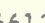
$20.070 \quad 20.047$

12.0
2.1
2.2
2.3
2.4
2.5
2.6
2.7
2.8
2.9

$$
\begin{array}{rll}
19.841 & 19.819 & 19 \\
19.613 & 19.590 & 19 \\
19.384 & 19.361 & 19 \\
19.155 & 19.133 & 19 \\
18.927 & 18.904 & 18 \\
18.698 & 18.675 & 18 \\
18.469 & 18.447 & 18 \\
18.241 & 18.218 & 18 \\
18.012 & 17.989 & 17 \\
17.784 & 17.761 & 17
\end{array}
$$

20.00

6613. 4.

4.

$4 \cdot 6$

$$
\begin{array}{rrr}
5117.555 & 17.532 & 17 \\
17.326 & 17.304 & 17 \\
17.098 & 17.075 & 17 \\
16.869 & 16.846 & 1 \\
16.641 & 16.618 & 1 \\
16.412 & 16.389 & 1 \\
16.184 & 16.161 & 1 \\
15.955 & 15.932 & 1 \\
15.726 & 15.704 & 1 \\
15.498 & 15.475 & 1
\end{array}
$$

19.750

19.727$$
19.933
$$$$
19.91
$$

$5115.269 \quad 15.247$

$\begin{array}{llll}15.041 & 15.018 & 15.224 & 15.20\end{array}$

$\begin{array}{ll}14.812 & 14.78 \\ 14.584 & 14.56\end{array}$

$\begin{array}{ll}14.355 & 14.33 \\ 14.127 & 14.104\end{array}$

$13.808 \quad 13.876 \quad 14.081$

$\begin{array}{lll}13.670 & 13.647 & 13.62 \\ 13.442 & 13.419 & 13.39\end{array}$

13.213

12.756
12.52
12.29

$12.290 \quad 12.050512 .482$

$12.071 \quad 12.048$ 12.025 12.2002

$\begin{array}{llll}11.842 & 11.820 & 11.797 & 11.774\end{array}$

11.6340 .59111 .568

$11.157 \quad 11.134$

$5110.700 \quad 10.677$

110.700
10.47
10.243

$\begin{array}{llll}10.243 & 10.421 & 10.426 & 10.403 \\ 10.10 .198 & 10.175\end{array}$

$09.787 \quad 00.792 \quad 09.969 \quad 09.947$

$\begin{array}{llll}09.558 & 09.536 & 09.513 & 09.49 \\ 09.330 & 09.307 & 09.284 & 09.26\end{array}$

$\begin{array}{llll}09.102 & 09.079 & 09.284 & 09.26 \\ 08.873 & 08.851 & 0.056 & 09.03 \\ 0828 & 08.80\end{array}$

$\begin{array}{ll}08.873 & 08.851 \\ 08.645 & 08.622\end{array}$

7.1
7.2
7.3

705

7.8
7.9

8.3
8.4

8.5

8.7
8.8

8.9

6619.

9.1
9.2
9.3

9.4
9.5
9.6

9.6

9.8
9.9 $\begin{array}{rrr}5108.417 & 08.394 & 08.371 \\ 08.188 & 08.165 & 08.1 \\ 07.960 & 07.937 & 07.914\end{array}$

\section{$07.732 \quad 07.70$}

$\begin{array}{ll}07.503 & 07.48 \\ 07.275 & 07.25\end{array}$

$\begin{array}{ll}07.047 & 07.024 \\ 06.819 & 06.7\end{array}$

$\begin{array}{ll}06.819 & 06.796 \\ 06.590 & 06.567 \\ 06.362 & 06.33\end{array}$

15106.134

05.905
05.677
05.6449

$\begin{array}{ll}05.677 & 05.6 \\ 05.449 & 05.426\end{array}$

$\begin{array}{ll}05.221 & 05.1 \\ 04.993 & 04.97\end{array}$

$\begin{array}{ll}04.993 & 04.970 \\ 04.764 & 04.7 \\ 04.536 & 04.5 \\ 04.308 & 04.28\end{array}$

$\begin{array}{ll}04.308 & 04.285 \\ 04.080 & 04.057\end{array}$

15103.85

103.852
03.623

$03.623 \quad 03.600$

$\begin{array}{ll}03.395 & 03.372 \\ 03.167 & 03.1 \\ 02.939 & 02.9\end{array}$

$\begin{array}{ll}02.939 & 02.916 \\ 02.711 & 02.6\end{array}$

$\begin{array}{lll}02.711 & 02.688 & 02.6 \\ 02.482 & 02.460 & 02.43 \\ 02.254 & 02.232 & 02.20\end{array}$

$\begin{array}{lll}02.026 & 02.003 & 01.98 \\ 01.798 & 01.775 & 01.752\end{array}$

\section{$\begin{array}{ll}19.521 & 19.498 \\ 19.293 & 19.270\end{array}$}

$\begin{array}{ll}19.064 & 19.04 \\ 18.835 & 18.812\end{array}$

18.607

$8.378 \quad 18.355$

7.92

17.692

$\begin{array}{ll}17.464 & 17.441 \\ 17.235 & 17.212\end{array}$

$17.006 \quad 16.984$

$16.549 \quad 16.526$

$16.321 \quad 16.298$

$\begin{array}{ll}15.092 & 16.069 \\ 15.864 & 15.841\end{array}$

$15.406 \quad 15.384$

$15.178 \quad 15.155$

$14.721 \quad 14.698$

$\begin{array}{ll}14.492 & 14.46 \\ 14.264 & 14.2 \\ 14.036 & 14.01\end{array}$

$\begin{array}{ll}14.036 & 14.013 \\ 3.807 & 13.784\end{array}$

$\begin{array}{ll}3.579 & 13.556 \\ 3.350 & 13.327\end{array}$

$13.122 \quad 13.09$

$\begin{array}{llll}19.704 & 19.681 & 19.658 & 19.635 \\ 19.475 & 19.453 & 19.430 & 19.407\end{array}$

$\begin{array}{llll}19.247 & 19.224 & 19.201 & 19.178\end{array}$

$\begin{array}{lllll}18.790 & 18.767 & 18.744 & 18.721 \\ 18.561 & 18.538 & 18.515 & 18.492\end{array}$

$\begin{array}{llll}18.332 & 18.309 & 18.287 & 18.264\end{array}$

$\begin{array}{llll}18.104 & 18.081 & 18.058 & 18.035\end{array}$

$\begin{array}{llll}17.646 & 17.624 & 17.601 & 17.578\end{array}$

$\begin{array}{llll}17.418 & 17.395 & 17.372 & 17.349 \\ 17.189 & 17.166 & 17.144 & 17.121\end{array}$

$16.961 \quad 16.938 \quad 16.915 \quad 16.892$

$\begin{array}{llll}16.732 & 16.709 & 16.687 & 16.664 \\ 16.504 & 16.481 & 16.458 & 16.435\end{array}$

$16.275 \quad 16.252 \quad 16.229 \quad 16.206$

$\begin{array}{llll}16.046 & 16.023 & 16.001 & 15.978 \\ 15.818 & 15.795 & 15.772 & 15.749\end{array}$

$\begin{array}{llll}15.589 & 15.566 & 15.544 & 15.521\end{array}$

$\begin{array}{llll}15.361 & 15.338 & 15.315 & 15.292\end{array}$

$\begin{array}{llll}15.132 & 15.109 & 15.086 & 15.064\end{array}$

$\begin{array}{llll}14.675 & 14.881 & 14.858 & 14.835\end{array}$

$\begin{array}{llll}14.447 & 14.424 & 14.401 & 14.378\end{array}$

$14.218 \quad 14.195 \quad 14 \cdot 173 \quad 14.150$

$\begin{array}{llll}13.761 & 13.738 & 13.716 & 13.693\end{array}$

$\begin{array}{llll}3.533 & 13.510 & 13.487 & 13.464 \\ 3.304 & 13.282 & 13.259 & 13.236\end{array}$

$13.076 \quad 13.053 \quad 13.030 \quad 13.007$

$\begin{array}{llllll}2.893 & 12.870 & 12.848 & 12.825 & 12.802 & 12.779\end{array}$

$\begin{array}{llllll}12.436 & 12.413 & 12.619 & 12.596 & 12.573 & 12.551 \\ 12.391 & 12.368 & 12.345 & 12.322\end{array}$

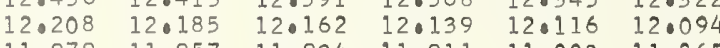

$\begin{array}{llllll}11.979 & 11.957 & 11.934 & 11.911 & 11.888 & 11.865 \\ 11.751 & 11.728 & 11.705 & 11.682 & 11.660 & 11.637\end{array}$

$\begin{array}{llllll}11.523 & 11.500 & 11.477 & 11.454 & 11.431 & 11.408\end{array}$

$\begin{array}{llllll}1.294 & 11.271 & 11.248 & 11.226 & 11.203 & 11.180\end{array}$

$\begin{array}{llllll}1.066 & 11.043 & 11.020 & 10.997 & 10.974 & 10.952 \\ 10.837 & 10.815 & 10.792 & 10.769 & 10.746 & 10.723\end{array}$

$\begin{array}{llllll}10.609 & 10.586 & 10.563 & 10.540 & 10.518 & 10.495\end{array}$

$\begin{array}{llllll}10.381 & 10.358 & 10.335 & 10.312 & 10.289 & 10.266\end{array}$

$\begin{array}{llllll}10.152 & 10.129 & 10.106 & 10.084 & 10.061 & 10.038 \\ 0.1924 & 09.901 & 09.878 & 09.855 & 09.833 & 09.810\end{array}$

$\begin{array}{llllll}09.924 & 09.901 & 09.878 & 09.855 & 09.833 & 09.810 \\ 09.695 & 09.672 & 09.650 & 09.627 & 09.604 & 09.581\end{array}$

$\begin{array}{llllll}09.467 & 09.444 & 09.421 & 09.399 & 09.376 & 09.353 \\ 09.239 & 09.216 & 09.193 & 09.170 & 09.147 & 09.125\end{array}$

$\begin{array}{llllll}09.010 & 08.988 & 08.965 & 08.942 & 08.919 & 08.896\end{array}$

$\begin{array}{llllll}08.782 & 08.759 & 08.736 & 08.714 & 08.691 & 08.668 \\ 08.554 & 08.531 & 08.508 & 08.485 & 08.462 & 08.440\end{array}$

$\begin{array}{lllllll}08.348 & 08.325 & 08.302 & 08.280 & 08.257 & 08.234 & 08.211\end{array}$

$\begin{array}{llllllll}07.686 & 07.663 & 07.640 & 07.617 & 07.595 & 07.572 & 07.549 & 07.526\end{array}$

$\begin{array}{llllllll}07.458 & 07.435 & 07.412 & 07.389 & 07.366 & 07.344 & 07.321 & 07.298 \\ 07.229 & 07.207 & 07.184 & 07.161 & 07.138 & 07.115 & 07.092 & 07.070\end{array}$

$\begin{array}{lllllllll}07.001 & 06.978 & 06.956 & 06.933 & 06.910 & 06.887 & 06.864 & 06.841\end{array}$

$\begin{array}{llllllll}06.773 & 06.750 & 06.727 & 06.704 & 06.682 & 06.659 & 06.630 & 06.613\end{array}$

$\begin{array}{llllllll}06.316 & 06.294 & 06.271 & 06.248 & 06.225 & 06.202 & 06.179 & 06.157\end{array}$

0.276183

0.276183

0.276183

0.276182

0.276182
0.276182

0.276182

0.276182
0.276182

0.276182

0.27618 ?

0.276182

0.276182

0.276181

0.276181

0.276181

0.276181

0.27618

0.276181

0.276180

0.276180

0.276180

0.276180

0.276180

0.276180

0.276179

0.276179

0.276179
0.276179

0.276179

0.276179

0.276179

0.276179

0.276179

0.276178

0.276178

0.276178

0.276178

0.276178

0.276178

0.276177

0.276177

0.276177

0.276177

0.276177

0.276177
0.276177

0.276176

0.276176
0.276176

0.276176

0.276176

0.276176
0.276176

0.276176

0.276176
0.276175

1.825570

1.825597

1.825650

1.825677
1.825704

1.825731

1.825758
9.825785

1.825812

1.825839

1.825866

1.825892

1.825946

1.825973

1.826000

1. 826027

1.826054
1.826081

1.826108

1.826134

1.826161

1.826215

1.826269

1.826296

1.826323
1.826350

1.826376

$1 . \$ 26430$

1.82645 ?

1.876484

1.826511

1.826565

1.826592

1.826618

1.826645

1.826672

1.826699

1.826726

1.826753

1.826780

1.826807

1.826860

1.826914

0.276175

0.276175

0.27617

0.276175

0.276175

0.276175

0.276174
0.276174

1.826941

1.826968

1.826995
1.827022

1.827049

1.827075

1.827129

1.827183

1.827210

1.827237
1.827264

1.827291 


.02

.03

.04

.05

.06

.07

.08

.09

0.276170

0.276169

0.077616

0.276169 


.02

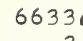

$$
\begin{array}{r}
63 \\
3 . \\
3 . \\
3 . \\
3 . \\
3 . \\
3 . \\
3 . \\
3 . \\
3.0
\end{array}
$$

6634.0

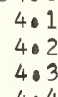

4.2
4.3
4.4

6635.0

5.1

5.3
5.4

5.4
5.5

5.6
5.7

5.8
5.9

6636.

6.1
6.2
6.3

6.4
6.5

6.6
6.7

6.7
6.8
6.9

6637.0
7.1
7.2
7.3
7.4
7.5
7.6
7.7
7.8
7.9

6638.

8.1
8.2
8.3

8.4
8.5

8.6

8.7
8.8

.

6639.

$$
\begin{aligned}
& 9.1 \\
& 9.2 \\
& 9.3 \\
& 9.4 \\
& 9.5 \\
& 9.0 \\
& 9.7 \\
& 9.0
\end{aligned}
$$

\subsection{0}

$15074.245 \quad 74.223$

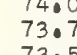

$\begin{array}{llll}73.791 & 73.095 & 73.973 \\ 73.5630 & 73.745\end{array}$

$\begin{array}{lll}73.563 & 73.541 & 73.518 \\ 73.336 & 73.313 & 73.291\end{array}$

73.10973 .086

$72.882 \quad 72.859 \quad 72.836$

$\begin{array}{ll}72.654 & 72.632 \\ 72.427 & 72.404\end{array}$

$72.200 \quad 72.177$

$$
\begin{aligned}
& \begin{array}{r}
71.97 \\
71.74
\end{array} \\
& 71.518 \\
& 71.29171 .268 \\
& 71.06471 .041 \\
& \begin{array}{ll}
70.837 & 70.814 \\
70.609 & 70.587
\end{array} \\
& \begin{array}{ll}
70.382 & 70.359 \\
70.155 & 70.132
\end{array}
\end{aligned}
$$

72.382 $69.474 \quad 69.451$ $\begin{array}{ll}69.246 & 69.224 \\ 69.019 & 68.097\end{array}$ $\begin{array}{ll}69.019 & 68.997 \\ 68.792 & 68.76\end{array}$ $\begin{array}{ll}68.565 & 68.54 \\ 68.338 & 68.31\end{array}$ $68.33868 .315 \quad 68.292$ $\begin{array}{ll}68.111 & 68.088 \\ 67.884 & 67.861\end{array}$

\subsection{7}

$67.656 \quad 67.634$

\section{$15067 \cdot 429$}

67.20267 .407

$66.975 \quad 66.953$

$\begin{array}{ll}66.748 & 66.726 \\ 66.521 & 66.49\end{array}$

$66.521 \quad 66.498 \quad 66.47$

$\begin{array}{lll}66.294 & 66.271 & 66.24\end{array}$

$\begin{array}{lll}66.067 & 66.044 & 66.022\end{array}$

$65.840 \quad 65.817 \quad 65.795 \quad 65.772$

$\begin{array}{ll}65.613 & 65.590 \\ 65.386 & 65.363\end{array}$

64.15965265 .136

64.932
64.90509 65.113

$64.705 \quad 64.682$

$64.478 \quad 64.455 \quad 64.432$

$64.251 \quad 64.228 \quad 64.205 \quad 64.183$

$\begin{array}{llll}64.024 & 64.001 & 63.978 & 63.95 \\ 63.797 & 63.774 & 63.752 & 63.729\end{array}$

$\begin{array}{llll}63.570 & 63.547 & 63.524 & 63.72 \\ 63.343 & 63.320 & 63.208 & 63.27\end{array}$

$\begin{array}{llll}63.343 & 63.320 & 63.298 & 63.275 \\ 63.116 & 63.093 & 63.070 & 63.048\end{array}$

62.66

$62.662 \quad 62.639$

$\begin{array}{lll}62.0612 & 62.59 \\ 62.390 & 62.367\end{array}$

$62.208 \quad 62.186 \quad 62.163 \quad 62.140$

$\begin{array}{llll}61.754 & 61.732 & 61.936 & 61.913 \\ 61.527 & 61.505 & 61.482 & 61.686\end{array}$

$\begin{array}{llll}61.527 & 61.505 & 61.482 & 61.45 \\ 61.301 & 61.278 & 61.255 & 61.232\end{array}$

$61.073 \quad 61.051 \quad 61.028 \quad 61.005$
$60.166 \quad 60.143$

$59.712 \quad 59.617$

$59.712 \quad 59.690 \quad 59.667$

$\begin{array}{llll}59.480 & 59.463 & 59.440 & 59.417\end{array}$

$59.032 \quad 50.009 \quad 58.086 \quad 58.191$

$\begin{array}{ll}58.805 & 58.78 \\ 58.578 & 58.55\end{array}$

$58.760 \quad 58$. $\begin{array}{lllllll}60.552 & 60.529 & 60.506 & 60.484 & 60.461 & 60.438 & 60.416 \\ 60.325 & 60.302 & 60.280 & 60.257 & 60.234 & 60.212 & 60.189\end{array}$ $\begin{array}{llllll}74.154 & 74.131 & 74.109 & 74.086 & 74.063 & 74.041 \\ 73.927 & 73.904 & 73.882 & 73.859 & 73.836 & 73.813\end{array}$ $\begin{array}{lllllll}73.700 & 73.677 & 73.654 & 73.631 & 73.609 & 73.586\end{array}$ $\begin{array}{lllllll}73.245 & 73.223 & 73.200 & 73.177 & 73.154 & 73.132\end{array}$ $\begin{array}{llllll}73.018 & 72.995 & 72.973 & 72.950 & 72.927 & 72.904 \\ 72.791 & 72.768 & 72.745 & 72.723 & 72.700 & 72.677\end{array}$ $\begin{array}{llllll}72.563 & 72.541 & 72.518 & 72.495 & 72.473 & 72.450\end{array}$ $\begin{array}{llllll}72.336 & 72.313 & 72.291 & 72.268 & 72.245 & 72.223 \\ 72.109 & 72.086 & 72.063 & 72.041 & 72.018 & 71.995\end{array}$

$\begin{array}{llllll}78.701 & 78.679 & 78.656 & 78.633 & 78.611 & 78.588\end{array}$ $\begin{array}{llllll}78.247 & 78.224 & 78.201 & 78.178 & 78.156 & 78.133\end{array}$ $\begin{array}{lllllll}77.792 & 77.769 & 77.746 & 77.724 & 77.701 & 77.678\end{array}$ $\begin{array}{llllll}77.337 & 77.314 & 77.292 & 77.269 & 77.246 & 77.224\end{array}$ $\begin{array}{lllllll}76.882 & 76.087 & 77.064 & 77.042 & 77.019 & 76.996\end{array}$ $\begin{array}{lllllll}76.428 & 76.405 & 76.382 & 76.359 & 76.337 & 76.314\end{array}$ $\begin{array}{llllll}76.200 & 76.177 & 76.155 & 76.132 & 76.109 & 76.087 \\ 75.973 & 75.950 & 75.927 & 75.905 & 75.882 & 75.850\end{array}$ $\begin{array}{llllll}75.746 & 75.723 & 75.700 & 75.677 & 75.655 & 75.632 \\ 75.518 & 75.495 & 75.473 & 75.450 & 75.427 & 75.405\end{array}$ $\begin{array}{lllllll}75.291 & 75.268 & 75.245 & 75.223 & 75.200 & 75.177\end{array}$ $\begin{array}{llllll}74.609 & 74.586 & 74.563 & 74.541 & 74.518 & 740\end{array}$ $\begin{array}{lllllll}71.882 & 71.859 & 71.836 & 71.814 & 71.791 & 71.768\end{array}$ $\begin{array}{llllll}71.654 & 71.632 & 71.836 & 71.814 & 71.791 & 71.768 \\ 71.058 & 71.564 & 71.541\end{array}$

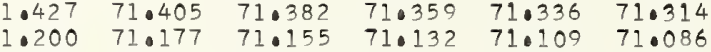
$\begin{array}{llllll}70.973 & 70.950 & 70.927 & 70.905 & 70.882 & 70.859\end{array}$ $\begin{array}{llllll}70.746 & 70.723 & 70.700 & 70.677 & 70.655 & 70.632\end{array}$ $\begin{array}{llllll}70.291 & 70.269 & 70.246 & 70.223 & 70.200 & 70.405\end{array}$ $\begin{array}{llllll}70.064 & 70.041 & 70.019 & 69.996 & 69.973 & 69.951 \\ 69.837 & 60.814 & 69.702 & 69.769 & 69.746 & 69.724\end{array}$ $\begin{array}{llllll}69.610 & 69.587 & 69.564 & 69.542 & 69.519 & 69.496\end{array}$

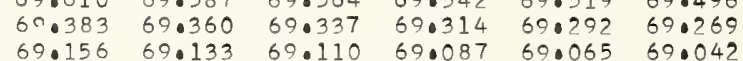
$\begin{array}{llllll}68.928 & 68.133 & 69.1110 & 69.087 & 69.065 & 69.042 \\ 68.98 & 68.883 & 68.860 & 68.838 & 68.815\end{array}$ $68.701 \quad 68.679 \quad 68.656 \quad 68.633 \quad 68.610 \quad 68.588$ $68.474 \quad 68.451 \quad 68.429 \quad 68.406 \quad 68.383 \quad 68.361$ $\begin{array}{llllll}68.247 & 68.224 & 68.202 & 68.179 & 68.156 & 68.133\end{array}$ $\begin{array}{llllll}68.020 & 67.9997 & 67.974 & 67.952 & 67.929 & 670906\end{array}$ $\begin{array}{llllll}67.566 & 67.543 & 67.520 & 67.498 & 67.475 & 670452\end{array}$ $\begin{array}{lllllll}67.339 & 67.316 & 67.293 & 67.271 & 67.248 & 67.225\end{array}$ $\begin{array}{llllll}67.111 & 67.089 & 67.066 & 67.043 & 67.021 & 66.998\end{array}$ $\begin{array}{llllll}66.657 & 66.0635 & 66.612 & 66.589 & 66.567 & 66.544\end{array}$ $\begin{array}{llllll}66.430 & 66.408 & 66.385 & 66.362 & 66.339 & 66.317\end{array}$ $\begin{array}{llllll}66.203 & 66.181 & 66.158 & 66.135 & 66.112 & 66.090\end{array}$ $\begin{array}{llllll}65.749 & 65.727 & 65.704 & 65.681 & 65.658 & 65.835\end{array}$ $\begin{array}{llllll}65.522 & 65.499 & 65.477 & 65.454 & 65.431 & 65.409\end{array}$ $65.068 \quad 65.045 \quad 650023 \quad 65.00064 .977 \quad 64.955$ $\begin{array}{llllll}64 \cdot 841 & 64.818 & 64 \cdot 796 & 64.773 & 64.750 & 64.728 \\ 640614 & 64.591 & 64.569 & 64.546 & 64.523 & 64.500\end{array}$ $\begin{array}{llllll}64.614 & 64.591 & 64.569 & 64.546 & 64.523 & 64.500 \\ 64.387 & 64.364 & 64.342 & 64.310 & 64.206 & 64.274\end{array}$ $\begin{array}{lllllll}64.160 & 64.137 & 64.115 & 64.092 & 64.069 & 64.047\end{array}$

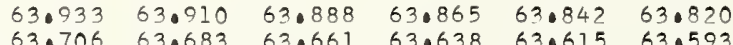
$\begin{array}{llllll}63.706 & 63.683 & 63.661 & 63.638 & 63.615 & 63.593 \\ 63.479 & 63.456 & 63.434 & 63.411 & 63.388 & 63.366\end{array}$ $\begin{array}{llllll}63.252 & 63.229 & 63.207 & 63.184 & 63.161 & 63.139 \\ 63.025 & 63.002 & 62.980 & 62.057 & 62.034 & 62.912\end{array}$ $\begin{array}{lllllll}62.798 & 62.776 & 62.753 & 62.730 & 62.708 & 62.685\end{array}$

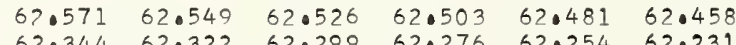
$\begin{array}{llllll}62.117 & 62.095 & 62.072 & 62.049 & 62.027 & 62.004\end{array}$ $\begin{array}{llllll}61.891 & 61.868 & 61.845 & 61.822 & 61.800 & 61.0777\end{array}$ $\begin{array}{llllll}1.664 & 61.641 & 61.618 & 61.595 & 61.573 & 61.550\end{array}$ $\begin{array}{llllll}0.210 & 61.187 & 61.164 & 61.1142 & 61.110 & 61.096\end{array}$ $60.983 \quad 60.960 \quad 60.937 \quad 60.915 \quad 60.892 \quad 60.869$

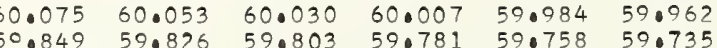
$59.622 \quad 59.599 \quad 59.576 \quad 59.553 \quad 59.531 \quad 59.508$ $59.395 \quad 59 \cdot 372 \quad 59 \cdot 349 \quad 59 \cdot 327 \quad 59 \cdot 304 \quad 59 \cdot 281$ $59.168 \quad 59 \cdot 145 \quad 59 \cdot 122 \quad 59 \cdot 100 \quad 59 \cdot 077 \quad 59 \cdot 054$

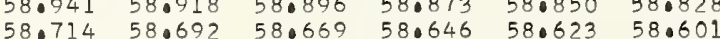
$\begin{array}{llllll}58.0147 & 58.692 & 58.669 & 58.646 & 58.623 & 58.601 \\ 58.487 & 58.465 & 58.442 & 58.419 & 58.397 & 58.374\end{array}$ $\begin{array}{llllllllll}5058.351 & 58.329 & 58.306 & 58.283 & 58.261 & 58.238 & 58.215 & 58.193 & 58.170 & 58.147\end{array}$ $\begin{array}{lllllllllll}9.2 & 57.898 & 57.875 & 57.852 & 57.830 & 57.807 & 57.784 & 57.762 & 57.739 & 57.716 & 57.694\end{array}$ $\begin{array}{lllllllllll}9.3 & 57.671 & 57.648 & 57.625 & 57.603 & 57.580 & 57.557 & 57.535 & 57.512 & 57.490 & 57.467 \\ 9.4 & 57.444 & 57.421 & 57.399 & 57.376 & 57.353 & 57.331 & 57.308 & 57.285 & 57.263 & 57.0240\end{array}$ $\begin{array}{lllllllllll}0.5 & 57.444 & 57.421 & 57.399 & 57.376 & 57.353 & 57.331 & 57.308 & 57.285 & 57.263 & 57.240\end{array}$ $\begin{array}{lllllllllll}0.6 & 57.217 & 57.195 & 57.172 & 57.149 & 57.126 & 57.104 & 57.081 & 57.059 & 57.036 & 57.013\end{array}$ $\begin{array}{lllllllllll}56.764 & 56.741 & 56.718 & 56.006 & 56.073 & 56.651 & 56.528 & 56.505 & 56.582 & 56.560\end{array}$ $\begin{array}{llllllllll}56.537 & 56.514 & 56.492 & 56.469 & 56.446 & 56.424 & 56.401 & 56.378 & 56.356 & 56.333 \\ 56.310 & 56.288 & 56.265 & 56.242 & 56.220 & 56.197 & 56.174 & 56.152 & 56.129 & 56.106\end{array}$ 001

0.276159

0.276159

0.276159

1.831216

0.276159

0.276159

0.276158

0.276158

0.276158

0.276158

0.276158
0.276158

1.831243

1.831290

1.831324

1.831378

1.831405

0.276158

0.276157

0.276157

0.276157

0.276157

0.276157

0.276157

0.276157

0.077615

0.276156

0.27615

0.276156

0.0276156

0.276156

0.276156

0.276155

0.276155

0.276155
0.276155

0.27615

0.276155
0.076155
0

0.27615

0.276154

0.276154

0.276154
0.276154

0.276154

0.276154

0.276154

D.

0.276153

1.831485

10831512

1.831566 1.831593

1.831620
1.831647 1.831673

1.831700
1.831727

0.27615 0.276153 0.27615 0.276153 0.276153 


$.02 \quad .03$

.04

6640.0

15056

$\begin{array}{lll}056.083 & 56.061 & 56.038 \\ 55.857 & 55.834 & 55.812 \\ 55.630 & 55.607 & 55.585 \\ 55.403 & 55.381 & 55.358 \\ 55.177 & 55.154 & 55.131 \\ 54.950 & 54.927 & 54.905 \\ 54.723 & 54.700 & 54.678 \\ 54.496 & 54.474 & 54.451 \\ 54.270 & 54.247 & 54.224 \\ 54.043 & 54.020 & 53.998\end{array}$

$$
641:
$$

$15053.816 \quad 53.794 \quad 530$ $\begin{array}{llllllllll}53.590 & 53.567 & 53.544 & 53.748 & 53.726 & 53.703 & 53.680 & 53.658 & 53.635 & 53.612\end{array}$ $\begin{array}{llllllllll}53.363 & 53.340 & 53.318 & 53.295 & 53.272 & 53.250 & 53.227 & 53.204 & 53.182 & 53.150\end{array}$ $\begin{array}{llllllllll}53.136 & 53.114 & 53.091 & 53.068 & 53.046 & 53.023 & 53.000 & 52.978 & 52.955 & 52.932\end{array}$ $\begin{array}{llllllllll}52.683 & 52.660 & 52.638 & 52.615 & 52.592 & 52.570 & 52.747 & 52.751 & 52.728 & 52.706\end{array}$

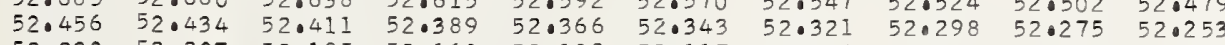
$\begin{array}{llllllllll}52.230 & 52.207 & 52.185 & 52.162 & 52.139 & 52.117 & 52.094 & 52.071 & 52.049 & 52.026\end{array}$ $\begin{array}{llllllllll}52.003 & 51.981 & 51.958 & 51.935 & 51.913 & 51.890 & 51.867 & 51.845 & 51.822 & 51.799 \\ 51.777 & 51.754 & 51.731 & 51.709 & 51.686 & 51.663 & 51.641 & 51.618 & 51.595 & 51.573\end{array}$

$(n-1) \times 1000$

$\lambda(n-1)$

0.276150

0.276150

0.276150
0.276150
0.27650

0.0276149

0.276149

0.276149
0.276149

0.276149

0.276149

0.276149

0.276148

0.276148

0.276148

0.276148

0.276148

0.0276148
0.276147
0.27649

0.276147

0.276147
0.276147

0.276147
0.276147
0.27614

0.0276147

0.076146

0.276146

0.276146

0.276146
0.276146

0.076146

0.276146
0.276145

0.276145

0.276145
0.276145
0.2765

0.276145

0.276145

0.276145

0.276145

0.276144
0.0276144
0.27644

0.276144
0.0276144
0.27644

0.276144
0.276144
0.227614

0.276144
0.276144

0.276144

0.276143
0.276143
0

列

0.276143

0.276143

0.276142

0.276142
0.276142
0

0.276142
0.276142

0.276142
0.276142
0.2762

0.276142
0.276142

0.276142
0.276141

0.276141

0.276141
0.276141

0.276141
0.27614
0.2761

0.276141
0.276141
0.027614

0.276141

0.276140
0.276140

0.276140
0.276140

0.276140

0.276140
0.276140
0.27610

0.276140

0.276140
0.276140

0.276140
0.276139

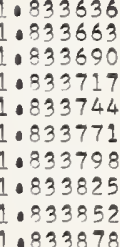

1.833905

1.833959

1.834013

1.834057

1.834120

1.234174

1.834228

1. 834282

1.834336

1.8343628
1.834389

1.834416

1.0834443
1.834470

1.834497

1. 0.834524

1.834578

1.834631

1.834658
1.834685

1.234712

1. 834739

1.834993

9.834847

1.834873

1.834927

1.834981

1.835008

1.835062

1.835089
1.835115

1.835142

1.835169
1.835196

1.835250

1.835277

1.835331

1.835324

1.835438

.835465

1.835519

1.835546
1.835573

.835599

1.835626
1.835653

1.835680

1.835734

1.835788

1.835815
1.835841

1.835868
1.835895

1.835922

1.835949
1.835976

1.836003

1.836057

1.836084
1.836110

1.836164

1.836191
1.836218

1.836245

1.836272
1.836299

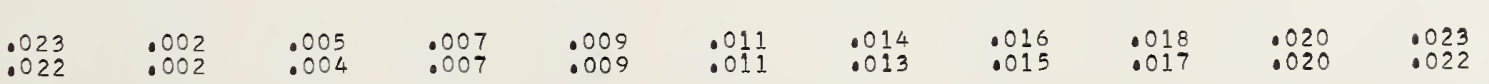




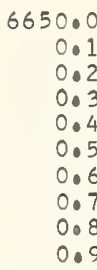

6651.0
1.1
1.2
1.3
1.4
1.5
1.6
1.7
1.8
1.9

665200

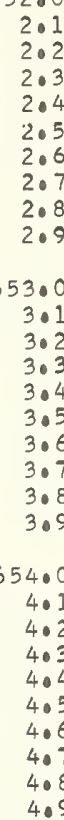

6655.

5.1
5.2
5.3
5.4
5.5
5.6
5.7
5.9

6656.0

6.9

6.:

6.4
6.5

6.6
6.7

6.8
6.9

6657

$$
\text { 望 }
$$

6658.0

$$
\begin{array}{r}
658 . \\
8 \\
8 . \\
8 . \\
8 . \\
8 \\
8 . \\
8 . \\
8 .
\end{array}
$$

$\begin{array}{llllllllll}33.217 & 33.420 & 33.398 & 33.375 & 33.353 & 33.330 & 33.307 & 33.285 & 33.262 & 33.240 \\ 33.172 & 33.149 & 33.126 & 33.104 & 33.081 & 33.059 & 33.036 & 33.014\end{array}$ $\begin{array}{lllllllllll}32.991 & 32.968 & 32.946 & 32.923 & 32.901 & 32.878 & 32.855 & 32.833 & 32.810 & 32.787 \\ 32.765 & 32.742 & 32.720 & 32.697 & 32.674 & 32.652 & 32.629 & 32.607 & 32.584 & 32.561\end{array}$ $\begin{array}{llllllllll}32.765 & 32.742 & 32.720 & 32.697 & 32.674 & 32.652 & 32.629 & 32.607 & 32.584 & 32.561 \\ 32.539 & 32.516 & 32.494 & 32.471 & 32.448 & 32.426 & 32.403 & 32.381 & 32.358 & 32.335\end{array}$ $\begin{array}{llllllllll}32.539 & 32.516 & 32.494 & 32.471 & 32.448 & 32.426 & 32.403 & 32.381 & 32.358 & 32.335 \\ 32.313 & 32.290 & 32.267 & 32.245 & 32.222 & 32.200 & 32.177 & 32.155 & 32.132 & 32.109\end{array}$ $\begin{array}{llllllllll}32.313 & 32.290 & 32.267 & 32.245 & 32.222 & 32.200 & 32.177 & 32.155 & 32.132 & 32.109 \\ 32.087 & 32.064 & 32.042 & 32.019 & 31.996 & 31.974 & 31.951 & 31.928 & 31.906 & 31.883\end{array}$ $\begin{array}{llllllllll}31.861 & 31.838 & 31.816 & 31.793 & 31.770 & 31.748 & 31.725 & 31.702 & 31.680 & 31.657\end{array}$ $\begin{array}{llllllllll}31.635 & 31.612 & 31.589 & 31.567 & 31.544 & 31.522 & 31.499 & 31.477 & 31.454 & 31.431\end{array}$ 31.160 $30.957 \quad 30.160 \quad 31.137 \quad 31.115$ $\begin{array}{llll}30.731 & 30.708 & 30.685 & 30.66\end{array}$ $\begin{array}{llll}30.505 & 30.482 & 30.460 & 30.43\end{array}$ $\begin{array}{llll}30.279 & 30.256 & 30.233 & 30.211 \\ 30.053 & 30.030 & 30.008 & 29.985\end{array}$ $30.05330 .030 \quad 30.008$ $29.827 \quad 29.804$ $\begin{array}{llll}29.601 & 29.578 & 29.556 & 29.533\end{array}$ $\begin{array}{llll}29.375 & 29.352 & 29.330 & 29.307 \\ 29.149 & 29.126 & 29.104 & 29.081\end{array}$ $31.0092 \quad 31.070$ $30.640 \quad 30.618$ $\begin{array}{ll}30.414 & 30.392 \\ 30.188 & 30.166\end{array}$ $\begin{array}{ll}30.188 & 30.166 \\ 29.962 & 29.940\end{array}$ $29.736 \quad 29.714$ $29.510 \quad 29.488$ 28.697
28.47 28.24528 .449 $\begin{array}{ll}28.245 & 28.223 \\ 28.019 & 27.997\end{array}$

28.878 $\begin{array}{lll}27.793 & 27.771 & 27.74 \\ 27.568 & 27.545 & 27.52\end{array}$ $\begin{array}{llll}27.568 & 27.545 & 27.522 & 27.500\end{array}$ $\begin{array}{ll}27.116 & 27.093 \\ 26.890 & 26.867\end{array}$ $\begin{array}{ll}27.296 & 27.274\end{array}$ $\begin{array}{ll}29.284 & 29.262 \\ 29.059 & 29.036\end{array}$ $31.273 \quad 310$

5026.664

$26.438 \quad 26.41$

$26.212 \quad 26.190 \quad 26.1$

$25.761 \quad 25.738$

$25.535 \quad 25.512 \quad 25.71$

$25.309 \quad 25.286 \quad 25.264 \quad 25.241$

$\begin{array}{ll}25.083 & 25.061 \\ 24.857 & 24.835\end{array}$

$24.631 \quad 24.609$

$15024 \cdot 406 \quad 24 \cdot 383$

$\begin{array}{ll}24.180 & 24.157 \\ 23.954 & 23.932\end{array}$

$23.728 \quad 23.706 \quad 23.683$

$\begin{array}{lll}23.503 & 23.480 & 23.45 \\ 23.277 & 23.254 & 23.23\end{array}$

$\begin{array}{lll}23.277 & 23.254 & 23.232 \\ 23.051 & 23.028 & 23.006\end{array}$

$\begin{array}{lll}22.599 & 22.577 & 22.554 \\ 22.374 & 22.351 & 22.329\end{array}$

$15022.148 \quad 22.126 \quad 22.10$

$\begin{array}{lll}21.922 & 21.900 & 21.877 \\ 21.697 & 21.674 & 21.65\end{array}$

$\begin{array}{lll}21.697 & 21.674 & 21.65 \\ 21.471 & 21.448 & 21.42\end{array}$

$21.020 \quad 20.097 \quad 20.075 \quad 21.178$

$\begin{array}{llll}20.794 & 20.771 & 20.749 & 20.726\end{array}$

$\begin{array}{lll}20.568 & 20.546 & 20.523 \\ 20.343 & 20.320 & 20.298 \\ 20.117 & 20.094 & 20.072\end{array}$

$19.666-19.869$

$19.440 \quad 19.417$

$\begin{array}{ll}19.214 & 19.192 \\ 18.989 & 18.96\end{array}$

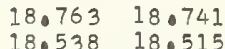

$18.312 \quad 18.289$

$\begin{array}{ll}18.086 & 18.064 \\ 17.861 & 17.838\end{array}$

$15017.635 \quad 17.613$

$\begin{array}{ll}17.410 & 17.387 \\ 17.184 & 17.161\end{array}$

16.958 16.93

$16.507 \quad 16.485$

$\begin{array}{ll}16.282 & 16.25 \\ 16.056 & 16.034\end{array}$

$\begin{array}{ll}15.831 & 15.808 \\ 15.605 & 15.583\end{array}$

$15015.380 \quad 15.357$

15.154

$\begin{array}{ll}14.929 & 14.9 \\ 14.703 & 14.681\end{array}$

$24.478 \quad 14.455$

$14.252 \quad 14.229$

$13.801 \quad 13.779$

$\begin{array}{lllllll}13.576 & 13.553 & 13.531 & 13.508 & 13.485 & 13.463 & 1 \\ 13.350 & 13.328 & 13.305 & 13.283 & 13.260 & 13.237 & 130\end{array}$

$19.846 \quad 19.824$

19.395

$19.169 \quad 19.14$

$18.718 \quad 18.696$

$\begin{array}{ll}18.492 & 18.47 \\ 18.267 & 18.244\end{array}$

28.833

$\begin{array}{ll}28.607 & 28.584 \\ 28.381 & 28.358 \\ 28.155 & 28.132\end{array}$

$27.929 \quad 27.906$

$\begin{array}{llll}31.047 & 31.025 & 31.002 & 30.979 \\ 30.821 & 30.798 & 30.776 & 30.753\end{array}$

$\begin{array}{llll}30.595 & 30.573 & 30.550 & 30.527\end{array}$

$\begin{array}{llll}30.369 & 30.347 & 30.324 & 30.301\end{array}$

$\begin{array}{llll}30.143 & 30.120 & 30.098 & 30.075 \\ 29.917 & 29.895 & 29.872 & 29.849\end{array}$

$\begin{array}{llll}29.691 & 29.669 & 29.646 & 29.623\end{array}$

$29.465 \quad 29.443 \quad 29.420 \quad 29.397$

$\begin{array}{llll}29 \cdot 239 & 29 \cdot 217 & 29 \cdot 194 & 29 \cdot 172 \\ 29.013 & 28.991 & 28.968 & 28.946\end{array}$

$\begin{array}{llll}28.787 & 28.765 \quad 28.742 \quad 28.720\end{array}$

$\begin{array}{llll}28.562 & 28.539 & 28.516 & 28.494 \\ 28.336 & 28.313 & 28.290 & 28.268\end{array}$

$\begin{array}{llll}28.110 & 28.087 & 28.065 & 28.042\end{array}$

$\begin{array}{llllll}27.703 & 27.680 & 27.658 & 27.635 & 27.613 & 27.590\end{array}$

$\begin{array}{llllll}27.4477 & 27.455 & 27.432 & 27.409 & 27.387 & 27.364\end{array}$

$\begin{array}{lllllll}27.251 & 27.229 & 27.206 & 27.183 & 27.161 & 27.138\end{array}$

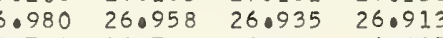

$\begin{array}{llll}26.754 & 26.732 & 26.709 & 26.687\end{array}$

$\begin{array}{llll}6.529 & 26.506 & 26.483 & 26.461 \\ 26.303 & 26.280 & 26.258 & 26.235\end{array}$

$26.077 \quad 26.054 \quad 26.032 \quad 26.009$

$\begin{array}{llll}25.851 & 25.828 & 25.806 & 25.783\end{array}$

$\begin{array}{llll}25.625 & 25.603 & 25.580 & 25.557\end{array}$

$\begin{array}{lllllll}25.444 & 25.422 & 25.399 & 25.377 & 25.354 & 25.332\end{array}$

$\begin{array}{llllll}25.219 & 25.196 & 25.173 & 250151 & 25 \cdot 128 & 25.106\end{array}$

$\begin{array}{llllll}24.993 & 24.970 & 24.948 & 24.925 & 24.903 & 24.880\end{array}$

$\begin{array}{ll}4.767 & 24.744 \\ 24.541 & 24.519\end{array}$

24.722

24.496

4.699

$\begin{array}{ll}24 \cdot 677 & 24 \cdot 654 \\ 24 \cdot 451 & 24.428\end{array}$

24.31524 .293

$\begin{array}{llll}24 \cdot 270 & 24 \cdot 248 & 24 \cdot 225 & 24 \cdot 203 \\ 24.044 & 24.022 & 23.990 & 23.977\end{array}$

$\begin{array}{llll}24.044 & 24.022 & 23.999 & 23.977 \\ 23.819 & 23.796 & 23.773 & 23.751\end{array}$

$\begin{array}{llllll}23.638 & 23.615 & 23.593 & 23.570 & 23.548 & 23.525 \\ 22.412 & 23.390 & 23.367 & 23.345 & 23.322 & 23.299\end{array}$

\begin{tabular}{llllll}
23.187 & 23.164 & 23.141 & 23.119 & 23.096 & 23.074 \\
\hline
\end{tabular}

$\begin{array}{llllll}22.735 & 22.713 & 22.690 & 22.667 & 22.645 & 22.622\end{array}$

$\begin{array}{llllll}22.735 & 22.713 & 22.690 & 22.667 & 22.645 & 22.622 \\ 22.509 & 22.487 & 22.464 & 22.442 & 22.419 & 22.396\end{array}$

$\begin{array}{llll}22.464 & 22.442 & 22.419 & 22.396 \\ 22.238 & 22.216 & 22.193 & 22.171\end{array}$

$\begin{array}{llllll}22.058 & 22.035 & 22.013 & 21.990 & 21.968 & 21.945\end{array}$

$\begin{array}{llllll}21.832 & 21.809 & 21.787 & 21.764 & 21.742 & 21.719 \\ 21.606 & 21.584 & 21.561 & 21.539 & 21.516 & 21.0494\end{array}$

$\begin{array}{llllll}21.381 & 21.358 & 21.336 & 21.313 & 21.291 & 21.268\end{array}$

$\begin{array}{llllll}21.155 & 21.133 & 21.110 & 21.088 & 21.065 & 21.042\end{array}$

$\begin{array}{llllll}20.929 & 20.907 & 20.884 & 20.862 & 20.839 & 20.817\end{array}$

$\begin{array}{llllll}20.704 & 20.681 & 20.659 & 20.636 & 20.614 & 20.591 \\ 20.478 & 20.456 & 20.433 & 20.410 & 20.388 & 20.365\end{array}$

$\begin{array}{llllll}20.252 & 20.230 & 20.207 & 20.185 & 20.162 & 20.140\end{array}$

$\begin{array}{llllll}19.801 & 19.779 & 19.756 & 19.734 & 19.711 & 19.688\end{array}$

$\begin{array}{llllll}19.350 & 19.327 & 19.305 & 19.282 & 19.260 & 19.237\end{array}$

$\begin{array}{lllllll}19.124 & 19.102 & 19.079 & 19.057 & 19.034 & 19.011\end{array}$

$\begin{array}{lllllll}18.899 & 18.876 & 18.853 & 18.831 & 18.808 & 18.786\end{array}$

$\begin{array}{llllll}18.673 & 18.650 & 18.628 & 18.605 & 18.583 & 18.560 \\ 18.447 & 18.425 & 18.402 & 18.380 & 18.357 & 18.335\end{array}$

$\begin{array}{llllll}18.447 & 18.425 & 18.402 & 18.380 & 18.357 & 18.335 \\ 18.222 & 18.199 & 18.177 & 18.154 & 18.131 & 18.109\end{array}$

$\begin{array}{llll}18.041 & 18.019 & 17.996 & 17.9 \\ 17.816 & 17.793 & 17.771 & 17.7\end{array}$

$\begin{array}{lllll}18.177 & 18.154 & 18.131 & 18.109\end{array}$

$17.590 \quad 17.56$

17.545

7.748

$17.725 \quad 17.703 \quad 17.680 \quad 17.658$

$\begin{array}{llllllll}17.139 & 17.116 & 17.094 & 17.071 & 17.049 & 17.026 & 17.003 & 16.981\end{array}$

$\begin{array}{lllllllll}16.913 & 16.891 & 16.868 & 16.846 & 16.823 & 16.801 & 16.778 & 16.755\end{array}$

$\begin{array}{llllllll}16.688 & 16.665 & 16.643 & 16.620 & 16.598 & 16.575 & 16.552 & 16.530 \\ 16.462 & 16.440 & 16.417 & 16.394 & 16.372 & 16.349 & 16.327 & 16.304\end{array}$

$\begin{array}{llllllll}16.237 & 16.214 & 16.192 & 16.169 & 16.146 & 16.124 & 16.101 & 16.079\end{array}$

$\begin{array}{llllllll}15.786 & 15.763 & 15.740 & 15.718 & 15.695 & 15.673 & 15.650 & 15.628\end{array}$

$\begin{array}{llllllll}15.334 & 15.312 & 15.289 & 15.267 & 15.244 & 15.222 & 15.199 & 15.177\end{array}$

$\begin{array}{llllllll}15.109 & 15.087 & 15.064 & 15.041 & 15.019 & 14.996 & 14.974 & 14.95\end{array}$

$\begin{array}{llllllll}14.883 & 14.861 & 14.838 & 14.816 & 14.793 & 14.771 & 14.748 & 14.726\end{array}$

$\begin{array}{llllllll}14.658 & 14.635 & 14.613 & 14.590 & 14.568 & 14.545 & 14 \cdot 523 & 14.500 \\ 14.432 & 14.410 & 14.387 & 14.365 & 14.342 & 14.320 & 14.297 & 14.275\end{array}$

$\begin{array}{lllllllll}14.207 & 14.184 & 14.162 & 14.139 & 14.117 & 14.094 & 14.072 & 14.049\end{array}$

$\begin{array}{lllllllll}13.981 & 13.959 & 13.936 & 13.914 & 13.891 & 13.869 & 13.846 & 13.824\end{array}$

$3.440 \quad 13.418 \quad 13.395 \quad 13.598$

$13.215 \quad 13.192 \quad 13.170 \quad 130149$$$
\begin{aligned}
& 12 \\
& 12 \\
& 12 \\
& 12 \\
& 11 \\
& 11 \\
& 11 \\
& 11 \\
& 110
\end{aligned}
$$

$\begin{array}{llllllllll}13.125 & 13.102 & 13.080 & 13.057 & 13.034 & 13.012 & 12.989 & 12.967 & 12.944 & 12.922 \\ 12.899 & 12.877 & 12.854 & 12.832 & 12.809 & 12.786 & 12.764 & 12.741 & 12.719 & 12.696 \\ 12.674 & 12.651 & 12.629 & 12.606 & 12.584 & 12.561 & 12.539 & 12.516 & 12.493 & 12.471\end{array}$

$\begin{array}{llllllll}12.629 & 12.606 & 12.584 & 12.561 & 12.539 & 12.516 & 12.493 & 12.471\end{array}$

$\begin{array}{llllllllll}223 & 12.200 & 12.178 & 12.155 & 12.133 & 12.110 & 12.088 & 12.065 & 12.043 & 12.020\end{array}$

$\begin{array}{llllllllll}1.997 & 11.975 & 11.952 & 11.930 & 11.907 & 11.885 & 11.862 & 11.840 & 11.817 & 11.795\end{array}$

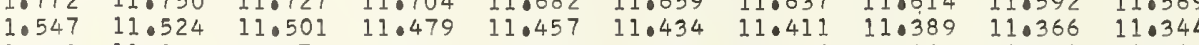

$11.096 \quad 11.073$

0.276139
0.276139

0.276139

0.276139

0.276139

0.276139

.276138

0.276138

0.276138

0.296138

0.276138
0.276138

0.276138

0.276138

0.276137

0.276137

0.276137

0.276137

0.276137
0.276137

0.276137

0.276137

0.276136

0.276136

.276136

0.276136

0.276136

0.276136

0.276135

0.276135

0.276135

0.276135

0.276135

0.276135

0.276135

0.276134

0.276134

.276134

0.276134

0.276134

0.276134

0.276134

0.276133

0.276133

0.276133

0.276133
0.276133

0.276133

0.276133

0.276133

0.276132

0.276132
0.276132

0.276132

0.276132

0.276132

0.276132

0.276132

0.276131

0.276131

0.276131

0.276131

0.27613

0.276131
0.276131

0.276131

0.276130

0.276130

0.276130

0.276130

0.276130

0.276130

1.836326

1.836379

1.836406

1.836433

1.836460

1.836487

1.836541

1.836594

1.836621

1.836648

1.836675

1.836729

1.836756

1.836783
1.836810

1.836836

1.836863

1.836890

1.836917
1.836944 


.04

0.276122

0.0276122
0.276122

0.276122

0.27612

0.0276121
0.276121

0.276121

0.0276121
0.076121

0.276120

0.276120

0.276120
0.276120
0.27620

0.276120
0.276120
0.27620

0.276120

0.276120
0.076120
0.27120

0.276119

0.276119
0.276110
0.2619

0.276119

0.27619
0.276119

0.27619
0.276119

.839122

1.839176

1.839203

1.839257

1.839284

1.839337

1.839364

1.839418

1.839445

1.83949

1.839553

1.839580
1.839606

1.839633
1.839660

1.839687

1.839714

1.839768
1.839795

1.839822

1.839848
1.839875

1.839902

1.839956

1.839983

1.840037

1.840090
1.840117

1.840144
1.840171

1.840225

1.840279
1.840306

1.840306
1.840333

1.840359

1.840386
1.840413

1.840440

1.840467

1.840521

1. 840548

1.840601

1.840628

1.840655
1.840682

1.840709

1.840736
1.840763

1.840790

1.:0408042

1.840897

1.840924

1.840978

1.841005

1.841032
1.841059

1.841086

$\underset{10.84139}{1.8412}$

0.276119

0.276118

0.0276118

0.027618
0.276118

0.276118
0.276118
0.27618

0.276118

1.841166

1.841220

1.841274

1.841328

1.841381

.841408

.841435

1.841489

1.841516

1.841570

1.841597
1.841623

1.841650

.010

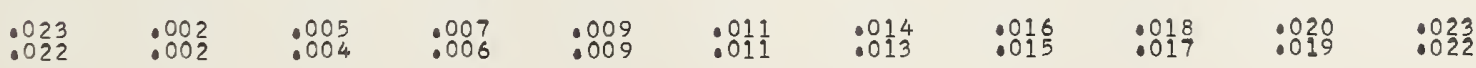


4]. $235 \quad 41.213 \quad 41$.

$\begin{array}{llll}.860 & 41.838 & 41.815 & 41.793\end{array}$ $4939.092 \quad 39.069$ 39.717
39.493 39.917
39.694

$40.788 \quad 40$

$40.565 \quad 40.543$

$40.118 \quad 40.096$

$39.895 \quad 39.873$ $\begin{array}{llll}38.645 & 38.623 & 38.600 & 38.578 \\ 38.422 & 38.400 & 38.377 & 38.355\end{array}$ $\begin{array}{llll}38.199 & 38.176 & 38.154 & 38.132\end{array}$ $\begin{array}{llll}37.975 & 37.953 & 37.931 & 37.908\end{array}$ $37.520 \quad 37.507$ $\begin{array}{ll}37.306 & 37.284 \\ 37.083 & 37.060\end{array}$

$\begin{array}{ll}37.484 & 37.462 \\ 37.261 & 37.230 \\ 37.038 & 37.016\end{array}$

14936.8

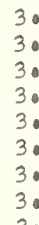

3.2

3.3 $34.628 \quad 34.606$ $\begin{array}{lll}34.160 & 34.137 & 34.115\end{array}$ $33.736 \quad 33.713 \quad 33.691 \quad 33.669$ $\begin{array}{lll}33.200 \quad 33.267 & 33.468\end{array}$

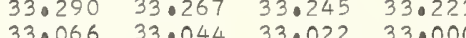
$\begin{array}{rrr}14930.167 & 30.145 & 30.123 \\ 29.944 & 29.922 & 29.900\end{array}$

$\begin{array}{lll}29.721 & 29.699 & 29 . \\ 29.498 & 29.476 & 29 \\ 29.276 & 29.253 & 29\end{array}$ $\begin{array}{llll}29.276 & 29.253 & 29.231 & 29.200 \\ 29.052 & 29.030 & 29.008 & 28.086\end{array}$ $\begin{array}{llllll}28.830 & 28.307 & 29.008 & 28.986 & 28.186 & 29.164 \\ 28.785 & 28.963 & 28.740 & 28.941 \\ 28.807 & 28.74\end{array}$ $\begin{array}{llll}28.607 & 28.584 & 28.562 & 28.540 \\ 28.384 & 28.362 & 28.339 & 28.317 \\ 28.161 & 28.138 & 28.116 & 28.094\end{array}$ $\begin{array}{ll}28.518 & 28.495 \\ 28.295 & 28.272 \\ 28.072 & 28.049\end{array}$ 36.172

$37 \cdot 150$
36.926

$\begin{array}{llllll}36.770 & 36.748 & 36.726 & 36.703 & 36.681 & 36.659\end{array}$ $\begin{array}{llllll}36.547 & 36.525 & 36.502 & 36.480 & 36.458 & 36.435 \\ 36.324 & 36.302 & 36.279 & 36.257 & 36.235 & 36.012\end{array}$ $\begin{array}{lllllll}36.101 & 36.078 & 36.056 & 36.034 & 36.011 & 35.989\end{array}$ \begin{tabular}{llllll}
35.654 & 35.632 & 35.610 & 35.811 & 35.788 & 35.768 \\
\hline
\end{tabular} $\begin{array}{llllll}35.431 & 35.409 & 35.387 & 35.364 & 35.342 & 35 \cdot 320 \\ 35.208 & 35.186 & 35.164 & 35.141 & 35.110 & 35.097\end{array}$ $34.985 \quad 34.963 \quad 34.940 \quad 34.918 \quad 34.896 \quad 34.874$ $34.539 \quad 34.516 \quad 34.494 \quad 34.472 \quad 34.450 \quad 34.427$ $\begin{array}{llllll}34.316 & 34.293 & 34.271 & 34.249 & 34.227 & 34.204 \\ 34.093 & 34.070 & 34.048 & 34.026 & 34.003 & 33.981\end{array}$ $\begin{array}{llllll}34.093 & 34.070 & 34.048 & 34.026 & 34.003 & 33.981 \\ 33.870 & 33.847 & 33.825 & 33.803 & 33.780 & 33.758\end{array}$ $\begin{array}{llllll}33.647 & 33.624 & 33.602 & 33.579 & 33.557 & 33.535 \\ 33.423 & 33.401 & 33.379 & 33.357 & 33.334 & 33.312\end{array}$ $32.200 \quad 33.178 \quad 33.156 \quad 33.133 \quad 33.111 \quad 33.089$ $\begin{array}{llll}4927.938 & 27.916 & 27 \cdot 894 & 27 \cdot 871\end{array}$ $\begin{array}{llll}27.715 & 27.693 & 27.671 & 27.64 \\ 27.492 & 27.470 & 27.448 & 27.426 \\ 27.269 & 27.247 & 27.225 & 27.203\end{array}$ $27.047 \quad 27.024 \quad 27.002 \quad 26.980$ $\begin{array}{llll}26.824 & 26.801 & 26.779 & 26.75 \\ 26.601 & 26.578 & 26.556 & 26.53\end{array}$ $27.849 \quad 27.827$ $26.378 \quad 26.356 \quad 26.333 \quad 26.311$ $\begin{array}{ll}27.626 & 27.6004 \\ 27.403 & 27.381\end{array}$

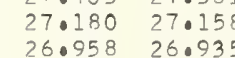
$\begin{array}{llll}26.958 & 26.935 & 26.91\end{array}$ $\begin{array}{llll}26.734 & 26.712 & 26.690\end{array}$ $25.932 \quad 25.910 \quad 25.888 \quad 25.865$

$14925 \cdot 709$

$8 \cdot 1$

8.2

8.4

8.5
8.6

8.7
8.8

\subsection{2
$9: 3$
$9: 4$}

9.4

9.6
9.7
9.8

$25.487 \quad 25.464$

$\begin{array}{llll}25.264 & 25.464 & 25.442 & 25.420\end{array}$

$25.041 \quad 250010 \quad 25 \cdot 219 \quad 25 \cdot 197$

$\begin{array}{llll}24 \cdot 818 & 24.796 & 24.773 & 24.751 \\ 24.595 & 24.573 & 24.551 & 24.528 \\ 24.372 & 24.350 & 24.328 & 24.306\end{array}$

$\begin{array}{llll}24.372 & 24.350 & 24 \cdot 328 & 24 \cdot 306 \\ 24.150 & 24.127 & 24.105 & 24.083 \\ 23.027 & 23.005 & 23.882 & 23.860\end{array}$

$\begin{array}{ll}23.927 & 23.905 \\ 23.704 & 23.682\end{array}$

14923.481 23.259

$23.250 \quad 23.459$

$\begin{array}{llll}23.036 & 23.236 & 23.414 & 23.414 \\ 23.014 & 22.091 & 23.192\end{array}$

$\begin{array}{llll}22.013 & 22.791 & 22.991 & 22.969\end{array}$ $22.590 \quad 22.56800$

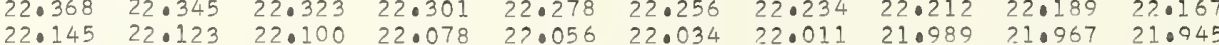
$\begin{array}{llllllllll}21.922 & 21.900 & 21.878 & 21.855 & 21.833 & 21.811 & 21.788 & 21.766 & 21.744 & 21.0722\end{array}$

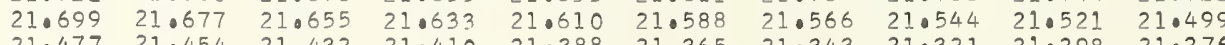

$\begin{array}{llllllllll} & .001 & .002 & .003 & .004 & .005 & .006 & .007 & .008 & .009 \\ .822 & : 882 & .884 & : 88 z & : 883 & : 811 & : 813 & .815 & : 819 & : 829\end{array}$

$\begin{array}{ll}0.276096 & 1.847083 \\ 0.776096 & 1.847110 \\ 0.276096 & 1.847137 \\ 0.276096 & 1.847164 \\ 0.276096 & 1.847191 \\ 0.276096 & 1.847218 \\ 0.276096 & 1.847245 \\ 0.276095 & 1.847271 \\ 0.276095 & 1.847298 \\ 0.276095 & 1.847325\end{array}$

0.276095

0.276095

0.276095
0.276095

0.276095
0.276095

0.276094

0.276094

0.276094
0.276094

1.847352

1. 847406

1.847433
1.847460

1.847487

1.847513

.847540
1.8475567

0.276094

0.0276094

0.276094

0.276094

0.276093
0.276093

0.276093

0.276093

1.847621

0.276093

0.276093

0.276093

0.276093
0.276092

0.276092

0.276092

$0.27600^{2} 2$

0.276092

0.276092

0.276092

0.27609

0.276091

0.27609

0.276091

0.27609

0.27609
0.276091
0.276090

0.276090

$0.276 n 00$

0.276000

0.276090

0.276090
0.276090

1.847648
1.847675

1.847702

1.847729

1.847756
1.84778

1.847809

1.847863

1.847890

1.847917

1.847071

: 847998

1. 848051

1. 8480785

1.848132

0.276090

0.276090

0.276090

0.276089

0.276089
0.276080
0.276089

0.776089

0.276089
0.276089

1.848150

1.848186

1. 848213

1.848267

1.848293

1.848320

1.848374

1.848428

1.848455

1.848482

1.848509

1.848536
1.848562

1.848589

1.848616

0.27608

0.276089

0.276088

0.027608

0.276088

0.276088

0.27608

0.276088

1.848697

1.848724
1.848751

1.848778

1. 848805

1.248831
1.848858

1. 848885

1.848912
1.848939

0.276088

0.276088

0.276087

0.276087

0.276087

0.276087 
$\begin{array}{llllll}21.165 & 21.143 & 21.120 & 21.098 & 21.076 & 21.054 \\ 20.942 & 20.920 & 20.898 & 20.875 & 20.853 & 20.831\end{array}$ \begin{tabular}{lllllllll}
20.786 & 20.764 & 20.742 & 20.720 & 20.697 & 20.675 & 20.653 & 20.630 & 20.608 \\
\hline
\end{tabular} $\begin{array}{lllllllll}20.319 & 20.297 & 20.274 & 20.252 & 20.230 & 20.207 & 20.185 & 20.163\end{array}$ $\begin{array}{lllllllll} & 20.096 & 20.074 & 20.052 & 20.029 & 20.007 & 19.985 & 19.962 & 19.940\end{array}$ $\begin{array}{lllllllll}19.651 & 19.628 & 19.606 & 19.584 & 19.562 & 190539 & 19.517 & 19.495\end{array}$

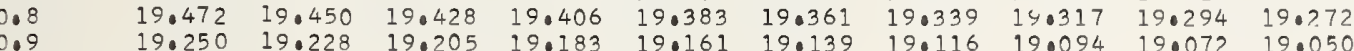

$\begin{array}{lllllllllll}6701.0 & 14919.027 & 19.005 & 18.983 & 18.960 & 18.938 & 18.916 & 18.894 & 18.871 & 18.849 & 18.827\end{array}$

$\begin{array}{lllllllllll}1.1 & 18.805 & 18.782 & 18.760 & 18.738 & 18.716 & 18.693 & 18.671 & 18.649 & 18.627 & 18.604 \\ 1.2 & 18.582 & 18.560 & 18.537 & 18.515 & 18.493 & 18.471 & 18.448 & 18.426 & 18.404 & 18.382\end{array}$

$\begin{array}{lllllllllll}1.2 & 18.582 & 18.560 & 18.537 & 18.515 & 18.493 & 18.471 & 18.448 & 18.426 & 18.404 & 18.382 \\ 1.3 & 18.359 & 18.337 & 18.315 & 18.293 & 18.270 & 18.248 & 18.226 & 18.204 & 18.181 & 18.159 \\ 1.4 & 18.137 & 18.115 & 18.092 & 18.070 & 18.048 & 18.026 & 18.003 & 17.981 & 17.059 & 17.036\end{array}$

$\begin{array}{lllllllllll}1.4 & 18.137 & 18 \cdot 115 & 18 \cdot 092 & 18 \cdot 070 & 18.048 & 18 \cdot 026 & 18 \cdot 003 & 170981 & 17 \cdot 959 & 17.936 \\ 1.5 & 17.914 & 177.892 & 17.870 & 17.847 & 17.825 & 17.803 & 17.781 & 17.758 & 17.736 & 17.914\end{array}$

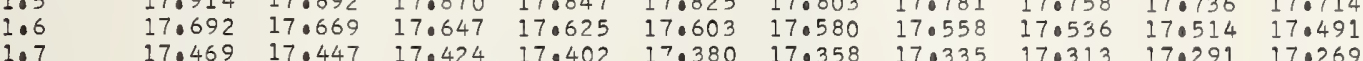

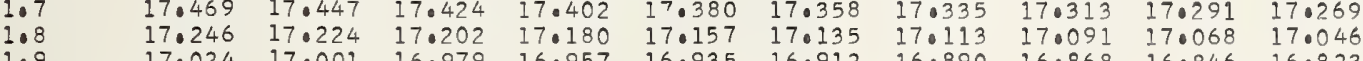

$\begin{array}{lllllllllll}6702.0 & 14916.801 & 16.779 & 16.757 & 16.734 & 16.712 & 16.690 & 16.668 & 16.646 & 16.623 & 16.601\end{array}$

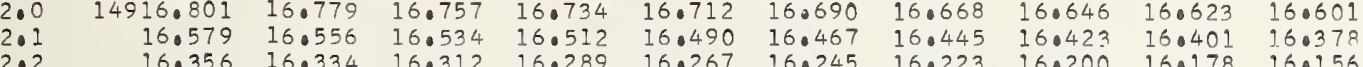

$\begin{array}{lllllllllll}2.1 & 16.579 & 16.556 & 16.534 & 16.512 & 16.490 & 16.467 & 16.445 & 16.423 & 16.401 & 16.378 \\ 2.2 & 16.356 & 16.334 & 16.312 & 16.289 & 16.267 & 16.245 & 16.223 & 16.200 & 160178 & 16.156 \\ 2.3 & 16.134 & 16.111 & 16.089 & 16.067 & 16.045 & 16.022 & 16.000 & 15.978 & 150955 & 150933 \\ 2.4 & 15.911 & 15.889 & 15.866 & 15.844 & 15.822 & 15.800 & 15.777 & 15.755 & 15.733 & 15.711\end{array}$

2.5

2.6

$15.688 \quad 15.666 \quad 15.644 \quad 150622$

$15.466 \quad 15.444 \quad 15.421 \quad 15.399$

2.8

$\begin{array}{llll}15.021 & 14.999 & 14.976 & 14.954 \\ 14.798 & 14.776 & 14.754 & 14.732\end{array}$

$5.822 \quad 15.800$

$15.377 \quad 15.577$

$15.555 \quad 15.533 \quad 15.510 \quad 15.488$

$15.332 \quad 15.310 \quad 150288 \quad 150266$

$\begin{array}{llllll}15.154 & 15.132 & 15.110 & 15.088 & 15.065 & 15.043\end{array}$

$\begin{array}{rrrrr}03.0 & 14914.576 & 14.554 & 14.531 & 14.509 \\ 3.1 & 14.353 & 14.331 & 14.309 & 14.287 \\ 3.2 & 14.331 & 14.109 & 14.086 & 14.064\end{array}$

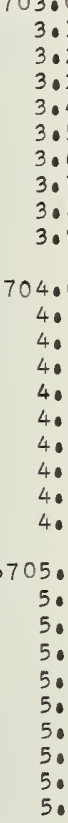

$14.131 \quad 14.109 \quad 14.086 \quad 14.064$

$\begin{array}{llll}13.686 & 13.664 & 13.641 & 13.619\end{array}$

$\begin{array}{llll}13.463 & 13.441 & 13.419 & 13.397\end{array}$

$\begin{array}{llll}13.241 & 13.219 & 13.197 & 13.17 \\ 13.018 & 12.996 & 12.974 & 12.952 \\ 12.796 & 12.774 & 12.752 & 12.729\end{array}$

$14.709 \quad 14.687$

$\begin{array}{llll}140887 & 140865 & 140843 & 140821 \\ 14.665 & 14.643 & 14.620 & 14.598\end{array}$

$\begin{array}{llllll}14.487 & 14.464 & 14.442 & 140420 & 14.398 & 14 \cdot 375 \\ 14.264 & 140242 & 140220 & 140198 & 140175 & 140153\end{array}$

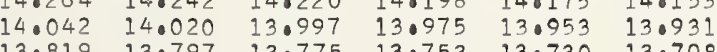
$\begin{array}{llllll}13.819 & 13.797 & 13.775 & 13.753 & 13.730 & 13.708 \\ 13.597 & 13.575 & 13.552 & 13.530 & 13.508 & 13.486\end{array}$ $\begin{array}{llllll}13.374 & 13.352 & 13.330 & 13.308 & 13.285 & 13.263\end{array}$ $\begin{array}{llll}12.796 & 12.774 & 12.752 & 12.729 \\ 12.573 & 12.551 & 12.529 & 12.507\end{array}$

12.93013 .130

$12.707 \quad 12.685$

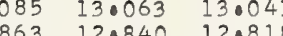

$\begin{array}{llllllllll}912.351 & 12.329 & 12.307 & 12.284 & 12.262 & 12.240 & 12.218 & 12.195 & 12.173 & 12.151 \\ 12.129 & 12.106 & 12.084 & 12.062 & 12.040 & 12.017 & 11.995 & 11.973 & 11.951 & 11.928 \\ 11.906 & 11.884 & 11.862 & 11.839 & 11.017 & 11.795 & 11.0773 & 11.751 & 11.728 & 11.906\end{array}$

$\begin{array}{llllllllll}912.351 & 12.329 & 12.307 & 12.284 & 12.262 & 12.240 & 12.218 & 12.195 & 12.173 & 12.151 \\ 12.129 & 12.106 & 12.084 & 12.062 & 12.040 & 12.017 & 11.995 & 11.973 & 11.951 & 11.928 \\ 11.906 & 11.084 & 11.862 & 11.839 & 11.817 & 11.705 & 11.773 & 11.751 & 11.728 & 11.906\end{array}$

$\begin{array}{llllllllll}912.351 & 12.329 & 12.307 & 12.284 & 12.262 & 12.240 & 12.218 & 12.195 & 12.173 & 12.151 \\ 12.129 & 12.106 & 12.084 & 12.062 & 12.040 & 12.017 & 11.995 & 11.973 & 11.951 & 11.928 \\ 11.906 & 11.084 & 11.862 & 11.839 & 11.017 & 11.705 & 11.773 & 11.751 & 11.728 & 11.906\end{array}$

$\begin{array}{llllllllll}912.351 & 12.329 & 12.307 & 12.284 & 12.262 & 12.240 & 12.218 & 12.195 & 12.173 & 12.151 \\ 12.129 & 12.106 & 12.084 & 12.062 & 12.040 & 12.017 & 11.995 & 11.973 & 11.951 & 11.928 \\ 11.906 & 11.084 & 11.862 & 11.839 & 11.817 & 11.705 & 11.773 & 11.751 & 11.728 & 11.906\end{array}$

$12.440 \quad 12.418 \quad 12.396 \quad 12.373$

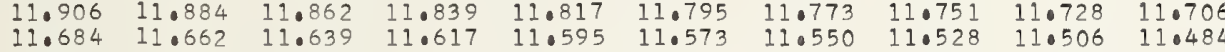

$11.461 \quad 11.430 \quad 11.417 \quad 11.395 \quad 11.372 \quad 11.350 \quad 11.328 \quad 11.306 \quad 11.583 \quad 11.261$

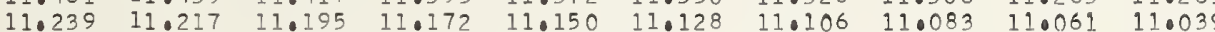

$\begin{array}{llllllllll}11.016 & 10.994 & 10.972 & 10.950 & 10.928 & 10.905 & 10.883 & 10.861 & 10.839 & 10.817\end{array}$

$\begin{array}{llllllllll}10.794 & 10.772 & 10.750 & 10.727 & 16.705 & 10.683 & 10.661 & 10.639 & 10.616 & 10.59 \\ 10.572 & 10.550 & 10.527 & 10.505 & 10.483 & 10.461 & 10.438 & 10.416 & 10.394 & 10.372\end{array}$

$10.349 \quad 10.327$

14910.127

10.105

10.083

10.060

$09.905 \quad 09.88$

$09.682 \quad 09.660$

$09.238 \quad 09.215$

$\begin{array}{ll}09.860 & 09.83 \\ 09.638 & 09.615\end{array}$

$10.260 \quad 10.238$

$\begin{array}{llll}10.438 & 10.416 & 10.394 & 10.372 \\ 10.216 & 10.194 & 10.172 & 10.149\end{array}$

$\begin{array}{lllllll}10.038 & 10.016 & 090994 & 090971 & 090949 & 090927\end{array}$

$\begin{array}{llllllll}09.416 & 09.315 & 0.593 & 09.571 & 09.549 & 09.527 & 09.504 & 09.482\end{array}$

$\begin{array}{lllllllll}0.993 & 09.193 & 09.171 & 09.149 & 09.126 & 09 \cdot 104 & 09 \cdot 082 & 09 \cdot 060 & 09.037\end{array}$

$\begin{array}{llllllllllll}08.793 & 08.771 & 08.749 & 08.726 & 08.704 & 08.682 & 08.660 & 08.637 & 08.615 & 08.593\end{array}$

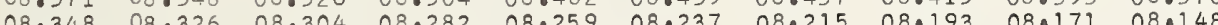

$\begin{array}{llllllllll}08.126 & 08.104 & 08.081 & 08.059 & 08.037 & 08.015 & 07.993 & 07.970 & 07.948 & 07.926\end{array}$

0.276085

0.276085

0.276085

0.276085

0.276085

0.276085

0.276084

0.276084

0.276084

0.276084

0.276084
0.276083

0.276083

0.276083

27608

27608

0.276083
0.276083

0.27608

0.276083
0.276082

0.27608

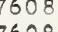

0.27608

0.276081

0.276081

0.27608

0.27608

0.27608

0.27608

0.276080

0.276080

0.27608

.276080

0.276080

0.276080

0.276079

0.276079

6706.0

6.0
6.0
6.0
6.
6.5
6.6
6.7
6.0
6.0

14907.904

$07.904 \quad 07.8$

$07.859 \quad 07.83$

$\begin{array}{llllll}07.815 & 07.792 & 07.770 & 07.748 & 07.726 & 07.704\end{array}$

0.27607

0.276079 $\begin{array}{llllllllll}07.237 & 07.215 & 07.192 & 07.170 & 07.148 & 07.125 & 07.103 & 07.081 & 07.059 & 07.037 \\ 0.014 & 06.992 & 06.970 & 06.048 & 06.926 & 06.903 & 06.881 & 06.859 & 06.837 & 06.815\end{array}$ $\begin{array}{llllllllll}06.792 & 06.770 & 06.748 & 06.726 & 06.703 & 06.681 & 06.659 & 06.637 & 06.614 & 06.592\end{array}$ $\begin{array}{llllllllll}06.570 & 06.548 & 06.526 & 06.503 & 06.481 & 06.459 & 06.437 & 06.414 & 06.392 & 06.370\end{array}$ $\begin{array}{llllllllll}06.348 & 06.325 & 06.303 & 06.281 & 06.259 & 06.237 & 06.214 & 06.192 & 06.170 & 06.148\end{array}$

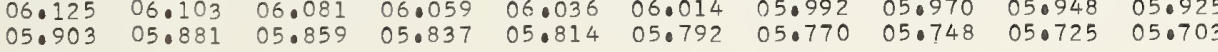

0.276079

0.276079

0.276079

0.276078

0.276078

.850015

.05006

850096
.850323

.850149

.850203

1.850257

1.85031

1.850365

.850418

1.850472

85049

1.850580

. 350634

.850687

.850714

. 850741

.350795

.850849

1.850876

850929

850983

1.851010

1.851064

9.851118

1.851145

1.851198
1.851225

.85125

1.859 .279

1.851333

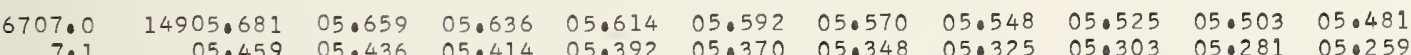
$\begin{array}{lllllllllll}05.459 & 05.436 & 05.414 & 05.392 & 05.370 & 05.348 & 05.325 & 05.303 & 05.281 & 05.259\end{array}$

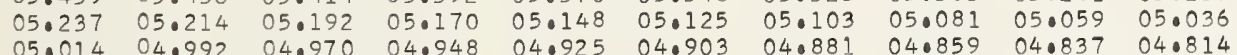
$\begin{array}{llllllllll}04.792 & 04.770 & 04.748 & 04.725 & 04.703 & 04.681 & 04.659 & 04.636 & 04.614 & 04.592\end{array}$ $\begin{array}{llllllllll}04.570 & 04.548 & 04.525 & 04.503 & 04.481 & 04.459 & 04.437 & 04.414 & 04.392 & 04.370\end{array}$ $\begin{array}{llllllllll}04.348 & 04.325 & 04.303 & 04.281 & 04.259 & 04.237 & 04.214 & 04.192 & 04.170 & 04.148\end{array}$

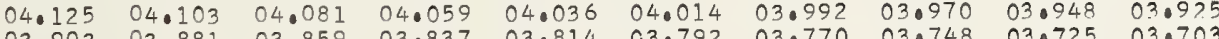
$\begin{array}{llllllllll}03.903 & 03.881 & 03.859 & 03.837 & 03.814 & 03.792 & 03.770 & 03.748 & 03.725 & 03.703 \\ 03.681 & 03.659 & 03.636 & 03.614 & 03.592 & 03.570 & 03.548 & 03.525 & 03.503 & 03.481\end{array}$

0.276078

0.276078

0.276078
0.276078

0.276078

0.276078
0.276077

0.276077

0.276077
0.276077

1.851387

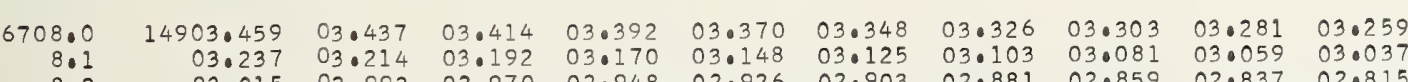

0.276077 $\begin{array}{llllllllll}03.015 & 02.992 & 02.970 & 02.948 & 02.926 & 02.903 & 02.881 & 02.859 & 02.837 & 02.815\end{array}$ $\begin{array}{llllllllll}02.792 & 02.770 & 02.748 & 02.726 & 02.703 & 02.6881 & 02.659 & 02.637 & 02.615 & 02.592\end{array}$ $\begin{array}{llllllllll}02.570 & 02.548 & 02.526 & 02.504 & 02.481 & 02.459 & 02.437 & 02.415 & 02.392 & 02.370\end{array}$

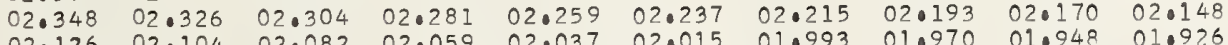
$\begin{array}{llllllllll}02.126 & 02.104 & 02.082 & 02.059 & 02.037 & 02.015 & 01.993 & 01.970 & 01.948 & 01.9786\end{array}$ $\begin{array}{llllllllll}01.904 & 01.882 & 01.859 & 01.837 & 01.815 & 01.793 & 01.771 & 01.748 & 01.726 & 01.704\end{array}$ $\begin{array}{llllllllll}01.682 & 01.659 & 01.637 & 01.615 & 01.593 & 01.571 & 01.548 & 01.526 & 01.504 & 01.482 \\ 01.0460 & 01.437 & 01.415 & 01.393 & 01.371 & 01.349 & 01.326 & 01.304 & 01.282 & 01.260\end{array}$

0.276077

0.276077

0.276077

0.276076

0.276076

1.851414

1.851467

1.851521

1.851548

9.851602

9.851656

1.851683

1.851736

1.851763

1.851897

1.851844

0.276076

0.276076

0.276076

0.276076

0.276075

0.276075

0.276075

1.851925

1.851978

1.852005

1.852059

1.852113
1.852140

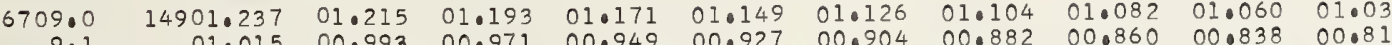
$\begin{array}{llllllllll}0.793 & 00.771 & 00.749 & 00.726 & 00.704 & 00.682 & 00.660 & 00.638 & 00.615 & 00.593\end{array}$ $\begin{array}{llllllllll}0.571 & 00.549 & 00.527 & 00.505 & 00.482 & 00.460 & 00.438 & 00.416 & 00.394 & 00.371\end{array}$ $00.127 \quad 00.105 \quad 00.083 \quad 00.060 \quad 00.038 \quad 00.016 * 99.994 * 99.972 * 99.949 * 99.927$

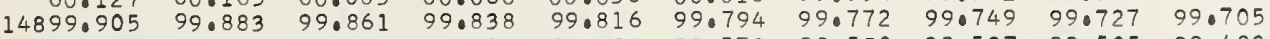

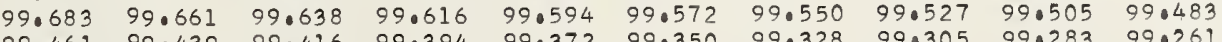

$\begin{array}{llll}99.461 & 99.439 & 99.416 & 99.394\end{array}$

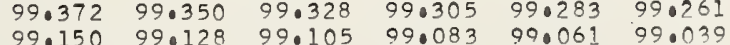

0.276075

1.852994

1.852221

1.852301

1.852328

1.852382

.0252436

$$
.001
$$$$
.002
$$$$
.003
$$

.004

.005

.006

.007

.008

010

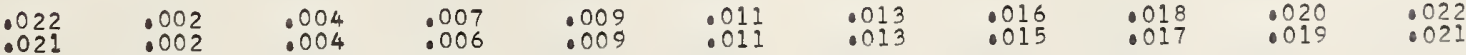


$\begin{array}{llllllllll}43.334 & 43.312 & 43.290 & 43.267 & 43.2685 & 43.446 & 43.424 & 43.401 & 43.379 & 43.357 \\ 43.111 & 43.089 & 43.066 & 43.044 & 43.022 & 42.999 & 43.200 & 43.178 & 43.156 & 43.133 \\ 4 & 42.977 & 42.954 & 42.932 & 42.910\end{array}$ $\begin{array}{llllllllll}43.117 & 43.089 & 43.066 & 43.044 & 43.022 & 42.999 & 42.977 & 42.954 & 42.932 & 42.910 \\ 42.887 & 42.865 & 42.843 & 42.820 & 42.798 & 42.776 & 42.753 & 42.731 & 42.709 & 42.687\end{array}$ $\begin{array}{llllllllll}42.664 & 42.642 & 42.620 & 42.597 & 42.575 & 42.553 & 42.530 & 42.508 & 42.485 & 42.463\end{array}$ $\begin{array}{llllllllll}42.441 & 42.418 & 42.396 & 42.374 & 42.351 & 42.329 & 42.307 & 42.285 & 42.262 & 42.240\end{array}$ $\begin{array}{llllllllll}42.217 & 42.195 & 42.173 & 42.151 & 42.128 & 42.106 & 42.083 & 42.061 & 42.039 & 42.017\end{array}$

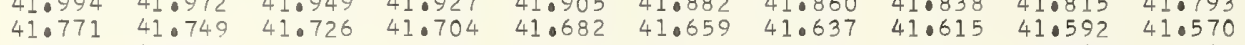
4941.324

5.2

5.4
5.5

\section{$4930.167 \quad 30.14$}

$29.944 \quad 29.922 \quad 20.00123 \quad 30.100$

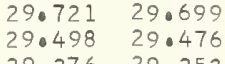

$\begin{array}{ll}29.276 & 29.25 \\ 29.052 & 29.03\end{array}$

$\begin{array}{llll}28.830 & 28.0307 & 29.008 & 29.28 \\ 28.98\end{array}$

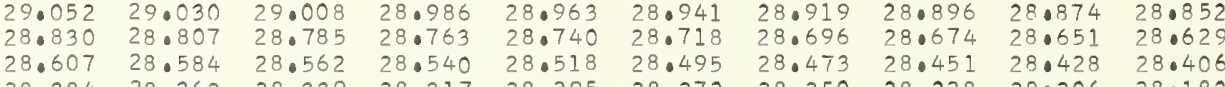

$\begin{array}{llll}36.726 & 36.703 & 36.6881 & 36.659\end{array}$ $\begin{array}{llll}36.279 & 36.257 & 36.235 & 36.0 .12\end{array}$ $\begin{array}{llll}35.833 & 35.811 & 350788 & 35.766\end{array}$ $35.0187 \quad 35.588 \quad 35.565 \quad 35.543$ $\begin{array}{llll}35.164 & 35.141 & 35.119 & 35.097\end{array}$ $34.539034 .516 \quad 34.494 \quad 340472 \quad 34.450 \quad 340.27$ $\begin{array}{llllll}34.093 & 34.070 & 34.048 & 340.026 & 34.0273 & 340.091\end{array}$ $\begin{array}{llllll}33.870 & 33.847 & 33.825 & 33.803 & 33.0780 & 33.0758 \\ 33.647 & 33.624 & 33.602 & 330579 & 33.557 & 33.535\end{array}$ $\begin{array}{llllll}33.423 & 33.401 & 33.0379 & 33.357 & 33.334 & 33.312\end{array}$ $\begin{array}{llllll}32.977 & 32.955 & 32.933 & 32.910 & 32.888 & 32.866\end{array}$

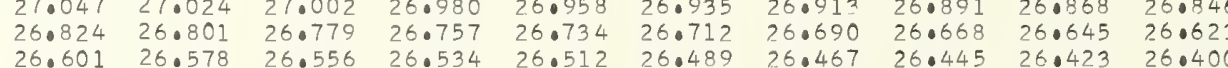

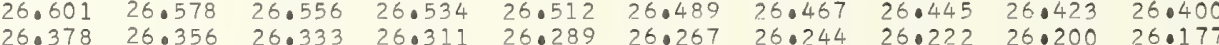
$\begin{array}{llllllllll}26.155 & 26.133 & 26.111 & 26.088 & 26.066 & 26.044 & 26.021 & 25.9999 & 25.077 & 250955 \\ 25.932 & 25.910 & 25.888 & 25.865 & 25.843 & 25.821 & 25.799 & 250776 & 25 \cdot 754 & 25.732\end{array}$

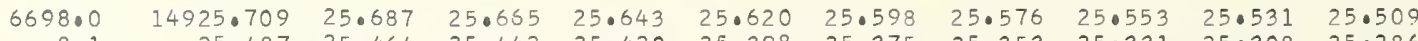

$\begin{array}{lllllllllll}8.1 & 25.487 & 25.464 & 25.442 & 25 \cdot 420 & 25 \cdot 0398 & 25.375 & 25 \cdot 353 & 25 \cdot 331 & 25 \cdot 308 & 25.5286\end{array}$

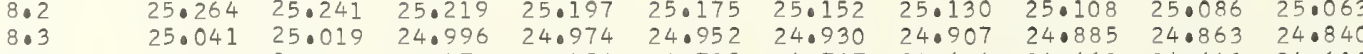

$\begin{array}{lllllllllll}8.4 & 24.818 & 24.796 & 24.773 & 24.751 & 24.0729 & 24.707 & 240684 & 24 \cdot 662 & 24.640 & 24.618\end{array}$

$\begin{array}{lllllllllll}8.5 & 24.555 & 24.573 & 24.551 & 24.528 & 24.506 & 24.484 & 24 \cdot 462 & 24.4439 & 240417 & 24.399\end{array}$

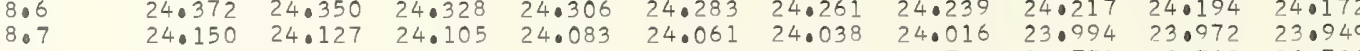

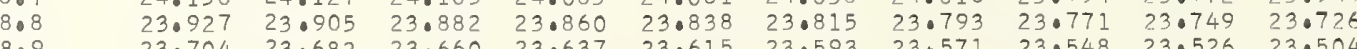

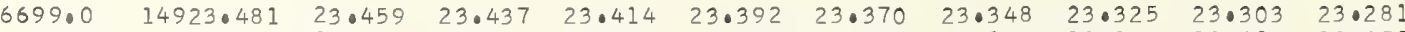

$\begin{array}{lllllllllll}9.1 & 23.259 & 23.236 & 23.214 & 23.192 & 23.170 & 23.147 & 23.125 & 23.103 & 23.080 & 23.058\end{array}$

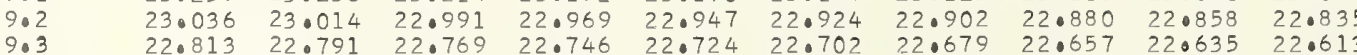

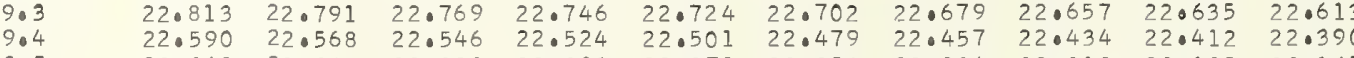

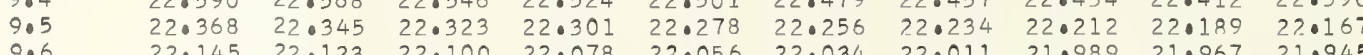

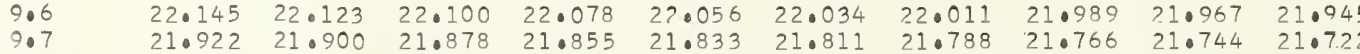

$\begin{array}{lllllllllll}9.7 & 21.922 & 21.900 & 21.0878 & 21.855 & 21.833 & 21.811 & 21.0788 & 21.766 & 21.744 & 21.0722 \\ 9.8 & 21.0699 & 21.077 & 21.055 & 21.633 & 21.010 & 21.058 & 21.0566 & 21.0544 & 210521 & 21.0499\end{array}$

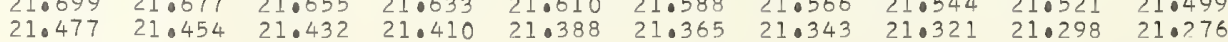

0.276096

0.276096

0.27608

0.276096

0.0078

0.276005

0.276095

0.276095

0.276095

0.276095
0.276095
0.276095

0.276095

0.276094

0.276094

0.276094

0.276094

0.276094

0.276094

0.276094

0.276093

0.276093

0.276093

0.276093

0.276093

0.276093

0.276093

0.276092

0.276092

0.276092

0.276092

0.276092

0.276092

0.276091

0.27609

0.27609

0.276091

0.276091

0.276091

0.276091

0.276090

0.776090

0.276000

0.076090

0.276090
0.276090

0.276090

0.276090
0.276090
0.276099

0.276090
0.276089
0.227609

0.276089

0.276089

0.275089

0.276089

0.276089

0.276089

0.276089

0.276088

0.276088

0.27608

0.276088

0.276088

0.276088 0.276088

0.276087

0.276087

0.276087

0.276087

0.276087
0.276087

0.276087

(

0.276086
0.276086

0.276086

0.276086

0.276086
0.276086

0.276086

0.276086

.047352

1.847406

1.847433

1.847460
1.847487

.847513

. 847540

1.847567
1.847594

1.847621

1.847648

1.847675
.847702

1.847729

1.847756
1.847782

1.847809
1.847836

1.847863

1.847890

1.847917

1.847944

9.847998

1.848025

1.848051

1.848105

1.848132

1.848159

1.848186

1.848213
1.848240

1.848267

1.84829

1.848320
1.848347

1. 848374

1.848428

1.848455

1.04848

.848509
1.848536

1.848536
1.848562

1.848589

1.848616

1. 848697

1.048724

10.848751

1.0448805

1.849831

1.848858
1.849885

1.849885
1.848912

1.848939

1.848966

1.848993

1.849020

1.849047
1.849073

1.849100

1.849127

.849181

1.849208

1.849235 1.849262 1.849316 1.849342 1.849369 1.849396
1.849423 1.849450
1.849477

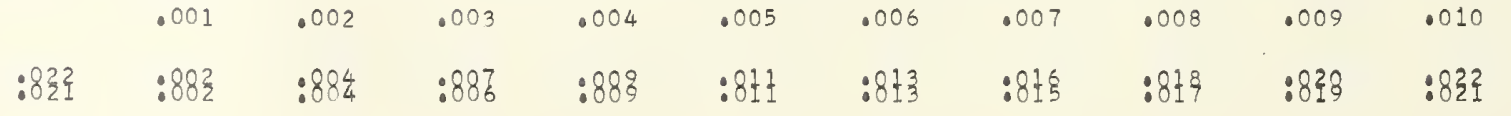


$\begin{array}{rrrrrrrrrrr}6700 \cdot 0 & 14921.254 & 21.232 & 21.209 & 21.187 & 21.165 & 21.143 & 21.120 & 21.098 & 21.076 & 21.054\end{array}$

$\begin{array}{lllllllllll}0.2 & 20.809 & 20.786 & 20.764 & 20.742 & 20.720 & 20.697 & 20.675 & 20.653 & 20.630 & 20.608\end{array}$

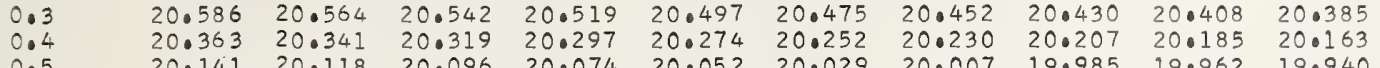

$\begin{array}{llllllllllll}0.5 & 20.141 & 20.118 & 20.096 & 20.074 & 20.052 & 20.029 & 20.007 & 190985 & 190.962 & 190940 \\ 0.6 & 19.918 & 19.896 & 19.873 & 19.851 & 19.829 & 19.807 & 19.784 & 19.762 & 19.740 & 19.718\end{array}$

$\begin{array}{llllllllllll}0.7 & 19.695 & 19.673 & 19.651 & 19.628 & 19.606 & 19.584 & 19.562 & 190539 & 19.517 & 190495\end{array}$

$\begin{array}{lllllllllll}0.8 & 19.472 & 19.450 & 19.428 & 19.406 & 19.383 & 19.361 & 19.339 & 14.317 & 190294 & 19.772 \\ 0.9 & 19.250 & 19.228 & 19.205 & 19.183 & 19.161 & 19.139 & 190116 & 19.094 & 190072 & 19.050\end{array}$

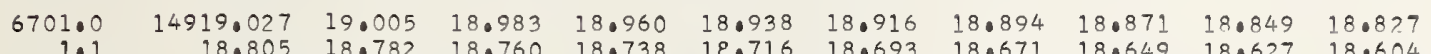

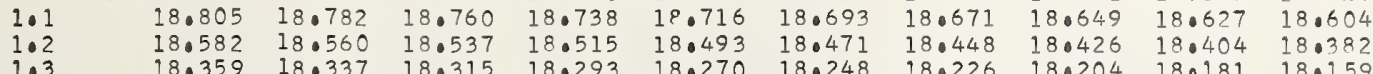

$\begin{array}{lllllllllll}1.2 & 18.5882 & 18.560 & 18.537 & 18.515 & 18.493 & 18.471 & 18.448 & 18.426 & 18.404 & 18.382 \\ 1.3 & 18.359 & 18.337 & 18.315 & 18.293 & 18.270 & 18.248 & 18.226 & 18.204 & 180181 & 18.159 \\ 1.4 & 18.137 & 18.115 & 18.092 & 18.070 & 18.048 & 18.026 & 18.03 & 17.081 & 17059 & 17.036\end{array}$

$\begin{array}{lllllllllll}1.4 & 18.137 & 18.115 & 18.092 & 18.070 & 18 \cdot 048 & 18.026 & 18.003 & 17.981 & 17.959 & 17.936 \\ 1.5 & 17.914 & 17.892 & 17.0970 & 17.847 & 17.825 & 17.803 & 17.781 & 17.758 & 17.736 & 17.714\end{array}$

$\begin{array}{lllllllllll}1.06 & 17.692 & 17.669 & 17.647 & 17.625 & 17.603 & 17.580 & 17.558 & 17.536 & 170514 & 17.714 \\ 1.6 & 17.469 & 17.447 & 17.424 & 17.402 & 17.380 & 17.358 & 17.335 & 17.313 & 170291 & 170269\end{array}$

$\begin{array}{lllllllllll}1.7 & 17.469 & 17.447 & 17.424 & 17.402 & 17.380 & 17.358 & 17.335 & 17.313 & 170291 & 170269 \\ 1.8 & 17.246 & 17.224 & 17.202 & 17.180 & 17.157 & 17.135 & 17.113 & 17.091 & 170068 & 17.046 \\ 1.9 & 17.024 & 17.001 & 16.970 & 16.957 & 16.935 & 16.912 & 16.890 & 16.868 & 16.846 & 16.823\end{array}$

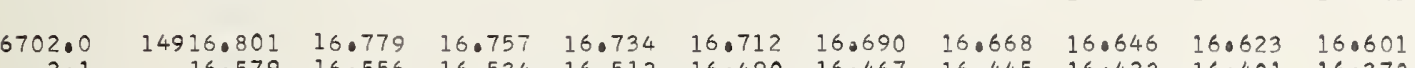

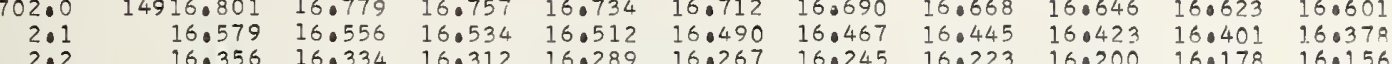

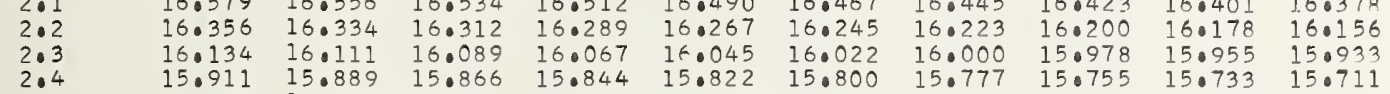

$2 \cdot 5$

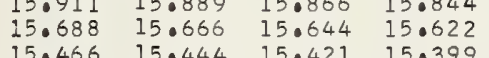

2.6
2.7

$\begin{array}{llllllllll}15.466 & 15.444 & 15.421 & 15.399 & 15.377 & 15.355 & 15 \cdot 332 & 15.310 & 15.288 & 15.266 \\ 15.243 & 15.221 & 15.199 & 15.177 & 15.154 & 15.132 & 15.110 & 15.088 & 15.065 & 15.043 \\ 15.021 & 14.999 & 14.976 & 14.954 & 14.932 & 14.910 & 14.887 & 140865 & 14.843 & 14.821\end{array}$

$\begin{array}{ll}16.045 & 16.022 \\ 15.822 & 15.800 \\ 1520\end{array}$

$\begin{array}{ll}15.599 & 15.577 \\ 15.377 & 15.355\end{array}$

$\begin{array}{llll}15.000 & 150.978 & 150.955 & 150933 \\ 15.777 & 150755 & 150733 & 150711\end{array}$

$\begin{array}{lllllllllll}2.8 & 15.021 & 14.999 & 14.976 & 14.954 & 14.932 & 14.910 & 14.887 & 140865 & 140843 & 14.821 \\ 2.9 & 14.798 & 14.776 & 14.754 & 14.732 & 14.709 & 14.687 & 14.665 & 140643 & 14.620 & 14.598\end{array}$

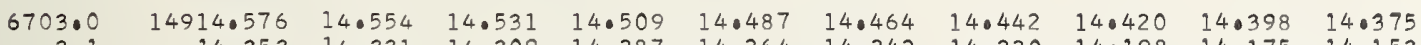

$\begin{array}{lllllllllll}3.1 & 14.353 & 14.331 & 14.309 & 14.287 & 14.264 & 14.242 & 14.220 & 140198 & 140175 & 140153 \\ 3.2 & 14.131 & 14.109 & 14.086 & 14.064 & 14.042 & 14.020 & 13.097 & 13.975 & 13.053 & 130031\end{array}$

$\begin{array}{lllllllllll}3.2 & 14.131 & 14.109 & 14.086 & 14.064 & 14.042 & 14.020 & 13.997 & 13.975 & 13.953 & 13.931 \\ 3.3 & 13.908 & 13.886 & 13.864 & 13.842 & 13.819 & 13.797 & 13.775 & 13.753 & 13.730 & 13.908\end{array}$

$\begin{array}{llllllllllll}3.4 & 13.686 & 13.664 & 13.641 & 13.619 & 13.597 & 13.575 & 13.552 & 13.530 & 13.508 & 13.486 \\ 3.5 & 13.463 & 13.441 & 13.419 & 13.397 & 13.374 & 13.352 & 13.330 & 13.308 & 13.285 & 13.263\end{array}$

$\begin{array}{lllllllllll}3.5 & 13.463 & 13.441 & 13.419 & 13.397 & 13.374 & 13.352 & 13.330 & 13.308 & 13.285 & 13.263 \\ 3.6 & 13.241 & 13.219 & 13.197 & 13.174 & 13.152 & 13.130 & 13.107 & 13085 & 13.063 & 13.041\end{array}$

$\begin{array}{lllllllllll}3.7 & 13.018 & 12.996 & 12.974 & 12.952 & 12.930 & 12.907 & 12.885 & 12.863 & 12.840 & 12.818\end{array}$

$\begin{array}{lllllllllll}3.8 & 12.796 & 12.774 & 12.752 & 12.729 & 12.707 & 12.685 & 12.662 & 12.640 & 12.618 & 12.596\end{array}$

$\begin{array}{rrrrrrrrrrr}6704.0 & 14912.351 & 12.329 & 12.307 & 12.284 & 12.262 & 12.240 & 12.218 & 12.195 & 12.173 & 12.151 \\ 4.1 & 12.129 & 12.106 & 12.084 & 12.062 & 12.040 & 12.017 & 11.995 & 11.973 & 11.051 & 11.928 \\ 4.2 & 11.906 & 11.884 & 11.862 & 11.839 & 11.817 & 11.795 & 11.773 & 11.751 & 11.728 & 11.706\end{array}$

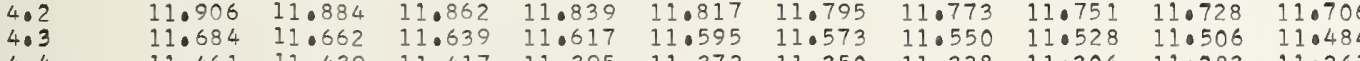

$\begin{array}{lllllllllll}4.4 & 11.461 & 11.439 & 11.417 & 11.395 & 11.372 & 11.350 & 11.328 & 11.306 & 11.283 & 11.261 \\ 4.5 & 11.239 & 11.217 & 11.95 & 11.172 & 11.150 & 11.08 & 11.106 & 11.083 & 11.061 & 11.039\end{array}$

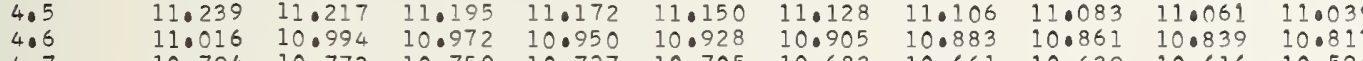

$\begin{array}{lllllllllll}4.7 & 10.794 & 10.772 & 10.750 & 10.727 & 10.705 & 10.683 & 10.661 & 10.639 & 10.616 & 10.817\end{array}$

$\begin{array}{lllllllllll}4.8 & 10.572 & 10.550 & 10.527 & 10.505 & 10.483 & 10.461 & 10.438 & 10.416 & 10.394 & 10.372\end{array}$

$\begin{array}{rrrrrrrrrrr}6705.0 & 14910.127 & 10.105 & 10.083 & 10.060 & 10.038 & 10.016 & 09.994 & 09.971 & 09.949 & 09.927\end{array}$

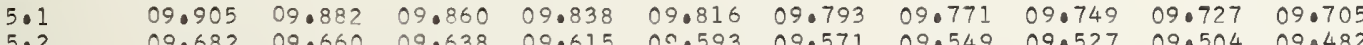

$\begin{array}{lllllllllll}5.2 & 09.682 & 09.660 & 09.638 & 09.615 & 00.593 & 09.571 & 09.549 & 09.527 & 09.504 & 09.482 \\ 5.3 & 09.460 & 09.438 & 09.416 & 09.393 & 09.371 & 09.349 & 09.327 & 09.304 & 09.282 & 09.260\end{array}$

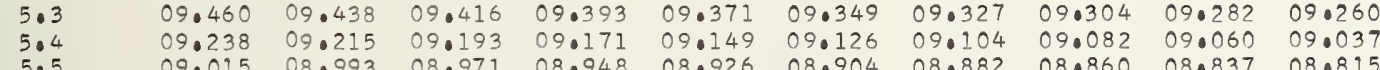

$\begin{array}{lllllllllll}5.5 & 09.015 & 08.993 & 08.971 & 08.948 & 08.926 & 08.904 & 08.882 & 08.860 & 08.837 & 08.815\end{array}$

$\begin{array}{llllllllllll}5.6 & 08.793 & 08.771 & 08.749 & 08.726 & 08.704 & 08.682 & 08.660 & 08.637 & 08.615 & 08.593 \\ 5.7 & 08.571 & 08.548 & 08.526 & 08.504 & 08.482 & 08.459 & 08.437 & 08.415 & 08.393 & 08.370\end{array}$

$\begin{array}{lllllllllll}5.8 & 08.348 & 08.326 & 08.304 & 08.282 & 08.259 & 08.237 & 08.215 & 08.193 & 08.171 & 08.148\end{array}$

$\begin{array}{rrrrrrrrrrr}6706.0 & 14907.904 & 07.881 & 07.859 & 07.837 & 07.815 & 07.792 & 07.770 & 07.748 & 07.726 & 07.704 \\ 6.1 & 07.681 & 07.659 & 07.637 & 07.615 & 07.592 & 07.570 & 07.548 & 07.526 & 07.504 & 07.481 \\ 6.2 & 07.459 & 07.437 & 07.415 & 07.392 & 07.370 & 07.348 & 07.326 & 07.303 & 07.281 & 07.259\end{array}$

$\begin{array}{lllllllllll}6.2 & 07.459 & 07.437 & 07.415 & 07.392 & 07.370 & 07.348 & 07.326 & 07.303 & 07.281 & 07.259\end{array}$

$\begin{array}{lllllllllll}6.3 & 07.237 & 07.215 & 07.192 & 07.170 & 07.148 & 07.125 & 07.103 & 07.081 & 07.059 & 07.037 \\ 6.4 & 07.014 & 06.992 & 06.970 & 06.948 & 06.926 & 06.903 & 06.881 & 06.859 & 06.837 & 06.815\end{array}$

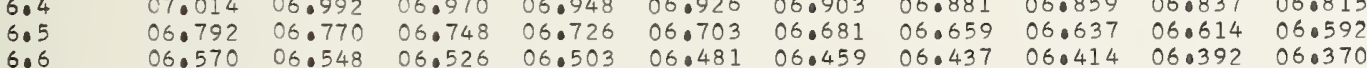

$\begin{array}{llllllllllll}6.6 & 06.7970 & 06.548 & 06.526 & 06.503 & 06.481 & 06.459 & 06.437 & 06.414 & 06.392 & 06.370\end{array}$

$\begin{array}{llllllllllll}6.7 & 06.348 & 06.325 & 06.303 & 06.281 & 06.259 & 06.237 & 06.214 & 06.192 & 06.170 & 06.148\end{array}$

$\begin{array}{lllllllllll}6.8 & 06.125 & 06.103 & 06.081 & 06.059 & 06.036 & 06.014 & 05.992 & 05.970 & 05.948 & 050925 \\ 6.9 & 05.903 & 05.881 & 05.859 & 05.837 & 05.814 & 05.792 & 05.770 & 05.748 & 05.725 & 05.703\end{array}$

$\begin{array}{lllllllllll}6707.0 & 14905.681 & 05.659 & 05.636 & 05.614 & 05.592 & 05.570 & 05.548 & 05.525 & 05.503 & 05.481\end{array}$

$\begin{array}{lllllllllll}7.1 & 05.459 & 05.436 & 05.414 & 05.392 & 05.370 & 05.348 & 05.325 & 05.303 & 05.281 & 05.259 \\ 7.2 & 05.237 & 05.214 & 05.192 & 05.170 & 05.148 & 05.125 & 05.103 & 05.081 & 05.059 & 05.036\end{array}$

$\begin{array}{lllllllllll}7.2 & 05.237 & 05.214 & 05.192 & 05.170 & 05.148 & 05.125 & 05.103 & 05.081 & 05 \cdot 059 & 05.036 \\ 7.3 & 05.014 & 04.992 & 04.970 & 04.948 & 04.925 & 04.903 & 04.881 & 04.859 & 04.837 & 04.814\end{array}$

$\begin{array}{llllllllllll}7.4 & 04.792 & 04.770 & 04.748 & 04.725 & 04.703 & 04.681 & 04.659 & 04.636 & 04.614 & 04.592\end{array}$

$\begin{array}{lllllllllll}7.5 & 04.570 & 04.548 & 04.525 & 04.503 & 04.481 & 04.459 & 04.437 & 04.414 & 04.392 & 04.0370 \\ 7.6 & 04.348 & 04.325 & 04.303 & 04.281 & 04.259 & 04.237 & 04.214 & 04.192 & 04.170 & 04.148\end{array}$

$\begin{array}{lllllllllll}7.7 & 04.125 & 04.103 & 04.081 & 04.059 & 04.036 & 04.014 & 03.992 & 03.970 & 03.948 & 03.095\end{array}$

$\begin{array}{llllllllll}03.903 & 03.881 & 03.859 & 03.837 & 03.814 . & 03.792 & 03.770 & 03.748 & 03.725 & 03.703 \\ 03.681 & 03.659 & 03.636 & 03.614 & 03.592 & 03.570 & 03.548 & 03.525 & 03.503 & 03.481\end{array}$

$\begin{array}{ll}0.276085 & 1.849773 \\ 0.276085 & 1.849800 \\ 0.276085 & 1.849827 \\ 0.276085 & 1.849854 \\ 0.276085 & 1.849880 \\ 0.276085 & 1.849907 \\ 0.276085 & 1.849934 \\ 0.276085 & 1.849961 \\ 0.276085 & 1.849988 \\ 0.276085 & 1.850015\end{array}$

0.276084

0.276084

0.276084

0.276084

276084

0.276083

0.276083

(1)

0.276083

0.276083
0.276083

0.27608

0.27608

0.276082

.276082

0.276082
0.276082

(1)

.276082

0.276081
0.276081

0.276081

0.276081

0.276081

0.276081

0.0 .276081

0.276081
0.276081

0.276080

0.276080

0.276080

0.276080

0.276080

0.276080

0.0276079

1.850042

1.850123

.850176

1.850230

.850257
.850284

0.276079

.850311

850338

.8853918

850445

.85049

- 850580

85060

.850634

850687

.850741

1.850768

1.850822

0.276079

0.2760 .79

0.276079

0.276078

0.276078

0.276078

0.276078

0.276078
0.276078
0.0276078

0.276078

0.276077

0.276077

1.850849

0.276077

.850903

1.850956

1.851010

1.851064

1.851118

1.851145

1.851198

1.851252

1.851279

.851333
1.851360

1.851387

.851440

1.851467

1.851521

1.055975

1.851602

$\begin{array}{lllllllllll}6708.0 & 14903.459 & 03.437 & 03.414 & 03.392 & 03.370 & 03.348 & 03.326 & 03.303 & 03.281 & 03.259\end{array}$ $\begin{array}{llllllllll}03.237 & 03.214 & 03.192 & 03.170 & 03.148 & 03.125 & 03.103 & 03.081 & 03.059 & 03.037\end{array}$ $\begin{array}{llllllllll}03.015 & 02.992 & 02.970 & 02.948 & 02.926 & 02.903 & 02.881 & 02.859 & 02.837 & 02.815\end{array}$

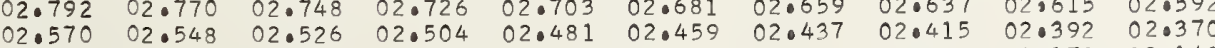

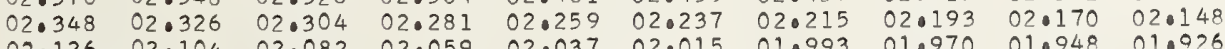
$\begin{array}{llllllllll}02.126 & 02.104 & 02.082 & 02.059 & 02.037 & 02.015 & 01.993 & 01.970 & 01.948 & 01.928\end{array}$ $\begin{array}{llllllllll}01.904 & 01.882 & 01.859 & 01.837 & 01.815 & 01.793 & 01.771 & 01.748 & 01.726 & 01.704 \\ 01.682 & 01.659 & 01.637 & 01.615 & 01.593 & 01.571 & 01.548 & 01.526 & 01.504 & 01.482\end{array}$ $\begin{array}{llllllllll}01.460 & 01.437 & 01.415 & 01.393 & 01.371 & 01.349 & 01.326 & 01.304 & 01.28 \text { ? } & 01.260\end{array}$

0.276077

0.276077

0.276077

0.276076

(2)

0.276076

1.851656

1.851683
1.851709

1.851736

10851763

1.851817

1.851844

$0 . ? 76076$

1.851925

1.851978

1.852005
.852032

1.852059

1.852113

0.276076

$\begin{array}{lllllllllll}6709.0 & 14901.237 & 01.215 & 01.193 & 01.171 & 01.149 & 01.126 & 01.104 & 01.082 & 01.060 & 01.037\end{array}$

$\begin{array}{lllllllllll}9.1 & 01.015 & 00.993 & 00.971 & 00.949 & 00.927 & 00.904 & 00.882 & 00.860 & 00.838 & 00.816 \\ 9.2 & 00.793 & 00.771 & 00.749 & 00.726 & 0.904 & 00.582 & 00.660 & 00.638 & 00.615 & 00.593\end{array}$

$\begin{array}{lllllllllll}9.3 & 0.0 .571 & 00.5549 & 00.527 & 00.505 & 00.482 & 00.460 & 00.438 & 00.416 & 00.394 & 00.371\end{array}$

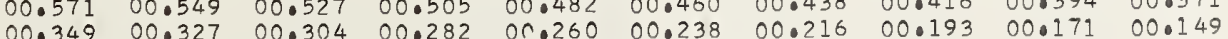

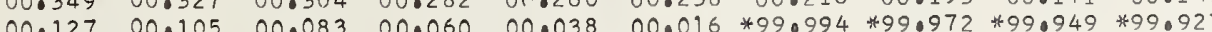

$\begin{array}{llllllllll}14899.905 & 99.883 & 99.861 & 99.838 & 99.816 & 99.794 & 99.772 & 990749 & 99.727 & 99.705\end{array}$

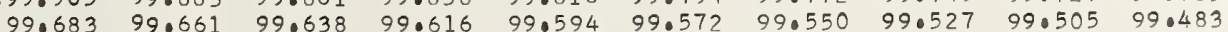

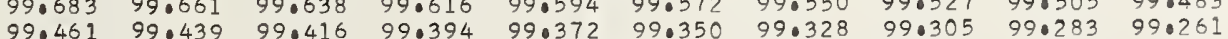

$99.239 \quad 99.216 \quad 99.194 \quad 99.172$

$99.150 \quad 99.128 \quad 990105 \quad 99.083 \quad 99.061 \quad 99.039$

0.276076
0.276076
0.276076

0.276076

0.276076

0.276075
0.276075

0.276075

.852167

\begin{tabular}{|c|c|c|c|c|c|c|c|c|c|c|}
\hline & .001 & .002 & .003 & .004 & .005 & .006 & .007 & .008 & .009 & .010 \\
\hline $\begin{array}{r}.022 \\
.021\end{array}$ & $\begin{array}{l}.002 \\
.002\end{array}$ & $\begin{array}{l}.004 \\
.004\end{array}$ & .007 & $\begin{array}{l}.009 \\
.009\end{array}$ & .011 & $\begin{array}{r}.013 \\
.013\end{array}$ & $\begin{array}{l}.016 \\
.015\end{array}$ & $\begin{array}{l}.018 \\
.017\end{array}$ & $\begin{array}{l}.020 \\
.019\end{array}$ & $\begin{array}{l}.022 \\
.021\end{array}$ \\
\hline
\end{tabular}


$97.307 \quad 97.507 \quad 97.485$

96.575

$6.774 \quad 9607$

$\begin{array}{llll}96.575 & 96.552 & 96.530 & 96.730 \\ 96.353 & 96.331 & 96.308 & 96.286\end{array}$ $\begin{array}{llll}96.131 & 96.109 & 96.308 & 96.286\end{array}$ $\begin{array}{llll}95.909 & 95.887 & 95.865 & 95.842\end{array}$ $\begin{array}{llll}95.687 & 95.665 & 95.643 & 95.620 \\ 95.465 & 95.443 & 95.421 & 95.398\end{array}$ $95.243 \quad 95.221 \quad 95.199 \quad 95.177$ $\begin{array}{llll}95.021 & 94.999 & 94.977 & 94.955 \\ 94.799 & 94.777 & 94.755 & 94.733\end{array}$

96.70896 .686

97.107 $\begin{array}{lll}97.085 & 97.063 & 97.041 \\ 96.863 & 96.841 & 96.819\end{array}$

$2 \cdot 1$

$2 \cdot 2$

2.4

2.5

2.7
2.8

2.8
2.9

6713.0

$$
\begin{array}{r}
3.1 \\
3.2 \\
3.3 \\
3.4 \\
3.5 \\
3.6
\end{array}
$$$$
\begin{aligned}
& 3.7 \\
& 3.8 \\
& 3.9
\end{aligned}
$$

6715.

5.

5.3
5.4

5.4
5.5

5.6
5.7
5.8

5.8
5.9

6716.

6.2

6.2
6.3
6.4

6.4

6.6

6.8
6.9

7.1

$7 \cdot 3$
7.4
7.5

7.6
7.7
7.8

7.8
7.9

6718.

18.0
8.1
8.2
8.3
8.4
8.5
8.6
8.7
8.8
8.9

92.137

$91.693 \quad 91.67$

$\begin{array}{ll}91.471 & 91.449 \\ 91.250 & 91.227\end{array}$

$91.028 \quad 91.005$

$\begin{array}{ll}90.806 & 90.784 \\ 90.584 & 90.562 \\ 90.362 & 90.340\end{array}$

$94.533 \quad 94.511$

$\begin{array}{ll}94.311 & 94.289 \\ 94.089 & 94.067 \\ 93.867 & 93.845\end{array}$

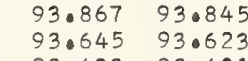

$\begin{array}{ll}93.423 & 93.401 \\ 93.202 & 93.180\end{array}$

$\begin{array}{ll}93.202 & 93.180 \\ 92.980 & 92.958 \\ 92.758 & 92.736\end{array}$

$\begin{array}{llllll}96.708 & 96.686 & 96.664 & 96.641 & 96.619 & 96.597 \\ 96.486 & 96.464 & 96.442 & 96.419 & 96.397 & 96.375\end{array}$

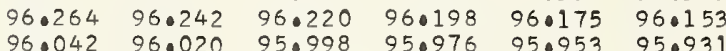

$\begin{array}{llllll}95.820 & 95.798 & 95.776 & 95.754 & 95.731 & 95.709\end{array}$

$\begin{array}{llllll}95.598 & 95.576 & 95.554 & 95.532 & 95.509 & 95.487 \\ 95.376 & 95.354 & 95.332 & 95.310 & 95.288 & 95.265\end{array}$

$95.154 \quad 95.132 \quad 95.110 \quad 95.088 \quad 95.066 \quad 950265$

$\begin{array}{llllll}94.932 & 94.910 & 94.888 & 94.866 & 94.844 & 94.822\end{array}$

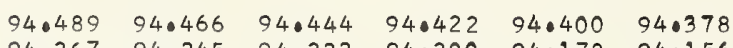

$\begin{array}{llllll}94.045 & 94.245 & 94.222 & 94.200 & 94.178 & 94.156 \\ & 94.023 & 94.000 & 93.978 & 93.956 & 93.934\end{array}$

$\begin{array}{llllll}9.823 & 93.801 & 93.778 & 93.756 & 93.734 & 93.712\end{array}$

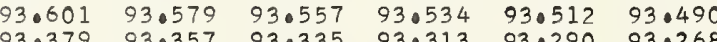

$\begin{array}{llllll}93.157 & 93.135 & 93.335 & 93.313 & 93.290 & 93.268 \\ & 93.113 & 93.091 & 93.069 & 93.046\end{array}$

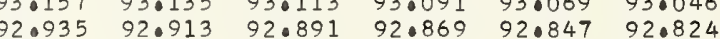

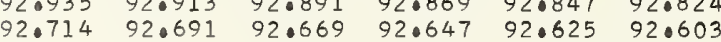

$92.536 \quad 92.514$ 4890.1
89.9

$89.919 \quad 89.896$

$89.254-89.453$

$89.032 \quad 89.01$

$\begin{array}{ll}88.810 & 88.788 \\ 88.588 & 88.565\end{array}$

$\begin{array}{ll}88.365 & 88.344 \\ 88.145 & 88.123\end{array}$

$92.314 \quad 92.292$

$\begin{array}{ll}92.092 & 92.070 \\ 91.870 & 91.848\end{array}$

(1)

$91.427 \quad 91.405$

$\begin{array}{ll}91.205 & 91.183 \\ 90.983 & 90.961\end{array}$

$\begin{array}{rrr}0.761 & 90.739 & 90 \\ 90.540 & 90.517 & 900\end{array}$

$\begin{array}{llllll}2.270 & 92.248 & 92.226 & 92.203 & 92.181 & 92.159\end{array}$

$\begin{array}{llllll}92.048 & 92.026 & 92.004 & 91.981 & 91.959 & 91.937 \\ 91.826 & 91.804 & 91.782 & 91.760 & 91.738 & 91.715\end{array}$

$\begin{array}{llllll}9.604 & 91.582 & 91.560 & 91.538 & 91.738 & 91.715 \\ & 91.493\end{array}$

$\begin{array}{llllll}1.383 & 91.360 & 91.338 & 91.316 & 91.294 & 91.272 \\ 91.161 & 91.138 & 91.116 & 91.094 & 91.072 & 91.050\end{array}$

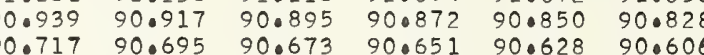

$\begin{array}{llllll}90.495 & 90.695 & 90.673 & 90.651 & 90.628 & 90.606 \\ & 90.473 & 90.451 & 90.429 & 90.407 & 90.385\end{array}$

$$
90.31890 .296
$$

87.701 .48

$87.480 \quad 87.458$

$87.036 \quad 87.014$

$86.815 \quad 86.79$

$86.371 \quad 86 \cdot 349$

$85.928 \quad 85.906$

\section{$\begin{array}{ll}89.874 & 89.852 \\ 89.552 & 89.630 \\ 80.431 & 89.400\end{array}$}

$\begin{array}{llllll}90.052 & 90.030 & 90.007 & 89.985 & 89.963 & 89.941\end{array}$ $\begin{array}{llllll}89.830 & 89.808 & 89.786 & 89.763 & 89.741 & 89.719\end{array}$ $\begin{array}{llllll}89.608 & 89.586 & 89.564 & 89.542 & 89.520 & 89.497 \\ 89.386 & 89.364 & 89.342 & 89.320 & 89.298 & 89.276\end{array}$ $\begin{array}{lllllll}89.165 & 89.143 & 89.120 & 89.098 & 89.076 & 89.054\end{array}$ $\begin{array}{llllll}88.721 & 88.699 & 88.677 & 88.655 & 88.633 & 88.610\end{array}$ $\begin{array}{lllllllll}88.544 & 88.522 & 88.500 & 88.477 & 88.455 & 88.433 & 88.411 & 88.389\end{array}$ $\begin{array}{llllllll}88.322 & 88.300 & 88.278 & 88.256 & 88.233 & 88.211 & 88.189 & 88.167 \\ 88.100 & 88.078 & 88.056 & 88.034 & 88.012 & 87.990 & 87.967 & 87.945\end{array}$ 0.276075 276074 0.276074 0.276074 0.276074

0.276074 0.276074 0.276074 0.276073 0.276073 0.276073 0.276073

0.276073 0.276073 0.276073
0.276072 0.276072 0.276072 0.276072 0.276072 0.276072 1.852490 1.852543 1.852570
1.852597 1.852624 1.852651 1.852678
1.852705

0.276072 0.276072 0.276071 0.276071 0.276071 0.276071 0.276071
0.276071

1.852732

1.852759

1.852785
1.852812 1.852839 1.852893 1.852893
1.852920 1.852947 0.27607 0.27607
0.27607 0.276070 0.276070
0.276070 0.276070 0.276070 0.276070
0.276070

1. 853001 1.853028
1.853054 1.853081 1.853108
1.853135 1.853262 1.853216 1.853243

0.276070 0.276070 0.276069 0.276069 0.276069 0.276069 0.276069 0.276069

1.853270 1.853296 1.853323
1.853350 1.853377 1.853404 1.853431 1.853458 1.853485
1.853512 $\begin{array}{llllllllll}14885.706 & 85.684 & 85.662 & 85.640 & 85.618 & 85.595 & 85.573 & 85.551 & 85.529 & 85.507\end{array}$ $85.485 \quad 85.462 \quad 85.440 \quad 85.418$ $\begin{array}{llllllllll}85.263 & 85.241 & 85.219 & 85.196 & 85.174 & 85.152 & 85.130 & 85.108 & 85.086 & 85.063 \\ 85.041 & 85.019 & 84.997 & 84.975 & 84.953 & 84.931 & 84.908 & 84.886 & 84.864 & 84.842\end{array}$ $\begin{array}{llllllllll}84.576 & 84.354 & 84.554 & 84.532 & 84.509 & 84.487 & 84.465 & 84.443 & 84.421 & 84.399\end{array}$ $\begin{array}{llllllllll}84.155 & 84.333 & 84.111 & 84.310 & 84.288 & 84.266 & 84.243 & 84.221 & 84.199 & 84.177\end{array}$ $\begin{array}{llllllllll}83.933 & 83.911 & 83.889 & 83.867 & 83.845 & 83.823 & 83.800 & 83.778 & 83.756 & 83.734\end{array}$

0.27606

0.276068

0.276068

0.276068

0.276068

0.276068

0.276068

0.276068
0.276068

1.853539 $\begin{array}{llllllllll}883.490 & 83.468 & 83.446 & 83.424 & 83.401 & 83.379 & 83.357 & 83.335 & 83.313 & 83.291\end{array}$

0.276068 0.276067 0.276067 0.276067 0.276067 0.276067 0.276067
0.276067 0.276067

1.853565
1.853592 1.853592 1.853646 1.853700 1.853727 1.853754
1.853781

1.853808 1.853834 1.853861
1.853888 1. 853915 1. 853942 1.853969 1.853996 1.854023 1.854077 1.854103 1.854130
1.854157 1.854184 1.854184 1.854211 1.854238 1.854292 1.854319

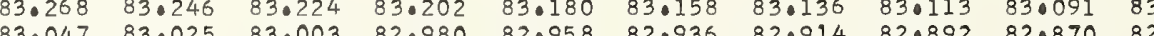
$\begin{array}{llllllllll}82.825 & 82.803 & 82.781 & 82.759 & 82.737 & 82.715 & 82.692 & 82.670 & 82.648 & 82.626\end{array}$ $\begin{array}{lllllllllll}82.604 & 82.582 & 82.560 & 82.537 & 82.515 & 82.493 & 82.471 & 82.449 & 82.427 & 82.405\end{array}$ $\begin{array}{lllllllll} & 82.270 & 82.249 & 820227 & 82.205 & 82.183 \\ \end{array}$ $\begin{array}{llllllllll}81.939 & 81.917 & 81.895 & 81.873 & 81.851 & 81.828 & 81.806 & 81.784 & 81.762 & 81.740\end{array}$ $\begin{array}{llllllllll}81.718 & 81.696 & 81.573 & 81.651 & 81.629 & 81.507 & 81.585 & 81.563 & 81.541 & 81.518 \\ 81.496 & 81.474 & 81.452 & 81.430 & 81.408 & 81.385 & 81.363 & 81.341 & 81.319 & 81.297\end{array}$

0.276066 0.276066 0.276066
0.276066
0.0276066 0.276066 0.27606 0.276066 0.276066
0.276066 1.854346
1.854372 1.854399 1.854426 


\begin{tabular}{|c|c|c|c|}
\hline & & & \\
\hline & 76.381 & 76.359 & \\
\hline & 76.160 & 76.137 & 76.115 \\
\hline 5.9 & 75.938 & & 75.894 \\
\hline 5.73 & 75.717 & & .672 \\
\hline 5.51 & 75.495 & & \\
\hline 5.296 & 75.274 & 75.252 & 230 \\
\hline & 75.053 & 75.031 & .009 \\
\hline 4.854 & 74.831 & 74.809 & 74.787 \\
\hline
\end{tabular}

$\begin{array}{llllll}76.757 & 76.735 & 76.713 & 76.691 & 76.669 & 76.646 \\ 76.536 & 76.514 & 76.492 & 76.469 & 76.447 & 76.425\end{array}$

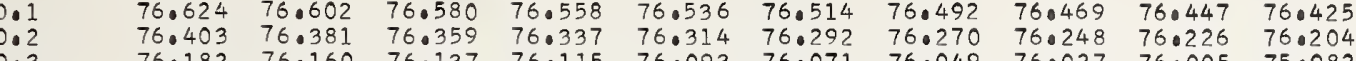
$\begin{array}{lllllllllll}0.3 & 76.182 & 76.160 & 76.137 & 76.115 & 76.093 & 76.071 & 76.049 & 76.027 & 76.005 & 75.982\end{array}$ $\begin{array}{llllllllllll}0.4 & 75.960 & 75.938 & 75.916 & 75.894 & 75.872 & 75.850 & 75.827 & 75.805 & 75.783 & 75.761 \\ 0.5 & 75.739 & 75.717 & 75.695 & 755072 & 75.650 & 75.628 & 75.606 & 75.584 & 755.562 & 75.540\end{array}$ $\begin{array}{lllllllllll}0.6 & 75.518 & 75.495 & 75.473 & 75.451 & 75.429 & 75.407 & 750385 & 750363 & 75.341 & 750318\end{array}$

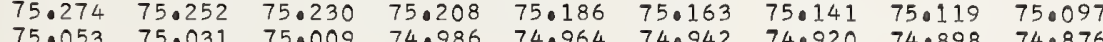
0.9 $74.854 \quad 74.831$

$$
\begin{array}{rllll}
874.632 & 74.610 & 74.588 & 74.566 & 740 \\
74.411 & 74.389 & 74.367 & 74.345 & 74 \\
74.190 & 74.167 & 74.145 & 74.123 & 740 \\
73.968 & 73.946 & 73.924 & 73.902 & 7308
\end{array}
$$$$
\begin{array}{llllll}
74.986 & 74.964 & 74.942 & 74.920 & 74.898 & 74.876 \\
74.765 & 74.743 & 74.721 & 74.6999 & 74.677 & 74.654
\end{array}
$$$$
73.968 .73 .046-74.145 .74 .123
$$$$
73.747 \quad 73.725
$$

$$
68.2
$$

0.276064

0.276064

0.276064

0.276064

0.276064

0.276064

0.276063

0.276063

0.276063

0.276063
0.27606

0.276063

0.276062

0.276062

0.276062

0.276062
0.276062

0.276062

0.276062

0.276062

0.276062

0.276061

0.27606
0.27606

0.27606

0.27606

0.276061

0.276060

0.276060

0.276060

0.276060

0.276060

0.276060
0.276060
0.276060

0.276060
0.276060

0.276059

0.276059
0.276059

0.276059

0.276059

0.276059
0.276059
0.276059

0.276059

0.276059

0.276058

0.276058

0.276058

0.276058
0.276058

0.0276058

0.276058

0.276058
0.276057

0.27605
0.276057
0.276057

0.276057

0.276057

0.276057

0.276057

0.276057
0.276057

0.276056

0.276056

0.276056

0.276056
0.276056

0.276056

0.276056

0.276056
0.276056

0.276056

0.276055

0.276055
0.276055

0.27605

0.276055

0.276055

0.27605

0.276054

0.276054

0.276054
0.276054

1.855133

1.855179

I. 855233

1.855260

1.855314

1.855341

1.855368
1.855393

1.855422

9.855448

1.855502

1.855529

1.855583

1.855610
1.855637

1.855684

1.855691

1.855717

1.855771
1.855798

1.855825

1.855852

1.855879
1.855906

885933

1.853960

1.855986
1.856013

1.856040

1.856067

1.856094
1.856121

1.856148

1.856175
1.856202

1.856229

.8856255

1.856309

1.856336

1.856363
1.856390

1.856417

1. 856474

1.856498

1.856524
1.856551 


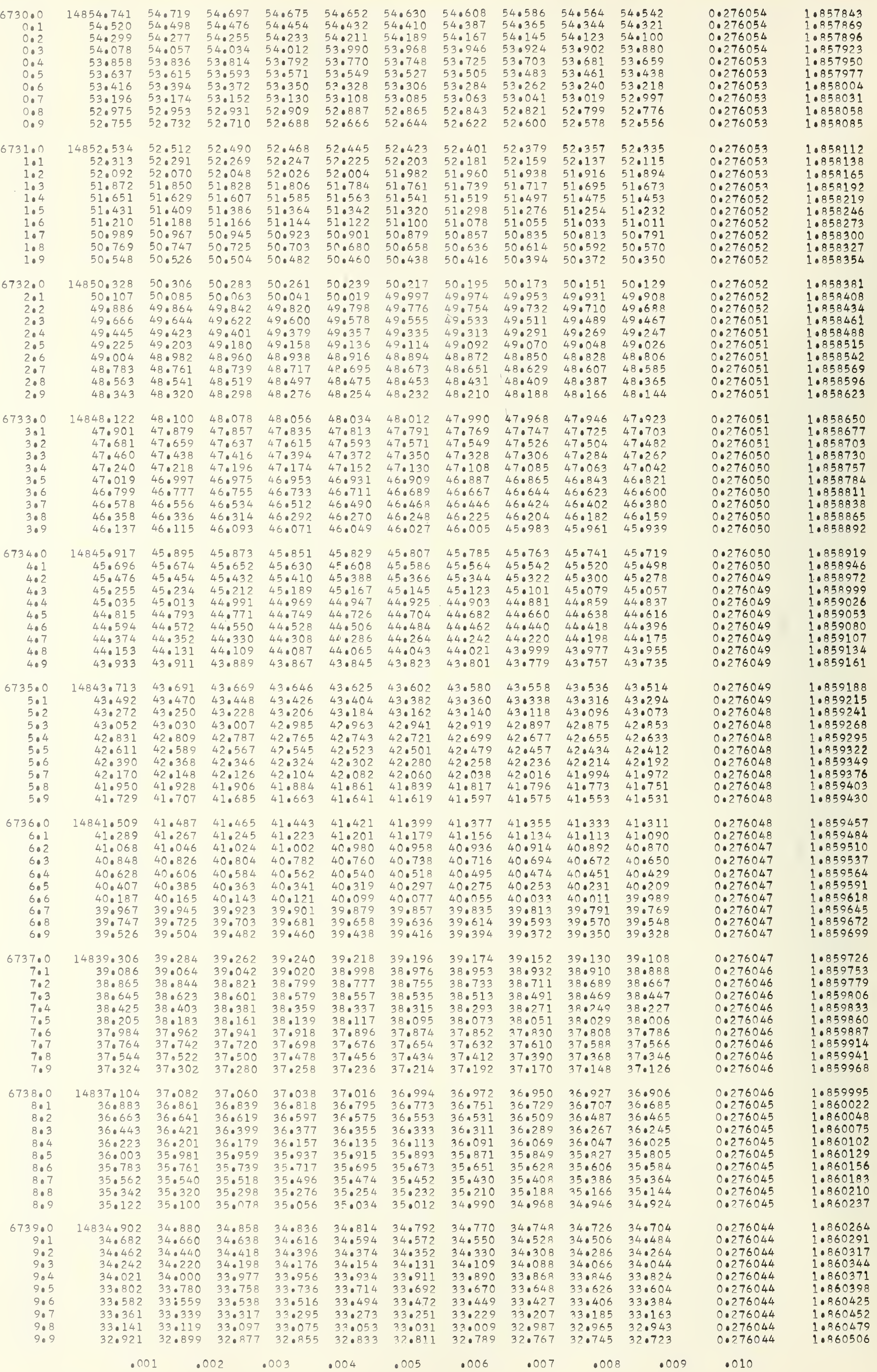

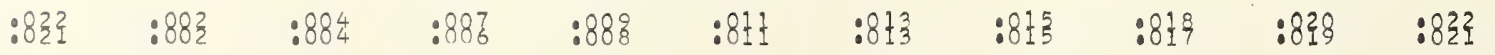




$$
\begin{array}{rlllll}
32.701 & 32.679 & 32.657 & 32.635 & 32.613 & 32.591 \\
32.481 & 32.459 & 32.437 & 32.415 & 32.393 & 32.371 \\
32.261 & 32.239 & 32.217 & 32.195 & 32.173 & 32.151 \\
32.041 & 32.019 & 31.997 & 31.975 & 31.953 & 31.931 \\
31.821 & 31.799 & 31.777 & 31.755 & 31.733 & 31.711 \\
31.601 & 31.579 & 31.557 & 31.535 & 31.513 & 31.491 \\
31.381 & 31.359 & 31.337 & 31.315 & 31.293 & 31.271 \\
31.161 & 31.139 & 31.117 & 31.095 & 31.073 & 31.051 \\
30.941 & 30.919 & 30.897 & 30.875 & 30.853 & 30.831 \\
30.721 & 30.699 & 30.677 & 30.655 & 30.633 & 30.611
\end{array}
$$

$\begin{array}{ll}32.569 & 32.547 \\ 32.349 & 32.327\end{array}$

$\begin{array}{ll}32.525 & 32.503 \\ 32.305 & 32.283\end{array}$

0.276043

$32.129 \quad 32.107 \quad 32.085 \quad 32.063$

0.276043

$31.469 \quad 31.667 \quad 31.645 \quad 31.623$

0.27604

.276043

0.276043

0.276043

14830.501

$\begin{array}{ll}31.117 & 31.095 \\ 30.897 & 30.875\end{array}$

$31.073 \quad 31.051$

$\begin{array}{llll}1.249 & 31.227 & 31.205 & 31.183\end{array}$

$\begin{array}{llll}30.809 & 30.787 & 30.765 & 30.743\end{array}$

.27604

$1: 1$
1.2
$1: 3$
1.5
1.5
$1: 7$
1.9

$\begin{array}{ll}30.281 & 30.259 \\ 30.061 & 30.039\end{array}$

$30.457 \quad 30.435$

$30.633 \quad 30.61$

$\begin{array}{lll}30.369 & 30.347 & 30.325\end{array}$

$29.841 \quad 29.819$

$\begin{array}{ll}29.621 & 29.599 \\ 29.401 & 29.379\end{array}$

$\begin{array}{lll}29.401 & 29.379 & 29.35\end{array}$

$\begin{array}{ll}28.961 & 28.939 \\ 28.741 & 28.719\end{array}$

$28.741 \quad 28.719 \quad 28.697$

29.995

$\begin{array}{ll}30.193 & 30.171 \\ 29.973 & 29.951\end{array}$

30.149

$\begin{array}{lll}29.555 & 29.533 & 29.511 \\ 29.335 & 29.313 & 29.291\end{array}$

$\begin{array}{lll}29.335 & 29.313 & 29.291 \\ 29.115 & 29.093 & 29.071\end{array}$

$\begin{array}{lll}29.929 & 29.907 & 29.885\end{array}$

30.303

0.276042
0.27604
0.0276042

0.776042
0.276042
0.276042

0.276042
0.276042

0.27604

0.276042
0.276041

6742.
2
2
2
2
2.
2.6
2.7
2.

14828.

28.30128 .27

(27.86123.059

$27.641727 .020 \quad 27.817$

$27.421 \quad 27.399$

27.20

27.377

26.762

$26.959 \quad 26.938$

26.32

28.675
28.455

$\begin{array}{ll}28.873 & 28.851 \\ 28.653 & 28.63\end{array}$

$\begin{array}{ll}29.247 & 29.225 \\ 29.203\end{array}$

$\begin{array}{llll}8.829 & 28.807 & 28.785 & 28.76\end{array}$

0.276041

0.276041

0.276041

0.276041

.276041

0.276041

0.276040

6743.

$\begin{array}{rrrrrrrrrrr}3.0 & 14826.102 & 26.080 & 26.058 & 26.036 & 26.014 & 25.992 & 25.970 & 25.948 & 25.926 & 25 \cdot 904 \\ 3.1 & 25.882 & 25.860 & 25.838 & 25.816 & 25.794 & 25.772 & 25.750 & 25.728 & 25.706 & 25.684 \\ 3.0 & 25.6662 & 25.640 & 250618 & 25.596 & 25.574 & 55.552 & 25.530 & 25.508 & 250486 & 250464\end{array}$

$26 \cdot 520$
$26 \cdot 300$

26.498

9.916

$27.114 \quad 27.09$

$27.070 \quad 27.048 \quad 27.245$
27.026

$\begin{array}{llll}850 & 26.828 & 26.806 & 26.78\end{array}$

$\begin{array}{llllll}26.454 & 26.432 & 26.410 & 26.608 & 26.586 & 26.564\end{array}$

0.276040

$3 \cdot 2$

$\begin{array}{ll}25.662 & 25.640 \\ 25.442 & 25.421\end{array}$

$\begin{array}{ll}25.223 & 25.201 \\ 25.003 & 24.981\end{array}$

$24.783 \quad 24.761$

$3 \cdot 6$

$\begin{array}{ll}24.563 & 24 \cdot 541 \\ 24.343 & 24.321\end{array}$

$\begin{array}{ll}24.959 & 24.937 \\ 24.739 & 24.717\end{array}$

$24 \cdot 123$

$24.519 \quad 24.497$

3.8
3.9

6744.0

4.1

14823.904

$23.904 \quad 23.88$

$23.464 \quad 23.662$

23.24423 .22

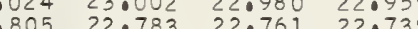

$\begin{array}{llll}22.585 & 22.563 & 22.541 & 22.519\end{array}$

$\begin{array}{llll}22.365 & 22.343 & 22.321 & 22.29\end{array}$

$\begin{array}{ll}22.145 & 22.123 \\ 21.926 & 21.904\end{array}$

$\begin{array}{ll}2.101 & 22.079 \\ 1.882 & 21.860\end{array}$

$\begin{array}{llll}14821.706 & 21.684 & 21.662 & 21.640\end{array}$

$\begin{array}{llll}21.486 & 21.464 & 21.442 & 21.420 \\ 21.266 & 21.245 & 21.223 & 21.200\end{array}$

$\begin{array}{llll}21.047 & 21.025 & 21.003 & 20.981\end{array}$

$\begin{array}{llll}20.827 & 20.805 & 20.783 & 20.761\end{array}$

$\begin{array}{llll}20.607 & 20.585 & 20.563 & 20.541 \\ 20.388 & 20.366 & 20.344 & 20.322\end{array}$

$20.168 \quad 20.146 \quad 20.124 \quad 20.102$

$\begin{array}{llll}19.948 & 19.926 & 19.904 & 19.882 \\ 19.728 & 19.706 & 19.684 & 19.663\end{array}$

$\begin{array}{lllll}14819.509 & 19.487 & 19.465 & 19.443\end{array}$ $\begin{array}{llll}19.289 & 19.267 & 19.245 & 19.223\end{array}$

6746

6.

6.3

6.4 $\begin{array}{llll}18.850 & 18.828 & 18.806 & 18.784\end{array}$ $\begin{array}{llll}18.630 & 18.608 & 18.586 & 18.56\end{array}$ $18.411 \quad 18.389 \quad 18.367 \quad 18.34$ $\begin{array}{llll}18.191 & 18.169 & 18.147 & 18.12\end{array}$

6. $\begin{array}{llll}17.971 & 17.949 & 17.927 & 17.90 \\ 17.751 & 17.730 & 17.708 & 17.68\end{array}$ $\begin{array}{llll}17.751 & 17.730 & 17.708 & 17.686 \\ 17.532 & 17.510 & 17.488 & 17.466\end{array}$

6747.0

$\begin{array}{llll}14817.312 & 17.290 & 17.268 & 17.246\end{array}$

$\begin{array}{llll}16.873 & 16.851 & 16.829 & 16.807\end{array}$

$\begin{array}{llll}16.653 & 16.632 & 16.610 & 16.588 \\ 16.434 & 16.412 & 16.390 & 16.368\end{array}$

$16.214 \quad 16.102$

$15.995 \quad 15.973 \quad 15.951 \quad 16.148$

$\begin{array}{llll}15.775 & 15.753 & 15.731 & 15.70\end{array}$

$\begin{array}{llll}15.556 & 15.534 & 15.512 & 15.490 \\ 15.336 & 15.314 & 15.292 & 15.270\end{array}$

$24.915 \quad 24.893$

$\begin{array}{ll}24.695 & 24.673 \\ 24.475 & 24.453\end{array}$

$\begin{array}{lll}25.530 & 25.508 & 25.48\end{array}$

$\begin{array}{lllll}25.091 & 25.069 & 25.267 & 25.245\end{array}$

$\begin{array}{llll}24.871 & 24.849 & 24.827 & 24.805\end{array}$

$\begin{array}{lllll}24.651 & 24.629 & 24.607 & 24.58\end{array}$

0.276040

.276040

0.276040

0.276039
0.276039

1.860533

1.8060613

86066

.860694

1.960742

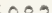

.860882

1.860963

1.86107

1.861129

1.861313

0.276039
0.276039
0.27609

0.276039

0.276039

0.276039
0.276038

1.861340

1.861394

1.861447

1. 861501

1.861555

1.861609

1.861663

$1: 8617716$

$22.497 \quad 22.475 \quad 22.453 \quad 22.431 \quad 22.409 \quad 22.387$

$\begin{array}{llllll}22.277 & 22.255 & 22.233 & 22.211 & 22.189 & 22.167 \\ 22.057 & 22.035 & 22.013 & 21.992 & 21.970 & 21.948\end{array}$

$\begin{array}{llllll}21.618 & 21.596 & 21.574 & 21.552 & 21.530 & 21.508\end{array}$

$\begin{array}{llllll}21.398 & 21.376 & 21.354 & 21.332 & 21.310 & 21.288 \\ 21.179 & 21.156 & 21.135 & 21.113 & 21.091 & 21.069\end{array}$

$\begin{array}{llllll}20.959 & 20.937 & 20.915 & 20.893 & 20.871 & 20.849 \\ 20.739 & 20.717 & 20.695 & 20.673 & 20.651 & 20.629\end{array}$

$\begin{array}{llllll}20.519 & 20.717 & 20.695 & 20.673 & 20.651 & 20.629\end{array}$

$\begin{array}{llllll}20.300 & 20.278 & 20.256 & 20.234 & 20.212 & 20.190\end{array}$

$\begin{array}{llllll}20.080 & 20.058 & 20.036 & 20.014 & 19.992 & 19.970 \\ 19.860 & 19.838 & 19.816 & 19.794 & 19.772 & 19.750 \\ 19.641 & 19.619 & 19.597 & 19.575 & 19.553 & 19.531\end{array}$

0.276038

0.276038

0.276038

0.276038

0.276038

0.276037

0.276037

1.861770

1.861824

1.861878

1.861932

1.961959

1.862012

.862039
1.862066

.862093
1.862120

0.276037

0.276037
0.276037

0.276037

1. 862147

$\begin{array}{llllll}19.201 & 19.179 & 19.157 & 19.135 & 19.113 & 19.091\end{array}$

$\begin{array}{llllll}18.982 & 18.960 & 18.938 & 18.916 & 18.894 & 18.872 \\ 18.762 & 18.740 & 18.718 & 18.696 & 18.674 & 18.652\end{array}$

$\begin{array}{lllllll}18.542 & 18.520 & 18.498 & 18.476 & 18.454 & 18.432\end{array}$

$\begin{array}{llllll}18.323 & 18.301 & 18.279 & 18.257 & 18.235 & 18.213 \\ 18.103 & 18.081 & 18.059 & 18.037 & 18.015 & 17.993\end{array}$

$\begin{array}{llllll}7.883 & 17.861 & 17.839 & 17.817 & 17.795 & 17.773 \\ \end{array}$

0.8276037
0.276077
0.027609

0.276036

1.862201

1.862228

.862281

8.62335

0.276036

.862389

0.276036

0.276036

0.276036

0.276035

0.276035
0.276035

0.276035

0.276035

0.276035

0.276034

0.276024

$\begin{array}{llllllllll}14.019 & 13.997 & 13.975 & 13.953 & 13.931 & 13.909 & 13.887 & 13.865 & 13.843 & 13.821 \\ 13.799 & 13.777 & 13.755 & 13.734 & 13.712 & 13.690 & 13.668 & 13.646 & 13.624 & 13.602\end{array}$

$\begin{array}{llllllllll}13.580 & 13.558 & 13.536 & 13.514 & 13.492 & 13.470 & 13.448 & 13.426 & 13.404 & 13.082 \\ 13.030 & 13.338 & 13.316 & 13.204 & 13.272 & 13.250 & 13.029 & 13.207 & 13.185 & 13.163\end{array}$

$\begin{array}{llllllllll}13.141 & 13.119 & 13.097 & 13.075 & 13.053 & 13.031 & 13.009 & 12.987 & 12.965 & 12.943\end{array}$

0.276034

0.276034

0.276034

0.276034

0.276023

0.276033

.862416

.862470

1.862550

1862577

1.862631

1.862685

.862739

(1.80

1.862819

.262873

.862927

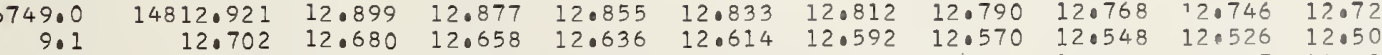

$\begin{array}{lllllllllll}12.483 & 12.460 & 12.438 & 12.417 & 12.395 & 12.373 & 12.351 & 12.329 & 12.307 & 12 . ? 85\end{array}$

$\begin{array}{llllllllll}12.263 & 12.241 & 12.219 & 12.197 & 12.175 & 12.153 & 12.131 & 12.109 & 12.087 & 12.065 \\ 12.044 & 12.022 & 12.000 & 11.978 & 11.956 & 11.934 & 11.912 & 11.890 & 11.868 & 11.846\end{array}$

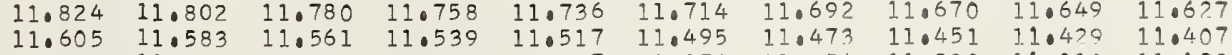

$\begin{array}{llllllllll}11.605 & 11.583 & 11.561 & 11.539 & 11.517 & 11.495 & 11.473 & 11.451 & 11.429 & 11.407 \\ 11.385 & 11.363 & 11.341 & 11.319 & 11.297 & 11.276 & 11.254 & 11.232 & 11.210 & 11.188\end{array}$

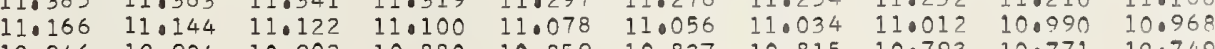

9.8

$.001 \quad .002$

$.003 \quad .004$

.005

.006

.007

.008

.009

.010

1.862981

1.863008

1.863062

.863088
.862115

1.963142

.062196

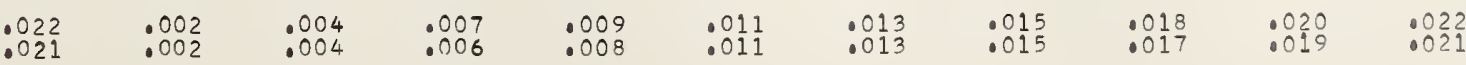


$\begin{array}{rrrrrrrrrrr}6750.0 & 14810.727 & 10.705 & 10.683 & 10.661 & 10.639 & 10.617 & 10.595 & 10.573 & 10.551 & 10.529 \\ 0.9 & 10.507 & 10.485 & 10.464 & 10.442 & 10.420 & 10.398 & 10.376 & 10.354 & 10.332 & 10.310\end{array}$

$\begin{array}{lllllllllll}0.1 & 10.507 & 10.485 & 10.464 & 10.442 & 10.420 & 10.398 & 10.376 & 10.354 & 10.332 & 10.310 \\ 0.2 & 10.288 & 10.266 & 10.244 & 10.222 & 10.200 & 10.178 & 10.156 & 10.135 & 10.113 & 10.091\end{array}$ $\begin{array}{lllllllllll}0.3 & 10.069 & 10.047 & 10.025 & 10.003 & 09.981 & 09.959 & 09.937 & 09.915 & 09.893 & 09.871 \\ 0.4 & 09.849 & 09.827 & 09.805 & 09.783 & 09.761 & 09.740 & 09.718 & 09.696 & 09.674 & 09.652\end{array}$ $\begin{array}{lllllllllll}0.4 & 09.849 & 09.827 & 09.805 & 09.783 & 09.761 & 09.740 & 09.718 & 09.696 & 09.674 & 09.652 \\ 0.5 & 09.630 & 09.608 & 09.586 & 09.564 & 09.542 & 09.520 & 09.498 & 09.476 & 09.454 & 09.432\end{array}$

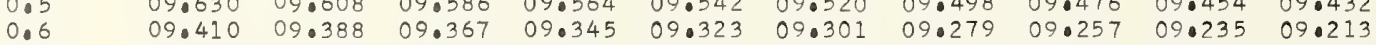
$\begin{array}{lllllllllll}0.7 & 09.191 & 09.169 & 09.147 & 09.125 & 09.104 & 09.081 & 09.059 & 09.037 & 09.016 & 08.994\end{array}$ $\begin{array}{lllllllllll}0.8 & 08.972 & 08.950 & 08.928 & 08.906 & 08.884 & 08.862 & 08.840 & 08.818 & 08.796 & 08.774 \\ 0.9 & 08.752 & 08.730 & 08.708 & 08.687 & 08.665 & 08.643 & 08.621 & 08.599 & 08.577 & 08.555\end{array}$ 0.276033 0.276033 0.276033 0.0276033 0.276032 0.276032 0.276032 0.276032 06.559

0.276032

0.276032

0.276032

0.276032

0.276031

603

0.276031

0.276031

0.27603

0.27603

0.276031

0.276030

0.276030

0.276030

6753.0

$03.928-03.125$

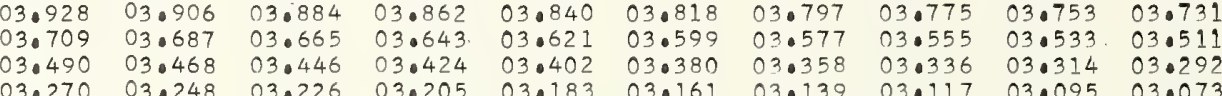

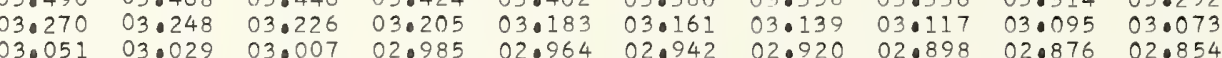

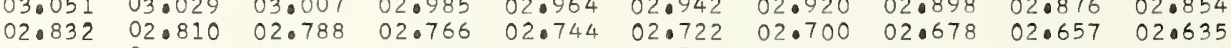

$\begin{array}{llllllllll}02.613 & 02.591 & 02.569 & 02.547 & 02.525 & 02.503 & 02.481 & 02.459 & 02.437 & 02.416\end{array}$

675400

$\begin{array}{llllllllll}02.394 & 02.372 & 02.350 & 02.328 & 02.306 & 02.284 & 02.262 & 02.240 & 02.219 & 02.197 \\ 02.175 & 02.153 & 02.131 & 02.109 & 02.087 & 02.065 & 02.043 & 02.021 & 01.999 & 01.977\end{array}$

4.1
4.2
4.3
4.4
4.5
4.6
4.7
4.8
409

6755.0

5.12

5.3
5,4

5.4
5.5
5.6

5.6

5.8

6756.0

6.1

6.3

6.4

6.6

6.7
6.8
6.8

6.9

6757.0

7.2

7.4
7.5
7.6

$7: 6$
$7: 7$
7.8

6758.0

8.1

8.2

8.4

8.6

8.6
8.7
8.8

8.9

6759.0

9.1
9.2
9.3
9.4
9.5
9.6
9.7
9.8
9.9

$14801.956 \quad 01.934$

\section{$\begin{array}{lll}01.736 & 01.934 & 01.91\end{array}$}

$01.517 \quad 01.495$

$01.298 \quad 01.276 \quad 01.254$

$\begin{array}{lll}00.860 & 00.057 & 01.03\end{array}$

00.641

00.202
99.983

14799.76

99.545
99.326

99.107

98.888
98.669

98.450

98.231

97.793

\section{$\begin{array}{ll}00.619 & 00.59 \\ 00.400 & 00.37\end{array}$}

00.18
99.961

99.742

99.523

99.085

98.647

98.209

99.720
99.50
99.28
99.06
98.84
98.62
98.40
98.187
97.968
97.74

01.89

01.67

01.86

01.846

14797.574

97.35
97.136
96.917

$96.917 \quad 97.11$

$\begin{array}{ll}96.698 & 96.895 \\ 96.676\end{array}$

$96.479 \quad 96.457$

$\begin{array}{ll}96.260 & 96.238 \\ 96.041 & 96.019\end{array}$

$\begin{array}{ll}95.822 & 95.800 \\ 95.603 & 95.581\end{array}$

14795.384

95.165
94.946
94.727

94.727

94.50894 .486

$94.070 \quad 94.048$

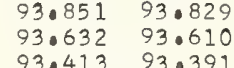

01.01

01.649

01.627

$\begin{array}{lllll}01.824 & 01.802 & 01.780 & 01.758 \\ 027 & 01.605 & 01.583 & 01.561 & 01.539\end{array}$ 93.41

14793.194

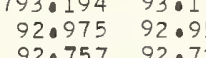

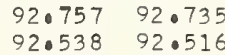

$92.319 \quad 92.297$

$92.100 \quad 92.078$

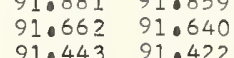

97.530

00.57

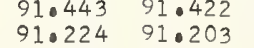

$97.092 \quad 97.2890$

$96.873 \quad 96.85$

$96.435 \quad 96.413$

$96.216 \quad 96.194$

$$
00
$$

$00.753-00.750$

.969
.750
.531
0.312

$\begin{array}{llll}0.947 & 00.926 & 00.904 & 00.882\end{array}$

4791.006

$90.787 \quad 90.765$

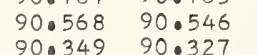

$90.130 \quad 90.10$

$89.912 \quad 89.890$

$\begin{array}{ll}95.778 & 95.75 \\ 95.559 & 95.537\end{array}$

89.474890 .671

$\begin{array}{ll}95.340 & 95.318 \\ 95.121 & 95.09\end{array}$

$\begin{array}{ll}95.121 & 95.099 \\ 94.902 & 94.880 \\ 94.683 & 94.661\end{array}$

$94.464 \quad 94.442$

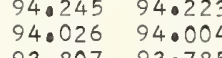

00.312

$00.509 \quad 00.487 \quad 00.465 \quad 00.443$

$0.290 \quad 00.268 \quad 00.246 \quad 00.224$

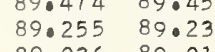

93.588
93.370

93.785
93.567

$99.677 \quad 99.655$

99.852

90.049

$0.027 \quad 00.005$

0.276030

0.276030

0.276030
0.276030

0.276030

0.276029

0.276029

0.276029

0.276029

0.276029
0.276020
0.076029

0.276029

0.278028

0.276028

0.276028

0.276028

0.276028

0.276028
0.276028

0.276028

0.276027

0.276027
0.276027
0.276027

0.276027

0.276027
0.276027

0.276027

0.276027

0.276027

0.276026

0.276026

0.276026

0.276026
0.276026

1.863223

1.863277

1.863304

1.863331

1.863384

4.863411

1.0863492

1.863546

1.863573
1.863600

1.863627

1.863653

1.863709

1.863734

1. 963761

1.863788

1.863842

1.863896

1.863922

1.863949

1.864003

1.864030

1.864057
1.864084

1.864111

1.864165

1.864191

1.864191

1.864245

1.864299

1.864326

10864353

1.864407

1. 864434

1.864487

1.864568

1.864595

1.864622
1.864649

1.864676

1.864703

1.864730
1.864756 


.02

.03

.04

.05
$\begin{array}{rlllllllll}788.818 & 88.796 & 88.774 & 88.752 & 88.730 & 88.708 & 88.687 & 88.665 & 88.643 & 88.621 \\ 88.599 & 88.577 & 88.555 & 88.533 & 88.511 & 88.490 & 88.468 & 88.446 & 88.424 & 88.402 \\ 88.380 & 88.358 & 88.336 & 88.314 & 88.033 & 88.271 & 88.249 & 88.227 & 88.205 & 8.003\end{array}$

$$
\begin{array}{r}
6760.0 \\
0.1 \\
0.2 \\
0.3 \\
0.4 \\
0.5 \\
0.5 \\
0.7 \\
0.9 \\
0.9
\end{array}
$$
$\begin{array}{lllllllllll}88.380 & 88.358 & 88.336 & 88.314 & 88.2293 & 88.271 & 88.249 & 88.227 & 88.205 & 88.183\end{array}$ $\begin{array}{llllllllll}87.161 & 88.140 & 88.118 & 88.096 & 88.074 & 88.052 & 88.030 & 88.008 & 87.987 & 870965 \\ 87.943 & 87.921 & 87.899 & 87.877 & 87.855 & 87.833 & 87.811 & 87.790 & 87.768 & 87.746\end{array}$ $\begin{array}{lllllllllll}87.724 & 87.702 & 87.680 & 87.658 & 87.056 & 87.615 & 87.593 & 87.571 & 87.549 & 87.527 \\ 87.505 & 87.483 & 87.462 & 87.440 & 87.418 & 87.396 & 87.374 & 87.352 & 87.330 & 87.303\end{array}$ $\begin{array}{llllllllll}87.286 & 87.265 & 87.462 & 87.440 & 87.418 & 87.396 & 87.374 & 87.352 & 87.330 & 87.302\end{array}$ $\begin{array}{llllllllll}87.068 & 87.046 & 87.024 & 87.002 & 87.199 & 87.177 & 87.155 & 87.133 & 87.112 & 87.090 \\ 86.980 & 86.958 & 86.936 & 86.915 & 86.893 & 86.871\end{array}$

0.276015

0.0276015
0.276015

0.0276015
0.276015

0.276015

0.276015
0.276015
02276015

0.076015
0.276015
0.276

0.276014
0.276014

0.276014

0.0276014
0.0276014

0.276014
0.276014

0.276014

0.2276014
0.276014
0.276014

0.276013
0.276013

0.276013
0.276013

0.276013

0.276013
0.276013

0.276013

0.276013

.866236

1.866263
1.866290

1.866344

1.866398

1.866451

1.866505

1.866532

1.866586

1.866613

1.866667

1.866720

1.8667474

1.866801

1. 866855

1.866882

1.866936

1.866990

1.867016

1.867070

1.867097
1.867124

.867151
1.867178

1.867205
1.867232

1.867259

1.867312

1.867339

1.867393

1.867420
1.867447

1.867474
1.867501

1.867528

1.867581

1.867608
1.867635

1.867662

1.867716

1.867770

1.867797

1.867850

10867877

1.867931

10867958

1.868012

1.868066

1. 868093

1.868146

1.868173

1.868200
1.868227

1.868254
1.868281

1.868335

1.868389

1.868415

1.868469

1.868496

1.868523
1.868550

1.868550
1.868577

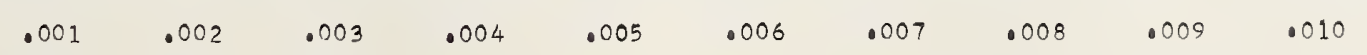

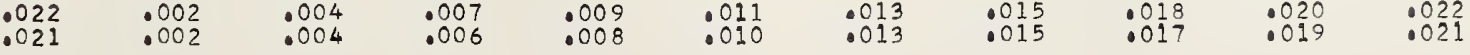




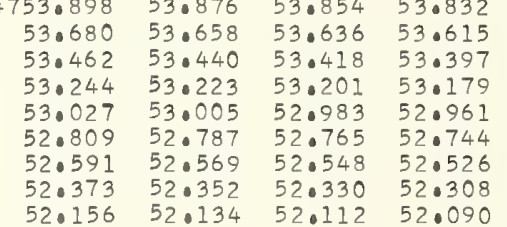

.04

.05

.06

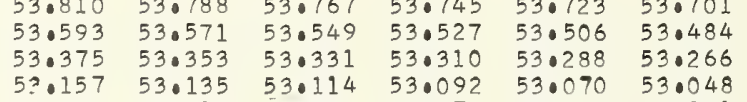

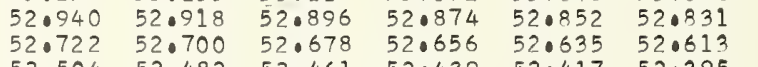

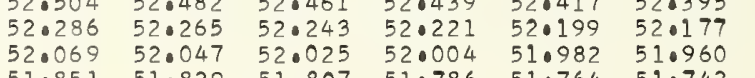
$\begin{array}{llllll}51.633 & 51.612 & 51.590 & 51.568 & 51.546 & 51.525\end{array}$ $\begin{array}{llllll}51.416 & 51.0124 & 51.372 & 51.0350 & 51.329 & 51.0307 \\ 510198 & 51.176 & 51.155 & 51.133 & 51.111 & 51.089\end{array}$ 307
089
871
654 0.276005 0.276005 0.276005 0.276005 0.276004 0.276004

0.276004 0.276004 0.276004 0.276004 0.276004 0.276003 0.278003

0.276003 0.276003 0.27600 0.276003
0.276003 0.276003 0.27600 0.276002 0.276002
0.276002 $\lambda(n-1)$

\begin{tabular}{|c|c|}
\hline $\begin{array}{l}0.276011 \\
0.276011 \\
0.0276011 \\
0.027611 \\
0.0276011 \\
0.0276011 \\
0.27011 \\
0.276011 \\
0.0276011 \\
0.0276010\end{array}$ & 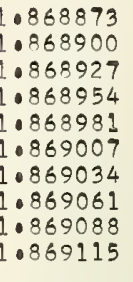 \\
\hline $\begin{array}{l}0.276010 \\
0.027010 \\
0.02761010 \\
0.2761010 \\
0.0276010 \\
0.276010 \\
0.276010 \\
0.27010 \\
0.276010 \\
0.27610 \\
0.276009\end{array}$ & 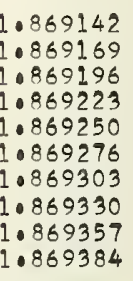 \\
\hline $\begin{array}{l}0.276009 \\
0.276009 \\
0.027600 \\
0.276009 \\
0.276009 \\
0.27609 \\
0.276009 \\
0.276009 \\
0.27600 \\
0.276008 \\
0.27008\end{array}$ & $\begin{array}{l}1.869411 \\
1.86438 \\
1.864465 \\
1.86492 \\
1.865519 \\
1.86946 \\
1.865572 \\
1.86959 \\
1.869526 \\
1.869653\end{array}$ \\
\hline $\begin{array}{l}0.276008 \\
0.276008 \\
0.276008 \\
0.276008 \\
0.276008 \\
0.276008 \\
0.276008 \\
0.276008 \\
0.27608 \\
0.276007 \\
0.276007\end{array}$ & $\begin{array}{l}1.869680 \\
1.869707 \\
1.869734 \\
1.86961 \\
1.869888 \\
1.869815 \\
1.869841 \\
1.86988 \\
1.869895 \\
1.869922\end{array}$ \\
\hline $\begin{array}{l}776007 \\
776007 \\
760007 \\
776007 \\
760007 \\
760007 \\
760007 \\
796006 \\
76000\end{array}$ & $\begin{array}{l}1.869949 \\
1.869976 \\
1.087003 \\
1.870030 \\
1.870057 \\
1.870084 \\
1.870111 \\
1.870137 \\
1.870164 \\
1.870191\end{array}$ \\
\hline
\end{tabular}

0.276006 1.870218 1.870245 1.870272 1.870326 1.870353 1.870380
1.870407 1.870433
1.870460 10870487 1.870514 1.870568 1.870595 1.880622 11.870649 1.870702 10870756

1.870810 1.870837 1.870864 . . 1.0870972 1.871025 1.871052 1.871079 10871106 1. 8711130 1.871187 1.871241 1.871268 
$\begin{array}{llllll}.106 & 45.084 & 45.063 & 45.041 & 45.019 & 44.997 \\ .889 & 44.867 & 44.845 & 44.823 & 44.802 & 44.780\end{array}$ $743.019 \quad 42.997$

0.275993
0.275993

0.275993

0.275993
0.275993

0.275992

0.275992

0.275992
0.275992

1.871294
1.871321
1.871348
1.871375
1.871402
.871429
1.871456
1.871483
1.871510
1.871537

1.871563

1.871644

1.871698

1.871752

1.871833

1.871886
1.871913

1.871940
1.871967

1.872021

1.872075

1.872102
1.872129

1.872155
1.872182

1.872236

1.872263
1.872290

1.872317

1.872371

1.872398

1.872451
1.872478

1.872532

1.872559
1.872586

$\frac{1.872640}{1.872667}$

1.872694

1.872747

1.872794
1.872801

1.872855

1.873178

1.873205
1.873232

1.873259
1.873286

1. 873312

1.873366

1.873393
1.893420

1.873447

$\frac{1}{1.873474}$

1.873528

1.873581

1.873608

1.873635 
$\begin{array}{rrrllllllll}790.0 & 14723.477 & 23.456 & 23.434 & 23.412 & 23.391 & 23.369 & 23.347 & 23.326 & 23.304 & 23.282 \\ 0.1 & 23.260 & 23.239 & 23.217 & 23.195 & 23.174 & 23.152 & 23.130 & 23.109 & 23.087 & 23.065 \\ 0.2 & 23.044 & 23.022 & 23.000 & 22.979 & 22.957 & 22.935 & 22.914 & 22.892 & 22.870 & 22.849\end{array}$

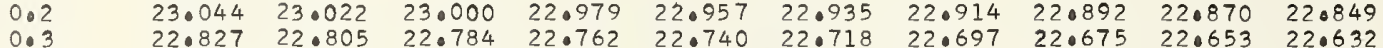

$\begin{array}{lllllllllll}0.3 & 22.827 & 22.805 & 22.784 & 22.762 & 22.740 & 22.718 & 22.697 & 22.675 & 22.653 & 22.632 \\ 0.4 & 22.610 & 22.588 & 22.567 & 22.545 & 22.523 & 22.502 & 22.480 & 22.458 & 22.437 & 22.415 \\ 0.5 & 22.393 & 22.372 & 22.350 & 22.328 & 22.306 & 22.285 & 22.263 & 22.241 & 22.220 & 22.198\end{array}$

$76 \quad 22.15$

22.13322 .11

0.8

$21.960 \quad 21.938 \quad 21.916$

$\begin{array}{ll}22.523 & 22.502 \\ 22.306 & 22.285\end{array}$

21.526

$14721.309 \quad 21.287$

$1: 1$
$1: 2$
$1: 3$

1.3
1.4
1.5

1.5
1.6
1.7

1.7
1.8
1.9

$\begin{array}{ll}21.092 & 21.07 \\ 20.876 & 20 .\end{array}$

$\begin{array}{llll}20.659 & 20.637 & 20.8316 & 20.81 \\ 20.516 & 20.594\end{array}$

$\begin{array}{llll}20.442 & 20.421 & 20.399 & 20.377 \\ 20.225 & 20.204 & 20.182 & 20.160\end{array}$

$\begin{array}{llll}20.009 & 19.987 & 19.965 & 19.944\end{array}$

6792.

$\begin{array}{llll}19.575 & 19.554 & 19.532 & 19.510\end{array}$

$\begin{array}{llll}19.358 & 19.337 & 19.315 & 19.293\end{array}$

$\begin{array}{llllll}22.090 & 22.068 & 22.046 & 22.025 & 22.003 & 21.981 \\ 21.873 & 21.851 & 21.830 & 21.808 & 21.786 & 21.764\end{array}$

2.

$2 \cdot 2$

2.4

2.6

2.8

14719.14219 .120

$\begin{array}{ll}18.925 & 18.90 \\ 18.708 & 18.68\end{array}$

$19.098 \quad 19.077$

$\begin{array}{llll}18.253 & 18.232 & 18.210\end{array}$

$\begin{array}{llll}17.842 & 17.820 & 17.798 & 17.777\end{array}$

$\begin{array}{llll}17.625 & 17.603 & 17.582 & 17.560\end{array}$

$17.192 \quad 17.170$

$\begin{array}{ll}17.365 & 17 \cdot 343 \\ 17.148 & 17.127\end{array}$

6793.0

$3 \cdot 1$

3.3

3.4

3.6

3.8

$14716.975 \quad 16.953$

$16.758 \quad 16.737 \quad 16.71$

$\begin{array}{llll}16.542 & 16.520 & 16.715 & 16.693\end{array}$

$\begin{array}{llll}16.325 & 16.303 & 16.498 & 16.477\end{array}$

$15.892 \quad 15.870 \quad 15.86$

$\begin{array}{llllll}15.675 & 15.653 & 15.632 & 15.610 & 15.589 & 15.567\end{array}$

$\begin{array}{lllllll}15.458 & 15.437 & 15.415 & 15.394 & 15.372 & 15.350\end{array}$

$\begin{array}{ll}15.242 & 15.22 \\ 15.025 & 15.00\end{array}$

6794
4
40
40
40
4
4
4
4
4
4

679500

5.1

$5 \cdot 3$

$5 \cdot 6$

5.8

6796

96.
6.1
6.2
6.3
6.0
6.5
6.0
6.7
6.
6.9

$4 \cdot 1$

4.4

4.6
4.7

4.9

$14.592 \quad 1405$

$\begin{array}{llllll}13.943 & 13.021 & 13.890 & 13.0948 & 140072 & 14.05\end{array}$

$\begin{array}{llllll}13.726 & 13.704 & 13.683 & 13.661 & 13.639 & 13.61\end{array}$

$\begin{array}{llllll}13.293 & 13.271 & 13.250 & 13.444 & 13.423 & 13.40 \\ 13.206 & 13.18\end{array}$

$\begin{array}{llllll}12.860 & 12.838 & 12.816 & 12.795 & 12.773 & 12.75\end{array}$

14712.643

$12.427-12.622$

$12.210 \quad 12.405$

$11.994 \quad 11.972$

$\begin{array}{ll}11.777 & 11.756 \\ 11.561 & 11.539\end{array}$

$\begin{array}{ll}11.344 & 11.32 \\ 11.128 & 11.106\end{array}$

$\begin{array}{ll}10.911 & 10.890 \\ 10.695 & 10.673\end{array}$

$12.600 \quad 12.578$

$\begin{array}{ll}12.557 & 12.535 \\ 12.340 & 12.318\end{array}$

$\begin{array}{llll}12.167 & 12.145 & 12.124 & 12.102 \\ 11.950 & 11.929 & 11.907 & 11.885\end{array}$

$\begin{array}{llll}11.734 & 11.712 & 11.691 & 11.669\end{array}$

$\begin{array}{ll}11.517 & 11.496 \\ 11.301 & 11.279\end{array}$

$\begin{array}{ll}11.474 & 11.452 \\ 11.258 & 11.236\end{array}$

$\begin{array}{llll}11.084 & 11.063 & 11.041 & 11.020 \\ 10.868 & 10.846 & 10.825 & 10.80\end{array}$

$\begin{array}{llll}21.613 & 21.591 & 21.569 & 21.548\end{array}$

0.275992

0.275992
0.275992
0.275992

0.275992

0.275992
0.275991

0.275991

0.27599

0.275991

0.275991

0.27599

0.275991

0.275990

0.275990

0.275990

0.275990
0.275990

$\begin{array}{llll}19.662 & 19.640 & 19.619 & 19.597\end{array}$

$\begin{array}{llll}19.445 & 19.424 & 19.402 & 19.380 \\ 19.228 & 19.207 & 19.185 & 19.163\end{array}$

0.275990

$\begin{array}{llll}19.012 & 18.990 & 18.968 & 18.947 \\ 18.795 & 18.773 & 18.752 & 18.730\end{array}$

$\begin{array}{llll}18.578 & 18.557 & 18.535 & 18.513 \\ 18.362 & 18.340 & 18.318 & 18.297\end{array}$

$\begin{array}{llll}18.145 & 18.123 & 18.102 & 18.080 \\ 17.928 & 17.907 & 17.885 & 17.863\end{array}$

$\begin{array}{llll}17.712 & 17.690 & 17.668 & 17.647\end{array}$

$\begin{array}{llll}17.495 & 17.473 & 17.452 & 17.430 \\ 17.278 & 17.257 & 17.235 & 17.213\end{array}$

0.275990

0.275990

0.27598

0.27598

0.275989

0.275989

$\begin{array}{llll}16.845 & 16.823 & 16.802 & 16.780 \\ 16.628 & 16.607 & 16.585 & 16.563\end{array}$

$\begin{array}{llll}16.412 & 16.390 & 16.368 & 16.347\end{array}$

$\begin{array}{llll}16.195 & 16.173 & 16.152 & 16.130\end{array}$

$\begin{array}{llll}15.762 & 15.740 & 15.719 & 15.697\end{array}$

$\begin{array}{llll}15.545 & 15.523 & 15.502 & 15.480\end{array}$

$\begin{array}{llll}15.329 & 15.307 & 15.285 & 15.264\end{array}$

0.275989

0.275989
0.27598

0.275988

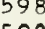

0.275988

0.275988
0.275988

0.275988

$\begin{array}{llll}14.679 & 140657 & 14.636 & 14.614\end{array}$

0.275988

0.27598

$\begin{array}{llll}14.029 & 14.007 & 13.086 & 13.964\end{array}$

$13.596 \quad 13.574$

$\begin{array}{llll}13.379 & 13.358 & 13.336 & 13.315\end{array}$

75987

0.275987

0.275987
0.275987

0.275987

0.275987

$12.513 \quad 12.492 \quad 120470-120448$

0.275987

0.275987
0.275987

0.275087

0.275986

0.275986

0.275986

0.275986

0.275986
0.275986

$\begin{array}{llllllllll}10.262 & 10.240 & 10.219 & 10.197 & 10.175 & 10.154 & 10.132 & 10.110 & 10.089 & 10.067\end{array}$

$\begin{array}{llllllllll}09.829 & 09.807 & 09.786 & 09.764 & 09.742 & 09.721 & 09.699 & 09.677 & 09.656 & 09.634\end{array}$

$\begin{array}{llllllllll}09.613 & 09.591 & 09.569 & 09.548 & 09.526 & 09.504 & 09.483 & 09.461 & 09.439 & 09.418\end{array}$

$\begin{array}{llllllllll}09.396 & 09.375 & 09.353 & 09.331 & 09.309 & 09.288 & 09.266 & 09.245 & 09.223 & 09.201\end{array}$

$\begin{array}{llllllllll}09.180 & 09.158 & 09.136 & 09.115 & 09.093 & 09.072 & 09.050 & 09.028 & 09.007 & 08.985\end{array}$

$\begin{array}{llllllllll}0.963 & 08.942 & 08.920 & 08.898 & 08.877 & 08.855 & 08.833 & 08.812 & 08.790 & 08.768\end{array}$

$\begin{array}{llllllllll}08.747 & 08.725 & 08.704 & 08.682 & 08.660 & 08.639 & 08.617 & 08.595 & 08.574 & 08.552 \\ 08.531 & 08.509 & 08.487 & 08.466 & 08.444 & 08.422 & 08.401 & 08.379 & 08.357 & 08.336\end{array}$

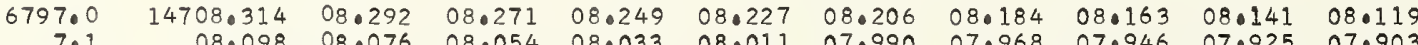

$\begin{array}{lllllllllll}7.1 & 08.098 & 08 \cdot 076 & 08.054 & 08.033 & 08.011 & 07.990 & 07.968 & 07.946 & 07.925 & 07.903 \\ 7.2 & 07.881 & 07.860 & 07.838 & 07.816 & 07.795 & 07.773 & 07.751 & 07.730 & 07.708 & 07.687\end{array}$

$\begin{array}{llllllllllll}7.3 & 07.665 & 07.643 & 07.622 & 07.600 & 07.578 & 07.557 & 07.535 & 07.514 & 07.492 & 07.470\end{array}$

$\begin{array}{lllllllllll}07.449 & 07.427 & 07.405 & 07.384 & 07.362 & 07.341 & 07.319 & 07.297 & 07.276 & 07.254\end{array}$

$\begin{array}{lllllllllll}07.232 & 07.211 & 07.189 & 07.167 & 07.146 & 07.124 & 07.103 & 07.081 & 07.059 & 07.038\end{array}$

$\begin{array}{llllllllll}07.016 & 06.994 & 06.973 & 06.951 & 06.929 & 06.908 & 06.886 & 06.865 & 06.843 & 06.821\end{array}$

$\begin{array}{lllllllllll}7.7 & 06.800 & 06.778 & 06.756 & 06.735 & 06.713 & 06.692 & 06.670 & 06.648 & 06.626 & 06.605 \\ 7.8 & 06.583 & 06.562 & 06.540 & 06.518 & 06.497 & 06.475 & 06.453 & 06.432 & 06.410 & 06.389 \\ 7.9 & 06.367 & 06.345 & 06.324 & 06.302 & 06.281 & 06.259 & 06.237 & 06.216 & 06.194 & 06.172\end{array}$

$\begin{array}{lllllllllll}7.8 & 06.583 & 06.562 & 06.540 & 06.518 & 06.497 & 06.475 & 06.453 & 06.432 & 06.410 & 06.389 \\ 7.9 & 06.367 & 06.345 & 06.324 & 06.302 & 06.281 & 06.259 & 06.237 & 06.216 & 06.194 & 06.172 \\ & & & & & & & \end{array}$

0.275986

0.275986

0.275986

0.275986

0.275985

0.275985

0.275985

0.275985
0.275985

1.873985

1.874012
1.874039

1.874066

1.874120

1.874147

2. 874200

1.874254

10874281

1.874335

1.874362

1.874443

1.874469
1.874496

1.874523

1.874550
1.874577

1.874604

1.874631
1.874658

1.874685

1.874712

1.874739
1.874765

1.874792

1.874819

1.874846

1.874900

1.874954

1.874954
1.874981

1.875008

1.875035

0.275985

0.275985

0.275985

0.275985

0.275984

0.275984
0.275984

0.275984

0.275984

$\begin{array}{lllllllllll}6798.0 & 14706.151 & 06.129 & 06.107 & 06.086 & 06.064 & 06.042 & 06.021 & 05.999 & 05.978 & 05.956\end{array}$

$\begin{array}{lllllllllll}8.1 & 05.934 & 05.913 & 05.891 & 05.870 & 05.848 & 05.826 & 05.805 & 05.783 & 05.761 & 05.740 \\ 8.2 & 05.718 & 05.696 & 05.675 & 05.653 & 05.631 & 05.610 & 05.588 & 05.567 & 05.545 & 05.523\end{array}$

$\begin{array}{lllllllllll}8.2 & 05.718 & 05.696 & 05.675 & 05.653 & 05.631 & 05.610 & 05.588 & 05.567 & 05.545 & 05.523 \\ 8.3 & 05.502 & 05.480 & 05.458 & 05.437 & 05.415 & 05.394 & 05.372 & 05.350 & 05.329 & 05.307\end{array}$

$\begin{array}{lllllllllll}8.4 & 05.285 & 05.264 & 05.242 & 05.221 & 05.199 & 05.177 & 05.156 & 05.134 & 05.112 & 05.091\end{array}$

$\begin{array}{lllllllllll}8.5 & 05.069 & 05.047 & 05.026 & 05.004 & 04.983 & 04.961 & 04.939 & 04.918 & 04.896 & 04.874 \\ 8.6 & 04.853 & 04.831 & 04.810 & 04.788 & 04.766 & 04.745 & 04.723 & 04.701 & 04.680 & 04.658\end{array}$

$\begin{array}{lllllllllll}8.6 & 04.853 & 04.831 & 04.810 & 04.788 & 04.766 & 04.745 & 04.723 & 04.701 & 04.680 & 04.658 \\ 8.7 & 04.636 & 04.615 & 04.593 & 04.572 & 04.550 & 04.528 & 04.507 & 04.485 & 04.464 & 04.442\end{array}$

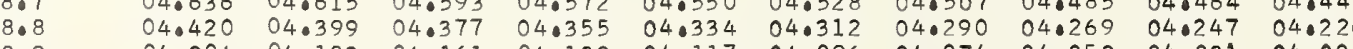

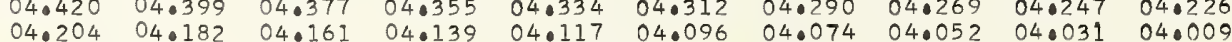

0.275984

0.275984

0.275984

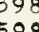

0.275983

0.275983
0.275983

0.275983

0.275983

1.875061

1.875088
1.875115

1.87 .51 .42

1.875169

1.875223
1.875250

1.875304

1.875331

1.875357

1.875411

1.875438

1.875465

1.875519

1.875546

1.875600

1.875626

1.875653

1.875680

1.875734

1.875761

1.875788

1.875842

1.875869

1.875896

1.875922
1.875949

1.875976

1.876030

1.876057

1.876111

10876138

1.876165

1.876192
1.876219

1.876219
1.876245

1.876272

1.876299

.876353
.876380

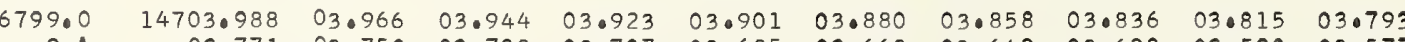

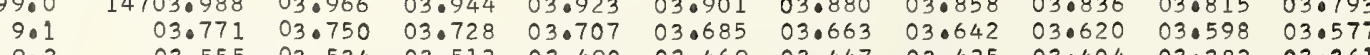

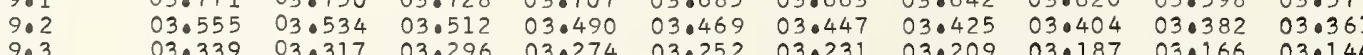

0.275983

1.876407

0.275983

1.876434

0.275983

0.275982

1.876461

$\begin{array}{llllllllll}03.123 & 03.101 & 03.079 & 03.058 & 03.036 & 03.015 & 02.993 & 02.971 & 02.950 & 02.928\end{array}$

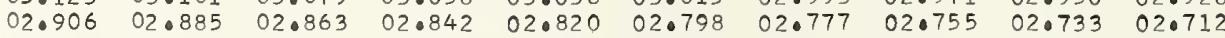

$\begin{array}{llllllllll}02.690 & 02.668 & 02.647 & 02.625 & 02.604 & 02.582 & 02.560 & 02.539 & 02.517 & 02.496 \\ 02.474 & 02.452 & 02.431 & 02.409 & 02.388 & 02.366 & 02.344 & 02.323 & 02.301 & 02.279\end{array}$

9.6

$02.258 \quad 02.236 \quad 02.2$ 


.05

6800.0

$\begin{array}{ll}.01 .825 & 01.804\end{array}$

$\begin{array}{lll}01.609 & 01.587 & 010 \\ 01.393 & 01.371 & 010\end{array}$

0.3

0.5
0.6
0.7

$\begin{array}{ll}01.177 & 01.155 \\ 00.961 & 00.939\end{array}$

$00.944 \quad 00.723 \quad 00.917$

$\begin{array}{ll}0.7428 & 00.723 \\ 00.512 & 00.290\end{array}$

$\begin{array}{lll}00.312 & 00.290 & 00.269\end{array}$

$\begin{array}{rrr}0.8 & 00.096 & 00.074 \\ 0.9 & 14699.880 & 99.858\end{array}$

6801.0

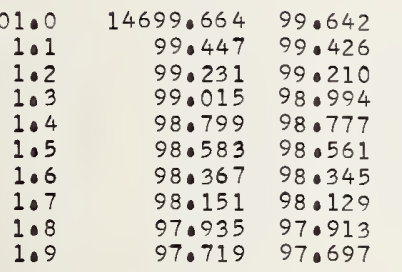

6802.0

2.1
2.2
2.3

2.3

2.4

2.6
2.7

2.8

$\begin{array}{rl}14697.503 & 97.481 \\ 97.286 & 97.265\end{array}$

$\begin{array}{ll}97.070 & 97.049 \\ 96.854 & 96.833\end{array}$

$\begin{array}{ll}96.638 & 96.617 \\ 96.422 & 95.401\end{array}$

$96.206 \quad 96.185$

$\begin{array}{ll}95.990 & 95.969 \\ 95.774 & 95.753 \\ 95.558 & 95.536\end{array}$

6803.0

3.0
3.2
3.
3.
3.
3.0
3.7
3.0
3.0

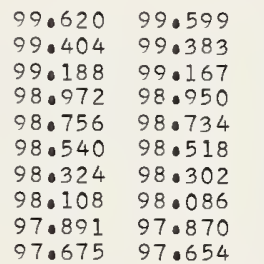

$\begin{array}{llllll}01.739 & 01.717 & 01.696 & 01.674 & 01.652 & 01.631 \\ 01.523 & 01.501 & 01.479 & 01.458 & 01.436 & 01.415 \\ 01.307 & 01.285 & 01.263 & 01.242 & 01.220 & 01.198\end{array}$

$(n-1) \times 1000$

$\lambda(n-1)$

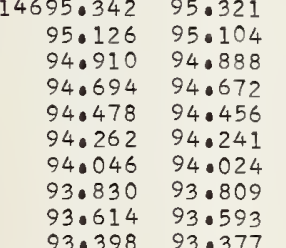

$\begin{array}{lll}97.459 & 97.438 & 97 . \\ 97.243 & 97.222 & 970 \\ 97.027 & 97.005 & 94.0\end{array}$

$\begin{array}{ll}97.027 & 97.005 \\ 96.811 & 96.790 \\ 96.595 & 96.573\end{array}$

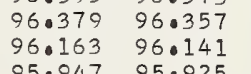

$\begin{array}{ll}95.947 & 95.925 \\ 95.731 & 95.709\end{array}$

$01.0090 \quad 01.285$

01.263

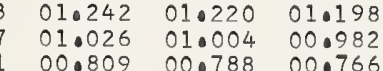

0.0275982

0.275982

0.275981
0.275981

0.275981

0.275981

0.275981

$\frac{1.876676}{1.876703}$

.876730

$\begin{array}{llllll}00.658 & 00.636 & 00.615 & 00.593 & 00.572 & 00.555 \\ 00.442 & 00.420 & 00.398 & 00.377 & 00.355 & 00.334\end{array}$

275981

1.87681

.87686

0.275981

0.275980

0.275980
0.275980

0.275980

0.275980
0.275980
0.275980

0.275980

1.876891

.275980

0.275980

0.27597

0.075979

0.275979

1.876945

1.876999

1.877053

1.877106

1.877160
1.877187

0.27597

1.877214

1.877268
1.877295

1.877322

1.877376

1.877402

1.877456

0.275979

0.275979

1.877483
1.877510

$\begin{array}{rlllllll}5.299 & 95.277 & 95.256 & 95.234 & 95.213 & 95.191 & 95.169 & 950148 \\ 5.083 & 95.061 & 95.040 & 95.018 & 94.996 & 94.975 & 94.953 & 94.932\end{array}$

$\begin{array}{llllllll}94.867 & 94.845 & 94.824 & 94.802 & 94.781 & 94.759 & 94.737 & 94.716\end{array}$

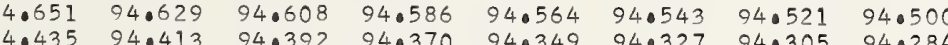

94.219994 .197

$\begin{array}{rr}94.003 & 93.981 \\ 93.787 & 93.765\end{array}$

$94.176 \quad 94.370$

$\begin{array}{llll}94 \cdot 349 & 94 \cdot 327 & 94 \cdot 305 & 94 \cdot 284 \\ 94 \cdot 133 & 94.111 & 94.089 & 94.068\end{array}$

0.275978

.877537

1.877564

1.877618

0.275978

1.877672

0.275978

6804.0

14693.182

$\begin{array}{llllllllll}93.182 & 93.161 & 93.139 & 93.117 & 93.096 & 93.074 & 93.053 & 93.031 & 93.010 & 92.988 \\ 92.966 & 92.945 & 92.923 & 92.902 & 92.880 & 92.858 & 92.837 & 92.0115 & 92.794 & 92.772 \\ 92.750 & 92.720 & 92.0707 & 92.686 & 92.664 & 92.642 & 92.521 & 02.509 & 92.578 & 92.556\end{array}$

93.13993 .117

$\begin{array}{llllll}93.744 & 93.722 & 93.701 & 93.679 & 93.657 & 93.636 \\ 93.528 & 93.506 & 93.485 & 93.463 & 93.442 & 93.420\end{array}$

0.27597

$\begin{array}{lllllllll}92.513 & 92.707 & 92.686 & 92.664 & 92.642 & 92.621 & 92.599 & 92.578 & 92.556\end{array}$

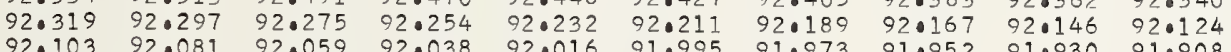

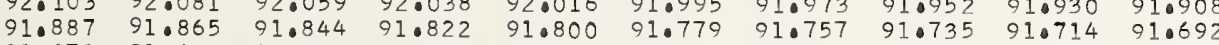

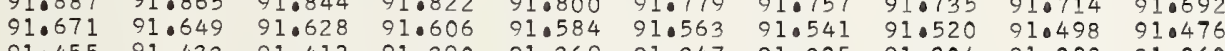

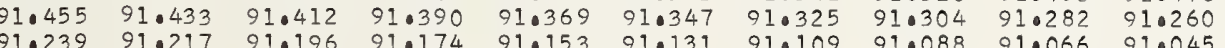

0.27599

0.275978

0.275977

0.275977

0.275977

1.877698

1.877752

1.877806

8877833

1.877860

.877914

1.877968

6805.0

691.02391 .002

$\begin{array}{ll}90.980 & 90.958 \\ 90.764 & 90.742\end{array}$

$90.937 \quad 90.915 \quad 90.894 \quad 90.872 \quad 90.850 \quad 90.829$

0.0275077

0.275977

$\begin{array}{lllllllllll}90.591 & 90.570 & 90.548 & 90.527 & 96.505 & 90.484 & 90.462 & 90.440 & 90.419 & 90.391\end{array}$

$\begin{array}{llllllllll}90.375 & 90.354 & 90.332 & 90.311 & 90.289 & 90.267 & 90.246 & 90.224 & 90.203 & 90.181\end{array}$

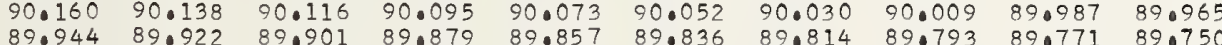

$\begin{array}{llllllllll}89.944 & 89.922 & 89.901 & 89.879 & 89.857 & 89.836 & 89.814 & 89.793 & 89.771 & 89.750 \\ 89.728 & 89.706 & 89.685 & 89.663 & 89.642 & 89.620 & 89.598 & 89.577 & 89.555 & 89.534\end{array}$

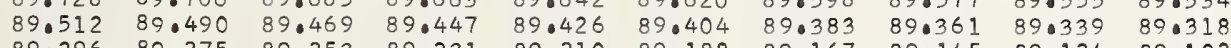

$\begin{array}{llllllllll}89.296 & 89.275 & 89.253 & 89.231 & 80.210 & 89.188 & 89.167 & 89.145 & 89.124 & 89.102 \\ 89.080 & 89.059 & 89.037 & 89.016 & 88.994 & 88.973 & 88.951 & 88.929 & 88.908 & 88.886\end{array}$

0.275976

0.275976

0.275976

0.275976

0.275976

6806

806
6
6
6
6
6
6
6
6
6
6

$\begin{array}{rrr}14688.865 & 88.843 \\ .1 & 88.649 & 88.627\end{array}$

0.27597

0.275976

0.275975

0.275975

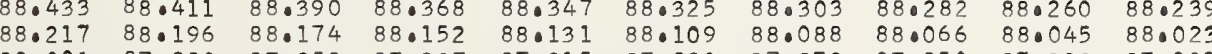

$\begin{array}{lllllllllll}88.001 & 87.980 & 87.958 & 87.937 & 87.915 & 87.893 & 87.872 & 87.850 & 87.829 & 87.807\end{array}$

$\begin{array}{llllllllll}87.786 & 87.764 & 87.742 & 87.721 & 87.699 & 87.678 & 87.656 & 87.635 & 87.613 & 87.591\end{array}$

$\begin{array}{llllllllll}87.574 & 87.548 & 87.527 & 87.505 & 87.483 & 87.462 & 87.440 & 87.419 & 87.397 & 87.376\end{array}$

0.275975

0.275975

0.275975
0.275975

87.138
$86.922 \quad 86.901$

$87.095 \quad 87.073$

$\begin{array}{llllll}87.268 & 87.246 & 87.224 & 87.203 & 87.181 & 87.160 \\ 87.052 & 87.030 & 87.009 & 86.987 & 86.966 & 86.944\end{array}$

6807.

14686

$\begin{array}{lll}86.707 & 86.685 & 8 \\ 86.491 & 86.469 & 8 \\ 86.275 & 86.254 & 8 \\ 86.059 & 86.038 & 8 \\ 85.844 & 85.822 & 8 \\ 85.628 & 85.606 & 8 \\ 85.412 & 85.391 & 8 \\ 85.197 & 85.175 & 8 \\ 84.981 & 84.959 & 8 \\ 84.765 & 84.744 & 8\end{array}$

$6.664 \quad 86.642$

$86.620 \quad 86.599 \quad 86.577 \quad 86.556 \quad 86.534 \quad 86.512$

0.27597

0.275975
0.275974

0.275974

0.275974

00275974
0.275974

0.275974

0.275974

0.275974

$\begin{array}{lllllllllll}6808.0 & 14684.549 & 84.528 & 84.506 & 84.485 & 84.463 & 84.442 & 84.420 & 84.398 & 84 \cdot 377 & 84.355\end{array}$

$\begin{array}{lrlllllllll}8.1 & 84.334 & 84.312 & 84.291 & 84.269 & 84.247 & 84.226 & 84.204 & 84.183 & 84.161 & 84.140 \\ 8.2 & 84.118 & 84.096 & 84.075 & 84.053 & 84.032 & 84.010 & 83.989 & 83.967 & 83.945 & 83.924\end{array}$

$\begin{array}{lllllllllll}8.2 & 84.118 & 84.096 & 84.075 & 84.053 & 84.032 & 84.010 & 83.989 & 83.967 & 83.945 & 83.924 \\ 8.3 & 83.902 & 83.881 & 83.859 & 83.838 & 83.816 & 83.795 & 83.773 & 83.751 & 83.730 & 83.708\end{array}$

$\begin{array}{lllllllllll}8.3 & 83.902 & 83.881 & 83.859 & 83.838 & 83.816 & 83.795 & 83.773 & 83.751 & 83.730 & 83.708 \\ 8.4 & 83.687 & 83.665 & 83.643 & 83.622 & 83.600 & 83.579 & 83.557 & 83.536 & 83.514 & 83.493\end{array}$

$\begin{array}{llllllllllll}8.5 & 83.471 & 83.449 & 83.428 & 83.406 & 83.385 & 83.363 & 83.342 & 83.320 & 83.298 & 83.277\end{array}$

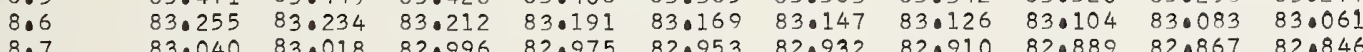

$\begin{array}{lllllllllll}8.7 & 83.040 & 83.018 & 82.996 & 82.975 & 82.953 & 82.932 & 82.910 & 82.889 & 82.867 & 82.846\end{array}$

$\begin{array}{lllllllllll}8.8 & 82.824 & 82.803 & 82.781 & 82.759 & 82.738 & 82.716 & 82.695 & 82.673 & 82.651 & 82.630 \\ 8.9 & 82.608 & 82.587 & 82.565 & 82.544 & 82.522 & 82.501 & 82.479 & 82.457 & 82.436 & 82.414\end{array}$

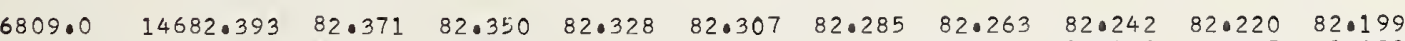

$\begin{array}{llllllllllll}9.1 & 82.177 & 82.156 & 82.134 & 82.112 & 82.091 & 82.069 & 82.048 & 82.026 & 82.005 & 81.983\end{array}$

$\begin{array}{lllllllllll}9.2 & 81.962 & 81.940 & 81.918 & 81.897 & 81.875 & 81.854 & 81.832 & 81.811 & 81.789 & 81.767\end{array}$

$\begin{array}{lllllllllll}9.3 & 81.746 & 81.724 & 81.703 & 81.681 & 81.660 & 81.638 & 81.616 & 81.595 & 81.573 & 81.552 \\ 9.4 & 81.530 & 81.509 & 81.487 & 81.466 & 81.444 & 81.422 & 81.401 & 81.379 & 81.358 & 81.336\end{array}$

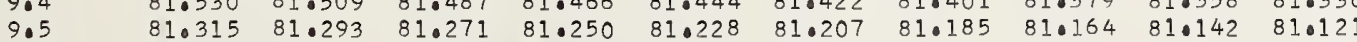

$\begin{array}{llllllllllll}9.6 & 81.099 & 81.078 & 81.056 & 81.034 & 81.013 & 80.991 & 80.970 & 80.948 & 80.927 & 80.905\end{array}$

$\begin{array}{lllllllllll}9.7 & 80.884 & 80.862 & 80.840 & 80.819 & 80.797 & 80.776 & 80.754 & 80.733 & 80.711 & 80.689\end{array}$

9.8

$\begin{array}{llll}80.668 & 80.646 & 80.840 & 80.819 \\ 80.452 & 80.431 & 80.409 & 80.603\end{array}$

$\begin{array}{llllll}80.582 & 80.560 & 80.538 & 80.517 & 80.495 & 80.474 \\ 80.366 & 80.344 & 80.323 & 80.301 & 80.280 & 80.258\end{array}$

0.0275974
0.275973

0.275973

0.275973

0.275973
0.275973

0.275973

0.275973
0.275973

1.878021
1.878048

1.878048
1.898075

.878102

9.878156

.078210

1.878237

0.275973

0.275973

0.275972
0.275972

0.275972

0.275972

0.275972

0.275972

0.275972

1.878290

. 878317

1.878344
1.878371

1.878398

1.878452

1.878506

1.878560

1.878586

1.878640

1. 8878667

1.878721

.878775

1.878829

1.878856

1.878882

1.878936

1.878963

1.878990

1.879044

1.879098

1.879125

1.879152
1.879178

1.879205
1.879232

1.879259

1.879286

.879340

.010

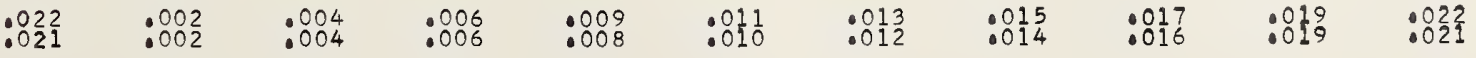




\begin{tabular}{|c|c|c|c|c|c|c|c|c|c|c|c|c|}
\hline $\begin{array}{l}10.0 \\
0.1 \\
0.2 \\
0.3 \\
0.4 \\
0.5 \\
0.6 \\
0.7 \\
0.8 \\
0.9\end{array}$ & $\begin{array}{r}14680.237 \\
80.021 \\
79.806 \\
79.590 \\
79.375 \\
79.159 \\
78.943 \\
78.728 \\
78.512 \\
78.297\end{array}$ & $\begin{array}{l}80.215 \\
80.000 \\
79.784 \\
79.569 \\
79.353 \\
79.137 \\
78.922 \\
78.706 \\
78.491 \\
78.275\end{array}$ & $\begin{array}{l}80.194 \\
79.978 \\
79.762 \\
79.547 \\
79.331 \\
79.116 \\
78.900 \\
78.685 \\
78.469 \\
78.254\end{array}$ & $\begin{array}{l}80.172 \\
79.957 \\
79.741 \\
79.525 \\
79.310 \\
79.094 \\
78.879 \\
78.663 \\
78.448 \\
78.232\end{array}$ & $\begin{array}{l}80.151 \\
79.935 \\
79.719 \\
70.504 \\
79.288 \\
79.073 \\
78.857 \\
78.642 \\
78.426 \\
78.211\end{array}$ & $\begin{array}{l}80.129 \\
79.913 \\
79.698 \\
79.482 \\
79.267 \\
79.051 \\
78.836 \\
78.620 \\
78.405 \\
78.189\end{array}$ & $\begin{array}{l}80.107 \\
79.892 \\
79.676 \\
79.461 \\
79.245 \\
79.030 \\
78.814 \\
78.599 \\
78.383 \\
78.168\end{array}$ & $\begin{array}{l}80.086 \\
79.870 \\
79.655 \\
79.439 \\
79.224 \\
79.008 \\
78.792 \\
78.577 \\
78.362 \\
78.146\end{array}$ & $\begin{array}{l}80.064 \\
79.849 \\
79.633 \\
79.418 \\
79.202 \\
78.987 \\
78.771 \\
78.556 \\
78.340 \\
78.125\end{array}$ & $\begin{array}{l}80.043 \\
79.827 \\
79.612 \\
79.396 \\
79.181 \\
78.965 \\
78.750 \\
78.534 \\
78.318 \\
78.103\end{array}$ & $\begin{array}{l}0.275972 \\
0.275972 \\
0.275971 \\
0.275971 \\
0.275971 \\
0.275971 \\
0.275971 \\
0.275971 \\
0.275971 \\
0.275971\end{array}$ & $\begin{array}{l}1.879367 \\
1.879394 \\
1.879421 \\
1.879448 \\
1.879475 \\
1.879501 \\
1.879528 \\
1.879555 \\
1.879582 \\
1.879609\end{array}$ \\
\hline $\begin{array}{l}11: 0 \\
1: 1 \\
1: 2 \\
1: 3 \\
1: 4 \\
1.5 \\
1.6 \\
1.7 \\
1.8 \\
1.9\end{array}$ & $\begin{array}{r}14678.081 \\
77.866 \\
77.650 \\
77.435 \\
77.219 \\
77.004 \\
76.788 \\
76.573 \\
76.357 \\
76.142\end{array}$ & $\begin{array}{l}78 \cdot 060 \\
77 \cdot 844 \\
77 \cdot 629 \\
77 \cdot 413 \\
77 \cdot 198 \\
76.982 \\
76.767 \\
76.551 \\
76.336 \\
76.121\end{array}$ & $\begin{array}{l}78.038 \\
77.823 \\
77.607 \\
77.392 \\
77.076 \\
76.961 \\
76.745 \\
76.530 \\
76.314 \\
76.099\end{array}$ & $\begin{array}{l}78.017 \\
77.801 \\
77.586 \\
77.370 \\
77.155 \\
76.939 \\
76.724 \\
76.508 \\
76.293 \\
76.077\end{array}$ & $\begin{array}{l}77.995 \\
77.780 \\
77.564 \\
77.349 \\
77.133 \\
76.918 \\
76.702 \\
76.487 \\
76.271 \\
76.056\end{array}$ & $\begin{array}{l}77.974 \\
77.758 \\
77.543 \\
77.327 \\
77.112 \\
76.896 \\
76.681 \\
76.465 \\
76.250 \\
76.034\end{array}$ & $\begin{array}{l}77.952 \\
77.737 \\
77.521 \\
77.306 \\
77.090 \\
76.875 \\
76.659 \\
76.444 \\
76.228 \\
76.013\end{array}$ & $\begin{array}{l}77.931 \\
77.715 \\
77.500 \\
77.284 \\
77.069 \\
76.853 \\
76.638 \\
76.422 \\
76.207 \\
75.991\end{array}$ & $\begin{array}{l}77.909 \\
77.694 \\
77.048 \\
77.263 \\
77.047 \\
76.832 \\
76.616 \\
76.401 \\
76.185 \\
75.970\end{array}$ & $\begin{array}{l}77.887 \\
77.672 \\
77.456 \\
77.241 \\
77.026 \\
76.810 \\
76.595 \\
76.379 \\
76.164 \\
75.948\end{array}$ & $\begin{array}{l}0.275971 \\
0.275971 \\
0.275970 \\
0.275970 \\
0.275970 \\
0.275970 \\
0.275970 \\
0.275970 \\
0.275970 \\
0.275970\end{array}$ & $\begin{array}{l}1.879636 \\
1.879663 \\
1.879690 \\
1.879717 \\
1.879744 \\
1.879770 \\
1.879797 \\
1.879824 \\
1.879851 \\
1.879878\end{array}$ \\
\hline $\begin{array}{r}812.0 \\
2.1 \\
2.2 \\
2.3 \\
2.4 \\
2.5 \\
2.6 \\
2.7 \\
2.8 \\
2.9\end{array}$ & $\begin{array}{r}14675.927 \\
75.711 \\
75.496 \\
75.280 \\
75.065 \\
74.850 \\
74.634 \\
74.419 \\
74.203 \\
73.988\end{array}$ & $\begin{array}{l}75.905 \\
75.690 \\
75.474 \\
75.259 \\
75.044 \\
74.828 \\
74.613 \\
74.397 \\
74.182 \\
73.967\end{array}$ & $\begin{array}{l}75.884 \\
75.668 \\
75.453 \\
75.237 \\
75.022 \\
74.807 \\
74.591 \\
74.376 \\
74.160 \\
73.945\end{array}$ & $\begin{array}{l}75.862 \\
75.647 \\
75.431 \\
75.216 \\
75.001 \\
74.785 \\
74.570 \\
74.354 \\
74.139 \\
73.924\end{array}$ & $\begin{array}{l}75.840 \\
75.625 \\
75.410 \\
75.194 \\
74.979 \\
74.763 \\
74.548 \\
74.333 \\
74.117 \\
73.902\end{array}$ & $\begin{array}{l}75.819 \\
75.604 \\
75.388 \\
75.173 \\
74.958 \\
74.742 \\
74.527 \\
74.311 \\
74.096 \\
73.880\end{array}$ & $\begin{array}{l}75.797 \\
75.582 \\
75.367 \\
75.151 \\
74.936 \\
74.720 \\
74.505 \\
74.290 \\
74.074 \\
73.859\end{array}$ & $\begin{array}{l}75.776 \\
75.561 \\
75.345 \\
75.130 \\
74.914 \\
74.099 \\
74.084 \\
74.268 \\
74.053 \\
73.837\end{array}$ & $\begin{array}{l}75.754 \\
75.539 \\
75.324 \\
75.108 \\
74.893 \\
74.677 \\
74.462 \\
74.247 \\
74.031 \\
73.816\end{array}$ & $\begin{array}{l}75.733 \\
75.518 \\
75.302 \\
75.087 \\
74.871 \\
74.656 \\
74.441 \\
74.225 \\
74.010 \\
73.794\end{array}$ & $\begin{array}{l}0.275970 \\
0.775970 \\
0.275969 \\
0.275969 \\
0.275969 \\
0.275969 \\
0.275969 \\
0.275969 \\
0.275969 \\
0.275969\end{array}$ & $\begin{array}{l}1.879905 \\
1.879932 \\
1.879959 \\
1.879986 \\
1.880013 \\
1.880040 \\
1.880066 \\
1.880093 \\
1.880120 \\
1.880147\end{array}$ \\
\hline $\begin{array}{r}813.0 \\
3.1 \\
3.2 \\
3.3 \\
3.4 \\
3.5 \\
3.6 \\
3.7 \\
3.8 \\
3.9\end{array}$ & $\begin{array}{r}14673.773 \\
73.557 \\
73.342 \\
73.127 \\
72.911 \\
72.696 \\
72.481 \\
72.265 \\
72.050 \\
71.835\end{array}$ & $\begin{array}{l}73 \cdot 751 \\
73 \cdot 536 \\
73 \cdot 320 \\
73 \cdot 105 \\
72.890 \\
72.674 \\
72.459 \\
72.244 \\
72.028 \\
71.813\end{array}$ & $\begin{array}{l}73.730 \\
73.514 \\
73.299 \\
73.084 \\
72.868 \\
72.653 \\
72.437 \\
72.222 \\
72.007 \\
71.792\end{array}$ & $\begin{array}{l}73.708 \\
73.493 \\
73.277 \\
73.062 \\
72.847 \\
72.631 \\
72.416 \\
72.201 \\
71.985 \\
71.770\end{array}$ & $\begin{array}{l}73.687 \\
73.471 \\
73.256 \\
73.041 \\
72.825 \\
72.610 \\
72.394 \\
72.179 \\
71.964 \\
71.749\end{array}$ & $\begin{array}{l}73.665 \\
73.450 \\
73.234 \\
73.019 \\
72.804 \\
72.588 \\
72.373 \\
72.158 \\
71.942 \\
71.727\end{array}$ & $\begin{array}{l}73 \cdot 644 \\
73 \cdot 428 \\
73.213 \\
72.997 \\
72.782 \\
72.567 \\
72 \cdot 351 \\
72.136 \\
71.921 \\
71.705\end{array}$ & $\begin{array}{l}73.622 \\
73.407 \\
73.191 \\
72.976 \\
72.760 \\
72.545 \\
72.330 \\
72.115 \\
71.899 \\
71.684\end{array}$ & $\begin{array}{l}73.600 \\
73.385 \\
73.170 \\
72.954 \\
72.739 \\
72.524 \\
72.308 \\
72.093 \\
71.878 \\
71.662\end{array}$ & $\begin{array}{l}73.579 \\
73.364 \\
73 \cdot 148 \\
72.933 \\
72.718 \\
72.502 \\
72.287 \\
72.071 \\
71.856 \\
71.641\end{array}$ & $\begin{array}{l}0.275969 \\
0.275969 \\
0.275968 \\
0.275968 \\
0.275968 \\
0.275968 \\
0.275968 \\
0.275968 \\
0.275968 \\
0.275968\end{array}$ & $\begin{array}{l}1.880174 \\
1.880201 \\
1.880328 \\
1.880255 \\
1.880282 \\
1.880309 \\
1.880336 \\
1.880363 \\
1.880389 \\
1.880416\end{array}$ \\
\hline $\begin{array}{r}6814.0 \\
4.1 \\
4.2 \\
4.3 \\
4.4 \\
4.5 \\
4.6 \\
4.7 \\
4.8 \\
4.9\end{array}$ & $\begin{array}{r}14671.619 \\
71.404 \\
71.189 \\
70.973 \\
70.758 \\
70.543 \\
70.327 \\
70.112 \\
69.897 \\
69.682\end{array}$ & $\begin{array}{l}71.598 \\
71.382 \\
71.167 \\
70.952 \\
70.736 \\
70.521 \\
70.306 \\
70.091 \\
69.875 \\
69.660\end{array}$ & $\begin{array}{l}71.576 \\
71.361 \\
71.146 \\
70.930 \\
70.715 \\
70.500 \\
70.285 \\
70.069 \\
69.854 \\
69.639\end{array}$ & $\begin{array}{l}71.555 \\
71.339 \\
71.124 \\
70.909 \\
70.694 \\
70.478 \\
70.263 \\
70.047 \\
69.832 \\
69.617\end{array}$ & $\begin{array}{l}71.533 \\
71.318 \\
71.103 \\
70.887 \\
70.672 \\
70.457 \\
70.241 \\
70.026 \\
69.811 \\
69.596\end{array}$ & $\begin{array}{l}71.512 \\
71.296 \\
71.081 \\
70.866 \\
70.651 \\
70.435 \\
70.220 \\
70.005 \\
69.789 \\
69.574\end{array}$ & $\begin{array}{l}71.490 \\
71.275 \\
71.060 \\
70.844 \\
70.629 \\
70.414 \\
70.198 \\
69.983 \\
69.768 \\
69.552\end{array}$ & $\begin{array}{l}71.469 \\
71.253 \\
71.038 \\
70.823 \\
70.607 \\
70.392 \\
70.177 \\
69.961 \\
69.746 \\
69.531\end{array}$ & $\begin{array}{l}71.447 \\
71.232 \\
71.016 \\
70.801 \\
70.586 \\
70.370 \\
70.155 \\
69.940 \\
69.725 \\
69.509\end{array}$ & $\begin{array}{l}71.425 \\
71.210 \\
70.995 \\
70.780 \\
70.564 \\
70.349 \\
70.134 \\
69.918 \\
69.703 \\
69.488\end{array}$ & $\begin{array}{l}0.275968 \\
0.275968 \\
0.275967 \\
0.275967 \\
0.275967 \\
0.275967 \\
0.275967 \\
0.275967 \\
0.275967 \\
0.275967\end{array}$ & $\begin{array}{l}1.880443 \\
1.880470 \\
1.880497 \\
1.880524 \\
1.880551 \\
1.880578 \\
1.880605 \\
1.880632 \\
1.880659 \\
1.880685\end{array}$ \\
\hline $\begin{array}{r}6815.0 \\
5.1 \\
5.2 \\
5.3 \\
5.4 \\
5.5 \\
5.6 \\
5.7 \\
5.8 \\
5.9\end{array}$ & $\begin{array}{r}14669.466 \\
69.251 \\
69.036 \\
68.821 \\
68.605 \\
68.390 \\
68.175 \\
67.960 \\
67.745 \\
67.529\end{array}$ & $\begin{array}{l}69.445 \\
69 \cdot 230 \\
69.014 \\
68.799 \\
68.584 \\
68.369 \\
68.153 \\
67.938 \\
67.723 \\
67.508\end{array}$ & $\begin{array}{l}69.423 \\
69.208 \\
68.993 \\
68.778 \\
68.562 \\
68.347 \\
68.132 \\
67.917 \\
67.702 \\
67.486\end{array}$ & $\begin{array}{l}69.402 \\
69.187 \\
68.971 \\
68.756 \\
68.541 \\
68.326 \\
68.110 \\
67.895 \\
67.680 \\
67.465\end{array}$ & $\begin{array}{l}60.380 \\
69.165 \\
68.950 \\
68.735 \\
68.519 \\
68.304 \\
68.089 \\
67.874 \\
67.658 \\
67.443\end{array}$ & $\begin{array}{l}69.359 \\
69.144 \\
68.928 \\
68.713 \\
68.498 \\
68.283 \\
68.067 \\
67.852 \\
67.637 \\
67.422\end{array}$ & $\begin{array}{l}69.337 \\
69.122 \\
68.907 \\
68.692 \\
68.476 \\
68.261 \\
68.046 \\
67.831 \\
67.615 \\
67.400\end{array}$ & $\begin{array}{l}69.316 \\
69.100 \\
68.885 \\
68.670 \\
68.455 \\
68.240 \\
68.024 \\
67.809 \\
67.594 \\
67.379\end{array}$ & $\begin{array}{l}69.294 \\
69.079 \\
68.864 \\
68.649 \\
68.433 \\
68.218 \\
68.003 \\
67.788 \\
67.572 \\
67.357\end{array}$ & $\begin{array}{l}69.273 \\
69.057 \\
68.842 \\
68.627 \\
68.412 \\
68.197 \\
67.981 \\
67.766 \\
67.551 \\
67.336\end{array}$ & $\begin{array}{l}0.275967 \\
0.275967 \\
0.275966 \\
0.275966 \\
0.275966 \\
0.275966 \\
0.275966 \\
0.275966 \\
0.275966 \\
0.275966\end{array}$ & $\begin{array}{l}1.880712 \\
1.880739 \\
1.880766 \\
1.880793 \\
1.880820 \\
1.880847 \\
1.880874 \\
1.880901 \\
1.880928 \\
1.880955\end{array}$ \\
\hline $\begin{array}{r}6816.0 \\
6.1 \\
6.2 \\
6.3 \\
6.4 \\
6.5 \\
6.6 \\
6.7 \\
6.8 \\
6.9\end{array}$ & $\begin{array}{r}14667.314 \\
67.099 \\
66.884 \\
66.669 \\
66.453 \\
66.238 \\
66.023 \\
65.808 \\
65.593 \\
65.378\end{array}$ & $\begin{array}{l}67.293 \\
67.077 \\
66.862 \\
66.647 \\
66.432 \\
66.217 \\
66.002 \\
65.787 \\
65.571 \\
65.356\end{array}$ & $\begin{array}{l}67.271 \\
67.056 \\
66.841 \\
66.626 \\
66.410 \\
66.195 \\
65.980 \\
65.765 \\
65.550 \\
65.335\end{array}$ & $\begin{array}{l}67.250 \\
67.035 \\
66.819 \\
66.604 \\
66.389 \\
66.174 \\
65.959 \\
65.743 \\
65.528 \\
65.313\end{array}$ & $\begin{array}{l}67.228 \\
67.013 \\
66.798 \\
66.583 \\
66.368 \\
66.152 \\
65.937 \\
65.722 \\
65.507 \\
65.292\end{array}$ & $\begin{array}{l}67.207 \\
66.991 \\
66.776 \\
66.561 \\
66.346 \\
66.131 \\
65.916 \\
65.700 \\
65.485 \\
65.270\end{array}$ & $\begin{array}{l}67.185 \\
66.970 \\
66.755 \\
66.540 \\
66.324 \\
66.109 \\
65.894 \\
65.679 \\
65.464 \\
65.249\end{array}$ & $\begin{array}{l}67 \cdot 164 \\
66.948 \\
66.733 \\
66.518 \\
66.303 \\
66.088 \\
65.873 \\
65.657 \\
65.442 \\
65.227\end{array}$ & $\begin{array}{l}67.142 \\
66.927 \\
66.712 \\
66.497 \\
66.281 \\
66.066 \\
65.851 \\
65.636 \\
65.421 \\
65.206\end{array}$ & $\begin{array}{l}67.120 \\
66.905 \\
66.690 \\
66.475 \\
66.260 \\
66.045 \\
65.830 \\
65.614 \\
65.399 \\
65.184\end{array}$ & $\begin{array}{l}0.275966 \\
0.275965 \\
0.275965 \\
0.275965 \\
0.275965 \\
0.275965 \\
0.275965 \\
0.275965 \\
0.275965 \\
0.275965\end{array}$ & $\begin{array}{l}1.880981 \\
1.881008 \\
1.881035 \\
1.881062 \\
1.881089 \\
1.881116 \\
1.881143 \\
1.881170 \\
1.881197 \\
1.881224\end{array}$ \\
\hline $\begin{array}{r}817.0 \\
7.1 \\
7.2 \\
7.3 \\
7.4 \\
7.5 \\
7: 6 \\
7: 7 \\
7.8 \\
7.9\end{array}$ & $\begin{array}{r}14665.163 \\
64.948 \\
64.732 \\
64.517 \\
64.302 \\
64.087 \\
63.872 \\
63.657 \\
63.442 \\
63.227\end{array}$ & $\begin{array}{l}65.141 \\
64 \cdot 926 \\
64 \cdot 711 \\
64.496 \\
64.281 \\
64.066 \\
63.850 \\
63.635 \\
63.420 \\
63.205\end{array}$ & $\begin{array}{l}65 \cdot 120 \\
64.905 \\
64.689 \\
64.474 \\
64.259 \\
64.044 \\
63.829 \\
63.614 \\
63.399 \\
63.184\end{array}$ & $\begin{array}{l}65.098 \\
64.883 \\
64.668 \\
64.453 \\
64.238 \\
64.023 \\
63.807 \\
63.592 \\
63.377 \\
63.162\end{array}$ & $\begin{array}{l}65.077 \\
64.862 \\
64.646 \\
64.431 \\
64.216 \\
64.001 \\
63.786 \\
63.571 \\
63.356 \\
63.141\end{array}$ & $\begin{array}{l}65.055 \\
64.840 \\
64.625 \\
64.410 \\
64.195 \\
63.979 \\
63.764 \\
63.549 \\
63.334 \\
63.119\end{array}$ & $\begin{array}{l}65.034 \\
64.818 \\
64.603 \\
64.388 \\
64.173 \\
63.958 \\
63.743 \\
63.528 \\
63.313 \\
63.098\end{array}$ & $\begin{array}{l}65.012 \\
64.797 \\
64.582 \\
64.367 \\
64.152 \\
63.937 \\
63.721 \\
63.506 \\
63.291 \\
63.076\end{array}$ & $\begin{array}{l}64.991 \\
64.775 \\
64.560 \\
64.345 \\
64.130 \\
63.915 \\
63.700 \\
63.485 \\
63.270 \\
63.055\end{array}$ & $\begin{array}{l}64.969 \\
64.754 \\
64.539 \\
64.324 \\
64.109 \\
63.894 \\
63.678 \\
63.463 \\
63.248 \\
63.033\end{array}$ & $\begin{array}{l}0.275965 \\
0.275964 \\
0.275964 \\
0.275964 \\
0.275964 \\
0.275964 \\
0.275964 \\
0.275964 \\
0.275964 \\
0.275964\end{array}$ & $\begin{array}{l}1.881251 \\
1.881277 \\
1.881304 \\
1.881331 \\
1.881358 \\
1.881385 \\
1.881412 \\
1.881439 \\
1.881466 \\
1.881493\end{array}$ \\
\hline $\begin{array}{r}5818.0 \\
8.1 \\
8.2 \\
8.3 \\
8.4 \\
8.5 \\
8.6 \\
8.7 \\
8.8 \\
8.9\end{array}$ & $\begin{array}{r}14663.012 \\
62.797 \\
62.582 \\
62.366 \\
62.151 \\
61.936 \\
61.721 \\
61.506 \\
61.291 \\
61.076\end{array}$ & $\begin{array}{l}62 \cdot 990 \\
62 \cdot 775 \\
62.560 \\
62.345 \\
62 \cdot 130 \\
61.915 \\
61.700 \\
61.485 \\
61.270 \\
61.055\end{array}$ & $\begin{array}{l}62.969 \\
62.754 \\
62.539 \\
62.323 \\
62.108 \\
61.893 \\
61.678 \\
61.463 \\
61.248 \\
61.033\end{array}$ & $\begin{array}{l}62.947 \\
62.732 \\
62.517 \\
62.302 \\
62.087 \\
61.872 \\
61.657 \\
61.442 \\
61.227 \\
61.012\end{array}$ & $\begin{array}{l}62.926 \\
62.711 \\
62.496 \\
62.281 \\
62.066 \\
61.850 \\
61.635 \\
61.420 \\
61.205 \\
60.990\end{array}$ & $\begin{array}{l}62.904 \\
62.689 \\
62.474 \\
62.259 \\
62.044 \\
61.829 \\
61.614 \\
61.399 \\
61.184 \\
60.969\end{array}$ & $\begin{array}{l}62.883 \\
62.668 \\
62.453 \\
62.237 \\
62.022 \\
61.807 \\
61.592 \\
61.377 \\
61.162 \\
60.947\end{array}$ & $\begin{array}{l}62.861 \\
62.646 \\
62.431 \\
62.216 \\
62.001 \\
61.786 \\
61.571 \\
61.356 \\
61.141 \\
60.926\end{array}$ & $\begin{array}{l}62.840 \\
62.625 \\
62.409 \\
62.195 \\
61.979 \\
61.764 \\
61.550 \\
61.334 \\
61.119 \\
60.904\end{array}$ & $\begin{array}{l}62.818 \\
62.603 \\
62.388 \\
62.173 \\
61.958 \\
61.743 \\
61.528 \\
61.313 \\
61.098 \\
60.883\end{array}$ & $\begin{array}{l}0.275964 \\
0.275963 \\
0.275963 \\
0.275963 \\
0.275963 \\
0.275963 \\
0.275963 \\
0.275963 \\
0.275963 \\
0.275963\end{array}$ & $\begin{array}{l}1.881520 \\
1.881547 \\
1.881573 \\
1.881600 \\
1.881627 \\
1.881654 \\
1.881681 \\
1.881708 \\
1.881735 \\
1.881762\end{array}$ \\
\hline $\begin{array}{r}819.0 \\
9.1 \\
9.2 \\
9.3 \\
9.4 \\
9.5 \\
9.6 \\
9.7 \\
9.8 \\
9.9\end{array}$ & $\begin{array}{r}14660.861 \\
60.646 \\
60.431 \\
60.216 \\
60.001 \\
59.786 \\
59.571 \\
59.357 \\
59.142 \\
58.927\end{array}$ & $\begin{array}{l}60.840 \\
60.625 \\
60.410 \\
60.195 \\
59.980 \\
59.765 \\
59.550 \\
59.335 \\
59.120 \\
58.905\end{array}$ & $\begin{array}{l}60.818 \\
60.604 \\
60.388 \\
60.173 \\
59.958 \\
59.744 \\
59.528 \\
59.313 \\
59.099 \\
58.884\end{array}$ & $\begin{array}{l}60.797 \\
60.582 \\
60.367 \\
60.152 \\
59.937 \\
59.722 \\
59.507 \\
59.292 \\
59.077 \\
58.862\end{array}$ & $\begin{array}{l}60.775 \\
60.560 \\
60.345 \\
60.130 \\
59.915 \\
59.700 \\
59.485 \\
59.271 \\
59.056 \\
58.841\end{array}$ & $\begin{array}{l}60.754 \\
60.539 \\
60.324 \\
60.109 \\
59.894 \\
59.679 \\
59.464 \\
59.249 \\
59.034 \\
58.819\end{array}$ & $\begin{array}{l}60.732 \\
60.517 \\
60.302 \\
60.087 \\
59.872 \\
59.658 \\
59.443 \\
59.228 \\
59.012 \\
58.798\end{array}$ & $\begin{array}{l}60.711 \\
60.496 \\
60.281 \\
60.066 \\
59.851 \\
59.636 \\
59.421 \\
59.206 \\
58.991 \\
58.776\end{array}$ & $\begin{array}{l}60.689 \\
60.474 \\
60.259 \\
60.044 \\
59.829 \\
59.615 \\
59.400 \\
59.185 \\
58.970 \\
58.755\end{array}$ & $\begin{array}{l}60.668 \\
60.453 \\
60.238 \\
60.023 \\
59.808 \\
59.593 \\
59.378 \\
59.163 \\
58.948 \\
58.733\end{array}$ & $\begin{array}{l}0.275963 \\
0.275962 \\
0.275962 \\
0.275962 \\
0.275962 \\
0.275962 \\
0.275962 \\
0.275962 \\
0.275962 \\
0.275962\end{array}$ & $\begin{array}{l}1.881789 \\
1.881816 \\
1.881843 \\
1.881869 \\
1.881896 \\
1.881923 \\
1.881950 \\
1.881977 \\
1.882004 \\
1.882031\end{array}$ \\
\hline
\end{tabular}

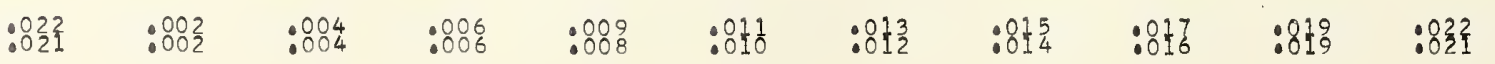


$\begin{array}{rrrrrrrrrrr}6820.0 & 14658.712 & 58.690 & 58.669 & 58.647 & 58.626 & 58.604 & 58.583 & 58.561 & 58.540 & 58.518 \\ 0.1 & 58.497 & 58.475 & 58.454 & 58.432 & 58.411 & 58.389 & 58.368 & 58.346 & 58.325 & 58.303\end{array}$

6822.0

2.
2.
2.
2.
2.
2.0
2.
2.

6823.0

323.0

$3 \cdot 3$

3.4

3.6

3.8
3.9

6824.0

4.1

4.

4.3

4.5

4.6
4.7

4.8

6825.0

5.1

5.3

5.4
5.5

5.6

5.8

6826.0

6.2

6.2
6.3
6.4

6.5

6.6

6.8

6827.

827
7
7
7
7
7
7
7
7
70

6828

828.

6829
9
9
9
9
9
9
9
907
90 $\begin{array}{lllllllllll}0.1 & 58.497 & 58.475 & 58.454 & 58.432 & 58.411 & 58.389 & 58.368 & 58.346 & 58.325 & 58.303 \\ 0.2 & 58.282 & 58.260 & 58.239 & 58.217 & 58.196 & 58.174 & 58.153 & 58.131 & 58.110 & 58.088\end{array}$

$\begin{array}{lllllllllll}0.3 & 58.067 & 58.045 & 58.024 & 58.002 & 57.981 & 57.959 & 57.938 & 57.917 & 57.895 & 57.874 \\ 0.4 & 57.852 & 57.830 & 57.809 & 57.788 & 57.766 & 57.745 & 57.723 & 57.702 & 57.680 & 57.659\end{array}$

$\begin{array}{llllllllllll}0.4 & 57.852 & 57.830 & 57.809 & 57.788 & 57.766 & 57.745 & 57.723 & 57.702 & 57.680 & 57.659 \\ 0.5 & 57.637 & 57.616 & 57.594 & 57.573 & 57.551 & 57.530 & 57.508 & 57.487 & 57.465 & 57.444\end{array}$

$\begin{array}{lllllllllll}0.6 & 57.422 & 57.401 & 57.379 & 57.358 & 57.336 & 57.315 & 57.293 & 57.272 & 57.250 & 57.229\end{array}$

$\begin{array}{llllllllllll}0.7 & 57.207 & 57.186 & 57.164 & 57.143 & 57.121 & 57.100 & 57.078 & 57.057 & 57.035 & 57.014 \\ 0.8 & 56.992 & 56.971 & 56.949 & 56.928 & 56.906 & 56.885 & 56.863 & 56.842 & 56.021 & 56.799\end{array}$

$\begin{array}{lllllllllll}0.8 & 56.992 & 56.971 & 56.949 & 56.928 & 56.906 & 56.885 & 56.863 & 56.842 & 56.821 & 56.799 \\ 0.9 & 56.778 & 56.756 & 56.734 & 56.713 & 56.692 & 56.670 & 56.649 & 56.627 & 56.605 & 56.584\end{array}$

$\begin{array}{lllll}14656.563 & 56.541 & 56.520 & 56.498 & 56 .\end{array}$ $\begin{array}{lllllllll}56.348 & 56.326 & 56.305 & 56.283 & 56.477 & 56.455 & 56.434 .56 \cdot 412 & 56.391 & 56.369\end{array}$ $\begin{array}{llllllllll}56.133 & 56.111 & 56.090 & 56.068 & 56.047 & 56.240 & 56.219 & 56.197 & 56.176 & 56.154 \\ 55.918 & 55.897 & 55.026 & 56.004 & 55.983 & 55.961 & 55.930\end{array}$ $\begin{array}{lllllllllll}55.918 & 55.897 & 55.875 & 55.854 & 55.832 & 55.811 & 55.789 & 55.768 & 55.746 & 55.725 \\ 55.703 & 55.682 & 55.660 & 55.639 & 55.617 & 55.596 & 55.574 & 55.553 & 55.531 & 55.510\end{array}$ $\begin{array}{lllllllllll}55.488 & 55.467 & 55.445 & 55.424 & 55.402 & 55.381 & 55.359 & 55.338 & 55.316 & 55.295\end{array}$ $\begin{array}{llllllllll}55.273 & 55.252 & 55.231 & 55.209 & 55.187 & 55.166 & 55.145 & 55.123 & 55.102 & 55.080\end{array}$ $\begin{array}{llllllllll}55.059 & 55.037 & 55.016 & 54.994 & 54.973 & 54.951 & 54.930 & 54.908 & 54.887 & 54.865\end{array}$ $\begin{array}{lll}54.844 & 54 \cdot 822 & 54 \cdot 801 \\ 54.629 & 54.608 & 54.586\end{array}$

54.779
54.565

$\begin{array}{ll}54.758 & 54.736 \\ 54.543 & 54.522\end{array}$

14654.4144

$\begin{array}{ll}54.119 & 54.393 \\ 53.18 & 54.178\end{array}$

$\begin{array}{ll}53.985 & 53.963 \\ 53.770 & 53.74\end{array}$

53.555
53.534

$53.125 \quad 53.10$

$52.911 \quad 52.889 \quad 52.868$

$\begin{array}{lll}52.696 & 52.674 & 52.65 \\ 52.481 & 52.460 & 52.43\end{array}$

52.052

$51.622 \quad 51.601$

$51.407 \quad 51.386$

$\begin{array}{llll}1.193 & 51.171 & 51.150 & 51.128\end{array}$

$\begin{array}{llll}50.978 & 50.956 & 50.935 & 50.914\end{array}$

$\begin{array}{llll}50.763 & 50.742 & 50.720 & 50.69 \\ 50.548 & 50.527 & 50.506 & 50.48 \\ 50.334 & 50.312 & 50.291 & 50.270\end{array}$

14650.119

49.905

49.690
49.475

49.261

49.046

48.617

48.402

50.312

0.098

49.668

49.454

49.024

48.810

$48 \cdot 595$

14647.973

47.758

47.543

47.95

$47.328-47.307$

$46.900 \quad 46.878 \quad 47.071$

$\begin{array}{ll}46.685 & 46.664 \quad 46.642\end{array}$

$40.47146 .449 \quad 46.428460406$

$\begin{array}{llll}46.256 & 46.234 & 46.213 & 46.192\end{array}$

$\begin{array}{llll}45.51 & 45.569 & 45.54\end{array}$

$\begin{array}{llll}45.183 & 45.162 & 45.140 & 45.119\end{array}$

$44.969 \quad 44.947 \quad 44.926 \quad 44.904$

$\begin{array}{llll}4.540 & 44.518 & 44.497 & 44.475\end{array}$

$44.325 \quad 44.304 \quad 44.28$

$43.896 \quad 43.87$

643.682
43.467 43.660

$43.253 \quad 43.23$

$\begin{array}{ll}43.038 & 43.017 \\ 42.824 & 42.802\end{array}$

$42.609 \quad 42.58$

$42.395 \quad 42.373$

42.180

41.752

14641.537

$\begin{array}{ll}41.323 & 41.301 \\ 41.108 & 41.087\end{array}$

$40.894 \quad 40.87$

$40.679 \quad 40.65$

$\begin{array}{llll}40.250 & 40.229 & 40.422 & 40.401\end{array}$

$40.036 \quad 40.015 \quad 39.993 \quad 39.97$

$\begin{array}{llll}39.822 & 39.800 & 39.779 & 39.757 \\ 39.607 & 39.586 & 39.564 & 39.543\end{array}$

$39.350 \quad 39.32$

$39.179 \quad 39.372$

$38.179 \quad 39.157 \quad 39.136$

$\begin{array}{llll}38.750 & 38.729 & 38.707 & 38.900\end{array}$

$\begin{array}{llll}38.536 & 38.514 & 38.493 & 38.471\end{array}$

$\begin{array}{llll}38.321 & 38.300 & 38.278 & 38.257\end{array}$

$\begin{array}{llll}37.893 & 37.871 & 37.850 & 37.828\end{array}$

$\begin{array}{llll}37.678 & 37.657 & 37.635 & 37.614 \\ 37.464 & 37.443 & 37.421 & 37.400\end{array}$

$$
.001
$$$$
.002
$$

\begin{abstract}
.003
\end{abstract}

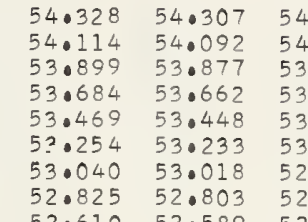

54.715
54.500

.693

54.672
54.457

$54 \cdot 651$
54.436

$.285 \quad 54.264 \quad 54.242 \quad 54.221$

$\begin{array}{llll}5.856 & 53.049 & 54.028 & 54.006 \\ 53.834 & 53.813 & 53.791\end{array}$

$\begin{array}{llll}.211 & 53.190 & 53.168 & 53.147 \\ .997 & 52.975 & 52.054 & 52.932\end{array}$

$\begin{array}{llllll}.0825 & 52.803 & 52.782 & 52.760 & 52.739 & 52.717\end{array}$

$52.395 \quad 52.374 \quad 52.352 \quad 52.331 \quad 52.309 \quad 52.288$

0.275962

0.27596

0.27596

0.275961

.275961

0.275961

0.275961

0.275960

0.275960

0.275960

0.275960

0.275960

0.275960
0.275960

0.275960

0.775959
0.275959

0.275959

0.275959
0.275959
0.0275959

0.275959

.0275959
.0275050
0.075959

0.275959

0.275959

0.0275958

0.275958

0.275958

0.275958
0.275958
0.275958

0.275958
0.275958

0.275958

0.275957

0.275957

0.275957

0.275957

0.275957

0.275957
0.275956
0.275956

0.275956

0.27595

0.275956

0.275956

0.275956

0.27595
0.075955

0.27595

0.275955
0.275955
0.275955

0.275955

0.275955
0.275955
0.275955

0.275955

0.275955

0.275955
0.275954
0.0275954

0.275954

0.275954

0.275054

0.275954

0.275954

0.275954

0.275953

0.275953

0.275953

0.275953

0.275953

0.00275953

0.275953

0.275952

0.275952

0.275952

0.275952

0.275952

0.275952

1088205

$1.882 \$ 12$
.082139

1.882192

1.882219
1.882246

1.882273
.882300

1.982327

1.832381

.882408
1.882435

1.882462

1.882515

1.882542

1.882596

.889623

1.882677

1.882731

1.882758
1.882784

1.882811

1.882865

1.882892

1.882946

1.882973

1.883027

.883054

1.883080
1.883107

1.883134
1.883161

1.883161

1.883215

1.883242

1.883269
1.883296

1.883296

1.883350
1.883377

1.883403

. 883430

1.8883457
1.883484

1.883511

1.883538
1.883565

1.883592

1.883619

1.883699

1.883726
1.883753

1.883780

1.883807

1883834

1.883888

1.883942

1.883969

1.884022

1.884049

1.884103

1.884157

1.884211

1.884238
1.884265

1.884292
1.884318

1.884345

1.884399

1.884426
1.884453

1.884480

1.884534

1.884561
1.884588

1. 884614

1.984668

.884695
.884722

.005 


$\begin{array}{rlll}14637.250 & 37.228 & 37.207 & 37.185 \\ 37.035 & 37.014 & 36.993 & 36.971 \\ 36.821 & 36.800 & 36.778 & 36.757 \\ 36.607 & 36.585 & 36.564 & 36.542 \\ 36.392 & 36.371 & 36.349 & 36.328 \\ 36.178 & 36.157 & 36.135 & 36.114 \\ 35.964 & 35.942 & 35.921 & 35.900 \\ 35.750 & 35.728 & 35.707 & 35.685 \\ 35.535 & 35.514 & 35.493 & 35.471 \\ 35.321 & 35.300 & 35.278 & 35.257\end{array}$

$.04 \quad .05$

$\begin{array}{llll}14635.107 & 35.086 & 35.064 & 35.042\end{array}$

$1: 1$
$1: 2$
$1: 3$
1.4
$1: 5$
$1: 6$
1.7
1.8
1.9

68320

2.1
2.2
2.3
2.4
2.5
2.6
2.7
2.8
2.9

6833.0

3.1
3.2
3.3

3.3

3.5
3.6

6834.0

401
4.2
4.3

4.3

4.5
4.6

4.7
4.8

4.9

6835.0
5.1
5.2
5.3
5.4
5.5
5.6
5.7
5.8
5.9

6836.

6.1

6.3

6.0

6.6

6.8

6837.

$7: 1$

703

7.02
7.5
7.6
7.07

70.0

6838.

$$
\text { , }
$$

$\begin{array}{llllll}37.164 & 37.142 & 37.121 & 37.100 & 37.078 & 37.057 \\ 36.050 & 36.928 & 36.907 & 36.885 & 36.864 & 36.843\end{array}$ $\begin{array}{lllllll}36.950 & 36.928 & 36.907 & 36.885 & 36.864 & 36.843 \\ 36.735 & 36.714 & 36.693 & 36.671 & 36.650 & 36.628\end{array}$ $\begin{array}{llllll}36.521 & 36.500 & 36.478 & 36.457 & 36.435 & 36.414\end{array}$ $\begin{array}{llllll}36.307 & 36.285 & 36.264 & 36.242 & 36.221 & 36.200 \\ 36.093 & 36.071 & 36.050 & 36.028 & 36.007 & 35.985\end{array}$ $\begin{array}{lllllll}35.878 & 35.857 & 35.835 & 35.814 & 35.793 & 35.771\end{array}$ $\begin{array}{llllll}35.235 & 35.214 & 35.193 & 35.171 & 35.150 & 35.128\end{array}$

$35.021 \quad 35.000 \quad 34.978 \quad 34.957 \quad 340935 \quad 34.914$ $\begin{array}{llllll}34.807 & 34.786 & 34.764 & 34.743 & 34.721 & 34.700\end{array}$

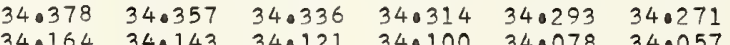
$\begin{array}{llllll}34.1950 & 34.143 & 34.121 & 34.100 & 34.078 & 34.057 \\ 33.929 & 33.907 & 33.886 & 33.864 & 33.843\end{array}$ $\begin{array}{llllll}33.736 & 33.714 & 33.693 & 33.672 & 33.650 & 33.629\end{array}$ $\begin{array}{llllll}3 . .522 & 33.500 & 33.479 & 33.457 & 33.436 & 33.415\end{array}$ $\begin{array}{llllll}33.093 & 33.072 & 33.050 & 33.029 & 33.008 & 32.986\end{array}$

$\begin{array}{llllll}32.879 & 32.858 & 32.836 & 32.815 & 32.793 & 32.772\end{array}$ $\begin{array}{llllll}32.451 & 32.429 & 32.408 & 32.386 & 32.365 & 32.344\end{array}$

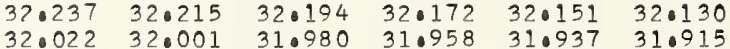
$\begin{array}{llllll}31.808 & 31.787 & 31.766 & 31.744 & 31.723 & 31.701\end{array}$ $\begin{array}{llllll}31.594 & 31.573 & 31.551 & 31.530 & 31.509 & 31.487 \\ 31.380 & 31.350 & 31.337 & 31.316 & 31.294 & 31.273\end{array}$

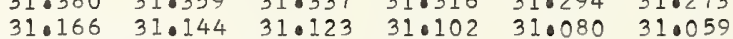
$\begin{array}{lllllll}30.952 & 30.930 & 30.909 & 30.887 & 30.866 & 30.845\end{array}$ $\begin{array}{llllll}30.738 & 30.716 & 30.695 & 30.673 & 30.652 & 30.630\end{array}$ $\begin{array}{llllll}30.309 & 30.288 & 30.266 & 30.245 & 30.224 & 30.202\end{array}$ $\begin{array}{lllllll}30.095 & 30.074 & 30.052 & 30.031 & 30.010 & 29.988\end{array}$ $\begin{array}{llllll}29.667 & 29.646 & 29.624 & 29.603 & 29.581 & 29.560\end{array}$ $\begin{array}{llllll}29.453 & 29.432 & 29.410 & 29.389 & 29.367 & 29.346\end{array}$ 29.23529 .210320 .196201752015320 .132 $\begin{array}{llllll}28.811 & 28.789 & 28.768 & 28.746 & 28.725 & 28.704\end{array}$

$\begin{array}{lllllll}28.597 & 28.575 & 28.554 & 28.533 & 28.511 & 28.490\end{array}$ $\begin{array}{llllll}28.383 & 28.361 & 28.340 & 28.318 & 28.297 & 28.276 \\ 28.169 & 28.147 & 28.126 & 28.104 & 28.083 & 28.062\end{array}$ $\begin{array}{llllll}27.954 & 27.933 & 27.912 & 27.890 & 27.869 & 27.848\end{array}$ $\begin{array}{llllll}27.526 & 27.505 & 27.484 & 27.676 & 27.655 & 27.0634 \\ 27.0312 & 27.291 & 27.0270 & 27.462 & 27.441 & 27.419\end{array}$ $\begin{array}{llllll}27.312 & 27.291 & 27.270 & 27.248 & 27.227 & 27.206\end{array}$ $\begin{array}{llllll}26.884 & 27.077 & 27.056 & 27.034 & 27.013 & 26.991\end{array}$

$\begin{array}{llllll}26.456 & 26.435 & 26.414 & 26.392 & 26.371 & 26.349\end{array}$ $\begin{array}{llllll}26.243 & 26.221 & 26.200 & 26.178 & 26.157 & 26.136 \\ 26.029 & 26.007 & 25.986 & 25.964 & 25.943 & 25.922\end{array}$ $\begin{array}{llllll}25.815 & 25.793 & 25.772 & 25.750 & 25.729 & 25.708\end{array}$ $\begin{array}{llllll}25.601 & 25.579 & 25.558 & 25.536 & 25.515 & 25.494 \\ 25.387 & 25.365 & 25.344 & 25.323 & 25.301 & 25.280\end{array}$ $\begin{array}{llllll}25.387 & 25.365 & 25.344 & 25.323 & 25.301 & 25.280\end{array}$ $\begin{array}{llllll}25.173 & 25.151 & 25.130 & 25 \cdot 108 & 25.087 & 25.066 \\ 24.959 & 24.937 & 24.916 & 24.895 & 24.873 & 24.852\end{array}$ $\begin{array}{llllll}24.745 & 24.723 & 24.702 & 24.681 & 24.659 & 24.638\end{array}$ $\begin{array}{llllllllll}4624.402 & 24 \cdot 381 & 24.360 & 24.338 & 24 \cdot 317 & 24.295 & 24 \cdot 274 & 24 \cdot 253 & 24.231 & 24 \cdot 210\end{array}$ $\begin{array}{llllllllll}24.189 & 24.167 & 24.146 & 24.124 & 24.103 & 24.082 & 24.060 & 24.039 & 24.017 & 23.996\end{array}$ $\begin{array}{llllllllll}23.975 & 23.953 & 23.932 & 23.910 & 23.889 & 23.868 & 23.846 & 23.825 & 23.803 & 23.782\end{array}$ $\begin{array}{llllllllll}23.547 & 23.525 & 23.504 & 23.483 & 23.461 & 23.440 & 23.418 & 23.397 & 23.376 & 23.354\end{array}$ $\begin{array}{llllllllll}23.333 & 23.312 & 23.290 & 23.269 & 23.247 & 23.226 & 23.204 & 23.183 & 23.162 & 23.140\end{array}$ $\begin{array}{llllllllll}23.119 & 23.098 & 23.076 & 23.055 & 23.033 & 23.012 & 22.991 & 22.969 & 22.948 & 22.927\end{array}$ $\begin{array}{llllllllll}22.905 & 22.884 & 22.862 & 22.841 & 22.820 & 22.798 & 22.777 & 22.755 & 22.734 & 22.713\end{array}$

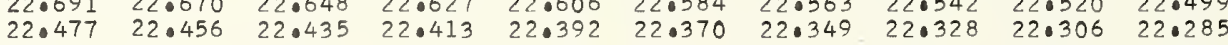
$\begin{array}{llllllllll}22.050 & 22.028 & 22.007 & 21.985 & 21.964 & 21.943 & 21.921 & 21.900 & 21.879 & 21.857\end{array}$ $\begin{array}{llllllllll}21.622 & 21.600 & 21.579 & 21.558 & 21.536 & 21.515 & 21.494 & 21.472 & 21.451 & 21.429\end{array}$

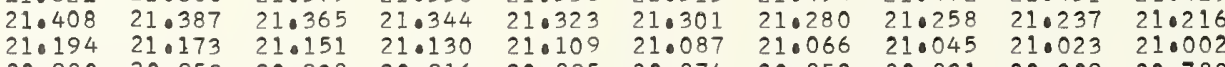
$\begin{array}{llllllllll}20.980 & 20.959 & 20.938 & 20.916 & 20.895 & 20.874 & 20.852 & 20.831 & 20.809 & 20.788\end{array}$ $\begin{array}{llllllllll}20.766 & 20.745 & 20.724 & 20.702 & 20.681 & 20.660 & 20.638 & 20.617 & 20.595 & 20.574 \\ 20.553 & 20.531 & 20.510 & 20.489 & 20.467 & 20.446 & 20.424 & 20.403 & 20.382 & 20.360\end{array}$

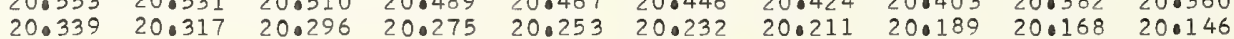

$\begin{array}{llllllllll}14620.125 & 20.104 & 20.082 & 20.061 & 20.040 & 20.018 & 19.997 & 19.975 & 19.954 & 19.933\end{array}$ $\begin{array}{llllllllll}19.911 & 19.890 & 19.869 & 19.847 & 19.826 & 19.804 & 19.783 & 19.761 & 19.740 & 19.719 \\ 19.698 & 19.676 & 19.655 & 19.633 & 10.612 & 19.591 & 19.569 & 19.548 & 19.526 & 19.505\end{array}$ $\begin{array}{llllllllll}19.698 & 19.676 & 19.655 & 19.633 & 10.612 & 19.591 & 19.569 & 19.548 & 19.526 & 19.505 \\ 19.484 & 19.462 & 19.441 & 19.419 & 19.398 & 19.377 & 19.355 & 19.334 & 19.313 & 19.291\end{array}$

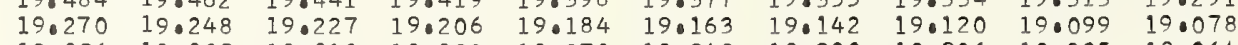
$\begin{array}{llllllllll}19.056 & 19.035 & 19.013 & 18.992 & 18.970 & 18.949 & 18.928 & 18.906 & 18.885 & 18.864\end{array}$ $\begin{array}{llllllllll}18.842 & 18.821 & 18.800 & 18.778 & 18.757 & 18.735 & 18.714 & 18.693 & 18.671 & 18.650\end{array}$ $\begin{array}{llllllllll}18.629 & 18.607 & 18.586 & 18.564 & 18.543 & 18.522 & 18.500 & 18.479 & 18.458 & 18.436\end{array}$ $\begin{array}{llllllllll}18.415 & 18.393 & 18.372 & 18.351 & 19.329 & 18.308 & 18.286 & 18.265 & 18.244 & 18.222 \\ 18.201 & 18.180 & 18.158 & 18.137 & 18.116 & 18.094 & 18.073 & 18.052 & 18.030 & 18.009\end{array}$

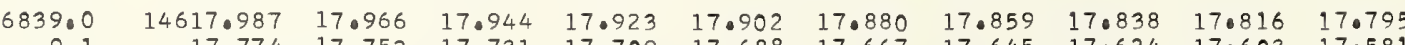

$\begin{array}{llllllllllll}9.1 & 17.774 & 17.752 & 17.731 & 17.709 & 17.688 & 17.667 & 17.645 & 17.624 & 17.603 & 17.581 \\ 9.2 & 17.560 & 17.538 & 17.517 & 17.496 & 17.474 & 17.453 & 17.432 & 17.410 & 17.389 & 17.367\end{array}$

$\begin{array}{llllllllllll}9.2 & 17.560 & 17.538 & 17.517 & 17.496 & 17.474 & 17.453 & 17.432 & 17.410 & 17.389 & 17.367 \\ 9.3 & 17.346 & 17.325 & 17.303 & 17.282 & 17.261 & 17.239 & 17.218 & 17.197 & 17.175 & 17.154\end{array}$ $\begin{array}{llllllllll}17.346 & 17.325 & 17.303 & 17.282 & 17.261 & 17.239 & 17.218 & 17.197 & 17.175 & 17.154 \\ 17.132 & 17.111 & 17.090 & 17.068 & 17.047 & 17.026 & 17.004 & 16.983 & 16.961 & 16.940\end{array}$

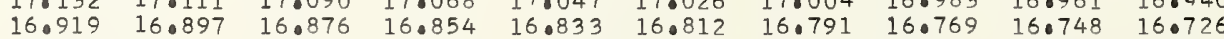
$\begin{array}{llllllllll}16.705 & 16.684 & 16.662 & 16.641 & 16.620 & 16.598 & 16.577 & 16.555 & 16.534 & 16.513\end{array}$

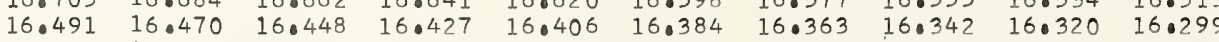

$\begin{array}{lllllllllll}9.7 & 16.491 & 16.470 & 16.448 & 16.427 & 16.406 & 16.384 & 16.363 & 16.342 & 16.320 & 16.299 \\ 9.8 & 16.278 & 16.256 & 16.235 & 16.214 & 16.192 & 16.171 & 16.149 & 16.128 & 16.107 & 16.085 \\ 9.9 & 16.064 & 16.042 & 16.021 & 16.000 & 15.978 & 15.957 & 15.936 & 15.914 & 15.893 & 15.872\end{array}$ $(n-1) \times 1000 \quad \lambda(n-1)$

$\begin{array}{ll}0.275952 & 1.884749 \\ 0.275951 & 1.884776 \\ 0.275951 & 1.884803 \\ 0.275951 & 1.884830 \\ 0.275951 & 1.884857 \\ 0.275951 & 1.884884 \\ 0.275951 & 1.884910 \\ 0.275951 & 1.884937 \\ 0.275951 & 1.884964 \\ 0.275951 & 1.884991\end{array}$

0.275951 0.275950 0.275950 0.275950 0.275950 0.275950 0.275950 0.275950

0.275950 0.27594

0.27594

0.275949

0.27594

0.275940

0.275949

0.275949

0.27594

0.275948

0.75048

0.275948

0.275948

0.275948

0.27594

0.275948

0.275948

0.275947

0.275947
0.275947

0.275947

0.27594

0.275947

0.275947

1.885018 1.885045

1.885099

1.885126

1.885180

1.885207
1.885233

1.885260

0.275947

0.275946

0.275946
0.275946

0.275946

.275946

0.275946

0.275946

0.275946
0.275946

0.275946

0.275945

0.27594

0.275945

0.275945

0.275945

0.275945
0.275945

0.275945

0.275944

0.275944

0.275944

0.275944
0.275944

0.275944

0.275944
0.275944

0.275944
0.275944

0.275944

0.275943

0.275943

0.275943

0.275943

0.275943

0.275943

0.27594

.885287

1.885314

1.885368

1.885395
1.885422

1.885449

1.885476

1.885503
1.885529

1.885556

1.885583

1.885610

1. 885654

1.885691

1.885718

1.885772

1.885825

1.885852

1.885879

1.885933

1.885960

1.886014

1.886068

1.886095

1.886122

1.886148
1.886175

1.886202

1.886229

1.886256

1.886283

1.886310
1.886337

0.275943

0.275942

0.275942

0.275942

0.275942

0.275942

0.275942

0.275942

1.886364

1.886391

1.886418

1.886471

1. 886498

1. 886525

1.886552

1.886606

1.886633

1. 886660

1.886687
1.886714

9.886741

1.88676

1.886821

1.886875

1.886902

1.886929
1.886956 


.04

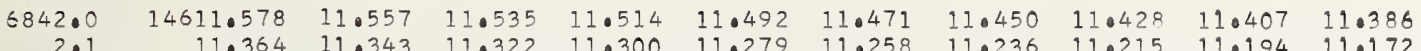

$\begin{array}{lllllllllll}2.1 & 11.364 & 11.343 & 11.322 & 11.300 & 11.279 & 11.258 & 11.236 & 11.21 .5 & 11.194 & 11.172 \\ 2.2 & 11.15 & 11.130 & 11.108 & 11.087 & 11.065 & 11.044 & 11.023 & 11.001 & 10.980 & 10.959\end{array}$

$\begin{array}{lllllllllll}2.3 & 10.937 & 10.916 & 10.895 & 10.873 & 10.852 & 10.831 & 10.809 & 10.788 & 10.767 & 10.745 \\ 2.4 & 10.724 & 10.703 & 10.681 & 10.660 & 10.639 & 10.617 & 10.596 & 10.574 & 10.553 & 10.532\end{array}$

6844.0 07.52

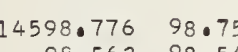

0.275941

0.275941

0.275941

0.275941

0.275941

0.275940

0.775940

0.275940

0.275940

0.275940

$0.275940 \quad 1.887979$

0.275929

0.275939

0.275939

0.275939

0.275939

0.275939

0.275938

0.275938

0.275938

0.275938

0.275938
0.275938

0.275938

0.275939
0.075937

0.0275937

0.275937
0.275937

0.275937

0.275937
0.275937

0.275937

0.275936

0.275936

0.275936

0.275936

0.275936

0.275936

0.275936

0.275935

0.275935

0.275935

0.275935

0.275935

0.275935
0.275935

0.275935

0.275935
0.275934

0.275934

0.275934

0.275934

0.275934

0.275934

0.275934

0.275933
0.275933

0.275933
0.275933

0.275933

0.275933
0.275933
0.275933

0.275933
0.275933

0.275933

0.275933
0.275932
0.0275932

0.275932
0.275932

0.275932

0.275032
0.275932

0.275932

0.275932
0.275932

1.888038

1.888059

1.888113
1.888140

1.888167
1.888194

1.888248

1.888248

1.898301

1.888355
1.888382

1.838409

1.888436

1.888490

1.888517

1.888544
1.888571

1.888598

1.888624

1.888678

1.888705
1.888732

1.888786

1.888840

1.888867

1.888894 
6850.0

0.0

0.3
0.4

0.4
0.5

0.6

0.8
0.9

6851.

$1:$

1.3

1. 4

1.6

1.8
1.9

6852.

2.

$2 \cdot 3$

2.5

2.6

2.8
2.9

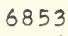

6854

$4 \cdot 1$
$4 \cdot 2$
$4 \cdot 3$
4.5
$4 \cdot 5$
4.6
407
4.5
4.9

6855.0

5.1

5.3

$5 \cdot 4$

5.6
5.7

5.8
5.9

6856.0

6.2

6.3

6.4
6.5

6.6
6.7

6.8
6.9

6857.

7.1
7.2
7.3

7.

7.5

7.7
7.8

7.8
7.9

6858.0
8.1
8.2
8.3
8.4
8.5
8.6
8.7
8.8
8.

6859.
9
9.1
9.0
9.0
9.0

\begin{abstract}
94.300
94.08
\end{abstract}
$\begin{array}{lllllllll}.066 & 94.045 & 94.023 & 94.002 & 93.981 & 93.950 & 93.938 & 03.917 & 93.896\end{array}$

$\begin{array}{llllllllll}93.874 & 93.853 & 93.832 & 93.810 & 93.789 & 93.768 & 93.746 & 93.725 & 93.704 & 93.683\end{array}$

$93.448 \quad 93.427 \quad 93.406 \quad 93.384 \quad 93.363 \quad 03.342 \quad 93.320 \quad 93.209 \quad 03.278 \quad 93.456$

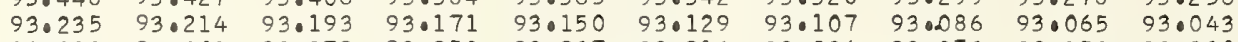

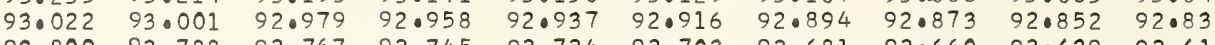

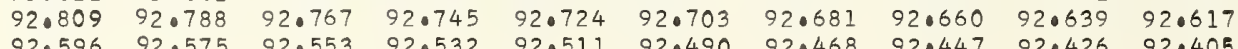

14592.383

32.36
9170

$91.957 \quad 91.936$

$91.744 \quad 91.723$

$91.318 \quad 91.29$

$91.105 \quad 91.084$

$90.679 \quad 90.658$

90.04190 .01

$\begin{array}{ll}89.828 & 89.806\end{array}$

$89.402 \quad 89.380$

$\begin{array}{ll}89.189 & 89.168 \\ 88.976 & 88.955\end{array}$

$\begin{array}{ll}88.976 & 88.955 \\ 88.763 & 88.742 \\ 88.550 & 88.529\end{array}$

$\begin{array}{ll}88.550 & 88.529 \\ 88.337 & 88.316\end{array}$

14588.12588 .10

87.9

$87.699 \quad 87.670$

$87.486 \quad 87.465$

$87.443 \quad 87.422$

$\begin{array}{llll}87.060 & 87.039 & 87.017 & 86.996\end{array}$

$86.847 \quad 86.826 \quad 86.805 \quad 86.783$

$\begin{array}{llll}86.635 & 86.613 & 86.592 & 86.571 \\ 86.422 & 86.400 & 86.379 & 86.358\end{array}$

$86.209 \quad 86.187$

$14585.996 \quad 85.975$

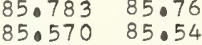

$85.358 \quad 85.336$

$85.145 \quad 85 \cdot 123$

$84.719 \quad 84.698$

$\begin{array}{ll}84.506 & 84.485 \\ 84.294 & 84.273\end{array}$

84.08184 .060

$83.658 \quad 83.847$

$83.443 \quad 83.422 \quad 83.613$

$\begin{array}{llll}83.443 & 83.422 & 83.400 & 83.592\end{array}$

$\begin{array}{lll}83.017 \quad 82.096 \quad 83.187 & 83.166\end{array}$

$\begin{array}{llll}82.805 & 82.783 & 82.762 & 82.741 \\ 82.592 & 82.571 & 82.549 & 82.528\end{array}$

$82.592 \quad 82.571 \quad 82.549 \quad 82.52$

$82.167 \quad 82.145 \quad 82.124 \quad 82.10$

$14581.741 \quad 81.720$

$81.528 \quad 81.720 \quad 81.698$

$\begin{array}{llll}1.528 & 81.507 & 81.486 & 81.465\end{array}$

$81.3103 \quad 81.082 \quad 81.273 \quad 81.25$

$\begin{array}{llll}80.890 & 80.869 & 80.848 & 80.827\end{array}$

$\begin{array}{llll}80.678 & 80.656 & 80.635 & 80.614 \\ 80.465 & 80.444 & 80.422 & 80.401\end{array}$

$\begin{array}{llll}80.465 & 80.444 & 80.422 & 80.401 \\ 80.252 & 80.231 & 80.210 & 80.189\end{array}$

$80.040 \quad 80.019$

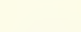

$579.615 \quad 79.593$

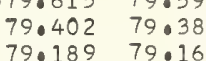

$\begin{array}{ll}79.189 & 79.168 \\ 78.977 & 78.956\end{array}$

$\begin{array}{llll}78.764 & 78.743 & 78.934 & 78.91 \\ 78.552 & 78.0530 & 78.522 & 78.700\end{array}$

$\begin{array}{llll}78.552 & 78.530 & 78.509 & 78.48\end{array}$

$\begin{array}{llll}78.339 & 78.318 & 78.297 & 78.27\end{array}$

$\begin{array}{llll}78.126 & 78.105 & 78.084 & 78.063 \\ 77.914 & 77.893 & 77.871 & 77.850 \\ 77.701 & 77.680 & 77.659 & 77.638\end{array}$

$14577.489 \quad 77.468$

$\begin{array}{lll}77.276 & 77.468 & 77.446 \\ 77.064 & 77.042 & 77.23 \\ 76.02\end{array}$

$\begin{array}{lll}76.851 & 76.830 & 76.80\end{array}$

$76.809 \quad 76.787$
$76.596 \quad 76.575$

$\begin{array}{llll}76.426 & 76.405 & 76.596 & 76.57 \\ 76.384 & 76.362\end{array}$

$76.214 \quad 76.192 \quad 76.171$

$\begin{array}{llll}75.789 & 75.767 & 75.746 & 75.725 \\ 75.576 & 75.555 & 75.533 & 75.512\end{array}$

\begin{abstract}
$4575.364 \quad 75.342 \quad 75.321$
\end{abstract}
$\begin{array}{ll}75.364 & 75.34 \\ 75.151 & 75.130 \\ 74.938 & 74.917\end{array}$

$\begin{array}{lllll}74.938 & 74.917 & 74.109 & 75.087\end{array}$

$\begin{array}{lllll}74.726 & 74.705 & 74.684 & 74.66\end{array}$

$\begin{array}{llll}74.301 & 74.280 & 74.271 & 74.450 \\ 74.259 & 74.237\end{array}$

$\begin{array}{llll}74.089 & 74.067 & 74.046 & 74.025\end{array}$

$\begin{array}{llll}73.876 & 73.855 & 73.834 & 73.81\end{array}$

$\begin{array}{llll}73.664 & 73.643 & 73.621 & 73.600 \\ 73.451 & 73.430 & 73.409 & 73.388\end{array}$ $\begin{array}{llllll}92.298 & 92.277 & 92.255 & 92.234 & 92.213 & 92.191 \\ 92.085 & 92.064 & 92.042 & 92.021 & 92.000 & 91.979\end{array}$

$\begin{array}{llllll}92.085 & 92.064 & 92.042 & 92.021 & 92.000 & 91.979 \\ 91.872 & 91.851 & 91.829 & 91.808 & 91.787 & 91.766\end{array}$

$\begin{array}{llllll}91.872 & 91.851 & 91.829 & 91.808 & 91.787 & 91.766 \\ 91.659 & 91.638 & 91.616 & 91.595 & 91.574 & 91.552\end{array}$

$\begin{array}{llllll}91.233 & 91.212 & 91.190 & 91.169 & 91.148 & 91.126 \\ 91.020 & 90.999 & 90.977 & 90.956 & 90.935 & 90.914\end{array}$

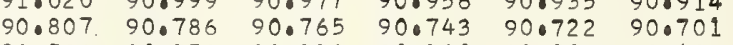

$\begin{array}{llllll}90.594 & 90.573 & 90.552 & 90.530 & 90.509 & 90.488 \\ 90.381 & 90.360 & 90.339 & 90.317 & 90.296 & 90.275\end{array}$

$\begin{array}{llllll}90.168 & 90.147 & 90.126 & 90.104 & 90.083 & 90.062\end{array}$

$\begin{array}{lllllll}89.742 & 89.721 & 89.700 & 89.679 & 89.657 & 89.636 \\ 89.530 & 89.508 & 89.487 & 89.466 & 89.444 & 89.423\end{array}$

$\begin{array}{llllll}89.530 & 89.508 & 89.487 & 89.466 & 89.444 & 89.423 \\ 89.317 & 89.295 & 89.274 & 89.253 & 89.231 & 89.210\end{array}$

$\begin{array}{lllllll}80.104 & 89.083 & 89.061 & 89.040 & 89.019 & 88.997 \\ 88.891 & 88.870 & 88.848 & 88.827 & 88.806 & 88.784\end{array}$

$\begin{array}{lllllll}88.891 & 88.870 & 88.848 & 88.827 & 88.806 & 88.784 \\ 88.678 & 88.657 & 88.635 & 88.614 & 88.593 & 88.571\end{array}$

$\begin{array}{lllllll}88.678 & 88.657 & 88.635 & 88.614 & 88.593 & 88.571 \\ 88.465 & 88.444 & 88.422 & 88.401 & 88.380 & 88.359\end{array}$

$\begin{array}{lllllll}88.252 & 88.231 & 88.210 & 88.188 & 88.167 & 88.146\end{array}$

$\begin{array}{llllll}87.826 & 87.805 & 87.784 & 87.762 & 87.741 & 87.720\end{array}$

$\begin{array}{llllll}87.614 & 87.592 & 87.571 & 87.550 & 87.528 & 87.507 \\ 87.401 & 87.379 & 87.358 & 87.337 & 87.316 & 87.294\end{array}$

$\begin{array}{llllll}86.975 & 86.954 & 86.932 & 86.911 & 86.890 & 86.869\end{array}$

$\begin{array}{lllllll}86.762 & 86.741 & 86.720 & 86.698 & 86.677 & 86.656\end{array}$

$\begin{array}{llllll}86.337 & 86.315 & 86.294 & 86.273 & 86.251 & 86.230 \\ 86.124 & 86.102 & 86.081 & 86.050 & 86.038 & 86.017\end{array}$

$\begin{array}{lllllll}85.911 & 85.890 & 85.868 & 85.847 & 85.826 & 85.804\end{array}$

$\begin{array}{llllll}85.698 & 85.677 & 85.656 & 85.634 & 85.613 & 85.592\end{array}$

$\begin{array}{llllll}85.485 & 85.464 & 85.443 & 85.421 & 85.400 & 85.379 \\ 85.272 & 85.251 & 85.230 & 85.209 & 85.187 & 85.166\end{array}$

$\begin{array}{lllllll}85.060 & 85.038 & 85.017 & 84.996 & 84.974 & 84.953\end{array}$

$\begin{array}{llllll}84.847 & 84.826 & 84.804 & 84.783 & 84.762 & 84.741 \\ 84.634 & 84.613 & 84.592 & 84.570 & 84.549 & 84.528\end{array}$

$\begin{array}{llllll}84.422 & 84.400 & 84.379 & 84.358 & 84.336 & 84.315\end{array}$

$\begin{array}{llllll}84.208 & 84.187 & 84.166 & 84.145 & 84.124 & 84 \cdot 102\end{array}$

$\begin{array}{llllll}83.570 & 83.549 & 83.528 & 83.506 & 83.485 & 83.464\end{array}$

$\begin{array}{llllll}83.145 & 83.124 & 83.102 & 83.081 & 83.060 & 83.039\end{array}$

$\begin{array}{llllll}82.507 & 82.485 & 82.464 & 82.656 & 82.634 & 82.613 \\ & 82.443 & 82.422 & 82.401\end{array}$

$\begin{array}{llllll}82.294 & 82.273 & 82.251 & 82.230 & 82.209 & 82.188\end{array}$

$\begin{array}{llllll}81.656 & 81.635 & 81.614 & 81.592 & 81.571 & 81.550\end{array}$

$\begin{array}{llllll}81.231 & 81.209 & 81.188 & 81.167 & 81.146 & 81.124\end{array}$

$\begin{array}{llllll}81.018 & 80.997 & 80.975 & 80.954 & 80.933 & 80.912\end{array}$

$\begin{array}{llllll}80.805 & 80.784 & 80.763 & 80.741 & 80.720 & 80.699\end{array}$

$\begin{array}{llllll}80.580 & 80.572 & 80.550 & 80.529 & 80.508 & 80.486\end{array}$

$\begin{array}{llllll}79.955 & 70.033 & 70.012 & 70.891 & 80.082 & 80.061\end{array}$

$\begin{array}{llllll}79.742 & 79.721 & 79.700 & 79.679 & 79.657 & 79.636\end{array}$

$\begin{array}{lllllll}79.530 & 79.508 & 79.487 & 79.466 & 79.445 & 79.423\end{array}$

$\begin{array}{llllll}79.317 & 79.296 & 79.275 & 79.253 & 79.232 & 79.211\end{array}$

$\begin{array}{llllll}79.104 & 79.083 & 79.062 & 79.041 & 79.019 & 78.998 \\ 78.892 & 78.871 & 78.849 & 78.828 & 78.807 & 78.786\end{array}$

$\begin{array}{llllll}78.679 & 78.658 & 78.637 & 78.615 & 78.594 & 78.573\end{array}$

$\begin{array}{llllll}78.467 & 78.445 & 78.424 & 78.403 & 78.382 & 78.360\end{array}$

$\begin{array}{llllll}78.254 & 78.233 & 78.211 & 78.190 & 78.169 & 78.148 \\ 78.042 & 78.020 & 77.999 & 77.978 & 77.956 & 77.935\end{array}$

$\begin{array}{llllll}77.829 & 78.020 & 77.999 & 77.978 & 77.956 & 77.935 \\ 77.808 & 77.786 & 77.765 & 77.744 & 77.723\end{array}$

$\begin{array}{llllll}77.595 & 77.574 & 77.552 & 77.531 & 77.510\end{array}$

$\begin{array}{lllllll}77.404 & 770383 & 77 \cdot 361 & 77 \cdot 340 & 77 \cdot 319 & 77 \cdot 297\end{array}$

$\begin{array}{llllll}77 \cdot 191 & 77 \cdot 170 & 77 \cdot 149 & 77 \cdot 127 & 77 \cdot 106 & 77 \cdot 085\end{array}$

$\begin{array}{llllll}76.9919 & 76 \cdot 958 & 76 \cdot 936 & 76 \cdot 915 & 76.894 & 76 \cdot 872\end{array}$

$\begin{array}{llllll}76.554 & 76.045 & 76.724 & 76.702 & 76.681 & 76.660 \\ 76.511 & 76.490 & 76.469 & 76.447\end{array}$

$\begin{array}{llllll}76.341 & 76.320 & 76.299 & 76.277 & 76.256 & 76.235\end{array}$

$\begin{array}{llllll}76.129 & 76.107 & 76.086 & 76.065 & 76.044 & 76.022\end{array}$

$\begin{array}{llllll}75.916 & 75.895 & 75.873 & 750852 & 750831 & 75.810\end{array}$

$\begin{array}{llllll}75.703 & 75.682 & 75.661 & 75.640 & 75.619 & 75.597 \\ 75.491 & 75.470 & 75.448 & 75.427 & 75.406 & 75.385\end{array}$

$\begin{array}{llllll}75 \cdot 278 & 75 \cdot 257 & 75 \cdot 236 & 75 \cdot 215 & 75 \cdot 193 & 75 \cdot 172\end{array}$

$\begin{array}{llllll}75.066 & 75.045 & 75.024 & 75 \cdot 002 & 74 \cdot 981 & 74 \cdot 960 \\ 74.854 & 74.832 & 74.811 & 74.790 & 740768 & 74.747\end{array}$

$\begin{array}{lllllll}74.641 & 74.620 & 74.599 & 74.577 & 74.556 & 74.535\end{array}$

$\begin{array}{llllll}74 \cdot 429 & 74 \cdot 407 & 74 \cdot 386 & 74 \cdot 365 & 74 \cdot 344 & 74 \cdot 322 \\ 74 \cdot 216 & 740195 & 74 \cdot 174 & 74015 ? & 74 \cdot 131 & 740110\end{array}$

$\begin{array}{llllll}76.004 & 73.982 & 73.961 & 73.940 & 73.919 & 73.897\end{array}$

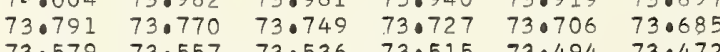

$\begin{array}{llllll}73.579 & 73.557 & 73.536 & 73.515 & 73.494 & 73.472 \\ 73.366 & 73.345 & 73.324 & 73.302 & 73.281 & 73.260\end{array}$ $\begin{array}{llllll}91.446 & 91.425 & 91.016 & 91.595 & 91.574 & 91.552 \\ & 91.403 & 91.382 & 91.361 & 91.340\end{array}$

$\begin{array}{llllll}89.955 & 89.934 & 89.913 & 89.891 & 89.870 & 89.849\end{array}$

$\begin{array}{llllll}88.039 & 88.018 & 87.997 & 87.975 & 87.954 & 87.933 \\ 87.826 & 87.805 & 87.784 & 87.762 & 87.741 & 87.720\end{array}$

$\begin{array}{llllll}87.188 & 87.167 & 87.358 & 87.337 & 87.316 & 87.294 \\ & 87.124 & 87.103 & 87.082\end{array}$

$\begin{array}{llllll}83.783 & 83.762 & 83.741 & 83.719 & 83.698 & 83.677\end{array}$

$\begin{array}{llllll}82.932 & 82.911 & 82.890 & 82.868 & 82.847 & 82.826\end{array}$

$\begin{array}{llllll}82.081 & 82.060 & 82.039 & 82.018 & 81.996 & 81.975\end{array}$

0.275932

0.275932

0.275931

0.275931

0.275931

0.275931

0.275931

0.275931

0.275930

0.275930
0.275930

0.275930

0.275930

0.275930

0.275930

0.275930
0.275929

0.275929

0.275929

0.275929

0.275929

0.275929

0.275929

0.275929

0.275928

0.275928

0.275928

0.275928

0.275928

0.275928

0.275928

0.275928

0.275927

0.275927

0.275927

0.275927

0.275927

0.275927

0.275927

0.275926
0.275926

0.275926

0.775926

0.275926

0.275926

0.275926

0.275926

0.275925

0.27592

0.275925

0.275925

0.27592

0.275925

0.275925
0.275925

0.275924

0.275924

0.275924

0.27592

0.275924

0.275924

0.275924

0.275924

0.275923

0.275923
0.275923

0.275923

0.27592

0.275923
0.275923

.890132

1.890159
1.890185

1.890212

.890266

.890293

.800390

.890347

1. 890374

1.890401

1.890428

.890455
1.890481

1.890508

1.890535
1.890562

.890589

1.890616
1.890643

1.890670 


$\begin{array}{rllll}4573.239 & 73.218 & 73.196 & 73.175 & 73 \\ 73.026 & 73.005 & 72.984 & 72.963 & 72 . \\ 72.814 & 72.793 & 72.771 & 72.750 & 72 \\ 72.002 & 72.580 & 72.559 & 72.538 & 72 \\ 72.389 & 72.368 & 72.347 & 72.325 & 72 \\ 72.177 & 72.156 & 72.134 & 72.113 & 72 \\ 71.964 & 71.943 & 71.922 & 71.901 & 71 \\ 71.0752 & 71.731 & 71.709 & 71.688 & 71 \\ 71.540 & 71.518 & 71.497 & 71.476 & 71 \\ 71.327 & 71.306 & 71.285 & 71.264 & 710\end{array}$

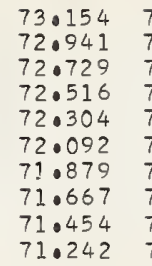

72.970

$\begin{array}{ll}920 & 73.1 \\ 72.8 & 798 \\ 72.687\end{array}$

.111
.899
.687
.474

$\begin{array}{llll}73.090 & 73.069 & 73.047 \\ 9 & 72.878 & 72.856 & 72.835\end{array}$

$\begin{array}{lllll}72.049 & 72.028 & 72.007 & 71.985\end{array}$

$\begin{array}{llll}71.837 & 71.816 & 71.794 & 71.773 \\ 71.024 & 71.603 & 71.582 & 71.561\end{array}$

$\begin{array}{rrr}1.0 & 14571.115 & 71.094 \\ 1.1 & 70.902 & 70.881\end{array}$

$\begin{array}{rl}6861 & .0 \\ 1 & : 1 \\ 1 & .2 \\ 1 & .04 \\ 1 & .5 \\ 1 & .6 \\ 1.7 \\ 1.8 \\ 1.09\end{array}$

$\begin{array}{ll}70.902 & 70.881 \\ 70.690 & 70.669 \\ 70.478 & 70.456 \\ 70.265 & 70.244\end{array}$

$1.072 \quad 71.051$

71.030

71.412

71.391

71.37071 .348

$70.265 \quad 70.244 \quad 70.435 \quad 70.414$

$\begin{array}{llll}70.053 & 70.034 & 70.223 & 70.202 \\ 70.010 & 69.989\end{array}$

$69.628 \quad 69.607 \quad 69.586 \quad 69.77$

$\begin{array}{ll}69.416 & 69.395 \\ 69.204 & 69.182\end{array}$

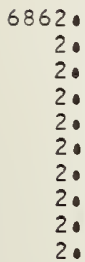

14568.991

$\begin{array}{lllllll}68.991 & 68.970 & 68.949 & 68.928 & 68.906 & 68.88 \\ 68.779 & 68.758 & 68.737 & 68.715 & 68.694 & 68.67\end{array}$

$\begin{array}{ll}69.374 & 69 \cdot 352 \\ 69.161 & 69.140\end{array}$

70.818

$70.393-70.371$

70.180
69.968

$60.968 \quad 69.947 \quad 69.1386$

$\begin{array}{lllll}70.987 & 70.966 & 70.045 & 70.024\end{array}$

$\begin{array}{llll}70.987 & 70.966 & 70.045 & 70.974 \\ 70.775 & 70.754 & 70.732 & 70.711 \\ 70.563 & 70.541 & 70.0520 & 70.490\end{array}$

$\begin{array}{llll}70.350 & 70.329 & 70.308 & 70.287\end{array}$

$69.926 \quad 69.904 \quad 690883 \quad 69.862$

$69.713 \quad 69.692 \quad 690671 \quad 69.650$

$\begin{array}{llllll}69.543 & 69.522 & 69.501 & 69.480 & 69.458 & 69.437\end{array}$

69.07

$69.267 \quad 69.246 \quad 69.225$

$68.864 \quad 68.843 \quad 68.821 \quad 68.800$

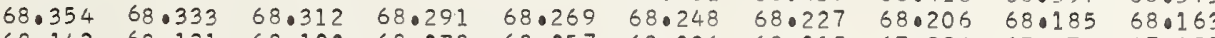

$\begin{array}{llllllllll}68.142 & 68.121 & 68 \cdot 100 & 68 \cdot 078 & 68.057 & 68 \cdot 036 & 68.015 & 67.994 & 67 \cdot 972 & 67.951\end{array}$

$\begin{array}{lllllllllll}67.717 & 67.696 & 67.675 & 67.0554 & 67.633 & 67.611 & 67.590 & 67.569 & 67.548 & 67.526\end{array}$

$\begin{array}{llllllllll}67.505 & 67.484 & 67.463 & 67.441 & 67.420 & 67.399 & 67.378 & 67.357 & 67.335 & 67.314\end{array}$

$\begin{array}{llllllllll}67.293 & 67.272 & 67.250 & 67.229 & 67.208 & 67.187 & 67.166 & 67.144 & 67.123 & 67.102 \\ 67.081 & 67.059 & 67.038 & 67.017 & 66.996 & 66.974 & 66.953 & 66.932 & 66.011 & 66.890\end{array}$

$\begin{array}{rllllllllll}6863.0 & 14566.868 & 66.847 & 66.826 & 66.805 & 66.783 & 66.762 & 66.741 & 66.720 & 66.699 & 66.677\end{array}$

$\begin{array}{lllllllllll}3.1 & 66.656 & 66.635 & 66.614 & 66.593 & 66.571 & 66.550 & 66.529 & 66.508 & 66.486 & 66.465 \\ 3.2 & 66.444 & 66.423 & 66.401 & 66.380 & 66.359 & 66.338 & 66.317 & 66.295 & 66.274 & 66.253\end{array}$

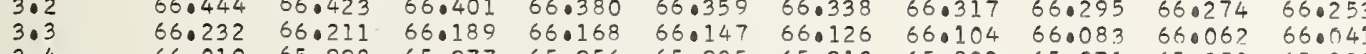

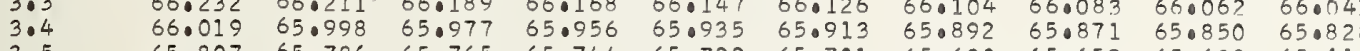

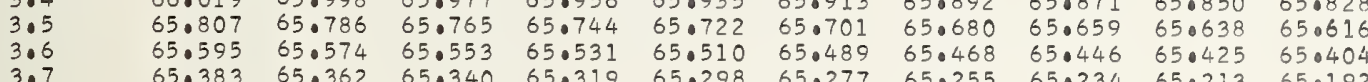

3.8
3.9

$65.383 \quad 65.362-65.340 \quad 65.310$

65.17165 .150

$\begin{array}{ll}65.340 & 65.319 \\ 65.128 & 65.107\end{array}$

65.255

$65.446 \quad 650425 \quad 650404$

640958

64.937

65.298
65.086
64.874

65.06
64.85

6864.0

4.
40
40
4.
40
40
4.7
40
4.9

6456.746

$64.746 \quad 64.725 \quad 64.704$

64.683

64.66164 .640

$\begin{array}{lllll}64.831 & 64 \cdot 810 & 64.789 & 64.768\end{array}$

0.275922

0.0275922

0.275921

0.027592

0.27592

0.275921

0.2759

0.275921

0.275920

0.0275920

0.275920

0.275920

0.275920

0.275920

0.275919

0.275910

0.275919

0.275919

0.275919
0.275919

0.275910

0.275918

0.275918

0.275918

0.275918

0.275918

0.275918

0.275917

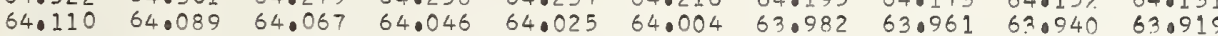
$\begin{array}{llllllllll}63.897 & 63.876 & 63.855 & 63.834 & 63.813 & 63.792 & 63.770 & 63.749 & 63.728 & 63.707\end{array}$

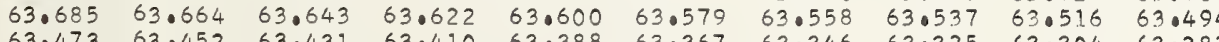
$\begin{array}{llllllllll}63.473 & 63.452 & 63.431 & 63.410 & 63.388 & 63.367 & 63.346 & 63.325 & 63.304 & 63.282 \\ 63.261 & 63.240 & 63.0210 & 63.197 & 63.176 & 63.155 & 63.134 & 63.113 & 63.091 & 63.070\end{array}$

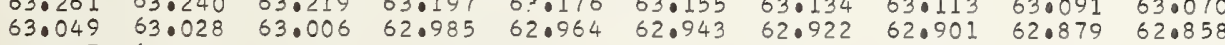

0.0275917

0.275917

0.275917
0.275917

$\begin{array}{llllllllll}620837 & 62.816 & 62.794 & 62.773 & 62.752 & 62.731 & 62.709 & 62.688 & 62.667 & 62.646\end{array}$

0.275917

6865.0

$14562 \cdot 625$ $62.412 \quad 62.603$

62.58
62.370

62.56

$62.540 \quad 62.519$

0.275917

0.2275917
0.275917 $\begin{array}{llllllll}61.946 & 1.925 & 69.903 & 61.882 & 61.861 & 61.840 & 61.819 & 61.797\end{array}$

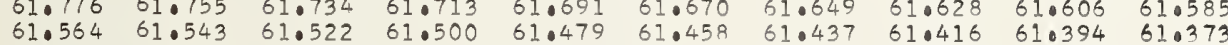

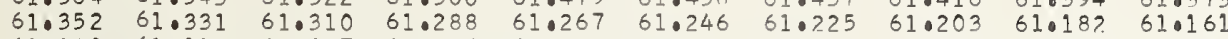

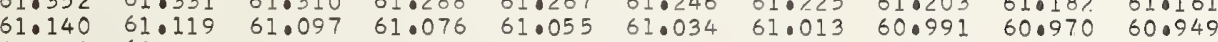
$\begin{array}{llllllllll}60.928 & 60.907 & 60.885 & 60.864 & 60.843 & 60.822 & 60.800 & 60.779 & 60.758 & 60.737 \\ 60.716 & 60.694 & 60.673 & 60.652 & 60.631 & 60.610 & 60.589 & 60.567 & 60.546 & 60.525\end{array}$

0.275916

0.275916

0.0275916

0.275916

0.275916

$\begin{array}{rrrrrrrrrrr}6866.0 & 14560.504 & 60.483 & 60.461 & 60.440 & 60.419 & 60.398 & 60.376 & 60.355 & 60.334 & 60.313 \\ 6.1 & 60.292 & 60.270 & 60.249 & 60.228 & 60.207 & 60.186 & 60.164 & 60.143 & 60.122 & 60.101\end{array}$

$\begin{array}{lllllllllll}6.1 & 60.292 & 60.2 .70 & 60.249 & 60.228 & 60.207 & 60.186 & 60.164 & 60.143 & 60.122 & 60.101 \\ 6.2 & 60.080 & 60.058 & 60.037 & 60.016 & 50.995 & 50.074 & 59.952 & 59.931 & 59.910 & 59.889\end{array}$

$\begin{array}{llllllllllll}6.2 & 60.080 & 60.058 & 60.037 & 60.016 & 59.995 & 59.974 & 59.952 & 59.931 & 59.910 & 59.889 \\ 6.3 & 59.868 & 59.846 & 59.825 & 50.804 & 50.783 & 59.761 & 59.740 & 59.710 & 59.698 & 59.677\end{array}$

$59655-59063450.0250 .590804$

$\begin{array}{lllll}59.508 & 59.507 & 59.486 & 59.465\end{array}$ $59.43150 .422 \quad 59.401 \quad 59.380 \quad 59.35959 .33759 .316 \quad 59.295 \quad 59.274 \quad 59.253$ $\begin{array}{llllllllll}59.019 & 58.998 & 58.977 & 58.056 & 58.935 & 58.913 & 58.892 & 58.871 & 58.850 & 58.828\end{array}$ $\begin{array}{lllllllllll}58.807 & 58.786 & 58.765 & 58.744 & 58.723 & 58.701 & 58.680 & 58.659 & 58.638 & 58.617 \\ 58.595 & 58.574 & 58.553 & 58.532 & 58.510 & 58.489 & 58.468 & 58.447 & 58.426 & 58.405\end{array}$

0.275916

0.275916

0.275915

0.275915

0.275915
0.275915

0.275915
0.275915

0.275915
0.275915

0.275914

0.275914

0.275914

0.275914
0.275914

1.893065 $\begin{array}{llllllllll}58.171 & 58.150 & 58.129 & 58.108 & 58.087 & 58.065 & 58.044 & 58.023 & 58.002 & 57.980\end{array}$ $\begin{array}{llllllllll}57.974 & 57.938 & 57.917 & 57.896 & 57.875 & 57.853 & 57.832 & 57.811 & 57.790 & 57.768 \\ 57.747 & 57.726 & 57.705 & 57.684 & 57.663 & 57.641 & 57.620 & 57.599 & 57.578 & 57.557\end{array}$ $\begin{array}{llllllllll}57.535 & 57.514 & 57.493 & 57.472 & 57.451 & 57.429 & 57.408 & 57.387 & 57.366 & 57.345 \\ 57.323 & 57.302 & 57.281 & 57.260 & 57.239 & 57.218 & 57.196 & 57.175 & 57.154 & 57.133\end{array}$ $\begin{array}{llllllllll}57.111 & 57.090 & 57.069 & 57.048 & 57.027 & 57.005 & 56.984 & 56.963 & 56.947 & 56.921 \\ 56.899 & 56.878 & 56.857 & 56.836 & 56.815 & 56.793 & 56.772 & 56.751 & 56.730 & 56.700\end{array}$

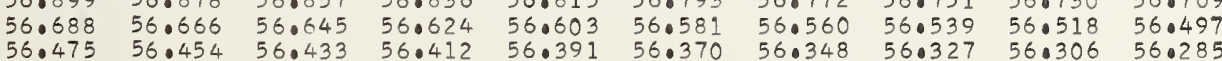

0.275914

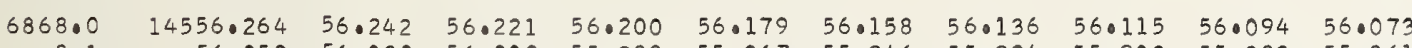

$\begin{array}{lrlllllllll}8.1 & 56.052 & 56.030 & 56.009 & 55.988 & 55.967 & 55.946 & 55.924 & 55.903 & 55.882 & 55.861\end{array}$

$\begin{array}{lllllllllll}8.2 & 55.840 & 55.818 & 55.797 & 55.776 & 55.755 & 55.734 & 55.713 & 55.691 & 55.670 & 55.649\end{array}$ $\begin{array}{llllllllll}55.628 & 55.607 & 55.585 & 55.564 & 55.543 & 55.522 & 55.500 & 55.479 & 55.458 & 55.437\end{array}$ $\begin{array}{llllllllll}55.416 & 55.395 & 55.373 & 55.352 & 55.331 & 55.310 & 55.289 & 55.268 & 55.246 & 55.225 \\ 55.204 & 55.183 & 55.161 & 55.140 & 55.119 & 55.098 & 55.077 & 55.056 & 55.034 & 55.013\end{array}$ $\begin{array}{lllllllllll}55.204 & 55.183 & 55.161 & 55.140 & 55.119 & 55.098 & 55.077 & 55.056 & 55.034 & 55.013 \\ 54.992 & 54.971 & 54.950 & 54.928 & 54.907 & 54.886 & 54.865 & 54.844 & 540823 & 54.801\end{array}$ $\begin{array}{lllllllllll}54.780 & 54.759 & 54.738 & 54.716 & 54.695 & 54.674 & 54.653 & 540632 & 540611 & 54.589\end{array}$

$\begin{array}{lllllllllll}8.8 & 54.568 & 54.547 & 54.526 & 54.505 & 54.483 & 54.462 & 54.441 & 54.420 & 54.399 & 54.378 \\ 8.9 & 54.356 & 54.335 & 54.314 & 54.293 & 54.272 & 54.250 & 54.229 & 54.208 & 54.187 & 54.166\end{array}$

0.275914

0.275914

0.275913

0.275913

0.275913

.893110

.893146
.893173

.893227

1.893281

1.893308
1.893334

1.893361

1.893415

1.893442

893469
1.893496

893523
.893550

1.893577

- 893631

.893684

.893738

1.893765
1.893792

10381

1.893846

.893900

1.893927

1.893954
1.893980

.894007

1.894061

1.894088

1.894142

1.894169

1.894223

1.89425

1.894776
1.894303

1.894330
1.894357

1.894384

1.894438

1.894465

1.894519

1.894546

1.894573

.894626

1.894653

1.894707

1.894734

1.894788

1.894815

1.894842
1.894869

1.894896

.894922
1.894949

1.894976

1.895003

1.895057

1.895084

1.895111

1.895165

0.275913

1.895192
1.895219

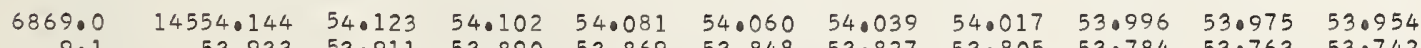
$\begin{array}{lllllllllll}53.933 & 53.911 & 53.890 & 53.869 & 53.848 & 53.827 & 53.805 & 53.784 & 53.763 & 53.742\end{array}$ $\begin{array}{llllllllll}53.721 & 53.699 & 53.678 & 53.657 & 53.636 & 53.615 & 53.594 & 53.572 & 53.551 & 53.530 \\ 53.509 & 53.488 & 53.467 & 53.445 & 53.424 & 53.403 & 53.382 & 53.360 & 53.339 & 53.318\end{array}$ $\begin{array}{llllllllll}53.297 & 53.276 & 53.255 & 53.233 & 53.212 & 53.191 & 53.170 & 53.149 & 53.127 & 53.106\end{array}$ $\begin{array}{llllllllll}53.085 & 53.064 & 53.043 & 53.022 & 53.000 & 52.979 & 52.958 & 52.937 & 52.916 & 52.894\end{array}$ $\begin{array}{lllllllllll}52.873 & 52.852 & 52.831 & 52.810 & 52.788 & 52.767 & 52.746 & 52.725 & 52.704 & 52.683\end{array}$ $\begin{array}{llllllllll}52.661 & 52.640 & 52.619 & 52.598 & 52.577 & 52.556 & 52.534 & 52.513 & 52.492 & 52.471\end{array}$ $\begin{array}{llllllllll}52.450 & 52.428 & 52.407 & 52.386 & 52.365 & 52.344 & 52.322 & 52.301 & 52.280 & 52.250\end{array}$ $\begin{array}{lllllllllll}52.238 & 52.217 & 52.195 & 52.174 & 52.153 & 52.132 & 52.111 & 52.089 & 52.068 & 52.047\end{array}$

0.275913

1.895245

0.275913

0.275913

0.275912

0.27591

0.275912

0.275912
0.275912

.895299

1.895326

1.895380

1.895407

1.895434

1.895461
1.895488

$$
.001
$$

$$
.002
$$

.003

.004

.005

.006

.007

.008

.009

.010

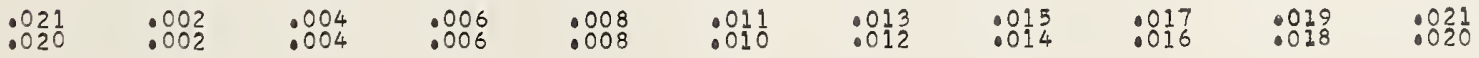


$\begin{array}{llllllllll}51.026 & 52.005 & 51.984 & 51.962 & 51.941 & 51.920 & 51.899 & 51.878 & 51.856 & 51.835 \\ 51.793 & 51.772 & 51.751 & 51.729 & 51.708 & 51.687 & 51.666 & 51.645 & 51.624\end{array}$

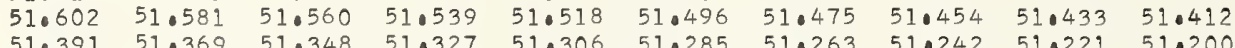

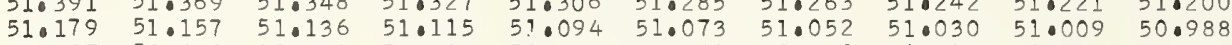
$\begin{array}{llllllllll}50.967 & 50.946 & 50.925 & 50.903 & 50.882 & 50.861 & 50.840 & 50.819 & 50.797 & 50.776\end{array}$ $\begin{array}{llllllllll}50.755 & 50.734 & 50.713 & 50.692 & 50.670 & 50.649 & 50.628 & 50.607 & 50.586 & 50.564\end{array}$ $\begin{array}{llllllllll}50.543 & 50.522 & 50.501 & 50.480 & 50.459 & 50.437 & 50.416 & 50.395 & 50.374 & 50.353\end{array}$ 50.120

\subsection{9}

$50.077 \quad 50.056$

1.1

1.2
1.3

1.4

1.5
1.6

1.7

1.8
1.9

6872

2. 3

2.5

2.7

2.8

6873.0

3.

3.2

3.4

3.6

3.8

4549.908

$$
\begin{array}{rr}
59.696 & 49.675 \\
49.484 & 49.463
\end{array}
$$

$49.273 \quad 49.252$

$\begin{array}{ll}49.061 & 49.040 \\ 48.849 & 48.828\end{array}$

$\begin{array}{ll}48.638 & 48 \cdot 616 \\ 48.426 & 48.405\end{array}$

$48.426 \quad 48 \cdot 405$

$\begin{array}{ll}48.214 & 48 \cdot 193 \\ 48.002 & 47.981\end{array}$

$49.866 \quad 49.844$

$\begin{array}{ll}49.442 & 49.633 \\ 49.421\end{array}$

49.230
49.019

48.807

$\begin{array}{ll}48.595 & 48.574 \\ 48.384 & 48.362\end{array}$

$\begin{array}{ll}48.384 & 48.362 \\ 48.172 & 48.151\end{array}$

$50.247 \quad 50.22$

48

$\begin{array}{llllll}49.823 & 49.802 & 49.781 & 49.760 & 40.739 & 49.718 \\ 49.612 & 49.590 & 49.569 & 49.548 & 49.527 & 49.506\end{array}$

$\begin{array}{llllll}49.400 & 49.379 & 49.358 & 49.336 & 49.315 & 49.294\end{array}$

$\begin{array}{lllllll}49.188 & 49.167 & 49.146 & 49.125 & 49.103 & 49.08 ?\end{array}$

$\begin{array}{llllll}48.765 & 48.744 & 48.722 & 48.701 & 48.680 & 48.659\end{array}$

$\begin{array}{llllll}48.553 & 48.532 & 48.510 & 48.489 & 48.468 & 48.447\end{array}$

$\begin{array}{llllll}48.129 & 48.120 & 48.299 & 48.278 & 48.257 & 48.235\end{array}$

$$
\begin{array}{llll}
14547.791 & 47.770 & 47.748 & 47.727
\end{array}
$$

1.895515
1.805542

1. 895568

1.895595
1.895622

1.895649
1.895676

1.895703
1.895730

1. 895757

1.895784

1.895811
1.895838

1.895865

1.895891
1.895918

1.895945

1.895972
1.895999

1.896026

1.896053

1.896080
1.896107

1.896134

1.896188

1. 896214

1.896241
1.896268
1.896295

1.896322

1.896349

1.896376
1.896403
1.806430

1.896457

1.896484

1.896511

1. 896564

1.896591 


.02

.03

\subsection{5}

30.86530 .854

$\begin{array}{ll}30.664 & 30.643 \\ 30.453 & 30.431 \\ 30 & 30\end{array}$

$30.241 \quad 30.220$

$29.819 \quad 29.798$

$\begin{array}{ll}29.508 & 29.587 \\ 29.397 & 29.376\end{array}$

$\begin{array}{ll}29.186 & 29.164 \\ 28.974 & 28.953\end{array}$

$\begin{array}{ll}30.833 & 30.812 \\ 30.622 & 30.600 \\ 30.410 & 30.389 \\ 30.199 & 30.178 \\ 29.988 & 29.967 \\ 29.777 & 29.756 \\ 29.566 & 29.544 \\ 29.354 & 29.333 \\ 29.143 & 29.122 \\ 28.932 & 28.911\end{array}$

.04

.05

.06

.07

.08

.09

$(n-1) \times 1000$

$\lambda(n-1)$

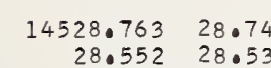

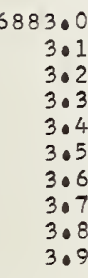

0.275902

0.275902

0.275902

0.275901

0.275901

0.275901

0.275901

0.275901

0.275901

0.275901

0.275901

0.275900

0.275900

0.275900

0.275900
0.275900

0.275900

0.275900
0.275900

0.275900

0.275899

0.275899

0.27589

0.275899
0.275899

0.275899

0.275899
0.275899

0.275899
0.275898

0.275898

0.275898

0.275898

0.275898
0.275898

0.275898

0.275898

0.275897

0.275897
0.275897

0.275897

0.275897

0.275897
0.275897
0.275897

0.275897

0.275897
0.275897
0.275897

0.275896
0.275896

0.275896

0.275896
0.275896
0.275896

0.275896
0.275896

0.275896

0.275896
0.275896

0.275896
0.275895

0.275895

0.275895

0.27589

0.275895

0.275895

0.275895

0.275895

0.275895
0.275894

0.275894

0.275894

0.275894

0.275894
0.275894

0.275894

0.275894

0.275894

0.275893
0.275893

0.275893

0.275893
0.275893

0.275893

0.275893

0.275893

0.275893

0.275893
0.275892

1.898206

.898233

1.898287

1.898314

.898368

1.898422

1.8984 .49

1.898475

$\frac{1}{1.898502}$

1.898556

1.898583

1.898637

1.898664

1.898718

1.898745

1.8987722

10898825

1.898879

1.898906

1.898960

1.899014

1.899068

1.899095

1.899121

1.899148

10899202

10899229

1.899283

1.899310

10899337

1.899391

1.899418

1.899471

1.899498

1.899552

1.899579

1.899633

1.8996660

1.899714 


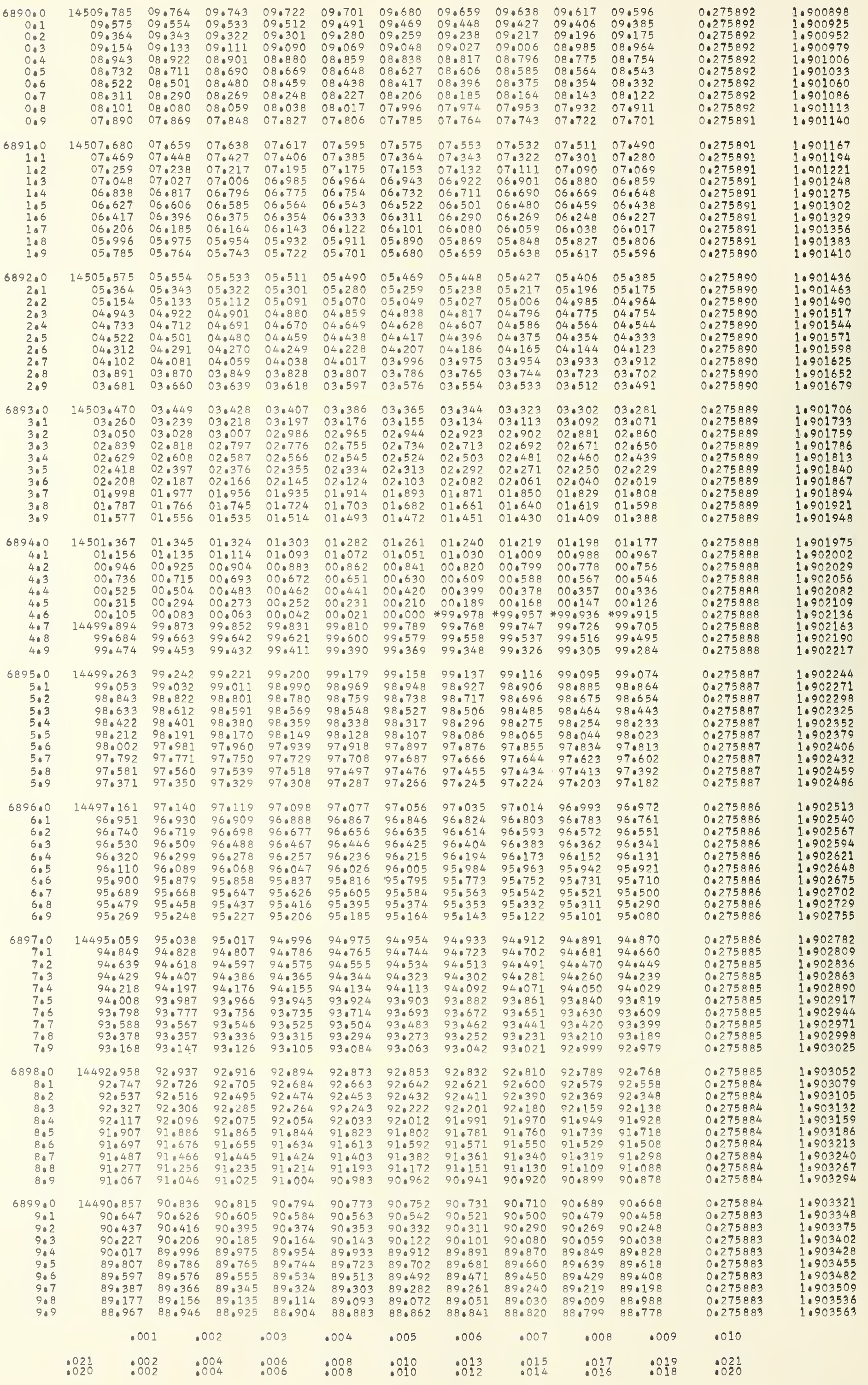


$\begin{array}{rrrrrrrrrrr}6900.0 & 14488.757 & 88.736 & 88.715 & 88.694 & 88.673 & 88.652 & 88.631 & 88.610 & 88.589 & 88.568 \\ 0.1 & 88.547 & 88.526 & 88.505 & 88.484 & 88.453 & 88.442 & 88.421 & 88.400 & 88.379 & 88.358\end{array}$

$\begin{array}{llllllllllll}0.2 & 88.537 & 88.316 & 88.295 & 88.274 & 88.253 & 88.232 & 88.211 & 88.190 & 88.169 & 88.148\end{array}$ $\begin{array}{llllllllllll}0.3 & 88.127 & 88.106 & 88.085 & 88.064 & 88.043 & 88.022 & 88.001 & 87.980 & 87.959 & 87.938 \\ 0.4 & 87.017 & 87.896 & 87.875 & 87.054 & 87.833 & 87.812 & 87.791 & 87.770 & 87.749 & 87.928\end{array}$ $\begin{array}{lllllllllll}0.4 & 87.917 & 87.896 & 87.875 & 87.854 & 87.833 & 87.812 & 87.791 & 87.770 & 87.749 & 87.728 \\ 0.5 & 87.707 & 87.686 & 87.665 & 87.644 & 87.623 & 87.602 & 87.581 & 87.560 & 87.539 & 87.518\end{array}$ $\begin{array}{llllllllllll}0.6 & 87.497 & 87.476 & 87.455 & 87.434 & 87.413 & 87.392 & 87.371 & 87.350 & 87.329 & 87.308\end{array}$ $\begin{array}{lllllllllll}0.7 & 87.287 & 87.266 & 87.245 & 87.224 & 87.203 & 87.182 & 87.161 & 87.140 & 87.119 & 87.098\end{array}$

$0.8 \quad 87.077 \quad 87.056 \quad 87.035 \quad 87.014 \quad 860$

$\begin{array}{llllll}86.993 & 86.972 & 86.951 & 87.140 & 87.119 & 87.098 \\ 86.930 & 86.909 & 86.888\end{array}$

$14486.657 \quad 86.636 \quad 86.615 \quad 86.594$

\section{$86.447 \quad 86.426 \quad 86.405 \quad 86.384$}

$\begin{array}{llllll}86.573 & 86.552 & 86.531 & 86.510 & 86.489 & 86.468\end{array}$ $\begin{array}{llll}85.818 & 85.797 & 85.776 & 85.755 \\ 85.608 & 85.587 & 85.566 & 85.545\end{array}$ $\begin{array}{llll}85.398 & 85.377 & 85.356 & 85.335\end{array}$ $\begin{array}{llll}85.188 & 85.167 & 85.146 & 85.125 \\ 84.978 & 84.957 & 84.936 & 84.015\end{array}$

$\begin{array}{lll}86.363 & 86.342 & 86.32 \\ 86.153 & 86.132 & 86.11\end{array}$

$\begin{array}{lll}86.153 & 86.132 & 86.111 \\ 85.943 & 85.922 & 85.901\end{array}$

$85.734 \quad 85.713$

$85.524 \quad 85.503 \quad 85.482$

$85.104 \quad 85.083$

$\begin{array}{llll}84.768 & 84.747 & 84.726 & 84.705\end{array}$

$84 \cdot 89$

85.083
84.873
84.653

85.272

$86.300 \quad 86.279 \quad 86.058$

$\begin{array}{lll}86.090 & 86.069 & 86.048\end{array}$

$\begin{array}{lll}85.880 & 85.859 & 85.839 \\ 85.671 & 85.650 & 85.629\end{array}$

$85.461 \quad 85.440 \quad 85.419$

$85.251 \quad 85.230 \quad 85.209$

$84.621 \quad 84.600 \quad 84078$

6902.0

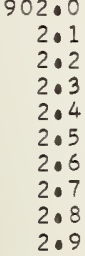

$\begin{array}{rlll}14484 \cdot 558 & 84.537 & 84.516 & 84.495 \\ 84.348 & 84.327 & 84.307 & 84.286\end{array}$

$84.474 \quad 84.453 \quad 84.432 \quad 84.411 \quad 84.390 \quad 84.369$ $\begin{array}{lllllllll}84.34 & 84.245 & 84.223 & 84.202 & 840181 & 84.160\end{array}$ $\begin{array}{llllllllll}83.929 & 83.908 & 83.887 & 83.866 & 83.845 & 83.824 & 83.803 & 83.782 & 83.761 & 83.740\end{array}$

$\begin{array}{lll}2.3 & 83.929 & 83.908 \\ 2.4 & 83.719 & 83.698\end{array}$

$\begin{array}{llllll}83.635 & 83.624 & 83.593 & 83.572 & 83.551 & 83.530\end{array}$

$\begin{array}{llllll}83.425 & 83.404 & 83.383 & 83.362 & 83.341 & 83.320\end{array}$

$\begin{array}{llllll}83.215 & 83.194 & 83.173 & 83.152 & 83.132 & 83.111 \\ 83.006 & 82.985 & 82.964 & 82.943 & 82.022 & 82.901\end{array}$

6903.0

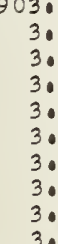

690400

4.

4.

4.3

4.6

4.0

4.8
4.9

6905

5.1

5.2
5.3
5.4

5.3
5.5

5.6

5.7
5.8
5.9

6906
0.275883

0.275883

0.275882

0.275882

0.275882

0.275882
0.275882

0.275882

0.275882

0.275882

0.275881

0.275881
0.275881

0.275882

0.275881

0.275881

0.275881

0.275880

0.275880

0.275880

0.275880
0.275880

0.275880

0.027580

0.0275899

0.27879

0.275879

0.275879

0.775879

0.027579
0.2727879
0.6279

0.275878

878

0.027578
0.275878
0.2787

0.275878
0.27878

0.0275878

0.027578
0.275878
0.2787

0.027577
0.275877

$0: 275577$
0.275877

0.275877
0.275877

0.275877

0.275877

0.275877

0.275877
0.275876
0.275876

0.275876

0.275876
0.275876

0.275876
0.275876

0.275876

0.0275876

0.275876

0.0275875

0.275875
0.275875

0.275875
0.275975

0.275875
0.27875

0.275875

0.0275875
0.0275875

0.0275875

0.075974

0.0275874
0.27874

0.275874

0.0275874

0.275874

0.275874

0.275874

0.275874
0.275874

0.275873

0.275873

0.275873

0.275873

1.903805
1.903832

.903859

.903886

1.903940

1.903967
1.903994

1.904021

1.904048

1.904101

.904128

1.904155
1.904182

1904209

1.904263

1.904317

1.004371

1.904398

1.904424

1.904478
1.904505

1.904532

1.904586

1.904613
1.904640

1. 904667

1.904694
1.904721

1.904747
1.904774

1.904828

1.904855

1.904936

1.904963

1.904990
1.905017

1.905044
1.905071

1.90509 


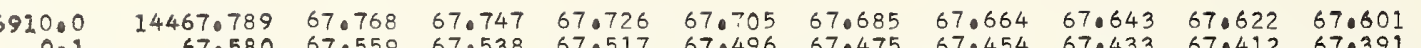
$\begin{array}{lllllllllll}0.1 & 67.580 & 67.559 & 67.538 & 67.517 & 67.496 & 67.475 & 67.454 & 670433 & 67.412 & 670391 \\ 0.0 & 67.370 & 67.040 & 67.328 & 67.0307 & 67.287 & 67.266 & 67.245 & 67.224 & 67.203 & 670102\end{array}$ $\begin{array}{lllllllllll}0.3 & 67.161 & 67.140 & 67.119 & 67.098 & 67.077 & 67.056 & 67.035 & 67.015 & 66.994 & 66.973\end{array}$

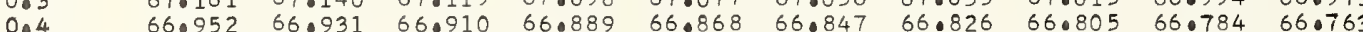
$\begin{array}{llllllllllll}0.5 & 66.742 & 66.721 & 66.700 & 66.679 & 66.658 & 66.638 & 66.617 & 66.596 & 66.575 & 66.554\end{array}$ $\begin{array}{lllllllllll}0.6 & 66.533 & 66.512 & 66.491 & 66.470 & 66.449 & 66.428 & 66.407 & 66.386 & 66.366 & 66.345\end{array}$ $\begin{array}{llllllllll}66.324 & 66.303 & 66.282 & 65.261 & 66.240 & 66.219 & 66.198 & 66.177 & 66.156 & 66.135\end{array}$ $\begin{array}{lllllllllll}0.8 & 66.114 & 66.093 & 66.072 & 66.052 & 66.031 & 66.010 & 65.989 & 65.968 & 650947 & 650926 \\ 0.9 & 65.905 & 65.884 & 65.863 & 65.842 & 65.821 & 65.800 & 65.779 & 65.758 & 65.737 & 65.717\end{array}$ $\begin{array}{rllll}14465.696 & 65.675 & 65.654 & 65.633 & 6506 \\ 65.486 & 65.465 & 65.045 & 65.424 & 65.04\end{array}$

$\begin{array}{lllllllll}65.654 & 65.633 & 65.612 & 65.591 & 65.570 & 65.549 & 65.528 & 65.507\end{array}$ $\begin{array}{lllllllllll}1.1 & 65.486 & 65.465 & 65.445 & 65.424 & 65.403 & 65.382 & 65.361 & 65.340 & 65.319 & 65.298 \\ 1.2 & 65.277 & 65.256 & 65.235 & 65.214 & 65.193 & 65.172 & 65.151 & 65.130 & 65.110 & 65.089\end{array}$ $\begin{array}{lllllllllll}1.3 & 65.068 & 65.047 & 65.026 & 65.005 & 64.984 & 64.963 & 640.942 & 64.921 & 64.900 & 64.879 \\ 1.3 & 64.859 & 64.837 & 64.817 & 64.796 & 64.775 & 64.754 & 64.733 & 64.712 & 64.691 & 64.670\end{array}$ 1.5

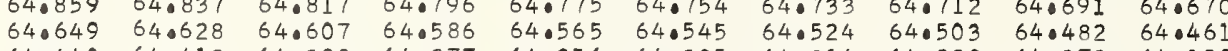

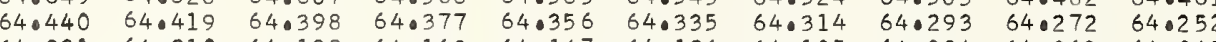
1.8

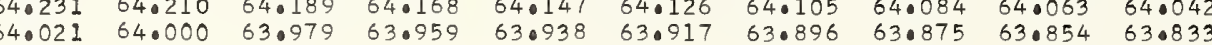

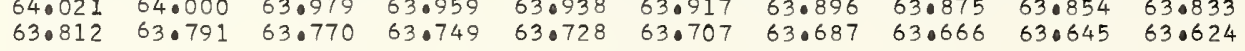

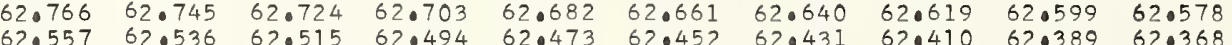

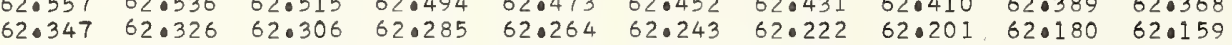

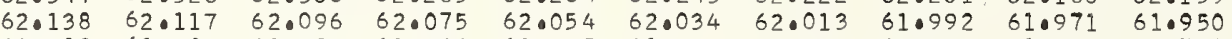
$\begin{array}{llllllllll}61.929 & 61.908 & 61.887 & 61.866 & 61.845 & 61.824 & 61.803 & 61.783 & 61.762 & 61.741 \\ 61.720 & 61.699 & 61.678 & 61.657 & 61.636 & 61.615 & 61.594 & 61.573 & 61.552 & 61.531\end{array}$

$$
\begin{aligned}
& 4457 . \\
& 57 \\
& 56 . \\
& 56.70 \\
& 56.0 \\
& 56.28 \\
& 56.07 \\
& 55.86 \\
& 55.65 \\
& 55 .
\end{aligned}
$$

4453.14

53.127 $52.939 \quad 52.918 \quad 52.897$ $\begin{array}{llll}52.730 & 52.709 & 52.897 & 52.876 \\ 52.688 & 52.667\end{array}$ $\begin{array}{llll}52.521 & 52.500 & 52.479 & 52.45 \\ 52.312 & 52.291 & 52.270 & 52.24\end{array}$ $\begin{array}{lll}52.103 & 52.082 & 52.061 \\ 51.894 & 51.873 & 51.85\end{array}$ $\begin{array}{llllllllll}51.685 & 51.664 & 51.643 & 51.622 & 51.602 & 51.581 & 51.560 & 51.539 & 51.518 & 51.497 \\ 51.476 & 51.455 & 51.435 & 51.414 & 51.393 & 51.372 & 51.351 & 51.330 & 51.300 & 51.288\end{array}$

$$
\begin{array}{r}
14451 \\
50 \\
50 \\
50 \\
50 \\
50 \\
49 \\
49 \\
49 \\
49 \\
\hline
\end{array}
$$$$
\begin{array}{lllllllllll}
5 & 0.059 & 51.038 & 51.017 & 50.996 & 50.975 & 50.954 & 50.933 & 50.912 & 50.892 & 50.871
\end{array}
$$

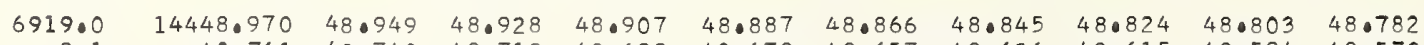

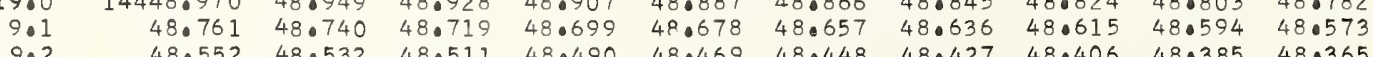

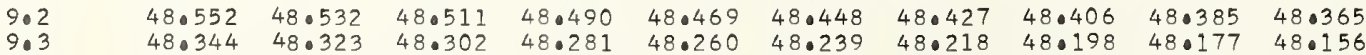

$\begin{array}{lllllllllll}9.3 & 48.344 & 48.323 & 48 \cdot 302 & 48.281 & 48 \cdot 260 & 48.239 & 48.218 & 48 \cdot 198 & 48 \cdot 177 & 48 \cdot 156 \\ 9.4 & 48.135 & 48.114 & 48.093 & 48.072 & 48.051 & 48.030 & 48.010 & 47.989 & 470968 & 470947\end{array}$

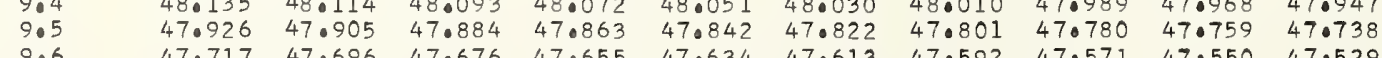

$\begin{array}{llllllllllll}9.6 & 47.717 & 47.696 & 47.676 & 47.655 & 47.634 & 47.613 & 47.592 & 47.571 & 470550 & 47.529\end{array}$

$\begin{array}{lllllllllll}9.7 & 47.508 & 47.488 & 47.467 & 47.446 & 47.425 & 47.404 & 47.383 & 47.362 & 47.341 & 47.320 \\ 9.8 & 47.300 & 47.279 & 47.258 & 47.237 & 47.216 & 47.195 & 47.174 & 47.154 & 47.133 & 47.112\end{array}$

9.8

$\begin{array}{lll}47.300 & 47.279 & 47.25 \\ 47.091 & 47.070 & 47.049\end{array}$

.001

.002

.003

\begin{abstract}
.004
\end{abstract}

$\begin{array}{ll}0.275873 & 1.906282 \\ 0.275873 & 1.906309 \\ 0.275873 & 1.906336 \\ 0.275873 & 1.906363 \\ 0.275873 & 1.906390 \\ 0.275872 & 1.9006417 \\ 0.275872 & 1.9006443 \\ 0.275872 & 1.9006470 \\ 0.275872 & 1.906499 \\ 0.275872 & 1.906524\end{array}$

0.275872

0.275872

0.275872
0.275872

0.275872

0.275871

0.275871

0.275871
0.275871

1.906551

1.906578

1.906632

1.906659

1.906713

1.906740

1.906766
1.906793

0.275871

0.275871

0.275871

0.275870

0.275870

0.275870

0.275870

0.275870
0.275870

0.275870

0.275870
0.275870
0.275860

0.275860

0.275869

0.275869

0.275869

0.275869

0.275869
0.275869

0.275869

0.275868

0.275868
0.275868

0.275868
0.275868

0.275868

0.275868

0.275868

0.275868

0.275868

0.275868
0.275868
0.275868

0.275868

0.275867
0.275867
0.275867

1.906820

1.9068874

1.906901

1.906955

1.907009

1.907036

1.907090

1.907116

1.907170

1.907197

1.907251

1.907305

0.275867

1.907359

1.907386

1.907413

1.907466

1.907520

1.907547

1.907574

$0.275867 \quad 1.007897$

$\begin{array}{ll}0.275867 & 1.907924 \\ 0.275867 & 1.907924\end{array}$

$\begin{array}{ll}0.275867 & 1.907978 \\ 0.275867 & 1.908005\end{array}$

$0.275867 \quad 1.9080032$

$0.275867 \quad 1.908059$

$\begin{array}{ll}0.275866 & 1.908086 \\ 0.275866 & 1.908113\end{array}$

$\begin{array}{ll}0.275866 & 1.908113 \\ 0.275866 & 1.908139\end{array}$

0.275866

0.275866
0.275866
0.275866

0.275866

0.275866

0.275866

0.275866

0.275866

0.275865

1.908166

1.908193

1.908247

1.908274

1.908301

1.908355

$0.275865 \quad 1.908436$

$0.275865 \quad 1.908463$

$0.275865 \quad 1.008516$

$0.275865 \quad 1.908543$

$\begin{array}{ll}0.275865 & 1.908570 \\ 0.275865 & 1.908597\end{array}$

0.275865

1.908624

1.908678

$0.275864 \quad 1.908705$

$0.275864 \quad 1.908732$

$0.275864 \quad \underline{1} .908759$

$0.275864 \quad 1.908812$

$0.275864 \quad 1.908839$

$0.275864 \quad 1.908866$

$\begin{array}{ll}0.275864 & 1.908893 \\ 0.275863 & 1.908920\end{array}$

$0.275863 \quad 1.908947$

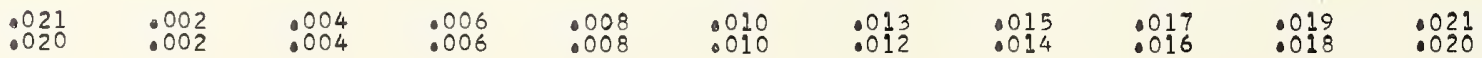


$\begin{array}{llllll}46.799 & 46.778 & 46.757 & 46.736 & 46.715 & 46.694 \\ 46.590 & 46.569 & 46.548 & 46.527 & 46.506 & 46.485\end{array}$ $\begin{array}{llll}46.464 & 46.444 & 46.423 & 46.402 \\ 46.256 & 46.235 & 46.214 & 46.193\end{array}$ $46.047 \quad 46.026$ $45.838 \quad 45.818$ $45.630 \quad 45.609$ $46.214 \quad 46.193$ $\begin{array}{llllll}46.381 & 46.360 & 46.339 & 46.318 & 46.297 & 46.277\end{array}$ $\begin{array}{llllll}46.172 & 46.151 & 46.130 & 46.110 & 46.089 & 46.068 \\ 45.964 & 45.943 & 45.922 & 45.901 & 450880 & 45.859\end{array}$ $45.212 \quad 45.191$ $\begin{array}{ll}45.588 & 45.567 \\ 45.379 & 45.358 \\ 45.170 & 45.150\end{array}$ $45.964 \quad 45.943 \quad 45.922$ $45.546 \quad 45.734$ 45.713 45.003 $\begin{array}{llllll}45.129 & 45.108 & 45.087 & 45.066 & 45.045 & 45.024\end{array}$

6921.0

$\begin{array}{rrrrrr}1.0 & 14444.795 & 44.774 & 44.753 & 44.732 & 440 \\ 1.1 & 44.586 & 44.565 & 44.544 & 44.523 & 440 \\ 1.2 & 44.0377 & 44.356 & 44.336 & 44.315 & 440\end{array}$

$$
\begin{aligned}
& 1: 1 \\
& 1.2 \\
& 1: 3 \\
& 1.4 \\
& 1.5 \\
& 1: 6 \\
& 1.7 \\
& 1.8 \\
& 1.9
\end{aligned}
$$

$\begin{array}{lllllllllll}1.2 & 44.377 & 44.356 & 44.336 & 44.315 & 44.294 & 44.273 & 44.251 & 440440 & 44 \cdot 419 & 44.398 \\ 1.231 & 44.210 & 440189\end{array}$

$\begin{array}{llllllllllll}1.3 & 44.169 & 44.148 & 44.127 & 44.106 & 44.085 & 44.064 & 44.043 & 44.023 & 44.002 & 43.1881 \\ 1.4 & 43.960 & 43.0939 & 43.918 & 43.897 & 43.0876 & 43.856 & 43.835 & 43.0214 & 43.793 & 43.772\end{array}$

$\begin{array}{lllll}1.4 & 43.960 & 43.939 & 43.918 & 43.897 \\ 1.5 & 43.751 & 43.730 & 43.709 & 43.689\end{array}$

$\begin{array}{llllll}1.6 & 43.542 & 43.522 & 43.501 & 43.480\end{array}$

$\begin{array}{lllll}1.7 & 43.334 & 43.313 & 43.292 & 43.271 \\ 1.8 & 43.125 & 43.104 & 43.083 & 43.063\end{array}$

$43.668 \quad 43.647 \quad 43.626 \quad 43.605 \quad 43.584 \quad 43.563$

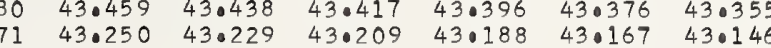

6924.0

4.1
4.2
4.3

4.0

4.4
4.5
4.6

$4 \cdot 6$
$4 \cdot 7$
$4 \cdot 8$

4.8

6925.

5.0
5.0
5.0
5.0
5.0
50.6
5
5
5.0

4438
38
37
37
37
37
37
36
36
36

$$
\begin{aligned}
& 438.5 \\
& 38.3 \\
& 38.1 \\
& 37.9 \\
& 37.7 \\
& 37.4 \\
& 37.2 \\
& 37.07 \\
& 36.8 \\
& 36.6
\end{aligned}
$$

0.275863
0.275863
0.275863

0.275863

0.27586

0.275863

0.275863

0.275862

0.275862

0.275862

0.275862

0.275862

0.275862

0.275862

0.275861

0.275861

0.275861
0.275861

0.275861
0.275861

0.275861
0.275861

0.275861
0.275861

0.27586

0.275861

0.275860

0.275860
0.275860
0.275860

0.275860

0.275860
0.275860
0.27580

0.275860
0.275860
0.275860

0.275860

0.275859

0.275859
0.275859

0.275859
0.275859

0.275859
0.275859

0.275859

0.275859
0.275859

0.275859

0.275859

0.275858

0.275858
0.275858

0.275858

0.275858

0.275858

0.275858

0.275858

0.275857

0.275859

0.275857

0.275857

0.275857

0.275857
0.275857

0.275857

0.275856

0.275856

0.275856

0.275856
0.275856

0.275856

0.275856
0.275856

0.275856
0.275856
0.275855

0.275856

0.275855

0.275855
0.275855

0.275855

0.275855

0.275855
0.275855

0.275835

0.275855
0.275854
0.275854

0.275854
0.275854

0.275854
0.275854

0.275854

0.275854

0.275854

0.275854

10908974

1.909028

1.909082

1.909136

1.909189

1.909243

.909270

.909324

1.909351

.909405

1.909459

1.909512

1.909566

1.909593
1.909620

1.909674

1.909701

1.909728
1.909755

1.909782

1.909809
1.909836

1.909862

1.909916

1.909943

1.909970

1.910024

1.910051
1.910078

1.910105

1.910132

1.910159
1.910186

1.910212

1.910266

1.910320

1.910347

1.910401

1.910428
1.910455

1.910482

.910535

1.910589

1.910616

1.910670

1.910699

1.910751

1.910805

1.910859

1.910912

1. 0910939

1.910966

1.0911020

1.911047

1.911101

9:911128

1.911182

1.911235

1.911262

10911289

1.911316

1.911397

1.911424

1.911478

1. 911505

1.911559

1.911612

.010

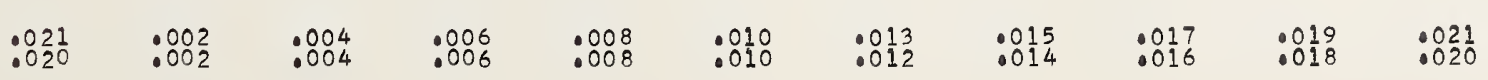


$\begin{array}{rrlllllllll}6930.0 & 14426.035 & 26.014 & 25.994 & 25.973 & 25.952 & 25.931 & 25.910 & 25.890 & 25.869 & 25.848\end{array}$ $\begin{array}{llllllllllll}0.1 & 25.827 & 25.806 & 25.786 & 25.765 & 25.744 & 25.723 & 25.702 & 25.681 & 25.661 & 25.640\end{array}$ $\begin{array}{lllllllllll}0.2 & 25.619 & 25.598 & 25.577 & 25.556 & 25.536 & 25.515 & 25.494 & 25.473 & 25.452 & 25.432 \\ 0.3 & 25.411 & 25.390 & 25.369 & 25.348 & 25.328 & 25.307 & 25.286 & 25.265 & 25.244 & 25.223\end{array}$ $\begin{array}{lllllllllll}0.4 & 25.203 & 25.182 & 25.161 & 25.140 & 25.119 & 25.099 & 25.078 & 25.057 & 25.036 & 25.015\end{array}$ $\begin{array}{lllllllllll}0.5 & 24.995 & 24.974 & 24.953 & 24.932 & 24.911 & 24.891 & 24.870 & 24.849 & 24.828 & 24.807\end{array}$ $\begin{array}{lllllllllll}0.6 & 24.786 & 24.765 & 24.745 & 24.724 & 24.703 & 24.682 & 24.661 & 24.641 & 24.620 & 24.599 \\ 0.7 & 24.578 & 24.557 & 24.536 & 24.516 & 24.495 & 24.474 & 24.453 & 24.432 & 24.412 & 24.391\end{array}$

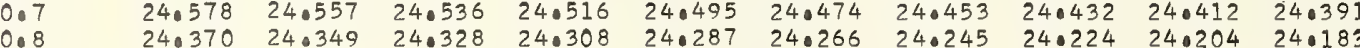

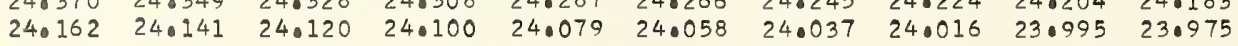

$\begin{array}{lllllllllll} & .001 & .002 & .003 & .004 & .005 & .006 & .007 & .008 & .009 & .010 \\ .021 & .002 & .004 & .808 & .088 & .818 & .013 & : 815 & .813 & .819 & .821\end{array}$ 


$\begin{array}{ll}05.249 & 05.228 \\ 05.041 & 05.020 \\ 04.834 & 04.813 \\ 04.626 & 04.605 \\ 04.418 & 04.398 \\ 04.211 & 04.190 \\ 04.003 & 03.983 \\ 03.796 & 03.775 \\ 03.588 & 03.568 \\ 03.381 & 03.360\end{array}$

05.207
05.000
04.792
04.584
04.377
04.169
03.962
03.754
03.547
0303

05.186

05.16

05.145

$\begin{array}{llll}05.124 & 05.103 & 05.083 & 05.062\end{array}$

$\begin{array}{lllllll}04.751 & 04.730 & 04.709 & 04.688 & 04.667 & 04.647\end{array}$

$\begin{array}{llllllll}04.564 & 04.543 & 04.522 & 04.501 & 04.481 & 04.460 & 04.439\end{array}$

$\begin{array}{llllll}04.335 & 04.315 & 04.294 & 04.273 & 04.252 & 04 \cdot 232\end{array}$

$\begin{array}{llllll}04.335 & 04.315 & 04.294 & 04.273 & 04 \cdot 252 & 04.232 \\ 04.128 & 04.107 & 04.086 & 04.066 & 04.045 & 04.024\end{array}$

$\begin{array}{ll}03.588 & 03.568 \\ 03.381 & 03.360\end{array}$

03.94103 .920

03.900

03.879

$03.879 \quad 03.858$

6941.

$14403.173 \quad 03.152$

$02.966 \quad 02.945$

$\begin{array}{ll}02.551 & 02.530 \\ 02.343 & 02.323\end{array}$

$02.136 \quad 02.115$

$01.928 \quad 01.907$

01.72101 .700

$\begin{array}{ll}01.514 & 01.493 \\ 01.306 & 01.285\end{array}$

6942.0

2.

$00.099 \quad 01.078$

$00.684 \quad 00.663$

26900.248

00.06100 .041

$14399.854 \quad 99.833$

99.43999 .41

14399.024

3.2
3.3

3.4

3.5

3.7

3.8
3.9

694400

4.1

$4 \cdot 2$

4.4

4.6

4.7
4.8

4.9

6945.0

5.

5.

5.

5.6

5.8

6946.0

6
6
6
6
6
6
6
6
6
6
60

$$
\begin{array}{rlll}
399.024 & 99.004 & 98.983 & 98.962 \\
98.817 & 98.796 & 98.776 & 98.755 \\
98.609 & 98.589 & 98.568 & 98.547 \\
98.402 & 98.381 & 98.361 & 98.340
\end{array}
$$$$
\begin{array}{llll}
98.195 & 98.174 & 98.153 & 98.133 \\
97.987 & 97.967 & 97.946 & 97.925
\end{array}
$$

$\begin{array}{llll}97.780 & 97.759 & 97.739 & 97.718\end{array}$

$97.573 \quad 97.552 \quad 97.531 \quad 97.510$

$\begin{array}{llll}97.365 & 97.345 & 97.324 & 97.303 \\ 97.158 & 97.137 & 97.116 & 97.096\end{array}$

$\begin{array}{llllll}03.505 & 03.484 & 03.4464 & 03.6513 & 03.630 & 03.609\end{array}$

$\begin{array}{llllll}0.298 & 03.277 & 03.256 & 03.235 & 03.215 & 03.194\end{array}$

0.275844

0.275844
0.275844

0.275844

0.275844

0.275844

.275843

0.275843

0.275843

(2.27s

0.275843

0.275843

0.275843

0.275842

0.275842

0.275842

0.275842

0.275842

0.275842

0.275841

0.275841

0.275841

0.275841
0.075841
0.275841

0.275841

0.275841

$\begin{array}{llll}14396.951 & 96.930 & 96.909 & 96.888\end{array}$

$96.743 \quad 96.723 \quad 96.702 \quad 96.681$

$\begin{array}{llll}96.536 & 96.515 & 96.495 & 96.474 \\ 96.329 & 96.308 & 96.287 & 96.266\end{array}$

$\begin{array}{llll}96.121 & 96.101 & 96.080 & 96.059 \\ 95.914 & 95.893 & 95.873 & 95.852\end{array}$

$95.707 \quad 95.686 \quad 95.66595 .645$

$\begin{array}{llll}95.500 & 95.479 & 95.458 & 95.437 \\ 95.292 & 95.272 & 95.251 & 95.230\end{array}$

$\begin{array}{llll}95.292 & 95.272 & 95.251 & 95.230 \\ 95.085 & 95.064 & 95.043 & 95.023\end{array}$

$\begin{array}{llll}14394.878 & 94.857 & 94.836 & 94.816\end{array}$

$\begin{array}{llll}94.670 & 94.650 & 94.629 & 94.608 \\ 94.463 & 94.442 & 94.422 & 94.401\end{array}$

$94.256 \quad 94.235 \quad 94.214 \quad 94.194$

$94.049 \quad 94.028 \quad 94.007 \quad 93.987$

$\begin{array}{llll}93.841 & 93.821 & 93.800 & 93.779\end{array}$

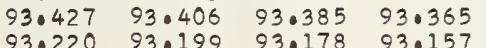

$93.012 \quad 92.992 \quad 92.971 \quad 92.950$

$\begin{array}{llll}14392.805 & 92.785 & 92.764 & 92.743\end{array}$

$\begin{array}{llll}92.598 & 92.577 & 92.557 & 92.536 \\ 92.391 & 92.370 & 92.349 & 92.329\end{array}$

$92.184 \quad 92.163 \quad 92.142 \quad 92.122$

$91.977 \quad 91.956 \quad 91.935 \quad 91.914$

$91.562 \quad 91.541 \quad 91.521 \quad 91.500$

$91.355 \quad 91.334 \quad 91.313 \quad 91.293$

$90.94190 .920 \quad 90.899 \quad 90.879$

6947.0

14390.73490 .713$.

$\begin{array}{lllll}7.1 & 90.526 & 90.506 & 90.485 & 90.464\end{array}$

7.2

7.4

7.5

$90.112 \quad 90.091 \quad 90.07190 .050$

$89.905 \quad 89.884 \quad 89.863 \quad 89.843$

$89.698 \quad 89.677 \quad 89.656 \quad 89.636$

$\begin{array}{llll}89.491 & 89.470 & 89.449 & 89.429 \\ 89.284 & 89.263 & 89.242 & 89.221\end{array}$

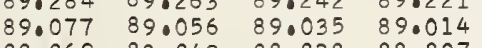

88.86988 .849

$\begin{array}{rlll}4388.662 & 88.641 & 88.621 & 88.600 \\ 88.455 & 88.434 & 88.414 & 88.393\end{array}$

$88.248 \quad 88.227 \quad 88.207 \quad 88.186$

$88.041 \quad 88.020 \quad 88.000 \quad 87.979$

$\begin{array}{llll}87.834 & 87.813 & 87.793 & 37.77\end{array}$

$\begin{array}{llll}87.627 & 87.606 & 87.585 & 87.565 \\ 87.420 & 87.399 & 87.379 & 87.358\end{array}$

$\begin{array}{llll}87.420 & 87.399 & 87.379 & 87.358 \\ 87.213 & 87.192 & 87.171 & 87.151\end{array}$

$\begin{array}{llll}87.213 & 87.192 & 87.171 & 87.151 \\ 87.006 & 86.985 & 86.964 & 86.944\end{array}$

86.799

6949.0

14386

$886.592 \quad 86.571 \quad 86.5$

$\begin{array}{llll}86.385 & 86.364 & 86.343 \quad 86.323\end{array}$

$85.97185 .1550 \quad 86.136 \quad 86.115$

$85.764 \quad 85.743 \quad 85.722 \quad 85.702$

$85.557 \quad 85.536 \quad 85.515 \quad 85.49$

$\begin{array}{llll}85.350 & 85.329 & 85.308 & 85.28 \\ 85.143 & 85.122 & 85.101 & 85.08\end{array}$

$\begin{array}{lllllllllll}9.7 & 85.143 & 85.122 & 85.101 & 85.081 & 85.060 & 85.039 & 85.019 & 84.998 & 84.977 & 84.956 \\ 9.8 & 84.936 & 84.915 & 84.894 & 84.874 & 84.853 & 84.832 & 84.812 & 84.791 & 84.770 & 84.750 \\ 9.9 & 84.729 & 84.708 & 84.687 & 84.667 & 84.646 & 84.625 & 84.605 & 84.584 & 84.563 & 84.543\end{array}$

$\begin{array}{llllll}98.298 & 98.278 & 98.257 & 98.236 & 98.215\end{array}$

$\begin{array}{llllll}9.490 & 97.469 & 97.448 & 97.428 & 97.407 & 97.386\end{array}$

$\begin{array}{llllll}97.282 & 97.262 & 97.241 & 97.220 & 97.199 & 97.179 \\ 97.075 & 97.054 & 97.034 & 97.013 & 96.992 & 96.972\end{array}$

$\begin{array}{llllll}96.868 & 96.847 & 96.826 & 96.806 & 96.785 & 96.764\end{array}$

$\begin{array}{llllll}96.660 & 96.640 & 96.619 & 96.598 & 96.578 & 96.557 \\ 96.453 & 96.432 & 96.412 & 96.391 & 96.370 & 96.349\end{array}$

$\begin{array}{llllll}96.246 & 96.225 & 96.204 & 96.184 & 96.163 & 96.142\end{array}$

$\begin{array}{llllll}9.039 & 96.018 & 95.997 & 95.976 & 950955 & 95.935 \\ & 95.811 & 95.790 & 95.769 & 95.748 & 95.728\end{array}$

$\begin{array}{llllll}95.624 & 95.603 & 95.583 & 95.562 & 95.541 & 95.520\end{array}$

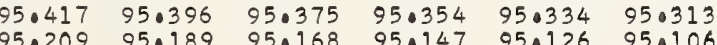

$\begin{array}{llllll}95.002 & 94.981 & 94.961 & 94.940 & 94.919 & 94.898\end{array}$

$94.795 \quad 940774 \quad 940753 \quad 940733 \quad 94.712 \quad 94.691$

$\begin{array}{llllll}94.588 & 94.567 & 94.546 & 94.525 & 94.505 & 94.484 \\ 94.380 & 94.360 & 94.339 & 94.318 & 94.297 & 94.277\end{array}$

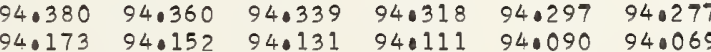

$93.966 \quad 93.945 \quad 93.924 \quad 93.904 \quad 93.883 \quad 93.862$

$\begin{array}{llllll}93.759 & 93.738 & 93.717 & 93.696 & 93.676 & 93.655\end{array}$

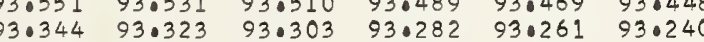

$\begin{array}{rlllll}92.137 & 93.116 & 93.095 & 93.075 & 93.054 & 93.033 \\ 92.909 & 92.888 & 92.867 & 92.847 & 92.826\end{array}$

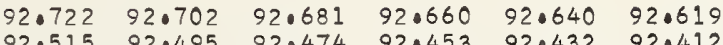

$\begin{array}{llllll}92.515 & 92.495 & 92.474 & 92.453 & 92.432 & 92.412\end{array}$

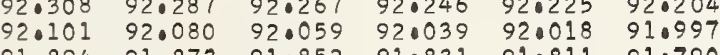

$\begin{array}{llllll}.894 & 91.873 & 91.852 & 91.831 & 91.811 & 91.790\end{array}$

$\begin{array}{llllll}91.686 & 91.666 & 91.645 & 91.624 & 91.604 & 91.583 \\ 91.479 & 91.459 & 91.438 & 91.417 & 91.396 & 91.376\end{array}$

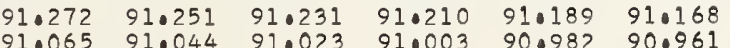

$\begin{array}{llllll}90.858 & 90.837 & 90.816 & 90.796 & 90.775 & 90.754\end{array}$

$\begin{array}{llllll}90.651 & 90.630 & 90.609 & 90.589 & 90.568 & 90.547\end{array}$

$\begin{array}{llllll}90.236 & 90.216 & 90.195 & 90.174 & 90.154 & 90.133\end{array}$

$90.029 \quad 90.008 \quad 89.988 \quad 89.967 \quad 89.946 \quad 89.926$

$\begin{array}{llllll}89.822 & 89.801 & 89.781 & 89.760 & 89.739 & 89.719 \\ 89.615 & 89.594 & 89.573 & 89.553 & 89.532 & 89.511\end{array}$

$\begin{array}{llllll}89.408 & 89.387 & 89.366 & 89.346 & 89.325 & 89.304\end{array}$

$\begin{array}{llllll}89.201 & 89.180 & 89.159 & 89.139 & 89.118 & 89.097 \\ 88.994 & 88.973 & 88.952 & 88.932 & 88.911 & 88.890\end{array}$

$\begin{array}{llllll}88.787 & 88.766 & 88.745 & 88.724 & 88.704 & 88.683\end{array}$

$\begin{array}{llllll}88.579 & 88.559 & 88.538 & 88.517 & 88.497 & 88.476\end{array}$

$\begin{array}{lllllll}88.165 & 88.145 & 88.124 & 88.103 & 88.082 & 88.062\end{array}$

$\begin{array}{lllllll}87.958 & 87.937 & 87.917 & 87.896 & 87.875 & 87.855 \\ 87.751 & 87.730 & 87.710 & 87.689 & 87.668 & 87.648\end{array}$

$\begin{array}{lllllll}87.544 & 87.523 & 87.503 & 87.482 & 87.461 & 87.441\end{array}$

$\begin{array}{lllllll}87.337 & 87.316 & 87.296 & 87.275 & 87.254 & 87.234\end{array}$

$\begin{array}{llllll}86.023 & 86.902 & 86.881 & 86.861 & 86.840 & 86.819\end{array}$

$\begin{array}{llllll}86.923 & 86.902 & 86.881 & 86.861 & 86.840 & 86.819\end{array}$

$\begin{array}{llllll}86.509 & 86.488 & 86.468 & 86.447 & 86.426 & 86.405\end{array}$

$\begin{array}{llllll}86.095 & 86.281 & 86.260 & 86.240 & 86.219 & 86.198 \\ 86.054 & 86.054 & 86.033 & 86.012 & 85.991\end{array}$

$\begin{array}{llllll}85.888 & 85.867 & 85.847 & 85.826 & 85.805 & 85.785\end{array}$

$\begin{array}{lllllll}85.681 & 85.660 & 85.640 & 85.619 & 85.598 & 85.578\end{array}$

$\begin{array}{lllllll}85.474 & 85.453 & 85.433 & 85.412 & 85.391 & 85.370\end{array}$

$\begin{array}{llllll}85.267 & 85.246 & 85.226 & 85.205 & 85.184 & 85.164 \\ 85.060 & 85.039 & 85.019 & 84.998 & 84.977 & 84.956\end{array}$

$\begin{array}{lllllllllll}9.7 & 85.143 & 85.122 & 85.101 & 85.081 & 85.060 & 85.039 & 85.019 & 84.998 & 84.977 & 84.956 \\ 9.8 & 84.936 & 84.915 & 84.894 & 84.874 & 84.853 & 84.832 & 84.812 & 84.791 & 84.770 & 84.750 \\ 9.9 & 84.729 & 84.708 & 84.687 & 84.667 & 84.646 & 84.625 & 84.605 & 84.584 & 84.563 & 84.543\end{array}$

0.275840

0.275840

0.275840

0.275840

0.275840

0.275840

0.275840

0.275839

0.275839

0.275839

0.00275839

0.275839

0.275839

0.275839
0.275839

1.914359

1.914412

- 914439

1.914493

.914520

1.914574

1.914628

1.914655

1.914709

014762

1.914826

1.914870

1.914897

1.914951

1.914978

1.915032

1.915085

1. 915112

0.275838

0.275838

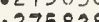

0.275838

0.275838

0.275838

0.275838

0.275838

0.275837

0.275837

0.275837
0.275837

0.275837

0.275837
0.275837
0.275837

0.275837

0.275837

0.275836

0.275836
0.275836

0.275836
0.275836

0.275836

0.275836

0.0275836

0.275836

1.0915166

1.0915220

1.015247

.915301

1.015328

1.0915382
1.0915409

1.915435

1.915462

1. 915516

1915543

1.915597

1.915651

1.915705

1.915732

1.915785

- 915839

.915866

1.915920

0.275836

0.275836

0.27583

0.27583

0.275835

0.27583

0.275835

0.275835

1.915974

.916001

1.916055

1. 0916109

10916162

.0916216

.0916243
1.91670
.096299

1.916297 


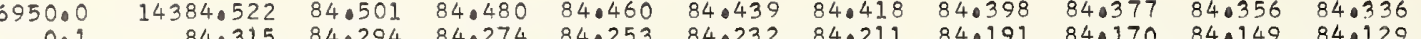
$\begin{array}{lllllllllll}0.1 & 84.315 & 84.294 & 84.274 & 84.253 & 84.232 & 84.211 & 84.191 & 84.170 & 84.149 & 84.129 \\ 0.2 & 84.108 & 84.087 & 84.067 & 84.046 & 84.025 & 84.005 & 83.984 & 83.963 & 83.942 & 83.922\end{array}$ $\begin{array}{lllllllllll}0.2 & 84.108 & 84.087 & 84.067 & 84.046 & 84.025 & 84.005 & 83.984 & 83.963 & 83.942 & 83.922 \\ 0.3 & 83.901 & 83.880 & 83.860 & 83.839 & 83.818 & 83.797 & 83.777 & 83.756 & 83.735 & 83.715\end{array}$ $\begin{array}{llllllllllll}0.4 & 83.694 & 83.673 & 83.653 & 83.632 & 83.611 & 83.591 & 83.570 & 83.549 & 83.528 & 83.508\end{array}$ $\begin{array}{llllllllllll}0.5 & 83.487 & 83.466 & 83.446 & 83.425 & 83.404 & 83.384 & 83.363 & 83.342 & 83.322 & 83.301\end{array}$ $\begin{array}{lllllllllll}0.6 & 83.280 & 83.259 & 83.239 & 83.218 & 83.197 & 83.177 & 83.156 & 83.135 & 83.115 & 83.094 \\ 0.7 & 83.073 & 83.052 & 83.032 & 83.011 & 82.990 & 82.970 & 82.949 & 82.928 & 82.008 & 82.887\end{array}$ $\begin{array}{lllllllllll}0.8 & 82.866 & 82.846 & 82.825 & 82.804 & 82.783 & 82.763 & 82.742 & 82.721 & 82.701 & 82.680\end{array}$ $\begin{array}{llllllllll}82.659 & 82.639 & 82.618 & 82.597 & 82.577 & 82.556 & 82.535 & 82.515 & 82.494 & 82.473\end{array}$

$$
\text { it: }
$$

6952.0

$$
\begin{array}{r}
952 \\
2 \\
2 \\
2 \\
2 \\
2 \\
2 \\
2 \\
2
\end{array}
$$

\begin{tabular}{|c|c|}
\hline 0.275835 & $1 \cdot 917051$ \\
\hline 0.27 & \\
\hline 0.275834 & 1.9 \\
\hline 0.275834 & 1.917132 \\
\hline $\begin{array}{l}0.275834 \\
0.275834\end{array}$ & $\begin{array}{l}1.917159 \\
1.917186\end{array}$ \\
\hline $\begin{array}{l}0.275834 \\
0.275834\end{array}$ & 1.917212 \\
\hline 0.275834 & 90 \\
\hline 275834 & 1.917266 \\
\hline 275834 & 1.917293 \\
\hline 0.275834 & 1.9173 \\
\hline $\begin{array}{l}0.275834 \\
0.275834\end{array}$ & \\
\hline $\begin{array}{l}0.275834 \\
0.275833\end{array}$ & 10917401 \\
\hline 0.275833 & 10917428 \\
\hline $\begin{array}{l}275833 \\
275823\end{array}$ & \\
\hline $\begin{array}{l}275833 \\
275833\end{array}$ & $\frac{1}{1}: 91$. \\
\hline $\begin{array}{l}275833 \\
27583\end{array}$ & 1.917 \\
\hline .275833 & 10917 \\
\hline 0.275833 & 1.9 \\
\hline 33 & \\
\hline $\begin{array}{l}275833 \\
275832\end{array}$ & $\begin{array}{l}1.917643 \\
1.917670\end{array}$ \\
\hline 275832 & 1.9176 \\
\hline 75832 & 1.917 \\
\hline $\begin{array}{l}275832 \\
725832\end{array}$ & 1.917 \\
\hline $\begin{array}{l}275832 \\
275832\end{array}$ & $\begin{array}{l}1.917 \\
1.917\end{array}$ \\
\hline 275832 & 1.917832 \\
\hline & \\
\hline & \\
\hline $\begin{array}{r}.275832 \\
.275832\end{array}$ & $\begin{array}{r}1.0917912 \\
1.917939\end{array}$ \\
\hline $\begin{array}{r}275831 \\
275831\end{array}$ & 1.917 \\
\hline .275831 & 1.917993 \\
\hline & $\begin{array}{l}1.918020 \\
1.918047\end{array}$ \\
\hline 0275831 & 1.9 \\
\hline 275831 & \\
\hline
\end{tabular}

0.275831 0.275831 0.275830 0.275830

0.275830

0.275830

0.275830

0.275830

0.275830
0.275830

0.275830

0.275830
0.275829

0.275829

0.275829

0.275829

0.275829

0.275829
0.275829

0.275829

0.275829

0.275828

0.27582

0.275828

0.275828

0.275828

0.275828
0.275828

0.275828

0.27582

0.275828
0.275827
0.275827

0.275827
0.275827

0.275877

0.275827

0.275827

0.275827

0.275827
0.275827
0.275827

0.275827

0.275827
0.275826
0.275826

0.275826
0.275826

0.275826

0.275826
0.275826

0.275826

0.275826

0.275826

0.275825

0.275825
0.275825

10918128

1. 918182

1.918209

1.918263

1.918289

1.918316

1.918370

1.918397

1.918424
1.0918451

1.918451

1.918505

1.918559

1.918586

1.918613

10918666

1.918793

1.918747

1.918774

1.918801

1.918855
1.918882

1.918936

1.918963
1.918990

1.919016

1.919043

1.919070
1.0919097

1).919124

1.919178

1. 919205

1.919232

1.919286

1.919313

1.91 .9366

1.919393
1.919420

1.919474

1.919501

1.919528
1.919555

1.919582

1.919609

1.919663

1.919690

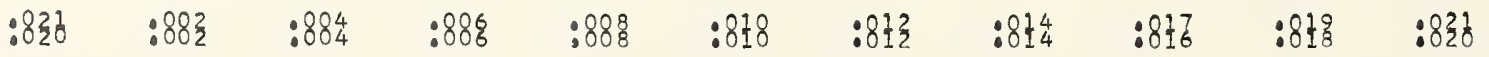


$\begin{array}{rrrrrrrrrrr}6960.0 & 14363.854 & 63.834 & 63.813 & 63.793 & 63.772 & 63.751 & 63.731 & 63 \cdot 710 & 63.689 & 63.669 \\ 0.1 & 63.648 & 63.627 & 63.607 & 63.586 & 63.566 & 63.545 & 63.524 & 63.504 & 63.483 & 63.462\end{array}$

$\begin{array}{llllllllllll}0.2 & 63.442 & 63.421 & 63.400 & 63.380 & 63.359 & 63.339 & 63.518 & 63.297 & 63.483 & 63.462 \\ 0.3 & 63.235 & 63.215 & 63.194 & 63.173 & 63.153 & 63.132 & 63.111 & 63.091 & 63.277 & 63.256\end{array}$

$\begin{array}{llllllllllll}0.3 & 63.235 & 63.215 & 63.194 & 63.173 & 63.153 & 63.132 & 63.111 & 63.091 & 63.070 & 63.050 \\ 0.4 & 63.029 & 63.008 & 62.988 & 62.967 & 62.947 & 62.926 & 62.905 & 62.885 & 62.864 & 62.843\end{array}$

$\begin{array}{lllllllllll}0.5 & 62.823 & 62.802 & 62.781 & 62.761 & 62.740 & 62.719 & 62.699 & 62.678 & 62.658 & 62.637\end{array}$

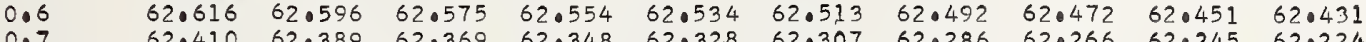

$\begin{array}{lllllllllll}0.7 & 62.410 & 62.389 & 62.369 & 62.348 & 62.32 .8 & 62.307 & 62.286 & 62.266 & 62.245 & 62.224\end{array}$

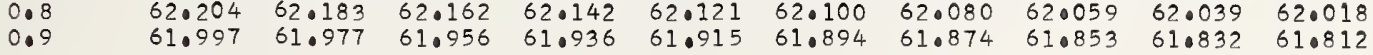

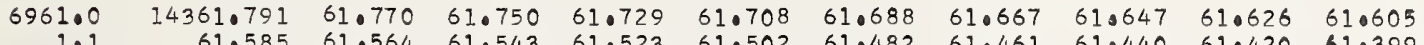

$\begin{array}{lllllllllll}1.1 & 61.585 & 61.564 & 61.543 & 61.523 & 61.502 & 61.482 & 61.461 & 61.440 & 61.420 & 61.399\end{array}$

$\begin{array}{lllllllllll}1.2 & 61.378 & 61.358 & 61.337 & 61.316 & 61.296 & 61.275 & 61.255 & 61.234 & 61.213 & 61.193 \\ 1.3 & 61.172 & 61.151 & 61.131 & 61.110 & 61.089 & 61.069 & 61.048 & 61.028 & 61.007 & 60.986\end{array}$

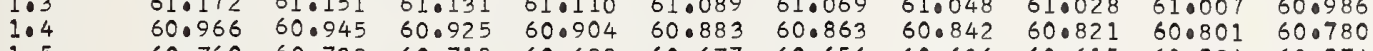

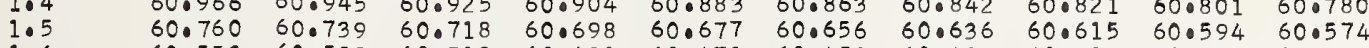

$\begin{array}{lllllllllll}1.6 & 60.553 & 60.533 & 60.512 & 60.491 & 60.471 & 60.450 & 60.429 & 60.409 & 60.388 & 60.368\end{array}$

$\begin{array}{llllllllllll}1.7 & 60.347 & 60.326 & 60.306 & 60.285 & 60.264 & 60.244 & 60.223 & 60.203 & 60.182 & 60.161\end{array}$

$\begin{array}{lllllllllll}1.8 & 60.141 & 60.120 & 60.099 & 60.079 & 60.058 & 60.037 & 60.017 & 59.996 & 59.976 & 59.955 \\ 1.9 & 59.934 & 59.914 & 59.893 & 59.873 & 59.852 & 59.831 & 59.811 & 59.790 & 59.769 & 59.749\end{array}$

$\begin{array}{llllllllll}14359.728 & 59.708 & 59.687 & 59.666 & 59.646 & 59.625 & 59.604 & 59.584 & 59.563 & 59.542\end{array}$

$\begin{array}{lllllllllll}2.1 & 59.522 & 59.501 & 59.481 & 59.460 & 59.439 & 59.419 & 59.398 & 59.377 & 59.357 & 59.336\end{array}$

$\begin{array}{lllllllllll}2.2 & 59.316 & 59.295 & 59.274 & 59.254 & 59.233 & 59.213 & 59.192 & 59.171 & 59.151 & 59.130 \\ 2.3 & 59.109 & 59.089 & 59.068 & 59.047 & 59.027 & 59.006 & 58.985 & 58.965 & 58.944 & 58.924\end{array}$

$\begin{array}{lllllllllll}2.3 & 59.109 & 59.089 & 59.068 & 59.047 & 59.027 & 59.006 & 58.985 & 58.965 & 58.944 & 58.924 \\ 2.4 & 58.903 & 58.882 & 58.862 & 58.841 & 58.821 & 58.800 & 58.779 & 58.759 & 58.738 & 58.718\end{array}$

$\begin{array}{lllllllllll}2.5 & 58.697 & 58.676 & 58.656 & 58.635 & 58.614 & 58.594 & 58.573 & 58.552 & 58.532 & 58.511 \\ 2.5 & 58.491 & 58.470 & 58.449 & 58.429 & 58.408 & 58.388 & 58.367 & 58.346 & 58.0326 & 58.305\end{array}$

$\begin{array}{lllllllllll}2.6 & 58.491 & 58.470 & 58.449 & 58.429 & 58.408 & 58.388 & 58.367 & 58.346 & 58.326 & 58.305 \\ 2.7 & 58.284 & 58.264 & 58.243 & 58.223 & 58.202 & 58.181 & 58.161 & 58.140 & 58.119 & 58.099\end{array}$

$\begin{array}{lllllllllll}2.7 & 58.284 & 58.264 & 58.243 & 58.223 & 58.202 & 58.181 & 58.161 & 58.140 & 58.119 & 58.099\end{array}$

$\begin{array}{lllllllllll}2.8 & 58.078 & 58.058 & 58.037 & 58.016 & 57.996 & 57.975 & 57.954 & 57.934 & 57.913 & 570893 \\ 2.9 & 57.872 & 57.851 & 57.831 & 57.810 & 57.790 & 57.769 & 57.748 & 57.728 & 57.707 & 57.686\end{array}$

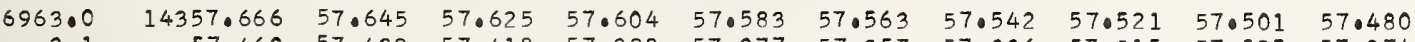

$\begin{array}{lllllllllll}3.1 & 57.460 & 57.439 & 57.418 & 57.398 & 57.377 & 57.357 & 57.336 & 57.315 & 57.295 & 57.274 \\ 3.2 & 57.254 & 57.233 & 57.0212 & 57.192 & 57.177 & 57.150 & 57.130 & 57.109 & 57.088 & 57.068\end{array}$ $\begin{array}{lllllllllll}57.254 & 57.233 & 57.212 & 57.192 & 57.171 & 57.150 & 57.130 & 57.109 & 57.088 & 57.068\end{array}$ $\begin{array}{llllllllll}57.047 & 57.027 & 57.006 & 56.985 & 56.965 & 56.944 & 56.923 & 56.903 & 56.882 & 56.862 \\ 56.841 & 56.820 & 56.800 & 56.779 & 56.759 & 56.738 & 56.717 & 56.697 & 56.676 & 56.656\end{array}$ $\begin{array}{lllllllllll}56.635 & 56.614 & 56.594 & 56.573 & 56.552 & 56.532 & 56.511 & 56.491 & 56.470 & 56.449\end{array}$ $\begin{array}{llllllllll}56.429 & 56.408 & 56.388 & 56.367 & 56.346 & 56.326 & 56.305 & 56.284 & 56.264 & 56.243\end{array}$ $\begin{array}{llllllllll}56.223 & 56.202 & 56.181 & 56.161 & 56.140 & 56.120 & 56.099 & 56.078 & 56.058 & 56.037\end{array}$ $\begin{array}{lllllllllll}56.016 & 55.996 & 55.975 & 55.955 & 55.934 & 55.913 & 55.893 & 55.872 & 55.851 & 55.83\end{array}$

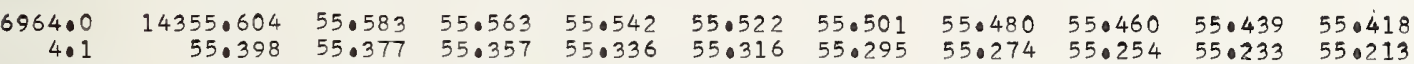

$\begin{array}{llllllllllll}4.1 & 55.398 & 55.377 & 55.357 & 55.336 & 55.316 & 55.295 & 55.274 & 55.254 & 55.233 & 55.213 \\ 4.2 & 55.192 & 55.171 & 55.151 & 55.130 & 55.109 & 55.089 & 55.068 & 55.048 & 55.027 & 55.006\end{array}$

$\begin{array}{llllllllllll}4.3 & 54.986 & 54.965 & 54.944 & 54.924 & 54.903 & 54.883 & 54.862 & 54.841 & 54.821 & 54 \cdot 800 \\ 4.4 & 54.780 & 54.759 & 54.738 & 54.718 & 54.597 & 54.677 & 54.656 & 54.635 & 54.615 & 54.594\end{array}$ $\begin{array}{llllllllll}54.780 & 54.759 & 54.738 & 54.718 & 54.697 & 54.677 & 54.656 & 54.635 & 54 \cdot 615 & 54.594 \\ 54.574 & 54.553 & 54.532 & 54.512 & 54.491 & 54.470 & 54.450 & 54.429 & 54.409 & 54.388\end{array}$ $\begin{array}{llllllllll}54.367 & 54.347 & 54.326 & 54.306 & 54.285 & 54.264 & 54.244 & 54.223 & 54.203 & 54.182\end{array}$ $\begin{array}{llllllllll}54.161 & 54.141 & 54.120 & 54.099 & 54.079 & 54.058 & 54.038 & 54.017 & 53.996 & 53.976\end{array}$ $\begin{array}{llllllllll}53.955 & 53.935 & 53.914 & 53.893 & 53.873 & 53.852 & 53.831 & 53.811 & 53.790 & 53.770 \\ 53.749 & 53.729 & 53.708 & 53.687 & 53.667 & 53.546 & 53.625 & 53.605 & 53.584 & 53.564\end{array}$ $\begin{array}{rlllllllll}14353.543 & 53.522 & 53.502 & 53.481 & 53.461 & 53.440 & 53.420 & 53 \cdot 399 & 53.378 & 53 \cdot 358 \\ 53.337 & 53.317 & 53.296 & 53.275 & 53.255 & 53.234 & 53.213 & 53.193 & 53.172 & 53.15\end{array}$ $\begin{array}{llllllllll}53.337 & 53.317 & 53.296 & 53.275 & 53.255 & 53.234 & 53.213 & 53 \cdot 193 & 53.172 & 53.152 \\ 53.137 & 53.110 & 53.090 & 53.069 & 53.049 & 53.028 & 53.007 & 52.987 & 52.966 & 52.946\end{array}$ $\begin{array}{llllllllll}52.925 & 52.905 & 52.884 & 52.863 & 52.843 & 52.822 & 52.801 & 52.781 & 52.760 & 52.740\end{array}$ $\begin{array}{lllllllllll}52.719 & 52.698 & 52.678 & 52.657 & 52.637 & 52.616 & 52.595 & 52.575 & 52.554 & 52.534 \\ 52.513 & 52.492 & 52.472 & 52.451 & 52.430 & 52.410 & 52.389 & 52.369 & 52.348 & 52.327\end{array}$

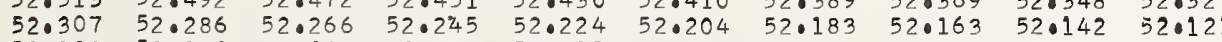

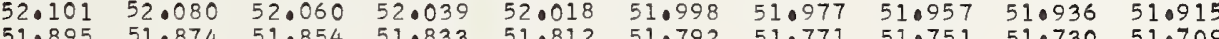
$\begin{array}{llllllllll}51.895 & 51.874 & 51.854 & 51.833 & 51.812 & 51.792 & 51.771 & 51.751 & 51.730 & 51.709 \\ 51.689 & 51.668 & 51.647 & 51.627 & 51.606 & 51.586 & 51.565 & 51.545 & 51.524 & 51.503\end{array}$

0.275824
0.275824

1.919959
1.919986

0.275824

0.27582

1.920013

0.275824
0.275824

0.275824

0.275824

0.275824

0.275824

0.275823

0.0275823

0.275823

0.275823

5

0.275823

.920040

1.920093

1.920120

1.920174

1.920202

1.920228

1.920282

.920309

1.920336

1.920390

1.920417

0.275822

0.275822
0.275822

0.275822
0.275822

0.275822

0.275822

0.275822
0.275822

0.275822
0.275822

1.920551

1.920578

1.920605
1.920632

1.920659

1.920686

$1 \cdot 920713$

$0.0275821 \quad 1.0920820$

$\begin{array}{ll}0.275821 & 1.02082087\end{array}$

.

0.0275821

0.275821

0.275821
0.275821

1.920874

1.920928

1.920982

0.275820

1.921036

0.275820

1.921090

0.275820
0.275820

0.275820

0.275820

0.275820

0.275820

1.921117

1.921144
1.921170

1.921197

10921224

1.921251

1.921305
1.921332

6966.0

6.
6.
6.
60
6.
6.0
6.
6.
6.

6.5

6.6

6.8

6967.0

7.0
70
70
70
70
70
7.0

6968.0

8.
8
8
8
8
8.
8.7
8
8.8
6969
9
9
9
9
9
9
9
9
9

$14351.483 \quad 51.46$

$51.277 \quad 51.256$

$\begin{array}{ll}51.071 & 51.0 \\ 50.865 & 50.8\end{array}$

$50.659 \quad 50.638$

$50.453 \quad 50.432$
$50.247 \quad 50.226$

$50.041 \quad 50.02$

$\begin{array}{ll}49.835 & 49.81 \\ 49.629 & 49.608\end{array}$

$\begin{array}{llllllll}51.441 & 51.421 & 51.400 & 51.380 & 51.359 & 51.339 & 51.318 & 51.297\end{array}$ $\begin{array}{llllllll}51.235 & 51.215 & 51.194 & 51.174 & 51.153 & 51.132 & 51.112 & 51.091\end{array}$ \begin{tabular}{llllllll}
51.030 & 51.009 & 50.988 & 50.968 & 50.947 & 50.926 & 50.906 & 50.885 \\
\hline
\end{tabular} $\begin{array}{llllllll}50.823 & 50.803 & 50.782 & 50.762 & 50.741 & 50.721 & 50.700 & 50.679 \\ 50.617 & 50.597 & 50.576 & 50.556 & 50.535 & 50.514 & 50.494 & 50.473\end{array}$ $\begin{array}{llllllll}50.411 & 50.391 & 50.370 & 50.350 & 50.329 & 50.308 & 50.288 & 50.267\end{array}$ $\begin{array}{llllllll}50.206 & 50.185 & 50.164 & 50.144 & 50.123 & 50.103 & 50.082 & 50.061\end{array}$

0.275820

0.27581

0.275819

0.275819

0.275819

0.275819

1.921359

1.921386

1.921413

1.921467

1.921494

.921547

1.921574

0.275819

0.275819

0.275818

$\begin{array}{llllllllll}49.217 & 49.196 & 49.176 & 49.155 & 49.134 & 49.114 & 49.093 & 49.073 & 49.052 & 49.031\end{array}$

$\begin{array}{llllllllll}49.017 & 48.990 & 48.970 & 48.949 & 48.929 & 48.908 & 48.887 & 48.867 & 48.846 & 48.826\end{array}$

$\begin{array}{lllllllllll}48.599 & 48.578 & 48.558 & 48.537 & 48.517 & 48.496 & 48.475 & 48.455 & 48.434 & 48.414\end{array}$

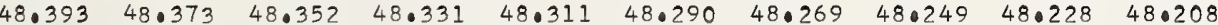

$\begin{array}{lllllllllll}48.187 & 48.166 & 48.146 & 48.125 & 48.105 & 48.084 & 48.063 & 48.043 & 48.022 & 48.002\end{array}$

$\begin{array}{llllllllll}47.981 & 47.961 & 47.940 & 47.919 & 47.899 & 47.878 & 47.858 & 47.837 & 47.817 & 47.796\end{array}$

$47.775 \quad 47.755 \quad 47.734 \quad 47.714$

$\begin{array}{llll}47.652 & 47.631 & 47.611 & 47.590\end{array}$

0.275818

0.275818

0.275818

0.275818

$\begin{array}{llllllllll}14347.364 & 47.343 & 47.322 & 47.302 & 47.281 & 47.260 & 47.240 & 47.219 & 47.199 & 47 \cdot 178\end{array}$ $47.157 \quad 47.137 \quad 47.116 \quad 47.096 \quad 470$

$\begin{array}{lllllllllll}46.952 & 46.931 & 46.911 & 46.890 & 46.869 & 46.849 & 46.828 & 46.807 & 46.787 & 46.766\end{array}$

$\begin{array}{llllllllll} & 46.663 & 46.643 & 46.622 & 46.602 & 46.581 & 46.561\end{array}$

$\begin{array}{lllllllllll}46.334 & 46.313 & 46.293 & 46.272 & 46.450 & 46.437 & 46.416 & 46.396 & 46.375 & 46.355\end{array}$

$\begin{array}{llllllllll}46.338 & 46.108 & 46.087 & 46.066 & 46.046 & 46.035 & 46.211 & 46.190 & 46.169 & 46.149\end{array}$

$\begin{array}{llllllllll}46.128 & 46.108 & 46.087 & 46.066 & 46.046 & 46.025 & 46.005 & 450984 & 450964 & 450943\end{array}$

$\begin{array}{llllllllll}45.716 & 45.696 & 45.675 & 45.655 & 45.634 & 45.614 & 45.593 & 45.572 & 45.552 & 45.539\end{array}$

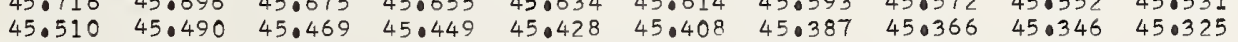

0.275818

0.275818

0.275817
0.275817

0.275817

0.275817

0.275817

0.275817

0.275817

0.275817

0.275817
0.275816

0.275816

0.275816

0.275816

0.2275816
0.275816

1.921628

1.921682

1.921709

1.921736

1.921763

1. 921817

1.921844

1.921897

1.921924
1.921951

1.921978

1.922005

1.922032
1.922059

1.922059
1.922086

1.922113

1.922167

1.922194

1.922248

10922274 $\begin{array}{lllllllllll}44.481 & 44.461 & 44.440 & 440420 & 440399 & 440379 & 440358 & 440337 & 440317 & 440296\end{array}$ $\begin{array}{llllllllll} & & \end{array}$ $\begin{array}{lllllllllll} & 43.843 & 43.823 & 43.802 & 43.782 & 43.761 & 43.740 & 43.720 & 43.699 & 43.679\end{array}$ $\begin{array}{llllllllll}43.658 & 43.638 & 43.617 & 43.596 & 43.576 & 43.555 & 43.535 & 43.514 & 43.494 & 43.473\end{array}$

.010

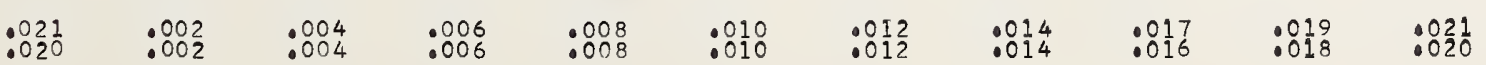


$\begin{array}{llllll}43.164 & 43.144 & 43.123 & 43.103 & 43.082 & 43.061\end{array}$ $\begin{array}{llllllllll}42.629 & 42.609 & 42.588 & 42.568 & 47.547 & 42.526 & 42.506 & 42.485 & 42.465 & 42.444\end{array}$ $\begin{array}{llllllllll}42.423 & 42.403 & 42.382 & 42.362 & 42.341 & 42.321 & 42.300 & 42.279 & 42.259 & 42.238\end{array}$ $\begin{array}{lllllllllll}42.218 & 42.197 & 42.177 & 42.156 & 42.135 & 42.115 & 42.094 & 42.074 & 42.053 & 42.033\end{array}$ $42.012 \quad 41.991 \quad 41.971 \quad 41.950 \quad 41$ $\begin{array}{llll}41.806 & 41.786 & 41.765 & 41.744 \\ 41.601 & 41.580 & 41.559 & 41.539\end{array}$ 41.395

14341.189 $40.983 \quad 40.963$ $\begin{array}{llll}40.778 & 40.973 & 40.942 & 40.922\end{array}$ $\begin{array}{llll}40.778 & 40.757 & 40.736 & 40.716 \\ 40.572 & 40.551 & 40.531 & 40.510\end{array}$

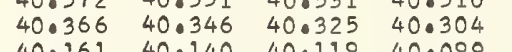
$\begin{array}{llll}40.161 & 40.140 & 40.119 & 40.099 \\ 39.955 & 39.934 & 39.914 & 39.893\end{array}$ $\begin{array}{llll}39.955 & 39.934 & 39.914 & 39.893 \\ 39.749 & 39.729 & 39.708 & 39.687\end{array}$ $\begin{array}{llll}39.749 & 39.729 & 39.708 & 39.687 \\ 39.543 & 39.523 & 39.502 & 39.482\end{array}$ $39.338 \quad 39.317$

6972.0

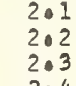

$\begin{array}{llllll}41.930 & 41.909 & 41.888 & 41.868 & 41.847 & 41.827\end{array}$ $\begin{array}{llllll}41.724 & 41.703 & 41.683 & 41.662 & 41.642 & 41.621 \\ 41.518 & 41.498 & 41.477 & 41.457 & 41.436 & 41.415\end{array}$ $41.312 \quad 41.292 \quad 41.271 \quad 41.251 \quad 41.230 \quad 41.210$

$41.107 \quad 41.086 \quad 41.066 \quad 41.045 \quad 41.025 \quad 41.004$ $\begin{array}{lllllll}40.695 & 40.675 & 40.654 & 40.634 & 40.613 & 40.592\end{array}$ $\begin{array}{lllllll}40.490 & 40.469 & 40.448 & 40.428 & 40.407 & 40.387\end{array}$ $\begin{array}{llllll}40.284 & 40.263 & 40.243 & 40.222 & 40.202 & 40.181\end{array}$ $\begin{array}{llllll}40.078 & 40.058 & 40.037 & 40.016 & 390996 & 39.975\end{array}$ $39.667 \quad 39.62 \quad 39.831 \quad 39.811 \quad 39.790439 .770$ $\begin{array}{llllll}39.461 & 39.440 & 39.420 & 39.399 & 39.379 & 39.358\end{array}$ $\begin{array}{lllllll}39.050 & 39.029 & 39.009 & 38.988 & 38.968 & 38.947\end{array}$ $\begin{array}{lllllll}38.844 & 38.824 & 38.803 & 38.782 & 38.762 & 38.741\end{array}$ $\begin{array}{llllll}38.638 & 38.618 & 38.597 & 38.577 & 38.556 & 38.536 \\ 38.433 & 38.412 & 38.392 & 38.371 & 38.351 & 38.330\end{array}$ $\begin{array}{llllll}38.227 & 38.207 & 38.186 & 38.165 & 38.145 & 38.124\end{array}$ $\begin{array}{llllll}38.021 & 38.001 & 37.980 & 37.960 & 37.939 & 37.919 \\ 37.816 & 37.795 & 37.775 & 37.754 & 37.734 & 37.713\end{array}$ $\begin{array}{llllll}37.810 & 37.795 & 37.775 & 37.754 & 37.734 & 37.713 \\ 37.610 & 37.590 & 37.569 & 37.549 & 37.528 & 37.507\end{array}$ $\begin{array}{llllll}37.405 & 37.384 & 37.364 & 37.343 & 37.322 & 37.302\end{array}$ $\begin{array}{llllll}370199 & 37.178 & 37.158 & 370137 & 37.117 & 370096\end{array}$ $\begin{array}{ll}37.035 & 37.014 \\ 36.829 & 36.808\end{array}$ $\begin{array}{ll}36.623 & 36.603 \\ 36.418 & 36.397\end{array}$ $36.212 \quad 36.192$ $35.801 \quad 35.781$ $\begin{array}{lll}350801 & 35.781 \\ 35.595 & 35.575 \\ 1\end{array}$ $36.993 \quad 36.973 \quad 36.952 \quad 36.932 \quad 36.911 \quad 36.891$ $\begin{array}{lllllll}36.582 & 36.562 & 36.541 & 36.521 & 36.500 & 36.0479\end{array}$ $36.377 \quad 36.356 \quad 36.335 \quad 36.315 \quad 36.294 \quad 36.274$ $36.171 \quad 36.151 \quad 36.130 \quad 36.109 \quad 36.089 \quad 36.068$ $\begin{array}{llllll}35.760 & 35.739 & 35.719 & 35.0698 & 35.6778 & 35.657\end{array}$ $\begin{array}{lllllll}35.554 & 35.534 & 35.513 & 35.493 & 350472 & 350451\end{array}$ $\begin{array}{llllll}35.349 & 35.328 & 35.308 & 35.287 & 35.267 & 35.246\end{array}$ $35.143 \quad 35.123 \quad 350102 \quad 35.082 \quad 35.061 \quad 35.040$

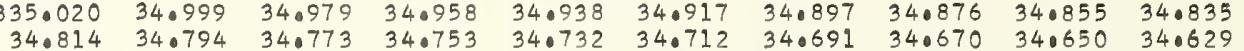

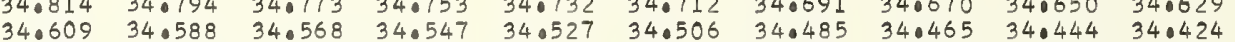

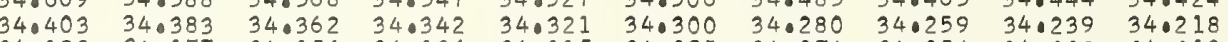

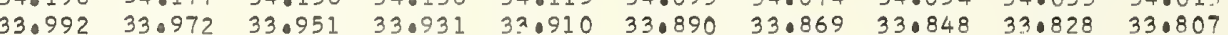
$\begin{array}{llllllllll}33.787 & 33.766 & 33.746 & 33.725 & 33.705 & 33.084 & 330663 & 330643 & 33.622 & 33.602\end{array}$

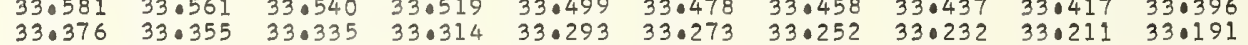

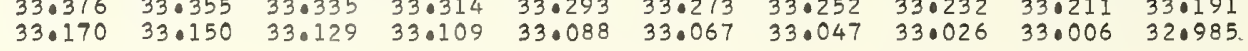

0.275816

0.275816

0.275816

0.275815

0.275815

0.275815

0.275815

0.275815

0.275815

0.275815

0.275814

0.275814

0.275814

0.275814

0.275814

0.275814

0.275814
0.275813

0.275813

0.275 .813

0.275813
0.275813

0.275813

0.275813

0.275813

0.275813

0.275812

0.275812
0.275812

0.275812

0.275812
0.275812

0.275812
0.275812

0.275812

0.275819

0.275811
0.275811

0.275811

0.275811
0.275811

0.27581

0.275811

0.275811
0.275810

0.275810
0.275810

1.922436

1.922463
1.922490

1.922517
1.922544

1.922571

1.922598
1.922624

1.922651

1.922705

1.922759

1.922786

1.922840

1.922894

1.922921

0.275810

0.295810

0.275810

0.275810

0.275810

0.275810

0.275809

1.922975

1.923001

1.923055

1.923082

1.923109

1.923163

1.923190
1.923217

1.923244

1.923298

1.923325

1.923352

1.923405

1.923432
1.923459

1.923486

0.275809

0.275809

0.275809

0.275809

0.275809

0.275809

0.275808

1.923513

1.923540
1.923567

1.923594

1.923648

1.923675

1.923702

1.923782

1.923809
1.923836

1.923863

1.923890
1.993917

1.923944

1.923998

1.924052

1.924079

1.924105
1.924132 


.05

$\begin{array}{rl}422.698 & 22.677 \\ 22.492 & 22.472 \\ 22.287 & 22.067 \\ 22.082 & 22.062 \\ 21.877 & 21.856 \\ 21.672 & 21.651 \\ 21.466 & 21.446 \\ 21.261 & 21.241 \\ 21.056 & 21.036 \\ 20.851 & 20.831\end{array}$

$\begin{array}{llll}22.656 & 22.636 & 22.615 & 22 \\ 22.451 & 22.431 & 22.410 & 2 \\ 22.046 & 22.225 & 22.205 & 2 \\ 22.041 & 22.020 & 22.000 & 2 \\ 21.08 & 210 & 21.815 & 21.795\end{array}$

$\begin{array}{lllll}22.595 & 22.574 & 22.554 & 22.533 & 22.513 \\ 22.390 & 22.369 & 22.349 & 22.328 & 22.308\end{array}$

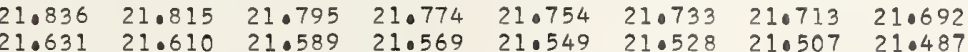

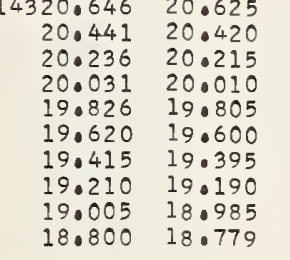

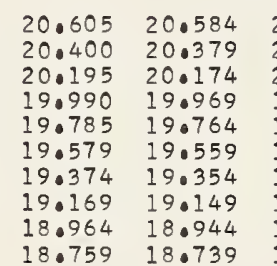

20.974 20.

$\begin{array}{lllll}.159 & 21.138 & 21.118 & 21.097 & 21.077\end{array}$

0.275806

0.275806

0.275806

0.275806

0.275806

0.275805

0.275805

0.275805

0.275805

0.275805

0.275805

0.275804

0.275804
0.275804

0.275804
0.275804
0.0275804

0.275804

0.275804

0.275804

0.275804

0.275804

027580
0.27580

0.27580
0.275800

0.0275803

02275803
0.275803
0.227803

0.2758

0.275889
0.02758
0.025

0.27580
0.07580

0.0275802
0.275802

0.0275802

0.275802
0.275802
0.275822

0.275802
0.275802

0.275802

0.275802
0.275802

0.275801

0.027581
0.27501

0.275801
0.275801

0.275801

0.275801

0.275801

0.275801

0.275800

0.275800

0.275800
0.275800

0.275800
0.275800

0.275800

0.275800
0.275800
0.275800

0.275800
0.275800

0.275799

0.275799
0.275790

0.275799

0.275799
0.275799

0.275799

0.275799
0.275799

0.275799

0.275799
0.275798

0.275798
0.275798

0.275798

0.275798
0.275798

0.275798
0.275798
0.275798

0.275798
0.275798

0.275798
0.275798
0.275798
0.275798

0.275798

0.275797

0.275797

0.275797
0.275797

$\lambda(n-1)$

1.925129

1.925156

1.925209

1.925263

1.925317

1. 92535374

1.925398

1.925452

1.925506

1.925533

1.925586

1.925640

1.925667

1.925694
1.925721
0.025748

1.925775

1.925829

1.925856

1.925937

1.925990

1.926044

1.926098

1.926125

1.926179

1.926206
1.926233

1.926260

1.926314

1.926367

1.926421

0926475
.926502

1.926502

1.926556

1.996610

1.926664

1.926717

1.926744

1.926798

1.926825

1.926879

.926933

1.926960
1.926987

1.927014

1.927041

1.927094

1.927121

1.927175
1.927202

1.927256

1.927283

1.927310
1.927337

1.927364
1.927399

1.927418

1.927471

1.927498
1.927525

1.927552
1.927579

1.927606

1.927633

1.927660

10927687
1.927714

1.927768
1.927795

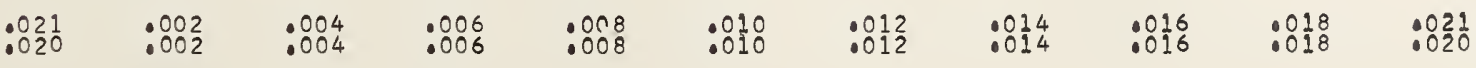


14296.072 95.867
95.663 $95.254 \quad 95.234$

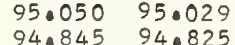
$\begin{array}{ll}94.845 & 94.825 \\ 94.641 & 94.620\end{array}$ $\begin{array}{ll}94.437 & 94.416 \\ 94.232 & 94.212\end{array}$

14294.028

$$
\begin{array}{rr}
294.028 & 94.007 \\
93.823 & 93.803
\end{array}
$$

93.61993 .8593

93.210930394

$93.006 \quad 92.985$

$92.802 \quad 92.781$

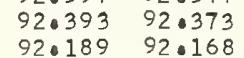
4291.984

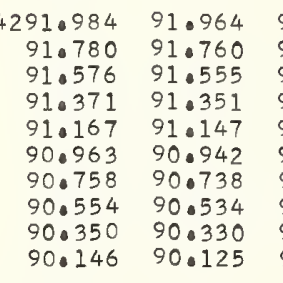

$$
\begin{array}{r}
89.757 \\
89.533
\end{array}
$$

\begin{tabular}{|c|}
\hline $\begin{array}{l}7579797 \\
756700\end{array}$ \\
\hline 027599 \\
\hline 275 \\
\hline 275 \\
\hline $\begin{array}{r}0.275796 \\
0.2759\end{array}$ \\
\hline 0 \\
\hline
\end{tabular}

$0.275796-1.998091$

0.27596

0.275796

0.275796

0.275796

0.0275795

0.275795
0.275795

1.928118

1.0928172

1.9928225

1.028252

1.9028306
1.9928333

0.27579

0.0275795

0.075795

0.275795

0.275795
0.275944

0.275794
0.027574

1.928360

1.0928414

10928441

$\frac{1}{1} .092844685$

1.028522

1.028576

0.275794

0.275794

0.275794
0.275994
0.27594

0.275794

0.275794

0.275794

0.275794

0.275793

1.928629

1.928656

1.928710

10928739

1. 0.9287649

1.928818

0.275793

0.275793
0.275793
0.275793

0.275793

0.275793

0.275793

0.275793

0.275793

\begin{tabular}{|c|}
\hline .275792 \\
\hline $\begin{array}{l}0.27592 \\
0.275792\end{array}$ \\
\hline $\begin{array}{l}: 279592 \\
0275792\end{array}$ \\
\hline $\begin{array}{l}77579 \\
7570\end{array}$ \\
\hline $\begin{array}{l}0.275792 \\
0.375792\end{array}$ \\
\hline 0.275792 \\
\hline
\end{tabular}

10928872

0.275791

0.27579

0.275791

0.275791

0.275791

0.275791

0.275791
0.275791

1.928899

1.0928926

1.028979

1.929006

1.929033
1.929060

1.929087

1.0929114
1.929141

0.275791

0.275790

0.275790

0.075790

0.275790

0.275790

0.275790
0.275790

1.929437

1.929464

1.0929491

1.029545

1
1.90295572
1.9929599

1.929626

10929653

0.275790
0.275789
0.275789

0.275789
0.27578

0.275789

0.275789
0.275789
0

0.0275789

0.275789
0.0275789
0

1.929707

10929733

1.929787

1.0929814

1.0929868

1.0929895

0.275789
0.275789
0.027599

0.275789

0.275788

0.275788

0.275788

0.275788
0.275788

0.275788

1.929976

1.930003

1.930057

1.930084

1.930137

1
1.99301164
1.930191 





